



Catalog of Hymenoptera in America North of Mexico 


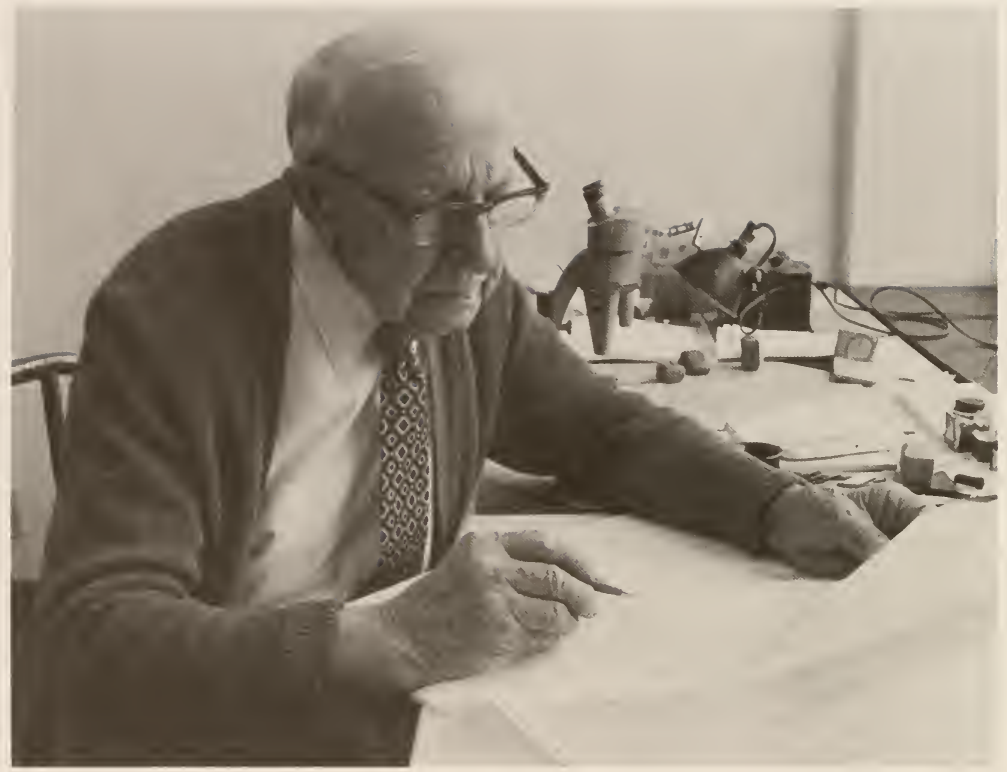

Carl F. W. Muesebeck

This catalog is dedicated to our cherished colleague with affectionate regard for his kindliness and with admiration for his distinguished scholarly contributions to our knowledge of North American Hymenoptera for more than half a century. 


\title{
Catalog of \\ Hymenoptera in America \\ North of Mexico
}

\author{
Prepared cooperatively by \\ specialists on the various groups of Hymenoptera \\ under the direction of \\ Karl V. Krombein and Paul D. Hurd, Jr. \\ Smithsonian Institution \\ and
}

David R. Smith and B. D. Burks

Systematic Entomology Laboratory,

Insect Identification and Beneficial Insect Introduction Institute

Science and Education Administration,

United States Department of Agriculture

\section{VOLUME 1}

Symphyta and Apocrita (Parasitica)

SMITHSONIAN INSTITUTION PRESS

Washington, D.C. 
Library of Congress Cataloging in Publication Data Main entry under title:

Catalog of Hymenoptera in American north of Mexico.

"An outgrowth of ... Hymenoptera of America north of Mexico, synoptic catalog (1951) including the first and second supplements (1958, 1967)"

Includes index.

CONTENTS: v.1. Symphyta and Apocrita (Parasitica). - v. 2. Apocrita (Aculeata)

1. Hymenoptera - North America. 2. Insects North America. I. Krombein, Karl V.

QL567.1.A1C37 595.7'9'097 78-606008 


\section{Contents}

Introduction by Karl V. Krombein, Paul D. Hurd, and David R. Smith........................... v v Hymenoptera by Karl V. Krombein and Paul D. Hurd, Jr............................................ 1

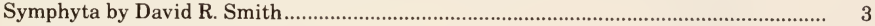

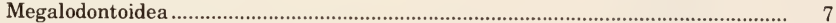

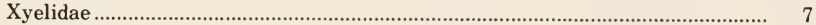

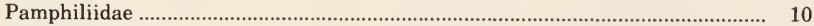

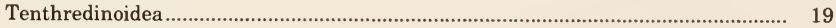

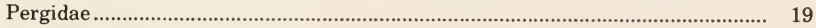

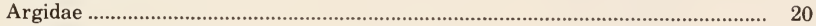

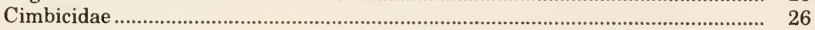

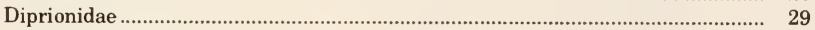

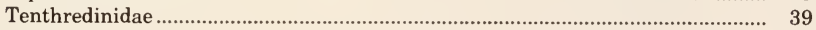

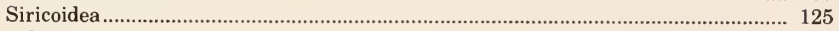

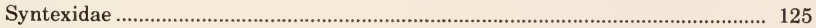

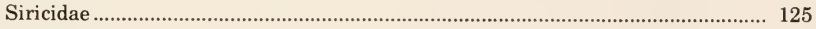

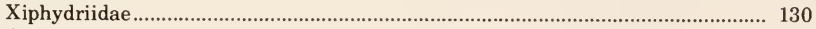

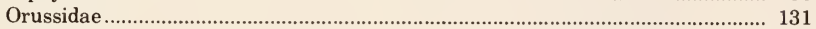

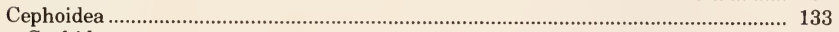

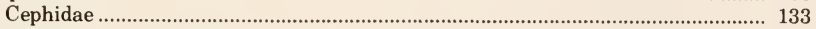

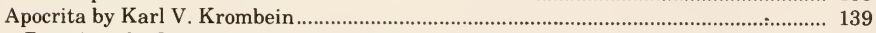

Parasitica by Paul M. Marsh and Robert W. Carlson ................................................. 141

Ichneumonoidea by Paul M. Marsh and Robert W. Carlson ................................... 143

Braconidae by Paul M. Marsh ............................................................................. 144

Aphidiidae by Paul M. Marsh …....................................................................... 295

Hybrizontidae by Paul M. Marsh ........................................................................... 313

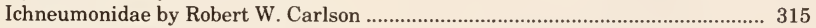

Stephanidae by Robert W. Carlson ............................................................... 740

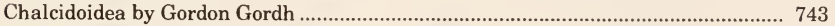

Torymidae (except Agaoninae) by E. E. Grissell................................................ 748

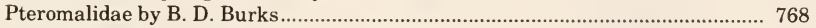

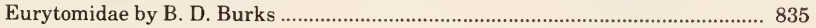

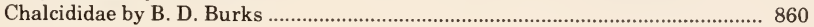




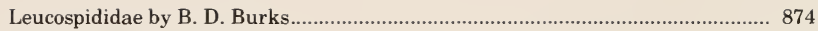

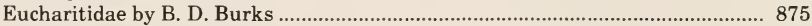

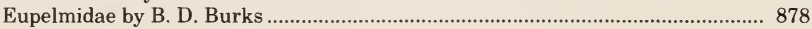

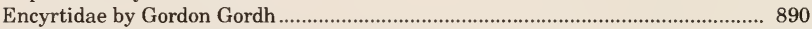

Eulophidae by B. D. Burks ................................................................................ 967

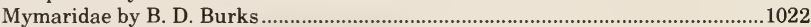

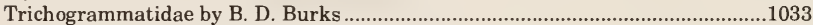

Unplaced Taxa in Chalcidoidea by B. D. Burks ..................................................1042

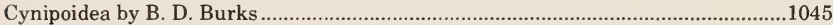

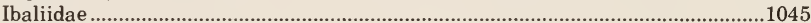

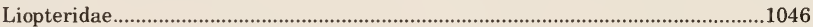

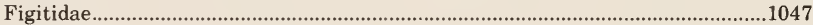

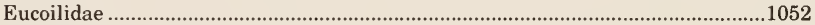

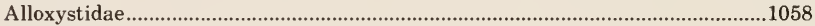

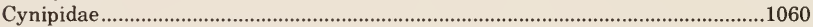

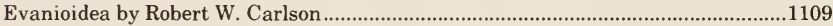

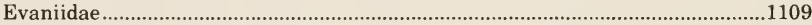

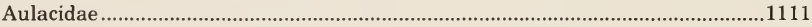

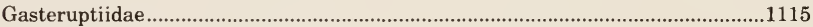

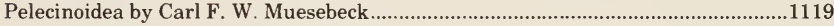

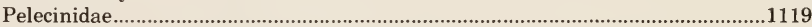

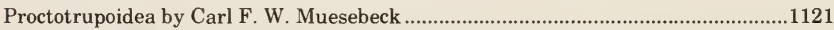

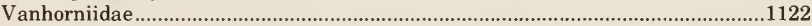

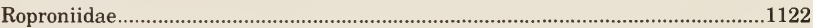

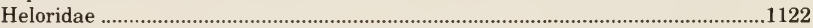

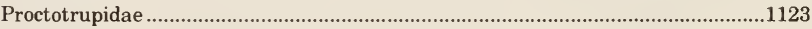

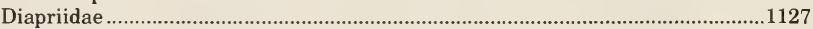

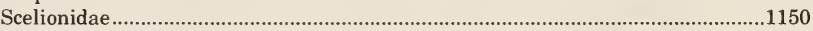

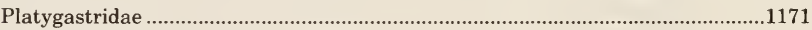

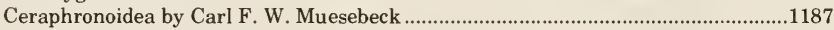

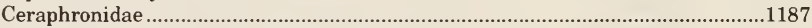

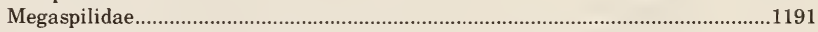

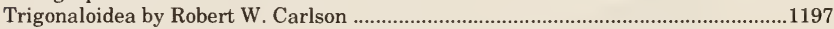

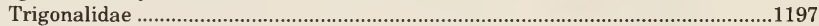

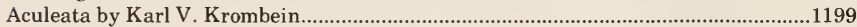

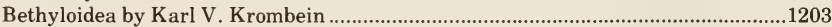

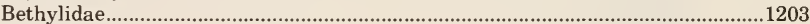

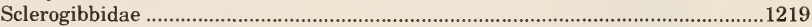

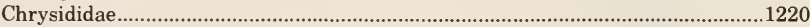

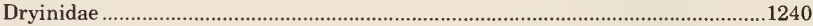

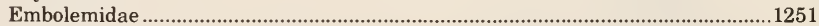

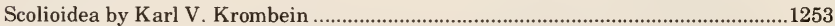

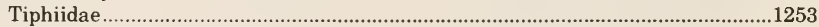

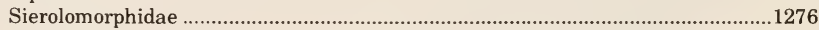

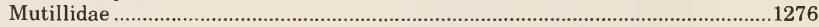

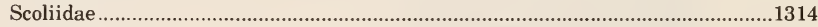

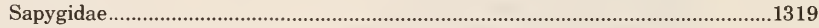

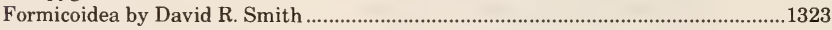

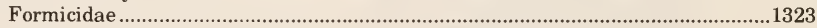

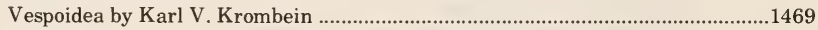

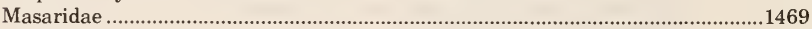

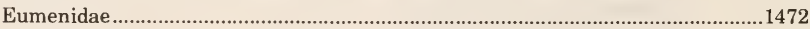

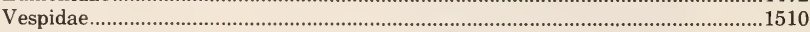




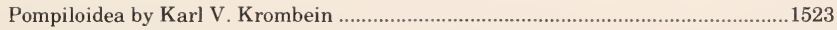

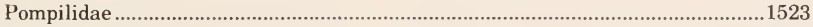

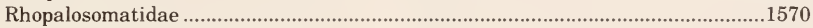

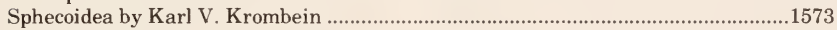

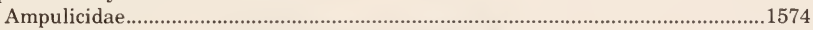

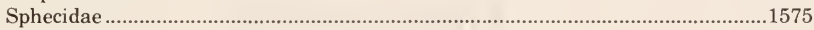

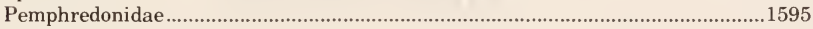

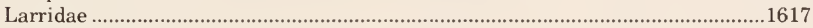

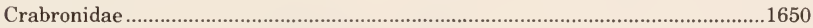

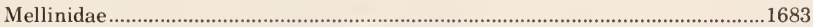

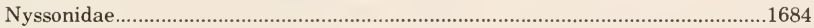

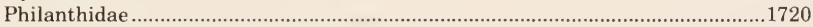

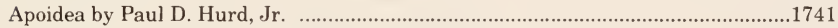

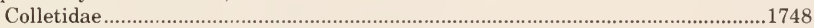

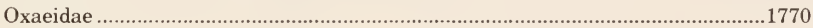

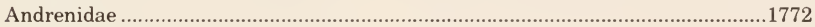

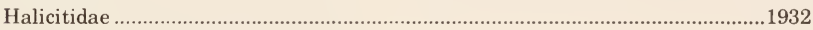

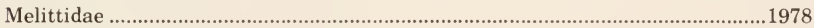

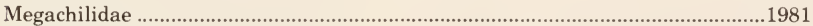

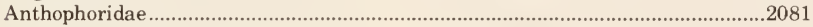

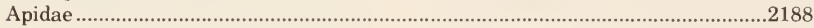

Institutional Affiliation of Contributing Authors

Smithsonian Institution: Paul D. Hurd, Jr., Karl V. Krombein, Carl F. Muesebeck U.S. Department of Agriculture: B. D. Burks, Robert W. Carlson, E. E. Grissell, Paul M. Marsh, David R. Smith

University of California, Riverside: Gordon Gordh 


\title{
Introduction
}

\author{
By \\ Karl V. Krombein, \\ Paul D. Hurd, Jr., \\ and \\ David R. Smith
}

This catalog, which is an outgrowth of the highly successful Hymenoptera of America North of Mexico Synoptic Catalog (1951), including the first and second supplements (1958, 1967), provides simultaneously, by use of computer technology (Krombein, Mello and Crockett, 1974. Ent. Soc. Amer., Ann. $20: 24-29$ ), a printed version as well as a computer-queriable data base of the basic systematic, biological, and morphological information on the order Hymenoptera as it occurs in America north of Mexico. While the format of the present catalog closely parallels that of the original catalog, every effort has been made to increase the information content to fulfill better the needs of the biological community. This has been accomplished chiefly by the introduction of textbook prose at most higher category levels, by the presentation of explanatory or descriptive comments as appropriate, and by the inclusion of more complete listings of citations to taxonomic, biological, and morphological literature at all hierarchical levels together with parenthetical annotations concerning the content for many of these citations. Similarly, the data about hosts, parasites, prey, predators, and pollen sources are covered more fully than in the original catalog. Since these data have been reported in various ways and under differing names in the primary literature, an attempt has been made to organize this information and present it, usually, alphabetically even though sometimes such data have been recorded in the literature with scientific or vernacular names or both. Although many of these names have been checked for accuracy, no consistent attempt has been made to verify that the names agree with current usage or status. While those authors of zoological names are usually abbreviated in the citation of hosts, parasites, and the like, the authors of the scientific botanical names are not included. Elsewhere in the catalog, the last name of an author is cited in full, but without initials. Since the technology employed in the preparation of this catalog precluded the use of diacritical marks, these have been omitted and consequently, as in the case of the umlaut, a variant spelling has been substituted as appropriate.

The International Code of Zoological Nomenclature (1961) including the intent and preamble of the Code and of any pertinent opinions usually has been followed. Thus a name in current usage as deterimned by the code is employed, but mention is made, as appropriate, that an application is pending before the International Commission of Zoological Nomenclature.

An attempt has been made to record all the recent taxa, with their synonyms, described 
from, or known to occur in, the political divisions of the conterminous United States, Canada, Alaska, and Greenland. Insofar as known, all species introduced from other countries and liberated in America north of Mexico for biological control purposes have been listed. Some of these have never been recovered and, apparently, were unsuccessful in establishing themselves. For each such species a statement has been included, following the distribution, that the species was liberated but did not become established.

As in the original catalog, the arrangement is systematic for species-groups and higher categories insofar as our present knowledge and the limitations of a linear arrangement permit. The generic and subgeneric concepts represented in this arrangement are based upon what are believed to be the correct typespecies. In each instance the type-species is cited together with the authority for the selection. Where designations of type-species have been found to be invalid under the International Code of Zoological Nomenclature, new type-species designations, believed to be valid, are given in the catalog. Generic synonymy is included under the generic headings except where subgenera are recognized, in which cases such synonymy is given under the subgeneric names, and references to revisional or other papers are listed under the appropriate higher category.

The arrangement of species within genera, subgenera, and species groups is alphabetical. Where subspecies are recognized, the subspecific names are placed in alphabetical order under the species to which they belong; and varieties are listed under the particular species or subspecies in which they were described. In each case the specific, subspecific, or infrasubspecific, name is followed by an indication of the known distribution, and by brief statements, as appropriate, of preferred habitats or the like, hosts, parasites, prey, predators, or pollen sources. Much of this information on synonymy, distribution, ecology, hosts, parasites, prey, and so forth has not been published previously. The type localities are usually recorded for those forms that are known only from the localities where the type specimens were obtained. Otherwise the distribution is usually shown by states and provinces, or by other means such as life zones.

Since unquestionably a catalog is indispensable in the support of systematic and other biological research, no effort has been spared toward making this catalog as useful as possible to all of the scientific community interested in these fascinating insects.

\section{LITERATURE COVERAGE}

All authors have attempted to include all pertinent references to synonyms, revisions, taxonomy, biology, and morphology beginning with 1758 , the publication date of the 10 th edition of "Systema Naturae" by Linnaeus. The cut-off dates vary for the several sections of the catalog and are as follows: Symphyta through 1974 ;

Ichneumonoidea through 1976 ;

Chalcidoidea-Torymidae (except Agaoninae) and Encyrtidae through 1976; other families and Agaoninae through 1972;

Cynipoidea through 1972;

Evanioidea through 1976;

Pelecinoidea, Proctotrupoidea, and Ceraphronoidea through 1972 ;

Trigonaloidea through 1976 ;

Bethyloidea and Scolioidea through 1975;

Formicoidea through mid-1975;

Vespoidea, Pompiloidea, and. Sphecoidea through 1975; and

Apoidea through 1976.

All authors have included some references subsequent to the dates listed above. 


\section{LITERATURE CITATIONS}

The source for journal abbreviations is Whitlock, C., 1939, Abbreviations used in the Department of Agriculture for titles of publications, United States Department of Agriculture Miscellaneous Publication No. 337, 278 pages. Abbreviations for other titles and journals not found in Whitlock essentially follow the same format and abbreviations that she recommends. Book titles are usually shortened to omit irrelevant adjectives and include abbreviations, e.g.: Wheeler and Wheeler, 1963. The Ants of North Dakota, p. - , is cited as Wheeler and Wheeler, 1963. Ants of N. Dak., p. - C Certain lengthy nonserial titles are also abbreviated, e.g.: Say, 1824. In Keating, Narr. Long's 2nd Exped., v. 2 (App.), p. - , rather than Say, 1824. In Keating, Narrative of an Expedition to the Source of St. Peter's River, Lake Winnepeek ...., etc. The titles are intended to be uniform throughout the catalog, but, in a work of this magnitude, there will naturally be some deviations. The abbreviations should be adequate to find the cited publication.

\section{SYMBOLS AND ABBREVIATIONS}

Certain symbols and abbreviations are frequently used in this catalog. Though there may be slight variations in some, they are generally as follows:

(!)-lapsus or misspelling of a scientific name.

" $"=\hat{o}$ or " $\delta "=q$-incorrect sex determination.

of ( o misdet.) or o ( $q$ misdet.) -only one of the sexes described belongs to the species cataloged.

ㅇ-female.

$\hat{o}$-male.

ఫ̧-worker.

4 -soldier.

ab.-aberration.

app.-appendix.

cent.-central. changed status-used after a species-group name to indicate a rank different from that previously accorded to it; not necessarily the same as new status.

desig.-designated; e.g., in type-species designation, "Desig. by Rohwer, 1911."

e., east.-east, eastern.

emend.-emendation.

fasc.-fascicle.

fig., figs.-figure, figures.

h.-heft.

n. comb.-new combination; used after a species-group name to indicate a new generic assignment.

n. name-new name; used after a genusgroup or species-group name to indicate a substitute name for a homonym.

N. name-New name; used after a bibliographic citation to indicate a previously proposed name.

Nom. nud.-Nomen nudum.

n. s.-new series.

n. status-new status; used where a taxon is here accorded a rank different from that which it had previously.

N. syn.-New synonymy; used to indicate a synonym newly proposed in this catalog.

n., no., north.-north, northern.

n.e., northeast.-northeast, northeastern.

n.w., northwest.-northwest, northwestern.

orig. desig.-original designation; used to indicate type-species designation.

p., pp.-page, pages.

pl., pls._plate, plates.

preocc.-preoccupied; used after a genusgroup or species-group name to indicate a homonym.

pt._part.

revised status-revised status; used to denote a taxon that has been removed from synonymy.

ser.-series.

s., so., south.- south, southern.

s.e., southeast.-southeast, southeastern.

s.w., southwest.-southwest, southwestern.

sp., spp.—species.

ssp., sspp.—subspecies. 
subg.-subgenus.

transcont.-transcontinental.

v., vol.-volume.

var.-variety.

w., west.-west, western.

\section{FAUNAL ZONES}

$\begin{array}{ll}\text { Bor. } & \text { Boreal } \\ \text { Canad. } & \text { Canadian } \\ \text { Huds. } & \text { Hudsonian } \\ \text { Transit. } & \text { Transition } \\ \text { Austr. } & \text { Austral } \\ \text { U. Austr. } & \text { Upper Austral } \\ \text { L. Austr. } & \text { Lower Austral } \\ \text { Alleghan. } & \text { Alleghanian } \\ \text { Austrorip. } & \text { Austroriparian } \\ \text { Carol. } & \text { Carolinian } \\ \text { Sonor. } & \text { Sonoran } \\ \text { U. Sonor. } & \text { Upper Sonoran } \\ \text { L. Sonor. } & \text { Lower Sonoran }\end{array}$

\section{GEOGRAPHICAL NAMES}

Abbreviation

Political Unit

Ala.

Alaska

Alta.

Ariz.

Ark.

B.C.

Calif.

Canada

Colo.

Conn.

Del.

D.C.

Fla.

Ga.

Greenland

Idaho

Ill.

Ind.

Iowa

Kans.
Ky.

La.

Labrador

Maine

Man.

Mass.

Md.

Mexico

Mich.

Minn.

Miss.

Mo.

Mont.

N. B.

N. C.

N. Dak.

Nebr.

Nev.

Newfoundland

N. H.

N. J.

N. Mex.

N. S.

N. W. T.

N. Y.

Ohio

Okla.

Ont.

Oreg.

Pa.

P. E. I

Que.

R. I.

Sask.

S. C.

S. Dak.

Tenn.

Tex.

U. S.

Utah

Vt.

Va.

Wash.

W. Va.

Wis.

Wyo.

Yukon
Kentucky

Louisiana

Labrador, Newfoundland (Labrador)

Maine

Manitoba

Massachusetts

Maryland

Mexico

Michigan

Minnesota

Mississippi

Missouri

Montana

New Brunswick

North Carolina

North Dakota

Nebraska

Nevada

Newfoundland, Newfoundland (insular)

New Hampshire

New Jersey

New Mexico

Nova Scotia

Northwest Territories

New York

Ohio

Oklahoma

Ontario

Oregon

Pennsylvania

Prince Edward Island

Quebec

Rhode Island

Saskatchewan

South Carolina

South Dakota

Tennessee

Texas

United Statẹs

Utah

Vermont

Virginia

Washington (state)

West Virginia

Wisconsin

Wyoming

Yukon Territory 


\section{TAXONOMIC AND NOMENCLATURAL CHANGES}

The catalog contains one undiagnosed new species in the Ichneumonidae, Pterocormus clasma Carlson, p. 521, proposed for the taxon misidentified as Ichreumon canadensis Cresson by Heinrich (1961).

The catalog contains one undiagnosed new genus also in the Ichneumonidae, Woldstedtius Carlson, type-species Bassus biguttatus Gravenhorst, p. 719, proposed for Syrphoctonus Foerster sensu Dasch (1964).

The following new names are proposed to replace preoccupied names:

\section{Tenthredinidae}

Pachynematus gamus Smith for Pachynematus graminis Marlatt (1896) .......p. 58 Nematus attus Smith for Amauronematus dyari Marlatt (1896) ............ 68 Amauronematus peralus Smith for Nematus pectoralis Cresson (1880) ........p. 80

\section{Ichneumonidae}

Oedomopsis davisi Carlson for Trophon ? nasutus Cresson (1868) ........... 366

Gelis cushmani Carlson for Hemiteles apantelis Cushman (1927) ............. 405

Oresbius shumaginensis Carlson for Stiboscopus ferrugineus Ashmead (1902) ...p. 438

Pterocormus dionymus Carlson for Ichneumon anonymus Heinrich (1961) .....p. 522

Casinaria affinisima Carlson for Casinaria affinis Walley (1947) ............. 635

\section{Pteromalidae}

Mesopolobus fuscipedes Burks for Platyterma fuscipes Ashmead (1896) ....... p. 816

\section{Eurytomidae}

Harmolita ovatella Burks for Harmolita ovata Phillips and Emery (1919) .....p. 840

\section{Eulophidae}

Syntomosphyrum orgyiazele Burks for Tetrastichomyia orgyiae Girault (1916) ..p.1005

\section{Diapriidae}

Trichopria kiefferi Muesebeck for Diapria montana Kieffer (1906) .............1147

\section{Scelionidae}

Trimorus contractus Muesebeck for Gryon flavipes Ashmead (1893) . . . . . . . p.1162

\section{Ceraphronidae}

A phanogmus harringtoni Muesebeck for A phanogmus salicicola Harrington (1899) p.1190

\section{Megaspilidae}

Deudrocerus obscurellus Muesebeck for Atritomus californicus Kieffer (1906) ..p.1194

\section{Masaridae}

Exiparagia richardsi Bohart for Psiloglossa simplicipes Rohwer (1909) ......... p.1470

\section{Philanthidae}

Cerceris bolingeriana Krombein for Cerceris bolingeri Scullen (1972) ........p.1730

\section{Anthophoridae}

Triepeolus mitchelli Hurd for Triepeolus sublunatus Mitchell (1962) . . . . . . p.2094

There are a number of other nomenclatural and taxonomic changes. These are considered of lesser bibliographic importance than the new names, so tabulations of them are deferred to Volume 3 which will also contain the indexes and a table of the number of valid genera and species for each family and higher category. These nomenclatural and taxonomic changes are as follows :

A number of generic transfers are made. They are usually cited in the text as xantianum (Saussure), n. comb. The authority 
responsible for the transfer is the author of that section unless the name of another specialist is included.

There are also a number of instances where a taxon formerly considered to be a species is treated here as a subspecies of another taxon, or where a taxon.formerly considered to be a subspecies is now raised to specific rank. The authority responsible for the change is the author of that section unless the name of another specialist is included. These are usually cited in the text as clavatum johannis (Richards), n. status or alba Rohwer, n. status.

The words-changed status-occasionally follow the author of a species-group name. This indicates that the taxon has a rank different from that accorded it elsewhere. It is not the same as new status for it reflects a change which has already been published.

In a few taxa, the words-revised statusfollow the author of a species-group name. This denotes a taxon which has been removed from synonymy.

There are a few new synonyms at the genus-group level and numerous new synonyms at the species-group level. These are indicated by the abbreviation N. syn. following the bibliographic citation of the new synonym. As noted above, the synonymy is to be attributed to the author of the section unless the name of another specialist appears in parentheses following the abbreviation N. syn.

\section{Volume 3}

It is intended that Volume 3 will contain separate indexes to the taxa of Hymenoptera, and to their hosts, parasites, prey, predators, and pollen and nectar sources. Preparation of the indexes has already begun, and we anticipate that the tapes for Linotron production will be sent to the Government Printing Office during 1978. We will also include in Volume 3 a tabulation of the number of valid genera and species for each family and higher category, and lists of the nomenclatural and taxonomic changes other than the new names which are listed above.

\section{Acknowledgments}

Preparation of the catalog and funding for its publication have had the enthusiastic support of Porter M. Kier, Director, National Museum of Natural History (NMNH), Smithsonian Institution (SI) and of Lloyd V. Knutson, Chairman, Insect Identification and Beneficial Insect Introduction Institute, U.S. Depart- ment of Agriculture. The catalog in its printed form could not have been achieved without their help, and we are most grateful that their assistance was available whenever we required it.

We are indebted to a host of cooperating hymenopterists for generous assistance which 
has greatly enhanced the content and quality of the catalog. The aid furnished has involved such diverse activities as reviewing preliminary drafts of various sections, and providing new information on taxonomy, synonymy, distribution, and biology.

In the Symphyta, H. E. Milliron, formerly of the Biosystematics Research Institute (BRI), Agriculture Canada, Ottawa, reviewed parts of the manuscript and provided information, as did H. R. Wong, Northern Forest Research Centre, Edmonton, Alberta, for Pristiphora Latr. H. Greenbaum, University of Florida, Gainesville, furnished data on Florida sawflies.

The accuracy of host names in the Parasitica was checked by the following specialists: Smithsonian Institution-J. F. G. Clarke, D. R. Davis, W. D. Duckworth, T. L. Erwin, W. D. Field, and R. C. Froeschner; Systematic Entomology Laboratory (SEL), U. S. Department of Agriculture-D. C. Ferguson, R. J. Gagné, R. D. Gordon, A. B. Gurney, J. L. Herring, R. W. Hodges, J. M. Kingsolver, J. P. Kramer, A. S. Menke, D. M. Miller, L. M. Russell, C. W. Sabrosky, D. R. Smith, T. J. Spilman, M. B. Stoetzel, E. L. Todd, R. E. Warner, and R. E. White. D. M. Weisman (SEL) identified the remains of some lepidopterous larvae which served as hosts.

Specialists who were helpful in the Ichneumonoidea were: L. E. Caltagirone, University of California, Albany, and C. C. Loan (BRI), who reviewed parts of the manuscript on Braconidae; C. van Achterberg, Waarder, The Netherlands, W. R. M. Mason (BRI), R. D. Shenefelt, University of Wisconsin, Madison, and R. Wharton, University of California, Berkeley, who provided advice and information on Braconidae; H. K. and M. C. Townes, American Entomological Institute, Ann Arbor, Michigan, who provided information and advice on Ichneumonidae; and P. M. Marsh (SEL), who proofed the first-phase computer printouts for Mesochorinae, Diplazontinae, Oxytorinae and Orthocentrinae, and the thirdphase edit for Ichneumoninae.

Z. Boucek, Commonwealth Institute of Entomology, London, and M. Graham, Oxford University, provided much information on Chalcidoidea, and D. P. Annecke, Plant Pro- tection Research Institute, Pretoria, South Africa, advised on the placement of some species assigned erroneously to Aphycus Mayr. A special debt of gratitude is due C. F. W. Muesebeck who painstakingly proofed all edit phases of the computer printouts for Encyrtidae and Torymidae and all but the first-phase edits of all other families of Chalcidoidea.

D. B. Krombein provided welcome assistance by helping to proof the manuscripts and printouts for all superfamilies of aculeate wasps. F. D. Parker, Bee Biology and Systematics Laboratory, Utah State University, Logan, furnished biological data for a number of Utah wasps.

We are grateful to R. M. Bohart, University of California, Davis, for reviewing the manuscript on Chrysididae and for considerable other assistance which included information on new synonyms and distribution in the Elampinae and Chrysididinae, and the assignment of taxa to species groups in Chrysis L. H. E. Evans, Colorado State University, Fort Collins, reviewed the section on Bethylidae.

In the Scolioidea, the late J. C. Bradley, Cornell University, Ithaca, New York, and J. G. Betrem, Deventer, The Netherlands, reviewed the manuscript on Scoliidae, and H. W. Allen, Moorestown, New Jersey, that on Tiphiinae. W. E. Ferguson, San Jose State University, California, and C. E. Mickel, University of Arizona, Tueson, furnished information on synonymy and taxonomy of some Mutillidae.

R. R. Snelling, Los Angeles County Museum, California, and M. R. Smith, Arlington, Virginia, reviewed the section on Formicoidea. J. F. Watkins II, Baylor University, Waco, Texas, reviewed the section on Dorylinae, and A. C. Cole, University of Tennessee, Knoxville, that on Pogonomyrmex Mayr. A. Francoeur, University of Québec, Chicoutimi, provided information on the fusca group of Formica L.

O. W. Richards, British Museum (Natural History), London, and R. M. Bohart reviewed the entire manuscript for Vespoidea. J. van der Vecht, Putten, The Netherlands, recommended the systematic sequence adopted in the Eumenidae and reviewed the manuscript. 
M. J. West-Eberhard, Universidad del Valle, Cali, Colombia, and R. R. Snelling reviewed the manuscript on Vespidae and supplied data on taxonomy and biology. J. E. Gillaspy, Texas A \& I University, Kingsville, provided information on Polistes Latr.

H. E. Evans reviewed the manuscript on Pompilidae, and F. E. Kurczewski, University of Syracuse, N. Y., contributed some prey records.

R. M. Bohart and A. S. Menke generously made available a copy of their manuscript, "Sphecid Wasps of the World," which was most helpful in assembling the section on Sphecoidea; Menke, in addition, reviewed the catalog manuscript for this superfamily. Other specialists contributed data on the groups mentioned after their names: R. E. Coville, University of California, Berkeley (taxonomy and distribution of Trypoxyloninae); J. E. Gillaspy (Bembicinae); F. E. Kurczewski (biology of Larridae and Crabronidae) ; R. C. Miller, Cornell University (taxonomy, distribution, and biology of Crabronidae); W. J. Pulawski, Wroclaw, Poland (taxonomy and distribution of Tachysphex Kohl) ; and D. Vincent. University of Maryland, College Park (taxonomy and distribution of Passaloecus Shuck.).

E. G. Linsley, University of California, Berkeley, reviewed the entire manuscript on Apoidea and offered valuable suggestions. C. D. Michener, University of Kansas, Lawrence, discussed with the author of that section the biology and systematics of bees; many of his suggestions have been incorporated in the classification adopted. The following specialists have cooperated by contributing data on the groups specified after their names: G. E. Bohart, Bee Biology and Systematics Laboratory, Utah State University, Logan (taxonomy and biology of Apoidea); W. E. LaBerge, Illinois Natural History Survey, Urbana (taxonomy of Andrenidae and Anthophoridae) ; U. N. Lanham, University of Colorado, Boulder (taxonomy of Apoidea); M. A. Lieftinck, Rhenen, The Netherlands (taxonomy of Anthophoridae); A. Løken, University of Bergen, Norway (taxonomy of Apidae) ; T. B. Mitchell, North Carolina State University, Raleigh (taxonomy of Apoidea) ; J. S. Moure, Universidade
Federal do Paraná, Curitiba, Brazil (taxonomy of Apoidea) ; F. D. Parker (taxonomy and biology of Apoidea); J. G. Rozen, Jr., American Museum of Natural History, New York, New York (taxonomy and biology of Apoidea) ; R. R. Snelling (taxonomy of Hylaeus F.) ; R. W. Thorp, University of California, Davis (taxonomy and biology of Apidae); P. H. Timberlake, University of California, Riverside (taxonomy of Apoidea); and T. J. Zavortink, University of San Francisco, California (taxonomy of Anthophoridae).

C. W. Sabrosky (SEL) has been helpful to all of us in the discussion of abstruse nomenclatural problems. J. F. Gates Clarke (SI) participated patiently in philosophical discussions of a wide variety of subjects pertaining to the catalog. G. C. Steyskal (SEL) was the resource person for the grammar of scientific names and other linguistic matters.

Computerization of the catalog and its production by the computer-driven Linotron required the highly skilled technical expertise of specialists in computer storage and applications. James F. Mello, formerly Chief of the Data Processing (ADP) Program at NMNH, carefully analyzed the 1951 Hymenoptera Catalog and developed the data analysis matrix which governed entry of information into the computer. R. Creighton, Manager, Information Retrieval and Indexing Division, Office of Computer Services (OCS), SI, devised the programs for editing, arranging, querying, and displaying data from the manuscripts. J. J. Crockett, Manager, Software Systems and Program Maintenance (OCS), developed the program for conversion of the computerized data to special magnetic tapes capable of driving the Photo Typesetting Unit, the Mergenthaler Linotron 1010, in the Government Printing Office. T. G. Gautier, Chief (ADP), and D. Bridge, Operations Manager (ADP), maintained daily collaboration with the Editorial Board in assignment of clerical assistance, and production of the edit phases, merge files, and SELGPO printouts.

Finally, we are most grateful for the careful, accurate typing of the manuscripts for computer entry by the corps of dedicated clerk typists. R. M. Garlick served with the 
program as principal typist from its inception until his reassignment in mid-1976 as a computer technician; he also trained the other assigned typists. P. R. Brown is currently the only typist assigned full time. Other typists who worked for varying lengths of time during the six years of manuscript production and computer entry were: L. E. Back, L. M. Bybell, R. Cloyed, L. E. Hatton, M. Monahan, L. G. Oliver, J. Peabody, P. A. Sunkel, and M. F. Ward. 


\title{
Order HYMENOPTERA
}

\author{
By KaRL V. Krombein AND PAUL D. HURd, JR.
}

The Hymenoptera is one of the largest orders of insects with more than 20,000 species in America north of Mexico, most of which are beneficial and many of which are of considerable economic importance to agriculture and forestry either as parasites or predators of pests or as pollinators of more than 100 commercially grown crops. Among the relatively few injurious Hymenoptera are the sawflies, some of which are serious defoliators or stem-borers of trees or crops.

Taxonomy: Fabricius, 1804. Systema Piezatorum, 439 pp., 1 p. of errata, 3 pp. of index. - Panzer, 1806. Kritische Revision der Insektenfauna Deutschlands, v. 2, Hymenoptera, 271 pp. 2 pls. Cited in text as Krit. Rev. Insektenf. Deutschlands. - Andre, 1879-1913, Species des Hymenopteres d'Europe et d'Algerie, vols. 1-11. Cited in text as Spec. Hym. Eur. Alg. -Cameron, 1883-1900. In Godman and Salvin, Biologia Centrali-Americana. Hymenoptera; vol. 1, pp. 1-487, 20 pls., 1883-1900; vol. 2, pp. 413, 13 pls., 1888-1900. Cited in text as Cameron, Biol. Cent.-Amer., Hym. - Cresson, 1887. Amer. Ent. Soc., Trans., Sup. Vol., pp. 1-350 (key to No. Amer. families, genera and catalog of spp.). - Dalla Torre, 1892-1902. Cat. Hym., 10 vols. (world spp.). - Schulz, 1906. Spolia Hymenopterologica, 355 pp., 11 figs., 1 pl. Cited in text as Spolia Hym. - Viereck, et al., 1917 (1916). Conn. State Geol. and Nat. Hist. Survey, Bul. 22: 1-824, 10 pls., 15 text figs. (keys to Conn. spp.). - Boerner, 1919. Biol. Zentbl. 39: 145-186, 6 figs. (phylogeny). - Schroeder, 1925. Handb. d. Ent. 3: 712-825, figs. 593-705. - Tillyard, 1926. The Insects of Australia and New Zealand, pp. 252-307, 53 figs., 2 pls. -Schmiedeknecht, 1930. Die Hymenopteren Nord- und Mitteleuropas, 2nd ed., 1062 pp., 127 figs. Cited in text as Hym. Mitteleuropas. - Brues and Melander, 1932. Mus. Compar. Zool., Bul. 73: 471-526, figs. 887-971 (keys to families, adults, and larvae). - Handlirsch and Meixner, 1933. In Krumbach, Handb. d. Zool., v. 4, Insecta 2, pp. 895-1036. - Comstock, 1940. An Introduction to Entomology, pp. 884-1007. -Essig, 1942. College Entomology, pp. 619-727. - Imms, 1948. A General Textbook of Entomology, ed. 7, pp. 544-615. - Lanham, 1951. Ent. Soc. Amer., Ann. 44: 614-628, 27 figs. (phylogeny based on wing venation). - Muesebeck, Krombein, Townes et al., 1951. U. S. Dept. Agr., Agr. Monog. 2, 1,420 pp., 1 map (catalog of species north of Mexico).

- Michener, 1953. Kans. Univ. Sci. Bul. 35: 993-995 (larvae, key to certain families). - Richards, 1956. Hymenoptera, Introduction and Keys to Families. Handbooks Ident. Brit. Ins., Roy. Ent. Soc., London 6, pt. 1, 94 pp., 197 text figs., 11 pls. -Boucek et al., 1957. In Klic Zvireny CSR (keys to the fauna of Czechoslovakia), ed. by Kratochvil, pp. 35-406, 1108 figs. - Bradley, 1958 (1956). Tenth Internatl. Congr. Ent. Proc. 1: 265-269 (phylogeny). - Krombein et al., 1958. U. S. Dept. Agr., Agr. Monog. 2, Sup. 1, 305 pp. 
(supplement to catalog of species north of Mexico). - Berland, 1958. Atlas des Hymenopteres de France. I, Tenthredes, Parasites, Porte-aiguillon (Bethyloides, pars), 155 pp., 14 pls. II, Porte-aiguillon (Bethyloides (fin), Scolioides, Formicoides, Pompiloides, Vespoides, Sphecoides, Apoides), 184 pp., 14 pls. - Oeser, 1961. Zool. Mus. Berlin, Mitt. 37: 75-85, figs. 106-107 (phylogeny based on ovipositor). - Krombein, Burks et al., 1967. U. S. Dept. Agr., Agr. Monog. 2, Sup. 2, 584 pp. (supplement to catalog of species north of Mexico). - Malyshev, 1968. Genesis of Hymenoptera and phases of their evolution $319 \mathrm{pp}$. (English translation by Richards and Uvarov). - Borror and DeLong, 1970. An Introduction to the Study of Insects, ed. 3, pp. 537-616, figs. 495-577. - Riek et al., 1970. In The Insects of Australia, C. S. I. R. O., pp. 867-959, 40 figs. - Richards, 1972 (1971). Ent. Essays to Commemorate Retirement of Prof. K. Yasumatsu, pp. 1-13, 10 figs. (thoracic spiracles in classification). - Rasnitsyn, 1971. XIII Internatl. Congr. Ent., Proc. 1: 289 (origin). - Koenigsmann, 1976. Deut. Ent. Ztschr. (n.f. 23) 4-5: 253-279, 4 figs. (phylogeny).

Biology: Bishoff, 1927. Biologie de Hymenopteren, 598 pp., 224 figs. -Fulmek, 1957. Naturhist. Mus. Wien, Ann. 61: 110-227 (aphid parasites and predators). - Itwata, 1972 (1971). Evolution of Instinct: comparative Studies of Hymenoptera Behavior, $503 \mathrm{pp}$. (Japanese edition). - Farish, 1972. Anim. Behavior 20: 662-676 (grooming behavior). -Iwata, 1976. Evolution of Instinct: Comparative Ethology of Hymenoptera, 535 pp., frontisp., 50 figs. (English translation, Natl. Tech. Inform. Serv., PB 257052).

Morphology: Snodgrass, 1911. U. S. Natl. Mus., Proc. 39: 37-91, 16 pls., 19 text figs. (thorax). -rohwer and Gahan, 1916. Ent. Soc. Wash., Proc. 18: 20-76, 3 pls. (wing venation). -Comstock, 1918. The Wings of Insects, pp. 362-381, pl. 10, text figs. 380-405.

-Snodgrass, 1935. Principles of Insect Morphology, 667 pp., 319 figs. - Ross, 1936. Ent. Soc. Amer., Ann. 29: 99-111, 2 pls. (wing venation). - Snodgrass, 1941. Smithsn. Inst., Misc. Collect. 99 (14): 1-86, 33 pls., 6 text figs. (male genitalia). - Reid, 1941. Roy. Ent. Soc. London, Trans. 91: 367-446, 81 figs. (thorax of wingless and brachypterous spp.).

-Richards, 1956. Roy Ent. Soc. London, Proc. (A) 31: 99-104, 7 figs. (interpretation of thoracic venter). - Short, 1959. Roy. Ent. Soc., London, Trans. 111: 175-203, 11 figs. (abdominal musculature). - Oeser, 1961. Zool. Mus. Berlin, Mitt. 37: 3-119, 107 figs. (female ovipositor). - Daly, 1963. Ent. Soc. Amer., Ann. 56: 295-306 (thoracic musculature). -Smith, 1970. Ent. Soc. Amer., Ann. 63: 1-27 (evolutionary morphology of external genitalia). -Eady, 1974. Jour. Ent., Ser. B, 43: 63-72 (wing venation). 


\title{
Suborder SYMPHYTA
}

\author{
By DAVID R. SMITH
}

The suborder Symphyta, commonly known as sawflies and horntails, has also been recorded in the early literature under the names Chalastogastra, Sessiliventria, or Phyllophaga and Xylophaga. The suborder includes about 10,000 world species grouped into about 1,000 genera and 12 families. Representatives are found on all continents except for Antarctica, and they are also absent on many of the more isolated islands of the world such as Hawaii and many other Pacific islands. The most northern record is that for Pachynematus parvilabris (Thomson) on Ward Hunt Island in Canada, $83^{\circ} 05^{\prime} \mathrm{N}$., and several species are found as far south as Tierra del Fuego. The North American fauna consists of around 1,000 species in 10 families. The two families that have no living representatives in North America are the Megalodontidae and Blasticotomidae, both of which are Palearctic, though the Blasticotomidae is represented in North America by the fossil species Paremphytus ostentus Brues from the Miocene of Florissant, Colorado. The Blasticotomidae contains only several species, very secretive and rarely found, the larvae of which bore in the stems of ferns. Living forms may yet be discovered on this con tinent. Other than the families discussed here, a number of fossil families have been described, most all $f_{1} \rightarrow m$ the Old World. These are Anaxyelidae, Gigasiricidae, Karatavitidae, Myrmiciidae, Parapamphiliidae, Pararchexyelidae, Paroryssidae, Pseudosiricidae, Sepulcidae, Xyelotomidae, and Xyelydidae.

The common name sawfly, applied to merabers of most families, is derived from their flylike appearance and the sawlike female ovipositor which is used to cut open plant tissue for insertion of eggs. The name horntail is usually applied to members of the family Siricidae, the females of which have a long slender ovipositor. Adults of the suborder may be distinguished from other Hymenoptera by the abdomen which is broadly joined to the thorax, the trochanters which are always two-segmented and the hindwing which usually has three closed basal cells. The larvae of most sawflies are entirely different from other Hymenoptera larvae and are most often confused with those of Lepidoptera, though sawfly larvae lack crochets on the prolegs, have only one pair of ocelli, and normally have more than five pairs of prolegs. Some larvae, especially those modified for an internal existence, resemble the grublike larvae of other Hymenoptera but normally have a projection at the apex of the abdomen and vestiges of thoracic legs.

The higher classification of the Symphyta in most universal use at present is that proposed by Ross (1937) and Benson (1938). The suborder is divided into two major series, the Orthandria and Strophandria basically separated by the male genitalia which remains normal in the former but is turned $180^{\circ}$ prior to eclosion in the latter. The Strophandria is expressed as the superfamily Tenthredinoidea. The Orthandria have been further divided on the basis of characters of the mesosternum and head capsule into three superfamilies, the Megalodontoidea, Siricoidea, and Cephoidea. Some authors have recognized the superfamily Xyeloidea including only the family Xyelidae. This has some merit, as both positions of male genitalia are found, the orthan- 
drous in the Macroxyelinae and strophandrous in the Xyelinae.

All members of this suborder are phytophagous except for the family Orussidae which is parasitic on other wood-boring insects. Host plants and habits are various. Many larvae are external feeders on the foliage of the host, but others are leaf miners, gall formers on twigs, petioles, leaves, or buds, leaf-edge rollers, stem borers, wood borers, or petiole miners. Because of their plant feeding habits, many sawflies are pests of ornamental plants, agricultural crops, or forest stands. Their occurrence is normally local, but outbreaks in forests may be extensive, covering many thousands of acres and resulting in considerable growth loss or death of trees. Appearance in epidemic proportions is commonly sporadic, suddenly appearing for a year or more then practically disappearing for several years, probably being kept under control by their natural parasite-predator-disease complex. Some of the most destructive species are aliens which were accidentally introduced from abroad and found a vacuum for development without natural enemies. Many parasites have been introduced to help combat these pests. Some of the more important sawflies are those that feed on timber species, roses, apples, pears, peaches, and wheat and other grain crops. On the other hand, a few sawflies have been used beneficially, or at least have been attempted for use in the biological control of weeds. One species, Ucona acaenae Smith (=Antholcus varinervis of authors), was introduced into New Zealand from Chile in the early 1930's to help control the spread of Acaena. This attempt was only partially successful. Another species, Priophorts morio (Lepeletier), was released in Hawaii from the western United States to help control the spread of Rubus on the islands, but this attempt failed.

The life cycle of many sawflies follows a similar pattern, though with many variations. Adults of most species fly in spring and early summer and are very short-lived. It is difficult to keep individual adults alive in captivity for much more than a few days although the actual flight of a species may extend over several weeks or months. Some adults may not feed but some may feed on moisture, nectar and pollen of flowers, leaf pubescence, or other insects. The most productive areas for collecting are in vegetation on edges of rivers or streams, marshes, open and scrubby woodland, or undisturbed meadows. The catkins of willows and alders are especially productive for many groups. Oviposition is in the foliage, stems, twigs, or wood, and the eggs are most always inserted in the plant tissue though some Pamphiliidae may glue their eggs to the leaf surface. Larval feeding time varies, but usually lasts about two weeks. Many larvae, especially Diprionidae, feed gregariously at first but later disperse to other parts of the host. After feeding is completed the larva molts into a non-feeding stage called the prepupa or resting stage. The prepupa normally leaves the host in search of a site for pupation. This may be in a cell in the ground or litter, in a papery cocoon in the ground, in some other substance such as wood, stems of the host or nearby plants, or fruits of other plants. The prepupal stage differs morphologically from the feeding stages, especially in the shape of the mandibles and sometimes color pattern. Some larvae with spines loose these in the final molt. If there is a single generation, the prepupa will remain in its cocoon or cell the rest of the summer and pupate the following spring. However, depending on the species, latitude, or diapause requirements, there may be several generations a year, or it may take several years to complete the cycle.

The following references are to general articles on the Symphyta. Some, such as Maxwell, 1955 , in morphology, pertain to many species and the reference is not repeated under each species. Under some species, such as Pristiphora erichsonii (Hartig), a listing of all biological references would take many more pages, and the references are selected or pertain to some recent synopsis which contains a good bibliography. Some of the new distribution records, hosts, and taxonomic changes are taken from unpublished notes. Only those taxonomic changes cited as being new have not before appeared in the literature.

I am indebted to several colleagues for reviewing parts of this section and or providing some of the information contained herein: H. E. Milliron, formerly with the Biosystematies Research Institute, Agriculture Canada, Ottawa and other authorities of the Institute for allowing study of their sawfly collection; H. R. Wong, Northern Forest Research Centre, Canadian Forestry Service Edmonton, Alberta, Canada; and H. Greenbaum, Department of Entomology, University of Arkansas Fayetteville.

Taxonomy: Norton, 1867-1869. Amer. Ent. Soc., Trans. 1: 31-84, 193-280; 2: 211-242, 321-368 (N. Amer. catalog). -Cresson, 1880. Amer. Ent. Soc., Trans. 8: 53-68 (N. Amer. catalog). -Dalla Torre, 1894. Cat. Hym., v. 1, 459 pp. (world catalog). - Ashmead, 1898. Canad. Ent. 30: 141-145, 177-183, 205-213, 225-232, 249-257, 281-287, 305-316 (classification, keys to 
genera). -Konow, 1905. In Wytsman, Gen. Ins., fasc. 27,27 pp.; fasc. 28,14 pp.; fasc. 29 , 176 pp. (world catalog). - Dyar, 1893-1895. Canad. Ent. 25: 244-248; 26: 42-45, 185-189; 27 : 191-196, 208-212 (larvae). - Dyar, 1895 Amer. Ent. Soc., Trans. 22: 301-312 (larvae) -Dyar, 1897. N. Y. Ent. Soc., Jour. 5: 18-30, 190-201 (larvae) -Dyar, 1898. Canad. Ent. 30: 173-176 (larvae) -Dyar, 1898. N. Y. Ent. Soc., Jour. 6: 121-138 (larvae)-Dyar, 1900. N. Y. Ent. Soc., Jour. 8: 26-31 (larvae). - Rohwer, 1911. Ent. Soc. Wash., Proc. 13: 215-224

(classification). - Rohwer, 1911. U. S. Dept. Agr., Bur. Ent., Tech. Ser. 20, pt. 2, pp. 69-109 (genotypes and work of Ashmead). - Rohwer, 1911 Ent. News 22: 218-219 (additions and correction to "genotypes"). -Enslin, 1912-1918. Deut. Ent. Ztschr., Beih. 790 pp.

(Tenthredinoidea of middle Europe). - MacGillivray, 1913. Ent. Soc. Ont., Ann. Rpt. 44: 54-75 (larvae). - MacGillivray, 1916. Conn. State Geol. and Nat. Hist. Survey Bul. 22: 25-175. - Yuasa, 1923. Ill. Biol. Monog. 7(4): 1-168 (N. Amer. larvae). - Ross, 1937. Ill. Biol. Monog. 15(2): 1-173 (generic revision, N. Amer.). - Benson, 1938. Roy. Ent. Soc. London, Trans. 87: 353-384 (world classification). - Benson, 1951. Handb. for Ident. of Brit. Ins., v. 6, pt. 2(a): 1-49; 1952, v. 6, pt. 2(b): 51-137; 1958, v. 6, pt. 2(C): 139-252. - Lorenz and Kraus, 1957. Die Larvalsystematik der Blattwespen, 339 pp. (larvae of European species). -Ross, 1960. Amer. Ent. Soc., Trans. 85: 315-321 (early history of sawfly study in N. Amer.). - Benson, 1962. Brit. Mus. (Nat. Hist.) Ent., Bul. 12: 381-409 (Holarctic sawflies). -Rasnitsyn, 1969. Origin and evolution of the lower Hymenoptera, $187 \mathrm{pp}$. (fossil).

Biology: Rohwer, 1915. Ent. Soc. Wash., Proc. 17: 195-198 (mating habits). -Benson, 1950. Soc. Brit. Ent., Trans. 10: 45-142 (natural history of Brit. sawflies). -Wong, 1954. Canad. Ent. 86: 154-158 (sawflies on white birch in Man., Sask.). - Neilson, 1958. Canad. Ent. 90: 229-234 (life histories of sawflies in low-bush blueberry fields in N. B. ). - Raizenne, 1957. Canada Dept. Agr. Pub. 1009, 45 pp. (forest sawflies of s. Ont. and their parasites).

-Lindquist, 1959. Canad. Ent. 91: 625-627 (leaf mining sawflies on birch). - Lindquist and Miller, 1970. Ent. Soc. Ont., Proc. 100: 117-123 (free-feeding sawflies on birch and alder in Ont.). - Lindquist and Miller, 1971. Ent. Soc. Ont., Proc. 102: 118-122 (larvae feeding on spruce and balsam fir in Ont.).

Morphology: Marlatt, 1891. Ent. Soc. Wash., Proc. 2: 115-117 (final molting of larvae). -Marlatt, 1894. Ent. Soc. Wash., Proc. 3: 78-82 (neuration of wings). - MacGillivray, 1906. U. S. Natl. Mus., Proc. 29: 569-654 (wings). - Van Dine, 1906. Hawaii. Ent. Soc., Proc. 1: 19-22 (comparative anatomical study of mouthparts). -Crampton, 1919. Ent. Soc. Wash., Proc. 21: 129-155 (genitalia and terminal abdominal structure of males and larvae). -Middleton, 1921. Ent. Soc. Wash., Proc. 23: 139-144 (terminal abdominal structures). - Middleton, 1921. Ent. Soc. Wash., Proc. 23: 173-192 (suggested homologies between larvae and adults). - Boulange, 1924. Mem. et Travaux des Facultes Catholiques de Lille 28: 1-444 (genitalia). - Taylor, 1931. Roy. Phys. Soc., Proc. 22: 41-70 (morphology of the tenthredinid head). - Taylor, 1931. Ent. Soc. Amer., Ann. 24: 451-466 ("Dyar's Rule", its application to sawfly larvae). - Malloch, 1936. Inaugural- Dissertation, Erlangung der Doktorwurde, Philosophischen Fakultat der Friedrich- Wilhelms-Universitat zu Berlin, 55 pp. (thorax and cenchri). - Parker, 1934. Bol. Lab. Zool. Gen. e Agr. Portici 28: 159-191 (anatomy of larvae, with special reference to head). - Ross, 1936 Ent. Soc. Amer., Ann. 29: 99-111 (ancestry of wing venation). - Ross, 1945. Ent. News 56: 261-268 (genitalia: terminology and study techniques). - Maxwell, 1955. Canad. Ent. 87 (sup. 1): 1-132 (comparative internal larval anatomy). - Arora, 1956. Panjab Univ., Res. Bul., Zool. 90: 85-119 (relationship of Symphyta to other insect orders based on adult external morphology). - Togashi, 1965. Kontyu 33: 230-234 (rectal papillae). - Togashi, 1970. Mushi 43 (sup.): 1-114 (comparative morphology of internal reproductive organs). - Kenchington, 1972. Jour. Ent. 46: 111-116 (variations in silk gland morphology among larvae). 



\section{Superfamily MEGALODONTOIDEA}

\section{Family XYELIDAE}

A small family of primitive sawflies better represented in North America than in other parts of the northern hemisphere. Most of the family is associated with conifers; only members of the tribe Macroxyelini are associated with deciduous trees.

Revision: Ross, 1932. Ent. Soc. Amer., Ann. 25: 153-169 (Nearctic).

Taxonomy: Klima, 1937. In Hedicke, Hym. Cat. pt. 4, 12 pp. (catalog). - Benson, 1945. Roy.

Ent. Soc. London, Proc., Ser. B: Taxonomy 14: 34-37 (generic classification, world).

-Burdick, 1959. Kans. Ent. Soc., Jour. 32: 120-122 (fossil). - Rasnitsyn, 1964. Paleontol.

Jour. No. 1, pp. 88-96 (fossil). - Rasnitsyn, 1965. Polski Pismo Ent. 35: 483-519 (Xyelinae of world). - Rasnitsyn, 1966. Paleontol. Jour. No. 4, pp. 69-85 (fossil). -Smith, 1967. Ent. Soc. Amer., Ann. 60: 376-384 (larvae).

\section{SUBFAMILY XYELINAE \\ TRIBE XYELINI \\ Genus XYELA Dalman}

Pinicola Brebisson, 1818. Soc. Philomath. de Paris, Bul. des Sci., p. 116. Preocc.

Type-species: Pinicola julii Brebisson. Desig. by Rohwer, 1911.

Xyela Dalman, 1819. Svenska Vetensk. Akad., Handl. 40: 122.

Type-species: Xyela pusilla Dalman. Desig. by Curtis, 1824.

Mastigocera Klug, 1827. In Berthold, Latreille's Nat. Fam. Thierr. p.442.

Tritokreion Schilling, 1825. Schles. Gesell. f. Vaterland. Kult. Ubers., Arb. 2: 43. No

included species.

Neoxyela Curran, 1923. Canad. Ent. 55: 20.

Type-species: Neoxyela alberta Curran. Monotypic.

Xyelatana Benson, 1938. Roy. Ent. Soc. London, Proc., Ser. B: Taxonomy 7: 35.

Type-species: Xyela longula Dalman. Orig. desig.

Larvae of most species of Xyela live and feed in the developing staminate cones of Pinus species. One species, gallicaulis, forms shoot galls. Adults fly early in the spring and are commonly found in large numbers on the catkins of Salix or Alnus near their host plants.

Revision: Rohwer, 1913. U. S. Natl. Mus., Proc. 45: 265-281. - Burdick, 1961. Calif. Univ.,

Pubs., Ent. 17: 285-353 (also biology).

alberta (Curran). Alta., Mont., Wyo., Calif. Host: Pinus contorta.

Neoxyela alberta Curran, 1923. Canad. Ent. 55: 20. , o. 
alpigena (Strobl). Que. and Maine to Md.w. to Utah and N. Mex.; Holaretic. Host: Pinus strobus.

Pinicola alpigena Strobl, 1895. Wien. Ent. Ztg. 14: 277. $९, ~ ð$.

Xyela brunneiceps Rohwer, 1913. U. S. Natl. Mus., Proc. 45: 269. ๆ.

Xyela kamtshatica Gussakovskij, 1935. Faune URSS, Ins. Hym., T. 2, 1: 133..

Xyela middlekauffi Burdick, 1961. Calif. Univ., Pubs., Ent. 17: 343..

Taxonomy: Benson, 1962. Brit. Mus. (Nat. Hist.) Bul. Ent. 12: 385.

bakeri Konow. Que. to Fla. w. to B. C. and Calif. Ecology: Widespread. Host: Pinus elliottii, P. palustris, $P$. ponderosa, $P$. sabiniana, $P$. virginiana.

Xyela bakeri Konow, 1898. Ent. Nachr. 24: 328.

Xyela negundinis Cockerell. 1907. Canad. Ent. 39: 324.

Xyela salicis Rohwer, 1913. U. S. Natl. Mus., Proc. 45: 271. ठ.

Xyela intrabilis MacGillivray, 1923. Brooklyn Ent. Soc., Bul. 18: 53. ठ。.

Biology: Ebel, 1966. Ent. Soc. Amer., Ann. 59: 127-129.

californica Rohwer. Calif.

Xyela californica Rohwer, 1913. U. S. Natl. Mus., Proc. 45: 272. ठ'.

cheloma Burdick. Idaho, Nev., B. C., Wash., Oreg. Host: Pinus ponderosa.

Xyela cheloma Burdick, 1961. Calif. Univ., Pubs., Ent. 17: 336. \&, ठ.

concava Burdick. Utah, Nev., Calif. Host: Pinus monophylla, P. ponderosa.

Xyela concava Burdick, 1961. Calif. Univ., Pubs., Ent. 17: 342. ‡, §.

deserti Burdick. Nev., Calif. Host: Pinus monophylla.

Xyela deserti Burdick, 1961. Calif. Univ., Pubs., Ent. 17: 347. १, ठ.

dodgei Greenbaum. Fla. (Cedar Key).

Xyela dodgei Greenbaum, 1973. Fla. Ent. 57: 104-106. ¿.

gallicaulis Smith. Va., Ga. Ecology: Larva feeds inside and forms galls on shoots. Host: Pinus echinata, P. elliottii, P. taeda.

Xyela gallicaulis Smith, 1970. Ga. Ent. Soc., Jour. 5: 69-72. ๆ, ठ. larva.

linsleyi Burdick. Idaho, B. C., Wash., Calif. Host: Pinus ponderosa(?).

$X$ yela linsleyi Burdick, 1961. Calif. Univ., Pubs., Ent. 17: 344. $q$, o.

lunata Burdick. Calif. Host: Pinus coulteri, P. sabiniana.

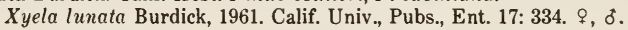

minor Norton. Que. to Fla. w. to B. C. and Calif. Ecology: Widespread. Host: Pinus coulteri, $P$. elliottii, $P$. muricata, $P$. palustris, $P$. ponderosa, $P$. sabiniana, $P$. taeda, $P$. virginiana.

Xyela minor Norton, 1868. Amer. Ent. Soc., Trans. 2: 349. $\$$.

Xyela luteopicta Cockerell, 1902. Canad. Ent. 34: 194. ठ.

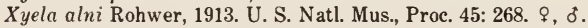

Xyela winnemanae Rohwer, 1913. U. S. Natl. Mus., Proc. 45: 268. ๆ.

Xyela errans Rohwer, 1913. U. S. Natl. Mus., Proc. 45: 269.

Xyela dissimilis Rohwer, 1913. U. S. Natl. Mus., Proc. 45: 270. 9.

Xyela nevadensis Rohwer, 1913. U. S. Natl. Mus., Proc. 45: 271. .

Xyela coloradensis Rohwer, 1913. U. S. Natl. Mus., Proc. 45: 272. ठ. N. syn.

Biology: Ebel, 1966. Ent. Soc. Amer., Ann. 59: 127-129.

Morphology: Daly, 1963. Ent. Soc. Amer., Ann. 56: 299.

obscura (Strobl). Newfoundland to Fla. w. to N. W. T., B. C. and Calif.; Holarctic. Ecology:

Widespread. Host: Pinus banksiana, $P$. palustris, $P$. ponderosa, $P$. virginiana.

Pinicola julii var. obscura Strobl, 1895. Wien. Ent. Ztg. 14: 277. ?.

Xyela japonica Rohwer, 1910. U. S. Natl. Mus., Proc. 39: 99. ․

Xyela pini Rohwer, 1913. U. S. Natl. Mus., Proc. 45: 267. ๆ, ठ.

Xyela slossonae Rohwer, 1913. U. S. Natl. Mus., Proc. 45: 270. ๆ, ठ.

Xyela similis Rohwer, 1913. U. S. Natl. Mus., Proc. 45: 271. ठ.

Taxonomy: Benson, 1962. Brit. Mus. (Nat. Hist.) Bul. Ent. 12: 385.

Biology: Ebel, 1966. Ent. Soc. Amer., Ann. 59: 127-129. 
priceae Burdick. Calif. Host: Pinus coulteri.

Xyela priceae Burdick, 1961. Calif. Univ., Pubs., Ent. 17: 339. ९, ठ.

radiatae Burdick. Calif. Host: Pinus radiata(!)

Xyela radiatae Burdick, 1961. Calif. Univ., Pubs., Ent. 17: 337. ९, ठ.

serrata Burdick. Calif. Host: Pinus muricata.

Xyela serrata Burdick, 1961. Calif. Univ., Pubs., Ent. 17: 341. \&.

styrax Burdick. D. C., Ga., Md., N. Y., Va. Host: Pinus virginiana.

Xyela styrax Burdick, 1961. Calif. Univ., Pubs., Ent. 17: 345 , ठో.

\section{TRIBE PLERONEURINI}

\section{Genus PLERONEURA Konow}

Pleroneura Konow, 1897. Ent. Nachr. 23: 56.

Type-species: Xyela dahli Hartig. Desig. by Rohwer, 1911.

Pleuroneura Ashmead, 1898. Psyche 8: 214. Emend.

Manoxyela Ashmead, 1898. Psyche 8: 214.

Type-species: Manoxyela californica Ashmead. Orig. desig.

Larvae of this genus live in the developing shoots and buds of Abies.

Revision: Rohwer, 1910. Canad. Ent. 42: 88-93. -Ross, 1932. Ent. Soc. Amer., Ann. 25: 156-159.

Taxonomy: Smith, 1967. Ent. Soc. Amer., Ann. 60: 382-383 (larvae), - Smith, 1967. Ent. Soc. Wash., Proc. 69: 182-183 (species synonymy).

aldrichi Ross. Idaho, Oreg., Nev., Calif. Host: Abies.

Pleroneura aldrichi Ross, 1932. Ent. Soc. Amer., Ann. 25: 158-159. \&, ठ.

brunneicornis Rohwer. N. S., N. B., Maine, Que., Ont., N. Y., Minn. Host: Abies balsamea, A. concolor.

Pleroneura bruneicomis(!) Rohwer, 1910. Canad. Ent. 42: 89..

Pleroneura brunneicornis Rohwer, 1910. Canad. Ent. 42: 220.

Pleroneura borealis Felt, 1917. Canad. Ent. 49: 220. ‡, ð.

Biology: Webb and Forbes, 1951. Canad. Ent. 83: 181-183.

californica (Ashmead). Wyo., Alta., Utah, B. C., Oreg., Calif. Host: Abies spp.

Manoxyela californica Ashmead, 1898. Psyche 8: 214. ठ.

Pleroneura fulvicornis Rohwer, 1910. Canad. Ent. 42: 89. ठో.

Pleroneura schwarzi Rohwer, 1910. Canad. Ent. 42: 220. ․

koebelei Rohwer. Idaho, Oreg., Calif. Host: Abies spp.

Pleroneura koebelei Rohwer, 1910. Canad. Ent. 42: 90. ठో.

lutea Rohwer. Idaho, Oreg., Nev., Calif.

Pleroneura lutea Rohwer, 1910. Canad. Ent. 42: 90. ठ̋.

\section{SUBFAMILY MACROXYELINAE}

TRIBE XYELECIINI

\section{Genus XYELECIA Ross}

Xyelecia Ross, 1932. Ent. Soc. Amer., Ann. 25: 159.

Type-species: Xyelecia nearctica Ross. Orig. desig.

nearctica Ross. "Mont. and Colo.", Idaho, Oreg., Calif. Ecology: Larvae live in shoots. Host: Abies spp.

Xyelecia nearctica Ross, 1932. Ent. Soc. Amer., Ann. 25: 160..

Taxonomy: Smith, 1964. Pan-Pacific Ent. 40: 54-56 (male). - Smith, 1967. Ent. Soc. Amer., Ann. 60: 381-382 (larva). 


\section{TRIBE MACROXYELINI}

\section{Genus MACROXYELA Kirby}

Macroxyela Kirby, 1882. List Hym. Brit. Mus. v. 1, p. 351.

Type-species: Xyela ferruginea Say. Orig. desig.

Protoxyela MacGillivray, 1912. Canad. Ent. 44: 295.

Type-species: Xyela aenia(!) Norton. Orig. desig.

Larvae of this genus feed on the leaves of deciduous trees.

Revision: Ross, 1932. Ent. Soc. Amer., Ann. 25: 164-166.

aenea (Norton). La., Mo., Tex.

Xyela aenea Norton, 1872. Amer. Ent. Soc., Trans. 4: 86. రో.

bicolor MacGillivray. Ohio, Ill.

Macroxyela bicolor MacGillivray, 1912. Canad. Ent. 44: 294. ठో.

Macroxyela bicolor var. harti Ross, 1932. Ent. Soc. Amer., Ann. 25: 166. o.

ferruginea (Say). Ont. and Mass. s. to Va. w. to Nebr., Kans. and Okla.; one record from Moscow, Idaho. Host: Ulmus.

Xyela ferruginea Say, 1824. In Keating, Narr. Long's 2nd Exped. v.2, (App.), p. 310..

Xyela infuscata Norton, 1861. Boston Soc. Nat. Hist., Proc. 8: 224. ठ̋.

Macroxyela obsoleta MacGillivray, 1912. Canad. Ent. 44: 294. .

Macroxyela distincta MacGillivray, 1912. Canad. Ent. 44: 295. ․

Taxonomy: Smith, 1967. Ent. Soc. Amer., Ann. 60: 379-380 (larva).

Biology: Garlick, 1923. Canad. Ent. 55: 256-257.

\section{Genus MEGAXYELA Ashmead}

Megaxyela Ashmead, 1898. Psyche 8: 214.

Type-species: Xyela major Cresson. Orig. desig.

Odontophyes Konow, 1899. Wien. Ent. Ztg. 18: 42.

Type-species: Pleroneura aviingrata Dyar. Monotypic.

Paraxyela MacGillivray, 1912. Canad. Ent. 44: 294.

Type-species: Xyela tricolor Norton. Orig. desig.

Larvae of this genus feed on the leaves of deciduous trees.

Revision: Ross, 1932. Ent. Soc. Amer., Ann. 25: 161-164.

bicoloripes (Rohwer). Pa., Va., Miss.

Odontophyes bicoloripes Rohwer, 1924. Ent. Soc. Wash., Proc. 26: 215. ๆ.

major (Cresson). N. Y. to Fla. w. to Kans., Okla., Tex. Host: Carya illinoiensis.

Xyela major Cresson, 1880. Amer. Ent. Soc., Trans. 8: 34. ๆ, ठै.

Odontophyes ferruginea Bridwell, 1906. Ent. News 17: 94 . $९$.

Megaxyela langstoni Ross, 1936. Ent. News 47: 131. + , ठ. N. syn.

Taxonomy: Smith, 1967. Ent. Soc. Amer., Ann. 60: 380-381 (larva).

tricolor (Norton). N. Y., Ill., Kans. Host: Carya, Juglans cinerea.

Xyela tricolor Norton, 1862. Ent. Soc. Phila., Proc. 1: 114. o".

Pleroneura aviingrata Dyar, 1898. Psyche 8: 213. $\uparrow$, larva. N. syn.

Taxonomy: Smith, 1967. Ent. Soc. Amer., Ann. 60: 381 (larva).

\section{Family PAMPHILIIDAE}

Commonly called webspinning sawflies, the larvae live solitarily or socially in a web or in a rolled leaf held by silk. The subfamily Cephalciinae is associated with conifers, and the subfamily Pamphiliinae is associated with deciduous trees or shrubs. Adults of most species are large, dorsoventrally flattened insects, and are sometimes common around the flowers of their host plants in the spring.

Taxonomy: Klima, 1937. In Hedicke, Hym. Cat., pt. 3, 84 pp. (catalog). - Benson, 1945. Roy.

Ent. Soc. London, Proc. Ser. B: Taxonomy 14: 25-33 (generic classification, world). 


\section{Subfamily CEPHALCIINAE}

Members of this subfamily are associated with conifers. There are two tribes and one, the Cephalciini, occurs in North America; the other, Caenolydini, is Palaearctic.

\section{TRIBE CEPHALCIINI}

\section{Genus CEPHALCIA Panzer}

Cephalcia Jurine, 1801. Intell. Blatt Litt.-Ztg. Erlangen 1: 163. Suppressed, Internatl. Comm. Zool. Nomencl. Op. 135, 1939.

Cephalcia Panzer, 1805. Faunae Ins. German. heft 86, pls. $8,9$.

Type-species: Cephalcia arvensis Panzer. Desig. by Rohwer, 1911.

Cephaleia Jurine, 1807. Nouv. Meth. Class. Hym. Dipt. 67, t. 2, f. 7.

Liolyda Ashmead, 1898. Canad. Ent. 30: 209.

Type-species: Lyda frontalis Westwood. Orig. desig.

Revision: Middlekauff, 1958. Calif. Univ., Pubs., Ent. 14: 132-149. -Eidt, 1969. Canad. Ent. Soc., Mem. No. 59, 56 pp. (taxonomy, morphology, larval descriptions, life histories for most of North American species).

californica Middlekauff. Alta., Mont., Wyo., B. C., Calif. Host: Pinus contorta, P. ponderosa. Cephalcia californica Middlekauff, 1958. Calif. Univ., Pubs., Ent. 14: 135. 9.

distincta (MacGillivray). Newfoundland to N. Y., w. to Ont. and Mich. Host: Abies balsamea, Tsuga canadensis.

Cephaleia distincta MacGillivray, 1912. Canad. Ent. 44: 296. ठో.

Cephalcia rossi Middlekauff, 1958. Calif. Univ., Pubs., Ent. 14: 147. ๆ.

fascipennis (Cresson). Que., N. S., Maine, N. H. w. to B. C. Host: Picea engelmanni, P. glauca, $P$. mariana, $P$. pungens, $P$. mubens.

Lyda fascipennis Cresson, 1880. Amer. Ent. Soc., Trans. 8: 31..

Pamphilius fasciipennis Dalla Torre, 1894. Cat. Hym., v. 1, p. 427. Emend.

Cephaleia criddlei MacGillivray, 1912. Canad. Ent. 44: 296. $९$.

Cephaleia dissipator MacGillivray, 1923. III. Univ., Bul. 20(50): 8. §.

Biology: Eidt, 1965. Canad. Ent. 97: 148-153.

frontalis (Westwood). Ont. and Mich. s. to Ga. Host: Pinus resinosa, probably other pines.

Lyda frontalis Westwood, 1874. Thesaurus Ent. Oxon., p. 110, pl. 20, fig. 7. ठ์.

Caenolyda onekama MacGillivray, 1923. Ill. Univ., Bul. 20(50): 8..

fulviceps (Rohwer). Que., N. B., N. H., Conn., N. J., Ont., Ark. Host: Pinus resinosa, P. banksiana.

Cephaleia fulviceps Rohwer, 1910. Canad. Ent. 42: 90. ㅇ.

hopkinsi (Rohwer). Ariz. Host: Pinus ponderosa(?). An adult collection record.

Cephaleia hopkinsi Rohwer, 1910. Canad. Ent. 42: 217. ठ์.

marginata Middlekauff. N. S. and Que. s. to Va., W. Va. Host: Pinus resinosa, P. strobus.

Cephalcia marginata Middlekauff, 1953. Pan-Pacific Ent. 29: 133. ๆ, ठ́.

Biology: Daviault, 1956. Canad. Ent. 88: 488-492.

Morphology: Rivard, 1955. Canad. Ent. 87: 382-399.

nigra Middlekauff. N. S., N. B., Maine, Mich. Host: Picea glauca.

Cephalcia nigra Middlekauff, 1958. Calif. Univ., Pubs., Ent. 14: 143..

provancheri (Huard). Newfoundland s. to N. C., w. to Yukon, Alaska and s. in w. mountains to Colo., Utah, Nev., and Calif. Ecology: Widespread. Host: Picea engelmanni, P. glauca, $P$. mariana, $P$. mubens, $P$. sitchensis.

Lyda provancheri Huard, 1879. Nat. Canad. 11: 148. 6 .

Lyda nigropectus Cresson, 1880. Amer. Ent. Soc., Trans. 8: 32..

Pamphilius mathematicus Kirby, 1882. List Hym. Brit. Mus., v. 1, p. 348. o.

Cephaleia punctata Rohwer, 1908. Canad. Ent. 40: 177. 9.

semidea (Cresson). Que., N. B., Maine, N. H., Conn., N. Y., Ont., Mich. Host: Picea glauca, P. mariana.

Lyda semidea Cresson, 1880. Amer. Ent. Soc., Trans. 8: 31. ㅇ. 
Caenolyda nortoni Rohwer, 1910. Canad. Ent. 42: 91. 9.

Cephaleia jenseni MacGillivray, 1912. Canad. Ent. 44: 297. ?.

\section{Genus ACANTHOLYDA Costa}

Revision: Middlekauff, 1958. Calif. Univ., Pubs., Ent. 14: 1-132.

\section{Genus ACANTHOLYDA Subgenus ACANTHOLYDA Costa}

Acanthocnema Costa, 1859. In Costa, Fauna Regno. Napoli, Imen. v. 3, p. 2. No included species. Suppressed, Internatl. Comm. Zool. Nomencl. Op. 290, 1954.

Type-species: Tenthredo erythrocephala Linnaeus. Desig. by Benson, 1945.

Acantholyda Costa, 1894. Prosp. Imen. Ital., v. 3, p. 232.

Type-species: Tenthredo erythrocephala Linnaeus. Desig. by Rohwer, 1910.

apicalis (Westwood). N. C., Ga., Fla., Miss. Host: Pinus taeda.

Lyda apicalis Westwood, 1874. Thesaurus Ent. Oxon. p. 11, pl. 20, fig. 8. ठ.

atripes (Cresson). N. J., Pa., Md., N. C., Ga., Ark.

Lyda atripes Cresson, 1880. Amer. Ent. Soc., Trans. 8: 27..

erythrocephala (Linnaeus). Conn., N. Y., N. J., Pa., Ont.; Europe to Japan and Korea. Introd., first found in Pa. in 1925. Host: Pinus austriaca, P. densiflora, P. montana, P. mughus, $P$. nigra, $P$. pungens, $P$. resinosa, $P$. strobus, $P$. sylvestris. Pine false webworm.

Tenthredo erythrocephala Linnaeus, 1758. Syst. Nat. Ed. 10, v. 1, p. 558.

Biology: Griswold, 1939. Jour. Econ. Ent. 32: 467-468. —Eidt and McPhee, 1963. Canad. Dept.

For., For. Ent. Path. Branch, Bimonthly Prog. Rpt. 19: 2.

marginiventris (Cresson). Mass., N. Y., N. J., Va., N. C.

Lyda marginiventris Cresson, 1880. Amer. Ent. Soc., Trans. 8: 29..

pini Rohwer. Que., Ont., and Mich. s. to Ga. Host: Pinus resinosa(?). An adult collection record.

Acantholyda pini Rohwer, 1911. U. S. Natl. Mus., Proc. 41: 377..

Acantholyda modesta MacGillivray, 1923. Brooklyn Ent. Soc., Bul. 18: 53..

poeppigii (Brischke and Zaddach). Pa., N. C., Ga.

Lyda Poppigii Brischke and Zaddach, 1865. Phys. Okonom. Gesell. Konigsberg., Schr. 6: 123. ‥

runcinata Middlekauff. Tex., Colo., N. Mex., Ariz.

Acantholyda (Acantholyda) runcinata Middlekauff, 1958. Calif. Univ., Pubs., Ent. 14: 89. ๆ, ठै.

tesselata (Klug). Que. and Mass. s. to Ga. and w. to Minn. Host: Pinus banksiana, P. resinosa.

Lyda tesselata Klug, 1808. Mag. Gesell. Naturf. Freunde Berlin 2: 276. $९$.

Lyda abdominalis Norton, 1862. Ent. Soc. Phila., Proc. 1: 199. ?.

\section{Genus ACANTHOLYDA Subgenus ITYCORSIA Konow}

Itycorsia Konow, 1897. K. K. Naturhist. Hofmus., Ann. 12: 13.

Type-species: Tenthredo hieroglyphica Christ. Desig. by Rohwer, 1910.

aequorea Middlekauff. Calif.

Acantholyda (Itycorsia) aequorea Middlekauff, 1958. Calif. Univ., Pubs., Ent. 14: 93. $\uparrow, ~ \delta$.

albomarginata (Cresson). Mich. w. to Colo., Alaska and Calif. Host: Pinus monophylla, P. muricata, $P$. ponderosa.

Lyda albomarginata Cresson, 1880. Amer. Ent. Soc., Trans. 8: 30. ๆ.

Itycorsia Kincaidi Rohwer, 1910. Canad. Ent. 42: 91..

angulata (MacGillivray). N. B. and Que. s. to N. C. and w. to Minn. Host: Pinus austriaca, P. banksiana, $P$. densiflora, $P$. rigida, $P$. strobus.

Itycorsia angulata MacGillivray, 1912. Canad. Ent. 44: 295. ?.

atrata (Cresson). Idaho, Nev., B. C., Wash., Oreg., Calif. Host: Tsuga heterophylla, Abies concolor(?).

Lyda atrata Cresson, 1880. Amer. Ent. Soc., Trans. 8: 30. đ.

Itycorsia balata MacGillivray, 1923. Ill. Univ., Bul. 20(50): 18. ₹. 
aurigera Middlekauff. Calif.

Acantholyda (Itycorsia) aurigera Middlekauff, 1958. Calif. Univ., Pubs., Ent. 14: 100. $\$$.

balanata (MacGillivray). Alaska, B.C., Oreg., Calif. Host: Pseudotsuga menziesii, Picea sitchensis, Picea sp., Abies sp., Tsuga sp.

Itycorsia balanata MacGillivray, 1923. Ill. Univ., Bul. 20(50): 18..

bicolorata (Norton). Maine, N. Y., Md., Ark.

Lyda bicolorata Norton, 1869. Amer. Ent. Soc., Trans. 2: 332. ๆ.

brunnicans (Norton). Mont., Wyo., and Colo. w. to B. C. and Calif. Host: Pinus contorta, P. ponderosa, $P$. radiata, $P$. sabiniana.

Lyda brunnicans Norton, 1864. Ent. Soc. Phila., Proc. 3: 15. ㅇ.

Lyda discolor Cresson, 1880. Amer. Ent. Soc., Trans. 8: 26..

Lyda morrisoni Cresson, 1880. Amer. Ent. Soc., Trans. 8: 27..

Lyda nevadensis Cresson, 1880. Amer. Ent. Soc., Trans. 8: 28. ठ.

Pamphilius brunneicans Dalla Torre, 1894. Cat. Hym., v. 1, p. 423. Emend.

brunniceps (Cresson). N. B., Que., Mass., N. Y., Ont., Minn.

Lyda brunniceps Cresson, 1880. Amer. Ent. Soc., Trans. 8: 29. $\$$.

Pamphilius brunneiceps Dalla Torre, 1894. Cat. Hym., v. 1, p. 423. Emend.

bucephala (Cresson). Mont., B. C., Wash., Oreg., Calif. Host: Pseudotsuga menziesii, Abies concolor(?).

Lyda bucephala Cresson, 1880. Amer. Ent. Soc., Trans. 8: 29. §.

Lyda olympia MacGillivray, 1893. Canad. Ent. 25: 243. ơ.

burkei Middlekauff. Calif. Host: Pinus radiata.

Acantholyda (Itycorsia) burkei Middlekauff, 1958. Calif. Univ., Pubs., Ent. 14: 108. ๆ, ठ.

chicoutimiensis (Huard). Ont., Que. Host: Picea mariana; Pinus banksiana(?).

Lyda chicoutimiensis Huard, 1879. Nat. Canad. 11: 149..

Taxonomy: Comeau, 1957. Nat. Canad. 84: 29 (nomenclature).

circumcincta (Klug). N. B., Que., Pa., Ga., Fla. Host: Pinus banksiana, P. clausa.

Lyda circumcincta Klug, 1808. Mag. Gesell. Naturf. Freunde Berlin 2: 279. ९.

crocina Middlekauff. Idaho, Calif. Host: Pinus muricata, $P$. sabiniana.

Acantholyda (Itycorsia) crocina Middlekauff, 1958. Calif. Univ., Pubs., Ent. 14: 113. ๆ, ठ.

depressa Middlekauff. Ariz.

Acantholyda (Itycorsia) depressa Middlekauff, 1958. Calif. Univ., Pubs., Ent. 14: 115. ठ.

floridana Greenbaum. North. Fla. Host: Pinus elliottii var. elliottii, P. clausa(?).

Acantholyda (Itycorsia) floridana Greenbaum, 1975. Fla. Ent. 58: 47-51., , larva.

luteomaculata (Cresson). N. B. to Conn. w. to Ohio and Minn. Host: Pinus banksiana, P. strobus, $P$. sylvestris.

Lyda luteomaculata Cresson, 1880. Amer. Ent. Soc., Trans. 8: 28..

maculiventris (Norton). Labrador s. to N. C., w. to Wyo., B. C. and Calif. Ecology:

Widespread. Host: Abies balsamea, Picea glauca, P. mariana(?), Pinus strobus(?).

Lyda maculiventris Norton, 1869. Amer. Ent. Soc., Trans. 2: 333. ठ.

Itycorsia nivea Rohwer, 1910. Canad. Ent. 42: 92..

Acantholyda ferruginea Felt, 1917. Canad. Ent. 49: 192. ठ.

nigripes (Cresson). Nev., Oreg., Calif.

Lyda nigripes Cresson, 1880. Amer. Ent. Soc., Trans. 8: 28. ठ.

nigrita (Cresson). Nev., Calif.

Lyda nigrita Cresson, 1880. Amer. Ent. Soc., Trans. 8: 30. ठ.

ochrocera (Norton). Que. to Pa. w. to Wis.

Lyda ochrocera Norton, 1869. Amer. Ent. Soc., Trans. 2: 332. ๆ, ठ.

ruficeps (Harrington). Que. s. to N. C. and w. to Minn.; B. C. Host: Pinus banksiana, P. contorta, $P$. resinosa.

Pamphilius meficeps Harrington, 1893. Canad. Ent. 25: 62..

terminalis (Cresson). Colo., Nev., Wash., Oreg., Calif.

Lyda terminalis Cresson, 1880. Amer. Ent. Soc., Trans. 8: 29..

Itycorsia ballista MacGillivray, 1923. Ill. Univ., Bul. 20(50): 19. ๆ. 
thalictra Middlekauff. Tex., N. Mex. Host: Pinus edulis(?).

Acantholyda (Itycorsia) thalictra Middlekauff, 1958. Calif. Univ., Pubs., Ent. 14: 126. $\$$. verticalis (Cresson). Minn., Nebr., and Colo. w. to B. C. and Calif. Host: Pinus contorta, P. monticola, $P$. ponderosa, $P$. radiata.

Lyda verticalis Cresson, 1880. Amer. Ent. Soc., Trans. 8: 26..

Lyda similaris Cresson, 1880. Amer. Ent. Soc., Trans. 8: 27..

Lyda montivaga Cresson, 1880. Amer. Ent. Soc., Trans. 8: 28. $\delta$.

Lyda mifiventris Cresson, 1880. Amer. Ent. Soc., Trans. 8: 29. ठ.

Itycorsia luteopicta Rohwer, 1910. Canad. Ent. 42: 92. ?.

zappei (Rohwer). Que. to N. J. w. to Mich. Host: Pinus austriaca, P. rigida, P. strobus.

Itycorsia zappei Rohwer, 1920. U. S. Natl. Mus., Proc. 57: 209. १, ठ.

\section{SUBFAMILY PAMPHILIINAE}

Members of this subfamily are associated with deciduous trees and shrubs. The Nearctic species of Neurotomini are confined to plants of the family Rosaceae. There are two tribes, and both tribes are Holarctic.

\section{TRIBE NEUROTOMINI}

\section{Genus NEUROTOMA Konow}

Neurotoma Konow, 1897. K. K. Naturhist. Hofmus., Ann. 12: 18.

Type-species: Tenthredo flaviventris Retzius. Desig. by Rohwer, 1910.

Neurotoma subg. Gongylocorsia Konow, 1897. K. K. Naturhist. Hofmus., Ann. 12: 19.

Type-species: Lyda mandibularis Zaddach. Monotypic.

Gongylocorisa(!) Ashmead, 1898. Canad. Ent. 30: 208.

Revision: Middlekauff, 1940. Canad. Ent. 72: 201-206 (adults and larvae). - Middlekauff, 1958. Calif. Univ., Pubs., Ent. 14: 149-158.

crataegi Middlekauff. Mass., N. Y., Mich., Ill., Wis., Man. Host: Crataegus succulenta, C. brainerdi.

Neurotoma crataegi Middlekauff, 1940. Canad. Ent. 72: 202..

fasciata (Norton). Que. to Fla. w. to Wis. and Mo. Host: Prenus serotina, P. pennsylvanica.

Lyda fasciata Norton, 1862. Ent. Soc. Phila., Proc. 1: 200..

Biology: Pearsall, 1902. Canad. Ent. 34: 214-216.

inconspicua (Norton). Que. and Mass. to Pa. w. to S. Dak., Mont. and B. C., Ark. and Kans. Host: Prunus americana, $P$. cerasus, $P$. besseyi, $P$. davidiana, $P$. domestica, $P$. nana, $P$. nigra, $P$. pennsylvanica, $P$. virginiana, and probably other speeies of Prunus. Plum webspinning sawfly.

Lyda inconspicua Norton, 1869. Amer. Ent. Soc., Trans. 2: 350..

Lyda spoliana Williams, 1896. S. Dak. Agr. Expt. Sta., Bul. 48: 14-17. ๆ, ठ.

Lyda rufipes Marlatt, 1896. In Williams, S. Dak. Agr. Expt. Sta., Bul. 48: 17. ๆ, ठ.

Biology: Severin, 1920. S. Dak. State Ent. Tech. Bul. 1, 53 pp. - Severin, 1920. S. Dak. Agr.

Expt. Sta., Bul. 190: 224-251.

willi Middlekauff. N. Y., Pa. Host: Crataegus sp.(?). An adult collection record.

Neurotoma willi Middlekauff, 1958. Calif. Univ., Pubs., Ent. 14: 158. ठ。.

Taxonomy: Middlekauff, 1965. N. Y. Ent. Soc., Jour. 73: 238 (female, distribution, host).

\section{TRIBE PAMPHILIINI}

\section{Genus PAMPHILIUS Latreille}

Pamphilius Latreille, 1802. Hist. Nat. Crust. Ins., v. 8, p. 303.

Type-species: Tenthredo sylvatica Linnaeus. Monotypic.

Lyda Fabricius, 1804. Systema Piezatorum, p. 43.

Type-species: Tenthredo sylvatica Linnaeus. Desig. by Curtis, 1831.

Anoplolyda Costa, 1894. Prosp. Imen. Ital., v. 3, p. 233.

Type-species: Lyda alternans Costa. Desig. by Rohwer, 1910. 
Kelidoptera Konow, 1897. K. K. Naturhist. Hofmus., Ann. 12: 20.

Type-species: Lyda maculipennis Stein. Monotypic.

Bactroceros Konow, 1897. K. K. Naturhist. Hofmus., Ann. 12: 21.

Type-species: Tenthredo vafer Linnaeus. Desig. by Rohwer, 1910.

Pseudocephaleia Zirngiebl, 1937. Embrik Strand 60. Geburtst. Festschr. (Riga) 3: 339.

Type-species: Pseudocephalcia brachycerus Zirngiebl. Monotypic.

Pamphilius subg. Onycholyda Takeuchi, 1938. Tenthredo 2: 218.

Type-species: Pamphilius sulphureipes Kirby. Orig. desig.

Since this section was completed, Benes (1972) defined the genera of the Pamphiliini. He recognized four genera: Pseudocephaleia Zirngiebl, Kelidoptera Konow, Pamphilius Latreille, and Onycholyda Takeuchi. The latter two genera are found in North America, and, of the species listed below in Pamphilius, the following would belong in Onycholyda: amplectus, excavatus, luteicornis, multisignatus, nigritibialis, quebecensis, mifofasciatus, and sitkensis.

These species that belong in Onycholyda are the ones that are found ir. couplets 2 to 9 and 24 to 31 in Middlekauff's (1964) key.

Revision: Middlekauff, 1964. Calif. Univ., Pubs., Ent. 38: 1-80.

Taxonomy: Benes, 1972. Acta Ent. Bohem. 69: 378-395 (generic classification of the

Pamphiliini). - Benes, et al., 1973. Bul. Zool. Nomencl. 30: 95-96 (request for designation

of Pamphilius viriditibialis Takeuchi as type-species of Onycholyda Takeuchi).

amplectus (Fabricius). Maine to Fla. w. to Ill. and Tex. Host: Rubus.

Lyda amplecta Fabricius, 1804. Systema Piezatorum, p. 46.

Lyda plagiata Klug, 1808. Mag. Gesell. Naturf. Freunde Berlin, 2: 278. ๆ.

Lyda insignis Brischke and Zaddach, 1865. Phys. Okonom. Gesell. Konigsberg., Schr. 6: 179. $\delta$.

burquei (Provancher). Que., Ont., Va.

Lyda burquei Provancher, 1878. Nat. Canad. 10: 204..

cinctus Harrington. Que., N. Y., Ont., Mich., Wis.

Pamphilius cinctus Harrington, 1893. Canad. Ent. 25: 62..

excavatus (Norton). Que. to Va. w. to Minn.; B. C. Host: Cornus stolonifera.

Lyda excavata Norton, 1869. Amer. Ent. Soc., Trans. 2: 337. ठ.

greenei Rohwer. Conn., Pa., Mich.

Pamphilius greenei Rohwer, 1913. U. S. Natl. Mus., Proc. 45: 273..

infuscatus Middlekauff. Maine, Que., Ont., Alta., B. C. Host: Populus tremuloides.

Pamphilius infuscatus Middlekauff, 1964. Calif. Univ., Pubs., Ent. 38: 24. ₹, ठ.

luteicornis (Norton). N. S. and N. B. s. to Fla. w. to Ill., Minn. and Alta. Host: Rubus.

Lyda luteicomis Norton, 1869. Amer. Ent. Soc., Trans. 2: 339. \&.

Lyda harringtoni Provancher, 1886. Addit. Corr. Faune Ent. Canada Hym. p. 17..

Pamphilius ocellatus Rohwer, 1910. Canad. Ent. 42: 218. ․

Pamphilius rubi Rohwer, 1910. Canad. Ent. 42: 219. 9.

Pamphilius dentatus MacGillivray, 1912. Canad. Ent. 44: 297. ๆ, ठ์.

Pamphilius fletcheri MacGillivray, 1912. Canad. Ent. 44: 298. ๆ, ơ.

Biology: Fletcher, 1900. Rpt. Ent. Bot. Dom. Expt. Farm Ottawa, Sess. Paper 8a: 180-181 (multisignata, nec Norton). - Walden, 1913. Conn. (State) Agr. Expt. Sta., Ann. Rpt., 36: 236-240 (dentatus). - Britton, 1913. Jour.Econ. Ent. 6: 197-199 (dentatus).

multisignatus (Norton), Ont., Mich., Ill. w. to Colo., N. Mex., and B. C.

Lyda multisignata Norton, 1864. Ent. Soc. Phila., Proc. 3: 15. §.

Lyda cavifrons Cresson, 1865. Ent. Soc. Phila., Proc. 4: 246. ठ。.

Lyda multicincta(!) Norton, 1869. Amer. Ent. Soc., Trans. 2: 332.

Bactroceros pugnax Rohwer, 1908. N. Y. Ent. Soc., Jour. 16: 103. \&. Preoce.

Anoplolyda saeva Rohwer, 1910. Canad. Ent. 42: 218. N. name.

nigritibialis Rohwer. Que. to N. C. w. to S. D., Colo., and Alta.

Pamphilius nigritibialis Rohwer, 1912. U. S. Natl. Mus., Proc. 43: 205. ठ.

Pamphilius transversus MacGillivray, 1912. Canad. Ent. 44: 297. "○"=ठ́.

ochreipes (Cresson). Que. to N. C. and Ala., w. to Alaska and B. C. Host: Viburmum opulus. Lyda ochreipes Cresson, 1880. Amer. Ent. Soc., Trans. 8: 30.. 
Lyda perplexa Cresson, 1880. Amer. Ent. Soc., Trans. 8: 31. ๆ.

Biology: Lindquist and Harnden, 1970. Canad. Ent. 102: 95-97. ocreatus (Say). Que. to N. C. w. to Ill., Man., Minn. Host: Corylus, Cormus(?).

Lyda ocreata Say, 1836. Boston Jour. Nat. Hist. 1: 222. §.

Biology: Dyar, 1895. Ent. News 6: 199-200 (with larva description).

pacificus (Norton). Colo., Idaho, w. to B. C. and Calif. Host: Rosa californica. Lyda pacifica Norton, 1869. Amer. Ent. Soc., Trans. 2: 338. + .

Lyda melliventris Cresson, 1880. Amer. Ent. Soc., Trans. 8: 32. ð.

Biology: Middlekauff, 1964. Calif. Univ. Pubs., Ent. 38: 41-42.

palachei (Ashmead). Alaska (Kodiak).

Bactroceros palachei Ashmead, 1902. Wash. Acad. Sci., Proc. 4: 254..

pallimaculus (Norton). Que. to Ga., w. to Colo. and B. C. Host: Rosa(?). An adult collection record.

Lyda pallimacula Norton, 1869. Amer. Ent. Soc., Trans. 2: 337...

Lyda pallidimacula Dalla Torre, 1894. Cat. Hym., v. 1, p. 435. Emend.

persicum MacGillivray. Que. to Fla. w. to Minn., Nebr., Tex. Ecology: A pest of peach. Host: Prunus persica, Prunus serotina.

Pamphilius persicum MacGillivray, 1907. Canad. Ent. 39: 308..

Pamphilius perseae Rohwer, 1926. In Leonard, Cornell Univ. Agr. Expt. Sta., Mem. 101: 872. Emend.

Pamphilius persicus Klima, 1937. Hym. Cat., pt. 3, p. 45. Emend.

Pamphilius unalatus MacGillivray, 1920. Brooklyn Ent. Soc., Bul. 15: 112. 9.

Biology: Walden, 1907. U. S. Dept. Agr., Bur. Ent. Bul. 67: 85-87. - Walden, 1908. Conn.

(State) Agr. Expt. Sta., Ann. Rpt., pp. 285-300.

Morphology: Crampton, 1919. Ent. Soc. Wash., Proc. 21: 219 (genitalia).

phyllisae Middlekauff. N. B. to N. C. w. to Ill. and Minn. Host: Quercus rubra.

Pamphilius phyllisae Middlekauff, 1964. Calif. Univ., Pubs., Ent. 38: 49. ๆ, ð.

Biology: Eidt and Nichols, 1970. Canad. Ent. 102: 53-63.

pullatus (Cresson). Newfoundland to Va., w. to Ill., Mo. Host: Viburmum dentatum. Lyda pullata Cresson, 1880. Amer. Ent. Soc., Trans. 8: 31..

quebecensis (Provancher). Que. to N. C., w. to Mich.

Lyda quebecensis Provancher, 1878. Nat. Canad. 10: 205..

rileyi (Cresson). Conn. to W. Va., w. to Mich., Iowa, Mo. Host: Amelanchier.

Lyda rileyi Cresson, 1880. Amer. Ent. Soc., Trans. 8: 32..+

Pamphilius subcavifrons Rohwer, 1910. Canad. Ent. 42: 219. ठ.

rufofasciatus (Norton). Newfoundland to Ga. w. to Minn., Man., Colo., Alta.; Siberia.

Lyda mifo-fasciata Norton, 1869. Amer. Ent. Soc., Trans. 2: 340. $\subsetneq$.

Lyda mifocincta Cresson, 1880. Amer. Ent. Soc., Trans. 8: 32. ठ.

Taxonomy: Benes, 1972. Acta Ent. Bohem. 69: 388 (in Onycholyda; a holarctic sp.).

semicinctus (Norton). Que. to N. C. w. to Tenn. and Ind. Host: Amelanchier canadensis, Amelanchier sp., Pymus malus, Prunus virginiana. Some may not represent true hosts.

Lyda semicincta Norton, 1862. Ent. Soc. Phila., Proc. 1: 144. $\uparrow$.

sitkensis (Kincaid). Idaho, Nev., Alaska, B. C., Wash., Oreg., Calif. Host: Rubus parviflorus, $R$. vitifolius, and probably other species of Rubus.

Bactroceros sitkensis Kincaid, 1900. Wash. Acad. Sci., Proc. 2: 344. ๆ.

Pamphilius fulvifrons Rohwer, 1910. Canad. Ent. 42: 218. .

Pamphilius fortuitus MacGillivray, 1923. Ill. Univ., Bul. 20(50): 27..

Biology: Middlekauff, 1964. Calif. Univ., Pubs., Ent. 38: 62-63.

uniunguis Middlekauff. N. C., Man., Minn.

Pamphilius uniunguis Middlekauff, 1964. Calif. Univ., Pubs., Ent. 38: 65..

vernalis Middlekauff. Man., Nebr.

Pamphilius vernalis Middlekauff, 1964. Calif. Univ., Pubs., Ent. 38: 66. ๆ. 


\section{UNPLACED TAXA OF PAMPHILIIDAE}

Lyda canadensis Norton, 1869. Amer. Ent. Soc., Trans. 2: 336 . §. No locality given.

Tarpa scripta Say, 1824. In Keating, Narr. Long's 2nd Exped., v. 2, (App.), p. 312. N. W. T. and Ark. 



\section{Superfamily TENTHREDINOIDEA}

\section{Family PERGIDAE}

This is a highly diversified and large family in the Neotropical and Australian regions. Only one genus is found for certain in North America north of Mexico.

Taxonomy: Benson, 1938. Roy. Ent. Soc. London, Trans. 87: 376-382 (key to subfamilies of world).

\section{SUBFAMILY ACORDULECERINAE}

\section{Genus ACORDULECERA Say}

Acordulecera Say, 1836. Boston Jour. Nat. Hist. 1: 209.

Type-species: Acordulecera dorsalis Say. Monotypic.

Thulea Say, 1836. Boston Jour. Nat. Hist. 1: 213.

Type-species: Thulea nigra Say. Monotypic.

Perantherix Westwood, 1874. Thesaurus Ent. Oxon., p. 109.

Type-species: Perantherix pumilio Westwood. Monotypic.

Acorduleceros Konow, 1898. Ent. Nachr. 24: 250.

This genus is confined to the New World where the largest number of species are found in South America. In the United States and Canada, species of this genus are most abundant in the eastern deciduous forests though several species are found as far west as Arizona. These western forms have not been identified and are not listed below. The adults are small with short, six-segmented antennae, and the larvae feed externally on the foliage of the host plants.

dorsalis Say. Que. to Fla. w. to Iowa, Okla., Tex. Host: Quercus, Carya, Juglans, Castanea.

Either a species highly variable in coloration or a species complex.

Acordulecera dorsalis Say, 1836. Boston Jour. Nat. Hist. 1: 209. ๆ, ठ.

Acordulecera saginata Provancher, 1882. Nat. Canad. 13: 290. $\subsetneq$.

Acorduleceros biclinius Konow, 1898. Ent. Nachr. 24: 253.. .

Acordulecera media MacGillivray, 1908. Canad. Ent. 40: 168. ๆ.

Acordulecera minima MacGillivray, 1908. Canad. Ent. 40: 168..

Acordulecera maxima MacGillivray, 1908. Canad. Ent. 40: 168. ․

Acordulecera maura MacGillivray, 1908. Canad. Ent. 40: 168..

Acordulecera marina MacGillivray, 1908. Canad. Ent. 40: 170. o.

Acordulecera munda MacGillivray, 1908. Canad. Ent. 40: 169. ․

Acordulecera antennata Rohwer, 1912. U. S. Natl. Mus., Proc. 43: 246. ठ゚. N. syn.

Acordulecera foveata Rohwer, 1912. U. S. Natl. Mus., Proc. 43: 247. $₹$, ठ.

Acordulecera erythrogastra Rohwer, 1912. U. S. Natl. Mus., Proc. 43: 248. . N. syn.

Acordulecera parva Rohwer, 1912. U. S. Natl. Mus., Proc. 43: 248. ठ̃. N. syn.

Acordulecera caryae Rohwer, 1912. U. S. Natl. Mus., Proc. 43: 248. ‡, ठ. 
Acordulecera nigrata Rohwer, 1912. U. S. Natl. Mus., Proc. 43: 249. ९. N. syn. Acordulecera portiae Rohwer, 1912. U. S. Natl. Mus., Proc. 43: 249. $\$$. Acordulecera basirufa Rohwer, 1912. U. S. Natl. Mus., Proc. 43: 250. १. N. syn. Acordulecera flavipes Rohwer, 1912. U. S. Natl. Mus., Proc. 43: 250.. Acordulecera nigritarsis Rohwer, 1912. U. S. Natl. Mus., Proc. 43: 250. ․ Acordulecera quercus Rohwer, 1912. U. S. Natl. Mus., Proc. 43: 251.. N. syn. Acordulecera hicoriae Rohwer, 1917. U. S. Natl. Mus., Proc. 53: 157.. . N. syn. Acordulecera meleca MacGillivray, 1921. Brooklyn Ent. Soc., Bul. 16: 23. ठै. Acordulecera musta MacGillivray, 1921. Brooklyn Ent. Soc., Bul. 16: 23. ठँ.

maculata MacGillivray. N. Y., Pa., Ill. Acordulecera maculata MacGillivray, 1908. Canad. Ent. 40: 169. ؟, ठ゚.

mellina MacGillivray. Conn. to Ga. w. to Mich., Ill., Okla. Acordulecera mellina MacGillivray, 1908. Canad. Ent. 40: 169.. Acordulecera mixta MacGillivray, 1908. Canad. Ent. 40: 169. ९, ठ. pellucida (Konow). Mass. and $\mathrm{Pa}$. w. to Nebr., Kans., Tex. Acorduleceros pellucidus Konow, 1898. Ent. Nachr. 24: 253. 9. Acordulecera minuta MacGillivray, 1908. Canad. Ent. 40: 169. 9. Acordulecera scutellata Rohwer, 1912. U. S. Natl. Mus., Proc. 43: 247. ९, ठ. N. syn.

Taxonomy: Smith, 1973. Ent. Soc. Wash., Proc. 75: 30.

\section{SubFAMILy LOBOCERATINAE}

\section{Genus SKELOSYZYGONIA Malaise}

Skelosyzygonia Malaise, 1935. Ent. Tidskr. 56: 161.

Type-species: Skelosyzygonia spinipes Malaise. Orig. desig.

The single species in this genus was recorded from Texas; this is a dubious record for this Brazilian form.

spinipes Malaise. "Tex.”; Brazil (Rio de Janeiro).

Skelosyzygonia spinipes Malaise 1935. Ent. Tidskr. 56: 161. ठे.

Taxonomy: Conde, 1939 Deut. Ent. Gesell., Mitt. 9: 49 (“Tex.” record).

\section{Family ARGIDAE}

This family is cosmopolitan. It is the second largest sawfly family, with over 800 species. The tropical regions of the world contain the largest number of species, over 100 species of Arge alone having been described from tropical Africa. Over 300 species of the family have been described from the Neotropical Region, even though the fauna there is virtually unexplored. In America north of Mexico, the greater number of species is found in the southwestern United States. Hosts and habits are various, but most species feed externally on the foliage of the host plant in the larval stage. Only one North American species is known to be a leafminer, Schizocerella pilicornis (Holmgren) in purslane.

Taxonomy: Benson, 1938. Roy. Ent. Soc. London, Trans. 87: 371-375 (key to subfamilies, world). - Malaise, 1941. Ent. Tidskr. 62: 131-140 (key to world genera). -Wong, 1951. Ont. Ent. Soc., 82nd Ann. Rpt., p. 53 (cocoons). -Benson, 1963. Ann. and Mag. Nat. Hist. (13) 5: 631 (tribes of Arginae and genera of Scobini). - Smith, 1969. Amer. Ent. Soc., Trans. 95: 439-457 (Nearctic genera). - Smith, 1972. Amer. Ent. Soc., Trans. 98: 163-184 (N. Amer. larvae).

\section{SUBFAMILy ARGINAE}

\section{Genus ARGE Schrank}

Cryptus Jurine, 1801. Intell. Blatt. Litt.-Ztg. Erlangen, v. 1, p. 163. Suppressed by

Internatl. Comm. Zool. Nomencl., Op. 135, 1936.

Arge Schrank, 1802. Fauna Boica, p. 209.

Type-species: Tenthredo enodis Linnaeus. Desig. by Rohwer, 1911.

Hylotoma Latreille, 1802. Hist. Nat. Crust. Ins., v. 3, p. 302. 
Type-species: Tenthredo rosae Linnaeus. Monotypic.

Corynia Imhof and Labram, 1836. Ins. Schweiz., p. 23.

Type-species: Corynia rosarum Imhof and Labram. Desig. by Rohwer, 1911.

Acanthoptenos Ashmead, 1898. Canad. Ent. 30: 212.

Type-species: Acanthoptenos weithii Ashmead. Orig. desig.

Rhopalospiria Enderlein, 1920. Gesell. f. Naturf. Freunde, Sitzber. 9: 116. N. syn.

Type-species: Rhopalospiria mubiginosa (Beauvois). Orig. desig.

A large genus not represented only in the Neotropical and Australian regions. This is the most widespread genus in North America and is found from Canada and Alaska south to northern Mexico. The larvae feed on the foliage of their hosts. Several of the segregates below are species complexes, the taxonomy of which is yet to be worked out.

abdominalis (Leach), Ga., Fla.

Hylotoma abdominalis Leach, 1817. Zool. Misc., v. 3, p. 123..

borealis (Kirby). N. B., Maine, Mass., Ont. (St. Martin Falls, Hudson's Bay).

Hylotoma borealis Kirby, 1882. List Hym. Brit. Mus., v. 1, p. 66..

caerulea (Dalla Torre). Maine to Md.

Hylotoma coerulea Norton, 1864. Ent. Soc. Phila., Proc. 3: 5. ९. Preoce. by Latreille, 1805.

Hylotoma caemilea Dalla Torre, 1894. Cat. Hym., v. 1, p. 327. N. name.

clavicornis (Fabricius). Newfoundland to Alaska s. to Ga., N. Mex., Calif.; Holarctic (?).

Ecology: Widespread. Host: Amelanchier, Azalea, Betula, Carpinus, Corylus,

Crataegus, Prunus, Salix. A species complex.

Tenthredo clavicornis Fabricius, 1793. Ent. System., v. 2, p. 108. $\%$.

Hylotoma virescens Klug, 1814. Mag. Gesell. Naturf. Freunde Berlin 6: 296. $\subsetneq$, ð.

Hylotoma MacLeayi Leach, 1817. Zool. Misc., v. 3, p. 122..

Hylotoma analis Leach, 1817. Zool. Misc., v. 3, p. 123. ठ.

Hylotoma mellina Cresson, 1880. Amer. Ent. Soc., Trans. 8: 3. ९.

Hylotoma cyra Kirby, 1882. List Hym. Brit. Mus., v. 1, p. 66. .

Hylotoma mentzeliae Cockerell, 1898. Ann. and Mag. Nat. Hist. (7)2: 456. N. syn.

Acanthoptenos weithii Ashmead, 1898. Canad. Ent. 30: 212.

Arge inops Konow, 1906. Ztschr. System. Hym. Dipt. 6: 181. ठ.

Hylotoma nigrescens Rohwer, 1909. Canad. Ent. 41: 13. ठో. N. syn.

Hylotoma onerosa MacGillivray, 1923. Psyche 30: 80. $\%$, ð.

Hylotoma sparta MacGillivray, 1923. Ill. Univ., Bul. 20(50): 18. ๆ, ठ.

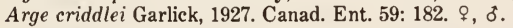

Arge imitans Garlick, 1927. Canad. Ent. 59: 182. ९, ठे.

Biology: Jack, 1891. Psyche 6: 11 (macleayi). -Will, 1947. Pa. Acad. Sci., Proc. 16: 47-49 (macleayi). -Will, 1959. Pa. Acad. Sci., Proc. 33: 219 (macleayi).

coccinea (Fabricius). Conn. to Fla. w. to Tex. Host: Rhus spp.

Hylotoma coccinea Fabricius, 1804. Systema Piezatorum, p. 24.

Tenthredo rubiginosa Beauvois, 1805. Ins. Afr. Amer., v. 2, p. 98. ๆ. N. syn.

Hylotoma miniata Klug, 1814. Mag. Gesell. Naturf. Freunde Berlin 6: 298. ठ。.

Hylotoma rubra Klug, 1814. Mag. Gesell. Naturf. Freunde Berlin 6: 299..

Hylotoma erythrosoma Leach, 1817. Zool. Misc., v. 3, p. 124. ․ N. syn.

Hylotoma scutellata Lepeletier, 1823. Monog. Tenthred., p. 47.

Hylotoma sphinx Kirby, 1882. List Hym. Brit. Mus., v. 1, p. 68. ठे. N. syn.

humeralis (Beauvois). Maine to Fla. w. to Minn., Kans., Tex. Host: Poison-ivy.

Tenthredo humeralis Beauvois, 1805. Ins. Afr. Amer., v. 2, p. 99..

Hylotoma sanguinea Klug, 1814. Mag. Gesell. Naturf. Freunde Berlin 6: 299. ㅇ.

Hylotoma scutellata Say, 1836. Boston Jour. Nat. Hist. 1: 211. ․ N. syn.

Hylotoma grandis Rohwer, 1909. Canad. Ent. 41: 14. ठ. N. syn.

ochropa (Gmelin). Ont.; Europe to Siberia, Middle East. Introduced (?) into N. Amer. Host: Rosa.

Tenthredo ochropus Gmelin, 1790. In Linnaeus, Syst. Nat., Ed. 13, v. 1, pt. 5, p. 2657.

Taxonomy: Malaise and Benson, 1934. Archiv for Zool. 26A: 7-8, 13 (=rosae of authors, nec Linnaeus). 
pectoralis (Leach). Maine to Fla. w. to Ont., Sask., Mich., Ill., Mo., Tex. Host: Alnus, Betula, Corylus, Crataegus, Salix. Birch sawfly. Probably a species complex.

Hylotoma pectoralis Leach, 1817. Zool. Misc., v. 3, p. 124..

Hylotoma dulciaria Say, 1824. In Keating, Narr. Long's 2nd Exped., (App.). p. 314..

Arge salicis Rohwer, 1912. U. S. Natl. Mus., Proc. 43: 206.,$\delta$.

Biology: Schwarz, 1909. Ent. Soc. Wash., Proc. 11: 106-108. -Wong, 1954. Canad. Ent. 86:

154. - Smirnoff, 1971. Ent. Soc. Quebec, Ann. 16: 86-88 (protozoan parasite).

scapularis (Klug). Maine to Fla. w. to Ont., Minn., Mo., Tex. Host: Alnus, Betula, Quercus,

Ulmus. Probably a species complex.

Hylotoma scapularis Klug, 1814. Mag. Gesell. Naturf. Freunde Berlin 6: 299. ठ̊.

Hylotoma xanthothorax Leach, 1817. Zool. Misc., v. 3, p. 124..+

Hylotoma calcanea Say, 1836. Boston Jour. Nat. Hist. 1: 211.

Biology: Jack, 1891. Psyche 6: 11.

spiculata (MacGillivray). Ariz.; Mexico.

Hylotoma spiculata MacGillivray, 1907. Canad. Ent. 39: 308. ․

\section{SUBFAMILy ATOMACERINAE}

\section{Genus ATOMACERA Say}

Atomacera Say, 1836. Boston Jour. Nat. Hist. 1: 212.

Type-species: Atomacera debilis Say. Desig. by Malaise, 1937.

Micrarge Ashmead, 1898. Canad. Ent. 30: 213.

Type-species: Atomacera mificollis Norton. Orig. desig.

Braunsiola Konow, 1899. Ent. Nachr. 25: 312.

Type-species: Braunsiola truculenta Konow. Monotypic.

Spegazziniella Jorgensen, 1913. Buenos Aires Mus. Nac. de Hist. Nat., An. 25: 260.

Type-species: Spegazziniella ovata Jorgensen. Monotypic.

Argina Forsius, 1925. Arkiv for Zool. 17A: 2. Preocc.

Type-species: Argina nubilipennis Forsius. Monotypic.

Arginella Forsius, 1926. Notulae Ent. 5: 207. N. name for Argina.

A genus distributed throughout most of the New World but more highly developed in the tropics. Larvae feed on the foliage of the host plant.

Revision: Malaise, 1942. Ent. Tidskr. 63: 107-110 (Neotropical species). - Smith, 1969. Amer.

Ent. Soc., Trans. 95: 440-446 (Nearctic species).

debilis Say. Ont., Mass. to Fla. w. to Minn., Kans., Ark. Host: Desmodium canadense, D. glutinosum, and probably other species; Lespedeza.

Atomacera debilis Say, 1836. Boston Jour. Nat. Hist. 1: 212. ठँ.

Atomacera ruficollis Norton, 1864. Ent. Soc. Phila., Proc. 3: 6. ․

Atomacera desmodii Dyar, 1900. N. Y. Ent. Soc., Jour. 8: 26. + , ऽ. Larva.

Taxonomy: Smith, 1972. Amer. Ent. Soc., Trans. 98: 167 (larva).

Biology: Dyar, 1900. N. Y. Ent. Soc., Jour. 8: 26. -Weiss and Lott, 1923. Ent. News 34: 167.

- Lindquist and Trinnell, 1965. Canad. Ent. 97: 181-184.

decepta Rohwer. Conn. to Fla. w. to Mo., Tex. Host: Hibiscus militaris, H. moscheutos hybrid. Atomacera decepta Rohwer, 1911. U. S. Natl. Mus., Proc. 41: 382 ..

Taxonomy: Smith, 1972. Amer. Ent. Soc., Trans. 98: 167 (larva).

Biology: Dyar, 1900. N. Y. Ent. Soc., Jour. 8: 26 (ruficollis, nec Norton). -Tippins, 1965.

Jour. Econ. Ent. 58: 161.

ebena Smith. S. Ariz.

Atomacera ebena Smith, 1969. Amer. Ent. Soc., Trans. 95: 445..

\section{SUBFAMILY STERICTIPHORINAE}

\section{Genus STERICTIPHORA Billberg}

Sterictiphora Billberg, 1820. Enum. Ins. Mus. Billberg, p. 99. 
Type-species: Hylotoma furcata Fabricius. Monotypic.

Schizocerus Berthold, 1827. Nat. Fam. Thierr., p. 441.

Type-species: Hylotoma furcata Villers. Desig. by Westwood, 1840.

Cyphona Dahlbom, 1835. Conspectus Tenthred., Siricid., Oryssin. Scan., p. 8.

Type-species: Hylotoma furcata Villers. Desig. by Rohwer, 1911.

A small Holarctic genus. Larvae feed on the foliage of the host plants most of which appear to be species of Prunus.

Revision: Smith, 1969. Amer. Ent. Soc., Trans. 95: 446-455.

cruenta Smith. Maine to N. C. w. to Mich. Host: Prunus pennsylvanicus.

Sterictiphora cruenta Smith, 1969. Amer. Ent. Soc, Trans. 95: 450. ․

maura (Cresson). Utah, Nev., Oreg., Calif. Host: Prunus

Schizocera maura Cresson, 1880. Amer. Ent. Soc., Trans. 8: 3. ठ.

prunivora (Dyar). Maine s. to N. Y., Pa. Host: Prunns, Amelanchier.

Schizocerus prunivorus Dyar, 1897. N. Y. Ent. Soc., Jour. 5: 23. larva.

sericea (Norton). Maine to N. J., Pa. w. to Ill.

Schizocerus sericeus Norton, 1867. Amer. Ent. Soc., Trans. 1: 55 . \&.

serotina Smith. Maine to Va. Host: Prunus serotina.

Sterictiphora serotina Smith, 1969. Amer. Ent. Soc., Trans. 95: 452. ९, ठ̊.

Taxonomy: Smith, 1972. Amer. Ent. Soc., Trans. 98: 169 (larva).

transversa Smith. Md., Alta., Alaska.

Sterictiphora transversa Smith, 1969. Amer. Ent. Soc., Trans. 95: 454. ․

\section{Genus APROSTHEMA Konow}

Aprosthema Konow, 1899. Ent. Nachr. 25: 149.

Type-species: Hylotoma brevicornis Fallen. Desig. by Rohwer, 1911.

Lyrola Ross, 1937. Ill. Biol. Monog. 15(2): 55.

Type-species: Schizocera brunniventris Cresson. Orig. desig.

A small Holarctic genus with two Nearctic representatives, both of which are found in western North America.

Revision: Smith, 1971. Amer. Ent. Soc., Trans. 97: 546-549.

breviantennatum Smith. Oreg., Calif.

A prosthema breviantennatum Smith, 1971. Amer. Ent. Soc., Trans. 97: 546. , ơ.

brunniventre (Cresson). Wash., Oreg., Nev., Calif. Host: Hosackia.

Schizocera brunniventris Cresson, 1880. Amer. Ent. Soc., Trans. 8: 2. १, ठ.

Schizocera tristis Cresson, 1880. Amer. Ent. Soc., Trans. 8: 52. १, ठ.

Schizocera tristis var. fumipennis Dyar, 1893. Canad. Ent. 25: 195. ๆ, ठ, larva.

Taxonomy: Smith, 1972. Amer. Ent. Soc., Trans. 98: 170 (larva).

Biology: Dyar, 1893. Canad. Ent. 25: 195.

\section{Genus NEOPTILIA Ashmead}

Neoptilia Ashmead, 1898. Canad. Ent. 30: 213.

Type-species: Neoptilia mexicana Ashmead. Orig. desig.

Pseudocyphona Ashmead, 1898. Canad. Ent. 30: 211.

Type-species: Pseudocyphona mexicana Ashmead. Orig. desig.

Rhagonyx Konow, 1903. Ztschr. System. Hym. Dipt. 3: 108.

Type-species: Rhagonyx lituratus Konow. Monotypic.

A small genus known only from southwestern United States south to Ecuador.

Revision: Smith, 1971. Amer. Ent. Soc., Trans. 97: 537-543.

malvacearum (Cockerell). Tex., N. Mex., Ariz.; Mexico. Host: Althaea rosea, Malvastrum, Malva, Sphaeralcea.

Nematoneura malvacearum Cockerell, 1894. U. S. Dept. Agr., Insect Life 7: 253. ९, ठ.

Taxonomy: Smith, 1972. Amer. Ent. Soc., Trans. 98: 179 (larva). 
Biology: Cockerell, 1894. U. S. Dept. Agr., Insect Life 7: 251-253. tora Smith. S. Tex.

Neoptilia tora Smith, 1971. Amer. Ent. Soc., Trans. 97: 540. ९, ठ๋.

\section{Genus PTENUS Kirby}

Ptenos Norton, 1872. Amer. Ent. Soc., Trans. 4: 77. Preocc. by Gray, 1843.

Type-species: Ptenos niger Norton. Desig. by Rohwer, 1911.

Ptenus Kirby, 1882. List Hym. Brit. Mus., v. 1, p. 51. N. name.

Ptenellus Malaise, 1937. Ent. Tidskr. 58: 56.

Type-species: Ptenos nigripectus(!) Norton. Orig. desig.

This genus is found only in the New World and is distributed from southwestern United States to northern South America.

Revision: Smith, 1970. Amer. Ent. Soc., Trans. 96: 79-101.

apulatus Greenbaum. Ariz.

Ptenus apulatus Greenbaum, 1975 (1974). Pan-Pacific Ent. 50: 423-425. \&.

bicolor Smith. Tex.; Mexico. Host: Acacia famesiana.

Ptenus bicolor Smith, 1970. Amer. Ent. Soc., Trans. 96: 83. ९, ठ.

Taxonomy: Smith, 1972. Amer. Ent. Soc., Trans. 98: 176 (larva).

imus Smith. Tex.; Mexico.

Ptenus imus Smith, 1970. Amer. Ent. Soc., Trans. 96: 84. ․

jocus Smith. Ariz. (Patagonia Mts.).

Ptenus jocus Smith, 1970. Amer. Ent. Soc., Trans. 96: 86..

magnus Smith. W. Tex., N. Mex., Ariz.

Ptenus magnus Smith, 1970. Amer. Ent. Soc., Trans. 96: 86. ९, ठ.

modestius Smith. Tex., Ariz., s. Calif. Host: Adults collected from mesquite.

Ptenus modestius Smith, 1970. Amer. Ent. Soc., Trans. 96: 88. ₹, ơ.

nigropectus (Norton). Miss., La., Tex. Host: Acacia angustissima, Desmanthus(?).

Ptenos nigropectus Norton, 1872. Amer. Ent. Soc., Trans. 4: 77. ठ.

parvus Smith. W. Tex., Ariz. Host: Adults collected from Acacia.

Ptenus parvus Smith, 1970. Amer. Ent. Soc., Trans. 96: 92. ९, ठ.

patulus Smith. Ariz.

Ptenus patulus Smith, 1970. Amer. Ent. Soc., Trans. 96: 94. ๆ, ठ.

texanus (Norton). Tex.; Mexico.

Ptilia texana Norton, 1869. Amer. Ent. Soc., Trans. 2: 367. ठ.

Ptenos niger Norton, 1872. Amer. Ent. Soc., Trans. 4: 77. ठ̊.

torridus Smith. Ariz.

Ptenus torridus Smith, 1970. Amer. Ent. Soc., Trans. 96: 96...

vanus Smith. N. Mex., Ariz.; Mexico.

Ptenus vanus Smith, 1970. Amer. Ent. Soc., Trans. 96: 96. ^, ठ.

vargus Smith. Tex.; Mexico.

Ptenus vargus Smith, 1970. Amer. Ent. Soc., Trans. 96: 98. ؟.

\section{Genus SCHIZOCERELLA Forsius}

Schizocerella Forsius, 1927. Notulae Ent. 7: 19.

Type-species: Schizocerella axillaris Forsius. Orig. desig.

Sofus Malaise, 1937. Ent. Tidskr. 58: 137.

Type-species: Schizocera pilicomis Holmgren. Orig. desig.

Sterictiphora subg. Leston Ross, 1937. Ill. Biol. Monog. 15(2): 54.

Type-species: Schizocerts zabriskei Webster and Malley. Orig. desig.

Taxonomy: Benson, 1963. Ann. and Mag. Nat. Hist. (13) 5: 631. -Smith, 1971. Ar

Soc., Trans. 97: 543-546. 
pilicornis (Holmgren). N. Y. and Ont. to Fla. w. to Wash., Oreg., Calif. and to Argentina.

Ecology: Leafminer. A larva of this species may mine a Portulaca leaf, leave it, and then mine a succession of leaves before becoming full grown. The mature larva pupates in the soil. Host: Portulaca. Introduced into Australia.

Schizocera pilicornis Holmgren, 1868. Eug. Resa I, Zool. I, Ins. p. 391. ९, ơ.

Schizoceros lateralis Konow, 1899. Buenos Aires Mus. Nac. de Hist. Nat., An. 6: 404. $ๆ$.

Shizocerus zabriskei Webster and Malley, 1900. Canad. Ent. 32: 51.

Schizocerus sericeiformis Rohwer, 1908. N. Y. Ent. Soc., Jour. 16: 112. ঠ.

Schizocerus lineatus Rohwer, 1909. Canad. Ent. 41: 12. ?.

Schizocerus collaris Rohwer, 1909. Canad. Ent. 41: 13..

Schizocerus johnsoni MacGillivray, 1909. Canad. Ent. 41: 403. ․

Schizocerella axillaris Forsius, 1927. Notulae Ent. 7: 19.

Schizocerella scapularis Forsius, 1927. Notulae Ent. 7: 19..

Taxonomy: Smith, 1972. Amer. Ent. Soc., Trans. 98: 171 (larva).

Biology: Webster and Malley, 1900. Canad. Ent. 32: 51-54. - Garlick, 1922. Canad. Ent. 54: 240. - Force, 1965. Calif. Dept. Agr. Bul., v. 54, pp. 157-160.

\section{Genus SPHACOPHILUS Provancher}

This genus is found only in the New World, where most of its representatives are found from southwestern United States to South America. A few species extend north through the central plains region to central Canada.

Revision: Smith, 1971. Amer. Ent. Soc., Trans. 97: 549-580.

\section{Genus SPHACOPHILUS Subgenus SPHACOPHILUS Provancher}

Sphacophilus Provancher, 1889. Addit. Corr. Faune Ent. Canada Hym., Sup., p. 427.

Type-species: Sphacophilus crawii Provancher. Monotypic.

crawii Provancher. Idaho, Oreg. s. to N. Mex., Ariz., Calif.

Sphacophilus crawii Provancher, 1889. Addit. Corr. Faune Ent. Canada Hym., Sup., p. 427. \&.

invitus (Cresson). Wash. s. to Colo., Ariz., Calif.

Schizocera invita Cresson, 1880. Amer. Ent. Soc., Trans. 8: 3. ?.

\section{Genus SPHACOPHILUS Subgenus LITOCOLUS Smith}

Sphacophilus subg. Litocolus Smith, 1971. Amer. Ent. Soc., Trans. 97: 556.

Type-species: Atomacera cellularis Say. Orig. desig.

Known hosts for this subgenus are members of the plant family Convolvulaceae.

apiculus Smith. S. Ariz.

Sphacophilus (Litocolus) apiculus Smith, 1971. Amer. Ent. Soc., Trans. 97: 556..

cellularis (Say). Conn. to Fla. w. to Ont., Minn., Nebr., Ark. Host: Ipomoea, Convolvulus.

Atomacera cellularis Say, 1836. Boston Jour. Nat. Hist. 1: 213..+

Schizocerus ebenus Norton, 1867. Amer. Ent. Soc., Trans. 1: 55.0 .

Schizocerus privatus Norton, 1867. Amer. Ent. Soc., Trans. 1: 56..

Taxonomy: Smith, 1972. Amer. Ent. Soc., Trans. 98: 174 (larva).

Biology: Riley and Howard, 1888. U. S. Dept. Agr., Insect Life 1: 43-45. -Marlatt, 1892. U.

S. Dept. Agr., Insect Life 5: 24-27.

orthius Smith. Ariz.

Sphacophilus (Litocolus) orthizus Smith, 1971. Amer. Ent. Soc., Trans. 97: 558..

orus Smith. Ariz.

Sphacophilus (Litocolus) orus Smith, 1971. Amer. Ent. Soc., Trans. 97: 559. ๆ, ơ.

partitus Smith. Ariz. (Chiricahua Mts.).

Sphacophilus (Litocolus) partitus Smith, 1971. Amer. Ent. Soc., Trans. 97: 560. ․

quixus Smith. Tex., Ariz. Host: Ipomoea(?).

Sphacophilus (Litocolus) quixus Smith, 1971. Amer. Ent. Soc., Trans. 97: 561. ๆ, ơ. 


\section{Genus SPHACOPHILUS Subgenus CEOCOLUS Smith}

Sphacophilus subg. Ceocolus Smith, 1971. Amer. Ent. Soc., Trans. 97: 562. Type-species: Schizocerus abdominalis Cresson. Orig. desig.

Known hosts for species of this subgenus are members of the plant family Leguminosae. These sawflies appear to be most common in the prairie regions of central North America.

abdominalis (Cresson). N. C.; S. Dak., Ill. w. to Colo., N. Mex. Host: Psoralea.

Schizocemus abdominalis Cresson, 1865. Ent. Soc. Phila., Proc. 4: 243. ठ’.

albicosta Smith. Idaho, Wash., Oreg. Host: Psoralea.

Sphacophilus (Ceocolus) albicosta Smith, 1971. Amer. Ent. Soc., Trans. 97: 563. ․ đ. apios (Ross). N. C., Ill., Kans. Host: Desmodium, Psoralea.

Sterictiphora apios Ross, 1933. Ent. Soc. Wash., Proc. 35: 13. ९, ठ, larva.

Sterictiphora apios form atrescens Ross, 1933. Ent. Soc. Wash., Proc. 35: 14. ९, §.

Biology: Ross, 1933. Ent. Soc. Wash., Proc. 35: 13-19.

argutus Smith. Ariz. (Tucson Mts.).

Sphacophilus (Ceocolus) argutus Smith, 1971. Amer. Ent. Soc., Trans. 97: 566. ९. crenus Smith. W. Tex.

Sphacophilus (Ceocolus) crenus Smith, 1971. Amer. Ent. Soc., Trans. 97: 567. \&, ¿. dissensus Smith. Ariz. (Indian Pine).

Sphacophilus (Ceocolus) dissensus Smith, 1971. Amer. Ent. Soc., Trans. 97: 568. . hamus Smith. S. Ariz.

Sphacophilus (Ceocolus) hamus Smith, 1971. Amer. Ent. Soc., Trans. 97: 568. , ठ. memmonius Smith. S. Calif. (Algadones Sand Dune, Imperial Co.).

Sphacophilus (Ceocolus) memmonius Smith, 1971. Amer. Ent. Soc., Trans. 97: 570.. nigriceps (Konow). Man., Minn., Ill. w. to Alta., Wyo., Colo., N. Mex., Tex. Host: Petalostemum. Brachyphatnus nigriceps Konow, 1906. Ztschr. System. Hym. Dipt. 6: 251. §.

Schizocerus nortoni Rohwer, 1909. Canad. Ent. 41: 11. o.

Taxonomy: Smith, 1972. Amer. Ent. Soc., Trans. 98: 175 (larva). oblatus Smith. N. Mex., Ariz.

Sphacophilus (Ceocolus) oblatus Smith, 1971. Amer. Ent. Soc., Trans. 97: 576. . plumiger (Klug). N. C., Ga., Fla. Host: Petalostemum.

Hylotoma plumiger Klug, 1814. Mag. Gesell. Naturf. Freunde Berlin 6: 306. \&. "New York" (!).

Cryptus Klugii Leach, 1817. Zool. Misc., v. 3, p. 125. ๆ, ठ.

Taxonomy: Smith, 1973. Ent. Soc. Wash., Proc. 75: 28-29.

precarius Smith. Ga., Fla.

Sphacophilus (Ceocolus) precarius Smith, 1971. Amer. Ent. Soc., Trans. 97: 578. ؟. rallus Smith. Ariz. (Santa Catalina Mts.).

Sphacophilus (Ceocolus) rallus Smith, 1971. Amer. Ent. Soc., Trans. 97: 578. ‥ triangularis Smith. Ariz. (Douglas).

Sphacophilus (Ceocolus) triangularis Smith, 1971. Amer. Ent. Soc., Trans. 97: 580..

\section{Family CIMBICIDAE}

These are large, robust sawflies, and the larvae are all external leaf feeders. The family is found in most of the world except for the Ethiopian and Australian regions and contains about 130 species.

Taxonomy: Benson, 1938. Roy. Ent. Soc. London, Trans. 87: 369-372 (key to world subfamilies). -Townes, 1962. U. S. Natl. Mus., Bul. 216, p. 67 (Clavellariidae). 


\section{Subfamily ABIINAE \\ Genus ZARAEA Leach}

Zaraea Leach, 1817. Zool. Misc., v. 3, p. 113.

Type-species: Tenthredo fasciata Linnaeus. Monotypic.

Members of this Holarctic genus are associated with the plant family Caprifoliaceae.

americana Cresson. Quebec to Alaska s. to Pa., Nebr., N. Mex., Calif. Ecology: Widespread. Host: Symphoricarpos, Lonicera.

Zaraea americana Cresson, 1880. Amer. Ent. Soc., Trans. 8: 1. ‥

Biology: Britton, 1925. Conn. Agr. Expt. Sta., Bul. 265: 341. -Kieffer, 1933. Jour. Econ. Ent. 26: 293. -Middlekauff, 1956. Jour. Econ. Ent. 49: 701.

inflata Norton. Mass. to Pa. w. to Nebr., Colo. Host: Lonicera. Honeysuckle sawfly.

Zaraea inflatus Norton, 1861. Boston Soc. Nat. Hist., Proc. 8: 151. ‡.

Abia caprifolium Norton, 1867. Amer. Ent. Soc., Trans. 1: 46. १.

Biology: Thomas, 1881. Tenth Rpt., State Ent. Ill. 1880 p. 66.

kennicotti (Norton). N. Y., Ill., Mo., Kans., Tex.

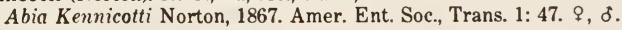

lonicerae (Linnaeus). N. Y. to Md. w. to Ohio; Europe. Introduced into N. Amer. Host:

Lonicera, Symphoricarpos.

Tenthredo lonicerae Linnaeus, 1758. Syst. Nat., Ed. 10, p. 559.

Abia nigricornis Leach, 1817. Zool. Misc., v. 3, p. 113. \&, ð.

Taxonomy: Benson, 1946. Ent. Monthly Mag. 82: 101-102.

SubFamily CimbicinaE

\section{Genus TRICHIOSOMA Leach}

Trichiosoma Leach, 1817. Zool. Misc., v. 3, p. 108.

Type-species: Tenthredo lucomum Linnaeus. Desig. by Curtis, 1825.

A Holarctic genus with about 20 species. Adults are large and densely hairy sawflies and may girdle twigs of their host plant with their powerful mandibles. This genus is in need of study. Adults show extreme variation in color and external structure and a thorough study will be necessary to determine the correct status of the segregates listed below.

aleutianum Cresson. Alaska (Aleutian Islands).

Trichiosoma triangulum var. aleutiana Cresson, 1880. Amer. Ent. Soc., Trans. 8:1..

arcticum Kirby. N. W. T. (Ft. Simpson, MacKenzie R.).

Trichiosoma arcticum Kirby, 1882. List Hym. Brit. Mus., v. 1, p. 10. ठ.

lanuginosum Norton. Calif.

Trichiosoma lanuginosum Norton, 1867. Amer. Ent. Soc., Trans. 1: 44. ‡.

triangulum Kirby. Que. to Alaska s. to Pa., Colo., Calif. Ecology: Widespread. Host: Alnus, Betula, Populus, Fraxinus, Prunus, Salix.

Trichiosoma triangulum Kirby, 1837. Fauna Bor.-Amer., v. 4, p. 254.

Abia cerasi Fitch, 1857. N. Y. State Agr. Soc., Trans. 1856, 16: 385.

Trichiosoma bicolor Norton, 1861. Boston Soc. Nat. Hist., Proc. 8: 150. ठ.

Trichiosoma crassum Kirby, 1882. List Hym. Brit. Mus., v. 1, p. 11. ๆ.

Trichiosoma Taylori Provancher, 1886. Addit. Corr. Faune Ent. Canada Hym., p. 20. $\$, ~ \delta$.

Trichiosoma confusum MacGillivray, 1916. Conn. State Geol. and Nat. Hist. Survey Bul. 22: 103., , $\delta$.

Trichiosoma spicatum MacGillivray, 1916. Conn. State Geol. and Nat. Hist. Survey Bul. 22: 103. $\delta$.

Trichiosoma confundum MacGillivray, 1923. Canad. Ent. 55: 161. ?. 


\section{Genus CIMBEX Olivier}

Crabro Geoffroy, 1762. Hist. Abregee des Insectes, v. 2, p. 261. Suppressed by Internatl. Comm. Zool. Nomencl., Op. 144, 1936. Publication unavailable for nomenclatorial purposes, Internatl. Comm. Zool. Nomencl., Op. 228, 1954.

Type-species: Crabro humeralis Fourcroy. Desig. by Bradley, 1919.

Clavellarius Olivier, 1789. Encycl. Meth., Dict. Ins., v. 4, p. 22. Suppressed by Internatl. Comm. Zool. Nomencl., Op. 216, 1954.

Type-species: Tenthredo lutea Linnaeus. Desig. by Latreille, 1810.

Cimbex Olivier, 1790. Encycl. Meth., Dict. Ins., v. 5, p. 762. N. name for Clavellarius Olivier.

Clavellaria Lamarck, 1801. Systeme Anim. Sans Vert., p. 264. Emend.

A Holarctic genus with about 17 species whose members are the largest of sawflies. Adults have large, powerful mandibles with which they may sometimes girdle the twigs of their host. Members of this genus show considerable variation in color and structure, and an intensive study is required to determine the validity of the segregates listed below.

Taxonomy: Ross and Burke (!), 1947. Bul. Zool. Nomencl., pp. 201-202 (status of the name Clavellarius Olivier, 1789).

americana Leach. Newfoundland to Alaska s. to N. C., Colo., Oreg. Ecology: Widespread. Host: Acer, Alnus, Betula, Ostrya, Populus, Prunus, Salix, Tilia, Ulmus. Elm sawfly. Cimbex americana Leach, 1817. Zool. Misc., v. 3, p. 105. ð.

Cimbex violacea Lepeletier, 1823. Monog. Tenthred., p. 27. \&.

Cimbex luctifera Klug, 1829. Gesell. Naturf. Freunde Berlin 1(2): 85. \&, ð.

Cimbex La Portei Lepeletier, 1833. Soc. Ent. France, Ann. 2: 454..

Cimbex Viardi Lepeletier, 1833. Soc. Ent. France, Ann. 2: 454..

Cimbex ulmi Harris, 1841. Rpt. Ins. Mass. Injurious to Veg., p. 374.

Cimbex Dahlbomi Guerin 1845. Inconogr. Regne Anim., v. 7 (Ins.), p. 398. \&.

Cimbex lateralis Guerin, 1845. Inconogr. Regne Anim., v. 7 (Ins.), p. 398. $\%$.

Cimbex kirbyi Brulle, 1846. In Lepeletier, Hist. Nat. Ins., Hym. v. 4, p. 672 ..

Cimbex americana var. alba Norton, 1867. Amer. Ent. Soc., Trans. 1: 42 ..

Cimbex americana var. nortoni MacGillivray, 1916. Conn. State Geol. and Nat. Hist.

Survey Bul. 22: 104. .

Crabro americana var. mubrosa Ross, 1932. Canad. Ent. 64: 250. ð.

Biology: Harris, 1841. Rpt. Ins. Mass. Injurious to Veg., p. 374. - Webster, 1890. U. S. Dept. Agr., Insect Life 2: 228-230. - Townsend, 1892. Canad. Ent. 24: 126. -Aldrich, 1892.

Canad. Ent. 24: 144. - Severin and Severin, 1908. Wis. Acad. Sci., Arts and Letters, Trans. 16: 61-76. - Severin, 1920. S. Dak. State Ent., Circ. 22, 4 pp. -Wong, 1954. Canad. Ent. 86: 154. - Lipa and Smirnoff, 1971. Bul. Acad. Pol. Sci., Ser. Sci. Biol. 19: 269-274 (a protozoan parasite). - Stein, 1974. U. S. Dept. Agr., Forest Pest Leaflet 142, 6 pp.

Morphology: Severin and Severin, 1908. Ent. Soc. Amer., Ann. 1: 87-101 (female reproductive organs). - Severin and Severin, 1908. Ent. Soc. Amer., Ann. 1: 196-205 (male reproductive organs). - Severin and Severin, 1908. Wis. Acad. Sci., Arts and Letters, Trans. 16: 39-60 (digestive canal).

pacifica Cresson. Colo., Wash., Oreg., Calif. Host: Salix.

Cimbex pacifica Cresson, 1880. Amer. Ent. Soc., Trans. 8: 1. \&, o.

Biology: Schuh and Mote, 1948. Oreg. State Coll. Agr., Expt. Sta. Bul. 449: 128.

rubida Cresson. Nev., Calif. Host: Salix.

Cimbex rubida Cresson, 1880. Amer. Ent. Soc., Trans. 8: 1. ‡.

semidea Cresson. Maine, N. H., Ont., Mich.

Cimbex semidea Cresson, 1880. Amer. Ent. Soc., Trans. 8: 1. ?.

Cimbex hudsonica Kirby, 1882. List. Hym. Brit. Mus., v. 1, p. 8.. 


\section{Family DIPRIONIDAE}

A small family found in the coniferous forests of the Northern Hemisphere with about 91 world species in 11 genera. Though more common in the cool northern regions, representatives are found as far south as north Africa, Pakistan, north India, Thailand, El Salvador, and Cuba. Hosts are restricted to conifers; consequently, they are commonly called conifer sawflies. Larvae defoliate the host, and sporadic outbreaks may occur in forest stands resulting in loss of growth and sometimes tree mortality. Many are also a nuisance in plantations, nurseries, and ornamental plantings. All larvae feed on the needles except for those of Augomonoctenus libocedrii Rohwer which feeds in the developing cones of incense cedar. In addition to the foliage, some may also feed on the tender bark of new twigs. Most larvae are gregarious at first but later disperse on the tree in search of new food. Overwintering is either as an egg in the needles or as a prepupa in a cocoon in the forest litter. Adults are short-lived and are most easily obtained by rearing. Depending on the species and sometimes the latitude, there may be from one to five generations a year; however, sometimes it takes more than one year to complete a life cycle. Diapause is common in many species.

Because this is an economically important group, literature references are numerous. The literature cited here for many species is not complete and would take many more pages. Some early literature, expecially prior to 1943 , is not reliable because the taxonomy has changed to such an extent that it is impossible to tell to which species the articles refer. The taxonomy of some groups, Neodiprion in particular, is still flexuous.

Taxonomy: Benson, 1939. Bul. Ent. Res. 30: 339-342 (genera of world). -Benson, 1945. Bul. Ent. Res. 36: 163-164 (world classification). -Gussakovskii, 1947. Faune de L'URSS, Ins. Hym., v. 2, 234 pp. (Palaearctic species). - Benson, 1954. Roy. Ent. Soc. London, Proc., Ser. B: Taxonomy 23: 115-118 (world genera of Monocteninae). - Wong, 1951. Ont. Ent. Soc., Ann. Rpt. 82, pp. 63, 66 (cocoons). - Smith, 1974. Ent. Soc. Wash., Proc. 76: 409-418 (key to N. Amer. genera; list world spp.).

Biology: Craighead, 1950. U. S. Dept. Agr., Misc. Pub. 657, pp. 542-591 (eastern forests). - Raizenne, 1957. Canad. Dept. Agr., Pub. 1009, pp. 11-24 (sawflies of s. Ont. and their parasites). - Bird, 1955. Canad. Ent. 87: 124-127 (virus diseases). -Atwood, 1961. Ont. Ent. Soc., Proc. 1960, 91: 205-215 (current status in Ont.). - Coppel and Benjamin, 1965. Ann. Rev. Ent. 10: 69-96 (binomics of Nearctic pine-feeding diprionids). - Ryvkin, 1969. Beitr. Ent. 19: 595-605 (complexes of natural enemies). - Philogene, 1971. Ent. Soc. Quebec, Ann. 16: 112-119 (diapause). - Baker, 1972. U. S. Dept. Agr., Misc. Pub. 1175, pp. 439-453 (eastern forests). - Knerer and Atwood, 1973. Science 179: 1090-1099 (polymorphism and speciation).

\section{SUBFAMILY MONOCTENINAE}

Larvae of this subfamily feed on Cupressaceae.

\section{Genus MONOCTENUS Dahlbom}

Monoctenus Dahlbom, 1835. Conspectus Tenthred., Siricid., Oryssin. Scand., p. 7. Type-species: Tenthredo juniperi Linnaeus. Monotypic.

A small holarctic genus with about 10 species. The genus also extends into Mexico.

fulvus (Norton). Ont., Ill., Kans., Okla., Tex. Host: Juniperus virginiana.

Lophyrus fulvus Norton, 1872. Amer. Ent. Soc., Trans. 4: 86. ๆ.

Lophyrus (Monoctenus) juniperi Marlatt, 1888. Kans. Acad. Sci., Trans. 10: 82. $q$, o . Preocc. by Linnaeus, 1758 .

Monoctenus unicolor Marlatt, 1890. Ent. Soc. Wash., Proc. 2: 125. N. name for juniperi Marlatt.

Biology: Marlatt, 1888. Kans. Acad. Sci., Trans. 10: 80-82. - Smith, 1943. Kans. State Bd. Agr., Rpt. 62: 385.

melliceps (Cresson). Mass., Ont.

Lophyrus melliceps Cresson, 1880. Amer. Ent. Soc., Trans. 8: 26. $q$. 
suffusus (Cresson). Que., Maine, Mass., Conn., Ont., N. Y. Host: Juniperns virginiana, Thuja occidentalis.

Lophymis suffusus Cresson, 1880. Amer. Ent. Soc., Trans. 8: 26. $q$.

Monoctenus juniperinus MacGillivray, 1894. Canad. Ent. 26: 328.. N. syn.

Biology: Britton, 1925. Conn. (State) Agr. Expt. Sta., Bul. 265: 336. -Brown, 1940. Canada

Dept. Agr., Forest Ins. Survey, 4th Ann. Rpt. for 1939, p. 18.

\section{Genus AUGOMONOCTENUS Rohwer}

Augomonoctenus Rohwer, 1918. Ent. Soc. Wash., Proc. 20: 81.

Type-species: Augomonoctenus libocedrii Rohwer. Orig. desig.

An exclusively North American genus, where it is found in Oregon, California, and Arizona. The Arizona species is unidentified.

libocedrii Rohwer. Oreg., Calif. Ecology: Larvae feed inside cones. Host: Libocedrus decurrens.

Augomonoctenus libocedrii Rohwer, 1918. Ent. Soc. Wash., Proc. 20: 81..

Biology: Middlekauff, 1967. Pan-Pacific Ent. 43: 272.

pilosus Middlekauff. Calif. (Cholame, San Luis Obispo Co.).

Augomonoctenus pilosus Middlekauff, 1967. Pan-Pacific Ent. 43: 272. ․

SubFamily DIPRIONINAE

Larvae of this subfamily feed on Pinaceae.

\section{Genus ZADIPRION Rohwer}

Neodiprion subg. Zadiprion Rohwer, 1918. Ent. Soc. Wash., Proc. 20: 83.

Type-species: Diprion grandis Rohwer. Orig. desig.

A small genus of four or five species, two of which are found in the United States, the others in Mexico.

Revision: Middleton, 1931. Ent. Soc. Wash., Proc. 33: 165-170. - Smith, 1971. Ent. Soc. Wash., Proc. 73: 187-197.

Taxonomy: Smith, 1974. Ent. Soc. Wash., Proc. 76: 415 (key to spp.). rohweri (Middleton). Colo, N. Mex., Utah, Nev., Calif. Host: Pinus monophylla, P. edulis.

Neodiprion (Zadiprion) rohweri Middleton, 1931. Ent. Soc. Wash., Proc. 33: 166. १, ð. townsendi (Cockerell). S. Dak., Nebr., Colo., N. Mex., Ariz. Host: Pinus ponderosa.

Lophyrus townsendi Cockerell, 1898. Ann. and Mag. Nat. Hist. (ser. 7) 2: 457..

Diprion grandis Rohwer, 1912. U. S. Natl. Mus., Proc. 43: 208. ‡, §.

Biology: Swenk, 1911. Nebr. Agr. Expt. Sta., Ann. Rpt. 24, pp. 1-33 ("bull pine sawfly").

\section{Genus NEODIPRION Rohwer}

Neodiprion Rohwer, 1918. Ent. Soc. Wash., Proc. 20: 83.

Type-species: Lophyrus lecontei Fitch. Orig. desig.

All species of Neodiprion are found in North America. The only Palaearctic species, N. sertifer, was accidentally introduced. In North America, representatives of this genus are found as far south as El Salvador. Neodiprion contains most of the destructive species of Diprionidae in North America. Damage is caused by larval defoliation of valuable timber species in forest stands, plantations, and ornamental plantings. Outbreaks occur sporadically, sometimes over extensive areas and result in loss of growth and occasionally tree mortality. Life cycles differ between species. In general, oviposition is in the needles of the host and the larvae feed gregariously at first but later spread out in search of new food. Feeding may be on the new or old growth, or both. Mature larvae go into the ground and spin a tough, papery cocoon in which they pupate. Overwintering is either as an egg in the foliage or in a cocoon in the ground, and there may be from one to five generations per year depending on the species and climate. 
The taxonomy of this genus is based on female genitalia, though in many cases it is necessary to have larvae and accompanying biological data for correct determination. Determination of a single stage is sometimes not possible. Characters have not been found for separation of males. A number of confusing species complexes remain to be studied, and the listing below is not so clear-cut as it appears. Some complexes may represent a single species with a number of geographic or food plant races or may represent a number of separate species units. Complications arise when apparently similar larvae produce different adults and different larvae produce similar adults. Further taxonomic work on Neodiprion will have to involve studies of all stages and biologies of each form from different parts of their ranges. Those who encounter Neodiprion in the field are urged to rear adults, keep associated larvae of each instar, and take notes on their life cycles.

Revision: Atwood and Peck, 1943. Canad. Jour. Res., Sect. D., Zool. Sci. 21: 109-144 (pine feeding species of e. Canada). - Ross, 1955. Forest Sci. 1: 196-209 (N. Amer. species).

Taxonomy: West, Horwood, Bourns, and Hudson, 1959. Ent. Soc. Ont., Rpt. 89: 58-68 (serological and chromatographic studies). - Wallace, 1964. Canad. Ent. 96: 162 (spectrophotometry in taxonomy). - Schaefer and Wallace, 1967. Canad. Ent. 99: 574-577 (larval hemolymph amino acids as a taxonomic character).

Biology: Keen, 1938. U. S. Dept. Agr., Misc. Pub. 273 (rev. 1952), pp. 116-120 (western forests). - Schaffner, 1943. Jour. Forestry 41: 580-588 (conifer sawflies in n. e. states). -Atwood, 1943. In Atwood and Peck, Canad. Jour. Res., Sect. D, Zool. Sci. 21: 123-137 (pine feeding species in e. Canada). - Craighead, 1950. U. S. Dept. Agr., Misc. Pub. 657, pp. 550-557 (eastern forests). - McCormick and Andresen, 1961. Amer. Mus. Nov. 2032, 6 pp. (in s. N. J.). - MacAloney and Schmiege, 1962. U. S. Dept. Agr., Forest Service, Lake States Forest Expt. Sta. Paper 100, 42 pp. (conifer insects). - Baker, 1972. U. S. Dept. Agr., Misc. Pub. 1175, pp. 439-450 (eastern forests).

\section{SPECIES GROUP LECONTE!}

abbotii (Leach). Que., Ont. to Fla. w. to Wis. Host: Pinus caribaea, P. echinata, P. elliottii var. densa, $P$. heterophylla, $P$. palustris, $P$. resinosa, $P$. taeda.

Lophymis Abbotii Leach, 1817. Zool. Misc., v. 3, p. 120. . .

Lophyrus Fabricii Leach, 1817. Zool. Misc., v. 3, p. 120. ?.

Lophyrus americanus Leach, 1817. Zool. Misc., v. 3, p. 120.? .

Lophyrus rileyi Cresson, 1880. Amer. Ent. Soc., Trans. 8: 25. ․ .

Neodiprion (Neodiprion) eximina Rohwer, 1921. U. S. Natl. Mus., Proc. 59: 92. . .

Neodiprion (Neodiprion) ferrugineum Middleton, 1933. Canad. Ent. 65: 82. . .

Neodiprion flemingi Peck, 1943. in Atwood and Peck, Canad. Jour. Res., Sect. D, Zool. Sci. 21: 121. ․

Biology: Atwood, 1943. In Atwood and Peck, Canad. Jour. Res., Sect. D. Zool. Sci. 21: 132-133 (larva, biology of flemingi). - Hetrick, 1956. Forest Sci. 2: 181 (as abbottii). - Finlayson, 1963. Canad. Ent. 95: 475-476 (parasites). -Baker, 1972. U. S. Dept. Agr., Misc. Pub. 1175, p. 447.

compar (Leach). N. B., Que., Ont., Va., N. C., Ga., Fla. Host: Pinus banksiana, P. resinosa, and probably other pines.

Lophyrus compar Leach, 1817. Zool. Misc., v. 3, p. 120. \&.

Lophyrus lateralis Cresson, 1880. Amer. Ent. Soc., Trans. 8: 25..

Neodiprion lanielensis Peck, 1943. In Atwood and Peck, Canad. Jour. Res., Sect. D, Zool. Sci. 21: 115 . $₹, \delta$.

Biology: Atwood, 1943. In Atwood and Peck, Canad. Jour. Res., Sect. D, Zool. Sci. 21: 132 (larva, biology of lanielensis).

dubiosus Schedl. Ont., Wis. and probably adjacent states and provinces. Host: Pinus banksiana.

Neodiprion dubiosus Schedl, 1933. Ztschr. f. Angew. Ent., Beihefte 20: 449. Larva.

Taxonomy: Schedl, 1935. Deut. Ent. Gesell. Mitt. 6: 39-44 (adults). - Becker, Wilkinson, and Benjamin, 1966. Ent. Soc. Amer., Ann. 59: 173-178 (female, larva; separation from related species). 
Biology: Schedl, 1937. Ztschr. f. Angew. Ent., Beihefte 24: 51-54. - Schedl, 1939. Internatl.

Kong. Ent., Berlin 1938, sect. 7, bd. 3, pp. 2053-2103.

excitans Rohwer. Del., Va. to Fla. w. to Ill., Okla., Tex.; Brit. Honduras(?), El Salvador(?). Host: Pinus clausa, $P$. echinata, $P$. elliottii, P. glabra, $P$. palustris, $P$. rigida, $P$. serotina, $P$. taeda.

Neodiprion (Neodiprion) excitans Rohwer, 1921. U. S. Natl. Mus., Proc. 59: 93. १, ठ.

Biology: Hetrick, 1956. Forest Sci. 2: 182 ("exitans"). - Hetrick, 1959. Fla. Ent. 42: 159.

-Fatzinger, 1964. Jour. Econ. Ent. 57: 412 (larval survival of subfreezing temperatures).

-Wilkinson, 1964. Jour. Econ. Ent. 57: 786 (collection of cocoons in tree bands).

-Wilkinson, 1964. Canad. Ent. 96: 1142 (development in relation to oviposition and pine needle growth). - Thatcher, 1967. U. S. Dept. Agr., Forest Pest Leaflet 105, 4 pp.

-Wilkinson, 1968. Fla. Ent. 51: 199. - Wilkinson, 1971. Fla. Ent. 54: 343-344 (on Pinus

clausa in Fla.). - Baker, 1972. U. S. Dept. Agr., Misc. Pub. 1175, pp. 449-450. - Doggett, 1972. Jour. Econ. Ent. 65: 701-702 (in N. C.).

hetricki Ross. Va., S. C. Host: Pinus taeda, P. serotina.

Neodiprion hetricki Ross, 1955. Forest Sci. 1: 202. , ð.

Biology: Hetrick, 1956. Forest Sci. 2: 182. - Baker, 1972. U. S. Dept. Agr., Misc. Pub. 1175, p. 450 (hosts).

lecontei (Fitch). N. B., Que., Ont. to Fla. w. to Minn., Mo., Ark., Tex. Ecology: Larvae feed on many species of native and exotic pines, but adults oviposit only on hard pines. This species shows a preference for trees less than $15 \mathrm{ft}$. high and is often a problem in nurseries and plantations. Larvae may feed on the tender bark of young twigs as well as on pine needles. Host: Pinus banksiana, $P$. sylvestris, $P$. clausa, $P$. echinata, $P$. elliottii, $P$. palustris, $P$. resinosa, $P$. rigida, $P$. taeda, $P$. virginiana are preferred hosts. The following are sometimes attacked when growing with the preferred hosts: Pinus contorta, $P$. densiflora, $P$. monticola, $P$. mugho, $P$. nigra, $P$. ponderosa, $P$. strobus, $P$. thumbergii, Cedrus deodara, Larix laricina, Picea abies, Thuja occidentalis. Redheaded pine sawfly.

Lophyrus lecontei Fitch, 1858. N. Y. State Agr. Soc., Trans. 17: 744.

Biology: Middleton, 1921. Jour. Agr. Res. 20: 741-760. - Middleton, 1922. U. S. Dept. Agr., Farmers' Bul. 1259, 3 pp. - Beal, 1942. Jour. Forestry 40: 562-563 (host mortality).

-Schaffner, 1951. U. S. Dept. Agr., Leaflet 296, 4 pp. - Baldwin and House, 1954. Canad. Jour. Zool. 32: 9-15 (effects of thermal conditioning in larva). -Green, 1954. Canad. Ent. 86: 261-274 (humidity reactions and water balance of larva). -Green, 1954. Canad. Ent. 86: 371-376 (function of eyes and antenna in orientation). - Benjamin, 1955. U. S. Dept. Agr., Tech. Bul. 1118, 57 pp. (biology, control, literature prior to 1954). -MacAloney, 1957. U. S. Dept. Agr., Forest Pest Leaflet 14, 4 pp. - Griffiths, 1960. Canad. Ent. 92: 430-435 (oviposition). - Finlayson, 1963. Canad. Ent. 95: 478-480 (parasites). - Wilson, 1970. U. S. Dept. Agr., Forest Pest Leaflet 14 (rev.), 6 pp. - Baker, 1972. U. S. Dept. Agr., Misc. Pub. 1175 , pp. 439-441.

maurus Rohwer. Ont., Wis., Minn. Host: Pinus banksiana.

Neodiprion (Neodiprion) maurus Rohwer, 1918. Ent. Soc. Wash., Proc. 20: 89. \&, ð.

Biology: Atwood, 1943. In Atwood and Peck, Canad. Jour. Res., Sect. D, Zool. Sci. 21: 131. - Tripp and Wallace, 1965. Canad. Dept. Forestry, Forest Ent. and Path. Branch Ann. Rpt. 1965, p. 95.

merkeli Ross. Ga., Fla. Host: Pinus elliottii var. densa. Slash pine sawfly. Neodiprion merkeli Ross, 1961. Ent. Soc. Amer., Ann. 54: 452. ^, ठ.

Biology: Wilkinson, 1965. Fla. Ent. 48: 271. -Wilkinson, 1968. Fla. Ent. 51: 199. (a hybrid of N. warreni X N. excitans? ). - Wilkinson, 1971. Ent. Soc. Amer., Ann. 64: 241-247 (oviposition pattern; descriptions of stages).

nigroscutum Middleton. Ont., Mich., Wis. Host: Pinus banksiana is preferred, but also on $P$. resinosa, $P$. strobus.

Neodiprion (Neodiprion) nigroscutum Middleton, 1933. Canad. Ent. 65: 80. .

Taxonomy: Wallace and Sipple, 1958. Jour. Econ. Ent. 51: 125 (distribution). 
Biology: Becker and Benjamin, 1967. Canad. Ent. 99: 146-159.

pinetum (Norton). Newfoundland to N. C. w. to Ill., Iowa, Mo. Ecology: Found especially in ornamental plantings of white pine. Host: Pinus strobus, to a much lesser extent Pinus echinata, $P$. mugho, $P$. resinosa, $P$. rigida. White pine sawfly.

Lophyrus pinetum Norton, 1869. Amer. Ent. Soc., Trans. 2: 328. .

Lophymis pinetorum Dalla Torre, 1894. Cat. Hym., v. 1, p. 297. Emend.

Biology: Britton, 1925. Conn. (State) Agr. Expt. Sta., Bul. 265: 337. - Brown, 1938. Ont. Ent. Soc., Ann. Rpt. 1937, p. 14. - Pierson, 1943. Maine Forestry Comm., Ed. 5, p. 55. - Atwood, 1943. In Atwood and Peck, Canad. Jour. Res., Sect. D, Zool. Sci. 21: 128. - Reeks and Smith, 1945. Acad. Nat. 2: 10. - Finlayson, 1963. Canad. Ent. 95: 481-482 (parasites). -Baker, 1972. U. S. Dept. agr., Misc. Pub. 1175, p. 446.

pinusrigidae (Norton). Maine, Mass., N. Y., N. J. Host: Pinus rigida, P. echinata. Lophymus pinus-rigida Norton, 1868. In Packard, Guide Study Ins., p. 228.

Lophyms Akhursti Norton, 1869. Amer. Ent. Soc., Trans. 2: 234. \&.

Lophyrus pini-rigidae Packard, 1881. Ins. Injurious Trees, pp. 399-400. Emend.

Biology: Schaffner, 1943. Jour. Forestry 41: 587.

pratti banksianae Rohwer. N. B., Que. w. to Man., Mich., Wis., Minn. Host: Pinus banksiana; also on Pinus resinosa and P. sylvestris if grown with preferred host. Jack pine sawfly. Neodiprion (Neodiprion) banksianae Rohwer, 1925. Ent. Soc. Wash., Proc. 27: 115. \&, o. Neodiprion (Neodiprion) ontarioensis Middleton, 1933. Canad. Ent. 65: 83..

Biology: Atwood, 1943. In Atwood and Peck, Canad. Jour. Res., Sect. D, Zool. Sci. 21: 130. -Green, 1954. Canad. Ent. 86: 261-274 (humidity reactions and water balance of larva). -Ghent, 1955. Canad. Ent. 87: 229-238 (oviposition). - Shenefelt and Benjamin, 1955. Wis. Agr. Col., Ext. Cir. 500: 30-31. - Green and de Freitas, 1955. Canad. Ent. 87: 427 (frass drop studies). - Ghent, 1957. Canad. Jour. Zool. 36: 175-183 (feeding orientation). - Ewan, 1957. U. S. Dept. Agr., Forest Pest Leaflet 17, 4 pp. -Ghent, 1960. Behaviour 16: 110-148 (group feeding behavior of larvae). - Griffiths, 1960. Canad. Ent. 92: 653-658 (parasites). -Finlayson, 1963. Canad. Ent. 95: 482-483 (parasites), - Moens and Atwood, 1963. Canad. Ent. 95: 779-782 (inheritance of larva color pattern). - McLeod, 1968. Canad. Bi-Monthly Res. Notes 24: 5-6 (in Que.). -Tostowaryk, 1971. Ent. Soc. Amer., Ann. 64: 1424-1427 (relationship between parasitism and predation). - Baker, 1972. U. S. Dept. Agr., Misc. Pub. 1175, pp. 442-443.

Morphology: Ghent, 1956. Canad. Ent. 88: 17-23 (linear increment in width of head capsule). pratti paradoxicus Ross. N. S., N. B., Maine s. to Md. Host: Pinus banksiana, P. rigida, $P$. sylvestris, P. echinata.

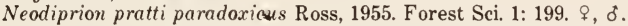

Biology: Forbes, Underwood, Cuming, and Eidt, 1961. Canad. Dept. Forestry, Forest Ent. and Path. Branch, Ann. Rpt. 1961, p. 27. - Baker, 1972. U. S. Dept. Agr., Misc. Pub. 1175, p. 443.

pratti pratti (Dyar). N. J. to N. C. w. to Ohio, Ind., Ill., Ky. Host: Pinus virginiana, P. echinata are preferred hosts, but also on Pinus rigida, $P$. taeda, $P$. palustris, $P$. resinosa, and Picea abies.

Lophyrus pratti Dyar, 1899. Ent. Soc. Wash., Proc. 4: 262..

Neodiprion (Neodiprion) dyari Rohwer, 1918. Ent. Soc. Wash., Proc. 20: 85. \&, ð.

Biology: Hetrick, 1956. Forest Sci. 2: 183. - McIntyre and Dutky, 1961. Jour. Econ. Ent. 54: 809-810 (virus for control). - Bobb, 1963. Jour. Econ. Ent. 56: 618-621. - Morris,

Schroeder, and Bobb, 1963. Pine sawfly in Va., Va. Div. Forestry, 42 pp. - Schaefer, 1964.

U. S. Forest Service, Res. Paper WO-2, 8 pp. - Bobb, 1965. Jour. Econ. Ent. 58: 925-926

(parasites, predators). -Baker, 1972. U. S. Dept. Agr., Misc. Pub. 1175, pp. 441-442.

Morphology: Schaefer, 1965. Canad. Ent. 97: 941-945 (fatty acids). - Schaefer, Kaplanis, and Robbins, 1965. Jour. Ins. Physiol. 11: 1013-1021 (relations of sterols to two host plants).

rugifrons Middleton. Ont., Wis. Host: Pinus banksiana.

Neodiprion (Neodiprion) mifrons Middleton, 1933. Canad. Ent. 65: 79. ९.

Taxonomy: Becker, Wilkinson, and Benjamin, 1966. Ent. Soc. Amer., Ann. 59: 173-178. 
Biology: Wilkinson, Becker, and Benjamin, 1966. Ent. Soc. Amer., Ann. 59: 786-792. - Baker, 1972. U. S. Dept. Agr., Misc. Pub. 1175, p. 447.

swainei Middleton. N. B., Que. w. to Man., Mich., Wis., Minn. Host: Pinus banksiana is preferred, but also on Pinus resinosa, $P$. strobus, and $P$. sylvestris if near preferred host. Swaine jack pine sawfly.

Neodiprion (Neodiprion) swainei Middleton, 1931. Ent. Soc. Wash., Proc. 33: 171. \&, o.

Biology: Atwood, 1943. In Atwood and Peck, Canad. Jour. Res., Sect. D, Zool. Sci. 21: 137. -Ghent and Wallace, 1958. Forest Sci. 4: 264-272 (oviposition), - Wallace and Sipple, 1958. Jour. Econ. Ent. 51: 125 (in Mich.). -Franklin, 1959. Ent. News 70: 62. -Smirnoff, 1959. Canad. Ent. 91: 246-248 (predators). - Smirnoff, 1960. Canad. Ent. 92: 957-958 (migration phenomenon). -Smirnoff, 1961. Jour. Ins. Path. 3: 29-46 (virus diseases). - McLeod, 1961. Canad. Ent. 93: 888 (extracting cocoons from soil). - Tripp, 1961. Canad. Ent. 93: 40 (parasites). -Benjamin and Underwood, 1953. Jour. Econ. Ent. 46: 703. - Tripp, 1962. Canad. Ent. 94: 908 (parasites). - Lyons, 1962. Canad. Ent. 94: 49-58 (effect of aggregation on egg and larval survival). - Finlayson, 1963. Canad. Ent. 95: 483-484 (parasites). - Pilon, Tripp, McLeod, and Ilnitzky, 1964. Canad. Ent. 96: 1450 (temperature influence on prespinning eonymphs). - Becker and Benjamin, 1964. Canad. Ent. 96: 589-599. - Lyons, 1964. Canad. Ent. 96: 1373-1407 (spatial distribution, sampling), -Lyons, 1964. Ont. Ent. Soc., Proc. 94: 5-37. - Tripp, 1965. Canad. Ent. 97: 92. -McLeod, 1966. Canad. Ent. 98: 430-447 (cocoon distribution). - Pilon, 1966. Canad. Ent. 98: 789 (temperature and humidity influence on life span of adults). - Smirnoff, 1967. Canad. Ent. 99: 242-248 (virus diseases). -Smirnoff, 1967. Jour. Ins. Path. 9: 269-271 (virus diseases). -Smirnoff, 1967. Canad. Ent. 99: 214-216 (detecting viruses). - Smirnoff, 1968. Canad. Ent. 100: 313-318 (cysts in pupae). -Lyons, 1970. Canad. Ent. 102: 68-84 (reproductive capacity). -McLeod, 1970. Forestry Chronicle 46: 1-8 (epidemiology). - Tostowaryk, 1971. Ent. Soc. Amer., Ann. 64: 1424-1427 (relationship between parasitism and predation). - Philogene and Benjamin, 1971. Jour. Ins. Physiol. 17: 1711-1716 (diapause as influenced by temperature and photoperiod). -Philogene, 1971. Canad. Jour. Zool. 49: 449-450 (sensitivity of larvae to light). -Smirnoff, 1971. Phytoprotection 52: 24-27 (management of blueberry fields to protect surrounding jack pine stands against swainei). - Smirnoff, 1971. Canad. Ent. 103: 356-362 (transmission of disease by means of swainei parasites). - Philogene and Benjamin, 1971. Canad. Ent. 103: 1705-1715 (temperature and photoperiod effect on immature stages and adults). -Baker, 1972. U. S. Dept. Agr., Misc. Pub. 1175, pp. 444-445.

taedae linearis Ross. Ohio, S. C. w. to Ill., Mo., Tex. Host: Pinus taeda, P. echinata. Neodiprion taedae linearis Ross, 1955. Forest Sci. 1: 199, 204. ๆ, ठ.

Biology: Warren and Coyne, 1958. Ark. Agr. Expt. Sta., Bul. 602, 23 pp. -Coyne, 1959. U. S. Dept. Agr., Forest Pest Leaflet 34, 4 pp. - Wingfield and Warren, 1971. Kans. Ent. Soc., Jour. 44: 491-500 (effect of temperature on cocoon stage). - Wingfield and Warren, 1972. Kans. Ent. Soc., Jour. 45: 1-6 (effect of photoperiod on development). - Baker, 1972. U. S. Dept. Agr., Misc. Pub. 1175, pp. 443-444.

taedae taedae Ross. Va. and probably adjacent states. Host: Pinns taeda, to a lesser extent Pinus echinata, $P$. virginiana.

Neodiprion taedae taedae Ross, 1955. Forest Sci. 1: 199, 204. ‡, ठ.

Biology: Hetrick, 1941. Jour. Econ. Ent. 34: 373-377 (americanum, nec Leach). - Hetrick, 1956. Forest Sci. 2: 183. - Baker, 1972. U. S. Dept. Agr., Misc. Pub. 1175, p. 443.

virginiana Rohwer. Va., W. Va., N. C., Tenn., Fla. Host: Pinus virginiana, P. clausa. Records in literature, especially from Canada and the North Central states, pertaining to virginiana are probably not this species. Species limits for this probable complex are not yet settled.

Neodiprion (Neodiprion) virginiana Rohwer, 1918. Ent. Soc. Wash., Proc. 20: 87., ,.

Neodiprion (Neodiprion) affinis Rohwer, 1918. Ent. Soc. Wash., Proc. 20: 88. \&, §.

warreni Ross. Fla., La., Ark. Host: Pinus echinata, P. glabra.

Neodiprion warreni Ross, 1961. Ent. Soc. Amer., Ann. 54: 451. ㅇ, o.

Biology: Wilkinson, 1968. Fla. Ent. 51: 199. 
SPECIES GROUP SERTIFER

abietis (Harris). Newfoundland to Alaska s. to Maine, Mich., Minn., Calif. Ecology: Widespread. Host: Abies balsamea, A. concolor, A. magnifica, Picea glauca, $P$. mariana, $P$. engelmannii, $P$. sitchensis, Tsuga heterophylla, Psendotsuga menziesii. Biologically different material has been reared from different hosts, and there are slight differences in structure and color between populations of this species complex. Balsam fir sawfly. Lophyrus abietis Harris, 1841. Rpt. Ins. Mass. Injurious to Veg., p. 376. Larva.

Biology: Bird, 1929. Ont. Ent. Soc., Ann. Rpt. 1929, pp. 76-82. - Brown, 1933. Canad. Dept. Agr., Forest Biol. Pub. 2, 4 pp. - Brown, 1941. Canad. Dept. Agr., Pub. 712: 50.

-Schaffner, 1943. Jour. Forestry 41: 583. - Pierson, 1943. Maine Forest Comm., Ed. 5, p. 17. - Reeks and Smith, 1945. Acad. Nat. 2: 10. - Struble, 1957. Forest Sci. 3: 306-310 (in Calif.). - Struble, 1959. Jour. Forestry 57: 510-511 (egg sampling). - Finlayson, 1963. Canad. Ent. 95: 476-478 (parasites). -Tripp and Wallace, 1965. Canad. Dept. Forestry, Forest Ent. and Path. Br., Ann. Rpt. 1965, p. 95. - Baker, 1972. U. S. Dept. Agr., Misc. Pub. 1175, pp. 446-447. - Knerer and Atwood, 1973. Science 179: 1090-1099 (behavior; splitting the $N$. abietis complex).

burkei Middleton. Mont., Wyo. Host: Pinus contorta. Lodgepole sawfly. Neodiprion (Neodiprion) burkei Middleton, 1931. Ent. Soc. Wash., Proc. 33: 174. ๆ, ơ.

Biology: Burke, 1932. U. S. Dept. Agr., Cir. 224: 11-19.

deleoni Ross. Wash. (North Port). Host: Abies grandis. Neodiprion deleoni Ross, 1955. Forest Sci. 1: 200, 205. ९, ठ.

demoides Ross. Calif. (Yosemite Natl. Pk.). Host: Pinus albicaulis. Neodiprion demoides Ross, 1955. Forest Sci. 1: 201, 205. \&, o.

edulicolus Ross. Colo., N. Mex., Utah, Nev. Host: Pinus edulicolus, P. monophylla. Neodiprion edulicolus Ross, 1955. Forest Sci. 1: 201, 206. १, ठ.

Biology: McGregor and Sandin, 1968. Canad. Ent. 100: 51-57.

fulviceps (Cresson). Mont., Colo. w. to Oreg., Calif.; Mexico. Host: Pinus ponderosa, P. jeffreyi, $P$. lambertiana, $P$. radiata, $P$. coulteri. Either a variable species or a confusing species complex.

Lophyrus fulviceps Cresson, 1880. Amer. Ent. Soc., Trans. 8: 25..

Biology: Dahlsten, 1961. Canad. Ent. 93: 182-195 (Neodiprion sp.). - Stark and Dahlsten, 1961. Canad. Ent. 93: 443-450 (cocoon distribution), - Stark and Dahlsten, 1965. Canad. Ent. 97: 550-552 (egg distribution). -Dahlsten, 1966. Canad. Ent. 98: 1055-1083 (biological differences indicate several distinct populations). - Dahlsten, 1967. Ecology 48: 275.

Morphology: Daly, 1963. Ent. Soc. Amer., Ann. 56: 303.

gillettei (Rohwer). Colo., N. Mex., Ariz.; Mexico. Host: Pinus ponderosa. Lophyris gillettei Rohwer, 1908. N. Y. Ent. Soc., Jour. 16: 113. १, ठ.

mundus Rohwer. Oreg., Calif. Host: Pinus ponderosa.

Neodiprion (Neodiprion) mundus Rohwer, 1918. Ent. Soc. Wash., Proc. 20: 86. 9.

nanulus contortae Ross. Alta., Idaho, Oreg. Host: Pinus contorta, P. ponderosa.

Neodiprion nanulus contortae Ross, 1955. Forest Sci. 1: 201, 207. \&, ठ.

nanulus nanulus Schedl. N. S., N. B. to N. J. w. to Man., Sask., Wis. Host: Pinus resinosa, P. banksiana, $P$. contorta, $P$. rigida, $P$. echinata, $P$. mugho. Red pine sawfly. Neodiprion nanulus Schedl, 1933. Ztschr. f. Angew. Ent., Beihefte 20: 449. Larva.

Taxonomy: Schedl, 1935. Deut. Ent. Gesell., Mitt. 6: 41-44 (adults).

Biology: Schedl, 1937. Ztschr. f. Angew. Ent., Beihefte 24: 51. - Schedl, 1939. Internatl. Kong. Ent., Berlin 1938, sect. 7, bd. 3, pp. 2053-2056. - Atwood, 1943. In Atwood and Peck, Canad. Jour. Res., Sect. D, Zool. Sci. 21: 134. -Cannola, Waters, and Nason, 1959. Jour. Econ. Ent. 52: 600 (sequential sampling of eggs). - Kapler and Benjamin, 1960. Forest Sci. 6: 253 (biology in Wis.). - Underwood, 1960. Canad. Ins. Pest Rev. 38: 32. -McCormick and Andresen, 1961. Amer. Mus. Nov. 2032, 6 pp. - Finlayson, 1963. Canad. Ent. 95: 480-481 (parasites). - Tripp and Wallace, 1965. Canad. Dept. Forestry, Forest Ent. and Path. Br., Ann. Rpt. 1965, p. 95.-Underwood, 1967. Canad. Ent. 99: 1114-1116 (parasites). -Baker, 1972. U. S. Dept. Agr., Misc. Pub. 1175, pp. 445-446. 
scutellatus Rohwer. Idaho, Wash. Host: Pseudotsuga menziesii.

Neodiprion (Neodiprion) scutellatus Rohwer, 1918. Ent. Soc. Wash., Proc. 20: 86..

Biology: Smith, 1962. Pan-Pacific Ent. 38: 189 (parasites; as scutellaris(!)).

sertifer (Geoffroy). Maine, Ont. to N. J. w. to S. Dak., Iowa, Mo.; Europe to Japan, Korea. Accidentally introduced, first found in N. J. in 1925. Host: Pinus austriaca, P. cembra, $P$. banksiana, $P$. densiflora, $P$. echinata, $P$. montana, $P$. mugho, $P$. nigra, $P$. ponderosa, $P$. resinosa, $P$. rigida, $P$. strobus, $P$. sylvestris, $P$. thunbergii, and many other pines in Eurasia. European pine sawfly.

Tenthredo sertifera Geoffroy, 1785. In Fourcroy, Ent. Paris. v. 2, p. 378.

Tenthredo pectinata mufa Retzius, 1783. Genera et Species Insectorum, p. 74. Preocc. on pg. 71.

Tenthredo pini mufa Villers, 1789. Linn. Ent. 3: 88.

Tenthredo juniperi Christ, 1791. Naturgesch. Class. Nomencl., Ins. p. 432.

Tenthredo rufa Latreille, 1807. Gen. Crust. Ins., v. 3, p. 230.

Lophyrus piceae Lepeletier, 1823. Monog. Tenthred., p. 56. ๆ, o.

Lophyrus basalis Matsumura, 1915. Dai-Nippon Gaityu Zensho 2: 288.

Biology: Soraci, 1939. N. Y. Ent. Soc., Jour. 47: 124. -Schaffner, 1939. Jour. Econ. Ent. 32: 887-888. - Hamilton, 1941. Natl. Shade Tree Conf., Proc. 17: 110-118. - Schaffner, 1943. Jour. Forestry 41: 583. -Girth and McCoy, 1946. N. J. Dept. Agr., Cir. 363, 18 pp. -Bird and Whalen, 1953. Canad. Ent. 85: 433 (virus). -Bird, 1953. Canad. Ent. 85: 437-446 (virus diseases). -Baldwin and House, 1954. Canad. Jour. Zool. 32: 9 (thermal conditioning effects on larva). - Benjamin, Larson, and Drooz, 1955. Jour. Forestry 53: 359. - Finlayson and Finlayson, 1958. Canad. Ent. 90: 223-225 (parasites). -Wilson, 1966. Jour. Econ. Ent. 59: 1043-1049 (effect of population levels on young scotch pines). - Griffiths, 1959. Canad. Ent. 91: 501-512. -Ghent, 1959. Canad. Jour. Zool. 37: 267 (oviposition). -Will, 1960. Pa. Acad. Sci., Proc. 34: 229. - Finlayson, 1960. Canad. Ent. 92: 20-40 (parasites). -Lyons and Griffiths, 1962. Canad. Ent. 94: 994 (development in cocoons). - Wallace and Sullivan, 1963. Canad. Ent. 95: 1051-1066 (effect of temperature on development in cocoon). - Lyons, 1964. Ont. Ent. Soc., Proc. 95: 5-37. - Lyons, 1964. Canad. Ent. 96: 1373 (spatial distribution). - Wilson, 1965. U. S. Dept. Agr., Forest Pest Leaflet 98, 8 pp. - Henson, 1965. Canad. Ent. 97: 773 (rearing techniques). —Sullivan, 1965. Canad. Ent. 97: 970 (ability of eggs to withstand low winter temperatures). - Sullivan and Wallace, 1965. Canad. Jour. Zool. 43: 233-245 (photoperiodism in development). - Austara, 1966. Norske Skogsforsoksv. Meddel. 21: 5-15. - Rose and Sipple, 1966. Canad. Ent. 98: 39-45 (cocoon and parasite distribution). - Wilson, 1966. U. S. Dept. Agr., Forest Pest Leaflet 99, 4 pp. -Wallace and Sullivan, 1966. Canad. Jour. Zool. 44: 147 (geographic variation in photoperiod reaction). - Sullivan and Wallace, 1967. Canad. Ent. 99: 834-850 (temperature and photoperiod effect on diapause). - Griffiths, 1968. Canad. Ent. 100: 1095-1099 (parasites). -Sullivan and Wallace, 1968. Canad. Jour. Zool. 46: 959-963. -Sullivan and Wallace, 1968. Canad. Jour. Zool. 46: 1082-1083 (photoperiod response). -Griffiths, 1969. Canad. Ent. 101: 673-713 (parasites). - Wilson, 1971. U. S. Dept. Agr., Forest Pest Leaflet (rev.), 6 pp. - Austara 1971. Norsk. Ent. Tidsskr. 18: 45-48 (cold hardiness in eggs).

-Baker, 1972. U. S. Dept. Agr., Misc. Pub. 1175, pp. 447-448. -Eisner, et al. 1974. Science 184: 996-999 (defensive use of a plant resin).

Morphology: Watson, 1955. Canad. Ins. Pest Rev. 33: 229 (gynandromorphs). - Togashi, 1958. Kontyu 25: 6-12 (internal reproductive organs). -Marek, 1963. Ceskoslov. Spolec. Zool. Vest. 27: 115-124 (physiology). - Pschorn-Walcher, 1970. Ztschr. f. Angew. Ent. 66: 63-68 (morphological differences between alpine and lowland populations).

tsugae Middleton. Mont., Idaho, Alaska, B. C., Wash., Oreg. Host: Tsuga heterophylla is preferred, but also on Tsuga mertensiana, Picea sitchensis, and Abies amabilis when adjacent to preferred host. Hemlock sawfly.

Neodiprion (Neodiprion) tsugae Middleton, 1933. Canad. Ent. 65: 77. ㅇ, ठ.

Biology: Hopping and Leech, 1936. Canad. Ent. 68: 71-91. - Furniss and Dowden, 1941 Jour.

Econ. Ent. 34: 46-52. - Downing, 1959. U. S. Dept. Agr., Forest Pest Leaflet 31, 4 pp.

-Torgersen, 1969. Ent. Soc. Brit. Columbia, Proc. 66: 53-62 (parasites). —Schmiege, 1970. 
U. S. Dept. Agr., Forest Pest Leaflet 31, 4 pp. - Hard and Schmiege, 1968. U. S. Dept.

Agr., Forest Service Paper, PNW-65, 11 pp. (in s. e. Alaska). - Hard, 1971. U. S. Dept.

Agr., Forest Service, Res. Note, Pacific Northwest Forest and Range Expt. Sta. 157, 8 pp. ventralis Ross. Colo. Host: Pinus ponderosa.

Neodiprion ventralis Ross, 1955. Forest Sci. 1: 201, 206. ९, ठ.

werneri Ross. Ariz. (Pinelino Mts., Hospital Flat, $9000 \mathrm{ft}$.).

Neodiprion werneri Ross, 1955. Forest Sci. 1: 200, 205. $\subsetneq$.

UNPLACED TAXA OF NEODIPRION ROHWER

Two of the following species were described from males. Because the taxonomy of Neodiprion is based primarily on females, they cannot be placed.

abdominalis (Say), n. comb. "North-west Territory."

Lophyrus abdominalis Say, 1824. In Keating, Narr. Long's 2nd Exped., v. 2 (App.), p. 315. ‥

edwardsii (Norton). Calif.

Lophyrus edwardsii Norton, 1869. Amer. Ent. Soc., Trans. 2: 330. ठ์.

hypomelas (Rohwer). Colo.

Lophyrus hypomelas Rohwer, 1908. N. Y. Ent. Soc., Jour. 16: 113. đ.

\section{Genus DIPRION Schrank}

Pteronus Jurine, 1801. Intell. Blatt. Litt-Ztg. Erlangen, v. 1, p. 163. Suppressed by Internatl. Comm. Zool. Nomencl., Op. 157, 1936.

Diprion Schrank, 1802. Fauna Bioca, v. 2, p. 209.

Type-species: Tenthredo pini Linnaeus. Desig. by Rohwer, 1910.

Lophyrus Latreille, 1802. Hist. Nat. Crust. Ins., v. 3, p. 302. Preocc. by Poli, 1791.

Type-species: Tenthredo pini Linnaeus. Monotypic.

Anachoreta Gistel, 1848. Naturgesch. Thierr. f. hoh. Schul., p. 9. N. name for Lophyrus Latreille.

Cristiger Gistel, 1848. Naturgesch. Thierr. f. hoh. Schul., p. 144.

Type-species: Tenthredo pini Linnaeus. Monotypic.

A Palaearctic genus of five or six species, one of which has been introduced into North America.

similis (Hartig). Que., Maine, Ont. to Va. w. to Minn., Ind.; Europe. Introduced, first recorded in Conn. in 1914, probably entering on imported nursery stock. Host: Pinus banksiana, $P$. cembra, $P$. divaricata, $P$. flexilis, $P$. montana, $P$. monticola, $P$. mugho, $P$. resinosa, $P$. rigida, $P$. strobus, $P$. sylvestris, $P$. taeda, $P$. virginiana, and many other pines in

Europe. Introduced pine sawfly.

Lophyrus similis Hartig, 1834. Forstl. Convers.-Lex., p. 987 b.

Lophyrus eremita Thomson, 1871. Hym. Scand., v. 1, p. 62.

Diprion simile var. atroscutellatum Enslin, 1916. Forstl. Naturw Ztschr. 14: 9.

Diprion simile var. claristernis Enslin, 1916. Forstl. Naturw. Ztschr. 14: 9.

Biology: Britton, 1916. Jour. Econ. Ent. 9: 281-282. -Zappe, 1917. Jour. Econ. Ent. 10: 188-190. - Middleton, 1923. U. S. Dept. Agr., Bul. 1182, 21 pp. - Hartley, 1923. Jour. Econ. Ent. 16: 386-388 (in Pa.; parasites). -Munro, 1935. Canad. Ent. 67: 137-140. - Peirson, 1943. Maine Forest Comm., Ed. 5, p. 15. - Schaffner, 1943. Jour. Forestry 41: 587. - Will, 1944. Pa. Acad. Sci., Proc. 18: 49. -Tsao and Hodson, 1956. Jour. Econ. Ent. 49: 400. -Coppel, 1960. Ent. Soc. Amer., Ann. 53: 847 (cocoons as habitats for other Arthropods). -Coppel, Casida, and Dauterman, 1960. Ent. Soc. Amer., Ann. 53: 510-512 (sex attractants). - Anderson and Schmiege, 1961. U. S. Dept. Agr., Forest Service, Lake States Forest Expt. Sta. Paper 88, p. 7. - Mertins, 1961. Wis. Acad. Sci. Arts and Letters, Trans. 59: 127-168. - Finlayson, 1962. Canad. Ent. 271-282 (parasites). - Casida, Coppel, and Watanabe, 1963. Jour. Econ. Ent. 56: 18-24. -Wilson, 1966. U. S. Dept. Agr., Forest Pest Leaflet 99, 4 pp. - Mertins and Coppel, 1971. Ann. Ent. Soc., Amer. 64: 1191-1192 (sexual behavior in gynandromorphs). - Baker, 1972. U. S. Dept. Agr., Misc. Pub. 1175, pp. 450-451. 
Morphology: Mertins and Coppel, 1972. Ent. Soc. Amer., Ann. 65: 33-38 (abdominal glands in female).

\section{Genus GILPINIA Benson}

Gilpinia Benson, 1939. Bul. Ent. Res. 30: 341.

Type-species: Lophyrus polytomus Hartig. Orig. desig.

A Palaearctic genus of about 24 species, two of which have been introduced into North America. In Asia, representatives of this genus are found as far south as Pakistan, northern India, and Thailand. In many references, the species below have been assigned to the genus Diprion.

frutetorum (Fabricius). Que., Maine, Ont. s. to N. J., Pa.; Europe to Siberia. Accidentally introduced, first found in Mass, and R. I. in 1932. Host: Pinus sylvestris, $P$. resinosa are favored, but also found on Pinus banksiana, $P$. strobus, $P$. mugho, $P$. nigra, and $P$. cembra in North America, and other pines in Eurasia.

Tenthredo frutetorum Fabricius, 1793. Ent. System., v. 2, p. 111.

Lophyrus variegatus Hartig, 1834. Forstl. Convers.-Lex., p. 990.

Lophyrus thom soni Konow, 1884. Deut. Ent. Ztschr. 28: 312.

Diprion frutetorum var. lutescens Enslin, 1916. Forstl. Naturw. Ztschr. 14: 13.

Diprion frutetorum var. luteolum Enslin, 1916. Forstl. Naturw. Ztschr. 14: 13.

Biology: Gray, 1938. Ont. Ent. Soc., Ann. Rpt. 1937, pp. 50-51. - Schaffner, 1943. Jour.

Forestry 41: 586. - Schaffner, 1944. Conn. State Ent., 43rd Rpt., 1943, Bull. 481, pp.

310-311. - Hsin, 1935. Ztschr. f. Angew. Ent., Beihefte 22: 254, 255-260, 267-271, 289-292

(biological study in Germany). - de Oliveira and Juillet, 1969. Phytoprotection 50: 59-69.

-Baker, 1972. U. S. Dept. Agr., Misc. Pub. 1175, pp. 451-452.

hercyniae (Hartig). Newfoundland, Que., Ont. to Pa. w. to Man.; Europe. Accidentally introduced, first found in Ont. in 1922 and in N. H. in 1929; first serious infestation was at Gaspe, Que. in 1930. Host: Picea glauca, P. mubens, P. mariana, P. abies, P. excelsa, $P$. pungens, $P$. sitchensis, and other species of spruce in infested areas here and in Europe. European spruce sawfly. Prior to 1941, the species found in North America was referred to under the name polytomum (Hartig).

Lophyrus hercyniae Hartig, 1837. Fam. Blattwespen und Holzwespen, nebst Einleitung Naturgesch. Hym., p. 123.

Taxonomy: Smith, 1938. Nature 141: 121. -Smith, 1941. Sci. Agr. 21: 245-305 (cytology and parthenogenesis). - Reeks, 1941. Canad. Ent. 73: 181-187 (hercyniae and polytomum as distinct species). - Balch, Reeks, and Smith, 1941. Canad. Ent. 73: 198-202. - Forster, 1949. Canad. Ent. 81: 112.

Biology: Dowden, 1931. Tree Pest Leaflet 34,4 pp. - Balch and Simpson, 1932. Canad. Ent. 64: 162-163. - Balch, 1934. Canad. Dept. Agr., Div. Forest Ins., Special Cir., 6 pp. - Balch, 1936. Canad. Ent. 68: 23-31. - MacAloney, 1936. Tree Pest Leaflet 6, 4 pp. - MacAloney, 1936. Jour. Forestry 34: 125-129. - Atwood, 1938. Ont. Ent. Soc., Ann. Rpt. 1937, pp. 48-50. -Peirson and Nash, 1939. Maine Forest Comm., 22nd Bien. Rpt. 1937-1938, pp. 79-96.

-Balch, 1939. Jour. Econ. Ent. 32: 412-418. - Dowden, 1939. Jour. Econ. Ent. 32: 619-624. - Prebble, 1941. Canad. Jour. Res. 19: 295-322, 323-346, 350-362 (diapause). -Brown, 1941. Canad. Dept. Agr., Pub. 712, 5 pp. - Goebeil, 1941. Canad. Jour. Res. 19: 363-382 (diapause). -Goebeil, 1942. Jour. Econ. Ent. 35: 677-679 (diapause). - Schaffner, 1943. Jour. Forestry 41: 585-586. - Balch and Bird, 1944. Sci. Agr. 25: 65-80. - Reeks and Smith, 1945. Acad. Nat. 2: 10. - Morris, 1949. Mich. Univ. School Forestry and Conserv., Bul. 12, 58 pp. - Morris, 1951. Canad. Ent. 83: 133-147. - Finlayson and Finlayson, 1958. Canad. Ent. 90: 584 (parasites). - Finlayson, 1960. Canad. Ent. 92: 922-941 (parasites). - Balch, 1960. Canad. Ent. 92: 301. - Martineau, 1963. Canad. Ent. 95: 317. - Neilson and Morris, 1964. Canad. Ent. 96: 773-784 (regulation in Maritime Provinces, 1937-1963). - Monteith, 1967. Canad. Ent. 99: 682-685 (responses to food plant and tachinid parasite). - Baker, 1972. U. S. Dept. Agr., Misc. Pub. 1175, pp. 452-453. -Wong, 1972. Canad. Ent. 104: 755-756 (spread in Man.).

Morphology: Reeks, 1937. Canad. Ent. 69: 257-264 (adult). 


\section{Family TENTHREDINIDAE}

This is the largest sawfly family with over 5,000 world species. Representatives of the Tenthredinidae are found in all regions of the world, but it is a dominant family only in the Northern Hemisphere where their predominance increases northwards. Most members of this family are cylindrical, wasplike insects ranging in size from $2.5 \mathrm{~mm}$. to about $15 \mathrm{~mm}$. in length. Most have nine-segmented antennae though some have fewer and some more. Habits and host plants are diverse. Most larvae feed externally on the foliage of the host plant, but some are leafminers, gallformers, or shootborers. Most larvae are caterpillarlike.

The division of the family into subfamilies has always been controversial, and there are nearly as many different arrangements as authors. There are current differences between North American and European workers. Eight subfamilies are utilized in this catalog, most of the units being the same as those previously recognized in the North American literature. Most are readily separated on the basis of wing venational differences.

For general references to this family, see those listed under Suborder Symphyta.

\section{SUBFAMILY SELANDRIINAE}

Members of this subfamily are associated with ferns, grasses, and sedges. The Selandriinae are poorly represented in the northern regions of the world, but it is one of the dominant groups in the tropics; for example, nearly 200 species have been described from the Americas south of the United States.

Revision: Smith, 1969. U. S. Dept. Agr. Tech. Bul. 1398, 48 pp. (Nearctic species).

Taxonomy: Malaise, 1963. Ent. Tidskr. 84: 159-215 (key to world genera).

\section{TRIBE STRONGYLOGASTRINI}

\section{Genus ERIOCAMPIDEA Ashmead}

Eriocampidea Ashmead, 1898. Canad. Ent. 30: 256.

Type-species: Eriocampidea arizonensis Ashmead. Orig. desig.

Cockerellonis MacGillivray, 1908. Canad. Ent. 40: 365.

Type-species: Cockerellon is occidentalis MacGillivray. Orig. desig.

A small genus found from southwestern United States into Mexico.

arizonensis Ashmead. N. Mex., Ariz.; Mexico.

Eriocampidea arizonensis Ashmead, 1898. Canad. Ent. 30: 256..

Cockerellonis occidentalis MacGillivray, 1908. Canad. Ent. 40: 365. ㅇ (?).

\section{Genus HEMITAXONUS Ashmead}

Hemitaxonus Ashmead, 1898. Canad. Ent. 30: 311.

Type-species: Taxonus dubitatus Norton. Orig. desig.

Epitaxonus MacGillivray, 1908. Canad. Ent. 40: 365.

Type-species: Taxonus albidopictus Norton. Orig. desig.

Sahlbergia Forsius, 1910. Meddel. Soc. Fauna et Flora Fenn. 36: 49.

Type-species: Sahlbergia struthiopteridis Forsius. Monotypic.

Larvae of this holarctic genus feed on ferns. Mature larvae may bore into soft wood or other substances where they pupate or overwinter.

Revision: Smith, 1966. Ent. Soc. Wash., Proc. 68: 113-120.

albidopictus (Norton). N. S., N. B., Que. to Ala. w. to Minn., Iowa, Kans. Host: Onoclea sensibilis.

Taxonus albido-pictus Norton, 1868. Amer. Ent. Soc., Trans. 2: 213. ๆ, ठ.

Taxonus amicus Norton, 1868. Amer. Ent. Soc., Trans. 2: 213. $९$, ठ.

Hemitaxonus rufopectus Rohwer, 1910. U. S. Natl. Mus., Proc. 41: 204. \&.

dubitatus (Norton). N. S., N. B., Que. to N. C. w. to Minn., Ill., Tex. Host: Onoclea sensibilis.

Taxonus dubitatus Norton, 1862. Boston Soc. Nat. Hist., Proc. 9: 119. १, ठ. 
Biology: Dyar, 1897. N. Y. Ent. Soc., Jour. 5: 20. - Krombein, 1960. Ent. News 71: 30 (in sumach pith).

multicinctus Hall. Maine, Md., Ont., Ohio. Host: Athyrium thelypteroides.

Hemitaxonus multicinctus Hall, 1917. Ent. Soc. Wash., Proc. 19: 28. Egg, larva.

Biology: Hall, 1917. Ent. Soc. Wash., Proc. 19: 28.

primarius Smith. B. C., Oreg., Calif.

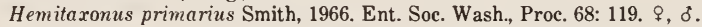

\section{Genus STRONGYLOGASTER Dahlbom}

Tenthredo subg. Strongylogaster Dahlbom, 1835. Conspectus Tenthred., Siricid., Oryssin. Scand., p. 13.

Type-species: Tenthredo cingulata Fabricius. Desig. by MacGillivray, 1908.

Thrinax Konow, 1885. Wien. Ent. Ztg. 4: 19.

Type-species: Thrinax contigua Konow. Desig. by MacGillivray, 1908.

Pseudotaxonus Costa, 1894. Prosp. Imen. Ital., p. 157.

Type-species: Tenthredo filicis Klug. Monotypic.

Polystichophagus Ashmead, 1898. Canad. Ent. 30: 310.

Type-species: Tenthredo filicis Klug. Orig. desig.

Prototaxonus Rohwer, 1910. Canad. Ent. 42: 49.

Type-species: Prototaxonus typicus Rohwer. Monotypic.

Larvae of this genus feed on the underside of fronds of ferns. Mature larvae may bore into soft wood, bark of trees, or other substances for overwintering and pupation. Adults are found around their host plants in the spring months. The genus is holarctic with about 25 world species. Some authors consider Thrinax and Pseudotaxonus as distinct genera.

distans Norton. Colo., Utah w. to B. C., Wash., Oreg., Calif. Host: Pteridium aquilinum.

Strongylogaster distans Norton, 1868. Amer. Ent. Soc., Trans. 2: 220..+

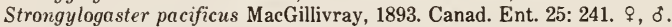

Biology: Beer, 1955. Kans. Univ. Sci. Bul. 37: 223-249.

impressata Provancher. N. S., N. B., Que. to N. C. w. to Minn., Colo., N. Mex. Host: Pteridium aquilinum(?).

Strongylogaster im pressata Provancher, 1878. Nat. Canad. 10: 170. $q$.

Strongylogaster luctuosus Provancher, 1885. Addit. Corr. Faune Ent. Canada Hym., p. 12. ․

Taxonus rufipes Harrington, 1889. Canad. Ent. 21: 97. o.

Thrinax pullatus MacGillivray, 1921. Psyche 28: 34 . $\delta$.

macula (Klug). Ont., B. C.; Europe to Japan. Host: Athyrium and Pteridium. These hosts were recorded in Europe.

Tenthredo (Allantus) macula Klug, 1814. Mag. Gesell. Naturf. Freunde Berlin 8: 217. ․

Thrinax intermedia Konow, 1885. Wien. Ent. Ztg. 4: 22 . $?$.

Thrinax contigua Konow, 1885. Wien. Ent. Ztg. 4: 22. + , ठ.

multicincta Norton. N. S., N. B., Que. to Fla. w. to Minn., Ill. Host: Pteridium aquilinum.

Strongylogaster multicinctus Norton, 1862. Ent. Soc. Phila., Proc. 1: 143. \&.

Strongylogaster annulosus Norton, 1868. Amer. Ent. Soc., Trans. 2: 211. ?.

Strongylogaster longulus Norton, 1868. Amer. Ent. Soc., Trans. 2: 216. ठ.

Strongylogaster alboannulatus Rohwer, 1912. U. S. Natl. Mus., Proc. 43: 237..

Strongylogaster annulosus var. cingulescens Ross, 1932. Canad. Ent. 64: 250. \&, ๖.

Biology: Hogh, 1966. Kans. Ent. Soc., Jour. 39: 347-354.

polita Cresson. Conn., Ont., N. Y.

Strongylogaster politus Cresson, 1880. Amer. Ent. Soc., Trans. 8: 20..

Strongylogaster politus Provancher, 1882. Nat. Canad. 13: 296.. . Preoce.

remota Rohwer. Que., $\mathrm{Pa}$.

Strongylogaster remotus Rohwer, 1912. U. S. Natl. Mus., Proc. 43: 237..

rufigastra (Kincaid). Alaska, B. C.

Paraselandria nifigastra Kincaid, 1900. Wash. Acad. Sci., Proc. 2: 346. ๆ. 
soriculatipes Cresson. N. B., Que. to Md. w. to Minn., Ill. Host: Pteridium aquilinum. Strongylogaster soriculatipes Cresson, 1880. Amer. Ent. Soc., Trans. 8: 20. ₹. Strongylogaster soriculatus Provancher, 1882. Nat. Canad. 13: 296..

Biology: Dyar, 1895. Amer. Ent. Soc., Trans. 22: 310.

tacita (Norton). N. B., Que. to Fla. w. to Wis., Ill. Ecology: Adults collected from Pteridium aquilinum.

Tenthredo (Allantus) tacita Harris, 1835. In Hitchcock, Rpt. Geol. Mineral. Bot. Zool. Mass., p. 583. Nom. nud.

Allantus tacitus Norton, 1860. Boston Jour. Nat. Hist. 7: 246. $९, ~ §$.

Strongylogaster unicus Norton, 1862. Boston Soc. Nat. Hist., Proc. 9: 120. ๆ.

tibialis Cresson. Idaho, B. C., Wash., Oreg., Calif. Host: Pteridium aquilinum.

Strongylogaster tibialis Cresson, 1880. Amer. Ent. Soc., Trans. 8: 19..

Selandria marginata Provancher, 1885. Addit. Corr. Faune Ent. Canada Hym., p. 8.. Strongylogaster primativus MacGillivray, 1893. Canad. Ent. 25: 241. ₹.

Prototaxonus typicus Rohwer, 1910. Canad. Ent. 42: 50. ๆ, ठ.

Biology: Beer, 1955. Kans. Univ. Sci. Bul. 37: 223-249.

tuberculiceps Rohwer. Fla.; Bermuda(?), specimen may be mislabeled.

Strongylogaster tuberculiceps Rohwer, 1911. U. S. Natl. Mus., Proc. 41: 396. क.

Strongylogaster melanogaster Rohwer, 1911. U. S. Natl. Mus., Proc. 41: 397. ơ.

\section{TRIBE ANEUGMENINI}

\section{Genus ANEUGMENUS Hartig}

Emphytus subg. Aneugmenus Hartig, 1837. Fam. Blattwespen und Holzwespen, nebst Einleitung Naturgesch. Hym., p. 253.

Type-species: Tenthredo (Emphytus) coronata Klug. Monotypic.

Colposelandria Enslin, 1912. Tijdschr. v. Ent. 55: 110.

Type-species: Colposelandria jacobsoni Enslin. Orig. desig.

Selandria subg. Atoposelandria Enslin, 1913. Deut. Ent. Ztschr., Beih., p. 197.

Type-species: Selandria furstenbergensis Konow. Orig. desig.

Polyselandria MacGillivray, 1914. Canad. Ent. 46: 104.

Type-species: Selandria floridana MacGillivray. Orig. desig.

Larvae of this holarctic genus feed on ferns. In North America, the genus extends into Mexico.

Revision: Ross, 1930. Canad. Ent. 62: 184-189.

flavipes (Norton). Newfoundland to Fla. w. to Man., Minn., Colo. Host: Pteridium aquilinum. Selandria flavipes Norton, 1862. Boston Soc. Nat. Hist., Proc. 7: 222. ๆ, ơ.

Aneugmenus flavitarsis Rohwer, 1911. U. S. Natl. Mus., Proc. 41: 390. ๆ.

Aneugmenus flavipes occidentalis Rohwer, 1911. U. S. Natl. Mus., Proc. 41: 390..

floridella Ross. Ga., Fla.

Selandria floridana MacGillivray, 1895. Canad. Ent. 27: 281. đ. Preocc. by Cresson, 1880.

Selandria (Aneugmenus) flavipes var. floridella Ross, 1930. Canad. Ent. 62: 189. N. name for floridana MacGillivray.

padi (Linnaeus). B. C., Wash., Oreg.; Europe to Siberia, N. Africa, Asia Minor. Probably introduced. Host: Pteridium aquilinum.

Tenthredo padi Linnaeus, 1761. Fauna Suecica, Ed. 2, p. 390.

Tenthredo (Allantus) stramineipes Klug, 1818. Mag. Gesell. Naturf. Freunde Berlin 8: 75. q, o.

Tenthredo (Emphytus) coronata Klug, 1818. Mag. Gesell. Naturf. Freunde Berlin 8: 276..

Tenthredo albipes Lepeletier, 1823. Monog. Tenthred., p. 105.

Selandria mifitarsis Brulle, 1832. Exped. Moree, Zool., v. 2, p. 394..

Selandria analis Thomson, 1871. Hym. Scand., v. 1, p. 239..

Selandria cereipes Vollenhoven, 1873. Tijdschr. v. Ent. 16: 13.

Selandria vollenhoveni Gribodo, 1880. Soc. Ent. Ital., Bul. 12: 7.

Selandria bimaculata Cobelli, 1892. Verh. Ges. Wien. 42: 71. §. 
Selandria oglobleni Dovnar-Zapolskii, 1930. Rev. Russe d'Ent. 24: 90 . ๆ. Selandria urbis Ross, 1930. Canad. Ent. 62: 186..

Taxonomy: Benson, 1968. Brit. Mus. (Nat. Hist.) Ent., Bul. 22: 134.

scutellatus Smith. Ariz.; Mexico. Ecology: Adults collected from ferns.

Anengmenus scutellatus Smith, 1969. U. S. Dept. Agr. Tech. Bul. 1398, p. 28. ๆ, ठ.

\section{Genus BIRKA Malaise}

Birka Malaise, 1944. Arkiv for Zool. 35A: 4.

Type-species: Tenthredo (Allantus) cinereipes Klug. Orig. desig.

European species of this genus feed on grasses and sedges.

nordica Smith. Man., Alta., Yukon, Alaska, B. C.

Birka nordica Smith, 1969. U. S. Dept. Agr., Tech. Bul. 1398, p. 29. \&, ð.

\section{Genus NESOSELANDRIA Rohwer}

Nesoselandria Rohwer, 1910. U. S. Natl. Mus., Proc. 37: 657.

Type-species: Paraselandria imitatrix Ashmead. Orig. desig.

Neobusarbia Takeuchi, 1928. Formosa Nat. Hist. Soc., Trans. 18: 40.

Type-species: Neobusarbia flavipes Takeuchi. Orig. desig.

Melisandra Benson, 1939. Ent. Monthly Mag. 75: 110.

Type-species: Selandria morio (Fabricius) Enslin. Orig. desig.

Most species of this genus are found in Asia.

morio (Fabricius). Que., N. H., N. Y., Ont., B. C.; Europe to Siberia, Japan.

Tenthredo morio Fabricius, 1781. Species Insectorum, v. 1, p. 414.

Tenthredo ulmi Schrank, 1802. Fauna Boica, p. 237.

Tenthredo (Selandria) tristis Lepeletier, 1823. Monog. Tenthred., p. 106. ․ ઠ .

Emphytus infuscatus Eversmann, 1847. Soc. Imp. Nat. Moscou, Bul. 20: 29..

Selandria Fabricii Konow, 1885. Wien. Ent. Ztg. 4: 300.

Aneugmenus brunneus Magretti, 1886. Soc. Ent. Ital., Bol. 18: 25.

\section{Genus EUSTROMBOCEROS Rohwer}

Stromboceros subg. Eustromboceros Rohwer, 1911. U. S. Natl. Mus., Proc. 41: 394.

Type-species: Stromboceros (Eustromboceros) melanopterus Rohwer. Orig. desig.

Stromboceros subg. Prostromboceros Rohwer, 1912. U. S. Natl. Mus., Proc. 43: 235.

Type-species: Stromboceros (Eustromboceros) melanopterus Rohwer. Orig. desig.

A small genus found from Arizona to Central America.

Taxonomy: Smith, 1971. Amer. Ent. Soc., Trans. 97: 532-533.

rufocaudatus Smith. S. Ariz.

Eustromboceros rufocaudatus Smith, 1969. U. S. Dept. Agr., Tech. Bul. 1398, p. 30. ơ.

\section{Genus STROMBOCERIDEA Rohwer}

Stromboceros subg. Stromboceridea Rohwer, 1911. U. S. Natl. Mus., Proc. 41: 392.

Type-species: Stromboceros (Stromboceridea) pilosulus Rohwer. Orig. desig.

Petersiana Jorgensen, 1913. Buenos Aires Mus. Nac de Hist. Nat., An. 24: 278.

Type-species: Petersiniana(!) niveana Jorgensen. Monotypic.

Goniocerus Malaise, 1942. Ent. Tidskr. 63: 93 N. syn.

Type-species: Stromboceros albilabris Konow. Orig. desig.

This is a rather large genus found from southern Arizona to northern Argentina.

nigricans (Norton). S. Ariz. to Guatemala.

Strongylogaster nigricans Norton, 1868. Amer. Ent. Soc., Trans. 2: 223. ₹, ð.

Selandria curialis Cresson, 1880. Amer. Ent. Soc., Trans. 8: 15. ?.

Stromboceros (Eustromboceros) leucostomus Rohwer, 1911. U. S. Natl. Mus., Proc. 41: 395. q. 
Taxonomy: Smith, 1971. Amer. Ent. Soc., Trans. 97: 526 (lectotype for nigricans).

\section{TRIBE SELANDRIINI}

\section{Genus BRACHYTHOPS Haliday}

Coryna Lepeletier and Serville, 1825. Encycl. Meth., Ins., v. 10, p. 567. Preocc. by Bosc, 1802.

Type-species: Tenthredo scapularis Lepeletier and Serville. Desig. by Rohwer, 1911.

Brachythops Haliday, 1839. In Curtis, Brit. Ent., v. 16, p. 764.

Type-species: Brachythops seminigra Haliday. Monotypic.

Paraselandria Ashmead, 1898. Canad. Ent. 30: 255.

Type-species: Selandria flavens Klug. Orig. desig.

Selandridea Rohwer, 1911. U. S. Natl. Mus., Proc. 41: 388.

Type-species: Selandridea vanduzeei Rohwer. Orig. desig.

Pseudoselandria MacGillivray, 1914. Canad. Ent. 46: 103.

Type-species: Pseudoselandria oxalata MacGillivray Orig. desig.

A small holarctic genus closely related to the Palaearctic Selandria Leach. Larvae of this genus feed on sedges.

flavens (Klug). Labrador to Alaska s. to N. Y., Wis., Colo.; Europe to Siberia. Host: Carex.

Tenthredo (Allantus) flavens Klug, 1818. Mag. Gesell. Naturf. Freunde Berlin 8: 48., o.

Tenthredo (Coryna) scopularis Lepeletier and Serville, 1825. Encycl. Meth. Ins., v. 10, p. 567. ?.

Phyllotoma puella Fallen, 1829. Monog. Tenthred. Suec., p. 30. ९, ठ์.

Brachythops seminigra Haliday, 1839. In Curtis, Brit. Ent., v. 16, p. 764.

Selandria flavescens Thomson, 1870. Opusc. Ent., 2nd Fasc., p. 291.

Selandria decolorata Cresson, 1880. Amer. Ent. Soc., Trans. 8: 15. ठ゚.

Selandridea vanduzeei Rohwer, 1911. U. S. Natl. Mus., Proc. 41: 388. ๆ, ó.

Selandria flavens var. flavior Enslin, 1913. Deut. Ent. Ztschr., Beih., p. 144.

Pseudoselandria oxalata MacGillivray, 1914. Canad. Ent. 46: 103..

wuestneii (Konow). Que., N. W. T., Man., Alta., Yukon, Alaska; Europe. Host: Carex.

Selandria wustneii Konow, 1885. Wien. Ent. Ztg. 4: 122. ₹, ठ.

\section{TRIBE ADELESTINI}

\section{Genus ADELESTA Ross}

Adelesta Ross, 1937. Ill. Biol. Monog. 15(2): 68.

Type-species: Selandria nova Norton. Orig. desig.

The single species in this genus is found in North America only.

nova (Norton). N. S., N. B., Que., Maine.

Selandria nova Norton, 1867. Amer. Ent. Soc., Trans. 1: 254. \&.

\section{TRIBE HEPTAMELINI}

\section{Genus HEPTAMELUS Haliday}

Melicerta Stephens, 1835. Illus. Brit. Ent., v. 7, p. 94. Preocc. by Schrank, 1803.

Type-species: Melicerta ochroleuca Stephens. Monotypic.

Heptamelus Haliday, 1855. Nat. Hist. Rev., v. 2, p. 60.

Type-species: Melicerta ochroleuca Stephens. Monotypic.

Caenoneura Thomson, 1870. Opusc. Ent., 2nd Fasc., p. 270.

Type-species: Caenoneura dahlbomi Thomson. Monotypic.

Most species of this genus are found in Asia.

ochroleucus (Stephens). B. C. (Squamish, Diamond Head Trail); Europe, Japan. Ecology:

Larva bores downward in stems of ferns. Host: Athyrium, Polypodium, and Blechnum.

These hosts were recorded in Europe.

Melicerta ochroleuca Stephens, 1835. Illus. Brit. Ent., v. 7, p. 95. 
Caenoneura dahlbomi Thomson, 1870. Opusc. Ent., 2nd Fasc., p. 271. \&.

\section{SubFamily DOLERINAE}

The two genera in this subfamily are both widespread throughout the subarctic and temperate regions of the Northern Hemisphere; one species is known from Uganda. Dolerus contains about 125 and Loderus about 16 world species. Larvae feed on horsetails, grasses, sedges, and rushes. A few species may be of importance when feeding in cultivated crops. Adults fly early in the spring and are found in their host-plant communities, on nearby flowers such as those of Crataegus and Prunus, or on willow catkins. Some may feed on the sap of sugar maple. There is normally a single generation a year, and mature larvae overwinter in an earthen cell in the ground. Species of this subfamily can be collected in large numbers. The time of emergence of the adults can be accurately predicted, yet, very little biological work has been done. Larvae for so few species have been associated that it is impossible to identify them beyond genus.

Revision: Ross, 1931. Ill. Biol. Monog. 12(3): 1-116.

Taxonomy: Ross, 1935. Ent. Soc. Wash., Proc. 37: 88-93. - Benson, 1956. Roy. Ent. Soc.

London, Proc., Ser. B: Taxonomy 25: 55-63. - Benson, 1962. Brit. Mus. (Nat. Hist.) Ent., Bul. 12: 388-389 (holarctic species).

\section{Genus DOLERUS Panzer}

Dolerus Jurine, 1801 (May). Intell. Blatt. Litt.-Ztg. Erlangen, v. 1, p. 163. Suppressed by Internatl. Comm. Zool. Nomencl. Op. 135, 1939.

Type-species: Tenthredo gonager Fabricius. Desig. by Latreille, 1810.

Dolerus Panzer, 1801 (September). Faunae Ins. German., heft 82, pl. 11.

Type-species: Dolerus pedestris Panzer. Monotypic.

Dosytheus Leach, 1817. Zool. Misc., v. 3, p. 127.

Type-species: Tenthredo eglanteriae Fabricius. Desig. by Brulle, 1846.

\section{SPECIES GROUP UNICOLOR}

asper Zaddach. Mass., Conn., Mich., Ind., S. Dak., Alaska; Europe, Siberia. Host: Cyperaceae and Gramineae.

Dolerus asper Zaddach, 1859. Programm Friedr. Col. Konigsberg, p. 21. ठ.

Dolerus tectus MacGillivray, 1914. Canad. Ent. 66: 104. ๆ, §.

Dolerus asper megapteroides Muche, 1964. Reichenbachia 4: 31-33. ๆ (male misdet.).

borealis MacGillivray. Idaho, Wash., Oreg.

Dolerus borealis MacGillivray, 1893. Canad. Ent. 25: 238..

Dolerus nominatus MacGillivray, 1923. Insecutor Inscitiae Menstruus 11: 34. ๆ.

illini Ross. Mass., N. Y. w. to Alta., S. Dak., Colo. Ecology: Adults collected in Equisetum, Eleocharis, and Carex habitats.

Dolerus illini Ross, 1931. Ill. Biol. Monog. 12(3): 39. ^, ठ.

Dolemes illini var. mufilobus Ross, 1931. Ill. Biol. Monog. 12(3): 41. ठో.

nativus MacGillivray. Colo., Oreg.

Dolerus nativus MacGillivray, 1923. Insecutor Inscitiae Menstruus 11: 32. ठ.

Dolerus nectareus MacGillivray, 1923. Insecutor Inscitiae Menstruus 11: 33. ठ。.

neocollaris narratus MacGillivray. B. C., Idaho, Wash., Oreg.

Dolerus narratus MacGillivray, 1923. Canad. Ent. 55: 65. ๆ, ठ.

Dolerus nocuus MacGillivray, 1923. Insecutor Inscitiae Menstruus 11: 34. ?.

neocollaris neocollaris MacGillivray. Que., N. Y. w. to Mont., Nebr., Colo.

Dolerus neocollaris MacGillivray, 1908. Canad. Ent. 40: 127. ९, ठ์.

Dolerus refugus MacGillivray, 1908. Canad. Ent. 40: 127. $\subsetneq$.

nitens Zaddach. N. H. to Md., w. to Mich., Ohio, Ill., Wash., Oreg.; Europe. Ecology: Probably grasses and sedges are hosts; adults sometimes swept from cultivated grass crops. Host: Festuca sp.

Dolerus coracinus Stephens, 1835. Illus. Brit. Ent., v. 7, p. 87. Preocc. by Klug, 1814.

Dolerus nitens Zaddach, 1859. Programm Friedr. Col. Konigsberg, p. 16. ๆ, ठ.

Dolerus anthracinus Thomson, 1871. Hym. Scand., v. 1, p. 291. Preocc. by Klug, 1814.

Dolerus varispinus Konow, 1884. Deut. Ent. Ztschr. 28: 344. Preocc. by Hartig, 1837. 
Dolerus coruscans Konow, 1890. Wien. Ent. Ztg. 9: 10. N. name for anthracinus Thomson. Dolerus wanda Ross, 1935. Ent. Soc. Wash., Proc. 37: 91. \&.

Biology: Kamm, 1975. Environ. Ent. 4: 312-314.

unicolor (Beauvois). Que. to Ga. w. to Man., S. Dak., Colo. Host: Phleum pratense.

Tenthredo unicolor Beauvois, 1805. Ins. Afr. Amer., p. 97. ठ.

Tenthredo thoracinus Beauvois, 1805. Ins. Afr. Amer., p. 97. 9.

Dolemus arvensis Say, 1824. In Keating, Narr. Long's 2nd Exped., v. 2 (App.), p. 319..

Dolerus thoracicus Kirby, 1882. List Hym. Brit. Mus., v. 1, p. 230.

Biology: Riley and Marlatt, 1891. U. S. Dept. Agr., Insect Life 4: 168-179. -Forbes, 1885. 14th Rpt. State Ent. Ill., p. 100.

\section{Species Group Sericeus}

kennedyi Ross. Ohio.

Dolerus kennedyi Ross, 1935. Ent. Soc. Wash., Proc. 37: 90..

sericeus centralis Ross. Ill.

Dolerus sericeus centralis Ross, 1931. Ill. Biol. Monog. 12(3): 46. ‡, ठ.

sericeus neosericeus MacGillivray. N. B. to N. Y. w. to Wis.

Dolerus neosericeus MacGillivray, 1908. Canad. Ent. 40: 125. ?.

Dolerus necosericeus (!) MacGillivray, 1923. Ill. Univ. Bul. 20(50): 13.

sericeus parasericeus MacGillivray. N. Y., B. C.

Dolemis parasericeus MacGillivray, 1908. Canad. Ent. 40: 125. $\%$.

Dolerus polysericeus MacGillivray, 1908. Canad. Ent. 40: 125. ?.

sericeus sericeus Say. Que. to Del. w. to B. C., Minn., Mo.

Dolerus sericeus Say, 1824. In Keating, Narr. Long's 2nd Exped., v. 2 (App.), p. 320. $\subsetneq$.

Dolerus colosericeus MacGillivray, 1908. Canad. Ent. 40: 125. ?.

Dolemus monosericeus MacGillivray, 1908. Canad. Ent. 40: 126. , §.

\section{SPEcies Group Collaris}

abdominalis (Norton). Mass. to Ga. w. to Ill., Kans.

Dosytheus abdominalis Norton, 1861. Boston Soc. Nat. Hist., Proc. 8: 153. $q$, o.

agcistus MacGillivray. Maine to Va. w. to Man., Mont., Wyo, Colo., Calif. Ecology: Adults collected in Equisetum - Carex habitats.

Dolerus agcistus MacGillivray, 1908. Canad. Ent. 40: 129..

Dolemes agcistus var. maroa Ross, 1931. Ill. Biol. Monog. 12(3): 61. ․ N. syn.

bicolor (Beauvois). Que. to Va. w. to Man., Wis., Nebr., Kans.

Tenthredo bicolor Beauvois, 1805. Ins. Afr. Amer., p. 96. $q$.

Dolerus lesticus MacGillivray, 1914. Canad. Ent. 46: 105. $९$. N. syn.

Dolerus graenicheri MacGillivray, 1914. Canad. Ent. 46: 107. ․ N. syn.

Dolerus bicolor var. nigrita Ross, 1931. Ill. Biol. Monog. 12(3): 59. ๆ. N. syn.

clypealis Ross. Mich., N. W. T., Alta., Mont., Colo., Utah, Wash., Oreg., Calif.

Dolerus clypealis Ross, 1931. Ill. Biol. Monog. 12(3): 50. ₹.

Dolerus clypealis var. nigrilabris Ross, 1931. Ill. Biol. Monog. 12(3): 51. ?.

collaris Say. Que. to Pa. w. to B. C., Mont., Colo. Host: Eleocharis(?).

Dolerus collaris Say, 1823. West. Quart. Rptr. 2: 720. .

Dosythezts maculicollis Norton, 1861. Boston Soc. Nat. Hist., Proc. 8: 153..

Dolerus icterus MacGillivray, 1908. Canad. Ent. 40: 127. \&.

Dolerus collaris var. erebus Ross, 1931. Ill. Biol. Monog. 12(3): 55. ․

distinctus Norton. Oreg., Calif.

Dolerus distinctus Norton, 1872. Amer. Ent. Soc., Trans. 4: 82. ․

eurybis Ross. Que., Maine w. to Man., Minn., Colo.

Dolemis eurybis Ross, 1931. Ill. Biol. Monog. 12(3): 65. ९, ơ.

idahoensis Ross. Idaho (Moscow).

Dolerus idahoensis Ross, 1931. Ill. Biol. Monog. 12(3): 63. ९.

interjectus Ross. Idaho, Wash., Calif.

Dolerus interjectus Ross, 1931. Ill. Biol. Monog. 12(3): 63. १, ठ. 
moramus Ross. N. Y., Ill., Minn. Colo.

Dolerus moramus Ross, 1931. Ill. Biol. Monog. 12(3): 62. ๆ, ठ.

neoagcistus MacGillivray. Maine, Ont. to Va. w. to Nebr., Kans., Miss.

Dolerus neoogcistus MacGillivray, 1923. Brooklyn Ent. Soc., Bul. 18: 55. .

Dolerus neostugnus MacGillivray, 1923. Brooklyn Ent. Soc., Bul. 18: 55. ๆ.

nortoni Ross. Maine, Ont. to Md. w. to Mich., Ill.

Dolerus nortoni Ross, 1931. Ill. Biol. Monog. 12(3): 51. \&, ð.

Dolerus nortoni var. nigritella Ross, 1931. Ill. Biol. Monog. 12(3): 53. ₹.

osagensis Ross. N. J., Okla.

Dolerus osagensis Ross, 1935. Ent. Soc. Wash., Proc. 37: 89. , ð.

piercei Rohwer. N. J., Nebr., Kans.

Dolerus piercei Rohwer, 1909. Canad. Ent. 41: 10. ㅇ.

salmani Ross. Calif.

Dolerus salmani Ross, 1935. Ent. Soc. Wash., Proc. 37: 88. , ð.

versus Norton. N. Y. to Va. w. to Ohio, Mo., Tex.

Dolerus versa Norton, 1867. Amer. Ent. Soc., Trans. 1: 239. , ऽ.

Species Group Similis

aprilis (Norton). Que. to Va. w. to Sask., Colo. Host: Equisetum.

Dosytheus aprilis Norton, 1861. Boston Soc. Nat. Hist., Proc. 8: 152..

Dolerus dysporus MacGillivray, 1908. Canad. Ent. 40: 128. 9 .

Dolerus nocivus MacGillivray, 1923. Ill. Univ. Bul. 20(50): 12. ․

apriloides MacGillivray. Que., Conn. w. to Man., Minn., Ill.

Dolerus apriloides MacGillivray, 1908. Canad. Ent. 40: 126. $q$.

coloradensis Cresson. Mont., Wyo., Colo., N. Mex., Ariz.

Dolerus coloradensis Cresson. 1880. Amer. Ent. Soc., Trans. 8: 11. १, ठ․

elderi Kincaid. Newfoundland to Alaska s. to N. J., Ill., N. Mex., Utah, Calif.; Europe to

Siberia. Ecology: Widespread. Host: Equisetum.

Dolerus pusillus Jakovlev, 1891. Soc. Ent. Rossica, Horae 26: 32.. Preocc. by Lepeletier, 1823.

Dolerus elderi Kincaid, 1900. Wash. Acad. Sci., Proc. 2: 259. ૧, ઠ.

Dolerus cohaesus MacGillivray, 1908. Canad. Ent. 40: 128. ‥

Dolerus nutricius MacGillivray, 1923. Canad. Ent. 55: 159. ठ์.

Loderus acriculus MacGillivray, 1923. Ill. Univ. Bul. 20(50): 20..

Dolerus nyctelius MacGillivray, 1923. N. Y. Ent. Soc., Jour, 30: 163. ठ.

Dolerus nemorosus MacGillivray, 1923. N. Y. Ent. Soc., Jour. 30: 164. ๆ.

Dolerus pullulus Zhelochovtsev, 1928. Zool. Anz. 79(3-4): 107. ․, ठ.

Dolerus elderi var. auraneus Ross, 1931. Ill. Biol. Monog. 12(3): 69. \&, ठ.

Dolemus elderi var. mibicanus Ross, 1931. Ill. Biol. Monog. 12(3): 70. ๆ, ठ.

Dolerus elderi var. melanus Ross, 1931. Ill. Biol. Monog. 12(3): 70. , ठ์.

Taxonomy: Benson, 1956. Roy. Ent. Soc. London, Proc., Ser. B: Taxonomy 25: 55.

nasutus MacGillivray. Alta., Mont., Colo., N. Mex., B. C., Idaho, Wash., Oreg., Calif.

Dolerus nasutus MacGillivray, 1923. Canad. Ent. 55: 65. ?.

Dolerus nugatorius MacGillivray, 1923. Canad. Ent. 55: 66. ․ ठ.

Dolerus novellus MacGillivray, 1923. Canad. Ent. 55: 67..+

similis nescius MacGillivray. B. C., Wash., Nev.

Dolerus nescius MacGillivray, 1923. Ill. Univ. Bul. 20(50): 12. ?.

similis similis (Norton). Newfoundland to Alaska s. to Va., Ky., Tex., N. Mex., Calif. Ecology:

Widespread. Host: Equisetum.

Dosytheus similis Norton, 1861. Boston Soc. Nat. Hist., Proc. 8: 152. क.

Dolerus tibialis Cresson, 1880. Amer. Ent. Soc., Trans. 8: 52 . ơ.

Dolerus conjugatus MacGillivray, 1908. Canad. Ent. 40: 128. ๆ.

Dolerus plesius MacGillivray, 1908. Canad. Ent. 40: 129. ․

Dolerus inspectus MacGillivray, 1908. Canad. Ent. 40: 128. ठ.

Dolerus stugnus MacGillivray, 1908. Canad. Ent. 40: 129. ㅇ.

Dolerus acritus MacGillivray, 1908. Canad. Ent. 40: 130. ㅇ. 
Dolerus simulans Rohwer, 1909. Canad. Ent. 41: 10. ㅇ.

Dolerus inspiratus MacGillivray, 1914. Canad. Ent. 46: 105. \&.

Dolerus nefastus MacGillivray, 1923. Canad. Ent. 55: 66. ․

Dolerus nicaeus MacGillivray, 1923. Canad. Ent. 55: 68..+

Dolemes novicius MacGillivray, 1923. Canad. Ent. 55: 67. ․ .

Dolerus nummarius MacGillivray, 1923. Canad. Ent. 55: 159. ๆ.

Dolerus nummatus MacGillivray, 1923. Canad. Ent. 55: 159. ․

Dolerus nervosus MacGillivray, 1923. Insecutor Inscitiae Menstruus 11: 31..

Dolerus nimbosus MacGillivray, 1923. Insecutor Inscitiae Menstruus 11: 33. ণ, o.

Dolerus necessarius MacGillivray, 1923. Insecutor Inscitiae Menstruus 11: 35. $\%$.

Dolerus similis var. conjectus Ross, 1931. Ill. Biol. Monog. 12(3): 80.

Dolerus similis var. nordanus Ross, 1931. Ill. Biol. Monog. 12(3): 80. \&, ð.

Dolerus similis var. fumatus Ross, 1931. Ill. Biol. Monog. 12(3): 81. ๆ, ठे.

tejoniensis (Norton). N. Mex., Utah, Nev., Oreg., Calif.

Dosytheus Tejoniensis Norton, 1861. Boston Soc. Nat. Hist., Proc. 8: 154. \&.

Dolerus coccinifera Norton, 1872. Amer. Ent. Soc., Trans. 4: 82..

Dolerus coccinifer Dalla Torre, 1894. Cat. Hym., v. 1, p. 4. Emend.

yukonensis yukonensis Norton. Alta., Alaska; Eurasia. Host: Equisetum. Other subspecies are Palaearctic.

Dolerus similis var. yukonensis Norton, 1872. Amer. Ent. Soc., Trans. 4: 82. ठ"

Dolerus lateralis Konow, 1895. Wien. Ent. Ztg. 14: 75..

Dolerus articola Kiaer, 1898. Tromsoe Mus. Aarsh. 19: 58.

Dolerus nuntius MacGillivray, 1923. Canad. Ent. 55: 158. ㅇ.

Dolerus nundin us MacGillivray, 1923. Canad. Ent. 55: 159. ð.

Taxonomy: Benson, 1956. Roy. Ent. Soc. London, Proc., Ser. B: Taxonomy 25: 58-59.

\section{SPECIES Group Gessneri}

gessneri konowi MacGillivray. Alaska, B. C., Wash., Oreg., Calif.; Siberia. Host: Equisetum. D. gessneri gessneri Andre is European.

Dolerus konowi MacGillivray, 1914. Canad. Ent. 46: 106. $q$, o.

Dolerus numerosus MacGillivray, 1923. Canad. Ent. 55: 67. ․, o.

Dolerus nidulus MacGillivray, 1923. Insecutor Inscitiae Menstruus 11: 31. ๆ.

Dolerus kamtchaticus Malaise, 1932. Arkiv for Zool. 23A: 18. ․, o.

Taxonomy: Benson, 1956. Roy. Ent. Soc. London, Proc., Ser. B: Taxonomy 25: 59.

pratensis (Linnaeus). Ill., Man., Alta.; Europe to Siberia. Host: Equisetum.

Tenthredo pratensis Linnaeus, 1758. Syst. Nat., Ed. 10, p. 556. ๆ.

Tenthredo (Dolerus) dubius Klug, 1814. Mag. Gesell. Naturf. Freunde Berlin 8: 299. $\subsetneq$, ð.

Tenthredo (Dolerts) timida Klug, 1814. Mag. Gesell. Naturf. Freunde Berlin 8: 300. ๆ, ठे.

Tenthredo (Dolemis) deserta Klug, 1814. Mag. Gesell. Naturf. Freunde Berlin 8: 300. ठ́.

Dolerus frisoni Ross, 1931. Ill. Biol. Monog. 12(3): 91. ठ.

Taxonomy: Malaise and Benson, 1934. Arkiv for Zool. 26A: 5 (D. pratensis of authors, not

L.=D. germanicus (Fabricius)). - Benson, 1962. Brit. Mus. (Nat. Hist.) Ent., Bul. 12: 389.

subfasciatus neoaprilis MacGillivray. Newfoundland to N. W. T., Alaska s. to N. Y., Ill., Nebr., Colo. Ecology: Widespread. Host: Equisetum. D. subfasciatus subfasciatus Smith is found in Japan.

Dolerus neoaprilis MacGillivray, 1908. Canad. Ent. 40: 126. ?.

Dolerus nivatus MacGillivray, 1923. N. Y. Ent. Soc., Jour. 31: 164. \&.

Taxonomy: Benson, 1956. Roy. Ent. Soc. London, Proc., Ser. B: Taxonomy 25: 59.

\section{Genus LODERUS Konow}

Loderus Konow, 1890. Deut. Ent. Ztschr. 34: 240.

Type-species: Tenthredo pratorum Fallen. Orig. desig.

Taxonomy: Benson, 1956. Roy. Ent. Soc. London, Proc., Ser. B: Taxonomy 25: 62 (status of N. Amer. forms). 
eversmanni acidus MacGillivray. Que., Maine to Pa. w. to Alaska, Ill.; East Asia. Host: Equisetum. L. eversmanni eversmanni (Kirby) is European.

Loderus acidus MacGillivray, 1923. Ill. Univ. Bul. 20(50): 20. ९, ठั.

genucinctus niger Rohwer. Wash., Oreg., Calif. Host: Equisetum. L. genucinctus genucinctus (Zaddach) is Palaearctic.

Loderus niger Rohwer, 1910. Canad. Ent. 42: 49. $\$$, o. Preocc. in Dolerus but not in Loderus.

Dolemes napaeus MacGillivray, 1923. Canad. Ent. 55: 65. ․

Dolemis nepotulus MacGillivray, 1923. Canad. Ent. 55: 68. ठँ.

Doleris nauticus MacGillivray, 1923. Insecutor Inscitiae Menstruus 11: 35. ๆ.

pratorum albifrons (Norton). Newfoundland to Alaska s. to N. Y., Nebr., Calif.; East Asia. Host: Equisetum. L. pratorum pratorum (Fallen) is European.

Dosytheus apricus var. albifrons Norton, 1861. Boston Soc. Nat. Hist., Proc. 8: 152. 9.

Dolerus minusculus MacGillivray, 1908. Canad. Ent. 40: 126..

Loderns accuratus MacGillivray, 1923. Ill. Univ. Bul. 20(50): 19. ?.

vestigialis apricus (Norton). N. B. to Va. w. to Alaska, Man., Wash., Nebr., Colo. Host: Equisetum. L. vestigialis vestigialis (Klug) is European.

Tenthredo (Dosytheus) aprica Harris, 1835. In Hitchcock, Rpt. Geol. Mineral. Bot. Zool. Mass., p. 583. Nom. nud.

Dosytheus apricus Norton, 1861. Boston Soc. Nat. Hist., Proc. 8: 152..

Dolerus luctatus MacGillivray, 1908. Canad. Ent. 40: 127. ?.

Dolemis femur-rubrum Rohwer, 1909. Canad. Ent. 41: 9. 9.

Loderus acerbus MacGillivray, 1923. Ill. Univ. Bul. 20(50): 19..

Loderes alticinctus MacGillivray, 1923. Ill. Univ. Bul. 20(50): 20. .

Loderus ancisus MacGillivray, 1923. Ill. Univ. Bul. 20(50): 21. ๆ.

\section{SubFamily SUSANINAE}

Revision: Smith, 1969. Ent. Soc. Wash., Proc. 71: 13-23.

\section{Genus SUSANA Rohwer and Middleton}

Susana Rohwer and Middleton, 1932. Ent. Soc. Wash., Proc. 34: 93.

Type-species: Susana cupressi Rohwer and Middleton. Orig. desig.

Members of this exclusively North American genus feed on plants of the family Cupressaceae.

annulata Smith. Calif. (San Mateo Co., Marin Co.). Ecology: Adults collected from Cupressus macrocarpa.

Susana annulata Smith, 1969. Ent. Soc. Wash., Proc. 71: 22. ๆ, ठ.

cupressi Rohwer and Middleton. S. Calif. Host: Cupressus.

Susana cupressi Rohwer and Middleton, 1932. Ent. Soc. Wash., Proc. 34: 94. ๆ, ठ.

fuscala Wong and Milliron. B. C. Host: Juniperus scopulorum.

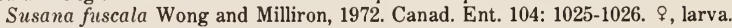

juniperi (Rohwer). N. Mex. (Las Vegas Hot Springs). Host: Juniperus.

Platycampus juniperi Rohwer, 1911. U. S. Natl. Mus., Proc. 41: 386..

oregonensis Smith. Idaho, Nev., Oreg. Host: Juniperus.

Susana oregonensis Smith, 1969. Ent. Soc. Wash., Proc. 71: 21. ๆ.

punctata Smith. Calif. (Inyo Co.). Ecology: Adult collected from Juniperus.

Susana punctata Smith, 1969. Ent. Soc. Wash., Proc. 71: 19..

rufa Smith. N. Mex., Ariz. (Chiricahua Mts.).

Susana mifa Smith, 1969. Ent. Soc. Wash., Proc. 71: 21. $\subsetneq$.

\section{SUbFamily NEMATINAE}

The Nematinae are a large and diverse group, especially in habits and host plants. It is the dominant sawfly group in the arctic and subarctic regions of the world where they comprise nearly the entire sawfly fauna. Their abundance decreases rapidly southward and only a few species extend into Mexico. Only two species, both Pristiphora, are known from South America. 
Larval habits range from free leaf feeders to gall formers, others are leaf edge rollers, leaf miners, and some live and feed inside the fruits of rosaceous plants. The taxonomy of many groups is imperfectly known and few have been recently studied. Because of their abundance in the arctic region, many represent holarctic species, and a worker is met with the major obstacle of having to become familiar with the innumerable forms described from Eurasia. Variation is another factor since the extreme arctic climate may influence major morphological and color differences within species. For example, females of Amauronematus abnormis (Holmgren) are normally brachypterous, but females with normal wings also exist. Some of the gall forming groups apparently contain species complexes where there are practically no adequate morphological characters for species separation and where identity may have to be based on specific host records and accompanying biological information. Extensive field work and knowledge of the world fauna will be essential to the study of most groups, and such facilities are not available to most taxonomists.

Revision: Marlatt, 1896. U. S. Dept. Agr. Div. Ent. Tech. Ser. 3, 135 pp.

Biology: Marlatt, 1895. Ent. Soc. Wash., Proc. 3: 263-267 (notes on some gall forming species).

\section{TRIBE CLADIINI}

Revision: Rohwer and Middleton, 1922. U. S. Natl. Mus., Proc. 60: 1-46 (also biology).

-Smith, 1974. Amer. Ent. Soc., Trans. 100: 1-28.

\section{Genus CLADIUS IHiger}

Cladius Illiger, 1807. Mag. Insektenk. 6: 190.

Type-species: Tenthredo difform is Panzer. Desig. by Latreille, 1810.

Only one of several species of this holarctic genus is found in North America.

difformis (Panzer). N. S., Que. to B. C. s. to Va., Ky., Mo., Calif.; Europe to Siberia. Ecology:

Widespread, common on cultivated roses. Host: Rosa. Bristly rose slug.

Tenthredo difformis Panzer, 1799. Faunae Ins. German. 6: 62.

Nematus crassicornis Stephens, 1835. Illus. Brit. Ent., v. 7, p. 28.

Tenthredo (Cladius) isomera Harris, 1835. In Hitchcock, Rpt. Geol. Mineral. Bot. Zool. Mass., p. 583. Nom. nud.

Cladius isomerus Norton, 1861. Boston Soc. Nat. Hist., Proc. 8: 223. 9.

Cladius gracilicornis Konow, 1884. Deut. Ent. Ztschr. 28: 314 . १, ठ.

Cladius major Cobelli, 1892. Zool.-Bot. Gesell. Wien, Verh. 42: 70. $\uparrow$.

Biology: Murtfeldt, 1890. U. S. Dept. Agr., Ent. Bul. 22: 78. -Chittenden, 1908. U. S. Dept. Agr., Bur. Ent. Circ. 105, 6 pp. - Middleton, 1922. In Rohwer and Middleton, U. S. Natl.

Mus., Proc. 60: 13. -Middleton, 1922. U. S. Dept. Agr., Farmers' Bul. 1252, 4 pp.

\section{Genus PRIOPHORUS Dahlbom}

Nematus subg. Priophorus Dahlbom, 1835. Conspectus Tenthred., Siricid., Oryssin., Scand., p. 4.

Type-species: Priophorus pilicomis Dahlbom. Desig. by Rohwer, 1911.

Stevensia Brulle, 1846. In Lepeletier, Hist. Nat. Ins., Hym., v. 4, p. 667. No species included.

Type-species: Priophorus varines(!) Lepeletier. Desig. by Rohwer, 1922. Rohwer must have meant Pristiphora varipes Lepeletier.

betulae Rohwer. Newfoundland to N. Y.w. to Alta., S. Dak. Host: Betula.

Priophorus betulae Rohwer, 1922. In Rohwer and Middleton, U. S. Natl. Mus., Proc. 60: 27. , o.

infuscatus (MacGillivray). Ont., N. H., N. Y. w. to Mich., Ill. Host: Salix, Populus(?).

Craterocercus iufuscatus MacGillivray, 1916. Conn. State Geol. and Nat. Hist. Survey Bul. 22: 106. ..

Trichiocampus pacatus MacGillivray, 1921. Ent. News 32: 48..+

Trichiocamipus paetulus MacGillivray, 1921. Ent. News 32: 48. .

Trichiocampus palliolatus MacGillivray, 1921. Ent. News 32: 49. ․ 
Priophorus salicivons Rohwer, 1922. In Rohwer and Middleton, U. S. Natl. Mus., Proc. 60: 29. ๆ, ठे.

morio (Lepeletier). N. B. to B. C. s. to Pa., Mich., Mont., Calif.; Europe to Siberia. Ecology: Widespread. Host: Rubus. Introduced into New Zealand and Tasmania; attempted introduction into Hawaii from Oreg. and Calif. to aid in biological control of Rubus.

Cladius morio Lepeletier, 1823. Monog. Tenthred., p. 58. १, ठ.

Nematus brullei Dahlbom, 1835. Conspectus Tenthred., Siricid., Oryssin. Scand., p. 7.

Cladius tener Zaddach, 1859. Programm Friedr. Col. Konigsberg, p. 11. ?.

Cladius tristis Zaddach, 1859. Programm Friedr. Col. Konigsberg, p. 11. ㅇ, §.

Priophorus rubivomis Rohwer, 1922. In Rohwer and Middleton, U. S. Natl. Mus., Proc. 60: 28. ㅇ.

Priophorus montanus Rohwer, 1922. In Rohwer and Middleton, U. S. Natl. Mus., Proc. 60: 31. . .

Priophorus mibi Rohwer, 1922. In Rohwer and Middleton, U. S. Natl. Mus., Proc. 60: 32. ㅇ.

Biology: Essig and Hoskins, 1944. Calif. Dept. Agr., Ext. Serv. Cir. 87: 37. -Smith and Kido,

1949. Hilgardia 19: 43-54. - Nakao, 1967. Hawaii. Ent. Soc., Proc. 19: 339.

pallipes (Lepeletier). Newfoundland to Alaska s. to Va., Tenn., Ill., Colo., Oreg.; Eurasia.

Ecology: Widespread. Host: Prunus, Crataegus, Alnus.

Tenthredo albipes Fallen, 1808. Svenska Ventensk. Akad., Handl. 29: 110. Preocc. by

Geoffroy, 1785.

Cladius pallipes Lepeletier, 1823. Monog. Tenthred., p. 59. ^, ð.

Pristiphora varipes Lepeletier, 1823. Monog. Tenthred., p. 61. $\delta$.

Cladius immunis Stephens, 1835. Illus. Brit. Ent., v. 7, p. 23.

Nematus melarostigma Stephens, 1835. Illus. Brit. Ent., v. 7, p. 35.

Cladius aequalis Norton, 1872. Amer. Ent. Soc., Trans, 4: 78. ð’.

Priophomis discors Konow, 1894. Wien. Ent. Ztg. 13: 88.

Cladius solitaris Dyar, 1895. Canad. Ent. 27: 192. 9 , larva.

Priophorus modestius MacGillivray, 1921. Ent. News 32: 49. ?.

Priophorus munditus MacGillivray, 1921. Ent. News 32: 50..

Priophorus crataegi Rohwer, 1922. In Rohwer and Middleton, U. S. Natl. Mus., Proc. 60: 26. ‥

Priopharus pruni Rohwer, 1922. In Rohwer and Middleton, U. S. Natl. Mus., Proc. 60: 32. , o.

Priophorus virginianus Rohwer, 1922. In Rohwer and Middleton, U. S. Natl. Mus., Proc. 60: 34. ․

Priophorus plesizts Rohwer, 1922. In Rohwer and Middleton, U. S. Natl. Mus., Proc. 60: 35. ‥

Biology: Middleton, 1922. In Rohwer and Middleton, U. S. Natl. Mus., Proc. 60: 1-46 (notes following descriptions of species listed above).

\section{Genus TRICHIOCAMPUS Hartig}

Cladius subg. Trichiocampus Hartig, 1837. Fam. Blattwespen und Holzwespen, nebst Einleitung Naturgesch. Hym., p. 176.

Type-species: Nematus grandis Lepeletier. Desig. by Rohwer, 1911.

gregarius (Dyar). Maine to $\mathrm{Pa}$. w. to Ont., Mich. Host: Populus.

Cladius (Trichiocampus) gregarius Dyar, 1895. Canad. Ent. 27: 191. १, o, larva.

Biology: Middleton, 1922. In Rohwer and Middleton, U. S. Natl. Mus., Proc. 60: 11.

simplicicornis (Norton). N. S. to N. Y. w. to Sask.; N. Mex. and Calif. Host: Salix, sometimes Populus.

Cladius simplicicorn is Norton, 1869. Amer. Ent. Soc., Trans. 2: 367. ठ.

Priophorus irregularis Dyar, 1900. N. Y. Ent. Soc., Jour. 8: 28. ठ. Larva.

Trichiocampus patchiae MacGillivray, 1921. Ent. News 32: 48. ․

Priophorus moratus MacGillivray, 1921. Ent. News 32: 50. ๆ.

Biology: Middleton, 1922. In Rohwer and Middleton, U. S. Natl. Mus., Proc. 60: 9. 
viminalis (Fallen). Newfoundland to N. J. w. to Mich.; B. C.; Greenland; Europe and north Asia. Independently introduced into both east and west N. Amer.; first found in N. Y. in 1880's. Host: Populus, sometimes Salix.

Tenthredo viminalis Fallen, 1808. Svenska Vetensk. A kad., Handl. 29: 177.

Nematus grandis Lepeletier, 1823. Monog. Tenthred., p. 61. \&.

Cladius eucera Bouche, 1834. Naturgesch. des Ins., p. 140. $\uparrow, ~ \delta$.

Cladius luteicornis Stephens, 1835. Illus. Brit. Ent., v. 7, p. 24.

Cladius luteiventris Dahlbom, 1836. Prodrom. Hym. Scand., p. 102.

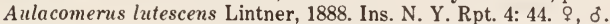

Platycampus victoria MacGillivray, 1920. Canad. Ent. 52: 61. ๆ.

Biology: Middleton, 1922. In Rohwer and Middleton, U. S. Natl. Mus., Proc. 60: 7. - Viereck, 1925. Canad. Ent. 57: 43. -Beique, 1961. Canad. Ent. 93: 1085-1097. - Smirnoff and

Beique, 1959. Canad. Ent. 91: 379-381 (polyhedral disease).

\section{TRIBE NEMATINI}

\section{Genus HOPLOCAMPA Hartig}

Hoplocampa Hartig, 1837. Fam. Blattwespen und Holzwespen, nebst Einleitung Naturgesch. Hym., p. 276.

Type-species: Tenthredo (Allantus) brevis Klug. Desig. by Rohwer, 1911.

Macgillivraya Ashmead, 1898. Canad. Ent. 30: 257. Preocc. by Forbes, 1852.

Type-species: Macgillivraya oregonensis Ashmead. Orig. desig.

Macgillivrayella Ashmead, 1899. In Smith, Ins. of N. J., p. 606. N. name for Macgillivraya.

Larvae of this holarctic genus live and feed inside the fruits of Rosaceae. Species that attack cultivated crops such as cherries, pears, and apples may be serious pests. Adults emerge in the spring when their host plant is in bloom and the females oviposit in the ovaries. Sometimes adults can be collected in large numbers from their host blossoms. The larvae feed in the developing fruit of the host, the fruit usually falling off when the larvae mature. The larvae enter the ground where they overwinter. All species are single brooded.

Revision: Rohwer, 1911. U. S. Dept. Agr. Bur. Ent. Tech. Ser. 20(4): 139-148. -Ross, 1943.

Amer. Ent. Soc., Trans. 69: 61-92 (as Holocampa (!)).

Taxonomy: Benson, 1968. Brit. Mus. (Nat. Hist.) Ent., Bul. 22: 199 (key to three species groups).

Biology: Bird, 1927. Ent. Soc. Amer., Ann. 20: 481-487.

alpestris Rohwer. Alta., Mont., Colo., B. C., Wash. Ecology: Adults collected from Amelanchier flowers.

Hoplocampa (Hoplocampa) alpestris Rohwer, 1911. U. S. Dept. Agr. Bur. Ent. Tech. Ser. 20(4): 142. \&, o.

bioculata Rohwer. Colo., Utah, Idaho, B. C., Wash., Oreg., Calif. Ecology: Adults collected from Amelanchier flowers.

Hoplocampa bioculata Rohwer, 1908. Canad. Ent. 40: 179. ‥

Hoplocampa (Hoplocampa) koebelei Rohwer, 1911. U. S. Dept. Agr. Bur. Ent. Tech. Ser. 20(4): 142. ?.

Hoplocampa padusa MacGillivray, 1923. Ill. Univ. Bul. 20(50): 17. ठ.

brevis (Klug). R. I., Conn., Ont., N. Y., Pa., Md.; Europe. Introduced, first found in Ontario in 1964. Host: Pyrus. An economic pest of pear.

Tenthredo (Allantus) brevis Klug, 1814. Mag. Gesell. Naturf. Freunde Berlin 8: 53. \&.

Taxonomy: Dustan, 1966. Canad. Ent. 98: 267 (occurrence in Canada). - Smith, 1966. U. S.

Dept. Agr., Coop. Econ. Ins. Rpt. 16(12): 228-230 (separation of brevis and testudinea adults and larvae).

Biology: Thomas, 1936. Ann. Appl. Biol. 23: 633-639. 
cookei (Clarke). B. C., Idaho, Wash., Oreg., Calif. Host: Prunus. A pest of cultivated cherries. Cherry fruit sawfly.

Dolerus cookei Clarke, 1906. Canad. Ent. 38: 351. \&, ð.

Hoplocampa (Hoplocampa) californica Rohwer, 1911. U. S. Dept. Agr., Bur. Ent. Tech. Ser. 20(4): 123. $९, \delta$.

Biology: Foster, 1913. U. S. Dept. Agr., Bur. Ent. Bul. 116, pp. 73-79. -Essig, 1914. Calif. State Comm. Hort., Monthly Bul., p. 31. - Duruz, 1922. Calif. Dept. Agr., Monthly Bul. 9(4): 393-399. - Essig and Hoskins, 1944. Calif. Dept. Agr., Ext. Serv. Cir. 87: 47.

halcyon (Norton). Maine to N. C. w. to Alta., Ill. Host: Amelanchier.

Tenthredo (Selandria) halcyon Harris, 1835. In Hitchcock, Rpt. Geol. Mineral. Bot. Zool. Mass., p. 583. Nom. nud.

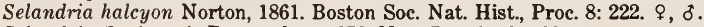

Selandria flavicornis Provancher, 1878. Nat. Canad. 10: 100. ठ́.

Hoplocampa (Hoplocampa) xantha Rohwer, 1911. U. S. Dept. Agr., Bur. Ent. Tech. Ser. 20(4): 144. ․

Morphology: Bird, 1926. Ent. Soc. Amer., Ann. 19: 268-279 (external anatomy of adult).

-Bird, 1927. Ent. Soc. Amer., Ann. 20: 481-486 (external anatomy of larva).

idaho Ross. Idaho, Wash., Oreg.

Hoplocampa idaho Ross, 1943. Amer. Ent. Soc., Trans. 69: 81. + , ठ.

lacteipennis Rohwer. Maine to N. Y. w. to Man., Alta., Mont., Colo. Host: Prunus virginiana and probably other species of Prinus.

Hoplocampa (Macgillivrayella) lacteipennis Rohwer, 1910. Canad. Ent. 42: 244..

Hoplocampa (Macgillivrayella) xanthura Rohwer, 1910. Canad. Ent. 42: 244. ठ.

Hoplocampa (Macgillivrayella) pallida Rohwer, 1911. U. S. Dept. Agr., Bur. Ent. Tech. Ser. 20(4): 141.. .

Biology: Bird, 1928. Sci. Agr. 8: 479-501.

makila Ross. Oreg.

Hoplocampa makila Ross, 1943. Amer. Ent. Soc., Trans. 69: 68..

marlatti Rohwer. Maine to Ga. w. to Alta., Iowa, Colo. Ecology: Adults collected from flowers of wild cherry, Prunus sp.

Hoplocampa (Hoplocampa) marlatti Rohwer, 1911. U. S. Dept. Agr., Bur. Ent. Tech. Ser. 20(4): 143.,$+ \delta$.

montanicola Rohwer. Maine, Ont. to B. C. s. to N. Y., Mich., S. Dak., Colo., Utah, Calif. Ecology: Widespread. Host: Prunus virginiana and probably other species of Prunus.

Hoplocampa (Hoplocampa) montanicola Rohwer, 1911. U. S. Dept. Agr., Bur. Ent. Tech.

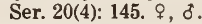

Hoplocampa (Hoplocampa) orbitalis Rohwer, 1911. U. S. Dept. Agr., Bur. Ent. Tech. Ser. 20(4): 141. ㅇ.

Hoplocampa (Hoplocampa) occidentalis Rohwer, 1911. U. S. Dept. Agr., Bur. Ent. Tech. Ser. 20(4): 144. \&, ठ。.

Biology: Bird, 1927. Ent. Soc. Amer., Ann. 20: 481-486 (xantha, not Rohwer).

nalema Ross. Wash. (Mt. Rainier).

Hoplocampa nalema Ross, 1943. Amer. Ent. Soc., Trans. 69: 82.,$~ ð$.

neneti Ross. Maine, N. H., Ont. Ecology: Adults collected from Amelanchier.

Hoplocampa neneti Ross, 1943. Amer. Ent. Soc., Trans. 69: 77. ठౌ.

oregonensis (Ashmead). Mont., Idaho, Oreg.

Macgillivraya oregonensis Ashmead, 1898. Canad. Ent. 30: 257. ९, ठ.

oskina Ross. Maine, N. Y. w. to Mich., Iowa, Kans. Ecology: Adults collected from Crataegus flowers.

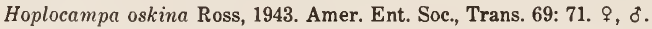

pallipes MacGillivray. N. H., N. Y. to Mich.; Alta. w. to B. C., Oreg., Calif. Ecology: Adults collected from Amelanchier flowers.

Hoplocampa pallipes MacGillivray, 1893. Canad. Ent. 25: 239..

Hoplocampa (Hoplocampa) nevadensis Rohwer, 1911. U. S. Dept. Agr., Bur. Ent. Tech. Ser. 20(4): 143. . 
ritcheri Ross. N. C., Ill., Wash. Ecology: Adults collected from Crataegus flowers.

Hoplocampa ritcheri Ross, 1943. Amer. Ent. Soc., Trans. 69: 72. ๆ, ठ.

sialica Ross. Maine to Md. w. to Mich. Ecology: Adults collected from Amelanchier flowers.

Hoplocampa sialica Ross, 1943. Amer. Ent. Soc., Trans. 69: 67. १, ð.

spala Ross. B. C., Oreg.

Hoplocampa spala Ross, 1943. Amer. Ent. Soc., Trans. 69: 83. ¿.

stricklandi Ross. Maine, N. Y., Mich., Alta.

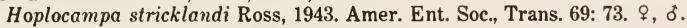

testudinea (Klug). N. H., Vt., Mass., R. I., Conn., N. Y., N. J.; B. C.; Europe. Accidentally introduced into both east and west N. Amer., first found in N. Y. in 1939 and in B. C. in 1940. Host: Malus malus. A pest of apples.

Tenthredo (Allantus) testudinea Klug, 1814. Mag. Gesell. Naturf. Freunde Berlin 8: 60..

Biology: Miles, 1932. Ann. Appl. Biol. 14: 420-431. - Downes and Andison, 1942. Ent. Soc.

Brit. Columbia, Proc. 39: 13-16. - Pyenson, 1943. Jour. Econ. Ent. 36: 218-221.

texas Ross. Tex. Ecology: Adults collected from Crataegus flowers.

Hoplocampa texas Ross, 1943. Amer. Ent. Soc., Trans. 69: 68. ๆ, ठ.

\section{Genus CAULOCAMPUS Rohwer}

Caulocampus Rohwer, 1912. U. S. Natl. Mus., Proc. 43: 239.

Type-species: Priophorus acericaulis MacGillivray. Orig. desig.

Revision: Smith, 1968. Ent. Soc. Wash., Proc. 70: 126-129.

acericaulis (MacGillivray). Conn., Ont., N. Y., Md., Ala., Mich., Ill. Ecology: Larva mines in leaf petioles. Host: Acer.

Priophorus acericaulis MacGillivray, 1906. Canad. Ent. 38: 306..

Biology: Britton, 1906. Ent. News 17: 313-320.

matthewsi Smith. N. Y.

Caulocampus matthewsi Smith, 1968. Ent. Soc. Wash., Proc. 70: 128. ๆ.

\section{Genus HEMICHROA Stephens}

\section{Genus HEMICHROA Subgenus HEMICHROA Stephens}

Hemichroa Stephens, 1835. Illus. Brit. Ent., v. 7, p. 55.

Type-species: Tenthredo alni Linnaeus. Desig. by Westwood, 1840.

Leptocerca Hartig, 1837. Fam. Blattwespen und Holzwespen, nebst Einleitung Naturgesch. Hym., p. 228.

Type-species: Tenthredo alni Linnaeus. Desig. by Rohwer, 1911.

Engages Gistel, 1848. Naturgesch. Thierr. f. hoh Schul., p. 9. N. name for Leptocerca Hartig.

Leptocercus Thomson, 1871. Hym. Scand., v. 1, p. 76. Emend.

crocea (Geoffroy). Newfoundland to Alaska s. to Conn., N. Y., N. Mex., Idaho, Oreg.; Europe to Siberia. Ecology: Widespread. Host: Alnus. Striped alder sawfly.

Tenthredo crocea Geoffroy, 1785. In Fourcroy, Ent. Paris, p. 364.

Tenthredo rifa Panzer, 1799. Faunae Ins. German., v. 6, t. 72, fig. 2.

Hemichroa stigma Stephens, 1835. Illus. Brit. Ent., v. 7, p. 55.

Dineura unicolor Rudow, 1872. Stettin Ent. Ztg. 30: 218.

Nematus ardens Zaddach, 1882. Phys. Okonom. Gesell. Konigsberg., Schr. 23: 133.

Dineura americana Provancher, 1882. Nat. Canad. 13: 292..

Hemichroa pallida Ashmead, 1890. Colo. Biol. Assoc., Bul. 1: 15. $q$.

Hemichroa dyari Rohwer, 1918. Ent. Soc. Wash., Proc. 20: 171. ๆ, o.

Hemichroa washingtonia Rohwer and Middleton, 1931. Ent. Soc. Wash., Proc. 34: 97. \&, ठ.

Biology: Ross, 1932. Canad. Ent. 64: 247-248. - Hopping, 1937. Canad. Ent. 69: 243-249.

-Reeks and Smith, 1945. Acad. Nat. 2: 11. 


\section{Genus HEMICHROA Subgenus VARNA Ross}

Hemichroa subg. Varna Ross, 1937. Ill. Biol. Monog. 15(2): 79.

Type-species: Nematus militaris Cresson. Orig. desig.

amelanchieridis (Rohwer). Maine, Que. to N. Y.; Alta. to Colo. w. to B. C., Oreg. Host:

Amelanchier.

Pteronidea amelanchieridis Rohwer, 1920. U. S. Natl. Mus., Proc. 57: 215..

militaris (Cresson). Ont. to Alaska s. to R. I., Pa., Ill., Mont., Nev. Ecology: Widespread. Host: Prunus, Amelanchier.

Nematus militaris Cresson, 1880. Amer. Ent. Soc., Trans. 8: 7..

Nematus thoracicus Harrington, 1893. Canad. Ent. 21: 58. ․

\section{Genus CRATEROCERCUS Rohwer}

Craterocercus Rohwer, 1911. U. S. Natl. Mus., Proc. 41: 385.

Type-species: Hemichroa phytophagica Dyar. Orig. desig.

Larvae of this exclusively North American genus feed on Quercus.

Revision: Rohwer, 1918. Ent. Soc. Wash., Proc. 20: 162-165. -Smith, 1969. Ent. Soc. Wash., Proc. 71: 153-161.

albipes (Cresson). Oreg., Nev., Calif. Ecology: Adults collected from Quercus.

Mesoneura albipes Cresson, 1880. Amer. Ent. Soc., Trans. 8: 11..

Craterocercus californicus Rohwer, 1917. U. S. Natl. Mus., Proc. 53: 234. $\uparrow$.

cordleyi MacGillivray. Oreg., Calif.

Craterocercus cordleyi MacGillivray, 1923. Ill. Univ. Bul. 20(50): 9..

fraternalis (Norton). N. H. to Pa. w. to Wis., Ill., Kans., Tex. Host: Quercus alba.

Hemichroa fraternalis Norton, 1872. Amer. Ent. Soc., Trans. 4: 81. ठ。.

Craterocercus quercivorus Rohwer, 1918. Ent. Soc. Wash., Proc. 20: 164. \&, ๖.

Craterocercus cervinus MacGillivray, 1923. Ill. Univ. Bul. 20(50): 9..

Craterocercus circulus MacGillivray, 1923. Ill. Univ. Bul. 20(50): 9. ؟.

furcatus Smith. Conn., N. J., Ill.

Craterocercus furcatus Smith, 1969. Ent. Soc. Wash., Proc. 71: 160..

obtusus (Klug). Conn. to Fla. w. to Ill., Kans., Ark., Tex. Host: Quercus alba, Q. coccinea.

Tenthredo (Allantus) obtusa Klug, 1814. Mag. Gesell. Naturf. Freunde Berlin 8: 55..

Hemichroa albidovariata Norton, 1872. Amer. Ent. Soc., Trans. 4: 81. ๆ.

Hemichroa phytophagica Dyar, 1898. N. Y. Ent. Soc., Jour. 6: 125. + , larva.

Craterocercus floridanus Rohwer, 1912. U. S. Natl. Mus., Proc. 43: 238. ๆ, ơ.

\section{Genus PLATYCAMPUS Schiodte}

Leptopus Hartig, 1837. Fam. Blattwespen und Holzwespen, nebst Einleitung Naturgesch. Hym., p. 184. Preocc. by Mayer, 1835.

Type-species: Nematus (Leptopus) hypogastricus Hartig. Monotypic.

Platycampus Schiodte, 1839. Mag. Zool. (ser. 2) 1: 20, footnote; pl. 6-10. N. name for Leptopus Hartig.

Erasminus Gistel, 1848. Naturgesch. Thierr. f. hoh Schul., p. 9. N. name for Leptopus Hartig.

Camponiscus Newman, 1869. Entomologist 4: 215.

Type-species: Camponiscus healaei Newman. Monotypic.

A small holaretic genus with two North American representatives.

albostigmus (Rohwer). N. S., Maine to Alaska s. to N. Y., Mich., Minn., Colo., Nev., Wash. Ecology: Widespread.

Camponiscus albostigmus Rohwer, 1908. N. Y. Ent. Soc., Jour. 16: 105. ९.

americanus (Marlatt), Que., Maine to Alaska s. to Pa., N. Mex., Idaho. Ecology: Widespread.

Host: Populus.

Camponiscus americanus Marlatt, 1896. Canad. Ent. 28: 251. ९, ठ’.

Camponiscus smithi Rohwer, 1908. N. Y. Ent. Soc., Jour. 16: 105. ९.

Platycampus vierecki MacGillivray, 1920. Canad. Ent. 52: 60. ๆ. 


\section{Genus ANOPLONYX Marlatt}

Anoplonyx Marlatt, 1896. U. S. Dept. Agr. Div. Ent. Tech. Ser. 3: 18.

Type-species: Nematus pectoralis Lepeletier. Desig. by Rohwer, 1911.

Marlattia Ashmead, 1898. Canad. Ent. 30: 287.

Type-species: Hemichroa laricis Marlatt. Orig. desig.

Larvae of this holarctic genus feed on Larix.

Taxonomy: Wong, 1955. Canad. Ent. 87: 224-227 (larvae). -Woods, 1962. Ent. Soc. Brit.

Columbia, Proc. 59: 17 (species in B. C.).

canadensis Harrington. Newfoundland to Maine w. to Yukon, n. B. C., Sask., Minn. Host: Larix laricina.

Anoplonyx canadensis Harrington, 1902. Canad. Ent. 34: 94.9.

Platycampus (Anoplonyx) itascus Rohwer and Middleton, 1932. Ent. Soc. Wash., Proc. 34: 96. ठ.

laricivorus (Rohwer and Middleton). Mont., B. C., Idaho. Host: Larix occidentalis.

Platycampus (Anoplonyx) laricivorus Rohwer and Middleton, 1932. Ent. Soc. Wash., Proc. 32: 95 . $\%$, o.

luteipes (Cresson). Newfoundland to Maine, N. H. w. to Yukon, n. B. C., Minn., Ill. Host: Larix laricina.

Dineura luteipes Cresson, 1880. Amer. Ent. Soc., Trans. 8:11. ठ'.

Hemichroa laricis Marlatt, 1896. Canad. Ent. 28: 257. $९$.

Biology: Reeks and Smith, 1945. Acad. Nat. 2:11.

Morphology: Bracken, 1961. Canad. Ent. 93: 573-593.

occidens Ross. Mont., B. C., Idaho, Oreg. Host: Larix occidentalis.

Platycampus (Anoplonyx) laricis Rohwer and Middleton, 1932. Ent. Soc. Wash., Proc. 34:

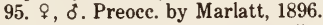

Anoplonyx occidens Ross, 1937. Ill. Biol. Monog. 15(2): 82. N. name.

\section{Genus ADELOMOS Ross}

Adelomos Ross, 1935. Canad. Ent. 67: 201.

Type-species: Adelomos cleone Ross. Orig. desig.

cleone Ross. Ky., Ill.

Adelom os cleone Ross, 1935. Canad. Ent. 67: 202. .

\section{Genus NEOPAREOPHORA MacGillivray}

Neopareophora MacGillivray, 1908. Canad. Ent. 40: 289.

Type-species: Neopareophora martini MacGillivray. Orig. desig.

Dineuridea Rohwer, 1912. U. S. Natl. Mus., Proc. 43: 240.

Type-species: Marlattia erythrothorax Rohwer. Orig. desig.

A small Nearctic genus with several unidentified species in addition to those listed below.

Revision: Ross, 1935. Canad. Ent. 67: 204-205.

erythrothorax (Rohwer). Fla. (Jacksonville).

Marlattia erythrothorax Rohwer, 1911. U. S. Natl. Mus., Proc. 41: 385 . ๆ.

litura (Klug). N. B., Que. to Va. w. to Ill. Ecology: First instar larvae feed inside the buds, subsequent instars feed on the leaves. Host: Vaccinium, especially low-bush blueberry.

Dineura litura Klug, 1814. Mag. Gesell. Naturf. Freunde Berlin 8: 83..

Dineura linitus Norton, 1867. Amer. Ent. Soc., Trans. 1: 240. ․

Dineura lateralis Norton, 1867. Amer. Ent. Soc., Trans. 1: 240..

Neopareophora martini MacGillivray, 1908. Canad. Ent. 40: 289..

Biology: Maxwell, 1953. Canad. Ins. Pest Rev. 31(1): 100. - Neilson, 1955. Canad. Ent. 87:

356-357. - Neilson, 1958. Canad. Ent. 90: 229-234. 


\section{Genus NEMATINUS Rohwer}

Nematinus Rohwer, 1911. U. S. Dept. Agr., Bur. Ent. Tech. Ser. 20: 99.

Type-species: Tenthredo abdominalis Panzer. Orig. desig.

A holaretic genus which is found in North America from N. S. to Alaska south to N. Y., Mich., S. Dak., Colo., and Calif. This genus has not been studied, and the following is merely a list of the described species with their type localities.

ochreatus (Rohwer). N. B. (St. John).

Pteronus ochreatus Rohwer, 1910. U. S. Natl. Mus., Proc. 38: 198. ๆ.

oronus (Kincaid). Alaska (Yukatat Bay).

Pachynematus oronus Kincaid, 1900. Wash. Acad. Sci., Proc. 2: 347. ๆ.

pontanioides (Marlatt). Oreg. (Mt. Hood).

Nematus pontanioides Marlatt, 1896. U. S. Dept. Agr., Div. Ent. Tech. Ser. 3: 89..

unicolor (Dyar). N. Y. (Keene Valley). Host: Betula alba.

Nematus unicolor Dyar, 1895. Amer. Ent. Soc., Trans. 22: 308. Larva. Dyar's description precedes that of Marlatt, 1896; previous listings give Marlatt as author.

\section{Genus PACHYNEMATUS Konow}

Pachynematus Konow, 1890. Deut. Ent. Ztschr., pp. 233, 238, 246.

Type-species: Nematus capreae Panzer. Desig. by Rohwer, 1911.

Known hosts for this genus in North America are grasses, sedges, and dock. Some species in Europe also feed on Salicaceae and Coniferae. Several species reared from wheat and other grain crops may be of economic importance. So far as is known, the grass feeding species are single brooded with the flight and feeding activities occurring early in the spring. Some of the species on sedges apparently have several generations a year. Very little biological work has been done. The taxonomy of this genus is almost entirely based on males. Females of a number of species cannot be separated; consequently, the lists of unplaced taxa below. Larvae are commonly collected, but so few have been associated with the adults that it is impossible to identify them except to genus.

Taxonomy: Ross, 1945. Ent. Soc. Wash., Proc. 47: 105-120 (key to N. Amer. species).

-Benson, 1948. Ent. Monthly Mag. 84: 58-65 (British species). -Benson, 1962. Brit. Mus.

(Nat. Hist.) Ent., Bul. 12: 405-406 (holarctic species). -Benson, 1963. Roy. Ent. Soc.

London, Proc., Ser. B: Taxonomy 32: 162-164 (Rumicis group).

\section{Species Group Clitellatus}

anolita Ross. Kans., Tex., Mont., Colo. Host: Wheat.

Pachyrematus apicalis Marlatt, 1896. U. S. Dept. Agr., Div. Ent. Tech. Ser. 3: 107. ơ. Preoce. in Pachynematus by apicalis Hartig.

Pachynematus anolita Ross, 1951. In Muesebeck et. al., U. S. Dept. Agr., Agr. Monog. 2: 39. N. name for apicalis Marlatt.

auratus Marlatt. N. Y., Ohio, Ind., Ill., Iowa, Kans., Mont.

Pachynematus auratus Marlatt, 1896. U. S. Dept. Agr., Div. Ent. Tech. Ser. 3: 99. ‡, §.

elibrichellus (Cameron). N. H. to Alaska; aretic Eurasia. Host: Carex.

Nematus clibrichellus Cameron, 1878. Fauna Scotland, v. 1, p. 32. $\delta$.

Nematus Thomsoni Cameron, 1882. Ent. Soc. London, Trans., p. 540., , o.

Nematus clibrichensis Cameron, 1885. Monog. Brit. Phytophagous Hym., v. 2, p. 88. ठै.

Pachynematus pubescens Marlatt, 1896. U. S. Dept. Agr., Div. Ent. Tech. Ser. 3: 100. $q$.

Pachynematus gotarius Kincaid, 1900. Wash. Acad. Sci., Proc. 2: 348. ठ̃.

Pachynematus venustus MacGillivray, 1921. Calif. Acad. Sci., Proc. (ser. 4) 11(14): 190. $q$, $\delta$.

Pachynematus vernus MacGillivray, 1921. Calif. Acad. Sci., Proc. (ser. 4) 11(14): 191. ठ.

clitellatus (Lepeletier). Labrador, Que.; Europe. Introduced ?. Host: Gramineae.

Tenthredo capreae Panzer, 1799. Faunae Ins. German, v. 6, p. 65, t. 8. Preocc. by Linnaeus, 1758.

Nematus clitellatus Lepeletier, 1823. Monog. Tenthred., p. 62..

Nematus trisignatus Foerster, 1854. Naturh. Ver. Rheinlande, Verh. 11: 292. ๆ. 
clypeatus Marlatt. Man., Minn., Alta., Mont.

Pachynematus clypeatus Marlatt, 1896. U. S. Dept. Agr., Div. Ent. Tech. Ser. 3: 102.. excisus (Thomson). Greenland; arctic Europe.

Nematus excisus Thomson, 1862. Svenska Vetensk. Akad., Ofvers. Forh. 19: 628..

extensicornis (Norton). Maine, Ont. to Md. w. to Alta., Mont., Wyo., Colo.; Europe. Host: Wheat, probably other Gramineae.

Nematus extensicornis Norton, 1861. Boston Soc. Nat. Hist., Proc. 8: 159. ठै.

Nematus marylandicus Norton, 1864. Ent. Soc. Phila., Proc. 3: 7. $९$.

Nematus aureopectus Norton, 1867. Amer. Ent. Soc., Trans. 1: 219...

Pachynematus affinis Marlatt, 1896. U. S. Dept. Agr., Div. Ent. Tech. Ser. 3: 97. ๆ, ơ.

Pachynematus tritici Marlatt, 1896. U. S. Dept. Agr., Div. Ent. Tech. Ser. 3: 106. ठ.

Pachynematus foveolatus Konow, 1903. Ztschr. System. Hym. Dipt. 3: 379. ๆ, ठ๋.

Pachynematus truncatus Benson, 1948. Ent. Monthly Mag. 84: 62. ठै.

jamesi Ross. Colo., Utah.

Pachynematus jamesi Ross, 1945. Ent. Soc. Wash., Proc. 47: 112. o.

kirbyi (Dahlbom). Que. to Alaska s. to Maine, Pa., Ill., Iowa, S. Dak., Mont.; Europe to Siberia. Ecology: Widespread. Host: Carex.

Nematus kirbyi Dahlbom, 1835. Clavis Hym. Syst., p. 40. ¿.

Nematus flaviventris Hartig, 1840. Stettin Ent. Ztg. 1: 24.

Nematus diaphanus Eversmann, 1847. Soc. Nat. Moscou, Bul. 20: 19.

Nematus umbripennis Eversmann, 1847. Soc. Nat. Moscou, Bul. 20: 20.

Nematus turgidus Zaddach, 1875. Phys. Okonom. Gesell. Konigsberg, Schr. 16: 82.

Nematus suadus Cresson, 1880. Amer. Ent. Soc., Trans. 8: 10. ․

Pachynematus zaddachi Konow, 1903. Ztschr. System. Hym. Dipt. 3: 377. \&, o.

Pachynematus infumatus Marlatt, 1896. U. S. Dept. Agr., Div. Ent. Tech. Ser. 3: 107. ð。.

Pachynematus refractarius MacGillivray, 1921. N. Y. Ent. Soc., Jour. 29: 31. ?.

miscus Ross. Oreg., Calif.

Pachynematus miscus Ross, 1945. Ent. Soc. Wash., Proc. 47: 114. ठ.

Taxonomy: Middlekauff, 1955. Pan-Pacific Ent. 31: 196.

moerens (Foerster). Alta., Alaska; Europe. Host: Gramineae.

Nematus moerens Foerster, 1854. Naturh. Ver. Rheinlande, Verh. 11: 294. $q$.

Nematus pleuralis Thomson, 1862. Ofvers. Svensk. Vet. Akad., Forh. 19: 628.

Pachynematus falonus Ross, 1945. Ent. Soc. Wash., Proc. 47: 113. ठे.

nevadensis Marlatt. Nev.

Pachynematus nevadensis Marlatt, 1896. U. S. Dept. Agr., Div. Ent. Tech. Ser. 3: 110. ð.

nigritibialis Rohwer. N. Y., Mich., Ohio, Ill., Nebr., Kans.

Pachynematus nigritibialis Rohwer, 1909. Canad. Ent. 41: 17. \&.

painteri Ross. Kans., Idaho. Host: Wheat.

Pachynematus painteri Ross, 1945. Ent. Soc. Wash., Proc. 47: 115. ๆ, ơ.

parvilabris (Thomson). N. W. T., Greenland; arctic Europe. Specimen collected on Ward Hunt Is., $83^{\circ} 05^{\prime} \mathrm{N}$. May be the most northerly sawfly found.

Nematus parvilabris Thomson, 1862. Ofvers. Svensk. Vet. Akad., Forh. 19: 638. \&, ठ.

Pachynematus inopinatus Lindqvist, 1949. Notulae Ent. 28: 82.

Pachynematus abstmısus Lindqvist, 1949. Notulae Ent. 28: 83.

setator Ross. N. Y., Ind., Ill., Oreg. Host: Festuca.

Pachynematus setator Ross, 1945. Ent. Soc. Wash., Proc. 47: 113. o.

Biology: Kamm, 1975. Environ. Ent. 4: 312-314 (in Oreg.).

smithae Ross. N. H.; Europe.

Pachynematus smithae Ross, 1945. Ent. Soc. Wash., Proc. 47: 116. ठ.

sporax Ross. Sask., Idaho, Wash., Oreg., Calif. Host: Wheat.

Pachynematus sporax Ross, 1945. Ent. Soc. Wash., Proc. 47: 115. ठ.

Taxonomy: Middlekauff, 1955. Pan-Pacific Ent. 31: 196-198 (female).

Biology: Armitage, 1954. Calif. Dept. Agr., Bul. 54: 73. 
thoracicus Marlatt. Mont.

Pachynematus thoracicus Marlatt, 1896. U. S. Dept. Agr., Div. Ent. Tech. Ser. 3: 108. ठ์. uvator Ross. Utah, B. C., Wash.

Pachynematus uvator Ross, 1945. Ent. Soc. Wash., Proc. 47: 114. ठ.

\section{UnPlaced Taxa of Group Clitellatus}

The following species were described from females. Because species separation of Pachynematus is based mostly on males, they can not be placed as yet.

absyrtus MacGillivray. Oreg.

Pachynematus absyrtus MacGillivray, 1923. Ill. Univ. Bul. 20(50): 27..

academus MacGillivray. Oreg.

Pachynematus academus MacGillivray, 1923. Ill. Univ. Bul. 20(50): 27..

ater (MacGillivray). Wash.

Messa ater MacGillivray, 1893. Canad. Ent. 25: 238..

coloradensis Marlatt. Colo.

Pachynematus coloradensis Marlatt, 1896. U. S. Dept. Agr., Div. Ent. Tech. Ser. 3: 101.. ebenus (Cresson). Colo.

Aulacomerus? ebenus Cresson, 1880. Amer. Ent. Soc., Trans. 8: 10..

gamus Smith, n. name. Nev.

Pachynematus graminis Marlatt, 1896. U. S. Dept. Agr., Div. Ent. Tech. Ser. 3: 101.. Preocc. in Pachynematus by Cameron, 1874.

hoodi Marlatt. Oreg. (Mt. Hood).

Pachynematus hoodi Marlatt, 1896. U. S. Dept. Agr., Div. Ent. Tech. Ser. 3: 104..

luteipes (Cresson), n. comb. Nev.

Nematus luteipes Cresson, 1880. Amer. Ent. Soc., Trans. 8: 6..

pleuricus (Norton). Colo.

Nematus pleuricus Norton, 1867. Amer. Ent. Soc., Trans. 1: 208..

robinsonae (Rohwer). Colo.

Lygaeonematus robinsonae Rohwer, 1915. U. S. Natl. Mus., Proc. 49: 212 ..

stigmatus (Norton). Mass.

Tenthredo (Nematus) stigmatus Harris, 1835. In Hitcheock, Rpt. Geol. Mineral. Bot. Zool. Mass., p. 583. Nom. nud.

Nematus stigmatus Norton, 1861. Boston Soc. Nat. Hist., Proc. 8: 161. ?.

Species Group Vagus

aurantiacus Marlatt. Que. to N. Y. w. to Alta., Mont., Ill. Host: Carex.

Pachynematus aurantiacus Marlatt, 1896. U. S. Dept. Agr., Div. Ent. Tech. Ser. 3: 95. , ơ.

Pachynematus punctulatus Marlatt, 1896. U. S. Dept. Agr., Div. Ent. Tech. Ser. 3: 103. ๆ.

Pachynematus allegatus MacGillivray, 1923. Canad. Ent. 55: 162. .

corniger (Norton). Newfoundland to Ga. w. to Minn., Kans. Host: Carex.

Nematus corniger Norton, 1861. Boston Soc. Nat. Hist., Proc. 8: 159. ठ.

Nematus subalbatus Norton, 1864. Ent. Soc. Phila., Proc. 3: 7..

Pachynematus repertus MacGillivray, 1921. N. Y. Ent. Soc., Jour. 29: 31..

Pachynematus remissus MacGillivray, 1921. N. Y. Ent. Soc., Jour. 29: 32. ․ Synonymy of remissus may be questionable.

montivagus Marlatt. N. H.

Pachynematus montivagus Marlatt, 1896. U. S. Dept. Agr., Div. Ent. Tech. Ser. 3: 101.. obductus (Hartig). Mass. to B. C. s. to N. Y., Colo., Nev.; Greenland; Iceland, Europe to Siberia. Ecology: Widespread. Host: Gramineae.

Nematus obductus Hartig, 1837. Fam. Blattwespen und Holzwespen, nebst Einleitung Naturgesch. Hym., p. 201. \&, ठ.

Nematus conductus Ruthe, 1859. Stettin Ent. Ztg. 20: 306..+

Nematus graminis Cameron, 1874. Ent. Monthly Mag. 10: 221..

Nematus palliventris Cresson, 1880. Amer. Ent. Soc., Trans. 8: 5. ㅇ.

Pachynematus boulderensis Rohwer, 1920. U. S. Natl. Mus., Proc. 57: 218. 9. 
rufocinctus MacGillivray. Conn.

Pachynematus rufocinctus MacGillivray, 1916. Conn. State Geol. and Nat. Hist. Survey Bul. 22: 117. + , ठे.

vagus (Fabricius). Ont. to Alta., Idaho s. to N. Y., Ill., Minn., Mont.; Europe to Siberia. Ecology: Widespread. Host: Carex, Salix.

Tenthredo vaga Fabricius, 1781. Species Insectorum, v. 1, p. 415.

Nematus leucogaster Hartig, 1840. Stettin Ent. Ztg. 1: 23.

Nematus inconspicuus Kirby, 1882. List Hym. Brit. Mus., v. 1, p. 141. $\$$.

Pachynematus corticosus MacGillivray, 1901. N. Y. State Mus., Bul. 47: 584. \&.

Pachynematus roscidus MacGillivray, 1901. N. Y. Ent. Soc., Jour. 29: 31..

UNPLACED TAXa OF GROUP VAGAS

abdominalis Marlatt. Wash.

Pachynematus abdominalis Marlatt, 1896. U. S. Dept. Agr., Div. Ent. Tech. Ser. 3: 104. ๆ. carolinensis Marlatt. N. C.

Pachynematus carolinensis Marlatt, 1896. U. S. Dept. Agr., Div. Ent. Tech. Ser. 3: 109. ठ.

koebelei Marlatt. Oreg.

Pachynematus koebelei Marlatt, 1896. U. S. Dept. Agr., Div. Ent. Tech. Ser. 3: 108. ठँ.

robustiformis Rohwer. Colo.

Pachynematus robustiformis Rohwer, 1908. N. Y. Ent. Soc., Jour. 16: 108. $\uparrow$.

robustus Marlatt. Mont.

Pachynematus robustus Marlatt, 1896. U. S. Dept. Agr., Div. Ent. Tech. Ser. 3: 102..

SPECIES GROUP RUMicis

freyi Lindqvist. N. W. T., Yukon; Europe to Siberia.

Pachynematus freyi Lindqvist, 1949. Notulae Ent. 28: 81..

rumicis (Linnaeus). Man., Alaska; Iceland, Europe to Siberia. Host: Rumex.

Tenthredo rumicis Linnaeus, 1758. Syst. Nat., Ed. 10, v. 1, p. 559.

Nematus flavipennis Cameron, 1876. Ent. Monthly Mag. 12: 189..

\section{Genus PIKONEMA Ross}

Pikonema Ross, 1937. Ill. Biol. Monog. 15(2): 86.

Type-species: Nematus dimmockii Cresson. Orig. desig.

Larvae of this Nearctic genus feed on species of Picea.

Revision: Ross, 1938. Ent. Soc. Wash., Proc. 40: 17-20 (adults and larvae).

Taxonomy: Wong, 1951. Ont. Ent. Soc., Ann. Rpt. 1951, p. 65 (cocoons).

alaskensis (Rohwer). Newfoundland to Alaska s. to Mass., Mich., Minn., Wyo., Idaho, B. C.

Ecology: Widespread. Host: Picea canadensis, $P$. engelmannii, $P$. excelsa, P. glauca, $P$. mariana, $P$. mibens, $P$. pungens, $P$. sitchensis, $P$. abies. Yellowheaded spruce sawfly.

Pachynematus alaskensis Rohwer, 1911. U. S. Natl. Mus., Proc. 41: 387. + , ठ.

Pachynematus piceae Rohwer, 1911. U. S. Natl. Mus., Proc. 41: 387. ๆ, ठे.

Biology: Brown, 1938. Ont. Ent. Soc., Ann. Rpt. 1937, p. 14. -Nash, 1939. Jour. Econ. Ent. 32: 330-334. - Brown, 1941. Canad. Dept. Agr., Pub. 712, p. 6. - Schaffner, 1943. Jour.

Forestry 41: 585. - Reeks and Smith, 1945. Acad. Nat. 2: 11. - Bradley, 1951. Canad. Ent. 83: 130. (parasites), -Wilson, 1962. U. S. Dept. Agr., Forest Pest Leaflet 69, 4 pp.

dimmockii (Cresson). Newfoundland to N. W. T., B. C. s. to N. B., N. H., Man., Colo., Wyo., Idaho. Ecology: Widespread. Host: Picea canadensis, $P$. engelmannii, P. glauca, $P$. mariana, $P$. rubens, $P$. sitchensis, $P$. abies. Greenheaded spruce sawfly.

Nematus dimmockii Cresson, 1880. Amer. Ent. Soc., Trans. 8: 6..

Nematus ochreatus Harrington, 1889. Canad. Ent. 21: 95..

Biology: Brown, 1938. Ont. Ent. Soc., Ann. Rpt. 1937, p. 14. - Brown, 1941. Canad. Dept. Agr., Pub. 712, p. 6. - Reeks and Smith, 1945. Acad. Nat. 2: 11.

ruralis (Cresson). Oreg., Calif., Nev.

Nematus ruralis Cresson, 1880. Amer. Ent. Soc., Trans. 8: 5 . ๆ. 


\section{Genus EITELIUS Kontuniemi}

Eitelius Kontuniemi, 1966. Ann. Ent. Fenn. 31: 46.

Type-species: Pachynematus dentatus Lindqvist. Orig. desig.

Prior to 1967, the species below was placed in the genus Micronematus Konow which is now a synonym of Pristiphora.

Taxonomy: Wong, 1967. Canad. Ent. 99: 1101-1104.

gregarius (Marlatt). N. S., Mass., Conn., N. J. Host: Salix.

Pachynematus gregarius Marlatt, 1896. Canad. Ent. 28: 256. \&, ठ.

Pachynematus rarus MacGillivray, 1921. N. Y. Ent. Soc., Jour. 29: 30. ९.

Pontania decrepita MacGillivray, 1921. N. Y. Ent. Soc., Jour. 29: 33..

\section{Genus PRISTIPHORA Latreille}

Pristiphora Latreille, 1810. Consid. Generales Crust. Arachn. Ins., p. 294.

Type-species: Pteronus testaceus Jurine. Orig. desig.

Diphadnus Hartig, 1837. Fam. Blattwespen und Holzwespen, nebst Einleitung

Naturgesch. Hym., p. 225.

Type-species: Nematus fuscicornis Hartig. Desig. by Rohwer, 1911.

Lygaeonematus Konow, 1890. Deut. Ent. Ztschr., pp. 233, 238, 247.

Type-species: Nematus pini Retzius. Desig. by Rohwer, 1911.

Micronematus Konow, 1890. Deut. Ent. Ztschr., pp. 233, 239, 248.

Type-species: Nematus pullus Foerster. Desig. by Rohwer, 1911.

Gymnonychus Marlatt, 1896. U. S. Dept. Agr., Div. Ent. Tech. Ser. 3: 122.

Type-species: Gymnonychus califormicus Marlatt. Orig. desig.

Neotomostethus MacGillivray, 1908. Canad. Ent. 40: 290.

Type-species: Neotomostethus hyalinus MacGillivray. Orig. desig.

Pristiphora subg. Sala Ross, 1937. Ill. Biol. Monog. 15(2): 85. Preocc. by Walker, 1867.

Type-species: Nematus chloreus Norton. Orig. desig.

Lygaeonematus subg. Lygaeotus Lindqvist, 1952. Notulae Ent. 32: 82. Invalid, type-species not designated.

Lygaeonematus subg. Lygaeophora Lindqvist, 1952. Notulae Ent. 32: 82. Invalid, type-species not designated.

A large, nearly cosmopolitan genus with diverse host plants. Two species from southern Brazil are the only known South American Nematinae. Several phyletic lines are evident in this genus which will eventually allow separation into more convenient species groupings.

Revision: Marlatt, 1896. U. S. Dept. Agr. Div. Ent. Tech. Ser. 3: 113-125.

Taxonomy: Benson, 1962. Brit. Mus. (Nat. Hist.) Ent., Bul. 12: 394-396 (holaretic species). abbreviata (Hartig). Ont., Conn. to Va. w. to Wis., Kans., Colo., Utah; B. C., Wash., Oreg.,

Calif.; Europe. Ecology: A pest of pear trees. Larva feeds on foliage. Introduced. Host:

Pyrus communis. California pearslug.

Nematus abbreviatus Hartig, 1837. Fam. Blattwespen und Holzwespen, nebst Einleitung Naturgesch. Hym., p. 205. \%.

Gymnonychus californicus Marlatt, 1896. U. S. Dept. Agr., Div. Ent. Tech. Ser. 3: 122. .

Taxonomy: Smith, 1967. Ent. Soc. Wash., Proc. 69: 92 (distribution). -Wong, 1967. Canad.

Ent. 99: 1101 (compared with species of Eitelius).

Biology: Nougaret, Davidson, and Newcomer, 1916. U. S. Dept. Agr., Bul. 438, 24 pp.

Morphology: Zocchi, 1948. Bol. Ent. Bologna 17: 225-232 (external structure of adult and larva).

acidovalva Wong. N. B., Que. w. to B. C., Calif. Host: Salix.

Pristiphora acidovalva Wong, 1969. Canad. Ent. 101: 970. , $\delta$.

Biology: Lindquist and Miller, 1969. Canad. Ent. 101: 973-975 (also description of larva). aphanta Wong and Ross. Que., Ont., N. Y.

Pristiphora aphauta Wong and Ross, 1960. Canad. Ent. 92: 196. \&. 
aquilegiae (Vollenhoven). Ont.; Europe. Introduced. Host: Aquilegia.

Nematus aquilegiae Vollenhoven, 1866. Tidskr. v. Ent. 11: 202. ‡.

Biology: MeNay, 1963. Canad. Ins. Pest Rev. 41: 103. - McNay, 1964. Phytoprotection 45: 91.

banksi Marlatt. N. Y. to N. C.; Wyo. Host: Vaccinium.

Pristiphora banksi Marlatt, 1896. U. S. Dept. Agr. Div. Ent. Tech. Ser. 3: 117. \& (male misdet.).

bivittata (Norton). Prince Edward Is., N. B. w. to B. C. s. to N. C., Ill., Iowa, Oreg. Ecology: Widespread. Host: Spiraea.

Nematus bivittatus Norton, 1861. Boston Soc. Nat. Hist., Proc. 8: 158. $q$.

Nematus luteolus Norton, 1867. Amer. Ent. Soc., Trans. 1: 200. o.

Pachynematus occidentalis Marlatt, 1896. U. S. Dept. Agr., Div. Ent. Tech. Ser. 3: 109. ठ.

Pristiphora dyari Marlatt, 1896. U. S. Dept. Agr., Div. Ent. Tech. Ser. 3: 118. ๆ. N. syn.

Pristiphora koebelei Marlatt, 1896. U. S. Dept. Agr., Div. Ent. Tech. Ser. 3: 119.

Pristiphora occidentalis Marlatt, 1896. U. S. Dept. Agr., Div. Ent. Tech. Ser. 3: 121. ठ。. Preocc. by occidentalis Marlatt on p. 109 of same publication.

Periclista patchi MacGillivray, 1923. Ill. Univ. Bul. 20(50): 29. ๆ.

Biology: Neilson, 1958. Canad. Ent. 90: 229-234.

borea (Konow). Labrador, Que. w. to Alaska, B. C.; Europe. Host: Betula, Salix.

Lygaeonematus boreus Konow, 1904. Ztschr. System. Hym. Dipt. 4: 253. ๆ, ơ.

Nematus astutus Cameron, 1885. Monog. Brit. Phytophagous Hym., v. 2, p. 77.. Synonymy may be questionable.

Pachynematus lapponicus Enslin, 1916. Deut. Ent. Ztschr., Beih., p. 463. ๆ, ơ.

Taxonomy: Benson, 1962. Brit. Mus. (Nat. Hist.) Ent., Bul. 12: 395.

breadalbanensis (Cameron). Que., N. W. T., Man., Colo., Alta., Yukon, Alaska, B. C.; Europe.

Nematus breadalbanensis Cameron, 1882. London Ent. Soc., Trans., p. 531.

Nematus Whitei Cameron, 1878. Fauna Scotland, v. 1, p. 35. $\delta$. Synonymy may be questionable.

Lygaeonematus tromsoensis Kiaer, 1898. Tromsoe Mus. Aarsh. 19: 48.

Lygaeonematus corpulentus Konow, 1904. Ztschr. System. Hym. Dipt. 4: 252. ९, o.

Lygaeonematus arcticola Enslin, 1916. Deut. Ent. Ztschr., Beih., p. 514. ๆ, o.

cadma Wong and Ross. Ont., Sask., Alaska, B. C. Host: Betula.

Pristiphora cadma Wong and Ross, 1960. Canad. Ent. 92: 198..+

carolinensis Marlatt. N. C.

Pristiphora carolinensis Marlatt, 1896. U. S. Dept. Agr., Div. Ent. Tech. Ser. 3: 120. ठ。. Possibly belongs in Pachynematus.

chlorea (Norton). N. B. to Fla. w. to Man., Oreg., Tex. Host: Quercus.

Nematus chloreus Norton, 1867. Amer. Ent. Soc., Trans. 1: 221. $?$.

Nematus pallifrons Cresson, 1880. Amer. Ent. Soc., Trans. 8: 6. ठ.

Nematus decoratus Provancher, 1888. Addit. Corr. Faune Ent. Canada Hym., p. 349. ơ.

Pteronus quercus Marlatt, 1896. U. S. Dept. Agr., Div. Ent. Tech. Ser. 3: 67. ?. Preoce. in Pristiphora by Hartig, 1837.

Nematus pergandei Marlatt, 1896. U. S. Dept. Agr., Div. Ent. Tech. Ser. 3: 90 ..

Amauronematus vacalus MacGillivray, 1923. Ill. Univ. Bul. 20(50): 6. ․ N. syn.

cincta Newman. Newfoundland w. to N. W. T., Alaska s. to Ala., Tenn., Mich., Minn., Colo., B. C.; Europe. Ecology: Widespread. Host: Betula, Vaccinium, Salix.

Pristiphora cincta Newman, 1837 (January). Ent. Mag. 4: 259.

Nematus quercus Hartig, 1837 (March). Fam. Blattwespen und Holzwespen, nebst Einleitung Naturgesch. Hym., p. 188.

Tenthredo borealis Zetterstedt, 1838. Ins. Lapponica 1: 353 ..

Nematus idiota Norton, 1867. Amer. Ent. Soc., Trans. 1: 177. ठ.

Nematus identidem Norton, 1867. Amer. Ent. Soc., Trans. 1: 177. 9.

Pristiphora hoodi Marlatt, 1896. U. S. Dept. Agr. Div. Ent. Tech. Ser. 3: 119. ๆ. Synonymy questionable.

Pristiphora coloradensis Marlatt, 1896. U. S. Dept. Agr. Div. Ent. Tech. Ser. 3: 121. ठ。. Synonymy questionable.

Pristiphora idiotiformis Rohwer, 1910. U. S. Natl. Mus., Proc. 38: 199. ९. 
Pristiphora cincta ab. nigriventris Hellen, 1943. Notulae Ent. 23: 71

Biology: Neilson, 1958. Canad. Ent. 90: 229-234 (idiota on Vaccinium).

coactula (Ruthe). Labrador w. to N. W. T., Alaska; Colo.; Europe. Host: Salix, Vaccinium(?).

Nematus coactulus Ruthe, 1859. Stettin Ent. Ztg. 20: 307. \&.

Nematus winnipeg Norton, 1867. Amer. Ent. Soc., Trans. 1: 198..

Nematus alpinus Thomson, 1871. Hym. Scand., v. 1, p. 98. $\%$, ¿.

Lygaeonematus pachyvalvis Konow, 1904. Ztschr. System. Hym. Dipt. 4: 253. ९, ठ.

Lygaeonematus winnipegensis Konow, 1905. In Wytsman, Gen. Ins., v. 29, p. 68. Emend. of winnipeg.

Pristiphora dawsoni Rohwer, 1908. N. Y. Ent. Soc., Jour. 16: 109. \&.

Taxonomy: Benson, 1962. Brit. Mus. (Nat. Hist.) Ent., Bul. 12: 395.

elaphita Wong and Ross. Sask., N. Mex., Alta., B. C., Calif.

Pristiphora elaphita Wong and Ross, 1960. Canad. Ent. 92: 194..

erichsonii (Hartig). Newfoundland to Alaska s. to Md., W. Va., Mich., Ill., Minn., Mont., Idaho, Oreg.; Europe to Japan. Ecology: Widespread. Possibly introduced. Host: Larix laricina, L. occidentalis, L. lyallii, and European and Asian larch species and hybrids. Larch sawfly. Numerous papers have appeared on this destructive species; therefore, it is feasible to give only selected references below.

Nematus Leachei Dahlbom, 1835. Conspectus Tenthred., Siricid., Oryssin. Scand., p. 10. Nom. nud.

Nematus Leachii Dahlbom, 1835. Clavis Hym., p. 27. Larva. Suppressed by Internatl. Comm. Zool. Nomencl., Opinion 906, 1970, Bul. Zool. Nomencl. 27: 8.

Nematus erichsonii Hartig, 1837. Fam. Blattwespen und Holzwespen, nebst Einleitung Naturgesch. Hym., p. 187. .

Nematus notabilis Cresson, 1880. Amer. Ent. Soc., Trans. 8: 7. ๆ.

Taxonomy: Coppel and Leius, 1958. 10th Internatl. Cong. Ent., Proc. 1: 231-238 (variations in populations from Canada, Great Britain, and Japan). - Wong, 1974. Canad. Ent. 106:

1121-1131 (identification and origin of strains in N. Amer.).

Biology: Ives, 1955. Canad. Ent. 87: 301-311 (moisture and selection of cocoon sites). -Ives, 1955. Canad. Jour. Zool. 33: 370-388 (estimation of egg populations). - Drooz, 1956. U. S. Dept. Agr., Forest Pest Leaflet 8, 4 pp. (rev. 1967). -Graham, 1956. Forest Sci. 2: 132-160 (Lake states). - Ruppel, 1958. Ent. Soc. Brit. Columbia, Proc. 55: 32-35 (history in B. C.). - Buckner, 1958. 10th Internatl. Cong. Ent., Proc. 4: 353-361 (mammal predators). -Ives and Prentice, 1958. Canad. Ent. 90: 331-338 (sampling techniques). - Ives and Prentice, 1959. Canad. Ent. 91: 496-500 (estimates of parasitism). - Graham and Satterlund, 1959. Forest Sci. 5: 28-36 (weather and water levels on cocoons), -Ives and Turnock, 1959. Canad. Ent. 91: 650-661 (estimates of cocoon populations). - Buckner, 1959. Canad. Ent. 91: 275-282 (cocoon predation by mammals). - Turnock, 1960. Canad. Ent. 92: 500-516. -Drooz, 1960. U. S. Dept. Agr., Tech. Bul. 1212, 52 pp. (biology and control; references to most of literature up to 1956). - Turnock, 1960. Canad. Ent. 92: 659-662 (estimation of adult populations). - Maw, 1960. Ent. Gaz. 11: 43-49 (Great Britain). -Ives, 1960. Canad. Ent. 92: 668-674. - Heron, 1961. Canad. Ent. 93: 431-433 (temperature and post-diapause development). - Nairn, et al., 1962. Canad. Ent. 94: 242-255 (outbreaks and effects on forest stands). - Turnock and Ives, 1962. Canad. Ent. 94: 897-902 (cocoon mortality). -Ives, 1962. Canad. Ent. 94: 256-268 (mortality of eggs and larvae). - Ives, 1963. Canad. Ent. 95: 887-892 (defoliation effect on larval survival). - Pschorn-Walcher and Eichhorn, 1963. Comm. Inst. Biol. Control, Tech. Bul. 3: 51-82 (ecology and natural control in central Europe). - Frilli, 1964. Milan Univ. Cattolica Sacro Cuore Fac. Agr., Ann. 4: 528-586 (morpho-biological studies). - Buckner and Turnock, 1965. Ecology 46: 223-226 (avian predators). - Ives and Nairn, 1966. Canad. Ent. 98: 768-777 (water levels and overwintering survival). - Schmiege, 1966. Canad. Ent. 98: 671-672 (Alaska). -Smirnoff, 1966. Jour. Invert. Path. 8: 360-364 (a microsporidian parasite). -Turnock and McLeod, 1966. Ent. Soc. Manitoba, Proc. 22: 55-60 (n. Man.). - Heron, 1966. Canad. Ent. 98: 561-578 (reproductive capacity). - Ives, 1967. Canad. Ent. 99: 1121-1131 (mortality causes). - Heron, 1967. Canad. Ent. 99: 1150-1155 (heat tolerance of larvae). - Elliott and 
Muldrew, 1967. Canad. Ent. 99: 321-323 (rearing cage). - Muldrew, 1967. Canad. Ent. 99: 312-321 (biology and dispersal of an introduced parasite). - Ives, 1967. Canad. Ent. 99: 607-622 (invertebrate predators and prey). - Ives, 1968. Manitoba Ent. 2: 5-36 (population dynamics techniques). - Ives, 1968. Canad. Ent. 100: 373-385 (survival and water levels). -Smirnoff, 1968. Jour. Invert. Path. 10: 417-424 (diseases). - Smirnoff and Chu, 1968. Jour. Invert. Path. 10: 12 (microsporidian infection). - Heron, 1968. Canad. Ent. 100: 470-475 (dyes as markers for behavioral studies). - Turnock and Muldrew, 1968. Forest Chronicle 44: 38 (control by introduced parasite). - Harman, 1970. Chesapeake Sci. 11: 183-190 (Md.). - Harman, 1971. Chesapeake Sci. 12: 40-44 (natural mortality of feeding and cocooning stages). - Heron, 1971. Canad. Ent. 103: 1153-1155 (temperature tolerance of pronymphs and pupae).

Morphology: Wong, 1956. Canad. Ent. 88: 545 (gynandromorphs and intersexes). -Wong, 1963. Canad. Ent. 95: 897-920 (external morphology of male, female, and larva).

gelida Wong. N. W. T., Yukon, Alaska, Alta., Colo. Pristiphora gelida Wong, 1968. Jour. Nat. Hist. 2: 185. $\&$, ठ.

geniculata (Hartig). Newfoundland, Ont. s. to W. Va.; Europe to Siberia. Introduced. Host: Sorbus. Mountain ash sawfly. Nematus geniculatus Hartig, 1840. Stettin Ent. Ztg. 1: 26.. Nematus cheilon Zaddach, 1883. Phys. Okonom. Gesell. Konigsberg, Schr. 24: 145. \&, ð.

Biology: Schaffner, 1936. Jour. Econ. Ent. 29: 469. - Forbes and Daviault, 1964. Canad. Ent. 96: 1117-1133. - Smirnoff, 1968. Jour. Invert. Path. 10: 436-437 (virus disease).

gronblomi (Lindqvist). Alaska; N. Europe. Lygaeotus gronblomi Lindqvist, 1952. Notulae Ent. 32: 101. ๆ, ठ.

hucksena Wong and Ross. B. C. Pristiphora hucksena Wong and Ross, 1960. Canad. Ent. 92: 104..

hyalina (MacGillivray). N. Y. Neotomostethus hyalinus MacGillivray, 1908. Canad. Ent. 40: 290. ๆ.

jocularis Cresson. Oreg., Nev. Pristiphora jocularis Cresson, 1880. Amer. Ent. Soc., Trans. 8: 3. ९, ๖.

labradoris (Norton). Labrador, Ont., N. W. T., Man., Alta., Yukon. Nematus labradoris Norton, 1867. Amer. Ent. Soc., Trans. 1: 196. ?.

lata (Cresson). Oreg., Nev.

Nematus latus Cresson, 1880. Amer. Ent. Soc., Trans. 8: 4..+

lativentris (Thomson). N. W. T., Man., Alaska; Europe. Nematus lativentris Thomson, 1871. Hym. Scand., v. 1, p. 99. $₹$, o. Nematus scoticus Cameron, 1881. Ent. Soc. London, Proc., p. 365 .. Nematus extremus Holmgren, 1883. Ent. Tidskr. 4: 148. ‡, ठँ.

Pristiphora buccoda Kincaid, 1900. Wash. Acad. Sci., Proc. 2: 350. $९$.

Lygaeonematus apicola Konow, 1904. Ztschr. System. Hym. Dipt. 4: 254. ‡, §. Synonymy of apicola may be questionable.

Taxonomy: Benson, 1962. Brit. Mus. (Nat. Hist.) Ent., Bul. 12: 395.

leechi Wong and Ross. Mont., Idaho, B. C., Wash. Host: Larix occidentalis. Pristiphora leechi Wong and Ross, 1960. Canad. Ent. 92: 193. + ,.

lena Kincaid. Newfoundland to N. W. T., Alaska; Wyo., Colo. Host: Picea. Pristiphora lena Kincaid, 1900. Wash. Acad. Sci., Proc. 2: 351. ¿.

maura Rohwer. Que., N. W. T., Yukon, Alaska, Man., Alta., Colo. Pristiphora maura Rohwer, 1908. N. Y. Ent. Soc., Jour. 16: 109. ठ.

melanocarpa (Hartig). Que., N. W. T., Yukon, Alaska, Man.; Europe. Host: Betula. Nematus melanocarpus Hartig, 1840. Stettin Ent. Ztg. 1: 27. ?. Nematus wustneii Stein, 1885. Wien. Ent. Ztg. 4: 304. $\%$, ठ.

Pristiphora ortinga Kincaid, 1900. Wash. Acad. Sci., Proc. 2: 349. ․ N. syn.

micronematica Malaise. N. W. T., Man.; Europe to Siberia. Host: Salix. Pristiphora micronematica Malaise, 1932. Arkiv for Zool. 23A: 58. .

Lygaeonematus (Lygaeophora) leucostoma Lindqvist 1952. Notulae Ent. 32: 108. \&, o. 
Taxonomy: Benson, 1962. Brit. Mus. (Nat. Hist.) Ent., Bul. 12: 394. - Lindqvist, 1971. Notulae Ent. 51: 128-129.

mollis (Hartig). Labrador to N. W. T., Alaska s. to N. C., Colo.; Europe. Host: Vaccinium.

Nematus mollis Hartig, 1837. Fam. Blattwespen und Holzwespen, nebst Einleitung

Naturgesch. Hym., p. 201.

Pachynematus orarius Kincaid, 1900. Wash. Acad. Sci., Proc. 2: 348 ..

Pachynematus penegalensis Enslin, 1911. Deut. Ent. Ztschr. 2: 176..

Lygaeonematus mollis var. albipes Lindqvist, 1942. Notulae Ent. 22: 107.

Lygaeonematus mollis var. rufonotata Lindqvist, 1942. Notulae Ent. 22: 107.

Pachynematus kontkaneni Lindqvist, 1960. Notulae Ent. 40: 35..

nigra Marlatt. Wash.

Pristiphora nigra Marlatt, 1896. U. S. Dept. Agr., Div. Ent. Tech. Ser. 3: 114..

paedida (Konow). Alaska; Europe to Siberia.

Lygaeonematus paedidus Konow, 1904. Ztschr. System. Hym. Dipt. 4: 253.

Pristiphora kamtchatica Malaise, 1932. Arkiv for Zool. 23A: 56. ‡, ठ.

pallidiventris (Fallen). Labrador to Alaska s. to Md., Mich., Iowa, Calif.; Europe to Japan.

Ecology: Widespread. Host: Rubus, Geum, Potentilla, and other Rosaceae. These hosts were recorded in Europe.

Nematus pallidiventris Fallen, 1808. Svenska Vetensk. Akad., Handl. 29: 120..

Pristiphora myosotidis Stephens, 1835. Illus. Brit. Ent., v. 7, p. 25.

Nematus ephippiger Hartig, 1840. Stettin Ent. Ztg. 1: 24. 9.

Nematus flavicornus Tischbein, 1846. Stettin Ent. Ztg. 7: 77. 9.

Nematus nigricans Eversmann, 1847. Soc. Nat. Moscou, Bul. 20: 16..

Nematus caudalis Eversmann, 1847. Soc. Nat. Moscou, Bul. 20: 16. §.

Nematus breviusculus Eversmann, 1847. Soc. Nat. Moscou, Bul. 20: 17. 9.

Nematus gemellus Foerster, 1854. Naturh. Ver. Rheinlande, Verh. 11: 425..

Nematus cirrhostomus Zaddach, 1882. Phys. Okonom. Gesell. Konigsberg., Schr. 23: 195. \&.

Pristiphora zella Rohwer, 1909. Canad. Ent. 41: 20. 9 . N. syn.

Pristiphora pallicoxa Rohwer, 1910. U. S. Natl. Mus., Proc. 38: 200. \&. N. syn.

Pristophora(!) xanthotrachela Rohwer, 1913. U. S. Natl. Mus., Proc. 45: 281.. N. syn.

Pristiphora pallidiventris var. haemorrhoidalis Enslin, 1916. Deut. Ent. Ztschr., Beih., p.

526. $९, \delta$.

Pristiphora pallidiventris var. stigmatica Enslin, 1916. Deut. Ent. Ztschr., Beih., p. 526.. .

Pristiphora ostiaria MacGillivray, 1920. Canad. Ent. 52: 236. + , ठ. N. syn.

Nematus (Pristiphora) pallidiventris var. flaviapex Hellen, 1948. Notulae Ent. 28: 45.

Nematus (Pristiphora) pallidiventris var. nigrofemoratus Hellen, 1948. Notulae Ent. 28: 45.

paloma Wong and Ross. N. Y. to Fla. w. to Ill.

Pristiphara paloma Wong and Ross, 1960. Canad. Ent. 92: 196. $\$$.

parbeta Wong and Ross. Man., Alaska. Host: Betula papyrifera.

Pristiphora parbeta Wong and Ross, 1960. Canad. Ent. 92: 198. ठ.

pseudocoactula (Lindqvist). Man. (Churchill); Europe.

Lygaeonematus (Lygaeonematus) pseudocaactula Lindqvist, 1952. Notulae Ent. 32: 115. , d.

relativa Norton. $\mathrm{N}$. W. T.

Pristiphora relativa Norton, 1867. Amer. Ent. Soc., Trans. 1: 177..

reuteri (Lindqvist). Maine, N. H., Man.; Europe. Host: Salix.

Lygaeonematus (Lygaeophora) reuteri Lindqvist, 1960. Notulae Ent. 40: 33. ९, ठ.

Taxonomy: Benson, 1962. Brit. Mus. (Nat. Hist.) Ent., Bul. 12: 395. - Vikberg, 1966. Ann.

Ent. Fenn. 32: 252-253 (larva).

rufipes Lepeletier. Newfoundland to B. C. s. to N. C., Tenn. Mo., Colo., Utah, Calif.; Europe to Siberia. Ecology: Widespread. Host: Ribes.

Pristiphora pallipes Lepeletier, 1823. Monog. Tenthred., p. 60. $\$$. Preocc. in Pristiphora by Fallen, 1808.

Pristiphora rufipes Lepeletier, 1823. Monog. Tenthred., p. 60. 9.

Pristiphora fusca Lepeletier, 1823. Monog. Tenthred., p. 60. ठ. 
Tenthredo (Nematus) pallicornis Harris, 1835. In Hitchcock, Rpt. Geol. Mineral. Bot. Zool. Mass., p. 583. Nom. nud.

Tenthredo (Nematus) labrata Harris, 1835. In Hitcheock, Rpt. Geol. Mineral. Bot. Zool. Mass., p. 583. Nom. nud.

Nematus appendiculatus Hartig, 1837. Fam. Blattwespen und Holzwespen, nebst Einleitung Naturgesch. Hym., p. 202. ?.

Nematus (Diphadnus) fuscicornis Hartig, 1837. Fam. Blattwespen und Holzwespen, nebst Einleitung Naturgesch. Hym., p. 225 ..

Nematus cathoraticus Foerster, 1854. Naturh. Ver. Rheinlande, Verh. 11: 325.9.

Nematus pallicornis Norton, 1861. Boston Soc. Nat. Hist., Proc. 8: 160. + .

Nematus pallicornis var. labratus Norton, 1861. Boston Soc. Nat. Hist., Proc. 8: 160..

Nematus vitreipennis Kawall, 1864. Soc. Nat. Moscou, Bul. 37: 295. ๆ.

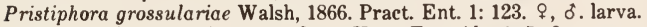

Nematus peletieri Andre, 1880 . Spec. Hym. Eur. Alg. 1: 5 ..

Nematus pumilus Zaddach, 1883. Phys. Okonom. Gesell. Konigsberg., Schr. 24: 172. ơ.

Nematus hypobalius Zaddach, 1884. Phys. Okonom. Gesell. Konigsberg., Schr. 25: 154. ^.

Nematus ghilianii Costa, 1894. Prosp. Imen. Ital. 3: 73.

Biology: Miles, 1932. Bul. Ent. Res. 23: 10-15.

serrula Wong and Ross. Maine, N. H., B. C., Wash., Oreg., Calif.

Pristiphora serrula Wong and Ross, 1960. Canad. Ent. 92: 196. \&.

siskiyouensis Marlatt. N. S. to N. W. T., Yukon, Alaska s. to Va., Wis., Calif. Ecology:

Widespread. Host: Betula, Alnus

Pristiphora siskiyouensis Marlatt, 1896 U. S. Dept. Agr. Div. Ent. Tech. Ser. 3: 116. \&, ठ.

Pristiphora betulavora Rohwer, 1920. U. S. Natl. Mus., Proc. 57: 219. ๆ, ठ'.

Taxonomy: Middleton, 1922. U. S. Natl. Mus., Proc. 61: 24 (larva).

Biology: Wong, 1954. Canad. Ent. 86: 154.

staudingeri (Ruthe). Labrador to Alaska s. to Man., Colo., Alta.; Europe to Siberia. Host: Salix.

Nematus staudingeri Ruthe, 1859. Stettin Ent. Ztg. 20: 306. $\&$, ১.

Nematus circularis Kincaid, 1900. Wash. Acad. Sci., Proc. 2: 350. ९. N. syn.

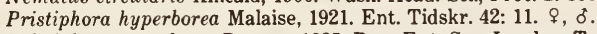

Pristiphora asperlatus Benson, 1935. Roy. Ent. Soc. London, Trans. 83: 36. \&, ठ.

sycophanta Walsh. Labrador to Alaska s. to Conn., Va., Mo., Colo., Oreg. Ecology: Widespread. Host: Salix.

Pristiphora sycophanta Walsh, 1866. Ent. Soc. Phila., Proc. 6: 263. 9.

Pristiphora tibialis Norton, 1867. Amer. Ent. Soc., Trans. 1: 76..

Nematus trivialis Kirby, 1882. List Hym. Brit. Mus., v. 1, p. 140. Unnecessary n. name for tibialis Norton.

Pristiphora murtfeldtiae Marlatt, 1896. U. S. Dept. Agr., Div. Ent. Tech. Ser. 3: 117..

Pristiphora anaka Kincaid, 1900. Wash. Acad. Sci., Proc. 2: 350. ․ N. syn.

valvangula Wong and Ross. N. Y. (?)

Pristiphora valvangula Wong and Ross, 1960. Canad. Ent. 92: 194. ठั.

venatta Wong and Ross. Idaho.

Pristiphora venatta Wong and Ross, 1960. Canad. Ent. 92: 196. ․

\section{Genus CROESUS Leach}

Croesus Leach, 1817. Zool. Misc., v. 3, p. 129.

Type-species: Tenthredo septentrionalis Linnaeus. Monotypic.

A small holarctic genus characterized by the enlarged, flattened hind basitarsus. Larvae feed externally on the foliage of the host plant.

Revision: Benson, 1963. Ent. Tidskr. 84: 25 (world species groups). -Smith, 1972. Ent. Soc.

Wash., Proc. 74: 169-180 (Nearctic species, adults and larvae).

castaneae Rohwer. N. Y., Pa., Md., Va., Ky. Host: Castanea dentata.

Croesus castaneae Rohwer, 1915. U. S. Natl. Mus., Proc. 49: 213. १, ठ. 
Taxonomy: Middleton, 1922. U. S. Natl. Mus., Proc. 61 : 14 (larva). curvarius Smith. Conn. Host: Corylus.

Croesus curvarius Smith, 1972. Ent. Soc. Wash., Proc. 74: 175. \&, larva.

latitarsus Norton. Que. to Fla. w. to Alaska, B. C., Utah. Host: Betula. Dusky birch sawfly. Craesus(!) latitarsus Norton, 1862. Ent. Soc. Phila., Proc. 1: 199..+

Biology: Jack, 1888. Psyche 5: 41. - Brown, 1940. Canad. Dept. Agr., Forest Ins. Survey 4th Ann. Rpt., p. 16. - Wong, 1954. Canad. Ent. 86: 154.

varus (Villaret). Que. (Montreal); Europe. Introduced (?). Host: Alnus. Nematus varus Villaret, 1832. Soc. Ent. France, Ann. 1: 306. ¿..

Taxonomy: Buckle, 1930. Canad. Ent. 62: 21 (record of only known specimen taken in N. Amer.).

\section{Genus NEMATUS Panzer}

Nematus Panzer, 1801. Faune Ins. German., heft 82, pl. 10.

Type-species: Tenthredo (Nematus) lucida Panzer. Monotypic.

Hypolaepus Kirby, 1882. List Hym. Brit. Mus., v. 1, p. 324.

Type-species: Hypolaepus abbotii Kirby. Monotypic.

Holcocneme Konow, 1890. Deut. Ent. Ztschr., pp. 233, 238, 246.

Type-species: Tenthredo crassa Fallen. Desig. by Rohwer, 1911.

Pteronidea Rohwer, 1911. U. S. Dept. Agr. Bur. Ent. Tech. Ser. 20: 98.

Type-species: Nematus ventralis Say. Orig. desig.

A large holarctic genus associated with various trees and shrubs. The larvae are external leaf feeders.

Revision: Marlatt, 1896. U. S. Dept. Agr., Div. Ent. Tech. Ser. 3: 44-75, 87-90.

Taxonomy: Benson, 1962. Brit. Mus. (Nat. Hist.) Ent., Bul. 12: 404-405 (holarctic species).

SPECIES GRoup ABbotI

abbotii (Kirby). Ont. to Ga. w. to Wis., Ill. Host: Robinia.

Hypolaepus abbotii Kirby, 1882. List Hym. Brit. Mus., v. 1, p. 324 ..

crassus (Fallen). N. W. T. (Mackenzie River, Reindeer Depot); Eurasia. Host: Betula, Populus, Salix, Rumex. These hosts recorded in Europe.

Tenthredo crassa Fallen, 1808. Svenska Vetensk. Akad., Handl. 29: 106.

Nematus sulcipes Hartig, 1840. Stettin Ent. Ztg. 1: 23. ९, ठ̀.

Nematus longispinis Kriechbaumer, 1885. Correspbl. Naturh. Ver. Regensburg 39: 13.

laticulus (Norton). N. Y. to N. C. w. to Wis., S. Dak., Ill.

Croesus laticulus Norton, 1869. Amer. Ent. Soc., Trans. 2: 368.. .

Nematus procidentius Rohwer, 1912. U. S. Natl. Mus., Proc. 43: 245. ठ。.

Amauronematus rufipes Marlatt, 1896. U. S. Dept. Agr., Div. Ent. Tech. Ser. 3: 78. ठ

SPECIES Group Ventralis

chalceus (Marlatt). Mont., Alaska, B. C., Wash. Host: Salix(?), Alnus(?).

Amauronematus chalceus Marlatt, 1896. U. S. Dept. Agr., Div. Ent. Tech. Ser. 3: 84 . .

erratus (MacGillivray). Maine, Man., Alaska. Host: Populus.

Pteronidea erratus MacGillivray, 1923. N. Y. Ent. Soc., Jour. 31: 170. ․

exactus (MacGillivray). Maine.

Pteronidea exactus MacGillivray, 1920. Canad. Ent. 52: 235. ठ。.

Amauronematus vanus MacGillivray, 1921. N. Y. Ent. Soc., Jour. 29: 27..

Amauronematus venaticus MacGillivray, 1921. N. Y. Ent. Soc., Jour. 29: 29. ठో.

fulvicrus Provancher. Que. to N. Y. w. to Alta., Colo. Host: Salix, Populus(?).

Nematus fulvicrus Provancher, 1882. Nat. Canad. 13: 291. ․

Messa salicis Ashmead, 1890. Colo. Biol. Assoc., Bul. 1: 15. Preocc. in Nematus by Linnaeus, 1758.

Nematus salicicola Dalla Torre, 1894. Cat. Hym., v. 1, p. 257. N. name for salicis Ashmead.

Pteronidea evanida MacGillivray, 1920. Canad. Ent. 52: 233. ?, ð. 
hudsoniimagnus Dyar. Maine to N. J. w. to Alaska, Man., Ill., Tex. Host: Populus.

Nematus Hudsonii magnus Dyar, 1895. Amer. Ent. Soc., Trans. 23: 306. $\%$, larva. This name is available under Article 26(A) of the Internatl. Code Zool. Nomencl.

Pteronus populi Marlatt, 1896. U. S. Dept. Agr., Div. Ent. Tech. Ser. 3: 59. .

Pteronus hudsonii Marlatt, 1896. U. S. Dept. Agr., Div. Ent. Tech. Ser. 3: 59. ९. Emend.

Pteronus lombardae Marlatt, 1896. U. S. Dept. Agr., Div. Ent. Tech. Ser. 3: 73. ठో.

Pteronidea edura MacGillivray, 1920. Canad. Ent. 52: 233.

Pteronidea effusa MacGillivray, 1920. Canad. Ent. 52: 233. $\subsetneq$.

Pteronidea effeta MacGillivray, 1920. Canad. Ent. 52: 234. 9.

Pteronidea emerita MacGillivray, 1920. Canad. Ent. 52: 234. ๆ.

Pteronidea erudita MacGillivray, 1920. Canad. Ent. 52: 234.. .

iridescens Cresson. Mont., Wyo., Utah w. to B. C., Wash., Oreg., Calif.; Mexico. Host: Salix. Nematus iridescens Cresson, 1880. Amer. Ent. Soc., Trans. 8: 5. ठో.

Pteronus occidentalis Marlatt, 1896. U. S. Dept. Agr., Div. Ent. Tech. Ser. 3: 48. ९. N. syn.

limbatus Cresson. N. B., Que. to Pa. w. to Sask., Ohio. Host: Salix, Populus.

Nematus limbatus Cresson, 1880. Amer. Ent. Soc., Trans. 8: 8. ‡.

Pteronus harringtoni Marlatt, 1896. U. S. Dept. Agr., Div. Ent. Tech. Ser. 3: 53. ‡, ð.

Pteronus fylesi Marlatt, 1896. U. S. Dept. Agr., Div. Ent. Tech. Ser. 3:54. \&, ठ。.

ventralis Say. Que. to N. C. w. to Alta., Mont., Colo. Host: Salix. Willow sawfly.

Nematus ventralis Say, 1824. In Keating, Narr. Long's 2nd Exped., v. 2 (App.), p. 315.. .

Nematus suratus Fitch, 1856. N. Y. Agr. Soc., Trans. 3: 315..

Pteronus latus Marlatt, 1896. U. S. Dept. Agr., Div. Ent. Tech. Ser. 3: 48. \&. Preoce. by

Nematus latus Cresson, 1880.

Hypolaepus viereckii Bradley, 1903. Canad. Ent. 35: 47..

Pteronidea edita MacGillivray, 1920. Canad. Ent. 52: 235. ठ์.

Biology: Howard, 1888. U. S. Dept. Agr., Insect Life 1: 33-37. - Rohwer, 1915. Ent. Soc. Wash., Proc. 17: 197 (mating habits).

Morphology: Judd, 1955. Ont. Ent. Soc., 85th Ann. Rpt. 1954, p. 32 (anatomy and histology of digestive tract of larva).

\section{SPECIES GROUP ATRICEPS}

atriceps (Marlatt). Wis., Colo., Utah w. to B. C., Wash., Oreg., Calif.

Pteronus atriceps Marlatt, 1896. U. S. Dept. Agr., Div. Ent. Tech. Ser. 3: 52. $q$.

Pteronus californicus Marlatt, 1896. U. S. Dept. Agr., Div. Ent. Tech. Ser. 3: 60. ^. N. syn.

auratus (Marlatt). Wash., Oreg., Calif.

Pteronus auratus Marlatt, 1896. U. S. Dept. Agr., Div. Ent. Tech. Ser. 3: 60. \&.

Amauronematus coquilletti Marlatt, 1896. U. S. Dept. Agr., Div. Ent. Tech. Ser. 3: 84 . ₹.

N. syn.

coloradensis (Marlatt). Alta., Mich., N. Dak., Ariz. w. to Oreg., Calif.

Pteronus coloradensis Marlatt, 1896. U. S. Dept. Agr., Div. Ent. Tech. Ser. 3: 52. , ठ。.

\section{SPECIES GRoup ERYTHROGASTER}

carpini (Marlatt). Conn., N. Y., N. J., Fla. Host: Carpinus.

Pteronus carpini Marlatt, 1898. Canad. Ent. 30: 303..

corylus Cresson. Mass. to Md. w. to Mich., Ill. Host: Corylus.

Nematus corylus Cresson, 1880. Amer. Ent. Soc., Trans. 8: 8. \&.

Pteronus coryli Konow, 1905. In Wytsman, Gen. Ins., v. 29, p. 55. Emend.

erythrogaster Norton. Que. to Fla. w. to Minn., Ill. Host: Alnus.

Nematus erythrogaster Norton, 1865. Ent. Soc. Phila., Proc. 4: 8..

Pteronus dyari Marlatt, 1896. U. S. Dept. Agr., Div. Ent. Tech. Ser. 3: 58. ৎ, ठ.

Pteronidea pulchella Rohwer, 1913. U. S. Natl. Mus., Proc. 45: 279. 9.

Pteronidea alnivora Rohwer, 1920. U. S. Natl. Mus., Proc. 57: 213. १, ठ.

Taxonomy: Middleton, 1922. U. S. Natl. Mus., Proc. 61: 22 (larva).

latifasciatus Cresson. N. B. to Pa. w. to Ont., Mich. Host: Betula.

Nematus latifasciatus Cresson, 1880. Amer. Ent. Soc., Trans. 8: 7. ९.

Nematus rufocinctus Harrington, 1893. Canad. Ent. 25: 58. ․ N. syn. 
Species Group Magnus

magnus (Marlatt). Que., Maine. Host: Salix.

Pteronus magnus Marlatt, 1896. U. S. Dept. Agr., Div. Ent. Tech. Ser. 3: 67..

SPECIES Group OLIGospilus

attus Smith, n. name. Que., Maine to N. Y. and Mich. Host: Populus.

Amauronematus dyari Marlatt, 1896 (October). Canad. Ent. 28: 255. \&, ð. Preoce. by

Pteronus dyari Marlatt, 1896(February), U. S. Dept. Agr., Div. Ent. Tech. Ser. 3: 58.

costillensis (Rohwer). Colo.

Pteronus costillensis Rohwer, 1908. N. Y. Ent. Soc., Jour. 16: 106. ‥

effrenatus (MacGillivray). Alaska.

Pteronidea effrenatus MacGillivray, 1923. N. Y. Ent. Soc., Jour. 31: 171. ๆ.

excavatus (Marlatt), n. comb. No. Amer., locality unknown.

Amauronematus excavatus Marlatt, 1896. U. S. Dept. Agr., Div. Ent. Tech. Ser. 3: 85. ‡.

excessus (MacGillivray). Alaska.

Pteronidea excessus MacGillivray, 1923. N. Y. Ent. Soc., Jour. 31: 170. \&.

currani Ross. B. C., Oreg. Host: Populus.

Pteronidea nigriventris Curran, 1926. Canad. Ent. 58: 233. $९$, o. Preocc. in Nematus by Holmgren, 1883.

Nematus currani Ross, 1951. In Muesebeck, et al., U. S. Dept. Agr., Agr. Monog. 2: 45. N. name.

hypomelas (Rohwer). Colo.

Pteronus hypomelas Rohwer, 1908. Canad. Ent. 40: 48. .

kukukiana (Kincaid), n. comb. Alaska.

Pontania kukukiana Kincaid, 1900. Wash. Acad. Sci., Proc. 2: 356. $\%$.

lipovskyi Smith. Maine, N. H., Mass., N. J., Pa., Md., Va., Ala. Host: Azalea.

Nematus lipovskyi Smith, 1974. Ent. Soc. Wash., Proc. 76: 205-206..

notatus (Rohwer). Colo.

Pteronus notatus Rohwer, 1908. Canad. Ent. 40: 49..

oligospilus Foerster. Que. to Alaska s. to Va., Ind., Kans., Colo., Calif.; Mexico; Europe to Himalayas. Ecology: Widespread. Host: Salix.

Nematus oligospilus Foerster, 1854. Naturh. Ver. Rheinlande, Verh. 11: 284. .

Nematus mendicus Walsh, 1866. Ent. Soc. Phila., Proc. 6: 261. ․

Nematus trivittatus Norton, 1867. Amer. Ent. Soc., Trans. 1: 218..

Nematus dorsivittatus Cresson, 1880. Amer. Ent. Soc., Trans. 8: 10. ๆ.

Nematus salicivorus Cameron, 1882. Ent. Monthly Mag. 18: 194.

Nematus sylvestris Cameron, 1884. Ent. Monthly Mag. 20: 266.

Pteronus koebelei Marlatt, 1896. U. S. Dept. Agr., Div. Ent. Tech. Ser. 3: 71..

Pteronidea vanduzeei Rohwer, 1913. U. S. Natl. Mus., Proc. 45: 280..

Pteronidea elelea MacGillivray, 1923. Canad. Ent. 55: 162..

pinguidorsum Dyar. Maine to N. Y. w, to Sask., N. Dak. Host: Betula.

Nematus pinguidorsum Dyar, 1895. Amer. Ent. Soc., Trans. 22: 303. Larva.

Amauronematus vacivus MacGillivray, 1921. N. Y. Ent. Soc., Jour. 29: 28. ð. N. syn.

Biology: Wong, 1954. Canad. Ent. 86: 154.

reticulatus Holmgren. Labrador to Alaska s. to N. H., Man.; Europe to Siberia. Ecology: Widespread. Host: Vaccinium.

Nematus reticulatus Holmgren, 1883. Ent. Tidskr. 4: 143. 9.

Nematus marionellus Holmgren, 1883. Ent. Tidskr. 4: 144.

Nematus occipitalis Holmgren, 1883. Ent. Tidskr. 4: 144.

Nematus anceps Holmgren, 1883. Ent. Tidskr. 4: 145.

Nematus mysticus Holmgren, 1883. Ent. Tidskr. 4: 145.

Nematus parvulus Holmgren, 1883. Ent. Tidskr. 4: 146.

Nematus picticollis Holmgren, 1883. Ent. Tidskr. 4: 147.

Nematus lientericus Holmgren, 1883. Ent. Tidskr. 4: 146.

Pontania popofiana Kincaid, 1900. Wash. Acad. Sci., Proc. 2: 353. ९, ð.

Pontania glinka Kincaid, 1900. Wash. Acad. Sci., Proc. 2: 355. ९, ð. 
Pontania tenuitarsis Konow, 1901. Ztschr. System. Hym. Dipt. 1: 130.

Pontania poppii Konow, 1904. Ztschr. System. Hym. Dipt. 4: 230.

Pontania forsiusi Enslin, 1915. Deut. Ent. Ztschr., Beih., p. 354.

Amauronematus alberich Benson, 1934. Ann. and Mag. Nat. Hist. 14: 208.

Pteronidea nubium Benson, 1935. Ent. Soc. London, Trans. 83: 30.

Amauronematus alsius Benson, 1935. Ent. Soc. London, Trans. 83: 32.

Pteronidea leptostigma Lindqvist, 1957. Notulae Ent. 37: 111.

Pteronidea nigrita Lindqvist, 1957. Notulae Ent. 37: 113.

Pteronidea wolteri Lindqvist, 1957. Notulae Ent. 37: 115. \&.

Pteronidea roberti Lindqvist, 1957. Notulae Ent. 37: 117.

Pteronidea lindbergi Lindqvist, 1957. Notulae Ent. 37: 105.

Pteronidea mitilipes Lindqvist, 1959. Notulae Ent. 39: 59. 9.

Pteronidea sulciceps Lindqvist, 1959. Notulae Ent. 39: 57..

Pteronidea aspera Lindqvist, 1959. Notulae Ent. 39: 58.

Pteronidea thunbergi Lindqvist, 1959. Notulae Ent. 39: 58.

Taxonomy: Benson, 1961. Resultats des recherches scientifiques entreprises au Parc

National Suisse, Band VII, pp. 192-193.

subpallidus (MacGillivray), n. comb. N. W. T.

Pontania subpallida MacGillivray, 1919. Rpt. Canad. Arctic Exped. 1913-1918, v. 3G, p. 11G. .

tibialis Newman. Ont. , Maine to Fla. w. to Minn., Kans., Colo., Ark., Ariz.; Wash., Oreg.;

Europe. Host: Robinia pseudacacia, Gleditsia triacanthos. Introduced with host into

Europe.

Nematus tibialis Newman, 1837. Ent. Mag. 4: 260. 9.

Nematus trilineatus Norton, 1867. Amer. Ent. Soc., Trans. 1: 215. ․

Nematus similaris Norton, 1880. U. S. Dept. Agr., Ann. Rpt. for 1879, p. 224..

Nematus robiniae Forbes, 1885. State Ent. Ill. Rpt. 14: 116. ․

Pteronus solitarius Rohwer, 1908. N. Y. Ent. Soc., Jour. 16: 107..

vancouverensis (Marlatt). Maine to Alaska s. to Pa., Iowa, Colo., Ariz., Calif. Ecology:

Widespread. Host: Populus.

Pteronus vancouverensis Marlatt, 1896. U. S. Dept. Agr., Div. Ent. Tech. Ser. 3: 70. ‡, ठ.

Amauronematus californicus Marlatt, 1896. U. S. Dept. Agr., Div. Ent. Tech. Ser. 3: 85.

Preocc. by Pteronus californicus Marlatt, p. 60 of same publication. N. syn.

Pachynematus vernalis Rohwer, 1909. Canad. Ent. 41: 18. ․ N. syn.

Pteronus wrighti Rohwer, 1911. Ent. Soc. Wash., Proc. 13: 31. N. name for Amauronematus californicus Marlatt.

Amauronematus valerius MacGillivray, 1923. Ill. Univ. Bul. 20(50): 6. §. N. syn.

Biology: Brown, Eads, and Clark, 1969. Jour. Econ. Ent. 62: 672 (Nematus sp.).

villosus Thomson. N. W. T.; Europe.

Nematus villosus Thomson, 1862. Ofvers. Svensk. Vetensk. Akad., Forh. 19: 629. .

viridescens Cameron. Maine, Ont., N. Y., Man., Sask., Alaska; Europe. Host: Betula.

Nematus viridescens Cameron, 1885. Monog. Brit. Phytophagous Hym., v. 2, p. 122.

Pteronus hyalinus Marlatt, 1896. U. S. Dept. Agr., Div. Ent. Tech. Ser. 3: 67. 9. N. syn.

Biology: Wong, 1954. Canad. Ent. 86: 158 (hyalinus).

zebratus (Kincaid). Alaska.

Pteronus zebratus Kincaid, 1900. Wash. Acad. Sci., Proc. 2: 357. ๆ.

\section{SPECIES GROUP RIBESII}

cockerelli (Rohwer). Colo.

Pteronus cockerelli Rohwer, 1909. Canad. Ent. 41: 88..

edwardsii Cresson. Calif.

Nematus edwardsii Cresson, 1880. Amer. Ent. Soc., Trans. 8: 7..

equina (MacGillivray). Maine.

Pteronidea equina MacGillivray, 1920. Canad. Ent. 52: 235. ९.

foveatus (Marlatt). Wash., Oreg.

Pteronus foveatus Marlatt, 1896. U. S. Dept. Agr., Div. Ent. Tech. Ser. 3: 55. 9. 
Pteronidea electra MacGillivray, 1923. Ill. Univ. Bul. 20(50): 30..

jugicola Thomson. Man. (Churchill); Europe. Host: Salix.

Nematus jugicola Thomson, 1871. Hym. Scand., v. 1, p. 146..

marlattii Dyar. N. H. Host: Alnus.

Nematus Marlattii Dyar, 1895. Amer. Ent. Soc., Trans. 22: 305. $\uparrow$, larva.

nigropectus Cresson. Wash., Oreg., Nev.

Nematus nigropectus Cresson, 1880. Amer. Ent. Soc., Trans. 8: 6. ㅇ.

Pteronus bicolor Marlatt, 1896. U. S. Dept. Agr., Div. Ent. Tech. Ser. 3: 56.. Questionable synonym.

ostryae (Marlatt). N. J. to Va. Host: Ostrya.

Pteronus ostryae Marlatt, 1896. Canad. Ent. 28: 252..

ribesii (Scopoli). Que., Ont. to Wash. s. to D. C., Ohio, Ill., Mo., Kans., Colo., Oreg.; Europe to Caucasus. Ecology: Widespread. Introduced. Host: Ribes. Imported currantworm.

Tenthredo ribesii Scopoli, 1763. Ent. Carn., p. 280.

Tenthredo ventricosa Latreille, 1805. Hist. Nat. Crust. Ins., v. 13, p. 131.

Tenthredo salicis Fallen, 1808. Svenska Vetensk. Akad., Handl. 29: 118. ๆ.

Nematus dimidiata Lepeletier, 1823. Monog. Tenthred., p. 68. ?.

Nematus trimaculata Lepeletier, 1823. Monog. Tenthred., p. 69..

Nematus grossulariae Moore, 1831. Lit. and Phil. Soc. Manchester, Mem. 2: 114-134.

Nematus depressa Hartig, 1840. Stettin Ent. Ztg. 1: 24..

Nematus macrocera Hartig, 1840. Stettin Ent. Ztg. 1: 25. ठ.

Nematus ribis Dufour, 1847. Soc. Ent. France, Ann. 2: 571-581., o.

Pteronus longicornis Marlatt, 1896. U. S. Dept. Agr., Div. Ent. Tech. Ser. 3: 72. ð. Preocc.

by Nematus longicomis Eschscholtz, 1822.

Pteronus arapahonum Cockerell, 1906. Ent. News 17: 220. o.

Pteronidea ribesii var. feminina Enslin, 1916. Deut. Ent. Ztsehr., Beih., p. 419.

Pteronidea ribesii var. konowi Enslin, 1916. Deut. Ent. Ztschr., Beih., p. 420.

Pteronidea aceris Rohwer, 1915. U. S. Natl. Mus., Proc. 49: 211..

Pteronidea equatia MacGillivray, 1923. Ill. Univ. Bul. 20(50): 30. ठ.

Biology: Caesar and Garlick, 1920. Canad. Ent. 52: 106-108. - Kemner, 1924. Centralanst. for Forsoksv. pa Jordbruksomradet Meddel. 43: 1-33 (in Sweden). -Miles, 1932. Bul. Ent. Res. 23: 1-6. - Walden, 1933. Conn. Agr. Expt. Sta., Bul. 346: 416-427. - Rautapaa, 1970. Ann.

Ent. Fenn. 36: 118-120 (feeding deterrents, host preference).

Morphology: Middleton, 1921. Ent. Soc. Wash., Proc. 23: 173 (terminal abdominal structures). -Snodgrass, 1928. Smith. Misc. Coll. 81: 121. -Shafiq, 1954. Jour. Microscopical Sci. 95:

93-114 (embryonic development).

salicisodoratus Dyar. Maine to Va. w. to Wis., Ill., Ark. Host: Salix, Populus.

Nematus salicis-odoratus Dyar, 1894. Canad. Ent. 26: 187. क, ठ, larva.

Pteronus odoratus Marlatt, 1896. U. S. Dept. Agr., Div. Ent. Tech. Ser. 3: 65. Emend.

Pteronus comelli Marlatt, 1896. U. S. Dept. Agr., Div. Ent. Tech. Ser. 3: 65. $q$, ơ.

Pteronidea winnanae Rohwer, 1911. U. S. Natl. Mus., Proc. 41: 386. §.

Pteronidea mendicana Rohwer, 1920. U. S. Natl. Mus., Proc. 57: 214. ๆ.

Pteronidea plesia Rohwer, 1920. U. S. Natl. Mus., Proc. 57: 216. ․

Pontania dotata MacGillivray, 1921. N. Y. Ent. Soc., Jour. 21: 34. ð.

Taxonomy: Middleton, 1922. U. S. Natl. Mus., Proc. 51: 21 (larva of plesia).

Biology: Warren, 1957. Kans. Ent. Soc., Jour. 30: 11.

superbus (Provancher). Que., N. H.

Eriocampa superba Provancher, 1885. Addit. Corr. Faune Ent. Canada, Hym., p. 351..

Pteronus antennatus Marlatt, 1896. U. S. Dept. Agr., Div. Ent. Tech. Ser. 3: 61. ६.

tricolor (Marlatt). N. H.

Pteronus tricolor Marlatt, 1896. U. S. Dept. Agr., Div. Ent. Tech. Ser. 3: 56. .

umbratus Thomson. Ont., Que., Wash. (?), Oreg. (?).; Europe. Host: Alnus, Betula.

Nematus umbratus Thomson, 1871. Hym. Scand., v. 1, p. 142..

Nematus collinus Cameron, 1882. Ent. Soc. London, Trans., p. 534. ๆ. 
unicolor (Marlatt). Calif.

Pteronus unicolor Marlatt, 1896. U. S. Dept. Agr., Div. Ent. Tech. Ser. 3: 72 ..

\section{UnPlaced Taxa of Nematus Panzer}

integer Say. Ind.

Tenthredo (Nematus) integra Harris, 1835. In Hitcheock, Rpt. Geol. Mineral. Bot. Zool. Mass., p. 583. Nom. nud.

Nematus integer Say, 1836. Boston Jour. Nat. Hist. 1: 218..

minutus (Marlatt). Wash. (Olympia).

Pachynematus minutus Marlatt, 1896. U. S. Dept. Agr., Div. Ent. Tech. Ser. 3: 110. ठ。. nigristigmus (Provancher). Que.

Emphytus nigristigma Provancher, 1888. Addit. Corr. Faune Ent. Canada, Hym., p. 348. †.

obscurus Norton. Mass.

Nematus obscurus Norton, 1861. Boston Soc. Nat. Hist., Proc. 8: 160. ๆ.

pacificus (Marlatt). Wash. (Olympia).

Pteronus pacificus Marlatt, 1896. U. S. Dept. Agr., Div. Ent. Tech. Ser. 3: 49..

semirufus Kirby. Mass.

Tenthredo (Nematus) fulvipes Harris, 1835. In Hitcheock, Rpt. Geol. Mineral. Bot. Zool. Mass., p. 583. Nom. nud.

Nematus fulvipes Norton, 1861. Boston Soc. Nat. Hist., Proc. 8: 159. . Preocc. by Fallen, 1808.

Nematus semimufus Kirby, 1882. List Hym. Brit. Mus., v. 1, p. 148. N. name for fulvipes Norton.

Nematus flavipes(!) Smith, 1966. Ent. Soc. Wash., Proc. 68: 248.

tetraopsis Provancher. Calif.

Nematus tetraopsis Provancher, 1895. Nat. Canad. 22: 79. ․

wrangeli (Marlatt). Alaska.

Pachynematus wrangeli Marlatt, 1896. U. S. Dept. Agr., Div. Ent. Tech. Ser. 3: 109. ठ .

Pteronus rivularis Kincaid, 1900 . Wash. Acad. Sci., Proc. 2: 358. ठ.

\section{Genus PONTANIA Costa}

Pontania Costa, 1859. Fauna del Regno di Napoli, Imen., pt. 3, p. 20.

Type-species: Nematus gallicola Stephens. Desig. by Marlatt, 1896.

Larvae of this large, holarctic genus form closed, pea-shaped or bean-shaped galls on the leaves of Salix or Populus. This genus is in need of revision, and the following is primarily a list of the described species and their type localities except for the work by Benson (1960). Though Benson (1960) established species groups, many of the North American forms have not been studied adequately to permit such an arrangement.

Revision: Marlatt, 1896. U. S. Dept. Agr., Div. Ent. Tech. Ser. 3: 20-43.

Taxonomy: Benson, 1960. Brit. Mus. (Nat. Hist.) Ent., Bul. 8: 369-384. -Benson, 1962. Brit.

Mus. (Nat. Hist.) Ent., Bul. 12: 403-404 (holarctic species).

Biology: Smith, 1970. Ent. Soc. Amer., Ann. 63: 36-51.

Morphology: Smith, 1968. Ent. Soc. Amer., Ann. 61: 1389-1407.

agilis (Cresson). Nev.

Nematus agilis Cresson, 1880. Amer. Ent. Soc., Trans. 8: 9. ठั.

aretica (MacGillivray). N. W. T., Yukon, Alaska, Man. Ecology: Forms leaf galls. Host: Salix reticulata.

Euura arctica MacGillivray, 1919. Rpt. Canad. Arctic Exped. 1913-1918, v. 3G, p. 5G..

Euru arbortiva MacGillivray, 1919. Rpt. Canad. Aretic Exped. 1913-1918, v. 3G, p. 4G. ․

Pontania delicatula MacGillivray, 1919. Rpt. Canad. Arctic Exped. 1913-1918, v. 3G, p. 8G. o.

Pontania deminuta MacGillivray, 1919. Rpt. Canad. Arctic Exped. 1913-1918, v. 3G, p. 9G. \&. 
Taxonomy: Benson, 1960. Brit. Mus. (Nat. Hist.) Ent., Bul. 8: 377. - Vikberg, 1970. Ann. Ent. Fenn. 36: 19 (not holarctic).

arctophilae Benson. Man. (Churchill). Ecology: Ovipositing on Salix arctophila.

Pontania arctophilae Benson, 1960. Brit. Mus. (Nat. Hist.) Ent., Bul. 8: 373. \&.

atriventris Marlatt. Oreg. (Mt. Hood).

Pontania atriventris Marlatt, 1896. U. S. Dept. Agr., Div. Ent. Tech. Ser. 3: 38. .

beckettae Benson. Man. (Churchill). Ecology: Produces pea-shaped galls attached to midvein on underside of leaves. Host: Salix planifolia, S. discolor, S. glauca, S. reticulata.

Pontania beckettae Benson, 1960. Brit. Mus. (Nat. Hist.) Ent., Bul. 8: 378. , gall.

borealis Marlatt. N. Y. Ecology: Produces galls. Host: Salix sericea.

Pontania borealis Marlatt, 1898. Canad. Ent. 30: 302..

brachycarpae Rohwer. Colo. Ecology: Adult collected from Salix brachycarpae.

Pontania brachycarpae Rohwer, 1908. Canad. Ent. 40: 46..+

bruneri Marlatt. Wyo. (Robinson's Ranch). Ecology: Produces leaf galls. Host: Salix longifolia.

Pontania bruneri Marlatt, 1896. U. S. Dept. Agr., Div. Ent. Tech. Ser. 3: 35. \&, gall.

californica Marlatt. Calif. Ecology: Produces a leaf gall. Host: Salix.

Pontania californica Marlatt, 1896. U. S. Dept. Agr., Div. Ent. Tech. Ser. 3: 38. ‡, ơ, gall.

consors Marlatt. N. Y. Ecology: Produces leaf galls. Host: Salix sericea.

Pontania consors Marlatt, 1898. Canad. Ent. 30: 302. ๆ, ठ゚.

crassicornis Rohwer. Ont. Ecology: Produces galls. Host: Salix humilis.

Pontania crassicornis Rohwer, 1912. U. S. Natl. Mus., Proc. 43: 241. ठँ.

crassipes (Thomson). N. W. T., Yukon, Man., Alaska; n. Europe, Switzerland. Ecology: In Europe, makes pea-shaped galls on main vein usually on underside of leaves. Host:

Salix herbacea, S. polaris, S. arctica, S. retusa, S. arbuscula, S. myrsinites, $S$. lapponum, $S$. reticulata.

Nematus crassipes Thomson, 1871. Hym. Scand, v. 1, p. 162..

Nematus herbaceae Cameron, 1875. Glasgow Nat. Hist. Soc., Proc. 2: 304.

Pontania ora Kineaid, 1900. Wash. Acad. Sci., Proc. 2: 354. $\&$.

Pontania atrata MacGillivray, 1919. Rpt. Canad. Arctic Exped. 1913-1918, v. 3G, p. 6G. o. Pontania lorata MacGillivray, 1919. Rpt. Canad. Arctic Exped. 1913-1918, v. 3G, p. 8G. ठ.

Pontania polaris Malaise, 1920. Ent. Tidskr. 40: 112.

Pontania enslini Zirngiebl, 1937. Festschr. zum 60 Geburtst. von Prof. Dr. Embrik Strand 3: 337.

Pontania arbusculae Benson, 1941. Ent. Soc. London, Proc. 10: 134.

Pontania algida Benson, 1941. Ent. Soc. London, Proc. 10: 134.

Pontania aquilonis Benson, 1941. Ent. Soc. London, Proc. 10: 135.

Taxonomy: Benson, 1960. Brit. Mus. (Nat. Hist.) Ent., Bul. 8: 379.

Biology: Vikberg, 1970. Ann. Ent. Fenn. 36: 18 (in Finland).

daedalus MacGillivray. N. Y.

Pontania daedalus MacGillivray, 1921. N. Y. Ent. Soc., Jour. 29: 33..

dedecora MacGillivray. N. Y.

Pontania dedecora MacGillivray, 1921. N. Y. Ent. Soc., Jour. 29: 32.

demissa MacGillivray. N. Y.

Pontania demissa MacGillivray, 1921. N. Y. Ent. Soc., Jour. 29: 33. ?.

derosa MacGillivray. N. Y.

Pontania derosa MacGillivray, 1921. N. Y. Ent. Soc., Jour. 29: 34. ‡.

devincta MacGillivray. Maine.

Pontania devincta MacGillivray, 1921. N. Y. Ent. Soc., Jour. 29: 34. ‡, ठ.

dolichura (Thomson). Man. (Churchill); n. Europe, Austria, Switzerland. Ecology: Produces Galls. Host: Salix planifolia, S. purpurea, S. phylicifolia, S. nigricans, S. arbuscula, S. lapponum, S. myrsinites, S. lanata, S. glabra, S. incana, S. retusa, S. sachalinensis. These hosts were recorded in Europe, except for $S$. planifolia which was recorded in Canada.

Nematus dolichurus Thomson, 1871. Hym. Scand., v. 1, p. 164. ․ ઠ. 
Nematus femoralis Cameron, 1875. Glasgow Nat. Hist. Soc., Proc. 2: 295.

Pontania robbinsi Benson, 1935. Ent. Soc. London, Trans. 83: 26.

Taxonomy: Benson, 1960. Brit. Mus. (Nat. Hist.) Ent., Bul. 8: 380.

Biology: Vikberg, 1970. Ann. Ent. Fenn. 36: 13 (in Finland).

dubius (Marlatt). Mass.

Pteronus dubius Marlatt, 1896. U. S. Dept. Agr., Div. Ent. Tech. Ser. 3: 74. ơ.

gracilis Marlatt. Va. Ecology: Produces a leaf gall. Host: Salix.

Pontania gracilis Marlatt, 1896. U. S. Dept. Agr., Div. Ent. Tech. Ser. 3: 39. $\subsetneq$, gall.

hoppingi (Ross). B. C., Wash. Ecology: Produces a leaf gall. Host: Salix.

Pteronus kincaidi Marlatt, 1896. U. S. Dept. Agr., Div. Ent. Tech. Ser. 3: 55. \&, §. Preocc. by Pontania kincaidi Marlatt, p. 33.

Euura hoppingi Ross, 1937. Ill. Biol. Monog. 15(2): 88. N. name.

kincaidi Marlatt. Wash. (Olympia).

Pontania kincaidi Marlatt, 1896. U. S. Dept. Agr., Div. Ent. Tech. Ser. 3: 33..

lucidae Rohwer. Ont. Ecology: Produces galls. Host: Salix lucida.

Pontania lucidae Rohwer, 1912. U. S. Natl. Mus., Proc. 43: 242. ९, ठ์.

monile Marlatt. Utah (American Fork Canyon). Ecology: Produces leaf galls. Host: Salix.

Pontania monile Marlatt, 1896. U. S. Dept. Agr., Div. Ent. Tech. Ser. 3: 43. gall, larva.

myrtillifoliae Benson. Man. (Churchill). Host: Salix myrtillifolia.

Pontania myrtillifoliae Benson, 1960. Brit. Mus. (Nat. Hist.) Ent., Bul. 8: 372..

pacifica Marlatt. Calif. Ecology: Produces a leaf gall. Host: Salix lasiolepis.

Pontania pacifica Marlatt, 1896. U. S. Dept. Agr., Div. Ent. Tech. Ser. 3: 35..

Biology: Caltagirone, 1964. Ent. Soc. Amer., Ann. 57: 279-291.

peninsularis Kincaid. Alaska.

Pontania peninsularis Kincaid, 1900. Wash. Acad. Sci., Proc. 2: 354..

petiolaridis Rohwer. Ont. Ecology: Produces a leaf gall. Host: Salix petiolaris.

Pontania petiolaridis Rohwer, 1917. In Cosens, Ont. Ent. Soc., Ann. Rpt. 47: 18-19. ․, ð.

Pontania petiolaris Felt, 1917. N. Y. State Mus., Bul. 200: 34.

placenta (Norton). Labrador.

Nematus placentus Norton, 1867. Amer. Ent. Soc., Trans. 1: 213.,$\delta$.

proxima (Lepeletier). Maine, Ont., N. Y.; Europe. Ecology: Produces reddish leaf galls in rows on each side of midrib. Probably introduced with host. Host: Salix fragilis, S. alba.

Willow redgall sawfly.

Nematus proximus Lepeletier, 1823. Monog. Tenthred., p. 67..

Nematus gallicola Stephens, 1835. Illus. Brit. Ent., v. 7, p. 36.

Messa hyalina Norton, 1864 . Ent. Soc. Phila., Proc. 4: 8 . 9 .

Hoplocampa gallicola Cameron, 1877. Ent. Monthly Mag. 14: 156.

Euura flavipes Cameron, 1885. Monog. Brit. Phytophagous Hym., v. 2, p. 211.

Biology: Carleton, 1939 Linn. Soc. London, Jour. 40: 575-624.

pumila Rohwer. N. B.

Pontania pumila Rohwer, 1910. U. S. Natl. Mus., Proc. 38: 198. + , ơ.

pyriformis Marlatt. Calif. (Placer Co.). Ecology: Produces a leaf gall. Host: Salix californica (?).

Pontania pyriformis Marlatt, 1896. U. S. Dept. Agr., Div. Ent. Tech. Ser. 3: 43. gall, larva.

resinicola Marlatt. Calif. (Los Angeles). Ecology: Produces leaf galls. Host: Salix californica.

Pontania resinicola Marlatt, 1896. U. S. Dept. Agr., Div. Ent. Tech. Ser. 3: 30. ๆ, ơ, gall.

rugulosa Marlatt. Mich. Ecology: "reared (?) from willow gall."

Pontania rugulosa Marlatt, 1896. U. S. Dept. Agr., Div. Ent. Tech. Ser. 3: 41. ठ.

s-desmodioides (Walsh). Ill. Ecology: Produces a leaf gall. Host: Salix humilis.

Nematus s. desmodioides Walsh, 1866. Ent. Soc. Phila., Proc. 6: 257. \&, o, gall, larva.

Nematus salicis-desmodioides Dalla Torre, 1894. Cat. Hym., v. 1, p. 259. Emend.

s-pisum (Walsh). Ill. Ecology: Produces a leaf gall. Host: Salix discolor.

Nematus s. pisum Walsh, 1866. Ent. Soc. Phila., Proc. 6: 258. \&, o, gall, larva.

Nematus salicis-pisum Thomas, 1881. State Ent. Ill. Rpt. 10: 68. gall, larva. 
s-pomum (Walsh). Ill. Ecology: Produces a leaf gall. Host: Salix.

Nematus s. pomum Walsh, 1866. Ent. Soc. Phila., Proc. 6: 255. ̊, §, gall, larva.

Nematus hospes Walsh, 1866. Ent. Soc. Phila., Proc. 6: 261. ๆ, ठ.

Nematus salicis-pomum Thomas, 1881. State Ent. Ill. Rpt. 10: 68. gall, larva.

Pontania pomum Marlatt, 1896. U. S. Dept. Agr., Div. Ent. Tech. Ser. 3: 36. Emend.

stigmatalis Marlatt. Oreg. (Mt. Hood).

Pontania stigmatalis Marlatt, 1896. U. S. Dept. Agr., Div. Ent. Tech. Ser. 3: 39.

subatrata MacGillivray. Alaska.

Pontania subatrata MacGillivray, 1921. Calif. Acad. Sci., Proc. (ser. 4) 11: 189. ठ. sublorata MacGillivray. Alaska.

Pontania sublorata MacGillivray, 1921. Calif. Acad. Sci., Proc. (ser. 4) 11: 190. ठ. sulphurea Marlatt. Mont., Nev.

Pontania sulphurea Marlatt, 1896. U. S. Dept. Agr., Div. Ent. Tech. Ser. 3: 41. \&, §. truncata Marlatt. Calif.

Pontania truncata Marlatt, 1896. U. S. Dept. Agr., Div. Ent. Tech. Ser. 3: 38..

\section{Genus PHYLLOCOLPA Benson}

Phyllocolpa Benson, 1960. Ent. Monthly Mag. 96: 60.

Type-species: Nematus leucapsis Tischbein. Orig. desig.

Larvae of this holarctic genus live in rolled leaves or rolled leaf edges of Salix or Populus. This genus is in need of study. The following is mostly a list of described species with their type localities without regard to possible synonymy. Benson (1960) established two species groups.

Revision: Marlatt, 1896. U. S. Dept. Agr., Div. Ent. Tech. Ser. 3: 24-30 (Pontania, Group I). -Ross, 1929. Ent. Soc. Wash., Proc. 31: 91-97 (Marlatt's Group I of Pontania).

Taxonomy: Benson, 1960. Brit. Mus. (Nat. Hist.) Ent., Bul. 8: 380-381 (section A of Pontania). - Benson, 1962. Brit. Mus. (Nat. Hist.) Ent., Bul. 12: 403 (holarctic species).

Biology: Smith, 1970. Ent. Soc. Amer., Ann. 63: 36-51.

Morphology: Smith, 1968. Ent. Soc. Amer., Ann. 61: 1389-1407.

acuminata (Marlatt). Mich.

Pontania acuminata Marlatt, 1896. U. S. Dept. Agr., Div. Ent. Tech. Ser. 3: 32 ..

acutiserra (Lindqvist). Man. (Churchill); Lapland, Scotland. Host: Salix.

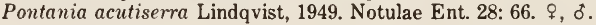

Biology: Vikberg, 1970. Ann. Ent. Fenn. 36: 11 (in Finland).

agama (Rohwer). Calif.

Pontania agama Rohwer, 1912. U. S. Natl. Mus., Proc. 43: 242 ..

Pontania foveata Rohwer, 1912. U. S. Natl. Mus., Proc. 43: 243..

bozemani (Cooley). Sask., Alta., Mont. Host: Populus. Poplar leaffolding sawfly.

Pontania bozemani Cooley, 1903. Canad. Ent. 35: 197. ๆ, ठ.

Biology: Cooley, 1903. Mont. Agr. Expt. Sta. Bul. 46: 113-118.

coriacea (Benson). Alta. (Lake Louise); Scandinavia, Switzerland. Host: Salix.

Nematus (Pontania) coriacea Benson, 1953. Ent. Monthly Mag. 89: 150. ९, ơ.

Biology: Vikberg, 1970. Ann. Ent. Fenn. 36: 12 (in Finland).

cressoni (Marlatt). Wash.

Pontania cressoni Marlatt, 1896. U. S. Dept. Agr., Div. Ent. Tech. Ser. 3: 26. \&.

excavata (Marlatt). Colo., Alaska, Calif.; Europe to Siberia. Ecology: Larva lives in rolled leaf edge. Host: Salix petandra.

Pontania excavata Marlatt, 1896. U. S. Dept. Agr., Div. Ent. Tech. Ser. 3: 30. ๆ, o.

Pontania megacephala Rohwer, 1908. Canad. Ent. 40: 47. $\delta$.

Pontania destricta MacGillivray, 1923. N. Y. Ent. Soc., Jour. 31: 168. ๆ.

Pontania apicifrons Malaise, 1932. Arkiv for Zool. 23A: 33. ․ ठ.

Pontania carinifrons Benson, 1940. Ent. Monthly Mag. 76: 210. ‡, ઠ.

Taxonomy: Benson, 1960. Ent. Monthly Mag. 96: 60. 
Biology: Vikberg, 1970. Ann. Ent. Fenn. 36: 11 (in Finland).

leavitti (Rohwer). N. B.

Pontania leavitti Rohwer, 1910. U. S. Natl. Mus., Proc. 38: 199..

leucostoma (Rohwer). Colo.

Pontania leucostoma Rohwer, 1908. Canad. Ent. 40: 45. ठ̊.

mariana (Ross). B. C. (Vancouver). Ecology: Larva makes a leaf fold. Host: Populus balsamifera.

Pontania mariana Ross, 1929. Ent. Soc. Wash., Proc. 31: 91. ‡, ठ, larva.

marlatti (Ross). Oreg.

Pontania marlatti Ross, 1929. Ent. Soc. Wash., Proc. 31: 93. \&.

melanosoma (Rohwer). Colo.

Pontania melanosoma Rohwer, 1908. Canad. Ent. 40: 48.

mellina (Cresson). Nev.

Nematus mellinus Cresson, 1880. Amer. Ent. Soc., Trans. 8: 10. ๆ.

nevadensis (Cresson). Nev.

Nematus nevadensis Cresson, 1880. Amer. Ent. Soc., Trans. 8: 9. ‡, ठ".

nigripecta (Rohwer), n. comb. Calif.

Pontania nevadensis var. nigripecta Rohwer, 1912. U. S. Natl. Mus., Proc. 43: 243. ^, ठ઼.

nigrita (Marlatt), n. comb. Mich.

Pontania nigrita Marlatt, 1896. U. S. Dept. Agr., Div. Ent. Tech. Ser. 3: 27. \&.

parva (Cresson). Nev.

Nematus parvus Cresson, 1880. Amer. Ent. Soc., Trans. 8: 5. ‡.

pectoralis (Marlatt). Ill. (Algonquin).

Pontania pectoralis Marlatt, 1896. U. S. Dept. Agr., Div. Ent. Tech. Ser. 3: 31..

pepii (Ross). Mont. (Florence).

Pontania pepii Ross, 1929. Ent. Soc. Wash., Proc. 31: 96. ๆ.

popuella (Ross). Man., S. Dak. Ecology: Larva makes a leaf fold. Host: Populus deltoides.

Pontania popuella Ross, 1929. Ent. Soc. Wash., Proc. 21: 93. ๆ, ơ.

populi (Marlatt). Mass., Conn., Ont., N. J. Host: Populus.

Pontania populi Marlatt, 1896. Canad. Ent. 28: 253. ?.

robusta (Marlatt). D. C. (?), Mich.

Pontania robusta Marlatt, 1896. U. S. Dept. Agr., Div. Ent. Tech. Ser. 3: 32. ๆ, ठ.

stipata (MacGillivray), n. comb. Alaska.

Pontania stipata MacGillivray, 1921. Calif. Acad. Sci., Proc. (ser. 4) 9: 188.

terminalis (Marlatt). N. Y. Host: Salix.

Pontania terminalis Marlatt, 1896. Canad. Ent. 28: 253. \&, o.

tundra (Kincaid). Alaska.

Pontania tundra Kincaid, 1900. Wash. Acad. Sci., Proc. 2: 352. ९, ठ.

utensis (Rohwer), n. comb. Colo.

Pontania utensis Rohwer, 1908. N. Y. Ent. Soc., Jour. 16: 107. \&.

\section{Genus EUURA Newman}

Two subgenera have been proposed, Euura for those species whose larvae form stem, twig, or petiole galls on Salix, and Gemmura for those species whose larvae form bud galls on Salix. This genus is in need of study. The following is primarily a list of described species with their type localities without regard to possible synonymy. According to Smith (1968) conventional use of morphological characters for species separation is impossible in this group and identification may have to be based on specific host data and biological information; therefore, the exact identity of many of the described species may never be known.

Revision: Rohwer, 1909. N. Y. Ent. Soc., Jour. 17: 7-25.

Taxonomy: Benson, 1962. Brit. Mus. (Nat. Hist.) Ent., Bul. 12: 402-403 (holarctic species).

-Smith, 1968. Ent. Soc. Amer., Ann. 61: 1389-1407 (Calif. species). 
Biology: Smith, 1968. Ent. Soc. Amer., Ann. 61: 1389-1407. - Smith, 1970. Ent. Soc. Amer., Ann. 63: 36-51.

Morphology: Smith, 1968. Ent. Soc. Amer., Ann. 61: 1389-1407. - Smith, 1972. Int. Jour. Ins. Morph. and Embryol. v. 1, 1: 321-365 (external genitalia of Euura).

\section{Genus EUURA Subgenus EUURA Newman}

Euura Newman, 1837(January). Ent. Mag. 4: 259.

Type-species: Euura gallae Newman. Desig. by Rohwer, 1911.

Nematus subg. Cryptocampus Hartig, 1837(March). Fam. Blattwespen und Holzwespen, nebst Einleitung Naturgesch. Hym., p. 221.

Type-species: Nematus (Cryptocampus) medullaris Hartig. Desig. by Rohwer, 1911.

albiricta Cresson. Nev.

Euura albiricta Cresson, 1880. Amer. Ent. Soc., Trans. 8: 4. + .

atra (Jurine). N. B., Que., Ont., Alta.; Europe. Ecology: Attacks many of the narrow-leaved willows. Host: Salix repens, S. viminalis, S. fragilis, S. purpurea, S. babylonica, S. alba var. vitellina.

Pteronus ater Jurine, 1807. Nouv. Meth. Class. Hym., p. 6, fig. 6b..

Cryptocampus angustus Hartig, 1837. Fam. Blattwespen und Holzwespen, nebst Einleitung Naturgesch. Hym., p. 222.

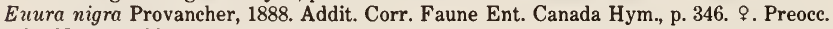
by Norton, 1867.

Biology: MacCall and Titus, 1972. Canada Dept. Environment, Forestry Service, Bi-Monthly Research Notes 28: 8.

bakeri (Rohwer). Calif. Ecology: Produces a stem gall. Host: Salix.

Cryptocampus bakeri Rohwer, 1910. Canad. Ent. 42: 51. + , ठ。.

bebbianae (Rohwer). Colo. Ecology: Produces a stem gall. Host: Salix ? bebbiana.

Cryptocampus bebbianae Rohwer, 1909. N. Y. Ent. Soc., Jour. 17: 18. ๆ, ठ́.

breweriae Smith. Calif. (inner Coast Ranges, Yolo Co., Napa Co.). Ecology: Produces a stem gall. Host: Salix breweri.

Euura (Euura) breweriae Smith, 1968. Ent. Soc. Amer., Ann. 61: 1405. \&, ठ, gall.

cooperae Cockerell. N. Mex. Ecology: Produces a stem gall on narrow-leaved willow. Host: Salix.

Euura cooperae Cockerell, 1901. Ann. and Mag. Nat. Hist. (ser. 7) 7: 337..+

cosensii Rohwer. Ont. Ecology: Produces a petiole gall. Host: Salix humilis.

Euura cosensii Rohwer, 1915. U. S. Natl. Mus., Proc. 49: 213. , ठ.

exiguae Smith. Calif. (north of Transverse Ranges up to $750 \mathrm{~m}$.). Ecology: Produces a stem gall. Host: Salix exiguae.

Euura (Euura) exiguae Smith, 1968. Ent. Soc. Amer., Ann. 61: 1402. ₹, ठ, gall.

geyerianae Smith. Oreg. (Klamath Co.), and probably s. in Calif. Sierras. Ecology: Produces a stem gall. Host: Salix geyeriana.

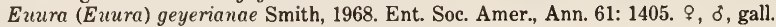

lasiolepis Smith. Calif. (Monterey Co. to Mendocino Co. west to Sierra Nevada). Ecology: Makes a stem gall. Host: Salix lasiolepis.

Euura (Euıra) lasiolepis Smith, 1968. Ent. Soc. Amer., Ann. 61: 1406. \&, ठ, gall.

lemmoniae Smith. Calif. (Sierra Nevada and adjacent ranges from Mt. Lassen and s.). Ecology: Produces a stem gall. Host: Salix lemmonii.

Euura (Euura) lemmoniae Smith, 1968. Ent. Soc. Amer., Ann. 61: 1406. ๆ, o, gall. macgillivrayi (Rohwer). Colo. Ecology: Produces a stem gall. Host: Salix luteosericea.

Cryptocampus macgillivrayi Rohwer, 1909. N. Y. Ent. Soc., Jour. 17: 16. \&, ơ. maura (Rohwer). Colo. Ecology: Adult collected from Salix.

Cryptocamipus maura Rohwer, 1909. N. Y. Ent. Soc., Jour. 17: 23. ?, ठ.

minuta MacGillivray. Jowa.

Euura minuta MacGillivray, 1914. Canad. Ent. 46: 366. $ๆ$.

moenia MacGillivray. Oreg.

E zura moenia MacGillivray, 1923. Ill. Univ. Bul. 20(50): 17. ९, ઠ. 
nigrella Rohwer. Ont.

Euura nigrella Rohwer, 1912. U. S. Natl. Mus., Proc. 43: 241..

nigra Norton. Labrador.

Euura orbitalis var. nigra Norton, 1867. Amer. Ent. Soc., Trans. 1: 71. \&.

orbitalis Norton. Conn., N. Y. Ecology: Adults collected from Salix.

Euura orbitalis Norton, 1862. Ent. Soc. Phila., Proc. 1: 144. ๆ, ठ.

pallistigmus (Rohwer). N. B.

Cryptocampus pallistigmus Rohwer, 1910. U. S. Natl. Mus., Proc. 38: 200. $\subsetneq$, ઠ.

parva Rohwer. Colo.

Euura parva Rohwer, 1908. Canad. Ent. 40: 176. ‥

perdita Rohwer. Colo. Ecology: Produces galls. Host: Salix.

Euura perdita Rohwer, 1909. Canad. Ent. 41: 20. ๆ, ઠే.

propinqua (Rohwer). N. Mex. Ecology: Produces a stem gall. Host: Salix.

Cryptocampus propinqua Rohwer, 1909. N. Y. Ent. Soc., Jour. 17:24. §.

salicicola Smith. Ill. Ecology: Produces a stem gall. Host: Salix alba.

Euura salicicola Smith, 1879. North Amer. Ent. 1: 41. ₹, o.

scoulerianae Smith. Calif. (Sierra Nevada and adjacent ranges from Mt. Shasta southward). Ecology: Produces a stem gall. Host: Salix scouleriana.

Euura (Euura) scoulerianae Smith, 1968. Ent. Soc. Amer., Ann. 61: 1406. \&, ð, gall.

serissimae Rohwer. Ont. Ecology: Produces a petiole gall. Host: Salix serissima.

Euura serissimae Rohwer, 1912. U. S. Natl. Mus., Proc. 43: 240..

s-gemma Walsh. Ill. Ecology: Produces twig galls. Host: Salix humilis.

Euura s. gemma Walsh, 1866. Ent. Soc. Phila., Proc. 6: 250. §, ठ, gall, larva.

Euura genuina Norton, 1867. Amer. Ent. Soc., Trans. 1: 79. ₹, o, gall.

s-nodus Walsh. Ont., Mich., Ohio., Ill. Ecology: Produces a stem gall. Host: Salix interior.

Euura s. nodus Walsh, 1866. Ent. Soc. Phila., Proc. 6: 253. ठ.

Cryptocampus salicis-nodus Dalla Torre, 1894. Cat. Hym., v. 1, p. 278. Emend.

Cryptocampus nodus Konow, 1905. In Wytsman, Gen. Ins., v. 29, p. 51. Emend.

Biology: Judd, 1954. Canad. Ent. 86: 542-546.

8-ovum Walsh. N. Y., Ill. Ecology: Produces a twig gall. Host: Salix.

Euura s. ovum Walsh, 1866. Ent. Soc. Phila., Proc. 6: 252. ๆ, §, gall.

Euura perturbans Walsh, 1866. Ent. Soc. Phila., Proc. 6: 254. ₹, ठ̀, gall.

Euura salicis-ovum Thomas, 1881. State Ent. Ill. Rpt. 10: 69. gall, larva.

s-ovulum Walsh. Ill. Ecology: Produces a stem gall. Host: Salix humilis.

Euura s. ovulum Walsh, 1866. Ent. Soc. Phila., Proc. 6: 253. gall, larva.

Cryptocampus salicis-ovulum Dalla Torre, 1894. Cat. Hym., v. 1, p. 278. Emend.

\section{Genus EUURA Subgenus GEMMURA Smith}

Euura subg. Gemmura Smith, 1968. Ent. Soc. Amer., Ann. 61: 1401.

Type-species: Cryptocampus mucronatus Hartig. Orig. desig.

brachycarpae Rohwer. Colo.

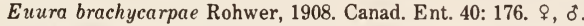

lanatae Malaise. Man. (Churchill), Alta. (Lake Louise); n. Europe. Ecology: Produces bud galls. Host: Salix lanata, S. calcicola.

Euura lanatae Malaise, 1920. Ent. Tidskr. 40: 105. \&, ठ.

mucronata (Hartig). Man. (Churchill), Alaska; Europe. Ecology: Larva feeds inside buds of many species of willow. Host: Salix.

Nematus (Cryptocampuis) mucronatus Hartig, 1837. Fam. Blattwespen und Holzwespen, nebst Einleitung Naturgesch. Hym., p. 223. $\&$, ठ.

Euura nigritarsis Cameron, 1885. Monog. Brit. Phytophagous Hym., v. 2, p. 214.

Euura insularis Kincaid, 1900. Wash. Acad. Sci., Proc. 2: 352. , ठ。.

Taxonomy: Benson, 1962. Brit. Mus. (Nat. Hist.) Ent., Bul. 12: 402. 


\section{Genus AMAURONEMATUS Konow}

Amauronematus Konow, 1890. Deut. Ent. Ztschr., pp. 233, 237, 246.

Type-species: Nematus fallax Lepeletier. Desig. by Rohwer, 1911.

Pontoprista Malaise, 1921. Ent. Tidskr. 42: 12.

Type-species: Pontoprista suavis var. fusca Malaise. Desig. by Ross, 1937.

A large holarctic genus common in the arctic and subarctic regions. This genus is in need of study. Several phyletic lines are evident which will eventually allow more convenient species groupings.

Taxonomy: Benson, 1962. Brit. Mus. (Nat. Hist.) Ent., Bul. 12: 396-402 (holarctic species). abnormis (Holmgren). Baffin Is., N. W. T., Alaska; n. Europe, Switzerland, Siberia. Females are commonly brachypterous.

Nematus abnormis Holmgren, 1883. Ent. Tidskr. 4: 148. \&.

Amauronematus tolli Konow, 1907. E. Zoologie 1: 20.

Amauronematus aulatus MacGillivray, 1919. Rpt. Canad. Arctic Exped. 1913-1918, v. 3G, p. $16 \mathrm{G}$.

Taxonomy: Benson, 1962. Brit. Mus. (Nat. Hist.) Ent., Bul. 12: 401.

amentorum (Foerster). N. H. to Oreg. s. to Va., Mich., Wis., Colo.; Greenland; Iceland; Europe to Siberia. Ecology: Widespread. Larva feeds on catkins. Host: Salix.

Nematus amentomum Foerster, 1854. Naturh. Ver. Rheinlande, Verh. 11: 337. .

Nematus suavis Ruthe, 1859. Stettin Ent. Ztg. 20: 308.

Pontania atra Marlatt, 1896. U. S. Dept. Agr., Div. Ent. Tech. Ser. 3: 37. ․ N. syn.

Pontania maura Rohwer, 1908. Canad. Ent. 40: 47. . N. syn.

Pontania amientivora Rohwer, 1915. U. S. Natl. Mus., Proc. 49: 209..

Pontoprista kamtchatica Malaise, 1931. Arkiv for Zool. 23A: 53. \&.

arcticola (Dalla Torre). N. W. T., Alaska; arctic Europe and Siberia. Host: Salix.

Nematus arcticus Thomson, 1871. Hym. Scand., v. 1, p. 134. 9 . Preoce. by Holmgren, 1869.

Nematus arcticola Dalla Torre, 1894. Cat. Hym., v. 1, p. 207. N. name.

Amauronematus arcticola Enslin, 1915. Deut. Ent. Ztschr., Beih., p. 389. N. name.

Amauronematus mcluckiei Benson, 1935. Roy. Ent. Soc. London, Trans. 83: 31. ‡, ð.

Taxonomy: Benson, 1962. Brit. Mus. (Nat. Hist.) Ent., Bul. 12: 398.

azaleae Marlatt. N. H. Host: Azalea. Recorded from other eastern states but records are based on larvae and their identity is not certain.

Amauronematus azaleae Marlatt, 1896. Canad. Ent. 28: 254. ‡, ठ.

Biology: Smith, 1974. Ent. Soc. Wash., Proc. 76: 204.

borealis (Marlatt), Greenland (Disco Is.).

Nematus borealis Marlatt, 1892. In Fox, Acad. Nat. Sci. Phila., Proc. 44: 133. ð.

brunneus (Norton). Md., Wis., Sask., Kans., Colo., Utah.

Nematus brunneus Norton, 1864. Ent. Soc. Phila., Proc. 43: 244..

Amauronematus knabi Rohwer, 1912. U. S. Natl. Mus., Proc. 43: 244. ?. N. syn.

completus MacGillivray. Alaska.

Amauronematus completus MacGillivray, 1919. Rpt. Canad. Aretic Exped. 1913-1918, v. $3 \mathrm{G}$, p. $13 \mathrm{G}$.

comstocki Marlatt. N. Y.

Amauronematus comstocki Marlatt, 1896. U. S. Dept. Agr., Div. Ent. Tech. Ser. 3: 77. $\subsetneq$. cooki Marlatt. Mich.

Amauronematus cooki Marlatt, 1896. U. S. Dept. Agr., Div. Ent. Tech. Ser. 3: 79. ठँ.

digestus MacGillivray. Alaska.

Amauronematus digestus MacGillivray, 1919. Rpt. Canad. Arctic Exped. 1913-1918, v. 3G, p. $14 \mathrm{G}$.

egnatia (MacGillivray). Alta.

Pteronidea egnatia MacGillivray, 1923. Canad. Ent. 55: 162..

enavata (MacGillivray). Maine.

Pteronidea enavata MacGillivray, 1920. Canad. Ent. 52: 236.. 
fallax (Lepeletier). N. S., Ont. to N. W. T., Yukon, Alaska s. to N. Y., Colo., Oreg.; Europe. Ecology: Widespread. Host: Salix.

Nematus fallax Lepeletier, 1823. Monog. Tenthred., p. 64. \&, ð.

Nematus trifurcatus Kirby, 1882. List Hym. Brit. Mus., v. 1, p. 148.

Amauronematus similis Marlatt, 1896. Canad. Ent. 28: 255..

Pontania quadrifasciatus MacGillivray, 1919. Rpt. Canad. Arctic Exped. 1913-1918, v. 3G, p. 10G. ?.

Amauronematus vescus MacGillivray, 1921. N. Y. Ent. Soc., Jour. 29: 30. ․ N. syn. Amauronematus veneficus MacGillivray, 1923. N. Y. Ent. Soc., Jour. 31: 169. ․ N. syn. Amauronematus nuorbinjargi Saarinen, 1949. Ann. Ent. Fenn. 15: 57.

Amauronematus glacialis Saarinen, 1950. Ann. Ent. Fenn. 16: 45.

Amauronematus amicula Saarinen, 1950. Ann. Ent. Fenn. 16: 47.

Amauronematus subnitens Saarinen, 1950. Ann. Ent. Fenn. 16: 49.

Amauronematus septentrionalis Saarinen, 1950. Ann. Ent. Fenn. 16: 54.

Amauronematus festivus Saarinen, 1950. Ann. Ent. Fenn. 16: 58.

Amauronematus propinquus Saarinen, 1950. Ann. Ent. Fenn. 16: 60.

Nematus trifurcus Benson, 1962. Brit. Mus. (Nat. Hist.) Ent., Bul. 12: 399. Misspelling of trifurcatus Kirby.

Taxonomy: Benson, 1962. Brit. Mus. (Nat. Hist.) Ent., Bul. 12: 399.

gracilis Marlatt. Mass., N. Y.

Amauronematus gracilis Marlatt, 1896. U. S. Dept. Agr., Div. Ent. Tech. Ser. 3: 78. 9.

groenlandicus Malaise. N. W. T., Alaska; Greenland; n. Europe. Host: Salix (?).

Amauronematus groenlandicus Malaise, 1933. Skr. om Svalb. og Ischavet 53: 3. ․

A mauronematus carbonarius Hellen, 1951. Acta Univ. Lund (n. s.) 46: 71.

Taxonomy: Benson, 1962. Brit. Mus. (Nat. Hist.) Ent., Bul. 12: 396-397.

hebes Konow. N. W. T.; Europe.

Amauronematus hebes Konow, 1907. Akad. Nauk. Fiz.-Mat. Otd. Zap. 18(3): 17. \&. Amauronematus pristiphorinus Malaise, 1931. Arkiv for Zool. 23A: 2.

Taxonomy: Benson, 1962. Brit. Mus. (Nat. Hist.) Ent., Bul. 12: 397.

helleni Lindqvist. Baffin Is., Que., N. W. T., Man.; Scandinavia.

Amauronematus helleni Lindqvist, 1941. Notulae Ent. 21: 65. ค, ठ.

Taxonomy: Benson, 1962. Brit. Mus. (Nat. Hist.) Ent., Bul. 12: 397.

histrio (Lepeletier). Maine to Alaska s. to Ill., Colo.; Eurasia. Ecology: Widespread. Host: Salix.

Nematus histrio Lepeletier, 1823. Monog. Tenthred., p. 63. ๆ.

Nematus luteotergum Norton, 1861. Boston Soc. Nat. Hist., Proc. 8: 161. ๆ.

Nematus fur Walsh, 1866. Ent. Soc. Phila., Proc. 6: 263. ठ.

Nematus concolor Norton, 1867. Amer. Ent. Soc., Trans. 1: 196. ठ。.

Nematus violaceipennis Norton, 1867. Amer. Ent. Soc., Trans. 1: 201. đ.

Nematus discolor Cresson, 1880. Amer. Ent. Soc., Trans. 8: 8..

Nematus glenelgensis Cameron, 1882. Ent. Soc. London, Trans., p. 535.

Amauronematus viscendus MacGillivray, 1921. N. Y. Ent. Soc., Jour. 29: 28. ๆ, ð.

hulteni Malaise. Man., N. W. T., Yukon; Siberia.

Amauronematus variabilis var. hulteni Malaise, 1931. Arkiv for Zool. 23A: 43. ๆ, ठ.

Taxonomy: Benson, 1962. Brit. Mus. (Nat. Hist.) Ent., Bul. 12: 397.

indicatus MacGillivray. Alaska (Camden Bay).

Amauronematus indicatus MacGillivray, 1919. Rpt. Canad. Arctic Exped. 1913-1918, v. 3G, p. 14G.

isolatus Kincaid. N. W. T., Alaska.

Amauronematus isolatus Kincaid, 1900. Wash. Acad. Sci., Proc. 2: 358. ๆ.

Amauronematus magnus MacGillivray, 1919. Rpt. Canad. Arctic Exped. 1913-1918, v. 3G, p. 17G. N. syn.

Amauronematus veridicus MacGillivray, 1923. N. Y. Ent. Soc., Jour. 31: 170..

itelmena (Malaise). Man., N. W. T.; Siberia. Ecology: Adult collected from Salix alexensis.

Pontoprista itelmena Malaise, 1931. Arkiv for Zool. 23A: 54. ㅇ. 
leptocephalus (Thomson). Man.; aretic Eurasia.

Nematus leptocephalus Thomson, 1862. Ofvers. Svensk. Vet. Akad., Forh. 19: 632..

leucolaenus (Zaddach). Ont., Man., N. W. T., Sask., Alta., Yukon, Alaska; Eurasia.

Nematus lencolaenus Zaddach, 1882. Phys. Okonom. Gesell. Konigsberg., Schr. 23: 196..+

Pontania unga Kincaid, 1900. Wash. Acad. Sci., Proc. 2: 354 ..+

Pteronidea egeria MacGillivray, 1923. Canad. Ent. 55: 161. ․ N. syn.

Amauronematus saarineni Lindqvist, 1945. Notulae Ent. 25: 106.

Taxonomy: Benson, 1962. Brit. Mus. (Nat. Hist.) Ent., Bul. 12: 402.

lineatus (Harrington). Maine, Ont., N. Y. w. to Ill., Nebr., Kans. Host: Salix.

Nematus lineatus Harrington, 1893. Canad. Ent. 25: 59..

Amauronematus lincolnensis Rohwer, 1909. Canad. Ent. 41: 19. ․

Biology: Ross, 1935. Ill. State Acad. Sci., Trans. 28: 261-262 (life history; female, male, larva described).

longicaudus (Hellen). Man., B. C.; Lapland.

Nematus (Amauronematus) longicauda Hellen, 1948. Notulae Ent. 27: 113..

microphyes (Foerster). Ont. (Ottawa); Europe. Host: Salix.

Nematus microphyes Foerster, 1854. Naturh. Ver. Rheinlande, Verh. 11: 344..+

Pontoprista romani Malaise, 1921. Ent. Tidskr. 42: 14.

Pontoprista nana Lindqvist, 1949. Notulae Ent. 28: 68.

neglectus (Kirby). Que., Ont., IIl., N. W. T., Man., Colo., Yukon, B. C.; Lapland, Siberia. Host: Salix.

Nematus neglectus Kirby, 1882. List Hym. Brit. Mus., v. 1, p. 147. ․

Amauronematus intermedius Malaise, 1931. Arkiv for Zool. 23A: 39.

Amauronematus spiniserra Malaise, 1921. Ent. Tidskr. 42: 119.

Taxonomy: Benson, 1962. Brit. Mus. (Nat. Hist.) Ent., Bul. 12: 400-401. - Lindqvist, 1972.

Notulae Ent. 52: 69 .

nigriventris (Holmgren). Alaska; $n$. Europe.

Nematus nigriventris Holmgren, 1883. Ent. Tidskr. 4: 146. ․

Amauronematus varianus MacGillivray, 1919. Rpt. Canad. Arctic Exped. 1913-1918, v. 3G, p. 16G. + (male misdet.). N. syn.

Pteronidea melanostoma Rohwer, 1920. U. S. Natl. Mus., Proc. 57: 212. ‥ N. syn.

nigrofemoratus (Cresson). Nev.

Nematus nigrofemoratus Cresson, 1880. Amer. Ent. Soc., Trans. 8: 4. ?.

nitidipleuris Malaise. Man. (Churchill); Greenland; Europe, Siberia.

Amauronematus nitidipleuris Malaise, 1931. Arkiv for Zool. 23A: 45. ?.

Taxonomy: Benson, 1962. Brit. Mus. (Nat. Hist.) Ent., Bul. 12: 402.

orbitalis Marlatt. Colo., Oreg.

Amauronematus orbitalis Marlatt, 1896. U. S. Dept. Agr., Div. Ent. Tech. Ser. 3: 80..

oregonensis Marlatt. Oreg. (Mt. Hood).

Amauronematus oregonensis Marlatt, 1896. U. S. Dept. Agr., Div. Ent. Tech. Ser. 3: 80..

peralus Smith, n. name. Colo., Nev.

Nematus pectoralis Cresson, 1880. Amer. Ent. Soc., Trans. 8: 9. \& Preocc. by Lepeletier, 1823.

polaris (Holmgren). N. W. T., Alta., Alaska; n. Europe. Host: Salix.

Nematus polaris Holmgren, 1883. Ent. Tidskr. 4: 143. ‥

Pontania islandica Kincaid, 1900. Wash. Acad. Sci., Proc. 2: 355. ?.

Pteronus shumagensis Kincaid, 1900. Wash. Acad. Sci., Proc. 2: 357. $\$$.

Pteronidea parriserrata Lindqvist, 1944. Notulae Ent. 24: 23.

Amauronematus leucopyga Lindqvist, 1948. Notulae Ent. 28: 69.

Amauronematus subpolaris Lindqvist, 1948. Notulae Ent. 28: 71.

Pteronidea bipicta Lindqvist, 1959. Notulae Ent. 39: 56.

Pteronidea sordidiapex Lindqvist, 1959. Notulae Ent. 39: 57.

Taxonomy: Benson, 1961. Ergeb. Wiss. Unters. Schweiz. Nat. Parks 7(N. F.)(44): 190. 
pravus Konow. Alaska; n. Eurasia. Host: Salix.

Amauronematus pravus Konow, 1896. Termes. Fuzetek 18: 176. \&.

rapax (Cresson). Nev.

Nematus rapax Cresson, 1880. Amer. Ent. Soc., Trans. 8: 4. ठ.

sagmarius Konow. Ont., Man., N. W. T., Alta., Alaska; Eurasia. Host: Salix.

Amauronematus sagmarius Konow, 1896. Termes. Fuzetek 18: 177., , ऽ.

Amauronematus viduatinus Malaise, 1931. Arkiv for Zool. 23A: 40.

Taxonomy: Benson, 1962. Brit. Mus. (Nat. Hist.) Ent., Bul. 12: 399.

semilacteus (Zaddach). B. C (Vernon); n. and cent. Europe. Host: Salix.

Nematus semilacteus Zaddach, 1883. Phys. Okonom. Gesell. Konigsberg., Schr. 24: 148..

Taxonomy: Vikberg and Kontuniemi, 1971. Ann. Ent. Fenn. 37: 89-95 (male, female, larva). stordalensis (Strand). Baffin Is., Ellesmere Is., N. W. T., Alaska; Siberia.

Nematus stordalensis Strand, 1905. Second Norw. Aretic Exped. "Fram" Rpt., no. 3, p. 7. ㅇ, $\delta$.

Nematus marginifer Strand, 1905. Second Norw. Arctic Exped. "Fram" Rpt., no. 3, p. 8. ठ.

Amauronematus cogitatus MacGillivray, 1919. Rpt. Canad. Arctic Exped. 1913-1918, v. 3G, p. 15G.

Taxonomy: Benson, 1962. Brit. Mus. (Nat. Hist.) Ent., Bul. 12: 400. -Vikberg, 1970. Ann.

Ent. Fenn. 36: 84-91 (description, distribution, separation from related species).

tillbergi Malaise. N. W. T., Alaska; aretic Europe and Siberia. Host: Salix. Amauronematus tillbergi Malaise, 1920. Ent. Tidskr. 40: 125. . Amauronematus rex Benson, 1948. Ent. Monthly Mag. 84: 32. ๆ.

Taxonomy: Lindqvist, 1972. Notulae Ent. 52: 71.

trifasciatus (MacGillivray). N. W. T.

Pontania trifasciata MacGillivray, 1919. Rpt. Canad. Arctic Exped. 1913-1918, v. 3G, p. 11G. ?.

variator (Ruthe). Man., N. W. T., Yukon, Alaska; Eurasia. Host: Salix.

Nematus variator Ruthe, 1859. Stettin Ent. Ztg. 20: 308. \&.

Taxonomy: Benson, 1962. Brit. Mus. (Nat. Hst.) Ent., Bul. 12: 398-399.

venerandus MacGillivray. Maine.

Amauronematus venerandus MacGillivray, 1921. N. Y. Ent. Soc., Jour. 29: 30. ठ.

ventosus MacGillivray. Alaska.

Amauronematus ventosus MacGillivray, 1923. N. Y. Ent. Soc., Jour. 31: 169..

verbosus MacGillivray. Maine.

Amauronematus verbosus MacGillivray, 1921. N. Y. Ent. Soc., Jour. 29: 29..

vicinalis (Cresson). Calif.

Nematus vicinalis Cresson, 1880. Amer. Ent. Soc., Trans. 8: 4. \&.

viduatus (Zetterstedt). Ont., Sask.; Europe.

Tenthredo viduata Zetterstedt, 1838. Ins. Lap., v. 1, p. 351. .

Amauronematus viduatoides Lindqvist, 1959. Notulae Ent. 39: 127.

Taxonomy: Benson, 1962. Brit. Mus. (Nat. Hist.) Ent., Bul. 12: 402.

whitneyi Rohwer. Alaska.

Amauronematus whitneyi Rohwer, 1920. U. S. Natl. Mus., Proc. 57: 216. \&.

xanthus Rohwer. Nebr.

Amauronematus xanthus Rohwer, 1909. Canad. Ent. 41: 18. ?.

\section{Genus DECANEMATUS Malaise}

Decanematus Malaise, 1931. Arkiv for Zool. 23A: 31.

Type-species: Decanematus longiserra Malaise. Orig. desig.

A small genus found in northern Canada and northern Europe.

Revision: Wong, 1968. Canad. Ent. 100: 84-86. 
dulichus Wong. N. W. T. (Reindeer Depot, MacKenzie Delta).

Decanematus dulichus Wong, 1968. Canad. Ent. 100: 84..

\section{TRIBE PSEUDODINEURINI}

\section{Genus PSEUDODINEURA Konow}

Dolerus subg. Pelmatopus Hartig, 1837. Fam. Blattwespen und Holzwespen, nebst

Einleitung Naturgesch. Hym., p. 244. Preocc. by Fischer de Waldheim, 1824.

Type-species: Dolemis (Pelmatopus) minutus Hartig. Monotypic.

Pseudodineura Konow, 1885. Wien. Ent. Ztg. 4: 297.

Type-species: Tenthredo (Allantus) parvula Klug. Desig. by Rohwer, 1911.

Phyllopais Hering, 1934. Internatl. Ent. Ztschr. 28: 353. N. name for Pelmatopus Hartig.

Several unidentified species are known from western United States.

parva (Norton). Maine to Pa. w. to Ill. Ecology: Leafminer. Host: Hepatica.

Dineura parvus Norton, 1867. Amer. Ent. Soc., Trans. 1: 241. ठ.

\section{Genus KERITA Ross}

Kerita Ross, 1937. Ill. Biol. Monog. 15 (2): 80.

Type-species: Kerita fidala Ross. Orig. desig.

An unidentified species is also known from the western United States.

fidala Ross. Ill. Ecology: A leafminer. Host: Mertensia.

Kerita fidala Ross, 1937. Ill. Biol. Monog. 15 (2): 80 . ९.

\section{TRIBE PRISTOLINI}

Revision: Wong, 1968. Canad. Ent. 100: 1049-1057.

\section{Genus PRISTOLA Ross}

Pristola Ross, 1945. Pan-Pacific Ent. 21: 153.

Type-species: Pristola macnabi Ross. Orig. desig.

clarki Wong. Colo. (Echo Lake, Mt. Evans, 10,600 ft.).

Pristola clarki Wong, 1968. Canad. Ent. 100: 1050. $\uparrow, ~ \delta$.

macnabi Ross. Newfoundland, N. H., Man., Alta., B. C., Idaho, Oreg. Ecology: Larva lives in berries. Host: Vaccinium membranaceum.

Pristola macnabi Ross, 1945. Pan-Pacific Ent. 21: 154.,$\delta$.

\section{Genus MELASTOLA Wong}

Melastola Wong, 1968. Canad. Ent. 100: 1053.

Type-species: Gymnonychus resinicolor Marlatt. Orig. desig.

ferruginosa Wong. Alaska, B. C., Wash.

Melastola ferruginosa Wong, 1968. Canad. Ent. 100: 1054. ‡, ठ.

resinicolor (Marlatt). Alaska.

Gymnonychus resinicolor Marlatt, 1896. U. S. Dept. Agr., Div. Ent. Tech. Ser. 3: 125. .

Pachynematus sahlbergi Konow, 1908. Ztschr. System. Hym. Dipt. 8: 83. §.

\section{UNPLACED TAXa OF NEMATINAE}

The following species are of questionable generic assignment due to inadequate descriptions and inaccessibility, loss, or poor condition of type material. Three species described by Cameron from northern Mexico are included; though not strictly within the scope of this Catalog, they undoubtedly represent southern extensions of northern species.

Hoplocampa? atriceps Kirby, 1882. List Hym. Brit. Mus., v. 1, p. 168. Ga.

Nematus calais Kirby, 1882. List Hym. Brit. Mus., v. 1, p. 144. 9 . Arctic America, MacKenzie River.

Nematus castaneus Kirby, 1882. List Hym. Brit. Mus., v. 1, p. 147. ?. Hudson Bay, Canada, St. Martin's Falls, Albany River. 
Nematus crassus Eschscholtz, 1822. Entomographien, p. 213. Isle of Unalaska, Alaska. Preoce. by Fallen, 1808; see obtusus Kirby.

Nematus extraneus Kirby, 1882. List Hym. Brit. Mus., v. 1, p. 142. + Hudson Bay, Canada, St. Martin's Falls, Albany River.

Nematus fallax Norton, 1867. Amer. Ent. Soc., Trans. 1: 198. ¿े. Labrador. Preoce. by

Lepeletier, 1823; see nortonii Dalla Torre.

Nematus hudsonicus Norton, 1867. Amer. Ent. Soc., Trans. 1: 207. ९. Fort Good Hope, MacKenzie River, N. W. T., Canada.

Nematus inquilinus Walsh, 1866. Ent. Soc. Phila., Proc. 6: 260. ค, ð. Rock Island, Ill. Ecology: "Bred from Cecidomyidous gall S. rhodoides Walsh."

Nematus lateralis Norton, 1867. Amer. Ent. Soc., Trans. 1: 211. \&. Maine, N. Y.

Nematus longicornis Eschscholtz, 1822. Entomographien, p. 98. Unalaska Isle, Alaska.

Nematus longicornis Say, 1835. Boston Jour. Nat. Hist. 1: 219. Iowa. Preocc. by Eschscholtz, 1822; see longulicornis Norton.

Nematus longulicornis Norton, 1867. Amer. Ent. Soc., Trans. 1: 214. N. name for longicornis Say.

Nematus malacus Norton, 1867. Amer. Ent. Soc., Trans. 1: 196. \&. Labrador.

Euura mexicana Cameron, 1884. Ent. Soc. London, Trans., p. 482. N. Sonora, Mexico.

Nematus mexicanus Cameron, 1884. Ent. Soc. London, Trans., p. 481. N. Sonora, Mexico.

Nematus monela Norton, 1867. Amer. Ent. Soc., Trans. 1: 198. ठ. Labrador.

Tenthredo (Nematus) monochroma Harris, 1835. In Hitchcock, Rpt. Geol. Mineral. Bot. Zool. Mass., p. 583. Nom. nud.

Nematus monochroma Norton, 1861. Boston Soc. Nat. Hist., Proc. 8: 161. ?. Mass.

Hemichroa nigricans Cameron, 1884. Ent. Soc. London, Trans., p. 482. N. Sonora, Mexico.

Nematus nigritus Norton, 1861. Boston Soc. Nat. Hist., Proc. 8: 159. ठ. Conn.

Nematus nortonii Dalla Torre, 1894. Cat. Hym., v. 1, p. 246. N. name for fallax Norton.

Nematus obtusus Kirby, 1882. List Hym. Brit. Mus., v. 1, p. 148. N. name for crassus

Eschscholtz.

Nematus proximatus Norton, 1861. Boston Soc. Nat. Hist., Proc. 8: 160. ?. Maine, Mass., Conn.

Nematus quercicola Walsh, 1866. Ent. Soc. Phila., Proc. 6: 260. Nom. nud.

Nematus rufo-fasciatus Norton, 1867. Amer. Ent. Soc., Trans. 1: 205. \&. MacKenzie River, N.

W. T., Canada.

Pontania salicum Cockerell, 1905. In Aldrich, Smiths. Misc. Coll., v. 46, p. 163. Nom. nud.

Nematus satkatchewan Norton, 1867. Amer. Ent. Soc., Trans. 1: 200. ^. "Lake

Sathkatchewan."

Nematus sumptus Norton, 1867. Amer. Ent. Soc., Trans. 1: 207. ठ. Maine.

Nematus vertebratus Say, 1836. Boston Jour. Nat. Hist. 1: 218. ๆ. Ind.

\section{SUBFAMILY HETERARTHRINAE}

Most of these sawflies are small black insects, among the smallest of the Tenthredinidae. Larvae of the Caliroini feed externally, skeletonizing the foliage of the host, and larvae of the Heterarthrini and Fenusini are all leafminers.

Revision: Smith, 1971. U. S. Dept. Agr., Tech. Bul. 1420, 84 pp. (adults and larvae of Nearctic species). - Smith, 1973. Ent. Soc. Wash., Proc. 75: 337-345 (Neotropical species).

Taxonomy: Smith, 1967. Ent. Soc. Wash., Proc. 69: 277-284 (review of subfamily in N. Amer.).

\section{TRIBE CALIROINI}

\section{Genus ENDELOMYIA Ashmead}

Endelomyia Ashmead, 1898. Canad. Ent. 30: 256.

Type-species: Selandria rosae Harris. Orig. desig.

aethiops (Fabricius). Que., Conn. to Va. w. to B. C., Oreg.; Europe. Ecology: Widespread; a common pest of cultivated roses. Host: Rosa. Rose-slug.

Tenthredo aethiops Fabricius, 1781. Species Insectorum, v. 1, p. 416.

Tenthredo (Selandria) atratula Dahlbom, 1835. Conspectus Tenthred., Sircid., Oryssin.

Scand., p. 10.

Selandria rosae Harris, 1841. Rpt. Ins. Mass. Injurious to Veg., p. 380. 
Eriocampa Livonensis Gimmerthal, 1844. Stettin Ent. Ztg. 5: 38. ค. Eriocampa nitida Tischbein, 1846. Stettin Ent. Ztg. 7: 113.

Tenthredo (Selandria) dolosa Eversmann, 1847. Soc. Nat. Moscou, Bul. 20: 33..

Selandria sorror Vollenhoven, 1869. Tijdschr. v. Ent. 12: 123.

Eriocampa testaceipes Cameron, 1874. Ent. Monthly Mag. 11: 128. ठ.

Poecilosoma nigricolle Cameron, 1882. Monog. Brit. Phytophagous Hym., v. 1, p. 218.

Biology: Riley, 1892. U. S. Dept. Agr., Insect Life 5: 6-11. -Chittenden, 1908. U. S. Dept. Agr., Cir. 105, 12 pp. - Middleton, 1922. U. S. Dept. Agr., Farmers' Bul. 1252, 14 pp.

-Miles, 1935. Ann. Appl. Biol. 22: 116-133.

\section{Genus CALIROA Costa}

Caliroa Costa, 1859. Fauna del Regno di Napoli, Imen., pt. 3, p. 59.

Type-species: Caliroa sebetia Costa. Monotypic.

Eriocampoides Konow, 1890. Deut. Ent. Ztschr., p. 239.

Type-species: Tenthredo limacina Retzius. Desig. by MacGillivray, 1909.

Periclistoptera Ashmead, 1898. Canad. Ent. 30: 255.

Type-species: Monostegia alba Norton. Orig. desig.

Larvae of this genus are sluglike in appearance and feed on the underside of the foliage of the host. Host records not listed below are Acer, Ceanothus, and Cotoneaster, all from larvae that cannot be identified. Larvae have not been associated with adults for many species and are all very similar; therefore, adults are needed in most cases for species determination.

annulipes (Klug). Ont.; Europe. Host: Betzla papyrifera.

Tenthredo (Allantus) annulipes Klug, 1814. Mag. Gesell. Naturf. Freunde Berlin 8: 70.

cerasi (Linnaeus). Que., Ont. to Fla. w. to B. C., Wash., Oreg., Calif., N. Mex.; Eurasia; Africa; Argentina, Chile, Uruguay; Australia, Tasmania, New Zealand; China. Ecology:

Widespread; most commonly a pest of pear trees. Probably native to Europe and introduced to other parts of the world, including N. Amer., by commerce. Host: Pyrus, Prinus, Crataegus, Sorbus, and probably many other Rosaceae. Pear-slug.

Tenthredo cerasi Linnaeus, 1758. Syst. Nat., Ed. 10, p. 557.

Tenthredo limacina Retzius, 1783. Genera et Species Insectorum, p. 73.

Tenthredo cerasi Peck, 1799. Mass. Agr. Rpt., p. 9.

Tenthredo (Allantus) adumbrata Klug, 1814. Mag. Gesell. Naturf. Freunde Berlin 8: 64.. Caliroa laudata MacGillivray, 1909. Canad. Ent. 41: 356. ․

Caliroa lacinata MacGillivray, 1909. Canad. Ent. 41: 357. ९.

Biology: Peck, 1799. Mass. Agr. Rpt., p. 9. - Harris, 1841. Rpt. Ins. Mass. Injurious to Veg., p. 383. - Winchell, 1865. Boston Soc. Nat. Hist., Proc. 9: 321-325. -Riley, 1870. Amer. Ent. and Bot. 2: 296. - Marlatt, 1897. U. S. Dept. Agr., Cir. 26 (ser. 2), 7 pp. - Webster, 1912. N. Y. Ent. Soc., Jour. 20: 125-130 (number of moults). -Webster, 1912. Iowa Agr. Expt. Sta., Bul. 130: 167-193. - Wilson, 1913. Oreg. Agr. Expt. Sta., Rpt. for 1911-12, pp. 217.

-Ewing, 1917. Ent. Soc. Amer., Ann. 10: 330-336 (parthenogenesis). - Britton, 1921. Conn.

(State) Agr. Expt. Sta., Bul. 226: 199-201. -Miles, 1935. Ann. Appl. Biol. 22: 116-133.

-Carl, 1972. Ztschr. Angew. Ent. 71: 58-83.

distincta Smith. B. C., Oreg., Nev., Calif.

Caliroa distincta Smith, 1971. U. S. Dept. Agr., Tech. Bul. 1420, p. 17. .

fasciata (Norton). Ont., Maine to Va. w. to Iowa, Ill. Host: Quercus velutina, Q. palustris, Q. rubra, and probably other oaks.

Selandria fasciata Norton, 1864. Ent. Soc. Phila., Proc. 3: 9..+

floridana Smith. Fla.

Caliroa floridana Smith, 1971. U. S. Dept. Agr., Tech. Bul. 1420, p. 19..

hyalina Smith. Oreg. Ecology: Adults collected from cherry.

Caliroa hyalina Smith, 1971. U. S. Dept. Agr. Tech. Bul. 1420, p. 19. १, ठै.

labrata MacGillivray. Alta., B. C., Oreg., Nev., Calif. Host: Salix.

Caliroa labrata MacGillivray, 1909. Canad. Ent. 41: 360. ठ์.

liturata MacGillivray. Conn. to Fla. w. to Mont., Colo., La. Host: Prunus, peach, and plum. Caliroa liturata MacGillivray, 1909. Canad. Ent. 41: 349. . 
Caliroa lineata MacGillivray, 1909. Canad. Ent. 41: 350..

Caliroa loricata MacGillivray, 1909. Canad. Ent. 41: 351. ․

Caliroa (Eriocampoides) amygdalina Rohwer, 1911. Ent. News 22: 263. ๆ, ठ.

Biology: Cushman, 1911. U. S. Dept. Agr., Bur. Ent. Bul. 97: 91-102.

lobata MacGillivray. Vt. to Va. w. to Iowa, Tex. Host: Quercus palustris, Q. velutina, and probably other oaks.

Caliroa lobata MacGillivray, 1909. Canad. Ent. 41: 355. \&.

lorata MacGillivray. Maine to Ala. w. to Wis. Host: Castanea dentata.

Caliroa lorata MacGillivray, 1909. Canad. Ent. 41: 355. \&.

Eriocampoides castaneae Rohwer, 1917. U. S. Natl. Mus., Proc. 53: 152. ${ }^{\circ}$

lunata MacGillivray. Newfoundland to Va. w. to Mich., Ill., Tex.

Caliroa lunata MacGillivray, 1909. Canad. Ent. 41: 353. .

Caliroa lata MacGillivray, 1909. Canad. Ent. 41: 361. $९$.

nyssae Smith. Pa. to Ga. w. to Miss. Host: Nyssa sylvatica.

Caliroa nyssae Smith, 1971. U. S. Dept. Agr., Tech. Bul. 1420, p. 25. \&, ১.

obsoleta (Norton). Ont., Mass. to Ga. w. to Minn., Iowa, Ill. Host: Quercus alba, Q. stellata, Q. prinus, and probably other oaks.

Selandria obsoleta Norton, 1867. Amer. Ent. Soc., Trans. 1: 254. 9.

Selandria quercus alba Norton, 1867. Amer. Ent. Soc., Trans. 1: 258. + ,.

Selandria quercus-alba Cresson, 1880. Amer. Ent. Soc., Trans. 8: 60. Emend.

Eriocampoides quercus Konow, 1905. In Wytsman, Gen. Ins., v. 29, p. 74. Emend.

petiolata Smith. Pa., Md., Va. Host: Quercus palustris.

Caliroa petiolata Smith, 1971. U. S. Dept. Agr., Tech. Bul. 1420, p. 28. ๆ, ð.

quercuscoccineae (Dyar). Maine to N. C. w. to Minn., Ill., Mo., La. Host: Quercus coccinea, Q. velutina, $Q$. palustris, $Q$. alba, and probably other oaks.

Monostegia quercus-coccineae Dyar, 1894. Canad. Ent. 26: 42. §, larva.

\section{TRIBE HETERARTHRINI}

\section{Genus HETERARTHRUS Stephens}

Phyllotoma Fallen, 1829. Monog. Tenthred. Suec., p. 25. Preocc. by Leach, 1819.

Type-species: Phyllotoma vagans Fallen. Desig. by Rohwer, 1911.

Heterarthrus Stephens, 1835. Illus. Brit. Ent., v. 7, p. 94.

Type-species: Tenthredo (Emphytus) ochropoda Klug. Monotypic.

Decatria Stephens, 1835. Illus. Brit. Ent., v. 7, p. 94.

Type-species: Decatria fuscipennis Stephens. Monotypic.

Druida Newman, 1838. Ent. Mag. 5: 484.

Type-species: Druida parviceps Newman. Monotypic.

Heterarthus Cameron, 1882. Monog. Brit. Phytophagous Hym., v. 1, p. 282. Emend.

Phlebatrophia MacGillivray, 1909. Canad. Ent. 41: 345.

Type-species: Phlebatrophia mathesoni MacGillivray. Monotypic.

This genus is Palaearctic with one introduced species in North America. All larvae are leafminers.

nemoratus (Fallen). Newfoundland, N. S., N. B., Que., Maine, N. H., Mass., N. Y., Ont.; Europe.

Ecology: A leafminer. Introduced, first found at Pictou, N.S. in 1908. Host: Betula.

Hylotoma nemorata Fallen, 1808. Svenska Vetensk. Akad., Handl. 29: 47.

Phyllotoma nemoralis Fallen, 1829. Monog. Tenthred. Suec., p. 35.

Fenusa parviceps Newman 1837. Ent. Mag. 4: 261.

Phyllotoma tenella Zaddach, 1859. Programm Friedr. Col. Konigsberg, p. 28..

Phlebatrophia mathesoni MacGillivray, 1909. Canad. Ent. 41: 345. ?.

Biology: Pierson, 1929. Jour. Econ. Ent. 22: 588-594. -Pierson, Taylor, and Wilkins, 1930.

Maine Forest Service, Cir. 1, 8 pp. - Glasgow, 1932. Jour. Econ. Ent. 25: 693-695.

-Pierson and Brower, 1936. Maine Forest Service and Hardwood Assoc., Bul. 11, 37 pp.

-Gobeil, 1937. Prov. de Quebec Min. des Terre et Forets, Bul. 1, 7 pp. - Lindquist, 1959.

Canad. Ent. 91: 625-627. 


\section{TRIBE FENUSINI}

\section{Genus METALLUS Forbes}

Metallus Forbes, 1885. State Ent. Ill. Rpt. 14: 87.

Type-species: Metallus rubi Forbes. Monotypic.

Entodecta Konow, 1886. Wien. Ent. Ztg. 5: 184.

Type-species: Tenthredo (Allantus) pumila Klug. Desig. by MacGillivray, 1909.

Polybates MacGillivray, 1909. Ent. Soc. Amer., Ann. 2: 264.

Type-species: Polybates slossonae MacGillivray. Monotypic.

bensoni Smith. N. Y., B. C.

Metallus bensoni Smith, 1971. U. S. Dept. Agr., Tech. Bul. 1420, p. 34..+

capitalis (Norton). Newfoundland to N. Y. w. to Ill.; Alaska, B. C., Oreg. Ecology: A leafminer. Host: Rubus.

Selandria capitalis Norton, 1867. Amer. Ent. Soc., Trans. 1: 247..

Entodecta humilis Konow, 1908. Ztschr. System. Hym. Dipt. 8: 84..

Polybates slossonae MacGillivray, 1909. Ent. Soc. Amer., Ann. 2: 265..

Polybates secundus Rohwer, 1910. U. S. Natl. Mus., Proc. 38: 202..

rohweri MacGillivray. N. S., Maine to Fla. w. to Ont., Wis., Ill., Mo. Ecology: A leafminer.

Host: Rubus.

Metallus mibi Forbes, 1885. State Ent. Ill. Rpt. 14: 87. §. Preoce. by Boie, 1848.

Metallus rohweri MacGillivray, 1909. Ent. Soc. Amer., Ann. 2: 267. $ๆ$.

Metallus bethunei MacGillivray, 1914. Canad. Ent. 46: 366. $\$$, ঠ.

Biology: Houghton, 1908. Ent. News 19: 212-216 (capitalis, not Norton). - Houghton, 1910.

Del. Col. Agr. Expt. Sta., Bul. 87: 3-15 (capitalis, not Norton). -Daniel, 1928. N. Y. State

Agr. Expt. Sta., Tech. Bul. 133: 3-38.

\section{Genus MESSA Leach}

Messa Leach, 1817. Zool. Misc., v. 3, p. 126.

Type-species: Tenthredo hortulana Klug. Monotypic.

Fenusella Enslin, 1914. Deut. Ent. Ztschr., Beih., p. 270.

Type-species: Fenusa Wustneii Konow. Orig. desig.

Melanobates MacGillivray, 1916. Conn. State Geol. and Nat. Hist. Survey, Bul. 22: 158.

Type-species: Parabates leucostomus Rohwer. Monotypic.

hortulana (Klug). Mass.; Europe. Ecology: A leafminer. Introduced (?). Host: Populus.

Tenthredo (Emphytus) hortulana Klug, 1814. Mag. Gesell. Naturf. Freunde Berlin 8: 276. ‥

Phaenusa doederleinii Destefani, 1883. Nat. Sicil. 3: 12. $\&$, $\delta$.

Phaenusa ticinensis Magretti, 1886. Soc. Ent. Ital., Bul. 18: 25..+

leucostoma (Rohwer). N. B., Minn., Iowa, Colo., Alta., Wash., Oreg., Calif. Ecology: Adults collected from Populus.

Parabates leucostoma Rohwer, 1910. U. S. Natl. Mus., Proc. 38: 202. 9.

Blennocampa amara MacGillivray, 1923. Canad. Ent. 55: 161. \&.

nana (Klug). Maine, Mass., N. Y., Ont.; Europe. Ecology: A leafminer. Introduced, first recorded from Maine in 1967. Host: Betula.

Tenthredo (Allantus) nana Klug, 1814. Mag. Gesell. Naturf. Freunde Berlin 8: 72.

Tenthredo intercus Zetterstedt, 1838. Ins. Lapp., v. 1, p. 340.

Fenusa quercus Cameron, 1885. Monog. Brit. Phytophagous Hym., v. 2, p. 222.

Biology: Lindquist and Thomson, 1970. Canad. Ent. 102: 108-111.

populifoliella (Townsend). N. B. to Conn. w. to Man., S. Dak., Colo., N. Mex., Ariz., Calif.

Ecology: A leafminer. Host: Populus.

Blennocam pa populifoliella Townsend, 1893. Canad. Ent. 25: 304.

Scolioneura populi Marlatt, 1895. Ent. Soc. Wash., Proc. 3: 235 . १, ठ.

Scolioneura luteopicta Rohwer, 1911. U. S. Natl. Mus., Proc. 3: 235. ‡, ð. 
Biology: Townsend, 1892. U. S. Dept. Agr., Insect Life 4: 26-27 (Cottonwood leafminer). -Townsend, 1892. Zoe 3: 234-236 (Tineidae ? larvae). - Underwood and Titus, 1968.

Canad. Ent. 100: 407-411. -Brown and Eads, 1969. Jour. Econ. Ent. 62: 672-674. wuestneii (Konow). Que. to Alaska s. to Colo., Calif.; Europe. Ecology: A leafminer. Host: Salix.

Fenusa wustneii Konow, 1894. Wien. Ent. Ztg. 13: 91. ๆ, ठั.

Fenusa alaskana Kincaid, 1900. Wash. Acad. Sci., Proc. 2: 345.

\section{Genus SETABARA Ross}

Parabates MacGillivray, 1909. Ent. Soc. Amer., Ann. 2: 262. Preocc.

Type-species: Parabates histrionicus MacGillivray. Orig. desig.

Setabara Ross, 1951. In Muesebeck, et al., U. S. Dept. Agr., Agr. Monog. 2: 31. N. name.

A monotypic genus found only in western North America.

histrionica (MacGillivray). Colo., Idaho, Nev., Wash., Oreg., Calif. Ecology: Adults collected from Prunus.

Parabates histrionicus MacGillivray, 1909. Ent. Soc. Amer., Ann. 2: 263. १.

\section{Genus BIDIGITUS Smith}

Bidigitus Smith, 1967. Ent. Soc. Wash., Proc. 69: 280.

Type-species: Profenusa platani Burks. Orig. desig.

platani (Burks). Calif. Ecology: A leafminer. Host: Platanus racemosa.

Profenusa platanae(!) Burks, 1957. Ent. News 68: 207. §, ठ์.

Biology: Brown and Eads, 1965. Calif. Agr. Expt. Sta., Bul. 818: 14, 22-32.

\section{Genus PROFENUSA MacGillivray}

Profenusa MacGillivray, 1914. Canad. Ent. 46: 364.

Type-species: Profenusa collaris MacGillivray. Monotypic.

Gunnea Malaise, 1964. Ent. Tidskr. 85: 33.

Type-species: Tenthredo pygmaea Klug. Orig. desig.

alumna (MacGillivray). Maine to Va. w. to Wis., Ill. Ecology: A leafminer. Host: Quercus rubra and probably other oaks. References to alumna as a leafminer of Betula are actually thom somi (Konow).

Messa alumna MacGillivray, 1923. Ill. Univ. Bul. 20(50): 23. \&.

Messa a mica MacGillivray, 1923. Ill. Univ. Bul. 20(50): 23. ठ.

Messa appota MacGillivray, 1923. Ill. Univ. Bul. 20(50): 24. ঠे.

Profenusa mainensis Smith, 1966. Ent. Soc. Amer., Ann. 59: 720. \&, larva.

canadensis (Marlatt). Que., Ont. to D. C. w. to Iowa, Mo., Ark. Ecology: A leafminer. Host: Crataegus, to a lesser extent Prunus.

Scolioneura canadensis Marlatt, 1895. Ent. Soc. Wash., Proc. 3: 235..

Profenusa collaris MacGillivray, 1914. Canad. Ent. 46: 364 . ๆ, ठ.

Biology: Parrott and Fulton, 1915. N. Y. Agr. Expt. Sta., Bul. 411: 551-580. - Parrott and Fulton, 1915. Jour. Agr. Res. 5: 519-528. - Hamilton, 1943. N. Y. Agr. Expt. Sta., Bul. 703: 59-61. - Hamilton, 1950. Jour. Econ. Ent. 43: 694-696.

inspirata (MacGillivray). Oreg., Nev., Calif. Ecology: A leafminer. Host: Quercus.

Parabates inspiratus MacGillivray, 1909. Ent. Soc. Amer., Ann. 2: 264..

lucifex (Ross). Maine, Ont., N. Y., Ill. Ecology: Leafminer. Host: Quercus alba, Q. macrocarpa.

Fenusa lucifex Ross, 1936. Ill. State Acad. Sci., Trans. 29: 266..

Biology: Lindquist and Jackson, 1965. Canad. Dept. Forestry, Bimonthly Prog. Rpt. 21(4): 1.

thomsoni (Konow). Que., Maine, Vt., Conn., Ont., Man.; Ecology: A leafminer. Introduced. Host: Betula.

Fenusa thomsoni Konow, 1886. Wien. Ent. Ztg. 5: 270. ․ 
Biology: Lindquist, 1959. Canad. Ent. 91: 625-627 (alumna, not MacGillivray). - Watson, 1959. Canad. Ent. 91: 618-625 (alumna not MacGillivray). - Martin, 1960. Canad. Ent. 92 : 376-384.

\section{Genus NEFUSA Ross}

Nefusa Ross, 1951. In Muesebeck et al., U. S. Dept. Agr., Agr. Monog. 2, p. 31.

Type-species: Nefusa anita MacGillivray. Orig. desig.

The single species in this genus is known only from North America.

ambigua (Norton). Que., Maine to Tenn. w. to Wis. Ecology: A leafminer. Host: Viola.

Fenusa ambiguus Norton, 1867. Amer. Ent. Soc., Trans. 1: 225. đ.

Messa anita MacGillivray, 1923. Ill. Univ. Bul. 20(50): 23. ․

Biology: Shaw, 1940. Jour. Econ. Ent. 33: 951 (Fenusa sp.).

\section{Genus PROLATUS Smith}

Prolatus Smith, 1967. Ent. Soc. Wash., Proc. 69: 282.

Type-species: Prolatus artus Smith. Orig. desig.

A monotypic genus known only from western North America.

artus Smith. Oreg.

Prolatus artus Smith, 1967. Ent. Soc. Wash., Proc. 69: 283. , ठ (?).

\section{Genus FENUSA Leach}

Fenusa Leach, 1817. Zool. Misc., v. 3, p. 126.

Type-species: Tenthredo (Emphytus) pumila Klug. Monotypic.

Kaliosysphinga Tischbein, 1846. Stettin Ent. Ztg. 7: 79.

Type-species: Kaliosysphinga dohrnii Tischbein. Monotypic.

Aphadnurus Costa, 1859. Fauna del Regno di Napoli, Imen., pt. 3, p. 40.

Type-species: Aphadnurus tantillus Costa. Monotypic.

Caliosysphinga Konow, 1905. In Wytsmann, Gen. Ins., v. 29, p. 89. Emend.

Kaliofenusa Viereck, 1910. N. J. State Mus., Ann. Rpt. 1909, p. 591.

Type-species: Fenusa ulmi Sundevall. Monotypic.

A genus of several species most of which are holarctic though two of them were probably introduced into this continent.

dohrnii (Tischbein). Newfoundland to Pa. w. to B. C., Oreg., Utah., N. Mex.; Europe; Japan; S. Africa. Ecology: A widespread leafminer. Host: Alnus. European alder leafminer.

Kaliosysphinga dohrmii Tischbein, 1846. Stettin Ent. Ztg. 7: 80.

Fenusa curtis Norton, 1861. Ent. Soc. Phila., Proc. 1: 199. $q$.

Phaenusa melanopoda Cameron, 1876. Glasgow Nat. Hist. Soc., Proc. 3: 6.

Fenusa nigricans Thomson, 1870. Opusc. Ent., 2nd Fasc., p. 271.

Fenella westwoodi Cameron, 1882. Monog. Brit. Phytophagous Hym., v. 1, p. 289.

Biology: Slingerland, 1905. N. Y. (Cornell) Agr. Expt. Sta. Bul. 233: 49-62. -Frankenhuyzen, 1970. Ent. Ber. 30: 49-52 (in Netherlands).

pusilla (Lepeletier). Newfoundland to Md. w. to Ont., Minn., Iowa; Wash., Oreg.; Europe. Ecology: A leafminer. Introduced, first reported in Conn. in 1925. Host: Betula. Birch leafminer.

Tenthredo (Emphytus) pumila Klug, 1814. Mag. Gesell. Naturf. Freunde Berlin 8: 277. Preocc.

Dolerus (Fenusa?) pusillus Lepeletier, 1823. Monog. Tenthred., p. 120.

Tenthredo pygmaea Zetterstedt, 1838. Ins. Lapp., v. 1, p. 340. $९$, ठै.

Aphadnurus tantillus Costa, 1859. Fauna del Regno di Napoli, Imen., pt. 3, p. 41. $\delta$.

Fenutsa fuliginosa Healy, 1869. Entomologist 4: 225-227.

Fenusa minima Brischke, 1883. Schrift. Naturf. Gesell. Danzig 4: 264. ๆ. 
Biology: Britton, 1925. Conn. (State) Agr. Expt. Sta. Bul. 265: 340. - Friend, 1931. Jour.

Econ. Ent. 24: 171-177. - Friend, 1933. Conn. (State) Agr. Expt. Sta. Bul. 348: 291-364.

-Cheng and LeRoux, 1965. Ent. Soc. Quebec, Ann. 10: 173-188. - Schread, 1971. Conn.

(State) Agr. Expt. Sta. Bul. 693: 5-19. - Cheng and LeRoux, 1970. Canad. Ent. 102:

995-1002 (factors in survival of immature stages).

ulmi Sundevall. Que., Ont., Mass., N. Y., Mich.; Europe. Ecology: A leafminer. Introduced.

Host: Ulmus. Elm leafminer.

Fenusa ulmi Sundevall, 1844. Skand. Naturf. Forhandl., p. 249.

Fenusa intermedia Thomson, 1871. Hym. Scand., v. 1, p. 186. 9.

Messa alsia MacGillivray, 1923. Ill. Univ. Bul. 20(50): 22. ․

Biology: Felt, 1898. N. Y. State Mus., Bul. 5(23): 237 (an elm leafminer). -Slingerland, 1905.

N. Y. (Cornell) Agr. Expt. Sta. Bul. 233: 49-62.

\section{Genus FENELLA Westwood}

Fenella Westwood, 1840. Introduct. Modern Class. Ins., v. II, p. 54.

Type-species: Fenella nigrita Westwood. Monotypic.

Melinia Costa, 1859. Fauna del Regno di Napoli, Imen., pt. 3, p. 41.

Type-species: Melinia minutissima Costa. Desig. by Rohwer, 1911.

Paraphyllotoma Forsius, 1930. Notulae Ent. 10: 103.

Type-species: Paraphyllotoma judaica Forsius Orig. desig.

Taxonomy: Benson, 1953. Roy. Ent. Soc. London, Proc., Ser. B: Taxonomy 22: 136-138 (key to

European species).

nigrita Westwood. Conn., Ont., Mich.; Europe. Ecology: A leafminer. Introduced (?). Host:

Potentilla, Agrimonia. Agrimonia was recorded as a host-plant in Europe.

Fenella nigrita Westwood, 1840. Introduct. Modern Class. Ins., v. II, p. 54.

\section{SUBFAMILY BLENNOCAMPINAE}

A diverse subfamily with various hosts. Most of these sawflies are small to medium, stout insects. Most larvae are external leaf feeders, and adults fall and feign death when disturbed.

Revision: Smith, 1969. U. S. Dept. Agr., Tech. Bul. 1397, 179 pp. (adults and larvae of Nearctic species).

\section{TRIBE LYCAOTINI}

Revision: Smith, 1973. Pan-Pacific Ent. 49: 93-101 (S. Amer.).

Taxonomy: Benson, 1966. Roy. Ent. Soc. London, Proc., Ser. B: Taxonomy 35: 75-77 (key to world genera).

\section{Genus BLENNOGENERIS MacGillivray}

Blennogeneris MacGillivray, 1923. Ill. Univ. Bul. 20(50): 8.

Type-species: Blennocampa typicella MacGillivray. Monotypic.

Lycaotella Ross, 1932. Canad. Ent. 64: 41.

Type-species: Selandria (Hoplocampa) spissipes Cresson. Orig. desig.

coloradensis (Rohwer). Man., Colo., Idaho, Utah, Wash,

Lycaota coloradensis Rohwer, 1911. U. S. Natl. Mus., Proc. 41: 384.

gittinsi Smith. Idaho, Wash.

Blennogeneris gittinsi Smith, 1969. U. S. Dept. Agr. Tech. Bul. 1397, p. 24. ؟.

spissipes (Cresson), Ont., Minn., Colo. w. to B. C., Wash., Oreg., Calif. Ecology: Larva lives in terminal bud gall. Host: Symphoricarpos.

Selandria (Hoplocampa) spissipes Cresson, 1880. Amer. Ent. Soc., Trans. 8: 14. $\$$.

Selandria (Hoplocampa) lenis Cresson, 1880. Amer. Ent. Soc., Trans. 8: 14. ¿.

Lycaota breneri Rohwer, 1908. N. Y. Ent. Soc., Jour. 14: 104. ๆ. N. syn.

Lycaota spissipes brunnents Rohwer, 1911. U. S. Natl. Mus., Proc. 41: 384 ..

Blennocampa typicella MacGillivray, 1923. Ill. Univ. Bul. 20(50): 8. ठ.

Biology: Ross, 1932. Canad. Ent. 64: 42-44. 


\section{Genus LYCAOTA Konow}

Lycaota Konow, 1903. Ztschr. System. Hym. Dipt. 3: 147.

Type-species: Selandria sodalis Cresson. Desig. by Rohwer, 1911.

bouquetensis Smith. S. Calif.

Lycaota bouquetensis Smith, 1969. U. S. Dept. Agr., Tech. Bul. 1397, p. 29.. janetae Smith. Oreg., Calif. Ecology: Adult collected from Symphoricarpos.

Lycaota janetae Smith, 1969. U. S. Dept. Agr., Tech. Bul. 1397, p. 29. ๆ, ठ. sodalis (Cresson). Sask., Colo., Utah w. to B. C., Wash., Oreg.

Selandria sodalis Cresson, 1880. Amer. Ent. Soc., Trans. 8: 14. ๆ.

Lycaota fusca Rohwer, 1908. Canad. Ent. 40: 180. ठ。.

\section{TRIBE TOMOSTETHINI}

\section{Genus TOMOSTETHUS Konow}

Tomostethus Konow, 1886. Wien. Ent. Ztg. 5: 184, 214.

Type-species: Tenthredo nigrita Fabricius. Desig. by Rohwer, 1911.

A small holarctic genus.

multicinctus (Rohwer). Mass., Ont. to N. C. w. to S. Dak., Kans., Okla., Tex.; Oreg., Calif. Host:

Fraxinus americana, $F$. oregona. Brown-headed ash sawfly.

Monophadnus multicinctus Rohwer, 1909. Canad. Ent. 41: 90. ठ.

Biology: Sasscer, 1911. Ent. Soc. Wash., Proc. 13: 107-110. - Langford and McConnell, 1935.

Jour. Econ. Ent. 28: 208-210. - MacNay, 1957. Canad. Ins. Pest Rev. 35: 184. - Armitage, 1950. Calif. Dept. Agr., Bul. 39: 183.

\section{Genus TETHIDA Ross}

Tethida Ross, 1937. Ill. Biol. Monog. 15(2): 96.

Type-species: Tenthredo cordigera Beauvois. Orig. desig.

This genus contains a single North American species.

cordigera (Beauvois). N. B., Que. to Fla. w. to Sask., Mont., S. Dak., Nebr., Kans., Tex. Host:

Fraxinus americana, $F$. nigra, $F$. pennsylvanica. Black-headed ash sawfly.

Tenthredo cordigera Beauvois, 1809. Ins. Afr. Amer., p. 97. $\subsetneq$.

Tenthredo (Selandria) barda Harris, 1835. In Hitchcock, Rpt. Geol. Mineral. Bot. Zool. Mass., p. 583. Nom. nud.

Tenthredo bardus Say, 1836. Boston Jour. Nat. Hist. 1: 218..

Selandria dubia Cresson, 1865. Ent. Soc. Phila., Proc. 4: 244. ․

Biology: Osborne, 1884. Canad. Ent. 16: 148-152. -Osborne, 1884. Ont. Ent. Soc., Ann. Rpt.

15: 32-34. - Packard, 1890. U. S. Ent. Comm. Rpt. 4 (Bul. 7, rev.), p. 544.

\section{TRIBE PHYMATOCERINI}

\section{Genus PHYMATOCERA Dahlbom}

Tenthredo subg. Phymatocera Dahlbom, 1835. Conspectus Tenthred., Siricid., Oryssin. Scand., p. 11.

Type-species: Tenthredo (Allantus) aterrima Klug. Monotypic.

Pectinia Brulle, 1846. In Lepeletier, Hist. Nat. Ins., Hym., p. 664.

Type-species: Tenthredo (Allantus) aterrima Klug. Orig. desig.

Melanoselandria Ashmead, 1900. In Smith, N. J. State Bd. Agr. Ann. Rpt. 27: 606. Nom. nud.

Hypargyricus MacGillivray, 1908. Canad. Ent. 40: 290.

Type-species: Hypargyricus infuscatus MacGillivray. Orig. desig.

Melanoselandria MacGillivray, 1909. Canad. Ent. 41: 404.

Type-species: Melanoselandria zabriskiei MacGillivray. Monotypic.

Species of this holarctic genus are associated with Liliaceae. 
fumipennis (Norton). Que. to Ala. w. to Wis., Ill., Mo. Host: Smilacina.

Selandria fumipennis Norton, 1861. Boston Soc. Nat. Hist., Proc. 8: 222. ㅇ, ठ.

offensa (MacGillivray). Que., Maine to B. C. s. to Ont., Ill., Colo., Utah, Calif. Host: Smilacina.

Paracharactus offensus MacGillivray, 1923. Ill. Univ. Bul. 20(50): 28. ๆ.

racemosae Smith. Que. to N. C. w. to Wis., Ill.; B. C. Ecology: Adults collected from

Smilacina(?), Polygonatum(?).

Phymatocera racemosae Smith, 1969. U. S. Dept. Agr., Tech. Bul. 1397, p. 49. ९, ठ.

similata (MacGillivray). Ont., N. Y. to B. C. s. to Mich., Ill., Iowa, Nebr., Colo., Utah, Calif.

Host: Smilacina.

Rhadinoceraea similata MacGillivray, 1908. Canad. Ent. 40: 290. 9.

Hypargyricus infuscatus MacGillivray, 1908. Canad. Ent. 40: 290. $\%$.

Rhadinoceraea lucida Rohwer, 1912. U. S. Natl. Mus., Proc. 43: 229. ؟.

smilacinae Smith. Que. to Va. w. to Wis., Ill. Ecology: Adults collected from Smilacina and Polygonatum.

Phymatocera smilacinae Smith, 1969. U. S. Dept. Agr., Tech. Bul. 1397, p. 55. ๆ, ơ.

\section{UnPlaced Taxa of Phymatocera Dahlbom}

rusculla (MacGillivray). Oreg. (Marys Peak).

Monophadnus ruscullus MacGillivray, 1923. Psyche 30:80. ठ.

zabriskiei (MacGillivray). No locality.

Melanoselandria zabriskiei MacGillivray, 1909. Canad. Ent. 41: 404.

\section{Genus PARACHARACTUS MacGillivray}

Paracharactus MacGillivray, 1908. Canad. Ent. 40: 292.

Type-species: Paracharactus obscuratus MacGillivray. Orig. desig.

Dicrostema Benson, 1952. Handb. Ident. Brit. Ins., v. 6, pt. 2(b), p. 101.

Type-species: Selandria gracilicomis Zaddach. Orig. desig.

A small holarctic genus. Adults are most commonly collected by sweeping grasses and sedges.

montivagus (Cresson). Mont., Idaho, Wash., Oreg., Nev., Calif.

Selandria montivaga Cresson, 1880. Amer. Ent. Soc., Trans. 8: 13..

Selandria scelesta Cresson, 1880. Amer. Ent. Soc., Trans. 8: 14. ठँ.

niger (Harrington), Que., Maine to Md. w. to Minn., Iowa, Kans. Host: Carex.

Phymatocera nigra Harrington, 1889. Canad. Ent. 21: 96..

Monophadnus distinctus MacGillivray, 1908. Canad. Ent. 40: 291..

Tomostethus nortonii MacGillivray, 1908. Canad. Ent. 40: 291. ๆ.

rudis (Norton). Que., Maine to Ga. w. to Sask., S. Dak., Colo.

Selandria rudis Norton, 1861. Boston Soc. Nat. Hist., Proc. 8: 221..

Selandria mefula Norton, 1861. Boston Soc. Nat. Hist., Proc. 8: 221. ठ.

Paracharactus obscuratus MacGillivray, 1908. Canad. Ent. 40: 293. ๆ.

\section{Genus RHADINOCERAEA Konow}

Species of this holarctic genus are associated with Liliaceae and Iridaceae.

Genus RHADINOCERAEA Subgenus RHADINOCERAEA Konow

Rhadinoceraea Konow, 1886. Wien. Ent. Ztg. 5: 184, 211.

Type-species: Tenthredo (Allantus) micans Klug. Desig. by Rohwer, 1911.

brysonensis Smith. Calif. (Bryson).

Rhadinoceraea (Rhadinoceraea) brysonensis Smith, 1969. U. S. Dept. Agr., Tech. Bul. 1397, p. 67.. .

ctenidium Smith. Calif. (Mt. Pinos, Kern Co., $8900 \mathrm{ft}$. ).

Rhadinoceraea (Rhadinoceraea) ctenidizm Smith, 1969. U. S. Dept. Agr., Tech. Bul. 1397, p. 67 . 9 .

nigra (Rohwer). S. Calif. Host: Calochortus venustus.

Paracharactus niger Rohwer, 1912. U. S. Natl. Mus., Proc. 43: 231. ๆ. 
utahensis Smith. N. Utah.

Rhadinoceraea (Rhadinoceraea) utahensis Smith, 1969. U. S. Dept. Agr., Tech. Bul. 1397,

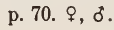

\section{Genus RHADINOCERAEA Subgenus VERATRA Smith}

Rhadinoceraea subg. Veratra Smith, 1969. U. S. Dept. Agr. Tech. Bul. 1397, p. 70.

Type-species: Selandria nubilipennis Norton. Orig. desig.

aldrichi (MacGillivray). Alta., Idaho, B. C., Wash., Oreg., Nev., Calif. Host: Veratrum.

Pareophora aldrichi MacGillivray, 1923. Ill. Univ. Bul. 20(50): 28. $९$, ¿.

insularis (Kincaid). Alaska, B. C., Wash., Oreg., Calif. Host: Veratrum.

Monophadnus insularis Kincaid, 1900. Wash. Acad. Sci., Proc. 2: 346. đ.

jacintensis Smith. S. Calif.

Rhadinoceraea (Veratra) jacintensis Smith, 1969. U. S. Dept. Agr., Tech. Bul. 1397, p. 75. ㅇ, $\delta$.

nubilipennis (Norton). N. B., Que. s. to N. C. Host: Veratrum.

Selandria nubilipennis Norton, 1867. Amer. Ent. Soc., Trans. 1: 252. \&, ठ.

Neopareophora scelesta MacGillivray, 1908. Canad. Ent. 40: 289. ․

Monophadnus planus MacGillivray, 1921. Brooklyn Ent. Soc., Bul. 16: 23. đ. Preocc. by Klug, 1814.

Monophadnus vapularis Benson, 1930. Entomologist 63: 107. N. name for planus MacGillivray.

\section{Genus LAGONIS Ross}

Lagonis Ross, 1937. Ill. Biol. Monog. 15(2): 99.

Type-species: Selandria nevadensis Cresson. Orig. desig.

A small genus known from western North America and east Asia.

nevadensis (Cresson). Alta., Wyo., Utah w. to B. C., Wash., Oreg., Calif. Host: Sambucus. Selandria nevadensis Cresson, 1880. Amer. Ent. Soc., Trans. 8: 13. ․

Paracharactus leucostomus Rohwer, 1912. U. S. Natl. Mus., Proc. 43: 230..+

\section{Genus MONOPHADNUS Hartig}

Tenthredo subg. Monophadnus Hartig, 1837. Fam. Blattwespen und Holzwespen, nebst Einleitung Naturgesch. Hym., p. 271.

Type-species: Tenthredo albipes Gmelin. Desig. by Ashmead, 1898.

Monophadnus subg. Doderia Malaise, 1935. Ent. Tidskr. 56: 167.

Type-species: Tenthredo (Allantus) spinolae Klug. Orig. desig.

aequalis MacGillivray. Ont., Maine to Md. w. to Alta., Colo. Host: Ranunculus.

Monophadnus aequalis MacGillivray, 1908. Canad. Ent. 40: 292. ๆ.

Monophadnus plicatus MacGillivray, 1908. Canad. Ent. 40: 292. , ठ.

Monophadnus transversus MacGillivray, 1908. Canad. Ent. 40: 292. ๆ.

Monophadnus truncatus Rohwer, 1912. U. S. Natl. Mus., Proc. 43: 232 ..

assaracus MacGillivray. Oreg.

Monophadnus assaracus MacGillivray, 1923. Ill. Univ. Bul. 20(50): 26. o.

bakeri Smith. Md., Va., Ill., Mont., Kans.

Monophadnus bakeri Smith, 1969. U. S. Dept. Agr., Tech. Bul. 1397, p. 86. \&.

californicus (Rohwer). Oreg., Calif. Host: Ranunculus.

Neocharactus californicus Rohwer, 1909. Canad. Ent. 41: 89..

Monophadnoides conductus MacGillivray, 1923. Ill. Univ. Bul. 20(50): 24. .

contortus (MacGillivray). Mont., Idaho, B. C., Oreg., Calif.

Monophadnoides contorta MacGillivray, 1923. Psyche 30: 78. ‡.

Monophadnus aeratus MacGillivray, 1923. Psyche 30: 79. ¿.

Aphanisus absitus MacGillivray, 1923. Ill. Univ. Bul. 20(50): 7. ๆ.

Aphanisus occiduus MacGillivray, 1923. Ill. Univ. Bul. 20(50): 7..

lattini Smith. N. H., Mass., Conn., Wis., Man., Minn.

Monophadnus lattini Smith, 1969. U. S. Dept. Agr., Tech. Bul. 1397, p. 91. ‡, ơ. 
pallescens (Gmelin). Newfoundland to N. Y. w. to Mich.; B. C.; Europe. Introduced (?). Host: Ranunculus. The host was recorded in Europe.

Tenthredo albipes Gmelin, 1790. In Linnaeus, Syst. Nat., Ed. 13, p. 2667. Preocc. by Geoffroy, 1785.

Tenthredo pallescens Gmelin, 1790. In Linnaeus, Syst. Nat., Ed. 13, p. 2668.

Selandria tiliae Norton, 1861. Boston Soc. Nat. Hist., Proc. 8: 221. \&.

Monophadnus bipunctatus MacGillivray, 1908. Canad. Ent. 40: 292. ?.

Monophadnus furvus Benson, 1930. Entomologist 63: 107. Unnecessary n. name for bipunctata MacGillivray, but also preocc. by Konow, 1898 .

\section{Genus STETHOMOSTUS Benson}

Stethomostus Benson, 1939. Ent. Monthly Mag. 75: 111.

Type-species: Tenthredo fuliginosa Schrank. Orig. desig.

fuliginosus (Schrank). N. S., Que. to Md. w. to Mich.; Europe; Japan. Introduced (?). Host: Ranunculus.

Tenthredo fuliginosa Schrank, 1781. Enum. Ins. Austriae, p. 334.

Tenthredo (Selandria) fuscus Lepeletier, 1823. Monog. Tenthred., p. 106. ठ.

Tenthredo (Selandria) fraxini Lepeletier, 1823. Monog. Tenthred., p. 106. \&, ठ.

Monophadnus fukaii Rohwer, 1910. U. S. Natl. Mus., Proc. 39: 108. ๆ, ठ’.

\section{Genus EUTOMOSTETHUS Enslin}

Tomostethus subg. Eutomostethus Enslin, 1914. Deut. Ent. Ztschr., Beih., p. 286.

Type-species: Tenthredo luteiventris Klug. Orig. desig.

Tomostethus subg. Atomostethus Enslin, 1914. Deut. Ent. Ztschr., Beih. p. 287.

Type-species: Tenthredo ephippium Panzer. Orig. desig.

Tomostethopsis Sato, 1928. Insecta Matsumurana 2: 178.

Type-species: Tomostethopsis metallicus Sato. Orig. desig.

Forsia Malaise, 1932. Arkiv for Zool. 23: 29.

Type-species: Forsia tomostethi Malaise. Orig. desig.

Most of the species of this genus are found in Asia.

ephippium (Panzer). Newfoundland, N. S., Que., Ont. s. to Md.; Tex.; B. C., Wash.; Europe, N. Africa, Asia Minor. Introduced (?). Host: Poa and other Gramineae. Hosts recorded in Europe.

Tenthredo ephippium Panzer, 1798. Faunae Ins. German., heft 52, pl. 5. \&.

Selandria inhabilis Norton, 1861. Boston Soc. Nat. Hist., Proc. 8: 220. 9.

luteiventris (Klug). N. S., Que. to Md. w. to Mich.; Alta., B. C., Wash., Oreg.; Europe. Ecology: Larva bores in sterile shoots of Juncus until last instar when it emerges and feeds externally, according to European observations. Introduced (?). Host: Juncus.

Tenthredo luteiventris Klug, 1814. Mag. Gesell. Naturf. Freunde Berlin 8: 56.

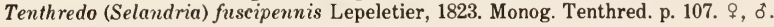

\section{TRIBE BLENNOCAMPINI}

\section{Genus ARDIS Konow}

Ardis Konow, 1886. Wien. Ent. Ztg. 5: 184, 188.

Type-species: Tenthredo (Allantus) bipunctata Klug. Desig. by Rohwer, 1911.

Valco Ross, 1937. Ill. Biol. Monog. 15(2): 99.

Type-species: Selandria irrogata Cresson. Orig. desig.

A small holarctic genus associated with roses.

atrata (Harrington). B. C., Wash., Oreg., Calif. Ecology: Adults collected from Rosa.

Monophadnus atratus Harrington, 1894. Canad. Ent. 26: 193. ठో.

Monophadnoides circina MacGillivray, 1923. Ill. Univ. Bul. 20(50): 24. ơ.

Paracharactus obtentus MacGillivray, 1923. Ill. Univ. Bul. 20(50): 28. ๆ. 
brunniventris (Hartig). Maine to N. W. T. s. to N. C., Ill., N. Mex., Calif.; Europe to Siberia, Japan. Ecology: Widespread. Larva bores and feeds in shoots of wild and cultivated roses. Host: Rosa. Previous reports of Ardis sulcata (Cameron) in N. Amer. were based on a misidentification and pertain to this species.

Tenthredo (Allantus) bipunctata Klug, 1814. Mag. Gesell. Naturf. Freunde Berlin 8: 215. . Preocc. by Muller, 1776 .

Tenthredo (Monophadnus) brunniventris Hartig, 1837. Fam. Blattwespen und Holzwespen, nebst Einleitung Naturgesch. Hym., p. 274. $\%$.

Selandria irrogata Cresson, 1880. Amer. Ent. Soc., Trans. 8: 13..

Aphanisus odoratus MacGillivray, 1908. Canad. Ent. 40: 296. 9.

Aphanisus parallelus MacGillivray, 1923. Ill. Univ. Bul. 20(50): 7..

Taxonomy: Smith, 1965. Pan-Pacific Ent. 41: 9-10 (synonymy). —Smith, 1966. Ent. Soc. Amer., Ann. 59: 1292 (larva separated from related species).

Biology: Eide, 1948. Jour. Econ. Ent. 41: 819-821. -Middlekauff, 1958. Pan-Pacific Ent. 34: 202.

\section{Genus MONARDIS Enslin}

Monardis Enslin, 1914. Deut. Ent. Ztschr., Beih., p. 284.

Type-species: Tenthredo plana Klug. Monotypic.

pulla Smith. Sask. to Colo., Utah and w. to B. C.

Monardis pulla Smith, 1969. U. S. Dept. Agr., Tech. Bul. 1397, p. 114. ㅇ.

\section{Genus APAREOPHORA Sato}

Apareophora Sato, 1928. Insecta Matsumurana 2: 185.

Type-species: Apareophora forsythiae Sato Orig. desig.

This small genus is found in east Asia and North America.

dyari (Benson). N. B. to N. Y. and Ont. Host: Spiraea salicifolia.

Blennocompa spiraeae Dyar, 1895. Canad. Ent. 27: 194. $\uparrow$, §, larva. Preocc. by Brischke and Zaddach, 1883.

Blennocampa dyari Benson, 1930. Entomologist 63: 107. N. name.

Biology: Dyar, 1895. Canad. Ent. 27: 194.

rossi Smith. Maine w. to Wis., Minn.

Apareophora rossi Smith, 1969. U. S. Dept. Agr., Tech. Bul. 1397, p. 118. \&, ठ์.

\section{Genus EUPAREOPHORA Enslin}

Eupareophora Enslin, 1914. Deut. Ent. Ztschr., Beih., p. 283.

Type-species: Blennocampa exarmata Thomson. Monotypic.

Only two species are known, the type-species from Europe and the species below.

parca (Cresson). N. B. to Md. w. to Sask., N. Dak., Iowa, Kans., Tex.; Oreg., Calif. Host.

Fraxinus pennsylvanica, $F$. nigra, $F$. americana, $F$. oregona, Carya illinoensis,

Chionanthus(?).

Selandria parca Cresson, 1880. Amer. Ent. Soc., Trans. 8: 13. ठ.

Periclista chionanthi Dyar, 1898. N. Y. Ent. Soc., Jour. 6: 132. $\uparrow$, larva.

Monophaduus minutus MacGillivray, 1908. Canad. Ent. 40: 291..

Pareophora guana MacGillivray, 1923. Ill. Univ. Bul. 20(50): 28. ठ.

Pareophora guara MacGillivray, 1923. Brooklyn Ent. Soc., Bul. 18: 54..

Biology: Packard, 1890. U. S. Ent. Comm. Rpt. 5 (Bul. 7, rev.), p. 545 (Selandria sp.).

\section{Genus PERICLISTA Konow}

Larvae of this genus feed on the foliage of Quercus and Carya. The genus is holarctic as well as being found in Chile and southern Argentina.

Revision: Stannard, 1949. Amer. Ent. Soc., Trans. 75: 7-42. 


\section{Genus PERICLISTA Subgenus PERICLISTA Konow}

Periclista Konow, 1886. Wien. Ent. Ztg. 5: 184, 186.

Type-species: Tenthredo (Allantus) lineolata Klug. Desig. by Rohwer, 1911.

Mogerus MacGillivray, 1895. Canad. Ent. 27: 281. Unnecessary n. name for Periclista Konow.

Isodyctium Ashmead, 1898. In Dyar, N. Y. Ent. Soc., Jour. 6: 127.

Type-species: Mogerus caryicolus Dyar. Orig. desig.

Apericlista Enslin, 1914. Deut. Ent. Ztschr., Beih., p. 265.

Type-species: Tenthredo albipennis Zaddach. Orig. desig.

Neoclista Malaise, 1964. Ent. Tidskr. 85: 22.

Type-species: Periclista andrei Konow. Orig. desig.

Cormaria Malaise, 1964. Ent. Tidskr. 85: 22.

Type-species: Cornaria fumipennis Malaise. Monotypic.

Taxonomy: Benson, 1968. Brit. Mus. (Nat. Hist.) Ent., Bul. 22: 152-153 (key to European species).

\section{Species Group Lineolata}

albicollis (Norton). Maine, Ont. to Va. w. to Man., Iowa, Kans., Okla., Tex. Host: Quercus alba, Q. ilicifolia, Q. macrocarpa, Q. rubra, Q. velutina.

Selandria albicollis Norton, 1872. Amer. Ent. Soc., Trans. 4: 85. ठ.

Periclista mutabilis Konow, 1904. Ztschr. System. Hym. Dipt. 4: 241. ๆ, ठ.

Periclista quercus Rohwer, 1912. U. S. Natl. Mus., Proc. 43: 232. ๆ, ठ.

linea Stannard. Oreg., Calif. Host: Quercus agrifolia.

Periclista linea Stannard, 1949. Amer. Ent. Soc., Trans. 75: 19. ९, ठ.

Biology: Beer, 1955. Kans. Ent. Soc., Jour. 28: 19-26 (also description of larva).

media (Norton). N. H., Mass. to Fla. w. to Man., Wis., Iowa. Host: Quercus alba.

Selandria media Norton, 1864. Ent. Soc. Phila., Proc. 3: 9. ๆ, ठ.

Selandria (Hoplocampa) floridana Cresson, 1880. Amer. Ent. Soc., Trans. 8: 12. o.

Periclista purpuridorsum Dyar, 1898. N. Y. Ent. Soc., Jour. 6: 129. ९, ठ.

Periclista confusa MacGillivray, 1908. Canad. Ent. 40: 291..

Periclista similaris Rohwer, 1917. U. S. Natl. Mus., Proc. 53: 155. ․

Taxonomy: Middleton, 1922. U. S. Natl. Mus., Proc. 61: 4-6 (larva, similaris).

naranga Stannard. Calif.

Periclista naranga Stannard, 1949. Amer. Ent. Soc., Trans. 75: 20..

spicula Stannard. Calif.

Periclista spicula Stannard, 1949. Amer. Ent. Soc., Trans. 75: 21. $\delta$.

\section{Species Group Melanocephala}

bipartita (Cresson). Mass. to Fla. w. to Mo., Tex. Host: Quercus coccinea.

Selandria (Blennocampa) bipartita Cresson, 1880. Amer. Ent. Soc., Trans. 8: 12. ठ.

Mogerus emarginatus MacGillivray, 1895. Canad. Ent. 25: 281. ठै.

Isodyctium murtfeldtiae Dyar, 1898. N. Y. Ent. Soc., Jour. 6: 135. ؟.

diluta (Cresson). Maine, Ont. to Fla. w. to Wis., Kans., Tex. Host: Quercus alba, Q. prinus. Selandria (Monophadnus) diluta Cresson, 1880. Amer. Ent. Soc., Trans. 8: 12 .. Isodyctium subgregarium Dyar, 1898. N. Y. Ent. Soc., Jour. 6: 134. ९, ठ.

Taxonomy: Smith, 1969. U. S. Dept. Agr., Tech. Bul. 1397, p. 127 (male).

entella MacGillivray. Oreg., Calif. Ecology: Adults collected from Quercus.

Periclista entella MacGillivray, 1923. Ill. Univ. Bul. 20(50): 29. ठै.

Taxonomy: Smith, 1969. U. S. Dept. Agr., Tech. Bul. 1397, p. 128 (female).

marginicollis (Norton), Conn., Ont. to Fla. w. to Iowa, Kans., Okla., Tex. Host: Carya, Quercus alba(?).

Tenthredo (Allantus) marginicollis Harris, 1835. In Hitchcock, Rpt. Geol. Mineral. Bot.

Zool. Mass., p. 583. Nom. nud.

Selandria marginicollis Norton, 1861. Boston Soc. Nat. Hist., Proc. 8: 220. $\subsetneq$.

Mogerus caryicolus Dyar, 1897. N. Y. Ent. Soc., Jour. 5: 193. ^, ठ. 
Isidyctium(!) atratum MacGillivray, 1908. Canad. Ent. 40: 290. \&.

Periclista hicoriae Rohwer, 1917. U. S. Natl. Mus., Proc. 53: 154..

Periclista xanthognatha Rohwer, 1917. U. S. Natl. Mus., Proc. 53: 156. .

Periclista plesia Rohwer, 1920. U. S. Natl. Mus., Proc. 57: 211. ๆ.

Periclista pecanivora Rohwer, 1920. U. S. Natl. Mus., Proc. 57: 212..

Taxonomy: Middleton, 1922. U. S. Natl. Mus., Proc. 61: 2-4 (larva). -Smith, 1969. U. S. Dept. Agr., Tech. Bul. 1397, p. 129 (larva).

rileyi (Cresson). Fla., Ill., Mo., Tex.

Selandria (Monophadnus) rileyi Cresson, 1880. Amer. Ent. Soc., Trans. 8: 13. ?.

Isodyctium floridense Dyar, 1898. N. Y. Ent. Soc., Jour. 6: 134. ?.

stannardi Smith. Iowa, Tex.

Periclista stannardi Smith, 1969. U. S. Dept. Agr., Tech. Bul. 1397, p. 130. \&.

sulfurana Stannard. N. Y., Mich., 1ll., Iowa. Host: Quercus.

Periclista sulfurana Stannard, 1949. Amer. Ent. Soc., Trans. 75: 28. \&, đ.

SPECIES GRoup CaLifornica

californica Rohwer. Calif.

Periclista californica Rohwer, 1917. U. S. Natl. Mus., Proc. 53: 154. §.

electa MacGillivray. Oreg., Calif. Ecology: Adults collected from Quercus.

Periclista electa MacGillivray, 1923. Psyche 30: 80. ¿'.

vergorba Stannard. Calif.

Periclista vergorba Stannard, 1949. Amer. Ent. Soc., Trans. 75: 32...

\section{Genus PERICLISTA Subgenus NEOCHARACTUS MacGillivray}

Neocharactus MacGillivray, 1908. Canad. Ent. 40: 293.

Type-species: Neocharactus bakeri MacGillivray. Monotypic.

Aphanisus MacGillivray, 1908. Canad. Ent. 40: 295.

Type-species: Aphanisus lobatus MacGillivray. Orig. desig.

bakeri (MacGillivray). Calif. Ecology: Adults collected from Quercus agrifolia.

Neocharactus bakeri MacGillivray, 1908. Canad. Ent. 40: 293. ठ.

Periclista leucostoma Rohwer, 1909. Canad. Ent. 41: 397. $९, \delta$.

inaequidens (Norton). N. H. to Md. w. to Wis., Ill., Tex. Host: Quercus alba.

Selandria inaequidens Norton, 1872. Amer. Ent. Soc., Trans. 4: 84..

Isodyctiun infrequens Dyar, 1898. N. Y. Ent. Soc., Jour. 6: 134. ๆ.

pallipes (Provancher). Calif. Ecology: Adults collected from Quercus agrifolia, Q. wislizenï. Monophadnus pallipes Provancher, 1895. Nat. Canad. 22: 80.,$~ ठ$.

Periclista occidentalis Rohwer, 1909. Canad. Ent. 41: 398. ๆ, ठ.

subtruncata Dyar. N. Y. to Fla. w. to Ill., Tex. Host: Quercus coccinea.

Tenthredo (Allantus) labiata Klug, 1818. Mag. Gesell. Naturf. Freunde Berlin 8: 73. $\$$.

Preocc. by Geoffroy, 1785.

Periclista subtruncata Dyar, 1898. N. Y. Ent. Soc., Jour. 6: 131. \&.

Aphanisus lobatus MacGillivray, 1908. Canad. Ent. 40: 295..

Aphanisus muricatus MacGillivray, 1908. Canad. Ent. 40: 296..

\section{Genus MONOPHADNOIDES Ashmead}

Monophadnoides Ashmead, 1898. Canad. Ent. 30: 253.

Type-species: Monophadnus mibi Harris. Orig. desig.

Claremontia Rohwer, 1909. Canad. Ent. 41: 397.

Type-species: Claremontia typica Rohwer. Orig. desig.

Monophadnus subg. Psendomonophadnus Malaise, 1935. Ent. Tidskr. 56: 167.

Type-species: Tenthredo geniculata Hartig. Orig. desig.

Monophadnus subg. Pseudoblennocampa Malaise, 1935. Ent. Tidskr. 56: 167.

Type-species: Tenthredo (Allantus) tenuicornis Klug. Orig. desig.

A holarctic genus mostly associated with Rosaceae though the host for only one North American species is known. 
atratus (MacGillivray). N. W. T. (Norman Wells), Alaska s. to Oreg.

Blennocampa atrata MacGillivray, 1893. Canad. Ent. 25: 239. \%.

Erythraspides ashmeadi Kincaid, 1900. Wash. Acad. Sci., Proc. 2: 345. ₹, ठ.

conspiculatus MacGillivray. N. S., Ont. s. to N. C., Tenn.

Monophadnoides conspiculata MacGillivray, 1908. Canad. Ent. 40: 293. ․

geniculatus (Hartig). Labrador to N. W. T. s. to Ga., Ark., Tex., Colo., Calif.; Europe and Asia. Ecology: Widespread. Host: Rubus. An extremely variable species in N. Amer.

Raspberry sawfly.

Tenthredo geniculatus Hartig, 1837. Fam. Blattwespen und Holzwespen, nebst Einleitung Naturgesch. Hym., p. 274.

Selandria (Hoplocampa) rubi Harris, 1845. In Darling, New Haven Hort. Soc., Trans., p. 13.

Selandria nigella Cresson, 1880. Amer. Ent. Soc., Trans. 8: 12..

Monophadnus hudsonicus Kirby, 1882. List Hym. Brit. Mus., v. 1, p. 176. ठ.

Monophadnus atracornis MacGillivray, 1893. Canad. Ent. 25: 239. ९.

Blennocampa Gillettei Weldon, 1907. Canad. Ent. 39: 304..

Monophadnoides conspicu us MacGillivray, 1908. Canad. Ent. 40: 293..

Monophadnoides consobrinus MacGillivray, 1908. Canad. Ent. 40: 294. ๆ.

Monophadnoides concessus MacGillivray, 1908. Canad. Ent. 40: 294..

Monophadnoides crassus MacGillivray, 1908. Canad. Ent. 40: 294. ๆ.

Monophadnoides conspersus MacGillivray, 1908. Canad. Ent. 40: 294. ๆ.

Monophadnoides costalis MacGillivray, 1908. Canad. Ent. 40: 295. ․

Monophadnoides coracinus MacGillivray, 1908. Canad. Ent. 40: 295. ठ.

Monophadnoides collaris MacGillivray, 1908. Canad. Ent. 40: 295..+

Aphanisus nigritus MacGillivray, 1908. Canad. Ent. 40: 296..

Aphanius(!) lenis Rohwer, 1909. Canad. Ent. 41: 309. \&, ठ.

Monophadnoides corytus MacGillivray, 1923. Psyche 30: 79. ठ.

Monophadnoides consonus MacGillivray, 1923. Ill. Univ. Bul. 20(50): 25. ๆ.

Monophadnoides constitutus MacGillivray, 1923. Ill. Univ. Bul. 20(50): 25..

Monophadnoides curiosus MacGillivray, 1923. Ill. Univ. Bul. 20(50): 25.. .

Monophadnoides kincaidi MacGillivray, 1923. Ill. Univ. Bul. 20(50): 26. ․

Monophadnoides shawi MacGillivray, 1923. Ill. Univ. Bul. 20(50): 26. ๆ, ठ.

Paracharactus obversus MacGillivray, 1923. Ill. Univ. Bul. 20(50): 28. ๆ.

Biology: Harris, 1850. New England Farmer 2: 33. -Saunders, 1873. Canad. Ent. 5: 101-103. - Riley, 1877. Ill. State Ent. Rpt. 6: 61. - Saunders, 1885. Canad. Ent. 17: 1-2. - Petit, 1900. Mich. Agr. Expt. Sta., Bul. 180: 137-138. - Lowe, 1898. N. Y. State Agr. Expt. Sta., Bul. 150, pp. 251-262.

osgoodi Smith. Maine, N. H., Ont.

Monophadnoides osgoodi Smith, 1969. U. S. Dept. Agr., Tech. Bul. 1397, p. 146. \&.

pauper (Provancher). Labrador to Md. w. to Alta., Colo.

Selandria paupera Provancher, 1882. Nat. Canad. 13: 293. $q$.

Monophadnoides cordatus MacGillivray, 1908. Canad. Ent. 40: 294. ๆ.

Blennocampa abnorma MacGillivray, 1908. Canad. Ent. 40: 296. ठै.

Blennocampa antennata MacGillivray, 1908. Canad. Ent. 40: 296.

Blennocampa acuminata MacGillivray, 1908. Canad. Ent. 40: 297..

Blennocampa adusta MacGillivray, 1908. Canad. Ent. 40: 297. 9.

Blennocampa angulata MacGilivray, 1908. Canad. Ent. 40: 297..

Blennocampa aperta MacGillivray, 1908. Canad. Ent. 40: 297. 9.

Erythraspides tuckeri Rohwer, 1909. Canad. Ent. 41: 145. 9.

Paracharactus nigrisomus Rohwer, 1912. U. S. Natl. Mus,, Proc. 43: 231. §.

quebecensis Smith. Que.

Monophadnoides quebecensis Smith, 1969. U. S. Dept. Agr., Tech. Bul. 1397, p. 150..

typicus (Rohwer). B. C. to Calif.

Claremontia typica Rohwer, 1909. Canad. Ent. 41: 397. ๆ. 


\section{TRIBE CERATULINI}

\section{Genus CERATULUS MacGillivray}

Ceratulus MacGillivray, 1908. Canad. Ent. 40: 454.

Type-species: Ceratulus spectabilis MacGillivray. Orig. desig.

Only a single species is known for this genus.

spectabilis MacGillivray. Tex. Host: Cissus incisa.

Ceratulus spectabilis MacGillivray, 1908. Canad. Ent. 40: 454. + , ठ.

\section{TRIBE WALDHEIMIINI}

\section{Genus WALDHEIMIA Brulle}

Waldheimia Brulle, 1846. In Lepeletier, Hist. Nat. Ins. Hym., p. 665.

Type-species: Tenthredo brasiliensis Lepeletier. Orig. desig.

Zarca Cameron, 1878. Ent. Soc. London, Trans. p. 142.

Type-species: Zarca apicalis Cameron. Monotypic.

Parazarca Ashmead, 1898, In Dyar, N. Y. Ent. Soc., Jour. 6: 128. N. syn.

Type-species: Parazarca fumipennis Ashmead. Orig. desig.

Calozarca Ashmead, 1898. In Dyar, N. Y. Ent. Soc., Jour. 6: 129. N. syn.

Type-species: Selandria fascipennis Norton. Orig. desig.

A large genus found from southwestern United States to Argentina. Of the more than 70 described species, only one reaches north of Mexico.

Revision: Malaise, 1949. Arkiv for Zool. 42A: 33-58 (key to species).

bedeae Smith. S. Ariz.; Mexico.

Waldheimia bedeae Smith, 1969. U. S. Dept. Agr., Tech. Bul. 1397, p. 156. $q$.

\section{Genus ERYTHRASPIDES Ashmead}

Erythraspides Ashmead, 1898. In Dyar, N. Y. Ent. Soc., Jour. 6: 128.

Type-species: Tenthredo pygmaea Say. Orig. desig.

A small genus found also in Mexico and Central America.

carbonarius (Cresson). Maine, Ont. to Ga. w. to Sask., Colo., Tex. Host: Oenothera.

Selandria carbonaria Cresson, 1880. Amer. Ent. Soc., Trans. 8: 12. ․

Selandria parva Cresson, 1880. Amer. Ent. Soc., Trans. 8: 12. ¿.

Blennocampa abjecta MacGillivray, 1921. Brooklyn Ent. Soc., Bul. 16: 22. ㅇ.

Blennocampa absona MacGillivray, 1921. Brooklyn Ent. Soc., Bul. 16: 22. ð’.

vitis (Harris). N. H. to Fla. w. to Iowa, Ark., La. Host: Vitis. Grape sawfly.

Tenthredo pygmaea Say, 1824. In Keating, Narr. Long's 2nd Exped. (App.) p. 318. \%, ơ. Preocc. by Klug, 1814.

Tenthredo (Selandria) vitis Harris, 1835. In Hitchcock, Rpt. Geol. Mineral. Bot. Zool. Mass., p. 586. Nom. nud.

Selandria vitis Harris, 1841. Rpt. Ins. Mass. Injurious to Veg., Ed. 1, p. 378.

Selandria caryae Norton, 1869. In Packard, Guide Study Ins., p. 224. Adults only, larvae are Eriocampa juglandis (Fitch).

Biology: Horsfall, 1929. Ent. News 40: 174-177.

\section{Genus HALIDAMIA Benson}

Halidamia Benson, 1939. Ent. Monthly Mag. 75: 111.

Type-species: Blennocampa affinis (Fallen). Orig. desig.

The single species in this genus was probably introduced into North America.

affinis (Fallen). Conn. to Md. w. to Ont., Wis.; Europe. Probably introduced. Host: Galium.

Host recorded in Europe.

Hylotoma affinis Fallen, 1807. Svenska Vetensk. Akad., Handl. 28: 207.

Hylotoma assimilis Fallen, 1807. Svenska Vetensk. Akad., Handl. 28: 204.. 
Tenthredo (Allantus) hyalina Klug, 1814. Mag. Gesell. Naturf. Freunde Berlin 8: 58. . Blennocampa formosella Costa, 1882. Rend. Accad. Sci. fis Napoli, p. 198.

\section{SUBFAMILY ALLANTINAE}

Members of this subfamily are associated with various plants. Some hosts are strawberries, raspberries, roses, violets, and dogwood. After feeding is completed, larvae of many species bore into fruits, wood, or other suitable substances for pupating or overwintering. The occurrence of larvae in these secondary hosts is sometimes more significant if in cultivated fruits or structural wood, but it is purely incidental depending on their proximity to the true host plant. Adults of this subfamily are medium to large sawflies and may be either rather stout or elongated.

\section{TRIBE ERIOCAMPINI}

\section{Genus PSEUDOSIOBLA Ashmead}

Pseudosiobla Ashmead, 1898. Canad. Ent. 30: 308.

Type-species: Allantus excavatus Norton. Orig. desig.

cephalanthi Rohwer. Mass., N. Y., Mo. Host: Cephalanthus occidentalis.

Pseudosiobla cephalanthi Rohwer, 1911. U. S. Natl. Mus., Proc. 41: 404. ठ.

excavata (Norton). Maine to Fla. w. to Ill., Tex. Host: Cephalanthus.

Allantus excavatus Norton, 1862. Ent. Soc. Phila., Proc. 1: 143..

Siobla robusta Kirby, 1882. List Hym. Brit. Mus., v. 1, p. 253. \&.

Taxonus floridanus Provancher, 1888. Addit. Corr. Faune Ent. Canada Hym., p. 352. ठ。.

\section{Genus ERIOCAMPA Hartig}

Eriocampa Hartig, 1837. Fam. Blattwespen und Holzwespen, nebst Einleitung Naturgesch. Hym., p. 279.

Type-species: Tenthredo ovata Linnaeus. Desig. by Rohwer, 1911.

Eriocampa subg. Brachyocampa Zirngiebl, 1956. Munchen Ent. Gesell. Mitt. 46: 326.

Type-species: Eriocampa dorpatica Konow. Orig. desig.

juglandis (Fitch). N. B., Que., Ont. to N. C. w. to Minn., Nebr. Host: Juglans.

Tenthredo (Allantus) obesa Harris, 1835. In Hitchcock, Rpt. Geol. Mineral. Bot. Zool.

Mass., p. 583. Nom. nud.

Selandria? juglandis Fitch, 1857. N. Y. State Agr. Soc., Trans. 16: 467. Larva.

Allantus obesus Norton, 1860. Boston Jour. Nat. Hist. 7: 260. ठ.

Sciapteryx rotundus Norton, 1867. Amer. Ent. Soc., Trans. 1: 242. ‥

Eriocampa rotundiformis Rohwer, 1909. Canad. Ent. 41: 16. ó.

ovata (Linnaeus). Que., Mass., N. Y., Ont., B. C., Wash.; Europe. Probably introduced independently into east and west N. Amer. Host: Alnus ribra.

Tenthredo ovata Linnaeus, 1761. Fauna Suecica, Ed. 2, p. 392.

Tenthredo gossypina Retzius, 1783. Genera et Species Insectorum, p. 72.

Tenthredo leucogona Schrank, 1802. Fauna Boica, v. 2, p. 251.

Biology: Bouchard, 1961. Ent. Soc. Quebec, Ann. 6: 69-80. - Borden and Dean, 1971. Ent. Soc.

Brit. Columbia, Proc. 68: 26-28 (in B. C.).

Morphology: Hsin, 1935. Ztschr. Angew. Ent. 22: 253-294 (epidermal glands of larva).

\section{Genus DIMORPHOPTERYX Ashmead}

Dimorphopteryx Ashmead, 1898. Canad. Ent. 30: 308.

Type-species: Allantus pinguis Norton. Orig. desig.

Revision: Rohwer, 1915. U. S. Natl. Mus., Proc. 48: 445-448.

Taxonomy: Middleton, 1915. U. S. Natl. Mus., Proc. 48: 497-501 (larvae).

abnormis Rohwer. Ont., Maine to N. C. w. to Sask., Mont., Ill. Host: Prunus, Pyrus, Amelanchier, Crataegus.

Dimorphopteryx abnormis Rohwer, 1911. U. S. Natl. Mus., Proc. 41: 406. ๆ, ठ.

Dimorphopteryx desidiosus MacGillivray, 1923. Ill. Univ. Bul. 20(50): 10. ؟. 
Dimorphopteryx ithacus MacGillivray, 1923. Ill. Univ. Bul. 20(50): 10..

Dimorphopteryx salinus MacGillivray, 1923. Ill. Univ. Bul. 20(50): 11. ๆ.

autumnalis Rohwer. Va., Wis. Host: Quercus.

Dimorphopteryx autumnalis Rohwer, 1915. U. S. Natl. Mus., Proc. 48: 447..

Dimorphopteryx quercivora Rohwer, 1915. U. S. Natl. Mus., Proc. 48: 448. ơ.

melanognathus Rohwer. Newfoundland to Va. w. to Ont., Mich. Host: Betula papyrifera.

Dimorphopteryx melanognathus Rohwer, 1910. U. S. Natl. Mus., Proc. 38: 205..

Dimorphopteryx enucleatus MacGillivray, 1923. Ill. Univ. Bul. 20(50): 10..

Dimorphopteryx scopulosus MacGillivray, 1923. Ill. Univ. Bul. 20(50): 12. ؟.

Biology: Dyar, 1895. Amer. Ent. Soc., Trans. 22: 311 (pinguis, not Norton). -Dyar, 1897. N.

Y. Ent. Soc., Jour. 8: 199. (pinguis, not Norton).

pinguis (Norton). N. S., P. E. I., N. B., Que. to Va. w. to Sask., Colo. Host: Alnus, Betula.

Allantus pinguis Norton, 1860. Boston Jour. Nat. Hist. 7: 244..+

Sciapteryx punctum Provancher, 1878. Nat. Canad. 10: 72. ठ.

Dimorphopteryx pinguis errans Rohwer, 1911. U. S. Natl. Mus., Proc. 41: 406. $q$, ठ.

Dimorphopteryx coloradensis Rohwer, 1915. U. S. Natl. Mus., Proc. 49: 206..

Dimorphopteryx oronis MacGillivray, 1923. Ill. Univ. Bul. 20(50): 11. \&.

Dimorphopteryx morsei MacGillivray, 1923. Ill. Univ. Bul. 20(50): 11. ؟.

Biology: Wong, 1954. Canad. Ent. 86: 154.

virginicus Rohwer. $\mathrm{Pa}$., Ohio s. to $\mathrm{Ga}$. Host: Castanea dentata.

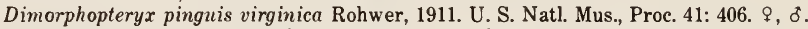

Dimorphopteryx castaneae Rohwer, 1915. U. S. Natl. Mus., Proc. 48: 447. $ๆ$, ઠ.

\section{TRIBE EMPRIINI}

\section{Genus EMPRIA Lepeletier}

Empria Lepeletier, 1828. Encycl. Meth., Dict. Ins., p. 571.

Type-species: Dolerus (Empria) pallimacula Lepeletier. Desig. by Brulle, 1846.

Poecilostoma Dahlbom, 1835. Conspectus Tenthred., Siricid., Oryssin. Scand., p. 13.

Type-species: Tenthredo guttatum Fallen. Desig. by Rohwer, 1911.

Prosecris Gistel, 1848. Naturgesch. Thierr. f. hoh. Schul., p. 10. Unnecessary n. name for Poecilostoma.

Poecilosoma Thomson, 1870. Opusc. Ent. 2: 265. Emend. of Poecilostoma. Preocc. by

Huebner, 1819, and four others.

Poecilostomidea Ashmead, 1898. Canad. Ent. 30: 256.

Type-species: Emphytus maculatus Norton. Orig. desig.

Tetratneura Äshmead, 1898. Canad. Ent. 30: 256.

Type-species: Selandria ignotus Norton. Orig. desig.

Tetraneura Konow, 1905. In Wytsman, Gen. Ins., v. 29, pp. 102, 171. Emend. Preocc. by

Hartig, 1814.

Parataxonus MacGillivray, 1908. Canad. Ent. 40: 367.

Type-species: Taxonus multicolor Norton. Orig. desig.

Leucempria Enslin, 1913. Deut. Ent. Ztschr., Beih., p. 187.

Type-species: Tenthredo candidata Fallen. Orig. desig.

Empria subg. Triempria Enslin, 1914. Deut. Ent. Ztschr., Beih., p. 213.

Type-species: Empria tridens Konow. Orig. desig.

Species of this holarctic genus show considerable color variation; consequently the long list of synonymies under some species. This genus also extends into Mexico.

Revision: Ross, 1936. Pan-Pacific Ent. 12: 172-178.

alpina Benson. N. W. T., B. C.; Europe. Host: Salix spp.

Empria alpina Benson, 1938. Soc. Brit. Ent., Trans. 5: 190, 195. ๆ, ठ.

candidata (Fallen). Que., Maine, N. H., N. W. T., Man., Alta., Yukon, B. C. Alaska; Europe to

Siberia. Host: Betula.

Tenthredo candidata Fallen, 1807. Svenska Vetensk. Akad., Handl. 28: 105.

Tenthredo (Allantus) repanda Klug, 1814. Mag. Gesell. Naturf. Freunde Berlin 8: 77.. 
Taxonomy: Benson, 1962. Brit. Mus. (Nat. Hist.) Ent., Bul. 12: 390 (distribution).

coryli (Dyar). N. H., N. Y. w. to Wis., lowa, Mo. Host: Corylus.

Harpiphorus maculatus var. coryli Dyar, 1897. N. Y. Ent. Soc., Jour. 5: 194. \&, larva.

Empria mellipes Rohwer, 1910. Canad. Ent. 42: 175. ․

Empria caetrata MacGillivray, 1911. Canad. Ent. 43: 305. \&.

Biology: Dyar, 1897. N. Y. Ent. Soc., Jour. 5: 194.

ignota (Norton). Maine to Pa. w. to Alaska, B. C., Wash., Oreg., Calif. Ecology: Widespread. Adult captured from Salix.

Selandria ignotus Norton, 1867. Amer. Ent. Soc., Trans. 1: 257. \&.

Monostegia kincaidi MacGillivray, 1893. Canad. Ent. 25: 239. ․

Empria calda MacGillivray, 1911. Canad. Ent. 43: 307. $\$$.

Empria cata MacGillivray, 1911. Canad. Ent. 43: 307. §.

Empria castigata MacGillivray, 1911. Canad. Ent. 43: 309. $ๆ$.

Empria casca MacGillivray, 1911. Canad. Ent. 43: 310. .

Empria evecta MacGillivray, 1911. Canad. Ent. 43: 310. $\$$.

Empria confirmata MacGillivray, 1911. Canad. Ent. 43: 341. \&.

Empria concitata MacGillivray, 1911. Canad. Ent. 43: 342. ठ.

Empria culpata MacGillivray, 1911. Canad. Ent. 43: 343..

Empria cerina MacGillivray, 1921. Psyche 28: 34 . $\uparrow, \delta$.

Empria cirrha MacGillivray, 1923. Ill. Univ. Bul. 20(50): 16. $q$.

Empria cithara MacGillivray, 1923. Ill. Univ. Bul. 20(50): 17..

improba (Cresson). Maine, Ont. w. to N. W. T., Alaska, B. C., Oreg., Colo., Calif. Ecology:

Widespread. Adults collected from Salix.

Emphytus improbus Cresson, 1880. Amer. Ent. Soc., Trans. 8: 11. ๆ.

Empria salicis Rohwer, 1910. Canad. Ent. 42: 174., ঠ.

Empria contexta MacGillivray, 1911. Canad. Ent. 43: 345. \&.

maculata (Norton). Newfoundland to N. C. w. to Alaska, B. C., Oreg., Calif. Ecology:

Widespread; recorded from nearly every state in its range. Sometimes a pest of cultivated strawberries. Host: Fragaria, Potentilla, Rubus.

Emphytus maculatus Norton, 1861. Boston Soc. Nat. Hist., Proc. 8: 157. ๆ, ठ.

Poecilostoma convexa MacGillivray, 1909. Canad. Ent. 41: 402. ९.

Empria distincta Rohwer, 1910. Canad. Ent. 42: 173. ㅇ.

Empria submaculata Rohwer, 1910. Canad. Ent. 42: 174., o.

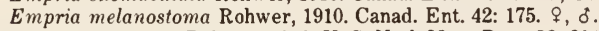

Monosoma maura Rohwer, 1910. U. S. Natl. Mus., Proc. 38: 204..

Empria callosa MacGillivray, 1911. Canad. Ent. 43: 305. \&.

Empria celsa MacGillivray, 1911. Canad. Ent. 43: 306. ๆ.

Empria callida MacGillivray, 1911. Canad. Ent. 43: 306. 9.

Empria caprina MacGillivray, 1911. Canad. Ent. 43: 307. ๆ, §.

Empria casta MacGillivray, 1911. Canad. Ent. 43: 308. + , ঠ.

Empria celebrata MacGillivray, 1911. Canad. Ent. 43: 308. ๆ.

Empria captiosa MacGillivray, 1911. Canad. Ent. 43: 308..

Empria caeca MacGillivray, 1911. Canad. Ent. 43: 308. ๆ.

Empria cariosa MacGillivray, 1911. Canad. Ent. 43: 309. \&.

Empria candidula MacGillivray, 1911. Canad. Ent. 43: 310..

Empria canora MacGillivray, 1911. Canad. Ent. 43: 310..+

Empria cauta MacGillivray, 1911. Canad. Ent. 43: 311. 9.

Empria condensa MacGillivray, 1911. Canad. Ent. 43: 342..

Empria cumulata MacGillivray, 1911. Canad. Ent. 43: 343. \&.

Empria curata MacGillivray, 1911. Canad. Ent. 43: 345 . $९$.

Empria cuneata MacGillivray, 1911. Canad. Ent. 43: 345..

Empria cupida MacGillivray, 1911. Canad. Ent. 43: 346..

Empria schwarzi Rohwer, 1911. U. S. Natl. Mus., Proc. 41: 398. ๆ.

Empria cadurca MacGillivray, 1923. Canad. Ent. 55: 158. \&, ठ.

Biology: Riley, 1867. Prairie Farmer, May, p. 348. - Petit, 1899. Mich. Agr. Expt. Sta. Bul. 175: 365. -Webster, 1915. Iowa Agr. Expt. Sta. Bul. 162, 20 pp. - Webster, 1916. Iowa Acad. Sci., Proc. 23: 291-297. - Neiswander, 1944. Ohio Agr. Expt. Sta. Bul. 651: 35. 
mexicana (Cameron). N. Mex., Ariz.; Mexico.

Poecilosoma mexicanum Cameron, 1883. Biol.-Cent. Amer., v. 1, p. 34.

Empria arizonensis Rohwer, 1910. Canad. Ent. 42: 174. $?$.

multicolor (Norton). N. B., Que. to Ga. w. to Alta., Wash., Oreg., Calif. Ecology: Widespread. Host: Alnus, Betula papyrifera, B. lutea.

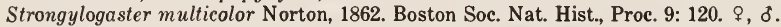

Emphytus hullensis Provancher, 1886. Addit. Corr. Faune Ent. Canada Hym., p. 25. ठँ.

Empria carbasea MacGillivray, 1911. Canad. Ent. 43: 341..+

Aphilodyctium maculatum Rohwer, 1911. U. S. Natl. Mus., Proc. 41: 408. 9.

Aphilodyctium multicolor erythrogastrum Rohwer, 1911. U. S. Natl. Mus., Proc. 41: 408. ९, ठ̊.

Biology: Wong, 1954. Canad. Ent. 86: 154.

nordica Ross. N. W. T., Man.

Empria nordica Ross, 1936. Pan-Pacific Ent. 12: 175..

obscurata (Cresson). Maine to Pa. w. to N. W. T., Alaska, B. C., Wash., Oreg., Calif. Ecology: Widespread; sometimes a pest of cultivated strawberries. Host: Fragaria. Either a variable species or a species complex.

Selandria obscurata Cresson, 1880. Amer. Ent. Soc., Trans. 8: 15., đ.

Poecilosoma punctulata Weldon, 1907. Canad. Ent. 39: 304. ९, o.

Empria affinis Rohwer, 1910. Canad. Ent. 42: 173. $\%$.

Empria caudelli Rohwer, 1910. Canad. Ent. 42: 173. .

Empria cava MacGillivray, 1911. Canad. Ent. 43: 306..

Empria cauduca MacGillivray, 1911. Canad. Ent. 43: 309..

Empria capillata MacGillivray, 1911. Canad. Ent. 43: 341..

Empria condita MacGillivray, 1911. Canad. Ent. 43: 342..

Empria contorta MacGillivray, 1911. Canad. Ent. 43: 343. .

Empria conferta MacGillivray, 1911. Canad. Ent. 43: 344..

Empria concreta MacGillivray, 1911. Canad. Ent. 43: 344. $\subsetneq$.

Empria conciliata MacGillivray, 1911. Canad. Ent. 43: 344. $\subsetneq$.

Empria concisa MacGillivray, 1911. Canad. Ent. 43: 346..

Empria costata MacGillivray, 1914. Canad. Ent. 46: 103..

Empria fragariae Rohwer, 1914. Jour. Econ. Ent. 7: 479. \&.

Empria cista MacGillivray, 1923. Ill. Univ. Bul. 20(50): 16. + .

Empria cistula MacGillivray, 1923. Ill. Univ. Bul. 20(50): 16. $\%$.

Biology: Malley, 1889. U. S. Dept. Agr., Insect Life 2: 137-140 (ignota, not Norton). - Malley, 1890. U. S. Dept. Agr., Insect Life 3: 9-12 (ignota, not Norton), - Osborn and Gossard, 1892. Iowa Agr. Expt. Sta. Bul. 18: 512-514 (ignota, not Norton). - Webster, 1915. Iowa Agr. Expt. Sta., Bul. 162, 20 pp. (fragariae). -Webster, 1916. Iowa Acad. Sci., Proc. 23: 291-297 (fragariae).

\section{Genus PHRONTOSOMA MacGillivray}

Phrontosoma MacGillivray, 1908. Canad. Ent. 40: 366.

Type-species: Phrontosoma atrum MacGillivray. Orig. desig.

A small, exclusively North American genus. One unidentified species extends the distribution of this genus to western United States.

belfragei (Cresson). Mass. to Pa. w. to Ont., Wis., Kans., Tex. Ecology: Adults collected from Cornus.

Selandria belfragei Cresson, 1880. Amer. Ent. Soc., Trans. 8: 15. ๆ.

Caliroa nortonia MacGillivray, 1894. Canad. Ent. 24: 324. $\delta$.

Phrontosoma atrum MacGillivray, 1908. Canad. Ent. 40: 367. ठ.

Phrontosoma daeckei MacGillivray, 1908. Canad. Ent. 40: 367. ๆ.

Phrontosoma collaris MacGillivray, 1908. Canad. Ent. 40: 367..

\section{Genus MONOSOMA MacGillivray}

Monsoma(!) MacGillivray, 1908. Canad. Ent. 40: 368. 
Type-species: Taxomus inferentia Norton. Orig. desig.

Monosoma Viereck, 1910. N. J. State Mus., Ann. Rpt. 1909, p. 583. Emend.

A small genus with two species, one Nearctic the other Palaearctic.

inferentia (Norton). Newfoundland to N. C. w. to Minn., Ill, Host: Alnus.

Poecilostoma inferentia Norton, 1868. Amer. Ent. Soc., Trans. 2: 224. ð.

Strongylogaster albosectus Provancher, 1878. Nat. Canad. 10: 168..

Monophadnus lineatus Kirby, 1882. List Hym. Brit. Mus., v. 1, p. 177. \&. A questionable synonym.

Monosoma inferentia var. andronosa Ross, 1932. Canad. Ent. 64: 249. 9.

\section{Genus MONOSTEGIA Costa}

Monostegia Costa, 1859. Fauna del Regno di Napoli, Imen., pt. 3, p. 60.

Type-species: Tenthredo (Allantus) luteola Klug. Desig. by Ross, 1951.

Poecilosoma subg. Nematoceros Konow, 1896. Wien. Ent. Ztg. 15: 52, 54.

Type-species: Tenthredo (Allantus) luteola Klug. Monotypic.

abdominalis (Fabricius). Que., Ont. to N. J., Pa. w. to Ohio; Europe to Siberia. Probably introduced. Host: Lysimachia nummularia, L. vulgaris, L. terrestris, Anagallis.

Tenthredo abdominalis Fabricius, 1798. Sup. Ent. System., p. 216. \&.

Tenthredo (Allantus) luteola Klug, 1814. Mag. Gesell. Naturf. Freunde Berlin 8: 48.

Monostegia martini MacGillivray, 1908. Canad. Ent. 40: 366. ?.

Monostegia nearctica Rohwer, 1912. U. S. Natl. Mus., Proc. 43: 209. ९, ठ.

Biology: Price, 1970. Canad. Ent. 102: 491-495.

\section{Genus AMETASTEgIA Costa}

Ametastegia Costa, 1882. Accad. delle Sci. Fis. e Mat. Napoli, Rend. 21(10): 198.

Type-species: Ametastegia fulvipes Costa. Monotypic.

Aomodyctium Ashmead, 1898. Canad. Ent. 30: 309. No included species.

Type-species: Strongylogaster abnormis Provancher. Desig. by Rohwer, 1911.

Protemphytus Rohwer, 1909. Canad. Ent. 41: 92.

Type-species: Emphytus coloradensis Weldon. Monotypic.

Emphytina Rohwer, 1911. U. S. Natl. Mus., Proc. 41: 399.

Type-species: Emphytina pulchella Rohwer. Orig. desig.

Simplemphytus MacGillivray, 1914. Canad. Ent. 46: 363.

Type-species: Simplemphytus pacificus MacGillivray. Monotypic.

Unitaxonus MacGillivray, 1921. Psyche 28: 32.

Type-species: Unitaxonus repentinus MacGillivray. Orig. desig.

Species of this holarctic genus feed on herbaceous plants. On maturing, larvae bore into soft substances to form a pupal cell. This secondary host may be apples, other fruits, soft wood, or pith of other plants. Such records as hosts for species of this genus do not constitute the true host on which the larvae feed.

Revision: Ross, 1937. Arb. uber Morph. u. Taxonom. Ent. 4: 84-91.

aperta (Norton). Newfoundland to N. C. w. to Mich., Colo.

Tenthredo (Emphytus) aperta Harris, 1835. In Hitchcock, Rpt. Geol. Mineral. Bot. Zool. Mass., p. 583. Nom. nud.

Emphytus apertus Norton, 1861. Boston Nat. Hist. Soc., Proc. 8: 155. 9.

Emphytus lencostoma Rohwer, 1908. N. Y. Ent. Soc., Jour. 16: 110. . Preocc. by Costa, 1890.

Emphytina plesia Rohwer, 1911. U. S. Natl. Mus., Proc. 41: 402. N. name.

articulata (Klug). Que., Maine to Fla.w. to Minn., Iowa, Ark., Tex. Host: Rumex, Polygonum.

Tenthredo (Emphytus) articulatus Klug, 1814. Mag. Gesell. Naturf. Freunde Berlin 8: 284. o.

Dolerus inomatus Say, 1824. In Keating, Narr. Long's 2nd Exped., v. 2, (App.) p. 319. ๆ.

Emphytus halitus MacGillivray, 1923. Ill. Univ. Bul. 20(50): 14. ?.

Taxonomy: Smith, 1973. Ent. Soc. Wash., Proc. 75: 29. 
coloradensis (Weldon). Labrador, Colo., Alta., B. C., Oreg., Calif. Emphytus coloradensis Weldon, 1907. Canad. Ent. 39: 304. ठ. Emphytus hiulcus MacGillivray, 1923. Ill. Univ. Bul. 20(50): 15. ๆ.

equiseti (Fallen). Que., Maine to N. C. w. to Alaska, Oreg.; Europe to Siberia. Ecology: Widespread. Host: Rumex, Polygonum.

Tenthredo equiseti Fallen, 1808. Svenska Vetensk. Akad., Handl. 29: 60.

Tenthredo (Allantus) bicolor Klug, 1814. Mag. Gesell. Naturf. Freunde Berlin 8: 204. $\%, \delta$. Tenthredo bizonata Zetterstedt, 1838. Ins. Lapp., v. 1, p. 344. \&.

Taxonus innominatus MacGillivray, 1901. N. Y. State Mus. Bul. 47: 585. ‡. Strongylogastroidea depressata MacGillivray, 1921. Psyche 28: 31..

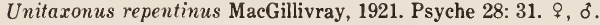

Unitaxonus rumicis MacGillivray, 1921. Psyche 28: 31..+

Hemitaxomus dedititius MacGillivray, 1923. Psyche 30: 77. o.

Strongylogastroidea rufocinctella MacGillivray, 1923. Ill. Univ. Bul. 20(50): 32. ๆ.

glabrata (Fallen). N. S., Que. to Md. w. to B. C., Wash., Oreg.; Europe to Siberia. Ecology: Widespread. If adjacent to host, larva commonly bores into apples or other fruits to pupate. Host: Rumex. Dock sawfly.

Tenthredo glabrata Fallen, 1808. Svenska Vetensk. Akad., Handl. 29: 108.

Tenthredo (Allantus) agilis Klug, 1814. Mag. Gesell. Naturf. Freunde Berlin 8: 208., , . Tenthredo (Allantus) rufipes Lepeletier, 1823. Monog. Tenthred., p. 239. ?.

Taxonus nigrisoma Norton, 1862. Boston Soc. Nat. Hist., Proc. 9: 119. .

Strongylogaster abnormis Provancher, 1885. Addit. Corr. Faune Ent. Canada Hym., p. 10. \&, $\delta$.

Strongylogastroidea potulenta MacGillivray, 1923. Ill. Univ. Bul. 20(50): 31. ؟.

Biology: Chittenden and Titus, 1905. U. S. Dept. Agr. Bul. 54: 40-43. -Webster, 1908. Jour. Econ. Ent. 1: 310-311 (in apples). - Dustan and Gilliatt, 1216. Ent. Soc. Nova Scotia, Proc., pp. 45-48. - Newcomer, 1916. U. S. Dept. Agr., Bul. 265, 40 pp. - Blackman and Stage, 1924. N. Y. State Col. Forestry, Syracuse Univ., Tech. Pub. 17, v. 24, p. 153 (in dead and decaying hickory). -Zuk, 1961. Ent. Soc. Brit. Columbia, Proc. 58: 21 (boring holes in cedar siding).

pallipes (Spinola). Newfoundland to Md. w. to B. C., Oreg., Calif.; Europe to Siberia; Iceland. Ecology: Widespread. Host: Viola. Violet sawfly.

Tenthredo pallipes Spinola, 1808. Insectorum Liguriae, v. 2, p. 19.

Tenthredo (Emphytus) grossulariae Klug, 1814. Mag. Gesell. Naturf. Freunde Berlin 8: 283. ㅇ.

Dolerus leucopodus Lepeletier, 1823. Monog. Tenthred., p. 119...

Tenthredo pallipes Provancher, 1878. Nat. Canad. 10: 66. $\$$, ठ. Homonym and Synonym.

Emphytus canadense Kirby, 1882. List Hym. Brit. Mus., v. 1, p. 204. N. name for pallipes

Provancher.

Emphytus pallidipes Dalla Torre, 1894. Cat. Hym., v. 1, p. 119. Emend.

Empria cavata MacGillivray, 1911. Canad. Ent. 43: 305 . $९$.

Empria cetaria MacGillivray, 1921. Psyche 28: 33 . $\$$.

Emphytus halesus MacGillivray, 1923. Ill. Univ. Bul. 20(50): 13..+

Emphytus heroicus MacGillivray, 1923. Ill. Univ. Bul. 20(50): 14. ๆ.

Emphytus hiatus MacGillivray, 1923. Ill. Univ. Bul. 20(50): 14. ․

Emphytus hospitus MacGillivray, 1923. Ill. Univ. Bul. 20(50): 15..

Emphytus hyacinthus MacGillivray, 1923. Ill. Univ. Bul. 20(50): 16. ؟.

Biology: Dyar, 1894. Canad. Ent. 26: 185 (canadensis).

recens (Say). Newfoundland to Ala. w. to Alaska, B. C., Oreg. Ecology: Widespread. Host:

Polygonum. Several species are currently going under this name.

Emphytus recens Say, 1836. Boston Jour. Nat. Hist. 1: 221. ठ.

Emphytus stramineipes Cresson, 1880. Amer. Ent. Soc., Trans. 8: 52. ๆ. A questionable synonym.

Emphytus angustus Kincaid, 1900. Wash. Acad. Sci., Proc. 2: 360. ¿. A questionable synonym.

Emphytina pulchella Rohwer, 1911. U. S. Natl. Mus., Proc. 41: 400..

Emphytina pallidiscapa Rohwer, 1911. U. S. Natl. Mus., Proc. 41: 401.,$\delta$. 
Emphytina virginica Rohwer, 1911. U. S. Natl. Mus., Proc. 41: 401..

Emphytus yuasi MacGillivray, 1921. Psyche 28: 31. ?.

tener (Fallen), Que., Ont. to Va. w. to B. C., Wash., Oreg.; Europe to Siberia. Ecology:

Widespread. Host: Rumex.

Tenthredo tener Fallen, 1808. Svenska Vetensk. Akad., Handl. 29: 109.

Tenthredo (Emphytus) patellatus Klug, 1814. Mag. Gesell. Naturf. Freunde Berlin 8: 283.

\&, $\delta$.

Dolerus luctuosus Lepeletier, 1823. Monog. Tenthred., p. 119. ₹, ठ.

Dolerus nigritus Lepeletier, 1823. Monog. Tenthred., p. 120. ठ.

Simplemphytus pacificus MacGillivray, 1914. Canad. Ent. 46: 363. ९, ઠ.

Emphytina vanduzeei Rohwer, 1915. U. S. Natl. Mus., Proc. 49: 205. ९.

Empria columna MacGillivray, 1923. Brooklyn Ent. Soc., Bul. 18: 54..

Emphytus haliartus MacGillivray, 1923. Ill. Univ. Bul. 20(50): 14..

Emphytus haustus MacGillivray, 1923. Ill. Univ. Bul. 20(50): 14. ठ.

\section{Genus APHILODYCTIUM Ashmead}

Aphilodyctium Ashmead, 1898. Canad. Ent. 30: 310.

Type-species: Strongylogaster rubripes Cresson. Orig. desig.

Polytaxonus MacGillivray, 1908. Canad. Ent. 40: 368.

Type-species: Taxonus robustus Provancher. Orig. desig.

The single species in this genus is found only in North America.

Taxonomy: Ross, 1937. Arb. uber Morph. u. Taxonom. Ent. 4: 90.

fidum (Cresson). Que., Maine to Md. w. to B. C., Wash., Oreg., Calif. Ecology: Widespread.

Host: Rosa.

Strongylogaster fidus Cresson, 1880. Amer. Ent. Soc., Trans. 8: 19. 9.

Strongylogaster mibripes Cresson, 1880. Amer. Ent. Soc., Trans. 8: 20. १.

Taxomus robustus Provancher, 1882. Nat. Canad. 13: 294..

Taxomus parens Provancher, 1889. Addit. Corr. Faune Ent. Canada Hym., p. 9.

Taxonus lenis Rohwer, 1908. N. Y. Ent. Soc., Jour. 16: 110. ‡, ð.

Aphilodyctium mibripes nigritarsis Rohwer, 1911. U. S. Natl. Mus., Proc. 41: 408. ๆ, ठे. Taxomus inclinatus MacGillivray, 1923. Psyche 30: 78. ठ.

\section{TRIBE ALLANTINI}

\section{Genus ALLANTUS Panzer}

Allantus Panzer, 1801. Faunae Ins. German., heft 82, pl. 12.

Type-species: Tenthredo (Allantus) togatus Panzer. Monotypic.

Emphytus Klug, 1813. Mag. Gesell. Naturf. Freunde Berlin 7: 273.

Type-species: Tenthredo cincta Linnaeus. Desig. by Curtis, 1833.

This is a much larger genus in the Palaearctic region. Three of the seven North American forms were introduced.

Revision: Ross, 1937. Arb. uber Morph. u. Taxonom. Ent. 4: 91.

Taxonomy: Wong, 1966. Canad. Ent. 98: 852-854.

albolabris (Rohwer). Sask., Alaska, B. C., Wash., Oreg.

Emphytus mellipes var. albolabris Rohwer, 1917. U. S. Natl. Mus., Proc. 53: 152..

Emphytus gemitus MacGillivray, 1923. N. Y. Ent. Soc., Jour. 31: 163. \&.

basalis (Klug). Newfoundland, N. Y., Tenn.; Europe to Siberia, China. Introduced. Host: Rosa.

Tenthredo (Emphytus) basalis Klug, 1814. Mag. Gesell. Naturf. Freunde Berlin 8: 282. ठ.

cinctus (Linnaeus). Newfoundland to Va. w. to B. C., Wash.; Europe to Siberia. Ecology:

Widespread; most commonly a pest of cultivated roses. Introduced (?). Host: Rosa,

Fragaria. Curled rose sawfly.

Tenthredo cinctus Linnaeus, 1758. Syst. Nat., Ed. 10, v. 1, p. 557.

Tenthredo togatus Zetterstedt, 1838. Ins. Lapp., v. 1, p. 342. \&, ठ.

Dolerus cingulatus Blanchard, 1840. Hist. Nat. Ins., v. 3, p. 240.

Emphytus neglectus Zaddach, 1859. Programm Friedr. Col. Konigsberg, p. 27. o. 
Emphytus cinctipes Norton, 1867. Amer. Ent. Soc., Trans. 1: 229. ₹, ð.

Biology: Jack, 1889. Psyche 5: 279. - Britton, 1916. Conn. (State) Agr. Expt. Sta., Ann. Rpt. 1915, pt. 2, pp. 185-186. - Middleton, 1922. U. S. Dept. Agr., Farmers' Bul. 1252, 4 pp.

- McNay, 1958. Canad. Ins. Pest Rev. 36: 141 (on strawberry).

Morphology: Will, 1933. Pa. Acad. Sci., Proc. 7: 30-32 (wing venation variations).

mellipes (Norton). N. B., Que. to Fla. w. to Alta., Colo. Host: Fragaria.

Tenthredo (Emphytus) mellipes Harris, 1835. In Hitchcock, Rpt. Geol. Mineral. Bot. Zool. Mass., p. 583 . Nom. nud.

Emphytus mellipes Norton, 1861. Boston Soc. Nat. Hist., Proc. 8: 155. \&.

Emphytus gillettei MacGillivray, 1902. In Johnson, Colo. Expt. Sta., Ann. Rpt. 15: 113..

Biology: Johnson, 1902. Colo. Expt. Sta., Ann. Rpt. 15: 113-114.

nigritibialis Rohwer. N. J., Va; Siberia, China. Possibly introduced. Host: Rosa(?). May be only a color form of cinctus (L.).

Allantus cinctus nigritibialis Rohwer, 1911. U. S. Natl. Mus., Proc. 41: 407. 9 . Described from specimens intercepted in New Jersey from Hong Kong.

umbonatus Wong. Ont., Man., Sask., Alta. Host: Betula.

Allantus umbonatus Wong, 1966. Canad. Ent. 98: 852. ๆ.

viennensis (Schrank). N. Y. (Tompkins Co.); Europe. Introduced. Host: Rosa, Rubus.

Tenthredo Viennensis Schrank, 1781. Enum. Ins. Austr., p. 331.

Taxonomy: Smith, 1975. Coop. Econ. Ins. Rpt. 25 (10): 163-165 (first U. S. record).

Biology: Kartasheva, 1964. Zasch. Rast. ot Vred. i Boleznei 9 (10): 41-42. - Scheibelreiter, 1973. Ztschr. Angewandte Ent. 72: 243-244.

\section{Genus MACREMPHYTUS MacGillivray}

Macremphytus MacGillivray, 1908. Canad. Ent. 40: 368.

Type-species: Harpiphorus varianus Norton. Orig. desig.

Larvae of this North American genus feed on Cormus species of the osier dogwood group. After feeding, larvae sometimes bore into wood to form pupal cells.

lovetti MacGillivray. Alta., Mont., B. C., Idaho, Oreg. Ecology: Adults collected from Cornus.

Macremphytus lovetti MacGillivray, 1923. Psyche 30: 77..

semicornis (Say). Newfoundland to N. Y. w. to B. C. (Terrace), Man., Minn., Ill. Host: Cornus.

Emphytus semicomis Say, 1836. Boston Jour. Nat. Hist. 1: 220. $\%$.

Macremphytus bicornis MacGillivray, 1923. Ill. Univ. Bul. 20(50): 21. ?.

tarsatus (Say). N. B., Que. to Fla. w. to Minn., Ill., Kans., Tex. Host: Cornus sp., C. alternifolia.

Tenthredo (Emphytus) tarsata Harris, 1835. In Hitchcock, Rpt. Geol. Mineral. Bot. Zool.

Mass., p. 583. Nom. nud.

Emphytus tarsatus Say, 1836. Boston Jour. Nat. Hist. 1: 220..

Emphytus bollii Norton, 1872. Amer. Ent. Soc., Trans. 4: 80..

Harpiphorus intermedius Dyar, 1900. N. Y. Ent. Soc., Jour. 8: 30. ๆ, larva.

testaceus (Norton). Maine, Ont. to Ga. w. to Man., Minn., Colo. Host: Cormus sp., C. stolonifera C. candidissima.

Emphytus (Harpiphorus) testaceus Norton, 1861. Boston Soc. Nat. Hist., Proc. 8: 156..

Emphytus (Harpiphorus) varianus Norton, 1861. Boston Soc. Nat. Hist., Proc. 8: 156. , o.

Emphytus (Harpiphorus) versicolor Norton, 1867. Amer. Ent. Soc., Trans. 1: 230..

Biology: Jack, 1889. Garden and Forest 2: 520. - Riley and Howard, 1890. U. S. Dept. Agr., Insect Life 2: 239-243. -Will, 1944. Pa. Acad. Sci., Proc. 18: 48. -Will, 1959. Pa. Acad. Sci., Proc. 33: 214.

Morphology: Kreiger, Gilvert, and Wilkinson, 1970. Jour. Econ. Ent. 63: 1322-1323

(microsomal mixed-function oxidase activity). 


\section{Genus TAXONUS Hartig}

Taxonus Hartig, 1837. Fam. Blattwespen und Holzwespen, nebst Einleitung Naturgesch. Hym., p. 297.

Type-species: Tenthredo (Allantus) nitida Klug. Desig. by Rohwer, 1911.

Ermilia Costa, 1859. Fauna del Regno di Napoli, Imen., pt. 3, p. 106.

Type-species: Ermilia pulchella Costa. Monotypic.

Strongylogastroidea Ashmead, 1898. Canad. Ent. 30: 308.

Type-species: Allantus apicalis Say. Orig. desig.

Parasiobla Ashmead, 1898. Canad. Ent. 30: 308.

Type-species: Allantus mifocinctus Norton. Orig. desig.

Hypotaxonus Ashmead, 1898. Canad. Ent. 30: 311.

Type-species: Allantus pallipes Say. Orig. desig.

This genus is better represented in east Asia and eastern North America than in other parts of the world. Judging from the few records, plants of the Rosaceae serve as hosts.

borealis MacGillivray. Newfoundland to N. C., Tenn. w. to Mich., Wis.

Taxonus borealis MacGillivray, 1895. Canad. Ent. 27: 78..

epicera (Say). N. H., Ont. to N. C. w. to Wis., Ill. Kans., Tex.

Allantus epicera Say, 1836. Boston Jour. Nat. Hist. 1: 216. o.

pallicoxus (Provancher). N. S., N. B., Que. to Va. w. to Alta., Ill. Host: Fragaria.

Tenthredo (Taxonus) unicinctus Norton, 1862. Boston Soc. Nat. Hist., Proc. 9: 119. ‡, ठ. Preocc. by Brulle, 1832.

Strongylogaster pallicoxus Provancher, 1885. Addit. Corr. Faune Ent. Canada Hym., p. 11. १, ठ゚.

Strongylogaster pallidicoxis Dalla Torre, 1894. Cat. Hym., v. 1, p. 137. Emend.

Strongylogastroidea mifocinctana MacGillivray, 1923. Ill. Univ. Bul. 20(50): 31..

pallidicornis (Norton). Que., Maine, Ont. to Fla. w. to Wis., Ill., La. Host: Rubus.

Strongylogaster pallidicomis Norton, 1868. Amer. Ent. Soc., Trans. 2: 216..

pallipes (Say). N. H. to Ga., Ala. w. to Mich., Ill.

Allantus pallipes Say, 1823. West. Quart. Rptr. 2: 72.

Strongylogaster pallidipes Dalla Torre, 1894. Cat. Hym., v. 1, p. 137. Emend.

Strongylogastroidea rufula MacGillivray, 1923. Ill. Univ. Bul. 20(50): 32. ๆ.

proximus (Provancher). Que., Maine, Ont. s. to Ga.

Strongylogaster proximus Provancher, 1885. Addit. Corr. Faune Ent. Canada Hym., p. 12. ?.

Strongylogastroidea rufinerva MacGillivray, 1923. Ill. Univ. Bul. 20(50): 31..

rufocinctus (Norton). Que., Maine, Ont. to N. C. w. to Minn., Ill., Ark.

Allantus mufocinctus Norton, 1860. Boston Jour. Nat. Hist. 7: 248. ₹, ठ'.

Taxonus (Parasiobla) mufocinctus virginicus Rohwer, 1911. U. S. Natl. Mus., Proc. 41: 405.

ๆ.

Strongylogastroidea unicinctella MacGillivray, 1923. Ill. Univ. Bul. 20(50): 33. \&.

spiculatus (MacGillivray). Maine to N. C., Tenn. w. to Ohio, W. Va.

Strongylogastroidea spiculata MacGillivray, 1908. Canad. Ent. 40: 369. \&.

terminalis (Say). N. S., N. B., Que., Ont. to Fla. w. to Minn., Ill., Tex.

Tenthredo terminalis Say, 1824. In Keating, Narr. Long's 2nd Exped., v. 2 (App.), p. 318. ㅇ, $\delta$.

Tenthredo (Allantus) melisoma Harris, 1835. In Hitchcock, Rpt. Geol. Mineral. Bot. Zool. Mass., p. 583. Nom. nud.

Allantus apicalis Say, 1836. Boston Jour. Nat. Hist. 1: 216.

Allantus abdominalis Norton, 1860. Boston Jour. Nat. Hist. 7: 238. ๆ, ठ.

Allantus mellosus Norton, 1860. Boston Jour. Nat. Hist. 7: 287.,$\delta$.

Strongylogaster mifoculus MacGillivray, 1894. Canad. Ent. 26: 327. ‡.

Strongylogastroidea confusa MacGillivray, 1908. Canad. Ent. 40: 369. ․

Strongylogastroidea shermani MacGillivray, 1923. Ill. Univ. Bul. 20(50): 32.. 


\section{SUBFAMILY TENTHREDININAE}

This subfamily contains most of the larger and more colorful members of the Tenthredinidae. Though commonly collected, hosts and life histories are known for very few species.

Taxonomy: Benson, 1959. Roy. Ent. Soc. London, Proc., Ser. B: Taxonomy 28: 121-127 (tribes).

\section{TRIBE PERINEURINI}

\section{Genus LEUCOPELMONUS MacGillivray}

Leucopelmonus MacGillivray, 1916. Conn. State Geol. and Nat. Hist. Survey Bul. 22: 83.

Type-species: Leucopelmonus annulatus MacGillivray. Monotypic.

annulicornis (Harrington). Newfoundland, Que., Ont. s. to N. C.

Tenthredo confusus Norton, 1869. Amer. Ent. Soc., Trans. 2: 241. ठ. Preocc. by Lepeletier, 1823.

Tenthredopsis? annulicornis Harrington, 1893. Canad. Ent. 25: 61. ๆ, ठ์.

Perineura turbata Rohwer, 1911. U. S. Natl. Mus., Proc. 41: 408., ó.

Leucopelmonus annulatus MacGillivray, 1916. Conn. State Geol. and Nat. Hist. Survey, Bul. 22: 83. .

\section{TRIBE SCIAPTERYGINI}

\section{Genus ZASCHIZONYX Ashmead}

Zaschizonyx Ashmead, 1898. Canad. Ent. 30: 257.

Type-species: Hoplocampa montana Cresson. Orig. desig.

Opisthoneura Ashmead, 1898. Canad. Ent. 30: 287.

Type-species: Opisthoneura Crevecoeuri Ashmead. Orig. desig.

Revision: Ross, 1929. Canad. Ent. 61: 272-273.

Taxonomy: Benson, 1959. Roy. Ent. Soc. London, Proc., Ser. B: Taxonomy 28: 127.

montana (Cresson). Ont., Minn., Ill., Iowa, Mo. w. to B. C., Wash., Oreg., Calif. Host:

Symphoricarpos.

Selandria montana Cresson, 1865. Ent. Soc. Phila., Proc. 4: 244. $\uparrow$.

Selandria (Hoplocampa) gentilis Cresson, 1880. Amer. Ent. Soc., Trans. 8: 14. ð.

Opisthoneura Crevecoeuri Ashmead, 1898. Canad. Ent. 30: 287.

Zaschisonyx(!) montana var. drabula Ross, 1929. Canad. Ent. 61: 272. ․

Zaschisonyx(!) montana subsp. occidentalis Ross, 1929. Canad. Ent. 61: 272. ९.

pluricincta (Norton). Ariz., Calif.

Macrophya pluricinctus Norton, 1862. Boston Soc. Nat. Hist., Proc. 9: 118. ๆ, ठ.

Macrophya albipes Provancher, 1895. Nat. Canad. 22: 95. \&, §. Preocc. by Geoffroy, 1785.

Labidia doanei Rohwer, 1909. Canad. Ent. 41: 91. .

Macrophya provancheri Rohwer, 1909. Canad. Ent. 41: 328. N. name for albipes

Provancher.

Macrophya nigricomis Rohwer, 1909. Canad. Ent. 41: 329. \&, ठ.

Macrophya occidentalis Rohwer, 1909. Canad. Ent. 41: 330. ठँ.

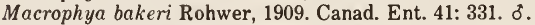

Macrophya truncata Rohwer, 1909. Canad. Ent. 41: 331. \&, ठ.

Macrophya pluricinctella Rohwer, 1909. Canad. Ent. 41: 332. क.

Macrophya multicincta Rohwer, 1909. Canad. Ent. 41: 333. \&.

Macrophya melanostoma Rohwer, 1909. Canad. Ent. 41: 333. ?.

Macrophya napensis Rohwer, 1911. U. S. Natl. Mus., Proc. 41: 410. ९.

Morphology: Matsuda, 1957. Kans. Ent. Soc., Jour. 30: 99-108 (head).

\section{TRIBE TENTHREDOPSINI}

\section{Genus AGLAOSTIGMA Kirby}

Aglaostigma Kirby, 1882. List Hym. Brit. Mus., v. 1, p. 325. 
Type-species: Aglaostigma eburneiguttatum Kirby. Monotypic.

Laurentia Costa, 1890. Accad. delle Sci. Fis. e Mat. Napoli, Rend. (ser. 2) 4: 173. Preocc. by Ragonot, 1888.

Type-species: Laurentia craverii Costa. Monotypic.

Bivena MacGillivray, 1894. Canad. Ent. 24: 328.

Type-species: Bivena maria MacGillivray. Orig. desig.

Homoeoneura Ashmead, 1898. Canad. Ent. 30: 313.

Type-species: Pachyprotasis delta Provancher. Orig. desig.

Neopus Viereck, 1910. In Smith, N. J. State Mus., Ann. Rpt. 1909, p. 585.

Type-species: Tenthredo quattuardecimpunctatus Norton. Orig. desig.

Macrophyopsis Enslin, 1913. Deut. Ent. Ztschr., Beih., p. 128.

Type-species: Macrophya nebulosa Andre. Orig. desig.

Astochus MacGillivray, 1914. Canad. Ent. 46: 107.

Type-species: Astochus fletcheri MacGillivray. Orig. desig.

Kincaidia MacGillivray, 1914. Canad. Ent. 46: 107.

Type-species: Tenthredopsis ruficorna MacGillivray. Orig. desig.

Parallomma Malaise, 1933. Ent. Tidskr. 54: 53.

Type-species: Rhogogaster lichtwardti Konow. Orig. desig.

Neurosiobla Conde, 1935. Notulae Ent. 14: 79.

Type-species: Nenrosiobla malaisei Conde. Orig. desig.

Laurentina Malaise, 1937. Rev. d'Ent. Franc. 4: 44.

Type-species: Laurentina ruficornis Malaise. Orig. desig.

Revision: Ross, 1943. Ent. Soc. Wash., Proc. 45: 79-84.

dilutum (Cresson). Calif.

Tenthredo diluta Cresson, 1880. Amer. Ent. Soc., Trans. 8: 24 . 9.

quattuordecimpunctatum (Norton), Que., Maine, Ont. s. to N. C. Host: Podophyllum peltatum.

Tenthredo 14-punctatus Norton, 1862. Ent. Soc. Phila., Proc. 1: 143. \&, ठ.

rubens (Cresson). Idaho, Nev. B. C., Wash., Oreg., Calif.

Tenthredo rubens Cresson, 1880. Amer. Ent. Soc., Trans. 8: 24. ठ.

Tenthredo Edwardsii Cresson, 1880. Amer. Ent. Soc., Trans. 8: 24..

Tenthredo atravenus MacGillivray, 1895. Canad. Ent. 27: 283. ¿.

Astochus fletcheri MacGillivray, 1914. Canad. Ent. 46: 108. ๆ.

Astochus aldrichi MacGillivray, 1914. Canad. Ent. 46: 137. $९$.

Tenthredo racilia MacGillivray, 1923. N. Y. Ent. Soc., Jour. 31: 112. ठ.

Tenthredo refractaria MacGillivray, 1923. N. Y. Ent. Soc., Jour. 31: 113..+

ruficornum (MacGillivray). Wash., Oreg.

Tenthredopsis ruficorna MacGillivray, 1893. Canad. Ent. 25: 242. ๆ.

semiluteum (Norton). Que., Maine to S. C. w. to Mont., Iowa, Kans. Host: Impatiens biflora.

Tenthredo semiluteus Norton, 1862. Boston Soc. Nat. Hist., Proc. 9: 121. ₹, ơ.

Pachyprotasis delta Provancher, 1878. Nat. Canad. 10: 108. $\%$.

Bivena maria MacGillivray, 1894. Canad. Ent. 26: 328. \&.

jocosa (Provancher). Que., N. H., Mass., Man.

Tenthredo jocosa Provancher, 1882. Nat. Canad. 13: 298. .

Harpiphorus varipictus Harrington, 1889. Canad. Ent. 21: 96. ?.

Aglaostigma dentatum Ross, 1943. Ent. Soc. Wash., Proc. 45: 82. ९, ठे.

veedee Ross. Calif.

Aglaostigma veedee Ross, 1943. Ent. Soc. Wash., Proc. 45: 81., ,

\section{TRIBE TENTHREDININI}

\section{Genus LAGIUM Konow}

Lagium Konow, 1904. Ztschr. System. Hym. Dipt. 4: 246.

Type-species: Tenthredo atroviolaceum Norton. Orig. desig.

Revision: Rohwer, 1912. U. S. Natl. Mus., Proc. 43: 213. 
atroviolaceum (Norton). Que. to Va. w. to Wis., Ill., Kans. Host: Sambucus.

Tenthredo (Allantus) atroviolacea Harris, 1835. In Hitchcock, Rpt. Geol. Mineral. Bot. Zool. Mass., p. 583. Nom. nud.

Allantus atroviolaceus Norton, 1860. Boston Jour. Nat. Hist. 7: 255. \&, ઠ.

Teuthredo atroviolacea var. peratra Dyar, 1897. N. Y. Ent. Soc., Jour. 5: 192. ठ̊, larva.

Lagium angulabre Rohwer, 1912. U. S. Natl. Mus., Proc. 43: 215. ठ.

Lagium planifrons Rohwer, 1912. U. S. Natl. Mus., Proc. 43: 216. $\uparrow$, ઠ.

tardum (Norton). Mass. to Ga. w. to Wis., Ill., Kans.

Teuthredo (Allantus) tarda Harris, 1835. In Hitchcock, Rpt. Geol. Mineral. Bot. Zool. Mass., p. 583. Nom. nud.

Allantus tardus Norton, 1860. Boston Jour. Nat. Hist. 7: 246. $q, ~ \delta$.

Lagium erythrogastrum Rohwer, 1912. U. S. Natl. Mus., Proc. 43: 214. ๆ.

\section{Genus RHOGOGASTER Konow}

Rhogogaster Konow, 1884. Deut. Ent. Ztschr. 28: 257.

Type-species: Tenthredo viridis Linnaeus. Desig. by Rohwer, 1911.

Rhogogastera Konow, 1885. Wien. Ent. Ztg. 4: 123. Emend.

Primarily a Palaearctic genus with only four species in North America. Three of the six species groups separated by Benson (1965) are represented on this continent.

Revision: Ross, 1943. Pan-Pacific Ent. 19: 129-136.

Taxonomy: Benson, 1965. Roy. Ent. Soc. London, Proc., Ser. B: Taxonomy 34: 105-112 (world species and species groups).

\section{SPEcies Group Lateraria}

addenda (Cresson). Mont. and Colo. w. to B. C., Wash., Oreg., Calif. Tenthredo addenda Cresson, 1880. Amer. Ent. Soc., Trans. 8: 23. ؟. Tenthredo vittatipes Cresson, 1880. Amer. Ent. Soc., Trans. 8: 24. ठ. Rhogogaster truncatus Rohwer, 1912. U. S. Natl. Mus., Proc. 43: 211. ๆ. Rhogogaster pitohatus Rohwer, 1912. U. S. Natl. Mus., Proc. 43: 211..

lateraria (Cresson). Alta., Mont., Nev. w. to B. C., Wash., Oreg., Calif. Tenthredo lateraria Cresson, 1880. Amer. Ent. Soc., Trans. 8: 23. ₹. Tenthredo retosta MacGillivray, 1923. N. Y. Ent. Soc., Jour. 31: 109. ठ'.

\section{Species Group Californica}

californica (Norton). Que. to Yukon s. to N. Y., Man., N. Mex., Utah, Calif.; Norway. Host: Populus balsamifera, $P$. tremuloides.

Tenthredo californicus Norton, 1862. Ent. Soc. Phila., Proc. 1: 198..

Tenthredopsis Evansii Harrington, 1889. Canad. Ent. 21: 98..

Tenthredo ripula MacGillivray, 1923. N. Y. Ent. Soc., Jour. 31: 109. ठ.

Rhogogaster polaris Lindqvist, 1964. Notulae Ent. 44: 121. ठ.

Taxonomy: Benson, 1965. Roy. Ent. Soc. London, Proc. Ser. B: Taxonomy 34: 108.

\section{Species Group VIRIDIS}

viridis (Linnaeus). Yukon and Alaska s. to Man., Mont., Calif.; Eurasia, Japan. Host: Salix, Populus, Alnus, Ranunculus, Filipendula, Stellaria, Circaea. These hosts recorded in Europe.

Tenthredo viridis Linnaeus, 1758. Syst. Nat., Ed. 10, v. 1, p. 557..

Rhogogastera ruga MacGillivray, 1923. Canad. Ent. 55: 160..

Rhogogastera respectus MacGillivray, 1923. N. Y. Ent. Soc., Jour. 31: 165. ๆ.

Rhogogaster similis Lindqvist, 1958. Notulae Ent. 38: 68.

Taxonomy: Benson, 1963. Notulae Ent. 43: 137-138 (wear and damage of saws).

Morphology: Zacwilichowska, 1953. Polski Pismo Ent. 23: 114-128 (innervation and sense organs in wings). 


\section{Genus ISCHYROCERAEA Kiaer}

Ischyroceraea Kiaer, 1898. Tromsoe Mus. Aarsh. 19: 68.

Type-species: Ischyroceraea hyperborea Kiaer. Monotypic.

The species below is sometimes given in the genus Eniscia Thomson, 1870 . However, the only valid type-species designation of Eniscia is Tenthredo consobrina Klug as designated by Rohwer, 1911. Because of this Eniscia is a synonym of Sciapteryx Stephens, 1835, a Palaearctic genus.

Taxonomy: Smith, 1974. Coop. Econ. Ins. Rpt. 24 (35): 707-710 (first N. Amer. record). arctica (Thomson). Alaska (Umiat); Siberia, Scandinavia.

Eniscia aretica Thomson, 1870. Opusc. Ent. 2: 300.

Ischyroceraea hyperborea Kiaer, 1898. Tromsoe Mus. Aarsh. 19: 68.

\section{Genus TENTHREDO Linnaeus}

Tenthredo Linnaeus, 1758. Syst. Nat., Ed. 10, v. 1, p. 343.

Type-species: Tenthredo scrophulariae Linneaus. Desig. by Latreille, 1810 .

Labidia Provancher, 1886. Addit. Corr. Faune Ent. Canada Hym., p. 21.

Type-species: Labidia columbiana Provancher. Monotypic.

Parastatis Kirby, 1881. Ent. Monthly Mag. 18: 107.

Type-species: Parastatis indica Kirby. Monotypic.

Rethrax Cameron, 1899. Manchester Lit. Phil. Soc., Mem. and Proc. 43: 33.

Type-species: Rethrax carinata Cameron. Monotypic.

Fethalia Cameron, 1902. Bombay Nat. Hist. Soc., Trans. 14: 439.

Type-species: Fethalia nigra Cameron. Monotypic.

Clydostomus Konow, 1908. Ztschr. System. Hym. Dipt. 8: 19.

Type-species: Clydostomus cestatus Konow. Desig. by Rohwer, 1911.

Tenthredella Rohwer, 1910. U. S. Natl. Mus., Proc. 39: 117.

Type-species: Tenthredo atra Linnaeus. Orig. desig.

Zamacrophya Rohwer, 1912. U. S. Natl. Mus., Proc. 39: 221.

Type-species: Zamacrophya nigrilabris Rohwer. Orig. desig.

Probably the largest sawfly genus, with over 700 described world species. Adults are large and many are brightly colored. They are commonly found on flowers of various plants where they feed on nectar and pollen and may also be factors in pollination. Adults are also predaceous on other arthropods. Hosts and biologies are known for very few species. European authors have devised their own species groups within the genus; however, until the North American forms are studied in relation to the world fauna, the species groups below are retained from previous catalogs.

Taxonomy: Rohwer, 1912. U. S. Natl. Mus., Proc. 43: 225-226 (key to species of Labidia [originalis group]). -Smulyan, 1923. Boston Soc. Nat. Hist., Proc. 36: 385-465 (New England species).

\section{SPECIES GROUP ORIGINALIS}

anomocera Rohwer. Alta., Wyo., Colo. w. to B. C., Oreg., Calif.

Tenthredo (Labidia) anomocemis Rohwer, 1912. U. S. Natl. Mus., Proc. 43: 223..

Tenthredo (Labidia) alienatus Rohwer, 1912. U. S. Natl. Mus., Proc. 43: 224. ?.

Tenthredo (Labidia) anomus Rohwer, 1912. U. S. Natl. Mus., Proc. 43: 225 ..

devia (Konow). Alaska (Aleutian Islands to Popof Is.); Japan, N. Siberia to N. Europe. Allantus devius Konow, 1900. Ent. Nachr. 26: 124. ?.

Allantus heraclei Kincaid, 1900. Wash. Acad. Sci., Proc. 2: 364. $\subsetneq$, ð. Preocc. by Rudow, 1872.

Allantus alaskanus Enslin, 1910. Rev. Russe d'Ent. 10: 371. N. name for heraclei Kincaid.

Taxonomy: Benson, 1959. Roy. Ent. Soc. London, Proc., Ser. B: Taxonomy 28: 98.

maxima (Norton). Alta., Mont., Wyo., Colo., N. Mex. w. to Wash., Oreg., Calif.

Allantus unicinctus Norton, 1864. Ent. Soc. Phila., Proc. 3: 9. १, ठ. Preocc. by Brulle, 1832.

Allantus maximus Norton, 1867. Amer. Ent. Soc., Trans. 1: 263.. 
Allantus unicinctulus Dalla Torre, 1894. Cat. Hym., v. 1, p. 80. N. name for unicinctus Norton.

ocampa Ross. Ariz.; Mexico.

Zamacrophya nigrilabris Rohwer, 1912. U. S. Natl. Mus., Proc. 43: 222. \&, §. Preoce. by Friwaldozky, 1876.

Tenthredo ocampa Ross, 1951. In Muesebeck, et al., U. S. Dept. Agr., Agr. Monog. 2: 71. N. name for nigrilabris Rohwer.

opima (Cresson). Colo. w. to B. C., Wash., Oreg., Calif.

Allantus opimus Cresson, 1880. Amer. Ent. Soc., Trans. 8: 15. ^, §.

Labidia Columbiana Provancher, 1886. Addit. Corr. Faune Ent. Canada Hym., p. 21. $\delta$.

Tenthredo (Labidia) opimus coloradensis Rohwer, 1912. U. S. Natl. Mus., Proc. 43: 224. ๆ.

originalis (Norton). Labrador $\mathrm{s}$. to N. Y.

Allantus originalis Norton, 1867. Amer. Ent. Soc., Trans. 1: 261. ․

retura Ross. Nev., Calif.

Allantus nigriceps Cresson, 1880. Amer. Ent. Soc., Trans. 8: 16. ₹, §. Preocc. by Spinola, 1851.

Tenthredo retura Ross, 1951. In Muesebeck, et al., U. S. Dept. Agr., Agr. Monog. 2: 71. N. name for nigriceps Cresson.

subnigriceps (Rohwer). N. Mex., Utah w. to Wash., Oreg., Calif.

Allantus subnigriceps Rohwer, 1909. Canad. Ent. 41: 148. ?.

Species Group Piceocincta

piceocincta (Norton). Ont. to Alaska s. to N. H., N. Y., B. C., Wash.

Allantus piceocinctus Norton, 1860. Boston Jour. Nat. Hist. 7: 249. .

Allantus cogitans Provancher, 1878. Nat. Canad. 10: 163..

Tenthredo basilaris Provancher, 1878. Nat. Canad. 10: 196. . Preoce. by Say, 1824.

Tenthredo hudsoni Kirby, 1882. List Hym. Brit. Mus., v. 1, p. 318. ?. A questionable synonym.

Allantus robustus Provancher, 1885. Addit. Corr. Faune Ent. Canada Hym., p. 8..

Tenthredo ruficoxa Provancher, 1885. Addit. Corr. Faune Ent. Canada Hym., p. 14..

Tenthredo ventricus MacGillivray, 1895. Canad. Ent. 27: 284. ठ.

Tenthredo sicatus MacGillivray, 1900. Canad. Ent. 32: 179. ठ.

Tenthredo lunatus MacGillivray, 1900. Canad. Ent. 32: 180. $\%$.

Tenthredo harrimani Kincaid, 1900. Wash. Acad. Sci., Proc. 2: 363. ๆ.

Tenthredo cynthia Enslin, 1912. Arch. f. Naturgesch. 6: 105. N. name for basilaris

Provancher.

Tenthredo neoslossoni MacGillivray, 1914. Canad. Ent. 46: 138. ㅇ.

Tenthredo yuasi MacGillivray, 1920. Brooklyn Ent. Soc., Bul. 15: 112. ๆ.

Tenthredo smetica MacGillivray, 1920. Brooklyn Ent. Soc., Bul. 15: 113. \&.

Tenthredo reputinella MacGillivray, 1923. Ill. Univ. Bul. 20(50): 33. ¿े.

\section{SPECIES GRoup BASILARIS}

basilaris Say. N. S., N. B., Que. to N. C. w. to Alta., Minn., Colo., N. Mex.

Tenthredo (Allantus) coronatus Harris, 1835. In Hitchcock, Rpt. Geol. Mineral. Bot. Zool. Mass., p. 583. Nom. nud.

Tenthredo basilaris Say, 1824. In Keating, Narr. Long's 2nd Exped. (App.) p. 316..

Allantus universus MacGillivray, 1923. Ill. Univ. Bul. 20(50): 6. ๆ.

Tenthredo rumina MacGillivray, 1923. Canad. Ent. 55: 160. ?.

fernaldii MacGillivray. Maine, Ont. to Pa. w. to Minn., Colo.

Allantus dubius Norton, 1860. Boston Jour. Nat. Hist. 7: 241. \&. Preoce. by Strom, 1768.

Tenthredo fernaldii MacGillivray, 1900. Canad. Ent. 32: 177. .

perplexa MacGillivray. Alaska s. to Oreg.

Tenthredo perplexus MacGillivray, 1897. N. Y. Ent. Soc., Jour. 5: 104. ๆ.

Tenthredo commata Konow, 1908. Ztschr. System Hym. Dipt. 8: 90. ‡, ठ。.

Tenthredo rabula MacGillivray, 1923. N. Y. Ent. Soc., Jour. 31: 112. ठ.

Tenthredo rima MacGillivray, 1923. N. Y. Ent. Soc., Jour. 31: 110. ठ. 


\title{
Species Group Olivacea
}

olivacea Klug. Yukon, Alaska; Europe to Siberia.

Tenthredo (Allantus) olivacea Klug, 1814. Mag. Gesell Naturf. Freunde Berlin 8: 193. \&, $\delta$.

Tenthredo dissimulans Kincaid, 1900. Wash. Acad. Sci. , Proc. 2: 363. ๆ, ठ์.

Rhogogastera respersus MacGillivray, 1923. N. Y. Ent. Soc., Jour. 31: 165. ठ.

\author{
SPECIES GROUP RUFOPECTA
}

mellicoxa Provancher. Ont. to Va. w. to Minn., W. Va.

Tenthredo mellicoxa Provancher, 1878. Nat. Canad. 10: 198. ๆ, ठ.

repleta MacGillivray. Wash., Oreg.

Tenthredo repleta MacGillivray, 1923. N. Y. Ent. Soc., Jour. 31: 111. ๆ, ठ.

rufopecta (Norton). N. B. to N. C. w. to Wis.

Allantus rufopectus Norton, 1860. Boston Jour. Nat. Hist. 7: 255. ๆ, ठ.

rurigena MacGillivray. N. B., Que., Ont. to N. Y. w. to Minn., Colo.

Tenthredo lineata Provancher, 1878. Nat. Canad. 10: 198. ๆ. Preocc. by Christ, 1791.

Tenthredo mirigena MacGillivray, 1923. Ill. Univ. Bul. 20(50): 36. ๆ.

SPECIES GROUP PECTORALIS

associata Enslin. Calif.

Allantus limbatus Cresson, 1880. Amer. Ent. Soc., Trans. 8: 17. ๆ. Preocc. by Klug, 1814.

Tenthredo associata Enslin, 1912. Arch. f. Naturgesch. 6: 103. N. name for limbatus Cresson.

Tenthredo cryptella Ross, 1951. In Muesebeck, et al., U. S. Dept. Agr., Agr. Monog. 2: 73. N. name for limbatus Cresson.

pectoralis Norton. Idaho, Colo. w. to Alaska, B. C., Wash., Oreg., Calif.

Tenthredo pectoralis Norton, 1864. Ent. Soc. Phila., Proc. 3: 11. ठ.

Tenthredo variegatus Norton, 1864. Ent. Soc. Phila., Proc. 3: 12. ठ. A questionable synonym.

Allantus afflictus Cresson, 1880. Amer. Ent. Soc., Trans. 8: 17.,$\delta$.

Allantus nevadensis Cresson, 1880. Amer. Ent. Soc., Trans. 8: 17. ๆ, ठँ.

Allantus occidaneus Cresson, 1880. Amer. Ent. Soc., Trans. 8: 18..

Tenthredo parvula Cresson, 1880. Amer. Ent. Soc., Trans. 8: 22. §. Preoce. by Lepeletier, 1823.

Tenthredo lateralba MacGillivray, 1897. N. Y. Ent. Soc., Jour. 5: 108..

Tenthredo aldrichii MacGillivray, 1900. Canad. Ent. 32: 183. $९$.

Tenthredo atracostus MacGillivray, 1900. Canad. Ent. 32: 183. \&.

Tenthredo nigrifascia MacGillivray, 1900. Canad. Ent. 32: 184. $\subsetneq$.

Tenthredo savagei MacGillivray, 1900. Canad. Ent. 32: 184..

Tenthredo coenobita Enslin, 1912. Arch. f. Naturgesch. 6: 104. N. name for parvula

Cresson.

Tenthredo remissa MacGillivray, 1923. N. Y. Ent. Soc., Jour. 31: 114. ठ.

Tenthredo reperta MacGillivray, 1923. N. Y. Ent. Soc., Jour. 31: 115. ๆ.

Tenthredo replata MacGillivray, 1923. N. Y. Ent. Soc., Jour. 31: 115...

Tenthredo reticentia MacGillivray, 1923. N. Y. Ent. Soc., Jour. 31: 114. ๆ.

Tenthredo refuga MacGillivray, 1923. N. Y. Ent. Soc., Jour. 31: 167. ๆ.

Tenthredo rota MacGillivray, 1923. Ill. Univ. Bul. 20(50): 34. ๆ.

Tenthredo minosa MacGillivray, 1923. Ill. Univ. Bul. 20(50): 36..

Tenthredo ruta MacGillivray, 1923. Ill. Univ. Bul. 20(50): 37..

SPECIES Group ANGULIFERA

angulifera (Norton). N. B., Que. to Pa. w. to Mich., Ohio.

Allantus angulifer Norton, 1860. Boston Jour. Nat. Hist. 7: 252.,$\delta$.

carolina (Rohwer). N. C., Ohio.

Tenthredella carolina Rohwer, 1913. U. S. Natl. Mus., Proc. 45: 275. ๆ.

dissimilis (Norton). Maine, N. Y.

Allantus dissimilis Norton, 1860. Boston Jour. Nat. Hist. 7: 250. ․

Tenthredo bilineatus MacGillivray, 1895. Canad. Ent. 27: 282. \&. 
fisheri (Rohwer). N. J., Md., Va., Ill.

Tenthredella fisheri Rohwer, 1913. U. S. Natl. Mus., Proc. 45: 276. \&.

glacialis (Ross). Ill.

Tenthredella glacialis Ross, 1931. Ent. Soc. Amer., Ann. 24: 110. ९, ठ.

lobata (Norton). N. Y. to N. C. w. to Wis.

Allantus lobatus Norton, 1860. Boston Jour. Nat. Hist. 7: 253. \&.

mantha Ross. Conn. w. to Wis., Ill.

Tenthredella lobata maculosa Smulyan, 1915. Canad. Ent. 47: 324. \&, o. Preoce. by

Lepeletier, 1823.

Tenthredo mantha Ross, 1951. In Muesebeck, et al., U. S. Dept. Agr., Agr. Monog. 2: 73. N. name.

\section{Species Group Leucostoma}

einctitibiis Norton. N. H., N. Y. w. to Alta.

Tenthredo cinctitibiis Norton, 1869. Amer. Ent. Soc., Trans. 2: 239. \&.

Tenthredo decorata Provancher, 1878. Nat. Canad. 10: 200. \&. A questionable synonym.

erythromera Provancher. Que., S. Dak., Colo. w. to Alaska, B. C., Wash., Oreg., Calif.

Tenthredo erythromera Provancher, 1885. Addit. Corr. Faune Ent. Canada Hym., p. 13. \&.

Tenthredo atrocoerulea Provancher, 1885. Addit. Corr. Faune Ent. Canada Hym., p. 13. \&.

Tenthredo nigricostata Provancher, 1885. Addit. Corr. Faune Ent. Canada Hym., p. 14. \&.

Tenthredo terminalis Provancher, 1885. Addit. Corr. Faune Ent. Canada Hym., p. 14. $\delta$.

Preoce. by Smith, 1878.

Tenthredo nigrisoma Harrington, 1894. Canad. Ent. 26: 195. ․ Preocc.

Tenthredo chaonica Enslin, 1912. Arch. f. Naturgesch. 6: 105. N. name for terminalis

Provancher.

Tenthredo regula MacGillivray, 1923. N. Y. Ent. Soc., Jour. 31: 166. ๆ.

Tenthredo requieta MacGillivray, 1923. N. Y. Ent. Soc., Jour. 31: 167. ?.

fraternalis (Ross). Alta., B. C.

Tenthredella fraternalis Ross, 1931. Ent. Soc. Amer., Ann. 24: 113. ?.

fumipennis Norton. Calif.

Tenthredo fumipennis Norton, 1869. Amer. Ent. Soc., Trans. 2: 236. ठ.

leucostoma Kirby. N. S. to Pa. w. to Alta., S. Dak., Colo.

Tenthredo mifipes Say, 1824. In Keating, Narr. Long's 2nd Exped. (App.) p. 317. \&. Preocc. by Linnaeus, 1758.

Tenthredo leucostoma Kirby, 1837. Fauna Bor.-Amer., v. 4, p. 256.

Tenthredo rufopedibus Norton, 1864. Ent. Soc. Phila., Proc. 3: 15. ठ̊.

Taxonomy: Benson, 1962. Brit. Mus. (Nat. Hist.) Ent., Bul. 12: 392 (Possibly a geographical race of Tenthredo atra Linnaeus, a widespread species in Eurasia).

mellipes Rohwer. Colo.

Tenthredo mellipes Rohwer, 1909. Canad. Ent. 41: 105. \&.

nigritibialis MacGillivray. Wash.

Tenthredo nigritibialis MacGillivray, 1897. N. Y. Ent. Soc., Jour. 5: 107. ठ.

nimbipennis Cresson. Md., Ill., Ark., Tex.

Tenthredo nimbipennis Cresson, 1872. Amer. Ent. Soc., Trans. 4: 155. \&.

remea MacGillivray. Oreg.

Tenthredo remea MacGillivray, 1923. N. Y. Ent. Soc., Jour. 31: 107. \&.

Tenthredo remora MacGillivray, 1923. N. Y. Ent. Soc., Jour. 21: 108. ठ.

ruficollis Harrington. B. C.

Tenthredo mificollis Harrington, 1894. Canad. Ent. 26: 195..

ruma MacGillivray. $\mathrm{Pa}$.

Tenthredo mima MacGillivray, 1923. 1ll. Univ. Bul. 20(50): 36. ठ.

subcoerulea Eschscholtz. Que. to Alaska s. to Fla., Colo., Calif. Ecology: Widespread.

Tenthredo subcoerulea Eschscholtz, 1822. Entomographien, p. 91.

Allantus flavomarginis Norton, 1860. Boston Jour. Nat. Hist. 7: 254..

Tenthredo melanosoma Harrington, 1894. Canad. Ent. 26: 194... 
Tenthredo pallipunctus MacGillivray, 1895. Canad. Ent. 27: 282. + . A questionable synonym.

Tenthredo sahlbergii Konow, 1908. Ztschr. System. Hym. Dipt. 8: 91. ๆ, ठ.

SPECIES GROUP OCCIDENTALIS

bella Cresson. Colo.

Tenthredo bella Cresson, 1880. Amer. Ent. Soc., Trans. 8: 21..

occidentalis Cresson. Ont. (?), Wyo., Colo.

Tenthredo occidentalis Cresson, 1880. Amer. Ent. Soc., Trans. 8: 23. ๆ.

Tenthredo vapida Kirby, 1882. List Hym. Brit. Mus., v. 1, p. 315. ९, ठ. A questionalbe synonym.

Tenthredo ferrugineipes var. pikei Rohwer, 1909. Canad. Ent. 41: 107. .

Tenthredo varifrons Rohwer, 1909. Canad. Ent. 41: 110. ऊ. A questionable synonym.

subrufescens Kirby. Ont.

Tenthredo subrufescens Kirby, 1882. List Hym. Brit. Mus., v. 1, p. 311..

\section{SpECIES Group Grandis}

colon Klug. Labrador, N. B., N. H. w. to Alaska; Europe, Asia Minor, Siberia. Host: Viburnum, Salix, Rosa, Corylus, Sorbus. These hosts recorded in Europe.

Tenthredo (Allantus) colon Klug, 1814. Mag. Gesell. Naturf. Freunde Berlin 8: 182. ๆ, ó.

Tenthredo eburneifrons Kirby, 1882. List Hym. Brit. Mus., v. 1, p. 306 . ?.

Tenthredo nigricollis Kirby, 1882. List Hym. Brit. Mus., v. 1, p. 308..+

Taxonomy: Benson, 1962. Brit. Mus. (Nat. Hist.) Ent., Bul. 12: 392 (Tenthredo livida of American authors, not Linnaeus).

grandis (Norton). N. B., Que., Ont. s. to N. C.

Allantus grandis Norton, 1860. Boston Jour. Nat. Hist. 7: 239..

Tenthredo antennata Kirby, 1882. List Hym. Brit. Mus., v. 1, p. 308..

Tenthredo dubitatus MacGillivray, 1897. N. Y. Ent. Soc., Jour. 5: 103. o.

SPECIES GROUP VERTICALIS

borealis Kirby. Ont., N. Y. w. to Alta., Minn.

Tenthredo cingulata Provancher, 1878. Nat. Canad. 10: 196. + . Preocc.

Tenthredo borealis Kirby, 1882. List Hym. Brit. Mus., v. 1, p. 318..

Tenthredo rutila MacGillivray 1923. Canad. Ent. 55: 160. $\uparrow$.

verticalis Say. N. B., Que., Ont. to N. C. w. to Minn.

Tenthredo verticalis Say, 1824. In Keating, Narr. Long's Exped. (App.) p. 317..

Tenthredo causatus MacGillivray, 1900. Canad. Ent. 32: 178. ơ.

Tenthredo rubripes MacGillivray, 1900. Canad. Ent. 32: 178. ठ.

Species Group SEMirufa

attracta Norton. "English River."

Tenthredo attractus Norton, 1869. Amer. Ent. Soc., Trans. 2: 240. \&.

concessa Norton. Ont. to Pa. w. to Alta., S. Dak., Mont., Colo. Host: Betula.

Allantus tricolor Norton, 1860. Boston Jour. Nat. Hist. 7: 247. . Preoce.

Tenthredo concessus Norton, 1869. Amer. Ent. Soc., Trans. 2: 238. १.

Tenthredo barnstoni Kirby, 1882. List Hym. Brit. Mus., v. 1, p. 314. ₹, ठ. A questionable synonym.

Tenthredo cressonii Kirby, 1882. List. Hym. Brit. Mus., v. 1, p. 315..

Tenthredo uniformis Kirby, 1882. List Hym. Brit. Mus., v. 1, p. 317. ․

Tenthredella rohweri Smulyan, 1915. Canad. Ent. 47: 323. N. name for tricolor Norton.

Tenthredella tricolor var. savanna Ross, 1931. Ent. Soc. Amer., Ann. 24: 116. ․

Biology: Dyar, 1895. Amer. Ent. Soc., Trans. 12: 312.

eximia Norton. Maine to N. J. w. to Alta., Colo.

Tenthredo eximius Norton, 1869. Amer. Ent. Soc., Trans. 2: 231. ๆ, ઠ.

Tenthredo pallicoxa Provancher, 1878. Nat. Canad. 10: 201. . . A questionable synonym.

Tenthredo nova MacGillivray, 1897. N. Y. Ent. Soc., Jour. 5: 105. ?. 
ferrugineipes Cresson. Idaho, Colo., N. Mex. w. to Alaska, B. C., Oreg., Calif. Tenthredo ferrugineipes Cresson, 1880. Amer. Ent. Soc., Trans. 8: 22. \&.

Tenthredo sectilis Cresson, 1880. Amer. Ent. Soc., Trans. 8: 22..

Tenthredo luteipes Cresson, 1880. Amer. Ent. Soc., Trans. 8: 21. \&. A questionable synonym.

Tenthredo terminatus MacGillivray, 1895. Canad. Ent. 27: 283..

Tenthredo aequalis MacGillivray, 1895. Canad. Ent. 27: 284. ․

Tenthredo mibrisommus MacGillivray, 1900. Canad. Ent. 32: 181..

Tenthredo retinentia MacGillivray, 1923. N. Y. Ent. Soc., Jour. 31: 166. \&.

Tenthredo rubrica MacGillivray, 1923. 1ll. Univ. Bul. 20(50): 35. ؟.

lacticincta Cresson. Nev., Calif.

Tenthredo lacticincta Cresson, 1880. Amer. Ent. Soc., Trans. 8: 21. + , ठ.

olivatipes MacGillivray. Wash., Calif.

Allantus interruptus Norton, 1867. Amer. Ent. Soc., Trans. 1: 263. ठ. Preoce. by Fabricius, 1804.

Tenthredo olivatipes MacGillivray, 1900. Canad. Ent. 32: 180. ․

Tenthredo asella Enslin, 1912. Arch. f. Naturgesch. 6: 103. N. name for interruptus

Norton.

ornaticeps (Cresson). Nev., Calif.

Allantus ornaticeps Cresson, 1880. Amer. Ent. Soc., Trans. 8: 16., , ర.

pallicola MacGillivray. N. H., Alta., N. Mex.

Tenthredo pallicola MacGillivray, 1895. Canad. Ent. 27: 80..

Tenthredo pallicola var. beulahensis Rohwer, 1909. Canad. Ent. 41: 108. ๆ.

pleuralis Cresson. Colo.

Tenthredo pleuralis Cresson, 1865. Ent. Soc. Phila., Proc. 4: 245.,$+ \delta$.

Tenthredo utensis Rohwer, 1909. Canad. Ent. 41: 109. $\%$.

rabida MacGillivray. Oreg.

Tenthredo rabida MacGillivray, 1923. N. Y. Ent. Soc., Jour. 31: 110..

ralla MacGillivray. Oreg.

Tenthredo ralla MacGillivray, 1923. N. Y. Ent. Soc., Jour. 31: 111. ‡.

reduvia MacGillivray. Oreg.

Tenthredo reduvia MacGillivray, 1923. N. Y. Ent. Soc., Jour. 31: 108. 9.

Tenthredo rabiosa MacGillivray, 1923. N. Y. Ent. Soc., Jour. 31: 112. §.

resima MacGillivray. Oreg.

Tenthredo resima MacGillivray, 1923. N. Y. Ent. Soc., Jour. 31: 109. \&.

rubeola Cresson. Nev.

Tenthredo mibeola Cresson, 1880. Amer. Ent. Soc., Trans. 8: 23. ठ.

rubicunda MacGillivray. N. H.

Tenthredo rubicunda MacGillivray, 1923. Ill. Univ. Bul. 20(50): 34. ‡.

semirufa Norton. N. H. to N. C. w. to Idaho, Colo. Host: Betula.

Allantus signatus Norton, 1860. Boston Jour. Nat. Hist. 7: 247. . Preocc. by Scopoli, 1763.

Tenthredo semirufus Norton, 1864. Ent. Soc. Phila., Proc. 3: 12..

Tenthredo semirubra Norton, 1864. Ent. Soc. Phila., Proc. 3: 14..+

Tenthredo thora Kirby, 1882. List Hym. Brit. Mus., v. 1, p. 310., o. A questionable synonym.

Tenthredo remota MacGillivray, 1895. Canad. Ent. 27: 81. 9.

Tenthredo junghannsii MacGillivray, 1900. Canad. Ent. 32: 179..

Tenthredo denotata Enslin, 1912. Arch. f. Naturgesch. 6: 105. Unnecessary n. name for basilaris MacGillivray, 1897.

Tenthredo mina MacGillivray, 1923. Ill. Univ. Bul. 20(50): 36. ๆ.

Tenthredo misticana MacGillivray, 1923. Ill. Univ. Bul. 20(50): 37. \&.

Tenthredo rissa MacGillivray, 1923. Ill. Univ. Bul. 20(50): 37. ؟.

Taxonomy: Dyar, 1897. N. Y. Ent. Soc., Jour. 5: 19 (larva and host of remota MacGillivray). variata Norton. Colo., Wash.

Tenthredo variatus Norton, 1864. Ent. Soc. Phila., Proc. 3: 12., o.

Tenthredo capitatus MacGillivray, 1897. N. Y. Ent. Soc., Jour. 5: 108. ๆ. 
varipicta Norton. Alaska s. to Nev., Calif.

Tenthredo varipictus Norton, 1868. Amer. Ent. Soc., Trans. 2: 234. \&.

Tenthredo scaevola Cresson, 1880. Amer. Ent. Soc., Trans. 8: 20. 9.

Tenthredo magnifica MacGillivray, 1893. Canad. Ent. 25: 240. 9.

Tenthredo linipes MacGillivray, 1897. N. Y. Ent. Soc., Jour. 5: 104. ठ。.

\section{SPECIES Group SECUNDA}

nortoni (Smulyan). Mass., N. Y., N. J.

Tenthredo angulatus Norton, 1864. Ent. Soc. Phila., Proc. 3: 13. ठ. Preoce. by Westwood, 1838.

Tenthredella nortoni Smulyan, 1915. Canad. Ent. 47: 321. ठ.

relativa Rohwer. Nebr.

Tenthredo relativus Rohwer, 1909. Canad. Ent. 41: 108..

rhammisia MacGillivray. B. C., Wash., Oreg.

Tenthredo rhammisia MacGillivray, 1923. Ill. Univ. Bul. 20(50): 33..

rutata MacGillivray. N. J.

Tenthredo mitata MacGillivray, 1923. Ill. Univ. Bul. 20(50): 38. \&.

secunda MacGillivray. N. H., Mass., N. Y., Ont.

Tenthredo secundus MacGillivray, 1897. N. Y. Ent. Soc., Jour. 5: 105. .

Tenthredo simulatus MacGillivray, 1897. N. Y. Ent. Soc., Jour. 5: 105..

stricklandi (Ross). Alta., Idaho, Alaska, Oreg.

Tenthredella stricklandi Ross, 1931. Ent. Soc. Amer., Ann. 24: 117. ९, ठ’.

vellosa Ross. Conn.

Tenthredo formosus Norton, 1864. Ent. Soc. Phila., Proc. 3: 14. $\$$, đ. Preoce. by Klug, 1814.

Tenthredo vellosa Ross, 1951. In Muesebeck, et al., U. S. Dept. Agr., Agr. Monog. 2: 77. N. name.

\section{Species Group Xantha}

macgillivrayi (Smulyan). N. B., Que., Vt. w. to Alta.

Tenthredella macgillivrayi Smulyan, 1915. Canad. Ent. 47: 323. ․

mellina (Norton). Maine.

Allantus mellinus Norton, 1860. Boston Jour. Nat. Hist. 7: 248. $\uparrow, ~ \delta$.

obscuripennis Cresson. Oreg., Nev., Calif.

Tenthredo obscuripennis Cresson, 1880. Amer. Ent. Soc., Trans. 8: 20. ․

Tenthredo mibella Cresson, 1880. Amer. Ent. Soc., Trans. 8: 22. ð.

prosopa Stannard. N. Y. to Ga.

Tenthredo prosopa Stannard, 1947. Ent. Soc. Amer., Ann. 40: 434. \&, ठ.

redimacula MacGillivray. N. H., Ont.

Tenthredo vittata Kirby, 1882. List Hym. Brit. Mus., v. 1, p. 319. . Preocc. by

Kriechbaumer, 1869.

Tenthredo redimacula MacGillivray, 1895. Canad. Ent. 27: 78. 9.

Tenthredo consoma Enslin, 1912. Arch. f. Naturgesch. 6: 105. N. name for vittata Kirby.

xantha Norton. Maine, Ont. to Alaska s. to Minn., N. Mex., S. Dak., Utah, Calif. Ecology: Widespread. Host: Rubus(?).

Tenthredo xanthus Norton, 1864. Ent. Soc. Phila., Proc. 3: 13. ?.

Tenthredo ruficolor Norton, 1868. Amer. Ent. Soc., Trans. 2: 228..

Tenthredo nupera Cresson, 1880. Amer. Ent. Soc., Trans. 8: 22. ठ. A questionable synonym.

Tenthredo castanea Kirby, 1882. List Hym. Brit. Mus., v. 1, p. 319.. .

Allantus mebricus Provancher, 1885. Addit. Corr. Faune Ent. Canada Hym., p. 9..

Tenthredo reliquia MacGillivray, 1923. N. Y. Ent. Soc., Jour. 31: 168. ๆ.

Tenthredo resticula MacGillivray, 1923. N. Y. Ent. Soc., Jour. 31: 168. ?.

Biology: Smith and Kido, 1949. Hilgardia 19: 54 (host). 
bigemina (Dyar). B. C. s. to Nev., Calif.

Allantus annularis Norton, 1867. Amer. Ent. Soc., Trans. 1: 262., o. Preoce. by Schrank, 1776.

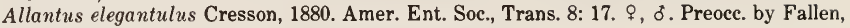
1808.

Labidia opimus var. bigeminus Dyar, 1893. Canad. Ent. 25: 195. 9.

Tenthredo obliquatus MacGillivray, 1897. N. Y. Ent. Soc., Jour. 5: 105. ๆ, ठ.

Tenthredo elegantula oregona Rohwer, 1911. U. S. Natl. Mus., Proc. 41: 411 . 9.

Tenthredo admeta Enslin, 1912. Arch. f. Naturgesch. 6: 103. N. name for annularis Norton.

Tenthredo arethusa Enslin, 1912. Arch. f. Naturgesch. 6: 103. N. name for elegantulus Cresson.

\section{UNPLACED TAXa OF TENTHREdo LinNaEUS}

Most of the species in the following list were described from males and belong to groups in which it is impossible to identify this sex with any degree of certainty.

alpestris Rohwer. Colo.

Tenthredo alpestris Rohwer, 1909. Canad. Ent. 41: 146. ठ.

auraria Konow. Alaska (Ft. Wrangel).

Tenthredo auraria Konow, 1899. Ent. Nachr. 25: 7..

bivittata Kincaid. Alaska.

Tenthredo bivittata Kincaid, 1900. Wash. Acad. Sci., Proc. 2: 364 . $q$.

cinctitibiis abdominalis (Smulyan), n. comb. N.H.

Tenthredella cinctitibiis abdominalis Smulyan, 1915. Canad. Ent. 47: 324. . Preoce. by Fabricius, 1798.

discrepans Norton. Ont.

Tenthredo discrepans Norton, 1868. Amer. Ent. Soc., Trans. 2: 235. ठ.

divergens Rohwer. Colo.

Tenthredo divergens Rohwer, 1909. Canad. Ent. 41: 112. ठ.

diversiceps Rohwer. N. B.

Tenthredo diversiceps Rohwer, 1910. U. S. Natl. Mus., Proc. 38: 208. ठ.

frigida MacGillivray. N. H., Wash.

Tenthredo frigida MacGillivray, 1895. Canad. Ent. 27: 80. ठ.

hyalina MacGillivray. N. Y.

Tenthredo hyalina MacGillivray, 1897. N. Y. Ent. Soc., Jour. 5: 108. §. Preoce.

hypoleuca Rohwer. Colo.

Tenthredo hypoleuca Rohwer, 1909. Canad. Ent. 41: 147. ठ.

juga Konow. Alaska.

Tenthredo juga Konow, 1908. Ztschr. System. Hym. Dipt. 8: 89..

lovetti Benson. Oreg.

Tenthredo rustica MacGillivray, 1923. N. Y. Ent. Soc., Jour. 31: 113. ठ. Preocc. by Linnaeus, 1758.

Tenthredo lovetti Benson, 1930. Entomologist 63: 107. N. name.

magnata MacGillivray. Wash.

Tenthredo magnatus MacGillivray, 1897. N. Y. Ent. Soc., Jour. 5: 107. ठో.

messica MacGillivray. Wash.

Tenthredo messica MacGillivray, 1897. N. Y. Ent. Soc., Jour. 5: 107. ठ์.

messicaeformis Rohwer. Colo.

Tenthredo messicaeformis Rohwer, 1909. Canad. Ent. 41: 147. ठ.

mimula Cresson. Colo.

Tenthredo mimula Cresson, 1880. Amer. Ent. Soc., Trans. 8: 23. ठ.

morosa Cresson. Colo.

Tenthredo morosa Cresson, 1880. Amer. Ent. Soc., Trans. 8: 23. ठ์. 
mutans Norton. Canada.

Tenthredo mutans Norton, 1869. Amer. Ent. Soc., Trans. 2: 236. ơ.

nigricoxi MacGillivray. Wash.

Tenthredo nigricoxi MacGillivray, 1900. Canad. Ent. 32: 181, ठ.

pallipectis MacGillivray. Wash.

Tenthredo pallipectis MacGillivray, 1897. N. Y. Ent. Soc., Jour. 5: 106. ð。.

reflua MacGillivray. Oreg.

Tenthredo reflua MacGillivray, 1923. N. Y. Ent. Soc., Jour. 31: 111. ठં.

reposita MacGillivray. Oreg.

Tenthredo reposita MacGillivray, 1923. N. Y. Ent. Soc., Jour. 31: 116. $\delta$.

reputina MacGillivray. Oreg.

Tenthredo reputina MacGillivray, 1923. N. Y. Ent. Soc., Jour. 31: 114. o.

resegmina MacGillivray. Oreg.

Tenthredo resegmina MacGillivray, 1923. N. Y. Ent. Soc., Jour. 31: 115. $\delta$.

restricta MacGillivray. Oreg.

Tenthredo restricta MacGillivray, 1923. N. Y. Ent. Soc., Jour. 31: 110. ð.

resupina MacGillivray. Oreg.

Tenthredo resupina MacGillivray, 1923. N. Y. Ent. Soc., Jour. 31: 113. ठ.

retroversa MacGillivray. Alaska.

Tenthredo retroversa MacGillivray, 1923. N. Y. Ent. Soc., Jour. 31: 164. ठ'.

rotula MacGillivray. N. Y.

Tenthredo rotula MacGillivray, 1923. Ill. Univ. Bul. 20(50): 34. ठ́.

rudicula MacGillivray. Maine.

Tenthredo midicula MacGillivray, 1923. Ill. Univ. Bul. 20(50): 35. ๆ.

rufescens (Norton). Maine.

Allantus mefescens Norton, 1860. Boston Jour. Nat. Hist. 7: 245. ‡.

rufostigma MacGillivray. Idaho.

Tenthredo mefostigmus MacGillivray, 1895. Canad. Ent. 27: 283. ơ.

rusticula MacGillivray. Alaska.

Tenthredo rusticula MacGillivray, 1923. N. Y. Ent. Soc., Jour. 31: 166. ठ. sectiliformis Rohwer. Colo.

Tenthredo sectiliformis Rohwer, 1909. Canad. Ent. 41: 145. ๆ.

slossonii MacGillivray. N. H.

Tenthredo slossonii MacGillivray, 1900. Canad. Ent. 32: 179. ठో.

stigmata MacGillivray. Wash.

Tenthredo stigmatus MacGillivray, 1897. N. Y. Ent. Soc., Jour. 5: 108. ơ.

suavis Cresson. Nev.

Tenthredo suavis Cresson, 1880. Amer. Ent. Soc., Trans. 8: 21. ठ.

titusi Rohwer. Colo.

Tenthredo titusi Rohwer, 1909. Canad. Ent. 41: 111. ठั.

varians Norton. Canada.

Tenthredo varians Norton, 1868. Amer. Ent. Soc., Trans. 2: 235. ठ".

ventralis (Say). Ark.

Allantus ventralis Say, 1823. West. Quart. Rptr. 2: 71.

zelmira Rohwer. Colo.

Teuthredo zelmimus Rohwer, 1909. Canad. Ent. 41: 109. ठ.

zetes Kirby. Ont.

Tenthredo zetes Kirby, 1882. List Hym. Brit. Mus., v. 1, p. 312. ठ’.

TRIBE MACROPHYINI

Genus MACROPHYA Dahlbom

Tenthredo subg. Macrophya Dahlbom, 1835. Conspectus Tenthred., Siricid., Oryssin. Scand., p. 11. 
Type-species: Tenthredo rusticus Linnaeus Desig. by Westwood, 1840. T. rusticus in sense of authors at that time.

Zalagium Rohwer, 1912. U. S. Natl. Mus., Proc. 43: 216.

Type-species: Zalagium clypeatum Rohwer. Orig. desig.

A large holarctic genus. Little is known of the hosts and biologies for most species.

Taxonomy: Middleton, 1922. U. S. Natl. Mus., Proc. 61: 6-11 (larvae), -Ross, 1931. Ent. Soc. Amer., Ann. 24: 119-128 (species with white apical antennal segments). - Malaise and Benson, 1934. Arkiv for Zool. 26A: 4-5 (Tenthredo rustica L. is Argidae; T. rustica auct., nec Linnaeus= Macrophya montana (Scopoli)).

alba MacGillivray. Que. to $\mathrm{Pa}$. w. to Wis., Ind.

Macrophya pulchella alba MacGillivray, 1895. Canad. Ent. 27: 285. \&, §.

Macrophya zonata Konow, 1899. Wien. Ent. Ztg. 18: 44. Unnecessary N. name for alba.

annulipes Cresson. Nev., Calif.

Macrophya annulipes Cresson, 1880. Amer. Ent. Soc., Trans. 8: 18..

bifasciata (Say). Conn. to Fla. w. to Okla., Tex.

Tenthredo (Allantus) media Harris, 1835. In Hitchcock, Rpt. Geol. Mineral. Bot. Zool.

Mass., p. 583. Nom. nud.

Allantus bifasciatus Say, 1823. West. Quart. Rptr. 2: 72..

Macrophya medius Norton, 1861. Boston Soc. Nat. Hist., Proc. 9: 118.

Macrophya texana Cresson, 1880. Amer. Ent. Soc., Trans. 8: 52. ๆ, o.

Macrophya zabriskiei Rohwer, 1912. U. S. Natl. Mus., Proc. 43: 218., , ठ.

castaneae Rohwer. Va. Host: Castanea dentata.

Macrophya castaneae Rohwer, 1917. U. S. Natl. Mus., Proc. 53: 151. ठ.

cinctula (Norton). Conn. to Ga. w. to Minn., Ill.

Tenthredo atroviolacea var. cinctulus Norton, 1869. Amer. Ent. Soc., Trans. 2: 240. $\subsetneq$.

Allantus dejectus Norton, 1860. Boston Jour. Nat. Hist. 7: 249. §. A questionable synonym.

Macrophya abbotii Kirby, 1882. List Hym. Brit. Mus., v. 1, p. 269. ठ゚.

Zalagium clypeatum Rohwer, 1912. U. S. Natl. Mus., Proc. 43: 217. ठँ.

coquilletti (Rohwer). Calif.

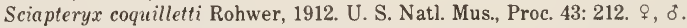

fascialis Norton. N. Y. to Md. w. to Mich., Ill.

Macrophya fascialis Norton, 1867. Amer. Ent. Soc., Trans. 1: 276..

Macrophya fascialis var. puella Ross, 1931. Ent. Soc. Amer., Ann. 24: 123. ๆ, ó.

flavicoxae (Norton). N. B., Ont. to Ga. w. to Alta., Wis.

Allantus flavicoxae Norton, 1860. Boston Jour. Nat. Hst. 7: 258. .

Allantus incertus Norton, 1860. Boston Jour. Nat. Hist. 7: 258. 6.

Selandria canadensis Provancher, 1885. Addit. Corr. Faune Ent. Canada Hym., p. 7. $q$. Macrophya flavicoxis Dalla Torre, 1894. Cat. Hym., v. 1, p. 52. Emend.

formosa (Klug). Mass. to Fla. w. to Ohio.

Tenthredo (Allantus) formosa Klug, 1814. Mag. Gesell. Naturf. Freunde Berlin 8: 115.. Allantus bicinctus Norton, 1860. Boston Jour. Nat. Hist. 7: 241. ๆ, ठ.

fumator Norton. Colo., Idaho w. to B. C., Wash., Oreg., Calif.

Macrophya fumator Norton, 1867. Amer. Ent. Soc., Trans. 1: 279.. .

Macrophya maura Cresson, 1880. Amer. Ent. Soc., Trans. 8: 18..

Macrophya jugosa Cresson, 1880. Amer. Ent. Soc., Trans. 8: 18. ^.

Macrophya bicolorata Cresson, 1880. Amer. Ent. Soc., Trans. 8: 18..

Macrophya fumatrix Kirby, 1882. List Hym. Brit. Mus., v. 1, p. 275. Misspelling ?.

Synairema pacifica Provancher, 1885. Addit. Corr. Faune Ent. Canada Hym. p. 15..

Perineura kincaidia MacGillivray, 1895. Canad. Ent. 27: 7..

Macrophya obrussa MacGillivray, 1923. Ill. Univ. Bul. 20(50): 22. §.

goniphora (Say). N. Y. to Ga., Ala.

Allantus goniphorus Say, 1836. Boston Jour. Nat. Hist. 1: 216.,$\delta$.

intermedia (Norton). Conn., N. Y. w. to Wis., Nebr., Mo.

Allantus intermedius Norton, 1860. Boston Jour. Nat. Hist. 7: 242. १, §.

Macrophya simillima Rohwer, 1917. Ent. News 28: 265. $९$, ઠ. 
nebraskensis Rohwer. Nebr.

Macrophya sambuci Rohwer, 1909. Canad. Ent. 41: 15. \&. Preocc. by Latreille, 1805.

Macrophya nebraskensis Rohwer, 1912. U. S. Natl. Mus., Proc. 43: 220. N. name.

nigra (Norton). N. H. to Ala. w. to Ill., Kans.

Allantus niger Norton, 1860. Boston Jour. Nat. Hist. 7: 239. ९.

nigristigma Rohwer. Conn., Pa., W. Va. Host: Hicoria.

Macrophya nigristigma Rohwer, 1912. U. S. Natl. Mus., Proc. 43: 219. .

Macrophya melanopleura MacGillivray, 1914. Canad. Ent. 46: 139..

Taxonomy: Middleton, 1922. U. S. Natl. Mus., Proc. 61 : 9 (larva).

pulchella (Klug). Ont., Conn. to Va. w. to Wis., Nebr., Colo., Miss. Host: Aster, Solidago, Rudbeckia.

Tenthredo (Allantus) pulchella Klug, 1814. Mag. Gesell. Naturf. Freunde Berlin 8: 121. ठ.

Allantus flavolineatus Norton, 1860. Boston Jour. Nat. Hist. 7: 259. + , o.

Macrophya lineata Norton, 1867. Amer. Ent. Soc., Trans. 1: 269..

Macrophya zoe Kirby, 1882. List Hym. Brit. Mus., v. 1, p. 270..+

Macrophya crassicomis Provancher, 1888. Addit. Corr. Faune Ent. Canada Hym., p. 352.

ઈ. A questionable synonym.

Macrophya lineatana Rohwer, 1912. U. S. Natl. Mus., Proc. 43: 220. §.

Macrophya confusa MacGillivray, 1914. Canad. Ent. 46: 139. ․

pulchelliformis Rohwer. Nebr.

Macrophya pulchelliformis Rohwer, 1909. Canad. Ent. 41: 15. ठ.

pulcherrima Kirby. Fla.

Macrophya pulcherrima Kirby, 1882. List Hym. Brit. Mus., v. 1, p. 275. $\delta$.

pumila Norton. Alaska s. to Calif.

Macrophya pumilus Norton, 1867. Amer. Ent. Soc., Trans. 1: 272. ठ.

Macrophya oregona Cresson, 1880. Amer. Ent. Soc., Trans. 8: 19. ๆ.

Macraphya obaereta MacGillivray, 1923. Ill. Univ. Bul. 20(50): 21. ؟.

Macrophya oregona var. dukiae Ross, 1931. Ent. Soc. Amer., Ann. 24: 122. ₹, o.

punctumalbum (Linnaeus). Ont.; Europe to Caucasus. Introduced (?). Host: Fraxinus, Ligustrum. Hosts recorded in Europe.

Tenthredo punctum album Linnaeus, 1767. Syst. Nat., Ed. 12, p. 924.

Tenthredo erythropus Schrank, 1776. Beitr. z. Naturgesch., p. 86.

subviolacea Cresson. Calif.

Macrophya subviolacea Cresson, 1880. Amer. Ent. Soc., Trans. 8: 18..

succincta Cresson. Conn., N. Y. to Ga. w. to Sask., Mont., Kans., Tex.

Macrophya succincta Cresson, 1880. Amer. Ent. Soc., Trans. 8: 19. ?.

Macrophya xanthonota Rohwer, 1912. U. S. Natl. Mus., Proc. 43: 218. ९.

trisyllaba (Norton). N. B., Que. to Md. w. to Alta., Wis., Ill., Ala. Host: Sambucus.

Tenthredo (Allantus) trisyllabus Harris, 1835. In Hitchcock, Rpt. Geol. Mineral. Bot. Zool. Mass., p. 583. Nom. nud.

Allantus trisyllabus Norton, 1860. Boston Jour. Nat. Hist. 7: 238. \&.

Macrophya trisyllabus var. sinannula Ross, 1931. Ent. Soc. Amer., Ann. 24: 127. ๆ, o.

Taxonomy: Dyar, 1897. N. Y. Ent. Soc., Jour. 5: 192 (larva). -Middleton, 1922. U. S. Natl. Mus., Proc. 61: 8 (larva).

trosula (Norton). N. H. to Va. w. to Minn., Ill.

Tenthredo (Allantus) trosula Harris, 1835. In Hitcheock, Rpt. Geol. Mineral. Bot. Zool. Mass., p. 583. Nom. nud.

Allantus trosula Norton, 1860. Boston Jour. Nat. Hist. 7: 244. 9.

Macrophya albifacies Kirby, 1882. List Hym. Brit. Mus., v. 1, p. 271. $\subsetneq$.

Macrophya dyari Rohwer, 1911. U. S. Natl. Mus., Proc. 41: 410. §.

Macrophya omata MacGillivray, 1914. Canad. Ent. 46: 139..

varia (Norton). N. B., Que. to N. Y. w. to Man., Minn., Ill.

Allantus varius Norton, 1860. Boston Jour. Nat. Hist. 7: 240. \&.

Macrophya eurythmia Norton, 1867. Amer. Ent. Soc., Trans. 1: 276. ๆ, ठ์.

Macrophya nidonea MacGillivray, 1895. Canad. Ent. 27: 77. ठં.

Macrophya varius var. festana Ross, 1931. Ent. Soc. Amer., Ann. 24: 124. ๆ. 
Macrophya varius var. nordicola Ross, 1931. Ent. Soc. Amer., Ann. 24: 125., ,. zonalis Norton. Que. to Md. w. to Minn.

Macrophya zonalis Norton, 1864. Ent. Soc. Phila., Proc. 3: 11. \&.

\section{UNPLACED TAXa OF MaCrophya DAHLbOM}

The names in the following list fall into a difficult complex previously known as the Epinota complex. The species are merely listed without regard to possible synonymy.

albilabris Harrington. Ont. (Ottawa).

Macrophya albilabris Harrington, 1893. Canad. Ent. 25: 60. రో.

albomaculata (Norton). Maine, Conn. Host: Viburnum(?).

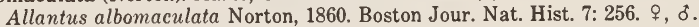

bellula MacGillivray. N. J.

Macrophya bellula MacGillivray, 1923. Brooklyn Ent. Soc., Bul. 18: 55. \&.

bilineata MacGillivray. Conn., Ill. Host: Viburnum(?).

Macrophya bilineata MacGillivray, 1916. Conn. State Geol. and Nat. Hist. Survey, Bul. 16: 96. ㅇ.

cassandra Kirby. N. Y.

Macrophya cassandra Kirby, 1882. List Hym. Brit. Mus., v. 1, p. 273. ?.

cesta (Say). U. S.

Allantus cestus Say, 1836. Boston Jour. Nat. Hist. 1: 216. ․, đ๋.

contaminata Provancher. Canada.

Macrophya contaminata Provancher, 1878. Nat. Canad. 10: 105. $q$.

Macrophya fuscoterminata Rohwer, 1911. U. S. Natl. Mus,, Proc. 41: 410. $q$.

epinota (Say). N. H. to Va. w. to Kans., Colo. Host: Sambucus.

Tenthredo (Allantus) sambuci Harris, 1833. In Hitcheock, Rpt. Geol. Mineral. Bot. Zool. Mass., p. 586. Nom. nud.

Allantus epinotus Say, 1836. Boston Jour. Nat. Hist. 1: 215. ㅇ, §.

Taxonomy: Middleton, 1922. U. S. Natl. Mus., Proc. 61: 6 (larva).

errans Rohwer. $\mathrm{Pa}$.

Macrophya errans Rohwer, 1911. U. S. Natl. Mus., Proc. 41: 411..

externa (Say). Mo., Kans. Host: Carya.

Allantus externus Say, 1823. West. Quart. Rptr., p. 72..

externiformis Rohwer. Wis.

Macrophya externiformis Rohwer, 1912. U. S. Natl. Mus., Proc. 43: 220..

fistula MacGillivray. N. Y. Macrophya fistula MacGillivray, 1920. Brooklyn Ent. Soc., Bul. 15: 114..

flaccida MacGillivray. N. Y. Macrophya flaccida MacGillivray, 1920. Brooklyn Ent. Soc., Bul. 15: 113. ๆ.

flicta MacGillivray. N. Y. Macrophya flicta MacGillivray, 1920. Brooklyn Ent. Soc., Bul. 15: 114..

fuliginea Norton. Ill. Macrophya fuligineus Norton, 1867. Amer. Ent. Soc., Trans. 1: 273.. Macrophya fuliginosa Dalla Torre, 1894. Cat. Hym., v. 1, p. 52. Misspelling.

melanota Rohwer. Ill. Macrophya melanota Rohwer, 1912. U. S. Natl. Mus., Proc. 43: 219. $\%$.

minuta MacGillivray. N. Y. Macrophya minuta MacGillivray, 1895. Canad. Ent. 27: 286. §ै.

mixta MacGillivray. N. H. Host: Viburmum(?). Macrophya mixta MacGillivray, 1895. Canad. Ent. 27: 77..

pannosa (Say). U. S. Allantus pannosus Say, 1836. Boston Jour. Nat. Hist. 1: 217. ๆ, §’.

propinqua Harrington. Canada. Macrophya propinqua Harrington, 1889. Canad. Ent. 21: 97.. 
proximata Norton. Conn.

Macrophya proximata Norton, 1867. Amer. Ent. Soc., Trans. 1: 270..

punctata MacGillivray. N. Y.

Macrophya punctata MacGillivray, 1895. Canad. Ent. 27: 285. ㅇ.

raui Rohwer. Mo.

Macrophya raui Rohwer, 1917. Ent. News 28: 264. $q$, ठ.

tibiator Norton. Ont. to Ga. w, to Ill., Kans. Host: Sambucus.

Macrophya tibiator Norton, 1864. Ent. Soc. Phila., Proc. 3: 10. $९, ~ \delta$.

\section{Genus PACHYPROTASIS Hartig}

Pachyprotasis Hartig, 1837. Fam. Blattwespen und Holzwespen, nebst Einleitung Naturgesch. Hym., p. 295.

Type-species: Tenthredo rapae Linnaeus. Desig. by Westwood, 1840.

Lithracia Cameron, 1902. Bombay Nat. Hist. Soc., Jour. 14: 441.

Type-species: Lithracia flavipes Cameron. Monotypic.

This genus is better represented in Eurasia. Only a single holarctic species is found in North America.

rapae (Linnaeus). Newfoundland to Alaska s. to N. C., Tenn., Mo., N. Mex., Calif.; Europe to Siberia. Ecology: Widespread. Host: Solidago, Scrophularia, Betonica, Fraximus, Antirrhinum. These hosts recorded in Europe.

Tenthredo rapae Linnaeus, 1767. Syst. Nat., Ed. 12, p. 926.

Tenthredo nigrofasciata Eschscholtz, 1822. Entomographien, p. 96. A questionable synonym.

Macrophya (Pachyprotasis) omega Norton, 1867. Amer. Ent. Soc., Trans. 1: 280. ๆ, o .

Synairema Americana Provancher, 1885. Canad. Ent. 17: 50. ?.

Rhogogaster sayi Rohwer, 1908. N. Y. Ent. Soc., Jour. 16: 111. 9.

Macrophya obnata MacGillivray, 1923. Ill. Univ. Bul. 20(50): 22. 9.

UNPLACED TAXA OF TENTHREDINIDAE

Tenthredo (Nematus) melanocephala Harris, 1835. In Hitcheock, Rpt. Geol. Mineral. Bot. Zool. Mass., p. 583. Nom. nud.

Emphytus platycerus Say, 1836. Boston Jour. Nat. Hist. 1: 220. o. Ind. 



\section{Superfamily SIRICOIDEA}

\section{Family SYNTEXIDAE}

Taxonomy: Benson, 1935. Ann. and Mag. Nat. Hist., ser. 10, 16: 536. - Ross, 1937. Ill. Biol. Monog. 15(2): 110 (Syntectidae). - Klima, 1937. In Hedicke, Hym. Cat., pt. 2, p. 53 (catalog).

\section{Genus SYNTEXIS Rohwer}

Syntexis Rohwer, 1915. Ent. Soc. Wash., Proc. 17: 115.

Type-species: Syntexis libocedrii Rohwer. Orig. desig.

libocedrii Rohwer. Idaho (?), Oreg., Calif. Ecology: Larvae are wood borers. Host: Libocedrus decurrens, Juniperus occidentalis, and Thuja plicata(?).

Syntexis libocedrii Rohwer, 1915. Ent. Soc. Wash., Proc. 17: 115. \&.

Taxonomy: Middlekauff, 1964. Pan-Pacific Ent. 40: 257 (male, host, distribution).

- Middlekauff, 1975 (1974). Pan-Pacific Ent. 50: 288-290 (larva).

Biology: Wickman, 1967. Ent. Soc. Amer., Ann. 60: 1291-1294. - Westcott, 1971. Pan-Pacific

Ent. 47: 310 (hosts, distribution).

\section{Family SIRICIDAE}

Larvae of this family are wood borers, members of the Siricinae in coniferous trees and those of the Tremicinae in angiosperm trees. The North American species are not known to attack sound trees, only those that have been weakened or recently felled. Fire damaged trees are particularly attractive to adults for oviposition, and large populations may build up in recent burns. The boring of the larvae reduces the quality of lumber and the emergence of the adults may damage buildings where they may bore through plaster walls, carpeting, and hardwood floors to exit. In Europe, Urocerns gigas gigas (L.) has been reported to cut through metal and lead telephone cables. Because of their habits, some species have been spread by commerce to many parts of the world, and it is not uncoinmon to find them out of their normal range.

The family is cosmopolitan except perhaps for South America. About 85 species in 9 genera are known from the world. The common names horntails or woodwasps are sometimes used for this family.

Revision: Bradley, 1913. Jour. Ent. and Zool. 5: 1-36 (N. Amer. species). - Benson, 1943. Bul. Ent. Res. 34: 27-51 (world genera), - Middlekauff, 1960. Calif. Ins. Survey, Bul. 6(4): 59-77 (Calif. species).

Taxonomy: Johnson, 1928. Boston Soc. Nat. Hist., Bul. 49: $2-7$ (New England species).

-Hedicke, 1938. Hym. Cat., pt. 6, 32 pp. (world catalog). - Benson, 1938. Roy. Ent. Soc. 
London, Trans. 87: 359 (genera and subfamilies). - Maa, 1949. Notes d'Ent. Chinoise (Mus. Heude) 13: 11-189.

Biology: Hanson, 1939. Bul. Ent. Res. 30: 27-76 (biology and parasites). -Wickman, 1964.

Canad. Ent. 96: 508-510 (measuring populations). -Cameron, 1965. Commonwealth Inst.

Biol. Control, Tech. Bul. 5, 31 pp. (hosts and parasites of Siricinae). - Stillwell, 1966.

Forest Science 12: 121-128 (fungus associations). -Morris, 1967. B. C. Ent. Soc., Jour. 64: 60-63 (Hosts in B. C.).

Morphology: Tonapi, 1958. Roy. Ent. Soc. London, Trans. 110: 492 (spiracular structure and mechanisms).

\section{SUBFAmILy SIRICINAE}

\section{Genus SIREX Linnaeus}

Sirex Linnaeus, 1761. Fauna Suecica, Ed. 2, p. 396.

Type-species: Sirex juvencus Linnaeus. Desig. by Curtis, 1829.

Paururus Konow, 1896. Wien. Ent. Ztg. 15: 41, 43.

Type-species: Sirex juvencus Linnaeus. Desig. by Rohwer, 1911.

Taxonomy: Cameron, 1967. Canad. Ent. 99: 18-24 (Calif. species).

Biology: Kirk, 1974. Ga. Ent. Soc., Jour. 9: 139-144 (Sirex and parasites in s.e. U. S.).

areolatus (Cresson). Va., Fla.; Colo., N. Mex. w. to B. C., Wash., Oreg., Calif. Host: Cupressus macrocarpa, Juniperus occidentalis, Libocedrus decurrens, Pinus contorta, P. jeffreyi, $P$. lambertiana, $P$. radiata, $P$ seudotsuga menziesii, Sequoia sempervirens, Taxodium distictum. Found less frequently on pines than on other hosts. Adventive in Europe emerging from lumber.

Urocerus areolatus Cresson, 1867. Amer. Ent. Soc., Trans. 1: 375..

Sirex gracilis Westwood, 1874. Thesaurus Ent. Oxon, p. 114. 9.

Urocerus caeruleus Cresson, 1880. Amer. Ent. Soc., Trans. 8: 34. \&.

Sirex apicalis Kirby, 1882. List Hym. Brit. Mus., v. 1, p. 377. ठ.

Biology: Chamberlin, 1949. Pan-Pacific Ent. 25: 118. - DeLeon, 1952. Pan-Pacific Ent. 28: 85. -Westcott, 1971. Pan-Pacific Ent. 47: 310 (hosts).

behrensii (Cresson). Idaho, Nev., Wash., Oreg., Calif. Host: Cupressus macrocarpa, Pinus jeffreyi, $P$. lambertiana, $P$. pondersa, $P$. radiata. Adventive in eastern states emerging from buildings.

Urocerus behrensii Cresson, 1880. Amer. Ent. Soc., Trans. 8: 35..

Morphology: Daly, 1963. Ent. Soc. Amer., Ann. 56: 301.

cyaneus Fabricius. Newfoundland to B. C. s. to N. C., Ill., Kans., N. Mex., Calif.; Europe. Host: Abies balsamea, A. concolor, A. lasiocarpa, Larix europea, L. laricina, Picea glauca,

Pinus spp., Pseudotsuga menziesii. Blue horntail. The relationship between cyaneus and juvencus juvencus (L.) needs clarification.

Sirex cyaneus Fabricius, 1781. Species Insectorum, v. 1, p. 419. ๆ.

Sirex duplex Shuckard, 1837. Mag. Nat. Hist. (n. s.) 1: 630. \&, ठ.

Urocerus nitidus Harris, 1841. Rpt. Ins. Mass. Injurious to Veg., p. 391..

Sirex abbotii Kirby, 1882. List Hym. Brit. Mus., v. 1, p. 378. ठ.

Sirex hirsutus Kirby, 1882. List Hym. Brit. Mus., v. 1, p. 380. ơ.

Taxonomy: Benson, 1943. Bul. Ent. Res. 34: 38.

Biology: Chrystal, 1928. Bul. Ent. Res. 19: 219-247 (in England). - Chrystal and Myers, 1928. Bul. Ent. Res. 19: 67-77 (natural enemies, England). - Chrystal and Myers, 1928. Empire Forestry Jour. 7: 145-154 (biology and parasites). - Hanson, 1939. Bul. Ent. Res. 30: 27 (parasites, in Britain). - Parkin, 1941. Nature 147: 329 (fungus association). - Parkin, 1942. Ann. Appl. Biol. 29: 268-274 (fungus association, hypopleural organs).

edwardsii Brulle. Que. to Ga. and Ala. w. to Sask., Wis., Ark. Host: Picea abies, Pinus echinata, $P$. rigida, $P$. strobus.

Sirex Edwardsii Brulle, 1846. In Lepeletier, Hist. Nat. Ins. Hym., v. 4, p. 645.. Urocerus zonatus Norton, 1869. Amer. Ent. Soc., Trans. 2: 257. ठँ. 
Sirex fulvocinctus Westwood, 1874. Thesaurus Ent. Oxon, p. 114. ․

Sirex abaddon Westwood, 1874. Thesaurus Ent. Oxon, p. 115..

Paurums hopkinsi Ashmead, 1904. Canad. Ent. 36: 64. 9 , ठ์.

juvencus californicus (Ashmead). Alta., Mont., Wyo., N. Mex., Utah, w. to B. C., Wash., Oreg., Calif.; Mexico. Host: Cupressus macrocarpa, Larix occidentalis, Pinus contorta, $P$. jeffreyi, $P$. ponderosa, Pseudotsuga menziesii.

Paumirus californicus Ashmead, 1904. Canad. Ent. 36: 64..+

Sirex obesus Bradley, 1913. Jour. Ent. and Zool. 5: 12. ․

Taxonomy: Benson, 1963. Ent. Monthly Mag. 98: 252 (a subsp. of juvencus). -Cameron, 1967. Canad. Ent. 99: 18 (male).

Biology: Cameron, 1968. Pan-Pacific Ent. 44: 168 (from bolts of Pinus ponderosa injured by atmospheric pollution).

juvencus juvencus (Linnaeus). Labrador, Newfoundland, N. S., N. B., N. J., Yukon, B. C.; Eurasia. Host: Abies balsamea, A. lasiocarpa, Pinus contorta. Recorded from species of Abies, Larix, Picea, and Pinus in Europe and Asia. Occasionally intercepted in New Zealand, Australian, and Philippine ports in lumber. Probably more common in North America than expected.

Ichneumon juvencus Linnaeus, 1758. Syst. Nat., Ed. 10, v. 1, p. 560.

Sirex nigricornis Acerbi, 1802. Trav. North Cape, v. 2, p. 253. Preoce.

Sirex dubia Kirby, 1882. List Hym. Brit. Mus., v. 1, p. 375. N. name for nigricomis Acerbi. Sirex australis Kirby, 1882. List Hym. Brit. Mus., v. 1, p. 383. ?.

Sirex Leseleuci Tournier, 1890. Ent. Geneve 1: 220.

Paururus sucineiceps Koornneef, 1935. Tijdschr. Ent. 78: xix.

Sirex juvencus var. atricorris Kjellander, 1945. Kungl. Fysiograf. Sallskap. Lund, Forh. 15: 126.

Taxonomy: Benson, 1943. Bul. Ent. Res. 34: 37. -Benson, 1945. Ent. Monthly Mag. 81: 67-68. -Benson, 1963. Ent. Monthly Mag. 98: 252.

Biology: Chrystal, 1928. Bul. Ent. Res. 19: 223. - Stillwell, 1966. Forest Science 12: 121-128

(associated fungus, in N. B., N. S.). -Morris, 1967. B. C. Ent. Soc., Jour. 64: 60-63 (hosts and distribution in B. C. and Yukon).

longicauda Middlekauff. Idaho, Colo., N. Mex., Utah, w. to Oreg., Calif. Host: Abies concolor, A. magnifica, Pinus ponderosa, Pseudotsuga menziesii. Adventive in eastern states emerging from lumber.

Sirex longicauda Middlekauff, 1948. Pan-Pacific Ent. 24: 189. ?.

Taxonomy: Middlekauff, 1962. Pan-Pacific Ent. 38: 31-32 (male).

Biology: Wickman, 1964. Pan-Pacific Ent. 40: 259-261 (oviposition).

nigricornis Fabricius. Que. to Fla. w. to Sask., Wis., Ohio, Ark., La. Host: Pinus echinata, $P$. strobus, $P$. virginiana.

Sirex nigricomis Fabricius, 1781. Species Insectorum, v.1, p. 418. 9.

Sirex morio Westwood, 1874. Thesaurus Ent. Oxon, p. 115.. .

Paurumus pinicolus Ashmead, 1898. Canad. Ent. 30: 179..

Biology: Webster, 1895. Ohio Farmer, p. 177.

noctilio Fabricius. Ont., Man.?; Eurasia. Holarctic(?). Host: None recorded in N. Amer.; in Europe, Abies, Larix, Picea, Pinus, Pseudotsuga; in N. Z. and Australia, Pinus radiata, Pinus spp. Introduced into New Zealand, Australia, and Tasmania where it is a serious pest.

Sirex noctilio Fabricius, 1793. Ent. System., v. 2, p. 130.

Urocerus Feisthameli Brulle, 1833. Exped. Sci. de Moree, v. 3, p. 387.

Sirex melanoceros Thomson, 1871. Hym. Scand., v. 1, p. 328.

Paumurus atlantidis Ghigi, 1909. Bol. Soc. Ent. Ital. 60: 163.

Taxonomy: Benson, 1943. Bul. Ent. Res. 34: 37. -Benson, 1962. Brit. Mus. (Nat. Hist.) Ent., Bul. 12: 385 . 
Biology: Clark, 1933. New Zealand Jour. Sci. and Tech. 15: 188-190. -Miller and Clark, 1935. Bul. Ent. Res. 26: 149 (New Zealand). - Hanson, 1939. Bul. Ent. Res. 30: 27-76.

-Rawlings, 1948. New Zealand Jour. Forestry 5: 411. - Rawlings and Wilson, 1949. New Zealand Jour. Forestry 6: 20 (hosts susceptibility). —Gourlay, 1951. Bul. Ent. Res. 42: 21 (parasitized by an orussid, New Zealand). - Irvine, 1962. Victoria's Resources 4: 40 (hosts, habits, damage in Australia, Tasmania). - Taylor, 1962. Ent. Rec. and Jour. Var. 74: 273 (intercepted in S. Africa). - Coutts, 1965. Australian Dept. Natl. Develop. Forest and Timber Bur., Bul. 41: 3. - Morgan and Stewart, 1966. Roy. Soc. New Zealand, Trans. Zool. 7: 195. -Mucha, 1967. Australian Forest Res. 3: 3 (habits, hosts). -Zondag, 1969. New Zealand Jour. Sci. 12: 732-747 (nematode parasite). - Neumann, 1970. Australian Ent. Soc. Jour. 9: 168-169 (white eyed forms and gynandromorphs).

varipes Walker. Mont., B. C., Wash., Oreg., Nev., Calif. Host: Abies magnifica, A. lasiocarpa, Picea sitchensis, Pinus ponderosa. Adventive in eastern states emerging from timber. Probably only a color form of juvencus juvencus or $j$. californicus.

Sirex varipes Walker, 1866. In Lord, Naturalist in Vancouver Is. and B. C. v. 2, p. 342 . \&.

Taxonomy: Benson, 1943. Bul. Ent. Res. 34: 37, 48. -Benson, 1963. Ent. Monthly Mag. 98 : 252 (hybrid of juvencus juvencus (L.) X juvencus californicus (Ashmead)).

\section{Genus UROCERUS Geoffroy}

Urocerus Geoffroy, 1785. in Fourcroy, Ent. Parisiensis, pt. 2, p. 363. Type-species: Ichneumon gigas Linnaeus. Monotypic.

Xanthosirex Semenov-Tian-Shanskii, 1921. Rev. Russe d'Ent. 17: 86. Type-species: Xanthosirex phantasma Semenov-Tian-Shanskii. Orig. desig.

albicornis (Fabricius). New foundland to B. C. s. to N. C., Mich., Mo., N. Mex., Calif. Host: Abies amabalis, A. balsamea, A. fraseri, A. lasiocarpa, Larix laricina, L. occidentalis, Picea engelmanni, P. mariana, P. sitchensis, Pinus sp., Pseudotsuga menziesii, Thuja plicata, Tsuga heterophylla. Adventive in Britain emerging from lumber.

Sirex albicornis Fabricius, 1781. Species Insectorum, v. 1, p. 419. ?.

Urocerus abdominalis Harris, 1841. Rpt. Ins. Mass. Injurious to Veg., p. 392. $\delta$.

Sirex stephensii Kirby, 1882. List Hym. Brit. Mus., v. 1, p. 375 . \&.

Biology: Lintner, 1898. N. Y. State Mus., Ann. Rpt. 51: 338-340. -Chrystal, 1928. Bul. Ent. Res. 19: 223. - Reeks and Smith, 1945. Acad. Nat. 2: 12. - Belyea, 1952. Canad. Ent. 84: 325-335.

californicus Norton. Mont., Colo., N. Mex. w. to B. C., Wash., Oreg. Calif.; Mexico. Host: Abies balsamea, A. concolor, A. lasiocarpa, A. magnifica, A. nobilis, Larix occidentalis, Libocedrus decurrens, Picea engelmanni, P. sitchensis, Pinus contorta, P. lambertiana, $P$. ponderosa, Pseudotsuga menziesii, Tsuga heterophylla. Adventive in Britain emerging from lumber.

Uroceris albicomis var. californicus Norton, 1869. Amer. Ent. Soc., Trans. 2: 360. ․

Uroceris fulvus Cresson, 1880. Amer. Ent. Soc., Trans. 8: 35. ठ.

Urocerus flavipennis Kirby, 1882. List Hym. Brit. Mus., v. 1, p. 380 . ๆ.

Biology: Benson, 1945. Ent. Monthly Mag. 81: 67 (England, in lumber from B. C. and w. U. S.). - Wickman, 1964. Pan-Pacific Ent. 40: 259 (hosts; oviposition).

cressoni Norton. N. S., N. B., Que., Ont. to Fla. w. to Wis., Minn. Host: Abies balsamea, A. fraseri, Picea sp., Pinus rigida, $P$. taeda.

Urocerus cressoni Norton, 1864. Ent. Soc. Phila., Proc. 3: 16. ․

Urocerus tricolor Provancher, 1869. Nat. Canad. 1: 17. $\%$.

Sirex dimidiatus Westwood, 1874. Thesaurus Ent. Oxon, p. 115. ๆ.

Sirex Fiskei Ashmead, 1904. Canad. Ent. 36: 63. ๆ.

Urocemis cressoni var. unicolor Bradley, 1913. Jour. Ent. and Zool. 5: 22. ๆ.

gigas flavicornis (Fabricius). Labrador to Alaska s. to N. H., Colo., N. Mex., Ariz., Calif.; Mexico. Host: Abies lasiocarpa, Larix occidentalis, Picea sitchensis, Pinus contorta, Pseudotsuga menziesii. U. gigas gigas (L.) is Palaearctic. Adventive in Britain and Brazil emerging from lumber.

Sirex flavicomis Fabricius, 1781. Species Insectorum, v. 1, p. 418.

Sirex bizonatus Stephens, 1835. Illus. Brit. Ent., v. 7, p. 342. 
Sirex latifasciatus Westwood, 1874. Thesaurus Ent. Oxon., p. 114. ठ.

Urocerus riparius MacGillivray, 1893. Canad. Ent. 24: 244. J'.

Taxonomy: Benson, 1943. Bul. Ent. Res. 34: 40. -Ries, 1946. Ent. News 57: 218 (adventive in Brazil).

Biology: Chapman, 1954. Ecology 35: 44 (summit-frequenting insects of western mountains). taxodii (Ashmead). D. C. and Va. to Fla. w. to Mo. Host: Taxodium distichum.

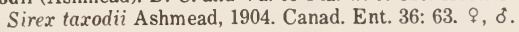

\section{Genus XERIS Costa}

Xeris Costa 1894 Prospetto Imen. Ital. 3: 259.

Type-species: Ichneumon spectrim Linnaeus. Monotypic.

Revision: Maa, 1949. Notes d'Ent. Chinoise (Mus. Heude) 13: 79-89.

morrisoni indecisus (MacGillivray). Idaho, Utah, Nev., B. C., Wash., Oreg., Calif. Host: Abies concolor, A. grandis, A. lasiocarpa, Larix occidentalis, Libocedrus decurrens, Picea sitchensis, Pinus contorta, P. ponderosa, Pseudotsuga menziesii, Tsuga heterophylla.

Urocerus indecisus MacGillivray, 1893. Canad. Ent. 25: 243. ठ̊.

morrisoni morrisoni (Cresson). Colo, Ariz. Host: Abies concolor, Picea pungens, Psendotsuga menziesii.

Urocerus morrisoni Cresson, 1880. Amer. Ent. Soc., Trans. 8: 35. ๆ, ठ.

spectrum spectrum (Linnaeus). N. B. to Wash. s. to Conn., Mich., Colo., Ariz., Calif.; Eurasia, China, Formosa, N. Africa. Host: Abies la siocarpa, Larix occidentalis, Picea pungens, Pinus contorta, Pseudotsiga menziesii. Recorded from same host genera in Europe and Asia.

Ichneumon spectrum Linnaeus, 1758. Syst. Nat., Ed. 10, v. 1, p. 560..

Sirex nanus Muller, 1776. Zool. Dan. Prodr. p. 151.

Sirex emarginatus Fabricius, 1793. Ent. System., v. 2, p. 128.

Urocerus caudatus Cresson, 1865. Ent. Soc. Phila., Proc. 4: 247. \&.

Sirex melancholicus Westwood, 1874. Thesaurus Ent. Oxon, p. 116. o.

spectrum townesi Maa. Mont., B. C., Wash., Oreg., Nev., Calif. Host: Abies concolor, A. grandis, A. lasiocarpa, Picea sitchensis, Pinus contorta, Pseudotsuga menziesii, Tsuga heterophylla.

Xeris spectrum townesi Maa, 1949. Notes d'Ent. Chinoise (Mus. Heude) 13: 88. ९, ठ̊.

tarsalis (Cresson). Wash., Oreg., Calif.; Mexico. Host: Cupressus macrocarpa, Thuja plicata?, Juniperus occidentalis, Libocedrus decurrens.

Urocerus tarsalis Cresson, 1880. Amer. Ent. Soc., Trans. 8: 52. ․

Xeris macgillivrayi Bradley, 1913. Jour. Ent. and Zool. 5: 24. ९.

Biology: Westcott, 1971. Pan-Pacific Ent. 47: 310 (host).

\section{SUBFAMILY TREMICINAE}

\section{Genus TREMEX Jurine}

Tremex Jurine, 1807. Nouv. Method. Class. Hym. Dipt., p. 80.

Type-species: Sirex fuscicomis Fabricius. Desig. by Latreille, 1810.

Xyloterns Hartig, 1837. Fam. Blattwespen und Holzwespen, nebst Einleitung Naturgesch.

Hym., p. 385. Preocc.

Type-species: Sirex fuscicomis Fabricius. Desig. by Rohwer, 1911.

Xyloecematizm Heyden, 1868. Berlin. Ent. Ztschr. 2: 227. N. name for Xyloterus Hartig.

About 22 world species are recognized, only one of which is found in North America. Our representative is extremely variable in coloration, and earlier authors designated races or subspecies to distinguish these variant forms.

columba (Linnaeus). N. S., N. B., and Que. to Fla. w. to the Rockies, Colo., Utah, Ariz., s. Calif.

Host: Acer, Ulmus, Quercus, Hicoria, Fagns, and probably other deciduous trees.

Usually in dead or dying trees. Pigeon tremex.

Sirex colımba Linnaeus, 1763. Amoenitates Academicae, v. 6, p. 412. ?. 
Sirex pennsylvanicus DeGeer, 1773. Mem. Serv. Hist. des Ins., v. 3, p. 593.

Sirex cinctus Drury, 1773. Illus. Nat. Hist., v. 2, p. 72. .

Sirex americana Christ, 1791. Naturgesch. Class. Nomencl. Ins., p. 412..

Tremex obsoletris Say, 1823. West. Quart. Rptr. 2: 73. ठ.

Tremex sericeus Say, 1823. West. Quart. Rptr. 2: 73. 9.

Tremex servillei Brulle, 1846. In Lepeletier, Hist. Nat. Ins., Hym. 4: 645..

Tremex maurus Westwood, 1874. Thesaurus Ent. Oxon., p. 116. $\delta$.

Tremex hospes Cockerell, 1889. Colo. Biol. Assn. Rpt. 10: [3]. Nom. nud.

Tremex columba race aureus Bradley, 1913. Jour. Ent. and Zool. 5: 26. 9.

Taxonomy: Yuasa, 1922. Ill. Biol. Monog. 7: 115-116 (larva).

Biology: Herrick, 1935. Ins. Enemies of Shade Trees, pp. 188-189. - Blackman and Stage, 1924. N. Y. State Col. Forestry, Syracuse Univ., Tech. Pub. 17, 24: 156. -Laurent, 1931. Ent. News 42: 67. - Smith, et al., 1943. Kans. State Bd. Agr. Rpt. 62: 387. -Beal and Massey, 1945. Duke Univ., School Forestry Bul. 10: 70, 155. - Fattig, 1949. Ent. News 60: 71. - Stillwell, 1965. Canad. Ent. 97: 783-784 (Hypopleural organs). - Stillwell, 1967.

Canad. Ent. 99: 685-689 (in N. B.).

Morphology: Holway, 1935. Psyche $42: 17$ (pretarsus).

\section{Genus ERIOTREMEX Benson}

Eriotremex Benson, 1943. Bul. Ent. Res. 34: 42.

Type-species: Tremex smithi Cameron. Orig. desig.

This genus of about 10 species is found in southeast Asia. The single species taken in the United States is undoubtedly an introduction.

Taxonomy: Benson, 1943. Bul. Ent. Res. 34: 42 (key to spp.). -Maa, 1949. Notes d'Ent.

Chinoise (Mus. Heude) 13: 127-134, 175-176. - Maa, 1956. Hawaii. Ent. Soc., Proc. 16: 91-92

(key to females).

formosanus (Matsumura). Ala. (Covington Co., Coffee Co.); Formosa; Indochina. Ecology: In Ala., emerged from firewood (water-oak tree) in home. Accidentally introduced.

Tremex formosanus Matsumura, 1912. Thous. Ins. Japan, Sup., v. 4, p. 21, pl. 43, fig. 12. ₹.

\section{Family XIPHYDRIIDAE}

Larvae of this family are wood borers in dead or dying angiosperm trees. Healthy trees and sound wood are not attacked. Adults sometimes emerge from firewood brought into homes, consequently arousing concern. The family is cosmopolitan with about 82 species in 22 genera; only one genus is found in North America.

Revision: Rohwer, 1918. Ent. News 29: 105-111.

Taxonomy: Hedicke, 1938. Hym. Cat., pt. 7, 17 pp. (world catalog). -Maa, 1949. Notes d'Ent. Chinoise (Mus. Heude) 13: 20-76 (world classification), -Benson, 1954. Roy. Ent. Soc. London, Trans. 105: 151-158. (world classification).

Biology: Yuasa, 1922. Ill. Biol. Monog. 7: 112-114. - Schaffner and Middleton, 1949. In Craighead, U. S. Dept. Agr., Misc. Pub. 657, p. 587.

\section{SUBFAMILY XIPHYDRIINAE}

\section{Genus XIPHYDRIA Latreille}

Xiphydria Latreille, 1802. Hist. Nat. Crust. Ins., v. 3, p. 304.

Type-species: Ichneumon camelus Linnaeus. Monotypic.

Hybonotus Klug, 1803. Monog. Siricum German., p. 8.

Type-species: Ichreumon camelus Linnaeus. Desig. by Rohwer, 1911.

Xiphydra(!) Panzer, 1806. Krit. Rev. Insektenf. Deutschlands, v. 2, p. 56.

Xiphiura Fallen, 1813. Spec. Nov. Hym. Disp. Meth. p. 11.

Xiphidria(!) Provancher, 1875. Nat. Canad. 7: 373.

Xiphidion Provancher, 1875. Nat. Canad. 7: 374. 
Type-species: Xiphidion canadensis Provancher. Monotypic. Hyponotus(!) Enslin, 1917. Deut. Ent. Ztschr., pp. 704, 706. Preocc.

abdominalis Say. Ont. to N. C. w. to Wis., Iowa. Host: Acer, Tilia americana.

Xiphydria abdominalis Say, 1824. In Keating, Narr. Long's 2nd Exped., v. 2 (App.), p. 311. \&.

Xiphydria attenuata Norton, 1862. Ent. Soc. Phila., Proc. 1: 214. ठ.

Xiphydria rufiventris Cresson, 1880. Amer. Ent. Soc., Trans. 8: 34. ९.

Taxonomy: Rohwer, 1921. U. S. Natl. Mus., Proc. 59: 83.

canadensis Provancher. Que., Va.

Xiphydria canadensis Provancher, 1875. Nat. Canad. 7: 373. .

hicoriae Rohwer. Ont., Mass. to N. J., Pa. w. to Ohio, Ill. Host: Carya, Ulmus.

Xiphydria hicoriae Rohwer, 1918. Ent. News 29: 109. ‡, ठั.

Biology: Blackman and Stage, 1924. Syracuse Univ., N. Y. State Col. Forestry, Tech. Pub. 17, 24: 155 .

maculata Say. N. B., Ont. to Md., w. to Man., Minn., Iowa, Kans., Tex.; Calif. (?). Host: Acer, Malus malus, Tilia americana(?).

Xiphydria maculata Say, 1836. Boston Jour. Nat. Hist. 1: 221. ơ.

Xiphydria albicornis Harris, 1841. Rpt. Ins. Mass. Injurious to Veg., p. 392. .

Biology: Harrington, 1884. Ont. Ent. Soc., Ann. Rpt. 14: 17, 40-42. - Rohwer, 1915. Ent. Soc. Wash., Proc. 17: 195 (mating habits).

mellipes Harris. N. S. to N. C. w. to N. W. T., B. C., Oreg., Mont., Minn., Ill. Host: Alnus, Fagus, Betula alleghaniensis, B. lenta, B. occidentalis.

Xiphydria mellipes Harris, 1841. Rpt. Ins. Mass. Injurious to Veg., p. 393..

Xiphydria walshii Westwood, 1874. Thesaurus Ent. Oxon., p. 113. ठ.

Xiphidion Canadensis Provancher, 1875. Nat. Canad. 7: 374. \&. Preocc.

Xiphydria provancheri Cresson, 1880. Amer. Ent. Soc., Trans. 8: 49. N. name for canadensis Provancher.

Biology: Rohwer, 1918. Ent. News 29: 110. - Yuasa, 1922. Ill. Biol. Monog. 7: 113.

tibialis Say. N. S., Que. to Fla. w. to Wis., Ill., Kans. Host: Acer, Betula nigra, Carpinus caroliniana, Crataegus, Fagus, Malus, Quercus, Rhus typhina, Tilia americana, Ulmus.

Xiphydria tibialis Say, 1824. In Keating, Narr. Long's 2nd Exped., v. 2 (App.), p. 312..

Xiphydria erythrogaster Ashmead, 1903. Canad. Ent. 35: 233. o..

Xiphydria champlaini Rohwer, 1921. U. S. Natl. Mus., Proc. 59: 84. ९, ठ์.

Biology: Packard, 1890. U. S. Dept. Agr., Ent. Comm. Rpt. 5: 483-484.

\section{Family ORUSSIDAE}

Larvae of this family are believed to be parasites of wood boring insects, particularly beetle larvae. Guiglia schauinslandi (Ashmead) of New Zealand has been documented as a parasite of the siricid, Sirex noctilio (Fabricius). Adults are most commonly collected from standing or downed dead trees on which they have a characteristic upward and downward or back and forth running pattern. The family is cosmopolitan and contains about 66 species in 14 genera with the bulk of the species found in the tropical regions.

Revision: Bradley, 1901. Amer. Ent. Soc., Trans. 27: 317-318. -Rohwer, 1912. U. S. Natl. Mus., Proc. 43: 141-158.

Taxonomy: Benson, 1935. Rhodesian Mus., Occ. Papers No, 4, 10 pp. (world genera). -Guiglia, 1943. Genova Mus. Civ. Stor. Nat., Ann. 62: 85-111 (world catalog). - Benson, 1938. Ann. and Mag. Nat. Hist. 2: 1-15 (world genera). - Benson, 1955. Roy. Ent. Soc. London, Proc., Ser. B: Taxonomy 24: 13-23 (world classification). -Guiglia, 1957. Genova Mus. Civ. Stor. Nat., Ann. 69: 48-59 (suppl. to world catalog). -Guiglia, 1965. In Ferriere and van der Vecht, Cat. Hym., pt. 1, 18 pp. (world catalog). 
Biology: Burke, 1917. Ent. Soc. Wash., Proc. 19: 87-89. - Rohwer and Cushman, 1917. Ent. Soc. Wash., Proc. 19: 89-98 (suborder Idiogastra), - Cooper, 1953. Rochester Acad. Sci., Proc. 10: 38-68 (habits, oviposition, female anatomy of eastern Orussus).

\section{SUBFAMILy ORUSSINAE}

\section{Genus ORUSSUS Latreille}

Orussus Latreille, 1796. Precis Caract. Gen. Ins., p. 111.

Type-species: Oryssus coronatus Fabricius. Desig. by Latreille, 1810.

Oryssus Fabricius, 1798. Sup. Ent. System., p. 218. Emend.

maurus (Harris). Mass.

Oryssus maurus Harris, 1841. Rpt. Ins. Mass. Injurious to Veg., p. 394. ๆ.

occidentalis (Cresson). Colo., N. Mex. w. to B. C., Wash., Oreg., Calif.

Oryssus occidentalis Cresson, 1879. Ent. Soc. Phila., Proc. 7: ix. ९, ð.

Oryssus modestus Rohwer, 1912. U. S. Natl. Mus., Proc. 43: 150. $\uparrow$, melanic.

Oryssus abietes Rohwer, 1912. U. S. Natl. Mus., Proc. 43: 153., , ð.

Oryssus pini Rohwer, 1912. U. S. Natl. Mus., Proc. 43: 154. 9.

Oryssus relativus Rohwer, 1912. U. S. Natl. Mus., Proc. 43: 155. ๆ.

Oryssus hopkinsi Rohwer, 1912. U. S. Natl. Mus., Proc. 43: 155. ס', partial melanic.

Taxonomy: Rohwer and Cushman, 1917. Ent. Soc. Wash., Proc. 19: 89-98. -Yuasa, 1922. Ill. Biol. Monog. 7: 118.

Biology: Burke, 1917. Ent. Soc. Wash., Proc. 19: 87-89. -Powell and Turner, 1969.

Pan-Pacific Ent. 45: 73-74 (oviposition behavior).

Morphology: Parker, 1934. Bol. Lab. Zool. Gen. e Agr. Portici 28: 159-191 (larval anatomy). sayii (Westwood). Ont., Maine to Md. w. to Ill.

Oryssus sayii Westwood, 1835. Zool. Jour. 5: 440. “o" "=q.

Oryssus terminalis Newman, 1838. Ent. Mag. 5: 486. ․

Oryssus haemorrhoidalis Harris, 1841. Rpt. Ins. Mass. Injurious to Veg., p. 394. $\$$.

Oryssus affinis Harris, 1841. Rpt. Ins. Mass. Injurious to Veg., p. 394. ठै.

Biology: Blackman and Stage, 1924. Syracuse Univ., N. Y. State Col. Forestry, Tech. Pub. 17, 24: 154 (in hickory). - Pratt, 1938. Psyche 45: 94-95. - Cooper, 1953. Rochester Acad. Sci., Proc. 10: 38-68.

thoracicus (Ashmead). Ariz., Wash., Oreg., Calif.

Oryssus thoracicus Ashmead, 1898. Canad. Ent. 30: 178. " $\sigma "=q$.

\section{SUBFAMILY OPHRYNOPINAE}

\section{Genus OPHRYNOPUS Konow}

Ophrynopus Konow, 1897. Termes. Fuzetek 20: 605.

Type-species: Ophrynopus andrei Konow. Desig. by Rohwer, 1911.

Ophrynella Ross, 1937. Ill. Biol. Monog. 15(2): 113.

Type-species: Oryssus nigricans Cameron. Orig. desig.

This genus contains 7 Neotropical species, one of which reaches Texas. An unidentified species has been collected in Arizona.

nigricans (Cameron). Tex.; Guatemala.

Oryssus nigricans Cameron, 1883. Biol. Cent.-Amer., Hym. v. 1, p. 69. .

\section{Genus KULCANIA Benson}

Kulcania Benson, 1935. Rhodesian Mus., Occ. Papers No. 4, pp. 2, 5.

Type-species: Ophrynopus costaricensis Bischoff. Orig. desig.

An unidentified species belonging to this genus has been collected in Florida. 


\section{Superfamily CEPHOIDEA}

\section{Family CEPHIDAE}

The Cephidae are called stem sawflies because of the habit of the larvae which bore and feed in grass stems, berry canes, or stems or twigs of various shrubs or trees. Those species whose hosts are cultivated grains may be serious pests. The adults are slender, cylindrical, ichneumon-like insects and may be found around the host plant. Adults of Cephini are commonly attracted to yellow flowers in the vicinity of the host. About 13 genera and 100 species are recognized for the world, most of which are Palaearctic.

Revision: Ries, 1937. Amer. Ent. Soc., Trans. 63: 259-324 (Nearctic species). - Middlekauff, 1969. Calif. Ins. Surv., Bul. 11: 1-18 (keys to Nearctic genera and species; emphasis on Calif. species).

Taxonomy: Middleton, 1917. Ent. Soc. Wash., Proc. 19: 174-179 (larvae). -Benson, 1935. Ann. and Mag. Nat. Hist., (10) 16: 535-553 (world genera). - Klima, 1937. In Hedicke, Hym. Cat., pt. 2, pp. 1-51 (world catalog). - Benson, 1946. Roy. Ent. Soc. London, Trans. 96: 89-108 (world classification; keys to subfamilies, tribes, genera).

\section{SubFAMILy CEPHINAE}

\section{TRIBE HARTIGIINI}

\section{Genus CAENOCEPHUS Konow}

Caenocephus Konow, 1896. Wien. Ent. Ztg. 15: 151.

Type-species: Caenocephus jakowleffi Konow. Monotypic.

The only other species in this genus is found in Siberia.

aldrichi Bradley. B. C., Wash., Idaho, Oreg., Calif. Host: Conizm maculatum(?). An adult collection record.

Caenocephus aldrichi Bradley, 1905. Canad. Ent. 37: 363. ․

Caenocephus konowi Bradley, 1905. Canad. Ent. 37: 363. ठా.

Taxonomy: Middlekauff, 1952. Pan-Pacific Ent. 28: 108 (distribution; possible host).

\section{Genus HARTIGIA Schiodte}

Hartigia Schiodte, 1838. In Kroyer, Naturhist. Tidsskr., v. 2, p. 332.

Type-species: Astatus satyrus Panzer. Desig. by Boie, 1855.

Cerobractus Costa, 1860. Fauna del Regno di Napoli, Imen., pt. 3, p. 9.

Type-species: Cerobractus major Costa. Monotypic.

Macrocephus Schlechtendal, 1878. Ent. Nachr. 4: 153. 
Type-species: Macrocephus ulmariae Schlechtendal. Monotypic.

Cephosoma Gradl, 1881. Ent. Nachr. 7: 294.

Type-species: Cephosoma syringae Gradl. Monotypic.

Copiosoma Kirby, 1882. List Hym. Brit. Mus., v. 1, p. 364. Error for Cephosoma Gradl ?.

Adirus Konow, 1899. Ent. Nachr. 25: 74.

Type-species: Cephus trimaculatus Say. Monotypic.

Paradirus Dovnar-Zapolskii, 1931. Mus. Zool. Acad. Sci. Leningrad, Ann. 32: 39.

Type-species: Paradirus algiricus Dovnar-Zapolskii. Monotypic.

Larvae of this genus bore in stems of roses and berries. Of 15 species, only 3 are found in North America.

cowichana Ries. B. C., Wash., Oreg. Host: Rosa.

Hartigia cowichana Ries, 1937. Ent. News 48: 82 ..

cressonii (Kirby). Mont., Nev., Oreg., Calif. Host: Rosa, Rubus.

Cephus abdominalis Cresson, 1880. Amer. Ent. Soc., Trans. 8: 33. ९. Preocc.

Cephus cressonii Kirby, 1882. List Hym. Brit. Mus., v. 1, p. 403. N. name.

Biology: Essig, 1912. Calif. Comm. Hort., Monthly Bul. 1: 889-901. -Essig, 1926. Ins. of

West. No. Amer., pp. 775-776. - Middlekauff, 1969. Calif. Ins. Surv., Bul. 11: 5-6.

trimaculata (Say). Que. to Fla. w. to B. C., Wash., Idaho, Utah, La.; Mexico. Host: Rosa, Rubus.

Cephus trimaculatus Say, 1824. In Keating, Narr. Long's 2nd Exped., v. 2, (App.), p. 313. \&, $\delta$.

Cephus mexicanus Guerin, 1845. Iconogr. Regn. Animal. Ins. 3: 403.

Phylloecus bicinctus Provancher, 1875. Nat. Canad. 7: 375..+

Cephus bifasciatus Cresson, 1880. Amer. Ent. Soc., Trans. 8: 33..

Cephus fasciatus Cresson, 1880. Amer. Ent. Soc., Trans. 8: 33. १.

Macrocephus nigripennis Ghigi, 1915. Redia 10: 306. १, ठ.

Biology: Britton, 1923. Conn. (State) Agr. Expt. Sta., Bul. 247: 372. -Champlain, 1924. Jour.

Econ. Ent. 17: 648.

\section{Genus JANUS Stephens}

Janus Stephens, 1835. Illus. Brit. Ent., v. 7, p. 107.

Type-species: Janus connectens Stephens. Desig. by Westwood, 1840.

Phylloecus Newman, 1838. Ent. Mag. 5: 485.

Type-species: Phylloecus faunus Newman. Monotypic.

Ephippionotus Costa, 1860. Fauna del Regno di Napoli, Imen., pt. 3, Cefidei, p. 11.

Type-species: Ephippionotus luteiventris Costa, Monotypic.

Larvae of this genus bore in the stems of bushes and trees. Janus compressus (Fabricius) of Europe and Janus piri Okamoto and Muramatzu of the Far East are pests of pear trees. About 19 world species are known.

abbreviatus (Say). Ont. to Va. w. to Man., Minn., Ill. Host: Populus, Salix. Willow shoot sawfly.

Cephus abbreviatus Say, 1824. In Keating, Narr. Long's 2nd Exped., v. 2, (App.), p. 314. 9. Xiphydria basalis Say, 1837. Boston Jour. Nat. Hist. 1: 222..

Cephus heteropteris Norton, 1861. Boston Soc. Nat. Hist., Proc. 8: 224. ठ.

Cephus interruptus Provancher, 1888. Addit. Corr. Faune Ent. Canada, Hym. p. 355. ₹, ठ.

Biology: Middleton, 1917. Ent. Soc. Wash., Proc. 19: 176. - Britton, 1918. Conn. (State) Agr.

Expt. Sta., Bul. 203: 359. - Zappe, 1926. Conn. (State) Agr. Expt. Sta., Bul. 275: 322.

bimaculatus (Norton). Que. and Maine to Md. w. to Minn., Ill. Host: Viburnum lentago, V. pminifolizm.

Phylloecus bimaculatus Norton, 1868. Amer. Ent. Soc., Trans. 2: 346. १, ठ.

Cephus quadriguttatus Westwood, 1874. Thesaur. Ent. Oxon., p. 111, pl. 20, fig. 11. \&.

integer (Norton). Newfoundland to Md. w. to Man., Wash., Iowa. Host: Ribes. Currant stem girdler.

Cephus integer Norton, 1861. Boston Soc. Nat. Hist., Proc. 8: 224. ؟. 
Janus flaviventris Fitch, 1862. N. Y. State Agr. Soc., Trans. 21: 852.

Biology: Slingerland, 1897. Cornell Univ., Agr. Expt. Sta., Bul. 126: 41-53. -Middleton, 1917. Ent. Soc. Wash., Proc. 19: 176. - Britton, 1921. Conn. (State) Agr. Expt. Sta., Bul. 226: 201-204.

rufiventris (Cresson), Oreg., Calif.

Cephus rufiventris Cresson, 1880. Amer. Ent. Soc., Trans. 8: $33 . \uparrow$.

\section{TRIBE CEPHINI}

\section{Genus CEPHUS Latreille}

Astatus Jurine, 1801. Intell. Blatt. Litt.-Ztg. Erlangen, v. 1, p. 163. Suppressed by Internatl. Comm. Zool. Nomencl., Opinion 135, 1936.

Type-species: Sirex pygmaeus Linnaeus. Monotypic.

Cephus Latreille, 1802. Hist. Nat. Crust. Ins., v. 3, p. 303.

Type-species: Sirex pygmaeus Linnaeus. Desig. by Latreille, 1810.

Perinistilus Ghigi, 1904. Ann. Mus. Napoli 1: 26.

Type-species: Cephus politissimus Costa. Monotypic.

Peronistilomorphus Pic, 1916. Echange 33: 381.

Type-species: Peronistilomorphus berytensis Pic. Monotypic.

Cephus subg. Fossulocephus Pic, 1917. Echange 34: 2.

Type-species: Cephus (Fossulocephus) cintriniventris Pic. Monotypic.

Pseudocephus Dovnar-Zapolskii, 1931. Mus. Zool. Acad. Sci. Leningrad, Ann. 32: 47.

Type-species: Cephus pulcher Tischbein. Orig. desig.

Of the 25 to 30 world species only 2 are found in North America and one of these is an introduction. Larvae bore in the stems of grasses and may be serious pests in cultivated grain crops.

einctus Norton. Man., Mich., Ohio, Mo., Ark. w. to Alta., Wash., Oreg., Calif. Ecology: Most serious crop damage is in the wheat growing areas of the north central states and south central provinces. The preferred host is wheat, but to a lesser extent spring rye, barley, and timothy; also native grasses. Host: Triticum aestivum, Secale cereale, Hordeum vulgare, Phleum pratense, Agropyron, Beckmannia, Bromus, Calamagrostis, Calamovilfa, Deschampsia, Elymus, Festuca, Stipa. One or more species in the preceding genera may be suitable hosts. Wheat stem sawfly.

Cephus cinctus Norton, 1872. Amer. Ent. Soc., Trans. 4: 86. o.

Cephus occidentalis Riley and Marlatt, 1891. U. S. Dept. Agr., Insect Life 4: 177., , o. Cephus graenicheri Ashmead, 1898. Canad. Ent. 30: 182. ₹, రో.

Biology: Ainslie, 1920. U. S. Dept. Agr., Bul. 841, 27 pp. -Ainslie, 1929. U. S. Dept. Agr., Tech. Bul. 157, 23 pp. - Wallace and McNeal, 1966. U. S. Dept. Agr., Tech. Bul. 1350, 50 pp. (history; damage; distribution; hosts; biology; control; breeding for sawfly resistance; extensive bibliography to work prior to 1966 , much to large to repeat here). -McWilliams, Pesho, and Hodgin, 1970. Jour. Econ. Ent. 63: 993-994 (plastic light-filters for field studies of behavior). - Villacorta, Bell, and Callenbach, 1971. Jour. Econ. Ent. 64: 749-751

(influence of high temperature and light on post-diapause development).

Morphology: Holmes, 1970. Canad. Ent. 102: 713-715 (sexing larvae).

pygmaeus (Linnaeus). Ont., Mass., Conn., N. Y., N. J., Pa., Del., Md., N. C.; Europe. Ecology: Found mostly on cultivated grasses, primarily wheat, but to a lesser extent barley, rye, and the uncultivated cheat grass. Introduced, first found in Ont. and N. Y. in the 1880's. Host: Triticum aestivum, Secale cereale, Hordeum vulgare, Bromus secalinus.

European wheat stem sawfly.

Sirex pygmaeus Linnaeus, 1766. Syst. Nat., Ed. 12, p. 929.

Tenthredo longicomis Geoffroy, 1785. in Fourcroy, Ent. Paris. p. 378.

Tenthredo polygona Gmelin, 1790. Syst. Nat., v. 5, p. 2670.

Banchus spinipes Panzer, 1801. Faunae Ins. German., heft 73, pl. 17.

Astatus floralis Klug, 1803. Monog. Siricum German., p. 53.

Banchus viridator $\mathrm{F}$ abricius, 1804. Systema Piezatorum, p. 127.

Cephus subcylindricus Gravenhorst, 1807. Vergl. Uebers. Zool. Syst., p. 274. 
Cephus Leskii Lepeletier, 1823. Monog. Tenthred., p. 20.

Cephus atripes Stephens, 1835. Illus. Brit. Ent., v. 7, p. 105.

Cephus flavisternus Costa, 1882. Accad. delle Sci. Fis. e Mat. Napoli, Rend., p. 198. $\subsetneq$.

Cephus clypealis Costa, 1894. Prosp. Imen. Ital., v. 3, p. 250. ठ.

Cephus notatus Kokujev, 1910. Rev. Russe d'Ent. 10: 132. ?.

Cephus tanaiticus Dovnar-Zapolskii, 1926. N. Caucasian Plant Protection Station, Bul. 1: 2, 5.

Biology: Comstock, 1889. Cornell Univ., Agr. Expt. Sta., Bul. 11: 127-142. -Chittenden, 1892. U. S. Dept. Agr., Insect Life 4: 344. - Ries, 1926. Jour. Agr. Res. 32: 277-295. —Udine, 1941. U. S. Dept. Agr. Circ. 607, 9 pp. -Wallace and McNeal, 1966. U. S. Dept. Agr., Tech. Bul. 1350, 50 pp. (history; damage; distribution; hosts; biology; control; breeding for sawfly resistance; extensive bibliography to work prior to 1966, too large to repeat here).

Morphology: Parker, 1934. Bol. Lab. Zool. Gen. e Agr. Portici 28: 159-191 (larval anatomy).

\section{Genus CALAMEUTA Konow}

Calameuta Konow, 1896. Wien. Ent. Ztg. 15: 151.

Type-species: Cephus filiformis Eversmann. Desig. by Rohwer, 1911.

Monoplopus Konow, 1896. Wien. Ent. Ztg. 15: 151.

Type-species: Tenthredo saltuum (Linnaeus), Fabricius nec Linnaeus. Desig. by Rohwer, 1911.

Haplocephus Benson, 1935. Ann. and Mag. Nat. Hist., (10) 16: 544.

Type-species: Haplocephus aureus Benson. Orig. desig.

In addition to the single North American representative, there are about 15 Palaearctic species.

clavata (Norton). Idaho, Wash., Oreg., Calif. Host: Grasses. Specific hosts not known.

Phylloecus clavata Norton, 1869. Amer. Ent Soc., Trans. 2: 345 ..

Taxonomy: Benson, 1946. London Ent. Soc., Trans. 96: 103-104.

\section{Genus TRACHELUS Jurine}

Astatus Panzer, 1801. Faunae Ins. German., heft 83, pl. 12. Preocc.

Type-species: Sirex troglodyta Fabricius. Desig. by Rohwer, 1911.

Trachelus Jurine, 1807. Nouv. Method. Class. Hym. Dipt., p. 70.

Type-species: Sirex tabidus Fabricius. Monotypic.

Cepha Billberg, 1820. Enum. Ins. Mus. Billberg, p. 98.

Type-species: Sirex tabidus Fabricius. Monotypic.

Ateuchopus Konow, 1896. Wien. Ent. Ztg. 15: 151.

Type-species: Ateuchopus armenius Konow. Desig. by Rohwer, 1911.

Eumetabolus Schulz, 1906. Spolia Hym., p. 211.

Type-species: Sirex troglodyta Fabricius. Desig. by Rohwer, 1911.

Trachelastatus Morice and Durrant, 1915. Ent. Soc. London, Trans. p. 383. N. name for

Cepha Billberg.

Neateuchopus Benson, 1935. Ann. and Mag. Nat. Hist., (10) 16: 543.

Type-species: Neateuchopus tigris Benson. Orig. desig.

Microcephus Benson, 1935. Ann. and Mag. Nat. Hist., (10) 16: 545.

Type-species: Monoplopus judaicus Konow. Orig. desig.

The 6 species in this genus are found in the Mediterranean Region with one species introduced into North America. Larvae bore in the stems of various grasses.

tabidus (Fabricius). N. Y., N. J., Pa., Del., Md., Va., W. Va., Mich., Ohio; Europe, N. Africa, Asia Minor. Ecology: Found on cultivated grasses such as wheat, barley, rye, and oats.

No wild grass host is known in N. Amer. May not now occur in N. Y., N. J., and e. Pa due to competition with Cephus pygmaeus. Introduced, first found in N. J. prior to 1899. Host: Triticum aestivum, Secale cereale, Hordeum vulgare, Avena. Black grain stem sawfly.

Sirex tabidus Fabricius, 1775. Systema Ent., p. 326.

Sirex macilentus Fabricius, 1793. Ent. Syst., v. 2, p. 131. 
Cephus mandibularis Lepeletier, 1823. Monog. Tenthred., p. 19.

Cephus nigritus Lepeletier, 1823. Monog. Tenthred., p. 20.

Cephus vittatus Costa, 1878. Accad. delle Sci. Fis. e Mat. Napoli, Atti. 7: 14.

Calamenta(!) johnsoni Ashmead, 1900. N. J. State Bd. Agr. Ann. Rpt. Sup., p. 600.

Biology: Gahan, 1920. U. S. Dept. Agr., Bul. 834, 18 pp. -Hauser, 1935. Jour. Econ. Ent. 28: 457-458. - Hauser, 1936. Ohio Agr. Expt. Sta. Bimonthly Bul. 21: 109-111. - Udine, 1941. U. S. Dept. Agr. Circ. 607, 9 pp. - Wallace and MeNeal, 1966. U. S. Dept. Agr., Tech. Bul. $1350,50 \mathrm{pp}$. (history; damage; distribution; hosts; biology; control; breeding for sawfly resistance; extensive bibliography to work prior to 1966 , too large to repeat here).

Morphology: Parker, 1934. Bol. Lab. Zool. Gen. e Agr. Portici 28: 159-191 (larval anatomy). 



\section{Suborder APOCRITA}

By KaRL V. KROMBEIN

This suborder includes a vast and diverse assemblage of species-level taxa, and many more genus- and family-level taxa than does the suborder Symphyta. Other names used in the past for the suborder include Petioliventres or Petiolata, Clistogastra and Heterophaga. Common names applied to the major groups of Apocrita include braconid and ichneumonid wasps, chalcid flies or wasps, gall wasps, ants, true wasps and bees. The first three groups are sometimes placed in the Division Parasitica or Terebrantia, and the latter three in the Division Aculeata. More detailed information is included under the divisional headings.

There are several important characters separating the Apocrita from the Symphyta. The apparent thorax is separated from the apparent abdomen by a constriction. What appears to be the thorax actually consists of the true thorax to which is fused the first abdominal segment (propodeum); the apparent thorax is sometimes termed the mesosoma or alitrunk. What appears to be the entire abdomen is termed the gaster or metasoma. The venation, especially that of the hind wing, is reduced in size and has fewer veins and cells than in Symphyta. The larvae are maggot-like and apodous; some have fleshy pseudopods on the thorax or abdomen which assist in very limited locomotion but which are not homologous with the thoracic prolegs found in most sawflies.

The majority of larval Apocrita, including the most primitive, are entomophagous. However, phytophagy has developed independently in many higher groups such as some Chalcidoidea, most Cynipoidea, a few Vespoidea and the Apoidea.

There are some fifteen times as many Apocrita recorded from North America as Symphyta. However, it is virtually certain that this ratio will be substantially increased in the future when the smaller Parasitica are more thoroughly collected and studied.

Taxonomy: Rasnitsyn, 1975. Akad. Nauk SSSR, Palaeont. Inst., Trans. 147: 1-132, 8 pls. (Mesozoic Apocrita). - Rasnitsyn, 1975. Akad. Nauk SSSR, Zool. Zhur. 54: 848-860, 1 pl. (early evolution).

Biology: Clausen, 1940. Entomophagous Insects, 688 pp., 257 figs. 



\title{
Division PARASITICA
}

\author{
By Paul M. Marsh and Robert W. Carlson
}

The divisional name applies to those groups of nonsocial Apocrita in which the ovipositor always retains the function of egg placement (i.e. is never modified to be only a stinging organ) and in which the species: (1) are usually ectoparasites or endoparasites of other insects or spiders, and, less frequently, phytophagous; (2) are never provisioners of nests; and (3) are mostly incapable of stinging human beings. The latter fact appears to result largely from the relative smallness of most Parasitica; they generally are not physically capable of piercing the human epidermis with the ovipositor. However, collectors of Ichneumonidae know by experience that a significant proportion of the species above median ichneumonid size are capable of stinging humans. Whether any Parasitica of families other than Ichneumonidae are capable of stinging humans is unknown to us, but it seems likely that a few of the largest Braconidae would have this capability. Probably all or nearly all females of Parasitica, when grasped in ways that do not restrict abdominal movement, make reflexive stinging movememts; similar defensive movements are also made by males of at least some species. Some of the ectoparasitic members of this division have stings which paralyze the host permanently, and the stings of ectoparasitic species in general are more venemous than those of endoparasitic species (see Iwata, 1976). However, there are presumably numerous species of both types which do not have venemous stings.

The dividing point between the divisions Parasitica and Aculeata is rendered arbitrary by the fact that the latter includes numerous ectoparasitic species (but no endoparasitic ones) as well as by the fact that there are no differences in biology or structure which apply to all the members of either group. Recognition of the two groups is a matter of tradition and convenience.

The habits and life histories of Parasitica are too diverse to be delved into here. Limited discussions will be found in the introductions for some of the genera and supergeneric taxa.

Biology: Clausen, 1940. Entomophagous Insects, p. 3-342. - Doutt, 1959. Ann. Rev. Ent. 4:161-182. - Hagen, 1964. In DeBach, Biol. Control Insect Pests and Weeds, p. 168-246. -Askew, 1971. Parasitic Insects, p. 113-184. - Iwata, 1976. Evol. Instinct, Compar. Ethol. Hym., Eng. ed., p. 1-84. 



\title{
Superfamily ICHNEUMONOIDEA
}

\author{
By Paul M. Marsh and Robert W. Carlson
}

Present data on numbers of species ranks the Ichneumonoidea as the largest superfamily of Hymenoptera. It includes the bulk of the larger Parasitica, most ichneumonoids being over $5 \mathrm{~mm}$ in length and a few being longer than $50 \mathrm{~mm}$. A greater percentage of Ichneumonoidea than other Parasitica have the ovipositor conspicuously exposed, but, on the other hand, a very significant portion of Ichneumonoidea have ovipositors that protrude scarcely or not at all beyond the median dorsal extremeties of the apical tergites. Townes (1975) discussed the Hymenoptera (mostly Ichneumonoidea) with the longest ovipositors; he cited a species of "Iphiaulax?" (Braconidae) with an ovipositor 14 times the length of the body.

The distinguishing characters of Ichneumonoidea are: the usual fusion of the costal and subcostal veins of the fore wing; the long antennae, which are usually more than 14-segmented; and the 2-segmented hind trochanters (the other trochanters usually also being 2 -segmented). The characters are for the most part shared by the Braconidae, Aphidiidae, Hybrizontidae, Ichneumonidae, and Stephanidae, the five families here considered to comprise the Ichneumonoidea. In the case of the Stephanidae, however, there is some question about the correctness of placement in the Ichneumonoidea (see Townes, 1969, p. 3). The larval head capsule of stephanids is considerably different from those of other ichneumonoid families (personal commun., J. R. T. Short, 1976), and in stephanids the costa and subcosta are more distinctly separated than in other ichneumonoid families. Nevertheless, we believe it best to leave the Stephanidae in the Ichneumonoidea until further studies are made.

The Aphidiidae and Hybrizontidae are sometimes treated as subfamilies of Braconidae (see van Achterberg, 1976). Some early 19th Century authors referred to the combination of the latter three groups as the "Ichneumonidum adscitorum" (?unauthentic Ichneumonidae) which they distinguished from the "Ichneumonidum genuinorum" (genuine Ichneumonidae). The distinction largely resulted from Jurine's (1807) classification of the veins and cells of hymenopterous fore wings and his provision of terms for some of the veins and cells (e.g. "nervi recurrentes"). Eady (1974) provided an excellent discussion of the way in which the Jurinean system of wing vein and cell nomenclature was modified and expanded by those who adopted Jurine's ideas. He reviewed the systems of wing vein nomenclature which are currently used for Braconidae and compared them with usages for Aphidiidae, Ichneumonidae, and other Hymenoptera. He proposed an "interim method [in order] to overcome the more frequently voiced objections to ... [the Comstock-Needham] system without adding to the confusion or obstructing progress toward uniformity."

It was apparently by mutual agreement that Gravenhorst (1819) and Nees ab Esenbeck (1819) decided to specialize on the Ichneumonidorum genuinorum and Ichneumonidorum adscitorum, respectively. In the papers referred to, they simultaneously outlined their plans for the monographs which are here cited in the sections to which they pertain. Thunberg $(1822,1824)$ chose to 
ignore the revolutionary advances in classification made possible by the work of Jurine and reverted to lumping all of the Ichneumonoidea under the generic name Ichneumon (see introduction to Ichneumonidae). Consequently, Thunberg's work was largely ignored prior to Roman's (1912) study of his type specimens.

The actual number of species in the Ichneumonoidea can only be estimated. The Braconidae contains about 2,000 described species in North America and about 10,000 worldwide; the Ichneumonidae about 3,000 in North America and about 15,000 worldwide. However, the total number of species is estimated to be 60,000 worldwide in the Ichnuemonidae (Townes, 1969, p. 7) and 40,000 in the Braconidae.

Except for Hybrizontidae and Stephanidae, the families of Ichneumonoidea occur in all zoographical regions and in all terrestrial habitats. In the Ichnuemonidae the Western Palearctic fauna is best known followed by the Nearctic, whereas the reverse seems to be true for the Braconidae. As in the case of Chalcidoidea, most of our knowledge of the Ichneumonoidea has been derived from species of economic importance to agriculture. For the vast majority of species, there is little or no knowledge of biology.

The ichneumonoids are parasitic on nearly all groups of insects as well as on spiders, and all stages of these hosts are attacked. Aphidiidae, many Braconidae, and possibly Hybrizontidae (hosts of latter unknown) attack paurometabolous insects, while no paurometabolous hosts are known for Ichneumonidae or Stephanidae. The only ichneumonoids which attack adults of holometabolous insects are certain euphorine and blacine Braconidae. Aside from the limitations which have been mentioned, large numbers of Ichneumonoidea are polyphagous and the limits of the host range seem to be related more to the host habitat than to the taxonomy of the host.

The only families of Ichneumonoidea which are known to include hyperparasitic species are Ichneumonidae and Braconidae, but only a very few Braconidae could be regarded as hyperparasitic (i.e. a few Euphorinae which attack adult Ichneumonidae). The fact that hyperparasitism is much more prevalent in the Ichneumonidae than in the Braconidae is explained largely (but not in the case of mesochorine and eucerotine Ichneumonidae) by the fact that certain Ichneumonidae have the habit of attacking hosts which are confined within silken cocoons (e.g. sawfly prepupae, ichneumonoid prepupae, spider eggs, chrysopid eggs, etc.), while this habit has not developed among Braconidae. Further discussion of host relations is deferred to the introductions to the various taxa.

Taxonomy: Jurine, 1807. Nouv. Meth. Class. Hym. Dipt. v. 1, 324 p. and 14 pl. -Gravenhorst, 1819 (1818). Nova Acta Leopoldina 9: 281-298. - Nees ab Esenbeck, 1819 (1818). Nova

Acta Leopoldina 9: 299-310. - Thunberg, 1822; 1824. Acad. Imp. des Sci. St. Petersburg,

Mem. 8: 249-281 (key); 9: 285-368. - Ashmead, 1900. U. S. Natl. Mus., Proc. 23: viii and 220

p. (classification of Ichneumonoidea and Evanioidea). - Roman, 1912. Zool. Bidr. Uppsala

1: 231-293. - Viereck, 1914. U. S. Natl. Mus., Bul. 83: v and 186 p. (type-species of

Ichneumonoidea and Evanioidea). - Viereck, 1921. U. S. Natl. Mus., Proc. 59: 129-150 (sup. to Viereck, 1914). - Townes, 1969. Amer. Ent. Inst., Mem. 11: 2-7. -Eady, 1974. Jour. Ent. (B) 43: 63-72. -Townes, 1975. Ent. News 86: 123-127. - van Achterberg, 1976. Tijdschr. v. Ent. 119: 33-78.

\title{
Family BRACONIDAE
}

\author{
By PaUl M. Marsh
}

This is a large and important group of mostly primary parasites. They are closely allied with the Ichneumonidae and can be distinguished by the absence of the second recurrent vein in the forewing. The classification used in this catalog departs somewhat from the former catalog but is, nevertheless, a conservative arrangement and is based on studies made by Telenga (1952), Tobias (1967) and Capek $(1969,1970)$. This arrangement reflects as much as possible relationships among the groups with respect to morphology--larval as well as adult--and biology. The subfamilies Doryctinae, Braconinae, Exothecinae and Rogadinae form a morphologically similar group of unspecialized Braconidae called the Cyclostomi in reference to the circular opening formed by the clypeus and mandibles. The Doryctinae, Braconinae and Exothecinae are ectoparasites of cryptic host larvae, usually permanently paralyzing the host, and are considered to be the most primitive groups. The Rogadinae, which are endoparasites of lepidopterous larvae, represent the transition from external to internal parasitism which is exhibited by the 
remainder of the Braconidae, or the Acyclostomi.

The subfamilies are arranged in this catalog essentially in phylogenetic order from the least specialized to the most specialized. However, within each subfamily the genera are arranged in alphabetical order as are the species within each genus. The names used for the hosts are the latest acceptable names which were available at the time the manuscripts were prepared. Where a North American species occurs in other geographical areas, only the North American hosts for that parasite are listed.

Taxonomy: Foerster, 1862. Naturh. Ver. Rheinlande, Verh. 19: 225-288. - Dalla Torre, 1898. Cat. Hym. v. 4, p. 1-323. - Ashmead, 1900. U. S. Natl. Mus., Proc. 23: 104-149. -Szepligeti, 1904. In Wytsman, Gen. Ins., fasc. 22 a-b, 253 p. -Riegel, 1948. Ent. Soc. Amer., Ann. 4: 439-448 (wings). - Muesebeck and Walkley, 1951. In Muesebeck, et al., U. S. Dept. Agr., Agr. Monog. 2, p. 90-184. - Telenga, 1952. Izd. Akad. Nauk Ukrain. S.S.R., Kiev, 139 p. (English translation made in 1969 by Israel Program for Scientific Translations). - Short, 1952. Roy. Ent. Soc. London, Trans. 103: 27-84 (larval tax.). - Muesebeck, 1958. In Krombein, U. S. Dept. Agr., Agr. Monog. 2, Supl. 1, p. 18-36. -Marsh, 1963. Ent. Soc. Amer., Ann. 56: 522-527 (key to subfam.). - Shenefelt, 1965. Beit. z. Ent. 15: 201-500 (literature on Braconidae). - Tobias, 1967. Ent. Obozr. 46: 645-669. - Muesebeck, 1967. In Krombein and Burks, U. S. Dept. Agr., Agr. Monog. 2, Supl. 2, p. 27-60. - Tobias, 1968. Acad. Sci. U. S. S. R., special issue, p. 3-43. - Capek, 1969. Ent. Soc. Wash., Proc. 71: 304-312. -Shenefelt, 1969. Hym. Cat., part 4, p. 1-176 (cat. World spp.). - Shenefelt, 1970. Hym. Cat., parts 5 and 6, p. 177-428 (cat. World spp.). -Capek, 1970. Canad. Ent. 102: 846-875. - Marsh, 1971. Ent. Soc. Amer., Ann. 64: 841-850 (key to No. Amer. genera). -Tobias, 1971. Trudy Vses. Ent. Obshe. 54: 156-268 (keys to subfamilies and genera; English translation, 1975, Coop. State Res. Serv., U. S. Dept. Agr. and Nat. Sci. Found.). - Shenefelt, 1972. Hym. Cat., part 7, p. 429-668 (cat. World spp.). - Shenefelt, 1973. Hym. Cat., parts 9 and 10, p. 669-936 (cat. World spp.). - Capek, 1973. Acta Inst. Forestalis Zoolenensis 1973: 259-268 (key to final instar larvae). - Shenefelt, 1974. Hym. Cat., part 11, p. 937-1113 (cat. World spp.). - Dudarenko, 1974. Ent. Obozr. 53: 114-129. -Papp, 1974. Folia Ent. Hung. (N. S.) 27: 109-133. - Shenefelt, 1975. Hym. Cat., part 12, p. 1114-1262 (cat. World spp.). - Shenefelt and Marsh, 1976. Hym. Cat., part 13, p. 1263-1424 (cat. World spp.). - van Achterberg, 1976. Tijdschr. v. Ent. 119: 33-78 (key to subfam.).

Biology: Matthews, 1974. Ann. Rev. Ent. 19: 15-32 (review of literature).

Morphology: Tobias and Dudarenko, 1974. Jour. Zool. 3: 65-72. -Dudarenko, 1974. Ent. Obozr. 53: 114-129. - Tobias, 1975. Ent. Obozr. 54: 137-150.

\section{SUBFAMILY DORYCTINAE}

This subfamily is probably the most primitive group of the Braconidae. Most species are ectoparasites of wood boring beetle larvae, but a few attack lepidopterous larvae and sawfly larvae. Although the subfamily represents a large and rather homogeneous group of genera, it has been divided into several subfamilies and tribes by past workers. It is treated here as defined by Marsh $(1965,1967,1970)$ which includes the subfamily Spathiinae of the previous catalog.

Taxonomy: Marsh, 1965. Ent. Soc. Amer., Ann. 58: 668-699 (review of No. Amer. genera). -Marsh, 1967. Ent. Soc. Wash., Proc. 69: 359-360 (status of tribes). -Marsh, 1970. Ent. Soc. Wash., Proc. 72: 313 (notes on subfamily definition). - Marsh, 1973. Wash. Acad. Sci., Jour. 63: 69-72. - Shenefelt and Marsh, 1976. Hym. Cat., part 13, p. 1263-1424 (cat. World spp.).

\section{Genus ACROPHASMUS Enderlein}

Acrophasmus Enderlein, 1912. Arch. f. Naturgesch. 78(A)(2): 16. Type-species: Acrophasmus exilis Enderlein. Orig. desig.

Most of the North American species of this Western Hemisphere genus were incorrectly placed in the genus Doryctinus prior to 1968 . The meager host records suggest that parasitism is restricted to the powder post beetles of the families Bostrichidae and Lyctidae.

Revision: Marsh, 1968. Ent. Soc. Wash., Proc. 70: 101-107 (No. Amer. spp.).

Taxonomy: Shenefelt and Marsh, 1976. Hym. Cat., part 13, p. 1372-1373 (cat. World spp.). 
arizonensis Marsh. Ariz.

Acrophasmus arizonensis Marsh, 1968. Ent. Soc. Wash., Proc. 70: 102. \&, ठ.

atriventris (Cresson). Pa., Fla., Kans., Ark., Tex., N. Mex.; Mex.

Exothecus atriventris Cresson, 1872. Amer. Ent. Soc., Trans. 4: 189. \&.

Doryctes longicauda Ashmead, 1889 (1888). U. S. Natl. Mus., Proc. 11: 626. . Preoce. by Giraud, 1857.

Doryctes ashmeadii Dalla Torre, 1898. Cat. Hym., v. 4, p. 232. N. name for longicauda Ashmead.

Hormiopterus caudatus Brues, 1907. Wis. Nat. Hist. Soc., Bul. 5: 62..

Taxonomy: Marsh, 1973. Wash. Acad. Sci., Jour. 63: 69.

butleri Marsh. Ariz.

Acrophasmus butleri Marsh, 1968. Ent. Soc. Wash., Proc. 70: 103. \&, ð.

ferrugineus Marsh. Pa. s. to Fla.; Miss., Mo., Tex. Host: Lyctus planicollis Lec. Acrophasmus ferrugineus Marsh, 1968. Ent. Soc. Wash., Proc. 70: 103. $९$, o.

immigrans (Beardsley). N. C., S. C., Fla., La.; Hawaii. Host: Lyctus sp., L. striatus Melsh. Doryctes immigrans Beardsley, 1961. Haw. Ent. Soc., Proc. 16: 362. ๆ.

Acrophasmus lycti Marsh, 1968. Ent. Soc. Wash., Proc. 70: 105.,$~ ठ$.

Taxonomy: Marsh, 1973. Wash. Acad. Sci., Jour. 63: 69.

scobiciae (Marsh). Calif. Host: Scobicia declivis (Lec.).

Doryctodes scobiciae Marsh, 1966. Amer. Ent. Soc., Trans. 92: 513. १.

Taxonomy: Marsh, 1973. Wash. Acad. Sci., Jour. 63: 69.

secundus (Muesebeck and Walkley). Mass., R. I., Pa., N. J., Va., Ga., Mich., Ohio, Mo., La., Tex.

Heterospilus texanus Ashmead, 1896. Amer. Ent. Soc., Trans. 23: 214. ס. Preocc. in

Doryctinus by Ashmead, 1889 (1888).

Doryctinus secundus Muesebeck and Walkley, 1951. U. S. Dept. Agr., Agr. Monog. 2, p. 178. N. name for texonus Ashmead, 1896.

\section{Genus AIVALYKUS Nixon}

Aivalykus Nixon, 1938. Roy. Ent. Soc. London, Proc. (B) 7: 152.

Type-species: Aivalykus electes Nixon. Orig. desig.

Taxonomy: Shenefelt and Marsh, 1976. Hym. Cat., part 13, p. 1352-1353 (cat. World spp.). nearcticus Marsh. N. H., N. C., Fla., Tex. Host: Phloeotribus frontalis (Oliv.).

Aivalykus nearcticus Marsh, 1965. Ent. Soc. Amer., Ann. 58: 677. १, ठ.

\section{Genus ALLORHOGAS Gahan}

Allorhogas Gahan, 1912. Ent. Soc. Wash., Proc. 14: 3.

Type-species: Allorhogas gallicola Gahan. Orig. desig.

Host records indicate that some species of Allorhogas are associated with gall making insects, particularly cynipids on oaks. However, no definite host associations have been made with these galls and it is likely that the hosts are insects other than the gall makers themselves. One species has been reared from a cerambycid.

Taxonomy: Shenefelt and Marsh, 1976. Hym. Cat., part 13, p. 1265-1267 (cat. World spp.). arizonensis (Ashmead). Ariz. Ecology: Reared from cynipid gall on oak.

Bracon (?) arizonensis Ashmead, 1889 (1888). U. S. Natl. Mus., Proc. 11: 616 \&, ơ.

bruesi (Muesebeck and Walkley). Mass.

Acrisis americanus Brues, 1907. Wis. Nat. Hist. Soc., Bul. 5: 160. ¿. Preocc. in Miocolus by Ashmead, 1894.

Miocolus bruesi Muesebeck and Walkley, 1951. U. S. Dept. Agr., Agr. Monog. 2, p. 182. N. name for americanus Brues.

Taxonomy: Muesebeck, 1964. Ent. Soc. Wash., Proc. 66: 88.

gallicola Gahan. Mass., Conn., Md., Va. Ecology: Reared from galls of Neuroterus quercusbatatus (Fitch), Callirhytis seminosa (Bass.), and "old horned gall on pin oak."

Allorhogas gallicola Gahan, 1912. Ent. Soc. Wash., Proc. 14: 4. ९, o. 
pallidiceps (Perkins). Fla.; Hawaii, South Pacific Islands, Southeast Asia, India, South Africa.

Ecology: Frequently reared from wood crates on ships. This species was probably

accidentally introduced into North and South America. Host: Oeme rigida (Say),

$X$ ylotrechus quadripes Chev., Chlorophorus annularis F.

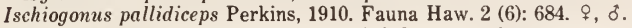

Doryctes strioliger Kieffer, 1921. Inst. Sci. Saigon, Bul. Agr. 3: 134. १, oे.

Monolexis brugirouxi Cheesman, 1928. Ann. and Mag. Nat. Hist. (10) 1: 185. 9.

Taxonomy: Marsh, 1973. Wash. Acad. Sci., Jour. 63: 69.

\section{Genus APTENOBRACON Marsh}

Aptenobracon Marsh, 1965. Ent. Soc. Amer., Ann. 58: 675.

Type-species: Aptenobracon formicoides Marsh. Orig. desig.

formicoides Marsh. Va., Ga., Kans., Tex. Host: Mordellistena sp. on Vemonia interior Sm.,

Trichobaris texana Lec., "goldenrod galls."

Aptenobracon formicoides Marsh, 1965. Ent. Soc. Amer., Ann. 58: 675. §, ठै.

\section{Genus CALLIHORMIUS Ashmead}

Callihormius Ashmead, 1900. U. S. Natl. Mus., Proc. 23: 148.

Type-species: Pambolus bifasciatus Ashmead. Orig. desig.

Revision: Marsh, 1966. Ent. Soc. Wash., Proc. 68: 240-246 (No. Amer. spp.).

bifasciatus (Ashmead). Maine s. to Fla., w. to Mo. and Tex.; Calif. Host: Anthaxia viridicomis

(Say), Mastogenius subcyaneus (Lec.), Xylotrechus quadrimaculatus (Hald.).

Pambolus bifasciatus Ashmead, 1892. Psyche 6:289. $ๆ, \delta$.

stigmatus Marsh. N. J., Fla., La., Tex. Ecology: Reared from buprestid in avocado.

Callihormius stigmatus Marsh, 1966. Ent. Soc. Wash., Proc. 68: 243. ๆ, ठ.

texanus Marsh. Fla., Tex.

Callihormius texanus Marsh, 1966. Ent. Soc. Wash., Proc. 68: 245. \&.

werneri Marsh. Ariz.

Callihormius werneri Marsh, 1966. Ent. Soc. Wash., Proc. 68: 246. ๆ.

\section{Genus CURTISELLA Spinola}

Curtisella Spinola, 1853. Accad. Sci. Torino, Mem. 13: 30.

Type-species: Curtisella pimploides Spinola. Monotypic.

Neorhyssa Szepligeti, 1902. Termes. Fuzetek 25: 57.

Type-species: Neorhyssa nigra Szepligeti. Monotypic.

Lissophrymnus Cameron, 1911. Timehri (3)1: 312.

Type-species: Lissophrymnus annulicaudus Cameron. Monotypic.

Subcurtisella Roman, 1924. Arkiv f. Zool. 16: 33.

Type-species: Subcurtisella waterstoni Roman. Monotypic.

Polystenoides Muesebeck, 1950. Ent. Soc. Wash., Proc. 52: 79.

Type-species: Polystenoides lignicola Muesebeck. Orig. desig.

Taxonomy: Roman, 1924. Arkiv f. Zool. 16: 38. - Marsh, 1971. Ent. Soc. Amer., Ann. 64: 844.

- Marsh, 1973. Wash. Acad. Sci., Jour. 63: 70. —Shenefelt and Marsh, 1976. Hym. Cat., part 13, p. 1373-1374 (cat. World spp.).

lignicola (Muesebeck). Pa., Md., N. C.

Polystenoides lignicola Muesebeck, 1950. Ent. Soc. Wash., Proc. 52: 79. ९, ठ.

\section{Genus DENDROSOTER Wesmael}

Dendrosoter Wesmael, 1838. Nouv. Mem. Acad. Sci. Bruxelles 11: 137.

Type-species: Bracon protuberans Nees. Monotypic.

Bracon subg. Eurybolus Ratzeburg, 1848. Ichn. d. Forstins., v. 2, p. 32.

Type-species: Bracon (Eurybolus) curtisii Ratzeburg. Desig. by Viereck, 1914.

Caenopachys Foerster, 1862. Naturh. Ver. Rheinlande, Verh. 19: 239.

Type-species: Bracon (Eurybolus) hartigii Ratzeburg. Orig. desig. 
Revision: Muesebeck, 1938. Ent. Soc. Wash., Proc. 40: 281-287 (No. Amer. spp.). - Nixon, 1939. Roy. Ent. Soc. London, Proc. (B) 8: 1-11 (Indian and African spp.). -Telenga, 1941. Fauna U. S. S. R., v. 5, n. 3, pp. 72-80, 388-389 (some Eur. spp.).

Taxonomy: Shenefelt and Marsh, 1976. Hym. Cat., part 13, p. 1269-1276 (cat. World spp.). chansleri Marsh. N. Mex.

Dendrosoter chansleri Marsh, 1967. Ent. Soc. Wash., Proc. 69: 246..+

integer Muesebeck. Idaho, Oreg., Calif. Host: Phloeosinus cupressi Hopk., P. setosus Bruck, P. vandykei Swaine, Scolytus praeceps Lec.

Dendrosoter integer Muesebeck, 1938. Ent. Soc. Wash., Proc. 40: 287. ‡, ठ.

protuberans (Nees). Va., Ohio, Mich., Wis., Mo., Colo.; Europe. Introduced from France. Host: Scolytus multistriatus (Marsham).

Bracon protuberans Nees, 1834. Hym. Ichn. Aff. Monog., v. 1, p. 121. ?.

Taxonomy: Marsh, 1967. Ent. Soc. Wash., Proc. 69: 246.

Biology: Russo, 1938. Lab. Ent. Agr. Portici, Bol. 2: 244-255 (in Italy). - Kennedy, 1970. Ent.

Soc. Amer., Ann. 63: 351-358.

scaber Muesebeck. Mont., N. Mex., Ariz., Oreg., Calif. Host: Cylindrocopturus longulus (Lec.), Pityophthorus sp.

Dendrosoter scaber Muesebeck, 1938. Ent. Soc. Wash., Proc. 40: 286. ९, ơ.

scolytivorus (Viereck and Rohwer). S. Dak., Colo., Idaho, Ariz., Calif. Host: Ips confusus (Lec.), I. oregonis (Fitch).

Caenopachys scolytivorus Viereck and Rohwer, 1913. In Rohwer, U. S. Natl. Mus., Proc. 45: 536. $\delta$.

sulcatus Muesebeck. N. Y. s. to Fla., w. to Wis. and Tex. Host: Dendroctonus frontalis Zimm., Ips avulsus (Eichh.), I. grandicollis (Eichh.).

Dendrosoter sulcatus Muesebeck, 1938. Ent. Soc. Wash., Proc. 40: 284. , ð.

\section{Genus DORYCTES Haliday}

Doryctes Haliday, 1836. Ent. Mag. 4: 43.

Type-species: Bracon obliteratus Nees. Desig. by Erichson, 1837. The type-species of Doryctes is in the sense of Nees, not Haliday.

Ischiogonus Wesmael, 1838. Nouv. Mem. Acad. Sci. Bruxelles 11: 125.

Type-species: Ischiogonus erythrogaster Wesmael. Desig. by Viereck, 1914.

Udamolcus Enderlein, 1920 (1918). Arch. f. Naturgesch. 84(A)(11): 142.

Type-species: Udamolcus herero Enderlein. Orig. desig.

Pristodoryctes Kieffer, 1921. Inst. Sci. Saigon, Bul. Agr. 3: 133.

Type-species: Pristodoryctes striativentris Kieffer. Monotypic.

Paradoryctes Granger, 1949. Inst. Sci. Madagascar, Mem. (A) 2: 102.

Type-species: Paradoryctes coxalis Granger. Orig. desig.

Revision: Nixon, 1939. Ann. and Mag. Nat. Hist. (11) 3: 481-506 (Indian and African spp.).

-Telenga, 1941. Fauna U. S. S. R., v. 5, n. 3, pp. 92-108, 392-395 (some Eur. spp.). - Marsh, 1969 (1968). Amer. Ent. Soc., Trans. 94: 379-405 (No. Amer. spp.).

Taxonomy: Marsh, 1973. Wash. Acad. Sci., Jour. 63: 70. - Shenefelt and Marsh, 1976. Hym. Cat., part 13, p. 1277-1295 (cat. World spp.).

anatolikus Marsh. Que. s. to Fla., w. to Minn. and N. Mex. Host: Agrilus bilineatus (Weber), Dendroctonus frontalis Zimm., Neoclytus acuminatus (F.).

Doryctes anatolikus Marsh, 1969 (1968). Amer. Ent. Soc., Trans. 94: 384. \&, ơ.

brachynervus Marsh. Ariz., Nev., Wash., Oreg., Calif. Host: Chrysobothris caurina Horn.

Doryctes brachynervus Marsh, 1969 (1968). Amer. Ent. Soc., Trans. 94: 386. §, §.

buoculus Marsh. D. C., N. C.

Doryctes buoculus Marsh, 1969 (1968). Amer. Ent. Soc., Trans. 94: 388. ๆ.

californicus Marsh. Alta., Calif.

Doryctes californicus Marsh, 1969 (1968). Amer. Ent. Soc., Trans. 94: 388. १, o.

erythromelas (Brulle). No. Amer. Host: Neoclytus acuminatus (F.).

Syngaster erythromelas Brulle, 1846. In Lepeletier, Hist. Nat. Ins. Hym., v. 4, p. 458. o. 
Syngaster rufiventris Brulle, 1846. In Lepeletier, Hist. Nat. Ins. Hym., v. 4, p. 458. $\subsetneq$.

Bracon radiatus Cresson, 1872. Amer. Ent. Soc., Trans. 4: 185. 9.

Bracon disjunctus Cresson, 1872. Amer. Ent. Soc., Trans. 4: 186. 9.

Syngaster migosus Provancher, 1886. Addit. Corr. Faune Ent. Canada Hym., p. 122. " $\delta "=$ †.

Doryctes apacheus Viereck, 1907. Amer. Ent. Soc., Trans. 33: 383. §.

Doryctes femurrubrum Viereck, 1907. Amer. Ent. Soc., Trans. 33: 384. §.

eucrinus Marsh. Calif.

Doryctes eucrinus Marsh, 1969 (1968). Amer. Ent. Soc., Trans. 94: 391. ๆ, ð.

exhalans (Say). Ind.

Bracon exhalans Say, 1828. Contrib. Maclur. Lyc. Phila. 1: 77. Holotype lost; possibly same species as erythromelas (Brulle).

fartus (Provancher). Canada, Alaska, northern U. S.

Syngaster fartus Provancher, 1880. Nat. Canad. 12: 163..

Syngaster macilentis Provancher, 1880. Nat. Canad. 12: 163. ‡, ठ.

Syngaster atripes Provancher, 1886. Addit. Corr. Faune Ent. Canada Hym., p. 122..

Rhogas rugosulus Provancher, 1888. Addit. Corr. Faune Ent. Canada Hym., p. 374. $\$$.

Rhysipolis? biformis Ashmead, 1893. Canad. Ent. 25: 68. ๆ, ठ.

infuscus Marsh. Mass., Pa., Ark.

Doryctes infuscus Marsh, 1969 (1968). Amer. Ent. Soc., Trans. 94: 394. \&.

macrocaudus Marsh. Mass. s. to N. C., w. to Mich. and Iowa.

Doryctes macrocaudus Marsh, 1969 (1968). Amer. Ent. Soc., Trans. 94: 394. \&, ð.

maculipennis Rohwer. Ariz., Calif. Host: Agrilus angelicus Horn, Anthaxia sp., Chramesus sp.

Doryctes maculipennis Rohwer, 1919. Ent. Soc. Wash., Proc. 21: 7. ๆ, ठ.

pacificus (Provancher). Mont., B. C. s. to Calif. Host: Dicerca sp.

Phylax pacificus Provancher, 1885. Canad. Ent. 17: 117..

Phylax niger Provancher, 1885. Canad. Ent. 17: 117. ठ".

pyrrhus Marsh. Utah, Wash., Calif.

Doryctes pyrrhus Marsh, 1969 (1968). Amer. Ent. Soc., Trans. 94: 398. ९, ठ.

rufipes (Provancher). Southern Canada, northern U. S. Host: Agrilus anxius Gory, $A$. cephalicus Lec., Astylopsis macula (Say), Callidium violaceum L., Xylotrechus quadrimaculatus (Hald.).

Phylax rufipes Provancher, 1880. Nat. Canad. 12: 175..

slossonae Marsh. Que., N. H., Man.

Doryctes slossonae Marsh, 1969 (1968). Amer. Ent. Soc., Trans. 94: 400. ₹, o.

\section{Genus DORYCTINUS Roman}

Doryctinus Roman, 1910. Ent. Tidskr. 31: 122.

Type-species: Exothecus rugulosus Cresson. Orig. desig.

Taxonomy: Marsh, 1968. Ent. Soc. Wash., Proc. 70: 112.

marshi Greenbaum. Fla.

Doryctinus marshi Greenbaum, 1975. Fla. Ent. 58: 213. 9.

rugulosus (Cresson). Tex.

Exothecus rugulosus Cresson, 1872. Amer. Ent. Soc., Trans. 4: 190. $९$.

Doryctes texanus Ashmead, 1889 (1888). U. S. Natl. Mus., Proc. 11: 627. ๆ.

\section{Genus ECPHYLUS Foerster}

Ecphylus Foerster, 1862. Naturh. Ver. Rheinlande, Verh. 19: 237.

Type-species: Bracon sileseacus Ratzeburg. Orig. desig.

Sactopus Ashmead, 1900. U. S. Natl. Mus., Proc. 23: 146.

Type-species: Sactopus schwarzii Ashmead. Orig. desig.

Paraecphylus Ashmead, 1900. U. S. Natl. Mus., Proc. 23: 147.

Type-species: Paraecphylus websteri Ashmead. Orig. desig.

Sycosoter Picard and Lichtenstein, 1917. Soc. Ent. France, Bul. 16: 285. 
Type-species: Sycosoter lavagnei Picard and Lichtenstein. Orig. desig.

Revision: Telenga, 1941. Fauna U. S. S. R., v. 5, n. 3, pp. 49-54, 383-384 (some Eur. spp.). -Marsh, 1965. Ent. Soc. Amer., Ann. 58: 678-690 (No. Amer. spp.). - Hedqvist, 1967. Ent. Tidskr. 88: 66-71 (some Eur. spp.).

Taxonomy: Muesebeck, 1935. Ent. Soc. Wash., Proc. 37: 21-22. -Shenefelt and Marsh, 1976. Hym. Cat., part 13, p. 1344-1352 (cat. World spp.).

Biology: Russo, 1938. Lab. Ent. Agr. Portici, Bol. 2: 287-307 (Ecphylus sileseacus (Ratz.) in Italy). -Marsh, 1965. Ent. Soc. Amer., Ann. 58: 679-680.

arcuatus Muesebeck. Idaho, Oreg., Calif. Host: Scolytus subscaber Lec., S. ventralis Lec. Ecphylus arcuatus Muesebeck, 1935. Ent. Soc. Wash., Proc. 37: 23. ९, ठ.

bicolor Rohwer. Wyo., B. C., Wash., Calif. Host: Pityogenes knechteli Swaine. Ecphylus bicolor Rohwer, 1913. U. S. Natl. Mus., Proc. 45: 540..

Ecphylus pityogeni Marsh, 1965. Ent. Soc. Amer., Ann. 58: 690. Nom. nud.

californicus Rohwer. Mont., Idaho, Wash., Oreg., Calif. Host: Phloeosinus cupressi Hopk., $P$. punctatus Lec., $P$. sequoiae Hopk., $P$. setosus Bruck, $P$. swainei Bruck, $P$. vandykei Swaine, Pseudohylesinus nebulosus (Lec.), Scolytus sp., S. laricis Blkm., S. unispinosus Lec.

Ecphylus californicus Rohwer, 1913. U. S. Natl. Mus., Proc. 45: 539. ?.

chramesi Marsh. Tex., Ariz. Host: Chramesus sp. The original description states that this species was reared from Chramesus robiniae but this is apparently a manuscript species name.

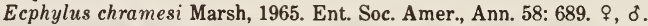

costaricensis Matthews. Md., D. C.; Costa Rica. Host: Styphlosoma granulatum Blandf. (in Costa Rica).

Ecphylus costaricensis Matthews, 1969. Ga. Ent. Soc., Jour. 4:117. ₹, ठ.

flavus Marsh. Miss., La. Host: Lyctus sp., Xylobiops basilaris (Say).

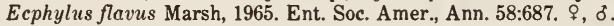

hicoriae Rohwer. N. Y., Pa., N. C. Host: Scolytus quadrispinosus Say. Ecphylus hicoriae Rohwer, 1919. Canad. Ent. 51:161. + , ठ.

hubbardi Rohwer. Ariz.

Ecphylus hubbardi Rohwer, 1913. U. S. Natl. Mus., Proc. 45:538..

hypothenemi Ashmead. Mass., Ohio, W. Va., Tex., Colo., N. Mex., Ariz., Wash., Calif. Host: Hypothenemus sp., Pityophthorus sp., P. hopkinsi (Blkm.).

Ecphylus hypothenemi Ashmead, 1896. Amer. Ent. Soc., Trans. 23: 215. ๆ, ठ.

Paraecphylus websteri Ashmead, 1900. U. S. Natl. Mus., Proc. 23: 147. 9.

kansensis Marsh. Kans.

Ecphylus kansensis Marsh, 1965. Ent. Soc. Amer., Ann. 58: 682. \&.

leechi Marsh. Calif. Host: Pseudopityophthorus pubipennis (Lec.).

Ecphylus leechi Marsh, 1965. Ent. Soc. Amer., Ann. 58: 681. ‡, ठ̀.

leptosulcus Marsh. Ohio, W. Va., N. C. Host: Pityophthorus sp., P. liquidambarus Blkm., Pseudopityophthorus minutissimus (Zimm.), P. pruinosus (Eichh.).

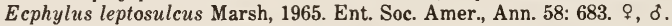

lepturgi Rohwer. N. C., Kans., N. Mex., Nev. Host: Pityophthorus sp., Urgleptes facetus (Say).

Ecphylus lepturgi Rohwer, 1913. U. S. Natl. Mus., Proc. 45: 540. $q$.

lycti Rohwer. Fla., Tex., Calif. Host: Leperisinus californicus Swaine, Lyctus sp., L. planicollis Lec., Synoxylon sp.

Ecphylus lycti Rohwer, 1913. U. S. Natl. Mus., Proc. 45: 538..

nigriceps Ashmead. W. Va.

Ecphylus nigriceps Ashmead, 1896. Amer. Ent. Soc., Trans. 23: 216..

optilus Marsh. Fla. Host: Pityophthorus sp.

Ecphylus optilus Marsh, 1965. Ent. Soc. Amer., Ann. 58: 683. ९, ठ.

pacificus Marsh. S. Dak. s. to Colo., w. to Oreg. and Calif. Host: Cryphalus pubescens Hopk., Pityogenes knechteli Swaine, Pityophthorus sp., P. carmeli Swaine.

Ecphylus pacificus Marsh, 1965. Ent. Soc. Amer., Ann. 58: 686.,$\delta$. 
Biology: Deyrup, 1975. Conif. For. Biome, Ecosystem Anal. Stu., Univ. Wash., Bul. 6, p. 79-80.

pallidus Ashmead. D. C., W. Va., Va., N. C., S. C. Ecology: Associated with Micracis swainei Blkm. in Salix nigra.

Ecphylus pallidus Ashmead, 1896. Amer. Ent. Soc., Trans. 23: 215. ९, ठ.

rohweri Muesebeck. N. Mex., Ariz., Calif.

Ecphylus schwarzi Rohwer, 1913. U. S. Natl. Mus., Proc. 45: 538.. Preoce. by Ashmead, 1900.

Ecphylus rohweri Muesebeck, 1935. Ent. Soc. Wash., Proc. 37: 23. N. name for schwarzi Rohwer.

schwarzii (Ashmead). N. Y. s. to N. C. Host: Dendroctonus frontalis Zimm., Pityophthorus sp.

Sactopus schwarzii Ashmead, 1900. U. S. Natl. Mus., Proc. 23: 146. ठ́.

Ecphylus johnsoni Rohwer, 1913. U. S. Natl. Mus., Proc. 45: 539. १.

texanus Brues. Tex.

Ecphylus texanus Brues, 1907. Wis. Nat. Hist. Soc., Bul. 5: 111. ๆ.

unifasciatus Marsh. Tex.

Ecphylus unifasciatus Marsh, 1965. Ent. Soc. Amer., Ann. 58: 685..+

Genus GLYPTOCOLASTES Ashmead

Glyptocolastes Ashmead, 1900. U. S. Natl. Mus., Proc. 23: 142.

Type-species: Glyptocolastes texanus Ashmead. Orig. desig.

Glyptodoryctes Ashmead, 1900. U. S. Natl. Mus., Proc. 23: 144.

Type-species: Heterospilus caryae Ashmead. Orig. desig.

Revision: Marsh, 1968. Ent. Soc. Wash., Proc. 70: 107-110.

caryae (Ashmead). N. Y. s. to Fla., w. to Mich. and Tex. Host: Scobicia bidentata (Horn).

Heterospilus caryae Ashmead, 1896. Amer. Ent. Soc., Trans. 23: 214. \&, ठ.

Hormiopterus claripennis Brues, 1907. Wis. Nat. Hist. Soc., Bul. 5: 61. \&.

texanus Ashmead. Tex., Ariz. Host: Dendrobiella quadrispinosa (Lec.).

Glyptocolastes texanus Ashmead, 1900. U. S. Natl. Mus., Proc. 23: 142. ๆ, ठ.

\section{Genus HECABOLUS Curtis}

Hecabolus Curtis, 1834. Brit. Ent., v. 11, p. 507.

Type-species: Hecabolus sulcatus Curtis. Orig. desig.

Anisopelma Wesmael, 1838. Nouv. Mem. Acad. Sci. Bruxelles 11: 134.

Type-species: Anisopelma belgicum Wesmael. Monotypic.

Taxonomy: Shenefelt and Marsh, 1976. Hym. Cat., part 13, p. 1354-1357 (cat. World spp.). sulcatus Curtis. Fla., Colo., Ariz., Calif.; Europe. Probably adventive. Host: Acmaeodera sp.

Hecabolus sulcatus Curtis, 1834. Brit. Ent., v. 11, p. 507. .

Anisopelma belgicum Wesmael, 1838. Nouv. Mem. Acad. Sci. Bruxelles 11: 135. \&.

\section{Genus HETEROSPILUS Haliday}

Rogas subg. Heterospilus Haliday, 1836. Ent. Mag. 4: 40, 46.

Type-species: Rogas (Heterospilus) quaestor Haliday. Monotypic.

Bracon subg. Synodus Ratzeburg, 1848. Ichn. d. Forstins., v. 2, p. 31. Preoce. by Gronovius, 1763, and Latreille, 1828.

Type-species: Bracon incompletus Ratzeburg. Monotypic.

Caenophanes Foerster, 1862. Naturh. Ver. Rheinlande, Verh. 19: 236. N. name for Synodus Ratzeburg.

Telebolus Marshall, 1888. In Andre, Spec. Hym. Eur. Alg., v. 4, p. 202.

Type-species: Telebolus corsicus Marshall. Monotypic.

Kareba Cameron, 1904. Invert. Pac. 1: 50.

Type-species: Kareba flavipes Cameron. Desig. by Viereck, 1914.

Anacatostigma Enderlein, 1920 (1918). Arch. f. Naturgesch. 84(A)(11): 131.

Type-species: Anacatostigma paradoxum Enderlein. Orig. desig. 
A predominately Western Hemisphere genus with a large number of species, most of which are undescribed. Most species, where records are available, are parasites of coleopterous larvae, but a few species attack lepidopterous larvae, and one Holarctic species is a parasite of sawfly larvae.

Revision: Fischer, 1960. Polskie Pismo Ent. 30: 33-64 (Eur. spp.).

Taxonomy: Marsh, 1969. Ent. Soc. Wash., Proc. 71: 210-214 (lectotype desig. No. Amer. spp.). -Marsh, 1973. Wash. Acad. Sci., Jour. 63: 70. - Shenefelt and Marsh, 1976. Hym. Cat., part 13, p. 1298-1313 (cat. World spp.).

aciculatus (Provancher). Calif.

Macrocentrus aciculatus Provancher, 1888. Addit. Corr. Faune Ent. Canada Hym., p. 380. ․

anobiidivorus Muesebeck. Fla. Host: Falsogastrallus librinocens (Fish.).

Heterospilus anobiidivorus Muesebeck, 1939. Ent. Soc. Wash., Proc. 41: 62. \&.

anthaxiae (Ashmead). Pa. s. to Fla., w. to Wis. and Iowa. Host: Agrilus sp., Anthaxia viridicomis (Say).

Caenophanes anthaxiae Ashmead, 1893. Canad. Ent. 25: 77. $९, ~ ð$.

appalachicola (Viereck). Kans.

Diachasma appalachicola Viereck, 1905. Kans. Acad. Sci., Trans. 19: 272 ..

atratus (Ashmead). Colo., Calif.

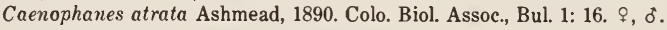

atriceps (Ashmead). Md., Va., S. C., Fla., Mo.

Caenophanes atriceps Ashmead, 1893. Canad. Ent. 25: 76. $q$.

beaticatus (Provancher). N. Y. s. to Va., w. to Ont. and Minn. Host: Clytus ruricola (Oliv.), Xyletinus peltatus (Harr.).

Syngaster beaticatus Provancher, 1880. Nat. Canad. 12: 162. $?$.

bruchi Viereck. Md. s. to Fla., w. to Iowa and Tex. Host: Amblycerus robiniae (F.), Bruchus sp., Gibbobruchus mimus (Say).

Heterospilus bruchi Viereck, 1910 (1909). Ent. Soc. Wash., Proc. 11: 210. \&, o.

cephi Rohwer. N. Y., Pa., Ont.; Europe. Host: Cephus pygmaeus (L.).

Heterospilus cephi Rohwer, 1925. Wash. Acad. Sci., Jour. 15: 178. \&, ¿.

Heterospilus basifurcatus Fischer, 1960. Polskie Pismo Ent. 30: 38. ๆ.

Taxonomy: Marsh, 1973. Wash. Acad. Sci., Jour. 63: 70.

Biology: Hill and Smith, 1931. Jour. Agr. Res. 43: 597-609.

chittendenii (Ashmead). Va.

Caenophanes chittendenii Ashmead, 1893. Canad. Ent. 25: 77. ๆ, ठ.

consimilis (Ashmead). U. S.

Caenophanes consimilis Ashmead, 1893. Canad. Ent. 25: 75..

etiellae Rohwer. Fla.; Puerto Rico. Host: Etiella zinckenella (Treit.), Fundella pellucens Zell. Heterospilus etiellae Rohwer, 1925. Wash. Acad. Sci., Jour. 15: 179. \&, ठ.

eurostae Viereck. Conn., Pa. Ecology: Reared from galls of Eurosta solidaginis (Fitch).

Heterospilus eurostae Viereck, 1917 (1916). Conn. State Geol. and Nat. Hist. Survey, Bul. 22: 238. ․

flavicollis (Ashmead). D. C., Va.

Caenophanes flavicollis Ashmead, 1893. Canad. Ent. 25: 75..

floridanus (Ashmead). Fla.

Caenophanes floridanus Ashmead, 1893. Canad. Ent. 25: 76. ๆ.

hylotrupidis (Ashmead). W. Va. Host: Semanotus ligneus (F.).

Caenophanes hylotrupidis Ashmead, 1893. Canad. Ent. 25: 78. ๆ, ઠ.

koebelei (Ashmead). Calif. Host: Prodoxus aenescens Riley, P. marginatus Riley, Tegeticula maculata (Riley). All of these hosts are from the stems or pods of Yucca.

Caenophanes Koebelei Ashmead, 1893. Canad. Ent. 25: 77., ,

languriae (Ashmead). Que. s. to Fla., w. to Mich., Colo., and Tex. Host: Languria erythrocephalus Blatch.

Caenophanes languriae Ashmead, 1893. Canad. Ent. 25: 77. ९, ơ. 
leptostyli Rohwer. Maine, N. Y., Pa., Va., N. C. Host: Amniscus collaris Hald.

Heterospilus leptostyli Rohwer, 1913. U. S. Natl. Mus., Proc. 45: 536. ९, ठ.

liopodis (Brues). Mass., Md. Host: Sternidius alpha (Say).

Coeloides liopodis Brues, 1910. Wis. Nat. Hist. Soc., Bul. 8: 79. ९.

longicaudus (Ashmead). Mass. s. to Fla., Ala., and Miss. Host: Xyletinus peltatus (Harr.).

Caenophanes longicandus Ashmead, 1893. Canad. Ent. 25: 75..

melanocephalus Rohwer. Tex. Host: Olycella junctolineella (Hulst), Pseudoschinia elautalis (Grote).

Heterospilus melanocephalus Rohwer, 1925. Wash. Acad. Sci., Jour. 15: 181. $\uparrow$.

melleus (Ashmead). Md., Fla. Host: Eteobalea sernotella (Chamb.), Gnorimoschema gallaeasteriella (Kell.).

Caenophanes melleus Ashmead, 1893. Canad. Ent. 25: 77. ९, o.

mordellistenae Viereck. Ont., Ohio. Host: Mordellistena andreae ustulata Lec.

Heterospilus mordellistenae Viereck, 1911. U. S. Natl. Mus., Proc. 39: 403..

pityophthori (Ashmead). Va., W. Va. Host: Pityophthoms sp.

Rhyssalus pityophthori Ashmead, 1893. Canad. Ent. 25: 69. \&.

Caenophanes pityophthori Ashmead, 1893. Canad. Ent. 25: 78. o.

prodoxi (Riley). N. C., Ky., Mo., La., Kans., Tex., Ariz. Host: Prodoxus quinquepunctellus (Chamb.).

Exothecus prodoxi Riley, 1880. Amer. Ent. 3: 156. ๆ, ठ.

prosopidis Viereck. La., Okla., Tex., Ariz., Wash., Calif.; Mexico. Host: Acanthoscelides daleae Johnson, A. homi (Pic), Algarobius prosopis (Lec.).

Heterospilus prosopidis Viereck, 1910. U. S. Natl. Mus., Proc. 38: 381. ๆ, ठ.

scolyticida (Ashmead). N. Y. s. to N. C. Host: Scolytus quadrispinosus Say.

Lysitermis scolyticida Ashmead, 1893. Canad. Ent. 25: 74. ?.

Heterospilus blackmanni Rohwer, 1919. Canad. Ent. 51: 161. \&, ১.

Taxonomy: Marsh, 1973. Wash. Acad. Sci., Jour. 63: 71.

selandriae (Ashmead). U. S. Host: Caliroa cerasi (L.)(?).

Rhyssalus (?) selandriae Ashmead, 1889 (1888). U. S. Natl. Mus., Proc. 11: 629. \&.

shoshonea (Viereck). Wyo.

Doryctomorpha shoshonea Viereck, 1907. Amer. Ent. Soc., Trans. 33: 382. \&.

striatus Muesebeck and Walkley. Md., Va., Fla., Iowa.

Caenophanes aciculatus Ashmead, 1893. Canad. Ent. 25: 76. \&, ठ. Preocc. by Provancher, 1888.

Heterospilus striatus Muesebeck and Walkley, 1951. U. S. Dept. Agr., Agr. Monog. 2, p. 180. N. name for aciculatus Ashmead.

\section{Genus HISTEROMERUS Wesmael}

Histeromerus Wesmael, 1838. Nouv. Mem. Acad. Sci. Bruxelles 11: 63.

Type-species: Histeromerus mystacinus Wesmael. Monotypic.

canadensis Ashmead. Que. s. to N. C., w. to Ont. and Minn.; B. C. Host: Anobium punctatus

DeG., Hemicoelus carinatus (Say), Lyctus sp.

Histeromerus canadensis Ashmead, 1891. Canad. Ent. 23: 7. \&.

\section{Genus LELUTHIA Cameron}

Leluthia Cameron, 1887. Biol. Cent.-Amer., Hym., v. 1, p. 392.

Type-species: Leluthia mexicana Cameron. Desig. by Viereck, 1914.

Russellia Muesebeck, 1950. Ent. Soc. Wash., Proc. 52: 78. Preoce. by Vargas, 1943.

Type-species: Heterospilus? astigma Ashmead. Orig. desig.

Russellella Muesebeck and Walkley, 1951. U. S. Dept. Agr., Agr. Monog. 2, p. 178. N. name for Russellia Muesebeck.

Revision: Marsh, 1967. Ent. Soc. Wash., Proc. 69: 359-364 (No. Amer. spp.). 
astigma (Ashmead). Que., Pa., Md., W. Va., Va., N. C., Ohio, Iowa, Okla., Tex., Wyo., Utah, Ariz., Calif.; Mexico. Host: Agrilus sp., A. difficilis Gory, A. politus (Say).

Heterospilus? astigma Ashmead, 1896. Amer. Ent. Soc., Trans. 23: 215. ठ.

floridensis Marsh. Fla. Host: Cryptorhynchus fallax Lec.

Leluthia floridensis Marsh, 1967. Ent. Soc. Wash., Proc. 69: 362. ९, o.

mexicana Cameron. Okla., Tex., N. Mex., Ariz., Calif.; Mexico.

Leluthia mexicana Cameron, 1887. Biol. Cent.-Amer., Hym., v. 1, p. 392..

Russellia prosopidis Muesebeck, 1950. Ent. Soc. Wash., Proc. 52: 78. ๆ, o.

\section{Genus LIOBRACON Szepligeti}

Liobracon Szepligeti, 1901. Termes. Fuzetek 24: 361.

Type-species: Liobracon singularis Szepligeti. Monotypic.

Parabinarea Brues, 1912. Ent. Soc. Amer., Ann. 5: 210.

Type-species: Parabinarea manni Brues. Monotypic.

Hyboderia Enderlein, 1920 (1918). Arch. f. Naturgesch. 84(A)(11): 134.

Type-species: Hyboderia collare Enderlein. Orig. desig.

Triderodon Enderlein, 1920 (1918). Arch. f. Naturgesch. 84(A)(11): 136.

Type-species: Triderodon hoffmannsi Enderlein. Orig. desig.

Taxonomy: Marsh, 1970. Ent. Soc. Wash., Proc. 72: 313-317. -Shenefelt and Marsh, 1976.

Hym. Cat., part 13, p. 1316-1318 (cat. World spp.).

aquilonius Marsh. Tex.; Mexico, Giatemala.

Liobracon aquilonius Marsh, 1970. Ent. Soc. Wash., Proc. 72: 314. \&, ठ.

\section{Genus MONOLEXIS Foerster}

Monolexis Foerster, 1862. Naturh. Ver. Rheinlande, Verh. 19: 237.

Type-species: Monolexis fuscicomis Foerster. Orig. desig.

Taxonomy: Marsh, 1965. Ent. Soc. Amer., Ann. 58: 677-678. - Shenefelt and Marsh, 1976.

Hym. Cat., part 13, p. 1358-1360 (cat. World spp.).

fuscicornis Foerster. Cosmopolitan. Host: Lyctus brunneus (Steph.), L. linearis (Goeze), L. planicollis Lec., Trogoxylon parallelopipedum (Melsh.).

Monolexis fuscicornis Foerster, 1862. Naturh. Ver. Rheinlande, Verh. 19: 237.

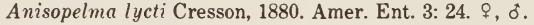

Anisopelma utilis Cresson, 1880. Amer. Ent. 3: 24. ๆ, ठ。.

Anisopelma minima Cresson, 1880. Amer. Ent. 3: 24. ․

\section{Genus ODONTOBRACON Cameron}

Odontobracon Cameron, 1887. Biol. Cent.-Amer., Hym., v. 1, p. 384.

Type-species: Odontobracon nigriceps Cameron. Desig. by Viereck, 1914.

Revision: Marsh, 1970. Pan-Pacific Ent. 46: 277-282 (No. Amer. spp.).

Taxonomy: Shenefelt and Marsh, 1976. Hym. Cat., part 13, p. 1365-1366 (cat. World spp.). californicus Rohwer. Calif.

Odontobracon californicus Rohwer, 1917. U. S. Natl. Mus., Proc. 53: 169. $q$, ð.

cellulus Marsh. Tex., N. Mex., Ariz., Calif.; Mexico.

Odontobracon cellulus Marsh, 1970. Pan-Pacific Ent. 46: 279. ₹, ठ.

grandis Ashmead. Ariz.; Baja Calif.

Odontobracon grandis Ashmead, 1894. Calif. Acad. Sci., Proc. 4: 122..

montanus Cameron. N. C. s. to Fla., w. to Tex.; Central America.

Odontobracon montanus Cameron, 1887. Biol. Cent.-Amer., Hym., v. 1, p. 384..

Odontobracon crassiventris Cameron, 1887. Biol. Cent.-Amer., Hym., v. 1, p. 384..

nigriceps Cameron. Mass. s. to Fla., w. to Wis., Utah, and Ariz.; Mexico, Guatemala. Host:

Elaphidionoides villosum (F.), Oncideres cingulata (Say), O. rhodosticta (Bates).

Odontobracon nigriceps Cameron, 1887. Biol. Cent.-Amer., Hym., v. 1, p. 385. $q$.

Odontobracon elaphidiovoms Rohwer, 1917. U. S. Natl. Mus., Proc. 53: 168. \&, ठ. 
oemeovorus Rohwer. Pa., Md., Fla., Ala., Mich., Ill., Tex. Host: Oeme rigida (Say). Odontobracon oemeovorus Rohwer, 1917. U. S. Natl. Mus., Proc. 53: 167..

\section{Genus ONTSIRA Cameron}

Ontsira Cameron, 1900. Manchester Lit. and Phil. Soc., Mem. and Proc. 44: 89.

Type-species: Ontsira reticulata Cameron. Monotypic.

Doryctes subg. Doryctodes Hellen, 1927. Acta Soc. Fauna Flora Fenn. 56: 40.

Type-species: Rogas imıperator Haliday. Orig. desig.

Revision: Marsh, 1966. Amer. Ent. Soc., Trans. 92: 503-517 (No. Amer. spp. as genus

Doryctodes).

Taxonomy: Fahringer, 1930. Opusc. Bracon., v. 3, p. 144. -Telenga, 1941. Fauna U. S. S. R., v. 5, n. 3, p. 85-92, 389-392. - Marsh, 1973. Wash. Acad. Sci., Jour. 63: 71. - Shenefelt and Marsh, 1976. Hym. Cat., part 13, p. 1322-1327 (cat. World spp.).

antica (Wollaston). N. H. s. to W. Va.; Europe.

Clinocentrus anticus Wollaston, 1858. Ann. and Mag. Nat. Hist. (3) 1: 24. ₹.

Doryctes gallicus Reinhard, 1865. Berlin. Ent. Ztschr. 9: 248. \&, ठ.

Doryctes incertus Ashmead, 1889 (1888). U. S. Natl. Mus., Proc. 11: 627. ๆ.

carinata (Ashmead). Mass., D. C., Va., Iowa, Mo., Ark., S. Dak., Kans.

Rhyssalus carinatus Ashmead, 1889 (1888). U. S. Natl. Mus., Proc. 11: 630. ठ゚.

imperator (Haliday). No. Amer.; Europe.

Rogas imperator Haliday, 1836. Ent. Mag. 4: 46..

Ischiogonus zonatus Wesmael, 1838. Nouv. Mem. Acad. Sci. Bruxelles 11: 127. .

Bracon praecisus Ratzeburg, 1852. Ichn. d. Forstins., v. 3, p. 36. ๆ.

Syngaster cingulatus Provancher, 1880. Nat. Canad. 12: 162..

krombeini (Marsh). Md., Mich., Ohio, Ky., Mo., Ark.

Doryctodes krombeini Marsh, 1966. Amer. Ent. Soc., Trans. 92: 511. १.

mellipes (Ashmead). Que. s. to Fla., w. to Ont. and Mo. Host: Callidium sp.

Doryctes mellipes Ashmead, 1889 (1888). U. S. Natl. Mus., Proc. 11: 627. \&.

occipitalis (Marsh). Calif.

Doryctodes occipitalis Marsh, 1966. Amer. Ent. Soc., Trans. 92: 512. ‡, ठ.

tuberculata (Marsh). Md., D. C., Va., Ga., Ky., Tenn. Host: Nyctobates sp.

Doryctodes tuberculatus Marsh, 1966. Amer. Ent. Soc., Trans. 92: 514. ๆ, ठ’.

wasbaueri (Marsh). Wash., Calif.

Doryctodes wasbaueri Marsh, 1966. Amer. Ent. Soc., Trans. 92: 515. ‡, ठ̋.

\section{Genus PAMBOLIDEA Ashmead}

Pambolidea Ashmead, 1900. U. S. Natl. Mus., Proc. 23: 147.

Type-species: Pambolidea yuma Ashmead. Orig. desig.

Revision: Marsh, 1965. Ent. Soc. Amer., Ann. 58: 674-675.

barberi Marsh. Tex.; Mexico. Host: Xylobiops texanus (Horn).

Pambolidea barberi Marsh, 1965. Ent. Soc. Amer., Ann. 58: 674., , o.

yuma Ashmead. Tex., Ariz. Host: Micracis sp.

Pambolidea yuma Ashmead, 1900. U. S. Natl. Mus., Proc. 23: 147. đo.

\section{Genus PEDINOTUS Szepligeti}

Pedinotus Szepligeti, 1902. Termes. Fuzetek 25: 56.

Type-species: Pedinotus brasiliensis Szepligeti. Monotypic.

Goniogmus Enderlein, 1920 (1918). Arch. f. Naturgesch. 84(A)(11): 139.

Type-species: Goniogmus fermugineus Enderlein. Orig. desig.

Taxonomy: Marsh, 1970. Ent. Soc. Wash., Proc. 72: 315-317.

ferrugineus (Enderlein). Tex.; Mexico.

Goniogmus ferrugineus Enderlein, 1920 (1918). Arch. f. Naturgesch. 84(A)(11): 139. \&. 


\section{Genus PIOSCELUS Muesebeck and Walkley}

Pioscelus Muesebeck and Walkley, 1951. U. S. Dept. Agr., Agr. Monog. 2, p. 180.

Type-species: Hedysomus wichitus Viereck. Orig. desig.

borealis (Ashmead). Ont.

Caenophanes borealis Ashmead, 1891. Canad. Ent. 23: 2..

Taxonomy: Marsh, 1973. Wash. Acad. Sci., Jour. 63: 71.

wichitus (Viereck). Md., Fla., Ohio, Tenn., Miss., Wis., Ill., Iowa, Kans. Ecology: "reared from eggs of cicada." This record needs to be confirmed.

Hedysomus wichitus Viereck, 1907. Amer. Ent. Soc., Trans. 33: 404. ठँ.

Heterospilus beameri Rohwer, 1925. Wash. Acad. Sci., Jour. 15: 177. \&, ठ.

\section{Genus PTESIMOGASTER Marsh}

Ptesimogaster Marsh, 1965. Ent. Soc. Amer., Ann. 58: 691.

Type-species: Ptesimogaster parkeri Marsh. Orig. desig.

Taxonomy: Matthews and Marsh, 1969. Ent. Soc. Wash., Proc. 71: 94-98.

gundlachi (Cresson). Fla.; West Indies.

Stenophasmus gundlachi Cresson, 1865. Ent. Soc. Phila., Proc. 4: 85. 9.

Stenophasmus cubensis Cresson, 1865. Ent. Soc. Phila., Proc. 4: 86. 9.

Stenophasmus pusillus Cresson, 1865. Ent. Soc. Phila., Proc. 4: 87. ठँ.

parkeri Marsh. Tex., Ariz.; Mexico.

Ptesimogaster parkeri Marsh, 1965. Ent. Soc. Amer., Ann. 58: 693. \&, ð.

\section{Genus RHACONOTUS Ruthe}

Rhaconotus Ruthe, 1854. Stettin. Ent. Ztg. 15: 349.

Type-species: Rhaconotus aciculatus Ruthe. Monotypic.

Hedysomus Foerster, 1862. Naturh. Ver. Rheinlande, Verh. 19: 238.

Type-species: Hedysomus elegans Foerster. Orig. desig.

Hormiopterus Giraud, 1869. Soc. Ent. France, Ann. (4) 9: 478.

Type-species: Hormiopterus Ollivieri Giraud. Monotypic.

Rhadinogaster Szepligeti, 1908. Leyden Mus., Notes 29: 223.

Type-species: Rhadinogaster testacea Szepligeti. Desig. by Viereck, 1914.

Euryphrymnus Cameron, 1910. Wien. Ent. Ztg. 29: 100.

Type-species: Euryphrymnus testaceiceps Cameron. Monotypic.

Revision: Nixon, 1941. Ann. and Mag. Nat. Hist. (11) 7: 473-503 (Indian and Afr. spp.,

redescr. of type-species). - Telenga, 1941. Fauna U. S. S. R., v. 5, n. 3, p. 68-70, 387 (some Eur. spp.). - Granger, 1949. Inst. Sci. Madagascar, Mem. (A)2: 126-137 (Madag. spp.).

-Marsh, 1976. Ent. Soc. Wash., Proc. 78: 389-403 (No. Amer. spp.).

Taxonomy: Marsh, 1973. Wash. Acad. Sci., Jour. 63: 72. —Shenefelt and Marsh, 1976. Hym.

Cat., part 13, p. 1334-1343 (cat. World spp.).

atratus Marsh. N. H., Mass., N. Y., Md., Mich., Minn.

Rhaconotus atratus Marsh, 1976. Ent. Soc. Wash., Proc. 78: 392. ๆ, ठ.

badius Marsh. Ind., Nebr., Alta., Wash.

Rhaconotus badius Marsh, 1976. Ent. Soc. Wash., Proc. 78: 393. \&.

barri Marsh. Idaho. Ecology: Reared from Eurotia lantana Moq. infested with Acmaeodera immaculata Horn.

Rhaconotus barri Marsh, 1976. Ent. Soc. Wash., Proc. 78: 394. \&, ठ.

brevicaudus Marsh. Mass., Ont.

Rhaconotus brevicaudus Marsh, 1976. Ent. Soc. Wash., Proc. 78: 395.

canadensis Marsh. Sask.

Rhaconotus canadensis Marsh, 1976. Ent. Soc. Wash., Proc. 78: 396. + , ठ. 
cressoni Muesebeck and Walkley. Md. s. to Fla., w. to Kans., Nev., and Calif.; Mex. Host: Cylindrocopturus adspersus (Lec.), Lixus scrobicollis Boh.

Hormius? aciculatus Cresson, 1872. Amer. Ent. Soc., Trans. 4: 190. \&. Preocc. by Ruthe, 1854.

Rhaconotus cressoni Muesebeck and Walkley, 1951. U. S. Dept. Agr., Agr. Monog. 2, p. 181. N. name for aciculatus Cresson.

fasciatus (Ashmead). Md. s. to Fla., w. to Iowa and Tex. Host: Conotrachelus sp., Lixus concavus Say.

Hormiopterus fasciatus Ashmead, 1893. Amer. Ent. Soc., Trans. 20: 43. \&.

graciliformus (Viereck). Md. s. to Fla., w. to Iowa, Colo., and Ariz.; N. Dak., Alta.

Hormiopterus graciliformus Viereck, 1911. U. S. Natl. Mus., Proc. 40: 183. ₹, ठ.

phalarus Marsh. Tex.

Rhaconotus phalarus Marsh, 1976. Ent. Soc. Wash., Proc. 78: 401. ९.

\section{Genus RHOPTROCENTRUS Marshall}

Rhoptrocentrus Marshall, 1897. In Andre, Spec. Hym. Eur. Alg., v. 5 bis, p. 99.

Type-species: Rhoptrocentrus piceus Marshall. Monotypic.

piceus Marshall. Pa. s. to Fla.; Calif.; Europe. Host: Hylotrupes bajulus (L).

Rhoptrocentrus piceus Marshall, 1897. In Andre, Spec. Hym. Eur. Alg., v. 5 bis, p. 100..

\section{Genus SPATHIUS Nees}

Spathius Nees, 1818. Nova Acta Acad. Caes. Leop. Car. 9: 301.

Type-species: Cryptus clavatus Panzer. Monotypic.

Stenophasmus Smith, 1859. Linn. Soc. London, Jour., Zool. 3: 169.

Type-species: Stenophasnius ruficeps Smith. Monotypic.

Euspathius Foerster, 1862. Naturh. Ver. Rheinlande, Verh. 19: 236. Emend.

Rhacospathius Cameron, 1905. Spolia Zeylanica 3: 86.

Type-species: Rhacospathius striolatus Cameron. Monotypic.

Revision: Nixon, 1943. Roy. Ent. Soc. London, Trans. 93: 173-456 (Old World spp.).

-Matthews, 1970. Amer. Ent. Inst., Contr. 4(5): 1-86 (No. Amer. spp.).

Taxonomy: Shenefelt and Marsh, 1976. Hym. Cat., part 13, p. 1386-1424 (cat. World spp.). aphenges Matthews. Alta., Idaho, B. C., Wash., Oreg., Calif. Host: Conophthorus coniperda (Schwarz), Ips latidens (Lec.), Phloeotribus lecontei Schedl, Scolytus abietis Blkm.

Spathius aphenges Matthews, 1970. Amer. Ent. Inst., Contr. 4(5): 51. ‡, ठ。.

benefactor Matthews. Que. s. to N. C., w. to N. Dak. and Kans. Host: Hylurgopinus rufipes (Eichh.), Leperisinus aculeatus (Say), Magdalis armicollis (Say), M. barbita (Say), $M$. inconspicua Horn, Saperda tridentata Oliv., Scolytus multistriatus (Marsham), S. migulosus Ratz. This species has been studied extensively under the name canadensis Ashmead. According to Matthews (1970), all references to Spathius reared from elm refer to benefactor, not to canadensis.

Spathius benefactor Matthews, 1970. Amer. Ent. Inst., Contr. 4(5): 61. १, ठ์.

Biology: Kaston, 1937. Conn. Agr. Expt. Sta., Bul. 396, p. 351-353. -Kaston, 1939. Conn. Agr.

Expt. Sta., Bul. 420, p. 33-35. - Robert, 1951. Assoc. Canad.-Fr. Adv. Sci., Ann. 17: 139-140.

-Robert, 1961 (1960). Ent. Soc. Que., Ann. 6: 122-143. All references are to canadensis

Ashmead.

brachyurus Ashmead. Que. s. to N. C., w. to Wis. and Tenn. Host: Dryocoetes autographus (Ratz.), Pissodes approximatus Hopk., P. strobi (Peck).

Rhopalophorus fasciatus Provancher, 1886. Addit. Corr. Faune Ent. Canada Hym., p. 129. ๆ. Preocc. by Walker, 1874 .

Spathius abdominalis Riley, 1890. In Riley and Howard, U. S. Dept. Agr., Insect Life 2: 350. Nom. nud.

Spathius brevicaudus Ashmead, 1892. In Hopkins, U. S. Dept. Agr., Insect Life 4: 258. Nom. nud.

Spathius brachyurus Ashmead, 1893. Canad. Ent. 25: 73. ๆ. 
Spathius dignus Muesebeck and Walkley, 1951. U. S. Dept. Agr., Agr. Monog. 2, p. 169. N. name for fasciatus Provancher.

brevipalpus Matthews. N. C., S. C., Tex.

Spathius brevipalpus Matthews, 1970. Amer. Ent. Inst., Contr. 4 (5): 29..

brunneus Ashmead. Md., W. Va., Fla. Host: Agrilus fallax Say, Scolytus muticus Say.

Spathius brunneus Ashmead, 1893. Canad. Ent. 25: 72. $\uparrow$.

calligaster Matthews. Que. s. to S. C., w. to Ill. Host: Melasis pectinicornis Melsh.

Spathius calligaster Matthews, 1970. Amer. Ent. Inst., Contr. 4(5): 35. §, ठ。.

canadensis Ashmead. Canada and northern U. S. s. to N. C., S. Dak., and Wash. Host:

Cryphalus sp., Dryocoetes autographus (Ratz.), Ips pini (Say), Orthotomicus caelatus (Eichh.), Pityophthorus balsameus Blkm., Polygraphus mufipennis (Kirby), Scolytus piceae (Swaine). Host records for canadensis reared from elm apparently all refer to benefactor Matthews.

Spathius canadensis Ashmead, 1891. Canad. Ent. 23: 2..+

Spathius clavipennis (!) Ashmead, 1892. In Hopkins, U. S. Dept. Agr., Insect Life 4: 257. Nom. nud.

Spathius claripennis Ashmead, 1893. Canad. Ent. 25: 72. o.

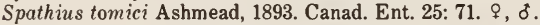

comes Matthews. N. S. and Que. s. to Md., w. to Wis. Host: Chrysobothris pusilla Cast., Melanophila fulvoguttata (Harr.).

Spathius comes Matthews, 1970. Amer. Ent. Inst., Contr. 4(5): 59., ,.

elegans Matthews. Que. s. to Fla., w. to Ont. and Ala.; Nebr., Kans., Wash. Ecology: Reared from powderposted wood infested with Hadrobregmus sp.

Spathius elegans Matthews, 1970. Amer. Ent. Inst., Contr. 4(5): 39. $९$, $\delta$.

evansi Matthews. Que. s. to Fla., w. to Wyo. and N. Mex.

Spathius evansi Matthews, 1970. Amer. Ent. Inst., Contr. 4(5): 42., ,.

exarator (Linnaeus). Mass., Conn.; Europe.

Ichneumon exarator Linnaeus, 1758. Syst. Nat., 10th ed., v. 1, p. 564.

floridanus Ashmead. Que. s. to Fla., w. to Ont., Kans., and Tex. Host: Chrysobothris sp., C. femorata (Oliv.), Magdalis olyra (Herbst), Xylotrechus colonus (F.).

Spathius floridanus Ashmead, 1893. Canad. Ent. 25: 71. ․

honestor (Say). Ind.

Bracon honestor Say, 1828. Contrib. Maclur. Lyc. Phila. 1: 78. Holotype lost. Original description indicates that this species is probably a Spathius but there are no further statements that would help place the species.

impus Matthews. Que. s. to Fla., w. to Mich. and La. Host: Phloeosinus sp., P. canadensis Swaine, $P$. dentatus (Say).

Spathius impus Matthews, 1970. Amer. Ent. Inst., Contr. 4(5): 56. ^, ठ.

laflammei Provancher. Que. s. to N. C., w. to Wis. and Kans. Host: Magdalis olyra (Herbst).

Spathius Laflammei Provancher, 1880. Nat. Canad. 12: 164. $\$$.

longipetiolatus Ashmead. Fla.

Spathius longipetiolatus Ashmead, 1893. Canad. Ent. 25: 70. ठ。.

marshi Matthews. Que., N. Y., Pa., Md., Va., Mich., Tenn., Ill., Iowa, Kans.

Spathius marshi Matthews, 1970. Amer. Ent. Inst., Contr. 4(5): 30. ๆ, ठ.

pallidus Ashmead. Mass. s. to Ga., w. to Tex. Host: Dendroctonus frontalis Zimm., Ips avulsus (Eichh.), I. grandicollis (Eichh.), Pissodes approximatus Hopk., P. nemorensis Germ.

Spathius pallidus Ashmead, 1893. Canad. Ent. 25: 74..+

parvulus Matthews. S. Dak., Colo., N. Mex. Host: Ips sp.

Spathius parvulus Matthews, 1970. Amer. Ent. Inst., Contr. 4(5): 55. \&, ठ.

sequoiae Ashmead. Alta. s. to N. Mex., w. to Alaska and Calif. Host: Alniphagus aspericollis Lec., Cryphalus pubescens Hopk., Dendroctonus obesus (Mann.), D. pseudotsugae Hopk., Lechriops califoricus (Lec.), Phloeosinus punctatus Lec., P. sequoiae Hopk., Pissodes sp., Pseudohylesinus nebulosus (Lec.), P. sericeus (Mann.), Scolytus sp., S. laricis Blkm., S. tsugae Swaine, S. unispinosus Lec., S. ventralis Lec.

Spathius sequoiae Ashmead, 1889 (1888). U. S. Natl. Mus., Proc. 11: 625..

Spathius californicus Ashmead, 1893. Canad. Ent. 25: 70. ठ. 
Spathius brunneri Viereck, 1912. U. S. Natl. Mus., Proc. 42: 627. 9.

Biology: Deyrup, 1975. Conif. For. Biome, Ecosystem Anal. Stu., Univ. Wash., Bul, 6, p. 76-77.

simillimus Ashmead. N. B. s. to Va., w. to Wis. Host: Agrilus anxius Gory, A. bilineatus (Weber), Phymatodes aereum (Newman).

Spathius simillimus Ashmead, 1893. Canad. Ent. 25: 73. ९, o.

stigmatus Matthews. Que. s. to Va., w. to Ont. and Ill.; Tex. Host: Magdalis olyra (Herbst), Xyloterinus politus (Say).

Spathius stigmatus Matthews, 1970. Amer. Ent. Inst., Contr. 4(5): 32. \&, ठ.

trifasciatus Riley. N. Y.s. to N. C.; Miss., Mo., Kans., Tex. Host: Scolytus quadrispinosus Say. Spathius trifasciatus Riley, 1873. Ins. Mo. Ann. Rpt. 5: 106. १, o.

Spathius unifasciatus Ashmead, 1893. Canad. Ent. 25: 72..+

\section{Genus STENOCORSE Marsh}

Stenocorse Marsh, 1968. Ent. Soc. Wash., Proc. 70: 110.

Type-species: Glyptocolastes bruchivorus Crawford. Orig. desig.

Taxonomy: Marsh, 1968. Ent. Soc. Wash., Proc. 70: 110-112.

bruchivora (Crawford). Tex., Ariz.; Mexico, Canal Zone, Peru, Hawaii. Host: Acanthoscelides quadridentatus (Schaeffer), Algarobius prosopis (Lec.), Megacerus sp., Mimosestes sallaei (Sharp).

Glyptocolastes bruchivorus Crawford, 1909. Ent. Soc. Wash., Proc. 11: 203. ㅇ, ठ.

\section{SUBFAMILY BRACONINAE}

Most species of this large subfamily are external parasites of lepidopterous and coleopterous larvae, but a few attack dipterous and sawfly larvae. The group is very much in need of study, particularly the genera from a world-wide viewpoint.

\section{Genus ATANYCOLIMORPHA Viereck}

Atanycolimorpha Viereck, 1913. U. S. Natl. Mus., Proc. 44: 557.

Type-species: Atanycolimorpha winnemanae Viereck. Orig. desig.

alaskensis (Ashmead). Alaska.

Bracon alaskensis Ashmead, 1889 (1888). U. S. Natl. Mus., Proc. 11: 615. ๆ.

croceiventris (Cresson). Colo.

Bracon croceiventris Cresson, 1865. Ent. Soc. Phila., Proc. 4: 301. ठ".

dissitus (Cresson). Ga., Ark., S. Dak., Tex., Wyo., Colo., Utah, Oreg.

Bracon dissitus Cresson, 1865. Ent. Soc. Phila., Proc. 4: 300. $ๆ$.

Bracon orbitalis Cresson, 1872. Amer. Ent. Soc., Trans. 4: 184. ‡, ठ.

montanensis (Ashmead). Mont.

Bracon montanensis Ashmead, 1889 (1888). U. S. Natl. Mus., Proc. 11: 615. ๆ.

provancheri (Dalla Torre). Que., Conn., N. Y., N. J., Md., La., Ark.

Bracon inquisitor Provancher, 1880. Nat. Canad. 12: 138. F. Preoce. by Erichson, 1848.

Bracon provancheri Dalla Torre, 1898. Cat. Hym., v. 4, p. 285. New name for inquisitor

Provancher.

Atanycolimorpha winnemanae Viereck, 1913. U. S. Natl. Mus., Proc. 44: 557. 9.

\section{Genus ATANYCOLUS Foerster}

Atanycolus Foerster, 1862. Naturh. Ver. Rheinlande, Verh. 19: 238.

Type-species: Ichneumon denigrator Linnaeus. Orig. desig.

Coelobracon Dalla Torre, 1898. Cat. Hym., v. 4, p. 295.

Type-species: Ichneumon denigrator Linnaeus. Desig. by Muesebeck and Walkley, 1951.

Melanobracon Ashmead, 1900. U. S. Natl. Mus., Proc. 23: 138.

Type-species: Bracon simplex Cresson. Orig. desig.

Atanycolidea Viereck, 1912. U. S. Natl. Mus., Proc. 42: 617. 
Type-species: Bracon migosiventris Ashmead. Orig. desig.

Species in this genus are external parasites of coleopterous larvae, particularly Cerambycidae and Buprestidae.

Revision: Shenefelt, 1943. Wash. State Col., Res. Studies 11: 51-163 (No. Amer. spp.). anocomidis Cushman. Que. s. to Pa. and Tex., w. to B. C. and Calif. Host: Acanthocinus sp., Buprestis maculativentris Say, Melanophila drummondi (Kby.), Semanotus ligneus (F.).

Atanycolus anocomidis Cushman, 1931. U. S. Natl. Mus., Proc. 79 (14): 14., ,. arcasuturalis Shenefelt. N. H.

Atanycolus arcasuturalis Shenefelt, 1943. Wash. State Col., Res. Studies 11: 121. \&. calophrys Shenefelt. Man., Utah.

Atanycolus calophrys Shenefelt, 1943. Wash. State Col., Res. Studies 11: 95., , charus (Riley). Que. and N. B. s. to Ga., w. to Alta. and Tex. Host: Agrilus anxius Gory, Chrysobothris femorata (Oliv.).

Bracon charus Riley, 1875. Ins. Mo. Ann. Rpt. 7: 75. 9.

comosifrons Shenefelt. Mass. s. to Fla., w. to Colo. and Tex. Host: Dendroctonus frontalis Zimm., Graphisurus sp., Rhagium inquisitor (L.).

Atanycolus comosifrons Shenefelt, 1943. Wash. State Col., Res. Studies 11: 111. ?, §. crassicruris Shenefelt. Mass., Fla., Minn., Iowa, Kans., Tex., Ariz.

Atanycolus crassicruris Shenefelt, 1943. Wash. State Col., Res. Studies 11: 124. \&. cryptaspis Shenefelt. Conn., N. Y., N. J., S. C.

Atanycolus cryptaspis Shenefelt, 1943. Wash. State Col., Res. Studies 11: 103. $\uparrow, ð$. dichrous (Brulle). "No. Amer."

Bracon dichrous Brulle, 1846. In Lepeletier, Hist. Nat. Ins. Hym., v. 4, p. 398..

disputabilis (Cresson). Colo.

Bracon disputabilis Cresson, 1865. Ent. Soc. Phila., Proc. 4: 300..

femoratae Shenefelt. Ariz. Host: Chrysobothris femorata (Oliv.).

Atanycolus femoratae Shenefelt, 1943. Wash. State Col., Res. Studies 11: 139. \&, ठ.

fuscorbitalis Shenefelt. Maine, N. Y.

Atanycolus fuscorbitalis Shenefelt, 1943. Wash. State Col., Res. Studies 11: 87. ‡, ठ.

hicoriae Shenefelt. N. Y., Mich., N. Dak. Host: Agrilus champlaini Frost.

Atanycolus hicoriae Shenefelt, 1943. Wash. State Col., Res. Studies 11: 129.,$\delta$.

impressifrons Shenefelt. N. Y., Pa., Md., W. Va., N. C., Mich., La., Kans., Tex., N. Mex., Ariz., Calif. Host: Megacyllene sp.

Atanycolus impressifrons Shenefelt, 1943. Wash. State Col., Res. Studies 11: 101. \&, ठ. latabdominalis Shenefelt. Ill.

Atanycolus latabdominalis Shenefelt, 1943. Wash. State Col., Res. Studies 11: 119..

lineola (Brulle). "Carolina."

Bracon lineola Brulle, 1846. In Lepeletier, Hist. Nat. Ins. Hym., v. 4, p. 397..

lissogastrus Shenefelt. N. H., N. Y., Pa., Ont.

Atanycolus lissogastrus Shenefelt, 1943. Wash. State Col., Res. Studies 11: 92..

longicauda Shenefelt. Que., N. Y., N. J., Mich., Wis., Minn.

Atanycolus longicauda Shenefelt, 1943. Wash. State Col., Res. Studies 11: 85. ९, ठ.

longifemoralis Shenefelt. Mont., Idaho, Nev., B. C., Wash., Oreg., Calif. Host: Hylotrupes sp., Melanophila drummondi (Kby.), M. gentilis Lec.

Atanycolus longifemoralis Shenefelt, 1943. Wash. State Col., Res. Studies 11: 76., o.

malii Shenefelt. Colo., Oreg., Calif. Host: Chrysobothris mali Horn.

Atanycolus malii Shenefelt, 1943. Wash. State Col., Res. Studies 11: 136. ‡, ठ.

megophthalmus Shenefelt. Idaho.

Atanycolus megophthalmus Shenefelt, 1943. Wash. State Col., Res. Studies 11: 80. ^, ð.

melanophili Shenefelt. Wis. Host: Melanophila fulvoguttata (Harr.).

Atanycolus melanophili Shenefelt, 1943. Wash. State Col., Res. Studies 11: 81. \&, ð.

microcellus Shenefelt. Ont.

Atanycolus microcellus Shenefelt, 1943. Wash. State Col., Res. Studies 11: 89. \&, ठ. 
microstigmatus Shenefelt. Wis.

Atanycolus microstigmatus Shenefelt, 1943. Wash. State Col., Res. Studies 11: 93. \&.

montivagus (Cresson). Nebr., Colo., N. Mex.

Bracon montivagus Cresson, 1865. Ent. Soc. Phila., Proc. 4: 229. ๆ, ठ.

nigropyga Shenefelt. N. Y., Va., Minn., Nebr.

Atanycolus nigropyga Shenefelt, 1943. Wash. State Col., Res. Studies 11: 90..

niteofrons Shenefelt. Minn.

Atanycolus niteofrons Shenefelt, 1943. Wash. State Col., Res. Studies 11: 84. \&, o.

obliquus (Provancher). Canada.

Bracon obliquus Provancher, 1880. Nat. Canad. 12: 141. \&.

octocolae Shenefelt. Ariz., Calif. Host: Chrysobothris octocola Lec.

Atanycolus octocolae Shenefelt, 1943. Wash. State Col., Res. Studies 11: 127. \&, ๖.

parvacavus Shenefelt. Oreg.

Atanycolus parvacavus Shenefelt, 1943. Wash. State Col., Res. Studies 11: 109..

phaeostethus Shenefelt. Va., Tex.

Atanycolus phaeostethus Shenefelt, 1943. Wash. State Col., Res. Studies 11: 83. o.

pilosiventris Shenefelt. Que., R. I., N. Y., N. C., Ga., Fla., Man.

Atanycolus pilosiventris Shenefelt, 1943. Wash. State Col., Res. Studies 11: 131 . \&, ð.

rugosiventris (Ashmead). Mass. s. to Fla., w. to Minn. and Ariz. Host: Chrysobothris femorata (Oliv.).

Bracon rugosiventris Ashmead, 1889 (1888). U.S. Natl. Mus., Proc. 11: 131. $ๆ, ~ \delta$. Atanycolidea apicalis Rohwer, 1913. U. S. Natl. Mus., Proc. 45: 533. ठ, "६" = ठ.

simplex (Cresson). No. Amer. Host: Agrilus bilineatus (Weber), Chrysobothris sp., Phymatodes aereus (Newm.), Rhagium inquisitor (L.), Saperda discoidea F., S. tridentata Oliv, Xylotrechus sp., X. nauticus (Mann.).

Bracon simplex Cresson, 1872. Amer. Ent. Soc., Trans. 4: 184. $q$.

tranquebaricae Shenefelt. Fla.; Bahamas. Host: Chrysobothris tranquebarica (Gmel.).

Atanycolus tranquebaricae Shenefelt, 1943. Wash. State Col., Res. Studies 11: 134. \&, ठ.

triangulifera (Viereck). Ariz.

Iphiaulax triangulifera Viereck, 1907. Amer. Ent. Soc., Trans. 33: 384. \&.

ulmicola (Viereck). Que,. s. to Fla., w. to N. Dak. and Ariz. Host: Saperda discoidea F., S.

tridentata Oliv.

Melanobracon ulmicola Viereck, 1906. Amer. Ent. Soc., Trans. 32: 176. ๆ, ১.

Biology: Kaston, 1937. Conn. (State) Agr. Expt. Sta. Bul. 396, p. 355-358.

\section{Genus BRACON Fabricius}

Bracon Fabricius 1804. Systema Piezatorum, p. 102.

Type-species: Ichneumon minutator Fabricius. Desig. by Internatl. Comn. Zool.

Nomencl., Opinion 162, 1945.

Braco Wesmael, 1838. Nouv. Mem. Acad. Sci. Bruxelles 11: 7. Emend.

Microbracon Ashmead, 1890. Colo. Biol. Assoc., Bul. 1: 15.

Type-species: Microbracon sulcifrons Ashmead. Monotypic.

Habrobracon Johnson, 1895. Ent. News 6: 324.

Type-species: Bracon gelechiae Ashmead. Desig. by Viereck, 1914.

Amicoplidea Ashmead, 1900. U. S. Natl. Mus., Proc. 23: 118.

Type-species: Phylax palliventris Provancher. Orig. desig.

Macrodyctizm Ashmead, 1900. U. S. Natl. Mus., Proc. 23: 138.

Type-species: Bracon euurae Ashmead. Orig. desig.

Tropidobracon Ashmead, 1900. U. S. Natl. Mus., Proc. 23: 139.

Type-species: Bracon gastroideae Ashmead. Orig. desig.

Most species are external parasites of lepidopterous and coleopterous larvae, but a few species parasitize larvae of flies and sawflies.

Revision: Muesebeck, 1925. U. S. Natl. Mus., Proc. 67 (8): 1-85 (No. Amer. spp.). 
acrobasidis Muesebeck. N. J., Fla., Ark. Host: Acrobasis caryae Grote, A. caryivorella Rag., A. comptoniella Hulst.

Bracon acrobasidis Muesebeck, 1963. Ent. News 74: 158. $ๆ, \delta$.

aequalis Provancher. Canada.

Bracon aequalis Provancher, 1880. Nat. Canad. 12: 141. $\subsetneq$.

agathymi Muesebeck. Tex., Ariz. Host: Agathymus mcalpinei (Freem.), A. neumoegini (Edw.).

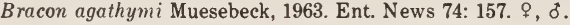

americanus (Ashmead). N. S., Que., Iowa, Colo., Idaho, Ariz., Yukon.

Trachyusa americana Ashmead, 1890. Colo. Biol. Assoc., Bul. 1: 18. ठ.

analcidis Ashmead. Ky., Tenn., Iowa, Mo., Ark. Host: Sphenophorus parvulus Gyll., Tyloderma fragariae (Riley).

Bracon analcidis Ashmead, 1889 (1888). U. S. Natl. Mus., Proc. 11: 619..

angelesius Provancher. Calif. Host: Euura sp., Pontania sp. This species is also recorded from a dipterous gall on Mimulus which needs to be confirmed.

Bracon angelesius Provancher, 1888. Addit. Corr. Faune Ent. Canada Hym., p. 372. ․

Bracon cecidomyiae Ashmead, 1889 (1888). U. S. Natl. Mus., Proc. 11: 616..

Bracon euurae Ashmead, 1889 (1888). U. S. Natl. Mus., Proc. 11: 621..+

apicatus Provancher, N. Y., Ga., Ont., Mich.

Bracon apicatus Provancher, 1880. Nat. Canad. 12: 143. $\subsetneq$.

argutator Say. S. C., Ind., Iowa, Mo., Tex. Host: Saluria sp.

Bracon argutator Say, 1836. Boston Jour. Nat. Hist. 1: 253..

atricollis Ashmead. Mass., Conn., N. J., Del., Va., Ga., Fla., Ohio, Mich., Ill., Mo., S. Dak., Wash. Bracon atricollis Ashmead, 1889 (1888). U. S. Natl. Mus., Proc. 11: 622. ๆ.•

Microbracon nawaasorum Viereck, 1917 (1916). Conn. State Geol. and Nat. Hist. Survey, Bul. 22, p. 207.

bembeciae (Walley). B. C., Wash., Oreg. Host: Pennisetia marginata (Harr.).

Microbracon bembeciae Walley, 1932. Canad. Ent. 64: 186. ․

brachyurus Ashmead. Ont., Iowa, Tenn.

Bracon brachyurus Ashmead, 1891. Canad. Ent. 23: 1..

brevicornis Wesmael. No. Amer.(?); Europe, Asia, No. Africa. Introduced from Europe, Asia, and North Africa. Liberated in several states and provinces but not known to be established. Host: Heliothis virescens (F.), H. zea (Boddie), Ostrinia nubilalis (Hbn.), Pectinophora gossypiella (Saund.).

Bracon brevicornis Wesmael, 1838. Nouv. Mem. Acad. Sci. Bruxelles 11: 23. ๆ, ð.

bruchivorus Muesebeck. Utah, Ariz., Calif. Host: Acanthoscelides sp.

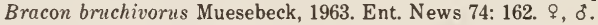

canadensis (Ashmead). Ont.

Opius canadensis Ashmead. 1891. Canad. Ent. 23: 4. ठ.

caulicola (Gahan). Mass. s. to S. C., w. to Wis., Kans., and Ark.; Idaho. Host: Heliodines ionis Clarke, Onychobaris subtonsa Lec., Ostrinia nubilalis (Hbn.), O. obrumbratalis (Led.), O. penitalis (Grote), Suleima helianthana (Riley), Vitacea polistiformis (Harr.).

Microbracon caulicolo Gahan, 1922. U. S. Natl. Mus., Proc. 61 (24): 2. ₹, ठ’.

Biology: Wester, 1956. Ent. Soc. Wash., Proc. 58: 283-284.

cephi (Gahan). Minn., Iowa, N. Dak., Mont., southwest. Canada. Host: Cephus cinctus Nort. Microbracon cephi Gahan, 1918. Ent. Soc. Wash., Proc. 20: 19. ๆ, ठ’.

Biology: Nelson and Farstad, 1953. Canad. Ent. 85: 103-107. - Holmes, et al., 1963. Canad. Ent. 95: 113-126.

cerambycidiphagus (Muesebeck). Pa., Ont., Mich., Wis., Mo. Host: Dectes texanus Lec., Oberea sp., O. praelonga Casey, O. tripunctata (Swed.).

Microbracon cerambycidiphagus Muesebeck, 1925. U. S. Natl. Mus., Proc. 67 (8): 76. ‡, ठ. cinctus (Provancher). Canada.

Phylax cinctus Provancher, 1880. Nat. Canad. 12: 175. ð. 
connecticutorum (Viereck). Conn.

Microbracon connecticutorım Viereck, 1917 (1916). Conn. State Geol. and Nat. Hist. Survey, Bul. 22, p. 209.

cookii Ashmead. Mich.

Bracon cookii Ashmead, 1889 (1888). U. S. Natl. Mus., Proc. 11: 624. §.

eryptorhynchi (Muesebeck). Mass. Host: Cryptorhynchus lapathi (L.).

Microbracon cryptorhynchi Muesebeck, 1931. U. S. Natl. Mus., Proc. 79 (16): 16. ๆ, ơ.

curtus (Provancher). Que., Ont., Mich., Minn., Okla., Idaho, Ariz.

Phylax curtus Provancher, 1886. Addit. Corr. Faune Ent. Canada Hym., p. 130. ९, đ̋.

cuscutae Muesebeck. D. C. Host: Smicronyx tychoides Lec.

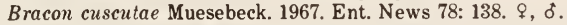

eushmani (Muesebeck). Pa. s. to Fla., w. to Colo. and Tex.; Ariz., Calif.; Virgin Isl., West Indies. Host: Acrobasis caryae Grote, $A$. caryivorella Rag., $A$. hebecella Hulst, $A$. indigenella (Zell.), Choristoneura fumiferana (Clem.), Desmia funeralis (Hbn.), Dioryctria disclusa Heinr., Grapholitha prunivora (Walsh), Mesocondyla gastralis (Guen.), Psorosina hammondi (Riley), Rhyacionia frustrana (Comst.).

Habrobracon variabilis Cushman, 1914. Ent. Soc. Wash., Proc. 16: 103. ‡, ð. Preocc. by Provancher, 1888.

Microbracon cushmani Muesebeck, 1925. U. S. Natl. Mus., Proc. 67 (8): 29. N. name for variabilis Cushman.

erucarum (Cushman). Okla., Mont., Wyo., Colo., Idaho, Utah, Ariz., Oreg., Calif. Host: Barbara colfaxiana taxifoliella (Busck), Euxoa sp.

Habrobracon erucarum Cushman, 1920. U. S. Natl. Mus., Proc. 58: 291. ‡, o.

furtivus Fyles. Que. s. to N. C., w. to Iowa. Host: Gnorimoschema gallaeasteriella (Kell.), G. gallaesolidaginis (Riley).

Bracon furtivus Fyles, 1892. Canad. Ent. 24: 35..

Bracon fungicola Ashmead, 1894. Cincinnati Soc. Nat. Hist., Jour. 17: 46. ๆ.

Biology: Miller, 1963. Ohio Jour. Sci. 63: 73.

gastroideae Ashmead. Mass., N. Y., Pa., Ohio, Ont., Mich., Ill., Minn., Iowa, S. Dak., Kans., Tex., Colo., Calif. Host: Gastrophysa cyanea Melsh.

Bracon gastroideae Ashmead, 1889 (1888). U. S. Natl. Mus., Proc. 11: 617. ơ.

gelechiae Ashmead. No. Amer.; West Indies, Bermuda, India. Host: Anacampsis fragariella Busck, Ancylis comptana fragariae (W. and R.), Anthophila pariana (Clerck), Archips argyrospilus (Wlkr.), Argyrotaenia citrana (Fern.), Chionodes hibiscella (Busck), Cnephasia longana (Haw.), Coleophora malivorella Riley, Desmia funeralis (Hbn.), Dichomeris marginella (F.), Dioryctria disclusa Heinr., D. reniculella (Grote), Elasmopalpus lignosellus (Zell.), Epiblema strenuanum (Wlkr.), Exoteleia dodecella (L.), Gelechia sp., Grapholitha molesta (Busck), Heliodines nyctaginella Gibson, Keiferia inconspicuella (Murtf.), Ostrinia nubilalis ( $\mathrm{Hbn}$.), Papaipema sp., Paralobesia viteana (Clem.), Pectinophora gossypiella (Saund.), Phthorimaea operculella (Zell.), Psilocorsis quercicella Clem., Psorosina hammondi (Riley), Pterophorus periscelidactylis Fitch, Pyrausta signatalis (Wlkr.), Rhyacionia buoliana (Schiff.), R. bushnelli (Busck), Sparganothis sulphurana (F.), Spilonota ocellana (D. and S.), Stegasta bosqueella (Chamb.), Thymelicus lineola (Ochs.).

Bracon gelechiae Ashmead, 1889 (1888). U. S. Natl. Mus., Proc. 11: 623. ๆ, ठ.

Bracon notaticeps Ashmead, 1889 (1888). U. S. Natl. Mus., Proc. 11: 624.

Habrobracon johannseni Viereck, 1912. U. S. Natl. Mus., Proc. 42: 622. §.

Habrobracon tetralophae Viereck, 1912. U. S. Natl. Mus., Proc. 42: 623. $९$.

Habrobracon diversicolor Viereck, 1912. Ent. News 32: 174. \&.

Biology: Poos, 1928. Ent. Soc. Wash., Proc. 30: 149. -Gupta, 1951. Nature 168: 793.

- Narayanan and Rao, 1955. Beitr. z. Ent. 5: 36-60. - Wester, 1956. Ent. Soc. Wash., Proc.

58: 284. - Ahmad and Muzaffar, 1976. Entomophaga 21: 235-238.

Morphology: Narayanan and Rao, 1955. Beitr. z. Ent. 5: 286-293 (female reproductive system). 
gemmaecola (Cushman). Mass., Conn., N. J., Md., Va., Fla., Ohio, Tenn., Mo., Ark., N. Dak., S. Dak., Nebr., Tex., Mont., Colo., Ariz. Host: Rhyacionia buoliana (Schiff.), R. frustrana (Comst.), R. bushnelli (Busck), R. neomexicana (Dyar), R. subtropica Miller.

Microbracon gemmaecola Cushman, 1927. Jour. Agr. Res. 34: 740. ₹, ठ.

geraei (Muesebeck). N. J., Fla., Ohio, Iowa, Ark., S. Dak., Kans., Ariz. Host: Geraeus sp., Trichobaris sp.

Microbracon geraei Muesebeck, 1925. U. S. Natl. Mus., Proc. 67 (8): 74. ๆ, ठ'.

gossypii Muesebeck. S. C., Ga., Fla., Miss., Ark., La., Tex. Host: Anthonomus grandis Boh. Bracon gossypii Muesebeck, 1963. Ent. News 74: 161. $९$, ठ。.

gracilis (Provancher). Que.

Phylax gracilis Provancher, 1886. Addit. Corr. Faune Ent. Canada Hym., p. 131. ठో.

hebetor Say. Cosmopolitan. Host: Anagasta kuehniella (Zell.), Cadra cautella (Wlkr.), Ephestia elutella (Hbn.), Galleria mellonella (L.), Laetilia coccidivora (Comst.), Moodna sp., Phthorimaea operculella (Zell.), Plodia interpunctella (Hbn.), Sitotroga cerealella (Oliv.), Vitula edmansae (Pack.).

Bracon hebetor Say, 1836. Boston Jour. Nat. Hist. 1: 252. $\&, \delta$.

Bracon dorsator Say, 1836. Boston Jour. Nat. Hist. 1: 253. ₹, ठ.

Bracon juglandis Ashmead, 1889 (1888). U. S. Natl. Mus., Proc. 11: 621. ठ.

Habrobracon beneficientior Viereck, 1911. U. S. Natl. Mus., Proc. 40: 182. ๆ, ठ.

Bracon breviantennatus de Stefani, 1919. Inform. R. R. Osserv. Fitopatol. e Intorno ad Alcuni Ins. Dannosi alle Derr. Aliment., Min. Agr. (Palermo, Italy), p. 44. $\uparrow, \delta$. Habrobracon pectinophorae Watanabe, 1935. Insecta Matsumurana 10: 44. $\uparrow, \delta$.

Taxonomy: Lal, 1946. Indian Jour. Ent. 8: 85-88. -Puttarudriah and Channa Basavanna, 1956. Bul. Ent. Res. 47: 183-191.

Biology: Graf, 1917. U. S. Dept. Agr., Bul. 427, p. 39-40 (as Habrobracon johannseni Vier.). -Payne, 1933. Biol. Bul. 65: 187-205. - Payne, 1934. Ecol. Monog. 4: 1-46. -Clover and Chatterjee, 1936. Indian Acad. Sci., Proc. 3: 195-211. - Harries, 1937. Ohio Jour. Sci. 37: 165-171. - Soliman, 1940. Soc. Fouad d'Ent., Bul. 24: 215-247. - Soliman, 1941. Soc. Fouad d'Ent., Bul. 25: 1-97. - Martin, 1947. Introduct. Genetics Habrobracon juglandis Ashm., 205 p. - Beard, 1952. Conn. (State) Agr. Expt. Sta., Bul. 562, p. 1-27. - Kanungo, 1955. Current Sci. 24: 59. -Grosch, La Chance, and Sullivan, 1955. Ent. Soc. Amer., Ann. 48: 415-416. -Grosch, 1959. Ent. Soc. Amer., Ann. 52: 294-298. - Clark, 1963. Ent. Soc. Amer., Ann. 56: 616-619. - Rotary and Gerling, 1973. Environ. Ent. 2: 134-138.

Morphology: Schluter, 1933. Ztschr. f. Morph. u. Oekol. der Tiere 27: 488-517. -Bender, 1943. Ent. Soc. Amer., Ann. 36: 537-545. -Grosch, 1952. Jour. Morph. 91: 221-236.

helianthi (Muesebeck). Fla., Tex. Host: Isophrictis sp. Microbracon helianthi Muesebeck, 1926. U. S. Natl. Mus., Proc. 69 (7): 1. \&, ठ.

hemimenae (Rohwer). Md., Fla. Host: Hemimene plummeriana (Busck).

Microbracon hemimenae Rohwer, 1915. U. S. Natl. Mus., Proc. 49: 232..

hobomok (Viereck). Conn., N. Y., Md., Mich., Iowa.

Micrabracon hobamak Viereck, 1917 (1916). Conn. State Geol. and Nat. Hist. Survey, Bul. 22, p. 208.

hyslopi (Viereck). Colo., Idaho, Utah, Wash., Oreg., Calif. Host: Cnephasia longana (Haw.), Etiella zinckenella schisticolor Zell., Hypera nigrirostris (F.), Platyptilia carduidactyla (Riley), $P$. williamsii Grin.

Microbracon hyslopi Viereck, 1912. U. S. Natl. Mus., Proc. 42: 142..

jani Muesebeck. Minn., Miss. Host: Janus abbreviatus (Say).

Bracon jani Muesebeck, 1963. Ent. News 74: 164. ₹, ठ。.

juncicola Ashmead. N. S. s. to Fla., w. to Ont., N. Dak., and Tex.; Utah, B. C. Host: Coleophora alniella Heinr., C. laricella (Hbn.), C. viburniella Clem., Etiella zinckenella (Treit.), Keiferia inconspicuella (Murtf.), $K$ lycopersicella (Wlsm.).

Bracon juncicola Ashmead, 1889 (1888). U. S. Natl. Mus., Proc. 11: 520. \&.

Bracon melanaspis Ashmead, 1891. Canad. Ent. 23: 1. .

Microbracon sebequanash Viereck, 1917 (1916). Conn. State Geol. and Nat. Hist. Survey, Bul. 22, p. 206. . 
kirkpatricki (Wilkinson). Tex.?, A riz.?; Africa. Introduced from Kenya. Liberated in Tex. and Ariz. but not known to be established. Host: Anthonomous grandis Boh., Pectinophora gossypiella (Saund.).

Microbracon kirkpatricki Wilkinson, 1927. Bul. Ent. Res. 18: 33. ‡, ठ.

Biology: Cross, et al., 1969. Jour. Econ. Ent. 62: 448-454. - Bryan, et al., 1971. Jour. Econ.

Ent. 64: 1236-1241. - Engroff and Watson, 1975. Ent. Soc. Amer., Ann. 68: 1121-1125.

konkapoti (Viereck). Conn.

Microbracon konkopoti Viereck, 1917 (1916). Conn. State Geol. and Nat. Hist. Survey, Bul. 22, p. 207.

laemosacci (Muesebeck). Ariz. Host: Laemosaccus sp.

Microbracon laemosacci Muesebeck, 1925. U. S. Natl. Mus., Proc. 67 (8): 56. ९, ઠ.

laspeyresiae (Walley). Ont., Ga. Host: Laspeyresia caryana (Fitch).

Microbracon laspeyresiae Walley, 1935. Canad. Ent. 67: 58. + , o.

lineatellae (Fischer). Calif.(?); Middle East. Introduced from Lebanon. Liberated in Calif. but not known to be established. Host: Anarsia lineatella Zell.

Habrobracon lineatellae Fischer, 1968. Pflanzenschutz-Berichte 37: 98. \&, o.

Biology: Laing and Caltagirone, 1969. Canad. Ent. 101: 135-142.

lissogaster Muesebeck. Mont. Host: Cephus cinctus Nort.

Bracon lissogaster Muesebeck, 1953. Ent. Soc. Wash., Proc. 55: 150. ๆ, ठ.

Biology: Somsen and Luginbill, 1956. U. S. Dept. Agr., Tech. Bul. 1153, p. 1-7.

lutus Provancher. Que. s. to N. C., w. to Ont., Iowa, and Tenn. Host: Achatodes zeae (Harr.), Archanara oblonga (Grote), Epiblema scudderianum (Clem.), Hendecaneura shawiana (Kearf.), Lixus scrobicollis Boh., Papaipema lysimachiae Bird, P. nebris (Guen.).

Bracon lutus Provancher, 1880. Nat. Canad. 12: 142..

Bracon lixi Ashmead, 1893. Canad. Ent. 25: 67..

mellitor Say. No. Amer.; Hawaii. Host: Acrobasis vaccinii Riley, Anthonomus albopilosus Dietz, A. eugenii Cano, A. fulvus Lec., A. grandis Boh., A. signatus Say, A. squamosus Lec., Craponius inaequalis (Say), Chalcodermus aeneus Boh., Conotrachelus nenuphar (Hbst.), Cylas formicarius elegantulus (Sum.), Elasmopalpus lignosellus Zell., Frumenta nundinella (Zell.), Grapholitha molesta (Busck), Homoeosoma electellum (Hulst), Hypera nigrirostris (F.), Laspeyresia caryana (Fitch), Lema collaris Say, Mompha stellella Busck, Ostrinia nubilalis ( $\mathrm{Hbn}$.$) , Paralobesia viteana (Clem.),$ Pectinophora gossypiella (Saund.), Platyptilia sp., Rhinocyllus conicus (Froel.), Rhyacionia adana Heinr., $R$. frustrana (Comst.), Rhynchites bicolor (F.), Smicraulax tuberculatus Pierce, Smicronyx constrictus (Say), S. scapalis (Lec.), Sparganothis sulphurana (F.), Stibadium spumosum Grote, Tachypterellus quadrigibbus (Say), Tyloderma foveolata (Say).

Bracon mellitor Say, 1836. Boston Jour. Nat. Hist. 1: 256. o.

Bracon xanthostigma Cresson, 1865. Ent. Soc. Phila., Proc. 4: 303. ๆ.

Bracon vernoniae Ashmead, 1889 (1888). U. S. Natl. Mus., Proc. 11: 619. ㅇ (o misdet.). Bracon anthonomi Ashmead, 1893. U. S. Dept. Agr., Insect Life 5: 185. ठे.

Microbracon pembertoni Bridwell, 1919 (1918). Hawaii. Ent. Soc., Proc. 4: 115. \&, o.

Biology: Folsom, 1936. Jour. Econ. Ent. 29: 111-116. -Adams, Cross, and Mitchell, 1969.

Jour. Econ. Ent. 62: 889-895. - McGovern and Cross, 1974. Ent. Soc. Amer., Ann. 67:

520-521. - Barfield, Bottrell, and Smith, 1977. Environ. Ent. 6: 133-137.

meromyzae Gahan. Del., Md., Ohio, Mich., Minn., Iowa, Ark., N. Dak., S. Dak., Kans., Idaho, Utah, Ariz., Calif. Host: Meromyza americana Fitch.

Bracon (Tropidobracon) meromyzae Gahan, 1913. U. S. Natl. Mus., Proc. 46: 432. ๆ, ơ.

metacomet (Viereck). Conn.

Microbracon metacomet Viereck, 1917 (1916). Conn. State Geol. and Nat. Hist. Survey, Bul. 22, p. 208. .

montowesi (Viereck). Maine, Conn., Pa., N. J., Ont. Host: Anchylopera platanana Clem., Caulocampus acericaulis (MacG.), Paraclemensia acerfoliella (Fitch).

Microbracon montowesi Viereck, 1917 (1916). Conn. State Geol. and Nat. Hist. Survey, Bul. 22, p. 208. ९, §. 
nanus Provancher. Canada, Ind., Iowa, Kans.

Bracon nauus Provancher, 1880. Nat. Canad. 12: 143. $q, \delta$.

nevadensis Ashmead. Idaho, Ariz., Wash., Oreg., Calif. Host: Chrysobothris deleta Lec., Synanthedon bibionipennis (Bdvl.).

Bracon nevadensis Ashmead, 1889 (1888). U. S. Natl. Mus., Proc. 11: 623. .

niger (Provancher). Que.

Opius niger Provancher, 1888. Addit. Corr. Faune Ent. Canada Hym., p. 381. \&.

nigridorsum Ashmead. Ont., Mich., Iowa, S. Dak.

Bracon nigridorsum Ashmead, 1891. Canad. Ent. 23: 2. ?.

nigropectus Provancher. Canada, Vt., Mass., Ohio, Iowa, Ark.

Bracon nigropectus Provancher, 1880. Nat. Canad. 12: 143. $\%$.

nitidulus Dalla Torre. Canada, Maine, Idaho. Host: Pissodes sp.

Bracon nitidus Provancher, 1883. Nat. Canad. 14: 16. \&, ठ. Preocc. by Smith, 1858.

Bracon nitidulus Dalla Torre, 1898. Nat. Canad. v. 4, p. 280. N. name for nitidus Provancher.

nuperus Cresson. Ont., U. S. except New England; Mexico. Host: Homoeosoma electellum (Hulst), Isophrictis sp., Orellia mificauda (F.), Polychrosis rhoifructana Kearf. This species has also been recorded as being reared from Herina frondescentiae (L.), a european species, Neaspilota achilleae Johnson, and Orthoris crotchii Lec., all of which need to be confirmed.

Bracon nuperus Cresson, 1872. Amer. Ent. Soc., Trans. 4: 187..

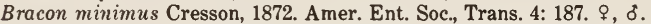

Bracon politus Provancher, 1888. Addit. Corr. Faune Ent. Canada Hym., p. 373. $\delta$.

oenotherae (Muesebeck). Mass., N. J., Md., Va., Ga., Ohio, Tenn., Ont., Minn., Nebr., Tex., Calif. Host: Mompha eloisella (Clem.).

Microbracon oenotherae Muesebeck, 1925. U. S. Natl. Mus., Proc. 67 (8): 62. , §.

palliventris (Provancher). Mass., N. Y., Ohio, Ont., Mich., Oreg. Host: Epiblema strenuanum (Wlkr.).

Phylax palliventris Provancher, 1880. Nat. Canad. 12: 174..

Bracon auripes Provancher, 1888. Addit. Corr. Faune Ent. Canada Hym., p. 372..

Zele pallidiventris Dalla Torre, 1898. Cat. Hym., v. 4, p. 78. Emend.

papaipemae (Gahan). N. Y., Mich., Minn. Host: Papaipema frigida (Smith).

Microbracon papaipemae Gahan, 1922. U. S. Natl. Mus., Proc. 61: 4. ?.

pascuensis Shenefelt. Mich., Kans., Tex.

Bracon pascuensis Shenefelt, 1944. Kans. Ent. Soc., Jour. 17: 74. \&, ठ.

piceiceps Viereck. Kans.

Bracon piceiceps Viereck, 1905. Kans. Acad. Sci., Trans. 19: 268. ठ.

piger Wesmael. Oreg., Calif.; Europe. Introduced from France. Host: Cnephasia sp., Etiella zinckenella (Treit.).

Bracon piger Wesmael, 1838. Nouv. Mem. Acad. Sci. Bruxelles 11: 48. ๆ.

Biology: Parker, 1951. U. S. Dept. Agr., Tech. Bul. 1036, p. 8-11. -Clausen, 1956. U. S. Dept. Agr., Tech. Bul. 1139, p. 87.

pini (Muesebeck). N. S., N. B., Que., Maine, Vt., N. H., Mass., Conn., N. Y., Pa., Va., Ont., Mich., Alta., Mont., Colo., Idaho, B. C., Wash., Oreg., Calif. Host: Cylindrocopturus furnissi

Buch., C. longulus (Lec.), Pissodes fasciatus Lec., P. strobi (Peck), P. schwarzi Hopk., P. terminalis Hopping, Podapion gallicola Riley.

Microbracon pini Muesebeck, 1925. U. S. Natl. Mus., Proc. 67 (8): 52.,$+ \delta$.

Biology: Taylor, 1929. Ent. Amer. 10: 1-12. - Deyrup, 1975. Conif. For. Biome Ecosystem

Anal. Stud., Univ. of Wash., Bul. 6, pp. 81-83.

pityophthori (Muesebeck). N. Mex. Host: Pityophthorus sp.

Microbracon pityophthori Muesebeck, 1925. U. S. Natl. Mus., Proc. 67 (8): 55..

platynotae (Cushman). Ga., La., Tex., Calif.; Mexico. Host: Heliothis zea (Boddie), Lineodes integra (Zell.), L. intermupta Zell., Pectinophora gossypiella (Saund.), Pilemia periusalis (Wlkr.), Platynota stultana Wlsm.

Habrobracon platynotae Cushman, 1914. Ent. Soc. Wash., Proc. 16: 104. \&, ð. 
podunkorum (Viereck). Conn., Va., Ohio, Mich., Iowa, Mo. Host: Aristotelia absconditella (Wlkr.).

Microbracon podunkorum Viereck, 1917 (1916). Conn. State Geol. and Nat. Hist. Survey, Bul. 22, p. 207.

politiventris (Cushman). N. S. s. to Va., w. to B. C. and Calif.; La. Host: Ancylis comptana fragariae (W. and R.), Archips rosanus (L.), Argyrotaenia pinatubana (Kearf.), $A$. velutinana (Wlkr.), Choristoneura conflictana (Wlkr.), C. fumiferana (Clem.), C. accidentalis Freem., C. parallela (Rob.), C. pinus Freem., C. rosaceana (Harr.), Conotrachelus nenuphar (Hbst.), Dioryctria reniculella (Grote), Grapholitha molesta (Busck), Pandemis lamprasana (Rob.), Paralobesia viteana (Clem.), Rhyacionia buoliana (Schiff.).

Habrabracon politiventris Cushman, 1919. U. S. Natl. Mus., Proc. 55: 517. $q$.

Biology: McKnight, 1971. Ent. Soc. Amer., Ann. 64: 620-624.

psilocorsi (Viereck). Md., Tex. Host: Arogalea cristifasciella (Chamb.).

Microbracon psilocorsi Viereck, 1912. U. S. Natl. Mus., Proc. 42: 143. \&, ठ.

punctatus (Muesebeck). N. Y., Pa., Md., N. C., Ga., Fla., Mich., Wis., Ill., Ala., Iowa, Ark., La., Tex. Host: Anthonomus nubilis Lec., Cylas formicarius elegantulus (Sum.), Endalus celatus Burke, Faustinus cubae (Boh.). Also recorded from Listronotus oregonensis Lec. which needs to be confirmed.

Micrabracan punctatus Muesebeck, 1925. U. S. Natl. Mus., Proc. 67 (8): 24..

pygmaeus Provancher. South. Canada, U. S. Host: Argyrotaenia citrana (Fern.), Coleophora innotabilis Braun, C. laricella $\mathrm{Hbn}$., C. leucochrysella Clem., C. malivarella Riley, C. pruniella Clem., C. serratella (L.), C. volckei Heinr.

Bracon pygmaeus Provancher, 1880. Nat. Canad. 12: 144. + , ơ.

Bracon junci Ashmead, 1889 (1888). U. S. Natl. Mus., Proc. 11: 619. ๆ, ơ.

Bracon trifolii Ashmead, 1889 (1888). U. S. Natl. Mus., Proc. 11: 622. ठ.

Bracon kansensis Viereck, 1905. Kans. Acad. Sci., Trans. 19: 268. ․

Micrabracon coleophorae Rohwer, 1915. U. S. Natl. Mus., Proc. 49: 231. + , o.

Microbracon massasoit Viereck, 1917 (1916). Conn. State Geol. and Nat. Hist. Survey, Bul. 22 , p. 207.

Biology: Doner, 1934. Ent. Soc. Amer., Ann. 27: 435-442.

pyralidiphagus (Muesebeck). N. J. s. to Fla.; Mich., La., Tex., Colo., Ariz.

Microbracon pyralidiphagus Muesebeck, 1925. U. S. Natl. Mus., Proc. 67 (8): 34 . .

quinnipiacorum (Viereck). Conn., N. J., Pa., Md., Va., Fla., Mich., Ind., Tenn., Iowa, Ark., S. Dak., Tex., Ariz.

Micrabracon quinnipiacorum Viereck, 1917 (1916). Conn. State Geol. and Nat. Hist. Survey, Bul. 22, p. 207.

radicis Shenefelt. Wis. Host: Hylobius radicis Buch.

Bracon radicis Shenefelt, 1960. Canad. Ent. 92: 872. ₹, o.

rhyacioniae (Muesebeck). Que. w. to Sask.; N. Dak., S. Dak., Nebr., Mont., Colo., N. Mex., Ariz., Idaho, Calif. Host: Barbara colfaxiana (Kearf.), Dioryctria auranticella (Grote), Eacosma recissoriana Heinr., E. tocullionana Heinr., Laspeyresia youngana (Kearf.), Rhyacionia frustrana (Comst.), $R$. bushnelli (Busck), $R$. neomexicana (Dyar).

Microbracon rhyacioniae Muesebeck, 1931. U. S. Natl. Mus., Proc. 79 (16): 15. \&, o.

rhyssomati Ashmead. Ohio, Ill. Host: Rhyssomatus annectans Casey, $R$. lineaticollis (Say).

Bracon rhyssemati Ashmead, 1894. Cincinnati Soc. Nat. Hist., Jour. 17: 46. ठ。.

rosaceani Muesebeck. Oreg. Host: Charistoneura rosaceana (Harr.).

Bracon rosaceani Muesebeck, 1963. Ent. News 74: 160. ㅇ, ð.

rudbeckiae (Muesebeck). Iowa, Ark., N. Dak., Kans., Tex., N. Mex., Ariz. Host: Anthonomus squamosus Lec.

Microbracon rudbeckiae Muesebeck, 1925. U. S. Natl. Mus., Proc. 67 (8): 45. ๆ, ơ.

rufomarginatus Ashmead. W. Va.

Bracon rufomarginatus Ashmead, 1893. Canad. Ent. 25: 68. ‥ 
sanninoideae (Gahan). Ont. s. to Ga., w. to Wis., Kans., and Ark. Host: Alcathoe caudata (Harr.), Podosesia syringae fraxini Lugg., Synanthedon exitiosa (Say), S. rhododendri (Beut.).

Microbracon sanninoideae Gahan, 1917. U. S. Natl. Mus., Proc. 53: 196. \&, ð. scanticorum (Viereck). Conn., Ill.

Microbracon scanticornm Viereck, 1917 (1916). Conn. State Geol. and Nat. Hist. Survey, Bul. 22, p. 207.

sesiae (Muesebeck). Conn., N. Y., Colo. Host: Janus integer (Nort.), Synanthedon tipuliformis (Clerck).

Microbracon sesiae Muesebeck, 1925. U. S. Natl. Mus., Proc. 67 (8): 53. $q$, ð.

sphenophori (Muesebeck). Mo., Ark. Host: Sphenophorus callosus (Oliv.).

Microbracon sphenophori Muesebeck, 1925. U. S. Natl. Mus., Proc. 67 (8): 25. ९, ठ̊.

sulcifrons (Ashmead). Colo.

Microbracon sulcifrons Ashmead, 1890. Colo. Biol. Assoc., Bul. 1: 15. ठ.

tachypteri (Muesebeck). N. Y., W. Va., Wis., Kans., Colo. Host: Tachypterellus consors cerasi List, T. quadrigibbus (Say), T. q. magnas List.

Microbracon tachypteri Muesebeck, 1925. U. S. Natl. Mus., Proc. 67 (8): 68 ..

tenuiceps (Muesebeck). Que. s. to Va. and Tenn., w. to Ont. and Kans.; Tex., Idaho, Nev., Wash. Host: Hypera meles (F.), H. nigrirostris (F.).

Microbracon tenuiceps Muesebeck, 1925. U. S. Natl. Mus., Proc. 67 (8): 46. ․

tenuis Muesebeck and Walkley. Alaska.

Macrodyctium politum Ashmead, 1902. Wash. Acad. Sci., Proc. 4: 252. ₹. Preocc. by Provancher, 1888.

Microbracon ashmeadi Muesebeck, 1925. U. S. Natl. Mus., Proc. 67 (8): 42 . N. name for politum Ashmead; preocc. by Morrison, 1917.

Bracon tenuis Muesebeck and Walkley, 1951. U. S. Dept. Agr., Agr. Monog. 2, p. 168. N. name for ashmeadi Muesebeck.

terebella Wesmael. N. Y., Pa., Ohio; Europe. Host: Cephus cinctus Nort., C. pygmaeus (L.), Trachelus tabidus (F.). This species was also introduced into Ont., N. Dak., and Mont. from Europe but apparently not established.

Braco terebella Wesmael, 1838. Nouv. Mem. Acad. Sci. Bruxelles 11: 57. . .

Biology: Salt, 1931. Bul. Ent. Res. 22: 527-534.

thurberiphagae (Muesebeck). Tex., Ariz.; Mexico, West Indies. Host: Ancylostomia stercorea (Zell.), Anthonomus grandis thurberiae Pierce, Thurberiphaga diffusa (Barnes).

Microbracon thurberiphagae Muesebeck, 1925. U. S. Natl. Mus., Proc. 67 (8): 54. ๆ, ठ.

Biology: Bennett, 1960. Bul. Ent. Res. 50: 747-749.

tychii (Muesebeck). Utah, Idaho, Calif. Host: Etiella zinckenella (Treit.), Tychius lineellus Lec., T. semisquamosus Lec.

Microbracon tychii Muesebeck, 1925. U. S. Natl. Mus., Proc. 67 (8): 51. ๆ, ð.

uncas (Viereck). Conn.

Microbracon uncas Viereck, 1917 (1916). Conn. State Geol. and Nat. Hist. Survey, Bul. 22, p. 208.

variabilis (Provancher). Que. s. to Ga., w. to Minn. and Tex.; Idaho. Host: Acrobasis caryae Grote, A. mibrifasciella Pack., Blastodacna sp., Conotrachelus nenuphar (Hbst.), Paralobesia viteana (Clem.), Tachypterellus quadrigibbus (Say), T. q. magnas List. Opins variabilis Provancher, 1888. Addit. Corr. Faune Ent. Canada Hym., p. 382. ठै.

Bracon tortricicola Ashmead, 1889 (1888). U. S. Natl. Mus, Proc. 11: 621. ๆ.

Biology: Nickels, Pierce, and Pinkney, 1950. U. S. Dept. Agr., Tech. Bul. 1011, p. 9-12. - Balduf, 1968. Ent. Soc. Amer., Ann. 61: 467-468.

wawequa (Viereck). Conn.

Microbracon wawequa Viereck, 1917 (1916). Conn. State Geol. and Nat. Hist. Survey, Bul. 22, p. 206.

xanthonotus Ashmead. N. H., Va., Minn., Colo., N. Mex., Idaho, Utah, Ariz., Wash., Oreg., Calif. Host: Malacosoma californicum californicum (Pack.), M. c. fragile (Stretch), M. c. 
pluviale (Dyar), M. c. recenseo Dyar, M. constrictum (Hy. Edw.), M. disstria Hbn., Orgyia leucostigma (Smith), O. pseudotsugata (McD.), O. vetusta (Bdvl.), Sabulodes caberatae (Gn.).

Bracon xanthonotus Ashmead, 1889 (1888). U. S. Natl. Mus., Proc. 11: 618. ๆ, ১. Bracon (Habrobracon) hopkinsi Viereck, 1910. U. S. Natl. Mus., Proc. 38: 380. ๆ, ठ. Habrobracon mali Viereck, 1913. U. S. Natl. Mus., Proc. 44: 641. ๆ, ठ.

Biology: McKenzie, 1935. Calif. Agr. Expt. Sta., Bul. 592, p. 20-21.

\section{Genus COELOIDES Wesmael}

Coeloides Wesmael, 1838. Nouv. Mem. Acad. Sci. Bruxelles 11: 59.

Type-species: Coeloides scolyticida Wesmael. Desig. by Shenefelt, 1943.

Syntomomelus Kokujev, 1902. Rev. Russe d'Ent. 3: 163.

Type-species: Syntomomelus rossicus Kokujew. Monotypic.

Habrobraconidea Viereck, 1912. U. S. Natl. Mus., Proc. 43: 578.

Type-species: Habrobraconidea bicoloripes Viereck. Orig. desig.

Coeloidina Viereck, 1921. U. S. Natl. Mus., Proc. 59: 133.

Type-species: Coeloides melanotus Wesmael. Orig. desig.

Cerobracon Viereck, 1926. Canad. Ent. 58 (3): 54.

Type-species: Bracon secundus Dalla Torre. Orig. desig.

Species are external parasites of larvae of wood boring Coleoptera.

brunneri Viereck. Mont. s to N. Mex., w. to Wash. and Calif. Host: Dendroctonus pseudotsugae Hopk. Other host records need to be confirmed.

Coeloides brunneri Viereck, 1911. U. S. Natl. Mus., Proc. 41: 293. ९, o .

Coeloides scolyti Cushman, 1931. Wash. Acad. Sci., Jour. 21: 303. १, ठ.

Biology: Ryan, 1962. Ent. Soc. Amer., Ann. 55: 403-409. - Ryan and Rudinsky, 1962. Canad.

Ent. 94: 748-763. - Ryan, 1963. Ent. Soc. Amer., Ann. 56: 639-648. - Richerson and

Borden, 1971. Entomophaga 16: 95-99. - Richerson and Borden, 1972. Canad. Ent. 104:

1235-1250, 1877-1881. - Deyrup, 1975. Conif. For. Biome Ecosystem Anal. Stud., Univ. of Wash., Bul. 6, p. 87-90.

Morphology: Richerson, Borden, and Hollingdale, 1972. Canad. Jour. Zool. 50: 909-913 (antenna).

crocator (Kirby). No. Amer. ("lat. 65").

Bracon crocator Kirby, 1837. Fauna Bor.-Amer., v. 4, p. 261. 9.

dendroctoni Cushman. Que.; S. Dak. s. to Ariz., w. to B. C. and Calif.; Alaska. Host: Dendroctonus obesus (Mann.), D. ponderosae Hopk., D. rufipennis (Kby.), Ips confusus (Lec.), I. emarginatus (Lec.), I. oregonis (Eichh.), I. perturbatus (Eichh.), I. pilifrons Swaine, Orthothomicus caelatus (Eichh.).

Coeloides dendroctoni Cushman, 1931. Wash. Acad. Sci., Jour. 21: 303. \&, ठ์.

Biology: De Leon, 1935. Ent. Soc. Amer., Ann. 28: 411-424. - Reid, 1963. Canad. Ent. 95: 233-235. - Deyrup, 1975. Conif. For. Biome Ecosystem Anal. Stud., Univ. of Wash., Bul. 6, p. 90 .

Morphology: De Leon, 1934. N. Y. Ent. Soc., Jour. 42: 297-317.

pissodis (Ashmead). N. S. and N. B. s. to Ga., w. to Tex.; Ont., Wis., Minn., Wyo. Host: Dendroctonus frontalis Zimm., Ips calligraphus (Germar), I. grandicollis (Eichh.),

Pissodes approximatus Hopk., P. nemorensis Germar, P. strobi (Peck).

Bracon pissodis Ashmead, 1889 (1888). U. S. Natl. Mus., Proc. 11: 617..

Habrobraconidea bicoloripes Viereck, 1912. U. S. Natl. Mus., Proc. 43: 579. $९$.

Biology: Taylor, 1929. Ent. Amer. 10: 22-26.

promontorii (Dalla Torre). Canada, N. H., Pa.

Bracon striatus Provancher, 1880. Nat. Canad. 12: 140. ठ. Preocc. by Brulle, 1846.

Bracon promontorii Dalla Torre, 1898. Cat. Hym., v. 4, p. 285. N. name for striatus

Provancher.

rufovariegatus (Provancher). Canada.

Bracon rufovariegatus Provancher, 1880. Nat. Canad. 12: 142. + ,. 
scolytivorus (Cresson). Que. s. to N. C.; Mo. Host: Neoclytus acuminatus (F.), Scolytus quadrispinosus Say.

Bracon scolytivorus Cresson, 1873. In Riley, Ins. Mo., Ann. Rpt. 5: 106. ९, ১.

Bracon longicandus Provancher, 1880. Nat. Canad. 12: 142. ₹, ठ. Preocc. by Brulle, 1846.

Bracon canadensis Dalla Torre, 1898. Cat. Hym., v. 4, p. 261. N. name for longicaudus

Provancher.

secundus (Dalla Torre). Que., Maine, N. H., N. C., Minn. Host: Pissodes dubius Rand.

Bracon nigripes Provancher, 1886. Addit. Corr. Faune Ent. Canada Hym., p. 121. \&, o. Preocc. by Brulle, 1846.

Bracon secundus Dalla Torre, 1898. Cat. Hym., v. 4, p. 288. N. name for nigripes Provancher.

vancouverensis (Dalla Torre). B. C.

Bracon striatus Provancher, 1888. Addit. Corr. Faune Ent. Canada Hym., p. 432. o. Preocc. by Brulle, 1846.

Bracon vancouverensis Dalla Torre, 1898. Cat. Hym., v. 4, p. 293. N. name for striatus Provancher.

\section{Genus COMPSOBRACON Ashmead}

Compsobracon Ashmead, 1900. U. S. Natl. Mus., Proc. 23: 138.

Type-species: Exothecus magnificus Ashmead. Orig. desig.

Macronura Szepligeti, 1906. Mus. Nat. Hung., Ann. 4: 581.

Type-species: Iphiaulax mirabilis Szepligeti. Desig. by Viereck, 1914.

magnificus (Ashmead). Tex.

Exothecus magnificus Ashmead, 1889 (1888). U. S. Natl. Mus., Proc. 11: 624..

\section{Genus CYANOPTERUS Haliday}

Cyanopterus Haliday, 1835. Ent. Mag. 3: 22.

Type-species: Ichneumon flavator Fabricius. Monotypic.

Bracambus Szepligeti, 1896. Termes. Fuzetek 19: 168.

Type-species: Ichneumon flavator Fabricius. Monotypic.

Coeloidimorpha Viereck, 1913. U. S. Natl. Mus., Proc. 44: 558.

Type-species: Bracon (Melanobracon) webbi Viereck. Orig. desig.

laevis (Provancher). Que., Maine, Pa., Ga., Mich., Miss., Minn., Mont., Calif.

Bracon laevis Provancher, 1880. Nat. Canad. 12: 138. $\%$.

Bracon (Melanobracon) webbi Viereck, 1909. U. S. Dept. Agr. Bur. Ent., Bul. 58: 54..

\section{Genus IPHIAULAX Foerster}

Iphiaulax Foerster, 1862. Naturh. Ver. Rheinlande, Verh. 19: 234.

Type-species: Bracon impostor Scopoli. Orig. desig.

Ipobracon Dalla Torre, 1898. Cat. Hym., v. 4, p. 296.

Type-species: Bracon nigrator Zetterstedt. Desig. by Muesebeck and Walkley, 1951.

Digonogastra Viereck, 1912. U. S. Natl. Mus., Proc. 42: 621.

Type-species: Bracon epicus Cresson. Orig. desig.

Monogonogastra Viereck, 1912. U. S. Natl. Mus., Proc. 42: 625.

Type-species: Bracon atripectus Ashmead. Orig. desig.

Iphianlacidea Fahringer, 1926. Opusc. Bracon., v. 1, p. 189.

Type-species: Bracon impostor Scopoli. Desig. by Muesebeck and Walkley, 1951.

agrili (Ashmead). Que. and N. B. s. to Ga., w. to N. Dak. and Ariz. Host: Agrilus sp., Oberea praelonga Casey.

Bracon agrili Ashmead, 1889 (1888). U. S. Natl. Mus., Proc. 11: 612. \&, ठ.

americanus Provancher. Que., N. Y., Pa., Va.

Iphianlax americanus Provancher, 1888. Addit. Corr. Faune Ent. Canada Hym., p. 371.. atripectus (Ashmead). Calif.

Bracon atripectus Ashmead, 1889 (1888). U. S. Natl. Mus., Proc. 11: 614. ?. 
augustus Viereck. Conn.

Iphiaulax (Monogonogastra) augustus Viereck, 1917 (1916). Conn. State Geol. and Nat.

Hist. Survey, Bul. 22, p. 210..

cinnabarinus Viereck. Tex., N. Mex., Ariz.

Iphiaulax cinnabarinus Viereck, 1905. Kans. Acad. Sci., Trans. 19: 286. ․

epicus (Cresson). Fla., Mich., Ill., Iowa, Ark., Tex., Ariz.

Bracon epicus Cresson, 1872. Amer. Ent. Soc., Trans. 4: 183..

erythrogaster (Brulle). $\mathrm{Pa}$.

Bracon erythrogaster Brulle, 1846. In Lepeletier, Hist. Nat. Ins. Hym., v. 4, p. 401. 9.

erythrus (Viereck). Tex., N. Mex., Ariz., Calif.

Vipio erythrus Viereck, 1905. Kans. Acad. Sci., Trans. 19: 284. ठँ.

eurygaster (Brulle). Maine, Conn., N. Y., Pa., N. J., Mich., Ind., S. Dak. Host: Saperda concolor Lec.

Bracon eurygaster Brulle, 1846. In Lepeletier, Hist. Nat. Ins. Hym., v. 4, p. 400..

faustus (Cresson). Kans., Tex., Ariz.; Mexico. Host: Ataxia sp., A. hubbardi Fish.

Bracon faustus Cresson, 1872. Amer. Ent. Soc., Trans. 4: 185..

koebelei (Ashmead). Calif.

Bracon koebelei Ashmead, 1889 (1888). U. S. Natl. Mus., Proc. 11: 613. ठ์.

manteri Nettleton. Ga., Fla., Ala., Miss. Host: Oiketicus abbottii Grote, Thyridopteryx ephemeraeformis (Haw.).

Iphiaulax manteri Nettleton, 1938. Ent. Soc. Amer., Ann. 31: 15. ९, ठ.

melanogaster Viereck. Kans.

Iphiaulax melanogaster Viereck, 1905. Kans. Acad. Sci., Trans. 19: 270..

militaris Viereck. Pa., N. J., Md., Kans.

Iphiaulax militaris Viereck, 1905. Kans. Acad. Sci., Trans. 19: 269. ؟.

orbita (Brulle). D. C.

Bracon orbita Brulle, 1846. In Lepeletier, Hist. Nat. Ins. Hym., v. 4, p. 399. 9.

ornatus (Provancher). Canada.

Bracon ornatus Provancher, 1880. Nat. Canad. 12: 141. ๆ, ó.

Iphiaulax decoratus(!) Provancher, 1888. Addit. Corr. Faune Ent. Canada Hym., p. 371.

palliventris (Cresson). Mich., "Colo. Terr."

Bracon palliventris Cresson, 1865. Ent. Soc. Phila., Proc. 4: 301. \&.

Bracon pallidiventris Dalla Torre, 1898. Cat. Hym., v. 4, p. 282. Emend.

perepicus Viereck. Tex., N. Mex., Ariz.

Iphiaulax perepicus Viereck, 1905. Kans. Acad. Sci., Trans. 19: 285..

propinquus Viereck. Ariz.

Iphiaulax propinquus Viereck, 1905. Kans. Acad. Sci., Trans. 19: 286. ๆ.

rugiceps (Cresson). Tex.

Bracon rugiceps Cresson, 1872. Amer. Ent. Soc., Trans. 4: 184. .

sanguineus (Provancher). Ariz., Calif.

Bracon sanguineus Provancher, 1888. Addit. Corr. Faune Ent. Canada Hym., p. 372. \&.

\section{Genus VIPIO Latreille}

Vipio Latreille, 1804. Nouv. Dict. Hist. Nat. 24: 173.

Type-species: Ichneumon desertor Fabricius. Desig. by Foerster, 1862.

Glyptomorpha Holmgren, 1868. Eug. Resa II, Zool. I, Ins., p. 427.

Type-species: Glyptomorpha ferruginea Holmgren. Monotypic.

Pseudovipio Szepligeti, 1896. Termes. Fuzetek 19: 230.

Type-species: Bracon inscriptor Nees. Desig. by Viereck, 1914.

Euvipio Szepligeti, 1904. In Wytsmann, Gen. Ins., v. 22, p. 14.

Type-species: Euvipio mufa Szepligeti. Monotypic.

Zavipio Viereck, 1914. U. S. Natl. Mus., Bul. 83: 156.

Type-species: Vipio marshalli Schmiedeknecht. Orig. desig.

belfragei (Cresson). Ga., Ind., Ill., Mo., Tex. Host: Sphenophorus cariosus (Oliv.).

Bracon belfragei Cresson, 1872. Amer. Ent. Soc., Trans. 4: 186.. 
coloradensis Ashmead. Mont., Wyo., Colo., N. Mex., Idaho, Utah, Ariz.

Vipio coloradensis Ashmead, 1889 (1888). U. S. Natl. Mus., Proc. 11: 611. .

croceus (Cresson). "Colo. Terr."

Bracon croceus Cresson, 1865. Ent. Soc. Phila., Proc. 4: 302. ₹.

moneilemae Gahan. Utah, Calif.; Mexico. Host: Moneilema sp.

Vipio moneilemae Gahan, 1930. U. S. Natl. Mus., Proc. 77 (8): 3. ९, ठ.

piceipectus Viereck. Kans.

Vipio peceipectus Viereck, 1905. Kans. Acad. Sci., Trans. 19: 269. \&.

rugator (Say). N. J. s. to Fla., w. to Wis., Kans., and Tex.; Mexico.

Bracon rugator Say, 1836. Boston Jour. Nat. Hist. 1: 251. ?.

Bracon mavoritus Cresson, 1872. Amer. Ent. Soc., Trans. 4: 186. ९.

Bracon novitus Cresson, 1872. Amer. Ent. Soc., Trans. 4: 186. ठै.

schwarzii (Ashmead). Ga., Fla., Mich., Iowa.

Bracon Schwarzii Ashmead, 1889 (1888). U. S. Natl. Mus., Proc. 11: 615..

texanus (Cresson). S. C., Tenn., Iowa, Tex.

Bracon texanus Cresson, 1872. Amer. Ent. Soc., Trans. 4: 187..

uniformis (Cresson). "Colo. Terr."

Bracon uniformis Cresson, 1865. Ent. Soc. Phila., Proc. 4: 302..

\section{SubFamily EXOTHECINAE}

The genera in this group were included in the Rogadinae in the previous catalog although they were placed in a distinct subfamily by earlier workers. Separation from the Rogadinae appears justified since the Exothecinae are apparently external parasites of lepidopterous, coleopterous, and sawfly larvae, the Rogadinae being internal parasites of lepidopterous larvae. The genera included here are in need of revision and the generic placement of the North American species which follows should be considered only provisional until a thorough study is made of the group.

Taxonomy: Shenefelt, 1975. Hym. Cat., part 12, p. 1115-1163 (cat. World spp.).

\section{TRIBE EXOTHECINI}

\section{Genus ACRISIS Foerster}

Acrisis Foerster, 1862. Naturh. Ver. Rheinlande, Verh. 19: 236.

Type-species: Acrisis gracilicornis Foerster. Orig. desig.

Euchasmus Marshall, 1888. In Andre, Spec. Hym. Eur. Alg., v. 4, p. 210.

Type-species: Euchasmus exiguus Marshall. Monotypic.

Episigalphus Ashmead, 1900. U. S. Natl. Mus., Proc. 23: 125.

Type-species: Episigalphus minutessimus(!) Ashmead. Orig. desig.

Taxonomy: Muesebeck, 1935. Ent. Soc. Wash., Proc. 37: 175-177 (No. Amer. spp.). -Marsh, 1965. Ent. Soc. Amer., Ann. 58: 690. - Shenefelt and Marsh, 1976. Hym. Cat., part 13, p. 1343-1344 (cat. World spp.).

americana (Ashmead). Pa., Mich., Ind.

Pygostolus americanus Ashmead, 1894. Cincinnati Soc. Nat. Hist., Jour. 17: 47. "ઠ" =. minutissima (Ashmead). Wis., Ill., La., S. Dak.

Episigalphus minutessimus(!) Ashmead, 1900. U. S. Natl. Mus., Proc. 23: 125..

\section{Genus ALLOBRACON Gahan}

Allobracon Gahan, 1915. U. S. Natl. Mus., Proc. 49: 94.

Type-species: Diachasma pilosipes Ashmead. Orig. desig.

One undescribed species in North America.

\section{Genus COLASTES Haliday}

Colastes Haliday, 1833. Ent. Mag. 1: 266.

Type-species: Colastes braconius Haliday. Monotypic.

Exothecus Wesmael, 1838. Nouv. Mem. Acad. Sci. Bruxelles 11: 73. 
Type-species: Exothecus affinis Wesmael. Desig. by Foerster, 1862.

The synonymy of Exothecus with Colastes needs to be confirmed by examination of the type-species. There is no doubt, however, that many species associated with Colastes at present are not congeneric with the type-species.

Taxonomy: Shenefelt, 1975. Hym. Cat., part 12, p. 1115-1122 (cat. World spp.). alaskensis (Ashmead). Alaska.

Exothecus alaskensis Ashmead, 1902. Wash. Acad. Sci., Proc. 4: 252.

orchesiae (Ashmead). Mich., Iowa. Host: Orchesia castanea Melsh.

Rhysipolis orchesiae Ashmead, 1889 (1888). U. S. Natl. Mus., Proc. 11: 625. 9.

polypori Mason. Que., Man., Wis. Ecology: Reared from the shelf fungus Polyporus betulinus on birch.

Colastes polypori Mason, 1968. Canad. Ent. 100: 715. + , ठ์.

Nomina Nuda in Colastes Haliday

Colastes basalis Ashmead, 1899. In Smith, Ins. of N. J., p. 597.

Colastes microrhopalae Riley, 1890. In Riley and Howard, U. S. Dept. Agr., Insect Life 2: 351.

\section{Genus GNAPTODON Haliday}

Opius subg. Gnaptodon Haliday, 1837. Ent. Mag. 4: 220.

Type-species: Bracon pumilio Nees. Monotypic.

Diraphus Wesmael, 1838. Nouv. Mem. Acad. Sci. Bruxelles 11: 89.

Type-species: Diraphus pygmaeus Wesmael. Monotypic.

This genus has traditionally been placed in the Opiinae, but Tobias (1967) and Capek (1970) have placed it with the Exothecini, which appears to be correct. Morphologically, the genus resembles other genera in this tribe. Species are internal parasites of leaf mining lepidopterous larvae and are apparently restricted to the family Nepticulidae.

Revision: Fischer, 1965. Polskie Pismo Ent. 35: 168-182 (No. Amer. spp.). -Fischer, 1967.

Beitr. z. Ent. 17: 969-973 (No. and So. Amer. spp.).

Taxonomy: Tobias, 1967. Ent. Obozr. 46: 661. -Capek, 1970. Canad. Ent. 102: 861, 871.

-Fischer, 1971. Index World Opiinae, p. 127-128 (cat. World spp.). - Shenefelt, 1975. Hym.

Cat., part 12, p. 1123-1125 (cat. World spp.).

Biology: Bachmaier, 1965. Veroff. Zool. Staatssamml. Munchen 9: 139.

bicolor Fischer. Va., N. C.

Gnaptodon bicolor Fischer, 1965. Polskie Pismo Ent. 35: 169. ๆ, o.

glaber Fischer. Va., Fla., Utah. Host: Nepticula castaneaefoliella Chamb.

Gnaptodon glaber Fischer, 1965. Polskie Pismo Ent. 35: 171. , ठ。.

longicauda Fischer. Md.

Gnaptodon longicauda Fischer, 1965. Polskie Pismo Ent. 35: 172..

nepticulae (Rohwer). Que., N. Y., Md., D. C., Va., Mich., Wis., Ill., La., N. Mex., Ariz. Host:

Nepticula castaneaefoliella Chamb.

Gnamptodon nepticulae Rohwer, 1915. U. S. Natl. Mus., Proc. 49: 229. १, ठ.

Gnaptodon pulchrigaster Fischer, 1965. Polskie Pismo Ent. 35: 176. ๆ, ठ์.

Taxonomy: Marsh, 1974. Ent. Soc. Wash., Proc. 76: 285.

recticarinatus Fischer. Yukon.

Gnaptodon recticarinatus Fischer, 1965. Polskie Pismo Ent. 35: 177. ठ.

rugulosus Fischer. N. Y., Oreg.

Gnaptodon migulosus Fischer, 1965. Polskie Pismo Ent. 35: 179. ๆ, ১.

sinuatus Fischer. Labrador, Yukon.

Gnaptodon sinuatus Fischer, 1965. Polskie Pismo Ent. 35: 181. ๆ, ð.

Nomen Nudum in GNaptodon Haliday

Gnamptodon flavibasilaris Ashmead, 1905. In Nason, Ent. News 16: 298. 


\section{Genus ONCOPHANES Foerster}

Oncophanes Foerster, 1862. Naturh. Ver. Rheinlande, Verh. 19: 241.

Type-species: Exothecus minutus Wesmael. Orig. desig.

E pirhyssalus Ashmead, 1900. U. S. Natl. Mus., Proc. 23: 142

Type-species: Epirhyssalus californicus Ashmead. Orig. desig.

Revision: Muesebeck, 1935. Ent. Soc. Amer., Ann. 28: 241-246 (No. Amer. spp.).

Taxonomy: Shenefelt, 1975. Hym. Cat., part 12, p. 1125-1130 (cat. World spp.).

americanus (Weed). Que. s. to Va., w. to Iowa and Kans.; Wash., Oreg. Host: Acleris minuta

(Rob.), Amorbia humerosana Clem., Ancylis comptana fragariae (W. and R.), Archips

cerasivoranus (Fitch), Argyrotaenia velutinana (Wlkr.), Aroga trialbamaculella

(Chamb.), Caloptilia sp., Choristoneura fumiferana (Clem.), C. rosaceana (Harr.),

Endothenia hebesana (Wlkr.), Eulia ministrana (L.), Filatima persicaeella (Murtf.),

Hedia cyanana (Murtf.), Janus integer (Nort.), Platynota flavedana Clem., P. idaeusalis

(Wlkr.), Psilocorsis sp., Sparganothis flavibasana (Fern.), S. sulphurana (F.).

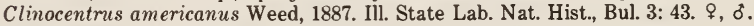

Rhyssalus atriceps Ashmead, 1889 (1888). U. S. Natl. Mus., Proc. 11: 628. \&, ठ.

Rhyssalus similis Ashmead, 1889 (1888). U. S. Natl. Mus., Proc. 11: 628. ठै.

Rhyssalus loxoteniae Ashmead, 1889 (1888). U. S. Natl. Mus., Proc. 11: 628. \&, o.

Biology: Zeller and Schuh, 1944. Oreg. Agr. Exp. Sta., Bul. 418, p. 48. - Schaffner, 1959. U. S.

Dept. Agr., Misc. Pub. 767, p. 66. - Bennett, 1961. Tenn. Acad. Sci., Jour. 36: 353.

betulae Muesebeck. Maine, Mich., Wis. Host: Anthophila pariana (Clem.). This species has also been recorded from Heterarthrus nemoratus (Fall.) which needs to be confirmed.

Oncophanes betulae Muesebeck, 1935. Ent. Soc. Amer., Ann. 28: 245..

Biology: Schaffner, 1959. U. S. Dept. Agr., Misc. Pub. 767, p. 66.

californicus (Ashmead). Wash., Oreg., Calif.

Epirhyssalus californicas(!) Ashmead, 1900. U. S. Natl. Mus., Proc. 23: 142. ค.

nigriventris Muesebeck. Conn., D. C., Md., Fla., Mich., Wis., Iowa.

Oncophanes nigriventris Muesebeck, 1935. Ent. Soc. Amer., Ann. 28: 243. ?.

pusillus Muesebeck. Wis., Minn. Host: Trichotaphe levisella Fyles.

Oncophanes pusillus Muesebeck, 1967. Ent. News 78: 136. ․

\section{Genus PHANOMERIS Foerster}

Phanomeris Foerster, 1862. Naturh. Ver. Rheinlande, Verh. 19: 235.

Type-species: Exothecus abnormis Wesmael. Orig. desig.

Phaenomeris Dalla Torre, 1898. Cat. Hym., v. 4, p. 252. Emend.

Taxonomy: Muesebeck, 1932. Ent. Soc. Wash., Proc. 34: 81-83. -Shenefelt, 1975. Hym. Cat., part 12, p. 1130-1133 (cat. World spp.).

borealis Walley. Baffin Isl.

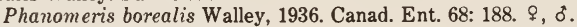

mellipes (Provancher). Canada.

Opius pallipes Provancher, 1880. Nat. Canad. 12: 164. ơ. Preocc. by Wesmael, 1835.

Opius mellipes Provancher, 1880. Nat. Canad. 12: 164, footnote.

metalli Muesebeck. Maine, N. Y., Va., Mich., Wis. Host: Cameraria bethunella Chamb., Metallus rohweri MacG.

Phanomeris metalli Muesebeck, 1932. Ent. Soc. Wash., Proc. 34: 82. , ठ์.

phyllotomae Muesebeck. Maine; Europe. Introduced from Austria. Host: Fenusa pusilla (Lep.), Heterarthrus nemoratus (Fall.).

Phanomeris phyllotomae Muesebeck, 1932. Ent. Soc. Wash., Proc. 34: 83. $\uparrow$, o.

Biology: Dowden, 1941. U. S. Dept. Agr., Tech. Bul. 757, p. 11-16. -Dowden, 1962. U. S.

Dept. Agr., Agr. Handb. 226, p. 63.

Morphology: Dowden, 1941. U. S. Dept. Agr., Tech. Bul. 757, p. 11-16.

propinquus (Walley). Baffin Isl., Que.

Exothecus propinquus Walley, 1936. Canad. Ent. 68: 190.. 


\section{Genus PSEUDOGNAPTODON Fischer}

Pseudognaptodon Fischer, 1965. Polskie Pismo Ent. 35: 182.

Type-species: Pseudognaptodon curticauda Fischer. Orig. desig.

Revision: Fischer, 1965. Polskie Pismo Ent. 35: 182-187 (No. Amer. spp.). -Fischer, 1967.

Beitr. z. Ent. 17: 973-975 (No. and So. Amer. spp.).

curticauda Fischer. Tex; Mexico.

Pseudognaptodon curticauda Fischer, 1965. Polskie Pismo Ent. 35: 183. ९, ठ.

omissus Fischer. N. C., Fla.

Pseudognaptodon omissus Fischer, 1965. Polskie Pismo Ent. 35: 185. @.

\section{Genus RHYSIPOLIS Foerster}

Rhysipolis Foerster, 1862. Naturh. Ver. Rheinlande, Verh. 19: 235.

Type-species: Rogas (Colastes) mediator Haliday. Orig. desig.

Taxonomy: Shenefelt, 1975. Hym. Cat., part 12, p. 1133-1137 (cat. World spp.).

pallipes (Provancher). Que., Maine, N. H., Mich. Host: Caloptilia fraxinella (Ely).

Doryctes pallipes Provancher, 1888. Addit. Corr. Faune Ent. Canada Hym., p. 375.

Daryctes pallidipes Dalla Torre, 1898. Cat. Hym., v. 4, p. 234. Emend.

Nomen NUdum in RHysipolis Foerster

Rhysipolis phoxopteridis Riley, 1890. In Riley and Howard, U. S. Dept. Agr., Insect Life 2: 350.

\section{Genus XENARCHA Foerster}

Xenarcha Foerster, 1862. Naturh. Ver. Rheinlande, Verh. 19: 235.

Type-species: Colastes lustrator Haliday. Orig. desig.

Zamegaspilus Ashmead, 1900. U. S. Natl. Mus., Proc. 23: 141.

Type-species: Zamegaspilus hopkinsi Ashmead. Orig. desig.

Taxonomy: Muesebeck, 1956. Ent. Soc. Wash., Proc. 58: 34. - Shenefelt, 1975. Hym. Cat., part 12, p. 1137-1138 (cat. World spp.).

hopkinsi (Ashmead). Md., W. Va., Va., N. C., Tenn., Iowa, Ark.

Zamegaspilus hopkinsi Ashmead, 1900. U. S. Natl., Mus., Proc. 23: 141.

Rhogas melanothorax Viereck, 1905. Kans. Acad. Sci., Trans. 19: 267. ‡.

\section{Genus XENOSTERNUM Muesebeck}

Xenosternum Muesebeck, 1935. Ent. Soc. Amer., Ann. 28: 246.

Type-species: Xenosternum arnigis Muesebeck. Orig. desig.

ornigis Muesebeck. Tenn., Mo., Ark., Kans., Tex. Host: Fascista cercerisella (Chamb.),

Paramix sp.

Xenosternum ornigis Muesebeck, 1935. Ent. Soc. Amer., Ann. 28: 247. $९, ~ \delta$.

\section{TRIBE HORMIINI}

Taxonomy: Hedqvist, 1963. Ent. Tidskr. 84: 30-61 (given subfamily rank; key to genera of

World). -Capek, 1970. Canad. Ent. 102: 864-865.

\section{Genus CANTHAROCTONUS Viereck}

Cantharoctonus Viereck, 1912. U. S. Natl. Mus., Proc. 42: 617.

Type-species: Cantharoctonus stramineus Viereck. Orig. desig.

brunneus Hedqvist. Fla.

Cantharoctonus brunneus Hedqvist, 1963. Ent. Tidskr. 84: 38. ๆ.

canadensis Mason. Newfoundland, N. S., N. B., Que., Man., Sask. Host: Bucculatrix canadensisella (Chamb.).

Cantharoctonus canadensis Mason, 1968. Canad. Ent. 100: 723. ๆ, ठ. 


\section{Genus HORMIUS Nees}

Hormius Nees, 1818. Nov. Act. Acad. Caes. Leop. Car. 9: 305.

Type-species: Bracon moniliatus Nees. Monotypic.

Taxonomy: Shenefelt, 1975. Hym. Cat., part 12, p. 1143-1148 (cat. World spp.). albipes Ashmead. Ariz.; Baja Calif.

Hormius albipes Ashmead, 1895. Calif. Acad. Sci., Proc. 5: 544.. americanus Ashmead. Colo.

Hormius americanus Ashmead, 1890. Colo. Biol. Assoc. Bul. 1: 16..

Biology: Basinger, 1938. Hilgardia 11: 663-664.

completus (Provancher). Que., Md., D. C., Va., Ohio, Ind., Calif. Host: Argyrotaenia citrana (Fern.).

Ephedrus completus Provancher, 1886. Addit. Corr. Faune Ent. Canada Hym., p. 156. ㅇ.

Zele basalis Provancher, 1888. Addit. Corr. Faune Ent. Canada Hym., p. 380. $\%$.

Hormius erythrogaster Ashmead, 1893. Amer. Ent. Soc., Trans. 20: 41. ó.

dispar (Brues). N. H., N. Y., Md., D. C., N. C., Mich., Ill., Mo., Ark., Tex.

Pambolus(?) dispar Brues, 1907. Wis. Nat. Hist. Soc., Bul. 5: 110. $\subsetneq$.

Hormius micropterus Hedqvist, 1963. Ent. Tidskr. 84: 51. $?$.

melleus (Ashmead). Mo.

Oncophanes melleus Ashmead, 1889 (1888). U. S. Natl. Mus., Proc. 11: 630..

moniliatus (Nees). Greenland; Europe.

Bracon moniliatus Nees, 1812 (1811). Mag. Gesell. Naturf. Freunde Berlin 5: 36. ‡.

tsugae Mason. Que., Ont. Host: Coleotechnites apicitripunctella (Clem.), C. piceaella (Kearf.).

Hormius tsugae Mason, 1968. Canad. Ent. 100: 724. + , ¿.

vulgaris Ashmead. Fla., Mo., Ark. Host: Psorosina hammondi (Riley), Tetralopha robustella Zell., T. subcanalis (Wlkr.).

Hormius vulgaris Ashmead, 1893. Amer. Ent. Soc., Trans. 20: 43. \&, ठ.

\section{Genus MONITORIELLA Hedqvist}

Monitoriella Hedqvist, 1963. Ent. Tidskr. 84: 44.

Type-species: Monitoriella elongata Hedqvist. Orig. desig.

Taxonomy: Hedqvist, 1963. Ent. Tidskr. 84: 44-49 (key to spp.).

elongata Hedqvist. Tex.; Mexico, Honduras. Ecology: Reared from galls on Philodendron.

Monitoriella elongata Hedqvist, 1963. Ent. Tidskr. 84: 46. ‡, ठ.

\section{Genus NOSERUS Foerster}

Noseris Foerster, 1862. Naturh. Ver. Rheinlande, Verh. 19: 241.

Type-species: Noserus facialis Foerster. Orig. desig.

pomifoliellae (Ashmead). Mo. Host: Bucculatrix pomifoliella Clem.

Bracon pomifoliellae Ashmead, 1889 (1888). U. S. Natl. Mus., Proc. 11: 620. ठ。.

\section{Genus PARAHORMIUS Nixon}

Parahormius Nixon, 1940. Ann. and Mag. Nat. Hist. (11) 5: 473.

Type-species: Parahormius jason Nixon. Orig. desig.

Taxonomy: Shenefelt, 1975. Hym. Cat., part 12, p. 1151-1153 (cat. World spp.). atriceps (Ashmead). Fla., Tex.

Hormius atriceps Ashmead, 1893. Amer. Ent. Soc., Trans. 20: 42. + , ‘.

pallidipes (Ashmead). Md., N. C., Colo., Utah, Calif.; Hawaii. Host: Keiferia lycopersicella

(Wlsm.), Phthorimaea operculella (Zell.).

Hormius pallidipes Ashmead, 1893. Amer. Ent. Soc., Trans. 20: 42..

secundus (Viereck). Kans.

Diachasma secunda Viereck, 1905. Kans. Acad. Sci., Trans. 19: 273..+ 
trilineatus (Ashmead). Va. Host: Coleophora laticomella Clem.

Rhyssalus(!) trilineatus Ashmead, 1889 (1888). U. S. Natl. Mus., Proc. 11: 629. ð.

NOMEN NUdUM IN HORMIINI

Hormiogaster slossonae Ashmead, 1900. In Slosson, Ent. News 11: 320.

\section{TRIBE PAMBOLINI}

Taxonomy: Hedqvist, 1963. Ent. Tidskr. 84: 30-61 (incl. in Hormiinae).

\section{Genus CHREMYLUS Haliday}

Chremylus Haliday, 1833. Ent. Mag. 1: 266.

Type-species: Chremylus elaphus Haliday. Monotypic.

Penecerus Wesmael. 1838. Nouv. Mem. Acad. Sci. Bruxelles 11: 70.

Type-species: Hormius rubiginosus Nees. Monotypic.

Paramesocrina Nagamori, 1925. Annot. Zool. Jap. 10: 349.

Type-species: Paramesocrina tineavora Nagamori. Monotypic.

elaphus Haliday. Conn., N. Y., Fla., Ohio, Mo., S. Dak., Oreg.; Europe, Japan. Host: Nititinea fuscipunctella (Haw.), Tinea pellionella (L.), Tineola biselliella (Hum.).

Chremylus elaphus Haliday, 1833. Ent. Mag. 1: 266.

Hormius rubiginosus Nees, 1834. Hym. Ichn. Aff. Monog., v. 1, p. 156. \&.

Bracon transversus Say, 1836. Boston Jour. Nat. Hist. 1: 256..

Chremylus terminalis Ashmead, 1893. Amer. Ent. Soc., Trans. 20: 39. ๆ.

Chremylus nigriceps Ashmead, 1893. Amer. Ent. Soc., Trans. 20: 40. $\$$, ठ.

Chremylus japonicus Ashmead, 1906. U. S. Natl. Mus., Proc. 30: 200. ?.

Paramesocrina tineavora Nagamori, 1925. Annot. Zool. Jap. 10: 349.

Biology: Mason, 1948. Ent. Soc. Amer., Ann. 41: 28-40.

Nomen Nudum in Chremylus Haliday

Chremylus nigriventris Ashmead, 1905. In Nason, Ent. News 16: 298.

\section{Genus PAMBOLUS Haliday}

Pambolus Haliday, 1836. Ent. Mag. 4: 49.

Type-species: Rogas (Pambolus) biglumis Haliday. Monotypic.

Phaenodus Foerster, 1862. Naturh. Ver. Rheinlande, Verh. 19: 241.

Type-species: Phaenodus pallipes Foerster. Orig. desig.

Parapambolus Dahl, 1912. Beitr. z. Naturdenkmalpfl. 3: 555.

Type-species: Parapambolus mifigaster Dahl. Orig. desig.

Taxonomy: Shenefelt, 1975. Hym. Cat., part 12, p. 1159-1163 (cat. World spp.).

americanus (Ashmead). N. Y. s. to Fla., w. to Kans.

Arraphis americana Ashmead, 1892. Psyche 6:289. $\delta$.

Arraphis minuta Ashmead, 1892. Psyche 6: 289. ठ.

Phaenodus caddous Viereck, 1908 (1907). Amer. Ent. Soc., Trans. 33: 403. 9.

\section{SUBFAMILY ROGADINAE}

This is a specialized group of cyclostomate genera in which all species are internal parasites of lepidopterous larvae; pupation takes place within the mummified host larva which often retains its original shape.

Taxonomy: Shenefelt, 1975. Hym. Cat., part 12, p. 1162-1262 (cat. World spp.).

\section{Genus ALEIODES Wesmael}

Aleiodes Wesmael, 1838. Nouv. Mem. Acad. Sci. Bruxelles 11: 94.

Type-species: Aleiodes heterogaster Wesmael. Desig. by Viereck, 1914.

Schizoides Wesmael, 1838. Nov. Mem. Acad. Sci. Bruxelles 11: 94 (footnote).

Type-species: Aleiodes heterogaster Wesmael. Autotypic. 
Taxonomy: Shenefelt, 1975. Hym. Cat., part 12, p. 1163-1185 (cat. World spp.).

abdominalis Cresson. Que., N. Y., Pa., D. C., Ohio, Mich., Ill., Iowa, S. Dak.

Aleiodes abdominalis Cresson, 1869. Amer. Ent. Soc., Trans. 2: 379..

Aleiodes lectus Cresson, 1869. Amer. Ent. Soc., Trans. 2: 379. ठ.

aciculatus Cresson. N. Y., Pa., Md., D. C., Fla., Ohio, Iowa, Mo., Ark., La., S. Dak., Colo., Utah.

Host: Feltia ducens Wlkr., F. subgothica (Haw.), Pseudaletia unipuncta (Haw.).

Aleiodes aciculatus Cresson, 1869. Amer. Ent. Soc., Trans. 2: 381. ‡, ðै.

parasiticus Norton. Que. s. to Md., w. to Ont., S. Dak., and Colo. Host: Syngrapha epigaea

(Grote).

Aleiodes parasiticus Norton, 1869. Amer. Ent. Soc., Trans. 2: 327..

\section{Genus BUCCULATRIPLEX Viereck}

Bucculatriplex Viereck, 1912. U. S. Natl. Mus., Proc. 43: 577.

Type-species: Bracon bucculatricis Ashmead. Orig. desig.

There is some evidence that species of this genus depart somewhat from the typical rogadine biology in that pupation apparently takes place within the host pupa. More studies need to be made to confirm this.

bucculatricis (Ashmead). Maine s. to D. C., w. to S. Dak.; Fla., Wash., Oreg. Host: Bucculatrix ainsliella Murt., B. canadensisella (Chamb.), Cameraria hamadryadella (Clem.). Also recorded from Heterarthrus nemoratus (Fall.) which needs to be confirmed.

Bracon bucculatricis Ashmead, 1889 (1888). U. S. Natl. Mus., Proc. 11: 618. ठ。.

Bacculatriplex secundus Viereck, 1917 (1916). Conn. State Geol. and Nat. Hist. Survey, Bul. 22, p. 765 . .

Ademon leptogaster Fischer, 1965. Polskie Pismo Ent. 35: 198. ठో.

Taxonomy: Marsh, 1974. Ent. Soc. Wash., Proc. 76: 285.

Biology: Schaffner, 1959. U. S. Dept. Agr., Misc. Pub. 767, p. 65.

\section{Genus CLINOCENTRUS Haliday}

Clinocentrus Haliday, 1833. Ent. Mag. 1: 266.

Type-species: Clinocentrus umbratilis Haliday. Monotypic.

Neorhyssalus Baker, 1917. Philippine Jour. Sci. 12: 286.

Type-species: Neorhyssalus compositus Baker. Orig. desig.

Heterogamoides Fullaway, 1919. Straits Br. Roy. Asiatic Soc., Jour. 80: 43.

Type-species: Heterogamoides muirii Fullaway. Orig. desig.

Taxonomy: Shenefelt, 1975. Hym. Cat., part 12, p. 1187-1193 (cat. World spp.).

fumiferanae Muesebeck. N. Y., Minn. Host: Choristoneura fumiferana (Clem.).

Clinocentrus fumiferanae Muesebeck, 1965. Ent. News 76: 72. + , ठ.

mellipes (Ashmead). N. Y., Md., D. C., Va., Ont., S. Dak.

Rhogas mellipes Ashmead, 1891. Canad. Ent. 23: $3 . " \sigma "=\wp$.

tarsalis Ashmead. N. Y., Ohio, Mo.

Clinocentrus tarsalis Ashmead, 1894. Cincinnati Soc. Nat. Hist., Jour. 17: 47..

NOMEN Nudum in Clinocentrus Haliday

Clinocentrus minimus Ashmead, 1905. In Nason, Ent. News 16: 298.

\section{Genus PELECYSTOMA Wesmael}

Pelecystoma Wesmael, 1838. Nouv. Mem. Acad. Sci. Bruxelles 11: 91.

Type-species: Rogas luteus Nees. Desig. by Foerster, 1862.

Triraph is Ruthe, 1855. Stettin. Ent. Ztg. 16: 292.

Type-species: Exothecus discolor Ruthe. Monotypic.

Taxonomy: Shenefelt, 1975. Hym. Cat., part 12, p. 1206-1209 (cat. World spp.).

discoideum (Cresson). N. Y., Pa., N. J., Md., D. C., Fla., Mich., Ill.

Aleiodes discoideus Cresson, 1869. Amer. Ent. Soc., Trans. 2: 380. \&. 
eupoeyae Ashmead. Fla. Host: Alarodia slossoniae (Pack.).

Pelecystoma eupoeyiae(!) Ashmead, 1897. Canad. Ent. 29: 113. \&.

harrisinae (Ashmead). Pa., Va., N. C., Fla., Ark., Tex.; Mexico, Cuba. Host: Harrisina americana (Guer.), Lithacodes fasciola (H.-S.).

Rhogas harrisinae Ashmead, 1889 (1888). U. S. Natl. Mus., Proc. 11: 632. o.

\section{Genus PETALODES Wesmael}

Petalodes Wesmael, 1838. Nouv. Mem. Acad. Sci. Bruxelles 11: 123.

Type-species: Petalodes unicolor Wesmael. Monotypic.

Taxonomy: Walley, 1941. Canad. Ent. 73: 213-215. - Shenefelt, 1975. Hym. Cat., part 12, p. 1209-1211 (cat. World spp.).

palmatus Walley. Ont., Wis., Minn., Utah, B. C., Calif. Host: Nycteola cinereana N. and D. Petalodes palmatus Walley, 1941. Canad. Ent. 73: 214..

ufei Walley. B. C., Nev., Calif. Host: Ufeus plicatus Grote.

Petalodes ufei Walley, 1941. Canad. Ent. 73: 215. ㅇ, o.

\section{Genus POLYSTENIDEA Viereck}

Polystenidea Viereck, 1911. U. S. Natl. Mus., Proc. 40: 186.

Type-species: Polystenidea parksi Viereck. Orig. desig.

metacomet Viereck. Conn.

Polystenidea metacomet Viereck, 1911. U. S. Natl. Mus., Proc. 40: 187. $q$.

Polystenidea metacomet Viereck, 1917 (1916). Conn. State Geol. and Nat. Hist. Survey, Bul. 22, p. 238. .

parksi Viereck. Ill., La., Kans., Okla., Tex.

Polystenidea parksi Viereck, 1911. U. S. Natl. Mus., Proc. 40: 186. ठ́.

\section{Genus ROGAS Nees}

Rogas Nees, 1818. Nov. Act. Acad. Caes. Leop. Car. 9: 306.

Type-species: Ichneumon testaceus Fabricius. Desig. by Curtis, 1834 .

Rhogas Agassiz, 1846. Nomencl. Zool., Index Univ., p. 325. Emend.

Nebartha Walker, 1860. Ann. and Mag. Nat. Hist. (3) 5: 310.

Type-species: Nebartha macropodides Walker. Monotypic.

Camptocentrus Kriechbaumer, 1894. Berl. Ent. Ztschr. 39: 61.

Type-species: Camptocentrus testaceus Kriechbaumer. Monotypic.

Taxonomy: Shenefelt, 1975. Hym. Cat., part 12, p. 1215-1256 (cat. World spp.).

atricornis Cresson. S. Dak., Kans., Tex., Ariz. Host: Protoleucania sp.

Rogas atricornis Cresson, 1872. Amer. Ent. Soc., Trans. 4: 188. $?$.

autographae Viereck. Idaho, Wash., Oreg., Calif. Host: Autographa californica (Speyer).

Rhogas autographae Viereck, 1910. U. S. Natl. Mus., Proc. 38: 381. \&, o.

borealis Thomson. Greenland; Europe.

Rogas (Aleiodes) borealis Thomson, 1891. Opusc. Ent. 16: 1679..

burrus (Cresson). Conn., Ill., S. Dak.; Mexico. Host: Acronicta hasta Guen., A. lobeliae Guen.

Aleiodes burrus Cresson, 1869. Amer. Ent. Soc., Trans. 2: 381. ‡, ð.

carinatus (Ashmead). Tex.

Rhysipolis carinatus Ashmead, 1889 (1888). U. S. Natl. Mus., Proc. 11: 625. ठో.

cerurae Ashmead. Calif. Host: Cemira sp.

Rhogas cerurae Ashmead, 1889 (1888). U. S. Natl. Mus., Proc. 11: 634. \&, o.

cockerelli Viereck. Kans.

Rhogas cockerelli Viereck, 1905. Kans. Acad. Sci., Trans. 19: 266. ठ.

femoratus (Cresson). W. Va.

Aleiodes femoratus Cresson, 1869. Amer. Ent. Soc., Trans, 2: 382. \&.

fulvus (Cresson). Canada.

Aleiodes fulvus Cresson, 1869. Amer. Ent. Soc., Trans. 2: 381. , ð. 
fumipennis (Cresson). N. H., Mass., Conn., N. Y., Del., Mich., Ohio, Tenn., Wis., Ill., Miss., Iowa, Mo. Host: Cressonia juglandis (Smith).

Aleiodes fumipennis Cresson, 1869. Amer. Ent. Soc., Trans. 2: 378. 9.

geometrae Ashmead. Iowa, Mo., N. Dak., S. Dak. Host: Paleacrita vernata (Peck).

Rhogas geometrae Ashmead, 1889 (1888). U. S. Natl. Mus., Proc. 11: 633. ठँ.

granulatus DeGant. Ohio, Mich.

Rogas granulata DeGant, 1930. Ent. Soc. Wash., Proc. 32: 163..

graphicus Cresson. Iowa, S. Dak., Kans., Tex., Wyo., Colo., N. Mex., Ariz.

Rogas graphicus Cresson, 1872. Amer. Ent. Soc., Trans. 4: 188. ठో.

harrimani Ashmead. Alaska.

Rhogas harrimani Ashmead, 1902. Wash. Acad. Sci., Proc. 4: 253. ठ.

hyphantriae Gahan. N. B., Maine. Host: Hyphantria cunea (Drury).

Rogas hyphantriae Gahan, 1922. U. S. Natl. Mus., Proc. 61 (24): 1. \&, ठ.

Biology: Bogavac, 1955. Plant Prot. (Belgrade), No. 32, p. 17-30. -Tadic, 1959. Internatl.

Congr. Crop Prot., Proc. 4, v. 1, p. 874.

Morphology: Dustan, 1922. Acadian Ent. Soc., Proc. 8: 84-89.

indianensis Muesebeck and Walkley. Ind.

Bracon rugulosus Say, 1836. Boston Jour. Nat. Hist. 1: 255. Preocc. by Nees, 1812.

Rogas indianensis Muesebeck and Walkley, 1951. U. S. Dept. Agr., Agr. Monog. 2, p. 171.

N. name for rugulosus Say.

indicus Cameron. Alaska.

Rhogas indicus Cameron, 1910. Wien. Ent. Ztg. 29: 3. ठ.

Taxonomy: Mather, 1957. Zool. Soc. Calcutta, Proc., Mookerjee Mem. Vol., p. 350.

indiscretus Reardon. New England(?); India. Liberated in New England but not known to be established. Introduced from India. Host: Lymantria dispar (L.).

Rogas indiscretus Reardon, 1970. Ent. Soc. Wash., Proc. 72: 473. १, ठ.

Biology: Reardon, et al., 1973. Environ. Ent. 2: 125-126.

laphygmae Viereck. Ga., Fla., La., Tex.; Cuba, Nicaragua. Host: Pseudaletia unipuncta (Haw.), Spodoptera exigua (Hbn.), S. frugiperda (Smith), S. ornithogalli (Guen.).

Rogas laphygmae Viereck, 1912. U. S. Natl. Mus., Proc. 43: 581..

mandibularis Cresson. Ohio, Ga., Ill., Miss., Iowa, Ark., Kans., Tex.

Rogas mandibularis Cresson, 1872. Amer. Ent. Soc., Trans. 4: 188. ठో.

melleus (Cresson). Mass.

Aleiodes melleus Cresson, 1896. Amer. Ent. Soc., Trans. 2: 382. ठँ.

molestus Cresson. Ark., La., S. Dak., Tex., Wyo., Utah. Host: Autographa sp., Pseudoplusia includens (Wlkr.), Trichoplusia ni (Hbn.).

Rogas molestus Cresson, 1872. Amer. Ent. Soc., Trans. 4: 188. ?.

nigricoxis Viereck. N. Mex.

Rhogas nigricoxis Viereck, 1903. Amer. Ent. Soc., Trans. 29: 97. ठ.

nolophanae Ashmead. Del. s. to N. C. and La., w. to Minn., S. Dak., and Kans. Host: Balsa malana (Fitch), Plathypena scabra (F.).

Rhogas nolophanae Ashmead, 1889 (1888). U. S. Natl. Mus., Proc. 11: 634..

Biology: Lentz and Pedigo, 1974. Ent. Soc. Amer., Ann. 67: 678-680.

perplexus Gahan. Tex., N. Mex., Ariz., Calif. Host: Heliothis zea (Boddie), Peridroma saucia (Hbn.), Trichoplusia ni (Hbn.).

Rogas perplexus Gahan, 1917. U. S. Natl. Mus., Proc. 53: 205. + , ठ.

platypterygis Ashmead. Va., Iowa, Md., La. Host: Drepana arcuata Wlkr.

Rhogas platypterygis Ashmead, 1889 (1888). U. S. Natl. Mus., Proc. 11: 633. ․, ठ.

politiceps Gahan. N. C. s. to Fla., w. to Tex. Host: Anicla infecta (Ochs.), Pseudaletia unipureta (Haw.).

Rogas politiceps Gahan, 1917. U. S. Natl. Mus., Proc. 53: 206. ९, ठ.

pubescens Ashmead. Wis., Ill.

Rhogas pubescens Ashmead, 1889 (1888). U. S. Natl. Mus., Proc. 11: 632. ठో. 
quebecensis Provancher. Que., Ind., S. Dak.

Rogas quebecensis Provancher, 1880. Nat. Canad. 12: 145. \&.

rileyi (Cresson). N. J., Del., Ohio, Mo., Kans.

Aleiodes Rileyi Cresson, 1869. Amer. Ent. Soc., Trans. 2: 382. ९, ठ.

rufocoxalis Gahan. S. Dak., Colo., Ariz., Calif. Host: Autoplusia egena (Guen.), Peridroma saucia (Hbn.), Trichoplusia ni (Hbn.).

Rogas rufocoxalis Gahan, 1917. U. S. Natl. Mus., Proc. 53: 207. ‡, §.

sanctihyacinthi Provancher. Que.

Rogas Sancti-Hyacinthi Provancher, 1880. Nat. Canad. 12: 146..+

scrutator (Say). U. S., south. Canada. Host: Choreutis augustella Clarke, Ichthyura inclusa $\mathrm{Hbn}$.

Bracon scrutator Say, 1836. Boston Jour. Nat. Hist. 1: 254. ๆ, ठ.

Aleiodes canadensis Cresson, 1869. Amer. Ent. Soc., Trans. 2: 380. ๆ.

simillimus Ashmead. N. H., S. C., Fla., Ark.

Rhogas simillimus Ashmead, 1889 (1888). U. S. Natl. Mus., Proc. 11: 633. ठै.

stigmator (Say). Canada, north. U. S. Host: Acronicta americana Harr., A. dactylina (Grote), A. hastulifera (Smith), A. oblinita (Smith), Alsophila pometaria (Harr.), Malacosoma americanum (F.), Simyra henrici Grote.

Bracon stigmator Say, 1824. In Keating, Narr. Long's 2nd Exped. 2: App. p. 323.

Aleiodes intermedius Cresson, 1869. Amer. Ent. Soc., Trans. 2: 380. ๆ, ठ".

terminalis (Cresson). Canada, U. S. Host: Amathes smithi (Snell.), Nephelodes emmedonia violans Guen., Pseudaletia unipuncta (Haw.), Spodoptera frugiperda (Smith), S. ornithogalli (Guen.).

Aleiodes terminalis Cresson, 1869. Amer. Ent. Soc., Trans. 2: 379. ๆ, o.

Biology: Pennington, 1916. Jour. Econ. Ent. 9: 401-406.

texanus (Cresson). Mich., Tex.

Aleiodes texanus Cresson, 1869. Amer. Ent. Soc., Trans. 2: 378. ․

waldeni (Viereck). Conn.

Aleiodes waldeni Viereck, 1917 (1916). Conn. State Geol. and Nat. Hist. Survey, Bul. 22, p. 236. $\delta$.

Nomina Nuda in Rogas NeES

Rhogas desmiae Ashmead, 1890. In Riley and Howard, U. S. Dept. Agr., Insect Life 3: 352.

Rhogas fuscicaudus Viereck, 1909. In Withington, Kans. Acad. Sci., Trans. 22: 329.

Rhogas plecypterygia Ashmead, 1905. In Nason, Ent. News 16: 298.

Genus TETRASPHAEROPYX Ashmead

Tetrasphaeropyx Ashmead, 1889 (1888). U. S. Natl. Mus., Proc. 11: 634.

Type-species: Rogas pilosus Cresson. Monotypic.

pilosus (Cresson). Fla., Tex.; Mexico.

Rogas pilosis Cresson, 1872. Amer. Ent. Soc., Trans. 4: 189..+

\section{Genus YELICONES Cameron}

Yelicones Cameron, 1887. Biol. Cent.-Amer., Hym., v. 1, p. 387.

Type-species: Yelicones violaceipennis Cameron. Desig. by Viereck, 1914.

Rhopalotoma Cameron, 1911. Timehri 1: 318.

Type-species: Rhopalotoma crassitarsis Cameron. Monotypic.

Pectenopius Fischer, 1961. Naturhist. Mus. Wien., Ann. 64: 156.

Type-species: Pectenopius paradoxus Fischer. Orig. desig.

Taxonomy: Shenefelt, 1975. Hym. Cat., part 12, p.1261-1262 (cat. World spp.).

delicatus (Cresson). N. Y. s. to Fla., w. to Kans. and Tex. Host: Caristanius decoloralis

(Wlkr.), Nephopteryx uvinella (Rag.), Psorosina hammondi (Riley).

Rogas delicatus Cresson, 1872. Amer. Ent. Soc., Trans. 4: 189. ठ. 


\section{SUbFamily METEORIDEINAE}

Taxonomy: Capek, 1965 (1964). 12th Internatl. Cong. Ent., Proc., p. 98-99. -Tobias, 1967. Ent. Obozr. 46: 662. - Capek, 1969. Ent. Soc. Wash., Proc. 71: 307.

\section{Genus METEORIDEA Ashmead}

Meteoridea Ashmead, 1900. U. S. Natl. Mus., Proc. 23: 129.

Type-species: Meteoridea longiventris Ashmead. Orig. desig.

Benama Nixon, 1946. Bul. Ent. Res. 32: 98.

Type-species: Benama hutsoni Nixon. Orig. desig.

Until 1965, this genus was placed in the tribe Diospilini, subfamily Helconinae. It was placed in its own subfamily by Capek (1965) on the basis of morphology and biology. Species of Meteoridea parasitize larvae of Lepidoptera but pupation takes place within the host pupal case, which is unique among braconid parasites of lepidopterous larvae.

Taxonomy: Shenefelt and Muesebeck, 1957. Ent. Soc. Wash., Proc. 59: 129-130. - Capek, 1965 (1964). 12th Intl. Cong. Ent., Proc., p. 98-99. - Shenefelt, 1970. Hym. Cat., part 5, p.

215-216. (cat. World spp.).

compressiventris Shenefelt and Muesebeck. Wis.

Meteoridea compressiventris Shenefelt and Muesebeck, 1957. Ent. Soc. Wash., Proc. 59: 131. + .

longiventris Ashmead. Fla.

Meteoridea longiventris Ashmead, 1900. U. S. Natl. Mus., Proc. 23: 129.

\section{SubFamily HELCONINAE}

Host records indicate that species in this group are internal parasites of wood-boring coleopterous larvae.

Taxonomy: Shenefelt, 1970. Hym. Cat., part 5, p. 177-220 (cat. World spp.). -Watanabe, 1972. Insecta Matsumurana 35: 11-16 (review World genera).

\section{TRIBE HELCONINI}

Revision: Tobias, 1967. Zool. Inst. Acad. Sci. U. S. S. R., Trans. 41: 222-238 (some Eur. spp.). -Watanabe, 1972. Insecta Matsumurana 35: 1-11 (Jap. spp.).

\section{Genus EUMACROCENTRUS Ashmead}

Eumacrocentrus Ashmead, 1900. U. S. Natl. Mus., Proc. 23: 120.

Type-species: Helcon americanus Cresson. Orig. desig.

americanus (Cresson). Canada, Conn., N. Y., Pa., Md., W. Va., Va., Mich.

Helcon americanus Cresson, 1873. Canad. Ent. 5: 84..

Petalodes(?) americanus Ashmead, 1889 (1888). U. S. Natl. Mus., Proc. 11: 631. ठै.

\section{Genus HELCON Nees}

Helcon Nees, 1814 (1812). Mag. Gesell. Naturf. Freunde Berlin 6: 216.

Type-species: Helcon tardator Nees. Desig. by Lepeletier and Serville, 1825. There is a question whether Lepeletier and Serville (1825. In Olivier, Encycl. Method.

10: 42) actually designated Helcon tardator as the type-species. However,

Westwood (1839) also designated tardator as the type-species of Helcon.

Gymnoscelus Foerster, 1862. Naturh. Ver. Rheinlande, Verh. 19: 255.

Type-species: Helcon tardator Nees. Orig. desig.

Edyia Cameron, 1905. Straits Branch Roy. A siat. Soc., Jour. 44: 108. Cameron spelled the generic name Ediya on page 108 and Edyia on page 109 of the above publication, which appeared in July, 1905. In August, 1905 (Ann. and Mag. Nat. Hist. (7) 16: 159) Cameron again described the genus spelling the name Edyia, which is now the accepted spelling.

Type-species: Edyia annulicornis Cameron. Monotypic.

Coelostephanus Kieffer, 1911. Soc. Ent. de France, Ann. 80: 232.

Type-species: Coelostephanus mufus Kieffer. Monotypic. 
Revision: Fahringer, 1933. Ztschr. f. Angew. Ent. 20: 307-323 (Eur. spp.). -Watanabe, 1972. Insecta Matsumurana 35: 2-3 (Jap. spp.)

Taxonomy: Shenefelt, 1970. Hym. Cat., part 5, p. 192-196 (cat. World spp.).

fulvipes Cresson. Alta., Mont., Colo., Utah, B. C., Wash., Oreg., Calif. Host: Xylotrechus undulatus (Say).

Helcon fulvipes Cresson, 1865. Ent. Soc. Phila., Proc. 4: 292..

pedalis Cresson. Canada; Maine s. to N. C.; Wis., Utah, Wash., Oreg. Host: Callidium antennatum Newm., Neoclytus muricatulus (Kby.), Xylotrechus annosus (Say).

Helcon pedalis Cresson, 1873. Canad. Ent. 5: 85. $\uparrow$, ơ.

texanus Cresson. Tex.

Helcon texanus Cresson, 1872. Amer. Ent. Soc., Trans. 4: 179. §.

yukonensis (Ashmead). Ohio, Idaho, Wash., Oreg., Alaska.

Gymnoscelis yukonensis Ashmead, 1889 (1888). U. S. Natl. Mus., Proc. 11: 656..

\section{Genus WROUGHTONIA Cameron}

Wroughtonia Cameron, 1899. Manchester Lit. and Phil. Soc., Mem. and Proc. 43: 56. Type-species: Wroughtonia cornuta Cameron. Monotypic.

Helconidea Viereck, 1914. U. S. Natl. Mus., Bul. 83: 67.

Type-species: Helcon aequator Nees. Orig. desig.

Duportia Kieffer, 1921. Inst. Sci. Saigon, Bul. Agr. 3: 131.

Type-species: Duportia cincticornis Kieffer. Orig. desig.

Revision: Watanabe, 1972. Insecta Matsumurana 35: 3-7 (Jap. spp., generic synonymy).

Taxonomy: Shenefelt, 1970. Hym. Cat., part 5, p. 196-201 (cat. World spp.). -Marsh, 1974.

Ent. Soc. Wash., Proc. 70: 287.

borealis (Cresson). Maine, N. Y., Pa., Va., N. C., S. C. Host: Obrium maculatum (Oliv.).

Helcon borealis Cresson, 1873. Canad. Ent. 5: 83. ठ.

castaneae (Viereck). Conn., N. C., Ga.

Helcon castaneae Viereck, 1912. U. S. Natl. Mus., Proc. 42: 623. ₹, ठ.

ferruginea (Brues). Pa. s. to Ga.; Ala., Tex., Colo. Host: Neoclytus acuminatus (F.), Phymatodes varius (F.), Xylobiops basilaris (Say).

Helcon fermigineus Brues, 1907. Wis. Nat. Hist. Soc., Bul. 5: 158. 9.

frigida (Cresson). Mont., Idaho, B. C., Wash., Oreg., Calif.

Helcon frigidus Cresson, 1873. Canad. Ent. 5: 84..

grandis (Ashmead). La.

Helcon grandis Ashmead, 1889 (1888). U. S. Natl. Mus., Proc. 11: 655..

ligator (Say). Que. s. to Fla., w. to Ont., N. Dak., and Tex.; Oreg. Host: Agrilus anxius Gory, A. egenus Gory, Clytoleptus albofasciatus (L. and G.), Magdalis armicollis (Say), Neoclytus acuminatus (F.), Obrium maculatum (Oliv.), O. mufulum Gahan, Xylotrechus colonus (F.), X. quadrimaculatus (Hald.).

Bracon ligator Say, 1824. In Keating, Narr. Long's 2nd Exped., v. 2, p. 323. \&.

Helcon dentipes Brulle, 1846. In Lepeletier, Hist. Nat. Ins. Hym., v. 4, p. 479. $\subsetneq$.

Helcon albitarsis Cresson, 1873. Canad. Ent. 5: 83. ठ.

necydalidis (Cushman). Idaho, B. C., Wash., Oreg., Calif. Host: Leptura obliterata Hald., Necydalis laevicollis Lec.

Helconidea necydalidis Cushman, 1931. U. S. Natl. Mus., Proc. 79: 10. ๆ, ð.

occidentalis (Cresson). Que., N. B., Maine, N. H., W. Va., N. C., Ont., Mich., Wis., Wyo., Colo., Idaho, Nev., B. C., Wash., Oreg., Calif. Host: Semanotus litigiosus (Casey), S. ligneus (F.), Tetropium cinnamopteron Kby., T. velutinum Lec.

Helcon occidentalis Cresson, 1865. Ent. Soc. Phila., Proc. 4: 292. ठ'.

Helcon tetrapodii Ashmead, 1892. In Hopkins, U. S. Dept. Agr., Insect Life 4: 252. Nom. nud. 


\section{TRIBE CENOCOELIINI}

\section{Genus CENOCOELIUS Westwood}

Cenocoelius Westwood, 1840. Introd. Mod. Classif. Ins., v. 2, Gen. Synop., p. 62. Type-species: Cenocoelius flavifrons Westwood. Monotypic.

Capitonius Brulle, 1846. In Lepeletier, Hist. Nat. Ins. Hym., v. 4, p. 544.

Type-species: Capitonius bifasciatus Brulle. Monotypic.

Laccophrys Foerster, 1862. Naturh. Ver. Rheinlande, Verh. 19: 257.

Type-species: Laccophrys magdalini Foerster. Orig. desig.

Aulacodes Cresson, 1865. Ent. Soc. Phila., Proc. 4: 8.

Type-species: Aulacodes nigriventris Cresson. Monotypic.

Lestricus Reinhard, 1865. Berlin. Ent. Ztschr. 9: 265.

Type-species: Alysia rubriceps Ratzeburg. Desig. by Muesebeck and Walkley, 1951.

Promachus Cresson, 1887. Amer. Ent. Soc., Trans., Sup. Vol., p. 61.

Type-species: Promachus sanguineiventris Ashmead. Desig. by Viereck, 1914.

Revision: Rohwer, 1914. Canad. Ent. 46: 316-322 (No. Amer. spp. in genus Capitonius).

Taxonomy: Shenefelt, 1970. Hym. Cat., part 5, p. 178-185 (cat. World spp.).

ashmeadii Dalla Torre. Que. s. to Fla., w. to Ont., S. Dak. and Tex. Host: Hyperplatys aspera (Say), H. maculata Hald., Neoclytus acuminatus (F.), Sternidius alpha alpha (Say), S. a. vicinus (Hald.), S. cinereus (Lec.), S. fascicularis (Harr.), Urgleptes facetus (Say), $U$. signatus (Lec.).

Capitonius mibriceps Provancher, 1886. Addit. Corr. Faune Ent. Canada Hym., p. 135. ㅇ. Preocc. by Ratzeburg, 1844.

Promachus rubriceps Ashmead, 1889 (1888). U. S. Natl. Mus., Proc. 11: 653. §ै. Preocc. by Ratzeburg, 1844.

Cenocoelius Ashmeadii Dalla Torre, 1898. Cat. Hym., v. 4, p. 72. N. name for mebriceps Ashmead.

Capitonius provancheri Rohwer, 1914. Canad. Ent. 46: 321. N. name for mbriceps Provancher.

caryae (Rohwer). N. J., Pa., N. C., Mo. The original description states that this species is probably parasitic on Synoxylon in hickory. This record needs to be confirmed.

Capitonius caryae Rohwer, 1914. Canad. Ent. 46: 318..+

erythrogastra (Rohwer). N. Y., Pa., W. Va., N. C. Host: Saperda discoidea F.

Capitonius erythrogastra Rohwer, 1914. Canad. Ent. 46: 317. ?.

leptostyli (Rohwer). Pa., Md., Va., N. C., Iowa. Host: Leptostylus sp., Urgleptes signatus (Lec.).

Capitonius leptostyli Rohwer, 1914. Canad. Ent. 46: 319. ठ.

nigrisoma (Rohwer). N. C., S. C., Ga., Miss., La., Tex. Ecology: Frequently associated with Dendroctonus frontalis Zimm.

Capitonius nigrisoma Rohwer, 1914. Canad. Ent. 46: 320. ?, ठ.

sanguineiventris (Ashmead). Ohio, Mich., Wis., Mo. Host: Agrilus horni Kerr., Oberea schaumii Lec.

Promachus sanguineiventris Ashmead, 1889 (1888). U. S. Natl. Mus., Proc. 11: 653. ?.

saperdae (Ashmead). Que. s. to Md., w. to S. Dak. and Tex. Host: Saperda candida F., S. discoidea F., S. tridentata Oliv.

Promachus saperdae Ashmead, 1889 (1888). U. S. Natl. Mus., Proc. 11: 653.

Coenocelius(!) politifrons Viereck, 1905. Kans. Acad. Sci., Trans. 29: 279. ठో.

tenuicornis (Rohwer). Fla.

Capitonius tenuicornis Rohwer, 1914. Canad. Ent. 46: 321. 9.

\section{TRIBE DIOSPILINI}

This group is very much in need of study and many of the North American species are probably wrongly placed in their present genera.

\section{Genus BAEACIS Foerster}

Baeacis Foerster, 1878. Naturh. Ver. Rheinlande, Verh. 35: 70. 
Type-species: Aspigonus abietis Ratzeburg. Desig. by Viereck, 1914.

One undescribed species occurs in North America.

\section{Genus DIOSPILUS Haliday}

Diospilus Haliday, 1833. Ent. Mag. 1: 262.

Type-species: Diospilus oleraceus Haliday. Monotypic.

Allochromus Marshall, 1902. Agr. Prat. Pays Chauds 1: 643.

Type-species: Allochromus trimeroderi Marshall. Monotypic.

Taxonomy: Shenefelt, 1970. Hym. Cat., part 5, p. 208-214 (cat. World spp.).

californicus Rohwer. Calif.

Diospilus californicus Rohwer, 1917. U. S. Natl. Mus., Proc. 53: 164. ९.

curticaudus Gahan. La.; Mex. Host: Altica litigata Fall.

Diospilus curticaudus Gahan, 1927. U. S. Natl. Mus., Proc. 71 (4): 1..

fomitis Mason. Que., Ont., Man., Sask. Host: Dorcatoma falli White.

Diospilus fomitis Mason, 1968. Canad. Ent. 103: 719. \&, ठ.

neoclyti Rohwer. Colo. Host: Neoclytus caprae (Say).

Diospilus neoclyti Rohwer, 1917. U. S. Natl. Mus., Proc. 53: 165. ठ́.

washingtonensis Rohwer. Wash. Host: Zilora hispida Lec.

Diospilus washingtonensis Rohwer, 1917. U. S. Natl. Mus., Proc. 53: 163. ․

\section{Genus DYSCOLETES Westwood}

Dyscolus Haliday, 1837 (1836). Ent. Mag. 4: 39. Preocc. by Dejean, 1831.

Type-species: Dyscolus lancifer Haliday. Monotypic.

Dyscoletes Westwood, 1840. Introd. Mod. Classif. Ins., v. 2, Gen. synop., p. 62. N. name for Dyscolus Haliday.

Revision: Mason, 1976. Canad. Ent. 108: 855-858.

canadensis Mason. Vt., N. Y., N. C., Ont., Alta., Idaho, B. C., Alaska. Host: Boreus brumalis Fitch.

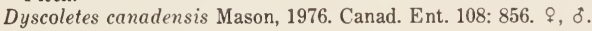

\section{Genus TAPHAEUS Wesmael}

Taphaeus Wesmael, 1835. Nouv. Mem. Acad. Sci. Bruxelles 9: 189.

Type-species: Taphaeus irregularis Wesmael. Desig. by Viereck, 1914.

Anostenus Foerster, 1862. Naturh. Ver. Rheinlande, Verh. 19: 257.

Type-species: Taphaeus irregularis Wesmael. Orig. desig.

polydrusi (Gahan). N. Y. Host: Polydrusus impressifrons Gyll.

Diospilus polydmısi Gahan, 1916. N. Y. Agr. Expt. Sta. Geneva, Tech. Bul. 56, p. 23. \&.

Taxonomy: Marsh, 1974. Ent. Soc. Wash., Proc. 76: 287.

\section{SUBFAMILy ZELEINAE}

This group has been placed in the Macrocentrinae and in the Helconinae by various workers. I have chosen to follow Tobias (1967) in giving it subfamily rank. The genus Zemiotes was recently taken out of synonymy with Meteorus by Mason (1973) and placed as a distinct genus related to $Z$ ele. The subfamily name correctly spelled Zelinae is preoccupied in the Hemiptera. The basis for the present spelling, Zeleinae, is a precedent set by Opinion 140 of the International Commission of Zoological Nomenclature, 1943. Species are solitary endoparasites of lepidopterous larvae.

Taxonomy: Tobias, 1967. Ent. Obozr. 46: 661.

\section{Genus ZELE Curtis}

Zele Curtis, 1832. Brit. Ent., v. 9, p. 415.

Type-species: Zele testaceator Curtis. Orig. desig.

Phylax Wesmael, 1835. Nouv. Mem. Acad. Sci. Bruxelles 9: 159. Preocc. by Dahl, 1823. 
Type-species: Rogas annulicomis Nees. Desig. by Westwood, 1840.

Homolobus Foerster, 1862. Naturh. Ver. Rheinlande, Verh. 19: 256.

Type-species: Phylax discolor Wesmael. Orig. desig.

Phylacter Reinhard, 1863. Berlin. Ent. Ztschr. 7: 248. N. name for Phylax Wesmael.

Taxonomy: Shenefelt, 1970. Hym. Cat., part 5, p. 220-227 (cat. World spp.).

mellea (Cresson). No. Amer. Host: Agrotis venerabilis Wlkr., Amathes smithi (Snell.), Feltia subterranea (F.), Spodoptera frugiperda (J. E. Sm.), S. ornithogalli (Guen.). Other records need confirmation.

Phylax melleus Cresson, 1872. Amer. Ent. Soc., Trans. 4: 178..

Zele crassicalcaratus Viereck, 1905. Kans. Acad. Sci., Trans. 19: 259. ठ゚.

Taxonomy: Marsh, 1974. Ent. Soc. Wash., Proc. 76: 287.

truncator Say. Ind. Type lost; exact placement uncertain.

Bracon truncator Say, 1828. Contrib. Maclur. Lyc. Phila. 1: 78.

\section{Genus ZEMIOTES Foerster}

Zemiotes Foerster, 1862. Naturh. Ver. Rheinlande, Verh. 19: 253.

Type-species: Perilitus albitarsis Nees. Orig. desig.

Taxonomy: Fischer, 1957. Opusc. Zool., n. 3, p. 1-5 (key to Eur. spp.). -Mason, 1973. Ent.

Soc. Wash., Proc. 75: 213-215 (generic reinstatment and transfer).

alaskensis (Ashmead). Canada, N. C., Alaska. Host: Eupithecia sp.

Dyscoletes alaskensis Ashmead, 1902. Wash. Acad. Sci., Proc. 4: 247. ठ์.

erassifemur (Muesebeck). Ill., S. Dak., Kans., Tex.

Meteorus crassifemur Muesebeck, 1939. Ent. Soc. Wash., Proc. 41: 84 ..

levis (Muesebeck). Wyo., N. Mex., Calif.

Meteorus levis Muesebeck, 1923. U. S. Natl. Mus., Proc. 63: 11. ‡.

maximus (Muesebeck). Maine s. to Ga., w. to Minn., Colo., and Tex.

Meteorus maximus Muesebeck, 1923. U. S. Natl. Mus., Proc. 63: 13. ?.

niveitarsis (Cresson). N. S. s. to Ga., w. to Ont. and Tenn.; Alaska, Oreg. Host: Acrobasis betulella Hulst, $A$. comptoniella Hulst, $A$. ostryella Ely, $A$. mebrifasciella Pack., $A$.

secundella Ely, A. sylviella Ely, Nephopteryx subcaesiella (Clem.), N. virgatella (Clem.), Rheumaptera hastata (L.).

Perilitus niveitarsis Cresson, 1872. Canad. Ent. 4: 81. + , ‘.

pallitarsis (Cresson), Que. s. to Va.; Ohio, Mich.

Perilitus pallitarsis Cresson, 1872. Canad. Ent. 4: 81. ơ.

reticulatus (Muesebeck). Newfoundland, Maine, N. H., Idaho, Alaska, B. C., Wash., Calif. Host: Semiothisa granitata (Gn.), S. sexmaculata (Pack.).

Meteorus reticulatus Muesebeck, 1923. U. S. Natl. Mus., Proc. 63: 14. ๆ, ठ.

\section{SUBFAMILY MACROCENTRINAE}

\section{Genus MACROCENTRUS Curtis}

Macrocentrus Curtis, 1833. Ent. Mag. 1: 187.

Type-species: Macrocentrus bicolor Curtis. Monotypic.

Amicroplus Foerster, 1862. Naturh. Ver. Rheinlande, Verh. 19: 256.

Type-species: Bracon collaris Spinola. Orig. desig.

Chaonia Cresson, 1865. Ent. Soc. Phila., Proc. 4: 59. Preocc. by Stephens, 1828. N. syn.

Type-species: Chaonia xanthostigma Cresson. Desig. by Viereck, 1914.

Hymenochaonia Dalla Torre, 1898. Wien. Ent. Ztg. 17: 100. N. name for Chaonia Cresson.

N. syn.

Fhogra Cameron, 1901. New Zeal. Inst., Trans. 33: 104.

Type-species: Fhogra mibromaculata Cameron. Monotypic.

Leptozele Cameron, 1910. Tijdschr. v. Ent. 53: 52.

Type-species: Leptozele trimaculatus Cameron. Monotypic.

Dolichozele Viereck, 1911. U. S. Natl. Mus., Proc. 40: 182.

Type-species: Dolichozele koebelei Viereck. Monotypic. 
Metapleurodon Enderlein, 1920. Arch. f. Naturgesch. 84 (A) (11): 213.

Type-species: Macrocentrus ceylonicus Enderlein. Orig. desig.

Paniscozele Enderlein, 1920. Arch. f. Naturgesch. 84 (A) (11): 214.

Type-species: Paniscozele sumatrana Enderlein. Orig. desig.

Pachymerella Enderlein, 1920. Arch. f. Naturgesch. 84 (A) (11): 217.

Type-species: Pachymerella maculicoxa Enderlein. Orig. desig.

All species are endoparasites of lepidopterous larvae, and the gregarious forms are apparently polyembryonic. Species are frequently caught in light traps.

Revision: Muesebeck, 1932. U. S. Natl. Mus., Proc. 80 (23): 1-55 (No. Amer. spp.). -Eady and Clark, 1964. Ent. Gaz. 15: 97-127 (Eur. spp.).

Taxonomy: Shenefelt, 1969. Hym. Cat., part 4, p. 143-174 (cat. World spp.).

affinis Muesebeck. N. H., N. Y., Mich., Minn., Utah, Idaho.

Macrocentris affinis Muesebeck, 1932. U. S. Natl. Mus., Proc. 80 (23): 42 . ?.

ancylivorus Rohwer. No. Amer. Host: Acleris oxycoccana (Pack.), Anacampsis sp., Ancylis comptana fragariae (W. and R.), Canarsia sp., Epiblema strenuanum (Wlkr.),

Exartema sericoranum Wlsm., Grapholitha molesta (Busck), Halisidota ingens Hy.

Edw., Homoeosoma electellum (Hulst), Melissopus latiferranus (Wlsm.), Paralobesia

viteana Clem., Phalonia hospes Wlsm., Phthorimaea operculella (Zell.), Rhyacionia

frustrana (Comst.), Sparganothis sulphurana (F.), Stegasta bosqueella (Chamb.). This

species is one of the more important parasites of the oriental fruit moth (Grapholitha

molesta) and the strawberry leafroller (Ancylis comptana fragariae).

Macrocentrus ancylivorus Rohwer, 1923. Ent. Soc. Wash., Proc. 25: 168. ๆ, ठ.

Biology: Fink, 1926. Jour. Agr. Res. 12: 1121-1134. -Daniel, 1932. N. Y. State Agr. Expt.

Sta., Tech. Bul. 187, p. 3-101. - Haeussler, 1932. Jour. Agr. Res. 45: 79-100. -Garman and

Brigham, 1933. Conn. Agr. Expt. Sta., Bul. 356: 73-116. - Finney, Flanders and Smith,

1947. Hilgardia 17: 437-483. -Allen, 1962. U. S. Dept. Agr., Tech. Bul. 1265, p. 15-24.

-Putnam, 1963. Canad. Ent. 95: 1022-1023. The references listed above are only a few of

the important ones that have been published. For a complete list of references, see

Shenefelt (1969. Hym. Cat., part 4, p. 144-146).

atratus Muesebeck. P. E. I. s. to Fla.; Wis., Iowa, Ariz., B. C.

Macrocentrus atratus Muesebeck, 1932. U. S. Natl. Mus., Proc. 80 (23): 23 ..

bradleyi Daniel. N. S., Mich.

Macrocentrus bradleyi Daniel, 1933. Canad. Ent. 65: 25. ๆ.

canarsiae Muesebeck. Mass., N. Y., Ont., Ohio, Mich., Iowa, Ark., Kans., S. Dak. Host:

Canarsia sp., Psorosina hammondi (Riley).

Macrocentrus canarsiae Muesebeck, 1932. U. S. Natl. Mus., Proc. 80 (23): 26..

Macrocentmis insularis Muesebeck, 1932. U. S. Natl. Mus., Proc. 80 (23): 27. 9.

cerasivoranae Viereck. Canada, U. S. Host: Archips argyrospilus (Wlkr.), A. cerasivoranus

(Fitch), A. fervidanus (Clem.), A. infumatanus (Zell.).

Macrocentrus cerasivoranae Viereck, 1912. U. S. Natl. Mus., Proc. 42: 623. ९, ठ.

clypeatus Muesebeck. N. H. s. to Va.; Mich., Calif.

Macrocentrus clypeatus Muesebeck, 1932. U. S. Natl. Mus., Proc. 80 (23): 28. ₹, ठ์.

crambi (Ashmead). N. H., Mass., N. Y., Pa., N. J., Del., Md., Va., Fla., Tenn., Ind., Ill., Ark., La.,

S. Dak. Host: Crambus mutabilis Clem., C. trisectus (Wlkr.), C. zeellus Fern.

Amicoplus(!) crambi Ashmead, 1894. Cincinnati Soc. Nat. Hist., Jour. 17: 48. ठ'.

crambivorus Viereck. Canada s. to Fla., w. to Idaho. Host: Chrysoteuchia topiaria (Zell.),

Crambus caliginosellus Clem., C. trisectus (Wlkr.).

Macrocentrus (Amicroplus) crambivorus Viereck, 1911. U. S. Natl. Mus., Proc. 40: 183. , o.

Macrocentrus (Amicroplus) plesius Viereck, 1913. U. S. Natl. Mus., Proc. 44: 556. \&, ठ. crassipes Muesebeck. Que., Vt., N. Y., Ont., Sask., Alta., Mont. Host: Crymodes devastator

(Brace).

Macrocentrus crassipes Muesebeck, 1932. U. S. Natl. Mus., Proc. 80 (23): 13. १, ठ".

crocidophorae Muesebeck. N. C., S. C., La. Host: Crocidophora pustuliferalis Led.

Macrocentrus crocidophorae Muesebeck, 1932. U. S. Natl. Mus., Proc. 80 (23): 22. ठ. 
cuniculus Walley. N. B., Ont., Wis., Man., S. Dak., Sask., Mont., Colo., Idaho, Calif. Host: Petrova albicapitana albicapitana (Busck), P. a. arizonensis (Heinr.), P. metallica (Busck).

Macrocentrus cuniculus Walley, 1933. Canad. Ent. 65: 260..

delicatus Cresson. Que. s. to Fla., w. to Man. and Tex. Host: Aristotelia absconditella (Wlkr.), Caristanius sp., Chionodes sp., Epiblema strenuanum (Wlkr.), E. tripartitanum (Zell.), Episimus argutanus (Clem.), Euzophera ostricolorella Hulst, Grapholitha molesta (Busck), G. tristrigana (Clem.), Gretchena bolliana (Sling.), Hendecaneura shawiana (Kearf.), Laspeyresia pomonella (L.), Ostrinia nubilalis (Hbn.), Papaipema nebris (Guen.), Proteoteras willingana (Kearf.), Rhopobota naevana (Hbn.), Tetralopha scortealis (Led.), T. subcanalis (Wlkr.). This species is a common parasite of the oriental fruit moth (Grapholitha molesta) and the ragweed borer (Epiblema strenuanum).

Macrocentrus delicatus Cresson, 1872. Amer. Ent. Soc., Trans. 4: 178. ‡, ð.

Biology: Allen, 1962. U. S. Dept. Agr., Tech. Bul. 1265, p. 19, 24-25.

dioryctriae Muesebeck. Md. s. to Fla.; Miss., Ark. Host: Dioryctria abietella (D. and S.), D. amatella (Hulst), D. clarioralis (Wlkr.), D. disclusa Hein., Eucosma sp.

Macrocentrus dioryctriae Muesebeck, 1967. Fla. Ent. 50: 60. ๆ, ठే.

exartemae Walley. Que., Maine, N. J., Ont. Host: Choristoneura rosaceana (Harr.), Exartema cornanum Heinr., E. fasciatanum Clem., E. footinanum (Fern.), E. valdanum McD.

Macrocentrus exartemae Walley, 1932. Canad. Ent. 64: 183. $ๆ$.

grandii Goidanich. Holarctic. Introduced from France, Japan and Korea. Host: Ostrinia nubilalis ( $\mathrm{Hbn}$.). This species, which is an important parasite of the European corn borer, was incorrectly identified in early introductions to North America as Macrocentrus gifuensis Ashmead.

Macrocentrus grandii Goidanich, 1937. Inst. Ent. Univ. Bologna, Bol. 9: 196. .

Taxonomy: Eady and Clark, 1964. Ent. Gaz. 15: 121-122.

Biology: Parker, 1931. U. S. Dept. Agr., Tech. Bul. 230, p. 1-63 (as gifuensis Ashmead). -Clausen, 1956. U. S. Dept. Agr., Tech. Bul. 1139, p. 113 (as gifuensis Ashmead).

gravitarsis Muesebeck. N. Mex., Oreg., Calif. Host: Halisidota argentata Pack., H. ingens Hy. Edw.

Macrocentrus gravitarsis Muesebeck, 1938. Ent. Soc. Wash., Proc. 40: 170. \&.

impressus Muesebeck. N. S. s. to Fla., w. to Ont., Wis. Host: Psilocorsis cryptolechiella (Chamb.), P. reflexella Clem.

Macrocentrus impressus Muesebeck, 1932. U. S. Natl. Mus., Proc. 80 (23): 24..

incompletus Muesebeck. Sask. s. to Kans. and N. Mex., w. to Alta., Oreg., and Ariz. Host: Euxoa auxiliaris (Grote).

Macrocentrus incompletus Muesebeck, 1932. U. S. Natl. Mus., Proc. 80 (23): 12. \&, đ.

infumatus Muesebeck. Mich. Host: Schoenobius melinellus (Clem.). The original description of infumatus lists Schoenobius melinellus only as probably being the host.

Macrocentrus infumatuus(!) Muesebeck, 1938. Ent. Soc. Wash., Proc. 40: 172. ठ.

innuitorum Walley. N. W. T. (Baffin Isl.; Keewatin Dist.).

Macrocentrus innuitorum Walley, 1936. Canad. Ent. 68: 187. + , o.

instabilis Muesebeck. Vt. s. to Fla., w. to Ont. and Tex.; Wash. Host: Acrobasis betulella Hulst, $A$. caryae Grote, A. caryivorella Rag., A. hebescella Hulst, A. juglandis (LeB.), A. nuxvorella Nuenzig, A. rubrifasciella Pack., Coleophora malivorella Riley, Grapholitha molesta (Busck), Homaledra sabalella (Chamb.), Laspeyresia caryana (Fitch), L. pomonella (L.), Rhyacionia rigidana (Fern.).

Macrocentrus instabilis Muesebeck, 1932. U. S. Natl. Mus., Proc. 80 (23): 34. ₹, o.

Macrocentrus laspeyresiae Muesebeck, 1932. U. S. Natl. Mus., Proc. 80 (23): 37. ๆ, ơ.

Biology: Nickels, Pierce, and Pinkney, 1950. U. S. Dept. Agr., Tech. Bul. 1011, p. 8-9. -Allen, 1962. U. S. Dept. Agr., Tech. Bul. 1265, p. 26. - Balduf, 1968. Ent. Soc. Amer., Ann. 61: 466. iridescens French. Que. s. to Mass., w. to B. C. and Calif. Host: Archips argyrospilus (Wlkr.), A. cerasivoranus (Fitch), A. rosanus (L.), Cheimophila salicella (Hbn.), Choristoneura conflictana (Wlkr.), C. fractivittana (Clem.), C. fumiferana (Clem.), C. rosaceana (Harr.), 
Ennomos subsignarius (Hbn.), Harpipteryx frustrella (Wlsm.), H. xylostella (L.), Spilonota ocellana (D. and S.).

Macrocentrus iridescens French, 1880. Canad. Ent. 12: 43. ?, ठ.

Macrocentrus amicroploides Viereck, 1912. U. S. Natl. Mus., Proc. 43: 579. , ð.

longicornis Provancher. Que., Mich., Ohio, Minn.

Macrocentrus longicornis Provancher, 1880. Nat. Canad. 12: 173. ठ.

marginator (Nees). Holaretic. Host: Gretchena bolliana (Sling.), Laspeyresia cupressana (Kearf.), Podosesia syringae fraxini (Lugger), Synanthedon americana (Beut.), S. castaneae Busck, S. exitiosa (Say), S. pictipes (G. and R.), S. tipuliformis (Clerck), Zeiraphera ratzburgiana Sax.

Bracon marginator Nees, 1812 (1811). Gesell. Naturf. Freunde Berlin, Mag. 5: 14. ㅇ. Macrocentrus aegeriae Rohwer, 1915. Ent. Soc. Wash., Proc. 17: 56. $९$.

Taxonomy: Eady and Clark, 1964. Ent.Gaz. 15: 113.

mellipes Provancher. Que., Mont., B. C.

Macrocentrus mellipes Provancher, 1880. Nat. Canad. 12: 172..

nigridorsis Viereck. Que. and N. S. s. to D. C., w. to B. C. and Calif. Host: Archips purpuranus (Clem.), Choristoneura conflictana (Wlkr.), C. parallella (Rob.), Clepis melaleucana (Wlkr.), C. persicana (Fitch), Exartema fasciatanum Clem., E. inomatanum Clem., Gnorimoschema sp., Pyrausta sp., Sciaphila duplex (Wlsm.), Sparganothis sp.

Macrocentrus nigridorsis Viereck, 1924. Canad. Ent. 56: 68. ๆ, ð.

Macrocentrus harrisi DeGant, 1930. Ent. Soc. Wash., Proc. 32: 164. ๆ.

nigripectus Muesebeck. Mass., N. J. Host: Ancylis sp.

Macrocentrus nigripectus Muesebeck, 1932. U. S. Natl. Mus., Proc. 80 (23): 31. ๆ, ð.

nuperus Cresson. Md., Ga., Tex., Ariz. Host: Desmia funeralis (Hbn.).

Macrocentrus nuperus Cresson, 1872. Amer. Ent. Soc., Trans. 4: 178. ๆ.

pallisteri DeGant. Mass. s. to Fla., w. to Ont. and Tex.; Alta., Ariz., Calif. Host: Epiblema obfuscanum Dyar, E. otiosanum (Clem.), E. scudderianum (Clem.), E. strenuanum (Wlkr.), Grapholitha molesta (Busck), Ostrinia nubilalis (Hbn.). The last host mentioned above was listed as questionable in the original catalog.

Macrocentrus paediscae Riley, 1891. U. S. Dept. Agr., Insect Life 3: 59. Nom. nud.

Macrocentrus pallisteri DeGant, 1930. Ent. Soc. Wash., Proc. 32: 65. 9.

pectoralis Provancher. Que. s. to N. C.; Ohio, S. Dak.

Macrocentrus pectoralis Provancher, 1880. Nat. Canad. 12: 173. đ.

Macrocentrus fuscipennis Muesebeck, 1932. U. S. Natl. Mus., Proc. 80 (23): 43..

peroneae Muesebeck. Newfoundland, Que., N. B., Maine, Ont., Minn. Host: Acleris variana (Fern.), Archippus packardianus (Fern.), Argyrotaenia occultana Freem., Choristoneura fumiferana (Clem.).

Macrocentrus peroneae Muesebeck, 1932. U. S. Natl. Mus., Proc. 80 (23): 17..

pulchripennis Muesebeck. Idaho, Utah.

Macrocentrus pulchripennis Muesebeck, 1932. U. S. Natl. Mus., Proc. 80 (23): 40. ․

pyraustae Viereck. Mass., Conn., N. Y., Md., Mich., Mo. Host: Macrobotys pertextalis (Led.), M. theseusalis (Wlkr.). The type series for this species is recorded as being only an apparent parasite of Macrobotys theseusalis.

Macrocentrus pyraustae Viereck, 1917 (1916). Conn. State Geol. and Nat. Hist. Survey, Bul. 22, p. 220. .

reticulatus Muesebeck. Md. s. to Fla. and Ala.; Mich., Ill.

Macrocentrus reticulatus Muesebeck, 1932. U. S. Natl. Mus., Proc. 80 (23): 25..

robustus Muesebeck. Mass., N. Y., N. J., Fla. Host: Ostrinia nubilalis (Hbn.), Tetralopha robustella Zell.

Macrocentrus robustus Muesebeck, 1932. U. S. Natl. Mus., Proc. 80 (23): 29. ๆ, ठ.

seminiger Muesebeck. Utah, Ariz., Calif.

Macrocentrus seminiger Muesebeck, 1932. U. S. Natl. Mus., Proc. 80 (23): 41. .

terminalis (Ashmead). N. H. s. to N. J., w. to Minn. and Mo.; Alta.

Zele terminalis Ashmead, 1889 (1888). U. S. Natl. Mus., Proc. 11: 652. ð. 
texanus Muesebeck. Ga., Fla., Kans., Tex., Ariz.; Mexico.

Macrocentrus texanus Muesebeck, 1932. U. S. Natl. Mus., Proc. 80 (23): 49 ..

uniformis Provancher. N. S. s. to Fla., w. to Man. and Kans. Host: Alypia langtoni Coup., A. octomaculata (F.), Anavitrinella pampinaria (Gn.), Caripeta angustiorata (Wlkr.),

Plathypena scabra (F.), Psychomorpha epimenis (Drury), Semiothisa granitata (Gn.).

Macrocentrus uniformis Provancher, 1880. Nat. Canad. 12: 173..

utilis Muesebeck. Md., Fla., Ind., Ala., Iowa, Kans. Host: Ostrinia obumbratalis (Led.).

Macrocentrus utilis Muesebeck, 1932. U. S. Natl. Mus., Proc. 80 (23): 35. + , ó.

\section{NOMina NUdA IN MACROCENTRUS CURTIS}

Macrocentrus atriceps Cresson, 1909. In Tucker, Kans. Acad. Sci., Trans. 22: 293.

Macrocentrus gelechiae Ashmead, 1890. In Riley and Howard, U. S. Dept. Agr., Insect Life 3: 59.

Macrocentrus solidaginis Ashmead, 1890. In Riley and Howard, U. S. Dept. Agr., Insect Life 3: 59 .

\section{SUBFAMILY AGATHIDINAE}

The genera in this subfamily form a rather homogeneous and uniform group. Between 1917 and 1945 , this subfamily went under the name Braconinae due to nomenclatural problems with the type-species of Cremnops and Bracon. In 1945, use of the name Agathidinae was made possible by the International Commission in its Opinion 162.

All species are endoparasites of lepidopterous larvae.

Revision: Muesebeck, 1927. U. S. Natl. Mus., Proc. 69 (16): 1-73 (No. Amer. spp., as subfamily Braconinae).

Taxonomy: Gahan, 1917. U. S. Natl. Mus., Proc. 53: 197. - Hincks, 1943. Entomologist 76: 221-222. - Marsh, 1961. Ent. Soc. Amer., Ann. 54: 852 (key No. Amer. genera). - Shenefelt, 1970. Hym. Cat., part 6, p. 307-428 (cat. World spp.).

\section{Genus AENIGMOSTOMUS Ashmead}

Aenigmostomus Ashmead, 1900. U. S. Natl. Mus., Proc. 23: 128.

Type-species: Microdus longipalpus Cresson. Orig. desig.

longipalpus (Cresson). Mass., Ga., Mich., Ind., Ill., Mo., N. Dak., S. Dak., Nebr., Kans., Wyo., Colo., Idaho, Utah, Wash.

Microdus? longipalpus Cresson, 1865. Ent. Soc. Phila., Proc. 4: 299. $\%$.

\section{Genus AGATHIRSIA Westwood}

Agathirsia Westwood, 1882. Tijdschr. Ent. 25: 20.

Type-species: Agathirsia rufula Westwood. Desig. by Viereck, 1914.

Agathona Westwood, 1882. Tijdschr. Ent. 25: 22.

Type-species: Agathona sericans Westwood. Monotypic.

Paragathis Ashmead, 1889 (1888). U. S. Natl. Mus., Proc. 11: 638.

Type-species: Microdus thoracicus Cresson. Monotypic.

Revision: Muesebeck, 1927. U. S. Natl. Mus., Proc. 69 (16): 12-15 (U. S. spp.).

Taxonomy: Shenefelt, 1970. Hym. Cat., part 6, p. 310-311 (cat. World spp.).

cressoni Muesebeck and Walkley. Tex., Colo., N. Mex.

Microdus thoracicus Cresson, 1872. Amer. Ent. Soc., Trans. 4: 181. \&, o. Preocc. in Microdus by Nees, 1834.

Agathirsia cressoni Muesebeck and Walkley, 1951. In Muesebeck, et al., U. S. Dept. Agr.,

Agr. Monog. 2, p. 116. N. name for thoracicus Cresson.

nigricauda (Viereck). Tex., Colo., N. Mex., Ariz.

Crassomicrodus nigricaudus Viereck, 1905. Kans. Acad. Sci., Trans. 19: 288. ơ.

testacea Muesebeck. Tex., N. Mex., Ariz., Nev., Calif.; Mex. Host: Acontia cretata (G. and R.).

This host, reported by Bibby (1961. Jour. Econ. Ent. $54: 331)$ needs to be confirmed.

Agathirsia testacea Muesebeck, 1927. U. S. Natl. Mus., Proc. 69 (16): 13. ₹. 


\section{Genus AGATHIS Latreille}

Agathis Latreille, 1804. Nouv. Dict. Hist. Nat., v. 24, p. 173. No species included.

Type-species: Agathis malvacearum Latreille. Subsequent monotypy. First included species, by Latreille, 1805, Hist. Nat. Crust. Ins. 13: 125.

Bassus Fabricius, 1804. Systema Piezatorum, p. 93.

Type-species: Ichneumon calculator Fabricius. Desig. by Curtis, 1825.

Microdus Nees, 1814 (1812). Mag. Gesell. Naturf. Freunde Berlin 6: 184.

Type-species: Ichneumon calculator Fabricius. Desig. by Westwood, 1839.

Diplozon? Haliday, 1833. Ent. Mag. 1: 263.

Type-species: Ichneumon calculator Fabricius. Monotypic.

Microdus subg. Therophilus Wesmael, 1837. Nouv. Mem. Acad. Sci. Bruxelles 10: 15.

Type-species: Microdus (Therophilus) conspicuus Wesmael. Desig. by Viereck, 1914.

Cenostomus Foerster, 1862. Naturh. Ver. Rheinlande, Verh. 19: 246.

Type-species: Cenostomus lugubris Foerster. Orig. desig.

Eumicrodus Foerster, 1862. Naturh. Ver. Rheinlande, Verh. 19: 247. N. name for Microdus Nees.

Agathiella Szepligeti, 1902. Termes. Fuzetek 25: 73.

Type-species: Agathiella pedunculata Szepligeti. Monotypic.

Metriosoma Szepligeti, 1902. Termes. Fuzetek 25: 74.

Type-species: Metriosoma munda Szepligeti. Monotypic.

Neomicrodus Szepligeti, 1908. Mus. Nat. Hungarici, Ann. 6: 421.

Type-species: Neomicrodus boliviensis Szepligeti. Monotypic.

Lissagathis Cameron, 1911. Nova Guinea 9 (Zool. 2) Hym., p. 245.

Type-species: Lissagathis bicarinata Cameron. Monotypic.

Bassus subg. Aerophilopsis Viereck, 1913. U. S. Natl. Mus., Proc. 44: 555.

Type-species: Bassus (Aerophilopsis) erythrogaster Viereck. Orig. desig.

Ioxia Enderlein, 1920 (1918). Arch. f. Naturgesch. 84 (A) (11): 199.

Type-species: Ioxia faceta Enderlein. Orig. desig.

Alabagrus Enderlein, 1920 (1918). Arch. f. Naturgesch. 84 (A) (11): 203.

Type-species: Alabagrus citreistigma Enderlein. Orig. desig.

Ditropia Enderlein, 1920 (1918). Arch. f. Naturgesch. 84 (A) (11): 210.

Type-species: Ditropia strigata Enderlein. Orig. desig.

Liyptia Enderlein, 1920 (1918). Arch. f. Naturgesch. 84 (A) (11): 210.

Type-species: Liyptia rufiventris Enderlein. Orig. desig.

Agathellina Enderlein, 1920 (1918). Arch. f. Naturgech. 84 (A) (11): 211.

Type-species: Agathellina columbiana Enderlein. Orig. desig.

Revision: Muesebeck, 1927. U. S. Natl. Mus., Proc. 69 (16): 22-70 (No. Amer. spp.). -Telenga, 1955. Fauna U.S.S.R., v. 5, n. 4, p. 244-267 (Eur. spp.).

Taxonomy: Muesebeck, 1927. U. S. Natl. Mus., Proc. 69 (16): 22. - Hincks, 1943. Entomolgist

76: 223. - Shenefelt, 1970. Hym. Cat., part 6, p. 311-366 (cat. World spp.).

abdominalis (Muesebeck). Mich., Fla., S. Dak., La., Tex., Colo., Ariz.

Bassus abdominalis Muesebeck, 1927. U. S. Natl. Mus., Proc. 69 (16): 35. १, ơ.

aciculata (Ashmead). Tex., Ariz.

Microdus aciculatus Ashmead, 1889 (1888). U. S. Natl. Mus., Proc. 11: 639. ๆ, ઠ.

aerobasidis (Cushman). N. J. s. to Fla.; Miss., La., N. Dak., Kans., Tex., Colo., N. Mex. Host:

Acrobasis caryae Grote, A. caryivorella Rag., A. evanescentella Dyar, A. exsulella

(Zell.), A. juglandis (Le B.), A. nuxvorella Neunzig, A. peplifera Dyar, A. stigmella

Dyar, Blastodacna curvilineella (Chamb.), Choristoneura fumiferana (Clem.), $C$.

houstonana (Grote), Laspeyresia ingens Heinr., Rhyacionia frustrana (Comst.).

Bassus acrobasidis Cushman, 1920. U. S. Natl. Mus., Proc. 58: 289. ๆ, ठ.

Biology: Nickels, Pierce and Pinkney, 1950. U. S. Dept. Agr., Tech. Bul. 1011, p. 6-8.

agilis (Cresson). Que. s. to Fla., w. to Alta. and Tex. Host: Acleris minuta Rob., Archips cerasivoranus (Fitch), A. fervidanus (Clem.), A. infumatanus (Zell.), A. rileyanus (Grote), Aristotelia absconditella Wlkr., Epiblema strenuanum (Wlkr.), Homona 
fervidana Wlkr., Microbotys theseusalis (Wlkr.), Ostrinia nubilalis ( $\mathrm{Hbn}),$.0 . obumbratalis (Led.), Pyrausta futilalis (Led.), Spilonota ocellana (D. and S.). Microdus agilis Cresson, 1873. Canad. Ent. 5: 52..

Agathis quaesitor Provancher, 1880. Nat. Canad. 12: 176..

annulipes (Cresson). No. Amer. Host: Acrobasis sp., Anacampsis innocuella (Zell.), Ancylis comptana (Froel.), Archips semiferanus (Wlkr.), Coelostathma discopunctana Clem.(?), Charistoneura conflictana (Wlkr.), Eumarozia malachitana (Zell.), Grapholitha interstinctana (Clem.), Laspeyresia caryana (Fitch), Paralobesia viteana Clem., Proteoteras moffatiana Fern., Sciaphila duplex (Wlsm), Strepsicrates smithiana (Wlsm.).

Microdus annulipes Cresson, 1873. Canad. Ent. 5: 53. ㅇ.

Microdus earinoides Cresson, 1873. Canad. Ent. 5: 54. .

Microdus grapholithae Ashmead, 1889 (1888). U. S. Natl. Mus., Proc. 11: 639..

Microdus albocinctus Ashmead, 1889 (1888). U. S. Natl. Mus., Proc. 11: 639. ؟.

Bassus waldeni Viereck, 1917 (1916). Conn. State Geol. and Nat. Hist. Survey, Bul. 22, p. 229. ㅇ.

atripes Cresson. Colo., N. Mex., Utah, Idaho, Nev., Ariz., B. C., Wash., Calif.

Agathis atripes Cresson, 1865. Ent. Soc. Phila., Proc. 4: 296. ठ.

azygos (Viereck). S. Dak., Kans., Tex., Ariz.

Lytopylus azygos Viereck, 1905. Kans. Acad. Sci., Trans. 19: 267. ․

Microdus agathoides Viereck, 1905. Kans. Acad. Sci., Trans. 19: 277. \&.

bakeri (Muesebeck). Mich., Minn., Colo., Alaska, Wash., Calif.

Bassus bakeri Muesebeck, 1927. U. S. Natl. Mus., Proc. 69 (16): 42..

binominata Muesebeck. Que. and Ont. s. to Va. Host: Choristoneura fumiferana (Clem.), Coleophora laricella Hbn., Coleotechnites coniferella Kearf., C. piceaella (Kearf.), Epiblema desertana (Zell.), Epinotia nanana (Treits.), Petrova comstockiana (Fern.), Phalonia mitilana Hbn., Rhyacionia buoliana (Schiff.).

Microdus bicolor Provancher, 1880. Nat. Canad. 12: 179. . Preoce. by Brulle, 1846.

Agathis binominata Muesebeck, 1958. In Krombein, U. S. Dept. Agr., Agr. Monog. 2, Sup. 1, p. 26. N. name for bicolor Provancher.

brevicornis (Muesebeck). Man., Idaho, Utah, Oreg., Nev., Calif.

Bassus brevicornis Muesebeck, 1927. U. S. Natl. Mus., Proc. 69 (16): 56. ९, ठ̊.

buttricki (Viereck). Maine s. to Fla., w. to S. Dak., Colo., and Tex. Host: Acrobasis rubrifasciella Pack., Homoeosoma electellum (Hulst.), Isophrictis sp., Phalonia rutilana Hbn., $P$. straminoides Grote, $P$. voxcana Kearf.

Bassus (Lytopylus) buttricki Viereck, 1917 (1916). Conn. State Geol. and Nat. Hist. Survey, Bul. 22, p. 229. .

calcarata (Cresson). Que. s. to Fla.; Ont., Minn., Wis., Mich., Mo., Tex. Host: Acrobasis betulella Hulst., $A$. caryalbella Ely, $A$. caryivorella Rag., $A$. comptoniella Hulst., $A$. indiginella (Zell.), A. minimella Rag., A. rubrifasciella Pack., A. stigmella Dyar, Croesia albicomana (Clem.), Epismus argutanus (Clem.), Exartema permandanum Clem., E. sericoranum Wlsm., Psilocorsis sp., Sparganothis sulphurana (F.).

Microdus calcaratus Cresson, 1873. Canad. Ent. 5: 51. ․

Biology: Balduf, 1966. Ent. Soc. Amer., Ann. 59: 1038-1049.

californica (Muesebeck). Idaho, Oreg., Calif.

Bassus californicus Muesebeck, 1927. U. S. Natl. Mus., Proc. 69 (16): 64. ₹, ठ̊.

cincta (Cresson). Que. s. to Fla., w. to N. Dak. and Kans.; Oreg. Host: Acleris sp., Anacampsis fragariella Busck, Argyrotaenia velutiana (Wlkr.), Chrysopora hermannella (F.), Cnephasia longana (Haw.), Coleophora alniella Heinr., C. atlantica Heinr., C. cinerella Chamb., C. fuscedinella Zell., C. laricella $\mathrm{Hbn}$., C. salicivorella McD., C. tiliaefoliella Clem., C. ulmifoliella McD., Dichomeris ligulella (Hbn.), Grapholitha molesta (Busck.), Homadaula anisocentra (Merg.), Nephopteryx sp., Platynota idaeusalis (Wlkr.), Scrobipalpa atriplicella (Rosler.).

Microdus cinctus Cresson, 1873. Canad. Ent. 5: 53. \&, ठ゚.

Microdus pimploides Viereck, 1905. Kans. Acad. Sci., Trans. 19: 276. ठँ. 
Bassus winkleyi Viereck, 1917 (1916). Conn. State Geol. and Nat. Hist. Survey, Bul. 22, p. 229. .

coleophorae (Rohwer). Conn., Pa., Va., W. Va., Idaho. Host: Coleophora laricella Hbn., C. leucochrysella Clem., C. malivorella Riley.

Bassus coleophorae Rohwer, 1915. U. S. Natl. Mus., Proc. 49: 230.9.

Bassus pyrifolii Viereck, 1917 (1916). Conn. State Geol. and Nat. Hist. Survey, Bul. 22, p. 229. $?$.

conspicua (Wesmael). Mass., Conn., Pa., Del., Md., Va., W. Va., Ind.; Europe. Host: Grapholitha molesta (Busck), Laspeyresia pomonella (L.). Introduced also into Wash. from Del. but apparently not established.

Microdus (Therophilus) conspicuus Wesmael, 1837. Nouv. Mem. Acad. Sci. Bruxelles 10: 17. $\%$, o.

Earinus zonatus Marshall, 1885. Roy. Ent. Soc. London, Trans. 1885: 268. o’.

Bassus carpocapsae Cushman, 1915. U. S. Natl. Mus., Proc. 48: 508..

crassicornis (Muesebeck). Fla., Iowa.

Bassus crassicornis Muesebeck, 1927. U. S. Natl. Mus., Proc. 69 (16): 43. ๆ.

eupressi Muesebeck and Walkley. N. Mex., Idaho, Calif.

Bassus parvus Muesebeck, 1932. Wash. Acad. Sci., Jour. 22: 331. \&, ð. Preocc. by Viereck, 1903.

Agathis cupressi Muesebeck and Walkley, 1951. In Muesebeck, et al., 1951, U. S. Dept. Agr., Agr. Monog. 2, p. 119. N. name for parvus Muesebeck.

difficilis (Muesebeck). N. C., Ga., Fla., Miss., Ark., La., Tex. Host: Acrobasis indigenella (Zell.), Nephopteryx crassifasciella Rag., N. subcaesiella (Clem.), N. uvinella (Rag.).

Bassus difficilis Muesebeck, 1927. U. S. Natl. Mus., Proc. 69 (16): 46. ?, ठ’.

dimidiator (Nees). Que. s. to D. C., w. to Ont. and Mo.; Alta., Wash., Oreg.; Europe. Host: Acleris variana (Fern.), Archips cerasivoranus (Fitch), Spilonota ocellana (D. and S.). This species is a common parasite of the eyespotted bud moth, Spilonota ocellana, in Europe and North America; several more hosts have been recorded in the literature for North America (under the name laticinctus Cresson) but most need to be confirmed.

Microdus dimidiator Nees, 1834. Hym. Ichn. Aff. Monog., v. 1, p. 146..+

Microdus laticinctus Cresson, 1873. Canad. Ent. 5: 53. ¿.

Microdus ocellanae Richardson, 1913. Canad. Ent. 45: 211. ๆ.

Taxonomy: Sadava and Miller, 1967. Canad. Ent. 99: 441 (syn. of laticinctus).

Biology: Silvestri, 1922. Lab. Zool. Agr. Portici, Bol. 16: 272. -Dondale, 1954. Canad. Ent. 86:

40-44 (as laticinctus). - Stultz, 1954. Canad. Ent. 86: 96-98 (as laticinctus).

discolor (Cresson). Mass. s. to Fla., w. to Mich., Iowa and Tex. Host: Ancylis comptana (Froel.), Lineodes interrupta (Zell.).

Microdus discolor Cresson, 1873. Canad. Ent. 5: 52. ₹, o.

Bassus brittoni Viereck, 1917 (1916). Conn. State Geol. and Nat. Hist. Survey, Bul. 22, p. 229. . .

diversa (Muesebeck). Conn., N. Y., N. J., Va., Mich., Ohio, Ind.; Japan. Introduced from Japan. Host: Grapholitha molesta (Busck).

Bassus diversus Muesebeck, 1933. Ent. Soc. Wash., Proc. 35: 48. .

Biology: Clausen, 1956. U. S. Dept. Agr., Tech. Bul. 1139, p. 72-73. -Allen, 1962. U. S. Dept. Agr., Tech. Bul. 1256, p. 30-31.

erythrogaster (Viereck). Conn. s. to Ga., w. to Mich., Kans., and La. Host: Epiblema strenuanum (Wlkr.).

Bassus (Aerophilopsis) erythrogaster Viereck, 1913. U. S. Natl. Mus., Proc. 44: 555. ठ.

festiva Muesebeck. N. Y., N. J.; China, India. Introduced from China. Host: Grapholitha molesta (Busck), G. pruinivora (Walsh).

Agathis festiva Muesebeck, 1953. Ent. Soc. Wash., Proc. 55: 149. ๆ, ठ.

Biology: Allen, 1962. U. S. Dept. Agr., Tech. Bul. 1265, p. 31-34.

floridana (Muesebeck). Fla.

Bassus floridanus Muesebeck, 1927. U. S. Natl. Mus., Proc. 69 (16): 31. §ో. 
gibbosa (Say). No. Amer. Host: Coleophora sp., Keiferia inconspicuella (Murtf.), Mompha eloisella Clem., M. stellella Busck, Papaipema nebris f. nitela (Guen.), Phthorimaea operculella (Zell.), Stomopteryx sp., Strobisia iridipennella Clem.

Bassus gibbosus Say, 1836. Boston Jour. Nat. Hist. 1: 250. ㅇ.

Microdus pygmaeus Cresson, 1872. Amer. Ent. Soc., Trans. 4: 182. , б. Agathis scrutator Provancher, 1886. Addit. Corr. Faune Ent. Canada Hym., p. 137..+ Microdus dispar Provancher, 1886. Addit. Corr. Faune Ent. Canada Hym., p. 138.. Microdus meridionalis Viereck, 1903. Amer. Ent. Soc., Trans. 29: 96. ठ̊. Microdus wichitaensis Viereck, 1905. Kans. Acad. Sci., Trans. 19: 276.. Microdus castaneicinctus Viereck, 1905. Kans. Acad. Sci., Trans. 19: 276..

Biology: Odebiyi and Oatman, 1972. Ent. Soc. Amer., Ann. 65: 1104-1114.

imitata (Cresson). Mass., N. Y.

Microdus imitatus Cresson, 1873. Canad. Ent. 5: 51. ㅇ.

immaculata (Gahan). La., Tex. Host: Symmetrischema striatella (Murtf.) ?. Host needs to be confirmed.

Bassus immaculatus Gahan, 1919. U. S. Natl. Mus., Proc. 55: 118. ๆ.

laticeps (Muesebeck). Mass., D. C., Tex., Ariz.

Bassus laticeps Muesebeck, 1927. U. S. Natl. Mus., Proc. 69 (16): 53..

malivorellae Shenefelt. Maine, W. Va. Host: Coleophora malivorella Riley.

Bassus brevicauda Muesebeck, 1932. Wash. Acad. Sci., Jour. 22: 332. + . Preocc. by Reinhard, 1867.

Agathis malivorellae Shenefelt, 1970. Hym. Cat., part 6, p. 342. N. name for brevicauda Muesebeck.

marginatifrons (Muesebeck). Ala.

Bassus marginatifrons Muesebeck, 1927. U. S. Natl. Mus., Proc. 69 (16): 30..

metzneriae Muesebeck. Que., N. H., Mass., Conn., N. Y., Ohio, Mich., N. Dak. Host: Metzneria lappella (L.).

Agathis metzneriae Muesebeck, 1967. In Juhala, Ent. Soc. Amer., Ann. 60: 95. $q$, o.

Biology: Juhala, 1967. Ent. Soc. Amer., Ann. 60: 95-97.

nigricoxa (Provancher). Ont., N. B., N. Y., N. J., Pa., Mich.

Microdus nigricoxus Provancher, 1886. Addit. Corr. Faune Ent. Canada Hym., p. 138. \&.

nigripes Cresson. Mass., Fla.; N. Dak. s. to Kans. and N. Mex., w. to Alta., Wash., Oreg., and

Calif. Host: Phaneta bucephaloides (Wlsm.).

Agathis nigripes Cresson, 1865. Ent. Soc. Phila., Proc. 4: 297. ․

Agathis nigriceps Provancher, 1895. Nat. Canad. 22: 96. ㅇ.

Agathis wyomingensis Viereck, 1905. Kans. Acad. Sci., Trans. 19: 284. ㅇ.

nigrotrochanterica (Viereck). Ga., Fla., Kans., Ariz.

Microdus nigrotrochantericus Viereck, 1905. Kans. Acad. Sei., Trans. 19: 275..

ninanae (Muesebeck). Ariz., Calif. Host: Laspeyresia ninana (Dyar).

Bassus ninanae Muesebeck, 1927. U. S. Natl. Mus., Proc. 69 (16): 48. ๆ, ठै.

nucicola (Muesebeck). Wash., Oreg., Calif. Host: Melissopus latiferranus (Wlsm.).

Bassus nucicola Muesebeck, 1940. Ent. Soc. Wash., Proc. 42: 91. ๆ, ð゙.

Biology: Dohanian, 1942. Jour. Econ. Ent. 35: 386-387.

perforator Provancher. Que. s. to D. C., w. to Alta. and S. Dak.

Agathis perforator Provancher, 1880. Nat. Canad. 12: 177. $\%$.

Agathis femorator Provancher, 1880. Nat. Canad. 12: 177..

Bracon (Agathis) sassacus Viereck, 1917 (1916). Conn. State Geol. and Nat. Hist. Survey, Bul. 22, p. 231. \&, ठ́.

Bracon (Agathis) bradfordensis Viereck, 1917 (1916). Conn. State Geol. and Nat. Hist.

Survey, Bul. 22, p. 231. ठ.

petiolata (Muesebeck). N. Mex.

Bassus petiolatus Muesebeck, 1932. Wash. Acad. Sci., Jour. 22: 332. ค, ð.

pini (Muesebeck). Maine s. to Va. and Ohio. Host: Evetria sp., Petrova comstockiana (Fern.), $P$. houseri Miller, Rhyacionia frustrana (Comst.).

Bassus pini Muesebeck, 1940. Ent. Soc. Wash., Proc. 42: 92. ๆ. 
Biology: Miller, 1953. Ohio Jour. Sci. 53: 62.

pumila (Ratzeburg). P. E. I. s. to Pa., w. to Ont. and Wis.; Mont., Idaho.; Europe. Introduced from Europe. Host: Coleophora laricella $\mathrm{Hbn}$.

Microdus pumilus Ratzeburg, 1844. Ichn. d. Forstins., v. 1, p. 57., , ठ.

Biology: Dowden, 1962. U. S. Dept. Agr., Agr. Handb. 226, p. 47.

quebecensis (Provancher). Que.

Microdus quebecensis Provancher, 1880. Nat. Canad. 12: 178..

reticulata (Muesebeck). Ill., Mo., Kans.

Bassus reticulatus Muesebeck, 1932. Wash. Acad. Sci., Jour. 22: 332. ९, ơ.

rubripes Cresson. Mass. s. to Fla., w. to Ont. and La.; Wyo., Idaho, Calif. Host: Coleophora cratipennella Clem., Grapholitha molesta (Busck).

Agathis rubripes Cresson, 1872. Amer. Ent. Soc., Trans. 4: 183. \&.

rufofemorata (Muesebeck). Ohio, Fla., Iowa, Ark., Nebr., Kans.

Bassus rufofemoratus Muesebeck, 1927. U. S. Natl. Mus., Proc. 69 (16): 36. ๆ.

rugareolata (Viereck). Conn.

Bassus migareolatus Viereck, 1917 (1916). Conn. State Geol. and Nat. Hist. Survey, Bul. 22, p. $229 . \delta^{\circ}$.

sancta (Say). Mass. s. to Fla., w. to Mich., Nebr., and Tex. Host: Macrobotys pertextalis (Led.).

Bassus sanctus Say, 1836. Boston Jour. Nat. Hist. 1: 249..

semirubra Brulle. $\mathrm{Pa}$.

Agathis semi-rubra Brulle, 1846. In Lepeletier, Hist. Nat. Ins. Hym., v. 4, p. 494. §.

simillima (Cresson). Mass. s. to Fla., w. to Ont., S. Dak., and Kans.; Wash. Host: E piblema carolinana (Wlsm.), E. obfuscanum Dyar, E. otiosanum (Clem.), E. scudderianum (Clem.), E. strenuanum (Wlkr.), Grapholitha tristrigana Clem., Papaipema nebris (Guen.).

Microdus smillimus Cresson, 1873. Canad. Ent. 5: 51. ๆ, ơ.

spiracularis (Muesebeck). U. S.; Mex. Host: Cogia hippalus outis (Skin.), Erynnis zarucco (Luc.), Gesta gesta (H.-S.), Systasea pulverulenta (Feld.).

Bassus spiracularis Muesebeck, 1927. U. S. Natl. Mus., Proc. 69 (16): 38. ?.

stigmatera (Cresson). Fla., La.; West Indies, So. Amer. Introduced from Argentina. Host: Diatraea saccharalis (F.).

Microdus stigmaterus Cresson, 1865. Ent. Soc. Phila., Proc. 4: 65. ๆ, ठั.

Microdus diatraeae Turner, 1918. Bul. Ent. Res. 9: 82. \&.

Microdus crossi Brethes, 1927. Rev. Indus. Agr. Tucuman 17: 163..

Alabagrus citreistigma Enderlein, 1920 (1918). Arch. f. Naturgesch. 84: 203. \&.

Biology: Myers, 1932. Roy. Ent. Soc. London, Trans. 80: 125-126. -Jaynes, 1933. U. S. Dept. Agr., Tech. Bul. 363, p. 18-19. - Wilson, 1941. Fla. Ent. 24: 55-57.

tenuiceps (Muesebeck). Ariz.

Bassus tenuiceps Muesebeck, 1927. U. S. Natl. Mus., Proc. 69 (16): 47. ๆ, ठ゚.

terminata (Cresson). S. Dak., Nebr., Okla., Tex., Colo. Host: Isophrictis sp., Pyroderces rileyi (Wlsm.).

Microdus terminatus Cresson, 1865. Ent. Soc. Phila., Proc. 4: 298. ठే.

Orgilus terminalis Ashmead, 1889 (1888). U. S. Natl. Mus., Proc. 11: 640. ठँ.

Microdus terminator Dalla Torre, 1898. Cat. Hym., v. 4, p. 136. Emend.

texana (Cresson). N. Y. s. to Fla., w. to Kans. and Tex. Host: Microthyris anormalis (Guen.), Pachyzancla thesiusalis Wlkr., Pantographa limata G. and R., Pilema periusalis (Wlkr.), Pilocrocis ramentalis (Led.), P. tripunctata (F.)?, Sylepta silicalis (Gn.), Syngamia haemorrohoidalis (Guen.).

Microdus texanus Cresson, 1872. Amer. Ent. Soc., Trans. 4: 181. ठ.

Biology: Needham, 1955. Ecology 36: 349-350.

tibiator Provancher. Canada and U. S. except southeast. states.

Agathis tibiator Provancher, 1880. Nat. Canad. 12: 177. 9.

Agathis parvus Viereck, 1903. Amer. Ent. Soc., Trans. 29: 96. + ,.

Bracon (Agathis) solidaginis Viereck, 1917 (1916). Conn. State Geol. and Nat. Hist.

Survey, Bul. 22, p. 231. o. 
unicolor (Schrottky). Calif.; Argentina. Liberated in Calif. but not known to be established. Introduced from Argentina. Host: Phthorimaea operculella (Zell.).

Orgilus unicolor (Schrottky), 1902. Mus. Nac. Hist. Nat. B. Aires, An. 8: 102. $\%$.

Agathis unicolorata Shenefelt, 1970. Hym. Cat., part 6, p. 364. Unnecessary n. name for unicolor Schrottky.

usitata (Gahan). Mass. Host: Acrobasis vaccinii Riley.

Bassus usitatus Gahan, 1919. U. S. Natl. Mus., Proc. 55: 119. ๆ, ठ.

verticalis (Cresson). Tex.

Microdus verticalis Cresson, 1872. Amer. Ent. Soc., Trans. 4: 182..

Nomina Nuda in Agathis Latreille

Microdus johnsoni Ashmead, 1900 (1899). In Smith, Ins. of N. J., p. 592.

Microdus latiannulipes Ashmead, 1902. In Slosson, Ent. News 13: 6.

Microdus solidaginis Ashmead, 1900 (1899). In Smith, Ins. of N. J., p. 592.

Microdus tortricus Ashmead, 1890. In Riley and Howard, U. S. Dept. Agr., Insect Life 3: 17.

Microdus tricoloripes Ashmead, 1902. In Slosson, Ent. News 13: 6.

\section{Genus CRASSOMICRODUS Ashmead}

Crassomicrodus Ashmead, 1900. U. S. Natl. Mus., Proc. 23: 128.

Type-species: Microdus fulvescens Cresson. Orig. desig.

Epimicrodus Ashmead, 1900. U. S. Natl. Mus., Proc. 23: 129.

Type-species: Microdus divisus Cresson. Orig. desig. Cited as diversus by Ashmead.

Revision: Muesebeck, 1927. U. S. Natl. Mus., Proc. 69 (16): 15-22 (U. S. spp.).

Taxonomy: Shenefelt, 1970. Hym. Cat., part 6, p. 380-382 (cat. World spp.).

apicipennis Muesebeck. Iowa, Mo., Tex., Mont., Wyo., Oreg., Calif.

Crassomicrodus apicipennis Muesebeck, 1927. U. S. Natl. Mus., Proc. 69 (16): 18. ๆ, o.

divisus (Cresson). Mass. s. to Fla., w. to Ont., Colo., and Ariz.

Microdus divisus Cresson, 1873. Canad. Ent. 5: 52. o'.

Orgilus rileyi Ashmead, 1889 (1888). U. S. Natl. Mus., Proc. 11: 640..

Microdus diversus(!) Cresson: Ashmead, 1900. U. S. Natl. Mus., Proc. 23: 129.

fulvescens (Cresson), Kans. and Tex., w. to Wash. and Calif.; Mexico.

Microdus fulvescens Cresson, 1865. Ent. Soc. Phila., Proc. 4: 297. .

medius (Cresson). Iowa, Kans., Tex., Colo., N. Mex., Ariz., Idaho, Wash.

Microdus medius Cresson, 1865. Ent. Soc. Phila., Proc. 4: 298. ¿.

muesebecki Marsh. Nev., Calif.

Crassomicrodus muesebecki Marsh, 1960. Pan-Pacific Ent. 36: 153. , ð.

nigriceps (Cresson). Tex., Colo., Calif.

Microdus nigriceps Cresson, 1872. Amer. Ent. Soc., Trans. 4: 182..

nigrithorax Muesebeck. Colo., Nev., Calif.; Mexico.

Crassomicrodus nigrithorax Muesebeck, 1927. U. S. Natl. Mus., Proc. 69 (16): 17. ९, ठ์.

pallens (Cresson). Mass. s. to Fla., w. to Ill. and Tex.; Calif.

Microdus pallens Cresson, 1873. Canad. Ent. 5: 53. ठ゚.

\section{Genus CREMNOPS Foerster}

Cremnops Foerster, 1862. Naturh. Ver. Rheinlande, Verh. 19: 246.

Type-species: Agathis deflagrator Nees. Orig. desig.

Bracon of authors, not Fabricius refers to Crem nops Foerster. See Opinion 162, International Commission on Zoological Nomenclature, 1945.

Revision: Morrison, 1917. U. S. Natl. Mus., Proc. 52: 305-343 (No. Amer. spp.). - Marsh, 1961.

Ent. Soc. Amer., Ann. 54: 851-861 (No. Amer. spp.).

Taxonomy: Shenefelt, 1970. Hym. Cat., part 6, p. 382-391 (cat. World spp.).

ashmeadi (Morrison). Md., Ky., Ind., Ill., Minn., Iowa, S. Dak., Kans., Alta.

Bracon ashmeadi Morrison, 1917. U. S. Natl. Mus., Proc. 52: 329. ․, ठ. 
californicus (Morrison). Wyo. s. to N. Mex., w. to Wash. and Calif.

Bracon californicus Morrison, 1917. U. S. Natl. Mus., Proc. 52: 331. ๆ.

Bracon aionos Shenefelt, 1937. Canad. Ent. 69: 205. $\%$.

comstocki (Morrison). Que. s. to Fla., w. to Alta., Idaho, and Tex.

Bracon comstocki Morrison, 1917. U. S. Natl. Mus., Proc. 52: 323. ‡, ठ.

crassifemur (Muesebeck). Tex., N. Mex., Ariz., Calif.; Mexico.

Bracon crassifemur Muesebeck, 1927. U. S. Natl. Mus., Proc. 69 (16): 9. ठ。.

haematodes (Brulle). Pa. s. to Fla., w. to Colo. and Ariz.; Oreg., Calif. Host: Loxostege rantalis (Guen.).

Agathis haematodes Brulle, 1846. In Lepeletier, Hist. Nat. Ins. Hym., v. 4, p. 502. 9.

Agathis liberator Brulle, 1846. In Lepeletier, Hist. Nat. Ins. Hym., v. 4, p. 502. ९. N. syn.

Agathis meabilis Cresson, 1872. Amer. Ent. Soc., Trans. 4: 183. १, ठૈ.

kelloggii (Morrison). Nev., Calif.

Bracon kelloggii Morrison, 1917. U. S. Natl. Mus., Proc. 52: 327. ‡, ठ.

Bracon discoidea Morrison, 1917. U. S. Natl. Mus., Proc. 52: 329. Citation of an Ashmead manuscript name.

melanoptera Ashmead. Wash., Oreg., Nev., Calif.; Baja Calif., Mexico.

Cremnops melanoptera Ashmead, 1894. Calif. Acad. Sci., Proc. (2) 4: 125. o*.

montrealensis (Morrison). Que. and N. S. s. to N. C. and Ala., w. to Sask. and Tex. Host: Evergestis straminalis $\mathrm{Hbn}$.

Bracon montrealensis Morrison, 1917. U. S. Natl. Mus., Proc. 52: 326. ९, ठ์.

nigrosternum (Morrison). No. Amer.

Bracon nigrosternum Morrison, 1917. U. S. Natl. Mus., Proc. 52: 322..

Bracon szepligetii Morrison, 1917. U. S. Natl. Mus., Proc. 52: 334. १, ठ๋.

shenefelti Marsh. Nev., Calif.

Cremnops shenefelti Marsh, 1961. Ent. Soc. Amer., Ann. 54: 857. ๆ, ठ’.

slossonae (Morrison). Fla. Host: Epicorsia mellinalis (Hbn.).

Bracon slossonae Morrison, 1917. U. S. Natl. Mus., Proc. 52: 318. ๆ.

virginiensis (Morrison). No. Amer.

Bracon virginiensis Morrison, 1917. U. S. Natl. Mus., Proc. 52: 341. १, ठ.

vulgaris (Cresson). No. Amer. Host: Loxostege commixtalis (Wlkr.), L. rantalis (Guen.), L. sticticalis (L.).

Agathis vulgaris Cresson, 1865. Ent. Soc. Phila., Proc. 4: 295..

Agathis media Cresson, 1865. Ent. Soc. Phila., Proc. 4: 295. ठ.

Agathis exoratus Cresson, 1872. Amer. Ent. Soc., Trans. 4: 182. ठ์.

Biology: Simmonds, 1947. Bul. Ent. Res. 38: 145-155.

washingtonensis (Shenefelt). Nebr., Colo., Idaho, Utah, B. C., Wash., Oreg., Nev., Calif.

Bracon washingtonensis Shenefelt, 1937. Canad. Ent. 69: 206. ๆ, ठ̊.

\section{Genus EARINUS Wesmael}

Microdus subg. Earinus Wesmael, 1837. Nouv. Mem. Acad. Sci. Bruxelles 10: 8.

Type-species: Microdus nitidulus Nees. Desig. by Muesebeck and Walkley, 1951.

Diatmetzs Foerster, 1862. Naturh. Ver. Rheinlande, Verh. 19: 246.

Type-species: Bassus gloriatorius Panzer. Orig. desig.

Taxonomy: Shenefelt, 1970. Hym. Cat., part 6, p. 404-408 (cat. World spp.).

limitaris (Say). Que. and N. S. s. to Va., w. to B. C. and Calif. Host: Grapholitha sp., Xylomyges dolosa Grote.

Bassus limitaris Say, 1835. Boston Jour. Nat. Hist. 1: 250. ๆ.

zeirapherae Walley. Newfoundland w. to Alaska and B. C.; Va., Mich., N. Mex., Oreg., Calif.

Host: Acleris hudsoniana (Wlkr.), Choristoneura rosaceana (Harr.), Rhyacionia adana

Heinr., Zeiraphera griseana (Hbn.), Z. canadensis $\mathrm{M}$. and $\mathrm{F}$.

Earinus zeirapherce Walley, 1935. Canad. Ent. 67: 55. , đ’. 


\section{Genus MEGAGATHIS Kriechbaumer}

Megagathis Kriechbaumer, 1894. Berlin. Ent. Ztschr. 39: 311.

Type-species: Megagathis natalensis Kriechbaumer. Monotypic.

Adiathlipsis Enderlein, 1920 (1918). Arch. f. Naturgesch. 84 (A) (11): 194.

Type-species: Adiathlipsis fasciata Enderlein. Orig. desig.

Taxonomy: Shenefelt, 1970. Hym. Cat., part 6, p. 419-422 (cat. World spp.).

cressoni (Cameron). Tex.; Mexico, Cent. Amer., West Indies.

Agathis albitarsis Cresson, 1865. Ent. Soc. Phila., Proc. 4: 63. ९, ठ. Preocc. in Agathis by Spinola, 1840.

Agathis cressoni Cameron, 1887. Biol. Cent.-Amer., Hym., v. 1, p. 398. N. name for albitarsis Cresson.

\section{Genus ZELOMORPHA Ashmead}

Neophylax Ashmead, 1900. U. S. Natl. Mus., Proc. 23: 119. Preocc. by M'Lachlan, 1871.

Type-species: Neophylax snyderi Ashmead. Orig. desig.

Zelomorpha Ashmead, 1900. U. S. Natl. Mus., Proc. 11: 129.

Type-species: Zelomorpha arizonensis Ashmead. Orig. desig.

Ahngeria Kokujev, 1902. Ent. Obozr. 2: 6.

Type-species: Ahngeria transcaspia Kokujev. Monotypic.

Xanthomicrodus Cameron, 1904. Rec. Albany Mus. 1: 157.

Type-species: Xanthomicrodus iridipennis Cameron. Monotypic.

Lisitheria Cameron, 1904. Entomologist 37: 306.

Type-species: Lisitheria nigricornis Cameron. Monotypic.

Spilomicrodus Cameron, 1911. Timehri (3) 1: 323.

Type-species: Spilomicrodus nigriceps Cameron. Monotypic.

Caenophylax Schulz, 1911. Zool. Ann. 4: 88. N. name for Neophylax Ashmead.

Zelomorpha subg. Zelomorphidea Viereck, 1912. U. S. Nat]. Mus., Proc. 42: 630.

Type-species: Zelomorpha (Zelomorphidea) melanota Viereck. Orig. desig.

Taxonomy: Shenefelt, 1970. Hym. Cat., part 6, p. 425-427 (cat. World spp.).

arizonensis Ashmead. Tex., N. Mex., Ariz., Calif.; Baja Calif., Mexico.

Zelomorpha arizonensis Ashmead, 1900. U. S. Natl. Mus., Proc. 23: 129.

fascipennis (Cresson). Fla.; Cuba.

Microdus fascipennis Cresson, 1865. Ent. Soc. Phila., Proc. 4: 65. ․

\section{SUBFAMILY OPIINAE}

Most of the recent literature on the Opiinae has been published by Fischer and the arrangement of the subfamily presented here follows that of Fischer (1973). All species are solitary endoparasites of dipterous larvae with pupation occurring in the host puparium. Records of lepidopterous and coleopterous hosts are doubtful and need to be confirmed.

Revision: Gahan, 1915. U. S. Natl. Mus., Proc. 49: 63-95 (No. Amer. spp.). -Fischer, 1964.

Polskie Pismo Ent. 34: 197-530 (No. Amer. spp.). - Fischer, 1965. Polskie Pismo Ent. 35:

3-212 (No. Amer. spp.).

Taxonomy: Fischer, 1971. Index World Opiinae, 189 p. (cat. World spp.). -Fischer, 1973. Das

Tierreich, lief. 91 , p. 55-61 (keys to World tribes and genera).

\section{TRIBE ADEMONINI}

Taxonomy: Fischer, 1973. Das Tierreich, lief 91, p. 59-60 (key to genera).

Genus ADEMON Haliday

Ademon Haliday, 1833. Ent. Mag. 1: 266.

Type-species: Ademon descrescens Haliday. Monotypic.

Lytacra Foerster, 1862. Naturh. Ver. Rheinlande, Verh. 19: 258.

Type-species: Lytacra stygia Foerster. Orig. desig.

Giardinaia Destefani Perez, 1902. Zool. Jahrb., Abt. f. Syst. 15: 631. 
Type-species: Giardinaia urinator Destefani Perez. Monotypic.

Analostania Viereck, 1916. Biol. Soc. Wash., Proc. 29: 165.

Type-species: Analostania tenuipes Viereck. Orig. desig.

Species of this genus are parasites of aquatic leaf mining Diptera and are apparently restricted to the genus Hydrellia.

Revision: Fischer, 1965. Polskie Pismo Ent. 35: 197-208 (No. Amer. spp.).

Taxonomy: Fischer, 1971. Index World Opiinae, p. 18-19 (cat. World spp.).

Biology: Destefani Perez, 1902. Zool. Jahrb., Abt. f. Syst. 15: 625-634. -Rimsky-Korsakov. 1933. Handb. Biol. Arbeitsmethoden, Abt. 9, Teil 7, p. 255. -Burghele, 1959. Univ. C. I.

Parhon, Ann., Ser. St. Naturii 22: 143-169.

niger (Ashmead). N. Y., D. C., Va., Mich., Wis., Ill., Minn., Utah. Host: Hydrellia sp.

Clinocentrus niger Ashmead, 1895. Ill. State Lab. Nat. Hist., Bul. 4: 276. đ̋.

Analostania tenuipes Viereck, 1916. Biol. Soc. Wash., Proc. 29: 165. ․

ovalis Fischer. Mich. Host: Hydrellia sp.

Ademon ovalis Fischer, 1965. Polskie Pismo Ent. 35: 203. ․

satanas Fischer. Mich.

Ademon satanus Fischer, 1965. Polskie Pismo Ent. 35: 205. ๆ.

\section{Genus EUOPIUS Fischer}

Euopius Fischer, 1967. Beitr. Ent. 17: 959.

Type-species: Neopius macrops Fischer. Orig. desig.

Taxonomy: Fischer, 1965. Polskie Pismo Ent. 35: 187-197 (No. Amer. spp., in Neopius). -Fischer, 1967. Beitr. Ent. 17: 959-969 (Nearctic and Neotr. spp.). -Fischer, 1969.

Entomophaga 14: 129-147 (Nearctic, Neotr., and Orient. spp.). - Fischer, 1971. Index World Opiinae, p. 15-17 (cat. World spp.).

albipalpus (Fischer). Fla.

Neopius albipalpus Fischer, 1965. Polskie Pismo Ent. 35: 188. ठే.

analis (Fischer). Fla., Miss.

Neopius analis Fischer, 1965. Polskie Pismo Ent. 35: 190. ๆ, ठँ.

cubitalis (Fischer). Md., Ga., Fla., Ont., Mich., Tex.

Neopius cubitalis Fischer, 1965. Polskie Pismo Ent. 35: 193. ๆ, ठ.

macrops (Fischer). Conn., N. Y., Md., Fla., Ont., Mich., Ohio.

Neopius macrops Fischer, 1965. Polskie Pismo Ent. 35: 195. १, ठ..

\section{TRIBE DESMIOSTOMATINI}

Taxonomy: Fischer, 1973. Das Tierreich, lief. 91, p. 61 (key to genera).

\section{Genus DESMIOSTOMA Foerster}

Desmiostoma Foerster, 1862. Naturh. Ver. Rheinlande, Verh. 19: 260.

Type-species: Opius parvulus Wesmael. Orig. desig.

Taxonomy: Fischer, 1967. Ztschr. Arbeit. Osterr. Entom. 19: 64. - Fischer, 1973. Das

Tierreich, lief. 91, p. 567.

additivum (Fischer). Que., N. Y., Cal.

Opius (Opius) additivus Fischer, 1965. Polskie Pismo Ent. 35: 5. ठ.

parvulum (Wesmael). N. Y., N. C., S. C., Tenn., Mich., Minn., Sask., Ariz., B. C., Wash., Calif.;

Europe. Host: Agromyza sp., Liriomyza propepusilla (Frost).

Opius parvulus Wesmael, 1835. Nouv. Mem. Acad. Sci. Bruxelles 9: 139. ๆ, ठँ.

Opius (Opius) nudiscutum Fischer, 1964. Polskie Pismo Ent. 34: 373. ๆ, ơ.

\section{Genus DORYCTOBRACON Enderlein}

Doryctobracon Enderlein, 1920 (1918). Arch. f. Naturgesch. 84 (A) (11): 144.

Type-species: Doryctobracon conjugens Enderlein. Orig. desig. 
Parachasma Fischer, 1967. Beitr. Neotr. Fauna 5: 7.

Type-species: Opius zeteki Muesebeck. Orig. desig.

Taxonomy: Fischer, 1967. Beitr. Neotr. Fauna 5: 7-11 (in Parachasma). -Fischer, 1971.

Index World Opiinae, p. 36-38 (cat. World spp., in Parachasma).

anastrephilum (Marsh), n. comb. Fla. Host: Anastrepha interrupta Stone, A. suspensa (Loew).

Parachasma anastrephilum Marsh, 1970. Fla. Ent. 53: 31. ๆ, ठ.

cereus (Gahan), n. comb. Fla.; Mexico, Panama, Trinidad, Brazil. Introduced from Trinidad.

Host: Anastrepha suspensa (Loew).

Opius cereus Gahan, 1919, Ent. Soc. Wash., Proc. 21: 169. ठ.

\section{TRIBE OPIINI}

Taxonomy: Fischer, 1973. Das Tierreich, lief. 91, p. 60 (key to subtribes and genera).

\section{SUBTRIBE BIOSTERINA}

\section{Genus BIOSTERES Foerster}

Biosteres Foerster, 1862. Naturh. Ver. Rheinlande, Verh. 19: 259.

Type-species: Bracon carbonarius Nees. Orig. desig.

Zetetes Foerster, 1862. Naturh. Ver. Rheinlande, Verh. 19: 258. Preocc. by Cabanis, 1860. Type-species: Zetetes ultor Foerster. Orig. desig.

Chilotrichia Foerster, 1862. Naturh. Ver. Rheinlande, Verh. 19: 258.

Type-species: Opius blandus Haliday. Orig. desig.

Stenospilus Foerster, 1862. Naturh. Ver. Rheinlande, Verh. 19: 259.

Type-species: Stenospilus vagator Foerster. Orig. desig.

Rhabdospilus Foerster, 1862. Naturh. Ver. Rheinlande, Varh. 19: 259.

Type-species: Opius placidus Haliday. Orig. desig.

Opiellus Ashmead, 1900. Canad. Ent. 32: 368. N. name for Zeietes Foerster.

Celiestella Cameron, 1903. Ztschr. Syst. Hym. Dipt. 3: 343.

Type-species: Celiestella testaceipes Cameron. Monotypic.

Diachasmimorpha Viereck, 1913. U. S. Natl. Mus., Proc. 44: 641.

Type-species: Diachasmimorpha comperei Viereck. Orig. desig.

Revision: Fischer, 1965. Polskie Pismo Ent. 35: 115-155 (N. Amer. spp. as subgenus of Opius).

Taxonomy: Fischer, 1967. Abt. Zool. Bot. Landsmus. Joanneum Graz, Mitt. 26: 159

(resurrection to generic rank). - Fischer, 1971. Index World Opiinae, p. 19-32 (cat. World

spp.). - Fischer, 1973. Das Tierreich, lief. 91, p. 485-486 (synonymy, subgenera).

aietes Fischer. Oreg.

Biosteres aietes Fischer, 1970. Polskie Pismo Ent. 40: 763. ㅇ.

anthomyiae (Ashmead). Conn., N. Y., N. J., Mich., Ill., Minn., Colo., Idaho. Host: Pegomya bicolor (Wied.), P. hyoscyami hyoscyami (Panz.).

Opizus anthomyiae Ashmead, 1889 (1888). U. S. Natl. Mus., Proc. 11: 654 . ․

Opius (Desmiostoma) novaeangliae Viereck, 1917 (1916). Conn. State Geol. and Nat. Hist. Survey, Bul. 22, p. 183. + .

argos Fischer. S. C., Wash.

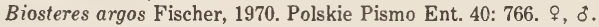

californicus (Fischer). Calif.

Opizs (Biosteres) californicus Fischer, 1865. Polskie Pismo Ent. 35: 140..

carbonarius (Nees). Ont., Minn., Colo., Alaska, Yukon, B. C., Wash., Calif.; Europe.

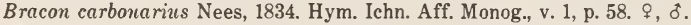

Opius procemis Wesmael, 1835. Nouv. Mem. Acad. Sci. Bruxelles 9: 156. ठ.

Opius impressus Wesmael, 1835. Nouv. Mem. Acad. Sci. Bruxelles 9: 157. ठ.

Taxonomy: van Achterberg, 1975. Ent. Ber. 35: 175-176.

distractus (Fischer). Wyo.

Opius (Biosteres) distractus Fischer, 1965. Polskie Pismo Ent. 35: 119. ठ。. 
foveolatus (Ashmead). Mass. s. to Md., w. to S. Dak. Host: Pegomya sp., P. hyoscyami hyoscyami (Panz.).

Opius foveolatus Ashmead, 1889 (1888). U. S. Natl. Mus., Proc. 11: 654. ð.

haemorrhoeus (Haliday). N. Y., Ont., Mich.; Europe.

Opius haemorrhoeus Haliday, 1837. Ent. Mag. 4: 219. $?$, ठ.

Opius castoneiventris Thomson, 1895. Opusc. Ent., fasc. 20, p. 2201. ๆ, §.

incertus (Fischer). Ont., Alta., Wyo., Colo., N. Mex., Alaska, Calif.

Opius (Biosteres) incertus Fischer, 1965. Polskie Pismo Ent. 35: 123. \&, ठ.

jason Fischer. Md.

Biosteres jason Fischer, 1970. Polskie Pismo Ent. 40: 768. 9.

juglandis (Muesebeck). Ariz. Host: Rhagoletis juglandis Cress.

Opius juglandis Muesebeck, 1961. Brooklyn Ent. Soc., Bul. 56: 57. ९, ठ.

kukakensis (Ashmead). Mich., N. Dak., Colo., Alaska, Oreg.

Desmiostoma kukankense Ashmead, 1902. Wash. Acad. Sci., Proc. 4: 251.,$+ \delta$.

longicaudatus Ashmead. Fla.; Oriental and Australian Regions, Hawaii. Introduced from Hawaii. Host: Anastrepha suspensa (Loew).

Biosteres longicaudatus Ashmead, 1905. U. S. Natl. Mus., Proc. 28: 970 ..+

Biology: Baranowski, 1974. Fruit Fly News 3: 17. -Greany, et al., 1976. Entomophaga 21: 207-215. -Ashley, Greany, and Chambers, 1977 (1976). Fla. Ent. 59: 391-396.

melleus (Gahan). N. S., Maine, N. H., Vt., N. Y., N. J., Fla., Ohio, Minn. Host: Rhagoletis cingulata cingulata (Loew), $R$. cornivora Bush, $R$. mendax Curran, $R$. pomonella (Walsh), R. suavis (Loew).

Opius melleus Gahan, 1915. U. S. Natl. Mus., Proc. 49: 73..+

Biosteres rhagoletis Richmond, 1915. Canad. Ent. 47: 294. ₹, ठ.

Biology: Lathrop and Newton, 1933. Jour. Agr. Res. 46: 143-160.

numerosus (Fischer), Colo., Alaska, B. C., Oreg., Calif.

Opius (Biosteres) numerosus Fischer, 1965. Polskie Pismo Ent. 35: 149. , ঠ。.

placidus (Haliday). Ont., N. Y., Mich., Minn., N. Dak., S. Dak., Kans., Colo.; Europe.

Opius placidus Haliday, 1837. Ent. Mag. 4: 217. $q$.

Opizis melanocerıs Wesmael, 1838. Nouv. Mem. Acad. Sci. Bruxelles 11: 149. ๆ.

Opius tarsator Thomson, 1895. Opusc. Ent., fasc. 20, p. 2193. ㅇ.

Biosteres indotatus Viereck, 1905. Kans. Acad. Sci., Trans. 19: 273. ठ.

politus (Provancher). Canada, Maine, N. Y., Mich.

Opius politus Provancher, 1883. Nat. Canad. 14: 16. §.

quebecensis (Provancher), Que., Maine, N. Y., Mich., Minn. Host: Pegomya sp., Scaptomyza (Mesoscaptomyza) adusta (Loew).

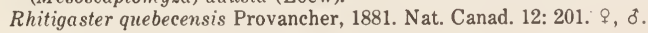

retractus (Fischer). Idaho.

Opius (Biosteres) retractus Fischer, 1965. Polskie Pismo Ent. 35: 135. ठ.

sanguineus (Ashmead). Md., D. C., Ga., Fla., Ill., Mo., La., Tex., Ariz. Host: Zonosemata electa (Say), Z. vittigera (Coq.).

Phaedrotoma? sanguinea Ashmead, 1889 (1888). U. S. Natl. Mus., Proc. 11: 655. \&, ठ̊.

Biology: Cazier, 1962. Pan-Pacific Ent. 38: 184-186.

spinaciae (Thomson). Que., Maine, N. Y., Ont., Wis., Minn., Utah, Idaho, Alaska, Wash., Calif.; Europe. Host: Hylemya platura (Meig.), Pegomya hyoscyami hyoscyami (Panz.), P. h. betae (Curtis).

Opius spinaciae Thomson, 1895. Opusc. Ent., fasc. 20, p. 2200. ठ.

Opius pegomyiae Gahan, 1917. U. S. Natl. Mus., Proc. 53: 201. ๆ, ठ.

Opius (Chilotrichia) hyoscyamiellus Viereck, 1925. Canad. Ent. 57: 278. ठో.

Biology: Kaufman, 1937. Ztschr. f. Pflanzenkrank. 47: 75-85.

stonehamensis Fischer. Que.

Biosteres stonehamensis Fischer, 1970. Polskie Pismo Ent. 40: 771. ९, ठ. 


\section{Genus DIACHASMA Foerster}

Diachasma Foerster, 1862. Naturh. Ver. Rheinlande, Verh. 19: 259.

Type-species: Opius fulgidus Haliday. Orig. desig.

Bathystomus Foerster, 1862. Naturh. Ver. Rheinlande, Verh. 19: 235.

Type-species: Bathystomus xanthopus Foerster. Orig. desig. Atoreuteus Foerster, 1862. Naturh. Ver. Rheinlande, Verh. 19: 241.

Type-species: Atoreuteus striatus Foerster. Orig. desig.

Revision: Fischer, 1965. Polskie Pismo Ent. 35: 155-165 (No. Amer. spp., as subgenus of Opius).

Taxonomy: Fischer, 1967. Abt. Zool. Bot. Landsmus. Joanneum Graz, Mitt. 26: 159 (resurrection to generic rank). - Fischer, 1971. Index World Opiinae, p. 33-36 (cat. World spp.).

alloeum (Muesebeck), Que., N. B., Maine, Conn., N. Y., Pa., Fla., Ont., Mich., Wis., Minn. Host: Rhagoletis mendax Curran, $R$. pomonella (Walsh).

Opius alloeus Muesebeck, 1956. Ent. News 67: 101. $९$, ठ․

Biology: Boush and Baerwald, 1967. Ent. Soc. Amer., Ann. 60: 865-866.

columbicola (Fischer), S. C.

Opius (Diachasma) columbicola Fischer, 1965. Polskie Pismo Ent. 35: 158. ð.

ferrugineum (Gahan). Ont. s. to N. J.; Fla., S. Dak. Host: Rhagoletis cingulata cingulata (Loew), R. fausta (0. S.).

Opius ferrugineus Gahan, 1915. U. S. Natl. Mus., Proc. 49: 75. \&, ð.

Taxonomy: Muesebeck, 1956. Ent. News 67: 99-101.

muliebre (Muesebeck). Wash., Oreg., Calif. Host: Rhagoletis sp., $R$. cingulata indifferens Curran.

Opius muliebris Muesebeck, 1956. Ent. News 67: 100. \&.

nigrifactum (Fischer). Wis.

Opius (Diachasma) nigrifactus Fischer, 1965. Polskie Pismo Ent. 35: 163. ð.

\section{SUBTRIBE OPIINA}

\section{Genus EURYTENES Foerster}

Eurytenes Foerster, 1862. Naturh. Ver. Rheinlande, Verh. 19: 259.

Type-species: Opius abnormis Wesmael. Orig. desig.

Taxonomy: Fischer, 1965. Polskie Pismo Ent. 35: 165-167.

abnormis (Wesmael). S. C., Ont., Minn., Sask., N. Dak., Mont.; Europe.

Opius abnormis Wesmael, 1835. Nouv. Mem. Acad. Sci. Bruxelles 9: 117. ९, ठ゚.

\section{Genus OPIUS Wesmael}

Opius Wesmael, 1835. Nouv. Mem. Acad. Sci. Bruxelles 9: 115.

Type-species: Opius pallipes Wesmael. Desig. by Muesebeck and Walkley, 1951.

Psyttalia Walker, 1860. Ann. and Mag. Nat. Hist. (3) 5: 311.

Type-species: Psyttalia testacea Walker. Monotypic.

Xynobius Foerster, 1862. Naturh. Ver. Rheinlande, Verh. 19: 235.

Type-species: Xynobius pallipes Foerster. Orig. desig.

Holconotus Foerster, 1862. Naturh. Ver. Rheinlanide, Verh. 19: 259. Preocc. by Agassiz, 1854.

Type-species: Opius comatus Wesmael. Orig. desig.

Apodesmia Foerster, 1862. Naturh. Ver. Rheinlande, Verh. 19: 259.

Type-species: Apodesmia taeniata Foerster. Orig. desig.

Allotypus Foerster, 1862. Naturh. Ver. Rheinlande, Verh. 19: 259.

Type-species: Opius irregularis Wesmael. Orig. desig.

Phaedrotoma Foerster, 1862. Naturh. Ver. Rheinlande, Verh. 19: 260.

Type-species: Phaedrotoma depeculator Foerster. Orig. desig.

Eutrichopsis Foerster, 1862. Naturh. Ver. Rheinlande, Verh. 19: 260. 
Type-species: Eutrichopsis munda Foerster. Orig. desig.

Therobolus Foerster, 1862. Naturh. Ver. Rheinlande, Verh. 19: 260.

Type-species: Opius ruficeps Wesmael. Orig. desig.

Hypocynodus Foerster, 1862. Naturh. Ver. Rheinlande, Verh. 19: 260.

Type-species: Opius crassipes Wesmael. Orig. desig.

Cryptonastes Foerster, 1862. Naturh. Ver. Rheinlande, Verh. 19: 260.

Type-species: Cryptonastes tersus Foerster. Orig. desig.

Hypolabis Foerster, 1862. Naturh. Ver. Rheinlande, Verh. 19: 260.

Type-species: Opius pallipes Wesmael. Orig. desig.

Biophthora Foerster, 1862. Naturh. Ver. Rheinlande, Verh. 19: 260.

Type-species: Opius bajulus Haliday. Orig. desig.

Nosopoea Foerster, 1862. Naturh. Ver. Rheinlande, Verh. 19: 260.

Type-species: Opius cingulatus Wesmael. Orig. desig.

Utetes Foerster, 1862. Naturh. Ver. Rheinlande, Verh. 19: 261.

Type-species: Opius testaceus Wesmael. Orig. desig.

Misophthora Foerster, 1862. Naturh. Ver. Rheinlande, Verh. 19: 266.

Type-species: Misophthora laevigata Foerster. Orig. desig.

Aclisis Foerster, 1862. Naturh. Ver. Rheinlande, Verh. 19: 267.

Type-species: Aclisis isomera Foerster. Orig. desig.

Aulonotus Ashmead, 1900. Canad. Ent. 32: 368. N. name for Holconotus Foerster.

Mesostoma Cameron, 1905. Tijdschr. Ent. 48: 42.

Type-species: Mesostoma testaceipes Cameron. Monotypic.

Tolbia Cameron, 1907. Linn. Soc. London, Trans. (2) 12: 84.

Type-species: Tolbia scaevolae Cameron. Monotypic.

Brachycentrus Szepligeti, 1907. Mus. Natl. Hist. Nat. Paris, Bul. 1907: 35. Preocc. by Curtis, 1834.

Type-species: Brachycentrus minutus Szepligeti. Monotypic.

Hexaulax Cameron, 1910. Soc. Ent. 25: 25.

Type-species: Hexaulax mificeps Cameron. Monotypic.

Baeocentrum Schulz, 1911 (1909). Zool. Ann. 4: 65. N. name for Brachycentrus Szepligeti.

Eristernaulax Viereck, 1913. U. S. Natl. Mus., Proc. 46: 362.

Type-species: Eristermaulax leucotaenia Viereck. Orig. desig.

Neopius Gahan, 1917. U. S. Natl. Mus., Proc. 53: 203.

Type-species: Neopius carinaticeps Gahan. Orig. desig.

Fischer (1973) has recently established several subgenera for the genus Opius. However, since this was done only for the Palaearctic groups, I was unable to assign the Nearctic species to their proper subgenera.

Revision: Fischer, 1964. Polskie Pismo Ent. 34: 197-530 (No. Amer. spp.). -Fischer, 1965.

Polskie Pismo Ent. 35: 3-212 (No. Amer. spp.).

Taxonomy: Fischer, 1971. Index World Opiinae, p. 38-123 (cat. World spp.). - Fischer, 1973.

Das Tierreich, lief. 91, p. 67-71 (subgenera). -Marsh, 1974. Ent. Soc. Wash., Proc. 76: 286

(synonymy).

aberrans Viereck. Que. s. to S. C., w. to Ont. and Kans.

Opizs aberrans Viereck, 1905. Kans. Acad. Sci., Trans. 19: 271. 9.

Opius (Opius) crabtreeanus Fischer, 1964. Polskie Pismo Ent. 34: 470..

Opius (Opius) masoni Fischer, 1964. Polskie Pismo Ent. 34: 480. ․, ठ.

Opius (Opius) suffixus Fischer, 1964. Polskie Pismo Ent. 34: 493. ơ.

Taxonomy: Marsh, 1974. Ent. Soc. Wash., Proc. 76: 286.

aciurae Fischer. N. C., Fla. Host: Myoleja limata (Coq.).

Opius (Opius) aciurae Fischer, 1964. Polskie Pismo Ent. 34: 272. ९, ठ์.

adductus Fischer. N. Y., Calif. Host: Agromyza sp.

Opius (Opius) adductus Fischer, 1964. Polskie Pismo Ent. 34: 413. ๆ, o.

alachuanus Fischer. Fla.

Opius (Opius) alachuanus Fischer, 1964. Polskie Pismo Ent. 34: 379. ․

alconanus Fischer. Mich.

Opius (Opias) alconanus Fischer, 1964. Polskie Pismo Ent. 34: 416. ๆ. 
Opius (Opius) apertus Fischer, 1964. Polskie Pismo Ent. 34: 417. ठे.

Taxonomy: Marsh, 1974. Ent. Soc. Wash., Proc. 76: 286.

americanus Gahan. Pa., N. C., Ga., Ill.

Opius americanus Gahan, 1915. U. S. Natl. Mus., Proc. 49: 91 . ठ.

Opius (Opius) extraordinarius Fischer, 1965. Polskie Pismo Ent. 35: 9. ठ์.

Taxonomy: Marsh, 1974. Ent. Soc. Wash., Proc. 76: 286.

amplus (Ashmead). Newfoundland, Que., Mich., Minn., Iowa, Colo., Alta., Idaho, B. C., Oreg., Alaska. Host: Agromyza albitarsis Meig.

Adelura ampla Ashmead, 1890. Colo. Biol. Assoc., Bul. 1: 19. 9.

anastrephae Viereck. Fla. Host: Anastrepha suspensa (Loew).

Opius (Utetes) anastrephae Viereck, 1913. U. S. Natl. Mus., Proc. 44: 563. ९, ठ.

anaximandri Fischer. N. H.

Opius anaximandri Fischer, 1970. Polskie Pismo Ent. 40: 774. ๆ.

anaximensis Fischer. N. H.

Opius anaximensis Fischer, 1970. Polskie Pismo Ent. 40: 776..

angustistriatus Fischer. N. Y., S. C.

Opius (Opius) angustistriatus Fischer, 1964. Polskie Pismo Ent. 34: 353. \&.

antennatus Fischer. S. C.

Opius (Opius) antennatus Fischer, 1965. Polskie Pismo Ent. 35: 65. ठౌ.

antrimensis Fischer. Mich.

Opius (Opius) antrimensis Fischer, 1965. Polskie Pismo Ent. 35: 91. ठ́.

apicalis Gahan. Conn. s. to S. C., w. to N. Dak. and Colo.; Calif. Host: Liriomyza sp. Opius apicalis Gahan, 1915. U. S. Natl. Mus., Proc. 49: 85. , ठ゚.

Opius (Allotypus) exareolatus Viereck, 1917 (1916). Conn. State Geol. and Nat. Hist.

Survey, Bul. 22, p. 183.,

Taxonomy: Marsh, 1974. Ent. Soc. Wash., Proc. 76: 286.

aquaticus Muesebeck. Oreg., Calif. Host: Hydrellia griseola (Fall.).

Opius hydrelliae Muesebeck, 1933. Ent. Soc. Wash., Proc. 35: 197.. Preocc. by

Rimsky-Korsokov, 1925.

Opius aquaticus Muesebeck, 1967. In Krombein and Burks, U. S. Dept. Agr., Agr. Monog. 2, 2nd suppl., p. 48. N. name for hydrelliae Muesebeck.

Opius hydrellianus Fischer, 1971. Index World Opiinae, p. 74. N. name for hydrelliae Muesebeck.

aridis Gahan. Colo., N. Mex., Ariz., Calif. Host: Cerodontha (Cerodontha) dorsalis (Loew), Liriomyza sp., L. munda Frick.

Opius aridis Gahan, 1913. Canad. Ent. 45: 147., , రా.

atrocoxalis (Ashmead). Colo.

Homophyla atrocoxalis Ashmead, 1890. Colo. Biol. Assoc., Bul. 1: 18. ९.

aureliae Fischer. Colo., Alaska, B. C., Wash.; Europe.

Opius (Opius) aureliae Fischer, 1957. Deut. Ent. Ztschr., N. F., 4: 343. \&.

baldufi Muesebeck. Mich., Wis., Ill., Minn. Host: Rhagolet is basiola (O. S.).

Opius baldufi Muesebeck, 1950 (1949). Canad. Ent. 81: 256. ๆ, ठ’.

Biology: Balduf, 1959. Ill. Biol. Monog. 26: 32-40.

basicastaneus Fischer. S. C.

Opius (Opius) basicastaneus Fischer, 1964. Polskie Pismo Ent. 34: 501. ठ.

basiniger Viereck. Pa., Md., Va., Minn., Iowa, Mo., S. Dak., Kans., Tex., Colo. Opins basiniger Viereck, 1905. Kans. Acad. Sci., Trans. 19: 270.. Opius foersteri Gahan, 1915. U. S. Natl. Mus., Proc. 49: 83. , ơ.

Taxonomy: Marsh, 1974. Ent. Soc. Wash., Proc. 76: 286.

bidentis Fischer. Fla. Opius (Opius) bidentis Fischer, 1964. Polskie Pismo Ent. 34: 360. ๆ, ठ.

bigdeltanus Fischer. Alaska, Calif.

Opius (Opius) bigdeltanus Fischer, 1965. Polskie Pismo Ent. 35: 67. ‡, ઠ. 
blantoni Fischer. Que., Alaska, B. C., Wash., Oreg., Calif.

Opius (Opius) blantoni Fischer, 1964. Polskie Pismo Ent. 34: 338. ๆ.

Opius (Opius) vockerothi Fischer, 1964. Polskie Pismo Ent. 34: 348. १, ơ.

Taxonomy: Marsh, 1974. Ent. Soc. Wash., Proc. 76: 286.

bromensis Fischer. Que.

Opius (Opius) bromensis Fischer, 1965. Polskie Pismo Ent. 35: 93. १.

brooki Fischer. Fla., Tenn., Miss., Iowa.

Opius (Opius) brooki Fischer, 1965. Polskie Pismo Ent. 35: 95. ९, ठ.

brownsvillensis Fischer. Tex.

Opius (Opius) brownsvillensis Fischer, 1965. Polskie Pismo Ent. 35: 97. ९, ठ.

bruneipes Gahan. Md., Fla., Alta., Calif. Host: Liriomyza munda Frick. Opius bruneipes Gahan, 1913. Canad. Ent. 45: 148. १, ठ.

brunneitarsis Gahan. Mich., Iowa.

Opius brunneitarsis Gahan, 1915. U. S. Natl. Mus., Proc. 49: 77. $ๆ$.

Opius (Opius) ingens Fischer, 1965. Polskie Pismo Ent. 35: 11. ․

Taxonomy: Marsh, 1974. Ent. Soc. Wash., Proc. 76: 286.

brunneiventris Cresson. Kans., Tex., Ariz.

Opius brunneiventris Cresson, 1872. Amer. Ent. Soc., Trans. 4: 178. ठे.

brunescens Fischer, N. Y.

Opius (Opius) brunescens Fischer, 1964. Polskie Pismo Ent. 34: 340. \&, ठ.

canaliculatus Gahan. Md., Ill., Minn., Man.

Opius canaliculatus Gahan, 1915. U. S. Natl. Mus., Proc. 49: 80. ‡.

canimensis Fischer. N. Y., N. C., S. C., B. C.

Opius (Opius) canimensis Fischer, 1965. Polskie Pismo Ent. 35: 78. ๆ, ठ.

cannonbeachensis Fischer. Oreg.

Opius cannonbeachensis Fischer, 1970. Polskie Pismo Ent. 40: 779. ९.

carinus Fischer. N. C.

Opius (Opius) carinus Fischer, 1964. Polskie Pismo Ent. 34: 253. ठో.

castaneigaster Fischer. N. Y., N. C., S. C., Ga., Ont., Ohio, Tenn., Wis., Minn.

Opius (Opius) castaneigaster Fischer, 1964. Polskie Pismo Ent. 34: 419. ९, ठ.

chapmani Fischer. Mass., N. Y., Wash.

Opius (Opius) chapmani Fischer, 1964. Polskie Pismo Ent. 34: 311. o.

chewaucanus Fischer. Oreg.

Opius (Opius) chewaucanus Fischer, 1965. Polskie Pismo Ent. 35: 31. ๆ.

cincticornis Gahan. Newfoundland, Que., Maine, N. Y., N. J., Md., N. C., Mich., Sask., B. C. The species has been recorded as a parasite of Heterarthrus nemoratus (Fall.) which needs to be confirmed.

Opius cincticornis Gahan, 1915. U. S. Natl. Mus., Proc. 49: 78..

cinctus Provancher. N. S., Que., N. Y., N. C., Ont., Mich., Ohio, Ill., Minn., Sask., Utah, Yukon, Alaska, Wash., Calif.

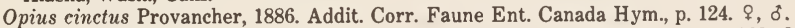

Prosapha hyalina Provancher, 1888. Addit. Corr. Faune Ent. Canada Hym., p. 393. \&.

clellanvillensis Fischer. S. C.

Opius (Opius) clellanvillensis Fischer, 1964. Polskie Pismo Ent. 34: 454. 9.

clevelandensis Fischer. N. Y., S. C.

Opius (Opius) clevelandensis Fischer, 1964. Polskie Pismo Ent. 34: 421. ๆ, ठ゙.

cochisensis Fischer. Ariz.

Opius (Opius) cochisensis Fischer, 1965. Polskie Pismo Ent. 35: 80. १.

coleogaster Fischer. Fla.

Opius (Opius) coleogaster Fischer, 1964. Polskie Pismo Ent. 34: 399. ९, ठ̛.

coloradensis Gahan. Colo.

Opius coloradensis Gahan, 1915. U. S. Natl. Mus., Proc. 49: 83..

columbiacus Fischer. N. Y., N. C., S. C., Minn., Ariz.

Opius (Opius) columbiacus Fischer, 1964. Polskie Pismo Ent. 34: 466. ๆ, o. 
comatus Wesmael. N. Y., Md., S. C., Minn., B. C.; Europe.

Opius comatus Wesmael, 1835. Nouv. Mem. Acad. Sci. Bruxelles 9: 145. ‡, ठ.

complicans Fischer. N. Y., N. C., S. C., Tenn., Alta., Idaho, B. C., Wash., Calif.

Opius (Opius) complicans Fischer, 1965. Polskie Pismo Ent. 35: 69. ๆ, ठ́.

confundens Fischer. S. C., Fla., La., Tex.

Opius (Opius) confundens Fischer, 1964. Polskie Pismo Ent. 34: 381. \&, ठ.

convergitalis Fischer. N. C.

Opius (Opius) convergitalis Fischer, 1964. Polskie Pismo Ent. 34: 468. ๆ.

coriaceus Gahan. N. Y. s. to Fla., w. to La. Host: Cerodontha (Cerodontha) dorsalis (Loew).

Opius coriaceus Gahan, 1917. U. S. Natl. Mus., Proc. 53: 201., ơ.

crandalli Fischer. Ariz.

Opius (Opius) crandalli Fischer, 1964. Polskie Pismo Ent. 34: 312. \&.

crassiceps Gahan. N. Y., D. C., Va., S. C., Mich., Minn., Iowa, Colo.

Opius crassiceps Gahan, 1915. U. S. Natl. Mus., Proc. 49: 78. ๆ.

crescentensis Fischer. Calif.

Opius (Opius) crescentensis Fischer, 1965. Polskie Pismo Ent. 35: 33. ठั.

curtiarticulatus Fischer. Mass., N. Y., Sask.

Opius (Opius) curtiarticulatus Fischer, 1964. Polskie Pismo Ent. 34: 315. \&.

curticubitalis Fischer. Wash., Calif. Host: Agromyza sp., Phytomyza atricornis Meig.

Opius (Opius) curticubitalis Fischer, 1965. Polskie Pismo Ent. 35: 35. ๆ, ठ์.

deiphobe Fischer. N. C.

Opius deiphobe Fischer, 1970. Polskie Pismo Ent. 40: 782. ๆ.

demosthenis Fischer. S. C.

Opius demosthenis Fischer, 1970. Polskie Pismo Ent. 40: 787...

diastatae (Ashmead). N. Y., S. C., Fla., Ind., Ala., Wis., Minn. Host: Agromyza parvicornis Loew.

Bracon diastatae Ashmead, 1889 (1888). U. S. Natl. Mus., Proc. 11: 617..

differentiarius Fischer. N. Y., N. C.

Opius (Opius) differentiarius Fischer, 1965. Polskie Pismo Ent. 35: 7. ð.

dimensis Fischer. N. Y., Minn.

Opius (Opius) dimensis Fischer, 1964. Polskie Pismo Ent. 34: 362. 9.

dimidiatus (Ashmead). No. Amer.; West Indies. Host: Agromyza sp., Cerodontha (Cerodontha) dorsalis (Loew), Liriomyza sp., L. munda Frick, L. trifolii (Burgess), Phytobia sp., Phytomyza opacae Kulp.

Adelura dimidiatus Ashmead, 1889 (1888). U. S. Natl. Mus., Proc. 11: 647. ð’.

Eutrichopsis agromyzae Viereck, 1912. U. S. Natl. Mus., Proc. 42: 622. ․

dizygomyzae Fischer. N. Y., Calif. Host: Dizygomyza sp.

Opius (Opius) dizygomyzae Fischer, 1965. Polskie Pismo Ent. 35: 37. ९, ठ.

douglasanus Fischer. Kans.

Opius (Opius) douglasanus Fischer, 1965. Polskie Pismo Ent. 35: 84. ðð.

downesi Gahan. N. Y., Ont., Mich., B. C., Wash. Host: Rhagoletis berberis Curran, $R$. pomonella (Walsh), R. tabellaria (Fitch).

Opius downesi Gahan, 1919. Ent. Soc. Wash., Proc. 21: 164. 9.

Opius (Opius) berberidis Fischer, 1964. Polskie Pismo Ent. 34: 358. ९, ठ์.

Taxonomy: Marsh, 1974. Ent. Soc. Wash., Proc. 76: 286.

dreisbachi Fischer. Mich.

Opius (Opius) dreisbachi Fischer, 1964. Polskie Pismo Ent. 34: 385. ९, ठ.

dubitarius Fischer. N. Y.

Opius (Opius) dubitarius Fischer, 1965. Polskie Pismo Ent. 35: 39. ९, ð.

eastridgeanus Fischer. Ga., Tenn., Wis., Wash.

Opius (Opius) eastridgeanus Fischer, 1965. Polskie Pismo Ent. 35: 41. ๆ.

ehrhorni Gahan. Calif.

Opius ehrhorni Gahan, 1915. U. S. Natl. Mus., Proc. 49: 87.. 
empedoplis Fischer. Md.

Opius empedoplis Fischer, 1970. Polskie Pismo Ent. 40: 790. \&.

euwattacooanus Fischer. N. Y., Md., S. C., Mich.

Opius (Opius) euwattacooanus Fischer, 1964. Polskie Pismo Ent. 34: 505. ๆ, ठ.

farmingdalicus Fischer. N. Y.

Opius (Opius) farmingdalicus Fischer, 1964. Polskie Pismo Ent. 34: 475. ठ์.

Opius (Opius) cinereifactus Fischer, 1965. Polskie Pismo Ent. 34: 503. ९, ठ .

Opius (Opius) farmingdalensis Fischer, 1965. Polskie Pismo Ent. 34: 507.. .

Taxonomy: Marsh, 1974. Ent. Soc. Wash., Proc. 76: 286.

flaviceps Gahan. Que. s. to N. J.; Minn., Iowa.

Opius flaviceps Gahan, 1915. U. S. Natl. Mus., Proc. 49: 76..

foutsi Fischer. R. I., Md.

Opius (Opius) foutsi Fischer, 1964. Polskie Pismo Ent. 34: 401. 9.

Opius (Opius) westerlyanus Fischer, 1964. Polskie Pismo Ent. 34: 528. ․

Taxonomy: Marsh, 1974. Ent. Soc. Wash., Proc. 76: 286.

frequens Fischer. Que., Maine, N. Y., Ont., Mich., Minn., Man., Wash., Oreg. Host: Rhagoletis fausta (0.S.).

Opius (Opius) frequens Fischer, 1964. Polskie Pismo Ent. 34: 279. १, ઠ .

fulvicollis Thomson. Que., Maine, N. Y., Pa., Ont.; Europe. Host: Pegomya hyoscyami hyoscyami (Panz.).

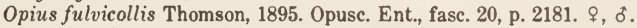

Opius cupidus Gahan, 1919. Ent. Soc. Wash., Proc. 21: 162. $\%$.

Biology: Bremer and Kaufman, 1928. Arbeit. Biol. Reichs. Land-und Forstw. 16: 526-533.

-Kaufman, 1937. Ztschr. Pflanzenkrank. 47: 75-85.

gahani Muesebeck. N. Y., Pa., Md., Va., Mich., Wis., Ill., Tenn., Minn., Man.

Opius fuscipennis Gahan, 1915. U. S. Natl. Mus., Proc. 49: 79. $\%$, ठ. Preocc. by Wesmael, 1835.

Opius gahani Muesebeck, 1931. U. S. Natl. Mus., Proc. 79 (16): 11. N. name for fuscipennis Gahan.

Opius (Opius) gahanoides Fischer, 1964. Polskie Pismo Ent. 34: 283..

Taxonomy: Marsh, 1974. Ent. Soc. Wash., Proc. 76: 286.

gainesvillensis Fischer. Md., N. C., Fla.

Opius (Opius) gainesvillensis Fischer, 1964. Polskie Pismo Ent. 34: 402. ๆ, ð.

glasgowi Fischer. N. Y., S. Dak. Host: Rhagoletis cingulata cingulata (Loew).

Opius (Opius) glasgowi Fischer, 1964. Polskie Pismo Ent. 34: 286. ठ́.

globiformis Fischer. N. Y., Md., Ont., Mich., Wis.

Opius (Opius) globiformis Fischer, 1964. Polskie Pismo Ent. 34: 497. \&, ઠ.

globigaster Fischer. N. Y. s. to S. C.

Opius (Opius) globigaster Fischer, 1964. Polskie Pismo Ent. 34: 387. \&, ठ.

Opius (Opius) grafi Fischer, 1964. Polskie Pismo Ent. 34: 389. ₹, ठ.

Taxonomy: Marsh, 1974. Ent. Soc. Wash., Proc. 76: 286.

gracillariae Gahan. Ohio, Minn., Mo., Kans. This species has been recorded as a parasite of Porphyrosela desmodiella (Clem.) which needs to be confirmed.

Bracon gracillariae Ashmead, 1890. U. S. Dept. Agr., Insect Life 2: 349. Nom. nud.

Opius gracillariae Gahan, 1915. U. S. Natl. Mus., Proc. 49: 90..

gravicornis Fischer, Que.

Opius (Opius) gravicornis Fischer, 1964. Polskie Pismo Ent. 34: 230. ठ.

hancockanus Fischer. N. Y.

Opius (Opius) hancockanus Fischer, 1964. Polskie Pismo Ent. 34: 426. ๆ.

hardmanni Fischer. Wash., Oreg., Calif.

Opius (Opius) hardmanni Fischer, 1964. Polskie Pismo Ent. 34: 211. ๆ, ठ.

hartleyi Fischer. Alaska.

Opius (Opius) hartleyi Fischer, 1964. Polskie Pismo Ent. 34: 258. \&. 
heroicus Fischer. N. C.

Opius heroicus Fischer, 1970. Polskie Pismo Ent. 40: 792. ․

hoffmanni Fischer. Ga., Mich., Minn. Host: Phytobia (Nemorimyza) posticata (Meig.).

Opius (Opius) hoffmanni Fischer, 1964. Polskie Pismo Ent. 34: 391. ๆ, ơ.

hollisterensis Fischer. Idaho.

Opius (Opius) hollisterensis Fischer, 1964. Polskie Pismo Ent. 34: 328. ๆ.

Opius (Opius) hagermanicus Fischer, 1965. Polskie Pismo Ent. 35: 43..

Taxonomy: Marsh, 1974. Ent. Soc. Wash., Proc. 76: 286.

hubbelli Fischer. Ont., Mich.

Opius (Opius) hubbelli Fischer, 1965. Polskie Pismo Ent. 35: 101. \&.

igneus Fischer. N. Y., N. C., S. C., Fla.; Cuba.

Opius (Opius) igneus Fischer, 1964. Polskie Pismo Ent. 34: 477. १, ठ์.

Opius (Opius) pinkbedsanus Fischer, 1964. Polskie Pismo Ent. 34: 488. ๆ, §.

Taxonomy: Marsh, 1974. Ent. Soc. Wash., Proc. 76: 286.

ignifer Fischer. N. Y.

Opius (Opius) ignifer Fischer, 1964. Polskie Pismo Ent. 34: 232..

ilicis Nixon. B. C.; Europe. Introduced from England. Host: Phytomyza ilicis (Curt.). Opius ilicis Nixon, 1939. Ent. Monthly Mag. 75: 80. ๆ, ठ์.

Biology: Cameron, 1941. Parasitology 31: 8-39.

interjectus Fischer. Fla.

Opius (Opius) interjectus Fischer, 1965. Polskie Pismo Ent. 35: 86..

intermissus Fischer. N. Y., S. C.

Opius (Opius) intermissus Fischer, 1964. Polskie Pismo Ent. 34: 428. ९, ơ.

irregularis Wesmael. N. Y., N. C., B. C., Wash., Oreg.; Europe.

Opius irregularis Wesmael, 1835. Nouv. Mem. Acad. Sci. Bruxelles 9: 132. ९, ठ์.

isolatae Fischer. Wash., Calif. Host: Agromyza isolata Mall. Opius (Opius) isolatae Fischer, 1964. Polskie Pismo Ent. 34: 478. ๆ, ठ.

ithacensis Fischer. N. Y., Minn. Opius (Opius) ithacensis Fischer, 1964. Polskie Pismo Ent. 34: 239. ९.

jacobi Fischer. Que., N. Y., Alaska, B. C., Wash., Oreg., Calif.

Opius (Opius) jacobi Fischer, 1964. Polskie Pismo Ent. 34: 329. ९, ठ.

juniperi Fischer. Man., Ariz.

Opius (Opius) juniperi Fischer, 1964. Polskie Pismo Ent. 34: 288. ๆ, ठ.

karesuandensis Fischer. Yukon, Alaska; Sweden. Opius (Opius) karesuandensis Fischer, 1964. Polskie Pismo Ent. 34: 241. ९, o.

kinleyensis Fischer. Alaska. Opius (Opius) kinleyensis Fischer, 1964. Polskie Pismo Ent. 34: 317. ๆ, ठ゚.

krombeini Fischer. Va.

Opius (Opius) krombeini Fischer, 1964. Polskie Pismo Ent. 34: 367. १.

labradorensis Fischer. Labrador.

Opius (Opius) labradorensis Fischer, 1965. Polskie Pismo Ent. 35: 13. ๆ.

lansingensis Fischer. N. Y., S. C., Mich.

Opius (Opius) lansingensis Fischer, 1965. Polskie Pismo Ent. 35: 103. ๆ, ठे.

latitemporalis Fischer. N. Y.

Opius (Opius) latitemporalis Fischer, 1964. Polskie Pismo Ent. 34: 509. ठో.

lectoides Gahan. N. S., Md., Ont., Oreg. Host: Rhagoletis cornivora Bush, $R$. pomonella (Walsh), R. zephyria Snow.

Opius lectoides Gahan, 1930. U. S. Natl. Mus., Proc. 77 (8): 2. १, ठ.

lectus Gahan. N. S., N. B., Que., Maine, Vt., N. Y., Ont., Mich., Calif. Host: Rhagoletis fausta (O. S.), R. mendax Curran, $R$. pomonella (Walsh), R. tabellaria (Fitch).

Opius lectus Gahan, 1919. Ent. Soc. Wash., Proc. 21: 167. ๆ, ठั.

leevingensis Fischer. Calif.

Opius (Opius) leevingensis Fischer, 1964. Polskie Pismo Ent. 34: 369. o. 
lemnaphilae Muesebeck. N. Y. Host: Lemnaphila scotlandae Cress.

Opius lemnaphilae Muesebeck, 1939. Ent. Soc. Wash., Proc. 41: 59. ๆ, ठ.

Biology: Scotland, 1939. Ent. Soc. Amer., Ann. 32: 716-717. -Scotland, 1940. N. Y. Ent. Soc., Jour. 48: 323-325.

lemonensis Fischer. Ariz.; Mexico. Opius (Opius) lemonensis Fischer, 1964. Polskie Pismo Ent. 34: 319. ๆ, ơ.

liriomyzae Fischer. N. C., Calif. Host: Liriomyza propepusilla Frost. Opius (Opius) liriomyzae Fischer, 1964. Polskie Pismo Ent. 34: 260. ठ.

longicubitalis Fischer. N. Y., N. C., S. C., Ont., Mich., Minn., Man., Alta., B. C., Wash. Opius (Opius) longicubitalis Fischer, 1965. Polskie Pismo Ent. 35: 46. ๆ, ơ.

luteiceps Viereck. Kans. Opius luteiceps Viereck, 1905. Kans. Acad. Sci., Trans. 19: 271. ठ.

macrocerus Thomson. Mich.; Europe.

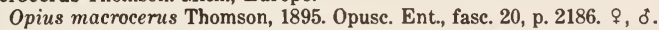

Opius hians Stelfox, 1949. Ent. Monthly Mag. 85: 306. \%, ठ.

malivorellae Fischer. Mass., W. Va., Fla., Mich., Miss., Iowa, N. Dak., S. Dak. This species was recorded as a parasite of Coleophora malivorella which needs to be confirmed.

Opius (Opius) malivorellae Fischer, 1964. Polskie Pismo Ent. 34: 213. ‡, §.

mandibularis Gahan. R. I., N. Y., Md., D. C., Ga., Fla., La., Calif.; West Indies. Host: Agromyza sp., Hylemya (Paregle) radicum (L.), Phytobia (Amauromyza) maculosa (Mall.), Phytomyza atricomis Meig.

Opius mandibularis Gahan, 1915. U. S. Natl. Mus., Proc. 49: 81. ๆ, ठ๋.

martini Fischer. Fla.

Opius (Opius) martini Fischer, 1965. Polskie Pismo Ent. 35: 105. ๆ.

mediopectus Fischer. Wash.

Opius (Opius) mediopectus Fischer, 1965. Polskie Pismo Ent. 35: 48. o.

microsomaticus Fischer. Wash.

Opius (Opius) microsomaticus Fischer, 1965. Polskie Pismo Ent. 35: 15. ๆ.

middlekauffi Fischer. Calif. Host: Pegomya hyoscyami hyoscyami (Panz.).

Opius (Opius) middlekauffi Fischer, 1964. Polskie Pismo Ent. 34: 244. + , ठ.

montanus (Ashmead). Mich., Colo., Calif. Host: Liriomyza sp.

Adelura montana Ashmead, 1890. Colo. Biol. Assoc., Bul. 1: 19..

myakkensis Fischer. Fla.

Opius (Opius) myakkensis Fischer, 1964. Polskie Pismo Ent. 34: 404. ð.

nanus Provancher. Calif.

Opius nanus Provancher, 1888. Addit. Corr. Faune Ent. Canada Hym., p. 382. ๆ, ð.

nigritellae Fischer. Calif.

Opius (Opius) nigritellae Fischer, 1964. Polskie Pismo Ent. 34: 342. ․

nigrocastaneus Viereck. N. Y., Iowa, Kans.

Opius nigrocastaneus Viereck, 1905. Kans. Acad. Sci., Trans. 19: 272. ð.

Opius (Opius) amensis Fischer, 1964. Polskie Pismo Ent. 34: 309. ๆ, ठ́.

Taxonomy: Marsh, 1974. Ent. Soc. Wash., Proc. 76: 286.

niobe Fischer. N. Y., Md.

Opius niobe Fischer, 1970. Polskie Pismo Ent. 40: 794. $ๆ$.

nitidulator (Nees). Ont., Sask., Wyo., Colo., Alta., B. C., Calif.; Europe. Host: Pegomya hyoscyami hyoscyami (Panz.).

Bracon nitidulator Nees, 1834. Hym. Ichn. Aff. Monog., v. 1, p. 56. ठ.

Opius vittatus Ruschka, 1915. Ztschr. Angew. Ent. 2: 395. ‡, ठ.

nomininguensis Fischer. Que.

Opius (Opius) nomininguensis Fischer, 1965. Polskie Pismo Ent. 35: 50. ๆ.

northearolinensis Fischer. N. Y., Md., N. C., Ont., Mich., Tex.

Opius (Opius) northcarolinensis Fischer, 1964. Polskie Pismo Ent. 34: 513. ๆ, ठ.

notaulicus Fischer. Que., Mass., R. I.

Opius (Opius) notaulicus Fischer, 1964. Polskie Pismo Ent. 34: 217. ๆ, ठ. 
oralis Fischer. Kans.

Opius (Opius) oralis Fischer, 1965. Polskie Pismo Ent. 35: 52. ^.

ordinarius Fischer. Wash., Oreg., Calif. Host: Agromyza sp., Liriomyza sp.

Opius (Opius) ordinarius Fischer, 1964. Polskie Pismo Ent. 34: 450. $\%$, ð.

ornatigaster Fischer. Calif. Host: Agromyza sp.

Opius (Opius) ornatigaster Fischer, 1964. Polskie Pismo Ent. 34: 515. ๆ.

ornatus Fischer. N. Y. s. to S. C.; Mich., Minn.

Opius (Opius) ornatus Fischer, 1964. Polskie Pismo Ent. 34: 262. ९, ơ.

oscinidis (Ashmead). N. Y. s. to Ga.; Ind., Kans. Host: Chlorops sp., Phytomyza plantaginis R. D.

Rhyssalus oscinidis Ashmead, 1889 (1888). U. S. Natl. Mus., Proc. 11: 630. ठ. Opius (Opius) pusilloides Fischer, 1964. Polskie Pismo Ent. 34: 433. \&, ठ́.

Taxonomy: Marsh, 1974. Ent. Soc. Wash., Proc. 76: 286.

otiosus Gahan. Tex. Host: Agromyza parvicornis Loew.

Opius otiosus Gahan, 1917. U. S. Natl. Mus., Proc. 53: 202. ^, ১.

pallas Fischer. S. C.

Opius pallas Fischer, 1970. Polskie Pismo Ent. 40: 797..

pallidipalpalis Fischer. Md., N. C., S. C.

Opius (Opius) pallidipalpalis Fischer, 1964. Polskie Pismo Ent. 34: 482. \&, ठ. Opius (Opius) paratakomanus Fischer, 1964. Polskie Pismo Ent. 34: 484..

Taxonomy: Marsh, 1974. Ent. Soc. Wash., Proc. 76: 287.

pallipes Wesmael. Alta., Wash., Oreg., Calif.

Opius pallipes Wesmael, 1835. Nouv. Mem. Acad. Sci. Bruxelles 9: 118. ஒ, đ.

Opius pallidipes Marshall, 1891. Ent. Soc. London, Trans. 1891: 27. Emend.

pandora Fischer. S. C.

Opius pandora Fischer, 1970. Polskie Pismo Ent. 40: 799..

paradisiacus Fischer. Fla.

Opius (Opius) paradisiacus Fischer, 1964. Polskie Pismo Ent. 34: 456. ९.

paralleliformis Fischer. N. Y.

Opius (Opius) paralleliformis Fischer, 1964. Polskie Pismo Ent. 34: 452. đo.

parawattacooanus Fischer. S. C., B. C.

Opius (Opius) parawattacooanus Fischer, 1964. Polskie Pismo Ent. 34: 517. ๆ.

parkeranus Fischer. Ariz.

Opius (Opius) parkeranus Fischer, 1964. Polskie Pismo Ent. 34: 458..

parkercreekensis Fischer. S. C., Ariz., Calif.

Opius (Opius) parkercreekensis Fischer, 1964. Polskie Pismo Ent. 34: 486. \&.

parvifossa Fischer. Que., N. B., N. S., Vt., N. Y., Ont., Mich., Tenn., Wis., Minn., Kans.

Opius (Opius) parvifossa Fischer, 1964. Polskie Pismo Ent. 34: 294. १, ठ̌.

paulior Fischer. Que.

Opius (Opius) paulior Fischer, 1965. Polskie Pismo Ent. 35: 107..

paulus Fischer. Calif. Host: Agromyza sp., Phytobia (Calycomyza) jucunda (Wulp).

Opius (Opius) paulus Fischer, 1965. Polskie Pismo Ent. 35: 109. ठ̊.

pauper Fischer. Wash., Oreg., Calif. Host: Agromyza sp.

Opius (Opius) pauper Fischer, 1964. Polskie Pismo Ent. 34: 519. , ठ゚.

pechumani Fischer. Ariz.

Opius pechumani Fischer, 1970. Math.-Naturw. Kl. Osterr. Akad. Wiss., Anz. 1970, no. 1, p.

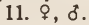

peleus Fischer. S. C.

Opius peleus Fischer, 1970. Polskie Pismo Ent. 40: 802. ठ์.

Opius telephosi Fischer, 1970. Polskie Pismo Ent. 40: 812..

Taxonomy: Marsh, 1974. Ent. Soc. Wash., Proc. 76: 287.

pendulus Haliday. Que., Maine, N. Y., Ont.; Europe.

Opius pendulus Haliday, 1837. Ent. Mag. 4: 205. ๆ, ๖. 
pequodorum Viereck. Conn., S. C., Fla.

Opius (Hypolabis) pequodorum Viereck, 1917 (1916). Conn. State Geol. and Nat. Hist.

Survey, Bul. 22, p. 183 . ?.

Opius (Opius) testaceifactus Fischer, 1964. Polskie Pismo Ent. 34: 220. \&, ơ.

Taxonomy: Marsh, 1974. Ent. Soc. Wash., Proc. 76: 287.

perminutus Fischer. Calif. Host: Phytomyza sp.

Opius (Opius) perminutus Fischer, 1964. Polskie Pismo Ent. 34: 332. ๆ, ठ.

perpygmaeus Fischer. Md., S. C.

Opius (Opius) perpygmaeus Fischer, 1964. Polskie Pismo Ent. 34: 521. ९, ठ์.

petiolaris Fischer. Fla.

Opius (Opius) petiolaris Fischer, 1965. Polskie Pismo Ent. 35: 56. ठో.

phoenicensis Fischer. Idaho, Ariz., Calif. Host: Liriomyza sp.

Opius (Opius) phoenicensis Fischer, 1965. Polskie Pismo Ent. 35: 71. १, ठ’.

piceus Thomson. Que., Wash.; Europe.

Opius piceus Thomson, 1895. Opusc. Ent., fasc. 20, p. 2198..

pickensanus Fischer. N. Y., Pa., N. C., S. C., Minn.

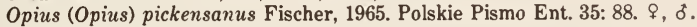

pilosinotum Fischer. N. Y.

Opius (Opius) pilosinotum Fischer, 1964. Polskie Pismo Ent. 34: 522. ๆ.

pilosus Fischer. Calif.

Opius (Opius) pilosus Fischer, 1964. Polskie Pismo Ent. 34: 333..

pisgahensis Fischer. N. Y., N. C.

Opius (Opius) pisgahensis Fischer, 1964. Polskie Pismo Ent. 34: 323. ठ.

polyzonius Wesmael. N. Y., Md., Ont., Wis., Minn., N. Dak., Sask., B. C.; Europe.

Opius polyzonius Wesmael, 1835. Nouv. Mem. Acad. Sci. Bruxelles 9: 136. ९, ठ์.

porteri Fischer. Fla.

Opius (Opius) porteri Fischer, 1964. Polskie Pismo Ent. 34: 431..

prolongatus Fischer. S. C.

Opius (Opius) prolongatus Fischer, 1964. Polskie Pismo Ent. 34: 459. 9.

provancheri Dalla Torre. N. Y. s. to Ga., w. to Ont. and Iowa; Kans., Colo., Ariz.

Opius muficeps Provancher, 1886. Addit. Corr. Faune Ent. Canada Hym., p. 124. \&. Preoce.

by Wesmael, 1835.

Opius provancheri Dalla Torre, 1898. Cat. Hym., v. 4, p. 64. N. name for muficeps

Provancher.

Opius demodokos Fischer, 1970. Polskie Pismo Ent. 40: 785. ९, ठั.

Taxonomy: Marsh, 1974. Ent. Soc. Wash., Proc. 76: 287.

pseudocolumbiacus Fischer. N. C.

Opius (Opius) pseudocolumbiacus Fischer, 1964. Polskie Pismo Ent. 34: 489. ơ.

pseudoromensis Fischer. N. Y.

Opius (Opius) pseudoromensis Fischer, 1965. Polskie Pismo Ent. 35: 58..

punctipes Fischer. S. C., Fla.

Opius (Opius) punctipes Fischer, 1964. Polskie Pismo Ent. 34: 405. ๆ.

Opius (Opius) cellulosus Fischer, 1965. Polskie Pismo Ent. 35: 29. १, ठ์.

Taxonomy: Marsh, 1974. Ent. Soc. Wash., Proc. 76: 287.

rainierensis Fischer. Wash.

Opius (Opius) rainierensis Fischer, 1964. Polskie Pismo Ent. 34: 344. ९.

relativus $\mathrm{Fischer}$. S. C.

Opius (Opius) relativus Fischer, 1964. Polskie Pismo Ent. 34: 435. ९, ठ.

restrictus Fischer. Md., S. C.

Opius (Opius) restrictus Fischer, 1964. Polskie Pismo Ent. 34: 407. १, ơ.

resupinus Fischer. Calif.

Opius (Opius) resupinus Fischer, 1964. Polskie Pismo Ent. 34: 409. ₹. 
rheasilviae Fischer. N. Y.

Opius rheasilviae Fischer, 1970. Polskie Pismo Ent. 40: 804. ๆ.

richardsi Fischer. Calif.

Opius (Opius) richardsi Fischer, 1965. Polskie Pismo Ent. 35: 111..

richmondi Gahan. Maine, Minn. Host: Rhagoletis pomonella (Walsh).

Opius richmondi Gahan, 1919. Ent. Soc. Wash., Proc. 21: 165. \%, §.

robsonensis Fischer. B. C., Wash.

Opius (Opius) robsonensis Fischer, 1964. Polskie Pismo Ent. 34: 300. , ठ.

romensis Fischer. N. Y.

Opius (Opius) romensis Fischer, 1965. Polskie Pismo Ent. 35: 59. ९.

romensoides Fischer. Que.

Opius (Opius) romensoides Fischer, 1965. Polskie Pismo Ent. 35: 61. ð.

rosicola Muesebeck. Wis., Ill., Minn., Sask., Wash., Oreg., Calif. Host: Rhagoletis basiola (0.

$\mathrm{S}.), R$. cingulata indifferens Curran.

Opius rosicola Muesebeck, 1950 (1949). Canad. Ent. 81: 254. ๆ, ठ.

Biology: Balduf, 1959. Ill. Biol. Monog. 26: 32-40.

rudiformis Fischer. Ont.; Europe.

Opius (Opius) rudiformis Fischer, 1958. Beitr. z. Ent. 8: 201. 9.

rudis Wesmael. Maine, N. Y., N. J., Ont., Minn., N. Dak., Sask., Idaho, Utah, Calif.; Europe. Host: Agromyza sp.

Opius rudis Wesmael, 1835. Nouv. Mem. Acad. Sci. Bruxelles 9: 141. ₹, ठ.

Neopius carinaticeps Gahan, 1917. U. S. Natl. Mus., Proc. 53: 204. ̊, ó.

ruficolor Fischer. Fla.

Opius (Opius) ruficolor Fischer, 1964. Polskie Pismo Ent. 34: 492. ․

rufipleurum Fischer. N. Y., S. C.

Opius (Opius) rufipleurum Fischer, 1964. Polskie Pismo Ent. 34: 264. ‡, ð.

rufocinctus Gahan. Md., N. C., S. C., Ill., Mo., Kans.

Opius rufocinctus Gahan, 1915. U. S. Natl. Mus., Proc. 49: 84..

sabroskyi Fischer. Va.

Opius (Opius) sabroskyi Fischer, 1964. Polskie Pismo Ent. 34: 396. \&, ๖.

salmonensis Fischer. N. Y., Minn., B. C.

Opius (Opius) salmonensis Fischer, 1964. Polskie Pismo Ent. 34: 438. ?.

severini Fischer. Que., N. Y., Mich., Iowa, S. Dak., Colo., Utah, Alta.

Opius (Opius) severini Fischer, 1964. Polskie Pismo Ent. 34: 223.,$~ ð$.

shuleri Fischer. S. C.

Opius (Opius) schuleri Fischer, 1964. Polskie Pismo Ent. 34: 524. ठ.

sierraanchaensis Fischer. Ariz.

Opius (Opius) sierraanchaensis Fischer, 1964. Polskie Pismo Ent. 34: 346. ठ.

similarius Fischer. N. Y., N. C., Minn., Wash. Host: Phytomyza delphiniae Frost.

Opius (Opius) similarius Fischer, 1964. Polskie Pismo Ent. 34: 267. $९, \delta$.

smithi Fischer. D. C., Va., S. C.

Opius (Opius) smithi Fischer, 1964. Polskie Pismo Ent. 34: 410. १, ठ.

southcarolinensis Fischer. S. C.

Opius (Opius) southcarolinensis Fischer, 1964. Polskie Pismo Ent. 34: 526. ठ.

stenopectus Fischer. S. C.

Opius (Opius) stenopectus Fischer, 1964. Polskie Pismo Ent. 34: 461. ठ.

striativentris Gahan. N. Y. s. to Ga. and Ala.; Ohio, Mich., Kans. Host: Phytomyza ilicicola Loew, P. ilicis Curtis.

Opius striativentris Gahan, 1915. U. S. Natl. Mus., Proc. 49: 89. \&, ð.

succineus Gahan. Ont. and N. Y. s. to N. C., w. to Alta. Host: Agromyza parvicornis Loew, Liriomyza sp.

Opius succineus Gahan, 1913. Canad. Ent. 45: 149. ^, ठ. 
suturalis Gahan. Tex., Ariz., Nev., Calif. Host: Haplomyza sp., Liriomyza sp., L. munda Frick, L. pictella (Thomson), L. propepusilla Frost.

Opius suturalis Gahan, 1913. Canad. Ent. 45: 146. o.

sybille Fischer. D. C.

Opius sybille Fischer, 1970. Polskie Pismo Ent. 40: 807. \&.

tabellariae Fischer. N. Y., Minn. Host: Rhagoletis tabellaria (Fitch).

Opius (Opius) tabellariae Fischer, 1964. Polskie Pismo Ent. 34: 305. ९, ठ.

tablerockensis Fischer. S. C.

Opius (Opius) tablerockensis Fischer, 1964. Polskie Pismo Ent. 34: 250. \&, ठ.

takomaanus Fischer. N. Y., Md., S. C.

Opius (Opius) takomaanus Fischer, 1965. Polskie Pismo Ent. 35: 20. ð.

tangens Fischer. Fla.

Opius (Opius) tangens Fischer, 1964. Polskie Pismo Ent. 34: 442. ․

telamonis Fischer. S. C.

Opius telamonis Fischer, 1970. Polskie Pismo Ent. 40: 810. \&.

telramundi Fischer. S. C.

Opius telramundi Fischer, 1970. Polskie Pismo Ent. 40: 815. ९.

thalis Fischer. S. C.

Opius thalis Fischer, 1970. Polskie Pismo Ent. 40: 817. \&.

tibialis (Ashmead). Mass. s. to Ga.; Minn. Host: Liriomyza melanopyga (Loew).

Adelura tibialis Ashmead, 1893. Canad. Ent. 25: 79. $\delta$.

Opius (Opius) extiratus Fischer, 1964. Polskie Pismo Ent. 34: 473. ठे.

Taxonomy: Marsh, 1974. Ent. Soc. Wash., Proc. 76: 287.

townesi Fischer. Md., Va.

Opius (Opius) townesi Fischer, 1965. Polskie Pismo Ent. 35: 22. १, ð.

troyensis Fischer. N. Y.

Opius (Opius) troyensis Fischer, 1964. Polskie Pismo Ent. 34: 325. \&.

turneri Gahan. N. Y., Va., S. C., Fla., Ont., Mich., Wis., Miss., Minn., Alta., B. C. Opius turneri Gahan, 1919. Ent. Soc. Wash., Proc. 21: 163. \&, ठ.

utahensis Gahan. Que., Mass., Del., Va., Fla., Ohio, Tenn., Minn., Iowa, S. Dak., Utah. Host: Agromyza parvicornis Loew.

Opius utahensis Gahan, 1913. Canad. Ent. 45: 145. \&, ð.

virentis Fischer. Del., Va., Ohio, Mo., Kans. Host: Melanagromyza virens (Loew).

Opius (Opius) virentis Fischer, 1965. Polskie Pismo Ent. 35: 113. १, ठ.

walleyi Fischer. Fla.

Opius (Opius) walleyi Fischer, 1964. Polskie Pismo Ent. 34: 444. o.

wattacooanus Fischer. S. C.

Opius (Opius) wattacooanus Fischer, 1965. Polskie Pismo Ent. 35: 63. ð.

weemsi Fischer. N. Y., N. C.

Opius (Opius) weemsi Fischer, 1964. Polskie Pismo Ent. 34: 446. ९, ठ.

UNPLACED TAXON OF OPIINAE

Trigonospilus hopkinsi Ashmead, 1901. U. S. Natl. Mus., Proc. 23: 134. Type lost, exact generic placement uncertain.

\section{SUBFAMILY ALYSIINAE}

This subfamily, sometimes called the "exodont braconids," is characterized by widely spaced mandibles with teeth that curve outward and do not touch when closed. The hosts are dipterous larvae with pupation taking place within the host puparium. Most North American genera and species are unstudied.

Taxonomy: Griffiths, 1964. Beitr. z. Ent. 14: 830-832. -Shenefelt, 1974. Hym. Cat., part 11, p. 937-1113 (cat. World spp.). 


\section{TRIBE DACNUSINI}

Griffiths (see references below) has studied the European species but also made extensive revisions of the World genera. Most of the described North American species are placed in the genera below according to his concepts

Hosts are restricted to the dipterous family Agromyzidae.

Taxonomy: Griffiths, 1964. Beitr. z. Ent. 14: 823-913 (includes diagnoses and key to World genera). -Griffiths, 1966. Beitr. z. Ent. 16: 551-605, 775-951. -Griffiths, 1967. Beitr. z.

Ent. 17: 654-696. -Griffiths, 1968. Beitr. z. Ent. 18: 5-152.

Biology: Griffiths, 1964. Beitr. z. Ent. 14: 823-913. -Griffiths, 1966. Beitr. z. Ent. 16: 551-605, 775-951. -Griffiths, 1967. Beitr. z. Ent. 17: 654-696. -Griffiths, 1968. Beitr. z. Ent. 18: 5-152.

\section{Genus CHAENUSA Haliday}

Alysia subg. Chaenusa Haliday, 1839. Hym. Brit., fasc. 2, p. 19.

Type-species: Bracon conjugens Nees. Monotypic.

Chorebidea Viereck, 1914. U. S. Natl. Mus., Bul. 83: 32.

Type-species: Alysia (Chorebus) nereidum Haliday. Orig. desig.

Chorebidea Nixon, 1943. Ent. Monthly Mag. 79: 28. Preocc. by Viereck, 1914.

Type-species: Alysia (Chorebus) naiadum Haliday. Orig. desig.

Chorebidella Riegel, 1950. Ent. News 61: 125.

Type-species: Chorebidella bergi Riegel. Orig. desig.

Taxonomy: Griffiths, 1964. Beitr. z. Ent. 14: 847-848, 859 (generic syn. and diag.).

-Shenefelt, 1974. Hym. Cat., part 11, p. 1030-1033 (cat. World spp.).

bergi (Riegel). Conn., N. Y., Mich., Minn., Kans. Host: Hydrellia ascita Cress., H. cruralis Coq.

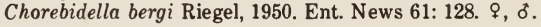

quadriceps (Ashmead). N. Y.

Brachystropha quadriceps Ashmead, 1901. N. Y. State Mus., Bul. 47: 587. ð.

\section{Genus CHOREBUS Haliday}

Chorebus Haliday, 1833. Ent. Mag. 1: 264.

Type-species: Bassus affinis Nees. Desig. by Viereck, 1914. The type-species is in the sense of Haliday 1833, not 1839.

Ametria Foerster, 1862. Naturh. Ver. Rheinlande, Verh. 19: 274.

Type-species: Alysia (Dacnusa) uliginosa Haliday. Orig. desig.

Gyrocampa Foerster, 1862. Naturh. Ver. Rheinlande, Verh. 19: 276.

Type-species: Bassus affinis Nees. Orig. desig.

Stiphrocera Foerster, 1862. Naturh. Ver. Rheinlande, Verh. 19: 276.

Type-species: Stiphrocera nigricornis Foerster. Orig. desig.

Phaenolexis Foerster, 1862. Naturh. Ver. Rheinlande, Verh. 19: 276.

Type-species: Alysia petiolata Nees. Orig. desig.

Etriptes Nixon, 1943. Ent. Monthly Mag. 79: 30.

Type-species: Alysia (Dacnusa) talaris Haliday. Orig. desig.

Paragyrocampa Tobias, 1962. Akad. Nauk. U. S. S. R. Trudy Zool. Inst. 31: 119.

Type-species: Paragyrocampa ophthalmica Tobias. Orig. desig.

Taxonomy: Griffiths, 1964. Beitr. z. Ent. 14: 848-852, 859-860 (generic syn., diag.). -Griffiths,

1968. Beitr. z. Ent. 18: 113-136 (key to some Eur. spp.). - Shenefelt, 1974. Hym. Cat., part

11, p. 1033-1070 (cat. World spp.).

agromyzae (Gahan). Del., Ind. Host: Phytobia (Poemyza) angulata (Loew).

Dacnusa agromyzae Gahan, 1913. Canad. Ent. 45: 153. ?, đ.

alaskensis (Ashmead). Alaska.

Gyrocampa alaskensis Ashmead, 1902. Wash. Acad. Sci., Proc. 4: 242. ?.

aquaticus Muesebeck. Minn., Calif. Host: Hydrellia griseola (Fallen).

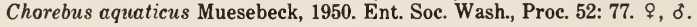


astigmus (Ashmead). N. Y.

Rhizarcha astigma Ashmead, 1901. N. Y. State Mus., Bul. 47: 587. ९, ð.

confusus (Ashmead). Mich.

Dacnusa confusa Ashmead, 1889 (1888). U. S. Natl. Mus., Proc. 11: 650. ठ.

crassitelus (Provancher). Ont., Mich., Iowa.

Dacnusa crassitelus Provancher, 1886. Addit. Corr. Faune Ent. Canada Hym., p. 148..

flavocinctus (Ashmead). D. C., Tenn.

Dacnusa flavocincta Ashmead, 1889 (1888). U. S. Natl. Mus., Proc. 11: 651. ठ.

gracilis (Nees). Ont., B. C.; Europe. Introduced from England. Host: Psila (Chamaepsila) rosae (F.).

Alysia gracilis Nees, 1834. Hym. Ichn. Aff. Monog., v. 1, p. 257. \&, ठ.

harringtoni (Ashmead). Alaska.

Rhizarcha harringtoni Ashmead, 1902. Wash. Acad. Sci., Proc. 4: 242. ठ.

iridicolus (Gahan). Pa., Fla. Host: Phytobia (Dizygomyza) thompsoni Frick. The host was misident. as laterella Zett.

Dacnusa iridicola Gahan, 1919. U. S. Natl. Mus., Proc. 55: 115. ‥

laeviceps (Cresson). Tex.

Dacnusa laeviceps Cresson, 1872. Amer. Ent. Soc., Trans. 4: 191. ๆ.

minimus (Cresson). Tex.

Dacnusa minima Cresson, 1872. Amer. Ent. Soc., Trans. 4: 191. ð.

parvus (Provancher). Que.

Rhitigaster parvus Provancher, 1883. Nat. Canad. 14: 18..

rondanii (Giard). Mass.; Europe. Host: Ophiomyia simplex (Loew).

Dacnusa rondanii Giard, 1904. Soc. Ent. de France, Bul. 87: 181.

Dacnusa galba Nixon, 1944. Ent. Monthly Mag. 80: 90, 93. ठ.

Taxonomy: Griffiths, 1967. Beitr. z. Ent. 17: 669-671.

sachemellus (Viereck). Conn.

Dacnusa sachemella Viereck, 1917 (1916). Conn. State Geol. and Nat. Hist. Survey, Bul. 22, p. 213..

spatulatus (Provancher). Ont.

Dacnusa spatulata Provancher, 1886. Addit. Corr. Faune Ent. Canada Hym., p. 149. §.

\section{Genus COELINIDEA Viereck}

Coelinidea Viereck, 1913. U. S. Natl. Mus., Proc. 44: 555.

Type-species: Stephanus niger Nees. Orig. desig.

Eriocoelinius Viereck, 1913. U. S. Natl. Mus., Proc. 44: 555.

Type-species: Coelinius longulus Ashmead. Orig. desig.

Taxonomy: Griffiths, 1964. Beitr. z. Ent. 14: 844-847, 857-858 (generic syn., diag., considered as subgenus of Coelinizis Nees). - Shenefelt, 1974. Hym. Cat., part 11, p. 1070-1074 (cat. World spp.).

ferruginea Gahan. Ont. s. to Mo., w. to Alta., Oreg., and Ariz. Host: Meromyza americana Fitch.

Coelinidea fermuginea Gahan, 1913. U. S. Natl. Mus., Proc. 46: 434. ९, ठ.

hopkinsii (Ashmead). N. S. and Que. s. to Va., w. to Man., Colo., and Tex.

Coelinius Hopkinsii Ashmead, 1893. Canad. Ent. 25: 79..

linearis (Provancher). Que:

Microctonus linearis Provancher, 1886. Addit. Corr. Faune Ent. Canada Hym., p. 127. \&.

longula (Ashmead). Colo.

Coelinius longulus Ashmead, 1889 (1888). U. S. Natl. Mus., Proc. 11: 651. ठ'.

meromyzae (Forbes). Maine s. to Md., w. to Oreg. and Calif. Host: Meromyza americana Fitch.

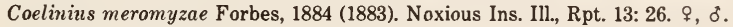

Coelinius nigripes Ashmead, 1890. Colo. Biol. Assoc., Bul. 1: 19. ठ̊. N. syn. 
occom Viereck. Conn.

Coelinidea occom Viereck, 1917 (1916). Conn. State Geol. and Nat. Hist. Survey, Bul. 22, p. 212. ठ.

\section{Genus DACNUSA Haliday}

Alysia subg. Dacnusa Haliday, 1833. Ent. Mag. 1: 264.

Type-species: Bracon areolaris Nees. Desig. by Muesebeck and Walkley, 1951.

A phanta Foerster, 1862. Naturh. Ver. Rheinlande, Verh. 19: 273.

Type-species: Aphanta hospita Foerster. Orig. desig.

Agonia Foerster, 1862. Naturh. Ver. Rheinlande, Verh. 19: 274.

Type-species: Alysia (Dacnusa) abdita Haliday. Orig. desig.

Pachysema Foerster, 1862. Naturh. Ver. Rheinlande, Verh. 19: 274.

Type-species: Alysia (Dacnusa) macrospila Haliday. Orig. desig.

Brachystropha Foerster, 1862. Naturh. Ver. Rheinlande, Verh. 19: 274.

Type-species: Brachystropha monticola Foerster. Orig. desig.

Tanystropha Foerster, 1862. Naturh. Ver. Rheinlande, Verh. 19: 275.

Type-species: Tanystropha haemarrhoa Foerster. Orig. desig.

Rhizarcha Foerster, 1862. Naturh. Ver. Rheinlande, Verh. 19: 275.

Type-species: Bracon areolaris Nees. Orig. desig.

Liposcia Foerster, 1862. Naturh. Ver. Rheinlande, Verh. 19: 276.

Type-species: Liposcia discolor Foerster. Orig. desig.

Radiolaria Provancher, 1886. Addit. Corr. Faune Ent. Canada Hym., p. 154.

Type-species: Radiolaria clavata Provancher. Monotypic.

Taxonomy: Griffiths, 1964. Beitr. z. Ent. 14: 853-854, 860-861 (generic syn., diag.). - Griffiths, 1966. Beitr. z. Ent. 16: 892-899 (key to Eur. spp.). - Shenefelt, 1974. Hym. Cat., part 11, p. 1081-1100 (cat. World spp.).

clavata (Provancher). Que.

Radiolaria clavata Provancher, 1886. Addit. Corr. Faune Ent. Canada Hym., p. 155. $q$. dubiosa (Ashmead). Alaska.

Liposcia dubiosa Ashmead, 1902. Wash. Acad. Sci., Proc. 4: 243. ठे.

oscinidis Ashmead. Mo. Ecology: Found with Oscinis sp. on honeysuckle.

Dacnusa oscinidis Ashmead, 1889 (1888). U. S. Natl. Mus., Proc. 11: 650. ?.

scaptomyzae Gahan. N. Y., Md., D. C. Host: Scaptomyza flaveola (Meig.).

Dacnusa scaptomyzae Gahan, 1913. Canad. Ent. 45: 150. ९, ơ.

Nomina Nuda in Dacnusa Haliday

Pachysema americana Ashmead, 1905. In Nason, Ent. News 16: 293.

Tanystropha americana Ashmead, 1899. In Smith, Ins. of N. J., p. 586.

Dacnusa illinoisensis Ashmead, 1905. In Nason, Ent. News 16: 293.

Rhizarcha nigripes Ashmead, 1902. In Slosson, Ent. News 13: 321.

Rhizarcha rubricincta Ashmead, 1905. In Nason, Ent. News 16: 293.

Dacnusa smithii Ashmead, 1899. In Smith, Ins. of N. J., p. 586.

\section{Genus EXOTELA Foerster}

Exotela Foerster, 1862. Naturh. Ver. Rheinlande, Verh. 19: 274.

Type-species: Exotela cyclogaster Foerster. Orig. desig.

Mesora Foerster, 1862. Naturh. Ver. Rheinlande, Verh. 19: 275.

Type-species: Alysia (Dacnusa) glivipes Haliday. Orig. desig.

Toxela Nixon, 1943. Ent. Monthly Mag. 79: 29.

Type-species: Alysia (Dacnusa) glivipes Haliday. Orig. desig.

Antrusa Nixon, 1943. Ent. Monthly Mag. 79: 30.

Type-species: Dacnusa melanocera Thompson. Orig. desig.

One undescribed species occurs in North America.

Taxonomy: Griffiths, 1964. Beitr. z. Ent. 14: 854-855, 862 (generic syn., diag.). - Griffiths,

1966. Beitr. z. Ent. 16: 588-589, 876-878 (key to Eur. spp.). - Shenefelt, 1974. Hym. Cat., part 11, p. 1101-1105 (cat. World spp.). 


\section{Genus SYMPHYA Foerster}

Aenone Haliday, 1838. Ent. Mag. 5: 214. Preocc. by Lamarck, 1818.

Type-species: Sigalphus mandibularis Nees. Desig. by Westwood, 1839.

Oenone Haliday, 1839. Hym. Brit. 2: 3. Emend. Preocc. by Lamarck, 1818.

Symphya Foerster, 1862. Naturh. Ver. Rheinlande, Verh. 19: 273.

Type-species: Sigalphus mandibularis Nees. Orig. desig.

Taxonomy: Rohwer, 1914. Ent. News 25: 168-172 (No. Amer. spp.). -Griffiths, 1964. Beitr. z.

Ent. 14: 858-859 (generic syn., diag.). - Shenefelt, 1974. Hym. Cat., part 11, p. 1109-1111

(cat. World spp.).

agromyzae Rohwer. Conn., N. Y., D. C. Host: Phytobia pruinosa (Coq.).

Sympha(!) agromyzae Rohwer, 1914. Ent. News 25: 171. 9.

belfragei (Ashmead). Tex.

Oenone belfragei Ashmead, 1889 (1888). U. S. Natl. Mus., Proc. 11: 649. ९, ठั.

lucida Rohwer. Wash.

Sympha(!) lucida Rohwer, 1914. Ent. News 25: 169. ठ.

nigricornis Rohwer. Colo.

Sympha(!) nigricornis Rohwer, 1914. Ent. News 25: 170..

portlandica Rohwer. Minn., Oreg.

Sympha(!) portlandica Rohwer, 1914. Ent. News 25: 170. ठ.

sericea (Provancher). Ont., W. Va., Mich.

Oenone sericea Provancher, 1888. Addit. Corr. Faune Ent. Canada Hym., p. 394..

\section{TRIBE ALYSIINI}

Taxonomy: Fischer, 1971. Polskie Pismo Ent. 41: 22-25 (key to World genera).

\section{Genus ALYSIA Latreille}

Alysia Latreille, 1804. Nouv. Dict. Hist. Nat., v. 24, p. 173.

Type-species: Ichneumon manducator Panzer. Monotypic.

Cechenus Illiger, 1807. In Rossi, Fauna Etrusca, v. 2, p. 54.

Type-species: Ichneumon manducator Panzer. Monotypic.

Bassus Nees, 1814 (1812). Mag. Gesell. Naturf. Freunde Berlin 6: 201.

Type-species: Ichneumon manducator Panzer. Desig. by Muesebeck and Walkley, 1951.

Epiclista Foerster, 1862. Naturh. Ver. Rheinlande, Verh. 19: 264.

Type-species: Epiclista erythrogaster Foerster. Orig. desig.

Goniarcha Foerster, 1862. Naturh. Ver. Rheinlande, Verh. 19: 265.

Type-species: Alysia lucicola Haliday. Orig. desig.

Anarcha Foerster, 1862. Naturh. Ver. Rheinlande, Verh. 19: 265.

Type-species: Anarcha notabilis Foerster. Orig. desig.

Strophaea Foerster, 1862. Naturh. Ver. Rheinlande, Verh. 19: 265.

Type-species: Alysia rufidens Nees. Orig. desig.

Revision: Fischer, 1971. Polskie Pismo Ent. 41: 25-59 (some Eur. spp.).

Taxonomy: Fischer, 1971. Polskie Pismo Ent. 41: 25 (generic syn.). - Shenefelt, 1974. Hym.

Cat., part 11, p. 939-955 (cat. World spp.).

alticola (Ashmead). Que., Colo., B. C., Oreg., Calif.

Pentapleura alticola Ashmead, 1890. Colo. Biol. Assoc., Bul. 1: 18...

amabilis Dalla Torre. "North America."

Alysia fuscipennis Brulle, 1846. In Lepeletier, Hist. Nat. Ins., Hym., v. 4, p. 516. ठ。.

Preocc. by Haliday, 1838.

Alysia amabilis Dalla Torre, 1898. Cat. Hym., v. 4, p. 44. N. name for fuscipennis Brulle.

cariosa Marsh. Tex., Ariz. Ecology: Found with carrion-infesting flies.

Alysia cariosa Marsh, 1968. Ent. Soc. Wash., Proc. 70: 209. ₹, ठ. 
Biology: Lindquist, 1932. Jour. Econ. Ent. 25: 414-415 (as Alysia ridibunda Say). - Roberts, 1935. Jour. Agr. Res. 50: 481-484 (as Alysia ridibunda Say). - Lindquist, 1940. Ent. Soc.

Amer., Ann. 33: 104-112 (as Alysia ridibunda Say).

coxalis (Ashmead). Alaska.

Anarcha coxalis Ashmead, 1902. Wash. Acad. Sci., Proc. 4: 241. ठ。.

fossulata Provancher. Alaska, Calif. Host: Blow flies.

Alysia fossulata Provancher, 1888. Addit. Corr. Faune Ent. Canada Hym., p. 391..

Biology: Roberts, 1935. Jour. Agr. Res. 50: 484.

lucens Provancher. Canada.

Alysia lucens Provancher, 1881. Nat. Canad. 12: 202..

manducator (Panzer). Europe; Greenland.

Ichneumon manducator Panzer, 1799. Faune Ins. German., heft 72, no. 4..

micans (Viereck). N. Mex.

Anarcha micans Viereck, 1903. Amer. Ent. Soc., Trans. 29: 93. ?.

ridibunda Say. Ont. s. to Fla., w. to Kans. and Tex. Host: Oxysarcodexia ventricosa (Wulp);

dung-feeding flies. All references to Alysia ridibunda Say as a parasite of

carrion-feeding flies refer to Alysia cariosa Marsh.

Alysia ridibunda Say, 1828. Contrib. Maclur. Lyc. Phila. 1: 77. ठ.

Opius macrocephalus Provancher, 1886. Addit. Corr. Faune Ent. Canada Hym., p. 123. ؟.

Taxonomy: Burgess and Wingo, 1968. Ent. Soc. Wash., Proc. 70: 207. -Marsh, 1968. Ent. Soc. Wash., Proc. 70: 208-209.

Biology: Burgess and Wingo, 1968. Ent. Soc. Wash., Proc. 70: 204-208 (host indicated as Ravinia assidua (Wlkr.) which is a misident. of Oxysarcodexia ventricosa (Wulp)).

\section{Genus APHAERETA Foerster}

Aphaereta Foerster, 1862. Naturh. Ver. Rheinlande, Verh. 19: 264.

Type-species: Alysia cephalotes Haliday. Orig. desig.

Trichesia Provancher, 1881. Nat. Canad. 12: 203.

Type-species: Trichesia auripes Provancher. Monotypic.

Trinaria Provancher, 1886. Addit. Corr. Faune Ent. Canada Hym., p. 149.

Type-species: Trinaria pilicornis Provancher. Monotypic.

Aphaerete Dalla Torre, 1898. Cat. Hym., v. 4, p. 41. Emend.

Revision: Fischer, 1966. Reichenbachia 6: 155-173 (No. Amer. spp.).

Taxonomy: Shenefelt, 1974. Hym. Cat., part 11, p. 956-964 (cat. World spp.).

colei Marsh. Mass., Conn., Pa. Host: Aulacigaster leucopeza (Meig.).

Aphaereta colei Marsh, 1969. Ent. Soc. Wash., Proc. 71: 418. ๆ, ठ.

dipterica Fischer. Newfoundland, Md. Ecology: Found with "Diptera in shell of snail."

Aphaereta dipterica Fischer, 1966. Reichenbachia 6: 156. ๆ, ठ.

excavata McComb. Ga. Host: Sarcophaga sp.

Aphaereta excavata McComb, 1960. Ent. News 71: 176. ९, ठ์.

genevensis Fischer. N. Y. Host: Dryomyzidae?

Aphaereta genevensis Fischer, 1966. Reichenbachia 6: 161. + , o.

ithacensis Fischer. N. Y.

Aphaereta ithacensis Fischer, 1966. Reichenbachia 6: 162. \&, ठ.

juddi Fischer. Ont., Mich., Ohio. Ecology: In "puparium in snail."

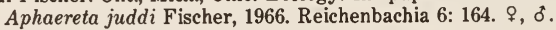

masoni McComb. Ont., Utah, Idaho. Host: Cordilura sp.

Aphaereta masoni McComb, 1960. Ent. News 71: 177. $९$, $\delta$.

muesebecki Marsh. Va., Ky., S. C., Ga., Fla., Miss., Ark. Host: Fannia canalicularis (L.), Musca domestica L.

Aphaereta muesebecki Marsh, 1969. Ent. Soc. Wash., Proc. 71: 417. \&, ठ.

Aphaereta soronastes Mason, 1971. Ent. Soc. Wash., Proc. 73: 139. §, ठै. 
pallipes (Say). North America; Hawaii. Host: Atrichomelina pubera (Loew), Blaesoxipha kellyi (Aldr.), Calycomyza jucunda (Wulp), Haematobia irritans (L.), Helicobia rapax (Wlkr.), Hylemya antiqua (Meig.), H. brassicae (Bouche), H. platura (Meig.), Lucilia sp., Musca autumnalis DeG., M. domestica L., Muscina assimilis (Fallen), Orthiellia caesarion (Meig.), Oxysarcodexia ventricosa (Wulp), Ravinia derelicta (Wlkr.), $R$. latisetosa Parker, R. lherminieri (Rob.-Desv.), R. querula (Wlkr.), Sarcophaga aldrichi Parker, S. houghi Aldr., Tritoxa flexa (Wied.).

Alysia pallipes Say, 1828. Contrib. Maclur. Lyc. Phila. 1: 77.

Trichesia auripes Provancher, 1881. Nat. Canad. 12: 203. ๆ, ठ.

Tinaria pilicornis Provancher, 1886. Addit. Corr. Faune Ent. Canada Hym., p. 149.. Aphaereta muscae Ashmead, 1889 (1888). U. S. Natl. Mus., Proc. 11: 646. \%, ó. Aphaereta californica Ashmead, 1889 (1888). U. S. Natl. Mus., Proc. 11: 647. ९. Aphaereta oscinidis Ashmead, 1889 (1888). U. S. Natl. Mus., Proc. 11: 647.. Aphaereta pallidipes Dalla Torre, 1898. Cat. Hym., v. 4, p. 42. Emend.

Aphaereta delosa Viereck, 1905. Kans. Acad. Sci., Trans. 19: 283. ๆ, $\delta$.

Aphaereta subtricarinata Viereck, 1905. Kans. Acad. Sci., Trans. 19: 283..

Aphaereta pegomyiae Brues, 1907. Extr. MS. Rpt. Minn. State Ent., p. 4. $\%$,.

Aphaereta sarcophagae Gahan, 1914. U. S. Natl. Mus., Proc. 48: 158. ‡, ठ.

Taxonomy: McComb, 1958. Ent. Soc. Wash., Proc. 60: 223-224.

Biology: Salkeld, 1959. Canad. Ent. 91: 93-97. - Hauser and Wingo, 1967. Jour. Econ. Ent. 60:

731-733. - Thomas and Wingo, 1968. Jour. Econ. Ent. 61: 148-152.

Morphology: Salkeld, 1959. Canad. Ent. 91: 93-97 (larvae).

scirpi Fischer. Mich. Host: Diptera, unknown species in Scirpus occidentalis Chase.

Aphaereta scirpi Fischer, 1966. Reichenbachia 6:170. $\uparrow, \delta$.

varipedis Fischer. N. Y., Va., W. Va. Host: Cordilura varipes (Wlkr.).

Aphaereta varipedis Fischer, 1966. Reichenbachia 6: 171. ๆ, ठ.

\section{Genus ASOBARA Foerster}

Asobara Foerster, 1862. Naturh. Ver. Rheinlande, Verh. 19: 267.

Type-species: Alysia tabida Nees. Orig. desig.

Spanista Foerster, 1862. Naturh. Ver. Rheinlande, Verh. 19: 267.

Type-species: Spanista mufescens Foerster. Orig. desig.

Taxonomy: Fischer, 1971. Polskie Pismo Ent. 41: 68. -Shenefelt, 1974. Hym. Cat., part 11, p.

964-966 (cat. World spp.).

fungicola (Ashmead). Conn., Ohio, Ill.

Phaenocarpa (Spanista) fungicala Ashmead, 1894. Cincinnati Soc. Nat. Hist., Jour. 17: 49. $\delta$.

Asobara lineata Viereck, 1917 (1916). Conn. State Geol. and Nat. Hist. Survey, Bul. 22, p. 213. .

tabida (Nees). Conn., Pa.; Europe. Host: Drosophila melanogaster Meig.

Alysia tabida Nees, 1834. Hym. Ichn. Aff. Monog., v. 1, p. 252. ‥

Spanista mufescens Foerster, 1862. Naturh. Ver. Rheinlande, Verh. 19: 267.

Alysia anomala Thomson, 1895. Opusc. Ent., fasc. 20, p. 2290. ㅇ.

\section{Genus ASPILOTA Foerster}

Aspilota Foerster, 1862. Naturh. Ver. Rheinlande, Verh. 19: 268.

Type-species: Alysia muficornis Nees. Orig. desig.

Dinotrema Foerster, 1862. Naturh. Ver. Rheinlande, Verh. 19: 268.

Type-species: Dinotrema erythropa Foerster. Orig. desig.

Spanomeris Foerster, 1862. Naturh. Ver. Rheinlande, Verh. 19: 268.

Type-species: Spanomeris pullo Foerster. Orig. desig.

Dipiesta Foerster, 1862. Naturh. Ver. Rheinlande, Verh. 19: 268.

Type-species: Alysia compressa Haliday. Orig. desig.

Panerema Foerster, 1862. Naturh. Ver. Rheinlande, Verh. 19: 263.

Type-species: Panerema inops Foerster. Orig. desig. 
Scotioneurus Provancher, 1886. Addit. Corr. Faune Ent. Canada Hym., p. 152, 156.

Type-species: Scotioneurus stenostigma Provancher. Desig. by Gahan, 1913.

Revision: Fischer, 1969. Acta Ent. Mus. Natl. Pragae 38: 91-114. - Fischer, 1969. Ent. Soc. Wash., Proc. 71: 361-368. - Fischer, 1969. Portici Lab. Ent. Agr., Bol. 27: 55-78. - Fischer, 1969. Osterr. Akad. Wiss. Math.-Nat. Kl., Sitzber. 178: 243-259. -Fischer, 1969. Redia 51: 187-209. - Fischer, 1970. Naturhist. Mus. Wien, Ann. 74: 91-127. All above references are to No. Amer. spp.

Taxonomy: Fischer, 1969. Acta Ent. Mus. Natl. Pragae 38: 91 (generic syn.). - Shenefelt, 1974. Hym. Cat., part 11, p. 966-982 (cat. World spp.).

acutistigma Fischer. Alaska. Aspilota acutistigma Fischer, 1969. Redia 51: 191. ठ.

alexanderi Fischer. Newfoundland. Aspilota alexanderi Fischer, 1969. Acta Ent. Mus. Natl. Pragae 38: 100. ठ。. angusticornis Fischer. Newfoundland, Md., Colo. Aspilota angusticornis Fischer, 1969. Acta Ent. Mus. Natl. Pragae 38: 102., ơ. armillariae Fischer. D. C., Va. Ecology: Bred from the fungi Armillaria mellea (Vahl ex Fr.) Kummar and Clitocybla (probably Clitocybe). Aspilota armillariae Fischer, 1969. Redia 51: 194. \&.

astigma (Provancher). Que., Pa., Md., Mich., Colo. Alysia astigma Provancher, 1883. Nat. Canad. 14: 18.. Aspilota astigma Provancher, 1888. Addit. Corr. Faune Ent. Canada Hym., p. 393.. astoriensis Fischer. Ore. Aspilota astoriensis Fischer, 1969. Redia 51: 196..

bakeri Fischer. Mass. Aspilota bakeri Fischer, 1969. Redia 51: 199..

brachybasis Fischer. Md. Aspilota brachybasis Fischer, 1969. Portici Lab. Ent. Agr., Bol. 27: 60.. bucculatricis Fischer. Newfoundland, Maine. Aspilota bucculatricis Fischer, 1969. Portici Lab. Ent. Agr., Bol. 27: 60.. capitata Fischer. Md. Aspilota capitata Fischer, 1969. Osterr. Akad. Wiss. Math.-Nat. Kl., Sitzber. 178: 245.. caudatula Fischer. Md., Ga., Mich., Wis., Ill., Kans., Colo. Aspilota caudatula Fischer, 1969. Osterr. Akad. Wiss. Math.-Nat. Kl., Sitzber. 178: 247. ९, $\delta$ o.

claricornis Fischer. Fla., Colo. Aspilota claricornis Fischer, 1969. Osterr. Akad. Wiss. Math.-Nat. Kl., Sitzber. 178: 249.. clayensis Fischer. Fla. Aspilota clayensis Fischer, 1969. Acta Ent. Mus. Natl. Pragae 38: 103.. columbiana Viereck. Kans. Aspilota columbiana Viereck, 1905. Kans. Acad. Sci., Trans. 19: 282.. communis Fischer. Maine, Mass., Ill. Aspilota communis Fischer, 1969. Osterr. Akad. Wiss. Math.-Nat. Kl., Sitzber. 178: 250. ^, ठै.

compressigaster Fischer. Md. Aspilota compressigaster Fischer, 1969. Ent. Soc. Wash., Proc. 71: 363. . convexula Fischer. Colo. Aspilota convexula Fischer, 1970. Naturhist. Mus. Wien, Ann. 74: 109. ठे. cultrata Fischer. Md. Aspilota cultrata Fischer, 1970. Naturhist. Mus. Wien, Ann. 74: 111.. curtibasis Fischer. Md. Aspilota curtibasis Fischer, 1970. Naturhist. Mus. Wien, Ann. 74: 113. \&. disstriae Fischer. Vt. Aspilota disstriae Fischer, 1969. Acta Ent. Mus. Natl. Pragae 38: 105. ؟. 
divergens Fischer. W. Va., Mich.

Aspilota divergens Fischer, 1970. Naturhist. Mus. Wien, Ann. 74; 95. \&.

dreisbachi Fischer. Mich., Ill.

Aspilota dreisbachi Fischer. 1969. Acta Ent. Mus. Natl. Pragae 38: 107..

ephemera Viereck. Conn.

Aspilota ephemera Viereck, 1917 (1916). Conn. State Geol. and Nat. Hist. Survey, Bul. 22, p. 213. $\delta$.

fasciatae Fischer. N. J., Md., Colo. Host: Phalacrotophora epeirae (Brues). Original description states host as Phora fasciata which is a misidentification of Phalacrotophora epeirae.

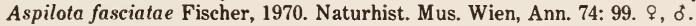

floridensis Shenefelt. Fla.

Aspilota cubiceps Fischer, 1969. Acta Ent. Mus. Natl. Pragae 38: 92.. Preocc. by Bischoff, 1932.

Aspilota floridensis Shenefelt, 1974. Hym. Cat., part 11, p. 972. N. name for cubiceps Fischer.

foliformis Fischer. Ala.

Aspilota foliformis Fischer, 1969. Acta Ent. Mus. Natl. Pragae 38: 108. \&.

foutsi Fischer. Md.

Aspilota foutsi Fischer, 1970. Naturhist. Mus. Wien, Ann. 74: 115. ?.

girlanda Fischer. N. Y.

Aspilota girlanda Fischer, 1970. Naturhist. Mus. Wien, Ann, 74: 118. o.

insularis Fischer. B. C.

Aspilota insularis Fischer, 1969. Ent. Soc. Wash., Proc. 71: 365..

krombeini Fischer. Md.

Aspilota krombeini Fischer, 1970. Naturhist. Mus. Wien, Ann. 74: 120..

latitergum Fischer. Md.

Aspilota latitergum Fischer, 1969. Osterr. Akad. Wiss. Math.-Nat. Kl., Sitzber. 178: 252. .

lobidens Fischer. Fla.

Aspilota lobidens Fischer, 1970. Naturhist. Mus. Wien, Ann. 74: 97..

longibasis Fischer. Md.

Aspilota longibasis Fischer, 1969. Redia 51: 201. ठ.

melabasis Fischer. Colo.

Aspilota melabasis Fischer, 1969. Portici Lab. Ent. Agr., Bol. 27: 65. ๆ.

miraculosa Fischer. Md.

Aspilota miraculosa Fischer, 1969. Ent. Soc. Wash., Proc. 71: 366. §.

ordinaria Fischer. Md., Va., Colo.

Aspilota ordinaria Fischer, 1970. Naturhist. Mus. Wien, Ann. 74: 122. ₹, ठ.

parallela Fischer. Md.

Aspilota parallela Fischer, 1970. Naturhist. Mus. Wien, Ann. 74: 101. ð.

parvistigma Fischer. Md.

Aspilota parvistigma Fischer, 1970. Naturhist. Mus. Wien, Ann. 74: 103. ठ'.

paupera Fischer. Md., D. C., Va., Colo.

Aspilota paupera Fischer, 1969. Acta Ent. Mus. Natl. Pragae 38: 110. ๆ, ठ.

petiolata (Provancher). Que., N. Y., Wis.

Rhopalophorus petiolatus Provancher, 1886. Addit. Corr. Faune Ent. Canada Hym., p. 128. ㅇ.

Ischnocarpa atricornis Ashmead, 1889 (1888). U. S. Natl. Mus., Proc. 11: 648. ‡, §. phyllotomae Fischer. Maine, Mich.

Aspilota phyllotomae Fischer, 1970. Naturhist. Mus. Wien, Ann. 74: 124. §, ठ. saileri Fischer. Conn., Md.

Aspilota saileri Fischer, 1969. Redia 51: 203..

shannoni Fischer. Md.

Aspilota shannoni Fischer, 1969. Portici Lab. Ent. Agr., Bol. 27: 69. ․ 
signifrons (Viereck). Ind., Wis., Kans.

Dinotrema signifrans Viereck, 1906. Amer. Ent. Soc., Trans. 32: 177. §.

sinibasis Fischer. Colo.

Aspilota sinibasis Fischer, 1969. Portici Lab. Ent. Agr., Bol. 27: 72..

sitkensis (Ashmead). Alaska.

Delocarpa sitkensis Ashmead, 1902. Wash. Acad. Sci., Proc. 4: 242..

smithi Fischer. N. J.

Aspilota smithi Fischer, 1969. Redia 51: 206. ^, ð.

stenostigma (Provancher). Mass., Md., Ont., Wis.

Scotioneurus stenostigma Provancher, 1886. Addit. Corr. Faune. Ent. Canada Hym., p. 157. ?.

subcompressa (Ashmead). Calif.

Adelura subcompressa Ashmead, 1889 (1888). U. S. Natl. Mus., Proc. 11: 647..

subcubicus Fischer. Md.

Aspilota subcubicus Fischer, 1969. Acta Ent. Mus. Natl. Pragae 38: 112. ๆ, ठ.

supramedia Fischer. Va.

Aspilota supramedia Fischer, 1969. Portici Lab. Ent. Agr., Bol. 27: 76..

sylvaticae Fischer. Iowa. Ecology: "Reared from larva in rotting Collybia radicata."

Aspilota sylvaticae Fischer, 1969. Osterr. Akad. Wiss. Math.-Nat. Kl., Sitzber. 178: 256. ९, o.

\section{Genus DAPSILARTHRA Foerster}

Dapsilarthra Foerster, 1862. Naturh. Ver. Rheinlande, Verh. 19: 267.

Type-species: Alysia apii Curtis. Orig. desig.

Adelura Foerster, 1862. Naturh. Ver. Rheinlande, Verh. 19: 267. Preocc. by Bonapart, 1854.

Type-species: Alysia florimela Haliday. Orig. desig.

Opisendea Foerster, 1862. Naturh. Ver. Rheinlande, Verh. 19: 266.

Type-species: Opisendea tenuicomis Foerster. Orig. desig.

Grammospila Foerster, 1862. Naturh. Ver. Rheinlande, Verh. 19: 269.

Type-species: Alysia isabella Haliday. Orig. desig.

Adelurola Strand, 1928 (1926). Arch. Naturgesch. 92 (A) (8): 51. N. name for Adelura Foerster.

Neocarpa Fischer, 1966. Naturh. Mus. Wien, Ann. 69: 185.

Type-species: Neocarpa amplidens Fischer. Orig. desig.

Taxonomy: Fischer, 1971. Polskie Pismo Ent. 41: 76.

americana (Brues). Wis.

Orthostigma americana Brues, 1907. Wis. Nat. Hist. Soc., Bul. 5: 59..

Taxonomy: Fischer, 1973. Naturh. Mus. Wien, Ann. 77: 256-258 (redescr.).

barthii (Brues). Wis. Host: Temnostoma bombylans (F.).

Asobara barthii Brues, 1907. Wis. Nat. Hist. Soc., Bul. 5: 57. \&, o.

Taxonomy: Fischer, 1973. Naturh. Mus. Wien, Ann. 77: 258-260 (redescr.).

rufiventris (Nees). Calif.

Bassus rufiventris Nees, 1814 (1812). Mag. Gesell. Naturf. Freunde Berlin 6: 213. \&.

Alysia (Alysia) flaviventris Haliday, 1838. Ent. Mag. 5: 240. .

Alysia (Phaenocarpa) gracilicornis Thomson, 1895. Opusc. Ent., fasc. 20, p. 2283. ‡, ठ.

\section{Genus DINOSTIGMA Fischer}

Dinostigma Fischer, 1966. Naturhist. Mus. Wien, Ann. 69: 182.

Type-species: Dinostigma muesebecki Fischer. Orig. desig.

muesebecki Fischer. $\mathrm{Pa}$.

Dinostigma muesebecki Fischer, 1969. Naturhist. Mus. Wien, Ann. 69: 183. १. 


\section{Genus GLYPHOGASTER Muesebeck and Walkley}

Glyphogaster Muesebeck and Walkley, 1951. In Muesebeck et al., U. S. Dept. Agr., Agr. Monog. 2, p. 148.

Type-species: Acrobela tachinae Ashmead. Orig. desig.

tachinae (Ashmead). Maine, N. H., Conn.

Acrobela tachinae Ashmead, 1898 (1897). Ent. Soc. Wash., Proc. 4: 170..

\section{Genus HOPLITALYSIA Ashmead}

Hoplitalysia Ashmead, 1900. U. S. Natl. Mus., Proc. 23: 105.

Type-species: Hoplitalysia slossonae Ashmead. Orig. desig.

slossonae Ashmead. W. Va., Fla., Tex.

Hoplitalysia slossonae Ashmead, 1900. U. S. Natl. Mus., Proc. 23: 105.

\section{Genus IDIASTA Foerster}

Idiasta Foerster, 1862. Naturh. Ver. Rheinlande, Verh. 19: 265.

Type-species: Alysia maritima Haliday. Orig. desig.

Rhacalysia Cameron, 1910. Wien. Ent. Ztg. $29: 9$.

Type-species: Rhacalysia rufobalteata Cameron. Monotypic.

Taxonomy: Konigsmann, 1960. Beitr. z. Ent. 10: 624-654. - Shenefelt, 1974. Hym. Cat., part 11, p. 993-995 (cat. World spp.).

longicornis (Provancher). Ont.

Rhopalophorus longicomis Provancher, 1886. Addit. Corr. Faune Ent. Canada Hym., p. 129. $\%$.

Alysia completa Provancher, 1886. Addit. Corr. Faune Ent. Canada Hym., p. 147..

macrocera Ashmead. N. H., Ont., Mich., Colo., B. C.

Idiasta macrocera Ashmead, 1891. Canad. Ent. 23: 5. o.

provancheri (Dalla Torre), Que.

Alysia nigriceps Provancher, 1881. Nat. Canad. 12: 203. . Preocc. by Cresson, 1865.

Alysia provancheri Dalla Torre, 1898. Cat. Hym., v. 4, p. 48. N. name for nigriceps

Provancher.

\section{Genus OENONOGASTRA Ashmead}

Oenonogastra Ashmead, 1900. U. S. Natl. Mus., Proc. 23: 105.

Type-species: Mesocrina microrhopalae Ashmead. Orig. desig.

microrhopalae (Ashmead). N. Y. s. to Fla., w. to Iowa and Tex. Host: Calycomyza ipomaeae

(Frost). The record of Microrhopala xerene (Newn.) (Coleoptera) as a host is

undoubtedly an error.

Mesocrina microrhopalae Ashmead, 1896. Amer. Ent. Soc., Trans. 23: 217. ठ。.

Taxonomy: Fischer, 1967. Naturhist. Mus. Wien, Ann. 70: 128-130 (redescr.).

\section{Genus ORTHOSTIGMA Ratzeburg}

Orthostigma Ratzeburg, 1844. Ichn. d. Forstins., v. 1, p. 53.

Type-species: A phidius flavipes Ratzeburg. Monotypic.

Ischnocarpa Foerster, 1862. Naturh. Ver. Rheinlande, Verh. 19: 268.

Type-species: Alysia pumila Nees. Orig. desig.

Delocarpa Foerster, 1862. Naturh. Ver. Rheinlande, Verh. 19: 268.

Type-species: Delocarpa praedo Foerster. Orig. desig.

Revision: Fischer, 1969. Acta Ent. Mus. Natl. Pragae 38: 82-90 (No. Amer. spp.).

Taxonomy: Shenefelt, 1974. Hym. Cat., part 11, p. 997-1001 (cat. World spp.).

crassinervis (Fischer), n. comb. Mo.

Aspilota crassinervis Fischer, 1969. Acta Ent. Mus. Natl. Pragae 38: 94. ठ.

dyari Fischer. B. C.

Orthostigma dyari Fischer, 1969. Acta Ent. Mus. Natl. Pragae 38: 83. ๆ. 
monotonum Fischer. Md.

Orthostigma monotonum Fischer, 1969. Acta Ent. Mus. Natl. Pragae 38: 85. $\uparrow$.

ovalis (Provancher). Que.

Rhitigaster ovalis Provancher, 1886. Addit. Corr. Faune Ent. Canada Hym., p. 146. $q$.

prebblei Fischer. N. S.

Orthostigma prebblei Fischer, 1969. Acta Ent. Mus. Natl. Pragae 38: 87..

sculleni Fischer. Oreg.

Orthostigma sculleni Fischer, 1969. Acta Ent. Mus. Natl. Pragae 38: 88. ๆ.

sheldoni (Fischer), n. comb. N. Y., N. J., Md., Colo.

Aspilota sheldoni Fischer, 1969. Acta Ent. Mus. Natl. Pragae 38: 95. ๆ, §.

terryvillensis (Fischer), n. comb. Conn.

Aspilota terryvillensis Fischer, 1969. Acta Ent. Mus. Natl. Pragae 38: 97. $९$.

\section{Genus PENTAPLEURA Foerster}

Pentapleura Foerster, 1862. Naturh. Ver. Rheinlande, Verh. 19: 264.

Type-species: Bassus pumilo Nees. Orig. desig.

Guathospila Fischer, 1966. Naturhist. Mus. Wien, Ann. 69: 210.

Type-species: Gnathospila quadridens Fischer. Orig. desig.

Taxonomy: Fischer, 1971. Polskie Pismo Ent. 41: 126-130 (Eur. spp.). - Shenefelt, 1974. Hym.

Cat., part 11, p. 1001-1003 (cat. World spp.).

foveolata Viereck. Conn.

Pentapleura foveolata Viereck, 1917 (1916). Conn. State Geol. and Nat. Hist. Survey, Bul. 22, p. 213. $\delta$.

quadridens (Fischer). Colo.

Gnathospila quadridens Fischer, 1966. Naturhist. Mus. Wien, Ann. 69: 210. $\subsetneq$.

triticaphis (Fitch). N. Y., Colo., Calif.

Toxares triticaphis Fitch, 1861 (1860). N. Y. State Agr. Soc., Trans. 20: 840.

\section{Genus PHAENOCARPA Foerster}

Phaenocarpa Foerster, 1862. Naturh. Ver. Rheinlande, Verh. 19: 267.

Type-species: Alysia picinervis Haliday. Orig. desig.

Homophyla Foerster, 1862. Naturh. Ver. Rheinlande, Verh. 19: 266.

Type-species: Alysia pullata Haliday. Orig. desig.

Mesothesis Foerster, 1862. Naturh. Ver. Rheinlande, Verh. 19: 266.

Type-species: Mesothesis bicolor Foerster. Orig. desig.

Asynaphes Provancher, 1886. Addit. Corr. Faune Ent. Canada Hym., p. 150.

Type-species: Asynaphes aciculata Provancher. Desig. by Viereck, 1914.

Kahlia Ashmead, 1900. U. S. Natl. Mus., Proc. 23: 107.

Type-species: Kahlia flavipes Ashmead. Orig. desig.

Holcalysia Cameron, 1905 (not 1910). Entomologist 38: 268.

Type-species: Holcalysia testaceipes Cameron. Monotypic.

Stiralysia Cameron, 1910. Wien. Ent. Ztg. 29: 7.

Type-species: Stiralysia testaceiventris Cameron. Monotypic.

Revision: Papp, 1966. Acta Zool. Acad. Sci. Hung. 12: 133-144 (Afr. spp.). -Papp, 1967.

Reichenbachia 8: 139-157 (Orient. spp.). - Papp, 1968. Beitr. z. Ent. 18: 569-603 (some Eur. spp.). - Papp, 1969. Acta Zool. Acad. Sci. Hung. 15: 379-389 (Neotr. spp.). -Fischer, 1970.

Ztschr. f. Angew. Ent. 57: 409-498 (Eur. spp.). - Fischer, 1974. Polskie Pismo Ent. 44:

103-230 (some No. Amer. spp.). - Fischer, 1975. Polskie Pismo Ent. 45: 279-356 (remainder of No. Amer. spp.).

Taxonomy: Shenefelt, 1974. Hym. Cat., part 11, p. 1003-1017 (cat. World spp.). aciculata (Provancher). Ont.

Asynaphes aciculata Provancher, 1886. Addit. Corr. Faune Ent. Canada Hym., p. 150.. acutinotum Fischer. Md.

Phaenocarpa acutinotum Fischer, 1974. Polskie Pismo Ent. 44: 109.. 
amara Fischer. N. Y., Md., D. C., N. C., S. C., Calif., Alaska.

Phaenocarpa amara Fischer, 1975. Polskie Pismo Ent. 45: 283. ९, ठ.

angustifossa Fischer. Labrador, Mich.

Phaenocarpa angustifossa Fischer, 1975. Polskie Pismo Ent. 45: 286. ‡, ठ.

antichaetae Fischer. N. Y. Host: Antichaeta melanosoma Melander.

Phaenocarpa antichaetae Fischer, 1974. Polskie Pismo Ent. 44: 112. ‡, ठ.

aristarchi Fischer. Md.

Phaenocarpa aristarchi Fischer, 1974. Polskie Pismo Ent. 44: 114. ठั.

astigmatica Fischer. N. C., Wash.

Phaenocarpa astigmatica Fischer, 1974. Polskie Pismo Ent. 44: 119. ९.

basirufa Fischer. N. C.

Phaenocarpa basimfa Fischer, 1974. Polskie Pismo Ent. 44: 122. + , đ.

bellatrix Fischer. N. Mex., Alaska.

Phaenocarpa bellatrix Fischer, 1975. Polskie Pismo Ent. 45: 288. , ઠ.

benjaminica Fischer. N. C.

Phaenocarpa benjaminica Fischer, 1974. Polskie Pismo Ent. 44: 125..

brachyptera Fischer. Ill., Calif.

Phaenocarpa brachyptera Fischer, 1974. Polskie Pismo Ent. 44: 127. ๆ, ơ.

brevicauda (Provancher). Que., Va., Mich., Iowa, N. Dak., S. Dak., Colo. Host: Ravinia (Chaetoravinia) assidua (Wlkr.).

Asynaphes brevicauda Provancher, 1886. Addit. Corr. Faune Ent. Canada Hym., p. 150..

bruesi Marsh. Minn. Host: Hylemya brassicae (Bouche).

Mesocrina pegomyiae Brues, 1907. Extr. MS. Rpt. Minn. State Ent., p. 3. Preocc. by Marshall, 1898.

Phaenocarpa briesi Marsh, 1974. In Shenefelt, Hym. Cat., part 11, p. 1005. N. name for pegomyiae Brues.

Taxonomy: Fischer, 1973. Naturh. Mus. Wien, Ann. 77: 252 (redescr.).

brunnicornis Fischer. Mich.

Phaenocarpa brunnicomis Fischer, 1974. Polskie Pismo Ent. 44: 132. ९.

ealifornica Fischer. Calif., Alaska.

Phaenocarpa californica Fischer, 1974. Polskie Pismo Ent. 44: 134.,$+ \delta$.

caudata (Provancher). Ont.

Alysia caudata Provancher, 1881. Nat. Canad. 12: 202. \&.

cellularis Fischer. N. Y. s. to N. C., w. to Mich.

Phaenocarpa cellularis Fischer, 1974. Polskie Pismo Ent. 44: 137. १, ठ’.

cephalotes Fischer. Ont.

Phaenocarpa cephalotes Fischer, 1975. Polskie Pismo Ent. 45: 291. ठ̊.

collorufa Fischer. N. H.

Idiolexis collaris Ashmead, 1902. In Slosson, Ent. News 13: 321. Nom. nud.

Phaenocarpa collorufa Fischer, 1974. Polskie Pismo Ent. 44: 140..

compressigaster Fischer. Oreg.

Phaenocarpa compressigaster Fischer, 1974. Polskie Pismo Ent. 44: 142...

conjuncta Fischer. Wash.

Phaenocarpa conjuncta Fischer, 1974. Polskie Pismo Ent. 44: 145. ठ̊.

convergens Fischer. Alaska.

Phaenocarpa convergens Fischer, 1974. Polskie Pismo Ent. 44: 147. ९.

convexinotum Fischer. Alaska.

Phaenocarpa convexinotum Fischer, 1975. Polskie Pismo Ent. 45: 293. ठ์.

costata Fischer. Va., N. C.

Phaenocarpa costata Fischer, 1974. Polskie Pismo Ent. 44: 150. ९, ठ́.

costulata Fischer. Mich., Oreg., Alaska.

Phaenocarpa costulata Fischer, 1974. Polskie Pismo Ent. 44: 152. ९, ठे.

curvata Fischer. Mich.

Phaenocarpa curvata Fischer, 1974. Polskie Pismo Ent. 44: 155. ठ. 
curvicurrens Fischer. Alaska.

Phaenocarpa curvicurrens Fischer, 1975. Polskie Pismo Ent. 45: 295. ठ.

differentiata Fischer. Alaska.

Phaenocarpa differentiata Fischer, 1975. Polskie Pismo Ent. 45: 298. ९, ठ์.

disjuncta Fischer. $\mathrm{Pa}$., Md., Va., Mich.

Phaenocarpa disjuncta Fischer, 1974. Polskie Pismo Ent. 44: 157. ๆ, ठ.

distinguenda Fischer. Colo.

Phaenocarpa distinguenda Fischer, 1974. Polskie Pismo Ent. 44: 160. ठో.

distributa Fischer. Que., N. Y., Pa., Mich.

Phaenocarpa distributa Fischer, 1974. Polskie Pismo Ent. 44: 162. ๆ, ठ.

divergens Fischer. N. Y., Va., Ky., B. C., Calif.

Phaenocarpa divergens Fischer, 1975. Polskie Pismo Ent. 45: 301. १, ठ.

divisa Fischer. Md.

Phaenocarpa divisa Fischer, 1974. Polskie Pismo Ent. 44: 166. §.

drosophilae Fischer. Alaska. Host: Drosophila melanogaster Meig.

Phaenocarpa drosophilae Fischer, 1975. Polskie Pismo Ent. 45: 303. ‡, ठ.

excisa Fischer. S. C.

Phaenocarpa excisa Fischer, 1974. Polskie Pismo Ent. 44: 168. ठ.

fervida Fischer. Wash., Oreg., Calif.

Phaenocarpa fervida Fischer, 1975. Polskie Pismo Ent. 45: 306. \&, ठ๋.

flammea Fischer. Colo.

Phaenocarpa flammea Fischer, 1975. Polskie Pismo Ent. 45: 309. ठ.

gaspeensis Fischer. Que.

Phaenocarpa gaspeensis Fischer, 1974. Polskie Pismo Ent. 44: 171. ठ.

hicoriae Fischer. $\mathrm{Pa}$.

Phaenocarpa hicoriae Fischer, 1974. Polskie Pismo Ent. 44: 173..

horribilis Fischer. Colo.

Phaenocarpa horribilis Fischer, 1974. Polskie Pismo Ent. 44: 176. ठ.

huronensis Fischer. Mich.

Phaenocarpa huronensis Fischer, 1975. Polskie Pismo Ent. 45: 311. ?.

idolica Fischer. N. C.

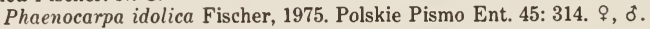

incerta Fischer. N. Y., S. C., Calif., Alaska.

Phaenocarpa incerta Fischer, 1975. Polskie Pismo Ent. 45: 317. ๆ, ठ.

indistincta Fischer. Que., Mich., Alaska.

Phaenocarpa indistincta Fischer, 1974. Polskie Pismo Ent. 44: 178. \&, ठ.

josephi Fischer. Alaska.

Phaenocarpa josephi Fischer, 1975. Polskie Pismo Ent. 45: 320. \&.

kansensis Shenefelt. Kans.

Kahlia flavipes Ashmead, 1900. U. S. Natl. Mus., Proc. 23: 107. Preocc. by Haliday, 1838.

Phaenocarpa kansensis Shenefelt, 1974. Hym. Cat., part, 11, p. 1009. N. name for flavipes Ashmead.

Phaenocarpa ashmeadi Fischer, 1974. Polskie Pismo Ent. 44: 117. N. name for flavipes Ashmead.

Taxonomy: Fischer, 1973. Naturh. Mus. Wien, Ann. 77: 245 (redescr.).

kinleyensis Fischer. Alaska.

Phaenocarpa kinleyensis Fischer, 1974. Polskie Pismo Ent. 44: 181. ๆ.

laevisulcata Fischer. Alaska.

Phaenocarpa laevisulcata Fischer, 1974. Polskie Pismo Ent. 44: 183..

leopoldi Fischer. N. C., Alaska.

Phaenocarpa leopoldi Fischer, 1974. Polskie Pismo Ent. 44: 186. \&, ठ.

leptura Fischer. N. Y., Md., W. Va., Alta.

Phaenocarpa leptura Fischer, 1975. Polskie Pismo Ent. 45: 322.,$~ ठ$. 
lyra Fischer. Alaska.

Phaenocarpa lyra Fischer, 1975. Polskie Pismo Ent. 45: 325. ㅇ.

mallochi Fischer. Md., Va.

Phaenocarpa mallochi Fischer, 1974. Polskie Pismo Ent. 44: 189. ๆ, ठ.

mediolobata Fischer. Alaska.

Phaenocarpa mediolobata Fischer, 1975. Polskie Pismo Ent. 45: 327. ․

naubinwayensis Fischer. Mich.

Phaenocarpa naubinwayensis Fischer, 1974. Polskie Pismo Ent. 44: 191. ð.

nigrata Fischer, Colo., Ariz., Calif., Alaska.

Phaenocarpa nigrata Fischer, 1975. Polskie Pismo Ent. 45: 330. ठ.

notaulica Fischer. Colo., Alaska.

Phaenocarpa notaulica Fischer, 1975. Polskie Pismo Ent. 45: 333. ๆ, o.

novomexicana Fischer. N. Mex.

Phaenocarpa novomexicana Fischer, 1975. Polskie Pismo Ent. 45: 335. ๆ, ơ.

orion Fischer. N. H., Mich., Minn., Alaska.

Phaenocarpa orion Fischer, 1975. Polskie Pismo Ent. 45: 338. ๆ, ठे.

pentagona Fischer. Md., Oreg., Alaska.

Phaenocarpa pentagona Fischer, 1974. Polskie Pismo Ent. 44: 196. ठ์.

periculosa Fischer. Mich., Alaska.

Phaenocarpa periculosa Fischer, 1974. Polskie Pismo Ent. 44: 199. ?.

picinervis (Haliday). N. Y., Md., D. C., S. C., Mich., Iowa, Kans., Colo., Idaho, Ariz., Oreg., Calif., Alaska; Europe.

Alysia (Alysia) picinervis Haliday, 1838. Ent. Mag. 5: 233. ๆ.

Phaenocarpa americana Ashmead, 1889 (1888). U. S. Natl. Mus., Proc. 11: 648. ․

pilioculata Fischer. Alaska.

Phaenocarpa pilioculata Fischer, 1974. Polskie Pismo Ent. 44: 204..

puberae Fischer. Sask. Host: Cordilura pubera L.

Phaenocarpa puberae Fischer, 1974. Polskie Pismo Ent. 44: 207. 9.

raptatrix Fischer. Oreg.

Phaenocarpa raptatrix Fischer, 1974. Polskie Pismo Ent. 44: 210. ๆ.

reticulata Fischer. Colo.

Phaenocarpa reticulata Fischer, 1974. Polskie Pismo Ent. 44: 212..

rossata Fischer. Mass.

Phaenocarpa rossata Fischer, 1974. Polskie Pismo Ent. 44: 215. ?.

rubriceps (Provancher). Que., Calif.

Alysia rubriceps Provancher, 1883. Nat. Canad. 14: 18. o.

Phaenocarpa rubricepes(!) Provancher, 1888. Addit. Corr. Faune Ent. Canada Hym., p. 392. ㅇ․

rugipars Fischer. N. Y.

Phaenocarpa rugipars Fischer, 1975. Polskie Pismo Ent. 45: 343. ๆ.

sculptata Fischer. Colo.

Phaenocarpa sculptata Fischer, 1975. Polskie Pismo Ent. 45: 345. §.

signicauda Fischer. Alaska.

Phaenocarpa signicauda Fischer, 1975. Polskie Pismo Ent. 45: 348..

sinefovea Fischer. S. C.

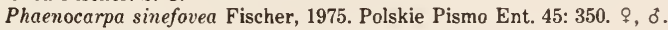

studiata Fischer. Alaska.

Phaenocarpa studiata Fischer, 1975. Polskie Pismo Ent. 45: 353. ๆ.

supramedia Fischer. Newfoundland, Fla.

Phaenocarpa supramedia Fischer, 1974. Polskie Pismo Ent. 44: 217. ठ.

tenebrosa Fischer. Colo., N. Mex., Ariz., Oreg.

Phaenocarpa tenebrosa Fischer, 1974. Polskie Pismo Ent. 44: 220. १, ठ.

umbrinervis Fischer. Alaska.

Phaenocarpa umbrinervis Fischer, 1974. Polskie Pismo Ent. 44: 223. ๆ. 
varipedis Fischer. W. Va. Host: Cordilura (Achaetella) varipes (Wlkr.).

Phaenocarpa varipedis Fischer, 1974. Polskie Pismo Ent. 44: 225. ๆ, ১.

\section{Genus PNEUMOSEMA Fischer}

Pneumosema Fischer, 1966. Naturhist. Mus. Wien, Ann. 69: 207.

Type-species: Pneumosema stigmaticum Fischer. Orig. desig.

stigmaticum Fischer. N. Y., W. Va.

Pnenmosema stigmaticum Fischer, 1966. Naturhist. Mus. Wien, Ann. 69: 208.,$\delta$.

\section{Genus SYNALDIS Foerster}

Synaldis Foerster, 1862. Naturh. Ver. Rheinlande, Verh. 19: 273.

Type-species: Bassus concolor Nees. Orig. desig.

Revision: Fischer, 1967. Polskie Pismo Ent. 37: 431-478 (No. Amer. spp.).

Taxonomy: Shenefelt, 1974. Hym. Cat., part 11, p. 1020-1024 (cat. World spp.).

acutidens Fischer. Mich.

Synaldis acutidens Fischer, 1967. Polskie Pismo Ent. 37: 434. ๆ.

alfalfae Fischer. Newfoundland, Calif.

Synaldis alfalfae Fischer, 1967. Polskie Pismo Ent. 37: 450. ‡, ठ.

altera Fischer. Md.

Synaldis altera Fischer, 1967. Polskie Pismo Ent. 37: 452. đo.

blantoni Fischer. N. Y.

Synaldis blantoni Fischer, 1967. Polskie Pismo Ent. 37: 436. ठ.

cabinica Fischer. Md.

Synaldis cabinica Fischer, 1967. Polskie Pismo Ent. 37: 467. ९, §.

difficilis Fischer. Md.

Synaldis difficilis Fischer, 1967. Polskie Pismo Ent. 37: 455. ठ..

exitiosae Fischer. Md., Va., Tex. Recorded as a parasite of Sanninoidea exitiosa (Say) which is not correct. However, this lepidopteran is reported to be parasitized by Helicobia rapax (Wlkr.) (Diptera: Sarcophagidae) and it is possible that Synaldis exitiosae is associated with this fly.

Synaldis exitiosae Fischer, 1967. Polskie Pismo Ent. 37: 440. ๆ, ठ.

glabrifovea Fischer. Mich., Ala.

Synaldis glabrifovea Fischer, 1967. Polskie Pismo Ent. 37: 442. @.

incisa Gahan. Conn., Ill., Kans.

Synaldis incisa Gahan, 1912. Ent. Soc. Wash., Proc. 14: 4. ९.

liliputana Fischer. Md.

Synaldis liliputana Fischer, 1967. Polskie Pismo Ent. 37: 444. ठ.

megaseliae Fischer. Md.

Synaldis megaseliae Fischer, 1967. Polskie Pismo Ent. 37: 459. ‡, ठ.

numerosa Fischer. N. Mex.

Synaldis numerosa Fischer, 1967. Polskie Pismo Ent. 37: 462. ९, o.

painteri Fischer. Ind.

Synaldis painteri Fischer, 1967. Polskie Pismo Ent. 37: 469. ^, ठ.

paraclypealis Fischer. Md.

Synaldis paraclypealis Fischer, 1967. Polskie Pismo Ent. 37: 472. o.

pygmaea Viereck. Conn.

Synaldis pygmaea Viereck, 1917 (1916). Conn. State Geol. and Nat. Hist. Survey, Bul. 22, p. 215.8 .

quinnipiacorum Viereck. Conn.

Synaldis quinnipiacorum Viereck, 1917 (1916). Conn. State Geol. and Nat. Hist. Survey, Bul. 22, p. 215. .

rotundidens Fischer. Md., Mich.

Synaldis rotundidens Fischer, 1967. Polskie Pismo Ent. 37: 437. §. 
segmentata Fischer. Md.

Synaldis segmentata Fischer, 1967. Polskie Pismo Ent. 37: 464. ๆ.

sensillosa Fischer. Md.

Synaldis sensillosa Fischer, 1967. Polskie Pismo Ent. 37: 448. ․

spiraculosa Fischer. Md.

Synaldis spiraculosa Fischer, 1967. Polskie Pismo Ent. 37: 448. ९.

trematosa Fischer. Mich.

Synaldis trematosa Fischer, 1967. Polskie Pismo Ent. 37: 474. ․

ulmicola Ashmead. Ohio, Mo., Kans.

Synaldis ulmicola Ashmead, 1889 (1888). U. S. Natl. Mus., Proc. 11: 651..

UNPLACED TAXa OF ALYSIINI

Dinotrema soror Brues, 1907. Wis. Nat. Hist. Soc., Bul. 5: 59. Type lost.

Nomina Nuda in Alysiuni

Mesothesis abdominalis Ashmead, 1905. In Nason, Ent. News 16: 293.

Coloboma americana Ashmead, 1905. In Nason, Ent. News 16: 293.

Aspilota davisii Ashmead, 1905. In Nason, Ent. News 16: 293.

Orthostigma delicata Ashmead, 1902. In Slosson, Ent. News 13: 321.

Delocarpa dimidiata Ashmead, 1905. In Nason, Ent. News 16: 293.

Aphaereta dolosa Viereck, 1928. N. Y. State Mus., Bul. 74: 179.

Cratospila ferrugineus Ashmead, 1905. In Nason, Ent. News 16: 293.

Mesocrina flaviventris Ashmead, 1897. In Slosson, Ent. News 8: 237.

Phaenocarpa slossonae Ashmead, 1902. In Slosson, Ent. News 13: 5.

Panerema thoracica Ashmead, 1899. In Smith, Ins. of N. J., p. 585.

\section{SUBFAMILY SIGALPHINAE}

This is a small group of genera that have been previously included in the subfamily Cheloninae because of the first three abdominal terga which form a solid carapace. However, the articulation between the first two abdominal terga is movable in the Sigalphinae. The biology is not known in detail but hosts are apparently lepidopterous larvae.

Taxonomy: De Saeger, 1948. Explor. Parc Natl. Albert, Mission G. F. de Witte, fasc. 53, p. 63-64 (key to genera). - Tobias, 1967. Ent. Obozr. 46: 659. -Shenefelt, 1973. Hym. Cat., part 10, p. 931-935 (cat. World spp.).

\section{Genus SIGALPHUS Latreille}

Sigalphus Latreille, 1802. Hist. Nat. Crust. Ins., v. 3, p. 327.

Type-species: Ichneumon irrorator Fabricius. Desig. by Viereck, 1914.

Sphaeropyx Illiger, 1807. Mag. Insektenk. 6: 192.

Type-species: Ichneumon irrorator Fabricius. Monotypic.

Rhytigaster(!) Wesmael, 1835. Nouv. Mem. Acad. Sci. Bruxelles 9: 206.

Rhitigaster Wesmael, 1835. Nouv. Mem. Acad. Sei. Bruxelles 9: 247.

Type-species: Ichneumon irrorator Fabricius. Desig. by Westwood, 1839.

Rhytidogaster Agassiz, 1846. Nomencl. Zool. Index Univ., p. 327. Emend.

bicolor (Cresson). Que. s. to Fla., w. to Man., Okla., and Miss. Host: Acronicta sp., $A$. clarescens $\mathrm{Gn}$.

Rhytigaster bicolor Cresson, 1880. Amer. Ent. Soc., Trans. 8: Proc. p. xvii. ๆ, ơ.

Biology: Cushman, 1913. Ent. Soc. Wash., Proc. 15: 157-160.

\section{SUbFamily CHELONINAE}

This is a distinctive group of braconids characterized by the rigid abdominal carapace formed by the fusion of the first three terga. The Triaspidinae have been associated with the Cheloninae on the basis of their similar abdominal structure, but their biologies, larval morphology and wing venation are all very different.

Species of the Cheloninae are typical egg-larval parasites of Lepidoptera, the adult ovipositing in the host egg but the parasite larva completing its development in the host larva. 
Taxonomy: Tobias, 1967. Ent. Obozr. 46: 657. -Capek, 1970. Canad. Ent. 102: 859. -Shenefelt, 1973. Hym. Cat., part 10, p. 813-931 (cat. World spp.).

\section{Genus ASCOGASTER Wesmael}

Ascogaster Wesmael, 1835. Nouv. Mem. Acad. Sci. Bruxelles 9: 226.

Type-species: Ascogaster instabilis Wesmael. Desig. by Foerster, 1862.

Cascogaster Baker, 1926. Phil. Jour. Sci. 31: 482.

Type-species: Cascogaster fullawayi Baker. Orig. desig.

Taxonomy: Shenefelt, 1973. Hym. Cat., part 10, p. 814-838 (cat. World spp.).

argentifrons (Provancher). Que., Pa., N. J., Ill. Host: Depressaria pastinacella (Dup.).

Chelonus argentifrons Provancher, 1886. Addit. Corr. Faune Ent. Canada Hym., p. 145. §.

flaviceps Ashmead. Que., N. Y., Mich., Ill., Tex.

Ascogaster flaviceps Ashmead, 1889 (1888). U. S. Natl. Mus., Proc. 11: 636. \&.

mimetica Viereck. N. Y., III., Iowa, Kans.

Ascogaster mimeticus Viereck, 1905. Kans. Acad. Sci., Trans. 19: 277. ๆ.

olethreuti Viereck. Colo., Wash. Host: Endothenia mibipunctana (Kearf.).

Ascogaster olethreuti Viereck, 1912. U. S. Natl. Mus., Proc. 42: 617. $९$, §.

provancheri Dalla Torre. Que., Conn., N. Y., N. J., Md., Ohio, Mich. Host: Taniva albolineana (Kearf.).

Ascogaster mifipes Provancher, 1886. Addit. Corr. Faune Ent. Canada Hym., p. 146. $q$. Preocc. by Latreille, 1809 .

Ascogaster provancheri Dalla Torre, 1898. Cat. Hym., v. 4, p. 196. N. name for rufipes Provancher.

provancheri var. vierecki Shenefelt. N. H., Conn., N. Y., N. J., Ont., Mich., Wisc., Minn. Host: Proteoteras moffatiana Fern.

Ascagaster provancheri var. pallidicomis Viereck, 1917 (1916). Conn. State Geol. and Nat. Hist. Survey, Bul. 22, p. 231. Preocc. by Curtis, 1837.

Ascogaster provancheri var. vierecki Shenefelt, 1973. Hym. Cat., part 10, p. 828. N. name for pallidicomis Viereck.

quadridentata Wesmael. N. S. s. to S. C., w. to B. C. and Calif.; Europe, Asia. Host: Desmia funeralis (Hbn.), Gelechia sp., Grapholitha molesta (Busck), G. prunivora (Walsh), Laspeyresia nigricana (Steph.), L. pomonella (L.), Paralobesia viteana (Clem.), Spilanota ocellana (D. and S.).

Ascogaster quadridentatus Wesmael, 1835. Nouv. Mem. Acad. Sci. Bruxelles 9: 237. $\&$, ઠ. Chelonus impressus Herrich-Schaeffer, 1838. Faunae Ins. Germ., p. 154.

Chelonus carpocapsae Viereck, 1909. Ent. Soc. Wash., Proc. 11: 43.

Biology: Rosenberg, 1934. Bul. Ent. Res. 25: 232-241. -Boyce, 1936. Canad. Ent. 68: 241-246. -Allen, 1962. U. S. Dept. Agr., Tech. Bul. 1265, p. 37-40.

Morphology: Rosenberg, 1934. Bul. Ent. Res. 25: 232-341.

rufa Muesebeck and Walkley. Md., S. C., Ga., Fla., Iowa, Kans., Colo., Ariz.

Ascogaster erythrothorax Viereck, 1916. Biol. Soc. Wash., Proc. 29: 166. ๆ. Preocc. by Marshall, 1897.

Ascogaster mifa Muesebeck and Walkley, 1951. U. S. Dept. Agr., Agr. Monog. 2, p. 143. N. name for erythrothorax Viereck.

Nomina Nuda in Ascogaster Wesmael

Ascogaster intermedius Ashmead, 1895. In Slosson, Ent. News 6: 317.

Ascogaster nigripes Ashmead, 1898. In Slosson, Ent. News 9: 253.

Ascogaster pallidicormis Ashmead, 1895. In Slosson, Ent. News 6: 317.

Ascogaster pilosifrons Ashmead, 1905. In Nason, Ent. News 16: 295.

Ascogaster proximus Ashmead, 1905. In Nason, Ent. News 16: 295. 


\section{Genus CHELONUS Panzer}

\section{Genus CHELONUS Subgenus CHELONUS Panzer}

Chelonus Panzer, 1806. Krit. Revis. Insektenf. Deutschlands, v. 2, p. 99.

Type-species: Ichneumon oculator Fabricius. Desig. by Curtis, 1837.

Trachionus Haliday, 1833. Ent. Mag. 1: 265.

Type-species: Chelonus mandibularis Haliday. Monotypic.

Davisania La Munyon, 1877. Nebr. Assoc. Adv. Sci., Proc. No page number.

Type-species: Davisania aughei La Munyon. Desig. by Viereck, 1914.

Arichelonus Viereck, 1913. U. S. Natl. Mus., Proc. 44: 641.

Type-species: Chelonus aculeatus Ashmead. Orig. desig.

Megachelonus Baker, 1926. Philipp. Jour. Sci. 31: 457.

Type-species: Megachelonus bidentatus Baker. Orig. desig.

The biological distinctness of the various subgenera proposed within the genus Chelonus is not clear, and a critical review of the entire group is needed.

Taxonomy: Shenefelt, 1973. Hym. Cat., part 10, p. 838-872 (cat. World spp.).

aculeatus Ashmead. N. Dak., Wyo., Colo.

Chelonus aculeatus Ashmead, 1890. Colo. Biol. Assoc., Bul. 1: 17..

altitudinus Viereck. Ill., Mo., S. Dak., Kans., Tex., Colo., N. Mex., Idaho; Mexico. Host:

Homoeosoma electellum (Hulst).

Chelonus altitudinis Viereck, 1905. Kans. Acad. Sci., Trans. 19: 278. $\%$.

annulipes Wesmael. Mass., Conn., N. Y., N. J., Del.; Europe. Introduced from Italy. Host: Ostrinia nubilalis (Hbn.). Other locality and host records for No. Amer. need to be confirmed.

Chelonus annulipes Wesmael, 1835. Nouv. Mem. Acad. Sci. Bruxelles 9: 221..

Biology: Vance, 1932. U. S. Dept. Agr., Tech. Bul. 294, 48 p. - Bradley and Arbuthnot, 1938.

Ent. Soc. Amer., Ann. 31: 259-269. - Harris, 1950. Iowa Yearbook of Agr. for 1949, p.

143-159. -Clausen, 1956. U. S. Dept. Agr., Tech. Bul. 1139, p. 90.

Morphology: Vance, 1932. U. S. Dept. Agr., Tech. Bul. 294, 48 p.

aughei (La Munyon). Nebr.

Davisania aughei La Munyon, 1877. Nebr. Assoc. Adv. Sci., Proc. No page number.

australis Viereck. N. Mex.

Chelonus australis Viereck, 1903. Amer. Ent. Soc., Trans. 29: 95. ठั.

basicinctus Provancher. Canada, N. H., Conn., Pa., Md., Mich., N. Dak.

Chelonus basicinctus Provancher, 1881. Nat. Canad. 12: 198..

basilaris (Say). Conn., $\mathrm{Pa}$.

Sigalphus basilaris Say, 1824. In Keating, Narr. Long's 2nd Exped., v. 2, p. 322.

connectens Cresson. Iowa, La., Tex.

Chelonus connectens Cresson, 1872. Amer. Ent. Soc., Trans. 4: 180..

electus Cresson. Tex., Colo., Calif. Host: Melitara sp., Ozamia sp.

Chelonus electus Cresson, 1872. Amer. Ent. Soc., Trans. 4: 180.,$~ ð$.

inanitus (Linnaeus). Calif.?; Europe, Asia. Liberated in Calif. but apparently not established. Introduced from France. Host: Etiella zinckenella (Treit.).

Cynips inanitus Linnaeus, 1767. Syst. Nat., 12th Ed., p. 919.

Biology: Clausen, 1956. U. S. Dept. Agr., Tech. Bul. 1139, p. 91-92. -Stone, 1965. U. S. Dept.

Agr., Tech. Bul. 1321, p. 26. - Rechav and Orion, 1975. Ent. Soc. Amer., Ann. 68: 457-462.

insularis Cresson. No. Amer., Cent. Amer., So. Amer., W. Indies. Host: Ephestia elutella (Hbn.), Feltia subterranea (F.), Heliothis zea (Boddie), Loxostege sticticalis (L.), Peridroma saucia (Hbn.), Spodoptera eridania (Cram.), S. exigua (Hbn.), S. frugiperda (Smith), S. ornithogalli (Guen.), S. praefica (Grote), Trichoplusia ni (Hbn.). Other records need confirmation.

Chelonus insularis Cresson, 1865. Ent. Soc. Phila., Proc. 4: 61..

Chelonus texanus Cresson, 1872. Amer. Ent. Soc., Trans. 4: 179.. .

Chelonus texanoides Viereck, 1905. Kans. Acad. Sci., Trans. 19: 286. ?. 
Chelonus exogyrus Viereck, 1905. Kans. Acad. Sci., Trans. 19: 287.. Chelonus bipustulatus Viereck, 1911. U. S. Natl. Mus., Proc. 40: 476. ९.

Biology: Pierce and Holloway, 1912. Jour. Econ. Ent. 5: 425-428 (as texanus). - Ullyett, 1949. Canad. Ent. 81: 25-44 (as texanus). - Vinson, 1975. Amer. Ent. Soc., Ann. 68: 381-384 (as texanus).

iridescens Cresson. Colo., Alaska. Other locality records need confirmation. Chelonus iridescens Cresson, 1865. Ent. Soc. Phila., Proc. 4: 294. ठ์.

knabi Viereck. N. J., Va., Ohio. Host: Chilo plejadellus Zinck.

Chelonus knabi Viereck, 1911. U. S. Natl. Mus., Proc. 40: 178. ९, ठ.

konkaputus Viereck. Conn., N. Y., Md., D. C.

Chelonus (Chelonus) konkaputus Viereck, 1917 (1916). Conn. State Geol. and Nat. Hist. Survey Bul. 22, p. 233.. .

laticinctus Cresson. Tex., Colo.

Chelonus laticinctus Cresson, 1872. Amer. Ent. Soc., Trans. 4: 180..

lunatus Haldeman. $\mathrm{Pa}$.

Chelonus lunatus Haldeman, 1849. Acad. Nat. Sci. Phila., Proc. 4: 203.

muesebecki McComb. S. Dak., Wyo., Colo., N. Mex., Utah, Ariz., Nev., Wash., Oreg., Calif., Yukon, Alaska.

Chelonus (Chelonus) muesebecki McComb, 1962. Ent. Soc. Wash., Proc. 64: 19. ๆ, o.

mysticorum Viereck. Conn.

Chelonus mysticorum Viereck, 1917 (1916). Conn. State Geol. and Nat. Hist. Survey Bul. 22, p. 233. o.

narayani Subba Rao. Tex.?; India. Liberated in Texas but not established. Introduced from India. Host: Pectinophora gossypiella (Saund.).

Chelonus narayani Subba Rao, 1955. Indian Jour. Ent. 17: 63. \&, ठ.

nebraskensis (La Munyon). Nebr.

Davisania nebraskensis La Munyon, 1877. Nebr. Assce. Adv. Sci., Proc. No page number.

parvus Say. Ind.

Chelonus parvus Say, 1836. Boston Jour. Nat. Hist. 1: 265.

phaloniae Mason. Man. Host: Phalonia hospes (Wlsm.).

Chelonus phaloniae Mason, 1959. Canad. Ent. 91: 49. ๆ, ơ.

pygmaeus Viereck. B. C.

Chelonus pygmaeus Viereck, 1925. Canad. Ent. 57: 72. ठे.

rufiventris Cresson. N. Dak., S. Dak., Colo. Host: Agrotis orthogonia Morr.

Chelonus rufiventris Cresson, 1865. Ent. Soc. Phila., Proc. 4: 293. ठ.

sassacus Viereck. Conn.

Chelonus (Chelonus) sassacus Viereck, 1917 (1916). Conn. State Geol. and Nat. Hist.

Survey Bul. 22, p. 233..

secundus (Viereck). B. C.

A richelonus secundus Viereck, 1926. Canad. Ent. 58: 55. ‥

sericeus (Say). No. Amer. Host: Feltia ducens (Wlkr.) ?.

Sigalphus sericeus Say, 1824. In Keating, Narr. Long's 2nd Exped., v. 2, p. 321...

Chelonus filicornis Cameron, 1887. Manchester Lit. and Phil. Soc., Mem. and Proc. 26: 135.

sobrinus Haldeman. Pa.

Chelonus sobrinus Haldeman, 1849. Acad. Nat. Sci. Phila., Proc. 4: 203.

\section{Genus CHELONUS Subgenus MICROCHELONUS Szepligeti}

Microchelonus Szepligeti, 1908. Mus. Nat. Hung., Ann. 6: 403.

Type-species: Microchelonus hungaricus Szepligeti. Monotypic.

Chelonella Szepligeti, 1908. Mus. Nat. Hung., Ann. 6: 403. Preocc. by Beneden and Hesse, 1863.

Type-species: Ascogaster basalis Curtis. Desig. by Viereck, 1914.

Neochelonella Hincks, 1943. Entomologist 76: 98. N. name for Chelonella Szepligeti.

Revision: McComb, 1968 (1967). Md. Agr. Expt. Sta., Bul. A-149, 148 pp. (No. Amer. spp.). 
Taxonomy: Shenefelt, 1973. Hym. Cat., part 10, p. 873-907 (cat. World spp.).

abnormalis McComb. Tex.

Chelonus (Microchelonus) abnormalis McComb, 1968 (1967). Md. Agr. Expt. Sta., Bul. A-149, p. 16. \&, ठ.

absonus McComb. Tex.

Chelonus (Microchelonus) absonus McComb, 1968 (1967). Md. Agr. Expt. Sta., Bul. A-149, p. 17. 9 .

aciculatus McComb. Que. s. to N. C., w. to Minn.

Chelonus (Microchelonus) aciculatus McComb, 1968 (1967). Md. Agr. Expt. Sta., Bul. A-149, p. 18. ?, ठ。.

acutigaster McComb. Nebr., Idaho, Calif. Host: Zelleria haimbachi Busck.

Chelonus (Microchelonus) acutigaster McComb, 1968 (1967). Md. Agr. Expt. Sta., Bul. A-149, p. 19. \&, o.

alius McComb. N. Y., Ont., Wis., Minn.

Chelonus (Microchelonus) alius McComb, 1968 (1967). Md. Agr. Expt. Sta., Bul. A-149, p.

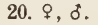

alpinus $\mathrm{McComb}$. Calif.

Chelonus (Microchelonus) alpinus McComb, 1968 (1967). Md. Agr. Expt. Sta., Bul. A-149, p. 21. $\delta$.

anthracinus McComb. Que.

Chelonus (Microchelonus) anthracinus McComb, 1968 (1967). Md. Agr. Expt. Sta., Bul. A-149, p. 22. ․

argutus McComb. Yukon.

Chelonus (Microchelonus) argutus McComb, 1968 (1967). Md. Agr. Expt. Sta., Bul. A-149, p. 23..

ashmeadii Dalla Torre. Colo.

Chelonus atripes Ashmead, 1890. Colo. Biol. Assoc., Bul. 1: 16. \&. Preocc. by Thomson, 1874.

Chelonus Ashmeadii Dalla Torre, 1898. Cat. Hym., v. 4, p. 199. N. name for atripes Ashmead.

auricornis McComb. Md., Va.

Chelonus (Microchelonus) auricornis McComb, 1968 (1967). Md. Agr. Expt. Sta., Bul. A-149, p. 25. ㅇ.

batrachedrae McComb. Mich. Host: Batrachedra praeangusta (Haw.).

Chelonus (Microchelonus) batrachedrae McComb, 1968 (1967). Md. Agr. Expt. Sta., Bul.

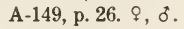

bickleyi McComb. Ariz.

Chelonus (Microchelonus) bickleyi McComb, 1968 (1967). Md. Agr. Expt. Sta., Bul. A-149, p. 27. $९, \delta$.

blackburni Cameron. Tex.?; Hawaii, Australia. Liberated in Texas but not established. Introduced from Hawaii. Host: Pectinophora gossypiella (Saund.).

Chelonus carinatus Cameron, 1881. Ent. Soc. London, Trans., p. 559.. . Preocc. by Provancher, 1881.

Chelonus blackburni Cameron, 1886. Manchester Lit. Phil. Soc., Mem. (ser. 3) 10: 242. N. name for carinatus Cameron.

Chelonus Cameronii Dalla Torre, 1898. Cat. Hym., v. 4, p. 200. N. name for carinatus Cameron.

brevicornis McComb. Fla.

Chelonus (Microchelonus) brevicornis McComb, 1968 (1967). Md. Agr. Expt. Sta., Bul. A-149, p. 30. \&, o.

brevifemur McComb. Calif.

Chelonus (Microchelonus) brevifemur McComb, 1968 (1967). Md. Agr. Expt. Sta., Bul. A-149, p. 31. + , ठ์.

bucculentus McComb. Mich., S. Dak., Utah.

Chelonus (Microchelonus) bucculentus McCómb, 1968 (1967). Md. Agr. Expt. Sta., Bul. A-149, p. 32. \&, ठ. 
burksi McComb. Tex.

Chelonus (Microchelonus) burksi McComb, 1968 (1967). Md. Agr. Expt. Sta., Bul. A-149, p. 33. $₹, \delta$.

carinatus Provancher. Que. s. to Fla.; Mich., Ont., S. Dak.

Chelonus carinatus Provancher, 1881. Nat. Canad. 12: 199..

Chelonus Provancheri Dalla Torre, 1898. Cat. Hym., v. 4, p. 206. Unnecessarily proposed as new name for carinatus Provancher.

caulicola McComb. N. Y., Ohio, Ind., S. Dak., Kans. Host: Aristotelia absconditella (Wlkr.), Mompha eloisella Clem., Ostrinia obumbratalis (Led.).

Chelonus (Microchelonus) caulicola McComb, 1968 (1967). Md. Agr. Expt. Sta., Bul. A-149, p. 35. $१$, ठ。.

cautus Cresson. La., Tex., Ariz.; Baja Calif., Mex., Cent. Amer.

Chelonus cautus Cresson, 1872. Amer. Ent. Soc., Trans. 4: 180. “ๆ” = ঠ.

Chelonus albobasilaris Ashmead, 1894. Calif. Acad. Sci., Proc. (2) 4: 123. ठ。.

Chelonus nucleolus Viereck, 1905. Kans. Acad. Sci., Trans. 19: 287..

ceanothi McComb. Ont. Host: Bucculatrix ceanothiella Braun.

Chelonus (Microchelonus) ceanothi McComb, 1968 (1967). Md. Agr. Expt. Sta., Bul. A-149, p. 38. + , ठ。.

cephelanthi McComb. Tex. Host: Phalonia cephalanthana Heinr.

Chelonus (Microchelonus) cephelanthi McComb, 1968 (1967). Md. Agr. Expt. Sta., Bul. A-149, p. 39. .

chrysogaster McComb. Iowa.

Chelonus (Microchelonus) chrysogaster McComb, 1968 (1967). Md. Agr. Expt. Sta., Bul. A-149, p. 39. ठ.

clypealis McComb. Ill., Iowa.

Chelonus (Microchelonus) clypealis McComb, 1968 (1967). Md. Agr. Expt. Sta., Bul. A-149, p. 40. $\delta$.

cnephasiae McComb. Wash., Oreg. Host: Cnephasia sp.

Chelonus (Microchelonus) cnephasiae McComb, 1968 (1967). Md. Agr. Expt. Sta., Bul. A-149, p. 42. , ठ。.

conformis McComb. Wis.

Chelonus (Microchelonus) conformis McComb, 1968 (1967). Md. Agr. Expt. Sta., Bul. A-149, p. 43. , ơ.

confusus McComb. S. Dak., Tex.

Chelonus (Microchelonus) confusus McComb, 1968 (1967). Md. Agr. Expt. Sta., Bul. A-149, p. 44 . $\$, \delta$.

convexus McComb. Calif.

Chelonus (Microchelonus) convexus McComb, 1968 (1967). Md. Agr. Expt. Sta., Bul. A-149, p. 45 . $\$, \delta$.

cosmopteridis McComb. Md. Host: Cosmopterix sp.

Chelonus (Microchelonus) cosmopteridis McComb, 1968 (1967). Md. Agr. Expt. Sta., Bul. A-149, p. 46. \&.

crassus McComb. Fla.

Chelonus (Microchelonus) crassus McComb, 1968 (1967). Md. Agr. Expt. Sta., Bul. A-149,

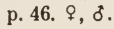

cushmani McComb. Va., Mo.

Chelonus (Microchelonus) cushmani MeComb, 1968 (1967). Md. Agr. Expt. Sta., Bul. A-149, p. 47. $\%$, o.

cylindricus MeComb. Wyo., Colo., Idaho, B. C., Wash.

Chelonus (Microchelonus) cylindricus McComb, 1968 (1967). Md. Agr. Expt. Sta., Bul. A-149, p. 48. ๆ, ठ.

declivus McComb. Que.

Chelonus (Microchelonus) declivus McComb, 1968 (1967). Md. Agr. Expt. Sta., Bul. A-149, p. 49. . 
disjunctus McComb. Md.

Chelonus (Microchelonus) disjunctus McComb, 1968 (1967). Md. Agr. Expt. Sta., Bul. A-149, p. 50. ठ.

disparilis McComb. Colo., Utah, Nev., B. C., Oreg., Calif.

Chelonus (Microchelonus) disparilis McComb, 1968 (1967). Md. Agr. Expt. Sta., Bul. A-149, p. 52. ९, ठ。.

dolicocephalus McComb. S. Dak., Mont., N. Mex., Ariz., Nev., Oreg., Calif.

Chelonus (Microchelonus) dolicocephalus McComb, 1968 (1967). Md. Agr. Expt. Sta., Bul. A-149, p. 53. \&, ठ.

dreisbachi McComb. Mass., N. Y., Pa., N. J., Md., Va., N. C., Mich., Ill.

Chelonus (Microchelonus) dreisbachi McComb, 1968 (1967). Md. Agr. Expt. Sta., Bul. A-149, p. 54. ९, ठ.

egregicolor Viereck. N. H. s. to D. C., w. to S. Dak. and Kans. Host: Laspeyresia pomonella (L.), Pyrausta futilalis (Led.).

Chelonus egregicolor Viereck, 1905. Kans. Acad. Sci., Trans. 19: 278. ठ.

Biology: Schaffner, 1959. U. S. Dept. Agr., Misc. Pub. 767, p. 64.

elasmopalpi McComb. Ga.; Jamaica. Host: Elasmopalpus lignosellus (Zell.).

Chelonus (Microchelonus) elasmopalpi McComb, 1968 (1967). Md. Agr. Expt. Sta., Bul. A-149, p. 56. $९, \delta$.

empherus McComb. Fla.

Chelonus (Microchelonus) empherus McComb, 1968 (1967). Md. Agr. Expt. Sta., Bul. A-149, p. 57. \&, ठ.

eucosmae McComb. N. Y., N. J., Ont., Mich., Wis. Host: Eucosma derelicta Heinr.

Chelonus (Microchelonus) eucosmae McComb, 1968 (1967). Md. Agr. Expt. Sta., Bul. A-149, p. 58. ๆ, ठ․

euphorbiae McComb. Ariz., Calif.

Chelonus (Microchelonus) euphorbiae McComb, 1968 (1967). Md. Agr. Expt. Sta., Bul. A-149, p. 60. .

eximius McComb. Que. s. to Md. and Ohio. Host: Coleotechnites piceaella (Kearf.), Phalonia mitilana $\mathrm{Hbn}$.

Chelonus (Microchelonus) eximius McComb, 1968 (1967). Md. Agr. Expt. Sta., Bul. A-149, p. 60 . + , $\delta$.

fissus Provancher. Que., Ont., Conn.

Chelonus fissus Provancher, 1880. Nat. Canad. 12: 199. ठ.

flavomarginalis McComb. Fla.

Chelonus (Microchelonus) flavomarginalis McComb, 1968 (1967). Md. Agr. Expt. Sta., Bul. A-149, p. 62 . ठ'.

fulgidus McComb. Conn., Ill.

Chelonus (Microchelonus) fulgidus McComb, 1968 (1967). Md. Agr. Expt. Sta., Bul. A-149, p. 62 ..

fumidus McComb. Calif.

Chelonus (Microchelonus) fumidus McComb, 1968 (1967). Md. Agr. Expt. Sta., Bul. A-149, p. 63 . ‥

fuscipennis McComb. N. S., Maine, Mass., N. Y., Md., Ont., Mich., Wis., N. Dak., Colo.

Chelonus (Microchelonus) fuscipennis McComb, 1968 (1967). Md. Agr. Expt. Sta., Bul.

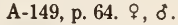

gossypicola McComb. Tex. Host: Pectinophora gossypiella (Saund.).

Chelonus (Microchelonus) gossypicola McComb, 1968 (1967). Md. Agr. Expt. Sta., Bul. A-149, p. 65. १, o.

gracilariae McComb. B. C. Host: Caloptilia murtfeldtella (Busck).

Chelonus (Microchelonus) gracilariae McComb, 1968 (1967). Md. Agr. Expt. Sta., Bul. A-149, p. 67. $९$, ठ.

gracilis McComb. Alta., Oreg., Calif.

Chelonus (Microchelonus) gracilis McComb, 1968 (1967). Md. Agr. Expt. Sta., Bul. A-149, p. 68 ., ऽ. 
grapholithae McComb. Tex. Host: Grapholitha packardi (Zell.).

Chelonus (Microchelonus) grapholithae McComb, 1968 (1967). Md. Agr. Expt. Sta., Bul. A-149, p. 69. ., '.

hadrogaster McComb. N. Dak., Idaho.

Chelonus (Microchelonus) hadrogaster McComb, 1968 (1967). Md. Agr. Expt. Sta., Bul. A-149, p. 70. ९, ठ์.

heliopae Gupta. La.?, Tex.?; India. Liberated in La. and Tex. but not established. Introduced from India. Host: Pectinophora gossypiella (Saund.).

Chelonus heliopae Gupta, 1955. Agra Univ. Jour. Res. 4: 209. \&, ठ.

hoppingi (Viereck). B. C.

Chelonella hoppingi Viereck, 1925. Canad. Ent. 57: 71. ९, ১.

hurdi McComb. Calif.

Chelonus (Microchelonus) hurdi McComb, 1968 (1967). Md. Agr. Expt. Sta., Bul. A-149, p. 73. ?.

hyalinus McComb. Tex.

Chelonus (Microchelonus) hyalinus McComb, 1968 (1967). Md. Agr. Expt. Sta., Bul. A-149, p. 74. $\uparrow, \delta$.

improcerus McComb. Calif.

Chelonus (Microchelonus) improcerus McComb, 1968 (1967). Md. Agr. Expt. Sta., Bul. A-149, p. 75 . .

insolitus McComb. Man. Host: Carposina niponensis ottawana Kearf.

Chelonus (Microchelonus) insolitus McComb, 1968 (1967). Md. Agr. Expt. Sta., Bul. A-149,

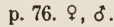

insuetus McComb. Que., Ont.

Chelonus (Microchelonus) insuetus MeComb, 1968 (1967). Md. Agr. Expt. Sta., Bul. A-149, p. 77. $\uparrow, \delta$.

isolatus McComb. P. E. I., Wis.

Chelonus (Microchelonus) isolatus McComb, 1968 (1967). Md. Agr. Expt. Sta., Bul. A-149, p. 78.,$\delta$.

keiferiae McComb. Va. Host: Keiferia inconspicuella (Murtf.).

Chelonus (Microchelonus) keiferiae McComb, 1968 (1967). Md. Agr. Expt. Sta., Bul. A-149, p. 79. $\&, \delta$.

krombeini McComb. Mass., Pa., Md., Ont.

Chelonus (Microchelonns) krombeini McComb, 1968 (1967). Md. Agr. Expt. Sta., Bul. A-149, p. 80 . \&.

laevifrons Cresson. Colo.

Chelonus laevifrons Cresson, 1865. Ent. Soc. Phila., Proc. 4: 294. “ $"$ " $=$ \&.

lavernae Ashmead. N. J., Ont., Ohio, Ill., Mo., Ala. Host: Mompha eloisella Clem.

Chelonus lavernae Ashmead, 1889 (1888). U. S. Natl. Mus., Proc. 11: 635. đo.

leptogaster McComb. Wyo., Calif.

Chelonus (Microchelonus) leptogaster McComb, 1968 (1967). Md. Agr. Expt. Sta., Bul. A-149, p. 83. \&.

longipalpis McComb. Ind., Ill.

Chelonus (Microchelonus) longipalpis McComb, 1968 (1967). Md. Agr. Expt. Sta., Bul. A-149, p. 84. \%, ס.

marshi McComb. Calif.

Chelonus (Microchelonus) marshi McComb, 1968 (1967). Md. Agr. Expt. Sta., Bul. A-149, p. $85 . \&, \delta$.

masoni McComb. Calif.

Chelonus (Microchelonns) masoni McComb, 1968 (1967). Md. Agr. Expt. Sta., Bul. A-149, p. $86 . \&, \delta$.

mccombi Marsh. Tex.

Chelonus (Microchelonus) aberrans McComb, 1968 (1967). Md. Agr. Expt. Sta., Bul. A-149, p. 15. $\uparrow, ~ \delta$. Preocc. by Tobias, 1964. 
Chelonus (Microchelonus) mecombi Marsh, 1974. Ent. Soc. Wash., Proc. 76: 285. N. name for aberrans McComb.

medicaginis McComb. Alta., S. Dak., Colo.

Chelonus (Microchelonus) medicaginis McComb, 1968 (1967). Md. Agr. Expt. Sta., Bul. A-149, p. 87. 9.

minimus Cresson. Tex.

Chelonus minimus Cresson, 1872. Amer. Ent. Soc., Trans. 4: 181. ․

montanus McComb. Calif.

Chelonus (Microchelonus) montanus McComb, 1968 (1967). Md. Agr. Expt. Sta., Bul. A-149, p. 89. \&, ठ。.

nanus Provancher. Canada.

Chelonus nanus Provancher, 1881. Nat. Canad. 12: 200. , ठ。.

niger $\mathrm{McComb}$. $\mathrm{Pa}$.

Chelonus (Microchelonus) niger McComb, 1968 (1967). Md. Agr. Expt. Sta., Bul. A-149, p. 90. + , o.

nigripennis Ashmead. D. C.

Chelonus nigripennis Ashmead, 1889 (1888). U. S. Natl. Mus., Proc. 11: 635. ठౌ.

pallidus Ashmead. Md.

Chelonus pallidus Ashmead, 1889 (1888). U. S. Natl. Mus., Proc. 11: 635. "१" = ठ์.

paradoxus McComb. Wis.

Chelonus (Microchelonus) paradoxus McComb, 1968 (1967). Md. Agr. Expt. Sta., Bul. A-149, p. 91. 9 .

paululus McComb. Fla.

Chelonus (Microchelonus) paululus McComb, 1968 (1967). Md. Agr. Expt. Sta., Bul. A-149, p. 92 . $\$, \delta$.

pecki McComb. Sask.

Chelonus (Microchelonus) pecki McComb, 1968 (1967). Md. Agr. Expt. Sta., Bul. A-149, p. 93. $\delta$.

pectinophorae Cushman. Tex.?; Korea, China, Japan, Formosa. Liberated in Tex. but not established. Introduced from Japan. Host: Pectinophora gossypiella (Saund.).

Chelonus (Chelonella) pectinophorae Cushman, 1931. U. S. Natl. Mus., Proc. 79 (14): 11. \&, $\delta$.

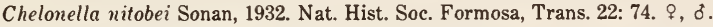

periplocae McComb. Calif. Host: Periploca nigra Hodges.

Chelonus (Microchelonus) periplocae McComb, 1968 (1967). Md. Agr. Expt. Sta., Bul. A-149, p. 96. .

Biology: Koehler and Tauber, 1964. Jour. Econ. Ent. 57: 566.

petrovae McComb. S. Dak., Nebr., Idaho, Calif. Host: Eucosma recissoriana Heinr., Rhyacionia bushnelli (Busck).

Chelonus (Microchelonns) petrovae McComb, 1965. Ent. News 76: 179. ९, ठ์.

phthorimaeae Gahan. N. J., Va., La., Tex., Colo., Idaho, Oreg., Calif.; Mex., Bermuda. Host: Keiferia inconspicuella (Murtf.), Phthorimaea operculella (Zell.), Tildenia gndmannella (Wlsm.).

Chelonus phthorimaeae Gahan, 1917. U. S. Natl. Mus., Proc. 53: 199. ९, ठ゙.

Biology: Graf, 1917. U. S. Dept. Agr., Bul. 427, p. 40-41 (as shoshoneanorum Viereck). plesius (Viereck). B. C.

Chelonella plesins Viereck, 1925. Canad. Ent. 57: 72. ð.

ponderosae McComb. Ariz.

Chelonus (Microchelonus) ponderosae McComb, 1968 (1967). Md. Agr. Expt. Sta., Bul. A-149, p. 99. $\&$, ठ.

procericornis McComb. Calif.

Chelonus (Microchelonus) procericornis McComb, 1968 (1967). Md. Agr. Expt. Sta., Bul. A-149, p. 100. . . 
prolatricornis McComb. P. E. I.

Chelonus (Microchelonus) prolatricornis McComb, 1968 (1967). Md. Agr. Expt. Sta., Bul. A-149, p. 101. ?.

proteus Gahan. Md. Host: Periploca gleditschiaeella (Chamb.).

Chelonus (Chelonella) proteus Gahan, 1919. U. S. Natl. Mus., Proc. 55: 116. ९, ơ.

prunicola McComb. Calif. Host: Leucoptera sp., Paraleucoptera heinrichi Jones.

Chelonus (Microchelonus) prunicola McComb, 1968 (1967). Md. Agr. Expt. Sta., Bul. A-149, p. 103. $\&$, $\delta$.

punctatus McComb. Calif.

Chelonus (Microchelonus) punctatus McComb. 1968 (1967). Md. Agr. Expt. Sta., Bul. A-149, p. 104. + , $。$.

punctipennis McComb. Ont.

Chelonus (Microchelonus) punctipennis McComb, 1968 (1967). Md. Agr. Expt. Sta., Bul. A-149, p. 106. $\&$, ס.

quadriceps McComb. Minn., S. Dak., Colo., Alaska.

Chelonus (Microchelonus) quadriceps McComb, 1968 (1967). Md. Agr. Expt. Sta., Bul. A-149, p. 107., ,.

recurvariae McComb. N. H., Pa., Ohio, Ont., Mich., Wis. Host: Exoteleia dodecella (L.), E. pinifoliella (Chamb.), Petrova albicapitana (Busck), Recurvaria sp.

Chelonus (Microchelonus) recurvariae McComb, 1968 (1967). Md. Agr. Expt. Sta., Bul. A-149, p. 108. ㅇ, $\delta$.

rubiginis McComb. La.

Chelonus (Microchelonus) mibiginis McComb, 1968 (1967). Md. Agr. Expt. Sta., Bul. A-149, p. 109. + , $\delta$.

rufiscapus Provancher. Que., P. E. I., N. S., Mass., N. Y., Va., N. C., Ont., Mich., Ind., Wis., Ill., S. Dak., B. C.

Chelonus mufiscapus Provancher, 1886. Addit. Corr. Faune Ent. Canada Hym., p. 144.. saileri McComb. Yukon, Alaska.

Chelonus (Microchelonus) saileri McComb, 1968 (1967). Md. Agr. Expt. Sta., Bul. A-149, p. 111. $\uparrow, \delta$.

salicis McComb. Calif. Host: Batrachedra salicipomonella Clem.

Chelonus (Microchelonus) salicis MeComb, 1968 (1967). Md. Agr. Expt. Sta., Bul. A-149, p. 112.,$+ \delta$.

sculleni McComb. Oreg.

Chelonus (Microchelonus) sculleni McComb, 1968 (1967). Md. Agr. Expt. Sta., Bul. A-149, p. 113. ?.

severini McComb. S. Dak.

Chelonus (Microchelonus) severini MeComb, 1968 (1967). Md. Agr. Expt. Sta., Bul. A-149, p. 114.,$\delta$.

shenefelti McComb. Wis.

Chelonus (Microchelonus) shenefelti McComb, 1968 (1967). Md. Agr. Expt. Sta., Bul.

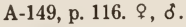

shoshoneanorum Viereck. Colo.

Chelonus shoshoneanorum Viereck, 1911. U. S. Natl. Mus., Proc. 39: 402. \&.

similis McComb. Calif.

Chelonus (Microchelonus) similis McComb, 1968 (1967). Md. Agr. Expt. Sta., Bul. A-149, p. 117. $\%, \delta$.

spinosus McComb. N. J., Ohio.

Chelonus (Microchelonus) spinosus McComb, 1968 (1967). Md. Agr. Expt. Sta., Bul. A-149, p. 118. $\%, \delta$.

subtuberculatus McComb. Sask., Colo., Yukon.

Chelonus (Microchelonus) subtuberculatus McComb, 1968 (1967). Md. Agr. Expt. Sta., Bul. A-149, p. 119. ๆ, ठ. 
suturalis McComb. Colo.

Chelonus (Microchelonus) suturalis McComb, 1968 (1967). Md. Agr. Expt. Sta., Bul. A-149, p. 120 . $९, \delta$.

tenuicornis McComb. Md., Va.

Chelonus (Microchelonus) tenuicomis McComb, 1968 (1967). Md. Agr. Expt. Sta., Bul. A-149, p. 121. ?.

teretiventris McComb. N. Dak., Colo.

Chelonis (Microchelonus) teretiventris McComb, 1968 (1967). Md. Agr. Expt. Sta., Bul. A-149, p. 122. \&, ठ์.

tuberculatus McComb. N. Mex.

Chelonus (Microchelonus) tuberculatus McComb, 1968 (1967). Md. Agr. Expt. Sta., Bul. A-149, p. 123. ?.

vulgaris McComb. S. Dak.

Chelonus (Microchelonus) vulgaris McComb, 1968 (1967). Md. Agr. Expt. Sta., Bul. A-149, p. 124 . .

walkleyae McComb. S. Dak.

Chelonus (Microchelonus) walkleyae McComb, 1968 (1967). Md. Agr. Expt. Sta., Bul. A-149, p. 124. ๆ, ठ์.

Nomina Nuda in Chelonus Panzer

Chelonus biannularis Ashmead, 1900 (1899). In Smith, Ins. of N. J., p. 591.

Chelonus corrugatus Harris, 1862. In Cresson, Ent. Soc. Phila., Proc. 1: 211.

Chelonus dislocatus Harris, 1862. In Cresson, Ent. Soc. Phila., Proc. 1: 211.

\section{Genus PHANEROTOMA Wesmael}

Phanerotoma Wesmael, 1838. Nouv. Mem. Acad. Sci. Bruxelles 11: 165.

Type-species: Chelonus dentatus Panzer. Desig. by Westwood, 1839.

Phanerogaster Wesmael, 1838. Nouv. Mem. Acad. Sci. Bruxelles 11: 165. Emend.

Phaenotoma Ashmead, 1894. Linn. Soc. London, Jour., Zool. 25: 123. Misspelling.

Sulydus du Buysson, 1897. Soc. Ent. France, Ann. 66: 354.

Type-species: Sulydus marshalli du Buysson. Monotypic.

Neophanerotoma Szepligeti, 1908. Notes Leyden Mus. 29: 227.

Type-species: Phanerotoma orientalis Szepligeti. Desig. by Viereck, 1914.

Phanerotomina Shestakov, 1930. Ent. Obozr. 24: 100.

Type-species: Phanerotomina gussakovskii Shestakov. Orig. desig.

Taxonomy: Shenefelt, 1973. Hym. Cat., part 10, p. 909-928 (cat. World spp.).

erythrocephala Rohwer. Ga., Wis., Mont., Colo., N. Mex., Calif. Host: Hedulia injectiva Heinr., Laspeyresia piperana (Kearf.), L. toreuta (Grote).

Phanerotoma erythrocephala Rohwer, 1917. U. S. Natl. Mus., Proc. 53: 166. \&, ठ。.

fasciata Provancher. Newfoundland, Ont. s. to Fla. and Tex., w. to N. W. T., B. C. and Oreg. Host: Acrobasis caryae Grote, Grapholitha interstinctana (Clem.), G. molesta (Busck),

G. packardi (Zell.), Laspeyresia anaranjada Miller, L. caryana (Fitch), L. ingens Heinr.,

L. nigricana (Steph.), L. pomonella (L.), Melissopus latiferreanus (Wlsm.). Prior to 1951, this species was frequently misidentified as tibialis (Haldeman).

Phanerotoma fasciata Provancher, 1881. Nat. Canad. 12: 200. \&.

Biology: Allen, 1962. U. S. Dept. Agr., Tech. Bul. 1265, p. 40-41.

flavitestacea Fischer. Calif.; Israel, Yugoslovia, North Africa, Spain. Introduced from Israel. Host: Ectomyelois ceratoniae (Zell.), Paramyelois transitella (Wlkr.).

Phanerotoma flavitestacea Fischer, 1959. Acta Mus. Maced. Sci. Nat. 6: 18. \&, ð.

Biology: Biliotti and Daumal, 1971. Zool. Ecol. Anim., Ann. 1: 379-394.

franklini Gahan. N. S. and Que. s. to Fla., w. to Ill. and Tex.; Calif. Host: Acrobasis vaccinii

Riley.

Phanerotoma franklini Gahan, 1917. U. S. Natl. Mus., Proc. 53: 200. १, ð. 
grapholithae Muesebeck. Conn., N. Y., N. J., Md., Va.; Japan, Korea, China. Introduced from Japan. Host: Grapholitha molesta (Busck), G. prunivora (Walsh), Laspeyresia pomonella (L.).

Phanerotoma grapholithae Muesebeck, 1933. Ent. Soc. Wash., Proc. 35: 50. ๆ, ơ.

inopinata Caltagirone. Calif.; Mexico, Baja Calif. Host: Paramyelois transitella (Wlkr.).

Phanerotoma inopinata Caltagirone, 1965. Pan-Pacific Ent. 41: 17. $९$, o.

laspeyresiae Rohwer. Mich., Mont., Idaho., B. C., Oreg., Calif. Host: Hedulia injectiva Heinr., Laspeyresia miscitata Heinr., L. piperana (Kearf.), L. toreuta (Grote).

Phanerotoma laspeyresia(!) Rohwer, 1915. U. S. Natl. Mus., Proc. 49: 230. ð.

longicauda Walley. N. S. and Que. s. to Fla., w. to Alta. and Tex.; Ariz., Calif.; Baja Calif. Host: Carposina sp.

Phanerotoma longicauda Walley, 1951. Canad. Ent. 83: 306. $q, \delta$.

planifrons (Nees). Calif.; Europe, North Africa, West and Central Asia, Siberia, Korea, Japan. Introduced from Hungary. Host: Etiella zinckenella (Treit.), Grapholitha molesta (Busck).

Sigalphus planifrons Nees, 1816 (1813). Gesell. Naturf. Freunde Berlin, Mag. 7: 259.

Taxonomy: Watanabe, 1940. Insecta Matsumurana 14: 88-89.

Biology: Parker, 1951. U. S. Dept. Agr., Tech. Bul. 1036, p. 12-16. -Clausen, 1956. U. S. Dept. Agr., Tech. Bul. 1139, p. 121.

recurvariae Cushman. Conn., Pa., Fla., Ont., Mich., Wis. Host: Recurvaria nanella (Hbn.), Spilonota ocellana (D. and S.).

Phanerotoma recurvariae Cushman, 1914. Ent. Soc. Wash., Proc. 16: 78. ․ §.

Biology: Sadava and Miller, 1967. Canad. Ent. 99: 436-442.

rhyacioniae Cushman. Md., Va., Ark., La., Miss. Host: Rhyacionia frnstrana (Comst.).

Phanerotoma rhyacioniae Cushman, 1927. Jour. Agr. Res. 34: 740. $\&$, ठ.

thapsina Walley. Fla., Tex., Ariz., Calif.; Mexico, Baja Calif.

Phanerotoma thapsina Walley, 1951. Canad. Ent. 83: 305. ९, ơ.

tibialis (Haldeman). Que., Maine, Conn., Pa., Del., Fla., Ont., Mich., Tenn., Ala., Wis., Ill., Minn., Ark., Kans., Tex.; Antigua. Host: Acrobasis betulella Hulst, $A$. caryae Grote, $A$. caryivorella Rag., A. mebrifasciella Pack., A. sylviella Ely, Tetralopha asperatella (Clem.).

Sigalphus tibialis Haldeman, 1849. Acad. Nat. Sci. Phila., Proc. 4: 203..+

Phanerotoma noctivaga Marshall, 1885. Roy. Ent. Soc. London, Trans. 1885: 112. ९, ठో.

Biology: Balduf, 1968. Ent. Soc. Amer., Ann. 61: 466-467.

toreutae Caltagirone. Mich., Wis. Host: Laspeyresia toreuta (Grote).

Phanerotoma torentae Caltagirone, 1967. Pan-Pacific Ent. 43: 126. ๆ, ठ.

Biology: Harbo and Kraft, 1969. Ent. Soc. Amer., Ann. 62: 214-220.

\section{SUBFAMILy ADELIINAE}

\section{Genus ADELIUS Haliday}

Adelius Haliday, 1833. Ent. Mag. 1: 262.

Type-species: Adelius subfasciatus Haliday. Monotypic.

Acaelius Haliday, 1834. Ent. Mag. 2: 231. Emend.

Acoelius Haliday, 1834. Ent. Mag. 2: 539. Emend.

Pleiomerus Wesmael. 1837. Nouv. Mem. Acad. Sci. Bruxelles 10: 67.

Type-species: Adelius subfasciatus Haliday. Monotypic.

Anomopterus Rohwer, 1914. Psyche 21: 80.

Type-species: Anomoptemis fasciipennis Rohwer. Orig. desig.

Myriola Shestakov, 1932. Zool. Anz. 99: 259.

Type-species: Myriola gussakovskii Shestakov. Monotypic.

This group, which is distinctive both morphologically and biologically, has been included in the Microgastrinae in the past. Recent workers (Capek, 1965; Nixon, 1965; Tobias, 1967) have 
proposed a separate subfamily for Adelius, and a few related genera, which has affinities with the Cheloninae as well as the Microgastrinae. Hosts are larvae of leaf mining microlepidoptera.

Revision: Muesebeck, 1922. U. S. Natl. Mus., Proc. 61 (15): 12-14 (No. Amer. spp.). -Telenga, 1955. Fauna U. S. S. R., v. 5, n. 4, p. 15-19 (some Eur. spp.).

Taxonomy: Capek, 1965. 12th Internatl. Cong. Ent., London, Proc. 1964, p. 98. --Nixon, 1965. Brit. Mus. (Nat. Hist.) Ent., Bul., Sup. 2, p. 8-10. -Tobias, 1967. Ent. Obozr. 46: 658.

-Shenefelt, 1973. Hym. Cat., part 7, p. 670-675 (cat. World spp.).

coloradensis Muesebeck. Ill., La., Colo.

Adelius coloradensis Muesebeck, 1922. U. S. Natl. Mus., Proc. 61 (15): 14. ठ.

fasciipennis (Rohwer). Va., Wis. Host: Ectoedemia phleophaga Busck. Anomopterns fasciipennis Rohwer, 1914. Psyche 21: 80. ๆ, o.

nigripectus Muesebeck. Ind. Host: Leaf miner in poplar.

Adelius nigripectus Muesebeck, 1922. U. S. Natl. Mus., Proc. 61 (15): 13. ð.

\section{SUBFAMILY MICROGASTRINAE}

All species of this, the largest subfamily of the Braconidae, are internal parasites of lepidopterous larvae. Some of the most important species in biological control belong to this group.

Revision: Muesebeck, 1922. U. S. Natl. Mus., Proc. 61 (15): 6-76 (No. Amer. spp.).

Taxonomy: Nixon, 1965. Brit. Mus. (Nat. Hist.) Ent., Bul., Sup. 2, p. 1-13. - Tobias, 1967. Ent. Obozr. 46: 657. -Capek, 1970. Canad. Ent. 102: 856-858.

\section{TRIBE MICROGASTRINI}

Revision: Nixon, 1965. Brit. Mus. (Nat. Hist.) Ent., Bul., Sup. 2, p. 6-284 (key World genera).

\section{Genus APANTELES Foerster}

Apanteles Foerster, 1862. Naturh. Ver. Rheinlande, Verh. 19: 245.

Type-species: Microgaster obscura Nees. Orig. desig.

Cotesia Cameron, 1891. Manchester Lit. and Phil. Soc., Mem. and Proc. (4) 4: 185.

Type-species: Cotesia flavipes Cameron. Monotypic.

Pseudapanteles Ashmead, 1898 (1897). Ent. Soc. Wash., Proc. 4: 166.

Type-species: Pseudapanteles annulicornis Ashmead. Desig. by Viereck, 1911.

Protapanteles Ashmead, 1898 (1897). Ent. Soc. Wash., Proc. 4: 166.

Type-species: Protapanteles ephyrae Ashmead. Desig. by Viereck, 1914.

Urogaster Ashmead, 1898 (1897). Ent. Soc. Wash., Proc. 4: 166.

Type-species: Urogaster vulgaris Ashmead. Desig. by Viereck, 1914.

Parapanteles Ashmead, 1900. U. S. Natl. Mus., Proc. 23: 131.

Type-species: Apanteles aletiae Riley. Orig. desig.

Glyptapanteles Ashmead, 1904. U. S. Natl. Mus., Proc. 28: 147.

Type-species: Glyptapanteles manilae Ashmead. Monotypic.

Cryptapanteles Viereck, 1910. Ent. Soc. Wash., Proc. 11: 209.

Type-species: Cryptapanteles rileyanus Viereck. Orig. desig.

Xestapanteles Cameron, 1910 (1909). Ztschr. f. Naturw. 81: 447.

Type-species: Xestapanteles latiannulatus Cameron. Monotypic.

Apanteles subg. Dolichogenidea Viereck, 1911. U. S. Natl. Mus., Proc. 40: 173.

Type-species: Apanteles (Dolichogenidea) banksi Viereck. Orig. desig.

Stenopleura Viereck, 1911. U. S. Natl. Mus., Proc. 40: 187.

Type-species: Apanteles sesamiae Cameron. Orig. desig.

Allapanteles Brethes, 1915. Buenos Aires Mus. Nac. de Hist. Nat., An. 27: 404.

Type-species: Allapanteles cecidiptae Brethes. Monotypic.

Revision: Muesebeck, 1921. U. S. Natl. Mus., Proc. 58: 483-576 (No. Amer. spp.). - Wilkinson, 1928. Bul. Ent. Res. 19: 79-146 (Indo-Austral. spp.). - Wilkinson, 1932. Roy. Ent. Soc.

London, Trans. 80: 301-344 (Afr. spp.). -Telenga, 1955. Fauna U. S. S. R., v. 5, n. 4, p.

21-147 (Eur. spp.). 
Taxonomy: Nixon, 1965. Brit. Mus. (Nat. Hist.) Ent., Bul., Sup. 2, p. 17-25 (key to spp.

groups). - Shenefelt, 1972. Hym. Cat., part 7, p. 429-668 (cat. World spp.).

absonus Muesebeck. Newfoundland, Ont., Maine, Wis., Minn., Man., Alta., Mont., Colo., N. Mex., Idaho, Utah, B. C., Wash., Oreg. Host: Acleris variana (Fern.), Archippus packardianus (Fern.), Argyrotaenia dorsalana (Dyar), Choristoneura fumiferana (Clem.), C. occidentalis Freem., Dioryctria reniculella (Grote), Epinotia nanana (Treits.), Griselda radicana Heinr., Taniva albolineana (Kearf.), Zeiraphera canadensis M. and F., $Z$. griseana (Hbn.), Z. fortunana (Kearf.), Z. improbana (Wlkr.).

Apanteles absonus Muesebeck, 1965. Ent. News 76: 71., , ठ.

Taxonomy: Mason, 1974. Canad. Ent. 106: 1098-1100.

acaudus (Provancher). Maine, Mass., R. I., Conn., N. Y., Va., Ont., Mich., Wis. Host: Hydria prunivorata (Ferg.), H. undulata (L.).

Microgaster acaudus Provancher, 1886. Addit. Corr. Faune Ent. Canada Hym., p. 142. , $\delta$.

Apanteles hydriae Muesebeck, 1921. U. S. Natl. Mus., Proc. 58: 561. $\subsetneq$, ठ.

aciculatus (Ashmead). Mo., Tex.; West Indies, Cent. Amer.

Urogaster aciculatus Ashmead, 1900. Roy. Ent. Soc. London, Trans. 1900: 289. ð.

Pseudapanteles sanctivincenti Ashmead, 1900. Roy. Ent. Soc. London, Trans. 1900: 291. \&, J. Preocc. by Ashmead, 1900: 279.

Apanteles thoracicus Muesebeck, 1921. U. S. Natl. Mus., Proc. 58: 534. N. name for sanctivincenti Ashmead, 1900: 291.

acrobasidis Muesebeck. Md., Fla., Miss. Host: Acrobasis caryae Grote (?), Gretchena bolliana (Sling.).

A panteles acrobasidis Muesebeck, 1921. U. S. Natl. Mus., Proc. 58: 509. \&.

acronyctae (Riley). N. H. s. to N. J., w. to Ont. and Mo.; Colo., Calif. Host: Acronicta dactylina (Grote), A. leporina (L.) (?), A. lepusculina Gn., A. oblinita (Smith), Merolonche lupini (Grote), Orgyia leucostigma (Smith) (?).

Microgaster acronyctae Riley, 1870. Ins. Mo., Ann. Rpt. 2: 120.

Apanteles acronyctae Riley, 1881. Acad. Sci. St. Louis, Trans. 4: 312. ð.

Apanteles orgyiae Ashmead, 1893. Ohio Expt. Sta., Bul. 1: 159. ․

agricola Viereck. Conn., N. C.

Apanteles (Protapanteles) agricola Viereck, 1917 (1916). Conn. State Geol. and Nat. Hist. Survey, Bul. 22, p. 192.. .

alaskensis (Ashmead). Mich., B. C., Calif., Alaska. Host: Gabriola dyari Tay., Oporinia autumnata (Gn.).

Protapanteles alaskensis Ashmead, 1902. Wash. Acad. Sci., Proc. 4: 247. ஒ, ð.

aletiae Riley. Fla., Ala.; West Indies. Host: Alabama argillacea (Hbn.), Gonodonta nutrix (Cram.).

Apanteles aletiae Riley, 1881. Acad. Sci. St. Louis, Trans. 4: 296, 298, 306. ․ đ.

algonquinorum Viereck. Conn.

Apanteles (Protapanteles) algonquinorum Viereck, 1917 (1916). Conn. State Geol. and Nat. Hist. Survey, Bul. 22, p. 196.

alticola (Ashmead). N. B., Maine, N. H., Colo., Utah, Idaho, Oreg., Calif., Alaska. Host: Amathes collaris (G. and R.), Diarsia rosaria (Grote), Euxoa ochrogaster (Gn.).

Protapanteles alticola Ashmead, 1902. Wash. Acad. Sci., Proc. 4: 248. ठ.

alypiae Muesebeck. Conn., N. Y. Host: Alypia octomaculata (F.).

Apanteles alypiae Muesebeck, 1922. U. S. Natl. Mus., Proc. 61 (15): 18. \&, ð.

americanus (Lepeletier). Fla., Miss., Okla., Tex., Ariz. Host: Erinnyis ello (L.), Manduca sp.

Microgaster americanus Lepeletier, 1825. Encycl. Meth. Ins. 10: 42. §, ठ.

Microgaster flaviventris Cresson, 1865. Ent. Soc. Phila., Proc. 4: 66.

Apanteles mexicanus Ashmead, 1895. Calif. Acad. Sci., Proc. 5: 545. ‡, ठ.

ammalonis Muesebeck. N. J. Host: Cycria tenera Hbn.

Apanteles ammalonis Muesebeck, 1926. U. S. Natl. Mus., Proc. 69 (7): 8. ․ §.

angaleti Muesebeck. La.(?), Tex.(?); India, Sumatra. Liberated in La. and Tex. but not established. Introduced from India. Host: Pectinophora gossypiella (Saund.).

Apanteles angaleti Muesebeck, 1954. Lab. Zool. Gen. Agr. Portici, Bol. 33: 61. ‡, §. 
anisotae Muesebeck. N. B. s. to Md.; Ont. Host: Anisota senatoria (Smith), A. stigma (F.), A. s. fuscosa Ferg., Dryocampa mibicunda (F.).

Apanteles anisotae Muesebeck, 1921. U. S. Natl. Mus., Proc. 58: 555. ‥

argynnidis Riley. Mass., N. Y., N. J., D. C., W. Va., Ky., Ill., Tex. Host: Epargyreus clarus (Cram.), Erynnis tristis tatius (Edw.), E. zarucco funeralis (S. and B.), Speyeria cybele (F.).

Apanteles argynnidis Riley, 1889. In Scudder, Butterflies East. U. S., p. 1904..

aristoteliae Viereck. N. B. s. to Pa., w. to Ont., Wash., and Calif.; La., Ariz. Host: Ancylis comptana fragaria (W. and R.), Argyrotaenia citrana (Fern.), Aristotelia fungivorella (Chamb.), Aroga trialbamaculella (Chamb.), Choristoneura fumiferana (Clem.), Dioryctria reniculella (Grote), Filatima persicaeella (Murtf.), Gelechia sp.

Apanteles (Apanteles) aristoteliae Viereck, 1912. U. S. Natl. Mus., Proc. 42: 613. ơ. Apanteles (Apanteles) gelechiae Viereck, 1912. U. S. Natl. Mus., Proc. 42: 615..

Biology: Basinger, 1938. Hilgardia 11: 661-663.

atalantae (Packard). Mass., Pa., N. J., W. Va., Ont., Mich., Wis., Iowa, Mo., Minn., N. Dak., Sask., Alta., Colo., Tex. Host: Nymphalis antiopa (L.), N. milberti (Godt.), Polygomia sp., Vanessa atalanta (L.).

Microgaster atalantae Packard, 1881 (1880). Boston Soc. Nat. Hist., Proc. 21: 28. ๆ, đ๋. autographae Muesebeck. Newfoundland, Que., Md., Va., S. C., Ga., Fla., Mich., La., S. Dak., Tex., Colo., Oreg. Host: Autographa sp., Autoplusia egena (Gn.), Pseudaletia unipuncta (Haw.), Pseudoplusia includens (Wlkr.), Rachiplusia ou (Gn.), Spodoptera frugiperda (Sm.), Trichoplusia ni (Hbn.).

Apanteles autographae Muesebeck, 1921. U. S. Natl. Mus., Proc. 58: 547. ๆ.

baldufi Muesebeck. N. Y., N. C., Ont., Mich., Minn. Host: Acrobasis betulella Hulst, $A$. rubrifasciella Pack., A. secundella Ely.

Apanteles baldufi Muesebeck, 1968. In Balduf, Ent. Soc. Amer., Ann. 61: 463. \&, ১’.

Biology: Balduf, 1968. Ent. Soc. Amer., Ann. 61: 464-465.

banksi Viereck. N. Y., Pa., Md., D. C., Va., Mich., Minn.

A panteles (Dolichogenidea) banksi Viereck, 1911. U. S. Natl. Mus., Proc. 40: 173..

bedelliae Viereck. Conn. s. to Va., w. to Ont., Kans., and La.; Utah, Ariz., Oreg., Calif. Host: Anomis erosa Hbn., Bedellia minor Busck, B. somnulentella (Zell.), Coleotechnites thujaeella Kearf., Cosmopterix sp., Lithocolletis tremuloidiella Braun, Paraleucoptera albella (Chamb.).

Apanteles (Protapanteles) bedelliae, Viereck. 1911. U. S. Natl. Mus., Proc. 40: 174. ๆ, ơ.

betheli Viereck. Colo. Host: Argyresthia sp.(?).

Apanteles (Apanteles) betheli Viereck, 1910. U. S. Natl. Mus., Proc. 39: 402. + , ठ.

bucculatricis Muesebeck. Calif. Host: Bucculatrix albertiella Busck, B. thurberiella (Busck). Apanteles bucculatricis Muesebeck, 1921. U. S. Natl. Mus., Proc. 58: 502. ๆ, ठ̊.

bushnelli Muesebeck. N. C., Fla., Iowa, S. Dak., Nebr., Mont., Calif. Host: Dioryctria abietella (D. and S.), D. clarioralis (Wlkr.), D. disclusa Heinr., Rhyacionia bushnelli (Busck), $R$. pasadenana (Kearf.).

Apanteles bushnelli Muesebeck, 1933. Ent. Soc. Wash., Proc. 35: 196. ‡, đ̃.

caberatae Muesebeck. Oreg., Calif. Host: Sabulodes caberata (Gn.).

Apanteles caberatae Muesebeck, 1956. Pan-Pacific Ent. 32: 26. ๆ, ठ.

cacoeciae Riley. U. S., Ont., Que. Host: Acrobasis caryae Grote, Archips argyrospilus (Wlkr.), A. cerasivoranus (Fitch), A. semiferanus (Wlkr.), Epiblema scudderianum (Clem.), Epinotia sp., Exartema valdanum McD., Gnorimoschema gallaesolidaginis (Riley), Grapholitha molesta (Busck), Sciaphila duplex (Wlsm.).

Apanteles cacoeciae Riley, 1881. Acad. Sci. St. Louis, Trans. 4: 305. \&, ơ.

Pseudapanteles gallaediploppi Ashmead, 1899. In Smith, Ins. of N. J., p. 593. Nom. nud.

caffreyi Muesebeck. Tex., Ariz.; Mexico, West Indies, Cent. Amer., Colombia.

Apanteles caffreyi Muesebeck, 1921. U. S. Natl. Mus., Proc. 58: 540. ‡, o.

californicus Muesebeck. Que., Ont., Alta., B. C., Idaho, Oreg., Calif. Host: Coleotechnites sp., C. gibsonella Kaerf., C. milleri (Busck), Epinotia meritana Heinr., Eucosma bobana Kearf.

Apanteles californicus Muesebeck, 1921. U. S. Natl. Mus., Proc. 58: 511. ‡, ઠ.. 
Biology: Telford, 1961. Jour. Econ. Ent. 54: 347-355. -Stark, 1961. Canad. Jour. Zool. 39: 894. canarsiae Ashmead. Conn. s. to Ga., w. to Ont. and Kans.; Calif. Host: Acrobasis betulella Hulst, Ancylis comptana (Froel.), Argyrotaenia velutinana (Wlkr.), Desmia funeralis (Hbn.), Dioryctria reniculella (Grote), Psorosina hammondi (Riley).

Apanteles canarsiae Ashmead, 1898. Ent. Soc. Wash., Proc. 4: 127. \$, ¿.

Apanteles (Apanteles) housatannuckorum Viereck, 1917 (1916). Conn. State Geol. and Nat. Hist. Survey, Bul. 22, p. 189, 198.

Apanteles (Apanteles) maquinnai Viereck, 1917 (1916). Conn. State Geol. and Nat. Hist. Survey, Bul. 22, p. 190, 199. .

carduicola (Packard). Mass. Host: Cynthia cardui (L.).

Microgaster carduicola Packard, 1881 (1880). Boston Soc. Nat. Hist., Proc. 21: 27. \&, ð.

carpatus (Say). Cosmopolitan. Host: Nititinea fuscipunctella (Haw.), Phercoeca utrella (Wlsm.), Tinea despecta Meyr., T. pellionella (L.), Tineola biselliella (Hum.), Trichophaga tapetzella (L.).

Microgaster carpata Say, 1836. Boston Jour. Nat. Hist. 1: 263..

Protapanteles hawaiiensis Ashmead, 1901. Fauna Hawaii. 1: 362 ..

Urogaster solitarius Ashmead, 1901. Ent. Soc. London, Trans. 1900, p. 287. $\$$. Preocc. by Ratzeburg, 1844.

Apanteles piceoventris Muesebeck, 1921. U. S. Natl. Mus., Proc. 58: 515. N. name for solitarius Ashmead.

Apanteles igae Watanabe, 1932. Insecta Matsumurana 7: 97..

Biology: Fallis, 1942. Canad. Jour. Res., Sect. D, Zool. Sci. 20: 13-19. -Key and Common, 1959. Austral. Jour. Zool. 7: 64.

cassianus Riley. Ill., Tex., Colo. Host: Colias eurytheme Bdvl., Eurema nicippe (Cram.). Apanteles cassianus Riley, 1881. Acad. Sci. St. Louis, Trans. 4: 307. ๆ, ठ̋.

cerurae Muesebeck. Conn., N. J. Host: Cerura sp., C. scitiscripta Wlkr.

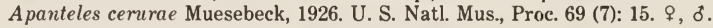

charadrae Muesebeck. D. C. Host: Charadra deridens (Guen.). Apanteles charadrae Muesebeck, 1921. U. S. Natl. Mus., Proc. 58: 567. ๆ, ठ.

choreuti Viereck. N. J., Va., N. C., S. C., Fla., Iowa, Tex. Host: Choreutis carduiella Kearf., Desmia funeralis (Hbn.), Dichomeris sp., Hellula undalis (F.).

Apanteles (Pseudapanteles) choreuti Viereck, 1912. U. S. Natl. Mus., Proc. 42: 627. \&, ठ. cinctiformis Viereck. N. Y. s. to Va., w. to Ont. and N. Dak.

Apanteles (Protapanteles) cinctiformis Viereck, 1911. U. S. Natl. Mus., Proc. 40: 176..

cingiliae Muesebeck. N. S., Que., Mass., Ont. Host: Cingilia catenaria (Drury), Enypia griseata Grossb., E. venata (Grote), Eupithecia gibsonata Tay., Nepytia canosaria (Wlkr.).

Apanteles cingiliae Muesebeck, 1931. U. S. Natl. Mus., Proc. 79 (16): 6. ‡, ð.

clavatus (Provancher). Canada; Maine s. to S. C., w. to Wis. and Ark; Oreg., Calif. Host: Archips argyrospilus (Wlkr.), Epinotia subviridis Heinr., Etiella zinckenella (Treit.), Grapholitha molesta (Busck).

Microgaster clavatus Provancher, 1881. Nat. Canad. 12: 196. ‡, ठ.

clisiocampae Ashmead. N. H., Conn., N. Y., N. J. Host: Malacosoma americanum (F.).

Apanteles clisiocampae Ashmead, 1903. In Fiske, N. H. Col. Agr. Expt. Sta., Tech. Bul. v: 229. ㅇ.

Biology: Fiske, 1903. N. H. Col. Agr. Expt. Sta., Tech. Bul. 6: 214-216.

cockerelli Muesebeck. Mich., Iowa, Mo., S. Dak., Nebr., Tex., N. Mex., Idaho, Oreg., Calif. Host: Isophrictus sp.

Apanteles cockerelli Muesebeck, 1921. U. S. Natl. Mus., Proc. 58: 524. ๆ.

compressiventris Muesebeck. Baffin Isl., Que., N. H., N. W. T.; Europe. Host: Phragmatobia fuliginosa (L.).

Apanteles compressiventris Muesebeck, 1921. U. S. Natl. Mus., Proc. 58: 535. ๆ, ð.

compressus Muesebeck. N. H., R. I., Mass. Host: Hypoprepia sp.

Apanteles compressus Muesebeck, 1919. Canad. Ent. 51: 114. ๆ, ठ. 
conanchetorum Viereck. N. S. s. to S. C., w. to Ont., S. Dak., and Kans. Host: Loxostege mancalis (Led.), L. rantalis (Guen.), Pholisora catullus (F.).

Apanteles (Apanteles) conanchetorum Viereck, 1917 (1916). Conn. State Geol. and Nat. Hist. Survey, Bul. 22: 199. ९.

congestiformis Viereck. Alaska.

Apanteles (Protapanteles) congestiformis Viereck, 1923. No. Amer. Fauna 46: 230. $९$, ơ.

congregatus (Say). No. Amer., Cent. Amer., So. Amer., West Indies. Host: Ceratomia catalpae (Bdvl.), Darapsa myron (Cram.), D. versicolor (Harr.), Dolba hylaeus (Drury),

Eumorpha acheman (Drury), E. pandorus ( $\mathrm{Hbn}$.), Hemaris diffin is (Bdvl.), Lapara bombycoides Wlkr., Manduca quinquemaculata (Haw.), M. sexta (L.), Paratrea plebeja (F.), Sphecodina abbottii (Swains.), Sphinx chersis (Hbn.), S. kalmiae Smith, Trichoplusia $n i$ (Hbn.).

Microgaster congregata Say, 1836. Boston Jour. Nat. Hist. 1: 262. ठै.

Microgaster utilis French, 1880. Canad. Ent. 12: 42. ㅇ, ठ.

Apanteles (Protapanteles) angustus Viereck, 1917 (1916). Conn. State Geol. and Nat. Hist. Survey, Bul. 22: 187, 194. ๆ.

Biology: Gilmore, 1938. Jour. Econ. Ent. 31: 712-715. - Worth, 1939. Ent. News 50: 137-141. -Fulton, 1940. Ent. Soc. Amer., Ann. 33: 240. - Lawson, 1959. Ent. Soc. Amer., Ann. 52: 743-744. - Rabb and Thurston, 1969. Ent. Soc. Amer., Ann. 62: 125-128. - Postley and Thurston, 1974. Jour. Econ. Ent. 67: 716-718. - Thurston, 1976. Environ. Ent. 5: 626-627. consimilis Viereck. Que. s. to Fla., w. to Man.; Miss., Tex.

Microgaster lateralis Provancher, 1886. Addit. Corr. Faune Ent. Canada Hym., p. 141.. Preoce. by Haliday, 1834.

Apanteles (Pseudapanteles) consimilis Viereck, 1911. U. S. Natl. Mus., Proc. 40: 177... crambi Weed. Md., Ohio, Ky., Tenn., Ill., Mo., Ark., S. Dak. Host: Crambus mutabilis Clem., C. trisectus (Wlkr.), C. zeellus Fern.

Apanteles crambi Weed, 1887. Ill. State Lab. Nat. Hist., Bul. 3, p. 8. ․

crassicornis (Provancher). Que. s. to Md., w. to Ont. and Iowa; Kans., Ariz.

Microgaster crassicomis Provancher, 1886. Addit. Corr. Faune Ent. Canada Hym., p. 142. \%.

cyaniridis Riley. Que., W. Va., Ill., Minn., Iowa, Utah. Host: Celastrina argiolus pseudargiolus (Bdvl. and Lec.), Incisalia henrici (G. and R.), Philotes battatoides bermardino B. and $\mathrm{MeD}$.

Apanteles cyaniridis Riley, 1889. In Seudder, Butterflies East. U. S., p. 1903..

dakotae Muesebeck. S. Dak., Idaho.

A panteles dakotae Muesebeck, 1921. U. S. Natl. Mus., Proc. 58: 525..

delicatus Howard. Conn. N. Y., D. C. Host: Orgyia leucostigma (Smith).

Apanteles delicatus Howard. 1897. U. S. Dept. Agr., Bur. Ent. Tech. Ser. 5: 24, 55. "ס" = q.

depressariae Muesebeck. N. S., Maine. Host: Depressaria pastinacella (Dup.).

Apanteles depressariae Muesebeck, 1931. U. S. Natl. Mus., Proc. 79 (16): 3. १, ठ.

depressus Viereck. Ind.

Apanteles (Stenopleura) depressus Viereck, 1912. U. S. Natl. Mus., Proc. 43: 582. ‡, ठ.

diacrisiae Gahan. Del. s. to S. C., w. to Kans. and La. Host: Dasychira basiflava (Pack.), Diacrisia virginica (F.), Estigmene acrea (Drury), Hyphantria cunea (Drury), Orgyia definita (Pack.), O. lezcostigma (Sm.).

Apanteles diacrisiae Gahan, 1917. U. S. Natl. Mus., Proc. 53: 198. + , ऽ.

diatraeae Muesebeck. Tex., Ariz.; Mexico, Cent. and So. Amer., West Indies. Host: Diatraea grandiosella Dyar, D. lineolata (Wlkr.), D. saccharalis (F.).

Apanteles diatraeae Muesebeck, 1921. U. S. Natl. Mus., Proc. 58: 520. \&, ð.

Biology: Davis, 1944. U. S. Dept. Agr., Tech. Bul. 871, p. 1-19.

dignus Muesebeck. Fla., Calif.; Mexico, West Indies, Hawaii. Host: Keiferia lycopersicella

(Wlsm.), Tildenia gudmannella (Wlsm.).

Apanteles dignus Muesebeck, 1938. Ent. Soc. Wash., Proc. 40: 203. ๆ, ठ̛.

Biology: Cardona and Oatman, 1971. Ent. Soc. Amer., Ann. 64: 996-1007. 
disputabilis (Ashmead). Kans., Tex.; West Indies, Brazil.

Urogaster disputabilis Ashmead, 1900. Ent. Soc. London, Trans. 2: 286. ๆ, ठ.

diversus Muesebeck and Walkley. Conn. Host: Acronicta oblinita (Smith).

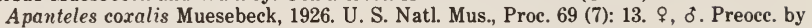
Szepligeti, 1911.

Apanteles diversus Muesebeck and Walkley, 1951. In Muesebeck, et al., U. S. Dept. Agr., Agr. Monog. 2, p. 127. N. name for coxalis Muesebeck.

dolichocephalus Muesebeck. Va., Mich., Ill.

Apanteles dolichocephalus Muesebeck, 1921. U. S. Natl. Mus., Proc. 58: 503. .

edwardsii Riley. Conn., Ohio, Mich., Minn., Iowa, Mo., Colo. Host: Vanessa atalanta (L.).

Apanteles edwardsii Riley, 1889. In Scudder, Butterflies East. U. S., p. 1901. ؟.

electrae Viereck. B. C. s. to Calif. and Tex. Host: Agapema galbina (Clem.), Automeris io (F.), Coloradia pandora Blake, Dirphia sp., Hemileuca burnsi Wats., H. chinatiensis (Tinkham), H. eglanterina (Bdvl.), H. electra Wright, H. hera (Harr.), H. nevadensis Stretch, $H$. oliviae Ckll., $H$. tricolor (Pack.).

Apanteles (Protapanteles) electrae Viereck, 1912. U. S. Natl. Mus., Proc. 42: 145. + ๖.

empretiae Viereck. Mass. s. to Fla., w. to Mo. and La. Host: Euclea delphinii Bdvl., Lithacodes fasciola (H.- S.), Parasa chloris (H.-S.), Sibine stimulea (Clem.).

Apanteles (Protapanteles) empretiae Viereck, 1913. U. S. Natl. Mus., Proc. 44: 562. ๆ, ठ. Apanteles (Apanteles) sibinidis Rohwer, 1915. U. S. Natl. Mus., Proc. 49: 227. $\uparrow, ~ \delta$.

Biology: Schaffner, 1959. U. S. Dept. Agr., Misc. Pub. 767: 60.

ensiger (Say). Maine s. to Fla., w. to Ont. and La.; Colo. Host: Crambus mutabilis Clem., $C$. zeellus Fern., Loxostege sp.

Microgaster ensiger Say, 1836. Boston Jour. Nat. Hist. 1: 260. ๆ (ð misdet.).

Microgaster femurnigmim Provancher, 1886. Addit. Corr. Faune Ent. Canada Hym., p. 142. "ᄋ" = $\delta$.

Apanteles trachynotus Viereck, 1912. U. S. Natl. Mus., Proc. 42: 616. ठ.

Apanteles nipmuckorum Viereck, 1917 (1916). Conn. State Geol. and Nat. Hist. Survey, Bul. 22, p. 200.

enypiae Mason. B. C. Host: Enypia griseata Grossb., E. moillietti Blkmr., E. venata (Grote).

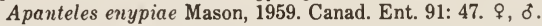

epiblemae Muesebeck. Del., Ga., Fla., Miss., Ark., Kans., Calif. Host: Bactra verutana Zell., Epiblema strenuanum (Wlkr.), Grapholitha molesta (Busck).

Apanteles epiblemae Muesebeck, 1935. Wash. Acad. Sci., Jour. 25: 280. §, ठ.

epinotiae Viereck. Maine s. to Fla., w. to N. Dak. and Tex.; Ariz. Host: Acrobasis caryivorella Rag., Episimus argutanus (Clem.), Grapholitha molesta (Busck), Gypsonoma salicicolana (Clem.), Homoeosoma electellum (Hulst), Laspeyresia caryana (Fitch), Phalonia sp., Pterophorus periscelidactylus Fitch, Rhyacionia sp., Tetralopha robustella Zell.

Apanteles (Apanteles) epinotiae Viereck, 1912. U. S. Natl. Mus., Proc. 42: 614. §.

Biology: Satterthwaite, 1948. Jour. Econ. Ent. 41: 730. -Nickels et al., 1950. U. S. Dept.

Agr., Tech. Bul. 1011: 4-6. - Allen, 1962. U. S. Dept. Agr., Tech. Bul. 1256: 34-35.

etiellae Viereck. Pa., Va., Iowa, Ark., Kans., Tex., Colo., N. Mex., Wash., Calif.; Mexico. Host: Canarsia sp., Etiella zinckenella (Treit.), Olycella junctolineella (Hulst), Psorosina hammondi (Riley), Ufa rubedinella (Zell.).

Apanteles (Pseudapanteles) etiellae Viereck, 1911. U. S. Natl. Mus., Proc. 40: 178. ठे.

Apanteles iselyi Cushman, 1919 Ent. Soc. Wash., Proc. 21: 120. ๆ, ठ.

euchaetis Ashmead. N. H., Mass., N. Y., Va., Mich., Ill., Tex. Host: Euchaetias egle (Drury).

Apanteles euchaetis Ashmead, 1897. Ent. Soc. Wash., Proc. 4: 159. ๆ, ठౌ.

euphydryidis Muesebeck. Maine, N. Y., N. J., Md. Host: Euphydryas phaeton (Drury).

Apanteles euphydryidis Muesebeck, 1921. U. S. Natl. Mus., Proc. 58: 564. ९, ठ.

feltiae Viereck. Mich., Ohio, Ind., Minn., Iowa, N. Dak., S. Dak., Sask., Utah, Ariz., Idaho, Calif. Host: Aristotelia absconditella (Wlkr.), Ostrinia obumbratalis (Led.).

Apanteles (Protapanteles) feltiae Viereck, 1912. U. S. Natl. Mus., Proc. 42: 625. $\uparrow$. 
fiskei Viereck. Mass., Wis., Mont., Wyo., Oreg. Host: Dasychira basiflava (Pack.), D. plagiata (Wlkr.).

A panteles (Protapanteles) fiskei Viereck, 1910. U. S. Natl. Mus., Proc. 38: 379. \&, ठ์.

flaviconchae Riley. Maine s. to Va., w. to Minn. and Tex.; Ida., Utah, Ariz., Wash. Host: Anthocaris midea (Hbn.), Autographa sp., Colias eurytheme Bdvl., C. philodice (Godart), Plathypena scabra (F.), Pseudaletia unipuncta (Haw.).

A panteles limenitidis form flaviconchae Riley, 1881. Acad. Sci. St. Louis, Trans. 4: 308.

Taxonomy: Muesebeck, 1947. Pan-Pacific Ent. 23: 21-22.

Biology: Muesebeck, 1947. Pan-Pacific Ent. 23: 21-22.

flavicornis Riley. Mo., Tex. Host: Erynnis juvenalis (F.). Apanteles flavicornis Riley, 1889. In Scudder, Butterflies East. U. S., p. 1905. ๆ, ठ.

flavipes (Cameron). Fla.; China, Asia, Austr., So. Pac., Mauritius, Madagascar. Introduced from India. Host: Diatraea saccharalis (F.).

Cotesia flavipes Cameron, 1891. Manchester Lit. and Phil. Soc., Mem. and Proc. (4) 4: 185. "६" = ठ.

Apanteles nonagriae Olliff, 1893. Agr. Gaz. N. S. Wales 4: 376, 381. ๆ, ठ.

A panteles (Stenopleura) simplicis Viereck, 1913. U. S. Natl. Mus., Proc. 44: 645. ๆ, §. Apanteles flavatus Ishida, 1915. Kansho Meichu Chosa Hokoku 1: 97.

Biology: Gifford and Mann, 1967. Jour. Econ. Ent. 60: 44-47.

flavovariatus Muesebeck. Mich., S. Dak., Oreg. Host: Isia isabella (Smith). A panteles flavovariatus Muesebeck, 1921. U. S. Natl. Mus., Proc. 58: 528. ๆ, ठ์.

floridanus Muesebeck. Fla. Host: Leucania latiuscula H.-S. Apanteles floridanus Muesebeck, 1921. U. S. Natl. Mus., Proc. 58: 537. ๆ, ઠ.

forbesi Viereck. Mass. s. to Fla., w. to N. Dak. and Kans.; Ariz., Oreg. Host: Feltia sp., Lacinipolia renigera (Steph.), L. stricta (Wlkr.), Pseudaletia unipuncta (Haw.). Apanteles (A panteles) forbesi Viereck, 1910. Ent. Soc. Wash., Proc. 11: 208.,$\delta$.

fulvipes (Haliday). Greenland; Europe. Microgaster fulvipes Haliday, 1834. Ent. Mag. 2: 249. ‡, ð.

fumiferanae Viereck. North. U. S., south. Canada. Host: Acleris variana (Fern.), Choristoneura fumiferana (Clem.), C. lambertiana (Busck), C. occidentalis Freem., C. pinus Freem., C. viridis Freem., Dioryctria abietella (D. and S.), D. reniculella (Grote), Epinotia nanana (Treit.), Taniva albolineana (Kearf.), Thymelicus lineola Ochs., Zeiraphera canadensis M. and F., Z. fortunana (Kearf.), Zelleria haimbachi Busck. Apanteles (Apanteles) fumiferanae Viereck, 1912. U. S. Natl. Mus., Proc. 42: 139. §, ठे.

Taxonomy: Mason, 1974. Canad. Ent. 106: 1088-1092.

Biology: Brown, 1946. Canad. Ent. 78: 121-129. -McGugan, 1955. Canad. Ent. 87: 178-187. -Miller, 1959. Canad. Ent. 91: 457-477. -McGugan and Blais, 1959. Canad. Ent. 91: 774.

-Lewis, 1960. Canad. Ent. 92: 881-891.

galleriae Wilkinson. Va., N. C., S. C., Ga., Fla., La., Kans.; France, Argentina, Mauritius, India. Host: Galleria mellonella (L.).

Apanteles galleriae Wilkinson, 1932. Stylops 1: 139.

gillettei Baker. Colo., Ariz. Host: Archips argyrospilus (Wlkr.). Apanteles gillettei Baker, 1895. Ent. News 6: 202. ๆ, ठ.

glacialis (Ashmead). B. C., Alaska. Host: Hyphantria textor (Harr.).

Protapanteles glacialis Ashmead, 1902. Wash. Acad. Sci., Proc. 4: 248. ठ。.

glomeratus (Linnaeus). U. S., Canada; Europe. Host: Pieris brassicae (L.), P. napi oleracea Harr., P. protodice Bdvl. and Lec., P. rapae (L.), Trichoplusia ni (Hbn.).

Ichneumon glomeratus Linnaeus, 1758. Syst. Nat., Ed. 10., v. 1, p. 568.

Microgaster reconditus Nees, 1834. Ichn. Aff. Monog., v. 1, p. 174. ₹, ơ.

Microgaster crataegi Ratzeburg, 1844. Ichn. d. Forstins., v. 1, p. 72.

Microgaster pieridis Packard, 1881 (1880). Boston Soc. Nat. Hist., Proc. 21: 26., ऽ. Preocc. by Bouche, 1834.

Microgaster congregatus pieridivora Riley, 1882. Amer. Nat. 16: 679. N. name for pieridis Packard. 
Glyptapanteles nawaii Ashmead, 1906. U. S. Natl. Mus., Proc. 30: 193. ९, ठ̊.

Biology: Faure, 1926. Contrib. a l'etude de la Pieride du Chon. Univ. Lyon, p. 41-52. - Hamilton, 1935. Ent. Monthly Mag. 71: 262-270. - Hamilton, 1936. Ent. Monthly Mag. 72: 25-27. -Johansson, 1951. Norsk. Ent. Tidsskr. B. 7 (4-5): 145-186. -Matsuzawa, 1955. Kagawa-Ken Agr. Col., Tech. Bul. 7, p. 60. - Clausen, 1956. U. S. Dept. Agr., Tech. Bul. 1139, p. 77. - Blunck and Wilbert, 1959. Internatl. Congr. Crop Prot., Proc. 4, v. 1, p. 1017. -Moiseeva, 1960. Leningrad. Vsesoiuzn. Inst. Rast., Trudy 14: 51. -Todd, 1962. N. Zeal. Jour. Sci. 5: 1-7 (distribution). - Parker, 1971. Jour. Econ. Ent. 64: 721-735. - Fuhrer and Keja, 1976. Ent. Exp. Appl. 19: 287-300.

Morphology: Marchal-Segault, 1974. Soc. Ent. France, Ann. 10: 987-993 (larvae). gordii Muesebeck. Maine, Conn. Host: Darapsa pholus (Cram.), Sphinx gordius Cram. Apanteles gordii Muesebeck, 1926. U. S. Natl. Mus., Proc. 69 (7): 9..

griffini Viereck. Que. s. to Fla., w. to S. Dak. and Tex.; Wash. Host: Agrotis gladiaria Morr., Euxoa auxiliaris (Grote), Feltia ducens (Wlkr.), F. subterranea (F.), Spodoptera omithogalli (Guen.).

Apanteles (Protapanteles) griffini Viereck, 1911. U. S. Natl. Mus., Proc. 40: 177. ๆ, ơ.

hadenae Muesebeck. N. J., Mich. Host: Grapholitha sp., Phosphila turbulenta Hbn. Apanteles hadenae Muesebeck, 1926. U. S. Natl. Mus., Proc. 68 (7): 14. ๆ, ơ.

halisidotae Muesebeck. Maine, Mass. Host: Halisidota maculata (Harr.).

Apanteles halisidotae Muesebeck, 1931. U. S. Natl. Mus., Proc. 79 (16): 5. १, ઠ๋.

halli (Packard). Greenland, N. W. T.

Microgaster Halli Packard, 1877. Amer. Nat. 11: 52.

harrisinae Muesebeck. Conn., Fla., Ariz., Calif. Host: Harrisina americana (Guer.), $H$. brillians $\mathrm{B}$. and $\mathrm{McD}$.

Apanteles harrisinae Muesebeck, 1953. Ent. Soc. Wash., Proc. 55: 150. ?, ơ.

Biology: Schaffner, 1959. U. S. Dept. Agr., Misc. Pub. 767, p. 60. -Clausen, 1961. Hilgardia 31: 613-638.

harti Viereck. D. C., Mich., Ohio, Tenn., Wis., Iowa. Host: Ostrinia obumbratalis (Led.), 0 . penitalis (Grote).

Apanteles harti Viereck, 1910. Ent. Soc. Wash., Proc. 11: 209. ๆ, o.

hemileucae Riley. Mass., Conn., N. Y., Fla., Minn., Mo., Kans., Oreg. Host: Automeris io (F.), Hemileuca maia (Drury).

Apanteles congregatus var. hemileucae Riley, 1881. Acad. Sci. St. Louis, Trans. 4: 309.

herbertii Ashmead. Fla.; West Indies. Host: Hystalea nysius Cram.

Apanteles herbertii Ashmead, 1900. Roy. Ent. Soc. London, Trans. 1900: 279..

hesperidivorus Viereck. Mass., Conn., Fla., Mo., La., Okla., Ariz., Calif. Host: Atalopedes campestris (Bdvl.), Erynnis sp., E. tristis (Bdvl.), Hylephila phyleus (Drury).

Apanteles (Protapanteles) hesperidivorus Viereck, 1912. U. S. Natl. Mus., Proc. 42: 626. \&, o.

homoeosomae Muesebeck. S. Dak., Mo., Tex., Wash.; Cuba. Host: Homoeosoma electellum (Hulst).

Apanteles homoesomae Muesebeck, 1933. Ent. Soc. Wash., Proc. 35: 193. ๆ, đ.

hyphantriae Riley. U. S., Canada; Mexico, Europe. Host: Homadaula anisocentra (Meyr.), Hyphantria cunea (Drury), H. textor (Harr.), Orgyia lencostigma (Smith).

Apanteles hyphantriae Riley, 1887. U. S. Dept. Agr., Ann. Rpt. for 1886, p. 533..

Biology: Tothill, 1922. Canada Dept. Agr., Tech. Bul. (n. s.) 3, p. 76-88. -Tadic, 1958 (1956).

10th Internatl. Congr. Ent., Proc. 4: 859-861.

impunctatus Muesebeck. La. Host: Diatraea saccharalis (F.).

Apanteles impunctatus Muesebeck, 1933. Ent. Soc. Wash., Proc. 35: 194. ๆ, ơ.

insignis Muesebeck. B. C., Calif. Host: Playtyptilia acanthodactyla (Hbn.), P. pica (Wlsm.), P. punctidactyla (Haw.).

Apanteles insignis Muesebeck, 1938. Ent. Soc. Wash., Proc. 40: 201. ๆ, ơ.

junoniae Riley. Mo., Kans. Host: Junonia coenia (Hbn.).

A panteles junoniae Riley, 1889. In Scudder, Butterflies East. U. S., p. 1907. ठ̛. 
koebelei Riley. Idaho, Calif. Host: Euphydryas chalcedona (D. and H.), E. editha (Bdvl.), E. e. monoensis G., E. e. nubigena (Behr.), Melitaea leanira (F. and F.), M. neumoegeni Skin., Nymphalis californica (Bdvl.).

Apanteles koebelei Riley, 1889. In Scudder, Butterflies East. U. S., p. 1904. ^, ठ’.

lacteicolor Viereck. New England, east. Canada.; Europe. Introduced from Europe. Host: Acronicta hasta Guen., Hyphantria cunea (Drury), Nygmia phaeorrhoea (Donov.), Lymantria dispar (L.).

Apanteles (Apanteles) lacteicolor Viereck, 1911. U. S. Natl. Mus., Proc. 40: 475. ₹, ठ.

Biology: Muesebeck, 1918. Jour. Agr. Res. 12: 191-206. -Clausen, 1956. U. S. Dept. Agr.,

Tech. Bul. 1139, p. 77. - Dowden, 1962. U. S. Dept. Agr, Agr. Handb. 226, p. 48.

laeviceps Ashmead. U. S., south. Canada. Host: Anacamptodes vellivolata (Hulst), Autographa sp., Eucirrhoedia pampina (Gn.), Euxoa auxiliaris (Grote), E. a. agrestis (Grote), E. ochrogaster (Gn.), Faronta diffusa (Wlkr.), Feltia ducens Wlkr., Lacinipolia meditata (Grote), Loxagrotis albicosta (Sm.), Luperina stipata (Morr.), Pseudaletia unipuncta (Haw.), Scotogramma sp., Spaelotis clandestina (Harr.), Spodoptera exigua (Hbn.), Trichoplusia ni (Hbn.).

Apanteles laeviceps Ashmead, 1890. Colo. Biol. Assoc., Bul. 1: 17. ‡, ठ.

laevicoxis Muesebeck. Miss., Fla.

Apanteles laevicoxis Muesebeck, 1921. U. S. Natl. Mus., Proc. 58: 505. ๆ.

langei Muesebeck. Calif. Host: Pyrausta subsequalis (Guen.).

Apanteles langei Muesebeck, 1938. Ent. Soc. Wash., Proc. 40: 202. ๆ, ठ.

laricellae Mason. N. B., N. S., Que., Ont., Wis., Idaho. Host: Argyresthia laricella Kearf., Coleophora laricella $\mathrm{Hbn}$.

Apanteles laricellae Mason, 1959. Canad. Ent. 91: 45. + , ठ.

Biology: Eidt and Sippell, 1961. Canad. Ent. 93: 16.

laspeyresiae Viereck. Mont., Idaho, B. C., Wash., Calif. Host: Hedulia injectiva Heinr., Laspeyresia miscitata Heinr., L. piperana (Kearf.), L. toreuta Grote.

Apanteles laspeyresia Viereck, 1913. U. S. Natl. Mus., Proc. 44: 556. ㅇ, ठ.

leucostigmus (Ashmead). Fla.; West Indies. Host: Urbanus proteus (L.).

Urogaster leucostigmus Ashmead, 1900. Roy. Ent. Soc. London, Trans. 1900: 289. ๆ, ठ.

limenitidis (Riley). Mass., Conn., Ohio, Ill., Iowa, Mo., Tex. Host: Anthocaris midea (Hbn.), Limenitis archippus (Cram.).

Microgaster limenitidis Riley, 1871. Ins. Mo., Ann. Rpt. 3: 158. , ठ.

liparidis (Bouche). New England(?); Palearctic Region. Liberated in New England but not established. Introduced from Europe. Host: Lymantria dispar (L.).

Microgaster liparidis Bouche, 1834. Naturg. Insekt., p. 152..

Microgaster nemorum Hartig, 1838 (1837). Jber. Fortschr. Forstwiss. Forstl. Naturk. 1: 252. $९$, o.

Glyptapanteles (Apanteles) japonicus Ashmead, 1906. U. S. Natl. Mus., Proc. 30: 193. + , $\delta$.

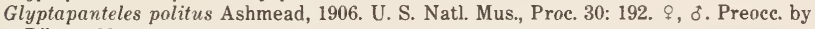
Riley, 1881.

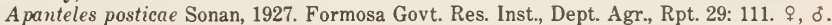

Apanteles awanomeigae Watanabe, 1942. Insecta Matsumurana 16: 148. N. name for politus Ashmead.

Biology: Burgess and Crossman, 1929. U. S. Dept. Agr., Tech. Bul. 86, p. 95-103.

longicornis (Provancher). Que. and N. B. s. to Va., w. to Minn. and Ill.; Alaska, Oreg. Host: Syngrapha epigaea (Grote).

Microgaster longicomis Provancher, 1886. Addit. Corr. Faune Ent. Canada Hym., p. 143. " $\delta "=$ ?.

Apanteles radiatus Ashmead, 1898. Ent. Soc. Wash., Proc. 4: 162. , ठ゚.

Biology: Wood and Neilson, 1960. Canad. Ent. 92: 760.

lunatus (Packard). U. S. Host: Papilio bairdii oregonins Edw., P. polyxenes F., P. p. asterius Stoll, P. zelicaon Lucas.

Microgaster lunatus Packard, 1881 (1880). Boston Soc. Nat. Hist., Proc. 21: 28.. 
luteipennis Muesebeck. Va. Host: Speyeria sp.(?).

Apanteles luteipennis Muesebeck, 1921. U. S. Natl. Mus., Proc. 58: 527..

lyciae Muesebeck. Maine. Host: Biston cognatoria (Guen.).

A panteles lyciae Muesebeck, 1926. U. S. Natl. Mus., Proc. 69 (7): 16. 9.

mahoniae Mason. Idaho, B. C. Host: Coryphista meadi Pack.

Apanteles mahoniae Mason, 1975. Canad. Ent. 107: 1133. ๆ, ठ.

marginiventris (Cresson). Del. s. to Fla., w. to Ind., Kans. and Tex.; Wis., Ariz., Calif.; Mexico, West Indies, So. Amer., Hawaii. Host: Agrotis ipsilon (Hufn.), Anagrapha falcifera (Kirby), Autographa precation is (Gn.), Autoplusia egena (Guen.), Heliothis virescens (F.), H. zea (Boddie), Hymenia perspectalis (Hbn.), H. recurvalis (F.), Leucania latiuscula H.-S., L. multisulca Wlkr., Peridroma sancia (Hbn.), Plathypena scabra (F.), Pseudaletia unipuncta (Haw.), Pseudoplusia includens (Wlkr.), Scotorythra caryopsis Meyr., Spodoptera eridania (Cram.), S. exigua (Hbn.), S. fmigiperda (Smith), S. ornithogalli (Guen.), S. praefica (Grote), Trichoplusia ni (Hbn.).

Microgaster marginiventris Cresson, 1865. Ent. Soc. Phila., Proc. 4: 67. ๆ, ठ̋.

Apanteles grenadensis Ashmead, 1900. Roy. Ent. Soc. London, Trans. 1900: 278. $\uparrow, \delta$. Apanteles laphygmae Ashmead, 1901. In Chittenden, U. S. Dept. Agr., Bur. Ent., Bul. 29, p. 36 . Nomen nudum.

Apanteles (Protapanteles) harnedi Viereck, 1912. U. S. Natl. Mus., Proc. 43: 580. $\subsetneq$.

Biology: Luginbill, 1928. U. S. Dept. Agr., Tech. Bul. 34, p. 68-69. -Vickery, 1929. U. S. Dept. Agr., Tech. Bul. 138, p. 25-28. - Boling and Pitre, 1970. Kans. Ent. Soc., Jour. 43: 465-470.

medicaginis Muesebeck. N. Mex., Utah, Ariz., Nev., Calif.; Mexico. Host: Colias enrytheme Bdvl.

Apanteles medicaginis Muesebeck, 1947. Pan-Pacific Ent. 23: 21.,$\delta$.

Biology: Michelbacher and Smith, 1943. Hilgardia 15: 369-397 (as Apanteles flaviconchae Riley), - Allen, 1958. Hilgardia 27: 515-541. - Allen and Smith, 1958. Hilgardia 28: 1-42. -Stern and Bowen, 1963. Ent. Soc. Amer., Ann. 56: 358-372.

megathymi Riley. N. C., S. C., Ga., La., N. Mex., Ariz., Calif.; Mexico. Host: Agathymus stephensi (Skin.), Megathymus comstocki Harb., M. ursus ursus Poling, M. yuccae martini (S. and T.), M. y. reinthali Freem., M. y. yuccae (Bdvl. and Lec.).

Apanteles megathymi Riley, 1881. Acad. Sci. St. Louis, Trans. 4: 304. ₹, ơ.

melanopus Viereck. Conn.

Apanteles (Apanteles) melanopus Viereck, 1917 (1916). Conn. State Geol. and Nat. Hist. Survey, Bul. 22, p. 190, 198.

melanoscelus (Ratzeburg). New England, east. Canada, B. C., Wash., Oreg.; Europe, N. Africa. Introduced from Europe. Host: Lymantria dispar (L.), Stilpnotia salicis (L.).

Microgaster melanoscelus Ratzeburg, 1844. Ichn. d. Forstins. 1: 74. ठ。.

Microgaster solitarius Ratzeburg, 1844. Ichn. d. Forstins. 1: 73. \&, ठ.

Taxonomy: Nixon, 1974. Bul. Ent. Res. 64: 469 (synonymy).

Biology: Crossman, 1922. U. S. Dept. Agr., Bul. 1028, p. 1-25 (melanoscelus). - Muesebeck and Dohanian, 1927. U. S. Dept. Agr., Bul. 1487, p. 1-34 (melanoscelus). -Parker, 1935. U. S. Dept. Agr., Tech. Bul. 477, p. 1-17 (solitarius). -Clausen, 1956. U. S. Dept. Agr., Tech. Bul. 1139, p. 79-80. -Dowden, 1962. U. S. Dept. Agr., Agr. Handb. 226, p. 48-49.

-Weseloh, 1973. Ent. Soc. Amer., Ann. 66: 854-855 (melanoscelus). - Weseloh, 1973. Jour. Ins. Physiol. 19: 2025-2033. - Van Sickle and Weseloh, 1974. N. Y. Ent. Soc., Jour. 82: 2-5. -Weseloh, 1974. Ent. Soc. Amer., Ann. 67: 583-587 (host recognition). - Weseloh and Anderson, 1975. Environ. Ent. 4: 33-36. -Weseloh, 1976. Environ. Ent. 5: 743-746, 1128-1132.

miantonomoi Viereck. Conn., Pa., Mich.

Apanteles (Apanteles) miantonomoi Viereck, 1917 (1916). Conn. State Geol. and Nat. Hist. Survey, Bul. 22, p. 198.

Apanteles (Apanteles) pequodomım Viereck, 1917 (1916). Conn. State Geol. and Nat. Hist. Survey, Bul. 22, p. 198. 
militaris (Walsh). No. Amer. Host: Epiglaea apiata (Grote), Euxoa auxiliaris (Grote), Feltia ducens Wlkr., Heliothis zea (Boddie), Leucania latiuscula H.-S., L. phragmatidicola Guen., Peridroma saucia (Hbn.), Pseudaletia unipuncta (Haw.), Spodoptera exigua (Hbn.), S. frugiperda (Smith), S. omithogalli (Guen.).

Microgaster militaris Walsh, 1861. Ill. State Agr. Soc., Trans. 4: 369..

Biology: Guppy, 1967. Canad. Ent. 99: 100. - Calkins and Sutter, 1976. Environ. Ent. 5: 147-150.

milleri Mason. N. B., Que., Vt., Ont., Mont., B. C., N. W. T. Host: Dioryctria reniculella (Grote), Parapandemis borealis Freem.

Apanteles milleri Mason, 1974. Canad. Ent. 106: 1093. ๆ, ১.

mimoristae Muesebeck. Fla., Tex. Host: Hymenia perspectalis (Hbn.), Mimoristo flavidissimalis (Grote), Olycella junctolineella (Hulst).

Apanteles mimoristae Muesebeck, 1922. U. S. Natl. Mus., Proc. 61 (15): 19. ९, ठ.

monticola Ashmead. Colo., N. Mex., Idaho, Calif.

Apanteles monticola Ashmead, 1890. Colo. Biol. Assoc., Bul. 1: 17. ठ.

morrisi Mason. N. B., Que., Ont., Wis., Man. Host: Choristoneura fumiferana (Clem.), C. pinus Freem.

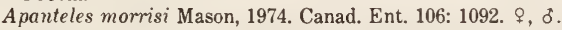

murtfeldtae Ashmead. Que. s. to N. C.; Ohio, Mo. Host: Ennomos subsignarius (Hbn.), Phigalia titea (Cram.).

Apanteles murtfeldtae Ashmead, 1897. Ent. Soc. Wash., Proc. 4: 159. ๆ, ठ.

nemoriae Ashmead. N. S. s. to Tenn., w. to Sask. Host: Alsophila pometaria (Harr.), Chlorochlamys chloroleucaria (Guen.), Erannis tiliaria (Harr.), Eupithecia filmata

Pears., E. gibsonata Tay., E. misemelata Grote, E. palpata Pack., Haematopius grataria (F.), Haploa lecontei (G.-M.), Operophtera brumata (L.), Pleuroprucha insulsaria (Guen.), Semiothisa granitata (Gn.).

Apanteles nemoriae Ashmead, 1897. Ent. Soc. Wash., Proc. 4: 160. ๆ, ठ’.

Apanteles (Protapanteles) winkleyi Viereck, 1917 (1916). Conn. State Geol. and Nat. Hist. Survey, Bul. 22, p. 192. ㅇ, ठ。.

neomexicanus Muesebeck. P. E. I. w. to B. C. and Alaska; Mich., N. Dak. s. to N. Mex., w. to Wash. and Calif.

Apanteles neomexicanus Muesebeck, 1921. U. S. Natl. Mus., Proc. 58: 529. ㅇ.

Apanteles caudatus Muesebeck, 1922. U. S. Natl. Mus., Proc. 6 (15): 16. ๆ, ठ.

nephoptericis (Packard). N. Y., Fla., Ont., Mich., Ind., Ill., Iowa, Colo., Nev., Oreg., Calif. Host: Anagasta kuehniella (Zell.), Vitula edmandsae edmandsae (Pack.), V. e. serratilineella Rag.

Microgaster nephoptericis Packard, 1864. Proc. Essex Inst. 4: 122. ठ.

Apanteles ephestiae Baker, 1895. Ent. News 6: 201. \&, ठ.

niger Muesebeck. N. Y., D. C., Va., Mich., Minn., S. Dak., Kans., Idaho.

Apanteles niger Muesebeck, 1921. U. S. Natl. Mus., Proc. 58: 532. , ઠ.

nigriceps (Ashmead.). N. C.; West Indies.

Urogaster nigriceps Ashmead, 1900. Roy. Ent. Soc. London, Trans. 1900: 284. ?.

nigricornis Muesebeck. Calif.; Mexico. Host: Ctenucha brumnea Stretch.

Apanteles nigricornis Muesebeck, 1921. U. S. Natl. Mus., Proc. 58: 538. \&, §.

nigrovariatus Muesebeck. Pa., Ga., Fla.

Apanteles nigrovariatus Muesebeck, 1921. U. S. Natl. Mus., Proc. 58: 523. ๆ.

ninigretorum Viereck. Conn.

Apanteles (Apanteles) ninigretorum Viereck, 1917 (1916). Conn. State Geol. and Nat. Hist. Survey, Bul. 22, p. 200.

nitens Muesebeck. Wyo., Colo., Oreg., Calif. Host: Agrotis aeneipennis Grote, Pseudaletia unipuncta (Haw.).

Apanteles nitens Muesebeck, 1921. U. S. Natl. Mus., Proc. 58: 556. ๆ, o.

noctuidiphagus Muesebeck. Conn.

Apanteles noctuidiphagus Muesebeck, 1926. U. S. Natl. Mus., Proc. 69 (7): 7. ๆ, ð. 
obscuricornis Viereck. Conn.

Apanteles (Protapanteles) obscuricomis Viereck, 1917 (1916). Conn. State Geol. and Nat. Hist. Survey, Bul. 22, p. 192. $\%$.

oidaematophori Muesebeck. Wis., Idaho. Host: Oidaematophorns lacteodactylus form kellicottii (Fish).

Apanteles oidematophori(!) Muesebeck, 1929. Ent. Soc. Wash., Proc. 31: 119. ㅇ.

olenidis Muesebeck. B. C. Host: Dasychira vagans (B. and McD.).

Apanteles olenidis Muesebeck, 1922. U. S. Natl. Mus., Proc. 61 (15): 18. ๆ, ठ.

ornigis Weed. N. S. and Que. s. to Va., w. to N. Dak. and Ark.; Utah, Oreg. Host: Bucculatrix ainsliella Murtf., Caloptilia burgessiella (Zell.), Lithocolletis blancardella (F.), L. crataegella Clem., L. malimalifoliella Braun, L. mariaeella Chamb., L. propinquinella Braun, L. robiniella Clem., Paromix geminatella (Pack.), Tischeria malifoliella Clem. Apanteles ornigis Weed, 1887. Ill. State Lab. Nat. Hist., Bul. 3: 6. + , §.

Protapanteles tortricis Ashmead, 1898 (1897). Ent. Soc. Wash., Proc. 4: 163. ९, o. Apanteles (Apanteles) braunae Viereck, 1912. U. S. Natl. Mus., Proc. 42: 614. ठ’.

Apanteles (Apanteles) lithocolletidis Viereck, 1912. U. S. Natl. Mus., Proc. 42: 615. ठ.

orobenae Forbes. D. C. s. to Fla., w. to Ariz. and Calif.; Ind., Ill., Conn.(?). Host: Evergestis rimosalis (Guen.).

Apanteles orobenae Forbes, 1883 (1882). Noxious Ins. Ill., Rpt. 12: 104. \&, ð.

paleacritae Riley. Canada; N. H. s. to Ga., w. to Mich. and Kans. Host: Alsophila pometaria (Harr.), Bomolocha deceptalis (Wlkr.), Cyclophora pendulinaria (Guen.), Ectropis crepuscularia (D. and S.), Enypia packardata Tay., E. venata (Grote), Erannis tiliaria (Harr.), Lambdina fiscellaria (Gn.), Nepytia canosaria (Wlkr.), Nyctobia anguilineata (G. and R.), Operophtera brumata (L.), Oporinia autumnata henshawi Swett, Paleacrita vernata (Peck), Phigalia titea (Cram.), Semiothisa granitata (Gn.), S. sexmaculata (Pack.), Zale sp.

Apanteles paleacritae Riley, 1881. Acad. Sci. St. Louis, Trans. 4: 313. ९, ठ๋.

Protapanteles ephyrae Ashmead, 1898 (1897). Ent. Soc. Wash., Proc. 4: 163. ठ。.

papaipemae Muesebeck. Mass., N. Y., Ohio, Iowa, Kans. Host: Bellura obliqua (Wlkr.), Papaipema maritima Bird, P. nebris (Guen.), P. stenoscelis (Dyar.).

A panteles papaipemae Muesebeck, 1921. U. S. Natl. Mus., Proc. 58: 526. ९, ठ̊.

paralechiae Muesebeck. N. B. s. to N. J., w. to Ont. and Wis.; Tenn., Utah, Calif. Host: Argyresthia freyella Wlsm., A. thuiella (Pack.), Coleotechnites thujaeella Kearf., Exotelia pinifoliella (Chamb.).

Apanteles paralechiae Muesebeck, 1931. U. S. Natl. Mus., Proc. 79 (16): 2. ९, ð’.

paranthrenidis Muesebeck. N. Y., Pa., Ohio, D. C., Fla., Miss., Tex., Utah, Calif.; Mexico. Host: Paranthrene a silipennis (Bdvl.), P. dollii (Neum.), P. robiniae (Hy. Edw.), Prionoxystus sp.

Apanteles paranthrenidis Muesebeck, 1921. U. S. Natl. Mus., Proc. 58: 506. ९, ð๋.

parastichtidis Muesebeck. Canada; Maine, Tenn., Mich. Host: Choristoneura conflictana (Wlkr.)?, Enargia decolor (Wlkr.), Hydriomena divisaria (Wlkr.), H. renunciata (Wlkr.), Sunira bicolorago (Guen.).

Apanteles parastichtidis Muesebeck, 1921. U. S. Natl. Mus., Proc. 58: 541..

petrovae Walley. Newfoundland, N. B., Que., S. C., Ont., Wis., Minn., N. Dak., Alta., Mont., B. C., Calif. Host: Barbara colfaxiana (Kearf.), Choristoneura fumiferana (Clem.), C. pinus Freem., Dioryctria auranticella (Grote), D. reniculella (Grote), Petrova albicapitana (Busck), P. pallipennis McD., Rhyacionia frustrana (Comst.), Zeiraphera canadensis M. and F.

Apanteles petrovae Walley, 1937. Canad. Ent. 69: 189. \&.

Taxonomy: Mason, 1974. Canad. Ent. 106: 1101-1102.

phigaliae Muesebeck. N. B., Mass., Ont. Host: Phigalia titea Cram.

Apanteles phigaliae Muesebeck, 1919. Canad. Ent. 51: 113. + ठ.

phlyctaeniae Muesebeck. Ohio, Ill. Host: Phlyctaenia coronata tertialis (Guen.)(?).

Apanteles phlyctaeniae Muesebeck, 1929. Ent. Soc. Wash., Proc. 31: 118. ๆ, ơ. 
phobetri Rohwer. Newfoundland w. to Alta.; Mass., N. J., Md., Va., N. C., Ky., Ind., Ill., l . Dak., Kans. Host: Acronicta americana Harr., Apantesis sp., Halisidota caryae (H arr.), $H$. harrisii Walsh, H. tesselaris (Smith), Panthea acronyctoides (Wlkr.), Phobetron pithecium (A. and S.).

Apanteles (Protapanteles) phobetri Rohwer, 1915. U. S. Natl. Mus., Proc. 49: 228..

pholisorae Riley. Md., D. C., S. C., Ill., Mo., Kans., Tex. Host: Pholisora catullus (F.), Staphylus mazans hayhursti (Edw.).

A panteles pholisoriae Riley, 1889. In Scudder, Butterflies East. U. S., p. 1909..

phthorimaeae Muesebeck. La. Host: Keiferia inconspicuella (Murtf.).

A panteles phthorimaeae Muesebeck, 1921. U. S. Natl. Mus., Proc. 58: 509..

plathypenae Muesebeck. Ont. s. to N. Y. and Ohio, w. to B. C. and Wash. Host: Anagra pha falcifera (Kirby), Autographa californica (Speyer), A. precationis (Gn.), Plathypena scabra (F.), Rachiplusia ou (Gn.), Scotogramma trifolii (Rott.).

Apanteles plathypenae Muesebeck, 1921. U. S. Natl. Mus., Proc. 58: 546. ‡, ठ.

plesius Viereck. N. J., Mich., Wis. Host: Sparganothis pettitana (Rob.).

Apanteles (Apanteles) plesius Viereck, 1912. U. S. Natl. Mus., Proc. 42: 615..

podunkorum Viereck. Conn., Va., W. Va., Ohio. Host: Ostrinia obumbratalis (Led.), Pyrausta futilalis (Led.).

A panteles (Stenopleura) podunkomum Viereck, 1912. U. S. Natl. Mus., Proc. 43: 583. 9.

politus Riley. Va., Fla., IIl., Mo. Host: Scolecocam pa liburna (Geyer).

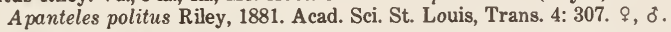

polychrosidis Viereck. N. B. and Que. s. to Fla., w. to Ont., S. Dak., and Kans.; Wash., Oreg., Alaska. Host: Anacampsis innocuella (Zell.), Archips argyrospilus (Wlkr.), $A$. cerasivoranus (Fitch), A. rosanus (L.), Argyrotaenia citrana (Fern.), A. juglandana (Fern.), Bucculatrix pomifoliella Clem., Caloptilia superbifrontella Clem., Choristoneura conflictana (Wlkr.), C. fumiferana (Clem.), C. pinus Freem., C. rosaceana (Harr.), Grapholitha molesta (Busck), Nephopteryx celtidella (Hulst), $N$. subcaesiella (Clem.), Paralobesia liriodendrana Kearf., P. viteana (Clem.).

A panteles (Apanteles) polychrosidis Viereck, 1912. U. S. Natl. Mus., Proc. 42: 615. §, ठ. porthetriae Muesebeck. N. H. (?), Mass. (?); Palearctic Region. Liberated in N. H. and Mass. but not established. Introduced from Europe. Host: Lymantria dispar (L.).

A panteles porthetriae Muesebeck, 1928. Ent. Soc. Wash., Proc. 30: 8. ๆ, ठ.

Biology: Raffa, 1977. Environ. Ent. 6: 57-59 (alternative hosts).

praesens Muesebeck. Calif.; Hawaii (introduced). Host: Anacamptodes fragilaria (Grossb.).

A panteles praesens Muesebeck, 1947. Pan-Pacific Ent. 23: 23. + ,.

pseudoglossae Muesebeck. Md., Mich., Minn. Host: E pizeuxis lubricalis Geyer.

A panteles pseudoglossae Muesebeck, 1921. U. S. Natl. Mus., Proc. 58: 512. ‡, ठ์.

pterophori Muesebeck. Mass. Host: Oidaematophorus homodactylus (Wlkr.).

Apanteles pterophori Muesebeck, 1926. U. S. Natl. Mus., Proc. 69 (7): 6. ๆ, ठ̊.

pyralidis Muesebeck. Md., D. C., Va., N. C., Ohio, Tenn., Wis., Iowa, Mo., Ark., S. Dak. Host: Loxostege rantalis (Guen.), Nomophila nearctica Munroe, Pyrausta futilalis (Led.).

A panteles pyralidis Muesebeck, 1921. U. S. Natl. Mus., Proc. 58: 551. १, ठ์.

pyraustae Viereck. Conn., Va., Ont., Mo. Host: Atteva punctella (Cram.), Pyrausta futilalis (Led.).

A panteles (Protapanteles) pyraustae Viereck, 1912. U. S. Natl. Mus., Proc. 42: 626. \&, ठ. pyrophilae Muesebeck. Mass., R. I., Conn., Ont. Host: Amphipyra pyramidoides $\mathrm{Gn}$.

Apanteles pyrophilae Muesebeck, 1926. U. S. Natl. Mus., Proc. 69 (7): 11. ९, ठ.

renaulti Mason. N. B., N. S., Que., Ont., Wis. Host: Coleotechnites gibsonella (Kearf.), C. piceaella (Kearf.).

Apanteles renaulti Mason, 1974. Canad. Ent. 106: 1100.,$\delta$.

robiniae (Fitch). N. Y. Host: Sinoe robiniella (Fitch).

Microgaster robiniae Fitch, 1859 (1858). N. Y. State Agr. Soc., Trans. 18: 836. ๆ, §. 
rohweri Muesebeck. N. B. s. to Va., w. to Ont. and Minn. Host: Acrobasis rubrifasciella Pack., Argyresthia sp., Lithocolletis tremuloidiella Braun, Neurobatha strigifinitella (Clem.). A panteles (Pseudapanteles) nigripes Rohwer, 1914 (1913). Ent. Soc. Wash., Proc. 15: 187. " $\delta "=$ ?. Preoce. by Ratzeburg, 1844 .

Apanteles rohweri Muesebeck, 1921. U. S. Natl. Mus., Proc. 58: 550. N. name for nigripes Rohwer.

rubecula Marshall. Mo., B. C., Calif.; Europe. Host: Pieris protodice Bdvl. and Lec., P. rapae (L.).

A panteles rubecula Marshall, 1885. Roy. Ent. Soc. London, Trans. 1885: 175..

Biology: Wilkinson, 1966. Jour. Econ. Ent. 59: 1012-1013. - Parker, 1971. Jour. Econ. Ent. 64: 721-735. - Parker, 1972. Environ. Ent. 1: 153-156.

rufocoxalis Riley. N. S. s. to Fla.; Mo., Tenn., La., Tex. Host: Lencania latiuscula H.-S., Nephelodes emmedonia form violans Guen., Pseudaletia unipuncta (Haw.).

A panteles congregatus var. mfocoxalis Riley, 1881. Acad. Sei. St. Louis, Trans. 4: 310.

salalicus Mason. Colo., Oreg., Calif. Host: Caloptilia rhoifoliella (Chamb.), Cnephasia longana (Haw.), Lithocolletis gaultheriella Wlsm.

A panteles salalicus Mason, 1959. Canad. Ent. 91: 42. \&.

salicifoliellae Mason. Ont. Host: Lithocolletis salicifoliella Chamb.

Apanteles salicifoliellae Mason, 1959. Canad. Ent. 91: 43. $९$, ठ.

sarrothripae Weed. Maine s. to Va., w. to Ont. and Mo. Host: Ichthyura albosigma (Fitch), I. inclusa Hbn., Nycteola frigidana (Wlkr.).

A panteles sarrothripae Weed, 1887. Ill. State Lab. Nat. Hist., Bul. 3: 6. ๆ, §.

schaffneri Muesebeck. Pa., N. J., Del., Va., Tex. Host: Euclea delphinii Bdvl., Parasa sp., Prolimacodes badia ( $\mathrm{Hbn}$.).

Apanteles schaffneri Muesebeck, 1931. U. S. Natl. Mus., Proc. 79 (16): 4 . 9.

schizurae Ashmead. Canada; N. H. s. to Fla., w. to Wis., Mo., and Miss.; Calif. Host: Heterocampa guttivitta (Wlkr.), Schizura concinna (Smith), S. unicornis (Smith).

Apanteles schizurae Ashmead, 1898. Ent. Soc. Wash., Proc. 4: 162. \&, ठ.

scitulus Riley. N. H. s. to Fla., w. to Ont., Nebr., and Tex. Host: Acronicta brimosa Guen., $A$. oblinita (Smith), Anomogyna elimata (Gn.), Dasychira basiflava (Pack.), D. plagiata (Wlkr.), Diacrisia virginica (F.), Pseudoplusia includens (Wlkr.), Simyra henrici (Grote).

Apanteles congregatus var. scitulus Riley, 1881. Acad. Sci. St. Louis, Trans. 4: 310.

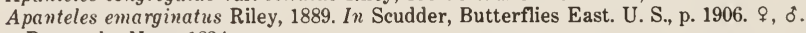
Preoce. by Nees, 1834.

A panteles parorgyiae Ashmead, 1898. Ent. Soc. Wash., Proc. 4: 161. \&, §.

Cryptapanteles rileyanus Viereck, 1910 (1909). Ent. Soc. Wash., Proc. 11: 210. N. name for emarginatus Riley.

scutellaris Muesebeck. Fla., Tex., Ariz., Calif.; Hawaii, Bulgaria. Host: Keiferia lycopersicella (Busck), Phthorimaea operculella (Zell.).

A panteles scutellaris Muesebeck, 1921. U. S. Natl. Mus., Proc. 58: 533. , ठ.

Biology: Graf, 1917. U. S. Dept. Agr., Bul. 427, p. 43 (as A panteles sp.; this is scutellaris rather than dignus as listed in first supplement of original eatalog).

sesiae Viereck. N. J., Va., D. C., Fla., Ind., Ark., Kans., Tex. Host: Synanthedon scitula (Harr.). A panteles (Psendapanteles) sesiae Viereck, 1912. U. S. Natl. Mus., Proc. 42: 146. ‡, ð.

smerinthi Riley. Maine, N. H., Mass., N. J., D. C., Ont., Ind., Mo., Tex., Calif. Host: Ipimorpha pleonectusa Grote, Paonias excaecata (Smith), Smerinthus cerisyi Kirby, S. jamaicensis (Drury).

Apanteles smerinthi Riley, 1881. Acad. Sci. St. Louis, Trans. 4: 311. \&, ơ.

solenobiae Walley. Que., Pa. Host: Solenobia walshella Clem.

Apanteles solenobiae Walley, 1935. Canad. Ent. 67: 59. .

sorghiellae Muesebeck. Mo., Ark., Tex. Host: Celama sorghiella (Riley).

Apanteles sorghiellae Muesebeck, 1933. Ent. Soc. Wash., Proc. 35: 195. \&, ठ์.

stagmatophorae Gahan. Md. Host: Periploca gleditschiaeella (Chamb.).

A panteles stagmatophorae Gahan, 1919. U. S. Natl. Mus., Proc. 55: 120. ๆ, ठे. 
starki Mason. Alta., Mont., Utah, Idaho, Nev., B. C. Host: Coleotechnites milleri (Busck), C. starki (Freem.), Eucosma recissoriana Heinr.

Apanteles starki Mason, 1960. Canad. Ent. 92: 140. ९, ơ.

subandinus Blanchard. Calif.; Argentina. Host: Phthorimaea operculella (Zell.).

Apanteles subandinus Blanchard, 1947. Arthropoda 1: 20..

teleae Muesebeck. Conn., Pa., Md. Host: Antheraea polyphemus (Cram.), Citheronia regalis (F.).

Apanteles teleae Muesebeck, 1926. U. S. Natl. Mus., Proc. 67 (7): 12..

terminalis Gahan. N. Y.s. to Fla., w. to Iowa, Colo., and Tex. Host: Crambus sp., C. mutabilis Clem.

Apanteles (Pseudapanteles) terminalis Gahan, 1912. Ent. Soc. Wash., Proc. 14: 2. ๆ, ơ.

theclae Riley. D. C. s. to Ga., w. to Colo. and Calif.; Idaho; Mexico. Host: Everes comyntas (Godt.), Plebejus icarioides (Bdv.), Strymon melinus (Hbn.), Thecla sp.

Apanteles theclae Riley, 1881. Acad. Sci. St. Louis, Trans. 4: 308. ๆ, ơ.

thompsoni Lyle. East. Canada, U. S. (?); Palearctic Region. Liberated in Mass., N. Y., Ohio, Mich., and Ont. but not established. Introduced from Europe. Host: Ostrinia nubilalis (Hbn.).

Apanteles thompsoni Lyle, 1927. Bul. Ent. Res. 17: 415. \&.

thujae Muesebeck. Maine, Ont. Host: Argyresthia thuiella (Pack.), Coleatechnites thujaeella Kearf.

A panteles thujae Muesebeck, 1935. Wash. Acad. Sci., Jour. 25: 281. ๆ, ठ.

thurberiae Muesebeck. Tex., Ariz.; Trinidad, Colombia. Host: Thurberiphaga diffusa (Barnes). Apanteles thurberiae Muesebeck, 1921. U. S. Natl. Mus., Proc. 58: 507. ๆ, ठ์.

tischeriae Viereck. Conn., Del., D. C., Ohio, Wis., Mo., Kans. Host: Argyrotaenia velutinana (Wlkr.), Paromix geminatella (Pack.), Tischeria malifoliella (Clem.).

Apanteles (Apanteles) tischeriae Viereck, 1912. U. S. Natl. Mus., Proc. 42: 140. ๆ, ठ์.

tmetocerae Muesebeck. N. S. Host: Spilonota ocellana (D. and S.).

Apanteles tmetocerae Muesebeck, 1921. U. S. Natl. Mus., Proc. 58: 560. ९, ठ์.

unicolor (Curtis). "Arctic regions of No. Amer."

Microgaster unicolor Curtis, 1835. Descr. Insects J. C. Ross 2nd Voyage Northwest Passage, App. p. LXII. ठ'.

victoriae Muesebeck. B. C.

A panteles vicloriae Muesebeck, 1921. U. S. Natl. Mus., Proc. 58: 531. ๆ.

websteri Muesebeck. N. B., Ohio (?), N. C., Ark. Host: Protoboarmia porcelaria (Gn.). Apanteles websteri Muesebeck, 1921. U. S. Natl. Mus., Proc. 58: 539. ₹, ठ́.

xylinus (Say). Que. s. to Fla., w. to Alta. and N. Mex. Host: Amathes c-nigrum (L.), Peridroma saucia (Hbn.).

Microgaster xylina Say, 1836. Boston Jour. Nat. Hist. 1: 262. ?.

Apanteles (Protapanteles) cushmani Viereck, 1912. U. S. Natl. Mus., Proc. 42: 144. ठँ.

Apanteles (Protapanteles) oxyacanthoidis Viereck, 1912. U. S. Natl. Mus., Proc. 43: 581. ๆ. A panteles (Protapanteles) lanificus Viereck, 1917 (1916). Conn. State Geol. and Nat. Hist. Survey, Bul. 22, p. 196.

yakutatensis Ashmead. Que., Utah, Idaho, Wash., Oreg., Calif., Alaska. Host: Amathes c-nigrum (L.), Autographa californica (Speyer), Antoplusia egena (Guen.).

Apanteles yakutatensis Ashmead, 1902. Wash. Acad. Sci., Proc. 4: 249. ?.

A panteles (Protapanteles) hyslopi Viereck, 1910. U. S. Natl. Mus., Proc. 38: 379. ‡, ठ์.

zizaniae Muesebeck. Del., D. C. Host: Diatraea sp.

Apanteles zizaniae Muesebeck, 1957. Ent. News 68: 22. ๆ, ठ̊.

Nomina Nuda in APANTEles Foerster

Apanteles alamedensis Ashmead, 1902. In Chittenden, Bur. Ent., U. S. Dept. Agr., Bul. 33, p. 58.

Apanteles algoniquinus Ashmead, 1905. In Nason, Ent. News 16: 295.

Urogaster carinaria Ashmead, 1905. In Nason, Ent. News 16: 296.

Apanteles catalpae Riley, 1906. In Burgess, Bur. Ent., U. S. Dept. Agr., Bul. 60, p. 73.

Apanteles columbianus Ashmead, 1905. In Nason, Ent. News 16: 296. 
Apanteles cramboides Ashmead, 1905. In Nason, Ent. News 16: 296.

Apanteles eupetheciae Ashmead, 1905. In Nason, Ent. News 16: 296.

Apanteles eupitheciae Ashmead, 1900. In Graenicher, Wis. Nat. Hist. Soc., Bul. 1: 80.

Apanteles nasoni Ashmead, 1905. In Nason, Ent. News 16: 296.

Apanteles notodontae Ashmead, 1897. In Slosson, Ent. News 8: 237.

Apanteles pergandei Ashmead, 1905. In Grossbeck, Ent. News 16: 133.

Apanteles rapae Ashmead, 1931. In Clausen, U. S. Dept. Agr., Cir. 168, p. 73.

Apanteles rileyanus Ashmead, 1906. In Sanderson, Bur. Ent., U. S. Dept. Agr., Bul. 59, p. 35.

\section{UNPLACEd TAXon of APANTEles Foerster}

Microgaster oleracea Taylor, 1860. American Agriculturist 19: 301. + . Host: Pontia oleracea Harris (=Pieris). The illustration which accompanies the description is not adequate in identifying this species. However, certain statements in the description and the fact that the author compares the species with glomeratus indicates that this species is probably the same as Apanteles glomeratus (L.)., a parasite of Pieris oleracea Harr.

\section{Genus DIRRHOPE Foerster}

Dirrhope Foerster, 1851. Naturh. Ver. Rheinlande, Verh. 8: 79.

Type-species: Dirrhope rufa Foerster. Monotypic.

Dirrhopa Schulz, 1906. Spolia Hym., p. 138. Emend.

The exact relationships of this genus are not clearly understood and it has been placed with the Microgastrinae by Muesebeck (1936) and Tobias (1967), and with the Adelinae by Telenga (1955) and Capek (1970).

Taxonomy: Muesebeck, 1936 (1935). Ent. Soc. Wash., Proc. 37: 173-174. -Telenga, 1955.

Fauna U. S. S. R., v. 5, n. 4, p. 14. -Tobias, 1967. Ent. Obozr. 46: 657. -Capek, 1969. Ent.

Soc. Wash., Proc. 71: 309. -Capek, 1970. Canad. Ent. 102: 870.

americana Muesebeck. Va., Mich., Tex. Host: Ectoedemia phleophaga Busck.

Dirrhope americana Muesebeck, 1936 (1935). Ent. Soc. Wash., Proc. 37: 174. \&, ơ.

\section{Genus HYPOMICROGASTER Ashmead}

Hypomicrogaster Ashmead, 1898 (1897). Ent. Soc. Wash., Proc. 4: 166. No included species. Type-species: Microgaster zonaria Say. Desig. by Ashmead, 1900.

Revision: Muesebeck, 1922. U. S. Natl. Mus., Proc. 61 (15): 20-26 (No. Amer. spp. in Microgaster). -Nixon, 1965. Brit. Mus. (Nat. Hist.) Ent., Bul. Sup. 2, p. 208-229 (World spp.).

Taxonomy: Shenefelt, 1973. Hym. Cat., part 9, p. 687-692 (cat. World spp.).

eedytolophae (Muesebeck). N. S. s. to Fla., w. to Ont., Nebr., and Tex.; Cent. Amer., West

Indies. Host: Arogalea cristifasciella (Chamb.), Caloptilia elongella (L.), Coleotechnites piceaella (Kearf.), Ecdytolopha insiticiana Zell., Grapholitha molesta (Busck),

Laspeyresia caryana (Fitch), L. pomonella (L.), Nephopteryx uvinella (Rag.), Ostrinia

obumbratalis (Led.), Psorosina hammondi (Riley), Walshia amorphella Clem.

Microgaster ecdytolophae. Muesebeck, 1922. U. S. Natl. Mus., Proc. 61 (15): 24. ९, ठ.

Taxonomy: Marsh, 1974. Ent. Soc. Wash., Proc. 76: 285.

Biology: Brandhorst, 1962. Ent. Soc. Amer., Ann. 55: 477. - Allen, 1962. U. S. Dept. Agr.,

Tech. Bul. 1265, p. 36.

schizurae (Muesebeck), n. comb. Maine, Mass., Pa., N. J., D. C., Mich., Ohio, Minn., Ark., N. Dak., Kans., B. C. Host: Heterocampa manteo (Dbldy.), Schizura concinna (Smith), S. leptinoides (Grote), S. unicormis (Smith).

Microgaster schizurae Muesebeck, 1922. U. S. Natl. Mus., Proc. 61 (15): 30. ๆ, ơ.

tiro (Reinhard). Newfoundland, P. E. I.; Europe. Host: Cnephasia virguareana (Treit.).

Microgaster tiro Reinhard, 1880. Deut. Ent. Ztschr. 24: 357. ९, o. 
zonaria (Say). Mass. s. to Va., w. to Wis. and Colo.; Fla., La., Canada. Host: Coleotechnites piceaella (Kearf.), C. thujaeella Kearf., Laspeyresia pomonella (L.), Neoerastria caduca (Grote), Plathypena scabra (F.).

Microgaster zonaria Say, 1836. Boston Jour. Nat. Hist. 1: 263. ․

Microgaster cinctus Provancher, 1881. Nat. Canad. 12: 196. ‥

Protapanteles recurvariae Ashmead, 1903. N. Y. Ent. Soc., Jour. 11: 144..

\section{Genus MICROGASTER Latreille}

Microgaster Latreille, 1804. Nouv. Dict. Hist. Nat., v. 24, p. 175.

Type-species: Ichneumon deprimator Fabricius. Desig. by Latreille, 1810.

Liganira Walker, 1860. Ann. and Mag. Nat. Hist. (3) 5: 308.

Type-species: Microgaster detractus Walker. Monotypic.

Microgaster subg. Hygroplitis Thomson, 1895. Opusc. Ent., fasc. 20, p. 2238, 2244.

Type-species: Microgaster missata Haliday. Desig. by Viereck, 1914.

Diolcogaster Ashmead, 1900. In Smith, Ins. of N. J., p. 594.

Type-species: Microgaster brevicauda Provancher. Monotypic.

Zadiolcogaster Viereck, 1913. U. S. Natl. Mus., Proc. 46: 366.

Type-species: Zadiolcogaster anomus Viereck. Orig. desig.

Microgaster subg. Lissogaster Bengtsson, 1926. Ent. Tidskr. 47: 64.

Type-species: Microgaster politus Marshall. Desig. by Muesebeck and Walkley, 1951.

Revision: Muesebeck, 1922. U. S. Natl. Mus., Proc. 61 (15): 20-43 (No. Amer. spp.). -Nixon, 1968. Brit. Mus. (Nat. Hist.) Ent., Bul. 22: 33-72 (some World spp.).

Taxonomy: Nixon, 1965. Brit. Mus. (Nat. Hist.) Ent., Bul. Sup. 2, p. 7. -Shenefelt, 1973.

Hym. Cat., part 9, p. 692-737 (cat. World spp.).

brevicauda Provancher. Que.

Microgaster brevicaudus Provancher, 1886. Addit. Corr. Faune Ent. Canada Hym., p. 140. ㅇ.

brittoni Viereck. Mass., Conn., N. Y., Ga., Ohio, Ont., Mich., Wis., Minn., Iowa.

Microgaster (Microgaster) brittoni Viereck, 1917 (1916). Conn. State Geol. and Nat. Hist. Survey, Bul. 22, p. 201.

canadensis Muesebeck. N. S. w. to B. C.; Maine, Mass., N. Y., Mich., Colo., Oreg., Calif. Host: Achatodes zeae (Harr.), Acleris variana (Fern.), Agonopterix posticella (Wlsm.), Anacampsis innocuella (Zell.), Ancylis comptana fragariae (W. and R.), Archips argyrospilus (Wlkr.), A. rosanus (L.), Choristoneura fumiferana (Clem.), Croesia albicomana (Clem.), E pinotia solicitana (Wlkr.), Sciaphila duplex (Wism.), Sparganothis diluticostana (Wlsm.), Stilpnotia salicis (L.).

Microgaster canadensis Muesebeck, 1922. U. S. Natl. Mus., Proc. 61 (15): 38. \&, ð๖.

congregatiformis Viereck. Mass., Conn., N. Y., N. J., Oni., Mich., Minn., Mont. Host: Endothenia hebesana (Wlkr.).

Microgaster (Microgaster) congregatiformis Viereck, 1917 (1916). Conn. State Geol. and Nat. Hist. Survey, Bul. 22, p. 202.

diaphaniae Muesebeck. Fla.; Cent. and So. Amer. Host: Diaphania indica (Saund.).

Microgaster diaphaniae Muesebeck, 1958. U. S. Natl. Mus., Proc. 107: 414. ๆ, o.

epagoges Gahan. Vt. s. to S. C., w. to Ont. and Mo.; Colo., B. C., Oreg. Host: Acleris chalybeana (Fern.), Anacampsis fragariella Busck, A. rhoifructella (Clem.), Archips argyrospilus (Wlkr.), A. griseus (Rob.), A. rosanus (L.), A. semiferanus (W!kr.), Argyrotaenia velutinana (Wlkr.), Choristoneura obsoletana (Wlkr.), Platynota flavedana Clem., Ostrinia penitalis (Grote), Rhyacionia frustrana (Comst.), Sparganothis pettitana (Rob.), S. putmanana Freem., S. sulphurana (F.), S. tristriata Kearf.

Microgaster epagoges Gahan, 1917. U. S. Natl. Mus., Proc. 53: 197. ๆ, ð.

Biology: Schaffner, 1949. U. S. Dept. Agr., Misc. Pub. 767, p. 62.

femoralamericanus Shenefelt. Idaho, Wash., Oreg., Calif.

Microgaster femoralis Muesebeck, 1922. U. S. Natl. Mus., Proc. 61 (15): 39. ๆ, ठ̊. Preocc. by Bouche, 1834 . 
Microgaster femoralamericanus Shenefelt, 1973. Hym. Cat., part 9, p. 706. N. name for femoralis Muesebeck.

gelechiae Riley. Que. s. to Va., w. to Ont., N. Dak., and Mo.; La. Host: Gnorimoschema gallaeasterella (Kell.), G. gallaesolidaginis (Riley).

Microgaster gelechiae Riley, 1869. Ins. Mo., Ann. Rpt. 1: 178. ९, ठ.

Biology: Judd, 1962. Amer. Micros. Soc., Trans. 81: 204.

gelechiae trichotaphae Walley. Ont. Host: Trichotaphe levisella Fyles.

Microgaster gelechiae var. trichotaphae Walley, 1932. Canad. Ent. 64: 186. đ.

harnedi Muesebeck. Mass., Va., S. C., Mich., Ohio, Ind., Miss., Mo., Wash. Host: Diatraea sp., Macrobotys pertextalis (Led.), Ostrinia obumbratalis (Led.), Pachyzancla thestealis (Wlkr.).

Microgaster harnedi Muesebeck, 1922. U. S. Natl. Mus., Proc. 61 (15): 23. \&.

hospes Marshall. Maine, N. Y., N. J., Md., Va., Ont., Ohio, Iowa, Kans., Colo., Utah; Europe. Host: Ancylis comptana (Forel.), A. c. fragariae (W. and R.), Argyresthia calliphanes Meyr.

Microgaster hospes Marshall, 1885. Roy. Ent. Soc. London, Trans. 1885: 257. $゚, ~ ð$.

Microgaster comptanae Viereck, 1911. U. S. Natl. Mus., Proc. 39: 403. \&.

leechi Walley. Mass., Pa., Md., Fla., Ont., Mich., Ohio, Minn., B. C., Oreg. Host: Macrobotys pertextalis (Led.).

Microgaster leechi Walley, 1935. Canad. Ent. 67: 57. ๆ.

melligaster Provancher. Que. s. to N. Y.; Ont., Mich., Iowa.

Microgaster melligaster Provancher, 1886. Addit. Corr. Faune Ent. Canada Hym., p. 143. ㅇ.

Microgaster rubricoxus Provancher, 1888. Addit. Corr. Faune Ent. Canada Hym., p. 386. "q" = ठ́.

novicius Marshall. Conn., Minn.; Europe. Host: Swammerdamia heroldella Hbn.

Microgaster novicius Marshall, 1885. Roy. Ent. Soc. London, Trans. 1885: 252. ९, ठ.

Microgaster swammerdamiae Muesebeck, 1922. U. S. Natl. Mus., Proc. 61 (15): 37. ๆ, ठै.

pantographae Muesebeck. Maine, Mass., N. Y., Va., Ont., Mich., Ohio, Ill., Iowa, Mo. Host: Argyrotaenia velutinana (Wlkr.), Fascista cercerisella (Chamb.), Pantographa limata (G. and R.).

Microgaster pantographae Muesebeck, 1922. U. S. Natl. Mus., Proc. 61 (15): 34..

peroneae Walley. Canada; Maine, D. C., Ohio, Wash., Alaska. Host: Acleris gloverana (Wlsm.), A. logiana (L.), A. variana (Fern.), Archips argyrospilus (Wlkr.), Sparganothis pettitana (Rob.).

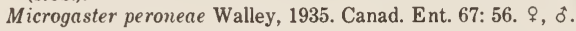

phthorimaeae Muesebeck. Wash., Oreg., Calif. Host: Amorbia essigana Busck, Anacampsis fragariella Busck, Aristotelia rhoisella Busck, Ephestiodes gilvescentella Rag., Phthorimaea operculella (Zell.), Platynota stultana (Wlsm.), Udea rubigalis (Gn.). Microgaster phthorimaeae Muesebeck, 1922. U. S. Natl. Mus., Proc. 61 (15): 40. ₹, ó.

Biology: Graf, 1917. U. S. Dept. Agr., Bul. 427, p. 44-45 (as Microgaster sp.).

scopelosomae Muesebeck. Mass. Host: Eupsilia devia (Grote).

Microgaster scopelosomae Muesebeck, 1926. U. S. Natl. Mus., Proc. 69 (7): 17. ๆ, §.

tibialis Nees. East. Canada, U. S. (?); Europe. Liberated in Mass., N. Y., Ohio, Mich., and Ont. but not established. Introduced from Europe. Host: Ostrinia nubilalis (Hbn.).

Microgaster tibialis Nees, 1834. Hym. Ichn. Affin. Monog., v. 1, p. 168. ஒ, ठ́.

Microgaster luctuosus Haliday, 1834. Ent. Mag. 2: 239. ठे.

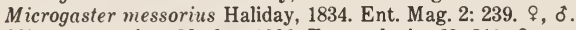

Microgaster pluto Morley, 1936. Entomologist 69: 211. ․

Nomen Nudum in Microgaster Latreille

Microgaster xylinoides Ashmead, 1895. In Webster, Canad. Ent. 27: 68.

\section{Genus MICROPLITIS Foerster}

Microplitis Foerster, 1862. Naturh. Ver. Rheinlande, Verh. 19: 245. 
Type-species: Microgaster sordipes Nees. Orig. desig.

Dapsilotoma Cameron, 1906. Bombay Nat. Hist. Soc., Jour. 17: 101.

Type-species: Dapsilotoma testaceipes Cameron. Monotypic.

Revision: Muesebeck, 1922. U. S. Natl. Mus., Proc. 61 (15): 43-72 (No. Amer. spp.). - Nixon, 1970. Brit. Mus. (Nat. Hist.) Ent., Bul. 25: 1-30 (some Eur. spp.).

Taxonomy: Shenefelt, 1973. Hym. Cat., part 9, p. 737-767 (cat. World spp.).

alaskensis Ashmead. Canada, Alaska, north. U. S. s. to N. Y., Mo, and Ariz. Host: Autographa californica (Spey.), A. precationis (Gn.), Dargida procincta (Grote), Plusia sp.,

Pseudaletia unipuncta (Haw.), Rachiplusia ou (Gn.), Trichoplusia ni (Hbn.).

Microplitis alaskensis Ashmead, 1902. Wash. Acad. Sci., Proc. 4: 249. ․

Biology: Guppy and Miller, 1970. Canad. Ent. 102: 1331.

autographae Muesebeck. Ida., N. Mex., Ariz. Host: Autographa californica (Spey.).

Microplitis autogra phae Muesebeck, 1922. U. S. Natl. Mus., Proc. 61 (15): 54. ₹, ठ.

bradleyi Muesebeck. Alta., Utah, B. C., Oreg., Calif. Host: Amphipyra tragopoginis (L.), Feralia jocosa (Gn.).

Microplitis bradleyi Muesebeck, 1922. U. S. Natl. Mus., Proc. 61 (15): 70 ..

brassicae Muesebeck. Nebr., Tex., Colo., N. Mex., Ariz., Calif. Host: Autographa californica (Spey.), Trichoplusia ni (Hbn.).

Microplitis brassicae Muesebeck, 1922. U. S. Natl. Mus., Proc. 61 (15): 60. \&, §.

carteri Walley. Alta.

Microplitis carteri Walley, 1932. Canad. Ent. 64: 185. ठ.

ceratomiae Riley. Que. and N. S. s. to D. C., w. to Oreg. and N. Mex. Host: Ceratomia amyntor (Geyer), Manduca sexta (L.), Paonias excaecata (Smith), Sphinx drupiferarum (Smith), S. gordius Cram., S. kalmiae Smith.

Microplitis ceratomiae Riley, 1881. Acad. Sci. St. Louis, Trans. 4: 303. \&, ठ.

Microplitis waldeni Viereck, 1917 (1916). Conn. State Geol. and Nat. Hist. Survey, Bul. 22, p. 204.

coactus Lundbeck. Greenland. Host: Noctua sp.

Microplitis coactus Lundbeck, 1896. Vid. Medd. Naturh. Foren. Kjobenhavn, p. 243..

coloradensis Muesebeck. Mich., Minn., Colo.

Microplitis coloradensis Muesebeck, 1922. U. S. Natl. Mus., Proc. 61 (15): 49. ठँ.

confusus Muesebeck. N. B., N. Y., Md., Ont., Mich., Ind, Minn., N. Dak., Tex. Host: Eucirrhoedia pampina (Gn.).

Microplitis confusus Muesebeck, 1922. U. S. Natl. Mus., Proc. 61 (15): 69. ๆ, ठ.

crenulatus (Provancher). Que., Mass., Mich.

Microgaster crenulatus Provancher, 1888. Addit. Corr. Faune Ent. Canada Hym. p. 387. "q" = $\delta$.

croceipes (Cresson). N. J. s. to Ga., w. to Utah, and Ariz.; Oreg. Host: Heliothis subflexa (Guen.), H. virescens (F.), H. zea (Boddie).

Microgaster croceipes Cresson, 1872. Amer. Ent. Soc., Trans. 4: 183..

Microplitis nigripennis Ashmead, 1905. In Quaintance and Brues, U. S. Dept. Agr., Bur.

Ent. Bul. 50, p. 122.

Biology: Lewis, 1970. Ent. Soc. Amer., Ann. 63: 67-70. - Jones and Lewis, 1971. Jour. Ins.

Physiol. 17: 921-927. - Barras, 1972. Comp. Biochem. Physiol. 43B: 941-947. - Vinson and

Lewis, 1972. Jour. Ins. Physiol. 18: 2123-2124. - Dahlman and Vinson, 1975. Comp.

Biochem. Physiol. 52B: 465-468. - Edson and Vinson, 1977. Jour. Ins. Physiol. 23: 5-8.

feltiae Muesebeck. Ind. s. to S. C. and Ala., w. to N. Dak., Wash., and Calif. Host: Agrotis gladiaria Morr., A. ipsilon (Hufn.), Feltia ducens Wlkr., F. subterranea (F.), Lacinipolia renigera (Steph.), Peridroma saucia (Hbn.).

Microplitis feltiae Muesebeck, 1922. U. S. Natl. Mus., Proc. 61 (15): 46.

Microgaster(!) feltiae Muesebeck, 1922. U. S. Natl. Mus., Proc. 61 (15): $62 . \delta$.

Biology: Putler and Thewke, 1970. Ent. Soc. Amer., Ann. 63: 645-648. 
gortynae Riley. N. Y., Pa., Va., Ohio, Miss., Wis., Iowa, Mo., Colo., Oreg. Host: Achatodes zea (Harr.), Hydroecia immanis Grote, Papaipema nebris (Guen.). P. pertincta Dyar.

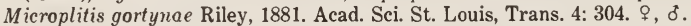

Biology: Balduf, 1929. Ohio Jour. Sci. 29: 219. - Decker, 1935. Iowa St. Col. Jour. Sci. 9: 571-572.

hyphantriae Ashmead. Mass., N. Y., N. J., Md., Fla., Ont., Mich., Ohio, Ind., Ill., Mo., Ark., N. Dak., Tex. Host: Acronicta furcifera Guen., A. hasta Guen., A. interrupta Guen., Hyphantria cunea (Drury), Xylena sp.

Microplitis hyphantriae Ashmead, 1898. Ent. Soc. Wash., Proc. 4: 164. ₹, ठ. kewleyi Muesebeck. Que. s. to D. C., w. to Ont. and Mo.; Calif. Host: Agrotis ipsilon (Hufn.), Amathes bicarnea (Guen.), Euxoa sp.

Microplitis kewleyi Muesebeck, 1922. U. S. Natl. Mus., Proc. 61 (15): 51.,$~ ठ$.

laticinctus Muesebeck. Que., Mass., N. Y., D. C., Ohio, Ala., Ill., Minn., Iowa. Microplitis laticinctus Muesebeck, 1922. U. S. Natl. Mus., Proc. 61 (15): 67.,$~ \delta$. latistigma Muesebeck. Md. Microplitis latistigma Muesebeck, 1922. U. S. Natl. Mus., Proc. 61 (15): 63..

longicauda Muesebeck. Colo., Idaho, Nev., Oreg., Calif. Microplitis longicaudus Muesebeck, 1922. U. S. Natl. Mus., Proc. 61 (15): 57..

mamestrae Weed. Mass., Conn., N. Y., N. J., Mich., Ohio, Wis., Ill., N. Mex., Utah. Host: Ceramica picta (Harr.).

Microplitis mamestrae Weed, 1887. Ill. State Lab. Nat. Hist., Bul. 3: 2. 9.

maturus Weed. Que. s. to Fla., w. to Ont., S. Dak., and La. Host: Caenurgina erechtea (Cram.), Drasteria sp.

Microplitis maturus Weed, 1888. Amer. Ent. Soc., Trans. 15: 294.,$+ ~ ð$.

Microplitis cincta Ashmead, 1891. Canad. Ent. 23: 3. ठ.

Microgaster tuckeri Viereck, 1905. Kans. Acad. Sci., Trans. 19: 274. 9.

mediator (Haliday). Greenland; Europe.

Microgaster mediator Haliday, 1834. Ent. Mag. 2: 235. $\subsetneq$, ¿.

Microgaster dorsalis Nees, 1834. Hym. Ichn. Affin. Monog., v. 1, p. 170. §.

Microgaster fulvicornis Wesmael, 1837. Nouv. Mem. Acad. Sci. Bruxelles 10: 44. \&, §.

Microplitis medianus Ruthe, 1860. Berlin. Ent. Ztschr. 4: 127. ․

melianae Viereck. Ont., N. Y., Ohio, Tenn., Mich., Ill., Minn., Iowa, Kans. Host: Faronta diffusa (Wlkr.), Heliothis zea (Boddie), Pseudaletia unipuncta (Haw.).

Microplitis melianae Viereck, 1911. U. S. Natl. Mus., Proc. 40: 185. ठ.

montanus Muesebeck. Nev., Calif. Host: Catocala verrilliana Grote.

Microplitis montanus Muesebeck, 1922. U. S. Natl. Mus., Proc. 61 (15): 71. ๆ, ठ.

muesebecki Marsh. N. H., Colo., Idaho, B. C., Wash., Calif.

Microplitis stigmaticus Muesebeck, 1922. U. S. Natl. Mus., Proc. 61 (15): 47. ๆ, o. Preoce. by Ratzeburg, 1844.

Microplitis muesebecki Marsh, 1974. Ent. Soc. Wash., Proc. 76: 285. N. name for stigmaticus Muesebeck.

nigritus Muesebeck. Colo.

Microplitis nigritus Muesebeck, 1922. U. S. Natl. Mus., Proc. 61 (15): 58. ๆ, ð. perplexus Muesebeck. Maine, Md., Ont., Mich., Ind., Minn., B. C.

Microplitis perplexus Muesebeck, 1922. U. S. Natl. Mus., Proc. 61 (15): 49. ?.

plutellae Muesebeck. N. Y., Va., S. C., Ont., Minn., Iowa, N. Dak., Sask., Colo., Utah, Idaho, Calif. Host: Plutella xylostella (L.), Trichoplusia ni (Hbn.).

Microplitis plutellae Muesebeck, 1922. U. S. Natl. Mus., Proc. 61 (15): 60. ㅇ, ठ。.

Biology: Harcourt, 1960. Canad. Ent. 92: 420-421. - Putman, 1968. Canad. Ent. 100: 11-16. quadridentatus (Provancher). Maine, N. H., Mass., N. Y., Ont., Mich., Ill., Minn., S. Dak. Host: Simyra henrici (Grote).

Microgaster 4-dentatus Provancher, 1886. Addit. Corr. Faune Ent. Canada Hym., p. 140. $\delta$. Microplitis terminatus Weed, 1888. Amer. Ent. Soc., Trans. 15: 295. $९$, ठ. 
quintilis Viereck. Conn.

Microplitis quintilis Viereck, 1917 (1916). Conn. State Geol. and Nat. Hist. Survey, Bul. 22, p. 204. $\delta$.

rugosus Muesebeck. N. J., Mich.

Microplitis rugosus Muesebeck, 1922. U. S. Natl. Mus., Proc. 61 (15): 48. ठ’.

scutellatus Muesebeck. Maine, N. Y., Mich., Ill., Iowa, S. Dak., Kans., Mont., Idaho, Wash., Oreg.

Microplitis scutellatus Muesebeck, 1922. U. S. Natl. Mus., Proc. 61 (15): 66.9.

striatus Muesebeck. Mich., Tex.

Microplitis striatus Muesebeck, 1922. U. S. Natl. Mus., Proc. 61 (15): 64. ठ̊.

varicolor Viereck. Que. and N. B. s. to Fla., w. to Ont., Utah, and Tex. Host: Leucania latiuscula H.-S., Plathypena scabra (F.), Pseudaletia unipuncta (Haw.), Syngrapha epigaea (Grote).

Microplitis varicolor Viereck, 1917 (1916). Conn. State Geol. and Nat. Hist. Survey, Bul. 22, p. 204.

Biology: Wood and Neilson, 1960. Canad. Ent. 92: 761. -Guppy and Miller, 1970. Canad. Ent. 102: 1331 .

Nomina Nuda in Microplitis Foerster,

Microplitis atrocoxalis Ashmead, 1905. In Nason, Ent. News 16: 296.

Microplitis bicolor Ashmead, 1900 (1899). In Smith, Ins. of N. J., p. 594.

Microplitis forbesii Ashmead, 1905. In Nason, Ent. News 16: 296.

Microplitis illinoisensis Ashmead, 1905. In Nason, Ent. News 16: 296.

Microplitis ohioensis Ashmead, 1905. In Nason, Ent. News 16: 296.

Microplitis similis Ashmead, 1905. In Nason, Ent. News 16: 297.

Microplitis sphingis Ashmead, 1905. In Nason, Ent. News 16: 297.

\section{Genus MIRAX Haliday}

Mirax Haliday, 1833. Ent. Mag. 1: 263.

Type-species: Mirax rufilabris Haliday. Monotypic.

Centistidea Rohwer, 1914. Psyche 21: 81.

Type-species: Centistidea ectoedemiae Rohwer. Orig. desig.

The exact relationships of this genus are not clearly understood. Telenga (1955) and Capek (1970) place it with the Adeliinae, but Tobias (1967) and Nixon (1965) place it in the Microgastrinae, the latter author suggesting a separate tribal position. Hosts are lepidopterous leaf miners.

Revision: Muesebeck, 1922. U. S. Natl. Mus., Proc. 61 (15): 10-12 (No. Amer. spp.).

Taxonomy: Telenga, 1955. Fauna U. S. S. R., v. 5, n. 4, p. 19. -Nixon, 1965. Brit. Mus. (Nat.

Hist.) Ent., Bul. Sup. 2, p. 8, -Tobias, 1967. Ent. Obozr. 46: 657. -Capek, 1969. Ent. Soc.

Wash., Proc. 71: 309. -Capek, 1970. Canad. Ent. 102: 870. - Shenefelt, 1973. Hym. Cat., part 9, p. 676-679 (cat. World spp.).

aspidiscae Ashmead. Que., Md., D. C., Fla. Host: Coptodisca splendoriferella (Clem.), Grapholitha prunivora (Walsh).

Mirax aspidiscae Ashmead, 1893. Psyche 6: 378. ๆ, o.

Mirax grapholithae Ashmead, 1893. Psyche 6: 378. ठ。.

coptodiscae Walley. B. C., Wash., Calif. Host: Coptodisca arbutiella Busck.

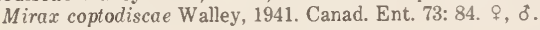

ectoedemiae (Rohwer). Va., Oreg., Calif. Host: Ectoedemia castaneae Busck, Marmara arbutiella Busck, Proleucoptera sp.

Centistidea ectoedemiae Rohwer, 1914. Psyche 21: 81. $\uparrow, ~ \delta$.

lithocolletidis Ashmead. N. J., D. C., S. C., Fla., Ont., Mich., Tenn., Tex. Host: Cameraria aceriella (Clem.), Leucanthiza dircella Braun.

Mirax lithocolletidis Ashmead, 1893. Psyche 6: 378. , ठ .

minuta Ashmead. Ohio, Fla., Tex. Host: Cameraria caryaefoliella (Clem.).

Mirax minuta Ashmead, 1893. Psyche 6: 378. ․ 
pallida Ashmead. Fla.

Mirax pallida Ashmead, 1893. Psyche 6: 379..

texana Muesebeck. Mich., Fla., Tex. Host: Bucculatrix sp.

Mirax texana Muesebeck, 1922. U. S. Natl. Mus., Proc. 61 (15): 11. ठ.

\section{Genus PROTOMICROPLITIS Ashmead}

Protomicroplitis Ashmead, 1898 (1897). Ent. Soc. Wash., Proc. 4: 166. No species included. Type-species: Microgaster mediata Cresson. Subsequent monotypy. First included species by Ashmead, 1900. Roy. Ent. Soc. London, Trans. 1900: 292.

Revision: Muesebeck, 1922. U. S. Natl. Mus., Proc. 61 (15): 20-32 (No. Amer. sp. in Microgaster). - Nixon, 1965. Brit. Mus. (Nat. Hist.) Ent., Bul. Sup. 2, p. 234-264 (World spp.).

Taxonomy: Nixon, 1965. Brit. Mus. (Nat. Hist.) Ent., Bul. Sup. 2, p. 234. -Shenefelt, 1973. Hym. Cat., part 9, p. 772-782 (cat. World spp.).

auripes (Provancher). Que. and N. B. s. to Va., w. to Ont., N. Dak., and Kans. Host: Faronta diffusa (Wlkr.), Pseudaletia unipuncta (Haw.).

Microgaster auripes Provancher, 1886. Addit. Corr. Faune Ent. Canada Hym. p. 141.. bakeri (Muesebeck). Md., Ga., Fla., Ill., Iowa, Mo., La., Nebr., Kans., Tex. Host: Tarachidia candefacta (Hbn.), T. erastrioides (Guen.).

Microgaster bakeri Muesebeck, 1922. U. S. Natl. Mus., Proc. 61 (15): 29. \&, đ.

Taxonomy: Marsh, 1974. Ent. Soc. Wash., Proc. 76: 287.

calliptera (Say). N. Y., N. C., Ga., Fla., Ind., Iowa, La., S. Dak., Nebr., Kans., Tex., Colo. Host: Platysenta sutor (Guen.), P. videns (Guen.).

Microgaster calliptera Say, 1836. Boston Jour. Nat. Hist. 1: 264.

Microgaster maculipennis Cresson, 1872. Amer. Ent. Soc., Trans. 4: 183. \&, ð.

facetosa (Weed). Ont. and N. Y. s. to Ga., w. to B. C. and Calif. Host: Argyrotaenia velutinana (Wlkr.), Elaphria versicolor (Grote), Euparthenos nubilis (Hbn.), Orthosia revicta (Morr.), Plathypena scabra (F.).

Microgaster facetosa Weed, 1888. Amer. Ent. Soc., Trans. 15: 296. १, ઠ̛.

Microgaster (Diolcogaster) solidaginis Viereck, 1917 (1916). Conn. State Geol. and Nat. Hist. Survey, Bul. 22, p. 202.

garmani Ashmead. Md., D. C., Va., Ky., Ill., Mo., Ark., La., Tex. Host: Ogdoconta cinereola (Guen.).

Protomicroplitis germani(!) Ashmead, 1900. U. S. Natl. Mus., Proc. 23: 132.

iridescens (Cresson). Fla.; Cuba. Host: Asciodes gordialis Gn.

Microgaster iridescens Cresson, 1865. Ent. Soc. Phila., Proc. 4: 68. १, ठ.

Taxonomy: Marsh, 1974. Ent. Soc. Wash., Proc. 76: 287.

mediatus (Cresson). Fla.; Cuba, Mexico.

Microgaster mediatus Cresson, 1865. Ent. Soc. Phila., Proc. 4: 66. ठ.

scotica (Marshall). Mich.; Europe.

Microgaster scotica Marshall, 1885. Roy. Ent. Soc. London, Trans. 1885: 251. ơ.

\section{TRIBE CARDIOCHILINI}

This group has, in the past, been placed as a tribe of the Helconinae or as a separate subfamily near the Microgastrinae. Recent workers (Telenga, 1955; Nixon, 1965; Capek, 1970) have placed it as a tribe within the Microgastrinae and I have chosen to follow this arrangement.

Taxonomy: Telenga, 1955. Fauna U. S. S. R., v. 5, n. 4, p. 212. - Nixon, 1965. Brit. Mus. (Nat. Hist.) Ent., Bul. Supl. 2, p. 6. - Capek, 1970. Canad. Ent. 102: 858, 870.

\section{Genus CARDIOCHILES Nees}

Cardiochiles Nees, 1818. Nov. Act. Acad. Caes. Leop. Car. 9: 307. No included species. Type-species: Ichneumon saltator Fabricius. Subsequent monotypy. First species included by Nees, 1834. Hym. Ichn. Affin. Monog., v. 1, p. 224. 
Toxoneuron Say, 1836. Boston Jour. Nat. Hist. 1: 258.

Type-species: Bracon (Toxoneuron) viator Say. Desig. by Viereck, 1914.

Tenthredoides Cresson, 1865. Ent. Soc. Phila., Proc. 4: 290.

Type-species: Tenthredoides seminiger Cresson. Monotypic.

Toxonevira Cresson, 1887. Amer. Ent. Soc., Trans., Suppl. Vol., p. 61, 154. Emend.

Ditherus Cameron, 1902. Bombay Nat. Hist. Soc., Jour. 14: 434.

Type-species: Ditherus ruficollis Cameron. Monotypic.

Schonlandella Cameron, 1904. Rec. Albany Mus. 1: 169.

Type-species: Schonlandella nigromaculata Cameron. Desig. by Viereck, 1914.

Emestiella Cameron, 1905. Spolia Zeylanica 3: 81.

Type-species: Emestiella nigromaculata Cameron. Monotypic.

Toxoneurum Schulz, 1906. Spolia Hym., p. 137. Emend.

Hartemita Cameron, 1910. Wien. Ent. Ztg. 29: 99.

Type-species: Hartemita latipes Cameron. Monotypic.

Psilommiscus Enderlein, 1912. Arch. f. Naturgesch. 78: 98.

Type-species: Psilommiscus sumatranus Enderlein. Monotypic.

Revision: Mao, 1945. Pan-Pacific Ent. 21: 125-134 (Mex. spp.). -Mao, 1949. U. S. Natl. Mus.,

Proc. 99: 229-266 (No. Amer. spp.).

Taxonomy: Shenefelt, 1973. Hym. Cat., part 9, p. 785-804 (cat. World spp.).

abdominalis (Cresson). D. C., Ill., La., Tex.

Toxoneuron abdominale Cresson, 1873. Canad. Ent. 5: 68. ठ.

apicalis (Cresson). N. J. s. to Fla.; Ill., Iowa, Ark., Kans., Ariz., Calif. Host: Adelphia petrella (Zell.), Ulophora sp.

Toxoneuron apicale Cresson, 1873. Canad. Ent. 5: 68. ठँ.

arugosus Mao. Ont. and N. J. s. to Ga., w. to Oreg., Calif., and Tex.

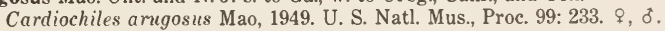

brevitarsis Mao. Calif.

Cardiochiles brevitarsis Mao, 1949. U. S. Natl. Mus., Proc. 99: 235. ․

californicus (Ashmead). Calif.

Toxoneura californicus Ashmead, 1894. Ent. Soc. Wash., Proc. 3: 50..

dignus Mao. Tex.

Cardiochiles dignus Mao, 1949. U. S. Natl. Mus., Proc. 99: 237. ๆ.

dilatus Mao. Calif.

Cardiochiles dilatus Mao, 1949. U. S. Natl. Mus., Proc. 99: 238. \&, §.

explorator (Say). Ohio, Ind., Ill., Miss., Mo., Ark., Kans., Okla., Tex., Colo., N. Mex., Ariz., Wash., Calif. Host: Loxostege rantalis (Guen.).

Bracon (Toxoneuron) explorator Say, 1836. Boston Jour. Nat. Hist. 1: 259.

floridanus (Ashmead). Ga., Fla., Ont., Ohio, Kans., Colo.; Mexico. Host: Epipaschia zelleri (Grote).

Toxoneura floridana Ashmead, 1894. Ent. Soc. Wash., Proc. 3: 50. ơ.

insculptus Mao. N. C., Fla. Host: Phthorimaea operculella (Zell.).

Cardiochiles insculptus Mao, 1949. U. S. Natl. Mus., Proc. 99: 241. ^, ठ.

Cardiochiles operculellus Mao, 1949. U. S. Natl. Mus., Proc. 99: pl. 4, fig. 8.

levis Mao. N. Mex., Nev., Calif.; Mexico.

Cardiochiles levis Mao, 1949. U. S. Natl. Mus., Proc. 99: 242., ,

magnus Mao. Iowa, Kans., Tex., Colo., N. Mex., Ariz. Host: Schinia sp.

Cardiochiles magnus Mao, 1949. U. S. Natl. Mus., Proc. 99: 243. ๆ, ठ゚.

minutus (Cresson). Que., Md., Va., Ont., Mich., Ill., Iowa, Tenn. Host: Aeaea ostryaeella Chamb.

Toxoneuron minutum Cresson, 1873. Canad. Ent. 5: 67. ․

nebrascensis Mao. Nebr.

Cardiochiles nebrascensis Mao, 1949. U. S. Natl. Mus., Proc. 99: 245. ․

nigricans Mao. Tex., Nev., Calif.

Cardiochiles nigricans Mao, 1949. U. S. Natl. Mus., Proc. 99: 246. ठ. 
nigriceps Viereck. D. C. s. to Fla., w. to Kans. and La.; Mexico. Host: Heliothis subflexa (Guen.), H. virescens (F.).

Cardiochiles nigriceps Viereck, 1912. U. S. Natl. Mus., Proc. 43: 578. \&, §.

Biology: Chamberlin and Tenhet, 1926. Jour. Agr. Res. 33: 21-27. - Vinson and Lewis, 1965. Jour. Econ. Ent. 58: 869-871. - Lewis and Brazzel, 1966. Jour. Econ. Ent. 59: 820-822. - Lewis, Brazzel and Vinson, 1967. Jour. Econ. Ent. 60: 615-616. - Lewis and Vinson, 1968. Ent. Soc. Amer., Ann. 61: 561-565. - Vinson, 1968. Ent. Soc. Amer, Ann. 61: 8-10. - Lewis and Vinson, 1968. Jour. Insect Physiol. 14: 613-626. - Lewis and Vinson, 1971. Ent. Soc. Amer., Ann. 64: 970-972. - Hays and Vinson, 1971. Anim. Behavior 19: 344-352. - Vinson, 1972. Ent. Soc. Amer., Ann. 65: 229-236. - Lewis, et al., 1972. Environ. Ent. 1: 1468-1471.

Morphology: Vinson, 1969. Ent. Soc. Amer., Ann. 62: 1414-1419.

nigroclypeus Viereck. Kans., Tex., Calif.

Cardiochiles nigroclypeus Viereck, 1905. Kans. Acad. Sci., Trans. 19: 275. ठ̊.

orizabae Cresson. Ga., Fla., Ala., Ark., La., Kans., Tex., Ariz.; Mexico.

Toxoneuron orizabae Cresson, 1873. Canad. Ent. 5: 67. ठँ.

pluto (Ashmead). Calif.

Toxoneura pluto Ashmead, 1894. Ent. Soc. Wash., Proc. 3: 49. “ๆ” = ठ.

pullus Mao. N. J., Fla., Ohio, Iowa, La., S. Dak., Kans., Tex., Utah, Oreg., Calif.

Cardiochiles amigosus var. pullus Mao, 1949. U. S. Natl. Mus., Proc. 99: 234. ९, ơ.

rubicundus Mao. N. Mex., Utah, Ariz.; Mexico.

Cardiochiles rubicundus Mao, 1949. U. S. Natl. Mus., Proc. 99: 250. \&.

rubidus Mao. N. Mex., Idaho, Ariz., Oreg., Calif.

Cardiochiles mibidus Mao, 1949. U. S. Natl. Mus., Proc. 99: 251. ६.

rufostigma Mao. Wash., Calif.

Cardiochiles mufostigma Mao, 1949. U. S. Natl. Mus., Proc. 99: 252. ๆ, ठै.

siminiger (Cresson). Iowa, Kans., Tex., Mont., Colo., N. Mex., Utah, Ariz., Calif.

Tenthredoides seminiger Cresson, 1865. Ent. Soc. Phila, Trans. 4: 291. १, ठ.

tennessensis Mao. Tenn.

Cardiochiles tennessensis Mao, 1949. U. S. Natl. Mus., Proc. 99: 254. ․

texensis Mao. Tex.; Mexico.

Cardiochiles texensis Mao, 1949. U. S. Natl. Mus., Proc. 99: 255. ․

thoracicus (Cresson). Ariz.; Mexico.

Toxoneuron thoracicum Cresson, 1873. Canad. Ent. 5: 68. ㅇ, o.

thurberiae Rohwer. Tex., Ariz.

Cardochiles(!) therberiae(!) Rohwer, 1920. U. S. Natl. Mus., Proc. 57: 226. “ $\delta "=q$.

tibiator (Say). Pa. s. to Fla.; Mich., Ky., Mo., Ark., Kans. Host: Nephopteryx celtidella (Hulst), $N$. crassifasciella Rag., $N$. dammersi floridensis Heinr., N. subcaesiella (Clem.), $N$. subfuscella (Rag.).

Bracon tibiator Say, 1824. In Keating, Narr. Long's 2nd Exped., v. 2, App., p. 322..

transversus Mao. Calif.

Cardiochiles transversus Mao, 1949. U. S. Natl. Mus., Proc. 99: 260. + , ơ.

truncus Mao. Nebr., Wyo., Colo.

Cardiochiles truncus Mao, 1949. U. S. Natl. Mus., Proc. 99: 261. ๆ, ठ.

viator (Say). Conn. and N. Y. s. to Va., w. to Mich. and Ill.; Tex., Wyo., Colo., N. Mex., Wash.

Bracon (Toxoneuron) viator Say, 1836. Boston Jour. Nat. Hist. 1: 258.

\section{SUBFAMILY ICHNEUTINAE}

\section{TRIBE ICHNEUTINI}

Species in this group are solitary endoparasites of sawfly larvae; oviposition takes place in the host egg but the parasite cocoon is formed within the host cocoon.

Taxonomy: Shenefelt, 1973. Hym. Cat., part 9, p. 805-812 (cat. World spp.). 


\section{Genus ICHNEUTES Nees}

Ichneutes Nees, 1816 (1813). Mag. Gesell. Naturf. Freunde Berlin 7: 275.

Type-species: Ichnentes reunitor Nees. Monotypic.

alaskensis Ashmead. Alaska.

Ichneutes alaskensis Ashmead, 1902. Wash. Acad. Sci., Proc. 4: 251. ठ̊.

bicarinatus (Ashmead). Ont.

Opius bicarinatus Ashmead, 1891. Canad. Ent. 23: 4. ठั.

bicolor Cresson. Mass., Mich., Minn., Mont. Host: Pristiphora erichsonii (Htg.).

Ichneutes bicolor Cresson, 1872. Canad. Ent. 4: 230. ․

fulvipes Cresson. Ill., Mich., Alta., Colo., Nev., Calif. Host: Euura sp.

Ichneutes fulvipes Cresson, 1872. Canad. Ent. 4: 231. ठ。.

pikonematis Mason. Maine, Minn., Canada. Host: Pikonema alaskensis (Roh.).

Ichneutes pikonematis Mason, 1968. Canad. Ent. 100: 721. ๆ, ठ゚.

popofensis Ashmead. Alaska.

Ichneutes popofensis Ashmead, 1902. Wash. Acad. Sci., Proc. 4: 250. ð.

reunitor Nees. Alaska; Europe.

Ichneutes reunitor Nees, 1816 (1813). Mag. Gesell. Naturf. Freunde Berlin 7: 276. ๆ, ठ.

\section{Genus ICHNEUTIDEA Ashmead}

Ichneutidea Ashmead, 1900. U. S. Natl. Mus., Proc. 23: 133.

Type-species: Ichneutes abdominalis Cresson. Orig. desig.

Proteropoides Viereck, 1909. Ent. Soc. Wash., Proc. 11: 42.

Type-species: Proteropoides hertzogi Viereck. Orig. desig.

abdominalis (Cresson). Fla., Iowa, Kans., Tex., Mont., Calif. Host: Sphacophilus plumiger (Klug).

Ichnentes abdominalis Cresson, 1872. Amer. Ent. Soc., Trans. 4: 179. ๆ.

proteroptoides Viereck. Que. s. to Fla., w. to S. Dak., Colo., and Tex.; Mexico. Host:

Schizocerella pilicornis (Holmgren).

Ischneutidea(!) proteroptoides Viereck, 1905. Kans. Acad. Sci., Trans. 19: 274. 9.

Ichneutidea secunda Rohwer, 1908. Ent. News 19: 419. $?$.

Proteropoides hertzogi Viereck, 1909. Ent. Soc. Wash., Proc. 11: 42. ․

\section{Genus PROTEROPS Wesmael}

Proterops Wesmael, 1835. Nouv. Mem. Acad. Sci. Bruxelles 9: 201.

Type-species: Proterops nigripennis Wesmael. Monotypic.

californicus Cresson. Wyo., Calif.

Proterops californicus Cresson, 1873. Canad. Ent. 5: 69. ơ.

\section{TRIBE MUESEBECKIINI}

The genera in this tribe were previously associated with the Microgastrinae, but Mason (1969) has shown that they are morphologically similar to the Ichneutinae. Host records indicate that species are parasites of leaf mining lepidopterous larvae.

Taxonomy: Mason, 1969. Ent. Soc. Wash., Proc. 71: 263-278 (key to World genera).

\section{Genus MUESEBECKIA Mason}

Muesebeckia Mason, 1957. Canad. Ent. 89: 355.

Type-species: Muesebeckia eximius Mason. Orig. desig.

Revision: Mason, 1969. Ent. Soc. Wash., Proc. 71: 265-274.

eximia Mason. Que., Ont., N. C.

Muesebeckia eximius Mason, 1957. Canad. Ent. 89: 355. ९, ơ.

\section{Genus OLIGONEURUS Szepligeti}

Oligoneurus Szepligeti, 1902. Termes. Fuzetek 25: 77. 
Type-species: Oligoneurus concolor Szepligeti. Monotypic.

One undescribed species occurs in North America.

\section{Genus PAROLIGONEURUS Muesebeck}

Paroligoneurus Muesebeck, 1931. U. S. Natl. Mus., Proc. 79 (16): 7.

Type-species: Paroligoneuris johnsoni Muesebeck. Orig. desig.

Taxonomy: Shenefelt, 1973. Hym. Cat., part 9, p. 681-682 (cat. World spp.).

johnsoni Muesebeck. Mass., N. J., S. C., Fla. Host: Nepticula sp.

Paroligoneurus johnsoni Muesebeck, 1931. U. S. Natl. Mus., Proc. 79 (16): 8..

\section{SUBFAMILy BLACINAE}

The genera included here are in need of considerable study and the arrangement below is a very conservative one. There are distinct differences in morphology and biologies among these genera, some showing affinities with the Helconinae, others with the Agathidinae. Nearly all of the North American genera are unstudied.

\section{TRIBE BLACINI}

This tribe constitutes the least homogeneous group of genera in the Blacinae. The biologies of Blacus species are not well established; van Achterberg (1976 (1975)) places this and related genera as a tribe of the Helconinae. Species of Centistes, Pygostolus, and Syrhizus are internal parasites of adult Coleoptera and have been placed in a separate subfamily by Capek (1969).

Revision: van Achterberg, 1976 (1975). Tijdschr. Ent. 118: 159-323.

\section{Genus BLACUS Nees}

\section{Genus BLACUS Subgenus BLACUS Nees}

Blacus Nees, 1818. Nov. Act. Acad. Caes. Leop. Car. 9: 306.

Type-species: Bracon humilis Nees. Desig. by Westwood, 1839.

Miocolus Foerster, 1862. Naturh. Ver. Rheinlande, Verh. 19: 237.

Type-species: Miocolus pallipes Foerster. Orig. desig.

Goniocormus Foerster, 1862. Naturh. Ver. Rheinlande, Verh. 19: 254.

Type-species: Blacus paganus Haliday. Orig. desig.

Taxonomy: Shenefelt, 1969. Hym. Cat., part 4, p. 15-26 (cat. World spp.). - Haeselbarth, 1973.

Staatssaml. Munchen, Veroffentl. 16: 69-170 (Eur. and Cent. Asian spp.). - van

Achterberg, 1976 (1975). Tijdschr. Ent. 118: 174-176 (key to subgenera).

Biology: Arnaud, 1952. Ent. News 63: 149-150 (swarming of males).

apodastus van Achterberg. Ont.

Blacus (Blacus) apodastus van Achterberg, 1976 (1975). Tijdschr. Ent. 118: 234. ․

asaphus van Achterberg. N. S., Man., Sask.

Blacus (Blacus) asaphus van Achterberg, 1976 (1975). Tijdschr. Ent. 118: 229..

caduceus van Achterberg. Que. s. to Ga., w. to B. C. and Oreg.

Blacus (Blacus) caduceus van Achterberg, 1976 (1975). Tijdschr. Ent. 118: 237. ‡, o.

cognatus van Achterberg. Wis., Sask., Ariz.

Blacus (Blacus) cognatus van Achterberg, 1976 (1975). Tijdschr. Ent. 118: 230. \&, ơ. cohibilis van Achterberg. Tex.

Blacus (Blacus) cohibilis van Achterberg, 1976 (1975). Tijdschr. Ent. 118: 228. ․

defectuosus Provancher. Ont., Wis., Sask., Colo., Utah.

Blacus defectuosus Provancher, 1886. Addit. Corr. Faune Ent. Canada Hym., p. 133.. exilis (Nees). Que., Ont., N. Y., N. C., Iowa, Ill., Wis., Colo., B. C.; Europe.

Bracon exilis Nees, 1812 (1811). Mag. Gesell. Naturf. Freunde Berlin 5: 19. ‡, ð. Aphidius lactucaphis Fitch, 1855 (1854). N. Y. State Agr. Soc., Trans. 14: 840.

Miocolus pallipes Foerster, 1862. Naturh. Ver. Rheinlande, Verh. 19: 237. Preocc. in Blacus by pallipes Haliday, 1835. 
Blacus nanus Ashmead, 1905. In Nason, Ent. News 16: 294. Nom. nud.

Blacus propallipes Shenefelt, 1969. Hym. Cat., part 4, p. 23. N. name for pallipes Foerster. humilis (Nees). Que., N. H., N. Y., W. Va., N. C., Ont., Wis., Sask., Colo., Ariz., Alta., B. C., Oreg., Calif., N. W. T., Alaska; Europe.

Bracon humilis Nees, 1812 (1811). Mag. Gesell. Naturf. Freunde Berlin 5: 19. १, ઠ.

Blacus (Blacus) trivialis Haliday, 1835. Ent. Mag. 3: 122. ๆ, ठ.

maryi maryi Hellen. Colo., Alta., B. C.; Europe.

Blacus maryi Hellen, 1958. Soc. Fauna Flora Fenn. 4: 23. ๆ.

maryi nidicola Hedqvist. Man., Yukon; Europe.

Blacus nidicola Hedqvist, 1974. Ent. Tidskr. 95: 184. \&.

masoni van Achterberg. Que., Wis., Man., Colo., Alta., B. C.

Blacus (Blacus) masoni van Achterberg, 1976 (1975). Tijdschr. Ent. 118: 235..

paganus Haliday. Que., N. C., Ga., Alta., B. C.; Europe.

Blacus (Blacus) paganus Haliday, 1835. Ent. Mag. 3: 122. + o.

Blacus brevicornis Ruthe, 1861. Berlin. Ent. Ztschr. 5: 146. $\%$.

rufipes (Ashmead). Ind.

Dimeris rufipes Ashmead, 1889 (1888). U. S. Natl. Mus., Proc. 11: 626. ․

\section{Genus BLACUS Subgenus GANYCHORUS Haliday}

Ganychorus Haliday, 1835. Ent. Mag. 3: 40.

Type-species: Bracon ruficom is Nees. Desig. by Westwood, 1839.

armatulus Ruthe. Ont.; Europe.

Blacus armatulus Ruthe, 1861. Berlin. Ent. Ztschr. 5: 137. ․

collaris (Ashmead). Que., Va., N. C.; Mexico, West Indies, So. Amer.

Ganychorus collaris Ashmead, 1894. Linn. Soc., Jour. 25: 131..

ruficornis (Nees). No. Amer.; Europe.

Bracon mificornis Nees, 1812 (1811). Mag. Gesell. Naturf. Freunde Berlin 5: 18. ९, ठ.

Microgaster bisstigmata Say, 1836. Boston Jour. Nat. Hist. 1: 264. o.

Blacus dentatus Hellen, 1958. Soc. Fauna Flora Fenn. 4: 21. ๆ.

Biology: Syrjamaki, 1976. Ent. Fenn., Ann. 42: 66-68 (swarming).

striatus van Achterberg. N. H., Canada, Alaska.

Blacus (Ganychorus) striatus van Achterberg, 1976 (1975). Tijdschr. Ent. 118: 207. \&, o.

\section{Genus BLACUS Subgenus HYSTEROBOLUS Viereck,}

Hysterobolus Viereck, 1913. U. S. Natl. Mus., Proc. 44: 559.

Type-species: Hysterobolus mallochi Viereck. Orig. desig.

mallochi (Viereck). Que., Md., Va.

Hysterobolus mallochi Viereck, 1913. U. S. Natl. Mus., Proc. 44: 560..

patulus van Achterberg. B. C.

Blacus (Hysterobolus) patulus van Achterberg, 1976 (1975). Tijdschr. Ent. 118: 219. \&.

redactus van Achterberg. Wis.

Blacus (Hysterobolus) redactus van Achterberg, 1976 (1975). Tijdschr. Ent. 118: 218. ๆ.

\section{Genus BLACUS Subgenus LEIOBLACUS van Achterberg}

Blacus subg. Leioblacus van Achterberg, 1976 (1975). Tijdschr. Ent. 118: 180.

Type-species: Blacus (Leioblacus) compressiventris van Achterberg. Orig. desig.

compressiventris van Achterberg. Que., N. H., N. C., S. C., Ga., Ont., B. C.

Blacus (Leioblacus) compressiventris van Achterberg, 1976 (1975). Tijdschr. Ent. 118: 182.

․

\section{Genus BLACUS Subgenus NEOBLACUS Ashmead}

Neoblacus Ashmead, 1900. U. S. Natl. Mus., Proc. 23: 122.

Type-species: Neoblacus rufipes Ashmead. Orig. desig. 
koenigi Fischer. Que., N. H., Mass., Md., Ont., Mich., Wis., Calif.; Europe.

Neoblacus mifipes Ashmead, 1900. U. S. Natl. Mus., Proc. 23: 122. Preocc. by Ashmead, 1889 (1888).

Blacus koenigi Fischer, 1962. Ztschr. Angew. Ent. 58: 333. ๆ, ठ.

\section{Genus BLACUS Subgenus TARPHEION van Achterberg}

Blacus subg. Tarpheion van Achterberg, 1976 (1975). Tijdschr. Ent. 118: 185.

Type-species: Blacus (Tarpheion) chillcotti van Achterberg. Orig. desig.

chillcotti van Achterberg. Ont., N. J., N. C., Ga.

Blacus (Tarpheion) chillcotti van Achterberg, 1976 (1975). Tijdschr. Ent. 118: 189..

Nomen Nudum in Blacus NeEs

Blacus lithocolletidis Ashmead, 1910. In Smith, N. J. State Mus., Rpt., p. 607.

\section{Genus CENTISTES Haliday}

Leiophron subg. Ancylus Haliday, 1833. Ent. Mag. 1: 261. Preocc. by Mueller, 1774.

Type-species: Leiophron (Ancylus) cuspidatus Haliday. Desig. by Viereck, 1914.

Leiophron subg. Centistes Haliday, 1835. Ent. Mag. 2: 462.

Type-species: Leiophron (Ancylus) cuspidatus Haliday. Monotypic.

Ancyllus Haldeman, 1842. Acad. Nat. Sci. Phila., Proc. 1: 191. N. name for Ancylus

Haliday. Gray (1821) also proposed the name Ancyllus, but apparently only as an emendation of Ancylus Mueller.

Euphoridea Ashmead, 1900. U. S. Natl. Mus., Proc. 23: 116.

Type-species: Euphoridea claripennis Ashmead. Orig. desig.

Liosigalphus Ashmead, 1900. U. S. Natl. Mus., Proc. 23: 125.

Type-species: Liosigalphus politus Ashmead. Orig. desig.

Taxonomy: Shenefelt, 1969. Hym. Cat., part 4, p. 26-28 (cat. World spp.).

claripennis (Ashmead). Mich., Ky., Iowa, Ark.

Euphoridea claripennis Ashmead, 1900. U. S. Natl. Mus., Proc. 23: 116.

excrucians (Haliday). Ont.; Europe. Host: Sitona scissifrons Say.

Leiophron (Ancylus) excrucians Haliday, 1835. Ent. Mag. 2: 461. ๆ.

Leiophron (Ancylus) lituratus Haliday, 1835. Ent. Mag. 2: 461. ๆ.

Biology: Loan, 1964 (1963). Ent. Soc. Ont., Proc. 94: 56-61 (as excrucians).

Morphology: Loan, 1963. Ent. Soc. Amer., Ann. 56: 605-606 (larvae; as lituratus).

laevis (Cresson). Que., Pa., Ohio, Mich., S. D. Host: Amara exarata Dejean.

Leiophron laevis Cresson, 1872. Canad. Ent. 4: 228. ठ.

Sigalphus trisectus Provancher, 1886. Addit. Corr. Faune Ent. Canada Hym., p. 143. ơ.

Eubadizon basilare Provancher, 1890. Nat. Canad. 19: 248..

Taxonomy: Mason, 1974. Ent. Soc. Wash., Proc. 76: 245.

politus (Ashmead). D. C.

Liosigalphus politus Ashmead, 1900. U. S. Natl. Mus., Proc. 23: 125.

\section{Genus PYGOSTOLUS Haliday}

Leiophron subg. Pygostolus Haliday, 1833. Ent. Mag. 1: 263.

Type-species: Cryptus stictus Fabricius. Monotypic.

Taxonomy: Shenefelt, 1969. Hym. Cat., part 4, p. 122-124 (cat. World spp.).

falcatus (Nees). P. E. I., Ont., Man. Introduced from Sweden. Host: Sitona hispidulus (F.), S. lineatus (L.). Loan and Thompson (1972) indicate that this species might be Holarctic or adventive and that the P. E. I. population probably did not develop from the colonies introduced in Ont. and Man.

Leiophron falcatus Nees, 1834. Hym. Ichn. Aff. Monog., v. 1, p. 44. $?$.

Biology: Loan and Holdaway, 1961. Bul. Ent. Res. 62: 473-488. - Loan, 1961. Jour. Econ. Ent. 54: 1026-1031. - Loan, 1963. Ent. Soc. Amer., Ann. 56: 605-606. - Loan, 1965. Jour. Econ.

Ent. 58: 798-799. - Loan and Thompson, 1972. Canad. Ent. 104: 779-780. 


\section{Genus SYRRHIZUS Foerster}

Syrrhizus Foerster, 1862. Naturh. Ver. Rheinlande, Verh. 19: 254.

Type-species: Syrrhizus delusorius Foerster, Orig. desig.

Taxonomy: Shenefelt, 1969. Hym. Cat., part 4, p. 133-134 (cat. World spp.).

agilis (Cresson). N. Y., Md., Va., Ohio, Ill.

Microctonus agilis Cresson, 1872. Canad. Ent. 4: 226. §.

diabroticae Gahan. Ohio, Ill. Host: Acalymma vittatum (F.).

Syrrhizus diabroticae Gahan, 1922. Ohio Jour. Sci. 22: 140. ?.

\section{TRIBE BRACHISTINI}

All species are apparently internal parasites of coleopterous larvae. This tribe, as proposed by Mason (1974), includes the genera listed under the Triaspidini of the previous catalog.

Taxonomy: Mason, 1974. Ent. Soc. Wash., Proc. 76: 235-246.

\section{Genus ALIOLUS Say}

Bracon subg. Aliolus Say, 1836. Boston Jour. Nat. Hist. 1: 259.

Type-species: Bracon (Aliolus) trilobatus Say. Desig. by Viereck, 1914.

Revision: Martin, 1956. Canada Dept. Agr. Pub. 965, p. 14-60 (No. Amer. spp.).

Taxonomy: Shenefelt, 1970. Hym. Cat., part 5, p. 269-273 (cat. World spp.).

bicornis Martin. U. S. (state not known).

Aliolus bicomis Martin, 1956. Canada Dept. Agr. Pub. 965, p. 39. ๆ.

bucculentis Martin. B. C.

Aliolus bucculentis Martin, 1956. Canada Dept. Agr. Pub. 965, p. 41..

canadensis (Provancher). Mass., N. Y., Canada.

Sigalphus canadensis Provancher, 1881. Nat. Canad. 12: 197. .

crabilli Martin. N. Y. s. to Ga., w. to Wis. and Ark.

Aliolus crabilli Martin, 1956. Canada Dept. Agr. Pub. 965, p. 59. ‡, §.

denticulatus Martin. N. Y., Pa., N. J., Md., D. C., Iowa.

Aliolus denticulatus Martin, 1956. Canada Dept. Agr. Pub. 965, p. 33. ๆ, ð.

evanidus Martin. Tex.

Aliolus evanidus Martin, 1956. Canada Dept. Agr. Pub. 965, p. 37. ठ̊.

fiskei (Rohwer). Pa., N. J., Md., Va., N. C. Host: Cossonus sp., Glipa octopunctata (F.).

Triaspis fiskei Rohwer, 1913. U. S. Natl. Mus., Proc. 45: 535..

indeprehensus Martin. Miss.

Aliolus indeprehensus Martin, 1956. Canada Dept. Agr. Pub. 965, p. 46..

marginatus Martin. N. Y., Va., Md., W. Va., Ohio, Mich., Tenn.

Aliolus marginatus Martin, 1956. Canada Dept. Agr. Pub. 965, p. 57. \&, o.

patei Martin. N. S. s. to S. C.; Ont., Ohio.

Aliolus patei Martin, 1956. Canada Dept. Agr. Pub. 965, p. 55. ९, §.

stanleyi Martin. Miss., Tex.

Aliolus stanleyi Martin, 1956. Canada Dept. Agr. Pub. 965, p. 53. ๆ, ठ์.

stictopleurus Martin. Pa., N. C., Mich., Miss. Host: Obrium rufulum Gah.

Aliolus stictopleurus Martin, 1956. Canada Dept. Agr. Pub. 965, p. 52. \&, ð.

tomoxiae (Rohwer). Pa., Md., D. C., Va., Mich., Kans. Host: Tomoxia lineella Lec.

Allodorus tomoxiae Rohwer, 1915. Ent. Soc. Wash., Proc. 17: 55. ๆ, ठ.

tridentatus Martin. Ariz.

Aliolus tridentatus Martin, 1956. Canada Dept. Agr. Pub. 965, p. 30..

trilobatus (Say). Md., W. Va., Va., Mich., Ind.

Bracon (Aliolus) trilobatus Say, 1836. Boston Jour. Nat. Hist. 1: 259. ठ. 
UNPLACED TAXa OF ALIOLUS SAY

Bracon (Aliolus) thoracicus Say, 1836. Boston Jour. Nat. Hist. 1: 260. Preoccupied in Triaspis by thoracicus Nees, 1812.

Triapsis sayi Muesebeck and Walkley, 1951. In Muesebeck, et al., U. S. Dept. Agr., Agr.

Monog. 2, p. 114. N. name for thoracicus Say.

\section{Genus ALLODORUS Foerster}

Allodorus Foerster, 1862. Naturh. Ver. Rheinlande, Verh. 19: 242.

Type-species: Sigalphus semirugosus Nees. Orig. desig.

Taxonomy: Mason, 1974. Ent. Soc. Wash., Proc. 76: 241.

calyptoides (Martin). Wis.

Aliolus calyptoides Martin, 1956. Canada Dept. Agr. Pub. 965, p. 31..

erassigaster (Provancher). Que., N. B., Maine, Pa., Wis., Minn., Alta., Idaho, B. C., Wash., Oreg.

Host: Pissodes dubius Rand., P. fasciatus Lec., P. strobi Peck.

Brachistes crassigaster Provancher, 1886. Addit. Corr. Faune Ent. Canada Hym., p. 132. $\%$, ठ.

Brachistes strigitergum Cushman, 1930 (1929). U. S. Natl. Mus., Proc. 76 (25): 15.. N. syn.

Biology: Deyrup, 1975. Conif. For. Biome Ecosystem Anal. Stud., Univ. of Wash., Bul. 6, pp. 73-74.

definitus (Muesebeck). Oreg., Calif. Host: Conophthomus ponderosae Hopk., Ernobius sp.

Eubadizon difinitum Muesebeck, 1957. Brooklyn Ent. Soc., Bul. 52: 53. १, ठ.

ernobii (Muesebeck). Oreg., Calif. Host: Ernobius sp.

Eubadizon ernobii Muesebeck, 1957. Brooklyn Ent. Soc., Bul. 52: 51. ๆ, ð.

\section{Genus EUBAZUS Nees}

This genus is restricted to those species which have a short abdomen and are parasites of Coleoptera larvae, as defined by Mason (1974).

\section{Genus EUBAZUS Subgenus EUBAZUS Nees}

Eubazus Nees, 1814 (1812). Mag. Gesell. Naturf. Freunde Berlin 6: 214.

Type-species: Eubazus pallipes Nees. Desig. by Viereck, 1914.

Eubadizon Nees, 1834. Hym. Ichn. Aff. Monog., v, 1, p. 233. Emend.

Eubadizus Nees, 1834. Hym. Ichn. Aff. Monog., v. 1, p. 233. Emend.

Taxonomy: Mason, 1974. Ent. Soc. Wash., Proc. 76: 239.

electus (Muesebeck). B. C., Oreg., Calif. Host: Phymatodes sp.

Eubadizon electum Muesebeck, 1957. Brooklyn Ent. Soc., Bul. 52: 54. .

pallipes Nees. N. Y., Pa., N. J., W. Va., Mich., Wis., Ill.; Europe.

Eubazus pallipes Nees, 1814 (1812). Mag. Gesell. Naturf. Freunde Berlin 6: 215. ๆ ( $\delta$ misdet.).

Eubadizon coxalis Nees, 1834. Hym. Ichn. Aff. Monog., v. 1, p. 235. ठ.

Helcon (Eubadizon) semistriatus Haliday, 1835. Ent. Mag. 3: 131. ¿.

Eubadizon americanus Cresson, 1872. Canad. Ent. 4: 230. १.

phymatodis (Ashmead). N. Y., Md., D. C., Va., Mich., Ill. Host: Phymatodes amoenus (Say).

Eubadizon phymatodis Ashmead, 1889 (1888). U. S. Natl. Mus., Proc. 11: 644. .

\section{Genus EUBAZUS Subgenus BRACHISTES Wesmael}

Brachistes Wesmael, 1835. Nouv. Mem. Acad. Sci. Bruxelles 9: 109.

Type-species: Brachistes rufïcoxis Wesmael. Desig. by Foerster, 1862.

Taxonomy: Mason, 1974. Ent. Soc. Wash., Proc. 76: 240.

atricornis (Ashmead). Calif.

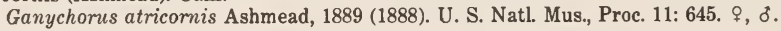


major (Cresson). Canada, Va., Ohio, Ind., Ill. Host: Magdalis barbita (Say).

Calyptus major Cresson, 1872. Canad. Ent. 4: 228. .

orchesiae (Ashmead). Conn., N. Y., Md., D. C., Ga., Mich., Ill., Iowa. Host: Bolitotherus cormutus (Panz.), Orchesia castanea Melsh.

Ganychorus orchesiae Ashmead, 1889 (1888). U. S. Natl. Mus., Proc. 11: 645..

rotundiceps (Cresson). Que. s. to Md., w. to Ont., N. Dak., and Iowa. Host: Magdalis armicollis (Say), M. barbita (Say), M. olyra (Hbst.).

Calyptus rotundiceps Cresson, 1872. Canad. Ent. 4: 228. ठ.

Calyptus magdalis Cresson, 1878. Psyche 2: 189. $\uparrow, \delta$.

Eubadizon submucronatus Provancher, 1880. Nat. Canad. 12: 171. ๆ, ઠ.

Brachistes magdali Brues, 1910. Wis. Nat. Hist. Soc., Bul. 8: 50. ๆ, ठ。.

salicicola (Muesebeck). Calif. Host: Dorytomus sp.

Eubadizon salicicola Muesebeck, 1957. Brooklyn Ent. Soc., Bul. 52: 55. ๆ, ð.

\section{Genus NEALIOLUS Mason}

Nealiolus Mason, 1974. Ent. Soc. Wash., Proc. 76: 241.

Type-species: Sigalphus curculionis Fitch. Orig. desig.

acutulus (Martin). N. Y.

Aliolus acutulus Martin, 1956. Canada Dept. Agr. Pub. 965, p. 19..

auriculatus (Martin). Colo.

Aliolus auriculatus Martin, 1956. Canada Dept. Agr. Pub. 965, p. 21. ₹, ठ.

collaris (Brues). Fla., Ark., Kans., Tex., N. Mex. Host: Conotrachelus nenuphar (Hbst.).

Calyptus collaris Brues, 1907. Wis. Nat. Hist. Soc., Bul. 5: 159. ․

crassipes (Martin). Pa., Md., S. C.

Aliolus crassipes Martin, 1956. Canada Dept. Agr. Pub. 965, p. 35. ๆ, ठ.

curculionis (Fitch). Que. s. to Fla., w. to Ont., Nebr., and Calif. Host: Anthonomus grandis

Boh., Coccotorus scutellaris (Lec.), Conotrachelus nenuphar (Hbst.), Craponius inaequalis (Say), Cylindrocopturus adspersus (Lec.), Hyperodes texana Stockton, Listronotus oregonensis (Lec.), Magdalis armicollis (Say), Rhinocyllus conicus (Froel.), Tyloderma foveolata Say. Shenefelt (1970) uses the name tibiator (Cresson) for this species under the false assumption that Sigalphus curculionis Fitch (1859) is preoccupied by Sigalphus curculionum Hartig (1847, presently in the genus Eubadizon).

Sigalphus curculionis Fitch, 1859. Country Gentleman 14: 221. ๆ.

Calyptus tibiator Cresson, 1872. Canad. Ent. 4: 229. ठ.

Aliolus inaratus Martin, 1956. Canada Dept. Agr. Pub. 965, p. 38. ठ.

Biology: Armstrong, 1958. Canad. Ent. 90: 16-17.

mexicanus (Cresson). Colo., N. Mex., Ariz.; Mexico.

Calyptus mexicanus Cresson, 1872. Canad. Ent. 4: 229. ठ.

rufus (Riley). N. Y.s. to Fla., w. to Ont. and Tex. Host: Anthonomus grandis Boh., Conotrachelus nenuphar (Hbst.), Tyloderma foveolata Say.

Sigalphus curculionis var. rufus Riley, 1871. Ins. Mo. Ann. Rpt. 3: 27. ․

\section{Genus SCHIZOPRYMNUS Foerster}

Schizoprymnus Foerster, 1862. Naturh. Ver. Rheinlande, Verh. 19: 242.

Type-species: Sigalphus obscurus Nees. Orig. desig.

Taxonomy: Martin, 1956. Canada Dept. Agr. Pub. 965, p. 98-101 (treated as subgenus of

Triaspis). - Shenefelt, 1970. Hym. Cat., part 5, p. 274-281 (cat. World spp.).

americanus Ashmead. Tex.

Schizoprymnus americanus Ashmead, 1889 (1888). U. S. Natl. Mus., Proc. 11: 636..

brevipennis (Melander and Brues). Mass.

Chelonus brevipennis Melander and Brues, 1903. Biol. Bul. 5: 20. ?.

phillipsi Viereck. Mich., Ind. Host: Mordellistena andreae ustulata Lec.

Schizoprymnus phillipsi Viereck, 1911. U. S. Natl. Mus., Proc. 39: 401. ๆ, ð๋. 
texanus (Cresson). N. H., W. Va., Ohio, Ont., Mich., Ill., Tex., Utah, Calif. Ecology: Reared from gall on Solidago.

Sigalphus texanus Cresson, 1872. Amer. Ent. Soc., Trans. 4: 179. "६" $=\delta$.

\section{Genus TRIASPIS Haliday}

Helcon subg. Triaspis Haliday, 1835. Ent. Mag. 3: 124.

Type-species: Sigalphus caudatus Nees. Desig. by Viereck, 1912.

Muiriella Fullaway, 1919. Roy. Asiatic Soc., Straits Branch, Jour. 80: 47.

Type-species: Muiriella concisa Fullaway. Orig. desig.

Revision: Martin, 1956. Canada Dept. Agr. Pub. 965, p. $64-97$ (No. Amer. spp.).

Taxonomy: Shenefelt, 1970. Hym. Cat., part 5, p. 281-301 (cat. World spp.).

abditiva Martin. N. Y., S. Dak.

Triaspis (Triaspis) abditiva Martin, 1956. Canada Dept. Agr. Pub. 965, p. 76. $q, \delta$. aequoris Martin. Kans.

Triaspis (Triaspis) aequoris Martin, 1956. Canada Dept. Agr. Pub. 965, p. 92. ๆ. aquila Martin. Que.

Triaspis (Triaspis) aquila Martin, 1956. Canada Dept. Agr. Pub. 965, p. 85. đo. halidayi Martin. S. Dak.

Triaspis (Triaspis) halidayi Martin, 1956. Canada Dept. Agr. Pub. 965, p. 89. đ.

kurtogaster Martin. N. Y. s. to Ga., w. to Ont. and La. Host: Anthonomus grandis Boh., Chalcodermus aenus Boh., C. collaris Horn., Conotrachelus nenuphar Hbst., Curculio sp., Otiorh ynchus ovatus (L.).

Triaspis (Triaspis) kurtogaster Martin, 1956. Canada Dept. Agr. Pub. 965, p. 90.. laticarinata Martin. B. C.

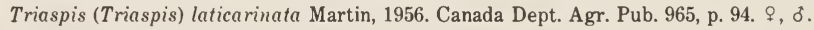
magnafoveae Martin. N. S., Ont., Mich., Ill., Alta.

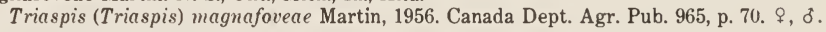
matercula Martin. S. Dak.

Triaspis (Triaspis) matercula Martin, 1956. Canada Dept. Agr. Pub. 965, p. 68.. ocellulata Martin. N. Y., Ont. Host: Ash seed weevil.

Triaspis (Tria spis) ocellulata Martin, 1956. Canada Dept. Agr. Pub. 965, p. 87. ๆ, o. odontochila Martin. N. Y., Va., Mich., La. Host: Podapion gallicola Riley.

Triaspis (Triaspis) odontochila Martin, 1956. Canada Dept. Agr. Pub. 965, p. 83. ㅇ, o. pissodis Viereck. Mont., Wyo., Idaho, Wash., Oreg., Calif. Host: Cylindrocopturus fumissi Buch., C. longulus (Lec.), Pissodes sp.

Triaspis pissodis Viereck, 1912. U. S. Natl. Mus., Proc. 42: 628. ๆ, ठ.

rectangulata Martin. S. Dak., Colo., Utah, Idaho.

Triaspis (Triaspis) rectangulata Martin, 1956. Canada Dept. Agr. Pub. 965, p. 74. \&, ð. stenochila Martin. Kans.

Triaspis (Triaspis) stenochila Martin, 1956. Canada Dept. Agr. Pub. 965, p. 78. ․ stenogaster Martin. Colo.

Triaspis (Triaspis) stenogaster Martin. 1956. Canada Dept. Agr. Pub. 965, p. 72. ๙, ơ. stictostiba Martin. Canada. Host: Bruchus rufimanus Boh.

Triaspis (Triaspis) stictostiba Martin, 1956. Canada Dept. Agr. Pub. 965, p. 82.. stilpnogaster Martin. Wis., Idaho, Calif.

Triaspis (Triaspis) stilpnogaster Martin, 1956. Canada Dept. Agr. Pub. 965, p. 66... thoracica (Curtis). Canada (?), U. S. (?): Europe, Asia, So. Amer., Austr. Liberated in B. C., $\mathrm{Pa}$., N. C., Ont., Idaho, Oreg., and Calif. but not known to be established. Introduced from Europe. Host: Brichus brachialis Fab., B. pisomım (L.), B. mifimanus Boh.

Sigalphus thoracicus Curtis, 1860. Farm Insects, p. 365. ․

virginiensis (Ashmead). Pa., N. J., Md., D. C., Va., Ohio, Ark. Host: Rhynchaenus pallicomis (Say).

Centistes virginiensis Ashmead, 1889 (1888). U. S. Natl. Mus., Proc. 11: 655. ?. 
xanthochila Martin. Ont.

Triaspis (Triaspis) xanthochila Martin, 1958. Canad. Ent. 90: 191. \&.

\section{Genus UROSIGALPHUS Ashmead}

Revision: Crawford, 1914. Insecutor Inscitiae Menstruus 2: 22-27 (No. Amer. spp.). -Martin, 1956. Canada Dept. Agr. Pub. 965, p. 102-137 (No. Amer. spp.). -Gibson, 1972. Ent. Soc. Amer., Misc. Pub. 8: 85-157 (No. and Cent. Amer. spp.).

Taxonomy: Shenefelt, 1970. Hym. Cat., part 5, p. 302-305 (cat. World spp.).

\section{Genus UROSIGALPHUS Subgenus BRUCHIUROSIGALPHUS Gibson}

Urosigalphus subg. Bruchiurosigalphus Gibson, 1972. Ent. Soc. Amer., Misc. Pub. 8: 94. Type-species: Urosigalphus bruchi Crawford. Orig. desig.

bruchi Crawford. La., Tex., Ariz., Calif.; Hawaii, Mexico. Host: Algarobius prosopis (Lec.), Amblycerus robiniae (F.), Mimosestes sallaei (Sharp).

Urosigalphus bruchi Crawford, 1907. N. Y. Ent. Soc., Jour. 15: 181. ‡, ठ.

bruchivorus Crawford. Ariz., Calif. Host: Algarobius prosopis (Lec.), Neltumius arizonensis (Sch.).

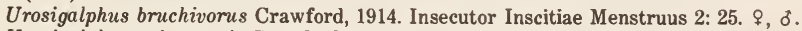

Urosigalphus arizonensis Crawford, 1914. Insecutor Inscitiae Menstruus 2: 25., , ঠ.

Urosigalphus truncatus Martin, 1956. Canada Dept. Agr. Pub. 965, p. 122..

ignotus Gibson. Calif.

Urosigalphus (Bruchiurosigalphus) ignotus Gibson, 1972. Ent. Soc. Amer., Misc. Pub. 8: 98. ㅇ.

neobruchi Gibson. Kans., Tex., Ariz.; Mexico. Host: Acanthoscelides quadridentatus (Sch.), Algarobius prosopis (Lec.), Amblycerus robiniae (F.), Merobruchus sp.

Urosigalphus (Bruchiurosigalphus) neobruchi Gibson, 1972. Ent. Soc. Amer., Misc. Pub. 8: 99. $९, \delta$.

salsola Gibson. Tex., Ariz.

Urosigalphus (Bruchiurosigalphus) salsola Gibson, 1972. Ent. Soc. Amer., Misc. Pub. 8: 100. $\%$, ठ.

\section{Genus UROSIGALPHUS Subgenus MICROUROSIGALPHUS Gibson}

Urosigalphus subg. Microurosigalphus Gibson, 1972. Ent. Soc. Amer., Misc. Pub. 8: 87.

Type-species: Urosigalphus femoratus Crawford. Orig. desig.

acutulus Gibson. Colo., Ariz.

Urosigalphus (Microurosigalphus) acutulus Gibson, 1972. Ent. Soc. Amer., Misc. Pub. 8: 89. $९$, ठ.

breviovipositorus Gibson. Kans., Tex., Colo., N. Mex., Ariz.; Mexico.

Urosigalphus (Microurosigalphus) breviovipositomus Gibson, 1972. Ent. Soc Amer., Misc. Pub. 8: 90 . $\subsetneq$, ठ์.

femoratus Crawford. Conn. s. to Ga., w. to S. Dak. and Ariz.; Mexico. Host: Anthonomus grandis Boh., Tyloderma foveolata Say.

Urosigalphus femoratus Crawford, 1914. Insecutor Inscitiae Menstruus 2: 26. ‡, ð.

Urosigalphus mohawkorum Viereck, 1917 (1916). Conn. State Geol. and Nat. Hist. Survey, Bul. 22, p. 234. $?$.

iowensis Gibson. Ill., Iowa, Nebr., Kans., N. Mex., Utah, Ariz.

Urosigalphus (Microurosigalphus) iowensis Gibson, 1972. Ent. Soc. Amer., Misc. Pub. 8: 92. $९, \delta$.

neomexicanus Crawford. Iowa, Mo., Ark., Tex., Colo., N. Mex., Ariz.

Urosigalphus neomexicanus Crawford, 1914. Insecutor Inscitiae Menstruus 2: 26. \&, ð.

\section{Genus UROSIGALPHUS Subgenus NEOUROSIGALPHUS Gibson}

Urosigalphus subg. Neourosigalphus Gibson, 1972. Ent. Soc. Amer., Misc. Pub. 8: 122.

Type-species: Urosigalphus robustus Ashmead. Orig. desig. 
hubbardi Crawford. Ariz., Calif. Host: Cylindrocopturus longulus (Lec.).

Urosigalphus hubbardi Crawford, 1914. Insecutor Inscitiae Menstruus 2: 23. ठో.

Urosigalphus pini Cushman, 1922. U. S. Natl. Mus., Proc. 60 (21): 26. ठ。.

neopunctifrons Gibson. Ariz; Mexico.

Urosigalphus (Neourosigalphus) neopunctifrons Gibson, 1972. Ent. Soc. Amer., Misc. Pub. 8: 125 . $\%, \delta$.

nigripes Crawford. Ariz.

Urosigalphus nigripes Crawford, 1914. Insecutor Inscitiae Menstruus 2: 24. ․

otidocephali Cushman. Pa., N. C. Host: Myrmex myrmex (Hbst.).

Urosigalphus otidocephali Cushman, 1922. U. S. Natl. Mus., Proc. 60 (21): 25. ơ.

punctifrons Crawford. N. Mex., Ariz; Mexico.

Urosigalphus punctifrons Crawford, 1914. Insecutor Inscitiae Menstruus 2: 24. $\delta$.

robustus Ashmead. Mass., Conn., N. J., Md., D. C., Va., Mich., Wis., Ark.

Urosigalphus robustus Ashmead, 1889 (1888). U. S. Natl. Mus., Proc. 11: 638. 9.

Urosigalphus wampanoagorum Viereck, 1917 (1916). Conn. State Geol. and Nat. Hist.

Survey, Bul. 22, p. 234.. .

\section{Genus UROSIGALPHUS Subgenus PARAUROSIGALPHUS Gibson}

Urosigalphus subg. Paraurosigalphus Gibson, 1972. Ent. Soc. Amer., Misc. Pub. 8: 128.

Type-species: Urosigalphus (Paraurosigalphus) dakotaensis Gibson. Orig. desig.

clarus Gibson. N. J., Md.

Urosigalphus (Paraurosigalphus) clarus Gibson, 1972. Ent. Soc. Amer., Misc. Pub. 8: 129. १, ó.

dakotaensis Gibson. Iowa, S. Dak., Nebr.

Urosigalphus (Paraurosigalphus) dakotaensis Gibson, 1972. Ent. Soc. Amer., Misc. Pub. 8: 130. $\uparrow, \delta$.

novissimus Gibson. Kans.

Urosigalphus (Paraurosigalphus) novissimus Gibson, 1972. Ent. Soc. Amer., Misc. Pub. 8: 131. $\delta$.

rugosocorpus Gibson. Ariz.

Urosigalphus (Paraurosigalphus) migosocorpus Gibson, 1972. Ent. Soc. Amer., Misc. Pub. 8: 132 . ठै.

\section{Genus UROSIGALPHUS Subgenus UROSIGALPHUS Ashmead}

Urosigalphus Ashmead, 1889 (1888). U. S. Natl. Mus., Proc. 11: 637.

Type-species: Urosigalphus armatus Ashmead. Orig. desig.

Rhyssosigalphus Cameron, 1904. Amer. Ent. Soc., Trans. 30: 260.

Type-species: Rhyssosigalphus rugosus Cameron. Monotypic.

anthonomi Crawford. Tex.; Mexico. Host: Anthonomus grandis Boh., Chalcodermus aeneus Boh.

Urosigalphus anthonomi Crawford, 1907. Canad. Ent. 39: 133. ‡, ठ.

armatus Ashmead. Md., W. Va., Va., Tenn. Host: Curculio caryatrypes (Boh.).

Urosigalphus armatus Ashmead, 1889 (1888). U. S. Natl. Mus., Proc. 11: 637. ९, ठ.

barberi Crawford. Pa. s. to Fla., w. to Wis. and N. Mex. Host: Curculio spp. in acorns, $C$. pardalis (Chitt.).

Urosigalphus barberi Crawford, 1914. Insecutor Inscitiae Menstruus 2: 23. @.

confusor Gibson. Tex., Ariz.

Urosigalphus (Urosigalphus) confusar Gibson, 1972. Ent. Soc. Amer., Misc. Pub. 8: 106. \&, ठ.

crassisculptus Cushman. Pa., Mich., Wis., Ill. Host: Curculio neocorylus Gibson.

Urosigalphus crassisculptus Cushman, 1922. U. S. Natl. Mus., Proc. 60 (21): $23 . \delta$.

curculionis Gibson. Que. s. to N. C., w. to Wis. and Ark. Host: Curculio nasicus (Say), C. strictus (Casey).

Urosigalphus (Urosigalphus) curculionis Gibson, 1972. Ent. Soc. Amer., Misc. Pub. 8: 108. \&, o. 
donnae Gibson. Conn. s. to Fla., w. to Wis. and Ark. Host: Curculio proboscideus F.

Urosigalphus (Urosigalphus) donnae Gibson, 1972. Ent. Soc. Amer., Misc. Pub. 8: 110., $\delta$.

floridaensis Gibson. Fla.

Urosigalphus (Urosigalphus) floridaensis Gibson, 1972. Ent. Soc. Amer., Misc. Pub. 8: 111. \&.

forbesi Martin. Que. s. to Ga., w. to Wis. and Tex. Host: Curculio sp., C. sulcatulus (Casey).

Urosigalphus forbesi Martin, 1956. Canada Dept. Agr. Pub. 965, p. 118..

muesebecki Gibson. N. J., S. C., Ga., Ky., Tenn., Wis., Iowa, Ill. Host: Curculio longidens Chitt., C. orthorhynchus (Chitt.).

Urosigalphus (Urosigalphus) muesebecki Gibson, 1972. Ent. Soc. Amer., Misc. Pub. 8: 115. \&, ठั.

neoarmatus Gibson. Colo.

Urosigalphus (Urosigalphus) neoarmatus Gibson, 1972. Ent. Soc. Amer., Misc. Pub. 8: 116. ㅇ.

nigrescens Martin. Ariz.

Urosigalphus nigrescens Martin, 1956. Canada Dept. Agr. Pub. 965, p. 115. ठ‡.

pardus Gibson. Calif. Host: Curculio pardus Chitt.

Urosigalphus (Urosigalphus) pardus Gibson, 1972. Ent. Soc. Amer., Misc. Pub. 8: 119. §, $\delta$.

rubidus Gibson. W. Va.

Urosigalphus (Urosigalphus) rubidus Gibson, 1972. Ent. Soc. Amer., Misc. Pub. 8: 119. ๆ. rufus Gibson. Ala. Host: Curculio sp.

Urosigalphus (Urosigalphus) mufus Gibson, 1972. Ent. Soc. Amer., Misc. Pub. 8: 120. $\subsetneq$.

subtropicus Gibson. Ga., Fla., Miss., N. Mex. Host: Curculio sulcatulus (Casey).

Urosigalphus (Urosigalphus) subtropicus Gibson, 1972. Ent. Soc. Amer., Misc. Pub. 8: 121. १, ठั.

\section{TRIBE ORGILINI}

Species in this group are internal parasites of lepidopterous larvae.

Taxonomy: Muesebeck, 1970. Smithsn. Contrib. Zool., n. 30, p. 1-2 (key to genera of subfamily Orgilinae).

\section{Genus CHARMON Haliday}

Charmon Haliday, 1833. Ent. Mag. 1: 262.

Type-species: Chamon cruentatus Haliday. Monotypic.

Provancheria Ashmead, 1900. U. S. Natl. Mus., Proc. 23: 109.

Type-species: Eubadizon gracilis Provancher. Orig. desig.

Taxonomy: Mason, 1974. Ent. Soc. Wash., Proc. 76: 235-245.

extensor (Linnaeus). Holarctic. Host: Ancylis comptana fragariae (W. and R.), Choristoneura murinana (Hbn.), Depressaria pastinacella (Dup.), Epinotia lindana (Fern.), E. nigricana (H.-S.), E. pusillana Peyer., Grapholitha molesta (Busck), Laspeyresia pomonella (L.), Spilonota lariciana Heinemann, Zeiraphera griseana (Hbn.), Z. rufimitrana (H.-S.).

Ichneumon extensor Linnaeus, 1758. Syst. Nat., Ed. 10, p. 564.

Charmon cruentatus Haliday, 1833. Ent. Mag. 1: 262.

Eubadizon pectoralis Nees, 1834. Hym. Ichn. Aff. Monog., v. 1, p. 236. १.

Eubadizon pleuralis Cresson, 1872. Canad. Ent. 4: 230. 9 , ठ。.

Biology: Capek, 1956. Biologia 11: 602. -Allen, 1962. U. S. Dept. Agr., Tech. Bul. 1265, p. 27-29.

gracilis (Provancher). Canada, Maine, N. H., Mass., Wis., Minn., Oreg., Calif. Host: Acleris variana (Fern.), Archips sp., Choristoneura fumiferana (Clem.), Coleotechnites 
apicitripunctella (Clem.), C. milleri (Busch), C. piceaella Kearf., C. starki (Freem.), Dioryctria reniculella (Grote), Eucordylea ducharmei Freem.

Eubadizon gracilis Provancher, 1880. Nat. Canad. 12. 171..

\section{Genus MICROTYPUS Ratzeburg}

Microtypus Ratzeburg, 1848. Ichn. d. Forstins., v. 2, p. 47.

Type-species: Microtypus wesmaelii Ratzeburg. Monotypic.

Taxonomy: Shenefelt, 1970. Hym. Cat., part 5, p. 264-266 (cat. World spp.).

dioryctriae Rohwer. Calif. Host: Dioryctria auranticella (Grote).

Microtypus dioryctriae Rohwer, 1920. U. S. Natl. Mus., Proc. 57: 227. ९, ð。.

\section{Genus ORGILUS Haliday}

Orgilus Haliday, 1833. Ent. Mag. 1: 262.

Type-species: Microdus obscurator Nees. Monotypic.

Ischius Wesmael, 1837. Nouv. Mem. Acad. Sci. Bruxelles 10: 20.

Type-species: Microdus obscurator Nees. Desig. by Muesebeck and Walkley, 1951.

Macropalpus Ratzeburg, 1844. Ichn. d. Forstins., v. 1, p. 56.

Type-species: Eubadizon leptocephalus Hartig. Monotypic.

Oresimus Ashmead, 1900. U. S. Natl. Mus., Proc. 23: 123.

Type-species: Eubadizon maculiventris Cresson. Monotypic.

Orgilomorpha Ashmead, 1900. U. S. Natl. Mus., Proc. 23: 129.

Type-species: Ganychorus gelechiae Ashmead. Monotypic.

Orgilus subg. Ischiolus Hellen, 1958. Soc. Fauna Flora Fennica. Fauna Fennica 4, p. 34.

Type-species: Microgaster rugosus Nees. Monotypic.

Species are endoparasites of lepidopterous larvae.

Revision: Muesebeck, 1970. Smithsn. Contrib. Zool., n. 30, 104 p. (No. Amer. spp.).

Taxonomy: Shenefelt, 1970. Hym. Cat., part 5, p. 252-263 (cat. World spp.).

ablusus Muesebeck. Ont., Minn.

Orgilus ablusus Muesebeck, 1970. Smithsn. Contrib. Zool., n. 30, p. 11. ؟.

absonus Muesebeck. Nev., Calif.

Orgilus absonus Muesebeck, 1970. Smithsn. Contrib. Zool., n. 30, p. 12. ९, ठ.

agrestis Muesebeck. Alta., Oreg.

Orgilus agrestis Muesebeck, 1970. Smithsn. Contrib. Zool., n. 30., p. 13. .

alacer Muesebeck. Nebr., Colo.

Orgilus alacer Muesebeck, 1970. Smithsn. Contrib. Zool., n. 30, p. 13. \&.

anthracinus Muesebeck. Que., N. W. T., B. C.

Orgilus anthracinus Muesebeck, 1970. Smithsn. Contrib. Zool., n. 30, p. 14. + , ð.

arcticus Muesebeck. Labrador, Yukon.

Orgilus arcticus Muesebeck, 1970. Smithsn. Contrib. Zool, n. 30, p. 15. \&, ð.

balsameae Muesebeck. Que., N. S., N. B., Maine, N. Y., W. Va., Ont., Mich., Wis. Host:

Coleotechnites sp., C. piceaella (Kearf.), Evagora sp., Zeiraphera sp.

Orgilus balsameae Muesebeck, 1970. Smithsn. Contrib. Zool., n. 30, p. 17. $\subsetneq$, ð.

boharti Muesebeck. Calif. Host: Crambus sp.

Orgilus boharti Muesebeck, 1970. Smithsn. Contrib. Zool, n. 30, p. 17. \&, ઠ.

buccatus Muesebeck. N. Y.

Orgilus buccatus Muesebeck, 1970. Smithsn. Contrib. Zool., n. 30, p. 18..

burksi Muesebeck. N. C.

Orgilus burksi Muesebeck, 1970. Smithsn. Contrib. Zool., n. 30, p. 18. ․

californicus (Provancher). Calif. Host: Phthorimaea operculella (Zell.).

Eubadizon californicus Provancher, 1888. Addit. Corr. Faune Ent. Canada Hym., p. 383. ․

capsicola Muesebeck. Tex. Host: Symmetrischema capsicum (B. and P.).

Orgilus capsicola Muesebeck, 1970. Smithsn. Contrib. Zool., n. 30, p. 20. ㅇ, ð。. 
cerinus Muesebeck. Ariz.

Orgilus cerinus Muesebeck, 1970. Smthsn. Contrib. Zool., n. 30, p. 21..

cinctus Muesebeck. Mass., N. Y.

Orgilus cinctus Muesebeck, 1970. Smithsn. Contrib. Zool., n. 30, p. 21. \&. citus Muesebeck. Que., Labrador, Ont., N. Dak.

Orgilus citus Muesebeck, 1970. Smithsn. Contrib. Zool., n. 30, p. 22. ९, ठ์.

clivicola Muesebeck. Colo.

Orgilus clivicola Muesebeck, 1970. Smithsn. Contrib. Zool., n. 30, p. 23. ․

cognatus Muesebeck. Utah.

Orgilus cognatus Muesebeck, 1970. Smithsn. Contrib. Zool., n. 30, p. 24..

coleophorae Muesebeck. Que. and N. S. s. to Va., w. to Ont. and Iowa; Alaska. Host:

Coleophora cretaticostella Clem., C. fuscedinella Zell., C. Iaricella Hbn., C. monardella McD., C. ulmifoliella McD., C. umbratica Braun, Coleotechnites thujaella Kearf.

Orgilus coleophorae Muesebeck, 1970. Smithsn. Contrib. Zool., n. 30, p. 24. , §.

coloradensis Muesebeck. Colo.

Orgilus coloradensis Muesebeck, 1970. Smithsn. Contrib. Zool., n. 30, p. 25. + , ठ.

compactus Muesebeck. Oreg.

Orgilus compactus Muesebeck, 1970. Smithsn. Contrib. Zool., n. 30, p. 26..

comptanae Muesebeck. Que. s. to Fla.; Ill., Miss. Host: Ancylis comptana (Froel.).

Orgilus comptanae Muesebeck, 1970. Smithsn. Contrib. Zool., n. 30, p. 27. ․, ơ.

conflictanae Muesebeck. Colo. Host: Choristoneura conflictana (Wlkr.).

Orgilus conflictanae Muesebeck, 1970. Smithsn. Contrib. Zool., n. 30, p. 28. \&.

consuetus Muesebeck. Md., W. Va., N. C., Fla., Ont., Mich., Wis., Ill., La., N. Dak. Host:

Laspeyresia caryana (Fitch), Valentinia glandulella (Riley).

Orgilus consuetus Muesebeck, 1970. Smithsn. Contrib. Zool., n. 30, p. 28. ९.

coracinus Muesebeck. Calif.

Orgilus coracinus Muesebeck, 1970. Smithsn. Contrib. Zool., n. 30, p. 29. ๆ.

cristatus Muesebeck. Calif.

Orgilus cristatus Muesebeck, 1970. Smithsn. Contrib. Zool., n. 30, p. 30. ㅇ.

cuneatus (Provancher). Que.

Blacus cuneatus Provancher, 1888. Addit. Corr. Faune Ent. Canada Hym., p. 383. $\subsetneq$.

detectiform is Viereck. Que. and N. B. s. to Ga., w. to Ont., S. Dak., and Iowa. Host: Crambus trisectus (Wlkr.).

Orgilus detectiformis Viereck, 1917 (1916). Conn. State Geol. and Nat. Hist. Survey, Bul. 22, p. 226. $\delta$.

detectus Provancher. Que.

Orgilus detectus Provancher, 1886. Addit. Corr. Faune Ent. Canada Hym., p. 139..+

dioryctriae Gahan. Colo., Calif. Host: Choristoneura lambertiana ponderosana Obraz., Coleotechnites milleri (Busck), Dioryctria auranticella (Grote).

Orgilus dioryctriae Gahan, 1919. U. S. Natl. Mus., Proc. 55: 121. + , o.

discrepans Muesebeck. Ariz.

Orgilus discrepans Muesebeck, 1970. Smithsn. Contrib. Zool., n. 30, p. 34. ९, ठ.

disparilis Muesebeck. Conn., D. C., Fla.

Orgilus disparilis Muesebeck, 1970. Smithsn. Contrib. Zool., n. 30, p. 35. ९, ठ์.

dissidens Muesebeck. Maine, N. Y., Ont.

Orgilus dissidens Muesebeck, 1970. Smithsn. Contrib. Zool. n. 30, p. 35. \&.

dolosus Muesebeck. Ont.

Orgilus dolosus Muesebeck, 1970. Smithsn. Contrib. Zool., n. 30, p. 36. ․

dreisbachi Muesebeck. Nebr., Okla., Ariz.

Orgilus dreisbachi Muesebeck, 1970. Smithsn. Contrib. Zool., n. 30, p. 37. ९, ơ.

ejuncidus Muesebeck. Maine.

Orgilus ejuncidus Muesebeck, 1970. Smithsn. Contrib. Zool., n. 30, p. 38. \&. 
elasmopalpi Muesebeck. N. C., S. C., Ga., Fla., Okla., Tex.; Jamaica. Host: Diatraea saccharalis (F.), Elasmopalpus lignosellus Zell.

Orgilns elasmopalpi Muesebeck, 1970. Smithsn. Contrib. Zool. n. 30, p. 38..

erythropus Muesebeck. Utah.

Orgilus erythropus Muesebeck, 1970. Smithsn. Contrib. Zool., n. 30, p. 39. ?.

exilis Muesebeck. Oreg.

Orgilus exilis Muesebeck, 1970. Smithsn. Contrib. Zool., n. 30, p. 40..

fallax Muesebeck. Calif.

Orgilus fallax Muesebeck, 1970. Smithsn. Contrib. Zool., n. 30, p. 41. .

femoralis Muesebeck. N. Dak., Colo., Idaho.

Orgilus femoralis Muesebeck, 1970. Smithsn. Contrib. Zool., n. 30, p. 42..

ferus Muesebeck. Mont., N. Mex., Idaho, Utah, Wash., Calif. Host: Aroga websteri Clarke. Orgilus ferus Muesebeck, 1970. Smithsn. Contrib. Zool. n. 30, p. 42. ९, ठ.

fictus Muesebeck. Pa., Mich.

Orgilus fictus Muesebeck, 1970. Smithsn. Contrib. Zool,, n. 30, p. 43..

fisheri Muesebeck. Conn.

Orgilus fisheri Muesebeck, 1970. Smithsn. Contrib. Zool., n. 30, p. 44. \&.

frigidus Muesebeck. N. W. T.

Orgilus frigidus Muesebeck, 1970. Smithsn. Contrib. Zool., n. 30, p. 45..

fulgens Muesebeck. Md., Mich.

Orgilus fulgens Muesebeck, 1970. Smithsn. Contrib. Zool., n. 30, p. 45. ơ.

gelechiae (Ashmead). Que. and N. S. s. to Fla., w. to Ont. and Tex. Host: Bucculatrix sp., Caloptilia sp., Cameraria hamadryadella (Clem.), Evippe prunifoliella Chamb., Lithocolletis sp., L. cincinnatiella Chamb.

Ganychorus? gelechiae Ashmead, 1889 (1888). U. S. Natl. Mus., Proc. 11: 645. \&.

Eubadizon lithocolletidis Viereck, 1912. U. S. Natl. Mus., Proc. 42: 622..

gelechiaevorus Cushman. N. J., Va., Fla., Ky., Ala., Iowa, Ark., Tex. Host: Aroga trialbamaculella (Chamb.), Grapholitha molesta (Busck), Laspeyresia caryana (Fitch). Orgilus gelechiaevora Cushman, 1920. U. S. Natl. Mus., Proc. 58: 291. ․

glacialis Muesebeck. Alaska.

Orgilus glacialis Muesebeck, 1970. Smithsn. Contrib. Zool., n. 30, p. 48..

gracilis (Brues). Man., Minn., N. Dak.

Blacus gracilis Brues, 1908. Wis. Nat. Hist. Soc., Bul. 6: 55. ․

gramineus Muesebeck. Alta.

Origilus gramineus Muesebeck, 1970. Smithsn. Contrib. Zool., n. 30, p. 49. \&.

grapholithae Muesebeck. Oreg. Host: Grapholitha conversana Wlsm.

Orgilus grapholithae Muesebeck, 1970. Smithsn. Contrib. Zool., n. 30, p. 50. ‡, ठ์.

hyalinus Muesebeck. Alta.

Orgilus hyalinus Muesebeck, 1970. Smithsn. Contrib. Zool., n. 30, p. 51. ð.

imitator Muesebeck. Tex., Oreg., Calif.; Mexico.

Orgilus imitator Muesebeck, 1970. Smithsn. Contrib. Zool., n. 30, p. 52. \&, ठ.

immarginatus Muesebeck. Ill., Fla., Miss. Host: Acrobasis juglandis (LeB.), Gretchena bolliana (Sling.), Laspeyresia caryana (Fitch).

Orgilus immarginatus Muesebeck, 1970. Smithsn. Contrib. Zool., n. 30, p. 52.,$~ \delta$.

impiger Muesebeck. Idaho, Utah, Nev., Calif.

Orgilus impiger Muesebeck, 1970. Smithsn. Contrib. Zool., n. 30, p. 53. \&.

indagator Muesebeck. Que., Mich., Ind., Minn., Iowa. Host: Trichotaphe levisella Fyles. Orgilus indagator Muesebeck, 1967. Ent. News 78: 135. $q, \delta$.

infrequens Muesebeck. Mass., Va., Fla., Tex.

Orgilus infrequens Muesebeck, 1970. Smithsn. Contrib. Zool., n. 30, p. 54. \&.

inopinus Muesebeck. Iowa, Ark., N. Dak.

Orgilus inopinus Muesebeck, 1970. Smithsn. Contrib. Zool., n. 30, p. 55. \&, ơ.

insularis Muesebeck. P. E. I., Ont.

Orgilus insularis Muesebeck, 1970. Smithsn. Contrib. Zool., n. 30, p. 55. \&. 
intermedius Muesebeck. Md., Va., Iowa.

Orgilus intermedius Muesebeck, 1970. Smithsn. Contrib. Zool., n. 30, p. 56. ९, ơ.

invictus Muesebeck. Labrador.

Orgilus invictus Muesebeck, 1970. Smithsn. Contrib. Zool., n. 30, p. 57..

laeviventris (Cresson). Tex.

Ischius laeviventris Cresson, 1872. Amer. Ent. Soc., Trans. 4: 182. ठ.

lateralis (Cresson). Que. s. to Fla., w. to Ont. and Tex.; Ariz., Calif.; Mexico. Host: Acrobasis caryae Grote, A. comptoniella Hulst, A. indigenella (Zell.), A. juglandis (LeB.), Choristoneura fumiferana (Clem.), Coleotechnites juniperella (Kearf.), C. mackiei (Keifer), C. piceaella (Kearf.), C. thujaella Kearf., Coleophora sp., C. laticomella Clem., C. ulmifoliella McD., Mompha sp., Nephopterix subfiscella (Rag.), Petrova albicapitana Busck.

Eubadizon lateralis Cresson, 1872. Canad. Ent. 4: 229. రా.

Orgilus kearfotti Ashmead, 1903. N. Y. Ent. Soc., Jour. 11: 144. o.

Biology: Nickels, Pierce and Pinkney, 1950. U. S. Dept. Agr., Tech. Bul. 1011, p. 12 (as Orgilus maculiventris).

lautus Muesebeck. Mich.

Orgilus lautus Muesebeck, 1970. Smithsn. Contrib. Zool., n. 30, p. 59..

lepidus Muesebeck. Calif. (?); Argentina, Uruguay. Liberated in Calif. but not known to be established. Introduced from Argentina and Uruguay. Host: Phthorimaea operculella (Zell.).

Orgilus lepidus Muesebeck, 1967. Ent. Soc. Wash., Proc. 69: 177. \&, ð.

Biology: Oatman, Platner and Greany, 1969. Ent. Soc. Amer., Ann. 62: 1407-1414. - Greany and Oatman, 1972. Ent. Soc. Amer., Ann. 65: 375-383.

levis Muesebeck. Fla.

Orgilus levis Muesebeck, 1970. Smithsn. Contrib. Zool., n. 30, p. 60. §.

lissus Muesebeck. Calif.

Orgilus lissus Muesebeck, 1970. Smithsn. Contrib. Zool., n. 30, p. 61. ๆ.

longiceps Muesebeck. East. U. S. (?); Japan. Liberated in eastern U. S. but not known to be established. Introduced from Japan. Host: Grapholitha molesta Busck.

Orgilus longiceps Muesebeck, 1933. Ent. Soc. Wash., Proc. 35: 52. ๆ, ठ’.

lunaris Muesebeck. Idaho, Calif.

Orgilus lunaris Muesebeck, 1970. Smithsn. Contrib. Zool., n. 30, p. 61. \&.

macrurus Muesebeck. Que., N. Y., Md., W. Va., Va., Ont., Colo.

Orgilus macrurus Muesebeck, 1970. Smithsn. Contrib. Zool., n. 30, p. 62. ๆ, ठ.

maculiventris (Cresson). Mass., Va., Fla., La., Tex. Host: Antaeotricha humilis (Zell.).

Eubadizon maculiventris Cresson, 1872. Amer. Ent. Soc., Trans. 4: 178. o.

medicaginis Muesebeck. Tex., N. Mex., Ariz., Calif.; Mexico.

Orgilus medicaginis Muesebeck, 1970. Smithsn. Contrib. Zool., n. 30, p. 64. ๆ, ó.

melissopi Muesebeck. Oreg., Calif. Host: Melissopus latiferranus (Wlsm.).

Orgilus melissopi Muesebeck, 1970. Smithsn. Contrib. Zool., n. 30, p. 65. \&, ơ.

mellipes (Say). W. Va., Va., Fla., Mich., Ind., Ala., Ill., Mo., La. Host: Keiferia inconspicuella (Murtf.), Phthorimaea operculella (Zell.).

Microgaster mellipes Say, 1836. Boston Jour. Nat. Hist. 1: 261. ठ.

Eubadizon incognitus Ashmead, 1889 (1888). U. S. Natl. Mus., Proc. 11: 644. ๆ.

mimicus Muesebeck. Calif.

Orgilus mimicus Muesebeck, 1970. Smithsn. Contrib. Zool., n. 30, p. 67..

modicus Muesebeck. Ga., Fla., Ark., La., Okla., Tex. Host: Stegasta bosquella (Chamb.).

Orgilus modicus Muesebeck, 1970. Smithsn. Contrib. Zool., n. 30, p. 68. \&, ơ.

momphae Muesebeck. N. Y., Pa., N. J., Va., Ont., Mich., Ohio, Minn. Host: Mompha eloisella Clem.

Orgilus momphae Muesebeck, 1970. Smithsn. Contrib. Zool., n. 30, p. 68. ๑, §.

monticola Muesebeck. Idaho.

Orgilus monticola Muesebeck, 1970. Smithsn. Contrib. Zool. n. 30, p. 69.. 
morulus Muesebeck. Que.

Orgilus momulus Muesebeck, 1970. Smithsn. Contrib. Zool., n. 30, p. 70. \&. mundus Muesebeck. Colo.

Orgilus mundus Muesebeck, 1970. Smithsn. Contrib. Zool., n. 30, p. 71. $\subsetneq$. nitidus Muesebeck. Tex., Ariz. Host: Elasmopalpus lignosellus (Zell.).

Orgilus nitidus Muesebeck, 1970. Smithsn. Contrib. Zool., n. 30, p. 72..

notabilis Muesebeck. Fla.

Orgilus notabilis Muesebeck, 1970. Smithsn. Contrib. Zool., n. 30, p. 72 ..

obscurator (Nees). Que., Mass., R. I., Conn., N. Y., N. J., W. Va., Ont., Mich., Ohio. Introduced from Europe. Host: Rhyacionia buoliana (Schiff.).

Microdus obscurator Nees, 1814 (1812). Mag. Gesell. Naturf. Freunde Berlin 6: 186. ๆ. Eubadizon leptocephalus Hartig, 1838. Jahresber. Fortschr. Forstw. 1: 268. \&, o.

Biology: Watson and Arthur, 1959. Canad. Ent. 91: 481. - Miller, 1960. Jour. Econ. Ent. 53: 318. - Juliet, 1960. Canad. Ent. 92: 342-346, 701-704. - Leius, 1960. Canad. Ent. 92: 371-375. -Dowden, 1962. U. S. Dept. Agr., Agr. Handb. 226, p. 62. -Syme and Green, 1972. Canad. Ent. 104: 523-530.

opacus Muesebeck. Ont., Pa., Va. Host: Scythris sp.

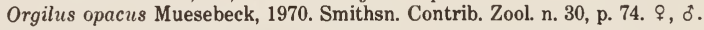

oregonensis Muesebeck. Oreg.

Orgilus oregonensis Muesebeck, 1970. Smithsn. Contrib. Zool., n. 30, p. 75. .

parallelus Muesebeck. B. C., Ont., Kans., Tex.

Orgilus parallelus Muesebeck, 1970. Smithsn. Contrib. Zool., n. 30, p. 76. \&.

pedalis Muesebeck. Alta.

Orgilus pedalis Muesebeck, 1970. Smithsn. Contrib. Zool., n. 30, p. 77..

persimilis Muesebeck. Idaho, Calif.

Orgilus persimilis Muesebeck, 1970. Smithsn. Contrib. Zool., n. 30, p. 77., , ర.

politus Muesebeck. Nebr., Kans.

Orgilus politus Muesebeck, 1970. Smithsn. Contrib. Zool., n. 30, p. 78..

pratensis Muesebeck. N. Dak., Alta.

Orgilus pratensis Muesebeck, 1970. Smithsn. Contrib. Zool., n. 30, p. 79. \&.

prolixus Muesebeck. Ont.

Orgilus prolixus Muesebeck, 1970. Smithsn. Contrib. Zool., n. 30, p. 80. \&.

proprius Muesebeck. Ga.

Orgilus proprius Muesebeck, 1970. Smithsn. Contrib. Zool., n. 30, p. 80 ..

pumilus Muesebeck. S. C.

Orgilus pımilus Muesebeck, 1970. Smithsn. Contrib. Zool., n. 30, p. 81. .

rasilis Muesebeck. Ariz.

Orgilus rasilis Muesebeck, 1970. Smithsn. Contrib. Zool., n. 30, p. 82 ..

rostratus Muesebeck. Md., Ohio, Wyo., Colo.

Orgilus rostratus Muesebeck, 1970. Smithsn. Contrib. Zool., n. 30, p. 82. ९, ठ.

scaber Muesebeck. N. B., Que., Ont., B. C., Wash., Oreg. Host: Coleophora serratella (L.). Orgilus scaber Muesebeck, 1970. Smithsn. Contrib. Zool., n. 30, p. 83. ₹, ठ์.

simulator Muesebeck. Mich.

Orgilus simulator Muesebeck, 1970. Smithsn. Contrib. Zool., n. 30, p. 84. ․

solidus Muesebeck. Ont.

Orgilus solidus Muesebeck, 1970. Smithsn. Contrib. Zool., n. 30, p. 85..

striatus Muesebeck. Calif.

Orgilus striatus Muesebeck, 1970. Smithsn. Contrib. Zool., n. 30, p. 86. \&.

strigosus Muesebeck. Wash., Calif.

Orgilus strigosus Muesebeck, 1970. Smithsn. Contrib. Zool., n. 30, p. 86. \&.

tenuis Muesebeck. Md.

Orgilus tenuis Muesebeck, 1970. Smithsn. Contrib. Zool., n. 30, p. 87..

tersus Muesebeck. S. C.

Orgilus tersus Muesebeck, 1970. Smithsn. Contrib. Zool., n. 30, p. 88 .. 
utahensis Muesebeck. Utah.

Orgilus utahensis Muesebeck, 1970. Smithsn. Contrib. Zool., n. 30, p. 88. ․

validus Muesebeck. Utah.

Orgilus validas Muesebeck, 1970. Smithsn. Contrib. Zool., n. 30, p. 89. $q$.

vallis Muesebeck. Calif.

Orgilus vallis Muesebeck, 1970. Smithsn. Contrib. Zool., n. 30, p. 90. ๆ, ð.

walleyi Muesebeck. Que., N. Y., Ont., Mich., Okla. Host: Stegasta bosqueella (Chamb.).

Orgilus walleyi Muesebeck, 1970. Smithsn. Contrib. Zool. n. 30, p. 91. ․, ठ.

zonalis Muesebeck. Ind. Host: Aristotelia absconditella (Wlkr.).

Orgilus zonalis Muesebeck, 1970. Smithsn. Contrib. Zool., n. 30, p. 92. \&, ઠ.

\section{Genus STANTONIA Ashmead}

Stantonia Ashmead, 1904. U. S. Natl. Mus., Proc. 28: 146.

Type-species: Stantonia flava Ashmead. Monotypic.

Mimagathis Enderlein, 1905. Zool. Anz. 28: 450.

Type-species: Mimagath is ashmeadi Enderlein. Desig. by Viereck, 1914.

Taxonomy: Muesebeck, 1970. Smithsn. Contrib. Zool., n. 30, p. 1. -Shenefelt, 1970. Hym.

Cat., part 5, p. 263-264, 266-268 (cat. World spp.).

carpocapsae Muesebeck. Va., N. C., Ky., Tex. Host: Desmia funeralis (Hbn.), Eustixia pupula

Hbn., Harrisina americana (Guer.), Laspeyresia pomonella (L.).

Stantonia carpocapsae Muesebeck, 1938. Ent. Soc. Wash., Proc. 40: 90. ㅇ.

UNPLACED TAXON OF BLACINAE

Blacus(?) longicaudus Provancher, 1886. Addit. Corr. Faune Ent. Canada Hym., p. 133..

\section{SUbFAMILy NEONEURINAE}

Species in this small group are internal parasites of ants and are rarely collected.

Revision: Muesebeck, 1922. U. S. Natl. Mus., Proc. 61 (15): 3-6 (No. Amer. spp.).

\section{Genus ELASMOSOMA Ruthe}

Elasmosoma Ruthe, 1858. Berlin. Ent. Ztschr. 2: 7.

Type-species: Elasmosoma berolinensa Ruthe. Monotypic.

Paramirax Ashmead, 1895. Ent. Soc. Wash., Proc. 3: 281.

Type-species: Paramirax schwarzi Ashmead. Monotypic.

Revision: Huddleston, 1976. Mus. Natl. Hung., Ann. Hist.-Nat. 68: 215-225.

bakeri Ashmead. Va., Iowa, Colo., N. Mex., Idaho, Calif.

Elasmosoma bakeri Ashmead, 1895. Ent. Soc. Wash., Proc. 3: 282. ठ.

pergandei Ashmead. Ont. s. to D. C.; N. Dak., Kans., Colo., Wash.; Mongolia. Host: Camponotus castaneus (Latr.), Formica integra Nyl., F. subsericea Say.

Elasmosoma pergandei Ashmead, 1895. Ent. Soc. Wash., Proc. 3: 283. \&.

petulans Muesebeck. Md., Ohio, Wyo. Host: Formica rubicunda Emery.

Elasmosoma petulans Muesebeck, 1941. Brooklyn Ent. Soc., Bul. 36: 200..

schwarzi (Ashmead). Pa., Md., D. C., Ga., Ind. Host: Formica schaufussi Mayr, Polyergus lucidus Mayr.

Paramirax schwarzi Ashmead, 1895. Ent. Soc. Wash., Proc. 3: 283. ?.

vigilans Cockerell. Wis., Colo. Host: Formica subpolita Mayr.

Elasmosoma vigilans Cockerell, 1909. Ent. Soc. Wash., Proc. 10: 168. ๆ.

\section{Genus NEONEURUS Haliday}

Neoneurus Haliday, 1838. Ent. Mag. 5: 213. No species included.

Type-species: Neoneurus halidaii Marshall. Subsequent monotypy. First included species by Marshall, 1897. Ent. Mon. Mag. 8: 149.

Ecclites Foerster, 1862. Naturh. Ver. Rheinlande, Verh. 19: 244.

Type-species: Ecclites clypeatus Foerster. Orig. desig.

One undescribed species occurs in North America. 


\section{SUBFAMILy EUPHORINAE}

This is the most specialized group of the Braconidae. Although the adult and larval morphology is rather homogenous, the subfamily can be divided into two groups from the viewpoint of biology: the Meteorini, most of which are parasites of lepidopterous larvae, and the Euphorini and Cosmophorini, which are parasites of nymphs and adult insects of various orders. Tobias $(1965,1966)$ has studied this group and included several other subfamilies and genera. However, his arrangement apparently groups together some rather unrelated elements and is, therefore, not followed in this catalog.

Revision: Muesebeck, 1936. U. S. Dept. Agr., Misc. Pub. 241, 38 p. (World genera, No. Amer. spp.).

Taxonomy: Tobias, 1965. Ent. Obozr. 44: 841-865. - Tobias, 1966. Ent. Obozr. 45: 612-633 (key to World genera). - Shenefelt, 1969. Hym. Cat., part 4, p. 4-137 (cat. World spp.).

\section{TRIBE METEORINI}

\section{Genus METEORUS Haliday}

Perilitus subg. Meteorus Haliday, 1835. Ent. Mag. 3: 24.

Type-species: Ichneumon pendulator Latreille. Desig. by Westwood, 1839.

Protelus Foerster, 1862. Naturh. Ver. Rheinlande, Verh. 19: 253.

Type-species: Bracon chrysophthalmus Nees. Orig. desig.

Saprotichnss Holmgren, 1868. Eug. Resa I, Zool. I, Ins., p. 430.

Type-species: Saprotichus chinensis Holmgren. Desig. by Viereck, 1914.

Pachythecus Cameron, 1912. Soc. Ent. 27: 84.

Type-species: Pachythecus mificeps Cameron. Desig. by Viereck, 1914.

Most species are endoparasites of larvae of Lepidoptera, but a few parasitize larvae of Coleoptera.

Revision: Muesebeck, 1923. U. S. Natl. Mus., Proc. 63: 1-44 (No. Amer. spp.).

Taxonomy: Tobias, 1966. Ent. Obozr. 45: 615-617. - Shenefelt, 1969. Hym. Cat., part 4, p. 48-101 (cat. World spp.).

acronyctae Muesebeck. Colo., N. Mex., Utah, Ariz. Host: Acronicta sp., Halisidota sp., $H$. ingens Hy. Edw., Hyphantria cunea (Drury).

Meteorus acronyctae Muesebeck, 1923. U. S. Natl. Mus., Proc. 63: 35. ๆ, o.

angustipennis Muesebeck. Mass., Conn., N. Y., Pa., N. J., Md., W. Va., Ohio, Tenn., Iowa.

Meteorus angustipemis Muesebeck, 1923. U. S. Natl. Mus., Proc. 63: 19. ๆ, o.

argyrotaeniae Johansen. Conn., Wis., N. Mex., B. C., Wash., Oreg., Calif., Alaska. Host: Acleris gloverana (Wlsm.), A. variana (Fern.), Archips argyrospilus (Wlkr.), Argyrotaenia citrana (Fern.), Spilonota ocellana (D. and S.).

Meteorns argyrotaeniae Johansen, 1949. Ent. Soc. Amer., Ann. 42: 319..

arizonensis Muesebeck. N. Mex., Ariz.

Meteorus arizonensis Muesebeck, 1923. U. S. Natl. Mus., Proc. 63: 34. ๆ, ठ́.

autographae Muesebeck. Newfoundland s. to Fla., w. to Wis. and La. Host: Acleris variana (Fern.), Agrotis ipsilon (Hufn.), Alsophila pometaria (Harr.), Anticarsia gemmatalis Hbn., Autographa sp., A. biloba (Steph.), Autoplusia egena (Guen.), Colias eurythema Bdvl., Evergestis stramminalis Hbn., Heliothis zea (Boddie), Orgyia leucostigma (Sm.), Peridroma saucia (Hbn.), Plathypena seabra (F.), Pseudaletia unipuncta (Haw.), Pseudoplusia includens (Wlkr.), Spodoptera eridania (Cram.), S. exiqua ( $\mathrm{Hbn}.), S$. frugiperda (Sm.), S. ornithogalli (Guen.), Trichoplnsia ni (Hbn.), Udea mbigalis (Guen.).

Meteorus antographae Muesebeck, 1923. U. S. Natl. Mus., Proc. 63: 30. ๆ, ơ.

bakeri Cook and Davis. N. B. s. to N. C., w. to Sask. and Utah; Wash. Host: Dasychira plagiata (Wlkr.), Halisidota argentata Pack., Hyphantria cunea (Drury), H. textor (Harr.).

Meteorus bakeri Cook and Davis, 1891. Mich. Agr. Expt. Sta., Bul. 73: 9. ठ̊. 
betulini Mason. Que., Pa., Md., Mich., Man. Host: Orchesia sp.

Meteorus betulini Mason, 1968. Canad. Ent. 100: 717. \%, ð.

campestris Viereck. U. S. and Canada. Host: Dioryctria reniculella (Grote), Loxostege commixtalis (Wlkr.), L. sticticalis (L.), Ostrinia nubilalis ( $\mathrm{Hbn}$.), O. penitalis (Grote), Phlyctaenia coronata tertialis (Guen.), Pyrausta futilalis (Led.), Sparganothis saracana Kearf.

Meteorus campestris Viereck, 1905. Kans. Acad. Sci., Trans. 19: 281..

Meteorus loxostegei Viereck, 1911. U. S. Natl. Mus., Proc. 39: 401. ¿.

Biology: Simmonds, 1947. Bul. Ent. Res. 38: 373-379.

cingiliae Muesebeck. N. B., Maine, N. H., Mass., R. I., N. Y., Ont. Host: Cingilia catenaria (Drury).

Meteorus cingiliae Muesebeck, 1926. U. S. Natl. Mus., Proc. 69: 3. ๆ, ð.

clinophthalmicus Shenefelt. Wis.

Meteorus clinophthalmicus Shenefelt, 1961. Ent. Soc. Wash., Proc. 63: 276. \&, ð.

cognatus Muesebeck. Que., Mich., Calif.

Meteorus cognatus Muesebeck, 1939. Ent. Soc. Wash., Proc. 41: 84..

communis (Cresson). North. U. S. s. to N. C., Colo. and Calif; Canada; Alaska. Host: Amphipyra pyramidoides Gn., Dargida procincta (Grote), Eupsilia sidus (Gn.), Grapholitha sp., Lithophane bethunei (G. and R.), L. laticinerea Grote, Malacosoma americanum (F.), Orthosia hibisci (Gn.), O. revicta (Morr.), Pseudaletia unipuncta (Haw.).

Perilitus communis Cresson, 1872. Canad. Ent. 4: 82. $q$, o.

Perilitus intermedius Cresson, 1872. Canad. Ent. 4: 82.

Meteomıs petiolariferus Viereck, 1917 (1916). Conn. State Geol. and Nat. Hist. Survey, Bul. 22, p. 223. ठँ.

Meteorus pretiosus Viereck, 1917 (1916). Conn. State Geol. and Nat. Hist. Survey, Bul. 22, p. 223. $\delta$.

datanae Muesebeck. Maine, Mass., Conn., Pa., N. J., N. C. Host: Datana angusii G. and R., D. integerrima G. and R., D. ministra (Drury).

Meteorus datanae Muesebeck, 1923. U. S. Natl. Mus., Proc. 63: 38. \&.

dimidiatus (Cresson). U. S. and Canada. Host: Desmia funeralis (Hbn.), E pizeuxis sp., Platynota flavedana Clem., P. idaeusalis (Wlkr.), P. stultana Wlsm., Xenotemna pallorana (Rob.).

Perilitus dimidiatus Cresson, 1872. Canad. Ent. 4: 83. ๆ, ठౌ.

Meteorus noctivagus Viereck, 1905. Kans. Acad. Sci., Trans. 19: 281..

euschausiae Muesebeck. Colo., N. Mex., Ariz., Wash.; Mexico. Host: Halisidota argentata Pack., H. ingens Hy. Edw.

Meteorus euschausiae Muesebeck, 1923. U. S. Natl. Mus., Proc. 63: 37. \&, ठ.

fumipennis Muesebeck. Ark., Ariz., B. C., Wash., Calif.

Meteorus fumipennis Muesebeck, 1923. U. S. Natl. Mus., Proc. 63: 20. 9.

hicoriae Muesebeck. Pa., Ohio.

Meteorus hicoriae Muesebeck, 1923. U. S. Natl. Mus., Proc. 63: 25. ․

humilis (Cresson). South. Canada and north. U. S. s. to Va. and N. Mex. Host: Nemapogon granellus (L.), Nemapon oregonellus (Busck), Orchesia castanea Melsh., Platydema ellipticum (F.).

Perilitus humilis Cresson, 1872. Canad. Ent. 4: 84.

Perilitus robustus Provancher, 1886. Addit. Corr. Faune Ent. Canada Hym., p. 125..

Meteorus orchesiae Ashmead, 1889 (1888). U. S. Natl. Mus., Proc. 11: 643. ㅇ, ð’.

Meteorus agilis Viereck, 1903. Amer. Ent. Soc., Trans. 29: 94., ठ.

hyphantriae Riley. U. S. and Canada; Mexico. Host: Acronicta sp., Alsophila pometaria (Harr.), Caenurgina erechtea (Cram.), Dasychira plagiata (Wlkr.), Faronta diffusa (Wlkr.), Halisidota argentata Pack., Hemileuca maia (Drury), Hyphantria cunea (Drury), Hypsoropha hormos Hbn., Malacosoma americanum (F.), M. disstria Hbn., Nepytia canosaria (Wlkr.), Olethreutes sp., Orygia leucostigma (Sm.), O. pseudotsugata McD., Paleacrita vernata (Peck), Peris pasta caeculalis Zell., Thymelicus lineola Ochs. Meteorus hyphantriae Riley, 1887. U. S. Dept. Agr. Ann. Rpt. for 1886, p. 532. \&, §’. 
Meteorns oecopsidis Ashmead, 1889 (1888). U. S. Natl. Mus., Proc. 11: 642. ठ。.

Meteorts floridarus Ashmead, 1889 (1888). U. S. Natl. Mus., Proc. 11: 642. ठ.

Meteorus relativus Viereck, 1905. Kans. Acad. Sci., Trans. 19: 280. ठð.

Meteorus triangularis Muesebeck, 1919. Canad. Ent. 51: 115. ๆ, ठे.

hypophloei Cushman. N. C., Ga., Fla., Miss., La., Tex., Wis., Mont., Wyo., N. Mex., Idaho,

Wash., Calif. Host: Corticeus sp., C. parallelus (Melsh.), Dendrocton us frontalis Zimm., D. ponderosae Hopk.

Meteorus hypophloei Cushman, 1931. Wash. Acad. Sci., Jour. 21: 302. ๆ, §.

Biology: DeLeon, 1933. Brooklyn Ent. Soc., Bul. 28: 32-36.

indagator (Riley). N. B. s. to Fla., w. to Ont., S. Dak., and Tex.; Calif. Host: Acrobasis betulella Hulst, $A$. caryae Grote, $A$. caryivorella Rag., A. comptoniella Hulst, $A$. coryliella Dyar, A. indigenella (Zell.), A.juglandis (LeB.), A. kearfottella Dyar, A. minimella Rag., A. rubrifasciella Pack., A. sylviella Ely, Dioryctria auranticella (Grote), D. disclusa Hein., Omphalocera dentosa Grote, Tetralopha militella Zell., $T$. platenella Clem., $T$. subcanalis (Wlkr.).

Perilitus indagator Riley, 1872. Ins. Mo. Ann. Rpt. 4: 43. ?.

Biology: Balduf, 1968. Ent. Soc. Amer., Ann. 61: 465-466.

japonicus Ashmead. New England (?); Japan, China, N. Afr. Liberated in New England but not known to be established. Introduced from Japan. Host: Lymantria dispar (L.).

Meteorus japonicus Ashmead, 1906. U. S. Natl. Mus., Proc. 30: 190. .

Meteorus nipponensis Viereck, 1912. U. S. Natl. Mus., Proc. 42: 624. 9.

islandicus (Ruthe), Greenland, N. W. T. Ecology: Occurs in arctic regions.

Perilitus islandicus Ruthe, 1859. Stettin. Ent. Ztg. 20: 317. $\%$, o.

laphygmae Viereck. Tex., N. Mex.; Mexico, Cent. Amer., north. So. Amer. Host: Autographa sp., Colias eurythene Bdvl., Elaphria nucicolora (Guen.), Feltia subterranea (F.), Heliothis zea (Boddie), Leucania latiuscula H.-S., Peridroma saucia (Hbn.), Pseudaletia unipuncta (Haw.), Semiothisa punctolineata (Pack.), Spodoptera eridania (Cram.), S. exigua (Hbn.), S. frugiperda (Sm.).

Meteorus laphygmae Viereck, 1913. U. S. Natl. Mus., Proc. 44: 560., , ¿.

leviventris (Wesmael). Holarctic, Neotropical. Host: Agrotis gladiaria Morr., A. ipsilon (Hufn.), A. malefida Guen., A. orthogonia Morr., Autographa californica (Spey.), Autoplusia egena (Gn.), Colias eurytheme Bdvl., Euxoa auxiliaris agrestis (Grote), E. excellens (Grote), E. messoria (Harr.), E. ochrogaster (G.), Feltia ducens Walkr., F. subterranea (F.), Hellula undalis (F.), Peridroma saucia (Hbn.), Scotogramma trifolii (Rott.), Spodoptera frugiperda (Sm.).

Perilitus leviventris Wesmael, 1835. Nouv. Mem. Acad. Sci. Bruxelles 9: 46. ๆ.

Perilitus vulgaris Cresson, 1872. Canad. Ent. 4: 83. ₹, ठ์.

Meteorus coquilletti Ashmead, 1889 (1888). U. S. Natl. Mus., Proc. 11: 642. ठँ.

Meteorus mellinervis Viereck, 1903. Amer. Ent. Soc., Trans. 29: 95. ?.

Meteorus mamestrae Viereck, 1913. U. S. Natl. Mus., Proc. 46: 364. ^, §.

pinifolii Mason. Que., Alta., B. C., Calif. Host: Coleotechnites milleri (Busck), C. piceaella (Kearf.), C. starki (Freem.), Zeiraphera canadensis M. and F.

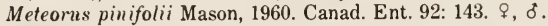

politus (Provancher). N. S. s. to Md., w. to B. C., Idaho, and Colo.

Perilitus politus Provancher, 1886. Addit. Corr. Faune Ent. Canada Hym., p. 126. \&, o.

provancheri Dalla Torre. Que.

Perilitus gracilis Provancher, 1886. Addit. Corr. Faune Ent. Canada Hym., p. 125.. Preoce. by Ratzeburg, 1852.

Meteorus provancheri Dalla Torre, 1898. Cat. Hym., v. 6, p. 112. N. name for gracilis Provancher.

proximus (Cresson). Mass., Conn., N. Y., N. J., Ont., Mich., Wis., Ill., Minn., N. Dak.

Perilitus proximus Cresson, 1872. Canad. Ent. 4: 83. ठँ.

Meteorus exareolatus Viereck, 1917 (1916). Conn. State Geol. Nat. Hist. Survey, Bul. 22: 224. $\delta$. 
pulchricornis (Wesmael). New England (?); Europe, N. Afr. Liberated in New England but not known to be established. Introduced from France. Host: Lymantria dispar (L.).

Perilitus pulchricormis Wesmael, 1835. Nouv. Mem. Acad. Sci. Bruxelles 9: 42. ๆ, ठ.

ruficeps (Nees). Que. (?), Ont. (?); Europe. Liberated in Que. and Ont. but not known to be established. Introduced from Europe. Host: Choristoneura fumiferana (Clem.).

Perilitus muficeps Nees, 1834. Hym. Ichn. Aff. Monog., v. 1, p. 39. ९, ó.

tauricornis (Provancher). Labrador s. to Md., w. to Ont. and Iowa; Fla., Tenn., Colo., Alaska.

Rhopalophorus tauricornis Provancher, 1880. Nat. Canad. 12: 168. 9.

terebratus Muesebeck. Mich. Host: Orchesia castanea Melsh. Host record needs to be confirmed.

Meteorus terebratus Muesebeck, 1923. U. S. Natl. Mus., Proc. 63: 24. ₹, ठ๋.

tersus Muesebeck. Idaho, Calif. Host: Amorbia essigana Busck, Orgyia psendotsugata McD., $O$. vetusta gulosa (Hy. Edw.), Sabulodes caberata (Gn.).

Meteorus tersus Muesebeck, 1956. Pan-Pac. Ent. 32: 25. + , ठั.

Biology: Fleschner, Ricker and Johnson, 1957. Calif. Avocado Soc., Ybk. 41: 115.

tetralophae Muesebeck. N. Y. s. to Fla., w. to Ont., Ind., and Iowa. Host: Dioryctria disclusa Heinr., Psorosina hammondi (Riley), Tetralopha asperatella (Clem.), T. robustella Zell., T. subcaralis (Wlkr.).

Meteorus tetralophae Muesebeck, 1926. U. S. Natl. Mus., Proc. 69: 2. .

tibialis Muesebeck. Que., N. Y., Ga., Ont., Wis. Host: Hyperplatys aspera (Say).

Meteorus tibialis Muesebeck, 1923. U. S. Natl. Mus., Proc. 63: 23. ๆ, ठ.

trachynotus Viereck. U. S. and Canada. Host: Acleris longiana (L.), A. variana (Fern.), Ancylis sp., A. comptana fragaria (W. and R.), Archips argyrospilus (Wlkr.), A. rosanus (L.), A. semiferanus (Wlkr.), Argyrotaenia citrana (Fern.), Choristoneura conflictana (Wlkr.), C. fumiferana (Clem.), C. lambertiana (Busck), C. occidentalis Freem., C. pinus Freem., Dioryctria reniculella (Grote), Epismus argutanus (Clem.), Evora hemidesma (Zell.), Grapholitha molesta (Busck), Platynota idaeusalis (Wlkr.), Sparganothis pettitana (Rob.), S. sulphurana (F.).

Meteorus trachynotus Viereck, 1912. U. S. Natl. Mus., Proc. 42: 142. ‡, ठ.

Meteorus archipsidis Viereck, 1912. U. S. Natl. Mus., Proc. 43: 580..

Biology: McGugan, 1955. Canad. Ent. 87: 178-187.

versicolor (Wesmael). New England, east. Canada; B. C., Wash.; China, Japan, N. Afr. Introduced from Europe. Host: Nygmia phaeorrhoea (Donov.), Orgyia antigua (L.), $O$. leucostigma (Sm.), Protoboamia porcelaria (Gn.), Stilpnotia salicis (L.).

Perilitus versicolor Wesmael, 1835. Nouv. Mem. Acad. Sci. Bruxelles 9: 43. ‡, §.

Perilitus bimaculatus Wesmael, 1835. Nouv. Mem. Acad. Sci. Bruxelles 9: 45. ๆ.

Perilitus brevicornis Ratzeburg, 1844. Ichn. d. Forstins. 1: 77. ๆ.

Meteorus decoloratus Ruthe, 1862. Berlin. Ent. Ztschr. 6: 48. ९.

Biology: Muesebeck, 1918. Jour. Agr. Res. 12: 191-206. - Burgess and Grossman, 1929. U. S. Dept. Agr., Tech. Bul. 86, p. 127-131. -Clausen, 1956. U. S. Dept. Agr., Tech. Bul. 1139, p. 114. -Dowden. 1962. U. S. Dept. Agr., Agr. Handb. 226, p. 60.

vitticollis (Holmgren). Calif.

Saprotichus vitticollis Holmgren, 1868. Eug. Resa I, Zool. I, Ins., p. 431. ठ.

Nomina Nuda in Meteorus Haliday

Meteorus areolatus Ashmead, 1902. In Slosson, Ent. News 13: 321.

Meteorus brevicandus Ashmead, 1890. In Riley and Howard, U. S. Dept. Agr., Insect Life 3: 57.

Sapotrichus johnsonii Ashmead, 1900 (1899). In Smith, Ins. N. J., p. 589.

Meteorns niger Ashmead, 1902. In Slosson, Ent. News 13: 321.

Meteorms notodontae Riley, 1890. In Riley and Howard, U. S. Dept. Agr., Insect Life 3: 57.

\section{TRIBE EUPHORINI}

Members of this tribe are chiefly endoparasites of adult insects, but the species of some groups parasitize nymphs of Heteroptera and Psocoptera. 
Biology: Muesebeck, 1963. Ent. Soc. Wash., Proc. 65: 306. -Tobias, 1965. Ent. Obozr. 44: 841-865.

\section{Genus ARIDELUS Marshall}

Aridelus Marshall, 1887. Ent. Soc. London, Trans., p. 66.

Type-species: Aridelus bucephalus Marshall. Monotypic.

Helorimorpha Schmiedeknecht, 1907. Hym. Mitteleuropas, p. 523.

Type-species: Helorimorpha egregia Schmiedeknecht. Monotypic.

Stictometeorus Cameron, 1909. Soc. Ent. 24: 9.

Type-species: Stictometeorus mifus Cameron. Monotypic.

Erythrometeorus Cameron, 1911. Timehri (Ser. 3) 1: 317.

Type-species: Erythrometeorus reticulatus Cameron. Monotypic.

Scipolabia Enderlein, 1920. Arch. f. Naturgesch. 84 (A) (11): 220.

Type-species: Scipolabia reticulata Enderlein. Orig. desig.

Species of this genus are parasites of nymphs and adults of Pentatomidae.

Revision: Muesebeck, 1936. U. S. Dept. Agr., Misc. Pub. 241, p. 6-8 (No. Amer. spp.). -Papp, 1965. Acta Zool. Hung. 11: 181-201 (World spp.).

Taxonomy: Shenefelt, 1969. Hym. Cat., part 4, p. 11-15 (cat. World spp.).

fisheri (Viereck). Pa. s. to Ga., w. to Kans. and Tex. Host: Euschistus servus euschistoides (Voll.).

Helorimorpha fisheri Viereck, 1909. Ent. News 20: 290. $₹$, ઠ์.

melanderi (Brues). Mass., N. Y., Pa., Md., Mich., Tenn.

Helorimorpha melanderi Brues, 1908. Ent. News 19: 363. ․

nigrithorax Muesebeck. Conn., Va., S. C., Tenn., Tex.

Aridelus nigrithorax Muesebeck, 1936. U. S. Dept. Agr., Misc. Pub. 241, p. 8..

\section{Genus CHRYSOPOPHTHORUS Goidanich}

Chrysopophthorus Goidanich, 1948. Ist. Ent. Univ. Bologna, Bol. 17: 83.

Type-species: Chrysopophthoms chrysopimaginis Goidanich. Orig. desig.

Parasitic on adults of Chrysopa.

Revision: Mason, 1964. Canad. Ent. 96: 1005-1017 (World spp.).

Taxonomy: Shenefelt, 1969. Hym. Cat., part 4, p. 29-30 (cat. World spp.).

americanus Mason. Mass., N. Y., Md., Va., Ohio, Mich., Ill., Tenn., Ark., La., Ariz., Calif. Host:

Chrysopa camea Stephans.

Chrysopophthorus americanus Mason, 1964. Canad. Ent. 96: 1012. \&, o.

\section{Genus CRYPTOXıLOS Viereck}

Cryptoxilos Viereck, 1911. U. S. Natl. Mus., Proc. 40: 180.

Type-species: Cryptoxilos dichromorphus Viereck. Orig. desig.

Meager host records indicate species are parasites of adult Scolytidae.

Taxonomy: Muesebeck, 1936. U. S. Dept. Agr., Misc. Pub. 241, p. 9-10. - Shenefelt, 1969.

Hym. Cat., part 4, p. 30 (cat. World spp.).

convergens Muesebeck. D. C., W. Va., Va., N. C. Host: Phloeotribus frontalis (Oliv.).

Euphorus phloeotribi Ashmead, 1893. In Chittenden, U. S. Dept. Agr., Insect Life 5: 249.

Nomen nudum.

Cryptoxilos convergens Muesebeck, 1936. U. S. Dept. Agr., Misc. Pub. 241, p. 9. ^, ठิ.

\section{Genus EUPHORIELLA Ashmead}

Euphoriella Ashmead, 1900. U. S. Natl. Mus., Proc. 23: 116.

Type-species: Labeo incertus Ashmead. Orig. desig.

Parasites of Psocoptera. In all known examples, the early instar nymph is parasitized and the mature parasite larva emerges from a mature host nymph or adult. 
Revision: Loan and New, 1972 (1971). Ent. Soc. Ont., Proc. 102: 92-108 (No. Amer. spp.).

Taxonomy: Muesebeck, 1936. U. S. Dept. Agr., Misc. Pub. 241, p. 25-27 (some No. Amer. spp.). - Shenefelt, 1969. Hym. Cat., part 4, p. 34-35 (cat. World spp.).

criddlei Loan and New. Ont.

Euphoriella criddlei Loan and New, 1972 (1971). Ent. Soc. Ont., Proc. 102: 105. \&, o.

foutsi Loan and New. Md., Iowa.

Euphoriella foutsi Loan and New, 1972 (1971). Ent. Soc. Ont., Proc. 102: 102. ๆ, ð.

hyalopsocidis Loan and New. Ont. Host: Hyalopsocus striatus (Wlkr.).

Euphoriella hyalopsocidis Loan and New, 1972 (1971). Ent. Soc. Ont., Proc. 102: 105. \&, ๖.

incerta (Ashmead). Fla.

Labeo incertus Ashmead, 1887. Ent. Amer. 3: 74. “o" = $\delta$.

kaladarensis Loan and New. Ont.

Euphoriella kaladarensis Loan and New, 1972 (1971). Ent. Soc. Ont., Proc. 102: 96. ९, ठ.

nixoni Loan and New. Maine.

Euphoriella nixoni Loan and New, 1972 (1971). Ent. Soc. Ont., Proc. 102: 95. o.

pacifica Muesebeck. Calif.

Euphoriella pacifica Muesebeck, 1936. U. S. Dept. Agr., Misc. Pub. 241, p. 26..

pallidifacia Loan and New. Que.

Euphoriella pallidifacia Loan and New, 1972 (1971). Ent. Soc. Ont., Proc. 102: 104. \&, ठ.

solidaginis Loan and New. Ont.

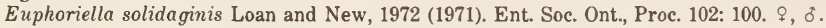

sommermanae Muesebeck. Conn. Host: Anomopsocus amabilis (Walsh).

Euphoriella sommermanae Muesebeck, 1956. Ent. Soc. Wash., Proc. 58: 148. ๆ, ơ.

Biology: Sommerman, 1956. Ent. Soc. Wash., Proc. 58: 149-152 (lists numerous species of nymphal and adult psocids from which she reared Hymenoptera, probably braconids, but only the one species listed above was definitely associated with Euphoriella sommermanae.).

\section{Genus HOLDAWAYELLA Loan}

Holdawayella Loan, 1967. Ent. Soc. Amer., Ann. 60: 241.

Type-species: Holdawayella tingiphaga Loan. Orig. desig.

Parasitic on nymphs and adults of Tingidae, particularly the genus Corythucha Stal.

Biology: Loan, Gerber, and Reid, 1971. Canad. Ent. 103: 1273-1284.

juglandis Loan. Ont. Host: Corythucha juglandis (Fitch). This parasite is bisexual and apparently restricted to $C$. juglandis on Juglans $\mathrm{sp}$.

Holdawayella juglandis Loan, 1971. Canad. Ent. 103: 1274. $\subsetneq$, ঠ.

tingiphaga Loan. Ont. Host: Corythucha coryli O. and D., C. heidemanni Drake, C. pruni 0. and D., C. ulmi O. and D. This parasite is parthenogenetic and shows an apparent field preference for C. heidemanni.

Holdawayella tingiphaga Loan, 1967. Ent. Soc. Amer., Ann. 60: 241. \&.

\section{Genus LEIOPHRON Nees}

Leiophron Nees, 1818. Nova Acta Acad. Leop. Carol. 9: 103. No species included.

Type-species: Leiophron apicalis Curtis. Desig. by Viereck, 1914. Desig. from three species first included by Haliday, 1833, Ent. Mag. 1: 263.

Euphoris Nees, 1834. Hym. Ichn. Aff. Monog., v. 2, p. 360.

Type-species: Euphomus pallicornis Nees. Monotypic.

Euphoriana Gahan, 1913. U. S. Natl. Mus., Proc. 46: 433.

Type-species: Euphoriana uniformis Gahan. Orig. desig.

Parasitic on nymphs of Miridae.

Revision: Muesebeck, 1936. U. S. Dept. Agr., Misc. Pub. 241: 28-33 (some No. Amer. spp.).

-Richards, 1967. Roy. Ent. Soc. London, Trans. 119: 171-186 (some Eur. spp.). - Loan, 
1974. Roy. Ent. Soc. London, Trans. 126: 222-238 (Eur. spp.). -Loan, 1975 (1974). Nat.

Canad. 101: 824-834 (No. Amer. spp.).

Taxonomy: Muesebeck, 1958. U. S. Natl. Mus., Proc. 107: 410-412. - Shenefelt, 1969. Hym.

Cat., part 4, p. 33-48 (cat. World spp.). - Loan and Bilewicz-Pawinska, 1973. Environ. Ent.

2: 271-278. - Loan, 1974. Roy. Ent. Soc. London, Trans. 126: 222 (syn. of Euphoriana).

Biology: Loan, 1975 (1974). Nat. Canad. 101: 822-824.

birdi Loan. Maine, N. Y., Pa.

Leiophrom birdi Loan, 1975 (1974). Nat. Canad. 101: 826. ơ.

borealis Loan. Ont.

Leiophron borealis Loan, 1975 (1974). Nat. Canad. 101: 826. §.

brevipetiolatus Loan. Colo.

Leiophron brevipetiolatus Loan, 1975 (1974). Nat. Canad. 101: 831. ठ.

cephalicus (Provancher). Ont., Colo.

Microctonus cephalicus Provancher, 1886. Addit. Corr. Faune Ent. Canada Hym., p. 127. o.

Euphorus spiniscapus Muesebeck, 1936. U. S. Dept. Agr., Misc. Pub. 241, p. 30..

Taxonomy: Loan, 1975 (1974). Nat. Canad. 101: 830.

compressus Loan. Calif.

Leiophron compressus Loan, 1975 (1974). Nat. Canad. 101: 828. ठ.

fumipennis Loan. Que.

Leiophron fumipennis Loan, 1975 (1974). Nat. Canad. 101: 832. ठ.

fuscipennis Loan. La.

Leiophron fuscipennis Loan, 1975 (1974). Nat. Canad. 101: 829..

grohi Loan. Maine, Ont.

Leiophron grohi Loan, 1975 (1974). Nat. Canad. 101: 829. ठ.

lygivora (Loan). Ont. Host: Lygus lineolaris (P. de B.).

Euphoriana lygivora Loan, 1970 (1969). Ent. Soc. Ont., Proc. 100: 193. \&.

maculipennis (Ashmead). Fla., Ont. Host: Diaphnocoris chloronis (Say).

Sierola maculipennis Ashmead, 1887. Ent. Amer. 3: 75. ₹.

muesebecki (Loan). Ont. Host: Lopidea marginalis (Reut.).

Euphoriana muesebecki Loan, 1970. Ent. Soc. Wash., Proc. 72: 441. ‡, ठ.

occipitalis (Muesebeck). Idaho, Ariz., Calif.

Enphorus occipitalis Muesebeck, 1936. U. S. Dept. Agr., Misc. Pub. 241, p. 29..

pallidipennis Loan. Ariz.

Leiophron pallidipennis Loan, 1975 (1974). Nat. Canad. 101: 830..

provancheri Loan. Tex.

Leiophron provancheri Loan, 1975 (1974). Nat. Canad. 101: 831. ?.

rufipennis Loan. Ont., Nebr.

Leiophron mfipennis Loan, 1975 (1974). Nat. Canad. 101: 833. ¿.

scitulus (Cresson). Ill.

Euphorus scitulus Cresson, 1872. Canad. Ent. 4: 227. ₹.

trygonotylidis Loan. Ont. Host: Trygonotylus coelestialium (Kirkaldy).

Leiophron trygonotylidis Loan, 1975 (1974). Nat. Canad. 101: 834. ९, ơ.

tuberculatus (Muesebeck). N. H., Ky., Ga., Fla.

Euphorus tuberculatus Muesebeck, 1936. U. S. Dept. Agr., Misc. Pub. 241, p. 31. ๆ, §.

uniformis (Gahan). Widely distributed in U. S. Host: Lygus elisus Van Duzee, L. hesperus

Knight, L. lineolaris (P. de B.), L. pratensis (L.).

Euphoriana uniformis Gahan, 1913. U. S. Natl. Mus., Proc. 46: 433. ९, ठ.

Biology: Clancy and Pierce, 1966. Jour. Econ. Ent. 59: 853-858.

\section{Genus MICROCTONUS Wesmael}

Microctonus Wesmael, 1835. Nouv. Mem. Acad. Sci. Bruxelles 9: 54.

Type-species: Perilitus aethiops Nees. Desig. by Foerster, 1862. 
Gamosecus Provancher, 1880. Nat. Canad. 12: 167.

Type-species: Gamosecus mellinus Provancher. Desig. by Viereck, 1914.

Parasitic on adult Coleoptera, particularly Chrysomelidae and Curculionidae.

Revision: Muesebeck, 1936. U. S. Dept. Agr., Misc. Pub. 241: 14-20 (some No. Amer. spp.).

Taxonomy: Loan, 1969. Ent. Soc. Wash., Proc. 71: 404-416 (key to No. Amer. spp.).

-Shenefelt, 1969. Hym. Cat., part 4, p. 101-115 (cat. World spp.). - Loan, 1975.

Entomophaga 20: 31-41 (Haliday types).

Biology: Smith, 1953. Ohio Jour. Sci. 53: 173-176 (host list). -Loan, 1969. Ent. Soc. Wash., Proc. 71: 409-410 (host list).

aethiopoides Loan. Maine s. to Va., w. to Ont. and Ohio; Calif.; Europe. Introduced from France. Host: Hypera meles (F.), H. nigrirostris (F.), H. postica (Gyll.), H. mumicis (L.), Sitona crinitus Hbst., S. hispidulus (F.).

Microctonus aethiopoides Loan, 1975. Entomophaga 20: 33. ๆ, ठ. According to Loan (1975), this species has been incorrectly identified as aethiops (Nees); most literature on aethiops in North America apparently refers to aethiopoides Loan.

Taxonomy: Fuester, 1970. Ent. Soc. Amer., Ann. 63: 1777-1778 (larval distinction).

Biology: Loan and Holdaway, 1961. Canad. Ent. 92: 1057-1079. -Coles and Putler, 1963. Jour. Econ. Ent. 56: 609-610. - Brunson and Coles, 1968. U. S. Dept. Agr., Prod. Res. Rpt. 101, p. 4 (distr., releases, recoveries). -Day, et al., 1971. Jour. Econ. Ent. 64: 190-193 (distr.). - Dysart and Day, 1976. U. S. Dept. Agr., Prod. Res. Rpt. 167, p. 4-5 (releases and recoveries). - Abu and Ellis, 1976. Environ. Ent. 5: 1040-1042.

Morphology: Loan and Holdaway, 1961. Canad. Ent. 93: 1059-1065.

alticae Loan. Oreg. Host: Altica bimarginata Say. Microctonus alticae Loan, 1969. Ent. Soc. Wash., Proc. 71: 414. ?.

barri Loan. Idaho.

Microctonus barri Loan, 1969. Ent. Soc. Wash., Proc. 71: 413. \&.

blapstini Loan. Ont. Host: Blapstinus metallicus (F.).

Microctonus blapstini Loan, 1967. Ent. Soc. Amer., Ann. 60: 231. \&, ठ.

Biology: Loan, 1967. Ent. Soc. Amer., Ann. 60: 238-239.

carabivorus Muesebeck. Md., Va., Tenn., Mich., Wis., Iowa, Idaho. Host: Galerita sp.

Microctonus carabivorus Muesebeck, 1936. U. S. Dept. Agr., Misc. Pub. 2, p. 16.

colesi Drea. Vt., Mass., R. I., Conn., N. Y., Pa., N. J., Del., Md., W. Va., Va., N. C., Ohio. Host: Hypera postica (Gyll.).

Microctonus colesi Drea, 1968. Ent. News 79: 98. १, ठ.

Taxonomy: Fuester, 1970. Ent. Soc. Amer., Ann. 63: 1777-1778 (larval distinction).

Biology: Brunson and Coles, 1968. U. S. Dept. Agr., Prod. Res. Rpt. 101, p. 4-5 (releases, recoveries as Microctonus sp.). - Day, et al., 1971. Jour. Econ. Ent. 64: 191-193 (distr.). -Dysart and Day, 1976. U. S. Dept. Agr., Prod. Res. Rpt. 167, p. 4 (releases and recoveries).

crepidoderae Loan. Ont. Host: Crepidodera spp.

Microctonus crepidoderae Loan, 1967. Ent. Soc. Amer., Ann. 60: 230. $\subsetneq$, ठ.

Biology: Loan, 1967. Ent. Soc. Amer., Ann. 60: 239-240.

cucumeridis Loan. Ont. Host: Epitrix cucumeris (Harr.).

Microctonus cucumeridis Loan, 1969. Ent. Soc. Wash., Proc. 71: 412. F.

disonychae Loan. Ont. Host: Disonycha triangularis (Say).

Microctonus disonychae Loan, 1967. Ent. Soc. Amer., Ann. 60: 233. ๆ, ð.

Biology: Loan, 1967. Ent. Soc. Amer., Ann. 60: 237-238.

eleodis (Viereck). Mich., Minn.; Sask. s. to Kans. and N. Mex., w. to Alta., Oreg. and Calif.

Host: Eleodes extricata (Say), E. hispilabris (Say), E. obsoleta (Say), E. opaca (Say), E. 
suturalis (Say), E. tricostata (Say), E. vandykei Blaisdell, Embaphion muricatum (Say), E. planum Horn.

Perilitus eleodis Viereck, 1913. U. S. Natl. Mus., Proc. 44: 561.,$~ \delta$.

epitricis (Viereck). N. J. s. to N. C., w. to Ont., Kans., and La.; B. C. Host: Epitrix cucumeris (Harr.), E. fasciata Blatchley, E. hirtipennis (Melsh.).

Perilitus epitricis Viereck, 1912. U. S. Natl. Mus., Proc. 42: 625. $\subsetneq$, ठ.

Biology: Loan, 1967. Ent. Soc. Amer., Ann. 60: 236-237.

gastrophysae (Ashmead). D. C., Va., S. C. Host: Gastrophysa cyanea Melsh., G. viridula (DeGeer).

Perilitus gastrophysae Ashmead, 1889 (1888). U. S. Natl. Mus., Proc. 11: 641..

glyptosceli Loan, Klein and Coppel. Wis. Host: Glyptoscelis pubescens (F.).

Microctonus glyptosceli Loan, Klein and Coppel, 1969. Ent. Soc. Wash., Proc. 71: 230. ^, ઠ. invictus Muesebeck. Ariz., Calif. Host: Trigonoscuta sp.

Microctonus invictus Muesebeck, 1961. Brooklyn Ent. Soc., Bul. 56: 59. \&, ð.

loani Mason. N. B., Que., Ont. Host: Altica ambiens alni Harr., A. corni Woods, Calligrapha philadelphica (L.).

Microctonus loani Mason, 1968. Canad. Ent. 100: 726. \&.

longitarsi Loan. Ont. Host: Longitarsus melanumıs (Melsh.).

Microctonus longitarsi Loan, 1969. Ent. Soc. Wash., Proc. 71: 411., o.

mellinus (Provancher). Mass., Md., D. C., Va., Ga., Fla., Mich., Tenn., Canada.

Gamosecus mellinus Provancher, 1880. Nat. Canad. 12: 168. $\subsetneq$.

muesebecki Loan. Ont. Host: Paria thoracica (Melsh.).

Microctonus muesebecki Loan, 1967. Ent. Soc. Amer., Ann. 60: 234. + , o.

Biology: Loan, 1967. Ent. Soc. Amer., Ann. 60: 240.

nigritus (Provancher). N. B., Que., Mich., Man. Host: Altica ambiens alni (Harr.).

Perilitus nigritus Provancher, 1888. Addit. Corr. Faune Ent. Canada Hym., p. 379. ठ.

pachylobii Muesebeck. Ga., Fla., Ark., La. Host: Pachylobius picivomis (Germar).

Microctonus pachylobii Muesebeck, 1961. Brooklyn Ent. Soc., Bul. 56: 58. ๆ, ठ.

psylliodis Loan. Ont. Host: Psylliodes punctulata Melsh.

Microctonus psylliodis Loan, 1969. Ent. Soc. Wash., Proc. 71: 410. ๆ, ठ.

pusillae Muesebeck. Colo., Ariz., Idaho, Wash. Host: Epitrix subcrinita Lec., Phyllotreta pusilla Horn.

Microctonus pusillae Muesebeck, 1936. U. S. Dept. Agr., Misc. Pub. 241, p. 20. ๆ, ठ́.

Biology: Chittenden and Marsh, 1920. U. S. Dept. Agr., Bul. 902, p. 13 (as Perilitus epitricis Viereck).

sitonae Mason. Ont. Host: Sitona scissifrons Say.

Microctonus sitonae Mason, 1960. Canad. Ent. 92: 436. $\subsetneq$, ठ.

Biology: Loan, 1963. Ent. Soc. Amer., Ann. 56: 605-611.

stelleri Loan. U. S. (?); France. Liberated in Vt., Mass., N. Y., Pa., N. J., Del., Md., Va., Mich., Ill., Ky., Wis. and Colo. but not known to be established. Introduced from France. Host: Hypera postica (Gyll.).

Microctonus stelleri Loan, 1972. Canad. Ent. 104: 1446. + , రั.

Biology: Drea, et al., 1972. Canad. Ent. 104: 1447-1456. - Dysart and Day, 1976. U. S. Dept. Agr., Prod. Res. Rpt. 167, p. 6 (releases).

vittatae Muesebeck. U. S., south. Canada; Hawaii, Japan, Korea. Host: Phyllotreta bipustulata (F.), P. cruciferae (Goeze), P. sinuata (Steph.), P. striolata (F.).

Microctonus vittatae Muesebeck, 1936. U. S. Dept. Agr., Misc. Pub. 241, p. 19. $\subsetneq$.

Biology: Nagasawa, 1943. Mushi 15: 103-107. - Nagasawa, 1943. Shokubutsu Oyobi Dobutsu 11: 460-466. - Nagasawa, 1947. Seibutsu 2: 48-52. - Nagasawa, 1948. Bul. Takarazuka Insectarium 58, 18 p. - Smith and Peterson, 1950. Jour. Econ. Ent. 43: 581-585. - Smith, 1952. Univ. Calif. Pub. Ent. 9: 315-344. -Loan, 1967. Ent. Soc. Amer., Ann. 60: 236. 
Nomen Nudum in Microctonus Wesmael

Microctonus dorsalis Ashmead, 1895. In Slosson, Ent. News 6: 317.

Genus MYIOCEPHALUS Marshall

Myiocephalus Marshall, 1897. In Andre, Spec. Hym. Eur. Alg., v. 5 bis, p. 218.

Type-species: Microctonus boops Wesmael. Monotypic.

Spilomma Morley, 1909. Ent. Monthly Mag. 45: 211.

Type-species: Spilomma falconivibrans Morley. Monotypic.

Hosts for this genus are not known, but one European species was associated with nests of the ant genus Formica.

Taxonomy: Muesebeck, 1936. U. S. Dept. Agr., Misc. Pub. 241: 21. - Shenefelt, 1969. Hym. Cat., part 4, p. 115-116 (cat. World spp.).

boops (Wesmael). Holarctic.

Microctonus boops Wesmael, 1835. Nouv. Mem. Acad. Sci. Bruxelles 9: 59. ㅇ.

Gamosecus laticeps Provancher, 1886. Addit. Corr. Faune Ent. Canada Hym., p. 126..

Aphidius hedini Fahringer, 1929. Arkiv. fur Zool. 21 (A): 2. ठ.

Taxonomy: Muesebeck, 1936. U. S. Dept. Agr., Misc. Pub. 241, p. 22. -Stary, 1959. Beitr.

Ent. 9: 187-188.

\section{Genus PERILITUS Nees}

Perilitus Nees, 1818. Nov. Acta Acad. Caes. Leop. Car. 9: 302.

Type-species: Bracon rutilis Nees. Desig. by Westwood, 1840.

Dinocampus Foerster, 1862. Naturh. Ver. Rheinlande, Verh. 19: 252.

Type-species: Bracon terminatus Nees. Orig. desig.

Species in this genus are parasitic on adult Coleoptera, particularly Coccinellidae and Chrysomelidae. Tobias (1965) treats Dinocampus as a distinct genus.

Taxonomy: Muesebeck, 1936. U. S. Dept. Agr., Misc. Pub. 241, p. 11-13 (No. Amer. spp.).

-Tobias, 1965. Ent. Obozr. 44: 842 (restored Dinocampus). - Shenefelt, 1969. Hym. Cat., part 4, p. 30-33, 117-122 (cat. World spp.).

Biology: Jackson, 1928. Zool. Soc. London, Proc. 1928: 597-630 (biol. of mutilis (Nees) in Europe). - Smith, 1953. Ohio Jour. Sci. 53: 175-176 (host list).

coccinellae (Schrank). Cosmopolitan. Host: Adonia variegata (Goeze), Coccinella californica Mann., C. novemnotata Hbst., C. quinquepunctata L., C. septempunctata L., C. trifascicta juliana Muls., Coleomegilla maculata fuscilabris (Muls.), C. m. maculata (DeGeer), C. m. lengi Timb., Cycloneda sanguinea (L.), Halyzia quattuordecimguttata (L.), Hippodamia convergens Guer.

Ichneumon coccinellae Schrank, 1802. Fauna Boica, v. 2, p. 310..

Bracon terminatus Nees, 1812 (1811). Mag. Gesell. Naturf. Freunde Berlin 5: 26. ๆ, ठ.

Euphorus sculptus Cresson, 1872. Canad. Ent. 4: 227. ․

Centistes americana Riley, 1888. U. S. Dept. Agr., Insect Life 1: 103..

Biology: Cushman, 1913. Ent. Soc. Wash., Proc. 15: 153-155. - Stich, 1929. Ztschr. f. Wiss. Insektenbiol. 24: 91-95. - Ibrahim, 1955. Soc. Ent. d' Egypte, Bul. 39: 414-416. - Hudon, 1959. Canad. Ent. 91: 63-64. - Walker, 1961. Ent. Monthly Mag. 97: 240-244. - Ford, 1971. Ent. Gaz. 22: 2. - Richerson and DeLoach, 1972. Ent. Soc. Amer., Ann. 65: 834-839.

-Benton and Crump, 1975. N. Y. Ent. Soc., Jour. 33: 60-63.

pyri (Viereck). Conn., N. J.

Dinocampus pyri Viereck, 1917 (1916). Conn. State Geol. and Nat. Hist. Survey, Bul. 22: 225.. .

Nomen Nudum in Perilitus Nees

Perilitus hopkinsi Ashmead, 1911. In Viereck, Ent. Soc. Wash., Proc. 13: 95. 


\section{Genus PERISTENUS Foerster}

Peristenus Foerster, 1862. Naturh. Ver. Rheinlande, Verh. 19: 25. Type-species: Microctonus barbiger Wesmael. Orig. desig.

Parasites of Miridae. In all known examples, the early instar nymph is parasitized and the mature parasite larva emerges from either the mature host nymph or adult.

Revision: Loan, 1974. Roy. Ent. Soc. London, Trans. 126: 207-222 (Eur. spp.). -Loan, 1975 (1974). Nat. Canad. 101: 835-859 (No. Amer. spp.).

Taxonomy: Loan, 1975 (1974). Nat. Canad. 101: 822-824.

Biology: Loan and Bilewicz-Pawinska, 1973. Environ. Ent. 2: 271-278. alni Loan. Ont.

Peristenus alni Loan, 1975 (1974). Nat. Canad. 101: 841. ㅇ.

bicolor Loan. Ont. Host: Slaterocorpis sp., S. atritibialis (Knight), S. brevitatus (Knight), S. stygicus (Say).

Peristenus bicolor Loan, 1975 (1974). Nat. Canad. 101: 852. ․, ð.

brimleyi Loan. Alta., B. C.

Peristenus brimleyi Loan, 1975 (1974). Nat. Canad. 101: 842. ९, ठे.

chlamydatidis Loan. Sask. Host: Chlamydatus sp.

Peristenus chlamydatidis Loan, 1975 (1974). Nat. Canad. 101: 848. ․

clematidis Loan. Ont. Host: Halticus uhleri (Knight).

Peristenus clematidis Loan, 1975 (1974). Nat. Canad. 101: 857. \&, ठ.

dicyphovora Loan. Ont.

Peristenus dicyphovora Loan, 1975 (1974). Nat. Canad. 101: 851. ९, ठ.

dumestris Loan. Ont. Host: Phytocoris sp.

Peristenus dumestris Loan, 1975 (1974). Nat. Canad. 101: 841.,$~ ð$.

juniperinus Loan. Ont. Host: Dichroosytus tinctipennis Knight.

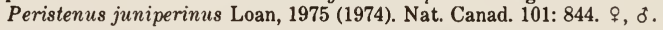

juniperoides Loan. Ont. Host: Bolteria luteifrons Knight.

Peristenus juniperoides Loan, 1975 (1974). Nat. Canad. 101: 844. ๑, ठ.

laricinae Loan. Ont.

Peristenus laricinae Loan, 1975 (1974). Nat. Canad. 101: 848. ९, ð.

levifrons (Muesebeck). Colo.

Euphorus levifrons Muesebeck, 1936. U. S. Dept. Agr., Misc. Pub. 241, p. 32. ð.

lonicerae Loan. Ont.

Peristenus lonicerae Loan, 1975 (1974). Nat. Canad. 101: 851. + , o.

nixoni Loan. Ont. Host: Neoborus canadensis Van Duzee.

Peristenus nixoni Loan, 1975 (1974). Nat. Canad. 101: 837. ‥

pallipes (Curtis). Holarctic. Host: Adelphocoris lineolatus (Goeze), A. rapidus (Say), Calocoris norvegicus (Gmelin), Chlamydatus sp., Labops hirtus Knight, Leptopterma dolobrata (L.), Lygus elisus Van Duzee, L. hesperus Knight, L. lineolaris (P. de B.).

Leiophron pallipes Curtis, 1833. Brit. Ent., v. 10, no. 476. + , ठ.

Microctonus barbiger Wesmael, 1835. Nouv. Mem. Acad. Sci. Bruxelles 9: 69. ‡, ठ.

Euphorus mellipes Cresson, 1872. Canad. Ent. 4: 227. o.

Microctonus pinctatus Provancher, 1883. Nat. Canad. 14: 17. ठ.

Euphorus tuberculifer Marshall, 1887. Ent. Soc. London, Trans. 1887: 57. ठ.

Brachistes nocturnus Viereck, 1905. Kans. Acad. Sci., Trans. 19: 279. ð.

Biology: Brindley, 1939. Roy. Ent. Soc. London, Proc., Ser. A: Gen. Ent. 14: 51-56. - Loan, 1965 (1964). Ent. Soc. Ont., Proc. 95: 115-121. - Lim and Stewart, 1976. Canad. Ent. 108: 815-821.

pini Loan. Ont.

Peristenus pini Loan, 1975 (1974). Nat. Canad. 101: 840. ठ.

plagiognathi (Loan). Ont. Host: Plagiognathus albonotatus Knight, P. cornicola Knight.

Leiophron plagiognathi Loan, 1966. Ohio Jour. Sci. 66: 89. + , ठ. 
Biology: Loan, 1966. Ohio Jour. Sci. 66: 91-94.

pseudopallipes (Loan). Northeast. No. Amer. Host: Lygus lineolaris (P. de B.), L. vanduzeei Knight.

Leiophron pseudopallipes Loan, 1970 (1969). Ent. Soe. Ont., Proc. 100: 189. \&, ठ.

Biology: Loan, 1970 (1969). Ent. Soc. Ont., Proc. 100: 192-193. - Lim and Stewart, 1976. Canad. Ent. 108: 815-821.

reidi Loan. Ont. Host: Plagiognathus sp., P. nigronitens (Knight).

Peristemus reidi Loan, 1975 (1974). Nat. Canad. 101: 846. $\%$, o.

salixidis Loan. Ont.

Peristenus salixidis Loan, 1975 (1974). Nat. Canad. 101: 846. ․

solidaginis Loan. Ont. Host: Slaterocoris atritibialis (Knight), S. breviatus (Knight), $S$. stygieus (Say).

Peristemus solidaginis Loan, 1975 (1974). Nat. Canad. 101: 848. ९, ð.

stygicus Loan. Calif; Europe. Introduced from France and Turkey. Host: Lygus hesperus Knight.

Peristenus stygicus Loan, 1973. Environ. Ent. 2: 272. ㅇ, ơ.

Biology: Drea, et al., 1973. Environ. Ent. 2: 278-280. - Butler and Wardecker, 1974. Jour.

Econ. Ent. 67: 132-133. - Van Steenwyk and Stern, 1976. Environ. Ent. 5: 931-934. - Van

Steenwyk and Stern, 1977. Jour. Econ. Ent. 70: 66-69.

tacamahacae Loan. Ont., N. S.

Peristenus tacamahacae Loan, 1975 (1974). Nat. Canad. 101: 857. ठ.

vitidis Loan. Ont. Host: Lygocoris vibruni (Knight), Taedia scrupeus (Say).

Peristemus vitidis Loan, 1975 (1974). Nat. Canad. 101: 839. ๆ, ơ.

wallisi Loan. B. C.

Peristenus uallisi Loan, 1975 (1974). Nat. Canad. 101: 859. , ઠ.

zingiberis Loan. Ont. Host: Macrotylus sexguttatus (Prov.).

Peristenus zingiberis Loan, 1975 (1974). Nat. Canad. 101: 852. o.

\section{Genus ROPALOPHORUS Curtis}

Ropalophorus Curtis, 1837. Guide Arr. Brit. Ins., p. 118.

Type-species: Microctonus clavicornis Wesmael. Orig. desig.

Rhopalophorus Blanchard, 1840. Hist. Nat. Anim. Articules 3: 331. Unjustified emendation; later incorrectly considered preoccupied by Rhopalophora Serville, 1834.

Eustalocerus Foerster, 1862. Naturh. Ver. Rheinlande, Verh. 19: 251. N. name for Rhopalophorus.

Parasites on adult bark beetles.

Taxonomy: Shenefelt, 1960. Ent. Soc. Amer., Ann. 53: 542-546. - Shenefelt, 1969. Hym. Cat., part 4, p. 124-125 (cat. World spp.).

wisconsinensis Shenefelt. Wis.

Ropalophorus wisconsinensis Shenefelt, 1960. Ent. Soc. Amer., Ann. 53: 543. \&.

\section{Genus STREBLOCERA Westwood}

Streblocera Westwood, 1833. Phil. Mag. and Jour. Sci. 3: 342.

Type-species: Streblocera fulviceps Westwood. Monotypic.

Eutanycerus Foerster, 1862. Naturh. Ver. Rheinlande, Verh. 19: 251.

Type-species: Eutanycerus halidayanus Foerster. Orig. desig.

Lecythodella Enderlein, 1912. Arch. f. Naturgesch. 78 (A) (2): 41.

Type-species: Lecythodella garleppi Enderlein. Orig. desig.

Cosmophoridia Hedqvist, 1955. Ent. Tidskr. 76: 93.

Type-species: Cosmophorus flaviceps Marshall. Orig. desig.

Revision: Watanabe, 1942. Insecta Matsumurana 16: 1-12 (World spp.). -DeSaeger, 1942.

Rev. Zool. Bot. Africaines 35: 376-385 (African spp.). - DeSaeger, 1946. Exploration Parc

Nat. Alert, fase. 50, p. 144-178 (African spp.). - Capek and Snoflak, 1959. Acta Soc. Ent.

Cech. 56: 343-354 (Eur. spp.). 
Taxonomy: Muesebeck, 1936. U. S. Dept. Agr., Misc. Pub. 241, p. 13-14. -Capek and Snoflak, 1959. Acta Soc. Ent. Cech. 56: 344. - Shenefelt, 1969. Hym. Cat., part 4, p. 125-129 (cat. World spp.).

pulvillicornis Walley and MacKay. Que., Ariz. Streblocera pulvillicornis Walley and MacKay, 1963. Canad. Ent. 95: 999..

\section{Genus SYNTRETUS Foerster}

Syntretus Foerster, 1862. Naturh. Ver. Rheinlande, Verh. 19:251.

Type-species: Microctonus vernalis Wesmael. Orig. desig.

Host records indicate that species of this genus are parasitic on adult Ichneumonidae and Bombidae.

Taxonomy: Muesebeck, 1936. U. S. Dept. Agr., Misc. Pub. 241, p. 22-25. -Shenefelt, 1969. Hym. Cat., part 4, p. 130-133 (cat. World spp.).

Biology: Cole, 1959. Ent. Monthly Mag. 95: 18-21. -Alford, 1968. Roy. Ent. Soc. London, Trans. 120: 375-393.

brevicornis Muesebeck. Pa., Del., N. C., Wis., Ill.

Snytretus brevicornis Muesebeck, 1936. U. S. Dept. Agr., Misc. Pub. 241, p. 24., ठ . venustus Muesebeck. Ala.

Syntretus venustus Muesebeck, 1936. U. S. Dept. Agr., Misc. Pub. 241, p. 23. ؟.

vigilax (Provancher). Que., N. H., N. Y., Ont., Minn., Colo., Calif.

Gamosecus vigilax Provancher, 1880. Nat. Canad. 12: 167. $\subsetneq$, ठ.

NOMEN Nudum in SYNTRETUS Foerster

Microctonus americanus Ashmead, 1900. In Smith, Insects N. J., p. 588 (teste Shenefelt, 1969.

Hym. Cat., part 4, p. 130).

\section{Genus WESMAELIA Foerster}

Wesmaelia Foerster, 1862. Naturh. Ver. Rheinlande, Verh. 19: 251.

Type-species: Wesmaelia pendula Foerster. Orig. desig.

The single species in this genus is parasitic on nymphs and adults of Nabidae.

Taxonomy: Muesebeck, 1936. U. S. Dept. Agr., Misc. Pub. 241, p. 20-21. - Shenefelt, 1969.

Hym. Cat., part 4, p. 134-135 (references).

pendula Foerster. Holarctic. Host: Nabis alternatus Parshley, N. americoferus Carayon, $N$. capsiformis Germar.

Wesmaelia pendula Foerster, 1862. Naturh. Ver. Rheinlande, Verh. 19: 251.

Wesmaelia cremasta Marshall. 1872. Ent. Monthly Mag. 8: 257. \&.

Wesmaelia americana Myers, 1917. U. S. Natl. Mus., Proc. 53: 293. $\leftarrow$, ઠ.

Wesmaelia asiatica Shestakov, 1932. Zool. Anz. 99: 261.

Biology: Hendrick and Stern, 1970. Ent. Soc. Amer., Ann. 63: 389. -Stoner, 1973. Ent. Soc.

Amer., Ann. 66: 471-473.

\section{TRIBE COSMOPHORINI}

Host records indicate that species are solitary endoparasites of adult Coleoptera. This tribe is composed of one Holarctic genus which has been placed in various groups, including its own subfamily. Most authors have placed it in the Euphorinae where it probably represents the most highly specialized group of the Braconidae.

\section{Genus COSMOPHORUS Ratzeburg}

Cosmophorus Ratzeburg, 1848. Ichn. d. Forstins., v. 2, p. 71.

Type-species: Cosmophorus klugii Ratzeburg. Monotypic.

Cosmophorus subg. Cosmophorinus Viereck, 1925. Canad. Ent. 57: 73.

Type-species: Cosmophomis hopkinsii Ashmead. Desig. by Muesebeck and Walkley, 1951. 
Revision: Hedqvist, 1955. Ent. Tidskr. 76: 92-98 (Eur. spp.). -Capek, 1958. Acta Ent. Mus. Natl. Pragae 32: 151-169 (Eur. spp.).

Taxonomy: Tobias, 1966. Ent. Obozr. 45: 612-615. -Shenefelt, 1969. Hym. Cat., part 4, p. 135-137 (cat. World spp.), - Loan and Matthews, 1973. Ent. Soc. Wash., Proc. 75: 205-208 (key to No. Amer. spp.).

capeki Loan and Matthews. N. Y. Host: Pityophthorus rhois Swaine.

Cosmophorus capeki Loan and Matthews, 1973. Ent. Soc. Wash., Proc. 75: 205. \&, ठ.

dendroctoni Viereck. N. B. Host: Dendroctonus simplex Lec.

Cosmophomis (Cosmophorinus) dendroctoni Viereck, 1925. Canad. Ent. 57: 73. ठ'.

hopkinsii Ashmead. N. H., N. Y., W. Va. Host: Pityokteines sparsus (Lec.), Pityophthomus sp., P. balsameus Black., Polygra phus poligraphus (L.).

Cosmophomis hopkinsii Ashmead, 1896. Amer. Ent. Soc., Trans. 23: 216. ๆ, ठ.

hypothenemi Brues. $\mathrm{Pa}$. Host: Hypothenemus sp.

Cosmophorus hypothememi(!) Brues, 1908. Wis. Nat. Hist. Soc., Bul. 6: 162. 9.

pityophthori Rohwer. Colo., Idaho, Wash., Calif. Host: Pityophthorus nitidulus (Mann.).

Cosmophomes pityophthori Rohwer, 1917. U. S. Natl. Mus., Proc. 53: 163. ₹, ơ.

\section{Family APHIDIIDAE}

By Paul M. Marsh

The family Aphididae is the only group in the parasitoid Hymenoptera (other than the chalcid Aphelininae genera Aphelinus, Mesidia and Mesidiopsis) which has aphids as its primary hosts. The family is closely related to the subfamily Euphorinae of the Braconidae and, until recently, has been classified as a subfamily of the Braconidae. However, most workers in this group classify the Aphidiidae as a distinct family, and I have chosen to follow this arrangement.

Two catalogs to the species of the World have recently been published: M. Mackauer and P. Stary (1967. Index of Entomophagous Insects; Hym. Ichneumonoidea, World Aphidiidae. Le Francois, Paris. 195 pp.), and M. Mackauer (1968. In Ferriere and van der Vecht (ed.), Hymenopterorum Catalogus (nova editio), part 3, Aphidiidae. Junk, The Hague. 103 pp.). Except for a few cases, I have followed the systematic arrangement of Mackauer (1968) in preparing the North American catalog which follows. Both catalogs mentioned above contain a complete list of references to taxonomy and biology and a complete list of aphid hosts for each species. In the North American catalog below, I have listed only selected references, and the reader is referred to the above publications for further references. Also, only those aphid hosts which occur in North America have been listed for each parasite species.

Revision: Gahan, 1911. Md. Agr. Expt. Sta., Bul. 152: 147-200 (No. Amer. forms). - Smith, 1944. The Aphidiinae of North America. Ohio State Univ. Contr. Zool. Ent. No. 6, xii + 154 pp. (No. Amer. forms).

Taxonomy: Stary, 1960. Acta Soc. Ent. Cech. 57: 238-252 (genera). -Mackauer, 1961. Beitr. z. Ent. 11: 96-154 (review British Museum types). -Mackauer, 1961. Beitr. z. Ent. 11: 792-803 (subfamilies, tribes, genera). - Mackauer, 1963. Canad. Ent. 95: 921-935 (review Baker types). - Mackauer and Stary, 1967. Index World Aphidiidae, pp. 1-195 (cat. World spp. and hosts). - Mackauer, 1968. Hym. Cat., part 3, pp. 1-103 (cat. World spp. and hosts). -Marsh, 1971. Ent. Soc. Amer., Ann. 64: 848-849 (key to No. Amer. genera).

Biology: Stary, 1966. Aphid Parasites of Czechoslovakia. Junk, The Hague. 242 pp. (particularly chapters VI-XIV, pp. 96-222 for a general summary of aphid parasite biology).

\section{SUBFAMILY EPHEDRINAE}

All species of this subfamily are solitary endoparasites of adult and larval aphids. Pupation is inside the mummified host aphid. The subfamily is cosmopolitan in distribution.

\section{Genus EPHEDRUS Haliday}

Aphidius subg. Ephedrus Haliday, 1833. Ent. Mag. 1: 261, 485.

Type-species: Bracon plagiator Nees. Monotypic. 
Elassus Wesmael, 1835. Nouv. Mem. Acad. Sci. Bruxelles 9: 85.

Type-species: Aphidius parcicomis Nees. Monotypic.

Revision: Gahan, 1911. Md. Agr. Expt. Sta., Bul. 152: 157-159 (No. Amer. spp.). - Stelfox, 1941. Roy. Irish Acad., Proc. 46: 125-142 (Irish spp.). - Smith, 1944. Aphidiinae of North America, pp. 15-21 (No. Amer. spp.). - Stary, 1958. Acta Faun. Ent. Mus. Natl. Pragae 3: 61-85 (Eur. spp., fossil spp.). - Stary, 1962. Opusc. Ent. 27: 87-98 (Eur. spp.). - Liu, 1968. Jour. Taiwan Agr. Res. 17: 35-48 (Taiwan spp.). - Takada, 1968. Insecta Matsumurana 30: 70-77 (Jap. spp.).

Taxonomy: Mackauer, 1961. Beitr. z. Ent. 11: 794, 798-799 (phylogeny, systematic position). -Mackauer, 1968. Hym. Cat., part 3, pp. 9-13 (cat. World spp.).

Biology: Mackauer and Stary, 1967. Index World Aphidiidae, pp. 15-21 (host list).

Morphology: Ivanova-Kasas, 1956. Ent. Obozr. 35: 245-261 (embryology). -Sedlag, 1956.

Deut. Zool. Gesell., Verh. 1956: 356-361 (female genitalia). - Eastop, 1966. Roy. Ent. Soc.

London, Proc. (A) 41: 42-44 (mouthparts).

brevis Stelfox. Canada, Colo., Alaska; Europe. Parasitic on aphids associated with Betula and Aluus.

Ephedrus brevis Stelfox, 1941. Roy. Irish Acad., Proc. 46: 140. ๆ, o.

Ephedrus picticorn is Stelfox, 1941. Roy. Irish Acad., Proc. 46: 138. ๆ, ठ.

californicus Baker. N. B., Que., Ont., Md., Mich., Alta., Idaho, Utah, Ariz., B. C., Oreg., Calif. Host: Acyrthosiphon pisum (Harr.), Dactyuotus ambrosiae (Thom.), Macrosiphum agrimoniellum (Ckll.), M. euphorbiae (Thomas), M. rosae (L.), Rhopalom yzus grabhami (Ckll.).

Ephedrus californicus Baker, 1909. Pomona Jour. Ent. 1: 23. ․

Ephedrus nigricornis Gahan, 1911. Md. Agr. Expt. Sta., Bul. 152: 159..

Ephedrus aestivalis Viereck, 1915. Calif. State Comm. Hort., Monthly Bul, 4: 286. ․ N. syn.

Taxonomy: Mackauer, 1963. Canad. Ent. 95: 923-924. - Mackauer and Finlayson, 1967. Canad.

Ent. 99: 1072-1074.

incompletus (Provancher). Ont., N. B. s. to Fla., w. to Kans.; Oreg. Host: Acyrthosiphon dirhodum (Wlkr.), A phis nasturtii Kalt., Aulacorthum sp., Dactynotus erigeronensis (Thom.), D. illini (H. and F.), D. rudbeckice (Fitch), Lipaphis erysimi (Kalt.), Macrosiphum agrimoniellum (Ckll.), M. euphorbiae (Thom.), M. liriodendri (Monell), $M$. rosae (L.), Microparsus variabilis Patch, Myzus cerasi (F.), M. certus (Wlkr.), $M$. persicae (Sulzer), Nercorylobium carpinicolens (Patch). This species is occasionally confused with Ephedrus califormicus Baker.

Perilitus incompletus Provancher, 1886. Addit. Corr. Faune Ent. Canada Hym., p. 126. o. Ephedrus incompletus Provancher, 1886. Addit. Corr. Faune Ent. Canada Hym., p. 156. $\subsetneq$. Scotioneurus dives Provancher, 1886. Addit. Corr. Faune Ent. Canada Hym., p. 157. ơ. Ephedrus rosae Withington, 1909. Kans. Acad. Sci., Trans. 22: 318. ๆ, ठ.

Biology: Withington, 1909. Kans. Acad. Sci., Trans. 22: 318-321. - Wheeler, 1923. Ent. Soc. Amer., Ann. 16: 1-29.

lacertosus (Haliday). Canada, Md., Mich., Colo., Alaska, Wash., Oreg.; Mex.; Europe. Host: Amphorophora agathonica Hottes, Macrosiphoniella absinthii (L.), Macrosiphum agrimoniellum (Ckll.), M. rosae (L.), Masonaphis maxima (Mason).

Aphidius (Ephedrus) lacertosus Haliday, 1833. Ent. Mag. 1: 486. ?, o.

Ephedrus lacertosus var. homostigma Fahringer, 1934. Arkiv f. Zool. 27(A): 13. ठ. Ephedrus muesebecki Smith, 1944. Aphidiinae of North America, p. 20. ๆ, ठ์.

Taxonomy: Mackauer, 1961. Beitr. z. Ent. 11: 99. - Sharma and Subba Rao, 1965 (1964). Indian Jour. Ent. 26: 458-459.

Biology: Dill, 1937. Naturf. Gesell. Aargau, Mitt. 20: 157-240.

palaestinensis Mackauer. Calif.?; Eastern Mediterranean. Liberated in Calif. but not known to be established. Host: Aph is craccivora Koch, A. gossypii Glover, Rhopalosiphum maidis (Fitch), R. padi (L.).

Ephedrus (Ephedrus) palaestimensis Mackauer, 1959. Beitr. z. Ent. 9: 867. ?, ơ. 
persicae Froggatt. Nearly world-wide distribution. Host: Aphis craccivora Koch, A. fabae Scop., A. gossypii Glover, A. pomi DeGeer, Brachycaudus cardui (L.), B. helichrysi (Kalt.), Brevicoryne brassicae (L.), Capitophorus sp., Dysaphis crataegi (Kalt.), D. plantaginea (Pass.), Hyadaphis foeniculi (Pass.), Macrosiphum euphorbiae (Thomas), $M$ yzus cerasi (F.), M. ligustri (Mosley), M. persicae (Sulzer), $M$. varians Dav., Phorodon humuli (Schrank), Rhopalosiphum maidis (Fitch), R. padi (L.), Toxoptera aurantii (Fonsc.), Vesiculaphis caricis (Full.).

Ephedrus persicae Froggatt, 1904. Agr. Gaz. N. S. W. 15: 611. ?.

Ephedrus nevadensis Baker, 1909. Pomona Jour. Ent. 1: 23., o.

Ephedrus nitidus Gahan, 1917. U. S. Natl. Mus., Proc. 53: 195..

Ephedrus vidali Quilis, 1931. Eos 7: 72. .

Ephedrus pulchellus Stelfox, 1941. Roy. Irish Acad. Sci., Proc. 46: 139. 9.

Ephedrus interstitialis Watanabe, 1941. Insecta Matsumurana 15: 139..

Ephedrus impressus Granger, 1949. Inst. Sci. Madagascar, Mem. (A) 2: 412. , ठ .

Ephedrus (Ephedrus) holmani Stary, 1958. Acta Faun. Ent. Mus. Natl. Pragae 3: 68. \&, o.

Taxonomy: Mackauer, 1962. Beitr. z. Ent. 12: 632-633. -Mackauer, 1963. Ztschr. f. Angew.

Ent. 52: 343-354. - Mackauer, 1963. Canad. Ent. 95: 924.

Biology: Stary, 1962. Entomophaga 7: 91-100. - Mackauer, 1965. Canad. Ent. 97: 1019-1021. plagiator (Nees). Calif. ?, Ill. ?; Palearctic. Liberated in Calif. and Ill. but not known to be established. Introduced from Taiwan and Japan. Host: Macrosiphum rosae (L.), Rhopalosiphum maidis (Fitch).

Bracon plagiator Nees, 1811. Gesell. Naturf. Freunde Berlin, Verh. 5: 17. \&, ઠ.

Aphidius parcicornis Nees, 1834. Hym. Ichn. Aff. Monog., v. 1, p. 16. \&, o.

E phedrus japonicus Ashmead, 1906. U. S. Natl. Mus., Proc. 30: 187. $\uparrow, ~ §$.

Biology: Jackson, et al., 1974. Environ. Ent. 3: 618-620.

\section{Genus TOXARES Haliday}

A phidius subg. Trionyx Haliday, 1833. Ent. Mag. 1: 261, 487. Preocc. by Geoffroy (1809) and Oken (1816).

Type-species: Aphidius (Trionyx) deltiger Haliday. Monotypic.

Toxares Haliday, 1840. In Westwood, Intro. Mod. Class. Ins., vol. 2, Generic synopsis. p. 65. New name for Trionyx Haliday.

Teronyx Haldeman, 1842. Acad. Nat. Sci. Phila., Proc. 1: 191. New name for Trionyx Haliday.

A Holarctic genus composed of two species, only one of which is found in North America. The host range is not clearly defined but it is possibly restricted to the subfamily Aphidinae.

deltiger (Haliday). Canada. Host: Acyrthosiphon caraganae (Cholod.), Dysaphis plantaginea (Pass.), Myzus certus (Wlkr.), M. persicae (Sulzer).

Aphidius (Trionyx) deltiger Haliday, 1833. Ent. Mag. 1: 487. ㅇ, o.

Ephedrus flaveolus Gyorfi, 1958. Acta Zool. Hung. 4: 131. ठ。.

\section{SUBFAMILy PRAINAE}

\section{Genus PRAON Haliday}

A phidius subg. Praon Haliday, 1833. Ent. Mag. 1: 261, 483.

Type-species: Bracon exoletus Nees. Monotypic.

Bracon subg. Achoristus Ratzeburg, 1852. Ichn. d. Forstins., v. 3, p. 31.

Type-species: Bracon (Achoristus) aphidiiformis Ratzeburg. Monotypic.

A phidaria Provancher, 1886. Addit. Corr. Faune Ent. Canada Hym., p. 152.

Type-species: Aphidaria simulans Provancher. Monotypic.

Species in this genus are solitary endoparasites of larval and adult aphids. Pupation is in a separate cocoon underneath the dead host aphid. The genus occurs in the Holarctic and Oriental Regions. 
Revision: Gahan, 1911. Md. Agr. Expt. Sta., Bul. 152: 161-166 (No. Amer. spp.). - Smith, 1944. Aphidiinae of North America, pp. 22-32 (No. Amer. spp.). - Mackauer, 1959. Beitr. z. Ent. 9: 810-865. (Eur. spp.).

Taxonomy: Mackauer, 1964. Beitr. z. Ent. 14: 685-687. - Mackauer, 1968. Hym. Cat., part 3, pp. 14-21 (cat. World spp.).

Biology: Ainslie, 1917. Ent. News 28: 364-367. -Mackauer, 1959. Beitr. z. Ent. 9: 812-815. - Mackauer and Stary, 1967. Index World Aphidiidae, pp. 23-34 (host list).

Morphology: Sedlag, 1956. Deut. Zool. Gesell., Verh. 1956: 356-361 (genitalia). -Mackauer, 1959. Beitr. z. Ent. 9: 812-815 (cocoon). - Schlinger and Hall, 1960. Ent. Soc. Amer., Ann. 53: 144-160 (genitalia, egg, larvae). - Eastop, 1966. Roy. Ent. Soc. London, Proc. (A) 41: 42-44 (mouthparts).

abjectum (Haliday). Greenland. Host: Aph is craccivora Koch, A. fabae Scop., A. farinosa Gmelin, A. sambuci L., Rhopalosiphum padi (L.).

Aphidius (Praon) abjectus Haliday, 1833. Ent. Mag. 1: 485. \&.

Bracon (Achoristus) aphidiiform is Ratzeburg, 1852. Ichn. d. Forstins., v. 3, p. 11..

aguti Smith. N. B. and Ont. s. to Va.; Mich., Idaho, Calif. Host: Acyrthosiphon pisum (Harr.), A. solani (Kalt.), Macrosiphoniella abrotani (Wlkr.), M. frigidicola G. and P.,

Macrosiphum euphorbiae (Thomas), M. rosae (L.), Myzus persicae (Sulzer), Neomyzus circumflexus (Buckton).

Praon aguti Smith, 1944. Aphidiinae of North America, p. 23. \&, ठ.

Biology: Sekhar, 1957. Ent. Soc. Amer., Ann. 50: 370-375. - Sekhar, 1958. Ent. Soc. Amer., Ann. 51: 1-7. - Sekhar, 1959. Current Sci. 28: 333-335. - Sekhar, 1960. Canad. Jour. Zool. 38: 593-603.

alaskense Ashmead. Alaska, Canada.

Praon alaskensis Ashmead, 1902. Wash. Acad. Sci., Proc. 4: 243. ठ.

americanum (Ashmead). Maine, Ind. Host: Macrosiphum avenae (F.), Myzus persicae (Sulzer), Rhopalosiphum padi (L.).

Diaeretus americanus Ashmead, 1889 (1888). U. S. Natl. Mus., Proc. 11: 669. §.

Diaeretus websteri Ashmead, 1889 (1888). U. S. Natl. Mus., Proc. 11: 669. ठ̊.

Diaeretus brunneiventris Ashmead, 1889 (1888). U. S. Natl. Mus., Proc. 11: 670. ठ。.

artemisaphis Smith. Utah, Wash. Host: Macrosiphoniella coweni (Hunter).

Praon artemisaphis Smith, 1944. Aphidiinae of North America, p. 26. \&.

cerasaphis (Fitch). N. Y. Single male in U. S. Natl. Mus. in poor condition; exact placement uncertain.

Trioxys cerasaphis Fitch, 1855 (1854). Agr. Soc. State N. Y., Trans. 14: 842.

coloradense Ashmead. Colo., Wash.

Praon coloradensis Ashmead, 1890. Colo. Biol. Assoc., Bul. 1: 20. ð.

exoletum palitans Muesebeck. N. J., Del., Md., Ky., Nebr., Kans., Colo., N. Mex., Utah, Ariz., Nev., B. C., Calif,; Mediterranean. Introduced from Southern Europe and Near East. Host: Therioaphis riehmi (Borner), T. trifolii (Monell). P. exoletum exoletum (Nees) is European.

Praon palitans Muesebeck, 1956. Brooklyn Ent. Soc., Bul. 51: 27. ९, ठ์.

Taxonomy: Mackauer, 1959. Beitr. z. Ent. 9: 832 (subspecies of exoletum Nees). -Stary, 1966. Aphid Parasites of Czechoslovakia, p. 42 (synonym of exoletum Nees).

Biology: Schlinger and Hall, 1959. Jour. Econ. Ent. 52: 154-157. - Schlinger and Hall, 1960. Ent. Soc. Amer., Ann. 53: 144-160. -Finney, et al., 1960. Jour. Econ. Ent. 53: 655-659.

-Force and Messenger, 1964. Ecology 45: 706-715. - Force and Messenger, 1965. Ecology 46: 853-859.

Morphology: Schlinger and Hall, 1960. Ent. Soc. Amer., Ann. 53: 144-160.

humulaphidis Ashmead. N. Y., Md., Va., Mich., Ohio, Ark., Tex. Host: Dactynotus illini (H. and F.).

Proon humulaphidis Ashmead, 1889 (1888). U. S. Natl. Mus., Proc. 11: 657. 9.

Praon virginiensis Ashmead, 1889 (1888). U. S. Natl. Mus., Proc. 11: 657. ․ 
myzophagum Mackauer. Calif. ?; Europe. Liberated in Calif. but not known to be established. Introduced from Israel. Host: Myzus certus (Wlkr.), M. persicae (Sulzer).

Praon volucre myzophagum Mackauer, 1959. Beitr. z. Ent. 9: 847. \%, ठ.

nanus Baker. Nev. Host: Rhopalosiphum fitchii (Sanderson).

Praon nanus Baker, 1909. Pomona Jour. Ent. 1: 23. ठ.

Taxonomy: Mackauer, 1963. Canad. Ent. 95: 925-926 (possibly synonym of Praon americanum Ashmead).

negundinis Smith. Canada, Ohio, Iowa. Host: Periphyllus lyropictus (Kess.), P. negundinis (Thomas).

Praon negundinis Smith, 1944. Aphidinae of North America, p. 27. १, o.

occidentale Baker. Canada, northern U. S. Host: Acyrthosiphon pisum (Harr.), A. solani

(Kalt.), A phis nasturtii Kalt., Macrosiphum euphorbiae (Thomas), M. rosae (L.), Myzus persicae (Sulzer).

Praon occidentalis Baker, 1909. Pomona Jour. Ent. 1: 23. ․

Taxonomy: Mackauer, 1963. Canad. Ent. 95: 926-927. -Mackauer and Finlayson, 1967. Canad. Ent. 99: 1059-1061.

Biology: Schlinger, 1960. Jour. Econ. Ent. 53: 151-154. - Schlinger and Hall, 1960. Ent. Soc. Amer., Ann. 53: 410.

pequodorum Viereck. U. S. and southern Canada. Host: Acyrthosiphon pisum (Harr.), A. solani (Kalt.).

Praon pequodomim Viereck, 1917 (1916). Conn. State Geol. and Nat. Hist. Survey, Bul. 22: 259. $\%$.

Taxonomy: Mackauer and Finlayson, 1967. Canad. Ent. 99: 1053-1057.

Biology: Shands, et al., 1965. Maine Agr. Expt. Sta., Bul. T19: 1-77. - Halfhill and Dickie, 1972. Environ. Ent. 1: 402-405 (history of releases).

simulans (Provancher). Md., Ont. Host: Dactynotus ambrosiae (Thomas), D. rudbeckiae (Fitch).

Aphidaria simulans Provancher, 1886. Addit. Corr. Faune Ent. Canada Hym., p. 153. , o.

Biology: Spencer, 1926. Ent. Soc. Amer., Ann. 19: 119-157.

unicum Smith. Colo., Utah, Wash., Calif. Host: Aphis spiraecola Patch, A. fabae Scop., A. rumicis L., Myzus persicae (Sulzer), Ovatus crataegarius (Wlkr.).

Praon unicus Smith, 1944. Aphidinae of North America, p. 30. \&, o.

Biology: Schlinger, 1960. Jour. Econ. Ent. 53: 151-154. -Schlinger and Hall, 1960. Ent. Soc. Amer., Ann. 53: 411.

volucre (Haliday). Ill.; Europe. Reportedly adventive from England.

Aphidius (Praon) volucris Haliday, 1833. Ent. Mag. 1: 484. , ठ์.

Biology: Mackauer and Stary, 1967. Index World Aphidiidae, pp. 33-34 (host list).

\section{SUBFAMILY APHIDIINAE}

All species are solitary endoparasites of larval and adult aphids, and pupation is inside the mummified host. The subfamily is cosmopolitan in distribution.

TRIBE APHIDIINI

\section{SUBTRIBE LYSIPHLEBINA}

\section{Genus LYSIPHLEBUS Foerster}

\section{Genus LYSIPHLEBUS Subgenus LYSIPHLEBUS Foerster}

Lysiphlebus Foerster, 1862. Naturh. Ver. Rheinlande, Verh. 19: 248.

Type-species: Bracon dissolutus Nees. Monotypic.

Members of the typical subgenus are not known in North America. 


\section{Genus LYSIPHLEBUS Subgenus ADIALYTUS Foerster}

Adialytus Foerster, 1863. Naturh. Ver. Rheinlande, Verh. 19: 249.

Type-species: Adialytus tenuis Foerster. Orig. desig.

The host range is apparently restricted to aphids in the subfamilies Chaitophorinae and Thelaxinae (Aphididae).

Taxonomy: Stary, 1960. Acta Soc. Ent. Cech. 57: 244 (redescription). -Stary, 1966. Aphid

Parasites of Czechoslovakia, pp. 80-92 (Eur. spp., in Lysiphlebus). - Mackauer, 1968. Hym.

Cat., part 3, pp. 23-24 (cat. World spp., host list). - Stary, 1975. Annot. Zool. Bot., n. 105, p. 1-9.

arvicola Stary. Canada.; Europe.

Lysiphlebus arvicola Stary, 1961. Polskie Pismo Ent. 31: 98. \&, o.

Lysiphlebus mackaneri Stary, 1961. Acta Faun. Ent. Mus. Natl. Pragae 7: 141. New name for Lysiphlebus innovatus Quilis sensu Mackauer (1960. Beitr. z. Ent. 10: 608) nec Quilis (1931. Eos 7: 39).

Lysiphlebus crocimus Mackauer, 1962. Deut. Ent. Gesell., Mitt. 21: 12. \&, ठ .

fuscicornis (Ashmead). Conn., Ont., Tenn., S. Dak., Mont., Idaho, Calif. Host: Aphis armoraciae Cowen, $A$. forbesi Weed.

Lipolexis fuscicorn is Ashmead, 1891. Canad. Ent. 23: 7. \&.

salicaphis (Fitch). N. Y., Ohio, Sask., Colo., Utah, Wash., Calif.; Palearctic. Host: Chaitophorns populicola (Thomas), C. viminalis (Monell).

Trioxys salicaphis Fitch, 1855 (1854). Agr. Soc. State N. Y., Trans. 14: 841. \&.

Trioxys populaph is Fitch, 1855 (1854). Agr. Soc. State N. Y., Trans. 14: 841. ठ.

Lipolexis salicaphidis Ashmead, 1889 (1888). U. S. Natl. Mus., Proc. 11: 671. \&, ठ.

A phidius (Diaeretus) laticephalus Telenga, 1953. Trudy Inst. Zool. Parazit. Tashkent 1: 172. ?.

Taxonomy: Gahan, 1911. Ent. Soc. Wash., Proc. 12: 182 (as Diaeretus salicaphis (Fitch)).

-Smith, 1944. Aphidiinae of North America, p. 102 (as Diaeretus salicaphis (Fitch)).

Biology: Schlinger and Hall, 1960. Ent. Soc. Amer., Ann. 53: 409.

\section{Genus LYSIPHLEBUS Subgenus PHLEBUS Stary}

Lysiphlebus subg. Phlebus Stary, 1975. Annot. Zool. Bot., n. 105, p. 6.

Type-species: A phidius fabarm Marshall. Orig. desig.

Revision: Gahan, 1911. Md. Agr. Expt. Sta., Bul. 152: 184-189 (No. Amer. spp.). -Smith, 1944. Aphidiinae of North America, pp. 76-84 (No. Amer. spp. as subgenus of Aphidius). - Mackauer, 1960. Portici Lab. Ent. Agr., Bol. 18: 230-256 (No. Amer. spp.). - Mackauer, 1960. Beitr. z. Ent. 10: 582-623 (Palearctic spp.).

Taxonomy: Stary, 1961. Acta Faun. Ent. Mus. Natl. Pragae 7: 131-142. - Mackauer, 1961.

Beitr. z. Ent. 11: 792-803. - Mackauer, 1968. Hym. Cat., part 3, pp. 24-30 (cat. World spp.).

-Stary, 1975. Annot. Zool. Bot., n. 105, p. 1-9.

Biology: Mackauer and Stary, 1967. Index World Aphidiidae, pp. 39-47 (host list).

Morphology: Trembly, 1964. Portici Lab. Ent. Agr., Bol. 22: 1-122 (mouthparts, genitalia, egg, larvae, cocoon). - Eastop, 1966. Roy. Ent. Soc. London, Proc. (A) 41: $42-44$ (mouthparts).

distinctus Mackauer. Idaho, Nev. Host: Microsiphum acophorum S. and K., M. oregonensis (Wilson).

Lysiphlebus (Lysiphlebus) distinctus Mackauer, 1960. Portici Lab. Ent. Agr., Bol. 18: 236. १, ठ์.

Aphidius (Lysiphlebus) knowltoni Smith, in part, 1944. Aphidinae of North America, p. 80.

fabarum (Marshall). Calif. ?; Palearctic. Liberated in Calif. but not known to be established. Introduced from Lebanon. Host: Aphidinae. Parasitic on most species of Aphidinae, on Myzus-Brachycandus series and, occasionally on Macrosiphum, Dactynotus, and related genera.

Aphidius fabarum Marshall, 1896. In Andre, Spec. Hym. Eur. Alg., v. 5, p. 599. , o. 
A phidius cardui Marshall, 1896. In Andre, Spec. Hym. Eur. Alg., v. 5, p. 593. + ठ. A phidius aurantii Pierantoni, 1907. Atti Ist. Sci. Nat. Napoli 59: 2. ․, ठ. Aphidius gomezi Quilis, 1930 (1929). Patol. Veg. Ent. Agr., Bol. 4: 55. ஒ, ठ. Aphidius janinii Quilis, 1930 (1929). Patol. Veg. Ent. Agr., Bol. 4: 61. ๆ, ठ. Lysiphlebus innovatus Quilis, 1931. Eos 7: 39. ๆ, ठ. Lysiphlebus moroderi Quilis, 1931. Eos 7: 43. ․, ð.

Lysiphlebus fabarum var. inermis Quilis, 1931. Eos 7: 46. ㅇ.

Taxonomy: Mackauer, 1960. Beitr. z. Ent. 10: 598-604, 612-617. - Mackauer, 1961. Beitr. z. Ent. 11: 136-138. Literature records prior to 1960 are of doubtful identity and may pertain to other Lysiphlebus species (Mackauer and Stary, 1967, Index World Aphidiidae, p. 42).

Biology: Quilis, 1930. Patol. Veg. Ent. Agr., Bol. 4: 49-64. -Quilis, 1931. Eos 7: 30-46. -Ivanova-Kass, 1956. Ent. Obozr. 35: 245-261 (embroyology). - Tremblay, 1964. Portici Lab. Ent. Agr., Bol. 22: 1-122. - Mackauer and Stary, 1967. Index World Aphidiidae, pp. 42-42 (host list).

flavidus Gahan. Ohio, Nebr., Colo. Host: A phis albipes Oestl., A. debilicornis G. and P., A phthargelia symphoricarpi (Thomas).

Lysiphlebus flavidus Gahan, 1911. Md. Agr. Expt. Sta., Bul. 152: 186..

knowItoni (Smith). Idaho, Utah, Wash. Host: Artemisaphis artemisicola (Wms.), Microsiphum acophorum $\mathrm{S}$. and $\mathrm{K}$.

Aphidius (Lysiphlebus) knowltoni Smith, in part, 1944. Aphidiinae of North America, p. 80. $\uparrow, \delta$.

testaceipes (Cresson). Very common throughout temperate North America and South America. Host: Aphidinae. Widely polyphagous; host range includes most species of Aphidinae, Myzus-Brachycaudus series and occasionally Macrosiphum and related genera (Mackauer and Stary, 1967. Index World Aphidiidae, p. 45).

Trioxys testaceipes Cresson, 1880. U. S. Dept. Agr. Ann. Rpt. for 1879, p. 208.. Aphidius citraphis Ashmead, 1880. Orange Insects, p. 70. $\subsetneq, \delta$. Adialytus maidaphidis Garman, 1885. In Forbes, Ill. State Ent., Rpt. 14: 31. ๆ, ठ. Aphidius flavicoxa Ashmead, 1888. Fla. Agr. Expt. Sta., Bul. 2: 23. + ,. Aphidaria basilaris Provancher, 1888. Addit. Corr. Faune Ent. Canada Hym., p. 396. $९$, $\delta$. Lysiphlebus minutus Ashmead, 1889 (1888). U. S. Natl. Mus., Proc. 11: 663, 664. , ð. Lysiphlebus piceiventris Ashmead, 1889 (1888). U. S. Natl. Mus., Proc. 11: 664. ठ, not ?. Lysiphlebus curcurbitaphidis Ashmead, 1889 (1888). U. S. Natl. Mus., Proc. 11: 665. $\uparrow, ~ \delta$. Lysiphlebus eragrostaphidis Ashmead, 1889 (1888). U. S. Natl. Mus., Proc. 11: 665. ๆ, ठ. Lysiphlebus coquilletti Ashmead, 1889 (1888). U. S. Natl. Mus., Proc. 11: 665. ๆ, ð. Lysiphlebus myzi Ashmead, 1889 (1888). U. S. Natl. Mus., Proc. 11: 666. \&, ð. Lysiphlebus gossypii Ashmead, 1889 (1888). U. S. Natl. Mus., Proc. 11: 667. ๆ, ठ. Lysiphlebus abutilaphidis Ashmead, 1889 (1888). U. S. Natl. Mus., Proc. 11: 667. ๆ, o. Lysiphlebus tritici Ashmead, 1889 (1888). U. S. Natl. Mus., Proc. 11: 668. ㅇ, ठ. Lysiphlebus persicaphidis Ashmead, 1889 (1888). U. S. Natl. Mus., Proc. 11: 668. ㅇ. Lysiphlebus baccharaphidis Ashmead, 1889 (1888). U. S. Natl. Mus., Proc. 11: 668. $\uparrow$, ठ. Aphidius persiaphis Cook, 1891. Mich. Agr. Col., Bul. 73: 12. ठ.

Aphidius (Lysiphlebus) chrysoaphidis Smith, 1944. Aphidinae of North America, p. 78. + , $\delta$.

Taxonomy: Mackauer, 1960. Portici Lab. Ent. Agr., Bol. 18: 244-249. -Mackauer, 1960. Beitr. z. Ent. 10: 612-617.

Biology: Sekhar, 1957. Ent. Soc. Amer., Ann. 50: 370-375. - Sekhar, 1959. Curr. Sci. 28: 333-335. - Sekhar, 1960. Canad. Jour. Zool. 38: 593-603. - Schlinger and Hall, 1960. Ent. Soc. Amer., Ann. 53: 407-409. - Mackauer and Stary, 1967. Index World Aphidiidae, pp. 45-46 (host list).

utahensis (Smith). Idaho, Utah, Calif. Host: Macrosiphoniella coweni (Hunter). Aphidius (Lysiphlebus) utahensis Smith, 1944. Aphidiinae of North America, p. 83. $\uparrow, \delta$.

viburnaphis (Fitch). N. Y. Considered as probably conspecific with testaceipes (Cresson) by Mackauer (1960. Portici Lab. Ent. Agr., Bol. 18: 253). Two syntypes in poor condition are in the U.S. National Museum.

Praon viburnaphis Fitch, 1855 (1854). Agr. Soc. State N. Y., Trans. 14: 841. 


\section{SUBTRIBE PROTAPHIDIINA}

\section{Genus CHAETOPAUESIA Mackauer}

Chaetopanesia Mackauer, 1967. Entomophaga 12: 141.

Type-species: Chaetopanesia talis Mackauer. Orig. desig.

crassicornis (Ashmead). Ont.

Aphidius crassicornis Ashmead, 1891. Canad. Ent. 23: 5. đo.

talis Mackauer. Ont.

Aphidius brevicomis Ashmead, 1891. Canad. Ent. 23: 6. ๆ. Nomen nudum.

Chaetopanesia talis Mackauer, 1967. Entomophaga 12: 142. ․

\section{Genus PAUESIA Quilis}

Panesia Quilis, 1931. Eos 7: 67.

Type-species: Panesia albuferensis Quilis. Orig. desig.

Aphidius subg. Paraphidius Stary, 1958. Acta Faun. Ent. Mus. Natl. Pragae 3: 91. New name for Protaphidius Ashmead of authors, not Ashmead, 1900.

Type-species: Aphidius californicus Ashmead. Orig. desig.

The genus Pauesia corresponds to Section II, Pinicolae, of the genus Aphidius Nees as defined by Haliday (1834. Ent. Mag. 2: 95). Prior to 1958, the species in Pauesia were included in various genera besides Aphidius: Szepligeti (1904. In Wytsman, Gen. Ins., fasc. 22, p. 185) placed these species in the genus Coelonotus Foerster; Smith (1944. Aphidiinae of North America, pp. 37-49) placed them in Aphidins (Protaphidius) Ashmead; Coelonotus Foerster as used by Thompson (1895. Opusc. Ent. 20: 2334) is a mispelling of Coelonotus Foerster. Hosts are restricted to aphids of the subfamily Lachninae. P. albuferensis Quilis, 1931, type-species of the genus, is now considered to be a synonym of Aphidius unilachni Gahan, 1926.

Revision: Smith, 1944. Aphidiinae of North America, pp. 37-49 (No. Amer. spp.). - Stary, 1960. Acta Faun. Ent. Mus. Natl. Pragae 6: 5-44 (Eur. spp.). - Watanabe and Takada, 1965. Insecta Matsumurana 28: 1-17 (Jap. spp.).

Taxonomy: Fahringer, 1937. Festschr. E. Strand 3: 240-245 (key Eur. spp.). - Mackauer 1961. Beitr. z. Ent. 11: 106-108. - Mackauer, 1968. Hym. Cat., part 3, pp. 31-39 (cat. World spp.).

Biology: Mackauer and Stary, 1967. Index World Aphidiinae, pp. 48-58 (host list).

bicolor (Ashmead). N. J. s. to Fla.; Ohio, Wis. Host: Cinara cronartii T. and P., C. pergandei (Wilson), C. pini (L.), C. strobi (Fitch).

Aphidius bicolor Ashmead, 1889 (1888). U. S. Natl. Mus., Proc. 11: 658. \&.

Aphidius (Protaphidius) scorpinicus Smith, 1944. Aphidinae of North America, p. 45. , o.

californica (Ashmead). Va., Ont., Ohio, S. Dak., Alta., B. C., Calif. Host: Schizolachnus piniradiatae (Davidson), S. parvus (Wilson).

Aphidius californicus Ashmead, 1889 (1888). U. S. Natl. Mus., Proc. 11: 660..

gillettei (Gahan). S. C., Ky., La., Ark., Colo. Host: Cinara sp.

Aphidius gillettei Gahan, 1911. Md. Agr. Expt. Sta., Bul. 152: 171. \&.

juniperaphidis (Gahan). Ohio, Colo., Idaho, B. C. Host: Cinara juniperi (DeG.), C. occidentalis (David.), C. pulverulens (G. and P.).

Aphidius juniperaphidis Gahan, 1911. Md. Agr. Expt. Sta., Bul. 152: 174. ९, ठ.

macrogaster (Ashmead). Ont. Host: Cinara abieticola (Cholod.).

Aphidius macrogaster Ashmead, 1891. Canad. Ent. 23: 5. ठ.

nigrovaria (Provancher). Calif. Host: Cincra sp.

Aphidius nigrovarius Provancher, 1888. Addit. Corr. Faune Ent. Canada Hym., p. 396. $\subsetneq$.

pinaphidis (Ashmead). Fla., La. Host: Cinara australis (Ashmead), C. longispinosa Tissot.

A phidius pinaphidis Ashmead, 1889 (1888). U. S. Natl. Mus., Proc. 11: 659. Nomen nudum.

Aphidius pinaphidis Ashmead, 1891. Canad. Ent. 23: 6. ๆ, o.

ponderosae (Muesebeck). B. C., Calif. Host: Cinara sp.

Aphidius (Protaphidius) ponderosae Muesebeck, 1958. Ent. News 69: 141. ๆ, ठ. 
procephali (Ashmead). Pa., D. C., Va., N. C., Ohio, Minn., Nebr., Wash. Host: Cinara pergandei (Wilson), C. abieticola (Cholod.).

A phidius procephali Ashmead, 1889 (1888). U. S. Natl. Mus., Proc. 11: 659. ठ。.

Aphidius (Protahpidius) prociphali Ashmead: Muesebeck and Walkley, 1951. U. S. Dept. Agr., Agr. Monog. 2, p. 93. Unjustified emendation.

salignae (Watanabe). Western U. S. (teste Mackauer, 1968. Hym. Cat., part 3, p. 37). Host:

Tuberolachnus salignus (Gmelin).

Aphidius salignae Watanabe, 1939. Insecta Matsumurana 13: 81 ., ,.

takomaensis (Smith). Md., Va., N. C., Sask., Colo. Host: Cinara hottesi (G. and P.), C. ponderosae (Wms.).

Aphidius (Protaphidius) takomaensis Smith, 1944. Aphidiinae of North America, p. 46. $q$, o.

varigata (Smith). Colo., B. C., Calif. Host: Cinara canatra H. and B., C. fornacula Hottes, C. hottesi (G. and P.).

Aphidius (Protaphidius) varigatus Smith, 1944. Aphidiinae of North America, p. 47..

xanthothera (Smith). East. Canada, N. C., S. C., Ala., Ark., Okla. Host: Cinara carolina Tissot, C. pergandei (Wilson), C. pinea (Mord.), C. strobi (Fitch), C. watsoni Tissot.

Aphidius (Protaphidius) xanthotherus Smith, 1944. Aphidiinae of North America, p. 48. $\%$, o.

\section{Genus XENOSTIGMUS Smith}

Aphidius subg. Xenostigmus Smith, 1944. Aphidiinae of North America, p. 36.

Type-species: A phidius bifasciatus Ashmead. Orig. desig.

bifasciatus (Ashmead). Canada, Md., Va., N. C., S. C., Fla., Nebr., Okla., Tex., Utah, Wash., Calif. Host: Cinara australis (Ashm.), C. carolina Tissot, C. hottsei (G. and P.), C. pseudotaxifoliae Palmer, C. taedae Tissot.

Aphidius bifasciatus Ashmead, 1891. Canad. Ent. 23: 6..

\section{SUBTRIBE APHIDIINA}

\section{Genus EUAPHIDIUS Mackauer}

A phidius subg. Euaphidius Mackauer, 1961. Beitr. z. Ent. 11: 110.

Type-species: A phidius pterocommae Ashmead. Orig. desig.

A small Holarctic genus whose host range is apparently restricted to Chaitophorinae and primitive Aphidinae, mainly Pterocomma species.

Taxonomy: Mackauer, 1961. Beitr. z. Ent. 11: 801 (raised to generic status).

cingulatus (Ruthe). Greenland, N. B., Mass., D. C., Mich., Ohio, Iowa, Utah, N. Mex., Calif.;

Europe, Iran. Host: Pterocomma bicolor (Oest.), P. populeum (Kalt.), P. populifoliae

(Fitch), P. salicis (L.), P. smithiae (Monell).

A phidius cingulatus Ruthe, 1859. Stettin. Ent. Ztg. 20: 315. $\%, \delta$.

Aphidius gregarius Marshall, 1872. Ent. Monthly Mag. 9: 123. ๆ, ठ์.

Aphidius pterocommae Ashmead, 1889 (1888). U. S. Natl. Mus., Proc. 11: 659. ठ.

Aphidius lachni Ashmead, 1889 (1888). U. S. Natl. Mus., Proc. 11: 660. ९, ठ̀.

A phidius pterocommae Marshall, 1896. In Andre, Spec. Hym. Eur. Alg., v. 5, p. 578. $q$.

setiger Mackauer. Canada; Europe. Host: Periphyllus lyropictus (Kessler), P. testudinaceus (Fernie).

Euaphidius setiger Mackauer, 1961. Portici Lab. Ent. Agr., Bol. 19: 273. ؟, ð.

\section{Genus APHIDIUS Nees}

Incubus Schrank, 1802. Fauna Boica 2: 315. Suppressed by Internatl. Comn. Zool.

Nomencl., Opinion 284, 1954.

Type-species: Ichneumon aphidum L. Monotypic.

Aphidius Nees, 1818. Nova Acta Acad. Caes. Leop. Car. 9: 302.

Type-species: A phidius avenae Haliday. Desig. by Internatl. Comn. Zool. Nomencl., Opinion 284, 1954. 
Theracmion Holmgren, 1872. Ofvers. K. Vet. Akad., Forh. 29: 99.

Type-species: Theracmion arcticus Holmgren. Monotypic.

A cosmopolitan genus of which many species are of doubtful identity. Host range is wide but mainly in the Aphididae.

Revision: Marshall, 1896. In Andre, Spec. Hym. Eur. Alg., v. 5, pp. 557-610 (Eur. spp.).

-Marshall, 1899. Ent. Soc. Lond., Trans. 1899: 37-71 (British spp.). -Gahan, 1911. Md.

Agr. Expt. Sta., Bul. 152: 166-183 (No. Amer. spp.). - Smith, 1944. Aphidiinae of North America, pp. 34-84 (No. Amer. spp.). - Stary, 1966. Aphid Parasites of Czechoslovakia, pp. 83-86 (some Eur. spp.). - Stary and Schlinger, 1967. Rev. Far East Asian Aphidiidae, pp. 11-30 (East Asian spp.).

Taxonomy: Hincks, 1951. Zool. Nomencl., Bul. 4: 18-19 (nomenclature). -Mackauer, 1961. Beitr. z. Ent. 11: 109-112. -Mackauer, 1968. Hym. Cat., part 3, pp. $42-58$ (cat. World spp.). -Stary, 1974. Ztschr. f. Angew. Ent. 77: 141-171.

Biology: Hartley, 1922. Ohio Jour. Sci. 22: 209-237. - Boese, 1936. Ztschr. f. Parasitenk. 8: 243-284. - Ullyett, 1938. Dept. Agr. For. Un. S. Afr., Sci. Bul. 178: 1-28. -Stary, 1966. Aphid Parasites of Czechoslovakia, pp. 51-61.

Morphology: Short, 1952. Roy. Ent. Soc. London, Trans. 103: 80-82 (larvae). -Ivanova-Kasas, 1956. Prob. Sovr. Embryol. 1956: 199-204 (embryology). -Ivanova-Kasas, 1956. Ent. Obozr. 35: 245-261 (embryology). - Sedlag, 1956. Deutch. Zool. Gesell., Verh. 1956: 356-361 (female genitalia). - Wiackowski, 1962. Polski Pismo Ent. 32: 253-310 (egg, larvae, cocoon, adult). -Eastop, 1966. Roy. Ent. Soc. London, Proc. (A) 41: $42-44$ (mouthparts). - Eady, 1969.

Roy. Ent. Soc. London, Proc., Ser. B., 38: 165-173 (petiole).

alius Muesebeck. Calif. Host: Macrosiphum euphorbiae (Thomas), M. rosae (L.). Aphidius (Aphidius) alius Muesebeck, 1958. Ent. News 69: 142. ๆ, ठ.

Biology: Schlinger, 1960. Jour. Econ. Ent. 53: 151-154. - Schlinger and Hall, 1960. Ent. Soc. Amer., Ann. 53: 405.

atropetiolatus Ashmead. Colo. Aphidius atropetiolatus Ashmead, 1890. Colo. Biol. Assn., Bul. 1: 20. ð.

avenaphis (Fitch). D. C., S. C., Ont., Mich., Ohio, Ind., Tenn., Mo., Calif. Host: Acyrthosiphon solani (Kalt.), Macrosiphum euphorbiae (Thomas), M. avenae (F.), Myzus persicae (Sulzer), Rhopalosiphum padi (L.).

Praon avenaphis Fitch, 1861. N. Y. State Agr. Soc., Trans. 20: 840.

Aphidius xanthus Ashmead, 1889 (1888). U. S. Natl. Mus., Proc. 11: 661. ठ.

Aphidius granariaphis Cook, 1890. Canad. Ent. 22: 125. $\$, \delta$.

colemani Viereck. Calif. ?; Mediterranean Europe, Asia, Africa, Australia, South America.

Liberated in California (as platensis) but not known to be established. Introduced from Brazil.

Aphidius colemani Viereck, 1912. U. S. Natl. Mus., Proc. 42: 141. $\&$, ð.

Aphidius platensis Brethes, 1913. Mus. Nac. Hist. Nat. B. Aires, An. 24: 41. $९$.

Aphidius hubrichi Brethes, 1913. Mus. Nac. Hist. Nat. B. Aires, An. 24: 41. "o" = ठ.

Aphidius porteri Brethes, 1915. Ann. Zool. Apl. 2: 13. ठ.

Aphidius aphidiphilus Benoit, 1955. Mus. Roy. Congo Belge, Ann. 36: 349. ‡, ð. Aphidius Leroyi Benoit, 1955. Mus. Roy. Congo Belge, Ann. 36: 350. .

Aphidius transcaspicus Telenga, 1958. Biol. Zh. Akad. Nauk Uzbekskoi 2: 55.,$\delta$.

Taxonomy: Stary, 1975. Acta Ent. Bohemoslov. 72: 156-163.

Biology: Millan, 1956. Revta Invest. Agr. Buenos Aires 10: 243-280. - Mackauer and Stary, 1967. Index World Aphidiidae, p. 83-84 (intro. into Calif. as platensis). - Stary, 1972.

Orient. Ins. 6: 359-370 (distr. and host range as platensis).

coloratus Baker. $\mathrm{Pa}$.

Aphidius coloratus Baker, 1909. Pomona Jour. Ent. 1: 24..

Taxonomy: Mackauer, 1963. Canad. Ent. 95: 928-930. 
coloratus var. ferruginosus Baker. Wis. Considered to be a species dubium by Mackauer, 1963.

A phidius coloratus var. ferruginosus Baker, 1909. Pomona Col. Jour. Ent. 1: 24. “o” =

Taxonomy: Mackauer, 1963. Canad. Ent. 95: 931.

confusus Ashmead. Utah, Ariz., Wash., Calif. Host: Dactynotus ambrosiae (Thomas), D. rudbeckiae (Fitch), Macrosiphoniella ludovicianae (Oestl.), Macrosiphum rosae (L.). Aphidius confusus Ashmead, 1889 (1888). U. S. Natl. Mus., Proc. 11: 662..

Biology: Schlinger, 1960. Jour. Econ. Ent. 53: 151-154. - Schlinger and Hall, 1960. Ent. Soc. Amer., Ann. 53: 405.

delicatus Baker. Nev.

A phidius delicatus Baker, 1909. Pomona Jour. Ent. 1: 24. ठ.

Taxonomy: Mackauer, 1963. Canad. Ent. 95: 928.

ervi Haliday. N. S. s. to Va. and Tenn., w. to Ont., Nebr., and Kans.; B. C., Wash., Oreg.; Europe, China, Taiwan, N. Afr., Mid. East. Introduced from France, Germany, Poland and Lebanon. However, according to Stary (1974), ervi may have occurred in North America prior to these releases. Host: Acyrthosiphon caragarae (Cholod.), A. pisum (Harr.), A phis sp., Aulacorthum solani (Kalt.), Macrosiphum spp., M. euphorbiae (Thomas), Microlophium evansi (Theo.), Myzus certus (Walk.), M. persicae (Sulzer), Rhopalosiphum padi (L.). The exact identity and host range of ervi can not be stated for certain until an extensive study of the group is made. The present classification and host list is based on Stary (1974).

A phidius (Aphidius) ervi Haliday, 1834. Ent. Mag. 2: 100. , ठ.

Aphidius ulmi Marshall, 1896. In Andre, Spec. Hym. Eur. Alg., v. 5, p. 576. ๆ, o.

Aphidius medicaginis Marshall, 1898. In Andre, Spec. Hym. Eur. Alg., v. 5bis, p. 249. , o.

Aphidius fumipennis Gyorfi, 1958. Acta Zool. Hung. 4: 133. o. .

Aphidius ervi nigrescens Mackauer, 1962. Beitr. z. Ent. 12: 642. ㅇ, o (in part).

A phidius caraganae Stary, 1963. Acta Ent. Mus. Natl. Pragae 55: 603. o, o .

Aphidius mirotarsi Stary, 1963. Acta Ent. Mus. Natl. Pragae 35: 605. क, ऽ。.

Taxonomy: Mackauer and Finlayson, 1967. Canad. Ent. 99: 1061-1066. -Stary, 1974. Ztschr. f. Angew. Ent. 77: 141-171.

Biology: Dunn, 1949. Bul. Ent. Res. 40: 97-122. -Mackauer, 1962. Ztschr. f. Angew. Ent. 50: 125-131. - Stary, 1962. Zool. Listy 11: 265-278. - Mackauer and Finlayson, 1967. Canad.

Ent. 99: 1061-1066. -Mackauer and Campbell, 1972. Ent. Soc. Br. Col., Jour. 69: 54-58.

- Halfhill and Dickie, 1972. Environ. Ent. 1: 402-405 (history of releases). -Campbell and

Mackauer, 1973. Ztschr. f. Angew. Ent. 74: 47-55. - Stary, 1974. Ztschr. f. Angew. Ent. 77 : 141-171.

floridaensis Smith. Fla., Tex. Host: Aphis gossypii Glover, Dactynotus sp., D. ambrosiae (Thomas).

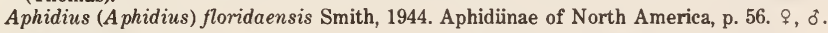

glacialis Ashmead. Alaska.

A phidius glacialis Ashmead, 1902. Wash. Acad. Sci., Proc. 4: 245. ㅇ.

hortensis Marshall. Ohio, Idaho, Utah, Wash.; Europe. Host: Liosomaphis berberidis (Kalt.). Aphidius hortensis Marshall, 1896. In Andre, Spec. Hym. Eur. Alg., v. 5, p. 590. $\%$, o. A phidius (Aphidius) berberidis Smith, 1944. Aphidiinae of North America, p. 54. $\$$, o.

kakimiaphidis Smith. Colo., Utah. Host: Kakimia cerei G. and P.

Aphidius (Aphidius) kakimiaphidis Smith, 1944. Aphidiinae of North America, p. 58., o.

matricariae Haliday. Holaretic. Host: A phis fabae Scopoli, A. gossypii Glover, A. helianthi Monell, A. nasturtii Kalt., A. rumicis L., Acrythosiphon solani (Kalt.), Brachycaudus cardui (L.), B. helichrysi (Kalt.), Brevicoryne brassicae (L.), Dysaphis plantaginea (Pass.), Hayhurstia atriplicis (L.), Myzus cerasi (F.), M. certus (Wlkr.), M. ligustri (Mosley), M. persicae (Sulzer), Neomyzus circumflexus (Buckton), Ovatus sp., Phorodon 
humuli (Schrank), Rhopalosiphum padi (L.), Roepkea crataegifoliae (Fitch), Toxoptera aurantii (Fonsc.).

Aphidius (A phidius) cirsii Haliday, 1834. Ent. Mag. 2: 101. \&. Preocc. by Curtis, 1831. Aphidius (Aphidius) matricariae Haliday, 1834. Ent. Mag. 2: 103. 9.

Aphidius (Aphidius) arundinis Haliday, 1834. Ent. Mag. 2: 104..

Aphidius phorodontis Ashmead, 1889 (1888). U. S. Natl. Mus., Proc. 11: 662. , ๖. A phidius polygoni Marshall, 1896. In Andre, Spec. Hym. Eur. Alg., v. 5, p. 602. $\uparrow, ~ \delta$. A phidius lychnidis Marshall, 1896. In Andre, Spec. Hym. Eur. Alg., v. 5, p. 607. $\delta$. Aphidius valentinus Quilis, 1931. Eos 7: 47. 9 .

Aphidius affinis Quilis, 1931. Eos 7: 48. ㅇ, $\delta$.

Aphidius arundinis var. obscuriforme Quilis, 1931. Eos 7: 50. ㅇ.

Aphidius renominatus Hincks, 1943. Ent. Monthly Mag. 79: 44. New name for Aphidius cirsii Haliday.

A phidius (A phidius) nigriteleus Smith, 1944. Aphidiinae of North America, p. 61. $\$, \delta$.

Taxonomy: Schlinger and Mackauer, 1963. Ent. Soc. Amer., Ann. 56: 648-653 (also covers

biology, distribution, and host range).

montanus Ashmead. Colo.

Aphidius montanus Ashmead, 1890. Colo. Biol. Assn., Bul. 1: 20. ð.

nigripes Ashmead. N. B. s. to N. C., w. to Minn. and Kans.; B. C., Wash., Calif. Host: Acyrthosiphon solani (Kalt.), Am phorophora sp., A phis nasturtii Kalt., Dactynotus ambrosiae (Thomas), D. erigeronensis (Thomas), Macrosiphum albifrons Essig, $M$. avenae (F.), M. creelii Davis, $M$. euphorbiae (Thomas), $M$. liriodendri (Monell), $M$. rosae (L.), Myzus persicae (Sulzer). Exact host range not established, but apparently a preference for Macrosiphum spp. Earlier associations of this species under the name pulcher Baker or ervi pulcher as a parasite of the pea aphid apparently all refer to pisivorus Smith. Specimens used by Smith (1941) to describe rosae Haliday in No. Amer. are actually nigripes.

Aphidius nigripes Ashmead, 1901. N. Y. State Mus., Bul. 47: 588. ð。. A phidius pulcher Baker, 1909. Pomona Jour. Ent. 1: 24. ․ N. syn.

Taxonomy: Smith, 1941. Aphidiinae of No. Amer. p. 71 (as rosae Hal.). -Mackauer, 1963. Canad. Ent. 95: 931-932 (as pulcher). - Stary, 1974. Ztschr. f. Angew. Ent. 77: 141-171 (as pulcher).

Biology: Schlinger, 1960. Jour. Econ. Ent. 53: 151-154. -Shands, et al., 1965. Maine Agr. Expt. Sta., Bul. T19: 1-77. - Sullivan and van den Bosch, 1971. Ent. Soc. Amer., Ann. 64: 389-394.

obscuripes Ashmead. Ont. s. to S. C., w. to N. Dak. and Colo.; Wash., Oreg. Host: A phis nasturtii Kalt., Acyrthosiphon solani (Kalt), Macrosiphum euphorbiae (Thomas), $M$. avenae (F.), Rhopalosiphum fitchii (Sand.), R. padi (L.).

A phidius obscuripes Ashmead, 1889 (1888). U. S. Natl. Mus., Proc. 11: 660. ๆ, ð.

ohioensis Smith. N. B., Ohio, Tenn., Ark., Kans., Idaho, Ariz., B. C., Wash., Calif. Host: Dactynotus ambrosiae (Thomas), D. mudbeckiae (Fitch), D. anomalae (H. and F.), D. erigeronensis (Thomas), D. illini (H. and F.), Macrosiphum euphorbiae (Thomas). Aphidius (Aphidius) ohioensis Smith, 1944. Aphidiinae of North America, p. 63. $q$, $\delta$. picipes (Nees). N. J. ?; Europe. Liberated in N. J. but not known to be established. Introduced from Europe. Host: Myzus persicae (Sulzer).

Bracon picipes Nees, 1811. Gesell. Naturf. Freunde Berlin, Mag. 5: 28. ๆ.

pisivorus Smith. No. Amer. Host: Acyrthosiphon pisim (Harris). Exact host range is not established for this species; earlier records of hosts other than the pea aphid apparently refer to nigripes Ashm. This species has erroneously been considered a synonym of pulcher; also, most of the specimens used by Smith (1941) to describe nigripes are actually pisivorus.

Aphidius pisivorus Smith, 1941. Ent. Soc. Amer., Ann. 34: 537. + , ¿.

Taxonomy: Smith, 1941. Aphidiinae of No. Amer., p. 60 (as nigripes in part). -Mackauer and Finlayson, 1967. Canad. Ent. 99: 1066-1070 (as ervi pulcher). - Stary, 1974, Ztschr. f. Angew. Ent. 77: 141-171. 
Biology: Cooke, 1963. U. S. Dept. Agr., Tech. Bul. 1287: 1-48 (as pulcher). -Mackauer and Finlayson, 1967. Canad. Ent. 99: 1066-1070 (as ervi pulcher). -Berry, 1969. Ent. Soc. Amer., Ann. 62: 1185-1189.

polygonaphis (Fitch). Que., N. B. s. to Fla. and La., w. to Wis. and Kans.; Utah. Host: Dactynotus ambrosiae (Thomas), D. midbeckiae (Fitch), D. luteola (Wms.), D. taraxaci (Kalt.), Macrosiphum euphorbiae (Thomas), M. liriodendri (Monell).

Praon polygonaphis Fitch, 1855 (1854). N. Y. State Agr. Soc., Trans. 14: 840.. Aphidius canadensis Provancher, 1881. Nat. Canad. 12: 204. ?.

A phidius obscurus Provancher, 1886. Addit. Corr. Faune Ent. Canada Hym., p. 152. $\delta$. Aphidius pallidus Ashmead, 1889 (1888). U. S. Natl. Mus., Proc. 11: 661. ๆ. Aphidius nigriceps Ashmead, 1891. Canad. Ent. 23: 6. ठં. Lysiphlebus succineus Viereck, 1904. Kans. Acad. Sci., Trans. 19: 282. \&.

propinquus Ashmead. Colo., Idaho, Calif., Alaska.

Aphidius propinquus Ashmead, 1902. Wash. Acad. Sci., Proc. 4: 245. o. A phidius frigidus Ashmead, 1902. Wash. Acad. Sci., Proc. 4: 246. + , $\delta$.

ribis Haliday. Northern U. S., southern Canada; Europe. Host: Cryptomyzus ribis (L.). Aphidius (Aphidius) ribis Haliday, 1834. Ent. Mag. 2: 104. ?.

Lysiphlebus ribaphidis Ashmead, 1889 (1888). U. S. Natl. Mus., Proc. 11: 664. \&. Aphidius scobiosae Marshall, 1896. In Andre, Spec. Hym. Eur. Alg., v. 5, p. 596. ๆ, o. Aphidius ribis Ashmead, 1898. Ent. Soc. Wash., Proc. 4: 167., ó.

Biology: Wheeler, 1923. Ent. Soc. Amer., Ann. 16: 1-29. -Mackauer, 1958. Ztschr. f. Angew. Ent. 43: 282-285. - Schlinger and Hall, 1960. Ent. Soc. Amer., Ann. 53: 407.

rosae Haliday. Holarctic. Host: Macrosiphum rosae (L.), M. liriodendri (Monell). A phidius (Aphidius) rosae Haliday, 1834. Ent. Mag. 2: 97. ९, ठ。.

Aphidius rosarum Nees, 1834. Hym. Ichn. Aff. Monog., v. 1, p. 19. + , o. Aphidius xanthostoma Bouche, 1834. Naturgesch. d. Ins. v. 1, p. 163. $₹$, o. Aphidius cancellatus Buckton, 1876. Monog. Brit. Aphides, v. 1, p. 111..

rubifolii Mackauer. B. C. Host: Masonaphis maxima Mason.

Aphidius rubifolii Mackauer, 1968. Ent. Soc. B. C., Jour. 65: 34. ๆ, ð.

salicis Haliday. N. B., Ont., Calif.; Palearctic. Host: Cavariella aegopodii (Scopoli), C. pastinacae (L.), Hyadaphis foeniculi (Pass.).

Aphidius (Aphidius) salicis Haliday, 1834. Ent. Mag. 2: 102. + , ठ.

A phidius restrictus Nees, 1834. Hym. Ichn. Aff. Monog., v. 1, p. 22. + .

Aphidius duodecimarticulatus Ratzeburg, 1852. Ichn. d. Forstins., v. 3, p. 62 . ㅇ.

Aphidius dauci Marshall, 1896. In Andre, Spec. Hym. Eur. Alg., v. 5, p. 601. §, ठ.

schimitscheki (Stary). B. C., Oreg.; Europe. Host: Elatobium abietinum Wlkr.

Lysaphidus schimitscheki Stary, 1960. Polskie Pismo Ent. 30: 363. ๆ, ठ.

Biology: von Scheller, 1963. Ztschr. f. Angew. Ent. 51: 258-284 (bionomics, as A phidius (Lysiphlebus) sp.). - Kloft, et al., 1964. Ztschr. f. Angew. Ent. 55: 180-181 (geographical distribution).

sicarius Mackauer. N. B.; Palearetic. Host: Betulaphis quadrituberculata (Kalt.), Calaphis sp. Aphidius sicarius Mackauer, 1961. Portici Lab. Ent. Agr., Bol. 19: 281. ₹, ठ́.

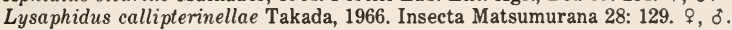

smithi Sharma and Subba Rao. Apparently widely distributed in U. S. and Canada; India, Pakistan. Introduced from India. Host: Acyrthosiphon pisum (Harris), Myzus persicae (Sulzer) (in laboratory). Exact host range not established.

A phidius (Aphidius) smithi Sharma and Subba Rao, 1959 (1958). Indian Jour. Ent. 20: 183. †, ช。.

Taxonomy: Mackauer and Finlayson, 1967. Canad. Ent. 99: 1070-1072. - Stary, 1974. Ztschr. f. Angew. Ent. 77: 141-171.

Biology: Hagen and Schlinger, 1960. Calif. Agr. 14: 5-6. -Wiakowski, 1960. Acad. Polon. Sci., Bul. 8: 503-508. - Wiakowski, 1962. Polskie Pismo Ent. 32: 253-310. - Mackauer and Bisdee, 1965. Ent. Soc. Ont., Proc. 95: 121-124. - Angalet and Coles, 1966. Jour. Econ. Ent. 59: 769-770. - Schlinger, et al., 1966. Ecology 47: 1049-1055. —van den Bosch, et al., 1967. 
Ecology 48: 993-1000. -Clancy, 1967. Jour. Econ. Ent. 60: 1743. -Fox, et al., 1967. Ent. Soc. Amer., Ann. 60: 1083-1087. - Thurston and Pass, 1967. Ent. Soc. Amer., Ann. 60: 708-709. - Mackauer, 1968. Entomophaga 13: 281-287. - Mackauer, 1970. Ent. Soc. Amer., Ann. 63: 342-343. - Stary, 1970. Lab. Ent. Agr. Portici, Boll. 28: 19-34. -Tamaki, et al., 1970. Ent. Soc. Amer., Ann. 63: 973-980. - Pass and Par, 1971. Jour. Econ. Ent. 64:

1150-1153. - Stary, 1971. Ent. Soc. Fr., Ann. (N. S.) 7: 351-355. - Halfhill and Dickie, 1972. Environ. Ent. 1: $402-405$ (history of releases). -Mackauer and Campbell, 1972. Environ. Ent. 69: 55-57. -Campbell and Mackauer, 1973. Ztschr. f. Angew. Ent. 74: 47-55. - Halfhill and Featherston, 1973. Environ. Ent. 2: 469-472. - Stary, 1974. Ztschr. f. Angew. Ent. 77: 141-171.

\section{Nomina Nuda in APHidius NeES}

A phidius fletcheri Ashmead, 1900. In Fletcher, Ent. Soc. Ont., Rpt. 30: 107. Aphidius washingtonensis Ashmead, 1900. In Johnson, Can. Ent. 32: 60.

\section{Genus LYSAPHIDUS Smith}

Aphidius subg. Lysaphidus Smith, 1944. Aphidiinae of North America, p. 72.

Type-species: Aphidius (Lysaphidus) adelocarinus Smith. Orig. desig.

Revision: Smith, 1944. Aphidiinae of North America, pp. 72-76 (No. Amer. spp.). - Stary, 1960. Polskie Pismo Ent. 30: 357-366 (Eur. spp.). - Stary, 1966. Aphid Parasites of Czechoslovakia, pp. 88-89 (Czech. spp.). - Takada, 1966. Insecta Matsumurana 38: 127-130 (Jap. spp.).

Taxonomy: Mackauer, 1968. Hym. Cat., part 3, pp. 59-60 (cat. World spp.).

Biology: Mackauer and Stary, 1967. Index World Aphidiidae, pp. 82-85 (host list). adelocarinus (Smith). Idaho, Utah, Calif. Host: Capitophorus shepherdiae G. and B., Pleotrichophorus glandulosus (Kalt.), Pseudoepameibaphis glauca G. and P., P. xenotrichus $\mathrm{K}$. and $\mathrm{S}$.

Aphidius (Lysaphidus) adelocarinus Smith, 1944. Aphidiinae of North America, p. 73. \&, o.

multiarticulatus (Ashmead). Ind., Okla.

Lysiphlebus multiarticulatus Ashmead, 1889 (1888). U. S. Natl. Mus., Proc. 11: 664. ठో. ramithyrus (Smith). Utah, Calif. Host: Pleotrichophorus gregarius (Knowl.), $P$. pseudoglandulosus (Palmer).

Apdidius (A phidus) ramithyrus Smith, 1944. Aphidiinae of North America, p. 75. \&, ठ. rosaphidis (Smith). N. B., N. J., N. C., Ohio. Host: Chaetosiphon sp., C. fragaefolii (Ckll.), C. potentillae (Wlkr.), C. thomasi H. R. L.

Aphidius (Lysaphidus) rosaphidis Smith, 1944. Aphidiinae of North America, p. 75. \&, $\delta$.

\section{Genus DIAERETIELLA Stary}

Diaeretiella Stary, 1960. Acta Soc. Ent. Cechosl. 57: 242.

Type-species: Aphidius rapae M'Intosh. Orig. desig.

Prior to 1960, species in Diaeretiella were included mainly in Aphidius Nees and Diaeretus Foerster. At the present, the genus is composed of one cosmopolitan species.

Taxonomy: Stary, 1960. Acta Soc. Ent. Cechosl. 57: 238-239, 242-243. - Stary, 1961. Acta Ent.

Mus. Natl. Pragae 34: 383-397. - Mackauer, 1961. Beitr. z. Ent. 11: 801. -Mackauer, 1964.

Beitr. z. Ent. 14: 53-58.

rapae (M'Intosh). Cosmopolitan. Host: Aphis craccivora Koch, A. fabae Scop., A. gossypii Glover, A. nasturtii Kalt., A. pomi DeG., A rumicis L., Brachycolus asparagi Mord., Brachycaudus helichrysi (Kalt.), B. mimexicolens (Patch), Brevicoryne brassicae (L.), Capitophorus sp., Dactynotus sp., Diuraphis noxius (Mord.), Hayhurstia atriplicis (L.), Hyadaphis foeniculi (Pass.), Lipaphis erysimi (Kalt.), Macrosiphum euphorbiae (Thomas), Myzus certus (Wlkr.), M. persicae (Sulzer), Protaphis sp., Rhopalosiphum fitchii (Sand.), $R$. maidis (Fitch), $R$. padi (L.), Schizaphis graminum (Rond.). This is one of the more important economic species in the Aphidiidae. Although it has a wide host 
range, including most species of Aphididae but with a preference for the

Myzus-Brachycaudus series, it is largely responsible for the natural control of its main host, the cabbage aphid, Brevicoryne brassicae (L.).

Aphidius rapae M'Intosh, 1855. Book of the Garden, v. 2, p. 194..+

Aphidius (Trionyx) rapae Curtis, 1860. farm Ins., p. 73. ?. Preoce. by M'Intosh, 1855.

Diaeretus chenopodii Foerster, 1867. In Kirchner, Cat. Hym. Eur., p. 125. Nomen nudum.

Trioxys piceus Cresson, 1880. U. S. Dept. Agr. Ann. Rpt. for 1879, p. 260. \&, ठ.

Lipolexis chenopodiaphidis Ashmead, 1889 (1888). U. S. Natl. Mus., Proc. 11: 671. ๆ, ठ.

Diaeretus ferruginipes Ashmead, 1890. In Riley and Howard, U. S. Dept. Agr., Insect Life 3: 61 . Nomen nudum.

A phidius brassicae Marshall, 1896. In Andre, Spec. Hym. Eur. Alg., v. 5, p. 597. ‡, ð.

Diaeretus californicus Baker, 1909. Pomona Jour. Ent. 1: 25. \&.

Lysiphlebus crawfordi Rohwer, 1909. Amer. Ent. Soc., Trans. 35: 135. १, ठ.

Diaeretus nipponensis Viereck, 1911. U. S. Natl. Mus., Proc. 40: 182. \&, ठ.

Aphidius (Diaeretus) obsoletus Kurdjumov, 1913. ent. Obozr. 13: 25. §, ð.

Diaeretus napus Quilis, 1931. Eos 7: 71. ․

Diaeretus croaticus Quilis, 1934. Eos 10: 8. \&, ठ.

Diaeretus plesiorapae Blanchard, 1940. Rev. Chil. Hist. Nat. 44: 45. , ठ.

Diaeretus aphidae Mukerji and Chatterjee, 1949. 36th Indian Sci. Cong., Proc. 3: 193.

Nomen nudum.

Diaeretus aphidum Mukerji and Chatterjee, 1950. Roy. Ent. Soc. London, Proc. (B) 19: 4. १, ठี.

Biology: Wheeler, 1923. Ent. Soc. Amer., Ann. 16: 17-19. - Schlinger and Hall, 1960. Ent. Soc. Amer., Ann. 53: 409. - Pimental, 1961. Jour. Econ. Ent. 54: 885-888. —Shands, et al., 1965. Maine Agr. Expt. Sta., Bul. T19: 61-62.

\section{TRIBE TRIOXINI}

\section{SUBTRIBE MONOCTONINA}

\section{Genus MONOCTONUS Haliday}

\section{Genus MONOCTONUS Subgenus MONOCTONUS Haliday}

A phidius subg. Monoctonus Haliday, 1833. Ent. Mag. 1: 487.

Type-species: A phidius (Monoctonus) caricis Haliday. Monotypic.

Monoctonus subg. Paramonoctonus Stary, 1959. Acta Soc. Ent. Cechosl. 56: 238.

Type-species: Monoctonus (Paramonoctonus) angustivalvus Stary. Orig. desig.

This genus includes Section I, Falcigeri, of the genus A phidius Nees as defined by Haliday (1834. Ent. Mag. 2: 94). These parasites seem to prefer the smaller host instars in the Aphidoidea, mainly subfamily Aphidinae.

Revision: Smith, 1944. Aphidiinae of North America, pp. 33-34 (No. Amer. spp.). - Stary, 1959. Acta Soc. Ent. Cechosl. 56: 237-250 (Eur. spp.). - Stary, 1966. Aphid Parasites of Czechoslovakia, pp. 70-72 (Czech. spp.). - Stary and Schlinger, 1967. Rev. Far East Asian Aphidiidae, pp. 77-81 (East Asian spp.).

Taxonomy: Mackauer, 1959. Senckenberg. Biol. 40: 179-180 (subgenera). - Mackauer, 1968. Hym. Cat., part 3, pp. 63-66 (cat. World spp.). - Stary and Smith, 1976. Ent. Soc. Wash., Proc. 78: 171-175 (distr., hosts, nomenclature).

Biology: Mackauer and Stary, 1967. Index World Aphidiidae, pp. 89-92 (host list).

caricis (Haliday). Maine, N. C., Minn., N. Dak., Wash.; Europe. Host: Aulacorthum solani

(Katl.), Pseudacaudella rubida (Borner).

A phidius (Monoctonus) caricis Haliday, 1833. Ent. Mag. 1: 261., , .

crepidis (Haliday). N. B., Que.; Europe. Host: Na sonovia ribisnigri (Mosley).

Aphidius (Aphidius) crepidis Haliday, 1834. Ent. Mag. 2: 94. ㅇ, ð.

Aphidius tuberculatus Wesmael, 1835. Nouv. Mem. Acad. Sci. Bruxelles 9: 80..

Monoctonus paludum Marshall, 1896. In Andre, Spec. Hym. Eur. Alg., v. 5, p. 548.. 
Biology: Griffiths, 1960. Bul. Ent. Res. 51: 303-319. - Griffiths, 1961. Bul. Ent. Res. 52: 147-163. - Mackauer, 1962. Canad. Ent. 94: 1089-1093.

nervosus (Haliday). Mich., Oreg., Calif., Alaska; Europe, Asia. Host: Acyrthosiphon pisum

(Harris), Amphorophora mubitoxica Knowl., Aphis rumicis L., Macrosiphum

californicum (Clarke), M. euphorbiae (Thomas), Masonaphis grindeliae Wms., Myzus

ornatus Laing, $M$. persicae (Sulzer), Rhopalosiphum padi (L.), Sitobion fragariae

(Wlkr.).

A phidius (Monoctonus) nervosus Haliday, 1833. Ent. Mag. 1: 488. ९, ठ.

Aphidius paulensis Ashmead, 1902. Wash. Acad. Sci., Proc. 4: 246. o, ठ.

Monoctonus secundus Viereck, 1915. Calif. State Comm. Hort. Monthly Bul. 4: 28. ९, ठ.

Taxonomy: Stary, 1974. Ztschr. Angew. Ent. 75: 212-224.

Biology: Calvert and van den Bosch, 1972. Ent. Soc. Amer., Ann. 65: 422-432, 773-779 (host range and specifictiy, biology, as paulensis). - Calvert, 1973. Ent. Soc. Amer., Ann. 66: 28-33 (host selection, as paulensis).

\section{Genus MONOCTONUS Subgenus HARKERIA Haliday}

Harkeria Cameron, 1900. Ann. Mag. Nat. Hist. 6: 537.

Type-species: Harkeria mufa Cameron. Monotypic.

rufus (Cameron). Maine, $\mathrm{Pa}$; Europe.

Harkeria rufa Cameron, 1900. Ann. Mag. Nat. Hist. 6: 538..+

Taxonomy: Stary and Smith, 1976. Ent. Soc. Wash., Proc. 78: 173-174.

\section{SUBTRIBE TRIOXINA}

\section{Genus BOREOGALBA Mackauer}

Boreogalba Mackauer, 1962. Canad. Ent. 94: 1107.

Type-species: Boreogalba gladifer Mackauer. Orig. desig.

gladifer Mackauer. Northeastern Canada, Alaska.

Boreogalba gladifer Mackauer, 1962. Canad. Ent. 94: 1108. $९$.

\section{Genus TRIOXYS Haliday}

\section{Genus TRIOXYS Subgenus BETULOXYS Mackauer}

Trioxys subg. Betuloxys Mackauer, 1960. Beitr. z. Ent. 10: 139.

Type-species: Trioxys compressicornis Ruthe. Orig. desig.

compressicornis Ruthe. Eastern Canada; Europe. Host: Euceraphis sp., E. punctipennis (Zett.).

Trioxys compressicomis Ruthe, 1859. Stett. Ent. Ztg. 20: 314. ㅇ. .

Trioxys testaceus Stelfox, 1948. Ent. Monthly Mag. 84: 102. $९$.

\section{Genus TRIOXYS Subgenus TRIOXYS Haliday}

A phidius subg. Trioxys Haliday, 1833. Ent. Mag. 1: 488.

Type-species: Aphidius cirsii Curtis. Monotypic.

Nevropenes Provancher, 1886. Addit. Corr. Faune Ent. Canada Hym., p. 153.

Type-species: Nevropenes ovalis Provancher. Monotypic.

Bioxys Stary and Schlinger, 1967. Rev. Far East Asian Aphidiidae, p. 32.

Type-species: Bioxys japonicus Stary and Schlinger. Orig. desig.

Revision: Gahan, 1911. Md. Agr. Expt. Sta., Bul. 152: 193-196 (No. Amer. spp.). - Smith, 1944. Aphidiinae of North America, pp. $84-98$ (No. Amer. spp.). -Mackauer, 1959. Beitr. z. Ent. 9: 144-179 (Eur. spp.). - Stary, 1966. Aphid parasites of Czechoslovakia, pp. 72-79, 89-91 (Czech. spp.). - Takada, 1966. Insecta Matsumurana 29: 23-36 (Jap. spp.). - Takada, 1968. Insecta Matsumurana 30: 110-116 (Jap. spp.). - Stary and Schlinger, 1967. Rev. Far East Asian Aphidiidae, pp. 32-33, 107-128 (East Asian spp.). 
Taxonomy: Mackauer, 1960. Beitr. z. Ent. 10: 137-160. - Mackauer, 1965. Canad. Ent. 97: 225-231. - Mackauer, 1968. Hym. Cat., part 3, pp. 68-78 (cat. World spp.).

Biology: Schlinger and Hall, 1961. Ent. Soc. Amer., Ann. 54: 34-45. - Mackauer and Stary, 1967. Index World Aphidiidae, pp. 94-101 (host list).

Morphology: Schlinger and Hall, 1961. Ent. Soc. Amer., Ann. 54: 34-45 (egg, larvae, adult). -Eastop, 1966. Roy. Ent. Soc. London, Proc. (A) 41: $42-44$ (mouthparts).

americeris Smith. Eastern Canada, Md., Fla., Ohio, Tenn., Mo. Host: Drepanaphis acerifoliae (Thomas), D. monelli (Davis).

Trioxys (Trioxys) americeris Smith, 1944. Aphidiinae of North America, p. 87. $\&, \delta$.

betulae Marshall. N. B., N. H., Que., Ont.; Palearctic. Host: Calaphis sp., C. betulaecoleus (Fitch), Symydobius oblongus (von Heyden).

Trioxys betulae Marshall, 1896. In Andre, Spec. Hym. Eur. Alg., v. 5, p. 553..

Taxonomy: Mackauer, 1965. Canad. Ent. 97: 226-227.

bonnevillensis Smith. Idaho, Utah. Host: Pleotrichophorus bitrichus (K. and S.), P. glandulosus (Kalt.), P. oestlundi (Knowl.), P. pseudoglandulosus (Palmer),

Pseudoepameibaphis glauca G. and P.

Trioxys (Trioxys) bonnevillensis Smith, 1944. Aphidiinae of North America, p. 88., ,.

complanatus Quilis. Canada, Ky., Wis., Minn., Iowa, Ark., Nebr., N. Mex., Utah, Ariz., Nev., Calif.; Mex., Europe, Middle East. Introduced from Southern Europe and Middle East. Host: Therioaphis riehmi (Borner), T. trifolii (Monell).

Trioxys complanatus Quilis, 1931. Eos 7: 78. ₹, ठั.

Trioxys utilis Muesebeck, 1956. Brooklyn Ent. Soc., Bul. 51: 26. ‡, ơ.

Taxonomy: Mackauer, 1959. Beitr. z. Ent. 9: 167-170 (pallidus group). -Mackauer, 1961.

Beitr. z. Ent. 11: 147 (as pallidus Haliday). - Mackauer, 1962. Beitr. z. Ent. 12: 653

(synonymy). - Mackauer, 1967. Entomophaga 12: 144 (key to pallidus group).

Biology: van den Bosch, et al., 1957. Jour. Econ. Ent. 50: 352-356. - van den Bosch, et al., 1959. Jour. Econ. Ent. 52: 136-154. - Finney, et al., 1960. Jour. Econ. Ent. 53: 655-659.

-Schlinger and Hall, 1961. Ent. Soc. Amer., Ann. 54: 34-45. - Hall, et al., 1962. Ent. Soc. Amer., Ann. 55: 566-568. - van den Bosch, et al., 1964. Ecology 45: 602-621. -Force and Messenger, 1964. Ent. Soc. Amer., Ann. 57: 405-413. -Force and Messenger, 1964. Ecology 45: 706-715. - Force and Messenger, 1965. Ecology 46: 853-859. Most references are to utilis Muesebeck.

exareolatus (Viereck). Conn. Host: Macrosiphum rosae (L.).

A phidius (Trioxys) exareolatus Viereck, 1917 (1916). Conn. State Geol. and Nat. Hist. Survey, Bul. 22: 260 . $\%$.

gahani Smith. N. J. Morphologically similar Trioxys species known from Europe suggest the host range of gahani to be restricted to the genus Chcetosiphon (Mackauer and Stary, 1967. Index World Aphidiidae, p. 98).

Trioxys (Trioxys) gahani Smith, 1944. Aphidiinae of North America, p. 92. + , o.

ibis Mackauer. N. B.; Europe. Host: Betulaphis quadrituberculata (Kalt.).

Trioxys (Pectoxys) ibis Mackauer, 1961. Portici Lab. Ent. Agr., Bol. 19: 288..

infrequens Smith. Western Canada, Colo. Morphologically similar species of Trioxys are parasitic on the genus Titanosiphon Nevsky or related aphids (Mackauer and Stary, 1967. Index World Aphidiidae, p. 99).

Trioxys (Trioxys) infrequens Smith, 1944. Aphidiinae of North America, p. 93..

ovalis (Provancher). Ont.

Nevropenes ovalis Provancher, 1886. Addit. Corr. Faune Ent. Canada Hym., p. 153.

Holotype lost, exact placement uncertain.

pallidus (Haliday). Oreg., Calif.; Palearctic. Introduced into Calif. from France. Host:

Chromaphis juglandicola (Kalt.), Eucallipterus tiliae (L.), Myzocallis coryli (Goeze),

Tuberculoides annulatus (Hartig).

Aphidius (Trioxys) pallidus Haliday, 1833. Ent. Mag. 1: 489. ․

Aphidius resolutus Nees, 1834. Hym. Ichn. Aff. Monog., v. 1, p. 24..

A phidius callipteri Marshall, 1896. In Andre, Spec. Hym. Eur. Alg., v. 5, p. 609. ð.

Trioxys pulcher Gautier and Bonnamour, 1924. Soc. Ent. de France, Bul. 1924: 43.. 
Taxonomy: Mackauer, 1959. Beitr. z. Ent. 9: 167-171. - Mackauer, 1961. Beitr. z. Ent. 11: 115-116, 147. - Mackauer, 1962. Beitr. z. Ent. 12: 652-653. - Hall, et al., 1962. Ent. Soc. Amer., Ann. 55: 566-568.

Biology: Fisher, et al., 1959. Diamond Walnut News 41: 18. - Hall, et al., 1962. Ent. Soc. Amer., Ann. 55: 566-568. - van den Bosch, et al., 1962. Jour. Econ. Ent. 55: 857-862. - van den Bosch, et al., 1971. Calif. Agr. 24: 9-10. - Frazer and van den Bosch, 1973. Environ. Ent. 2: 561-568.

\section{Genus BINODOXYS Mackauer}

Trioxys subg. Binodoxys Mackauer, 1960. Beitr. z. Ent. 10: 141.

Type-species: A phidius (Trioxys) angelicae Haliday. Orig. desig.

Prior to 1961, the species in Binodoxys were considered as part of the genus Trioxys Haliday. The host range is largely restricted to the aphid subfamily Aphidinae.

Revision: Smith, 1944. Aphidiinae of North America, pp. 84-98 (No. Amer. spp.). - Mackauer, 1959. Beitr. z. Ent. 9: 144-179 (Eur. spp.). - Stary, 1966. Aphid Parasites of Czechoslovakia, pp. 72-79, 89-91 (Czech. spp.). - Takada, 1966. Insecta Matsumurana 29: 23-36 (Jap. spp.). - Stary and Schlinger, 1967. Rev. Far East Asian Aphidiidae, pp. 107-128 (East Asian spp.). All these references are to revisions of species as part of the genus Trioxys Haliday.

Taxonomy: Mackauer, 1960. Beitr. z. Ent. 10: 141-148 (subgenera). - Mackauer, 1961. Beitr. z. Ent. 11: 802 (raised to generic status). - Mackauer, 1965. Canad. Ent. 97: 225-231 (notes on No. Amer. spp.). - Mackauer, 1968. Hym. Cat., part 3, pp. 75-80 (cat. World spp.).

Biology: Mackauer and Stary, 1967. Index World Aphidiidae, pp. 102-109 (host list). angelicae mediterraneus (Mackauer). Calif. ?; Middle East. Liberated in Calif. but not known to be established. Introduced from Israel and Lebanon. Host: Aphis craccivora Koch, $A$. fabae Scop., A. gossypii Glover, Toxoptera aurantii (Fonsc.).

Trioxys (Binodoxys) angelicae mediterraneus Mackauer, 1960. Beitr. z. Ent. 10: 142 (in part). $\uparrow, \delta$. According to Mackauer and Stary (1967. Index World Aphidiidae, p. 104) part of the original type series of this species included angelicae granatensis (Quilis) which is restricted to the western Mediterranean area.

carolinensis (Smith). Eastern Canada, Mass., N. C. Host: A phis oenotherae Oestl., A. pomi DeG.

Trioxys (Trioxys) carolinensis Smith, 1944. Aphidiinae of North America, p. 89. $\uparrow, \delta$. communis (Gahan). Calif. ?; Asia. Liberated in Calif. but not known to be established. Introduced from Taiwan. Host: Aphis gossypii Glover, Rhopalosiphum sp.

Trioxys communis Gahan, 1927. U. S. Natl. Mus., Proc. 70: 4. $\$, \delta$. coruscanigrans (Gahan). Colo., Idaho, Utah. Host: Macrosiphoniella coweni (Hunter), $M$. jonesi (G. and P.), M. frigidae (Oestl.).

Trioxys comscanigrans Gahan, 1911. Md. Agr. Expt. Sta., Bul. 152: 195. \&. cupressicola (Gahan). Calif. Host: Siphonatrophia cupressi (Swain), S. gravida (Knowl.).

Trioxys cupressicola Gahan, 1919. U. S. Natl. Mus., Proc. 55: 116. ‡, ð.

nearctaphidis Mackauer. N. J. Host: Nearctaphis bakeri (Cowen).

Binodoxys nearctaphidis Mackauer, 1965. Canad. Ent. 97: 229. $ๆ, ~ ઠ$.

palmerae (Smith). Colo. Host: Macrosiphum mentzeliae Wilson.

Trioxys (Trioxys) palmerae Smith, 1944. Aphidiinae of North America, p. 94. \&, ठ. rhagii (Ashmead). N. J., Ont., Mich. Host: Dactynotus atripes (G. and P.).

Trioxys rhagii Ashmead, 1889 (1888). U. S. Natl. Mus., Proc. 11: 670. ๆ.

\section{Genus ACANTHOCAUDUS Smith}

Trioxys subg. Acanthocaudus Smith 1944. Aphidiinae of North America, p. 96.

Type-species: Trioxys (Acanthocaudus) tissoti Smith. Orig. desig.

The host range of this Nearctic genus is apparently restricted to the aphid genus Dactynotus Rafinesque. 
Revision: Smith, 1944. Aphidiinae of North America, pp. 96-98.

Taxonomy: Mackauer, 1960. Beitr. z. Ent. 10: 138. - Mackauer, 1961. Ztschr. f. Parasitenk. 20: 586-587.

caudacanthus (Smith). Fla., Wis. Host: Dactynotus erigeronensis (Thomas), D. gravicomis (Patch).

Trioxys (Acanthocaudus) caudacanthus Smith, 1944. Aphidiinae of North America, p. 97. ๆ, ठี.

schlingeri (Muesebeck). B. C. Host: Dactynotus ambrosiae (Thomas).

Trioxys (Acanthocaudus) schlingeri Muesebeck, 1958. Ent. News 69: 144. ๆ, ठ.

tissoti (Smith). Eastern Canada, Fla. Host: Dactynotus mudbeckiae (Fitch), D. missellae H. R. L.

Trioxys (Acanthocaudus) tissoti Smith, 1944. Aphidiinae of North America, p. 96. ^, ๖.

\section{Family HYBRIZONTIDAE}

By PAul M. MARSh

The ore genus and two species which comprise this family in North America were placed in the family Braconidae under the subfamily Paxylommatinae in the original catalog. Authors who have published on this group are nearly evenly divided as to whether it should be given family or subfamily status, but I have chosen to treat it as a distinct family.

These wasps are relatively rare and their host relationships have not been satisfactorily established. They are found associated with ants and may be ant parasites; however, one record suggests parasitism of aphids.

Revision: Watanabe, 1946. Matsumushi 1: 24-31 (for World).

Taxonomy: Foerster, 1862. Naturh. Ver. Rheinlande, Verh. 19: 247 (key to genera).

-Marshall, 1891. In Andre, Spec. Hym. Eur. Alg., v. 5, pp. 619-628 (taxonomy, key to genera). -Ashmead, 1894. Ent. Soc. Wash., Proc. 3: 55-60 (taxonomy, key to genera). -Marshall, 1899. Ent. Soc. London, Trans. 1899: 73-79 (taxonomy, key to genera).

-Strand, 1914. Ent. Mitt. 3: 27-31 (taxonomy). - Donisthorpe and Wilkinson, 1930. Roy.

Ent. Soc. London, Trans. 78: 87-93 (taxonomy). - Schmiedeknecht, 1930. Hym.

Mitteleuropas, pp. 374-375 (key to genera). -Ceballos, 1943. Eos 19: 63-67 (taxonomy).

-Shenefelt, 1969. Hym. Cat., part 4, pp. 1-4 (cat. World spp.). - van Achterberg, 1976.

Ent. Berich. 36: 61-64 (subfamily status).

Biology: Webster, 1914. Jour. Econ. Ent. 7: 403-404 (No. Amer. host records). - Donisthorpe and Wilkinson, 1930. Roy. Ent. Soc. London, Trans. 78: 87-93 (review of biology).

\section{Genus HYBRIZON Fallen}

Hybrizon Fallen, 1813. Spec. Nov. Hym. Disp. Meth., p. 19. No species.

Type-species: Hybrizon latebricola Nees. By subsequent monotypy.

Paxylomma Brebisson, 1825. In Lepeletier and Serville, Encycl. Meth., Ins. v. 10, p. 23.

Type-species: Paxylomma buccatum Brebisson. Monotypic.

Plancus Curtis, 1833. Ent. Mag. 1: 188.

Type-species: Plancus apicalis Curtis. Monotypic.

Eurypterna Foerster, 1862. Naturh. Ver. Rheinlande, Verh. 19: 247.

Type-species: Paxylomma cremieri Romand. Orig. desig.

Eupachylomma Ashmead, 1894. Ent. Soc. Wash., Proc. 3: 58.

Type-species: Wesmaelia rileyi Ashmead. Orig. desig.

Ogkosoma Haupt, 1913. Ent. Gesell. Halle, Mitt. 5-7: 52.

Type-species: Ogkosoma schwarzi Haupt. Monotypic.

The names Paxyloma, Paxylomme, Paxyllomma, Paxylloma, and Pachylomma, used by various authors, are all to be considered emendations of Paxylomma.

flavocinctus (Ashmead), n. comb. Va.

Eupachylomma flavocincta Ashmead, 1894. Ent. Soc. Wash., Proc. 3: 59. ठ‡.

rileyi (Ashmead), n. comb. D. C., Va., Mich., Ind., Iowa. Host: Schiza phis graminum (Rond.).

Wesmaelia rileyi Ashmead, 1889 (1888). U. S. Natl. Mus., Proc. 11: 641. ․ 



\title{
Family ICHNEUMONIDAE
}

\author{
By Robert W. Carlson
}

Most of the members of this large family are parasites of holometabolous insects. A few species or groups of species parasitize spiders (egg sacs, spiderlings, or adults) or egg sacs of pseudoscorpions. No identified Ichneumonidae are known to be primary parasites of paurometabolous insects (cf. Clancy and Pierce, 1966). Further discussion of host relations is deferred to the introductions pertaining to genera or supergeneric categories. General information on the biology, host selection, or ecology of Ichneumonidae can be found in the discussions of Cushman (1926), Clausen (1940), Townes and Townes (1951, p. 184-185), and Townes $(1958,1962)$. Additional biological references were cited by Sachtleben (1962c).

According to the estimate of Townes $(1969$, p. 6$)$ the Nearctic fauna of Ichneumonidae includes slightly more than 8000 species, only 35 percent of which had been described. Of the 27 currently recognized subfamilies, only the Agriotypinae and Collyriinae have no species native to North America (one species of Collyriinae was introduced from Europe).

I have attempted to include most of the species known to have been released in North America for purposes of biological control. In a few cases, I knew from voucher material or had other reasons to suspect that the identifications which had been published in reference to releases were incorrect. When I lacked the information necessary for correcting the identifications of such species, they were excluded from the catalog. None of the species thus excluded are known to be established.

Lists of species synonymy for species not confined to America north of Mexico are as complete as I could make them. No synonyms were intentionally excluded by virtue of having been described from areas outside the geographic scope of this catalog.

Distributions given for species are self-explanatory. In the catalog of Townes and Townes (1951) numerous species which are not particularly common in collections, and some which actually are rather scarce, were cited as having distributions such as "transcont. in Transit. and U. Austr. Zones." Except in a very few cases, distributions of the latter type have been replaced by lists of states and provinces or by bracketing distributions such as: Que. w. to s. B. C., s. to n. Fla., N. Mex., and s. Calif.

In giving the geographic distributions of genera or supergeneric categories, and in some other discussions, I have used the terms Nearctic and Neotropic in reference to distributions in America north of Mexico and south of the United States, respectively. No alternatives were feasible.

Lists of hosts are arranged so that names of taxa belonging to the same family are in alphabetical sequence. The names of the families themselves would have been a very worthwhile addition, and their inclusion would not have been incompatible with the process of computerization. It is hoped that inclusion of them will be allowed in future editions of the catalog.

Although he did not refer to them by number (except on p. 49), Townes, (1969, p. 15-18) discussed the manner in which Opinions 157 and 159 of the International Commission on Zoological Nomenclature came to be published by Hemming (1945). I have looked into the various 
aspects of these cases and have found that Townes' statements about their history are correct (see Hemming, 1943). I also learned that Opinion 135, which pertains to suppression of the names of Jurine which were validated in 1801 (including Cryptus), has no validity on the same grounds. However, in $1973 \mathrm{I}$ discovered that Opinion 135 is of no consequence with respect to the homonymy of Cryptus Fabricius (1804) because the latter would be preoccupied by Cryptus Panzer (1804) if Cryptus Jurine (1801) had been suppressed. The fact that Panzer's usage of the name Cryptus predates the Fabrician usage is demonstrated by Fabricius' (1804, p. 35) citation of fascicle 88 of Panzer's "Faunae insectorum Germanicae", wherein Panzer (1804) validated the name Cryptus segmentarius, which is the type-species of Cryptus Jurine by subsequent monotypy and which is a synonym of Arge rustica (Linnaeus). After pondering this matter for a considerable time, I decided to use the name Cryptus Fabricius in the present catalog in spite of its homonymy for the following reasons: (1) the name Cryptus Jurine was never applied more than sparingly to sawflies of the genus Arge for a variety of reasons, the principal ones being the obscurity of the publication in which Cryptus Jurine (1801) appeared and the fact that most authors thought the name had been validated only by Jurine (1807) and treated it either as a junior homonym of Cryptus Fabricius or a junior synonym of Hylotomma (itself a junior synonym of Arge); (2) neither Cryptus Jurine nor Cryptus Panzer are likely to be hereafter treated as available names by specialists working on Symphyta; (3) the historic significance of the names Cryptus and Cryptinae for ichneumonology is secondary only to that of Ichneumon and Ichneumonidae.

Fitton and Gauld (1976, p. 249) apparently made independent discovery of the Fabrician citation of Panzer (1804, fasc. 88), and opted in favor of the group name Hemitelinae. I am not certain that the latter will gain wide acceptance among ichneumonid workers, a question which also influenced my decision in favor of Cryptus and Cryptinae. In any event, the paper of Fitton and Gauld did not appear until after the computerization of my manuscript for the Cryptinae, and it is not feasible for me to now alter my decision.

I have applied the names Ichneumon and Pimpla according to the type-species designations of Curtis (1828 and 1839, respectively). I regard application of the names Pimpla Fabricius (1804) and Pimplini to Coccygomimus and Echthromorphini, respectively (in accordance with the illegal Opinion 159), as a nomenclatural absurdity of incredible magnitude. Fabricius placed no species of Coccygomimus in Pimpla; he invariably placed them in Cryptus in 1804. Thus Ichneumon instigator Fabricius (the type-species of Pimpla according to Opinion 159) was not one of the species which Fabricius had included in Pimpla.

I regard $E$ phialtes Schrank (1802, p. 316) as an available name. Schrank's partial misidentification of the type-species (see his p. 269-270 description of Ichneumon compunctor linnaeus) makes it a case analogous to that of his genus Paniscus (see introductory discussion of Netelia), except for the fact that Paniscus is suppressed as a junior synonym of $O$ phion.

Questions of synonymy of supergeneric names have here been decided in favor of the oldest available supergeneric names having type-genera which are currently valid (i.e. not suppressed as junior objective or subjective synonyms). The resultant usage is largely in agreement with that in the paper by Fitton and Gauld (1976) on the ichneumonid supergeneric names other than those of Ichneumoninae. The most noteworthy differences between their usages and mine pertain to Ephialtini (not used here), Pimplini, and names based upon Cryptus.

The following is a discussion of some of the most important publications on Ichneumonidae pertinent to studies of the Nearctic fauna; to a limited extent, some of the authors are also discussed. Biographical data on these and additional authors who published on Ichneumonidae were compiled by Sachtleben (1962b, p. 720-726).

The first real specialist to study Ichmeumonidae was Gravenhorst (my reference to him as an ichneumonid specialist should not be misconstrued; he is also well known for his taxonomic work on certain Coleoptera, and he published on subjects other than entomology). In 1815 Gravenhorst published the first sizeable taxonomic paper that dealt strictly with Ichneumonidae. In 1819 he published a conspectus (i.e. outline) of the 1829 work that is the foundation for modern ichneumonology. The appearance of the latter work was preceded by Gravenhorst's (1820) paper on the ichneumonids of the Italian Piedmont and by Thunberg's $(1822,1824)$ revision of "Ichneumonidea," (Ichneumonoidea, Gasteruptiidae, and Aulacidae). Thunberg's revision was based largely upon Fabricius (1804), but the nine generic names which Fabricius had proposed for the species Thunberg treated were suppressed by Thunberg as synonyms of Ichneumon. This resulted in much homonymy, and Thunberg proposed many replacement names. Fortunate- 
ly, most of the replacement names are unavailable by virtue of having been proposed to replace senior homonyms.

Gravenhorst (1829), on the other hand, attempted to redefine the Fabrician genera of Ichneumonidae and give them phyletic meaning by excluding all but a few of the originally included species and adding others. With the exception of Gelis Thunberg (1827), Gravenhorst also utilized the generic names which had been proposed by other authors who had preceded him. Although Gravenhorst's generic nomenclature was not altogether sound with respect to present rules (see Townes, 1969, p. 10), many of the nomenclatural problems which surfaced in the early part of the 20th Century were not caused by anything Gravenhorst did (although he is culpable in the cases of Bassus and Xorides), and could not have been avoided by anything he could have foreseen. In the case of Pimpla, Gravenhorst (1819) did not indicate the precise group of species for which he would use the name in his familial (our generic) sense; therefore, Curtis (1828) could not have known that his choice of type-species would not agree with Gravenhorst's (1829) usage.

Townes (1959) described the general condition of the Gravenhorst collection. Additional information on the collection and its labeling were published by Townes (1965).

Foerster (1868) was the next person to publish a major work dealing with the entire family. All of the 489 genera newly described in his 1868 paper had no included species. Foerster intended that his generic names would apply to the European fauna, but the first included species, European or otherwise became the only ones eligible for selection as type-species. In many cases the type-species fixation was by subsequent monotypy (Internatl. Code Zool. Nomencl., art. 69 [A] [ii] [2]). Perkins (1962) dealt with the type-species of the Foerster genera, and except for the few cases in which corrections are made here or elsewhere, or in which species have been referred to Foerster genera since 1962, the type-species I have cited are those cited by Perkins.

Holmgren, Cresson, and Provancher were contemporaries who between 1855 and 1890 published many descriptions of new species of Ichneumonidae, and, in the case of Holmgren, many new genera also. The majority of the new species described by Cresson are Nearctic. Cresson's (1887) synopsis of Hymenoptera of America north of Mexico included keys to the subfamilies and genera of Ichneumonidae and a catalog of the species and their synonyms. Cresson (1916) published a list of species he had described, and he indicated which single specimen was to be regarded as the type for each; thus he selected lectotypes for those cases in which he had described a species from more than one specimen. His 1916 paper also included a list of all the papers he had published on Hymenoptera, but there is no published list which excludes those that do not involve Ichneumonidae. Cresson's (1928) paper (published posthumously) on the types of other authors concerns only those to be found in the collection at the Academy of Natural Sciences of Philadelphia. Therefore, in cases where all the type material of a given species was not deposited at the A. N. S. P., Cresson's citations of individual specimens may not constitute lectotype selection. It is apparent, however, that they were accepted as such by Townes $(1944,1945)$ and in cases where only one syntype (or only one syntype from the locality indicated as the type locality) was deposited at the A. N. S. P., Townes may technically be the lectotype selector.

Provancher dealt mostly with the Fauna of Canada, most particularly with that of Quebec. He published most of his original descriptions in "le Naturaliste canadien," but in 1883 published a compilation of them. Additions and corrections to the ichneumonid parts of this 1883 compilation were published by Provancher $(1886,1888,1889)$. Gahan and Rohwer $(1917,1918)$ selected lectotypes for many of Provancher's Hymenoptera (except bees). Barron (1975) restudied the Ichneumonidae in the Provancher collections. He located some types not found by Gahan and Rohwer and in some cases rejected lectotypes that Gahan and Rohwer had selected. In most cases, Barron's grounds for rejecting particular Gahan and Rohwer lectotypes seem valid, but in a number of the cases there was no proof that the Gahan and Rohwer lectotypes had not been syntypes. In those cases (which I discuss under the species in question) I have regarded the Gahan and Rohwer lectotypes as being valid. Barron discussed Provancher's life, collections., and methodology; he also tabulated Provancher's publications on Ichneumonidae (p. 414).

Holmgren dealt mainly with the fauna of Sweden, but did describe six species from California (Holmgren, 1869a) and seven from Greenland (Holmgren, 1869b, 1872). According to information published by Persson (1971) all of the California species were probably collected in the vicinity of San Francisco.

Thomson published on Ichneumonidae between 1783 and 1897, mostly in his "Opuscula en- 
tomologica"; the latter has continuous pagination, but is in most other respects a serial publication, and in this catalog I have bibliographically treated it as such. Thomson was an important adopter of Foerster names. In adopting them, however, he often altered their terminations (see Perkins, 1962, p. 387-390). The Thomson spellings have most recently been treated as emendations (see Walkley, 1958, p. 57; Perkins, 1962, p. 387; Townes, 1969, p. 13-14), and I have cited them as such in this catalog. However, Thomson never cited the original spellings in any of these cases, and although it is obvious in most cases that his spellings were deliberate, they technically should be treated as lapses. Thomson was good at finding characters for distinguishing genera, and also seems to have been very talented at distinguishing closely related species. His ability in the latter respect, at least, seems to have been much greater than that of any of his contemporaries who worked on Ichneumonidae. The weaknesses in Thomson's work stem from the fact that he apparently never traveled to study the collections even of prior Scandinavian workers (e.g. Holmgren, Thunberg, Woldstedt), but instead ignored their names (i.e. in the case of Thunberg) or attempted to identify their species from their descriptions. Many of Thomson's errors in the identification of the species of others are being corrected in current papers.

Ashmead published on Ichneumonidae between 1888 and 1906. His 1900 treatment of the Ichneumonoidea was hastily contrived and full of errors. It is based largely upon the generic keys of Foerster and, with respect to Ichneumonidae, is significant mostly for its fixation of some type-species and for the validation of new generic and specific names. Some of the names validated by Ashmead (1900) were discussed by Cushman (1942). Crawford (1900) published a list of Ashmead's entomological papers and an index to the generic names of Ashmead; there is no published list of only those Ashmead papers which involve Ichneumonidae.

The ichneumonid part (1901-1902) of Dalla Torre's catalog of Hymenoptera is, for the most part, bibliographically accurate and nearly complete. Those inaccuracies which are found in his catalog appear to have resulted from the fact that he either did not have all of the primary literature available to him or did not have time to check it. He connot be faulted on either account, but those who can feasibly check his cataloging of older works probably would be wise in doing so.

Viereck published a significant number of papers on Ichneumonidae and other Hymenoptera between 1902 and 1928, but is probably best known for his publications on the type- species of Ichneumonoidea $(1914,1921)$ and the Hymenoptera of Connecticut $(1917$, with other collaborating authors). His work on the ichneumonoid type-species was based largely upon Dalla Torre's catalog; some of his oversights of first inclusions of species in ichneumonid genera of Foerster could have been avoided if he had studied Dalla Torre's catalog more carefully. Viereck was not a careful worker, however, and the characters he used for distinguishing what he called genera and species were poorly chosen. Consequently, his 1917 treatment of the Ichneumonidae in Hymenoptera of Connecticut has served only to befuddle or mislead those who have attempted to use it. Apparently, there is no published list of Viereck's publications.

Roman (Sweden) and Cushman (U.S. A.) were specialists who published numerous papers on Ichneumonidae over periods of time that were largely overlapping (1903-1940 and 1913-1947, respectively). I have cited below the four taxonomic papers of Cushman (1921 [with Gahan], $1922,1928,1942)$ which deal with Ichneumonidae in a more or less general fashion. A complete listing of Cushman's publications was given by Townes (1957).

Roman $(1912,1932,1936)$ published important papers on ichneumonid type specimens of Thunberg and Linnaeus. His papers on the Ichneumonidae of Greenland are some of the most recent ones on the subject; these and other papers on Greenland Ichneumonidae were cited by Sachtleben (1962c, p. 923). Sachtleben (1962a, p. 171-173) listed most of Roman's papers on Ichneumonidae.

The Nearctic catalog of Ichneumonidae by Townes $(1944,1945)$ differs from the present catalog in showing all the published generic combinations for each species and in citing type localities and type repositories. Those types of Viereck cited in that catalog as being at the Conn. Agr. Expt. Sta. have since been transferred to the U.S. Natl. Museum. Other corrections to the 1944-1945 catalog of Townes were given by Townes (1973, p. 359-369).

The Nearctic catalog of Townes and Townes (1951) did not cite either the nomina nuda which had been cited in synonymy by Townes $(1944,1945)$ or those he had left unplaced $(1945, p$. 768-770). The nomina nuda are reinserted here because they have some historic significance, that significance being greatest when they pertain to specimens which subsequently became types of valid names. 
Short's $(1959,1970)$ study of final-instar larvae was more complete and detailed than that of Beirne (1941), and therefore seems to have had a greater impact upon the classification of Ichneumonidae. Although some specialists who work primarily with adults have recently incorporated larval studies into their taxonomic revisions, information about larvae has come chieftly from scientists, like Dr. Short, who are larval specialists. I believe that the information they have published has in some cases been misused by those who specialize in study of adult specimens. The latter sometimes accord as great a significance to structural characters of the head sclerites of final-instar larvae as to the sum total of the adult structural characters which have been studied. For example, Townes (1969, p. 28-29) based his assertion that Ichneumoninae and Cryptinae (=his Gelinae) are unrelated upon differences between the known larvae of the two groups. Townes believed the fact that "these two subfamilies ... resemble each other to a remarkable degree" ... "to be the result of hunting [for] hosts on foot," a habit shared by many members of both groups, but not all the members of either. The Ichneumoninae are internal pupal and larval-pupal parasites of Lepidoptera, while most of the Cryptinae are presumed to be external parasites of a variety of hosts, including Lepidoptera. The known larvae of these two groups differ accordingly. Because internal parasitism must evolve from external parasitism (or vise versa), I believe that it is illogical to regard the known larval differences as evidence indicating that the Ichneumoninae and Cryptinae are unrelated. I hope that this and similar questions are to be addressed in Dr. Short's revised and greatly expanded work on larvae which is nearly ready for publication (personal commun., J. R. T. Short, 1977).

Sachtleben's (1962a) bibliography of of Palearctic Ichneumonidae is an extremely valuable tool for those interested in the taxonomy or biology of Ichneumonidae. Additions and corrections to this bibliography were published by Sachtleben (1962b, p. 726- 731), and Sachtleben (1962c) provided a set of subject indices to the bibliography (e.g. indices to papers on morphology, ecology, physiology, parasitization of individually listed hosts, various taxonomic categories, etc.). It seems likely that in compiling this set of papers Sachtleben would not have found time for verifying dates of publication; this seems to be borne out by my observation regarding dates for various papers of Holmgren, for some of which I have established dates (i.e. years) of publication later than those cited by Sachtleben.

Much new species synonymy was published in the catalogs of Townes, Townes, and Gupta (1961), Townes, Momoi, and Townes (1965) and Townes and Townes $(1966,1973)$; some improvements in generic and supergeneric classification were also made, particularly in the 1961, 1965, and 1966 catalogs. Many additional changes in classification were made by Townes $(1969,1970 \mathrm{a}$, $1970 \mathrm{~b}, 1971$ ) in his treatment of the genera of the world (except Ichneumoninae). The fact that these works on the genera have been of great importance to the present catalog will be obvious from the fact that I have largely adopted Townes' arrangement of genera and supergeneric categories. However, the arrangement of the taxa in any classification is a superficial matter of secondary importance, and the ultimate value of Townes' volumes on the genera stems from the great amount of new and old real information that they have brought together.

Townes' (1969) estimate of the number of extant ichneumonid species as slightly fewer than 60,500 is rather frequently cited in publication and conversation. In a recent conversation I was told of an anonymous coleopterist who has estimated the size of the Curculionidae to be " 100,000 to 250,000 " species, and I have also heard claims that the Noctuidae and Chalcidoidea may exceed the Ichneumonidae in size. The fact that no persons have yet assembled the collections or the knowledge of them to allow them to make size estimates of the Noctuidae, Chalcidoidea, or Curculionidae that they are willing to publish would seem to attest to the ability and dedication of both of the Towneses. Uncertainties about the absolute and relative sizes of the groups mentioned will outlive those presently wondering about them. However, our present speculations serve to remind us that the number of persons working on the various aspects of systematics and biology of the taxa in any large insect group is far fewer than the number which can possibly satisfy the demand for information about those taxa.

Taxonomy: Jurine, 1801. In Panzer, Litteratur-Ztg. Erlangen, Intelligenzbl. 1: 163.

-Schrank, 1802. Fauna Boica, v. 2, p. 261-319. - Panzer, 1804. Faunae Ins. German., fasc.

88, pl. 17. -Fabricius, 1804. Systema Piezatorum, p. 35, 54-101, 112-123, 126-140. -Jurine,

1807. Nouv. Meth. Class. Hym. Dipt. v. 1, p. 49-51, 98-115, pl. 3, 6, 8. - Gravenhorst, 1815.

Monog. Ichn. Pedestrum, VIII and 110 p. - Gravenhorst, 1819 (1818). Nova Acta

Leopoldina 9: 281-298. —Gravenhorst, 1820. Acad. Sci. Torino, Mem. 24: 275-388. 
-Thunberg, 1822; 1824. Acad. Imp. des Sci. St. Petersburg, Mem. 8: 249-281 (key); 9: 285-368. - Thunberg, 1827. Soc. Sci. Upsala, Nova Acta 9: 199-204 (Gelis described). -Curtis, 1828. Brit. Ent., v. 5, pl. 214 (type-species desig. for Pimpla). -Gravenhorst, 1829. Ichn. Europaea, 3 v., xxxi and 2916 p. -Curtis, 1839. Brit. Ent., v. 16, pl. 728 (type-species desig. for Ichneumon). - Foerster, 1868. Naturh. Ver. Rheinlande, Verh. 25: 135-221. - Holmgren, 1869a (1868). Eug. Resa, pt. 2 (Zool.), sect. 1 (Ins.), p. 391-442. -Holmgren, 1869b. Svenska Vetensk.-Akad. Handl. (n. f.) 8 (5): 1-56. -Holmgren, 1872. Svenska Vetensk.-Akad., Ofvers. af ... Forhandl. 29: 97-105. -Thomson, 1873-1897. Opuse. Ent. 5: 455-527 (1873); 6: 589-612 (1874); 8: 732-777 (1877); 9: 850-936 (1883); 10: 939-1040 (1884); 11: 1043-1182 (1887); 12: 1185-1318 (1888); 13: 1321-1438 (1889); 14: 1441-1534 (1890); 15: 1601-1656 (1891); 16: 1752-1773 (1892); 17: 1862-1886 (1892); 18: 1889-1967 (1893); 19: 1971-2137 (1894); 21: 2343-2404 (1896); 22: 2407-2450 (1897); -Provancher, 1883. Petite Faune Ent. Canada, v. 2, p. 249-490, 752-803 (addit. et corr.), 819-830 (index).

-Provancher, 1886; 1888; 1889. Addit. Corr. Faune Ent. Canada Hym., p. 29-121; 356-370 (sup. aux addit.); 445-475 (index), errata. - Cresson, 1887. Amer. Ent. Soc., Trans., sup. vol. (for 1887), p. 38-52 (keys), 183-221 (catalog). -Ashmead, 1900. U. S. Natl. Mus., Proc. 23: 9-103, 104, 151-152, 161-190. - Dalla Torre, 1901; 1902. Cat. Hym., v. 3, pt. 1, p. 10-544; pt. 2, p. 545-1058, 1089. - Schmiedeknecht, 1902-1927; 1928-1936. Opusc. Ichn., 5 v., 44 fasc., 3570 p.; sup., 1 v., 25 fasc., 1875 p. - Crawford, 1909. Ent. Soc. Wash., Proc. 10: 126-156 (biog. and bibliog. of Ashmead). - Roman, 1912. Zool. Bidr. Uppsala 1: 231-293. - Viereck, 1914. U. S. Natl. Mus., Bul. 83, 186 p. - Morice and Durrant, 1915. Ent. Soc. London, Trans. 63: 339-370, 372-375, 388-390 (scholarly discussion of Jurine, 1801). -Cresson, 1916. Amer. Ent. Soc., Mem. 1: 12-64, 135-140. - Viereck, 1917 (1916). Conn. State Geol. and Nat. Hist. Survey Bul. 22: 243-360. - Gahan and Rohwer, 1917; 1918. Canad. Ent. 49: 298-308, 331-336, 391-400, 427-433; 50: 28-33, 101-106, 133-137, 166-171, 196-201. - Viereck, 1918; 1919. Biol. Soc. Wash., Proc. 31: 69-74; 32: 45, 198 (supergeneric names). -Cushman and Gahan, 1921. Ent. Soc. Wash., Proc. 23: 153-171 (Say's species of Ichneumonidae). - Viereck, 1921. U. S. Natl. Mus., Proc. 59: 129-150 (sup. to Viereck, 1914). -Cushman, 1922. U. S. Natl. Mus., Proc. 61 (8): 1-30. -Cresson, 1928. Amer. Ent. Soc., Mem. 5: 11-26. -Cushman, 1928. In Leonard, N. Y. (Cornell) Agr. Expt. Sta., Mem. 101: 920-960 (N. Y. list, Ichneumonidae). - Roman, 1932. Ent. Tidskr. 53: 1-16 (Linnaean types). - Roman, 1933. Ent. Tidskr. 54: 37-39 (type-species of some old ichneumonid genera). - Roman, 1936. Ent. Tidskr. 57: 1-5 (ichneumonid types of Linnaeus in Stockholm Mus.). - Hemming, 1939. Internatl. Comn. Zool. Nomencl., Opinions and Declarations 2: 9-12 (Opinion 135). -Beirne, 1941. Soc. Brit. Ent., Trans. 7: 124-190 -Cushman, 1942. U. S. Natl. Mus., Proc. 92: 277-289. - Hemming, 1943. Bul. Zool. Nomencl. 1: 70-86. - Townes, 1944; 1945. Amer. Ent. Soc., Mem. 11 (1): 1-477; 11 (2): 478-925. - Hemming, 1945. Internatl. Comn. Zool. Nomencl., Opinions and Declarations 2: 253-260, 277-289 (Opinions 157 and 159). -Townes and Townes, 1951. In Muesebeck, et al., U. S. Dept. Agr., Agr. Monog. 2: 184-409. -Townes, 1957. Ent. Soc. Wash., Proc. 59: 248-254 (bibliog. of Cushman's papers). -Walkley, 1958. In Krombein, U. S. Dept. Agr., Agr. Monog. 2, sup. 1, p. 36-62. - Townes, 1959. Ent. Soc. Wash., Proc. 61: 76-78. -Hopper, 1959. Ent. Soc. Wash., Proc. 61: 155-172 (pronunciation and derivation of genric names of Nearctic Ichneumonidae). - Short, 1959. U. S. Natl. Mus., Proc. 110: 391-511 (final-instar larvae). -Townes, 1961. Ent. Soc. Wash., Proc. 63: 103-113 (types of Nearctic ichneumonids in European museums). - Townes, Townes, and Gupta, 1961. Amer. Ent. Inst., Mem. 1: iv and 522 p. (Indo-Austalian catalog). -Sachtleben, 1962a. Beitr. z. Ent. 12: 1-242 (bibliog. Palearctic Ichneumonidae). - Perkins, 1962. Brit. Mus. (Nat. Hist.) Ent., Bul. 11: 385-483. - Sachtleben, 1962b. Beitr. z. Ent. 12: 720-731 (biographies, necrologies, and additions to Sachtleben, 1962a). - Sachtleben, 1962c. Beitr. z. Ent. 12: 915-939 (indices to Sachtleben, 1962a). - Townes, Momoi, and Townes, 1965. Amer. Ent. Inst., Mem. 5: v and 661 p. (Eastern Palearctic catalog). - Townes and Townes, 1966. Amer. Ent. Inst., Mem. 8: iii and 367 p. (Neotropic catalog). - Walkley, 1967. In Krombein and Burks, et al., U. S. Dept. Agr., Agr. Monog. 2, sup. 2, p. 60-213.

- Townes, 1969-1971. Amer. Ent. Inst., Mem. 11: ii and 300 p. (1969); 12: iv and 537 p. (1970 [1969]); 13: ii and 307 p. (1970 [1969]); 17: iii and 372 p. (1971) (genera of world, except Ichneumoninae). - Short, 1970. Roy. Ent. Soc. London, Trans. 122: 185-210 (sup. to Short, 1959). - Persson, 1971. Ent. Tidskr. 92: 164-172 (discussion of voyage of Eug. Resa; see Holmgren, 1869a). - Townes and Townes, 1973. Amer. Ent. Inst., Mem. 19: iv and 416 
p. (Ethiopian catalog). - Barron, 1975. Nat. Canad. 102: 387-591 (types of Provancher).

-Fitton and Gauld, 1976. Systematic Ent. 1: 247-258 (supergeneric names, except those of Ichneumoninae).

Biology: Cushman, 1926. Ent. Soc. Wash., Proc. 28: 5-6, 29-51. -Clausen, 1940.

Entomophagous Insects, p. 61-98. -Townes and Townes, 1951. In Muesebeck, et al., U. S.

Dept. Agr., Agr. Monog. 2: 184-185. - Townes, 1958. Jour. Econ. Ent. 51: 650-652.

-Townes, 1962. Verh. XI Internatl. Kong. f. Ent. Wien 1960, v. 2, p. 738-741.

-Sachtleben, 1962c. Beitr. z. Ent. 12: 924-939 (various biological indices to Sachtleben

1962a [see taxonomy refs.]). - Clancy and Pierce, 1966. Jour. Econ. Ent. 59: 855, 857.

Morphology: Peck, 1937. Canad. Jour. Res., Sect. D: Zool. Sci. 15: 221-274 -Sachtleben, 1962c. Beitr. z. Ent. 12: 923-924 (morphology indices to Sachtleben, 1962a [see taxonomy refs.]).

\section{SUbFamily PIMPLINAE}

Revision: Townes and Townes (et al.), 1960. U. S. Natl. Mus. Bul. 216 (pt. 2): 3-436.

Taxonomy: Cushman, 1921. U.S. Natl. Mus., Proc. 60 (4): 1-6 (key to tribes). -Oehlke, 1964. Ent. Abhandl. 29 (10): 533-590 (keys to Palearctic tribes and genera). -Finlayson, 1967.

Canad. Ent. 99 (1): 1-8 (final-instar larvae), - Oehlke, 1967. In Ferriere and Vecht, Hym.

Cat., pt. 2, 49 pp. (catalog, western Palearctic species). - Aubert, 1969. Ichn. Ouest-Pal. et

Leurs Hotes, pt. 1, 302 p. (catalog). -Townes, 1969. Amer. Ent. Inst., Mem. 11: 59-142 (genera of world).

Morphology: Pratt, 1939. Ent. Soc. Amer., Ann. 32: 727-742.

\section{TRIBE PIMPLINI}

Taxonomy: Perkins, 1943. Ann. and Mag. Nat. Hist. (ser. 11) 10: 249-273.

\section{Genus EXERISTES Foerster}

Exeristes Foerster, 1868. Naturh. Ver. Rheinlande, Verh. 25: 164.

Type-species: Pimpla roborator Gravenhorst. Monotypically included and desig. by Schmiedeknecht, 1888.

Eremochila Foerster, 1868. Naturh. Ver. Rheinlande, Verh. 25: 165.

Type-species: Pimpla ruficollis Gravenhorst. Monotypically included and desig. by Schmiedeknecht, 1888.

Members of this genus are usually parasites of Pyralidae or Olethreutidae.

comstockii (Cresson). Southern Que., s. to Fla., w. to B. C. and Calif. Host: Barbara colfaxiana siskiyouana (Kft.), B. colfaxiana taxifoliella (Bsk.), Eucosma monitorana Heinr., Laspeyresia caryana (Fitch), L. cupressana (Kft.)?, L. toreuta (Grt.), L. youngana (Kft.), Petrova albicapitana (Bsk.), P. comstockiana (Fern.), Rhyacionia buoliana (D. and S.), R. frustrana (Com.), R. rigidana (Fern.), Dioryctria amatella (Hulst), D. auranticella (Grt.), D. clariolaris (Wlk.), D. disclusa Heinr., D. zimmermanni (Grt.), Choristoneura fumiferana (Clem.).

Ephialtes Comstockii Cresson, 1880. In Comstock, U. S. Dept. Agr., Ann. Rpt. for 1879, p. 235. . .

Biology: Cushman, 1927. Jour. Agr. Res. 34: 616. - Miller, 1953. Ohio Jour. Sci. 53 (1): 60. -Arthur, 1963. Canad. Ent. 95: 1079-1085.

roborator (Fabricius). Eurasia. Introduced but never established in Ontario (1957-1958) and various points in the U. S. (1924-1932). Host: Ostrinia nubilalis Hbn., Rhyacionia buoliana (D. and S.). The hosts listed were the target species for introductions into North America, but other hosts have been recorded in Europe.

Ichneumon roborator Fabricius, 1793. Ent. System., v. 2, p. 170. $?$.

Pimpla longicauda Brulle, 1833, (1832). Exped. Sci. de Moree, v. 2, p. 379. 9.

Xorides aegypticus Walker, 1871. List Hym. Coll. ... Red Sea and Arabia, p. 3..

Pimpla flavipennis Rudow, 1883. Ent. Nachr. 9: 234. ․

Pimpla nodosa Rudow, 1883. Ent. Nachr. 9: 235. $\%$. 
Pimpla robusta Rudow, 1883. Ent. Nachr. 9: 238. .

Pimpla Schmiedeknechti Kriechbaumer, 1888. Ent. Nachr. 14: 339. ․

Pimpla brachycera Thomson, 1895. Opusc. Ent. 19: 2126..

Pimpla punctata Thomson, 1895. Opusc. Ent. 19: 2126. ?

Pimpla blattifera Tosquinet, 1896. Soc. Ent. Belg., Mem. 5: 310.

Pimpla schmiedeknechtii Dalla Torre, 1901. Cat. Hym., v. 3, p. 449. Emend.

Pimpla roboratrix Schulz, 1906. Spolia Hym., p. 104. Emend.

Pimpla pyraustae Okamoto, 1921. Hokkaido Agr. Expt. Sta., Bul. 12: 15. ठ์.

Biology: Fox, 1927. Natl. Res. Council, Rpt. 21, Ottawa, 58 pp. -Timon-David, 1931. Soc. de Biol. [Paris], Compt. Rend. 106: 829-831. - Baker and Jones, 1934. U. S. Dept. Agr., Tech. Bul. 460: 1-26.

ruficollis (Gravenhorst). Europe. Introduced in Conn. and N. Y. in 1935-1936 and 7 times in Ontario between 1933 and 1957 without becoming established. Host: Rhyacionia buoliana (D. and S. ). Other hosts are known in Europe, but $R$. buoliana was the target species for introductions in N. Amer.

Pimpla rufícollis Gravenhorst, 1829. Ichn. Europaea, v. 3, p. 153..

Pimpla variegata Ratzeburg, 1844. Ichn. d. Forstins., v. 1, p. 118..

Biology: Thorpe, 1930. Bul. Ent. Res. 21: 395. -Thorpe and Caudle, 1939. Parasitology 30: 523-528. -Juillet, 1959. Canad. Ent. 91: 709-719.

\section{Genus SCAMBUS Hartig}

Revision: Walley, 1960. In Townes and Townes, U. S. Natl. Mus. Bul. 216 (pt. 2): 14-79.

\section{Genus SCAMBUS Subgenus ENDROMOPODA Hellen}

Endromopoda Hellen, 1939. Notulae Ent. 19: 56.

Type-species: Pimpla melanopyga Gravenhorst. Orig. desig.

detritus (Holmgren). N. B. to s. B. C., s. to Ohio and Calif.; Europe. Host: Cephus cinctus Nort., C. pygmaeus (L.), Trachelus tabidus (F.).

Pimpla detrita Holmgren, 1860. Svenska Vetensk.-Akad. Handl. (ser. 4), 3(10): 23. ठ์,.

Biology: Salt, 1931. Bul. Ent. Res. 22: 519-526. - Holmes, 1953. Canad. Ent. 85: 339.

lithocolletidis (Ashmead). Calif. Host: Lithocolletis $\mathrm{sp}$. This is a new subgeneric placement. The host was reared from Grindelia robusta Nutt.

Pimpla lithocolletidis Ashmead, 1890 (1889). U. S. Natl. Mus., Proc. 12: 447. ठ。.

productus Walley. N. S., s. to R. I., w. to Alaska and Calif.

Scambus (Endromopoda) productus Walley, 1960. In Townes and Townes, U. S. Natl. Mus. Bul. 216 (pt. 2): 23. ठ, १.

rubescens Walley. Western N. Y., w. to Sask., s. to Kans. and Wyo.

Scambus (Endromopoda) mibescens Walley, 1960. In Townes and Townes, U. S. Natl. Mus. Bul. 216 (pt. 2): 19. ठ, ₹.

\section{Genus SCAMBUS Subgenus LISSOSCAMBUS Walley}

Scambus subg. Lissoscambus Walley, 1960. In Townes and Townes, U. S. Natl. Mus. Bul. 216 (pt. 2): 25.

Type-species: Scambus (Lissoscambus) arizonensis Walley. Orig. desig.

arizonensis Walley. Colo., Ariz; Mexico.

Scambus (Lissoscambus) arizonensis Walley, 1960. In Townes and Townes, U. S. Natl. Mus. Bul. 216 (pt. 2): 25. ठ, १.

\section{Genus SCAMBUS Subgenus ATELEOPHADNUS Cameron}

Ateleophadnus Cameron, 1905. Invertebrata Pacifica 1: 127.

Type-species: Ateleophadnus bicarinata Cameron. Monotypic.

deceptor Walley. Que., s. to N. Y., w. to B. C. and Colo.

Scambus (Ateleophadnus) deceptor Walley, 1960. In Townes and Townes, U. S. Natl. Mus.

Bul. 216 (pt. 2): $35 . \delta$,. 
granulosus Walley. N. S., s. to S. C., w. to N. W. T. and Calif. Host: Mompha eloisella (Clem.). Scambus (Atelophadnus) granulosus Walley, 1960. In Townes and Townes, U. S. Natl. Mus. Bul. 216 (pt. 2): 31. ठै, ?.

pterophori (Ashmead). Northern N. S., s. to S. C., w. to Alaska and Calif. Host: Periploca ceanothiella (Cosens), Gnorimoschema gallaeasteriella (Kell.), G. gallaesolidaginus (Riley), Mompha eloisella (Clem.), Achatodes zeae (Harris), Ancylis comptana (Froel.), Epiblema otiosanum (Clem.), E. scudderianum (Clem.), E. strenuanum (Wlk.), Grapholitha molesta (Bsk.), Laspeyresia pomonella (L.), Proteoteras aesculana Riley, Platyptilia carduidactyla (Riley), P. williamsi (Grin.), Ostrinia nubilalis ( $\mathrm{Hbn}$.$) ,$ Mononychus vulpeculus (F.), Ametastegia glabrata (Fallen).

Pimpla pterophori Ashmead, 1890 (1889). U. S. Natl. Mus., Proc. 12: 445 . \&.

Colpomeria litoralis Davis, 1898 (1897). Amer. Ent. Soc., Trans. 24: 367. ð.

Atelophadnus bicarinata Cameron, 1905. Invertebrata Pacifica 1: 128. ๆ.

Biology: Vinal and Caffrey, 1919. Mass. Agr. Expt. Sta., Bul. 189: 58. - Leiby, 1922. N. Y.

Ent. Soc., Jour. 30: 93. -Cushman, 1926. Ent. Soc. Wash., Proc. 28: 33. -Wilder; 1927.

Psyche 34: 227-229. - Balduf, 1929. Ohio Jour. Sci. 29: 224-226.

\section{Genus SCAMBUS Subgenus SCAMBUS Hartig}

Scambus Hartig, 1838. Jahresber. Fortschr. Forstwiss. Forstl. Naturk. 1: 267.

Type-species: Scambus sagax Hartig. Desig. by Viereck, 1914.

Tromera Foerster, 1868. Naturh. Ver. Rheinlande, Vehr. 25: 164.

Type-species: Pimpla pomorum Ratzeburg. Monotypically included and desig. by

Schmiedeknecht, 1888.

E piurus Foerster, 1868. Naturh. Ver. Rheinlande, Verh. 25: 164. Preocc. by Rafinesque, 1815.

Type-species: Pimpla calobata Gravenhorst. Here desig. from two species included by Woldstedt, 1877 (1876).

Troctocerus Woldstedt, 1877 (1876). Acad. Imp. des Sci. St. Petersburg, Bul. 22: 296.

Type-species: Troctocerus elegans Woldstedt. Monotypic.

Pseudopoemenia Kiss, 1924. Siebenbuerg. Ver. Naturw., Verh. u. Mitt. 72-74: 91.

Type-species: Pseudopoemenia annulata Kiss. Monotypic.

annulatus (Kiss), N. S., Que., N. H., N. W. T., Alaska and B. C.; Europe. Host: Spilonota ocellana (D. and S.). This species had been misidentified as Scambus nucum (Ratzeburg), a synonym of planatus Hartig, which is not known from North America.

Pseudopoemenia annulata Kiss, 1924. Siebenbuerg. Ver. Naturw., Verh. u. Mitt. 72-74: 92. б.

Pimpla lativentris Ulbricht, 1926. Konowia 5: 51. đ, ๆ. Preocc. by Rudow, 1881.

Pimpla trilobata Keler, 1937. Prace Wydz. Chorob. Roslin Panst. Inst. Nauk. Gosp. Wiejsk. w Bydgoszezy 16: 11. o, ?.

Taxonomy: Oehlke, 1966. Beitr. z. Ent. 16: 189.

aplopappi (Ashmead). Nebr., Colo., N. Mex., Idaho, Ariz., Wash., Calif. Host: Coleotechnites milleri (Bsk.), Etiella zinckenella (Treit.), Rhyacionia frustrana bushnelli (Bsk.), $R$. neomexicana (Dyar), Stomopteryx nigrella (Cham.).

Pimpla aplopappi Ashmead, 1890 (1889). U. S. Natl. Mus., Proc. 12: 446. ठ.

Scambus evetrivorus Rohwer, 1915. U. S. Natl. Mus., Proc. 49: 225..

atrocoxalis (Ashmead). Newfoundland (Labrador), N. W. T., Alta., Yukon, Alaska; Sweden.

Epiurus atrocoxalis Ashmead, 1902. Wash. Acad. Sci., Proc. 49: 225. ¿, $९$.

brevicornis (Gravenhorst). Newfoundland (Labrador) s. to N. J., w. to Alaska and Calif;; Greenland; Europe. Host: Anthophila pariana (Clerck), Choristoneura rosaceana (Harris), Laspeyresia nigricana (Steph.), Laspeyresia sp., Parlobesia viteana (Clem.), Spilonota ocellana (D. and S.).

Pimpla brevicornis Gravenhorst, 1829. Ichn. Europaea, v. 3, p. 211. ¿゙, ๆ.

Pimpla nigriscaposa Thomson, 1877. Opusc. Ent. 8: 755. đ, ?.

Pimpla punctiventris Thomson, 1877. Opusc. Ent. 8: 756. ठ, ๆ.

Pimpla (Epiurus) balearica Kriechbaumer, 1894. Ann. Hist. Nat. Madrid 23: 248. .

Epiurus bicoloripes Ashmead, 1902. Wash. Acad. Sci., Proc. 4: 201.. 
Phthorimus anomalus Morley, 1905. Ent. Soc. London, Trans. 53: 420. \&.

Pimpla euphrantae Schmiedeknecht, 1914. Ztschr. f. Angew. Ent. 1: 452. o, १.

Pimpla ameformis Keler, 1937. Prace Wydz. Chorob. Roslin Panst. Inst. Nauk. Gosp.

Wiejsk. w Bydgoszezy 16: 10. ঠ, १.

Biology: Stuart, 1957. Bul. Ent. Res. 48: 477-488.

buolianae (Hartig). Europe. Introduced in Ontario in 1956 and 1958, but apparently without becoming established. Host: Rhyacionia buoliana (D. and S.).

Pimpla Buolianae Hartig, 1838. Jahresber. Fortschr. Forstwiss. Forstl. Naturk. 1: 267. ठ, ९.

Pimpla flavotrochanterata Pfeffer, 1913. Ver. f. Vaterland. Naturk. in Wuerttemb., Jahresh. 69: 314. ?.

Biology: Leius, 1960. Canad. Ent. 92: 371. - Leius, 1961. Canad. Ent. 93: 1079. - Leius, 1962. Canad. Ent. 94: 1078. - Leius, 1963. Canad. Ent. 95: 202.

canadensis Walley. Northern Que., s. to N. S. and Maine, w. to Alaska and Calif. Host: Glypta fumiferanae (Vier.), Choristoneura conflictana (Wlk.).

Scambus (Scambus) canadensis Walley, 1960. In Townes and Townes, U. S. Natl. Mus. Bul. 216 (pt. 2): 38. ठ,.

decorus Walley. N. S. and Que., s. to Mich., w. to Alaska and Wash. Host: Amorbia humerosa (Clem.), Choristoneura fumiferana (Clem.), Coleophora pminiella Clem., C. fuscedinella Zell., Microsetia stipella (Hbn.), Graciliaria sp., Paraclemensia acerifoliella (Clem.), Phalonia mutilana (Hbn.), S pilonota ocellana (D. and S.).

Scambus (Scambus) decomis Walley, 1960. In Townes and Townes, U. S. Natl. Mus. Bul. 216 (pt. 2): 38. ठ, ?.

dioryctriae Walley. Sask., Alta. Host: Dioryctria reniculella (Grt.).

Scambus (Scambus) dioryctriae Walley, 1960. In Townes and Townes, U. S. Natl. Mus. Bul. 216 (pt. 2): $61 . \delta$, ?.

foliae (Cushman). Austria. Introduced in Maine, apparently without becoming established because of small number of individuals released (50 mated females). Host: Heterarthrus nemoratus (Fallen).

E piurus foliae Cushman, 1938. Wash. Acad. Sci., Jour. 28: 27. ठ,.

Biology: Dowden, 1941. U. S. Dept. Agr., Tech. Bul. 757: 8, 9, 11, 16-20.

hispae (Harris). N. S. s. to Ala., w. to Alaska and Calif. Host: Acrobasis betulella Hulst, $A$. comptoniella Hulst, $A$. mubrifasciella Pack., Anacampis innocuella (Zell.), Dryocampa mubicunda mibicunda (F.), Anthophila pariana (Clerck), Archips rosanus (L.), Choristoneura fumiferana (Clem.), C. pinus Free., Coleophora pruniella Clem., Episimus argutanus (Clem.), Exartema connectum $\mathrm{McD}$., Hedia variegana (Hbn.), Acleris minuta (Rob.), Grapholitha molesta (Bsk.), Tigrioides bicolor (Grt.), Malacosoma disstria Hbn., Psilocorsis sp., Spilonota ocellana (D. and S.), Tischeria sp., Thyridopteryx ephemeraeformis (Haw.), Rhyacionia buoliana (D. and S.), Heterarthrus nemoratus (Fallen), Metallus rohweri MacG., Anoplitus inaequalis (Weber), A. rosea (Weber), Arthrochlamys bebbianae Brown, Xenochalepus dorsalis (Thun.), Hyposoter fugitivus (Say).

Ichneumon Hispae Harris, 1833. In Hitcheock, Rpt. Geol. Mineral. Bot. Zool. Mass., p. 587. Nomen nudum.

Ichneumon hispae Harris, 1835. Boston Soc. Nat. Hist., Jour. 1: 149-150. \&.

Pimpla indagatrix Cresson, 1870. Amer. Ent. Soc., Trans. 3: 146. ठ.

Pimpla minuta Weed, 1887. Ill. State Lab. Nat. Hist., Bul. 3: 41. ठ.

Pimpla gossypii Ashmead, 1890 (1889). U. S. Natl. Mus., Proc. 12: 445..

Scambus (Scambus) tecumseh Viereck, 1917. Conn. State Geol. and Nat. Hist. Survey Bul. 22: 320. 9 . N. syn. In Walley's revision of Scambus this name is incorrectly applied to a species for which no name is apparently available.

Scambus (Eremochila) indagator (!) Viereck, 1917. Conn. State Geol. and Nat. Hist. Survey Bul. 22: 322.

Biology: Porter and Garman, 1923. Conn. (State) Agr. Expt. Sta., Bul. 246: 260. - Balduf, 1926. Canad. Ent. 58: 140. -Cushman, 1927. Jour. Agr. Res. 34: 616. -McConnell, 1928. 
Md. Agr. Exp. Sta., Bul. 298: 180. - Schaffner and Griswold, 1934. U. S. Dept. Agr., Misc. Pub. 188: 143. - Balduf, 1937. Ent. Soc. Wash., Proc. 39: 178. - Arthur, 1963. Canad. Ent. 95 (10): 1085-1086.

imparis Walley. Colo., Alta., Utah, B. C., Wash., Calif. Host: Zelleria haimbachi Bsk.

Scambus (Scambus) imparis Walley, 1960. In Townes and Townes, U. S. Natl. Mus. Bul. 216 (pt. 2): 51. ठ, ?.

longicorpus longicorpus Walley. Que., N. H., Ont., Sask., Alta., Alaska. Host: Dioryctria reniculella (Grt.), Laspeyresia youngana (Kft.).

Scambus (Scambus) longicorpus longicorpus Walley, 1960. In Townes and Townes, U. S. Nat. Mus. Bul. 216 (pt. 2): 44. ठ, ?.

longicorpus occidentalis Walley, Mont., Colo., B. C., Wash., Calif.

Scambus (Scambus) longicorpus occidentalis Walley, 1960. In Townes and Townes, U. S. Natl. Mus. Bul. 216 (pt. 2): 46. ठ, ?.

nigrifrons (Viereck). P. E. I., N. S., N. B., Mass., Mich. Host: Orgyia sp, O. leucostigma (J. E. S.).

Pimpla (Epiurus) nigrifrons Viereck, 1909. Ent. Soc. Wash., Proc. 11: 211. ठ, १.

protentus Walley. Colo., B. C., Wash. Ecology: The holotype emerged from cones of Picea sitchensis. Host: Laspeyresia sp.

Scambus (Scambus) protentus Walley, 1960. In Townes and Townes, U. S. Natl. Mus. Bul. 216 (pt. 2): 40. ठ', ?.

Scambus (Scambus) portentus (!) Walkley, 1967. In Krombein and Burks, U. S. Dept. Agr., Agr. Monog. 2, Sup. 2, p. 63.

sagax Hartig. Europe. Introduced in Ontario in 1956 and 1958, apparently without becoming established. Host: Rhyacionia buoliana (D. and S.), Petrova resinella (L.). The target species for the introductions in Ontario was $R$. buoliana.

Scambus sagax Hartig, 1838. Jahresber. Fortschr. Forstwiss. Forstl. Naturk. 1: 267. ठ, १. Pimpla linearis Ratzeburg, 1844. Ichn. d. Forstins. v. 1, p. 117. §, $\subsetneq$.

Pimpla atrocoxata Pfeffer, 1913. Ver. f. Vaterland. Naturk. in Wuerttemb., Jahresh. 69: 343. \&.

Biology: Harris, 1960. Canad. Jour. Zool. 38: 764. -Adlung and Sailer, 1963. Allg. Forst-u.

Jagd-Ztg. 134 (9): 232-233.

subtilis Walley. Oreg., Nev., Calif.

Scambus (Scambus) subtilis Walley, 1960. In Townes and Townes, U. S. Natl. Mus. Bul. 216 (pt. 2): 47. \&.

transgressus (Holmgren). Idaho, s. B. C., Wash., Oreg., Calif. Host: Grapholitha packardi (Zell.), Acleris variana (Fern.), Archips rosanus (L.), Choristoneura occidentalis Free., Anthophila pariana (Clem.), Coleophora laricella ( $\mathrm{Hbn}$.$) .$

Pimpla transgressus Holmgren, 1869 (1868). Eug. Resa, pt. 2 (Zool.), sect. 1 (Ins.), p. 405. ․

Epiurus innominatus Viereck, 1912. U. S. Natl. Mus., Proc. 42: 149..

\section{Genus SCAMBUS Subgenus ERYTHROSCAMBUS Walley}

Scambus subg. Erythroscambus Walley, 1960. In Townes and Townes, U. S. Natl. Mus. Bul. 216 (pt. 2): 77.

Type-species: Pimpla hirticauda Provancher. Orig. desig.

hirticauda (Provancher). Ariz., B. C., Wash., Calif. Host: Lithocolletis felinelle Hein., Setiostoma fernaldella Riley, Gracillaria sp.

Pimpla hirticauda Provancher, 1886. Addit. Corr. Faune Ent. Canada Hym., p. 116. $q$. Provancher erroneously gave the type locality as Ontario, but Walley (1960) established that Victoria, B. C. is the actual type locality.

\section{Genus CALL1EPHiaLTES Ashmead}

Calliephialtes Ashmead, 1900. U. S. Natl. Mus., Proc. 23: 54.

Type-species: Pimpla xanthothorax Ashmead. Monotypic and orig. desig. 
ferrugineus Cushman. Southern Fla.; Puerto Rico, Cuba. Host: Hypsipyla grandella (Zell.), Pectinophora gossypiella (Sdrs.). The specimens upon which these host records are based are from Puerto Rico.

Calliephialtes fermigineus Cushman, 1940. U. S. Natl. Mus., Proc. 88: 362. ․

grapholithae (Cresson). Mass., s. to Fla., w. to Mich. and Texas. Host: Acrobasis hebescella Hulst, A. juglandis (LeB.), A. rubrifasciella Pack., Carmenta texana (Hy. Ed.)?, Laspeyresia caryana (Fitch), Meskea dyspteraria Grt., Stagmatophora ceanothiella Cos., Thyridopteryx ephemeraeformis (Haw.), Megalopyge opercularis (J. E. S.).

Pimpla grapholithae Cresson, 1890. In Hamilton, Ent. News 1: 50. ठँ, १.

Pimpla xanthothorax Ashmead, 1890 (1889). U. S. Natl. Mus., Proc. 12: 446..+

Biology: Hamilton, 1890. Ent. News 1: 49 -Nickels, Pierce, and Pinkney, 1950. U. S. Dept. Agr., Tech. Bul. 1011: 12-14.

Morphology: Peck, 1937. Canad. Jour. Res., Sect. D (Zool. Sci.) 15: 248, 249, 252.

notandus (Cresson). Southern Que., s. to Fla., w. to s. B. C. and Calif. Host: Epiblema desertanum (Zell.), E. scudderianum (Clem.), E. strenuanum (Wlk.), "Gelechia" sp., Gnorimoschema baccharisella Bsk., G. gallaeasteriella (Kell.), G. gallaesolidaginis (Riley), Walshia "amorphella" Clem.

Pimpla notanda Cresson, 1870. Amer. Ent. Soc., Trans. 3: 148. đ, ?.

Biology: Riley, 1877. Mo. State Ent., Ann. Rept. 9: 98. - Leiby, 1922. N. Y. Ent. Soc., Jour. 30: 93 .

thurberiae Cushman. Southeastern N. Mex., Ariz.; Mexico, Costa Rica. Host: Anthonomus grandis thurberiae Pierce, Disholcaspis sp., Acrobasis nuxvorella Neun., Antron plumbeum (Weld).

Calliephialtes thurberiae Cushman, 1915. Ent. Soc. Wash., Proc. 17: 132. ठ, $९$.

\section{Genus PIMPLA Fabricius}

Pimpla Fabricius, 1804. Systema piezatorum, p. 112.

Type-species: Ichneumon manifestator Linnaeus. Desig. by Curtis, 1828. Members of this genus parasitize aculeate Hymenoptera which nest in wood. My reasons for using the name Pimpla rather than Ephialtes for this genus are given in the introductory discussion of the Ichneumonidae.

brevis (Morley). Que., Ont., Man., Sask., Alta.; Europe. Host: Megachile sp., M. inermis Prov., $M$. nivalis Friese.

Ephialtes brevis Morley, 1914. Rev. Ichn. Brit. Mus., v. 3, p. 23. ‡.

decumbens Townes. Iowa, Colo., B. C., Calif.

Pimpla decumbens Townes, 1960. In Townes and Townes, U. S. Natl. Mus. Bul. 216 (pt. 2): 102. $\delta$, ㅇ.

macra (Cresson). N. Y., Colo., Oreg., Calif. Host: Passaloecus sp. The host record given by Townes and Townes as "N. brevicornis" is a mistake for Dendroctonus brevicomis LeC., the pupal cells of which harbored the true host, Passaloecus sp.

Ephialtes macer Cresson, 1868. Canad. Ent. 1: 35. ?.

spatulata Townes. Que. s. to N. C., w. to B. C. and Calif.; Europe. Host: Euodynerus sp., Ancistrocerus lineativentris Cameron.

Pimpla spatulata Townes, 1960. In Townes and Townes, U. S. Natl. Mus. Bul. 216 (pt. 2): 106. $\delta, ?$.

\section{Genus LIOTRYPHON Ashmead}

Liogaster Kriechbaumer, 1890. Ent. Nachr. 16: 297. Preocc. by Meyer, 1844.

Type-species: Liogaster longulus Kriechbaumer. Monotypic.

Liotryphon Ashmead, 1900. Canad. Ent. 30: 368. New name for Liogaster Kriechbaumer.

Apistes Seyrig, 1927. Eos 3: 221. Preocc. by Fischer, 1823; Cuvier, 1829.

Type-species: Apistes perversus Seyrig. Monotypic. The type-species is regarded as a synonym of Liotryphon rufïcollis (Desvignes).

A pistephialtes Seyrig, 1928. Eos 4: 380. N. name for Apistes Seyrig. 
Neoephialtes Constantineanu and Pisica, 1970. An. Stiintifice Universitatii "Al. 1. Cuza" din Iasi, sect. II (Stiinte Nat.) a. Biol. Mong. 2: 18.

Type-species: Neophialtes foveolatus Constantineanu and Pisica. Monotypic and orig. desig.

arcticus (Roman). N. W. T., Alaska; Siberia.

Ephialtes arcticus Roman, 1926 (1914). Acad. Imp. des Sci. St. Petersburg, Mem., ser. 8 (cl. Phys. Math.) 29 (7): 6..

caudatus (Ratzeburg). Europe. Introduced in California in 1904 and 1905 and in the eastern U. S. A. in 1935 and 1936, apparently without becoming permanently established. Host: Laspeyresia pomonella (L.).

Pimpla caudata Ratzeburg, 1848. Ichn. d. Forstins., v. 2, p. 92. ․

Ephialtes brevivalvis Hensch, 1929; 1930 . Konowia 8: 159; 9: 75, 249. ठ, ๆ.

Neoephialtes foveolatus Constantineanu and Pisica, 1970. Stiintifice Universitatii "Al. 1.

Cuza" din Iasi, sect. II (Stiinte Nat.) a. Biol. Monog. 2: 19. ․

Taxonomy: Perkins, 1939. Bul. Ent. Res. 30: 307-308.

Biology: Whitaker, 1907. Calif. State Comm. Hort., Bien. Rpt. 2: 231-235.

coracinus (Townes), N. Y., N. J., Md., N. C., Tex.

A pistephialtes coracinus Townes, 1960. In Townes and Townes, U. S. Natl. Mus. Bul. 216 (pt. 2): 99. ¿, . .

dentatus (Townes). Colo., Alta., B. C., Oreg., Calif. Host: Enoclerus sphegus (F.), Thanasimus nigriventris (LeC.).

Apistephialtes dentatus Townes, 1960. In Townes and Townes, U. S. Natl. Mus. Bul. 216 (pt. 2): 97. ठँ, ९.

laspeyresiae (Uchida). Japan. Introduced in N. J. from 1934-1936, apparently without becoming established. Host: Grapholitha molesta (Bsk.).

Ephialtes laspeyresiae Uchida, 1932. Insecta Matsumurana 6: 160. §, ․

Biology: Allen, Holloway, and Haeussler, 1940. U. S. Dept. Agr. Cir. 561: 48.

masoni (Townes). Ont., Man., N. W. T., Alta., Alaska, Yukon.

Apistephialtes masoni Townes, 1960. In Townes and Townes, U. S. Natl. Mus. Bul. 216 (pt. 2): 93 . 9 .

nucicola (Cushman). Colo., N. Mex., Ariz., B. C. s. to Calif. Ecology: May parasitize lepidopterous inquilines in the galls of the Hymenoptera listed as hosts. Host: Andricus sp., Atrusca sp., Disholcaspis eldoradensis (Beut.), Pontania sp., Gnorimoschema baccharisella Bsk., Laspeyresia pomonella (L.), Periploca ceanothiella (Cosens), Proteoteras arizonae Kft., Walshia amorphella Clem., Melissopus latiferreanus (Wlsm.).

Calliephialtes nucicola Cushman, 1931. U. S. Natl. Mus., Proc. 79 (14): 5. ¿, ?.

petulcus (Cresson). Tex.; Mexico.

Pimpla petulca Cresson, 1872. Amer. Ent. Soc., Trans. 4: 165. ๆ.

punctulatus (Ratzeburg). Europe. Introduced in Idaho (year unknown), without attempts at recovery; lacking evidence to the contrary, it is here presumed to be unestablished.

Host: Laspeyresia pomonella (L.). Other hosts are known, but that listed was the target species for the introduction in Idaho.

Pimpla punctulata Ratzeburg, 1848. Ichn. d. Forstins., v. 2, p. 90 . $\%$.

E phialtes extensor Taschenberg, 1863. Ztschr. Gesam. Naturw. Halle 21: 255. ð, ९. This is the name which was applied to the material imported to Idaho.

E phialtes discolor Brischke, 1880. Naturf. Gesell. Danzig, Schr. (n. s.) 4 (4): 110. ơ, \&.

Liogaster longulus Kriechbaumer, 1890. Ent. Nachr. 16: 297..

Ephialtes macrurus Habermehl, 1916. Ztschr. f. Wiss. Insektenbiol. 12: 163. ₹. Preocc. by Thomson, 1895.

Ephialtes tener Hensch, 1929; 1930. Konowia 8: 140; 9: 75, 245. ð, ๆ.

Ephialtes vernalis Hensch, 1929; 1930. Konowia 8: 152; 9: 76 . ठ.

Ephialtes gracilentus Hensch, 1930. Konowia 9: 75. Nomen nudum.

Taxonomy: Perkins, 1939. Bul. Ent. Res. 30: 307-308.

Biology: Lyngnes, 1960. Norsk Ent. Tidsskr. 11: 122-134. 
variatipes (Provancher). Que., N. H. s. to Md., W. Va., w. to Minn. Host: Canarsia ulmiarrosorella (Clem.), Laspeyresia pomonella (L.), Grapholitha molesta (Bsk.).

E phialtes variatipes Provancher, 1886. Addit. Corr. Faune Ent. Canada Hym., p. 114. o. Pimpla stultor Davis, 1898 (1897). Amer. Ent. Soc., Trans. 24: 367. ठ.

Calliephialtes benefactor Cushman, 1931. U. S. Natl. Mus., Proc. 79 (14): 6. ठ, ๆ.

\section{Genus TOWNESIA Ozols}

Townesia Ozols, 1962. Latvijas Ent. 6: 12.

Type-species: Ephialtes tenuiventris Holmgren. Monotypic and orig. desig.

tenuiventris (Holmgren). Que. s. to Md., w. to B. C. and Calif.; Eurasia. Ecology: Known to parasitize aculeate Hymenoptera which nest in wood as well as sawflies which occupy abandoned pupal cells of Coleoptera in the bark of trees, particularly Pinus. Host: Trypoxylon figulus (L.), Chelostoma maxillosum (L.), Xiphydria sp., Strongylogaster sp., S. lineata (Christ). Except for Xiphydria sp., the preceding host records are European. The record for Xiphydria sp. needs confirming, and the host record given in the revision of Townes and Townes (1960) as Melanophila consputa LeC. appears to be incorrect according to card file data pertaining to the specimen in question.

Ephialtes tenuiventris Holmgren, 1859. Svenska Vetensk. Akad., Ofvers. af ... Forhandl. 16: 123. Nomen nudum.

Ephialtes tenuiventris Holmgren, 1860. Svenska Vetensk.- Akad., Handl. (ser. 4) 3 (10): 14. o, ?.

E phialtes geniculatus Brischke, 1864. Phys. Oekonom. Gesell. Koenigsberg, Schr. 5: 179. §. Uncertain syn.

Ephialtes pusio Walsh, 1873. Acad. Sci. St. Louis, Trans. 3: 111..

Ephialtes antefurcalis Thomson, 1877. Opusc. Ent. 8: 741. 9.

Ephialtes pacificus Harrington, 1894. Canad. Ent. 26: 24غ. ठ, 9.

Ephialtes incertus Hensch, 1929; 1930. Konowia 8: 149; 9: 76. ठ.

Ephialtes gracilis Hensch, 1930. Konowia 9: 76. Nomen nuduin.

Biology: Welke, 1966. Beitr. z. Ent. 9: 261-263.

\section{Genus ANASTELGIS Townes}

Anastelgis Townes, 1960. In Townes and Townes, U. S. Natl. Mus. Bul. 216 (pt. 2): 109.

Type-species: Anastelgis terminalis Townes. Orig. desig.

terminalis Townes. Wash., Calif.

Anastelgis terminalis Townes, 1960. In Townes and Townes, U. S. Natl. Mus. Bul. 216 (pt. 2): $110 . \delta$, . .

\section{Genus DOLICHOMITUS Smith}

Closterocerus Hartig, 1847. Naturw. Ver. Harz, Ber., 1846-1847, p. 18. Preocc. by Westwood, 1833.

Type-species: Closterocerus sericeus Hartig. Monotypic.

Dolichomitus Smith, 1877. Zool. Soc. London, Proc., p. 411.

Type-species: Dolichomitus longicauda Smith. Monotypic.

Mesoephialtes Schmiedeknecht, 1906. Opusc. Ichn., v.3, p. 1014.

Type-species: Mesoephialtes coracinus Schmiedeknecht. Monotypic. The

type-species is regarded as a subspecies of Dolichomitus zonatus (Cresson).

Diclosterocerus Viereck, 1914. U. S. Natl. Mus. Bul. 83: 45. New name for Closterocerus

Hartig.

Ichneumon subg. Exeristoidea Viereck, 1924. Canad. Ent. 56: 202.

Type-species: Ichneumon (Exeristoidea) watsoni Viereck. Orig. desig.

Tuberculephialtes Ozols, 1962. Latvijas Ent. 6: 19.

Type-species: Ichneumon tuberculatus Geoffroy. Orig. desig.

Members of this genus parasitize woodborers, usually Coleoptera. Ideally, the name Ephialtes would apply to this genus (see introductory discussion of the family). 
aciculatus (Hellen). Que., Yukon, B. C.; Europe. Host: Tetropium gabrieli Weise. This is a European host record.

E phialtes aciculatus Hellen, 1915. Soc. pro Fauna et Flora Fenn., Acta 40: 25. .

Ephialtes nodosus Gyorfi, 1941. Erdeszeti Kiserletek 43: 237, 247. " $\delta$ " = ?.

Morpnology: Noskiewicz and Chudoba, 1951. Polski Pismo Ent. 21: 43-46, 57-58.

buccatus Townes. Colo., B. C., Oreg.

Dolichomitus buccatus Townes, 1960. In Townes and Townes, U. S. Natl. Mus. Bul. 216 (pt. 2): 141. \&.

californicus Townes. Colo., N. Mex., Ariz., Idaho, Utah, B. C. s. to Calif. Host: Oeme costata LeC., Semanotus ligneus (F.).

Dolichomitus californicus Townes, 1960. In Townes and Townes, U. S. Natl. Mus. Bul. 216 (pt. 2): 146. ठे, ?.

cephalotes (Holmgren). Que., Sask., Alta.; Europe.

Ephialtes cephalotes Holmgren, 1859. Svenska Vetensk-Akad., Ofvers. af ... Forhandl. 16: 123. Nomen nudum.

E phialtes cephalotes Holmgren, 1860. Svenska Vetensk.-Akad. Handl. (ser. 4) 3 (10): 13..

Ephialtes longicauda Mocsary, 1897. Termes. Fuzetek 20: 644. ?. Preoce. in Dolichomitus by Smith, 1877.

Ichneumon (Exeristoidea) watsoni Viereck, 1924. Canad. Ent. 56: 202. ․

cuspidatus Townes. Calif. Host: Monochamus maculosus Hald.

Dolichomitus cuspidatus Townes, 1960. In Townes and Townes, U. S. Natl. Mus. Bul. 216 (pt. 2): 120. ठ, ?.

dolichosoma (Viereck). Pa., Md., N. C., S. C., Ga., Ala., Kans., Colo. Ecology: Parasitizes woodborers of angiosperms.

Ephialtes dolichosoma Viereck, 1912. U. S. Natl. Mus., Proc. 42: 637. ๆ.

flexilis Townes. Man., N. W. T., Yukon.

Dolichomitus flexilis Townes, 1960. In Townes and Townes, U. S. Natl. Mus. Bul. 216 (pt. 2): 142. ㅇ.

foxleei Townes. N. S. w. to B. C., s. to Colo. and Calif. Host: Acanthocinus sp.

Dolichomitus foxleei Townes, 1960. In Townes and Townes, U. S. Natl. Mus. Bul. 216 (pt. 2): 145 .. .

imperator (Kriechbaumer). N. S. s. to Tenn., w. to Alaska and Calif; Eurasia. Host: Asemum nitidum LeC., Xylotrechus sp., Monochamus sp.

E phialtes imperator Kriechbaumer, 1854. Stettin. Ent. Ztg. 15: 156. ․

Ephialtes occidentalis Cresson, 1865. Ent. Soc. Phila., Proc. 4: 269..

irritator (Fabricius). Maine s. to Ga., w. to Minn. and Tex. Host: Anoplodera proxima (Say), Astyleiopus variegatus (Hald.), Elaphidionoides incertus (New.), E. villosus (F.), Graphisurus sp., G. fasciatus (DeG.), Megacyllene caryae (Gah.), M. robiniae (Forst.), Obrium mufulum Gah., Pachyta lamed (L.), Saperda discoidea F., Stenocomis lineatus (Oliv.), Xylotrechus annosus (Say), Melandrya striata Say, Synchroa punctata New., Cryptorhynchus lapathi (L.), Chrysobothris sp., Synanthedon tipuliformis (Clerck).

Ichneumon irritator Fabricius, 1775. Systema Ent., p.336..

Biology: Chittenden, 1893. U. S. Dept. Agr., Insect Life 5: 257. -MacAndrews, 1933. Ent. Soc. Ontario, Ann. Rpt. 63: 50.

Morphology: Pratt, 1939. Ent. Soc. Amer., Ann. 32: 735, 737.

messor perlongus (Cresson). N. B. s. to Va., w. to B. C. and Calif. Host: Buprestis confluenta Say, Saperda calcarata Say, Saperda inornata Say., Xylocrius agassizi (LeC.). D. messor messor Gravenhorst is European.

Ephialtes perlongus Cresson, 1870. Amer. Ent. Soc., Trans. 3: 143. ठౌ.

Ephialtes gigas Walsh, 1873. Acad. Sci. St. Louis, Trans. 3: 110. + .

Dolichomitus messor sparsus Townes, 1960. In Townes and Townes, U. S. Natl. Mus. Bul. 216 (pt. 2): 132, 133. ठ์, ‡. N. syn. 
populneus (Ratzeburg). Ont., Sask., Colo., Wash.; Europe. Host: Saperda populnea (L.). This host is recorded from Europe, but one North American specimen has been reared from an unknown borer in Populus sp.

Ephialtes populneus Ratzeburg, 1848. Ichn. d. Forstins., v. 2, p. 100. §, $q$.

Ephialtes abbreviatus Thomson, 1877. Opusc. Ent. 8: 740. ठ, ?.

Taxonomy: Hinz, 1961. Deut. Ent. Ztschr. (N. F.) 8: 254-255.

pterelas (Say). N. B. s. to S. C., w. to B. C. and Oreg.; Europe.

Ichneumon (Pimpla) pterelas Say, 1829. Contrib. Maclurian Lyceum to Arts and Sci. 1: 71. ‥

Ephialtes discrepans Hensch, 1929; 1930. Konowia 8: 145; 9: 74. ठ.

Taxonomy: Cushman and Gahan, 1921. Ent. Soc. Wash., Proc. 23: 166.

pygmaeus (Walsh). N. H. s. to N. C., w. to B. C. and Calif. Host: Plectrura spinicauda Mann.

Ephialtes pygmaeus Walsh, 1873. Acad. Sci. St. Louis, Trans. 3: 111..

sericeus (Hartig). N. B., Que., Ont., Alaska, Yukon, B. C.; Europe. Host: Tetropium cinnamopterum Kby.

Closterocerus sericeus Hartig, 1847. Naturw. Ver. Harz, Ber. 1846-1847, p. 18. ð.

taeniatus Townes. Ariz., Calif. Host: Chrysobothris edwardsii Horn.

Dolichomitus taeniatus Townes, 1960. In Townes and Townes, U. S. Natl. Mus. Bul. 216 (pt. 2): 118. ठ์, ?.

terebrans nubilipennis (Viereck). N. S. s. to N. C., w. to B. C. and Calif. Host: Pissodes dubius Rand., $P$. engelmanni Hopk., $P$. fasciatus LeC., $P$. fraseri Hopk., $P$. rotundatus LeC. $D$. terebrans terebrans (Ratzeburg) occurs in Europe.

Exeristes nubilipennis Viereck, 1912. U. S. Natl. Mus., Proc. 42: 638. $q$.

Exeristes hyalinipennis Viereck, 1912. U. S. Natl. Mus., Proc. 42: 638..

Biology: Taylor, 1929. Ent. Amer. 10: 26-30, 68.

tuberculatus tuberculatus (Geoffroy). N. B. s. to N. Y., w. to Alaska and Oreg.; Europe, northern Asia (excluding Japan). Host: Hylobius pinicola (Coup.), Monochamus sp., $M$. scutellatus (Say). A second subspecies, D. t. jezoensis (Uchida), occurs in Japan.

Ichneumon tuberculatus Geoffroy, 1785. In Fourcroy, Ent. Parisiensis, v. 2, p. 385. ․

Ichneumon leucopterus Gmelin, 1790. In Linnaeus, Syst. Nat., Ed. 13, p. 2699. ठ ? Uncertain syn.

Ichneumon hyalinus Gmelin, 1790. In Linnaeus, Syst. Nat., Ed. 13, p. 2700. \&. Uncertain syn.

Ichneumon crispus Christ, 1791. Naturgesch. Class. Nomencl. Ins., p. 364. \&. Uncertain syn.

Ichneumon fluctuans Christ, 1791. Naturgesch. Class. Nomencl. Ins., p. 365. \&. Uncertain syn.

Ephialtes parallelus Thomson, 1888. Opusc. Ent. 12: 1248. $\%$.

Ephialtes dentiventris Hellen, 1915. Soc. Fauna et Flora Fenn., Acta 40: 29. . Uncertain syn.

Ephialtes pfefferi Habermehl, 1918. Ztschr. f. Wiss. Insektenbiol. 13: 165. \&.

Biology: Stroiny, 1951. Polskie Pismo Ent. 21: 140-144.

vitticrus Townes. Que. s. to Pa., w. to Wis. and Kans.

Dolichomitus vitticmıs Townes, 1960. In Townes and Townes, U. S. Natl. Mus. Bul. 216 (pt. 2): 148. $\delta$, . .

\section{Genus ACROPIMPLA Townes}

Selenaspis Roman, 1910. Ent. Tidskr. 31(2-3): 191. Preocc. by Bleeker, 1858; Leonardi, 1898.

Type-species: Hemipimpla alboscutellaris Szepligeti. Orig. desig.

Acropimpla Townes, 1960. In Townes and Townes, U. S. Natl. Mus. Bul. 216 (pt. 2): 159.

Type-species: Charitopimpla leucostoma Cameron. Orig. desig. Walkley (1967; In

Krombein and Burks, U. S. Dept. Agr., Agr. Monog. 2, sup. 2, p. 68) states that Acropimpla must have the same type-species as Selenaspis, but this is incorrect 
because Townes did not expressly propose Acropimpla as a replacement name for Selenaspis.

alboricta (Cresson). Newfoundland (Labrador) s. to S. C., w. to Alaska and Calif. Host: Acrobasis betulella Hulst, Anacampsis sp., Archips argyrospilus (Wlk.), Argyrotaenia pinatubana (Kft.), Choristoneura fumiferana (Clem.), C. rosaceana (Harris), E pisimus argutanus (Clem.), Gracilaria rhoifoliella Chamb., Pandemis limitata (Rob.),

Pantographa limata G. and R., Spilonota ocellana (D. and S.), Zotheca tranquilla Grt. Pimpla alboricta Cresson, 1870. Amer. Ent. Soc. Trans. 3: 147. $\delta$.

Pimpla investigatrix Walsh, 1873. Acad. Sci. St. Louis, Trans. 3: 142. ‥

Biology: Cushman, 1926. Ent. Soc. Wash., Proc. 28: 33.

pronexus Townes. N. B. s. to N. Y., w. to B. C. and Wyo. Host: Glypta fumiferanae (Vier.).

Acropimpla pronexus Townes, 1960. In Townes and Townes, U. S. Natl. Mus. Bul. 216 (pt. 2): 161 .. .

\section{Genus GREGOPIMPLA Momoi}

Gregopimpla Momoi, 1965. In Townes, Momoi, and Townes, Amer. Ent. Inst., Mem. 5: 601. Type-species: Pimpla kuwanae Viereck. Orig. desig.

According to Momoi (1965), members of this genus are usually gregarious parasites of Lepidoptera which spin cocoons.

inquisitor (Scopoli). Europe. Introduced in Ont. in 1955 for control of the native Choristoneura fumiferana (Clem.). Only a small number of individuals (38) were released, which would seem to have precluded establishment.

Ichneumon inquisitor Scopoli, 1763. Ent. Carn., p. 286. 9.

Ichneumon scanicus Geoffroy, 1785. In Fourcroy, Ent. Parisiensis, v. 2, p. 416..

Ichneumon albipes Gmelin, 1790. In Linnaeus, Syst. Nat., Ed. 13, v. 1, p. 2701. ठ.

Ichneumon variegatus Gmelin, 1790. In Linnaeus, Syst. Nat., Ed. 13, v. 1, p. 2701. ठో. Preocc. by Schrank, 1785.

Ichneumon aurifrons Gmelin, 1790. In Linnaeus, Syst. Nat., Ed. 13, v. 1, p. 2702..

Ichneumon annulatus Gmelin, 1790. In Linnaeus, Syst. Nat., Ed. 13, v. 1, p. 2702 ..

Ichneumon pennator Fabricius, 1793. Ent. System., v. 2, p. 171.. Preocc. by Fabricius, 1793, p. 155.

Ichneumon pinnator Thunberg, 1822; 1824. Acad. Imp. des Sci. St. Petersburg, Mem. 8: 274; 9: 348. N. name for I. pennator Fabricius, 1793, p. 155.

Pimpla flavipes Gravenhorst, 1829. Ichn. Europaea, v. 3, p. 197. ठ.

Pimpla pini Hartig, 1838. Jahresber. Fortschr. Forstw. 1: 253. đ, ?.

Pimpla pudibundae Ratzeburg, 1848. Ichn. d. Forstins., v. 2, p. 167. o, 9.

Pimpla inquisitrix Schulz, 1906. Spolia Hym., p. 104. Emend.

\section{Genus ISEROPUS Foerster}

Iseropus Foerster, 1868. Naturh. Ver. Rheinlande, Verh. 25: 164.

Type-species: Ichneumon graminellae Schrank. By subsequent monotypy from inclusion by Woldstedt, 1877. The type-species is considered to be a synonym of Iseropus stercorator (F.).

Cnemopimpla Cameron, 1903. Entomologist 36: 159.

Type-species: Cnemopimpla pilosa Cameron. Monotypic.

Members of this genus are gregarious parasites of insects (usually Lepidoptera) which spin flimsy cocoons. One to twenty adults may emerge from one host cocoon.

californiensis Cushman. Colo., N. Mex., Calif. Host: Malacosoma californicum californicum (Pack.), M. c. fragile Stretch, M. c. pluviale Dyar, Malacosoma sp.

Iseropus californiensis Cushman, 1940. Ent. Soc. Wash., Proc. 42: 58. ठ', ๆ. In his key, Cushman used the variant spelling "californicus." 
coelebs (Walsh). N. B. s. to Fla., w. to Minn. and Tex. Host: Orgyia leucostigma (J. E. S.), Orgyia sp., Malacosoma americanum (F.), M. disstria Hbn., "Olene" sp., Metallus rohweri MacG.

Ichneumon inquisitor Say, 1829. Contrib. Maclurian Lyceum to Arts and Sci. 1: 71.. Preocc. by Scopoli, 1763.

Pimpla coelebs Walsh, 1873. Acad. Sci. St. Louis, Trans. 3: 141. ð.

Pimpla inquisitoriella Dalla Torre, 1901. Cat. Hym., v. 3, p. 435. N. name for I. inquisitor Say.

Biology: Howard, 1897. U. S. Dept. Agr., Div. Ent. Bul. 7: 16. - Howard, 1897. U. S. Dept. Agr., Div. Ent. Tech. Ser. 5: 8-17, 23, 31, 54. - Howard, 1898. Ent. Soc. Ont., Ann. Rept. 28: 88. -Fiske, 1903. N. H. Agr. Expt. Sta., Tech. Bul. 6: 198-200. -Cushman, 1926. Ent. Soc. Wash., Proc. 28: 33. - Schaffner and Griswold, 1934. U. S. Dept. Agr., Misc. Pub. 188: 143.

Morphology: Peck, 1937. Canad. Jour. Res., Sect. D (Zool. Sci.) 15: 245-246. -Pratt, 1939. Ent. Soc. Amer., Ann. 32: 735.

stercorator orgyiae (Ashmead). N. S. s. to Md., w. to Alaska and Calif. Host: Choristoneura rosaceana (Harr.), Ctenucha virginica (Charp.), Halisidota sp., Orgyia sp., $O$.

leucostigma (J. E. S.), O. vetusta (Bdv.), Malacosoma sp., M. disstria Hbn., Simyra henrici (Grt.). Iseropus stercorator stercorator (Fabricius) occurs in Europe.

Pimpla orgyiae Riley, 1891. In Riley and Howard, U. S. Dept. Agr., Insect Life 3: 462. Nomen nudum.

Ictoplectis (!) orgyiae Ashmead, 1896. Amer. Ent. Soc., Trans. 23: 213. ๆ.

Pimpla (E piumus) brunneifrons Viereck, 1909. Ent. News 20: 291. ठั, ๆ.

Iseropus brunneifrons septentrionalis Cushman, 1940. Ent. Soc. Wash., Proc. 42: 56. §, ९.

Biology: Patch, 1921. Maine Agr. Expt. Sta., Bul. 302: 318. (as coelebs, misdet.).

\section{Genus TROMATOBIA Foerster}

Tromatobia Foerster, 1868. Naturh. Ver. Rheinlande, Verh. 25: 164.

Type-species: Pimpla variabilis Holmgren. Desig. by Ashmead, 1900 from ten species included by Schmiedeknecht, 1888.

Austropimpla Brethes, 1913. Buenos Aires, Mus. Nac. de Hist. Nat., An. 24: 40.

Type-species: Austropimpla huebrichi Brethes. Monotypic and orig. desig. Members of this genus are gregarious parasites of spider egg cocoons.

notator (Fabricius). N. C., Ga., Fla.; Cuba, Puerto Rico, Haiti, Guyana? Host: Argiope argentata (F.), Glyptocranium cornigerum (Hentz). The species was reared from the latter host in Fla., from the former in Puerto Rico.

Pimpla notator Fabricius, 1804. Systema Piezatorum, p. 115. 9.

Clistopyga? lateralis Cresson, 1865. Ent. Soc. Phila., Proc. 4: 34. ठ, ․

Ephialtes Cressoni Dewitz, 1881. Berlin. Ent. Ztschr. 25: 205. ๆ.

Pimpla notatrix Schulz, 1906. Spolia Hym., p. 104. Emend.

ovivora (Boheman). N. S. s. to S. C., w. to Alaska and Calif.; Mexico, Hawaii, Europe, n. Asia. Host: Araneus diadema L., A. solitarius (Emrtn.)., Argiope avara Thor., A. argentata (F.), Cyrtophora californiensis Keys.

Pimpla ovivora Boheman, 1821. Svenska Vetensk.-Akad. Handl. (ser. 3) 9: 336. ðे, ๆ.

Ichneumon vexatorius Thunberg, 1822; 1824. Acad. Imp. des Sci. St. Petersburg, Mem. 8: $281 ; 9: 368$. [female].

Ichneumon armillatorius Thunberg, 1822; 1824. Acad. Imp. des Sci. St. Petersburg, Mem. 8: 281; 9: 368. [male].

Pimpla angens Gravenhorst, 1829. Ichn. Europaea, v. 3, p. 162. ठ, १.

Pimpla scriptifrons Cresson, 1870. Amer. Ent. Soc., Trans. 3: 148. ९.

Pimpla vidua Walsh, 1873. Acad. Sci. St. Louis, Trans. 3: 140. ․

Pimpla parallela Thomson, 1877. Opusc. Ent. 8: 752. .

Pimpla albipes Brischke, 1891. Naturf. Gesell. Danzig, Schr. (n. s.) 7 (4): 63. ð. Synonymy uncertain.

Pimpla defensator Davis, 1898 (1897). Amer. Ent. Soc., Trans. 24: 267..

Pimpla defensatrix Schulz, 1906. Spolia Hym., p. 104. Emend.

Pimpla landerensis Viereck, 1906. Amer. Ent. Soc., Trans. 32: 243.. 
A pechtis rugulosa Morley, 1914. Rev. Ichn. Brit. Mus., v. 3, p. 34. \&.

Biology: Nielsen, 1923. Ent. Meddel. 14: 194-195. -Shaw, 1930. N. Y. Ent. Soc., Jour. 38: 465. rufopectus (Cresson). Maine s. to Fla., w. to Iowa and Tex. Host: Argiope aurantia (Lucas), $A$. trifasciata (Forsk.), Epeira sp. Townes (1960) treated rufopectus as a subspecies of ovivora, but the geographical range of ovivora extends throughout most of that of rufopectus. Morphological and biological differences discussed by Townes also indicate that these two taxa should be treated as separate species.

Pimpla rufopectus Cresson, 1870. Amer. Ent. Soc., Trans. 3: 148..

Biology: Champlain, 1922. Psyche 29: 97.

Morphology: Pratt, 1939. Ent. Soc. Amer., Ann. 32: 735.

variabilis (Holmgren). N. S. s. to Fla., w. to Alaska and Calif.; Europe; n. Asia.

Pimpla abdominalis Brulle, 1846. In Lepeletier, Hist. Nat. Ins. Hym., v. 4, p. 99. ठ. Preocc. by Gravenhorst, 1829.

Pimpla variabilis Holmgren, 1856 (1854). Svenska Vetensk.-Akad. Handl. 75: 88. o, १.

Pim pla rufovariata Cresson, 1870. Amer. Ent. Soc., Trans. 3: 149...

Polysphincta cingulata Provancher, 1875. Nat. Canad. 3: 141. $q$.

Pimpla epeirae Bignell, 1893. Ent. Monthly Mag. 29: 37. §, $९$.

Pimpla rufovariegata (!) Dalla Torre, 1901. Cat. Hym., v. 3, p. 448. Lapsus for rufovariata Cresson.

Pimpla Hibernica Morley, 1908. Ichn. Britannica, v. 3, p. 60. o, ․

Pimpla variabilis var. mificoxa Kokujev, 1913. Russ. Ent. Obozr. (Rev. Russe d'Ent.) 13: 167. ㅇ․

Polysphincta forsiusi Hellen, 1915. Soc. pro Fauna et Flora Fenn., Acta 40: 45. ठ์,.

Tromatobia sapporensis Uchida, 1928. Hokkaido Imp. Univ., Faculty Agr., Jour. 25: 54. ठ, ㅇ.

zonata (Davis). Mass. s. to Fla., w. to Ohio, Ill., and Tex. Host: Epeira undata (Oliv.).

Clistopyga zonata Davis, 1895. Ent. News 6: 198. $q$.

Biology: Hubbell, 1932. Ent. Soc. Amer. Ann. 35: 504.

\section{Genus ZAGLYPTUS Foerster}

Zaglyptus Foerster, 1868. Naturh. Ver. Rheinlande, Verh. 25: 166.

Type-species: Polysphincta varipes Gravenhorst. By subsequent monotypy from inclusion by Woldstedt, 1877.

Members of this genus parasitize spider egg cocoons and adults, sometimes simultaneously.

Biology: Nielsen, 1935. Ent. Meddel. 19: 206-215.

arizonicus Townes. Ariz.

Zaglyptus arizonicus Townes, 1960. In Townes and Townes, U. S. Natl. Mus. Bul. 216 (pt. 2): 192. .

pictilis Townes. Ga., Ala., Fla.; Cuba?

Zaglyptus pictilis Townes, 1960. In Townes and Townes, U. S. Natl. Mus. Bul. 216 (pt. 2): 194. $\delta, ?$.

varipes incompletus (Cresson). N. S. s. to Fla., w. to Alaska and Calif. Z. varipes varipes (Gravenhorst) occurs in Europe.

Pimpla incompleta Cresson, 1870. Amer. Ent. Soc., Trans. 3: 147. ๆ.

Pimpla animosa Cresson, 1872. Amer. Ent. Soc., Trans. 4: 165..+

Polysphincta Rubricapensis Provancher, 1873. Nat. Canad. 5: 470. 9.

Cylloceria Lemoinei Provancher, 1873. Nat. Canad. 5: 471. o.

Polysphincta pimploides Walsh, 1873. Acad. Sci. St. Louis, Trans. 3: 145. .

Polysphincta rufigaster Ashmead, 1890 (1889). U. S. Natl. Mus., Proc. 12: 447. ₹.

Polysphincta spinosa Davis, 1898 (1897). Amer. Ent. Soc., Trans. 24: 368..

\section{Genus CLISTOPYGA Gravenhorst}

Clistopyga Gravenhorst, 1829. Ichn. Europaea, v. 3, p. 132.

Type-species: Ichneumon incitator Fabricius. Desig. by Westwood, 1840. 
Ichneumonoglypta Blanchard, 1941. Soc. Ent. Argentina, Rev. 11: 9.

Type-species: Ichneumonoglypta lopez-richinii Blanchard. Monotypic and orig. desig.

Hymenomacropyga Uchida, 1941. Insecta Matsumurana 15 (3): 116.

Type-species: Hymenomacropyga latifrontalis Uchida. Monotypic and orig. desig.

The systematic position of Clistopyga within the Pimplinae has been unsettled. Meager evidence seems to indicate that Clistopyga spp. are parasitic upon egg sacs of species of spiders which place their egg sacs in crevices. Townes (1960) seems to have given special emphasis to this fact in removing Clistopyga from the Polysphinctini and placing it, along with Tromatobia and Zaglyptus, marginally within the Pimplini.

Biology: Nielsen, 1929. Ent. Meddel. 16: 366-368.

alutaria Townes. Ont., Del., N. C., Fla., Wis.

Clistopyga alutaria Townes, 1960. In Townes and Townes, U. S. Natl. Mus., Bul. 216 (pt. 2): 200. $\delta$, ․

atrata Cushman. Ariz., Oreg., Calif.

Clistopyga atrata Cushman, 1921. U. S. Natl. Mus., Proc. 60 (4): 14. ð’, ९.

canadensis Provancher. N. S. s. to Pa., w. to Alta. and Colo.; Europe.

Polysphincta acuta Provancher, 1880. Nat. Canad. 12: 44. .

Clistopyga Canadensis Provancher, 1880. Nat. Canad. 12: 46. \&.

Clistopyga sauberi Brauns, 1898. Ver. Freunde Naturgesch. Mecklenburg, Arch. 51: 70..

maculifrons Cushman. Mass. s. to N. C., w. to Minn. and Tex.

Clistopyga maculifrons Cushman, 1921. U. S. Natl. Mus., Proc. 60 (4): 12. ๆ.

manni Cushman. N. Mex., B. C., Calif. Host: Agelenopsis sp.; salticid spider.

Clistopyga manni Cushman, 1921. U. S. Natl. Mus., Proc. 60 (4): 12. ?.

nigrifrons Cushman. B. C., Calif. Host: Spider eggs. Notes in the U. S. Natl. Mus. indicate that Cushman's type-specimens were definitely reared from the egg sac of a spider, although the specimens are labled as "on spider nest."

Clistopyga nigrifrons Cushman, 1921. U. S. Natl. Mus., Proc. 60 (4): 11..

recurva (Say). N. J. s. to Fla., w. to Mo. and Tex.

Anomalon recurvus Say, 1836. Boston Jour. Nat. Hist. 1: 243. ठ, १.

Clistopyga annulipes Cresson, 1870. Amer. Ent. Soc., Trans. 3: 150. ९.

Clistopyga pulchripicta Ashmead, 1890 (1889). U. S. Natl. Mus., Proc. 12: 448. $\subsetneq$.

\section{Genus ALOPHOSTERNUM Cushman}

Alophosternum Cushman, 1933. U. S. Natl. Mus., Proc. 82: 7.

Type-species: Alophosternum foliicola Cushman. Monotypic and orig. desig.

foliieola Cushman. Maine, Mass., Calif. Host: Xenochalepus dorsalis (Thun.), Cameraria aceriella? Clem., C. corylisella (Chamb.), Paraclemensia acerifoliella (Fitch).

Alophosternum foliicola Cushman, 1933. U. S. Natl. Mus., Proc. 82: 8. ơ, ?.

\section{TRIBE POLYSPHINCTINI}

Members of this tribe are parasitic upon spiders. The larvae feed externally and solitarily, extracting the "juices" of an individual spider which remains active until the polysphinctine larva matures.

Biology: Nielsen, 1928-1937. Ent. Meddel. 14: 137-205 (1923); 16: 152-155 (1928), 366-368 (1929); 19: 192-215 (1935); 20: 25-28 (1937).

\section{Genus DREISBACHIA Townes}

Laufeia Tosquinet, 1903. Soc. Ent. de Belg., Mem. 10: 381. Preocc. by Simon, 1889.

Type-species: Laufeia mira Tosquinet. Monotypic.

Dreisbachia Townes, 1962. Ent. Soc. Wash., Proc. 64 (1): 38. N. name for Laufeia Tosquinet. 
navajo (Townes). Ariz.; Honduras. Ecology: Found along streams at an elevation of $5000 \mathrm{ft}$. in Arizona ; a spider of the genus Pisaurina was common along these streams.

Laufeia navajo Townes, 1960. In Townes and Townes, U. S. Natl. Mus. Bul. 216 (pt. 2): 223. $\delta$, $?$.

slossonae (Davis). N. B. s. to N. C., w. to Alaska and Calif.

Polysphincta slossonae Davis, 1895. In Slosson, Ent. News 6: 317. Nomen nudum.

Polysphincta slossonae Davis, 1898 (1897). Amer. Ent. Soc., Trans. 24: 368. \&.

\section{Genus SCHIZOPYGA Gravenhorst}

Schizopyga Gravenhorst, 1829. Ichn. Europaea, v. 3, p. 125.

Type-species: Schizopyga podagrica Gravenhorst. Desig. by Westwood, 1840.

Several recent publications erroneously state that this genus was described monotypically.

frigida Cresson. Maine s. to N. C., w. to B. C. and Calif.; Europe.

Schizopyga frigida Cresson, 1870. Amer. Ent. Soc., Trans. 3: 159. ؟.

Schizopyga atra Kriechbaumer, 1887. Ent. Nachr. 14: 87. ơ, ․

Polysphincta pontiaci Viereck, 1917. Conn. State Geol. and Nat. Hist. Survey Bul. 22: 317. б.

pulchra Walley. Mass., Ont., N. Y., N. J., N. C., Mich., Minn., B. C. Ecology: Occurs in marshy places. This species appears to be closely related to the European Schizopyga circulator (Panzer). Future study may show that pulchra is only a subspecies of circulator.

Schizopyga pulchra Walley, 1936. Canad. Ent. 68: 20..

\section{Genus ZABRACHY PUS Cushman}

Zabrachypus Cushman, 1920. U. S. Natl. Mus., Proc. 58: 37.

Type-species: Zabrachypus primus Cushman. Monotypic and orig. desig.

primus Cushman Md., Va., N. C., Ohio, N. Dak., Alta., B. C., Mont., Ariz.

Zabrachypus primus Cushman, 1920. U. S. Natl. Mus., Proc. 58: 37. \&.

\section{Genus ACRODACTYLA Haliday}

Barypus Haliday, 1837. In Curtis, Guide Arrangement Brit. Ins., ed. 2, p. 94. Nomen nudum.

Acrodactyla Haliday, 1839 (1838). Ann. Nat. Hist. 2: 117.

Type-species: Pimpla (Acrodactyla) degener Haliday. Desig. by Westwood, 1840.

Symphylus Foerster, 1871. Naturh. Ver. Rheinlande, Verh. 28: 105. Preocc. by Dallas, 1851.

Type-species: Symphylus hadrodactylus Foerster. Orig. desig.

Polemophthoris Schulz, 1911. Zool. Ann. (Wuerzburg). 4: 22. N. name for Symphylus Foerster.

degener (Haliday). Maine s. to N. C., w. to Alaska and Calif.; Europe. Host: Lepthyphantes obscurus (Blackwall), L. zebrinus (Menge), Microneta viaria (Blackwall), Pityohyphantes phrygianus (C. L. K.). These hosts were recorded in Europe.

Pimpla (Acrodactyla) degener Haliday, 1839 (1838). Ann. Nat. Hist. 2: 117. đँ,.

Acrodactyla degenera Schulz, 1906. Spolia Hym., p. 103. Emend.

Taxonomy: Sedivy, 1972. Acta Ent. Mus. Natl. Pragae 38: 73-79.

Biology: Morley, 1913. Ichn. Britannica, v. 3, p. 133-134. - Nielson, 1923. Ent. Meddel. 14:

163-170 (here misdet. as "Polysphincta pallipes").

jubata Townes. Colo., Yukon, Wash.

Acrodactyla jubata Townes, 1960. In Townes and Townes, U. S. Natl. Mus. Bul. 216 (pt. 2): 231. ?

ocellata Townes. Que., Maine, N. H., Conn., N. Y., Md., N. C., Mich. Host: Pityohyphantes phrygianus (C. L. K.).

Acradactyla ocellata Townes, 1960. In Townes and Townes, U. S. Natl. Mus., Bul. 216 (pt. 2): 232. ơ, + . 


\section{Genus COLPOMERIA Holmgren}

Colpomeria Holmgren, 1859. Svenska Vetensk.-Akad., Ofvers af ... Forhandl. 16: 126.

Type-species: Colpomeria laevigata Holmgren. Monotypic. Townes has most recently been treating Colpomeria as a synonym of Acrodactyla, apparently because of the structural intermediacies of one Formosan species, $C$. orientalis (Cushman). Except in $C$. orientalis, females of this genus have a prominent tooth on the front femur and a weaker one (sometimes vestigial) on the middle femur. The femoral teeth seem significant enough to warrant recognition of Colpomeria as a distinet genus; it also has secondary distinguishing features found only in a few species of Acrodactyla.

quadrisculpta (Gravenhorst). N. S. s. to Ga., w. to Alaska and Calif.; Eurasia. Host:

Tetragnatha laboriosa Hentz, T. obtusa C. L. K. In North America quadrisculpta is known to have been reared only from $T$. laboriosa.

Ichneumon quadrisculptus Gravenhorst, 1820. R. Accad. delle Sci. Torino, Mem. 24: 378. б.

Colpomeria laevigata Holmgren, 1859. Svenska Vetensk.-Akad., Ofvers. af ... Forhandl. 16: 127. $\delta, ?$.

Glypta mellithorax Riley, 1891. In Riley and Howard, U. S. Dept. Agr., Insect Life 3: 463. Nomen nudum.

Zaglyptus kincaidii Ashmead, 1894. U. S. Dept. Agr., Insect Life 6: 260. đ, ?.

Panteles mellithorax Ashmead, 1900 (1899). In Smith, N. J. State Bd. Agr., Ann. Rpt. 27, Sup., p. 575. Nomen nudum.

Polysphincta albocoxalis Ashmead, 1902. In Slosson, Ent. News 13: 320. Nomen nudum.

Colpomeria mellithorax Cushman, 1920. U. S. Natl. Mus., Proc. 58: 19. $\%$. The type locality is D. C.; on page 10 of the paper in which he described mellithorax, Cushman quoted notes which presumably pertain to the cocoon of the holotype of mellithorax, not to the female of Toxophoroides scitulus (Cresson).

Taxonomy: Aubert, 1969. Ichn. Ouest-Pal. et Leurs Hotes, pt. 1, p. 70.

Biology: Nielsen, 1937. Ent. Meddel. 20: 25-27. - Capener, 1938. Soc. Brit. Ent., Jour. 1: 209-210. - Howell, 1972. Entomophaga 17: 5-7.

\section{Genus ERUGA Townes}

Emiga Townes, 1960. In Townes and Townes, U. S. Natl. Mus. Bul. 216 (pt. 2): 238.

Type-species: Emiga lineata Townes. Orig. desig.

atrata Townes. Oreg., Ariz.; Mexico.

Emiga atrata Townes, 1960. In Townes and Townes, U. S. Natl. Mus. Bul. 216 (pt. 2): 238. $\delta$, $९$.

lineata Townes. Que. s. to N. C., w. to B. C. and Calif.

Emiga lineata Townes, 1960. In Townes and Townes, U. S. Natl. Mus. Bul. 216 (pt. 2): 239. $\delta$, + .

rufa Townes. Md., S. C., Mo. Host: Frontinella communis Hentz.

Emiga rufa Townes, 1960. In Townes and Townes, U. S. Natl. Mus. Bul. 216 (pt. 2): 240. ठ", \&.

\section{Genus PIOGASTER Perkins}

Piogaster Perkins, 1958. Entomologist 91: 263.

Type-species: Piogaster rugosa Perkins. Orig. desig. The type-species is considered to be a synonym of $P$. pilosator (Aubert).

maculata Townes. Calif.

Piogaster maculata Townes, 1960. In Townes and Townes, U. S. Natl. Mus. Bul. 216 (pt. 2): 241. .

\section{Genus OXYRRHEXIS Foerster}

Oxyrrhexis Foerster, 1868. Naturh. Ver. Rheinlande, Verh. 25: 166. 
Type-species: Cryptus carbonator Gravenhorst. Monotypically included and desig. by Schmiedeknecht, 1888.

carbonator texana (Cresson). Que. s. to Va., w. to B. C. and Calif. Host: Steatoda borealis (Hentz). O. carbonator carbonator occurs in Europe.

Polysphincta texana Cresson, 1870. Amer. Ent. Soc., Trans. 3: 149. ๆ.

Polysphincta vicina Provancher, 1873. Nat. Canad. 5: 470. ठ̊.

Polysphincta bicarinata Davis, 1898 (1897). Amer. Ent. Soc., Trans. 24: 368. §. Preocc. by Riley, 1871.

Taxonomy: Cushman, 1920. U. S. Natl. Mus., Proc. 58: 22.

\section{Genus POLYSPHINCTA Gravenhorst}

Polysphincta Gravenhorst, 1829. Ichn. Europaea, v. 3, p. 112.

Type-species: Polysphincta tuberosa Gravenhorst. Desig. by Westwood, 1840.

Ephialtomorpha Ashmead, 1906. In Slosson, Ent. News 17: 324. Nomen nudum.

Revision: Cushman, 1920. U. S. Natl. Mus., Proc. 58: 20-28.

albipes Cresson. Southern N. Y. s. to Fla., w. to Kans.

Polysphincta albipes Cresson, 1880. In Comstock, U. S. Dept. Agr., Ann. Rpt. for 1879, p. 208. $\delta$. The type specimen of albipes is lost, and the species had been of somewhat uncertain identity since being originally described from Florida. A female from Florida in the U.S. Natl. Mus. collection agrees with the original description except in having the head ferruginous instead of black. A paratype of eboripes Townes from Kansas approaches the Florida specimen in coloration and agrees very well structurally. I doubt that eboripes deserves subspecific distinction, and, therefore, it is synonymized below.

Polysphincta eboripes Townes, 1960. In Townes and Townes, U. S. Natl. Mus. Bul. 216 (pt.

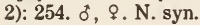

burgessii Cresson. N. S. s. to Md., w. to B. C., Oreg., and Colo.

Polysphincta Burgessii Cresson, 1870. Amer. Ent. Soc., Trans. 3: 149. ठ。.

Polysphincta rufopectus Provancher, 1875. Nat. Canad. 7: 140..

Polysphincta (Polysphincta) venatrix DeGant, 1933. U. S. Natl. Mus., Proc. 82: 4..

koebelei Howard. Wash., Calif. Host: Epeira sp.

Polysphincta (Zaglyptus) koebelei Howard, 1892. Ent. Soc. Wash., Proc. 2: 293..

limata Cresson. P. E. I. s. to N. C., w. to B. C., Oreg., and Colo.

Polysphincta limata Cresson, 1870. Amer. Ent. Soc., Trans. 3: 150. $\%$.

tuberosa bruneti Provancher. Que. s. to N. Y., w. to Alaska and Calif. P. tuberosa tuberosa occurs in Europe and northern Asia.

Polys phincta Bruneti Provancher, 1873. Nat. Canad. 5: 471. $\%$. Barron (1975) rejected the lectotype selected by Gahan and Rohwer (1918) and gave data for the specimen he regarded as the holotype.

Polysphincta brunetii Dalla Torre, 1901. Cat. Hym., v. 3, p. 401. Emend.

Ephialtomorpha slossonae Ashmead, 1906. In Slosson, Ent. News 17: 324. Nomen nudum. Polysphincta (Polysphincta) elongata Cushman, 1920. U. S. Natl. Mus., Proc. 58: 25. 9 .

Taxonomy: Gahan and Rohwer, 1918. Canad. Ent. 50: 169. - Barron, 1975. Nat. Canad. 102: 437.

\section{Genus ACROTAPHUS Townes}

Acrotaphus Townes, 1960. In Townes and Townes, U. S. Natl. Mus. Bul. 216 (pt. 2): 256.

Type-species: Epimecis wiltii Cresson. Orig. desig.

wiltii (Cresson). Maine s. to Fla., w. to Man. and Tex. Host: Neoscona arabesca (Walck.).

Epimecis Wiltii Cresson, 1870. Amer. Ent. Soc., Trans. 3: 143. §.

Biology: Shannon, 1913. Ent. Soc. Wash., Proc. 15: 162. -Gordh, 1971. Kans. Ent. Soc., Jour. 44: $171-172$.

\section{Genus SINARACHNA Townes}

Sinarachna Townes, 1960. In Townes and Townes, U. S. Natl. Mus. Bul. 216 (pt. 2): 258. 
Type-species: Polysphincta pallipes Holmgren. Orig. desig.

anomala (Holmgren). N. S. s. to Fla., w. to Alaska and Calif.; Mexico, Europe. Host: Dictyna foliacea (Hentz).

Polysphincta anomala Holmgren, 1860. Svenska Vetensk.-Akad. Handl. (ser. 4) 3: 34..

Polysphincta picticollis Thomson, 1888. Opusc. Ent. 12: 1254. ơ, ?.

Polysphincta dictynae Howard, 1888. U. S. Dept. Agr., Insect Life 1: 107. ơ.

Polysphincta minuta Davis, 1898 (1897). Amer. Ent. Soc., Trans. 24: 369. .

Zatypota anomala meridionator Aubert, 1960. Soc. Linn. de Lyon, Bul. Mens. 29: 32. ․ N. syn. Described from a single female from southern France.

Zatypota anomala meridionator Aubert, 1961 (1960). Vie et Milieu 11: 656. 9 . Second description of anomala meridionator as a new subspecies based on same unique specimen.

pallipes strigis (Howard). Maine s. to N. C., w. to Alaska and Calif. Host: Epeira foliata (Geoff.). S. pallipes pallipes occurs in Europe.

Polysphincta (Zatypota) strigis Howard, 1892. Ent. Soc. Wash., Proc. 2: 291..+

\section{Genus ZATYPOTA Foerster}

Zatypota Foerster, 1868. Naturh. Ver. Rheinlande, Verh. 25: 166.

Type-species: Ichneumon percontatorius Mueller. Desig. by Viereck, 1914 from five species included by Schmiedeknecht, 1888.

Polysphinctopsis Habermehl, 1917. Ztschr. f. Wiss. Insektenbiol. 13: 167.

Type-species: Polysphincta eximia Schmiedeknecht. Monotypic. This type-species is considered to be a synonym of $Z$. albicoxa (Walker).

Lycorinopsis Haupt, 1954. Deut. Ent. Ztschr. (N. F.) 1 (1-11): 110.

Type-species: Lycorinopsis rhombifer Haupt. Orig. desig.

Revision: Cushman, 1920. U. S. Natl. Mus., Proc. 58: 29-36.

alborhombarta (Davis). Va., Fla., Ariz.; Mexico.

Clistopyga alborhombarta Davis, 1895. Ent. News 6: 198. 9.

arizonica Townes. Ariz.

Zatypota arizonica Townes, 1960. In Townes and Townes, U. S. Natl. Mus. Bul. 216 (pt. 2): 271. $\delta$.

bohemani (Holmgren). Mont., B. C.; Europe.

Polysphincta Bohemani Holmgren, 1860. Svenska Vetensk.-Akad. Handl. (ser. 4) 3: 30..

Polysphincta bohemanii Dalla Torre, 1901. Cat. Hym., v. 3, p. 401. Emend.

cingulata Townes. N. S. s. to Ga., w. to Wis. and Colo.

Zatypota cingulata Townes, 1960. In Townes and Townes, U. S. Natl. Mus. Bul. 216 (pt. 2): 270. $\delta$.

crassipes Townes. S. C.

Zatypota crassipes Townes, 1960. In Townes and Townes, U. S. Natl. Mus. Bul. 216 (pt. 2): 278. ㅇ.

exilis Townes. Que., N. H.

Zatypota exilis Townes, 1960. In Townes and Townes, U. S. Natl. Mus. Bul. 216 (pt. 2): 269. ㅇ․

favosa Townes. Calif.

Zatypota favosa Townes, 1960. In Townes and Townes, U. S. Natl. Mus. Bul. 216 (pt. 2): 269. ㅇ․

luteipes Townes. Maine, Mass., Ont., Md., N. C.

Zatypota luteipes Townes, 1960. In Townes and Townes, U. S. Natl. Mus. Bul. 216 (pt. 2): 277. $\delta, \%$.

nigriceps (Walsh). N. S. s. to Fla., w. to B. C. and Calif.

Polysphincta nigriceps Walsh, 1873. Acad. Sci. St. Louis, Trans. 3: 144. o, o.

Polysphincta nigrita Walsh, 1873. Acad. Sci. St. Louis, Trans. 3: 144. o. Uncertain syn.

Clistopyga nigrocephala Davis, 1898 (1897). Amer. Ent. Soc., Trans. 24: 369. ơ.

Polysphincta (Zatypota) braucheri Cushman, 1920. U. S. Natl. Mus., Proc. 58: 33. ơ, ?.

Polysphincta (Zatypota) californiensis Cushman, 1920. U. S. Natl. Mus., Proc. 58: 34. ₹.

Polysphincta (Zatypota) crosbyi Cushman, 1920. U. S. Natl. Mus., Proc. 58: 35. ơ, ९. 
parva (Cresson). Que. s. to N. C., w. to Wis.

Glypta parva Cresson, 1870. Amer. Ent. Soc., Trans. 3: 155..

patellata Townes. B. C. s. to Calif.

Zatypota patellata Townes, 1960. In Townes and Townes, U. S. Natl. Mus. Bul. 216 (pt. 2): 268. ठ, ?.

percontatoria (Mueller). Que. and Ont. s. to N. Y. and Ohio, w. to Alaska and Calif.; Europe. Host: Araneus cucurbitinus Clerck, Meta segmentata Clerck, Theridium denticulatum Walck., $T$. varians Hahn. These hosts are recorded from Europe.

Ichneumon percontatorius Mueller, 1776. Zool. Danicae Prodromus, p. 154. $q$. The neotype designated by Aubert (1969) violates every provision in the Code regarding neotype selection and is therefore invalid. Aubert (1972) contended that usage of the name percontatoria by Townes (1960) and Oehlke (1967) violates the principle of first revisor. However, Townes (1960) stated that he applied the name according to the interpretation of Gravenhorst (1829), and certainly there is no logical basis for regarding Schmiedeknecht (1907) as first revisor as did Aubert (1972).

Polysphincta gracilis Holmgren, 1860. Svenska Vetensk.-Akad. Handl. (ser. 4) 3: 32. ठ*, ๆ. Polysphincta scutellaris Holmgren, 1860. Svenska Vetensk.-Akad. Handl. (ser. 4) 3: 33. $\delta$.

Polysphincta pulchrator Thomson, 1877. Opusc. Ent. 8: 757. ठ. The female lectotype selected by Aubert is invalid, and therefore this synonymy remains uncertain.

Polysphincta theridii Howard, 1892. Ent. Soc. Wash., Proc. 2: 292. ठ.

Polysphincta granulosa Davis, 1898 (1897). Amer. Ent. Soc., Trans. 24: 369. ๆ.

Lycorinopsis decorata Haupt, 1954. Deut. Ent. Ztschr. (N. F.) 1: 110. \&.

Lycorinopsis rhombifer Haupt, 1954. Deut. Ent. Ztschr. (N. F.). 1: 110. \&.

Taxonomy: Gravenhorst, 1829. Ichn. Europaea, v. 3, p. 120-122. -Schmiedeknecht, 1907.

Opusc. Ichn., v. 3, p. 1172. - Townes, 1960. In Townes and Townes, U. S. Natl. Mus. Bul. 216 (pt. 2): 276. - Aubert, 1969. Ichn. Ouest-Pal. et leurs Hotes, pt. 1, p. 77. - Aubert, 1972. Ent. Scand. 3: 10.

Biology: Nielsen, 1923. Ent. Meddel. 14: 170-172.

walleyi Townes. Que., Maine, Mass., Ont., Mich.

Zatypota walleyi Townes, 1960. In Townes and Townes, U. S. Natl. Mus. Bul. 216 (pt. 2): 272. $\delta, ~ q$.

\section{TRIBE ECHTHROMORPHINI}

In addition to the three nearly worldwide genera which occur in North America, this tribe includes five others, the largest and best known of these being Xanthopimpla, of the Old- and New-World tropics, and Echthromorpha, which is chiefly Indo-Australian. Species of Echthromorphini are usually internal parasites of pupae of Lepidoptera, but species of Itoplectis and, to a lesser extent, Coccygomimus sometimes parasitize Symphyta or Ichneumonoidea which spin cocoons in leaf litter or exposed situations.

Revision: Cushman, 1920. U. S. Natl. Mus., Proc. 58: 327-362 (Nearctic spp.). - Townes, 1940. Ent. Soc. Amer., Ann. 33: 283-323 (eastern Nearctic spp.). - Perkins, 1941. Roy. Ent. Soc., London, Trans. 91: 637-659 (British spp.).

Biology: Townes, 1939. Brooklyn Ent. Soc., Bul. 34: 29-30 (protective odors).

Morphology: Townes, 1940. Ent. Soc. Amer., Ann. 33: 285-287. (tarsal claws). -Obrtel, 1960. Brno Moravske Mus. Casopis, Vedy Prirodni 45: 195-202 (male genitalia and postgenital sclerites).

\section{Genus ITOPLECTIS Foerster}

Itoplectis Foerster, 1868. Naturh. Ver. Rheinlande, Verh. 25: 164.

Type-species: Ichneumon scanicus Villers. Desig. by Viereck, 1914 from two species included by Woldstedt, 1877.

Nesopimpla Ashmead, 1906. U. S. Natl. Mus., Proc. 30: 180.

Type-species: Nesopimpla naranyae Ashmead. Monotypic.

Exeristoides Uchida, 1928. Hokkaido Imp. Univ., Faculty Agr., Jour. 25: 51. 
Type-species: Pimpla spectabilis Matsumura. Monotypic and orig. desig. The type-species is considered to be a subspecies of I. alternans (Gravenhorst).

Revision: Porter, 1970. Acta Zool. Lilloana 26 (6): 65-103 (S. Amer. spp.).

behrensii (Cresson). Calif. Host: Phryganidia californica Pack. I. behrensii is not known to occur north of Marin Co., Calif.

Pimpla behrensii Cresson, 1879 (1878). Acad. Nat. Sci. Phila., Proc. 30: 377. đ,.

conquisitor (Say). N. S. s. to Fla., w. to B. C. and Ariz. Host: Hyaloscotes pithopoera (Dyar), Oiketicus abbotii Grt., Thyridopteryx ephemeraeformis (Haw.), Coleophora frischella (L.), C. pruniella Clem., Epermenia cicutaella Kft., Anacampsis inocuella (Zell.), Dichomeris marginella (F.), Choristoneura conflictana (Wlk.), C. fumiferana (Clem.), Choristoneura lambertiana (Bsk.), C. pinus Free., Aphelia alleniana (Fern.), Archips argyrospilus (Wlr.), A. cerasivoranus (Fitch), A. georgianus (Wlk.), A. rileyanus (Grt.), Argyrotaenia cockerellana (Kft.) A. pinatubana (Kft.), A. velutinana (Wlk.), Acleris hastiana (L.), A. minuta (Rob.), Cnephasia virgaureana Treit., Sparganothis pettitana (Rob.), S. flavibasana (Fern.), Xenotemna pallorana Rob., Ancylis comptana (Froel.), A. c. fragariae (W. and R.), Evora hemidesma (Zell.), Paralobesia viteana (Clem.), $R$ hyacionia buoliana (D. and S.), $R$. frustrana (Com.), $R$. frustrana bushnelli (Bsk.), Spilonota ocellana (D. and S.), Pterophorus periscelidactylus Fitch, Acrobasis betulella Hulst, A. caryvoriella Rag., A. juglandis (LeB.), A. kearfottella Dyar, A. rubrifasciella Pack., Dioryctria reniculella (Grt.), Diaphania hyalinata (L.), Ostrinia nubilalis (Hbn.), Cingilia catenaria (Drury), Lambdina fervidaria athasaria (Wlk.), L. fïscellaria fiscellaria (Gn.), Ennomos subsignarius ( $\mathrm{Hbn}$.$) , Nematocampa filamentaria \mathbf{G n}$., Rheumaptera hastata (L.), Dryocampa mibicunda rubicunda (F.), Malacosoma americanum (F.), M. disstria $\mathrm{Hbn} .$, M. californicum fragile (Stretch), Dasychira plagiata (Wlk.), Lymantria dispar (L.), Orgyia antiqua (L.), O. leucostigma (J. E. S.), Alabama argillacea (Hbn.), Anomis erosa $\mathrm{Hbn} .$, Exyra semicrocea (Gn.), Simyra henrici (Grt.), Trichoplusia ni (Hbn.), Lascoria ambigualis (Wlk.), Hyphantria cunea (Drury), Hemileuca sp., Urbanus proteus (L.), Thymelicus lineola (Ochs.), Pieris rapae (L.), Graphium marcellus (Cramer), Diprion similis (Htg.), Neodiprion abietis (Harr.), Rogas stigmator (Say), R. terminalis (Cr.), Dusona ellopiae (Wly.), Gambrus extrematus (Cr.), Hyposoter fugitivus (Say), Phobocampe clisiocampae (Weed), P. pallipes (Prov.). Ichneumon concitator (!) Harris, 1833. In Hitchcock, Rpt. Geol. Mineral. Bot. Zool. Mass. p. 587. Nomen nudum.

Cryptus conquisitor Say, 1836. Boston Jour. Nat. Hist. 1: 232. $\$$.

Cryptus pleurivinctus Say, 1836. Boston Jour. Nat. Hist. 1: 235. ठ, १.

Pimpla pictipes Walsh, 1873. Acad. Sci. St. Louis, Trans. 3: 135. $\$$. Preocc. by Gravenhorst, 1829.

Pimpla walshii Dalla Torre, 1901. Cat. Hym., v. 3, p. 454. N. name for P. pictipes Walsh. Pimpla conquisitrix Schulz, 1906. Spolia Hym., p. 104. Emend.

Ephialtes (Itoplectis) temnopleuris Cushman, 1920. U. S. Natl. Mus., Proc. 58: 350..

Biology: Gorham, 1847. DeBow's Rev. 3: 539-541. -Comstock, 1879. Rpt. on Cotton Insects, p. 198-200. - Riley, 1886. U. S. Dept. Agr., Ent. Comn. Rpt. 4: 111-113. - Weed and Fiske, 1900. U. S. Dept. Agr., Div. Ent. Bul. 26: 33-34. - Fiske, 1903. N. H. Agr. Expt. Sta., Tech. Bul. 6: 184-230. -Johnston, 1913. Jour. Econ. Ent. 6: 144-147. - Baird, 1918. Agr. Gaz.

Canada 5: 770-771. - Criddle, 1924. Ent. Soc. Ontario, Ann. Rpt. 54: 17-18. - Schedl, 1931. Ztschr. f. Angew. Ent. 18: 258-260. - Haden, 1935. Del. Agr. Expt. Sta., Bul. 194: 20-35. -Townes, 1940. Ent. Soc. Amer., Ann. 33: 318-320. - Leius, 1960. Canad. Ent. 92: 369-376. -Leius, 1961. Canad. Ent. 93: 771-780. - Arthur, 1962-1972. Canad. Ent. 94: 337-347 (1962); 95: 1078-1091 (1963); 97: 1000-1001 (1965); 98: 213-223 (1966); 104: 1251-1258 (1972).

Morphology: Peck, 1937. Canad. Jour. Res., Sect. D (Zool. Sci.) 15: 245, 452. - Pratt, 1939.

Ent. Soc. Amer., Ann. 32: 731.

curticauda brevacus Townes. Que., Maine, Ont., Vt., N. Y., Mich., Mont. I. curticauda curticauda (Kriechbaumer) occurs in Europe.

Itoplectis brevacus Townes, 1940. Ent. Soc. Amer., Ann. 33: 315..

evetriae Viereck. N. B. s. to n. Ga., w. to Alaska and Calif. Host: Barbara sp., B. colfaxiana siskiyouana (Kft.), B. colfaxiana taxifoliella (Bsk.), B. mappana Free., Zeiraphera sp. 
on Picea glauca, Choristoneura fumiferana (Clem.), Dioryctria cambiicola (Dyar), D. zimmermanni (Grt.), Rhyacionia buoliana (D. and S.).

Itoplectis evetriae Viereck, 1913. U. S. Natl. Mus., Proc. 44: 565. ठ.

Itoplectis plesia Rohwer, 1914. Ent. Soc. Wash., Proc. 15: 182. \&.

fustiger Townes. Que., N. Y., Pa., Mich., Ohio, Minn., N. Dak., Calif. This species is related to the European 1. clavicormis Thomson, and for a number of years was identified as clavicornis.

Itoplectis fustiger Townes, 1960. In Townes and Townes, U. S. Natl. Mus. Bul. 216 (pt. 2): 298. ㅇ, ㅇ.

maculator (Fabricius). Eurasia, n. Africa. Ecology: Sometimes hyperparasitic. Introductions were made in Ont. from 1948-1956 with the target species being the native Choristoneura fumiferana (Clem.). Cnephasia longana was the target species for introductions in Oreg. in 1949?, 1952, and 1954. Recoveries were made in Oreg. in 1950 and 1955, but maculator is not known to be established. Host: Cnephasia longana (Haw.). Numerous other European hosts are known.

Ichneumon maculator Fabricius, 1775. Systema Ent., p. 337. ․

Ichneumon Plaesseus Geoffroy, 1785. In Fourcroy, Ent. Parisiensis. v. 1, p. 417..

Ichneumon arlequinatus Geoffroy, 1785. In Fourcroy, Ent. Parisiensis. v. 1, p. 427. Sex not indicated.

Ichneumon scanicus Villers, 1789. Caroli Linnaei Ent., Faun. Suec. Descr. Aucta, v. 3, p. 190. ¿े?

Ichneumon lateratorius Thunberg, 1822; 1824. Acad. Imp. des Sci. St. Petersburg, Mem. 8: 279; 9: 362. ठ.

Pimpla vincta Snellen van Vollenhoven, 1873. Tijdschr. v. Ent. 16: 212. ๆ.

Pimpla cruentata Rudow, 1883. Ent. Nachr. 9: 235. ঠ, १.

Pimpla castaneiventris Kriechbaumer, 1894. Berlin. Ent. Ztschr. 39: 51. ๆ.

Pimpla sexpunctata Perez, 1895. Soc. Ent, de France, Ann. 64: 200..

Pimpla maculatrix Schulz, 1906. Spolia Hym., p. 104. Emend.

Itoplectis mufiventris Hellen, 1949. Finska Vetensk.-Soc., Comm. Biol. 8: 11. ठ, ๆ.

Biology: Goidanich, 1931. R. 1st. Super. Agr., Lab. di Ent., Bol. 4: 151-153. -Hardy, 1938.

Bul. Ent. Res. 29: 356.

quadricingulata (Provancher). Newfoundland s. to R. I., w. to Alaska and Calif.; Greenland. Host: Hyaloscotes fragmentella (Hy. Edw.), Gracilaria sp., Euceratia castella Wlsm., Dioryctria reniculella (Grt.), Anthophila pariana (Clem.), Carcina quercana (F.), Depressaria sp., Archips argyrospilus (Wlk.), A. rosanus (L.), Choristoneura fumiferana (Clem.), C. occidentalis Free., Cnephasia longana (Haw.), Acleris sp., Acleris variana (Fern.), Laspeyresia pomonella (L.), Rhyacionia buoliana (D. and S.), R. busckana Hein., Spilonota ocellana (D. and S.), Taniva albolineana (Kft.), Platyptilia sp., Lamdina fiscellaria lugubrosa (Hulst), Nepytia phantasmaria (Stkr.), Malacosoma sp., $M$. disstria Hbn., Orgyia pseudotsugata McD., Neodiprion sp., N. tsugae Midd. I. quadricingulata is closely related to I. alternans (Gravenhorst) of Eurasia and future study is likely to show that quadricingulata should be treated either as a synonym or as a subspecies of alternans.

Pimpla 4-cingulatus Provancher, 1880. Nat. Canad. 12: 38..

Pimpla (Itoplectis) Kolthoffi Aurivillius, 1890. Svenska Vetensk.-Akad., Bihang til Handl. (ser. 4) 15: 29. o, ?.

Pimpla kolthoffii Dalla Torre, 1901. Cat. Hym., v. 3, p. 438. Emend.

Itoplectis obesus Cushman, 1917. U. S. Natl. Mus., Proc. 53: 467. ठै, ๆ.

Ephialtes (Itoplectis) latus Cushman, 1920. U. S. Natl. Mus., Proc. 58: 345 ..

Ephialtes (Itoplectis) leavitti Cushman, 1920. U. S. Natl. Mus., Proc. 58: 345..

Ephialtes (Itoplectis) pacificus Cushman, 1920. U. S. Natl. Mus., Proc. 58: 345. ?. Preocc. by Harrington, 1894.

Ephialtes (Itoplectis) montana Cushman, 1920. U. S. Natl. Mus., Proc. 58: 346..

Ephialtes cacoeciae Viereck, 1924. Canad. Ent. 56: 64. ठ, ?.

Ephialtes (Itoplectis) esuchus Cushman, 1924. Ent. Soc. Wash., Proc. 26: 221. N. name for E. pacificus Cushman. 
Biology: Ryan, 1971. Ent. Soc. Amer., Ann. 64: 205-208. - Ryan and Medley, 1972. Ent. Soc. Amer., Ann. 65: 172-177.

vesca Townes. N. S., P. E. I., N. B., Maine, Colo., N. Mex., Ariz., Alaska, B. C., Calif. Host: Acleris variana (Fern.), Coleophora laricella (Hbn.), Coleotechnites milleri (Bsk.).

Itoplectis vesca Townes, 1960. In Townes and Townes, U. S. Natl. Mus. Bul. 216 (pt. 2): 297. $\delta, ?$.

viduata (Gravenhorst). N. W. T. s. to N. Mex., w. to B. C. and Calif.; Eurasia. Host: Ancylis comptana (Froel.), Autographa californica (Spey.), Choristoneura rosaceana (Harris), Colias eurytheme Bdv., Malacosoma sp., M. disstria $\mathrm{Hbn} .$, M. californicum fragile (Stretch), M. californicum pluviale (Dyar), Orgyia pseudotsugata McD., Hemileuca oliviae Ckll., Nymphalis californica (Bdv.).

Pimpla viduata Gravenhorst, 1829. Ichn. Europaea, v. 3, p. 214. ð.

Pimpla atrocoxalis Cresson, 1870. Amer. Ent. Soc., Trans. 3: 145..

Pimpla ovalis Thomson, 1877. Opusc. Ent. 8: 748. 9 .

Pimpla meridionalis Kriechbaumer, 1877. Ent. Nachr. 8: 120..

\section{Genus EPHIALTES Schrank}

Ephialtes Schrank, 1802. Fauna Boica, v. 2, p. 316. Some authors regard Ephialtes Schrank as an unavailable name by virtue of Opinion 159 of the Internatl. Comm. of Zool. Nomenclature, but I do not regard Opinion 159 as valid for reasons discussed in the introduction to the family.

Type-species: Ichneumon compunctor Linnaeus. Monotypic.

A pechthis Foerster, 1868. Naturh. Ver. Rheinlande, Verh. 25: 164.

Type-species: Ichneumon rufatus Gmelin. Desig. by Ashmead, 1900 (as "Pimpla rubata [!] Gravenhorst") from two species included by Woldstedt, 1877.

A pechtis Thomson, 1889. Opusc. Ent. 12: 1410. Emend.

Taiwatheronia Sonan, 1936. Nat. Hist. Soc. Formosa, Trans. 26: 256.

Type-species: Taiwatheronia mahasenae Sonan. Monotypic and orig. desig. The type-species is regarded as a synonym of Ephialtes taiwanus (Uchida).

Parapechthis Blanchard, 1936. Soc. Cient. Argentina, An. 122: 404.

Type-species: Parapechthis bazani Blanchard. Monotypic and orig. desig.

Taxonomy: Townes, 1957. Ent. Soc. Wash., Proc. 59: 118-119.

annulicornis annulicornis (Cresson). Que. s. to N. C., w. to Alta. and Tex. Host: Choristoneura fumiferana (Clem.), C. rosaceana (Harris). Contrary to the description and key in the revision of the Pimplinae by Townes and Townes (1960), a significant proportion of the males of this subspecies have white marks on the mesoscutum.

Pimpla annulicornis Cresson, 1870. Amer. Ent. Soc., Trans. 3: 147. ठ,.

annulicornis componotus (Davis), n. status. Idaho, N. Mex., B. C., Oreg., Calif. Host: Orgyia antiqua (L.), O. leucostigma (J. E. S.), O. pseudotsugata McD., Neophasia menapia (F. and F.).

Pimpla componotus Davis, 1898 (1897). Amer. Ent. Soc., Trans. 24: 367. ठ‡.

Apechthis pacificus Cushman, 1920. U. S. Natl. Mus., Proc. 58: 353. ठ' $९$. N. syn. Preocc. in Ephialtes by Harrington, 1894; Cushman, 1920. Townes (1960) treated pacificus as a species distinct from componotus on the basis of male color characteristics (he considered the female of componotus unknown) which do not even work for Cushman's type series of pacificus, which were from a single locality (Portland, Oreg.). Other specimens in the U.S. Natl. Mus. collection further indicate the need for placing pacificus as a synonym of componotus and the need for placing componotus as a subspecies of annulicornis.

ontario (Cresson). Newfoundland (Labrador) s. to N. Y., w. to Alaska and Calif. Host: Choristoneura conflictana (Wlk.), C. fumiferana (Clem.), C. pinus Free., Lambdina fiscellaria (Gn.), Nepytia canosaria (Wlk.).

Pimpla Ontario Cresson, 1870. Amer. Ent. Soc., Trans. 3: 146. రో.

Biology: Ryan, 1971. Ent. Soc. Amer., Ann. 64: 205-208. - Ryan and Medley, 1972. Ent. Soc. Amer., Ann. 65: 172-177.

Morphology: Peck, 1937. Canad. Jour. Res., Sect. D (Zool. Sci.) 15: 248. 
picticornis (Cresson). N. S. s. to N. C., w. to B. C. and Calif. Host: Choristoneura conflictana (Wlk.), C. rosaceana (Harris), Sciaphila sp., Spilonota ocellana (D. and S.).

Pimpla picticornis Cresson, 1870. Amer. Ent. Soc., Trans. 3: 146. ð.

Apechthis omatulus Walley, 1929. Canad. Ent. 68: 190. ठ.

quadridentatus (Thomson). Europe; n. Asia. Introduced, but not established, in Ont. and Que. in 1948,1949 , and 1956 for control of the native Choristoneura fumiferana (Clem.).

Ichneumon resinator (!) Thunberg, 1822; 1824. Acad. Imp. des Sci. St. Petersburg, Bul. 8: 275 ; 9: 349. Lapsus for and misidentification of Ichneumon resinellae Linnaeus, which is a braconid now placed in the genus Macrocentris.

Pimpla quadridentata Thomson, 1877. Opusc. Ent. 8: 749. ठ゚, ๆ.

Taxonomy: Townes, 1965. Polskie Pismo Ent. 35: 411.

rufatus (Gmelin). Europe; n. Asia. Introduced, but not established, in Ont. in 1950 for control of the native Choristoneura fumiferana (Clem.).

Ichneumon rufatus Gmelin, 1790. In Linnaeus, Syst. Nat., Ed. 13, v. 1, p. 2684. \&.

Pimpla flavonotata Holmgren, 1860. Svenska Vetensk.-Akad. Handl. (ser. 4) 3 (10): 19. ठ, ㅇ.

Pimpla rufithorax Strobl, 1901. Naturw. Ver. f. Steiermark, Mitt. 38: 11..

\section{Genus COCCYGOMIMUS Saussure}

Coccygomimus Saussure, 1890. In Grandidier, Hist. Madagascar, v. 20, Hym. 1, pl. 14, fig. 12.

Type-species: Coccygomimus madecassus Saussure. Monotypic.

Habropimpla Cameron, 1900. Manchester Lit. and Phil. Soc., Mem. and Proc. 44: 96.

Type-species: Habropimpla bilineata Cameron. Monotypic.

Lissotheronia Cameron, 1905. Spolia Zeylanica 3: 139.

Type-species: Lissotheronia flavipes Cameron. Monotypic.

Phytodiaetoides Morley, 1913. Fauna Brit. India, ... Hym., v. 3, p. 221.

Type-species: Phtyodiaetoides megaera Morley. Monotypic and orig. desig. The type-species is considered to be a synonym of Coccygomimus flavipalpis (Cameron).

Pimplidea Viereck, 1914. U. S. Natl. Mus., Proc. 83: 117.

Type-species: Pimpla pedalis Cresson. Monotypic and orig. desig.

Coelopimpla Brethes, 1916. Buenos Aires, Mus. Nac. de Hist. Nat., An. 27: 402.

Type-species: Coelopimpla amadei Brethes. Monotypic and orig. desig. The type-species is considered to be a synonym of Coccygomimus sumichrasti (Cresson).

Liotheronia Enderlein, 1919. Gesell. f. Naturf. Freunde z. Berlin, Sitzber. f. 1919, p. 147.

Type-species: Liotheronia kriegeri Enderlein. Monotypic and orig. desig. The type-species is considered to be a synonym of Coccygomimus aztecus (Cresson).

Dihyboplax Enderlein, 1919. Gesell. f. Naturf. Freunde z. Berlin, Sitzber. f. 1919, p. 148.

Type-species: Dihyboplax flavipennis Enderlein. Monotypic and orig. desig.

Neogabunia Brethes, 1927. Ent. Mitt. 16: 322.

Type-species: Neogabunia paulistana Brethes. Monotypic. The type-species is considered to be a synonym of Coccygomimus tomyris (Schrottky).

Pimpla subg. O podactyla Seyrig, 1932. Acad. Malagache, Mem. 11: 60.

Type-species: Pimpla (Opodactyla) waterloti Seyrig. Monotypic and orig. desig.

Pimpla subg. Oxypimpla Noskiewicz and Chudoba, 1951. Polskie Pismo Ent. 21: 42, 56.

Type-species: Ichneumon turionellae Linnaeus. Monotypic.

The name Pimpla has frequently been applied to this genus. My reasons for not doing so here are given in the introductory discussion of the family.

Revision: Porter, 1970. Studia Ent. 13: 1-192. (S. Amer. spp.).

aequalis (Provancher). N. S. s. to Fla., w. to Minn. and Tex. Host: Thyridopteryx ephemeraeformis (Haw.), Grapholitha molesta (Bsk.), Laspeyresia pomonella (L.), Paralobesia viteana (Clem.), Coleophora fuscedinella Zell., Acrabasis indiginella (Zell.),

Dichomerus "marginella" (F.), Coryphista meadi (Pack.), Tolype velleda (Stoll.).

Pimpla aequalis Provancher, 1880. Nat. Canad. 12: 36.. 
Meniscus Ashmeadii Provancher, 1888. Addit. Corr. Faune Ent. Canada Hym., p. 430.. Pimpla conquisitor var. rufuscula Davis, 1898 (1897). Amer. Ent. Soc., Trans. 24: 368. ๆ.

Biology: Breakley, 1930. Ent. Soc. Amer., Ann. 23: 187.

annulipes (Brulle). N. S. s. to Fla., w. to Minn. and Tex. Host: Podosesia syringae (Harris), Syanthedon pictipes (G. and R.), S. pyri (Harris), Grapholitha molesta (Bsk.),

Laspeyresia nigricana (Steph.), L. pomonella (L.), Rhyacionia buoliana (D. and S.), Gretchena bolliana (Sling.), Acrobasis caryae Grt., A. indiginella (Zell.), Salebriaria tenebrosella (Hulst).

Pimpla annulipes Brulle, 1846. In Lepeletier, Hist. Nat. Ins. Hym., v. 4, p. 102. ?.

Pimpla inflata Townes, 1940. Ent. Soc. Amer., Ann. 33: 306. đ。, ․

aquilonius (Cresson). Newfoundland (insular) s. to N. C., w. to Alaska and Calif.; Eurasia. Host: Coleophora fuscedinella Zell., Psilocorsis cryptolechiella (Cham.), Lambdina fiscellaria fiscellaria (Gn.), Spilonota ocellana (D. and S.), Rheumaptera hastata (L.). Townes (1960) has recognized a number of subspecies which he separated very unsatisfactorily and which do not make sense zoogeographically; therefore, they are not recognized here.

Pimpla aquilonia Cresson, 1870. Amer. Ent. Soc., Trans. 3: 145. ठ.

Pimpla flavicoxis Thomson, 1877. Opusc. Ent. 8: 747. ठ.

Meniscus marginatus Provancher, 1883. Nat. Canad. 14: 15. $q$.

Bassus cylindricus Provancher, 1889. Addit. Corr. Faune Ent. Canada Hym., p. 111. o, ๆ. Itoplectis exareolata Ashmead, 1901. Psyche 9: 147..

Pimpla yakutatensis Ashmead, 1902. Wash. Acad. Sci., Proc. 4: 200. ठ.

contemplator (Mueller). Europe. Introduced in 1964 in N. S. without becoming established. Host: Operophtera brumata (L.). Other European hosts are known, but O. brumata was the target host for the release in N. S.

Ichneumon contem plator Mueller, 1776. Zool. Danicae prodromus ..., p. 158. Sex not indicated.

Ichneumon geniculatus Geoffroy, 1785. In Fourcroy, Ent. Parisiensis, v. 2, p. 397. ㅇ?

Cryptus insignatorius Gravenhorst, 1807. Vergl. Uebers. Zool. Systeme, p. 264. $\%$.

Pimpla bilineata Brulle, 1846. In Lepeletier, Hist. Nat. Ins. Hym., v. 4, p. 98. ๆ. Syn.? dimidiatus Townes. Tex.

Coccygomimus dimidiatus Townes, 1960. In Townes and Townes, U. S. Natl. Mus. Bul. 216 (pt. 2): 350. ठ.

ellopiae (Harrington). N. Mex., Ariz., B. C. s. to Calif. Host: Lambdina somniaria (Hulst), Eucaterva variaria Grote.

Pimpla ellopiae Harrington, 1892. Canad. Ent. 24: 99. ð,.

Taxonomy: Townes, 1966. In Townes and Townes, Amer. Ent. Inst., Mem. 8: 28.

hesperus Townes. S. Dak.to N. Mex., w. to Alaska, Oreg. and Calif. Host: Rhyacionia frustrana bushnelli (Bsk.), Anarsia lineatella Zell., Udea mibigalis (Gn.), Lambdina fiscellaria lugubrosa (Hulst).

Coccygomimus hesperus Townes, 1960. In Townes and Townes, U. S. Natl. Mus., Bul. 216 (pt. 2): 338. $\delta$,, .

instigator (Fabricius). Eurasia; n. Africa. Introduced in 1906, 1907, and 1909 in New England without becoming established. Host: Lymantria dispar (L.). Many other European hosts are known, but $L$. dispar was the target host for attempts to establish instigator in New England.

Ichneumon instigator Fabricius, 1793. Ent. System. v. 2, p. 164. $ๆ$.

Pimpla processionae Ratzeburg, 1849. Stettin. Ent. Ztg. 10: 133. ठ.

Pimpla intermedia Holmgren, 1860. Svenska Vetensk.-Akad. Handl. (ser. 4) 3 (10): 19. ð, ㅇ.

Pimpla Aegyptica Schmiedeknecht, 1897. Illus. Wochenschr. f. Ent. 2: 633. ð, $q$.

Pimpla instigatrix Schulz, 1906. Spolia Hym., p. 104. Emend.

Apechthis flavipes Matsumura, 1912. Thousand Ins. Jap., Sup. 4, p. 144..+

Taxonomy: Masi, 1933. Soc. Ent. Ital., Bol. 65: 65. 
Biology: Howard and Fiske, 1911. U. S. Dept. Agr., Bur. Ent., Bul. 91: 237. -Schevy, 1912.

Messager Ent. 1: 4. -Picard, 1921. [Paris] Acad. des Sci., Compt. Rend. 172: 1617-1619.

-Faure, 1926. Contrib. Etud. ... Pieride du Chou et ses Pars. Hym., p. 77-86. - Lepiney, 1927. Ann. des Epiphyt. 13: 164. - Seyrig, 1932. Soc. Ent. de France, Ann. 101: 114. - Cals and Shaumar, 1965. Ann. des Sci. Nat. Zool. et Biol. Anim. 7: 768.

marginellus (Brulle). Southern Fla.; Cuba, Haiti, Jamaica, Puerto Rico.

Pimpla marginella Brulle, 1846. In Lepeletier, Hist. Nat. Ins. Hym., v. 4, p. 107. $\$$.

maurus (Cresson). Ohio, N. C., Ga., Fla., Tex. Host: Hemerocampa leucostigma (J. E. S.),, Orgyia sp.

Pimpla maura Cresson, 1870. Amer. Ent. Soc., Trans. 3: 145. ؟.

nudus (Townes). N. S. s. to Va., w. to Minn. and Ind. Host: Ostrinia nubilalis (Hbn.), Neodiprion sp.

Pimpla nuda Townes, 1940. Ent. Soc. Amer., Ann. 33: 306. \&.

pedalis (Cresson). Newfoundland (Labrador) s. to Va., w. to Alaska and Calif. Host: Archips argyrospilus (Wlk.), Argyrotaenia mariana (Fern.), sciaphila duplex (Walsh), Lambdina fiscellaria fïscellaria (Gn.), L. somniaria (Hulst), Protoboarmia porcelaria (Gn.), Malacosoma americanum (F.), $M$. californicum fragile (Stretch), $M$. disstria Hbn., Dasychira plagiata (Wlk.), Leucoma salicis (L.), Lymantria dispar (L.), Nygmia phaeorrhea (Don.), Orgyia antiqua badia Hy. Edw., O. leucostigma (J. E. S.), Heterocampa gutivitta (Wlk.), Acronicta sp., A. americana (Harr.), Ctenucha virginica (Charp.), Leucania linita Gn., Pseudaletia unipuncta (Haw.), Halisidota caryae (Harr.), H. maculata (Harr.), Isia isabella (J. E. S.), Epargyreus clarus (Cramer), Neophasia menapia (F. and F.), Gilpinia hercyniae (Htg.), Neodiprion sp.

Pimpla pedalis Cresson, 1865. Ent. Soc. Phila., Proc. 4: 268. $\delta$.

Biology: Howard and Fiske, 1911. U. S. Dept. Agr., Bur. Ent., Bul. 91: 137-138, 144, 147-149, 237-239. - Schedl, 1931. Ztschr. f. Agnew. Ent. 18: 268-270. - Finlayson, 1960. Canad. Ent. 92: 925. -Campbell, 1963. Canad. Ent. 95: 337.

punicipes (Cresson). Tex.; Mexico s. to Peru; Hawaii. Host: Platynota sp., Pectinophora gossypiella (Sdrs.). Neither of these hosts was recorded in N. Amer.

Pimpla punicipes Cresson, 1874 (1873). Acad. Nat. Sci. Phila., Proc. 25: 398. ㅇ.

Pimpla feralis Cresson, 1874 (1873). Acad. Nat. Sci. Phila., Proc. 25: 399. ơ.

Pimpla Hawaiiensis Cameron, 1887. Manchester Lit. and Phil. Soc., Mem. and Proc. (3) 10: 239. $\delta$.

Pimpla puniceipes Dalla Torre, 1901. Cat. Hym., v. 3, p. 446. Emend.

sanguinipes erythropus (Viereck). Idaho s. to N. Mex., w. to s. B. C. and Calif. Host: Laspeyresia pomonella (L.), Tholeria reversalis (Gn.), Zophodia convolutella (Hbn.), Coryphista meadi (Pack.), Eucaterva variaria Grt., Prochoerodea forficaria catenulata Grt., Malacosoma sp., $M$. californicum fragile (Stretch), $M$. incurvum incurvum (Hy. Eds.), Hemileuca sp., Diacrisia virginica (F.), Orgyia pseudotsugata McD., O. vetusta (Bdv.).

Pimpla (Pimpla) erythropus Viereck, 1909. Ent. News 20: 291..+

Biology: Pack, 1930. Utah Agr. Expt. Sta., Bul. 216: 10-11.

sanguinipes sanguinipes (Cresson). Tex.; Mexico s. to Peru. Host: Alabama argillacea (Hbn.). Pimpla sanguinipes Cresson, 1872. Amer. Ent. Soc., Trans. 4: 165..

Ephialtes (Ephialtes) sanguineipes (!) Cushman, 1920. U. S. Natl. Mus., Proc. 58: 335.

silvicola (Walley). B. C., Wash., Oreg.

Pimpla silvicola Walley, 1941. Canad. Ent. 73: 164. ơ, ㅇ.

sodalis longigenalis (Cushman). Colo., Calif. Ecology: Occurs in drier grass or sedge covered parts of high mountain meadows but is apparently not found in wet meadows.

Ephialtes (Ephialtes) longigenalis Cushman, 1920. U. S. Natl. Mus., Proc. 52: 332. \&.

sodalis sodalis (Ruthe). Northern Man., N. W. T., Yukon, Alaska; Greenland; Iceland; Europe.

Pimpla sodalis Ruthe, 1859. Stettin. Ent. Ztg. 20: 371. ठ, ₹.

Pimpla Nordenskioldii Holmgren, 1872. Svenska. Vetensk.-Adad., Ofvers. af ... Forhandl. 29 (6): 97 ..

Pimpla longiceps Thomson, 1877. Opusc. Ent. 8: 746. ¿, ९. 
stricklandi Townes. Que., Ont., n. Mich., Sask., Alta.

Coccygomimus stricklandi Townes, 1960. In Townes and Townes, U. S. Natl. Mus. Bul. 216 (pt. 2): $340 . \delta^{\circ}$,.

tenuicornis (Cresson). N. S. s. to N. Y., w. to e. B. C. and Colo. Host: Semiothisa sp., Synanthedon tipuliformis (Clerk).

Pimpla tenuicornis Cresson, 1865. Ent. Soc. Phila., Proc. 4: 267..

turionellae turionellae (Linnaeus). Eurasia; n. Africa. Introduced in 1950, 1955 in N. S.; 1952 in Que.; 1935- 1937, 1950-1954, 1956, 1958 in Ont.; 1906-1909 in New England (probably Mass.), 1935-1938 in Conn., N. Y., N. J.; 1937 in Minn. and Ida.; establishment has apparently not occurred, although a few recoveries have been reported in Ontario. Host: Rhyacionia buoliana (D. and S.), Lymantria dispar (L.), Laspeyresia pomonella (L.), Operophtera brumata (L.). Many other hosts are known, but these are the introduced pests which were target hosts for introductions of turionellae in North America; a number of native pests were target hosts for some of the introductions, however. $C$. turionellae moraguesi (Schmiedeknecht) occurs in northern Africa (Pimpla freyi Hellen is probably a synonym of $t$. moraguesi).

Ichneumon turionellae Linnaeus, 1758. Syst. Nat., Ed. 10, p. 564. $q$ (o misdet.).

Ichneumon variegatus Schrank, 1785. Neues Mag. Liebhaber Ent. 2: 327. $९$.

Cryptus examinator Fabricius, 1804. Systema Piezatorum, v. 2, p. 85 ..

Ichneumon cingulator Thunberg, 1822; 1824. Acad. Imp. des Sci. St. Petersburg, Mem. 8: $275 ; 9: 348$. ․

Ichneumon turionator Thunberg, 1822; 1824. Acad. Imp. des Sci. St. Petersburg, Mem. 8: 275; 9: 348. Emend.

Pimpla opacellata Desvignes, 1868. Ent. Monthly Mag. 4: 174. \&.

Pimpla examinatrix Schulz, 1906. Spolia Hym., p. 104. Emend.

Pimpla padellae Torka, 1918. Ent. Rundschau 35: 33. ઠं, ९.

Taxonomy: Roman, 1932. Ent. Tidskr. 53: 14. - Oehlke, 1967. In Ferriere and Vecht, Hym.

Cat., pt. 2, p. 32. - Aubert, 1969. Ichn. Ouest-Pal. et Leurs Hotes, pt. 1, p. 94-95.

Biology: Jackson, 1937. Roy. Ent. Soc. London, Proc. 12: 81-91. -Sylvestri, 1941. Lab. Ent.

Agr. [Portici], Bol. 5: 27-31. - Bronskill, 1959. Canad. Jour. Zool. 37: 655-688. - Arthur and

Wylie, 1959. Entomophaga 4: 297-301. - Harris, 1960. Canad. Jour. Zool. 38: 766.

varians Townes. Colo., N. Mex., Ariz., B. C., Wash., Oreg., Calif. Host: Laspeyresia pomonella (L.).

Coccygomimus varians Townes, 1960. In Townes and Townes, U. S. Natl. Mus. Bul. 216 (pt. 2): 333 . 9 . The male of the species was not identified with certainty.

\section{TRIBE THERONIINI}

Townes (1969) included the genera Perithous, Delomerista, and Pseudorhyssa in this tribe. Because the placement of these genera in the Theroniini was only provisional and because the name Delomeristini (Hellen, 1915) has priority over the name Theroniini (Cushman and Rohwer, 1920), the aforementioned genera are here placed in the Delomeristini. The genera of Theroniini occurring in North America are Theronia and Neotheronia, the latter being treated by Townes (1969) as a subgenus of Theronia. Because the division between Neotheronia and Theronia is not at all arbitrary, they are here treated as separate genera. The species of Neotheronia and Theronia are usually primary or secondary parasites of the pupae of Lepidoptera.

\section{Genus THERONIA Holmgren}

Revision: Gupta, 1962. Pacific Ins. Monogr. 4: 1-142 (Indo-Australian spp.).

\section{Genus THERONIA Subgenus THERONIA Holmgren}

Theronia Holmgren, 1859. Svenska Vetensk.-Akad., Ofvers af ... Forhandl. 16: 123.

Type-species: Pimpla flavicans (Fabricius). Monotypic. The type species is regarded as a synonym of Theronia atalantae (Poda).

Pseudacoenites Kriechbaumer, 1892. Ent. Nachr. 18: 219.

Type-species: Pseudacoenites moravicus Kriechbaumer. Monotypic. The type-species is regarded as a synonym of $T$. hilaris laevigata (Tschek). 
atalantae fulvescens (Cresson). N. B. s. to Va., w. to B. C. and Calif. Ecology: Adult females of this subspecies are known to hibernate, but it is not known that the subspecies overwinters exclusively in this way. Host: Choristoneura fumiferana (Clem.), Ennomos subsignarius (Hbn.), Lambdina somniaria (Hulst), Nepytia phantasmaria (Stkr.), Oreta rosea (Wlk.), Malacosoma americanum (F.), M. californicum fragile (Stretch), $M$. disstria $\mathrm{Hbn}$., Dasychira plagiata (Wlk.), Lymantria dispar (L.), Orgyia leucostigma (J. E. S.), O. pseudotsugata McD., Nygmia phaeorrhea (Don.), Leucoma salicis (L.), Hyalophora cecropia (L.), Nymphalis californica (Bdv.), Neophasia menapia (F. and F.), Enicospilus americanus (Christ), Gambrus extrematis (Cr.), Hyposoter fugitivus (Say), Itoplectis conquisitor (Say). T. atalantae atalantae (Poda) occurs in Europe. Pimpla fulvescens Cresson, 1865. Ent. Soc. Phila., Proc. 4: 268. ठ.

Theronia rufescens (!) Taylor, 1884. Canad. Ent. 16: 92.

Theronia fulvescens var. mellipennis Viereck, 1903. In Skinner, Amer. Ent. Soc., Trans. 29: 88. .

Theronia atalantae var. americana Krieger, 1906. Ztschr. System. Hym. Dipt. 6: 240. ठ, ㅇ.

Biology: Weed and Fiske, 1900. U. S. Dept. Agr., Div. Ent. Bul. 26: 33. - Fiske and Thompson, 1909. Jour. Econ. Ent. 2: 455-457. - Howard and Fiske, 1911. U. S. Dept. Agr., Bur. Ent., Bul. 91: 137, 141, 142, 144, 147-149, 236-237, 304. -Aldrich, 1912. Jour. Econ. Ent. 5: 87-88. - Evenden, 1924. Timberman 25 (May): 54. - Townes, 1940. Ent. Soc. Amer., Ann. 33: 286, 293. -Cole, 1956. U. S. Dept. Agr., Forest Serv., Intermountain Forest and Range Expt. Sta. Res. Note 29: 1. - Campbell, 1963. Canad. Ent. 95: 337.

Morphology: Peck, 1937. Canad. Jour Res., Sect. D (Zool. Sci.) 15: 245, 246, 248, 251, 252.

hilaris hilaris (Say). Southern Que. s. to N. C., w. to Minn. and Kans. Host: Halisidota caryae (Harris), H. maculata (Harris), Heterocam pa guttivitta (Wlk.), Symmerista canicosta (Hbn.), E pargyreus clarus (Cramer). T. (T.) hilaris laevigata (Tschek) is European and $T$. (T.) hilaris nigra Uchida occurs in northern Asia.

Ichneumon hilaris Say, 1829. Contrib. Maclurian Lyceum to Arts and Sci. 1: 71. $\delta$. Pimpla melanoce phala Brulle, 1846. In Lepeletier, Hist. Nat. Ins. Hym., v. 4, p. 99..

Taxonomy: Gupta, 1965. Twelfth Internatl. Cong. Ent., Proc., p. 834.

Morphology: Peck, 1937. Canad. Jour. Res., Sect. D (Zool. Sci.) 15: 245, 246, 248, 251, 252.

-Pratt, 1939. Ent. Soc. Amer., Ann. 32: 731, 737.

\section{Genus NEOTHERONIA Krieger}

Neotheronia Krieger, 1899. Naturf. Gesell. Leipzig, Sitzber. 14-15: 119.

Type-species: Theronia toltecta Cresson. Orig. desig. T. toltecta is regarded as a subspecies of Neotheronia nigrolineata (Brulle).

E pimecoideus Ashmead, 1900. U. S. Natl. Mus., Proc. 23: 52.

Type-species: Epimecoideus apicalis Ashmead. Monotypic and orig. desig.

Acrocremnus Brethes, 1926. Nunquam Otiosus-V (Buenos Aires), p. 7.

Type-species: Acrocremnus apicipennis Brethes. Monotypic.

bicincta floridana (Townes). Southern Ga., Fla. Host: Tromatobia mufopectus (Cr.).

Neotheronia bicincta bicincta (Cresson) occurs in Cuba, and a third subspecies, N. $b$. nubecularia (Dewitz), occurs in Puerto Rico.

Theronia bicincta floridana Townes, 1960. In Townes and Townes, U. S. Natl. Mus. Bul. 216 (pt. 2): 362 . ठ์, ९.

septemtrionalis Krieger. Md. s. to Fla., w. to Mo., e. Okla., and La.

Neotheronia septemtrionalis Krieger, 1905. Ztschr. System. Hym. Dipt. 5: 305. ठ.

Neotheronia winnemannae Viereck, 1913. U. S. Natl. Mus., Proc. 44: 567..

\section{TRIBE DELOMERISTINI}

The genera in this tribe may be related to those in the Theroniini, but the evidence is not conclusive. Neither is there conclusive evidence that the genera here placed in the Delomeristini are related to each other. 


\section{Genus PERITHOUS Holmgren}

The species of Perithous are parasites or hyperparasites of Sphecidae which nest in canes or twigs.

\section{Genus PERITHOUS subgenus PERITHOUS Holmgren}

Perithous Holmgren, 1859. Svenska Vetensk.-Akad., Ofvers af ... Forhandl. 16: 123. Type-species: Ephialtes albicinctus Gravenhorst. Desig. by Viereck, 1914.

divinator (Rossi). Que. s. to Conn. and $\mathrm{Pa}$., w. to Wis.; Europe. Adventive. Host: Pemphredon lethifer (Shuck.), P. lugubris (F.), Passaloecus gracilis (Curt.), Psenulus pallipes (Pzr.), Trypoxylon fignilum (L.), Omalus auratus (L.). Except for Pemphredon lethifer, which is recorded as a host in both North America and Europe, these hosts are recorded only in Europe. $P$. (P.) divinator appears to have entered the northeastern U. S. A. before 1931.

Ichneumon divinator Rossi, 1790. Fauna Etrusca, v. 2, p. 48..

Pimpla ephippiatoria Dufour and Perris, 1840. Soc. Ent. France, Ann. 9: 47. ठ, $९$.

Pimpla marginellatoria Dufour and Perris, 1840. Soc. Ent. France, Ann. 9: 48. ঠ, $९$. Synonymy uncertain.

Itoplectis rubi Habermehl, 1917. Ztschr. f. Wiss. Insektenbiol. 13: 117. ठ, ९.

Perithous pimplarius Haupt, 1938. Maerk. Tierwelt 3: 209..

Biology: Horstmann, 1964. Fauna Mitt. Norddeutschl. 2: 193-197. -Thomas, 1964. Mich. Acad. Sci., Arts, and Letters; Papers 49: 199-201. - Horstmann, 1967. Zool. Anz. 178: 95-102.

mediator neomexicanus (Viereck). Western Alta. s. to N. Mex., w. to B. C. and Calif. Host: Pemphredon confertim (Fox). P. (P.) mediator mediator (Fabricius) is European.

Pimpla neomexicana Viereck, 1903. In Skinner, Amer. Ent. Soc., Trans. 29: 88. .

Biology: Parker and Bohart, 1966. Pan-Pacific Ent. 42: 94.

mediator pleuralis (Cresson). Que. s. to S. C., w. to Sask., Kans., and La. Host: Pemphredon concolor Say, $P$. inornatus Say, $P$. harbecki Roh.?

Pimpla pleuralis Cresson, 1868. Canad. Ent. 1: 36.

Biology: Champlain, 1922. Psyche 29: 97. - Rheinhard, 1929. Nature Mag. 13: 155-157.

-Krombein, 1960. Ent. News 71: 31.

\section{Genus PERITHOUS Subgenus HYBOMISCHOS Baltazar}

Perithous subg. Hybomischos Baltazar, 1961. Natl. Inst. Sci. Tech., Manila, Monog. 7: 49. Type-species: Perithous (Hybomischos) galbus Baltazar. Orig. desig.

septemcinctorius (Thunberg). Mich.; Europe. Adventive. Host: Pemphredon spp., Psen (Mimumesa) dahlbomi (Wesm.), Psenulus fuscipennis (Dahl.). These hosts are recorded in Europe. One female was recently found in a spider web in Ann Arbor, Mich. by Torgerson (1972).

Ichneumon septemcinctorius Thunberg, 1822; 1824. Acad. Imp. des Sci. St. Petersburg, Mem. 8: 280; 9: 363. .

E phialtes varius Gravenhorst, 1829. Ichn. Europaea, v. 3, p. 254. o, $\uparrow$.

Perithous brunnescens Koornneef, 1951. Ent. Ber. 13: 249. $q$. Synonymy uncertain.

Perithous exiguus Haupt, 1954. Deut. Ent. Ztschr. 1: 108..

Perithous septemcinctorius meridionator Aubert, 1963. Vie et Milieu 14: 849. ठ', ९. Syn.?

Taxonomy: Torgerson, 1972. Great Lakes Ent. 5: 99.

\section{Genus DELOMERISTA Foerster}

Delomerista Foerster, 1868. Naturh. Ver. Rheinlande, Verh. 25: 164.

Type-species: Pimpla mandibularis Gravenhorst. Monotypically included and desig. by Schmiedeknecht, 1888.

Delomerista spp. have most often been reared from cocoons of sawflies, but they may also parasitize Lepidoptera. 
Revision: Walkley, 1960. In Townes and Townes, U. S. Natl. Mus. Bul. 216 (pt. 2): 362-367.

Morphology: Morris, Cameron, and Jepson, 1937. Bul. Ent. Res. 28: 360-361. (larvae).

borealis Walkley. Que., Colo., N. W. T., Yukon, Alaska.

Delomerista borealis Walkley, 1960. In Townes and Townes, U. S. Natl. Mus. Bul. 216 (pt. 2): 370. ‥

gelida Walkley. Que. s. to Pa., w. to Alaska and Calif.

Delomerista gelida Walkley, 1960. In Townes and Townes, U. S. Natl. Mus. Bul. 216 (pt. 2): 366. ㅇ.

japonica diprionis Cushman. N. S. s. to N. C., w. to Alaska and Calif. Host: Diprion similis (Htg.), Gilpinia frutetorum (F.), G. hercyniae (Htg.), Neodiprion lecontei (Fitch), N. nanulus nanulus Schedl, N. pratti banksianae Roh., N. sertifer (Geoff.), N. tsugae Midd. The subspecies japonica Cushman occurs in Japan.

Delomerista diprionis Cushman, 1939. Wash. Acad. Sci., Jour. 29: 398. ठ, ๆ.

Biology: Furniss and Dowden, 1941. Jour. Econ. Ent. 34: 49-51. -Griffiths, 1960. Canad. Ent. 92: 656.

Morphology: Finlayson, 1960. Canad. Ent. 92: 25-26 (larva).

laevis (Gravenhorst). Que., Maine, N. H., N. W. T., Tex.?, Alaska; Europe. Aubert $(1969,1972)$ stated that $D$. laevifrous (Thomson) is a species distinct from laevis, but gave no indication that he had ever studied the holotype of laevis.

Pimpla laevis Gravenhorst, 1829. Ichn. Europaea, v. 3, p. 180..

Pimpla texana Cresson, 1870. Amer. Ent. Soc., Trans. 3: 145. 9 . The holotype is recorded from Texas, probably in error.

Pimpla laevifrous Thomson, 1877. Opusc. Ent. 8: 750. ऽ, ?.

Pimpla laevifrons (!) Schmiedeknecht, 1888. Zool. Jahrb., Abt. f. System., Geog., u. Biol. Tiere 3: 534.

Pimpla levifrons Dalla Torre, 1901. Cat. Hym., v. 3, p. 438. Emend.

Pimpla levis Dalla Torre, 1901. Cat. Hym. v. 3, p. 439. Emend.

Taxonomy: Oehlke, 1966 (1965). Beitr. z. Ent. 15: 816. -Aubert, 1969. Ich. Ouest-Pal. et

Leurs Hotes, pt. 1, p. 98-99. - Aubert, 1972. Ent. Scand. 3: 10.

lepteces Walkley. Que., Colo., Alaska.

Delomerista lepteces Walkley, 1960. In Townes and Townes, U. S. Natl. Mus. Bul. 216 (pt. 2): 368. .

novita (Cresson). Que. s. to Va., w. to B. C. and Calif. Host: Macremphytus sp., Diprion similis (Htg.), Acrobasis rubrifasciella Pack., Exartema olivaceanum Riley, Eublemma minima (Gn.), Mononychus vulpeculus (F.). Hosts other than sawflies need verification.

Pimpla novita Cresson, 1870. Amer. Ent. Soc., Trans. 3: 146. $\subsetneq$.

Morphology: Finlayson, 1967. Canad. Ent. 99: 1247 (larva).

pfankuchi Brauns. U. S. (unknown locality); Europe. The origin of the specimen bearing Hopkins W. Va. No. 5928 is unknown.

Delomerista Pfankuchi Brauns, 1905. Ztschr. System. Hym. Dipt. 5: 131. ๆ.

\section{Genus PSEUDORHYSSA Merrill}

Pseudorhyssa Merrill, 1915. Amer. Ent. Soc., Trans. 41: 150.

Type-species: Pseudorhyssa sternata Merrill. Monotypic and orig. desig.

Revision: Kerrich, 1966. Entomologist 99: 44-46 (European spp.).

maculicoxis (Kriechbaumer). Que. s. to N. C., w. to Alta. and Calif.; Europe. Ecology: In North America the species has been associated with Rhyssa howdenorum Townes and Rhyssa persuasoria (L.) and is presumably cleptoparasitic on them. Kerrich (1966) has shown that Townes (1960) misidentified the holotype of Rhyssa approximator var. ruficoxis Kriechbaumer, and Kerrich palaced muficoxis as a synonym of alpestris (Holmgren), a species which does not occur in North America.

Rhyssa approximator var. maculicoxis Kriechbaumer, 1889. Ent. Nachr. 15: 318. \&. Kerrich (1966) incorrectly considered the name maculicoxis invalid because it was originally proposed as a varietal name that was "used in an aberrational sense." 
Pseudorhyssa sternata Merrill, 1915. Amer. Ent. Soc., Trans. 41: 150..+ Rhyssa praealpina Gyorfi, 1946. Fragm. Faunist. Hung. 9: 33. ․

Biology: Coutrier, 1949. Soc. Ent. de France, Bul. 54: 62-63. - Spradbury, 1969. Bul. Ent. Res. 59: 291-297.

Morphology: Spradbury, 1970. Roy. Ent. Soc. London, Proc., Ser. A: Biol. 45: 21-23, 24-25. 26, 27.

\section{TRIBE DIACRITINI}

This is a very small tribe erected by Townes, Momoi, and Townes (1965) to include only Diacritus, a Holarctic genus including three species. A second monotypic Japanese genus was added by Townes (1969).

\section{Genus DIACRITUS Foerster}

Diacritus Foerster, 1868. Naturh. Ver. Rheinlande, Verh. 25: 191.

Type-species: Mesoleptus muliebris Cresson. By subsequent monotypy from inclusion by Davis, 1895.

Phidias Snellen van Vollenhoven, 1898. Tijdschr. v. Ent. 21: 164. Preocc. by Rafinesque, 1815.

Type-species: Phidias aciculatus Snellen van Vollenhoven. Monotypic.

Stenolabis Kriechbaumer, 1894. Ent. Nachr. 20: 58.

Type-species: Stenolabis cingulata Kriechbaumer. Monotypic. The type-species is

regarded as a synonym of $D$. aciculatus (Snellen van Vollenhoven).

Taxonomy: Townes, 1957. Ent. Soc. Wash., Proc. 59: 16 (Townes here removed the genus from the Neoxoridini [=Poemeniini Townes] and placed it provisionally in the Oxytorinae [=Plectiscinae auct.], and the genus was also excluded from the Pimplinae in the Revision by Townes and Townes [1960]).

muliebris (Cresson). Que. s. to Va. and apparently w. to northwestern U. S.

Mesoleptus! muliebris Cresson, 1868. Amer. Ent. Soc., Trans. 2: 102. ठ.

Mesoleptus variabilis Provancher, 1875. Nat. Canad. 7 (4): 115. ठ. Barron (1975) rejected the "lectotype" selected by Gahan and Rohwer (1918) and gave data for the specimen he regarded as the holotype.

Mesostenus rufipes Provancher, 1875. Nat. Canad. 7 (8): $249 ; 7$ (9): 263. . .

Echthrus pediculatus Provancher, 1880. Nat. Canad. 12: 99. $\%$.

Mesostenus pluricinctus Provancher, 1886. Addit. Corr. Faune Ent. Canada Hym., p. 76. ‥

Plectiscidea (Aperileptus?) contentionis Viereck, 1917 (1916). Conn. State Geol. and Nat. Hist. Survey Bul, 22: 276. $\subsetneq$.

Taxonomy: Cushman, 1917. Ent. Soc. Wash., Proc. 19: 162-165. -Gahan and Rohwer, 1918. Canad. Ent. 50: 101. - Momoi, 1966. Kontyu 34: 3. - Barron, 1975. Nat. Canad. 102: 528, $534,552,580$.

\section{TRIBE NEOXORIDINI}

The name Neoxoridini Clement (1938) has priority over the names Eugaltini Townes (1949) or Poemeniini Townes (1951).

Revision: Rohwer, 1920. U. S. Natl. Mus., Proc. 57: 444-451 (as part of Xoridini). -Clement, 1938. Festschr. Embrik Strand, v. 4, p. 515-522 (western Palearctic spp.). -Oehlke, 1966 (1965). Beitr. z. Ent. 15: 881-892 (western Palearctic spp.).

Taxonomy: Townes, 1957. Ent. Soc. Wash., Proc. 59: 15-20 (genera of world).

\section{Genus POEMENIA Holmgren}

Ophiodes Hartig, 1847. Naturw. Ver. Harz, Ber. 1846-1847, p. 18. Preoce. by Wagler, 1830; Guenee, 1841.

Type-species: Ophiodes montanus Hartig. Monotypic. The type-species is regarded as a synonym of $P$. hectica (Gravenhorst). 
Poemenia Holmgren, 1859. Svenska Vetensk.-Akad., Ofvers af ... Forhandl. 16: 130.

Type-species: Poemenia notata Holmgren. Monotypic.

Calliclisis Foerster, 1868. Naturh. Ver. Rheinlande, Verh. 25: 169.

Type-species: Ephialtes hecticus Gravenhorst. Desig. by Viereck, 1914 from three species included by Schmiedeknecht, 1888.

Phthinodes Tschek, 1868. Zool.-Bot. Gesell. Wien, Verh. 18: 272.

Type-species: Ephialtes hecticus Gravenhorst. Monotypic.

Euxorides Cresson, 1870. Amer. Ent. Soc., Trans. 3: 167.

Type-species: Euxorides americanus Cresson. Monotypic.

Ophiogastra Ashmead, 1900. Canad. Ent. 32: 368. N. name for Ophiodes Hartig.

Lissonotopsis Habermehl, 1917. Ztschr. f. Wiss. Insektenbiol. 13: 234, 306.

Type-species: Lissonotopsis rufa Habermehl. Monotypic.

Members of this genus may all be parasites of aculeate Hymenoptera which nest in wood, abandoned plant galls, and similar situations.

Revision: Habeck and Townes, 1960. In Townes and Townes, U. S. Natl. Mus. Bul. 216 (pt. 2): 376-387.

albipes (Cresson). N. S. s. to S. C. and La., w. to B. C. and Calif.

Ephialtes albipes Cresson, 1870. Amer. Ent. Soc., Trans. 3: 143..

Morphology: Pratt, 1939. Ent. Soc. Amer., Ann. 32: 735.

americana americana (Cresson). N. S. s. to Fla., w. to Great Lakes. Host: Passaloecus cuspidatus $\mathrm{Sm}$.

Euxorides americanus Cresson, 1870. Amer. Ent. Soc., Trans. 3: 167. ?.

americana nebulosa Habeck and Townes. Ont., Colo., Ariz., B. C. s. to Calif. Ecology: This subspecies has been associated with Passaloecus relativus Fox, Osmia sp., Paratimia conicola Fisher, and Laspeyresia piperana (Bsk.) in rearings from cones of Pinus spp.

Poemenia americana nebulosa Habeck and Townes, 1960. In Townes and Townes, U. S. Natl. Mus., Bul. 216 (pt. 2): 383. ठ, ?.

pacifica Habeck and Townes. Wash. s. to Calif. Ecology: This species has been reared from galls of Disholcaspis truckeensis (Ash.) and also from the galls of another cynipid from which a "chrysid-like bee" also emerged. This species is closely related to Poemenia notata Holmgren.

Poemenia pacifica Habeck and Townes, 1960. In Townes and Townes, U. S. Natl. Mus. Bul. 216 (pt. 2): 385. ठै, ?.

thoracica (Cresson). Sask. s. to Colo., w. to B. C. and Calif. Host: Osmia lingnaria propinqua Cr.

Ephialtes thoracicus Cresson, 1879 (1878). Acad. Nat. Sci. Phila., Proc. 30: 377. 9.

Euxorides Vancouveriensis Provancher, 1888. Addit. Corr. Faune Ent. Canada Hym., p. 369. \&.

Ephialtes vancouverensis Harrington, 1894. Canad. Ent. 26: 249..

\section{Genus PODOSCHISTUS Townes}

Podoschistus Townes, 1960. Ent. Soc. Wash., Proc. 59: 18.

Type-species: Xorides vittifrons Cresson. Orig. desig.

vittifrons (Cresson). Maine s. to Ga., w. to Oreg. and Tex. Ecology: One specimen of this species was reared from Tetropium velutinum in Larix occidentalis, but otherwise vittifrons has been associated with or reared from borers in hardwoods. Host:

Tetropium velutinum LeC., Graphisurus fasciatus (DeG.).

Xorides vittifrons Cresson, 1868. Canad. Ent. 1: 37.. .

Podoschistus vittifrons schlingeri Townes, 1960. In Townes and Townes, U. S. Natl. Mus.

Bul, 216 (pt. 2): 388. . . N. syn.. The description of this synonym was based upon a single female from Utah which shows a minor difference in the coloration of the hind tibia, that difference not being found in the single male known to me from Oregon.

Morphology: Pratt, 1939. Ent. Soc. Amer., Ann. 32: 735. 


\section{Genus NEOXORIDES Clement}

Neoxorides Clement, 1938. Festschr. Embrik Strand, v. 4, p. 517.

Type-species: Xorides nitens Gravenhorst. Orig. desig.

Members of this genus are parasites of wood-boring Coleoptera, and are often collected on trunks of dead trees.

borealis (Cresson). Southern Man. s. to Colo. and Ariz., w. to s. B. C. and Calif. Host:

Melanophila drummondi (kby.), Tetropium velutinum LeC., Hylotrupes bajulus (L.).

The holotype of this species is recorded from "Hudson Bay Territory". N. borealis is

closely related to the European $N$. collaris (Gravenhorst), and may prove only to be a subspecies of it.

Xorides borealis Cresson, 1870. Amer. Ent. Soc., Trans. 3: 167..+

Xorides occidentalis Cresson, 1879 (1878). Acad. Nat. Sci. Phila., Proc. 30: 380..

caryae (Harrington). Que. s. to N. C., w. to Mich. Host: Saperda discoidea F.

Xorides caryae Harrington, 1891. Canad. Ent. 23: 132. ठ์,.+

Biology: Harrington, 1891. Canad. Ent. 23: 132. -Blackman and Stage, 1924. N. Y. State Col.

Forestry, Syracuse Univ., Tech. Pub. 17: 182.

pilulus Townes. N. B. s. to N. C., w. to n. N. W. T., Yukon, Oreg., and Colo. Ecology: This species appears to be a parasite of wood borers in both hardwoods and conifers. It is anomalous in being the widest ranging, yet least collected, of the Nearctic spp. of Neoxorides.

Neoxorides pilulus Townes, 1960. In Townes and Townes, U. S. Natl. Mus. Bul. 216 (pt. 2): 390. $\delta$, ‥

\section{TRIBE RHYSSINI}

The North American members of this tribe are all parasites of Siricoidea.

Revision: Rohwer, 1920. U. S. Natl. MUS., Proc. 57: 418-428.

\section{Genus RHYSSA Gravenhorst}

Rhyssa Gravenhorst, 1829. Ichn. Europaea, v. 3, p. 260.

Type-species: Ichneumon persuasorius Linnaeus. Desig. by Westwood, 1840.

Cryptocentrum Kirby, 1837. In Richardson, Swainson, and Kirby, Fauna Bor. Amer., v. 4, p. 260.

Type-species: Cryptocentrum lineolatum Kirby. Monotypic.

Pararhyssa Walsh, 1873. Acad. Sci. St. Louis, Trans. 3: 109.

Type-species: Rhyssa persuasoria (Linnaeus). Desig. by Viereck, 1914.

alaskensis Ashmead. Alta. s. to N. Mex., w. to s. Alaska and Calif.

Rhyssa alaskensis Ashmead, 1902. Wash. Acad. Sci., Proc. 4: 199. $\$$.

Rhyssa skinneri Viereck, 1903. In Skinner, Amer. Ent. Soc., Trans. 29: 87..

crevieri (Provancher). N. S. s. to N. C., w. to Minn. Host: Urocerus albicornis (F.). It remains to be proven that crevieri is distinct from lineolata (Kirby).

Epirhyssa Crevieri Provancher, 1880. Nat. Canad. 12: 17. ठ.

hoferi Rohwer. Colo., N. Mex., Ariz. Ecology: It appears that this species occurs in the lower reaches of forests of Pinus ponderosa and in the pinyon-juniper forest type. Males which are predominantly black with yellow markings (as opposed to red with yellow markings) have been collected since the species was treated in the revision of Townes and Townes (1960). Presumably, females with predominantly black ground color will also be found.

Rhyssa hoferi Rohwer, 1920. U. S. Natl. Mus., Proc. 57: 421. $\$$.

howdenorum Townes. Md., Va., N. C., Ga., ala., Nebr. Ecology: This species parasitizes siricids boring in Pinus spp.

Rhyssa howdenomum Townes, 1960. In Townes and Townes, U. S. Natl. Mus. Bul. 216 (pt. 2): 398. $\delta$, ․

lineolata (Kirby). N. S. s. to Ga., w. to B. C. and Oreg.; New Zealand, Australia. Host: Urocerus albicornis (F.), U. gigas flavicornis (F.), Sirex cyaneus F., S. edwardsii Brulle, 
S. noctilio F., Xeris sp. This species is adventive in New Zealand, there parasitizing Sirex noctilio, which is adventive from Europe. Subsequently, $R$. lineolata was introduced in Australia for control of $S$. noctilio.

Cryptocentrum lineolatum Kirby, 1837. In Richardson, Swainson, and Kirby, Fauna Bor. Amer., v. 4, p. 260 . ठ5.

Rhyssa albomaculata Cresson, 1864. Ent. Soc. Phila., Proc. 3: 318..

Taxonomy: Morley, 1909. Entomologist 42: 133. -Morley, 1910. Entomologist 43: 243.

-Zondag and Nuttall, 1961. New Zeal. Ent. 2 (6): 40-44 (identity and origin of New

Zealand population).

Biology: Gardiner, 1966. Canad. Ent. 98: 95-97 (oviposition).

Morphology: Pratt, 1939. Ent. Soc. Amer., Ann. 32: 733.

persuasoria persuasoria (Linnaeus). Newfoundland (insular) s. to Ga., w. to B. C. and Calif.; Eurasia; New Zealand, Australia. Host: Sirex areolatus (Cr.), S. noctilio F., Xeris sp., Syntexis libocedrii Rohwer. Sirex noctilio was the target species for the successful introductions of $R$. p. persuasoria into New Zealand and Australia from Europe, but the other host records are North American. Two Himalayan subspecies of $R$. persuasoria are recognized by Kamath and Gupta (1971).

Ichneumon persuasorius Linnaeus, 1758. Syst. Nat., ed. 10, v. 1, p. 562 . .

Ichneumon camelus Scopoli, 1763. Ent. Carn., p. 282. sex ?

Rhyssa marginalis Brulle, 1846. In Lepeletier, Hist. Nat. Ins. Hym., v. 4, p. 79..

Rhyssa lineolata Kriechbaumer, 1887. Ent. Nachr. 13: 81. $\%$. Uncertain syn. which is preocc. by Kirby, 1837.

Taxonomy: Kamath and Gupta, 1971. Oriental Ins. Monog. 2: 14 (key to subspecies).

-Spradbury and Radkowsky, 1974. Bul. Ent. Res. 64: 653-668 (geog. variation).

Biology: Franke, 1959. Photographie u. Forsch. 8: 1-9 (oviposition). -Ozols, 1962. Latvijas

Ent. 5: 29-40. - Klein, 1965. Ztschr. f. Angew. Ent. 56: 224. - Morgan and Stewart, 1966.

Roy. Soc. New Zeal. (Zool.), Trans. 8: 31-38 (habits and life history). - Hocking, 1968.

Australian Ent. Soc., Jour. 7: 1-5. - Spradbury, 1970. Animal Behavior 18: 103-114 (host

finding).

ponderosae Townes. Calif. Host: Sirex areolatus (Cr.).

Rhyssa ponderosae Townes, 1960. In Townes and Townes, U. S. Natl. Mus., Bul. 216 (pt. 2): $401 . \delta$,.

\section{Genus RHYSSELLA Rohwer}

Rhyssella Rohwer, 1920. U. S. Natl. Mus., Proc. 57: 422.

Type-species: Rhyssa nitida Cresson. Orig. desig.

Members of this genus parasitize Siricoidea which bore in hardwood trees or bushes and may be host specific to Xiphidriidae.

humida (Say). Maine s. to Ga., w. to Minn. and Miss. Host: Xiphidria abdominalis Say, X. tibialis Say.

Pimpla humida Say, 1836. Boston Jour. Nat. Hist. 1: 224. 9.

nitida (Cresson). Maine s. to Ga., w. to B. C. Host: Xiphidria canadensis Prov., X. maculata Say.

Rhyssa nitida Cresson, 1864. Ent. Soc. Phila., Proc. 3: 319. ठ.

Rhyssa canadensis Cresson, 1868. Canad. Ent. 1: 35 . .

Epirhyssa clavata Provancher, 1886. Addit. Corr. Faune Ent. Canada Hym., p. 115.

Biology: Kaston, 1937. Conn. (State) Agr. Expt. Sta., Bul. 396: 359.

Morphology: Pratt, 1939. Ent. Soc. Amer., Ann. 32: 733.

\section{Genus MEGARHYSSA Ashmead}

Thalessa Holmgren, 1859. Svenska Vetensk.-Akad., Ofvers af ... Forhandl. 16: 122. Preocc. by Adams, 1853. 
Type-species: Ichneumon clavator Fabricius. Desig. by Ashmead, 1900. The type-species is regarded as a synonym of $M$. gigas (Laxmann).

Megarhyssa Ashmead, 1900. Canad. Ent. 32: 368. N. name for Thalessa Holmgren. Megalorhyssa Schulz, 1906. Spolia Hym., p. 115. Emend.

Eurhyssa Derksen, 1941. Ztschr. f. Morph. U. Oekol. der Tiere 37: 721. Name invalid; type-species not designated except subsequently by Townes and Townes, 1951 as Ichneumon superbus Schrank.

In eastern North America the three species of Megarhyssa which are common in hardwood forests--atrata (Linnaeus), macrumus (Linnaeus), and greenei (Viereck)--all show rather marked, more or less clinal, geographic variation in the coloration of the wings, particularly in the females. Specimens from the northern range extremities often have wings which are nearly clear, while the wings of those from the southern range extremities are most deeply or most uniformly infuscate. In macrurus and greenei subspecific distinctions have been made near the southern extremities of the ranges, and in the case of atrata a subspecific distinction has been made near the northern extremity of the range. I do not believe it is meaningful to treat these particular peripheral variants as subspecies.

Revision: Michener, 1939. Pan-Pacific Ent. 15: 126-131.

Biology: Heatwole, Davis, and Wenner, 1962. Ztschr. f. Tierpsychol. 19: 652-664. - Heatwole, Davis, and Wenner, 1964. Amer. Midland Nat. 71: 374-381. -Cameron, 1965.

Commonwealth Inst. Biol. Control, Tech. Bul. 5: 22.

atrata (Fabricius). N. S. s. to Ga., w. to Wyo. and Tex. Host: Tremex columba (L.).

Ichneumon atratus Fabricius, 1781. Species Insectorum, v. 1, p. 436. 9.

Ichneumon tenebrator Thunberg, 1822; 1824. Acad. Imp. des Sci. St. Petersburg, Mem. 8: 266; 9:322. Unnecessarily proposed n. name for atratus Fabricius.

Rhyssa laevigata Brulle, 1846. In Lepeletier, Hist. Nat. Ins. Hym., v. 4, p. 78. ठ.

Megarhyssa atrata lineata Porter, 1957. Ent. News 68: 206. ․ N. syn.

Biology: Harris, 1842. Rpt. Ins. Mass. Injurious to Veg., p. 391. -Walsh, 1867. Pract. Ent. 2: 118. - Walsh and Riley, 1868. Amer. Ent. 1: 77. - Harrington, 1882. Canad. Ent. 14: 82. - Lintner, 1883. Cultivator and Country Gentleman 48: 561. - Harrington, 1883. Ent. Soc. Ontario, Ann. Rpt. 13: 23-24. - Harrington, 1887. Canad. Ent. 19: 206-209. - Harrington, 1888. Ent. Soc. Ontario, Ann. Rpt. 18: 25. - Lintner, 1897. Cultivator and Country Gentleman 62: 506. - Fyles, 1916. Ent. Soc. Ontario, Ann. Rpt. 46: 54, 57. -Macnamara, 1916. Ent. Soc. Ontario, Ann. Rpt. 46: 59. -Champlain, 1921. Ent. News 32: 241.

-Blackman and Stage, 1924. N. Y. State Col. Forestry, Syracuse Univ., Tech. Pub. 17: 178. -Klugh, 1932. Amer. Photog. 26: 158. - Kaston, 1937. Conn. (State) Agr. Expt. Sta., Bul. 396: 359. - Proctor, 1938. Biol. Survey Mt. Desert Region, v. 6, p. 406. -Fattig, 1949. Ent. News 40: 69-71.

Morphology: Snodgrass, 1933. Smithsn. Inst. Misc. Collect. 89 (8): 112-114.

greenei Viereck. N. S. s. to Fla., w. to Minn., e. Kans., and Miss. Host: Tremex columba (L.).

Megarhyssa greenei Viereck, 1910. In Smith, N. J. State Mus., Ann. Rpt. for 1909, p. 627. Nomen nudum.

Megarhyssa greenei Viereck, 1911. U. S. Natl. Mus., Proc. 40: 191. ठ, ๆ.

Megarhyssa greenei floridana Townes, 1960. U. S. Natl. Mus. Bul. 216 (pt. 2): 424.. N. syn.

Biology: Proctor, 1938. Biol. Survey Mt. Desert Region, v. 6, p. 406. -Townes, 1939.

Brooklyn Ent. Soc., Bul. 34: 29. - Fattig, 1949. Ent. News 40: 70-71.

Morphology: Pratt, 1939. Ent. Soc. Amer., Ann. 32: 737.

macrurus icterosticta Michener. Colo., N. Mex., Utah, Ariz. Presumably, $m$. icterosticta intergrades with the nominate subspecies in the Rocky Mountains, but intermediate specimens are apparently unknown.

Megarhyssa lunator icterosticta Michener, 1939. Pan-Pacific Ent. 15: 130. ठ, ?.

macrurus macrurus (Linnaeus). Maine s. to Fla., w. to w. S. Dak. and w. Tex.; n. Mexico. Host: Tremex columba (L.).

Ichneumon macrurus Linnaeus, 1771. Mantissa Plantarum, v. 2, p. 540...

Ichneumon lunator Fabricius, 1781. Species Insectorum, v. 1, p. 430... 
Ichneumon Georgicus Megerle, 1802. Appendix ad Cat. Ins., Quae Mense Novembris 1802 Vienne Austriae Auctionis Lege Vendita Fuere, p. 16..

Thalessa? histrio Kriechbaumer, 1890. Wien, Mus. der Naturgesch., Ann. 5: 487. ơ. Preocc. in Megarhyssa by Ichneumon histrio Christ, 1791.

Megalorhyssa lunatrix Schulz, 1906. Spolia Hym., p. 115. Emend.

Megarhyssa lunator phaeoptila Michener, 1939. Pan-Pacific Ent. 15: 129..

Biology: Harris, 1842. Rpt. Ins. Mass. Injurious to Veg., p. 391. -Emmons, 1854. Nat. Hist. N. Y. (pt. 5) v. 5, p. 194. -D'Urban, 1865. Ent. Monthly Mag. 2: 71. -Riley, 1870. Amer. Ent. 2: 96, 128. - Fletcher, 1881. Ent. Soc. Ontario, Ann. Rpt. 11: 67. - Harrington, 1882. Canad. Ent. 14: 82. - Harrington, 1883. Ent. Soc. Ontario, Ann. Rpt. 13: 23-24. - Gade, 1884. Brooklyn Ent. Soc., Bul. 7: 103. - Lintner, 1884. Cultivator and Country Gentleman 49: 331. - Riley, 1885. Brooklyn Ent. Soc., Bul. 7: 123. - Smith, 1885. Brooklyn Ent. Soc., Bul. 7: 124. - Riley, 1886. Ent. Soc. Wash., Proc. 1: 15. - Harrington, 1887. Canad. Ent. 19: 206-209. -Lintner, 1888. N. Y. State Mus. Nat. Hist., Rpt. 41: 35-42. - Harrington, 1888. Ent. Soc. Ontario, Ann. Rpt. 18: 25-27. - Riley, 1888. U. S. Dept. Agr., Insect Life 1: 168-179. - Lintner, 1889. N. Y. State Ent., Rpt. 4: 35-36. - Lintner, 1893. N. Y. State Mus. Nat. Hist., Rpt. 45: 163-166. - Lintner, 1897. Cultivator and Country Gentleman 62: 506. - Ashmead, 1900. N. J. State Bd. Agr., Ann. Rpt. 27 (sup.): 572. -Fyles, 1911. Ent. Soc. Ontario, Ann. Rpt. 41: 80. -Douglas, 1912. State Ent. Ind., Ann. Rpt. 4: 105. - Baldwin, 1914. State Ent. Ind., Ann. Rpt. 6: 51. -Fyles, 1916. Ent. Soc. Ontario, Ann. Rpt. 46: 54, 57. - Fyles, 1917. Ent. Soc. Ontario, Ann. Rpt. 47: 28. - Barlow, 1921. Ent. News, 32: 291. -Cushman, 1926. Ent. Soc. Wash., Proc. 28: 32. - McDaniel, 1933. Mich. Agr. Expt. Sta., Spec. Bul. 238: 37. - Woodbury, 1933. Ecol. Monog. 3: 191. -Abbott, 1934. N. Y. Ent. Soc., Jour. 42: 127-133. -Abbott, 1934. Psyche 41: 238-240. - Abbott, 1937. Ent. News 47: 263-264. - Kaston, 1937. Conn. (State) Agr. Expt. Sta., Bul. 396: 359. -Kelley, 1939. Nature Mag. 32: 379-380. - Townes, 1939. Brooklyn Ent. Soc., Bul. 34: 29. -Fattig, 1949. Ent. News 40: 69-71.

Morphology: Abbott, 1934. N. Y. Ent. Soc., Jour. 42: 127-133. -Abbott, 1934. Brooklyn Ent. Soc., Bul. 29: 39-41. - Abbott, 1935. Brooklyn Ent. Soc., Bul. 30: 10-13. -Peck, 1937.

Canad. Jour. Res., Sect. D (Zool. Sci.) 15: 237-240, 246, 247, 251.

Biology: Pratt, 1939. Ent. Soc. Amer., Ann. 32: 733.

Morphology: Snodgrass, 1941. Smithsn. Inst., Misc. Collect. 99 (14): 33-34.

nortoni (Cresson). Newfoundland (Labrador) s. to n. Ga., w. to Alaska and Calif.; New

Zealand, Australia. Ecology: Occurs in coniferous forests. Host: Urocemis albicornis (F.),

Xeris morrisoni (Cr.), Sirex sp., S. noctilio F. These host records are North American, except in the case of Sirex noctilio, which was the target species for the successful introductions into New Zealand and Australia. It seems very likely that nortoni will, at best, prove to be only subspecifically distinct from the Eurasian $M$. gigas (Laxmann).

Rhyssa nortoni Cresson, 1864. Ent. Soc. Phila., Proc. 3: 317..

Thalessa Quebecensis Provancher, 1873. Nat. Canad. 5: 447. ठ’, ๆ. Barron (1975) selected a lectotype.

Megarhyssa nortonii Dalla Torre, 1901. Cat. Hym., v. 3, p. 481. Emend.

Taxonomy: Barron, 1975. Nat. Canad. 102: 542-543.

Biology: Essig, 1926. Ins. of West. N. Amer., p. 795-796. - Proctor, 1938. Biol. Survey Mt.

Desert Region, v. 1, p. 406. - Madden, 1968. Nature [London] 218: 189-190. - Nuttal, 1973.

New Zeal. Ent. 5 (2): 112-117 (mating behavior).

\section{Genus EPIRHYSSA Cresson}

Epirhyssa Cresson, 1865. Ent. Soc. Phila., Proc. 4: 39.

Type-species: E pirhyssa speciosa Cresson. Desig. by Viereck, 1914.

Rhyssonota Kriechbaumer, 1890. Wien. Mus. der Naturgesch., Ann. 5 (3): 489.

Type-species: Rhyssonota tristis Kriechbaumer. Monotypic. Except for the single species occurring in the southwestern U. S., this genus is Neotropic. 
dietrichi Townes. Ariz.

Epirhyssa dietrichi Townes, 1960. In Townes and Townes, U. S. Natl. Mus. Bul. 216 (pt. 2): 414. $\delta$, ..

\section{SUbFAmILY LABENINAE}

Taxonomy: Townes, 1969. Amer. Ent. Inst., Mem. 11: 194-207 (tribes and genera of world; as Labiinae, =Labeninae).

\section{TRIBE LABENINI}

This is a small tribe, including five genera, only one of which has Nearctic species.

\section{Genus LABENA Cresson}

Labena Cresson, 1864. Ent. Soc. Phila., Proc. 3: 399.

Type-species: Cryptus grallator Say. Desig. by Viereck, 1914.

Caryoecus Walsh, 1866. Pract. Ent. 1: 30.

Type-species: Mesochorus fuscipennis Brulle. Monotypic.

Microtritus Kriechbaumer, 1889. Ent. Nachr. 15: 307.

Type-species: Microtritus apicalis Kriechbaumer. Monotypic.

Dyseidopus Kriechbaumer, 1890. Wien. Mus. der Naturgesch., Ann. 5: 489.

Type-species: Dyseidopus sericeus Kriechbaumer. Monotypic.

Neonotus Parrot, 1955 (1954). Linn. Soc. N. S. Wales, Proc. 79:230.

Type-species: Neonotus chadwickii Parrot. Monotypic and orig. desig.

This is a large Australian, Neotropic, and Nearctic genus.

Revision: Townes and Townes, 1960. U. S. Natl. Mus. Bul. 216 (pt. 2): 531-537.

grallator (Say). Mass. and s.e. Ont. s. to Fla., w. to Wis., Colo., and s.e. Calif.; Mexico? Ecology: Has geen reared from insects infesting Pinus and Taxodium, but is more often reared from borers in various angiosperms (trees, bushes, and vines). Host: Aneflomorpha sp.? in Lycium belandieri, cerambycid in Baccharis halimifolia, Knulliana cincta (Drury), Psyrassa unicolor (Rand.), Saperda puncticollis Say, Stenosphenus notatus (Oliv.), Agrilus sp., A. arcuatus (Say), Chrysobothris femorata (Oliv.), C. tranquebarica (Gmelin), Thrincopyge alacris LeC., Lixus scrobicollis Boh., Pissodes strobi (Peck). The geographic variation of grallator does not seem conducive to the recognition of subspecies.

Cryptus grallator Say, 1836. Boston Jour. Nat. Hist. 1: 236. $ๆ$.

Mesochorus fuscipennis Brulle, 1846. In Lepeletier, Hist. Nat. Ins. Hym., v. 4, p. 250. $ๆ$.

Labena a picalis Cresson, 1864. Ent. Soc. Phila., Proc. 3: $402 . ð$.

Labena grallatrix Schulz, 1906. Spolia Hym., p. 116. Emend.

Labena confusa Rohwer, 1920. U. S. Natl. Mus., Proc. 57: 411..

Labena confusa var. minor Rohwer, 1920. U. S. Natl. Mus., Proc. 57: 413..

Labena grallator xutha Townes, 1960. In Townes and Townes, U. S. Natl. Mus. Bul. 216 (pt. 2): 535. ơ, \&. N. syn.

Labena grallator ochreata Townes, 1960. In Townes and Townes, U. S. Natl. Mus. Bul. 216 (pt. 2): 535. o, ๆ. N. syn.

Labena grallator lutea Townes, 1960. In Townes and Townes, U. S. Natl. Mus. Bul. 216 (pt. 2): 536. ठ. N. syn.

Labena grallator balteata Townes, 1960. In Townes and Townes, U. S. Natl. Mus. Bul. 216(pt. 2): 536. ठ, ๆ. N. syn.

tinctipennis Rohwer. Central Ariz., s. B. C., Calif. Host: Dicerca horni Croteh.

Labena tinctipennis Rohwer, 1920. U. S. Natl, Mus., Proc. 57: 409. $ๆ$.

\section{TRIBE GROTEINI}

The members of this tribe are parasites of bees. Only one of the three genera is represented by North American species. 


\section{Genus GROTEA Cresson}

Grotea Cresson, 1864. Ent. Soc. Phila., Proc. 3: 397.

Type-species: Grotea anguina Cresson. Monotypic.

This is a small Neotropic and Nearctic genus. The hosts are twig-nesting bees of the genus Ceratina. More than one Ceratina larva is consumed by each Grotea larva, and the pollen loaves in the cells of the consumed Ceratina larvae are also eaten by larvae of Grotea.

Revision: Townes and Townes, 1960. U. S. Natl. Mus. Bul. 216 (pt. 2): 538-541 (Nearctic spp.). -Slobodchikoff, 1970. Pan-Pacific Ent. 46: 50-60 (Nearctic and Neotropic spp.).

anguina Cresson. Que. w. to Wis. and w. Iowa, s. to n.w. S. C., n. Miss., and s. Tex. Host: Ceratina calcarata Rbtsn., C. dupla Say, C. metallica H. S. S.

Grotea anguina Cresson, 1864. Ent. Soc. Phila., Proc. 3: 398. ठ, १.

Biology: Graenicher, 1905. Ent. News 16: 43-49. - Rau, 1922. Acad. Sci. St. Louis, Trans. 24:

43. -Rau, 1928. Ent. Soc. Amer., Ann. 21: 383. -Daly, Stage, and Brown, 1967. Ent. Soc.

Amer., Ann. 60: 1275.

californica Cresson. Northern Idaho and s. B. C. s. to s. Calif. Host: Ceratina acantha Prov., C. dallatorreana Friese, C. gigantea H. S. S., C. nanula Ckll., C. punctigena Ckll.

Grotea californica Cresson, 1879 (1878). Acad. Nat. Sci. Phila., Proc. 30: 370. \&.

Biology: Slobodchikoff. 1967. Pan-Pacific Ent. 43: 161-168. -Daly, Stage, and Brown, 1967.

Ent. Soc. Amer., Ann. 60: 1275-1277.

lokii Slobodchikoff. Colo., Ariz.; Mexico. This species was confused with anguina and californica in the revision of Grotea by Townes and Townes (1960).

Grotea lokii Slobodchikoff, 1970. Pan-Pacific Ent. 46: 60. §, ๆ.

\section{TRIBE BRACHYCYRTINI}

Revision: Walkley, 1956. U. S. Natl. Mus., Proc. 106: 315-329.

\section{Genus BRACHYCYRTUS Kriechbaumer}

Brachycyrtus Kriechbaumer, 1880. Zool.-Min. Ver. Regensburg, Corresp. BI. 34: 161.

Type-species: Brachycyrtus ornatus Kriechbaumer. Monotypic.

Proterocryptus Ashmead, 1906. U. S. Natl. Mus., Proc. 30: 174.

Type-species: Proterocryptus nawaii Ashmead. Monotypic.

Xanthocharops Morley, 1912. Linn. Soc. London, Trans. 15: 173.

Type-species: Xanthocharops primus Morley. Monotypic.

Vakau Cheesman, 1928. Ann. and Mag. Nat. Hist. (10) 1: 189.

Type-species: Vakau taitensis Cheesman. Monotypic and orig. desig.

Brachycyrtomorpha Blanchard, 1940. In Kreibom de la Vega, Tucuman Estac. Expt. Agr., Rev. Indus. y Agr. 3: 170. Nomen nudum (figure only).

Brachycyrtomorpha Blanchard, 1942. Soc. Cient. Argentina, An. 134: 105.

Type-species: Brachycyrtomorpha crossi Blanchard. Monotypic and orig. desig.

This is a small genus of worldwide distribution. The hosts are pupae or prepupae of Chrysopidae.

Revision: Townes and Townes, 1960. U. S. Natl. Mus. Bul. 216 (pt. 2): 542-544 (Nearctic spp.). ornatus Kriechbaumer. Pa., Md., Ohio, Mich., Ariz., s. B. C.; Mexico; Eurasia. Host: Chrysopid.

Brachycyrtus ornatus Kriechbaumer, 1880. Zool.-Min. Ver. Regensburg, Corresp.-Bl. 34: 163. ‥

Brachycyrtus chrysopae Walley, 1940. Canad. Ent. 72: 86 ..

pretiosus Cushman. Central and s. Fla. Host: Nodita pavida (Hagen), chrysopid pupae.

Brachycyrtus pretiosus Cushman, 1936. U. S. Nat. Mus., Proc. 84: 19. đ, 9.

\section{SUBFAMILY TRYPHONINAE}

Species of this subfamily are external parasites of the larvae of sawflies or Lepidoptera. The eggs of Tryphoninae are equipped with a holdfast which is often borne on a stalk or is derived 
from coiling of the stalk; it serves to fasten the eggs within the puncture the female makes in the skin of the host larva. According to Mason (1967), in species which parasitize sawflies, eclosion from the egg does not occur until after the host has spun its cocoon.

Taxonomy: Townes, 1969. Amer. Ent. Inst., Mem. 11: 143-193 (genera of world).

Biology: Mason, 1967. Canad. Ent. 99: 376.

\section{TRIBE PHYTODIETINI}

Members of this tribe are parasitic on larvae of Lepidoptera. The stalk of the egg is long, slender, and loosely coiled; in newly deposited eggs the stalk is elastic, but later becomes rigid so that its coiling serves to hold it firmly in the skin of the host.

Townes (1969) preferred to group the numerous species of this tribe into two genera, each with a number of subgenera. His use of more subgeneric than generic names seems to make the classification of this tribe discordant with his classification of the rest of the subfamily.

\section{Genus PHYTODIETUS Gravenhorst}

This genus is divided into four subgenera, two of which have North American species. The North American species are currently being revised by Dr. C. C. Loan, and publication of his revision may precede the appearance of this catalog.

Revision: Rohwer, 1920. U. S. Natl. Mus., Proc. 57: 460-468.

\section{Genus PHYTODIETUS subgenus NEUCHORUS Uchida}

Neuchorus Uchida, 1931. Insecta Matsumurana 5: 143.

Type-species: Neuchomis longicauda Uchida. Monotypic and orig. desig.

Doratistes Seyrig, 1932. Acad. Malgache, Mem. 11: 27. Described as a subgenus of

Phytodietus but treated nomenclaturally as a genus.

Type-species: Doratistes absyrtinus Seyrig. Orig. desig.

Taxonomy: Krebs, 1969. Canad. Ent. 101: 548-549 (key to Nearctic spp.).

rufipes pulcherrimus (Cresson). Atlantic to Cont. Divide in Transit. and U. Aust. Zones. Host:

Loxostege rantalis (Gn.), L. sticticalis (L.), Ostrinia obliteralis (Wlk.), Phlyctaenia

coronata tertialis $(\mathrm{Gn}$.$) . P$. (N.) mifipes rufipes Holmgren is European.

Mesoleptus pulcherrimus Cresson, 1868. Amer. Ent. Soc., Trans. 2: 101. ठ.

Phytodietus distinctus Cresson, 1870. Amer. Ent. Soc., Trans. 3: 166. ․

Phytodietus zonatus Provancher, 1874. Nat. Canad. 6: 79. $?$.

Mesostenus nobilis Provancher, 1882. Nat. Canad. 13: 363. $ๆ$.

Mesoleius telarius Provancher, 1886. Addit. Corr. Faune Ent. Canada Hym., p. 106. $q$.

Ctenopelma pulchra Ashmead, 1896. Amer. Ent. Soc., Trans. 23: 198. ठ'.

Taxonomy: Townes, 1969. Amer. Ent. Inst., Mem. 11: 147.

Biology: Balduf, 1929. Ohio Jour. Sci. 29: 233-234.

rutilus Krebs. Md., N. Y., Mich., Ky.

Phytodietus (Neuchomes) mutilus Krebs, 1969. Canad. Ent. 101: 549. đ, \&.

\section{Genus PHYTODIETUS Subgenus PHYTODIETUS Gravenhorst}

Phytodietus Gravenhorst, 1829. Ichn. Europaea 2: 928.

Type-species: Phytodietus astutus Gravenhorst. Desig. by Westwood, 1840.

Phytodiaetus Agassiz, 1846. Nomencl. Zool., Index Univ., p. 291. Emend.

burgessi (Cresson). Atlantic to $100^{\circ} \mathrm{W}$. in Transit. and U. Austr. Zones.

Tryphon Burgessi Cresson, 1868. Amer. Ent. Soc., Trans. 2: 105. $\delta$.

Tryphon burgessii Dalla Torre, 1901. Cat. Hym., v. 3, p. 293. Emend.

Phytodietus plesia Rohwer, 1920. U. S. Natl. Mus., Proc. 57: 465..+

californicus Cresson. Colo., Wash., Calif.

Phytodietus californicus Cresson, 1879 (1878). Acad. Nat. Sci. Phila., Proc. 30: 380..

clypearius Ashmead. Wyo., Alaska.

Phytodietus clypearius Ashmead, 1902. Wash. Acad. Sci., Proc. 4: 195. ठ, ๆ. 
Phytodietus flavifrons Ashmead, 1902. Wash. Acad. Sci., Proc. 4: 196. ơ.

facialis Rohwer. N. J., La., Tex. Host: Acrobasis comptoniella Hulst.

Phytodietus facialis Rohwer, 1920. U. S. Natl. Mus., Proc. 47: 462. \&.

fumiferanae Rohwer. Wyo., Colo., Ariz., B. C., Oreg. Host: Choristoneura lambertiana (Bsk.), $C$, occidentalis Free.

Phytodietus fumiferanae Rohwer, 1922. Canad. Ent. 54: 155. ơ, ‥

parvus Rohwer. Calif.

Phytodietus parvus Rohwer, 1920. U. S. Natl. Mus., Proc. 57: 463..

pleuralis Cresson. Atlantic to Tex., Colo., Ariz. Host: Acleris minuta (Rob.).

Phytodietus pleuralis Cresson, 1865. Ent. Soc. Phila., Proc. 4: 266. ơ.

Meniscus 4-cinctus Ashmead, 1894. In Webster, Cincinnati Soc. Nat. Hist., Jour. 17: 50. ઠ̋. Dr. C. C. Loan found the heretofore lost holotype among specimens he borrowed from the U.S. Natl. Museum and advised me of the present synonymy.

segmentator (Gravenhorst). Eurasia. Introduced in Ontario in 1956 for control of the native Choristoneura fumiferana (Clem.). Only a small number of individuals ( 35 males and 39 females) were released, which would seem to have precluded establishment.

Phytodietus segmentator Gravenhorst, 1829. Ichn. Europaea, v. 2, p. 944. ठ", ?.

vulgaris Cresson. Transcont. in Transit., Canad., Huds. Zones. Host: Argyrotaenia pinatubana (Kft.), Archips argyrospilus (Wlk.).

Phytodietus vulgaris Cresson, 1870. Amer. Ent. Soc., Trans. 3: 166. đ’, 9.

Mesoleius annulatus Provancher, 1886. Addit. Corr. Faune Ent. Canada Hym., p. 106.. . Preocc. by Brischke, 1871.

Biology: Fernald, 1891. Mass. Agr. Expt. Sta., Bul. 12: 9.

\section{Genus NETELIA Gray}

Until 1939 the generic name Paniscus Schrank (1801) was universally applied to the majority of species now placed in Netelia. The name Paniscus is now uniformly treated as an objective synonym of $O$ phion, thus reversal of this unfortunate change would cause more confusion than it would eliminate.

Members of this genus are nocturnal or crepuscular and are often attracted to lights. Because of similar habits and general appearance casual observers often confuse them with species of Ophioninae. Netelia females generally sting more painfully than those of Ophioninae, however.

Revision: Townes, 1939 (1938). Lloydia 1: 168-231.

Biology: Riley, 1869. Insects Mo., Ann. Rpt. 1: 89. -Cushman, 1913. Ent. Soc. Wash., Proc. 15: 155-157. - Vance, 1927. Ent. Soc. Amer., Ann. 20: 405-417. - Schaffner and Griswold, 1934. U. S. Dept. Agr., Misc. Pub. 188: 143-144.

Morphology: Whitmarsh, 1910. Ent. Soc. Amer., Ann. 3: 198, 204-208.

\section{Genus NETELIA Subgenus PAROPHELTES Cameron}

Paropheltes Cameron, 1907. Bombay Nat. Hist. Soc., Jour. 17: 1011.

Type-species: Paropheltes flavolineatus Cameron. Monotypic.

alaskensis (Ashmead). Alta., Wyo., Alaska.

Paniscus alaskensis Ashmead, 1902. Wash. Acad. Sci., Proc. 4: 237. ठં.

albovariegata (Provancher). Que., N. Y., Ohio, Ill., S. Dak.

Paniscus albovariegatus Provancher, 1874. Nat. Canad. 6: 106. ठ.

barberi (Cushman). N. S. s. to D. C., w. to B. C., Wash.

Paniscus pallens var. barberi Cushman, 1924. U. S. Natl. Mus., Proc. 64: 40. ‡, ठ.

ciliata Townes. Calif.

Netelia (Paropheltes) ciliata Townes, 1939 (1938). Lloydia 1: 180. ठ.

laticeps Townes. Ariz.

Netelia (Paropheltes) laticeps Townes, 1939 (1938). Lloydia 1: 181. ठో.

macroglossa Townes. B. C., Nev.

Netelia (Paropheltes) macroglossa Townes, 1939 (1938). Lloydia 1: 179. ठ์. 
picta Townes. Nev.

Netelia (Paropheltes) picta Townes, 1939 (1938). Lloydia 1: 181. ठో. radiata Townes. Kans., Ariz., Calif.

Netelia (Paropheltes) radiata Townes, 1939 (1938). Lloydia 1: 180. ठో. rimata Townes. B. C., Calif.

Netelia (Paropheltes) rimata Townes, 1939 (1938). Lloydia 1: $180 . \delta^{\circ}$. serrata Townes. N. Y., Ont., Iowa., S. Dak.

Netelia (Paropheltes) serrata Townes, 1939 (1938). Lloydia 1: 180. ठ.

tarsata (Brischke). N. S. s. to S. C., w. to Alta.; Eurasia.

Paniscus tarsatus Brischke, 1880. Naturf. Gesell. Danzig, Schr. 4 (4): 138. o, ๆ.

Parabatus terebrator Ulbricht, 1922. Konowia 1: 181. ठ, $९$.

\section{Genus NETELIA Subgenus PARABATES Foerster}

Parabates Foerster, 1868. Naturh. Ver. Rheinlande, Verh. 25: 150.

Type-species: Parabatus nigricarpus Thomson. Designated by Enderlein (1912) from four species included by Thomson (1888).

Parabatus Thomson, 1888. Opusc. Ent. 12: 1194. Emend. See the discussion pertaining to the subgenus Bessobates.

Opheltoideus Ashmead, 1900. U. S. Natl. Mus., Proc. 23: 95.

Type-species: Opheltoideus johnsoni Ashmead. Monotypic and orig. desig.

This subgenus is small, having one Nearctic and one European species.

johnsoni (Ashmead). N. H., N. C., Tenn., B. C.

Ctenacme monticola Ashmead, 1900. In Slosson, Ent. News 11: 320. Nomen nudum.

Opheltoideus johnsoni Ashmead, 1900. U. S. Natl. Mus., Proc. 23: 95. Sex not specified. No

type specimen can be found in the U.S. Natl. Museum collection.

Opheltoideus johnsonii Dalla Torre, 1901. Cat. Hym., v. 3, p. 83. Emend.

Parabates monticola Cushman, 1922. U. S. Natl. Mus., Proc. 61 (8): 20..

Taxonomy: Townes, 1969. Amer. Ent. Inst., Mem. 11: 151.

\section{Genus NETELIA Subgenus TOXOCHILUS Townes}

Netelia subg. Toxochilus Townes, 1939 (1938). Lloydia 1: 182.

Type-species: Paniscus clypeatus Cushman. Orig. desig.

This subgenus is known only from the Nearctic Region.

caviverticalis (Cushman). Colo.

Paniscus caviverticalis Cushman, 1924. U. S. Natl. Mus., Proc. 64 (20): 29..

clypeata (Cushman). Va., W. Va., Ill., Iowa, S. Dak., Colo., N. Mex.

Paniscus clypeatus Cushman, 1924. U. S. Natl. Mus., Proc. 64 (20): 29. ठ。. glabra Townes. Kans.

Netelia (Toxochilus) glabra Townes, 1939 (1938). Lloydia 1: 183. ठં, ९.

magniceps Townes. S. Dak., Mo., Kans., Colo., Ariz.

Netelia (Toxochilus) magniceps Townes, 1939 (1938). Lloydia 1: 184. §, ․

mystace Townes. Ariz.

Netelia (Toxochilus) mystace Townes, 1939 (1938). Lloydia 1: 184. ठో.

pulchra (Cushman). N. Mex.

Paniscus pulcher Cushman, 1924. U. S. Natl. Mus., Proc. 64 (20): 25. ९, ठ.

ultima Townes. S. Dak., N. Mex.

Netelia (Toxochilus) ultima T'ownes, 1939 (1938). Lloydia 1: 183. ठั, ९.

\section{Genus NETELIA Subgenus PROSTHODOCIS Enderlein}

Prosthodocis Enderlein, 1912. Stettin. Ent. Ztg. 73: 107, 141.

Type-species: Paniscus antefurcalis Szepligeti. Monotypic and orig. desig.

exserta (Cushman). R. I., N. Y. s. to Ala., w. to Mo.

Parabates exsertus Cushman, 1924. U. S. Natl. Mus., Proc. 64 (20): 47 . ๆ. 


\section{Genus NETELIA Subgenus NETELIA Gray}

Netelia Gray, 1860. Ann. and Mag. Nat. Hist. 5 (3): 341.

Type-species: Paniscus inquinatus Gravenhorst. Monotypic and orig. desig.

Bucheckerius Schulz, 1906. Spolia Hym., p. 280.

Type-species: Bucheckerius perforatus Schulz. Monotypic.

Scammatonotum Enderlein, 1914. In Michaelsen, Beitr. z. Kennt. ... Fauna

Deut.-Sudwestafrikas, v. 1, p. 231.

Type-species: Scammatonotum herero Enderlein. Monotypic and orig. desig.

Amebachia Uchida, 1928. Hokkaido Imp. Univ., Fac. Agr., Jour. 21: 198.

Type-species: Amebachia baibarana Uchida. Orig. desig.

This subgenus includes three-fourths of the Netelia species, and they are distributed throughout the world.

acuminata Townes. Mass. s. to Ala., w. to Minn., s. Calif.

Netelia (Netelia) acuminata Townes, 1939 (1938). Lloydia 1: 206. ơ, ₹.

affinis Townes. Wash., Nev.

Netelia (Netelia) affinis Townes, 1939 (1938). Lloydia 1: 206. đ.

blantoni Townes. R. I., N. Y., Pa., Va.

Netelia (Netelia) blantoni Townes, 1939 (1938). Lloydia 1: 214. ठ.

brevicornis brevicornis (Cushman). N. S. s. to Ala., w. to Mont., Tex.

Paniscus brevicornis Cushman, 1924. U. S. Natl. Mus., Proc. 64 (20): 27. ठ, ?.

brevicornis suturalis Townes. Alta. s. to Utah, w. to B. C., Oreg.

Netelia (Netelia) brevicomis suturalis Townes, 1939 (1938). Lloydia 1: 201. ठ, ₹.

brevicornis temporalis (Cushman). Southwestern Calif.

Paniscus temporalis Cushman, 1924. U. S. Natl. Mus., Proc. 64 (20): 30..

brunnea Townes. N. Y., Pa., Md., Va.

Netelia (Netelia) brinnea Townes, 1939 (1938). Lloydia 1: 209. ठં.

californica (Cushman). Southern B. C. to s. Calif. The species has not been collected more than 80 miles from the Pacific Coast.

Paniscus californicus Cushman, 1924. U. S. Natl. Mus., Proc. 64 (20): 36 ..

calva Townes. Va.

Netelia (Netelia) calva Townes, 1939 (1938). Lloydia 1: 210. ð.

caseadica Townes. Oreg.

Netelia (Netelia) cascadica Townes, 1939 (1938). Lloydia 1: 205. ठ.

caudata Townes. Va., Ill., Okla.

Netelia (Netelia) caudata Townes, 1939 (1938). Lloydia 1: 216. o.

chloris (Olivier). Que. s. to N. C., w. to Mont., Tex.

Ophion chloris Olivier, 1811. Encycl. Meth. Hist. Nat. Insectes, v. 8, p. 509. .

Ophion geminatus Say, 1829. Contrib. Maclurian Lycium to Arts and Sci. 1: 76 . Sex not stated.

Paniscus texanus Ashmead, 1890 (1889). U. S. Natl. Mus., Proc. 12: 425. ?.

Taxonomy: Townes, 1961. Ent. Soc. Wash., Proc. 63: 111.

cockerelli (Cushman). N. Mex., Utah, Ariz., Calif.

Paniscus cockerelli Cushman, 1924. U. S. Natl. Mus., Proc. 64 (20): 35 ..

cushmani Townes. B. C.

Netelia (Netelia) cushmani Townes, 1939 (1938). Lloydia 1: 206. ठ.

delicata Townes. Que. s. to Ala., w. to Minn., Kans.

Netelia (Netelia) delicata Townes, 1939 (1938). Lloydia 1: 212. ઠै, ․

densa Townes. N. Mex., Ariz.

Netelia (Netelia) densa Townes, 1939 (1938). Lloydia 1: 204. ð.

emorsa Townes. Fla.; Bermuda, W. Indies. This species may prove to be a syn. of subfusca (Cresson), which was described from Cuba.

Netelia (Netelia) emorsa Townes, 1939 (1938). Lloydia 1: 197. đ, ?.

falcata Townes. Vt., N. Y., Pa.

Netelia (Netelia) falcata Townes, 1939 (1938). Lloydia 1: 210. ठ, ?. 
heroica Townes. N. Y., Mich., Minn., Ariz.; Mexico.

Netelia (Netelia) heroica Townes, 1939 (1938). Lloydia 1: 213. ठ.

idioctenus Townes. N. Y., Va., S. C., Ala.

Netelia (Netelia) idioctenus Townes, 1939 (1938). Lloydia 1: 198..

inepta Townes. N. J., N. C., S. C., Ga.

Netelia (Netelia) inepta Townes, 1939 (1938). Lloydia 1: 215. ठ.

ingrata Townes. Ariz.

Netelia (Netelia) ingrata Townes, 1939 (1938). Lloydia 1: 216. ð.

lativectis Townes. N. Mex.

Netelia (Netelia) lativectis Townes, 1939 (1938). Lloydia 1: 212. ర.

leo arizonensis (Cushman). N. Mex., Ariz., s. Calif.; Mexico.

Paniscus arizonensis Cushman, 1924. U. S. Natl. Mus., Proc. 64 (20): 37. १.

leo leo (Cushman). Mass. s. to Ga., w. to Iowa, Tex.

Paniscus leo Cushman, 1924. U. S. Natl. Mus., Proc. 64 (20): 38. ๆ.

ligata Townes. Ariz.

Netelia (Netelia) ligata Townes, 1939 (1938). Lloydia 1: 205. ठ.

lucens Townes. Colo.

Netelia (Netelia) lucens Townes, 1939 (1938). Lloydia 1: 205. ઠో, ‥

macra Townes. Md., Va., Ill., Ariz.; W. Indies, Peru, Argentina.

Netelia (Netelia) macra Townes, 1939 (1938). Lloydia 1: 196. ठ.

microdon Townes. Va., S. C., Fla., Ala., Miss., Tex.

Netelia (Netelia) microdon Townes, 1939 (1938). Lloydia 1: 211. ठ, ?.

microtylus Townes. Ariz.

Netelia (Netelia) microtylus Townes, 1939 (1938). Lloydia 1: 210. ठ,.

mustela Townes. Ariz.

Netelia (Netelia) mustela Townes, 1939 (1938). Lloydia 1: 194. ठ’, ?.

nigripectus (Ashmead). Tex.

Paniscus nigripectus Ashmead, 1890 (1889). U. S. Natl. Mus., Proc. 12: 425 ..

nitida Townes. N. Y.

Netelia (Netelia) nitida Townes, 1939 (1938). Lloydia 1: 215. ठ.

obrepta Townes. Pa., Mich.

Netelia (Netelia) obrepta Townes, 1939 (1938). Lloydia 1: 215. ठ.

ocellata (Viereck). D. C. s. to Ga., w. to Sask., Ariz.; Bermuda, Peru. Host: Agrotis orthogonia Morr.

Paniscus ocellatus Viereck, 1909. Ent. Soc. Wash., Proc. 11: 211. $\delta, ~ ९$.

Paniscus immaculatus Morley, 1913. Rev. Ichn. Brit. Mus., v. 2, p. 109. $\%$.

Paniscus ocellatus var. microocellatus Cushman, 1924. U. S. Natl. Mus., Proc. 64 (20): 36. $\delta$, ?.

orba Townes. D. C., S. C.

Netelia (Netelia) orba Townes, 1939 (1938). Lloydia 1: 193. ठ.

ovalis Townes. R. I. s. to D. C., w. to Wis., Kans.

Netelia (Netelia) ovalis Townes, 1939 (1938). Lloydia 1: 212. ठ.

pallens occidentalis Townes. Tex., N. Mex., Ariz., B. C., Nev.

Netelia (Netelia) pallens occidentalis Townes, 1939 (1938). Lloydia 1: 208. ठै, ᄋ.

pallens pallens (Cushman). Atlantic States from N. Y. s. to Ga.

Paniscus pallens Cushman, 1924. U. S. Natl. Mus., Proc. 64 (20): 39. ठ’, ९.

palpalis Townes. Maine, Mass., N. Y., N. C.

Netelia (Netelia) palpalis Townes, 1939 (1938). Lloydia 1: 203. ठో.

pardalis (Cushman). Wyo. s. to N. Mex. w. to B. C., Calif.

Paniscus pardalis Cushman, 1924. U. S. Natl. Mus., Proc. 64 (20): 31. ठ̋.

Paniscus neomexicanus Cushman, 1924. U. S. Natl. Mus., Proc. 64 (20): 33 ..

percurrens Townes. Colo.

Netelia (Netelia) percurrens Townes, 1939 (1938). Lloydia 1: 207. ઠ. 
platypes (Cushman). Mass. s. to Ala., s. to Wis. Host: Acronicta radcliffei (Harv.).

Paniscus platypes Cushman, 1930 (1929). U. S. Natl. Mus., Proc. 76 (25): 6..

pluridens Townes. Wyo.

Netelia (Netelia) pluridens Townes, 1939 (1938). Lloydia 1: 202. ठ.

punctata Townes. Conn. s. to Va., w. to Mich., Tex.

Netelia (Netelia) punctata Townes, 1939 (1938). Lloydia 1: 208. ठ’, ?.

recta Townes. Ariz.

Netelia (Netelia) recta Townes, 1939 (1938). Lloydia 1: 193. ઠే, ?.

rectifascia Townes. Ariz.

Netelia (Netelia) rectifascia Townes, 1939 (1938). Lloydia 1: 216.

reflexa Townes. Tex.

Netelia (Netelia) reflexa Townes, 1939 (1938). Lloydia 1: 198. o.

sayi (Cushman). Que. s. to N. C., w. to S. Dak., Tex. Host: Amathes badinodis (Grt.), Heliothis zea (Bod.). This is the commonest species of the genus in the northeastern U. S.; it occurs throughout the summer and autumn.

Paniscus germinatus var. sayi Cushman, 1924. U. S. Natl. Mus., Proc. 64 (20): 41. ठ, ․

Biology: Vance, 1927. Ent. Soc. Amer., Ann. 20: 405-415.

spinipes (Cushman). Mass. s. to Ga., w. to Mont., Tex.; Mexico. Host: Heliothis zea (Bod.). Paniscus spinipes Cushman, 1924. U. S. Natl. Mus., Proc. 64 (20): 32. ठ, १.

Biology: Vance, 1927. Ent. Soc. Amer., Ann. 20: 405-417.

stigmata Townes. N. Y., N. J.

Netelia (Netelia) stigmata Townes, 1939 (1938). Lloydia 1: 202. §, ९.

strigilobus Townes. Calif. Host: Zale lunata (Drury).

Netelia (Netelia) strigilobus Townes, 1939 (1938). Lloydia 1: 207. ð, ९.

Biology: Hicks, 1933. Pan-Pacific Ent. 9: 49-52 (as Paniscus sp., possibly semirufus Holmgren).

townesi (Uchida). Calif.

Netelia (Netelia) unicolor Townes, 1939 (1938). Lloydia 1: 202. Preocc. in Netelia by Smith, 1874.

Paniscus townesi Uchida, 1939. Insecta Matsumurana 14: 45. N. name for unicolor Townes.

townsendi (Cushman). N. Mex.

Paniscus townsendi Cushman, 1924. U. S. Natl. Mus., Proc. 64 (20): 40..

trituberculata (Cushman). Ariz., Calif.

Paniscus trituberculatus Cushman, 1924. U. S. Natl. Mus., Proc. 64 (20): 26. ๆ.

turbans Townes. Ariz., Colo.

Netelia (Netelia) turbans Townes, 1939 (1938). Lloydia 1: 209. ठ.

umbone Townes. Calif.

Netelia (Netelia) umbone Townes, 1939 (1938). Lloydia 1: 207. $\delta$.

unguicularis (Cushman). R. I. s. to N. C., w. to Ill., Ala. Ecology: This species occurs in moist bottomland forests.

Paniscus unguicularis Cushman, 1924. U. S. Natl. Mus., Proc. 64 (20): 33. ठ, ๆ.

\section{Genus NETELIA Subgenus BESSOBATES Townes}

Netelia subg. Bessobates Townes, 1961. In Townes, Townes, and Gupta; Amer. Ent. Inst., Mem. 1: 93.

Type-species: Parabatus deceptor Morley. Orig. desig.

Because of careless bibliographic work, Bradley (1919) managed to find reason for applying the names Parabates Foerster and Parabatus Thomson to separate subgenera, the latter to what is now called Bessobates. It is evident that Bradley would not have wished to find reason for doing so if he had been aware of Enderlein's (1912) designation of Parabatus nigricarpus Thomson as the type-species of Parabates. Ironically, it is also quite obvious that if Viereck (1914) had been aware of the Enderlein designation for parabates, he would also have 
designated nigricarpus as the type-species of Parabatus, which would have prevented subsequent authors from applying these names to separate subgenera of Netelia, as did Townes for more than 20 years (1939 to 1961). Apparently recognizing that it was no longer feasible to treat some of the Thomson emendations of Foerster names as having been newly proposed for separate taxa, Townes (1961) abandoned his earlier stance on the issue with the proposal of Bessobates as a "new name for Parabatus as defined by Townes, 1939." Not only does it seem incorrect for Townes to have characterized his proposal of Bessobates in those terms, it is paradoxical for him to have done so without a word calling attention to or explaining his designation of Parabatus deceptor Morley as type-species instead of Ichneumon virgatus Geoffroy. Townes (1969) attributes the name Bessobates to Townes, Townes, and Gupta, but the wording of the proposal (yet alone the 1939 description) is clearly in the unadulterated style of the senior author, and it seems inappropriate for him to place part of the blame for it upon the junior authors.

Taxonomy: Enderlein, 1912. Stettin. Ent. Ztg. 73: 106. - Viereck, 1914. U. S. Natl. Mus., Bul. 83: 110. - Bradley, 1919. Ann. and Mag. Nat. Hist. (9) 3: 319-324. -Townes, 1969. Amer.

Ent. Inst., Mem. 11: 154.

deceptor (Morley). N. S. s. to Pa., w. to Alaska, Calif. Host: Schizura concinna (J. E. S.), Polia legitimata (Grt.).

Parabatus deceptor Morley, 1913. Rev. Ichn. Brit. Mus., v. 2, p. 129. ठ.

Parabates cristatoides Cushman, 1924. U. S. Natl. Mus., Proc. 64 (20): 46. ¿, $९$.

Parabates crassus Cushman, 1924. U. S. Natl. Mus., Proc. 64 (20): 47. + . Uncertain syn.

latungula (Thomson). Que. s. to Va., w. to Ont., Ill.; Eurasia.

Parabatus latungula Thomson, 1888. Opusc. Ent. 12: 1196. ठ์,.

longipalpus Townes. Que. s. to Ala., w. to Mich., Ill.

Parabatus smithi Cushman, 1924. U. S. Natl. Mus., Proc. 64 (20): 45. + . Preocc. in Netelia by Dalla Torre (1902).

Netelia (Parabatus) longipalpus Townes, 1939 (1938). Lloydia 1: 218. N. name for smithi Cushman.

rogersi Townes. N. Y., Pa., Md., Va., N. C.

Netelia (Parabatus) rogersi Townes, 1939 (1938). Lloydia 1: 219. ठ, ?.

sinus Townes. Md., Va., Ill.; Guatemala.

Netelia (Parabatus) sinus Townes, 1939 (1938). Lloydia 1: 220. ठ.

uncata Townes. D. C., S. C.

Netelia (Parabatus) uncata Townes, 1939 (1938). Lloydia 1: 218. ठ, ?.

UNPLACED TAXON OF NETELIA

appendiculata (Provancher). Que.

Paniscus appendiculatus Provancher, 1874. Nat. Canad. 6: 105. o. According to Barron

(1975) the holotype is lost.

Taxonomy: Townes, 1939 (1938). Lloydia 1: 222. - Barron, 1975. Nat. Canad. 102: 427-428.

\section{TRIBE OEDEMOPSINI}

This is a small tribe with nine genera, seven of which are represented by species in the Nearctic Region. Most of the species are apparently parasitic upon larvae of Lepidoptera, but Eclytus spp. parasitize sawfly larvae.

The names Thymarides (Thomson, 1883) and Eclytini (Townes, 1945) are junior synonyms of Oedemopsini (Woldstedt, 1877).

Taxonomy: Townes and Townes, 1945. Bol. Ent. Venezolana 4: 41-53 (out of date generic revision with keys for Neotropic species).

\section{Genus ECLYTUS Holmgren}

Eclytus Holmgren, 1857 (1855). Svenska Vetensk.-Akad. Handl. (n. f.) 1: 127.

Type-species: Eclytus ornatus Holmgren. Desig. by Viereck, 1912.

Zapedias Foerster, 1868. Naturh. Ver. Rheinlande, Verh. 25: 206. 
Type-species: Mesoleptus exornatus Gravenhorst. Included and desig. by Townes, Momoi, and Townes, 1965.

Anoplectes Kriechbaumer, 1896. Ent. Nachr. 23: 363.

Type-species: Anoplectes multicolor Kriechbaumer. Monotypic.

ornatus Holmgren. Newfoundland (Labrador) s. to N. C., w. to Alaska, Colo.; Europe.

Eclytus ormatus Holmgren, 1857 (1855). Svenska Vetensk.-Akad. Handl. (n. f.) 1: 127. ð, ๆ.

Eclytus perennis Davis, 1898 (1897). Amer. Ent. Soc., Trans. 24: 305. ठै, ๆ.

Spanotecnus flavopictus Ashmead, 1902. Wash. Acad. Sci., Proc. 4: 204. ठ.

\section{Genus HERCUS Townes}

Hercus Townes, 1969. Amer. Ent. Inst., Mem. 11: 157.

Type-species: Orthocentrus pleuralis Provancher. Orig. desig. There are three

Nearctic species, one of them undescribed.

fontinalis (Holmgren). Alaska; Europe.

Eclytus fontinalis Holmgren, 1857 (1855). Svenska Vetensk.-Akad. Handl. (n. f.) 1: 128. ठ, ‥

Eclytus yakutatensis Ashmead, 1902. Wash. Acad. Sci., Proc. 4: 204. ठ。.

Himertosoma schmiedeknechti Ashmead, 1902. Wash. Acad. Sci., Proc. 4: 194. o.

pleuralis (Provancher). N. S. s. to Va., w. to S. Dak. Host: Argyrotaenia pinatubana (Kft.), A. velutinana (Wlk.), Platynota idaeusalis (Wlk.) Acrobasis kearfottella Dyar.

Orthocentrus pleuralis Provancher, 1875. Nat. Canad. 7: 328 . $?$. The syntypes were not located by Barron (1975).

Calliphrurus? taeniogaster Viereck, 1912. U. S. Natl. Mus., Proc. 43: 585. ठै.

Taxonomy: Barron, 1975. Nat. Canad. 102: 533.

\section{Genus NELIOPISTHUS Thomson}

Neliopisthus Thomson, 1883. Opusc. Ent. 9: 907.

Type-species: Phytodietus elegans Ruthe. Monotypic.

Polysphinctomorpha Ashmead, 1900. U. S. Natl. Mus., Proc. 23: 59.

Type-species: Polysphinctomorpha luggeri Ashmead. Orig. desig.

Revision: Cushman, 1919. U. S. Natl. Mus., Proc. 56: 378-381. -Cushman, 1935. Wash. Acad. Sci., Jour. 25: 553-555.

densatus (Say). Maine s. to Md., w. to S. Dak., Ariz.

Anomalon densatus Say, 1836. Boston Jour. Nat. Hist. 1: 243..

Neliopisthus similis Cushman, 1919. U. S. Natl. Mus., Proc. 56: 379..

Taxonomy: Cushman and Gahan, 1921. Ent. Soc. Wash., Proc. 23: 155.

niger Cushman. Colo., Idaho, Ariz., Wash.

Neliopisthus niger Cushman, 1922. U. S. Natl. Mus., Proc. 60 (21): 12 . \&.

Neliopisthus longicauda Cushman, 1935. Wash. Acad. Sci., Jour. 25: 554. \&.

piceae Cushman. Maine, Minn., Oreg. Host: Coleotechnites piceaella (Kft.).

Neliopisthus piceae Cushman, 1935. Wash. Acad. Sci., Jour. 25: 555. §, ๆ.

semirufus (Provancher). Que. s. to Va., w. to Minn. Host: Psilocorsis sp.

Hemiteles semirufus Provancher, 1874. Nat. Canad. 6: 332. \&.

Polysphincta erythropleura Ashmead, 1896; 1902. In Slosson, Ent. News 7: 264; 13: 321.

Nomen nudum.

Polysphinctomorpha luggeri Ashmead, 1900. U. S. Natl. Mus., Proc. 23: 59..

Neliopisthus nigridorsum Cushman, 1919. U. S. Natl. Mus., Proc. 56: 379. \&.

\section{Genus THYMARIS Foerster}

Thymaris Foerster, 1868. Naturh. Ver. Rheinlande, Verh. 25: 151.

Type-species: Thymaris pulchricornis Brischke. By subsequent monotypy from inclusion by Brischke, 1880 . The Brischke types have been destroyed, and the interpretation of pulchricormis is based upon Pfankuch's (1906) placement of it as a synonym of Mesoleptus tener Gravenhorst (1829). Pfankuch later (1925) placed 
pulchricornis as a synonym of Hemiteles contaminatus Gravenhorst (1829), and Perkins (1962) treated contaminatus as a junior synonym of tener by virtue of page priority but did not state that he had examined the Gravenhorst types in question.

Thymarus Thomson, 1883. Opusc. Ent. 9: 908. Emend.

Townes (1969) says that there are two Nearctic species, one of them undescribed.

Taxonomy: Pfankuch, 1906. Ztschr. System. Hym. Dipt. 6: 82. - Pfankuch, 1925. Deut. Ent.

Ztschr. 4: 260. - Perkins, 1962. Brit. Mus. (Nat. Hist.) Ent., Bul. 11: 458. -Townes, 1969.

Amer. Ent. Inst., Mem. 11: 158-159.

negligere (Davis). N. J. s. to Ala., w. to Kans.

Eusterinx negligere Davis, 1897. Amer. Ent. Soc., Trans. 24: 246..

Callidiotes kansensis Brues, 1907. Wis. Nat. Hist. Soc., Bul. 5: 55. ؟.

Thymaris americanus Cushman, 1919. U. S. Natl. Mus., Proc. 56: 381. ơ, ᄋ.

\section{Genus ZAGRYPHUS Cushman}

Zagryphus Cushman, 1919. U. S. Natl. Mus., Proc. 56: 377.

Type-species: Mesoleptus nasutus Cresson. Monotypic and orig desig.

The name Campothreptus Foerster has been erroneously applied to this genus by Townes (e. g. 1969) who has treated Mesoleptus nasutus Cresson as its type-species. Cushman (1919) correctly argued that it was Tryphon nasutus Cresson and not Mesoleptus nasutus that Davis (1897) placed in Campothreptus. Therefore, Campothreptus is a synonym of Oedemopsis (which see).

Taxonomy: Davis, 1897. Amer. Ent. Soc., Trans. 24: 247. -Cushman, 1919. U. S. Natl. Mus.,

Proc. 56: 376-378. - Townes, 1969. Amer. Ent. Inst., Mem. 11: 159.

nasutus (Cresson). Pa. s. to Fla., w. to Minn. and Kans.; Mexico, Guatemala.

Mesoleptus? nasutus Cresson, 1868. Amer. Ent. Soc., Trans. 2: 103. ठ, $\uparrow$. The variant spelling "nastutus" appears on p. 103, but it is anonymously rejected in the errata (p. 398 [1869]).

Synchnoleter americanus Ashmead, 1896. Amer. Ent. Soc., Trans. 23: 196. ơ.

\section{Genus OEDEMOPSIS Tschek}

Oedemopsis Tschek, 1868. Zool.-Bot. Gesell. Wien, Verh. 18: 276.

Type-species: Oedemopsis rogenhoferi Tschek. Monotypic. The type-species is considered to be a synonym of $O$. scabricularis (Gravenhorst).

Hybophanes Foerster, 1868. Naturh. Ver. Rheinlande, Verh. 25: 166.

Type-species: Tryphon scabricularis Gravenhorst. Desig. by Viereck, 1914 from three species included by Schmiedeknecht, 1888.

Campothreptus Foerster, 1868. Naturh. Ver. Rheinlande, Verh. 25: 201. N. syn.

Type-species: Tryphon nasutus Cresson. By subsequent monotypy from inclusion by Davis, 1897. Although Davis (1897) treated Tryphon? nasutus Cresson as a synonym of Mesoleptus nasutus Cresson, his description applies only to the former (see discussion under Zagryphus). Davis' error in suppressing Tryphon nasutus as a synonym of Mesoleptus nasutus could only have been inadvertent -i.e. I do not see how it is possible that Davis' error could have been an error of judgement and hence do not believe that it is reasonable to argue that he misidentified Tryphon nasutus as Mesoleptus nasutus.

Zarhynchus Ashmead, 1900. U. S. Natl. Mus., Proc. 23: 59. Preocc. by Oberholser, 1899.

Type-species: Tryphon nasutus Cresson. Monotypic and orig desig.

Rhynchothyreus Ashmead, 1900. Canad. Ent. 32: 368. N. name for Zarhynchus Ashmead.

Oedematopsis Morley, 1908. Brit. Ichn. 3: 268. Emend. of Oedemopsis.

Details regarding my resurrection of the name Oedemopsis and its priority over Hybophanes will be given elsewhere.

davisi Carlson, n. name. Conn. s. to Va., w. to B. C., N. Mex.

Tryphon? nasutus Cresson, 1868. Amer. Ent. Soc., Trans. 2: 107. \&. Preoce. by

Gravenhorst, 1829. 


\section{Genus ATOPOTROPHOS Cushman}

Atopognathus Cushman, 1919. Ent. Soc. Wash., Proc. 21: 116. Preocc. by Bigot, 1881.

Type-species: Atopognathus collaris Cushman. Monotypic and orig. desig.

Atopotrophos Cushman, 1940. U. S. Natl. Mus., Proc. 88: 365. N. name for Atopognathus Cushman.

There are two Nearctic species, one undescribed.

bucephalus (Cresson). Md., D. C., Va., N. C., Ala.; Mexico.

Mesoleptus? bucephalus Cresson, 1868. Amer. Ent. Soc., Trans. 2: 36. ठ.

Atopognathus collaris Cushman, 1919. Ent. Soc. Wash., Proc. 21: 117. o, ๆ.

\section{TRIBE TRYPHONINI}

Nearly all members of this tribe are parasites of sawflies; Grypocentrus basalis Ruthe, a European species, has been reared from an eriocraniid microlepidopteran. Most of the genera are Holarctic.

Revision: Townes and Townes, 1949-1950 (1949). Ent. Soc. Amer., Ann. 42 (3 and 4): 321-396, 397-447 (Grypocentrus and Boethus excluded). - Kasparyan, 1973. Akad. Nauk, SSSR,

Zool. Inst., Fauna SSSR, (n. s.) 106, Hym. v. 3, pt. 1, 320 pp.

\section{Genus GRYPOCENTRUS Ruthe}

Grypocentrus Ruthe, 1855. Stettin. Ent. Ztg. 16: 52.

Type-species: Grypocentrus incisulus Ruthe. Desig. by Vierick, 1912.

A pimeles Foerster, 1868. Naturh. Ver. Rheinlande, Verh. 25: 205.

Type-species: A pimeles lusorius Davis. By subsequent monotypy from inclusion by Davis, 1898 (1897).

Cyrtocentrus Provancher, 1883. Nat. Canad. 14: 6.

Type-species: Cyrtocentrus quebecensis Provancher. Monotypic.

Some members of this genus are known to parasitize larvae of Fenusa spp., but one European species, G. basalis Ruthe, has been reared from an eriocraniid microlepidopteran.

Revision: Townes and Townes, 1951. Ent. Soc. Wash., Proc. 53: 301-307.

albipes Ruthe. Europe. Introduced in insular Newfoundland in 1973, but no recoveries have been reported. Host: Fenusa pusilla (Lep.). The host listed was the target species for the release in Newfoundland.

Grypocentrus albipes Ruthe, 1855. Stettin. Ent. Ztg. 16: 56. ơ, ९.

barbatus Townes. Alta., Calif.

Grypocentrus barbatus Townes, 1951. In Townes and Townes, Ent. Soc. Wash., Proc. 53: 304. $\delta, ?$.

crassidens Townes. Idaho, Colo.

Grypocentrus crassidens Townes, 1951. In Townes and Townes, Ent. Soc. Wash., Proc. 53: 304. $\delta, ?$.

flavipes (Provancher). Que. s. to N. C., w. to Wash., Calif.

Mesostenus flavipes Provancher, 1882. Nat. Canad. 13: 363. ơ.

Cyrtocentrus Quebecensis Provancher, 1883. Nat. Canad. 14: 6. ठँ.

Apimeles lusorius Davis, 1898 (1897). Amer. Ent. Soc., Trans. 24: 283...

spatulatus Townes. Calif.

Grypocentrus spatulatus Townes, 1951. In Townes and Townes, Ent. Soc. Wash., Proc. 53: 305. $\delta, ?$.

truncatus Townes. N. Y.

Grypocentrus truncatus Townes, 1951. In Townes and Townes, Ent. Soc. Wash., Proc. 53: 305. ర,. .

\section{Genus POLYBLASTUS Hartig}

Revision: Kasparyan, 1970. Ent. Obozr. 49: 852-868; 519-528 in Ent. Rev. (Palearctic spp.). 


\section{Genus POLYBLASTUS Subgenus POLYBLASTUS Hartig}

Polyblastus Hartig, 1837. Arch. f. Naturgesch. 3: 155.

Type-species: Tryphon varitarsus Gravenhorst. Desig. by Viereck, 1912.

atrox Townes. Que.

Polyblastus (Polyblastus) atrox Townes, 1949. In Townes and Townes, Ent. Soc. Amer. Ann. 42: 335. ठ์.

carbonarius (Gravenhorst). N. H., Alta.; Europe.

Tryphon carbonarius Gravenhorst, 1829. Ichn. Europaea 2: 141. ठ.

fulvilinealis Hall. Que. s. to N. C.

Polyblastus fulvilinealis Hall, 1919. Psyche 26: 155. o, ?.

palaemon Schiodte. Man., Alta.; Europe.

Polyblastus palaemon Schiodte, 1839 (1838). Rev. Zool. Soc. Cuv. 1: 140. .

Polyblastus pyramidatus Holmgren, 1857 (1855). Svenska Vetensk.-Akad. Handl. (n. f.) 1: 219. .

pedalis (Cresson). N. S. s. to N. C., w. to N. W. T., B. C., Calif.; U. S. S. R. Host: Cladius difformis (Panzer), Croesus latitarsus Nort., Apareophora dyari (Benson).

Tryphon pedalis Cresson, 1864. Ent. Soc. Phila., Proc. 3: 273. ठ.

Bassus Bouleti Provancher, 1874. Nat. Canad. 6: 32. . .

tibialis (Cresson). Que. s. to N. C., w. to N. W. T., B. C., Calif.

Tryphon tibialis Cresson, 1864. Ent. Soc. Phila., Proc. 3: $280 . " ~ \sigma o "=q$.

Tryphon annulipes Cresson, 1868. Amer. Ent. Soc., Trans. 2: 108. 9.

Prinopoda (!) media Hall, 1919. Psyche 26: 158..

varitarsus (Gravenhorst). Que. s. to Mass., w. to Alaska, Calif.; Eurasia. Host: Dolerus sp. The name "strobilator (Thunberg)" has been incorrectly used for this species; Ichneumon strobilator Thunberg is an emendation and misidentification of Ichneumon strobilellae Linnaeus.

Tryphon varitarsus Gravenhorst, 1829. Ichn. Europaea 2: 222. ठ, $\uparrow$.

Polyblastus subtilis Thomson, 1883. Opusc. Ent. 9: 900. .

Polyblastus variitarsus Dalla Torre, 1901. Cat. Hym., v. 3, p. 320. Emend.

Erromenus annulipes Ashmead, 1902. Wash. Acad. Sci., Proc. 4: 212. $?$.

wahlbergi rubescens Townes. N. S. w. to Alaska, w. to Pa., Ala., Sask., Alta. P. (P.) wahlbergi wahlbergi Holmgren is Eurasian.

Polyblastus (Polyblastus) wahlbergi mubescens Townes, 1949. In Townes and Townes, Ent. Soc. Amer., Ann. 42: 336. ơ, ₹.

\section{Genus POLYBLASTUS Subgenus COPHENCHUS Townes}

Polyblastus subg. Cophenchus Townes, 1949. In Townes and Townes, Ent. Soc. Amer., Ann. 42: 338.

Type-species: Polyblastus (Cophenchus) flexus Townes. Orig. desig.

botrys Townes. Que., N. H., Mass., Mich., Man.

Polyblastus (Cophenchus) botrys Townes, 1949. In Townes and Townes, Ent. Soc. Amer., Ann. 42: 339. ठँ, ?.

flexus Townes. Que., Alta., Utah, B. C.

Polyblastus (Cophenchus) flexus Townes, 1949. In Townes and Townes, Ent. Soc. Amer., Ann. 42: 339. ?.

\section{Genus POLYBLASTUS Subgenus LABROCTONUS Foerster}

Labroctonus Foerster, 1868. Naturh. Ver. Rheinlande, Verh. 25: 195.

Type-species: Tryphon articulatus Cresson. By subsequent monotypy from inclusion by Davis, 1897.

Nemioblastus Thomson, 1883. Opusc. Ent. 9: 901.

Type-species: Polyblastus albicoxa Thomson. Desig. by Viereck, 1914.

alatus Townes. N. Y., Pa., Md., D. C., Va.

Polyblastus (Labroctonus) alatus Townes, 1949. In Townes and Townes, Ent. Soc. Amer., Ann, 42: 345. $\delta$, $\uparrow$. 
articulatus (Cresson), Man., Alta.

Tryphon articulatus Cresson, 1868. Amer. Ent. Soc., Trans. 2: 110. \&.

bimacula Townes. Maine s. to N. C., w. to B. C., Wash.

Polyblastus (Labroctonus) bimacula Townes, 1949. In Townes and Townes, Ent. Soc. Amer., Ann. 42: 343, 396. ¿\%, $?$.

buccatus Townes. Wash., Calif.

Polyblastus (Labroctonus) buccatus Townes, 1949. In Townes and Townes, Ent. Soc. Amer., Ann. 42: 349. ठ" ?.

expletus Townes. Newfoundland (Labrador), Que., Maine, Vt., N. Y., Colo. Host: Nematus limbatus Cr.

Polyblastus (Labroctonus) expletus Townes, 1949. In Townes and Townes, Ent. Soc. Amer., Ann. 42: 349. o, $\%$.

galaphilus Townes. Que. s. to N. Y., w. to Wash., Oreg.

Polyblastus (Labroctonus) galaphilus Townes, 1949. In Townes and Townes, Ent. Soc. Amer., Ann. 42: 347. $\delta$, ?.

gloriosus (Davis). Que., Wash., Oreg., Calif.

Phaestus gloriosus Davis, 1898 (1897). Amer. Ent. Soc., Trans. 24: 292. ․

jugatus Townes. N. H.

Polyblastus (Labroctonus) jugatus Townes, 1949. In Townes and Townes, Ent. Soc. Amer., Ann. 42: 342. $\delta$.

peckae Townes. $\mathrm{N}$. H.

Polyblastus (Labroctonus) peckae Townes, 1949. In Townes and Townes, Ent. Soc. Amer., Ann. 42: 348. .

productus Townes. Wash.

Polyblastus (Labroctonus) productus Townes, 1949. In Townes and Townes, Ent. Soc. Amer., Ann. 42: 345. $\delta$, $?$.

provancheri Kasparyan. N. S. s. to Conn., w. to B. C., Calif. Host: Pontania sp., Pristiphora sycophanta Walsh.

Tryphon dorsalis Provancher, 1879. Nat. Canad. 11: 253. ९. Preoce. by Gravenhorst, 1829.

Polyblastus (Labroctonus) provancheri Kasparyan, 1970. Ent. Obozr. 49: 853. N. name for dorsalis Provancher.

rutilus Townes. Calif.

Polyblastus (Labroctonus) rutilus Townes, 1949. In Townes and Townes, Ent. Soc. Amer., Ann. 42: 344. $\delta$, $?$.

stenocentrus Holmgren. Colo., Alaska; Eurasia.

Polyblastus stenocentrus Holmgren, 1957 (1855). Svenska Vetensk.-Akad. Handl. (n. f.) 1: 215. $\delta, ?$.

\section{Genus CTENOCHIRA Foerster}

Ctenochira Foerster, 1855. Naturh. Ver. Rheinlande, Verh. 12: 226.

Type-species: Ctenochira bisinuata Foerster. Monotypic.

Ctenacme Foerster, 1868. Naturh. Ver. Rheinlande, Verh. 25: 196.

Type-species: Polyblastus scutellaris Thomson. Desig. by Morley, 1913 (as scutellatus Thomson [1888], which replaced the preoccupied scutellaris Thomson [1883] from four species species included by Thomson, 1883.

Scopiomis Foerster, 1868. Naturh. Ver. Reinlande, Verh. 25: 196.

Type-species: Polyblastus marginatus Holmgren. Desig. by Viereck, 1914 from four species included by Thomson, 1883.

Gemophaga Foerster, 1868. Naturh. Ver. Rheinlande, Verh. 25: 211.

Type-species: Gemophaga rufa Ashmead. By subsequent monotypy from inclusion by Ashmead, 1902.

Ctenacmus Thomson, 1883. Opusc. Ent. 9: 901. Emend.

Ctenacma Schulz, 1906. Spolia Hym., p. 99. Emend. of Ctenacme.

Pauroctenus Cameron, 1909. Bombay Nat. Hist. Soc., Jour. 19: 726.

Type-species: Pauroctenus pallipes Cameron. Monotypic.

Exochoblastus Schmiedeknecht, 1912. Opusc. Ichn., v. 5, p. 2401, 2468. 
Type-species: Exochoblastus oreophilus Schmiedeknecht. Monotypic.

Scopimenus Roman, 1937. Ent. Monthly Mag. 74: 64.

Type-species: Scopimenus pygobarbus Roman. Monotypic.

Coeloprosopon Bauer, 1958. Beitr. z. Ent. 8: 181.

Type-species: Coeloprosopon pectinatum Bauer. Monotypic.

adeps Townes. N. Y.

Ctenochira adeps Townes, 1949. In Townes and Townes, Ent. Soc. Amer., Ann. 42: 356. $\subsetneq$. analis (Cresson). Maine s. to N. C., w. to Oreg.

Tryphon analis Cresson, 1864. Ent. Soc. Phila., Proc. 3: 279. ठ์.

Tryphon occidentalis Cresson, 1868. Amer. Ent. Soc., Trans. 2: 109..

debilis Townes. Colo., Alta., Mont., Wash.

Ctenochira debilis Townes, 1949. In Townes and Townes, Ent. Soc. Amer., Ann. 42: 354. ठ, ‥

deplanata Townes. Mich., Colo.

Ctenochira deplanata Townes, 1949. In Townes and Townes, Ent. Soc. Amer., Ann. 42: 372. $\delta$, ․

dilatata (Provancher). Que. See discussion of Ctenochira niveicola (Ashmead).

Catocentrus dilatatus Provancher, 1875. Nat. Canad. 7: 316. “ $\delta "=\uparrow$.

Taxonomy: Barron, 1975. Nat. Canad. 102: 461-462.

extricata (Davis). Colo., Alta., Wash., Oreg.

Scopiomıs extricatus Davis, 1897. Amer. Ent. Soc., Trans. 24: 259..

ferrugata Townes. Wash.

Ctenochira ferrugata Townes, 1949. In Townes and Townes, Ent. Soc. Amer., Ann. 42: 370. ㅇ.

frigida (Cresson). Mich., Man., N. W. T., s. to Colo., w. to Alaska, Oreg. Host: Nematus oligospilus Foerster.

Bassus frigidus Cresson, 1868. Amer. Ent. Soc., Trans. 2: 111..

gagates Townes. Sask. w. to S. Dak., Colo., w. to Alaska, Wash.

Ctenochira gagates Townes, 1949. In Townes and Townes, Ent. Soc. Amer., Ann. 42: 359. $\delta$, .

gillettei (Davis). Que. s. to Pa., w. to Colo., Alta., Oreg.

Scopiomes gillettei Davis, 1897. Amer. Ent. Soc., Trans. 24: 258. 9.

Scopioris expansa Davis, 1897. Amer. Ent. Soc., Trans. 24: 258. ठ。.

Polyblastus scopioroides Hall, 1919. Psyche 26: 156. 9.

infans Townes. Man., Colo., Alaska.

Ctenochira infans Townes, 1949. In Townes and Townes, Ent. Soc. Amer., Ann. 42: 366. ठँ, .

inflata Townes. N. Y.

Ctenochira inflata Townes, 1949. In Townes and Townes, Ent. Soc. Amer., Ann. $42: 363$. ㅇ.

melina Townes. Que., Sask.

Polyblastus annulicornis Provancher, 1886. Addit. Corr. Faune Ent. Canada Hym., p. 108. “o" = ठ. Preocc. by Giraud, 1871.

Ctenochira melina Townes, 1949. In Townes and Townes, Ent. Soc. Amer., Ann. 42: 358.

N. name for annulicornis Provancher.

niveicola (Ashmead), revised status. Que. w. to s.e. Alaska, s. to D. C., w. N. C., s. Alta., and n. Calif. In their tribal revision, Townes and Townes (1949) treated niveicola as a subspecies of dilitata (Provancher) (which see). However, Dr. H. K. Townes said (personal commun., 1976) that Townes and Townes (1949) based their treatment on the "lectotype" selected by Gahan and Rohwer (1918). Barron (1975) rejected the Gahan and Rohwer "lectotype" in favor of the specimen which he regarded as the holotype.

According to Barron, the latter specimen does not agree with dilitata dilitata (Provancher) sensu Townes and Townes (1949). Therefore, niveicola is here raised to species status; its distribution is a composite of the distributions of the two subspecies of dilitata sensu Townes and Townes (1949).

Scorpiomus(!) alaskensis Ashmead, 1902. Wash. Acad. Sci., Proc. 4: 214. ๆ. 
Scorpiomes(!) niveicola Ashmead, 1902. Wash. Acad. Sci., Proc. 4: 214. ठં,.

Scopiorus plagosus Hall, 1919. Psyche 26: 159. $९$.

Taxonomy: Gahan and Rohwer, 1918. Canad. Ent. 50: 168. - Barron, 1975. Nat. Canad. 102: 461-462.

pectoralis Townes. Que., Ont., N. C.

Ctenochira pectoralis Townes, 1949. In Townes and Townes, Ent. Soc. Amer., Ann. 42: 364. $\delta$, ?.

picta Townes. N. Y., N. C., B. C., Wash.

Ctenochira picta Townes, 1949. Ent. Soc. Amer., Ann. 42: 370..

pikonematis Townes. Newfoundland (insular), Que., Mich., Oreg. Host: Pikonema alaskensis (Roh.), P. dimmockii (Cr.).

Ctenochira pikonematis Townes, 1949. In Townes and Townes, Ent. Soc. Amer., Ann. 42: 365. $\delta, ?$.

potens Townes. Alaska, B. C.

Ctenochira potens Townes, 1949. In Townes and Townes, Ent. Soc. Amer., Ann. 42: 364. \&. quebecensis (Provancher). Que., Mass., Ont., Kans., Colo. Host: Nematus limbatus Cr., N. ventralis Say.

Euceros quebecensis Provancher, 1874. Nat. Canad. 6: 30..

Tryphon flavifrons Fyles, 1893. Canad. Ent. 25: 107. ․

Scopiomis monticola Brues, 1907. Wis. Nat. Hist. Soc., Bul. 5: 56..+

rubicunda Townes. N. B.

Ctenochira rubicunda Townes, 1949. In Townes and Townes, Ent. Soc. Amer., Ann. 42: 369. \&.

rufa (Ashmead). N. H. s. to Pa., w. to Colo., Alaska, Wash.

Trophoctonus insularis Ashmead, 1902. Wash. Acad. Sci., Proc. 4: 215. ठ.

Gemophaga mifa Ashmead, 1902. Wash. Acad. Sci., Proc. 4: 223. ठ'.

subcrassa (Cresson). Mass., N. Y., N. J., Alta., B. C., Oreg.

Tryphon subcrassus Cresson, 1868. Amer. Ent. Soc., Trans. 2: 109. ठ, ๆ.

tetrica Townes. Colo.

Ctenochira tetrica Townes, 1949. In Townes and Townes, Ent. Soc. Amer., Ann. 42: 355. $q$.

\section{Genus ERROMENUS Holmgren}

Erromenus Holmgren, 1857 (1855). Svenska Vetensk.-Akad. Handl. (n. f.) 1: 221.

Type-species: Tryphon brunnicans Gravenhorst. Desig. by Viereck, 1912.

Aniarophron Foerster, 1868. Naturh. Ver. Rheinlande, Verh. 25: 162.

Type-species: Aniarophron niger Szepligeti. Desig. by Perkins, 1962 from three species included by Szepligeti, 1901.

Trichocalymma Foerster, 1868. Naturh. Ver. Rheinlande, Verh. 25: 196.

Type-species: Trichocalymma bipunctatum Woldstedt. Desig. by Viereck, 1914

from three species included by Woldstedt, 1877.

Trichocalymmus Thomson, 1883. Opuse. Ent. 9: 903. Emend.

Currania Viereck, 1924. Canad. Ent. 56: 300.

Type-species: Currania mirabilis Viereck. Monotypic and orig desig.

analis Brischke. Que., N. Y., Ont., S. Dak., Colo., Alaska, B. C., Wash.; Europe.

Erromenus analis Brischke, 1871. Phys.-Oekon. Gesell. Koenigsberg, Schr. 11: 95. o.

Currania mirabilis Viereck, 1924. Canad. Ent. 56: 301..

brevipes Townes. Wash.

Erromenus (Erromenus) brevipes Townes, 1949. In Townes and Townes, Ent. Soc. Amer., Ann. 42: 377. $\delta$, $९$.

caelator Townes. N. Y., Ont.

Erromenus (Erromenus) caelator Townes, 1949. In Townes and Townes, Ent. Soc. Amer., Ann. 42: 388. .

defrictus Townes. Md.

Erromenus (Erromenus) defrictus Townes, 1949. In Townes and Townes, Ent. Soc. Amer., Ann. 42: 383. ㅇ. 
dimidiatus (Cresson). N. S. w. to Alaska, s. to N. J., Kans., Calif. Ecology: Occurs in grassy areas. This is the most commonly collected Nearctic species of Erromenus.

Tryphon dimidiatus Cresson, 1868. Amer. Ent. Soc., Trans. 2: 108. ठ.

Tryphon atricoxus Walsh, 1873. Acad. Sci. St. Louis, Trans. 3: 104. ? ?

Scopiorus hiatus Davis, 1897. Amer. Ent. Soc., Trans. 24: 258. ठ, ․

dolichops Townes. Que. s. to Md., w. to Alaska, Ariz.

Erromenus (Erromenus) dolichops Townes, 1949. In Townes and Townes, Ent. Soc. Amer., Ann. 42: 391. $\uparrow, \delta$.

glabrosus Davis. Man., Wyo., Colo., Oreg., Calif.

Erromenus glabrosus Davis, 1897. Amer. Ent. Soc., Trans. 24: 260. ð.

labratus Townes. Calif.

Erromenus (Erromenus) labratus Townes, 1949. In Townes and Townes, Ent. Soc. Amer., Ann. 42: 390. ㅇ.

levis Townes. N. Y.

Erromenus (Erromenus) levis Townes, 1949. In Townes and Townes, Ent. Soc. Amer., Ann. 42: 378. $\delta$, $₹$.

marginatus Provancher. Que. s. to Pa., w. to B. C. and Wash. Host: Pristiphora bivittata (Nort.).

Erronemus (!) marginatus Provancher, 1883. Nat. Canad. 14: 10..

nasalis Townes. Que., N. H., R. I., N. Y., Ohio, Colo., Wash.

Erromenus (Erromenus) nasalis Townes, 1949. In Townes and Townes, Ent. Soc. Amer., Ann. 42: $389 . \delta, \%$.

planus Townes. N. Y., Sask., Alta., Calif.

Erromenus (Erromenus) planus Townes, 1949. In Townes and Townes, Ent. Soc. Amer., Ann. 42: 387 . $\delta$, + .

proteus Townes. Minn., Sask., Alta., Wash., Calif.

Erromenus (Erromenus) proteus Townes, 1949. In Townes and Townes, Ent. Soc. Amer., Ann. 42: 384. $\delta$, $?$.

punctulatus Holmgren. Que. s. to N. Y., w. to N. Mex., Alaska, and Oreg.; Eurasia.

Erromenus punctulatus Holmgren, 1857 (1855). Svenska Vetensk.-Akad. Handl. (n. f.) 1: 222. $\delta$.

Tryphon crassus Cresson, 1868. Amer. Ent. Soc., Trans. 2: 107. ठ, ๆ.

Tryphon tejonicus Cresson, 1879 (1878). Acad. Nat. Sci. Phila., Proc. 30: 372. ठ์.

Polyblastus leviculus Davis, 1897. Amer. Ent. Soc., Trans. 24: 263. ठ.

Aniarophron niger Szepligeti, 1901. In Mocsary and Szepligeti, Zool. Erg. drit. asiat.

Forschungsreise Grafen E. Zichy, v. 2 (Hym.), p. 141. “ $\delta "=?$.

scorteus Townes. Colo., Wash.

Erromenus (Erromenus) scorteus Townes, 1949. In Townes and Townes, Ent. Soc. Amer., Ann. 42: 379. $\delta$, ᄋ.

tonto Townes. Ariz.

Erromenus (Erromenus) tonto Townes, 1949. In Townes and Townes, Ent. Soc. Amer., Ann. 42: $390 . \delta$, + .

ungulatus Townes. N. Y., N. C., Ont., Wash.

Erromenus (Erromenus) ungulatus Townes, 1949. In Townes and Townes, Ent. Soc. Amer., Ann. 42: 386. ठ', ๆ.

variolae Townes. N. Y., N. J., Va., Kans.

Erromenus (Erromenus) variolae Townes, 1949. In Townes and Townes, Ent. Soc. Amer., Ann. 42: 393. $\delta$, + .

\section{Genus ADERAEON Townes}

Erromenus subg. Aderaeon Townes, 1949. In Townes and Townes, Ent. Soc. Amer., Ann. 42: 394.

Type-species: Erromenus bedardi Provancher. Monotypic and orig. desig.

Taxonomy: Kasparyan, 1971. Zool. Zhur. 50: 1586-1589 (Russ., Eng. summ.). 
bedardi (Provancher). N. S., N. B., Que., Ont., B. C. Host: Pikonema alaskensis (Roh.), P. dimmockii (Cr.).

Erronemus(!) Bedardi Provancher, 1879. Nat. Canad. 11: 266. ๆ.

\section{Genus MONOBLASTUS Hartig}

Monoblastus Hartig, 1837. Arch. f. Naturgesch. 3: 155.

Type-species: Monoblastus caudatus Hartig. Desig. by Viereck, 1914.

Otoblastus Foerster, 1868. Naturh. Ver. Rheinlande, Verh. 25: 201.

Type-species: Tryphon luteomarginatus Gravenhorst. By subsequent monotypy from inclusion by Thomson, 1883.

Coeloconus Foerster, 1868. Naturh. Ver. Rheinlande, Verh. 25: 203.

Type-species: Ichneumon brachyacanthus Gmelin. By subsequent monotypy from inclusion by Morley, 1911.

Catocentrus Walsh, 1873. Acad. Sci. St. Louis, Trans. 3: 89.

Type-species: Tryphon philanthoides Cresson. Monotypic.

Cerda Cameron, 1904. Amer. Ent. Soc., Trans. 30: 255.

Type-species: Cerda fuscipennis Cameron. Monotypic.

Idothrichus Schmiedeknecht, 1907. Hym. Mitteleuropas, p. 619.

Type-species: Phaestus sericeus Brischke. Monotypic.

Pseudopsilage Gregor, 1929. Tsechech. Realgym. Neu Titschein in Maehren, Jahresber. 1928-1929: 6.

Type-species: Pseudopsilage romani Gregor. Monotypic.

atroferia Townes. N. Y., Pa., N. C., Mich.

Monoblastus atroferia Townes, 1950 (1949). In Townes and Townes, Ent. Soc. Amer., Ann.

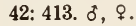

davisi (Townes). N. Y., Ont., Mich., Ill., Iowa.

Tryphon nigrum Davis, 1898 (1897). Amer. Ent. Soc., Trans. 24: 281. ठ. Preoce. by Gravenhorst, 1829.

Tryphon davisi Townes, 1944. Amer. Ent. Soc., Mem. 11: 155. N. name for nigrum Davis.

dionnei (Provancher). N. S., s. to Pa., w. to Minn.

Tryphon Dionnei Provancher, 1879. Nat. Canad. 11: 256..

eurus Townes. Md.

Monoblastus eurus Townes, 1950 (1949). In Townes and Townes, Ent. Soc. Amer., Ann. 42: 410. $\delta$.

favonius Townes. Calif.

Monoblastus favonius Townes, 1950 (1949). In Townes and Townes, Ent. Soc. Amer., Ann. 42: 409. ठे, ?.

feria feria (Davis). Que. s. to Fla., w. to Man. and Colo.

Otlophorus innumerabilis var. feria Davis, 1897. Amer. Ent. Soc., Trans. 24: 276. ठ, ?.

E pachtes(!) basilicus Davis, 1898 (1897). Amer. Ent. Soc., Trans. 24: 283. ठ, ๆ.

feria rossi Townes. Colo., B. C., Oreg., Calif.

Monoblastus feria rossi Townes, 1950 (1949). In Townes and Townes, Ent. Soc. Amer., Ann. 42: 412. $\delta$, $?$.

fuscipennis (Cameron). Tex.; Mexico.

Cerda fuscipennis Cameron, 1904. Amer. Ent. Soc., Trans. 30: 255. ठ.

Monoblastus phaeopteris Townes, 1950 (1949). In Townes and Townes, Ent. Soc. Amer., Ann. 42: 415. $\delta$.

Taxonomy: Townes and Townes, 1966. Amer. Ent. Inst., Mem. 8: 46 (syn.).

innumerabilis (Davis). Nev., Wash., Oreg., Calif.

Otlophorus innumerabilis Davis, 1897. Amer. Ent. Soc., Trans. 24: 278. ठ, १.

kaniacensis (Hall). Minn., Man., Mont., Wyo., Colo., Idaho, Utah, Ariz., Wash., Oreg. Ecology: On two separate occasions this species has been collected on Symphoricarpos bushes; in one instance the bushes were infested with sawfly larvae thought to be of the genus Blennocampa. Because Blennocampa is not known in N. Amer., it may have been a related genus in Blennocampinae.

Polyblastus kaniacensis Hall, 1919. Psyche 26: 156.. 
macer Townes. N. Y., N. J., Pa., Md., Va., Ohio.

Monoblastus macer Townes, 1950 (1949). In Townes and Townes, Ent. Soc. Amer., Ann. 42: 405. ठ, ๆ.

montezuma (Cameron). Que. s. to N. C., w. to B. C. and Calif.; Mexico.

Tryphon montezuma Cameron, 1886. Biol. Cent.-Amer., Hym., v. 1, p. 286. ठో.

Otlophorus affinis Ashmead, 1901. Psyche 9: 148. ठ.

philanthoides (Cresson). N. H., N. Y., Ill.

Tryphon philanthoides Cresson, 1868. Amer. Ent. Soc., Trans. 2: 110. ๆ.

proximus Townes. Idaho, Wash., Oreg., Calif.

Monoblastus proximus Townes, 1950 (1949). In Townes and Townes, Ent. Soc. Amer.,

Ann. 42: 403. $\delta$, $?$.

\section{Genus THIBETOIDES Davis}

Thibetoides Davis, 1897. Amer. Ent. Soc., Trans. 24: 205.

Type-species: Thibetoides flosamoris Davis. Monotypic.

Revision: Viktorov, 1964. Ent. Obozr. 43: 182-184; 91-92 in Ent. Rev. (Palearctic spp.).

flosamoris Davis. Wash., Oreg., Calif.

Thibetoides flosamoris Davis, 1897. Amer. Ent. Soc., Trans. 24: 205. ठో.

\section{Genus LAGOLEPTUS Townes}

Lagoleptus Townes, 1969. Amer. Ent. Inst., Mem. 11: 173.

Type-species: Lagoleptus palans Townes. Orig. desig.

palans Townes. N. Y., Pa., N. C., S. C.

Lagoleptus palans Townes, 1969. Amer. Ent. Inst., Mem. 11: 174.

\section{Genus BOETHUS Foerster}

Boethus Foerster, 1868. Naturh. Ver. Rheinlande, Verh. 25: 210.

Type-species: Boethus howardi Davis. Desig. by Viereck, 1914 from three species included by Davis, 1898 (1897).

Diplomorphus Giraud, 1872. Soc. Ent. de France, Ann. 1: 409.

Type-species: Diplomorphus thoracicus Giraud. Monotypic.

Aethalodes Kriechbaumer, 1890. Schweiz. Ent. Gesell., Mitt. 8: 207. Preocc. by Gahan, 1888.

Type-species: Aethalodes mesomelas Kriechbaumer. Desig. by Viereck, 1914.

Members of this genus parasitize the larvae of Argidae.

alaingens Davis. Calif.

Boethus alaingens Davis, 1898 (1897). Amer. Ent. Soc., Trans. 24: 291. ๆ.

glabranotus Davis. Mont.

Boethus glabranotus Davis, 1898 (1897). Amer. Ent. Soc., Trans. 24: 291..

nigripennis Cushman. N. Y., Ky., Ala. Host: Arge pectoralis (Leach).

Boethus nigripennis Cushman, 1922. U. S. Natl. Mus., Proc. 60 (21): 12. ठ, ๆ.

schizoceri (Riley and Howard). N. J. s. to Fla., w. to Minn. and La. Host: Sphacophilus cellularis (Say).

Eubadizon schizoceri Riley and Howard, 1888. U. S. Dept. Agr., Insect Life 1: 44. ? ?

Eubadizon schizoceratis Riley and Howard, 1889. U. S. Dept. Agr., Insect Life 1: XXXI (errata). Emend.

Boethus howardi Davis, 1898 (1897). Amer. Ent. Soc., Trans. 24: 290. ठ, ๆ.

Boethus aenigmaticus Viereck, 1905. Kans. Acad. Sci., Trans. 19: 314. ठ.

Boethus daeckei Viereck, 1909. Ent. Soc. Wash., Proc. 11: 210. ठ.

\section{Genus DYSPETES Foerster}

Dyspetes Foerster, 1868. Naturh. Ver. Rheinlande, Verh. 25: 201.

Type-species: Tryphon praerogator Gravenhorst. By subsequent monotypy from inclusion by Thomson, 1883. Tryphon praerogator Gravenhorst is a 
misidentification of Ichneumon praerogator Linnaeus, the available names for which are Dyspetes arrogator Heinrich (1949) and Dyspetes fracticeps Townes (1950 [1949]).

Dyspetus Thomson, 1883. Opusc. Ent. 9: 899. Emend.

Taxonomy: Townes and Townes, 1950 (1949). Ent. Soc. Amer., Ann. 42: 422 . -Perkins, 1962.

Brit. Mus. (Nat. Hist.) Ent., Bul. 11 (8): 419. - Townes, Momoi, and Townes, 1965. Amer.

Ent. Inst., Mem. 5: 105.

rufus (Provancher). Que.

Exetastes rufus Provancher, 1874. Nat. Canad. 6: 78. ð, ?.

\section{Genus COSMOCONUS Foerster}

Cosmoconus Foerster, 1868. Naturh. Ver. Rheinlande, Verh. 25: 203.

Type-species: Ichneumon elongator Fabricius. By subsequent monotypy from inclusion by Woldstedt, 1877.

Revision: Kasparyan, 1971. Vses. Ent. Obsh., Trudy 54: 286-307 (Palearctic spp.).

arcticus (Brues). Alaska, Wash., Oreg., Calif.

Polyblastus arcticus Brues, 1919. Rpt. Canad. Arctic Exped. 1913-18, v. 3G, p. 22..

canadensis (Provancher). N. S. s. to N. C., w. to Sask. and Colo.

Tryphon Canadensis Provancher, 1875. Nat. Canad. 7: 117. ठ, ?.

vallis Townes, n. status. Que., Md., Ill., Iowa, Tex.

Cosmoconus canadensis vallis Townes, 1950 (1949). In Townes and Townes, Ent. Soc.

Amer., Ann. 42: 425. $\delta$, ․

\section{Genus TRYPHON Fallen}

There are five subgenera, three being strictly Palearctic (including Tryphon), one being Holarctic (Symboethus), and one being strictly Nearctic (Noemon). Species of this genus are chiefly parasitic upon sawflies of the subfamily Dolerinae.

Revision: Kasparyan, 1969. Ent. Obozr. 48: 639-662 and 899-918; 407-419 and 572-584 in Ent.

Rev. (Palearctic spp.).

\section{Genus TRYPHON Subgenus NOEMON Foerster}

Noemon Foerster, 1868. Naturh. Ver. Rheinlande, Verh. 25: 207.

Type-species: Noemon palmaris Davis. Desig. by Viereck, 1914 from three species included by Davis, 1898 (1897).

californicus Cresson. Calif.

Tryphon califormicus Cresson, 1879 (1878). Acad. Nat. Sci. Phila., Proc. 30: 373. ठँ,.

coquilletti Townes. Calif.

Tryphon (Noemon) coquilletti Townes, 1950 (1949). In Townes and Townes, Ent. Soc.

Amer., Ann. 42: 432. o, ?.

hamatus Townes. Calif.

Tryphon (Noemon) hamatus Townes, 1950 (1949). In Townes and Townes, Ent. Soc.

Amer., Ann. 42: 432. ठ, ?.

lusorius Cresson. Calif.

Tryphon lusorius Cresson, 1879 (1878). Acad. Nat. Sci. Phila., Proc. 30: 373. ठ์.

machaerus Townes. Calif.

Tryphon (Noemon) machaerus Townes, 1950 (1949). In Townes and Townes, Ent. Soc.

Amer., Ann. 42: 431. ठ, ?.

palmaris (Davis). Southern Calif.

Noemon palmaris Davis, 1898 (1897). Amer. Ent. Soc., Trans. 24: 287. ठै, १.

\section{Genus TRYPHON Subgenus TRYPHON Fallen}

Tryphon Fallen, 1813. Spec. Nov. Hym. Disp. Meth., p. 16.

Type-species: Ichneumon rutilator Linnaeus. Desig. by Curtis, 1832.

Psilosage Foerster, 1868. Naturh. Ver. Rheinlande, Verh. 25: 203. 
Type-species: Tryphon ephippium Holmgren. By subsequent monotypy from inclusion by Morley, 1911.

Otitochilus Foerster, 1868. Naturh. Ver. Rheinlande, Verh. 25: 203.

Type-species: Tryphon trochanteratus Holmgren. By subsequent monotypy from inclusion by Woldstedt, 1877 (1876).

This subgenus is Palearctic.

\section{Genus TRYPHON Subgenus SYMBOETHUS Foerster}

Symboethus Foerster, 1868. Naturh. Ver. Rheinlande, Verh. 25: 204.

Type-species: Tryphon exclamationis Gravenhorst. Desig. by Viereck, 1914 from two species included by Morley, 1911.

Quadrigana Davis, 1897. Amer. Ent. Soc., Trans. 24: 280.

Type-species: Tryphon americanus Cresson. By subsequent monotypy from inclusion by Davis, 1898 (1897), p. 281.

alaskensis Ashmead. Sask., Alta., Alaska, Wash.

Polyblastus glacialis Ashmead, 1902. Wash. Acad. Sci., Proc. 4: 213.

Tryphon alaskensis Ashmead, 1902. Wash. Acad. Sci., Proc. 4: 215..

americanus Cresson. Que. s. to $\mathrm{Pa}$., w. to Minn. and Kans.

Tryphon americanus Cresson, 1864. Ent. Soc. Phila., Proc. 3: 276. ð.

Tryphon affinis Cresson, 1864. Ent. Soc. Phila., Proc. 3: 277..

communis Cresson. N. S. s. to Pa., w. to Alaska, Alta., and N. Mex. Two or more species may be confused under this name.

Tryphon communis Cresson, 1868. Amer. Ent. Soc., Trans. 2: 103 o, ?.

Tryphon clypeatus Provancher, 1875. Nat. Canad. 7: 309, 311. $\delta$. The alternate spelling "clypealis" appeared on p. 309.

Tryphon pediculatus Provancher, 1886. Addit. Corr. Faune Ent. Canada Hym., p. 102. ठ. Tryphon communis var. atripes Davis, 1898 (1897). Amer. Ent. Soc., Trans. 24: 282. ठ, ๆ. Grypocentrus rufiterminalis Hall, 1919. Psyche 26: 157..

foraminatus Townes, N. status. S. D. s. to Colo., w. to B. C. and Calif. The egg of this species is more elongate than that of communis.

Tryphon (Symboethus) communis foraminatus Townes, 1950 (1949). In Townes and Townes, Ent. Soc. Amer., Ann. 42: 442. ठ, $९$.

illotus Townes. Wash.

Tryphon (Symboethus) illotus Townes, 1950 (1949). In Townes and Townes, Ent. Soc. Amer., Ann. 42: 443. $\delta$.

mystax Townes. N. B. w. to Alaska, s. to N. H., Colo., and Wash.

Tryphon (Symboethus) mystax Townes, 1950 (1949). In Townes and Townes, Ent. Soc. Amer., Ann. 42: 437. $\delta$, $\%$.

rempeli Townes. Sask., Wash., Oreg.

Tryphon (Symboethus) rempeli Townes, 1950 (1949). In Townes and Townes, Ent. Soc. Amer., Ann. 42: 435. $\delta$, ㅇ.

seminiger Cresson. N. S. w. to Alaska, s. to Md., Ill., N. Mex., and Calif.

Tryphon seminiger Cresson, 1864. Ent. Soc. Phila., Proc. 3: 278. 9.

Metopius terminalis Ashmead, 1890 (1889). U. S. Natl. Mus., Proc. 12: 438. ठ์.

townesi Walkley. Que., Maine, N. H., Vt., Mich., Colo.

Tryphon (Symboethus) humeralis Townes, 1950 (1949). In Townes and Townes, Ent. Soc. Amer., Ann. 42: 438. ठ, ९. Preocc. by Gravenhorst, 1829.

Tryphon (Symboethus) townesi Walkley, 1958. In Krombein, et al., U. S. Dept. Agr., Agr. Monog. 2, Sup. 1, p. 41. N. name for humeralis Townes.

viator Townes. Que. w. to Alta., s. to Pa., Mo., and Colo.

Tryphon (Symboethus) viator Townes, 1950 (1949). In Townes and Townes, Ent. Soc. Amer., Ann. 42: 443. ठ', ?. 


\section{TRIBE EXENTERINI}

The name Cteniscini Woldstedt (1877) is often used for this tribe, but Exenterini Foerster (1868) seems to be favored as much by recent authors; because the latter name has the additional advantage of being oldest, it is used here.

Revision: Davis, 1897. Amer. Ent. Soc., Trans. 24: 227-240. - Kerrich, 1952. Brit. Mus. (Nat.

Hist.) Ent., Bul. 2: 307-459. (Old World spp.).

\section{Genus ORTHOMISCUS Mason}

Orthomiscus Mason, 1955. Canad. Jour. Zool. 33: 63.

Type-species: Orthomiscus platyura Mason. Orig. desig.

Taxonomy: Mason, 1962. Canad. Ent. 94: 1273-1274.

leptura Mason. Que., N. H., Vt., Ont., Calif.

Orthomiscus leptura Mason, 1955. Canad. Jour. Zool. 33: 64. ठँ, ๆ.

platyura Mason. Que. w. to Mich., s. to Md. and Alta.

Orthomiscus platyura Mason, 1955. Canad. Jour. Zool. 33: 66. ठ, ९.

\section{Genus EXCAVARUS Davis}

Excavarus Davis, 1897. Amer. Ent. Soc., Trans. 24: 233.

Type-species: Cteniscus annulipes Cresson. Desig. by Viereck, 1914.

Taxonomy: Mason, 1962. Canad. Ent. 94: 1293-1296.

annulipes (Cresson). N. B. w. to Minn., s. to S. C. and Ill. Host: Croesus latitarsus Nort.

Cteniscus annulipes Cresson, 1868. Amer. Ent. Soc., Trans. 2: 112. “б” = ९.

etrocaulus etrocaulus Mason. Alta., Colo., B. C., Oreg.

Smicroplectrus etrocaulus etrocaulus Mason, 1956. Canad. Jour. Zool. 34: 149. ð, ९.

etrocaulus eurus Mason. N. B., Que., Mass., Mich., Minn.

Smicroplectrus etrocaulus eurus Mason, 1956. Canad. Jour. Zool. 34: 150..

velox (Walley). Que., Maine, Ont., Sask., N. Mex., Alta., B. C. Host: Pikonema alaskensis (Roh.), P. dimmockii (Cr.).

Smicroplectrus velox Walley, 1937. Canad. Ent. 69: 132. ؟.

\section{Genus EXYSTON Schiodte}

Exyston Schiodte, 1839. Mag. Zool., sect. 3, (ser. 2) 1 (pl. 6-9): 12.

Type-species: Ichneumon cinctulus Gravenhorst. Monotypic.

Tricamptus Foerster, 1868. Naturh. Ver. Rheinlande, Verh. 25: 194.

Type-species: Exenterus pratorum Woldstedt. By subsequent monotypy from inclusion by Woldstedt, 1877.

Diaborus Foerster, 1868. Naturh. Ver. Rheinlande, Verh. 25: 195.

Type-species: Cteniscus (Diaborus) sedulus Woldstedt. Desig. by Viereck, 1912

from two species included by Woldstedt, 1877. The type-species is regarded as a synonym of Exyston pratorum (Woldstedt).

Anecphysis Foerster, 1868. Naturh. Ver. Rheinlande, Verh. 25: 195.

Type-species: Anecphysis curvineura Davis. By subsequent monotypy from inclusion by Davis, 1897.

Parexyston Kerrich, 1952. Brit. Mus. (Nat. Hist.) Ent., Bul. 2: 392.

Type-species: Exyston calcaratus Thomson. Monotypic and orig. desig.

According to Mason (1959) most of the species are found in grassy places. He presumed that they are mainly parasitic upon "sod-feeding" Dolerinae, but the only North American species so far reared (maculosum [Provancher]) parasitizes Pristiphora spp. (Nematinae) on Salix and Vaccinium.

Revision: Mason, 1959. Canad. Jour. Zool. 37: 1067-1115.

atrum Mason. B. C., Wash., Oreg.

Exyston (Anecphysis) ater Mason, 1959. Canad. Jour. Zool. 37: 1095. §, ๆ. 
austelli Mason. Mass. s. to N. C.

Exyston (Anecphysis) austelli Mason, 1959. Canad. Jour. Zool. 37: 1078. ठ์, ९.

boreotis Davis. N. Y., Mich., Sask., Wyo., Colo., N. Mex., Alta.

Exyston boreotis Davis, 1897. Amer. Ent. Soc., Trans. 24: 238. ð.

Exyston nigroscutum Davis, 1897. Amer. Ent. Soc., Trans. 24: 237. ठँ.

Exyston contracta Davis, 1897. Amer. Ent. Soc., Trans. 24: 238. ठ. Uncertain syn.; Mason

(1959) suggested that contracta might alternatively prove to be a senior synonym of spinulosum Mason.

Taxonomy: Mason, 1959. Canad. Jour. Zool. 37: 1082-1084, 1112-1113. -Townes, 1969. Amer.

Ent. Inst., Mem. 11: 186.

californicum Mason. Alta. s. to Colo., w. to Alaska and Calif.

Exyston (Anecphysis) californicus Mason, 1959. Canad. Jour. Zool. 37: 1093. ठ, ๆ.

chamaeleon Mason. Ont., N. W. T. w. to Yukon, s. to S. Dak., N. Mex. and Calif.

Exyston (Exyston) chamaeleon Mason, 1959. Canad. Jour. Zool. 37: 1099. ठै, १.

clavatum (Cresson). N. S. w. to B. C., s. to Va., Ill., Kans., and Calif.

Cteniscus clavatus Cresson, 1864. Ent. Soc. Phila., Proc. 3: 284. ठ.

Cteniscus abdominalis Cresson, 1865. Ent. Soc. Phila., Proc. 4: 264. 9.

Exyston abdominalis Ashmead, 1896. Amer. Ent. Soc., Trans. 23: 197. ठ. Preocc. by above synonym, abdominalis Cresson, 1865.

Rhimphalea erythrogaster Viereck, 1917 (1916). Conn. State Geol. and Nat. Hist. Survey Bul. 22: 296. ㅇ.

excelsum (Cresson). Wyo., Colo.

Cteniscus excelsus Cresson, 1865. Ent. Soc. Phila., Proc. 4: 262. 9.

flavens Davis. Mass., N. J., Ga., Tex.

Exyston flavens Davis, 1897. Amer. Ent. Soc., Trans. 24: 237. ๆ.

hadrum Mason. Mich., Minn., Sask., Colo., Alta.

Exyston (Anecphysis) hadros Mason, 1959. Canad. Jour. Zool. 37: 1080. ठ, ๆ.

humerale Davis. Newfoundland (insular) w. to Sask., s. to Minn., Kans., and Mont.

Exyston humeralis Davis, 1897. Amer. Ent. Soc., Trans. 24: 239. ठ.

Exyston articulatus Davis, 1897. Amer. Ent. Soc., Trans. 24: 239. ठ̊.

illinois Mason. Que., Ont., Mich., Ill., Iowa.

Exyston (Exyston) illinois Mason, 1959. Canad. Jour. Zool. 37: 1103. ठ’, ๆ.

lophotum Mason. N. W. T., Sask., Alta., B. C., Wash., Calif.

Exyston (Anecphysis) lophotos Mason, 1959. Canad. Jour. Zool. 37: 1091. ठ, ๆ.

maculosum (Provancher). N. S. w. to B. C., s. to N. C., Ill., Ariz., and Calif. Host: Pristiphora bivattata (Nort.), $P$. cincta Newman, $P$. sycophanta Walsh.

Mesoleptus maculosus Provancher, 1875. Nat. Canad. 7: 114. “ๆ" = $\delta$.

Exyston (Anecphysis) tectus Mason, 1959. Canad. Jour. Zool. 37: 1073. ठ, १.

Taxonomy: Barron, 1975. Nat. Canad. 102: 502 (syn.).

marginatum (Provancher). Northern Que. w. to Alaska, s. to N. C., Mich., Colo., and Calif.

Exyston marginatum Provancher, 1886. Addit. Corr. Faune Ent. Canada Hym., p. 99..

Anecphysis curvineura Davis, 1897. Amer. Ent. Soc., Trans. 24: 234..

Exyston nigreo Davis, 1897. Amer. Ent. Soc., Trans. 24: 236. ठ。.

politum Davis. Mont., Wyo., Calif.

Exyston politus Davis, 1897. Amer. Ent. Soc., Trans. 24: 240..

reniforme Mason. Colo., Alta., B. C., Oreg., Calif.

Exyston (Anecphysis) reniformis Mason, 1959. Canad. Jour. Zool. 37: 1089. ठ’, ᄋ.

speciosum Davis. Alta. s. to Colo., w. to B. C. and Calif.

Exyston speciosus Davis, 1897. Amer. Ent. Soc., Trans. 24: 237. ठ.

spinulosum Mason. N. W. T. w. to Alaska, s. to Iowa, Kans., Wyo., and Wash.; Kamchatka.

Exyston (Anecphysis) spinulosus Mason, 1959. Canad. Jour. Zool. 37: 1086. ठั, ?.

variatum Provancher. N. S. w. to B. C., s. to N. C., Ill, and N. Dak. Ecology: Occurs at forest edges and along woodland paths, but not in grasslands or meadows.

Exyston variatus Provancher, 1877. Nat. Canad. 9: 15. ๆ. 
Exyston variatus Provancher, 1879. Nat. Canad. 11: 249. . Preocc. by Provancher, 1877. Contrary to the discussion of Barron (1975), Provancher indicated this as being a description of a new species. The variant spelling "vaiatus" also appears on p. 249. Exyston abdominalis var. rufinus Davis, 1897. Amer. Ent. Soc., Trans. 24: 239..

Taxonomy: Barron, 1975. Nat. Canad. 102: 581 (discussion of lectotype). venustum (Cresson). S. Dak., Sask., Colo., Utah, B. C., Wash.

Cteniscus venustus Cresson, 1865. Ent. Soc. Phila., Proc. 4: 263. ‡.

\section{Genus SMICROPLECTRUS Thomson}

Microplectron Foerster, 1868. Naturh. Ver. Rheinlande, Verh. 25: 195. Preocc. by Streubel, 1842 and Dahlbom, 1857.

Type-species: Exenterus erosus Holmgren. By subsequent monotypy from inclusion by Woldstedt, 1877 (1876).

Smicroplectrus Thomson, 1883. Opusc. Ent. 9: 888.

Type-species: Exenterus jucundus Holmgren. Desig. by Viereck, 1914.

Anderis Davis, 1897. Amer. Ent. Soc., Trans. 24: 233.

Type-species: Cteniscus albilineatus Walsh. Desig. by Viereck, 1914.

Auderis Davis, 1898 (1897). Amer. Ent. Soc., Trans. 24: 348 (errata). Emend.

Revision: Mason, 1956. Canad. Jour. Zool. 34: 124-151 (including Excavarus).

apicatus (Provancher). Que., Maine, N. Y., Ont., Colo., Alta., B. C. Host: Nematus currani Ross.

Cteniscus apicatus Provancher, 1879. Nat. Canad. 11: 263. " $\delta "=q$.

californicus (Cresson). Que. w. to B. C., s. to N. C., Minn., Ariz., and Calif.

Ctenistes(!) californicus Cresson, 1879 (1878). Acad. Nat. Sci. Phila., Proc. 30: 374. đ.

Smicroplectrus disseptus Walley, 1933. Canad. Ent. 65: 256. \&.

eburneus Mason. Ont., Tex.

Smicroplectrus eburneus Mason, 1956. Canad. Jour. Zool. 34: 141. ๆ.

incompletus Walley. N. S. w. to Alta., s. to Pa. and Ariz. Host: Pikonema sp.

Smicroplectrus incompletus Walley, 1937. Canad. Ent. 69: 134. \&.

jucundus albilineatus (Walsh). Que. w. to Alaska, s. to Colo. and Calif. S. jucundus jucundus (Holmgren) is Palearctic.

Cteniscus albilineatus Walsh, 1873. Acad. Sci. St. Louis, Trans. 3: 107. " ${ }^{\circ} "=q$.

robustus Walley. Que. w. to Alta., s. to N. Y., Mich., and Nev. Ecology: Observed on Populus ovipositing on Nematus sp. Host: Nematus sp.

Smicroplectrus robustus Walley, 1937. Canad. Ent. 69: 135. \&.

takomae Mason. N. W. T., Alaska, Wash.

Smicroplectrus takomae Mason, 1956. Canad. Jour. Zool. 34: 131. §, \&.

walleyi Mason. Que., N. Y., Pa., Md., Va., Ont., Ohio, Ky., Nebr.

Smicroplectrus walleyi Mason, 1956. Canad. Jour. Zool. 34: 132. ð, §.

\section{Genus ACROTOMUS Holmgren}

Acrotomus Holmgren, 1857 (1855). Svenska Vetensk.-Akad. Handl. (n. f.) 1: 222.

Type-species: Tryphon lucidulus Gravenhorst. Desig. by Viereck, 1912.

Delotomus Foerster, 1868. Naturh. Ver. Rheinlande, Verh. 25: 194, 215. Unnecessary n. name for Acrotom us Holmgren.

Taxonomy: Mason, 1962. Canad. Ent. 94: 1285-1287.

succinctus (Gravenhorst). N. Y., Ont., Mich.; Europe. Adventive.

Tryphon succinctus Gravenhorst, 1829. Ichn. Europaea, v. 2, p. 166. ơ, ๆ.

\section{Genus CTENISCUS Haliday}

Cteniscus Haliday, 1832. In Curtis, Brit. Ent., v. 9, no. 399.

Type-species: Tryphon sexilituratus Gravenhorst. Monotypic. The type-species is regarded as a synonym of Cteniscus pedatorius (Panzer).

Eudiaborus Kerrich, 1952. Brit. Mus. (Nat. Hist.) Ent., Bul. 2: 415. 
Type-species: Diaborus pallitarsis Thomson. Orig. desig. The type-species is regarded as a synonym of Cteniscus scalaris (Gravenhorst).

The name Cteniscus has not traditionally applied to this genus, the change in application being made by Townes, Townes, and Gupta (1965) in compliance with the fact that Tryphon sexilituratus Gravenhorst was the only species originally included; (see Townes, 1969); other names mentioned in the original description (e.g. Cteniscus aurifluus) were then nomina nuda. Prior to the description of Eudiaborus, the name Diaborus Foerster had been incorrectly applied to this genus.

Revision: Mason, 1955. Canad. Jour. Zool. 33: 21-63 (as Eudiaborus).

Taxonomy: Kerrich, 1952. Brit. Mus. (Nat. Hist.) Ent., Bul. 2: 314-316, 415-416. -Townes, Townes, and Gupta, 1965. Amer. Ent. Inst., Mem. 5: 113. - Townes, 1969. Amer. Ent. Inst., Mem. 11: 188-190. - Kerrich, 1975. Polskie Pismo Ent. 40: 125-126.

devius (Mason). Man., Colo., Alaska; Europe.

Eudiaborus devius Mason, 1955. Canad. Jour. Zool. 33: 34.

dorsalis Cresson. N. S. w. to Alaska, s. to N. Y., Ill., Colo., and Calif.

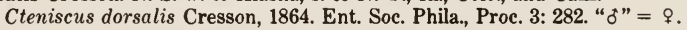

Cteniscus mediatus Cresson, 1864. Ent. Soc. Phila., Proc. 3: 282. ठ.

eximius (Mason). N. Y.

Eudiaborus eximius Mason, 1955. Canad. Jour. Zool. 33: 33. $\subsetneq$.

flavicireus (Mason). Ont., Ohio, S. C., Ind. Host: Pristiphora sp.

Eudiaborus flavicircus Mason, 1955. Canad. Jour. Zool. 33: 27. ð,.

glutiniatus (Roman). Maine, B. C., Alaska; N. Eurasia.

Diaborus glutiniatus Roman, 1909. In Hamburg, Naturw. Unters. Sarekgebirges, v. 4, p. 282. $\delta, ?$.

leptonyx (Mason). Newfoundland (Labrador) w. to Alaska, s. to Man., Colo., Ariz., and Calif. Eudiabomı leptonyx Mason, 1955. Canad. Jour. Zool. 33: 37. ठ",.

luminosus (Mason). N. Y.

Eudiaborus luminosus Mason, 1955. Canad. Jour. Zool. 33: 40..+

maculiventris maculiventris (Ashmead). Newfoundland (Labrador) w. to B. C., s. to Mass. and Colo.

Diaborus maculiventris Ashmead, 1896. Amer. Ent. Soc., Trans. 23: 197. ¿.

Diaborus ignipes Davis, 1897. Amer. Ent. Soc., Trans. 24: 231. \&.

maculiventris sexmaculatus (Ashmead). N. W. T., N. Man., Alaska. More northwestern than the nominate subspecies, $m$. sexmaculatus probably having decended from a Palearctic-Beringian glacial refugium. A third subspecies, $m$. borioalpinus Kerrich, occurs in Europe and is rather similar to m. sexmaculatus.

Diabomis sexmaculatus Ashmead, 1902. Wash. Acad. Sci., Proc. 4: 212. ठ。.

nigrocephalus (Davis). Conn., Md., Ga.

Diaborus nigrocephalus Davis, 1897. Amer. Ent. Soc., Trans. 24: 232...

promediatus arizonicus (Mason). N. Mex., Ariz.

Eudiaborus promediatus arizonicus Mason, 1955. Canad. Jour. Zool. 33: 60. \&.

promediatus cressoni (Mason). N. Y. w. to s. Ont. and Mich., s. to Va. Host: Nematus salicisodoratus Dyar.

Eudiaborus promediatus cressoni Mason, 1955. Canad. Jour. Zool. 33: 59. §, ९.

promediatus promediatus (Mason). Newfoundland (insular) w. to Alaska, s. to N. S., s. Ont., Minn., Colo., and B. C. Host: Nematus currani Ross, Hemichroa crocea (Geoff.).

Eudiaborus promediatus promediatus Mason, 1955. Canad. Jour. Zool. 33: 56. đ,

pulchellus (Mason). Mass., N. J., Pa., Md., Mich.

Eudiaborus pulchellus Mason, 1955. Canad. Jour. Zool. 33: 50. ð, ๆ.

pyelechus (Mason). Mass., N. J., Pa., Md., Mich.

Eudiaborus pyelechus Mason, 1955. Canad. Jour. Zool. 33: 25. ঠ, ९.

scaphuloides (Mason). Que., Maine, R. I., Md., Ont., Mich., Idaho.

Eudiaborus scaphuloides Mason, 1955. Canad. Jour. Zool. 33: 40. ठ, ?. 
similis (Davis). Que. w. to Alaska, s. to N. H., Nebr., Colo., and Calif. The division of this species into four subspecies by Mason (1955) is rather unconvincing.

Diaborus similis Davis, 1897. Amer. Ent. Soc., Trans. 24: 231. $q$ (ठ misdet.).

Diaborus nebraskensis Davis, 1897. Amer. Ent. Soc., Trans. 24: 232. ठँ.

Diaborus citrifrons Ashmead, 1902. Wash. Acad. Sci., Proc. 4: 212. ¿.

Cteniscus vitticollis Cresson, 1868. Amer. Ent. Soc., Trans. 2: 113. “ $"=$ ?.

\section{Genus SCAPNETES Townes}

Scapnetes Townes, 1969. Amer. Ent. Inst., Mem. 11: 190.

Type-species: Exenterus ornatus Walsh. Orig. desig. Enigmatically, Townes (1969) added the qualifying phrase "as interpreted by Mason, 1956" to his type-species designation, but then went on to point out, in effect, that Mason (1956) had confused two species under the name ornatus.

ornatus (Walsh). N. S., N. B., Que., N. H., Conn., S. C., Ga., Fla., Ont., Mich.

Exenteron (!) ornatus Walsh, 1873. Acad. Sci. St. Louis, Trans. 3: 105. ð.

Taxonomy: Mason, 1956. Canad. Jour. Zool. 34: 120-124.

rufus (Provancher). Que.

Cteniscus rufus Provancher, 1876. Nat. Canad. 8: 318..

Taxonomy: Townes, 1969. Amer. Ent. Inst., Mem. 11: 190.

\section{Genus EXENTERUS Hartig}

Exenterus Hartig, 1837. Arch. f. Naturgesch. 1: 156.

Type-species: Ichneumon marginatorius Fabricius. Monotypic.

Actenonyx Foerster, 1868. Naturh. Ver. Rheinlande, Verh. 25: 195. Preocc. by White, 1846.

Type-species: Ichneumon marginatorius Fabricius. By subsequent monotypy from inclusion by Viereck, 1911.

Picroscopus Foerster, 1868. Naturh. Ver. Rheinlande, Verh. 25: 195.

Type-species: Tryphon ictericus Gravenhorst. By subsequent monotypy from inclusion by Thomson, 1883.

Members of this genus are parasitic upon the larvae of Diprionidae.

Revision: Cushman, 1940. U. S. Dept. Agr. Misc. Pub. 354: 1-14. -Cushman, 1943. Canad.

Ent. 75: 169-174 (additions and corrections to 1940 revision).

Taxonomy: Finlayson, 1963. Canad. Ent. 95: 468-488 (key to final-instar larvae). - Mason, 1967. Canad. Ent. 95: 375-384 (egg structure specializations).

abruptorius (Thunberg). Que., Ont.; Eurasia. Introduced. Host: Neodiprion sertifer (Geoff.), $N$. lecontei (Fitch), N. pratti banksianae Roh. Dowden (1960) stated that E. abruptorius is known to be established in N. J., but no specimens of abruptorius from N. J. can be found in the U.S. Natl. Museum collection; lacking evidence to the contrary, I assume that the N. J. record for abriptorius is based upon incorrectly identified specimens.

Ichneumon abruptorius Thunberg, 1822; 1824. Acad. Imp. des Sci. St. Petersburg, Mem. 8: $279 ; 9: 360$. ठै (\% misdet.).

Exenterus cingulatorius Holmgren, 1857 (1855). Svenska Vetensk.-Akad. Handl. (n. f.). 1: 229. ㅇ.

Exenterus coreensis Uchida, 1930. Hokkaido Imp. Univ., Faculty Agr., Jour. 25: 270. §,.

Taxonomy: Finlayson, 1960. Canad. Ent. 92: 28 (larva).

Biology: Morris, 1937. Bul. Ent. Res. 28: 525-534. -Salt, 1941. Cambridge Phil. Soc., Biol.

Rev. 16: 256. - Wilkes, 1942. Ent. Soc. Ontario, Ann. Rpt. for 1941, p. 41-44. - Guryanova,

1972. Zool. Zhur. 51: 845-854 (Russ. with Ent. sum.).

adspersus Hartig. Eurasia. Introduced in N. B. in 1938 and possibly in mixture with other Exenterus spp. at other Canadian localities between 1933 and 1939, apparently without becoming established. The target host for introductions in Canada was Gilpinia hercyniae (Htg.), but I find no record of adspersus having been reared from hercyniae 
during the period in which hercyniae has been resurrected from snonymy with Gilpinia polytoma (Htg.) (i.e. since 1939).

Exenterus adspersus Hartig, 1838. Jahresber. Fortschr. Forstwiss. Forstl. Naturk. 1: 271. o, $q$.

Exenterus lepidus Holmgren, 1857 (1855). Svenska Vetensk.-Akad. Handl. (n. f.) 1: 231. ठ. Exenterus laricinus Thomson, 1888. Opusc. Ent. 12: 1254. ․

Exenteris oleaceus Uchida, 1931. Insecta Matsumurana 5: 146..

Taxonomy: Beirne, 1941. Soc. Brit. Ent., Trans. 7: 180-181 (final-instar larva). -Iwata, 1958; 1960. Acta Hym. 1: 69; 163 (egg and ovary).

Biology: Morris, Cameron, and Jepson, 1937. Bul. Ent. Res. 28: 375-376.

affinis Rohwer. Que., Maine, Ont. Host: Gilpinia hercyniae (Htg.), Neodiprion abietis (Harris). Exenterus affinis Rohwer, 1920. U. S. Natl. Mus., Proc. 57: 225. §.

Taxonomy: Finlayson, 1960. Canad. Ent. 92: 928 (final-instar larva).

amictorius (Panzer). N. S. s. to n. W. Va., w. to N. Dak.; Europe. Introduced. Host: Gilpinia hercyniae (Htg.), Diprion similis (Htg.), Neodiprion lecontei (Fitch), N. nanulus nanulus Schedl, N. sertifer (Geoff.), N. swainei (Midd.).

Ichneumon marginatorius Fabricius, 1793. Ent. System., v. 2, p. 145. (female). Preocc. by Rossi, 1790.

Ichneumon amictorius Panzer, 1801. Faunae Ins. German., fasc. 80, pl. 14. 9.

Ichneumon sulcatorius Thunberg, 1822; 1824. Acad. Imp. des Sci. St. Petersburg, Mem. 8: $279 ; 9 ; 359$. ठ․ ㅇ.

Taxonomy: Finlayson, 1960. Canad. Ent. 92: 28-30 (final-instar larva).

Biology: Scheidter, 1934. Ztschr. f. Pflanzenkrank. 44: 369, 500-502. - Wilkes, 1924. Ent. Soc. Ontario, Ann. Rpt. for 1941, p. 41-44. - McLeod, 1972. Canad. Ent. 104: 1313-1330.

canadensis Provancher. Que. s. to Fla., w. to Wis. and La. Host: Neodiprion abietis (Harris), $N$. excitans Roh., N. lecontei (Fitch), N. pinetum (Nort.), N. swainei Midd., N. virginiana Roh. For many years the name canadensis has been erroneously applied to nigrifrons Rohwer (which see).

Exenterus Canadensis Provancher, 1883. Nat. Canad. 14: 9. ठ, ๆ.

Exenterus diprioni Rohwer, 1915. U. S. Natl. Mus., Proc. 49: 222. ९. Synonymy according to Barron (1975).

Exenterus diprionis Cushman, 1940. U. S. Dept. Agr. Misc. Pub. 354: 4. Unjustified emend.

Taxonomy: Finlayson, 1963. Canad. Ent. 95: 489-490 (final-instar larva, as diprionis).

-Barron, 1975. Nat. Canad. 102: 440.

Biology: Barclay, 1938. Ent. Soc. Ontario, Ann. Rpt. 69: 29-31 (as diprioni). -Griffiths, 1969.

Canad. Ent. 101: 673-713.

confusus Kerrich. N. B., Que., Ont.; Eurasia. Introduced. Host: Gilpinia hercyniae (Htg.), Neodiprion namulus nanulus Schedl. This species was misidentified as Exenterns claripennis Thomson in the revision by Cushman (1940).

Exenterus confusus Kerrich, 1952. Brit. Mus. (Nat. Hist.) Ent., Bul. 2: 361. ठ, ๆ.

Taxonomy: Finlayson, 1960. Canad. Ent. 92: 926-927 (final-instar larva).

Biology: Reeks, 1952. Canad. Ent. 84: 79-85 (as claripennis).

hullensis Provancher. Que., N. H., Ont., Mich.

Exenterus Hullensis Provancher, 1886. Addit. Corr. Faune Ent. Canada Hym., p. 104. o, ㅇ.

lophyri Viereck. Nebr., Ariz. Host: Zadiprion townsendi (Ckll.).

Exenterus lophyri Viereck, 1911. U. S. Natl. Mus., Proc. 39: 404. ․

Biology: Swenk, 1911. Nebr. Agr. Expt. Sta., Ann. Rpt. 24: 26-28.

nigrifrons Rohwer. N. S. to Fla., w. to Minn. and Tex. Host: Gilpinia hercyniae (Htg.), Neodiprion abbotii (Leach), N. abietis (Harris), N. excitans Roh., N. lecontei (Fitch), N. nanulus nanulus Schedl, N. pratti banksiance Roh., N. migifrons Midd., N. sertifer (Geoff.), N. swainei Midd., N. taedae linearis Ross. Preceding the work of Barron (1975) 
on the Provancher types, authors (most importantly Cushman, 1940) have incorrectly applied the name canadensis Provancher to this species; Cushman (1940) based his usage upon the erroneous assertion that there had been a male holotype of canadensis, and he applied the name according to the first-revisor principle because only a female specimen had then been found in the Provancher collection under the name canadensis.

Exenterus nigrifrons Rohwer, 1920. U. S. Natl. Mus., Proc. 57: 225. "o " $=\delta^{\circ}$.

Exenterus flavissimus Cushman, 1940. U. S. Dept. Agr. Misc. Pub. 354: 12. o, ๆ.

Taxonomy: Short, 1959. U. S. Natl. Mus., Proc. 110: 425 (final-instar larva, as canadensis). -Finlayson, 1960. Canad. Ent. 92: 26-28 (final-instar larva, as canadensis). - Barron, 1975. Nat. Canad. 102: 440.

Biology: Barclay, 1938. Ent. Soc. Ontario, Ann. Rpt. 69: 29-31 (as "canadensis Auct."). -Bobb, 1965. Jour. Econ. Ent. 58: 925 (as canadensis).

pini Cushman. Nebr., Mont., Colo., Idaho, Ariz., Nev., Calif. Host: Neodiprion edulicolus Ross. Exenterus pini Cushman, 1940. U. S. Dept. Agr. Misc. Pub. 354: 13. ․

platypes Cushman. Que., N. C., Ont., Minn. Host: Neodiprion pratti banksianae Roh.

Exenterus platypes Cushman, 1943. Canad. Ent. 75: 173..+

Taxonomy: Finlayson, 1963. Canad. Ent. 95: 489-490 (final-instar larva).

Biology: Griffiths, 1960. Canad. Ent. 92: 654.

tricolor Roman. Europe. Introduced in N. B. (1937-1939), Que. (1936-1940), N. H. (1938), and Vt. (1939); a 1946 recovery in N. B. indicates that the species may be established there.

Host: Gilpinia hercyniae ( $\mathrm{Htg}$.). The host listed was the target species for introductions in North America.

Exenterus tricolor Roman, 1913. Ent. Tidskr. 34: 127. ơ, ๆ.

Taxonomy: Finlayson, 1960. Canad. Ent. 92: 928-929 (final-instar larva).

Biology: Morris, Cameron, and Jepson, 1937. Bul. Ent. Res. 28: 369-375. -Barelay, 1938. Ent.

Soc. Ontario, Ann. Rpt. 69: 29-31.

tsugae Cushman. Mont., B. C., Idaho, Oreg., Calif. Host: Neodiprion tsugae Midd., N. scutellatus Roh.

Exenterus tsugae Cushman, 1940. U. S. Dept. Agr. Misc. Pub. 354: 13. ठ', ๆ.

Biology: Furniss and Dowden, 1941. Jour. Econ. Ent. 34: 49.

vellicatus Cushman. Newfoundland (insular), N. S., P. E. I., N. B., Que., Maine, N. Y., Ont. Introduced. Host: Gilpinia hercyniae (Htg.).

Exenterus vellicatus Cushman, 1940. U. S. Dept. Agr. Misc. Pub. 354: 7. §, ᄋ.

Taxonomy: Finlayson, 1960. Canad. Ent. 92: 928-930 (final-instar larva).

Biology: Morris, Cameron, and Jepson, 1937. Bul. Ent. Res. 28: 377 (as Exenterus sp.).

walleyi Cushman. N. B., Ont., Ind. Host: Neodiprion abietis (Harris), N. nanulus nanulus Schedl, N. sertifer (Geoff.).

Exenterus walleyi Cushman, 1943. Canad. Ent. 75: 171. ¿े, ๆ.

Taxonomy: Finlayson, 1960. Canad. Ent. 92: 29-30 (final-instar larva).

\section{Genus ERIDOLIUS Foerster}

Anisoctenion Foerster, 1868. Naturh. Ver. Rheinlande, Verh. 25: 194.

Type-species: Acrotomus xanthopus Holmgren. By subsequent monotypy from inclusion by Schmiedeknecht, 1907. The type-species is considered to be a synonym of Eridolius alacer (Gravenhorst).

Eridolius Foerster, 1868. Naturh. Ver. Rheinlande, Verh. 25: 195.

Type-species: Exenterus pygmaeus Holmgren. By subsequent monotypy from inclusion by Thomson, 1883 .

Until recently the name Cteniscus was applied to this genus because Eridolius aurifluus (Haliday) was incorrectly regarded as the type-species of Cteniscus (see discussion under Cteniscus). Eridolius is Holarctic with many species of boreal distribution. Many of the species occurring in the Nearctic Region are undescribed. 
Taxonomy: Mason, 1962. Canad. Ent. 94: 1291 (generic limits, as Cteniscus). - Townes, 1969. Amer. Ent. Inst., Mem. 11: 191-192.

clypeatus (Cresson). Que. w. to Alaska, s. to $\mathrm{Pa}$., Colo., and Oreg.

Cteniscus clypeatus Cresson, 1868. Amer. Ent. Soc., Trans. 2: 113. \&.

consors (Cresson). Que., N. H., Conn., Md., Ont., Tex., Nev.

Cteniscus consors Cresson, 1868. Amer. Ent. Soc., Trans. 2: 113..

flavicoxae (Cresson). Mass., Del.

Cteniscus flavicoxae Cresson, 1864. Ent. Soc. Phila., Proc. 3: 283..

Taxonomy: Mason, 1962. Canad. Ent. 94: 1291.

gnathoxanthus (Gravenhorst). Que., Alaska; Europe.

Tryphon gnathoxanthus Gravenhorst, 1829. Ichn. Europaea, v. 2, p. 147..

marginatus (Thomson). Transcont. in Huds. Zone; Europe.

Cteniscus marginatus Thomson, 1883. Opusc. Ent. 9: 892. ठ, १.

Cteniscus nigrofemoralis Ashmead, 1902. Wash. Acad. Sci., Proc. 4: 211. o.

Taxonomy: Roman, 1909. In Hamburg, Naturw. Unters. Sarekgebirges, v. 4, p. 286. -Mason, 1951. In Muesebeck, Krombein, and Townes, U. S. Dept. Agr., Agr. Monog. 2: 227 (syn.).

orbitalis (Cresson). Que., Maine, N. Y., Pa., Ont.

Cteniscus orbitalis Cresson, 1864. Ent. Soc. Phila., Proc. 3: $293 . " ~ \sigma ”=q$.

praeustus (Holmgren). Alaska, Wash.; Eurasia.

Exenterus praeustus Holmgren, 1857 (1855). Svenska Vetensk.-Akad. Handl. (n. f.) 1: 245. ․

pygmaeus (Holmgren). Transcont. in Arctic (s. part) and Huds. Zones; n. Europe.

Exenterus pygmaeus Holmgren, 1857 (1855). Svenska Vetensk.-Akad. Handl. (n. f.) 1: 245. ㅇ.

Microplectron alaskensis Ashmead, 1902. Wash. Acad. Sci., Proc. 4: 212. ठ.

Taxonomy: Mason, 1951. In Muesebeck, Krombein, and Townes, U. S. Dept. Agr., Agr. Monog. 2: 228 (syn.).

\section{TRIBE IDIOGRAMMATINI}

This tribe includes Idiogramma and the fossil genus Urotryphon described by Townes (1973) from Cretaceous amber ( 80 to 90 million years old) collected in the U. S. S. R.

Taxonomy: Townes, 1973. Ent. Soc. Wash., Proc. 75: 282-287.

\section{Genus IDIOGRAMMA Foerster}

Idiogramma Foerster, 1867. In Kirchner, Cat. Hym. Europae, p. 67. Nomen nudum. The nomen nudum Idiogramma euryops Foerster also appears on p. 67.

Idiogramma Foerster, 1868. Naturh. Ver. Rheinlande, Verh. 25: 163.

Type-species: Idiogramma euryops Schmiedeknecht. By subsequent monotypy from inclusion by Schmiedeknecht, 1868.

Macrochasmus Thomson, 1888. Opusc. Ent. 12: 1279.

Type-species: Macrochasmus alysiinus Thomson. Monotypic.

Lysiognatha Ashmead, 1895. Ent. Soc. Wash., Proc. 3: 276.

Type-species: Lysiognatha comstockii Ashmead. Monotypic.

Members of this Holarctic genus parasitize larvae of Xyela in the staminate cones of Pinus. Oviposition occurs at about the time when the Xyela larval development is nearing completion, which apparently just precedes the time the host pine sheds its pollen. The eggs of Idiogramma hatch after the host has dropped to the ground and formed its earthen pupal cell.

Revision: Cushman, 1937. Wash. Acad. Sci., Jour. 27: 438-444. - Townes and Townes, 1951.

Ent. Soc. Wash., Proc. 53: 308-313.

Taxonomy: Perkins, 1940. Entomologist 73: 55. -Cushman, 1942. Ent. Soc. Wash., Proc. 44:

54 (generic syn.).

Biology: Burdick, 1961. Calif. Univ., Pubs. Ent. 17: 319-320. 
bridwelli (Cushman). Md., Va., Fla. Ecology: Associated with Pinus virginiana. Host: Xyela sp.

Lysiognatha bridwelli Cushman, 1937. Wash. Acad. Sci., Jour. 27: 444. ठ, ?.

comstockii (Ashmead). Ont., N. Y., Md., D. C., Va. Ecology: Associated with Pinus divaricata and $P$. virginiana.

Lysiognatha comstockii Ashmead, 1895. Ent. Soc. Wash., Proc. 3: 276. ơ, ๆ.

Lysiognatha sulcata Cushman, 1937. Wash. Acad. Sci., Jour. 27: 442. §, क.

contortae Townes. Utah, Ariz., Calif. Ecology: Associated with Pinus contorta, P. muricata, and $P$. ponderosa.

Idiogramma contortae Townes, 1951. In Townes and Townes, Ent. Soc. Wash., Proc. 53: 310. $\delta, ?$.

fraterna Townes. Utah, Ariz., Calif. Ecology: Associated with Pinus contorta and $P$. ponderosa.

Idiogramma fraternus Townes, 1951. In Townes and Townes, Ent. Soc. Wash., Proc. 53: 312. $\delta, ~ \%$.

longicauda (Cushman). Md., Va., Ga., Ala. Ecology: Associated with Pinus taeda and $P$. virginiana. Host: Xyela sp.

Lysiognatha longicauda Cushman, 1937. Wash. Acad. Sci., Jour. 27: 443. ठ, \&.

titana Burdick. Calif. Ecology: Associated with Pinus coulteri.

Idiogramma titana Burdick, 1958. Pan-Pacific Ent. 34: 159. ð, ?.

\section{SUBFAMILY EUCEROTINAE}

\section{Genus EUCEROS Gravenhorst}

Euceros Gravenhorst, 1829. Ichn. Europaea, v. 3, p. 368.

Type-species: Euceros crassicornis Gravenhorst. Monotypic.

Eumesius Westwood, 1840. Introd. Mod. Classif. Ins., v. 2, p. 153. Unnecessary n. name for Euceros Gravenhorst, which is not preocc. by Eucera Scopoli, 1770.

Omaloceros Giraud, 1857. Zool.-Bot. Gesell. Wien, Verh. 7: 163. Unnecessary n. name for Euceros Gravenhorst.

Tautozelus Foerster, 1868. Naturh. Ver. Rheinlande, Verh. 25: 212.

Type-species: Euceros egregius Holmgren. Included and desig. by Perkins, 1962.

The type species is regarded as a synonym of $E$. serricornis Haliday.

Eucerus(!) Verhoeff, 1892. Ent. Nachr. 18: 4.

Pseudasthenara Uchida, 1930. Hokkaido Imp. Univ., Faculty Agr., Jour. 25: 276.

Type-species: Asthenara rufocincta Ashmead. Monotypic and orig. desig.

This is the only genus in the Eucerotinae; it is moderate sized, and its distribution is Holarctic, Australian (one undescribed sp.), and Ethiopian (one Madagascan sp.). The genus was placed in the Tryphoninae (as tribe Eucerotini) by Townes (1969), apparently based upon the similarities between the final instar larvae of Euceros and Exenterus (cf. Finlayson [1960, p. 34]), but the egg, the early larval instars, the adult, and the biology of Euceros differ so greatly from those of Tryphoninae or any other Ichneumonidae that the genus is here placed in a subfamily of its own, as was done by Perkins (1959). Barron (1977) has published a revision of the Nearctic species; I regret that it was not feasible for me to revise the present treatment of Euceros accordingly.

Euceros eggs are stalked and greatly resemble those of Chrysopidae; they are deposited on foliage near early-instar larvae of a carrier host (defoliating sawflies or Lepidoptera). The planidial first larval instar of Euceros remains upon its empty chorion at the top of the egg stalk until it is able to attach to a passing carrier host. Although a Euceros planidium obtains enough fluid from the carrier host to sustain itself, it is an obligate hyperparasite and cannot develop further on the carrier host; its chance for completing its development depends upon the host being parasitized (presumably most often subsequently) by another ichneumonid (it seems reasonable to expect rearings from larger Braconidae also). The time at which a Euceros planidium enters its true host is not known for certain and may vary according to the true host's mode of parasitism (true hosts include external as well as internal parasites). When the true host is an internal larval parasite (e.g. Phobocam pe or Olesicampe), it appears likely that the first-instar Euceros planidium remains externally attached to the carrier host until the mature larva of the 
true host has killed the carrier host and emerged from it. When the true host is an internal larval-pupal parasite (a species of Anomaloninae being recorded as a host of Euceros frigidis Cresson) it would be necessary for the Euceros planidium to bore through the integument of the carrier host in order to reach the true host. There appear to be seven or eight larval instars; during the first four stadia, the Euceros larvae are internal parasites, but during the last three or four stadia they are external parasites.

Revision: Barron, 1977 (1976). Nat. Canad. 103: 285-375.

Taxonomy: Perkins, 1959. Handb. Ident. Brit. Ins., v. 7, pt. 2 (ai), p. 14. -Townes, 1969. Amer. Ent. Inst., Mem. 11: 193-194.

Morphology: Finlayson, 1960. Canad. Ent. 92: 34, 37 (final-instar larva). - Tripp, 1961. Canad. Ent. 93: 41-43, 45-48, 49, 56, 57 (ovariole, egg, first-instar larva, final-instar larva).

-Varley, 1965 (1964). Ent. Monthly Mag. 100: 114, 115-116 (first-instar larva).

albomarginatus Cushman. N. H., N. Y., Pa., Ohio.

Scorpioms(!) albomarginatus Ashmead, 1902. In Slosson, Ent. News 13: 320. Nomen nudum.

Euceros albomarginatus Cushman, 1922. U. S. Naíl. Mus., Proc. 61 (8): 12.. angulicornis Walley. B. C.

Euceros angulicornis Walley, 1932. Canad. Ent. 64: 246. ठ์, १.

canadensis Cresson. Que., N. H., Vt., N. Y., Ont., Ohio, Mich.

Euceros Canadensis Cresson, 1869. Canad. Ent. 1: 103. $\%$.

digitalis Walley. Ont.

Euceros digitalis Walley, 1932. Canad. Ent. 64: 242. ठ.

faciens Davis. Wash., Oreg. Ecology: Reared from a parasite of Neodiprion tsugae Midd.

Euceros faciens Davis, 1897. Amer. Ent. Soc., Trans. 24: 256. ơ.

flavescens Cresson. Conn., W. Va.

Euceros flavescens Cresson, 1869. Canad. Ent. 1: 105. ठ, ․

frigidus Cresson. Que., Maine, Ont., Man., B. C. Host: Casinaria semiothisae Wly.?, Endasys subclavatus (Say), Lamachus sp., Olesicampe lophyri (Riley), sp. of Anomaloninae near Therion, Tryphoninae.

Euceros frigidus Cresson, 1869. Canad. Ent. 1: 105..

Biology: Finlayson, 1960. Canad. Ent. 92: 34, 36. - Tripp, 1961. Canad. Ent. 93: 40-58. medialis Cresson. Que. s. to N. C., w. to Alta.

Euceros medialis Cresson, 1869. Canad. Ent. 1: 105. $\%$.

neodiprioni Walley. Que., Md. Ecology: Reared from a parasite of Neodiprion sp.

Euceros neodiprioni Walley, 1932. Canad. Ent. 64: 245. ठ。, ‡.

obesus Davis. N. Y., Ill.

Euceros obesus Davis, 1897. Amer. Ent. Soc., Trans. 24: 255..

sanguineus Davis. Colo.

Euceros sanguineus Davis, 1897. Amer. Ent. Soc., Trans. 24: 255. ð, ९.

thoracicus Cresson. Que., Maine, N. H., Conn., N. Y., Pa., Ont., Man. Ecology: Reared from parasites of Caripeta divisata Wlk., Hydriomena divisaria (Wlk.), Semiothisa

"granitata" auct., Neodiprion sp., N. swainei Midd., N. sp. in virginiana complex, and Pristiphora (Htg.).

Euceros Couperii Cresson, 1869. Canad. Ent. 1: 104. ठे.

Euceros thoracicus Cresson, 1869. Canad. Ent. 1: 105. o.

Euceros couperi Dalla Torre, 1901. Cat. Hym., v. 3, p. 326. Emend.

Scorpiorus(!) flavopictus Ashmead, 1902. In Slosson, Ent. News 13: 6. Nomen nudum.

Euceros vierecki Hertzog, 1909. Ent. News 20: 245. “ $\% "=?$.

Euceros decorus Walley, 1932. Canad. Ent. 64: 244. ठ。, + .

\section{SUBFAmily ADELOGNATHINAE}

\section{Genus ADELOGNATHUS Holmgren}

Adelognathus Holmgren, 1857 (1855). Svenska Vetensk.-Akad. Handl. (n. f.) 1: 196. 
Type-species: Adelognathus brevicomis Holmgren. Desig. by Viereck, 1912.

Pammicra Foerster, 1868. Naturh. Ver. Rheinlande, Verh. 25: 181.

Type-species: Hemiteles dorsalis Gravenhorst. By subsequent monotypy from inclusion by Thomson, 1883.

Synaema Foerster, 1868. Naturh. Ver. Rheinlande, Verh. 25: 201.

Type-species: Adelognathus brevicornis Holmgren. Monotypically included and desig. by Viereck, 1914. Perkins (1962) incorrectly stated that species had been included by Szepligeti (1911), but Szepligeti merely placed Synaema as a synonym of Adelognathus, which does not constitute inclusion of species.

Notomeris Foerster, 1868. Naturh. Ver. Rheinlande, Verh. 25: 201.

Type-species: Adelogmathus difformis Holmgren. By subsequent monotypy from inclusion by Thomson, 1888. According to Perkins (1943) the species identified as A. difform is Holmgren by Thomson is A. thomsoni Schmiedeknecht.

Cnemischys Foerster, 1868. Naturh. Ver. Rheinlande, Verh. 25: 201.

Type-species: Adelognathus (Cnemischus) pilosus Thomson. Desig. by Townes, 1944 from two species included by Thomson, 1888 .

Pammicrus Thomson, 1883. Opusc. Ent. 9: 880. Emend.

Cnemischus Thomson, 1888. Opusc. Ent. 12: 1277. Emend.

Townes (1969) treated Adelognathus as the only genus in the Adelognathinae; the genus is Holarctic and of moderate size. Several species have been reared from larvae or sawflies; in one case the Adelognathus larvae are known to have fed externally and gregariously.

Taxonomy: Szepligeti, 1911. In Wytsman, Gen. Ins., fasc. 144, p. 50. - Perkins, 1943. Roy.

Ent. Soc. London, Trans. 93: 95-97. - Townes and Townes, 1951. In Muesebeck et al., U. S. Dept. Agr., Agr. Monog. 2: 209-210. - Perkins, 1962. Brit. Mus. (Nat. Hist.) Ent., Bul. 11: 414, 439, 442, 455. -Townes, 1969. Amer. Ent. Inst., Mem. 11: 207-208.

americanus Cushman. N. H. Ecology: The holotype was collected on the alpine region of Mt. Washington, N. H.

Trachyporthus(!) americanus Ashmead, 1897. In Slosson, Ent. News 8: 237. Nomen nudum.

Adelognathus americanus Cushman, 1922. U. S. Natl. Mus., Proc. 61 (8): 2..

brevicornis Holmgren. Que., N. Y.; Europe.

Adelognathus brevicornis Holmgren, 1857 (1855). Svenska Vetesk.-Akad. Handl. (n. s.) 1: 197. $\delta$, . .

Adelognathus limbatus Thomson, 1888. Opusc. Ent. 12: 1275. ?.

dorsalis (Gravenhorst). Que., Maine, N. H., Md., N. C., Ohio, Mich.; Europe.

Hemiteles dorsalis Gravenhorst, 1829. Ichn. Europaea, v. 2, p. 838. ठ์, ․

Hemiteles tener Provancher, 1874. Nat. Canad. 6: 333. " 0 " $=$.

Notomiris(!) glabrosus Davis, 1896. In Slosson, Ent. News 7: 264. Nomen nudum.

Notomeris glabrosus Davis, 1897. Amer. Ent. Soc., Trans. 24: 242..

Adelognathus deganti Cushman, 1933. U. S. Natl. Mus., Proc. 82 (14): 14..

flavopictus Davis. N. Y., W. Va., Mich., Ill., Minn., s.w. B. C., Oreg. Host: "Nematus" sp. The male syntype in the collection of the U. S. Natl. Museum, which bears Hopkins W. Va. no. 3494, was reared by Hopkins (1893) from larvae of "Nematus sp. a" collected in Monongalia Co., W. Va. on "Yellow Locust" (=Gleditsia triacanthos?); it emerged on May 30.

Adelognathus briviceps Ashmead, 1893. In Hopkins, W. Va. Agr. Expt. Sta., Bul. 32: 216. Nomen nudum.

Adelognathus flavopictus Davis, 1897. Amer. Ent. Soc., Trans. 24: 242. ơ, १.

pallipes (Gravenhorst). Que., N. H., N. Y., Md., D. C., N. C., Minn.; Europe. Host: Macremphytus testaceus (Nort.), sawfly larvae.

Plectiscus pallipes Gravenhorst, 1829. Ichn. Europaea, v. 2, p. 981. \&.

Adelognathus Ruthei Holmgren, 1857 (1855). Svenska Vetensk.-Akad. Handl. (n. f.) 1: 198. o, ?.

Catalytus pallipes Ashmead, 1890 (1889). U. S. Natl. Mus., Proc. 12: 419. đo, ․ Preoec. in Adelognathus by Gravenhorst, 1829 and Holmgren, 1857.

Plectiscus pallidipes Dalla Torre, 1901. Cat. Hym., v. 3, p. 24. Emend. of P. pallipes Gravenhorst. 
Hemiteles pallidipes Dalla Torre, 1902. Cat. Hym., v. 3, p. 660. Emend. of C. pallipes Ashmead; preocc. in Adelognathus by Dalla Torre, 1901, p. 24 and p. 31.

Adelognathus persimilis Cushman, 1922. U. S. Natl. Mus., Proc. 61 (8): 3. N. name for $C$. pallipes Ashmead.

Taxonomy: Thomson, 1883. Opusc. Ent. 9: 878-879 (syn.). -Townes, 1944. Amer. Ent. Soc., Mem. 11: 144 (syn.).

\section{SUBFAMILY XORIDINAE}

There are four genera, all of which have Nearctic species.

Revision: Rohwer, 1920. U. S. Natl. Mus., Proc. 57: 428-444, 451-460.

\section{Genus ISCHNOCEROS Gravenhorst}

Ischnoceros Gravenhorst, 1829. Ichn. Europaea, v. 2, p. 949.

Type-species: Ichneumon rusticus Geoffroy. Desig. by Viereck, 1914.

Mitroboris Holmgren, 1859. Svenska Vetensk.-Akad., Ofvers. af ... Forhandl. 16: 131.

Type-species: Xorides (Odontomemis) cornutus Ratzeburg. Monotypic. The

type-species is regarded as a synonym of Ischnoceros misticus (Geoffroy).

This is a small Holarctic genus.

clivulus Townes. Northeastern Calif.

Ischnoceros clivulus Townes, 1957. Ent. Soc. Wash., Proc. 59: 21. @.

\section{Genus APLOMERUS Provancher}

Platysoma Provancher, 1885. Canad. Ent. 17: 115. Preocc. by Leach, 1817; Lienard, 1832; and Brandt, 1835.

Type-species: Platysoma tibialis Provancher. Monotypic.

A plomerus Provancher, 1886. Addit. Corr. Faune Ent. Canada Hym., p. 119. N. name for Platysoma Provancher.

Anodontomerus Ashmead, 1900. U. S. Natl. Mus., Proc. 23: 61, 163. Unnecessary n. name for Aplomerus Provancher; Ashmead did not state his reason for proposing his n. name for Aplomerus (on page 61 he erroneously indicated that he was describing a "new genus"), and one can only suppose that he may have thought Aplomerus to be preocc. by Aplomera Macquart, 1839 .

Haplomerus Dalla Torre, 1901. Cat. Hym., v. 3, p. 392. Invalid name proposed in synonymy.

This is a small Holarctic and Neotropic (one undescribed Mexican sp.) genus.

Revision: Townes (H.) and Townes (G.), 1960 In Townes (H.) and Townes (M.), U. S. Natl.

Mus. Bul. 216 (pt. 2): 439-447.

arugosus Townes and G. Townes. Northwestern Wyo. Ecology: The unique holotype was collected at an elevation of $6500 \mathrm{ft}$. in Shoshone Canyon, Wyo.

Aplomerus arugosus Townes (H.) and Townes (G.), 1960. In Townes (H.) and Townes (M.), U. S. Natl. Mus. Bul. 216 (pt. 2): 446..

buprestivorus Rohwer. Northwestern Ariz., s.w. Oreg., n.e. and s.w. Calif. Ecology: The holotype and paratype were collected as cocooned pupae or prepupae in a buprestid gallery in Cercocarpus parvifolius at Ashland, Oreg.

Aplomerus buprestivoris Rohwer, 1920. U. S. Natl. Mus., Proc. 57: 453. \&.

lineatulus (Say). Que. s. to e. N. C., w. to Wis., Iowa, and n.e. Kans.

Anomalon lineatulus Say, 1836. Boston Jour. Nat. Hist. 1: 244. ठ.

Aplomeris foutsi Rohwer, 1920. U. S. Natl. Mus., Proc. 57: 454. ?.

Aplomerus decorus Viereck, 1926. Canad. Ent. 58: 55. ․

Taxonomy: Cushman and Gahan, 1921. Ent. Soc. Wash., Proc. 23: 157 (syn.). -Townes, 1944. Amer. Ent. Soc., Mem. 11: 115 (syn.). 
robustus Townes and G. Townes. Southwestern B. C., w. Wash., w. Oreg., n. Calif. Ecology: Specimens have been reared from dead coniferous trees infested with Buprestidae and Cerambycidae.

Aplomemis robustus Townes (H.) and Townes (G.), 1960. In Townes (H.) and Townes (M.),

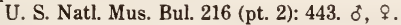

tibialis (Provancher). Southern B. C., Oreg., n. Calif. Ecology: A large series was collected on fallen trunks of Pinus contorta which had been killed by Dendroctonus and had disintegrated to the point of losing nearly all their bark.

Platysoma tibialis Provancher, 1885. Canad. Ent. 17: 115.

\section{Genus ODONTOCOLON Cushman}

Odontomerus Gravenhorst, 1829. Ichn. Europaea, v. 3, p. 851. Preocc. by Leach, 1819. Type-species: Ichneumon dentipes Gmelin. Desig. by Westwood, 1840.

Odontocolon Cushman, 1942. Ent. Soc. Wash., Proc. 44: 179. N. name for Odontomerns Gravenhorst.

This is a large Holarctic genus.

Revision: Townes and Townes, 1960. U. S. Natl. Mus. Bul. 216 (pt. 2): 448-489.

abdominale abdominale (Cresson). Southeastern Wyo., Colo., n.w. Mont., n. Idaho, n.e. Utah, Ariz.

Odontomerus abdominalis Cresson, 1865. Ent. Soc. Phila., Proc. 4: 289..

abdominale fergusoni Townes. Southwestern Alta., s.e. B. C., n.e. Wash.

Odontocolon abdominale fergusoni Townes, 1960. In Townes and Townes, U. S. Natl. Mus. Bul. 216 (pt. 2): 464 . ठ, ․.

aethiops (Cresson). Colo., s.w. Alta., n.w. Mont., s.e. B. C., n. Idaho, n. Calif. Host: Cerambycid in Pinus contorta.

Odontomerus aethiops Cresson, 1865. Ent. Soc. Phila., Proc. 4: 289. ठ, ؟.

alaskense (Rohwer). South-coastal Alaska. Closely related to the European 0 . punctulatum (Thomson); alaskense had been suppressed as a synonym of punctulatum by Townes (1944) but was removed from synonymy by Townes and Townes (1960).

Odontomerus alaskensis Rohwer, 1913. U. S. Natl. Mus., Proc. 45: 360..

Taxonomy: Townes, 1944. Amer. Ent. Soc., Mem. 11: 112-113. -Townes and Townes, 1960. U.

S. Natl. Mus. Bul. 216 (pt. 2): 460.

albotibiale (Bradley). N. S. s. to n. Fla., w. to Minn. and Iowa.

Odontomerus albotibialis Bradley, 1918. Brooklyn Ent. Soc., Bul. 13: 103. \&.

Odontomerus striatus Cushman, 1930. U. S. Natl. Mus., Proc. 77 (3): 14. ९. Preocc. by Brulle, 1846.

Odontocolon aciculatus Cushman, 1942. Ent. Soc. Wash., Proc. 44: 182. N. name for Odontomerus striatus Cushman.

Taxonomy: Cushman, 1942. Ent. Soc. Wash., Proc. 44: 182 (misidentification corrected).

atripes (Rohwer). N. S. w. to w. Alta., s. to e. N. C., n.e. Ala., and n. Ill.

Odontomerus atripes Rohwer, 1913. U. S. Natl. Mus., Proc. 45: 358. ¿, ؟.

bicolor (Cresson). Pa., n. Va., n.w. S. C., n. Ga., n.e. Ala., e. Tex. Ecology: Two specimens from Call, Texas were apparently collected as cocooned pupae or prepupae from beneath the bark of logs and stumps of Pinus palustris which had been cut several years before.

Odontomerus bicolor Cresson, 1870. Amer. Ent. Soc., Trans. 3: 169. $\$$.

brevicaudum (Cushman). Southwestern Alta., n.w. Mont., n. Idaho, s. B. C., Wash.

Odontomerus brevicaudus Cushman, 1930. U. S. Natl. Mus., Proc. 77 (3): 7. ९. Because Cushman used the spelling brevicaudus instead of brevicauda, the name is to be regarded as an adjective rather than a noun.

canadense (Provancher). N. S., Que., Maine, N. H., N. Y., w. N. C., Ont., Mich., n.e. Minn. Host: Serropalpus sp. in Fraser fir.

Odontomemis Canadensis Provancher, 1877. Nat. Canad. 9: 16. \&.

Odontomerus tibialis Cushman, 1930. U. S. Natl. Mus., Proc. 77 (3): 11. đ’, ९. 
Taxonomy: Cushman, 1942. Ent. Soc. Wash., Proc. 44: 182 (syn. and correction of misidentification of canadense).

cilipes Townes. Southeastern Ariz. Ecology: Known only from the holotype which was collected in the Chiricahua Mts., Ariz.

Odontocolon cilipes Townes, 1960. In Townes and Townes, U. S. Natl. Mus. Bul. 216 (pt. 2): 454 . . .

curtum Townes. Northwestern Calif. Ecology: Two of the paratypes emerged from "Laurel," presumably Umbellaria californica.

Odontocolon curtum Townes, 1960 In Townes and Townes, U. S. Natl. Mus. Bul. 216 (pt. 2): 470 . ठ․ 9 .

depressum Townes. Colo. Ecology: Known only from the holotype which was collected at an elevation of $9400 \mathrm{ft}$. in Rocky Mt. Natl. Park, Colo.

Odontocolon depressum Townes, 1960. In Townes and Townes, U. S. Natl. Mus. Bul. 216 (pt. 2): 459. ?.

dichroum (Rohwer). Northern Idaho, s. B. C., Wash., Oreg., n. Calif.

Odontomerus dichrous Rohwer, 1913. U. S. Natl. Mus., Proc. 45: 361. ๆ.

dreisbachi Townes. Northwestern Mich. Ecology: Known only from the holotype which was collected on Isle Royale, Mich.

Odontocolon dreisbachi Townes, 1960. In Townes and Townes, U. S. Natl. Mus. Bul. 216 (pt. 2): 480 . .

formicoides Townes. Northern Ariz. Ecology: Known only from the holotype which was collected in a stand of Populus, Picen, and Abies at an elevation of $9700 \mathrm{ft}$. on Humphreys Peak, Ariz.

Odontocolon formicoides Townes, 1960. In Townes and Townes, U. S. Natl. Mus. Bul. 216 (pt. 2): 458 . $\delta$.

mellipes (Say). Mass. w. to S. Dak., s. to e. and w. N. C., n.w. S. C., and n.e. Kans. Host: Parandra (Neandra) brunnea (F.).

Anomalon mellipes Say, 1829. Contrib. Maclurian Lyceum to Arts and Sci. 1: 75. . Odontomerns errans Rohwer, 1913. U. S. Natl. Mus., Proc. 45: 360..

ochropus Townes. Que. w. to s. B. C., s. to n.w. S. C., e. Tenn., s. Minn., Ariz. and n. Idaho. Ecology: Three paratypes from Falls Church, Va. emerged from pine infested with Anoplodera rubrica (Say) and A. vagans (Oliv.); one paratype from Inglenook, $\mathrm{Pa}$. emerged from hemlock infested with A. rubrica and Metacmaeops vittatus (Swed.); one paratype from D. C. was collected as an adult in its cocoon, which was extracted from rotten beech wood.

Odontocolon ochropus Townes, 1960. In Townes and Townes, U. S. Natl. Mus. Bul. 216 (pt. 2): $482 . \dot{\delta}$, .

parvum Townes. Northwestern Wyo., n. Colo., n. Idaho, s. B. C., Wash., n.w. Oreg.

Odontocolon parvum Townes, 1960. In Townes and Townes, U. S. Natl. Mus. Bul. 216 (pt. 2): $472 . \delta$, $\%$.

polymorphum Cushman. Southwestern B. C., n.w. Wash., w. Oreg. Ecology: Thirteen paratypes were reared from a branch of Alnus (presumably rubra) infested with Anobiidae, and two other specimens emerged from a board of Umbellaria californica infested by Lyctus cavicollis LeC. and the anobiid, Ptilinus basilis LeC. The adults can be wingless, brachypterous (brachypterous male not known), or fully winged.

Odontocolon polymorphum Cushman, 1942. Ent. Soc. Wash., Proc. 44: 180. ठ̀, ?.

pullum Townes. Southern B. C., e. Calif. The four type specimens included one wingless female.

Odontocolon pullum Townes, 1960. In Townes and Townes, U. S. Natl. Mus. Bul. 216 (pt. 2): $456 . \delta, \%$.

punctatum (Cushman). Northwestern Wyo., n. Idaho, s. B. C., w. Wash., e. Oreg., and e. Calif. Ecology: Notes in the U.S. Natl. Museum indicate that the holotype was "emerging? from [a] wood wasp? burrow in [a] dead grand fir," from which Leptura obliterata Hald. also emerged (cf. Cushman, 1930); one specimen was extracted from Abies along with 
two immature adults and a larva of a siricid (="Tremex") and is labeled (incorrectly?) as being a parasite of "Tremex."

Odontomerus punctatus Cushman, 1930. U. S. Natl. Mus., Proc. 77 (3): 12..

sierrae Townes. Eastern Calif.

Odontocolon sierrae Townes, 1960. In Townes and Townes, U. S. Natl. Mus. Bul. 216 (pt. 2): 471. $\delta$, ‥

strangaliae (Rohwer). Que. s. to N. C., w. to e. Minn. and central Ala. Host: Strangalina luteicornis (F.) in grape, "Leptura" sp. in rotten oak branch.

Odontomerus strangaliae Rohwer, 1917. U. S. Natl. Mus., Proc. 53: 158..

vicinum (Cresson). Que. w. to s.e. B. C., s. to n. Va., s. Ohio, n. Colo., and e. Oreg. Host:

Dicerca divaricata (Say) in Aluus sp., D. divaricata? in Betula nigra, D. obscura F. in hackberry.

Odontomerus vicinus Cresson, 1870. Amer. Ent. Soc., Trans. 3: 168. ठં.

\section{Genus XORIDES Latreille}

There are ten subgenera, only two of which have Nearctic species.

Revision: Townes and Townes, 1960. U. S. Natl. Mus. Bul. 216 (pt. 2): 489-530 (subgenera of world and Nearctic spp.).

\section{Genus XORIDES Subgenus EXOMUS Townes}

Xorides subg. Exomus Townes, 1960. In Townes and Townes, U. S. Natl. Mus. Bul. 216 (pt. 2): 496.

Type-species: Anomalon humerale Say sensu Townes and Townes (1960). Orig. desig.

A single variable species in known.

humeralis (Say). Newfoundland (Labrador) w. to B. C., s. to Fla., Tex., s.e. Ariz., and s. Calif.; Mexico. Host: Neoclytus acuminatus (F.) in Ilex opaca, Phymatodes testaceous (L.) in red oak, Xylotrechus undulatus (Say)? in Abies lasiocarpa. The six "subspecies" of Townes and Townes (1960) are too poorly defined and based upon too few specimens to be worth recognizing.

Anomalon humerale Say, 1829. Contrib. Maclurian Lyceum to Arts and Sci. 1: 74..+

Xylonomus australis Cresson, 1870. Amer. Ent. Soc., Trans. 3: 167..

Xylonomus Lavallensis Provancher, 1874. Nat. Canad. 6: 59..

Xylonomus (Moerophora) piceatus Rohwer, 1913. U. S. Natl. Mus., Proc. 45: 357. N. syn.

Xorides (Exomus) humeralis mexicanus Townes, 1960. In Townes and Townes, U. S. Natl. Mus. Bul. 216 (pt. 2): 497. ․ N. syn.

Xorides (Exomus) humeralis sierrae Townes, 1960. In Townes and Townes, U. S. Natl. Mus. Bul. 216 (pt. 2): 500. ठ, ‥ N. syn.

Xorides (Exomus) humeralis excomptus Townes, 1960. In Townes and Townes, U. S. Natl. Mus. Bul. 216 (pt. 2): 500. ठ, ๆ. N. syn.

Xorides (Exomus) humeralis chiricensis Townes, 1960. In Townes and Townes, U. S. Natl. Mus. Bul. 216 (pt. 2): 501. ๆ. N. syn.

\section{Genus XORIDES Subgenus Xorides Latreille}

Xorides Latreille, 1809. Gen. Crust. Ins., v. 4, p. 4.

Type-species: Ichneumon indicatorius Latreille. Monotypic.

Xylonomus Gravenhorst, 1829. Ichn. Europaea, v. 3, p. 819.

Type-species: Ichneumon irrigator Fabricius. Desig. by Curtis, 1831.

Sterotrichus Foerster, 1868. Naturh. Ver. Rheinlande, Verh. 25: 169.

Type-species: Xylonomus pilicornis Gravenhorst. By subsequent monotypy from inclusion by Brischke, 1880. The type-species is regarded as a synonym of $X$. fuligator (Thunberg).

Sichelia Foerster, 1868. Naturh. Ver. Rheinlande, Verh. 25: 169.

Type-species: Xylonomus filiformis Gravenhorst. By subsequent monotypy from inclusion by Schmiedeknecht, 1888 . 
Rhadina Foerster, 1868. Naturh. Ver. Rheinlande, Verh. 25: 170. Preoce. by Billberg, 1828.

Type-species: Xylonomus ater Gravenhorst. Monotypically included and desig. by Schmiedeknecht, 1888.

Rhadinopimpla Schulz, 1906. Zool. Ann. 4: 23. N. name for Rhadina Foerster.

Xylonomimus Clement, 1938. Festschr. Embrik Strand, v. 4, p. 539.

Type-species: Xylonomus gracilicornis Gravenhorst. Orig. desig.

Neoxylonomus Clement, 1838. Festschr. Embrik Strand, v. 4, p. 566. Preocc. by Szepligeti, 1914.

Type-species: Neoxylonomus strandi Clement. Monotypic.

Amphixylonomus Benoit, 1952. Soc. Ent. de Belg., Bul. et Ann. 88: 136. Described as a subgenus, but treated nomenclaturally as a genus.

Type-species: Amphixylonomus konduensis Benoit. Monotypic and orig. desig.

This is a large subgenus of Holarctic, Oriental, Australian? (one sp. described as being from New Guinea), and Ethiopian (one sp.) distribution.

albopictus (Cresson). Que. s. to n. Ga., w. to central N. Dak., e. Nebr., and n.e. Tex. Ecology: Parasite of Coleoptera which bore in hardwoods. Host: Saperda discoidea F., S. tridentata Oliv., Scolytus multistriatus (Mar.)?

Xyolonomus albopictus Cresson, 1870. Amer. Ent. Soc., Trans. 3: 168. ‡.

Xorides Canadensis Provancher, 1875. Nat. Canad. 7: 248. ठ.

Xylonomus (Moerophora) duplicatus Rohwer, 1913. U. S. Natl. Mus., Proc. 45: 356. ठ。.

atrox Townes. Southeastern B. C. Known only from the holotype.

Xorides (Xorides) atrox Townes, 1960. In Townes and Townes, U. S. Natl. Mus. Bul. 216 (pt. 2): 520 . .

boharti Townes. Northwestern Calif.

Xorides (Xorides) boharti Townes, 1960. In Townes and Townes, U. S. Natl. Mus. Bul. 216 (pt. 2): 508. ठ, ㅇ.

calidus (Provancher). Que. w. to s.e. Sask., s. to e. N. C. and Tex. Host: Amniscus macula (Say) in Castanea dentata, Curius dentatus Newm. in juniper, cerambycid in Castanea dentata.

Xylonomus calidus Provancher, 1886. Addit. Corr. Faune Ent. Canada Hym., p. 119..

Xylonomus pulcher Ashmead, 1890 (1889). U. S. Natl. Mus., Proc. 12: 450..

Aplomerus nasonii Davis, 1895. Amer. Ent. Soc., Trans. 22: 32. ठ.

Xorides callidus(!) Townes and Townes, 1951. U. S. Dept. Agr., Agr. Monog. 2: 205.

californicus (Cresson). Colo., n. N. Mex., n. Ariz., w. Mont., n. Idaho, s. B. C., Wash., Oreg., n. Calif. Host: Buprestis viridisuturalis N. and W. in Populus trichocarpa, Chalcophora angulicollis (LeC.) in Pinus ponderosa, Alaus oculatus (L.)?, sesiid? in Pinus ponderosa.

Xylonomus californicus Cresson, 1879 (1878). Acad. Nat. Sci. Phila., Proc. 30: 380..

Xylonomus catomus Davis, 1898 (1897). Amer. Ent. Soc., Trans. 24: 372. ₹.

cincticornis cincticornis (Cresson). Southwestern Alta. and s. B. C., s. to n. N. Mex., n. Idaho, and e. and n.w. Oreg. Host: Anoplodera chrysocoma (Kby.)? in Pinus ponderosa scopulorum.

Xylonomus cincticornis Cresson, 1865. Ent. Soc. Phila., Proc. 4: 288.. .

Xylonomus (Moerophora) modestus Rohwer, 1913. U. S. Natl. Mus., Proc. 45: 358. ठ.

cincticornis rufus Townes. Central Oreg., n.e. Calif.

Xorides (Xorides) cincticornis rufus Townes, 1960. I $u$ Townes and Townes, U. S. Natl. Mus. Bul. 216 (pt. 2): 530. ठ, ㅇ.

eastoni (Rohwer). Mass., Conn., Wis., s. B. C.

Xylonomus (Moerophora) eastoni Rohwer, 1913. U. S. Natl. Mus., Proc. 45: 356..

frigidus (Cresson). Que., Maine, Vt., Colo., n. Idaho, interior Alaska, s. Yukon, s.w. B. C., n.e. Wash.

Xylonomus frigidus Cresson, 1870. Amer. Ent. Soc., Trans. 3: 168..

Xylonomus (Xylonomus) plesius Rohwer, 1913. U. S. Natl. Mus., Proc. 45: 354..

Xylonomus (Moerophora) yukonensis Rohwer, 1913. U. S. Natl. Mus., Proc. 45: 355 .. 
harringtoni Rohwer. Que., Vt., N. Y., Ont. Host: Dicerca divaricata (Say).

Xylonomus canadensis Harrington, 1891. Canad. Ent. 23: 133. §, ๆ. Preocc. in Xorides by Provancher, 1875.

Xorides harringtoni Rohwer, 1920. U. S. Natl. Mus., Proc. 57: 443. N. name for Xylonomus canadensis Harrington.

insularis (Cresson). Que., Colo., s. N. Mex., s.w. Alta., n. Idaho, n. Utah., s. Ariz., Interior Alaska, s. B. C., Wash., Oreg., n. Calif. Host: "Hylotrupes" sp. in Thuja plicata, Semanotus amethystinus (LeC.), S. ligneus am plus (Casey), Tetropium sp. in Larix occidentalis, $T$. sp. in Picea, cerambycid in Abies, cerambycid in Pinus monticola, Melanophila sp.?, M. drummondi (Kby.), buprestid in Pseudotsuga menziesii,

"Temnochila virescens [F.]" in redwood, "scolytid" in Pseudotsuga menziesii.

Poemeria(!) insularis Cresson, 1879 (1878). Acad. Nat. Sci. Phila., Proc. 30: 380..

maudae (Davis). Western Wash., w. Oreg., n.w. Calif. Ecology: One specimen emerged from Pseudotsuga menziesii.

Xylonomus maudae Davis, 1895. Amer. Ent. Soc., Trans. 22: 32. ․

medius Townes. Northern Idaho, n.w. Calif.

Xorides (Xorides) medius Townes, 1960. In Townes and Townes, U. S. Natl. Mus. Bul. 216 (pt. 2): 511. ठ, ?.

neoclyti (Rohwer). Colo., N. Mex., Ariz. Host: Neoclytus caprea (Say), Semanotus ligneus conformis (Casey), Chrysobothris femorata (Oliv.).

Moerophora neoclyti Rohwer, 1915. U. S. Natl. Mus., Proc. 49: 223. ð.

peniculus Townes. N. Y., N. J., Pa., e. S. C., e. Tex. Ecology: One paratype was extracted from the wood of Celtis occidentalis, and another paratype and the holotype emerged from the same host material.

Xorides (Xorides) peniculus Townes, 1960. In Townes and Townes, U. S. Natl. Mus. Bul. 216 (pt. 2): 506. ठे, ९.

pictus Townes. Western Calif.

Xorides (Xorides) pictus Townes, 1960. In Townes and Townes, U. S. Natl. Mus. Bul. 216 (pt. 2): 505 .

planus Townes. Colo., Ariz.

Xorides (Xorides) planus Townes, 1960. In Townes and Townes, U. S. Natl. Mus. Bul. 216 (pt. 2): 511. ठ, ?.

rileyi (Ashmead). N. Y. s. to n. Fla., w. to Minn. and Mo. Host: Anoplodera nitens (Forster)?, Phymatodes aereus (Newm.), P. testaceus (L.), Physocnemum andreae (Hald.), Xylotrechus colonus (F.), buprestid? in black oak, borer under willow bark.

Xylonomus rileyi Ashmead, 1889. In Fox, U. S. Dept. Agr., Insect Life 2: 197. Nomen nudum.

Xylonomus rileyi Ashmead, 1890 (1889). U. S. Natl. Mus., Proc. 12: 450. \&. The type-locality is presumably Kirkwood, Mo. because notes in the U. S. Natl. Museum pertaining to the number on the label of the holotype (Bureau of Entomology no. 2384) say: "parasite (and its cocoon) border [sic; presumably borer] under willow bark, April 20,1880 , from Miss Murtfeldt."

Xylonomus (Xylonomus) rufïcoxis Rohwer, 1913. U. S. Natl. Mus., Proc. 45 (no. 1986): 354. ㅇ.

Xylonomus (Xylonomus) lepturae Rohwer, 1913. U. S. Natl. Mus., Proc. 45 (no. 1991): 534. \%.

rudis Townes. Eastern Calif. Known only from the holotype.

Xorides (Xorides) ridis Townes, 1960. In Townes and Townes, U. S. Natl. Mus. Bul. 216 (pt. 2): 510.. .

semirufus Townes, Northern Fla. Known only from the holotype.

Xorides (Xorides) semimufus Townes, 1960. In Townes and Townes, U. S. Natl. Mus. Bul. 216 (pt. 2): 506. ㅇ.

stigmapterus floridanus (Ashmead). Northwestern S. C., s.e. Ga., n. Fla., s.e. Tex.

Xylonomus floridanus Ashmead, 1890 (1889). U. S. Natl. Mus., Proc. 12: 451.. 
stigmapterus stigmapterus (Say). Newfoundland (Labrador), n. Man., n. B. C., and s. Alaska s. to n.w. S. C., lowa, e. N. Dak., and central Alta. Host: Anoplodera proxima (Say), Dryobius sexnotatus Linsley?

Acoenitus stigmapterus Say, 1824. In Keating, Narr. Long's 2nd Exped., v. 2 (App.), p. 325 . ㅇ.

Xylonomus tartarus Morley, 1913. Fauna Brit. India, Hym., v. 3, p. 78. \&. According to Townes (1961) the holotype is erroneously labeled "India," which is presumed to be an error for Indiana.

Taxonomy: Townes, 1961. Ent. Soc. Wash., Proc. 63: 113, 175.

\section{SUBFAMILY CRYPTINAE}

This is the largest of ichneumonid subfamilies. Townes (1970) recognized 307 genera which he divided among three tribes, the Hemitelini (= Gelini), the Aptesini (=Echthrini), and the Cryptini (= Mesostenini). Most Cryptinae are external parasites.

Taxonomy: Townes, 1970 (1969). Amer. Ent. Inst., Mem. 12, 537 pp. (genera of world).

\section{TRIBE HEMITELINI}

This tribe includes most of the smaller Cryptinae. Many of the species oviposit into the egg cocoons of spiders or cocoons of beneficial insects such as Chrysopidae, Braconidae, or other Ichneumonidae. Species of a number of genera attack the puparia or larvae of cyclorrhaphous Diptera.

\section{SUBTRIBE CHIROTICINA}

Most of the species of this subtribe occur in the tropics or subtropics. There are 18 genera, but only the worldwide genus Chirotica has Nearctic species.

\section{Genus CHIROTICA Foerster}

Chirotica Foerster, 1868. Naturh. Ver. Rheinlande, Verh. 25: 173.

Type-species: Hemiteles insignis Gravenhorst. By subsequent monotypy from inclusion by Schmiedeknecht, 1897.

Allocota Foerster, 1868. Naturh. Ver. Rheinlande, Verh. 25: 173. Preocc. by Motschoulsky, 1860.

Type-species: Allocota confederatae Ashmead. By subsequent monotypy from inclusion by Ashmead, 1896.

Spinolia Foerster, 1868. Naturh. Ver. Rheinlande, Verh. 25: 173. Preocc. by Dahlbom, 1854; Costa, 1858; and Robineau-Desvoidy, 1863.

Type-species: Hemiteles maculipennis Gravenhorst. By subsequent monotypy from inclusion by Schmiedeknecht, 1897.

Syneches Foerster, 1868. Naturh. Ver. Rheinlande, Verh. 25: 173. Preocc. by Walker, 1852.

Type-species: Hemiteles thyridoptery $x$ Riley. By subsequent monotypy from inclusion by Ashmead, 1900 .

Diaglypta Foerster, 1868. Naturh. Ver. Rheinlande, Verh. 25: 176.

Type-species: Diaglypta radiata Ashmead. By subsequent monotypy from inclusion by Ashmead, 1895.

Deuterospinolia Dalla Torre, 1902. Cat. Hym. v. 3, p. 678. N. name for Spinolia Foerster.

Hymenosyneches Viereck, 1912. U. S. Natl. Mus., Proc. 42: 149. N. name for Syneches Foerster.

Aphadnus Cameron, 1907. Ann. and Mag. Nat. Hist. (7) 20: 26.

Type-species: Aphadnus rufipes Cameron. Monotypic. A. rufipes is regarded as a synonym of Chirotica decorata (Tosquinet), which is one of the intermediate species tending to merge Chirotica and Paraphylax Foerster (see Townes, 1970).

Between 1944 and 1962 the name Phobetes Foerster was used for this genus in North America. Perkins' (1962) correction of the type-species of Phobetes from Phobetes albinopennis Davis to Tryphon fuscicomis Holmgren transferred the name Phobetes to the Ctenopelmatinae, Eu- 
ryproctini. A similar correction also made by Perkins (1962), regarding the type-species of Chirotica, resulted in Chirotica being removed from synonymy with Gelis to take its present application.

Members of this genus parasitize Psychidae.

Taxonomy: Perkins, 1962. Brit. Mus. (Nat. Hist.) Ent., Bul. 11: 389, 413-414, 445. -Townes, 1970 (1969). Amer. Ent. Inst., Mem. 12: 21.

confederatae (Ashmead). Fla., Mo., La.; Cuba, Guatemala, Honduras. Host: Astala confederata (Grt.), Cryptothelea nigrita (B. and M.).

Hemiteles alaefasciatus Riley, 1890. In Riley and Howard, U. S. Dept. Agr., Insect Life 3: 153. Nomen nudum.

Allocota confederatae Ashmead, 1896. Amer. Ent. Soc., Trans. 23: 208. ๆ.

conspicua (Cresson). N. C., Tex. Host: Psychid.

Hemiteles conspicuus Cresson, 1872. Amer. Ent. Soc., Trans. 4: 161. $\subsetneq$.

Taxonomy: Walley, 1941. Canad. Ent. 73: 165.

sheppardi (Walley). Que., Ont., Fla., Idaho, B. C., Wash. Host: Hyaloscotes pithopoera (Dyar).

Allocota sheppardi Walley, 1941. Canad. Ent. 73: 165..

thyridopteryx (Riley). Mass. s. to Fla., w. to S. Dak. and s. Calif.; Mexico. Host: Astala edwardsii (Heyl.), Cryptoihelea gloveri (Pack.), C. nigrita (B. and M.), Oiketicus abbotii Grt., Thyridopteryx ephemeraeformis (Haw.). Three to six individuals emerge from a single host.

Hemiteles? thyridopteryx Riley, 1869. Mo. State Ent., Ann. Rpt. 1: 150. , o.

Hemiteles thyridopterigis Riley, 1881. U. S. Ent. Comn., Bul. 6: 65. Emend.

Phobetes albinopennis Davis, 1898 (1897). Amer. Ent. Soc., Trans. 24: 311. ठ。.

Hemiteles thyridopterigis var. leucozonatus Ashmead, 1890. In Riley and Howard, U. S. Dept. Agr., Insect Life 3: 152. Nomen nudum.

Hemiteles thyridopterigis var. fuscus Riley, 1890. In Riley and Howard, U. S. Dept. Agr., Insect Life 3: 152. Nomen nudum.

Biology: Balduf, 1937. Ent. Soc. Wash., Proc. 39: 177-178.

\section{SUBTRIBE ACROLYTINA}

Some members of this subtribe commonly oviposit into the cocoons of Braconidae or other Ichneumonidae. It is possible that some species may at least occasionally be primary parasites of cocoon spinning Lepidoptera, but I am not aware of information establishing this as fact.

\section{Genus CORMOBIUS Townes}

Cormobius Townes, 1970 (1969). Amer. Ent. Inst., Mem. 12: 32.

Type-species: Cormobius tenuis Townes. Monotypic and orig. desig.

There are two undescribed Nearctic species.

tenuis Townes. Md., S. C. Ecology: Two females (holotype and one paratype) were found crawling over the bark of a large standing dead Quercus.

Cormobius tenuis Townes, 1970 (1969). Amer. Ent. Inst., Mem. 12: 32 . ․

\section{Genus ENCRATEOLA Strand}

Encrates Foerster, 1868. Naturh. Ver. Rheinlande, Verh. 25: 180. Preocc. by Gistel, 1848.

Type-species: Hemiteles (Encratis[!]?) subimpressus Brischke. By subsequent monotypy from inclusion by Brischke, 1892. The type-species is considered to be a synonym of Encrateola laevigata (Ratzeburg).

Encrateola Strand, 1916. Arch. f. Naturgesch. (Abt. A) 81 (5): 77. N. name for Encrates Foerster.

laevigata longicornis (Provancher). Que., N. H., N. Y., Wash., Oreg. E. laevigata laevigata (Ratzeburg) occurs in Europe.

Hemiteles longicornis Provancher, 1882. Nat. Canad. 13: 361. ․

Taxonomy: Townes, 1970 (1969). Amer. Ent. Inst., Mem. 12: 34. -Barron, 1975. Nat. Canad.

102: 498 (lectotype selection). 


\section{Genus EUDELUS Foerster}

Eudelus Foerster, 1868. Naturh. Ver. Rheinlande, Verh. 25: 179.

Type-species: Hemiteles scabriculus Thomson. Monotypically included and desig. by Perkins, 1962.

Idemum Foerster, 1868. Naturh. Ver. Rheinlande, Verh. 25: 179.

Type-species: Hemiteles (Idemum) crassiformis Viereck. By subsequent monotypy from inclusion by Viereck, 1917.

Calliphrurus Foerster, 1868. Naturh. Ver. Rheinlande, Verh. 25: 210.

Type-species: Calliphrurus granulosus Davis. By subsequent monotypy from inclusion by Davis, 1898.

crassiformis (Viereck). Conn.

Hemiteles (Idemum) crassiformis Viereck, 1917 (1916). Conn. State Geol. and Nat. Hist.

Survey Bul. 22: 339-340. o.

granulosus (Davis). Ill.

Calliphrurus granulosus Davis, 1898 (1897). Amer. Ent. Soc., Trans. 24: 290. ठ。.

\section{Genus ISDROMAS Foerster}

Phatnacra Foerster, 1868. Naturh. Ver. Rheinlande, Verh. 25: 179.

Type-species: Hemiteles (Phatnacra) Monterai Lima. By subsequent monotypy from inclusion by Lima, 1948.

Isdromas Foerster, 1868. Naturh. Ver. Rheinlande, Verh. 25: 179.

Type-species: Acrolyta aletiae Ashmead. By subsequent monotypy from inclusion by Ashmead, 1900.

Larsephna Cameron, 1903. Entomologist 36: 97.

Type-species: Larsephna varipes Cameron. Desig. by Viereck, 1914.

Daictimorpha Viereck, 1912. U. S. Natl. Mus., Proc. 42: 636.

Type-species: Daictimorpha periviana Viereck. Monotypic and orig. desig.

lycaenae (Howard). Pa. s. to Ala., w. to Iowa and Tex. Host: A panteles aletiae Riley, $A$. congregatus (Say), Meteorus sp., Campoletis sp., Hyposoter fugitivus (Say).

Hemiteles lycaenae Howard, 1889. In Scudder, Butterflies East. U. S. and Canada, v. 3, p. 1880 . ㅇ.

Hemiteles aletiae Riley, 1890 (1889). In Ashmead, U. S. Natl. Mus., Proc. 12: 401. Nomen nudum.

Hemiteles bucculatricis Ashmead, 1890 (1889). U. S. Natl. Mus., Proc. 12: 401..

Hemiteles gracilariae Ashmead, 1890 (1889). U. S. Natl. Mus., Proc. : 401 . 9.

Orthopelma bedelliae Ashmead, 1890 (1889). U. S. Natl. Mus., Proc. 12: 415. ठठ.

Hemiteles selmae Riley, 1890. In Riley and Howard, U. S. Dept. Agr., Insect Life 3: 153.

Nomen nudum.

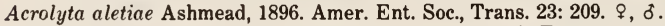

Sychnoporthus(!) tuckeri Viereck, 1905. Kans. Acad. Sci., Trans. 19: 315. ९.

\section{Genus ACROLYTA Foerster}

Acrolyta Foerster, 1868. Naturh. Ver. Rheinlande, Verh. 25: 174.

Type-species: Acrolyta empretiae Ashmead. Desig. by Viereck, 1914 from three species included by Ashmead, 1896.

Rhadinocera Foerster, 1868. Naturh. Ver. Rheinlande, Verh. 25: 177.

Type-species: Hemiteles (Rhadinocera) algonquinus Viereck. By subsequent monotypy from inclusion by Viereck, 1917.

Mosia Seyrig, 1952. Acad. Malgache, Mem. 39: 69.

Type-species: Mosia crassicomis Seyrig. Monotypic and orig. desig.

Parhemiteles Seyrig, 1952. Acad. Malgache, Mem. 39: 82.

Type-species: Parhemiteles flaviger Seyrig. Orig. desig.

alticola (Ashmead). Colo., Wash. Host: Apanteles sp.

Hemiteles alticola Ashmead, 1890. Colo. Biol. Assoc., Bul. 1: 22. ․ 
mesochori Ashmead. Conn., Pa., N. C., S. C., Ark. Host: Apanteles congregatus (Say).

Ashmead gave D. C. as the type locality, but the syntypes were actually sent to Riley from Norwalk, Conn. by D. N. Couch.

Hemiteles mesochoridis Riley, 1890. In Riley and Howard, U. S. Dept. Agr., Insect Life 3: 153. Nomen nudum.

Acrolyta mesochori Ashmead, 1896. Amer. Ent. Soc., Trans. 23: 208. 9.

nigricapitata (Cook and Davis). Que. s. to Tenn., w. to Iowa. Host: Apanteles melanoscelus (Ratz.), Meteomis communis (Cr.).

Hemiteles minutus Riley, 1890. In Riley and Howard, U. S. Dept. Agr., Insect Life 3: 153. Nomen nudum.

Hemiteles laticinctus Riley, 1890. In Riley and Howard, U. S. Dept. Agr., Insect Life 3: 153. Nomen nudum.

Mesochorus microgasteris Riley, 1890. In Riley and Howard, U. S. Dept. Agr., Insect Life 3: 156 . Nomen nudum.

Ischnocerus nigricapitatus Cook and Davis, 1891. Mich. Agr. Expt. Sta., Bul. 73: 11. $\subsetneq$. Acrolyta empretiae Ashmead, 1896. Amer. Ent. Soc., Trans. 23: 209..

Hemiteles laticinctus Ashmead, 1896. Amer. Ent. Soc., Trans. 23: 210. ठ.

Hemiteles (Rhadinocera) algonquinus Viereck, 1917 (1916). Conn. State Geol. and Nat. Hist. Survey Bul. 22: 340. ठ.

Biology: Muesebeck and Dohanian, 1927. U. S. Dept. Agr. Bul. 1487: 15.

washingtonensis (Cushman). Maine, N. H., N. Y., Mich. Townes (1970) placed this species as a synonym of alticola, but I have examined the holotypes of both and doubt that he is correct.

Stiboscopus washingtonensis Ashmead, 1906. In Slosson, Ent. News 17: 324. Nomen nudum.

Hemiteles (Isdromas) washingtonensis Cushman, 1922. U. S. Natl. Mus., Proc. 61 (8): 14. ㅇ.

Taxonomy: Townes, 1970 (1969). Amer. Ent. Inst., Mem. 12: 40.

\section{Genus INDOVIA Seyrig}

Indovia Seyrig, 1952. Acad. Malgache, Mem. 39: 132.

Type-species: Indovia decorata Seyrig. Orig. desig.

Townes (1970) synonymized Indovia with Stiboscopus Foerster, but a correction of the type-species of Stiboscopus from Stiboscopus thoracicus Ashmead to Hemiteles mandibularis Provancher makes Stiboscopus a synonym of Lysibia (which see). Hemiteles pinifoliae Cushman and Alegina laricellae Mason, which were placed in Stiboscopus by Townes, do not belong in Indovia and are here left in the subtribe Mastrina where they are placed provisionally in Mastrus.

Taxonomy: Townes, 1970 (1969). Amer. Ent. Inst., Mem. 12: 65-66. maculithorax (Ashmead), n. comb. Fla.; Puerto Rico, Virgin Isls., Lesser Antilles. Host:

Apanteles sp. There is a specimen in the U. S. Natl. Mus. collection which was reared from an A panteles cocoon in 1927 at Sanford, Fla. by W. E. Stone.

Hemiteles maculithorax Ashmead, 1895. Zool. Soc. London, Proc. 65: 780. ठ์.

Stiboscopus thoracicus Ashmead, 1890. Ent. Soc. London, Trans. 48: 267. ९, ठ.

Taxonomy: Townes and Townes, 1966. Amer. Ent. Inst., Mem. 8: 55 (syn.).

\section{Genus NEOPIMPLA Ashmead}

Neopimpla Ashmead, 1900. U. S. Natl. Mus., Proc. 23: 56.

Type-species: Neopimpla abbottii Ashmead. Monotypic and orig. desig.

Cyrtobasis Cushman, 1919. Ent. Soc. Wash., Proc. 21: 114. N. syn.

Type-species: Cyrtobasis rogae Cushman. Monotypic and orig. desig.

Microceratops Seyrig, 1952. Acad. Malgache, Mem. 39: 88. N. syn.

Type-species: Microceratops dentifrons Seyrig. Monotypic and orig. desig. 
Townes (1971) erroneously placed Neopimpla as a synonym of Astomaspis Foerster and declared that the type locality of N. abbottii Ashmead is Zululand in South Africa by virtue of his synonymizing abbottii with Caenopimpla crassa Morley (1926). However, the handwritten manuscript of Ashmead's (1900) classification of the Ichneumonoidea shows that his parenthetical eitation "Africa" was intended for Hemipimpla Saussure and not Neopimpla. Ashmead's use of the name abbottii for the type-species of Neopimpla was apparently a lapsus for the name he really intended and was caused by his confusion with his genus Erythropimpla (type-species: $E$. abbottii Ashmead). The only specimens ever to be found bearing a label with the name Neopimpla in Ashmead's handwriting are two of Cushman's paratypes of Cyrtobasis rogae. As noted by Cushman, these specimens run to Neopimpla in Ashmead's key to the I'implini.

Taxonomy: Cushman, 1919. Ent. Soc. Wash., Proc. 21: 116. -Townes, 1971. Ent. Soc. Wash., Prnc. 73: 445.

hicarinя^a (Riley), n. comb. Ill., Mo., Kans., Colo. Host: Rogas sp.

Polysphincta bicarinata Riley, 1871. Mo. State Ent., Ann. Rpt. 3: 71. ठ.

Neopimipla abbottii Ashmead, 1900. U. S. Natl. Mus., Proc. 23: 56.. N. syn.

Cyrtobasis rogae Cushman, 1919. Ent. Soc. Wash., Proc. 21: 115. ?.

\section{Genus DIAGLYPTIDEA Viereck}

Diaglyptidea Viereck, 1913. U. S. Natl. Mus., Proc. 46: 371.

Type-species: Diaglyptidea roepkei Viereck. Monotypic and orig. desig.

lavoiei (Provancher). Que., Maine, N. H., N. Y., Mich., Wis.

Phyadeuon Lavoiei Provancher, 1882. Nat. Canad. 13: 353. \&.

Hiemiteles pallipennis Provancher, 1882. Nat. Canad. 13: 360. ๆ, ठ.

\section{Genus LYSIBIA Foerster}

Pemon Foerster, 1868. Naturh. Ver. Rheinlande, Verh. 25: 174.

Type-species: Pemon proximum Perkins. Monotypically included and desig. by Perkins, 1962.

Lysibia Foerster, 1868. Naturh. Ver. Rheinlande, Verh. 25: 175.

Type-species: Hemiteles fulvipes Gravenhorst. Desig. by Townes, Momoi, and Townes, 1965 from three species included by Townes, Townes, and Gupta, 1961.

The type-species is regarded as a junior synonym of Lysibia nana (Gravenhorst). The designation of nana as type-species by Perkins (1962) is invalid because nana was not among the species included by Townes, Townes, and Gupta (1961).

Stiboscopus Foerster, 1868. Naturh. Ver. Rheinlande, Verh. 25: 182. N. syn.

Type-species: Hemiteles mandibularis Provancher. By subsequent monotypy from incl ision by [Ashmead $i n$ ] Slosson, 1896. Viereck $(1911,1914)$ and Perkins (1962) incorrectly believed Ashmead (1900) to be the oldest inclusion of species in Stiboscopus; consequently, Viereck's designation of Stiboscopus thoracicus Ashmead as the type-species of Stiboscopus is invalid.

Haplaspis Townes, 1944. Amer. Ent. Soc., Mem. 11: 190. N. syn.

Type-species: Hemiteles mandibularis Provancher. Orig. desig.

Between 1914 and 1944 the name Astomaspis Foerster was applied to this genus in the belief that Hemiteles fulvipes Gravenhorst was its type-species. In 1944 Townes corrected this error, but he made another in describing Astomaspis of authors as the new genus Haplaspis while overlooking the fact that the name Stiboscopus should have been applied instead; it should have occurred to him to investigate this possibility because of the fact that the combination "Stiboscopus mandibularis Slosson, ... 1896" is given in his synonymy for mandibularis (Provancher). Since 1961 the name Lysibia has been applied to this genus, and I here suppress Stiboscopus as a synonym of Lysibia because I have been urged not to suppress Lysibia. Stiboscopus sensu Townes (1970) and Townes and Townes (1973) was a confused mixture of species; the two Nearctic species, Hemiteles pinifoliae Cushman and Alegina laricellae Mason, belong in the subtribe Mastrina (i.e. where Townes had placed Stiboscopus) where I am placing them provisionally in the genus Mastrus; the other three species belong in Indovia, which is here placed in the subtribe Acrolytina. 
Taxonomy: Slosson, 1896. Ent. News 7: 264 (the combination "Stiboscopus mandibularis Prov." was almost certainly provided by Ashmead rather than Davis and was the first inclusion of a species in Stiboscopus). - Viereck, 1911. U. S. Natl. Mus., Proc. 40: 193 (incorrect designation of Stiboscopus thoracicus Ashmead as type-species of Stiboscopus). -Viereck, 1914. U. S. Natl. Mus., Bul. 83: 138 (oversight of first inclusion of species in Stiboscopus as well as type-species designation by Viereck, 1911). - Townes, Townes, and Gupta, 1961. Amer. Ent. Inst., Mem. 1: 123 (first inclusion of species in Lysibia).

-Perkins, 1962. Brit. Mus. (Nat. Hist.) Ent., Bul. 11: 436, 453. - Townes, 1970 (1969).

Amer. Ent. Inst., Mem. 12: 65. - Townes and Townes, 1973. Amer. Ent. Inst., Mem. 19: 76. mandibularis (Provancher). Que. s. to N. C., w. to Oreg. and Calif. Host: Apanteles glomeratus (L.), A. longicomis (Prov.), A. melanoscelus (Ratz.), A. scitulus Riley, A. xylinus (Say), A. yakutatensis Ash., Microplitus gortynae Riley. According to Townes and Townes (1951) the Gravenhorst names fulvipes and nana have been erroneously applied to this Nearctic species ( $L$. nana being Palearctic).

Hemiteles mandibularis Provancher, 1875. Nat. Canad. 7: 315..

Acrolyta smerinthi Ashmead, 1900. In Smith, N. J. State Bd. Agr., Ann. Rpt. 27, sup., p. 569. Nomen nudum.

Taxonomy: Townes and Townes, 1951. U. S. Dept. Agr., Agr. Monog. 2: 238.

Biology: Muesebeck and Dohanian, 1927. U. S. Dept. Agr., Bul. 1487: 14 (as fulvipes, misdet.). -Cushman, 1928. N. Y. (Cornell) Agr. Expt. Sta., Mem. 101: 929 (as nana, misdet.).

\section{SUBTRIBE HEMITELINA}

\section{Genus PLEUROGYRUS Townes}

Pleurogyrus Townes, 1970 (1969). Amer. Ent. Inst., Mem. 12: 44.

Type-species: Hemiteles hungerfordi Cushman. Orig. desig.

Members of this genus parasitize Gyrinidae which attach their pupal cases to the stems of aquatic plants a few inches above the water line.

Biology: Butcher, 1933. Ent. Soc. Amer., Ann. 26: 79-82.

cheboyganensis (Butcher). Mich. Host: Gyrinus sp.

Hemiteles cheboyganensis Butcher, 1933. Ent. Soc. Amer., Ann. 26: 77. ؟.

hungerfordi (Cushman). Mich. Host: Gyrinus sp.

Hemiteles hungerfordi Cushman, 1930 (1929). U. S. Natl. Mus., Proc. 76 (25): 4. ơ, १.

Taxonomy: Butcher, 1933. Ent. Soc. Amer., Ann. 26: 79.

\section{Genus OBISIPHAGA Morley}

Obisiphaga Morley, 1907. Brit. Ichn., v. 2, p. 59.

Type-species: A ptesis stenoptera Marshall. Monotypic.

According to Townes (1970) an undescribed species apparently belonging to this genus occurs in the northwestern U. S. The European O. stenoptera has been reared from the egg nests of a pseudoscorpion, Obisium $\mathrm{sp}$.

\section{Genus AROTREPHES Townes}

Arotrephes Townes, 1970 (1969). Amer. Ent. Inst., Mem. 12: 45.

Type-species: Cryptus pusillus Cresson. Orig. desig.

mitralis (Provancher). Que.

Platylabus mitralis Provancher, 1886. Addit. Corr. Faune Ent. Canada Hym., p. 37.. pusillus (Cresson). Mass., N. Y., Md., Ill. Ecology: Occurs in marshy meadows.

Cryptus pusillus Cresson, 1864. Ent. Soc. Phila., Proc. 3: 302.

\section{Genus XIPHULCUS Townes}

Xiphulcus Townes, 1970 (1969). Amer. Ent. Inst., Mem. 12: 46. 
Type-species: Hemiteles longulus Thomson. Orig. desig. The type-species is regarded as a synonym of $x$. floricolator (Gravenhorst).

Townes said "this is a moderate sized genus [he knew 15 species], of Holarctic distribution," but the Nearctic species known to him are apparently undescribed.

Taxonomy: Horstmann, 1974. Mus. Natl. Hungarici, Ann. Hist.-Nat. 66: 344 (European spp.).

\section{Genus HEMITELES Gravenhorst}

Hemiteles Gravenhorst, 1829. Ichn. Europaea, v. 2, p. 780.

Type-species: Hemiteles tristator Gravenhorst. Desig. by Westwood, 1840. The type-species is considered to be a synonym of $H$. bipunctator (Thunberg).

Ocymorus Foerster, 1868. Naturh. Ver. Rheinlande, Verh. 25: 180.

Type-species: Hemiteles cingulator Gravenhorst. Monotypically included and desig. by Townes, 1944. The type-species is considered to be a synonym of $H$. bipunctator (Thunberg).

Members of this genus apparently parsitize spider egg cocoons.

humeralis Provancher. Que. w. to Minn., s. to Tex.

Hemiteles humeralis Provancher, 1874. Nat. Canad. 6: 333..+

Stilpnus appendiculatus Provancher, 1886. Addit. Corr. Faune Ent. Canada Hym., p. 44. o.

\section{Genus ACLASTUS Foerster}

Microplex Foerster, 1868. Naturh. Ver. Rheinlande, Verh. 25: 175.

Type-species: Aclastus rufipes Ashmead. By subsequent monotypy from inclusion by Roman, 1909 .

Daetora Foerster, 1868. Naturh. Ver. Rheinlande, Verh. 25: 175.

Type-species: Hemiteles solutus Thomson. Monotypically included and desig. by Perkins, 1962.

Aclastus Foerster, 1868. Naturh. Ver. Rheinlande, Verh. 25: 175.

Type-species: Aclastus mifipes Ashmead. By subsequent monotypy from inclusion by Ashmead, 1902.

Opisthostenus Foerster, 1868. Naturh. Ver. Rheinlande, Verh. 25: 175.

Type-species: Hemiteles (Opisthostenus) etorofuensis Uchida. By subsequent monotypy from inclusion by Uchida, 1936.

flagellatus (Davis). Colo., Alta., Wash.

Proclitus flagellatus Davis, 1897. Amer. Ent. Soc., Trans. 24: 246. ठ.

gracilis (Thomson). Greenland: Eurasia.

Hemiteles gracilis Thomson, 1884. Opusc. Ent. 10: 989. $९$, ঠ.

Hemiteles solutus Thomson, 1884. Opusc. Ent. 10: 990. ठ, क.

Hemiteles minutus Bridgman, 1886. Ent. Soc. London, Trans. 34: 340. §, ๆ.

Taxonomy: Roman, 1916. Arkiv. for Zool. 10 (7): 6-7. - Roman, 1925 (1924). Arkiv, for Zool 17A (4): 14-15. -Jussila, 1965. Univ. Turku., Ann. (A, II) 34: 153.

karlukensis (Ashmead). Alaska.

Acrolyta karlukensis Ashmead, 1902. Wash. Acad. Sci., Proc. 4: 186. $\uparrow$.

nigritus (Ashmead). Alaska; e. U. S. S. R.

Stibeutes nigrita Ashmead, 1899 (1898). In Jordan, Fur Seals and Fur-seal Isls. No. Pacific, v. 4 , p. 338 . .

Spinolia minuta Ashmead, 1902. Wash. Acad. Sci., Proc. 4: 186. १. Preocc. in Aclastus by

Bridgman, 1886.

rufipes (Ashmead). Alaska.

Stiboscopus alaskensis Ashmead, 1902. Wash. Acad. Sci., Proc. 4: 171. ๆ.

Acrolyta aciculata Ashmead, 1902. Wash. Acad. Sci., Proc. 4: 186. ð.

Aclastus rufipes Ashmead, 1902. Wash. Acad. Sci., Proc. 4: 187.. 


\section{Genus POLYAULON Foerster}

Polyaulon Foerster, 1868. Naturh. Ver. Rheinlande, Verh. 25: 171.

Type-species: Polyaulon incertus Foerster. Desig. by Viereck, 1914 from 12 species included by Foerster, 1871.

Myersia Viereck, 1912. U. S. Natl. Mus., Proc. 43: 575.

Type-species: Myersia laminata Viereck. Monotypic and orig. desig.

Thaumatotypidea Viereck, 1912. U. S. Natl. Mus., Proc. 43: 577.

Type-species: Cremnodes tuberculatus Ashmead. Orig. desig.

Rhacodopteron Capek, 1956. Zool. Listy 5: 285. The author placed the genus in the Braconidae.

Type-species: Rhacodopteron stiavnicense Capek. Monotypic and orig. desig. bimaculatus (Ashmead). Ind.

Orthopelma bimaculatum Ashmead, 1890 (1889). U. S. Natl. Mus., Proc. 12: $416 . \delta$. canadensis (Harrington). B. C.

Cremnodes canadensis Harrington, 1894. Canad. Ent. 26: 213. \&.

Taxonomy: Strickland, 1912. Ent. Soc. Amer., Ann. 5: 115.

erythropa Ashmead. Va.

Orthopelma erythropa Ashmead, 1890 (1889). U. S. Natl. Mus., Proc. 12: 416 . ठ.

grandis (Cushman). B. C.

Myersia grandis Cushman, 1921. Ent. Soc. Wash., Proc. 23: 110. $\subsetneq$.

koebelei (Cushman). Wash., Oreg.

Thaumatotypidea koebelei Cushman, 1921. Ent. Soc. Wash., Proc. 23: 112. ठ.

laminatus (Viereck). Que. s. to Fla., w. to Ohio and Ala.

Myersia laninata Viereck, 1912. U. S. Natl. Mus., Proc. 43: 576..+

Myersia pallida Cushman, 1919. U. S. Natl. Mus., Proc. 55: 522..

Myersia johnsoni Cushman, 1921. Ent. Soc. Wash., Proc. 23: 110..

Myersia harringtoni Viereck, 1925. Canad. Ent. 57: 73. ๆ.

Taxonomy: Cushman, 1921. Ent. Soc. Wash., Proc. 23: 110.

niger (Viereck). B. C.

Myersia nigra Viereck, 1925. Canad. Ent. 57: 73. ठ.

spinulatus (Strickland). Conn.

Thaumatotypus spinulatus Strickland, 1912. Ent. Soc. Amer., Ann. 5: 116. $q$.

tuberculatus (Ashmead). Mont., Alaska, Calif. Host: Spider egg cocoon.

Cremnodes tuberculatus Ashmead, 1896. Amer. Ent. Soc., Trans. 23: 211. ․

Cremnodes alaskensis Ashmead, 1896. Amer. Ent. Soc., Trans. 23: 211..

Taxonomy: Strickland, 1912. Ent. Soc. Amer., Ann. 5: 115.

\section{SUBTRIBE GNYPETOMORPHINA}

\section{Genus ANUROTROPUS Cushman}

Anurotropıs Cushman, 1924. U. S. Natl. Mus., Proc. 64 (4): 4.

Type-species: Anurotropus minutus Cushman. Monotypic and orig. desig.

minutus Cushman. Conn., Ga., Mich., Ill., Minn.

Anurotropus minutus Cushman, 1924. U. S. Natl. Mus., Proc. 64 (4): 5. ठ, १.

\section{SUBTRIBE GELINA}

\section{Genus XENOLYTUS Foerster}

Xenolytus Foerster, 1868. Naturh. Ver. Rheinlande, Verh. 25: 174.

Type-species: Xenolytus mifipes Cameron. By subsequent monotypy from inclusion by Cameron, 1906.

Sternocryptus Roman, 1925 (1924). Arkiv for Zool. 17A (4): 12.

Type-species: Cryptus bitinctus Gravenhorst. Monotypic and orig. desig. Cryptus bitinctus Gravenhorst is an identification of Ichneumon bitinctus Gmelin. 
bitinctus (Gmelin). Maine, Ont., B. C., Calif.; Eurasia, New Zealand, Australia, Africa. Ecology: In England commonly found in warehouses, granaries, feedstores, and flour mills where it was most frequently associated with Tinea pallescentella Stainton, Endrosis sarcitrella (L.), and Hofmannophila pseudospretella (Stainton); a series was also reared from a birds nest (Richards, 1949). Adventive.

Ichneumon bitinctus Gmelin, 1790. In Linnaeus, Syst. Nat., ed. 13, v. 1, pt. 5, p. 2719.. Ichneumon expulsor Thunberg, 1922; 1924. Acad. Imp. des Sci. St. Petersburg, Mem. 8: 263; 9: 316. ․

Cryptus apicalis Gravenhorst, 1829. Ichn. Europaea, v. 2, p. 574..

Phygadeuon limatus Cresson, 1879 (1878). Acad. Nat. Sci. Phila., Proc. 30: 358..

Hemiteles occidentalis Harrington, 1894. Canad. Ent. 26: 213. ๆ.

Hemiteles destructivus Cameron, 1898. Manchester Lit. and Phil. Soc., Mem. and Proc. 42 (1): 26 .. .

Bathymetis antipoda Ashmead, 1900. Ent. News 11: 624..

Xenolytus mifïpes Cameron, 1906. So. African Mus., Ann. 5: 154. $\subsetneq$.

Taxonomy: Roman, 1912. Zool. Bidr. Uppsala 1: 254 (syn.). -Schmiedeknecht, 1932. Opusc. Ichn., Sup., fasc. 14, p. 41 (syn.). - Townes, Townes, and Gupta, 1961. Amer. Ent. Inst., Mem. 1: 125 (syn.). - Townes, 1970 (1969). Amer. Ent. Inst., Mem. 12: 52 (syn.).

Biology: Richards, 1949. Roy. Ent. Soc. London, Proc. (Ser. B [Taxonomy]) 18: 25-28 (speculation concerning hosts).

subspinosus (Provancher). Que., N. Y., Alta.

Hemiteles subspinosus Provancher, 1874. Nat. Canad. 6: 333. \&.

\section{Genus DICHROGASTER Doumerc}

Dichrogaster Doumerc, 1955. Soc. Ent. de France, Bul. (in Ann.) (3) 3: LXXXVIII.

Type-species: Microgaster perlae Doumerc: Monotypic. The type-species is considered to be a synonym of $D$. aestivalis (Gravenhorst).

Otacustes Foerster, 1868. Naturh. Ver. Rheinlande, Verh. 25: 174.

Type-species: Otacustes atriceps Ashmead. Desig. by Viereck, 1914 from two species included by Ashmead, 1894.

Microtomis Foerster, 1868. Naturh. Verh. Rheinlande, Verh. 25: 178.

Type-species: Microtomıs kichijoi Uchida. Desig. by Townes, 1957 from two species included by Uchida, 1940.

Xenobrachys Foerster, 1868. Naturh. Ver. Rheinlande, Verh. 25: 179.

Type-species: Hemiteles longicaudatus Thomson. Monotypically included and desig. by Perkins, 1962.

Brachycephalus Foerster, 1868. aturh. Ver. Rheinlande, Verh. 25: 179. Preocc. by

Fitzinger, 1826; Hollard, 1857; and Signoret, 1866.

Type-species: Hemiteles aestivalis Gravenhorst. Desig. by Townes, 1944 from four species included by Roman, 1925.

Brachycranium Ashmead, 1900. Canad. Ent. 32: 368. N. name for Brachycephalus

Foerster.

Chrysopoctonus Cushman, 1919. U. S. Natl. Mus., Proc. 55: 518.

Type-species: Otacustes atriceps Ashmead. Orig. desig.

Members of this genus parasitize cocoons of Chrysopidae and Hemerobiidae.

Revision: Horstmann, 1973. Ent. Scand. 4: 65-72 (European spp.).

Taxonomy: Cushman, 1924. U. S. Natl. Mus., Proc. 64 (4): 1 (key to N. Amer. spp.). bicolor (Cushman). Fla. Host: Nodita pavida (Hagen).

Chrysopoctonus bicolor Cushman, 1924. U. S. Natl. Mus., Proc. 64 (4): 1. ठ', ९.

chrysopae chrysopae (Ashmead). rev. status. Del., N. C., S. C., Fla., Miss. Host: Chrysopa bimaculata McCL., C. cubana Hagen, C. oculata Say, C. mufilabris Burm., C. sanchezi

Navas.

Otacustes chrysopae Ashmead, 1894. U. S. Dept. Agr., Insect Life 7: 243. ठँ.

Otacustes atriceps Ashmead, 1894. U. S. Dept. Agr., Insect Life 7: 244. ๆ. 
chrysopae patruelis (Cushman). Ariz., B. C. s. to Calif. Host: Chrysopa plorabunda Fitch. Chrysopoctonus patruelis Cushman, 1919. U. S. Natl. Mus., Proc. 55: 520. ठ, 9.

crassa (Provancher). Que. s. to D. C., w. to Oreg. Host: Chrysopa harrisii Fitch,C. nigricomis Burm., C. plorabunda Fitch, C. rufilabris Burm., Hemerobius sp. I believe that Townes and Townes (1951) were incorrect in treating chrysopae (Ashmead) and chrysopae patruelis (Cushman) as subspecies of crassa.

Hemiteles crassus Provancher, 1882. Nat. Canad. 13: 361. ¿.

Hemiteles rileyi Ashmead, 1890 (1889). U. S. Natl. Mus., Proc. 12: 402. ơ.

Hemiteles hemerobii Ashmead, 1890 (1889). U. S. Natl. Mus., Proc. 12: 404. ठ。.

Hemiteles hemerobiicola (!) Riley and Howard, 1890. U. S. Dept. Agr., Insect Life 3: 153.

Hemiteles mufiventris Riley, 1890. In Riley and Howard, U. S. Dept. Agr., Insect Life 3: 153. Nomen nudum.

Hemiteles euryptychiae Ashmead, 1896. Amer. Ent. Soc., Trans. 23: 210. . The correct data for the holotype of euryptychiae were cited by Riley under the above nomen nudum, mufiventris.

Hemiteles (Otacustes) cressoniformis Viereck, 1917 (1916). Conn. State Geol. and Nat. Hist. Survey Bul. 22: 339, 340. 9 .

Taxonomy: Cushman, 1919. U. S. Natl. Mus., Proc. 55: 520. -Townes and Townes, 1951. U. S. Dept. Agr., Agr. Monog. 2: 235.

\section{Genus GELIS Thunberg}

Gelis Thunberg, 1827. Soc. Sci. Upsala, Nov. Acta 9: 199.

Type-species: Mutilla acarorum Linnaeus. Desig. by Viereck, 1914.

Pezomachus Gravenhorst, 1829. Ichn. Europaea, v. 2, p. 867.

Type-species: Mutilla acarorum Linnaeus. Desig. by Curtis, 1835.

Pezolochus Foerster, 1850. Arch. f. Naturgesch. 16 (1): 71.

Type-species: Pezolochus mifipes Foerster. Monotypic.

Hemimachus Ratzeburg, 1852. Ichn. d. Forstins., v. 3, p. 157.

Type-species: Hemimachus fasciatus Ratzeburg. Desig. by Viereck, 1914.

Thaumatotypus Foerster, 1868. Naturh. Ver. Rheinlande, Verh. 25: 172.

Type-species: Thaumatotypus femoralis Brischke. By subsequent monotypy from inclusion by Brischke, 1881.

Plesiomma Foerster, 1868. Naturh. Ver. Rheinlande, Verh. 25: 176. Preocc. by Macquart, 1838. Placed as a synonym of Gelis by Townes (1970), but no species have ever been included.

Alegina Foerster, 1868. Naturh. Ver. Rheinlande, Verh. 25: 176.

Type-species: Algina(!) alaskensis Ashmead. By subsequent monotypy from inclusion by Ashmead, 1902.

Rhadiurgus Foerster, 1868. Naturh. Ver. Rheinlande, Verh. 25: 177. Preocc. by Loew, 1849.

Type-species: Hemiteles bicolorinus Gravenhorst. By subsequent monotypy from inclusion by Uchida, 1933 (June). The type-species is considered to be a synonym of Gelis cinctus (Linnaeus).

Aschistus Foerster, 1868. Naturh. Ver. Rheinlande, Verh. 25: 177.

Type-species: Hemimachus variabilis Ratzeburg. Desig. by Viereck, 1914 from two species included by Brischke, 1891. The type-species is considered to be a synonym of Gelis cursitans (Fabricius).

Blapsidotes Foerster, 1868. Naturh. Ver. Rheinlande, Verh. 25: 177.

Type-species: Hemiteles melanarius Gravenhorst. Monotypically included and desig. by Perkins, 1962.

Philonygmus Foerster, 1868. Naturh. Ver. Rheinlande, Verh. 25: 177.

Type-species: Philonygus(!) alaskensis Ashmead. Desig. by Viereck, 1914 from two species included by Ashmead, 1902.

Barydotira Foerster, 1868. Naturh. Ver. Rheinlande, Verh. 25: 178.

Type-species: Barydotira hammari Viereck. By subsequent monotypy from inclusion by Viereck, 1912.

Ilapinastes Foerster, 1868. Naturh. Ver. Rheinlande, Verh. 25: 179. 
Type-species: Hemiteles davidsonii Ashmead. By subsequent monotypy from inclusion by Ashmead, 1896.

Urithreptus Foerster, 1868. Naturh. Ver. Rheinlande, Verh. 25: 180. According to Perkins (1962) a male specimen of Gelis (species still unidentified) in the Foerster collection bears the name Urithreptus. No species included.

Terpiphora Foerster, 1868. Naturh. Ver. Rheinlande, Verh. 25: 185.

Type-species: Alegina alaskensis Ashmead. Monotypically included and desig. by Viereck, 1914.

Micromeson Strickland, 1912. Ent. Soc. Amer., Ann. 5: 137.

Type-species: Micromeson annulatum Strickland. Desig. by Viereck, 1914.

Pezomachus subg. Myrmicomorpha Viereck, 1913. U. S. Natl. Mus., Proc. 44: 566.

Type-species: Pezomachus (Myrmicomorpha) perniciosus Viereck. Monotypic and orig. desig.

Gelis subg. Leptogelis Ceballos, 1925. Eos 1: 155.

Type-species: Gelis (Leptogelis) ariasi Ceballos. Desig. by Townes, 1944.

Thaumatogelis Kupka, 1933. In Schmiedeknecht, Opusc. Ichn., Sup., fasc. 17, p. 7-8. Name invalid; type-species not designated.

Gelis subg. Cryptogelis Hellen, 1944. Notulae Ent. 24: 2. Name invalid; type-species not designated.

Gelis subg. Holcogelis Aubert, 1957. Muenchen. Ent. Gesell., Mitt. 47: 226.

Type-species: Pezomachus corruptor Foerster. Orig. desig.

Arctodeuon Hellen, 1967. Notulae Ent. 47: 100.

Type-species: Hemiteles glacialis Holmgren. Monotypic and orig. desig.

Rhadiurginus Hellen, 1967. Notulae Ent. 47: 109. N. name for Rhadiurgus Foerster.

Members of this genus are particularly well known as hyperparasites which attack the cocoons of Braconidae or other Ichneumonidae, but there are also many species which attack the egg cocoons of spiders. Apparently, some species of Gelis can sometimes be primary parasites in the cocoons of sawflies or small Lepidoptera.

Revision: Strickland, 1912. Ent. Soc. Amer., Ann. 5: 113-140 (of very limited use).

Taxonomy: Perkins, 1962. Brit. Mus. (Nat. Hist.) Ent., Bul. 11: 462. -Townes, 1970 (1969).

Amer. Ent. Inst., Mem. 12: 53-55.

aciculatus (Strickland). Tex.

Pezomachus foersteri Brues, 1910. Wis. Nat. Hist. Soc., Bul. 8: 69. ९. Preocc. by Bridgman, 1886.

Pezomachus aciculatus Strickland, 1912. Ent. Soc. Amer., Ann. 5: 136. N. name for foersteri Brues.

alegininus Carlson, n. name. Alaska.

Stiboscopus solitarius Ashmead, 1902. Wash. Acad. Sci., Proc. 4: 172. ठ. Preoce. in Gelis by Foerster, 1850. Because all of its known synonyms are also preoce., solitarius Ashmead is here given the new name alegininus in reference to its synonymy with the type-species of Alegina.

Algina(!) alaskensis Ashmead, 1902. Wash. Acad. Sci., Proc. 4: 188. + . Preocc. in Gelis by Ashmead, 1890.

Philonygus(!) alaskensis Ashmead, 1902. Wash. Acad. Sci., Proc. 4: 189. ठ. Preoce. in Gelis by Ashmead, 1890 and Ashmead, 1902, p. 188.

Ilapinastes incertus Ashmead, 1902. Wash. Acad. Sci., Proc. 4: 190. ठ. Preocc. in Gelis by Foerster, 1850.

Taxonomy: Townes, 1970 (1969). Amer. Ent. Inst., Mem. 12: 53. alogus (Viereck). Kans.

Pezomachus alogus Viereck, 1905. Kans. Acad. Sci., Trans. 19: 321. ठั.

alternatus (Cresson). Ill.

Pezomachus alternatus Cresson, 1872. Canad. Ent. 4: 64. 9.

annulatus (Strickland). $\mathrm{Pa}$., Md., Tex. Host: Spider eggs.

Micromeson annulatum Strickland, 1912. Ent. Soc. Amer., Ann. 5: 137..

apantelis Cushman. N. H., Mass., N. Y. Host: Apanteles melanoscelus (Ratz.).

Gelis a pantelis Cushman, 1927. Jour. Agr. Res. 34: 454. ठँ, १. 
Biology: Muesebeck and Dohanian, 1927. U. S. Dept. Agr. Bul. 1487: 16-17.

atratus (Ashmead). Colo., Alta., Utah. Host: A panteles sp.

Pezolochus atratus Ashmead, 1890. Colo. Biol. Assoc., Bul. 1: 22. .

Pezomachus utahensis Strickland, 1912. Ent. Soc. Amer., Ann. 5: 118. ?.

belfragei (Ashmead). Tex.

Hemiteles belfragei Ashmead, 1890 (1889). U. S. Natl. Mus., Proc. 12: 339..

Taxonomy: Townes, 1970 (1969). Amer. Ent. Inst., Mem. 12: 55.

bicoloratus (Cresson). Tex.

Mesoleptus bicoloratus Cresson, 1872. Amer. Ent. Soc., Trans. 4: 166. ठ。.

birkmani (Brues). Tex.

Pezomachus Birkmani Brues, 1903. Amer. Ent. Soc., Trans. 29: 121. ․

brevistylus (Strickland). Pa., N. Y.

Pezomachus brevistylus Strickland, 1912. Ent. Soc. Amer., Ann. 5: 119. ؟.

bruesii (Strickland). Mass., Pa. Host: Eggs of Gnaphosidae.

Pezomachus obesus Brues, 1910. Wis. Nat. Hist. Soc., Bul. 8: 71. $\%$. Preocc. in Gelis by Ashmead, 1902.

Pezomachus briesii Strickland, 1912. Ent. Soc. Amer., Ann. 5: 136. N. name for abesus Brues.

californicus (Ashmead). Calif.

Pezomachus californicus Ashmead, 1890 (1889). U. S. Natl. Mus., Proc. 12: 421..

canadensis (Cresson), Que., Ont., Ill., Mo., Wash.

Pezomachus canadensis Cresson, 1872. Canad. Ent. 4: 62..

Pezomachus Quebecensis Provancher, 1875. Nat. Canad. 7: 330. ․

caudatus (Rudow). Iowa. Ecology: Secondary parasite of Callosamia promethea (Drury).

Pezomachus caudatus Rudow, 1917. Ent. Ztschr. 30: 102..

Taxonomy: Townes and Townes, 1973. Amer. Ent. Inst., Mem. 19: 362.

cockerelli (Brues). Colo.

Pezomachus cockerelli Brues, 1910. Wis. Nat. Hist. Soc., Bul. 8: 68..

coloradensis (Strickland). Colo.

Pezomachus coloradensis Strickland, 1912. Ent. Soc. Amer., Ann. 5: 122. ‡.

columbianus (Ashmead). D. C. Host: Coleophora sp.

Hemiteles columbianus Ashmead, 1890 (1889). U. S. Natl. Mus., Proc. 12: $402 . \delta^{\circ}$.

compactus (Cresson). Ill.

Pezomachus compactus Cresson, 1872. Canad. Ent. 6: 63..

crassulus (Brues). Tex.

Pezomachus crassulus Brues, 1903. Amer. Ent. Soc., Trans. 29: 123. ๆ.

cushmani Carlson, n. name. Maine, N. H., Mass., N. Y., N. C., Wis., Alaska. Host: Apanteles melanoscelus (Ratz.), Porizon cupressi (Ashmead), Neodiprion tsugae Midd., Coleophor laricella (Hbn.).

Hemiteles apantelis Cushman, 1927. Jour. Agr. Res. 34: 453. o, ९. Preocc. in Gelis by Cushman, 1927, p. 454.

Taxonomy: Townes, 1970 (1969). Amer. Ent. Inst., Mem. 12: 55.

Biology: Muesebeck and Dohanian, 1927. U. S. Dept. Agr., Bul. 1487: 15.

davidsonii (Ashmead), Oreg., Calif. Host: Spider egg cocoon.

Hemiteles davidsonii Ashmead, 1896. In Davidson, Ent. News 7: 320...

debilis (Provancher). Ont.

Hemiteles debilis Provancher, 1886. Addit. Corr. Faune Ent. Canada Hym., p. 59. ठో.

delicatus (Cresson). Tex.

Mesoleptus delicatus Cresson, 1872. Amer. Ent. Soc., Trans. 4: 166. ठో.

dimidiaventris (Rudow). Iowa. Ecology: Apparently a secondary parasite of Papilio polyxenes F. Rudow apparently confused the name Papilio polyxenes with that of the European 
papilionid, Zerynthia hypermnestra (Scop.), which was known to Rudow by the synonymous name "Thais polyxena."

Pezomachus dimidiaventris Rudow, 1917. Ent. Ztschr. 30: 102..

Taxonomy: Townes and Townes, 1973. Amer. Ent. Inst., Mem. 19: 362.

delumbis (Brues). Wash.

Pezomachus delumbis Brues, 1910. Wis. Nat. Hist. Soc., Bul. 8: 75 ..

dispar (Strickland). Pa., Md. Host: Spider eggs.

Pezomachus dispar Strickland, 1912. Ent. Soc. Amer., Ann. 5: 125. ठ์, ๆ.

drassi (Riley). Ohio, Kans., Ariz. Host: Eggs of Gnaphosidae.

Hemiteles drassi Riley, 1892. In Howard, Ent. Soc. Wash., Proc. 2: 296. ठ.

Pezomachus homalommoides Viereck, 1905. Kans. Acad. Sci., Trans. 19: 294. ठ".

Pezomachus testaceicoxus Viereck, 1905. Kans. Acad. Sci., Trans. 19: 322. ठ์.

fenestralis (Brues). N. H.

Pezomachus fenestralis Brues, 1910. Wis. Nat. Hist. Soc., Bul. 8: 71. ठ.

ferruginosus (Strickland). B. C., Wash., Oreg. Ecology: Secondary parasite of Neodiprion tsugae Midd. according to Furniss and Dowden (1941).

Pezomachus insolens Brues, 1910. Wis. Nat. Hist. Soc., Bul. 8: 74. . Preocc. by Foerster, 1850.

Pezomachus ferruginosus Strickland, 1912. Ent. Soc. Amer., Ann. 5: 136. N. name for insolens Brues.

Biology: Furniss and Dowden, 1941. Jour. Econ. Ent. 34: 49.

foveatus (Brues). Mass.

Pezomachus foveatus Brues, 1910. Wis. Nat. Hist. Soc., Bul. 8: 73. ð.

gelechiae (Ashmead). Calif. Ecology: Data files in the U. S. Natl. Museum indicate that gelechiae was associated with Gnorimoschema operculella (Zell.) which were infesting potato tubers.

Exolytus gelechiae Ashmead, 1890 (1889). U. S. Natl. Mus., Proc. 12: 397. ठ.

gracillimus (Dalla Torre). R. I., N. Y., Pa., Tex.

Pezomachus gracilis Cresson, 1872. Canad. Ent. 4: 63. ९. Preoce. by Foerster, 1850.

Pezomachus gracillimus Dalla Torre, 1902. Cat. Hym., v. 3, p. 624. N. name for gracilis Cresson.

Pezomachus angularis Brues, 1903. Amer. Ent. Soc., Trans. 29: 122. \&.

Pezomachus cressonii Strickland, 1912. Ent. Soc. Amer., Ann. 5: 136. N. name for gracilis Cresson; cressonii Strickland preocc. by Dalla Torre, 1902.

habilis (Brues). Mass.

Pezomachus habilis Brues, 1910. Wis. Nat. Hist. Soc., Bul. 8: 72 ..

hammari (Viereck). Mass., Ark. Host: Casebearer on wild grape. Also reared as a secondary parasite of Acrobasis indigenella (Zell.).

Barydotira hammari Viereck, 1912. U. S. Natl. Mus., Proc. 43: 584..

Taxonomy: Townes, 1970 (1969). Amer. Ent. Inst., Mem. 12: 54.

inermis (Viereck). N. Mex.

Chirotica inermis Viereck, 1903. In Skinner, Amer. Ent. Soc., Trans. 29: 83. ठ.

insolitus (Howard). D. C. Ecology: Secondary parasite of Orgyia leucostigma (J. E. S.).

Pezomachus insolitus Howard, 1897. U. S. Dept. Agr. Bur. Ent. Tech. Ser. 5: 54. ठ’.

inutilis Cushman. Mass., Ohio, Ill. Host: Apanteles melanoscelus (Ratz.).

Gelis inutilis Cushman, 1927. Jour. Agr. Res. 34: 455. ð, ๆ.

Biology: Muesebeck and Dohanian, 1927. U. S. Dept. Agr. Bul. 1487: 16. keenii (Harrington). B. C.

Pezomachus Keenii Harrington, 1894. Canad. Ent. 26: 214. ๆ.

kukakensis (Ashmead). Alaska.

Theroscopus kukakensis Ashmead, 1902. Wash. Acad. Sci., Proc. 4: 191..

longipes (Strickland). Calif.

Pezomachus longipes Strickland, 1912. Ent. Soc. Amer., Ann. 5: 123.. 
longipes (Rudow). Iowa.

Pezomachus longipes Rudow, 1917. Ent. Ztschr. 30: 103. \&. Preocc. by Strickland, 1912; not renamed because of taxonomic uncertainties.

Taxonomy: Townes and Townes, 1973. Amer. Ent. Inst., Mem. 19: 362.

longistylus (Strickland). N. Amer.? Described from an unlabled specimen.

Pezomachus longistylus Strickland, 1912. Ent. Soc. Amer., Ann. 5: 120. ๆ.

lymensis (Strickland). Conn. Host: Eggs of Gnaphosidae.

Micromeson lymense Strickland, 1912. Ent. Soc. Amer., Ann. 5: 138..

macer (Cresson). Mass., N. Y., Pa., Md., Ohio, Ill., Tex. Host: Eggs of E peira foliata (Geoff.), Argiope sp.

Pezomachus macer Cresson, 1872. Canad. Ent. 4: 64. ठ.

Pezomachus flavocinctus Ashmead, 1890 (1889). U. S. Natl. Mus., Proc. 12: 421. ‡.

maculatus (Strickland). Calif.

Pezomachus maculatus Strickland, 1912. Ent. Soc. Amer., Ann. 5: 121..

manni (Strickland). Calif.

Pezomachus manni Strickland, 1912. Ent. Soc. Amer., Ann. 5: 132. ठ.

meabilis (Cresson). Mass. s. to Va., w. to Iowa and Kans. Host: Eggs of Agelenopsis naevia (Walck.).

Pezomachus meabilis Cresson, 1872. Canad. Ent. 4: 62.. .

Pezomachus dimidiatus Cresson, 1872. Canad. Ent. 4: 63.. .

Pezomachus similis Strickland, 1912. Ent. Soc. Amer., Ann. 5: 127. ð, ९.

Pezomachus nodosus Strickland, 1912. Ent. Soc. Amer., Ann. 5: 128. ๆ.

micariae (Howard). Mass., Pa., D. C. Host: Eggs of Micaria sp.

Pezomachus micariae Howard, 1892. Ent. Soc. Wash., Proc. 2: 294. ठ', १.

Hemiteles micarivora Riley, 1892. In Howard, Ent. Soc. Wash., Proc. 2: 295. ठ઼.

minimus (Walsh). Ill., Okla., Tex. Host: Apanteles militaris (Walsh).

Pezomachus minimus Walsh, 1861. III. State Agr. Soc., Trans. 4: 368. ó, ๆ.

Biology: Riley, 1870. Mo. State Ent., Ann. Rpt. 2: 52.

nigerrimus (Dalla Torre). Calif.

Pezomachus niger Provancher, 1888. Addit. Corr. Faune Ent. Canada Hym., p. 362.. Preocc. by Brischke, 1878.

Pezomachus nigerrimus Dalla Torre, 1902. Cat. Hym., v. 3, p. 630. N. name for niger Provancher.

nigriventris (Brues). Tex.

Pezomachus texanus var. nigriventris Brues, 1903. Amer. Ent. Soc., Trans. 29: 122. \&.

nigrofuscus (Strickland). $\mathrm{Pa}$.

Pezomachus nigrofuscus Strickland, 1912. Ent. Soc. Amer., Ann. 5: 133. ठ์.

nocuus Cushman. Mass., N. Y., N. J., Pa., Ohio, N. C. Host: Apanteles melanoscelus (Ratz.), Ichneumonidae.

Gelis nocuus Cushman, 1927. Jour. Agr. Res. 34: 455. ¿, ๆ.

Biology: Muesebeck and Dohanian, 1927. U. S. Dept. Agr. Bul. 1487: 16.

obesus (Ashmead). Alaska; Sweden.

Theroscopus mifipes Ashmead, 1902. Wash. Acad. Sci., Proc. 4: 191. ठ, १. Preocc. in Gelis by Bridgman, 1883.

Pezomachus obesus Ashmead, 1902. Wash. Acad. Sci., Proc. 4: 193. १.

Pezomachus auripes Strickland, 1912. Ent. Soc. Amer., Ann. 5: 134. ठँ.

Pezomachus insularis Strickland, 1912. Ent. Soc. Amer., Ann. 5: 136. N. name for T. rufipes Ashmead.

Taxonomy: Roman, 1909. In Hamberg, Naturw. Untersuch. Sarekgebirges Schwedish-

Lappland, v. 4, p. 230.

obscurus (Cresson). Maine s. to Va., w. to Kans. Host: Bucculatrix canadensisella Chamb., Coleophora laricella (Hbn.), C. salmani Heinr., A panteles canarsiae Ash., A. lacteicolor Vier., A. melanoscelus (Ratz.), Heterarthrus nemoratus (Fall.).

Pezomachus obscurus Cresson, 1872. Canad. Ent. 4: 62. . 
Pezolochus bucculatricis Ashmead, 1890 (1889). U. S. Natl. Mus., Proc. 12: 240. §, ๆ. Theroscopus americanus Ashmead, 1896. Amer. Ent. Soc., Trans. 23: 211. ठ.

Hemiteles ashmeadii Dalla Torre, 1902. Cat. Hym., v. 3, p. 643. N. name for T. americanus Ashmead, which was temporarily preocc. in Hemiteles.

Taxonomy: Muesebeck and Dohanian, 1927. U. S. Dept. Agr. Bul. 1487: 16, 17.

Biology: Muesebeck and Dohanian, 1927. U. S. Dept. Agr. Bul. 1487: 16, 17. -Friend, 1927. Conn. [State] Agr. Expt. Sta. Bul. 288: 449, 450.

Taxonomy: Cushman, 1927. Jour. Agr. Res. 34: 456. - Muesebeck and Dohanian, 1927. U. S. Dept. Agr. Bul. 1487: 16.

ottawaensis (Harrington). Conn., Ont., W. Va. Host: Eggs of Gnaphosidae?

Pezomachus ottaw'aensis Harrington, 1896. Canad. Ent. 28: 77. ․

Hemiteles ottawaensis Harrington, 1896: Canad. Ent. 28: 78. ठ. Preoce. in Gelis by

Harrington, 1896, p. 77.

pennsylvanicus (Strickland). $\mathrm{Pa}$.

Pezomachus pennsylvanicus Strickland, 1912. Ent. Soc. Amer., Ann. 5: 126..

perniciosus (Viereck). Tex. Host: Apanteles militaris (Walsh), Meteoms laphygmae Vier., Rogas laphygmae Vier.

Pezomachus (Mymicomorpha) perniciosa Viereck, 1913. U. S. Natl. Mus., Proc. 44: 566. ㅇ.

pettitii (Cresson). Que., R. I., Ont.

Pezomachus Pettitii Cresson, 1872. Canad. Ent. 4: 61. \&.

Pezomachus sulcatus Provancher, 1886. Addit. Corr. Faune Ent. Canada Hym., p. 77. $९$.

popofensis (Ashmead). Alaska.

Theroscopus popofensis Ashmead, 1902. Wash. Acad. Sci., Proc. 4: 192. ठ.

prosthesimae (Riley). Mass. Host: Eggs of Zelotes subterraneus (Koch).

Hemiteles prosthesimae Riley, 1892. In Howard, Ent. Soc. Wash., Proc. 2: 294. ठ.

pumilis (Foerster). Alaska; Europe.

Pezomachus pumilus Foerster, 1850. Arch. f. Naturgesch. 16 (1): 131. ․

Pezomachus alaskensis Ashmead, 1890 (1889). U. S. Natl. Mus., Proc. 12: 421..

Pezomachus nigrellus Ashmead, 1902. Wash. Acad. Sci., Proc. 4: 192. ठ, ๆ.

Pezomachus minutus Strickland, 1912. Ent. Soc. Amer., Ann. 5: 119. ๆ.

Taxonomy: Roman, 1909. In Hamberg, Naturw. Untersuch. Sarekgebirges

Schwedisch-Lappland, v. 4, p. 232.

robustus (Strickland). Ariz.

Pezomachus robustus Strickland, 1912. Ent. Soc. Amer., Ann. 5: 120. \&.

rotundiceps (Cresson). Tex.

Mesoleptus? rotundiceps Cresson, 1872. Amer. Ent. Soc., Trans. 4: 167. ð.

Hemiteles pallidus Ashmead, 1890 (1889). U. S. Natl. Mus., Proc. 12: 406. ठ. N. syn. The holotype of pallidus has not been found, and it is my belief that its holotype is actually the same specimen as the holotype of rotundiceps. Although Ashmead's description of the propodeum does not agree perfectly with the holotype of rotundiceps, Ashmead is not renouned for his accuracy. There are at least two cases where it is known with certainty that Ashmead redescribed unique specimens from the Belfrage Collection which had already been described by Cresson.

sessilis (Provancher). Que., N. Y., S. C., Ohio, Oreg.

Hemiteles sessilis Provancher, 1874. Nat. Canad. 6: 334. ․

Taxonomy: Townes, 1970 (1969). Amer. Ent. Inst., Mem. 12: 55.

spiraculus (Strickland). N. Y., N. C. Host: Microplitis gortynae Riley.

Pezomachus spiraculus Strickland, 1912. Ent. Soc. Amer., Ann. 5: 124..

Gelis microplitidis Gahan, 1922. U. S. Natl. Mus., Proc. 61: 5. ठ, ․

stanfordensis (Strickland). Calif.

Pezomachus stanfordensis Strickland, 1912. Ent. Soc. Amer., Ann. 5: 123. \&.

stigmaterus (Cresson). Tex.

Mesoleptus? stigmaterus Cresson, 1872. Amer. Ent. Soc., Trans. 4: 167. ठ̊. 
stigmatus (Ashmead). Colo.

Hemiteles stigmatus Ashmead, 1890. Colo. Biol. Assoc., Bul. 1: 21. §.

stricklandi Townes. Calif.

Cremnodes californicus Ashmead, 1890 (1889). Us. Natl. Mus., Proc. 12: 420. . Preocc. in Gelis by Ashmead, 1890 (1889), p. 421.

Pezomachus ashmeadii Strickland, 1912. Ent. Soc. Amer., Ann. 5: 135. N. name for $C$. californicus Ashmead. Preocc. in Gelis by Dalla Torre, 1902.

Gelis stricklandi Townes, 1944. Amer. Ent. Soc., Mem. 11: 202. N. name for P. ashmeadii Strickland.

tantillus (Cresson). R. I., Pa., Ill.

Pezomachus gentilis Cresson, 1872. Canad. Ent. 4: 61. đ, ․ Preocc. by Foerster, 1850.

Pezomachus tantillus Cresson, 1872. Canad. Ent. 4: 62. ๆ.

Pezomachus cressonii Dalla Torre, 1902. Cat. Hym., v. 3, p. 621. N. name for P.gentilis Cresson.

tenellus (Say). Que. s. to Ga., w. to s. Alaska and Calif.; Argentina; Hawaii. Host: A panteles lacteicolor Vier., A. melanoscelus (Ratz.), Bracon pygmaeus Prov., Meteorus acronyctae Mues., M. communis Cr.?, M. datanae Mues., M. hyphantriae Riley, $M$. versicolor (Wesm.), Microplitis gortynae Riley, Casinaria orgyiae (How.), Diadegma insulare (Cr.), Enicospilus americanus (Chirst), Gambrus extrematis (Cr.), Hyposoter fugitivus (Say), H. rivalis (Cresson), Oresbius tsugae Cush.), Phobocampe clisiocampae (Weed), Neodiprion abietis (Harris), N. sertifer (Geoff.), N. swainei Midd., N. tsugae Midd., Diprion similis (Htg.), Chrysopa harrisii Fitch, C. nigricornis Burm., C. rufilabris Burm., Bucculatrix sp., Coleophora frischella (L.), C. laricella Hbn., C. malivorella Riley, C. pruniella Clem., C. salmoni Heinr., C. serratella (L.).

Cryptus tenellus Say, 1836. Boston Jour. Nat. Hist. 1: 233. ㅇ.

Hemiteles nemativorus Walsh, 1869. Canad. Ent. 2: 11..

Hemiteles nemativorus var. fuscatus Walsh, 1869. Canad. Ent. 2: 12..

Hemiteles utilis Norton, 1869. Amer. Ent. Soc., Trans. 2: 326. ․

Hemiteles depressus Provancher, 1874. Nat. Canad. 6: 334. $९$.

Hemiteles melitaene Ashmead, 1890 (1889). U. S. Natl. Mus., Proc. 12: 399..

Hemiteles coleophorae Ashmead, 1890 (1889). U. S. Natl. Mus., Proc. 12: 400 ..

Hemiteles variegatus Ashmead, 1890 (1889). In Riley and Howard, U. S. Dept. Agr., Insect Life 3: 153. Nomen nudum.

Hemiteles sordidus Riley, 1890. I $u$ Riley and Howard, U. S. Dept. Agr., Insect Life 3: 153. Nomen nudum.

Hemiteles periliti Riley, 1890. In Riley and Howard, U. S. Dept. Agr., Insect Life 3: 153. Nomen nudum.

Hemiteles scolyti Ashmead, 1893. In Hopkins, W. Va. Agr. Expt. Sta. Bul. 31: 144. Nomen nudum.

Otacustes orgyiae Ashmead, 1896. Amer. Ent. Soc., Trans. 23: 209..

Otacustes periliti Ashmead, 1896. Amer. Ent. Soc., Trans. 23: 210..

Otacustes nigro-ornatus Cameron, 1908. Amer. Ent. Soc., Trans. 34: 244. ๆ.

Taxonomy: Cushman and Gahan, 1923. Ent. Soc. Wash., Proc. 23: 163.

Biology: Muesebeck and Dohanian, 1927. U. S. Dept. Agr. Bul. 1487: 12-14. - Doner, 1934.

Ent. Soc. Amer., Ann. 27: 442. - Doner, 1926. Ent. Soc. Amer., Ann. 29: 228.

Morphology: Dustan, 1923 (1922). Acadian Ent. Soc., Proc. 8: 75-78 (larva).

terebrator (Ratzeburg). Greenland; Europe. Host: Microplitus coactus Lundb. Pezomachus terebrator Ratzeburg, 1848. Ichn. d. Forstins., v. 2, p. 126. 9.

Taxonomy: Roman, 1916. Arkiv for Zool. 10 (22): 8.

texanus (Cresson). Tex.

Pezomachus texamus Cresson, 1872. Canad. Ent. 4: 64. 9.

uniformis (Dalla Torre). N. H. s. to Md., w. to Iowa. Host: Spider eggs.

Pezomachus unicolor Cresson, 1872. Canad. Ent. 4: 64. . Preocc. by Foerster, 1850.

Pezomachus uniformis Dalla Torre, 1902. Cat. Hym., v. 3, p. 635. N. name for P. unicolor Cresson. 
urbanus (Brues). N. Y.

Pezomachus urbanus Brues, 1910. Wis. Nat. Hist. Soc., Bul. 8: 70. ठ.

virginiensis (Ashmead), n. comb. Va., Ark. Ecology: Associated with Acrobasis indigenella (Zell.). This species had been incorrectly placed in the genus Mastrus since 1944 .

Hemiteles virginiensis Ashmead, 1890 (1889). U. S. Natl. Mus., Proc. 12: 404..

wheeleri (Brues). Ill.

Pezomachus wheeleri Brues, 1903. Amer. Ent. Soc., Trans. 29: 123. ?.

yakutatensis (Ashmead). Alaska.

Atractodes yakutatensis Ashmead, 1902. Wash. Acad. Sci., Proc. 4: 169. ठ.

\section{Genus AGASTHENES Foerster}

Asthenoptera Foerster, 1868. Naturh. Ver. Rheinlande, Verh. 25: 175.

Type-species: Hemiteles stagnalis Thomson. Included and desig. by Hellen, 1967.

Agasthenes Foerster, 1868. Naturh. Ver. Rheinlande, Verh. 25: 178.

Type-species: Hemiteles varitarsus Gravenhorst. Included and desig. by Perkins, 1962.

Arachnoleter Cushman, 1924. U. S. Natl. Mus., Proc. 64 (4): 2.

Type-species: Arachnoleter suezeyi Cushman. Monotypic and orig. desig.

Townes (1970) says that there are two undescribed Nearctic species. In the U. S. Natl. Museum collection there are specimens of one of them from Mich., Ind., and Minn.; this species parasitizes spider eggs, as does A. swezeyi (Cushman), which is known from India, Malaya, the Philippines, and Hawaii.

Taxonomy: Townes, 1970 (1969). Amer. Ent. Inst., Mem. 12: 57.

\section{SUBTRIBE MASTRINA}

\section{Genus PYGOCRYPTUS Roman}

Pygocryptus Roman, 1925 (1924). Arkiv for Zool. 17 A (4): 9.

Type-species: Phygadeuon grandis Thomson. Monotypic and orig. desig.

Revision: Torgerson, 1974. Canad. Ent. 106: 889-896 (Holarctic spp.).

coryopsis Torgerson. Calif.

Pygocryptus coryopsis Torgerson, 1974. Canad. Ent. 106: 895. \&.

cruentus Torgerson, n. status. Alta., B. C.

Pygocryptus echthroides cruentus Torgerson, 1974. Canad. Ent. 106: 893. ?.

echthroides echthroides (Townes). Que., Mich., Alaska, B. C., Oreg., Calif.

Cryptus brevicomis Provancher, 1886. Addit. Corr. Faune Ent. Canada Hym., p. 67. .

Preocc. by Gravenhorst, 1829 and Provancher, 1875.

Cryptus brevicinctus (!) Provancher, 1889. Addit. Corr. Faune Ent. Canada Hym., p. 452 (index).

Amydraulax echthroides Townes, 1944. Amer. Ent. Soc., Mem. 11: 174. N. name for $C$. brevicormis Provancher.

echthroides oribasus Torgerson. Colo., Ariz.

Pygocryptus echthroides oribasus Torgerson, 1974. Canad. Ent. 106: 893. o, ?.

erugatus Torgerson. Que. s. to N. C., w. to Mich.

Pygoeryptus entugatus Torgerson, 1974. Canad. Ent. 106: 894. ơ, ᄋ.

exilis Torgerson. Calif.

Pygocryptus exilis Torgerson, 1974. Canad. Ent. 106: 896. ठ.

exochus Torgerson. Que., N. Y., Md., S. C., Mich.

Pygocryptus exochus Torgerson, 1974. Canad. Ent. 106: 895. ठै, ?.

\section{Genus MASTRUS Foerster}

Perosis Foerster, 1868. Naturh. Ver. Rheinlande, Verh. 25: 169.

Type-species: Echthrus armatus Gravenhorst. Desig. by Viereck, 1914 from two species included by Schmiedeknecht, 1888. 
Daictes Foerster, 1868. Naturh. Ver. Rheinlande, Verh. 25: 176.

Type-species: Phygadeuon (Daictes) fukai Viereck. By subsequent monotypy from inclusion by Viereck, 1911 .

Aenoplex Foerster, 1868. Naturh. Ver. Rheinlande, Verh. 25: 176.

Type-species: Aenoplex betulaecola Ashmead. By subsequent monotypy from inclusion by Ashmead, 1896.

Mastrus Foerster, 1868. Naturh. Ver. Rheinlande, Verh. 25: 176.

Type-species: Phygadenon (Mastrus) neodiprioni Viereck. By subsequent monotypy from inclusion by Viereck, 1911.

Isadelphus Foerster, 1868. Naturh. Ver. Rheinlande, Verh. 25: 177.

Type-species: Hemiteles inimicus Gravenhorst. Monotypically included and desig. by Viereck, 1914.

Zoophthorus Foerster, 1868. Naturh. Ver. Rheinlande, Verh. 25: 180.

Type-species: Hemiteles (Zoophthorns) nigricaniformis Viereck. By subsequent monotypy from inclusion by Viereck, 1917.

Micromonodon Foerster, 1868. Naturh. Ver. Rheinlande, Verh. 25: 195.

Type-species: Hemicryptus tener Kriechbaumer. By subsequent monotypy from inclusion by Ashmead, 1900. Ashmead (1900) suppressed the monotypic genus Hemicryptus Kriechbaumer as a synonym of Micromonodon, which inferred inclusion of Hemieryptus tener Kriechbaumer in Micromonodon (cf. Perkins, 1962).

Cecidonomus Bridgman, 1880. Entomologist 13: 264.

Type-species: Cecidonomus gallicola Bridgman. Desig. by Viereck, 1914.

Hemicryptus Kriechbaumer, 1893. Ent. Nachr. 19: 152. Preocc. by Zittel, 1885.

Type-species: Hemicryptus tener Kriechbaumer. Monotypic.

Chaetomastrus Hellen, 1967. Notulae Ent. 47: 105.

Type-species: Hemiteles hirticeps Thomson. Monotypic and orig. desig.

Mastrus seems to be an extraordinarily heterogeneous assemblage of species, some of which may prove to belong in the subtribe Phygadeuontina. Dr. Klaus Horstmann will have significantly modified the generic synonymy prior to the appearance of this catalog.

Taxonomy: Ashmead, 1900. U. S. Natl. Mus., Proc. 23: 173, 212. - Perkins, 1962. Brit. Mus.

(Nat. Hist.), Bul. 11: 436.

aciculatus (Provancher). N. B. s. to Va., w. to s. Alaska and Calif. Host: Coccygomimus sanguinipes erythropus (Vier.), Itoplectis behrensii (Cr.), Meteoms niveitarsis (Cr.), Arge sp., Gilpinia hercyniae (Htg.), Zadiprion townsendi (Cock.), Neodiprion namulus Schedl, $N$. pinetum (Nort.), N. pratti pratti (Dyar), N. migifrons Midd., N. sertifer (Geoff.), N. swainei Midd., N. taedae linearis Ross, N. tsagae Midd., Lambdina fiscellaria fiscellaria (Gn.), Protoboarmia porcelaria (Gn.). The observations by Cushman (1919) cast suspicion upon records for aciculatus as a primary parasite of Lepidoptera.

Hemiteles aciculatus Provancher, 1886. Addit. Corr. Faune Ent. Canada Hym., p. 60. ơ.

Hemiteles ashmeadii Riley, 1890. In Riley and Howard, U. S. Dept. Agr., Insect Life 3: 153. Nomen nudum.

Hypocryptus vanconverensis Harrington, 1894. Canad. Ent. 26: 248. ठ.

Phygadeuon phryganidiae Ashmead, 1896. Amer. Ent. Soc., Trans. 23: 207..

Phygadenon (Aenoplex) argeae Viereck, 1911. U. S. Natl. Mus., Proc. 39: 405..

Phygadeuon (Mastrus) neodiprioni Viereck, 1911. U. S. Natl. Mus., Proc. 40: 195. \&.

Taxonomy: Townes, 1970 (1969). Amer. Ent. Inst., Mem. 12: 65 (syn.).

Biology: Cushman, 1919. U. S. Natl. Mus., Proc. 55: 524. - Reeks, 1938. Ent. Soc. Ont., Ann. Rpt. 69: 27.

Morphology: Finlayson, 1960. Canad. Ent. 92: 30-31 (final-instar larva). albiscapus (Ashmead). Tex.

Hemiteles albiscapus Ashmead, 1890 (1889). U. S. Natl. Mus., Proc. 12: 403. ठ์. annulatus (Ashmead). Calif. Host: Pupa of microlepidopteran.

Hemiteles annulatus Ashmead, 1890 (1889). U. S. Natl. Mus., Proc. 12: $402 . \delta^{\circ}$. 
Taxonomy: Townes, 1970 (1969). Amer. Ent. Inst., Mem. 12: 65.

autumnalis (Provancher). Que., R. I., N. Y.

Atractodes autumnalis Provancher, 1882. Nat. Canad. 13: 367. ठ, ๆ.

carpocapsae (Cushman). Pa. s. to Fla., w. to Oreg. and Calif. Host: Grapholitha molesta (Bsk.), Laspeyresia caryana (Fitch), L. pomonella (L.).

Aenoplex carpocapsae Cushman, 1915. U. S. Natl. Mus., Proc. 48: 509. ๆ.

Taxonomy: Cushman, 1917. U. S. Natl. Mus., Proc. 53: 461 (male described).

Biology: Flanders, 1926. Pan-Pacific Ent. 3: 44-45. - McClure, 1933. Ent. News 44: 48-49 (effects of sting on host). - MeClure, 1933. Ent. Soc. Amer., Ann. 26: 345-347 (variation in life cycle). - McClure, 1937. Nature Notes 4: 38-40. - Lloyd, 1956. Canad. Ent. 88: 80-89 (oviposition behavior).

caudatus (Provancher). Que., N. Y., Ont.

Echthrus candatus Provancher, 1875. Nat. Canad. 7: 313. ‥

Aenoplex longicauda Walley, 1934. Canad. Ent. 66: 240. $\%$.

cressoni (Riley). N. H., Mich., Ill., Mo. Host: Microgaster gelechiae Riley?, Gambrus nuncius (Say).

Hemiteles (?) Cressoni Riley, 1869. Mo. State Ent., Ann. Rpt. 1: 177. ठ.

Hemiteles compactus Ashmead, 1890 (1889). U. S. Natl. Mus., Proc. 12: 398. ๆ. Deseribed by virtue of Ashmeads' inclusion of "compactus Cresson" in a key; Ashmead did not realize compactus was a manuscript name on a specimen Cresson had identified for Riley (see Cushman, 1919).

Hemiteles cressonii Dalla Torre, 1902. Cat. Hym., v, 3, p. 647. Emend.

Taxonomy: Cushman, 1919. U. S. Natl. Mus., Proc. 55: 525-526. -Townes, 1970 (1969). Amer.

Ent. Inst., Mem. 12: 65.

extensor (Cushman). Calif.

Isadelphus extensor Cushman, 1919. U. S. Natl. Mus., Proc. 55: 527..

gigas (Provancher). Que., Ont., Mass., Conn., N. Y., N. J., Alta.

Hemiteles gigas Provancher, 1886. Addit. Corr. Faune Ent. Canada Hym., p. 59. $\delta$.

Platylabus giganticus Dalla Torre, 1902. Cat. Hym., v. 3, p. 783. Unnecessarily proposed n. name for H.gigas Provancher (April, 1886) which was not preoce. in Platylabus by Kriechbaumer (August, 1886).

Phygadeuon (Bachia?) tumidiformis Viereck, 1917 (1916). Conn. State Geol. and Nat. Hist. Survey Bul. 22: 335,336 . $\delta$.

Hemiteles (Zoophthorus) nigricaniformis Viereck, 1917 (1916). Conn. State Geol. and Nat. Hist. Survey Bul. 22: 338, 340. ó.

hydrophilus (Ashmead). N. S., Maine, N. Y. Host: Epinotia nanana (Treit.).

Hemiteles hydrophilus Ashmead, 1890 (1889). U. S. Natl. Mus., Proc. 12: 401..

intermedius (Cresson). Tex.

Phygadenon intermedius Cresson, 1874. Amer. Ent. Soc., Trans. 4: 160..

Taxonomy: Townes, 1970 (1969). Amer. Ent. Inst., Mem. 12: 65.

laplantei Mason. Newfoundland (insular) s. to Maine, w. to s. Alaska and Oreg. Host: Meteorts niveitarsis (Cr.), Gilpinia hercyniae (Htg.), Neodiprion nanulus nanulus Schedl, $N$. pratti banksianae Roh., N. swainei Midd., N. tsugae Midd., Heterarthrus nemoratus (Fall.), Pikonema alaskensis (Roh.), Pristiphora erichsonii (Htg.), Acleris gloverana (Wlshm.), A. variana (Fern.), Choristoneura fumiferana (Clem.), Lambdina fiscellaria fiscellaria (Gn.), L. f. lugubrosa (Hulst), Rhenmaptera hastata (L.).

Mastrus laplantei Mason, 1968. Canad. Ent. 100: 19. o, ?.

laricellae (Mason), n. comb. N. B., P. E. I., Ont., Wis., n.e. Calif. Host: Argyresthia laricella $\mathrm{Kft}$. This species is placed provisionally in Mastrus (see foregoing discussion under Lysibia).

Alegina laricellae Mason, 1961. Canad. Ent. 97: 4. §, ९.

Morphology: Eidt, 1962. Canad. Ent. 94: 32 (final-instar larva).

mueronatus (Provancher). N. H., Ont., Mass., Conn., N. J., Ga. Host: Gambrus sp. Hemiteles mucronatus Provancher, 1886. Addit. Corr. Faune Ent. Canada Hym., p. 58. o. 
Taxonomy: Townes, 1970 (1969). Amer. Ent. Inst., Mem. 12: 65.

pilifrons (Provancher). Que. s. to N. C., w. to B. C. and Calif. Host: Acronicta betulae (Riley), Grapholitha molesta (Bsk.), Laspeyresia pomonella (L.).

Orthocentrus pilifrons Provancher, 1879. Nat. Canad. 11: 279. "oๆ" = $\delta$.

Hemiteles cryptiformis Riley, 1890. In Riley and Howard, U. S. Dept. Agr., Insect Life 3: 153. Nomen nudum.

Aenoplex betulaecola Ashmead, 1896. Amer. Ent. Soc., Trans. 23: 208. $q$. Aenoplex plesiotypus Cushman, 1915. U. S. Natl. Mus., Proc. 48: 510..

Taxonomy: Cushman, 1917. U. S. Natl. Mus., Proc. 53: 460.

pinifoliae (Cushman), n. comb. Mass., La. Host: Exoteleia sp., E. pinifoliella (Chamb.). As with $M$. la ricellae (Mason), this species is placed provisionally in Mastrus (see foregoing discussion under Lysibia.

Hemiteles pinifoliae Cushman, 1933. U. S. Natl. Mus., Proc. 82 (14): 5. o, १.

polychrosidis (Cushman). R. I., N. Y., Pa. Host: Paralobesia viteana (Clem.).

Aenoplex polychrosidis Cushman, 1919. U. S. Natl. Mus., Proc. 55: 524. ơ, ๆ.

rubricornis (Ashmead). Va.

Hemiteles rubricornis Ashmead, 1890 (1889). U. S. Natl. Mus., Proc. 12: 405. \&.

Taxonomy: Townes, 1970 (1969). Amer. Ent. Inst., Mem. 12: 65.

rufipes (Ashmead). Alaska.

Aenoplex rufipes Ashmead, 1902. Wash. Acad. Sci., Proc. 4: 188. ठ.

Taxonomy: Townes, 1970 (1969). Amer. Ent. Inst., Mem. 12: 65.

smithii (Packard). Que. w. to Wash., s. to N. J., Ill., Colo., and Oreg. Host: Gambrus extrematis (Cr.), Ametastegia glabrata (Fall.).

Cryptus Smithii Packard, 1865. Boston Soc. Nat. Hist., Proc. 9: 346. o, ९.

Echthrus mebripes Provancher, 1883. Nat. Canad. 14: 16. $\%$.

Phaeogenes crassitelus Provancher, 1886. Addit. Corr. Faune Ent. Canada Hym., p. 41.. .

Aenoplex nigrosoma Cushman, 1917. U. S. Natl. Mus., Proc. 53: 460. ठ, ․

Taxonomy: Townes, 1970 (1969). Amer. Ent. Inst., Mem. 12: 65.

subspinosus (Provancher). Que., R. I., N. Y.

Phygadeuon subspinosus Provancher, 1882. Nat. Canad. 13: 336. đ.

\section{Genus AMYDRAULAX Cushman}

Amydraulax Cushman, 1922. U. S. Natl. Mus., Proc. 60 (21): 4.

Type-species: Amydraulax pulchra Cushman. Monotypic and orig. desig.

There is an undescribed species which apparently occurs in northern Mexico as well as in the southwestern U. S.; it has been reared from cones of Pinus ponderosa. The genus is not known to occur outside of the southwestern part of the Nearctic region.

pulchra Cushman. Calif. Ecology: The only host known for pulchra is a cerambycid which bores in the branches of Sequoia gigantea. Host: Callidium sequarium Fisher.

A miydraulax pulchra Cushman, 1922. U. S. Natl. Mus., Proc. 60 (21): 5 . ๆ.

\section{Genus APOTEMNUS Cushman}

Apotemnus Cushman, 1940. U. S. Natl. Mus., Proc. 88: 359.

Type-species: Cryptus truncatus Cushman. Monotypic and orig. desig.

Only the type-species is known.

truncatus Cushman. Oreg., Calif. Ecology: Reared from cones of Cupressus macrocarpa. Apotemnus truncatus Cushman, 1940. U. S. Natl. Mus., Proc. 88: 360. ?.

\section{Genus HELICOSTIZUS Foerster}

Brachycentrus Taschenberg, 1865. Ztschr. f. die Gesam. Naturw. Halle 25: 106. Preocc. by Curtis, 1834. 
Type-species: Cryptus pimplarius Taschenberg. Monotypic. The type-species is regarded as a synonym of $H$. restaurator restaurator (Fabricius).

Helcostizus Foerster, 1868. Naturh. Ver. Rheinlande, Verh. 25: 186.

Type-species: Cryptus brachycentrus Gravenhorst. By subsequent monotypy from inclusion by Schmiedeknecht, 1888. The type-species is regarded as a synonym of H. restaurator restaurator (Fabricius).

Cyrtocryptus Marshall, 1872. Cat. Brit. Hym., v. 3, p. 41.

Type-species: Cryptus brachycentrus Gravenhorst. Monotypic.

Mesocryptus Thomson, 1873. Opusc. Ent. 5: 519, 521.

Type-species: Cryptus brachycentrus Gravenhorst. Monotypic and orig. desig.

Heterocryptus Woldstedt, 1873. Bidr. till Kann. af Finlands Natur och Folk 21: 73.

Type-species: Cryptus brachycentrus Gravenhorst. Desig. by Viereck, 1914.

Astemaulax Viereck, 1912. U. S. Natl. Mus., Proc. 42: 632.

Type-species: Astermanlax fiskei Viereck. Monotypic and orig. desig.

Chenbergus Navas, 1930. Soc. Ent. de Espana, Bol. 13: 43. N. name for Brachycentrus Taschenberg.

This genus was formerly placed by Townes in the Cryptini, where it was a member of his now defunct subtribe Echthrina. Townes (1970) said little concerning his placement of Helcostizus in the Hemitelini, which leads me to suppose that he placed it here because he did not know what else to do with it. He mentioned Helcostizus as one of a number of genera showing "convergence toward" his newly erected subtribe Gabuniina (Cryptini), but said that in certain cases (without saying which cases) it is uncertain whether these genera should be placed in the Gabuniina or elsewhere.

Revision: Cushman, 1919. U. S. Natl. Mus., Proc. 55: 531-535. - Townes and Townes, 1962. U. S. Natl. Mus. Bul. 216 (pt. 3): 513-522.

Taxonomy: Townes, 1970 (1969). Amer. Ent. Inst., Mem. 12: 326.

annulicornis (Walsh). N. Y., Md., Va., Mich., Ill.?, Okla. Host: Elaphidionoides parallelus (Newm.)?

Echthrus annulicornis Walsh, 1873. Acad. Sci. St. Louis, Trans. 3: 159..+

Helcostizus bicarinatus Cushman, 1919. U. S. Natl. Mus., Proc. 55: 532. ․

Taxonomy: Cushman, 1924. U. S. Natl. Mus., Proc. 64 (4): 8.

collinus (Provancher). Que. Not included in the revision by Townes and Townes (1962) and probably synonymous with one of the taxa included.

Mesostenus collinus Provancher, 1879. Nat. Canad. 11 (no. 126): 111. o.

Taxonomy: Barron, 1975. Nat. Canad. 102: 453-454 (lectotype selected).

oxyura Townes. Ont., Mich.

Helcostizus oxyura Townes, 1962. In Townes and Townes, U. S. Natl. Mus. Bul. 216 (pt. 3): 517. ㅇ.

restaurator canadensis (Provancher). Que.s. to N. C., w. to Mich. Host: Atimia confusa (Say). $H$. restaurator restaurator (Fabricius) is Eurasian; its synonymy is listed by Townes, Momoi, and Townes (1965).

Mesochorus Canadensis Provancher, 1874. Nat. Canad. 6: 299. ‥

Asternaulax fiskei Viereck, 1912. U. S. Natl. Mus., Proc. 42: 632..

Taxonomy: Townes, Momoi, and Townes, 1965. Amer. Ent. Inst., Mem. 5: 204-205.

restaurator yukonensis (Ashmead). Northwestern N. W. T. w. to Alaska, s. to Ariz. and Calif. Host: Plectura spinicauda Mann. Townes and Townes (1962) distinguished rufiscutum Cushman as a separate subspecies, but the material they studied included nearly as many specimens which they classified as intermediate between rufiscutum and yukonensis as there were specimens identified as rufiscutum; therefore, I feel it is not practical to recognize rufiscutum as a distinct subspecies.

Pimpla yukonensis Ashmead, 1890 (1889). U. S. Natl. Mus., Proc. 12: 445. ?.

Helcostizus rufiscutum Cushman, 1919. U. S. Natl. Mus., Proc. 55: 533. ․ N. syn. subrectus Townes. Ariz.

Helcostizus subrectus Townes, 1962. In Townes and Townes, U. S. Natl. Mus. Bul. 216 (pt. 3): 517 . ㅇ. 
tibialis Townes. Ont., N. Y., Pa., Mich., Wis.

Helcostizus tibialis Townes, 1962. In Townes and Townes, U. S. Natl. Mus. Bul. 216 (pt. 3): 516. $\delta, ?$.

\section{Genus LOCHETICA Kriechbaumer}

Lochetica Kriechbaumer, 1892. Ent. Nachr. 18: 340.

Type-species: Phygadeuon pimplarius Thomson. Monotypic. The type-species is regarded as a synonym of $L$. Westoni (Bridgman).

This small Holarctic genus includes three Palearctic species and one undescribed species which occurs in the western U.S. (Townes, 1970).

Taxonomy: Townes, 1970 (1969). Amer. Ent. Inst., Mem. 12: 70.

\section{SUBTRIBE ETHELURGINA}

\section{Genus RHEMBOBIUS Foerster}

Rhembobius Foerster, 1868. Naturh. Ver. Rheinlande, Verh. 25: 184.

Type-species: Phygadeuon quadrispinus Gravenhorst. Monotypically included and desig. by Ashmead, 1900.

Ulothymus Foerster, 1868. Naturh. Ver. Rheinlande, Verh. 25: 185.

Type-species: Ichneumon perscrutator Thunberg. Monotypically included and desig. by Perkins, 1962.

Acanthocryptus. Thomson, 1873. Opusc. Ent. 5: 520, 521.

Type-species: Phygadeuon quadrispinus Gravenhorst. Monotypic and orig. desig.

This small Holarctic genus was removed from the Aptesini by Townes (1970), who discussed his reasons for transferring it to the Hemitelini. No other genus of Hemitelini is known to have species in which the adult females overwinter, but it is apparently not known if any Rhembobius sp. overwinters exclusively in this way. The known hosts are saprophagous Syrphidae.

Revision: Townes and Gupta, 1962. Amer. Ent. Inst., Mem. 2: 272-278.

Taxonomy: Townes, 1970 (1969). Amer. Ent. Inst., Mem. 12: 112.

abdominalis (Provancher). N. S. s. to Conn., w. to n. Alaska and Calif.; Hawaii. Host: Eumerus strigatus (Fall.), Merodon equestris (F.), Xylota sp. Townes and Gupta (1962) recognized three broadly overlapping subspecies.

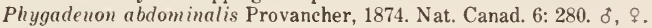

Phygadeuon 4-carinatus Provancher, 1875. Nat. Canad. 7: 180, 183. ठ.

Platylabus pacificus Harrington, 1894. Canad. Ent. 26: 210..

Rhembobins abdominalis montanus Townes and Gupta, 1962. Amer. Ent. Inst., Mem. 2: 275. ठ, ?.

Taxonomy: Cushman, 1930 (1929). U. S. Natl. Mus., Proc. 76 (25): 3.

parcus Townes. Mich., Man., Sask.

Rhembobius parcus Townes, 1962. In Townes and Gupta, Amer. Ent. Inst., Mem. 2: 273. ¿.?.

\section{Genus ETHELURGUS Foerster}

Tolmerus Foerster, 1868. Naturh. Ver. Rheinlande, Verh. 25: 177. Preocc. by Loew, 1849.

Type-species: Phygadeuon sodalis Taschenberg. Monotypically included and desig. by Townes and Townes, 1966.

Ethelurgus Foerster, 1868. Naturh. Ver. Rheinlande, Verh. 25: 180.

Type-species: Hemiteles (Ehtelurgus) lonicerae Viereck. By subsequent monotypy from inclusion by Viereck, 1917.

Nuneches Foerster, 1868. Naturh. Ver. Rheinlande, Verh. 25: 186.

Type-species: Phygadenon sodalis Taschenberg. Monotypically included and desig. by Perkins, 1962.

Zamicrotoridea Viereck, 1917 (1916). Conn. State Geol. and Nat. Hist. Survey Bul. 22: 340.

Type-species: Hemiteles (Zamicrotoridea) orbiform is Viereck. Monotypic. 
I have seen one undescribed Nearctic species in the U. S. Natl. Museum collection, but suppose that there are other undescribed Nearctic species because Townes (1970) said that Ethelurgus is a moderate sized genus. Males of Ethelurgus will not key to the subtribe Ethelurgina in Townes (1970) because only the females have the apical margin of the clypeus impressed.

Taxonomy: Townes, 1970 (1969). Amer. Ent. Inst., Mem. 12: 7, 72.

syrphicola (Ashmead). Conn. s. to S. C., w. to Oreg. Host: Allograpta obliqua (Say), Baccha (Ocyptamus) fascipennis Wied., Mesograpta polita (Say), Syrphus rectus 0. S.

Hemiteles syrphicola Ashmead, 1890 (1889). U. S. Natl. Mus., Proc. 12: 399..+

Hemiteles (Ethelurgus) lonicerae Viereck, 1917 (1916). Conn. State Geol. and Nat. Hist. Survey Bul. 22: 340 . ?.

Hemiteles (Zamicrotoridea) orbiformis Viereck, 1917 (1916). Conn. State Geol. and Nat. Hist. Survey Bul. 22: 340. $\delta$.

\section{SUbTRIBE ENDASEINA}

\section{Genus CHARITOPES Foerster}

Charitopes Foerster, 1868. Naturh. Verh. Rheinlande, Verh. 25: 181.

Type-species: Hemiteles (Charitopes) chrysopae Brischke. By subsequent monotypy from inclusion by Brischke, 1890.

Fianonia Seyrig, 1952. Acad. Malgache, Mem. 39: 31.

Type-species: Fianonia problematica Seyrig. Monotypic and orig. desig.

The species of this genus which have been reared are parasites of Hemerobiidae.

gastricus (Holmgren). Calif.

Hemiteles gastricus Holmgren, 1869 (1868). Eug. Resa, pt. 2 (Zool.), sect. 1 (Ins.), p. 401. \&.

Taxonomy: Townes, 1961. Ent. Soc. Wash., Proc. 63: 106.

mellicornis (Ashmead), n. comb. Mass. s. to S. C., w. to Minn. and Iowa. Host: Micromus posticus (Wlkr.).

Hemiteles mellicornis Ashmead, 1890 (1889). U. S. Natl. Mus., Proc. 12: 404. ९.

Charitopes mellicomis Townes, 1970 (1969). Amer. Ent. Inst., Mem. 12: 383. Nomen nudum.

piceiventris (Harrington). B. C.

Hemiteles piceiventris Harrington, 1894. Canad. Ent. 26: 213. ९.

Taxonomy: Townes, 1970 (1969). Amer. Ent. Inst., Mem. 12: 80.

plectiscinus (Roman). Greenland.

Phygadeuon plectiscinus Roman, 1916. Arkiv for Zool. 10 (22): 5. o, ?.

Taxonomy: Townes, 1961. Ent. Soc. Wash., Proc. 63: 111.

\section{Genus ADIASTOLA Foerster}

Adiastola Foerster, 1868. Naturh. Ver. Rheinlande, Verh. 25: 180.

Type-species: Adiastola americana Howard. By subsequent monotypy from inclusion by Howard, 1897.

Townes (1970) incorrectly treated Adiastola as a synonym of Mastrus.

Taxonomy: Townes, 1970 (1969). Amer. Ent. Inst., Mem. 12: 64.

columbiae (Viereck). D. C. Host: Iseropus coelebs (Walsh)?

Adiastola americana Howard, 1897. U. S. Dept. Agr., Div. Ent., Tech. Ser. 5: 54. ơ, ₹.

Temporarily preocc. in Hemiteles by Theroscopus americamis Ashmead, 1896.

Hemiteles columbiae Viereck, 1910. In Smith, N. J. State Mus., Ann. Rpt. for 1909, p. 631.

N. name for A. americana Howard.

\section{Genus MEDOPHRON Foerster}

Baryntica Foerster, 1868. Naturh. Ver. Rheinlande, Verh. 25: 184.

Type-species: Stylocryptus elegans Schmiedeknecht. Monotypically included and desig. by Perkins, 1962. 
Medophron Foerster, 1868. Naturh. Ver. Rheinlande, Verh. 25: 185.

Type-species: Medophron niger Brischke. By subsequent monotypy from inclusion by Brischke, 1881 . The type-species is regarded as a synonym of $M$. afflictor (Gravenhorst).

caudatus (Provancher). Que., s. Alaska.

Cryptus caudatus Provancher, 1875. Nat. Canad. 7: 314. $?$.

Bathymetis bicolor Ashmead, 1902. Wash. Acad. Sci., Proc. 4: 182. ठ", ₹.

dytiscivorus Mason. Ont. Host: Dytiscus fasciventris Say.

Medophrou dytiscivorus Mason, 1968. Canad. Ent. 100: 21. ơ, ?.

\section{Genus ENDASYS Foerster}

Endasys Foerster, 1868. Naturh. Ver. Rheinlande, Verh. 25: 184.

Type-species: Stylocryptus analis Thomson. Desig. by Viereck, 1914 from two species included by Roman, 1909.

Scinascopus Foerster, 1868. Naturh. Ver. Rheinlande, Verh. 25: 185.

Type-species: Plygadeuon cremargus Gravenhorst. By subsequent monotypy from inclusion by Brischke, 1891. The type-species is regarded as a synonym of $E$. parviventris (Gravenhorst).

Bachia Foerster, 1868. Naturh. Ver. Rheinlande, Verh. 25: 186. Preocc. by Gray, 1845.

Type-species: Phygadenon (Bachia) testaceipes Brischke. By subsequent monotypy from inclusion by Brischke, 1891.

Stylocryptus Thomson, 1873. Opusc. Ent. 5: 520, 521.

Type-species: Phygadeuon brevis Gravenhorst. Monotypic.

Bachiana Strand, 1928 (1926). Arch. f. Naturgesch. (A) 92 (8): 52. N. name for Bachia Foerster.

auriculiferus (Viereck). Conn., N. Y.

Phygadeuon (Bachia!) auriculiferus Viereck, 1917 (1916). Conn. State Geol. and Nat. Hist. Survey Bul. 22: 336. $\delta$.

bicolor (Lundbeck). Greenland.

Phygadeuon bicolor Lundbeck, 1897 (1896). Dansk Naturhist. For. Kjobenhavn, Vidensk. Meddel., p. 227. ₹.

Taxonomy: Roman, 1916. Arkiv for Zool. 10 (22): 4, 5.

maculatus (Provancher). Que. s. to Md., w. to Mich. and Ohio.

Phygadeuon maculatus Provancher, 1875. Nat. Canad. 7: 178, 182. \&.

monticola (Dalla Torre). Colo.

Phygadeuon montanus Cresson, 1864. Ent. Soc. Phila., Proc. 3: 309. . Preocc. (presently?) in Phygadeuon by Cryptus montanus Gravenhorst, 1829.

Phygadeuon monticola Dalla Torre, 1902. Cat. Hym., v. 3, p. 689. N. name for $P$. montanus Cresson.

mucronatus (Provancher). Que. s. to Va., w. to Mich. Host: Arge clavicornis (F.), A. pectoralis (Leach).

Phygadeuon mucronatus Provancher, 1879. Nat. Canad. 11: 73. ․

Melophron (!) abdominalis Ashmead, 1906. In Slosson, Ent. News 17: 324. Nomen nudum.

paludicola (Brues). Colo.

Oxytorus paludicola Brues, 1908. Wis. Nat. Hist. Soc., Bul. 6: 50. ơ.

pubescens (Provancher). Que. s. to Ga., w. to Alta. and Colo.

Phygadeuon pubescens Provancher, 1874. Nat. Canad. 6: 282. ঠ.

Phygadeuon dubius Provancher, 1874. Nat. Canad. 6: 283. $q$.

Alom ya pulchra Provancher, 1875. Nat. Canad. 7: 120. ठ.

Phygadeuon pallicoxus Provancher, 1879. Nat. Canad. 11: 75. ठ.

Phygadeuou pallidicoxus Dalla Torre, 1902. Cat. Hym., v. 3, p. 690. Emend.

rotundiceps (Provancher). Que.

Phygadeuou rotundiceps Provancher, 1877. Nat. Canad. 9: 12..

Taxonomy: Provancher, 1879. Nat. Canad. 11: 74. 
subclavatus (Say). N. B. s. to Fla., w. to Oreg. and Calif. Host: Gilpinia hercyniae (Htg.), Neodiprion excitans Roh., N. lecontei (Fitch), N. nanulus nanulus Schedl, N. pratti banksianae Roh., N. pratti pratti (Dyar), N. rugifrons Midd., N. sertifer (Geoff.), $N$. swainei Midd., N. taedae linearis Ross, N. tsugae Midd., N. virginiana Roh., Zadiprion townsendi (Cock.).

Cryptus subclaratus Harris, 1835. In Hitchcock, Rpt. Geol. Mineral. Bot. Zool. Mass., ed. 2, p. 584. Nomen nudum.

Cryptus subclavatus Say, 1836. Boston Jour. Nat. Hist. 1: 237..

Phygadeuon vulgaris Cresson, 1864. Ent. Soc. Phila., Proc. 3: 310..

Ichneumon inflatus Provancher, 1875. Nat. Canad. 7 (1): 24 (key); 7 (3): 83. o.

Platylabus ruficomis Provancher, 1886. Addit. Corr. Faune Ent. Canada Hym., p. 36, 38. $\delta$, ?.

Melophron (!) monticola Ashmead, 1900. In Slosson, Ent. News 11: 319. Nomen nudum.

Phygadenon (Bathymetis) patulus Viereck, 1911. U. S. Natl. Mus., Proc. 40: 193. ơ.

Phygadeuon (Bachia?) brittoni Viereck, 1917 (1916). Conn. State Geol. and Nat. Hist. Survey Bul. 22: 336 . $\delta$.

Taxonomy: Cushman and Gahan, 1921. Ent. Soc. Wash., Proc. 23: 162. -Finlayson, 1960.

Canad. Ent. 92: 25, 32 (final-instar larva).

Biology: Tripp, 1961. Canad. Ent. 93: 53. -Finlayson, 1963. Canad. Ent. 95: 491.

texanus (Cresson). Tex.

Phygadeuon texanus Cresson, 1872. Amer. Ent. Soc., Trans. 4: 160. ठ.

\section{Genus GLYPHICNEMIS Foerster}

Glyphicnem is Foerster, 1868. Naturh. Ver. Rheinlande, Verh. 25: 181.

Type-species: Phygadeuon vagabundus Gravenhorst. Monotypically included and desig. by Ashmead, 1900.

Gnathocryptus Thomson, 1873. Opusc. Ent. 5: 520, 521.

Type-species: Phygaderon vagabundus Gravenhorst. Monotypic and orig. desig.

Semiodes Harrington, 1894. Canad. Ent. 26: 247.

Type-species: Semiodes seminiger Harrington. Monotypic.

I have seen specimens representing what appear to be several undescribed Neartic species.

mandibularis (Cresson). Que. s. to Md., w. to B. C. and Calif.

Phygadeuon mandibularis Cresson, 1864. Ent. Soc. Phila., Proc. 3: 311. ๆ.

Ischnus ruficornis Provancher, 1875. Nat. Canad. 7 (4): 110. ठ.

Phygadeuon ruficomis Provancher, 1875. Nat. Canad. 7 (6): 179. ð. Preoce. in Phygadeuon by Gravenhorst, 1829 and in Glyphicnem is by Provancher, 1875, no. 4, p. 110.

Phygadeuon crassipes Provancher, 1875. Nat. Canad. 9: 11. $\%$.

Phygadeuon californicus Cresson, 1879 (1878). Acad. Nat. Sci. Phila., Proc. 30: 358. ơ.

Semiodes seminiger Harrington, 1894. Canad. Ent. 26: 247. ठ゚.

\section{SUBTRIBE BATHYTRICHINA}

This subtribe includes six genera, but only Baththrix, which is nearly worldwide in distribution, occurs in the Nearctic fauna.

\section{Genus BATHYTHRIX Foerster}

Ischnurgops Foerster, 1868. Naturh. Ver. Rheinlande, Verh. 25: 175.

Type-species: Cryptus claviger Taschenberg. Monotypically included and desig. by Viereck, 1914.

Steganops Foerster, 1868. Naturh. Ver. Rheinlande, Verh. 25: 175.

Type-species: Cryptus claviger Taschenberg. Monotypically included and desig. by Viereck, 1914.

Bathythrix Foerster, 1868. Naturh. Ver. Rheinlande, Verh. 25: 175.

Type-species: Bathythrix meteori Howard. Desig. by Viereck, 1914 from two species

included by Howard, 1897.

Panargyrops Foerster, 1868. Naturh. Ver. Rheinlande, Verh. 25: 182. 
Type-species: Cryptus claviger Taschenberg. Desig. by Viereck, 1914 from two species included by Schmiedeknecht, 1888.

Gausocentrus Foerster, 1868. Naturh. Ver. Rheinlande, Verh. 25: 198.

Type-species: Gausocentrus gyrini Ashmead. By subsequent monotypy from inclusion by Ashmead, 1894.

Stenoschema Foerster, 1868. Naturh. Ver. Rheinlande, Verh. 25: 220. Nomen nudum.

Leptocryptus Thomson, 1873. Opusc. Ent. 5: 521.

Type-species: Cryptus claviger Taschenberg. Desig. by Viereck, 1914 from nine species included by Thomson, 1884 .

Agenora Cameron, 1909. Bombay Nat. Hist. Soc., Jour. 19: 722.

Type-species: Agenora hirticeps Cameron. Monotypic.

Members of this genus oviposit into cocoons of various insects, often those of Braconidae or other Ichneumonidae.

Revision: Thomson, 1884. Opusc. Ent. 10: 963-966 (European spp.). -Cushman, 1920. U. S.

Natl. Mus., Proc. 58: 261-264. - Viereck, 1925. Canad. Ent. 57: 77-78.

areolaris (Cushman). Alaska, Oreg., Calif. Host: Neodiprion tsugae Midd.

Panargyrops areolaris Cushman, 1939. Wash. Acad. Sci., Jour. 29: 397. đ, ๆ.

claviger (Taschenberg). Que., Maine, Tex., Alta., Colo., B. C., Wash.; Eurasia. Host:

Ametastegia glabrata (Fall.).

Cryptus claviger Taschenberg, 1865. Ztschr. f. die Gesam. Naturw. Halle 25: 76. $\delta$.

Cryptus (Chaeretymma[!]) ater Brischke, 1880. Naturf. Gesell. Danzig, Schr. (n. f.) 5: 338. o, ㅇ.

Mesostenus sericeus Provancher, 1875. Nat. Canad. 7: 264. ठ.

Cryptus sericeifrons Provancher, 1879. Nat. Canad. 11 (no. 125): 132. ๆ.

Agenora hirticeps Cameron, 1909. Bombay Nat. Hist. Soc., Jour. 19: 722. ठ.

Bathythrix tibialis Cushman, 1917. U. S. Natl. Mus., Proc. 53: 458. o, १.

Panargyrops texanus Cushman, 1920. U. S. Natl. Mus., Proc. 58: 262. + . Preoce. in Bathythrix by Ashmead, 1890.

Panargyrops pacificus Cushman, 1920. U. S. Natl. Mus., Proc. 58: 262..

Thysiotorus (Panargyrops) tegularis Viereck, 1925. Canad. Ent. 57: 78..

Thysiotorus (Panargyrops) conjunctus Viereck, 1925. Canad. Ent. 57: 78. ठै, ९.

Taxonomy: Oehlke, 1966 (1965). Beitr. z. Ent. 15: 845-846.

fragilis (Viereck). N. Mex.

Plesiognathus (!) fragilis Viereck, 1903. In Skinner, Amer. Ent. Soc, Trans. 29: 82. ठ.

gyrinophaga (Cushman). N. Y., Ont., Mich., Iowa. Host: Gyrinus sp.

Gausocentmes gyrini Ashmead, 1894. Canad. Ent. 26: 25. ठ. Preoce. in Bathythrix by Hemiteles gyrini Parfitt, 1881.

Hemiteles gyrinophagus Cushman, 1930 (1929). U. S. Natl. Mus., Proc. 76 (25): 5. N. name for G. gyrini Ashmead.

Panargyrops insula DeGant, 1933. U. S. Natl. Mus., Proc. 82: 2. ঠ, ๆ.

Taxonomy: Townes, 1970 (1969). Amer. Ent. Inst., Mem. 12: 90 (syn.).

latifrons (Cushman). Southern Alaska, Wash., Oreg. Host: Neodiprion tsugae Midd., Meteorus sp.?

Thysiotorus latifrons Cushman, 1939. Wash. Acad. Sci., Jour. 29: 396. ठ, ๆ.

meteori (Howard). R. I. and N. Y. s. to Ga. and Miss. Host: Meteorus communis (Cr.), Iseropus coelebs (Walsh)?

Bathythrix meteori Howard, 1897. U. S. Dept. Agr., Div. Ent., Tech. Ser. 5: 53. ¿, ૧.

peregrina (Cresson). Que. s. to Va., w. to Iowa and Kans.

Mesoleptus? peregrimus Cresson, 1868. Amer. Ent. Soc., Trans. 2: 102. ठ, ९.

Panargyrops thoracicus Cushman, 1919. U. S. Natl. Mus., Proc. 55: 528. ๆ.

pimplae Howard. N. Y. s. to Va., w. to S. Dak. Host: Gambrus extrematis (Cr.), Iseropus coelebs (Walsh)?, Gyrinus sp.?

Bathyth rix pimplae Howard, 1897. U. S. Dept. Agr., Div. Ent., Tech. Ser. 5: 54..

Biology: Butcher, 1933. Ent. Soc. Amer., Ann. 26: 82. 
subargentea (Cresson). Pa., Alta., Idaho, Wash.

Cryptus subargenteus Cresson. 1864. Ent. Soc. Phila., Proc. 3: 302. ㅇ.

Exolytus sericeifrons Davis, 1898 (1897). Amer. Ent. Soc., Trans. 24: 355. . Preocc. in Bathythrix by Cryptus sericeifrons Provancher.

Thysiotoms (Panargyrops) seamansi Viereck, 1925. Canad. Ent. 57: 77.. texana (Ashmead). Tex.

Stilpnus texanus Ashmead, 1890 (1889). U. S. Natl. Mus., Proc. 12: 397. ๆ.

triangularis (Cresson). Maine w. to Wis., s. to Ala. Host: Apanteles melanoscelus (Ratz.), Meteorts versicolor (Wesm.), Hyposoter sp., Phobocampe geometrae (Ash.), Diprion similis (Htg.).

Mesoleptus triangularis Cresson, 1868. Amer. Ent. Soc., Trans. 2: 101. o.

Mesostenus pallipes Provancher, 1875. Nat. Canad. 7: 264. ․

Thysiotorus? smithi Cushman, 1920. U. S. Natl. Mus., Proc. 58: 263. ठ',.

Taxonomy: Cushman, 1939. Wash. Acad. Sci., Jour. 29: 396 (syn.).

\section{SUBTRIBE PHYGADEUONTINA \\ Genus OECOTELMA Townes}

Oecotelma Townes, 1970 (1969). Amer. Ent. Inst., Mem. 12: 94.

Type-species: Hemiteles cushmani Butcher. Monotypic and orig. desig.

cushmani (Butcher). Mich. Host: Gyrinus sp.

Hemiteles cushmani Butcher, 1933. Ent. Soc. Amer., Ann. 26: 76. ठ, ๆ.

\section{Genus SULCARIUS Townes}

Sulcarius Townes, 1970 (1969). Amer. Ent. Inst., Mem. 12: 95.

Type-species: Hemiteles hellbachi Schmiedeknecht. Orig. desig.

Species of this genus apparently parasitize larvae of caddisflies whose cases are left exposed by the receding waters of vernal ponds or intermittent streams.

biannulatus (Gravenhorst). Minn.?, Ill.?; Europe. Host: Limnephilus indivisus Walker. North American specimens were identified as biamulatus by Roman (1925) and Mickel and Milliron (1939), but the question of conspecificity of Neartic and Paleartic specimens has apparently not been readdressed; therefore, the occurrence of biannulatus in North America remains unsubstantiated.

Hemiteles biannulatus Gravenhorst, 1829. Ichn. Europaea, v. 2, p. 846..

Hemiteles Hellbachi Schmiedeknecht, 1905. Opusc. Ichn., v. 2, p. 851. \&. Syn. verified by Dr. Klaus Horstmann (personal commun., 1976).

Hemiteles bianulatus (!) Oehlke and Townes, 1969. Beitr. z. Ent. 19: 400.

Taxonomy: Roman, 1925 (1924). Arkiv for Zool. 17 A (4): 16. - Hellen, 1967. Notulae Ent. 47: 107. - Oehlke and Townes, 1969. Beitr. z. Ent. 19: 400. - Townes, 1970 (1969). Amer. Ent. Inst., Mem. 12: 96.

Biology: Mickel and Milliron, 1939. Ent. Soc. Amer., Ann. 42: 578-580.

bicornutus (Ashmead). Mo.

Hemiteles bicomutus Ashmead, 1890 (1889). U. S. Natl. Mus., Proc. 12: 403. ठ.

Taxonomy: Townes, 1970 (1969). Amer. Ent. Inst., Mem. 12: 96.

glacialis (Ashmead). B. C. The type-locality (Lowe Inlet, B. C.) was erroneously recorded by

Townes (1944) as an Alaskan locality.

Philonygus (!) glacialis Ashmead, 1902. Wash. Acad. Sci., Proc. 4: 189. ठ.

Taxonomy: Townes, 1944. Amer. Ent. Soc., Mem. 11: 186. - Townes, 1970 (1969). Amer. Ent. Inst., Mem. 12: 96.

\section{Genus ORTHIZEMA Foerster}

Orthizema Foerster, 1868. Naturh. Ver. Rheinlande, Verh. 25: 178. 
Type-species: Hemiteles (Orthizema) omatus Brischke. By subsequent monotypy from inclusion by Brischke, 1890. The type-species is regarded as a synonym of $O$. subannulatum (Bridgman).

Naetes Foerster, 1868. Naturh. Ver. Rheinlande, Ver. 25: 185.

Type-species: Hemiteles (Naites[!]) rufus Brischke. By subsequent monotypy from inclusion by Brischke, 1892. The type-species is regarded as a synonym of $O$. hadrocerus (Thomson).

Phyzelus Foerster, 1868. Naturh. Ver. Rheinlande, Verh. 25: 185.

Type-species: Phyzelus fasciatus Brischke. By subsequent monotypy from inclusion by Brischke, 1888. Townes and Gupta (1962) disputed Perkins' (1962) synonymy of fasciatus with Aptesis flagitator (Rossi) on the premise that A. flagitator does not agree with the original description of fasciatus (the holotype of fasciatus having been destroyed), and Townes (1970) placed fasciatus as a synonym of $O$. hadrocerus (Thomson).

Townes (1970) stated that Orthizema is a large genus of Holarctic distribution, but did not state how many undescribed Nearctic species he has seen.

Taxonomy: Perkins, 1962. Brit. Mus. (Nat. Hist.) Ent., Bul. 11: 446. -Townes and Gupta, 1962. Amer. Ent. Inst., Mem. 2: 247. -Townes, 1970 (1969). Amer. Ent. Inst., Mem. 12: 97-98.

testaceipes (Cushman). N. H., N. Y., Pa.

Adiastola testaceipes Ashmead, 1906. In Slosson, Ent. News 17: 324. Nomen nudum.

Lymeon! testaceipes Cushman, 1922. U. S. Natl. Mus., Proc. 61 (8): 17. ?.

\section{Genus UCHIDELLA Townes}

Itamus Foerster, 1868. Naturh. Ver. Rheinlande, Verh. 25: 179. Preocc. by Schmidt-Goebel, 1846.

Type-species: Hemiteles (Itamus) okamotoi Uchida. By subsequent monotypy from inclusion by Uchida, 1936. The type-species is regarded as a synonym of $U$. marginata (Uchida).

Uchidella Townes, 1957. Ent. Soc. Wash., Proc. 59: 109. N. name for Itamus Foerster.

Except for one species known from Taiwan, Uchidella is said to be a Holarctic genus of moderate size (see Townes, 1970). There are no described Nearctic species.

Taxonomy: Townes, 1970 (1969). Amer. Ent. Inst., Mem. 12: 99.

\section{Genus GNOTUS Foerster}

Gnotus Foerster, 1868. Naturh. Ver. Rheinlande, Verh. 25: 179.

Type-species: Hemiteles tenuicornis Gravenhorst. Included and desig. by Perkins,

1962. The type-species is regarded as a synonym of $G$. tenuipes (Gravenhorst).

chionops (Gravenhorst). N. Y., Pa., Md., Mich.; Japan; Europe. Townes (1970) stated that chionops is Holarctic without mentioning specific localities outside Europe; these he communicated to me personally and stated that he regards the European, Japanese, and Nearctic specimens he has seen as belonging to three separate subspecies.

Hemiteles chionops Gravenhorst, 1829. Ichn. Europaea, v. 2, p. 797. ठ.

Taxonomy: Townes, 1970 (1969). Amer. Ent. Inst., Mem. 12: 100.

\section{Genus HEDYLUS Foerster}

Hedylus Foerster, 1868. Naturh. Ver. Rheinlande, Verh. 25: 183.

Type-species: Hedylus crassicomis Ashmead. By subsequent monotypy from inclusion by Ashmead, 1899.

This genus is transferred from the Endaseina where Townes (1970) placed it as a synonym of Medophron. Although the type-species of Hedylus somewhat resembles Medophron species in the structure of the head and ovipositor, it differs from Medophron species so greatly in wing venation and petiolar structure that it seems illogical to suggest any close phyletic relationship 
between Hedylus and Medophron. In Hedylus crassicornis the nervellus is reclivous, the discoidella is absent, the apical portion of the mediella is very strongly curved, and the petiole has the apex of the sternite opposite the spiracles. In Townes' (1970) key to the genera of Phygadeuontina $H$. crassicornis runs to Stibeutes.

Taxonomy: Townes, 1970 (1969). Amer. Ent. Inst., Mem. 12: 81, 92-94.

brooksi (Brooks), n. comb. W. Va. Host: Craponius inaequalis (Say). This species was placed in Stibentes by Townes (1970); it seems more a misfit in Stibeutes than in Hedylus.

Stiboscopus brooksi Ashmead, 1906. In Brooks, W. Va. Agr. Expt. Sta., Bul. 100: 240.

Nomen nudum.

Stiboscopus brooksi Brooks 1918. U. S. Dept. Agr., Bul. 730: 14..

Taxonomy: Townes, 1970 (1969). Amer. Ent. Inst., Mem. 12: 100, 395.

crassicornis Ashmead. N. H., Wis.; e. U. S. S. R.

Hedylus crassicomis Ashmead, 1899 (1898). In Jordan, Fur Seals and Fur Seal Isls. No. Pacific, v. 4, p. 339..

\section{Genus STIBEUTES Foerster}

Stibeutes Foerster, 1850. Arch. f. Naturgesch. 16 (1): 76.

Type-species: Stibeutes gravenhorstii Foerster. Desig. by Ashmead, 1900.

Chamaezelus Foerster, 1868. Naturh. Ver. Rheinlande, Verh. 25: 181.

Type-species: Stibeutes heinemami Foerster. Monotypically included and desig. by Perkins, 1962.

Schizopleuron subg. Schizopleuron Aubert, 1968. Soc. Ent. de. Mulhouse, Bul. 24: 6 .

Described as Schizopleuron n. genus or Medophron subg. Schizopleuron n. subg.

Type-species: Medophron (Schizopleuron) tricinctor Aubert. Monotypic. The type-species was alternatively described as Schizopleuron tricinctor Aubert.

yuasai (Bradley). N. Y.

Phygadeuon (Stibeutes) yuasai Bradley, 1918. Brooklyn, Ent. Soc., Bul. 13: 99. .

\section{Genus THEROSCOPUS Foerster}

Theroscopus Foerster, 1850. Arch. f. Naturgesch. 16 (1): 72.

Type-species: Pezomachns pedestris Gravenhorst. Desig. by Viereck, 1914. P. pedestris Gravenhorst is an identification of Ichneumon pedestris Fabricius.

Chamerpes Foerster, 1868. Naturh. Ver. Rheinlande, Verh. 25: 172.

Type-species: Pezomachus hemipterus Gravenhorst. Monotypically included and desig. by Viereck, 1914. P. hemipterus Gravenhorst is an identification of Ichneumon hemipterus Fabricius which Viereck referred to as "Hemiteles hemipterus Gravenhorst."

Eriplanus Foerster, 1868. Naturh. Ver. Rheinlande, Verh. 25: 180.

Type-species: Hemiteles (Eriplanus) metacomet Viereck. By subsequent monotypy from inclusion by Viereck, 1917.

Phyrtus Foerster, 1868. Naturh. Verh. Rheinlande, Verh. 25: 181.

Type-species: Pezomachus hemipterus Gravenhorst. Monotypically included and desig. by Ashmead, 1900. P. hemipterus Gravenhorst is an identification of Ichneumon hemipterus Fabricius which Ashmead referred to as "Hemiteles hemiptemes Gravenhorst."

Thysiotorus Foerster, 1868. Naturh. Ver. Rheinlande, Verh. 25: 181.

Type-species: Hemiteles (Physiotorus[!]) brevipennis Brischke. Desig. by Viereck, 1914 from two species included by Dalla Torre, 1902. Dalla Torre made the apparently erroneous assumption that Physiotorus was a typographical error for Thysiotorus. Cushman (1939) and Perkins (1962) suggest that Physiotorus was a lapsus Brischke made for Phyrtus instead of a typographical error for Thysiotorus.

Odontoneura Foerster, 1868. Naturh. Ver. Rheinlande, Verh. 25: 185. N. syn.

Type-species: Phygadeuon annulicornis Thomson. Monotypically included and desig. by Perkins, 1962. The systematic position of the type-species is discussed by Frilli (1973). 
Aenoplegimorpha Viereck, 1912. U. S. Natl. Mus., Proc. 42: 147.

Type-species: Aenoplegimorpha phytonomi Viereck. Monotypic and orig. desig.

Townes (1970) said that Theroscopus "is a large genus of Holarctic distribution; the hosts are probably various small cocoons."

Taxonomy: Cushman, 1939. Wash. Acad. Sci., Jour. 29: 395-396. - Perkins, 1962. Brit. Mus.

(Nat. Hist.) Ent., Bul. 11: 392. - Townes, 1970 (1969). Amer. Ent. Inst., Mem. 12: 101.

-Frilli, 1973. Entomologica 9: 95.

nigriceps (Ashmead). Calif.

Hemiteles nigriceps Ashmead, 1890 (1889). U. S. Natl. Mus., Proc. 12: 400..

Taxonomy: Townes, 1970 (1969). Amer. Ent. Inst., Mem. 12: 101.

ruficoxus (Provancher), Que. s. to Conn., w. to Alta. and Utah.; Eurasia. Adventive? Host:

Hypera postica (Gyll.). The name which has most frequently been applied to this species

is micator (Gravenhorst), but the original description of Ichneumon micator

Gravenhorst (1807) cannot apply to this species primarily because Gravenhorst specifically described the female (male not described) as having the scape yellowish-brown and only the apices of abdominal tergites 1 and 2 yellowish-brown; in addition, the micator female apparently has black coxae. Cushman (1922) apparently based his suppression of Aenoplegimorpha phytonomi as a synonym of micator upon a specimen in the U.S. Natl. Museum collection identified as micator by Schmiedeknecht. The European concept of micator apparently had evolved from Gravenhorst's (1829) expanded definition of the species. Dr. Klaus Horstmann told me (personal commun., 1976) that Gravenhorst (1829) described a senior synonym of ruficoxus, and its identity will probably be published prior to the appearance of this catalog.

Hemiteles ruficoxus Provancher, 1874. Nat. Canad. 6: 331. o, ?.

Phygadeuon comutus Provancher, 1882. Nat. Canad. 13 (no. 155): 334 (key); 13 (no. 156): 356. ㅇ. .

Hemiteles politus Bridgman, 1883. Ent. Soc. London, Trans. 31: 146. \&. Uncertain syn.; placed as a synonym of micator by Horstmann (1972).

Phaeogenes recticornis Provancher, 1886. Addit. Corr. Faune Ent. Canada Hym., p. 42. o', ․

Aenoplegimorpha phytonomi Viereck, 1912. U. S. Natl. Mus., Proc. 42: 147. ठ゚.

Hemiteles (Eriplanus) metacomet Viereck, 1917 (1916). Conn. State Geol. and Nat. Hist. Survey Bul. 22: 340 . $?$.

Phygadeuon silesiacus Habermehl, 1919. Ztschr. f. Wiss. Insectenbiol. 15: 104.. Uncertain syn.; placed as a synonym of micator by Habermehl (1926).

Taxonomy: Gravenhorst, 1807. Vergl. Uebers. Zool. Systeme, p. 260. -Gravenhorst, 1829.

Ichn. Europaea, v. 2, p. 832. -Cushman, 1922. Ent. Soc. Wash., Proc. 24: 64. - Roman,

1925 (1924). Arikiv for Zool. 17 A (4): 15-16. - Habermehl, 1926. Deut. Ent. Ztschr. (for

1926), p. 331. - Horstmann, 1972. Entomologist 105: 220.

Biology: Webster, 1912. U. S. Dept. Agr., Bur. Ent., Bul. 112: 34. - Boulanger, 1969. Ent. Soc. Wash., Proc. 71: 149-150.

seapiphorus (Provancher), Que., Mass., R. I., N. Y.

Atractodes scapiphoms Provancher, 1874. Nat. Canad. 6: 151. ठै.

Taxonomy: Townes, 1939. Canad. Ent. 71: 92. - Barron, 1975. Nat. Canad. 102: 561.

\section{Genus MEGACARA Townes}

Megacara Townes, 1970 (1969). Amer. Ent. Inst., Mem. 12: 102.

Type-species: Phygadeuon lucens Provancher. Orig. desig.

This is a small Holarctic genus, with lucens (Provancher) being the only described Nearctic species.

lucens (Provancher). Que., Wash.

Phygadeuon lucens Provancher, 1874. Nat. Canad. 6: 281..+ 


\section{Genus PHYGADEUON Gravenhorst}

Phygadeuon Gravenhorst, 1829. Ichn. Europaea, v. 2, p. 635.

Type-species: Phygadenon flavimanus Gravenhorst. Desig. by Westwood, 1840.

Apterophygas Foerster, 1868. Naturh. Ver. Rheinlande, Verh. 25: 172.

Type-species: A pterophygus(!) paradoxus Bridgman. By subsequent monotypy from inclusion by Bridgman, 1889 .

Gunopaches Foerster, 1868. Naturh. Ver. Rheinlande, Verh. 25: 174.

Type-species: Gunopaches crassus Perkins. Monotypically included and desig. by Perkins, 1962.

Habromma Foerster, 1868. Naturh. Ver. Rheinlande, Verh. 25: 176.

Type-species: Habromma nigrum Ashmead. By subsequent monotypy from inclusion by Ashmead, 1902.

Pantolispa Foerster, 1868. Naturh. Ver. Rheinlande, Verh. 25: 178.

Type-species: Gunopaches crassus Perkins. Monotypically included and desig. by Perkins, 1962.

Isochresta Foerster, 1868. Naturh. Ver. Rheinlande, Verh. 25: 181.

Type-species: Isoch resta unicincta Ashmead. By subsequent monotypy from inclusion by Ashmead, 1902.

Bathymetis Foerster, 1868. Naturh. Ver. Rheinlande, Verh. 25: 182.

Type-species: Phygadeuon (Bathymetis) cylindricus Brischke. Desig. by Viereck, 1914 from two species included by Brischke, 1891.

Iselix Foerster, 1868. Naturh. Ver. Rheinlande, Verh. 25: 182.

Type-species: Phygadenon nitidus Gravenhorst. Desig. by Viereck, 1914 from seven species included by Dalla Torre, 1902.

Homelys Foerster, 1868. Naturh. Ver. Rheinlande, Verh. 25: 182. Preocc. by Meyer, 1844.

Type-species: Phygadeuon lapponicus Thomson. By subsequent monotypy from inclusion by Roman, 1909 .

Emoctona Foerster, 1868. Naturh. Ver. Rheinlande, Verh. 25: 183.

Type-species: Phygadeuon rugulosus Gravenhorst. Monotypically included and desig. by Perkins, 1962.

Zaphleges Foerster, 1868. Naturh. Ver. Rheinlande, Verh. 25: 184.

Type-species: Phygadeuon leucostigmus Ashmead. By subsequent monotypy from inclusion by Ashmead, 1900.

Phygadeuon subg. Ischnocryptus Kriechbaumer, 1892. Ent. Nachr. 18: 351.

Type-species: Phygadenon nitidus Gravenhorst. Desig. by Viereck, 1914.

Members of this large genus parasitize the pupae of cyclorrhaphous Diptera.

aciculatus Provancher. Que., N. H., N. Y., Minn., Alta.

Phygadezon aciculatus Provancher, 1882. Nat. Canad. 13 (no. 155): 336 (key); 13 (no. 156): 356. $\delta$.

alaskensis (Ashmead), n. comb. Alaska. The holotype has been found.

Microcryptus alaskensis Ashmead, 1902. Wash. Acad. Sci., Proc. 4: 184. ठ。.

albirictus Cresson. Calif.

Phygadenon albirictus Cresson, 1879 (1878). Acad. Nat. Sci. Phila., Proc. 30: 358. ðे.

americanus (Cushman). Maine, N. H., N. Y.

Epitomus americanus Ashmead, 1902. In Slosson, Ent. News 13: 320. Nomen nudum.

Plesignathus americanus Cushman, 1922. U. S. Natl. Mus., Proc. 61 (8): 23. ๆ.

canadensis (Provancher). Que.

Stilpuus Canadensis Provancher, 1875. Nat. Canad. 7: 112. ठ.

capitalis Provancher. Que., Ont., N. Y.

Phygadeuon capitalis Provancher, 1886. Addit. Corr. Faune Ent. Canada Hym., p. 57. ठ。.

cephalicus Provancher. Que., N. C.

Phygadenon cephalicus Provancher, 1882. Nat. Canad. 13 (no. 155): 335 (key); 13 (no. 156): 354. $\delta$.

coloradensis (Ashmead). Colo.

Nematomicrus coloradensis Ashmead, 1890 (1889). U. S. Natl. Mus., Proc. 12: 395.. 
cylindraceus Ruthe. Greenland; Europe. Host: Fucellia fucorum (Fall.), Spaziphora hydrom yzina (Fall.).

Phygadeuon cylindraceus Ruthe, 1859. Stettin. Ent. Ztg. 20: 367. o, ?.

Phygadeuon sudvoldensis Morley, 1947 (1946). Suffolk Nat. Soc., Trans. 6: 37. ठ, ?.

Taxonomy: Roman, 1916. Arkiv for Zool. 10 (22): 5. - Aubert, 1975. Soc. Ent. de Mulhouse, Bul. 31: 15 (syn.).

Biology: Nielsen, 1907. Meddel. om Groenland 39: 385. - Baines and Finlayson, 1949. Ent. Monthly Mag. 85: 150-151.

epochrae Viereck. Mont. Host: Epochra canadensis (Loew).

Phygadeuon (Plesignathus) epochrae Viereck, 1913. U. S. Natl. Mus., Proc. 44: 567. ơ, ?.

hudsonicus (Cresson). "Hudson's Bay Territory."

Stilpnus hudsonicus Cresson, 1868. Amer. Ent. Soc., Trans. 2: 95. ठ゚.

laticinctus Ashmead. Colo.

Phygadeuon laticinctus Ashmead, 1890. Colo. Biol. Soc., Bul. 1: 21..

lechevallieri Provancher. Que.

Phygadeuon Lechevallieri Provancher, 1882. Nat. Canad. 13 (no. 155): 334 (key); 13 (no. 156): 356. . .

manitouensis (Viereck). N. Y., Colo., Wash.

Hemiteles (Diaglypta!) manitouensis Viereck, 1905. Kans. Acad. Sci., Trans. 19: 290. ð.

melanocerus Viereck. Que., R. H., Conn., N. Y., Sask.

Phygadeuon (Plesignathus) melanocerus Viereck, 1917 (1916). Conn. State Geol. and Nat. Hist. Survey Bul. 22: 336. ठ.

mignaulti Provancher. Que.

Phygadeuon Mignaulti Provancher, 1882. Nat. Canad. 13 (no. 155): 334 (key); 13 (no. 156): 355 . ?.

Phygadeuon mignaultii Dalla Torre, 1902. Cat. Hym., v. 3, p. 688. Emend.

montivagus (Ashmead). Colo.

Phaeogenes montivagus Ashmead, 1890 (1889). U. S. Natl. Mus., Proc. 13: 394.

nortoni Viereck. Conn., N. Y. Townes (1970) seems to have suggested that this species may not belong in Phygadeuon.

Phygadenon (Plesignathus) nortoni Viereck, 1917 (1916). Conn. State Geol. and Nat. Hist. Survey Bul. 22: 336 . ठ.

Taxonomy: Townes, 1970 (1969). Amer. Ent. Inst., Mem. 12: 103.

ovalis Provancher. Que., N. Y.

Phygadeuon ovalis Provancher, 1875. Nat. Canad. 7: 180. đo,.

parallelus Provancher. Que. Townes (1944) incorrectly suppressed parallelus as a synonym of $P$. canadensis (Provancher).

Phygadeuon parallelus Provancher, 1882. Nat. Canad. 13 (no. 155): 335 (key); 13 (no. 156): 356. ठ.

pisinnus Walkley. Colo.

Ichneumon exiguus Cresson, 1864. Ent. Soc. Phila., Proc. 3: 182. ९. Preoce. in Phygadeuon by Gravenhorst, 1829 .

Phygadeuon pisinnus Walkley, 1958. In Krombein et al., U. S. Dept. Agr., Agr. Monog. 2, Sup. 1, p. 45. N. name for I. exiguus Cresson.

pumilus (Cresson). N. H., R. I., N. Y., N. J., Del.

Cryptus pumilus Cresson, 1864. Ent. Soc. Phila., Proc. 3: 301. ९.

Taxonomy: Townes, 1970 (1969). Amer. Ent. Inst., Mem. 12: 103.

quadriceps (Ashmead). Alaska; e. U. S. S. R.

Bachia nigra Ashmead, 1899 (1898). In Jordan, Fur Seals and Fur Seal Isls. No. Pacific, v. 4, p. 340. $\%$. Preoce. in Phygadeuou by Provancher, 1874 and 1876. The association of the female holotype of Bachia nigra (described from Ostrov Bering [i.e. Bering Isl.], U. S. S. R.) with the male holotypes of the following synonyms (described from Alaska [Unga Isl. and St. Paul Isl.]) should be considered tentative.

Bathymetis ungae Ashmead, 1902. Wash. Acad. Sci., Proc. 4: 180. ठ。. 
Bathymetis quadriceps Ashmead, 1902. Wash. Acad. Sci., Proc. 4: 181. o. Bathymetis simulator Ashmead, 1902. Wash. Acad. Sci., Proc. 4: 184. ठ.

Taxonomy: Cushman, 1922. U. S. Natl. Mus., Proc. 60 (21): 3. - Walkley, 1958. In Krombein et al., U. S. Dept. Agr., Agr. Monog. 2, Sup. 1, p. 45.

quintilis Viereck. Conn.

Phygadeuon (Plesignathus) quintilis Viereck, 1917 (1916). Conn. State Geol. and Nat. Hist. Survey Bul. 22: 336 . ?.

sanctipauli (Ashmead). Alaska.

Stiboscopus sanctipauli Ashmead, 1902. Wash. Acad. Sci., Proc. 4: 171. ๆ.

Stiboscopus mandibularis Ashmead, 1902. Wash. Acad. Sci., Proc. 4: 172. đ. N. syn.

Preocc. in Phygadeuon by Cresson, 1864 .

Bathymetis nigricomis Ashmead, 1902. Wash. Acad. Sci., Proc. 4: 177. ठ, ?. N. syn.

Bathymetis imitator Ashmead, 1902. Wash. Acad. Sci., Proc. 4: 177. ठ, ?. N. syn.

Bathymetis simulans Ashmead, 1902. Wash. Acad. Sci., Proc. 4: 178. ๆ. N. syn.

Bathymetis rubrocincta Ashmead, 1902. Wash. Acad. Sci., Proc. 4: 178. đ, ₹. N. syn.

Bathymetis simillima Ashmead, 1902. Wash. Acad. Sci., Proc. 4: 179. ठ, ?. N. syn.

Bathymetis confusa Ashmead, 1902. Wash. Acad. Sci., Proc. 4: 180. ¿, ๆ. N. syn.

Plesiognathus (!) rubrocinctus Ashmead, 1902. Wash. Acad. Sci., Proc. 4: 184. ס. Preocc. in Phygadeuon by Ashmead, 1902, p. 178.

scabrosus (Provancher). Que.

Hemiteles scabrosus Provancher, 1874. Nat. Canad. 6: 332..

Taxonomy: Gahan and Rohwer, 1917. Canad. Ent. 49: 429. - Barron, 1975. Nat. Canad. 102: 560 (rejection of lectotype selected by Gahan and Rohwer, 1917).

slossonae Cushman. N. H.

Bathymetis slossonae Ashmead, 1906. In Slosson, Ent. News 17: 324. Nomen nudum.

Phygadeuon slossonae Cushman, 1922. U. S. Natl. Mus., Proc. 61 (8): 21..

solidus Lundbeck. Greenland.

Phygadeuon solidus Lundbeck, 1897 (1896). Dansk. Naturhist. For., Vidensk. Meddel. (for 1896), p. 225 ..

Taxonomy: Roman, 1916. Arkiv for Zool. 10 (22): 2.

subfuscus Cresson. Que., Mass., N. Y., Ohio, Ill., Iowa.

Phygadeuon subfuscus Cresson, 1864. Ent. Soc. Phila., Proc. 3: 311. \&.

Platylabus crassicomis Provancher, 1886. Addit. Corr. Faune Ent. Canada Hym., p. 37..

timidus Cresson. Tex.

Phygadeuon timidus Cresson, 1872. Amer. Ent. Soc., Trans. 4: 161. §.

townsendi (Ashmead). Mich.

Hemiteles townsendi Ashmead, 1890 (1889). U. S. Natl. Mus., Proc. 12: 405. o.

Hemiteles tounsendii Dalla Torre, 1902. Cat. Hym., v. 3, p. 667. Emend.

unicinctus (Ashmead). Alaska.

Habromma nigrum Ashmead, 1902. Wash. Acad. Sci., Proc. 24: 188. ठ. Preocc. in Phygadeuon by Provancher, 1874 and 1876 and by Bachia nigra Ashmead, 1899.

Isochresta unicincta Ashmead, 1902. Wash. Acad. Sci., Proc. 4: 190. ठ.

Taxonomy: Cushman, 1922. U. S. Natl. Mus., Proc. 60 (21): 3.

vernalis (Brues). Mass.

Microcryptus (Theroscopus) vernalis Brues, 1910. Wis. Nat. Hist. Soc., Bul. 8: 77..

victoriensis Townes. B. C.

Centeterus canadensis Harrington, 1894. Canad. Ent. 26: 210. \&. Preocc. in Phygadeuon by Provancher, 1875.

Phygadeuon victoriensis Townes, 1944. Amer. Ent. Soc., Mem. 11: 226. N. name for $C$.

canadensis Harrington.

zapotecus Cresson. Pa., Tenn., S. C.; Mexico.

Phygadeuon zapotecus Cresson, 1873. Acad. Nat. Sci. Phila., Proc. 25: 140. ठ̊. 


\section{Genus CERATOPHYGADEUON Viereck}

Ceratophygadeuon Viereck, 1924. Canad. Ent. 56: 110.

Type-species: Ceratophygadeuon taeniatus Viereck. Monotypic.

Remonzia Seyrig, 1952. Acad. Malgache, Mem. 39: 21.

Type-species: Remonzia impostor Seyrig. Monotypic.

Remonzia subg. Euremonzia Aubert, 1965. Soc. Ent. Mulhouse, Bul. 21: 17.

Type-species: Remonzia (Euremonzia) parvicaudator Aubert. Monotypic and orig. desig.

Townes' (1970) description and key characters for this genus are partly inaccurate and misleading. In making his description and choosing the characters to use in his key to the genera of the Phygadeuontina, Townes appears to have neglected the type-species of Ceratophygadenon and based his description and key mainly upon a group of species (which I will call the perditus group) whose members are at least in part parasitic upon the larvae of Stratiomyidae. However, even the males of the perditus group (and occasionally the females as well) often have two median apical teeth on the clypeus instead of the "single median tooth" described by Townes. Viereck described Ceratophygadeuon as having the "clypeus bituberculate at [the] apex." which roughly agrees with the two specimens of the type-species I have seen and with Townes' figure of that species (One of the specimens is like Townes figure in having what could be described as a single bifid clypeal tooth). In addition to its sharp facial tubercle (whence the name Ceratophygadeuon), the type-species has a rather unusual mandible which is short, very broad basally, narrowed very little from base to apex, and transversely concave on its outer surface; in the two examined specimens, both of the mandibular teeth have been worn down, but probably were almost equal in length. In species of the perditus group, the mandible is long, narrow, rather strongly tapered somewhat internal to the upper tooth, which seems to agree with what little Townes says concerning the mandible of Ceratophygadeuon. I do not know if either of the names Remonzin or Euremonzia would be applicable to members of the perditus group.

Taxonomy: Townes, 1970 (1969). Amer. Ent. Inst., Mem. 12: 94, 104, 399.

brevacus (Townes). Que., N. Y., Mich., Minn., Sask.

Platylabus aciculatus Provancher, 1886. Addit. Corr. Faune Ent. Canada Hym., p. 36, 37.

¡. Formerly preocc. in Phygadeuon by Provancher, 1882. The variant spelling "acilatus" which appears on p. 37 of the "Additions" was rejected in favor of aciculatus by Provancher (1889) in the errata (p. 476) of the same work.

Phygadeuon brevacus Townes, 1944. Amer. Ent. Soc., Mem. 11: 220. N. name for Platylabus aciculatus Provancher.

perditus (Provancher). Que., Ont., N. Y., Sask.

Cryptus perditus Provancher, 1886. Addit. Corr. Faune Ent. Canada Hym., p. 73. ơ.

provancheri (Walkley). Que.

Platylabus cincticornis Provancher, 1886. Addit. Corr. Faune Ent. Canada Hym., p. 38.. Formerly preocc. in Phygadeuon by Cresson, 1864.

Phygadeuon provancheri Walkley, 1958. In Krombein et al., U. S. Dept. Agr., Agr. Monog. 2, Sup. 1, p. 45. N. name for Platylabus cincticomis Provancher.

taeniatus Viereck. Que., Ont., Sask.; Sweden.

Ceratophygadeuon taeniatus Viereck, 1924. Canad. Ent. 56: 111. \&.

Phygadenon conifrons Roman, 1925 (1924). Arkiv for Zool. 17 A (4): 10..

Taxonomy: Roman, 1938. Ent. Tidskr. 59: 35 (syn.).

\section{SUBTRIBE STILPNINA}

So far as is known members of this subtribe are parasites of cyclorrhaphous Diptera, ovipositing into late-instar larvae and emerging from puparia.

\section{Genus STILPNUS Gravenhorst}

Stilpnus Gravenhorst, 1829. Ichn. Europaea, v. 1, p. 664.

Type-species: Stilpnus gagates Gravenhorst. Desig. by Curtis, 1832.

Xestophyes Foerster, 1868. Naturh. Ver. Rheinlande, Verh. 25: 189. 
Type-species: Xestophya fallax Foerster. Desig. by Ashmead, 1900 from two species included by Foerster, 1876.

Polyrhembia Foerster, 1868. Naturh. Ver. Rheinlande, Verh. 25: 189.

Type-species: Hemiteles tenebricosus Gravenhorst. Included and desig. by Foerster, 1876.

Xestophya Foerster, 1876. Naturh. Ver. Rheinlande, Verh. 33: 27. Emend.

Townes (1970) said Stilpnus is a moderately large genus, known from the Holarctic and Neotropic regions.

Taxonomy: Townes, 1970 (1969). Amer. Ent. Inst., Mem. 12: 106.

gagates (Gravenhorst). Que. s. to N. C., w. to Alaska and Calif.; Honduras, Chile; Europe.

Host: Fannia canicularis (L.).

Ichneumon gagates Gravenhorst, 1807. Vergl. Uebers. Zool. Systeme, p. 263. [female].

Stilpuus americanus Cresson, 1868. Amer. Ent. Soc., Trans. 2: 95. ठ', ९.

Megastylus politus Provancher, 1875. Nat. Canad. 7: 331. ठ.

Hemiteles orbicularis Provancher, 1879. Nat. Canad. 11 (no. 124): 123. " $\delta "=q$.

Stilpnus anthomyidiperda Viereck, 1912. U. S. Natl. Mus., Proc. 42: 644. ठ, क.

Stilpnus gagates var. Robinsoni Roman, 1922. In Skottsberg, Nat. Hist. Juan Fernandez and Easter Isl., v. 3, p. 293. ‥

Taxonomy: Townes and Townes, 1966. Amer. Ent. Inst., Mem. 8: 56 (syn.). -Townes, 1970

(1969). Amer. Ent. Inst., Mem. 12: 106 (syn.).

Biology: Legner, 1966. Jour. Econ. Ent. 59: 999.

laevis Provancher. Que.

Stilpnus laevis Provancher, 1882. Nat. Canad. 13: 332..

Stilpus levis Dalla Torre, 1902. Cat. Hym., v. 3, p. 738. Emend.

tenebricosus (Gravenhorst). Greenland, Alaska; Europe.

Hemiteles tenebricosus Gravenhorst, 1829. Ichn. Europaea, v. 2, p. 785. ठ.

Ichneumon vitidulator Zetterstedt, 1838. Insecta Lapponica ... Hym., p. 362. "ठ" =

Taxonomy: Roman, 1918. Arkiv for Zool. 12 (2): 30-31 (syn.).

\section{Genus MESOLEPTUS Gravenhorst}

Mesoleptus Gravenhorst, 1829. Ichn. Europaea, v. 2, p. 3.

Type-species: Ichneumon laevigatus Gravenhorst. Desig. by Curtis, 1837.

Exolytus Holmgren, 1859 (1858). Svenska Vetensk.-Akad., Ofvers af ... Forhandl. 15: 328.

Type-species: Ichneumon laevigatus Gravenhorst. Monotypic and orig. desig.

Exolytus Foerster, 1868. Naturh. Ver. Rheinlande, Verh. 25: 189. Preocc. by Holmgren, 1858.

Type-species: Ichneumon laevigatus Gravenhorst. Included and desig. by Foerster, 1876.

Gravenhorst's concept of Mesoleptus included elongate Ichneumonidae of diverse affinities. The species placed in Mesoleptus by Provancher and Cresson were of comparable diversity, but most European authors restricted the application of the name to a group of species now in the Ctenopelmatinae: Euryproctini.

borealis (Davis). "Hudson Bay Territory."

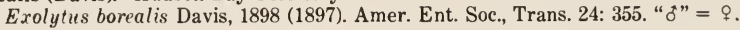
davisii (Dalla Torre). Colo.

Exolytus petiolaris Davis, 1898 (1897). Amer. Ent. Soc., Trans. 24: 355. ठ. Preocc. in Mesoleptus by Thomson, 1884 .

Exolytus davisii Dalla Torre, 1902. Cat. Hym., v. 3, p. 727. N. name for E. petiolaris Davis. declivus (Provancher). Que., Ont., N. Y., Oreg. Host: Sepedon fuscipennis Loew, Pherbiella schoenherri maculata (Cr.).

Hemiteles declivus Provancher, 1886. Addit. Corr. Faune Ent. Canada Hym., p. 60. §, $\uparrow$.

Atractodes sepedontis Ashmead, 1901. In Needham and Betten, N. Y. State Mus. Bul. 47: 588. ๆ.

Taxonomy: Barron, 1975. Nat. Canad. 102: 459 (lectotype selected). 
glaucus (Davis). N. Y., Mich.

Exolytus glaucus Davis, 1898 (1897). Amer. Ent. Soc., Trans. 24: 354. ơ, ९.

ignotus Cresson. N. Y., Ohio, W. Va.

Mesoleptus! ignotus Cresson, 1868. Amer. Ent. Soc., Trans. 2: 103. ๆ.

Exolytus melanoscelis DeGant, 1933. U. S. Natl. Mus., Proc. 83: 3. ؟.

ithacae (Ashmead), Que., Ont., Conn., N. Y., N. J.

Pyracmon incompletum Provancher, 1886. Addit. Corr. Faune Ent. Canada Hym., p. 90.

. Preoce. in Mesoleptus by Provancher, 1875.

Exolytus ithacae Ashmead, 1896. Amer. Ent. Soc., Trans. 23: 206. \&.

\section{Genus ATRACTODES Gravenhorst}

Atractodes Gravenhorst, 1829. Ichn. Europaea, v. 3, p. 739.

Type-species: Atractodes bicolor Gravenhorst. Desig. by Westwood, 1840.

Zetesima Foerster, 1876. Naturh. Ver. Rheinlande, Verh. 33: 27.

Type-species: Zetesima rufipes Foerster. Monotypic and orig. desig. The name of the type-species is preocc. in Atractodes by Provancher, 1874.

Asyncrita Foerster, 1876. Naturh. Ver. Rheinlande, Verh. 33: 29.

Type-species: Atractodes foveolatus Gravenhorst. Orig. desig.

aciculatus (Davis). N. H., N. Y.

Exolytus aciculatus Davis, 1898 (1897). Amer. Ent. Soc., Trans. 24: 354. ơ, ๆ.

alamagnus (Davis). Colo.

Exolytus alamagnus Davis, 1898 (1897). Amer. Ent. Soc., Trans. 24: 355. ठ์.

alaskensis (Ashmead). Alaska, Wash., Oreg.

Exolytus alaskensis Ashmead, 1902. Wash. Acad. Sci., Proc. 4: 167. ๆ.

Exolytus seldoviae Ashmead, 1902. Wash. Acad. Sci., Proc. 4: 168. ठ.

Taxonomy: Townes, 1970 (1969). Amer. Ent. Inst., Mem. 12: 107 (syn.).

ambiguus Ruthe. Alaska; n. Eurasia. Ecology: Occurs in moist biotypes (see Petersen, 1956). Atractodes ambiguns Ruthe, 1859. Stettin. Ent. Ztg. 20: 377..

Exolytus ungae Ashmead, 1902. Wash. Acad. Sci., Proc. 4: 167. ठ, ?.

Exolytus insularis Ashmead, 1902. Wash. Acad. Sci., Proc. 4: 168. ๆ.

Atractodes truncator Roman, 1909. In Hamberg, Naturw. Untersuch. Sarekgebirges

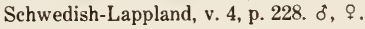

Taxonomy: Roman, 1928. In Lindroth, Goteborgs K. Vetensk. Vitterhets-Samhalles Handl. (5B) 1 (4): 20 (syn.). - Townes, 1944. Amer. Ent. Soc., Mem. 11: 229 (syn.).

Biology: Petersen, 1956. I $n$ Fridhriksson and Tuxen, Zool. Iceland, v. 3, pt. 49-50, p. 70.

americanus (Ashmead). N. H., N. Y., N. C., S. C., Tenn., Kans. Ecology: Found in late fall at carrion.

Ischnus americanus Ashmead, 1890 (1889). U. S. Natl. Mus., Proc. 12: 394. \&.

arcticus Holmgren. Greenland; n. Eurasia.

Atractodes arcticus Holmgren, 1872. Svenska Vetensk.-Akad., Ofvers af ... Forh. 29 (6): 99. $\delta$.

Taxonomy: Roman, 1916. Arkiv for Zool. 10 (22): 8. - Roman, 1934. Ann. and Mag. Nat. Hist. (10) 14: 607-608.

ashmeadi Cushman. N. H.

Asyncrita compressa Ashmead (!), 1897. In Slosson, Ent. News 8: 237. Lapsus for and misidentification of Stilpuus? compressus Cresson (compare Ashmead, 1900 with Cushman, 1922).

Atractodes ashmeadi Cushman, 1922. U. S. Natl. Mus., Proc. 61 (8): 6. ๆ.

Taxonomy: Ashmead, 1900. In Smith, N. J. State Bd. Agr., Ann. Rpt. 27, sup., p. 568.

aterrimus Holmgren. Greenland.

Atractodes aterrimus Holmgren, 1872. Svenska Vetensk.-Akad., Ofvers af ... Forh. 29 (6): 98. $\delta$.

Taxonomy: Roman, 1916. Arkiv for Zool. 10 (22): 9. - Roman, 1934. Ann. and Mag. Nat. Hist. (10) 14: 607 (description of female). 
brevissimus (Dalla Torre). N. H., R. I., N. Y., Mich., Wash.

Exolytus brevis Davis, 1898 (1897). Amer. Ent. Soc., Trans. 24: 355. . Preocc. by Foerster, 1876.

Exolytus brevissimus Dalla Torre, 1902. Cat. Hym., v. 3, p. 727. N. name for E. brevis Davis.

Atractodes serpedontes (!) Ashmead, 1902. In Slosson, Ent. News 13: 6. Lapsus for and misidentification of Atractodes sepedoutis Ashmead, a synonym of Mesoleptus declivus (Cresson).

Atractodes serpedontus Cushman, 1922. U. S. Natl. Mus., Proc. 61 (8): 7.

Taxonomy: Townes, 1970 (1969). Amer. Ent. Inst., Mem. 12: 107 (syn.).

compressus (Cresson). Colo.

Stilpnuss compressus Cresson, 1865. Ent. Soc. Phila., Proc. 4: 260. ठ.

cultus (Davis). Colo.

Exolytus cultus Davis, 1898 (1897). Amer. Ent. Soc., Trans. 24: 355. ९.

fatuus Townes. N. Mex.

Phygadeuon polita Viereck, 1903. In Skinner, Amer. Ent. Soc., Trans. 29: 82. o. Preocc. in Atractodes by Provancher, 1874 and Ashmead, 1890.

Atractodes fatuus Townes, 1944. Amer. Ent. Soc., Mem. 11: 231. N. name for P. polita Viereck.

gillettei (Ashmead). Colo.

Seleucus gillettei Ashmead, 1896. Amer. Ent. Soc., Trans. 23: 206. ठ.

grandis Cushman. N. H.

Exolytus grandis Ashmead, 1900. In Slosson, Ent. News 11: 320. Nomen nudum.

Atractodes grandis Cushman, 1922. U. S. Natl. Mus., Proc. 61 (8): 7..

kincaidi (Ashmead). Alaska.

Exolytus perplexus Ashmead, 1902. Wash. Acad. Sci., Proc. 4: 165. ठ.

Exolytus sanctipauli Ashmead, 1902. Wash. Acad. Sci., Proc. 4: 166.

Exolytus kincaidi Ashmead, 1902. Wash. Acad. Sci., Proc. 4: 167. 9.

Taxonomy: Townes, 1970 (1969). Amer. Ent. Inst., Mem. 12: 107 (syn.).

laphroscopoides (Viereck). Ariz.

Hemiteles (Diaglypta!) laphroscopoides Viereck, 1905. Kans. Acad. Sci., Trans, 19: 294. ठ.

necrix Mason. S. C. Ecology: Occurs on carrion.

Atractodes necrix Mason, 1971. In Payne and Mason, Ent. Soc. Wash., Proc. 73: 139. $\$$.

nigricoxus Provancher. Que., Mass.

Atractodes nigricoxus Provancher, 1882. Nat. Canad. 13: 368. o.

Atractodes nigricoxatus Dalla Torre, 1902. Cat. Hym., v. 3, p. 722 . Unecessary n. name for nigricoxus Provancher; not preocc. by nigricoxis Foerster, 1876.

pacificus Townes. B. C.

Angitia Americana Harrington, 1894. Canad. Ent. 26: 246. 9 . Preocc. in Atractodes by Ashmead, 1890.

Atractodes pacificus Townes, 1944. Amer. Ent. Soc., Mem. 11: 232. N. name for Angitia americana Harrington.

politus (Provancher). Que.

Campoplex politus Provancher, 1874. Nat. Canad. 6: 144. . Preocc. by Foerster, 1868. Not renamed because of uncertain synonymy.

popofensis (Ashmead). Alaska; e. U. S. S. R.

Exolytus niger Ashmead, 1899 (1898). In Jordan, Fur Seals and Fur Seal Isls. No. Pacific, v. 4, p. 338. . Preocc. in Atractodes by Brulle, 1846.

Exolytus popofensis Ashmead, 1902. Wash. Acad. Sci., Proc. 4: 166. ơ, ?.

Atractodes ebeninus Walkley, 1958. In Krombein et al., U. S. Dept. Agr., Agr. Monog. 2 sup. 1, p. 45. N. name for $E$. niger Ashmead; this n. name was unnecessary because it was proposed when popofensis was already standing as a junior synonym of $E$. niger.

rufiventris (Ashmead). Mich., S. Dak.

Seleucus rufiventris Ashmead, 1896. Amer. Ent. Soc., Trans. 23: 207. \&.

Exolytus dakotaensis Davis, 1898 (1897). Amer. Ent. Soc., Trans. 24: 354. ơ. 
Taxonomy: Townes, 1970 (1969). Amer. Ent. Inst., Mem. 12: 107 (syn.).

ungensis (Ashmead). Sask., Alaska.

Exolytus ungensis Ashmead, 1902. Wash. Acad. Sci., Proc. 4: 169...

Exolytus mibrocinctus Ashmead, 1902. Wash. Acad. Sci., Proc. 4: 169. ơ.

\section{SUBTRIBE CREMNODINA}

\section{Genus CREMNODES Foerster}

Cremnodes Foerster, 1850. Arch. f. Naturgesch. 16 (1): 72.

Type-species: Ichneumon atricapillus Gravenhorst. Orig. desig.

Caenomeris Foerster, 1868. Naturh. Ver. Rheinlande, Verh. 25: 174.

Type-species: Xestophya nigripes Ashmead. Monotypically included and desig. by

Townes, 1944.

Stygera Foerster, 1868. Naturh. Ver. Rheinlande, Verh. 25: 176.

Type-species: Stygera rufipes Perkins. Monotypically included and desig. by

Perkins, 1962.

Cremnias Roman, 1939. Ent. Tidskr. 60: 186. Unecessary n. name for Cremnodes Foerster, which is not preocc. by Gerst, 1858. Roman thought Cremnodes was described by Foerster in 1868 .

Taxonomy: Perkins, 1962. Brit. Mus. (Nat. Hist.) Ent., Bul. 11: 397-398, 411, 415, 454.

nigripes (Ashmead). Alaska.

Xestophya polita Ashmead, 1902. Wash. Acad. Sci., Proc. 4: 162. ठ, ?.

Xestophya nigripes Ashmead, 1902. Wash. Acad. Sci., Proc. 4: 163. ठ.

UNPLACED TAXA OF HEMITELINI

Hemiteles nigricans Provancher, 1882. Nat. Canad. 13: 360. ऽ. Que.

Taxonomy: Barron, 1975. Nat. Canad. 102: 514.

\section{TRIBE APTESINI}

In transferring the genus Echthrus to the group he formerly called the Hemigastrini, Townes (1970) changed the name of the group to Echthrini because of his preference to base supergeneric group names upon the oldest included genus rather than upon the oldest supergeneric name; following the latter practice would have resulted in his retention of the name Hemigastrini. Because of my belief that Hemigaster actually belongs in the group Townes (1970) called the subtribe Baryceratina (tribe Cryptini), the name Hemigastrina is here applied to that subtribe.

Most Aptesini oviposit into the cocoons of sawflies, but the species of Echthrus and Demopheles parasitize wood boring Coleoptera, and Polytribax parasitizes Lepidoptera.

Revision: Townes and Gupta, 1962. Amer. Ent. Inst., Mem. 2: 1-305.

Taxonomy: Townes, 19701969). Amer. Ent. Inst., Mem. 12: 111-140 (genera of world).

\section{Genus DEMOPHELES Foerster}

Demopheles Foerster, 1868. Naturh. Ver. Rheinlande, Verh. 25: 186.

Type-species: Phygadeuon caliginosus in the sense of Thomson (1873). By subsequent monotypy from inclusion by Ashmead, 1900. Ashmead (1900) suppressed the monotypic genus Mecocryptus as a synonym of Demopheles, thereby including the type-species of Mecocryptus (which see) in Demopheles (cf. Perkins, 1962).

Mecocryptus Thomson, 1873. Opusc. Ent. 5: 520, 521.

Type-species: Phygadeuon caliginosus Gravenhorst, not as restricted by Taschenberg and Frilli. Monotypic and orig. desig. Thomson did not say that he was applying the name caliginosus to Gravenhorst's female, but this is implied by the fact that on the same two pages he described a new genus and species, Stenocryptus nigriventris, for what he believed to be Phygadeuon caliginosus 
"Taschenberg;" Taschenberg applied the name caliginosus to Gravenhorst's male and validated the name Phyyadeuon comptor for Gravenhorst's female. Frilli (1975) selected Gravenhorst's male as the lectotype of caliginosus, leaving corruptor as the valid name for P. caliginosus in the sense of Thomson.

A single species of Holarctic distribution is known; it was revised by Townes (1963) to include four subspecies, the European $D$. cormuptor corruptor, the Japanese $D$. corruptor atripes Townes, and two Nearctic ones.

Revision: Townes, 1963. Ent. Soc. Wash., Proc. 65: 47-50.

Taxonomy: Gravenhorst, 1829. Ichn. Europaea, v. 2, pp. 645-646. -Taschenberg, 1865. Ztsch. f. die Gesam. Naturw. Halle 25: 22, 49. - Ashmead, 1900. U. S. Natl. Mus., Proc. 23: 177, 214. - Perkins, 1962. Brit. Mus. (Nat. Hist.) Ent., Bul. 11: 416. -Frilli, 1975 (1974). Soc.

Ent. Ital., Mem. 53: 127-129.

corruptor maturus (Provancher). Que. s. to Ga., w. to w. Ont. and possibly Alta. Host: Clytus ruricola (Oliv.). The Alta. record is based upon a male from Edmonton, and the distinction between the Nearctic subspecies is so far based only upon females.

Phygadeuon maturus Provancher, 1879. Nat. Canad. 11: 68. $\$$.

corruptor rufatus Townes. Colo., N. Mex., Wash.

Demopheles corruptor rufatus Townes, 1963. Ent. Soc. Wash., Proc. 65: 49. $\%$.

\section{Genus JAVRA Cameron}

Cnemocryptus Cameron, 1903. Manchester Lit. and Phil. Soc., Mem. and Proc. 47 (14): 38.

Type-species: Cnemocryptus validicomis Cameron. Monotypic. The type-species is regarded as a synonym of $J$. parviceps Cameron.

Javra Cameron, 1903. Manchester Lit. and Phil. Soc., Mem. and Proc. 47 (14): 47.

Type-species: Javra particeps Cameron. Monotypic.

Finchra Cameron, 1907. Ztschr. System. Hym. Dipt. 7: 463.

Type-species: Finchra gracilis Cameron. Monotypic.

Monocryptus Hellen, 1956. Notulae Ent. 36: 135.

Type-species: Cratocryptus opacus Thomson. Monotypic.

This genus is Holarctic and Oriental, with most of the species occurring in Asia.

glaesaria Townes. R. I., N. Y., Ont.

Javra glaesaria Townes, 1962. In Townes and Gupta, Amer. Ent. Inst., Mem. 2: 13. \&.

rugata Townes. Va., Ohio.

Javra rugata Townes, 1962. In Townes and Gupta, Amer. Ent. Inst., Mem. 2: 12..

\section{Genus PARMORTHA Townes}

Parmortha Townes, 1962. In Townes and Gupta, Amer. Ent. Inst., Mem. 2: 14.

Type-species: Parmortha pleuralis atripes Townes. Orig. desig. P. pleuralis atripes is regarded as a synonym of $P$. pleuralis albomaculata (Ashmead).

This is a small genus of Holarctic distribution. The hosts are allantine sawflies which pupate in the stems of weeds and shrubs.

circumcincta circumeincta (Provancher). Que. w. to e. B. C., s. to n. S. C. and Colo.

Cryptus circumcinctus Provancher, 1879. Nat. Canad. 11 (no. 125): 132. ơ.

circumeineta flavipes (Harrington). Alta. s. to Colo., w. to B. C. and Calif. Host: Ametastegia glabrata (Fall.).

Cryptus flavipes Harrington, 1894. In Townes and Gupta, Amer. Ent. Inst., Mem. 26: 212. ?.

parvula (Gravenhorst). N. S. and n. Ont. w. to Alaska, s. to N. J. and Oreg; Eurasia. Host: Ametastegia glabrata (Fall.).

Cryptus parvulus Gravenhorst, 1829. Ichn. Europaea, v. 2, p. 459. \& ( $\delta$ misdet.).

Cryptus erythropus Gravenhorst, 1829. Ichn. Europaea, v. 2, p. 469. ơ.

Cryptus velox Harris, 1835. In Hitcheock, Rpt. Geol. Mineral. Bot. Zool. Mass., ed. 2, p. 584. Nomen nudum.

Cryptus velox Cresson, 1864. Ent. Soc. Phila., Proc. 3: 293.. 
Cryptus osculatus Provancher, 1874. Nat. Canad. 6: 178. $\delta$.

Isotina(!) tibialis Ashmead, 1897. In Slosson, Ent. News 8: 237. Nomen nudum.

pleuralis arctica Townes. Northern Que., N. W. T., Alaska. P. pleuralis pleuralis (Thomson) occurs in Europe, and P. pleuralis albomaculata (Ashmead) occurs in Japan.

Parmortha pleuralis arctica Townes, 1962. In Townes and Gupta, Amer. Ent. Inst., Mem. 2: 19. $\delta, ?$.

pleuralis signata (Provancher). Southern Que. w. to s. Alaska, s. to N. C. and Wash. Host: Ametastegia glabrata (Fall.).

Cryptus quebecensis Provancher, 1874. Nat. Canad. 6: 179..

Cryptus signatus Provancher, 1874. Nat. Canad. 6: 179..+

Parmortha pleuralis alpina Townes, 1962. In Townes and Gupta, Amer. Ent. Inst., Mem. 2: 22. ๆ. N. syn.

Taxonomy: Barron, 1975. Nat. Canad. 102: 540, 566-567 (discussion of Provancher types).

\section{Genus CRATOCRYPTUS Thomson}

Cratocryptus Thomson, 1873. Opusc. Ent. 5: 521.

Type-species: Cryptus furcator Gravenhorst. Desig. by Viereck, 1914.

This genus includes only two species which Townes (1970) said "might better be treated as subspecies."

Taxonomy: Townes, 1970 (1969). Amer. Ent. Inst., Mem. 12: 128.

petilus Townes. Que., Ont., Mich., B. C. Host: Cephalcia sp.

Cratocryptus petilus Townes, 1962. In Townes and Gupta, Amer. Ent. Inst., Mem. 2: 26. o, ㅇ.

\section{Genus CUBOCEPHALUS Ratzeburg}

Cubocephalus Ratzeburg, 1848. Ichn. d. Forstins., v. 2, p. 121.

Type-species: Cryptus fortipes Gravenhorst. Monotypic. The type-species is regarded as a synonym of Cubocephalus distinctor (Thunberg).

Ecporthetor Foerster, 1868. Naturh. Ver. Rheinlande, Verh. 25: 184.

Type-species: Cryptus fortipes Gravenhorst. Monotypically included and desig. by Ashmead, 1900.

Pammachus Foerster, 1868. Naturh. Ver. Rheinlande, Verh, 25: 184.

Type-species: Stenocryptus nigriventris Thomson. By subsequent monotypy from inclusion by Ashmead, 1900. Ashmead (1900) suppressed the monotypic genus Stenocryptus as a synonym of Pammachus, thereby including S. nigriventris (cf. Perkins, 1962).

Chaeretymma Foerster, 1868. Naturh. Ver. Rheinlande, Verh. 25: 187.

Type-species: Cryptus anatorius Gravenhorst. Monotypically included and desig. by Schmiedeknecht, 1890.

Stenocryptus Thomson, 1873. Opusc. Ent. 5: 520, 521.

Type-species: Stenocryptus nigrivent is Thomson. Monotypic and orig. desig.

Microcryptus Thomson, 1873. Opusc. Ent. 5: 520, 521.

Type-species: Cryptus erythrinus Gravenhorst. Monotypic.

Planocrypt us Heinrich, 1949. Muenchner Ent. Gesell., Mitt. 35-39: 56.

Type-species: Planocryptus mirabilis Heinrich. Orig. desig.

This is a large Holarctic genus. The few available rearing records indicate that the species parasitize sawflies which pupate in plant tissue, under bark, etc.

Taxonomy: Ashmead, 1900. U. S. Natl. Mus., Proc. 23: 31, 186, 218. -Perkins, 1962. Brit.

Mus. (Nat. Hist.) Ent., Bul. 11: 442.

alacris (Cresson). Newfoundland (Labrador) s. to n.w. S. C., w. to Alaska and Calif. Host:

Ametastegia glabrata (Fallen). In the tribal revision of Townes and Gupta (1962),

Townes recognized four subspecies, three of which were sympatric.

Cryptus alacris Cresson, 1864. Ent. Soc. Phila., Proc. 3: 306. $q$.

Leptobatus Canadensis Provancher, 1875. Nat. Canad. 7 (5): 145. ․ N. syn. 
Mesostenus nigricomis Provancher, 1875. Nat. Canad. 7 (9): 264. ठో. Temporarily preocc. in Cryptus by Brulle, 1846.

Cryptus eburmiefrons Provancher, 1879. Nat. Canad. 11 (no. 125): 133. ठ.

Cryptus mellipes Provancher, 1886. Addit. Corr. Faune Ent. Canada Hym., p. 68. $q$.

Cryptus erythropygus Provancher, 1886. Addit. Corr. Faune Ent. Canada, Hym., p. 69.. N. syn.

Phygadeuon ater Ashmead, 1890. Colo. Biol. Assoc., Bul. 1: 20.. . N. syn.

Cryptus La'ogleri Dalla Torre, 1902. Cat. Hym., v. 3, p. 576. N. name for M. nigricomis Provancher.

Chaeretymma minuta Cushman, 1917. U. S. Natl. Mus., Proc. 53: 465. §’, ๆ. N. syn.

Taxonomy: Barron, 1975. Nat. Canad. 102: 441, 453-454, 464, 467, 508, 528-529 (discussion of

Provancher types).

annectus Townes. N. S. w. to n. Alaska, s. to N. H., N. Mex., and Calif.

Phaeogenes nigricornis Provancher, 1882. Nat. Canad. 13: 330. ठ. Preoce. in Cubocephalus by Mesostenus nigricomis Provancher, 1875.

Cryptus spissicornis Provancher, 1888. Addit. Corr. Faune Ent. Canada Hym., p. 361.. Preocc. by Provancher, 1886 .

Cubocephalus annectus Townes, 1944. Amer. Ent. Soc., Mem. 11: 234. N. name for Cryptus spissicomis Provancher.

Cubocephalus atricomis Townes, 1944. Amer. Ent. Soc., Mem. 11: 235. N. name for P. nigricomis Provancher, 1888.

annulatus (Cresson), Que. w. to Alta., s. to w. N. C. Ecology: Two specimens emerged from the canes of raspberries which were infested by Agrilus aurichalceus Redt.

Phygadeuon ammulatus Cresson, 1864. Ent. Soc. Phila., Proc. 3: 308. ๆ.

Cryptus ruficoxus Provancher, 1875. Nat. Canad. 7 (6): 176. ó.

aquilonius Townes and Gupta. Newfoundland (Labrador) w. to n. B. C., Yukon, and Alaska; also Colo.

Cubocephalns aquilonius Townes and Gupta, 1962. Amer. Ent. Inst., Mem. 2: 53. ठ, ․

ardens Townes. N. H., Ont., Mich., Wis., Colo., Alaska.

Cubocephalus ardens Townes, 1962. In Townes and Gupta, Amer. Ent. Inst., Mem. 2: 109. ठ.

armillatus Walkley. Que.

Cryptus collaris Provancher, 1886. Addit. Corr. Faune Ent. Canada Hym., p. 71. Preoce. by Rudow, 1883 .

Cubocephalus armillatus Walkley, 1958. In Krombein et al., U. S. Dept. Agr., Agr. Monog. 2, Sup. 1, p. 45. N. name for Cryptus collaris Provancher.

ashmeadii (Harrington). Mont., Ariz., B. C., Wash., Oreg., Calif. Host: Ametastegia glabrata (Fall.), Trypoxylon sp.

Chaeretymma ashmeadii Harrington, 1894. Canad. Ent. 26: 212. \&.

atriclunis Townes and Gupta. Maine w. to B. C., s. to N. J. and s. Mich.

Cubocephalus atriclunis Townes and Gupta, 1962. Amer. Ent. Inst., Mem. 2: 56. ठ, ९.

baldaufii (Dalla Torre). Que. w. to Sask., s. to N. Y., Ind., and Minn.

Cryptus scutellatus Provancher, 1877. Nat. Canad. 9: 12. ठ. Preoce. by Smith, 1858.

Cryptus baldaufii Dalla Torre, 1902. Cat. Hym., v. 3, p. 563. N. name for Cryptus scutellatus Provancher.

brevicornis (Taschenberg). Northern Que., n. Mich., Colo., n. Yukon, Alaska; Europe.

Phygadeuon brevicornis Taschenberg, 1865. Ztschr. f. die Gesam. Naturw. Halle 25: 48. .

caligneus Townes. N. C.

Cubocephalus caligneus Townes, 1962. In Townes and Gupta, Amer. Ent. Inst., Mem. 2: 109. ?.

callicerus Townes. N. S., Que., N. Y., Ont., Mich., Ohio.

Cubocephalus callicerus Townes, 1962. In Townes and Gupta, Amer. Ent. Inst., Mem. 2: 115. $\delta$, ?.

carnosus Townes. Que., N. H., Mich., Ohio.

Cubocephalus carnosus Townes, 1962. In Townes and Gupta, Amer. Ent. Inst., Mem. 2: 114. $\delta$, ?. 
cincticornis (Cresson). Que. s. to Pa., w. to Mich. and Ill.

Phygadeuon cincticomis Cresson, 1864. Ent. Soc. Phila., Proc. 3: 309. \&.

contractus Townes and Gupta. Newfoundland (Labrador) w. to n. Yukon and Alaska, s. to N. Y., Mich., Colo., and Wash.

Cubocephalus contractus Townes and Gupta, 1962. Amer. Ent. Inst., Mem. 2: 46. ơ, १.

denticulatus denticulatus Townes. Que., Maine, Vt., N. Y., Mich.

Cubocephalus denticulatus derticulatus Townes, 1962. In Townes and Gupta, Amer. Ent. Inst., Mem. 2: 43. ¿, ?.

denticulatus obscuripes Townes. Alaska.

Cubocephalus denticulatus obscuripes Townes, 1962. In Townes and Gupta, Amer. Ent. Inst., Mem. 2: 42. \&.

dreisbachi Townes. Que. s. to Conn., w. to Alta. and Kans. Townes (1962) said this species "is very close to $C$. ashmeadii and may prove to be an eastern subspecies of it."

Cubocephalus dreisbachi Townes, 1962. In Townes and Gupta, Amer. Ent. Inst., Mem. 2: 94. $\delta$, ?.

euryops Townes. Vt., Ont., Mich., Minn.

Cubocephalus euryops Townes, 1962. In Townes and Gupta, Amer. Ent. Inst., Mem. 2: 64. $\delta$, ?.

flavipes Townes. N. Y., Mich.

Cubocephalus flavipes Townes, 1962. In Townes and Gupta, Amer. Ent. Inst., Mem. 2: 72. $\delta, ?$.

hebes Townes. Sask., Mont.

Cubocephalus hebes Townes, 1962. In Townes and Gupta, Amer. Ent. Inst., Mem. 2: 66. $\delta$, †.

hirtipes hirtipes Townes. Alta. s. to N. Mex., w. to Wash. and Calif.

Cubocephalus hirtipes hirtipes Townes, 1962. In Townes and Gupta, Amer. Ent. Inst., Mem. 2: 122. o, ?.

hirtipes trachodes Townes. N. H. Ecology: Occurs above timberline on Mt. Washington. Cubocephalus hirtipes trachodes Townes, 1962. In Townes and Gupta, Amer. Ent. Inst., Mem. 2: 122. o, ?.

impressus (Provancher). Que. s. to n. Ga., w. to Minn. and Colo.

Ischnus impressus Provancher, 1875. Nat. Canad. 7: 112. ठ.

incisus atriventris Townes and Gupta. Ariz.

Cubochephalus incisus atriventris Townes and Gupta, 1962. Amer. Ent. Inst., Mem. 2: 44. q.

incisus incisus Townes and Gupta. N. Y., Mich.

Cubochephalus incisus incisus Townes and Gupta, 1962. Amer. Ent. Inst., Mem. 2: 45. ठ', i.

incognitus (Provancher). Que., Vt., Mass., N. Y., Ont., Mich., Wyo.

Cryptus incognitus Provancher, 1886. Addit. Corr. Faune Ent. Canada Hym., p. 70. ठठ.

inhabilis (Provancher). Que. w. to Alta. and Wash., s. to e. Tenn., Colo., and Calif.

Phygadeuon inhabilis Provancher, 1877. Nat. Canad. 9: 11. ?.

Cubochephalus inhabilis umbonater Townes, 1962. In Townes and Gupta, Amer. Ent. Inst., Mem. 2: 87. ठँ, १. N. syn.

laticeps (Cresson). N. B. s. to S. C., w. to Minn., S. Dak., Tex., and Calif.

Cryptus laticeps Cresson, 1872. Amer. Ent. Soc., Trans. 4: 157. ठ.

lissopleuris Townes and Gupta. Maine, N. Y., Pa., s. w. N. C.

Cubocephalus lissopleuris Townes and Gupta, 1962. Amer. Ent. Inst., Mem. 2: 59. ó.

longicaudus (Provancher). Que. s. to Ga., w. to Minn.

Cryptus longicaudus Provancher, 1886. Addit. Corr. Faune Ent. Canada Hym., p. 68..

Cryptus schmuckii Dalla Torre, 1902. Cat. Hym., v. 3, p. 588. Unnecessary n. name for Cryptus longicaudus Provancher; the latter not preocc. by Cryptus longicauda Brulle.

maurus (Cresson). Que., ont., Mich., N. W. T., Alta., B. C., Calif.

Echthrus? maurus Cresson, 1879 (1878). Acad. Nat. Sci. Phila., Proc. 30: 381 .. 
miarus Townes and Gupta. Maine, N. H., N. Y., n.w. S. C., Mich., Wis.

Cubocephalus miarus Townes and Gupta, 1962. Amer. Ent. Inst., Mem. 2: 54. o, ?.

micans Townes. P. E. I. s. to N. Y., w. to Minn.

Cubocephalus micans Townes, 1962. In Townes and Gupta, Amer. Ent. Inst., Mem. 2: 112. ¿. ‥

molaris Townes and Gupta. Que., N. Y., Ont., Minn., Wyo., Colo., N. Mex., Yukon, B. C., Oreg., Calif.

Cubocephalus molaris leechi Townes and Gupta, 1962. Amer. Ent. Inst., Mem. 2: 50. ઠ. N. syn.

Cubocephalus molaris molaris Townes and Gupta, 1962. Amer. Ent. Inst., Mem. 2: 50. ठ, ․

Cubocephalus molaris cervinus Townes and Gupta, 1962. Amer. Ent. Inst., Mem. 2: 51. ठ', ค. N. syn.

nigriventris (Thomson). Que. w. to B. C., s. to s.w. N. C., Mich., Colo., and Oreg; Eurasia. In describing nigriventris Thomson stated that it is the species for which Taschenberg (1865) had used the name Phygadeuon caliginosus Gravenhorst (1829). Apparently Thomson was mistaken because Taschenberg applied the name caliginosus to Gravenhorst's male, and a male which was selected as lectotype of caliginosus by Frilli (1975) was identified by Frilli as a species of Phygadeuon.

Stenocryptus nigriventris Thomson, 1874. Opusc. Ent. 6: 604. o, ?.

Taxonomy: Gravenhorst, 1829. Ichn. Europaea, v. 2, p. 645-646. - Taschenberg, 1865. Ztschr. f. die Gesam. Naturw. Halle 25: 22, 49. -Frilli, 1975 (1974). Soc. Ent. Ital., Mem. 53: 127-129.

nitidus nitidus (Provancher). N. S. w. to Alta., s. to Pa. and Mich.

Mesostemus nitidus Provancher, 1874. Nat. Canad. 6: 301. o.

Cryptus occidentalis Provancher, 1875. Nat. Canad. 7: 314. + .

Phygadeuon nitidulus Provancher, 1879. Nat. Canad. 11: 70. Unnecessarily proposed $n$.

name for M. nitidus; although nitidus was preoce. in Phygadeuon by Gravenhorst, 1829, Provancher could have used the name mificoxus for the species because he suppressed Mesostemus ruficoxus (as "ruficomis [!]") Provancher and Cryptus ruficoxus

Provancher as synonyms of nitidulus.

Cryptus ignotus Provancher, 1886. Addit. Corr. Faune Ent. Canada Hym., p. 73. o.

Cryptus mellicoxus Provancher, 1886. Addit. Corr. Faune Ent. Canada Hym., p 75. o.

nitidus totus Townes. Western Wyo., Alaska, B. C., Wash., Oreg., n. Calif.

Cubocephalus nitidus totus Townes, 1962. In Townes and Gupta, Amer. Ent. Inst., Mem. 2: $79 . \delta, ?$.

pallidus (Cresson). Que. w. to B. C., s. to n.w. S C., Ark., and Kans. In the tribal revision of Townes and Gupta (1962), Townes recognized two subspecies which were largely sympatric.

Mesoleptus vultus Cresson, 1864. Ent. Soc. Phila., Proc. 3: 268. o.

Cryptus pallidus Cresson, 1864. Ent. Soc. Phla., Proc. 3: 307 \%.

Cryptus spissicornis Provancher, 1886. Addit. Corr. Faune Ent. Canada Hym., p. 68. ơ, ๆ. N. syn.

pentagonalis (Provancher). Ont. According to Barron (1975) pentagonalis was incorrectly suppressed as a synonym of Cubocephalus alacris canadensis (Provancher) (= alacris Cresson) by Townes (1962), the latter author apparently having erroneously disregarded the lectotype selected by Gahan and Rohwer (1917).

Cryptus pentagonalis Provancher, 1886. Addit. Corr. Faune Ent. Canada Hym., p. 66. ơ, १.

Taxonomy: Gahan and Rohwer, 1917. Canad. Ent. 49: 394. - Townes, 1962. In Townes and

Gupta, Amer. Ent. Inst., Mem. 2: 89-91. - Barron, 1975. Nat. Canad. 102: 528-529.

personatus Townes. Wash., Oreg., Calif.

Cubocephalus personatus Townes, 1962. Iu Townes and Gupta, Amer. Ent. Inst., Mem. 2: 105. o, ?. 
pictus Townes. Mich., ?n.w. S. C. Townes said that "the correlation of the males [from Mich.] and the female [from S. C.] of this species involves much conjecture, and may not be correct."

Cubocephalus pictus Townes, 1962. In Townes and Gupta, Amer. Ent. Inst., Mem. 2: 111. $\delta$,.

prolixus phaeolepis Townes and Gupta. B. C., Oreg., Calif.

Cubocephalus prolixus phaeolepis Townes and Gupta, 1962. Amer. Ent. Inst., Mem. 2: 48. $\delta, ?$.

prolixus prolixus Townes and Gupta. Que. s. to N. Y., w. to Man. and S. Dak.

Cubocephalus prolixus prolixus Townes and Gupta, 1962. Amer. Ent. Inst., Mem. 2: 49. ơ, \&.

rectus (Provancher). Que. s. to N. Y., w. to Minn.

Cryptus rectus Provancher, 1886. Addit. Corr. Faune Ent. Canada Hym., p. 75. ơ.

rufibasis Townes and Gupta. Mich.

Cubocephalus rufibasis Townes and Gupta, 1962. Amer. Ent. Inst., Mem. 2: 63. ․

scorteus Townes. Northern Que., Yukon.

Cubocephalus scorteus Townes, 1962. In Townes and Gupta, Amer. Ent. Inst., Mem. 2: 70. o, ?.

semifulvus Townes. Alaska, Wash.

Cubocephalus semifulvus Townes, 1962. In Townes and Gupta, Amer. Ent. Inst., Mem. 2: 71. $\delta, ?$.

semirufus (Brulle). Mass. s. to N. C., w. to Mich. Ecology: One male specimen was reared in association with Macremplytus sp.

Cryptus semi-rufus Brulle, 1846. In Lepeletier, Hist. Nat. Ins. Hym., v. 4, p. 195. \&.

Mesoleptus eximius Cresson, 1868. Amer. Ent. Soc., Trans. 2: 100. ठ.

sternolophus Townes. N. Y., Pa., Ohio, Mich., N. Mex., Alaska, Calif.

Cubocephalus sternolophus Townes, 1962. In Townes and Gupta, Amer. Ent. Inst., Mem. 2: 74. $\delta$, $९$.

subpolitus Townes. Que., Conn., N. Y., Minn.

Cubocephalus subpolitus Townes, 1962. In Townes and Gupta, Amer. Ent. Inst., Mem. 2: 120. ठั. ?.

tincticoxis Townes. Colo., B. C., Oreg., Calif.

Cubocephalus tincticoxis Townes, 1962. In Townes and Gupta, Amer. Ent. Inst., Mem. 2: 55. ठ.

\section{Genus ORESBIUS Marshall}

Oresbius Marshall, 1867. Ent. Monthly Mag. 3: 193.

Type-species: Oresbius castaneus Marshall. Monotypic.

Opidnus Foerster, 1868. Naturh. Ver. Rheinlande, Verh. 25: 185.

Type-species: Aptesis (Pezoports) tsugae Cushman. Included and desig. by Townes and Townes, 1951.

Townes (1970) said that this large Holarctic genus has the most northerly distribution of any aptesine genus. He said that about half of the arctic species have brachypterous females, which contributes to their scarcity in collections.

Taxonomy: Townes, Momoi, and Townes, 1965. Amer. Ent. Inst, Mem. 5: 157 (syn.).

-Townes, 1970 (1969). Amer. Ent. Inst., Mem. 12: 131.

albicoxus (Provancher). Que., N. W. T., and Alaska, s. to Md., Mich., Ariz., and Calif. Host: Pristiphora erichsonii (Htg.). In the tribal revision of Townes and Gupta (1962), Townes recognized two subspecies which were largely sympatric.

Cryptus brevicornis Provancher, 1875. Nat. Canad. 7 (6): 176. §. Preoce. by Gravenhorst, 1829.

Mesostenus albicoxus Provancher, 1975. 1875. 7 (6): 266. ठ̊.

Cryptus ferrugineus Ashmead, 1890 (1889). U. S. Natl. Mus., Proc. 12: 412. ๆ. Preoce. by Smith, 1861 and 1879. N. syn. 
Cryptus Schoberi Dalla Torre, 1902. Cat. Hym., v. 3, p. 588. N. name for C. ferrugineus Ashmead. N. syn.

Cryptus koebelei Rohwer, 1917. U. S. Natl. Mus., Proc. 53: 158. Unnecessarily proposed n. name for C. ferrugineus Ashmead. N. syn.

Taxonomy: Barron, 1975. Nat. Canad. 102: 419-420, 436 (n. comb. and lectotype selection). Alexanderi (Townes), n. comb. Que., Vt., Alta.

Opidnus alexanderi Townes, 1962. In Townes and Gupta, Amer. Ent. inst., Mem. 2: 145. ठ, q.

aniptus (Townes), n. comb. Colo., Alaska, Calif.

Opidnus aniptus Townes, 1962. In Townes and Gupta, Amer. Ent. Inst., Mem. 2: 151. ठै, ?.

arridens (Gravenhorst). N. H., Mass., N. Y., Ont., Mich., B. C.; Eurasia. Adventive? The species is not known to have been collected in North America before 1946.

Phygadeuon arridens Gravenhorst, 1829. Ichn. Europaea, v. 2, p. 654. ठ.

ciliatus (Townes), n. comb. Que.

Opidnus ciliatus Townes, 1962. In Townes and Gupta, Amer. Ent. Inst., Mem. 2: 164. \&.

cognatus (Townes), n. comb. Norhtern que. s. to N. Y., w. to B. C. and Calif.

Opidnus cognatus Townes, 1962. In Townes and Gupta, Amer. Ent. Inst., Mem. 2: 148. ठ, ㅇ.

dorsator (Ashmead), n. comb. Alaska.

Centeterus dorsator Ashmead, 1902. Wash. Acad. Sci., Proc. 4: 161.

fulvibasis (Townes), n. comb. Que. s. to s.e. N. C., w. to Minn.

Opidnus fulvibasis Townes, 1962. In Townes and Gupta, Amer. Ent. Inst., Mem. 2: 144. ठ, ?.

lindrothi (Townes), n. comb. Alaska.

Opidnus lindrothi Townes, 1962. In Townes and Gupta, Amer. Ent. Inst., Mem. 2: 158..

major (Townes), n. comb. Northern Que., N. H. Ecology: In N. H. this species occurs above timberline on Mt. Washington.

Opidnus major Townes, 1962. In Townes and Gupta, Amer. Ent. Inst., Mem. 2: 156. $\delta$.

mucronatus (Townes), n. comb. Maine, Mass., N. Y., Mich.

Opidnus mucronatus Townes, 1962. In Townes and Gupta, Amer. Ent. Inst., Mem. 2: 150. §, ?.

nivarius (Brues), n. comb. Alaska.

Aptesis nivarius Brues, 1919. Rpt. Canad. Arctic Exped. 1913-18, v. 3G, p. 21. ?.

orbitus (Townes), n. comb. N. H., n. Yukon. Ecology: In N. H. this species occurs above timberline on Mt. Washington.

Opidnus orbitus Townes, 1962. In Townes and Gupta, Amer. Ent. Inst., Mem. 2: 157. $\delta$.

oresbius (Townes), n. comb. B. C., Wash.

Opidnus oresbius Townes, 1962. In Townes and Gupta, Amer. Ent. Inst., Mem. 2: 136. ठ์.

parallelus (Townes), n. comb. Que., N. H., N. Y., Man., Colo.

Opidnns parallelus Townes, 1962. In Townes and Gupta, Amer. Ent. Inst., Mem. 2: 165. ठ, q.

quadriceps (Townes), n. comb. Northwestern N. W. T., Alaska.

Opidnus quadriceps Townes, 1962. In Townes and Gupta, Amer. Ent. Inst., Mem. 2: 168. $\delta$, . .

rufinotum (Townes), n. comb. Northern Alaska. Townes (1962) said that minotum "may prove to be a subspecies of $O$.tumulus."

Opidnus minotum Townes, 1962. In Townes and Gupta, Amer. Ent. Inst., Mem. 2: 161. §.

shumaginensis Carlson, n. name. Alaska.

Stiboscopus fermegineus Ashmead, 1902. Wash. Acad. Sci., Proc. 4: 173. 9. Preocc. in Oresbius by Cryptus fermegineus Ashmead, 1890; in the tribal revision of Townes and Gupta (1962), Townes did not rename Stiboscopus ferrigineus because Cryptus ferrugineus Ashmead is an unavailable primary homonym which could not interfere with the use of the name Stiboscopus ferruginens; S. fermgineus is renamed here 
because if it were to have had a junior synonym one would not be at liberty to use the name $S$. ferrugineus until such time as it was placed in a different genus than $C$. ferrugineus Ashmead.

sublaevis (Townes), n. comb. Wyo., Colo., Wash. Ecology: Occurs on mountains near timberline. Opidnus sublaevis sublaevis Townes, 1962. In Townes and Gupta, Amer. Ent. Inst., Mem. 2: $134 . \delta$,. .

Opidnus sublaevis miltomerus Townes, 1962. In Townes and Gupta, Amer. Ent. Inst., Mem. 2: 135. ठ. N. syn.

taeniatus (Townes), n. comb. Northern Que., N. H., N. W. T., n. Yukon. Ecology: In N. H. this species occurs above timberline on $\mathrm{Mt}$. Washington.

Phygadeuon alticola Ashmead, 1897 In Slosson, Ent. News 8: 237. Nomen nudum.

Opidnus taeniatus Townes, 1962. In Townes and Gupta, Amer. Ent. Inst., Mem. 2: 154. o, q.

tegularis (Provancher). N. S. s. to Pa., w. to Wyo. and Colo. Host: Pristiphora erichsonii (Htg.).

Phygadeuon tegularis Provancher, 1874. Nat. Canad. 6: 282. .

Ichneumon decoratus Provancher, 1875. Nat. Canad. 7 (1): 25 (key); 7 (3): 83. ơ.

Ischuus placidus Provancher, 1875. Nat. Canad. 7 (4): 110. ठँ.

Phygadeuon orbitalis Provancher, 1882. Nat. Canad. 13 (no. 155): 335 (key); 13 (no. 156): 354. o.

Phygadeuon nigriceps Provancher, 1886. Addit. Corr. Faune Ent. Canada Hym., p. 52. .

Phygadeuon (Scinascopus!) orbitaliformis Viereck, 1917 (1916). Conn. State Geol. and Nat. Hist. Survey Bul. 22: 336. ठ。.

Taxonomy: Barron, 1975. Nat. Canad. 102: 459, 514, 522, 532, 573 (Provancher types revised). teres (Townes), n. comb. Northern Yukon, Alaska.

Opidnus teres Townes, 1962. In Townes and Gupta, Amer. Ent. Inst., Mem. 2: 167. ठ, $\uparrow$.

tibialis (Townes), n. comb. Northern Que., n.e. N. W. T., n. Yukon, Alaska.

Opidnus tibialis Townes, 1962. In Townes and Gupta, Amer. Ent. Inst, Mem. 2: 163. ठ", ๆ.

trifasciatus (Ashmead), n. comb. Northern Que., N. W. T., n. Yukon, Alaska.

Microcryptus trifasciatus Ashmead, 1902. Wash. Acad. Sci., Proc. 4: 184. ठ.

tsugae (Cushman). Newfoundland (Labrador) w. to s. Alaska, s. to N. C., Colo., Ariz. and Calif. Host: Neodiprion tsugae Midd. The characters used by Townes (1962) for subspecific differentiation are neither strong nor entirely in agreement with the material he studied.

Aptesis (Pezoports) tsugae Cushman, 1939. Wash. Acad. Sci., Jour. 29: 394. ð’,.

Opidnus tsugae ruficoxa Townes, 1962. In Townes and Gupta, Amer. Ent. Inst., Mem. 2: 138. ठै, ₹. N. syn.

Opiduus tsugae interior Townes, 1962. In Townes and Gupta, Amer. Ent. Inst., Mem. 2: 139. ¿, ९. N. syn.

Opidnus tsagae inflatus Townes, 1962. in Townes and Gupta, Amer. Ent. Inst., Mem. 2: 140. ․ N. syn.

Biology: Furniss and Dowden, 1941. Jour. Econ. Ent 34: 49, 51.

tumulus (Townes), n. comb. N. W. T., Yukon, Alaska.

Opidnus tumulus Townes, 1962. In Townes and Gupta, Amer. Ent. Inst., Mem. 2: 160. male, female.

vockerothi (Townes), n. comb. Northern Que.

Opidnus vockerothi Townes, 1962. In Townes and Gupta, Amer. Ent. Inst., Mem. 2: 166. ठ, †.

vultuosus (Townes), n. comb. Newfoundland (Labrador), Que., n. Mich., N. W. T., Alaska.

Opidnus vultuosus Townes, 1962. In Townes and Gupta, Amer. Ent. Inst., Mem. 2: 152. o, १.

\section{Genus POLYTRIBAX Foerster}

Polytribax Foerster, 1868. Naturh. Ver. Rheinlande, Verh. 25: 183. 
Type-species: Phygadeuon (Polytribax) pallescens Viereck. By subsequent monotypy from inclusion by Viereck, 1911.

Plesignathus Foerster, 1868. Naturh. Ver. Rheinlande, Verh. 25: 183.

Type-species: Phygadenon fulvescens Cresson. By subsequent monotypy from inclusion by Ashmead (1900) as "Plesiognathus flavescens Cress." Ashmead's N. J. record for this species is apparently based upon a misidentified female of Polytribax contiguus (Cresson).

Neleophron Foerster, 1868. Naturh. Ver. Rheinlande, Verh. 25: 184.

Type-species: Cryptus arrogans Gravenhorst. Monotypically included and designated by Perkins, 1962.

Epiphobus Foerster, 1868. Naturh. Ver. Rheinlande, Verh. 25: 185.

Type-species: Cryptus rufipes Gravenhorst. Monotypically included and desig. by Townes and Gupta, 1962.

Steriphocryptus cameron, 1903. Entomologist 36: 233.

Type-species: Steriphocryptus luteus Cameron. Monotypic.

Chasmocryptus Uchida, 1936. Insecta Matsumurana 11: 16.

Type-species: Plectocryptus hokkaidensis Uchida. Monotypic and orig. desig. The type-species is regarded as a synonym of $P$. penetrator (Smith).

Members of this Holarctic genus parasitize the pupae and possibly prepupae of Lepidoptera.

Taxonomy: Ashmead, 1900. In Smith, N. J. State Bd. Agr., Ann. Rpt. 27, Sup., p. 568 (first inclusion of a species in Plesignathus).

contiguus (Cresson). N. S. w. to N. Dak., s. to N. C., n. Ga., and Kans. The coloration of the male is similar to that of the males in some species of Cratichneumon.

Ischnus contiguus Cresson, 1864. Ent. Soc. Phila., Proc. 3: 190. ठ.

Phygadeuon major Cresson, 1864. Ent. Soc. Phila., Proc. 3: 308. ․

erotehii erotchii (Cresson). Newfoundland (insular) w. to Alaska, s. to Pa., S. Dak., and s. B. C.

Phygadeuon Crotchii Cresson, 1879 (1878). Acad. Nat. Sci. Phila., Proc. 30: 357..

crotehii fumipennis Townes and Gupta. Colo., N. Mex., Ariz., s.e. B. C. and Calif.

Polytribax crotchii fumipennis Townes and Gupta, 1962. Amer. Ent. Inst., Mem. 2: 179. ð.

crotehii hesperus Townes and Gupta. Southern B. C., w. Oreg., Calif.

Polytribax crotchii hesperus Townes and Gupta, 1962. Amer. Ent. Inst., Mem. 2: 180. ð.

fulvescens (Cresson). B. C. s. to Calif.

Phygadeuon fulvescens Cresson, 1879 (1878). Acad. Nat. Sci. Phila., Proc. 30: 359...

pallescens (Viereck). Que. s. to n.w. S. C., w. to Minn., Kans., and Ariz.; Mexico. Host:

Heterocampa guttivitta (Wlk.), Lambdina pellucidaria (G. and R.), Epargyreus clarus (Cramer).

Phygadeuon (Polytribax) pallescens Viereck, 1911, U. S. Natl. Mus., Proc. 39: 406. ơ, ?.

\section{Genus GIRAUDIA Foerster}

Giraudia Foerster, 1868. Naturh. Ver. Rheinlande, Verh. 25: 184.

Type-species: Cryptus congmiens Gravenhorst. Monotypically included and desig. by Ashmead, 1900.

Calocryptus Thomson, 1873. Opusc. Ent. 5: 519, 521.

Type-species: Cryptus congruens Gravenhorst. Monotypic.

Pseudocryptus Kriechbaumer, 1893. Ent. Nachr. 19: 120.

Type-species: Cryptus grisescens Gravenhorst. Monotypic.

This is a Holaretic genus of moderate size.

ferruginea (Cushman). R. I., N. Y., Md., D. C., Ont., Mich. Host: Tomostethus multicinctus (Roh.).

Aptesis ferruginea Cushman, 1935. Wash. Acad. Sci., Jour. 25: 550. ठ์,.

fulva fulva Townes and Gupta. Western Wash., w. Oreg., n.w. Calif.

Giraudia fulva fulva Townes and Gupta, 1962. Amer. Ent. Inst., Mem. 2: 190. ठ, ९.

fulva nigrithorax Townes and Gupta. Colo., N. Mex., Alta., Idaho, Utah, s.e. B. C., e. Oreg. Giraudia fulva nigrithorax Townes and Gupta, 1962. Amer. Ent. Inst., Mem. 2: 190. ơ, ?. 
leucospis Townes and Gupta. Calif.

Giraudia leucospis Townes and Gupta, 1962. Amer. Ent. Inst., Mem. 2: 196. ठ.

minor Townes and Gupta. N. C., S. C.

Giraudia minor Townes and Gupta, 1962. Amer. Ent. Inst., Mem. 2: 196. ठ, ๆ.

plana (Provancher). Que. s. to n.e. Ga., w. to Minn. and Iowa.

Phygadeuon plauus Provancher, 1874. Nat. Canad. 6: 283. \&.

Mesostenus ruficoxus Provancher, 1875. Nat. Canad. 7: 266. ठ. Uncertain syn.

Phygadeuon robustus Provancher, 1879. Nat. Canad. 11: 75. ๆ.

Mesostenus provancheri Dalla Torre, 1902. Cat. Hym., v. 3, p. 546. Unnecessary n. name

for $M$. ruficoxus; the latter not preocc. by Mesosteuus ruficoxis Brulle.

punctifera Townes and Gupta. Que. s. to Ga., w. to Wis.

Giraudia punctifera Townes and Gupta, 1962. Amer. Ent. Inst., Mem. 2: 194. §, ๆ.

rufa (Provancher). Que. s. to w. N. C., w. to Minn.

Cryptus rufus Provancher, 1874. Nat. Canad. 6 (6): 177 (key); 6 (7): 202. o.

semiflava Townes and Gupta. Que., Maine, N. Y., Mich., N. Mex.

Girandia semiflava Townes and Gupta, 1962. Amer. Ent. Inst., Mem. 2: 191. §, ?.

subaequalis Townes and Gupta. N. Y., s.w. N. C., n.w. S. C., n.e. Ga.

Girandia subaequalis Townes and Gupta, 1962. Amer. Ent. Inst., Mem. 2: 197. ठ, \&.

\section{Genus SCHENKIA Foerster}

Schenkia Foerster, 1868. Naturh. Ver. Rheinlande, Verh. 25: 184.

Type-species: Phygadeuon graminicola Gravenhorst. Monotypically included and desig. by Ashmead, 1900.

Ecpaglus Foerster, 1868. Naturh. Ver. Rheinlande, Verh. 25: 185.

Type-species: Cryptus brevicomis Gravenhorst. Monotypically included and desig. by Ashmead, 1900.

Scheuckia Dalla Torre, 1901. Wien. Ent. Ztg. 20: 51. Emend.

This is a Holarctic genus of moderate size.

amphileuca Townes and Gupta. N. Y., Mich., Minn.

Schenkia amphilenca Townes and Gupta, 1962. Amer. Ent. Inst., Mem. 2: 201. §,..

graminicola (Gravenhorst). Que. s. to N. Y., w. to n. Yukon, Oreg., and Colo; Europe. Townes and Gupta (1962) recognized three subspecies.

Cryptus brevicornis Gravenhorst, 1829. Ichn. Europaea, v. 2, p. 511. o.

Cryptus humilis Gravenhorst, 1829. Ichn. Europaea, v. 2, p. 604. ठ.

Phygadeuon graminicola Gravenhorst, 1829. Ichn. Europaea, v. 2, p. 673. ๆ.

Phygadeuon rectus Provancher, 1875. Nat. Canad. 7: 178. ठ.

Phaeogenes tuberculifer Provancher, 1882. Nat. Canad. 13: 331. “९” = $\delta$.

Cryptus pubesceus Provancher, 1886. Addit. Corr. Faune Ent. Canada Hym., p. 72. Preoce. by Fonscolombe, 1850.

Cryptus Hechfellueri Dalla Torre, 1902. Cat. Hym., v. 3, p. 574. N. name for C. pubescens Provancher.

Schenkia graminicola hesperus Townes and Gupta, 1962. Amer. Ent. Inst., Mem. 2: 207. ठ, ค. N. syn.

iridescens (Cresson). Newfoundland (Labrador) w. to Alaska, s. to S. C., Ill., Colo., and Oreg.

Ischuus iridescens Cresson, 1864. Ent. Soc. Phila., Proc. 3: 193. ठ。.

Cryptus brevicauda Ashmead, 1890 (1889). U. S. Natl. Mus., Proc. 12: 412. .

Scherkia iridescens pumila Townes and Gupta, 1962. Amer. Ent. Inst., Mem. 2: 211. ठ, ?. N. syn.

Schenkia iridescens oreas Townes and Gupta, 1962. Amer. Ent. Inst., Mem. 2: 212. ठ, १. N. syn.

Scherkia iridescens melanops Townes and Gupta, 1962. Amer. Ent. Inst., Mem. 2: 216. ठ, ๆ. N. syn.

leucopus Townes and Gupta, N. Y., N. J., n.w. S. C., Ohio, Mich.

Scherkia leucopus Townes and Gupta, 1962. Amer. Ent. Inst., Mem. 2: 217. ठ, \&. 
lonchura Townes and Gupta. Yukon.

Schenkia lonchura Townes and Gupta, 1962. Amer. Ent. Inst., Mem. 2: 217..

parallela evittata Townes and Gupta. Wash.

Schenkia parallela evittata Townes and Gupta, 1962. Amer. Ent. Inst., Mem. 2: 209..

parallela parallela Townes and Gupta. N. H. s. to s.w. S. C., w. to Sask.

Schenkia parallela parallela Townes and Gupta, 1962, Amer. Ent. Inst., Mem. 2: 208. ठ", ․

\section{Genus MEGAPLECTES Foerster}

Megaplectes Foerster, 1868 Naturh. Ver. Rheinlande, Verh. 25: 186.

Type-species: Ichneumon monticola Gravenhorst. By subsequent monotypy from inclusion by Schmiedeknecht, 1890.

Iocryptus Thomson, 1873. Opusc. Ent. 5: 472.

Type-species: Phygadeuon regius Taschenberg. Monotypic. The type-species is regarded as a synonym of $M$. monticola monticola (Gravenhorst).

Megaloplectes Schulz, 1906. Spolia Hym., p. 124. Emend.

There is a single Holarctic species.

monticola blakei (Cresson). Newfoundland (Labrador) w. to Yukon, s. to w. N. C., Mịch., Man., and Oreg. M. monticola monticola (Gravenhorst) is European.

Ichneumon Blakei Cresson, 1864 Ent. Soc. Phila., Proc. 3: 139. ठ.

Cryptus insignis Provancher, 1874. Nat. Canad. 6: 178. ๆ.

Hoplismenus stygicus Provancher, 1886. Addit. Corr. Faune Ent. Canada. Hym., p. 34. ơ. monticola dentatus Uchida. Yukon, Alaska; n. A sia.

Megaplectes monticola var. dentata Uchida, 1930. Hokkaido Imp. Univ., Faculty Agr., Jour. 25: 304. ठ", ?.

\section{Genus PLEOLOPHUS Townes}

Pleolophus Townes, 1962. In Townes and Gupta, Amer. Ent. Inst., Mem. 2: 223.

Type-species: Phygadeuon basizonus Gravenhorst (sensu Townes). Orig. desig.

This is a Holarctic genus of moderate size.

annulosus Townes. Maine, N. Y., Mich.

Pleolophus annulosus Townes, 1962. In Townes and Gupta, Amer. Ent. Inst., Mem. 2: 226. $\delta$.

astrictus Townes. Maine, N. H., Mass., Conn., N. Y., Mich., Alaska.

Pleolophus astrictus Townes, 1962. In Townes and Gupta, Amer. Ent. Inst., Mem. 2: 242. ¿. ?.

basizonus (Gravenhorst). N. B., Que., N. J., Ont., Mich., Ohio; Eurasia. Introduced from Europe. Host: Gilpinia hercyniae (Htg.), Neodiprion lecontei (Fitch), N. nanulus nanulus Schedl, N. pratti banksianae Roh., N. sertifer (Geoff.), N. swainei Midd.

Cryptus varicolor Gravenhorst, 1829. Ichn. Europaea, v. 2, p. 603. ठ.

Phygadeuon basizonus Gravenhorst, 1829. Ichn. Europaea, v. 2, p. 748..

Phygadeuon pteronorum Hartig, 1838. Jahresber. Fortschr. Forstwiss. Forstl. Naturk. 1: 273. $\delta$, ?.

Microcryptus basizonius(!) Thomson, 1883. Opusc. Ent. 9: 863.

Microcryptus curtulus Kriechbaumer, 1891. Ent. Nachr. 17: 171. $\delta$.

Taxonomy: Oehlke, 1966 (1965). Beitr. z. Ent. 15: 829-831 (syn. and description).

Biology: Seyrig, 1932 Soc. Ent. de France, Ann. 101: 111-112. - Finlayson and Reeks, 1936.

Canad. Ent. 68: 164, 166. - Morris, Cameron, and Jepson, 1937. Bul. Ent. Res. 28: 349-355

(in part). -Green, 1938. Ent. Soc. Ontario, Ann. Rpt. 69: 32-34. - Pierson and Nash, 1939.

Maine Forest Commr., Bien. Rpt. 22: 85. - Finlayson and Green, 1940. Canad. Ent. 72:

236-238. - Lovaszy, 1940. Ann. Ent. Fenn. 6: 64-65. - Kangas, 1941. Ann. Ent. Fenn. 7:

10-27. - Reeks, 1953. Canad. Jour. Agr. Sci. 33: 407, 408, 416-417. - Hein, 1956. Nederland.

Boschbouw.-Tijdschr. 28: 283-297. - Finlayson and Finlayson, 1957. Canad. Ent. 89: 
507-509. - Niklas and Franz, 1957. Biol. Bundesanst. f. Land. u. Forstw. (Berlin-Dahlem), Mitt. 89: 22-23. - Finlayson and Finlayson, 1958. Canad. Ent. 90: 223-224. - Finlayson, 1958. Canad. Ent. 90: 557-563. - Finlayson, 1960 (1959). Ent. Monthly Mag. 95: 216. -Finlayson, 1961 (1960). Ent. Monthly Mag. 96: 177. - Finlayson, 1961. Canad. Ent. 93: 626-628. - Finlayson, 1961. Canad. Ent. 93: 799-801. - Griffiths, 1961. Canad. Ent. 93: 1005-1010. -Griffiths, 1969. Canad. Ent. 101: 673-713, 907-914. - Price, 1970. Science 170: 546-547. - Price, 1970. Canad. Ent. 102: 1102-1111. - Price, 1970. Ecology 51: 445-454. -Price, 1971. Ecology 52: 587-596. -Price, 1972. Canad. Ent. 104: 129-140.

Morphology: Finlayson, 1960. Canad. Ent. 92: 33, 35, 44 (final-instar larva).

borrori Townes. Maine.

Pleolophus borrori Townes, 1962. In Townes and Gupta, Amer. Ent. Inst., Mem. 2: 228. ₹. elypealis Townes. Alaska.

Pleolophus clypealis Townes, 1962. In Townes and Gupta, Amer. Ent. Inst., Mem. 2: 242 $\delta$ o.

contractus Townes. B. C. s. to Calif. Host: Pristiphora erichsonii (Htg.).

Pleolophus contractus Townes, 1962. In Townes and Gupta, Amer. Ent. Inst., Mem. 2: 237. $\delta$, .

coriaceus Townes. Sask., Alta.

Pleolophus coriaceus Townes, 1962. In Townes and Gupta, Amer. Ent. Inst., Mem. 2: 229. $\delta$.

furvus Townes. Colo.

Pleolophus furvus Townes, 1962. In Townes and Gupta, Amer Ent. Inst., Mem. 2: 228. ठ。.

grossus Townes. N. Y., Mich., N. Dak., and B. C., s. to w. N. C., Kans., and Oreg.

Pleolophus grossus Townes, 1962. In Townes and Gupta, Amer. Ent. Inst., Mem. 2: 229. ठ, ㅇ.

indistinctus (Provancher). N. B. s. to w. N. C., w. to Sask. and Iowa. Host: Neodiprion abbotii (Leach), N. abietis (Harris), N. lecontei (Fitch), N. nanulus nanulus Schedl, N. pratti banksiance Roh., N. sertifer (Geoff.), N. suainei Midd., Gilpinia hercyniae (Htg.), Pristiphora erichsonii (Htg.), Pikonema alaskensis (Roh.).

Cryptus micropterus Say, 1836. Boston Jour. Nat. Hist. 1: 238. ?. Preocc. in Pleolophus by Ichneumon micropterus Gravenhorst.

Phaeogenes indistinctus Provancher, 1886. Addit. Corr. Faune Ent. Canad. Hym., p. 43. o. Cryptus segregatus Provancher, 1886. Addit. Corr. Faune Ent. Canada Hym., p. 73. $\delta$.

Aptesis pterigia Bradley, 1918. Brooklyn Ent Soc., Bul. 13: 100. N. name for $C$. microptemis Say.

Biology: Price, 1970. Science 170: 546-547. - Price, 1970. Ecology 51: 445-454. - Price, 1970. Ent. Soc. Amer., Ann. 63: 1502-1509. - Price, 1971. Ecology 52: 587-596.

Morphology: Finlayson, 1960. Canad. Ent. 92: 31-33, 44 (final-instar larva).

nigribasis Townes. Colo., N. Mex.

Pleolophus nigribasis Townes, 1962. In Townes and Gupta, Amer. Ent. Inst., Mem. 2: 237. ठ․

pilatus Townes. Newfoundland (Labrador), Mich., Minn.

Pleolophus pilatus Townes, 1962. In Townes and Gupta, Amer. Ent. Inst., Mem. 2: 227. ठँ, q.

rubrocinctus rubrocinctus (Provancher). Que. s. to N. Y., w. to Mich.

Phygadenon rubrocinctus Provancher, 1874. Nat. Canad. 6: 280. 9.

Phaeogenes aterrimus Provancher, 1882. Nat. Canad. 13: 330. ठँ.

rubrocinctus rufifemur Townes. Sask. s. to Colo, w. to Alaska and Calif.

Pleolophus mbrociuctus mififemur Townes, 1962. In Townes and Gupta, Amer. Ent. Inst., Mem. 2: 233. $\delta$, $९$.

\section{Genus RHYTURA Townes}

Rhytura Townes, 1962. In Townes and Gupta, Amer. Ent. Inst., Mem. 2: 244.

Type-species: Rhytura peudens Townes. Monotypic and orig desig. 
Only one species is known.

pendens Townes. Que. s. to n. Ga., w. to Minn.

Rhytura pendens. Townes, 1962. In Townes and Gupta, Amer. Ent. Inst., Mem. 2: 244. ठ, q.

\section{Genus APTESIS Foerster}

Aptesis Foerster, 1850. Arch. f. Naturgesch. 16 (1): 71, 82.

Type-species: Ichneumon sudeticus Gravenhorst. Desig. by Viereck, 1914. The type-species is regarded as a synonym of $A$. nigrocincta (Gravenhorst).

Pezoportis Foerster, 1868. Naturh. Ver. Rheinlande, Verh. 25: 181. Preoce. by Illiger, 1811 and Klug, 1842.

Type-species: Pezomachus nigrocinctus (Gravenhorst). Monotypically included and desig. by Ashmead, 1900. The type-species designation is Gravenhorst's 1929 identification of Ichneumon nigrocinctus Gravenhorst, 1815.

Aptesis subg. Clypeodiodon Aubert, 1968. Soc. Ent. Mulhouse, Bul. 24: 7.

Type-species: Aptesis (Clypeodiodon) flavifaciator Aubert. Monotypic. As "Aptesis Clypeodion subg nov. flavifaciator sp. nov."

This is a large Holaretic genus. Townes (1970) said that "the species occur mostly in natural meadows."

Taxonomy: Townes, 1970 (1969). Amer. Ent. Inst., Mem. 12: 139.

albifrons Townes. N. Y.

Aptesis albifrons Townes, 1962. In Townes and Gupta, Amer. Ent. Inst., Mem. 2: 267. ס. alpestris Townes. Colo., Idaho., Ariz., B. C., Wash., Oreg., Calif.

Aptesis alpestris Townes, 1962. In Townes and Gupta, Amer. Ent. Inst. Mem. 2: 255. ઠ, anaula Townes. S. C.

Aptesis anaulus Townes, 1962. In Townes and Gupta, Amer. Ent. Inst., Mem. 2: 272. ठ. atrox Townes. Ohio.

Aptesis atrox Townes, 1962. In Townes and Gupta, Amer. Ent. Inst., Mem. 2: 269. .

breviaria Townes. N. Y., Mich., Ohio, Minn.

Aptesis breviaria Townes, 1962. In Townes and Gupta, Amer. Ent. Inst., Mem. 2: 253. ठ, ㅇ.

catulus Townes. N. Y., N. J., Md., Va., N. C., Kans.

Aptesis catulus Townes, 1962. In Townes and Gupta, Amer. Ent. Inst., Mem. 2: 263. ठ, ᄋ. fastigata Townes. Alta., Wyo., Oreg., Calif.

Aptesis fastigata Townes, 1962. In Townes and Gupta, Amer. Ent. Inst., Mem. 2: 267. ठ, ㅇ.

fuscitibia Townes. Maine, Mass., R. I., N. Y., w. N. C., Mich.

Aptesis fuscitibia Townes, 1962. In Townes and Gupta, Amer. Ent. Inst., Mem. 2: 262. o, ㅇ.

gracilis Townes. Northern Mich., Alta.

Aptesis gracilis Townes, 1962. In Townes and Gupta, Amer. Ent. Inst., Mem. 2: 251. ð. incompta Townes. Northwestern S. C.

Aptesis incompta Townes, 1962. In Townes and Gupta, Amer. Ent. Inst., Mem. 2: 265. ठ, ㅇ.

inculta Townes. Que. s. to w. N. C., w. to Mich.

Aptesis inculta Townes, 1962. In Townes and Gupta, Amer. Ent. Inst., Mem. 2: 257. o, ᄋ.

lissopleuris Townes. Western N. C. Ecology: Between altitudes of $4600 \mathrm{ft}$. and $5750 \mathrm{ft}$.

Aptesis lissoplenris Townes, 1962. In Townes and Gupta, Amer. Ent. Inst., Mem. 2: 257. ㅇ. scabra Townes. Md.

Aptesis scabra Townes, 1962. In Townes and Gupta, Amer. Ent. Inst., Mem. 2: 266.. . segnis femorata Townes. Sask., Alta., Wyo., Colo., Calif.

Aptesis seguis femorata Townes, 1962. In Townes and Gupta, Amer. Ent. Inst., Mem. 2: 260. $\delta$, ㅇ. 
segnis segnis (Provancher). Que., Maine, N. H. N. Y., n.w. S. C., Mich. Ecology: I have seen a long series of males collected in Malaise traps placed in the crowns of Abies balsamifera. Host: Profenusa canadensis (Marl.).

Phygadeuon segnis Provancher, 1877. Nat. Canad. 9: 11. \&.

Pezoporus (Schenkia) tenthredinarum Rohwer, 1915. U. S. Natl. Mus., Proc. 49: 216. o, ?.

Biology: Parrott and Fulton, 1915. N. Y. Agr. Expt. Sta., Bul. 411: 552, 572.

subguttata (Gravenhorst). Europe. Introduced in N. B., Que., and Ont. in 1937 and 1938, apparently without becoming established. Host: Gilpinia hercyniae (Htg.). The host listed was the target species for the introductions in North America, although a small number of individuals was released in an infestation of Neodiprion lecontei (Fitch). Although the number of individuals released against $G$. hercyniae at some places was large (as many as 6108 males and 10974 females) A. subgnttata has not been found in North America since 1939 when it was recovered from G. hercyniae in Parke Reserve, Kamouraska Co., Que.

Cryptus subguttatus Gravenhorst, 1829. Ichn. Europaea, v. 2, p. 610. ठ.

Cryptus contractus Gravenhorst, 1829. Ichn. Europaea, v. 2, p. 617. ठ.

Taxonomy: Oehlke, 1966 (1965). Beitr. z. Ent. 15: 835-836 (syn.).

Morphology: Finlayson, 1960. Canad. Ent. 92: 931, 932, 939 (final-instar larva).

verrucata Townes. Maine, N. H., N. Y., Ohio, Mich.

Aptesis verrucata Townes, 1962. In Townes and Gupta, Amer. Ent. Inst., Mem. 2: 252. ठ, ?.

yosemite Townes. Wyo., Calif.

Aptesis yosemite Townes, 1962. In Townes and Gupta, Amer. Ent. Inst., Mem. 2: 254. ठ', ㅇ.

\section{Genus OXYTAENIA Foerster}

Oxytaenia Foerster, 1868. Naturh. Ver. Rheinlande, Verh. 25: 182.

Type-species: Oxytaenia rufolineata Cameron. By subsequent monotypy from inclusion by Cameron, 1904.

Townes (1970) said that he saw 13 species, all of which are Neotropic except for the fact that one of them has a Nearctic subspecies.

Taxonomy: Townes, 1970 (1969). Amer. Ent. Inst., Mem. 12: 140.

barda carolina (Townes). Que. s. to w. N. C., w. to Mich. and Kans. O. barda barda (Cresson) occurs in Mexico.

Aptesis barda carolina Townes, 1962. In Townes and Gupta, Amer. Ent. Inst., Mem. 2: 271. $\delta, ?$.

\section{Genus ECHTHRUS Gravenhorst}

Echthrus Gravenhorst, 1829. Ichn. Europaea, v. 3, p. 861.

Type-species: Ichneumon reluctator Linnaeus. Desig. by Westwood, 1840.

Sphaetes Bremi, 1849 Stettin. Ent. Ztg. 10: 95.

Type-species: Sphaetes crassicrus Bremi. Monotypic.

Karaechthrus Uchida, 1929. Insecta Matsumurana 3: 176.

Type-species: Karaechthrus tuberculatus Uchida. Monotypic and orig. desig.

Bioleter Meyer, 1930. Zool. Mus. Akad. Nauk. SSSR, Ezheg. 31: 169.

Type-species: Bioleter eous Meyer. Monotypic and orig. desig.

Townes and Townes (1962) placed this small Holarctic genus in the Cryptini (=Mesostenini), subtribe Echthrina along with four other genera, but only Echthrus was transferred to the present tribe by Townes (1970).

Revision: Townes and Townes, 1962. U. S. Natl. Mus., Bul. 216 (pt. 3): 486-501.

Taxonomy: Townes, 1970 (1969). Amer. Ent. Inst., Mem. 12: 112, 113, 130. 
abdominalis Cresson. N. S. w. to B. C., s. to N. Y., Minn., N. Mex., and Calif. Townes and Townes (1962) recognized four subspecies.

Echthrus abdominalis Cresson, 1868. Canad. Ent. 1: 37. \&.

Mesochorus Saint-Cyri Provancher, 1874. Nat. Canad. 6: 299..

Dyseidopus vancoucerensis Bradley, 1902. Ent. News 13: 307. ठ. N. syn.

Echthrus abdominalis dimidiatus Townes, 1962. In Townes and Townes, U. S. Natl. Mus. Bul. 216 (pt. 3): 491 . ठ, ㅇ. N. syn.

Echthrus abdominialis infuscus Townes, 1962. In Townes and Townes, U. S. Natl. Mus. Bul. 216 (pt. 3): 492 . ठ, ‥ N. syn.

adillae adillae Davis. Newfoundland (Labrador), n. Ont., Alta., Mont., Wyo., Idaho, Alaska, B.

C., Wash., n. Oreg. Host: Paranthrene robinize (Hy. Edwards).

Echthrus adillae Davis, 1895. Amer. Ent. Soc., Trans. 22: 32. o.

Echthrus adillae nigriventris Townes, 1962. In Townes and Townes, U. S. Natl. Mus. Bul. 216 (pt. 3): 497. ठ, क. N. syn.

Echthrus adillae semimber Townes, 1962. In Townes and Townes, U. S. Natl. Mus. Bul. 216 (pt. 3): 498. ठ, ๆ. N. syn.

adillae rubidus Townes. Nev., s. Oreg., Calif.

Echthrus adillae rubidus Townes, 1962. In Townes and Townes, U. S. Natl. Mus. Bul. 216 (pt. 3): 499. ठ, ?.

adillae tibialis Townes. Que., Maine, N. Y., Ont., Va.

Echthrus adillae tibialis Townes, 1962. In Townes and Townes, U. S. Natl. Mus. Bul. 216 (pt. 3): 500. ठ, ․ .

Echthrus adillae brunners Townes, 1962. In Townes and Townes, U. S. Natl. Mus. Bul. 216 (pt. 3): 501. §, ?. N. syn.

niger Cresson. N. S. w. to n. B. C., s. to N. C., Ohio, Minn., and s. Alta. Host: Anoplodera proxima (Say)?, Saperda candida F., S. discoidea F. Townes and Townes (1962) recognized three subspecies, two of which were almost completely sympatric and had ranges which broadly overlapped that of the third subspecies.

Echthrus niger Cresson, 1868. Canad. Ent. 1: 37..

Echthrus rufopedibus Harrington, 1893. Canad. Ent. 25: 31. ․ N. syn.; name invalid because it is in the dative case.

Echthrus niger emaculatus Townes, 1962. In Townes and Townes, U. S. Natl. Mus. Bul. 216(pt. 3): 494. §, ๆ. N. syn.

\section{TRIBE CRYPTINI}

Just as the Cryptinae is the largest of ichneumonid subfamilies, the Cryptini is the largest tribe in the subfamily. Although the greatest numbers of genera and species of Cryptini occur in the tropics, the tribe is well represented in North America. Townes (1970) implies that the species of Cryptini search for their hosts primarily among foliage rather than in the soil or ground litter and differ from the species of Aptesini and Hemitelini in this respect as well as in having larger average size.

Townes (1970) divided the Cryptini (=Mesostenini) into subtribes which are partly for convenience and partly to show what he believed to be some of the natural groupings of genera. In the hope that this classification is actually an improvement over that of Townes and Townes (1962), the former is adopted here with little modification.

Revision: Townes and Townes, 1962. U. S. Natl. Mus. Bul. 216 (pt. 3): 1-602.

Taxonomy: Townes, 1970 (1969). Amer. Ent. Inst., Mem. 12: 141-346 (genera of world).

\section{SUbTRIBE AGROTHEREUTINA}

\section{Genus APSILOPS Foerster}

Apsilops Foerster, 1868. Naturh. Ver. Rheinlande, Verh. 25: 182.

Type-species: Cryptus hirtifrons Ashmead. By subsequent monotypy from inclusion by Ashmead, 1896.

Heterotypus Foerster, 1868. Naturh. Ver. Rheinlande, Verh. 25: 183. 
Type-species: Ichneumon cinctorius Fabricius. Monotypically included and desig. by

Townes, Townes, and Gupta, 1961.

Dapanus Foerster, 1868. Naturh. Ver. Rheinlande, Verh. 25: 183.

Type-species: Ichneumon cinctorius Fabricius. Monotypically included and desig. by Ashmead, 1900.

Sobas Foerster, 1868. Naturh. Ver. Rheinlande, Verh. 25: 187. Preocc. by Pascoe, 1863.

Type-species: Ichneumon cinctorius Fabricius. Monotypically included and desig. by Schmiedeknecht, 1890.

Trichocryptus Thomson, 1873. Opusc. Ent. 5: 520, 521.

Type-species: Cryptus cinctorius Gravenhorst. Monotypic. The type-species is Gravenhorst's identification of Ichneumon cinctorius Fabricius.

Neostricklandia Viereck, 1925. Canad. Ent. 57: 75.

Type-species: Neostricklandia sericata Viereck. Monotypic. and orig. desig.

Trichestema Cushman, 1927. U. S. Natl. Mus., Proc. 72 (13): 9.

Type-species: Trichestema helcostizoides Cushman. Monotypic and orig. desig.

The members of this small Holarctic genus parasitize aquatic or subaquatic Pyraloidea. There is an undescribed species which is known from Fla. and Cuba; it has been reared from Samea multiplicalis $\mathrm{Gn}$.

bicolor (Cushman). Ont. and Mass., s. to Md., w. to Alta., Wash. and Calif. Host: Schoenobius melinellus (Clem.).

Trichocryptus bicolor Cushman, 1927. U. S. Natl. Mus., Proc. 72 (13): 8 ..

Trichocryptus atlanticus Cushman, 1930 (1929). U. S. Natl. Mus., Proc. 76 (25): 3. \&.

hirtifrons (Ashmead). Ont. and Mass. s. to Fla., w. to Minn. and Tex. Host: Nymphula sp.

Cryptus hirtifrons Ashmead, 1890 (1889). U. S. Natl. Mus., Proc. 12: 411. ठ.

Cryptus cyaniventris Riley, 1890. In Riley and Howard, U. S. Dept. Agr., Insect Life 3: 154. Nomen nudum.

Taxonomy: Cushman, 1927. U. S. Natl. Mus., Proc. 72 (13): 7.

Biology: Hart, 1895. Ill. Nat. Hist. Survey, Bul. 4: 178-179.

sericata (Viereck). Que. w. to Alta., s. to Mass., Mich., and S. Dak. Host: Occidentalia

comptulatalis (Hulst), Stenochilo forbesellus (Fern.).

Neostricklandia sericata Viereck, 1925. Canad. Ent. 57: 75. ๆ.

Trichestema helcostizoides Cushman, 1927. U. S. Natl. Mus., Proc. 72 (13): 9. 9.

Biology: Frohne, 1939. Amer. Micros. Soc., Trans. 58: 234, 325, 347.

\section{Genus AGROTHEREUTES Foerster}

Agrothereutes Foerster, 1850. Arch. f. Naturgesch. 16 (1): 71.

Type-species: Pezomachus abbreviator Gravenhorst. Desig. by Viereck, 1914. The

type-species is Gravenhorst's identification of Ichneumon abbreviator Fabricius.

Spilocryptus Thomson, 1873. Opusc. Ent. 5: 472, 501.

Type-species: Spilocryptus zygaenarum Thomson. Desig. by Viereck, 1914. The

type-species is regarded as a synonym of A. fumipennis (Gravenhorst).

Dayro Cameron, 1902. Ann. and Mag. Nat. Hist. (7) 9: 209.

Type-species: Dayro pilosus Cameron. Monotypic.

This Holarctic genus has a greater number of species in Eurasia than in North America.

abbreviator iridescens (Cresson). Northern Que. w. to Alaska, s. to N. C., La., Kans., Sask., and Alta. Host: Gilpinia hercyniae (Htg.), Heterarthrus nemoratus (Fall.), Neodiprion abietis (Harris), N. lecontei (Fitch), N. sertifer (Geoff.), Pristiphora erichsonii (Htg.), Paraclemensia acerifolia (Fitch), Paralobesia viteana (Clem.). A. abbreviator abbreviator (Fabricius) occurs in Europe. In their tribal revision, Townes and Townes (1962) divided iridescens into two arbitrarily and unnaturally separated subspecies supposedly based upon a combination of color and female wing length (normal versus brachypterus).

Cryptus iridesceus Cresson, 1864. Ent. Soc. Phila., Proc. 3: 296. §.

Cryptus soror Cresson, 1864. Ent. Soc. Phila., Proc. 3: 296. ठे. 
Phygadeuon similaris Provancher, 1886. Addit. Corr. Faune Ent. Canada Hym., p. 57. đ. N. syn.

Cryptus albonotatus Provancher, 1886. Addit. Corr. Faune Ent. Canada Hym., p. 75. o. Aptesis major Davis, 1893. Ent. News 4: 32. ९. N. syn.

Spilocryptus propodeum Cushman, 1920. U. S. Natl. Mus., Proc. 58: 253. ¿.

Agrothereutes microalatus Cushman, 1927. U. S. Natl. Mus., Proc. 72 (13): 4. ๆ. N. syn.

Agrothereutes slossonae Cushman, 1927. U. S. Natl. Mus., Proc. 72 (13): 4. ․ N. syn.

Morphology: Finlayson, 1960. Canad. Ent. 92: 931, 932, 939 (final-instar larva).

abbreviator rufopectus Cushman. Alta. s. to N. Mex., w. to B. C. and Calif. Host: Neodiprion tsugae Midd., Pristiphora erichsonii (Htg.), Laspeyresia nigricana (Steph.).

Agrothereutes rufopectus Cushman, 1927. U. S. Natl. Mus., Proc. 72 (13): 4 ..

alutarius Townes. N. W. T., Yukon, Alaska.

Agrothereutes alutarius Townes, 1962. In Townes and Townes, U. S. Natl. Mus. Bul. 216 (pt. 3): 47. $\delta$, ?.

cimbeivorus (Cushman). Que. w. to B. C., s. to N. H., Mich., S. Dak., Colo., and Calif. Host: Cimbex americana Leach.

Spilocrptus(!) cimbcivorus Cushman, 1924. U. S. Natl. Mus., Proc. 64(4): 8. o, \&.

Agrothereutes cimbicinorus Walkley, 1958. In Krombein et al., U. S. Dept. Agr., Agr.

Monog. 2, Sup. 1, p. 46. Unjustified emendation.

grandis Townes. Conn. s. to n.w. S. C., w. to Ohio.

Agrothereutes grandis Townes, 1962. In Townes and Townes, U. S. Natl. Mus. Bul. 216 (pt. 3): $46 . \delta$, ..

lophyri (Norton). Newfoundland (insular) w. to B. C., s. to Fla., Ala., Ill., and Minn. Host: Neodiprion abietis (Harris), N. excitans Roh., N. lecontei (Fitch), N. nanulus nanulus Schedl, N. nigroscutum Midd., N. pratti banksianae Roh., Diprion similis (Htg.).

Cryptus Lophyri Norton, 1869. Amer. Ent. Soc., Trans. 2: 326. ¿,.

Agrothereutes lophyri ontariensis Townes, 1962. In Townes and Townes, U. S. Natl. Mus. Bul. 216 (pt. 3): $60 . \delta$, ๆ. N. syn.

Agrothereutes lophyri obscums Townes, 1962. In Townes and Townes, U. S. Natl. Mus. Bul. 216 (pt. 3): $61 . \delta$, ๆ. N. syn.

mandator americanus Townes. Que. w. to B. C., s. to N. J., Mich., Colo., and Wash. Host: Cimbex americana Leach., Trichiosoma triangulum Kirby. A. mandator mandator (Linnaeus) is European. About eight individuals of manducator americanus emerge from a single host cocoon.

Agrothereutes mandator americanus Townes, 1962. In Townes and Townes, U. S. Natl. Mus. Bul. 216 (pt. 3): $68 . \delta$, ․

montanus Townes. Colo. Ecology: The unique holotype was collected at an elevation of 11,000 ft. in Rocky Mountain National Park.

Agrothereutes montanus Townes, 1962. In Townes and Townes, U. S. Natl. Mus. Bul. 216 (pt. 3): 48 . .

neodiprionis (Cushman). Wash., Oreg., Calif. Host: Neodiprion tsngae Midd.

Spilocryptus neodip rionis Cushman, 1939. Wash. Acad. Sci., Jour. 29: 393. ठ́,.

pallipennis Townes. Calif. Ecology: The species is known from two specimens which were swept from Artemesia foliage at elevations of 8000 and $8500 \mathrm{ft}$.

Agrothereutes pallipennis Townes, 1962. In Townes and Townes, U. S. Natl. Mus. Bul. 216 (pt. 3): 49. ठै, क.

\section{Genus GAMBRUS Foerster}

Kaltenbachia Foerster, 1868. Naturh. Ver. Rheinlande, Verh. 25: 187.

Type-species: Cryptus ornatus Gravenhorst. By subsequent monotypy from inclusion by Brischke, 1888 ? The type-species is regarded as a synonym of $G$. incubitor (Linnaeus).

Gambrus Foerster, 1868. Naturh. Ver. Rheinlande, Verh. 25: 188.

Type-species: Gambrus (Cryptus) maculatus Brischke. By subsequent monotypy from inclusion by Brischke, 1888. The type-species is regarded as a synonym of $G$. incubitor (Linnaeus). 
Hygrocryptus Thomson, 1873. Opusc. Ent. 5: 513.

Type-species: Cryptus carnifex Gravenhorst. Desig. by Viereck, 1914.

Allocryptus Viereck, 1917. Conn. State Geol. and Nat. Hist. Survey Bul. 22: 333.

Type-species: Agrothereutes (Allocryptus) hyslopi Viereck. Monotypic.

This is a Holarctic genus which is rather arbitrarily distinguished from Agrothereutes and Aritranis.

apicatus (Provancher). N. S., Que., Maine, Vt., N. Y., Ont., Ohio, Sask. Ecology: This species has been reared from galls of Eurra on Salix, but appears to be too large to be a parasite of Euura and may parasitize Lepidoptera which occupy the galls secondarily.

Cryptus apicatus Provancher, 1874. Nat. Canad. 6 (6): 178 (key); 6 (7): 204 . .

Cryptus cinctus Provancher, 1875. Nat. Canad. 7: 175. ó. Preoce. by Fabricius, 1805.

bituminosus (Cushman). Mass., Conn., N. Y., N. J., Ga., Ill., Minn., La., Calif. Ecology: This species has been collected on Spartina in salt marshes. Host: Diatraea sp., Ostrinia nubilalis (Hbn.), O. obumbratalis (Led.), O. penitalis (Grt.), Sphenophorns pertinax (Oliv.).

Cryptoideus bituminosus Cushman, 1924. U. S. Natl. Mus., Proc. 64 (4): 6..

canadensis burkei (Viereck). California. Host: Orgyia leucostigma (J. E. S.), O. vetusta (Bdv.). Malacosoma californicum californicum (Pack.).

Cryptus (Gambrus) burkei Viereck, 1909. Ent. News 20: 291. ठ。, .

canadensis canadensis (Provancher). N. S. w. to B. C., s. to N. C., Kans., Ariz., and Oreg. Host: Malacosoma americanum (F.), M. califomicum fragile (Stretch), $M$. disstria Hbn., Laspeyresia pomonella (L.), Archips cerasivoranus (Fitch), Thymelicus lineola (Ochs.). In their tribal revision, Townes and Townes (1962) divided this subspecies into two with very broadly overlapping ranges.

Nematopodius Canadensis Provancher, 1875. Nat. Canad. 7: 268. o.

Spilocryptus exareolatus Viereck, 1903. In Skinner, Amer. Ent. Soc., Trans. 29: 81. ठ̊. N. syn.

extrematis (Cresson). N. S. w. to B. C., s. to D. C., Kans., Utah, and Calif. Host: Hyalophora cecropia (L.), H. columbia (S. I. S.), H. euryalus (Bdv.), H. gloveri (Stkr.).

Cryptus extrematis Cresson, 1864. Ent. Soc. Phila., Proc. 3: 404. ๆ.

Cryptus samiae Packard, 1865. Boston Soc. Nat. Hist., Proc. 9: 345. ठ̊, ๆ.

Echthrus Provancheri Provancher, 1885. Canad. Ent. 17: 116. o, १. The evidence given by Barron (1975) does not seem sufficient for attributing authorship to Brodie (in Provancher) rather than to Provancher.

Spilocryptus cecropiae Habermehl, 1919. Ztschr. f. Wiss. Insekten-Biol. 14: 239. ๆ.

Taxonomy: Barron, 1975. Nat. Canad. 102: 536.

Biology: Riley, 1872. Mo. State Ent., Ann. Rpt. 4: 110-111. - Harrington, 1891. Ent. Soc.

Ontario, Ann. Rpt. 21: 67. -Smith, 1908. Jour. Econ. Ent. 1: 294-297. - Marsh, 1937.

Ecology 18: 107-111. - Marsh, 1937. Ent. Soc. Amer., Ann. 30: 40-42. - Marsh, 1938. N. Y.

Ent. Soc., Jour. 46: 27.

Morphology: Riederer, 1890. N. Y. Micros. Soc., Jour. 46: 27.

nuncius (Say). N. B. w. to w. N. W. T., s. to Ala. and La. Host: Callosamia angulifera (Wlk.), C. promethia (Drury), Antheraea polyphemus (Cramer), Samia cynthia (Drury).

Cryptus nuncius Say, 1836. Boston Jour. Nat. Hist. 1: 237..

polyphemi Townes. N. S. w. to B. C., s. to Fla., Tex., N. Mex. and Oreg. Host: Antheraea polyphemus (Cramer).

Cryptus sordidus Provancher, 1886. Addit. Corr. Faune Ent. Canada Hym., p. 67.. Preoce. by Tschek, 1870.

Gambrus polyphemi Townes, 1945. Amer. Ent. Soc., Mem. 11: 809. N. name for $C$. sordidus Provancher.

tunicularubra (Fyles). Southern Que. Host: Gnorimoschema gallaeasteriella (Kell.). The lectotype is apparently the only remaining specimen reared by Fyles. Fyles mentioned having encountered this ichneumonid repeatedly in his work on the biology of the host, 
but apparently the host has not been reared frequently since then. Perhaps tunicularubra will prove to be a melanic variant of $G$. ultimus (Cresson).

Trychosis tunicula-rubra Fyles, 1896. Canad. Ent. 28: 148. o, ?.

ultimus (Cresson). N. S. w. to Oreg., s. to Fla., Tex., Ariz., and Calif.; Hawaii. Host: Acrobasis caryae Grt., Herpetogramma bipunctalis (F.), Loxostege sticticalis (L.), Ostrinia nubilalis (Hbn.), Phlyctaenia coronata tertialis (Gn.), Udea mbigalis (Gn.), Astala confederata (Grt.), Hyaloscotes pithopoera (Dyar), Thyridopteryx ephemeraeform is (Haw.), Platynota flavedana Clem., Ancylis comptana (Froel.), Grapholitha molesta (Bsk.), Paralobesia viteana (Clem.), Coleophora sp., Pectinophora gossypiella (Sdrs.), Exyra semicrocen (Gn.), Neogalea esula (Druce), Simyra henrici (Grt.), Trichoplusia ni (Hbn.), Bathyplectes curculionis (Thom.).

Cryptus ultimus Cresson, 1864. Ent. Soc. Phila., Proc. 3: 305. ․

Cryptus incertus Cresson, 1864. Ent. Soc. Phila., Proc. 3: 306. 9 . Preocc. by Ratzeburg, 1852.

Phygadeuon longicomis Provancher, 1886. Addit Corr. Faune Ent. Canada Hym., p. 52. $q$. Hemiteles annulicom is Ashmead, 1890 (1889). U. S. Natl. Mus., Proc. 12: 403. ?.

Agrothereutes (Allocryptus) hyslopi Viereck, 1917 (1916). Conn. State Geol. and Nat. Hist. Survey Bul. 22: 333 . .

Spilocryptus exannulatus Cushman, 1919. U. S. Natl. Mus., Proc. 55: 529. §, \&.

Hoplocryptus incertulus Cushman, 1925. Wash. Acad. Sci., Jour. 15: 390. N. name for C. incertus Cresson.

Biology: Fink, 1932. Jour. Agr. Res. 44: 555, 556. - Haden, 1935. Del. Univ. Agr. Expt. Sta., Bul. 194: 33-35.

yukonensis Townes. N. W. T., Yukon, Alaska.

Gambrus yukonensis Townes, 1962. In Townes and Townes, U. S. Natl. Mus. Bul. 216 (pt. 3): $79 . \delta, \%$.

\section{Genus ARITRANIS Foerster}

Aritranis Foerster, 1868. Naturh. Ver. Rheinlande, Verh. 25: 187.

Type-species: Cryptus explorator Tschek. Desig. by Viereck, 1914. from two species included by Tschek, 1870 .

Hoplocryptus Thomson, 1873. Opusc. Ent. 5: 508.

Type-species: Hoplocryptus binotulus Thomson. Desig. by Viereck, 1914. The type-species is regarded as a synonym of $A$. fugitiva (Gravenhorst).

This Holaretic genus is arbitrarily distinguished from Gambrus.

affabilis (Provancher). Que. s. to w. N. C., w. to Minn. and Kans. Host: Cephus pygmaeus (L.), Trachelus tabidus (F.), Phlyctaenia coronata tertialis (Gn.).

Cryptus affabilis Provancher, 1877. Nat. Canad. 9: 13. ․

albicollaris albicollaris (Cresson). Que. s. to N. C., w. to Mont. and Tex. Host: Phlyctaenia coronata tertialis (Gn.).

Cryptus albicollaris Cresson, 1872. Amer. Ent. Soc., Trans. 4: 158. ९.

albicollaris clypeata Townes. Wash., Calif.

Aritranis albicollaris clypeata Townes, 1962. In Townes and Townes, U. S. Natl. Mus. Bul. 216 (pt. 3): 114. ठ, ?.

barberi Townes. Md.

Aritranis barberi Townes, 1962. In Townes and Townes, U. S. Natl. Mus. Bul. 216 (pt. 3): 111. $\delta$.

byrsina Townes. Que. s. to Ga., w. to Wis., Kans., and La. Host: Achatodes zeae (Harris), Papaipema sp. in Sambucus pith, "Oberea sp." in raspberry stem. It does not seem likely that $A$. byrsina would be a primary parasite of Oberea.

Aritranis byrsina Townes, 1962. In Townes and Townes, U. S. Natl. Mus. Bul. 216 (pt. 3): 102. $\delta, ?$.

imitator (Provancher). Que. w. to n. Yukon, s. to R. I., Ohio, Colo., and Calif. Host: Hoplitis (Cyrtosmia) hypocrita (Ckll.).

Cryptus imitator Provancher, 1877. Nat. Canad. 9: 13. ९. 
Aritran is imitator nigriventris Townes, 1962. In Townes and Townes, U. S. Natl. Mus. Bul. 216 (pt. 3): 121. ठ, ?. N. syn.

Aritranis imitator monticola Townes, 1962. In Townes and Townes, U. S. Natl. Mus., Bul. 216 (pt. 3): $124 . \delta$, ๆ. N. syn.

Aritranis imitator ruficauda Townes, 1962. In Townes and Townes, U. S. Natl. Mus. Bul. 216 (pt. 3): $125 . \delta$, ๆ. N. syn.

linnae linnae Townes. Que., N. Y., Ont., Mich., Minn., Sask., Alta.

Aritranis linnae linnae Townes, 1962. In Townes and Townes, U. S. Natl. Mus. Bul. 216 (pt. 3): 105. ठ, ?.

linnae pacifica Townes. Calif.

Aritranis limue pacifica Townes, 1962. In Townes and Townes, U. S. Natl. Mus. Bul. 216 (pt. 3): 106. ठ, ?.

notata new comeri (Cushman). Mont., Ida., B. C., Wash., Oreg. Host: Ametastegia glabrata (Fall.), Allantus cinctus (L.).

Caenocryptus newcomeri Cushman, 1917. U. S. Natl. Mus., Proc. 53: 463. ঠ, ९..

notata notata (Provancher). Que. s. to w. N. C., w. to Alaska, Alta, and Colo. Host: Ametastegia glabrata (Fall.), Ancistrocerus birenimaculatus (Sauss.), "Odynerus" sp. in Rhus stem.

Cryptus Belangeri Provancher, 1874. Nat. Canad. 6 (6): 177 (key); 6 (7): 201. ․ The holotype was not located by Barron (1975).

Cryptus notatus Provancher, 1874. Nat. Canad. 6 (6): 177 (key); 6 (7): 202. ठ̋. A specimen presumed to be the holotype was located by Barron (1975).

Cryptus elongatus Provancher, 1882 (Dec.). Nat. Canad. 13: 362. ठ. Preocc. by Rudow, 1882 (Nov.).

Oronotus albomaculatus Ashmead, 1896. Amer. Ent. Soc., Trans. 23: 205. ð.

Taxonomy: Barron, 1975. Nat. Canad. 102: 433, 466, 520.

notata sierrae Townes. Calif. Host: Ancistrocerus spilogaster Cam., Leptochilus tetradymia Parker, Megachile gentilis $\mathrm{Cr}$.

Aritranis notata sierrae Townes, 1962. In Townes and Townes, U. S. Natl. Mus. Bul. 216 (pt. 3): 120. $\delta$, \&.

nubecula Townes. R. I., Fla., Mich., Tex.

Aritranis nubecula Townes, 1962. In Townes and Townes, U. S. Natl. Mus. Bul. 216 (pt. 3): 109. ठ, ㅇ.

zoesmairi (Dalla Torre). Que. s. to w. N. C., w. to Wis. Host: Ceratina dupla Say. Individual larvae consume two to five host larvae.

Cryptus ornatus Provancher, 1886. Addit. Corr. Faune Ent. Canada Hym., p. 63 (key).. Preocc. by Gravenhorst, 1829.

Cryptus scutellatus Provancher, 1886. Addit. Corr. Faune Ent. Canada Hym., p. 69. \&. Preocc. by Smith, 1858 and Provancher, 1877. This is species number 39 in Provancher's treatment of Cryptus; the same number is used by Provancher for $C$. omatus in his key to the species of Cryptus; the fact that the synonymy between the two names pertaining to species number 39 is objective was substantiated by Provancher (1889).

Cryptus gracilis Provancher, 1886. Addit. Corr. Faune Ent. Canada Hym., p. 74. ठ. Preocc. by Gravenhorst, 1829.

Cryptus Zoesmairi Dalla Torre, 1902. Cat. Hym., v. 3, p. 595. N. name for C. scutellatus Provancher and C. omatus Provancher.

Habrocryptus graenicheri Viereck, 1904. Ent. News 15: 333. ९.

Taxonomy: Provancher, 1889. Addit. Corr. Faune Ent. Canada Hym., p. 452.

Biology: Graenicher, 1905. Ent. News 16: 43-49.

\section{Genus PYCNOCRYPTUS Thomson}

Pycnocryptus Thomson, 1873. Opusc. Ent. 5: 500.

Type-species: Cryptus peregrinator Gravenhorst. Monotypic. The type-species is Gravenhorst's misidentification of Ichnenmon peregrinator Linnaeus; the specimens which Gravenhorst identified as peregrinator are now identified as $P$. director (Thunberg). 
Cylindrocryptus Ceballos, 1921. Soc. Espan. de Hist. Nat., Bol. 21: 50.

Type-species: Cylindrocryptus nitidus Ceballos. Monotypic and orig. desig.

This is a small Holarctic genus.

alexanderi Townes. Vt.

Pycnocryptus alexanderi Townes, 1962. In Townes and Townes, U. S. Natl. Mus. Bul. 216 (pt. 3): 128. $\delta$.

director (Thunberg). P. E. I. s. to N. C., w. to Mont. and Colo.; Europe. Adventive.

Ichneumon director Thunberg, 1822. Acad. Imp. des Sci. St. Petersburg, Mem. 8: 270. ठ.

freemani Townes. N. B., Alta., Alaska.

Pycnocryptus freemani Townes, 1962. In Townes and Townes, U. S. Natl. Mus. Bul. 216 (pt. 3): 127. \%.

platyaspis Townes. Northern Que., n. Man., Wyo.

Pycnocryptus platyaspis Townes, 1962. In Townes and Townes, U. S. Natl. Mus. Bul. 216 (pt. 3): 127. + .

\section{Genus HIDRYTA Foerster}

Hidryta Foerster, 1868. Naturh. Ver. Rheinlande, Verh. 25: 187.

Type-species: Brachycryptus erythrocerus Thomson. Desig. by Viereck, 1914 from four species included by Dalla Torre, 1902.

Brachycryptus Thomson, 1873. Opusc. Ent. 5: 487.

Type-species: Brachycryptus erythrocerus Thomson. Desig. by Viereck, 1914.

Euthycryptus Jussel, 1907. Vorarlberger Landes-Mus., Jahresber. 44: 71.

Type-species: Euthycryptus scrobiculifer Jussel. Monotypic.

This is a small Holarctic genus.

frater (Cresson). Newfoundland (Labrador) s. to Va., w. to Oreg. and Calif.; Eurasia. Ecology: Adults occur among the coarse grasses and sedges of wet meadows.

Cryptus frater Cresson, 1864. Ent. Soc. Phila., Proc. 3: 303..+

Cryptus sordidus Tschek, 1870. Zool.-Bot. Gesell. Wien, Verh. 20: 409. ․

Brachycryptus erythrocerus Thomson, 1873. Opusc. Ent. 5: 488..

nigricoxa (Provancher). N. S. s. to w. N. C., w. to Minn.

Cryptus nigricoxus Provancher, 1888. Addit. Corr. Faune Ent. Canada Hym., p. 361. $\delta$.

Brachycryptus niger Cushman, 1926. U. S. Natl. Mus., Proc. 67 (23): 7. ठ.

\section{Genus IDIOLISPA Foerster}

Idiolispa Foerster, 1868. Naturh. Ver. Rheinlande, Verh. 25: 188.

Type-species: Bassus analis Gravenhorst. Desig. by Viereck, 1914 from two species included by Tschek, 1870.

Liocryptus Thomson, 1873. Opusc. Ent. 5: 489.

Type-species: Bassus analis Gravenhorst. Monotypic.

Paracryptus Szepligeti, 1916. Mus. Natl. Hungarici, Ann. 14: 251.

Type-species: Paracryptus hungaricus Szepligeti. Monotypic.

This is a small Holaretic genus.

aestivalis Townes. Que. s. to Ga. w. to Iowa, Kans., and Tex.

Idiolispa aestivalis Townes, 1962. In Townes and Townes, U. S. Natl. Mus. Bul. 216 (pt. 3): 331. $\delta, \%$.

albisoleata (Walsh). Que., Maine, N. H., Va., Ont., Mich., Minn., Iowa, Ariz., n.w. N. W. T., Alaska.

Cryptus! albisoleatus Walsh, 1873. Acad. Sci. St. Louis, Trans. 3: 80. $\delta$.

analis analis (Gravenhorst). Newfoundland (Labrador) s. to Va., w. to Yukon, e. B. C., and Colo.; Eurasia. In their tribal revision, Townes and Townes (1962) divided this 
subspecies into two, with the nominate form occupying nearly the entire range of the other segregate.

Bassus analis Gravenhorst, 1807. Vergl. Uebers. Zool. Systeme, p. 266. Sex not indicated. In their tribal revision, Townes and Townes (1962) point out that the original description of analis does not fit the taxon for which the name has traditionally been used; lacking other evidence to indicate that Gravenhorst's original type material did not include specimens of this taxon, they selected a lectotype which preserves the traditional usage.

Ichneumon cursor Thunberg, 1822; 1824. Acad. Imp. des Sci. St. Petersburg, Mem. 8: 256; 9: 298. ․ Preocc. by Schrank, 1780.

Cryptus elevatus Zetterstedt, 1838. Insecta Lapponica, sect. 2, p. 370. .

Cryptus limatus Cresson, 1864. Ent. Soc. Phila., Proc. 3: 298. ․ N. syn.

Ischnus lentus Provancher, 1875. Nat. Cand. 7: 110. ठ, ?.

analis ignea Townes. Southern Sask. s. to N. Mex., w. to s. B. C. and Calif.

Idiolispa analis ignea Townes, 1962. In Townes and Townes, U. S. Natl. Mus. Bul. 216 (pt. 3): 329. ,, .

\section{Genus TRYCHOSIS Foerster}

Trychosis Foerster, 1868. Naturh. Ver. Rheinlande, Verh. 25: 187.

Type-species: Cryptus titillator Gravenhorst. Included and desig. by Schmiedeknecht, 1890. The type-species is Gravenhorst's misidentification of Ichneumon titillator Linnaeus; the specimens which Gravenhorst identified as titillator are now identified as T. mesocastana (Tschek) (see van Rossem, 1967).

Phaedrophadnus Cameron, 1906. Bombay Nat. Hist. Soc., Jour. 17: 285.

Type-species: Phaedrophadnus striatus Cameron. Monotypic.

Ethaemorpha Viereck, 1913. U. S. Natl. Mus., Proc. 44: 565.

Type-species: Cryptus similis Cresson. Monotypic and orig. desig.

Orthocryptus Viereck, 1913. U. S. Natl. Mus., Proc. 44: 567.

Type-species: Cryptus monticola Ashmead. Monotypic and orig. desig.

There are a few species of this moderately large genus in the Oriental Region and one known from the Neotropic Region, but Trychosis is otherwise Holarctic. Some of the species have been reared from spider egg cocoons, and records of rearings from Lepidoptera may be erroneous.

Revision: van Rossem, 1966. Zool. Verh. 79, 40 pp. (European spp.).

Taxonomy: van Rossem, 1965. Bul. Zool. Nomencl. 22: 259-260 (proposal for use of plenary powers). - Perkins, 1966. Bul. Zool. Nomencl. 23: 8 (comment on lack of need for use of plenary powers). - van Rossem, 1966. Bul. Zool. Nomencl. 23: 8 (rebuttal of Perkins). -Sabrosky, 1967. Bul. Zool. Nomencl. 24: 73-74 (suggested changes for proposal of van Rossem). - International Commission on Zoological Nomenclature, 1974. Bul. Zool.

Nomencl. 31: 22-23 (unnecessary use of plenary powers).

albicaligata (Walsh). Conn. s. to Va., w. to Mich., Kans., and Tex. In their tribal revision, Townes and Townes (1962) suggest that albicaligata may prove to be a junior synonym of $T$. exulans (Cresson).

Cryptus albicaligatus Walsh, 1873. Acad. Sci. St. Louis, Trans. 3: 82 . $\delta$.

anagma Townes. Que. w. to B. C., s. to R. I., Ohio, S. Dak., and Calif.

Trychosis anagmus Townes, 1962. In Townes and Townes, U. S. Natl. Mus. Bul. 216 (pt. 3): $376 . \delta, \%$.

apicalis Townes. R. I. s. to Fla., w. to Minn.

Trychosis apicalis Townes, 1962. In Townes and Townes, U. S. Natl. Mus. Bul. 216 (pt. 3): 347. $\delta, ?$.

atrorubens Townes. Colo., Ariz., Nev., Calif.

Trychosis atrorubens Townes, 1962. In Townes and Townes, U. S. Natl. Mus. Bul. 216 (pt. 3): 369. ', . .

coxalis Townes. R. I. s. to S. C., w. to Mich. and Ala.

Trychos is coxalis Townes, 1962. In Townes and Townes, U. S. Natl. Mus. Bul. 216 (pt. 3): 346. $\delta, ?$. 
eyperia Townes. Newfoundland (Labrador) w. to w. N. W. T., s. to N. Y., Ohio, Colo., and n. Calif. Ecology: Adults occur among sedges in wet meadows.

Trychosis cyperia Townes, 1962. In Townes and Townes, U. S. Natl. Mus. Bul. 216 (pt. 3): 373. $\delta$, ?.

depilis Townes. Wyo., Idaho, Utah, s. B. C., Wash., Oreg., Calif. Townes suggests that depilis may be only "subspecifically distinct" from the sympatric T. reflexa Townes.

Trychosis depilis Townes, 1962. In Townes and Townes, U. S. Natl. Mus. Bul. 216 (pt. 3): 368. ठ, \&.

exulans (Cresson). Mass. s. to N. C., w. to Mich., Kans., and Tex. See text for T. albicaligata.

Cryptus exulans Cresson, 1872. Amer. Ent. Soc., Trans. 4: 157. " $\delta "=?$.

fuscata Townes. Newfoundland (Labrador), Que., Maine.

Trychosis fuscata Townes, 1962. In Townes and Townes, U. S. Natl. Mus. Bul. 216 (pt. 3): 356. $\delta, ?$.

kathrynae Townes. Que. w. to Sask., s. to N. J., W. Va., Mich. and Minn.

Trychosis kathrynae Townes, 1962. In Townes and Townes, U. S. Natl. Mus. Bul. 216 (pt. 3): $363 . \delta$, .

latidens Townes. Que. w. to Yukon, s. to Mass., Mich., Colo., and Oreg.

Trychosis latidens Townes, 1962. In Townes and Towes, U. S. Natl. Mus., Bul. 216 (pt. 3): 355. $\delta$, ?.

montivaga austrina Townes. N. Mex.

Trychosis montivaga anstrina Townes, 1962. In Townes and Townes, U. S. Natl. Mus. Bul. 216 (pt. 3): $341 . \delta$, ?.

montivaga montivaga (Provancher). N. S. w. to Yukon, s. to Va., Ill., Minn., and s. B. C.

Cryptus montivagus Provancher, 1877. Nat. Canad. 9: 12. 9.

Phygadenon fusiform is Provancher, 1886. Addit. Corr. Faune Ent. Canada Hym., p. 51. \&. nigripes Townes. Tex.

Trychosis nigripes Townes, 1962. In Townes and Townes, U. S. Natl. Mus. Bul. 216 (pt. 3): 345. $\delta$, \&.

peratra Townes, n. status. Newfoundland (insular) w. to B. C., s. to Va., Tex., and Calif.

Cryptus albitarsis Cresson, 1864. Ent. Soc. Phila., Proc. 3 (Sept.): 300 . ó. Preocc. in Cryptus by Cresson, 1864 (June). $T$. peratra is not sufficiently well collected to make it worthwhile proposing a new name for $C$. albitarsis in order to treat the eastern and western populations as separate subspecies. N. syn.

Trychosis albitarsis peratra Townes, 1962. In Townes and Townes, U. S. Natl. Mus. Bul. 216 (pt. 3): 359. ठ, ?.

reflexa Townes. S. Dak., Mont., and s. B. C., s. to Utah and Calif. Townes says reflexa "is very close to $T$. atrombens and is likely to prove [to be] a subspecies of it;" see also the text for $T$. depilis, above.

Trychosis reflexa Townes, 1962. In Townes and Townes, U. S. Natl. Mus. Bul. 216 (pt. 3): 371. $\delta$, \&.

sanderi (Dalla Torre). Colo. Known only from the holotype.

Cryptus monticola Ashmead, 1890 (1889). U. S. Natl. Mus., Proc. 12: 410 . . Preoce. by Cameron, 1885.

Cryptus Sanderi Dalla Torre, 1902. Cat. Hym., v. 3, p. 587. N. name for monticola Ashmead.

semirubra Townes. Que. w. to n.w. N. W. T., s. to R. I., Ohio, Minn., N. Mex., and Calif. Ecology: Has been reared from spider egg cocoons collected under rocks. Host: Eggs of drassid spider. The subspecies recognized by Townes and Townes (1962) suffer from being based upon too few specimens and, in two cases, from being based upon different characters in each sex (hind tarsal coloration in males and flagellar coloration in females). If the white banding on the female hind tarsus (contrary to the description of Townes and Townes [1962], in at least one female they placed in their nominate subspecies tarsal segments 2 through 4 are entirely white) does not correlate well with the extent of white coloration on the female flagellum, it does not seem logical to 
suppose that there could be a good correlation between the coloration of the male hind tarsus and the female flagellum.

Phygadenon annulatus Provancher, 1875. Nat. Canad. 7: 179. \&. Preocc. by Cresson, 1864.

Trychosis semiruber. Townes, 1944. Amer. Ent. Soc., Mem. 11: 254. N. name for $P$.

annulatus Provancher.

Trychosis semirubra pulla Townes, 1962. In Townes and Townes, U. S. Natl. Mus. Bul. 216 (pt. 3): 352. ठ, ๆ. N. syn.

Trychosis semimbra arizonica Townes, 1962. In Townes and Townes, U. S. Nat. Mus. Bul. 216 (pt. 3): $354 . \delta$, ๆ. N. syn.

similis (Cresson). N. S. s. to S. C., w. to Minn., Kans., and Tex. The two subspecies recognized by Townes and Townes (1962) were almost completely sympatric:

Cryptus similis Cresson, 1864. Ent. Soc. Phila., Proc. 3: 299. ?.

Trychosis similis badiarmus Townes, 1962. In Townes and Townes, U. S. Natl. Mus. Bul. 216 (pt. 3): $343 . \delta$, ?. N. syn.

subgracilis (Cresson). P. E. I. s. to Fla., w. to Colo. and Tex. Ecology: One specimen was reared from a head of $R$ udbeckia amplex.

Cryptus subgracilis Cresson, 1864. Ent. Soc. Phila., Proc. 3: 303. ‥

Cryptus mufoamulatus Provancher, 1874. Nat. Canad. 6 (6): 177 (key); 6 (7): 202.

sulcata Townes. Mass. s. to N. C., w. to Mich. and Kans.

Trychosis sulcata Townes, 1962. In Townes and Townes, U. S. Natl. Mus. Bul. 216 (pt. 3): 349. $\delta$, . .

\section{SUBTRIBE CRYPTINA}

Townes (1970) says that this is the dominant subtribe in the Holarctic Region. Most of the species appear to be parasites of the pupae or prepupae of Lepidoptera or Symphyta.

Taxonomy: Townes, 1970 (1969). Amer. Ent. Inst., Mem. 12: 158-159 (genera of world).

\section{Genus CAMERA Townes}

Camera Townes, 1962. In Townes and Townes, U. S. Natl. Mus. Bul. 216 (pt. 3): 432.

Type-species: Mesostenus euryaspis Cameron. Orig. desig.

Except for the species which ranges into Texas, this small genus is Neotropic.

euryaspis (Cameron). Tex.; Mexico.

Mesostenus euryaspis Cameron, 1885. Biol. Cent.-Amer., Hym., v. 1, p. 226. \&.

\section{Genus ISCHNUS Gravenhorst}

Ischnus Gravenhorst, 1829. Ichn. Europaea, v. 1, p. 638.

Type-species: Iclineumon porrectorins Fabricius. Desig. by Westwood, 1840. The type-species is regarded as a synonym of $I$. inquisitorius inquisitorius (Mueller).

Habrocryptus Thomson, 1873. Opusc. Ent. 5: 498.

Type-species: Cryptus assertorius Gravenhorst. Desig. by Viereck, 1914. The type-species is Gravenhorst's identification of Ichneumon assertorius Fabricius and is regarded as a synonym of $I$. inquisitorius inquisitorius (Mueller).

Aglaocryptus Cameron, 1903. Manchester Lit. and Phil. Soc., Mem. and Proc. 47 (14): 31.

Type-species: Aglaocryptus curvimaculatus Cameron. Desig. by Viereck, 1914.

Erythrocryptus Cameron, 1905. Invertebrata Pacifica 1: 126.

Type-species: Erythrocryptus mufus Cameron. Monotypic.

This moderately large genus is almost worldwide in distribution. The species are pupal parasites of Lepidoptera.

cinctipes (Walsh). Que. s. to Fla., w. to Minn. and Tex. Host: Ancylis comptana (Froel.), A. divisana Wlk., Paralobesia viteana (Clem.).

Cryptus cinctipes Walsh, 1873. Acad. Sci. St. Louis, Trans. 3: 72. ơ, ?.

Phygadezon fraterculus Provancher, 1886. Addit. Corr. Faune Ent. Canada Hym., p. 55. ₹.

Spilocryptus polychrosidis Cushman, 1917. U. S. Natl. Mus., Proc. 53: 461. ठ, o. 
inquisitorius assimilis (Uchida). Alaska; n.e. Asia. 1. inquisitorius inquisitorius (Mueller) occurs in Europe.

Habrocryptus assimilis Uchida, 1930. Hokkaido Imp. Univ., Faculty Agr., Jour. 25: 313..

inquisitorius atricollaris (Walsh). N. S. s. to w. N. C., w. to Alaska and Calif. Host: Archips argyrospilus (Wlk.), Choristoneura conflictana (Wlk.), C. fumiferana (Clem.), C. rosaceana (Harris), orange tortricid on azalea, Malacosoma disstria $\mathrm{Hbn}$. Townes and Townes (1962) split this subspecies into three which were very arbitrarily separated and had broadly overlapping ranges.

Cryptus atricollaris Walsh, 1873. Acad. Sci. St. Louis, Trans. 3: 72. ठ์, १.

Cryptus varius Provancher, 1874. Nat. Canad. 6 (6): 177 (key); 6 (7): 200 . o.

Ischnus exilis Provancher, 1875. Nat. Canad. 7: 111. o.

Cryptus atriceps Cresson, 1879 (1878). Acad. Nat. Sci. Phila., Proc. 30: 361. ๆ. N. syn.

Spilocryptus neomexicana Viereck, 1903 In Skinner, Amer. Ent. Soc., Trans. 29: 81. ठ.

Erythrocryptus mufus Cameron, 1905. Invertebrata Pacifica 1: 126. ․ N. syn.

Gambrus venablesi Viereck, 1924. Canad. Ent. 56: 65. ․

Ischmus inquisitorius pectoralis Townes, 1962. In Townes and Townes, U. S. Natl. Mus. Bul. 216 (pt. 3): 146. ठ, ‡. N. syn.

laevifrons Townes. Ariz.

Ischnus laevifrons Townes, 1962. In Townes and Townes, U. S. Natl. Mus. Bul. 216 (pt. 3): 156. $\delta$, ․

latus (Provancher). Que., Maine, N. H., Ont., Mich., Sask., Alta.

Cryptus latus Provancher, 1874. Nat. Canad. 6 (6): 178 (key); 6 (7): 204. . The holotype of this species was not located by Barron (1975); the original description seems to show that Townes and Townes (1962) were correct in removing latus from Cubocephalus where it had been placed by virtue of the incorrect synonymy of Provancher (1879).

Phygadeuon 3-annulatus Provancher, 1882. Nat. Canad. 13 (no. 155): 335 (key); 13 (no. 156): 355. \&. Preocc. by P. triannulatus Gravenhorst, 1829 .

Cryptus s-annulatus Provancher, 1886. Addit. Corr. Faune Ent. Canada Hym., p. 74. ơ. Preoce. in Ischnus by Provancher, 1882.

Ischmus fraterculus tricircularis Walkley, 1958. In Krombein, U. S. Dept. Agr., Agr. Monog. 2, Sup. 1, p. 46. N. name for P. 3-annulatus Provancher.

Taxonomy: Provancher, 1879. Nat. Canad. 11: 69 (incorrect syn.). - Townes and Townes,

1962. U. S. Natl. Mus. Bul. 216 (pt. 3): 135-136. - Barron, 1975. Nat. Canad. 102: 494, 575.

laurae Townes. S. C., Fla.

Ischnus laurae Townes, 1962. In Townes and Townes, U. S. Natl. Mus. Bul. 216 (pt. 3): 140. $\delta, ~ ?$.

lautus Townes. Southern B. C., Calif. Host: Grapholitha molesta (Bsk.).

Ischnus lautus Townes, 1962. In Townes and Townes, U. S. Natl. Mus. Bul. 216 (pt. 3): 163. $\delta, ?$.

minor Townes. Northern Que.w. to Alaska, s. to n. Ga., Minn., Ariz., and Calif. Host: Epinotia aceriella (Clem.), Paralobesia viteana (Clem.), Acleris variana (Fern.), Choristoneura fumiferana (Clem.).

Ischnus minor Townes, 1962. In Townes and Townes, U. S. Natl. Mus. Bul. 216 (pt. 3): 159. $\delta$, ?.

pinguis (Provancher), revised status. Que. s. to w. N. C., w. to Minn. Townes and Townes (1962) placed pinguis as a subspecies of latus; the fact that they saw "no real intergrades" between pinguis and latus leaves the status of pinguis in doubt because most of the latus specimens they studied were collected within the northern portion of the range of pinguis.

Phaeogenes pinguis Provancher, 1886. Addit. Corr. Faune Ent. Canada Hym., p. 43. . A lectotype was selected by Barron (1975).

Taxonomy: Townes and Townes, 1962. U. S. Natl. Mus. Bul. 216 (pt. 3): 136-137. -Barron, 1975. Nat. Canad. 102: 531.

politus Townes. Colo. Ecology: Occurs in the Rocky Mountains at timberline.

Ischnus politus Townes, 1962. In Townes and Townes, U. S. Natl. Mus. Bul. 216 (pt. 3): 162. \&. 
rhomboidalis (Walsh). Que. s. to e. Tenn., w. to N. Dak. and Colo. Host: Laspeyresia pomonella (L.).

Cryptus rhomboidalis Walsh, 1873. Acad. Sci. St. Louis, Trans. 3: 72 . q.

Cryptus amblytelarius Provancher, 1886. Addit. Corr. Faune Ent. Canada Hym., p. 70..

sparsus Townes. Que. s. to w. N. C., w. to Minn.

Ischnus sparsus Townes, 1962. In Townes and Townes, U. S. Natl. Mus. Bul. 216 (pt. 3): 141. $\delta, ?$.

velutinus Townes. Ariz. Ecology: Occurs in moist deciduous forests of mountains in central Ariz.

Ischnus velutinus Townes, 1962. In Townes and Townes, U. S. Natl. Mus. Bul. 216 (pt. 3): 155. $\delta$, ?.

\section{Genus GLABRIDORSUM Townes}

Glabridorsum Townes, 1970 (1969). Amer. Ent. Inst., Mem. 12: 174.

Type-species: Gambrus stokesii Cameron. Monotypic and orig. desig.

The eleven species (ten undescribed) known to Townes (1970) occur between Japan and Australia.

stokesii (Cameron). Australia. Introduced in N. J. and Va. in 1932 and in Idaho (date unknown

to me) apparently without becoming established. Host: Grapholitha molesta (Bsk.),

Laspeyresia pomonella (L.). The hosts listed were the target species for introductions in North America.

Gambruss Stokesii Cameron, 1912. Linn. Soc. N. S. Wales, Proc. 37 (1): 180..

Biology: Allen, Holloway, and Haeussler, 1940. U. S. Dept. Agr., Cir. 561: 50-51.

\section{Genus CHROMOCRYPTUS Ashmead}

Chromocryptus Ashmead, 1900. U. S. Natl. Mus., Proc. 23: 41.

Type-species: Chromocryptus albopictus Ashmead. Monotypic and orig. desig.

Mesostenimorpha Viereck, 1913. U. S. Natl. Mus., Proc. 44: 566.

Type-species: Cryptus nebraskensis Ashmead. Monotypic and orig. desig.

Neocryptopteryx Blanchard, 1947. Mus. Hist. Nat. Montevideo, Commun. Zool. 2 (no. 42): 1.

Type-species: Neocryptopteryx orientalis Blanchard. Monotypic and orig. desig.

Nothischnus Porter, 1967. Studia Ent. 10: 396.

Type-species: Nothischnus riverai Porter. Monotypic and orig. desig.

Periplasma Porter, 1967. Studia Ent. 10: 404.

Type-species: Periplasma tanaum Porter. Monotypic and orig. desig.

Townes (1970) said his reasons for regarding Chromocryptus as distinct from Trachysphyrus are not compelling. Because Townes and Townes (1962) had treated Chromocryptus as distinct from Trachysphyrus in their revision of the Nearctic Cryptini, it seems logical to do likewise here, thereby restricting the application of the name Trachysphyms to Neotropic species. Except for four species which occur in the Nearctic region, Chromocryptus is also Neotropic; the South American species are numerous.

Revision: Porter, 1967. Amer. Ent. Inst., Mem. 10: 1-168, in part (Neotropic spp., treated as part of genus Trachysphyrus).

Taxonomy: Townes, 1970. Amer. Ent. Inst., Mem. 12: 179-181.

mesorufus Cushman, revised status. Fla.; Mexico. In the U. S. Natl. Mus. collection there is a female collected in a blacklight trap at Miami, Fla. In their tribal revision, Townes and Townes (1962) treated mesorufus as a subspecies of planosae (Fitch).

Chromocryptus mesorufus Cushman, 1930. U. S. Natl. Mus., Proc. 76 (25): 2. ९.

planosae (Fitch). Mass., Conn., N. Y., Pa., Ohio, Mich., Ind., Ill., Nebr. Host: Epicnaptera americana (Harris), Tolype laricis (Fitch), T. velleda (Stoll), Halisidota tesselaris (J. E.

S.). Apparently, a number of adults may emerge from a single host.

Phygadeuon Planosae Fitch, 1856. N. Y. State Agr. Soc., Trans. 15: 501..

Cryptus nebraskensis Ashmead, 1890 (1889). U. S. Natl. Mus., Proc. 12: 412 . ?.

Chromocryptus albopictus Ashmead, 1900. U. S. Natl. Mus., Proc. 23: 41. ?. 
Agrothereutes (Itamoplex) cressoni Viereck, 1917 (1916). Conn. State Geol. and Nat. Hist. Survey Bul. 22: 332. ․

Taxonomy: Porter, 1974. Fla. Ent. 57: 335.

vandykei Townes, n. status. Calif.

Chromocyrptus planosae vandykei Townes, 1962. In Townes and Townes, U. S. Natl. Mus.

Bul. 216 (pt. 3): 258. ?.

weemsi (Porter), n. comb. Fla.

Trachysphyrus weemsi Porter, 1974. Fla. Ent. 57: 331. đ, ᄋ.

\section{Genus JOPPIDIUM Cresson}

Joppidium Cresson, 1872. Amer. Ent. Soc., Trans. 4: 160.

Type-species: Joppidium mubriceps Cresson. Desig. by Viereck, 1914.

Joppidium Walsh, 1873. Acad. Sci. St. Louis, Trans. 3: 69. Preocc. by Cresson, 1872.

Type-species: Joppidium ruficeps Walsh. Monotypic.

Joppoceras Ashmead, 1900. U. S. Natl. Mus., Proc. 23: 39, 40.

Type-species: "Cryptus" dubiosum Cresson. Monotypic and orig. desig. The

type-species designation is an error for Joppidium dubiosum Cresson.

Opisoxestus Ashmead, 1900. U. S. Natl. Mus., Proc. 23: 40.

Type-species: Opisoxestus ferrugineus Ashmead. Monotypic and orig. desig. The type-species is regarded as a synonym of J.caeruleipenne Cameron.

Isocryptus Brethes, 1927. Ent. Mitt. 16: 308.

Type-species: Isocryptus azureus Brethes. Monotypic. The type-species is regarded as a synonym of J. moerens moerens (Perty).

This Nearctic and Neotropic genus is of moderate size.

apicale Cresson. Pa. s. to Ga., w. to Kans. and Tex.

Joppidium apicale Cresson, 1872. Amer. Ent. Soc., Trans. 4: 160.. .

Joppidium ruficeps Walsh, 1873. Acad. Sci. St. Louis, Trans. 3: 70. ठ, १.

arizonicum Townes. Ariz.

Joppidium arizonicum Townes, 1962. In Townes and Townes, U. S. Natl. Mus. Bul. 216 (pt. 3): 312. $\delta$.

brochum brochum Townes. Okla., Tex.; Mexico.

Joppidium brochum brochum Townes, 1962. In Townes and Townes, U. S. Natl. Mus. Bul. 216 (pt. 3): 309. §, ९.

brochum fattigi Townes. Ky., N. C., Ga.

Joppidium brochum fattigi Townes, 1962. In Townes and Townes, U. S. Natl. Mus. Bul. 216 (pt. 3): 309. ठ์, ?.

densum Townes. Ariz.; Mexico.

Joppidium densum Townes, 1962. In Townes and Townes, U. S. Natl. Mus. Bul. 216 (pt. 3): $312 . \delta^{\circ}$, . .

discolor Townes. Ariz.

Joppidium discolor Townes, 1962. In Townes and Townes, U. S. Natl. Mus. Bul. 216 (pt. 3): 313. $\delta$.

dubiosum Cresson. Va., S. C., Ga., Ala.; Mexico.

Joppidium dubiosum Cresson, 1873. Acad. Nat. Sci. Phila., Proc. 25: 138. o, $?$.

Opisosextus (!) mficeps Szepligeti, 1916. Mus. Natl. Hungarici, Ann. 14: 240. ठ̊. Preoce. in

Joppidium by Walsh, 1873.

fuscipenne (Brulle). Ariz.; Mexico.

Cryptus fuscipennis Brulle, 1846. In Lepeletier, Hist. Nat. Ins. Hym., v. 4, p. 189..

Joppidium donabilis Cresson, 1873. Acad. Nat. Sci. Phila., Proc. 25: 139. o, १.

Joppidium yucatanense Cameron, 1885. Biol. Cent.-Amer., Hym., v. 1, p. 211. ๆ.

rubriceps Cresson. N. J. s. to Ga., w. to Mo. and Tex.

Joppidium rubriceps Cresson, 1872. Amer. Ent. Soc., Trans. 4: 160. ơ, १.

\section{Genus CAENOCRYPTUS Thomson}

Caenocryptus Thomson, 1873. Opuse. Ent. 5: 494. 
Type-species: Cryptus mufientris Gravenhorst. Desig. by Viereck, 1914.

Habrocryptoides Uchida, 1952. Insecta Matsumurana 18: 19.

Type-species: Habrocryptoides shikokuensis Uchida. Orig. desig.

Pseudischmus Walkley, 1954. Wash. Acad. Sci., Jour. 44: 219.

Type-species: Ischnus oregonensis Cushman. Monotypic and orig. desig.

The members of this moderate-sized Holarctic genus apparently parasitize sawflies and cocoon spinning Lepidoptera.

Taxonomy: Townes, 1970 (1969). Amer. Ent. Inst., Mem. 12: 189 (generic syn.).

erasus (Townes). Alta.

Habrocryptoides erasus Townes, 1962. In Townes and Townes, U. S. Natl. Mus. Bul. 216 (pt. 3): 175. ㅇ.

inflexus (Townes). Calif.

Habrocryptoides inflexus Townes, 1962. In Townes and Townes, U. S. Natl. Mus. Bul. 216 (pt. 3): 177..

lumbarius Townes. Calif.

Habrocryptoiles lumbarius Townes, 1962 In Townes and Townes, U. S. Natl. Mus. Bul. 216 (pt. 3): 174. ९.

luctuosus luctuosus (Cresson). Que. w. to s. Yukon, s. to N. Y., S. Dak., Colo., Calif. Host: Trichiosoma triangulum Kirby, Zaraea inflata Nort., sawfly on Tsuga heterophyla. C. luctuosus atrifemur (Townes) occurs in Japan and C. luctuosus holalpinus (Heinrich) occurs in Europe. In the tribal revision of Townes and Townes (1962), the latter was treated as a synonym of Cryptus luctuosus subquadratus Thomson. A bizarre situation developed when van Rossem (1969) treated holalpinus as an alpine subspecies of Cryptus luctuosus distinct from luctuosus subquadratus, followed by Townes (1970) treatment of subquadratus as a species not congeneric with luctuosus holalpinus; Townes (1970) placed subquadratus in Itamoplex (=Cryptus), while placing luctuosus and its subspecies in Caenocryptus. Both van Rossem (1969) and Townes (1970) had studied the lectotype of Cryptus subquadratus.

Cryptus luctuosus Cresson, 1864. Ent. Soc. Phila., Proc. 3: 290. $\$$.

Agrothereutes (Itamoplex) ebenus Viereck, 1917 (1916). Conn. State Geol. and Nat. Hist. Survey Bul. 22: 333 . ?.

Cryptus caligatus Cushman, 1927. U. S. Natl. Mus., Proc. 72 (13): 2. \&.

Taxonomy: van Rossem, 1969. Tijdschr. v. Ent. 112: 364-366. - Townes, 1970. Amer. Ent. Inst., Mem. 12: 190.

nitens (Townes). Calif.

Habrocryptoides nitens Townes, 1962. In Townes and Townes, U. S. Natl. Mus. Bul. 216 (pt. 3): 176.. .

oregonensis (Cushman). S. Dak., Wyo., Idaho, B. C., Wash., Oreg., Calif. Host: Neodiprion tsugae Midd.

Ischnus oregonensis Cushman, 1939. Wash. Acad. Sci., Jour. 29: 392. o, ๆ.

Habrocryptoides oregonensis coxalis Townes, 1962. In Townes and Townes, U. S. Natl. Mus. Bul. 216 (pt. 3): 167. $ๆ$. N. syn. Described from a single female.

pictus Townes). Ariz.

Habrocryptoides pictus Townes, 1962. In Townes and Townes, U. S. Natl. Mus. Bul. 216 (pt. 3): 173. $\delta$.

rufifrons (Walsh). R. I. s. to s. Fla., w. to Mich., Kans., and Tex.

Cryptus rufifrons Walsh, 1873. Acad. Sci. St. Louis, Trans. 3: 75..

virgeus ardalus (Townes). Colo., Ariz. Ecology: Occurs in relatively moist deciduous forests.

Habrocryptoides virgeus ardalus Townes, 1962. In Townes and Townes, U. S. Natl. Mus. Bul. 216 (pt. 3): 172. ర, ?.

virgeus virgeus (Townes). Mass. s. to S. C., w. to Wis. Host: Harrisina americana (G.-M.), Laspeyresia pomonella (L.)?

Habrocryptoides virgeus virgeus Townes, 1962. In Townes and Townes, U. S. Natl. Mus. Bul. 216 (pt. 3): 171 . ठ, ?. 


\section{Genus LANUGO Townes}

Lamugo Townes, 1962. In Townes and Townes, U. S. Natl. Mus. Bul. 216 (pt. 3): 259.

Type-species: Cryptus retentor Brulle. Orig. desig.

This small genus is Nearctic and Neotropic. The type-species has been reared from cocoons of Megalopygidae.

bicincta Townes. Kans.

Lanugo bicincta Townes, 1962. In Townes and Townes, U. S. Natl. Mus. Bul. 216 (pt. 3): 270. . .

brunnipennis Townes. Southern B. C., Wash., Calif.

Lamugo Brunnipennis Townes, 1962. In Townes and Townes, U. S. Natl. Mus. Bul. 216 (pt. 3): $275 . \delta^{\circ}$, ?.

cestus (Say). Southern Indiana, Tenn.

Cryptus cestus Say, 1836. Boston Jour. Nat. Hist. 1: 234. ๆ.

deserti Townes. Utah, Ariz., Calif. Ecology: One specimen was apparently reared as a secondary parasite of a sawfly on Pimus.

Lanugo deserti Townes, 1962. In Townes and Townes, U. S. Natl. Mus. Bul. 216 (pt. 3): 268. $\delta, ?$.

excincta Townes. Northwestern Kans., Colo., N. Mex., Utah, Ariz.

Lanugo excincta Townes, 1962. In Townes and Townes, U. S. Natl. Mus. Bul. 216 (pt. 3): 272. $\delta, ?$.

ferrugata Townes. Tex.

Lanugo ferrugata Townes, 1962. In Townes and Townes, U. S. Natl. Mus. Bul. 216 (pt. 3): 263. $\delta, ?$.

flavipennis Townes. Ariz.

Lanugo flavipennis Townes, 1962. In Townes and Townes, U. S. Natl. Mus. Bul. 216 (pt. 3): 271. $\delta, ?$.

longurius Townes. Ariz.

Lanugo longurius Townes, 1962. In Townes and Townes, U. S. Natl. Mus. Bul. 216 (pt. 3): 269. ․

picta Townes. Tex., Ariz.; Mexico.

Lamugo picta Townes, 1962. In Townes and Townes, U. S. Natl. Mus. Bul. 216 (pt. 3): 266. $\delta, ?$.

polita Townes. Ariz.

Lanugo polita Townes, 1962. In Townes and Townes, U. S. Natl. Mus. Bul. 216 (pt. 3): 271. \&.

retentor (Brulle). Va. s. to Fla., w. to Ind. and Tex. Host: Lagoa pyxidifera (J. E. S.), Megalopyge opercularis (J. E. S.).

Cryptus retentor Brulle, 1846. In Lepeletier, Hist. Nat. Ins. Hym., v. 4, p. 192. $\$$.

Cryptus comalensis Cresson, 1872. Amer. Ent. Soc., Trans. 4: 159..

Cryptus nigripennis Ashmead, 1890 (1889). U. S. Natl. Mus., Proc. 12: 411. \&.

schlingeri Townes. Calif.

Lanugo schlingeri Townes, 1962. In Townes and Townes, U. S. Natl. Mus. Bul. 216 (pt. 3): 262. \&.

sororia (Cresson). Tex., Ariz., Calif.; Mexico.

Cryptus sororius Cresson, 1872. Amer. Ent. Soc., Trans. 4: 159. §.

\section{Genus BUATHRA Cameron}

Buathra Cameron, 1903. Ent. Soc. London, Trans. 51: 233.

Type-species: Buathra rufiventris Cameron. Monotypic.

Bathycrisis Cameron, 1905. Spolia Zeylanica (Ceylon Jour. Sci., Sect. B) 3: 96.

Type-species: Bathycrisis striaticollis Cameron. Monotypic.

This is a Holarctic and Oriental genus of small or moderate size. According to van Rossem (1971) the separation between Buathra and Meringopus is rather difficult and arbitrary; he believed that Buathra could be merged into Meringopus. 
Revision: van Rossem, 1971. Tijdschr, v. Ent. 114: 201-208 (European spp.).

Taxonomy: van Rossem, 1969. Tijdschr. v. Ent. 112: 167, 169 (fig. and key to distinguish from Meringopus). - Townes, 1970 (1969). Amer. Ent. Inst., Mem. 12: 192-193 (referred

additional spp. to genus). - Townes, 1971. Amer. Ent. Inst., Mem. 17: 239 (syn. corrected).

erassifemur (Pratt). Idaho, s. B. C., Wash., Oreg., Calif.

Cryptus crassifemur Pratt, 1945. Amer. Midland Nat. 34: 582. §, ^.

dorsicarinata (Pratt). Alta. s. to Colo. and Ariz., w. to Alaska and Calif.

Cryptus dorsicarinatus Pratt, 1945. Amer. Midland Nat. 34: 612. ठ, ?.

Iaborator (Thunberg). Greenland; Newfoundland (Labrador) w. to Alaska, s. to N. Y., Wis., S. Dak., N. Mex., and Calif.; n. Eurasia. Host: Melanolophia imitata (Wlk.). The description of laborator given by van Rossem (1971) shows that Cryptus altonii Dalla Torre should be suppressed as a synonym rather than being recognized as a subspecies of laborator on the basis of the distinguishing characters used in the tribal revision of Townes and Townes (1962).

Ichneumon laborator Thunberg, 1822; 1824. Acad. Imp. des Sci. St. Petersburg, Mem. 8: 273 (key); 9: 344. [male].

Cryptus fabricii Schiodte, 1857. In Rink, Gronland Geog. og Statis. Beskrevet, v. 2, pt. 3, p. 62 . $\delta$,. . Placed as a synonym by van Rossem (1971).

Cryptus proximus Cresson, 1864. Ent. Soc. Phila., Proc. 3: 290. . Preocc. by Fonscolombe, 1850. N. syn.

Cryptus fulvipes Magretti, 1884. Soc. Ent. Ital., Bol. 16: 99. ठ.

Cryptus Altonii Dalla Torre, 1902. Cat. Hym., v. 3, p. 560. N. name for C. proximus Cresson.

Cryptus! sachalinensis Matsumura, 1911. Tohoku Imp. Univ., Col. Agr., Jour. 4 (1): 95..

Cryptus tarsoleucus var, takagii Uchida, 1930. Hokkaido Imp. Univ., Faculty Agr., Jour. 25: 306. $\delta$.

Trachysphyrus laborator satoi Townes, 1962. In Townes and Townes, U. S. Natl. Mus. Bul. 216 (pt. 3): 209. ․ N. syn. Described from a single specimen from Korea.

Taxonomy: Townes, Momoi, and Townes, 1965. Amer. Ent. Inst., Mem. 5: 180-181 (syn.).

lochmaia (Townes). Ariz. Ecology: Occurs in chaparral areas.

Trachysphyrus lochmaius Townes, 1962. In Townes and Townes, U. S. Natl. Mus. Bul. 216 (pt. 3): 216. $\delta$, $?$.

perplexa (Cresson), revised status. Idaho, w. Nev., s. B. C., Wash., Oreg., Calif. Townes and Townes (1962) treated perplexa as a subspecies of laborator. In one paragraph they stated that "intergrades between [perplexa] ... and altonii [now a syn. of laborator] are moderately common where the ranges of the two are adjacent or overlap." In a subsequent paragraph they stated that perplexa "intergrades with the subspecies alton ii rather freely in western Idaho and near the crest of the Sierra Nevada." The kinds of localities from which they record both taxa lead me to believe that the specimens they regarded as intergrades actually were not.

Cryptus proximus var.? perplexus Cresson, 1879 (1878). Acad. Nat. Sci. Phila., Proc. 30: 359.. .

Taxonomy: Townes and Townes, 1962. U. S. Natl. Mus. Bul. 216 (pt. 3): 213-214.

strigosa (Pratt). Wash., Oreg., Calif.

Cryptus strigosus Pratt, 1945. Amer. Midland Nat. 34: 583. ¿. ^.

\section{Genus CRYPTUS Fabricius}

Cryptus Fabricius, 1804. Systema Piezatorum, p. 70. Preoce. by Jurine, 1801 and Panzer, 1804.

Type-species: Cryptus viduatorius Fabricius. Desig. by Curtis, 1837.

Eucryptus Haldeman, 1842. Acad. Nat. Sci. Phila., Proc. 1: 191. N. name for Cryptus "(Hal.)," presumably Haliday. Haliday (1839) used the name Cryptus for Ichneumonidae in a paper describing insects whose names had been published as nomina nuda by Curtis (1837), who used the abbreviation "Hal." for Haliday and suppressed "Cryptus B. E." as a synonym of the sawfly name Scizocerus and used Cryptus "F[abricius]" for Ichneumonidae. 
Itamoplex Foerster, 1868. Naturh. Ver. Rheinlande, Verh. 25: 188.

Type-species: Cryptus american us Cresson. Desig. by Viereck, 1914 from three species included by Ashmead, 1900.

Plesiocryptus Cameron, 1903. Ztschr. f. System. Hym. Dipt. 3: 299.

Type-species: Plesiocryptus carinifrons Cameron. Monotypic.

This large genus is Holarctic, Oriental, and Ethiopian. The controversy regarding the name Cryptus remains unsettled. Even if Opinion 135 (see Hemming, 1939) were valid, Cryptus Fabricius (1804) would still be preoccupied by Cryptus Panzer (1804) (a subjective synonym of Arge), and Eucryptus Haldeman may be a valid replacement name for Cryptus Fabricius. Hemming's (1945) conclusion that "suspension [of the Rules] would not be essential in the case of Cryptus Panzer [1804]" is incorrect because Panzer's fascicle 88 (1804) of Fauna Insectorum Germanicae is shown to predate Fabricius's Systema Piezatorum by virtue of the fact that the former is cited on page 35 of the latter. Cryptus is used here because I feel that it is virtually certain that the majority of specialists presently studying Ichneumonidae would choose to suppress Cryptus. Jurine (1801), Cryptus. Panzer (1804), and Eucryptus Haldeman (if the latter is valid).

Revision: Pratt, 1945. Amer. Midland Nat. 34: 562-661. - van Rossem, 1969. Tijdschr. v. Ent. 112: 229-375 (western Palearctic spp.).

Taxonomy: Jurine, 1801. In Panzer, Intell. Blatt. Litt.-Ztg. Erlangen 21: 163. -Panzer, 1804.

Fauna Ins. German. fasc. 88, pl. 17. - Curtis, 1837. Guide Arrang. Brit. Ins., ed. 2, columns

81-115. - Haliday, 1839 (1838). Ann. Nat. Hist. 2: 114-116. - Hemming, 1939; 1945.

Internatl. Comn. Zool. Nomencl., Opinions and Declarations Rendered 2: 7-12 (Opinion

135); 2: 256 (Opinion 157).

albitarsis (Cresson). Newfoundland (Labrador) w. to w. N. W. T., s. to S. C., Ala., Tex., and Calif.; Mexico, Costa Rica. Host: Heliothis zeae (Bod.), Macronoctua onusta Grt., Grapholitha molesta (Bsk.), Psorosina hammondi (Riley), Tetralopha robastella Zell. According to van Rossem (1969), albitarsis may be conspecific with the Eurasian $C$. diance Gravenhorst.

Ichneumon vinctus Say, 1829. Contrib. Maclurian Lyceum to Arts and Sci. 1: 70. ठ. Preoce. by Schrank, 1781.

Ischnus albitarsis Cresson, 1864. Ent. Soc. Phila., Proc. 3 (June): 194. o.

Cryptus americamus Cresson, 1864. Ent. Soc. Phila., Proc. 3 (Sept.): 297. 9.

Cryptus nigricalceatus Walsh, 1873. Acad. Sci. St. Louis, Trans. 3: 77. ठ.

Cryptus nigricornis Provancher, 1874. Nat. Canad. 6 (6): 177 (key); 6 (7): 201. đ. Preocc. by Brulle, 1846.

Nematopodius coxatus Provancher, 1875. Nat. Canad. 7: 269. $\delta$.

Hoplismenus impar Provancher, 1879. Nat. Canad. 11: 3 . " $\delta "=?$.

Cryptus bicolor Smith, 1879. Deser. New Spp. Hym. in Coll. Brit. Mus., p. 231. 9. Preoce. by Lucas, 1846. N. syn.

Cryptus monticola Cameron, 1885. Biol. Cent.-Amer., Hym., v. 1, p. 203. + . Preoce. by Wesmael, 1840. N. syn.

Cryptus argentifrons Cameron, 1885. Biol. Cent.-Amer., Hym., v. 1, p. 204. ठ. N. syn. Cryptzs coloradensis Ashmead, 1890 (1889). U. S. Natl. Mus., Proc. 12: 408. ๆ. N. syn. Spilocryptus canarsiae Ashmead, 1898. Ent. Soc. Wash., Proc. 4: 124. ó.

Cryptus Eggeri Dalla Torre, 1902. Cat. Hym., v. 3, p. 569. N. name for bicolor Smith. N. syn.

Cryptus permeri Dalla Torre, 1902. Cat. Hym., v. 3, p. 585. N. name for nigricornis Provancher.

Cryptus consobrinus Viereck, 1906. Amer. Ent. Soc., Trans. 32: 225. ․ N. syn.

Cryptus inomatus Pratt, 1945. Amer. Midland Nat. 34: 612. ․ N. syn.

Taxonomy: van Rossem, 1969. Tijdschr. v. Ent. 112: 333, 336.

arcticus Schiodte. Greenland, n.e. N. W. T., Alaska, B. C., Calif.; Europe?

Cryptus arcticus Schiodte, 1857. In Rink, Gronland Geog. og Statis. Beskrevet, v. 2, pt. 3, p. 57. $\delta$, ?.

Cryptus lutescens: Tschek, 1872. Zool.-Bot. Gesell. Wien, Verh. 22: 234. ๆ. 
Taxonomy: Mason, 1968. Canad. Ent. 100: 17, 18 (fig. and differences from leechi Mason).

- van Rossem, 1969. Tijdschr. v. Ent. 112: 368 (syn.).

aridus Pratt. Colo., B. C., Idaho, Oreg., Calif.

Cryptus aridus Pratt, 1945. Amer. Midland Nat. 34: 618..

crassulus Pratt. Que., Mich.

Cryptus crassulus Pratt, 1945. Amer. Midland Nat. 34: 586..

krombeini (Townes). W. Va.

Trachysphyrus krombeini Townes, 1962. In Townes and Townes, U. S. Natl. Mus. Bul. 216 (pt. 3): 243. ․

latigenalis Pratt. Mont., Colo. Host: Loxostege sticticalis (L.).

Cryptus latigenalis Pratt, 1945. Amer. Midland Nat. 34: 611..

Biology: Ullyett, 1949; 1950. Canad. Ent. 81: 285-299; 82: 1-11 (misidentified as inormatus Pratt).

leechi Mason. Northeastern N. W. T.; n. Greenland.

Cryptus leechi Mason, 1968. Canad. Ent. 100: 17. ठै, ९.

mentigus Townes. Colo., N. Mex., Ariz., Alaska, Yukon, Wash., Oreg., Calif.

Trachysphyms mentigns mentigus Townes, 1962. In Townes and Townes, U. S. Natl. Mus. Bul. 216 (pt. 3): 234. ठ, ᄋ. Described from eight specimens from two localities in Arizona.

Trachysphyrus mentigus rufator Townes, 1962. In Townes and Townes, U. S. Natl. Mus., Bul. 216 (pt. 3): 235 . 9 . Described from one specimen from California. N. syn.

Trachysphyrus mentigus rhodomerns Townes, 1962. In Townes and Townes, U. S. Natl. Mus. Bul. 216 (pt. 3): 235. $\delta$, $?$. Because this form had by far the largest range (including Ariz. and Calif.) of the three forms of mentigus described by Townes it seems unusual that he did not make it the nominate form. N. syn.

minimus Pratt. Sask. s. to N. Mex., w. to Alta., e. Wash., e. Oreg., and Nev.

Cryptus minimus Pratt, 1945. Amer. Midland Nat. 34: 619. 9.

moschator iroquois (Viereck). Que. s. to N. J., w. to Mich. and Ohio. C. moschator moschator (Fabricius) is European.

Agrothereutes (Itamoplex) iroquois Viereck, 1917 (1916). Conn. State Geol, and Nat. Hist. Survey Bul. 22: 333. ?.

mutatus Pratt, revised status. Western Minn., e. S. Dak., Colo., s. Alta., Idaho, s. B. C., Wash., Oreg., Calif. In their tribal revison, Townes and Townes (1962) treated mutatus as one of three sympatric western subspecies of albitarsis (Cresson).

Cryptus curticaudus Pratt, 1945. Amer. Midland Nat. 34: 627..

Cryptus mutatus Pratt, 1945. Amer. Midland Nat. 34: 634. ठ, ?.

ocellaris Pratt, revised status. Western Nev., Oreg., Calif. In the tribal revision of Townes and Townes (1962), ocellaris was treated as a sympatric subspecies of aridus Pratt. Because these authors said that they had not seen any intergrades between the two taxa, ocellaris is here treated as a distinct species instead of being suppressed as a synonym of aridus.

Cryptus ocellaris Pratt, 1945. Amer. Midland Nat. 34: 617..

persimilis Cresson. N. S. w. to s. B. C., s. to S. C., Tex., s. Ariz., and s. Calif.

Cryptus persimilis Cresson, 1864. Ent. Soc. Phila., Proc. 3: 298. ?.

Cryptus picticoxus Walsh, 1873. Acad. Sci. St. Louis, Trans. 3: 82. ठ.

Cryptus citrinimaculatus Viereck, 1905. Kans. Acad. Sci., Trans. 19: 320. ठ。.

Cryptus associatus Pratt, 1945. Amer. Midland Nat. 34: 633. ?.

recurvatus Pratt. Tex., Ariz., Calif.; Mexico.

Cryptus recurvatus Pratt, 1945. Amer. Midland Nat. 34: 616..

rufovinctus Pratt, revised status. Idaho, Utah, Nev., s. B. C., Wash., Oreg., Calif. Host: Synanthedon bibionipennis (Bdv.), S. exitiosa (Say), Etiella zinckenella (Treit.), Autoplusia egena (Gn.), Trichoplusia $n i(\mathrm{Hbn}$.). In the tribal revision of Townes and Townes (1962), mfovinctus was treated as one of three sympatric western subspecies of albitarsis (Cresson).

Cryptus rufovinctus Pratt, 1945. Amer. Midland Nat. 34: 620. ठ, ९. 
rugifrons (Townes). Ariz., Calif.

Trachysphyrus mifrons Townes, 1962. In Townes and Townes, U. S. Natl. Mus. Bul. 216 (pt. 3): 255. o, ?.

ruralis Pratt. Southern Man., s. Sask, n. Colo., s. Alta., Ida., s. B. C.

Cryptus ruralis Pratt, 1945. Amer. Midland Nat. 34: 637..

scapulatus (Townes). Calif.

Trachysphyrus scapulatus Townes, 1962. In Townes and Townes, U. S. Natl. Mus. Bul. 216 (pt. 3): 241. $\delta, ?$.

sodalis rugosiscutum Pratt. Southern Oreg., Calif.

Cryptus rugosiscutum Pratt, 1945. Amer. Midland Nat. 34: 572. \&.

Taxonomy: Townes, 1970 (1969). Amer. Ent. Inst., Mem. 12: 194.

sodalis sodalis Cameron. Tex., Colo., N. Mex., Ariz.; Mexico.

Cryptus sodalis Cameron, 1885. Biol. Cent.-Amer., Hym., v. 1, p. 204. [female].

Cryptus crassisculptus Pratt, 1945. Amer. Midland Nat. 34: 573. 8 , ๆ. N. syn.

Cryptus flagellatus Pratt, 1945. Amer. Midland Nat. 34: 574.. . N. syn.

Trachysphyrus rugosiscutum binarius Townes, 1962. In Townes and Townes, U. S. Natl. Mus. Bul. 216 (pt. 3): 226. ?.

Taxonomy: Townes and Townes, 1966. Amer. Ent. Inst., Mem. 8: 70, 73. -Townes, 1970

(1969). Amer. Ent. Inst., Mem. 12: 194.

\section{Genus XYLOPHRURUS Foerster}

Xylophrurus Foerster, 1868. Naturh. Ver. Rheinlande, Verh. 25: 169.

Type-species: Echthms lancifer Gravenhorst. By subsequent monotypy from inclusion by Schmiedeknecht, 1888. The name of the type-species has been incorrectly suppressed as a synonym of Ichneumon dispar Thunberg; the latter is preocc. by Gmelin, 1790 .

Nyxeophilus Foerster, 1868. Naturh. Ver. Rheinlande, Verh. 25: 187.

Type-species: Cryptus bimaculatus Gravenhorst. Included and desig. by Thomson (1885). In placing species in Nyxeophilus, Thomson (1885) said "Nyxeophilus mihi," and Thomson (1897) said "Nyxeophilus Thomson," which led Perkins (1962) to treat Nyxeophilus Thomson as a proposal of a new genus, and this seems inconsistent with his p. 387 discussion of Thomson's use of the Foerster names. The type-species is regarded as a synonym of $X$. angustus (Dalman).

Macrocryptus Thomson, 1873. Opusc. Ent. 5: 486.

Type-species: Echthrus lancifer Gravenhorst. Monotypic.

Xylophruridea Viereck, 1912. U. S. Natl. Mus., Proc. 42: 646.

Type-species: Xylophruridea agrili Viereck. Monotypic and orig. desig.

Revision: Cushman, 1919. U. S. Natl. Mus., Proc. 55: 536-540 (as Cryptoideus).

Taxonomy: Thomson, 1885. Soc. Ent. France, Ann. (6) 5: 18. - Thomson, 1897. Opusc. Ent. 11: 2363. - Perkins, 1962. Brit. Mus. (Nat. Hist.) Ent., Bul. 11: 387, 439.

agrili (Viereck). Ont., W. Va., Mich., Kans. Host: Agrilus homi Kerr., A. vittaticollis Rand. Both of these hosts are root borers and pupate a short distance above the ground in the stems of their hosts.

Xylophruridea agrili Viereck, 1912. U. S. Natl. Mus., Proc. 42: 646..

Biology: Brooks, 1914. Jour. Agr. Res. 3: 184. - Brooks, 1923. U. S. Dept. Agr., Bur. Ent.,

Monthly Let. 108: 3. - Carlson, 1969. Amer. Ent. Inst., Contrib. 4 (3): 39.

bicolor bicolor (Cushman). Colo., Alta., Idaho, Alaska, B. C. Host: Oberea sp. on Salix, Saperda moesta LeC. The type locality is Fort Collins, Colo. (Holotype collected in May, [1896?] by C. F. Baker).

Cryptoideus bicolor Cushman, 1919. U. S. Natl. Mus., Proc. 55: 537..

bicolor maurus Townes. Que., Ont., Mich., Man. Host: Agrilus hormi Kerr.

Xylophrums bicolor manrus Townes, 1962. In Townes and Townes, U. S. Natl. Mus. Bul. 216 (pt. 3): 483 . $\delta$,.

Biology: Carlson, 1969. Amer. Ent. Inst., Contrib. 4 (3): 39. 
fasciatus fasciatus (Ashmead). Que., N. Y., Pa., Md., Mich., Tex. Host: Agrilus corylicola Fisher, A. homi Kerr.

Brachycentrus fasciatus Ashmead, 1890 (1889). U. S. Natl. Mus., Proc. 12: 413 ..

Cryptoideus rufus Cushman, 1919. U. S. Natl. Mus., Proc. 55: 538..

fasciatus hesperus Townes. Colo., Ariz., Calif. Host: Agrilus angelicus Horn.

Xylophrurus fasciatus hesperus Townes, 1962. In Townes and Townes, U. S. Natl. Mus. Bul. 216 (pt. 3): 481 . б, ?.

nubilipennis abdominalis Townes. Sask., Utah, B. C.

Xylophrurus mubilipennis abdominalis Townes, 1962. In Townes and Townes, U. S. Natl. Mus. Bul. 216 (pt. 3): 484 . ठ, ?.

nubilipennis luctuosus (Provancher). Que., N. H., Conn., N. Y., W. Va., Fla., Ont., Mich. Host: Agrilus cham plaini Frost, Oberea praelonga Casey, Saperda candida F., borer in Populus.

Mesochorus luctuosus Provancher, 1874. Nat. Canad. 6: 299. ․

Cryptoileus anthracinus Cushman, 1924. U. S. Natl. Mus., Proc. 64 (4): 7 . 9.

nubilipennis nubilipennis (Cresson). Colo. Host: Dicerca divaricata (Say).

Cryptus nubilipennis Cresson, 1864. Ent. Soc. Phila., Proc. 3: 291. ๆ.

sitkensis (Ashmead). Alaska, B. C., Wash., Oreg., Calif.

Cryptoideus sitkensis Ashmead, 1902. Wash. Acad. Sci., Proc. 4: 193..

Xylophrurus atroruber Townes, 1944. Amer. Ent. Soc., Mem. 11: 290. $\uparrow$. Validated as a

"new name" for Cryptoideus purpuripennis "Ashmead" (1900) and "Cushman" (1919), misidentifications of Cryptus purpuripennis Cresson (see discussion under Cryptoideus Ashmead).

Taxonomy: Ashmead, 1900. U. S. Natl. Mus., Proc. 23: 42 (validation of name Cryptoideus and misidentification of its type-species). - Cushman, 1919. U. S. Natl. Mus., Proc. 55: 539 (redescription of specimen misidentified as purpuripennis [Cresson] by Ashmead under the assumption that Ashmead's identification had been correct).

\section{Genus REPTATRIX Townes}

Reptatrix Townes, 1962. In Townes and Townes, U. S. Natl. Mus. Bul. 216 (pt. 3): 276.

Type-species: Cryptus crassipes Pratt. Monotypic and orig. desig.

A single species is known.

crassipes (Pratt). Wyo., Idaho, Utah, Wash., Oreg., Calif.

Cryptus crassipes Pratt, 1945. Amer. Midland Nat. 34: 585..

\section{Genus MERINGOPUS Foerster}

Meringopus Foerster, 1868. Naturh. Ver. Rheinlande, Verh. 25: 186.

Type-species: Cryptus recreator Fabricius. By subsequent monotypy from inclusion

by Tschek, 1870 . The type-species is regarded as a synonym of $M$. titillator

(Linnaeus).

Goniocryptus Thomson, 1973. Opusc. Ent. 5: 490.

Type-species: Ichneumon titillator Linnaeus. Desig. by Viereck, 1914.

This Holarctic genus is of moderate size.

Revision: van Rossem, 1969. Tijdschr. v. Ent. 112: 165-199 (European spp. plus some Asian ones).

Taxonomy: Townes, 1970.(1969). Amer. Ent. Inst., Mem. 12: 201-202 (list of Nearctic spp.).

asymmetricus asymmetricus (Pratt). Sask. w. to B. C., s. to Colo., n. Ariz., and n. Calif.

Cryptus asymmetricus Pratt, 1945. Amer. Midland Nat. 34: 587. o, ९.

asymmetricus mirabilis (Pratt). Southern Calif.

Cryptus mirabilis Pratt, 1945. Amer. Midland Nat. 34: 589..

calescens robustus (Cresson). Northern Man. w. to Alaska, s. to n. N. Mex., Utah, and n. Calif. Ecology: Occurs near timberline in grassy areas with scattered conifers. M. c. calescens 
(Gravenhorst) occurs in Europe and part of Asia and M. c. alaicus (Townes) occurs in

Tadzhik S. S. R. and Kirgiz S. S. R., U. S. S. R.

Cryptus robustus Cresson, 1864. Ent. Soc. Phila., Proc. 3: 289. ‥

Cryptus crassicorn is Cresson, 1864. Ent. Soc. Phila., Proc. 3: 292. $\delta$.

dirus (Cresson). Southern B. C. s. to Calif., e. to Idaho., Colo., and Ariz.

Cryptus dirus Cresson, 1879 (1878). Acad. Nat. Sci. Phila., Proc. 30: 359..

fasciatus (Townes). Ariz.

Trachysphyrus fasciatus Townes, 1962. In Townes and Townes, U. S. Natl. Mus. Bul. 216 (pt. 3): 188. ¿, ?.

genatus (Pratt). Southern Sask. and s. Alta., s. to N. Mex., Ariz., Nev. and n. Calif. Host:

Malacosoma californicum fragile (Streteh), $M$. disstria $\mathrm{Hbn}$.

Cryptus genatus Pratt, 1945. Amer. Midland Nat. 34: 570. ơ, ९.

nigerrimus murorum (Tschek). Northern Man., Calif.; n. Europe. M. nigerrimus nigerrimus

(Fonscolombe) is known from southern Europe and central Asia.

Cryptus muromum Tschek, 1872. Zool.-Bot. Gesell. Wien, Verh. 22: 234. o, ๆ.

Cryptus serratus Thomson, 1873. Opusc. Ent. 5: 478. ․

Taxonomy: van Rossem, 1969. Tijdschr. v. Ent. 112: 190, 191-193.

pacificus (Cresson). Southern B. C., Oreg., Calif.

Cryptus pacificus Cresson, 1879 (1878). Acad. Nat. Sei. Phila., Proc. 30: 361. $\delta$.

punicus (Cresson), revised status. Southern B. C., Wash., Oreg., Calif. The discussion in the tribal revision of Townes and Townes (1962) indicates that there was not sufficient evidence to treat punicus as a subspecies or synonym of relativus.

Cryptus punicus Cresson, 1879 (1878). Acad. Nat. Sci. Phila., Proc. 30: 364...

Cryptus californicuss Ashmead, 1890 (1889). U. S. Natl. Mus., Proc. 12: 411..

relativus (Cresson). Southern Alta. s. to N. Mex., w. to s. B. C. and Calif. Host: Sesia tibialis (Harris). This taxon was divided into two sympatric subspecies in the tribal revision of Townes and Townes (1962); intermediate specimens which I have seen among the material they studied contradict their discussion and indicate the need for placing Cryptus nitschei Dalla Torre as a synonym of relativus rather than giving it species status.

Cryptus relatieus Cresson, 1879 (1878). Acad. Nat. Sci. Phila., Proc. 30: 359. ‥

Cryptus pictifrons. Cresson, 1879 (1878). Acad. Nat. Sci. Phila., Proc. 30: 360. ठ์.

Cryptus violaceipenuis Ashmead, 1890 (1889). U. S. Natl. Mus., Proc. 12: 408. ¿, ๆ. Preocc. by Brulle, 1846. N. syn.

Cryptus leucopus Ashmead, 1890 (1889). U. S. Natl. Mus., Proc. 12: 409. ठ. Apparently preocc. in Cryptus by Ichueumon leucopus Gmelin, 1790. I. leucopus Gmelin was placed as a synonym of Cryptus tarsoleucus (Schrank) by Gravenhorst (1829), and Townes (1970) placed tarsoleucus in Itamoplex (=Cryptus). Neither tarsoleucus nor I. leucopus Gmelin was mentioned by van Rossem (1969) in his revision of the European species of Cryptus. N. syn.

Cryptus Nitschei Dalla Torre, 1902. Cat. Hym., v. 3, p. 581. N. name for C. violaceipennis Ashmead. N. syn.

Cryptus eleucopus Walkley, 1958. In Krombein et al., U. S. Dept. Agr., Agr. Monog. 2, sup. 1, p. 46. N. name for C. leucopus Ashmead. N. syn.

Taxonomy: Gravenhorst, 1829. Ichn. Europaea, v. 2, p. 449.-Townes, 1970 (1969). Amer. Ent. Inst., Mem. 12: 192.

serraticaudus (Pratt). Colo., Idaho, Utah., s. B. C., Wash., Oreg., Calif.

Cryptus serraticaudus Pratt, 1945. Amer. Midland Nat. 34: 594. ¿, ‡.

symmetricus bilobatus (Pratt). Northern Calif.

Cryptus bilobatus Pratt, 1945. Amer. Midland Nat. 34: 592. 9.

symmetricus symmetricus (Pratt). Colo., s. Alta., Utah, s. B. C.

Cryptus symmetricus Pratt, 1945. Amer. Midland Nat. 34: 590. ơ, ९.

tejonensis (Cresson). Alta. s. to N. Mex., w. to Alaska and Calif. In the tribal revision of Townes and Townes (1962) two subspecies with broadly overlapping ranges were recognized.

Cryptus tejouensis Cresson, 1879 (1878). Acad. Nat. Sci. Phila., Proc. 30: 360. \&. 
Cryptus rufopedibus Pratt, 1945. Amer. Midland Nat. 34: 597. ९. Name invalid; dative grammatical case.

Cryptus mimicus Pratt, 1945. Amer. Midland Nat. 34: 607. đ, ค. N. syn.

Cryptus temiporalis Pratt, 1945. Amer. Midland Nat. 34: 609. o, ․ N. syn.

Cryptus milosus Pratt, 1945. Amer. Midland Nat. 34: 615. ․ N. syn.

vancouverensis (Harrington). Southwestern B. C., w. Oreg., w. Calif. Host: Malacosoma sp.

Cryptus vancouverensis Harrington, 1894. Canad. Ent. 26: 211. ?.

\section{Genus COMPSOCRYPTUS Ashmead}

Cryptoideus Ashmead, 1900. U. S. Natl. Mus., Proc. 23: 42.

Type-species: Cryptus purpuripennis Cresson. Monotypic and orig. desig. The type-species was misidentified by Ashmead; the specimen Ashmead misidentified as purpuripennis is the holotype of Xylophrurus atromber Townes $(=X$. sitkensis [Ashmead]).

Compsocryptus Ashmead, 1900. U. S. Natl. Mus., Proc. 23: 43.

Type-species: Cryptus calipterus Say. Monotypic and orig. desig.

Callicryptus Ashmead, 1900. U. S. Natl. Mus., Proc. 23: 43.

Type-species: Cryptus fasciatus (!) Brulle. Monotypic and orig. desig. Dalla Torre (1902) regarded the type-species citation as a typographical error for $C$. fusco-fasciatus Brulle, while Viereck (1914) regarded it as a lapsus for $C$. fasciipennis Brulle. It seems that Viereck is probably correct, but both fuscofasciatus and fasciipennis are presently placed in Compsocryptus.

Stictocryptus Cameron, 1908. Amer. Ent. Soc., Trans, 34: 243. Preocc. by Cameron, 1907.

Type-species: Cryptus fasciipennis Brulle. Monotypic and orig. desig. Cameron made the type-species designation as Cryptus "fasciatipennis" Brulle, which is certainly a lapsus for fasciipennis.

Sophocryptus Mallo, 1961. Idia 165: 17. Nomen nudum.

This moderate sized genus is Nearctic and Neotropic.

Taxonomy: Dalla Torre, 1902. Cat. Hym., v. 3, p. 556. - Viereck, 1914. U. S. Natl. Mus., Bul. 83: 25.

apicalis Townes. Northwestern B. C. s. to Calif., e. to Idaho, Colo., and N. Mex.

Compsocryptus apicalis Townes, 1962. In Townes and Townes, U. S. Natl. Mus. Bul. 216 (pt. 3): 291. ठै, ᄋ.

aridus Townes. Wyo., Colo., Idaho, Utah, Ariz., Nev., Calif.

Compsocryptus aridus Townes, 1962. In Townes and Townes, U. S. Nalt. Mus. Bul. 216 (pt. 3): 289. $\delta, ?$.

buccatus (Cresson). Tex.; Mexico.

Cryptus buccatus Cresson, 1872. Amer. Ent. Soc., Trans. 4: 159. ठ, ९.

calipterus (Say). Northwestern Okla., Tex., N. Mex., Ariz., Calif.; Mexico. In their tribal revision, Townes and Townes (1962) treated the majority of specimens from Calif. as subspecifically distinct, but because the differences seem to be more or less clinal the subspecies are not recognized here.

Cryptus calipterus Say, 1836. Boston Jour. Nat. Hist. 1: 234. ₹.

Cryptus fulvus Taschenberg, 1876. Ztschr. f. Gesam. Naturw. 48: 66. §.

Ichneumon munerosus Cameron, 1885. Biol. Cent.-Amer., Hym., v. 1, p. 159. §.

Campsocryptus(!) brevicornis Cameron, 1905. Invertebrata Pacifica 1: 127. \&.

Cryptus (Mansa?) politicalypterus Viereck, 1905. Kans. Acad. Sci., Trans. 19: 293. ठ。.

crotchii (Cresson). Calif.

Cryptus crotchii Cresson, 1879 (1878). Acad. Nat. Sci. Phila., Proc. 30: 362. o, ?.

fasciipennis (Brulle). Southern Fla.; Cuba.

Cryptus fasciipennis Brulle, 1846. In Lepeletier, Hist. Nat. Ins. Hym., v. 4, p. 191. o, ?.

fletcheri (Provancher). Western Idaho, n. Utah, s. B. C., Oreg., n. Calif. C. fletcheri may not be distinct from C. turbatus (Cresson) (see Townes and Townes [1962]).

Cryptus Fletcheri Provancher, 1888. Addit. Corr. Faune Ent. Canada Hym., p. 361..

Taxonomy: Townes and Townes, 1962. U. S. Natl. Mus. Bul. 216 (pt. 3): 298. 
pallens Townes. Idaho, Utah, Oreg., Calif.

Compsocryptus pallens Townes, 1962. In Townes and Townes, U. S. Natl. Mus. Bul. 216 (pt. 3): 293. ठ, , .

purpuripennis (Cresson). Western Idaho, n. Utah, s. B. C., Wash., Oreg., Calif.

Cryptus purpuripennis Cresson, 1879 (1878). Acad. Nat. Sci. Phila., Proc. 30: 364. \&.

resolutus (Cresson). Southern Alta. s. to Colo., w. to Wash. and Calif.

Cryptus resolutus Cresson, 1879 (1878). Acad. Nat. Sci. Phila., Proc. 30: 363. o.

Cryptus Edwardii Cresson, 1879 (1878). Acad. Nat. Sci. Phila., Proc. 30: 363. ๆ.

Compsocryptus resolutus subfasciatus Townes, 1962. In Townes and Townes, U. S. Natl.

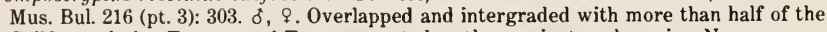

Calif. population Townes and Townes treated as the nominate subspecies. N. syn.

texensis Townes. Kans., Okla., Tex.; Mexico.

Compsocryptus texensis Townes, 1962. In Townes and Townes, U. S. Natl. Mus., Bul. 216 (pt. 3): 283. ठ, ?.

tricinctus Townes. Ga.?, Calif. Townes studied a specimen labeled Dewitt, Ga. and Thought that those data may be erroneous.

Compsocryptus tricinctus Townes, 1962. In Townes and Townes, U. S. Natl. Mus. Bul. 216 (pt. 3): 295. ठ, ?.

turbatus (Cresson). Western Idaho, n. Utah, Oreg., Calif.

Cryptus turbatus Cresson, 1879 (1878). Acad. Nat. Sci. Phila., Proc. 30: 363..

unicolor Townes. Central Calif.

Compsocryptus unicolor Townes, 1962. In Townes and Townes, U. S. Natl. Mus. Bul. 216 (pt. 3): 297. ठे, ९.

\section{SUBTRIBE HEMIGASTRINA}

It is may belief that the Old World genera Hemigaster, Litochila, and Mansa are unrelated to the genera here placed in the Aptesini and are most likely related to some of the eleven genera placed in the subtribe Baryceratina by Townes (1970) (compare Townes and Townes [1962]). Townes (1970) said it is almost certain that the genera he has grouped in the Baryceratina are not all related but are associated for convenience partly on convergent characters resulting from the habit of attacking cocoons of Limacodidae. Only three of the genera of Hemigastrina occur in the New World, and only two of these have North American species.

Taxonomy: Townes and Townes, 1962. U. S. Natl. Mus. Bul. 216 (pt. 3): 12 (list of genera placed in Baryceratina). -Townes, 1970 (1969). Amer. Ent. Inst., Mem. 12: 120-121, 205-215.

\section{Genus BARYCEROS Gravenhorst}

Baryceros Gravenhorst, 1829. Ichn. Europaea, v. 2, p. 777.

Type-species: Baryceros guttatus Gravenhorst. Monotypic.

Christolia Brulle, 1846. In Lepeletier, Hist. Nat. Ins. Hym., v. 4, p. 246.

Type-species: Christolia punctata Brulle. Monotypic.

Crypturopsis Ashmead, 1900. U. S. Natl. Mus., Proc. 23: 45.

Type-species: Crypturus texanus Ashmead. Monotypic and orig. desig.

Neochristolia Blanchard, 1936. Rev. Argentina de Ent. 1: 40.

Type-species: Neochristolia eucleidis Blanchard. Monotypic and orig. desig.

Most of the species of this large genus are Neotropic.

audax (Cresson). Que. s. to Ala., w. to Wis. and Kans. In the tribal revision of Townes and

Townes (1962) part of the specimens from the northern end of the distribution were

distinguished as a separate subspecies.

Mesostemus audax Cresson, 1878. Canad. Ent. 10: 207. $\subsetneq$.

Mesostenus exaptus Cresson, 1878. Canad. Ent. 10: 208..

Mesostemus Saundersi Cresson, 1878. Canad. Ent. 10: 208. ९. N. syn.

Mesostenus armatus Provancher, 1886. Addit. Corr. Faune Ent. Canada Hym., p. 76. ․ N. syn.

Mesostenus saundersii Dalla Torre, 1902. Cat. Hym., v. 3, p. 546. Emend. 
candidus (Cresson). Mass. s. to Fla., w. to Mich. and Kans.

Mesostenus candidus Cresson, 1878. Canad. Ent. 10: 206. ठ.

Crypturus albomaculatus Ashmead, 1890 (1889). U. S. Natl. Mus., Proc. 12: 414. ठ.

Crypturopsis abdominalis Cushman, 1929. U. S. Natl. Mus., Proc. 74 (16): 28. + . Preoce. in Baryceros by Cresson, 1873.

Christolia dumetorum Townes, 1944. Amer. Ent. Soc., Mem. 11: 271. N. name for Crypturopsis abdominalis Cushman.

fortis (Cresson). Pa., Md., W. Va., n. Ga., s. Mich., Ohio, Ky., e. Kans., e. Okla.

Mesostenus fortis Cresson, 1878. Canad. Ent. 10: 206. ․

halli Townes. Ariz.

Baryceros halli Townes, 1962. In Townes and Townes, U. S. Natl. Mus. Bul. 216 (pt. 3): 30. $\delta$.

texanus (Ashmead). Md. s. to Fla., w. to n. Mich. and e. Tex.; n.w. Mexico. Host: Alarodia slossoniae Pack.

Crypturus texanus Ashmead, 1890 (1889). U. S. Natl. Mus., Proc. 12: 413. ठ゙.

Crypturus Dyari Ashmead, 1897. Canad. Ent. 29: 113. ठ, ?.

\section{Genus WHYMPERIA Cameron}

Whymperia Cameron, 1903. Entomologist 36: 122.

Type-species: Whymperia carinifrous Cameron. Monotypic.

Protocryptus Schmiedeknecht, 1904. Opusc. Ichn., v. 2, p. 414.

Type-species: Protocryptus grandis Schmiedeknecht. Desig. by Viereck, 1914.

Zamansa Viereck, 1912. U. S. Natl. Mus., Proc. 42: 647.

Type-species: Cryptus aztecus Cresson. Monotypic and orig. desig.

Eleven species and subspecies are known, ten of them Neotropic.

tricolor Townes. Southern Ariz.

Whym peria tricolor Townes, 1962. In Townes and Townes, U. S. Natl. Mus. Bul 216 (pt. 3): 22.. .

\section{Subtribe MESOSTENINA}

\section{Genus CRYPTANURA Brulle}

Cryptanura Brulle, 1846. In Lepeletier, Hist. Nat. Ins. Hym., v. 4, p. 242.

Type-species: Cryptanura nigripes Brulle. Desig. by Viereck, 1914.

Mesostenus subg. Polyaenus Cresson, 1873. Acad. Nat. Sci. Phila., Proc. 25: 149.

Type-species: [Mesostenus] Polyaenus ectypus Cresson. Desig. by Viereck, 1914.

Polyaenidea Viereck, 1913. U. S. Natl. Mus., Proc. 46: 381.

Type-species: Polyaenidea pretiosa Viereck. Monotypic and orig. desig.

Except for the three species known to occur in North America, this very large genus is Neotropic.

Revision: Cushman, 1945. U. S. Natl. Mus., Proc. 96: 139-176.

banchiformis (Megerle). Mass. s. to Fla., w. to Mich., Kans., and Tex. In their tribal revision, Townes and Townes (1962) say that "the sting of this species is moderately severe and of long duration; one sting received by the senior author [while collecting] was still painful on the night of the third day."

Ichueumon Banchiformis Megerle, 1802. App. ad Cat. Ins., Quae Mense Novembris 1802 Vienne Austriae Auctionis Lege Vendita Fuere, p. 16. [male].

Mesostenus spinarius Brulle, 1846. In Lepeletier, Hist. Nat. Ins. Hym., v. 4, p. 227..

Mesostenus albopictus Cresson, 1864. Ent. Soc. Phila., Proc. 3: 312. đ. Preocc. by Smith, 1858.

Mesostenus Delawareusis Dalla Torre, 1901. Cat. Hym., v. 3, p. 540. N. name for $M$. albopictus Cresson.

compacta (Cresson). Southern Tex.; Mexico, Honduras.

Mesostenus (Mesostenus) compactus Cresson, 1873. Acad. Nat. Sci. Phila., Proc. 25: 153. ․

Cryptanura planiscutellata Cushman, 1945. U. S. Natl. Mus., Proc. 96: 152. . 
septentrionalis Cushman. Southern N. Y. s. to S. C., w. to Mo. and La.

Cryptazura septentrionalis Cushman, 1945. U. S. Natl. Mus., Proc. 96: 156. ?.

\section{Genus MESOSTENUS Gravenhorst}

Mesostenus Gravenhorst, 1829. Ichn. Europaea, v. 2, p. 750.

Type-species: Mesostenus transfuga Gravenhorst. Desig. by Westwood, 1840.

Stenaraeus Thomson, 1896. Opusc. Ent. 21: 2380.

Type-species: Mesostenus transfuga Gravenhorst, Desig. by Viereck, 1914.

Unlima Cameron, 1902. Ann. and Mag. Nat. Hist. (7) 9: 208.

Type-species: Unlima penetralis Cameron. Monotypic.

Derocentrus Cushman, 1919. Ent. Soc. Wash., Proc. 21: 113.

Type-species: Coleocentrus texamus Ashmead. Orig. desig.

This genus is of moderate size and nearly worldwide distribution.

Revision: Cushman, 1929. U. S. Natl. Mus., Proc. 74 (16): 40-50. - Porter, 1973. Acta Zool. Lilloana [Tucuman] 30: 227-267 (South American spp.).

Taxonomy: Porter, 1974. Acta. Zool. Lilloana [Tucuman] 31: 27-46 (additions to 1973 revision).

albinotatus promptus Cresson. N. B. w. to B. C., s. to w. N. C., S. Dak., Colo., and n. Calif. $M$. albinotatus albinotatus Gravenhorst is European.

Mesostenus promptus Cresson, 1878. Canad. Ent. 10: 209. ठ.

americanus Cresson. Que. s. to Va., w. to S. Dak. Barron (1975) resurrected the name brevipennis from synonymy with albinotatus promptus and placed temporalis as a synonym of brevipennis; he failed to note that Townes (1970) had placed temporalis as a synonym of americamus.

Mesostenus tarsatus Provancher, 1875. Nat. Canad. 7: 265. ठ̊. Preoce. by Cresson, 1865. The syntypes were not found by Barron (1975).

Mesostenus americanus Cresson, 1878. Canad. Ent. 10: 209. 9.

Exetastes brevipennis Provancher, 1882. Nat. Canad. 13: 363. Nomen nudum.

Exetastes brevipennis Provancher, 1883. Petite Faune Ent. Canada Hym., p. 386. o, o. N. syn.

Mesostenus temporalis Townes, 1962. In Townes and Townes, U. S. Natl. Mus., Bul. 216 (pt. 3): 441. $\delta$,, .

Taxonomy: Townes, 1970 (1969). Amer. Ent. Inst., Mem. 12: 224 (syn.). - Barron, 1975. Nat.

Canad. 102: 436-437, 572-573.

angustus Townes. R. I. s. to N. C., w. to e. Kans.

Mesostenus leucopus Ashmead, 1890 (1889). U. S. Natl. Mus., Proc. 12: 406. o. Preoce. by Brulle, 1846.

Mesostenus angustus Townes, 1944. Amer. Ent. Soc., Mem. 11: 284. N. name for leucopus Ashmead.

clitellatus Townes. N. S., w. to s. B. C., s. to Va. and n.e. Tex. Host: Saucrobotys futilalis (Led.).

Mesostenus clitellatus Townes, 1962. In Townes and Townes, U. S. Natl. Mus. Bul. 216 (pt. 3): $447 . \delta, ?$.

Morphology: Short, 1959. U. S. Natl. Mus., Proc. 110: 440, fig. 22B (final-instar larva). eisenii Ashmead. Md. s. to Ga., w. to Ohio and Tex.; Mexico.

Mesostenus eisenii Ashmead, 1894. Calif. Acad. Sci., Proc. (2) 4: 129. 9.

gracilis Cresson. N. S. s. to Ga., w. to s. B. C. and Calif.; Bermuda, Mexico. Host: Anagasta kueliniella (Zell.), Cadra figulilella (Greg.), Ephestia elutella (Hbn.), Euzophera semifuneralis (Wlk.), Homoeosoma electellum (Hulst), Laetilia coccidivora (Comst.), Ozamia fuscomaculella clarefacta Dyar, Laspeyresia caryana (Fitch).

Mesostenus gracilis Cresson, 1864. Ent. Soc. Phila., Proc. 3: 315. ठ.

Nematopodius orbitalis Ashmead, 1890. Colo. Biol. Assoc., Bul. 1: 21. ?.

Biology: Bare, 1942. Jour. Econ. Ent. 35: 186-187. 
liogaster Townes. Western N. W. T., Sask., Wyo., Idaho, B. C., Oreg., Calif.; Mexico.

Mesostemus liogaster Townes, 1962. In Townes and Townes, U. S. Natl. Mus. Bul. 216 (pt. 3): $440 . \delta, ?$.

longicaudis Cresson. N. Y., Minn., Nebr., and n. Calif., s. to S. C., Tex., and s. Calif.; Mexico. Host: Loxostege sticticalis (L.).

Mesostenus longicaudis Cresson, 1872. Amer. Ent. Soc., Trans. 4: 164. \&.

Mesostenus macilentus Cresson, 1878. Canad. Ent. 10: 210. o.

Mesostenus gracilipes Cresson, 1879 (1878). Acad. Nat. Sci. Phila., Proc. 30: 365. §.

Coleocentrus texanus Ashmead, 1890 (1889). U. S. Natl. Mus., Proc. 12: 444..

Mesostenus macrurus Dalla Torre, 1901. Cat. Hym., v. 3, p. 544. Unnecessary n. name for $M$. longicaudis Cresson, which is not preoce. by $M$. longicanda Brulle, 1846 .

Nematopodius exclamans Viereck, 1905. Kans. Acad. Sci., Trans. 19: 318. ?.

melanurus Cushman. Alta. Known only from the holotype.

Mesostemus melanurus Cushman, 1929. U. S. Natl. Mus., Proc. 74 (16): 47. ?.

sicarius Townes. N. C., Tex., s. Alta., Mont., Colo., Ariz., Calif.; Mexico. Ecology: Distribution seems to correlate with that of cacti of the genus Opuntia; one specimen emerged from a cocoon found in a cactus stem.

Mesostenus sicarius Townes, 1962. In Townes and Townes, U. S. Natl. Mus. Bul. 216 (pt. 3): 448. $\delta, ~ ?$.

thoracicus Cresson. Que. w. to B. C., s. to Fla., Tex., and s. Calif. Host: Acrobasis betulella Hulst, A. caryivorella Rag., Macrobotys theseusalis (Wlk.), Phlyctaeria extricalis (Gn.).

Mesostenus thoracicus Cresson, 1864. Ent. Soc. Phila., Proc. 3: 314. ठ, ?.

Mesostenus erythrogaster Ashmead, 1890 (1889). U. S. Natl. Mus., Proc. 12: 406 . ठ.

\section{Genus POLYCYRTUS Spinola}

Polycyrtus Spinola, 1840. Soc. Ent. de France, Ann. 9: 154.

Type-species: Polycyrtus histrio Spinola. Desig. by Viereck, 1914.

Cryptanuridimorpha Viereck, 1913. U. S. Natl. Mus., Proc. 46: 369.

Type-species: Cryptanuridimorpha elegans Viereck. Monotypic and orig. desig. $C$. elegans is a synonym of Polycyrtus vierecki Townes, 1966.

Cryptopterygimorpha Viereck, 1913. U. S. Natl. Mus., Proc. 46: 371.

Type-species: Cryptopterygimorpha tubulifera Viereck. Monotypic and orig. desig.

Polycyrtimorpha Viereck, 1913. U. S. Natl. Mus., Proc. 46: 383.

Type-species: Polycyrtimorpha amoenus Viereck. Monotypic and orig. desig.

Polycyrtus is a very large genus of the New World. Only one species is known from the Nearctic Region, but in view of the number of species known from Mexico and Cuba, it seems likely that additional species will be found in the southern U.S.

Revision: Cushman, 1931. U. S. Natl. Mus., Proc. 78 (14): 1-62.

neglectus Cushman. Mass. s. to Fla., w. to Wis. and e. Tex. Ecology: Occurs in moist forests.

Polycyrtus neglectus Cushman, 1926. U. S. Natl. Mus., Proc. 67 (23): 5. ठ․ ๆ.

Taxonomy: Cushman, 1929. U. S. Natl. Mus., Proc. 74 (16): 2, 4, 5, 51.

\section{SUBTRIBE GORYPHINA}

This subtribe includes 33 genera, 29 of which are restricted to the Old World. Only three of the genera occurring in the New World have Nearctic species.

\section{Genus DIAPETIMORPHA Viereck}

Diapetimorpha Viereck, 1913. U. S. Natl. Mus., Proc. 44: 564.

Type-species: Cryptus armatus Ashmead. Monotypic and orig. desig.

This is a large Nearctic and Neotropic genus.

Revision: Cushman, 1929. U. S. Natl. Mus., Proc. 74 (16): 29-37 (Nearctic spp.).

acadia Cushman. Md. s. to Fla., w. to Mo. and Tex.; Mexico.

Diapetimorpha acadia Cushman, 1929. U. S. Natl. Mus., Proc. 74 (16): 35. ठ, ๆ. 
alabama Cushman. Southern N. Y. s. to S. C., w. to e. Kans. and Ala.

Diapetimorpha alabama Cushman, 1929. U. S. Natl. Mus., Proc. 74 (16): 34. ठ, ?.

brunnea Townes. Southern Ga., Fla.

Diapetimorpha brunnea Townes, 1962. In Townes and Townes, U. S. Natl. Mus. Bul. 216 (pt. 3): 382. ठ" ?.

introita (Cresson). N. C. s. to Fla., w. to Tex.; Mexico.

Mesostenus introitus Cresson, 1872. Amer. Ent. Soc., Trans. 4: 162. ठ.

Mesostenus dejectus Cresson, 1872. Amer. Ent. Soc., Trans. 4: 163..+

Cryptus amatus Ashmead, 1890 (1889). U. S. Natl. Mus., Proc. 12: 411. ¿. Preoce. by Lucas, 1846.

Cryptus ashmeadii Dalla Torre, 1902. Cat. Hym., v. 3, p. 562. N. name for C. amuatus Ashmead.

macula confederata Cushman. Northern Va. s. to mid Fla., w. to e. Tex. Host: Pilocrosis tripunctata (F.). D. macula macula (Cameron) is Mexican.

Diapetimorpha confederata Cushman, 1929. U. S. Natl. Mus., Proc. 74 (16): 34..

macula ustulata Townes. Southern Fla. One would expect $m$. ustulata to be found in Cuba, particularly if the taxon really deserves being distinguished from $m$. confederata.

Diapetimorpha macula ustulata Townes, 1962. In Townes and Townes, U. S. Natl. Mus. Bul. 216 (pt. 3): 386. ठ", ९.

picta Townes. Southeastern Ga., s. Fla.

Diapetimorpha picta Townes, 1962. In Townes and Townes, U. S. Natl. Mus. Bul. 216 (pt. 3): 387. ठै, ๆ.

rufigaster Cushman. Md. s. to Fla., w. to s.e. Wis. and Tenn.

Diapetimorpha refigaster Cushman, 1929. U. S. Natl. Mus., Proc. 74 (16): 33. \&.

rugosa Townes. N. J. s. to S. C., w. to s.w. Wis., e. Kans., and Tex.

Diapetimorpha rugosa Townes, 1962. In Townes and Townes, U. S. Natl. Mus. Bul. 216 (pt. 3): 392. ठे, ๆ.

\section{Genus LISTROGNATHUS Tschek}

Townes (1970) recognized five subgenera, two of which have Nearctic species. In their tribal revision, Townes and Townes (1962) erroneously treated the name Listrognathus as being of feminine gender. If one chooses to ignore the provision in the Code (art. 30, [a], [i], [3]) regarding the genders of Greek generic names latinized with a change in termination, it is inconsistent to also ignore the scholarly work of Hopper (1959). Hopper regarded Listrognathus as masculine, which is apparently explained by his statement that "a large proportion of the compounds of Greek nouns are adjectives by Greek grammar and may be either masculine or feminine ..., and in such cases the gender must be considered to be determined by the first species included whose name is of definite gender" (in this case L. comutus Tschek).

Revision: Cushman, 1929. U. S. Natl. Mus., Proc. 74 (16): 15-22.

Taxonomy: Hopper, 1959. Ent. Soc. Wash., Proc. 61 (4): 158, 166 (nomenclature). -Townes, 1970 (1969). Amer. Ent. Soc., Mem. 12: 259-262.

\section{Genus LISTROGNATHUS Subgenus FENESTULA Townes}

Listrognathus subg. Fenestula Townes, 1962. In Townes and Townes, U. S. Natl. Mus. Bul. 216 (pt. 3): 408.

Type-species: Mesostenus paludatus Cresson. Orig. desig.

Townes (1970) said that there are three species, one Nearctic, one Japanese, and one Korean (undescribed).

paludatus californicus Townes. Calif. Host: Lepidopteran on Salix.

Listrognathus (Fenestula) paludata californica Townes, 1962. In Townes and Townes, U. S. Natl. Mus. Bul. 216 (pt. 3): $410 . \delta^{\circ}$,.

paludatus ocularis Townes. Ariz. Described from one specimen from the Chiricahua Mts.

Listrognathus (Fenestula) paludata ocularis Townes, 1962. In Townes and Townes, U. S. Natl. Mus. Bul. 216 (pt. 3): 411 . ?. 
paludatus paludatus (Cresson). Mich., w. Ohio, Ill., Minn., Man., Tex., Wyo., Colo., N. Mex., Yukon, Alaska, B. C., Oreg. Host: Cerura cinerea Wlk.

Mesostenus paludatus Cresson, 1872. Amer. Ent. Soc., Trans. 4: 162. o.

Listrognathus agnatus Cushman, 1929. U. S. Natl. Mus., Proc. 74 (16): 21 ..

\section{Genus LISTROGNATHUS Subgenus LISTROGNATHUS Tschek}

Listrognathus Tschek, 1870. Zool.-Bot. Gesell. Wien, Verh. 20: 153.

Type-species: Listrognathus comutus Tschek. Monotypic. L. comutus is regarded as a synonym of $L$. pubescens (Fonscolombe).

Mesostenoideus Ashmead, 1900. U. S. Natl. Mus., Proc. 23: 45.

Type-species: Mesostemus albomaculatus Cresson. Monotypic and orig. desig.

This is apparently the largest subgenus; it is Neotropic (species unidentified or undescribed), Holarctic, and Oriental. I have seen one undescribed species from southern Calif.

achelomus Townes. Md., Fla.

Listrognathus (Listrognathus) acheloma Townes, 1962. In Townes and Townes, U. S. Natl. Mus. Bul. 216 (pt. 3): 425. ?.

albomaculatus albomaculatus (Cresson). R. I., s. Ont., Mich., and Kans. s. to Fla. and Tex. Host: Gretchena bolliana (Sling.).

Mesostenus albomaculatus Cresson, 1864. Ent. Soc. Phila., Proc. 3: 313. ‥

Mesostenus leucocoxus Ashmead, 1890 (1889). U. S. Natl. Mus., Proc. 12: 407. ठ.

albomaculatus sagax (Provancher). Southern Que., Ont., and Alta. s. to W. Va. and Wis.

Mesostenus sagax Provancher, 1879. Nat. Canad. 11 (no. 126): 112. ?.

bicolor Townes. Ariz. Known only from the holotype, which was collected in Oak Creek Canyon.

Listrognathus (Listrognathus) bicolor Townes, 1962. In Townes and Townes, U. S. Natl. Mus. Bul. 216 (pt. 3): 414 . ?.

femoratus Townes. P. E. I., Que., Ont., Va., W. Va., Mich.

Listrognathus (Listrognathus) femorata Townes, 1962. In Townes and Townes, U. S. Natl. Mus. Bul. 216 (pt. 3): 415 . $\delta$,.

glomeratus Townes. N. J. s. to Fla., w. to Pa., W. Va., and Tex.

Listrognathus (Listrognathus) glomerata Townes, 1962. In Townes and Townes, U. S. Natl. Mus. Bul. 216 (pt. 3): 424. ठ, ๆ.

multimaculatus Cushman. Maine s. to N. J., w. to Minn. and Mo. Host: Tortricid on Gleditsia.

Listrognathus albomaculatus var. multimaculatus Cushman, 1929. U. S. Natl. Mus., Proc. 74 (16): 18. ․

nigrescens Townes. Wyo., N. Mex., Alta., Utah.

Listrognathus (Listrognathus) nigrescens Townes, 1962. In Townes and Townes, U. S. Natl. Mus. Bul. 216 (pt. 3): $416 . \delta, ?$.

nubilipennis (Cresson). N. C., Ga. Ecology: According to Porter (1963) this species occurs in cypress swamps. L. nubilipennis was known to Townes and Townes (1962) only from the female holotype; Porter (1963) discussed two males and two females collected on the North Carolina coastal plain.

Mesostemus nubilipennis Cresson, 1878. Canad. Ent. 10: 205. ?.

Taxonomy: Townes and Townes, 1962. U. S. Natl. Mus. Bul. 216 (pt. 3): 416. -Porter, 1963.

Ent. News 74: 19-21.

rufitibialis Cushman. N. J., Md., S. C., Ind., Okla., Tex.

Listrognathus albomaculatus var. Mfitibialis Cushman, 1929. U. S. Natl. Mus., Proc. 74 (16): $18 . \delta, \%$.

rufus Townes. N. Y., Kans.

Listrognathus (Listrognathus) rufa Townes, 1962. In Townes and Townes, U. S. Natl. Mus. Bul. 216 (pt. 3): 419 . $\delta$.

victoriensis (Harrington). Southern B. C., n. Calif.

Cryptus victoriensis Harrington, 1894. Canad. Ent. 26: 211..

Listrognathus multicolor Cushman, 1929. U. S. Natl. Mus., Proc. 74 (16): 20.. 


\section{Genus HYLOPHASMA Townes}

Hylophasma Townes, 1970 (1969). Amer. Ent. Inst., Mem. 12: 275.

Type-species: Hemisphragia debilis Townes. Monotypic and orig. desig.

According to Townes (1970) this genus is Neotropic, Nearctic, and eastern Palearctic and included seven undescribed species.

debile (Townes). Md., Va., Ohio, Tenn., La., Kans.

Hemisphragia debilis Townes, 1962. In Townes and Townes, U. S. Natl. Mus. Bul. 216 (pt. 3): 378. ठं, ?.

\section{SUBTRIBE LYMEONINA}

\section{Genus MALLOCHIA Viereck}

Mallochia Viereck, 1912. U. S. Natl. Mus., Proc. 43: 591.

Type-species: Mallochia agenioides Viereck. Monotypic and orig. desig.

This New World genus is of moderate size; there are fewer Nearctic species than Neotropic ones (most of which are undescribed).

Revision: Cushman, 1929. U. S. Natl. Mus., Proc. 74 (16): 13-15.

agenioides Viereck. R. I. s. to Fla., w. to Mich., e. Kans., and Ala.; Mexico.

Mallochia agenioides Viereck, 1912. U. S. Natl. Mus., Proc. 43: 591. ๆ.

frontalis Townes. N. J., Md., Va., N. C., e. Kans., Tex.

Mallochia froutalis Townes, 1962. In Townes and Townes, U. S. Natl. Mus. Bul. 216 (pt. 3): $96 . \delta$, . .

laevis Townes. Southeastern Ga., n.e. Fla.

Mallochia laevis Townes, 1962. In Townes and Townes, U. S. Natl. Mus. Bul. 216 (pt. 3): 97. $\delta, ?$.

strigosa (Cresson). Tex., Ariz.? In their tribal revision, Townes and Townes (1962) were uncertain that the female from Ariz. which they identified as strigosa was really conspecific with the male holotype from Texas.

Mesoleptus! strigosus Cresson, 1872. Amer. Ent. Soc., Trans. 4: 167. ठ.

\section{Genus LYMEON Foerster}

Lymeon Foerster, 1868. Naturh. Ver. Rheinlande, Verh. 25: 176.

Type-species: Lymeon anmulicomis Ashmead. By subsequent monotypy from inclusion by Ashmead, 1894.

Neomesostemus Schmiedeknecht, 1904. Opusc. Ichn., v. 2, p. 562.

Type-species: Neomesostenus tuheitensis Brues and Richardson. Desig. by Townes and Townes, 1966 from three species included by Brues and Richardson, 1913.

Christolimorpha Viereck, 1913. U. S. Natl. Mus., Proc. 44: 564.

Type-species: Christolimorpha plesius Viereck. Monotypic and orig. desig. The type-species is regarded as a synonym of $L$. fuscipennis (Brulle).

Zamastrus Viereck, 1913. U. S. Natl. Mus., Proc. 46: 385.

Type-species: Zamastrus photopsis Viereck. Monotypic and orig. desig.

Neogoryphus Roman, 1936. Ent. Tidskr. 57: 3.

Type-species: Ichnenmon ariolator Linnaeus. Monotypic and orig. desig.

Nasutocryptus Pratt, 1945. Amer. Midland Nat. 34: 560.

Type-species: Nasutocryptus nasutus Pratt. Monotypic and orig. desig.

Except for four Nearctic species, this very large genus is Neotropic. The females oviposit into cocoons of various sorts, including the egg cocoons of spiders.

bicinctus (Cresson). Southern Fla.; Cuba.

Hemiteles bicinctus Cresson, 1865. Ent. Soc. Phila., Proc. 4: 24..

Lymeon leiponeuron Townes, 1962. In Townes and Townes, U. S. Natl. Mus. Bul. 216 (pt. 3): 397. סे, . .

Taxonomy: Townes and Townes, 1966. Amer. Ent. Inst., Mem. 8: 89 (syn.). 
cinctiventris (Cushman). Md. s. to Fla., w. to Tex.

Mesostenus laticinctus Cresson, 1878. Canad. Ent. 10: 208. ९. Preocc. by Mesostenus? laticinctus Walker, 1874.

Mesostenus Cressonii Dalla Torre, 1901. Cat. Hym., v. 3, p. 539. N. name for M. laticinctus Cresson; preocc. by Ashmead, 1900.

Diapetimorpha cinctiventris Cushman, 1929. U. S. Natl. Mus., Proc. 74 (16): 32. N. name for M. cressonii Dalla Torre.

nasutus (Pratt). N. Mex.

Nasutocryptus nasutus Pratt, 1945. Amer. Midland Nat. 34: 561. \&.

orbus (Say). Southern N. Y. s. to Fla., w. to s. Wis., Kans., and Tex. Host: Coleophora sp., Homaledra sabalella (Chamb.), Phereoeca walsinghami (Bsk.), Grapholitha molesta (Bsk.), Astala confederata (G. and R.), Lineodes vulnifica Dyar, eggs of Zelotes sp., Hyposoter fugitivus (Say).

Cryptus orbus Say, 1836. Boston Jour. Nat. Hist. 1: 231. [female].

Mesostenus diligens Cresson, 1878. Canad. Ent. 10: 207. \&.

Lymeon annulicorn is Ashmead, 1894. U. S. Dept. Agr., Insect Life 7: 243. 9.

\section{Genus ACERASTES Cushman}

Acerastes Cushman, 1929. U. S. Natl. Mus., Proc. 74 (16): 53.

Type-species: Mesostemus pertinax Cresson. Monotypic and orig. desig.

Except for the widely distributed type-species which ranges into the Nearctic Region, this moderately large genus is Neotropic.

pertinax (Cresson). Md. s. to Fla., w. to Tex.; Mexico, West Indies, Honduras, Panama,

Venezuela, Brazil, Paraguay. Townes and Townes (1962) said that pertinax "appears to overwinter in southern Florida and near Brownsville, Tex., and to work northward each season."

Mesostemus pertinax Cresson, 1872. Amer. Ent. Soc., Trans. 4: 163..

Phytodietus ormatus Provancher, 1888. Addit. Corr. Faune Ent. Canada Hym., p. 431..

Taxonomy: Townes and Townes, 1966. Amer. Ent. Inst., Mem. 8: 98 (syn.),

Biology: Townes and Townes, 1962. U. S. Natl. Mus. Bul. 216 (pt. 3): 405.

\section{Genus POLYCYRTIDEA Viereck}

Polycyrtidea Viereck, 1913. U. S. Natl. Mus., Proc. 46: 382.

Type-species: Polycyrtidea gracilis Viereck. Monotypic and orig. desig.

Except for one species that ranges into the southern tip of Texas and one that occurs in Fla., this small genus is restricted to America south of the U.S.

Taxonomy: Townes, 1970 (1969). Amer. Ent. Inst., Mem. 12: 288.

floridana Porter. Northern Fla. Known only from the holotype.

Polycyrtidea floridana Porter, 1975. Fla. Ent. 58: 250. $\$$.

limitis Cushman. Southern Tex.; Mexico, Costa Rica. In their tribal revision, Townes and Townes (1962) said that limitis may prove to be only subspecifically distinct from $P$. flavopicta (Ashmead) which is known from Grenada and South America.

Polycyrtidea limitis Cushman, 1929. U. S. Natl. Mus., Proc. 74: (16): 52..

Taxonomy: Porter, 1975. Fla. Ent. 58: 248-250.

\section{Genus PACHYSOMOIDES Strand}

Pachysoma Szepligeti, 1916. Mus. Natl. Hungarici, Ann. 14: 290. Preocc. by Macleay, 1821 and five additional authors.

Type-species: Pachysoma albopictum Szepligeti. Monotypic.

Pachysomoides Strand, 1917. Internatl. Ent. Ztschr. 10: 137. N. name for Pachysoma Szepligeti.

Polistiphaga Cushman, 1925. Wash. Acad. Sci., Jour. 15: 391.

Type-species: Mesostenus arvalis Cresson. Monotypic and orig. desig. 
The species of this small New World genus are parasites of Polistes larvae.

Revision: Cushman, 1929. U. S. Natl. Mus., Proc. 74 (16): 55-57.

fulvus (Cresson). N. Y. s. to Fla., w. to s. B. C. and Calif.; Cuba, Mexico. Host: Polistes annularis (L.), P. apachus Sauss., P. carolina (L.), P. cubensis Lep., P. fuscatus fuscatus (F.).

Mesostenus! fulvus Cresson, 1864. Ent. Soc. Phila., Proc. 3: 316. ơ.

Mesostenus arvalis Cresson, 1872. Amer. Ent. Soc., Trans. 4: 163..

[Mesostenus] Mesostenus collaris Cresson, 1873. Acad. Nat. Sci. Phila., Proc. 25: 162. ठ.

Taxonomy: Townes and Townes, 1966. Amer. Ent. Inst., Mem. 8: 96 (syn.).

Biology: Dow, 1932. Psyche 39: 16. —Gaul, 1940. Canad. Ent. 70: 240-242. - Rau, 1941. Ent. Soc. Amer., Ann. 34: 364 .

stupidus (Cresson). N. C. s. to Fla., w. to s. Ill. and Tex.; West Indies and Mexico s. to South America; Hawaii. Host: Polistes annularis (L.), P. canadensis (L.), P. exclamans Vier., P. fuscatus fuscatus (F.).

[Mesostenus] Mesostenus stupidus Cresson, 1873. Acad. Nat. Sci. Phila., Proc. 25: 162. đ. Pach ysoma albopictum Szepligeti, 1916. Mus. Nat. Hungarici, Ann. 14: 290. ․

Polistiphaga zonata Cushman, 1929. U. S. Natl. Mus., Proc. 74 (16): 56. ?.

\section{SUBTRIBE CERATOCRYPTINA}

Of the 18 genera, 16 are confined to the Old World tropics.

Chamula Townes, 1962. In Townes and Townes, U. S. Natl. Mus. Bul. 216 (pt. 3): 430.

Type-species: [Mesostenus] Polycrytus reliquus Cresson. Monotypic and orig. desig.

This genus includes the type-species and an undescribed species from Venezuela.

reliqua (Cresson). Southwestern La.; Mexico. The female is unknown.

[Mesostenus] Polycrytus reliquus Cresson, 1873. Acad. Nat. Sci. Phila., Proc. 25: 146. ठ.

\section{SUBTRIBE OSPRYNCHOTINA}

Most of the nine genera are tropical, and the hosts are larvae of wasps which make nests entirely or partly of mud.

\section{Genus MESSATOPORUS Cushman}

Messatoporus Cushman, 1929. U. S. Natl. Mus., Proc. 74 (16): 8.

Type-species: Mesostenus discoidalis Cresson. Orig. desig.

This is a rather large genus of the New World; most of the species are Neotropic.

Revision: Cushman, 1929. U. S. Natl. Mus., Proc. 74 (16): 8-13.

compressicornis Cushman. Conn. s. to Fla., w. to Ohio and Ala. Host: Ancistrocerus tuberculocephalus sutterianus (Sauss.), Trypargilum collinum mubrocinctum (Pack.). In their tribal revision, Townes and Townes (1962) said that compressicomis may prove to be a subspecies of $M$. arcuatus (Cresson) which is known from Mexico.

Messatoporus compressicomis Cushman, 1929. U. S. Natl. Mus., Proc. 74 (16): 12. o, ?.

Messatoporus major Cushman, 1929. U. S. Natl. Mus., Proc. 74 (16): 13..

discoidalis (Cresson). Que. s. to S. C., w. to Minn. and Tex. Host: Auplopus mellipes mellipes (Say), Phanagenia bombycina (Cr.).

Mesostenus ferrum-equinum Walsh and Riley, 1869. Amer. Ent. 1: 133. Sex not indicated. Preocc. by Brulle, 1846.

Mesostenus discoidalis Cresson, 1872. Amer. Ent. Soc., Trans. 4: 162. ․

Mesostenus jocosus Provancher, 1874. Nat. Canad. 6: 300. ․

rufiventris Cushman. Que. w. to s. B. C., s. to Fla., s. Tex., Ariz., and n. Calif. Host: Auplopus sp., Phanagenia bombycina (Cr.)?, Trypoxylon sp.

Messatoporus rufiventris Cushman, 1929. U. S. Natl. Mus., Proc. 74 (16): 11.. 


\section{Genus ACRORICNUS Ratzeburg}

Acroricnus Ratzeburg, 1852. Ichn. d. Forstinsecten, v. 3, p. 92.

Type-species: Acroricnus schaumii Ratzeburg. Monotypic.

Xenodocon Foerster, 1855. Naturh. Ver. Rheinlande, Verh. 12: 237.

Type-species: Xenodocon mificomis Foerster. Monotypic. The type-species is regarded as a synonym of $A$. seductor (Scopoli).

Macrobatus Holmgren, 1856 (1854). Svenska Vetensk.-Akad. Handl. 75: 50.

Type-species: Cryptus macrobatus Gravenhorst. Monotypic.

Linoceras Taschenberg, 1865. Ztschr. f. die Gesam. Naturw. Halle 25: 105.

Type-species: Cryptus macrobatus Gravenhorst. Desig. by Viereck, 1914.

Leptobatides Buysson, 1896. In Andre, Spec. Hym. Eur. Alg., v. 6, p. 678, pl. 3.

Type-species: Leptobatides abeillei Buysson. Monotypic.

Agathobanchus Ashmead, 1900. U. S. Natl. Mus., Proc. 23: 97.

Type-species: Banchus aequatus Say. Monotypic and orig. desig. The type-species was misidentified by Ashmead, who based his description of Agathobanchus upon specimens of Agathilla bradleyi (Viereck) (see Cushman and Gahan, 1921).

This small genus is widely distributed in the northern hemisphere. The hosts are larvae of Eumenidae and Sphecidae.

Revision: Mitchell, 1950. Ent. Soc. Amer., Ann. 43: 249-261.

Taxonomy: Cushman and Gahan, 1921. Ent. Soc. Wash., Proc. 23: 158-159.

stylator aequatus (Say). N. S. s. to S. C., w. to Man. and Mo. Host: Ancistrocerus

birenimaculatus (Sauss.), A. adiabatus (Sauss.), Eumenes fraternus Say, Sceliph ron

caementariuu (Drury). The gradual south-to-north reduction in the amount of yellow pigmentation led Townes (1944) to divide this subspecies into two. The name aequatus was applied to the northern population, presumably to agree with Say's color description. Mitchell (1950) and Townes and Townes (1962) applied the name aequatus in the same manner. The inconsistencies in Say's color description of aequatus indicate that it would not be accurate enough to show that it applies to a specimen collected north of the type-locality (which was indicated as "Indiana," but which presumably would have been southwestern Indiana). Therefore, those wishing to recognize an arbitrary division of $A$. s. aequatus into two subspecies should apply the name aequatus to the southern population.

Banchus aequatus Say, 1836. Boston Jour. Nat. Hist. 1: 247. [male].

Cryptus junceus Cresson, 1864. Ent. Soc. Phila., Proc. 3: 295. ९. N. syn.

Atractodes Cloutieri Provancher, 1874. Nat. Canad. 6: 150. o, + .

Taxonomy: Cushman and Gahan, 1921. Ent. Soc. Wash., Proc. 23: 158. -Townes, 1944. Amer. Ent. Soc., Mem. 11: 296-297. - Mitchell, 1950. Ent. Soc. Amer., Ann. 43: 258-259. -Townes and Townes, 1962. U. S. Natl. Mus. Bul. 216 (pt. 3): 474.

Biology: Walsh and Riley, 1869. Amer. Ent. 1: 137.

stylator edwardsii (Cresson). Western Oreg., Calif. Host: Sceliphron caementarium (Drury).

Linoceras Edwardsii Cresson, 1879 (1878). Acad. Nat. Sci. Phila., Proc. 30: 365. ठ。.

stylator excelsus (Cresson). Western S. Dak., Colo. The range of this form is almost entirely overlapped by the southern end of the range of $s$. niger, which casts doubt upon the validity of the distinction between them.

Cryptus excelsus Cresson, 1864. Ent. Soc. Phila., Proc. 3: 293. o, ․

Acroricnus stylator axilaris Mitchell, 1950. Ent. Soc. Amer., Ann. 43: 259. ๆ. Synonymy

based upon data in the tribal revision of Townes and Townes (1962). N. syn.

stylator niger Mitchell. Alta. s. to Colo. w. to B. C., e. Wash., e. Oreg., and Utah.

Acroricnus stylator niger Mitchell, 1950. Ent. Soc. Amer., Ann. 43: 253. ठ, ?.

stylator stylator (Thunberg). Western N. W. T., n. B. C.; Eurasia.

Ichneumion stylator Thunberg, 1822; 1824. Acad. Imp. des Sci. St. Petersburg, Mem. 8: 265 (key); 9: 320. [male].

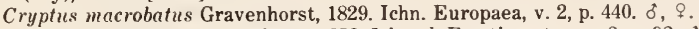

Acroricnus Schaumii Ratzeburg, 1852. Ichn. d. Forstinsecten, v. 3, p. 92 . o.

Xenodocon ruficornis Foerster, 1855. Naturh. Ver. Rheinlande, Verh. 12: 237.. 
Macrobatus clavator Holmgren, 1856 (1854). Svenska Vetensk.-Akad. Handl. 75: 50.

Unnecessary n. name for Cryptus macrobatus Gravenhorst.

stylator townesi Mitchell. N. Mex., Ariz.

Acroricnus stylator tounesi Mitchell, 1950. Ent. Soc. Amer., Ann. 43: 256. ठ, ₹.

\section{SUBTRIBE GABUNIINA}

The members of this subtribe are all thought to be parasitic upon wood-boring Coleoptera and Lepidoptera. Only two of the 23 genera have Nearetic species.

\section{Genus AGONOCRYPTUS Cushman}

Agonocryptus Cushman, 1929. U. S. Natl. Mus., Proc. 74 (16): 6.

Type-species: Mesostenus discoidaloides Viereck. Orig. desig.

This moderately large New World genus is Neotropic except for the one species which occurs in eastern North America.

discoidaloides (Viereck). Southern N. H. s. to Fla., w. to s. Wis., e. Kans., and Tex. Host:

Podosesia syringae (Harris), Eupogonius vestitus (Say), Psyrassa unicolor (Rand).

Mesostenus discoillaloides Viereck, 1905. Kans. Acad. Sci., Trans. 19: 319. ?.

\section{Genus CRYPTOHELCOSTIZUS Cushman}

Cryptohelcostizus Cushman, 1919. U. S. Natl. Mus., Proc. 55: 534.

Type-species: Cryptohelcostizus mufigaster Cushman. Monotypic and orig. desig.

This is a small Nearctic genus.

Revision: Cushman, 1940. U. S. Natl. Mus., Proc. 88: 357-359.

alamedensis (Ashmead). Western Tex., Utah, s. B. C., Oreg., Calif. Host: Agrilus angelicus

Horn, Chrysobothris mali Horn, Myrmex arizonicus (Schaef.).

Cryptus alamedensis Ashmead, 1890 (1889). U. S. Natl. Mus., Proc. 12: 409..

Cryptohelcostizus rufigaster Cushman, 1919. U. S. Natl. Mus., Proc. 55: 534. ठ’, .

caudatus Townes. Calif.

Cryptohelcostizus caudatus Townes, 1962. In Townes and Townes, U. S. Natl. Mus. Bul. 216 (pt. 3): 511..

chrysobothridis Cushman. Okla. Host: Chrysobothris sp. in Malus pumila.

Cryptohelcostizus chrysobothridis Cushman, 1940. U. S. Natl. Mus., Proc. 88: 358..

dichrous Viereck. N. J., Va., N. C., Ga., Mo., Tex.

Cryptohelcostizus dichrous Viereck, 1921. Psyche 28: 73. ठै, १.

fumipennis Townes. Ariz.

Cryptohelcostizus fumipennis Townes, 1962. In Townes and Townes, U. S. Natl. Mus. Bul. 216 (pt. 3): 507. . .

genalis Townes. Calif.

Cryptohelcostizus genalis Townes, 1962. In Townes and Townes, U. S. Natl. Mus. Bul. 216 (pt. 3): 507. + .

leiomerus Townes. Calif.

Cryptohelcostizus leiomerus Townes, 1962. In Townes and Townes, U. S. Natl. Mus. Bul. 216 (pt. 3): 506. .

maculosus Townes. Calif. Ecology: The holotype emerged from Prosopis.

Cryptohelcostizus maculosus Townes, 1962. In Townes and Townes, U. S. Natl. Mus. Bul. 216 (pt. 3): 512. ․

nigricans Townes. Ariz.

Cryptohelcostizus nigricans Townes, 1962. In Townes and Townes, U. S. Natl. Mus. Bul. 216 (pt. 3): 508. $\delta$,.

ornatus Cushman. Southern Ariz., Calif. Host: Chrysobothris deserta Horn. The type locality is Death Valley.

Cryptohelcostizns ornatus Cushman, 1940. U. S. Natl. Mus., Proc. 88: 359. ․ 


\section{SUBTRIBE SPHECOPHAGINA}

This subtribe includes the Holarctic genus Sphecophaga and two other genera which are restricted to the Old World. The hosts are pupae of Vespinae or Polistinae.

\section{Genus SPHECOPHAGA Westwood}

Sphecophaya Westwood, 1840. Introduct. Mod. Classif. Ins., v. 2, Synopsis Genera Brit. Ins., p. 57.

Type-species: Anomalon cesparum Curtis. Monotypic and orig. desig.

Chryonomon Desvignes, 1856. Cat. Brit. Ichn., p. 47.

Type-species: Anomalon lesparum Curtis. Monotypic.

Cacotropa Foerster, 1868. Naturh. Ver. Rheinlande, Verh. 25: 208.

Type-species: Cacotropa sericea Thomson. By subsequent monotypy from inclusion

by Thomson, 1888. The type-species is regarded as a synonym of $S$. vesparum respamem (Curtis).

There is a single species.

vesparum burra (Cresson). N. H. w. to B. C., s. to S. C., Ariz., and Calif. Host: Vespula arenaria (F.), V. maculata (L.), V. maculifrons (Buyss.). S. vespamem vesparum occurs in Europe. Both diapausing and nondiapausing larvae may develop on the same host pupa presumably from eggs deposited by a single v. burra female. Only females develop from nondiapausing larvae, and they usually differ somewhat in coloration from females which develop from diapausing larvae. Nondiapausing larvae spin a delicate, white cocoon, while diapausing larvae spin a tough, brown one.

Euceros burrus Cresson, 1869. Canad. Ent. 1: 104. ․

Sphecophagus[!]? praedator Zabriskie, 1894. N. Y. Ent. Soc., Jour. 2: 84. o, \&.

Biology: Couper, 1870. Canad. Ent. 2: 52-53. -Zabriskie, 1894. N. Y. Ent. Soc., Jour. 2: 81, 86. -Cushman, 1933. Ent. Soc. Wash., Proc. 35: 10-11. - Schmieder, 1939. Ent. News 50:

92-97, 125-131. - Leech, 1954. Pan-Pacific Ent. 30: 80.

\section{UNPLACED TAXA OF CRYPTINI}

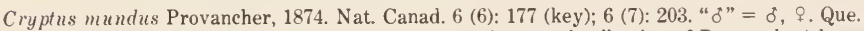
Barron (1975) said that the lectotype (no. 245 in second collection of Provancher) keyed to Cryptus ruralis Pratt, a species not known from Quebec. Townes' (1944) placement of mundus as a synonym of $C$. persimilis Cresson was based upon specimen no. 189 in Provancher's first collection (personal commun., Dr. H. K. Townes, 1975).

Taxonomy: Townes, 1944. Amer. Ent. Soc., Mem. 11: 280. - Barron, 1975. Nat. Canad. 102: 511-512.

\section{SubFamily ACAENITINAE}

Revision: Cushman and Rohwer, 1920. U. S. Natl. Mus., Proc. 57: 503-523. -Townes and

Townes, 1960. U. S. Natl. Mus. Bul. 216 (pt. 2): 544-579.

Taxonomy: Townes, 1971. Amer. Ent. Inst., Mem. 17: 159-179 (genera of world).

\section{TRIBE COLEOCENTRINI}

This Holarctic and Oriental tribe includes six genera, only two of which have North American species.

\section{Genus COLEOCENTRUS Gravenhorst}

Coleocentrus Gravenhorst, 1829. Ichn. Europaea, v. 3, p. 437.

Type-species: Ichneumon excitator Poda. Desig. by Westwood, 1840.

Macrocoleus Desvignes, 1850. Ent. Soc. London, Trans. (n. s.) 1: 13.

Type-species: Macrus longiventris Gravenhorst. Desig. by Viereck, 1914. The

type-species is regarded as a synonym of C. excitator (Poda).

This is a moderately large Holaretic and Oriental genus. 
flavipes (Provancher). N. S. s. to w. N. C. and e. Tenn., w. to n. and w. Ont. Host: Leptura sp.? Acoenites flavipes Provancher, 1874. Nat. Canad. 6: 80. + .

Acoenites Canadensis Provancher, 1880. Nat. Canad. 12: 10. ठ.

Coleocentrus minor Cushman, 1920. In Cushman and Rohwer, U. S. Natl. Mus., Proc. 57: 507. ‥

Coleocentme niger Cushman, 1920. In Cushman and Rohwer, U. S. Natl. Mus., Proc. 57: 508. ㅇ.

harringtoni Cushman. N. B., Que., N. H., Mass., N. Y., Pa., Ont., n.w. Mich., Minn.

Coleocentrus canadensis Harrington, 1892. Canad. Ent. 25: 29. $\$$. Preoce. in Coleocentrus by Provancher, 1880 .

Coleocentrus harringtoni Cushman, 1920. In Cushman and Rohwer, U. S. Natl. Mus., Proc. 57: 509. N. name for $C$. canadensis Harrington.

manni Cushman. Colo., B. C., Wash., Oreg.

Coleocentrus manni Cushman, 1920. In Cushman and Rohwer, U. S. Natl. Mus., Proc. 57: 512. $\delta$, . .

Coleocentrus manni coloradensis Townes, 1960. In Townes and Townes, U. S. Natl. Mus. Bul. 216 (pt. 2): 556. ठ․ N. syn.; described from only two specimens.

occidentalis occidentalis Cresson. Northwestern Mont., n. Idaho, s. B. C., Wash., Oreg.

Coleocentrus occidentalis Cresson, 1879 (1978). Acad. Nat. Sci. Phila., Proc. 30: 376. ㅇ.

occidentalis pulchripennis Cushman. Northeastern Calif.

Coleocentrus pulchripennis Cushman, 1920. In Cushman and Rohwer, U. S. Natl. Mus., Proc. 57: 512. .

pettiti Cresson. N. S. s. to w. N. C., w. to Minn. and Colo.

Coleocentrus Pettiti Cresson, 1868. Canad. Ent. 1: 35. $q$.

Coleocentmis Pettitii(!) Provancher, 1880. Nat. Canad. 12: 8.

Xenoschesis alpinensis Davis, 1894. In Slosson, Ent. News 5: 4. Nomen nudum.

Coleocentrus Pettitii Dalla Torre, 1901. Cat Hym., v. 3, p. 530. Emend.

quebecensis Provancher. N. S., N. B., Que., Maine, Ont., Mich., Minn., s.w. Mont.

Coleocentrus Quebecensis Provancher, 1874. Nat. Canad. 6: 79. 9.

rufocoxatus Pratt. P. E. I., N. B., Que., N. H., Vt., N. Y., Pa., Ont., w. N. W. T.

Coleocentrus rufocoxatus Pratt, 1936. Brooklyn Ent. Soc., Bul. 31: 11. \&.

rufus Provancher. N. S. w. to e. N. Dak., s. to e. N. C., n.w. S. C., n. Ga., and central Iowa.

Coleocentius rufus Provancher, 1876. Nat. Canad. 8: 316..

Coleocentmes similis Cushman, 1920. In Cushman and Rohwer, U. S. Natl. Mus., Proc. 57: 514. $\delta$, ㅇ.

\section{Genus MESOCLISTUS Foerster}

Mesoclistus Foerster, 1868. Naturh. Ver. Rheinlande, Verh. 25: 168.

Type-species: Acaenites mfipes Gravenhorst. By subsequent monotypy from inclusion by Schmiedeknecht, 1888.

Only the European type-species and one North American species are known.

cushmani Townes. Interior Alaska.

Mesoclistus cushmani Townes, 1960. In Townes and Townes, U. S. Natl. Mus. Bul. 216 (pt. 2): $560 . \delta$, ․

\section{TRIBE ACAENITINI}

This tribe includes eighteen genera; only three of these occur in the New World, and none occur in South America.

\section{Genus AROTES Gravenhorst}

Arotes Gravenhorst, 1829. Ichn. Europaea, v. 3, p. 446.

Type-species: Arotes albicinctus Gravenhorst. Monotypic.

Asthenomeris Foerster, 1868. Naturh. Ver. Rheinlande, Verh. 25: 168.

Type-species: Asthenomeris nigricoxis Schmiedeknecht. By subsequent monotypy from inclusion by Schmiedeknect, 1888. 
Sphalerus Kriechbaumer, 1878. Ent. Nachr. 4: 41.

Type-species: Sphalerus bifasciatus Kriechbaumer. Monotypic. The type-species is regarded as a synonym of $A$. albicinctus Gravenhorst.

Retanisia Cameron, 1886. Biol. Cent.-Amer., Hym., v. 1, p. 299.

Type-species: Retanisia facialis Cameron. Monotypic.

This moderate sized genus is Holarctic and Neotropic (mountains of Mexico and Guatemala). The known hosts include Cerambycidae, Melandryidae, Buprestidae, and Mordellidae.

amoenus Cresson. Que. w. to Minn., s. to w. N. C. and n. Ga. Host: Melandrya striata Say.

Acaenitus amoenus Harris, 1835. In Hitcheock, Rpt. Geol. Mineral. Bot. Zool. Mass., ed. 2, p. 586. Nomen nudum.

Arotes amoenus Cresson, 1868. Canad. Ent. 1: 34. \&.

Tropistes elegans Provancher, 1874. Nat. Canad. 6: 80. ठో.

decorus (Say). Mann. s. to Ga., w. to Wis., e. Kans., and e. Tex. Host: Tomoxia bidentata (Say).

Acaenitus decorus Say, 1836. Boston Jour. Nat. Hist. 1: 248. ㅇ (o misdet.).

maurus Rohwer. Northern Minn., w. Sask., central Alta., s.w. B. C. May be only subspecifically distinct from A. amoenus Cresson.

Arotes maurus Rohwer, 1920. In Cushman and Rohwer, U. S. Natl. Mus., Proc. 57: 517. $q$.

melleus (Say). N. Y., N. J., Pa., Md., D. C., w. N. C., s. Mich., s.w. Ind. Host: Metacmaeops vittatus (Swed.).

Acaenitus melleus Say, 1836. Boston Jour. Nat. Hist. 1: 249. ․

\section{Genus SPILOPTERON Townes}

Spilopteron Townes, 1960. In Townes and Townes, U. S. Natl. Mus. Bul. 216 (pt. 2): 568. Type-species: Spilopteron franclemonti Townes. Orig. desig.

This is a small Holarctic and Oriental genus.

formosum (Cresson). Que. w. to s.w. Man., s. to s.e. Ga. Host: Bellamira scalaris (Say).

Arotes formosus Cresson, 1868. Canad. Ent. 1: 34. ठ。.

Spilopteron formosum australe Townes, 1960. In Townes and Townes, U. S. Natl. Mus. Bul. 216 (pt. 2): 573 . ¿, ‥ N. syn.

franclemonti Townes. N. B. w. to s. Man., s. to N. Y., s. Ohio, and Minn.

Spilopteron franclemonti Townes, 1960. In Townes and Townes, U. S. Natl. Mus. Bul. 216 (pt. 2): 569. ठ, ₹.

occiputale (Cresson). Mass. w. to Mich., s. to e. N. C., n.w. S. C., and s. Ind. Host: Strangalia bicolor (Swed.).

Arotes occiputalis Cresson, 1869. Amer. Ent. Soc., Trans. 2: 260. ठ。.

Arotes apicalis Davis, 1898 (1897). Amer. Ent. Soc., Trans. 24: 366..

vicinum (Cresson). N. S. w. to s.w. N. W. T., s. to Va., Tex., Colo., and n.w. Oreg. Host: Anoplodera nigrella (Say), A. rubrica (Say)?, A. vagans (Oliv.)?, Metacmaeops vittatus (Swed.). The two "subspecies" recognized by Townes and Townes (1960) were largely sympatric.

Arotes vicinus Cresson, 1869. Amer. Ent. Soc., Trans. 2: 260. $\delta$.

Arotes venustus Cresson, 1869. Amer. Ent. Soc., Trans. 2: 260. ठ, १.

Arotes superbus Provancher, 1874. Nat. Canad. 6: 81. ठ, ?.

Spilopteron vicinum melanderi Townes, 1960. In Townes and Townes, U. S. Natl. Mus.

Bul. 216 (pt. 2): 575. ઠ, ค. N. syn.

\section{Genus YEZOCERYX Uchida}

Yezoceryx Uchida, 1928. Hokkaido Imp. Univ., Faculty Agr., Jour. 25: 36.

Type-species: Yezoceryx scutellaris Uchida. Monotypic and orig. desig.

This is a large Holarctic and Oriental genus; the majority of the species are Oriental.

rupinsulensis (Cresson). Central Mich., Ill., s.e. Minn.

Acoenitus rupinsulensis Cresson, 1870. Amer. Ent. Soc., Trans. 3: 143. \&. 


\section{SUBFAmILy LYCORININAE}

This is a small subfamily including three cosely related genera, only one of which occurs in the New World.

\section{Genus TOXOPHOROIDES Viereck}

Toxophoroides Cresson, 1874 (1873). Acad. Nat. Sci. Phila., Proc. 25: 406. Manuscript name cited in synonymy (i.e. nomen nudum). Townes (1970) regarded the name Toxophoroides as being validated by Viereck (1911); Townes opinion is (personal communication, 1975) that because Cresson did not adopt this name (Cresson said that it was an MS name which he had intended to use for the species he described on the following page as Lycorina! apicalis) it should be regarded as having been published in synonymy by Cresson. Those who agree with the present Code regarding the publication date and authorship of names which have been accepted as having been validated in synonymy, possibly could regard Toxophoroides as having been validated by Cresson.

Toxophoroides Viereck, 1911. U. S. Natl. Mus., Proc. 40: 195.

Type-species: Lycorina! apicalis Cresson. Monotypic and orig desig.

Chlorolycorina Cushman, 1920. U. S. Natl. Mus., Proc. 58: 9.

Type-species: Glypta scitula Cresson. Orig. desig.

This is a small Neotropic and Nearctic genus.

Revision: Cushman, 1920. U. S. Natl. Mus., Proc. 58: 7-13.

Taxonomy: Townes, 1970 (1969). Amer. Ent. Inst., Mem. 13: 3.

albomarginatus albomarginatus (Cresson). Maine w. to Man., s. to N. C., Ark., Kans., and Colo. Host: Psorosina hammondi (Riley), Anarsia lineatella Zell., Dichomerns bipunctella (Wlshm.), Archips rosaceana (Harris), Acleris minuta (Rob.), Grapholitha molesta (Bsk.).

Glypta albomarginata Cresson, 1870. Amer. Ent. Soc., Trans. 3: 157..

albomarginatus soror (Cushman). N. Mex., Ariz., Calif. Host: Acrobasis nuxvorella Neun.

Chlorolycorina soror Cushman, 1920. U. S. Natl. Mus., Proc. 58: 10..

glaucomatus Cushman. N. J., Pa., Md., N. C., Ohio, Mich.

Toxophoroides glaucomatus Cushman, 1920. U. S. Natl. Mus., Proc. 58: 12..

seitulus (Cresson). N. Y., N. J., Md., D. C., Va., N. C., Fla., Ind., Ky., Tenn. Host: Acrobasis jugland is (LeB.), Nephopteryx uvinella (Rag.), Tetralopha subcanalis (Wlk.), Arogalea cristifasciella (Chamb.), Gelechia albisparsella (Chamb.), Ancylis comptana (Froel.), "tineid" on apple, leaf feeder on Rubus allegheniensis.

Glypta scitula Cresson, 1870. Amer. Ent. Soc., Trans. 3: 155..

xanthozonatus (Ashmead). Southeastern N. C., s. Fla., Mo. Host: Tortricid on oak, Antaeotricha humilis (Zell), leaf roller on Vaccinium australe.

Glypta xanthozonata Ashmead, 1890 (1889). U. S. Natl. Mus., Proc. 12: 449. ठ。.

Taxonomy: Viereck, 1911. U. S. Natl. Mus., Proc. 40: 195 (syn.). _Cushman, 1920. U. S. Natl. Mus., Proc. 58: 11-12. - Walkley, 1967. In Krombein et al., U. S. Dept. Agr., Agr. Monog. 2, sup. 2 , p. 85 (syn.).

\section{SUBFAMILY COLLYRIINAE}

\section{Genus COLLYRIA Schiodte}

Pachymerus Gravenhorst, 1829. Ichn. Europaea, v. 3, p. 721. Preoce. by Thunberg, 1805 and Serville, 1825.

Type-species: Bassus calcitrator Gravenhorst. Desig. by Westwood, 1840.

Collyria Schiodte, 1839. Mag. Zool. (Ser. 2, sect. 3) 9 (insectes, pl. 6-10): 10. N. name for Pachymerus Gravenhorst.

This is a small Palearctic genus. The hosts are Cephidae. The eggs are inserted into the eggs of the host and the Collyria adults emerge from the cocoon of the host. 
coxator (Villers). N. Y., N. J., Pa., Del., Md., n. Va., Ont., Ohio; Eurasia; n. Africa. Introduced. Host: Cephus pygmaens (L.), Janus integer (Nort.). Despite repeated attempts to establish coxator in western Canada in the 1930's on the native Cephus cinctus Nort., it apparently no longer occurs there. Townes, Momoi, and Townes (1965) were apparently the first authors to suppress Collyria calcitrator (Gravenhorst) as a synonym of coxator, but Gravenhorst had placed calcitrator as a definite synonym of coxator in 1829 and uncharacteristically neglected to use the senior name.

Ichneumon coxator Villers, 1789. Caroli Linnaei Ent., v. 3, p. 193. Sex not indicated.

Bassus calcitrator Gravenhorst, 1807. Vergl. Uebers. Zool. Systeme, p. 266. ๆ.

Pachymerns puncticeps Thomson, 1877. Opuse. Ent. 8: 734..

Collyria calcitratrix Schulz, 1906. Spolia Hym., p. 122. Emend.

Taxonomy: Gravenhorst, 1829. Ichn. Europaea, v. 3, p. 727-729. - Kerrich, 1936. Soc. Brit.

Ent., Trans. 3: 63. - Kerrich, 1936. Soc. Brit. Ent., Jour. 1: 124. - Townes, Momoi, and

Townes, 1965. Amer. Ent. Inst., Mem. 5: 397-398.

Biology: Salt, 1931; 1932. Bul. Ent. Res. 22: 506; 23: 211-216. -Salt, 1934. Roy. Soc. London,

Proc. (Ser. B) 114: 457-460. - Salt and Laing, 1935. Nature [London] 135: 792. - Walker,

1937. Parasitology 29: 477-503. - Walker, 1940. Bul. Ent. Res. 3: 551-573. -Smith, 1948.

Ent. Soc. Ont., Ann. Rpt. 78: 39-44. - Smith, 1959. Canad. Ent. 91: 697-700.

\section{SUBFAMILY ORTHOPELMATINAE}

\section{Genus ORTHOPELMA Taschenberg}

Orthopelma Taschenberg, 1865. Ztschr. f. die Gesam. Naturw. [Halle] 25: 137.

Type-species: Hemiteles luteolator Gravenhorst. Desig. by Viereck, 1914.

Proedrus Foerster, 1868. Naturh. Ver. Rheinlande, Verh. 25: 147.

Type-species: Hemiteles luteolator Gravenhorst. By subsequent monotypy from inclusion by Thomson, 1889 .

This is the only genus in the subfamily; it is medium sized and Holarctic. The species are internal larval parasites of Cynipidae which make galls on Rosa, Rubus, and Ribes. Dr. John Barron has completed a revision of Orthopelma which will probably be published prior to the appearance of this catolog.

ealifornicum Ashmead. Northern Calif. Host: Cynipid gallmaker on wild currant. According to Ashmead, the syntypes were "reared in May, 1887, from a Rose gall," but the Koebele notes in the U.S. Natl. Museum say that they were reared from a cynipid which makes galls on wild currant and that the parasites of the cynipids emerged in May, 1888, from galls collected near Alameda Calif. in March, 1888.

Orthopelma californicum Ashmead, 1890 (1889). U. S. Natl. Mus., Proc. 12: 417. o, $q$.

coloradense Ashmead. Colo. Host: Diplolepis tuberculator (Ckll.).

Orthopelma coloradense Ashmead, 1890 (1889). U. S. Natl. Mus., Proc. 12: 418. ․

Orthopelma americanum Riley, 1890. In Riley and Howard, U. S. Dept. Agr., Insect Life 3: 154. Nomen nudum (also on same page as "americana").

diastrophi Ashmead. Conn., Ind.? Host: Diastrophus radicum Bass., Diplolepis radicum (O. S.). Apparently parasitizes cynipids which make galls on the roots of both Rosa and $R$ ubus.

Orthopelma diastrophi Ashmead, 1890 (1889). U. S. Natl. Mus., Proc. 12: 418. ठ, ९. The syntypes from the Riley collection are not likely to be from Mo. as Ashmead thought because the specimens do not appear to have been mounted by Riley and because the numbers they bear do not appear to be Riley numbers. Small circular labels bearing a "W" might indicate that these specimens came from F. M. Webster, who was then in Indiana. I recently learned that Webster's notes are in the U. S. Natl. Archives.

luteolator (Gravenhorst). Que., Mass., R. I., N. Y., Pa., Ont., Ind., Ariz.; Europe. Host: Diastrophus turgidus Bass., Diplolepis ignota (O. S.), D. rosae (L.), D. rosaefolii (Ckll.).

Ichnenmon mediator Thunberg, 1822: 1824. Acad. Imp. des Sci. St. Petersburg, Mem. 8: 269; 9: 332. 9 . Unavailable by virtue of preoccupation in Ichneumon by Pimpla mediator Fabricius, which was unnecessarily renamed Ichneumon modulator by 
Thunberg on key p. 271 (v. 8, 1822) and text p. 340 (v. 9, 1824). Although Thunberg never indicated that any of his names were replacement names until he cited the names being replaced in his 1824 text, it is imperative that we accept the fact that the renamed species (such as $P$. mediator Fabricius) were included in Ichneumon by Thunberg in his $1822 \mathrm{key}$. Otherwise, the numerous replacement names proposed in the key must instead be treated as proposals of new species. The only practical course is to continue to treat Thunberg's $(1822 ; 1824)$ replacement names as such, particularly in view of the fact that most of them have been unavailable because they were unnecessarily proposed. Without having heard the foregoing argument, Dr. H. K. Townes informed me (personal commun., 1975) that he would consider I. mediator Thunberg to be available were it not for the fact that the combination I. mediator (Fabricius) had been published by Jurine in 1807. I am not certain that the latter would have any bearing on the question.

Hemiteles luteolator Gravenhorst, 1829. Ichn. Europaea, v. 2, p. 826. ठ, ๆ.

Orthopelma mimutum Ashmead, 1890 (1889). U. S. Natl. Mus., Proc. 12: 416. ?. The type locality is Jamaica Plain, Mass. (not "Jamaica Plains, New York," as stated by Ashmead). Orthopelma rosaecola Ashmead, 1890 (1889). U. S. Natl. Mus., Proc. 12: 417. §, ๆ. Notes in the U.S. Natl. Museum indicate that the syntypes were reared from a cynipid gall on rose sent to Washington, D. C. by H. K. Morrison, Ft. Grant, Ariz.

Orthopelma thompsoni Brues, 1907. Wis. Nat. Hist. Soc., Bul. 5: 157. ठ, \&.

Taxonomy: Roman, 1912. Zool. Bidr. Uppsala 1: 267, 292.

occidentale Ashmead. Southwestern Wyo. Host: Diplolepis similis (Ash.).

Orthopelma occidentale Ashmead, 1890 (1889). U. S. Natl. Mus., Proc. 12: 417. ठ์.

ovale (Provancher). Que., Alta.

Hemiteles ovalis Provancher, 1874. Nat. Canad. 6: 332. đ, ?.

\section{SUBFAMILY ICHNEUMONINAE}

The Ichneumoninae is the second largest of ichneumonid subfamilies (only the Cryptinae being larger). The species are all internal parasites of Lepidoptera. The females of some species oviposit into larvae and some into fresh pupae, but the progeny always emerge from the pupa. The sexual dimorphism in structure and color is often marked, but the differences between species often are subtle, which not infrequently causes difficulty in identification and association of the sexes.

Historically, the Ichneumoninae have been divided into categories having names that were not derived from those of included genera. The names cyclopneusticae and particularly stenopneusticae are two which persist to some extent in current literature. The cyclopneusticae is composed of the Alomyini and Phaeogenini, while the stenopneusticae includes the remainder of the tribes of Ichneumoninae. The species of cyclopneusticae are parasites of microlepidoptera, while those of stenopneusticae generally parasitize macrolepidoptera. Accordingly, the species of cyclopneusticae are generally smaller than those of stenopneusticae.

Heinrich (1961-1962) published a revision of the stenopneusticae which applies mostly to northeastern North America. Many of the subspecies recognized or described in that work or its supplements (Heinrich, 1969-1976) are not recognized here, often because they merely represent ends and intermediate portions of clines. In some cases synonymy of these subspecific names is based upon specimens in the U. S. National Museum collection. In a few cases, subspecies are placed in synonymy because they are based upon too few specimens to demonstrate that they deserve recognition (particularly when there is no zoogeographical reason for expecting subspeciation).

Revision: Heinrich, 1961-1962 (Phaeogenini excluded). Canad. Ent. Sup. 15: 1-87 (1961 [1960]); 18: 89-205 (1961 [1960]); 21: 207-368 (1961); 23: 369-505 (1961); 26: 507-671 (1962);

27: 675-802 (1962); 29: 803-886 (1962). -Peck, 1964. Ent. Soc. Canada, Mem. 35: 887-925 (addenda, corrigenda, host-parasite list, and indices for Heinrich, 1961-1962). - Heinrich, 1969-1976. Nat. Canad. 96: 935-963 (1969); 98: 959-1026 (1971); 99: 173-211 (1972); 100: 461-465 (1973); 102: 753-782 (1976) (supplements to Heinrich, 1961-1962).

Taxonomy: Dasch, 1971. Ohio Jour. Sci. 71: 279-283 (key to stenopneusticae found overwintering as adult females, particularly in Ohio). 
Biology: Dasch, 1971. Ohio Jour. Sci. 71: 270-279 (overwintering sites preferred by stenopneusticae found overwintering as adult females, particularly in Ohio).

\section{TRIBE PHAEOGENINI}

The members of this tribe are parasites of microlepidoptera. Townes and Townes (1973) persisted in suppressing the name Phaeogenini as a synonym of Alomyini. Because this seems inconsistent with their recognition of a tribe Heterischnini, the Phaeogenini are here regarded as tribally distinct from the Alomyini.

Taxonomy: Perkins, 1959. Handb. Ident. Brit. Ins., v. 7, pt. 2 (ai), p. 68-111. - Townes and Townes, 1973. Amer. Ent. Inst., Mem. 19: 219-221 (Ethiopian cat.).

\section{SUBTRIBE HETERISCHNINA}

\section{Genus HETERISCHNUS Wesmael}

Heterischnus Wesmael, 1859. [Brussels] Acad. Roy. de Belg., Mem. 8: 83.

Type-species: Ichneumon pulex Mueller. Monotypic.

Rhexidermus Foerster, 1868. Naturh. Ver. Rheinlande, Verh. 25: 192.

Type-species: Rhexidermus japonicus Ashmead. By subsequent monotypy from inclusion by Ashmead, 1906.

Posocentrus Provancher, 1875. Nat. Canad. 7: 272.

Type-species: Posocentrus huardi Provancher. Monotypic.

Ischnopsidea Viereck, 1914. U. S. Natl. Mus. Bul. 83: 77.

Type-species: Ichneumon thoracicus Gravenhorst. Monotypic and orig. desig.

Aethiopischmus Heinrich, 1936. Paris, Mus. d'Hist. Nat., Mem. (n. s.) 4: 244. Name invalid as of 1936 because neither of the two species names validated was designated as type-species.

Aethiopischnus Heinrich, 1938. Acad. Malgache, Mem. 25: 127.

Type-species: Aethiopischnus olsoufieffi Heinrich. Monotypic and orig. desig.

Species of this genus are known from the Holarctic and Ethiopian Regions.

coloradensis (Cushman), n. comb. Colo. According to notes pertaining to the C. F. Baker collection, the holotype was collected by C. F. Baker on July 21, 1896 at an elevation of $10,000 \mathrm{ft}$. in Rabbit Ear's Pass, Colo.

Ischnopsidea coloradensis Cushman, 1920. U. S. Natl. Mus., Proc. 58: 253. \&.

huardi (Provancher). Que. s. to N. Y., w. to Alaska and Oreg.

Posocentrus Huardi Provancher, 1875. Nat. Canad. 7: 273..

Posocentrus Huarti(!) Provancher, 1879. Nat. Canad. 11: 251.

Phaeogenes recticaudus Provancher, 1886. Addit. Corr. Faune Ent. Canada Hym., p. 42.. Ischnopsidea alberta Cushman, 1927. U. S. Natl. Mus., Proc. 72 (13): 1. ․

\section{SubTRIBE PHAEOGENINA}

Taxonomy: Townes, Momoi, and Townes, 1965. Amer. Ent. Inst., Mem. 5: 415-423, 592-593

(cat. of E. Palearctic spp. and key to genera).

\section{Genus STENODONTUS Berthoumieu}

Gnathoxys Wesmael, 1845 (1844). [Brussels] Acad. Roy. de Belg., Nouveaux Mem. 18: 168. Preocc. by Westwood, 1842.

Type-species: Ichneumon marginellus Gravenhorst. Monotypic. The type-species was identified with a query by Berthomieu.

Stenodontus Berthoumieu, 1896. Soc. Ent. de France, Ann. 65: 346. N. name for Gnathoxys Wesmael.

This is a small Holarctic genus with two undescribed species occurring in North America. The known ranges of these species are: (1) Newfoundland (insular) s. to N. C., w. to Mich. and (2) Idaho and Wash. 


\section{Genus DICAELOTUS Wesmael}

Dicaelotus Wesmael, 1845 (1844). [Brussels] Acad. Roy. de Belg., Nouveax Mem. 18: 175. Type-species: Ichueumon pumilis Gravenhorst. Desig. by Ashmead, 1900.

Leptodemas Foerster, 1868. Naturh. Ver. Rheinlande, Verh. 25: 182.

Type-species: Leptodemas cariniscutis Cameron. By subsequent monotypy from inclusion by Cameron, 1906.

Deloglyptus Foerster, 1868. Naturh. Ver. Rheinlande, Verh. 25: 193.

Type-species: Deloglyptus punctiventris Thomson. By subsequent monotypy from inclusion by Thomson, 1891.

Cinxaelotus Holmgren, 1890 (1889). Ichn. Suecica, v. 3, p. 367.

Type-species: Cinxaelotus erythrogaster Holmgren. Monotypic.

Euryptilus Holmgren, 1890 (1889). Ichn. Suecica, v. 3, p. 375.

Type-species: Euryptilus kriechbaumeri Holmgren. Monotypic.

This is apparently a moderate sized genus of the Holarctic and Ethiopian Regions. Perkins (1959) placed Deloglyptus as a synonym of Dicaelotus because he thought the differences between them were rather weak. He said that if a division is made between them, other groups of species should also be split off as genera distinct from Dicaelotus. I assume, therefore, that Perkins's (1969) treatment of Deloglyptus as distinct from Dicaelotus was for the purpose of making the first revisor decision to suppress Leptodemas as a synonym of Deloglyptus. Consequently, I have not followed Townes and Townes (1973), who treated Deloglyptus as a distinct genus.

Taxonomy: Perkins, 1959. Handb. Ident. Brit. Ins., v. 7, pt. 2 (ai), p. 83. - Perkins, 1962. Brit. Mus. (Nat. Hist.) Ent., Bul. 11: 416, 435. -Townes and Townes, 1973. Amer. Ent. Inst., Mem. 19: 220.

attenuatus (Provancher). Que., Conn., w. B. C. Because the range, "Atlantic to Cont. Divide in Transit. and U. Austr. Zones," given by Townes and Townes (1951) conflicts with the type-localities of two of their synonyms, one is inclined to doubt the correctness of their synonymy and to wonder about the sort of data they generally used to make their sweeping generalizations about the ranges of species.

Phygadeuon attenuatus Provancher, 1882. Nat. Canad. 13 (no. 155): 334 (key); 13 (no. 156): 359. F. Barron (1975) said that the lectotype selected by Rohwer and Gahan (1918) is now represented only by the pin and labels.

Phaeogenes sectus Provancher, 1888. Addit. Corr. Faune Ent. Canada Hym., p. 358. o. Herpestomus flavicoxae Harrington, 1894. Canad. Ent. 26: 210. ठ.

Phygadeuon (Plesignathus) taeniatus Viereck, 1917 (1916). Conn. State Geol. and Nat. Hist. Survey Bul. 22: 335,336 . ठ.

Taxonomy: Gahan and Rohwer, 1918. Canad. Ent. 50: 135. -Townes and Townes, 1951. In

Muesebeck et al., U. S. Dept. Agr., Agr. Monog. 2: 279. - Barron, 1975. Nat. Canad. 102: $430,563$.

elypeatus (Cresson). Maine s. to N. C., w. to Ill.

Stilpuus clypeatus Cresson, 1868. Amer. Ent. Soc., Trans. 2: 95. ठै.

gelechiae (Ashmead). N. H., N. Y., Ont., Ohio. Host: Gnorimoschema gallaesolidaginis (Riley).

Phaeogenes gelechiae Ashmead, 1890 (1889). U. S. Natl. Mus., Proc. 12: 392. ơ, ?.

missouriensis (Ashmead). D. C., Mo. Ecology: The holotype of the synonym Phaeogenes hemiteloides was reared together with the type series of Emphytina pallidiscapa Rohwer (1911) (a synonym of Ametastegia recens [Say]) from beneath the bark at the base of a black birch (Betula nigra).

Phaeogenes missouriensis Ashmead, 1890 (1889). U. S. Natl. Mus., Proc. 12: 393. \&.

Phaeogenes hemiteloides Ashmead, 1890 (1889). U. S. Natl. Mus., Proc. 12: 393. \&.

Taxonomy: Rohwer, 1911. U. S. Natl. Mus., Proc. 41: 401 (discussion of Bureau of

Entomology notes).

pacificus (Ashmead). Md., W. Va., Alta., Calif.

Ischyrocnemis pacificus Ashmead, 1896. Amer. Ent. Soc., Trans. 23: 199. \& (male misdet.). 
ruficornis (Ashmead). Mo.? The holotype bears a label with what is apparently the illegible name of a collector and another label reading "Collection C. V. Riley;" as often as not, Ashmead was incorrect concerning localities for specimens in the Riley collection.

Phaeogenes ruficornis Ashmead, 1890 (1889). U. S. Natl. Mus., Proc. 12: 394. ₹.

\section{Genus ORONOTUS Wesmael}

Oronotus Wesmael, 1845 (1844). [Brussels] Acad. Roy. de Belg., Nouveaux Mem. 18: 213.

Type-species: Oronotus coarctus Wesmael. Monotypic. The type-species is regarded as a synonym of $O$. binotatus (Gravenhorst).

Fedalma Cameron, 1903. Ann. and Mag. Nat. Hist. (7) 13: 318.

Type-species: Fedalma tricolor Cameron. Monotypic.

Pramha Cameron, 1903. Ent. Soc. London, Trans. 51: 231.

Type-species: Pramha mandibularis Cameron. Monotypic.

Takanona Uchida, 1926. Hokkaido Imp. Univ., Faculty Agr., Jour. 18: 163.

Type-species: Takanona ishiyamana Uchida. Monotypic and orig. desig.

Taxonomy: Townes, Momoi, and Townes, 1965. Amer. Ent. Inst., Mem. 5: 420 (syn.).

vincibilis (Cresson), n. comb. N. H. s. to D. C., w. to Iowa and Ark.

Ichueumon vincibilis Cresson, 1867. Amer. Ent. Soc., Trans. 1: 312..

Phaeogenes decoloratus Cresson, 1877. Amer. Ent. Soc., Trans. 6: 203. ₹.

Phaeogenes discus Cresson, 1877. Amer. Ent. Soc., Trans. 6: 203. ठ.

Taxonomy: Townes, 1957. Ent. Soc. Wash., Proc. 59: 119 (generic transfer).

\section{Genus DIADROMUS Wesmael}

Diadromus Wesmael, 1845 (1844). [Brussels] Acad. Roy. de Belg., Nouveaux Mem. 18: 207. Type-species: Ichneumon troglodytes Gravenhorst. Desig. by Ashmead, 1900.

Thyraeella Holmgren, 1890 (1889). Ichn. Suecica, v. 3, p. 402.

Type-species: Ischuus collaris Gravenhorst. Monotypic.

erythrostomus (Cameron). Calif.

Stiboscopus erythrostomus Cameron, 1908. Amer. Ent. Soc., Trans. 34: 244. ๆ.

Taxonomy: Townes, 1961. Ent. Soc. Wash., Proc. 63: 113.

helvolus (Cresson). Eastern Que. s. to Va., w. to Sask., Colo., and Tex. Host: Sparganothis sulfureana (Clem.), Eudothenia hebesana (Wlk.).

Ichneumon helvolus Cresson, 1867. Amer. Ent. Soc., Trans. 1: 312. ๆ.

Ichneumon Magdalensis Provancher, 1890. Nat. Canad. 19: 248. ơ.

Taxonomy: Cresson, 1877. Amer. Ent. Soc., Trans. 6: 205.

marginatus (Provancher). N. Y., N. J., Md., Ont., Alta.

Phygadeuon marginatus Provancher, 1886. Addit. Corr. Faune Ent. Canada Hym., p. 56. o.

subtilicornis (Gravenhorst). Ont., Ohio, Ind., N. Dak., Kans., Utah, Wash., Oreg.; Eurasia. Host: Plutella xylostella (L.). Cushman (1935) suppressed Herpestomus plutellae Ashmead as a synonym of subtilicomis, and, after comparing North American and European specimens, I have concluded that Townes (1944) was incorrect in resurrecting plutellae from synonymy. Phaeogenes japonicus Ashmead was erroneously suppressed as a synonym of subtilicornis by Townes, Momoi, and Townes (1965).

Ichneumon subtilicomis Gravenhorst, 1829. Ichn. Europaea, v. 1, p. 592.. .

Diadromus imbellis Wesmael, 1845 (1844). [Brussels] Acad. Roy. de Belg., Nouveaux Mem. 18: 209. \&.

Herpestomus plutellae Ashmead, 1890 (1889). U. S. Natl. Mus., Proc. 12: 396. ठ。.

Taxonomy: Cushman, 1935. Wash. Acad. Sci., Jour. 25: 548. -Townes, 1944. Amer. Ent. Soc., Mem. 11: 305. - Townes, Momoi, and Townes, 1965. Amer. Ent. Inst., Mem. 5: 420.

Biology: Lloyd, 1942. Rev. Canad. de Biol. 1: 633-645. - Harcourt, 1963. In LeRoux et al.,

Ent. Soc. Canada, Mem. 32: 61. 


\section{Genus TEREBRAELLA Heinrich}

Terebraella Heinrich, 1972. Nat. Canad. 99: 211.

Type-species: Terebraella culiciops Heinrich. Monotypic and orig. desig.

culiciops Heinrich. Fla.

Terebraella culiciops Heinrich, 1972. Nat. Canad. 99: 211. o, ?.

\section{Genus COLPOGNATHUS Wesmael}

Colpognathus Wesmael, 1845 (1844). [Brussels] Acad. Roy. de Belg., Nouveaux Mem. 18: 174.

Type-species: Ichneumon celerator Gravenhorst. Monotypic.

helvus (Cresson). Que. s. to Ga., w. to Calif. Host: Platyptilia cardnidactyla (Riley).

Ichmenmon fungor Cresson, 1867. Amer. Ent. Soc., Trans. 1: 306. ठ.

Ichneumon helves. Cresson, 1867. Amer. Ent. Soc., Trans. 1: 312 ..

Cryptus certus Provancher, 1874. Nat. Canad. 6 (6): 177 (key); 6 (7): 200. o.

Phygadenon hilaris Provancher, 1874. Nat. Canad. 6: 284. “ $"=$ ?.

Cryptus ruficornis Provancher, 1879. Nat. Canad. 11 (no. 125): 139. ठ. Preoce. by Gravenhorst, 1829.

Taxonomy: Cresson, 1877. Amer. Ent. Soc., Trans. 6: 204, 206.

\section{Genus CENTETERUS Wesmael}

Centeterus Wesmael, 1845 (1844). [Brussels] Acad. Roy. de Belg., Nouveaux Mem. 18: 176. Type-species: Centeterus major Wesmael. Desig. by Ashmead, 1900.

euryptychiae (Ashmead). N. Y., Mich. Host: Epiblema scudderianum (Clem.). Ashmead erroneously stated that the two syntypes were from V: ashington, D. C. Notes made by T. Pergande show that he reared these specimens from galls (on Solidago) sent by D. S. Kellicott of Buffalo, N. Y.

Colpognathus euryptychiae Ashmead, 1890 (1889). U. S. Natl. Mus., Proc. 12: 395..

linearis (Provancher). Que., N. J., N. Mex. Host: Epiblema scudderianum (Clem.).

Cryptus linearis Provancher, 1886. Addit. Corr. Faune Ent. Canada Hym., p. 72. ठ.

Phaeogenes beulahensis Viereck, 1903. In Skinner, Amer. Ent. Soc., Trans. 29: 80 o'.

quadriceps (Cresson). Que. s. to Va., w. to Mich.

Ichneumon quadriceps Cresson, 1867. Amer. Ent. Soc., Trans. 1: 312. o, \&.

Taxonomy: Cresson, 1877. Amer. Ent. Soc., Trans. 6: 204.

tuberculifrons (Provancher). Que., Maine, N. Y., S. C., Ont.

Phygadeuon tuberculifrons Provancher, 1874. Nat. Canad. 6: 284..

Phygadenon fasciatus Provancher, 1886. Addit. Corr. Faune Ent. Canada Hym., p. 55.. .

\section{Genus AETHECERLS Wesmael}

Aethecerns Wesmael, 1845 (1844). [Brussels] Acad. Roy. de Belg., Nouveaux Mem. 18: 213. Type-species: Aethecerus dispar Wesmael. Desig. by Ashmead, 1900.

parvus (Provancher). Que., Maine, R. I., N. Y.

Ischnus parvus Provancher, 1875. Nat. Canad. 7: 112. 8. Barron (1975) rejected the

"lectotype" selected by Gahan and Rohwer (1917) because it is a specimen which

Provancher used only for his 1879 redescription; Barron gave label data for the specimen he regarded as the holotype.

Phaeogenes Farladeani Provancher, 1882. Nat. Canad. 13: 331..

Phaeogenes Falardeaui(!) Townes, 1944. Amer. Ent. Soc., Mem. 11: 302.

Taxonomy: Provancher, 1879. Nat. Canad. 11: 121. -Gahan and Rohwer, 1917. Canad. Ent. 49: 428. - Mason, 1960. Canad. Ent. 92: 145. - Barron, 1975. Nat. Canad. 102: 469, 527-528. pinifolii Mason. Alta., Calif. Host: Coleotechnites milleri (Bsk.), C. starki (Free.).

Aethecerus pinifolii Mason, 1960. Canad. Ent. 92: 145. ठ, ?. 


\section{Genus JETHSURA Cameron}

Jethsura Cameron, 1902. Amer. Ent. Soc., Trans. 28: 373.

Type-species: Jethsura feriuginea Cameron. Monotypic.

pyriformis (Provancher). Que., N. H., Mass., R. I., N. Y., N. Mex.

Ischnus pyriformis Provancher, 1875. Nat. Canad. 7: 109...

Jethsura ferruginea Cameron, 1902. Amer. Ent. Soc., Trans. 28: 374. 9.

Taxonomy: Provancher, 1879. Nat. Canad. 11: 40. -Townes, 1961. Ent. Soc. Wash., Proc. 63: 109.

\section{Genus PHAEOGENES Wesmael}

Phaeogenes Wesmael, 1845 (1844). [Brussels] Acad. Roy. de Belg., Nouveaux Mem. 18: 180.

Type-species: Phaeogenes primarius Wesmael. Desig. by Ashmead, 1900. The type-species is regarded as a synonym of $P$. semivulpinus (Gravenhorst).

Dirophanes Foerster, 1868. Naturh. Ver. Rheinlande, Verh. 25: 183.

Type-species: Phygadenon (Dirophanes) plesius Viereck. By subsequent monotypy from inclusion by Viereck, 1912.

Tycherus Foerster, 1868. Naturh. Ver. Rheinlande, Verh. 25: 192.

Type-species: Phaeogenes elongatus Thomson. Monotypically included and desig. by Perkins, 1962.

Proscus Holmgren, 1890 (1889). Ichn. Suecica, v. 3, p. 420.

Type-species: Phaeogenes cephalotes Wesmael. Desig. by Ashmead, 1900.

Townes, Momoi, and Townes (1965) distinguished Dirophanes from Phaeogenes, but the characters they ascribed to Dirophanes in their key do not fit the type-species very well. Their key also distinguishes Phaeogenes in the strict sense from "species placed in Phaeogenes with a query," but because the latter category includes most of the species presently in Phaeogenes it does not seem practical to adopt that classification here.

Taxonomy: Perkins, 1959. Handb. Ident. Brit. Ins., v. 7, pt. 2 (ai), p. 99-111. - Perkins, 1962.

Brit. Mus. (Nat. Hist.) Ent., Bul. 11: 461. -Townes, Momoi, and Townes, 1965. Amer. Ent.

Inst., Mem. 5: 593.

acaudus (Provancher). Que.

Phygadeuon acaudus Provancher, 1882. Nat. Canad. 13 (no. 155): 334 (key); 13 (no. 156): 358. 9.

areticus Cushman. N. C.?, Alta., Alaska, B. C., Wash., Calif.? Host: Acleris gloverana (Wlshm.), A. variana (Fern.).

Phaeogenes arcticus Cushman, 1920. U. S. Natl. Mus., Proc. 58: 251. ठ์, १.

Biology: Prebble and Graham, 1945. Brit. Columbia Lumberman 29: 38, 39, 88. arogae Gittens and Henry. Idaho, Oreg. Host: A roga websteri Clarke.

Phaeogenes arogae Gittens and Henry, 1966. Biol. Soc. Nev., Occas. Papers 12: 1. ठ, ․

ater Cresson. Que. s. to Miss., w. to Oreg. Host: Podosesia syringae (Harris), Synanthedon exitiosa (Say), S. pyri (Harris), S. scitula (Harris), S. tipuliform is (Clerck).

Phaeogenes ater Cresson, 1877. Amer. Ent. Soc., Trans. 6: 202. .

Amblyteles macrocephalus Provancher, 1886. Addit. Corr. Faune Ent. Canada Hym., p. 34. б.

eacoeciae Viereck. N. Y., Mich., Sask., Colo., N. Mex., Utah, Alaska, B. C. Host: Archips argyrospilus (Wlk.), Choristoneura conflictana (Wlk.).

Phaeogenes cacoeciae Viereck, 1924. Canad. Ent. 56: 66. o, ๆ.

Taxonomy: Allen, 1968. Ent. Soc. Amer., Ann. 61: 625, 626-627.

eynarae Bragg. N. H. w. to Wash., s. to Va., Mo., and Calif. Host: Platyptilia sp., P. carduidactyla (Riley).

Phaeogenes cynarae Bragg, 1971. Pan-Pacific Ent. 47: 58. ơ, ?.

Biology: Lange, 1941. Calif. Agr. Expt. Sta., Bul. 653: 24, 67.

epinotiae Cushman. Maine. Host: Epinotia nanana (Treit.), Coleotechnites piceaella (Kft.). Phaeogenes epinotiae Cushman, 1935. Wash. Acad. Sci., Jour. 25: 547. ơ, ?. 
gaspesianus Provancher. N. S., Que., Maine, Ont., Ohio, Alaska, B. C., Oreg. Host: Acleris variana (Fern.).

Phaeogenes Gaspesianus Provancher, 1882. Nat. Canad. 13: 331..

Phaeogenes pimploides Bradley, 1918. Brooklyn Ent. Soc., Bul. 13: 98. \&.

Morphology: Peck, 1937. Canad. Jour. Res., Sect. D (Zool. Sci.) 15: 246, 251.

gilvilabris Allen. N. Y., Pa., Mich., Wis. Host: Archips rosanus (L.), A. semiferanus (Wlk.), Sparganothis pettitana (Rob.).

Phaeogenes gilvilabris Allen, 1968. Ent. Soc. Amer., Ann. 61: 627. o, ९.

haeussleri Uchida. Sakhalin, Japan. Introduced in Conn., N. J., Md., N. C., S. C., and Ind. between 1934 and 1939, apparently without becoming established. Host: Grapholitha molesta (Bsk.). G. molesta was the target host for introductions of P. haenssleri in the U. S. Uchida (1933) gave a redescription for what he believed to be Phaeogenes japonicus Ashmead, and after learning that he had misidentified $P$. japonicus he published the name haeussleri in reference to his misidentification.

Phaeogenes haeussleri Uchida, 1935. Insecta Matsumurana 9: 82-83. ơ, ₹.

Taxonomy: Uchida, 1933. Insecta Matsumurana 7: 155-156.

Biology: Haeussler, 1940. U. S. Dept. Agr., Tech. Bul. 728: 42-43. -Iwata, 1961. Acta Hym. 1: 316 .

Morphology: Iwata, 1958. Acta Hym. 1: 71 (ovarian egg). - Iwata, 1961. Acta Hym: 1: 137 (ovary and egg).

hebe (Cresson). N. Y., Ill.

Ichneumon Hebe Cresson, 1867. Amer. Ent. Soc., Trans. 1: 306. đ, १.

hebrus (Cresson). Que. s. to Fla., w. to Wash.

Iclineumon hebrus Cresson, 1867. Amer. Ent. Soc., Trans. 1: 306. §, ‡.

Phygadenon insignis Provancher, 1875. Nat. Canad. 7: 179. $९$. Barron (1975) gave label data for the holotype.

Ichneumon ustus Provancher, 1882. Nat. Canad. 13 (no. 154): 305 (key); 13 (no. 155): 324. o ( $q$ misdet.). A lectotype was selected by Barron (1975).

Taxonomy: Allen, 1968. Ent. Soc. Amer., Ann. 61: 625-626. - Barron, 1975. Nat. Canad. 102: 490-491, 579 .

laevigatus (Cresson). Colo.

Ichneumon laevigatus Cresson, 1864. Ent. Soc. Phila., Proc. 3: 176. . Preoce. by Gravenhorst, 1820; not renamed here because of taxonomic uncertainties.

Phaeogenes levigatus Dalla Torre, 1902. Cat. Hym., v. 3, p. 746. Unjustified emend.; preocc. in Phaeogenes by I. laevigatus Cresson.

laricellae Mason. N. B., Ont., Wis., Oreg. Host: Argyresthia laricella Kft.

Phaeogenes laricellae Mason, 1961. Canad. Ent. 93: 3. o", ?.

Morphology: Eidt, 1962. Canad. Ent. 94: 32 (final-instar larva).

maculicornis hariolus (Cresson), n. status. N. S. w. to Alaska, s. to Mass., Mich., N. Mex., and Oreg. Host: Acleris variana (Fern.), Argyrotaenia dorsolana Dyar, Choristoneura conflictana (Wlk.), C. fumiferana (Clem.), C. oceidentalis Free., C. pinus Free., Croesia semipurpurana (Kft.).

Ichneumon hariolus Cresson, 1867. Amer. Ent. Soc., Trans. 1: 305. ๆ.

Phygadenon (Bathymetis) spinicoxus Viereck, 1905. Kans. Acad. Sci., Trans. 19: 289. ․ N. syn.

Phygadenon (Dirophanes) plesins Viereck, 1912. U. S. Natl. Mus., Proc. 42: 148..

Dirophanes banksianae Allen, 1967. Canad. Ent. 99: 893. \&.

Biology: Dixon and Benjamin, 1963. Jour. Econ. Ent. 56: 267.

Morphology: Peck, 1937. Canad. Jour. Res., Sect. D (Zool. Sci.) 15: 246, 251.

maculicornis maculicornis (Stephens). Europe. Introduced in Ont. in 1950, 1955, and 1956. At the time of release it was not suspected that the Nearctic maculicomis hariolus (Cresson) was conspecific. The target species for releases in Ont. was the native Choristoneura fumiferana (Clem.).

Ichneumon maculicornis Stephens, 1835. Illus. Brit. Ent., v. 7, p. 136. ठ, १. 
Phaeogenes scutellaris Wesmael, 1845 (1844). [Brussels] Acad. Roy. de Belg., Nouveaux Mem. 18: 183. .

Taxonomy: Morley, 1902. Ent. Monthly Mag. $38: 119$ (syn.), -Perkins, 1953. Brit. Mus. (Nat. Hist.) Ent., Bul. 3: 108.

mellinus (Provancher). Que. s. to N. J., w. to Mich. and Mo. Host: Ennomos subsignarius (Hbn.), Archips semiferamus (Wlk.), Croesia semipurpurana (Kft.).

Phaeogenes mellimus Provancher, 1875. Nat. Canad. 7: 315. 9. Barron (1975) rejected the "lectotype" selected by Gahan and Rohwer (1918), but thought the specimen fragment he regarded as the holotype to be conspecific with the Gahan and Rohwer "lectotype".

Taxonomy: Provancher, 1879. Nat. Canad. 11: 39. - Gahan and Rohwer, 1918. Canad. Ent. 50: 133. - Barron, 1975. Nat. Canad. 102: 507.

nigridens Wesmael. Mass.; Europe. Introduced. Host: Ostrinia nubilalis (Hbn.).

Phaeogenes nigridens Wesmael, 1845 (1844). [Brussels] Acad. Roy. de Belg., Nouveaux Mem. 18: 192. "?ं," ๆ.

Taxonomy: Cushman, 1932. In Smith, U. S. Dept. Agr., Tech. Bul. 331: 6 (redescription of adult). - Perkins, 1953. Brit. Mus. (Nat. Hist) Ent., Bul. 3: 133. -Allen, 1968. Ent. Soc. Amer., Ann. 61: 628-629.

Biology: Smith, 1932. U. S. Dept. Agr., Tech. Bul. 331: 21-45. -Baker, 1944. Ent. Soc. Wash., Proc. 46: 134. - Baker, Bradley, and Clark, 1945. U. S. Dept. Agr., Tech. Bul. 983: 113-119. -Arbuthnot, 1950. Jour. Econ. Ent. 43: 425.

Morphology: Goidanich, 1931. R. Ist. Super. Agr., Lab. di Ent., Bol. 4: 85-90. - Smith, 1932.

U. S. Dept. Agr., Tech. Bul. 331: 5-21.

ophthalmicus americanus Allen. Colo., Wash. P. ophthalmicus ophthalmicus Wesmael occurs in Europe.

Phaeogenes ophthalmicus americanus Allen, 1968. Ent. Soc. Amer., Ann. 61: 627. o, ?. orbus Provancher. Que.

Phaeogenes orbus Provancher, 1882. Nat. Canad. 13: 332. ó.

Taxonomy: Provancher, 1886. Addit. Corr. Faune Ent. Canada Hym., p. 41 (female described).

osrufus (Davis). Ill.

Eurylabus osrufus Davis, 1898 (1897). Amer. Ent. Soc., Trans. 24: 353. ๆ.

Eurylabus varufus(!) Nason, 1905. Ent. News 16: 148.

phycidis Ashmead, Que., N. H., Mass., Conn., N. Y., Minn. Host: Acrobasis betulella Hlst., A. rubrifasciella Pack., A. silviella Ely.

Phaeogenes phycidis Ashmead, 1898. In Dimmock and Ashmead, Ent. Soc. Wash., Proc. 4: 169. ․

Biology: Daviault, 1935. Nat. Canad. 62: 318, 319.

sitkensis (Ashmead). Southeastern Alaska. Known only from the holotype which has the thyridia only faintly indicated.

Eriplatys sitkensis Ashmead, 1902. Wash. Acad. Sci., Proc. 4: 162.

Taxonomy: Townes, 1944. Amer. Ent. Soc., Mem. 11: 302.

soriculatus (Provancher). Que., N. Y., N. C.

Cryptus soriculatus Provancher, 1881. Nat. Canad. 13: 362. ठ.

testaceicornis (Cameron). Nev.

Bathymetis testaceicomis Cameron, 1908. Amer. Ent. Soc., Trans. 34: 245. ๆ.

Taxonomy: Morley, 1914. Ann. and Mag. Nat. Hist. (8) 14: 409. -Townes, 1961. Ent. Soc.

Wash., Proc. 63: 104.

walshiae Ashmead. N. J. s. to Fla., w. to Ill., Kans., and Miss. Host: Walshia "amorphella" Clem., Ancylis comptana (Froel.), Epiblema strenuanum (Wlk.), Grapholitha molesta (Bsk.), Laspeyresia caryana (Fitch), Rhyacionia frustrana (Comst.), Phaloniidae. In the U. S. Natl. Museum collection there is a female specimen from Shady, Fla. having the 
apical tergites of the abdomen black; it demonstrates the impracticality of recognizing a northern and southern subspecies.

Phygadeuon walshiae Riley, 1890. In Riley and Howard, U. S. Dept. Agr., Insect Life 3: 153. Nomen nudum.

Phaeogenes walshiae Ashmead, 1896. Amer. Ent. Soc., Trans. 23: 205. ठ, १.

Phaeogenes (Centeterns) ineptifrons Gahan, 1919. U. S. Natl. Mus., Proc. 55: 113. ठ, ๆ.

Proseus ualshiae var. australis Cushman, 1933. U. S. Natl. Mus., Proc. 82: 5. ¿', ?. N. syn.

Biology: Haden, 1935. Univ. Del. Agr. Expt. Sta., Bul. 194: 20-35.

\section{TRIBE GYRODONTINI}

This is the Ichneumonini in the sense of Heinrich and, in part, the Joppini in the sense of Townes. It is a very large tribe of worldwide distribution. Heinrich (1967) divided the tribe into five subtribes, four of which are represented in North America.

Taxonomy: Heinrich, 1967. Synopsis and Reclassif. Ichneumoninae Stenopneusticae Africa

So. of Sahara, v. 1, p. 26-27; v. 3, p. 486-487 (keys to subtribes).

\section{SUBTRIBE GYRODONTINA}

\section{Genus CRATICHNEUMON Thomson}

Cratichneumon Thomson, 1893. Opusc. Ent. 18: 1945.

Type-species: Ichneumon luteiventris Gravenhorst. Desig. by Ashmead, 1900.

Lareiga Cameron, 1903. Ztschr. System. Hym., Dipt. 3: 13.

Type-species: Lareiga rufofemorata Cameron. Monotypic.

Belargea Cameron, 1903. Ztschr. System. Hym., Dipt. 3: 15.

Type-species: Belargea albomaculata Cameron. Monotypic. The type-species is regarded as a synonym of $C$. rufofemorata (Cameron).

Odontojoppa Cameron, 1903. Ztschr. System., Dipt. 3: 16, 177.

Type-species: Odontojoppa metallica Cameron. Monotypic.

Sycaonia Cameron, 1903. Ent. Soc. London, Trans. 51: 224.

Type-species: Sycaonia mifofacies Cameron. Monotypic.

Leptothecus Cameron, 1903. Entomologist 36: 240.

Type-species: Leptothecus mifomaculatus Cameron. Monotypic.

Tanyjoppa Cameron, 1904. Ztschr. System. Hym., Dipt. 4: 217.

Type-species: Tanyjoppa sanguineoplagiata Cameron. Monotypic.

Lissichneumon Cameron, 1906. Entomologist 39: 227.

Type-species: Lissichneumon levis Cameron. Monotypic.

Nimbolareiga Heinrich, 1969 (1968). Synopsis and Reclassif. Ichneumoninae

Stenopneusticae Africa So. of Sahara, v. 4, p. 933.

Type-species: Nimbolareiga merucapitis Heinrich. Monotypic and orig. desig.

This is a very large and widely distributed genus which is particulary difficult taxononomically.

Taxonomy: Townes and Townes, 1973. Amer. Ent. Inst., Mem. 19: 304 (generic syn.).

acronictae Heinrich. Que., Maine, N. Y., N. C. Host: Acronicta sp.

Cratichneumon acronictae Heinrich, 1961 (1960). Canad. Ent. Sup. 18: 125. ¿, ₹.

Taxonomy: Heinrich, 1971. Nat. Canad. 98: 984.

alternans (Provancher). Que., Maine.

Phygadeuon alterians Provancher, 1882. Nat. Canad. 13 (no. 155): 335 (key); 13 (no. 156): 358. ㅇ.

Taxonomy: Heinrich, 1971. Nat. Canad. 98: 986-989 (male described and included in key). anisotae Heinrich. Que. s. to Va., w. to Wis. Host: Anisota senatoria (J. E. S.), Dryocampa mibicunda rubicunda (F.).

Cratichneumon anisotae Heinrich, 1961 (1960). Canad. Ent. Sup. 18: 119. §, ๆ. annulatipes (Provancher). Que. s. to D. C., w. to Mich. and Mo.

Phaeogenes annulatipes Provancher, 1886. Addit. Corr. Faune Ent. Canada Hym., p. 43.. 
Amblyteles (Pterocormus) quintilis Viereck, 1917 (1916). Conn. State Geol. and Nat. Hist. Survey Bul. 22: 354,357 . $\delta$.

Cratichnermon annulatipes facetops Heinrich, 1961 (1960). Canad. Ent. Sup. 18: 147. ð. N. syn.

Taxonomy: Heinrich, 1959. Ent. News 70: 214 (syn.).

annulatus (Provancher). Que. s. to Pa., w. to Mich.

Mesostenus annulatus Provancher, 1875. Nat. Canad. 7: 265. ठ.

arizonensis (Viereck). Ariz. According to Heinrich (1961) this species is closely related to takomae Heinrich.

Ichnenmon (Eurylabus) arizonensis Viereck, 1905. Kans. Acad. Sci., Trans. 19: 295..+

ashmeadi (Schulz). Que., Maine, N. H., Colo., Alaska, B. C., Wash., Oreg.

Ichnenmon imitator Ashmead, 1902. Wash. Acad. Sci., Proc. 4: 151. ठ. Preoce. by Villers, 1789 .

Ichneamon Ashmeadi Schulz, 1906. Spolia Hym., p. 128. N. name for I. imitator Ashmead. astutus (Holmgren). Calif.

Ichnenmon astutus Holmgren, 1869 (1868). Eug. Resa, pt. 2 (Zool.), sect. 1 (Ins.), p. 394.

Taxonomy: Townes, 1961. Ent. Soc. Wash., Proc. 63: 106.

austropiceipes Heinrich. Ga., Miss.

Cratichneumon austropiceipes Heinrich, 1971. Nat. Canad. 98: 992. §, ?.

boreoalpinus Heinrich. Newfoundland (insular), N. H.

Cratichnenmon boreoalpinus Heinrich, 1961 (1960). Canad. Ent. Sup. 18: 168. .

boreovagans Heinrich. Que., Maine. According to Heinrich, this may be a northern variant of C. paraparatus Heinrich.

Cratichneumon boreovagans Heinrich, 1962. Canad. Ent. Sup. 29: 870. ․

brevipennis (Cresson). Maine, N. H., Mass., R. I., Pa., Md., Va., Fla., Ont., Iowa, Mo., Colo. Host: Faronta diffisa (Wlk.).

Ichneumon brevipennis Cresson, 1864. Ent. Soc. Phila., Proc. 3: 174...

Ischuns volens Cresson, 1864. Ent. Soc. Phila., Proc. 3: 192. o.

Ichnenmon brevipennis var. obsoletus Riley, 1877. Mo. State Ent., Ann. Rpt. 9: 55. .

Preocc. by Gmelin, 1790 and Fabricius, 1798; Heinrich (1961) erroneously stated that the holotype is lost.

Taxonomy: Heinrich, 1959. Ent. News 70: 214 (syn.). - Heinrich, 1961 (1960). Canad. Ent. Sup. 18: 170 .

broweri Heinrich. Maine.

Cratichneumon broweri Heinrich, 1971. Nat. Canad. 98: 998. ?.

carolinae Heinrich. N. C., Ga.

Cratichneumon carolinae Heinrich, 1971. Nat. Canad. 98: 991. ?.

eitrinops kincaidi (Ashmead). Sask., Alaska. C. citrinops citrinops (Wesmael) is European.

Ichreumon kincaidi Ashmead, 1902. Wash. Acad. Sci., Proc. 4: 152. ठ.

Cratichnenmon alaskensis Ashmead, 1902. Wash. Acad. Sci., Proc. 4: 157. ठ.

Taxonomy: Heinrich, 1959. Ent. News 70: 213 (status).

duplicatus (Say). Mass. s. to Va., w. to Wis.

Ichreumon duplicatus Say, 1836. Boston Jour. Nat. Hist. 1: 230. ठ゚.

Taxonomy: Townes and Townes, 1951. In Muesebeck et al., U. S. Dept. Agr., Agr. Monog. 2: 288.

erythroseuta Heinrich. Mass. Heinrich supposed that erythroscuta may prove to be the female of $C$. vaccinii Heinrich.

Cratichneumon erythroseuta Heinrich, 1961 (1960). Canad. Ent. Sup. 18: 142. \&.

expers Heinrich. N. C., n. Fla., Miss.

Cratichnentmon expers Heinrich, 1972. Nat. Canad. 99: 178. ठ, १.

Cratichneumon expers circumflavidus Heinrich, 1972. Nat. Canad. 99: 180. ․ N. syn.

facetus (Cresson). R. I. s. to N. C., w. to Mich. and Ky.

Ichnenmon facetus Cresson, 1867. Amer. Ent. Soc., Trans. 1: 311. o. 
ferrugops Heinrich. Que., Ont., Mich.

Cratichneumon ferrugops Heinrich, 1961 (1960). Canad. Ent. Sup. 18: 124. $q$.

flaschkai Heinrich. Colo.

Cratichneumon flaschkai Heinrich, 1973. Nat. Canad. 100: 461, 463. o, ๆ.

flavipectus (Provancher). Que. s. to Ga., w. to Mich. and Miss.

Cryptus flavipectus Provancher, 1879. Nat. Canad. 11 (no. 125): 134. “ๆ” =

Ichueumon pygmaeus Davis, 1898 (1897). Amer. Ent. Soc., Trans. 24: 350. \&. Preoce. by Poda, 1761.

Cratichneumon ericaeus Townes, 1944. Amer. Ent. Soc., Mem. 11: 335. N. name for I. pygmaeus Davis.

Cratichneumon flavipectus mississippi Heinrich, 1971. Nat. Canad. 98: 989. N. syn.

floridensis Heinrich. Fla.

Cratichneumon floridensis Heinrich, 1972. Nat. Canad. 99: 181. ठ, ‥

fuscior Heinrich. Ga.

Cratichneumon fuscior Heinrich, 1971. Nat. Canad. 98: 996. ㅇ.

georgius Heinrich. Southern Ga.

Cratichneumon georgins Heinrich, 1971. Nat. Canad. 98: 995. ‥

horani Heinrich. Northern Fla., Miss.

Cratichneumon horani Heinrich, 1972. Nat. Canad. 99: 180. ơ, ?.

howdeni Heinrich. N. C.

Cratichneumon houdeni Heinrich, 1961 (1960). Canad. Ent. Sup. 18: 172. \&.

insulae Heinrich. R. I., N. J.

Cratichneumon insulae Heinrich, 1961 (1960). Canad. Ent. Sup. 18: 151..

involutus (Cresson). Colo.

Ichneumon involutus Cresson, 1864. Ent. Soc. Phila., Proc. 3: 183. ๆ.

naumanni Heinrich. Ga.

Cratichneumon naumanni Heinrich, 1971. Nat. Canad. 98: 994. $\$$.

nigritarius acerbus (Cresson). Newfoundland (Labrador) s. to N. Y., w. to S. Dak. and Colo. Host: Isturgia truncataria (Wlk.), Protoboarmia porcelaria (Gn.), Semiothisa sexmaculata (Pack.). C. nigritarius nigritarius (Gravenhorst) is Eurasian.

Ichneumon acerbus Cresson, 1867. Amer. Ent. Soc., Trans. 1: 293. ð.

Ichnenmon corvinus Cresson, 1877. Amer. Ent. Soc., Trans. 6: 145. ․

Taxonomy: Heinrich, 1953. Wash. Acad. Sci., Jour. 43: 149-150.

paraparatus Heinrich. N. Y., N. J., Md., N. C., S. C. Heinrich's description of paraparatus was based upon 12 female specimens, apparently including the specimen ("neallotype") upon which Heinrich (1961) based his description of what was presumed to be the female of C. vinuulus (Cresson). Because the description of paraparatus was not accompanied by the description of a female which could more definitely be associated with vimulus males, the status of the name paraparatus seems dubious.

Cratichneumon paraparatus Heinrich, 1962. Canad. Ent. Sup. 29: 869..

Taxonomy: Heinrich, 1961 (1960). Canad. Ent. Sup. 18: 100, 138-140. - Heinrich, 1971. Nat.

Canad. 98: 988 (key including male thought possibly to be conspecific with paraparatus).

paratus (Say). Que. s. to Fla., w. to N. Dak. and Mo. Host: Lambdina pellucidaria (G. and R.), Heterocampa guttivitta (Wlk.), H. manteo (Dbldy.).

Ichneumon parata Say, 1829. Contrib. Maclurian Lyceum to Arts and Sci. 1: 68. ठ.

Ichneumon annulipes Cresson, 1864. Ent. Soc. Phila., Proc. 3: 170. \&.

Ichneumon pusillus Cresson, 1864. Ent. Soc. Phila., Proc. 3: 171. ․

Cratichnemmon paratus psendovinmulus Heinrich, 1961 (1960). Canad. Ent. Sup. 18: 137. ठ', ‥ N. syn.

pertenuis Heinrich. Maine, N. Y.

Cratichneumon pertenuis Heinrich, 1961 (1960). Canad. Ent. Sup. 18: 169. \&.

petuleus (Cresson). Southern Calif.

Ichneumon petulcus Cresson, 1877. Amer. Ent. Soc., Trans. 6: 185. ㅇ.

piceipes Heinrich. Que., Maine, Mich.

Cratichneumon piceipes Heinrich, 1961 (1960). Canad. Ent. Sup. 18: 130. ơ, ?. 
Taxonomy: Heinrich, 1971. Nat. Canad. 98: 993.

pilosulus (Provancher). Newfoundland (insular), Que., Maine, N. H., Pa., Mich., S. Dak. Ichneumon pilosulus Provancher, 1875. Nat. Canad. 7: 25. ?.

popofensis Ashmead. Que., Alaska. Although this species was recorded from Que. by Townes and Townes (1951), Heinrich (1961) did not mention the species in his revision of the stenopneusticae of the Northeast. Ashmead appears to have correctly associated the sexes of popofensis, and the suppression of popofensis as a synonym of yakutatensis Ashmead by Heinrich (1959) appears to be incorrect.

Cratichneumon popofensis Ashmead, 1902. Wash. Acad. Sci., Proc. 4: 159. ठँ, १.

Taxonomy: Townes and Townes, 1951. U. S. Dept. Agr., Agr. Monog. 2: 288. - Heinrich, 1959. Ent. News 70: 214.

promptus (Cresson). Que., Maine, N. H., Man. Host: Protoboarmia porcelaria (Gn.).

Ichneumon promptus Cresson, 1877. Amer. Ent. Soc., Trans. 6: 152. ठ, ₹.

proximus (Cresson). N. Y. s. to Ala., w. to Ill. Host: Symmerista canicosta Francl.

Ischnus proximus Cresson, 1864. Ent. Soc. Phila., Proc. 3: 187. ठ.

Ichneumon sagus Cresson, 1867. Amer. Ent. Soc., Trans. 1: 294. $q$ (male misdet.).

pseudanisotae Heinrich. N. Y., N. J., Md.

Cratichneumon pseudanisotae Heinrich, 1961 (1960). Canad. Ent. Sup. 18: 133. ㅇ.

pteridis Townes. Newfoundland (insular), Que., Maine, N. H., N. Y., Pa., Ont., Mich., Man., Alaska. Host: Ectropis crepuscularia (D. and S.), Protoboarmia porcelaria (Gn.), Semiothisa sp., Heterocampa guttivitta (Wlk.).

Phygadenon proximus Provancher, 1874. Nat. Canad. 6: 283. \&. Preoce. in Cratichneumon by Cresson, 1864 .

Cratichneumon pteridis Townes, 1944. Amer. Ent. Soc., Mem. 11: 339. N. name for $P$. proximus Provancher.

puncticoxa Heinrich. Que., Maine, Mass., N. Y., Pa., Mich.

Cratichneumon puncticoxa Heinrich, 1961 (1960). Canad. Ent. Sup. 18: 133. o, ․

Taxonomy: Heinrich, 1971. Nat. Canad. 98: 986 (amendments to description).

remanens Heinrich. Maine, N. Y., Md., N. C., Ont.

Cratichneumon remanens Heinrich, 1961 (1960). Canad. Ent. Sup. 18: 157. ठ。.

Taxonomy: Heinrich, 1971. Nat. Canad. 98: 988 (inclusion in revised key).

ritus Heinrich. Maine, Va., N. C., Ont., Mich., Ind., Iowa. Host: Phigalia titea (Cramer).

Cratichneumon ritus Heinrich, 1961 (1960). Canad. Ent. Sup. 18: 143. đ, ๆ.

rubricoides Heinrich. Que., Maine, N. Y., N. C., Mich.

Cratichneumon rubricoides Heinrich, 1961 (1960). Canad. Ent. Sup. 18: 165. ¿, ?.

Taxonomy: Heinrich, 1971. Nat. Canad. 98: 990-991 (additional differences from rubricus [Provancher]).

rubricops Heinrich. Que., Maine, N. Y., Ont.

Cratichneumon rubricops Heinrich, 1961 (1960). Canad. Ent. Sup. 18: 167. ठ, १.

Taxonomy: Heinrich, 1971. Nat. Canad. 98: 988 (inclusion of male in revised key).

rubricus (Provancher). P. E. I., Que., Maine, N. Y., Mich.

Phygadeton mubricus Provancher, 1882. Nat. Canad. 13 (no. 155): 335 (key); 13 (no. 156): 358. ㅇ.

Taxonomy: Heinrich, 1971. Nat. Canad. 98: 989 (inclusion of male in revised key).

russatus (Cresson). Colo., Ariz., Idaho, B. C., Wash., Oreg., Calif. Townes (1961) said that mussatus is probably a synonym of astutus (Holmgren).

Ichueumon russatus Cresson, 1877. Amer. Ent. Soc., Trans. 6: 183. \&.

Ichneumon (Barichneumon) citrinifacialis Viereck, 1905. Kans. Acad. Sci., Trans. 19: 297. o.

Taxonomy: Townes, 1961. Ent. Soc. Wash., Proc. 63: 106.

scitulus (Cresson). Que. s. to Va., w. to Ill.

Ischrus scitulus Cresson, 1864. Ent. Soc. Phila., Proc. 3: 193. ठో. 
Ichneumon nanus Cresson, 1877. Amer. Ent. Soc., Trans. 4: 184. \&. Preoce. by Ratzeburg, 1848.

Amblyteles nanodes Cushman, 1925. Wash. Acad. Sci., Jour. 15: 388. N. name for I. nanus Cresson.

Taxonomy: Heinrich, 1971. Nat. Canad. 98: 989 (inclusion of male in revised key).

signatipes (Cresson). Que. s. to D. C., w. to Kans. Townes and Townes (1951) said that signatipes males had often been misidentified as $C$. duplicatus (Say), and Heinrich $(1961,1962)$ erroneously suppressed signatipes as a synonym of C. $u^{\prime}$-album (Cresson) (which see).

Ichneumon signatipes Cresson, 1867. Amer. Ent. Soc., Trans. 1: 308. ․

Ichnenmon lobatus Provancher, 1875. Nat. Canad. 7 (1): 23 (key); 7 (3): 77 . $\delta$.

Ichneumon! (Stiboscopus!) oryxicomis Viereck, 1905. Kans. Acad. Sci., Trans. 19: 324. o. Amblyteles (Barichneumon!) duplicatiformis Viereck, 1917 (1916). Conn. State Geol. and Nat. Hist. Survey, Bul. 22: 354,360. d.

Taxonomy: Townes and Townes, 1951. In Muesebeck et al., U. S. Dept. Agr., Agr. Monog. 2: 289. - Heinrich, 1961 (1960); 1962. Canad. Ent. Sup. 18: 126-130; 29: 868.

suadus (Cresson). Que., Maine, R. I., Conn., N. Y., Pa., Ont., Wis.

Ichneumon suadus Cresson, 1877. Amer. Ent. Soc., Trans. 6: 160. $\delta$.

Taxonomy: Heinrich, 1971. Nat. Canad. 98: 988 (inclusion of male in revised key).

subfilatus Heinrich. Que. s. to N. C., w. to Mich. Host: Lambdina pellucidaria (G. and R.).

Cratichneumon subfilatus Heinrich, 1961 (1960). Canad. Ent. Sup. 18: 131. ठ, ๆ.

sublatus (Cresson). Que. s. to Va., w. to Ill. Host: Heterocampa binndata Wlk., H. guttivitta (Wlk.), Hydria prunivorata (Ferg.).

Ischnus sublatus Cresson, 1864. Ent. Soc. Phila., Proc. 3: 186. ठ.

Ichneumon prav'us Cresson, 1877. Amer. Ent. Soc., Trans. 6: 151. ๆ.

Biology: Patch, 1908. Maine Agr. Expt. Sta., Bul. 161: 340.

takomae Heinrich. Southern Maine?, Md.

Cratichneumon takomae Heinrich, 1961 (1960). Canad. Ent. Sup. 18: 116. o.

Taxonomy: Heinrich, 1971. Nat. Canad. 98: 984.

tyloidifer Heinrich. Maine, N. Y., N. J., Pa., Md., Va., N. C., Ont., Mich.

Cratichneumon tyloidifer Heinrich, 1961 (1960). Canad. Ent. Sup. 18: 115. $\delta$.

unifasciatorius (Say). Que. w. to s. B. C., s. to Fla., Utah, and Oreg. Host: Orgyia antiqua (L.), O. leucostigma (J. E. S.), Hemilenca sp., Diacrista virginica (F.), Halisidota argentata (Pack.), H. caryae (Harris), H. tesselaris (J. E. S.), Acronicta oblinita (J. E. S.).

Ichneumon unifasciatorius Say, 1825. Amer. Ent. 2: 48. ठ.

Ichneumon malacus Say, 1829. Contrib. Maclurian Lyceum to Arts and Sci. 1: 72.9.

Ichnentmon niger Brulle, 1846. In Lepeletier, Hist. Nat. Ins. Hym., v. 4, p. 302. ¿, ९.

Preocc. by Gmelin, 1790 and Fabricius, 1798.

Ichneumon Afer Cresson, 1864. Ent. Soc. Phila., Proc. 3: 138. ๆ.

Ichneumon scriptifrons Cresson, 1877. Amer. Ent. Soc., Trans. 6: 144. ð.

Ichneumon Vancouveriensis Provancher, 1885. Canad. Ent. 17: 114. o.

Ichneumon aterrimus Provancher, 1886. Addit. Corr. Faune Ent. Canada Hym., p. 30.. Preocc. by Foerster, 1771.

vaccinii Heinrich. Que., Maine, Pa., Ont., Mich.

Cratichneumon vaccinii Heinrich, 1961 (1960). Canad. Ent. Sup. 18: 141. ठ.

valdefuscus Heinrich. N. Y. s. to n. Fla., w. to La.

Cratichneumon valdefuscus Heinrich, 1972. Nat. Canad. 99: 177. o, ९.

vescus (Provancher). Que., Maine, N. H., Vt., N. Y., Pa., Ont., Mich., N. Mex., Alta., B. C. Host: Protoboarmia porcelaria (Gn.).

Ichneumon vescus Provancher, 1877. Nat. Canad. 9: 9. o.

vinnulus (Cresson). Que. s. to N. C., w. to Wis. and Ky.

Ischnus vinuulus Cresson, 1864. Ent. Soc. Phila., Proc. 3: 189. ¿.

Cratichneumon gracilior Heinrich, 1961 (1960). Canad. Ent. Sup. 18: 147. $\subsetneq$ (male misdet.).

Taxonomy: Heinrich, 1962. Canad. Ent. Sup. 29: 868 (syn.). 
vockerothi Heinrich. N. H. Ecology: The holotype was collected on the summit of Mt. Washington, N. H. (elevation 6100 to $6288 \mathrm{ft}$.).

Cratichneumon vockerothi Heinrich, 1961 (1960). Canad. Ent. Sup. 18: 158..

w-album (Cresson). Que. s. to Ga., w. to Wis. and Ala. Host: Heterocampa guttivitta (Wlk.), Dryocampa mbicunda rubicunda (F.). Heinrich $(1959,1961)$ erroneously applied the name $w$-album to $C$. signatipes (Cresson) because of the fact that Cresson's (1916) lectotype for $u^{\prime}$-album does not agree in decisive respects with the original description. Although Cresson made no mention of variation to indicate that he used more than one of his syntypes in writing his original description of $w$-album, the fact that he had more that one type-specimen is indicated by his statement: "Hab[itat]-- Pennsylvania (C. A. Blake); Delaware (Dr. Wilson); New Jersey (Cresson)." Unless it can be shown that Cresson's (1916) lectotype from $\mathrm{Pa}$. was not the specimen from $\mathrm{C}$. A. Blake, there is no basis for disregarding it as the legitimate lectotype. Although it is possible that Cresson's lectotype is not one of the original syntypes, but instead a specimen aquired later and used in making his 1867 expanded description of $x c^{-}-\mathrm{album}$, lack of agreement with the original description is not proof of this.

Ischnus W-album Cresson, 1864. Ent. Soc. Phila., Proc. 3: 191. o.

Ischnus variegatus Provancher, 1875. Nat. Canad. 7: 250. ठ.

Cratichneumon variegatus insignitus Heinrich, 1971. Nat. Canad. 98: 985. ठै, ๆ. N. syn.

Taxonomy: Cresson, 1867. Amer. Ent. Soc., Trans. 1: 309. -Cresson, 1877. Amer. Ent. Soc., Trans. 6: 179-180 (redescription based on specimens from Canada, N. H., and Mass.).

-Cresson, 1916. Amer. Ent. Soc., Mem. 1: 63 (lectotype selection). - Heinrich, 1959. Ent.

News 70: 190. - Heinrich, 1961 (1960). Canad. Ent. Sup. 18: 122-124, 126-127, 129.

yakutatensis Ashmead. Alaska.

Cratichneumon yakutatensis Ashmead, 1902. Wash. Acad. Sci., Proc. 4: 157. ठ.

\section{Genus CRYPTEFFIGIES Heinrich}

Aculichneumon subg. Crypteffigies Heinrich, 1961 (1960). Canad. Ent. Sup. 15: 17.

Type-species: Cratichneumon confusus Ashmead. Monotypic and orig. desig.

According to Heinrich (1969) Crypteffigies is Holarctic.

Taxonomy: Heinrich, 1961 (1960). Canad. Ent. Sup. 18: 178-180. - Heinrich, 1969 (1968).

Synopsis and Reclassif. Ichneumoninae Stenopneusticae Africa So. of Sahara, v. 5, p. 1106.

confusa (Ashmead). Que., N. Y., Alaska, B. C.

Cratichneumon confusus Ashmead, 1902. Wash. Acad. Sci., Proc. 4: 158. ठ.

Plectocryptus popofensis Ashmead, 1902. Wash. Acad. Sci., Proc. 4: 183. ?.

Plectocryptus yakutatensis Ashmead, 1902. Wash. Acad. Sci., Proc. 4: 183. ․

megalura Heinrich. Maine, Ont. Specimens in the U. S. Natl. Museum collection appear to indicate that megalurus will not likely prove to be deserving of anything more than suppression as a synonym of confusus.

Aculichneumon (Crypteffigies) confusus megalurus Heinrich, 1961 (1960). Canad. Ent. Sup. 18: 180, 205. \%. The alternate spelling "mogalurus" appears on p. 205.

Taxonomy: Heinrich, 1971. Nat. Canad. 98: 1003-1004 (description of male and elevation to species status).

\section{Genus HOMOTHERUS Foerster}

Homotherus Foerster, 1868. Naturh. Ver. Rheinlande, Verh. 25: 185.

Type-species: Ichneumon locutor Thunberg. Monotypically included and desig. by Perkins, 1960.

This is a small genus of Holarctic distribution.

Taxonomy: Perkins, 1960. Handb. Ident. Brit. Ins., v. 7, pt. 2 (aii), p. 153. - Heinrich, 1971.

Nat. Canad. 98: 1000 (key for some males).

erythromelas (MacLachlan). Northern N. W. T.; w. Greenland. Dr. W. R. M. Mason informed me that there are specimens from Greenland in the Canadian National Collection, but 
none from Canada. The holotype, which is from northern Ellesmere Island is apparently the only Canadian specimen known.

Ichneumon erythromelas MacLachlan, 1879 (1878). Linn. Soc. Zool., Jour. 14: 106..

Taxonomy: Strand, 1905. Rpt. Second Norwegian Aretic Exped. in the "Fram" 1898-1902, no. 3, p. 6. - Roman, 1930. Ann. and Mag. Nat. Hist. (10) 5: 282. - Heinrich, 1962. Canad. Ent.

Sup. 29: $871-872$.

magus (Wesmael). Newfoundland (insular); Greenland; Europe.

Ichneumon magus Wesmael, 1855. [Brussels] Acad. Roy. de Belg., Bul. 22: 389. ठ, ?.

Homotherus magus nearctis Heinrich, 1976 (1975). Nat. Canad. 102: 753, 766. ․ N. syn.

Based upon a single female from insular Newfoundland. The variant spelling

"neareticus" which appears on p. 583 (French resume and English abstract) is here rejected in favor of nearctis.

Phaeogenes nitidus Bridgman, 1886. Ent. Soc. London, Trans. 34: 337. ơ.

Taxonomy: Roman, 1938. In Carpenter, Ann. and Mag. Nat. Hist. (11) 1: 538. - Perkins, 1953.

Brit. Mus. (Nat. Hist.) Ent., Bul. 3: 116, 134, 136. -Perkins, 1960. Handb. Ident. Brit. Ins.,

v. 7 , pt. 2 (aii), p. $121,138,145,147$.

porcelariae Heinrich. Newfoundland (Labrador), N. B., Maine, Ont., Mich., Man. Host:

Eufilonia notataria (Wlk.), Protoboamia porcelaria (Gn.), Semiothisa sp.

Homotherus porcelariae Heinrich, 1961 (1960). Canad. Ent. Sup. 18: 173. ơ, ?.

pseudoporcelariae Heinrich. Newfoundland (insular), Maine.

Homotherus pseudoporcelariae Heinrich, 1971. Nat. Canad. 98: 1001. ठ, ९.

semiaoplus Heinrich. Newfoundland (insular), Que., Maine, W. Va., Mich.

Homotherus semicoplus Heinrich, 1961 (1960. Canad. Ent. Sup. 18: 173. o, \&.

smileyi Heinrich. N. Y.

Homotherus smileyi Heinrich, 1968. Nat. Canad. 95: 717. ठ, ?.

townesi Heinrich. Newfoundland (insular), Que., Maine, N. Y., N. C., Ont., Mich.

Homotherus tou'nesi Heinrich, 1961 (1960). Canad. Ent. Sup. 18: 175. o, ?.

\section{Genus EUPALAMUS Wesmael}

Eupalamns Wesmael, 1845 (1844). [Brussels] Acad. Roy. de Belg., Nouveaux Mem. 18: 14. Type-species: Eupalamus oscillator Wesmael. Monotypic.

Lagenesta Cameron, 1901. Ann. and Mag. Nat. Hist. (7) 7: 376.

Type-species: Lagenesta ferruginea Cameron. Monotypic.

Xestojoppa Cameron, 1901. Ann. and Mag. Nat. Hist. (7) 7: 379.

Type-species: Xestojoppa olivacea Cameron. Monotypic.

Cosmiojoppa Cameron, 1902. Ztschr. System. Hym. Dipt. 2: 395.

Type-species: Cosmiojoppa violaceipennis Cameron. Monotypic.

Lynteria Cameron, 1904. Ztschr. System. Hym. Dipt. 4: 220.

Type-species: Lynteria violaceipennis Cameron. Monotypic. The type-species is a synonym of E. cyanopteryx Townes, Townes, and Gupta.

Faesula Cameron, 1904. Ztschr. System. Hym. Dipt. 4: 338.

Type-species: Faesula maculata Cameron. Monotypic.

Mesophaduus Cameron, 1907. Tijdschr. v. Ent. 50: 75.

Type-species: Mesophadnus spilopterus Cameron. Monotypic.

Taxonomy: Townes, Momoi, and Townes, 1965. Amer. Ent. Inst., Mem. 5: 447 (syn.).

andersoni Heinrich. B. C.

Eupalamus audersoni Heinrich, 1961. Canad. Ent. Sup. 23: 385. ․ melacneme Heinrich. Que., Ont.

Eupalamus melacneme Heinrich, 1961. Canad. Ent. Sup. 23: 386. ठ, ๆ.

\section{Genus ANISOPYGUS Kriechbaumer}

Anisopygus Kriechbaumer, 1888. Wien. Mus. der Naturgesch., Ann. 3: 36.

Type-species: Amblyteles pseudonymus Wesmael. Monotypic. 
americanus Heinrich. Newfoundland (insular) w. to s. B. C., s. to Maine, Wis., and Calif. Host: Ichthyura apicalis Wlk.

Anisopygus americanns Heinrich, 1961. Canad. Ent. Sup. 23: 379. đo, ?.

pseudonymus neareticus Heinrich. Colo., Alta., B. C. Host: Notodontid. A. psendonymus pseudonymus (Wesmael) is Eurasian. Heinrich's description of p. nearcticus seems to indicate that the difference from the nominate form are so slight as to make the distinction of dubious worth.

Anisopygus pseudonymus nearcticus. Heinrich, 1961. Canad. Ent. Sup. 23: 378. o, ?.

\section{Genus MELANICHNEUMON Thomson}

Melanichnenmon Thomson, 1893. Opusc. Ent. 18: 1954.

Type-species: Ichneumon spectabilis Holmgren. Desig. by Ashmead, 1900.

Taxonomy: Heinrich, 1972. Nat. Canad. 99: 201-203 (key to spp. of southeastern U. S.).

absconditus (Provancher). Newfoundland (insular), Maine, N. H., N. C.?, Mich., Colo., Alta., Wash.

Ichnenmon absconditus Provancher, 1886. Addit. Corr. Faune Ent. Canada Hym., p. 31. o.

disparilis (Cresson). Maine s. to n. Fla., w. to Mich. and La.

Ichneumou disparilis Cresson, 1867. Amer. Ent. Soc., Trans. 1: 307. \&.

Melanichnenmon disparilis flavidops Heinrich, 1972. Nat. Canad. 99: 203. o, ๆ. N. syn.

dreisbachi Heinrich. Maine, Mich.

Melanichnemmon (Melanichneumon) dreisbachi Heinrich, 1962. Canad. Ent. Sup. 26: 585. $\delta$, ?.

flavicarina Heinrich. Que., Maine, Ont., Mich., Man. Host: Protoboarmia porcelaria (Gn.).

Melanichnenmon (Melanichnenmon) flavicarina Heinrich, 1962. Canad. Ent. Sup. 26: 594. $\delta$, $₹$. The variant spelling "fla rocarina" is on p. 583, but Peck (1964) made the first revisor decision in favor of flavicarina.

Melanichneumon flacocarina(!) Heinrich, 1973. Nat. Canad. 100: 465.

Taxonomy: Peck, 1964. Ent. Soc. Canada, Mem. 35: 892.

foxleei Heinrich. Southern B. C.

Melanichneumon (Melanichnenmon) foxleei Heinrich, 1962. Canad. Ent. Sup. 26: 586. ठ".

heiligbrodtii (Cresson). Fla., Tex.; Mexico.

Ichneumon Heiligbrodtii Cresson, 1877. Amer. Ent. Soc., Trans. 6: 168. ð.

Taxonomy: Heinrich, 1962. Canad. Ent. Sup. 26: 597-598 (redescription of male). - Heinrich, 1972. Nat. Canad. 99: 202, 204, 207 (inclusion of both sexes in keys).

honestus (Cresson). Md. s. to Fla., w. to s. Mich. and La.

Ichneumon honestus Cresson, 1867. Amer. Ent. Soc., Trans. 6: 170. ठ.

Melanichneumon honestus milleri Heinrich, 1972. Nat. Canad. 99: 205. ठ, ๆ. N. syn.

indecoratus Heinrich. P. E. I., Que., Maine, N. Y.?, Ont.

Melanichneumon (Melanichneumon) indecoratus Heinrich, 1962. Canad. Ent. Sup. 26: 589. $\delta$,. .

leviculops Heinrich. Newfoundland (insular), Que., Maine, Ont.

Melanichneumon (Melanichneumon) leviculops Heinrich, 1962. Canad. Ent. Sup. 26: 600. ㅇ.

Taxonomy: Heinrich, 1976 (1975). Nat. Canad. 102: 767-768 (male described).

leviculus (Cresson). Que. s. to N. C., w. to Mich. Host: Coryphista meadi (Pack.).

Ichneumon levieulus Cresson, 1877. Amer. Ent. Soc., Trans. 6: 170. ¿.

lissorufus Heinrich. Newfoundland (Labrador and insular), Que., Maine, N. Y., Ont., Mich.

Melanichnenmon (Melanichnemmon) lissorufus Heinrich, 1962. Canad. Ent. Sup. 26: 591. o, . .

Melanichneumon lissornfus radtkei Heinrich, 1976 (1975). Nat. Canad. 102: 768. ठో, ९. N. syn. Described from five specimens from one locality in insular Newfoundland.

margaritae Heinrich. Tenn., Ark.

Melanichneumon margaritae Heinrich, 1973. Nat. Canad. 100: 464. ठ, f. 
mystificans Heinrich. Ga.

Melanichnenmon mystificans Heinrich, 1972. Nat. Canad, 99: 207. §, ๆ.

neoleviculops Heinrich. Maine, Ohio.

Melanichneumon neoleviculops Heinrich, 1971. Nat. Canad. 98: 1015. ठ, ₹.

pluto (Viereck), revised status. N. Y., Ont., Mich., Ohio, N. Mex. The name pluto has been erroneously suppressed in synonymy since 1944 , most recently by Heinrich $(1959,1962)$, who did not realize that Ichnenmon nigripes Provancher is preoccupied.

Ichneumon nigripes Provancher, 1882. Nat. Canad. 13 (no. 154): 310 (key); 13 (no. 155): 324. ð. Preoce. by Gravenhorst, 1829.

Cratichneumon pluto Viereck, 1903. In Skinner, Amer. Ent. Soc., Trans. 29: 79. ठ.

Amblyteles ohioensis DeGant, 1933. U. S. Natl. Mus., Proc. 82 (11): 1. ठ, १.

Taxonomy: Townes, 1944. Amer. Ent. Soc., Mem. 11: 325. - Heinrich, 1959. Ent. News 70:

212. - Heinrich, 1962. Canad. Ent. Sup. 26: 601-602.

texanus (Cresson). Maine, R. I., N. Y., Mich., Tex., Alta. Discovery of the female of this species may show that it belongs in Vulgichneumon instead of Melanichneumon (see Heinrich, 1962).

Ichneumon texamus Cresson, 1877. Amer. Ent. Soc., Trans. 6: 159. ठ.

Taxonomy: Heinrich, 1962. Canad. Ent. Sup. 26: 632-633.

townesi Heinrich. R. I., N. Y., Mich.

Melanichneumon (Melanichnenmon) townesi Heinrich, 1962. Canad. Ent. Sup. 26: 596. o, q.

xanthogrammus (Ashmead). Kans., Tex.

Ichneumon xanthogrammus Ashmead, 1890 (1889). U. S. Natl. Mus., Proc. 12: 390. đo.

\section{Genus BARICHNEUMON Thomson}

Barichneumon Thomson, 1893. Opusc. Ent. 18: 1959.

Type-species: Ichnenmon anator Fabricius. Desig. by Ashmead, 1900.

Gurfyia Cameron, 1903. Ztschr. System. Hym. Dipt. 3: 178.

Type-species: Gurfyia albipilosa Cameron. Monotypic.

Harsaces Cameron, 1903. Entomologist 36: 238.

Type-species: Harsaces nigripes Cameron. Monotypic.

Darpasus Cameron, 1904. Ztschr. System. Hym. Dipt. 4: 344.

Type-species: Darpasus pilosus Cameron. Monotypic.

Stictichneumon Cameron, 1905. Spolia Zeylanica (Ceylon Jour. Sci., Sect. B) 3: 105.

Type-species: Stictichneumon macariae Cameron. Monotypic.

Taxonomy: Townes and Townes, 1966. Amer. Ent. Inst., Mem. 8: 261 (generic syn.).

- Heinrich, 1972. Nat. Canad. 99: 184-190 (keys to spp. of e. N. Amer.).

anator (Fabricius). Que. s. to Pa., w. to Minn. and Ill.; Europe. Host: Ostrinia nubilalis (Hbn.)?

Ichneumon anator Fabricius, 1793. Ent. System., v. 2, p. 169. Sex not indicated.

Ichneumon femoratorins Thunberg, 1822; 1824. Acad. Imp. des Sci. St. Petersburg, Mem. 8: $253 ; 9: 289$. [female].

Ichneumon bulimorius Thunberg, 1822; 1824. Acad. Imp. des Sci. St. Petersburg, Mem. 8: $255 ; 9: 295$. [female].

Ichneumon dealbator Thunberg, 1822; 1824. Acad. Imp. des Sci. St. Petersburg, Mem. 8: 272; 9: 341. Unnecessary n. name for 1 . anator Fabricius, which was not preocc. in Ichneumon by Bracon anator Fabricius.

Ichnenmon retusorius Thunberg, 1922; 1924. Acad. Imp. des Sci. St. Petersburg, Mem. 8: 278; 9: 355. [male].

Ichnenmon helvipes Cresson, 1867. Amer. Ent. Soc., Trans. 1: 310. ठ.

Phygadeuon niger Provancher, 1876. Nat. Canad. 8: 317. . Preoce. by Provancher, 1874.

Phygadenon ater (!) Provancher, 1878. Nat. Canad. 10: 299. Lapsus for P. niger

Provancher, 1876.

Phygadenon electus Provancher, 1886. Addit. Corr. Faune Ent. Canada Hym., p. 51. "o" = б. 
Taxonomy: Roman, 1912. Zool. Bidr. Uppsala 1: 240, 249, 255, 277 (syn.). - Heinrich, 1953. Wash. Acad. Sci., Jour. 43: 149. - Heinrich, 1959. Canad. Ent. 91: 806. -Heinrich, 1962. Canad. Ent. Sup. 26: 621-622.

archboldi Heinrich. Fla.

Barichneumon archboldi Heinrich, 1972. Nat. Canad. 99: 196. đ, ?.

californicus Heinrich. Calif.; Hawaii.

Barichneumon californicus Heinrich, 1971. Nat. Canad. 98: 1013. \&.

carolinensis Heinrich. N. C., Ga., Fla., La.

Barichneumon carolinensis Heinrich, 1972. Nat. Canad. 99: 199. ¿,.

crassipunctus Heinrich. Ga.

Barichneumon crassipunctus Heinrich, 1971. Nat. Canad. 98: 1009. ؟.

danieli Heinrich. N. Y.

Barichneumon danieli Heinrich, 1972. Nat. Canad. 99: 200. $\delta$.

excelsior (Heinrich). Que., Maine, Va., Ont., Mich., Ky.

Melanichneumon (Barichneumon) excelsior Heinrich, 1962. Canad. Ent. Sup. 26: 627..

Taxonomy: Heinrich, 1971. Nat. Canad. 98: 1005-1006 (male described).

flaviscuta Heinrich. Ga., Miss.

Barichneumon flaviscuta Heinrich, 1971. Nat. Canad. 98: 1007. đ, ?.

floridanus Heinrich. Fla.

Barichneumon floridanus Heinrich, 1972. Nat. Canad. 99: 198. ઠं, ९.

fuscosignatus Heinrich. Ga., Fla., Miss., La.

Barichneumon fuscosignatus Heinrich, 1972. Nat. Canad. 99: 197. \&, ?.

libens (Cresson). Maine s. to s. Fla., w. to Mich., Ill., and La.

Ichneumon libens Cresson, 1877. Amer. Ent. Soc., Trans. 6: 181. ð.

Taxonomy: Heinrich, 1972. Nat. Canad. 99: 194.

neosorex Heinrich. Ga., Fla., Miss., La.

Barichneumon neosorex Heinrich, 1972. Nat. Canad. 99: 195. ठ, ?.

peramoenus calliandros Heinrich. Fla.

Barichneumon peramoenus calliandros Heinrich, 1972. Nat. Canad. 99: 193. ठ,,.

peramoenus peramoenus (Heinrich). Que. s. to Ga., w. to Mich. and La.

Melanichneumon peramoenus Heinrich, 1962. Canad. Ent. Sup. 26: 631. ठ. Heinrich was uncertain as to the subgeneric placement of this species.

Taxonomy: Heinrich, 1972. Nat. Canad. 99: 192-193 (female described).

seticornutus Heinrich. Ga.

Barichneumon seticoruntus Heinrich, 1971. Nat. Canad. 98: 1011. ठ, ?.

sorex (Heinrich). Que. s. to Ga., w. to Mich. Heinrich (1972) said that sorex is "probably [a] synonym or subspecies of libens [(Cresson)]," and that the allotype male may actually be B. sphageti Heinrich.

Melanichneumon (Barichneumon) sorex Heinrich, 1962. Canad. Ent. Sup. 26: 624. ๆ (o misdet.?).

Taxonomy: Heinrich, 1972. Nat. Canad. 99: 186, 190, 191, 194.

soror (Cresson), Que. s. to Del., w. to Mich.

Ichneumon soror Cresson, 1864. Ent. Soc. Phila., Proc. 3: 185..+

Ichneumon bimaculatus Provancher, 1888. Addit. Corr. Faune Ent. Canada Hym., p. 357.

ঠ. Preocc. by Schrank, 1776; Gmelin, 1790; Christ, 1791; and Fabricius, 1793.

Ichneumon bimacularis Dalla Torre, 1902. Cat. Hym., v. 3, p. 863. N. name for $I$. bimaculatus Provancher.

sphageti Heinrich. Maine, N. Y., Miss. Ecology: The holotype was collected in a spruce (Picea mariana) bog.

Barichneumon sphageti Heinrich, 1971. Nat. Canad. 98: 1008. ?.

Taxonomy: Heinrich, 1972. Nat. Canad. 99: 194-195. 


\section{Genus VULGICHNEUMON Heinrich}

Melanichneumon subg. Vulgichneumon Heinrich, 1961 (1960). Canad. Ent. Sup. 15: 17. Type-species: Ichneumon brevicinctor Say. Monotypic and orig. desig.

Taxonomy: Heinrich, 1968 (1967). Synopsis and Reclassif. Ichneumoninae Stenopneusticae Africa So. of Sahara, v. 3, p. 615-616 (placement in Pterocormina [=Ichneumonina sensu Heinrich]). - Heinrich, 1971. Nat. Canad. 98: 1014 (placement in Gyrodontina [=Cratichneumonina]).

albomarginatus (Cresson). Que., Maine, N. H., Vt., N. Y., N. J., Ont., Mich., Ohio, Ind., Miss. Ichueumon albomarginatus Cresson, 1867. Amer. Ent. Soc., Trans. 1: 297. o.

brevicinctor (Say). Que. w. to B. C., s. to Fla., Tex., and Calif. Host: Achatodes zeae (Harris), Bleptina sp., Callopistria floridensis (Gn.), Lascoria ambigualis (Wlk.), Macronoctua onusta (Grt.), Plathypena scabra (F.), Psendaletia unipuncta (Haw.), Trichoplusia ni (Hbn.), Ostrinia nubilalis (Hbn.), Hyphantria cunea (Drury).

Ichuenmon brevicinctor Say, 1825. Amer. Ent. 2: 49. ठ.

Ichneumon extrematis Cresson, 1864. Ent. Soc. Phila., Proc. 3: 149. \&.

Ichneumon extrematatis (!) Cresson, 1867. Amer. Ent. Soc., Trans. 1: 290.

Phygadeuon niger Provancher, 1874. Nat. Canad. 6: 280. .

heleiobatos (Porter). N. J., Mich. Ecology: This species has been collected only in and around swamps where the vegetation was predominantly grasses interspersed with Salix bushes.

Melanichnenmon (Vulgichneumon) heleiobatos Porter, 1964. Psyche 71: 130. đ, ๆ.

mimicus (Cresson). Newfoundland (insular), Que., Maine, Mass., Conn., N. Y., Mich., S. Dak., Idaho, Oreg.

Ichneumon mimicus Cresson, 1867. Amer. Ent. Soc., Trans. 1: 300. ठ.

phaeogenops Heinrich. N. C., Fla., Miss.

Vulgichneumon phaeogenops Heinrich, 1972. Nat. Canad. 99: 209. ১, ๆ.

saevus (Cresson). Maine, N. Y., R. I., IIl.

Ichneumon saerus Cresson, 1867. Amer. Ent. Soc., Trans. 1: 296..

subcyaneus (Cresson). Que. s. to Ga., w. to B. C. and Calif.; Mexico? Host: Diacrisia virginica (F.), Hyphantria cunea (Drury), Tyria jacobaeae (L.).

Ichneumon pullatus Cresson, 1864. Ent. Soc. Phila., Proc. 3: 146. ठ.

Ichneumon cordatus Cresson, 1864. Ent. Soc. Phila., Proc. 3: 146. ठ. N. syn.

Ichneumon subcyaneus Cresson, 1864. Ent. Soc. Phila., Proc. 3: 148. ๆ.

Ichneumon solitus Cresson, 1877. Amer. Ent. Soc., Trans. 6: 144. ₹. N. syn.

Ichneumon odiosus Cresson, 1877. Amer. Ent. Soc., Trans. 6: 145. ठ. N. syn.

Ichnenmon nentralis Cresson, 1877. Amer. Ent. Soc., Trans. 6: 149. ठ. N. syn.

Taxonomy: Heinrich, 1959. Ent. News 70: 212. - Townes and Townes, 1966. Amer. Ent. Inst., Mem. 8: 264 (oversight of Heinrich [1959]).

terminalis (Cresson). Que. s. to N. C., w. to Minn. and Mo.

Ichneumon terminalis Cresson, 1864. Ent. Soc. Phila., Proc. 3: 184. \&.

Ichneumon finitimus Cresson, 1867. Amer. Ent. Soc., Trans. 1: 302 . "q" = $\delta$.

Mesostenus apicalis Provancher, 1875. Nat. Canad. 7: 266. ठ.

Phygadenon brevicaudus Provancher, 1886. Addit. Corr. Faune Ent. Canada Hym., p. 54. †.

Melanichnenmon (Vulgichneumon) terminalis carolinensis Heinrich, 1962. Canad. Ent. Sup. 26: 619. . . N. syn.

zebratus (Cresson). N. Y. w. to s. B. C., s. to Ga., Tex., and Calif. Host: Prochoerodes forficaria (Gn.).

Ichneumon zebratus Cresson, 1867. Amer. Ent. Soc., Trans. 1: 299. ^.

\section{Genus RICHTICHNEUMON Heinrich, n. status?}

Melanichneumon subg. Richtichneumon Heinrich, 1961 (1960). Canad. Ent. Sup. 15: 17. Type-species: Ichneumon residuus Say. Monotypic and orig. desig. 
belfragei (Cresson), n. comb. La., Tex., e. Wyo., s. w. Utah. The discovery of two females in the collection of the U.S. Natl. Museum shows that this species should be removed from Melanichneumon (see Heinrich, 1959) and placed in Richtichneumon by virtue of general agreement with Heinrich's definition of the latter.

Ichneumon Belfragei Cresson, 1872. Amer. Ent. Soc., Trans. 4: 156. ठ.

residuus (Say). Mass. s. to Md., w. to N. Dak. and Kans. Host: Alsophila pometaria (Harris).

Ichneumon residuus Say, 1829. Contrib. Maclurian Lyceum to Arts and Sci. 1: 73..

Ichneumon utilis Cresson, 1867. Amer. Ent. Soc., Trans. 1: 311. ¿.

Platylabus (Colocnema?) omniferrugineus Viereck, 1905. Kans. Acad. Sci., Trans. 19: 322. ․

Taxonomy: Cushman and Gahan, 1921. Ent. Soc. Wash., Proc. 23: 167.

virginicus (Cresson). W. Va.

Ichneumon virginicus Cresson, 1864. Ent. Soc. Phila., Proc. 3: 165. ठ.

Ichneumon ornatipes Cresson, 1867. Amer. Ent. Soc., Trans. 1: 294. ठ̀.

\section{Genus STENOBARICHNEUMON Heinrich}

Stenobarichneumon Heinrich, 1961 (1960). Canad. Ent. Sup. 15: 16.

Type-species: Ichneumon citator Thunberg. Monotypic and orig. desig.

This is a small genus of Holarctic and Neotropic distribution.

agitator Heinrich. Que., Maine, Ont., Mich.

Stenobarichneumon agitator Heinrich, 1962. Canad. Ent. Sup. 26: 639. §, १.

duplicans Heinrich. Maine.

Stenobarichneumon duplicans Heinrich, 1962. Canad. Ent. Sup. 26: 638. o, \&.

melanocephalus Heinrich. Newfoundland (insular).

Stenobarichneumon melanocephalus Heinrich, 1976 (1975). Nat. Canad. 102: 770. ठ.

pergracilis Heinrich. Newfoundland (insular), Que., Maine, Ont., Mich.

Stenobarichneumon pergracilis Heinrich, 1962. Canad. Ent. Sup. 26: 635. ठ゚, ९.

pygmaeops Heinrich. Newfoundland (insular), Que., Maine, Ont., Mich.

Stenobarichneumon pygmaeops Heinrich, 1962. Canad. Ent. Sup. 26: 637. đ, \&.

Stenobarichneumon pygmaeops insulanus Heinrich, 1976 (1975). Nat. Canad. 102: 771. ठ, . N. syn. The specimens in the type series, which are from two localities in insular Newfoundland, were described as showing, "on the average, a markedly increased melanism in comparison with populations from the type locality ([Dryden], Maine)."

saundersi (Cresson). Que., Maine, N. Y., Alta.

Ichneumon Saundersi Cresson, 1877. Amer. Ent. Soc., Trans. 6: 141 (key), 177, 211 (index). $\delta$. The spelling Saundersii appears on pages 177 and 211, but Walkley (1958) appears to have chosen the alternate spelling Saundersi.

Taxonomy: Walkley, 1958. In Krombein et al., U. S. Dept. Agr., Agr. Monog. 2, sup. 1, p. 49.

\section{Genus MENKOKIA Heinrich}

Melanichneumon subg. Menkokia Heinrich, 1934. Berlin Zool. Mus., Mitt. 20: 209.

Type-species: Melanichneumon (Menkokia) major Heinrich. Orig. desig.

This genus is Oriental and Nearctic. Heinrich $(1969,1971)$ placed the genus in the Pterocormina, but I doubt that he is correct.

Taxonomy: Heinrich, 1969 (1968). Synopsis and Reclassif. Ichneumoninae Stenopneusticae

Africa So. of Sahara, v. 5, p. 1147. - Heinrich, 1971. Nat. Canad. 98: 971-973.

blandii (Cresson). N. Y. s. to N. C., w. to Mich., Kans., and Ark.

Ischnus blandii Cresson, 1864. Ent. Soc. Phila., Proc. 3: 188. ठ.

\section{Genus RUBICUNDIELLA Heinrich}

Rubicundiella Heinrich, 1961 (1960). Canad. Ent. Sup. 15: 15.

Type-species: Ichneumon mucronatus Provancher. Monotypic and orig. desig. 
annulicornis (Ashmead). N. J., Ga., Fla., Mich, La. Host: Plathypena scabra (F.), Hellula rogatalis (Hulst), Herpetogramma sp., Udea rubigalis (Gn.).

Colpognathus annulicornis Ashmead, 1890 (1889). U. S. Natl. Mus., Proc. 12: 396..

blanchardi (Davis). Que., Maine, N. H., Mass., Mich.

Ichneumon blanchardi Davis, 1898 (1897). Amer. Ent. Soc., Trans. 24: 350. ?.

Ichneumon blanchardii Dalla Torre, 1902. Cat. Hym., v. 3, p. 865. Emend.

deuteromelas Heinrich. Maine, Mich., Yukon.

Rubicundiella deuteromelas Heinrich, 1962. Canad. Ent. Sup. 26: 573. ठ.

mucronata (Provancher). Que., Md., Kans.

Ichneumon mucronatus Provancher, 1875. Nat. Canad. 7 (1): 24 (key); 7 (3): 81 . “o" = б.

perturbatrix Heinrich. Maine w. to Oreg., s. to Ga., s. Tex., and Calif.; Bermuda; Hawaii. Host: Ostrinia nubilalis (Hbn.), Macronoctua on usta Grt., Spodoptera exigua (Hbn.).

Ichneumon rubicundus Cresson, 1864. Ent. Soc. Phila., Proc. 3: 176.. Preocc. by Geoffroy, 1785 .

Rubicundiella perturbatrix Heinrich, 1962. Canad. Ent. Sup. 26: 577. N. name for 1 . rubicundus Cresson.

Rubicundiella perturbans(!) Heinrich, 1972. Nat. Canad. 99: 195.

Biology: Wishart, 1949 (1948). Canad. Ent. 80: 118-137.

simplicior Heinrich. Southern Sask., s. w. B. C., w. Oreg. Host: Fishia discors (Grt.), Heliothis oninis (D. and S.), Synanthedon bibionipennis (Bdv.).

Rubicundiella simplicior Heinrich, 1962. Canad. Ent. Sup. 26: 575. đ, ?.

\section{Genus LIMONETHE Townes}

Limonethe Townes, 1946. Bol. Ent. Venezolana 5: 56.

Type-species: Ichneumon insolens Cresson. Orig. desig.

maurator (Brulle). Que. s. to Fla., w. to Minn. and Tex.

Joppa maurator Brulle, 1846. In Lepeletier, Hist. Nat. Ins. Hym., v. 4, p. 287. ठ, $q$.

Ichneumon insolens Cresson, 1867. Amer. Ent. Soc., Trans. 1: 302. $\delta, q$.

Joppa Canadensis Provancher, 1874. Nat. Canad. 6: 336. ‥

Tetragonochora mauratrix Schulz, 1906. Spolia Hym., p. 129. Emend.

\section{Genus CARINODES Hancock}

Carinodes Hancock, 1926. Entomologist 59: 189.

Type-species: Carinodes spinosus Hancock. Monotypic and orig. desig.

Ditremops Townes, 1946. Bol. Ent. Venezolana 5: 52.

Type-species: Ichneumon abjectus Cresson. Orig. desig.

This is a very large genus. Except for the two species with ranges that extend into the United States, Carinodes is Neotropic.

Taxonomy: Walkley, 1958. In Krombein et al., U. S. Dept. Agr., Agr. Monog. 2, Sup. 1, p. 48-49 (syn.). -Fitton, 1975. Studia Ent. 18: 381 (holotype of C. spinosus Hancock found). albipectus (Brulle). Fla.; Cuba, Jamaica.

Ichnenmon albipectus Brulle, 1846. In Lepeletier, Hist. Nat. Ins. Hym., v. 4, p. 306. ठ。.

Ichneumon burrus Cresson, 1865. Ent. Soc. Phila., Proc. 4: 14..+

Taxonomy: Townes and Townes, 1966. Amer. Ent. Inst., Mem. 8: 255 (syn.).

havanensis (Cameron). Fla.; Cuba, Puerto Rico, St. Croix. Host: Anticarsia gemmatalis Hbn.

The host record pertains to a Cuban specimen in the U. S. Natl. Museum collection.

Ichneumon(?) havanensis Cameron, 1906. Cuba, Estac. Expt. Agron., Informe, p. 277. o.

Taxonomy: Heinrich, 1937. Ann. and Mag. Nat. Hist. (10) 20: 262.

\section{Genus AOPLUS Tischbein}

Aoplus Tischbein, 1874. Stettin. Ent. Ztg. 35: 137.

Type-species: Aoplus inermis Tischbein. Monotypic.

Trachichneumon Viereck, 1912. U. S. Natl. Mus., Proc. 42: 645.

Type-species: Ichneumon confirmatus Cresson. Monotypic and orig. desig. 
cestus (Cresson). Idaho, B. C., Wash., Oreg. Host: Lambdina fiscellaria lugubrosa (Hulst), Melanolophia imitata (Wlk.).

Ichneumon cestus Cresson, 1877. Amer. Ent. Soc., Trans. 6: 182..

Platylabus opacitus Davis, 1898 (1897). Amer. Ent. Soc., Trans. 24: 353. ठ。.

confirmatus (Cresson). Que. s. to Ga., w. to Colo.

Ichneumon confirmatus Cresson, 1877. Amer. Ent. Soc., Trans. 6: 178. \&.

Phygadeuon potens Provancher, 1886. Addit. Corr. Faune Ent. Canada Hym., p. 47. $\uparrow$.

Phygadeuon jocosus Provancher, 1886. Addit. Corr. Faune Ent. Canada Hym., p. 53. $\uparrow$. This name was based upon the same type-specimen or specimens as was $P$. potens

Provancher, the latter being the name Provancher used in his key.

groenlandicus (Lundbeck). Greenland.

Ichneumon groenlandicus Lundbeck, 1897 (1896). Dansk Naturhist. For. Kjobenhavn, Vidensk. Meddel., p. 223. .

Taxonomy: Townes, 1961. Ent. Soc. Wash., Proc. 63: 108 (generic placement).

limbatae Heinrich. Mich., B. C. Host: Nematocampa filiamentaria Gn. Aoplus limbatae Heinrich, 1962. Canad. Ent. Sup. 26: 542. ठ, ?.

mathewi (Cameron). Southwestern B. C.

Ichneumon matheri Cameron, 1907. Entomologist 40: 277. ठ.

melanisticus Heinrich. Ont., Yukon.

Aoplus melanisticus Heinrich, 1962. Canad. Ent. Sup. 26: 547. ๆ.

moilietti Heinrich. Alta. Host: Enypia griseata Grossb.

Aoplus moilietti Heinrich, 1962. Canad. Ent. Sup. 26: 544,671. $९$. The name is a mispelling of a host name now in synonymy with $E$. griseata; the name appears as "moiletti Cress." on p. 671 (index).

monotonus Heinrich. Colo., Alta., B. C., Wash., Oreg., Calif. Host: Geometrid on Polygonum . Aoplus monotonus Heinrich, 1962. Canad. Ent. Sup. 26: 548. ठ', ?.

ochropis coloradensis Heinrich. Newfoundland (insular), Que., Colo., Alta.

Aoplus ochropis coloradensis Heinrich, 1962. Canad. Ent. Sup. 26: 556. ठ, ?.

ochropis ochropis (Gmelin). Alaska; Eurasia.

Ichneumon ochropis Gmelin, 1790. In Linnaeus, Syst. Nat., ed. 13, p. 2679. Sex not indicated.

Melanichneumon seldoviae Ashmead, 1902. Wash. Acad. Sci., Proc. 4: 155. ठ.

permutabilis Heinrich. Newfoundland (insular), s. to Md., w. to Mich. and Mo. Aoplus permutabilis permutabilis Heinrich, 1962. Canad. Ent. Sup. 26: 541. đ, ?. Aoplus permutabilis leucorbis Heinrich, 1962. Canad. Ent. Sup. 26: 542. ?.

pseudovelox Heinrich. Que., Maine, N. H., N. Y., Pa., Ont., Mich., Alta. Aoplus pseudovelox Heinrich, 1962. Canad. Ent. Sup. 26: 556. ठ, ๆ.

rarior Heinrich. Que., Ont.

Aoplus rarior Heinrich, 1962. Canad. Ent. Sup. 26: 546..

ruficeps sitkensis (Ashmead). Newfoundland (insular) w. to Alaska, s. to Maine, Mich., Colo., and Wash. Host: Macaria sp., Rheumaptera hastata (L.). A. ruficeps ruficeps (Gravenhorst) is Eurasian.

Ichmeumon vagans Provancher, 1875. Nat. Canad. 7 (1): 22 (key); 7 (2): 51. o. N. syn.; preocc. by Olivier, 1792 .

Ichneumon sitkensis Ashmead, 1902. Wash. Acad. Sci., Proc. 4: 152. ठ.

Ichneumon simulator Ashmead, 1902. Wash. Acad. Sci., Proc. 4: 153. o. Uncertain syn.; preocc. by Olivier, 1792 .

Taxonomy: Heinrich, 1959. Ent. News 70: 211 (syn.).

thujarum Heinrich. Que., Ont.

Aoplus thujarum Heinrich, 1962. Canad. Ent. Sup. 26: 543..

torpidus (Wesmael). Newfoundland (insular), Que., Maine, Ont., Mich., Alta.; Europe.

Ichneumon torpidns Wesmael, 1857. [Brussels] Acad. Roy. de Belg., Bul. 24: 385. §. 
velox (Cresson). Newfoundland (insular) w. to Alaska, s. to Pa., Ill., Colo., and Calif. Host: Lambdina fervidaria athasaria (Wlk.), L. fiscellaria fiscellaria (Gn.), L. fiscellaria lugubrosa (Hulst), Nepytia canosaria (Wlk.)., Symmerista leucitys Francl.

Ichneumon celox Cresson, 1864. Ent. Soc. Phila., Proc. 3: 185. \&.

Ichneumon puerilis Cresson, 1867. Amer. Ent. Soc., Trans. 1: 296. o.

Ichneumon mellicoxus Provancher, 1875. Nat. Canad. 7 (1): 21 (key); 7 (2): 48. ठ.

Phygadenon apicatus Provancher, 1875. Nat. Canad. 7 (6): 180..

Phygadeuou cressoni Provancher, 1876. Nat. Canad. 8: 318. ?.

Ichneumou occidentalis Harrington, 1894. Canad. Ent. 26: 210. ․

Biology: Schedl, 1931. Ztschr. f. Angew. Ent. 8: 270-273.

\section{Genus HEMIHOPLIS Heinrich}

Hemihoplis Heinrich, 1961 (1960). Canad. Ent. Sup. 15: 15.

Type-species: Hoplismenus teres Swift. Monotypic and orig. desig.

teres (Swift). N. Y. s. to Fla., w. to Mich., Ill., and La. Host: Precis lavimia Cr.

Hoplismenus teres Swift, 1946. Ent. Soc. Amer., Ann. 39: 409.

\section{Genus PLATYLABOPS Heinrich}

Platylabops Heinrich, 1950. Naturw. Mus. Aschaffenburg, Mitt. d. Sammelstelle f.

Schmarotzerbestimmung 27: 4.

Type-species: Platylabops hinzi Heinrich. Monotypic.

This is a small Holaretic genus.

apricus neareticus Heinrich. Maine, N. Y. P. apricus apricus (Gravenhorst) is European.

Platylabops apricus nearcticus Heinrich, 1962. Canad. Ent. Sup. 26: 648. o, \&.

eupitheciarum Heinrich. Alta., B. C. Host: Eupithecia ornata (Hulst), E. placidata Tay., E. unicolor (Hulst).

Platylabops eupitheciarum Heinrich, 1962. Canad. Ent. Sup. 26: 648. o.

fraterculus Heinrich. Newfoundland (insular), Maine, Vt., N. Y.

Platylabops fraterculus Heinrich, 1962. Canad. Ent. Sup. 26: 644. o, १.

holoerythrus Heinrich. Newfoundland (insular), B. C. Host: Eupithecia transcanadata MacK.

Platylabops holoerythrus Heinrich, 1962. Canad. Ent. Sup. 26: 645. ₹.

Taxonomy: Heinrich, 1976 (1975). Nat. Canad. 102: 771-772 (male described).

leucopsis (Ashmead). Wash., Oreg., Calif. According to Riley and Howard (1890), the holotype was reared from a "Tortricid pupa on oak."

Ichneumon leucopsis Ashmead, 1890 (1889). U. S. Natl. Mus., Proc. 12: 391. ó.

Biology: Riley and Howard, 1890. U. S. Dept. Agr., Insect Life 3: 152.

novaescotiae Heinrich. Newfoundland (insular), N. S. Heinrich (1976) made a subspecific distinction between the two specimens from which this species is known.

Platylabops pechi noiaescotiae Heinrich, 1962. Canad. Ent. Sup. 26: 643. \&.

Platylabops novascotiae(!) Peck, 1964. In Heinrich, Ent. Soc. Canada, Mem. 35: 918.

Platylabops noldescotiae nigrimembris Heinrich, 1976 (1975). Nat. Canad. 102: 773. ․ N. syn.

pecki Heinrich. Sask.

Platylabops pecki pecki Heinrich, 1962. Canad. Ent. Sup. 26: 642. ठ, १.

Taxonomy: Heinrich, 1976 (1975). Nat. Canad. 102: 773.

\section{UNPLACED TAXA OF GYRODONTINA}

Ichneumon limbifrous Cresson, 1864. Ent. Soc. Phila., Proc. 3: 182. ó. Colo.

Taxonomy: Townes, 1944. Amer. Ent. Soc., Mem. 11: 326.

Ichneumou pectoralis Say, 1829. Contrib. Maclurian Lyceum to Arts and Sci. 1: 72 . $\delta$. Southwestern Ind. Heinrich (1961) misinterpreted Say's use of the term pectus. In his writings on Hymenoptera, Say used both the terms pectus and postpectus, and it 
consequently seems evident that his usage of pectus is essentially synonymous with mesosternum. In his statement that the pectus of pectoralis is "black with a large yellow spot between the intermediate and posterior feet," Say presumably intended to write: intermediate and anterior feet.

Taxonomy: Say, 1836. Boston Jour. Nat. Hist. 1: 231 (coloration of propodeum). - Cushman and Gahan, 1921. Ent. Soc. Wash., Proc. 23: 166. - Heinrich, 1961 (1960). Canad. Ent. Sup. 18: $172-173$.

Ichneumon vultus Cresson, 1864. Ent. Soc. Phila., Proc. 3: 165. ठ. Colo.

Taxonomy: Townes, 1944. Amer. Ent. Soc., Mem. 11: 332.

\section{SUBTRIBE AMBLYTELESINA}

All available evidence seems to indicate that the females of species in this subtribe oviposit into the host larva rather than the pupa. In some of the genera, inseminated adult females are apparently the only overwintering life stage.

\section{Genus ECTOPIMORPHA Viereck}

Ectopimorpho Viereck, 1912. U. S. Natl. Mus., Proc. $43: 589$

Type-species: Ichneumon anceps Cresson. Monotypic and orig. desig.

This genus is apparently restricted to the Nearctic Region.

boops Heinrich. Calif.

Ectopimorpha boops Heinrich, 1961. Canad. Ent. Sup. 23: 494. ठั.

californica Heinrich. Calif.

Ectopimorpha californica Heinrich, 1961. Canad. Ent. Sup. 23: 486..

hiulca (Cresson). B. C. Known only from the holotype which, according to Cresson (1879), was collected at "Lake Lahache" (i.e. Lac la Hache), B. C.

Amblyteles hiulcus Cresson, 1877. Amer. Ent. Soc., Trans. 6: 172. " $\delta "=$ ?.

Taxonomy: Cresson, 1879 (1878). Acad. Nat. Sci. Phila., Proc. 30: 355-356.

hiulcops Heinrich. Sask., B. C.

Ectopimorpha hiulcops Heinrich, 1961. Canad. Ent. Sup. 23: 486..

indemnis (Cresson). Sask., B. C.

Ichueumon inderunis Cresson, 1877. Amer. Ent. Soc., Trans. 6: 172. “ $\delta "=$ ?.

limerodops Heinrich. Calif.

Ectopimorpha limerodops Heinrich, 1961. Canad. Ent. Sup. 23: 487...

Iuperinae Cushman. Newfoundland (insular), Maine, Mass., N. Y., Mich., Ohio, Iowa, Sask.? Host: Luperina stipata (Morr.).

Ectopimorpha luperinae Cushman, 1931. U. S. Natl. Mus., Proc. 79 (14): 1. ठ,.

Biology: Decker, 1930. Iowa Agr. Expt. Sta., Res. Bul. 125: 159. - Decker, 1935. Iowa State

Col. Jour. Sci. 9: 571.

scibilis (Cresson). Ill.

Ichneumon scibilis Cresson, 1877. Amer. Ent. Soc., Trans. 6: 183. $\delta$.

utahensis Heinrich. Utah.

Ectopimorpha utahensis Heinrich, 1961. Canad. Ent. Sup. 23: 493. ठ.

wilsoni (Cresson). Que. s. to Ga., w. to Iowa and Mo.

Ischnus wilsoni Cresson, 1864. Ent. Soc. Phila., Proc. 3: 188. ठ.

Ichneumou anceps Cresson, 1867. Amer. Ent. Soc., Trans. 1: 309.,$+ " \delta "=$ q. Preoce. by Villers, 1789.

Ichneumon wilsonii Dalla Torre, 1902. Cat. Hym., v. 3, p. 1017. Emend.

\section{Genus EXEPHANES Wesmael}

Exephanes Wesmael, 1845 (1844). [Brussels] Acad. Roy. de Belg., Nouveaux Mem. 18: 17. Type-species: Ichneumon hilaris Gravenhorst. Desig. by Ashmead, 1900.

Octatomus Tischbein, 1881. Stettin. Ent. Ztg. 42: 186. 
Type-species: Octatomus tricolor Tischbein. Monotypic. The type-species is regarded as a synonym of $E$. femoralis Brischke.

Heinrich (1976) placed Exephanes in the Pterocormina, but did not indicate his rationale for doing so.

Taxonomy: Heinrich, 1976 (1975), Nat. Canad. 102: 763.

californicus Heinrich. Colo., Utah, Ariz., Calif.

Exephanes californicus Heinrich, 1961. Canad. Ent. Sup. 23: 480. đ’,.

subfulvus (Cresson). Que.?, Sask., Colo., Alta.

Ichneumon subfulvus Cresson, 1865. Ent. Soc. Phila., Proc. 4: 258..

terminalis (Provancher). Newfoundland (insular), Que., Maine, Conn., Ont., Mich., Minn., s. N. W. T., Colo.

Phygadeuon terminalis Provancher, 1874. Nat. Canad. 6: 284. ․

Ichneumon caudatus Provancher, 1875. Nat. Canad. 7 (1): 24 (key); 7 (3): 82..

Ichneumon pomilius Provancher, 1877. Nat. Canad. 9: 9. ठ.

Phygadeuon Geddessii Provancher, 1886. Addit. Corr. Faune Ent. Canada Hym., p. 54.. Amblyteles Cookii Ashmead, 1890 (1889). U. S. Natl. Mus., Proc. 12: 392. ?.

Exephanes terminalis immaculatus Heinrich, 1961. Canad. Ent. Sup. 23: 479. đ, ?. N. syn.

\section{Genus LIMERODOPS Heinrich}

Limerodops Heinrich, 1949. Muenchner Ent. Gesell., Mitt. 35-39: 44.

Type-species: Amblyteles subsericans var. elongatus Brischke? Monotypic and, in part, orig. desig. Heinrich's original designation was "Amblyteles elongatus

Brischke $=A$. subsericans $\operatorname{Gr}[$ avenhorst $]$ partim $=A$. fossorius L[innaeus] (nach Roman [1932])." See discussion of type-species of Probolus.

This is a small genus of Holarctic distribution.

Taxonomy: Roman, 1932. Ent. Tidskr. 53: 6. - Heinrich, 1953. Wash. Acad. Sci., Jour. 43: 150. - Perkins, 1953. Brit. Mus. (Nat. Hist.) Ent., Bul. 3: 106. -Townes, Momoi, and Townes, 1965. Amer. Ent. Inst., Mem. 5: 503.

belangeri (Cresson). N. S. w. to Alaska, s. to N. Y., Mich., Colo., Wash. Host: Euxoa divergens (Wlk.).

Amblyteles Belangeri Cresson, 1877. Amer. Ent. Soc., Trans. 6: 190. ㅇ.

Cryptus dubius Provancher, 1886. Addit. Corr. Faune Ent. Canada Hym., p. 71. "

Preocc. by Taschenberg, 1865.

Taxonomy: Heinrich, 1953. Wash. Acad. Sci., Jour. 43: 150.

mariannae Heinrich. N. S., Maine, Mass., Ont., Mich.

Limerodops mariannae Heinrich, 1961. Canad. Ent. Sup. 23: 383. đ, ๆ.

\section{Genus NEAMBLYMORPHA Heinrich}

Neamblymorpha Heinrich, 1961 (1960). Canad. Ent. Sup. 15: 19.

Type-species: Ichneumon milvus Cresson. Monotypic and orig. desig.

A single species is known.

milva (Cresson). Newfoundland (insular) s. to N. C., w. to Mich.

Ichneumon (Ichneumon) milvus Harris, 1835. In Hitchcock, Rpt. Geol. Mineral. Bot. Zool. Mass., Ed. 2, p. 585 . Nomen nudum.

Ichneumon milvus Cresson, 1867. Amer. Ent. Soc., Trans. 1: 305. ð.

Ichneumon Clopini Provancher, 1875. Nat. Canad. 7: 250. ठ์.

\section{Genus EUTANYACRA Cameron}

Eutanyacra Cameron, 1903. Ent. Soc. London, Trans. 51: 227.

Type-species: Eutanyacra pallidicoxis Cameron. Monotypic.

This large genus is Neotropic, Holaretic, and Oriental. 
chillcotti Heinrich. Northern Que., N. W. T.

Eutanyacra chillcotti Heinrich, 1956. Canad. Ent. 88: 478. ơ, ?.

consignata (Cresson). Maine, Mass., N. Y., N. J., Md., W. Va., Ohio, Wis., Ill., Kans.

Ichneumon consignatus Cresson, 1867. Amer. Ent. Soc., Trans. 1: 298. ठ̊.

hiemans Heinrich. Que., Maine, Pa., Ont., Ohio, Mich.

Entanyacra hiemans Heinrich, 1961. Canad. Ent. Sup. 23: 436. ๆ.

improvisa (Cresson). N. S. s. to Md., w. to B. C. and Oreg. Host: Anomogyna perquiritata (Morr.), Ceramica picta (Harris).

Ichneumon improvisus Cresson, 1867. Amer. Ent. Soc., Trans. 1: 296. ठั.

Amblyteles tetricus Provancher, 1877. Nat. Canad. 9: 10. $\delta, ~ ?$.

Eutanyacra improvisa columbiana Heinrich, 1961. Canad. Ent. Sup. 23: 428. ठ, ๆ. N. syn.

melanotarsis Heinrich. Fla., La.

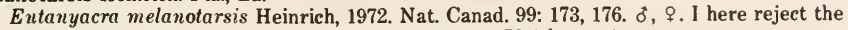
alternate spelling nigritarsis which appears on p. 173 (abstract).

miraculosa Heinrich. Maine.

Eutanyacra miraculosa Heinrich, 1961. Canad. Ent. Sup. 23: 434..

munifica (Cresson). N. S. s. to Va., w. to Sask.

Ichneumon nobilis Cresson, 1864. Ent. Soc. Phila., Proc. 3: 155. §. Preocc. by Wesmael, 1857.

Ichneumon munificus Cresson, 1867. Amer. Ent. Soc., Trans. 1: 290. N. name for I. nobilis Cresson.

Taxonomy: Heinrich, 1971. Nat. Canad. 98: 979-980.

perannulata (Hopper). Que., Maine, N. Y., Pa., W. Va.

Amblyteles perannulatus Hopper, 1938. Amer. Ent. Soc., Trans. 64: 98..

pycnopus Heinrich. D. C., Ont., Ohio, lowa, Ark.

Eutanyacra pycropus Heinrich, 1961. Canad. Ent. Sup. 23: 435. ¿̊, ९.

saguenayensis (Provancher). Que., Maine, Mich.

Ichneumon saguenayensis Provancher, 1888. Addit. Corr. Faune Ent. Canada Hym., p. 356. $\delta$.

solitaria Heinrich. Que., Maine, N. Y., Ont., Mich.

Eutanyacra solitaria Heinrich, 1961. Canad. Ent. Sup. 23: 442. ¿, 9.

succincta (Brulle). N. Y. s. to Tenn., w. to S. Dak. and Colo. Host: "A mathes c-nigrum (L.)."

Ichneumon succinctus Brulle, 1846. In Lepeletier, Hist. Nat. Ins. Hym., v. 4, p. 301. ठ.

Ichneumon sandix Cresson, 1864. Ent. Soc. Phila., Proc. 3: 174..

suturalis (Say). Newfoundland (Labrador) w. to N. W. T. and B. C., s. to N. J., Iowa, Colo., and Calif. Host: Actebia fennica (Tausch.).

Ichneumon (Ichneumon) suturalis Harris, 1835. In Hitchcock, Rpt. Geol. Mineral. Bot. Zool. Mass., Ed. 2, p. 585. Nomen nudum.

Ichneumon suturalis Say, 1836. Boston Jour. Nat. Hist. 1: 226..

Ichneumon Grotei Cresson, 1864. Ent. Soc. Phila., Proc. 3: 154. ठ̊.

Ichneumon propinquus Cresson, 1864. Ent. Soc. Phila., Proc. 3: 172. ९.

Morphology: Peck, 1937. Canad. Jour. Res., Sect. D (Zool. Sei.) 15: 246, 251.

trivittata Heinrich. Que.

Eutanyacra trivittata Heinrich, 1961. Canad. Ent. Sup. 23: 448. ठै, ๆ.

valdenigra Heinrich. Northern Que.

Eutanyacra valdenigra Heinrich, 1958. Canad. Ent. 90: 740. ठో.

validiceps Heinrich. Que., Maine, Ont., Mich.

Eutanyacra validiceps Heinrich, 1961. Canad. Ent. Sup. 23: 443. ơ, ๆ.

vilissima Heinrich. Que., Maine, Mass., N. Y., Md., W. Va., Ont., Mich.

Eutanyacra vilissima vilissima Heinrich, 1961. Canad. Ent. Sup. 23: 440. ठ, $?$.

Eutanyacra vilissima mibricosa Heinrich, 1961. Canad. Ent. Sup. 23: 441. ठ, ๆ. N. syn.

vilissimops Heinrich. Que.

Eutanyacra vilissimops Heinrich, 1971. Nat. Canad. 98: 980.. 


\section{Genus SETANTA Cameron}

Setanta Cameron, 1901. Ann. and Mag. Nat. Hist. (7) 7: 483.

Type-species: Setanta rufipes Cameron. Monotypic.

This genus is apparently Oriental, Neotropic, and Nearctic.

Taxonomy: Townes and Townes, 1966. Amer. Ent. Inst., Mem. 8: 322, 323 (inclusion in key). compta (Say), n. comb. Que. s. to Ga., w. to S. Dak. and Tex. I am grateful for the advice of

Dr. H. K. Townes regarding the generic placement of this species.

Ichneumion comptus Say, 1836. Boston Jour. Nat. Hist. 1: 229. ठै, ๆ.

Ichneumon atrifrons Cresson, 1864. Ent. Soc. Phila., Proc. 3: 157. ๆ.

Amblyteles marginatus Provancher, 1882. Nat. Canad. 13: 328..

\section{Genus NETANYACRA Heinrich}

Netanyacra Heinrich, 1968. Nat. Canad. 95: 709.

Type-species: Netanyacra nuevoleoni Heinrich. Orig. desig.

This genus is Nearctic and Neotropic. Since Netanyacra was described females of at least one of the species have been discovered, but no female of this genus has yet been described in the literature.

arizonae Heinrich. Ariz.

Netanyacra arizonae Heinrich, 1968. Nat. Canad. 95: 716. ठ.

dakotae Heinrich. S. Dak., Alta.

Netanyacra dakotae Heinrich, 1968. Nat. Canad. 95: 714. ठ.

leucopus Heinrich. Va., S. C., Ga., Fla., Ohio, Ky., Tenn., Mo., Ark., Kans., Tex. Host:

Lacinipolia renigera (Steph.).

Eutanyacra leucopus Heinrich, 1968. Nat. Canad. 95: 712. ठ.

\section{Genus DIPHYUS Kriechbaumer}

Diphyus Kriechbaumer, 1890. Ent. Nachr. 16: 184. Diphyus was probably a typographical error for "Diphyes," a variant spelling which also appeared on page 184 of

Kriechbaumer's paper (Diphyes appeared subsequently in both the author index [p. IV] and the taxonomic index [p. VII], but no choice between the two spellings was made in the errata [p. VIII]). Sharp (1892) and Berthoumieu (1896) accepted the spelling Diphyes, but Ashmead (1900) appears to have been the first author to have made a choice between the two spellings. It is fortunate that Ashmead selected Diphyus instead of Diphyes as the latter is preoccupied by Cuvier, 1817.

Type-species: Diphyus tricolor Kriechbaumer. Monotypic.

Pseudamblyteles Ashmead, 1900. U. S. Natl. Mus., Proc. 23: 18.

Type-species: Ichneumon palliatorius Gravenhorst. Monotypic and orig. desig.

Physcoteles Berthoumieu, 1904. In Wytsman, Gen. Ins., fasc. 18, p. 51.

Type-species: Ichneumon palliatorius Gravenhorst. Desig. by Viereck, 1914.

Antelca Morley, 1914. Ann. and Mag. Nat. Hist. (8) 14: 407. Nomen nudum.

This large genus is apparently Neotropic, Holarctic, and Oriental.

Taxonomy: Sharp, 1892 (1890). Zool. Rec. 27: 194. - Berthoumieu, 1896. Soc. Ent. de France, Ann. 65: 291. - Ashmead, 1900. U. S. Natl. Mus., Proc. 23: 17, 210. - Heinrich, 1968 (1967).

Ichneumoninae Stenopneusticae Africa So. of Sahara, v. 3, p. 649-651 (syn.).

allapsus (Cresson), n. comb. Colo., Alta., B. C.

Ichneumon allapsus Cresson, 1865. Ent. Soc. Phila., Proc. 4: 256. ơ.

amoenipes (Heinrich), n. comb. Que., Maine.

Pseudamblyteles amoenipes Heinrich, 1961. Canad. Ent. Sup. 23: 413. ₹. animosus (Cresson), n. comb. Colo., Alta.

Ichneumon animosus Cresson, 1864. Ent. Soc. Phila., Proc. 3: 164. ठ. 
apiculatus (Walkley), n. comb. Colo., Alta., Mont., Wyo., Idaho, Oreg. Host: Euxoa ochrogaster (Gn.).

Ichneumon apicalis Cresson, 1864. Ent. Soc. Phila., Proc. 3: 152. o. Preoce. by Wiedeman, 1824.

Pseudamblyteles apiculatus Walkley, 1958. In Krombein et al., U. S. Dept. Agr., Agr. Monog. 2, sup. 1, p. 50. N. name for $I$. apicalis Cresson.

bizonatus (Cresson). Que. w. to Alta., s. to Md., Ky., and Colo. Ecology: Labels on four female specimens in the U.S. Natl. Museum collection indicate that they were collected in caves in late July, October, and November in Ky. and Pa.; Dasch (1971) collected a specimen in flight in Ohio during January or February.

Ichneumon bizonatus Cresson, 1864. Ent. Soc. Phila., Proc. 3: 160. ?.

Biology: Dasch, 1971. Ohio Jour. Sci. 71: 277.

carbo (Heinrich), n. comb. Que., Maine, Ont.

Pseudamblyteles carbo Heinrich, 1961. Canad. Ent. Sup. 23: 407. ठ, ․

cockerelli (Viereck), n. comb. Colo., N. Mex.

Cratichneumon cockerelli Viereck, 1903. In Skinner, Amer. Ent. Soc., Trans. 29: 76. đ.

Cratichneumon skinneri Viereck, 1903. In Skinner, Amer. Ent. Soc., Trans. 29: 78. o.

comes (Cresson), n. comb. N. Y., Pa., Del., Mich., Ill. Heinrich failed to include this species in his 1961 treatment of Pseudamblyteles; in a supplement to that work, Heinrich (1969) gave a redescription of the male of comes based upon the "holotype" from "no locality," and a specimen from $\mathrm{Pa}$.; in the original description Cresson indicated that he had specimens from Ill. and Del., and Cresson (1916) selected a lectotype from Illinois which was "in good condition." The specimen referred to as the "holotype" by Heinrich (1969) had the "Sternites and hypopygium destroyed by dermestids."

Ichneumon comes Cresson, 1864. Ent. Soc. Phila., Proc. 3: 158. ठे.

Taxonomy: Cresson, 1916. Amer. Ent. Soc., Mem. 1: 24. - Heinrich, 1969. Nat. Canad. 96: 956-957.

discus (Cresson), n. comb. Colo.

Ichneumon diseus Cresson, 1864. Ent. Soc. Phila., Proc. 3: 168. o.

distinctipes (Heinrich). Que., Maine, N. Y., Md., N. C., Ont., Mich., Ohio., Ark. Ecology: Dasch (1971) collected a female in flight during January or February in Ohio.

Pseudamblyteles distinctipes Heinrich, 1961. Canad. Ent. Sup. 23: 409..

effigialis (Heinrich), n. comb. N. B., Que., Maine, Ont., Mich.

Pseudamblyteles effigialis Heinrich, 1961. Canad. Ent. Sup. 23: 407. o, ๆ.

euxoae Heinrich, n. status. Maine, Colo., N. Mex., Alta., B. C., Wash. Host: Euxoa messoria (Harris), E. ochrogaster (Gn.).

Ichneumon variegatus Cresson, 1864. Ent. Soc. Phila., Proc. 3: 153. ठ. Preoce. by Schrank, 1785 and Gmelin, 1790.

Diphyus variegatus euxoae Heinrich, 1969. Nat. Canad. 96: 960. đo, ․ N. syn.; because Heinrich's treatment of euxoae as a subspecies of variegatus was tentative, this synonymy is also tentative.

Diphyus variegatus orientis Heinrich, 1969. Nat. Canad. 96: 962.. . N. syn.; based upon a single female with "only slight" differences from females in the type series of euxoae.

Morphology: Peck, 1937. Canad. Jour. Res., Sect. D. (Zool. Sci.) 15: 246, 249, 251.

ferrugator (Swederus), n. comb. N. Amer.

Ichneumon ferrugator Swederus, 1787. Svenska Vetensk.-Akad., Handl. 8: 280. $\subsetneq$ ("male" misdet., = Spilichneumon female).

Taxonomy: Townes, 1961. Ent. Soc. Wash., Proc. 63: 107.

flebilis (Cresson). Que., Maine, N. H., Ont., Mich.

Ichneumon flebilis Cresson, 1877. Amer. Ent. Soc., Trans. 6: 181. ․

interstinctus (Heinrich). Que., Maine, N. H., Ont., Mich.

Pseudamblyteles interstinctus Heinrich, 1961. Canad. Ent. Sup. 23: 410. \&.

Psendamblyteles interdistinctus (!) Walkley, 1967. In Krombein et al., U. S. Dept. Agr., Agr. Monog. 2, sup. 2, p. 154. 
macilentus (Cresson), n. comb. Mich., Colo., Alta. Although this species had been recorded from Mich. by Townes and Townes (1951), it was not included in Heinrich's (1961-1962) treatment of the stenopneusticae of the Northeast.

Ichneumon macilentus Cresson, 1865. Ent. Soc. Phila., Proc. 4: 249. o.

Taxonomy: Townes and Townes, 1951. In Muesebeck et al., U. S. Dept. Agr., Agr. Monog. 2: 293.

micramoenus (Heinrich), n. comb. Maine.

Pseudamblyteles micramoenus Heinrich, 1961. Canad. Ent. Sup. 23: 420. 9.

nigrotergops (Heinrich). Que., Maine, Ont.

Pseudamblyteles nigrotergops Heinrich, 1961. Canad. Ent. Sup. 23: 417. .

Diphyus nigritergops (!) Heinrich, 1969. Nat. Canad. 96: 955.

nuncius (Cresson), n. comb. Oreg., Calif. Host: Euxoa (Chorizagrotis) auxiliaris (Grote).

Ichneumon nuncius Cresson, 1877. Amer. Ent. Soc., Trans. 6: 176. o.

ontariensis (Provancher), n. comb. Ont. This species was not included in Heinrich's (1961-1962) treatment of the stenopneusticae of the Northeast.

Ichneumon Ontariensis Provancher, 1886. Addit. Corr. Faune Ent. Canada Hym., p. 30. "ㅇ" = $\delta$.

ormenus (Cresson). Newfoundland (insular) w. to Alaska, s. to Pa., Mich., N. Mex., and Wash.

Ichneumon Ormenus Cresson, 1864. Ent. Soc. Phila., Proc. 3: 141. ?.

Ichneumon tenebrosus Cresson, 1864. Ent. Soc. Phila., Proc. 3: 145. o. Preocc. by Wesmael, 1845.

Ichneumon luctus Cresson, 1865. Ent. Soc. Phila., Proc. 4: 250. N. name for I. tenebrosus Cresson.

Ichueumon mellipes Cresson, 1867. Amer. Ent. Soc., Trans. 1: 295. ơ.

Ichneumon Quebecensis Provancher, 1875. Nat. Canad. 7 (1): 24 (key); 7 (3): 77. o.

Pseudamblyteles neomexicanus Ashmead, 1901. Psyche 9: 147. o.

populorum (Heinrich), n. comb. Sask., Alta. Host: Brachylonia populi (Stkr.).

Pseudamblyteles populorum Heinrich, 1961. Canad. Ent. Sup. 23: 418. ơ, १.

provancheri (Cushman), n. comb. Que., Maine, Md., Va., Ont., Mich., Mo.

Ichneumon bifasciatus Provancher, 1875. Nat. Canad. 7 (1): 23 (key); 7 (3): 75 . . Preocc. by Geoffroy, 1785 and Say, 1829.

Amblyteles provancheri Cushman, 1925. Wash. Acad. Sci., Jour. 15: 388. N. name for $I$. bifasciatus Provancher.

robustus (Cresson). Que. w. to Alaska, s. to Maine, Mich., Colo., and Idaho.

Ichneumon robustus Cresson, 1867. Amer. Ent. Soc., Trans. 1: 298. 9.

rubellus (Cresson). Colo., Alta., Wash., Calif.

Ichneumon rubellus Cresson, 1865. Ent. Soc. Phila., Proc. 2: 254. ठ. Preoce. by Gmelin, 1790; not renamed here because of the very great likelihood that other Cresson names will prove to be synonyms.

Taxonomy: Heinrich, 1959. Ent. News 70: 211.

subfuscus (Cresson), n. comb. Colo.

Ichneumon subfuscus Cresson, 1864. Ent. Soc. Phila., Proc. 3: 173..

taylorii (Harrington), n. comb. B. C., Oreg.

Ichneumon Taylorii Harrington, 1894. Canad. Ent. 26: 209. ठ.

walleyi (Heinrich), n. comb. Ont.

Pseudamblyteles walleyi Heinrich, 1961. Canad. Ent. Sup. 23: 416..

zebraticolor (Heinrich), Que., Maine, Ont.

Pseudamblyteles zebraticolor Heinrich, 1962. Canad. Ent. Sup. 29: 882. ठ.

\section{Genus CTENICHNEUMON Thomson}

Ctenichneumon Thomson, 1894. Opusc. Ent. 19: 2082.

Type-species: Ichneumon funereus Gravenhorst. Desig. by Ashmead, 1900. The type-species is Gravenhorst's identification of Ichneumon funereus Geoffroy.

Dochyteles Berthoumieu, 1904. In Wytsman, Gen. Ins., fasc. 18, p. 50.

Type-species: Ichneumon funereus Geoffroy. Desig. by Viereck, 1914. 
Naenaria subg. Neonaenaria Uchida, 1956. Insecta Matsumurana 20: 60.

Type-species: Naenaria (Neonaenaria) albomaculata Uchida. Orig. desig.

This rather large genus is Neotropic, Holarctic, and Oriental.

Taxonomy: Townes, Momoi, and Townes, 1965. Amer. Ent. Inst., Mem. 5: 505 (syn.). caeruleops Heinrich. Sask., B. C.

Ctenichneumon caeruleops Heinrich, 1961. Canad. Ent. Sup. 23: 461. đ’, \&.

columbianus Heinrich. N. Mex., Yukon, Alaska, B. C.

Ctenichneumon columbianus Heinrich, 1961. Canad. Ent. Sup. 23: 457. đ, ?.

excultus (Cresson). Que. w. to Alaska, s. to Va., Mich., Idaho, and Oreg.

Ichneumon excultus Cresson, 1867. Amer. Ent. Soc., Trans. 1: 293..

Ichneumon Stadoconensis Provancher, 1875. Nat. Canad. 7 (1): 22 (key); 7 (2): 50. ठ.

gracilior Heinrich. Que., Maine, Mich.

Ctenichneumon gracilior Heinrich, 1961. Canad. Ent. Sup. 23: 470. o, \&.

heteropus Heinrich. B. C.

Ctenichneumon heteropus Heinrich, 1961. Canad. Ent. Sup. 23: 454. ठ', ९.

holomelas Heinrich. Man.

Ctenichneumon holomelas Heinrich, 1961. Canad. Ent. Sup. 23: 460..

minor Heinrich. N. S. s. to W. Va., w. to Sask.

Ctenichneumon minor Heinrich, 1961. Canad. Ent. Sup. 23: 458. o, ?.

punctiscuta Heinrich. Mich., Man., B. C.

Ctenichneumon punctiscuta Heinrich, 1961. Canad. Ent. Sup. 23: 463..

rufibasis Heinrich. Que., Maine.

Ctenichenumon rufibasis Heinrich, 1961. Canad. Ent. Sup. 23: 469. ๆ.

ruidosensis (Cockerell). N. Mex., Calif.

Ichneumon ruidosensis Cockerell, 1898. Ann. and Mag. Nat. Hist. (7) 2: 456. ठ.

semicaeruleus (Cresson). Maine w. to Alta., s. to s.e. N. C., Ky., Kans., and S. Dak.

Ichneumon semicaeruleus Cresson, 1867. Amer. Ent. Soc., Trans. 1: 302. \&.

syphax (Cresson). Que. w. to Alta., s. to n. Ga. and Kans.

Ichneumon Syphax Cresson, 1864. Ent. Soc. Phila., Proc. 3: 181..

Ichneumon rufizonatus Cresson, 1864. Ent. Soc. Phila., Proc. 3: 183. 9.

Ichneumon electus Cresson, 1867. Amer. Ent. Soc., Trans. 1: 304. o.

Ichneumon nitidus Provancher, 1875. Nat. Canad. 7 (1): 24 (key); 7 (3): 79 . ठ. Barron

(1975) gave particulars concerning the specimen he regarded as holotype, which is a different specimen than Heinrich (1961) accepted as type.

Ichneumon Marianapolitanus Provancher, 1875. Nat. Canad. 7 (1): 24 (key)..

Ichneumon Marianapolitanensis(!) Provancher, 1875. Nat. Canad. 7 (3): 81.

Taxonomy: Heinrich, 1959. Ent. News 70: 208, 210. - Heinrich, 1961. Canad. Ent. Sup. 23:

472 (uncertainty about synonymy of 1 . electus Cresson). - Barron, 1975. Nat. Canad. 102:

505,520 .

townesi Heinrich. Maine, N. Y., Mich.

Ctenichnenmon townesi Heinrich, 1961. Canad. Ent. Sup. 23: 453. ठ, ๆ.

ultus (Cresson). Que. s. to S. C., w. to Mich. and Kans.

Ichneumon ultus Cresson, 1867. Amer. Ent. Soc., Trans. 1: 295. ठ.

Ichneumon rogalis Cresson, 1867. Amer. Ent. Soc., Trans. 1: 295. $\delta$.

\section{Genus PROBOLUS Wesmael}

Probolus Wesmael, 1845 (1844). [Brussels] Acad. Roy. de Belg., Nouveaux Mem. 18: 150.

Type-species: Ichneumon fossorius Gravenhorst. Monotypic. The type-species is Gravenhorst's (1829) apparently deliberate misidentification of $I$. fossorius

Linnaeus; the type-species is regarded as a synonym of $P$. culpatorius (Linnaeus). See also the type-species citation for Limerodops.

This is a small genus of Holarctic distribution. 
Taxonomy: Gravenhorst, 1829. Ichn. Europaea, v. 1, p. 163-166 (use of name I. fossorius). -Roman, 1932. Ent. Tidskr. 53: 5, 6 (identity of Linnaean types of 1 . culpatorius and $l$. fossorius). - Perkins, 1953. Brit. Mus. (Nat. Hist) Ent., Bul. 3: 106 (correction of Roman's misidentification of the type-specimen of $I$. fossorins Linnaeus).

detritus (Brulle). Que. s. to Ga., w. to Mich. and Ark.

Ichneumon detritus Brulle, 1846. In Lepeletier, Hist. Nat. Ins. Hym., v. 4, p. 302. ๆ.

Ichneumon indistinctus Provancher, 1875. Nat. Canad. 7 (1): 23 (key); 7 (3): 75 ..

Ichneumon illaetabilis Cresson, 1877. Amer. Ent. Soc., Trans. 6: 190. ठ。.

Ichneumon innotabilis(!) Ashmead, 1900. In Smith, N. J. Bd. Agr., Ann. Rpt. 27, sup., p. 567. Lapsus for I. illaetabilis.

Taxonomy: Townes, 1961. Ent. Soc. Wash., Proc. 63: 107 (syn.). - Barron, 1975. Nat. Canad. 102: 487.

expunetus (Cresson). Newfoundland (insular), Que., Maine, N. Y., Ont., Ohio, Mich., Man., Colo., Alaska?, B. C.

Ichneumon obliteratus Cresson, 1864. Ent. Soc. Phila., Proc. 3: 147. ð. Preoce. by Wesmael, 1855.

Ichneumon expunctus Cresson, 1867. Amer. Ent. Soc., Trans. 1: 290. N. name for I. obliteratus Cresson.

Trogus Provancheri Burque, 1879. Nat. Canad. 11 (no. 124): 128. ठ์.

\section{Genus TRICHOLABUS Thomson}

Tricholabus Thomson, 1894. Opusc. Ent. 19: 2113.

Type-species: Tricholabus femoralis Thomson. Desig. by Viereck, 1914.

Epiopelmidea Viereck, 1913. U. S. Natl. Mus., Proc. 46: 374.

Type-species: Epiopelmidea erythrogastra Viereck. Monotypic and orig. desig.

Otohimea Uchida, 1926. Hokkaido Imp. Univ., Faculty Agr., Jour. 18: 146.

Type-species: Otohimea nigra Uchida. Orig. desig.

This is a Holarctic and Neotropic genus of moderate size.

Taxonomy: Townes and Townes, 1966. Amer. Ent. Inst., Mem. 8: 254 (syn.).

adventicus (Hopper). N. Y. s. to Fla. and Ala.

Ichneumon adventicus Hopper, 1938. Amer. Ent. Soc., Trans. 64: 101. ठ.

citatus (Provancher). Que., Maine, Mich., S. Dak., Colo., Alaska.

Ichneumon citatus Provancher, 1877. Nat. Canad. 9: 8. o.

Amblyteles tricolor Davis, 1898 (1897). Amer. Ent. Soc., Trans. 24: 351. \& (male misdet. ?).

Ichneumon a picator Hopper, 1938. Amer. Ent. Soc., Trans. 64: 100. ठో.

foxleei Heinrich. B. C., Oreg., Calif.

Tricholabus foxleei Heinrich, 1961. Canad. Ent. Sup. 23: 396. ठ์, ?.

mitchelli Heinrich. Mass., N. Y., N. J., Del., Md., Va., N. C., S. C., Ga., Miss., Ark. Ecology:

Occurs in marshes, particularly salt marshes along the Atlantic coast and Gulf of

Mexico.

Tricholabus mitchelli Heinrich, 1961. Canad. Ent. Sup. 23: 395. ठ, ९.

nortonii (Cresson). Que. w. to Alaska, s. to Va., Ohio, S. Dak., and Alta.

Ichneumon Nortonii Cresson, 1867. Amer. Ent. Soc., Trans. 1: 304..

Ichneumon merus Cresson, 1877. Amer. Ent. Soc., Trans. 6: 148. o.

pax (Dalla Torre). Wash.

Ichneumon pacificus Davis, 1898 (1897). Amer. Ent. Soc., Trans. 24: 350. ठ゚. Preocc. by Cameron, 1887.

Ichneumon pax Dalla Torre, 1902. Cat. Hym., v. 3, p. 964. N. name for I. pacificus Davis.

\section{Genus SPILICHNEUMON Thomson}

Spilichneumon Thomson, 1894. Opusc. Ent. 19: 2087.

Type-species: Ichneumon occisorius Gravenhorst. Desig. by Ashmead, 1900. The type-species is Gravenhorst's identification of I. occisorius Fabricius.

Spiloteles Berthoumieu, 1904. I $u$ Wytsman, Gen. Ins., fasc. 18, p. 54.

Type-species: Ichneumon occisorius Fabricius. Desig. by Viereck, 1914. 
Pseudichneumon Kokujev, 1909. Acad. Imp. des Sci. St. Petersburg, Mus. Zool., Ann. 14: 12.

Type-species: Pseudichneumon primarius Kokujev. Monotypic.

This Holarctic and Oriental genus is apparently of moderate size.

borealis (Provancher). Newfoundland (insular), Que., Maine, Ont. Ecology: Heinrich (1971) said that "this species is confined to peat bogs, where it appears in the latter part of summer."

Amblyteles borealis Provancher, 1882. Nat. Canad. 13: 328. .

Taxonomy: Heinrich, 1971. Nat. Canad. 98: 974-975.

bronteus (Cresson). Newfoundland (insular), Que., Maine, Pa., Ont., Mich., Colo., B. C.?

Ichneumon Bronteus Cresson, 1864. Ent. Soc. Phila., Proc. 3: 144. ठ.

Ichneumon citrinus Provancher, 1886. Addit. Corr. Faune Ent. Canada Hym., p. 31. o. N. syn.; preocc. by Cresson, 1873; the information given by Heinrich (1968) indicates that this is the best disposition for the name 1 . citrinus Provancher until such time as it can be proven that the lectotype represents a valid species.

Taxonomy: Heinrich, 1968. Nat. Canad. 95: 722. - Heinrich, 1971. Nat. Canad. 98: 975-977. inconstans (Cresson). revised status. Newfoundland (insular) w. to N. W. T., s. to Va., Mich., Colo., and Ariz. Host: Crymodes devastator (Brace).

Ichneumon (Ichneumon) aleatorius Harris, 1835. In Hitchcock, Rpt. Geol. Mineral. Bot. Zool. Mass., Ed. 2, p. 585. Nomen nudum.

Ichneumon inconstans Cresson, 1864. Ent. Soc. Phila., Proc. 3: 153. ơ.

Ichneumon subrufus Cresson, 1864. Ent. Soc. Phila., Proc. 3: 168. ‡. Preocc. by Gmelin, 1790.

Ichneumon comes var. aleatorius Cresson, 1867. Amer. Ent. Soc., Trans. 1: 301. ¿.

Taxonomy: Heinrich, 1959. Ent. News 70: 209 (syn.).

kodiakensis (Ashmead). Alaska.

Cratichneumon kodiakensis Ashmead, 1902. Wash. Acad. Sci., Proc. 4: 157. ठ.

Taxonomy: Walkley, 1967. In Krombein et al., U. S. Dept. Agr., Agr. Monog, 2, sup. 2, p. 155. nubivagus (Cresson). Newfoundland (Labrador) w. to B. C., s. to N. Y. and Colo.

Ichneumon consimilis Cresson, 1864. Ent. Soc. Phila., Proc. 3: 163. ठ. Preocc. by Wesmael, 1845.

Ichneumon nubivagus Cresson, 1867. Amer. Ent. Soc., Trans. 1: 291. N. name for $I$. consimilis Cresson.

Ichneumon aequalis Provancher, 1875. Nat. Canad. 7 (1): 23 (key); 7 (3): 76. o.

Amblyteles fratermus Cresson, 1877. Amer. Ent. Soc., Trans. 6: 192. ठ.

Taxonomy: Heinrich, 1971. Nat. Canad. 98: 975-977 (female described and distinguished from female of $S$. bronteus).

pernigricornis Heinrich. Mont., Wyo., Utah.

Spilichneumon pernigricomis Heinrich, 1971. Nat. Canad. 98: 977. ठ, ?.

physcoteloides Heinrich. Que., Maine, Mass., Mich.

Spilichnenmon physcoteloides Heinrich, 1961 (1960). Canad. Ent. Sup. 18: 191. o, ․

superbus (Provancher). Newfoundland (insular) w. to N. W. T. and B. C., s. to Tex., N. Mex., and Calif.; Hawaii. Host: Euxoa (Chorizagrotis) auxiliaris (Grote), E. flavicollis (Smith), E. messoria (Harris), E. ochrogaster (Gn.), E. scandens (Riley), Feltia ducens Wlk., Pseudaletia unipuncta (Haw.).

Amblyteles superbus Provancher, 1886. Addit. Corr. Faune Ent. Canada Hym., p. 35. $q$.

Ichneumou koebelei Swezey, 1909. Hawaii Sugar Planters' Assoc. Expt. Sta., Div. Ent., Bul. 7: 30. ¿, $q$.

Taxonomy: Heinrich, 1959. Ent. News 70: 209 (syn.).

taos (Cresson). Que., Maine, Mass., N. Mex., Alta.

Amblyteles Taos Cresson, 1877. Amer. Ent. Soc., Trans. 6: 191. ‡.

valdetypicus Heinrich. Maine, Man.

Spilichneumon valdetypicus Heinrich, 1961 (1960). Canad. Ent. Sup. 18: 186.. 
Taxonomy: Heinrich, 1971. Nat. Canad. 98: 975 (variation).

\section{Genus OBTUSODONTA Heinrich}

Obtusodonta Heinrich, 1962. Canad. Ent. Sup. 29: 872.

Type-species: Spilichneumon obscuricolor Heinrich. Orig. desig.

This is a small genus of Holarctic distribution.

foxleei Heinrich. B. C.

Obtusodonta foxleei Heinrich, 1962. Canad. Ent. Sup. 29: 874. \&.

manitobae Heinrich. Man., Alta.

Obtusodonta manitobae Heinrich, 1962. Canad. Ent. Sup. 29: 874. १.

obscuricolor (Heinrich). Que., Maine, Conn., N. Y., Ont., Sask.

Spilichneumon? obscuricolor Heinrich, 1961 (1960). Canad. Ent. Sup. 18: 195. ठ, ?.

restricta (Cresson). Que., Maine, N. Y.

Ichnenmon restrictus Cresson, 1877. Amer. Ent. Soc., Trans. 6: 169. ठ.

Obtusodonta montana Heinrich, 1962. Canad. Ent. Sup. 29: 875. ठ, ?.

Taxonomy: Heinrich, 1971. Nat. Canad. $98: 983$ (syn.).

UNPLACED TAXa of Amblytelesina

The following species were not included in Heinrich's (1961-1962) work on the stenopneusticae of northeastern North America.

Amblyteles hudsonicus Cresson, 1877. Amer. Ent. Soc., Trans. 6: 192. \&. "Hudsons Bay

Territory."

Ichneumon cridosus Cresson, 1877. Amer. Ent. Soc., Trans. 6: 175. ð. Calif.

Ichneumon Dakota Cresson, 1867. Amer. Ent. Soc., Trans. 1: 302. ¿. "Dakota Territory."

Ichnentmon delicatus Cresson, 1865. Ent. Soc. Phila., Proc. 4: 253. ठ̀. Colo.

Ichneumon dictiosus Cresson, 1877. Amer. Ent. Soc., Trans. 6: 164. ठ. Kans.

Ichneumon (Barichneumon) Humphreyi Viereck, 1905. Kans. Acad. Sci., Trans. 19: 296. o. Ariz.

Ichneumon juxtus Cresson, 1864. Ent. Soc. Phila., Proc. 3: 163. ठં. Colo.

Ichneumon semissus Cresson, 1877. Amer. Ent. Soc., Trans. 6: 183. ९. Calif. According to Cresson (1879), the type locality is Mohave Desert, Calif.

Taxonomy: Cresson, 1879 (1878). Acad. Nat. Sci. Phila., Proc. 30: 354.

Ichueumon sequax Cresson. 1877. Amer. Ent. Soc., Trans. 61: 181. . Southern B. C. Ichneumon ventralis Cresson, 1865. Ent. Soc. Phila., Proc. 4: 250. ठ. Colo.

\section{SUbTRIBE PTEROCORMINA}

\section{Genus STENICHNEUMON Thomson}

Stenichneumon Thomson, 1893. Opusc. Ent. 18: 1964.

Type-species: Ichneumon pistorius Gravenhorst. Desig. by Schmiedeknecht, 1902. The type-species is regarded as a synonym of $S$. militarins militarius (Thunberg).

Myermo Cameron, 1901. Ann. and Mag. Nat. Hist. (7) 7: 523.

Type-species: Myermo rufipes Cameron. Monotypic. The type-species is regarded as a synonym of $S$. appropinquans (Cameron).

Chiaglas Cameron, 1902. Ann. and Mag. Nat. Hist. (7) 9: 152.

Type-species: Chiaglas nigripes Cameron. Monotypic.

Bolbomyschus Tosquinet, 1903. Soc. Ent. de Belg., Mem. 10: 342.

Type-species: Bolbomyschus albipictus Tosquinet. Monotypic.

The type-species is regarded as a synonym of $S$. nigripes (Cameron).

Stenichneumonoides Uchida, 1930. Insecta Matsumurana 9: 95.

Type-species: Ichneumon posticalis Matsumura. Orig. desig.

This is a moderate-sized genus of Neotropic, Holarctic, and Oriental distribution. 
Taxonomy: Townes and Townes, 1966. Amer. Ent. Inst., Mem. 8: 263. (syn.).

culpator cincticornis (Cresson). Newfoundland (insular), Que., N. W. T., Yukon, and Alaska, s. to n. Ga., Ill., Colo., and Wash. Host: Trichoplusia ni (Hbn.). S. culpator culpator

(Schrank) is Eurasian.

Ichneumon cincticomis Cresson, 1864. Ent. Soc. Phila., Proc. 3: 139. ๆ.

Ichneumon galenus Cresson, 1867. Amer. Ent. Soc., Trans. 1: 292. ठ.

Ichneumon mathewi Cameron, 1907. Entomologist 40: 277. ठ.

Taxonomy: Heinrich, 1953. Wash. Acad. Sci., Jour. 43: 149. - Townes, 1961. Ent. Soc. Wash., Proc. 63: 109 (syn.).

militarius leucopus Heinrich. N. B. w. to Alaska, s. to Maine, Mich., and B. C. Host: "Plusia" sp. S. militarius militarius (Thunberg) is Eurasian.

Stenichneumon militarius leucopus Heinrich, 1962. Canad. Ent. Sup. 26: 525. đ’,.

pallidipennis (Viereck). N. W. T., S. Dak., and N. Mex., w. to B. C. and Calif.

Cratichneumon pedalis var. pallidipennis Viereck, 1902. Ent. News 13: 87. ठ.

salvus (Cresson). P. E. I. w. to B. C., s. to N. H., Mich., and Oreg. This species appears to vary clinally from east to west. Heinrich (1962) recognized two subspecies; he used the name bioculatus for a transcontinental form; his nominate form apparently consisted only of some of the extreme variants from the western end of the range.

Ichneumon bioculatus Cresson, 1877. Amer. Ent. Soc., Trans. 6: 158. §, ९. N. syn.

Ichneumon salvus Cresson, 1877. Amer. Ent. Soc., Trans. 6: 166. ठ.

Cratichneumon rubicundus Bradley, 1904. Ztschr. System. Hym. Dipt. 4: 106..

\section{Genus PATROCLOIDES Heinrich}

Patrocloides Heinrich, 1961 (1960). Canad. Ent. Sup. 15: 16.

Type-species: Amblyteles perluctuosus Provancher. Monotypic and orig. desig.

This is a small Holaretic genus.

montanus (Cresson). Newfoundland (insular) w. to Wash., s. to n. Ga., N. Mex., and Calif. Host: Syngrapha sp., Trichoplasia ni (Hbn.).

Ichneumon montanus Cresson, 1864. Ent. Soc. Phila., Proc. 3: 141. o, ₹.

Patrocloides montanus occidentalis Heinrich, 1962. Canad. Ent. Sup. 26: 517. ?. N. syn.

perluctuosus (Provancher). Newfoundland (insular), w. to B. C., s. to Mass. and Mich. Host: Syngrapha epigaea (Grt.), S. selecta (Wlk.).

Amblyteles perluctuosus Provancher, 1877. Nat. Canad. 9: 10. " $\delta "=q$.

walleyi (Heinrich). Que., Ont., Wis., N. W. T., Alta.

Patroclus walleyi Heinrich, 1956. Canad. Ent. 88: 486. ठ', ?.

\section{Genus PATROCLUS Cresson}

Patroclus Cresson, 1873. Acad. Nat. Sci. Phila., Proc. 25: 104.

Type-species: Patroclus nigrocaeruleus Cresson. Desig. by Ashmead, 1900.

Pseudoamblyteles Heinrich, 1926. Deut. Ent. Ztschr. (1926), p. 255.

Type-species: Amblyteles homocerus Wesmael. Monotypic.

Ctenamblyteles Heinrich, 1928. Deut. Ent. Ztschr. (1928), p. 141. Unnecessary n. name for Pseudoamblyteles Heinrich (Pseudoamblyteles not preocc. by Pseudamblyteles Ashmead).

This is a small Neotropic and Holarctic genus.

Taxonomy: Townes and Townes, 1966. Amer. Ent. Inst., Mem. 8: 263 (syn.).

homocerus homocerus (Wesmael). Que. w. to Alaska, s. to Colo. and Utah; Eurasia. Townes, Momoi, and Townes (1965) recognized P. homocerus karafutonis (Uchida) as a distinct subspecies from Sakhalin.

Amblyteles homocerus Wesmael, 1854. [Brussels] Acad. Roy. de Belg., Bul. 21, Annexe aux Bul. 1853-1854, p. 120. ¿, ?.

Taxonomy: Townes, Momoi, and Townes, 1965. Amer. Ent. Inst., Mem. 5: 455. 


\section{Genus PROTOPELMUS Heinrich}

Protopelmus Heinrich, 1959. Ent. Soc. Wash., Proc. 61: 200.

Type-species: Trogus atrocaeruleus Cresson. Monotypic and orig. desig.

A single species is known.

atrocaeruleus (Cresson). Northeastern Md., Fla., La.; Mexico. Host: Ecpantheria muzina Oberthur, E. scribonia (Stoll).

Trogus atrocaeruleus Cresson, 1868. Amer. Ent. Soc., Trans. 2: 92. .

Trogus atrocoeruleus Dalla Torre, 1902. Cat. Hym., v. 3, p. 1032. Emend.

\section{Genus ORGICHNEUMON Heinrich}

Orgichneumon Heinrich, 1961 (1960). Canad. Ent. Sup. 15: 15.

Type-species: Ichneumon calcatorius Thunberg. Monotypic and orig. desig.

This is a small genus of Holarctic and Oriental distribution.

calcatorius (Thunberg). N. S. w. to B. C., s. to S. C., Tex., and Oreg.; Europe. Host: Dasychira grisefacta (Dyar)?, D. plagiata (Wlk.), Orgyia antiqua (L.), O. leucostigma (J. E. S.), O. pseudotsugata McD.

Ichneumon calcatorius Thunberg, 1822; 1824. Acad. Imp. des Sci. St. Petersburg, Mem. 8: 254; 9: 291. ?.

Ichneumon otiosus Say, 1829 Contrib. Maclurian Lyceum to Arts and Sci. 1: 69..

Ichneumon infidelis Cresson, 1867. Amer. Ent. Soc., Trans. 1: 296. ơ.

Ichneumon sylvanus Holmgren, 1880. Ent. Tidskr. 1: 27. ? (male misdet.).

Ichneumon (Cratichneumon) burkei Viereck, 1910. U. S. Natl. Mus., Proc. 38: 383. ó.

Ichneumon (Stenichneumon) calcatorius var. nigritarsis Schmiedeknecht, 1928. Opusc. Ichn., Sup., fasc. 4, p. 219. Syn.? Preocc. by Kriechbaumer, 1889.

Taxonomy: Roman, 1912. Zool. Bidr. Uppsala 1: 240 (syn.). - Heinrich, 1953. Wash. Acad.

Sci., Jour. 43: 148. - Heinrich, 1957 (1956). Canad. Ent. 88: 647-648. - Heinrich, 1959. Ent.

News 70: 211.

\section{Genus THYRATELES Perkins}

Thyrateles Perkins, 1953. Brit. Mus. (Nat. Hist.) Ent., Bul. 3: 149.

Type-species: Amblyteles camelinus Wesmael. Monotypic and orig. desig.

This is a small Holarctic genus which is rather arbitrarily separated from Pterocormus.

Taxonomy: Townes and Townes, 1973. Amer. Ent. Inst., Mem. 19: 263 (syn.).

amoenapex Heinrich. N. W. T.

Thyrateles amoenapex Heinrich, 1961. Canad. Ent. Sup. 21: 357..

caliginops Heinrich. Que. w. to Minn., s. to W. Va. and Ohio. Host: Vanessa atalanta (L.).

Thyrateles caliginops Heinrich, 1961. Canad. Ent. Sup. 21: 351. ठ, १.

camelinops Heinrich. Alta., B. C. Host: Nymphalis milberti (Goed.), Polygonia sp.

Thyrateles camelinops Heinrich, 1961. Canad. Ent. Sup. 21: 349. ठै, ๆ.

instabilis (Cresson). Maine, N. H., N. Y., N. J., Ont., Ohio, Mich., Ind., S. Dak., Calif. Host:

Colias eurytheme Bois., C. philodice Godt., Satymes sp.

Ichneumon instabilis Cresson, 1867. Amer. Ent. Soc., Trans. 1: 303. o, \&.

Biology: Dasch, 1971. Ohio Jour. Sci. 71: 278 (hibernation sites). - Heinrich, 1971. Nat. Canad.

98: 973 (hibernation site).

lugubrator (Gravenhorst). N. S. w. to B. C., s. to central Ga., Tex., and Calif.; Hawaii. Host: Cynthia cardui (L.), C. virginiensis (Drury), Nymphalis milberti (Godt.), Polygonia comma (Harris).

Ichneumon lugubrator Gravenhorst, 1807. Vergl. Uebers. Zool. Systeme, p. 256. [male].

Ichneumon rufiventris Brulle, 1846. In Lepeletier, Hist. Nat. Ins. Hym., v. 4, p. 301. o, ?.

Ichneumon incertus Cresson, 1864. Ent. Soc. Phila., Proc. 3: 180. $\$$. Preoce. by Sulzer, 1776 and Christ, 1791.

Ichneumon californicus Cresson, 1864. Ent. Soc. Phila., Proc. 3: 180. §.

Ichneumon hunterae Packard, 1881. Boston Soc. Nat. Hist., Proc. 21: 22. ठ, १. 
Ichneumon vulviventris (!) Nason, 1905. Ent. News 16: 148. Lapsus for I. mufiventris Brulle.

Taxonomy: Kriechbaumer, 1875. Stettin. Ent. Ztg. 36: 41. -Townes, 1961. Ent. Soc. Wash.,

Proc. 63: 108, 109, 169-170.

mormonus (Cresson). Que., Ont., Colo., Alta., Utah. Host: Polygonia sp.

Amblyteles mormonus Cresson, 1877. Amer. Ent. Soc., Trans. 6: 190. 9. According to Cresson (1879) the type locality is "Great Salt Lake, Utah."

Ichneumon adjunctus Provancher, 1886. Addit. Corr. Faune Ent. Canada Hym., p. 29. + .

Cratichneumon pedalis var. varitarsis Viereck, 1902. Ent. News 13: 87. \&.

Taxonomy: Cresson, 1879 (1878). Acad. Nat. Sci. Phila., Proc. 30: 355.

procax (Cresson). Ont., Alaska. Host: Nymphalis antiopa (L.).

Ichneumon procax Cresson, 1877. Amer. Ent. Soc., Trans. 6: 170. o.

Amblyteles torontosus Davis, 1898 (1897). Amer. Ent. Soc., Trans. 24: 351. ๆ.

\section{Genus PTEROCORMUS Foerster}

Brachyptemus Gravenhorst, 1829. Ichn. Europaea, v. 1, p. 673. Preocc. by Kugelman, 1794.

Type-species: Brachypterus means Gravenhorst. Monotypic. The type-species is regarded as a synonym of $P$. latrator (Fabricius).

Pterocormus Foerster, 1850. Arch. f. Naturgesch. 16: 71. N. name for Brachypterus

Gravenhorst.

Colobacis Cameron, 1900. New Zeal. Inst., Trans. 33: 110.

Type-species: Colobacis forticornis Cameron. Monotypic. The type-species is regarded as a synonym of $P$. lotatorius (Fabricius).

Tyanites Cameron, 1903. Entomologist 36: 95.

Type-species: Tyanites rufipes Cameron. Monotypic.

Vabsaris Cameron, 1903. Entomologist 36: 96.

Type-species: Vabsaris forticomis Cameron. Monotypic. The type-species is regarded as a synonym of $P$. rufipes (Cameron).

Euichneumon Berthoumieu, 1904. Gen. Ins., fasc. 18, p. 33.

Type-species: Ichneumon sarcitorius Linnaeus. Desig. by Townes, 1944.

Matsumuraius Ashmead, 1906: U. S. Natl. Mus., Proc. 30: 169.

Type-species: Matsumuraius grandis Ashmead. Monotypic. The type-species is regarded as a subspecies of $P$. primatorius (Forster).

Coreojoppa Uchida, 1926. Hokkaido Imp. Univ., Faculty Agr., Jour. 18: 63.

Type-species: Coreojoppa flavomaculata Uchida. Monotypic and orig. desig.

Bureschias Heinrich, 1936. K. Naturw. Inst. Sofia, Mitt. 9: 82.

Type-species: Bureschias balcanicus Heinrich. Orig. desig. The type-species is regarded as a synonym of $P$. tuberosus (Berthomieu).

This is a very large genus with species occurring throughout the Old and New World, but apparently with greater numbers of species in temperate areas.

Taxonomy: Townes and Townes, 1973. Amer. Ent. Inst., Mem. 19: 263 (syn.).

adonis (Viereck). N. Mex.

Cratichneumon adonis Viereck, 1903. In Skinner, Amer. Ent. Soc., Trans. 29: 77. ठ์.

alpestriform is (Viereck). Western Alaska.

Amblyteles (Pterocormus) alpestriformis Viereck, 1923. North Amer. Faune 46: 234.. .

Taxonomy: Heinrich, 1957 (1956). Canad. Ent. 88: 690-691.

amauropus (Heinrich), n. comb. Northern N. W. T.

Ichneumon amauropus Heinrich, 1956. Canad. Ent. 88: 481. ?.

ambulatorius (Fabricius). Newfoundland (nsular) w. to B. C., s. to Ga., Kans., N. Mex., and Oreg. Host: Crymodes devastator (Brace), Faronta diffusa (Wlk.), Luperina stipata (Morr.), Macronoctua onusta Grt., Papaipema circumlucens (Smith), P. nebris (Gn.), Pseudaletia unipuncta (Haw.).

Ichneumon ambulatorius Fabricius, 1775. Systema Ent., p. 329. [female].

Ichneumon multor Harris, 1833. In Hitchcock, Rpt. Geol. Mineral. Bot. Zool. Mass., p. 587.

Nomen nudum; uncertain syn. 
Ichneumon jucundus Brulle, 1846. In Lepeletier, Hist. Nat. Ins. Hym., v. 4, p. 305.. Ichneumon flavizonatus Cresson, 1864. Ent. Soc. Phila., Proc. 3: 156. ठ.

Ichneumon multor Cresson, 1867. Amer. Ent. Soc., Trans. 1: 299. ठ.

Taxonomy: Perkins, 1952. Entomologist 85: 66. - Heinrich, 1953. Wash. Acad. Sci., Jour. 43:

149. - Townes, 1961. Ent. Soc. Wash., Proc. 63: 106, 108, 168.

annulatorius (Fabricius). Newfoundland (insular) s. to Va., w. to Iowa.

Ichneumon annulatorius Fabricius, 1775. Systema Ent., p. 330. [male].

Ichneumon funestus Cresson, 1864. Ent. Soc. Phila., Proc. 3: 166. \&.

Ichneumon haesstans Provancher, 1875. Nat. Canad. 7 (1): 24 (key)..

Ichneumon hoesitans(!) Provancher, 1875. Nat. Canad. 7 (3): 80.

Taxonomy: Perkins, 1952. Entomologist 85: 67. -Townes, 1961. Ent. Soc. Wash., Proc. 63: $106,169$.

approximans (Provancher). Ont.

Ichneumon a pproximans Provancher, 1886. Addit. Corr. Faune Ent. Canada Hym., p. 32. $\delta$.

artemis (Viereck). Newfoundland (Labrador), n. Man., Colo., Alta.

Cratichneumon artemis Viereck, 1902. Ent. News 13: 87. + .

atrox (Cresson). Newfoundland (Labrador), Ont., Man., S. Dak., Colo., Alaska, B. C. Ichneumon atrox Cresson, 1877. Amer. Ent. Soc., Trans. 6: 151..

audax (Cresson). Colo.

Ichneumon audax Cresson, 1864. Ent. Soc. Phila., Proc. 3: 143. ð.

bimembris (Provancher). Que., Maine, N. H., N. Y., Pa., Md., Va., Ont., Mich., Alta. Ichneumon bimembris Provancher, 1877. Nat. Canad. 9: 8..

broweri (Heinrich), n. comb. Maine.

Ichneumon broweri Heinrich, 1961. Canad. Ent. Sup. 21: 337. ९.

browni (Heinrich), n. comb. Eastern Que.

Ichneumon browni Heinrich, 1961. Canad. Ent. Sup. 21: 277. ๆ.

Taxonomy: Heinrich, 1969. Nat. Canad. 96: 951.

browniops (Heinrich), n. comb. Maine.

Ichneumon browniops Heinrich, 1969. Nat. Canad. 96: 950..

byrdiae (Heinrich), n. comb. Northwestern N. W. T., n. Yukon. Host: Gynaephora rossi (Curt.). Ichneumon byrdiae Heinrich, 1956. Canad. Ent. 88: 479. ठै, ९.

byridops (Heinrich), n. comb. Southern Alaska.

Ichneumon byrdiops Heinrich, 1956. Canad. Ent. 88: 480. ๆ.

ealiginosus (Cresson). Newfoundland (insular), N. W. T., and Alaska, s. to W. Va., Mich., and Colo. Host: Polygonia gracilis (G. and R.), P. interrogationis (F.), P. satymus (Ed.).

Ichneumon caliginosus Cresson, 1864. Ent. Soc. Phila., Proc. 3: 144..

ealitergus (Cresson). Que., Maine, Mass., N. Y., Md., W. Va., Ont., Mich.

Ichneumon calitergus Harris, 1835. In Hitchcock, Rpt. Geol. Mineral. Bot. Zool. Mass., Ed. 2, p. 586. Nomen nudum.

Ichneumon calitergus Cresson, 1867. Amer. Ent. Soc., Trans. 1: 299..

canadensis (Cresson). N. S., N. B., Que., Maine, N. H., Ont., Ohio, Mich., Wis., Sask. Host: Ctenucha virginica (Charp.). Heinrich (1959b, 1961) incorrectly used the synonym trizonatus instead of canadensis as the valid name for this species; Heinrich's (1959a) selection of a new lectotype for canadensis (=clasma $\mathrm{n}$. sp., below) did not invalidate the lectotype selected by Cresson (1916) because lack of agreement with the original description is not sufficient proof that the lectotype selected by Cresson was not one of his original syntypes.

Ichneumon canadensis Cresson, 1867. Amer. Ent. Soc., Trans. 1: 308. ๆ.

Ichneumon trizonatus Provancher, 1877. Nat. Canad. 9: 8. ठ. N. syn.

Amblyteles ctenuchae Cushman, 1933. U. S. Natl. Mus., Proc. 82: 3. ๆ.

Taxonomy: Cresson, 1916. Amer. Ent. Soc., Mem. 1: 23. -Townes, 1944. Amer. Ent. Soc., Mem. 11: 382-383 (syn.). - Heinrich, 1959a, Ent. News 70: 104. - Heinrich, 1959b, Canad. Ent. 91: 806 (syn.). - Heinrich, 1961. Canad. Ent. Sup. 21: 238, 292-293. 
canadicola (Heinrich), n. comb. Newfoundland (insular), Que., Maine, Mass., Ont., Ohio, Mich. Ichneumon canadicola Heinrich, 1961. Canad. Ent. Sup. 21: 293..

centrator (Say). Que. w. to B. C., s. to N. C., Mo., and Oreg. Host: Isia isabella (J. E. S.). Ichneumon centrator Say, 1825. Amer. Ent. 2: 49. $\%$.

Ichneumon flavicornis Cresson, 1864. Ent. Soc. Phila., Proc. 3: 140. ठ.

Ichneumon fortis Provancher, 1875. Nat. Canad. 7 (1): 24 (key); 7 (3): 83. o.

cervulus (Provancher). Newfoundland (insular), Que., Maine, Ont., Mich., Alta. Ecology: Occurs in peat bogs. Although the specimen which Heinrich $(1961,1976)$ regarded as the "holotype" is not the valid lectotype selected by Gahan and Rohwer (1917), Barron (1975) indicated that the former specimen is conspecific with the lectotype.

Ichneumon cervulus Provancher, 1875. Nat. Canad. 7 (1): 24 (key); 7 (3): 83. ठ.

Phygadeuon terminatus Provancher, 1882. Nat. Canad. 13 (no. 155): 335 (key); 13 (no. 156): 357. . Preocc. by Gravenhorst, 1829.

Taxonomy: Gahan and Rohwer, 1917. Canad. Ent. 49: 430. - Heinrich, 1961. Canad. Ent. Sup. 21: 271. - Barron, 1975. Nat. Canad. 102: 448. - Heinrich, 1976 (1975). Nat. Canad. 102: 758-760 (syn.).

Biology: Heinrich, 1969. Nat. Canad. 96: 943 (habitat).

cessatorops (Heinrich), n. comb. Que., Alta., Yukon.

Ichneumon cessatorops Heinrich, 1956. Canad. Ent. 88: 484. ๆ.

Ichneumon cessatorops Kazubazuae Heinrich, 1956. Canad. Ent. 88: 485..

Taxonomy: Heinrich, 1961. Canad. Ent. Sup. 21: 319-320 (male described).

chasmodops (Heinrich), n. comb. Que., Maine, N. H., N. Y., Ont., Mich., Minn., Man.

Ichne umon chasmodops Heinrich, 1961. Canad. Ent. Sup. 21: 259. \& ( $\delta$ misdet.). Heinrich (1962) stated that the male he had misidentified as chasmodops is 1961 is actually the male of feralis (Cresson), and another male was associated with chasmodops and described.

Taxonomy: Heinrich, 1962. Canad. Ent. Sup. 29: 977-878.

citrifrons (Cresson). N. J., Pa., Ont., Mich., Ill.

Ichneumon citrifrons Cresson, 1867. Amer. Ent. Soc., Trans. 1: 307. §.

clarimontis (Cameron). Calif.

Ichneumon clarimontis Cameron, 1908. Amer. Ent. Soc., Trans. 34: 241. ठे.

Taxonomy: Townes, 1961. Ent. Soc. Wash., Proc. 63: 107.

clasma Carlson, n. sp. Newfoundland (insular) s. to N. Y., w. to Mich. and Ill. Host:

Pseudaletia unipuncta (Haw.). Heinrich (1961) gave a description of both the males and females of this species, but erroneously applied the name canadensis (Cresson) by virtue of his (1959) invalid selection of a new lectotype for canadensis (which see); Heinrich's new lectotype for $I$. canadensis Cresson is the holotype of $P$. clasma.

Ichneumon canadensis Cresson sensu Heinrich, 1961. Canad. Ent. Sup. 21: 238-240. đ’, ๆ.

Taxonomy: Heinrich, 1959. Ent. News 70: 104.

commodus (Davis). Utah, Wash.

Eurylabus commodus Davis, 1898 (1897). Amer. Ent. Soc., Trans. 24: 354. ठో.

compar (Cresson). Southwestern B. C.

Ichneumon compar Cresson, 1877. Amer. Ent. Soc., Trans. 6: 175. @.

conscopa (Heinrich), n. comb. Maine.

Ichneumon conscopa Heinrich, 1961. Canad. Ent. Sup. 21: 250. ?.

Taxonomy: Heinrich, 1971. Nat. Canad. 98: 969.

contractus (Ashmead). Alaska.

Amblyteles contractus Ashmead, 1890 (1889). U. S. Natl. Mus., Proc. 12: 393..

creperus (Cresson). Que., Ont., w. N. W. T., and Alaska, s. to Conn., Ohio, Colo., and s. B. C. Host: Actebia fennica (Tausch.).

Ichneumon creperus Cresson, 1867. Amer. Ent. Soc., Trans. 1: 298. ठ.

Amblyteles (Pterocormus) footei Viereck, 1917 (1916). Conn. State Geol. and Nat. Hist.

Survey Bul. 22: 353, 357. §. 
cupitus (Cresson). Idaho, Wash., Oreg., Calif.; Hawaii.

Ichneumon cupitus Cresson, 1877. Amer. Ent. Soc., Trans. 6: 175. ¿.

Taxonomy: Cresson, 1879 (1878). Acad. Nat. Sci. Phila., Proc. 30: 350 (redescription).

-Townes, Townes, and Gupta, 1961. Amer. Ent. Inst., Mem. 1: 383.

curticrus (Provancher). Que., Man.

Phygadeuon curticrus Provancher, 1888. Addit. Corr. Faune Ent. Canada Hym., p. 360. $\subsetneq$.

devinctor (Say). Que. w. to s.w. N. W. T. and B. C., s. to Ga., Mo., and Colo. Host: Cossus sp., Prionoxystus robiniae (Peck), Sthenopis thule (Stkr.).

Ichneumon devinctor Say, 1825. Amer. Ent. 2: 48. $ᄋ$.

Ichneumon tibialis Brulle, 1846. In Lepeletier, Hist. Nat. Ins. Hym., v. 4, p. 300. 9 . Preocc. by Geoffroy, 1785 .

Ichneumon montivagus Cresson, 1865. Ent. Soc. Phila., Proc. 4: 255. ð.

difficilis (Cresson). Wash., Calif.

Ichneumon difficilis Cresson, 1877. Amer. Ent. Soc., Trans. 6: 176. ð.

Taxonomy: Cresson, 1879 (1878). Acad. Nat. Sci. Phila., Proc. 30: 351.

dillerorum (Heinrich), n. comb. Maine.

Ichneumon dilleromum Heinrich, 1968. Nat. Canad. 95: 720. $\$$.

dionymus Carlson, n. name. Que. w. to Mich., s. to Va. and Ohio.

Ichneumon anonymus Heinrich, 1961. Canad. Ent. Sup. 21: 255. đ, \&. Preocc. by Cuvier, 1833.

dioryctiae (Heinrich), n. comb. N. B. Que., Maine, Ont., Mont. Host: Dioryctria reniculella (Grt.).

Ichneumon dioryctiae Heinrich, 1961. Canad. Ent. Sup. 21: 341. ð, ९.

Ichneumon dioryctriae Walkley, 1967. In Krombein et al., U. S. Dept. Agr., Agr. Monog. 2, sup. 2, p. 160. Unjustified emend. (Heinrich had spelled the host name "Dioryctia").

discoensis (Fox). Greenland. This species has not been treated in any of the papers on North American Ichneumoninae by Heinrich.

Ichneumon discoensis Fox, 1892. Acad. Nat. Sci. Phila., Proc. 44: 134. đ.

dorsalis (Cresson). Colo.

Ichneumon dorsalis Cresson, 1864. Ent. Soc. Phila., Proc. 3: 177. $\$$. Preocc. by Fabricius, 1798; not renamed here because the species has not been included in any recent revision, and therefore may prove to have synonyms.

egregiafacialis (Viereck). Colo.

Ichneumon (Barichneumon) egregiafacialis Viereck, 1905. Kans. Acad. Sci., Trans. 19: 291. o.

eurypus (Heinrich), n. comb. Que., Maine, Ont., s.w. N. W. T., Alta.

Ichneumon eurypus Heinrich, 1961. Canad. Ent. Sup. 21: 325. \&.

faciens (Davis). Alta., Idaho, Wash.

Ichneumon faciens Davis, 1898 (1897). Amer. Ent. Soc., Trans. 24: 350. ¿.

feralis (Cresson). Newfoundland (Labrador) s. to N. Y., w. to Alta. Host: Hepialus mustelinus Pack.? The male of this species was misidentified as that of chasmodops by Heinrich (1961); the error was corrected by Heinrich (1962).

Ichneumon feralis Cresson, 1867. Amer. Ent. Soc., Trans. 1: 301..

Taxonomy: Heinrich, 1961. Canad. Ent. Sup. 21: 230, 260-261. - Heinrich, 1962. Canad. Ent. Sup. 29: $877,879-880$.

feriens (Heinrich), n. comb. Newfoundland (insular) w. to Alaska, s. to N. Y., Mich., and s. B. C. Ichneumion feriens Heinrich, 1961. Canad. Ent. Sup. 21: 321. ठ, ?.

Taxonomy: Heinrich, 1969. Nat. Canad. 96: 944 (additional characters for distinguishing male).

festus (Cresson). Colo.

Ichneumon bipunctatus Cresson, 1865. Ent. Soc. Phila., Proc. 4: 253. ð. Preoce. by Gmelin, 1790, Schrank, 1802, and Cuvier, 1833.

Ichneumon festus Cresson, 1865. Ent. Soc. Phila., Proc. 4: 257. o. 
flavofacialis (Viereck). Colo.

Ichneumon (Probolus) flavofacialis Viereck, 1905. Kans. Acad. Sci., Trans. 19: 291. đ.

foxleei (Heinrich), n. comb. Wyo., Yukon, B. C.

Ichneumon foxleei Heinrich, 1961. Canad. Ent. Sup. 21: 309.. Preocc. secondarily by Ichneumon foxleei (Heinrich), 1961.

fuscifrons (Cresson). Que. w. to Minn., s. to Ill.

Ichneumon fuscifrons Cresson, 1864. Ent. Soc. Phila., Proc. 3: 166. \&.

gavisicolor (Heinrich), n. comb. Northern Que.

Ichneumon gavisicolor Heinrich, 1956. Canad. Ent. 88: 485. \&.

gestuosus (Cresson), n. comb. Maine, N. H., Ont. Host: Choristonenra fumiferana (Clem.). Ichneumon gestuosus Cresson, 1877. Amer. Ent. Soc., Trans. 6: 156. ․

Taxonomy: Heinrich, 1959. Ent. News 70: 207.

glacialis (Ashmead). Southeastern Alaska.

Ichneumon glacialis Ashmead, 1902. Wash. Acad. Sci., Proc. 4: 154. ठ.

glaucopygos (Heinrich), n. comb. Que., Maine, Mass., N. Y.

Ichneumon glaucopygos Heinrich, 1961. Canad. Ent. Sup. 21: 248. ․

Taxonomy: Heinrich, 1971. Nat. Canad. 98: 969.

gracilicornops (Heinrich), n. comb. Newfoundland (Labrador) s. to Maine, w. to Alta.

Ichneumon gracilicomops Heinrich, 1961. Canad. Ent. Sup. 21: 278. \&.

grandisops (Heinrich), n. comb. Conn., N. Y., w. N. C., Ohio.

Ichneumon grandisops Heinrich, 1961. Canad. Ent. Sup. 21: 305. ๆ.

Taxonomy: Heinrich, 1971. Nat. Canad. 98: 970-971 (male described).

hemimelanarius (Viereck). Ariz.

Ichneumon hemimelanarius Viereck, 1906. Amer. Ent. Soc., Trans. 32: 226. ठ.

heterocampae (Cushman). Que. s. to Md., w. to Mich. and Ohio. Host: Heterocampa guttivitta (Wlk.).

Amblyteles heterocampae Cushman, 1933. U. S. Natl. Mus., Proc. 82: 2..

Taxonomy: Heinrich, 1969. Nat. Canad. 96: 942.

heterodon (Heinrich), n. comb. N. Y., Ont., Ohio.

Ichneumon heterodon Heinrich, 1961. Canad. Ent. Sup. 21: 306. \&.

hiemalis (Cresson). Southwestern Alaska.

Ichneumon hiemalis Cresson, 1877. Amer. Ent. Soc., Trans. 6: 180. $\uparrow$.

hiltoni (Heinrich), n. comb. Maine. Ecology: Collected in a mountain meadow. Ichneumon hiltoni Heinrich, 1969. Nat. Canad. 96: 952. ㅇ.

hippisleyae (Heinrich), n. comb. Mich., s. Man. Ichneumon hippisleyae Heinrich, 1961. Canad. Ent. Sup. 21: 264. ^.

homoioden (Heinrich), n. comb. N. J., Mich. Ichneumon homoioden Heinrich, 1961. Canad. Ent. Sup. 21: 311. \&.

homorus (Heinrich), n. comb. Newfoundland (insular), N. B., Que., Maine, Vt., Ont., Mich. Ichnemmon homorus Heinrich, 1961. Canad. Ent. Sup. 21: 322. \&.

Taxonomy: Heinrich, 1969. Nat. Canad. 96: 945-946 (male described).

hospitus (Cresson). Maine, "Canada," Ill.

Ichneumon hospitus Cresson, 1867. Amer. Ent. Soc., Trans. 1: 306. ơ, ๆ.

Taxonomy: Heinrich, 1969. Nat. Canad. 96: 950.

hypermelanos (Heinrich), n. comb. Ont.

Ichneumon hypermelanos Heinrich, 1961. Canad. Ent. Sup. 21: 259..

infucatus (Cresson). Colo.

Ichneumon infucatus Cresson, 1865. Ent. Soc. Phila., Proc. 4: 252. ठ.

inurbanus (Cresson). W. Va., Ohio, Colo.

Ichneumon inurbauus Cresson, 1867. Amer. Ent. Soc., Trans. 1: 302.. 
klagesi (Viereck). Pa.

Ichneumon flavofacialis Viereck, 1906. Amer. Ent. Soc., Trans. 32: 245. ठ. Preoce. by Viereck, 1905.

Ichneumon klagesi Viereck, 1912. U. S. Natl. Mus., Proc. 43: 591. N. name for $I$. flavofacialis Viereck, 1905.

kodiakensis (Ashmead). Southwestern Alaska.

Ichneumon kodiakensis Ashmead, 1902. Wash. Acad. Sci., Proc. 4: 153. ס.

lachrymans (Provancher). Newfoundland (insular), Que., Maine, N. H., Mass., N. Y., Ont., Mich. Phygadeuon dorsalis Provancher, 1874. Nat. Canad. 6: 285. . Preoce. in Pterocormus by Cresson, 1864.

Ichneumon lachrymans Provancher, 1875. Nat. Canad. 7 (1): 24 (key); 7 (3): 78 . ठै. Barron (1975) did not prove that the lectotype selected by Gahan and Rohwer (1917) was not one of Provancher's two syntypes. Therefore, the new lectotype selected by Barron has no validity.

Taxonomy: Gahan and Rohwer, 1917. Canad. Ent. 49: 431. - Barron, 1975. Nat. Canad. 102: $463,492-493$.

lacunae (Heinrich), n. comb. Maine.

Ichneumon lacunae Heinrich, 1969. Nat. Canad. 96: 948..

laetus (Brulle). Que. w. to Alaska, s. to Va., and Iowa. Host: Pseudaletia unipuncta (Haw.). Ichnenmon laetus Brulle, 1846. In Lepeletier, Hist. Nat. Ins., Hym., v. 4, p. 303. ¿.

Ichneumon lencaniae Fitch, 1861. Boston Cultivator 23: 276. ?.

Ichneumon seminiger Cresson, 1864. Ent. Soc. Phila., Proc. 3: 167. \&.

lariae (Curtis), n. comb. Newfoundland (coastal Labrador), n. Que., N. H., N. W. T., n. Man.; Greenland.

Ichneumon Lariae Curtis, 1835. In Ross, Narrative of Second Voyage in Search of a No.-W. Passage 1829-33, App., p. Ixi. $?$.

Cratichneumon Aurivillii Roman, 1916. Arkiv for Zool. 10 (22): 5 . \&.

Ichneumon lariae subarcticus Heinrich, 1957 (1956). Canad. Ent. 88: 689. ९. N. syn.

Ichneumon lariae labradoris Heinrich, 1957 (1956). Canad. Ent. 88: 690. ․ N. syn.

leucocoxalis (Heinrich), n. comb. Maine, $\mathrm{Pa}$.

Ichneumon leucocoxalis Heinrich, 1961. Canad. Ent. Sup. 21: 266. ․

lewisii (Cresson), n. comb. N. Y. s. to n. Ga., w. to Iowa and Mo. Host: Apantesis sp.

Ichneumon Lewisii Cresson, 1864. Ent. Soc. Phila., Proc. 3: 177...

Ichneumon fulvopictus Ashmead, 1890 (1889). U. S. Natl. Mus., Proc. 12: 391. ठ. Heinrich (1961) erroneously stated that the holotype is from Mont.; it is from Mo.

Taxonomy: Heinrich, 1959. Ent. News 70: 207. - Heinrich, 1961. Canad. Ent. Sup. 21: 300-302.

longulus (Cresson). Colo.

Ichneumon longulus Cresson, 1864. Ent. Soc. Phila., Proc. 3: 171. ठð.

mainensis (Heinrich), n. comb. Maine.

Ichneumon mainensis Heinrich, 1962. Canad. Ent. Sup. 29: 880..

maius (Cresson). N. B., Que., Maine, Mass., Ont., Mich. Host: Tigroides bicolor (Grt.).

Ichneumon maius Cresson, 1867. Amer. Ent. Soc., Trans. 1: 307..

masoni (Heinrich), n. comb. Southwestern Alaska.

Ichneumon masoni Heinrich, 1956. Canad. Ent. 88: 479. .

melanarcticus (Heinrich), n. comb. Newfoundland (n. Labrador), e. Que. Ichneumon melanarcticus Heinrich, 1961. Canad. Ent. Sup. 21: 331..

mendax (Cresson). Que. s. to s. S. C., w. to Colo. and Tex. Ichneumon mendax Cresson, 1877. Amer. Ent. Soc., Trans. 6: 149..

Phygadeuon Guignardi Provancher, 1886. Addit. Corr. Faune Ent. Canada Hym., p. 50..

microferiens (Heinrich), n. comb. Newfoundland (insular), Ont., Man., Alta., Alaska.

Ichnenmon microferiens Heinrich, 1961. Canad. Ent. Sup. 21: 323..

Taxonomy: Heinrich, 1976 (1975). Nat. Canad. 102: 758 (male described).

mystificans (Heinrich), n. comb. Newfoundland (Labrador and insular), Maine, Mich.

Ichneumon mystificans Heinrich, 1961. Canad. Ent. Sup. 21: 342. ס". 
nanusniger (Heinrich), n. comb. Newfoundland (insular).

Ichneumon nanusniger Heinrich, 1976 (1975). Nat. Canad. 102: 760. ¿, ․

nearctivernus (Heinrich), n. comb. Maine, Ont., Mich., N. W. T., Sask., Alta., Yukon, Alaska. Ichneumon computatorins nearctivermus Heinrich, 1957 (1956). Canad. Ent. 88: 648. ?.

Taxonomy: Heinrich, 1961. Canad. Ent. Sup. 21: 339.

nebularum (Heinrich), n. comb. Newfoundland (Labrador), N. H.?

Ichneumon nebularum Heinrich, 1956. Canad. Ent. 88: 483. ?.

neomolitor (Heinrich), n. comb. Newfoundland (insular), Maine, Alta. Ecology: Occurs in spruce (Picea mariana) bogs.

Ichneumon neomolitor Heinrich, 1961. Canad. Ent. Sup. 21: 329. ९.

Biology: Heinrich, 1969. Nat. Canad. 96: 946-947.

neosarcitor (Heinrich), n. comb. Maine.

Ichneumon neosareitor Heinrich, 1961. Canad. Ent. Sup. 21: 244. ठ, १.

nereni emigrator (Heinrich), n. comb. Newfoundland (insular), P. E. I., Que., Maine, Ont. $P$. nereni nereni (Thomson) is Eurasian.

Ichnenmon nereni emigrator Heinrich, 1961. Canad. Ent. Sup. 21: 289. ठ, ․ Ichneumon emigrator Walkenaer, 1802 is apparently a lapsus for 1 . migrator Fabricius, 1785 and, therefore, would not preoccupy emigrator Heinrich.

nigrotergus (Davis). S. Dak.

Ichneumon nigrotergus Davis, 1898 (1897). Amer. Ent. Soc., Trans. 24: 350. ९.

Taxonomy: Heinrich, 1961. Canad. Ent. Sup. 23: 417.

nigrovariegatus (Provancher). Newfoundland (insular) s. to S. C., w. to Mich.

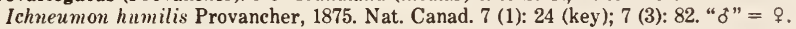

Preocc. by Wesmael, 1857.

Phygadeuon nigrovariegatus Provancher, 1875. Nat. Canad. 7 (6): 182.9.

Ichneumon humillimus Dalla Torre, 1902. Cat. Hym., v. 3, p. 923. N. name for Ichneumon humilis Provancher. Townes (1944) regarded I. humilis as replacing Phygadeuon dorsalis Provancher (formerly a synonym of humilus), but I do not think this view is tenable. I. humilis is the name which had been in use for the species most immediately preceding Dalla Torre's proposal of humillimus; therefore, it is logical to conclude that Dalla Torre proposed humilimus to replace humilis.

Taxonomy: Townes, 1944. Amer. Ent. Soc., Mem. 11: 399-400.

oblitus (Heinrich), n. comb. Que., Maine, N. Y., Ont., Mich., S. Dak.

Ichneumon oblitus oblitus Heinrich, 1961. Canad. Ent. Sup. 21: 234. o, ?.

Ichneumon oblitus polyglaucos Heinrich, 1961. Canad. Ent. Sup. 21: 236. ठ', ๆ.

ormsbyensis (Cameron). Nev.

Pseudamblyteles ormsbyensis Cameron, 1908. Amer. Ent. Soc., Trans. 34: 242. ठ゚.

palaearctops (Heinrich), n. comb. Newfoundland (insular).

Ichneumon palaearctops Heinrich, 1976 (1975). Nat. Canad. 102: 761. ठో.

paramajops (Heinrich), n. comb. Newfoundland (insular).

Ichneumon paramajops Heinrich, 1976 (1975). Nat. Canad. 102: 757..

parvus (Cresson). Ill., Mo., Kans.

Ichneumon parvus Cresson, 1864. Ent. Soc. Phila., Proc. 3: 159. ¿.

Ichneumon xanthopsis Ashmead, 1890 (1889). U. S. Natl. Mus., Proc. 12: 390. ठ์. Heinrich (1961) erroneously stated that the holotype of $I$. xanthopsis is from Mont.; it is a specimen from the C. V. Riley collection bearing no locality label; Ashmead probably just assumed (perhaps correctly) that it is from "St. Louis, Mo."

Taxonomy: Heinrich, 1961. Canad. Ent. Sup. 21: 345 (syn. questioned).

patroclus (Viereck). N. Mex.

Cratichneumon patroclus Viereck, 1903. In Skinner, Amer. Ent. Soc., Trans. 29: 78. ¿. pedalis (Cresson). Sask., Colo., Alta.

Ichneumou pedalis Cresson, 1864. Ent. Soc. Phila., Proc. 3: 141. ठ̊.

Taxonomy: Heinrich, 1961. Canad. Ent. Sup. 21: 313, 347. 
perlugubris (Heinrich), n. comb. Que., Sask.

Ichneumon perlugubris Heinrich, 1961. Canad. Ent. Sup. 21: 306. ₹.

peroratus (Cameron). Nev.

Psezdamblyteles peroratus Cameron, 1908. Amer. Ent. Soc., Trans. 34: 242. ठ์.

Taxonomy: Townes, 1961. Ent. Soc. Wash., Proc. 63: 112.

perretti (Heinrich), n. comb. Newfoundland (n. Labrador).

Ichneumon perretti Heinrich, 1956. Canad. Ent. 88: 482. ?.

pictifrons (Cresson). Alta., Mont., Colo.

Ichneumon pictifrons Cresson, 1864. Ent. Soc. Phila., Proc. 3: 160. ठ.

placidus (Provancher), Que., Maine, N. Y., Ont., Ohio, Alta., Utah.

Ichneumon placidus Provancher, 1875. Nat. Canad. 7 (1): 23 (key); 7 (3): 76. ठ.

polargus (Heinrich), n. comb. Newfoundland (n. Labrador), n. Ont., n. Man., Colo.?

Ichneumon polargns Heinrich, 1961. Canad. Ent. Sup. 21: 327. \&.

popofensis (Ashmead). Alta., Alaska.

Ichneumon popofensis Ashmead, 1902. Wash. Acad. Sci., Proc. 4: 154. ठో.

propitius (Cresson), n. comb. Que. w. to Sask., s. to Ga. and Tex.; s. Mexico. Host: Melitaea harrisii Scud., Phyciodes tharos (Drury).

Ichneumon propitius Cresson, 1872. Amer. Ent. Soc., Trans. 4: 156. ठ.

Ichneumon tharotis Packard, 1881. Boston Soc. Nat. Hist., Proc. 21: 22. .

Taxonomy: Heinrich, 1959. Ent. News 70: 207-208.

Biology: Swift, 1946. Ent. Soc. Amer., Ann. 39: 407-409.

pseudomaius (Heinrich), n. comb. Mass.

Ichneumon pseudomains Heinrich, 1961. Canad. Ent. Sup. 21: 280. ‡.

pseudovivax (Heinrich), n. comb. Maine.

Ichneumon pseudovivax Heinrich, 1961. Canad. Ent. Sup. 21: 286. ․

pseudowinkleyi (Heinrich), n. comb. Que., Maine, N. Y., Ont., Man., Alta.

Ichneumon pseudowinkleyi Heinrich, 1961. Canad. Ent. Sup. 21: 252. \&.

pumiliops (Heinrich), n. comb. Que., Maine, Mass., N. Y., Ohio.

Ichneumon pumiliops Heinrich, 1961. Canad. Ent. Sup. 21: 276. ․

Taxonomy: Heinrich, 1971. Nat. Canad. 98: 970 (variation).

purpuripennis (Cresson). Calif.

Ichneumon purpuripennis Cresson, 1877. Amer. Ent. Soc., Trans. 6: 175. $q$.

Taxonomy: Cresson, 1879 (1878). Acad. Nat. Sci. Phila., Proc. 30: 350.

pusillamoenus (Heinrich), n. comb. Newfoundland (insular), Que., Maine, Ont.

Ichneumion pusillamoenus Heinrich, 1961. Canad. Ent. Sup. 21: 272. ๆ.

Taxonomy: Heinrich, 1976 (1975). Nat. Canad. 102: 762-763 (male described).

putus (Cresson). Newfoundland (insular) s. to D. C., w. to Iowa. Host: Itame sulphurea (Pack.).

Ichneumon putus Cresson, 1877. Amer. Ent. Soc., Trans. 6: 173. \&.

pycnocephalus (Heinrich), n. comb. Yukon, B. C.

Ichneumon pycnocephalus Heinrich, 1961. Canad. Ent. Sup. 21: 223 (key), 261. @ The variant spelling "pycnocephalos" which appeared on p. 261 was rejected in favor of pycnocephalus by Peck (1964).

Taxonomy: Peck, 1964. Ent. Soc. Canada, Mem. 35: 892.

saucius (Cresson), n. comb. Que. w. to Mont., s. to N. C. and Ill. Host: Paranthrene perlucida (Bsk.), P. simulans (Grt.). In the U. S. Natl. Museum collection there are three males from Missoula, Mont. reared together with the type material of Paranthrene perlucida. I have seen several females which were collected in hibernation in Nov. and Dec. in Va. Ichneumon saucius Cresson, 1864. Ent. Soc. Phila., Proc. 3: 137. ๆ.

Ichneumon torvinus Cresson, 1867. Amer. Ent. Soc., Trans. 1: 292. ठ.

Taxonomy: Heinrich, 1959. Ent. News 70: 209 (syn.), - Heinrich, 1961. Canad. Ent. Sup. 21: 335-336; 23: 373. 
seditiosus (Cresson). Colo.

Ichneumon seditiosus Cresson, 1877. Amer. Ent. Soc., Trans. 6: 172..

semicoccineus (Cresson). N. Y., Del., Va., S. C. Heinrich (1961) erroneously stated that the "holotype" of semicoccineus is from "'Western Territory' (= Western U. S. A.);" in the original description Cresson said "Hab.. - Delaware and Virginia," and Cresson (1916) selected a lectotype from Virginia. Heinrich (1961) identified a paralectotype from Del. as semicoccineus, but the identity of the lectotype seems to remain an open question if the specimen Heinrich thought to be the "holotype" actually was labeled "Western Territory."

Ichneumon semicoccineus Cresson, 1864. Ent. Soc. Phila., Proc. 3: 179. ठ。.

Taxonomy: Cresson, 1867. Amer. Ent. Soc., Trans. 1: 291 (syn.). - Cresson, 1916. Amer. Ent. Soc., Mem. 1: 54. - Heinrich, 1959. Ent. News 70: 207 (syn.). - Heinrich, 1961. Canad. Ent. Sup. 21: 311-312.

similaris (Provancher). Newfoundland (n. Labrador) w. to Alaska, s. to Que. and Oreg.

Ichneumon similaris Provancher, 1875. Nat. Canad. 7: 26. ठँ.

Automalus nigropilosus Ashmead, 1902. Wash. Acad. Sci., Proc. 4: 148. ठో.

stagnophilos (Heinrich), n. comb. Newfoundland (insular), N. Y., Ont.

Ichneumon stagnophilos Heinrich, 1961. Canad. Ent. Sup. 21: 249..

Taxonomy: Heinrich, 1969. Nat. Canad. 96: 940 (male described).

subdolus (Cresson). N. S. w. to Alta., s. to w. N. C. and s. Mich.

Ichneumon subdolus Cresson, 1867. Amer. Ent. Soc., Trans. 1: 298..

Amblyteles (Pterocormus) quadrizonatus Viereck, 1917 (1916). Conn. State Geol. and Nat. Hist. Survey Bul. 22: 352, 357. ठో.

subrestrictus (Viereck). N. Mex.

Cratichneumon restrictus var. subrestrictus Viereck, 1903. In Skinner, Amer. Ent. Soc., Trans. 29: 77. $\delta$.

substituens (Heinrich), n. comb. Mass., Ohio.

Ichneumon substituens Heinrich, 1961. Canad. Ent. Sup. 21: 265..+

suburbanus (Heinrich), n. comb. N. S. w. to Alta., s. to Conn. and Mich.

Ichneumon suburbanus Heinrich, 1961. Canad. Ent. Sup. 21: 307. ठ, \&.

subversatus (Heinrich), n. comb. Que., Maine, Ont.

Ichneumon subversatus Heinrich, 1961. Canad. Ent. Sup. 21: 283..

trigemellus (Heinrich), n. comb. N. W. T., Man.

Ichneumon trigemellus Heinrich, 1956. Canad. Ent. 88: 484..

tritus (Heinrich), n. comb. Que., Maine, N. Y., Ont.

Ichneumon tritus Heinrich, 1961. Canad. Ent. Sup. 21: 256..

truculentus (Cresson). Que., N. H., Mich.

Ichneumon truculentus Cresson, 1877. Amer. Ent. Soc., Trans. 6: 150. ․

tumidifrons (Cresson). Mich., Ill.

Ichneumon tumidifrons Cresson, 1867. Amer. Ent. Soc., Trans. 1: 311. ๆ.

Taxonomy: Townes and Townes, 1951. In Muesebeck et al., U. S. Dept. Agr., Agr. Monog. 2: 297 (syn.). - Heinrich, 1961. Canad. Ent. Sup. 21: 267-268.

ultimus (Cresson). Que. s. to Md., w. to Mich. and Ohio.

Ichneumon ultimus Cresson, 1877. Amer. Ent. Soc., Trans. 6: 178. ๆ.

unalaskae (Ashmead). Southwestern Alaska.

Stenichneumon unalaskae Ashmead, 1902. Wash. Acad. Sci., Proc. 4: 148. ठठ.

uncinatus (Cresson). Ont., Mich., Alta., Alaska.

Ichneumon uncinatus Cresson, 1877. Amer. Ent. Soc., Trans. 6: 159.. .

valdopacus (Heinrich), n. comb. Maine, N. Y.

Ichneumon valdopacus Heinrich, 1961. Canad. Ent. Sup. 21: 286. ^. 
vecors (Cresson). "Hudson's Bay Territory." This species has not been included in any of the publications of Heinrich, not even those dealing with arctic and subarctic Ichneumoninae (Heinrich [1956, 1958]).

Ichneumon ventralis Cresson, 1867. Amer. Ent. Soc., Trans. 1: 308. ๆ. Preocc. by Cresson, 1865.

Ichneumon vecors Cresson, 1877. Amer. Ent. Soc., Trans. 6: 172. N. name for I. ventralis Cresson, 1867.

Taxonomy: Heinrich, 1956. Canad. Ent. 88: 477-487. - Heinrich, 1958. Canad. Ent. 90: 739-741.

versabilis (Cresson). Que., Maine, Vt., Mass., Conn., N. Y., Pa., Ohio, Mich. At least one and probably all of the host records quoted from the literature by Heinrich (1961) are based upon misidentifications.

Ichneumon versabilis Cresson, 1877. Amer. Ent. Soc., Trans. 6: 161. ठં.

Amblyteles (Pterocormus) brittoni Viereck, 1917 (1916). Conn. State Geol. and Nat. Hist. Survey Bul. 22: $347,348,358$. .

Taxonomy: Townes, 1944. Amer. Ent. Soc., Mem. 11: 397-398 (syn.). - Heinrich, 1959. Ent. News 70: 208. - Heinrich, 1961. Canad. Ent. Sup. 21: 281-283.

vicinus (Cresson). Mich.?, Ill. Heinrich (1961) knew this species only from the holotype and was uncertain whether it should be placed in Pterocormus or Cratichneumon.

Ichneumon vicinus Cresson, 1864. Ent. Soc. Phila., Proc. 3: 169. + . Preoce. by Cuvier, 1833 and Fonscolombe, 1847; not renamed here because of taxonomic uncertainties.

vinulentus (Cresson). Wyo., Colo., Alaska, Wash.

Ichneumon vinulentus Cresson, 1864. Ent. Soc. Phila., Proc. 3: 162. o.

vivax (Cresson). N. H., Ont., Ohio.

Ichneumon vivax Cresson, 1877. Amer. Ent. Soc., Trans. 6: 178. ๆ.

volesus (Cresson). N. S. w. to Alta., s. to N. Y., Mich., and Colo.

Ichneumon volesus Cresson, 1867. Amer. Ent. Soc., Trans. 1: 304..

Amblyteles balteatus Hopper, 1938. Amer. Ent. Soc., Trans. 64: 97. ठ. Preocc. in Pterocormus by Wesmael, 1845.

walleyi (Heinrich), n. comb. Maine, Ont.

Ichneumon walleyi Heinrich, 1961. Canad. Ent. Sup. 21: 338. . Preocc. secondarily by Ichneumon walleyi (Heinrich), 1961.

weemsi (Heinrich), n. comb. Fla. Host: Leucania latiuscula H.-S.

Ichneumon weemsi Heinrich, 1972. Nat. Canad. 99: 175. ठ', ?.

winkleyi (Viereck). N. B., Que., Maine, Conn., Ont., Ohio, Mich., Mo.?

Amblyteles (Pterocormus) winkleyi Viereck, 1917 (1916). Conn. State Geol. and Nat. Hist. Survey Bul. 22: $347,348,358$. .

Taxonomy: Heinrich, 1959. Ent. News 70: 208.

zelotypus (Cresson). Que., Maine, N. H., N. Y., N. J., W. Va., Ont., Ohio, Mich., Alta.

Ichneumon zelotypus Cresson, 1867. Amer. Ent. Soc., Trans. 1: 299. ठ゚.

Ichneumon lividulus Provancher, 1877. Nat. Canad. 9: 10..

Taxonomy: Heinrich, 1959. Ent. News 70: 209 (syn.).

\section{Genus CHASMIAS Ashmead}

Chasmodes Wesmael, 1845 (1844). [Brussels] Acad. Roy. de Belg., Nouveaux Mem. 18: 15.

Preocc. by Cuvier and Valenciennes, 1836.

Type-species: Ichneumon motatorius Gravenhorst. Desig. by Ashmead, 1900. The type-species is Gravenhorst's identification of $I$. motatorius Fabricius.

Chasmias Ashmead, 1900. U. S. Natl. Mus., Proc. 23: 17. N. name for Chasmodes Wesmael.

This is a very small Holarctic genus.

Taxonomy: Heinrich, 1961. Canad. Ent. Sup. 21: 211, 212, 336; 23: 373. -Townes, Momoi, and

Townes, 1965. Amer. Ent. Inst., Mem. 5: 458 (syn.). 
scelestus (Cresson). Maine s. to N. C., w. to Wis., Iowa, and La. Host: Achatodes zeae (Harris), Arzama sp., Papaipema cataphracta (Grt.), P. impecuniosa (Grt.), Parapamea buffaloensis (Grt.).

Ichneumon scelestus Cresson, 1864. Ent. Soc. Phila., Proc. 3: 148. \&.

\section{SUBTRIBE HOPLISMENINA}

\section{Genus HYBOPHORELLUS Schulz}

Hybophorus Tischbein, 1875. Stettin. Ent. Ztg. 36: 281. Preocc. by Waterhouse, 1853.

Type-species: Ichneumon aulicus Gravenhorst. Monotypic.

Hybophorellus Schulz, 1911 (1909). Zool. Ann. 4: 38. N. name for Hybophorus Tischbein.

This is a very small Holarctic genus.

baffinensis Heinrich. Northeastern N. W. T.

Hybophorellus baffinensis Heinrich, 1962. Canad. Ent. Sup. 26: 565. ð.

injucundus neareticus Heinrich. N. W. T. H. injucundus injucundus (Wesmael) is European.

Hybophorellus injucundus nearcticus Heinrich, 1957 (1956). Canad. Ent. 88: 650. ठ, ?.

townesi Heinrich. Southern Sask.

Hybophorellus townesi Heinrich, 1957 (1956). Canad. Ent. 88: 649. ১, १.

\section{Genus HOPLISMENUS Gravenhorst}

Hoplismenus Gravenhorst, 1829. Ichn. Europaea, v. 2, p. 409.

Type-species: Hoplismenus moestus Gravenhorst. Desig. by Westwood, 1840. The type-species is regarded as a synonym of $H$. albifrons Gravenhorst.

Peritaenius Foerster, 1868. Naturh. Ver. Rheinlande, Verh. 25: 190.

Type-species: Peritaenius bavaricus Clement. Included and desig. by Clement, 1927.

The type-species is regarded as a synonym of $H$. istrianus (Clement).

Rhysaspis Tischbein, 1874. Stettin. Ent. Ztg. 35: 139.

Type-species: Rhysaspis rugosus Tischbein. Monotypic.

Zanthojoppa Cameron, 1901. Ann. and Mag. Nat. Hist. (7) 7: 378.

Type-species: Zanthajoppa trilineata Cameron. Monotypic.

Xanthojoppa (!) Cameron, 1903. Ann. and Mag. Nat. Hist. (7) 11: 182.

Xanthojoppa Morley, 1915. Rev. Ichn. Brit. Mus., v. 4, p. 89. Emend.

Taeniaspis Clement, 1927. Konowia 6: 72.

Type-species: Taeniaspis flavitarsis Clement. Monotypic.

This is a moderate sized genus of Neotropic, Holarctic, and Oriental distribution.

Revision: Swift, 1946. Ent. Soc. Amer., Ann. 39: 397-407.

arizonensis Swift. Ariz.

Hoplismenus arizonensis Swift, 1946. Ent. Soc. Amer., Ann. 39: 404. ․

morulus flavitarsis (Cresson). Colo., N. Mex., Utah.

Trogus flavitarsis Cresson, 1865. Ent. Soc. Phila., Proc. 4: 264. ð.

morulus morulus (Say). P. E. I. s. to Va., w. to s.w. N. W. T. and Kans. Host: Cynthia cardui (L.)?, Nymphalis antiopa (L.), Polygonia comma (Harris), P. interrogationis (F.).

Ichneumon morulus Say, 1829. Contrib. Maclurian Lyceum to Arts and Sei. 1: 73..

Ichneumon calcaratus Provancher, 1875. Nat. Canad. 7 (1): 21 (key); 7 (3): 49. ठ. Preoce. by Rossi, 1794.

morulus pacificus Cresson. Mont., Ida., s. B. C., Wash., Oreg., Calif. Host: Nymphalis californica (Bdv.).

Hoplismenus pacificus Cresson, 1877. Amer. Ent. Soc., Trans. 6: 186. ठ, ๆ.

polyleucos Heinrich. Southern Ont.

Hoplismenus polyleucos Heinrich, 1962. Canad. Ent. Sup. 26: 659. ठ.

praeruptus Swift. Conn., N. Y., Ont.?, Wash.

Hoplismenus praeruptus Swift, 1946. Ent. Soc. Amer., Ann. 39: 407..

rutilus borealis Heinrich. Man., Sask., w. N. W. T.

Hoplismenus rutilus borealis Heinrich, 1962. Canad. Ent. Sup. 26: 657. ð, ๆ. 
rutilus rutilus (Cresson). P. E. I., Que., Maine, Mass., R. I., Conn., Pa., Va., Ont.

Ichneumon rutilus Cresson, 1864. Ent. Soc. Phila., Proc. 3: 169. ₹.

Ichneumon scutellatus Provancher, 1875. Nat. Canad. 7 (1): 24 (key); 7 (3): 78. of ( misdet.?). Preocc. by Geoffroy, 1785. Barron (1975) has shown that the specimen selected as lectotype by Gahan and Rohwer (1917) had been erroneously labeled, and Barron selected a valid lectotype.

Taxonomy: Gahan and Rohwer, 1917. Canad. Ent. 49: 432. - Barron, 1975. Nat. Canad. 102: 562.

rutilus transversus Davis. Wyo., Colo., Ida., Oreg.

Hoplismenus transversus Davis, 1898 (1897). Amer. Ent. Soc., Trans. 24: 351. ठ゚.

Hoplismenus mutilus tenuis Swift, 1946. Ent. Soc. Amer., Ann. 39: 407. ?.

\section{TRIBE ICHNEUMONINI}

With exception of the Old-World genus Lymantrichneumon, females of this tribe do not hibernate.

\section{SUBTRIBE ICHNEUMONINA}

\section{Genus SYSPASIS Townes}

Syspasis Townes, 1965. In Townes, Momoi, and Townes, Amer. Ent. Inst., Mem. 5: 429, 595,603 .

Type-species: Ichneumon scutellator Gravenhorst. Orig. desig.

This is a small Holaretic genus.

tauma (Heinrich), Que., Maine, N. Y., n.w. S. C., Ont., Mich., Minn.; Europe. Host: Tigroides bicolor (Grt.), Paraphia sp.?, Choristoneura fumiferana (Clem.).

Coelichneumon tauma Heinrich, 1951. Bonner Zool. Beitr. 2: 253. .

Taxonomy: Heinrich, 1953. Wash. Acad. Sci., Jour. 45: 148. - Heinrich, 1969. Nat. Canad. 96 : 939-940.

\section{Genus ICHNEUMON Linnaeus}

Ichneumon Linnaeus, 1758. Syst. Nat., ed. 10, p. 560.

Type-species: Ichneumon comitator Linnaeus. Desig. by Curtis, 1839.

Coelichneumon Thomson, 1893. Opuse. Ent. 18: 1901.

Type-species: Ichneumon lineator Gravenhorst. Desig. by Ashmead, 1900. The type-species is Gravenhorst's misidentification of $I$. lineator Fabricius; the latter is a species of Syspasis while I. lineator in the sense of Gravenhorst is regarded as a synonym of $I$. comitator Linnaeus.

Cyanojoppa Cameron, 1902. Ztschr. System. Hym. Dipt. 2: 398.

Type-species: Cyanojoppa rufo-femorata Cameron. Desig. by Viereck, 1914 from four species included by Cameron, 1903.

Taphanes Cameron, 1903. Entomologist 36: 239. Heinrich (1966) gave Taphanes subgeneric status.

Type-species: Taphanes rufiventris Cameron. Monotypic.

Spilojoppa Cameron, 1904. Entomologist 37: 208.

Type-species: Spilojoppa fulvipes Cameron. Monotypic. The type-species is a synonym of I. fulvimanus Townes, Townes, and Gupta.

Shalisa Cameron, 1904. Ztschr. System. Hym. Dipt. 4: 221.

Type-species: Shalisa fulvipes Cameron. Monotypic.

Lodryca Cameron, 1904. Ztschr. System. Hym. Dipt. 4: 223.

Type-species: Lodryca lineaticeps Cameron. Monotypic.

Eugyris Townes, 1946. Bol. Ent. Venezolana 5: 57.

Type-species: Ichneumon alvarado Cresson. Monotypic and orig. desig.

This is a large genus of Neotropic. Holarctic, and Oriental distribution.

Taxonomy: Townes and Townes, 1966. Amer. Ent. Inst., Mem. 8: 284-285 (syn.). - Heinrich, 1966. Ent. Tidskr. 87: 188-192. 
albicoxa (Heinrich), n. comb. N. Y., N. C., Ont., Mich., Wis.

Coelichneumon albicoxa Heinrich, 1961 (1960). Canad. Ent. Sup. 15: 81. ठ.

Taxonomy: Heinrich, 1971. Nat. Canad. 98: 964-965 (variation and female description).

ater Cresson. Que. w. to s.e. Alaska, s. to N. C., Ill., and Wash.

Ichneumon ater Cresson, 1864. Ent. Soc. Phila., Proc. 3: 138. \&.

azotus Cresson. Que. s. to Ala., w. to Mich., Kans., and Tex.

Ichneumon Azotus Cresson, 1864. Ent. Soc. Phila., Proc. 3: 150. ð.

Ichneumon agnitus Cresson, 1864. Ent. Soc. Phila., Proc. $3: 151$. $\$$.

barnstoni (Morley). Newfoundland (insular), Pa., Md., "Hudson Bay", Ont., Mich., Wis., Alta.

Coelichneumon barnstoni Morley, 1915. Rev. Ichn. Brit. Mus., v. 4, p. 130. of (female misdet.).

Taxonomy: Townes, 1961. Ent. Soc. Wash., Proc. 63: 105.

brunneri Rohwer. Maine w. to Idaho, s. to Va., lowa, w. Nebr., and Utah. Host: Dioryctria auranticella (Grt.), D. disclusa Heinr., D. zimmermanni (Grt.).

Ichneumon brunneri Rohwer, 1914. Ent. Soc. Wash., Proc. 15: 180. ¿, ?.

chalybeus Cresson. Mass., Mich.

Ichneumon chalybeus Cresson, 1877. Amer. Ent. Soc., Trans. 6: 146..

Ichneumon chalybaeus (!) Dalla Torre, 1902. Cat. Hym., v. 3, p. 873.

Coelichneumon chalybaeus Morley, 1915. Rev. Ichn. Brit. Mus., v. 4, p. 128. Emend.

citimus Cresson. N. H. Known only from the holotype.

Ichneumon citimus Cresson, 1877. Amer. Ent. Soc., Trans. 6: 144. ठ.

columbianus (Heinrich), n. comb. Mich., B. C.

Coelichneumon columbianus Heinrich, 1961 (1960). Canad. Ent. Sup. 15: 38. $\subsetneq$.

deliratorius cinctitarsis Provancher. P. E. I. w. to s. B. C., s. to N. C., Mich., and S. Dak.

Ichneumon varipes Provancher, 1875. Nat. Canad. 7 (1): 22 (key); 7 (2): 50. ठ̊. Preocc. by Gravenhorst, 1829.

Ichneumon signatipes Provancher, 1875. Nat. Canad. 7 (1): 22 (key); 7 (2): 52. ?. Preocc. by Cresson, 1867.

Ichneumon cinctitarsis Provancher, 1877. Nat. Canad. 9: 7. N. name for I. varipes Provancher.

Ichneumon stygicus Cresson, 1877. Amer. Ent. Soc., Trans. 6: 151. N. name for I. signatipes Provancher.

Taxonomy: Heinrich, 1959. Wash. Acad. Sci., Jour. 43: 149. - Heinrich, 1959. Canad. Ent. 91: 806. - Heinrich, 1961. Canad. Ent. Sup. 21: 331. - Heinrich, 1971. Nat. Canad. 98: 967.

duffieldi (Heinrich), n. comb. N. Y.

Coeiichneumon duffieldi Heinrich, 1971. Nat. Canad. 98: 965. ․

eximiops (Heinrich), n. comb. Maine, N. Y., Wis., Ill., Iowa, Kans. Host: Achatodes zeae (Harris).

Coelichneumon eximiops Heinrich, 1961 (1960). Canad. Ent. Sup. 15: 49. ơ, ๆ.

eximius Stephens. Newfoundland (insular) w. to Oreg., s. to Ga., Miss., Tex., and n. Mex.

Host: Arctiid?, Datana ministra (Drury), Abagrotis placida (Grt.), Acronicta sp.

Ichneumon eximius Stephens, 1833. Nomencl. Brit. Ins., ed. 2, app. Nomen nudum.

Ichneumon eximius Stephens, 1835. Illus. Brit. Ent., v. 7, p. 186. [female].

Ichneumon caeruleus Cresson, 1864. Ent. Soc. Phila., Proc. 3: 149. \&.

Taxonomy: Morley, 1902. Ent. Monthly Mag. 38: 120 (attempt to place from description). -Perkins, 1953. Brit. Mus. (Nat. Hist.) Ent., Bul. 3: 107, 110 (located specimen presumed to be eximius holotype). - Townes, 1961. Ent. Soc. Wash., Proc. 63: 107, 169 (confirmation of identity of presumed holotype of eximius). - Heinrich, 1969. Nat. Canad. 96: 939 (variation).

flagellator (Heinrich), n. comb. Colo., Calif. The holotype was collected in July at Fort Collins, Colo. in the 1890 's by C. F. Baker.

Coelichneumon flagellator Heinrich, 1961 (1960). Canad. Ent. Sup. 15: 71. \&. Preoce. in Ichneumon by I. flagellator Fabricius, apparently a forgotten species which would not be a species of Ichneumoninae. 
foxleei (Heinrich), n. comb. Southern B. C. Not to be confused nomenclatorially with Pterocormus foxleei (Heinrich).

Coelichneumon foxleei Heinrich, 1961 (1960). Canad. Ent. Sup. 15: 52. ․

histricus Cresson. P. E. I. w. to B. C., s. to w. N. C., Kans., and Idaho.

Ichneumon histricus Cresson, 1867. Amer. Ent. Soc., Trans. 1: 294. ¿.

Ichneumon germanus Cresson, 1877. Amer. Ent. Soc., Trans. 6: 143..

jejunus Cresson. Que. w. to B. C., s. to Fla. and Ariz. Host: Alypia octomaculata (F.).

Ischnus jejunus Cresson, 1864. Ent. Soc. Phila., Proc. 3: 186. ¿.

Ichnezmon apertus Cresson, 1867. Amer. Ent. Soc., Trans. 1: 293. ๆ.

leucographus (Heinrich), n. comb. Maine, Ont.

Coelichneumon leucographus Heinrich, 1961 (1960). Canad. Ent. Sup. 15: 39. ð,.

magniscopa (Heinrich), n. comb. Maine, Mass., N. Y., N. C., Fla., Ont.

Coelichneumon magniscopa Heinrich, 1961 (1960). Canad. Ent. Sup. 15: 37. đ’,.

masoni (Heinrich), n. comb. Southwestern B. C. Not to be confused nomenclatorially with Pterocormus masoni (Heinrich), 1956.

Coelichneumon masoni Heinrich, 1961 (1960). Canad. Ent. Sup. 15: 43. ․

maurus Cresson. Que. w. to N. W. T. and B. C., s. to Ga., Mo., and Utah.

Ichneumon Maurus Cresson, 1864. Ent. Soc. Phila., Proc. 3: 135. \&.

navus Say. Que. s. to Fla., w. to Mich., Kans., and Tex. Host: Hyphantria cunea (Drury), looper defoliating cypress, noctuid.

Ichneumon navus Say, 1836. Boston Jour. Nat. Hist. 1: 229. d, ․

Ichneumon cinctipes Provancher, 1875. Nat. Canad. 7 (1): 22 (key); 7 (2): 51. $\$$. Preoce. by Retzius, 1783.

neocitimus (Heinrich), n. comb. Southern N. W. T., s.w. Yukon.

Coelichneumon neocitimus Heinrich, 1961 (1960). Canad. Ent. Sup. 15: 79. đ, ․

neocretatus (Heinrich), n. comb. Newfoundland (insular), Que., Maine, N. Y., Ont., Mich., Kans.?, Sask.

Coelichneumon neocretatus Heinrich, 1961 (1960). Canad. Ent. Sup. 15: 51. đૈ, ૧.

neomexicanus (Heinrich), n. comb. N. Mex. The holotype was collected on Sept. 12 (not 13), 1916 by C[arl] Heinrich.

Coelichneumon neomexicanus Heinrich, 1961 (1960). Canad. Ent. Sup. 15: 40. ․

nigraticolor (Viereck). Que., Maine, Mass., R. I., Conn., Pa., Ont., Ohio, Mich.

Amblyteles (Chasmias ?) nigraticolor Viereck, 1917 (1916). Conn. State Geol. and Nat. Hist. Survey Bul. 22: 344, 355. ?.

nigrosignatus Viereck. Ariz. A brief redescription of the holotype is given by Heinrich (1961), but nigrosignatus was not included in his key; Heinrich said that it would run to pervagus Cresson.

Ichneumon (Barichneumon) nigrosignatus Viereck, 1905. Kans. Acad. Sci., Trans. 19: 297. o.

Taxonomy: Heinrich, 1961 (1960). Canad. Ent. Sup. 15: 82.

nudus (Heinrich), n. comb. Maine, Ga. The holotype (from Summerville, Ga.) is apparently the specimen identified as Ichneumon sp. by Fattig (1950).

Coelichneumon nudus Heinrich, 1961 (1960). Canad. Ent. Sup. 15: 40. đ.

Taxonomy: Fattig, 1950. Emory Univ. Mus. Bul. 9: 40. - Heinrich, 1969. Nat. Canad. 96:

937-939 (male described).

obscuratus (Heinrich), n. comb. Southern B. C.

Coelichneumon obscuratus Heinrich, 1961 (1960). Canad. Ent. Sup. 15: 45. 9 . Preoce. secondarily in Ichneumon by Habermehl, 1916 (Pterocormus subquadratus var. obscuratus [Habermehl]).

orpheus Cresson. Que. w. to B. C., s. to Va., Mo., Utah, and Oreg. Host: Ecpantheria scribonia (Stoll), notodontid.

Ichneumon Orpheus Cresson, 1864. Ent. Soc. Phila., Proc. 3: 136. \&.

pepticus Cresson. N. J.?, Mich., Ill., Iowa, Mo., Colo., Wash., Oreg.

Ichneumon pepticus Cresson, 1877. Amer. Ent. Soc., Trans. 6: 148. ठౌ. 
pervagus Cresson. Newfoundland (Labrador), N. S., Maine, N. H., Conn., N. Y., Mich., B. C. Host: Scoliopteryx libatrix (L.).

Ichneumon pervagus Cresson, 1877. Amer. Ent. Soc., Trans. 6: 148. ठ̊.

Amblyteles (Chasmias ?) pequoitorum Viereck, 1917 (1916). Conn. State Geol. and Nat. Hist. Survey Bul. 22: 345, 355. \&.

Taxonomy: Heinrich, 1959. Ent. News 70: 207 (syn.).

phaenomenon (Heinrich), n. comb. Maine, N. Y., Alta., Alaska.

Coelichneumon phaenomenon Heinrich, 1961 (1960). Canad. Ent. Sup. 15: 35. ठ,.

Taxonomy: Heinrich, 1971. Nat. Canad. 98: 962-963 (variation).

pomilioaeneus (Heinrich), n. comb. Maine.

Coelichneumon pomilioaeneus Heinrich, 1961 (1960). Canad. Ent. Sup. 15: 29, 50. ․ The alternate spelling "pomiloaeneus" (p. 29) was rejected in favor of pomilioaeneus by Peck, 1964.

Taxonomy: Peck, 1964. Ent. Soc. Canada, Mem. 35: 891.

pulcher Brulle. Maine, R. I., Conn., N. Y., D. C., n. Ga., s. Fla., Ont., Ark., La.; Mexico.

Ichneumon pulcher Brulle, 1846. In Lepeletier, Hist. Nat. Ins. Hym., v. 4, p. 304. \& (male misdet.).

Taxonomy: Townes, 1961. Ent. Soc. Wash., Proc. 63: 109.

pulcherior (Heinrich), n. comb. Mont., Colo., Ariz., B. C. Host: Phaeoura mexicanaria (Grt.). Coelichneamon pulcherior Heinrich, 1961 (1960). Canad. Ent. Sup. 15: 36..

pumilionobilis (Heinrich), n. comb. Newfoundland (insular), Maine, Ont., Mich.; Europe. Coelichneumion pumilionobilis Heinrich, 1951. Bonner Zool. Beitr. 2: 251. đ, $९$. Coelichneumon pumiliosimilis (!) Heinrich, 1953. Wash. Acad. Sci., Jour. 43: 148.

punctifer (Heinrich), n. comb. N. Y., Md., Va., Tex.

Coelichneumon punctifer Heinrich, 1961 (1960). Canad. Ent. Sup. 15: 77. đ, §.

quadraticeps (Heinrich), n. comb. Md., Va., W. Va., Mich.

Coelichneumon quadraticeps Heinrich, 1961 (1960). Canad. Ent. Sup. 15: 78. ơ, ९.

rubricoxa (Heinrich), n. comb. Calif.

Coelichneumon rubricoxa Heinrich, 1961 (1960). Canad. Ent. Sup. 15: 72. ठ̀, ९.

rubroaeneus (Heinrich), n. comb. Northeastern Calif.

Coelichneumon rubroaeneus Heinrich 1961 (1960). Canad. Ent. Sup. 15: 44..

sassacoides (Heinrich), n. comb. Southern B. C. s. to s. Calif.

Coelichneumon sassacoides Heinrich, 1961 (1960). Canad. Ent. Sup. 15: 42..

sassacus (Viereck). Que. s. to w. N. C., w. to Mich.

Amblyteles (Coelichneumon) sassacus Viereck, 1917 (1916). Conn. State Geol. and Nat.

Hist. Survey Bul. 22: 349, 360. 9 .

semilaevis Cresson. Eastern Que., N. W. T., B. C., Calif.

Ichneumon semilaevis Cresson, 1864. Ent. Soc. Phila., Proc. 3: 142..

Ichneumon semilevis Dalla Torre, 1902. Cat. Hym., v. 3, p. 989. Emend.

similior (Heinrich), n. comb. Maine, Ont.

Coelichneumon similior Heinrich, 1961 (1960). Canad. Ent. Sup. 15: 44. ․

terebratus (Heinrich), n. comb. Colo.

Coelichneumon terebratus Heinrich, 1961 (1960). Canad. Ent. Sup. 15: 70. ^.

terebrifer (Heinrich), n. comb. Va.

Coelichneumon terebrifer Heinrich, 1961 (1960). Canad. Ent. Sup. 15: 71. .

viola Cresson. N. Y. s. to Fla., w. to Wis., Nebr., and Ariz.

Ichneumon viola Cresson, 1864. Ent. Soc. Phila., Proc. 3: 137. $\%$.

Ichneumon vittifrons Cresson, 1864. Ent. Soc. Phila., Proc. 3: 143. ठ.

Ichneumon recens Cresson, 1877. Amer. Ent. Soc., Trans. 6: 153. ð.

vitalis Cresson. Maine w. to Oreg., s. to Ga., Ala., Colo., and Utah.

Ichneumon vitalis Cresson, 1877. Amer. Ent. Soc., Trans. 6: 149. \&.

walleyi (Heinrich), n. comb. Ont., B. C. Not to be confused with Pterocormus walleyi (Heinrich).

Coelichneumon walleyi Heinrich, 1961 (1960). Canad. Ent. Sup. 15: 77. ठ, \&. 


\section{Genus COELICHNEUMONOPS Heinrich}

Coelichneumonops Heinrich, 1958. Canad. Ent. 90: 739.

Type-species: Coelichneumonops vockerothi Heinrich. Orig. desig.

This is a small genus of Holarctic distribution.

cashmani Heinrich. Northern Yukon.

Coelichneumonops cashmani Heinrich, 1958. Canad. Ent. 90: 740. \&.

occidentalis (Roman). Northern Que., n.e. N. W. T.; Greenland.

Coelichneumon solutus var. occidentalis Roman, 1934. Ann. and Mag. Nat. Hist. (10) 14: 606. $\delta$.

Taxonomy: Heinrich, 1961 (1960). Canad. Ent. Sup. 15: 85. -Townes, 1961. Ent. Soc. Wash., Proc. 63: 105.

solutus (Holmgren). Northern Que., N. H.; n. Europe.

Ichneumon solutus Holmgren, 1864. Ichn. Suecica, v. 1, p. 145. ?.

Coelichneumonops vockerothi Heinrich, 1958. Canad. Ent. 90: 739. ¿’, ?.

Taxonomy: Heinrich, 1961 (1960). Canad. Ent. Sup. 15: 83-84.

walkleyae Heinrich. Southwestern B. C. Apparently known only from the holotype which was collected at Vancouver, B. C. on May 1, [19]04 (not 1940).

Coelichneumonops walkleyae Heinrich, 1961 (1960). Canad. Ent. Sup. 15: 85. ๆ.

\section{Genus PROTICHNEUMON Thomson}

Protichneumon Thomson, 1893. Opusc. Ent. 18: 1899.

Type-species: Ichneumon fusorius Linnaeus. Desig. by Ashmead, 1900.

Protichneumon subg. Metopichneumon Uchida, 1935. Insecta Matsumurana 10: 13.

Type-species: Protichneumon (Metopichneumon) superomediae Uchida. Monotypic and orig. desig.

This is a moderate sized Holarctic and Oriental genus which is rather arbitrarily separated from Ichneumon. The usual hosts are Sphingidae.

Taxonomy: Townes, Momoi, and Townes, 1965. Amer. Ent. Inst., Mem. 5: 530-531 (syn.). effigies Heinrich. Newfoundland (insular) w. to s. B. C., s. to Ga., Miss., Kans., and Colo.

Protichneumon effigies Heinrich, 1961 (1960). Canad. Ent. Sup. 15: 26. o, ?.

Protichneumon sartoris Heinrich, 1971. Nat. Canad. 98: 961. + . N. syn.; this synonymy is based upon the comparison of 19 females of effigies from throughout much of the range with a female from Ark. identified as sartoris by Mr. Heinrich through comparison with the holotype.

grandis (Brulle). Que. w. to s. B. C., s. to Fla., Kans., N. Mex., and Oreg. Host: Dryocampa rubicunda mibicunda (F.). Heinrich (1961) recognized three subspecies, all of which were raised to species status by Heinrich (1971). The specimens in the U. S. Natl. Museum collection show that variation of grandis throughout eastern North America does not permit the recognition of well defined northern and southern subspecies, yet alone species. Specimens also in the U. S. Natl. Museum collection from Colo., N. Mex., Utah, and Oreg. seem to indicate that victoriae Heinrich cannot be recognized as a distinct subspecies either.

Ichneumon grandis Brulle, 1846. In Lepeletier, Hist. Nat. Ins. Hym., v. 4, p. 300. $\$$.

Ichneumon ambiguus Cresson, 1864. Ent. Soc. Phila., Proc. 3: 161. ठ.

Ichneumon regnatrix Cresson, 1864. Ent. Soc. Phila., Proc. 3: 178. क.

Protichneumon grandis victoriae Heinrich, 1961 (1960). Canad. Ent. Sup. 15: 25. o, ९. N. syn.

Taxonomy: Heinrich, 1961. Canad. Ent. Sup. 15: 22-26. -Townes, 1961. Ent. Soc. Wash.,

Proc. 63: 108. - Heinrich, 1962. Canad. Ent. Sup. 29: 862. - Heinrich, 1971. Nat. Canad. 98: 962.

polytropus Heinrich. Southeastern N. C. Ecology: The host pupa from which the holotype was reared was found in a bark crevice on Taxodium distichum. Host: Sphingid. The 
species is apparently known only from the holotype, which may not be an entirely normal specimen; it emerged in the laboratory on Jan. 12, 1905 (host pupa collected Nov. $1,1904)$ and was apparently killed before it had completely hardened and darkened because the pupal skin had not been completely shed from either antenna.

Protichneumon polytropus Heinrich, 1961 (1960). Canad. Ent. Sup. 15: 22, 27. ठ. The variant spelling "polytropos" which appeared on page 22 was rejected in favor of polytropus by Heinrich (1962).

Taxonomy: Heinrich, 1962. Canad. Ent. Sup. 29: 862. radtkeorum Heinrich. N. Y., Pa., Md., Va., Fla., Kans.

Protichneumon radtkeorum Heinrich, 1971. Nat. Canad. 98: 962. Nomen nudum.

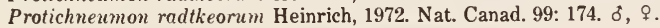

\section{Genus AMBLYJOPPA Cameron}

Amblyjoppa Cameron, 1902 (Apr.). Entomologist 35: 108.

Type-species: Amblyjoppa rufo-balteata Cameron. Desig. by Viereck, 1914.

Hadrojoppa Cameron, 1902 (Nov.). Ztschr. System. Hym. Dipt. 2: 396.

Type-species: Hadrojoppa annulitarsis Cameron. Monotypic.

Glyptojoppa Cameron, 1906. Entomologist 39: 229.

Type-species: Glyptojoppa sulcato Cameron. Monotypic.

Cnemojoppa Cameron, 1907. Tijdschr. v. Ent. 50: 77. Nomen nudum.

Cnemojoppa Heinrich, 1937. Ann. and Mag. Nat. Hist. (10) 20: 261, 277.

Type-species: Amblyjoppa rufipes Cameron. Monotypic and orig. desig.

This is a moderate sized genus of Oriental and Holaretic distribution.

Taxonomy: Townes, Momoi, and Townes, 1965. Amer. Ent. Inst., Mem. 5: 533 (syn.). magna (Cresson). Nebr., Colo.

Ichneumon magnus Cresson, 1865. Amer. Ent. Soc., Trans. 6: 191. đ.

\section{Genus CATADELPHOPS Heinrich}

Catadelphops Heinrich, 1962. Canad. Ent. Sup. 29: 863.

Type-species: Trogus buccatus Cresson. Monotypic and orig. desig.

buccatus (Cresson). Idaho, Nev., B. C., Wash., Oreg., Calif.

Trogus buccatus Cresson, 1877. Amer. Ent. Soc., Trans. 6: 199. .

\section{Genus NEAMBLYJOPPA Heinrich}

Neamblyjoppa Heinrich, 1962. Canad. Ent. Sup. 29: 865.

Type-species: Neamblyjoppa nasuta Heinrich. Monotypic and orig. desig.

nasuta Heinrich. Ariz.

Neamblyjoppa nasuta Heinrich, 1962. Canad. Ent. Sup. 29: 866. 9.

\section{Genus CATADELPHUS Wesmael}

Catadelphus Wesmael, 1854. [Brussels] Acad. Roy. de Belg., Bul. 22, App., p. 134.

Type-species: Ichneumon arrogator Fabricius. Monotypic.

This is a small Holaretic genus.

Taxonomy: Heinrich, 1971. Nat. Canad. 98: 967-968.

atrox (Cresson). S. Dak., Kans., Okla., Tex., Wyo., Colo., N. Mex., Alta., Calif. Host:

Proserpinus juanita (Stkr.). Specimens with uniformly infuscated wings have been recorded from all above listed localities except Alta., while specimens with banded wings ("var. marginipennis") are known from "Dakota Territory," Kans., Wyo., N. Mex., and Alta.

Trogus marginipennis Cresson, 1868. Amer. Ent. Soc., Trans. 2: 93. ठં. N. syn.

Trogus atrox Cresson, 1868. Amer. Ent. Soc., Trans. 2: 93..

ochraceus Heinrich. Okla.

Catadelphus ochraceus Heinrich, 1962. Canad. Ent. Sup. 29:813. ठ. 
ruberior Heinrich. Miss.

Catadelphus ruberior Heinrich, 1971. Nat. Canad. 98: 968. ơ, ?.

semiruber Hopper. Mich., w. Ont., Wyo., B. C.

Catadelphus semimber Hopper, 1939. Amer. Ent. Soc., Trans. 65: 342. ․

\section{TRIBE TROGUSINI}

Revision: Hopper, 1939. Amer. Ent. Soc., Trans. 65: 307-339, 344-345.

\section{SubTribe CALLAJOPPINA}

All species are thought to be parasites of Sphingidae.

Taxonomy: Heinrich, 1967. Synopsis and Reclassif. Ichneumoninae Stenopneusticae Africa

So. of Sahara, v. 1, p. 230, 233.

\section{Genus GNAMPTOPELTA Hopper}

Gnamptopelta Hopper, 1939. Amer. Ent. Soc., Trans. 65: 333.

Type-species: Trogus obsidianator Brulle. Orig. desig.

obsidianator austrina (Cresson). N. C., S. C., Ga., Fla.

Trogus austrinus Cresson, 1868. Amer. Ent. Soc., Trans. 2: 92. o, १.

obsidianator obsidianator (Brulle). Que. w. to Man., s. to Ga., s. La., Tex., and N. Mex.

Trogus obsidianator Brulle, 1846. In Lepeletier, Hist. Nat. Ins. Hym., v. 4, p. 299. “ๆ” = ऽ.

Taxonomy: Townes, 1961. Ent. Soc. Wash., Proc. 63: 113 (lectotype selection).

\section{Genus CALLAJOPPA Cameron}

Callajoppa Cameron, 1903. Entomologist 36: 236.

Type-species: Callajoppa bilineata Cameron. Monotypic. The type-species is regarded as a subspecies of $C$. cirrogaster (Schrank).

eirrogaster cirrogaster (Schrank). Ont.?; Europe. Townes, Momoi, and Townes (1965) seem to have implied that the two specimens in the Canadian National Collection which are labeled as being collected at Toronto, Ont. by A. Gibson are mislabeled. C. cirrogaster bilineata Cameron occurs in eastern Asia.

Ichneumon cirrogaster Schrank, 1781. Enum. Ins. Austriae, p. 348. ठో.

Ichneumon nigro-caudatus Retzius, 1783. Genera and Species Insectorum, p. 68. Sex not indicated.

Ichneumon crocatus Geoffroy, 1785. In Fourcroy, Ent. Parisiensis, v. 2, p. 399. ठ, ?.

Ichneumon lutorius Fabricius, 1787. Mantissa Insectorum, v. 1, p. 262. o, $q$.

Ichneumon cirrhogaster (!) Gmelin, 1790. In Linnaeus, Syst. Nat., ed. 13, v. 1, p. 2683.

Ichneumon rubricomutus Christ, 1791. Naturgesch. Class. Nomencl. Ins., p. 347. Sex not indicated.

Ichneumon dessinator Olivier, 1792. Encycl. Meth., Dict. Ins., v. 7, p. 174. Sex not indicated.

Ichneumon scutellaris Olivier, 1792. Encycl. Meth., Dict. Ins., v. 7, p. 198. Sex not indicated.

Ichneumon imperatorins Panzer, 1804. D. J. C. Schaefferi Iconum Ins. ... Syst., p. 201. Sex not indicated.

Ichneumon obscuratorius Gravenhorst, 1807. Vergl. Uebers. Zool. Systeme, p. 255. Sex not indicated. Possibly preocc. by Panzer, 1806-1809.

Trogus Atropos Curtis, 1828. Brit. Ent., v. 5, no. 234. Sex not indicated.

Ichneumon nigricaudatus Stephens, 1829. Nomencl. Brit. Ins., pt. 1, p. 349. Nomen nudum. Trogus atrocaudatus Stephens, 1835. Illus. Brit. Ent., v. 7, p. 271. Sex not indicated.

Trogus excellens Tischbein, 1882. Stettin. Ent. Ztg. 43: 485. ठ。.

Callajoppa cirrogastra Perkins, 1953. Brit. Mus. (Nat. Hist.) Ent., Bul. 3: 112. Emend.

Taxonomy: Hopper, 1939. Amer. Ent. Soc., Trans. 65: 331-332. - Heinrich, 1962. Canad. Ent. Sup. 29: 814-815. - Townes, Momoi, and Townes, 1965. Amer. Ent. Inst., Mem. 5: 539-540. 


\section{Genus TRICYPHUS Kriechbaumer}

Tricyphus Kriechbaumer, 1898. Ent. Nachr. 24: 4, 30.

Type-species: Tricyphus cuspidiger Kriechbaumer. Desig. by Viereck, 1914.

This small genus is Nearctic and Neotropic.

apicalis (Cresson). Vt. s. to Fla., w. to Mich. and Ill. Host: Sphinx kalmiae J. E. S.

Trogus apicalis Cresson, 1877. Amer. Ent. Soc., Trans. 6: 197. ?.

ater Hopper. Fla., Ill.

Tricyphus ater Hopper, 1939. Amer. Ent. Soc., Trans. 65: 339. ¿.

elegans (Cresson). P. E. I. s. to Fla., w. to Kans. Host: Darapsa myron (Cramer). Specimens with banded wings have been treated as subspecifically distinct under the name elegans elegans, but specimens with uniformly infuscated wings have been collected in the following states or provinces where banded winged specimens are also found (in some instances at the same localities): Mass., Conn., N. Y., Pa., D. C., Fla., Ont., and Ill.

Trogus elegans Cresson, 1868. Amer. Ent. Soc., Trans. 2: 94. .

Tricyphus vulpinus Szepligeti, 1900. Termes. Fuzetek 23: 288. ‥ N. syn.

Tricyphus elegans floridanus Heinrich, 1962. Canad. Ent. Sup. 29: 842. ঠ. N. syn.

Taxonomy: Townes, 1961. Ent. Soc. Wash., Proc. 63: 113.

\section{Genus TMETOGASTER Hopper}

Conocalama subg. Tmetogaster Hopper, 1939. Amer. Ent. Soc., Trans. 65: 321.

Type-species: Trogus nubilipennis Haldeman. Monotypic and orig. desig.

Taxonomy: Heinrich, 1962. Canad. Ent. Sup. 29: 836, 861.

nubilipennis (Haldeman). Maine s. to Ga., w. to Ill. Host: Darapsa myron (Cramer), Sphecodina abbottii (Swainson).

Trogus nubilipennis Haldeman, 1846. Acad. Nat. Sci. Phila., Proc. 3. 127. Sex not indicated.

\section{Genus CONOCALAMA Hopper}

Conocalama Hopper, 1939. Amer. Ent. Soc., Trans. 65: 319.

Type-species: Trogus brullei Cresson. Orig. desig.

This genus is Nearctic and Neotropic.

bolteri (Cresson). N. H., N. Y., Ont., Alta., w. N. W. T., B. C.

Trogus Bolteri Cresson, 1868. Amer. Ent. Soc., Trans. 2: 94 . ठ.

brullei (Cresson). N. H. s. to Ga., w. to Mich., Colo., and Tex. Host: Dolba hyloeus (Drury),

Manduca sexta (L.), Paonias astylus (Drury).

Trogus Brillei Cresson, 1877. Amer. Ent. Soc., Trans. 6: 196. đ’, ?.

canadensis (Provancher). Que. w. to Alta., s. to Ga. and Ill. Host: Paonias myops (J. E. S.).

Possibly a color phase of $C$. brullei according to Heinrich (1962).

Trogus Canadensis Provancher, 1877. Nat. Canad. 9: 2..

Trogus nigrocinctus Hasey, 1925. Ent. News 36: 306. ठ.

Taxonomy: Heinrich, 1959. Ent. News 70: 206, 207. - Heinrich, 1962. Canad. Ent. Sup. 29: 822-823.

catalinarum Heinrich. Ariz.

Conocalama catalinarum Heinrich, 1957. Canad. Ent. 89: 334. ठ.

copei (Cresson). Que., Maine, Pa., W. Va., Ont.

Trogus Copei Cresson, 1868. Amer. Ent. Soc., Trans. 2: 94 . ठ.

Conocalama copei heteropteryx Heinrich, 1962. Canad. Ent. Sup. 29: 822. o, ․ N. syn.

fuscalata Hopper. N. Y., Pa., Ont.

Conocalama (Conocalama) fuscalata Hopper, 1939. Amer. Ent. Soc., Trans. 65: 330. đo,.+

galbinata Hopper. N. Mex.

Conocalama (Conacalama) galbinata Hopper, 1939. Amer. Ent. Soc., Trans. 65: 328. ठ.

manitobae Heinrich. Southern Man.

Conocalama manitobae Heinrich, 1962. Canad. Ent. Sup. 29: 834. ð. 
occidentalis (Cresson). "Dakota Territory," Mont., Colo., s.e. Alaska, B. C., Oreg., Calif. Host: Smerinthus cerisyi Kby.

Trogus occidentalis Cresson, 1868. Amer. Ent. Soc., Trans. 2: 92.0 ò.

Conocalama (Conocalama) occidentalis var. luteata Hopper, 1939. Amer. Ent. Soc., Trans. 65: 326. $\delta, ?$.

Conocalama orientalis (!) Heinrich, 1962. Canad. Ent. Sup. 29: 818 (key). Lapsus for occidentalis.

quebecensis (Provancher). N. S., Que., Maine, Ont., Minn., Man., Alta., B. C., Oreg. Host: Eacles imperalis imperalis (Drury).

Trogus Quebecensis Provancher, 1874. Nat. Canad. 6: 335. ?.

rileyi (Cresson). Ill., S. Dak., Nebr., Kans., Colo., N. Mex. Heinrich (1962) and Walkley (1967) recognized two subspecies, and incorrectly gave species status to the junior synonym $T$. mellosus Cresson.

Trogus Rileyi Cresson, 1868. Amer. Ent. Soc., Trans. 2: 95. ․ An unlabeled specimen in the U.S. Natl. Museum collection appears to be the holotype.

Trogus mellosus Cresson, 1876 (1875). In Wheeler, Rept. Geog. and Geol. Explor. and Surveys W. of Hundredth Merid., v. 5 (zool.), p. 708. " $\delta "=$ ?. N. syn.

Taxonomy: Heinrich, 1962. Canad. Ent. Sup. 29: 829-830. - Walkley, 1967. In Krombein et al.,

U. S. Dept. Agr., Agr. Monog. 2, sup. 2, p. 169-170.

violipennis Hopper. Calif.

Conocalama (Conacalama) violipennis Hopper, 1939. Amer. Ent. Soc., Trans. 65: 327. ठ", i.

\section{SUBTRIBE TROGUSINA}

\section{Genus MACROJOPPA Kriechbaumer}

Macrojoppa Kriechbaumer, 1898. Ent. Nachr. 24: 21.

Type-species: Trogus blandita Cresson. Desig. by Ashmead, 1900.

Aglaojoppidea Viereck, 1913. U. S. Natl. Mus., Proc. 46: 368.

Type-species: Trogus fascipennis Cresson. Orig. desig.

This genus is mostly Neotropic, with one Nearctic species.

Taxonomy: Heinrich, 1962. Canad. Ent. Sup. 29: 845-846. -Townes and Townes, 1966. Amer.

Ent. Inst., Mem. 8: 275 (syn.).

fascipennis (Cresson). Tex.

Trogus fascipennis Cresson, 1877. Amer. Ent. Soc., Trans. 6: 196...

Trogus fasciipennis Dalla Torre, 1902. Cat. Hym., v. 3, p. 1033. Emend.

\section{Genus TROGUS Panzer}

Trogus Panzer, 1806. Krit. Rev. Insektenf. Deutschlands, v. 2, p. 80.

Type-species: Ichneumon coemlator Fabricius. Monotypic.

Dinotomus Foerster, 1868. Naturh. Ver. Rheinlande, Verh. 25: 188.

Type-species: Ichneumon lapidator Fabricius. Desig. by Ashmead, 1900 from three species included by Berthoumieu, 1896.

This genus is Neotropic, and Oriental.

edwardsii Cresson. Mont., Idaho, s. B. C., Wash. Host: Papilio eurymedon Lueas. A specimen in the U.S. Natl. Museum collection appearing to be intermediate between edwardsii and pennator (Fabricius) indicates that edwardsii is probably a subspecies or possibly only a color phase of the partially sympatric pennator.

Trogus Edwardsii Cresson, 1877. Amer. Ent. Soc., Trans. 6: 195. o.

Trogus Fletcherii Harrington, 1894. Canad. Ent. 26: 245. "o" = $\delta$.

flavipennis Cresson. Colo., N. Mex., Utah., Ariz.

Trogus flavipennis Cresson, 1864. Ent. Soc. Phila., Proc. 3: 287. ठ゚.

lapidator brevicaudae Heinrich. Southern Newfoundland (insular). Host: Papilio brevicauda Sdrs. Doubtfully distinct from lapidator panzeri Carlson.

Trogus lapidator brevicandae Heinrich, 1976 (1975). Nat. Canad. 102: 755. o, \&. 
lapidator panzeri Carlson. Yukon; n. Eurasia. Host: Papilio machaon L. T. lapidator lapidator (Fabricius) occurs in southern Europe and North Africa.

Ichneumon coerulator Fabricius, 1804. Systema Piezatorum, p. 68. ठ. Preoce. by Weber, 1795. When I proposed the replacement name $T$. lapidator panzeri, I stated that $I$. coerulator Fabricius, 1804 was preocc. by Fabricius, 1796, but I have since discovered that Weber (1795) preceded Fabricius (1796) in validating coerulator as an unnecessary replacement name for I. lapidator Fabricius, 1787 (instead of 1793).

Trogus panzeri Carlson, 1975. Ent. Soc. Wash., Proc 77: 305. N. name for 1 . coerulator Fabricius.

Taxonomy: Weber, 1795. Nomencl. Ent. Secundum Ent. System. Fabricii, p. 73. - Fabricius,

1796. Ent. System., Index Alphabeticus, p. $83,84$.

pennator (Fabricius). Que. w. to Wash., s. to Fla., Kans., Nev., and Calif. Host: Papilio brevicauda Sdrs., P. eurymedon Lucas, P. glaucus L., Papilio polyxenes asterius Stoll, $P$. mitulus Lucas, $P$. troilus L., $P$. zelicaon Lucas, Graphium marcellus (Cramer).

Ichneumon pennator Fabricius, 1793. Ent. System., v. 2, p. 155. [female].

Trogus vulpinus Gravenhorst, 1829. Ichn. Europaea, v. 2, p. 389. [female].

Trogus exesorius Brulle, 1846. In Lepeletier, Hist. Nat. Ins. Hym., v. 4, p. 298. ¿,. Ichneumon asteriae Jaeger, 1859. Life of No. Amer. Insects, p. 240. Sex not indicated. Macrojoppa californica Cameron, 1911. Soc. Ent. 26: 35. Sex not indicated.

Taxonomy: Townes, 1961. Ent. Soc. Wash., Proc. 63: 109, 110, 113.

pennator var. fulvipes Cresson, n. status. Newfoundland (insular), Que., Maine, N. H., Vt., Mass., N. Y., Ont., Mich., Man., Sask., Colo., B. C., Oreg. Host: Papilio brevicauda Sdrs., $P$. glaucus L., P. eurymedon Lucas. Because fulvipes appears to be a color phase (sympatric) rather than a subspecies of pennator, I have chosen to treat it as a "variety." Heinrich (1962) does not seem to have been objective in arguing that fulvipes is a species distinct from pennator. In collecting "dozens of specimens" of pennator and fulvipes in Maine he claimed to have seen only one "looking like an intergrade." He said "I would guess that the specimen is an erythristic fulvipes rather than a melanistic pennator; both types of variation are to be expected anyway, and would create the impression of intergrades without actually being such." In the U. S. Natl. Museum collection there are only five fulvipes specimens, while there are six (from Maine, Vt., Mass., $\mathrm{Pa}$., and Wash.) which impress me as being intergrades between pennator and var. fulvipes.

Trogus fulvipes Cresson, 1868. Amer. Ent. Soc., Trans. 2: 93. ‘.

Trogus apicatus Davis, 1898 (1897). Amer. Ent. Soc., Trans. 24: 352. ठे.

Taxonomy: Heinrich, 1962. Canad. Ent. Sup. 29: 849-850.

\section{TRIBE JOPPOCRYPTINI}

\section{Genus PLAGIOTRYPES Ashmead}

Plagiotrypes Ashmead, 1900. U. S. Natl. Mus., Proc. 23: 20.

Type-species: Ichneumon concinnus Say. Monotypic and orig. desig.

Neopyga Heinrich, 1930. Zool. Mus. Berlin, Mitt. 15: 545.

Type-species: Neopyga armata Heinrich. Desig. by Townes, 1944.

This small genus is Neotropic and Nearctic.

concinnus (Say). Southern N. H. s. to Fla., w. to Ill. and Tex.

Ichneumon concinnus Say, 1829. Contrib. Maclurian Lyceum to Arts and Sci. 1: 68. $q$ (not second female described).

Taxonomy: Cresson, 1877. Amer. Ent. Soc., Trans. 6: 194. - Cushman and Gahan, 1921. Ent. Soc. Wash., Proc. 23: 164.

\section{Genus NARTHECURA Townes}

Narthecura Townes, 1946. Bol. Ent. Venezolana 5: 50.

Type-species: Hoplismenus munitus Cresson. Orig. desig. 
This is a moderate sized Neotropic and Nearctic genus.

invadens Heinrich. N. Mex., Ariz.

Narthecura invadens Heinrich, 1962. Canad. Ent. Sup. 27: 682. ¿,.+

\section{Genus LOBAEGIS Townes}

Lobaegis Townes, 1946. Bol. Ent. Venezolana 5: 54.

Type-species: Ichneumon maritus Cresson. Orig. desig.

This is apparently a moderate sized Neotropic and Nearctic genus.

septentrionalis Heinrich. N. Y., Md., W. Va., S. C., Tenn., Ala.

Lobaegis septentrionalis Heinrich, 1962. Canad. Ent. Sup. 27: 684. ठ, \&.

\section{Genus PSEUDOPLATYLABUS Smits van Burgst}

Pseudoplatylabus Smits van Burgst, 1920. Ent. Ber. 5: 282.

Type-species: Pseudoplatylabus caudatus Smits van Burgst. Monotypic.

This is a small Holarctic and Oriental genus.

townesi Heinrich. R. I., N. Y., Md.

Pseudoplatylabus townesi Heinrich, 1962. Canad. Ent. Sup. 27: 686. o, ๆ.

violentus (Gravenhorst). Mich.; Europe.

Ichneumon violentus Gravenhorst, 1829. Ichn. Europea, v. 1, p. 613. [male].

Hoplismenus infaustus Wesmael, 1845 (1844). [Brussels] Acad. Roy. de Belg., Nouveaux Mem. 18: 110. ठ, ?.

Pseudoplatylabus caudatus Smits van Burgst, 1920. Ent. Ber. 5: 282. ㅇ.

\section{TRIBE LISTRODROMINI}

\section{SUBTRIBE LISTRODROMINA}

Species of Trogomorpha apparently parasitize Hesperiidae, but the normal hosts for other genera in this subtribe are Lycaenidae.

\section{Genus TROGOMORPHA Ashmead}

Trogomorpha Ashmead, 1900. U. S. Natl. Mus., Proc. 23: 15.

Type-species: Ichneumon trogiformis Cresson. Monotypic and orig. desig.

This is a small Neotropic and Nearctic genus.

arrogans (Cresson). Southern Texas; Mexico, Honduras, El Salvador, Costa Rica, Panama,

Colombia, Peru. Probably only a subspecies of T. trogiformis (Cresson).

Ichneumon arrogans Cresson, 1873. Acad. Nat. Sci. Phila., Proc. 25: 115. ठ, ․

Ichneumon panamensis Cameron, 1885. Biol. Cent.-Amer., Hym., v. 1, p. 158. ठ.

trogiformis (Cresson). Central N. Y., s. Ohio, and Mo. s. to Fla. and Tex.; Puerto Rico. Host: Ephyriades brunnea floridensis (B. and C.).

Ichneumon ferrugator Fabricius, 1793. Ent. System., v. 2, p. 154. Sex not indicated. Preocc. by Swederus, 1787. Townes (1961) apparently was unable to locate any type specimen and accepted Brulle (1846) as the first revisor of this name.

Ichneumon trogiformis Cresson, 1864. Ent. Soc. Phila., Proc. 3: 175. ठ.

Taxonomy: Brulle, 1846. In Lepeletier, Hist. Nat. Ins. Hym., v. 4, p. 295. -Townes, 1961.

Ent. Soc. Wash., Proc. 63: 107.

\section{Genus NEOTYPUS Foerster}

Neotypus Foerster, 1868. Naturh. Ver. Rheinlande, Verh. 25: 194.

Type-species: Ichneumon lapidator Fabricius, 1793 (not 1787). Desig. by Ashmead, 1900 from two species included by Holmgren, 1871. The type-species is regarded as a synonym of $N$. coreensis Uchida.

Cillimus Tosquinet, 1896. Soc. Ent. de Belg., Mem. 5: 122.

Type-species: Cillimus adomatus Tosquinet. Desig. by Ashmead, 1900. 
This is a small Palearctic, Oriental, and Ethiopian genus.

nobilitator nobilitator (Gravenhorst). Conn., N. J., Md., D. C., Va., Ohio, Ill., Mo., Wyo., Alta., Oreg.; Europe. Adventive. Host: Everes comyntas (Godt.). N. nobilitator orientalis Uchida occurs in eastern Asia.

Ichneumon nobilitator Gravenhorst, 1807. Vergl. Uebers. Zool. Systeme, p. 235..

Neotypus americanus Cushman, 1926. U. S. Natl. Mus., Proc. 67 (23): 1. ठ.

Taxonomy: Heinrich, 1933. Zool. Mus. Berlin, Mitt. 19: 155, 157.

\section{Genus ANISOBAS Wesmael}

Anisobas Wesmael, 1845 (1844). [Brussels] Acad. Roy de Belg., Nouveaux Mem. 18: 145.

Type-species: Ichneumon cingulatorius Gravenhorst. Desig. by Ashmead, 1900.

Lycaeniphilos Heinrich, 1933. Zool. Mus. Berlin, Mitt. 19: 158.

Type-species: Anisobas cephalotes Kriechbaumer. Monotypic and orig. desig.

This is a small Holaretic and Oriental genus.

angustior Heinrich. Newfoundland (insular), w. Tenn.

Anisobas angustior Heinrich, 1976 (1975). Nat. Canad. 102: 780..+

bicolor Cushman. Idaho, Utah, Nev., Ariz., B. C., Wash., Oreg., Calif. Host: Strymon adenostomatis (Hy. Edw.).

Anisobas bicolor bicolor Cushman, 1926. U. S. Natl. Mus., Proc. 67 (23): 2. ó, ๆ.

bicolor boreoaustralis Heinrich. Newfoundland (insular).

Anisobas bicolor boreoaustralis Heinrich, 1976 (1975). Nat. Canad. 102: 780 ..

coloradensis (Cresson). S. Dak., Colo., Idaho, Ariz.

Amblyteles coloradensis Cresson, 1877. Amer. Ent. Soc., Trans. 6: 193. \&.

luzernensis (Bradley). Que., Maine, N. Y., Pa., Ont., Mich. Host: Limacodid.

Platylabus luzernensis Bradley, 1903. Canad. Ent. 35: 282. ९.

Anisobas nearcticus Cushman, 1926. U. S. Natl. Mus., Proc. 67 (23): 2..

separatus (Davis). Ill., Tex., Ariz.

Eurylabus separatus Davis, 1898 (1897). Amer. Ent. Soc., Trans. 24: 353. "ठ" =.

texensis (Ashmead). Conn., Man., Nebr., Tex. Host: Incisalia niphon (Hbn.), Strymon falacer (Godt.).

Cryptus texensis Ashmead, 1890 (1889). U. S. Natl. Mus., Proc. 12: 410. “

Taxonomy: Townes and Townes, 1951. In Krombein et al., U. S. Dept. Agr., Agr. Monog. 2:

282 (syn.). - Heinrich, 1962. Canad. Ent. Sup. 27: 694-695.

\section{Genus DIACANTHARIUS Schmiedeknecht}

Diacantharius Schmiedeknecht, 1902. Opusc. Ichn., v. 1, p. 20.

Type-species: Diacantharius elegans Schmiedeknecht. Monotypic.

Lausoba Cameron, 1910 (1909). Amer. Ent. Soc., Trans. 35: 438.

Type-species: Lausoba forticeps Cameron. Monotypic.

Oedicephalopsis Heinrich, 1930. Zool. Mus. Berlin, Mitt. 15: 548.

Type-species: Oedicephalopsis peruens is Heinrich. Monotypic.

An undescribed species occurs in southern Texas. It has been reared from Strymon melinus melinus (Hbn.).

Taxonomy: Townes and Townes, 1966. Amer. Ent. Inst., Mem. 8: 272 (syn.).

\section{Genus DILOPHARIUS Townes}

Dilopharius Townes, 1966. In Townes and Townes, Amer. Ent. Inst., Mem. 8: 332.

Type-species: Hoplismenus otomitus Cresson. Monotypic and orig. desig.

An undescribed species occurs in southern Texas.

\section{TRIBE PLATYLABINI}

The members of this tribe are principally parasites of Geometridae. 


\section{Genus APAELETICUS Wesmael}

Apaeleticus Wesmael, 1845 (1844). [Brussels] Acad. Roy. de Belg., Nouveaux Mem. 18: 166. Type-species: Apaeleticus bellicosus Wesmael. Desig. by Ashmead, 1900. americanus Cushman. Maine, Md., D. C., Alta.?, Ariz.

Apaeleticus americanus Cushman, 1926. U. S. Natl. Mus., Proc. 67 (23): 4. ․ brunnescens Heinrich. Maine, Mich.

A paeleticus brunnescens Heinrich, 1962. Canad. Ent. Sup. 27: 793. ठ', ๆ.

\section{Genus CARLSONIA Heinrich}

Carlsonia Heinrich, 1971. Nat. Canad. 100: 461.

Type-species: Linycus perturbator Heinrich. Monotypic and orig. desig.

perturbator (Heinrich). Maine, Mich. Known from two males from Maine and one female from Mich.; the latter was collected with a Malaise trap situated at the edge of a rather large area of muskeg which then was rather dry.

Linycus perturbator Heinrich, 1971. Nat. Canad. 98: 1022. ठ.

\section{Genus LINYCUS Cameron}

Linycus Cameron, 1903. Entomologist 36: 234.

Type-species: Linycus mufipes Cameron. Monotypic.

Erythroischnus Cameron, 1904. Amer. Ent. Soc., Trans. 30: 252.

Type-species: Erythroischnus annulicornis Cameron. Monotypic.

This small genus is Neotropic, Holarctic, and Oriental.

barbarae Heinrich. Newfoundland (insular). Known from a single specimen. Heinrich made no direct comparison with the male specimens of Carlsonia perturbator (Heinrich) in his collection (holotype and paratype); his descriptions of the males of the two species seem to differ with respect to the tyloids. If the species actually differ, it remains to be determined whether the female presumed by Heinrich to be that of Carlsonia perturbator may not actually be that of Linycus barbarae.

Linycus barbarae Heinrich, 1976 (1975). Nat. Canad. 102: 779. ठ.

exhortator montanus Heinrich. Colo. L. exhortator exhortator (Fabricius) is Eurasian.

Linycus exhortator montanus Heinrich, 1962. Canad. Ent. Sup. 27: 781. ठ.

exhortator thoracicus (Cresson). Maine s. to Va., w. to Wis. and Mo.

Hoplismenus thoracicus Cresson, 1864. Ent. Soc. Phila., Proc. 3: 288. “ 0 ” = .

nigriceps Heinrich. Ariz., Alaska, B. C., Wash., Oreg. Males with the thorax extensively or completely black are known from Alpine, Ariz. (types of syn. arizonensis), Palmer, Alaska (types of syn. niger), and Juneau, Alaska.

Linycus nigriceps nigriceps Heinrich, 1962. Canad. Ent. Sup. 27: 782. ठ, ㅇ.

Linycus nigriceps arizonensis Heinrich, 1962. Canad. Ent. Sup. 27: 782. o. N. syn.

Linycus nigriceps alaskae Heinrich, 1962. Canad. Ent. Sup. 27: 782. o, ९. N. syn.

Linycus nigriceps niger Heinrich, 1962. Canad. Ent. Sup. 27: 783. ठ.. N. syn.

temporalis Heinrich. Maine.

Linycus temporalis Heinrich, 1971. Nat. Canad. 98: 1024. ठో.

\section{Genus NEOLINYCUS Heinrich}

Neolinycus Heinrich, 1971. Nat. Canad. 98: 1025.

Type-species: Neolinycus michaelis Heinrich. Monotypic and orig. desig.

michaelis Heinrich. Central Ga., n. Miss., La.

Neolinycus michaelis Heinrich, 1971. Nat. Canad. 98: 1025..+

Neolinycus michaelis georgianus Heinrich, 1972. Nat. Canad. 99: 210.. N. syn.

\section{Genus CYCLOLABUS Heinrich}

Cyclolabus Heinrich, 1936 (1935). Deut. Ent. Ztschr., p. 198.

Type-species: Platylabus nigricollis Wesmael. Orig. desig. 
This is a moderate sized genus of Holarctic and Oriental distribution.

albicinctus Heinrich. Newfoundland (insular), N. S. Host: Acasis viridata (Pack.). Cyclolabus albicinctus Heinrich, 1962. Canad. Ent. Sup. 27: 771. §, ^.

arizonae Heinrich. Ariz.

Cyclolabus arizonae Heinrich, 1962. Canad. Ent. Sup. 27: 765. o, ₹.

carolinensis Heinrich. Northwestern S. C., Mich.

Cyclolabus carolinensis Heinrich, 1962. Canad. Ent. Sup. 27: 764. ९.

dubiosus Perkins. Newfoundland (insular), N. S., Mich., Man., Colo., Alta., B. C., Wash., Calif.; Europe. Host: Eupithecia annulata (Hulst), E. filmata Pear., E. luteata Pack., $E$. palpata Pack. This species has been confused with $C$. pactor (Wesmael), which is not known to occur in the Nearctic region.

Cyclolabus dubiosus Perkins, 1953. Brit. Mus. (Nat. Hist.) Ent., Bul. 3: 156. đ, ․

gibsonatae Heinrich. Ont., B. C. Host: Eupithecia gibsonata Taylor.

Cyclolabus gibsonatae Heinrich, 1962. Canad. Ent. Sup. 27: 764. ․

gracilicornis gracilicornis Provancher. Newfoundland (Labrador and insular), Que., Maine, N. H., N. Y., N. C., Ont., Mich.

Phygadeuon gracilicomis Provancher, 1886. Addit. Corr. Faune Ent. Canada Hym., p. 56. \%.

gracilicornis subdentatus (Ashmead). Colo., Idaho, Alaska, B. C., Wash., Oreg., Calif.

Probolus subdentatus Ashmead, 1902. Wash. Acad. Sci., Proc. 4: 160. ठ.

Taxonomy: Heinrich, 1959. Ent. News 70: 216.

impressus impressus (Provancher). Newfoundland (insular), Que., Maine, N. H., Mass., N. Y., Ont., Mich.

Phygadeuon impressus Provancher, 1874. Nat. Canad. 6: 281...

Ichneumon erythropygus Provancher, 1875. Nat. Canad. 7 (1): 24 (key); 7 (3): 79 . "६" = $\delta$.

impressus infuseatus Heinrich. Southern Alta., s. B. C., Wash.

Cyclolabus impressus infuscatus Heinrich, 1962. Canad. Ent. Sup. 27: 760. đ, ๆ.

linycops Heinrich. Newfoundland (insular).

Cyclolabus linycops Heinrich, 1976 (1975). Nat. Canad. 102: 778. ठ.

lobatus Heinrich. Que., Maine, N. Y., Mich., Alta.

Cyclolabus lobatus lobatus Heinrich, 1962. Canad. Ent. Sup. 27: 761. ठ, ๆ.

Cyclolabus lobatus occidentalis Heinrich, 1962. Canad. Ent. Sup. 27: 761. . N. syn.

signatus (Provancher). Que., Maine, N. H.

Phygadeuon signatus Provancher, 1874. Nat. Canad. 6: 282..

\section{Genus PLATYLABUS Wesmael}

Platylabus Wesmael, 1845 (1844). [Brussels] Acad. Roy. de Belg., Nouveaux Mem. 18: 166. Type-species: Platylabus rufus Wesmael. Desig. by Ashmead, 1900.

Lamprojoppa Cameron, 1901. Ann. and Mag. Nat. Hist. (7) 7: 482.

Type-species: Lamprojoppa caerulea Cameron. Monotypic.

Pagarenes Cameron, 1903. Ztschr. System. Hym. Dipt. 3: 183.

Type-species: Pagarenes erythropus Cameron. Monotypic.

Chlorojoppa Cameron, 1907. Ztschr. System. Hym. Dipt. 7: 466.

Type-species: Chlorojoppa viridis Cameron. Monotypic.

This large genus is very widely distributed, although only one species in known from the Ethiopian region and none of the described Neotropic species have been recorded from South America.

abbreviatus Heinrich. Southern B. C.

Platylabus abbreviatus Heinrich, 1962. Canad. Ent. Sup. 27: 753..

alaskae Heinrich. Southwestern Alaska.

Platylabus alaskae Heinrich, 1962. Canad. Ent. Sup. 27: 721..

arizonae Heinrich. Ariz., Calif.

Platylabus arizonae Heinrich, 1962. Canad. Ent. Sup. 27: 715. §, $९$. 
berndi Heinrich. Que., Maine, Ont., Mich. Host: Geometrid.

Platylabus berndi Heinrich, 1962. Canad. Ent. Sup. 27: 731. ठ, ९.

Platylabus albidorsus Heinrich, 1962. Canad. Ent. Sup. 27: 740..

Taxonomy: Heinrich, 1971. Nat. Canad. 98: 1018-1019 (syn. and variation).

clarus (Cresson), Que. s. to S. C., w. to Colo. and N. Mex. Host: Abbottana clemataria (J. E. S.).

Ichneumon clarus Cresson, 1867. Amer. Ent. Soc., Trans. 1: 297..

Platylabus magnificus Provancher, 1886. Addit. Corr. Faune Ent. Canada Hym., p. 36. \&. columbiae Heinrich. B. C., Calif.

Platylabus columbiae Heinrich, 1962. Canad. Ent. Sup. 27: 716..

dilleri Heinrich. Maine.

Platylabus dilleri Heinrich, 1971. Nat. Canad. 98: 1021. ठ.

divisatae Heinrich. Newfoundland (insular), Que., B. C., Oreg. Host: Caripeta divisata Wlk. Platylabus divisatae Heinrich, 1962. Canad. Ent. Sup. 27: 709. ¿,.

duplificans Heinrich. Colo. Ecology: In Mountains at elevations between 9500 and $11000 \mathrm{ft}$. Platylabus duplificans Heinrich, 1962. Canad. Ent. Sup. 27: 726. ठ, ๆ.

erythrocoxa Heinrich. Newfoundland (insular), N. S., Maine, Mich., N. W. T., B. C., Calif. Platylabus erythrocoxa Heinrich, 1962. Canad. Ent. Sup. 27: 719. §, ๆ.

foxleei foxleei Heinrich. Southeastern Alaska, s. B. C.

Platylabus foxleei Heinrich, 1962. Canad. Ent. Sup. 27: 723. ơ,.

foxleei orientis Heinrich. Newfoundland (insular), Maine.

Platylabus foxlei(!) orientis Heinrich, 1976 (1975). Nat. Canad. 102: 777. đ, q.

gracilicornis (Viereck). N. Mex., Calif.

Cratichneumon gracilicomis Viereck, 1903. In Skinner, Amer. Ent. Soc., Trans. 29: 79..

hyperetis Heinrich. Maine, B. C. Host: Hyperetis amicaria (H.-S.).

Platylabus hyperetis Heinrich, 1962. Canad. Ent. Sup. 27: 707. ठ, \&.

imitans Heinrich. Que., Maine, B. C., Wash., Calif. Host: Eupithecia sp.

Platylabus imitans Heinrich, 1962. Canad. Ent. Sup. 27: 725. ठँ, ९.

incabus Davis. Ariz., Alaska, B. C., Oreg., Calif.

Platylabus incabus Davis, 1898 (1897). Amer. Ent. Soc., Trans. 24: 352 ..

lissosculptus Heinrich. Calif.

Platylabus lissosculptus Heinrich, 1962. Canad. Ent. Sup. 27: 742. ठో.

luteatae Heinrich. Newfoundland (insular), Que., Maine, Pa., Ont., Man., B. C., Oreg. Host: Eupithecia sp., E. luteata Pack.

Platylabus luteatae Heinrich, 1962. Canad. Ent. Sup. 27: 715. ठै, १.

Taxonomy: Heinrich, 1971. Nat. Canad. 98: 1018 (variation).

melanocoxa Heinrich. Mont., Colo., B. C., Wash., Calif. Host: Eupithecia annulata (Hulst).

This species has been misidentified as P. pedatorius (Fabricius), a Eurasian species.

Platylabus melanocoxa Heinrich, 1962. Canad. Ent. Sup. 27: 727. ठ, ९.

metallicus Bradley. Newfoundland (insular), Que., Maine, N. H., N. Y., Ont., Mich., B. C., Wash. Platylabus metallicus Bradley, 1903. Canad. Ent. 35: 280. ơ, ?.

Taxonomy: Heinrich, 1959. Ent. News 70: 215.

micheneri Heinrich. Calif.

Platylabus micheneri Heinrich, 1962. Canad. Ent. Sup. 27: 746. \&.

monotonops Heinrich. Mass., N. Y.

Platylabus monotonops Heinrich, 1962. Canad. Ent. Sup. 27: 744. ․

Taxonomy: Heinrich, 1971. Nat. Canad. 98: 1020.

monotonus Heinrich. N. H., N. Y., Alta., Ariz., Alaska, B. C. Host: Epirrita autumuata (Bork.), Itame anataria (Swett), I. quadrilinearia (Pack.).

Platylabus monotonus Heinrich, 1962. Canad. Ent. Sup. 27: 741. ठ, ९.

montanus Cresson. Newfoundland (insular), N. H., Mass., Mich., Wash.

Ichneumon vafer Cresson, 1877. Amer. Ent. Soc., Trans. 6: 178. “ๆ” = đ. Preocc. by Gmelin, 1790. 
Platylabus montanus Cresson, 1877. Amer. Ent. Soc., Trans. 6: 200..

Platylabus perkinsi Walkley, 1958. In Krombein et al., U. S. Dept. Agr., Agr. Monog. 2, sup. 1, p. 48. N. name for I. vafer Cresson.

opaculus americanus Heinrich. Newfoundland (insular), Que., Maine, N. Y., Ont., Mich., Alta., B. C., Wash., Oreg. P. opaculus opaculus Thomson occurs in Europe.

Platylabus opaculus americanus Heinrich, 1962. Canad. Ent. Sup. 27: 730. ठ, \&.

ornatus (Provancher). Newfoundland (insular), N. B. Que., Maine, N. Y., N. C., Ont., Mich., Sask., Alta., B. C., Wash., Calif. Host: Semiothisa "granitata" auct., S. oweni (Swett).

Phygadeuon omatus Provancher, 1875. Nat. Canad. 7: 181..

permodestus Heinrich. Colo., B. C., Wash., Calif.

Platylabus permodestus Heinrich, 1962. Canad. Ent. Sup. 27: 720. ठ, ९.

polymelas Heinrich. Newfoundland (insular), Colo., Ariz., s. B. C.

Platylabus polymelas Heinrich, 1962. Canad. Ent. Sup. 27: 754. ठ.

pseudhistrio Heinrich. Maine.

Platylabus pseudhistrio Heinrich, 1962. Canad. Ent. Sup. 27: 733. ð.

pulcher Cushman. Newfoundland (insular), Que., Maine, Ont., Mich., B. C. Host: Hydriomena renunciata columbiata Taylor.

Ichneumon lineolatus Provancher, 1875. Nat. Canad. 7 (1): 24 (key); 7 (3): 82 . \&. Preoce. by Gmelin, 1790.

Platylabus pulcher Cushman, 1922. U. S. Natl. Mus., Proc. 60 (21): 1..

rubricapensis Provancher. Newfoundland (insular), Que., Ont., Mich., S. Dak., Idaho, Oreg.

Platylabus Rubri Capensis Provancher, 1882. Nat. Canad. 13: 329. ९. Name invalid; not binomial.

Platylabus Rubricapensis Provancher, 1886. Addit. Corr. Faune Ent. Canada Hym., p. 35. Redescription with valid binomen.

Taxonomy: Heinrich, 1976 (1975). Nat. Canad. 102: 774 (male described).

rubristernatus Heinrich. Conn., N. Y., w. N. C., Ohio, Ill.

Platylabus rubristernatus Heinrich, 1962. Canad. Ent. Sup. 27: 713. \&.

semiopacus Heinrich. Colo.

Platylabus semiopacus Heinrich, 1962. Canad. Ent. Sup. 27: 730. ठ, §.

serratae Heinrich. N. B., Maine, Mich. Host: Euchlaena serrata (Drury)

Platylabus serratae Heinrich, 1962. Canad. Ent. Sup. 27: 738. ठ,.

sexmaculatae Heinrich. Newfoundland (insular), Maine, Alta. Host: Semiothisa sexmaculata (Pack.).

Platylabus sexmaculatae Heinrich, 1962. Canad. Ent. Sup. 27: 749...

Platylabus sexmaculatae postremus Heinrich, 1976 (1975). Nat. Canad. 102: 776. ठ. N. syn. Described from two males collected at the same place and time in insular Newfoundland.

Taxonomy: Heinrich, 1971. Nat. Canad. 98: 1019-1020 (male described).

sphageti Heinrich. Newfoundland (insular), Maine. Ecology: Occurs in spruce (Picea mariana) bogs.

Platylabus sphageti Heinrich, 1971. Nat. Canad. 98: 1020. $\subsetneq$.

subrubricus Heinrich. Maine, Man., Sask., Alta. Host: Eupithecia ravocostaliata Pack.

Platylabus subrubricus Heinrich, 1962. Canad. Ent. Sup. 27: 714. ठ, १.

tenuiformis Heinrich. Ariz.

Platylabus tenuiformis Heinrich, 1962. Canad. Ent. Sup. 27: 743. ठ, ९.

tibialis Ashmead. N. Mex., s.w. B. C., w. Wash.

Platylabus tibialis Ashmead, 1901. Psyche 9: 147..

Platylabus rainieri Heinrich, 1962. Canad. Ent. Sup. 27: 722. ठ, ९. N. syn.

vaferops Heinrich. B. C., Wash., Calif.

Platylabus vaferops Heinrich, 1962. Canad. Ent. Sup. 27: 751. ठै, ९.

\section{Genus DENTILABUS Heinrich}

Dentilabus Heinrich, 1975 (1974). Ann. Zool. 32: 147. 
Type-species: Platylabus variegatus Wesmael. Orig. desig.

This is a small Holarctic and Oriental genus. I am not altogether convinced that it is worthy of distinction from Platylabus, but include the single Nearctic species treated below on advice received from $\mathrm{Mr}$. Gerd Heinrich.

rufipes consors (Cresson), n. comb. Alta., Ariz., Alaska, B. C., Oreg., Calif. Host: Hydriomena sp., H. renunciata (Wlk.).

Platylabus consors Cresson, 1877. Amer. Ent. Soc., Trans. 6: 200. ð.

Platylabus califomicus Cresson, 1877. Amer. Ent. Soc., Trans. 6: 201. ๆ.

rufipes rufipes (Provancher), n. comb. Newfoundland (insular), Que., Maine.

Phygadeuon rufipes Provancher, 1875. Nat. Canad. 7: 181. .

Taxonomy: Heinrich, 1976 (1975). Nat. Canad. 102: 776-777 (male described).

\section{Genus ASTHENOLABUS Heinrich}

Stenolabus Heinrich, 1936 (1935). Deut. Ent. Ztschr., p. 197. Preocc. by Rechberg, 1910. Type-species: Platylabus latiscapus Thomson. Orig. desig.

Asthenolabus Heinrich, 1951. Bonner Zool. Beitr. 2: 240. N. name for Stenolabus Heinrich.

This small genus is Holarctic and Oriental.

agilis (Cresson). N. S., P. E. I., Que., and N. W. T., s. to Pa., Mich., Colo., and Oreg.

Eurylabus agilis Cresson, 1877. Amer. Ent. Soc., Trans. 6: 201. đ, ๆ.

Taxonomy: Heinrich, 1959. Ent. News 70: 215.

canadensis (Cresson). Maine, Pa., N. C., Mich., B. C., Wash.

Platylabus canadensis Cresson, 1877. Amer. Ent. Soc., Trans. 6: 200..

scutellatus (Provancher). Que., N. Y., Ont., Mich.

Ischnus scutellatus Provancher, 1875. Nat. Canad. 7: 111. ठ.

\section{Genus PRISTICEROS Gravenhorst}

Pristiceros Gravenhorst, 1829. Ichn. Europaea, v. 1, p. 635.

Type-species: Pristiceros serrarius Gravenhorst. Monotypic.

Neopristiceros Heinrich, 1961 (1960). Canad. Ent. Sup. 15: 13.

Type-species: Ichneumon lascivus Cresson. Monotypic and orig. desig.

Pristicerops Heinrich, 1962. Canad. Ent. Sup. 27: 786.

Type-species: Platylabus bakeri Davis. Orig. desig.

This is a small Holaretic and Oriental genus.

Taxonomy: Townes, Momoi, and Townes, 1965. Amer. Ent. Inst., Mem. 5: 514 (syn.).

- Heinrich, 1975 (1974). Ann. Zool. 32: 165-167 (description of Oriental sp. in Pristicerops)

bakeri (Davis). Newfoundland (insular), Que., Maine, N. H., N. Y., Mich., Minn., Alta., B. C.,

Wash. Host: Deilinia sp.

Platylabus bakeri Davis, 1898 (1897). Amer. Ent. Soc., Trans. 24: 352. ठ.

Pristicerops bakeri townesi Heinrich, 1962. Canad. Ent. Sup. 27: 789. ठ, ๆ. N. syn.

lascivus (Cresson). Que., Maine, N. Y., Md., W. Va., Ont. Mich., Ill., Wash.

Ichneumon la scivus Cresson, 1867. Amer. Ent. Soc., Trans. 1: $309 . " \sigma "=q$.

\section{Genus TROPICOLABUS Heinrich}

Tropicolabus Heinrich, 1959. Ent. News 70: 216.

Type-species: Platylabus foxi Davis. Monotypic and orig. desig.

This genus is Nearctic and presumably Neotropic.

foxi (Davis). N. J. Only the holotype is known.

Platylabus foxi Davis, 1898 (1897). Amer. Ent. Soc., Trans. 24: 353. ठ.

Platylabus foxii Dalla Torre, 1902. Cat. Hym., v. 3, p. 783. Emend. 


\section{Genus AMBLOPLISUS Heinrich}

Ambloplisus Heinrich, 1930. Zool. Mus. Berlin, Mitt. 15: 551.

Type-species: Ambloplisus primus Heinrich. Monotypic.

Thaumatoteles Hopper, 1938. Amer. Ent. Soc., Trans. 68: 103.

Type-species: Hoplismenus ornatus Cresson. Monotypic and orig. desig.

This is a small Nearctic and Neotropic genus.

ornatus (Cresson). N. Y., Md., w. N. C., Iowa. Heinrich (1962) stated that there is a specimen in the U. S. Natl. Museum collection from "Idaho," but that specimen is from Iowa.

Hoplismenus ornatus Cresson, 1869. Amer. Ent. Soc., Trans. 2: 92 . \&.

Hoplismenus ovatus(!) Berthoumieu, 1904. In Wytsman, Gen. Ins., fasc. 18, p. 30.

Taxonomy: Heinrich, 1962. Canad. Ent. Sup. 27: 790-791 (male described).

\section{Genus HYPOMECUS Wesmael}

Hypomecus Wesmael, 1945 (1844). [Brussels] Acad. Roy. de Belg., Nouveaux Mem. 18: 147. Type-species: Hypomecus albitarsis Wesmael. Monotypic.

This is a small Holaretic and Oriental genus.

quadriannulatus (Gravenhorst). Que., Colo., B. C., Wash., Calif.; Europe, n. Burma. Mesoleptus quadriannulatus Gravenhorst, 1829. Ichn. Europaea, v. 2, p. 13. ठ.

Hypomecus albitarsis Wesmael, 1845 (1844). [Brussels] Acad. Roy. de Belg., Nouveaux

Mem. 18: 147. ठ, + .

Hypomecus albitarsis var. carens Berthoumieu, 1896. Soc. Ent. de France, Ann. 65: 299. .

\section{SUBFAMILy METOPIINAE}

The members of this subfamily are internal parasites of Lepidoptera. Invariably, metopiines oviposit into the host larva and emerge as adults from the host pupa.

Revision: Townes and Townes, 1959. U. S. Natl. Mus. Bul. 216 [pt. 1]: 3-318.

Taxonomy: Townes, 1971. Amer. Ent. Inst., Mem. 17: 89-122 (genera of world).

\section{Genus PSEUDOMETOPIUS Davis}

Pseudometopius Davis, 1897. Amer. Ent. Soc., Trans. 24: 202.

Type-species: Metopius hagenii Cresson. Monotypic.

Tylocomnoides Uchida, 1940. Sapporo Nat. Hist. Soc., Trans. 16: 178.

Type-species: Tylocomnoides egawai Uchida. Monotypic and orig. desig.

Odontotylocommus Uchida, 1940. Sapporo Nat. Hist. Soc., Trans. 16: 179.

Type-species: Tylocomnoides pilosus Uchida. Monotypic and orig. desig.

The only species known are the one Nearctic and two Japanese species cited in the generic synonymy above.

hagenii (Cresson). Mass., Conn., Mich., Kans., Okla., Tex.

Metopius Hagenii Cresson, 1872. Amer. Ent. Soc., Trans. 4: 168. ^.

\section{Genus CHORINAEUS Holmgren}

Chorinaens Holmgren, 1858 (1856). Svenska Vetensk.-Akad. Handl. (n. f.) 1: 320.

Type-species: Exochus funebris Gravenhorst. Desig. by Viereck, 1912.

Polyrhabdus Walsh, 1873. Acad. Sci. St. Louis, Trans. 3: 98.

Type-species: Polyrhabdus cariniger Walsh. Monotypic.

This is a Holarctic genus of moderate size.

Revision: Aeschlimann, 1976 (1975). Soc. Ent. de France, Ann. (n. s.) 11: 723-744 (Western

Palearctic spp.).

aequalis Townes. Que., Ont., and Alta. s. to n. Va., w. N. C., and Mich.

Chorinaeus aequalis Townes, 1959. In Townes and Townes, U. S. Natl. Mus. Bul. 216 [pt. 1]: 21. $\delta$, ?. 
ealifornicus Ashmead. Alaska, B. C., Wash., Calif. Host: Acleris gloverana (Wlsm.).

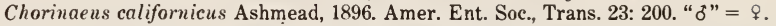

constrictus Davis. N. H., N. Y., Md., Va., w. N. C., e. Tenn., Ga. C. constrictus may prove to be a synonym of $C$. funebris carinatus (Cresson); compare Townes and Townes (1959, p. 27).

Chorinaeus constrictus Davis, 1897. Amer. Ent. Soc., Trans. 24: 209..

Taxonomy: Townes and Townes, 1959. U. S. Natl. Mus. Bul. 216 [pt. 1]: 26, 27.

emorsus Townes. N. S., N. H., Mich.

Chorinaeus emorsus Townes, 1959. In Townes and Townes, U. S. Natl. Mus. Bul. 216 [pt. 1]: 33. . .

excessorius Davis. Maine, Ont., and Minn. s. to Ala. and Kans.; also n. Utah and n. Calif. Host: Choristoneura fumiferana (Clem.), Ancylis comptana (Froel.).

Chorinaeus excessorius Davis, 1897. Amer. Ent. Soc., Trans. 24: 209..

funebris earinatus (Cresson). N. S., Que., Ont., s. Man., e. Alta., and s. B. C. s. to Md., Ala., and Tex. Host: Ancylis comptana (Froel.)?, Strepsicrates smithiana (Wlsm.), Archips semiferanus (Wlk.), Argyrotaenia velutinana (Wlk.), Anacampsis rhoifructella (Clem.), Tetralopha asperatella (Clem.), Aerobasis betulella Hulst.

Tryphon carinatus Cresson, 1864. Ent. Soc. Phila., Proc. 3: 273. ठ.

Polyrhabdus cariniger Walsh, 1873. Acad. Sci. St. Louis, Trans. 3: 98. ठ, ₹.

funebris funebris (Gravenhorst). Colo., Ariz., Idaho, Nev.; Eurasia. Host: Grapholitha conversana Wlsm. The neotype designated by Aeschlimann in his 1976 revision of Chorinaeus has no validity for a number of reasons, one of which is the fact that it is from Swedish Lappland.

Exochus funebris Gravenhorst, 1829. Ichn. Europaea, v. 1, p. 695. ơ ?

Chorinaeus funebris a. femoratus Hellen, 1937. Notulae Ent. 17: 56. ․ N. syn. (uncertain).

Chorinaeus funebris a. nigripes Hellen, 1937. Notulae Ent. 17: 56. ․ N. syn. (uncertain).

Chorinaeus funebris clarus Townes, 1959. In Townes and Townes, U. S. Natl. Mus. Bul. 216 [pt. 1]: 30. \&. N. syn.

Chorinaens funebris divisus Townes, 1959. In Townes and Townes, U. S. Natl. Mus. Bul. 216 [pt. 1]: 31. ९. N. syn.

Taxonomy: Kusigemati, 1967. Insecta Mastsumurana 30: 20-21 (no subspecies recognized).

Biology: Aeschlimann, 1974. Ent. Exp. Appl. 17: 488-489 (overwintering).

labiosus Townes. Western N. C., Mich.?

Chorinaeus labiosus Townes, 1959. In Townes and Townes, U. S. Natl. Mus. Bul. 216 [pt. 1]: 32. .

longicalear Thomson. Que. w. to B. C., s. to N. C., s. Wis., and Calif.; Eurasia. Host: Caripeta angustiorata Wlk.?, C. divisata Wlk., Hypagrytis piniata (Pack.), Protoboarmia porcelaria (Gn.), Semiothisa "granitata" auct., Choristoneura fumiferana (Clem.). Specimens with black hind femora (sometimes all femora black) are known from Que., Ont., Mich., Wash. Oreg., and Calif. The correct name for this species may be subcarinatus Holmgren. Roman (1925) suppressed longicalcar as a synonym of subcarinatus; he stated that Holmgren's type was lost, but that it appeared certain from the description that Holmgren's "male" of subcarinatus was a longicalcar female. It seems quite likely that Roman was correct, and I was prepared to accept Roman as first revisor. However, Dr. J.-P. Aeschlimann pointed out to me (personal commun., August, 1976) that Holmgren (1873) had in fact been first revisor and had suppressed subcarinatus as a synonym of $C$. cristator (Gravenhorst). A search is to be made for the subcarinatus type in places to which Holmgren is known to have sent material; if it is not found, and if no specimens of cristator having a black face are found, longicalcar must be suppressed as a synonym of subcarinatus.

Chorinaeus subcarinatus Holmgren, 1858 (1856). Svenska Vetensk.-Akad. Handl. (n. f.) 1: 321. \&? Syn.?

Chorinaens longicalcar Thomson, 1887. Deut. Ent. Ztschr. 31: 201. \&.

Chorinaeus pleturus Davis, 1897. Amer. Ent. Soc., Trans. 24: 211.. N. syn.

Chorinaeus longicalcar talaris Townes, 1959. In Townes and Townes, U. S. Natl. Mus. Bul. 216 [pt. 1]: 18. ठ, ๆ. N. syn. 
Chorinaeus longicalcar flavicrus Townes, 1959. In Townes and Townes, U. S. Natl. Mus. Bul. 216 [pt. 1]: 19. ठ, १. N. syn.

Chorinaeus longicalcar suralis Townes, 1959. In Townes and Townes, U. S. Natl. Mus. Bul. 216 [pt. 1]: 20. ¿, \&. N. syn.

Taxonomy: Holmgren, 1873. Svenska Vetensk.-Akad., Ofvers. af ... Forhandl. 30 (4): 78.

-Roman, 1925 (1924). Arkiv for Zool. 17A (4): 27 (syn.). - Aeschlimann, 1976 (1975). Soc.

Ent. de France, Ann. (n. s.) 11: 725, 737-738.

opacitus Davis. Ariz., Nev., Calif.

Chorinaeus opacitus Davis, 1897. Amer. Ent. Soc., Trans. 24: 210. ?.

recurvus Townes. N. H., N. Y.

Chorinaeus recurvus Townes, 1959. In Townes and Townes, U. S. Natl. Mus. Bul. 216 [pt. 1]: $31 . \delta, \uparrow$.

\section{Genus TRIECES Townes}

Trieces Townes, 1946. Bol. Ent. Venezolana 5: 60.

Type-species: Exochus texamus Cresson. Orig. desig.

According to Townes (1971), "this is a large genus of worldwide distribution." Described species occur in the Neotropic (Mexico), Holarctic, and Ethiopian regions.

Revision: Kusigemati, 1971. Kagoshima Univ., Faculty Agr., Mem. 8: 218-221 (Japanese spp.). -Aeschlimann, 1973. Soc. Ent. de France, Ann (n. s.) 9: 975-987 (western Palearctic spp.).

Taxonomy: Townes, 1971. Amer. Ent. Inst., Mem. 17: 97.

aquilus Townes. Western N. C.

Trieces aquilus Townes, 1959. In Townes and Townes, U. S. Natl. Mus. Bul. 216 [pt. 1]: 50. ㅇ.

arcuatus Townes. Md., w. N. C., Ont., Man. Host: Bomolocha bijugalis (Wlk.)?, B. deceptalis (Wlk.), noctuid on Comus.

Trieces arcuatus Townes, 1959. In Townes and Townes, U. S. Natl. Mus. Bul. 216 [pt. 1]: 56. \& (male misdet.).

Taxonomy: Walley, 1969. Canad. Ent. 101: 1100-1101.

bradleyi Townes. Maine, N. Y., Md.

Trieces bradleyi Townes, 1959. In Townes and Townes, U. S. Natl. Mus. Bul. 216 [pt. 1]: 52. ‥

calvatus Townes. Md., N. C., Tex.

Trieces calvatus Townes, 1959. In Townes and Townes, U. S. Natl. Mus. Bul. 216 [pt. 1]: 54. $\delta, ?$.

ciliosus Townes. Md., Va.

Trieces ciliosus Townes, 1959. In Townes and Townes, U. S. Natl. Mus. Bul. 216 [pt. 1]: 53.

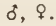

confusus Walley. Que., N. Y., Pa., Md., Va., w. N. C., Ont., Mich., Man. Host: Agonopteryx argillacea (Wlsm.).

Trieces confusus Walley, 1969. Canad. Ent. 101: 1098. ठ', ९.

costatus (Davis). N. B. w. to s. B. C., s. to N. Y., Minn., Colo., and n. Calif.

Chorinaeus costatus Davis, 1897. Amer. Ent. Soc., Trans. 24: 211. ठ,.

Chorinaeus pusillus Davis, 1897. Amer. Ent. Soc., Trans. 24: 211. ठ', 9.

crassipes Walley. Ont., Sask., s. B. C. Host: Meroptera pravella (Grt.), Anacampsis inocuella (Zell.), Compsolechia niveopulvella (Chamb.).

Trieces crassipes Walley, 1969. Canad. Ent. 101: 1102. ठ’, ๆ.

densus Townes. Mich.

Trieces densus Townes, 1959. In Townes and Townes, U. S. Natl. Mus. Bul. 216 [pt. 1]: 42. $\delta$, $\%$.

dentatus Townes. R. I., N. Y., Md., Ont. Host: Geometrid.

Trieces dentatus Townes, 1959. In Townes and Townes, U. S. Natl. Mus. Bul. 216 [pt. 1]: 55. $\delta, ?$. 
diffidens Townes. Que., N. Y., Ont., Mich.

Trieces diffidens Townes, 1959. In Townes and Townes, U. S. Natl. Mus. Bul. 216 [pt. 1]: 57. $\delta$, $\subsetneq$.

Taxonomy: Walley, 1969. Canad. Ent. 101: 1105-1106.

ejectus Townes. Northern Utah.

Trieces ejectus Townes, 1959. In Townes and Townes, U. S. Natl. Mus. Bul. 216 [pt. 1]: 46. $\delta$.

epinotiae Walley. Ont., Man., Colo., n. B. C. Host: Epinotia solandriana (L.), Pseudexentera oregonana (Wlsm.).

Trieces epinotiae Walley, 1969. Canad. Ent. 101: 1104. o, $९$.

flavifrons (Ashmead). Conn., Mich., Wis., Minn., S. Dak., Kans., Colo.

Chorinaeus flavifrons Ashmead, 1890 (1889). U. S. Natl. Mus., Proc. 12: 444..

flexus Walley. N. C.-Tenn. Ecology: The unique holotype was collected at an elevation of 5200 ft. in Great Smoky Mts. Nat. Park.

Trieces flexus Walley, 1969. Canad. Ent. 101: 1102..

fusus Townes. Mass., N. Y., Pa., N. J., Ont., Minn.

Trieces fusus Townes, 1959. In Townes and Townes, U. S. Natl. Mus. Bul. 216 [pt. 1]: 49. $\delta$, $q$.

integer Townes. Mass., R. I., N. Y., Va., w. N. C., Mich., Sask.

Trieces integer Townes, 1959. In Townes and Townes, U. S. Natl. Mus. Bul. 216 [pt. 1]: 48. $\delta$,. .

marlatti (Ashmead). R. I., e. N. C., Kans.

Chorinaeus marlatti Ashmead, 1896. Amer. Ent. Soc., Trans. 23: 200..

Chorinaeus marlattii Dalla Torre, 1901. Cat. Hym., v. 3, p. 221. Emend.

masoni Townes. Interior Alaska.

Trieces masoni Townes, 1959. In Townes and Townes, U. S. Natl. Mus. Bul. 216 [pt. 1]: 37. $\delta$, . .

onitis (Davis). N. S., Que., Maine, N. H., Ont., Man. Host: Nites betulella (Bsk.), Psilocorsis quercicella Clem., P. reflexella Clem., Tetralopha sp. on Fagus, Pseudexentera sp. on Quercus rubra, Acleris sp. on Quercus rubra.

Chorinaeus onitis Davis, 1897. Amer. Ent. Soc., Trans. 24: 210. ठ, ₹.

Taxonomy: Walley, 1969. Canad. Ent. 101: 1095-1098.

ruficoxa Walley. Southern Mich.

Trieces ruficoxa Walley, 1969. Canad. Ent. 101: 1101. ¿, $\%$.

sapineus litus Townes. Colo., Alta., B. C., Wash., Calif.

Trieces sapineus litus Townes, 1959. In Townes and Townes, U. S. Natl. Mus. Bul. 216 [pt. 1]: 44 . ..

sapineus sapineus Townes. Que., N. H., w. N. C., Mich., Minn.

Trieces sapineus sapineus Townes, 1959. In Townes and Townes, U. S. Natl. Mus. Bul. 216 [pt. 1]: 43. \&.

sparsus Townes. Vt. s. to e. S. C., w. to Minn.

Trieces sparsus Townes, 1959. In Townes and Townes, U. S. Natl. Mus. Bul. 216 [pt. 1]: 50.

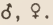

tegularis Townes. Eastern Calif. Ecology: Known only from the holotype, which was collected in an area of desert scrub at Lee Vining, Calif.

Trieces tegularis Townes, 1959. In Townes and Townes, U. S. Natl. Mus. Bul. 216 [pt. 1]: 40. .

teres Townes. Southern Man., Colo., n.e. Calif.

Trieces teres Townes, 1959. In Townes and Townes, U. S. Natl. Mus. Bul. 216 [pt. 1]: 41. ठ, ․

texanus (Cresson). N. J., Md., Fla., Kans., Tex.

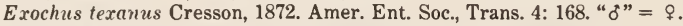

truncatus Walley. Tenn.

Trieces truncatus Walley, 1969. Canad. Ent. 101: 1101.. 
walleyi Townes. Que., Ont. Host: Herculia thymetusalis (Wlk.).

Trieces walleyi Townes, 1959. In Townes and Townes, U. S. Natl. Mus. Bul. 216 [pt. 1]: 47. $\delta$, \&.

\section{Genus METOPIUS Panzer}

\section{Genus METOPIUS Subgenus METOPIUS Panzer}

Metopius Panzer, 1806. Krit. Rev. Insektenf. Deutschlands, v. 2, p. 78

Type-species: Sphex vespoides Scopoli. Desig. by Viereck, 1912.

Peltastes Illiger, 1807. In Rossi, Fauna Etrusca, ed. 2, v. 2, p. 55.

Type-species: Ichneumon necatorius Fabricius. Desig. by Curtis, 1824. The

type-species is regarded as a synonym of $M$. vespoides (Scopoli).

Metopius subg. Peltopius Clement, 1927. In Sehmiedeknecht, Opusc. Ichn., v. 5, p. 3461, 3465.

Type-species: Sphex vespoides Scopoli. Desig. by Clement, 1930.

This is a large subgenus of Neotropic (Mexico), Holarctic, Oriental, Australian, and Ethiopian distribution.

galbaneus Townes. Southern Oreg. s. to s. Calif.

Metopius (Metopizs) galbaneus Townes, 1959. In Townes and Townes, U. S. Natl. Mus.

Bul. 216 [pt. 1]: 74. ठ" ? .

krombeini epixanthus Townes. Tex., Colo., Ariz.

Metiopius (Metiopius) krombeini epixanthus Townes, 1959. In Townes and Townes, U. S. Natl. Mus. Bul. 216 [pt. 1]: 71. ठ,,.

krombeini krombeini Townes. Southern N. Y., N. J., Md., Va., n. Ga., n. Mich., Wis., Ark., Okla. Ecology: Occurs in open stands of serubby oaks.

Metopius (Metopizs) krombeini krombeini Townes, 1959. In Townes and Townes, U. S. Natl. Mus. Bul. 216 [pt. 1]: 70. $\delta, ~ ๆ$.

mimicus Townes. Central Ariz.

Metopius (Metopius) mimicus Townes, 1959. In Townes and Townes, U. S. Natl. Mus. Bul. 216 [pt. 1]: $68 . \delta$, ․

pulchellus Cresson. Southeastern Wyo., Colo., N. Mex., n. Utah, Ariz.

Metopius pulchellus Cresson, 1865. Ent. Soc. Phila., Proc. 4: 271.

Metopius montanus Cresson, 1879. Amer. Ent. Soc., Trans. 7: xxviii in Proc. o. N. syn.

Metopius (Metopius) pulchellus sonora Townes, 1959. In Townes and Townes, U. S. Natl. Mus. Bul. 216 [pt. 1]: $73 . \delta^{\circ}$,. N. syn.

robustus concinnus Cresson. Nev., n.w. Calif.

Metopius concinnus Cresson, 1879. Amer. Ent. Soc., Trans. 7: xxviii in Proc. ơ.

robustus mirandus Cresson. Western Kans., Colo.

Metopius mirandus Cresson, 1879. Amer. Ent. Soc., Trans. 7: xxviii in Proc. 9.

Metopius grandior Viereck, 1905. Kans. Acad. Sci., Trans. 19: 314. ?.

robustus robustus Cresson. Southern N. Y. s. to Ga., w. to e. Kans.

Metopius robustus Cresson, 1879. Amer. Ent. Soc., Trans. 7: xxvii in Proc. $q$.

Metopius harbecki Skinner, 1906. Ent. News 17: 150. ठ.

vittatus Townes. Utah, n. Ariz., s. B. C., Oreg., Calif.

Metopius (Metopius) vittatus Townes, 1959. In Townes and Townes, U. S. Natl. Mus. Bul. 216 [pt. 1]: 76. $\delta$, ㅇ.

\section{Genus METOPIUS Subgenus CULTRARIUS Davis}

Cultrarius Davis, 1897. Amer. Ent. Soc., Trans. 24: 197.

Type-species: Metopius rileyi Marlatt. Monotypic.

This subgenus is not known to occur outside the Nearctic region.

birkmani Brues. Tex., s. Ariz., s. Calif.

Metopius birkmani Brues, 1907. Wis. Nat. Hist. Soc., Bul. 5: 56. of ( $q$ misdet.). 
comptus Cresson. Ga., S. Dak., Colo.

Metopius comptus Cresson, 1879. Amer. Ent. Soc., Trans. 7: xxviii in Proc..

Metopius laticinctus Cresson, 1879. Amer. Ent. Soc.,Trans. 7: xxix in Proc..

consector Townes. Va., s. Minn., Mo., s. S. Dak., Nebr., Kans., Colo.

Metopius (Cultrarius) consector Townes, 1959. In Townes and Townes, U. S. Natl. Mus.

Bul. 216 [pt. 1]: $83 . \delta$,.

pectoralis Townes. Mo., Tex.?

Metopius (Cultrarius) pectoralis Townes, 1959. In Townes and Townes, U. S. Natl. Mus. Bul. 216 [pt. 1]: 85 . o, १ ?

rileyi Marlatt. S. Dak., e. Nebr., n.e. Kans.

Metopius rileyi Marlatt, 1891. Ent. Soc. Wash., Proc. 2: 103. $q$.

rufipes Cresson. Eastern Nebr., Colo.

Metopius mifipes Cresson, 1865. Ent. Soc. Phila., Proc. 4: 270..

scapulatus Townes. Tex.

Metopius (Cultrarius) scapulatus Townes, 1959. In Townes and Townes, U. S. Natl. Mus. Bul. 216 [pt. 1]: $81 . \delta$.

scitulus Cresson. Nev.

Metopius scitulus Cresson, 1879. Amer. Ent. Soc., Trans. 7: xxix in Proc. ơ.

secundus Townes. N. Mex. The type locality is San Ignacio, not "San Janacia"' as misquoted from the label of the unique holotype by Townes and Townes.

Metopius (Cultrarius) secundus Townes, 1959. In Townes and Townes, U. S. Natl. Mus. Bul. 216 [pt. 1]: 89 ..

ultimatus Davis. N. J. w. to e. Nebr., s. to Miss. and e. Tex.

Metopius ultimatus Davis, 1897. Amer. Ent. Soc., Trans. 24: 199. ठ.

xanthostigma Ashmead. Md., Va., N. C., S. C., s.w. Minn., N. Dak.

Metopius xanthostigma Ashmead, 1890 (1889). U. S. Natl. Mus., Proc. 12: 438. o.

\section{Genus METOPIUS Subgenus PELTALES Townes}

Metopius subg. Peltales Townes, 1959. In Townes and Townes, U. S. Natl. Mus. Bul. 216 [pt. 1]: 91 .

Type-species: Metopius errantia Davis. Orig. desig.

This is a moderate sized subgenus of Neotropic and Nearctic distribution.

errantia arizonicus Townes. Southern Ariz.

Metopius (Peltales) errantius arizonicus Townes, 1959. In Townes and Townes, U. S. Natl. Mus. Bul. 216 [pt. 1]: 94 . .

errantia californicus Townes. Oreg., Calif.

Metopius (Peltales) errantius californicus Townes, 1959. In Townes and Townes, U. S. Natl. Mus. Bul. 216 [pt. 1]: 95. ơ,.

errantia errantia Davis. N. J., n. Va., Ont., n. Mich., n. Minn. Host: Geometrid.

Metopius errantia Davis, 1897. Amer. Ent. Soc., Trans. 24: 199..

Metopius (Peltales) errantius errantius Townes, 1959. In Townes and Townes, U. S. Natl. Mus. Bul. 216 [pt. 1]: 93 . Unjustified emend.

errantia floridanus Townes. Northern Fla.

Metopius (Peltales) errantius floridanus Townès, 1959. In Townes and Townes, U. S. Natl. Mus. Bul. 216 [pt. 1]: 94 ..

notatus Townes. Ala.

Metopius (Peltales) notatus Townes, 1959. In Townes and Townes, U. S. Natl. Mus. Bul. 216 [pt. 1]: 96 . \&.

\section{Genus METOPIUS Subgenus TYLOPIUS Townes}

Metopius subg. Tylopius Townes, 1959. In Townes and Townes, U. S. Natl. Mus. Bul. 216 [pt. 1]: 97.

Type-species: Metopius pinatorius Brulle. Orig. desig.

Tylopius is a Holarctic subgenus of moderate size. 
basalis basalis Cresson. Ga.?, Fla.

Metopius basalis Cresson, 1879. Amer. Ent. Soc., Trans. 7: xxvii in Proc. \&.

Metopius medianus Morley, 1912. Rev. Ichn. Brit. Mus., v. 1, p. 78. ठ. Syn.?

basalis heinrichi Townes. N. B., Maine, w. Ont., Wis. s.w. B. C. Host: Saturniid.

Metopius (Tylopius) basalis heinrichi Townes, 1959. In Townes and Townes, U. S. Natl.

Mus. Bul. 216 [pt. 1]: 104. o, ?.

bellus Cresson. Nev., s.w. Oreg., n.e. Calif.

Metopizts bellus Cresson, 1879. Amer. Ent. Soc., Trans. 7: xxviii in Proc. ơ.

edwardsii Cresson. Alta., Wash.

Metopizs edwardsii Cresson, 1879 (1878). Acad. Nat. Sci. Phila., Proc. 30: 376. đ์.

pollinctorius nevadensis Cresson. Nev., w. Wash., n.e. Calif. Host: Acronicta sp.

Metopius nevadensis Cresson, 1879. Amer. Ent. Soc., Trans. 7: xxviii in Proc. ơ,.

pollinctorius pollinctorius (Say). N. S. w. to s. B. C., s. to n. Fla. and Ill. Host: Gluphisia septentrionalis Wlk., Actias luna (L.)?, Acronicta oblinita (J. E. S.).

Peltastes pollinctorius Say, 1836. Boston Jour. Nat. Hist. 1: 245. o, ?.

Metopius cordiger Brulle, 1846. In Lepeletier, Hist. Nat. Ins. Hym., v. 4, p. 120. ठ.

\section{Genus TRICLISTUS Foerster}

Triclist us Foerster, 1868. Naturh. Ver. Rheinlande, Verh. 25: 161.

Type-species: Exochus podagricus Gravenhorst. Desig. by Morley, 1913 from five species included by Holmgren, 1873.

This is a large genus of worldwide distribution. Some species are often abundant. The interspecific differences are often somewhat obscure, and the males of some species cannot be distinguished.

Revision: Kusigemati, 1971. Kagoshima Univ., Faculty Agr., Mem. 8: 228-240 (Japanese spp.). -Aeschlimann, 1973. Schweiz. Ent. Gesell., Mitt. 46: 219-252 (western Palearctic spp.).

adustus Townes. Colo., Wash., Oreg., Calif.

Triclistus adustus Townes, 1959. In Townes and Townes, U. S. Natl. Mus. Bul. 216 [pt. 1]: 119. ?.

brunnipes (Cresson). Northern Man. w. to Yukon, s. to w. Iowa, N. Mex., Ariz., and Calif.

Exochus brunnipes Cresson, 1879 (1878). Acad. Nat. Sci. Phila., Proc. 30: 374. ․

Triclistus bruneipes Dalla Torre, 1901. Cat. Hym., v. 3, p. 218. Emend.

chosis Townes. Mass., N. Y., N. J., Pa., Md., D. C., Va., Ont.

Triclistus chosis Townes, 1959. In Townes and Townes, U. S. Natl. Mus. Bul. 216 [pt. 1]: 121. ‥

crassus Townes. P. E. I. w. to Yukon and Alaska, s. to N. Y., Wis., Colo., Ariz., and Calif.; e. U. S. S. R., n. Japan.

Triclistus crassus Townes, 1959. In Townes and Townes, U. S. Natl. Mus. Bul. 216 [pt. 1]: 110. $\delta$, ๆ.

Taxonomy: Kusigemati 1971. Kagoshima Univ., Faculty Agr., Mem. 8: 234-235.

emarginalus (Say). P. E. I. w. to s. B. C., s. to Fla., e. Kans., N. Mex., and n. Calif. Host:

Phlyctaenia extricalis (Gn.), Tetralopha robustella Zell., Tholeria reversalis (Gn.),

pyralid on Alnus incana, Archips argyrospilus (Wlk.), Argyrotaenia velutinana (Wlk.),

Croesia albicomana (Clem.), Platynota idaeusalis (Wlk.), Bucculatrix sp., Anthophila pariana (Clerck).

Ophion emarginalus Say, 1829. Contrib. Maclurian Lyceum to Arts and Sci. 1: 76. Sex not indicated.

Anomalon emarginatus (!) Say, 1835. Boston Jour. Nat. Hist. 1: 245.

Exochus fulvipes Cresson, 1864. Ent. Soc. Phila., Proc. 3: 285. ठ, १.

Taxonomy: Davis, 1897. Amer. Ent. Soc., Trans. 24: 222. -Ashmead, 1902. Wash. Acad. Sci., Proc. 4: 230. - Cushman and Gahan, 1921. Ent. Soc. Wash., Proc. 23: 169. - Townes and

Townes, 1959. U. S. Natl. Mus. Bul. 216 [pt. 1]: 113-116. 
evexus Townes. N. H. s. to Md., w. to s. Sask. and Colo. Host: Archips cerasivoranus (Fiteh), Acrobasis comptoniella Hulst.

Triclistus evexus Townes, 1959. In Townes and Townes, U. S. Natl. Mus. Bul. 216 [pt. 1]: 118. $\delta$, ․ .

melanocephalus (Cameron). Que. w. to w. S. Dak., s. to e. N. C. and Ariz.; n. Mexico.

Exochus melanocephalus Cameron, 1886. In Wytsman, Biol. Cent.-Amer., Hym., v. 1, p. 280. " $\delta "=$ ?.

Triclistus thoracicus Ashmead, 1896. Amer. Ent. Soc., Trans. 23: 210. ๆ.

minutus Carlson. Northwestern Va., s. Mich. Ecology: In Mich. seven specimens were collected with sweep nets on an upland field (abandoned farm site) with gravelly soil and a grass-herb plant cover; the field is surrounded by oak-hickory woodlands which are encroaching upon it at its edges.

Triclistus minutus Carlson, 1966. Mich. Ent. 1: 20. ठ, ๆ.

occidentis Townes. Western Alta., w. Wash., e. Calif.

Triclistus occidentis Townes, 1959. In Townes and Townes, U. S. Natl. Mus. Bul. 216 [pt. 1]: 116. ‥

podagricus (Gravenhorst). N. S., Que., Ont., Sask., Alta., Idaho, s.e. Alaska; Eurasia. Host: Zeiraphera fortunana (Kft.).

Exochus podagricus Gravenhorst, 1829. Ichn. Europaea, v. 2, p. 336. o, ?.

Triclistus nigritellus Holmgren, 1873. Svenska Vetensk.-Akad., Ofvers. af ... Forhandl. 30 (4): 60 ..

Taxonomy: Aeschlimann, 1973. Schweiz. Ent. Gesell., Mitt. 46: 233-235.

Biology: Baltensweiler, 1958. Schweiz. Anst. f. d. Forstl. Versuchsw., Mitt. 34: 121.

-Aeschlimann, 1974. Ent. Exp. Appl. 17: 488, 489-490 (overwintering).

propinquus (Cresson). Conn. s. to n. Ga., w. to Mich. and Ala.

Exochus propinquus Cresson, 1868. Amer. Ent. Soc., Trans. 2: 114. $9,(\delta$ misdet. ?).

pygmaeus (Cresson). N. S. w. to s. Alaska, s. to S. C., Ala., n.e. Kans., Colo., and Calif.; Eurasia. Host: Paralobesia viteana (Clem.), Acleris variana (Fern.). This is T. pallipes Holmgren (1873) in the sense of 20th Century European authors preceding Aeschlimann (1973). Overlooking the priority of pygmaeus, Townes and Townes (1959) erroneously suppressed it as a synonym of pallipes. Aeschlimann (1973) has shown that the pallipes "lectotype" selected by Aubert (1968) (=pygmaeus) is invalid, and selected a valid lectotype which is not conspecific with pygmaeus.

Exochus pygmaeus Cresson, 1864. Ent. Soc. Phila., Proc. $3: 285 . " \delta "=q$.

Triclistus taiwanensis Uchida, 1932. Hokkaido Imp. Univ., Faculty Agr., Jour. 25: 267. ð. N. syn. Placed as a syn. of T. pallipes Holmgren by Townes, Townes, and Gupta (1961).

Taxonomy: Townes and Townes, 1959. U. S. Natl. Mus. Bul. 216 [pt. 1]: 124-125. - Townes,

Townes, and Gupta, 1961. Amer. Ent. Inst., Mem. 1: 303 (syn.). - Aubert, 1968. Schweiz.

Ent. Gesell., Mitt. 41: 188 (invalid lectotype selected for pallipes). - Aeschlimann, 1973.

Schweiz. Ent. Gesell., Mitt. 46: 236-239.

Biology: Aeschlimann, 1974. Ent. Exp. Appl. 17: 488, 490-491 (overwintering). -Aeschlimann, 1975. Schweiz. Ent. Gesell., Mitt. 48: 165-171.

rectus Townes. Ariz., Calif.

Triclistus rectus Townes, 1959. In Townes and Townes, U. S. Natl. Mus. Bul. 216 [pt. 1]: 117. \&.

\section{Genus COLPOTROCHIA Holmgren}

There are two subgenera, one of which has no Nearctic species.

\section{Genus COLPOTROCHIA Subgenus COLPOTROCHIA Holmgren}

Colpotrochia Holmgren, 1856 (1854). Svenska Vetensk.-Akad. Handl. 75: 80.

Type-species: Ichneumon elegantulus Schrank. Monotypic. The type-species is

regarded as a synonym of $C$. cincta (Scopoli).

Alcocerus Foerster, 1868. Naturh. Ver. Rheinlande, Verh. 25: 161. 
Type-species: Tryphon trifasciatus Cresson. By subsequent monotypy from inclusion by Davis, 1897.

Exochoides Cresson, 1868. Amer. Ent. Soc., Trans. 2: 37.

Type-species: Exochoides mexicana Cresson. Desig. by Viereck, 1914.

Ischyrocnemopsis Ashmead, 1900. U. S. Natl. Mus., Proc. 23: 81.

Type-species: Exochoides texana Cresson. Monotypic and orig. desig.

Aithris Cameron, 1900. Manchester Lit. and Phil. Soc., Mem. and Proc. 44 (15): 106.

Type-species: Aithris coenutus Cameron. Monotypic.

Inoresa Cameron, 1909. Bombay Nat. Hist. Soc., Jour. 19: 724.

Type-species: Inoresa pilosa Cameron. Monotypic.

Sychnoleteroides Brethes, 1909. Buenos Aires Mus. Nac. de Hist. Nat., An. 19: 229.

Type-species: Sychnoleteroides flavus Brethes. Monotypic.

This is a large subgenus of Neotropic, Holarctic, and Oriental distribution.

crassipes (Provancher). Maine s. to S. C., w. to Wis.

Cteniscus crassipes Provancher, 1886. Addit. Corr. Faune Ent. Canada Hym., p. 109..

Barron (1975) was unable to locate any syntype.

Taxonomy: Barron, 1975. Nat. Canad. 102: 456.

fultoni Townes. Eastern Va., e. N. C., e. S. C.

Colpotrochia (Colpotrochia) fultoni Townes, 1959. In Townes and Townes, U. S. Natl. Mus.

Bul. 216 [pt. 1]: 132.. .

texana (Cresson). N. C., S. C., Ga., Fla.

Exochodes (!) texana Cresson, 1872. Amer. Ent. Soc., Trans. 4: 167. ठ̊.

Ischyrocnemis carolina Ashmead, 1890 (1889). U. S. Natl. Mus., Proc. 12: 443. ठో.

trifasciata (Cresson). N. S. s. to Ga., w. to Minn. and e. Kans.

Tryphon! trifasciatus Cresson, 1864. Ent. Soc. Phila., Proc. 3: 276. §.

\section{Genus PERIOPE Haliday}

Periope Haliday, 1838. Ann. Nat. Hist. 2: 114.

Type-species: Periope auscultator Haliday. Monotypic.

Monoplectron Holmgren, 1856 (1854). Svenska Vetensk.-Akad. Handl. 75: 81.

Type-species: Monoplectron zygaenator Holmgren. Monotypic. The type-species is regarded as a synonym of $P$. auscultator Haliday.

Oligoplectron Foerster, 1868. Naturh. Ver. Rheinlande, Verh. 25: 161, 218, 219.

Unnecessary n. name for Periope Haliday. The variant spelling Oligoplectrum appeared on p. 218.

Monoplectrochus Heinrich, 1949. Muenchen. Ent. Gesell., Mitt. 35-39: 109.

Type-species: Monoplectrochus hoerhammeri Heinrich. Monotypic and orig. desig.

This is a small Holaretic genus.

aethiops (Cresson). Que. w. to e. Alta., s. to n.w. S. C. and e. Nebr. Ecology: Occurs in late summer and early fall and is often found on flowers of Aster.

Tryphon aethiops Cresson, 1868. Amer. Ent. Soc., Trans. 2: 106. \&.

Chorinaeus pulchripes Provancher, 1883. Nat. Canad. 14: 12..

\section{Genus SPUDAEUS Gistel}

Trachyderma Gravenhorst, 1829. Ichn. Europaea, v. 3, p. 283. Preocc. by Latreille, 1829 (April).

Type-species: Trachyderma scabra Gravenhorst. Monotypic.

Spudaeus Gistel, 1848. Naturgesch. Thierr. f. Hoeh. Schul., p. xi. N. name for Trachyderma Gravenhorst.

Tylocomnus Holmgren, 1873. Svenska Vetensk.-Akad., Ofvers. af ... Forh. 30 (4): $76 \mathrm{~N}$. name for Trachyderma Gravenhorst.

This is a small Holaretic genus.

indigus (Davis). N. S. w. to B. C., s. to N. H., Mich., and Colo.

Tylecomnus (!) indigus Davis, 1897. Amer. Ent. Soc., Trans. 24: 204. ठ, ๆ. 
scaber umbrosus (Davis). Southern Alta. s. to Ariz., w. to s. B. C. and Calif. S. scaber scaber (Gravenhorst) is European.

Tylecomnus (!) umbrosus Davis, 1897. Amer. Ent. Soc., Trans. 24: 203. .

\section{Genus BOTHROMUS Townes}

Bothromus Townes, 1959. In Townes and Townes, U. S. Natl. Mus. Bul. 216 [pt. 1]: 142. Type-species: Tylecomnus (!) minoris Davis. Orig. desig.

This is a small Nearctic genus.

Revision: Walley, 1966. Canad. Ent. 98: 1272-1275.

bicolor Walley. Que., S. Dak., Alta., B. C., Wash.

Bothromus bicolor Walley, 1966. Canad. Ent. 98: 1273. ₹.

cruralis Townes. Northeastern Calif.

Bothromus minoris cruralis Townes, 1959. In Townes and Townes, U. S. Natl. Mus. Bul. 216 [pt. 1]: 144.. .

gibbus Townes. Ont., w. Colo., Alta., B. C. Host: Eupithecia ravocostaliata Pack. on willow, geometrid on willow.

Bothromus gibbus Townes, 1959. In Townes and Townes, U. S. Natl. Mus. Bul. 216 [pt. 1]: 145. $\delta, ?$.

minoris (Davis). Que., Maine, N. H., N. Y., Ont., Mich., Sask.?, s. B. C. Host: Eupithecia sp. on Ceanothns sanguineus, E. castigata $\mathrm{Hbn}$ ? on Betula papyrifera, geometrid on Alnus.

Tylecomnus (!) minoris Davis, 1897. Amer. Ent. Soc., Trans. 24: 204..

\section{Genus APOLOPHUS Townes}

Apolophus Townes, 1971. Amer. Ent. Inst., Mem. 17: 111.

Type-species: Apolophus borealis Townes. Monotypic and orig. desig.

This is a small Neotropic and Holaretic genus.

borealis Townes. Northern Mich., w. Oreg., n.w. Calif.; Germany.

Apolophus borealis Townes, 1971. Amer. Ent. Inst., Mem. 17: 112. \&.

\section{Genus LEURUS Townes}

Leurus Townes, 1946. Bol. Ent. Venezolana 5: 59.

Type-species: Exochus caeruliventris Cresson. Monotypic and orig. desig.

This is a small Neotropic and Nearctic genus. I have seen an undescribed species from eastern N. C.; hopefully, it will soon be described by Mr. T. P. Nuhn.

caeruliventris borealis Townes. Southeastern Mass. s. to Fla., w. to s. Mich., e. Kans. and La.

Host: Desmia funeralis ( $\mathrm{Hbn}$.). L. caeruliventris caeruliventris is Neotropic.

Leurus caeruliventris borealis Townes, 1959. In Townes and Townes, U. S. Natl. Mus. Bul. 216 [pt. 1]: 149. $\delta$, ?.

\section{Genus SETICORNUTA Morley}

Megatrema Cameron, 1907. Ztschr. System. Hym. Dipt. 7: 468. Preocc. by Leach, 1825 and Mayr, 1865.

Type-species: Megatrema albopilosa Cameron. Monotypic.

Seticornuta Morley, 1913. Fauna Brit. India, Hym., v. 3, pt. 1, p. 310.

Type-species: Seticornuta albicalcar Morley. Monotypic and orig. desig. The type-species is regarded as a synonym of S. albopitosa (Cameron).

This is a small Oriental and Holaretic genus.

apicalis (Cresson). R. I. s. to n. Fla., w. to Wis., Nebr., and Ala. Host: Acrobasis betulella

Hulst, $A$. caryivorella Rag., $A$. indigenella (Zell.), A. juglandis (LeB.), A. sylviella Ely.

Exochus apicalis Cresson, 1864. Ent. Soc. Phila., Proc. 3: 285 . “ $"=$ ॠ. 
terminalis (Ashmead). Que. s. to w. N. C., w. to e. Kans. Host: Tortricid, Nephopteryx virgatella (Clem.) on Robinia pseudoacocia, N. subcaesiella (Clem.).

Triclistus terminalis Ashmead, 1896. Amer. Ent. Soc., Trans. 23: 201. đ.

\section{Genus CARRIA Schmiedeknecht}

Carria Schmiedeknecht, 1924. Ent. Monthly Mag. 60: 112.

Type-species: Carria paradoxa Schmiedeknecht. Monotypic.

This is a small Holarctic and Australian genus.

dreisbachi californica Townes. Northeastern Calif.

Carria dreisbachi califormica Townes, 1959. In Townes and Townes, U. S. Natl. Mus. Bul. 216 [pt. 1]: 157. ठ, ๆ.

dreisbachi dreisbachi Townes. Que. w. to Sask., s. to w. N. C. and Ill.

Carria dreisbachi dreisbachi Townes, 1959. In Townes and Townes, U. S. Natl. Mus. Bul. 216 [pt. 1]: 155. $\delta, ~ ?$.

dreisbachi montana Townes. Colo., N. Mex., Ariz., w. Wash.

Carria dreisbachi montana Townes, 1959. In Townes and Townes, U. S. Natl. Mus. Bul. 216 [pt. 1]: 156. ठ, ᄋ.

inculcata Townes. N. J., Md., s.e. N. C., e. S. C.

Carria inculcata Townes, 1959. In Townes and Townes, U. S. Natl. Mus. Bul. 216 [pt. 1]: 158. $\delta$, ‥

\section{Genus MACROMALON Townes}

Macromalon Townes, 1959. In Townes and Townes, U. S. Natl. Mus. Bul. 216 [pt. 1]: 118. Type-species: Macromalon montanum Townes. Monotypic and orig. desig.

Only two species are known; one from India has been reared from Plutella xylostella (L.).

montanum Townes. Colo. Ecology: The type specimens were collected at elevations of 9400 , 9500 , and $11000 \mathrm{ft}$. in the Rocky Mountains.

Macromalon montanum Townes, 1959. In Townes and Townes, U. S. Natl. Mus. Bul. 216 [pt. 1]: 159. §, ?.

\section{Genus HYPSICERA Latreille}

Hypsicera Latreille, 1829. In Cuvier, Le Regne Anim., ed. 2, v. 5, p. 288.

Type-species: Ichneumon femoralis Gravenhorst. Monotypically included and desig. by Viereck, 1914. The type-species designation is Gravenhorst's 1820 identification of Ichneumon femoralis Geoffroy.

Metacoelus Foerster, 1868. Naturh. Ver. Rheinlande, Verh. 25: 161.

Type-species: Exochus femoralis Gravenhorst. Desig. by Viereck, 1914 from four species included by Holmgren, 1873. The type-species designation is Gravenhorst's 1829 identification of Ichneumon femoralis Geoffroy.

Polyclistus Foerster, 1868. Naturh. Ver. Rheinlande, Verh. 25: 161.

Type-species: Ichneumon femoralis Geoffroy. Desig. by Viereck, 1912 from three species included by Thomson, 1887 .

Plesioexochus Cameron, 1905. So. African Phil. Soc., Trans. 15: 202.

Type-species: Plesioexochus rufipes Cameron. Monotypic.

This large genus is Ethiopian, Oriental, and Holarctic. The largest number of species occur in the tropics of the Old World.

Revision: Kusigemati, 1971. Kagoshima Univ., Faculty Agr., Mem. 8: 253-261 (Japanese spp.). cuneata Townes. Maine, R. I., N. Y., Ont., Ohio, Alta., Ariz., Alaska, Calif.

Hypsicera cuneata cuneata Townes, 1959. In Townes and Townes, U. S. Natl. Mus. Bul. 216 [pt. 1]: 165. §, ?.

Hypsicera caneata opaca Townes, 1959. In Townes and Townes, U. S. Natl. Mus. Bul. 216 [pt. 1]: 166. §, ․ N. Nyn. 
curvator (Fabricius). N. S. w. to s. B. C., s. to Pa., Colo., and Wash.; Europe. Adventive. Host: Tinea pellionella (L.). Also occurs adventively in the Neotropic region according to

Townes and Townes (1959). Only females are known.

Ichneumon curvator Fabricius, 1793. Ent. System., v. 2, p. 177. [female].

Ichneumon mansuetor Gravenhorst, 1807. Vergl. Uebers. Zool. Systeme, p. 254. [female].

Hyperacmus tineae Riley, 1890. U. S. Dept. Agr., Insect Life 2: 213..

Hyperacmus ovatus Davis, 1897. Amer. Ent. Soc., Trans. 24: 218. ๆ.

Taxonomy: Townes and Townes, 1959. U. S. Natl. Mus. Bul. 216 [pt. 1]: 161, 163-164 (syn. distribution).

femoralis (Geoffroy). Que. w. to Wash., s. to e. N. C., Ark., Kans., and Calif.; Eurasia; S. Africa, Madagascar; Australia; Hawaii; Brazil, Argentina, Chile. Ecology: Often collected on windows in buildings. Adventive. Presumably a parasite of Lepidoptera which feed upon stored products.

Ichneumon femoralis Geoffroy, 1785. In Fourcroy, Ent. Parisiensis, v. 2, p. 396. [female?] Exochus laevis Cresson, 1864. Ent. Soc. Phila., Proc. 3: 286. đ̌, ?.

Metacoelus levis Dalla Torre, 1901. Cat. Hym., v. 3, p. 217. Emend.

Crypturus bonaerensis Schrottky, 1902. Buenos Aires Mus. Nac. de Hist. Nat., An. 8: 100. "s" =

Plesioexochus rufipes Cameron, 1905. So. African Phil. Soc., Trans. 15: 203. " $\delta "=q$.

Exochus platensis Brethes, 1924. Nunquam Otiosus-II (Buenos Aires), p. 10. [female].

Taxonomy: Townes and Townes, 1966. Amer. Ent. Inst., Mem. 8: 195-196 (syn.).

fulviceps Townes. Southwestern Va.

Hypsicera fulviceps Townes, 1959. In Townes and Townes, U. S. Natl. Mus. Bul. 216 [pt. 1]: 164 .. .

\section{Genus STETHONCUS Townes}

Stethoncus Townes, 1959. In Townes and Townes, U. S. Natl. Mus. Bul. 216 [pt. 1]: 167. Type-species: Stethoncus arcticus Townes. Monotypic and orig. desig.

This is a small Holarctic genus.

areticus Townes. Newfoundland (Labrador), n. Que., N. H., n. Man., interior Alaska. This is a subarctic species with a relict population on Mt. Washington, N. H.; the holotype is labeled as being from Fort Chimo, Labrador, which is now in Quebec.

Stethoncus arcticus Townes, 1959. In Townes and Townes, U. S. Natl. Mus. Bul. 216 [pt. 1]: 168 . ס, ㅇ.

\section{Genus SYNOSIS Townes}

Synosis Townes, 1959. In Townes and Townes, U. S. Natl. Mus. Bul. 216 [pt. 1]: 168.

Type-species: Synosis clepsydra Townes. Monotypic and orig. desig.

This is a small Holarctic and Neotropic genus.

Revision: Kusigemati, 1971. Kagoshima Univ., Faculty Agr., Mem. 8: 262-263 (Japanese spp.). clepsydra Townes. Que., Vt., Mass., N. Y., Mich., s. Ind., Wis., s. B. C., n.e. Calif.

Synosis clepsydra Townes, 1959. In Townes and Townes, U. S. Natl. Mus. Bul. 216 [pt. 1]: 169. $\delta, ?$.

\section{Genus EXOCHUS Gravenhorst}

Exochus Gravenhorst, 1829. Ichn. Europaea, v. 2, p. 328.

Type-species: Ichneumon gravipes Gravenhorst. Desig. by Viereck, 1912.

Amesolytus Foerster, 1868. Naturh. Ver. Rheinlande, Verh. 25: 161.

Type-species: Amesolytus ferrugineus Ashmead. By subsequent monotypy from inclusion by Ashmead, 1896.

Mima Davis, 1895. In Slosson, Ent. News 6: 317. Nomen nudum.

Mima Davis, 1897. Amer. Ent. Soc., Trans. 24: 206, 219. Preocc. by Meigen, 1820 and Westerlund, 1886.

Type-species: Mima washingtonensis Davis. Monotypic. 
Xanthexochus Morley, 1913. Fauna Brit. India, Hym., v. 3, pt. 1, p. 292.

Type-species: Xanthexochus scutellatus Morley. Monotypic and orig. desig.

This is a very large genus, apparently of worldwide distribution, although no species have been described from the Australian region.

Revision: Kusigemati, 1971. Kagoshima Univ., Faculty Agr., Mem. 8: 263-285 (Japanese spp.). albiceps Walsh. N. J., S. C., Ill.?, La.; Venezuela?

Exochus albiceps Walsh, 1873. Acad. Sci. St. Louis, Trans. 3: $96 . " \sigma "=\wp$.

Exochus sulcatus Townes, 1959. In Townes and Townes, U. S. Natl. Mus. Bul. 216 [pt. 1]: 211. $\delta$.

Taxonomy: Townes, 1972. Ent. Soc. Wash., Proc. 74: 259 (syn.).

albifrons Cresson. P. E. I. w. to Alta. and Wash., s. to Ala., N. Mex., and Calif. Host: Archips cerasivoranus (Fitch), A. fervidanus (Clem.), A. rileyanus (Grt.), Argyrotaenia velutinana (Wlk.), Choristoneura rosaceana (Harris), Platynota idaeusalis (Wlk.).

Exochus albifrons Cresson, 1868. Amer. Ent. Soc., Trans. 2: 114. \&.

annulicrus Walsh. N. B. w. to B. C., s. to w. N. C., Ill.?, Colo., and Ariz.

Exochus annulicrus Walsh, 1873. Acad. Sci. St. Louis, Trans. 3: 95. ठ.

armillosus Townes. P. E. I., Mass., N. Y., N. J., Wis., Alta.

Exochus armillosus Townes, 1959. In Townes and Townes, U. S. Natl. Mus. Bul. 216 [pt. 1]: 226. $\delta$, ㅇ.

atriceps Walsh. N. B. w. to Man., s. to Fla. and Tex.

Exoch us atriceps Walsh, 1873. Acad. Sci. St. Louis, Trans. 3: 95. ठ.

Exochus rufomaculatus Provancher. 1886. Addit. Corr. Faune Ent. Canada Hym., p. 113. ․

Exochus atriceps atricorpus Townes, 1959. In Townes and Townes, U. S. Natl. Mus. Bul. 216 [pt. 1]: 208. ठ, ९. N. syn.

brutus Townes. Que., Ont., N. Y., Pa., Md., w. N. C., Sask., Alta. Host: Phycitine pyralid on Tilia.

Exochus brutus Townes, 1959. In Townes and Townes, U. S. Natl. Mus. Bul. 216 [pt. 1]: 228. $\delta, ?$.

bryanti Townes. N. S., Ont., Alta.

Exochus bryanti Townes, 1959. In Townes and Townes, U. S. Natl. Mus. Bul. 216 [pt. 1]: 191. $\delta, ?$.

canidens Townes. N. Y., Pa., Mich., Alta.

Exochus canidens Townes, 1959. In Townes and Townes, U. S. Natl. Mus. Bul. 216 [pt. 1]: 250. \&.

capnodes Townes. Northwestern Calif.

Exochus capnodes Townes, 1959. In Townes and Townes, U. S. Natl. Mus. Bul. 216 [pt. 1]: 239. $\delta$.

cnemidotus Townes. Que., Mass., R. I., N. Y., Ont., Sask., Alta., Yukon, B. C.

Exochus cnemidotus Townes, 1959. In Townes and Townes, U. S. Natl. Mus. Bul. 216 [pt. 1]: 237. $\delta$,. .

cuneatus Townes. Maine. The holotype is labeled as being reared from Heterarthrus nemoratus (Fall.), but this host record is almost certainly incorrect.

Exochus cuneatus Townes, 1959. In Townes and Townes, U. S. Natl. Mus. Bul. 216 [pt. 1]: 255. $\delta$.

decoratus hebes Townes. Colo., Ariz., s.e. Alaska, B. C. Host: Acleris variana (Fern.). E. decoratus decoratus Holmgren is Eurasian.

Exochus decoratus hebes Townes, 1959. In Townes and Townes, U. S. Natl. Mus. Bul. 216 [pt. 1]: 264. .

decoratus scitulus Provancher. N. S. s. to Fla., w. to Minn. and Kans. Host: Acleris variana (Fern.), Argyrotaenia sp. on Abies, Tortricid on Abies, Epinotia aceriella (Clem.).

Exochus scitulus Provancher, 1877. Nat. Canad. 9: 15. ?. 
denotatus Townes. Que. s. to s.e. N. C., w. to Minn. Host: Zomaria sp., Z. intermptolineana (Fern.).

Exochus denotatus Townes, 1959. In Townes and Townes, U. S. Natl. Mus. Bul. 216 [pt. 1]: 206. $\delta, ?$.

dentifrons Townes. Que., Colo., N. Mex., Ariz., Oreg., Calif.

Exochus dentifrons Townes, 1959. In Townes and Townes, U. S. Natl. Mus. Bul. 216 [pt. 1]: 206. ơ, . .

dorsalis Cresson. Que. w. to s.e. Wash., s. to S. C. and Ala. Host: Meroptera pravella (Grt.) on sumac.

Exochus dorsalis Cresson, 1864. Ent. Soc. Phila., Proc. 3: 286. “

Amesolytus pictus Fyles, 1904. Canad. Ent. 36: 207. क. N. syn.; preocc. in Exochus by Holmgren, 1858.

Exochus pictilis Walkley, 1958. In Krombein et al., U. S. Dept. Agr., Agr. Monog. 2, sup. 1, p. 59. N. name for Amesolytus pictus Fyles.

Exochus dorsalis fylesi (!) Townes, 1959. In Townes and Townes, U. S. Natl. Mus. Bul. 216 [pt. 1]: 247. Lapsus for $E$. dorsalis pictilis Walkley.

elimatus Townes. Colo. Ecology: The type series was collected at an elevation of $9400 \mathrm{ft}$. in the Rocky Mts.

Exochus elimatus Townes, 1959. In Townes and Townes, U. S. Natl. Mus. Bul. 216 [pt. 1]: 194. ơ, ?.

enodis Townes. S. Dak., Colo., Ariz.

Exochus enodis Townes, 1959. In Townes and Townes, U. S. Natl. Mus. Bul. 216 [pt. 1]: 189. $\delta, ?$.

evetriae Rohwer. Northern Idaho, w. Wash., w. Oreg., n.w. Calif. Host: Barbara colfaxiana siskiyouana (Kft.), B. colfaxiana taxifoliella (Bsk.).

Exochus (Triclistus) evetriae Rohwer, 1920. U. S. Natl. Mus., Proc. 57: 223..

externus Townes. Oreg.

Exochus extermus Townes, 1959. In Townes and Townes, U. S. Natl. Mus. Bul. 216 [pt. 1]: 238. 9 .

fastigatus Townes. Maine, Mass., R. I. Host: Ancylis comptana (Froel.) on Arctostaphylos.

Exochus fastigatus Townes, 1959. In Townes and Townes, U. S. Natl. Mus. Bul. 216 [pt. 1]: 249. $\delta$, ?.

ferrugineus (Ashmead). Mass., Pa., Md., Fla., Iowa, S. Dak., Tex. Ecology: Possibly nocturnal. Amesolytus ferrugineus Ashmead, 1896. Amer. Ent. Soc., Trans. 23: 201. đ, ๆ.

flavifrontalis Davis. N. B., N. W. T., and Yukon s. to N. Y., Mich., Ariz., and Calif. Host: Tortricid.

Exochus flavifrontalis Davis, 1897. Amer. Ent. Soc., Trans. 24: 217. ơ, १.

Amerolytus (!) flavifrons Ashmead, 1906. In Slosson, Ent. News 17: 324. Nomen nudum.

Exochus alpinus Cushman, 1922. U. S. Natl. Mus., Proc. 61 (8): 13. ठ. Formerly preocc. in Exochus by Tryphon alpinus Zetterstedt, 1838.

Exochus montanus Walkley, 1958. In Krombein et al., U. S. Dept. Agr., Agr. Monog. 2, sup. 1, p. 59. N. name for E. alpinus Cushman.

genualis Townes. N. J., Md., W. Va., Va., n. Ga., Ohio.

Exochus genualis Townes, 1959. In Townes and Townes, U. S. Natl. Mus. Bul. 216 [pt. 1]: 233. $\delta$.

gravipes (Gravenhorst). N. S., Ont., Mich.; Eurasia. The "subspecies" E. gravipes mifiantennalis Uchida (1942) was described from a single male specimen from northeastern China; as it has not been included in any revision, its status as a subspecies of gravipes remains dubious.

Ichneumon gravipes Gravenhorst, 1820. R. Accad. delle Sci. Torino, Mem. 24: 384. §, \&.

Taxonomy: Uchida, 1942. Insecta Matsumurana 16: 126-127.

hiulcus Townes. Southeastern B. C.

Exochus hiulcus Townes, 1959. In Townes and Townes, U. S. Natl. Mus. Bul. 216 [pt. 1]: 216. \&. 
litus Townes. N. S., s.w. Alaska, w. Wash., w. Oreg., Nev., Calif.

Exochus litus Townes, 1959. In Townes and Townes, U. S. Natl. Mus. Bul. 216 [pt. 1]: 196. $\delta$, क.

mandibularis Cushman. N. H., Mich.

Polyclistus frontalis Ashmead, 1902. In Slosson, Ent. News 13: 321. Nomen nudum.

Exochus mandibularis Cushman, 1922. U. S. Natl. Mus., Proc. 61 (8): 13. "ס" =

megadon Townes. R. I., N. Y., N. J., Mich., Colo.

Exochus megadon Townes, 1959. In Townes and Townes, U. S. Natl. Mus. Bul. 216 [pt. 1]: 259. ․ .

mesodon Townes. R. I., Conn., N. Y.

Exochus mesodon Townes, 1959. In Townes and Townes, U. S. Natl. Mus. Bul. 216 [pt. 1]: 258. ㅇ.

mesorufus Townes. N. B., N. Y., Del., Ala.

Exochus mesorufus Townes, 1959. In Townes and Townes, U. S. Natl. Mus. Bul. 216 [pt. 1]: 232. o, $\%$.

mitratus atrocoxalis Cresson. N. B. w. to s. Man., s. to W. Va. and Tex. Host: Tortricid on Kalmia. According to Townes and Townes (1959) E. mitratus mitratus Gravenhorst and two other "subspecies" occur in Europe; they regarded a specimen from Japan as belonging to an undescribed subspecies.

Exochus atrocoxalis Cresson, 1868. Amer. Ent. Soc., Trans. 2: 114. \&.

Taxonomy: Townes and Townes, 1959. U. S. Natl. Mus. Bul. 216 [pt. 1]: 181.

mitratus orias Townes. Wyo., Alta., Utah, B. C., Wash., Oreg., Nev., Calif.

Exochus mitratus orias Townes, 1959. In Townes and Townes, U. S. Natl. Mus. Bul. 216 [pt. 1]: 182. ठं, ९.

montivagus Townes. Colo. Ecology: Known only from the holotype, which was collected at an elevation of $9400 \mathrm{ft}$. in the Rocky Mts.

Exochus montivagus Townes, 1959. In Townes and Townes, U. S. Natl. Mus. Bul. 216 [pt. 1]: 201. ㅇ.

nigripalpis subobscurus Townes. Calif. Host: Argyrotaenia citrana (Fern.), A. franciscana (Wlshm.), Platynota stultana (Wlshm.), rose leaf tier. E. nigripalpis nigripalpis Thomson is European.

Exochus nigripalpis subobscurus Townes, 1959. In Townes and Townes, U. S. Natl. Mus.

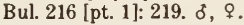

nigripalpis tectulum Townes. N. S. w. to B. C., s. to w. N. C., s. Wis., Colo., and n. Oreg. Host: Archips argyrospilus (Wlk.), $A$. rosanus (L.), Choristoneura fumiferana (Clem.), $C$. lambertiana ponderosana Obraz., C. occidentalis Free.

Exochus nigripalpis tectulum Townes, 1959. In Townes and Townes, U. S. Natl. Mus. Bul. 216 [pt. 1]: 218. ơ, ?.

ochreatus Townes. Ariz.

Exochus ochreatus Townes, 1959. In Townes and Townes, U. S. Natl. Mus. Bul. 216 [pt. 1]: 202. $\delta$.

ostentatus Davis. N. Y., N. J., Pa., Md., D. C., Ont., Ala., Minn., e. Alta.

Exochus ostentatus Davis, 1897. Amer. Ent. Soc., Trans. 24: 217. ठै.

peroniae Townes. N. S., N. B., Que., Maine, N. H., Vt., N. Y., s.w. Va., Ont., Mich., Colo., s. B.

C., Wash., Oreg. Host: Acleris variana (Fern.), Archippus packardianus (Fern.) on

Abies, Argyrotaenia sp.? on Abies, Clepsis melalencana (Wlk.), Croesia albicomana (Clem.) on scarlet oak.

Exochus peroniae Townes, 1959. In Townes and Townes, U. S. Natl. Mus. Bul. 216 [pt. 1]: 235. $\delta, ?$.

pictus xanthopsis Ashmead. N. S., Que., Maine, N. H., N. Y., w. N. C., e. Tenn. Ont., Colo., s. B. C., Wash., Oreg., n. Calif., E. pictus pictus Holmgren is European. One specimen in the U. S. Natl. Museum collection is labeled as being reared from Heterarthrus nemoratus (Fall.), but this host record is almost certainly incorrect (see E. cuneatus Townes).

Exochus xanthopsis Ashmead, 1896. Amer. Ent. Soc., Trans. 23: 201. ठ'. 
pleuralis Cresson. Mass., N. Y., Man., and Yukon s. to Md., Ill., Tex., and Ariz. Host: Ancylis comptana (Froel.), Anacampsis agrimoniella (Clem.), Acleris sp. on Viburnum.

Exochus pleuralis Cresson. 1864. Ent. Soc. Phila., Proc. 3: 286. ¿.

Exochus pallipes Cresson, 1864. Ent. Soc. Phila., Proc. 3: 287. ठ. Preocc. by Exochus pallipes (Motchulsky), 1863.

Exochus evectus Cresson, 1872. Amer. Ent. Soc., Trans. 4: 168.. .

Exochus pallidipes Dalla Torre, 1901. Hym. Cat., v. 3, p. 213. Emend.; Preocc. in Exochus by Dalla Torre, 1901, p. 48.

postfurcalis Townes. N. S. w. to Man., s. to N. C., Kans., and Colo. Host: Episimens argutanus (Clem.), Acleris oxycoccana (Pack.).

Exochus postfurcalis Townes, 1959. In Townes and Townes, U. S. Natl. Mus. Bul. 216 [pt. 1]: $242 . \delta$,. .

pullatus Townes. Northern Man., interior Alaska.

Exochus pullatus Townes, 1959. In Townes and Townes, U. S. Natl. Mus. Bul. 216 [pt. 1]: 197. $\delta, \%$.

quadradens Townes. Md.

Exochus quadradens Townes, 1959. In Townes and Townes, U. S. Natl. Mus. Bul. 216 [pt. 1]: 254. .

russeus Townes. Pa.?, N. Mex., Ariz.

Exochus russeus Townes, 1959. In Townes and Townes, U. S. Natl. Mus. Bul. 216 [pt. 1]: 188. $\delta, ?$.

rutilatus Townes. N. S., P. E. I., Que., Mass., N. Y., Pa., Md., e. N. C., Ont., Wis., s. B. C.

Exochus rutilatus Townes, 1959. In Townes and Townes, U. S. Natl. Mus. Bul. 216 [pt. 1]: 225. ¿, ?.

semirufus Cresson. N. S. s. to S. C., w. to Sask., e. Kans., and Tex.

Exochus semimufus Cresson, 1868. Amer. Ent. Soc., Trans. 2: 114. ठ, ๆ.

Mesoleius inflatifrons Provancher, 1886. Addit. Corr. Faune Ent. Canada Hym., p. 107..

Exochus rufigaster Ashmead, 1890 (1889). U. S. Natl. Mus., Proc. 12: 443..

Exochus solitarius Davis, 1897. Amer. Ent. Soc., Trans. 24: 216. ठ. Davis described solitarius from a composite specimen; this synonymy is based upon the abdomen, which was selected as lectotype by Townes (1945); the head and thorax are those of another Exochus sp. which Townes did not identify.

Taxonomy: Townes, 1945. Amer. Ent. Soc., Mem. 11: 587.

signifer Townes. Maine, N. Y., n. Ohio, Mich., Wis., Minn., Utah, Alaska, B. C.

Exochus signifer Townes, 1959. I $u$ Townes and Townes, U. S. Natl. Mus. Bul. 216 [pt. 1]: 240. ․

silus Townes. Northern Idaho, n. Utah, e. Calif. The type locality is River Heights (Cache Co.), Utah.

Exochus silus Townes, 1959. In Townes and Townes, U. S. Natl. Mus. Bul. 216 [pt. 1]: 261. ¿, $\uparrow$.

spilotus Townes. Coastal Maine, w. Ont., w. Wash. Host: Tortricid.

Exochus spilotus Townes, 1959. In Townes and Townes, U. S. Natl. Mus. Bul. 216 [pt. 1]: 245. ㅇ.

spinalis Townes. Central and s.w. Calif.; Honduras? Host: Clepsis peritana (Clem.).

Exochus spinalis Townes, 1959. In Townes and Townes, U. S. Natl. Mus. Bul. 216 [pt. 1]: 202. 오.

stenostoma Townes. Ariz., s. B. C., Wash., Oreg., Calif. Host: Cadra figulilella (Greg.).

Exochus stenostoma Townes, 1959. In Townes and Townes, U. S. Natl. Mus. Bul. 216 [pt. 1]: $179 . \delta$, $?$.

tenebrosus Townes. Northwestern Wyo., Colo., w. Wasn. Ecology: This species has been collected at elevations between $8850 \mathrm{ft}$. and $11600 \mathrm{ft}$. in the Rocky Mts. and at $4700 \mathrm{ft}$. in the Cascade Range.

Exochus tenebrosus Townes, 1959. In Townes and Townes, U. S. Natl. Mus. Bul. 216 [pt. 1]: $220 . \delta$,. 
transversus Townes. Ont., Sask.

Exochus transversus Townes, 1959. In Townes and Townes, U. S. Natl. Mus. Bul. 216 [pt. 1]: 241 .. .

turgidus Holmgren. Ont., Sask., and Mont. s. to n. Fla., La., N. Mex., and s. Calif.; Eurasia. Host: Petrova albicapitana (Bsk.), Dioryctria amatella (Hulst), D. auranticella (Grt.), D. disclusa Hein., D. reniculella (Grt.).

Exochus turgidus Holmgren, 1858 (1856). Svenska Vetensk.-Akad. Handl. (n. f.) 1: 312 ..

\section{SUBFAMILY BANCHINAE}

The distribution of this large subfamily is worldwide. The species are all thought to be internal larval parasites of Lepidoptera.

\section{TRIBE STILBOPINI}

This small tribe includes three genera, only one of which is known from the Nearctic region.

\section{Genus STILBOPS Foerster}

Stilbops Foerster, 1868. Naturh. Ver. Rheinlande, Verh. 25: 163.

Type-species: Pimpla vetula Gravenhorst. Desig. by Ashmead, 1900 from two species included by Schmiedeknecht, 1888.

A phanoroptrum Foerster, 1868. Naturh. Ver. Rheinlande, Verh. 25: 168.

Type-species: Lissonota mficomis Gravenhorst. By subsequent monotypy from inclusion by Thomson, 1877. The type-species is regarded as a synonym of $S$. abdominalis (Gravenhorst).

Aphanoroptra Thomson, 1877. Opusc. ent. 8: 736. Emend.

Aphanorrhoptrum Dalla Torre, 1901. Cat. Hym., v. 3, p. 528. Emend.

Eritrachymus Schmiedeknecht, 1913. Opusc. Ichn. v. 5, fasc. 24, p. 2709.

Type-species: Eritrachynus asper Schmiedeknecht. By subsequent monotypy from inclusion by Schmiedeknecht, 1913 (fasc. 25, p. 2724).

According to Townes (1970) this is a moderate sized genus of Holaretic and Oriental distribution. An undescribed species is known from Maryland. The European S. abdominalis (Gravenhorst) has been reared from the incurvarioid lepidopteran Adela reamurella (L.); its life cycle is apparently analogous to that of pionine Ctenopelmatinae, the egg being deposited inside that of the host and the adult emerging from the host after the latter has spun its cocoon.

Taxonomy: Short, 1957. Roy. Ent. Soc. London, Proc., Ser. B: Taxonomy 26: 175-176

(final-instar larva). - Perkins, 1962. Brit. Mus. (Nat. Hist.) Ent., Bul. 11: 405-406, 453.

-Townes, 1970 (1969). Amer. Ent. Inst., Mem. 13: 7.

\section{TRIBE GLYPTINI}

Ten genera are known. Three occur in the Nearctic region.

Revision: Momoi, 1963. Insecta Matsumurana 25: 98-117 (Japanese spp.).

\section{Genus SPHELODON Townes}

Sphelodon Townes, 1966. Amer. Ent. Inst., Mem. 8: 328.

Type-species: Glypta phoxopteridis Weed. Orig. desig.

Only three species have been described, but according to Townes this is a moderately large genus. It is principally Neotropic, but two species are Nearctic.

nomene (Davis). N. Y, Colo.

Glypta nomene Davis, 1898 (1897). Amer. Ent. Soc., Trans. 24: 370. .

phoxopteridis (Weed). N. H. w. to B. C., s. to s.e. Ga., Ala., and n. Tex. Host: Ancylis comptana (Froel.), Grapholitha interstinctana (Clem.), G. molesta (Bsk.), Amorbia

humerosana Clem., Choristoneura rosaceana (Harris), Platynota flavedana Clem.? on

Solanum, P. rostrana (Wlk.), tortricid on Gleditsia, Psilocorsis quercicella Clem., pyralid on ragweed.

Glypta phoxopteridis Weed, 1888. Ent. Amer. 4: 151. ․ 
Glypta leucozonata Ashmead, 1890 (1888). U. S. Natl. Mus., Proc. 12: 449. §.

\section{Genus APOPHUA Morley}

Apophua Morley, 1913. Fauna Brit. India, Hym., v. 3, pt. 1, p. 213.

Type-species: Apophua carinata Morley. Orig. desig.

Although only one Nearctic species is known, this is a fairly large Holarctic, Oriental, and Ethiopian genus.

Taxonomy: Cushman, 1933. Insecta Matsumurana 8: 20-23. - Momoi, 1965. Insecta

Matsumurana 28: 80-81.

simplicipes (Cresson), Maine w. to s. B. C., s. to D. C., Tex., Utah, and Wash. Host: Acleris minuta (Rob.), Archips argyrospilus (Wlk.), Choristoneura rosaceana (Harris), Sparganothis putmanana Free., tortricid on Gleditsia, Ancylis comptana (Froel.), Exartema footianum Clem., E. inornatonum Clem., Ennomos subsignarius ( $\mathrm{Hbn}$.), Malacosoma americanum (F.), Heterocampa bilineata (Pack.), Symmerista albifrons (J. E. S.), Zotheca tranquila (Grt.), Hemileuca sp.

Glypta simplicipes Cresson, 1870. Amer. Ent. Soc., Trans. 3: 156. đ, ?.

Glypta aldrichii Davis, 1898 (1897). Amer. Ent. Soc., Trans. 24: 370. đo, ๆ.

Glypta (Glypta) rosaceanae Viereck, 1926. Canad. Ent. 58: 55. ठ, १.

\section{Genus GLYPTA Gravenhorst}

Glypta Gravenhorst, 1829. Ichn. Europaea, v. 3, p. 3.

Type-species: Glypta sculpturata Gravenhorst. Desig. by Westwood, 1840.

Conoblasta Foerster, 1868. Naturh. Ver. Rheinlande, Verh. 25: 165.

Type-species: Glypta ceratites Gravenhorst. Desig. by Viereck, 1914 from two species included by Woldstedt, 1877.

Diblastomorpha Foerster, 1868. Naturh. Ver. Rheinlande, Verh. 25: 165.

Type-species: Glypta bicornis Desvignes. By subsequent monotypy from inclusion by Woldstedt, 1877. The type-species is homonymous with Glypta bicornis Boie, which is regarded as a senior synonym.

Hemiephialtes Ashmead, 1906. U. S. Natl. Mus., Proc. 30: 177.

Type-species: Hemiephialtes glyptus Ashmead. Monotypic.

Glypta subg. Foveoglypta Hellen, 1915. Soc. pro Fauna et Flora Fenn., Acta 40 (6): 57.

Type-species: Glypta (Foveoglypta) monstrosa Hellen. Monotypic.

This is a very large genus. The greatest number of species is found in the Holarctic region and a few species occur in the Neotropic and Oriental regions. The hosts are larvae of Lepidoptera which conceal themselves when feeding, such as in leaf rolls, buds, cones, stems, etc.

Taxonomy: Momoi, 1965. Insecta Matsumurana 28: 81-82.

albiscutellaris Walsh. Ill.? The holotype was destroyed in the 1871 Chicago fire, and apparently no concerted effort has been made to identify the species since it was described.

Glypta albiscutellaris Walsh, 1873. Acad. Sci. St. Louis, Trans. 3: 127. ठ.

animosa Cresson. Conn. s. to N. C., w. to Mich.

Glypta animosa Cresson, 1870. Amer. Ent. Soc., Trans. 3: 154..

aprilis Viereck. Northeastern Kans.

Glypta aprilis Viereck, 1905. Kans. Acad. Sci., Trans. 19: 316. ?.

areolata Viereck. Northern N. Mex.

Glypta areolata Viereck, 1903. In Skinner, Amer. Ent. Soc., Trans. 29: 89..

borealis Cresson. "Canada," Colo.

Glypta borealis Cresson, 1870. Amer. Ent. Soc., Trans. 3: 158. ठ.

brunneisigna Viereck. Northeastern Kans.

Glypta brinneisigna Viereck, 1905. Kans. Acad. Sci., Trans. 19: 316. ९.

californica Provancher. Calif.

Glypta californica Provancher, 1886. Addit. Corr. Faune Ent. Canada Hym., p. 117.. 
canadensis Cresson. Que., Maine, N. H., Vt., N. Y., Pa., Mich.

Glypta canadensis Cresson, 1870. Amer. Ent. Soc., Trans. 3: 157..

caulicola Cushman. N. J., s. Ont., and s.e. S. Dak. s. to Ga. and Kans. Host: Gnorimoschema gallaesolidaginis (Riley), Epiblema scudderianum (Clem.), E. strenuanum (Wlk.).

Glypta caulicola Cushman, 1933. U. S. Natl. Mus., Proc. 82 (14): 9. §, ?.

dakota Cresson. "Dakota [Territory]."

Glypta Dakota Cresson, 1870. Amer. Ent. Soc., Trans. 3: 158. ð, ․

davisii Dalla Torre. Northern Idaho.

Glypta longicauda Davis, 1898 (1897). Amer. Ent. Soc., Trans. 24: 370. . Preocc. by Hartig, 1838.

Glypta Davisii Dalla Torre, 1901. Cat. Hym., v. 3, p. 410. N. name for longicauda Davis.

divaricata (Say). Fla. The holotype was destroyed, and apparently no concerted effort has been made to identify the species from the original description.

Anomalon divaricatus Say, 1836. Boston Jour. Nat. Hist. 1: 244. Sex not indicated.

Taxonomy: Cushman and Gahan, 1921. Ent. Soc. Wash., Proc. 23: 155.

diversipes Walsh. Ill.? The holotype was destroyed in the 1871 Chicago fire, and apparently no concerted effort has been made to identify the species since it was described.

Glypta diversipes Walsh, 1873. Acad. Sci. St. Louis, Trans. 3: 125. ‡.

egregiafovea Viereck. Ariz.

Glypta egregiafovea Viereck, 1905. Kans. Acad. Sci., Trans. 19: 292. \&.

erratica Cresson. Vt. s. to n. Ga., w. to e. S. Dak.

Glypta erratica Cresson, 1870. Amer. Ent. Soc., Trans. 3: 152. ठ, ?.

evetriae Cushman. Western Mont., Wash., Oreg., w. Calif. Host: Barbara colfaxiana taxifoliella (Bsk.).

Glypta evetriae Cushman, 1917. U. S. Natl. Mus., Proc. 53: 469. ठั, ๆ.

exartemae Walley. N. Y., Ont. Host: Exartema viburnana $\mathrm{McD}$.

Glypta exartemae Walley, 1934. Canad. Ent. 66: 235. §, ‥

fumiferanae (Viereck). N. B. w. to B. C., s. to Pa., Wis., N. mex., Ariz., and n.w. Calif. Host: Sciaphila duplex (Wlsm.), Dioryctria reniculella (Grt.)?, Acleris variana (Fern.)?, Choristoneura fumiferana (Clem.), C. lambertiana (Bsk.), C. occidentalis Free., C. pinus Free., C. retiniana (Wlsm.), Orgyia pseudotsugata McD.?, Melanolophia imitata (Wlk.)? The few published records for this species as a parasite of Choristoneura conflictana (Wlk.) appear to be erroneous; all Glypta specimens I have seen which were reared from $C$. conflictana are $G$. inversa (Cresson), a few of which were misidentified as $G$. fumiferanae.

Conoblasta fumiferanae Viereck, 1912. U. S. Natl. Mus., Proc. 42: 148. ठં, ?.

Biology: Brown, 1947 (1946). Canad. Ent. 78: 138. -Jaynes, 1954. Jour. Econ. Ent. 47: 355. -Dodge, 1961. Canad. Ent. 93: 224.

Morphology: Peck, 1937. Canad. Jour. Res., Sect. D (Zool. Sci.) 15: 245, 246, 248, 249, 251.

haesitator Gravenhorst. Southern B. C.; Eurasia. Introduced between 1937 and 1944 in N. S., P. E. I., Que., B. C. and Wash.; established according to McLeod (1962), but apparently only in B. C. Host: Laspeyresia nigricana (Steph.). The host listed was the target species for releases in North America.

Glypta haesitator Gravenhorst, 1829. Ichn. Europaea, v. 3, p. 12. o, ?.

Glypta haesitatrix Schulz, 1906. Spolia Hym., p. 103. Emend.

Biology: Cameron, 1938. Bul. Ent. Res. 29: 282-296. -Wishart, 1939. Ent. Soc. Ontario, Ann.

Rpt. 70: 69-71. - Fulton, 1947. Ent. Soc. Brit. Columbia, Proc. 43: 25.

idahoensis Davis. Northern Idaho, s.e. Wash., w. Oreg.

Glypta idahoensis Davis, 1898 (1897). Amer. Ent. Soc., Trans. 24: 370. ․

impressa Davis. Northeastern Ill.

Glypta impressa Davis, 1898 (1897). Amer. Ent. Soc., Trans. 24: 371. ठै, ९.

infumata Walley. Que., Alta.

Glypta infumata Walley, 1934. Canad. Ent. 66: 236. $q$. 
inversa Cresson. Vt. w. to interior Alaska, s. to Conn., mich., N. Mex., and n.e. Calif. Host: Archips argyrospilus (Wlk.), Choristoneura conflictana (Wlk.), Sparganothis putmanana Free., Malacosoma disstria ( $\mathrm{Hbn}.), M$. californicum fragile (Str.). Glypta inversa Cresson, 1870. Amer. Ent. Soc., Trans. 3: 153...

kukakensis Ashmead. Southwestern Alaska.

Glypta kukakensis Ashmead, 1902. Wash. Acad. Sci., Proc. 4: 201..

longiventris Cresson. Que., N. Y., Ill.

Glypta longiventris Cresson, 1870. Amer. Ent. Soc., Trans. 3: 154. ठ.

macra Cresson. Que., Maine, N. Y., Ont., Colo., Alta.

Glypta macra Cresson, 1870. Amer. Ent. Soc., Trans. 3: 158. .

Glypta coloradensis Cresson, 1870. Amer. Ent. Soc., Trans. 3: 158. ठ.

Glypta ruficomis Provancher, 1873 (Dec.). Nat. Canad. 5: 473. ঠ. Preocc. by Walsh, 1873 (June?).

militaris Cresson. Ill.

Glypta militaris Cresson, 1870. Amer. Ent. Soc., Trans. 3: 154. ๆ.

monita Cresson. W. Va.

Glypta monita Cresson, 1870. Amer. Ent. Soc., Trans. 3: 155..

mutica Cushman. Conn. s. to N. C., w. to Iowa. Host: Paralobesia viteana (Clem.), Janus integer (Nort.)?

Glypta mutica Cushman, 1919. U. S. Natl. Mus., Proc. 55: 540. ઠ̛, ९.

popofensis Ashmead. Southwestern Alaska. The male syntype represents a different species than the female syntype.

Glypta popofensis Ashmead, 1902. Wash. Acad. Sci., Proc. 4: 201. ठ, ?.

pulchripes Cresson. W. Va.

Glypta pulchripes Cresson, 1870. Amer. Ent. Soc., Trans. 3: 153. $\%$.

rubripes Cresson. N. Y., N. J., w. N. C., "Canada," Mo.

Glypta rubripes Cresson, 1870. Amer. Ent. Soc., Trans. 3: 156. §, ๆ.

ruficornis Walsh. Ill.? The holotype was destroyed in the 1871 Chicago fire, and apparently no concerted effort has been made to identify the species since it was described.

Glypta ruficomis Walsh, 1873. Acad. Sci. St. Louis, Trans. 3: 129. ठ.

rufipleuralis Walsh. Ill.? The holotype was destroyed in the 1871 Chicago fire, and apparently no concerted effort has been made to identify the species since it was described.

Glypta rufipleuralis Walsh, 1873. Acad. Sci. St. Louis, Trans, 3: 125. ठં.

rufiscutellaris Cresson. Mass., Ont., Alta., and Wash. s. to Ga., Tex., Utah., and s.w. Calif.; Brazil?, Uruguay?; Australia? Host: Epiblema strenuanum (Wlk.), Grapholitha molesta (Bsk.), G. packardi (Zell.), G. prunivora (Walsh), Laspeyresia caryana (Fitch), L. pomonella (L.), Melissopus latiferreanus (Wlsm.), Croesia semipurpurana (Kft.). Glypta rufiscutellaris Cresson, 1870. Amer. Ent. Soc., Trans. 3: 153. ठ์, +.

Glypta brevis Cushman, 1915. U. S. natl. Mus., Proc. 48: 510. 9.

Biology: Allen and Lott, 1930. Ent. Soc. Wash., Proc. 32: 135-136. -Driggers, 1930. N. J. Agr. Expt. Sta. Bul. 510: 4-19. - Crawford, 1933. N. Y. Agr. Expt. Sta. Bul. 217: 1-29. -Merritt, 1933. Jour. Econ. Ent. 26: 788-792. - Pepper and Driggers, 1934. Ent. Soc. Amer., Ann. 27: 594-596. - Putman, 1935. Canad. Ent. 67: 46-48. Individual larvae consume two to five host larvae. - Van Steenburgh, 1935. Ent. Soc. Ontario, Ann. Rpt. 65: 69-72. - Haden, 1935. Del. Univ. Agr. Expt. Sta. Bul. 194: 11-42. - Montgomery, 1935. Jour. Econ. Ent. 28: 371-376.

Morphology: Peck, 1937. Canad. Jour. Res., Sect. D (Zool. Sci.) 15: 245, 246, 248, 249, 251. rufofasciata Cresson. Que., Maine, R. I., Conn., N. Y., Ont., Ill. Glypta mifofasciata Cresson, 1870. Amer. Ent. Soc., Trans. 3: 158. ठ.

succineipennis Viereck. Western Kans.

Glypta succineipennis Viereck, 1905. Kans. Acad. Sci., Trans. 19: 315..

tricincta Provancher. Eastern Que.

Glypta tricincta Provancher, 1890. Nat. Canad. 19: 248. ठ, $?$.

truncata (Provancher). Que., N. Y.

Clistopyga truncata Provancher, 1883. Nat. Canad. 14: 13. + . 
tuberculifrons Cresson. Ill.

Glypta tuberculifrons Cresson, 1870. Amer. Ent. Soc., Trans. 3: 152. ठ, ๆ.

varipes Cresson. Wyo., Colo., B. C., Wash.

Glypta varipes Cresson, 1865. Ent. Soc. Phila., Proc. 4: 267..

Glypta variipes Dalla Torre, 1901. Cat. Hym., v. 3, p. 417. Emend.

virginiensis Cresson. N. Y., N. J., Pa., W. Va.

Glypta virginiensis Cresson, 1870. Amer. Ent. Soc., Trans. 3: 157. ․

vulgaris Cresson. Mass.

Glypta vulgaris Cresson, 1870. Amer. Ent. Soc., Trans. 3: 154. đ’, १.

xanthogastra Cameron. Colo., N. Mex., Ariz.

Glypta xanthogastra Cameron, 1905. Invertebrata Pacifica 1: 128..

\section{Genus CEPHALOGLYPTA Obrtel}

Cephaloglypta Obrtel, 1956. Zool. Listy 5: 139.

Type-species: Cephaloglypta excavata Obrtel. Monotypic and orig. desig.

This genus is Palearctic; only two species are known.

laricis Momoi. Northern Japan. Introduced in N. B. in 1973; the fact that only 29 adults were released would seem to have precluded establishment. Host: Choristoneura diversana (Hbn.), Ptycholomoides aeriferanus (H.-S.). The target species for the release in N. B. was Choristoneura fumiferana (Clem.).

Cephaloglypta laricis Momoi, 1963. Insecta Matsumurana 25: 104. ठ, ?.

murinanae (Franz). Europe. Introduced in Ont. in 1950, 1955, and 1956, apparently without becoming established. Host: Choristoneura murinana ( $\mathrm{Hbn}$.). The target species for releases in Ont. was Choristoneura fumiferana (Clem.).

Glypta murinanae Franz, 1941. Ztschr. f. Angew. Ent. 27: 594. ठ, ๆ.

Glypta murinanae Bauer, 1942. Mitt. aus der Ent. Gesell. zu Halle 19: 11. ¿, ‡. Preocc. by Franz, 1941; n. syn.

Cephaloglypta excavata Obrtel, 1956. Zool. Listy 5: 140. ઠ. ․ N. syn.

Biology: Bucher, 1953. Canad. Jour. Agr. Sci. 33: 463. -Franz and Wellenstein, 1958. Ztschr.

f. Pflanzenkrank. 65: 21. - Capek, 1961. Ztschr. f. Angew. Ent. 48: 88. -Capek, 1963.

Ztschr. f. Angew. Ent. 51: 138. - Zwoelfer, 1963. Ztschr. f. Angew. Ent. 51: 348.

\section{TRIBE LISSONOTANINI}

This is a very large tribe. Twenty-six genera were recognized by Townes (1970); ten of them are represented by Nearctic species. The majority of the Nearctic species parasitize larvae of Lepidoptera which conceal themselves when feeding, such as in cones, buds, stems, leaf rolls, etc. Drs. H. K. and M. C. Townes expect to publish a revision of the Nearctic species in 1978.

Taxonomy: Townes, 1970 (1969). Amer. Ent. Inst., Mem. 13: 17-45 (genera of world).

\section{Genus MNIOES Townes}

Mnioes Townes, 1946. Bol. Ent. Venezolana 5: 58.

Type-species: Lamprouota jucunda Cresson. Monotypic and orig. desig.

This is a large genus which is restricted to the New World; all but one of the species are Neotropic.

lunatus Kennedy. Md., D. C., Va., e. N. C., S. C., s. Ind., Ky., Tenn., s.e. Okla., Colo.

Mnioes luruatus Kennedy, 1966. Mich. Ent. 1: 17. ठ, क.

\section{Genus LISSONOTA Gravenhorst}

Lissonota Gravenhorst, 1829. Ichn. Europaea, v. 3, p. 30.

Type-species: Ichneumon setosus Geoffroy. Desig. by Curtis, 1932. Curtis designated $I$. setosus as the type-species of Lampronota, his replacement name for Lissonota. 
Lampronota Curtis, 1832. Brit. Ent., v. 9, pl. 407. Unnecessary n. name for Lissonota Gravenhorst, which is not preocc. by Lissonotus Dalman, 1817.

Stilbonota Stephens, 1835. Illus. Brit. Ent., v. 7, p. 126.

Type-species: Lissonota sulphurifera Gravenhorst. Desig. by Viereck, 1914.

Meniscus Schiodte, 1839. Mag. Zool., Ins. 9: 10

Type-species: Ichneumon catenator Panzer. Desig. by Viereck, 1914.

Asynida Gistel, 1848. Naturgesch. Thierr. f. hoeh. Schul., p. ix. N. name for "Lissonotus Grav[enhorst]."

Bothynophrys Foerster, 1868. Naturh. Ver. Rheinlande, Verh. 25: 166.

Type-species: Ichneumon catenator Panzer. By subsequent monotypy from inclusion by Woldstedt, 1877.

Ensimus Foerster, 1868. Naturh. Ver. Rheinlande, Verh. 25: 167. Preocc. by Thomson, 1859.

Type-species: Lissonota dubia Holmgren. Desig. by Viereck, 1914 from four species included by Schmiedeknecht, 1888.

Amersibia Foerster, 1868. Naturh. Ver. Rheinlande, Verh. 25: 167, 214, 218. N. name for Meniscus Schiodte.

Bathycetes Foerster, 1868. Naturh. Ver. Rheinlande, Verh. 25: 167.

Type-species: Ichneumon catenator Panzer. Monotypically included and desig. by Schmiedeknecht, 1888.

Opisorhyssa Kriechbaumer, 1890. Wien. Mus. der Naturgesch., Ann. 5: 488.

Type-species: Opisorhyssa flavopicta Kriechbaumer. Monotypic. The type-species was described from "Amer. Sept. (?)," but is actually not a Nearctic species (personal commun., Dr. H. K. Townes, 1977).

Ctenopimpla Cameron, 1899. Manchester Lit. and Phil. Soc., Mem. and Proc. 43 (3): 189. Preocc. by Kriechbaumer, 1898.

Type-species: Ctenopimpla albomaculata Cameron. Monotypic.

Pimplopterus Ashmead, 1900. U. S. Natl. Mus., Proc. 23: 52.

Type-species: Pimplopterus alaskensis Ashmead. Monotypic and orig. desig.

Harrimaniella Ashmead, 1900. U. S. Natl. Mus., Proc. 23: 52. Transfer from synonymy with Cryptopimpla was advised by H. K. Townes (1976, personal communication).

Type-species: Harrimaniella yukakensis Ashmead. Monotypic and orig. desig.

Echthrodoca Schmiedeknecht, 1900. Zool. Jahrb., Abt. f. System., Geog., u. Biol. Tiere 13: 328.

Type-species: Lissonota conflagrata Gravenhorst. Desig. by Viereck, 1914.

Anarthronota Schmiedeknecht, 1900. Zool. Jahrb., Abt. f. System., Geog., u. Biol. Tiere 13: 330.

Type-species: Lissonota manca Brauns. Desig. by Viereck, 1914.

Cam pocineta Schmiedeknecht, 1900. Zool. Jahrb., Abt. f. System., Geog., u. Biol. Tiere 13: 343.

Type-species: Campocineta varicornis Schmiedeknecht. Monotypic.

Adelopimpla Schulz, 1906. Spolia Hym., p. 116. N. name for Ctenopimpla Cameron.

Stilbopoides Rohwer, 1913. Ent. Soc. Wash., Proc. 15: 183.

Type-species: Stilbopoides maculiventris Rohwer. Orig. desig.

Lophantium Clement, 1925. Konowia 4: 400.

Type-species: Lissonota clypealis Thomson. Orig. desig.

Gibbonota Heinrich, 1937. Polskie Pismo Ent. 14-15: 354.

Type-species: Gibbonota duplanae Heinrich. Monotypic and orig. desig.

Lissonotoides Benoit, 1955. Mus. du Congo Belge, Ann. Zool. 38: 29.

Type-species: Lissonotoides pectinatus Benoit. Monotypic and orig. desig.

This is a very large genus. According to Townes (1970) it is best represented in the Holarctic region, but has a nearly worldwide distribution.

Taxonomy: Townes, 1970 (1969). Amer. Ent. Inst., Mem. 13: 25-27 (new generic synonyms). acrobasidis (Ashmead). Southwestern Ind.

Polysphincta phycitis Riley, 1891. In Riley and Howard, U. S. Dept. Agr., Insect Life 3: 464. Nomen nudum.

Eusimus(!) acrobasidis Ashmead, 1896. Amer. Ent. Soc., Trans. 23: 212. ठ. The type-locality is Paxtons, Sullivan Co., Ind. (not "Paxton, Ohio"). 
aleutiana (Cresson), n. comb. Southwestern Alaska.

Mesoleius? aleutianus Cresson, 1879 (1878). Acad. Nat. Sci. Phila., Proc. 30: 371. ठ。.

argyresthiae (Walley), n. comb. N. S., N. B., Que., Ont., Wis. Host: Argyresthia laricella Kft.

Pimplopterus argyresthiae Walley, 1961. Canad. Ent. 93: 1. ठ, ?.

bibrevicincta (Davis). N. Y., Mich.

Lampronota bibrevicincta Davis, 1895. Amer. Ent. Soc., Trans. 22: 31 . 9.

breviventris (Walsh). Ill.? The synonymy and transfer from unplaced species of Ichneumonidae is based upon advice received from Drs. M. C. and H. K. Townes, (personal communications, 1977).

Lampronota pictiventris Walsh, 1873. Acad. Sci. St. Louis, Trans. 3: 119. ð.

Lampronota breviventris Walsh, 1873. Acad. Sci. St. Louis, Trans. 3: 120..

brunnea Cresson. Maine w. to Oreg., s. to Va., Kans., and Calif. Host: Achatodes zeae (Harris), Luperina stipata (Morr.), Papaipema cataphracta Grt., P. nebris (Gn.).

Lissonota brunnea Cresson, 1868. Canad. Ent. 1: 37. ․

Nadia apalachia Viereck, 1902. Canad. Ent. 34: 68. ठ'.

Biology: Decker, 1930; 1931. Iowa Agr. Expt. Sta., Res. Bul. 125: 160; 143: 345. - Decker, 1935. Iowa State Col. Jour. Sci. 9: 572.

coloradensis (Cresson). Man., Sask., Colo., Alta., B. C.

Lampronota coloradensis Cresson, 1870. Amer. Ent. Soc., Trans. 3: 165. \&.

conocola Rohwer, restored comb. Nebr., Ariz., B. C., Oreg., Calif. Host: Tinea defectella Zell., Eucosma recissoriana Heinr., Rhyacionia neomexicana (Dyar).

Lissonota conocola Rohwer, 1920. U. S. Natl. Mus., Proc. 57: 222. đ, क.

dakrumae (Ashmead), n. comb. Calif. Host: Cisthene faustinula f. fusca Str., Holcocera sp., Dioryctria ranthaenobares Dyar.

Meniscus dakrumae Riley, 1890. In Riley and Howard, U. S. Dept. Agr., Insect Life 3: 464. Nomen nudum.

Meniscus dakrumae Ashmead, 1896. Amer. Ent. Soc., Trans. 23: 212. ․ According to notes on file in the U.S. Natl. Museum the syntypes were reared from a species of Holcocera feeding on Lecanium and from Cisthene faustinula f. fusca Str. feeding on lichens.

Lissonota dioryctriae Rohwer, 1920. U. S. Natl. Mus., Proc. 57: 221..

davisi (Townes), n. comb. Southern Mich.

Lampronota angusta Davis, 1895. Amer. Ent. Soc., Trans. 22: 30. ๆ. Preoce. by Taschenberg, 1863.

Pimploptemes davisi Townes, 1944. Amer. Ent. Soc., Mem. 11: 452. N. name for Lampronota angusta Davis.

electra Viereck, restored comb. Northern N. Mex.

Lissonota electra Viereck, 1903. In Skinner, Amer. Ent. Soc., Trans. 29: 84..

evetriae Rohwer, restored comb. Central Colo. Host: Holcocera sp.?, Barbara colfaxiana taxifoliella (Bsk.).

Lissonota evetriae Rohwer, 1920. U. S. Natl. Mus., Proc. 57: 220. ס, ․ The type-locality is Cheyenne Mountain, Colo. (not "Cheyenne, Mountains, Colorado").

exigua (Cresson), n. comb. W. Va.

Lampronota exigua Cresson, 1870. Amer. Ent. Soc., Trans. 3: 164..

fenella Viereck, n. comb. Northern N. Mex.

Lissonota fenella Viereck, 1903. In Skinner, Amer. Ent. Soc., Trans. 29: 83.. .

Harrimaniella minor Viereck, 1903. In Skinner, Amer. Ent. Soc., Trans. 29: 87. ð.

frigida Cresson. Que. w. to s.w. Alaska, s. to Va. and Tex. Host: Crambus vulgivagellus Clem.

Lissonota frigida Cresson, 1868. Canad. Ent. 1: 36..

Lampronota exilis Cresson, 1870. Amer. Ent. Soc., Trans. 3: 165. ठ, ․

Lampronota imitatrix Walsh, 1873. Acad. Sei. St. Louis, Trans. 3: 121. ๆ.

Pimplopteris alaskensis Ashmead, 1900. U. S. Natl. Mus., Proc. 23: 52. ๆ.

Lissonota alaskensis Ashmead, 1902. Wash. Acad. Sci., Proc. 4: 197.. . Preoce. in

Lissonota by Ashmead, 1900.

Harrimaniella paeneimitatrix Viereck, 1905. Kans. Acad. Sci., Trans. 19: 317. ․ 
Lissonota sakala Cushman, 1942. U. S. Natl. Mus., Proc. 92: 287. N. name for L. alaskensis Ashmead.

hilaris (Cresson), n. comb. Calif.

Lampronota hilaris Cresson, 1879 (1878). Acad. Nat. Sci. Phila., Proc. 30: 378..

inconstans Cushman, restored comb. Western Oreg., s.w. Calif. Host: Melissopus latiferreanus (Wlsm.).

Lissonota inconstans Cushman, 1940. Ent. Soc. Wash., Proc. 42: 157. ठ, ๆ.

interpellata (Walsh), n. comb. Ill.? The holotype was destroyed in the 1871 Chicago fire.

Lampronota interpellata Walsh, 1873. Acad. Sci. St. Louis, Trans. 3: 118. ơ.

jacobi (Walley), n. comb. Southern B. C.

Asphragis jacobi Walley, 1942. Canad. Ent. 74: 234. ¿ै, $९$.

laevigata (Cresson). Que., N. Y., Ont., Alta.

Lampronota laevigata Cresson, 1870. Amer. Ent. Soc, Trans. 3: 162...

Lampronota levigata Dalla Torre, 1901. Cat. Hym., v. 3, p. 516. Emend.

macra (Cresson), n. comb. Del.

Lampronota macra Cresson, 1870. Amer. Ent. Soc., Trans. 3: 163. ð̋.

maculiventris (Rohwer), n. comb. Western Mont.

Stilbopoides maculiventris Rohwer, 1914. Ent. Soc. Wash., Proc. 15: 183. ठ, $\uparrow$.

montana (Cresson). Newfoundland (Labrador) w. to Alaska, s. to Va., N. Mex., and Nev. Host: Crymodes devastator (Brace), Protagrotis obscurus (B. and M.).

Lampronota montana Cresson, 1865. Ent. Soc. Phila., Proc. 4: 267..+

Exetastes consimilis Cresson, 1865. Ent. Soc. Phila., Proc. 4: 278. ठ.

Lampronota varia Cresson, 1870. Amer. Ent. Soc., Trans. 3: 164. ठ. N. syn.

Lampronota americana Cresson, 1870. Amer. Ent. Soc., Trans. 3: 164. ๆ. N. syn.

Lampronota amphimilaena Walsh, 1873. Acad. Sci. St. Louis, Trans. 3: 117. ठ. N. syn.

Lampronota gelida Cresson, 1879 (1878). Acad. Nat. Sci. Phila., Proc. 30: 377. ठ. N. syn.

Lampronota vivida Cresson, 1879 (1878). Acad. Nat. Sci. Phila., Proc. 30: 378. ठ. N. syn.

Lampronota Edwardsii Cresson, 1879 (1878). Acad. Nat. Sci. Phila., Proc. 30: 379. §. N. syn.

Lampronota puritana Ashmead, 1890 (1889). U. S. Natl. Mus., Proc. 12: 450. ․ N. syn.

Hammaniella(!) relativa Viereck, 1902. Canad. Ent. 34: 67. ठ. N. syn.

Echthrodoca clypearia Ashmead, 1902. Wash. Acad. Sci., Proc. 4: 199. ठ̊.

Harrimaniella ariel Viereck, 1903. In Skinner, Amer. Ent. Soc., Trans. 29: 86. o.

nigricornis (Provancher), Que., N. Y., N. Mex., Oreg. Host: Eucosma bobana Kft.

Lampronota nigricomis Provancher, 1873. Nat. Canad. 5: 476..

nigripes (Provancher). Southeastern Ont.

Lampronota nigripes Provancher, 1886. Addit. Corr. Faune Ent. Canada Hym., p. 118. $\uparrow$.

parallela Gravenhorst. Newfoundland (Labrador); Eurasia.

Lissonota parallela Gravenhorst, 1829. Ichn. Europaea, v. 3, p. 79. ठ, ९.

parva (Cresson). Maine w. to B. C., s. to D. C., Colo., and Calif.

Lampronota parva Cresson, 1870. Amer. Ent. Soc., Trans. 3: 163. 9.

penuria (Davis), n. comb. "Canada."

Aperileptus penuria Davis, 1897. Amer. Ent. Soc., Trans. 24: 244. ठ.

prionoxysti (Rohwer), n. comb. Northern Va. Host: Prionoxystus sp. in Castanea dentata.

Amersibia prionoxysti Rohwer, 1915. U. S. Natl. Mus., Proc. 49: 224. ठै, ๆ.

punctata (Cresson), Que. s. to N. C., w. to Colo.

Lampronata punctata Cresson, 1870. Amer. Ent. Soc., Trans. 3: 160 (key), 163. . The alternate spelling "punctulata" which appeared on p. 163 was rejected in favor of punctata by Cushman (1925).

Lampronota albifacies Provancher, 1873. Nat. Canad. 5: 475. ठ.

recurvariae Cushman, restored comb. Maine, N. Y.

Lissonota recurvariae Cushman, 1935. Wash. Acad. Sci., Jour. 25: 552. ठో, ९.

rubrica (Cresson). Que. s. to Ga., w. to Iowa.

Lampronota mibrica Cresson, 1870. Amer. Ent. Soc., Trans. 3: 165..

Lampronota humeralis Provancher, 1873. Nat. Canad. 5: 476. “o" = $\delta$. 
Lissonota philipi Viereck, 1917 (1916). Conn. State Geol. and Nat. Hist. Survey Bul. 22: 314. ठ․

scutellaris (Cresson). Que., Mass., N. Y., N. J., Ont., W. Va., Ill., Minn., Mo., Kans., n. N. Mex. Host: Synanthedon tipuliformis (Clerck), Filatima pseudoacaciella (Chamb.).

Lampronota scutellaris Cresson, 1870. Amer. Ent. Soc., Trans. 3: 161. ․

Meniscus Crevieri Provancher, 1874. Nat. Canad. 6: 29. 9.

Bathycetes nidia Viereck, 1903. In Skinner, Amer. Ent. Soc., Trans. 29: 85. 9.

segnis (Cresson), n. comb. Southwestern B. C.

Lampronota segnis Cresson, 1879 (1878). Acad. Nat. Sci. Phila., Proc. 30: 378. ठో.

sesiavora (Rohwer), n. comb. R. I., N. Y., N. J., Md., Va. Host: Synanthedon pyri (Harris), Grapholitha molesta (Bsk.)?

Stilbopoides sesiavora Rohwer, 1914. Ent. Soc. Wash., Proc. 15: 184. đ’, ९.

sexcineta (Ashmead), n. comb. Colo.

Pimpla sexcincta Ashmead, 1900. Colo. Biol. Assoc., Bul. 1: 24. ठ゚.

Taxonomy: Walkley, 1967. In Krombein et al., U. S. Dept. Agr., Agr. Monog. 2, sup. 2, p. 172. tegularis (Cresson). Que. s. to N. C., w. to Minn., Kans., and Tex. Ecology: Occurs in fall on flowers of Solidago. Host: Tortricid leaf roller on Solidago?, Oligia fractilinea (Grt.)? Incorrectly placed in Alloplasta by Barron (1975).

Lissonota rufipes Cresson, 1868. Canad. Ent. 1: 36. ․ Preocc. by Brischke, 1867.

Lampronota tegularis Cresson, 1870. Amer. Ent. Soc., Trans. 3: 163. ठ.

Arenetra Quebecensis Provancher, 1875. Nat. Canad. 7: 141. ठ.

Lampronota Provancheri Dalla Torre, 1901. Cat. Hym., v. 3, p. 518. N. name for Lampronota rufipes Provancher; because Lampronota mifipes Provancher is Provancher's (1880 and 1883) lapsus for Lampronota rufipes (Cresson) (cf. Provancher, 1873 ), the name provancheri is unavailable.

Taxonomy: Provancher, 1873. Nat. Canad. 5: 476. - Barron, 1975. Nat. Canad. 102: 539.

tropica (Davis), n. comb. Colo., s. Calif.

Aperileptus tropicus Davis, 1897. Amer. Ent. Soc., Trans. 24: 244. ठँ.

yakutatensis Ashmead, n. comb. Southeastern Alaska.

Pimplopterus yakutatensis Ashmead, 1902. Wash. Acad. Sci., Proc. 4: 197. 9.

yukakensis (Ashmead). Southwestern Alaska.

Harrimaniella yukakensis Ashmead, 1900. U. S. Natl. Mus., Proc. 23: 52. §.

Harrimaniella kukakensis(!) Ashmead, 1902. Wash. Acad. Sci., Proc. 4: 198.

Lissonota kukakensis Cushman, 1942. U. S. Natl. Mus., Proc. 92: 287. Unjustified emend.

\section{Genus LOXODOCUS Townes}

Loxodocus Townes, 1970 (1969). Amer. Ent. Inst., Mem. 13: 27.

Type-species: Lampronota pallorana Davis. Orig. desig.

This is a moderate sized genus of Nearctic and Neotropic (Mexico and probably Central America) distribution. Most of the species are Neotropic; at least half of them are undescribed.

palloranus (Davis). Mass., N. J., Pa., N. C.

Lampronota pallorana Davis, 1895. Amer. Ent. Soc., Trans. 22: 31. ․

\section{Genus ALLOPLASTA Foerster}

Alloplasta Foerster, 1868. Naturh. Ver. Rheinlande, Verh. 25: 167.

Type-species: Lissonota murina Gravenhorst. By subsequent monotypy from inclusion by Woldstedt, 1877. The type-species is regarded as a synonym of $A$. piceator piceator (Thunberg).

Asymmictus Foerster, 1868. Naturh. Ver. Rheinlande, Verh. 25: 200.

Type-species: Asymmictus iridescens Davis. Desig. by Viereck, 1914 from two species included by Davis, 1898.

Trysicampe Foerster, 1868. Naturh. Ver. Rheinlande, Verh. 25: 207.

Type-species: Ichneumon piceator Thunberg. Monotypically included and desig. by Perkins, 1962. 
Trichopimpla Cameron, 1903. Ztschr. System. Hym. Dipt. 3: 303.

Type-species: Trichopimpla pilosa Cameron. Monotypic.

This is a small Holarctic and Oriental genus.

piceator bullata (Davis). Pa., Alta., Mont., Idaho, Wash. A. piceator piceator (Thunberg) is Eurasian. Treatment of bullata as a subspecis of piceator is based upon unpublished information provided by Dr. H. K. Townes.

Lampronota bullata Davis, 1895. Amer. Ent. Soc., Trans. 22: 30. ․

superba iridescens (Davis). Nev.

Asymmictus iridescens Davis, 1898 (1897). Amer. Ent. Soc., Trans. 24: 325. “ๆ” = ð.

Taxonomy: Townes, 1970 (1969). Amer. Ent. Inst., Mem. 13: 29.

superba superba (Provancher). Que., Maine, N. H., Vt., Conn., N. Y., Wis., Tex.?, Sask.?, Colo.?

Meniscus superbus Provancher, 1874. Nat. Canad. 6: 30..+

\section{Genus ARENETRA Holmgren}

Lasiops Holmgren, 1856 (1854). Svenska Vetensk.-Akad. Handl. 75: 68. Preocc. by Meigen, 1838.

Type-species: Tryphon pilosella Gravenhorst. Monotypic.

A renetra Holmgren, 1859. Svenska Vetensk.-Akad., Ofvers. af ... Forhandl. 16: 127. N. name for Lasiops Holmgren.

This is a moderate sized Holarctic genus. The adults occur in late winter through mid-spring or in mid to late fall.

Taxonomy: Townes and Townes, 1951. In Muesebeck et al., U. S. Dept. Agr., Agr. Monog. 2: 310 .

canadensis Cresson. Southeastern Ont., Wis., w. Iowa, e. S. Dak., e. Wyo., Colo., N. Mex., s. Idaho, e. Wash.

Arenetra canadensis Cresson, 1868. Canad. Ent. 1: 36. ơ.

hirsutula Walley, revised status. Southern Mich., s.e. Minn., s. Sask. Resurrection from synonymy with canadensis based upon unpublished information provided by Dr. H. K. Townes.

Arenetra hirsutula Walley, 1931. Canad. Ent. 63: 169. ठ.

leucotaenia Viereck, revised status. Mass., N. Y., Md., D. C., n. Va., n.e. Kans. Resurrection from synonymy with nigrita based upon unpublished information provided by Dr. H. K. Townes.

Arenetra leucotaenia Viereck, 1905. Kans. Acad. Sci., Trans. 19: 318..

nigrita Cresson. N. H., Mass., Conn., N. J., Pa., n. Va., s. Wis., n. Miss., Iowa, e. S. Dak.

A renetra nigrita Cresson, 1870. Amer. Ent. Soc., Trans. 3: 159. ठ, ᄋ.

pallipes Harrington, revised status. Southeastern and n. Idaho, s.w. B. C., e. Wash., w. Oreg. Resurrection from synonymy with nigrita based upon unpublished information provided by Dr. H. K. Townes.

Arenetra pallipes Harrington, 1894. Canad. Ent. 26: 250. ơ.

A renetra pallidipes Dalla Torre, 1901. Cat. Hym., v. 3, p. 313. Unjustified emend.

rufipes Cresson, revised status. Que. w. to Alaska, s to s.e. N. Y., S. Dak., N. Mex., s. Idaho, and s. Oreg. Host: Euxoa sp. Resurrection from synonymy with nigrita based upon unpublished information provided by Dr. H. K. Townes.

Arenetra rufipes Cresson, 1870. Amer. Ent. Soc., Trans. 3: 159.. .

A renetra vernalis Walley, 1931. Canad. Ent. 63: 171. ९. N. syn.; identification labels of Dr. H. K. Townes on specimens in the U. S. Natl. Museum collection indicate that he will be treating vernalis as a sympatric subspecies of rufipes.

\section{UnPlaced TaXa of ARENETRa}

In the forthcoming revision of Drs. H. K. and M. C. Townes, the names below will presumably be suppressed as synonyms of one or two of the Arenetra species listed above (cf. Townes and Townes, 1951). 
Taxonomy: Townes and Townes, 1951. In Muesebeck et al., U. S. Dept. Agr., Agr. Monog. 2: 310.

A renetra occulta Walley, 1931. Canad. Ent. 63: 170. ¿. Southwestern B. C.

Arenetra ventralis Cresson, 1870. Amer. Ent. Soc., Trans. 3: 160. ठ. N. Y.

\section{Genus CRYPTOPIMPLA Taschenberg}

Cryptopimpla Taschenberg, 1863. Ztschr. f. die Gesam. Naturw. [Halle] 21: 292.

Type-species: Phytodietus blandus Gravenhorst. Desig. by Viereck, 1914.

Aphanodon Foerster, 1868. Naturh. Ver. Rheinlande, Verh. 25: 166.

Type-species: Phytodietus errabundus Gravenhorst. By subsequent monotypy from inclusion by Schmiedeknecht, 1888 .

Xenacis Foerster, 1868. Naturh. Ver. Rheinlande, Verh. 25: 167.

Type-species: Lissonota caligata Gravenhorst. By subsequent monotypy from inclusion by Brischke, 1880 .

Xenocornia Schmiedeknecht, 1900. Zool. Jahrb., Abt. f. System. 13: 334.

Type-species: Xenocomia solitaria Schmiedeknecht. Monotypic.

Trevoria Ashmead, 1900. U. S. Natl. Mus., Proc. 23: 50.

Type-species: Trevoria yukatatensis Ashmead. Monotypic and orig. desig.

Fintona Cameron, 1909. Bombay Nat. Hist. Soc., Jour. 19: 726.

Type-species: Fintona nigripalpis Cameron. Monotypic.

This is a moderate-sized genus of Holarctic, Oriental, and Ethiopian distribution. It is best represented in the Palearctic Region.

blanda jocosa (Cresson), n. status. Que. s. to W. Va., w. to Ill. C. blanda blanda (Gravenhorst) is European; treatment of jocosa as a subspecies of blanda is based upon unpublished information provided by Dr. H. K. Townes.

Lampronota! jocosa Cresson, 1870. Amer. Ent. Soc., Trans. 3: 162. ð.

Lampronota agilis Cresson, 1870. Amer. Ent. Soc., Trans. 3: 164. ₹.

Mesoleptus angustus Provancher, 1886. Addit. Corr. Faune Ent. Canada Hym., p. 96. ơ, ๆ.

Tryphon fractus Provancher, 1886. Addit. Corr. Faune Ent. Canada Hym., p. 101. ơ.

Polyblastus decoratus Provancher, 1886. Addit. Corr. Faune Ent. Canada Hym., p. 107. "o" $=\delta$.

Polyblastus inomatus Provancher, 1886. Addit. Corr. Faune Ent. Canada Hym., p. 108. 9.

genalis obscurella (Cresson), n. status. Que., w. N. C., Wash., Calif. C. genalis genalis

(Thomson) is European; treatment of obscurella as a subspecies of genalis is based upon unpublished information provided by Dr. H. K. Townes.

Phytodietus obscurellus Cresson, 1879 (1878). Acad. Nat. Sci. Phila., Proc. 30: 379...

Aphanodon luctuosus Walley, 1934. Canad. Ent. 66: 237. ठै, ?.

pleuralis (Cresson). Que.s. to N. C., w. to Minn., Mo., and Tex. Host: Argyrotaenia velutinana (Wlk.). Generic placement on advise from H. K. Townes (1976, personal commun.).

Lampronota pleuralis Cresson, 1870. Amer. Ent. Soc., Trans. 3: 161. ठ, ?.

Lampronota occidentalis Cresson, 1870. Amer. Ent. Soc., Trans. 3: 161. ๆ.

Lampronota insita Cresson, 1870. Amer. Ent. Soc., Trans. 3: 162. ๆ.

Lampronota pulchella Cresson, 1870. Amer. Ent. Soc., Trans. 3: 162. ơ.

Lissonota cressoni Viereck, 1917 (1916). Conn. State Geol. and Nat. Hist. Survey Bul. 22:

314. Unnecessarily proposed $n$. name for Lampronota occidentalis Cresson.

yukatatensis (Ashmead). Southeastern Alaska.

Trevoria yukatatensis Ashmead, 1900. U. S. Natl. Mus., Proc. 23: 50. $\delta$.

Trevoria yakutatensis(!) Ashmead, 1902. Wash. Acad. Sci., Proc. 4: 198.

Trevoria yakutatensis Cushman, 1942. U. S. Natl. Mus., Proc. 92: 287. Unjustified emend.

\section{Genus ISOMERIS Townes}

Isomeris Townes, 1970 (1969). Amer. Ent. Inst., Mem. 13: 35.

Type-species: Lampronota marginata Provancher. Monotypic and orig. desig.

This is a small Neotropic and Nearctic genus. 
marginata (Provancher). Que., R. I., N. Y., Pa., Ont., W. Va. Host: Trichotaphe levisella Fyles. Lampronota marginata Provancher, 1873. Nat. Canad. 5: 474. $\&$.

\section{Genus SYZEUCTUS Foerster}

Diceratops Foerster, 1868. Naturh. Ver. Rheinlande, Verh. 25: 167.

Type-species: Pimpla bicornis Gravenhorst. Monotypically included and desig. by Schmiedeknecht, 1888.

Syzeuctus foerster, 1868. Naturh. Ver. Rheinlande, Verh. 25: 167.

Type-species: Ichneumon maculatorius Fabricius. Monotypically included and desig. by Schmiedeknecht, 1888 .

Syzeucta Thomson, 1889. Opusc. Ent. 13: 1415. Emend.

Meyva Cameron, 1899. Manchester Lit. and Phil. Soc., Mem. and Proc. 43 (3): 191.

Type-species: Meyva villosa Cameron. Monotypic.

Rhynchotrevoria Cameron, 1906. So. African Mus., Ann. 5: 125.

Type-species: Rhynchotrevoria rostrata Cameron. Monotypic.

Ephialtina Szepligeti, 1908. In Sjostedt, Kilimandjaro-Meru Exped., v. 8, p. 74.

Type-species: Ephialtina apicalis Szepligeti. Monotypic.

Leptoglyphis Brethes, 1927. Ent. Mitt. 16: 39.

Type-species: Leptoglyphis minasensis Brethes. Monotypic.

Paratanera Rao, 1953. Indian Forest Rec., New Ser., Ent. 8: 171.

Type-species: Paratanera indica Rao. Monotypic and orig. desig.

This is a large genus of Neotropic, Holarctic, Oriental, and Ethiopian distribution. Most of the species are tropical.

comptus (Davis). Que. w. to Iowa, s. to n. Ga. and e. Kans.

Meniscus comptus Davis, 1894. Canad. Ent. 26: 322..

elegans (Cresson). Maine s. to Fla., w. to Minn. and Mo. Host: Tetralopha aplastella (Hulst), T. asperatella (Clem.), $T$. robustella zell.

Meniscus elegans Cresson, 1870. Amer. Ent. Soc., Trans. 3: 165. ơ, क.

Meniscus Slossonae Davis, 1894. Canad. Ent. 26: 322. ․

epischniae epischniae Cushman. Southern Oreg., n. Calif. Host: Pima granitella (Rag.).

Syzeuctus epischniae Cushman, 1926. U. S. Natl. Mus., Proc. 67 (23): 9. ठै, १.

epischniae sigmoidalis Cushman, n. status. Eastern Que. Treatment of sigmoidalis as a subspecies of epischniae is based upon unpublished information supplied by Dr. H. K. Townes.

Syzeuctus sigmoidalis Cushman, 1926. U. S. Natl. Mus., Proc. 67 (23): 8. ठ, ๆ.

eximius Walley. Northwestern Iowa, s. Man., Colo., n.e. Oreg., Nev.; Mexico.

Syzeuctus eximius Walley, 1934. Canad. Ent. 66: 238. ठ, $q$.

\section{Genus EUdelebOEA Lopez Cristobal}

Eudeleboea Lopez Cristobal, 1935. La Plata Univ. Nac., Facultad de Agron., Rev. 20: 156. Type-species: Eudeleboea lopezi Lopez Cristobal. Monotypic.

Austrolissonota Blanchard, 1941. Dir. Sanid. Veg., Bol. Informativo 4 (14): 16. Nomen nudum.

This large genus is restricted to the New World. Most of the species are Neotropic.

Taxonomy: Townes, 1970 (1969). Amer. Ent. Inst., Mem. 13: 43-44 (N. Amer. spp. referred to genus).

michiganensis (Davis). Northern Va., n.w. S. C., s. Mich., Mo., n.e. Kans. Host: Stenoma schlaegeri Zell., Psilocors is reflexella Clem.

Meniscus Michiganensis Davis, 1894. Canad. Ent. 26: 323. ?.

mirabilis (Cresson). Newfoundland (insular) s. to N. C., w. to Mich., e. Kans., and Ariz. Host: Aroga trialbamaculella (Chamb.), Filatima pseudoacaciella (Chamb.)?, tortricid on Myrica asplenifolia.

Meniscus mirabilis Cresson, 1870. Amer. Ent. Soc., Trans. 3: 166... 
Clistopyga pleuralis Ashmead, 1890 (1889). U. S. Natl. Mus., Proc. 12: 448. ठ. Notes on file in the U.S. Natl. Museum indicate that the syntypes were possibly reared from

Filatima pseudoacaciella (Chamb.).

Meniscus ostentator Davis, 1894. Canad. Ent. 26: 321. ơ, १.

Asphragis pulcherrimus Ashmead, 1898. In Dimmock and Ashmead, Ent. Soc. Wash., Proc. 4: 170. $\delta$, .

subflava (Davis). N. C., S. C., Ga., Mo., Tex. Host: Caterpillar in Reullia sp.

Meniscus subflavus Davis, 1898 (1897). Amer. Ent. Soc., Trans. 24: 371. ơ, \&.

\section{Genus DIRADOPS Townes}

Diradops Townes, 1946. Bol. Ent. Venezolana 5: 59.

Type-species: Meniscus bethunei Cresson. Orig. desig.

This large genus is restricted to the New World. All but one of the species are Neotropic.

bethunei (Cresson). Ont. s. to central Ga., w. to n.e. Kans. Host: Heterocampa manteo (Dbldy.).

Meniscus Bethunei Cresson, 1869. Canad. Ent. 1: 105..

Meniscus! Johnsonii Davis, 1894. Canad. Ent. 26: 323..

\section{TRIBE BANCHINI}

This is a small tribe of worldwide distribution. Four of the nine currently recognized genera are represented by Nearctic species. The hosts are caterpillars of Lepidoptera which expose themselves when feeding. Drs. H. K. and M. C. Townes have essentially completed a revision of the Nearctic species and expect to publish it in 1978.

\section{Genus EXETASTES Gravenhorst}

Exetastes Gravenhorst, 1829. Ichn. Europaea, v. 3, p. 395.

Type-species: Ichneumon fornicator Fabricius. Desig. by Westwood, 1840.

Leptobatus Gravenhorst, 1829. Ichn. Europaea, v. 3, p. 432.

Type-species: Leptobatus ziegleri Gravenhorst. Desig. by viereck, 1914.

Semnophrys Foerster, 1868. Naturh. Ver. Rheinlande, Verh. 25: 158.

Type-species: Exetastes notatus Holmgren. Monotypically included and desig. by

Perkins, 1962.

Rhimphalea Foerster, 1868. Naturh. Ver. Rheinlande, Verh. 25: 202. Preocc. by Lerder, 1863.

Type-species: Rhimphalea brevicorpa Davis. By subsequent monotypy from inclusion by Davis, 1897.

Icyona Cameron, 1903. Ztschr. System. Hym. Dipt. 3: 340.

Type-species: Iconya mifipes Cameron. Monotypic. The type-species is an objective synonym of $E$. cameroni Townes.

Exetastes subg. Allexetastes Kokujev, 1904. Rev. Russe d'Ent. 4: 106.

Type-species: Exetastes (Allexetastes) komarovi Kokujev. Desig. by Viereck, 1914.

Rhynchexetastes Cameron, 1906. So. African Mus., Ann. 5: 102.

Type-species: Rhynchexetastes violaceipennis Cameron. Monotypic.

Tegona Morley, 1913. Fauna Brit. India, Hym., v. 3, p. 251.

Type-species: Tegona rufipes Morley. Monotypic. The type-species is regarded as a synonym of $E$. cameroni Townes.

Psuedexetastes Meyer, 1927. Konowia 6: 308.

Type-species: Pseudexetastes diakonovi Meyer. Monotypic and orig. desig.

This is a large genus of Neotropic, Holarctic, Oriental (except East Indies), and Ethiopian distribution. Most of the species occur in unforested terrain or in ecotones between forest and grassland.

Revision: Cushman, 1937. U. S. Natl. Mus., Proc. 84: 243-312.

abdominalis Cresson. Minn., Colo., Alta.

Exetastes abdominalis Cresson, 1865. Ent. Soc. Phila., Proc. 4: 276. ?.

affinis Cresson. Mich., Colo., Oreg.

Exetastes affinis Cresson, 1865. Ent. Soc. Phila., Proc. 4: 277. ९. 
albitarsis albitarsis Provancher. N. S. w. to interior Alaska, s. to $\mathrm{Pa}$ and Minn.

Exetastes albitarsis Provancher, 1874. Nat. Canad. 6: 78. 9.

Exetastes migosus Cushman, 1937. U. S. Natl. Mus., Proc. 84: 280. Unnecessary n. name for albitarsis Provancher, which is not preocc. by albitarsus Gravenhorst, 1829.

albitarsis concavus Cushman, n. status. Colo., Ariz.

Exetastes concavus Cushman, 1937. U. S. Natl. Mus., Proc. 84: 281. ठ์, ९.

albitarsis crassisculptus Cushman, n. status. Alta.?, s.e. Alaska, s. B. C., e. Wash., w. Oreg.

Exetastes crassisculptus Cushman, 1937. U. S. Natl. Mus., Proc. 84: 278. o, ๆ.

alternatipes Cushman. Central N. Mex.

Exetastes alternatipes Cushman, 1937. U. S. Natl. Mus., Proc. 84: 299..

alticola Cushman. Southwestern Colo., Wash.?

Exetastes alticola Cushman, 1937. U. S. Natl. Mus., Proc. 84: 284. §, ९.

angustoralis Cushman. Que. s. to n. Ga., w. to n. Wyo. and Nebr.

Exetastes angustoralis Cushman, 1937. U. S. Natl. Mus., Proc. 84: 291. o, \&.

bifenestratus Cushman. D. C., s. Ind., and Kans. s. to s. Fla. and s. Tex.; Cuba, Mexico. Host: Agrotis malefida $\mathrm{Gn}$.

Ichneumon bifasciatus Say, 1829. Contrib. Maclurian Lyceum to Arts and Sci. 1: 72.. Preocc. by Geoffroy, 1785 .

Exetastes bifenestratus Cushman, 1937. U. S. Natl. Mus., Proc. 84: 274. N. name for $I$. bifasciatus Say.

bioculatus Cresson. D. C., n. Va., Ky., n. Ill., n.e. Kans., Tex.

Exetastes bioculatus Cresson, 1872. Amer. Ent. Soc., Trans. 4: 169. ठ.

Rhimphalea brevicorpa Davis, 1897. Amer. Ent. Soc., Trans. 24: 274. 9.

bituminosus Cushman. Mass., n. Minn., and B. C. s. to central S. C., n. Ga., Mo., and N. Mex. Host: Abagrotis altemata (Grt.).

Exetastes bituminosus Cushman, 1937. U. S. Natl. Mus., Proc. 84: 300. ठ, १.

brevicornis Cushman. Eastern S. Dak., Sask., s. Alta.

Exetastes brevicomis Cushman, 1937. U. S. Natl. Mus., Proc. 84: 273. §, ९.

buccatus Cushman. Colo., Utah, s.w. Calif.

Exetastes buccatus Cushman, 1937. U. S. Natl. Mus., Proc. 84: 271. o, ?.

caeruleus Cresson. Mont., Colo., s. Yukon, s.e. Alaska.

Exetastes caeruleus Cresson, 1865. Ent. Soc. Phila., Proc. 4: 276. \&.

caliginosus (Walley). Southern Sask., e. Wyo.?, Alta. This species was not included in the revision of Cushman (1937).

Arenetra caliginosa Walley, 1931. Canad. Ent. 63: 168. §.

callipterus Cushman. Southern Ariz.

Exetastes callipterus Cushman, 1937. U. S. Natl. Mus., Proc. 84: 277. १.

carinatifrons Cushman. Southwestern Tex., N. Mex., Ariz.; Mexico.

Exetastes carinatifrons Cushman, 1937. U. S. Natl. Mus., Proc. 84: 255..

carinatus Cushman. Southern Tex.

Exetastes carinatus Cushman, 1937. U. S. Natl. Mus., Proc. 84: 258. 9.

coloradensis Cushman. Colo. Cushman did not give complete data for the holotype; according to C. F. Baker's notebook it was collected at Fort Collins, Colo. on June 2, 1894 by R. C. Stephenson.

Exetastes coloradensis Cushman, 1937. U. S. Natl. Mus., Proc. 84: 298. .

convergens Cushman. Ont., w. S. Dak., Wyo., Colo., s.w. Alta., w. Mont., Alaska, s. B. C., w. Oreg.

Exetastes subimpressus Cushman, 1937. U. S. Natl. Mus., Proc. 84: 288. ซ, ๆ. N. syn.

Exetastes nigribasis Cushman, 1937. U. S. Natl. Mus., Proc. 84: 289. ð, ๆ. N. syn.

Exetastes rufobalteatus Cushman, 1937. U. S. Natl. Mus., Proc. 84: 290. ठ, ๆ. N. syn.

Exetastes angustus Cushman, 1937. U. S. Natl. Mus., Proc. 84: 290. ๆ. N. syn.

Exetastes convergens Cushman, 1937. U. S. Natl. Mus., Proc. 84: 291. 9.

corvinus Cushman. Western Wash., w. Nev., Calif.

Exetastes corvinus Cushman, 1937. U. S. Natl. Mus., Proc. 84: 303. ?. 
deuteromaurus Dalla Torre. Calif.

Exetastes maurus Cresson, 1879 (1878). Acad. Nat. Sci. Phila., Proc. 30: 370. \&. Preoce. by Desvignes, 1856.

Exetastes deuteromaurus Dalla Torre, 1901. Cat. Hym., v. 3, p. 71. N. name for maurus Cresson.

dichrous Cushman. Colo., n.e. Calif.

Exetastes dichrous Cushman, 1937. U. S. Natl. Mus., Proc. 84: 302. $\subsetneq$.

dilutipes Cushman. Northwestern Wyo., s.w. Alta., s.w. B. C. Cushman failed to give complete data for the holotype; it was collected on Mt. Norquay, Banff Natl. Park, Alta. in a mountain meadow at an elevation between 5000 and $6000 \mathrm{ft}$.

Exetastes dilutipes Cushman, 1937. U. S. Natl. Mus., Proc. 84: 285. o, ९.

erythrogaster Cushman. Northern Colo., s.w. Alta., s. B. C., w. Oreg.

Exetastes erythrogaster Cushman, 1937. U. S. Natl. Mus., Proc. 84: 297. ठ, ․

Exetastes concoloripes Cushman, 1937. U. S. Natl. Mus., Proc. 84: 298. đo, ๆ. N. syn. Cushman did not give complete data for the holotype; it was collected at North Park, Colo. in July by C. F. Baker.

fascipennis Cresson. Colo., N. Mex., Alta., Ariz.

Exetastes flavitarsis Cresson, 1865. Ent. Soc. Phila., Proc. 4: 277. §.

Exetastes fascipennis Cresson, 1865. Ent. Soc. Phila., Proc. 4: 278. ๆ.

Exetastes Cressonii Dalla Torre, 1901. Cat. Hym., v. 3, p. 70. Unnecessary n. name for flavitarsis Cresson, which is not preocc. by E. flavitarsus Gravenhorst, 1829.

flavipennis Cresson. Mass., s. Mich., and w. Idaho s. to w. N. C., s. Ga., and Colo.; Mexico. Incorrectly treated as a subspecies of the Eurasian $E$. fornicator (Fabricius) by Townes and Townes (1966).

Exetastes flavipennis Cresson, 1865. Ent. Soc. Phila., Proc. 4: 275. ९.

Exetastes anthracinus Cushman, 1937. U. S. Natl. Mus., Proc. 84: 305 . o, ๆ. N. syn.

Exetastes geminus Cushman, 1937. U. S. Natl. Mus., Proc. 84: 306. ๆ. N. syn.

Taxonomy: Townes and Townes, 1966. Amer. Ent. Inst., Mem. 8: 137.

flavus Cushman. Northeastern Colo., N. Mex.

Exetastes flavus Cushman, 1937. U. S. Natl. Mus., Proc. 84: 265 ..

igneipennis Cushman. Northeastern Colo., N. Mex., Ariz.; Mexico.

Exetastes igneipennis Cushman, 1937. U. S. Natl. Mus., Proc. 84: 270. ठ́, ๆ.

illinoiensis (Walsh). Southern Mich., Ill., Minn., w. Iowa, Sask., Colo., Alta. Host: Cutworm.

Leptobatus illinoiensis Walsh, 1873. Acad. Sci. St. Louis, Trans. 3: 148..

infumatricus Cushman. B. C., w. Wash.

Exetastes infumatricus Cushman, 1937. U. S. Natl. Mus., Proc. 84: 283. ․

lasius Cushman. Eastern Nebr., Kans., s. Ariz., s.w. Calif. Host: Euxoa (Chorizagrotis) anxiliaris (Grt.).

Exetastes lasius Cushman, 1937. U. S. Natl. Mus., Proc. 84: 258. ठ, ๆ.

matricus Provancher. Que., Mass., Ont., s.w. S. Dak., Alta.

Exetastes matricus Provancher, 1879. Nat. Canad. 11: 213..

nervulus nervulus (Say). N. B. w. to w. Ont. and s.w. S. Dak., s. to w. N. C., n. Ga., and s. Ind. Banchus nervulus Say, 1836. Boston Jour. Nat. Hist. 1: 246. Sex not indicated.

Exetastes rufofemoratus Provancher, 1877. Nat. Canad. 9: 14. ‥ N. syn.

Exetastes exploratus Davis, 1898 (1897). Amer. Ent. Soc., Trans. 24: 365. ơ, ๆ.

Exetastes nervulus var. intermedius Cushman, 1937. U. S. Natl. Mus., Proc. 84: 310. ठ, ๆ. N. syn.

nervulus niger Cresson. Southwestern S. Dak. w. to s.w. Alta. and w. Oreg., s. to N. Mex. and Ariz.

Exetastes niger Cresson, 1865. Ent. Soc. Phila., Proc. 4: 275. ठ, ?.

Exetastes persimilis Cushman, 1937. U. S. Natl. Mus., Proc. 84: 306. ðँ, ๆ. N. syn.

obscurus Cresson. Mass., s. Man., and s. Wash. s. to e. N. C., n. Ga., Mo., and n.w. Oreg.; n.w.

Mexico? Host: Euxoa ochrogaster (Gn.).

Exetastes decoloratus Cresson, 1865. Ent. Soc. Phila., Proc. 4: 280. ठँ.

Exetastes obscurus Cresson, 1865. Ent. Soc. Phila., Proc. 4: 281. ․ 
ornatus Cushman. N. H., R. I., Conn., N. Y., N. J., Pa., Md., Ohio, Mich.

Exetastes ornatus Cushman, 1937. U. S. Natl. Mus., Proc. 84: 286. ठ’, ๆ.

pallidus Cushman. Northwestern S. Dak., Colo.

Exetastes pallidus Cushman, 1937. U. S. Natl. Mus., Proc. 84: 266. $\subsetneq$.

pectinatus Cushman. Sask., w. S. Dak., Colo., s.w. Alta., n.w. Mont., n.e. Calif.

Exetastes pectinatus Cushman, 1937. U. S. Natl. Mus., Proc. 84: 272. . $^{2}$

pictus Cushman. Western Tex., s. Ariz.; Mexico.

Exetastes pictus Cushman, 1937. U. S. Natl. Mus., Proc. 84: 260. ๆ.

pilosus Cushman. Western Oreg.

Exetastes pilosus Cushman, 1940. U. S. Natl. Mus., Proc. 88: 364. ठ, ๆ.

propinquus Cushman. N. J. s. to Fla., w. to central Tenn. and s. Tex. Ecology: Occurs on Solidago flowers.

Exetastes propinquus Viereck, 1910 (1909). In Smith, N. J. State Mus., Rpt. (for 1909), p. 618. Nomen nudum.

Exetastes propinquus Cushman, 1937. U. S. Natl. Mus., Proc. 84: 267. ठ, ๆ.

ridens Cushman. Northern Utah, Ariz., n. Idaho, s. B. C., e. Wash., n.w. Calif.

Exetastes ridens Cushman, 1937. U. S. Natl. Mus., Proc. 84: 262. ठ, ?.

ruficoxalis Cushman. S. Dak., Colo., Alta., Idaho, n. Utah, B. C., Wash.

Exetastes ruficoxalis Cushman, 1937. U. S. Natl. Mus., Proc. 84: 294. ð, ᄋ.

rufipes Cresson. Wyo., Colo., s. Idaho, Wash., Oreg., n. Calif.

Exetastes rufipes Cresson, 1865. Ent. Soc. Phila., Proc. 4: 277..

Exetastes purpureus Cushman, 1937. U. S. Natl. Mus., Proc. 84: 285..

Taxonomy: Cushman, 1940. U. S. Natl. Mus., Proc. 88: 364.

scutellaris Cresson. Western S. Dak., Colo., N. Mex., s. Alta., n. Utah, s.w. Calif.; n.w. Mexico?

Exetastes scutellaris Cresson, 1865. Ent. Soc. Phila., Proc. 4: 279. ठ, + .

Banchus caudatus Provancher, 1886. Addit. Corr. Faune Ent. Canada Hym., p. 121. ๆ.

septum Cushman. Southwestern Oreg., w. Calif. Host: Catabena lineolata Wlk.

Exetastes septum Cushman, 1937. U. S. Natl. Mus., Proc. 84: 257. ठ, ?.

suaveolens Walsh. N. B. s. to n. Ga., w. to s. Alta. Host: Cucullia asteroides $\mathrm{Gn}$.

Exetastes suaveolens Walsh, 1873. Acad. Sci. St. Louis, Trans. 3: 146. ठ, १.

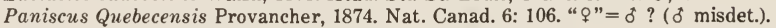

Provancher's description of the "female" agrees with suaveolens, but according to

Barron (1975) the only suaveolens female in the Provancher collections was collected too recently to be a syntype of E. Quebecensis. Because there are five suaveolens males in the Provancher collections which cannot be otherwise excluded as possible syntypes, it would seem logical to conclude that Provancher misdetermined the sex of his $E$. Quebecensis "female."

Taxonomy: Provancher, 1879. Nat. Canad. 11: 212 (syn.). - Barron, 1975. Nat. Canad. 102: 541-542.

zelotypus Cresson. Western Calif.

Exetastes zelotypus Cresson, 1879 (1878). Acad. Nat. Sci. Phila., Proc. 30: 370. ठ, ९.

\section{Genus AGATHILLA Westwood}

Agathilla Westwood, 1882. Tijdschr. v. Ent. 25: 23.

Type-species: Agathilla fulvopicta Westwood. Monotypic.

Three species are known. The type-species is Mexican, and an undescribed species occurs in Arizona.

bradleyi (Viereck). N. J., n. Va., n. Ohio, s. Ill., n.e. Kans. Host: Cirrophanus triangulifer Grt.

This is obviously the species upon which Ashmead (1900) based his description of

Agathobanchus; however, because Ashmead misidentified bradleyi as Banchus aequatus

Say, Agathobanchus is placed as a synonym of Acroricnus (which see) rather than

Agathilla.

Agathobanchus bradleyi Viereck, 1905. Kans. Acad. Sci., Trans. 19: 303. ð, १. 
Taxonomy: Ashmead, 1900. U. S. Natl. Mus., Proc. 23: 97. —Cushman and Gahan, 1921. Ent. Soc. Wash., Proc. 23: 158-159.

\section{Genus CERATOGASTRA Ashmead}

Ceratosoma Cresson, 1865. Ent. Soc. Phila., Proc. 4: 281. Preocc. by Adams and Reeve, 1850.

Type-species: Ceratosoma fasciata Cresson. Desig. by Viereck, 1914.

Ceratogastra Ashmead, 1900. Canad. Ent. 32: 368. N. name for Ceratosoma Cresson.

Two species are known, $C$. pulchricolor Aubert having been recently described from Turkestan.

ornata (Say). Mass., s. Ont., s. Wis., and n.e. Calif., s. to n. Fla., s. La., s. N. Mex., and s.e. Calif.; Mexico. Ecology: Numerous specimens in the U.S. Natl. Museum collection were collected by J. C. Bridwell and many of them are labeled as ovipositing in flowers of Ambrosia artemisiifolia; a few of them are labeled as ovipositing in flowers of Eupatorium. Bridwell collected numerous specimens on Solidago, but none of these are labeled as ovipositing in the flowers. According to Dr. H. K. townes (personal communication, 1976) the information on ornata given by Townes (1970) was in part personally communicated to him by Bridwell. According to Bridwell, ornata oviposits in newly hatched larvae of a species of Feltia (generic identification in need of confirmation) which oviposits in flowers of Compositae but whose larvae feed terrestrially (i.e. as cutworms on or in the ground). This account appears to be supported by a number of specimens labeled as being reared from cutworms. Host:

Feltia sp.?, cutworm.

Agathis polita Say, 1836. Boston Jour. Nat. Hist. 1: 225. ठ, १.

Agathis ormata Say, 1836. Boston Jour. Nat. Hist. 1: 226. ठँ.

Ceratosoma apicalis Cresson, 1865. Ent. Soc. Phila., Proc. 4: 282. ठै, ९. N. syn.

Ceratosoma fasciata Cresson, 1865. Ent. Soc. Phila., Proc. 4: 283. ๆ.

Ceratosoma rubyata Davis, 1898 (1897). Amer. Ent. Soc., Trans. 24: 366 ..

Ceratogastra trifasciata Cushman, 1927. U. S. Natl. Mus., Proc. 72 (13): 21. ๆ. N. syn.

Taxonomy: Cushman, 1927. U. S. Natl. Mus., Proc. 72 (13): 21-22. -Townes and Townes, 1951. In Muesebeck et al., U. S. Dept. Agr., Agr. Monog. 2: 319-320.

Biology: Townes, 1970 (1969). Amer. Ent. Inst., Mem. 13: 51.

\section{Genus BANCHUS Fabricius}

Banchus Fabricius, 1798. Sup. Ent. System., p. 209, 233.

Type-species: Banchus pictus Fabricius. Desig. by Curtis, 1836.

Corynephanus Wesmael, 1849. [Brussels] Acad. Roy. de Belg., Bul. de Cl. des Sci. 16 (1): 631.

Type-species: Banchus monileatus Gravenhorst. Monotypic.

Cidaphurus Foerster, 1868. Naturh. Ver. Rheinlande, Verh. 25: 159.

Type-species: Ichneumon volutatorius Linnaeus. By subsequent monotypy from inclusion by Woldstedt, 1877 .

Corynephanes(!) Marschall, 1873. Nomencl. Zool., p. 258.

Nawaia Ashmead, 1906. U. S. Natl. Mus., Proc. 30: 184.

Type-species: Nawaia japonica Ashmead. Monotypic.

This is a moderate sized genus of Neotropic (Sonora, Mexico), Holarctic, and Oriental distribution. About half of the Nearctic species are undescribed. Dr. Michael Fitton is preparing a revision of the western Palearctic species.

borealis Cresson. Ont.

Banchus borealis Cresson, 1868. Canad. Ent. 1: 33. " $\delta "=$ ๆ.

canadensis Cresson. Maine w. to e. Wash., s. to n. Ga.

Bauchus canadensis Cresson, 1868. Canad. Ent. 1: 34. o, ?.

cressonii (Viereck). Mass. s. to e. N. C., w. to Ill.

Cidaphurus cressonii Viereck, 1902. Canad. Ent. 34: 69.. 
flavescens Cresson. N. S. w. to s.w. B. C., s. to w. N. C., N. Mex., Ariz., and w. Oreg. Host: Barathra curialis (Sm.)., noctuid.

Ichneumon ferrugator Kirby, 1837. In Richardson, Fauna Bor.-Amer. v. 4, p. 258.. .

Preocc. by Swederus, 1787 and Fabricius, 1793.

Banchus flavescens Cresson, 1868. Canad. Ent. 1: 33. ठ.

Banchus ferrngineus Provancher, 1877. Nat. Canad. 9: 14..

Taxonomy: Townes, 1961. Ent. Soc. Wash., Proc. 63: 107.

inermis Provancher. Que. w. to s.w. B. C., s. to Conn., s.w. S. Dak., and w. Nev.

Banchus flavovariegatus Provancher, 1874. Nat. Canad. 6: 61. ठ, ᄋ.

Banchus inerm is Provancher, 1874. Nat. Canad. 6: 62. ․

Banchus polychromus Provancher, 1888. Addit. Corr. Faune Ent. Canada Hym., p. 366. "ㅇ" = $\delta$.

Banchus tricolor Cameron, 1905. Invertebrata Pacifica 1: 130. ঠ. Preocc. in Banchus by Schrank, 1802.

Banchus reparandus Schulz, 1906. Spolia Hym., p. 95. N. name for tricolor Cameron.

Taxonomy: Townes, 1961. Ent. Soc. Wash., Proc. 63 : 104 (syn.).

monileatus alticola (Ashmead). Colo., N. Mex.

Cidaphurus alticola Ashmead, 1901. Psyche 9: 148. ठ.

Banchus alticolus Townes, 1944. Amer. Ent. Soc., Mem. 11: 474. Unjustified emend.

monileatus monileatus Gravenhorst. Que., s.w. Alta., Alaska; Greenland; Eurasia.

Banchus monileatus Gravenhorst, 1829. Ichn. Europaea, v. 3, p. 393. ठै, ๆ.

Banchus formidabilis Provancher, 1874. Nat. Canad. 6: 61. ?.

Banchus (Corynephanes) groenlandicus Aurivillius, 1890. Svenska Vetensk.-Akad., Bihang til Handl. 15: 30. $\delta$, + .

nigrolineatus (Cameron). Southern Idaho, w. Nev., s.e. and w. Calif.

Cidaphurus nigrolineatus Cameron, 1905. Invertebrata Pacifica 1: 129. ठ。.

Taxonomy: Townes, 1961. Ent. Soc. Wash., Proc. 63: 105.

pallescens Provancher. Que. w. to s.w. B. C., s. to n. Ga. and w. Oreg.

Banchus pallescens Provancher, 1874. Nat. Canad. 6: 62..

Banchus insignis Provancher, 1874. Nat. Canad. 6: 63. o ? Provancher (1879) stated that what he had described as insignis in 1874 was actually a female; Barron (1975) failed to discuss Provancher's (1879) correction and regarded a male specimen as being the holotype of insignis.

Corynephanes tarsalis Ashmead, 1902. In Slosson, Ent. News 13: 321. Nomen nudum.

Taxonomy: Provancher, 1879. Nat. Canad. 11: 218. - Barron, 1975. Nat. Canad. 102: 490, 525. spinosus Cresson. Colo.

Banchus spinosus Cresson, 1865. Ent. Soc. Phila., Proc. 4: 274. “ $\delta "=q$.

superbus Cresson. Colo., N. Mex., s.w. Utah, n.w. Ariz., s.e. Oreg.

Banchus superbus Cresson, 1865. Ent. Soc. Phila., Proc. 4: 273. ठ.

\section{SUBFAMILY NEORHACODINAE}

This small subfamily includes two genera, only one of which occurs in the Nearctic region.

\section{Genus NEORHACODES Hedicke}

Rhacodes Ruschka, 1922. Arch. f. Naturgesch. (ser. A) 88 (5): 138. Preocc. by Koch, 1856.

Type-species: Rhacodes enslini Ruschka. Monotypic.

Neorhacodes Hedicke, 1922. Deut. Ent. Ztschr. (for 1922), p. 427. New name for Rhacodes Ruschka.

This is a small Holarctic and Neotropic genus. There appear to be several undescribed Nearctic species. The type-species, which is European, has been reared from the pemphredonine sphecid Spilomena troglodytes (V. d. L.). An undescribed species from W. Va. was reared from a pemphredonine in the galleries of an anobiid in a house timber.

Taxonomy: Horstmann, 1968. Ent. Nachr. 12: 33-36 (final-instar larva and adult of type-species). - Townes, 1971. Amer. Ent. Inst., Mem. 17: 240. 
brevicauda Cushman. Ariz.; s. Mexico.

Neorhacodes brevicauda Cushman, 1940. U. S. Natl. Mus., Proc. 88: 526. ð, ‡.

longicauda Cushman. Colo., Ariz.

Neorhacodes longicauda Cushman. 1940. U. S. Natl. Mus., Proc. 88: 526. ‡.

\section{SUBFAMILY CTENOPELMATINAE}

This is a large subfamily; its distribution is worldwide. but it is best represented in the Holarctic Region. The vast majority of the species are thought to be internal parasites of sawfly larvae; however, two species of Lathrolestes (one Neartic and one European) have been reared from primitive microlepidoptera of the family Eriocraniidae. The unreliable nature of Townes' (1970) keys to the genera appears to indicate that this subfamily is very difficult taxonomically.

Taxonomy: Townes, 1970 (1969). Amer. Ent. Inst., Mem. 13: 53-143 (genera of world).

\section{TRIBE CTENOPELMATINI}

Five genera are included in this small Holarctic tribe; four of them have nearctic species. The known hosts are Pamphiliidae.

\section{Genus CTENOPELMA Holmgren}

Ctenopelma Holmgren 1857 (1855). Svenska Vetensk.-Akad. Handl. 1: 117.

Type-species: Ctenopelma nigrum Holmgren. Desig. by Viereck, 1912.

Xaniopelma Tschek, 1868. Zool.-Bot. Gesell. Wien., Verh. 18: 443.

Type-species: Xaniopelma sericans Tschek. Monotypic. The type-species is regarded as a synonym of $C$. nigrum Holmgren.

Zachresta Foerster, 1868. Naturh. Ver. Rheinlande, Verh. 25: 151.

Type-species: Zachresta insignis Woldstedt. By subsequent monotypy from inclusion by Woldstedt, 1877. The type-species is regarded as a synonym of $C$. lucifer (Gravenhorst).

Diedrus Foerster, 1868. Naturh. Ver. Rheinlande, Verh. 25: 200.

Type-species: Diedrus areolatus Davis. Desig. by Viereck, 1914 from two species included by Davis, 1898.

Eryma Foerster, 1868 Naturh. Ver. Rheinlande, Verh. 25: 202. Preocc. by Meyer, 1840 and Albers, 1854.

Type-species: Eryma stygium Kriechbaumer. By subsequent monotypy from inclusion by Kriechbaumer, 1891. The type-species is regarded as a synonym of $C$. nigrum Holmgren.

Holmgrenia Kriechbaumer, 1877. Zool,-Mineral. Ver. Regensburg, Corresp.-Bl. 31: 146.

Preocc. by Foerster, 1868.

Type-species: Holmgrenia pulchra Kriechbaumer. Monotypic. The type-species is regarded as a synonym of $C$. xanthostigma Holmgren.

Kriechbaumeria Dalla Torre, 1885. Naturf. Gesell. Graubuendens, Jahresber. 28: 52. N. name for Holmgrenia Kriechbaumer.

Polyomoris Kriechbaumer, 1894. Ent. Nachr. 20: 60.

Type-species: Polyomorus gagatimus Kriechbaumer. Monotypic. The type-species is regarded as a synonym of $C$. luteum Holmgren.

Neoeryma Ashmead, 1898. Ent. Soc. Wash., Proc. 4: 169. N. name for Eryma Foerster.

Pseudobanchus Szepligeti, 1911. In Wytsman, Gen. Ins., fasc. 114, p. 79.

Type-species: Exetastes nigripennis Gravenhorst. Monotypic.

Polyhomoms Schulz, 1906. Spolia Hym., p. 99. Emend. of Polyomomis Kriechbaumer.

This is a Holaretic genus of moderate size.

areolatum (Davis). N. H.

Diedrus areolatus Davis, 1898 (1897). Amer. Ent. Soc., Trans. 24: 324. .

crassicorne Walley. Northern Ont.

Ctenopelma crassicome Walley. 1941. Canad. Ent. 73: 168. ठં, ९.

croceum Walley. Que. s. to Md., w. to Alta.

Ctenopelma croceum Walley, 1941. Canad. Ent. 73: 167. ठै, ๆ.

labradorense (Davis). Newfoundland (Labrador).

Diedrus labradorensis Davis, 1898 (1897). Amer. Ent. Soc., Trans. 24: 324. ․ 
nigricorne (Provancher). Maine, N. Y., Pa., Md., Ont., Alta.

Mesoleptus nigricornis Provancher, 1886. Addit. Corr. Faune Ent. Canada Hym., p. 99.. . sanguineum (Provancher). Que., N. Y., N. J., Alta.

Tryphon sanguineus Provancher, 1875. Nat. Canad. 7: 118. ð. A lectotype was selected by Townes (1939); Barron's (1975) rejection of it is invalid because Provancher stated that he had three males, and lack of agreement with the original description is not by itself sufficient proof that the lectotype selected by Townes (1939) was not one of Provancher's original syntypes.

Taxonomy: Townes, 1939. Canad. Ent. 71: 93. - Barron, 1975. Nat. Canad. 102: 560.

\section{Genus XENOSCHESIS Foerster}

There are two small Holaretic subgenera

Taxonomy: Walley, 1935. Canad. Ent. $62: 180$ (key to spp.).

\section{Genus XENOSCHESIS Subgenus XENOSCHESIS Foerster}

Xenoschesis Foerster, 1868. Naturh. Ver. Rheinlande, Verh. 25: 158.

Type-species: Exetastes fulvipes Gravenhorst. By subsequent monotypy from incluson by Jemiller, 1894 .

Homobia Foerster, 1868. Naturh. Ver. Rheinlande, Verh. 25: 198.

Type-species: Colpotrochia cinctiventris Ashmead. By subsequent monotypy from inclusion by Davis, 1897.

Glyptocentrus Kriechbaumer, 1894. Ent. Nachr. 20: 61.

Type-species: Exetastes fulvipes Gravenhorst. Monotypic.

cinctiventris (Ashmead). Newfoundland (insular), Maine, N. H., Mass., Pa., w. Calif. Host: Acantholyda sp.?, pamphilid on Pinus rigida.

Colpotrochia! cinctiventris Ashmead, 1896. Amer. Ent. Soc., Trans. 23: 200. "६" = $\$$.

Pyracmon clypeatum Ashmead, 1897. In Slosson, Ent. News 8: 237. Nomen nudum.

Exetastes abbreviatus Davis, 1898 (1897). Amer. Ent. Soc., Trans. 24: 366, ठ, ?.

Erigloea longitarsis Ashmead, 1906. In Slosson, Ent. News 17: 324. Nomen nudum.

Xenoschesis slossonae Cushman, 1915. Ent. Soc. Wash., Proc. 17: 140. $\%$.

\section{Genus XENOSCHESIS Subgenus POLYCINETIS Foerster}

Polycinetis Foerster, 1868. Naturh. Ver. Rheinlande, Verh. 25: 198.

Type-species: Notopygus resplendens Holmgren. By subsequent monotypy from inclusion by Woldstedt, 1877 .

Prosmorus Foerster, 1868. Naturh. Ver. Rheinlande, Verh. 25: 198.

Type-species: Notopygus resplendens Holmgren. By subsequent monotypy from inclusion by Thomson, 1895 .

Erigloea Foerster, 1868. Naturh. Ver. Rheinlande, Verh. 25: 202.

Type-species: Erigloea polita Kriechbaumer. Desig. by Viereck, 1914 from three species included by Kriechbaumer, 1891. The type-species is regarded as a synonym of $X$. $(P$.) resplendens (Holmgren).

Polycinetus Thomson, 1894. Opusc. Ent. 19: 1983. Emend.; preocc. by Gistel, 1848.

crassitarsus Walley. Southwestern Ont.

Xenoschesis crassitarsus Walley, 1935. Canad. Ent. 67: 181..

gracilis Cushman. N. H., s.w. Alta.

Xenoschesis gracilis Cushman, 1915. Ent. Soc. Wash., Proc. 17: 141. \&.

limatus (Cresson). Que., Conn., N. Y., N. J., Md.

Tryphon? limatus Cresson, 1864. Ent. Soc. Phila., Proc. 3: 274. "ठ" =

solitarius (Davis). Southern Mich.

Polycinetus solitarius Davis, 1898 (1897). Amer. Ent. Soc., Trans. 24: 307..

\section{Genus NOTOPYGUS Holmgren}

Notopygus Holmgren, 1857 (1855). Svenska Vetensk.-Akad. Handl. (n.f.) 1: 115.

Type-species: Notopygus emarginatus Holmgren. Desig. by Viereck, 1912. 
Antipygus Tschek, 1868. Zool.-Bot. Gesell. Wien, Verh. 18: 438.

Type-species: Antipygus megerlei Tschek. Monotypic.

This is a small Holaretic genus.

Taxonomy: Cushman, 1915. U. S. Natl. Mus., Proc. 48: 511.

cultus (Cresson). N. Y., N. J., Ill., s.e. S. Dak.

Mesoleptus cultus Cresson, 1868. Amer. Ent. Soc., Trans. 2: 99. "ס" =

Prosmosus(!) cymbaformus Davis, 1898 (1897). Amer. Ent. Soc., Trans. 24: 309..

Prosmomis cymbiformis Dalla Torre, 1901. Cat. Hym., v. 3, p. 371. Emend.

exeavatus Davis. Nev, w. Wash.

Notopygus excavatus Davis, 1898 (1897). Amer. Ent. Soc., Trans. 24: 309. \&. scutellatus Cushman. Northern Idaho.

Notopygus scutellatus Cushman, 1915. Ent. Soc. Wash., Proc. 17: 134. ?.

virginiensis Cushman. N. H., N. Y., Md., Va., e. N. C.

Notopygus virginiensis Cushman, 1915. U. S. Natl. Mus., Proc. 48: 511. ․

\section{Genus HOMASPIS Foerster}

Homaspis Foerster, 1868. Naturh. Ver. Rheinlande, Verh. 25: 198.

Type-species: Mesoleptus mufinus Gravenhorst. Desig. by Viereck, 1914 from four species included by Thomson, 1894.

Nehomaspis Heinrich, 1949. Muenchen. Ent. Gesell., Mitt. 35-39: 15, 81. Name invalid;

type-species not desig. except subsequently by Townes, Momoi, and Townes, 1965.

albipes Davis. N. Y., w. Calif.?

Homaspis albipes Davis, 1898 (1897). Amer. Ent. Soc., Trans. 24: 308. ․

interruptus (Provancher). Que.

Pariscus interruptus Provancher, 1874. Nat. Canad. 6: 107..

nigripes Cushman. N. Y., Colo., Wash.

Homaspis rigripes Cushman, 1915. Ent. Soc. Wash., Proc. 17: 134. ๆ.

rhadinus Davis. N. H.

Homaspis rhadinus Davis, 1898 (1897). Amer. Ent. Soc., Trans. 24: 308. ․

slossonae Cushman. Que., N. H., N. Y., Ont., Wash.

Homaspis slossonae Ashmead, 1897. In Slosson, Ent. News 8: 237. Nomen nudum.

Homaspis slossonae Cushman, 1922. U. S. Natl. Mus., Proc. 61 (8): 15. o".

\section{TRIBE PIONINI}

Sixteen genera are currently recognized. Only six of them have Nearctic species. It is thought that all members of this tribe oviposit into the egg or early larval instar of their sawfly hosts. The host larva is not killed until after it has reached the prepupal stage and spun its cocoon.

\section{Genus LETHADES Davis}

Lethades Davis, 1897. Amer. Ent. Soc., Trans. 24: 204.

Type-species: Adelognathus texanus Ashmead. Monotypic.

Townes (1970) said that this Holaretic genus includes ten Nearctic species, eight of which are undescribed.

Taxonomy: Townes, 1970 (1969). Amer. Ent. Inst., Mem. 13: 70.

kukakensis (Ashmead). Southwestern Alaska.

Trematopygus kukakensis Ashmead, 1902. Wash. Acad. Sci, Proc. 4: 212. ․

texanus (Ashmead). Tex.

Adelognathus texarus Ashmead, 1890 (1889). U. S. Natl. Mus., Proc. 12: 442. ․

\section{Genus HODOSTATES Foerster}

Gnesia Foerster, 1868. Naturh. Ver. Rheinlande, Verh. 25: 202. Preocc. by Doubleday, 1848.

Type-species: Gnesia caliroae Rohwer. Monotypically included and desig. by Rohwer, 1915.

Hodostates Foerster, 1868. Naturh. Ver. Rheinlande, Verh. 25: 202. 
Type-species: Hodostatus brevis Thomson. By subsequent monotypy from inclusion by Thomson, 1883 .

Hodostatus Thomson, 1883. Opusc. Ent. 9: 929. Emend.

Esigna Perkins, 1962. Brit. Mus. (Nat. Hist.) Ent., Bul. 11: 425. N. name for Gnesia Foerster.

One Nearctic and one European species are known.

rotundatus (Davis). N. H., N. J., n. Va. Host: Caliroa lorata MacG.?

Trematopygus rotundatus Davis, 1897. Amer. Ent. Soc., Trans. 24: 277. o, 9.

Gnesia caliroae Rohwer, 1915. U. S. Natl. Mus., Proc. 49: 220. + . Rohwer erroneously stated that notes under Hopkins' number 11381 pertaining to the holotype record the species as being reared from a species of Caliroa which feeds on $N$ yssa sylvatica.

Actually the notes record the holotype as having emerged on Aug. 10, 1913 from a larva of Caliroa (="Eriocampoides") collected on July 7. 1913 feeding on Castanea dentata. D. R. Smith has informed me (personal commun., 1976) that Caliroa lorata is the only species of its genus which he knows to feed on Castanea.

Taxonomy: Townes, 1970 (1969). Amer. Ent. Inst., Mem. 13: 70-71 (syn.).

\section{Genus TREMATOPYGUS Holmgren}

Trematopygus Holmgren, 1857 (1855). Svenska Vetensk.-Akad. Handl. (n. f.) 1: 179.

Type-species: Trematopygus ruficomis Holmgren. Desig. by Viereck, 1912.

Amorphognathon Foerster, 1868. Naturh. Ver. Rheinlande, Verh. 25: 203.

Type-species: Tryphon melanocerns Gravenhorst. By subsequent monotypy from inclusion by Kriechbaumer, 1897.

Rhigelus Foerster, 1868. Naturh. Ver. Rheinlande, Verh. 25: 208.

Type-species: Trematopygus kriechbaumeri Thomzon. Monotypically included and desig. by Perkins, 1962. The type-species is regarded as a synonym of Trematopygus melanocerns (Gravenhorst).

Aselasma Foerster, 1868. Naturh. Ver. Rheinlande, Verh. 25: 209.

Type-species: Tryphon vellicans Gravenhorst. Monotypically included and desig. by Townes, Momoi, and Townes, 1965.

Campoporns Foerster, 1868. Naturh. Ver. Rheinlande, Verh. 25: 210.

Type-species: Ichneumon dictator Thunberg. Monotypically included and desig. by Perkins, 1962. The name of the type-species is preocc. by Geoffroy, 1785; $I$. dictator Thunberg is regarded as a synonym of $T$. nigricomis (Holmgren).

Volucris Davis, 1897. Amer. Ent. Soc., Trans. 24: 269.

Type-species: Tryphon semirnfus Cresson. By subsequent monotypy from inclusion by Davis, 1898.

This is a Holarctic genus of moderate size.

semirufus (Cresson). Que. w. to s.w. B. C., s. to N. J., Ill., Colo., and w. Oreg.

Tryphon semirufus Cresson, 1864. Ent. Soc. Phila., Proc. 3: 278. $\%$.

Tryphon rufocinctus Cresson, 1864. Ent. Soc. Phila., Proc. 3: 280.

Tryphon tuberculifer Provancher, 1886. Addit. Corr. Faune Ent. Canada Hym., p. 103. "६ " $=\delta$.

Taxonomy: Davis, 1898 (1897). Amer. Ent. Soc., Trans. 24: 287, 332.

\section{Genus GLYPTORHAESTUS Thomson}

Rhaestus subg. Glyptorhaestus Thomson, 1894. Opusc. Ent. 19: 1976.

Type-species: Rhaestus punctatus Thomson. Desig. by Viereck, 1914.

Loxoneurus Schmiedeknecht, 1913. Opusc. Ichn., v. 5, fasc. 34, p. 2711.

Type-species: Loxoneurus thuringiacus Schmiedeknecht. By subsequent monotypy

from inclusion by Schmiedeknecht, 1913 (fasc. 35, p. 2752).

Oocenteter Cushman, 1935. Wash. Acad. Sci., Jour. 25: 556.

Type-species: Oocenteter tomostethi Cushman. Monotypic and orig. desig.

This is a Holaretic genus of moderate size. 
tomostethi (Cushman). Mass., Md., s.w. Iowa. Host: Tomostethus multicinctus (Roh.).

Oocenteter tomostethi Cushman, 1935. Wash. Acad. Sci., Jour. 25: 556. ठ, ๆ.

Biology: MeConnell, 1938. Ent. Soc. Wash., Proc. 40: 23.

\section{Genus RHORUS Foerster}

Rhorus Foerster, 1868. Naturh. Ver. Rheinlande, Verh. 25: 195.

Type-species: Tryphon mesoxanthus Gravenhorst. By subsequent monotypy from inclusion by Woldstedt, 1877 .

Monoblastus subg. Dolichoblastus Strobl, 1903 (1902) Naturw. Ver, f. Steiermark, Mitt. 39: 52.

Type-species: Monoblastus (Dolichoblastus) flavopictus Strobl. Monotypic.

Cyphanza Cameron, 1909. Bombay Nat. Hist. Soc., Jour. 19: 723.

Type-species: Cyphanza nigra Cameron. Monotypic. The name of the type-species is preocc. in Rhorus by Provancher, 1883 and Ashmead, 1902. Townes' (1970) proposal of the replacement name cameroni was apparently unnecessary because he did not indicate that the synonymy of Monoblastus orientalis Cameron (1909, p. 727) and Cyphanza nigra Cameron $(1909$, p. 723 ) by Townes, Townes, and Gupta (1961) had been incorrect. Therefore, $R$. cameroni Townes should be presumed to be a synonym of $R$. orientalis (Cameron).

This is a large genus of Holarctic distribution. The tryphonine name Monoblastus was incorrectly applied to some species of Rhorus, particularly before World War II.

Taxonomy: Cameron, 1909. Bombay Nat. Hist. Soc., Jour. 19: 723, 727. -Townes, Townes, and Gupta, 1961. Amer. Ent. Inst., Mem. 1: 217. - Townes, 1970 (1969). Amer. Ent. Inst., Mem. 13: 73.

clapini (Provancher). Que., Maine, Wash. Host: Trichiosoma triangulum Kirby.

Tryphon Clapini Provancher, 1876. Nat. Canad. 8: 327. “q" = $\delta$.

Tryphon clapinii Dalla Torre, 1901. Cat. Hym., v. 3, p. 293. Emend.

dufresnei (Provancher). Que., Md., N. C.

Tryphon Dufresnei Provancher, 1875. Nat. Canad. 7: 309. §, ๆ.

extirpatorius obscurellus (Cresson). Calif. $R$. extirpatorius extirpatorius (Gravenhorst) is

European.

Erromenus obscurellus Cresson, 1879 (1878). Acad. Nat. Sci. Phila., Proc. 30: 373.. extirpatorius punctifrons (Davis). Tex.

Monoblastus punctifrons Davis, 1897. Amer. Ent. Soc., Trans. 24: 261. ๆ.

extirpatorius varifrons (Cresson). Que. s. to Va., w. to Alta.

Tryphon varifrons Cresson, 1868. Amer. Ent. Soc., Trans. 2: 104. ơ.

Tryphon scutellaris Cresson, 1868. Amer. Ent. Soc., Trans. 2: 104..

Tryphon frontalis Cresson, 1868. Amer. Ent. Soc., Trans. 2: 109..

Tryphon variifrons Dalla Torre, 1901. Cat. Hym., v. 3, p. 303. Emend.

haemorrhoicus borealis (Ashmead). Southeastern Alaska. R. haemorrhoicus haemorrhoicus (Hartig) is Eurasian.

Monoblastus niger Ashmead, 1902. Wash. Acad. Sci., Proc. 4: 213. ठ. Preoce. in Rhorus by Provancher, 1883.

Phthorina(!) borealis Ashmead, 1902. Wash. Acad. Sci., Proc. 4: 225. ठ.

haemorrhoicus fusculosus (Davis). Que. s. to n. Va., w. to Mich. Host: Caliroa cerasi (L.).

Mesoleius niger Provancher, 1883. Nat. Canad. 14: 9. "६" = ठ. Formerly preocc. in

Mesoleius by Gravenhorst, 1829.

Trematopygus fusculosus Davis, 1897. Amer. Ent. Soc., Trans. 24: 277. ठ.

Mesoleius nigratus Dalla Torre, 1901. Cat. Hym., v. 3, p. 263. N. name for M. niger

Provancher.

Monoblastus caliroae Viereck, 1912. U. S. Natl. Mus., Proc. 42: 151. ठ̊, ๆ.

Trematopygus eriocampoididis Cushman, 1915. Ent. Soc. Wash., Proc. 17: 135. ठ, ९.

hervieuxii (Provancher). Que.

Tryphon hervieuxii Provancher, 1879. Nat. Canad. 11: 254.. 
pilosus (Davis). Mont., w. Wash.

Eryma pilosa Davis, 1897. Amer. Ent. Soc., Trans. 24: 274. $\delta$.

tristis (Provancher). Que., Maine, Conn., Ont. Host: Arge clavicomis (F.), Nematus ventralis Say, sawfly on poplar.

Erronemus(!) tristis Provancher, 1886. Addit. Corr. Faune Ent. Canada Hym., p. 110. $q$.

\section{Genus SYMPHERTA Foerster}

Symipherta Foerster, 1868. Naturh. Ver. Rheinlande, Verh. 25: 196.

Type-species: Tryphon burrus Cresson. Desig. by Viereck, 1914 from two species included by Davis, 1897 .

Stiphrosomus Foerster, 1868. Naturh. Ver. Rheinlande, Verh. 25: 198. preocc. by Fieber, 1858.

Type-species: Mesoleptus fuscicomis Gravenhorst. Desig. by Viereck, 1914 from six species included by Thomson, 1895. The type-species is Gravenhorst's identification of Ichneumon fuscicomis Gmelin, 1790, p. 2701 (not p. 2684).

Trapezocora Foerster, 1868. Naturh. Ver. Rheinlande, Verh. 25: 208.

Type-species: Mesoleptus antilope Gravenhorst. Included and desig. by Perkins, 1962.

Atrestes Foerster, 1868. Naturh. Ver. Rheinlande, Verh. 25: 209.

Type-species: Catoglyptus (Stiphrosomus) sulcatus Thomson. Monotypically included and desig. by Perkins, 1962.

Campogenes Foerster, 1868. Naturh. Ver. Rheinlande Verh. 25: 209.

Type-species: Mesoleptus antilope Gravenhorst. Monotypically included and desig. by Perkins, 1962.

Provancherella Dalla Torre, 1901. Cat. Hym., v. 3, p. 305.

Type-species: Baryceros rhopalocerus Provancher. Monotypic.

Eustiphrosomus Hincks, 1944. Roy. Ent. Soc. London, Proc. (ser. B) 13: 34. N. name for Stiphrosomus Foerster.

According to Townes (1970) this is a moderately large genus of Holarctic distribution.

Taxonomy: Townes, Momoi, and Townes, 1965. Amer. Ent. Inst., Mem. 5: 245 (syn.).

-Townes, 1970 (1969). Amer. Ent. Inst., Mem. 13: $81-82$ (spp. referred to genus).

aciculata (Davis). Mont.

Monoblastus aciculatus Davis, 1897. Amer. Ent. Soc., Trans. 24: 262. ठ.

burra (Cresson). Que. s. to s.e. Ga., w. to e. Iowa.

Tryphon burrus Cresson, 1868. Amer. Ent. Soc., Trans. 2: 108. $\%$.

Baryceros rhopalocerus Provancher, 1875. Nat. Canad. 7: 269. Barron (1975) appears to have had valid grounds for rejecting the lectotype selected by Gahan and Rohwer (1918).

Mesoleptus largus Provancher, 1886. Addit. Corr. Faune Ent. Canada Hym., p. 98. $\$$.

Taxonomy: Gahan and Rohwer, 1918. Canad. Ent. 50: 33. -Barron, 1975. Nat. Canad. 102: $493,545$.

clinata (Walley). Southwestern Alta.

Stiphrosomus clinatus Walley, 1937. Canad. Ent. 69: 190. \&.

fucata fucata (Cresson). Que. w. to s.w. Alta., s. to N. C., Colo., and n. Ariz.

Mesoleptus fucatus Cresson, 1868. Amer. Ent. Soc., Trans. 2: 99.

Mesoleptus erectus Provancher, 1875. Nat. Canad. 7: 317.

Mesoleptus laetus Provancher, 1879. Nat. Canad. 11: 231. “\%” = . Preoce. by

Gravenhorst, 1829.

Syndipnus erythrogaster Viereck, 1908. Amer. Ent. Soc., Trans. 33: 385. ठ.

fucata nigropleuralis (Davis). Nev.

Mesoleptus nigropleuralis Davis, 1898 (1897). Amer. Ent. Soc., Trans. 24: 317. ठै. 


\section{TRIBE PERILISSINI}

Eighteen genera are currently recognized; eleven of them are represented by native Nearctic species and a twelfth genus is represented by an introduced species. The tribe is apparently not known from the Australian Region.

\section{Genus SYNOECETES Foerster}

Synagrypnus Foerster, 1868. Naturh. Ver. Rheinlande, Verh. 25: 203.

Type-species: Synagrypnus blancoburgensis Schmiedeknecht. By subsequent monotypy from inclusion by Schmiedeknecht, 1914.

Synoecetes Foerster, 1868. Naturh. Ver. Rheinlande, Verh. 25: 203.

Type-species: Mesoleptus sedulus Cresson. Desig. by Viereck, 1914 from three species included by Davis, 1897.

Polyrhysia Foerster, 1868. Naturh. Ver. Rheinlande, Verh. 25: 204.

Type-species: Tryphon tenuicomis Gravenhorst. Desig. by Viereck, 1914 from two species included by Thomson, 1894 .

Polyrhysius Thomson, 1894. Opusc. Ent. 19: 1999. Emend.

This is a small Holarctic genus.

festivus (Cresson). N. H. w. to s. Alta., s. to Md., Ill., and Colo.

Tryphon festivus Cresson, 1864. Ent. Soc. Phila., Proc. 3: $279 . "$ " $"=q$.

Mesoleptus sedulus Cresson, 1868. Amer. Ent. Soc., Trans. 2: 97. "ठ̋" = .

\section{Genus COELORHACHIS Townes}

Coelorhachis Townes, 1966. In Townes and Townes, Amer. Ent. Inst., Mem. 8: 329.

Type-species: Mesoleptus decorosus Cresson. Monotypic and orig. desig.

According to Townes this is a moderately large genus which is Neotropic; at least one undescribed species occurs in Texas.

\section{Genus ZAPLETHOCORNIA Schmiedeknecht}

Zaplethocomia Schmeideknecht, 1912. Opusc. Ichn., v. 5, p. 2519.

Type-species: Ichneumon procurator Gravenhorst. By subsequent monotypy from inclusion by Schmiedeknecht, 1913.

Nictula Burks, 1952. Ent. Soc. Amer., Ann. 45: 88.

Type-species: Westwoodia fumipennis Provancher. Monotypic and orig. desig.

Parastadus Burks, 1952. Ent. Soc. Amer., Ann. 45: 92.

Type-species: Erigloea opulenta Davis. Monotypic and orig. desig.

This is a small Holarctic genus.

Taxonomy: Townes, 1970 (1969). Amer. Ent. Inst., Mem. 13: 88 (syn.).

fumipennis (Provancher). Que., N. H., N. Y.

Westwoodia fumipennis Provancher, 1875. Nat. Canad. 7: 329..

longipes (Davis). Tex.

Syndipnus longipes Davis, 1898 (1897). Amer. Ent. Soc., Trans. 24: 288..

opulenta (Davis). N. H., Mass., N. Y., N. J., Md.

Erigloea opulenta Davis, 1897. Amer. Ent. Soc., Trans. 24: 275..

\section{Genus NANIUM Townes}

Nanium Townes, 1967. In Walkley, in Krombein et al., U. S. Dept. Agr., Agr. Monog, 2, sup. 2, p. 174.

Type-species: Tryphon capitatus Cresson. Monotypic and orig. desig.

This is a small Neotropic and Nearctic genus.

capitatum (Cresson). N. H. s. to n. Fla., w. to Tex.

Tryphon capitatus Cresson, 1864. Ent. Soc. Phila., Proc. 3: 281. ठँ. 


\section{Genus TREMATOPYGODES Aubert}

Trematopygodes Aubert, 1968. Soc. Ent. de Mulhouse, Bul. 24: 69.

Type-species: Trematopygus aprilinus Giraud. Monoypic.

This is a small Holaretic genus.

Taxonomy: Townes, 1970 (1969). Amer. Ent. Inst., Mem. 13: 92-93 (redescription and additional spp. referred).

frontosus (Davis), n. comb. Wash. Dr. Henry K. Townes kindly informed me (personal commun., 1976) that his most recent notes on the lectotype indicate that this species belongs in Trematopygodes.

Labrossyta frontosa Davis, 1898 (1897). Amer. Ent. Soc., Trans. 24: 275. ๆ (ơ misdet.?). oculatus (Davis). Md., Tex.

Oetophorus oculatus Davis, 1897. Amer. Ent. Soc., Trans. 24: 252. .

osflavus (Davis). N. Y., Pa., Mich.

Oetophorus osflavus Davis, 1897. Amer. Ent. Soc., Trans. 24: 252..

\section{Genus AECHMETA Townes}

Aechmeta Townes, 1970 (1969). Amer. Ent. Inst., Mem. 13: 93.

Type-species: Ctenopelma indotata Davis. Orig. desig.

This is a Nearctic genus; only two species are known.

indotata (Davis). N. Y., Va., Ind., Ill., Iowa, Mo., n.e. Kans., Tex.

Ctenopelma indotata Davis, 1897. Amer. Ent. Soc., Trans. 24: 250. ठ, $q$.

Taxonomy: Burks, 1952. Ent. Soc. Amer., Ann. 45: 82, 84, 90.

primosa (Davis). N. H., Tex.

Ctenopelma primosa Davis, 1897. Amer. Ent. Soc., Trans. 24: 250. ठ.

Taxonomy: Burks, 1952. Ent. Soc. Amer., Ann. 45: 82-83.

\section{Genus OETOPHORUS Foerster}

Oetophorus Foerster, 1868. Naturh. Ver. Rheinlande, Verh. 25: 196.

Type-species: Mesoleius stretchii Cresson. Desig. by Viereck, 1914 from four species included by Davis, 1897.

Symphobus Foerster, 1868. Naturh. Ver. Rheinlande, Verh. 25: 199.

Type-species: Tryphon plezralis Cresson. By subsequent monotypy from inclusion by Davis, 1898 .

This is a small holaretic genus.

Taxonomy: Burks, 1952. Ent. Soc. Amer., Ann. 45: 97-98.

nasoni (Davis). Mich., Ill.

Oetophorus nasoni Davis, 1897. Amer. Ent. Soc., Trans. 24: 251..+

Oetophorus nasonii Dalla Torre, 1901. Cat. Hym., v. 3, p. 329. Emend.

Taxonomy: Burks, 1952. Ent. Soc. Amer., Ann. 45: 97-98. —Townes, 1970 (1969). Amer. Ent. Inst., Mem. 13: 94.

pleuralis (Cresson), Que.?, Mass., N. Y., N. J., Pa., Md., Va.?, B. C.?

Tryphon pleuralis Cresson, 1864. Ent. Soc. Phila., Proc. 3: 275..

stretchii (Cresson). Colo., s.w. B. C., n. Calif.

Mesoleius Stretchii Cresson, 1879 (1878). Acad. Nat. Sci. Phila., Proc. 30: 371..

\section{Genus PERILISSUS Holmgren}

Perilissus Holmgren, 1856 (1855). Svenska Vetensk.-Akad. Handl. 75: 63.

Type-species: Ichneumon filicomis Gravenhorst. Monotypic.

Spanotecnus Foerster, 1868. Naturh. Ver. Rheinlande, Verh. 25: 197.

Type-species: Ichneumon filicornis Gravenhorst. Desig. by Viereck, 1914 from four species included by Thomson, 1883. 
Ichnaeops Foerster, 1868. Naturh. Ver. Rheinlande, Verh. 25: 197.

Type-species: Perilissus lutescens Holmgren. Monotypically included and desig. by Perkins, 1962.

Polyoncus Foerster, 1868. Naturh. Ver. Rheinlande, Verh. 25: 197.

Type-species: Tryphon erythrocephalus Gravenhorst. Desig. by Viereck, 1914 from three species included by Thomson, 1883 .

Udenia Foerster, 1868. Naturh. Ver. Rheinlande, Verh. 25: 202.

Type-species: Perilissus (Udenia) herrichii Kriechbaumer. By subsequent monotypy from inclusion by Kriechbaumer, 1892.

Exacrodus Foerster, 1868. Naturh. Ver. Rheinlande, Verh. 25: 210.

Type-species: Exacrodus populans Morley. By subsequent monotypy from inclusion by Morley, 1913. The type-species is regarded as a synonym of $P$. cingulator (Morley).

Daugna Seyrig, 1935. Paris, Mus. d'Hist. Nat., Mem. (n. s.) 4: 29.

Type-species: Daugna allutandi Seyrig. Monotypic and orig. desig. The type-species is regarded as a synonym of $P$. testaceoides (Morley).

Pseudochorus Rao, 1953. Indian Forest Rec., New Ser., Ent. 8: 95.

Type-species: Pseudochorus kuriani Rao. Monotypic and orig. desig.

This large genus is known from the Holarctic, Oriental, and Ethiopian Regions, but is represented by only a few species in the latter two regions.

Revision: Burks, 1952. Ent. Soc. Amer., Ann. 45: 94-103.

araius Burks. N. H., Conn., N. Y., N. J., e. S. C., Ont., Mich., Tenn., Colo.

Perilissus araius Burks, 1952. Ent. Soc. Amer., Ann. 45: 101. ơ, ․

bicolor (Cresson). Que. s. to S. C., w. to Mich. and Ala.

Mesoleptus bicolor Cresson, 1864. Ent. Soc. Phila., Proc. 3: 269. §. Erroneously suppressed as a synonym of Prionopoda mificornis Ashmead in the revision of Burks (1952); P. bicolor (Cresson) is not preoce. in Perilissus by P. bicolor Brischke, 1878.

Prionopoda ruficornis Ashmead, 1896. Amer. Ent. Soc., Trans. 23: 198. đo.

coloradensis (Ashmead). Ont., N. Dak., Sask., Colo., Utah, Ariz., Calif.

Prionopoda coloradensis Ashmead, 1896. Amer. Ent. Soc., Trans. 23: 198. \&.

concolor (Cresson). N. B. s. to Va., w. to Mich., lowa, and Colo. Host: Dolerus sp. Townes (1970) placed concolor as a subspecies of $P$. filicornis (Gravenhorst); I have compared specimens of concolor and P. filicomis decoloratus (which see) and believe that concolor is specifically distinct.

Mesoleptus concolor Cresson, 1864. Ent. Soc. Phila., Proc. 3: 270. 9.

Cteniscus concolor Provancher, 1875. Nat. Canad. 7: 139. Preoce. in Perilissus by Cresson, 1864.

Taxonomy: Townes, 1970 (1969). Amer. Ent. Inst., Mem. 13: 95.

discolor (Cresson). Que. w. to Sask. and Idaho, s. to D. C., Kans., and Colo. Host: Empria coryli (Dyar).

Mesoleptus unicolor Cresson, 1864. Ent. Soe. Phila., Proe. 3: 271. [female].

Mesoleptus discolor Cresson, 1864. Ent. Soc. Phila., Proc. 3: 271. ठ. In his revision, Burks

(1952) incorrectly suppressed discolor as a synonym of unicolor, apparently having regarded page priority as grounds for disregarding Townes' (1945) first revisor decision. Townes (1970) placed discolor as a subspecies of P. filicomis (Gravenhorst), but Townes (1976, personal commun.) has confirmed my supposition that this was an error; it had been his intention to place Mesoleptus decoloratus Cresson (which see) as a subspecies of $P$. filicornis.

Pyracmon rufum Provancher, 1882. Nat. Canad. 13: 365..

Taxonomy: Townes, 1945. Amer. Ent. Soc., Mem. 11: 498. -Townes, 1970 (1969). Amer. Ent. Inst., Mem. 13: 95.

filicornis decoloratus (Cresson), n. status. N. S. w. to interior Alaska, s. to Pa., Ill., Colo., and

B. C. P. filicornis filicomis (Gravenhorst) is European.

Mesoleptus decoloratus Cresson, 1864. Ent. Soc. Phila., Proc. 3: 265. ठ.

Perilissus southwickii Ashmead, 1896. Amer. Ent. Soc., Trans. 23: 196. ठँ. 


\section{Genus ABSYRTUS Holmgren}

Absyrtus Holmgren, 1859 (1858). Svenska Vetensk.-Akad., Ofvers af ... Forh. 15: 323.

Type-species: Absyrtus luteus Holmgren. Monotypic. The type-species is regarded as a synonym of $A$. vicinator (Thunberg).

Eczetesis Foerster, 1868. Naturh. Ver. Rheinlande, Verh. 25: 196.

Type-species: Perilissus paniscoides Ashmead. By subsequent monotypy from inclusion by Davis, 1897.

This is a small Holaretic genus.

Revision: Cushman, 1924. U. S. Natl. Mus., Proc. 64 (20): 18-20.

arealis Cushman. N. H., N. Y., Pa., Md.

Absyrtus arealis Cushman, 1924. U. S. Natl. Mus., Proc. 64 (20): 19. o, $q$.

paniscoides (Ashmead). Vt. w. to Minn., s. to n. Ala. and Tex.

Perilissus paniscoides Ashmead, 1896. Amer. Ent. Soc., Trans. 23: 197. ㅇ (ð misdet.).

perilissoides Cushman. Conn., Ohio, Okla.

Absyrtus perilissoides Cushman, 1924. U. S. Natl. Mus., Proc. 64 (20): 19. ð, ๆ.

\section{Genus LOPHYROPLECTUS Thomson}

Lophyroplectus Thomson, 1883. Opusc. Ent. 9: 915.

Type-species: Paniscus oblogopunctatus Hartig. Monotypic.

Two species are known, one European and one Japanese.

oblongopunctatus (Hartig). Ont.; Europe. Introduced in N. S., N. B., Que., Maine and Ont. in 1935 through 1941 without becoming established; introduced again in Maine in 1958 and in Ont. in 1962 and 1964 and apparently established in Ont. Host: Neodiprion sertifer (Geoffroy). The host listed was the target species for the most recent introductions in Ont.

Ichneumon luteator Thunberg, 1822; 1824. Acad. Imp. des Sci. St. Petersburg, Mem. 8: 259; 9: 308. ․ Preocc. by Fabricius, 1798.

Paniscus oblongopunctatus Hartig, 1838. Jahresber. Fortschr. Forstwiss. Forstl. Naturk. 1: $272 . \delta$, .

Taxonomy: Roman, 1916. Zool. Bidr. Uppsala 1: 266, 291. -Oehlke, 1966 (1965). Beitr. z. Ent. 15: 855-856.

Biology: Pschorn-Walcher, 1967. Commonwealth Inst. Biol. Control, Tech. Bul. 8: 9-15, 44. -Griffiths, Rose, and Bird, 1971. Commonwealth Inst. Biol. Control (Trididad), Tech. Commun. 4: 107, 157, 158, 160-161. - Rose, 1977 (1976). Canad. Ent. 108: 1395-1398.

\section{Genus OPHELTES Holmgren}

Opheltes Holmgren, 1859 (1858). Svenska Vetensk.-Akad., Ofvers. af ... Forh. 15: 323. Type-species: Ichneumon glaucopterus Linnaeus, Monotypic.

Nephopheltes Cushman, 1924. U. S. Natl. Mus., Proc. 64 (20): 16.

Type-species: Nephopheltes japonicus Cushman. Monotypic and orig. desig.

This is a Holarctic genus including only two species.

glaucopterus barberi Cushman. Newfoundland (insular) w. to Alaska, s. to S. C., n. Ga., s.e.

Kans., Colo, and s.w. Oreg. Host: Cimbex americana Leach. O. glaucopterus

glaucopterus (Linnaeus) is Eurasian, and O.glaucopterus apicalis (Matsumura) occurs in northeastern Asia.

Campoplex flavipennis Provancher, 1874 (May). Nat. Canad. 6 (5): 143. ๆ. Preocc. by Cresson, 1874 (January).

Opheltes glaucopterus var. barberi Cushman, 1924. U. S. Natl. Mus., Proc. 64 (20): 16... Opheltes glaucopterus galbipennis Walkley, 1958. In Krombein et al., U. S. Dept. Agr., Agr. Monog. 2, Sup. 1, p. 54. N. name for C. flavipennis Provancher. N. syn.

Biology: Orcutt and Aldrich, 1892. S. Dak. Agr. Expt. Sta., Bul. 30: 5. -Fyles, 1894. Ent. Soc. Ontario, Ann. Rpt. 25: 54, 55. - Comeau, 1944. Ann. de L'Acfas (Montreal) 10: 103. 
Morphology: Whitmarsh, 1910. Ent. Soc. Amer., Ann. 3: 197, 204-206, 208.

\section{Genus LATHROLESTES Foerster}

Lathrolestes Foerster, 1868. Naturh. Ver. Rheinlande, Verh. 25: 196.

Type-species: Tryphon clypeatus Zetterstedt. Desig. by Viereck, 1914 from seven species included by Thomson, 1883

Laphyroscopus Foerster, 1868. Naturh. Ver. Rheinlande, Verh. 25: 197.

Type-species: Tryphon gorskii Ratzeburg. Desig. by Viereck, 1914 from three species included by Thomson, 1883.

Homalomma Foerster, 1868. Naturh. Ver. Rheinlande, Verh. 25: 198.

Type-species: Homalomma caliroae Rohwer. Included and desig. by Rohwer, 1915.

Ecclinops Foerster, 1868. Naturh. Ver. Rheinlande, Verh. 25: 201.

Type-species: Tryphon orbitalis Gravenhorst. Desig. by Viereck, 1914 from seven species included by Thomson, 1883.

Camporychus Foerster, 1868. Naturh. Ver. Rheinlande, Verh. 25: 208.

Type-species: Lathrolestes marginatus Thomson. Monotypically included and desig. by Townes, 1970.

Luphyroscopus Thomson, 1883. Opusc. Ent. 9: 915. Emend.

Lathrolestus Thomson, 1883. Opusc. Ent. 9: 916. Emend.

Tryphonopsis Brauns, 1898. Ver. Freunde Naturgesch. Mecklenburg, Arch. 51: 62.

Type-species: Tryphonopsis ensator Brauns. Monotypic.

Ritzemabosia Smits van Burgst, 1912. Tijdschr. v. Ent. 55: 269.

Type-species: Ritzemabosia meridionalis Smits van Burgst. Monotypic.

Culmina Benoit, 1955. Mus. Roy. Congo Belge, Tervuren, Ann. (ser. 8, Sci. Zool.) 38: 32.

Type-species: Culmina ruwenzorica Benoit. Monotypic and orig. desig.

This is a large genus of Neotropic, Holarctic, Oriental, and Ethiopian distribution. The majority of the species occur in the Holarctic Region. Most species presumably parasitize sawflies, but a European species identified as $L$. clypeatus (Zetterstedt) has been reared from two species of the primitive microlepidopteran family Eriocraniidae and L. mnemonicae (Rohwer) has also been reared from an eriocraniid.

caliroae (Rohwer). Northern Va., n. Ala. Host: Caliroa sp. on Nyssa sylvatica, Caliroa sp. on Quercus prinus.

Homalomma caliroae Rohwer, 1915. U. S. Natl. Mus., Proc. 49: 218..+

Homalomma eriocompoides Rohwer, 1915. U. S. Natl. Mus., Proc. 29: 219. \&.

constrictus (Provancher). Que.

Phygadeuon constrictus Provancher, 1882. Nat. Canad. 13 (no. 155): 336; 13 (no. 156): 357. o.'

iladus (Davis). Que., N. Y., R. I., Md., n. Ga., Ont. Host: Metallus rohweri MacG.

Spanotecnus iladus Davis, 1898 (1897). Amer. Ent. Soc., Trans. 24: 303. ơ.

Lathrolestes visscheri DeGant, 1933. U. S. Natl. Mus., Proc. 82 (11): 5. o.

Lathrolestes metalli Cushman, 1933. U. S. Natl. Mus., Proc. 82 (14): 10. ơ.

Taxonomy: Townes, 1970 (1969). Amer. Ent. Inst., Mem. 13: 100 (syn.).

luteolator (Gravenhorst). N. Y., w. N. C., n. Ga., Wis.; Europe.

Mesoleptus luteolator Gravenhorst, 1829. Ichn. Europaea, v. 2, p. 42. ठ.

Tryphon Gorskii Ratzeburg, 1852. Ichn. d. Forstins., v. 3, p. 126. ठ.

Polyoncus suburbe Davis, 1898 (1897). Amer. Ent. Soc., Trans. 24: 306 ..

Taxonomy: Pfankuch, 1906. Ztschr. System. Hym. Dipt. 6: 22 (syn.). -Townes, 1944. Amer.

Ent. Soc., Mem. 11: 502 (syn.).

mentalis (Davis). N. H., N. C., n. Ga.

Polyoncus mentalis Davis, 1898 (1897). Amer. Ent. Soc., Trans. 24: 306...

Monoblastus nigriventris Ashmead, 1902. In Slosson, Ent. News 12: 321. Nomen nudum.

mnemonicae (Rohwer). Northern Va. Host: Dyseriocrania griseocapitella (Wlshm.). Notes in the U.S. Natl. Museum seem to indicate that this host record is correct. The host is a 
leaf-mining microlepidopteran of the primitive family Eriocraniidae; it spins a cocoon in the soil.

Sympherta mnemonicae Rohwer, 1914. Ent. Soc. Wash., Proc. 16: 141. ठં, ๆ. nasoni Davis. Ill.?, Sask., Colo., Alta., Mont.

Lathrolestes nasoni Davis, 1897. Amer. Ent. Soc., Trans. 24: 264. १ (ơ misdet.?).

Latholestes similis Davis, 1897. Amer. Ent. Soc., Trans. 24: 265..

Lathrolestes nasonii Dalla Torre, 1901. Cat. Hym., v. 3, p. 321. Emend.

nigricollis (Thomson). Europe. Introduced in insular Newfoundland in 1973; because only ten adults were released, establishment would seem to have been precluded. Host: Fenusa pusilla (Lep.). The host cited was the target species for the release of nigricollis in Newfoundland.

Perilissus (Luphyroscopus) nigricollis Thomson, 1883. Opusc. Ent. 9: 915. ठ.

Perilissus minutus Bridgman, 1888 (1887). Ent. Soc. London, Trans. 35: 370. ð. syn.?

obscurellus (Davis). Conn., N. Y.

Spanotecnus obscurellus Davis, 1898 (1897). Amer. Ent. Soc., Trans. 24: 304 ..

pictus Cushman. Eastern S. Dak.

Phytodietus truncatus Davis, 1898 (1897). Amer. Ent. Soc., Trans. 24: 371. ९. Preocc. in Lathrolestes by Provancher, 1888.

Lathrolestes pictus Cushman, 1933. U. S. Natl. Mus., Proc. 82 (14): 11. ठ.

Lathrolestes cinctus Townes, 1945. Amer. Ent. Soc., Mem. 11: 502. N. name for $P$. truncatus Davis.

Taxonomy: Townes, 1970 (1969). Amer. Ent. Inst., Mem. 11: 100.

platynus (Davis). Southern Mich.

Polyoncus platynus Davis, 1898 (1897). Amer. Ent. Soc., Trans. 24: 306. ठ.

Polyoncus unicus Davis, 1898 (1897). Amer. Ent. Soc., Trans. 24: 306. .

rufigaster Cushman. Maine, Va., N. C., Ont., Ohio. Host: Metallus rohweri MacG., sawfly on blackberry, leaf miner.

Lathrolestes rufigaster Cushman, 1933. U. S. Natl. Mus., Proc. 82 (14): 13. ठै, १.

scutellatus (Ashmead). D. C., n. Va.

Prionopoda scutellata Ashmead, 1890 (1889). U. S. Natl. Mus., Proc. 12: 441 ..

tomostethi (Cushman). Mass., N. Y., Ohio. Host: Tomostethus multicinctus (Roh.).

Perilissus tomostethi Cushman, 1935. Wash. Acad. Sci., Jour. 25: 558. o', ?.

truncatus (Provancher). Western N. C.?. s.w. B. C.

Mesochorus truncatus Provancher, 1888. Addit. Corr. Faune Ent. Canada Hym., p. 365. $\subsetneq$.

\section{TRIBE SCOLOBATINI}

This small Neotropic, Holarctic, and Oriental tribe includes three genera, two of which are represented in North America.

\section{Genus PHYSOTARSUS Townes}

Physotarsus Townes, 1966. In Townes and Townes, Amer. Ent. Inst., Mem. 8: 139, 330.

Type-species: Tryphon maculipennis Cresson. Orig. desig.

This is apparently a moderate-sized genus with one or more undescribed species occurring in Texas.

\section{Genus SCOLOBATES Gravenhorst}

Scolobates Gravenhorst, 1829. Ichn. Europaea, v. 2, p. 357.

Type-species: Scolobates crassitarsus Gravenhorst. Desig. by Westwood, 1840.

Aglyphus Giraud, 1872. Soc. Ent. de France, Ann. (ser. 5) 1: 411.

Type-species: Aglyphus nigripennis Giraud. Monotypic.

Parabraconia Schmiedeknecht, 1914. Opuse. Ichn., v. 5, p. 2803.

Type-species: Parabraconia nigripennis Schmiedeknecht. By subsequent monotypy from inclusion by Schmiedeknecht, 1925. of S. nigripennis (Giraud); both names are preocc. by Scolobates nigripennis Sichel, 1860. The type-species is regarded 
as a synonym of $S$. nigripennis (Giraud); both names are preocc. by Scolobates nigripennis Sichel, 1860.

This is a small Holaretic and Oriental genus.

auriculatus (Fabricius). N. H., Mass., N. Y., Pa., Md., Ont., Mich., Tex., n. B. C. Ecology: Three specimens in the U. S. Natl. Museum collection were collected in July from snow at an altitude of $7000 \mathrm{ft}$. at London Hill Mine, Bear Lake, B. C. Host: Arge clavicornis (F.), A. pectoralis (Leach), A. scapularis (Klug).

Ichneumon auriculatus Fabricius, 1804. Systema Piezatorum, p. 69.

Ichneumon auriculator Thunberg, 1822; 1824. Acad. Imp. des Sci. St. Petersburg, Mem. 8: $266 ; 9$ : 323. Emend.

Ichneumon elevator Thunberg, 1822; 1824. Acad. Imp. des Sci. St. Petersburg, Mem. 8: 266; 9: 323. ठ. Preoce. by Panzer, 1799.

Scolobates crassitarsus Gravenhorst, 1829. Ichn. Europaea, v. 2, p. 360. đ, ๆ.

Scolobates hylotomae Kriechbaumer, 1877. Ent. Nachr. 3: 135. đ, ๆ.

Prionopoda canadensis Harrington, 1892. Canad. Ent. 24: 98. ๆ.

Scolobates auriculatus var. niger Roman, 1917. Ent. Tidskr. 38: 273. ค. Syn.?

Scolobates auriculatus var, nigrifacies Teunissen, 1953. Tijdschr. v. Ent. 96: 16. ९. Syn.?

Taxonomy: Holmgren, 1859 (1858). Svenska Vetensk.-Akad., Ofvers af ... Forh. 15: 330 (syn.). -Roman, 1912. Zool. Bidr. Uppsala 1: 235, 252 (syn.). - Bauer, 1961. Beitr. z. Ent. 11: 745 (syn.).

Biology: Pschorn-Walcher and Kriegl, 1965. Ztschr. f. Angew. Ent. 56: 268-269.

\section{TRIBE MESOLEIINI}

This is a large Holarctic tribe. Taxonomically, it is possibly the most difficult group of Ichneumonidae. This seems to be reflected in the fact that to use Townes' (1970) key to the genera it is particularly necessary to have a collection including reliably identified representatives of the various genera.

Taxonomy: Townes, 1970 (1969). Amer. Ent. Inst., Mem. 13: 104-127 (genera of world).

\section{Genus OTLOPHORUS Foerster}

Otlophorus Foerster, 1868. Naturh. Ver. Rheinlande, Verh. 25: 202.

Type-species: Tryphon vepretorum Gravenhorst. Desig. by Viereck, 1914 from five species included by Thomson, 1895.

Neales Foerster, 1868. Naturh. Ver. Rheinlande, Verh. 25: 204.

Type-species: Tryphon vepretorum Gravenhorst. By subsequent monotypy from inclusion by Kriechbaumer, 1897.

Dialges Foerster, 1868. Naturh. Ver. Rheinlande, Verh. 25: 206.

Type-species: Tryphon vepretorum Gravenhorst. By subsequent monotypy from inclusion by Kriechbaumer, 1897.

Aeolometis Foerster, 1868. Naturh. Ver. Rheinlande, Verh. 25: 207.

Type-species: Scolobates italicus Gravenhorst. By subsequent monotypy from inclusion by Thomson, 1892.

Tachyporthus Foerster, 1868. Naturh. Ver. Rheinlande, Verh. 25: 210.

Type-species: Scolobates italicus Gravenhorst. By subsequent monotypy from inclusion by Kriechbaumer, 1901.

Holmgrenia Foerster, 1868. Naturh. Ver. Rheinlande, Verh. 25: 213.

Type-species: Holmgrenia lanceolata Davis. Desig. by Viereck, 1914 from six species included by Davis, 1898.

Aelometis Thomson, 1894. Opuse. Ent. 19: 2034. Emend.

Otlophorinus Hincks, 1944. Roy. Ent. Soc. London, Proc. (ser. B) 13: 35.

Type-species: Mesoleius pulverulentus Holmgren. Orig. desig.

This a moderate-sized genus of Holarctic distribution.

fissus (Provancher). Que., N. Y., R. I.

Mesoleius fissus Provancher, 1879. Nat. Canad. 11: 257. ठ. 
lanceolatus (Davis). N. Y., Ont., Colo., w. Wash.

Holmgrenia lanceolata Davis, 1898 (1897). Amer. Ent. Soc., Trans. 24: 294. ð, ‡.

\section{Genus ATITHASUS Foerster}

Atithasus Foerster, 1868. Naturh. Ver. Rheinlande, Verh. 25: 210.

Type-species: Atithasus stellarius Davis. By subsequent monotypy from inclusion by Davis, 1898.

A single species is known.

bimaculatus (Ashmead). N. H., Pa., Va., Ind., Ill., Iowa, e. Kans., Tex.

Grypocentrus bimaculatus Ashmead, 1896. Amer. Ent. Soc., Trans. 23: 199. $\%$.

Atithasus stellarius Davis, 1898 (1897). Amer. Ent. Soc., Trans. 24: 291. ð’, ๆ.

\section{Genus BARYTARBES Foerster}

Polytrera Foerster, 1868. Naturh. Ver. Rheinlande, Verh. 25: 202.

Type-species: Mesoleius (Barytarbus) laeviusculus Thomson. Desig. by Viereck, 1914 from two species included by Thomson, 1892 .

Isodiaeta Foerster, 1868. Naturh. Ver. Rheinlande, Verh. 25: 204.

Type-species: Tryphon segmentarius Gravenhorst. Monotypically included and desig. by Perkins, 1962. The type-species is Gravenhorst's identification of Ichneumon segmentarizs Fabricius.

Hybristes Foerster, 1868. Naturh. Ver. Rheinlande, Verh. 25: 210. Preocc. by Reichenbach, 1850.

Type-species: Tryphon adpropinquator Gravenhorst. Monotypically included and desig. by Townes, Momoi, and Townes, 1965.

Barytarbes Foerster, 1868. Naturh. Ver. Rheinlande, Verh. 25: 212.

Type-species: Tryphon colon Gravenhorst. Desig. by Viereck, 1914 from five species included by Thomson, 1883.

Barytarbus Thomson, 1883. Opusc. Ent. 9: 931. Emend.

Polytreres Thomson, 1892. Opusc. Ent. 17: 1873. Emend.

This is a Holaretic genus of moderate size.

Taxonomy: Townes, 1970 (1969). Amer. Ent. Inst., Mem. 13: 116 (Nearctic spp. assigned). antennatus (provancher). Que., N. Y.?

Mesoleius antennatus Provancher, 1877. Nat. Canad. 9: 15. $\$$. Barron's (1975) rejection of the lectotype selected by Gahan and Rohwer (1918) appears to be valid inasmuch as Provancher did not indicate that he had more than one specimen.

Mesoleius antennatus Provancher, 1879. Nat. Canad. 11: 260. + . Preocc. by Provancher, 1877; Provancher's 1879 description is apparently an inadvertent second description as a new species of the same specimen he described in 1877.

Taxonomy: Gahan and Rohwer, 1918. Canad. Ent. 50: 31. -Barron, 1975. Nat. Canad. 102: 426.

compos (Davis). "Canada," Mich.

Alexeter compos Davis, 1898 (1897). Amer. Ent. Soc., Trans. 24: 321. ठ.

honestus (Cresson). Que., N. H., Conn., N. Y., N. J., Pa., Ill.

Mesoleptus honestus Cresson, 1868. Amer. Ent. Soc., Trans. 2: 98. đं, १.

Mesoleptus albifrons Cresson, 1868. Amer. Ent. Soc., Trans. 2: 98. "o" = $\delta$.

provancheri (Cushman). Que., N. Y., Pa., Mich.

Mesoleptus variabilis Provancher, 1883. Nat. Canad. 14: 7. ९. Preocc. by Provancher, 1875.

Mesoleptus provancheri Cushman, 1917. Ent. Soc. Wash., Proc. 19: 165. N. name for $M$. variabilis Provancher, 1883.

\section{Genus ALEXETER Foerster}

Alexeter Foerster, 1868. Naturh. Ver. Rheinlande, Verh. 25: 199. 
Type-species: Mesoleptus ruficornis Gravenhorst. Desig. by Viereck, 1914 from three species included by Woldstedt, 1877. The type-species is regarded as a synonym of $A$. sectator (Thunberg).

Adranes Foerster, 1868. Naturh. Ver. Rheinlande, Verh. 25: 205. Preocc. by LeConte, 1850.

Type-species: Tryphon multicolor Gravenhorst. Monotypically included and desig. by Townes, Momoi, and Townes, 1965.

Zemiophron Foerster 1868. Naturh. Ver. Rheinlande, Verh. 25: 206.

Type-species: Mesoleius laevissimus Strobl. Monotypically included and desig. by Perkins, 1962.

This is a large Holarctic genus.

Taxonomy: Townes, 1970 (1969). Amer. Ent. Inst., Mem. 13: 116-117 (Nearctic spp. assigned).

canaliculatus (Provancher). Que. w. to s.e. Alaska, s. to D. C. and n. Calif.

Paniscus canaliculatus Provancher, 1874. Nat. Canad. 6: 105. o.

Paniscus albotarsatus Provancher, 1874. Nat. Canad. 6: 106. ơ.

difficilis (Davis). Colo., s.w. Alta., w. Wash.

Rhaestes difficilis Davis, 1898 (1897). Amer. Ent. Soc., Trans. 24: 312. ð.

innoxius (Cresson). Nev., s. B. C., w. Wash.

Mesoleptus innoxius Cresson, 1879 (1878). Acad. Nat. Sci. Phila., Proc. 30: 371. ơ.

lucens (Provancher). Que., N. H., N. C., n. Ga., s. Mich.

Campoplex lucens Provancher, 1874. Nat. Canad. 6: 144. o. Barron (1975) regarded the holotype of $C$. lucens as being lost; therefore, application of the name should be based upon the synonymy of Townes (1945).

Mesoleptus riparius Davis, 1898 (1897). Amer. Ent. Soc., Trans. 24: 315. ð゙, ๆ.

Hadrodactylus affinis Ashmead, 1902 In Slosson, Ent. News 13: 6. Nomen nudum.

Taxonomy: Townes, 1945. Amer. Ent. Soc., Mem. 11: 514. - Barron, 1975. Nat. Canad. 102: 499-500.

luteifrons (Cresson). Southwestern N. W. T.

Mesoleptus luteifrons Cresson, 1868. Amer. Ent. Soc., Trans. 2: 99. ठ’.

notatus Davis. Alta., w. Wash., Oreg.

Alexeter notatus Davis, 1898 (1897). Amer. Ent. Soc., Trans. 24: 321. ð.

scapularis (Cresson). N. H., R. I., Conn., N. Y., N. J., Md.

Mesoleptus scapularis Cresson, 1868. Amer. Ent. Soc., Trans. 2: 98. §.

\section{Genus PROTARCHUS Foerster}

Protarchus Foerster, 1868. Naturh. Ver. Rheinlande, Verh. 25: 201.

Type-species: Tryphon rufus Gravenhorst. By subsequent monotypy from inclusion by Woldstedt, 1877. The type-species is regarded as a synonym of $P$. testatorius (Thunberg).

Zacalles Foerster, 1868. Naturh. Ver. Rheinlande, Verh. 25: 201.

Type-species: Zacalles magnus Davis. By subsequent monotypy from inclusion by Davis, 1898.

Protarchoides Cushman, 1922. U. S. Natl. Mus., Proc. 61 (8): 25.

Type-species: Protarchoides longipes Cushman. Monotypic and orig. desig.

This is a small Holarctic genus.

Revision: Walley, 1938. Canad. Ent. 70: 230-232.

longipes (Cushman). Que., Maine, N. H., n. Mich., s. B. C. Host: Trichiosoma sp.

Psilosarge(!) longipes Ashmead, 1902. In Slosson, Ent. News 13: 321. Nomen nudum.

Protarchoides longipes Cushman, 1922. U. S. Natl. Mus., Proc. 61 (8): 26..

Protarchoides mandibularis Cushman, 1924. U. S. Natl. Mus., Proc. 64(20): 9..

magnus (Davis). N. H., N. Y.

Zacalles magnus Davis, 1898 (1897). Amer. Ent. Soc., Trans. 24: 283. ๆ.

mellipes (Provancher). Northern Ont., s. Alta., B. C.

Coleocentrus mellipes Provancher, 1886. Addit. Corr. Faune Ent. Canada Hym., p. 113. §ँ. Contrary to Barron (1975) the lectotype was selected by Walley (1938). 
Protarchoides pallipes Cushman, 1927. U. S. natl. Mus., Proc. 72 (13): 15. 9.

Taxonomy: Walley, 1938. Canad. Ent. 70: 231 (syn. and lectotype selection). - Barron, 1975.

Nat. Canad. 102508

pallidicornis (Walley). Northern Ont.

Protarchoides pallidicomis Walley, 1938. Canad. Ent. 70: 231. ․

\section{Genus LAMACHUS Foerster}

Zaphthora Foerster, 1868. Naturh. Ver. Rheinlande, Verh. 25: 206.

Type-species: Tryphon eques Hartig. Monotypically included and desig. by Townes, Momoi, and Townes, 1965.

Adexioma Foerster, 1868. Naturh. Ver. Rheinlande, Verh. 25: 206.

Type-species: Adexioma angularia Davis. By subsequent monotypy from inclusion by Davis, 1898 .

Lamachus Foerster, 1868. Naturh. Ver. Rheinlande, Verh. 25: 206

Type-species: Tryphon lophyrum Hartig. Desig. by Viereck, 1914 from six species included by Thomson, 1892. Included by Thomson as T. lophyrorum "Hartig," lophyrorum being an emendation of Ratzeburg, 1844. The type-species is regarded as a synonym of $L$. frutetorum (Hartig).

Torocamptus Schmiedeknecht, 1913. Opusc. Ichn. v. 5, p. 2797.

Type-species: Tryphon eques Hartig. By subsequent monotypy from inclusion by Schmiedeknecht, 1914.

Bathyglyptus schmiedeknecht, 1913. Opusc. Ichn., v. 5, p. 2802. Preocc. by Case, 1911.

Type-species: Bathyglyptus australis Schmiedeknecht. By subsequent monotypy from inclusion by Schmiedeknecht, 1914.

This is a Holaretic genus of moderate size. The species parasitize Diprionidae.

albopictus Cushman. Japan. Introduced in N. B. in 1939, but the small number of individuals (22) released would seem to have precluded establishment. The target species for the release in N. B. was Gilpinia hercyniae (Htg.).

Lamachus albopictus Cushman, 1937. Insecta Matsumurana 12: 37. ¿, ?.

angularius (Davis). Southern Idaho, Wash., w. Oreg. Host: Neodiprion scutellatus Roh., N. tsugae Midd.

Adexioma angularia Davis, 1898 (1897). Amer. Ent. Soc., Trans. 24: 284. .

Lamachus oregon Cushman, 1939. Wash. Acad. Sci., Jour. 29: 401. d, ?.

coalitorius (Thunberg). Europe. Introduced in N. S., N. B., Que., N. H., Vt., Mass., and Ont. between 1936 and 1940, apparently without becoming established. The target species for releases in North America was Gilpinia hercyniae (Htg.).

Ichneumon coalitorius Thunberg, 1822; 1824. Acad. Imp. des Sci. St. Petersburg, Mem. 8: 278; 9: 358. [male].

Mesoleizs opthalmicus Holmgren, 1857 (1855). Svenska Vetensk.-Akad. Handl. (n. f.) 1: 162. $\delta$. In placing the names below in synonymy with ophthalmicus, Oehlke (1966) apparently overlooked the fact that Roman (1912) had suppressed ophthalmicus as a synonym of coalitorizs.

Mesoleins marginatus Brischke, 1871. Phys.-Oekonom. Gesell. Koenigsberg, Schr. 11: 74. ঠ. N. syn.

Mesoleins spectabilis Holmgren, 1876. Svenska Vetensk.-Akad. Handl. (n. f.) 13: 8. ․ N. syn.

Taxonomy: Roman, 1912. Zool. Bidr. Uppsala 1: 244, 291. -Oehlke, 1966 (1965). Beitr. z. Ent. 15: 861-862.

Biology: Morris, Cameron, and Jepson, 1937. Bul. Ent. Res. 28: 369. -Finlayson and Finlayson, 1958. Canad. Ent. 90: 587-589.

contortionis Davis. Maine s. to n. Fla., w. to Wis. and Ark. Host: Gilpinia hercyniae (Htg.), Neodiprion abietis (Harris), N. lecontei (Fitch), N. nanulus nanulus Schedl, N. pratti banksianae Roh.

Lamachus? contortionis Davis, 1898 (1897). Amer. Ent. Soc., Trans. 24: 284. 9.

Lagarotis diprioni Rohwer, 1915. U. S. Natl. Mus., Proc. 49: 217. ठ, १. 
eques (Hartig). Europe. Introduced in N. B., Que., Vt., N. J., and Ont. between 1936 and 1941, apprently without becoming established. Host: Neodiprion sertifer (Geoff.). The host cited was one of the target species for releases in North America; the other target species was Gilpinia hercyniae (Htg.).

Tryphon eques Hartig, 1838. Jahresber. Fortschr. Forstwiss. Forstl. Naturk. 1: 272. [male, female].

Mesoleius silvarum Holmgren, 1876. Svenska Vetensk.-Akad. Handl. (n. f.) 13: 10. o,.

Taxonomy: Oehlke, 1966 (1965). Beitr. z. Ent. 15: 858-859.

Biology: Pschorn-Walcher, 1967. Commowealth Inst. Biol. Control, Tech. Bul. 8: 15-18, 45.

lophyri (Ashmead). N. B., Maine, N. H., Mass., Ont., Wis. Host: Neodiprion abietis (Harris), N. abbotii (Leach), N. nanulus nanulus Schedl, N. pinetum (Nort.), N. pinusrigidae (Nort.), N. pratti banksianae Roh.

Neoeryma lophyri Ashmead, 1898. In Dimmock and Ashmead, Ent. Soc. Wash., Proc. 4: 169. o, $\%$.

ruficoxalis (Cushman). Maine, Ont., s. Man. Neodiprion abietis (Harris).

Labrossyta ruficoxalis Cushman, 1919. Ent. Soc. Wash., Proc. 21: 118. ?.

Lamachus ruficornis(!) Cushman, 1939. Wash. Acad. Sci., Jour. 29: 400.

tsugae Cushman. Que., Ont., w. Oreg. Host: Neodiprion abbotii (Leach), N. nanulus nanulus Schedl, N. pratti banksianae Roh., N. tsugae Midd.

Lamachus tsugae Cushman, 1939. Wash. Acad. Sci., Jour. 29: 401. ठ, १.

virginianus (Rohwer). Mass., Va., e. N. C., Ohio. Host: Neodiprion lecontei (Fitch). Probably not distinct from L. lophyri (Ashmead).

Lagarotis virginianus Rohwer, 1915. U. S. Natl. Mus., Proc. 49: 218. ठ.

\section{Genus NEOSTROBLIA Heinrich}

Neostroblia Heinrich, 1953. Wien. Ent. Gesell., Ztschr. 38: 211.

Type-species: Mesoleius mificollis var. pseudolituratus Strobl. Monotypic and orig. desig.

This Holarctic genus includes two described species. The type-species is European.

incessans (Davis). N. H., Colo.? The lectotype was collected on Mt. Washington, N. H. by A. T. Slosson, apparently in the "alpine region."

Rhaestes incessans Davis, 1898 (1897). Amer. Ent. Soc., Trans. 24: 311. ?.

Taxonomy: Townes, 1970 (1969). Amer. Ent. Inst., Mem. 13: 119.

\section{Genus SCOPESIS Foerster}

Scopesis Foerster, 1868. Naturh. Ver. Rheinlande, Verh. 25: 209.

Type-species: Mesoleius guttiger Holmgren. Desig. by Viereck, 1914 from eleven species included by Thomson, 1894. Perkins (1962) regarded the type-species as being a synonym of $S$. bicolor (Gravenhorst).

Scoparches Foerster, 1868. Naturh. Ver. Rheinlande, Verh. 25: 211.

Type-species: Tryphon bicolor Gravenhorst. Monotypically included and desig. by Perkins, 1962.

Scopesus Thomson, 1894. Opusc. Ent. 19: 2028. Emend.

Hyposyntactus Ashmead, 1902. Wash. Acad. Sci., Proc. 4: 217.

Type-species: Hyposyntactus flavifrons Ashmead. Monotypic.

This is a Holarctic genus of moderate size.

Taxonomy: Townes, 1970 (1969). Amer. Ent. Inst., Mem. 13: 120 (Nearctic spp. assigned). gesticulator tarda (Provancher). Que. w. to Alaska, s. to n. Ga., Mich., Colo., and Oreg. S. gesticulator gesticulator (Thunberg) is Eurasian.

Tryphon tardus Provancher, 1875. Nat. Caniad. 7: 119. .

Mesoleius! laetus Cresson, 1879 (1878). Acad. Nat. Sci. Phila., Proc. 30: 372. ठ. Formerly preocc. in Mesoleptus by Gravenhorst, 1829. 
Lampronota nigropicta Davis, 1895. Amer. Ent. Soc., Trans. 22: 31. §. Syn.?; regarded as a subspecies distinct from gesticulator tarda by Townes (1970), but evidently would have a range entirely overlapped by $g$. tarda.

Mesoleptus distinctus Davis, 1898 (1897). Amer. Ent. Soc., Trans. 24: 314. ơ, ९. Syn.? Preocc. by Cresson, 1864.

Mesoleptus nigralis Davis, 1898 (1897). Amer. Ent. Soc., Trans. 24: 314. क. Syn.?

Mesoleptus pictus Davis, 1898 (1897). Amer. Ent. Soc., Trans. 24: 315. o, o. Syn.?

Presumably the species described in Davis' key as distinctus.

Mesoleptus Vancouveriensis Dalla Torre, 1901. Cat. Hym. v. 3, p. 365. N. name for Mesoleius laetus Cresson.

Scoposis(!) monticola Ashmead, 1902. In Slosson, Ent. News 13: 6. Nomen nudum.

Hyposyntactus flavifrons Ashmead, 1902. Wash. Acad. Sci., Proc. 4: 217. ठ.

Scopesis monticola Cushman, 1922. U. S. Natl. Mus., Proc. 61 (8): 26. ठ, ๆ. Syn.?

rufonotatus fidelis (Davis). N. H., N. Y., N. C., n. Ga., w. Wash. S. rufonotatus rufonotatus (Holmgren) is European.

Mesoleius fidelis Davis, 1898 (1897). Amer. Ent. Soc., Trans. 24: 297. ð’, ९.

\section{Genus HIMERTA Foerster}

Ithagenes Foerster, 1868. Naturh. Ver. Rheinlande, Verh. 25: 158. Preocc. by Agassiz, 1846. Type-species: Ichneumon defectivus Gravenhorst. Monotypically included and desig. by Townes, 1970 .

Himerta Foerster, 1868. Naturh. Ver. Rheinlande, Verh. 25: 200.

Type-species: Euryproctus (Himertus) bisannulatus Thomson. Desig. by Viereck, 1914 from two species included by Thomson, 1883.

Clepsiporthus Foerster, 1868. Naturh. Ver. Rheinlande, Verh. 25: 200.

Type-species: Mesoleptus rubiginosus Cresson. Desig. by Viereck, 1914 from four species included by Davis, 1898.

Enoecetis Foerster, 1868. Naturh. Ver. Rheinlande, Verh. 25: 211.

Type-species: Enoecetis scutellaris Kriechbaumer. By subsequent monotypy from inclusion by Kriechbaumer, 1897.

Dolioctenus Foerster, 1868. Naturh. Ver. Rheinlande, Verh. 25: 212.

Type-species: Ichneumon defectivus Gravenhorst. Monotypically included and desig. by Perkins, 1962.

Himertus Thomson, 1883. Opusc. Ent. 9: 926. Emend.

Neoprotarchus Cushman, 1924. U. S. Natl. Mus., Proc. 64 (20): 10.

Type-species: Neoprotarchus ater Cushman. Monotypic and orig. desig.

Daisetsuzania Uchida, 1930. Hokkaido Imp. Univ., Faculty Agr., Jour. 25: 289.

Type-species: Daisetsuzania albifrons Uchida. Monotypic and orig. desig.

This is a Holarctic genus of moderate size.

annulata (Davis). Northern Mich.

Lampronota annulata Davis, 1895. Amer. Ent. Soc., Trans. 22: 31. ठ.

atra (Cushman). Alta., n.w. Calif.

Neoprotarchus ater Cushman, 1924. U. S. Natl. Mus., Proc. 64 (20): 10. “

flavida (Davis). N. H., e. N. C., Mich., Mo., S. Dak., Kans., Alta., w. Wash.

Clepsiporthus flavidus Davis, 1896. In Slosson, Ent. News 7: 264. Nomen nudum.

Clepsiporthus flavidus Davis, 1898 (1897). Amer. Ent. Soc., Trans. 24: 326. ․

Himertus dakota Cushman, 1927. U. S. Nat. Mus., Proc. 72 (13): 14 oे ?, ९.

rubiginosa (Cresson). Alta., s.w. B. C., Wash., Calif.

Mesoleins? rubiginosus Cresson, 1879 (1878). Acad. Nat. Sci. Phila., Proc. 30: 372. o.

\section{Genus RHINOTORUS Foerster}

Spudaea Foerster, 1868. Naturh. Ver. Rheinlande, Verh. 25: 211. Preocc. by Snellen van Vollenhoven, 1867.

Type-species: Tryphon leucostomus Gravenhorst. Desig. by Viereck, 1914 from

three species included by Thomson, 1883 .

Rhinotomis Foerster, 1868. Naturh. Ver. Rheinlande, Verh. 25: 211. 
Type-species: Spudaea longicomis Schmiedeknecht. Included and desig. by Perkins, 1962.

Spudaeus Thomson, 1883. Opusc. Ent. 9: 932. Emend. Preoce. by Gistel, 1848.

Prospudaea Hincks, 1944. Roy. Ent. Soc. London, Proc., Ser. B: Taxonomy 13: 35. N. name for Spudaea Foerster.

This is a small Holaretic genus.

ovalis (Davis). N. H., Mich., Colo., w. Wash.

Spudaea ovale Davis, 1898 (1897). Amer. Ent. Soc., Trans. 24: 291. ơ, ९.

Taxonomy: Townes, 1970 (1969). Amer. Ent. Inst., Mem. 13: 122.

\section{Genus ARBELUS Townes}

Arbelus Townes, 1970 (1969). Amer. Ent. Inst., Mem. 13: 122.

Type-species: Mesoleius idahoensis Davis. Orig. desig.

This is a Holarctic genus of moderate size. There are five undescribed or undetermined Nearctic species.

idahoensis (Davis). Colo., n. Idaho, w. Wash., n.w. Oreg.

Mesoleius idahoensis Davis, 1898 (1897). Amer. Ent. Soc., Trans. 24: 297. ठ', ๆ. Suppressed as a synonym of $M$. nuperis Davis by Townes (1945); apparently resurrected from synonymy by Townes (1970).

Taxonomy: Townes, 1945. Amer. Ent. Soc., Mem. 11: 515.

intimatus (Davis). Mont.?, Colo., Wash.

Mesoleptus intimatus davis, 1898 (1897). Amer. Ent. Soc., Trans. 24: 317. ठ.

nuperus (Davis). N. H., N. Y.

Mesoleius nuperus Davis, 1898 (1897). Amer. Ent. Soc., Trans. 24: 296..

\section{Genus CAMPODORUS Foerster}

Phagesorus Foerster, 1868. Naturh. Ver. Rheinlande, Verh. 25: 212.

Type-species: Tryphon caligatus Gravenhorst. Monotypically included and desig. by Townes, Momoi, and Townes, 1965.

Campodorus Foerster, 1868. Naturh. Ver. Rheinlande, Verh. 25: 213.

Type-species: Mesoleius melanogaster Holmgren. Monotypically included and desig. by Perkins, 1962.

Cuboscopesis Heinrich, 1952. Ann. and Mag. Nat. Hist. (12) 5: 1080.

Type-species: Cuboscopesis epachthoides Heinrich. Monotypic and orig. desig.

According to Townes (1970), this is a very large Holarctic genus.

Taxonomy: Townes, 1970 (1969). Amer. Ent. Inst., Mem. 13: 123-124.

alaskensis (Ashmead). Southwestern Alaska.

Calliphrumis alaskensis Ashmead, 1902. Wash. Acad. Sci., Proc. 4: 220. ठ, ๆ.

aquilonaris (Walkley). Southwestern Alaska.

Calliphrums frigidus Ashmead, 1902. Wash. Acad. Sci., Proc. 4: 222. ठ. Formerly preocc. in Mesoleius by Holmgren, 1857.

Mesoleius aquilonaris Walkley, 1958. In Krombein et al., U. S. Dept. Agr. Agr. Monog. 2,

Sup. 1, p. 56. N. name for Calliphrurus frigidus Ashmead.

clypeatus (Ashmead). Southwestern Alaska.

Calliphrumis clypeatus Ashmead, 1902. Wash. Acad. Sci., Proc. 4: 220. $९$ (ơ misdet.). contractus (Davis). Alta.

Mesoleius contractus Davis, 1898 (1897). Amer. Ent. Soc., Trans. 24: 297. . Preocc. by

Holmgren, 1857; not renamed because of uncertain synonymy.

convexus (Davis). N. H.

Mesoleius convexus Davis, 1898 (1897). Amer. Ent. Soc., Trans. 24: 298. \&. 
Taxonomy: Townes, 1945. Amer. Ent. Soc., Mem. 11: 519 (suppressed as syn. of Mesoleius visoris Davis). - Townes, 1970 (1969). Amer. Ent. Inst., Mem. 13: 124 (regarded as not congeneric with $M$. visoris).

euurae (Ashmead). Northeastern Calif. Host: Pontania resinicola (Marl.). Bassus euurae Ashmead, 1890 (1889). U. S. Natl. Mus., Proc. 12: 440. o.

insularis (Ashmead). Southwestern Alaska, Wash.

Zootrephes insularis Ashmead, 1902. Wash. Acad. Sci., Proc. 4: 225. ठ.

kukakensis (Ashmead). Southwestern Alaska.

Calliphrurus kukakensis Ashmead, 1902. Wash. Acad. Sci., Proc. 4: 222. .

lituratus (Holmgren). Southeastern N. W. T.?; n. Eurasia. Recorded from Akpatok Isl., N. W. T. by Poulton (1934); specimen apparently identified by C. Ferriere.

Mesoleius lituratus Holmgren, 1857 (1855). Svenska Vetensk.-Akad. Handl. (n. f.) 1: 147. o.

Mesoleius Sahlbergi Woldstedt, 1874. Bidr. till Kann. Finlands Nat. 21: 44..

Mesoleius (Saotus) mubidus Thomson, 1883. Opusc. Ent. 9: 935. 9 . Syn.?; suppressed as a syn. of lituratus "var." Sahlbergi by Roman (1909).

Mesoleius sahlbergii Dalla Torre, 1901. Cat. Hym., v. 3, p. 266. Emend.

Taxonomy: Roman, 1909. In Hamberg, naturw. Untersuch. Sarekgebirges

Schwedisch-Lappland, v. 4, p. 346. - Poulton, 1934. Ann. and Mag. Nat. Hist. (10) 14: 53.

- Hellen, 1950. Notulae Ent. 30: 29 (syn.). -Townes, Momoi, and Townes, 1965. Amer.

Ent. Inst., Mem. 5: 262 (generic placement).

picens (Davis). Colo., Alta.

Holmgrenia picens Davis, 1898 (1897). Amer. Ent. Soc., Trans. 24: 294..

sexcarinatus (Ashmead). Alaska.

Polyterus sexcarinatus Ashmead, 1902. Wash. Acad. Sci., Proc. 4: 217..

\section{Genus SMICROLIUS Thomson}

Syndipnus subg. Smicrolius Thomson, 1895. Opusc. Ent. 19: 2008.

Type-species: Syndipnus (Smicrolius) parvicalcar Thomson. Monotypic.

According to Townes (1970) this small Holaretic genus includes two undescrioed Nearctic species.

Taxonomy: Townes, 1970 (1969). Amer. Ent. Inst., Mem. 13: 124.

\section{Genus MESOLEIUS Holmgren}

Mesoleius Holmgren, 1856 (1854). Svenska Vetensk.-Akad. Handl. 75: 69.

Type-species: Tryphon aulicus Gravenhorst. Desig. by Viereck, 1912.

Allocritus Foerster, 1868. Naturh. Ver. Rheinlande, Verh. 25: 211.

Type-species: Mesoleius tenuiventris Holmgren. Monotypically included and desig. by Perkins, 1962.

Cryptocentrus Walsh, 1873. Acad. Sci. St. Louis, Trans. 3: 156. Preocc. by Ehrenberg, 1837.

Type-species: Tryphon submarginatus Cresson. Monotypic.

Mesolizus Pfankuch, 1906. Ztschr. System. Hym. Dipt. 6: 85. Emend.

Alfkenia Pfankuch, 1906. Ztschr. System. Hym. Dipt. 6: 89. Syn.?

Type-species: Ichneumon integrator Mueller. Monotypic.

Habrodemus Schmiedeknecht, 1913. Opusc. Ichn., v. 5, p. 2799.

Type-species: Mesoleius elongatus Brischke. By subsequent monutypy from inclusion by Schmiedeknecht, 1914.

This is a large Holaretic genus.

Taxonomy: Townes, 1970 (1969). Amer. Ent. Inst., Mem. 13: 125 (restriction of definition and list of Nearctic spp. remaining in genus).

articularis Davis. Sask., Colo.?, Wash.

Mesoleius articularis Davis, 1898 (1897). Amer. Ent. Soc., Trans. 24: 300..+

audax Davis. N. H.

Mesoleius audax Davis, 1898 (1897). Amer. Ent. Soc., Trans. 24: 299.. 
conformus Davis. N. H., R. I., Alta.

Mesoleius conformus Davis, 1898 (1897). Amer. Ent. Soc., Trans. 24: 300. §, १.

cressoni (Davis). Tex.

Holmgrenia cressoni Davis, 1898 (1897). Amer. Ent. Soc., Trans. 24: 293. ९.

Holmgrenia cressonii Dalla Torre, 1901. Cat. Hym., v. 3, p. 270. Emend.

excavatus (provancher). Que.

Tryphon excavatus Provancher, 1875. Nat. Canad. 7: 310. $\delta$.

Taxonomy: Barron, 1975. Nat. Canad. 102: 468.

insidiosus (Cresson). N. H., Mass., N. Y., Pa., Ont., Ohio, Mich., Iowa, Colo.

Mesoleptus insidiosus Cresson, 1868. Amer. Ent. Soc., Trans. 2: 98. ठ.

Mesoleius convergens Davis, 1898 (1897). Amer. Ent. Soc., Trans. 24: 296. १.

Mesoleins visoris Davis, 1898 (1897). Amer. Ent. Soc., Trans. 24: 296. ठ, ९.

Taxonomy: Townes, 1970 (1969). Amer. Ent. Inst., Mem. 13: 125 (syn.).

minor (Ashmead). Southwestern Alaska.

Calliphrumus affinis Ashmead, 1902. Wash. Acad. Sci., Proc. 4: 221. \&. Preocc. in

Mesoleins by Brischke, 1892.

Calliphrurus minor Ashmead, 1902. Wash. Acad. Sci., Proc. 4: 221. ठ, १.

Mesoleius congener Walkley, 1958. In Krombein et al., U. S. Dept. Agr., Agr. Monog. 2, Sup. 1, p. 55, 56. N. name for C. affiris Ashmead.

Taxonomy: Townes, 1970 (1969). Amer. Ent. Inst., Mem. 13: 125 (syn.).

pertinax Davis. Maine, N. H.

Mesoleius pertinax Davis, 1898 (1897). Amer. Ent. Soc., Trans. 24: 299. đ, ؟.

pulchranotus Davis. N. Y.?, Tex. Host: Periclista media (Nort.)?

Mesoleius pulchranotus Davis, 1898 (1897). Amer. Ent. Soc., Trans. 24: 298. ठ.

stejnegeri Ashmead. Eastern U. S. S. R. The type locality is Ostrov Bering (i.e. Bering Isl.), U. S. S. R.; this was incorrectly indicated as an Alaskan locality in previous Nearctic catalogs of Ichneumonidae. However, it seems likely that the species will be found in the Aleutian Islands.

Mesoleius stejnegeri Ashmead, 1899 (1898). In Jordan, Fur Seals and Fur Seal Isls. No. Pacific, v. 4, p. 337.. .

submarginatus (Cresson). Que., N. W. T.?, and B. C., s. to N. C., Ill., and Colo.

Tryphon? submarginatus Cresson, 1864. Ent. Soc. Phila., Proc. 3: 274. ठ์.

tarsalis (Cresson). Que., R. I., Conn., N. Y., Md., N. C., Alta. Host: Croesus latitarsus Nort.

Tryphon tarsalis Cresson, 1868 Amer. Ent. Soc., Trans. 2: 106. \& ( $\delta$ misdet.?).

tenthredinis Morley. Newfoundland (insular) w. to n. Alta. and central B. C., s. to n. Md., Wis., and Mont.; Europe; Japan. Introduced. Host: Pristiphora erichsonii (Htg.), Gilpinia hercyniae (Htg.). Parasitism of G. hercyniae appears at most to be very occasional. Effectiveness as a parasite of $P$. erichsonii decreased greatly as a resistant strain of erichsonii capable of encapsulating the eggs of $M$. tenthredinis spread throughout much of the present Nearctic range of erichsonii. Attempts to diversify the gene pool of the North American population of tenthredinis (English origin) by releasing specimens from Bavaria which are resistant to egg encapsulation are presumably too recent (1963 through 1969) for signs of success to be evident.

Mesoleius tenthredinis Morley, 1912. In Hewitt, Canada Expt. Farms, Bul. (ser.2) 10: 26. ¿. ?.

Mesoleius romani Teunissen, 1945. Leyden Rijks Mus. van Natuurlijke Hist., Zool. Meded. 25: 209. ठ, $९$.

Taxonomy: Townes and Townes, 1951. In Muesebeck et al., U. S. Dept. Agr., Agr. Monog. 2: 334 (syn.).

Biology: Hewitt, 1912. Canada Expt. Farms, Bul. (ser. 2) 10: 25-28. -Graham, 1931. Canad. Ent. 63: 99-102. - Hopping, Leach, Hugh, and Morgan, 1943. Sci. Agr. 24: 58. - Lejeune, 1946. Canada Dept. Agr., Sci. Serv., Div. Ent., Forest Insect Invest., Bi-mon. Prog. Rpt. 3 (2): 2-3. - Drooz, 1953. Jour. Econ. Ent. 46: 828. - Graham, 1953. Quebec Soc. Prot. Plants, Ann. Rpt. 35: 61. - Muldrew, 1953. Canad. Jour. Zool. 31: 313. -Muldrew, 1956. Forestry 
Chron. 32: 21. -Drooz, 1957. Jour. Econ. Ent. 50: 212. - Drooz, 1960. U. S. Dept. Agr., Tech. Bul. 1212: 29-32. -McGugan and Coppel, 1962. In McCleod, McGugan, and Coppel, Commonwealth Inst. Biol. Control, Tech. Commun. 2: 110-114. - Turnock and Muldrew, 1971. Commonwealth Inst. Biol. Control, Tech. Commun. 4: 177-180, 181-182, 186-188.

Morphology: Finlayson, 1960. Canad. Ent. 92: 933-935 (final-instar larva).

\section{Genus HYPERBATUS Foerster}

Hyperbatus Foerster, 1868. Naturh. Ver. Rheinlande, Verh. 25: 210.

Type-species: Mesoleius segmentator Holmgren. Monotypically included and desig. by Townes, Momoi, and Townes, 1965.

According to Townes (1970) this genus includes the Eurasian type-species and three undescribed Nearctic species.

Taxonomy: Townes, 1970 (1969). Amer. Ent. Inst., Mem. 13: 126.

\section{Genus SAOTIS Foerster}

Saotis Foerster, 1868. Naturh. Ver. Rheinlande, Verh. 25: 210.

Type-species: Mesoleius (Saotus) brevispina Thomson. Desig. by Viereck, 1914 from five species included by Thomson, 1883 .

Saotus Thomson, 1883. Opusc. Ent. 9: 933. Emend.

This is a Holarctic genus of moderate size.

clypeatus (Ashmead). Southwestern Alaska, w. Wash.

Exolytus clypeatus Ashmead, 1902. Wash. Acad. Sci., Proc. 4: 168. \&.

hoeli Roman. Eastern Greenland.

Saotis Hoeli Roman, 1933. Norges Svalbard-og Ishavs-undersokelser, Skrifter om

Svalbard og Ishavet 53: 9. .

Taxonomy: Roman, 1934. Ann. and Mag. Nat. Hist. (10) 14: 609 (variation).

mellipes (Provancher). Que.

Echthrus mellipes Provancher, 1874. Nat. Canad. 6: 60. \& (o misdet.).

\section{Genus ANONCUS Townes}

Anoncus Townes, 1970 (1969). Amer. Ent. Inst., Mem. 13: 127.

Type-species: Mesoleius striatus Davis. Orig. desig.

Townes said that this is a large Holaretic genus.

confusus (Ashmead). Southwestern Alaska.

Calliphrumis confusus Ashmead, 1902. Wash. Acad. Sci., Proc. 4: 223. ठ'.

perplexus (Ashmead). Southwestern Alaska.

Calliphrumes perplexus Ashmead, 1902. Wash. Acad. Sci., Proc. 4: 222. o.

striatus (Davis). Que., Maine, N. H., Colo.

Mesoleius striatues Davis, 1898 (1897). Amer. Ent. Soc., Trans. 24: 299. đ, \&.

Dizemon regalis Davis, 1898 (1897). Amer. Ent. Soc., Trans. 24: 312. ๆ.

zebratus (Davis). N. Y.

Mesoleptus zebratus Davis, 1898 (1897). Amer. Ent. Soc., Trans. 24: 316. ơ, ९.

\section{UNPLACED TAXA OF MESOLEIINI}

The following were treated as species of Mesoleius by Townes and Townes (1951). Presumably, they are species whose types had not been studied recently enough by Townes to enable him to assign them to genera in accordance with his 1970 treatment of the genera of Ctenopelmatinae. The types of the Provancher species were studied by Barron (1975), who cited the generic placements of Townes and Townes and Townes (1951) without indicating that they either remained correct or had become obsolete.

Taxonomy: Townes and Townes, 1951. In Muesebeck et al., U. S. Dept. Agr., Agr. Monog. 2: 332, 333, 334. - Barron, 1975. Nat. Canad. 102: 445, 448, 545, 554-555. 
Eclytus robustus Provancher, 1883. Nat. Canad. 14: 8. ९. Que.

Mesoleius Chicoutimiensis Provancher, 1888. Addit. Corr. Faune Ent. Canada Hym., p. 368.. Que.

Mesoleius comeaui Townes, 1945. Amer. Ent. Soc., Mem. 11: 511. N. name for Tryphon canaliculatus Provancher (which see).

Mesoleius groenlandicus Roman, 1930. Ann. and Mag. Nat. Hist. (10) 5: 285. ठ. Greenland.

Taxonomy: Townes, 1961. Ent. Soc. Wash., Proc. 63: 110.

Tryphon canaliculatus Provancher, 1875. Nat. Canad. 7: 116. \&. Que. Formerly preocc. in Mesoleius by Provancher, 1874; replaced in 1945 by Mesoleius comeaui Townes (which see).

Tryphon rufopectus Provancher, 1888. Addit. Corr. Faune Ent. Canada hym., p. 367. “ $\delta ”=~ \&$. Que.

\section{TRIBE EURYPROCTINI}

This tribe is Neotropic, Holarctic, and Oriental, but the majority of the taxa occur in the Holarctic region only. Of the sixteen genera currently recognized, twelve have Nearctic species.

\section{Genus SYNOMELIX Foerster}

Zemiophora Foerster, 1868. Naturh. Ver. Rheinlande, Verh. 25: 203.

Type-species: Tryphon scutulatus Hartig. By subsequent monotypy from inclusion by Thomson, 1894 .

Synomelix Foerster, 1868. Naturh. Ver. Rheinlande, Verh. 25: 206.

Type-species: Synomelix sieboldii Kriechbaumer. By subsequent monotypy from inclusion by Kriechbaumer, 1897. Perkins (1962) regarded the type-species as being synonymous with $S$. albipes (Gravenhorst).

Zemiophorus Thomson, 1894. Opusc. Ent. 19: 2000. Emend.

This is a small Holarctic genus. Perkins (1962) disputed Townes (1945) suppression of Zemiophora as a synonym of Synomelix.

Taxonomy: Townes, 1945. Amer. Ent. Soc., Mem. 11: 521. - Perkins, (1962). Brit. Mus. (Nat.

Hist.) Ent., Bul. 11: 457, 464.

fasciata (Davis). Mass.

Dialges fasciatus Davis, 1898 (1897). Amer. Ent. Soc., Trans. 24: 286. ठै.

longitarsis (Ashmead). Southwestern Alaska.

Sychnoportus longitarsis Ashmead, 1902. Wash. Acad. Sci., Proc. 4: 216. ठठ.

obesa (Davis). Que., R. I., N. Y., Pa., Va., w. N. C., n. Ga.

Stiphrosomus obesa Davis, 1898 (1897). Amer. Ent. Soc., Trans. 24: 312 ..

signatipes (Cresson). "Hudson's Bay Territory."

Tryphon signatipes Cresson, 1868. Amer. Ent. Soc., Trans. 2: 105. ․

\section{Genus SYNODITES Foerster}

Zootrephes Foerster, 1868. Naturh. Ver. Rheinlande, Verh. 25: 162. This name was suppressed as a synonym of Synodites by Townes, Momoi, and Townes (1965) who were acting as first revisors. It should be noted that volume 25 of Naturh. Ver. Rheinlande, Verh. was published in two halves; Zootrephes appeared in the first half and Synodites appeared in the second half. If it is subsequently shown that the second half or the author's separates it would, of course, be necessary to suppress Synodites as a synonym of Zootrephes. Zootrephes.

Type-species: Bassus (Zootrephes) hilaris Woldstedt. By subsequent monotypy from inclusion by Woldstedt, 1880 .

Sychnoportus Foerster, 1868. Naturh. Ver. Rheinlande, Verh. 25: 208, 220. The variant spelling Sychnoporthus appeared on p. 220.

Type-species: Sychnoportus rufopectus Ashmead. By subsequent monotypy from inclusion by Ashmead, 1898.

Listrota Foerster, 1868. Naturh. Ver. Rheinlande, Verh. 25: 209. 
Type-species: Phobetes canadensis Harrington. By subsequent monotypy from inclusion by Davis, 1898 .

Polyterus Foerster, 1868. Naturh. Ver. Rheinlande, Verh. 25: 209.

Type-species: Polyterus franconiaensis Davis. Desig. by Viereck, 1914 from two species included by Davis, 1898.

Synodites Foerster, 1868. Naturh. Ver. Rheinlande, Verh. 25: 211.

Type-species: Tryphon assimilis Holmgren. Desig. by Viereck, 1914 from five species included by Thomson, 1894. The type-species is regarded as a synonym of $S$. notatus (Gravenhorst).

Camponastes Foerster, 1868. Naturh. Ver. Rheinlande, Verh. 25: 212.

Type-species: Camponastes basilicus Davis. By subsequent monotypy from inclusion by Davis, 1898.

Sarcorychus Foerster, 1868. Naturh. Ver. Rheinlande, Verh. 25: 212.

Type-species: Tryphon notatus Gravenhorst. Monotypically included and desig. by Perkins, 1962.

Zootrephus Thomson, 1890. Opusc. Ent. 14: 1486. Emend.

Synodytes Thomson, 1894. Opusc. Ent. 19: 2001. Emend.

basilicus (Davis). Vt., Wash.

Camponastes basilicus Davis, 1898 (1897). Amer. Ent. Soc., Trans. 24: 292..

canadensis (Harrington). Southwestern B. C., Wash.

Phobetes canadensis Harrington, 1894. Canad. Ent. 26: 248..

consors (Davis), Que., N. H.

Mesoleius consors Davis 1898 (1897). Amer. Ent. Soc., Trans. 24: 297. ๆ.

franconiaensis (Davis). N. H., R. I.

Polyterus Franconiaensis Davis, 1898 (1897). Amer. Ent. Soc., Trans. 24: 289. .

olympiae (Ashmead). Maine, N. H., Mass., Conn., N. Y., n. Va., w. Wash. Host: Nematus erythrogaster Nort., N. ventralis Say, willow sawfly, tenthredinid on Populus tremuloides.

Mesoleius olympiae Ashmead, 1896. Amer. Ent. Soc., Trans. 23: 199. ð’, ?.

Sychnoportus rufopectus Ashmead, 1898. In Dimmock and Ashmead, Ent. Soc. Wash., Proc. 4: 169. " $\delta "=$ ?.

virginiensis (Ashmead). Que., N. H., Va., N. C., n. Ga. Host: Sawfly on white birch. Bassus virginiensis Ashmead, 1890. (1889). U. S. Natl. Mus., Proc. 12: 440. $\%$. Mesoleius piritanicus Davis, 1898 (1897). Amer. Ent. Soc., Trans. 24: 299.. Polyterus albipectus Walley, 1937. Canad. Ent. 69: 192. đ, ?.

\section{Genus PANTORHAESTES Foerster}

Trophoctonus Foerster, 1868. Naturh. Ver. Rheinlande, Verh. 25: 206

Type-species: Tryphon xanthostomus Gravenhorst. Desig. by Viereck, 1914 from two species included by Thomson, 1894.

Pantorhaestes Foerster, 1868. Naturh. Ver. Rheinlande, Verh. 25: 206.

Type-species: Tryphon xanthostomus Gravenhorst. By subsequent monotypy from inclusion by Pfankuch, 1906.

This is a small Holaretic genus.

Taxonomy: Townes, 1970 (1969). Amer. Ent. Inst., Mem. 13: 132 (status of Nearctic spp. changed).

assiduus assiduus (Cresson). Mass., Mich., Sask.

Mesoleptus assiduus Cresson, 1868. Amer. Ent. Soc., Trans. 2: 97. ठౌ.

assiduus excavatus (Davis). Mont.

Erigloea excavata Davis, 1897. Amer. Ent. Soc., Trans. 24: 275. $\subsetneq$.

xanthostomus frontalis (Davis). Que. w. to Alta., s. to D. C., Ind., and Colo. P. xanthostomus xanthostomus (Gravenhorst) occurs in Europe.

Dialges frontalis Davis, 1898 (1897). Amer. Ent. Soc., Trans. 24: 285. ठँ, ९.

Dialges frontalis var. tricolor Davis, 1898 (1897). Amer. Ent. Soc., Trans. 24: 285. ठ,.

Dialges frontalis var. rivalis Davis, 1898 (1897). Amer. Ent. Soc., Trans. 24: 286.. 


\section{Genus MESOLEPTIDEA Viereck}

Mesoleptidea Viereck, 1912 (Sept. 30). Ent. Soc. Wash., Proc. 14: 176.

Type-species: Mesoleptus cingulatus Gravenhorst. Orig. desig.

Gnathonophorus Schmiedeknecht, 1912 (Nov.). Opusc. Ichn., v. 5, p. 2519.

Type-species: Gnathonophorus moricei Schmiedeknecht. By subsequent monotypy from inclusion by Schmiedeknecht, 1913.

This is a Holaretic genus of moderate size.

decens (Cresson). Que., Maine, N. H., Conn., N. Y., Pa., Va., Colo. Host: Sawfly on Sambucus. Mesoleptus decens Cresson, 1868. Amer. Ent. Soc., Trans. 2: 101. ठ.

flavifrons (Cresson). N. H., R. I., N. Y., N. J.

Mesoleptus flavifrons Cresson, 1864. Ent. Soc. Phila., Proc. 3: 269. ठ'.

Taxonomy: Townes, 1970 (1969). Amer. Ent. Inst., Mem. 13: 133 (generic transfer).

kodiakensis (Ashmead). Southwestern Alaska.

Hypocryptus kodiakensis Ashmead, 1902. Wash. Acad. Sci., Proc. 4: 208. ठ.

unalaskae (Ashmead). Southwestern Alaska.

Mesoleptus unalaskae Ashmead, 1902. Wash. Acad. Sci., Proc. 4: 210. \&.

\section{Genus ANISOTACRUS Schmiedeknecht}

Anisotacrus Schmiedeknecht, 1913. Opusc. Ichn., v. 5, fasc. 34 (June), p. 2710; v. 5, fasc. 35 (Nov.), p. 2725. Schmiedeknecht indicated on p. 2725 that this is a new name for "Epachtus Thomson, Opusc. entom. XIX, p. 1999 (non Epacthes Foerster, 1868)." However, it seems clear from his discussion that rather than proposing a replacement name for Epachtus because he believed it to be preoccupied by Epachthes, he proposed it in the sense that he regarded Epachtus Thomson as being a misidentification of Epachthes Foerster. That is, he was proposing a "new name" for Epachthes Foerster sensu Thomson. Schmiedeknecht indicated that Thomson placed two unrelated species in Epachtus, Tryphon erythropalpus "Gravenhorst" and Mesoleius tenellus Holmgren;

Schmiedeknecht placed Tryphon erythropalpus (desig. as the type-species of Epachthes by Viereck, 1914) in Trematopygus and proposed his "new name for Epachtus" only for Mesoleius tenellus Holmgren.

Type-species: Mesoleius tenellus Holmgren. Monotypic.

This is a Holarctic genus of moderate size.

popofensis (Ashmead). Southwestern Alaska, Alta.

Hypocryptus popofensis Ashmead, 1902. Wash. Acad. Sci., Proc. 4: 208. " $\delta "=\uparrow$.

spatiosus (Davis). Que., N. Y., R. I.

Sychnoleter spatiosus Davis, 1898 (1897). Amer. Ent. Soc., Trans. 24: 306. \&.

truncatus (Davis). N. Y., "Canada," Mont.

Clepsiporthus truncatus Davis, 1898. Amer. Ent. Soc., Trans. 24: 326. ठ, ๆ.

\section{Genus HADRODACTYLUS Foerster}

Dizemon Foerster, 1868. Naturh. Ver. Rheinlande, Verh. 25: 199.

Type-species: Mesoleptus typhae Gravenhorst. By subsequent monotypy from inclusion by Kriechbaumer, 1891. The type-species is Gravenhorst's identification of and lapsus for Ichneumon tiphae Geoffroy. The taxonomy of H.tiphae is discussed by Idar (1974).

Hadrodactylus Foerster, 1868. Naturh. Ver. Rheinlande, Verh. 25: 199.

Type-species: Ichneumon tiphae Geoffroy. Desig. by Viereck, 1914 from two species included by Woldstedt, 1877.

Zemiodes Foerster, 1868. Naturh. Ver. Rheinlande, Verh. 25: 200.

Type-species: Mesoleptus erythropus Kriechbaumer. Desig. by Perkins, 1962 from two species included by Kriechbaumer, 1891.

Narcopoea Foerster, 1868. Naturh. Ver. Rheinlande, Verh. 25: 204. 
Type-species: Mesoleptus typhae Gravenhorst. By subsequent monotypy from inclusion by Kriechbaumer, 1891. See above discussion of type-species of Dizemon.

Meropaches Schmiedeknecht, 1913. Opusc. Ichn., v. 5, p. 2705.

Type-species: Meropaches bulsanensis Schmiedeknecht. Monotypic.

This is a large Holarctic genus. The usual hosts are presumed to be sawflies of the genus Dolerus.

Taxonomy: Idar, 1974. Ent. Scand. 5: 23 (discussion bearing on identity of Ichneumon tiphae Geoffroy).

coxatus (Davis). N. Y. s. to Va., w. to s.w. S. Dak.

Hadrodactylus elongatus var. coxatus Davis, 1898 (1897). Amer. Ent. Soc., Trans. 24: 320. $\delta$, + .

elongatus (Cresson). Mass., Alta.

Mesoleptus elongatus Cresson, 1868. Amer. Ent. Soc., Trans. 2: 96. ठ',.

femoratus (Davis). Colo. See Hadrodactylus seldoviae (Ashmead).

Catoglyptus femoratus Davis, 1898 (1897). Amer. Ent. Soc., Trans. 24: 310. o, १.

Taxonomy: Townes, 1945. Amer. Ent. Soc., Mem. 11: 489. -Townes, 1970 (1969). Amer. Ent. Inst., Mem. 13: 80.

flavicornis (provancher). Que.

Mesoleptus flavicornis Provancher, 1879. Nat. Canad. 11: 228..+

inceptus (Cresson). Que. w. to s.w. B. C., s. to N. C., Iowa, and Colo.

Mesoleptus inceptus Cresson, 1868. Amer. Ent Soc., Trans. 2: 96. ठ, ๆ.

Mesoleptus propinquus Cresson, 1868. Amer. Ent. Soc., Trans. 2: 97. ठ.

Zemiodes coloradensis Davis, 1898 (1897). Amer. Ent. Soc., Trans. 24: 323. ठै, ९.

laurentianus (Provancher). Que.

Tryphon Laurentianus Provancher, 1875. Nat. Canad. 7: 118. $\delta$.

longicornis (Cresson). N. H., N. Y., Del., Mich.

Mesoleptus longicornis Cresson, 1864. Ent. Soc. Phila., Proc. 3: 270. ठ.

magnacornis (Davis). Wash.

Zemiodes magnacomis Davis, 1898 (1897). Amer. Ent. Soc., Trans. 24: 324. ठ.

seldoviae (Ashmead). N. Y., Pa., N. C., Mich., Colo., Alta. Idaho, Alaska.

Hadrodactylus elongatus var. femoratus Davis, 1898 (1897). Amer. Ent. Soc., Trans. 24: 320. $\delta$, $\uparrow$. Preocc. in Hadrodactylus by Davis, 1898, p. 310.

Hypocryptus seldoviae Ashmead, 1902. Wash. Acad. Sci., Proc. 4: 209. ठ, ๆ.

seminiger (Provancher). Que., Pa., Ont., Colo., Mont., Nev.

Paniscus seminiger Provancher, 1874. Nat. Canad. 6: 107. ๆ ( $\delta$ misdet.).

Hadrodactylus ruficornis Davis, 1898 (1897). Amer. Ent. Soc., Trans. 24: 320. ๆ.

tibialis (Ashmead). Southwestern Alaska, w. Wash.

Hypocryptus tibialis Ashmead, 1902. Wash. Acad. Sci., Proc. 4: 209. ठ์.

variegatipes (Ashmead). Southwestern Alaska.

Hypocryptus variegatipes Ashmead 1902. Wash. Acad. Sci., Proc. 4: 208. ठँ.

\section{Genus SYNDIPNUS Foerster}

Polypystis Foerster, 1868. Naturh. Ver. Rheinlande, Verh. 25: 208.

Type-species: Tryphon lateralis Gravenhorst. Desig. by Viereck, 1914 from two species included by Roman, 1909.

Syndipnus F'oerster, 1868. Naturh. Ver. Rheinlande Verh. 25: 209.

Type-species: Euryproctus (Syndipnus) macrocerus Thomson. Desig. by Viereck, 1914 from nine species included by Thomson, 1883.

Tlemon Foerster, 1868. Naturh. Ver. Rheinlande, Verh. 25: 209.

Type-species: Tlemon delicatus Ashmead. By subsequent monotypy from inclusion by Ashmead, 1902.

Dicksonia Holmgren, 1881 (1880). Novas Species Ins. Cura et Labore A. E. Nordenskioldii e Novaia Semlia Coactorum, p. 11.

Type-species: Dicksonia arctica Holmgren. Monotypic. 
Neastus Holmgren, 1883. In Holmgren and Aurivillius, Ent. Tidskr. 4: 154.

Type-species: Neastus laeviceps Holmgren. Monotypic.

Anaglymmus Roman, 1914. Arkiv for Zool. 9 (2): 3.

Type-species: Anaglymmus incisus Roman. Desig. by Viereck, 1921.

This is a moderately large Holaretic genus.

Revision: Walley, 1940. Canad. Ent. 72: 135-145.

Taxonomy: Walley, 1945. Canad. Ent. 77: 41-43 (additions to revision).

alaskensis Walley. Northeastern N. W. T., interior Alaska.

Syndipnus alaskensis Walley, 1940. Canad. Ent. 72: 138. ¿, ․

conformis (Holmgren). Western Sask.; Europe.

Trematopygus conformis Holmgren, 1857 (1855). Svenska Vetensk.-Akad. Handl. (n. f.) 1: 183. o.

delicatus (Ashmead). Southwestern Alaska, Sask. Not included in the revision by Walley (1940).

Tlemon delicatus Ashmead, 1902. Wash. Acad. Sci., Proc. 4: 216. ठ.

gaspesianus (Provancher). Que. Host: Pikonema alaskensis (Roh.). According to Townes and Townes (1951), S. gaspesianus is "transcont. in Canad. Zone."

Tryphon gaspesianus Provancher, 1879. Nat. Canad. 11: 252. ?.

Taxonomy: Townes and Townes, 1951. In Muesebeck et al., U. S. Dept. Agr., Agr. Monog. 2: 337.

lateralis (Gravenhorst). N. H., s. Alta.; Europe. Host: Pachynematus extensicornis (Nort.).

Tryphon lateralis Gravenhorst, 1829. Ichn. Europaea, v. 1, p. 690. [male].

Syndipnus punctiscuta Thomson, 1894. Opuse. Ent. 19: 2005. ठ, ㅇ.

Taxonomy: Pfankuch, 1907. Ztschr. System. Hym. Dipt. 7: 19 (syn.).

pannicularius (Holmgren). Interior Alaska; n. Europe.

Mesoleius pannicularius Holmgren, 1857 (1855). Svenska Vetensk.-Akad. Handl. (n. f.) 1: 178. ?.

phygadeuontoides Walley. Northern Man.

Syndipnus phygadeuontoides Walley, 1945. Canad. Ent. 77: 42. \&.

probatus Walley. N. Y., Ont. Host: Nematus sp. on poplar.

Syndipnus probatus Walley, 1940. Canad. Ent. 72: 144. ठ, १.

rubiginosus Walley. P. E. I., N. B., Que., Maine, Ont., n. Minn., s. Man., Sask. Host: Pikonema alaskensis (Roh.), P. dimmockii (Cress.).

Syndipnus mibiginosus Walley, 1940. Canad. Ent. 72: 140. ơ, ?.

ungavae Walley. Northern Que.

Syndipnus ungavae Walley, 1940. Canad. Ent. 72: 139..

\section{Genus HYPAMBLYS Foerster}

Hypamblys Foerster, 1868. Naturh. Ver. Rheinlande, Verh. 25: 212.

Type-species: Mesoleizus transfuga Holmgren. Desig. by Viereck, 1914 from four species included by Thomson, 1894 .

Apystus Foerster, 1868. Naturh. Ver. Rheinlande, Verh. 25: 212.

Type-species: Tryphon albopictus Gravenhorst. Monotypically included and desig. by Perkins, 1962.

Lathrophagus Foerster, 1868. Naturh. Ver. Rheinlande, Verh. 25: 213.

Type-species: Mesoleius buccatus Holmgren. Monotypically included and desig. by Perkins, 1962.

This is a Holarctic genus of moderate size.

albifacies (Provancher). Mass., N. Y., Ont.

Mesostenus albifacies Provancher, 1888. Addit. Corr. Faune Ent. Canada Hym., p. 362. ․

albopictus (Gravenhorst). Maine, s.e. and s.w. Alaska, central Wash., n.w. Calif.; Europe. Host:

Anoplonyx laricivorus (R. and M.), Pristiphora abbreviata (Htg.).

Tryphon albopictus Gravenhorst, 1829. Ichn. Europaea, v. 2, p. 255. ठ. 
Mesoleius transfuga Holmgren, 1857 (1855). Svenska Vetensk.-Akad. Handl. (n. f.) 1: 164. b, 9 .

Calliphrums popofensis Ashmead, 1902. Wash. Acad. Sci., Proc. 4: 221..+

Calliphrurus glacialis Ashmead, 1902. Wash. Acad. Sci., Proc. 4: 222. ठ.

Mesoleins gymnonychi Rohwer, 1920. U. S. Natl. Mus., Proc. 57: 223. \&.

Taxonomy: Pfankuch, 1907. Ztschr. System Hym. Dipt. 7: 18 (syn.). -Townes, 1945. Amer.

Ent. Soc., Mem. 11: 527 (syn.).

Biology: Hinz, 1961. Schweiz. Ent. Gesell., Mitt. 34: 4.

conformis (Walley). Ont., N. C., w. Oreg.

Ipoctonus conformis Walley, 1933. Canad. Ent. 65: 257. o, ․

\section{Genus PHOBETES Foerster}

Phobetes Foerster, 1868. Naturh. Ver. Rheinlande, Verh. 25: 198.

Type-species: Tryphon fuscicomis Holmgren. Desig. by Viereck, 1914 from two species included by Thomson, 1889 .

Ipocton us Foerster, 1868. Naturh. Ver. Rheinlande, Verh. 25: 199. Preocc. by Heine, 1860.

Type-species: Ichneumon chrysostomus Gravenhorst. Desig. by Viereck, 1914 from three species included by Thomson, 1889.

Philotymma Foerster, 1868. Naturh. Ver. Rheinlande, Verh. 25: 209.

Type-species: Ichneumon chrysostomus Gravenhorst. Desig. by Townes, Momoi, and Townes, 1965 from four species included by Townes, Townes, and Gupta, 1961.

Phobetus Thomson, 1889. Opusc. Ent. 13: 1430. Emend. Preoce. by LeConte, 1856.

Griphodes Kriechbaumer, 1894. Termeszet. Fuzetek 17: 57.

Type-species: Griphodes caligatus Kriechbaumer. Monotypic.

Phobetellus Hincks, 1944. Roy. Ent. Soc. London, Proc., Ser. B: Taxonomy 13: 34. N. name for Phobetus Thomson.

Ipoctonimus Hincks, 1944. Roy. Ent. Soc. London, Proc., Ser. B: Taxonomy 13: 35. N. name for Ipoctonus Foerster.

Troctonus Townes, 1944. Amer. Ent. Soc., Mem. 11: 21. Nomen nudum.

This is a moderately large genus of Neotropic, Holaretic, and Oriental distribution. The majority of the species occur in the Holarctic region.

egregius (Davis). Wash.

Mesoleptus egregius Davis, 1898 (1897). Amer. Ent. Soc., Trans. 24: 317. ठ. Preocc. secondarily in Mesoleptus if Exolytus egregius Foerster is a species of Mesoleptus.

rufigaster (Provancher). Ont.

Tryphon mifigaster Provancher, 1886. Addit. Corr. Faune Ent. Canada Hym., p. 104.. The lectotype selected by Gahan and Rohwer (1918) was rejected by Mason (1955). Barron (1975) selected a new lectotype.

Taxonomy: Gahan and Rohwer, 1918. Canad. Ent. 50: 200. - Townes, 1945. Amer. Ent. Soc., Mem. 11: 163 (syn.). -Mason, 1955. Canad. Jour. Zool. 33: 20. - Barron, 1975. Nat. Canad. 102: 551 .

striatus (Davis). Maine, Colo., Alta., Wash.; Mexico. Host: Ametastegia glabrata (Fall.)

Mesoleptus striatus Davis, 1898 (1897). Amer. Ent. Soc., Trans. 24: 318. ठ。.

Mesoleptus torpens Davis, 1898 (1897). Amer. Ent. Soc., Trans. 24: 318. đ, क.

Mesoleptus scrupulosus Davis, 1898 (1897). Amer. Ent. Soc., Trans. 24: 318. ơ, \&.

Mesoleins balteatus Cushman, 1919. U. S. Natl. Mus., Proc. 55: 541. \&.

uniformis (Provancher). Que., Ont., Alta. Host: Trichiosoma triangulum Kby.

Campoplex unicolor Provancher, 1874. Nat. Canad. 6: 144. ठ. Formerly preoce. in Mesoleptus by Cresson, 1864.

Mesoleptus uniform is Provancher, 1879. Nat. Canad. 11: 232. N. name for C. unicolor Provancher.

\section{Genus HYPERALLUS Foerster}

Gastroporus Foerster, 1868. Naturh. Ver. Rheinlande, Verh. 25: 206. 
Type-species: Hyperallus caliroae Viereck. Monotypically included and desig. by Perkins, 1962.

Hyperallus Foerster, 1868. Naturh. Ver. Rheinlande, Verh. 25: 210.

Type-species: Hyperallus caliroae Viereck. By subsequent monotypy from inclusion by Viereck, 1911.

Only one species is known.

caliroae Viereck. N. Y., Va., La., n.e. Kans. Host: Caliroa liturata MacG., C. sp. on Quercus rubra.

Hyperallus caliroae Viereck, 1911. U. S. Natl. Mus., Proc. 40: 189. §, $९$.

Polyterus calirone Rohwer, 1915. U. S. Natl. Mus., Proc. 49: 221. o. Preocc. in Hyperallus by Viereck, 1911.

Hyperallus virginiensis Townes, 1945. Amer. Ent. Soc., Mem. 11: 528. N. name for $P$. caliroae Rohwer.

Taxonomy: Townes, 1970 (1969). Amer. Ent. Inst., Mem. 13: 138 (syn.).

Biology: Cushman, 1911. U. S. Dept. Agr., Bur. Ent. Bul. 97, pt. 5, p. 101-102.

\section{Genus OCCAPES Townes}

Occapes Townes, 1970 (1969). Amer. Ent. Inst., Mem. 13: 138.

Type-species: Occapes sierrae Townes. Orig. desig.

This is a small Holarctic genus.

sierrae Townes. Northern Calif.

Occapes sierrae Townes, 1970 (1969). Amer. Ent. Inst., Mem. 13: 139. ơ, o.

\section{Genus EURYPROCTUS Holmgren}

Euryproctus Holmgren, 1857 (1855). Svenska Vetensk.-Akad. Handl. (n. f.) 1: 109.

Type-species: Mesoleptus annulatus Gravenhorst. Desig. by Viereck, 1912.

Sychnoleter Foerster, 1868. Naturh. Ver. Rheinlande, Verh. 25: 197.

Type-species: Mesoleptus geniculosus Gravenhorst. Monotypically included and desig. by Thomson, 1889 .

Hypocryptus Foerster, 1868. Naturh. Ver. Rheinlande, Verh. 25: 198.

Type-species: Mesoleptus (Hypocryptus) testaceicornis Brischke. By subsequent monotypy from inclusion by Brischke, 1892. The type-species is regarded as a synonym of $E$. mundus (Gravenhorst).

Xenonastes Foerster, 1868. Naturh. Ver. Rheinlande, Verh. 25: 208.

Type-species: Euryproctus alpinus Holmgren. Monotypically included and desig. by Townes, Momoi, and Townes, 1965.

Fovaya Cameron, 1903. Ztchr. System. Hym. Dipt. 3: 341.

Type-species: Fovaya annulicornis Cameron. Monotypic.

This large genus is Holarctic and Oriental (a few spp.).

Revision: Davis, 1898 (1897). Amer. Ent. Soc., Trans. 24: 327-330.

albocinctus Davis. N. H.

Euryproctus albocinctus Davis, 1898 (1897). Amer. Ent. Soc., Trans. 24: 328. ․

albopunctus Davis. N. H.

Euryroctus albopunctus Davis, 1898 (1897). Amer. Ent. Soc., Trans. 24: 328. §, १.

annulatipes (Provancher). Que.

Mesoleptus annulatipes Provancher, 1886. Addit. Corr. Faune Ent. Canada Hym., p. 93, 96.

$\delta$. The alternate spelling cinctipes on p. 93 (key) was rejected in favor of anmulatipes

by Barron (1975).

Taxonomy: Barron, 1975. Nat. Canad. 102: 424.

bituminosus Davis. N. H., Mass., Minn., Alta., Idaho, Wash., Oreg.

Euryproctus bituminosus Davis, 1898 (1897). Amer. Ent. Soc., Trans. 24: 328..

clavatus (Provancher). Que.

Exetastes clavatus Provancher, 1883. Petite Faune Ent. Canada Hym., p. 386... 
curvator Davis. Que. s. to n. Ga., w. to Mich.

Tryphon annulatus Provancher, 1875. Nat. Canad. 7: 119.. . Preocc. in Euryproctus by Gravenhorst, 1829. The holotype located by Barron (1975) supplants the "lectotype" selected by Gahan and Rohwer (1918).

Euryproctus curvator Davis, 1898 (1897). Amer. Ent. Soc., Trans. 24: 329. ठ。.

Taxonomy: Gahan and Rohwer, 1918. Canad. Ent. 50: 32. - Barron, 1975. Nat. Canad. 102: 425-426.

dakotaensis Davis. Eastern S. Dak., n.e. Kans.

Euryproctus dakotaensis Davis, 1898 (1897). Amer. Ent. Soc., Trans. 24: 330. ठ’.

depressus (Provancher). Que., N. H.

Mesoleptus depressus Provancher, 1875. Nat. Canad. 7: 114. $\delta$. The holotype located by Barron (1975) supplants the "lectotype" selected by Gahan and Rohwer (1918).

Taxonomy: Gahan and Rohwer, 1918. Canad. Ent. 50: 32. - Barron, 1975. Nat. Canad. 102: 461.

latigaster (Provancher). Ont.

Mesostenus latigaster Provancher, 1886. Addit. Corr. Faune Ent. Canada Hym., p. 77. $q$.

longicornis (Provancher). Que., N. Y., Ont.

Mesostenus longicomis Provancher, 1874. Nat. Canad. 6: 300. ठ.

Tryphon Moyeni Provancher, 1875. Nat. Canad. 7 (4): 120. ठ。.

Mesoleptus longipes Provancher, 1875. Nat. Canad. 7 (9): 271. $\delta$. In view of the fact that the holotype is lost (Barron, 1975), I see no rationale for Townes (1945) failure to apply this name according to the actions of the first revisor, the first revisor being Provancher (1879), who suppressed longipes and longicomis (the latter then being preocc. in Mesoleptus by Cresson, 1864) as synonyms of Mesoleptus moyeni (Provancher).

Mesoleptus perditus Provancher, 1886. Addit. Corr. Faune Ent. Canada Hym., p. 97. $\delta$. Euryproctus moyenii Dalla Torre, 1901. Cat. Hym., v. 3, p. 348. Emend.

Taxonomy: Provancher, 1879. Nat. Canad. 11: 223. -Townes, 1945. Amer. Ent. Soc., Mem. 11: 543. - Barron, 1975. Nat. Canad. 102: 498, 499, 510, 529-530.

petiolatus Davis. N. H., N. Y., Pa., Mich.

Euryproctus petiolatus Davis, 1898 (1897). Amer. Ent. Soc., Trans. 24: 328. + . Suppressed as a synonym of Mesoleptus longipes Provancher by Townes (1945); see synonymy of preceding species, E. longicomis.

Taxonomy: Townes, 1945. Amer. Ent. Soc., Mem. 11: 534.

puritanicus Davis. Mass.

Euryproctus puritanicus Davis, 1898 (1897). Amer. Ent. Soc., Trans. 24: 330. \&.

ramis Davis. N. H., Alta., Colo.

Euryproctus sessilis Davis, 1898 (1897). Amer. Ent. Soc., Trans. 24: 329. ․

Euryproctus ramis Davis, 1898 (1897). Amer. Ent. Soc., Trans. 24: 329. ․

sentinis Davis. Maine, N. H., R. I., N. Y., Ont., Tex.

Euryproctus rufopictus Davis, 1898 (1897). Amer. Ent. Soc., Trans. 24: 330. $\$$.

Euryproctus sentinis Davis, 1898 (1897). Amer. Ent. Soc., Trans. 24: 330. ๆ.

\section{SUBFAMILY ANOMALONINAE}

This is a medium-sized subfamily of worldwide distribution. Gauld (1976) recognized only two tribes and 35 genera or subgenera as opposed to the four tribes and 37 genera recognized by Townes (1971). Although I am not entirely convinced that the several genera reduced to subgeneric status by Gauld should be treated as subgenera, and although I generally regard the subgeneric category as being a nomenclatural nuisance, I have nevertheless followed Gauld's classification here, because in its entirety it appears to be an excellent piece of work.

Taxonomy: Townes, 1971. Amer. Ent. Inst., Mem. 17: 122-159 (genera of world). -Gauld, 1976. Brit. Mus. (Nat. Hist.) Ent., Bul. 33: 1-135 (genera of world). 


\section{TRIBE GRAVENHORSTIINI}

Members of this tribe are internal parasites of Lepidoptera, ovipositing into the larvae and always emerging from the pupae.

\section{Genus HABRONYX Foerster}

Gauld (1976) recognized four subgenera, three of which are represented by Nearctic species.

Taxonomy: Townes, 1971. Amer. Ent. Inst., Mem. 17: 130-131. -Gauld, 1976. Brit. Mus. (Nat.

Hist.) Ent., Bul. 33: 31-41.

\section{Genus HABRONYX Subgenus HABRONYX Foerster}

Habronyx Foerster. 1860. Naturh. Ver. Rheinlande, Verh. 17: 147.

Type-species: Habronyx gravenhorstii Foerster, Monotypic. The type-species is regarded as a synonym of $H$. heros (Wesmael).

Acanthostoma Kriechbaumer, 1895. Naturf. Gesell. Leipzig, Sitzber. 19: 128.

Type-species: Acanthostoma japonicum Kriechbaumer. Monotypic. The type-species is regarded as a synonym of $H$. insidiator (Smith).

Macrostemma Shestakov, 1923. Mus. Zool., Russ. Acad. Sci., Ann. 24: 46.

Type-species: Macrostemma elegans Shestakov. Monotypic.

Formosanomalon Uchida, 1928. Hokkaido Imp. Univ., Faculty Agr., Jour. 21: 241.

Type-species: Formosanomalon baibarense Uchida. Monotypic and orig. desig.

This small subgenus is known from all zoogeographic regions. The "Marginal Index" of the Nearctic species disagrees with Gauld's (1976) definition of the subgenus Habronyx, and Gauld appears to have placed too much emphasis on this character in his key couplet which differentiates the subgenera Habronyx and Camposcopus.

luteopectus (Norton). Conn., N. Y., N. C., Mich.

Anomalon luteo-pectus Norton, 1863. Ent. Soc. Phila., Proc. 1: 363. ठ์.

Anomalon luteopectum Dalla Torre, 1901. Cat. Hym., v. 3, p. 167. Emend.

Gravenhorstia luteopecta Townes, 1951. In Townes and Townes, in Muesebeck et al., U. S. Dept. Agr., Agr. Monog. 2: 397. Emend.

Taxonomy: Townes, 1971. Amer. Ent. Inst., Mem. 17: 131.

magniceps (Cresson). N. Y., N. J., Pa., n. Va., Mich., Ill., n.e. Kans., n.e. Tex., s. Ariz. Host:

Geometrid?, Hemaris diffinis (Bdv.), Anisota oslari Roths., Dryocampa rubicunda rubicunda (F.).

Anomalon magniceps Cresson, 1872. Amer. Ent. Soc., Trans. 4: 170..

Anomalon fuliginosa Davis, 1898 (1897). Amer. Ent. Soc., Trans. 24: 356. ․ N. syn.

Taxonomy: Walkley, 1967. In Krombein et al., U. S. Dept. Agr., Agr. Monog. 2, sup. 2, p. 211

(generic placement).

\section{Genus HABRONYX Subgenus CAMPOSCOPUS Foerster}

Camposcopus Foerster, 1868. Naturh. Ver. Rheinlande, Verh. 25: 145.

Type-species: Camposcopus aclerivora Rohwer. Monotypically included and desig. by Rohwer, 1915.

Labrorychus Foerster, 1868. Naturh. Ver. Rheinlande, Verh. 25: 146.

Type-species: Anomalon nigricorne Wesmael. By subsequent monotypy from inclusion by Brischke, 1880 .

Blaptocampus Thomson, 1892. Opusc. Ent. 16: 1765.

Type-species: Anomalon nigricome Wesmael. Desig. by Viereck, 1914.

This is a small subgenus of Holarctic, Oriental, and Australian distribution.

aclerivorus (Rohwer). Maine, R. I., Pa., Mich., Minn. Host: Paralobesia viteana (Clem.), Acrobasis comptoniella Hulst, A. mubrifasciella Pack., Acleris sp., Argyrotaenia velutinana (Wlk.).

Camposcopus aclerivora Rohwer, 1915. U. S. Natl. Mus., Proc. 49: 226 .. 


\section{Genus HABRONYX Subgenus HABROCAMPULUM Gauld}

Habron yx subg. Habrocampulum Gauld 1976. Brit. Mus. (Nat. Hist.) Ent., Bul. 33: 38.

Type-species: Anomalon biguttatum Gravenhorst. Monotypic and orig. desig.

This is a small Holarctic subgenus. I am grateful to have been informed of the existence of a Nearctic species by Dr. Ian Gauld (personal commun., 1977). Dr. Gauld said that the Nearctic specimens he had seen were in the collection of the American Entomological Institute, Ann Arbor, Mich.

\section{Genus APHANISTES Foerster}

Aphanistes Foerster, 1868. Naturh. Ver. Rheinlande, Verh. 25: 145.

Type-species: Anomalon bellicosum Wesmael. Desig. by Viereck, 1914 from three species included by Brischke, 1880 .

Anochilacrum Enderlein, 1921. Stettin. Ent. Ztg. 82: 12.

Type-species: Anochilacrum flavigena Enderlein. Monotypic and orig. desig.

This is a large genus which is known from all zoogeographic regions except the Ethiopian. The Nearctic species are being revised by Dr. H. P. Hopper.

hyalinus (Norton). Que. s. to n. Ga., w. to Ill. Host: Datana contracta Wlk., Schizura concinna (J. E. S.), Symmerista albifrons (J. E. S.), Phosphila turbulenta Hbn., Halisidota caryae (Harris).

Anomalon hyaline Norton, 1863. Ent. Soc. Phila., Proc. 1: 361. 9.

Anomalon nigro-rufus Norton, 1863. Ent. Soc. Phila., Proc. 1: 361 ..

Anomalon basilicon Davis, 1898 (1897). Amer. Ent. Soc., Trans. 24: 359 . .

Anomalon edemae Davis, 1898 (1897). Amer. Ent. Soc., Trans. 24: 360. §, १.

puparum (Ashmead). Mid-coastal Calif. Host: Noctuid.

Agrypon puparum Ashmead, 1890 (1889). U. S. Natl. Mus., Proc. 12: 424. \&.

\section{Genus BARYLYPA Foerster}

Barylypa Foerster, 1868. Naturh. Ver. Rheinlande, Verh. 25: 146.

Type-species: Barylypa genalis Thomson. Desig. by Viereck, 1914 from two species included by Thomson, 1892 .

Laphyctes Foerster, 1868. Naturh. Ver. Rheinlande, Verh. 25: 146. Preocc. by Dujardin, 1844, Reichenbach, 1850, and Stal, 1853.

Type-species: Laphyctes insidiator Foerster. Desig. by Viereck, 1914 from three species included by Foerster, 1878.

Sarntheinia Dalla Torre, 1901. Wien. Ent. Ztg. 20: 52. N. name for Laphyctes Foerster.

Hadromanus Szepligeti, 1905. In Wytsman, Gen. Ins., fasc. 34, p. 14.

Type-species: Anomalon (Labrorychus) laevicoxe Schmiedeknecht. Monotypic.

Magnibucca Morley, 1913. Rev. Ichn. Brit. Mus., v. 2, p. 79.

Type-species: Magnibucca testacea Morley. Monotypic.

Trochiscomerus Meyer, 1931. Konowia 10: 8.

Type-species: Trochiscomerus schmiedeknechti Meyer. Monotypic.

This is a large genus of Neotropic, Holarctic, Oriental, and Australian distribution.

Taxonomy: Townes, 1971. Amer. Ent. Inst., Mem. 17: 139-140. -Gauld, 1976. Brit. Mus. (Nat.

Hist.) Ent., Bul. 33: 44-46.

elongata (Davis). Mich., S. Dak., Alta.

Anomalon elongatum Davis, 1898 (1897). Amer. Ent. Soc., Trans. 24: 35ं7. ठ, ९.

Anomalon bipartitana Davis, 1898 (1897). Amer. Ent. Soc., Trans. 24: 358. ठै.

irona Grimble. Northern Mich.

Barylypa irona Grimble, 1967. Canad. Ent. 99: 1332.

paeneferruginea (Viereck). Western Kans.

Anomalon paeneferrugineum Viereck, 1905. Kans. Acad. Sci., Trans. 19: 310. \&.

relicta (Fabricius). "North America."

Ophion relictus Fabricius, 1798. Sup. Ent. System., p. 236. [male]. 
Taxonomy: Townes, 1961. Ent. Soc. Wash., Proc. 63: 111. - Gauld, 1976. Brit. Mus. (Nat.

Hist.) Ent., Bul. 33: 47-48.

smithii (Davis). N. J., Ga.

Anomalon smithii Davis, 1898 (1897). Amer. Ent. Soc., Trans. 24: 357. đ.

sulcata (Provancher). Vt., R. I., N. Y., Ont.

Podogaster sulcatus Provancher, 1886. Addit. Corr. Faune Ent. Canada Hym., p. 90..

\section{Genus CORSONCUS Townes}

Corsoncus Townes, 1971. Amer. Ent. Inst., Mem. 17: 141.

Type-species: Anomalon magum Cresson. Monotypic and orig. desig.

This is a small Neotropic and Nearctic genus. The generic limits of Corsoncus were redefined by Gauld (1976). Except for $C$. nigricans (Cresson), the Nearctic species here newly placed in Corsoncus had been referred to Hadromanus (now a synonym of Barylypa) by Townes (1971). I have not seen the types of the species now placed in Corsoncus.

Taxonomy: Townes, 1971. Amer. Ent. Inst., Mem. 17: 140. - Gauld, 1976. Brit. Mus. (Nat.

Hist.) Ent., Bul. 33: 46-48.

apicalis (Cresson), n. comb. Kans., Colo.

Cremastus fulvescens var, apicalis Cresson, 1865. Ent. Soc. Phila., Proc. 4: 286. $q$.

Cremastus fulvescens var. seminiger Cresson, 1865. Ent. Soc. Phila., Proc. 4: 286. ơ, ?.

Anomalon fulvescens var. hemimelanus Viereck, 1905. Kans. Acad. Sci., Trans. 19: 310. ?.

clavatus (Davis), n. comb. S. C., Ga.

Anomalon clavatum Davis, 1898 (1897). Amer. Ent. Soc., Trans. 24: 357..

fulvescens (Cresson), n. comb. Colo., Ariz.

Cremastus fulvescens Cresson, 1865. Ent. Soc. Phila., Proc. 4: 285. §, १.

nigricans (Cresson), n. comb. Colo.

Cremastus fulvescens var. nigricans Cresson, 1865. Ent. Soc. Phila., Proc. 4: 286. ․

orbitalis (Cresson). Tex., Colo.

Anomalon orbitalis Cresson, 1872. Amer. Ent. Soc., Trans. 4: 170. ठ‡.

pallitarsis (Cresson), n. comb. N. Y., Del., W. Va., S. C., Tex. Host: Cirrophanus triangulifer

Grt.

Anomalon pallitarse Cresson, 1872. Amer. Ent. Soc., Trans. 4: 170. ठ.

Anomalon palliditarse Dalla Torre, 1901. Cat. Hym., v. 3, p. 168. Emend.

\section{Genus LIOPTERNA Townes}

Liopterna Townes, 1971. Amer. Ent. Inst., Mem. 17: 138.

Type-species: Liopterna schlingeri Townes. Monotypic and orig. desig.

A single species is known.

schlingeri Townes. Southern Calif. Known from a single male collected at a locality cited by Townes as 3 miles west of "Octoella Wells," Calif. It is apparent that this is a misspelling for Ocotilla Wells in San Diego County. The type-locality would presumably lie at the eastern edge of the Anza-Borrego Desert State Park.

Liopterna schlingeri Townes, 1971. Amer. Ent. Inst., Mem. 17: 138. o .

\section{Genus THERION Curtis}

Therion Curtis, 1829-1830. Guide to Arrangement Brit. Insects, p. 101.

Type-species: Ichneumon circumflexus Linnaeus. Desig. by Curtis, 1839.

Therium Agassiz, 1846. Nom. Zool., Index Univ., p. 368. Emend.

Exochilum Wesmael, 1849. [Brussels] Acad. Roy. de Belg., Bul. 16 (pt. 2): 119, 222.

Type-species: Ichneumon circumflexus Linnaeus. Monotypic. 
According to Townes (1971) this moderately large genus is known from all zoogeographic regions except the Australian Region.

Taxonomy: Townes, 1971. Amer. Ent. Inst., Mem. 17: 156-157.

circumflexum (Linnaeus). Que. w. to s.w. B. C., s. to N. J., N. Mex., and Calif.; Eurasia; n. Africa. Host: Acronicta dactylina hesperida Sm.?

Ichneumon circumflexus Linnaeus, 1758. Syst. Nat., ed. 10, v. 1, p. 566. [female].

Exochilum occidentale Cresson, 1879 (1878). Acad. Nat. Sci. Phila., Proc. 30: 366..

Anomalon nigrum Provancher, 1879. Nat. Canad. 11 (no. 127): 142. ठ,.+

Anomalon japonicum Cameron, 1906. Entomologist 39: 98. ․

Exochilum callosum Shestakov, 1923. Mus. Zool., Russ. Acad. Sci., Ann. 24: 44. Sex not indicated.

Exochilum tarsatum Shestakov, 1923. Mus. Zool., Russ. Acad. Sci., Ann. 24: 44. Sex not indicated.

Exochilum laricis Matsumura, 1926 (1925). Mus. Zool., Russ. Acad. Sci., Ann. 26: 36. $q$.

Exochilum circumflexum ab. nigroscutellata Hellen, 1926. Soc. pro Fauna et Flora Fenn., Acta 56 (6): 15 . ‥

Exochilum circumflexum var. nipponicum Uchida, 1928. Hokkaido Imp. Univ., Faculty Agr., Jour. 21: 236. ¿, ․

Taxonomy: Uchida, 1958. Insecta Matsumurana 21: 92-93 (syn). - Townes, Momoi, and

Townes, 1965. Amer. Ent. Inst., Mem. 5: 380-381 (syn.).

Morphology: Iwata, 1960. Acta Hym. 1: 169 (ovary and egg).

confusum (Ashmead). Va., N. C., S. C., Tex. Host: Acronicta americana (Harris), A. hastulifera (J. E. S.).

Schizoloma confusa Ashmead, 1890 (1889). U. S. Natl. Mus., Proc. 12: 426. ?.

Exochilum acronyctae Riley, 1890. In Riley and Howard, U. S. Dept. Agr., Insect Life 3: 155. Nomen nudum.

Exochilum acronyctae Ashmead, 1896. Amer. Ent. Soc., Trans. 23: 190. \&. Townes (1945) selected as lectotype the specimen which Ashmead erroneously recorded as being from D. C.; the type-locality is actually Va.

Taxonomy: Townes, 1945. Amer. Ent. Soc., Mem. 11: 724.

fuscipenne (Norton). N. B. w. to Hudson Bay and s. B. C., s. to Va., N. Mex., and Calif. Host: Estigmene acrea (Drury), Halisidota maculata (Harris), Acronicta americana (Harris), A. dactylina hesperida Sm., Merolonche lupini (Grt.).

Exochilum fuscipennis Norton, 1863. Ent. Soc. Phila., Proc. 1: 359 ..

Exochilum verticale Morley, 1913. Rev. Ichn. Brit. Mus., v. 2, p. 78..

Taxonomy: Townes, 1961. Ent. Soc. Wash., Proc. 63: 106.

longipes (Provancher). Tex., s.e. Wyo., Colo., Utah, Ariz., Nev., s. B. C., Oreg., Calif. Host: Heliothis sp., Spodoptera exigua (Hbn.).

Anomalon californicum Cresson, 1879 (1878). Acad. Nat. Sci. Phila., Proc. 30: 367. Preocc. in Anomalon by Cresson, 1879, p. 367 .

Heteropelma longipes Provancher, 1886. Addit. Corr. Faune Ent. Canada Hym., p. 120, 363. ס.

Anomalon simile Ashmead, 1890 (1889). U. S. Natl. Mus., Proc. 12: 423. ․

morio (Fabricius). N. S. w. to Wash., s. to s. Fla., s.e. Kans., and n.w. Nev.; Mexico. Host: Cycnia inopinata (Hy. Edw.), Diacrisia virginica (F.), Estigmene acrea (Drury), Halisidota maculata (Harris), Hyphantria cunea (Drury).

Ichneumon morio Fabricius, 1781. Species Insectorum, v. 1, p. 436. [female].

Ophion mundus Harris, 1835. In Hitchcock, Rpt. Geol. Min. Bot. Zool. Mass., ed. 2, p.585. . Nomen nudum.

Ophion mundus Say, 1836. Boston Jour. Nat. Hist. 1: 239. ð.

Anomalon flavipes Brulle, 1846. In Lepeletier, Hist. Nat. Ins. Hym. v. 4, p. 170. §, ᄋ.

Anomalon nigripennis Provancher, 1874. Nat. Canad. 6: 173. o (? misdet.?).

Taxonomy: Townes, 1961. Ent. Soc. Wash., Proc. 63: 109. 
nigripes Dreisbach. Mass., Conn., N. Y., Pa., n.w. Md., Mich. Host: Halisidota tessellaris (J. E. S.), Euthisanotia grata (F.).

Therion nigripes Dreisbach, 1947. N. Y. Ent. Soc., Jour. 55: 201. ð, ९.

petiolatum (Davis). Maine, N. Y., Mich., Wis., S. Dak.

Exochilum petiolatum Davis, 1898 (1897). Amer. Ent. Soc., Trans. 24: 356. ơ, ९.

sassacus Viereck. N. B. w. to Wash., s. to Ala. and Mo. Host: Cycnia inopinata (Hy. Edw.), C. tenera Hbn., Hyphantria cunea (Drury), H. textor (Harris).

Therion sassacus Viereck, 1917 (1916). Conn. State Geol. and Nat. Hist. Survey Bul. 22: 287. $\delta$.

Therion waccagum Viereck, 1917 (1916). Conn. State Geol. and Nat. Hist. Survey Bul. 22: 287. $\delta$.

tenuipes (Norton). Mass., Conn., N. Y., Md., N. C., S. C., Ind.

Exochilum tenuipes Norton, 1863. Ent. Soc. Phila., Proc. 1: 360 ..+

Exochilum diabolus Morley, 1913. Rev. Ichn. Brit. Mus., v. 2, p. 73. \&.

Taxonomy: Townes, 1961. Ent. Soc. Wash., Proc. 63: 106.

texanum (Ashmead). Mass. s. to e. N. C., w. to n.e. Kans. and Tex.; Mexico? Ecology: Flies around Smilax. Host: Psychomorpha epimenis (Drury).

Exochilum texanum Ashmead, 1890 (1889). U. S. Natl. Mus., Proc. 12: 426. ठ。.

varicolor (Viereck). N. B., Me., N. H., Vt., Conn., N. Y., Pa., Md., s.w. Va., w. N. C., N. Mex.

Exochilum varicolor Viereck, 1903. In Skinner, Amer. Ent. Soc., Trans. 29: 90. ठठ.

\section{Genus HETEROPELMA Wesmael}

Schizoloma Wesmael, 1849. [Brussels] Acad. Roy. de Belg., Bul. 16 (pt. 2): 120.

Type-species: Ichneumon amictus Fabricius. Monotypic.

Heteropelma Wesmael, 1849. [Brussels] Acad. Roy. de Belg., Bul. 16 (pt. 2): 120.

Type-species: Heteropelma calcator Wesmael. Monotypic.

Schizopoma Foerster, 1868. Naturh. Ver. Rheinlande, Verh. 25: 145, 220. Unnecessary n. name for Schizoloma Wesmael.

Tanypelma Townes, 1971. Amer. Ent. Inst., Mem. 17: 157.

Type-species: Heteropelma fulvicome Townes. Orig. desig.

In his revision of Heteropelma, Gauld (1976) recognized 17 species in the world. The genus is known from all zoogeographic regions except the Ethiopian Region.

Revision: Gauld, 1976. Brit. Mus. (Nat. Hist.) Ent., Bul. 34: 155-219 (spp. of the world).

Taxonomy: Townes, 1971. Amer. Ent. Inst., Mem. 17: 157-158 (syn.). -Gauld, 1976. Brit. Mus.

(Nat. Hist.) Ent., Bul. 33: 51-53.

datanae Riley. Que. w. to n. Minn., s. to s. Ga., s. La., and n.e. Kans. Host: Datana contracto

Wlk., D. integerrima G. and R., D. ministra (Drury), D. perspicua G. and R.

Anomalon flavicome Brulle, 1846. In Lepeletier, Hist. Nat. Ins. Hym., v. 4, p. 171. \&.

Preocc. by Say, 1823.

Heteropelma datanae Riley, 1888. U. S. Dept. Agr., Insect Life 1: 177. “‡” = §, १.

Heteropelma fulvicome(!) Morley, 1913. Rev. Ichn. Brit. Mus., v. 2, p. 68. Lapsus for and misidentification of Anomalon flavicornis Say.

Heteropelma fulvicome Townes, 1945. Amer. Ent. Soc., Mem. 11: 729. N. name for $A$.

flavicome Brulle.

Taxonomy: Gauld, 1976. Brit. Mus. (Nat. Hist.) Ent., Bul. 34: 185-187.

\section{Genus GRAVENHORSTIA Boie}

Gauld (1976) recognized four subgenera, only one of which has Nearctic species.

Taxonomy: Gauld, 1976. Brit. Mus. (Nat. Hist.) Ent., Bul. 33: 55-61.

\section{Genus GRAVENHORSTIA Subgenus GRAVENHORSTIA Boie}

Gravenhorstia Boie, 1856. Arch. f. Naturgesch. 2: 42.

Type-species: Gravenhorstia picta Boie. Monotypic. 
Odontopsis Foerster, 1868. Naturh. Ver. Rheinlande, Verh. 25: 150. Preocc. by Hasselt, 1823.

Type-species: Gravenhorstia picta Boie. Monotypically included and desig. by Viereck, 1914. Dalla Torre (1901) placed Odontopsis in synonymy with Gravenhorstia, but no species were thereby included, contrary to the statement of Perkins (1962).

This subgenus is confined to the Mediterranean Basin.

Taxonomy: Perkins. 1962. Brit. Mus. (Nat. Hist.) Ent., Bul. 11: 440.

\section{Genus GRAVENHORSTIA Subgenus ERIGORGUS Foerster}

Erigorgus Foerster, 1868. Naturh. Ver. Rheinlande, Verh. 25: 146.

Type-species: Anomalon fibulator Gravenhorst. Desig. by Perkins, 1962 from three species included by Brischke, 1880.

Sympratis Foerster, 1868. Naturh. Ver. Rheinlande, Verh. 25: 146.

Type-species: Anomalon fermigineus Norton. By subsequent monotypy from inclusion by Viereck, 1917.

Paranomalon Viereck, 1912. Ent. Soc. Wash., Proc. 14: 175.

Type-species: Ophion flavifrons Gravenhorst. Monotypic and orig. desig. See synonymy of $G$. (E.) cerinops (Gravenhorst).

This large subgenus is known from all zoogeographic regions except the Ethiopian Region.

Taxonomy: Perkins, 1962. Brit. Mus. (Nat. Hist.) Ent., Bul. 11: 422, 455. -Townes, 1971.

Amer. Ent. Inst., Mem. 17: 133-134.

ambigua (Norton). Mass.

Anomalon ambigutus Norton, 1863. Ent. Soc. Phila., Proc. 1: 362..

cerinops (Gravenhorst). Greenland?; Eurasia.

Ophion flavifrons Gravenhorst, 1807. Vergl. Uebers. Zool. Systeme, p. 267. Sex not indicated. Preocc. by Fabricius, 1798.

Anomalon cerinops Gravenhorst, 1829. Ichn. Europaea, v. 3, p. 658. ठ, $९$.

Ophion (Anomalon) pubescens Zetterstedt, 1840. Insecta Lapponica, Hym., p. 393. ठ์.

Taxonomy: Holmgren, 1860 (1858). Svenska Vetensk.-Akad. Handl. (n. f.) 2 (8): 20-21 (syn.).

-Lundbeck, 1897 (1896). Dansk Naturhist. For. Kjobenhavn, Vidensk. Meddel. (for 1896),

p. 235 (Greenland record).

curta (Norton). Maine w. to Alta., s. to Ark., Tex., and Colo.

Anomalon curtus Norton, 1863. Ent. Soc. Phila., Proc. 1: 362. ठ.

edwardsii (Cresson). Southwestern B. C.

Anomalon Edwardsii Cresson, 1879 (1878). Acad. Nat. Sci. Phila., Proc. 30: 367. ㅇ.

eureka (Ashmead). Southwestern S. Dak., Colo., w. Mont., s.w. B. C., s.e. Wash., n.e. Calif.

Anomalon(?) eureka Ashmead, 1890 (1889). U. S. Natl. Mus., Proc. 12: 423..

ferruginea (Norton). Tenn., Ga., Ill., Tex.

Anomalon ferrugineus Norton, 1863. Ent. Soc. Phila., Proc. 1: 363. ․

neglecta (Morley). Hudson Bay. The reference by Gauld (1976) to Therion neglectum (Morley) was, according to a letter I received from him in 1976, based upon Morley's male from N.S. The latter was excluded as a syntype by Morley's statement that "four pairs, including the type, were taken about Hudson's Bay in 1844, except a single male found ... in Nova Scotia." The identification by Townes (1961) was based upon a female syntype labeled "Hudsons Bay."

Exochilum neglectum Morley, 1913. Rev. Ichn. Brit. Mus., v. 2, p. 76. ð, ؟.

Taxonomy: Townes, 1961. Ent. Soc. Wash., Proc. 63: 106. -Gauld, 1976. Brit. Mus. (Nat.

Hist.) Ent., Bul. 33: 51.

propinqua (Cresson). Colo.

Anomalon propinquum Cresson, 1865. Ent. Soc. Phila., Proc. 4: 284. ठ。.

rotunda (Davis). Northeastern Kans.

Anomalon rotundus Davis, 1898 (1897). Amer. Ent Soc., 'Trans. 24: 360. ठ゚. 
rufula (Provancher). Que., N. H., Mass., N. Y., Md., n. Va., Ont., Ind.

Anomalon rufulum Provancher, 1886. Addit. Corr. Faune Ent. Canada Hym., p. 80..

semirufa (Norton). Que. w. to s.e. S. Dak., s. to Md., Tenn., and n.e. Kans.

Anomalon semi-rufus Norton, 1863. Ent. Soc. Phila., Proc. 1: 362 ..

suburbis (Davis). Northern Idaho.

Anomalon suburbe Davis, 1898 (1897). Amer. Ent. Soc., Trans. 24: 358. ठ, ๆ.

xanthopsis (Ashmead). Colo., w. Mont., n.e. Calif.

Anomalon xanthopsis Ashmead, 1890 (1889). U. S. Natl. Mus., Proc. 12: 423. ठँ.

\section{Genus TRICHOMMA Wesmael}

Trichomma Wesmael, 1849. [Brussels] Acad. Roy. de Belg., Bul. 16 (pt. 2): 119, 139.

Type-species: Anomalon (Trichomma) fulvidens Wesmael. Monotypic.

Trichomella Szepligeti, 1910. Leyden Mus., Notes 32: 91.

Type-species: Trichomma clavipes Krieger. Desig. by Viereck, 1914.

This moderately large genus is known from all zoogeographic regions except the Ethiopian Region.

enecator (Rossi). Eurasia. Introduced in N. J. in 1931 without becoming established. Host:

Grapholitha molesta (Bsk.). The host cited was the target species for the releases in N. J.

Ichneumon Enecator Rossi, 1790. Fauna Etrusca, v. 2, p. 48. 9.

Trichomma ruficoxis Foerster, 1860. Naturh. Ver. Rheinlande, Verh. 17: 149. $\$$.

Taxonomy: Krieger, 1904. Ztschr. System. Hym. Dipt. 4: 165-166.

Biology: Rosenberg, 1934. Bul. Ent. Res. 25: 214-217. -Telenga, 1934. Anz. f. Schaedlingsk. 10: 101-106. - Allen, Holloway, and Haeussler, 1940. U. S. Dept. Agr., Cir. 561: 59-60.

-Simmonds, 1944. Sci. Agr. 25: 1-30. -Zech, 1959. Ztschr. f. Angew. Ent. 44: 204.

maceratum (Cresson). Colo., s. Idaho, s.w. Utah, Calif. Host: Etiella zinkenella (Treit.), Melitara dentata (Grt.), Pima granitellum (Rag.), Barbara colfaxiana taxifoliella (Bsk.).

Anomalon maceratum Cresson, 1879 (1878). Acad. Nat. Sci. Phila., Proc. 30: 368. ठ์.

Trichomma granitellae Viereck, 1912. U. S. Natl. Mus., Proc. 42: 645. ঠ.

Trichomma epischniae Viereck, 1912. U. S. Natl. Mus., Proc. 42: 645. ๆ.

Taxonomy: Townes and Townes, 1951. In Muesebeck et al., U. S. Dept. Agr., Agr. Monog. 2: 396 (syn.).

reticulatum Davis. Southwestern Maine, N. Y., N. J., Ohio, s. Mich., e. Mo., n.e. Kans., B. C.? Host: Grapholitha molesta (Bsk.), Melissopus latiferreanus (WIsm.), Canarsia ulmiarrosorella Clem., Nephopteryx subfuscella (Rag.).

Trichomma reticulata Davis, 1898 (1897). Amer. Ent. Soc., Trans. 24: 361. ․

\section{Genus AGRYPON Foerster}

Agrypon Foerster, 1860. Naturh. Ver. Rheinlande, Verh. 17: 151.

Type-species: Ophion flaveolatum Gravenhorst. Desig. by Morley, 1913.

Trichonotus Cameron, 1905 (July). Roy. Asiatic Soc., Straits Branch, Jour. 44: 124. Preoce. by Schneider, 1801; Rafinesque, 1815; and Loew, 1857.

Type-species: Trichonotus reticulatus Cameron. Monotypic.

Trichionotus Cameron, 1905 (August). Ann. and Mag. Nat. Hist. (7) 16: 168.

Type-species: Trichionotus reticulatus Cameron. Monotypic. The holotype of the

type-species is also the holotype of Trichonotus reticulatus Cameron.

Odontagrypon Cameron, 1906. So. African Mus., Ann. 5: 90.

Type-species: Odontagrypon spilonotus Cameron. Desig. by Viereck, 1914.

Agrypon subg. Paragrypon Uchida, 1941. Insecta Matsumurana 15: 159.

Type-species: Gongropelma kikuchii Uchida. Orig. desig.

Dioborus Rao, 1953. Indian Forest Rec., New Ser., Ent. 8: 204.

Type-species: Dioborus indica Rao. Monotypic and orig. desig. The type-species is regarded as a synonym of A. nox Morley. 
This is a very large genus represented in all zoogeographic regions. The name Labrorychus was for many years incorrectly applied to a large part of the species in this genus because of an erroneous type-species designation by Viereck (1914). The names Trichonotus and Trichionotus were more recently applied to most of the species which had been in Labrorychus auct., but Gauld (1976) has suppressed them as synonyms of Agrypon. Gauld apparently did not know more than a few species intermediate between Agrypon and Trichionotus, but the discussion by Schmid (1970, p. 1539) appears to support Gauld's suppression of Trichionotus.

Taxonomy: Viereck, 1914. U. S. Natl. Mus., Bul. 83: 80. -Townes, 1957. Ent. Soc. Wash., Proc. 63: 115 (syn.). - Townes, Townes, and Gupta, 1961. Amer. Ent. Inst., Mem. 1: 311, 316 (syn.). - Perkins, 1962. Brit. Mus. (Nat. Hist.) Ent., Bul. 11: 433-434 (type-species correction). - Townes, Momoi, and Townes, 1965. Amer. Ent. Inst., Mem. 5: 373, 374 (syn.). -Walkley, 1967. In Krombein, U. S. Dept. Agr., Agr. Monog. 2, sup. 2, p. 211 (homonymy Trichonotus). - Schmid, 1970. Canad. Ent. 102: 1539-1541. - Townes, 1971. Amer. Ent. Inst., Mem. 17: 141-142, 143-144. -Gauld, 1976. Brit. Mus. (Nat. Hist.) Ent., Bul. 33: 66-68, 70.

aestivale (Viereck), n. comb. Mass., N. Y., Md., n. Va. Host: Archips fervidanus (Clem.). Labrorychus aestivalis Viereck, 1921. Psyche 28: 79..

alpinum (Davis), n. comb. N. Y., Ont., Mich., Wis.?, Sask., Colo., Idaho. Host: Thymelicus lineola (Ochs.)?, Choristoneura pinus Free.?

Anomalon alpinus Davis, 1898 (1897). Amer. Ent. Soc., Trans. 24: 360..

anale (Say), n. comb. Que. w. to Wash., s. to D. C. and s. Ill. Host: Orgyia leucostigma (J. E. S.), Malacosoma americanum (F.), M. califomicum fragile (Str.), M. disstria $\mathrm{Hbn}$., Ichthyura inclusa Hbn., Cycnia tenera $\mathrm{Hbn}$.

Ophion analis Say, 1829. Contrib. Maclurian Lyceum to Arts and Sci. 1: $75 . ?$.

Taxonomy: Cushman and Gahan, 1921. Ent. Soc. Wash., Proc. 23: 168.

boreale Ashmead, restored comb. East-central B. C.?

Agrypon boreale Ashmead, 1890 (1889). U. S. Natl. Mus., Proc. 12: 424. . The label of the holotype reads: "Ft. McLeod, Brit. Amer.; Aug., 1882." British America being synonymous with Canada, it is not altogether certain that the type-locality is $\mathrm{Ft}$. McLeod, B. C. rather than Ft. Macleod in southern Alta. (the latter being spelled [or misspelled] McLeod in an 1886 Atlas belonging to me). The two places should be different enough ecologically for this question to be resolved with relative certainty.

canadense (Provancher), n. comb. Que.

Anomalon canadensis Provancher, 1874. Nat. Canad. 6: 175..+

Taxonomy: Barron, 1975. Nat. Canad. 102: 439-440 (lectotype selected).

carinifer Schmid. Colo., s.w. Alta., s. B. C., n.e. Calif.

Agrypon carinifer Schmid, 1970. Canad. Ent. 102: 1540. ठ, ?.

chlamidiatum (Provancher), n. comb. Que., Maine?, N. H.?

Anomalon chlamidiatum Provancher, 1886. Addit. Corr. Faune Ent. Canada Hym., p. 82. ․

Atrometus flavifrons Ashmead, 1902. In Slosson, Ent. News 13: 6. Nomen nudum.

filiforme (Provancher), n. comb. Que.

Anomalon filiforme Provancher, 1886. Addit. Corr. Faune Ent. Canada Hym., p. 83. $\subsetneq$ ( $\delta^{*}$ misdet.?).

flaveolatum (Gravenhorst). N. S.?; Eurasia. A species identified as A. flaveolatum was introduced in N. S. from 1956 through 1958, and A. flaveolatum has been reported as being established there. Host: Operophtera brumata (L.). Schmid (1970) stated that Agrypon provancheri (Dalla Torre) may be a subspecies or synonym of A. flaveolatum; therefore, it needs to be corroborated that the species that is said to have been recovered in N.S. is not the one that had already been there prior to any releases of individuals from Europe, or, otherwise, that the introduced species really is $A$.

flaveolatum. The host cited was the target species for releases in N. S. of the species identified as A. flaveolatum.

Ichneumon auricapillhs Gmelin, 1790. In Linnaeus, Syst. Nat., ed. 13, v. 1, pt. 5, p. 2699. Sex not indicated. Syn.?

Ophion flaveolatum Gravenhorst, 1807. Vergl. Uebers. Zool. Systeme, p. 268. [male?]. 
Ichneumon laedator Thunberg, 1822; 1824. Acad. Imp. des Sci. St. Petersburg, Mem. 8: $264 ; 9: 318$. [female].

Ichneumon cribrator Thunberg, 1822; 1824. Acad. Imp. des Sci. St. Petersburg, Mem. 8: 264; 9: 318. [male].

Anomalon septentrionale Holmgren, 1857. Svenska Vetensk.-Akad., Ofvers. af ... Forhandl. 14: $179 . \delta$, $९$.

Taxonomy: Thomson, 1892. Opusc. Ent. 16: 1771 (syn.). - Roman, 1912. Zool. Bidr. Uppsala 1: 248, 261 (syn.). - Schmid, 1970. Canad. Ent. 102: 1541.

Biology: McGugan and Coppel, 1962. Commonwealth Inst. Biol. Control, Tech. Commun. 2: 65. - Embree, 1966. Canad. Ent. 98: 1160. - Embree, 1971. Commonwealth Inst. Biol. Contr., Tech. Commun. 4: 168, 169-170.

melleum (Cresson). R. I., Md., Va., Tex. Ecology: Occurs in "overgrown fields." Anomalon melleum Cresson, 1872. Amer. Ent. Soc., Trans. 4: 171..

metallicum (Norton). Mass., R. I., Mich.

Anomalon metallicus Norton, 1863. Ent. Soc. Phila., Proc. 1: 364..

prismaticum (Norton), n. comb. N. B.?, Que.?, Maine?, N. H.?, Vt.?, Mass., Conn., Ont.?, Ohio?, Minn.? Host: Ostrinia nubilalis (Hbn.)?, O. penitalis (Grt.)?, Archips cerasivoranus (Fitch)? The host and distribution data added by Walkley (1967) are based on specimens in the U. S. Natl. Museum collection. I have queried all of these because I do not feel assured that there is any material in the U.S. Natl. Museum collection which is reliably identified as $A$. prismaticum.

Anomalon prismaticus Norton, 1863. Ent. Soc. Phila., Proc. 1: 364 . ?.

Taxonomy: Walkley, 1967. In Krombein, U. S. Dept. Agr., Agr. Monog. 2, sup. 2, p. 211.

provancheri (Dalla Torre). N. S. w. to s.e. Alaska, s. to n. Ga., Iowa, Colo., Ariz., and Calif. Host: Melanolophia imitata (Wlk.), Operophtera bruceata (Hulst). No host data were cited by Schmid (1970).

Anomalon unicolor Provancher, 1886. Addit. Corr. Faune Ent. Canada Hym., p. 82.. Preoce. by Ratzeburg, 1874.

Anomalon Provancheri Dalla Torre, 1901. Cat. Hym., v. 3, p. 169. N. name for Anomalon unicolor Provancher.

Atrometus alaskensis Ashmead, 1902. Wash. Acad. Sci., Proc. 4: 233. ठ, ?.

Taxonomy: Walkley, 1958. In Krombein et al., U. S. Dept. Agr., Agr. Monog. 2, sup. 1, p. 61.

-Schmid, 1970. Canad. Ent. 102: 1540-1541.

pseudargioli (Howard). Mass., R. I., Conn., W. Va. Host: Celastrina pseudargiolus (B. and L.), Strymon melinus (Hbn.).

Anomalon pseudargioli Howard, 1889. In Scudder, Butterflies of East. U. S., v. 3, p. 1881. †.

\section{Genus PARANiA Morley}

Parania Morley, 1913. Rev. Ichn. Brit. Mus., v. 2, p. 96.

Type-species: Parania nototrachoides Morley. Monotypic. The type-species is regarded as a synonym of $P$. tricolor (Szepligeti).

This is a small Neotropic, Holarctic, Oriental, and Ethiopian genus. Until recently the name Atrometus was incorrectly applied to this genus.

Revision: Schmid, 1969. Canad. Ent. 101: 778-784.

Taxonomy: Townes, Townes, and Gupta, 1961. Amer. Ent. Inst., Mem. 1: 315-316 (syn.). -Townes, 1971. Amer. Ent. Inst., Mem. 17: 144-145, 153. - Gauld, 1976. Brit. Mus. (Nat.

Hist.) Ent., Bul. 33: 70-71.

badia (Schmid). Mass., Conn., N. Y., Ohio, s. Mich., w. N. Dak. Host: Archips argyrospilus (Wlk.).

Atrometus badius Schmid, 1969. Canad. Ent. 101: 779. d, + .

geniculata (Holmgren). N. S. w. to w.-cent. B. C., s. to n. Ga., Kans., s.w. N. Mex., and s. Calif.; Europe. Host: Psilcorsis sp., Homadaula an isocentra (Meyr.), Acleris variana (Fern.), 
Argyrotaenia velutinana (Wlk.), Choristoneura fumiferana (Clem.), C. lambertiana (Bsk.), Anchylopera nubeculana Clem., Ancylis comptana (Froel.), Grapholitha molesta (Bsk.), Phaneta amphorana (Wlsm.), Rhyacionia buoliana (D. and S.), R. frustrana bushnelli (Bsk.), R. f. fmestrana (Comst.), R. neomexicana (Dyar), Spilonota ocellana (D. and S.), Strepsicrates smithiana (Wlsm.), Anarsia lineatella Zell., Aroga

trialbamaculella (Chamb.), Acrobasis rubrifasciella Pack., Dioryctria reniculella (Grt.), Ostrinia nubilalis (Hbn.), Eublemma minimum (Gn.).

Anomalon geniculatum Holmgren, 1857. Svenska Vetensk.-Akad., Ofvers. af ... Forhandl. 14: 182 . ठ์, ?.

Angitia paediscae Riley, 1890. In Riley and Howard, U. S. Dept. Agr., Insect Life 3: 156. Nomen nudum.

Agrypon paediscae Ashmead, 1896. Amer. Ent. Soc., Trans. 23: 190, errata. ¿, $\uparrow$. The spelling praediscae appears on p. 190 and the correction paediscae appears in the errata, the errata evidently being published at the same time as the rest of the paper. The lectotype selected by Schmid (1969) is here rejected because it was not one of Ashmead's syntypes. Although Ashmead's syntypes included several specimens from Fortress Monroe (=Fort Monroe, Hampton), Va., it was indicated by Ashmead that they were specimens labeled 3422 with the superscript 01 . Notes in the U. S. Natl. Museum under that Bureau of Entomology number indicate that specimens so labeled were reared from the olethreutid Strepsicrates smithiana collected at Ft. Monroe on Myrica cerifera, but that Bureau number does not apply to specimens reared from other hosts. The specimen here rejected as lectotype is labeled as being reared from a lepidopteran on roots of grass. Among the labels of the female specimen here selected as lectotype are Ashmead's handwritten identification label and a label bearing the aforementioned Bureau of Entomology number and the date "10/7, 84" (i.e. July 10, 1884).

Anomalon clavipes Davis, 1898 (1897). Amer. Ent. Soc., Trans. 24: 359 . ठ。.

Podogaster evetrivorus Rohwer, 1914. Ent. Soc. Wash., Proc. 16: 142. o, ?.

obscura (Schmid), n. status. South-cent. Ariz. If this taxon proves to be conspecific with geniculata, it would almost certainly be better treated as a synonym of geniculata rather than as a subspecies thereof.

Atrometus geniculatus obscumis Schmid, 1969. Canad. Ent. 101: 783. o, ?.

\section{Genus METOA Townes}

Metoa Townes, 1971. Amer. Ent. Inst., Mem. 17: 147.

Type-species: Anomalon exile Provancher. Monotypic and orig. desig.

This is a Nearctic genus. Townes said that he had seen eight species.

exilis (Provancher). Que. s. to N. C., w. to Mich. Several host records were published in 1898 and 1911, but I suspect that they involve misidentifications of Anomalon exile and doubt that they would pertain to any species of Metoa.

Anomalon exile Provancher, 1874. Nat. Canad. 6: 175. $\%$

verbosa (Cresson), n. comb. Western Oreg. s. to s. Calif.

Anomalon verbosum Cresson, 1879 (1878). Acad. Nat. Sci. Phila., Proc. 30: 368. ठ,.

\section{Genus CALCANEUM Townes}

Calcaneum Townes, 1971. Amer. Ent. Inst., Mem. 17: 145.

Type-species: Calcaneum oporinum Townes. Monotypic and orig. desig.

This is a Nearctic genus. Specimens which I have seen from N. Mex. and s.e. Wash. appear to represent an undescribed species, and thus it appears that there are at least two species in the genus.

oporinum Townes. Conn., N. Y., N. J., Md., Va. Ecology: Occurs in fall in fields.

Calcaneum oporinum Townes, 1971. Amer. Ent. Inst., Mem. 17: 146. o, ?.

\section{Genus OPHIONELLUS Westwood}

Pharsalia Cresson, 1872. Amer. Ent. Soc., Trans. 4: 177. Preocc. by Thomson, 1864.

Type-species: Pharsalia texana Cresson. Desig. by Viereck, 1914. 
Ophionellus Westwood, 1874. Thesaurus Ent. Oxon., p. 128.

Type-species: Ophionellus fragilis Westwood. Monotypic.

Hymenopharsalia Morley, 1913. Rev. Ichn. Brit. Mus., v. 2, p. 97. N. name for Pharsalia Cresson. The volume in which Morley proposed this name was received by the Smithsonian Institution on May 2, 1913.

Parophionellus Brues and Richardson, 1913. Amer. Mus. Nat. Hist., Bul. 32: 495. Unnecessary n. name for Pharsalia Cresson. The paper in which this name was proposed is dated Oct. 7, 1913 and was received at the Smithsonian Institution on Oct. $11,1913$.

This large genus is confined to the New World, most of the species being Neotropic.

Revision: Cushman, 1922. U. S. Natl. Mus., Proc. 60 (21): 14-20.

Taxonomy: Townes, 1945. Amer. Ent. Soc., Mem. 11: 710 (syn.). -Gauld, 1976. Brit. Mus. (Nat. Hist.) Ent., Bul. 33: 82-84.

bridwelli (Cushman). Md., n. Va., S. C.

Hymenopharsalia bridwelli Cushman, 1922. U. S. Natl. Mus., Proc. 60 (21): 19..

foutsi (Cushman). Que., Maine, Mass., N. Y., Pa., Md., Ind., Mo., Mont., Ariz. Host: Homadaula anisocentra (Meyr.), Episimus argutanus (Clem.), Arogalea cristifasciella (Chamb.), gelechiid on Salix.

Hymenopharsalia foutsi Cushman, 1922. U. S. Natl. Mus., Proc. 60 (21): 18. ?.

texanus (Cresson). S. C., Ga., Kans., Tex., N. Mex., Calif.; Mexico.

Pharsalia texana Cresson, 1872. Amer. Ent. Soc., Trans. 4: 177..

virginiensis (Cresson). N. Y., Md., D. C., Va., W. Va., S. C., Ind., Mo.

Pharsalia virginiensis Cresson, 1872. Amer. Ent. Soc., Trans. 4: 177. " $0 "=q$.

\section{Genus OPHIOPTERUS Brulle}

Ophiopterus Brulle, 1846. In Lepeletier, Hist. Nat. Ins. Hym., v. 4, p. 153.

Type-species: Ophiopterus coarctatus Brulle. Monotypic.

Ophionopterus(!) Ashmead, 1900. U. S. Natl. Mus., Proc. 23: 87, 180, 215.

Ophionopterus Schulz, 1906. Spolia Hym., p. 96. Emend.

Ophionopterus Morley, 1912. Rev. Ichn. Brit. Mus., v. 1, p. 66. Emend. Preocc. by Schulz, 1906.

This is a small genus of Neotropic and Nearctic distribution.

cincticornis (Cresson). D. C., S. C., Ga., Ill., Tex.; Puerto Rico, Cuba, Mexico.

Trachynotus cincticornis Cresson, 1865. Ent. Soc. Phila., Proc. 4: 49. ठ', ?.

Ophiopterus ferruginens Cresson, 1873. Acad. Nat. Sci. Phila., Proc. 25: 380. ๆ.

Nototrachys(?) annulicomis Ashmead, 1890 (1889). U. S. Natl. Mus., Proc. 12: 422. ð’, ₹.

Taxonomy: Townes, 1945. Amer. Ent. Soc., Mem. 11: 711 (syn.).

UNPLACED TAXA OF GRAVENHORSTINI

Anomalon exrufum Walkley, 1958. In Krombein et al., U. S. Dept. Agr., Agr. Monog. 2, sup. 1, p. 62. N. name for Anomalon rufus Provancher (which see).

Anomalon nigritum Norton, 1863. Ent. Soc. Phila., Proc. 1: 363. ð. Mass. Gauld's (1976) placement of this species in Gravenhorstia (Erigorgus) was based upon a specimen from Mexico identified as $A$. nigritum by Morley (1913). Morley's identification could not serve to fix the identity of $A$. nigritum (the holotype of which is lost) unless it can be shown (1) that Morley's Mexican species also occurs in Mass. and (2) that specimens from Mass. also agree with Norton's description (the combination seeming very improbable).

Taxonomy: Morley, 1913. Rev. Ich. Brit. Mus., v. 2, p. 86. -Gauld, 1976. Brit. Mus. (Nat. Hist.) Ent., Bul. 33: 61.

Anomalon nigro-varium Brulle, 1846. In Lepeletier, Hist. Nat. Ins. Hym., v. 4, p. 172.. l'Amerique sept.; Bastard. The holotype has not been found.

Taxonomy: Norton, 1863. Ent. Soc. Phila., Proc. 1: 359. - Townes, 1961. Ent. Soc. Wash., Proc. 63: 104 (search for holotype). 
Anomalon rufus Provancher, 1874. Nat. Canad. 6: 174. $\$$. Que. Preoce. by Anomalon rufum Holmgren, 1857; replaced by Anomalon exrufum Walkley (which see). Barron (1975) did not find the holotype, but thought there was strong evidence that the holotype would be a species of Trichionotus.

Taxonomy: Barron, 1975. Nat. Canad. 102: 556-557.

Anomalon vivum Cresson, 1879 (1878). Acad. Nat. Sci. Phila., Proc. 30: 368. $\subsetneq$. Oreg. No type specimen was found by Cresson (1916).

Taxonomy: Cresson, 1916. Amer. Ent. Soc., Mem. 1: 63.

\section{TRIBE ANOMALONINI}

This tribe includes only two genera, Anomalon and Neogreeneia.

\section{Genus ANOMALON Panzer}

Anomalon Jurine, 1801. In Panzer, Litteratur-Ztg. Erlangen, Intelligenzbl. 1: 163. Nomen nudum.

Anomalon Panzer, 1804. Faunae Ins. German., heft 94, pl. 15.

Type-species: Anomalon cruentatus Panzer. Monotypic. The type-species is here regarded as a synonym of $A$. cruentatum (Geoffroy), n. comb.

Trachynotus Gravenhorst, 1829. Ichn. Europaea, v. 3, p. 713. Preocc. by Latreille, 1829 (April).

Type-species: Ophion foliator Fabricius. Monotypic. The type-species is here regarded as a synonym of $A$. cruentatum (Geoffroy).

Ochlerus Gistel, 1848. Naturgesch. Thierreichs $\mathrm{f}$. hoehere Schulen, p. xi. N. name for Trachynotus Gravenhorst. Preocc. by Spinola, 1837.

Nototrachys Marshall, 1872. Ent. Soc. London, Trans. 20: 259. N. name for Trachynotus Gravenhorst.

Ophioneura Cameron, 1904. Albany Mus., Rec. 1: 174.

Type-species: Ophioneura flavomaculata Cameron. Monotypic.

Stictophion Cameron, 1906. So. African Mus., Ann. 5: 85.

Type-species: Stictophion mifipes Cameron. Desig. by Viereck, 1914.

Erythrophion Cameron, 1906. So. African Mus., Ann. 5: 87.

Type-species: Erythrophion ferrugineus Cameron. Monotypic. The type-species is regarded as a synonym of $A$. mufipes (Cameron).

Anomalum Schulz, 1906. Spolia Hym., p. 96. Emend.

Trachyopterus Morley, 1912. Rev. Ichn. Brit. Mus., v. 1, p. 67.

Type-species: Trachyopterus primus Morley. Monotypic.

Pseudonototrachys Meyer, 1930. Konowia 9: 221.

Type-species: Pseudonototrachys pallidus Meyer. Monotypic. The type-species is regarded as a synonym of $A$. kozlovi (Kokujev).

Microcremastus Hedwig, 1961. Beitr. z. Naturkundlichen Forsch. Suedwestdeut. 19: 292.

Type-species: Microcremastus amseli Hedwig. Monotypic and desig. by Townes, 1971. The included taxa were M. amseli and M. amseli "f. flavus" Hedwig; for those who consider the latter to be an unavailable name, $M$. amseli is the type-species by monotypy.

This is a very large genus, known from all zoogeographic regions. As far as is known, the usual hosts are soil-dwelling larvae of Coleoptera, but an undescribed species from Maryland has been reared by Dr. J. F. G. Clarke from an undescribed species of Exartema (Lepidoptera: Olethreutidae) which in turn was reared from the seed heads of an unidentified species of annual plant which was growing in a swampy area where the basal portions of the plants were submerged in water. Oddly enough, this new species of Anomalon from Maryland is virtually indistinguishable from Anomalon californicum (Cresson), which is known to me from Hawaii and California (as far north as San Francisco) and apparently is found in relatively dry habitats.

californicum (Cresson). N. Mex.?, Ariz.?, mid-coastal and s. Calif.; Hawaii. The N. Mex. and Ariz. records are cited with a query because it appears that, as with ejuncidum (Say), a 
number of species have been confused under the name californicum (also see introduction to Anomalon).

Nototrachys californicus Cresson, 1879 (1878). Acad. Nat. Sci. Phila., Proc. 30: 366.. canadense (Provancher), revised status. Que. Cushman and Gahan (1921) suppressed canadense as a synonym of ejuncidum (which see).

Trachynotus Canadensis Provancher, 1879. Nat. Canad. 11 (no. 126): 119. \&. Preocc. in Anomalon by Agrypon canadense (Provancher), 1874.

Taxonomy: Cushman and Gahan, 1921. Ent. Soc. Wash., Proc. 23: 156 (syn.).

ejuncidum Say. "United States." It is my opinion that perhaps as many as ten species have been confused under this name; therefore, I have resurrected the names suppressed as synonyms of ejuncidum by Cushman and Gahan (1921) and Townes (1945) and leave it to a revisor to determine the application of the name ejuncidum.

Anomalon ejuncidus Say, 1836. Boston Jour. Nat. Hist. 1: 233, 241-242. \&.

Taxonomy: Cushman and Gahan, 1921. Ent. Soc. Wash., Proc. 23: 156. -Townes, 1945. Amer. Ent. Soc., Mem. 11: 708-709 (syn.).

fuscatum (Cresson), revised status. Fla.; Cuba. Townes (1945) suppressed fuscatum as a synonym of ejuncidum (which see).

Trachynotus fuscatus Cresson, 1865. Ent. Soc. Phila., Proc. 4: 50. đ’, १.

Taxonomy: Townes, 1945. Amer. Ent. Soc., Mem. 11: 708 (syn.).

reticulatum (Cresson). Colo. It is my opinion that, as with califoricum and ejuncidum, a number of species have been confused under the name reticulatum; therefore, for distribution I have cited only the type locality.

Trachynotus reticulatus Cresson, 1865. Ent. Soc. Phila., Proc. 4: 285. ठో.

texanum (Cresson), revised status. Central Tex. Cushman and Gahan (1921) suppressed texanum as a synonym of ejuncidum (which see).

Trachynotus texanus Cresson, 1872. Amer. Ent. Soc., Trans. 4: 169. \&.

Taxonomy: Cushman and Gahan, 1921. Ent. Soc. Wash., Proc. 23: 156.

\section{Genus NEOGREENEIA Viereck}

Neogreeneia Viereck, 1912. U. S. Natl. Mus., Proc. 42: 641.

Type-species: Neogreeneia picticornis Viereck. Monotypic and orig. desig.

This is a small Nearctic and Neotropic genus. No hosts are known. Townes (1971) believed that Neogreeneia represents little more than a distinct species group of the genus Anomalon. Despite his decided lumping tendency, Gauld (1976) retained Neogreeneia as a valid genus.

Taxonomy: Townes, 1971. Amer. Ent. Inst., Mem. 17: 124, 125-126. - Gauld, 1976. Brit. Mus.

(Nat. Hist.) Ent., Bul. 33: 88.

picticornis Viereck. N. Y.w. to s. Mich., s. to s. Fla. and n.e. Tex.

Neogreeneia picticomis Viereck, 1912. U. S. Natl. Mus., Proc. 42: 641. ๆ.

\section{SUBFAMILY CAMPOPLEGINAE}

This large subfamily is represented by three tribes, Nonnini, Hellwigiini, and Campoplegini. The latter tribe includes the vast majority of genera and species of Campopleginae and is the only tribe represented in America north of Mexico.

Taxonomy: Townes, 1970 (1969). Amer. Ent. Inst., Mem. 13: 143-193 (genera of world as "Porizontinae").

\section{TRIBE CAMPOPLEGINI}

Townes (1961) subdivided the Campoplegini into two tribes, and Townes (1970), 1971) maintained the same tribal classification. I do not feel that this classification has any particular practical or phyletic merit, and, therefore, recognize only a single tribe here.

The Campoplegini are internal parasites of the larvae (cf. Campoplex) of Lepidoptera, Symphyta, and Coleoptera. Campoplegine parasites of Symphyta and Coleoptera are far less nu- 
merous than those of Lepidoptera.

The genric classification adopted here is largely in agreement with that of Townes (1970). The few departures from that classification which are not based on more recent publications reflect my own thinking and predjudices regarding Campoplegini and the generic category in general.

Revision: Viereck, 1925; 1926. Canad. Ent. 57: 176-181, 198-204, 223-228, 296-303; 58: 2-8, $30-38,71-78,122-130,143-149,176-182,196-201,219-225,257-260,276-283$ (revision mostly of specimens in Canad. Natl. collection; systematically unsound and not usable for identification).

Taxonomy: Townes, 1961. In Townes, Townes, and Gupta, Amer. Ent. Inst., Mem. 1: 449-451. -Townes, 1970 (1969). Amer. Ent. Inst., Mem. 13: 148-193 (genera of world). - Townes, 1971. Amer. Ent. Inst., Mem. 17: 241. - Finlayson, 1975. Ent. Soc. Canada, Mem. 94: 137 p. (final-instar larvae of most genera in North America which have been reared).

\section{Genus SINOPHORUS Foerster}

Sinophorus Foerster, 1868. Naturh. Ver. Rheinlande, Verh. 25: 153.

Type-species: Limneria (Sinophorus) canarsiae Ashmead. By subsequent monotypy from inclusion by Ashmead, 1898.

Eulimneria Schmiedeknecht, 1907. Hym. Mitteleuropas, p. 600.

Type-species: Ichneumon albidus Gmelin. Desig. by Morley, 1913.

Campoplex subg. Campoletidea Viereck, 1912. U. S. Natl. Mus., Proc. 42: 634. N. syn.

Type-species: Campoplex (Campoletidea) caradrinae Viereck. Monotypic and orig. desig.

This moderately large genus is somewhat arbitrarily delineated from Campoplex. It is Neotropic, Holarctic, and Oriental, with the great majority of species occuring in the Holarctic Region. The species apparently occur in grasslands or sparsely wooded areas. The hosts are various Lepidoptera.

albicinctus (Viereck), n. comb. N. J.?, e. N. C.?, Sask., Colo., s.e. Wyo., s. Alta., s. B. C. Ecology: One of the specimens in the U.S. Natl. Museum collection was collected in the Rocky Mountains of Wyoming at an elevation of $9600 \mathrm{ft}$.

Pyracmon albicinctum Viereck, 1925; 1926. Canad. Ent. 57 (7): 180 (key); 58 (1): 4. o, .. alkae (Ellinger and Sachtleben). Eurasia. Introduced in Mass., Conn., R. I., N. Y., Pa., Ont., Ohio, and Mich. between 1920 and 1933; reported as recovered in Mass. and Mich. by Jones (1929), but apparently not established in any of the release areas. Host: Ostrinia nubilalis (Hbn.). In literature published before the description of alkae in 1928 and in some literature for more than ten years thereafter, the species was misidentified as crassifemur (Thomson). Dr. R. I. Sailer (see Syme, 1971) is of the opinion that alkae is conspecific with rufifemiur (Thomson), but I was unable to verify this by examining the rufifemur type. Material reared from both Ostrinia nubilalis and Rhyacionia buoliana (D. and S.) at the same locality would undoubtedly be very helpful in the solution of this question.

Limnerium alkae Ellinger and Sachtleben, 1928. Internatl. Corn Borer Invest., Sci. Rpts. 1: $115 . \delta$, ㅇ.

Taxonomy: Ellinger and Sachtleben, 1929. Internatl. Corn Borer Invest., Sci. Rpts. 2: 63-64. -Aubert, 1959 (1958). Soc. Ent. de France, Ann. 127: 160. -Oehlke, 1963. Beitr. z. Ent. 13: 403 (lectotype selection). - Syme, 1971. Commonwealth Inst. Biol. Control (Trinidad), Tech. Commun. 4: 196 (footnote).

Biology: Paillot, 1928. Internatl. Corn Borer Invest., Sci. Rpts. 1: 83-91. -Jones, 1929. U. S. Dept. Agr., Tech. Bul. 98: 3, 24-27 (as crassifemur). -Thompson and Parker, 1930. Jour. Agr. Res. 40: 321-345 (as crassifemur). -Goidanich, 1931. R. Ist. Super. Agr., Lab. di Ent., Bol, 4: 106-113. - Baker and Arbuthnot, 1933. Ent. Soc. Amer., Ann. 26: 297-302 (as crassifemur). -Clark, 1934. U. S. Dept. Agr., Tech. Bul. 455: 11, 20, 27, 31. - Baker, Bradley, and Clark, 1949. U. S. Dept. Agr., Tech. Bul. 983: 6, 8, 133-137, 141. - Adlung, 1963. Anz. f. Schaedlingsk. 36: 174. 
caradrinae (Viereck), n. comb. Southeastern Colo. Host: Spodoptera exigua (Hbn.)? Known to me only from the holotype and one other specimen, the former labeled as reared from $S$. exigua (as "Caradrina exigua") collected at Rocky Ford, Colo. The host record is queried because $S$. exigua is a much reared species, and it seems to me, therefore, that caradrinae may have been reared from some other noctuid which was misidentified as exigua.

Campoplex (Campoletidea) caradrinae Viereck, 1912. U. S. Natl. Mus., Proc. 42: 634. §ै. eruficinctus (Walkley). Southwestern N. Dak., Nebr., n.e. Kans., n.w. Tex., Sask., s. Alta., n. Utah, s. Ariz. Host: Heliothis oninis (D. and S.), H. zea (Bod.).

Pyracmon ruficinctum Viereck, 1925; 1926. Canad. Ent. 57 (7): 180 (key); 58 (1): 5. o. Formerly preocc. in Campoplex by Gravenhorst, 1829.

Cam poplex erificinctus Walkley, 1958. In Krombein et al., U. S. Dept. Agr., Agr. Monog. 2, sup. 1, p. 59. N. name for $P$. ruficinctum Viereck.

Taxonomy: Finlayson, 1975. Ent. Soc. Canada, Mem. 94: 21, 92, 135 (final-instar larva).

furus (Cresson), n. comb. N. Y. w. to Mich., s. to e. N. C. and Tex.

Limneria fura Cresson, 1872. Amer. Ent. Soc., Trans. 4: 173..

Limneria melanocoxa Ashmead, 1890 (1889). U. S. Natl. Mus., Proc. 12: 430. क. The holotype is the same specimen as the holotype of furus.

Limnerium melanocoxum Dalla Torre, 1901. Cat. Hym., v. 3, p. 99. Emend.

popofensis (Ashmead), n. comb. Southwestern Alaska. Known to me only from the Shumagin Islands (Popof Isl.) and Pribilof Islands (St. Paul Isl.), Alaska.

Zachresta popofensis Ashmead, 1902. Wash. Acad. Sci., Proc. 4: 234. o'.

rufifemur (Thomson). Eurasia. Introduced in Ont. in 1935 and 1955 through 1958; none of the suspected recoveries have been confirmed by identification of reared adult specimens (see Syme, 1971). Host: Rhyacionia buoliana (D. and S.). The host cited was the target species for releases of rufifemur in Ont.

Limneria rufifemur Thomson, 1887. Opusc. Ent. 11: 1106. [male, female].

Biology: Thorpe, 1930. Bul. Ent. Res. 21: 394. - Thorpe, 1932. Parasitology 24: 107-110.

- Thorpe and Caudle, 1939. Parasitology 30: 525, 527-528. -Juillet, 1959. Canad. Ent. 91:

713-716. - Wylie, 1960. Entomophaga 5: 119. - Pschorn-Walcher, 1960. Pflanzenschutz 25:

17. - Adlung and Sailer, 1963. Allg. Forst-u. Jagdztg. 134: 231, 233. - Schindler, 1965.

Ztschr. f. Angew. Ent. 55: 356. - Eichorn, Pschorn-Walcher, and Schroeder, 1965. Anz. f.

Schaedlingsk. 38: 107.

sulcatellus (Viereck), n. comb. Southern Sask., Wyo., s. Alta., w. Wash., n. Calif. Host: Loxostege sp., L. sticticalis (L.).

Campoplex (Campoplex) sulcatellus Viereck, 1925; 1926. Canad. Ent. 57 (9): 225 (key); 58 (5): 130. $\%$.

validus (Cresson). N. S. w. to s. B. C., s. to e. N. C., n.e. Kans., and n. N. Mex. Host: Macrobotys theseusalis (Wlk.), Nephopteryx uvinella(Rag.), Psorosina hammondi (Riley), Saucrobotys futilalis (Led.), Plathypena scabra (F.), Hyphantria cunea (Drury), H. textor Harris, Grapholitha molesta (Bsk.), Acleris minuta (Rob.). With the exception of Psorosina hammondi and Acleris minuta (the hosts of type-specimens of synonyms cited below), I have listed only hosts from labels of specimens which I have identified as validus. Some of the host records reported in the literature pertain to misidentified specimens in the U.S. Natl. Museum collection.

Mesoleptus? validus Cresson, 1864. Ent. Soc. Phila., Proc. 3: 258. ठ, q.

Mesoleptus montanus Cresson, 1865. Ent. Soc. Phila., Proc. 4: 261. $\uparrow$. Preocc. by

Gravenhorst, 1829.

Limneria excavata Provancher, 1875. Nat. Canad. 7: 146. 9.

Limneria teratis Weed, 1887. Ill. State Lab. Nat. Hist., Bul. 3: 40.. .

Limneria (Sinophoras) canarsiae Ashmead, 1898 (1897). Ent. Soc. Wash., Proc. 4: 126. ㅇ.

Limneria tristis(!) Dalla Torre, 1901. Cat. Hym., v. 3, p. 105. Lapsus for L. teratis Weed; also transferred to Limnerium as triste(!).

Amorphota angusta Viereck, 1906. Amer. Ent. Soc., Trans. 32: 180. @.

Campoplex (Ecphora) canadensis Viereck, 1925; 1926. Canad. Ent. 57 (8): 203 (key); 58 (11): 282. ․ . 
Campoplex (Campoplex) juxtus Viereck, 1925; 1926. Canad. Ent. 57 (9): 226 (key); 58 (6): 147. 9 .

Campoplex (Campoplex) militaris Viereck, 1925; 1926. Canad. Ent. 57 (9): 226 (key); 58 (6): 147. $\%$.

Biology: Timberlake, 1912. U. S. Dept. Agr., Bur. Ent., Tech. Ser. 19: 71-92. -Tothill, 1922.

Canad. Dept. Agr., Bul. (n. s.) 3: 74-76. -Morris, 1964. Canad. Ent. 96: 364, 365, 366-367.

-Morris, 1976. Canad. Ent. 108: 834, 835, 836.

Morphology: Cushman, 1926. Ent. Soc. Wash., Proc. 28: 43 (first instar larva).

xanthostomus (Gravenhorst). Eurasia; n. Africa. Reported as introduced in Orange Co., Calif. (apparently in 1948) without becoming established (see Clausen, 1956). No "voucher" specimens are present in the U. S. Natl. Museum collection; hence, I do not feel certain that the species released in Calif. was really $S$. xanthostomus or even a species of Sinophorus. The target species for the release of xanthstomus in Calif. was the native Paramyelois transitella (Wlk.).

Campoplex xanthostomus Gravenhorst 1829. Ichn. Europaea, v. 3, p. 460. o.

Campoplex deserticola Tosquinet, 1896. Soc. Ent. de Belg., Mem. 5: 412. ठ.

Taxonomy: Aubert, 1964. Soc. Ent. de France, Bul. 69: 159. -Townes, Momoi, and Townes, 1965. Amer. Ent. Inst., Mem. 5: 274 (lectotype selected). - Shaumar, 1966. Entomophaga 11: 458,461 (syn.).

Biology: Clausen, 1956. U. S. Dept. Agr., Tech. Bul. 1139: 23.

\section{Genus SESIOPLEX Viereck}

Campoplex subg. Sesioplex Viereck, 1912. U. S. Natl. Mus., Proc. 42: 644.

Type-species: Campoplex (Sesioplex) depressus Viereck. Monotypic and orig. desig.

Dr. Klaus Horstmann (personal commun., 1976) told me that he knew a European species which may be referable to Sesioplex, but depressus is the only species known to me. The name Sesioplex is here resurrected from synonymy because depressus has structural characteristics which make it a misfit in Campoplex or Sinophorus.

depressus (Viereck). Que. w. to Iowa, s. to n. Ga. and n.e. Kans. Host: Guorimoschema gallaesolidaginis (Riley).

Campoplex (Sesioplex) depressus Viereck, 1912. U. S. Natl. Mus., Proc. 42: 644. 9 . The holotype is labeled as follows: "from F. M. Webster; Feb. 3, [18]87; Par[asite] on Gelechia solidaginis; iss[ued] March 25, [18]87." This is certainly the specimen which Riley and Howard (1890) identified as "Limneria dimidiatus Cr[esson]," from "LaFayette, Ind., March 25, 1887." Because Webster was never stationed in La., Viereck's statement that the type locality is "Louisiana" is erroneous.

Sesioplex relativus Viereck, 1925. Canad. Ent. 57 (7): 177 (key); 57 (12): 298. ․

Taxonomy: Riley and Howard, 1890. U. S. Dept. Agr., Insect Life 3: 157.

Biology: Miller, 1963. Ohio Jour. Sci. 63: 71.

\section{Genus CAMPOPLEX Gravenhorst}

Campoplex Gravenhorst, 1829. Ichn. Europaea, v. 3, p. 453.

Type-species: Ichneumon difformis Gmelin. Desig. by Westwood, 1840.

Dioratica Foerster, 1868. Naturh. Ver. Rheinlande, Verh. 25: 153.

Type-species: Porizon borealis Zetterstedt. Monotypically included and desig. by

Townes, Momoi, and Townes, 1965.

Omorgus Foerster, 1868. Naturh. Ver. Rheinlande, Verh. 25: 153.

Type-species: Limneria mutabilis Holmgren. Desig. by Viereck, 1912 from 32

species included by Thomson, 1887. Horstmann (1969) suppressed mutabilis as a synonym of difformis (Gmelin).

Omorga Thomson, 1887. Opusc. Ent. 11: 1052, 1125. Emend.

Zatranosema Viereck, 1912. Ent. News 23: 45. Placed with a query as a synonym of Campoplex by Townes (1970). Proposed as a "new name" for Tranosema Foerster in the sense of Szepligeti as opposed to the sense of Thomson (see Tranosema). 
Type-species: Tranosema bicolor Szepligeti. Monotypic. Szepligeti (1911) applied the name Tranosema to three species, but two of them were placed in Tranosema with a query; therefore Zatranosema is monotypic.

Casinaria subg. Pseuderipternoides Viereck, 1917 (1916). Conn. State Geol. and Nat. Hist. Survey Bul. 22: 269.

Type-species: Mesoleptus porrectus Cresson. Monotypic and orig. desig.

This very large genus has a worldwide distribution. The hosts are principally microlepidoptera which feed in concealment (such as in leaf rolls, cases, buds, etc.). As with most Campoplegini, some Campoplex species apparently kill their hosts while the latter are in the larval stage and spin a cocoon after emerging from the host, but in an undetermined proportion of Campoplex species the cocoon is spun inside the pupal shell of the host. The latter is also the case for some (but definitely not all) species of Venturia. Dr. Klaus Horstmann is preparing a revision of the western Palearctic species of Campoplex.

Taxonomy: Szepligeti, 1911. In Wytsman, Gen. Ins., fasc. 114, p. 30. - Horstmann, 1969

(1968). Opusc. Zool. 102: 1. - Townes, 1970 (1969). Amer. Ent. Inst., Mem. 13: 151-152.

angularis Viereck. R. I., N. Y., N. J., Ont.

Campoplex (Campoplex) angularis Viereck, 1925; 1926. Canad. Ent. 57 (9): 226 (key); 58 (6): $148 . \delta^{2}$, ㅇ.

argenteus (Provancher). Que. w. to s. B. C., s. to n.w. S. C. Host: Epiblema strenuannm (Wlk.). Limneria argentea Provancher, 1874. Nat. Canad. 6: 147.. .

Campoplex (Campoplex) ontario Viereck, 1925; 1926. Canad. Ent. 57 (9): 226 (key); 58 (6): 148. ㅇ.

atridens Townes. N. Y., Pa., Ont., Ohio, Mich., Iowa, Colo., Mont., Idaho, Wash., Oreg. Host: Ancylis comptana (Froel.), Evora hemidesma (Zell.), Archips argyrospilus (Wlk.).

Campoplex (Campoplex) erythromera Viereck, 1925 (Sept.); 1926. Canad. Ent. 57 (9): 226 (key); 58 (6): 146. ठ̊. Preocc. in Camipoplex by Viereck, 1925 (July).

Campoplex atridens Townes, 1945. Amer. Ent. Soc., Mem. 11: 593. N. name for C. (C.) erythromera Viereck.

brachyurus Viereck. Que., N. H., Ont., Wis. Host: Bucculatrix canadensisella Chamb.

Zaporus minutus Ashmead, 1902. In Slosson, Ent. News 13: 321. Nomen nudum.

Nythobia mimuta Cushman, 1922. U. S. Natl. Mus., Proc. 61 (8): 19. \&. Preoce. in Campoplex by Dusona minuta (Holmgren), 1856; because of the homonymy, I had intended that $N$. minuta be newly suppressed here as a synonym of brachyurus even though I have seen only four specimens (including the two holotypes) and do not feel absoultely certain about the correctness of the synonymy. Because of a misunderstanding, the synonymy was published by Finlayson (1975).

Nemeritis brachyurus Viereck, 1925; 1926. Canad. Ent. 57 (7): 178 (key); 58 (7): 178. \&. In the 1926 portion of Viereck's paper as "Campoplex (Nemeritis) brachyurus."

Taxonomy: Finlayson, 1975. Ent. Soc. Canada, Mem. 94: 16, 19-20, 91, 135 (final-instar larva). cavus Viereck. Ont.

Campoplex (Campoplex) cavus Viereck, 1925; 1926. Canad. Ent. 57 (9): 226 (key); 58 (6): 149.. .

conocola (Rohwer). Eastern Ont. w. to B. C., s. to n. Fla., Ark., and s. Calif. Ecology: Parasitizes a variety of microlepidoptera which feed on Pinaceae, especially cone borers, but also species which feed in small branches or bark. Host: Barbara colfaxiana taxifoliella (Bsk.), Laspeyresia fletcherana Kft., Petrova albicapitana (Bsk.), Rhyacionia zozana (Kft.), Dioryctria amatella (Hulst), D. clarioral is (Wkl.), D. zimmermanni (Grt.), Tetralopha robustella Zell.?, Synanthedon novaroensis (Hy. Ed.).

Pyracmon conocola Rohwer, 1917. U. S. Natl. Mus., Proc. 53: 159. ơ, ๆ.

crassatus (Viereck), revised status. Que. w. to s.e. Sask., s. to n.w. S. C. and Ohio. Host: Exartema cornanum Heinr., E. permundanum Clem., Proteoteras willingana (Kft.). Townes (1945) and Barron (1975) have incorrectly applied the name hyalimus (Provancher) to this species, contrary to the valid lectotype selection of Gahan and Rohwer (1918). See the discussion under Synetaeris hyalina (Provancher).

Neonortonia crassata Viereck, 1925. Canad. Ent. 57 (7): 179 (key); 57 (12); 301. ơ. 
Campoplex (Campoplex) moderatus Viereck, 1925; 1926. Canad. Ent. 57 (9): 225 (key); 58 (6): 143. ․ N. syn.

Campoplex (Campoplex) deceptivus Viereck, 1925: 1926. Canad. Ent. 57 (9): 226 (key); 58 (6): 146. ‥ N. syn.

Taxonomy: Gahan and Rohwer, 1918. Canad. Ent. 50: 28. -Walley, 1933. Canad. Ent. 65:

254-255 (redescription of moderatus). - Townes, 1945. Amer. Ent. Soc., Mem. 11: 596-597.

- Barron, 1975. Nat. Canad. 102: 484.

dimidiatus (Cresson). Ill.

Mesoleptus! dimidiatus Cresson, 1864. Ent. Soc. Phila., Proc. 3: 265. 9. Preocc. in Campoplex by Dusona dimidiata (Brulle), 1846.

ecoxalis Walkley. N. H. Known only from the holotype which was collected on the top of Mt. Washington.

Phaedroctonus coxalis Ashmead, 1900. In Slosson, Ent. News 11: 319. Nomen nudum.

Cymodusa coxalis Cushman, 1922. U. S. Natl. Mus., Proc. 61 (8): 10. 9. Preoce. in Campoplex by Spinola, 1851.

Campoplex ecoxalis Walkley, 1958. In Krombein et al., U. S. Dept. Agr., Agr. Monog. 2, sup. 1, p. 59. N. name for Cymodusa coxalis Cushman.

epinotiae Viereck. Coastal Calif. Host: Epinotia arctostaphylana Kft. Known only from the holotype which is from Carmel, Calif.

Campoplex epinotiae Viereck, 1912. U. S. Natl. Mus., Proc. 43: 586. $q$.

erythromerus (Viereck). Ont.

Nemeritis erythromerus Viereck, 1925; 1926. Canad. Ent. 57 (7): 178 (key); 58 (7): 177. . In the 1926 part of Viereck's paper as "Campoplex (Nemeritis) erythromerus."

frustranae Cushman. Southeastern Mass. w. to n. Ohio, s. Ill., and s.w. Nebr., s. to central Ga., central Miss., and n.w. Ark. Host: Rhyacionia frustrana (Comst.), $R$. rigidana (Fern). Introduced in Nebr. following the accidental introduction of $R$. frustrana in pine plantations.

Campoplex frustranae Cushman, 1927 (June 2). Jour. Agr. Res. 34 (7): 620 (key), 621 (fig.). ‥

Taxonomy: Cushman, 1927 (June 24). Jour. Agr. Res. 34 (8): 739 (more complete description including differences of male).

Biology: Baumhofer, 1929. Jour. Econ. Ent. 22: 1001. -Cushman, 1932. Ent. Soc. Wash., Proc. 34: 28. -Dowden, 1962. U. S. Dept. Agr., Agr. Handb. 226: 37, 42, 51. -Eikenbary and Fox, 1968. Ent. Soc. Amer., Ann. 61: 1430-1433.

fusiformis (Provancher). N. B. s. to w. N. C., w. to s.w. Tex. Information at the American Entomological Institute, Ann Arbor, Mich. indicates that the synonymy below must be considered very tentative.

Limneria fusiform is Provancher, 1874. Nat. Canad. 6: 148. ․

Amorphota fermuginosa Viereck, 1906. Amer. Ent. Soc., Trans. 32: 220. .

Campoplex (Campoplex) grossulariflorae Viereck, 1917 (1916). Conn. State Geol. and Nat. Hist. Survey Bul. 22: 263 . + .

Campoplex (Campoplex) maquinnai Viereck, 1917 (1916). Conn. State Geol. and Nat. Hist. Survey Bul. 22: 263. ㅇ.

Campoplex (Campoplex) pentagoetomm Viereck, 1917 (1916). Conn. State Geol. and Nat. Hist. Survey Bul. 22: 263. ठ.

Neonortonia scaposa Viereck, 1925. Canad. Ent. 57 (7): 179 (key); 57 (12): 301. ठ.

Pseuderiptemoides deceptus Viereck, 1925. Canad. Ent. 57 (7): 179 (key); 57 (12): 302..

Pseuderipternoides neglectus Viereck, 1925. Canad. Ent. 57 (7): 179 (key); 57 (12): 302. ठ

Pseuderipternoides pulchellus Viereck, 1925. Canad. Ent. 57 (7): 179 (key); 57 (12): 303..

Campoplex (Campoplex) hullensis Viereck, 1925 (Sept); 1926. Canad. Ent. 57 (9): 225

(key); 58 (6): 144. . Preoce. in Campoplex by Viereck, 1925 (July).

Campoplex (Campoplex) signatus Viereck, 1925; 1926. Canad. Ent. 57 (9): 226 (key); 58 (6): 144 . $\delta$.

haywardi Blanchard. Bolivia, Uruguay, Argentina. Introduced in southern Calif. "after 1963" according to Leong and Oatman (1968), apparently without becoming established. Host: 
Phthorimaea operculella (Zell.). The host cited was the target species for introductions in Calif.

Campoplex haywardi Blanchard, 1942. In Hayward, Tucuman Estac. Expt. Agr., Rev. Indus. y Agr. 33: 83. Nomen nudum.

Campoplex haywardi Blanchard, 1947 (1946). Acta Zool. Lilloana 3: 295. o, ᄋ.

Biology: Leong and Oatman, 1968. Ent. Soc. Amer., Ann. 61: 26: 36.

hexagonalis (Viereck). Southern Alta.

Pseuderiptermoides hexagonalis Viereck, 1925. Canad. Ent. 57 (7): 179 (key); 57 (12): 302. ○.

hullensis (Viereck). Que.

Neonortonia hullensis Viereck, 1925. Canad. Ent. 57 (7): 179 (key); 57 (12): 301. §.

infumatus (Provancher). Que.

Limneria infumata Provancher, 1874. Nat. Canad. 6: 148. $\%$. The lectotype selected by Gahan and Rohwer (1918) is not conspecific with the lectotypes for the names suppressed as synonyms of infumatus by Townes (1945); see parallelus Viereck.

Taxonomy: Gahan and Rohwer, 1918. Canad. Ent. 50: 29. - Townes, 1945. Amer. Ent. Soc., Mem. 11: 597. - Barron, 1975. Nat. Canad. 102: 489 (confirmation of Gahan and Rohwer lectotype).

macer (Cresson). Colo.

Mesoleptus macer Cresson, 1865. Ent. Soc. Phila., Proc. 4: 262..

mellipes (Provancher). Que., Maine, Mass., Ont., Mich., Wis., S. Dak., Sask., n. Idaho, s. B. C. Host: Epinotia nanana (Treit.), Coleotechnites piceaella (Kft.), Eucordylea ducharmei Free., Exoteleia dodecella (L.), Coleophora laricella ( $\mathrm{Hbn.)}$, C. pruniella Clem. I suspect that the name mellipes and the other names listed as synonyms therof apply to one or more species which lose the second intercubitus in smaller specimens (i.e. those that develop on smaller hosts).

Limneria rufipes Provancher, 1874. Nat. Canad. 6: 149. . Preocc. in Campoplex by Gravenhorst, 1829 and Holmgren, 1872.

Limmeria mellipes Provancher, 1883. Petite Faune Ent. Canada, p. 831 (errata). N. name for L. mifipes Provancher. Barron (1975) and other authors have incorrectly concluded that this name was a lapsus and apparently were unaware of its proposal in the index of the Petite Faune.

Nemeritis melanomerus Viereck, 1925; 1926. Canad. Ent. 57 (7): 178 (key); 58 (7): 177. o. In the 1926 part of Viereck's paper as "Campoplex (Nemeritis) melanomerus."

Nemeritis decoratus Viereck, 1925; 1926. Canad. Ent. 57 (7): 179 (key); 58 (7): 180. ㅇ. In the 1926 part of Viereck's paper as "Campoplex (Nemeritis) decoratus."

Nemeritis laevis Viereck, 1925; 1926. Canad. Ent. 57 (7): 179 (key); 58 (7): 179. . In the 1926 part of Viereck's paper as "Campoplex (Nemeritis) laevis."

Phaedroctonus piceae Cushman, 1935. Wash. Acad. Sci., Jour. 25: 260. ठ, ९.

nigricinctus (Ashmead). N. J., D. C. Host: Small "tineid" on Betula nigra, Ametastegia recens (Say)?

Limneria nigricincta Ashmead, 1890 (1889). U. S. Natl. Mus., Proc. 12: 431. §’, ๆ.

Taxonomy: Townes and Townes, 1951. In Muesebeck et al., U. S. Dept. Agr., Agr. Monog. 2: 361 (lectotype selected).

nigricoxa (Provancher). Que. Known only from the lectotype. Notes I made in studying the lectotype in 1974 indicate that it may be a composite specimen.

Limneria nigricoxa Provancher, 1882. Nat. Canad. 13: 364. ?.

Limnerinm nigricoxum Dalla Torre, 1901. Cat. Hym., v. 3, p. 99. Emend.

Taxonomy: Gahan and Rohwer, 1918. Canad. Ent. 50: 29 (lectotype selected). - Barron, 1975.

Nat. Canad. 102: 516.

nolae (Ashmead). Que. s. to R. I., w. to Sask., Colo., and s. Calif. Host: Trichotaphe sp., Nola sp. on Salix, Cnephasia longana (Haw.).

Limneria nolae Ashmead, 1890 (1889). U. S. Natl. Mus., Proc. 12: 431. §, ९.

Campoplex (Hyposoter) fuscitarsatus Viereck, 1925; 1926. Canad. Ent. 57 (8): 203 (key); 58 (8): 199. ㅇ. 
Campoplex (Campoplex) aylmerensis Viereck, 1925; 1926. Canad. Ent. 57 (9): 226 (key); 58 (6): 148. ..

parallelus Viereck, revised status. Que., Mass., R. I., N. Y., Md., Ont., Mich., n.e. Kans. Host: Archips rosanus (L.), Ancylis comptana (Froel.), Grapholitha molesta (Bsk.), Holcocera modestella Clem., Depressaria cinereocostella Clem. The name parallelus and the two synonyms listed below were incorrectly suppressed as synonyms of infumatus (Provancher) by Townes (1945).

Campoplex (Hyposoter) parallelus Viereck, 1925; 1926. Canad. Ent. 57 (8): 204 (key); 58 (9): 219. ㅇ. .

Campoplex (Campoplex) alganquinorum Viereck, 1925; 1926. Canad. Ent. 57 (9): 226 (key); $58(6): 145$. . N. syn.

Campoplex (Campoplex) grimsbyensis Viereck, 1925; 1926. Canad. Ent. 57 (9): 226 (key); 58 (6): 145 . ㅇ. N. syn.

Taxonomy: Townes, 1945. Amer. Ent. Soc., Mem. 11: 597.

phthorimaeae (Cushman). Va.?, w. Calif. Host: Keiferia inconspicuella (Murtf.)?, K. Iycopersicella (Wlsm.), Phthorimaea operculella (Zell.), Heliothis zea (Bod.). I have not seen specimens from places other than Calif. which I could definitely identify as phthorimaeae, but would suppose that the range of the species is not restricted to Calif. The species was described from six males and four females; the male allotype and four of the other male paratypes are of the genus Diadegma, apparently an undescribed species. In the U.S. Nati. Museum collection I presently find only eight specimens of $C$. phthorimaeae reared from $P$. operculella by J. E. Graf, but there are 40 specimens of the Diadegma sp. which Graf reared from that host. Therefore, it seems likely that the discussion of Graf (1917) pertains more to the Diadegma sp. than to C. phthorimaeae. Whether the University of Calif. (Riverside) shipped both species to Hawaii (see Weber, 1951 ) and other parts of the World remains to be seen. Chittendon (1922) reported phthorimaeae as having been reared from Udea mibigalis $(\mathrm{Gn}$.$) , but that record pertains$ to yet another apparently undescribed species of Diadegma. See also Diadegma compressum (Cresson).

Omorgus phthorimaeae Cushman, 1915. Ent. Soc. Wash., Proc. 17: 138. o, f.

Biology: Graf, 1917. U. S. Dept. Agr., Bul. 427: 38-39. -Chittendon, 1922. Canad. Ent. 54: 174 (misidentified Diadegma sp.). - Weber, 1951. Hawaii. Ent. Soc., Proc. 14: 327.

polychrosidis Viereck. N. Y. s. to w. N. C., w. to Mich. and Ind. Host: Platyptilia carduidactlya (Riley), Paralobesia carduana (Bsk.).

Campoplex polychrosidis Viereck, 1912. U. S. Natl. Mus., Proc. 43: 586..

porrectus (Cresson). Que. w. to Sask., s. to e. N. C., n.w. S. C., and s.w. Kans.

Mesoleptus porrectus Cresson, 1864. Ent. Soc. Phila., Proc. 3: 266. ๆ.

Mesoleptus subtenuis Cresson, 1864. Ent. Soc. Phila., Proc. 3: 267. ठ.

Limneria ruficoxa Provancher, 1875. Nat. Canad. 7: 146. 9.

Limnerium ruficoxum Dalla Torre, 1901. Cat. Hym., v. 3, p. 103. Emend.

Olesicampa melanerythrogaster Viereck, 1905. Kans. Acad. Sci., Trans. 19: 306. ઠै,.

pyraustae Smith. Europe. Introduced between 1927 and 1933 in Mass., R. I., Conn., N. Y., and Ohio without becoming established. Host: Ostrinia nubilalis (Hbn.). The host cited was the target species for introductions in the United States.

Campoplex pyraustae Smith, 1931. Portici R. Scuola Super. di Agr., Lab. Zool. Gen. e Agr., Bol. 25: 257. $\delta$, $₹$. The holotype is now deposited in the U. S. Natl. Museum.

Taxonomy: Baker, Bradley, and Clark, 1949. U. S. Dept. Agr., Tech. Bul. 983: 144-147. relativus (Viereck). Southwestern Kans.

Amorphota relativa Viereck, 1905. Kans. Acad. Sci., Trans. 19: 307..

tecumseh Viereck. Mass., Pa., Ont., Alta., Alaska. Host: Holcocera modestella Clem., Scrobipalpa atriplicella (Rosler).

Campoplex (Campoplex) tecum seh Viereck, 1925; 1926. Canad. Ent. 57 (9): 225 (key); 58 (5): 130. $\delta$.

tineavora (Rohwer). Southwestern Oreg. Host: Tinea defectella Zell. Angitia timeavora Rohwer, 1917. U. S. Natl. Mus., Proc. 53: 160. o, ๆ. 
tortricidis (Cushman). N. H. w. to interior Alaska, s. to n.w. S. C., Colo., and n. Calif. Host: Grapholitha molesta (Bsk.), Paralobesia viteana (Clem.), Acleris variana (Fern.).

Omorgus tortricidis Cushman, 1915. Ent. Soc. Wash., Proc. 17: 137. ठै, १.

triannulatus (Cameron). Western Calif.

Eriborus? triannulatus Cameron, 1908. Amer. Ent. Soc., Trans. 34: 245. o.

Taxonomy: Townes, 1961. Ent. Soc. Wash., Proc. 63 : 106 (generic placement).

ultimus Viereck. Southwestern B. C., Wash., w. Oreg., n.w. Calif. Ecology: In the Canadian

National Collection there is a female specimen from Vancouver, B. C. which was reared

from an unknown host in Polystictus versicolor.

Campoplex (Campoplex) ultimus Viereck, 1925; 1926. Canad. Ent. 57 (9): 226 (key); 58 (6):

147. . Viereck cited Ottawa, Ont. as the type locality, but Mr. G. S. Walley has labeled

the lectotype as probably collected by Rev. G. W. Taylor in B. C.

uniformis (Viereck). Southwestern Alta.

Nemeritis uniform is Viereck, 1925; 1926. Canad. Ent. 57 (7): 178 (key); 58 (7): 177. ơ. In

the 1926 part of Viereck's paper as "Campoplex (Nemeritis) uniformis."

valens (Cresson). Colo.

Mesoleptus valens Cresson, 1865. Ent. Soc. Phila., Proc. 4: 261..

Casinaria compacta Davis, 1898 (1897). Amer. Ent. Soc., Trans. 24: 362. ๆ.

\section{Genus PORIZON Fallen}

Porizon Fallen, 1813. Spec. Nov. Hym. Disp. Meth., p. 18.

Type-species: Ichneumon moderator Linnaeus. Monotypic. Included as "Ophion

moderator Fabr[icius]" by Fallen, but cannot be treated as the Fabrician

identification of $I$. moderator Linnaeus because the description given by

Fabricius (1804 [where he placed moderator in Ophion]) does not add anything to the Linnaean description and alters it only insignificantly by omitting the phrase "ore tentaculato." Moreover, Fabricius did not indicate that he had aquired or had seen specimens of moderator (see further discussion below).

Phaedroctonus Foerster, 1868. Naturh. Ver. Rheinlande, Verh. 25: 153. N. syn.

Type-species: Phaedroctonus minutus Ashmead. By subsequent monotypy from inclusion by Ashmead, 1902.

For many years the name Porizon was applied to various Tersilochinae, especially to an assemblage of species (now placed in the genus Baryenemis) which did not include Porizon moderator in the sense of Fallen or of subsequent authors (moderator auct. being placed in Tersilochus). Accordingly, Viereck (1914) proposed the name Porizonidea to apply to Porizon of authors and suppressed Tersilochus as a synonym of Porizon. Roman (1932) discovered that $I$. moderator Linnaeus is a species of Campopleginae, but made no adjustment in the application of the name Porizon. Townes (1945) applied the name Tersilochini to "Porizonini" of authors (cf. Hincks, 1945), but the name Porizon continued to be used sporadically for various Tersilochinae, particularly before Townes and Townes (1951) applied the name "Porizonini" to the Campoplegini. Townes (1965) applied the name Porizon to Campoplex paniscus Gravenhorst, which he distinguished from "moderator Linnaeus." Horstmann (1970) discovered that Roman (1932) and Townes (1965) had not correctly identified the moderator type specimen, and had incorrectly suppressed Nemeritis cremastoides Holmgren as a synonym of moderator. Horstmann indicated moderator to be a species of Venturia; he erected the genus Leptocampoplex (which see) for cremastoides (i.e. Porizon sensu Townes [1965, 1970], in part), and placed paniscus, with uncertainty, as a synonym of Macrus filiventris Gravenhorst (see Macrus). As a consequence of the findings of Horstmann (1970), Townes (1971) indicated that Venturia should be suppressed as a synonym of Porizon.

In 1972 I borrowed a specimen of Porizon moderator from Dr. Horstmann and learned that the Nearctic Phaedroctonus temporalis Cushman is a junior synonym of moderator. In my opinion, Porizon is recognizable as a genus distinct from either Venturia or Campoplex, the separation from Campoplex being more subjective, as is suggested by Townes (1945) placement of the species here included in Porizon and by the fact that Townes (1970) continued to treat Phaedroctonus as a synonym of Campoplex.

There had never been much doubt that Fallen had intended the name Porizon to apply to 
what we now call Tersilochinae (cf. Hincks, 1945), and Horstmann $(1970,1971)$ studied a specimen of Probles rufipes (Holmgren) which had been identified as Porizon moderator by Fallen. For that reason, Horstmann (1970) suggested that an application for the suppression of the names Porizon and Porizontinae should be made to the International Commission on Zoological Nomenclature, and Fitton and Gauld (1976) suggested that the case needed to be referred to the Commission. If the facts revealed by Horstmann (1970) had been established soon after Roman (1932) published on the identity of Ichneumon moderator, it might then have been logical to seek a ruling that would have made Tersilochus rufipes Holmgren the type-species of Porizon. Acceptance of $I$. moderator Linnaeus as the type-species of Porizon would leave us with a zoological rather than nomenclatural problem, and would eliminate any need for making an application to the Commission. I believe that the option of regarding the nomenclatural problem as settled and striving to solve the zoological one is the option which would be most uniformly accepted. I believe that Dr. Horstmann concurs with me on this, and I am hopeful that Drs. Fitton and Gauld will also.

Porizon is a small genus of Holaretic and Neotropic (southern Mexico) distribution. Most of the species are parasitic on microleptidoptera which feed on coniferous trees, especially cone moths and needle miners. P. transfuga (Gravenhorst), which is placed in Porizon only provisionally, parasitizes Gracilaria syringella (F.), the lilac leaf miner, and two specimens of cupressi (Ashmead), which has otherwise been reared only from conifer-feeding hosts, were reared from a leaf tier on Rhamnus purshianus.

Taxonomy: Fabricius, 1804. Systema Piezatorum, p. 137. - Viereck, 1914. U. S. Natl. Mus., Bul. 83; 122, 144, 145. - Roman, 1932. Ent. Tidskr. 53: 9. - Townes, 1945. Amer. Ent. Soc., Mem. 11: 592, 593, 597, 598, 602, 73. - Hincks, 1945. Entomologist 78: 90 (including opinions of J. F. Perkins). - Townes and Townes, 1951. In Muesebeck et al., U. S. Dept. Agr., Agr. Monog. 2: 357-358. - Townes, 1965. Polskie Pismo Ent. 35: 410. -Townes, 1970 (1969).

Amer. Ent. Inst., Mem. 13: 151, 167-168, 278. - Horstmann, 1970. Bayer. Ent.,

Nachrichtenbl. 19: 77-79. - Townes, 1971. Amer. Ent. Inst., Mem. 17: 241. - Fitton and

Gauld, 1976. Systematic Ent. 1: 248-249.

argyresthiae (Rohwer), n. comb. Southwestern Oreg. Host: Argyresthia libocedrella Bsk. Known from a long series of specimens reared at Ashland, Oreg. in 1914.

Phaedroctonus argyresthiae Rohwer, 1917. U. S. Natl. Mus., Proc. 53: 162. ठ, ?.

cupressi (Ashmead), n. comb. Que., Maine, N. H., s.w. Va., w. N. C., w. Iowa., s.w. Alaska, w. Wash., n. Calif. Host: Periploca nigra Hodges, Epinotia nanana (Treit.), Argyresthia cupressella Wlsm., A. thuiella Pack., needle miner on Abies concolor, leaf tier on Rhamnus purshianus.

Limneria cupressi Ashmead, 1890 (1889). U. S. Natl. Mus., Proc. 12: 437. ๆ.

Phaedroctonus minutus Ashmead, 1902. Wash. Acad. Sci., Proc. 4: 235..

Phaedroctonus epinotiae Cushman, 1935. Wash. Acad. Sci., Jour. 25: 559. o, \&. Formerly preoce. in Campoplex by Viereck, 1912. N. syn.

Campoplex nanana Townes, 1945. Amer. Ent. Soc., Mem. 11: 598. N. name for P. epinotiae Cushman. N. syn.

laspeyresiae (Rohwer), n. comb. Colo., N. Mex., w. Mont., n. Idaho, s.e. Wash., s.w. Oreg., n.e. Calif. Host: Laspeyresia piperana (Kft.), L. toreuta (Grt.).

Meleborus(!) laspeyresiae Rohwer, 1917. U. S. Natl. Mus., Proc. 53: 161..

milleri (Rohwer), n. comb. Southwestern Oreg. Host: Dioryctria abietella (D. and S.). Known only from the holotype which is a rather poor specimen from Ashland, Oreg. This species is placed in Porizon only tentatively; the petiole is similar to that of Nemeritis spp., and the second intercubitus is present, although abnormally positioned in one of the fore wings of the holotype.

Angitia milleri Rohwer, 1917. U. S. Natl. Mus., Proc. 53: 159. 9.

moderator (Linnaeus). Vt., N. Y., Ont., N. Mex., w. Mont., Idaho, s.-coastal Akaska; Europe. Host: Laspeyresia youngana (Kft.). A 1972 letter I received from Dr. Klaus Horstmann says that males are apparently uncommon in Europe.

Ichneumon moderator Linnaeus, 1758. Syst. Nat., ed 10, v. 1, p. 564.. .

Campoplex flaviventris Ratzeburg, 1844. Ichn. d. Forstins., v. 1, p. 98. 9.

Limneria (Phaedroctonus) ensifera Brischke, 1880. Naturf. Gesell. Danzig, Schr. 4: 172. \&.

Phaedroctonus temporalis Cushman, 1935. Wash. Acad. Sci., Jour. 25: 560. \&. N. syn. 
Taxonomy: Roman, 1932. Ent. Tidskr. 53: 9 (misdet.). - Horstmann, 1970. Bayer. Ent., Nachrichtenbl. 19: 78-79. - Horstmann, 1973. Deut. Ent. Gesell., Mitt. 32: 9, 11.

transfuga (Gravenhorst), n. comb. Newfoundland (insular), N. B., Que., Ont.; Eurasia. Adventive. Host: Gracilaria syringella (F.). Not previously recorded from North America; the North American distribution given here is based upon specimens I have seen in the Canadian Natl. Collection and that of the U. S. Natl. Museum. I do not know that the species has been reared in North America, but it presumably was introduced in parasitized hosts on lilac (Syringa vulgaris). The species is placed in Porizon only provisionally; if related species exist, it should probably be placed with them in a separate genus.

Campoplex transfuga Gravenhorst, 1829. Ichn. Europaea, v. 3, p. 521. đ, \&.

Phaedroctomus transfugus Schmiedeknecht, 1909. Opusc. Ichn., v. 4, p. 1640. Emend.

Phaedroctonus syringellae Hedwig, 1944. Ztschr. f. Ent. [Breslau] 19 (3): 4. sex ?

Taxonomy: Horstmann, 1973. Deut. Ent. Gesell., Mitt. 32: 9, 11.

\section{Genus VENTURIA Schrottky}

Idechthis Foerster, 1868. Naturh. Ver. Rheinlande, Verh. 25: 154. Preocc. by Huebner, 1821.

Type-species: Idechthis oahuensis Ashmead. By subsequent monotypy from inclusion by Ashmead, 1901.

Venturia Schrottky, 1902. Buenos Aires, Mus. Nac. de Hist. Nat., An. 8: 102.

Type-species: Venturia argentina Schrottky. Orig. desig.

Devorgilla Cameron, 1907. Tijdschr. v. Ent. 50: 51 .

Type-species: Devorgilla dilatata Cameron. Monotypic.

Balcarcia Brethes, 1922. Soc. Cient. Argentina, An. 93: 133.

Type-species: Balcarcia bergi Brethes. Monotypic.

Notamorphota Blanchard, 1947 (1946). Acta Zool. Lilloana 3: 292. It is apparent that three of the figures in this paper are mislabeled. The figure labeled as being that of Notamorphota timocraticae (fig. 2, p. 293) is actually that of Sagaritis grioti Blanchard. The figure labeled as being that of Hyposoter denieriBlanchard (fig. 5, p. 301) is the one which should have been labeled $N$. timocraticae, and the figure labeled as being that of $S$. grioti (fig. 6, p. 304) is the one which should have been labeled $H$. denieri.

Type-species: Notamorphota timocraticae Blanchard. Monotypic and orig. desig.

Exidechthis walkley, 1958. In Krombein et al., U. S. Dept. Agr., Agr. Monog. 2, sup. 1, p.

59. N. name for Idechthis Foerster.

This rather large genus has a worldwide distribution, but the number of species occuring in temperate areas appears to be fewer than that occurring in tropical and subtropical areas. See biological discussion under Campoplex.

Revision: Horstmann, 1973. Deut. Ent. Gesell., Mitt. 32: 7-12 (European spp.).

Taxonomy: Townes and Townes, 1966. Amer. Ent. Inst., Mem. 8: 143 (syn.).

canescens (Gravenhorst). Southern Canada, s.e. Alaska, and continental U. S. A.; temperate and tropic areas around the world. Ecology: Most often found in buildings where grains or flour are stored. In the U.S. Natl. Museum collection there are two specimens reared from bumble bee nests, one from Anderson, S. C. and the other from Boulder Co., Colo. (the latter labeled "ex Ephestia sp."). Adventive. Host: Anagasta kuehniella (Zell.), Plodia interpunctella ( $\mathrm{Hbn}$.). The hosts listed are the ones most commonly parasitized in North America; for additional hosts and their significance see the very excellent paper by Salt (1976). Males are unknown in North America, occasional in northern Europe, but apparently more common in the Mediterranean Basin. The biology of this species has perhaps been studied more intensively than that of any other ichneumonid. The biological references cited below are the more important ones known to me, and I have no doubt overlooked some important papers, particularly those published more recently.

Campoplex canescens Gravenhorst, 1829. Ichn. Europaea, v. 3, p. 555. \&. Name of questionable validity because preocc. in Campoplex by Ichneumon canescens Gmelin, 1791 on p. 549 (in synonymy) of Gravenhorst's same volume. 
Cryptus ductilis Say, 1836. Boston Jour. Nat. Hist. 1: 233. 9.

Campoplex frumentarius Rondani, 1877. Soc. Ent. Ital., Bul. 9:169. Sex not indicated?

Nemeritis gracilis Tosquinet, 1896. Soc. Ent. de Belg., Mem. 5: 414. 9.

Omorga columbia Ashmead, 1899. In Johnson, U. S. Dept. Agr., Div. Ent., Bul. 20: 67.

Nomen nudum.

Idechthis oahuensis Ashmead, 1901. Fauna Hawaiiensis, v. 1, p. 355..

Lathrostizus insularis Ashmead, 1901. Fauna Hawaiiensis, v. 1, p. 355 ..+

Idechthis ephestiae Ashmead, 1903. In Fletcher, Ent. Soc. Ontario, Ann. Rpt. 33: 86. Nomen nudum.

Limnerium garrulum Cameron, 1905. Albany Mus., Rec. 1: 315 . $\$$.

Amorphota ephestia Froggatt, 1912 (Apr.). Agr. Gaz. N. S. Wales 23: 209. §, ९.

A morphota ephestiae Cameron, 1912 (Aug.). Linn. Soc. N. S. Wales, Proc. 37 (1): 187..

Mesochorus australicus Girault, 1925. Queensland Agr. Jour. 24: 541. 9.

Limnerium christianae Cheesman, 1928. Ann. and Mag. Nat. Hist. (10) 1: 191..

Angitia pyraustae Uchida, 1930. Insecta Matsumurana 4: 129..

Angitia compressa Hedwig, 1962. Naturw.-Mus. Aschaffenburg, Nachr. 68: 94..+

Taxonomy: Cushman and Gahan, 1921. Ent. Soc. Wash., Proc. 23: 161. -Townes, Townes, and Gupta, 1961. Amer. Ent. Inst., Mem. 1: 222 (syn.). -Townes, Momoi, and Townes, 1965. Amer. Ent. Inst., Mem. 5: 277 (syn.). - Horstmann, 1973. Beitr. z. Ent. 23: 131 (syn.). - Horstmann, 1973. Deut. Ent. Gesell., Mitt. 32: 9, 11. -Townes and Townes, 1973. Amer.

Ent. Inst., Mem. 19: 149 (syn.).

Biology: Candura, 1928. Portici R. Scuola Super. di Agr., Lab. Zool. Gen. e Agr., Bol. 21: 149-212. - Diamond, 1929. Ent. Soc. Ont., Ann. Rpt. 60: 84-89. - Thorpe, 1938; 1939. Roy.

Ent. Soc. London, Proc., Ser. A: Gen. Ent. 13: 58-59; 14: 47. - Narayanan, 1939. Nature [London] 144: 207. - Salt, 1941. Cambridge Phil. Soc., Biol. Rev. 16: 259-260. - Simmonds, 1943. Rev. Canad. de Biol. 2: 15-58. - Williams, 1951. Roy. Ent. Soc. London, Proc., Ser. A: Gen. Ent. 25: 49-58. -Fisher, 1961. Jour. Expt. Biol. 38: 267-275, 605-628. -Fisher, 1962.

Ecology 43: 314-316. - Takahashi, 1962. Jap. Jour. Appl. Ent. and Zool. 6: 160. -Salt, 1964. Roy. Ent. Soc. London, Trans. 161: 1-14. - Salt, 1965. Roy. Soc. London, Proc., Ser. B: Biol. Sci. 162: 303-318. -Corbet, 1968. Jour. Expt. Biol. 48: 291-304. -Corbet, 1971. Nature

[London] 232: 481-484. - Rogers, 1972. Ent. Expt. et Appl. 15: 190-194. - Rotherham, 1973.

Roy. Soc. London, Proc., Ser. B: Biol. Sei. 183: 337-350. -Amos and Salt, 1974. Jour. Ent.

(B) 43: 11-18. - Ganesalingam, 1974. Ent. Expt. et Appl. 17: 36-44. - Salt, 1975. Roy. Ent.

Soc. London, Trans. 127: 141-161. - Corbet and Rotherham, 1975. Roy. Ent. Soc. London,

Proc., Ser. A: Gen. Ent. 40: 67-72. - Salt, 1976. Ecological Ent. 1: 63-67.

erythropus (Ashmead), n. comb. Tex.

Limneria erythropus Ashmead, 1890 (1889). U. S. Natl. Mus., Proc. 12: 431 . ठ.

Limnerium erythropum Dalla Torre, 1901. Cat. Hym., v. 3, p. 95. Emend.

gelechiae (Ashmead), n. comb. N. Y., N. J., Mo., Ark., Kans., s.w. Tex. Host: Fascista cercerisella (Chamb.).

Limneria gelechiae Ashmead, 1890 (1889). U. S. Natl. Mus., Proc. 12: 432. . .

nigricoxalis (Cushman), n. comb. N. Y., Mich., and Ind., s. to s. Ga., and Ark. Host: Synanthedon exitiosa (Say), S. pictipes (G. and R.), Grapholitha molesta (Bsk.), Euzophera ostricolorella Hulst, E. semifuneralis (Wlk.).

Idechthis nigricoxalis Cushman, 1915. U. S. Natl. Mus., Proc. 48: 512. ơ, १.

nigriseapus (Viereck). Ont., Mich., and Ill., s. to e. N. C., n.w. S. C., and Ark. Host: Plathypena scabra (F.). This species is one of a group that is otherwise Neotropic and which is rather distinct from the group of species which includes argentina Schrottky and canescens (Gravenhorst).

Idechthis nigriscapus Viereck, 1921. Psyche 28: 77..

Idechthis mimicus Viereck, 1926. Roy. Soc. Canada, Proc. and Trans. (3) 20 (5): 185. ठ。.

sokanakiakorum (Viereck). Eastern Que., R. I., Conn., N. Y., N. J., Pa., Ky., Tenn.; Guatemala? In the U.S. Natl. Mus. collection there is a single male bearing the data "Guatemala: Amatitlan; VIII-6-1965; P. J. Spangler," which appears in every respect to be sokanakiakorum.

Casinaria (Idechthis) sokanakiakorum Viereck, 1917 (1916). Conn. State Geol. and Nat. Hist. Survey Bul. 22: 270. ठ。. 


\section{Genus CASINARIA Holmgren}

Casinaria Holmgren, 1859 (1858). Svenska Vetensk.-Akad., Ofvers. af ... Forhandl. 15: 325.

Type-species: Campoplex tenuiventris Gravenhorst. Monotypic and orig. desig.

Amorphota Foerster, 1868. Naturh. Ver. Rheinlande, Verh. 15: 151.

Type-species: Amorphota orgyiae Howard. By subsequent monotypy from inclusion by Howard, 1897.

Campotrephus Foerster, 1868. Naturh. Ver. Rheinlande, Verh. 25: 152.

Type-species: Campoplex tenuiventris Gravenhorst. Monotypically included and desig. by Viereck, 1914.

Horogenes Foerster, 1868. Naturh. Ver. Rheinlande, Verh. 25: 152. This name was incorrectly applied to what is now called Diadegma from about 1925 into the 1960 's (most uniformly after 1945).

Type-species: Campoplex tenuiventris Gravenhorst. By subsequent monotypy from inclusion by Brischke, 1880 .

Anempheres Foerster. 1868. Naturh. Ver. Rheinlande, Verh. 25: 154.

Type-species: Anempheres diaphaniae Viereck. By subsequent monotypy from inclusion by Viereck, 1911.

Nothanomalon Szepligeti, 1915. In Wytsman, Gen. Ins., fasc. 34, p. 39.

Type-species: Nothanomalon novoguineensis Szepligeti. Monotypic.

Trophocampa Schmiedeknecht, 1907. Hym. Mitteleuropas, p. 598.

Type-species: Campoplex mesozostus Gravenhorst. Monotypic and orig. desig.

Fiebrigia Viereck, 1912. U. S. Natl. Mus., Proc. 42: 638.

Type-species: Campoplex texanus Ashmead. Monotypic and orig. desig.

Neonortonia Viereck, 1912. U. S. Natl. Mus., Proc. 43: 592.

Type-species: Campoplex genuinus Norton. Monotypic and orig. desig.

Zastenomorpha Viereck, 1921. Psyche 28: 81.

Type-species: Zastenomorpha lamina Viereck. Monotypic.

Zastenogastra Viereck, 1925. Roy. Soc. Canada, Proc. and Trans. (3) 19 (5): 259.

Type-species: Zastenogastra graciliventris Viereck. Monotypically included and desig. by Viereck, 1926.

Nothanomaloides Uchida, 1928. Hokkaido Imp. Univ., Faculty Agr., Jour. 21: 273. Preocc. by Viereck, 1925.

Type-species: Nothanomaloides matsuyamensis Uchida. Monotypic and orig. desig.

Deltops Seyrig, 1935. Paris, Mus. d'Hist. Nat., Mem. (n. s.) 4: 84.

Type-species: Deltops granulicoxis Seyrig. Monotypic and orig. desig.

Longicharops Uchida, 1940. Insecta Matsumurana 14: 131. N. name for Nothanomaloides Uchida.

Neonortoniella Blanchard, 1947. Montevideo, Mus. Hist. Nat., Comun. Zool. 2: 4.

Type-species: Neonortoniella plusiae Blanchard. Monotypic and orig. desig.

Casinariodes Aubert, 1960. Soc. Ent. de Mulhouse, Bul. 16: 661.

Type-species: Casinaria monticola Thomson. Monotypic and orig. desig.

This large genus occurs in all zoogeographic regions. The hosts are various kinds of lepidopterous larvae, mostly those of macrolepidoptera which do not conceal themselves when feeding.

Revision: Walley, 1947. Sci. Agr. 27: 364-395.

affinisima Carlson, n. name. Que. w. to s. Alta., s. to e. S. C. and Colo.

Casinaria affinis Walley, 1947. Sci. Agr. 27: 394. o, ₹. Preocc. by Tschek, 1871.

Taxonomy: Finlayson, 1975. Ent. Soc. Canada, Mem. 94: 27, 96, 135 (final-instar larva). ambigua (Townes). Tex. Known only from the holotype.

Nematopodius texanus Ashmead, 1890 (1889). U. S. Natl. Mus., Proc. 12: 414. ठ. Preocc. in Casinaria by Campoplex texanus Ashmead, 1890 (p. 427) and by Dusona texana (Ashmead), 1890 (p. 427).

Charops ambigua Townes, 1945. Amer. Ent. Soc., Mem. 11: 607. N. name for N. texanus Ashmead.

canadensis Walley. Que., N. Y., Md., Ont., n. Mich.

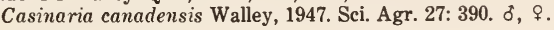

Taxonomy: Finlayson, 1975. Ent. Soc. Canada, Mem. 94: 26, 27-28, 96, 135 (final-instar larva). 
cavigena Walley. Southen B. C., s.w. Calif. Host: Geometrid. Casinaria cavigena Walley, 1947. Sci. Agr. 27: 379 ..

Taxonomy: Finlayson, 1975. Ent. Soc. Canada, Mem. 94: 26, 28, 97, 135 (final-instar larva, new distribution).

claviventris Holmgren. Ont., s. Sask.; Europe.

Casinaria claviventris Holmgren, 1860 (1858). Svenska Vetensk.-Akad. Handl. 2 (8): 49. ơ, ?.

Casinaria pinguis Walley, 1947. Sci. Agr. 27: 386. đ', ९.

Taxonomy: Townes and Townes, 1951. In Muesebeck et al., U. S. Dept. Agr., Agr. Monog. 2: 364 (syn.).

coloradensis Walley. Colo. Known from two specimens collected at Four-mile Hill, 8 mi. south of Steamboat Springs, Colo. on July 21, 1896, apparently by C. F. Baker.

Casinaria coloradensis Walley, 1947. Sci. Agr. 27: 371..

corrupta Walley. Southern Tex.

Casinaria corrupta Walley, 1947. Sci. Agr. 27: 385 . ठ" ?.

eupitheciae Viereck. Que. w. to s. B. C., s. to n.w. S. C., s. Wis., and w. Wash.; Ecuador? Host: Eupithecia gibsonata Tay., E. helveticaria Bdv., E. luteata Pack., E. miserulata Grt., E. palpata Pack.

Casinaria eupitheciae Viereck, 1912. U. S. Natl. Mus., Proc. 43: 586. ठ, \&.

Campoplex (Hypothereuthes) impetitus Viereck, 1925; 1926. Canad. Ent. 57 (8): 204 (key); 58 (9): 223 . .

Taxonomy: Finlayson, 1975. Ent. Soc. Canada, Mem. 94: 15, 26, 32, 100, 135 (final-instar larva).

forcipata Walley. N. B. w. to s. Alta., s. to Md., s. Ohio, s. w. Tex., s.e. N. Mex., Ariz., and s. Calif. Host: Itame pustularia (Gn.), Semiothisa "granitata" auct., S. oweni Swett, S. sexmaculata (Pack.), Malacosoma disstria $\mathrm{Hbn}$.

Casinaria forcipata Walley, 1947. Sci. Agr. 27: 393. ð, 9.

genuina (Norton). N. S. w. to s. B. C., s. to Del., Ill., Tex., N. Mex., and s. Wash. Host: Apantesis virgo (L.), Estigmene acrea (Drury), Hyphantria cunea (Drury), Acronicta oblinita (J. E. S.).

Campoplex genuinus Norton, 1863. Ent. Soc. Phila., Proc. 1: 367. ठ, ๆ.

Mesoleptus major Cresson, 1864. Ent. Soc. Phila., Proc. 3: 257. ठे.

Campoplex niger Provancher, 1879. Nat. Canad. 11 (no. 127): 148. \&. Preocc. by Brulle, 1846 and Provancher, 1874.

Anephares(!) rufipes Hancock, 1911. Nature Sketches in Temperate America, p. 177..

geometrae geometrae Walley. N. S., Que., N. Y., N. J., Md., W. Va., w. N. C., Ont. Host: Caripeta angustiorata Wlk., C. divisata Wlk., Eufidonia notataria Wlk., Paraphia piniata Pack., Protoboarmia porcelaria (Gn.), Semiothisa "granitata" auct.

Casinaria geometrae geometrae Walley, 1947. Sci. Agr. 27: 380. ơ,.

Taxonomy: Finlayson, 1975. Ent. Soc. Canada, Mem. 94: 27, 30-31, 99, 135 (final-instar larva).

geometrae occidentalis Walley. Southern B. C. s. to s.w. Calif. Host: Caripeta sp., Enypia venata (Grt.), Melanolophia imitata (Wlk.), Sabulodes caberata Gn., Semiothisa "granitata" auct.

Casinaria geometrae occidentalis Walley, 1947. Sci. Agr. 27: 382. ठ, ๆ.

Taxonomy: Finlayson, 1975. Ent. Soc. Canada, Mem. 94: 27, 31, 99, 135 (final-instar larva). grandis Walley. Fla., s. La., Tex. Host: Sibine stimulea (Clem.).

Campoplex texanus Ashmead, 1890 (1889). U. S. Natl. Mus., Proc. 12: 427. .. Preocc. in Casinaria by Dusona texana (Ashmead), 1890 (p. 427).

Casinaria grandis Walley, 1947. Sci. Agr. 27: 376. N. name for Campoplex texanus Ashmead.

infesta (Cresson). R. I. w. to s. Mich. and Iowa, s. to s. Fla. and Tex.; Mexico, Costa Rica, Argentina; Hawaii. Host: Desmia funeralis (Hbn.), Diaphania hyalinata (L.), Herpetogramma bipunctalis (F.), Hymenia fascialis Cram., $H$. perspectalis Hbn., $H$. 
recurvalis (F.), Mimorista flavidissimilis (Grt.), Ostrinia obliteralis (Wlk.), Udea mibigalis (Gn.), Autographa falcifera (Kby.), Ancylis comptana (Froel.).

Limneria infesta Cresson, 1872. Amer. Ent. Soc., Trans. 4: 172. ‥

Campoplex divisus Cresson, 1874 (1873). Acad. Nat. Sci. Phila., Proc. 25: 385. o.

Limneria sessilis Ashmead, 1890 (1889). U. S. Natl. Mus., Proc. 12: 433. . Preocc. by Provancher, 1875.

Limneria(?) erythrogaster Ashmead, 1890 (1889). U. S. Natl. Mus., Proc. 12: 434..

Limnerium Ashmeadii Dalla Torre, 1901. Cat. Hym., v. 3, p. 90. N. name for L. sessilis Ashmead.

Limnerium erythragastrum Dalla Torre, 1901. Cat. Hym., v. 3, p. 95. Emend.

Angitia autumnalis Viereck, 1906. Amer. Ent. Soc., Trans. 32: 181..

Anempheres diaphaniae Viereck, 1911. U. S. Natl. Mus., Proc. 40: 188..

Taxonomy: Townes, 1946. Bol. Ent. Venezolana 5: 36 (syn.).

Biology: Swezey, 1926. Hawaii. Ent. Soc., Proc. 6: 296. - Williams, 1931. Handb. Ins.

Hawaiian Sugar Cane Fields, p. 267-268. - Ball, Reeves, Boden, and Stone, 1935. U. S.

Dept. Agr., Tech. Bul. 463: 40. - Benham and Poinar, 1975. Jour. Invert. Path. 26: 181-191.

lamina (Viereck). Mass., N. Y., Pa., Md., n. Va., Ont., s. Ohio, Iowa. Host: Epargyreus clarus (Cram.).

Zastenomorpha lamina Viereck, 1921. Psyche 28: 81 ..

limenitidis (Howard). Que. w. to s. B. C., s. to D. C., s. Tex., and Ariz. Host: Dasychira basiflava (Pack.), D. plagiata (Wlk.), Orgyia antiqua (L.), O. leucastigma (J. E. S.), $O$. pseudotsugata (McD.), Malacosoma americanum (F.), Limenitis archippus (Cram.), Hyphantria cunea (Drury), Catocala antinympha (Hbn.).

Limneria limenitidis Howard, 1889. In Scudder, Butterflies of Eastern U. S., v. 3, p. 1883. o.

Amorphota orgyiae Howard, 1897. U. S. Dept. Agr., Div. Ent., Tech. Ser. 5: 53. ð, ๆ. Pseudocasinaria ceanathi Viereck, 1917 (1916). Conn. State Geol. and Nat. Hist. Survey Bul. 22: 270. ¿'.

Neonartonia gracilifarma Viereck, 1925. Canad. Ent. 57 (7): 179 (key); 57 (12): 300. §.

Taxonomy: Townes and Townes, 1951. In Muesebeck et al., U. S. Dept. Agr., Agr. Monog. 2: 365 (syn.). - Finlayson, 1975. Ent. Soc. Canada, Mem. 94: 27, 30, 98, 135 (final-instar larva).

Biology: Howard, 1897. U. S. Dept. Agr., Div. Ent., Tech. Ser. 5: 20-21.

melanolophiae Walley. Southern B. C. Host: Melanalophia imitata (Wlk.).

Casinaria melanolophiae Walley, 1959. Canad. Ent. 91: 565. ठ, ๆ.

Taxonomy: Finlayson, 1975. Ent. Soc. Canada, Mem. 94: 27, 31-32, 100, 135 (final-instar larva).

scabriformis Viereck. Mass. s. to n.w. S. C., w. to n.e. Kans. Host: Eupithecia miserulata Grt. Casinaria scabriformis Viereck, 1912. U. S. Natl. Mus., Proc. 42: 635..

Taxonomy: Townes, 1945. Amer. Ent. Soc., Mem. 11: 607.

semiothisae Walley. Que. w. to s. B. C., s. to D. C., Ark., and Oreg. Host: Caripeta divisata (Wlk.), Semiothisa bisignata wlk.), S. "granitata" auct., S. sexmaculata (Pack.). The cocoon description given by Finlayson (1975) contrasts with that in Walley's (1947) revision of Casinaria.

Casinaria semiothisae Walley, 1941. Canad. Ent. 73: 169. §, १.

Taxonomy: Finlayson, 1975. Ent. Soc. Canada, Mem. 94: 15, 26, 32-33, 100, 135 (final-instar larva).

tenuiceps Walley. Md., n. Ga.

Casinaria tenuiceps Walley, 1947. Sci. Agr. 27: 378. ¿, ?.

vadosa Walley. R. I., Md., n. Ga., Tex.

Casinaria vadosa Walley, 1947. Sci. Agr. 27: 395. ^.

\section{Genus CHAROPS Holmgren}

Charops Holmgren, 1859 (1858). Svenska Vetensk.-Akad., Ofvers. af ... Forhandl. 15: 324. 
Type-species: Campoplex decipiens Gravenhorst. Monotypic. The type-species is regarded as a synonym of Casinaria cantator (De Geer).

Zacharops Viereck, 1912. U. S. Natl. Mus., Proc. 42: 646.

Type-species: Charops annulipes Ashmead. Monotypic and orig. desig.

Gongropelma Enderlein, 1921. Stettin. Ent. Ztg. 83: 13.

Type-species: Gongropelma formosanum Enderlein. Orig. desig. The type-species is regarded as a synonym of $C$. bicolor (Szepligeti).

Most of the species in this fairly large genus occur in the tropics, and there is only a single Nearctic species. The cocoons of at least some of the species are suspended from foliage by a thread of silk. The hosts are various lepidopterous larvae which do not conceal themselves when feeding.

Revision: Gupta and Sharda Maheshwary, 1971 (1970). Oriental Insects 4: 453-480 (Indian spp.).

annulipes Ashmead. Que. s. to n. Fla., w. to n.e. Kans. and e. Tex.

Charops annulipes Ashmead, 1890 (1889). U. S. Natl. Mus., Proc. 12: 414. §o.

\section{Genus DUSONA Cameron}

Dusona Cameron, 1901 (1900). New Zeal. Inst., Trans. and Proc. 33: 107.

Type-species: Dusona stramineipes Cameron. Monotypic.

Delopia Cameron, 1903. Ztschr. System. Hym. Dipt. 3 (5): 304.

Type-species: Delopia cariniscutis Cameron. By subsequent monotypy from inclusion by Cameron, 1903 (3 [6]: 337-338 of same jour.).

Anisitsia Viereck, 1912. U. S. Natl. Mus., Proc. 42: 632. Preocc. by Eigenmann, 1903.

Type-species: Campoplex villosus Norton. Orig. desig.

Campoplegidea Viereck, 1912. U. S. Natl. Mus., Proc. 42: 644.

Type-species: Campoplex oxyacanthae Boie. Monotypic and orig. desig.

Pseudocasinaria Viereck, 1912. U. S. Natl. Mus., Proc. $42: 644$.

Type-species: Casinaria americana Ashmead. Monotypic and orig. desig.

Thymarimorpha Viereck, 1913. U. S. Natl. Mus., Proc. 46: 384.

Type-species: Thymarimorpha platygastra Viereck. Monotypic and orig. desig. The type-species is regarded as a synonym of $D$. gnara (Cresson).

Viereckiana Strand, 1914. Arch. f. Naturgesch. (A) 80 (1): 163. N. name for Anisitsia Viereck.

Zachrestinus Enderlein, 1921. Stettin. Ent. Ztg. 82: 38.

Type-species: Zachrestinus fractocristatus Enderlein. Monotypic and orig. desig.

Idiosomidea Viereck, 1925. Roy. Soc. Canada, Proc. and Trans. (3) 19 (5): 271.

Type-species: Campoplex photomorphus Viereck. Orig. desig.

Neodelopia Benoit, 1957. Inst. Sci. Madagascar, Mem. (E) 8: 314.

Type-species: Neodelopia pauliani Benoit. Monotypic and orig. desig.

This very large genus is known from all zoogeographic regions. The hosts are larvae of macrolepidoptera which feed on trees and shrubs and do not conceal themselves while feeding. More rearings in North America have been from Geometridae than from Lepidoptera of other families.

Revision: Walley, 1940. Sci. Agr. 20: 647-734.

Taxonomy: Townes and Townes, 1951. In Muesebeck et al., U. S. Dept. Agr., Agr. Monog. 2:

370 (syn.). - Townes, Momoi, and Townes, 1965. Amer. Ent. Inst., Mem. 5: 285-286 (syn.).

alia (Norton). Mass. The holotype is lost and no revisor has yet decided what name should be suppressed as a synonym of alia.

Campoplex alius Norton, 1863. Ent. Soc. Phila., Proc. 1: 367. $?$.

americana (Ashmead). Mass. w. to s. B. C., s. to Ala., n.e. Tex., and Colo.

Casinaria americana Ashmead, 1890. Colo. Biol. Assoc. Bul. 1: 22..+

Campoplegidea (Viereckiana) erythromera Viereck, 1926. Roy. Soc. Canada, Proc. and Trans. (3) 20 (5): 177.. 
argentea (Norton). Que., Mass., N. Y., N. J., Pa., Va., Ont., Mich., n. Ill., s. B. C. Host:

Symmerista albifrons (J. E. S.), S. canicosta Francl.

Campoplex argenteus Norton, 1863. Ent. Soc. Phila., Proc. 1: 365..

Campoplegidea citriscapa Viereck, 1925. Roy. Soc. Canada, Proc. and Trans. (3) 19 (5): 264. $\delta$, 9 .

assista (Norton). N. S. s. to S. C., w, to Mich.

Campoplex assistus Norton, 1863. Ent. Soc. Phila., Proc. 1: 367..

Campoplegidea (Viereckiana) curvata Viereck, 1926. Roy. Soc. Canada, Proc. and Trans. (3) 20 (5): 179. .

Campoplegidea (Viereckiana) citripes Viereck, 1926. Roy. Soc. Canada, Proc. and Trans.

(3) 20 (5): 179. ठ.

associata (Walley). Northeastern Mo., s.w. Ark., n.w. La.

Campoplegidea associata Walley, 1940. Sci. Agr. 20: 673. ơ, १.

australis (Walley). Md., n.w. S. C., Ont.

Campoplegidea australis Walley, 1940. Sci. Agr. 20: 715. ơ, ?.

bellula (Dalla Torre). N. S. w. to s. Alta., s. to Mich., n. Tex., Colo., and n.e. Calif.

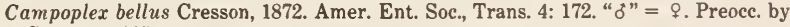
Cresson, 1865.

Campoplex bellulus Dalla Torre, 1901. Cat. Hym., v. 3, p. 138. N. name for C. bellus Cresson, 1872.

Campoplex photomorphus Viereck, 1905. Kans. Acad. Sci., Trans. 19: 309. ๆ.

Idiosomidea secunda Viereck, 1925. Roy. Soc. Canada, Proc. and Trans. (3) 19 (5): 272. ơ. Campoplegidea nitida Walley, 1940 Sci. Agr. 20: 713. ơ, ?.

Taxonomy: Townes and Townes, 1951. In Muesebeck et al., U. S. Dept. Agr., Agr. Monog. 2: 371 (syn.).

brachiator (Say). Que. s. to e. N. C. and n. Ga., w. to s. Mich., w. Ky., and n. Ala.

Ophion brachiator Say, 1836. Boston Jour. Nat. Hist. 1: 240. Sex not indicated.

Campoplex xanthogaster Brulle, 1846. In Lepeletier, Hist. Nat. Ins. Hym., v. 4, p. 159..

Taxonomy: Townes, 1961. Ent. Soc. Wash., Proc. 63: 105 (syn. of $C$. xanthogaster confirmed). canadensis (Walley). Ont., s.w. Alta., n. and s. B. C. Host: Enargia decolor Wlk., noctuid.

Campoplegidea canadensis Walley, 1940. Sci. Agr. 20: 665. ơ,.

confluens (Walley). Que., N. Y., Ont., Mich., Wis.

Campoplegidea confluens Walley, 1940. Sci. Agr. 20:673. o, + .

conformis (Walley). Southeastern Ariz. Known only from the holotype which was collected at Palmerlee, Ariz., a locality discussed by Townes and Linna (1963).

Campoplegidea conformis Walley, 1940 Sci. Agr. 20: 726..

Taxonomy: Townes and Linna, 1963. Ent. Soc. Wash., Proc. 65: 242 (obscure localities).

crassicornis (Provancher). N. B. w. to s. Alta., s. to N. Y., n. Ohio, and e. S. Dak. Host: Isia isabella (J. E. S.).

Limneria crassicornis Provancher, 1886. Addit. Corr. Faune Ent. Canada Hym., p. 88. o.

Campoplegidea crassata Viereck, 1925. Roy. Soc. Canada, Proc. and Trans. (3) 19 (5): 267. o.

Campoplegidea (Viereckiana) mimeticus Viereck, 1926. Roy. Soc. Canada, Proc. and Trans. (3) 20 (5): 175. o, ?.

Campoplegidea (Vierekiana) sessilis Viereck, 1926. Roy. Soc. Canada, Proc. and Trans. (3) 20 (5): 179. ठ.

Campoplegidea (Viereckiana) flavicoxa Viereck, 1926. Roy. Soc. Canada, Proc. and Trans.

(3) 20 (5): 180. ठ。.

deceptor (Walley). N. Y., Pa., D. C., n. Va., Ont., Ind., s.e. Sask.

Campoplegidea deceptor Walley, 1940. Sci. Agr. 20: 714. ơ, ๆ.

diversa (Norton). Mass., Conn., N. Y., Pa. Townes (1945) indicated that wyomingensis (Viereck) is the correct name for the species identified as diversa in Walley's (1940) revision of Dusona.

Campoplex diversus Norton, 1863. Ent. Soc. Phila., Proc. 1: 366. đ,.+

Taxonomy: Townes, 1945. Amer. Ent. Soc., Mem. 11: 632: 643. 
diversella (Walley). Que., N. Y., Mich., n.e. Kans., Tex.

Cam poplegidea diversella Walley, 1940. Sci. Agr. 20: 671. §, १.

diversicolor (Viereck). Que., N. Y., Ont.

Campoplegidea diversicolor Viereck, 1925. Roy. Soc. Canada, Proc. and Trans. (3) 19 (5): 265. \&.

downesi (Viereck). N. Mex., s.w. Alta., s.w. B. C. s. to s. Calif. Host: Homoglaea carbonaria (Harv.).

Campoplegidea downesi Viereck, 1925. Roy. Soc. Canada, Proc. and Trans. (3) 19 (5): 265. ठ, ?.

Campoplegidea planatella Viereck, 1925. Roy. Soc. Canada, Proc. and Trans. (3) 19 (5): 267. $\delta$.

Campoplegidea vadosa Viereck, 1925. Roy. Soc. Canada, Proc. and Trans. (3) 19 (5): 269 ..

Taxonomy: Townes, 1945. Amer. Ent. Soc., Mem. 11: 632 (syn.).

egregia (Viereck). Pa., Md., D. C., n. Va., Ohio, s. Mich., w. Ky., Ala., s. Tex.

Viereckiana egregia Viereck, 1916. Biol. Soc. Wash., Proc. 29: 167. ¿, १.

ellopiae (Walley). Maine, Ont., and n. Mich. s. to w. N. C. Host: Lambdina fiscellaria fiscellaria (Gn.).

Campoplegidea (Viereckiana) ellopiae Walley, 1929. Canad. Ent. 61: 22. ठ, ?.

Biology: Schedl, 1931. Ztschr. f. Angew. Ent. 18: 258-260.

experta (Cresson). Northern Va., s. Ind., w. Ky., s.e. Iowa, n.e. Kans., Okla., n. Tex.

Campoplex expertus Cresson, 1872. Amer. Ent. Soc., Trans. 6: 171. “ $\delta "=q$.

ferruginea Walkley. Southern Fla.

Dusona ferruginea Walkley, 1963. Ent. News 74: 239. 9.

flavescens (Walley). Tex., s. Ariz., Calif.; n. Mexico. Host: Anacamptodes fragillaria (Grossb.).

Campoplegidea flavescens Walley, 1940. Sci. Agr. 20: 710. \&. The holotype was collected at Phoenix, Ariz. on April 11, 1897, probably on Salix, by R. E. Kunze.

fossata (Viereck). Que., N. H., N. J., Pa., Ont., Man., Sask., s. Alta., w. Oreg.

Campoctonus fossatus Viereck, 1926. Roy. Soc. Canada, Proc. and Trans. (3) 20 (5): 182. ठ.

fuscitarsis (Viereck), Que. w. to s. Alta., s. to N. C. and n. Mich. Host: Eufidonia notataria (Wlk.).

Campoplegidea (Viereckiana) fuscitarse Viereck, 1926. Roy. Soc. Canada, Proc. and Trans. (3) 20 (5): 175..

glauca caliginosa (Walley). Sask., s. Alta., s.-coastal Alaska s. to n. Calif. Campoplegidea caliginosa Walley, 1940. Sci. Agr. 20: 693..

Taxonomy: Townes, 1945. Amer. Ent. Soc., Mem. 11: 634 (status change).

glauca glauca (Norton). Que. w. to Man., s. to Md. and n.e. Kans. Host: Lygris diversilineata (Hbn.), L. gracilineata (Gn.). A third, undescribed subspecies was recorded from Ariz. by Townes and Townes (1951).

Campoplex glaucus Norton, 1863. Ent. Soc. Phila., Proc. 1: 366. ๆ.

Campoplex dissitus Norton, 1863. Ent. Soc. Phila., Proc. 1: 367. $\$$.

Campoplegidea rossi Viereck, 1925. Roy. Soc. Canada, Proc. and Trans. (3) 19 (5): 268. $\delta$.

Taxonomy: Townes, 1945. Amer. Ent. Soc., Mem. 11: 633-634 (syn.). - Townes and Townes, 1951. In Muesebeck et al., U. S. Dept. Agr., Agr. Monog. 2: 372.

gracilis (Walley). Conn., N. Y., Pa., s.e. Ont., n. Ohio, Mich., s.w. Man.

Campoplegidea gracilis Walley, 1940. Sci. Agr. 20: 701. $\%$.

grahami (Walley). N. H., Colo., s.w. B. C. In the East this species apparently has been collected only on the top of Mt. Washington, N. H.

Campoplegidea grahami Walley, 1940. Sci. Agr. 20: 698. $\$$.

insolita (Walley). Que., Ont., s. Man.

Campoplegidea insolita Walley, 1940. Sci. Agr. 20: 681. \&.

interstitialis (Walley). Que., Mo.?

Campoplegidea interstitialis Walley, 1940. Sci. Agr. 20: 703. \&.

johnsoni (Walley). Eastern Mass., s.e. N. Y., N. J.

Campoplegidea johnsoni Walley, 1940. Sci. Agr. 20: 729. \&. 
laminata (Walley). Que. w. to s. Man., s. to Pa., n. Mich., and Tex.

Campoplegidea laminata Walley, 1940. Sci. Agr. 20: 680. ठ, ?.

lapponica kukakensis (Ashmead). Que. w. to s.w. Alaska, s. to N. Y., n. Mich., w. Ont., and s. Idaho. Host: Hydria prinivorata (Ferg.), Rheumaptera hastata (L.). D. lapponica lapponica (Holmgren) is European.

Zachresta kukakensis Ashmead, 1902. Wash. Acad. Sci., Proc. 4: 235. ठ.

Campoplegidea caudata Walley, 1940. Sci. Agr. 20: 686. ¿, $q$.

Taxonomy: Townes, 1945. Amer. Ent. Soc., Mem. 11: 635 (syn. and status change).

laticincta (Cresson). Que. w. to s. Alta. and w. Oreg., s. to n. Ga., n. Ohio, Colo., and n. Calif. Host: Heliothis sp., noctuid.

Campoplex laticinctus Cresson, 1865. Ent. Soc. Phila., Proc. 4: 283..

Campoplex nigripes Provancher, 1874. Nat. Canad. 6: 145. \&. Preocc. by Gravenhorst, 1829 and Brulle, 1846.

Campoplegidea brooksi Viereck, 1925. Roy. Soc. Canada, Proc. and Trans. (3) 19 (5): 264. $\delta$, ?.

lobata (Walley). Que., N. Y., n. Va., S. C., n. Ga., Ont., Man., s. B. C. Host: Semiothisa "granitata" auct., S. sexmaculata (Pack.).

Campoplegidea lobata Walley, 1940. Sci. Agr. 20: 713. ठ, ‡.

luctuosa (Provancher). Que., s.w. Alta., n. Idaho, Ariz., s. B. C. n. Calif. Host: Enypia venata (Grt.), Hydriomena divisaria (Wlk.), H. furcata (Thun.).

Campoplex luctuosus Provancher, 1875. Nat. Canad. 7: 145..

Anisitsia nigerrima Viereck, 1912. U. S. Natl. Mus., Proc. 43: 583. ९.

Taxonomy: Townes, 1945. Amer. Ent. Soc., Mem. 11: 636 (syn.).

magnifica (Walley). N. Y., n. Ala.

Campoplegidea magnifica Walley, 1940. Sci. Agr. 20: 727. ठ, १.

major (Cresson). Que., Mass., R. I., Pa., s. Mich., Man., N. Mex., s.w. B. C. Host: Schizura unicornis (J. E. S.), Abbottana clemataria (J. E. S.).

Campoplex major Cresson, 1879 (1878). Acad. Nat. Sci. Phila., Proc. 30: 369. \&.

Campoplegidea (Viereckiana) totalis Viereck, 1926. Roy. Soc. Canada, Proc. and Trans. (3) 20 (5): 174.. .

minor (Provancher). N. S. w. to s.-coastal Alaska, s. to n. Va., n. Mich., Colo., s.w. Mont., and s. B. C. Host: Eupithecia luteata Pack., E. transcanadata MacK.

Campoplex minor Provancher, 1879. Nat. Canad. 11 (no. 127): 150..

Pseudocasinaria decorata Viereck, 1926. Roy. Soc. Canada, Proc. and Trans. (3) 20 (5): 183. $\delta$.

Amorphota pacifica Viereck, 1926. Roy. Soc. Canada, Proc. and Trans. (3) 20 (5): 184. ठँ.

Campoplegidea mitis Walley, 1940. Sci. Agr. 20: 689. $\%$.

Campoplegidea maritima Walley, 1940. Sci. Agr. 20: 689..

Taxonomy: Townes, 1945. Amer. Ent. Soc., Mem. 11: 636-637 (syn.).

montrealensis (Viereck). N. S. s. to n. Ga., w. to Man.

Campoplegidea (Viereckiana) montrealensis Viereck, 1926. Roy. Soc. Canada, Proc. and Trans. (3) 20 (5): 181. ó.

nigritibialis (Viereck). Southern Idaho, s.w. B. C., Wash., n. Calif.

Campoplegidea (Viereckiana) nigritibialis Viereck, 1926. Roy. Soc. Canada, Proc. and Trans. (3) 20 (5): 178. \&.

obesa (Davis). Maine, Mass., N. Y., Pa., s.w. Va., Mich. This species with a long ovipositor was not included in Walley's (1940) revision of Dusona.

Zachrasta(!) obesa Davis, 1898 (1897). Amer. Ent. Soc., Trans. 24: 361. .

occidentalis (Davis). Southwestern B. C., w. Wash.

Campoplex occidentalis Davis, 1898 (1897). Amer. Ent. Soc., Trans. 24: 361. ठ, ๆ.

ocellata (Walley). Md., s. Tex.

Campoplegidea ocellata Walley, 1940. Sci. Agr. 20: 718. \&.

pallescens (Walley). Eastern N. C., Tenn., S. C., Ga., s. Fla.

Campoplegidea pallescens Walley, 1940. Sci. Agr. 20: 722. \&. 
pectoralis (Walley). Que., Ont., n. Mich., s. Sask., n. and s. Alta., s. B. C. Host: Deilinea bryantaria (Tay.).

Campoplegidea pectoralis Walley, 1940. Sci. Agr. 20: 686. ㅇ.

pilosa (Walley). Colo., Ariz., s.w. B. C., Oreg., n. Calif. Host: Enypia packardata Tay., E. venata (Grt.), Melanolophia imitata (Wlk.).

Campoplegidea pilosa Walley, 1940. Sci. Agr. 20: 733. ¿, ?.

planata (Viereck). Que., N. Y., Md., Ont., Mich., Ill. Host: Noctuid.

Campoplegidea planata Viereck, 1925. Roy. Soc. Canada, Proc. and Trans. (3) 19 (5): 267 . ㅇ.

pulchella (Walley). Southwestern Utah, n.w. Ariz., s. Calif.

Campoplegidea pulchella Walley, 1940. Sci. Agr. 20: 717. ð,, .

quebecensis (Walley). Que., Mass.

Campoplegidea quebecensis Walley, 1940. Sci. Agr. 20: 731..

relecta (Davis). N. H., N. Y., s.e. B. C.

Campoplex relectum Davis, 1898 (1897). Amer. Ent. Soc., Trans. 24: 361. ․

Campoplegidea egregiata Viereck, 1925. Roy. Soc. Canada, Proc. and Trans. (3) 19 (5): 266. \&.

Taxonomy: Townes, 1945. Amer. Ent. Soc., Mem. 11: 638 (syn.).

robusta (Walley). Mass., N. J., Pa., n. Ga., s. Ohio, s. Mich.

Campoplegidea robusta Walley, 1940. Sci. Agr. 20: 725. ठ, १.

rotunda (Walley). N. S., Que., Wash.

Campoplegidea rotunda Walley, 1940. Sci. Agr. 20: 697. $\subsetneq$.

rufescens (Walley). Southern N. Y. w. to s. Mich. and Iowa, s. to n. Va., Mo., and n.e. Kans.

Campoplegidea rufescens Walley, 1940. Sci. Agr. 20: 720. ठ, $\%$.

rufigaster (Walley). N. H. s. to s. Fla., w. to s. Mich. and w. Ky.

Campoplegidea rufigaster Walley, 1940. Sci. Agr. 20: 705. $\%$.

scalaria (Provancher), Que., Alta., Wash.

Campoplex scalarius Provancher, 1886. Addit. Corr. Faune Ent. Canada Hym., p. 84. $९$ ( $\delta$ misdet.).

Campoplex scalaris(!) Provancher, 1889. Addit. Corr. Faune Ent. Canada Hym., p. 449 (index).

Campoplegidea scalaris Walley, 1940. Sci. Agr. 20: 654, 706, 707. Emend.

seamansi (Viereck). Southern Man., Colo., s.w. Alta., s. B. C. Host: Geometrid, Choristoneura conflictana (Wlk.)?

Campoplegidea edmontonensis Viereck, 1925. Roy. Soc. Canada, Proc. and Trans. (3) 19 (5): 266. o.

Campoplegidea seamansi Viereck, 1925. Roy. Soc. Canada, Proc. and Trans. (3) 19 (5): 268. ‥

Amorphota bicoloripes Viereck, 1926. Roy. Soc. Canada, Proc. and Trans. (3) 20 (5): 184 ..

Taxonomy: Townes, 1945. Amer. Ent. Soc., Mem. 11: 639 (syn.).

semirufa (Provancher). Que., Vt., N. Y., Mich., Colo., s. B. C. Host: Pheosia rimosa Pack.

Campoplex semirufus Provancher, 1882. Nat. Canad. 13: 364. 9.

Campoplegidea okanaganensis Viereck, 1925. Roy. Soc. Canada, Proc. and Trans. (3) 19 (5): 270 . .

signata (Viereck). N. B., Que., N. C., Ont., n. Mich., Man., Sask., n. B. C. Host: Noctuid.

Campoplegidea signata Viereck, 1925. Roy. Soc. Canada, Proc. and Trans. (3) 19 (5): 262. $\delta$, ?.

simulans arizonensis (Walley). Southern Ariz.

Campoplegidea arizonensis Walley, 1940. Sci. Agr. 20: 709. đ’,.

Taxonomy: Townes and Townes, 1951. In Muesebeck et al., U. S. Dept. Agr., Agr. Monog. 2: 374 (status change).

simulans simulans (Walley). N. J., S. C.

Campoplegidea simulans Walley, 1940. Sci. Agr. 20: 704. ठ',. 
stricklandi (Viereck). Southwestern Alta.

Campoplegidea stricklandi Viereck, 1925. Roy. Soc. Canada, Proc. and Trans. (3) 19 (5): 269. ठ.

subtilis (Viereck). Southwestern Alta.

Campoplegidea (Viereckiana) subtilis Viereck, 1926. Roy. Soc. Canada, Proc. and Trans. (3) 20 (5): 176. . .

tepaneca (Cresson). Ariz.; Mexico, Guatemala? This species was not included in Walley's (1940) revision of Dusona.

Campoplex tepanecus Cresson, 1874. Acad. Nat. Sci. Phila., Proc. 25: 382. ठ์,.

texana (Ashmead). D. C., n. Ga., n.e. Kans., Tex., Wash.; Guatemala.

Casinaria texana Ashmead, 1890 (1889). U. S. Natl. Mus., Proc. 12: 427..

Taxonomy: Townes, 1945. Amer. Ent. Soc., Mem. 11: 640 (syn. corrected).

townsendi (Walley). N. Mex. Apparently known only from the type series which was collected at an elevation of $8000 \mathrm{ft}$. in the White Mts.

Campoplegidea townsendi Walley, 1940. Sci. Agr. 20: 703. o, \&.

tumida (Walley). Ariz., w. Oreg.

Campoplegidea tumida Walley, 1940. Sci. Agr. 20: 716..

turmalis (Walley). Southwestern Tex.

Campoplegidea turmalis Walley. 1940. Sci. Agr. 20: 711. ㅇ.

vara (Walley). N. S. w. to Sask., s. to N. J., Pa., and n. Mich.

Campoplegidea vara Walley, 1940. Sci. Agr. 20: 663. $\delta, ~ \&$.

variabilis (Franklin). N. S., Que., Maine, Mass. Host: Ematurga amitaria (Gn.). The record for variabilis as a parasite of Synchlora rubrifrontaria Pack. published by Schaffner and Griswold (1934) is based upon a misidentified specimen in the U. S. Natl. Museum collection. The specimen is now too badly damaged to be reidentified readily.

Campoplex variabilis Franklin, 1915. Ent. News 26: 356. . Preocc. by Campoplex variabilis (Bridgman), 1886.

Biology: Schaffner and Griswold, 1934. U. S. Dept. Agr., Misc. Pub. 188: 148.

varicoxa (Viereck), Que., N. H., N. Y., Pa., Md., n. and w. Ont., s. Alta., s.w. B. C. Host: Nemoria mimosaria (Gn.).

Campoplegidea (Viereckiana) varicoxa Viereck, 1926. Roy. Soc. Canada, Proc. and Trans.

(3) 20 (5): 180 . ठ.

Campoplegidea (Viereckiana) reticulata Viereck, 1926. Roy. Soc. Canada, Proc. and Trans. (3) 20 (5): 181. ó.

Pseudocasinaria paenealia Viereck, 1926. Roy. Soc. Canada, Proc. and Trans. (3) 20 (5): 182. ठ。.

vibecifera (Viereck). Ont.?, Mich.?, e. Sask. Host: Geometrid.

Campoplegidea vibecifera Viereck, 1925. Roy. Soc. Canada, Proc. and Trans. (3) 19 (5): 270. o.

vicina (Provancher). Que., Ont., Man. Host: Semiothisa "granitata" auct., S. sexmaculata (Pack.).

Campoplex vicinus Provancher, 1874. Nat. Canad. 6: 145. ơ, \&.

villosa (Norton). Que. w. to s. B. C., s. to w. N. C., s. Mich., n.e. Kans., N. Mex., and Oreg. Host: Pero sp.

Campoplex villosus Norton, 1863. Ent. Soc. Phila., Proc. 1: 365. ठ,.

vitticollis (Norton). Que. w. to s.e. Alaska, s. to n. Ga., n. Ala., Tex., N. Mex., and Ariz. Host: Caripeta divisata Wlk., Hypagrytis piniata (Pack.), Phigalea titea (Cram.), Malacosomia disstria (Hbn.)?

Campoplex vitticollis Norton, 1863. Ent. Soc. Phila., Proc. 1: 365. .

woodi (Viereck). Que., Pa., Md., n. Va., Ont., s. Ohio.

Campoplegidea (Viereckiana) woodi Viereck, 1926. Roy. Soc. Canada, Proc. and Trans. (3) 20 (5): 177.8.

Campoplegidea (Viereckiana) erythrosoma Viereck, 1926. Roy. Soc. Canada, Proc. and Trans. (3) 20 (5): 177.. 
wyomingensis (Viereck). N. S. w. to s. B. C., s. to s.w. Va., Ohio, and w. Wyo. In Walley's (1940) revision of Dusona, wyomingensis was incorrectly suppressed as a synonym of diversa (which see).

Campoplex wyomingensis Viereck, 1906. Amer. Ent. Soc., Trans. 32: 342. ठ.

Campoplegidea walleyi Viereck, 1925. Roy. Soc. Canada, Proc. and Trans. (3) 19 (5): 271. ㅇ.

Taxonomy: Townes, 1945. Amer. Ent. Soc., Mem. 11: 643 (wyomingensis resurrected).

\section{Genus LEPTOCAMPOPLEX Horstmann}

Leptocampoplex Horstmann, 1970. Bayer. Ent., Nachrichtenbl. 19: 78. Type-species: Nemeritis cremastoides Holmgren. Monotypic and orig. desig.

A single Holarctic species is known. The genus appears to be closely related to Menaka Gupta and Gupta (1971), from which Leptocampoplex differs principally by lacking the second intercubitus. The name Porizon was incorrectly applied to Leptocampoplex by Townes $(1965,1970)$; see the introductory discussion of Porizon.

Taxonomy: Townes, 1965. Polskie Pismo Ent. 35: 410 (as Porizon). —Townes, 1970 (1969).

Amer. Ent. Inst., Mem. 13: 157, 167-168, 278 (as Porizon). - Gupta and Gupta, 1971.

Oriental Insects 5: 111-116 (related Indian genus).

cremastoides (Holmgren). Ont., Mich.; Europe. Host: Ptilinus pectinicomis (L.)? Townes (1970) gave the Nearctic range as "eastern North America" in referring to what he regarded as being an undescribed Nearctic species. Horstmann (1970) stated that he believed the Nearctic specimens he had seen (apparently borrowed from Townes) to represent only an undescribed subspecies of cremastoides, differing from the European one in having the underside of the scape pale (i.e. "helle"). In view of the fact that the known Nearctic range of cremastoides is not similar to that of most Holarctic ichneumonid species, proof that cremastoides is not adventive in North America should precede validation of a name for the Nearctic population. The host record cited with a query above pertains to a specimen acquired from $A$. W. Stelfox by the U. S. Natl. Museum; the specimen is labeled "? parasitic on Ptilinus pectinicornis!"

Nemeritis cremastoides Holmgren, 1860 (1858). Svenska Vetensk.-Akad. Handl. (n. f.) 2: 105. ?.

Taxonomy: Townes, 1970 (1969). Amer. Ent. Inst., Mem. 13: 168, 278 (as "Porizon moderator," misdet.). - Horstmann, 1970. Bayer. Ent., Nachrichtenbl. 19: 79.

\section{Genus PYRACMON Holmgren}

Pyracmon Holmgren, 1859 (1858). Svenska Vetensk.-Akad., Ofvers. af ... Forhandl. 15: 326. Type-species: Porizon fumipennis Zetterstedt. Monotypic and orig. desig.

This is a small Holaretic genus. Townes (1970) knew five species, one of them being an undescribed Nearctic species. Dr. John Barron has informed me (personal commun., 1977) that the latter has been reared from Elateridae and will be described by Mr. G. S. Walley. Dr. Klaus Horstmann will probably have published a revision of the European species prior to the appearance of this catalog.

Taxonomy: Townes, 1970 (1969). Amer. Ent. Inst., Mem. 13: 169.

sepiella (Holmgren). N. H., Mich.; Eurasia. Host: Macropogon piceus LeC. Numerous additional Nearctic localities will presumably be given by Mr. G. S. Walley in a forthcoming paper.

Limneria sepiella Holmgren, 1860 (1858). Svenska Vetensk.-Akad. Handl. (n. f.) 2 (8): 63. $\delta$, ?.

Pyracmon sepiellum Townes, 1965. In Townes, Townes, and Gupta, Amer. Ent. Inst., Mem. 5: 283. Emend.

\section{Genus RHIMPHOCTONA Foerster}

Rhimphoctona Foerster, 1868. Naturh. Ver. Rheinlande, Verh. 25: 153. 
Type-species: Rhimphoctona rufipes Tschek. By subsequent monotypy from inclusion by Tschek, 1871. The type-species is regarded as a junior synonym of $R$. grandis (Fonscolombe).

Xylophylax Kriechbaumer, 1878. Ent. Nachr. 4: 210.

Type-species: Pyracmon (Parapyracmon) rufocoxalis Clement. Monotypically included and desig. by Townes, 1970 .

Helcostizidea Rohwer, 1913. Ent. Soc. Wash., Proc. 15: 185.

Type-species: Cubocephalus atrocoxalis Ashmead. Orig. desig.

Pyracmon subg. Parapyracmon Clement, 1924. Deut. Ent. Ztschr. (for 1924), p. 117-131.

Type-species: Pyracmon [Parapyracmon] rufocoxalis Clement. Desig. by Townes, 1970.

Pyracmonoides Viereck, 1925 (July). Canad. Ent. 57 (7): 177-178.

Type-species: Pyracmonoides separatum Viereck. Desig. by Viereck, 1925 (Dec.).

This is a small Holarctic genus.

Taxonomy: Townes, 1970 (1969). Amer. Ent. Inst., Mem. 13: 162-163 (generic syn. and referral of Nearctic spp.).

alaskensis (Ashmead). Alaska. More explicit locality data are presumably unavailable; one of the labels of each of the three syntypes says "U. S. N. M. Acc[ession] 25341," but it would be uncharacteristic for the Smithsonian Institution to have meaningful information pertaining to that number.

Cubocephalus alaskensis Ashmead, 1902. Wash. Acad. Sci., Proc. 4: 203..

atrocoxalis (Ashmead). Que. w. to interior Alaska, s. to n. Calif.

Cubocephalus atrocoxalis Ashmead, 1902. Wash. Acad. Sci., Proc. 4: 203. + . Described from "Alaska" and "Easton, Wash." The only syntype I have found bears a label with the same U.S. N. M. accession number as on labels of the syntypes of alaskensis (which see).

lipoparia (Viereck). Ont.

Pyracmonoides lipoparium Viereck, 1925. Canad. Ent. 57 (7): 178 (key); 57 (12): 299. ठั.

macdunnoughi (Viereck). Que., Alta., interior Alaska, w. Oreg.

Pyracmon macdunnoughi Viereck, 1925; 1926. Canad. Ent. 57 (7): 180 (key); 58 (1): 5 ..

macrocephala (Provancher). Que. w. to Mont., s. to w. N. C. and Idaho.

Limneria macrocephala Provancher, 1874. Nat. Canad. 6: 149. \&.

Pyrachmon(!) aldrichi Davis, 1898 (1897). Amer. Ent. Soc., Trans. 24: 363. ठ, $\%$.

Cubocephalus nigricornis Ashmead, 1902. Wash. Acad. Sci., Proc. 4: 203. $९$. Preocc. in Cubocephalus by Provancher, 1875.

Pyracmonoides succineum Viereck, 1925. Canad. Ent. 57 (7): 178 (key); 57 (12): 300. ठ̊.

Pyracmonoides trochantericum Viereck, 1925. Canad. Ent. 57 (7): 178 (key); 57 (12): 299. ¿.

separata (Viereck). Western Yukon.

Pyracmonoides separatum Viereck, 1925. Canad. Ent. 57 (7): 178 (key); 57 (12): 298. ठో, ๆ. vancouverensis (Harrington). Colo., s. Alta., Idaho, s.w. B. C., Wash., n. Calif.

Pyracmon vancouverensis Harrington, 1894. Canad. Ent. 26: 246. $९$.

xanthognatha (Rohwer). Westen Mont., Idaho, Wash., Oreg., n. Calif. Host: Cerambycid in bark of Abies concolor.

Helcostizidea xanthognatha Rohwer, 1914. Ent. Soc. Wash., Proc. 15: 186.9.

\section{Genus NEMERITIS Holmgren}

Nemeritis Holmgren, 1860 (1858). Svenska Vetensk.-Akad. Handl. (n. f.) 2 (8): 104.

Type-species: Campoplex macrocentrus Gravenhorst. Desig. by Viereck, 1914.

Pseudonemeritis Szepligeti, 1916. Mus. Natl. Hungarici, Ann. 14: 338.

Type-species: Pseudonemeritis minor Szepligeti. Desig. by Townes, 1970.

This is a Holarctic and Neotropic genus of small to moderate size. A number of species have been reared from Rhaphidiidae. Apparently hosts other than Rhaphidiidae are not known, which apparently explains the fact that in the New World Nemeritis is confined to western North America and Chile. 
Revision: Horstmann, 1973. Opusc. Zool. 125: 1-14 (European spp.). - Horstmann, 1975.

Polskie Pismo Ent. 45: 251-266 (elaboration).

macrurus (Viereck). Wyo., s. B. C., n. Calif.

Campoplex (Campoplex) macrurus Viereck, 1925; 1926. Canad. Ent. 57 (9): 226 (key); 58 (5): 146. ?.

\section{Genus BATHYPLECTES Foerster}

Canidia Holmgren, 1860 (1858). Svenska Vetensk.-Akad. Handl. (n. f.) 2 (8): 103. Preoce. by Thomson, 1857 .

Type-species: Canidia pusilla Holmgren. Desig. by Viereck, 1914.

Rhexineura Foerster, 1868. Naturh. Ver. Rheinlande, Verh. 25: 156.

Type-species: Campoplex exiguus .Gravenhorst. Monotypically included and desig. by Townes, 1970 .

Bathyplectes Foerster, 1868. Naturh. Ver. Rheinlande, Verh. 25: 156.

Type-species: Campoplex exiguus Gravenhorst. Monotypically included and desig. by Viereck, 1914.

Canidiella Ashmead, 1900. Canad. Ent. 32: 368. N. name for Canidia Holmgren.

Biolysia Schmiedeknecht, 1907. Hym. Mitteleuropas, p. 601.

Type-species: Nepiesta marginella Thomson. Monotypic.

This is a Holaretic genus of moderate size. Horstmann $(1973,1974)$ treated Biolysia as distinct from Bathyplectes to facilitate an easier distinction of the Palearctic genus Nepiesta. Because the species referable to Biolysia do not differ significantly in habits or life histories from other Bathyplectes species and because Bathyplectes bryanti Viereck is structurally intermediate, I prefer to treat Bathyplectes and Biolysia as synonymous. Known hosts include only weevils of the genus Hypera, but the majority of Bathyplectes species have not been reared. The native Nearctic species are poorly represented in collections, and the majority of them are undescribed.

Revision: Horstmann, 1974. Ent. Germ. 1: 58-81 (western Palearctic spp.).

Taxonomy: Townes, 1970 (1969). Amer. Ent. Inst., Mem. 13: 164-165 (syn.). - Horstmann,

1973. Polskie Pismo Ent. 43: 729-731 (discussion and inclusion in generic key).

anurus contractus (Thomson). Central Calif.; s.w. U. S. S. R., Iran, s. Yugoslovia?, s. Germany, n. Italy, n. France, Ireland. Introduced. Host: Hypera brunneipennis Boh. Besides $a$. contractus and a. anurus (Thomson), Horstmann (1974) recognized a. graecator Aubert (treated here below); he knew a. anurus from southern Sweden (lectotype), The Netherlands, and northern and middle Germany. I am not convinced that these subspecies will be treated as valid taxa when more specimens have been collected and studied, but I here accept them as valid because my knowledge of western Palearctic zoogeography is not adequate for rejecting them for reasons of being insufficiently sound zoogeographically. Dr. Richard Dysart informed me (personal commun., 1977) of the establishment in Calif. of a population he thought most likely to be principally of Iranian origin. For that reason I have applied the name a. contractus to it.

Canidia contracta Thomson, 1887. Opusc. Ent. 11: 1113..

Taxonomy: Horstmann, 1974. Ent. Germ. 1: 61, 66-67.

Biology: Fisher, Schlinger, and van den Bosch, 1961. Jour. Econ. Ent. 54: 196, 197 (as corvina, misdet.; introductions and cocoon jumping behavior).

anurus graecator Aubert. Southern N. H., s. Vt., Mass., Conn., N. Y., N. J., Pa., Del., Md., Va., W. Va., N. C., S. C., s.e. Ont., Ohio, s. Mich., s. Ind., Ky., Tenn., Mo., w. S. Dak., Okla.; s. Yugoslavia, Greece, middle and s. Italy, s. France, n. Africa. Introduced. Host: Hypera postica (Gyll.). According to Dysart and Day (1976) the bulk of the anurus individuals released in eastern North America were of "French [apparently southern] origin," although small numbers came from Sicily and the U. S. S. R.

Bathyplectes anura graecator Aubert, 1970. Soc. Ent. de Mulhouse, Bul. 26: 68. o, 9.

Taxonomy: Horstmann, 1974. Ent. Germ. 1: 61, 67. 
Biology: Kaufman, 1939. Ztschr. f. Angew. Ent. 26: 421-422 (as corvina, misdet.). -Baccetti, 1958. Redia 43: 226-253 (as corvina, misdet.). - Brunson and Coles, 1968. U. S. Dept. Agr., Prod. Res. Rpt. 101: 3-4, 7 (releases). - Day, 1970. Jour. Econ. Ent. 63: 586-589 (value of jumping cocoons). -Morrison and Pass, 1974. Jour. Econ. Ent. 67: 141-142. - Dysart and Day, 1976. U. S. Dept. Agr., Prod. Res. Rpt. 167: 2-3, 9-14, 39, 44-45 (releases and recoveries). -Gordh and Hendrickson, 1976. Ent. News 87: 271-274 (sexual behavior). -Dysart and Bingham, 1977. Coop. Plant Protect. Rpt. 2: 24-26 (recoveries). -Yeargan and Latheef, 1977. Environmental Ent. 6: 31-34.

bryanti Viereck. Southern Alta. Known only from the holotype, which was collected at Bilby, Alta.

Bathyplectes bryanti Viereck, 1925; 1926. Canad. Ent. 57 (9): 225 (key); 58 (9): 223. \&. In the 1926 part of Viereck's revision as "Campoplex (Bathyplectes) bryanti;" nowhere in the 1925 part of the revision was Bathyplectes indicated to be a subgenus of Campoplex.

curculionis (Thomson). Southern Que. w. to s. Alta. and Wash., s. to n. Ga., n. Miss., Europe, n. Africa. Introduced. Host: Hypera brunneipennis Boh., H. plantaginis (DeG.), H. postica (Gyll.). The lectotype selected by Townes, Momoi, and Townes (1965) may not pertain to the present species (see Horstmann, 1974). Thomson probably had no reared material, but indicated that curculionis is the species which Holmgren (1860) had misidentified as subcinctus (Gravenhorst). Under subcinctus, Holmgren in turn referred to Ratzeburg (1852, p. 82; cf. Ratzeburg, 1848, p. 82) who cited hosts of reared specimens. Specimens reared from $H$. postica and $H$. plantaginis were identified by Horstmann (1974) as var. 1 of B. curculionis. B. brevitor Aubert (1974) was described as a species related to curculionis, the description of brevitor being based upon two Yugoslavian specimens reared from $H$. plantaginis. If curculionis var. 1 of Horstmann (1974) proves not to be conspecific with curculionis, it seems probable that brevitor will prove to be the correct name for it.

Canidia curculionis Thomson, 1887. Opusc. Ent. 11: 1113. ․ Aubert (1960) gave descriptive notes concerning a female in the Thomson collection which he regarded as being the lectotype, but he did not cite a locality or other information pertaining to the labeling of that specimen; Townes, Momoi, and Townes (1965) selected a female lectotype from Stehag, Skane, Sweden, which had been labeled as lectotype by Aubert.

Taxonomy: Holmgren, 1860 (1858). Svenska Vetensk.-Akad. Handl. (n. f.) 2 (8): 103-104. -Aubert, 1960. Vie et Milieu 11: 490. - Townes, Momoi, and Townes, 1965. Amer. Ent. Inst., Mem. 5: 282. - Aubert, 1966. Opusc. Ent. 31: 130. - Aubert, 1974. Soc. Ent. de Mulhouse, Bul. 30: 2 (brevitor described). -Horstman, 1974. Ent. Germ. 1: 62, 73, 74-75.

Biology: Ratzeburg, 1848; 1852. Ichn. d. Forstins., v. 2, p. 82; v. 3, p. 82. -Webster, 1912. U. S. Dept. Agr., Bur. Ent., Bul. 112: 38. - Hagan, 1919. Calif. Dept. Agr., Monthly Bul. 8: 470. - List and Wakeland, 1919. Colo. State Ent., Cir. 24: 34. - Wakeland, 1920. Colo. State Ent., Cir. 28: 28. - Chamberlin, 1924. U. S. Dept. Agr., Dept. Cir. 301: 4, 6. -Chamberlin, 1926. Jour. Econ. Ent. 19: 302-310. -Newton, 1933. Colo. Agr. Col., Bul. 399: 18.

- Sorenson, 1934. Utah Acad. Sci., Proc. 11: 249-251. - Michelbacher and Essig, 1934. Jour. Econ. Ent. 27: 965. -Essig. and Michelbacher, 1934. Calif. Univ., Agr. Expt. Sta., Bul. 567: 63-67. - Keifer, 1935. Calif. Dept. Agr., Monthly Bul. 24: 350. -Michelbacher, 1936. Calif. Dept. Agr., Monthly Bul. 25: 392. - Kaufman, 1939. Ztschr. f. Angew. Ent. 26: 422-424. - Michelbacher, 1940. Hilgardia 13: 81-99. - Michelbacher, 1940. Jour. Econ. Ent. 33: 892-895. - Schweis, 1942. Nev. State Dept. Agr., Bien. Rpt. (for 1940-1942), p. 33. - Michelbacher, 1943. Calif. Agr. Expt. Sta., Bul. 677: 5, 10-20. - Hamlin, McDuffie, Lieberman, and Bunn, 1943. U. S. Dept. Agr., Farmers Bul. 1930: 6-8. - Hamlin, Lieberman, Bunn, McDuffie, Newton, and Jones, 1949. U. S. Dept. Agr., Tech. Bul. 975: 41-55. - van den Bosch, 1953. Jour. Econ. Ent. 46: 161-162. - Milliron, 1956. Jour. Econ. Ent. 49: 443. - Hobbs, Nummi and Virostek, 1959. Canad. Ent. 91: 562, 564-565. - van den Bosch and Dietrick, 1959. Ent. Soc. Amer., Ann. 52: 609-616. -Fisher, Schlinger, and van den Bosch, 1961. Jour. Econ. Ent. 54: 196. - Puttler, Jones, and Coles, 1961. Jour. Econ. Ent. 54: 878-880. - Coles and Puttler, 1963. Jour. Econ. Ent. 56: 609. — van den Bosch, 1964. Jour. Econ. Ent. 57: 195-196. - Dysart and Puttler, 1965. Jour. Econ. Ent. 58: 
1154-1155. - Butler and Ritchie, 1967. Jour. Econ. Ent. 60: 1239-1241. -M'Sadda, 1967. Rev. Zool. Agr. et Appl. 66: 13. - Salt and van den Bosch, 1967. Jour. Invert. Pathol. 9: 164-177. -Brunson and Coles, 1968. U. S. Dept. Agr., Prod. Res. Rpt. 101: 3, 8. - Horn, 1969. Jour. Econ. Ent. 61: 1469-1470. - Foster and Bishop, 1970. Idaho Agr. Expt. Sta., Res. Bul. 78: 2-20. - Richardson, Nelson, York, and Gyrisco, 1972 (1971). Canad. Ent. 103: 1653-1658. - Arbrust, DeWitt, and Roberts, 1972. Environmental Ent. 1: 391-393. - Miller, Smith, and White, 1972. Environmental Ent. 1: 471-473. - Cross and Simpson, 1972. Environmental Ent. 1: 631-633 (cocoon construction). - Casagrande, 1973. Canad. Ent. 105: 1119-1128. - Miller and White, 1973. Ga. Ent. Soc., Jour. 8: 233-236. - Duodu and Davis, 1974. Environmental Ent. 3: 396-398, 549-552, 705-710. - Walstrom, 1974. Jour. Econ. Ent. 67: 309-310. - Hower, 1974. Jour. Agr. Sci. 21: 2-3. - Pike and Burkhardt, 1974. Kans. Ent. Soc., Jour. 47: 405-411. - Gibson and Berberet, 1974. Ent. Soc. Amer., Ann. 67: 588-590. -Puttler, 1974. Environmental Ent. 3: 881-882. -Davis, 1974. Environmental Ent. 3: 1031-1032. - Parrish, 1974. Forage Insect Res. Conf., Proc. 17: 18-19. -Flessel, 1975. Jour. Econ. Ent. 68: 585-586. - Arbrust, 1975. Environmental Ent. 4: 931-934. - Berberet and Gisbon, 1976. Ent. Soc. Amer., Ann. 69: 205-208. - Dysart and Day, 1976. U. S. Dept. Agr., Prod. Res. Rpt. 167: 2-3, 46-47. - Bartell, Sanborn, and Wood, 1976. Environmental Ent. 5: 659-661. - Eklund and Simpson, 1977. Environmental Ent. 6: 69-71.

exiguus (Gravenhorst). Que. w. to s. B. C., s. to s. Va., central Mo., and central Oreg.; Europe. Adventive. Host: Hypera nigrirostris (F.), H. punctata (F.), H. rumicus (L.). This species apparently became established in North America along with one of the accidentally introduced hosts (most likely $H$. nigrirostris), but the oldest North American record known to me for exiguus is that for one of Viereck's paratypes of the synonym phytonomi. It was collected in Prince Edward Co., Ont. in 1890, and although I have not seen the specimen, I have little reason to doubt that it is a specimen of exiguus because there are a number of exiguus specimens in the U. S. Natl. Museum collection which were collected at Toronto, Ont. in 1896. The oldest United States record known to me is that for Viereck's paratype of the synonym etemankiakorum, which he collected in New Haven, Conn. in 1904 and which is in the U. S. National Museum collection. The oldest record known to me for western North America is 1918 (Puyallup, Wash.; June 15; L. P. Rockwood). The entry of B. exiguus into western North America may have been independent of its establishment in the East, because the adventive thelytokous European species of Gelis studied by Caldwell and Wilson (1975), as a parasite of $B$. curculionis in Indiana, was reared from B. exiguus in northwestern Oreg. (Forest Grove and Seaside) in 1928 (cf. Rockwood, 1920); I have not seen specimens of it collected in eastern North America before 1957. Dr. K. W. R. Zwart told me (personal commun., 1976) that this species of Gelis is apparently undescribed.

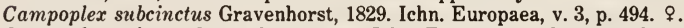

Campoplex exiguus Gravenhorst, 1829. Ichn. Europaea, v. 3, p. 499.. .

Campoplex (Bathyplectes) etemankiakorum Viereck, 1917 (1916). Conn. State Geol. and Nat. Hist. Survey Bul. 22: 263. $\delta$.

Bathyplectes phytonomi Viereck, 1925; 1926. Canad. Ent. 57 (9): 225 (key); 58 (9): 222. ठ", . In the 1926 part of Viereck's paper as "Campoplex (Bathyplectes) phytonomi" (see discussion under bryanti).

Taxonomy: Horstmann, 1974. Ent. Germ. 1: 62, 73, 75.

Biology: Rockwood, 1920. Canad. Ent. 52: 39. - Detweiler, 1923. Cornell Univ. Agr. Expt. Sta., Bul. 420: 19. - Chamberlin, 1933. Ent. Soc. Wash., Proc. 35: 106. - Sechriest and Treece, 1963. Ohio Agr. Expt. Sta., Res. Bul. 956: 23, - Caldwell and Wilson, 1975. Environmental Ent. 4: 333-336 (Gelis).

sessilis (Provancher), revised status. Que. In 1974 I studied the holotype (see Barron, 1975) and found that sessilis had been incorrectly suppressed as a synonym of exiguus by Townes (1945).

Limneria sessilis Provancher, 1875. Nat. Canad. 7: 148. $\%$.

Taxonomy: Townes, 1945. Amer. Ent. Soc., Mem. 11: 612. - Barron, 1975. Nat. Canad. 102: 566. 
stenostigma (Thomson). Southern N. H., Mass., N. Y., n. Del.?, s.e. Ont., n.e. Ohio, w. Colo.; w. U. S. S. R., s. Sweden s. to s. Germany and n. France. Introduced. Host: Hypera postica (Gyll.). B. stenostigma differs from other Bathyplectes species with known biologies in that its final-instar larva emerges from the host larva before the latter spins its cocoon. It is interesting that this biological difference in stenostigma would appear to correlate with its habit of spinning a double cocoon (see Brunson and Coles, 1968). The introductions in western Colo. were apparently accompanied by the accidental release and unfortunate establishment of the thelytokous hyperparasite which I have identified as Mesochorus nigripes (Ratzeburg) (which see).

Canidia stenostigma Thomson, 1887. Opusc. Ent. 11: 1114. $\delta$ ? ( $\$$ misdet.). Thomson failed to insert the sex symbols which usually preceded his statement of length, or range of lengths, for each species (in this case "Long. vix $4 \mathrm{~mm}$."), or perhaps omission of the sex symbols was a printers error. From Thomson's description of the ovipositor it is apparent that he had a female. Neither Thomson's length measurment, nor anything else in his description indicate that he had a male specimen or a second specimen of either sex. Therefore, the validity of Aubert's (1970) selection of a male lectotype labeled "Germ." (and relegation of a female specimen to paralectotype status) would appear to rest solely upon whether or not it can be disproved that the male was found near Aachen by Foerster, the only source Thomson cited for his specimen (or specimens) of stenostigma.

Taxonomy: Aubert, 1970. Soc. Linn. de Lyon, Bul. Mens. 39: 276-277. - Horstmann, 1974.

Ent. Germ. 1: 62, 70.

Biology: Brunson and Coles, 1968. U. S. Dept. Agr., Prod. Res. Rpt. 101: 5, 8 (as "sp.

Bagged" and "n. sp."). -Dysart and Coles, 1971. Ent. Soc. Amer., Ann. 64: 1361-1367.

-Dysart and Day, 1976. U. S. Dept. Agr., Prod. Res. Rpt. 167: 3, 14, 36, 39, 48-49 (releases and recoveries).

tristis (Gravenhorst). N. Y. w. to s. Mich. and e. Kans., s. to n.w. S. C. and n. Miss.; also central Calif.; s.w. Asia (U. S. S. R.), Europe. Introduced. Host: Hypera punctata (F.). The species is thelytokous, but males have been collected in N. J., Pa., Md., and Va. Possibly, males are even rarer in Europe because Horstmann (1974) had seen none.

Campoplex tristis Gravenhorst, 1829. Ichn. Europaea, v. 3, p. 492. \& ( ${ }^{\prime}$ misdet.?).

Canidia trochantella Thomson, 1887. Opusc. Ent. 11: 1114. 9.

Taxonomy: Horstmann, 1974. Ent. Germ. 1: 76, 77-78.

Biology: Dicke, 1937. Jour. Econ. Ent. 30: 375-376. - Puttler and Coles, 1962. Jour. Econ. Ent. 55: 831-833. - Dysart and Puttler, 1966. Jour. Econ. Ent. 59: 425-427.

\section{Genus CAMPOLETIS Foerster}

Sagaritis Holmgren, 1859 (1858). Svenska Vetensk.-Akad., Ofvers. af ... Forhandl. 15: 325. Preocc. by Billberg, 1820 and Huebner, 1821.

Type-species: Campoplex declinator Gravenhorst. Monotypic and orig. desig. The type-species is regarded as a synonym of $C$. dilatator (Thunberg).

Ecphora Foerster, 1868. Naturh. Ver. Rheinlande, Verh. 25: 154. Preocc. by Conrad, 1843.

Type-species: Campoplex viennensis Gravenhorst. Desig. by Viereck, 1914 from three species included by Thomson, 1887.

Campoletis Foerster, 1868. Naturh. Ver. Rheinlande, Verh. 25: 157.

Type-species: Mesoleptus tibiator Cresson. By subsequent monotypy from inclusion by Houghton, 1907.

Anilastus Foerster, 1868. Naturh. Ver. Rheinlande, Verh. 25: 157.

Type-species: Campoplex rapax Gravenhorst. Desig. by Viereck, 1914 from 27 species included by Thomson, 1887.

Anilasta Thomson, 1887. Opusc. Ent. 11: 1053, 1168. Emend.

Ecphoropsis Ashmead, 1900. Canad. Ent. 32: 368. N. name for Ecphora Foerster.

Sagaritopsis Hincks, 1944. Roy. Ent. Soc. London, Proc., Ser. B: Taxonomy 13: 36. N. name for Sagaritis Holmgren. 
This very large genus is known from all zoogeographic regions. The genus is rather difficult taxonomically, and there are no usable works treating the species of any large country or other major geographic area. Most of the species occur in unforested habitats and many of them parasitize Noctuidae; a species exceptional to both generalizations is C.pyralidis Walley.

Taxonomy: Walley, 1927. Canad. Ent. 59: 227-231 (key to spp. in Canadian National Collection).

apicata (Viereck). Ont.

Sagaritis apicata Viereck, 1925; 1926. Canad. Ent. 57 (8): 200 (key); 58 (5): 128. \&. In the 1926 portion of Viereck's revision as S. apicatus.

aprilis (Viereck). Conn., N. Y., N. J., n. Mich., w. Ont., S. Dak., s. B. C., w. Wash. Host: Polia purpurissata (Grt.), Xylomyges dolosa Grt., Enargia decolor (Wlk.).

Sagaritis aprilis Viereck, 1917 (1916). Conn. State Geol. and Nat. Hist. Survey "Bul. 22: 263. o'.

Sagaritis bigelowi Viereck, 1925; 1926. Canad. Ent. 57 (8): 198 (key); 58 (2): 33. 우

Sagaritis citrinus Viereck, 1925; 1926. Canad. Ent. 57 (8): 200 (key); 58 (5): 123. \&.

argentifrons (Cresson). Que. w. to s. B. C., s. to Va., Mo., s. Tex., Colo., and n. Calif. Host: Agrotis ipsilon (Hufn.), Anicla infecta (Ochs.), Lacinipolia renigera (Steph.), Crambus mutabilis Clem., C. zeelus Fern.

Mesoleptus dubitatus Cresson, 1864. Ent. Soc. Phila., Proc. 3: 259. \&. Formerly preocc. in Limnerium by Holmgren, 1860 .

Mesoleptus argentifrons Cresson, 1864. Ent. Soc. Phila., Proc. 3: 261. ठ.

Mesoleptus vicinus Cresson, 1864. Ent. Soc. Phila., Proc. 3: 268..

Limnerium provancheri Dalla Torre, 1901. Cat. Hym., v. 3, p. 102. N. name for $M$. dubitatus Cresson.

Sesioplex heliaeformis Viereck, 1925. Canad. Ent. 57 (7): 177 (key); 57 (12): 298. ๆ.

Sagaritis strigosus Viereck, 1925; 1926. Canad. Ent. 57 (8): 199 (key); 58 (3): 73. o, \&.

Sagaritis evansi Viereck, 1925; 1926. Canad. Ent. 57 (8): 199 (key); 58 (3): 74 ..

Sagaritis englishi Viereck, 1925; 1926. Canad. Ent. 57 (8): 199 (key); 58 (3): 75; 58 (5): 129. q. On p. 129 in the 1926 part of his revision Viereck made a correction to his 1925 key which makes it uncertain that the lectotype he selected in 1926 (p. 75) applies to the name validated in the 1925 key.

Sagaritis conspicuosus Viereck, 1925; 1926. Canad. Ent. 57 (8): 200 (key); 58(5): 123. ठ.

Sagaritis interruptus Viereck, 1925; 1926. Canad. Ent. 57 (8): 200 (key); 58 (5): 127, 129. ठे. The lectotype selected (in effect) by Viereck in 1926 (p. 127) does not apply with certainty to the name validated in the 1925 key because of errors in the latter which were corrected in 1926 (p. 129).

atkinsoni (Viereck). Southeastern Man., s. Sask., s. Alta., n. Idaho, e. Wash., w. Oreg.

Sagaritis atkinsoni Viereck, 1925; 1926. Canad. Ent. 57 (8): 199 (key); 58 (2): 38; 58 (5): 129.

Sagaritis teulonensis Viereck, 1925; 1926. Canad. Ent. 57(8): 200 (key); 58 (5): 124, 129. ठ, . The lectotype selected (in effect) by Viereck in 1926 (P. 124) does not apply with certainty to the name validated in the 1925 key because of errors in the latter which were corrected in 1926 (p. 129).

Biology: King and Atkinson, 1928. Ent. Soc. Amer., Ann. 21: 173-174, 185.

atypicus (Viereck). Que., Ont., s. Alta.

Sagaritis atypicus Viereck, 1925; 1926. Canad. Ent. 57 (8): 198 (key); 58 (2): 36. .

Sesioplex canadensis Cushman, 1930 (1929). U. S. Natl. Mus., Proc. 76 (25): 8. ठ, ?.

australis (Viereck). Southern Sask., Wyo., and N. Mex., w. to s. B. C. and w. Oreg. Host: Euxoa ochrogaster (Gn.).

Limnerium australis Viereck, 1903. In Skinner, Amer. Ent. Soc., Trans. 29: 91. \&. banksi (Viereck). Northern Va.

Campolex banksi Viereck, 1921. Psyche 28: 72..

californica (Holmgren). Calif.

Sagaritis californica Holmgren, 1869 (1868). Eug. Resa, pt. 2 (Zool.), sect. 1 (Ins.), p. 418. o.

Taxonomy: Townes, 1961. Ent. Soc. Wash., Proc. 63: 112 (note on type specimen). 
chlorideae Uchida. Japan, India. Introduced in southern Ga. in 1965 and possibly Ariz. in 1968 (personal commnun., J. R. Coulson, 1977), presumably without becoming established. Host: Phthorimaea operculella (Zell.)?, Heliothis armiger $(\mathrm{Hbn}),$.$H . assulta \mathrm{Gn}$. The target species for the release in Ga. was presumably either Heliothis virescens (F.), or $H$. zea (Bod.). In some literature the species was misidentified as Campoletis "perdistinctus" (Viereck).

Campoletis chlorideae Uchida, 1957. Kyushu Imp. Univ., Ent. Lab., Mushi 30: 29. ð,.

Taxonomy: Carlson, 1972. Ent. News 83: 77 (as Asian sp., probably undescribed). - Gupta, 1974. Oriental Insects 8: 112-115.

Biology: Gangrade, 1964. Ent. Soc. Amer, Ann. 57: 570-574.

clavata (Provancher). Que. s. to s.e. S. C., w. to n.e. Kans. Host: Heliothis zea (Bod.)?

Limneria clavata Provancher, 1875. Nat. Canad. 7: 148. " $"=\delta$.

Sagaritis conjunctiformis Viereck, 1917 (1916). Conn. State Geol. and Nat. Hist. Survey Bul. 22: 262. ర.

Sagaritis xanthotaenius Viereck, 1925; 1926. Canad. Ent. 57 (8): 198 (key); 58 (2): 37..

Sagaritis latus Viereck, 1925; 1926. Canad. Ent. 57 (8): 198 (key); 58 (2): 37. .

Sagaritis hexagonalis Viereck, 1925; 1926. Canad. Ent. 57 (8): 199 (key); 58 (2): 37; 58 (5): 129. $\delta$. The lectotype selected (in effect) by Viereck in 1926 (p. 37) does not apply with certainty to the name validated in the 1925 key because of errors in the latter which were corrected in 1926 (p. 129).

Sagaritis beaulieui Viereck, 1925; 1926. Canad. Ent. 57 (8): 199 (key); 58 (2): 38. ठ。.

Sagaritis basalis Viereck, 1925; 1926. Canad. Ent. 57 (8): 201 (key); 58 (5): 128. ơ, ๆ.

Sagaritis garretti Viereck, 1925; 1926. Canad. Ent. 57 (8): 201 (key); 58 (5): 129. o.

Sagaritis nigriscaposus var. mifitrochanteralis Walley, 1927. Canad. Ent. 59: 232..

Taxonomy: Provancher, 1886. Addit. Corr. Faune Ent. Canada Hym., p. 89 (sex of clavata syntypes stated to be male not "female"). - Gahan and Rohwer, 1917. Canad. Ent. 49: 433 (female "lectotype" inocorrectly selected for clavata). - Barron, 1975. Nat. Canad. 102: 451-452 (valid lectotype selected for clavata).

clitellaria (Walley). Southern B. C.

Sagaritis clitellarius Walley, 1927. Canad. Ent. 59: 232. ठ.

compacta (Provancher). Southern B. C., w. Wash.

Limneria compacta Provancher, 1884. In Taylor, Canad. Ent. 16: 91. Nomen nudum.

Limneria compacta Provancher, 1885. Canad. Ent. 17: 116. ๆ.

Sagaritis downsi Viereck, 1926. Canad. Ent. 58 (2): 36. [male].

Sagaritis downesi(!) Viereck, 1926. Canad. Ent. 58 (2): 36.

conjuncta (Cresson). Ill.

Mesoleptus conjunctus Cresson, 1864. Ent. Soc. Phila., Proc. 3: 262. ð, ๆ.

distincta (Provancher). Que., N. H., N. Y., Ont., n. Ill., Minn., s. Sask., s. B. C. Host: Catocala sp.

Limneria distincta Provancher, 1882. Nat. Canad. 3: 365. ․ Suppressed as a synonym of C. tibiator (Cresson) by Townes (1945); resurrected by Townes and Townes (1951). Walkley (1958) and Barron (1975) regarded distincta as unavailable by virtue of having been replaced by Cynıdusa provancheri Viereck (which see), but I do not believe they were correct. Walkley treated the name provancheri (Viereck) as the valid name for $C$. distincta, overlooking the fact that provancheri was preocc. in Campoletis by Dalla Torre, 1901.

Sagaritis apicalis Viereck, 1925; 1926. Canad. Ent. 57 (8): 198 (key); 58 (2): 36. ठ。.

Taxonomy: Townes, 1945. Amer. Ent. Soc., Mem. 11: 626. - Townes and Townes, 1951. In Muesebeck et al., U. S. Dept. Agr., Agr. Monog. 2: 367. - Walkley, 1958. In Krombein et al., U. S. Dept. Agr., Agr. Monog. 2, sup. 1, p. 59, 60. - Barron, 1975. Nat. Canad. 102: 462. diversa (Viereck). Southwestern Alta.

Sagaritis diversus Viereck, 1925; 1926. Canad. Ent. 57 (8): 198 (key); 58 (2): 33..

flavicincta (Ashmead). Mass. and s.e. Ont. w. to s.w. B. C., s. to central Fla., s. Tex., s. Ariz., and s. Calif:; Mexico s. to Uruguay. Host: Agrotis ipsilon (Hufn.), Dargida procincta (Grt.), Feltia subterranea (F.), Heliothis virescens (F.), H. zea (Bod.), Lacinipolia stricta 
(Wlk.), Pseudaletia unipuncta (Haw.), Spodoptera eridania (Cram.), S. frugiperda (J. E.

$\mathrm{S}$ ), S. ornithogalli (Gn.), Trichoplusia ni (Hbn.), Manduca quinquemaculata (Haw.),

Ostrinia nubilalis (Hbn.), Udea ribigalis (Gn.), Pieris rapae (L.).

Limneria flavicineta Ashmead, 1890 (1889). U. S. Natl. Mus., Proc. 12: 436. ठ̊.

Limnerium perdistinctus Viereck, 1905. Kans. Acad. Sci., Trans. 19: 304. ๆ.

Amorphota nocturna Viereck, 1905. Kans. Acad. Sci., Trans. 19: 308. ठ'.

Limnerium (Campoletis) prodeniae Viereck, 1911. U. S. Natl. Mus., Proc. 40: 190. ठ,.

Sagaritis trochanteralis Viereck, 1925; 1926. Canad. Ent. 57 (8): 199 (key); 58 (3): 75..

Sagaritis twinni Viereck, 1925; 1926. Canad. Ent. 57 (8): 200 (key); 58 (3): 72. ठै, ᄋ.

Sagaritis modestus Viereck, 1925; 1926. Canad. Ent. 57 (8): 201 (key); 58 (5): 126. ठో.

Taxonomy: Carlson, 1972. Ent. News 83: 75-82.

Biology: Luginbill, 1928. U. S. Dept. Agr., Tech. Bul. 34: 61-63 (as dubitatus, misdet.).

-Vickery, 1929. U. S. Dept. Agr., Tech. Bul. 138: 36-39 (as dubitatus, misdet.). - Wene,

1943. Jour. Econ. Ent. 36: 333-334 (as provancheri, misdet.). -Grayson, 1944. Jour. Econ.

Ent. 37: 712-713 (as provancheri, misdet.).

gorhami (Viereck). N. S.

Sagaritis gorhami Viereck, 1925; 1926. Canad. Ent. 57 (8): 199 (key); 58 (3): 73..

heliae (Ashmead). Va. Host: Epizuexis aemula ( $\mathrm{Hbn}$. ).

Limneria heliae Riley, 1890. In Riley and Howard, U. S. Dept. Agr., Insect Life 3: 158. Nomen nudum.

Limneria heliae Ashmead, 1896. Amer. Ent. Soc., Trans. 23: 194. ठ.

hoppingi (Viereck). Southern B. C., w. Wash.

Sagaritis hoppingi Viereck, 1925; 1926. Canad. Ent. 57 (8): 199 (key); 58 (3): 76. ठ.

imperfecta (Viereck). Ont.?, Sask.

Sagaritis imperfectus Viereck, 1925; 1926. Canad. Ent. 57 (8): 200 (key); 58 (5): 127, 129.. The lectotype selected (in effect) by Viereck in 1926 (p. 127) does not apply with certainty to the name validated in the 1925 key because of errors in the latter which were corrected in 1926 (p. 129).

incompleta (Viereck). Southeastern Ont.

Sagaritis incompletus Viereck, 1925; 1926. Canad. Ent. 57 (8): 199 (key); 58 (3): $71 . \delta$.

intermedia (Viereck). Utah, s. B. C., Wash., w. Oreg., n. Calif. Host: Neuronia sp.?

Sagaritis intermedius Viereck, 1925; 1926. Canad. Ent. 57 (8): 198 (key); 58 (2): 34. ठో.

Sagaritis trackas Viereck, 1925; 1926. Canad. Ent. 57 (8): 199 (key); 58 (3): 72 . ठ.

Sagaritis taylori Viereck, 1925; 1926. Canad. Ent. 57 (8): 201 (key); 58 (5): 126. ․

julia (Viereck). Southwestern Alta., s.w. Oreg., n.e. Calif. Host: Choreutis balsamorrhizella Bsk., C. silphiella (Grt.).

Sagaritis julius Viereck, 1925; 1926. Canad. Ent. 57 (8): 200 (key); 58 (5): 125. ठ。.

Taxonomy: Townes, 1945. Amer. Ent. Soc., Mem. 11: 627. -Carlson, 1972. Ent. News 83:

76-77.

kingi (Viereck). Southern Sask.

Sagaritis kingi Viereck, 1925; 1926. Canad. Ent. 57 (8): 200 (key); 58 (3): 77; 58 (5): 129. ؟.

linearis (Viereck). Southern Sask.

Sagaritis linearis Viereck, 1925; 1926. Canad. Ent. 57 (8): 200 (key); 58 (3): 76. ठ.

lipomerus (Viereck). Mass., N. Y., Pa., Ont., s. Sask., s. Alta.

Sagaritis lipomerus Viereck, 1925; 1926. Canad. Ent. 57 (8): 198 (key); 58 (2): 32. ठ, \&.

Sagaritis rufiscapus Viereck, 1925; 1926. Canad. Ent. 57 (8): 199 (key); 58 (3): 75. ठో.

longiceps (Roman). Greenland; n.e. U. S. S. R.

Ecphoropsis longiceps Roman, 1926 (1914). Acad. Imp. des Sci. St. Petersburg, Mem. (8) 29 (7): 13. $\delta$. The copy of Roman's paper in the file of the Systematic Entomology

Laboratory is labeled in Roman's handwriting as "Received July 1926, A. Rn." The copy in the library of the U.S. Natl. Museum was received by the Museum on April 8, 1927.

maia (Viereck). Southern B. C.

Sagaritis maius Viereck, 1925; 1926. Canad. Ent. 57 (8): 200 (key); 58 (5): 125, 129. ठ. The lectotype selected (in effect) by Viereck in 1926 (p. 125) does not apply with certainty to 
the name validated in the 1925 key because of errors in the latter which were corrected in 1926 (p. 129). Doubt also stems from the fact that the lectotype was collected in April. media (Viereck). Ont.

Sagaritis medius Viereck, 1925; 1926. Canad. Ent. 57 (8): 198 (key); 58 (2): 34. \&. melanocerus (Viereck). Southern Ont.

Sagaritis melanocerus Viereck, 1925; 1926. Canad. Ent. 57 (8): 200 (key); 58 (5): 123. ठ. melanomerus (Viereck). N. H. Known only from the lectotype, which was collected in the alpine region of Mt. Washington.

Sagaritis melanomerns Viereck, 1925; 1926. Canad. Ent. 57 (8): 200 (key); 58 (5): 122. ठ. nigricoxa (Viereck). Southern Alta.

Sagaritis nigricoxus Viereck, 1925; 1926. Canad. Ent. 57 (8): 199 (key); 58 (3): 74 ..

nigripes (Cresson). Ill., Sask., Alta.

Mesoleptus nigripes Cresson, 1864. Ent. Soc. Phila., Proc. 3: 267..

Mesoleptus hostilis Cresson, 1864. Ent. Soc. Phila., Proc. 3: 267. ¿.

nigriscaposa (Viereck). Southern Sask.

Sagaritis nigriscaposus Viereck, 1925; 1926. Canad. Ent. 57 (8): 201; 58 (5): 128. ¿े.

oxylus (Cresson). Que. w. to w. Wash., s. to s. Fla., Okla., and w. Oreg. Host: Achatodes zeae (Harris), Bellura densa (Wlk.), B. obliqua (Wlk.), Epiglaea apicata (Grt.), Nephelodes emmedonia f. violens $\mathrm{Gn}$., Oligia fractilinea (Grt.), Papaipema lysimachiae Bird, $P$. nebris (Gn.), Pseudaletia unipuncta (Haw.), Spodoptera frugiperda (J. E. S.).

Mesoleptus oxylus Cresson, 1864. Ent. Soc. Phila., Proc. 3: 262. ठै, $q$.

Limneria occidentalis Ashmead, 1890 (1889). U. S. Natl. Mus., Proc. 12: 432. ๆ.

Limneria nephelodis Riley, 1890. In Riley and Howard, U. S. Dept. Agr., Insect Life 3: 158. Nomen nudum.

Limneria nephelodis Ashmead, 1896. Amer. Ent. Soc., Trans. 23: 194. đ.

Limnerium lawrencei Viereck, 1906. Amer. Ent. Soc., Trans. 32: 178. ๆ.

Sagaritis ruficoxalis Viereck, 1916. Biol. Soc. Wash., Proc. 29: 170. ठ, ๆ.

Sagaritis nigrisignatus Viereck, 1925; 1926. Canad. Ent. 57 (8): 199 (key); 58 (3): 71. đ..

Sagaritis stramineiscapus Viereck, 1925; 1926. Canad. Ent. 57 (8): 201 (key); 58 (3): 126..

Biology: Lowry, 1927. N. H. Agr. Expt. Sta., Tech. Bul. 34: 22. -Beckwith and Driggers,

1928. N. J. Agr. Expt. Sta., Ann. Rpt. 48: 139. -Beckwith, 1929. N. Y. Ent. Soc., Jour. 37:

415. -Guppy, 1967. Canad. Ent. 99: 100-101.

pacifica (Walley). Western Wash., w. Oreg., n. Calif.

Sagaritis rufierus var. pacificus Walley, 1927. Canad. Ent. 59: 233, 234. ठ.

parasignata (Walley). Southeastern Sask.

Sagaritis parasignatus Walley, 1927. Canad. Ent. 59: 232..

patsuiketorum (Viereck). Maine w. to s. B. C., s. to w. N. C., n. Ala., N. Mex., n. Utah, and n. Calif.; s. Mexico? Host: Loxostege sticticalis (L.), Phlyctaenia coronata tertialis (Gn.), $P$. extricalis (Gn.), Udea rubigalis (Gn.), Grapholitha molesta (Bsk.). In the U. S. Natl. Museum collection there is a male specimen labeled as being collected in Oaxaca, Mexico by L. 0 . Howard. It remains to be seen whether I have correctly identified this specimen and whether it is correctly labeled.

Sagaritis patsuiketorum Viereck, 1917 (1916). Conn. State Geol. and Nat. Hist. Survey Bul. 22: 262. ․

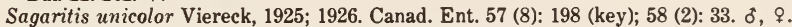

Sagaritis lipopus Viereck, 1925; 1926. Canad. Ent. 57 (8): 198 (key); 58 (2): 35. ․

Sagaritis cingulatus Viereck, 1925; 1926. Canad. Ent. 57 (8): 198 (key); 58 (2): 35. o.

Sagaritis melanosomus Viereck, 1925; 1926. Canad. Ent. 57 (8): 199 (key); 58 (3): 71. \&.

plena (Provancher). Que., s.w. Alta.

Limneria plena Provancher, 1875. Nat. Canad. 7: 146. $\$$.

Sagaritis chrystali Viereck, 1925. Canad. Ent. 57 (8): 200 (key); 58 (3): 77. १.

Taxonomy: Barron, 1975. Nat. Canad. 102: 532-533 (plena holotype).

pyralidis Walley. Que. s. to e. S. C., w. to s. Sask. and n.w. Ark. Host: Tetralopha aplastella Hulst, Acrobasis sp. on Myrica, A. betulella Hulst, A. caryivorella Rag., A. comptoniella 
Hulst, A. juglandis (LeB.), Jacoma nyssaecolella (Dyar), Meroptera pravella (Grt.), Nephopteryx subfuscella (Rag.), Salebriaria engeli (Dyar), Aristotelia sp.

Campoletis pyralidis Walley, 1970. Canad. Ent. 102: 1528. ó, ๆ.

Morphology: Finlayson, 1967. Canad. Ent. 102: 1257-1258 (as Compoletis n. sp.).

rufosignata (Viereck). Southern Ont.

Sagaritis rufosignatus Viereck, 1925; 1926. Canad. Ent. 57 (8): 198 (key); 58 (2): 34. ठో.

septentrionalis (Viereck). Mont., s.w. Alta., and s. B. C., s. to central Utah, w. Nev., and n. Calif. Host: Euxoa pallipennis $\mathrm{Sm}$.

Sagaritis septentrionalis Viereck, 1925; 1926. Canad. Ent. 57 (8): 200 (key); 58 (3): 76. ?.

Sagaritis aequalis Viereck, 1925; 1926. Canad. Ent. 57 (8): 200 (key); 58 (5): 122, 129. ơ, ?. The correction made by Viereck in 1926 (p. 129) suggests that the lectotype which he in effect selected in 1926 (p. 124) for S. laevis Viereck would apply to the name aequalis as validated in the 1925 key.

Sagaritis laevis Viereck, 1925; 1926. Canad. Ent. 57 (8): 200 (key); 58 (5): 124, 129. ð, ๆ. The correction made by Viereck in 1926 (p. 129) suggests that the lectotype which he in effect selected in 1926 (p. 122) for S. aequalis Viereck would apply to the name laevis as validated in the 1925 key.

Sagaritis muficrus Viereck, 1925; 1926. Canad. Ent. 57 (8): 201 (key); 58 (5): 127. o.

Sagaritis approximalis Walley, 1927. Canad. Ent. 59: 231. ठ.

Sagaritis vierecki Walley, 1927. Canad. Ent. 59: 233. o, $\uparrow$.

signata (Viereck). Southern B. C.

Sagaritis signatus Viereck, 1925; 1926. Canad. Ent. 57 (8): 199 (key); 58 (3): 72 ..

sonorensis (Cameron). Md., s. Ill., n. Colo., s.w. Alta., s.e. Wash., and n.w. Oreg., s. to e. S. C., n. Fla., s. Tex., s. Ariz., and s. Calif.; Cuba and Mexico s. to Peru. Host: Autographa californica (Spey.), Heliothis phloxiphaga (G. and R.), H. virescens (F.), H. zea (Bod.), Peridroma saucia (Hbn.), Plathypena scabra (F.)?, Spodoptera exigua (Hbn.), Trichoplusia ni (Hbn.), Anthocaris midea (Hbn.). In the earlier biological papers cited below, sonorensis was misidentified as perdistincta, now a synonym of flavicincta (which see). My 1972 paper was directed at eliminating the taxonomic confusion of sonorensis with flavicincta, but the unusual pattern of the distribution known for sonorensis in North America and the existence in the Canadian National Collection of a series of sonorensis specimens labeled as collected at an altitude of $7500 \mathrm{ft}$. (at Sunshine Lodge) in Banff Natl. Park, Alta. seem to indicate the need for further taxonomic study in connection with studies of host relations, etc.

Limneria sonorensis Cameron, 1886. Biol. Cent.-Amer., Hym., v. 1, p. 307. [female]. Limnerium (Angitia) websteri Viereck, 1910. U. S. Natl. Mus., Proc. 38: 382 . $\%$.

Taxonomy: Carlson, 1972. Ent. News 83: 75-82.

Biology: Noble and Graham, 1966. Jour. Econ. Ent. 59: 1118-1120. -Lingren, Guerra, Nickelsen, and White, 1970. Jour. Econ. Ent. 63: 518-522. - Hollingsworth, Harstack, and Lingren, 1970. Jour. Econ. Ent. 63: 1758-1761. - Hoelscher and Vinson, 1971. Ent. Soc. Amer., Ann. 64: 1373-1376. - Lingren and Noble, 1972. Jour. Econ. Ent. 65: 104-107. -Guillot and Vinson, 1972. Nature [London] 235: 169-170. - Vinson, 1972. Ent. Soc. Amer., Ann. 65: 229-236. - Vinson, 1972. Environmental Ent. 1: 409-413. - Vinson, 1972. Jour. Insect Physiol. 18: 1501-1516. - Norton, Vinson, and Thurston, 1974. Electron Micros. Soc. Amer., Proc. 32d: 140-141. - Wilson, Ridgway, and Vinson, 1974. Ent. Soc. Amer., Ann. 67: 271-274. - Norton and Vinson, 1974. Internatl. Jour. Insect Morph. and Embryol. 3: 305-306, 309-311, 314-315. - Wilson and Ridgway, 1974. Environmental Ent. 3: 714-717. (cocoon spinning). - Schmidt, 1974. Ent. Soc. Amer., Ann. 67: 835-844. - Wilson and Ridgway, 1975. Ent. Soc. Amer., Ann. 68: 191-196. - Norton, Vinson, and Stoltz, 1975. Cell Tissue Res. 162: 195-208. - Vinson, 1975. In Price, Evol. Strat. Paras. Insects and Mites, p. 29, 30, 31, 32, 34. - Dahlman and Vinson, 1976. Ent. Soc. Amer., Ann. 69: 523-524.

-Lingren, 1977. Environmental Ent. 6: 72-76.

striatipes (Ashmead). N. H., N. Mex. The type-locality (not mentioned by Ashmead) is "Top of [Las Vegas] range, [N. Mex.], betw[een] Sapello and Pecos Rivers, Ab[ou]t 11,000 ft. 
[elevation]." Townes and Townes (1951) indicated that the species is also known from Mt. Madison, N. H.

Limneria striatipes Ashmead, 1901. Psyche 9: 148. ㅇ (o misdet.).

taeniolata (Viereck). N. Mex. Known only from the holotype, which was collected at Beulah. Limnerium taeniolata Viereck, 1903. In Skinner, Amer. Ent. Soc., Trans. 29: 92. o.

tibialis (Viereck). Southern B. C., w. Wash.

Sagaritis tibialis Viereck, 1925; 1926. Canad. Ent. 57 (8): 200 (key); 58 (3): 77. \&.

tibiator (Cresson). Northern N. Y. s. to s.w. S. C. and n. Ala., w. to s.e. Iowa and n.e. Kans.

Host: Rhodophora gaurae (J. E. S.), geometrid on apple?

Mesoleptus tibiator Cresson, 1864. Ent. Soc. Phila., Proc. 3: 259. ठ.

Ischnoscopus taeniatus Viereck, 1905. Kans. Acad. Sci., Trans. 19: 305. \&.

yakutatensis (Ashmead). Southeastern Alaska.

Ischnoscopus yakutatensis Ashmead, 1902. Wash. Acad. Sci., Proc. 4: 236. ठै, ९.

\section{Genus CALLIDORA Foerster}

Pantropa Foerster, 1868. Naturh. Ver. Rheinlande, Verh. 25: 155.

Type-species: Limineria albovincta Holmgren. By subsequent monotypy from inclusion by Townes, 1970. The designation of Townes (1970) reads: "(Callidora annellata Thomson) = albovincta Holmgren." Article 68 (c) of the International Code of Zoological Nomenclature indicates that albovincta is the type-species by monotypy in spite of the intentions of Townes, which apparently were that it be annellata.

Callidora Foerster, 1868. Naturh. Ver. Rheinlande, Verh. 25: 157.

Type-species: Callidora annellata Thomson. Desig. by Viereck, 1914 from two species included by Thomson, 1887. The type-species is regarded as a synonym of C. albovincta (Holmgren).

Neocallidora Ozols, 1966. Latv. Ent. 11: 49.

Type-species: Campoplex analis Gravenhorst. Monotypic and orig. desig.

This is a small Holaretic and Oriental genus. No hosts are known.

Revision: Tigner, 1969. Mich. Ent. 2: 36-39 (spp. of world).

Taxonomy: Townes, 1970 (1969). Amer. Ent. Inst., Mem. 13: 165-166.

surata Tigner. Central Tenn., s.w. N. Dak., central S. Dak., s. Tex., e. Wyo., s. Alta., n. Utah.

Callidora surata Tigner, 1969. Mich. Ent. 2: 39. ठ, ९.

tegularis Tigner. Northeastern Pa., s.e. Mich.

Callidora tegularis Tigner, 1969. Mich. Ent. 2: 38. §, ९.

\section{Genus CYMODUSA Holmgren}

Cymodusa Holmgren, 1859 (1858). Svenska Vetensk.-Akad., Ofvers. af ... Forhandl. 15: 325.

Type-species: Cymodusa leucocera Holmgren. Monotypic and orig. desig.

Apparently the name leucocera is validated in this work by virtue of article 16 (a)

(vi) of the Internatl. Code of Zool. Nomenclature, even though Holmgren

indicated that he knew five Scandinavian species of Cymodusa.

Thersitia Schmiedeknecht, 1907. Hym. Mitteleuropas, p. 598.

Type-species: Thersitia egregia Schmiedeknecht. Monotypic. The type-species is regarded as a synonym of leucocera Holmgren.

This is a Neotropic, Holarctic, and Oriental genus of moderate size.

Revision: Gupta and Gupta, 1974. Oriental Insects 8: 1-14 (Oriental spp.).

distincta (Cresson). Maine w. to s. B. C., s. to n. Ga., n.e. Kans., Colo., and w. Oreg.

Mesoleptus subrubidus Cresson, 1864. Ent. Soc. Phila., Proc. 3: 264. ơ.

Mesoleptus distinctus Cresson, 1864. Ent. Soc. Phila., Proc. 3: 266. ๆ.

Limnerium vigilis Viereck, 1906. Amer. Ent. Soc., Trans. 32: 179. ठ.

Idechthis biconjunctus Viereck, 1906. Amer. Ent. Soc., Trans. 32: 180. ठ.

Campoplex (Nepiera) amasecontorum Viereck, 1917 (1916). Conn. State Geol. and Nat. History Survey Bul. 22: 266. ठे. 
Cymodusa plesius Viereck, 1925; 1926. Canad. Ent. 57 (7): 180 (key); 58 (1): 4 .. melanocera Viereck. N. H. w. to s. B. C., s. to w. N. C. and s. Idaho.

Cymodusa melanocera Viereck, 1925; 1926. Canad. Ent. 57 (7): 180 (key); 58 (1): 3. ठ。.

Cymodusa gracilicomis Viereck, 1925; 1926. Canad. Ent. 57 (7): 180 (key); 58 (1): 4 .. nigripes (Viereck). N. B., N. S.

Neonortonia nigripes Viereck, 1925. Canad. Ent. 57 (7): 179 (key); 57 (12): 300. ठ。.

Formerly preocc. in Campoplex by Gravenhorst, 1829 and Brulle, 1846.

Neonortonia laevissima Viereck, 1925. Canad. Ent. 57 (7): 179 (key); 57 (12): 301. o .

Taxonomy: Townes, 1945. Amer. Ent. Soc., Mem. 11: 598 (syn. and first revisor choice of names). -Walkley, 1958. In Krombein et al., U. S. Dept. Agr., Agr. Monog. 2, sup. 1, p. 59 (nigripes suppressed because of secondary homonymy). - Walkley, 1967. In Krombein et al., U. S. Dept. Agr., Agr. Monog. 2, sup. 2, p. 201 (transfer to Cymodusa as lávissima). partis (Viereck). Que.

Campoplex (Diadegma) partis Viereck, 1925; 1926. Canad. Ent. 57 (9): 227 (key); 58 (11): 280. ơ.

provancheri Viereck. N. S.

Cymodusa provancheri Viereck, 1925; 1926. Canad. Ent. 57 (7): 180 (key); 58 (1): 4 . ?. In 1926 (p. 4) Viereck, in effect, selected a lectotype for provancheri and, at the same place, wrote: "(Limneria) Cymodusa provancheri new name $=$ Cymodusa distincta Provancher, not Cresson." Walkley (1958) treated provancheri as a replacement name for Limneria distincta Provancher, and Barron (1975) concurred with Walkley, stating that "Viereck's designation of a holotype for provancheri is disallowed (Int. Code Zool. Nom. art. 72 (d))." Article 72 (d), however, has no bearing on this case because Viereck did not originally (i.e. 1925, p. 180) propose provancheri expressly as a replacement for any prior name. Moreover, my knowledge of Viereck's idiosyncrasies leads me to believe that he most likely proposed the name provancheri for what he thought to be Provancher's misidentification of distincta (Cresson). Viereck frequently used the term "new name" in that context. Although Viereck was very inconsistent, I regard it as unlikely that he would have regarded a specimen that Provancher never saw as being the holotype if he had intended the name provancheri to be a replacement name (cf. Viereck's proposal of the replacement name Ameloctonus taeniopus). Also see discussion under Campoletis distincta (Provancher).

Taxonomy: Walkley, 1958. In Krombein et al., U. S. Dept. Agr., Agr. Monog. 2, sup. 1, p. 59, 60. -Barron, 1975. Nat. Canad. 102: 462.

\section{Genus CYMODUSOPSIS Viereck}

Cymodusopsis Viereck, 1912. U. S. Natl. Mus., Proc. 43: 588.

Type-species: Cymodusopsis aristoteliae Viereck. Monotypic and orig. desig.

This is a small Neotropic and Nearctic genus.

aristoteliae Viereck. N. J., Mo., S. Dak., n.e. Kans. Host: A ristotelia pudibundella (Zell.). Cymodusopsis aristoteliae Viereck, 1912. U. S. Natl. Mus., Proc. 43: 588. §, ?.

\section{Genus SPUDASTICA Foerster}

Spudastica Foerster, 1868. Naturh. Ver. Rheinlande, Verh. 25: 155.

Type-species: Spudastica petiolaris Thomson. By-subsequent monotypy from inclusion by Thomson, 1887. The type-species is regarded as a synonym of kriechbaumeri (Bridgman).

Townes (1970) indicated that this Holarctic genus appears to be represented by one species which has a number of geographic variants. However, there appear to be at least two distinet species in North America. I have seen specimens from Mass., N. J., Md., and Va. which appear to represent an undescribed species which apparently occurs in swampy areas. S. kriechbaumeri has been reared from species of the noctuid genus Orthosia.

Taxonomy: Townes, 1970 (1969). Amer. Ent. Inst., Mem. 13: 169. 
canadensis Walley. Que., Ont., Colo. Ecology: A specimen which seems to agree with Walley's description of canadensis was reared from its cocoon which was collected under a stone at Garden of the Gods, El Paso Co., Colo.

Spudastica canadensis Walley, 1944. Canad. Ent. 76: 157. đ, ?.

\section{Genus MELOBORIS Holmgren}

Meloboris Holmgren, 1859 (1858). Svenska Vetensk.-Akad., Ofvers. af ... Forhandl. 15: 326.

Type-species: Meloboris gracilis Holmgren. Monotypic. Apparently the name gracilis is validated in this work by virtue of article 16 (a) (vi) of the Internatl. Code of Zool. Nomenclature, even though Holmgren indicated that he knew three Scandinavian species of Meloboris.

Pseudocymodusa Habermehl, 1922. Konowia 1: 105.

Type-species: Cymodusa elachistae Brischke. Monotypic. The type-species is regarded as a synonym of $M$. alternans (Gravenhorst).

Anoixis Townes, 1970 (1969). Amer. Ent. Inst., Mem. 13: 180. N. syn.

Type-species: Anoixis alophus Townes. Monotypic and orig. desig.

This is a small Holarctic genus. There are a number of undescribed Nearctic species. Apparently there are no host records. Townes $(1965,1970)$ treated Nepiera as a synonym of Meloboris, but I believe Nepiera is sufficiently different from Meloboris to warrant separation of the two.

Taxonomy: Townes, 1965. Polskie Pismo Ent. 35: 413-414. - Townes, 1970 (1969). Amer. Ent.

Inst., Mem. 13: 172-174, 180-181. - Horstmann, 1970. Bayer. Ent., Nachrichtenbl. 19: 81-82,

83.

alopha (Townes), n. comb. N. H., R. I., s. Ont., Mich. I have seen a pair of specimens in the

Canadian Natl. Collection which have the nervellus intercepted by the discoidella (cf.

Townes' fig. 170).

Anoixis alophus Townes, 1970 (1969). Amer. Ent. Inst., Mem. 13: 180. ð, ๆ.

\section{Genus NEPIERA Foerster}

Asinamora Foerster, 1868. Naturh. Ver. Rheinlande, Verh. 25: 155. N. syn.

Type-species: Ichneumon collector Thunberg. By subsequent monotypy from inclusion by Townes, Momoi, and Townes, 1965. The designation of Townes, Momoi, and Townes (1965) reads: "(Limneria concinna Holmgren) $=$ collector Thunberg." Article 68 (c) of the Internatl. Code of Zool. Nomenclature indicates that collector is the type-species by monotypy in spite of the intentions of Townes, Momoi, and Townes, which presumably were that it be concinna.

Nepiera Foerster, 1868. Naturh. Ver. Rheinlande, Verh. 25: 156.

Type-species: Limneria concinna Holmgren. By subsequent monotypy from inclusion by Thomson, 1887. The type-species is regarded as a synonym of $N$. collector (Thunberg).

This is a genus of small to moderate size. It is known to me only from the Neotropic, Holarctic, and Australian Regions, but the placement of the Ethiopian species Limneria helminda Holmgren in Meloboris by Townes and Townes (1973) would presumably indicate that helminda is a species of Nepiera.

Taxonomy: Townes, 1965. Polskie Pismo Ent. 35: 414. -Townes, Momoi, and Townes, 1965.

Amer. Ent. Inst., Mem. 5: 291. - Horstmann, 1970. Bayer. Ent., Nachrichtenbl. 19: 81-82,

83. - Townes and Townes, 1973. Amer. Ent. Inst., Mem. 19: 155.

basilaris (Provancher). Que.

Limneria basilaris Provancher, 1875. Nat. Canad. 7: 147. " $\delta "=q$. The specimen indicated as being the lectotype by Gahan and Rohwer (1917) and the holotype by Barron (1975) was incorrectly stated by them as being a male. My notes on the holotype indicate that is a female of the genus Nepiera, and that it is similar to and perhaps conspecific with benevola Gahan. My notes also indicate that the male in the Provancher collection does not have the hind coxa black; it thereby fails to agree with Provancher's original description. It represents an undescribed species of the genus Meloboris. In the U.S. 
Natl. Museum collection there is a female specimen, apparently conspecific with the latter, which was identified as "Nepiera basilaris" by Dr. H. K. Townes in 1942. I presume that the distribution given for basilaris by Townes and Townes (1951) pertains to that undescribed species of Meloboris.

benevola Gahan. Southern N. Mex., n. Utah., n.e. Oreg. Host: Colias eurytheme Bdv.

Nepiera benevola Gahan, 1914. U. S. Natl. Mus., Proc. 48: 157. ठ" ९.

curticauda (Viereck). Southern B. C., w. Wash., w. Oreg., n. Calif.

Campoplex (Diadegma) curticauda Viereck, 1925; 1926. Canad. Ent. 57 (8): 227 (key); 58 (11): 280 . $q$.

fuscifemora Graf. Western Wash. s. to s. Calif.; central Mexico. Host: Phthorimaea operculella (Zell.), Argyrotaenia citrana (Fern.), Heliothis zea (Bod.), Peridroma saucia (Hbn.), Spodoptera exigua (Hbn.), Trichoplusia ni (Hbn.), Cynthia cardui (L.).

Nepeira(!) benevola var. fuscifemora Graf, 1917 (Feb.). U. S. Dept. Agr., Bul. 427: 46, 47. . In the first line of the paragraph on p. 46 headed "Nepeira benevola var. fuscifemora Cushm." Graf said: "this parasite (fig. 44)." Figure 44 is on p. 47, and the fact that the name in its legend is "Nepeira benevola" (omitting var. fuscifemora) is of no significance. Walkley (1966) attempted to show that Graf figured benevola rather than fuscifemora because "the figure shows the hind femora with the apices and bases dark," which she asserted "is true of benevola but not of fuscifemora." Walkley failed to observe that Graf figured the inner surfaces of the femora, not the outer ones, and the pattern of coloration shown in Graf's figure is altogether typical for the inner femoral surfaces of fuscifemora, but has not been observed by me in specimens of benevola.

Nepiera benevola var. fuscifemora Gahan, 1917 (May). U. S. Natl. Mus., Proc. 53: 208. ठో, ९. Preocc. by Graf, 1917 (Feb.).

Taxonomy: Walkley, 1966. Ent. Soc. Wash., Proc. 68: 156.

marginata (Provancher). Que. w. to w. Wash., s. to w. N. C., Mo., s. N. Mex., and s. Calif. Host: Actebia fennica (Tausch.), Graphiphora smithi (Snell.), Pseudaletia unipuncta (Haw.), Cynthia cardui (L.), Vanessa atalanta (L.), Solenobia sp.

Campoplex marginatus Provancher, 1874. Nat. Canad. 6: 146. ठં,.

Limneria brevicauda Provancher, 1886. Addit. Corr. Faune Ent. Canada Hym. p. 88. ؟.

Limnerium brevicaudum Dalla Torre, 1901. Cat. Hym., v. 3, p. 91. Emend.

Campoplex (Ameloctonus) intimus Viereck, 1925; 1926. Canad. Ent. 57 (9): 224 (key); 58 (10): 260. .

Meloboris brevicauda Townes, 1970 (1969). Amer. Ent. Inst., Mem. 13: 281. Nomen nudum.

Taxonomy: Gahan and Rohwer, 1917; 1918. Canad. Ent. 49: 433; 50: 29 (Provancher type

specimens). - Barron, 1975. Nat. Canad. 102: 435, 504 (Provancher type specimens).

Biology: Guppy, 1961; 1967. Canad. Ent. 93: 569; 99: 96, 100.

oblonga (Viereck). Ont., n.w. Mich. Host: Ostrinia nubilalis (Hbn.).

Campoplex (Ameloctonus) oblongus Viereck, 1925; 1926. Canad. Ent. 57 (9): 224 (key); 58

(10): 260 .. .

unica (Viereck). Southeastern Ont.

Angitia (Dioctes) unicus Viereck, 1926. Canad. Ent. 58 (7): 182. ठో.

\section{Genus PHОВOCAMPE Foerster}

Hypothereutes Foerster, 1868. Naturh. Ver. Rheinlande, Verh. 25: 156.

Type-species: Hypotherentes(!) geometrae Ashmead. By subsequent monotypy from inclusion by Ashmead, 1898.

Phobocampe Foerster, 1868. Naturh. Ver. Rheinlande, Verh. 25: 156.

Type-species: Campoplex crassiusculus Gravenhorst. Desig. by Viereck, 1914 fror eight species included by Thomson, 1887.

Phobocampa Thomson, 1887. Opusc. Ent. 11: 1120. Emend.

This is a Neotropic, Holarctic, and Oriental genus of moderate size. It is hoped that completion of the task of preparing the present work will enable me to soon finish a long dormant revision of the Nearctic species. My partially completed manuscript treats 21 Nearctic species (including 
one not indigenous), but several years ago I received specimens of one or two additional species. The number of Palearctic species appears to be somewhat smaller. The small amount of Neotropic material I have seen included four species.

Most species normally parasitize only macrolepidoptera which do not conceal themselves when feeding. Many of the new host records which are given here are from specimens deposited in the Canadian National Collection by the Canadian Forest Insect Survey.

Taxonomy: Finlayson, 1975. Ent. Soc. Canada, Mem. 94: 56-62 (final-instar larvae).

Morphology: Finlayson, 1964. Canad. Ent. 96: 1155-1158 (caudal appendages of some final-instar larvae).

bicingulata bicingulata (Gravenhorst). Newfoundland (Labrador), s.w. Alta., w. N. W. T., Yukon, n.w. B. C., interior Alaska; n.w. Asia (U. S. S. R.), Europe. Specimens agreeing in coloration with this subspecies also occur in southern B. C. (as do intermediate specimens), but because they are not the preponderant form there, southern $B$. C. is treated as being within the range of the subspecies bicingulatus vernalis (Viereck). An undescribed subspecies is known from Colo., N. Mex., and Ariz., and bicingulata nipponensis Momoi is known from Japan.

Campoplex bicingulatus Gravenhorst, 1829. Ichn. Europaea, v. 3, p. 527. ठ' $९$.

Phobocampe bicingulata f. muficoxa Aubert, 1962. Rev. Franc. d'Ent. 29: 146. ठో, ९. N. syn.

bicingulata vernalis (Viereck), n. status. N. S. w. to n.e. Alta. and s. B. C., s. to s.w. S. C., n. Ala., e. Nebr., s. Sask., s.e. Alta., and s. Calif. Ecology: The only rearings have been from hosts (mostly Noctuidae) feeding on trees, but it is presumed that these rearings were from ecotones between forest and open areas; the habitat of $b$. vernalis appears to tend more toward the latter. The fact that $b$. vernalis is by far our most commonly collected form of Phobocampe appears to relate in part to the fact that it occurs in open weedy or grassy areas. Host: Anomogyna sp., Lithophane sp., Palthis angulalis (Hbn.), Syngrapha rectangula nargenta (Ottol.), Ichthyura sp., Eupithecia fletcherata Tay.

Campoplex (Hypothereutes) vernalis Viereck, 1917 (1916). Conn. State Geol. and Nat. Hist. Survey Bul. 22: 264 . . Incorrectly suppressed as a synonym of elyi (Viereck) by Townes and Townes (1951).

Campoplex (Hyposoter) stenus Viereck, 1925; 1926. Canad. Ent. 57 (8): 204 (key); 58 (9): 220. $\delta$.

Campoplex (Ameloctonus) speciosus Viereck, 1925; 1926. Canad. Ent. 57 (9): 223 (key); 58 (10): 257. .

Taxonomy: Townes and Townes, 1951. In Muesebeck et al., U. S. Dept. Agr., Agr. Monog. 2: 376.

clisiocampae (Weed). N. S. w. to central Alta. and s. B. C., s. to n.w. S. C., n.w. Ark., and n. Calif. Host: Malacosoma americanum (F.), M. californicum pluviale (Dyar), M. disstria Hbn., Datana ministra (Drury), D. perspicua (G. and R.), Heterocampa sp., Schizura concinna (J. E. S.), S. ipomeae (Dbldy.), S. semimufescens (Wlk.), S. unicomis (J. E. S.), Symmerista canicosta Francl., Paonias sp., Smerinthus jamaicensis (Drury), Sphinx sp., Operophtera brumata (L.), Actias luna (L.). Specimens reared from Operophtera brumata which I have seen were abnormal, and it seems unlikely that it is a suitable host for clisiocampae.

Ameloctonus clisiocampae Weed, 1903. In Fiske, N. H. Agr. Expt. Sta. Tech. Bul. 6: 230.

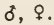

Campoplex (Ameloctonus) congeneris Viereck, 1925; 1926. Canad. Ent. 57 (9): 223 (key); 58 (10): 259. ․ N. syn.

Campoplex (Ameloctonus) certus Viereck, 1925; 1926. Canad. Ent. 57 (9): 223 (key); 58 (10): 257. ․ N. syn.

Biology: Fiske, 1903. N. H. Agr. Expt. Sta. Tech. Bul. 6: 188, 206-208, 223, 226.

confusa (Thomson). N. B. w. to n.w. B. C., s. to n.w. Pa., Ohio, s. Sask., s. Alta., and n. Calif.; Europe. Host: Nymphalis antiopa (L.), Polygonia faunus (Ed.), P. interrogationis (F.), $P$. satyrus (Ed.).

Phobocampa confusa Thomson, 1887. Opusc. Ent. 11: 1122. \& 
elyi (Viereck). Newfoundland (s. Labrador) w. to n. B. C., s. to e. and n.w. S. C., e. Nebr., Colo., and n. Calif. Host: Semiothisa sp. on Larix, S. sp. on spruce and fir, S. bicolorata (F.), S. bisignata (Wlk.), S. "granitata" auct., S. oweni (Swett), S. sexmaculata (Pack.), Lapara bombycoides Wlk.

Hypothereutes elyi Viereck, 1912. U. S. Natl. Mus., Proc. 43: 590. 9.

flavipes (Provancher). Que. w. to e.-central B. C., s. to n.w. S. C., Mich., s. Man., s. Sask.; s. Alta., and s. B. C. Host: Alsophila pometaria (Harris), Phigalea titea (Cram.), Protoboarmia porcelaria (Gn.), Dasychira sp., D. vagans (B. and McD.)?, Amphypyra pyramidoides $\mathrm{Gn}$., Catocala sp., noctuid, Orthosia revicta (Morr.), Zale sp.

Limneria flavipes Provancher, 1874. Nat. Canad. 6: 148. o.

Campoplex (Hypothereutes) acceptus Viereck, 1925; 1926. Canad. Ent. 57 (8): 204 (key); 58 (9): 224. ㅇ.

geometrae (Ashmead). N. S. w. to s. B. C., s. to n. Ga., n. Ala., n.e. Kans., w. S. Dak. and n.e. Calif. Host: Alsophila pometaria (Harris), Biston betularia cognataria (Gn.), Caripeta divisata Wlk., Erranis tiliaria tiliaria (Harris), E. tiliaria vancouverensis Hulst, Paleacrita vernata (Pack.). This species has been reared more frequently from Erranis tiliaria than from all other hosts combined.

Hypotherentes(!) geometrae Ashmead, 1898. In Dimmock and Ashmead, Ent. Soc. Wash., Proc. 4: 167. o.

Campoplex (Hypothereutes) concisus Viereck, 1925; 1926. Canad. Ent. 57 (8): 204 (key); 58 (9): 224. $\delta, ?$.

Campoplex (Ischnoscopus) angustus Viereck, 1925; 1926. Canad. Ent. 57 (9): 223 (key); 58 (8): 198. .

largo (Viereck), revised status. Que. w. to s. B. C., s. to w. N. C., Colo., and w. Oreg. Host: Trichoptilus lobidactylus (Fitch). Suppressed as a synonym of geometrae (Ashmead) by Townes (1945).

Campoplex (Ischnoscopus) largo Viereck, 1925; 1926. Canad. Ent. 57 (9): 223 (key); 58 (8): 198. ?.

Taxonomy: Townes, 1945. Amer. Ent. Soc., Mem. 11: 647.

pallida (Cushman). Mass., Conn., N. Y., N. J., s.e. Pa., Md. Host: Heterocampa guttivitta (Wlk.).

Callidora pallida Cushman, 1922. U. S. Natl. Mus., Proc. 60: 20. \&.

pallipes (Provancher). Que. w. to n.w. B. C., s. to e. N. C., Iowa, s. Man., N. Mex., Ariz., and n. Calif. Host: Noctuid, Syngrapha sp., S. alia interalia (Ottol.), S. rectangula nargenta (Ottol.), S. selecta (Wlk.), Orgyia antiqua (L.), O. definita (Pack.), O. leucostigma (J. E. S.), O. pseudotsugata McD.

Limneria pallipes Provancher, 1875. Nat. Canad. 7: 147. $\%$.

Limerium pallidipes Dalla Torre, 1901. Cat. Hym., v. 3, p. 101. Emend.

Campoplex (Campoplex) arcanus Viereck, 1925; 1926. Canad. Ent. 57 (9): 226 (key); 58 (6): 146. ㅇ.

tempestiva (Holmgren). Europe. Introduced in N. S. in 1955, 1957, 1961, and 1962 without becoming established. Host: Operophtera brumata (L.). The host cited was the target species for the introduction in N. S.; I have seen tempestiva specimens which were reared from other geometrid hosts, but none of the latter occur in North America. This species has frequently been misidentified as crassiuscula (Gravenhorst), the name under which the introductions in N. S. have been reported (e.g. McGugan and Coppel, 1962; Embree, 1971). Voucher material I have seen would appear to indicate that releases of tempestiva in $\mathrm{N}$. S. were accompanied by releases of about equal numbers of an undescribed species of Phobocampe which I also know as a parasite of Lymantria dispar (L.) and which has been misidentified as $P$. disparis (Viereck) in Japan (see unicincta [Gravenhorst]).

Limneria tempestiva Holmgren, 1860 (1858). Svenska Vetensk.-Akad. Handl. (n. f.) 2 (8): 94. $\delta, ?$.

Taxonomy: Aubert, 1972. Ent. Scand. 3: 149 (lectotype selection).

Biology: Wylie, 1960. Entomophaga 5: 120-121 (as "crassiuscula," presumably pertaining to spp., including tempestiva). - McGugan and Coppel, 1962. Commonwealth Inst. Biol. 
Control, Tech. Commun. 2: 66, 171. - Embree, 1971. Commonwealth Inst. Biol. Control,

Tech. Commun. 4: 170, 172, 174.

unicincta (Gravenhorst). Southeastern N. H., n.w. Mass., e.-central N. Y., n.e. Pa.; Europe. Introduced. Host: Lymantria dispar (L.). The native range of this species extends into eastern Europe, but unicincta is not known to me from Asia or from any European locality east of Moscow, U. S. S. R. It has been recorded as a parasite of Lymantria dispar in Japan (as Phobocampe disparis), but those records pertain to the undescribed species referred to above in the discussion of $P$. tempestiva, and they probably also pertain in part to Hyposoter vierecki Townes. I suspect that unicincta does not occur in Japan. Muesebeck and Parker (1933) found unicincta to be a univoltine species, this fact apparently explaining the relative ease with which it was established in the United States.

Campoplex unicinctus Gravenhorst, 1829. Ichn. Europaea, v. 3, p. 529. ㅇ (ơ misdet.). Lectotype here selected as the female in the Gravenhorst collection labeled as lectotype by Townes in 1964 and by me in 1969 and bearing Gravenhorst's small label marked " $\mathrm{f}$ " (see Townes, 1965, p. 405). In his description of confusa, Thomson (1887) indicated that he regarded Gravenhorst's description of the C. unicinctus male as applying to confusa, and Gravenhorst's description of the male seems to agree with Thomson's conclusion.

Hyposoter dis paris Viereck, 1911. U. S. Natl. Mus., Proc. 40: 478. ¿, $\%$. Lectotype here selected as the female in the U. S. Natl. Museum collection bearing Viereck's identification label and labels reading: "Gip Moth Lab No. 529 - 07; 20 Aug.; Type No. 13074 U. S. N. M." Muesebeck and Parker (1933, p. 335) saw notes which indicated that the type locality is probably Kiev, U. S. S. R.

Taxonomy: Thomson, 1887. Opusc. Ent. 11: 1122. -Townes, 1965. Polskie Pismo Ent. 35: 403-407 (labeling in the Gravenhorst collection of Ichneumonidae).

Biology: Howard and Fiske, 1911. U. S. Dept. Agr., Bur. Ent., Bul. 91: 191. - Howard, 1914. Ent. Soc. Amer., Ann. 7: 87 (establishment). - Burgess and Crossman, 1929. U. S. Dept. Agr., Tech. Bul. 86: 49-54. - Muesebeck and Parker, 1933. Jour. Agr. Res. 46: 335-347. -Semevskiy, 1973. Ent. Obozr. 52: 44 (probably the sp. misdet. as pulchella [Thomson]).

\section{Genus TRANOSEMA Foerster}

Tranosema Foerster, 1868. Naturh. Ver. Rheinlande, Verh. 25: 157.

Type-species: Tranosema arenicola Thomson. Desig. by Viereck, 1914 from three species included by Thomson, 1887.

This is a small Holarctic genus. I know only two species, both of which have Holaretic distributions. The species Limneria interrupta Holmgren and Campoplex (Angitia) rosanae Viereck, which were placed in Tranosema by Townes (1970), are here regarded as species of Diadegma (rosanae being a synonym of D. acronyctae [Ashmead]).

Taxonomy: Walley, 1966. Canad. Ent. 98: 832-835 (treatment of the two identified spp. occurring in the Nearctic Region). - Townes, 1970 (1969). Amer. Ent. Inst., Mem. 13: 176-177.

rostrale rostrale (Brischke). Que. w. to B. C., s. to n. N. Y., n. Mich., n. Minn., w. Mont., and w. Wash.; Europe. Host: Malacosoma californicum pluviale Dyar?, Aphelia alleniana (Fern.), Archips argyrospilus (Wlk.), A. rosanus (L), Choristoneura fumiferana (Clem.), C. lambertiana (Bsk.). T. rostrale abulum Momoi (1968) is known from Japan.

Limneria rostralis Brischke, 1880. Naturforsch. Gesell. Danzig, Schr. (n. f.) 4: 150. ð, $q$. Tranosema arenicola Thomson, 1887. Opusc. Ent. 11: 1138. đo, ?.

Tranosema arenicolum Dalla Torre, 1901. Cat. Hym., v. 3, p. 107. Emend. Campoplex (Angitia) cacoeciae Viereck, 1924. Canad. Ent. 56: 76. ๆ. N. syn.

Taxonomy: Momoi, 1968. Kontyu 36: 180-181. - Aubert, 1971. Soc. Ent. de Mulhouse, Bul. 27: 38 (syn.).

Biology: Zwoelfer, 1963. Ztschr. f. Angew. Ent. 51: 348. - Paradis and Leroux, 1965. Ent. Soc. Canada, Mem. 43: 49. 
taeniopus (Viereck). Newfoundland (s. Labrador), P. E. I., Que., Ont., s.e. Alaska, s.e. B. C., w. Wash.; Europe.

Hypothereutes annulipes Ashmead, 1902. Wash. Acad. Sci., Proc. 4: 236. ․ Formerly preocc. in Campoplex by Cresson, 1864.

Campoplex (Ameloctonus) taeniopus Viereck, 1925. Canad. Ent. 57 (9): 223. N. name for H. annulipes Ashmead.

\section{Genus DOLOPHRON Foerster}

Dolophron Foerster, 1868. Naturh. Ver. Rheinlande, Verh. 25: 155.

Type-species: Limneria pedella Holmgren. Monotypically included and desig. by Townes, 1970.

Townes (1970) said that this is a Holarctic genus including pedella and two undescribed species, one North American and one Japanese. D. pedella is the only species known to me; I have in the past identified as Dolophron a few Nearctic specimens which were sent to me for identification, but now regard those specimens as representing an unidentified species of Synetaeris.

pedella (Holmgren). Europe. Introduced in N. H. in 1931 without becoming established. Host: Heterarthrus nemoratus (Fall.). According to Dowden (1941) only 12 mated females were released in the attempt to establish pedella in $\mathrm{N}$. H. on H. nemoratus.

Limneria pedella Holmgren, 1860 (1858). Svenska Vetensk.-Akad. Handl. (n. s.) 2 (8): 73. $\delta$,. .

Tranosema pedellum Dalla Torre, 1901. Hym. Cat., v. 3, p. 107. Emend.

Synetaeris albicoxis Schmiedeknecht, 1909. Opusc. Ichn., v. 4, p. 1670. 9.

Taxonomy: Cushman, 1933. U. S. Natl. Mus., Proc. 82 (14): 16 (variation). -Hinz, 1964.

Entomophaga 9: 71 (lectotype selected), -Townes, 1970 (1969). Amer. Ent. Inst., Mem. 13: 175 (syn.).

Biology: Dowden, 1941. U. S. Dept. Agr., Tech. Bul. 757: 8, 9, 11, 22-25, 51.

\section{Genus SYNETAERIS Foerster}

Synetaeris Foerster, 1868. Naturh. Ver. Rheinlande, Verh. 25: 155.

Type-species: Synetaeris heteropus Thomson. Desig. by Viereck, 1914 from three species included by Thomson, 1887.

This is a small genus; it is known to me from the Holarctic and Ethiopian Regions. There are a number of unidentified or undescribed Nearctic species, some of which will probably prove to be Holaretic species that have already been described from Europe or Asia.

hyalina (Provancher), n. comb. Que.

Limneria hyalina Provancher, 1874. Nat. Canad. 6: 147. $q$ ( $\delta$ misdet.). Townes (1945) and Barron (1975) have applied this name to Campoplex crassatus (Viereck), contrary to the valid lectotype selection of Gahan and Rohwer (1918). Barron's rejection of the Gahan and Rohwer lectotype because of what he regarded as lack of agreement with the original description has no validity. Because Provancher stated that he had two females and one male, lack of agreement with the original description does not prove that the Gahan and Rohwer lectotype was not one of Provancher's syntypes. Gahan and Rohwer (1918) evidently thought the specimen agreed sufficiently well with the description to have been a syntype, and their lectotype selection stands as valid unless evidence of some other sort is found to prove that the specimen they selected was not a syntype.

Taxonomy: Gahan and Rohwer, 1918. Canad. Ent. 50: 28. -Townes, 1945. Amer. Ent. Soc., Mem. 11: 596-597. - Barron, 1975. Nat. Canad. 102: 484.

tenuifemur (Walley). N. B., Ont., e. B. C. Host: Choristoneura fumiferana (Clem.).

Synetaeris tenuifemur Walley, 1963. Canad. Ent. 95: 23. ठ, ?.

Biology: Miller and Renault, 1963. Canad. Ent. 95: 24-28.

\section{Genus PHILOSITUS Townes}

Philositus Townes, 1970 (1969). Amer. Ent. Inst., Mem. 13: 187. 
Type-species: Philositus enchophorus Townes. Monotypic and orig. desig.

A single species is known.

enchophorus Townes. Maine, Conn., N. Y., N. J., Pa., s.e. Va., Ont. w. Wash. Host: Tetralopha sp., T. aplastella Clem., lepidopteran on poplar.

Philositus enchophorus Townes, 1970 (1969). Amer. Ent. Inst., Me. 13: 188. ठ,

Taxonomy: Barron and Bisdee, 1977. Ent. Soc. Amer., Ann. 70: 48-50 (final-instar larva).

\section{Genus MACRUS Gravenhorst}

Macrus Gravenhorst, 1829. Ichn. Europaea, v. 3, p. 707.

Type-species: Macrus filiventris Gravenhorst. Desig. by Viereck, 1914.

Two species are known.

Revision: Horstmann, 1970. Bayer. Ent. Nachrichtenbl. 19: 80-81.

Taxonomy: Townes, 1970 (1969). Amer. Ent. Inst., Mem. 13: 178.

parvulus solenobiae (Ashmead). Maine, Mass., N. Y., N. J., Del., Mo. Host: Solenobia walshella Clem., Grapholitha molesta (Bsk.).

Limneria solenobiae Ashmead, 1890 (1889). U. S. Natl. Mus., Proc. 12: 433. ठँ.

Taxonomy: Horstmann, 1970. Bayer. Ent., Nachrictenbl. 19: 80, 83 (status revised).

\section{Genus ENYTUS Cameron}

Dioctes Foerster, 1868. Naturh. Ver. Rheinlande, Verh. 25: 153. Preocc. by Menetries, 1849 and Reichenbach, 1850.

Type-species: Campoplex exareolatus Ratzeburg. Deig. by Viereck, 1914 from two species included by Schmiedeknecht, 1907. The type-species is regarded as a synonym of $E$. apostata (Gravenhorst).

Enytus Cameron, 1905. Invertebrata Pacifica 1: 132.

Type-species: Enytus maculipes Cameron. Monotypic.

Inareolata Ellinger and Sachtleben, 1928. Internatl. Corn Borer Invest., Sci. Rpts. 1: 117. N. name for Dioctes Foerster.

This is a small to moderate-sized genus of Holarctic and Neotropic distribution. Contrary to the discussion of Horstmann (1970), Enytus can be recognized more or less as defined by Townes (1970).

Taxonomy: Townes, 1970 (1969). Amer. Ent. Inst., Mem. 13: 177-178. - Horstmann, 1970.

Bayer. Ent., Nachrichtenbl. 19: 82-83.

albipes (Provancher). Que., Conn., R. I., N. Y. The species was inadvertently placed in Casinaria by Barron (1975).

Porizon albipes Provancher, 1888. Addit. Corr. Faune Ent. Canada Hym., p. 364. + .

Nemeritis ocellatus Viereck, 1925; 1926. Canad. Ent. 57 (7): 178 (key); 58 (7): 179. ठ. In the 1926 part of Viereck's paper as "Campoplex (Nemeritis) ocellatus."

Taxonomy: Townes, 1970 (1969). Amer. Ent. Inst., Mem. 13: 178 (transfer to Enytus).

-Barron, 1975. Nat. Canad. 102: 420-421.

alticola (Cushman), n. comb. N. H. Known only from the holotype, which was collected on Mt. Washington.

Zaporus alticola Ashmead, 1906. In Slosson, Ent. News 17: 324. Nomen nudum.

Dioctes alticola Cushman, 1922. U. S. Natl. Mus., Proc. 61 (8): 11. ㅇ.

eureka (Ashmead). Southwestern Idaho, B. C. s. to s. Calif. Host: Archips argyrospilus (Wlk.), Argyrotaenia dorsalana (Dyar), Choristoneura rosaceana (Harris), Cnephasia longana (Haw.), Pandemis limitata (Rob.), Malacosoma californicum pluviale Dyar?, Acrobasis vaccinii Riley.

Limneria eureka Ashmead, 1890 (1889). U. S. Natl. Mus., Proc. 12: 436. ठ̊.

Enytus maculipes Cameron, 1905. Invertebrata Pacifica 1: 132..

Campoplex (Dioctes) rosaceanae Viereck, 1925; 1926. Canad. Ent. 57 (9): 227 (key); 58 (7): 181. ‥ 
montanus (Ashmead), n. comb. N. B. w. to interior Alaska, s. to Maine, Mich., N. Mex., and n. Calif.; Greenland; Europe. Host: Dioryctria sp.?, Zeiraphera sp., Z. fortunana Kft., Acleris variana (Fern.), Choristoneura fumiferana (Clem.), C. occidentalis Free., leaf roller on poplar, leaf tier on Vaccinium.

Ischnocerus montanus Ashmead, 1890 (1889). U. S. Natl. Mus., Proc. 12: 418..

Nemeritis conodor Viereck, 1925; 1926. Canad. Ent. 57 (7): 178 (key); 58 (7): 179. 9 . In the 1926 portion of Viereck's work as "Campoplex (Nemeritis) concolor[!]." N. syn.

Angitia (Inareolata) laticeps Roman, 1938. Ann. and Mag. Nat. Hist. (11) 1: 541. ठ, ๆ. Formerly preocc. in Diadegma by Viereck, 1925. N. syn.

Horogenes patens Townes, 1945. Amer. Ent. Soc., Mem. 11: 659. N. name for A. (I.) laticeps Roman.

Taxonomy: Horstmann, 1969; 1973. Beitr. z. Ent. 19: 441; 23: 132, 134.

obliteratus (Cresson). N. Y. and Ont. s. to n. Fla., w. to central Nebr. Host: Grapholitha molesta (Bsk.), Paralobesia viteana (Clem.), Rhyacionia frustrana (Comst.)?, Anthophila pariana (Clerck), Homadaula albizziae Clarke, Coleophora serratella (L.), Arogalea cristifasciella (Cham.), Acleris minuta (Rob.), Argyrotaenia velutinana (Wlk.).

Mesoleptus obliteratus Cresson, 1874. Ent. Soc. Phila., Proc. 3: 260. ․

Limneria elegans Weed, 1887. Ill. State Lab. Nat. Hist., Bul. 3: 40. ๆ.

Limneria salicicola Ashmead, 1890 (1889). U. S. Natl. Mus., Proc. 12: 437. \&. I believe that the data which Ashmead gave for the holotype may not apply to it (see discussion of the holotype of Diadegma acronyctae [Ashmead]).

Limneria salicicolum Dalla Torre, 1901. Cat. Hym., v. 3, p. 103. Emend.

Thymaris slingerlandana Ashmead, 1904. Canad. Ent. 36: 333..

Nemeritis dolichourus Viereck, 1925; 1926. Canad. Ent. 57 (7): 178 (key); 58 (7): 178. \&.

Biology: Boyce, 1947. Ent. Soc. Ont., Ann. Rpt. 77: 21, 22, 24, 27, 28, 29, 33. -Allen, 1962. U. S. Dept. Agr., Tech. Bul. 1265: 49-50. -Dustan and Boyce, 1966. Ent. Soc. Ont., Ann. Rpt. 96: $100,101,102$.

oculus (Viereck), n. comb. Ont., s.w. Alta. Host: Geometrid?, Operophtera bruceata (Hulst)? The host records are queried because Geometridae seem unlikely to be hosts for members of this genus.

Nemeritis oculus Viereck, 1925; 1926. Canad. Ent. 57 (7): 178 (key); 58 (7): 179. o. In the 1926 portion of Viereck's paper as "Campoplex (Nemeritis) oculus."

\section{Genus DIADEGMA Foerster}

Angitia Holmgren, 1859 (1858). Svenska Vetensk.-Akad., Ofvers. af ... Forhandl. 15: 327. Preocc. by Walker, 1858.

Type-species: Angitia glabricula Holmgren. Monotypic.

Diadegma Foerster, 1868. Naturh. Ver. Rheinlande, Verh. 25: 153.

Type-species: Campoplex crassicornis Gravenhorst. By subsequent monotypy from inclusion by Schmiedeknecht, 1907.

Pectenella Morley, 1915 (1916). Ichn. Britannica, v. 5, p. 65, 173, 174, 175, 183, 342, 364, 392. The preoccupied variant spelling Pectinella appeared on pages 65 and 183 (cee Townes, 1965).

Type-species: Angitia latungula Thomson. Monotypic.

Areolina Enderlein, 1921. Stettin. Ent. Ztg. 82: 41.

Type-species: Areolina imbecilla Enderlein. Monotypic and orig. desig.

Nothanomaloides Viereck, 1925. Roy. Soc. Canada, Proc. and Trans. (3) 19 (5): 272.

Type-species: Nothanomaloides stenosomus Viereck. Monotypic and orig. desig.

Neoarthula Rao, 1953. Indian Forest Rec., New Ser., Ent. 8: 179.

Type-species: Neoarthula pierisae Rao. Monotypic and orig. desig.

Diadegma subg. Neoangitia Horstmann, 1969. Beitr. z. Ent. 19: 414.

Type-species: Angitia glabricula Holmgren. Orig. desig.

This is a very large genus of worldwide distribution. Horstmann (1969) recognized three subgenera; he applied the name Nythobia Foerster to the largest subgenus. I am not convinced that the name Nythobia should be applied to anything other than its type-species, $N$. pusio (Holmgren). 
Revision: Walley, 1967. Canad. Ent. 99: 925-943 (spp. of the "stenosomus complex"). -Horstmann, 1969; 1973. Beitr. z. Ent. 19: 413-472; 23: 131-150 (European spp.).

Taxonomy: Townes, 1965. Polskie Pismo Ent. 35: 413-415. - Townes, 1970 (1969). Amer. Ent. Inst., Mem. 13: 178-179. - Townes and Townes, 1973. Amer. Ent. Inst., Mem. 19: 155 (generic syn. revised).

acronyctae (Ashmead). Newfoundland (insular) w. to s. Sask., s. to w. N. C., n. Mich. and Colo. Host: Ancylis comptana (Froel.), microlepidoptera on Salix, Acleris variana (Fern.), Archips rosanus (L.).

Limneria acronyctae Ashmead, 1896. Amer. Ent. Soc., Trans. 23: 194. ð. Ashmead cited no locality for the holotype, and the host data Ashmead cited are erroneous. Circumstantial evidence indicates that the data which Ashmead (1890) and Riley and Howard (1890) cited for the holotype of Limneria salicicola Ashmead (the latter say: "Inquilinous Lepid. Larvae in willow gall, London, Ontario, March 1872") apply also, if not exclusively, to the holotype of acronyctae. This appears to be supported by the fact that several acronyctae specimens in the Canadian Natl. Collection emerged from galls on willow. The latter were apparently referred to by Finlayson (1975).

Campoplex (Angitia) rosanae Viereck, 1924. Canad. Ent. 56: 68. ․ N. syn.

Campoplex (Ischnoscopus) alterus Viereck, 1925; 1926. Canad. Ent. 57 (9): 223 (key); 58 (8): 196. ‥ N. syn.

Taxonomy: Townes, 1970 (1969). Amer. Ent. Inst., Mem. 13: 177 (placed rosanae in Tranosema). - Finlayson, 1975. Ent. Soc. Canada, Mem. 94: 63, 64-65, $121,137$.

Biology: Ashmead, 1890 (1889). U. S. Natl. Mus., Proc. 12: 437. - Riley and Howard, 1890. U.

S. Dept. Agr., Insect Life 3: 158 (data for Limneria salicicola Ashmead).

acutum (Viereck). Idaho, B. C. s. to n. Calif. Host: Platyptilia carduidactyla (Riley). Other host records have been published, but I am reluctant to regard them as being correct without seeing specimens pertaining to them.

Campoplex (Hyposoter) vancouverensis Viereck, 1925; 1926. Canad. Ent. 57 (8): 203 (key); $58(8): 200$. ?.

Campoplex (Hyposoter) acutus Viereck, 1925; 1926. Canad. Ent. 57 (8): 203 (key); 58 (8): 200. $\%$.

Angitia platyptiliae Cushman, 1939. Pan-Pacific Ent. 15: 183. đ, ९.

Biology: Lange, 1941. Calif. Agr. Expt. Sta., Bul. 53: 22, 67.

aestivale (Viereck). N. S. w. to w. Ont., s. to n. Va. Host: Psilocorsis sp. on Myrica gale, $P$. cryptolechiella (Cham.), $P$. reflexella Clem.

Angitia aesitivalis Viereck, 1921. Psyche 28: 71..

Taxonomy: Walley, 1967. Canad. Ent. 99: 926, 933-934.

albertae (Walley). Northern Alta.

Angitia albertae Walley, 1929. Canad. Ent. 61: 191. \&.

albicinctum Walley. Colo. Known only from the holotype, which was collected near Bond at an elevation of $7000 \mathrm{ft}$.

Diadegma albicincta Walley, 1967. Canad. Ent. 99: 941. $\$$.

antennaellae (Walley). N. Y., n. Va., Ont. Host: Coleophora sp. on rose, C. alniella Heinr., C. serratella (L.).

Campoplex (Angitia) antennaellae Walley, 1932. Canad. Ent. 64: 182. $९$ (ơ misdet.).

blackburni (Cameron). Northwestern Oreg., w. Calif.; Hawaii. Adventive? Host: Phthorimaea operculella (Zell). I have seen six specimens from North America; three of them were collected in 1897 (two at Hood River, Oreg.; one at Baden, Calif.); two of them were reared from the host cited at Chino, Calif., apparently in 1920. Other hosts have been recorded in Hawaii by Swezey $(1907,1915)$. Reports of the occurrence of blackburni in Bermuda are almost certainly erroneous; they appear to pertain to compressum (Cresson). Species appearing to be related to blackburni are Oriental, suggesting that blackbumi may be adventive in North America as well as in Hawaii.

Limneria blackburni Cameron, 1883. Ent. Soc. London, Trans. 31: 192. [female]. Limneria hawaiiensis Cameron, 1886. Manchester Lit. and Phil. Soc., Mem. and Proc. (3) 10: 241. [female]. 
Biology: Swezey, 1907. Hawaii. Sugar Planters' Assoc., Expt. Sta., Bul., Ent. Ser. 5: 43-45; pl. 6, fig. 2. -Swezey, 1915. Hawaii. Ent. Soc., Proc. 3: 106-107.

buckelli (Viereck). Southern B. C.

Campoctonoides buckelli Viereck, 1925. Canad. Ent. 57 (7): 177 (key); 58 (12): 296. ․

californicum Walley. Western Wash., n.e. Calif.

Diadegma californica Walley, 1967. Canad. Ent. 99: 932. ठં, १.

carolina Walley. N. C.-Tenn. Known only from two localities situated on the border between N. C. and Tenn. in Gt. Smoky Mts. Natl. Park.

Diadegma carolina Walley, 1967. Canad. Ent. 99: 930. ठ์, ๆ.

chrysostictum (Gmelin), Que., Maine, Conn., N. Y., Ont., Mich., w. Wash., w. Oreg.; Eurasia. Adventive. Host: Anagasta kuehniella (Zell.), Galleria mellonella (L.), Plodia interpunctella $(\mathrm{Hbn}$.$) ?, borer in Iris pod.$

Ichneumon chrysostictos Gmelin, 1790. In Linnaeus, Syst. Nat., ed. 13, v. 1, p. 2721. .

Campoplex (Angitia) kiehtani Viereck, 1917 (1916). Conn. State Geol. and Nat. Hist. Survey Bul. 22: 265. 9 .

Campoplex (Angitia) woonandi Viereck, 1917 (1916). Conn. State Geol. and Nat. Hist. Survey Bul. 22: 265. $\delta$.

Angitia galleriae Cushman, 1920. U. S. Natl. Mus., Proc. 58: 266. §’, ․ N. syn.

Campoplex (Hyposoter) petiolatus Viereck, 1925; 1926. Canad. Ent. 57 (8): 204 (key); 58 (9): 221. ․

Campoplex (Hyposoter) curtus Viereck, 1925; 1926. Canad. Ent. 57 (8): 204 (key); 58 (9): 221. ㅇ.

Campoplex (Hyposoter) triangularis Viereck, 1925; 1926. Canad. Ent. 57 (8): 204 (key); 58 (9): 222 . ㅇ. .

Campoplex (Diadegma) costata Viereck, 1925; 1926. Canad. Ent. 57 (9): 227 (key); 58 (11): 279. ㅇ.

Campoplex (Eulimneria) bakeri Viereck, 1925. Canad. Ent. 57 (10): 278. ㅇ.

Angitia incipiens Walley, 1929. Canad. Ent. 61: 192. \&.

Horogenes chrysosticta corsicator Aubert, 1961. Soc. Ent. de France, Ann. 130: 183. ¿, $q$.

Diadegma chrysosticta orientator Aubert, 1965. Soc. Ent. de Mulhouse, Bul. 17: 67..

Taxonomy: Walley, 1959. In Fisher, Canad. Jour. Zool. 37: 429. -Horstmann, 1969; 1973.

Beitr. z. Ent. 19: 462, 465, 467, 468; 23: 132.

Biology: Thorpe, 1938. Roy. Ent. Soc. London, Proc., Ser. A: Gen. Ent. 13: 58-59. - Richards, 1949. Roy. Ent. Soc. London, Proc., Ser. B: Taxonomy 18: 31-32. -Fisher, 1959. Canad. Jour. Zool. 37: 429-446. -Fisher, 1961. Jour. Expt. Zool. 38: 267-275. -Fisher, 1962.

Ecology 43: 314-316.

combinatum (Holmgren). Greenland?; Europe. The species was recorded from Greenland by Roman (1933), but Roman's identification would be questionable in view of Horstmann's (1969) finding that the Holmgren collection no longer contains any type material of combinatum.

Limneria combinata Holmgren, 1860 (1858). Svenska Vetensk.-Akad. Handl. (n. s.) 2: (2): 62. ơ, ‥

Diadegma combinata alpinator Aubert, 1970. Soc. Ent. de. Mulhouse, Bul. 26: 69, §.

Taxonomy: Roman, 1933. Norges Svalbard-og Ishavs-undersokelser, Skrifter om Svalbard og Ishavet 53: 11. - Aubert, 1968. Schweiz. Ent. Gesell., Mitt. 41: 189. - Horstmann, 1969; 1973. Beitr. z. Ent. 19: 447-448; 23: 132, 137.

compressum (Cresson). Maine, S. Dak., and Utah, s. to Va., Tex., and s. Calif.; Bermuda, n. Mexico. Host: Phthorimaea operculella (Zell.), Paralobesia viteana (Clem.), Frechinia helianthiales (Murt.).

Mesoleptus compressus Cresson, 1864. Ent. Soc. Phila., Proc. 3: 260. ठ์.

Limneria ferrugineipes Ashmead, 1890 (1889). U. S. Natl. Mus., Proc. 12: 432 . $\delta$.

Idecthis(!) paenerivalis Viereck, 1906. Amer. Ent. Soc., Trans. 32: 216. o, ๆ.

Campoplex (Angitia) oedemisiformis Viereck, 1917 (1916). Conn. State Geol. and Nat.

Hist. Survey Bul. 22: 265. ठ'.

Campoplex (Campoplex) ruficoxalis Viereck, 1925; 1926. Canad. Ent. 57 (9): 226 (key); 58 (6): $144 ; 58$ (7): 176. o. 
comptoniellae (Viereck). Que. w. to Minn., s. to Pa. Host: Acrobasis betulella Hulst, $A$. caryivorella Rag., A. comptoniella Hulst, A. mibrifasciella Pack., A. sylviella Ely. Cushman indicated that four of his paratypes, which are labeled "ex tortricid," were reared from "Gelechia trialbamaculella Chambers or (Olethreutes) Peronea permutana Duponche." Therefore, neither of the present equivalents of those names can be cited with any certainty as a host.

Campoplex (Hyposoter) comptoniellae Viereck, 1925; 1926. Canad. Ent. 57 (8): 204 (key); 58 (9): 219. ठ, ?.

Campoplex digitatus Cushman, 1926. U. S. Natl. Mus., Proc. 67 (23): 11. ठ์, ९.

crassulum Walley. N. S., Maine, N. Y., Ont. Host: Coleophora asterosella McD., C. granifera Braun.

Diadegma crassula Walley, 1967. Canad. Ent. 99: 935. o, ९.

discoocellellae (Viereck). D. C. Host: Chionodes violaceofusca (Zell.).

Limnerium (Horogenes) discoocellellae Viereck, 1911. U. S. Natl. Mus., Proc. 39: 404..

falciferum Walley. Southwestern Alta.

Diadegma falcifera Walley, 1967. Canad. Ent. 99: 938. 9.

fenestrale (Holmgren). Oreg.?; Eurasia. Specimens in the U. S. Natl. Museum collection appear to indicate that fenestrale was released against and recovered from Cnephasia longana (Haw.) in Oregon in 1950. Host: Cnephasia longana (Haw.). My identification of the specimens reared from Cnephasia longana is based upon agreement with a specimen identified as fenestrale by Dr. Klaus Horstmann; the latter was in turn compared with the fenestrale lectotype in 1976 and differed from it only in having the hind tibia more strongly infuscate apically and basally. It should be mentioned here that the lectotype selected by Townes, Momoi, and Townes (1965) is invalid by virtue of the prior selection of another specimen by Hinz (1964). Horstmann (1969) mentioned having specimens in his collection which were reared from Plutella xylostella (L.) but gave no other host records. Walley (1929) stated that there were "five specimens [in the Canadian National Collection] from Ottawa, Ont., Sept., 1924 (A. Richardson) which answer to the description of A[ngitia] fenestralis (Holmg.)." The occurrence of fenestrale in Ont. has not been confirmed.

Limneria fenestralis Holmgren, 1860 (1858). Svenska Vetensk.-Akad. Handl. (n. f.) 2 (8): 59. $\delta$, ?.

Taxonomy: Walley, 1929. Canad. Ent. 61: 193. -Boyd, 1934. Soc. Brit. Ent., Trans. 1: 135-138 (variation and comparison with eucerophagum Horstmann, which was misdet. as "Angitia cerophaga [Gravenhorst]"). - Hinz, 1964. Entomophaga 9: 70. - Townes, Momoi, and Townes, 1965. Amer. Ent. Inst., Mem. 5: 296-297. - Horstmann, 1969; 1973. Beitr. z. Ent. 19: 460-461; 23: 133. - Gupta, 1974. Oriental Insects 8: 104-105.

Biology: Hardy, 1939. Bul. Ent. Res. 29: 352-355, 356, 357, 365, 371 (as compared with eucerophagum [= "cerophaga"]). - Lloyd, 1942. Rev. Canad. de Biol. 1: 633-634 (as compared with eucerophagum [= "cerophaga"]).

glabriculum (Holmgren). Newfoundland (n. Labrador), n. Que., n. Yukon; Europe.

Angitia glabricula Holmgren, 1859 (1858). Svenska Vetensk.-Akad., Ofvers. af ... Forhandl. 15: 327 . o, ?.

Diadegma frigida Walley, 1967. Canad. Ent. 99: 941. ơ, ९.

Taxonomy: Horstmann, 1969; 1973. Beitr. z. Ent. 19: 427-428: 23: 133, 141.

groenlandicum (Roman). Western Greenland. Horstmann (1969) placed groenlandicum as a synonym (with a query) of $D$. trochanteratum (Thomson). In 1976 I studied the trochanteratum lectotype and the groenlandicum holotype; I compared my homotype for the former with the holotype of the latter and do not think it possible that the two names are synonymous.

Anilasta groenlandica Roman, 1916. Arkiv. for Zool. 10 (22): 11. ?.

Taxonomy: Roman, 1934. Ann. and Mag. Nat. Hist. (10) 14: 610. - Horstmann, 1969. Beitr. z. Ent. 19: 456. 
hospitum (Holmgren). Northwestern Calif. Known only from the lectotype which was almost certainly collected in the San Francisco vicinity, particularly in view of the fact that it was collected by Kinberg (see Persson, 1971, p. 169).

Limneria hospita Holmgren, 1869 (1868). Eug. Resa, pt. 2 (Zool.), sect. 1 (Ins.), p. 416. ơ.

Taxonomy: Townes, 1961. Ent. Soc. Wash., Proc. 63: 110 (lectotype selection). - Persson,

1971. Ent. Tidskr. 92: 164-172 (discussion of Eug. Resa voyage).

insulare (Cresson). N. H. w. to s. B. C., s. to s. Fla., s. Tex., and s. Calif.; West Indies and Mexico s. to Venezuela; Hawaii. Host: Hellula undalis (F.), Plutella armoraciae Bsk., $P$. xylostella (L.).

Mesoleptus insularis Cresson, 1865. Ent. Soc. Phila., Proc. 4: 15. đ.

Limneria polynesialis Cameron, 1883. Ent. Soc. London, Trans. 31: 191. ․

Campoplex (Angitia) hellulae Viereck, 1912. U. S. Natl. Mus., Proc. 42: 631. \&.

Angitia plutellae Viereck, 1912. U. S. Natl. Mus., Proc. 43: 583.. . N. syn.

Campoplex (Hyposoter) pygmaeus Viereck, 1925; 1926. Canad. Ent. 57 (8): 204 (key); 58 (9): 220. ․ N. syn.

Sagaritis congregator Walley, 1926. Canad. Ent. 58 (9): 225; 58 (10): 240. ઠ์, ๆ. Described on p. 225, but name deleted there through printer's error; name provided on p. 240 . N. syn.

Taxonomy: Timberlake, 1918. Hawaii. Ent. Soc., Proc. 3: 400. -Townes, 1945. Amer. Ent. Soc., Mem. 11: 653-654, 660 .

Biology: Marsh, 1917. Jour. Agr. Res. 10: 8. - Harcourt, 1960. Canad. Ent. 92: 420-421, 422, 423-426. - Harcourt, 1962. Ent. Soc. Ontario, Ann. Rpt. 93: 71. - Harcourt, 1963. In

LeRoux, Ent. Soc. Canada, Mem. 32: 56, 57, 61-62, 64.

interruptum pterophorae (Ashmead). N. S. w. to interior Alaska, s. to Pa., Mich., and n. Calif. Host: Archips rosanus (L.), Argyrotaenia citrana (Fern.), Choristoneura conflictana (Wlk.), C. rosaceana (Harris), Cnephasia longana (Haw.), "Tortrix" on apple, "Tortrix" on filbert, olethreutid on rose, Spilonota ocellana (D. and S.). D. interruptum interruptum (Holmgren) is European, and I have not studied specimens of it other than the lectotype; therefore, I have little basis for judging the soundness of the subspecific distinction of the Nearctic population (see Townes, 1970). I am in agreement with Horstmann (1973) that placement of the present species in Diadegma is more justifiable than was Townes' (1970) placement of it in Tranosema, but I am not yet willing to accept Horstmann's suppression of interruptum as a synonym of praerogator (Linnaeus), in spite of his statement (1973) that the type of praerogator is a typical interruptum male. My confidence in the opinions of Dr. Horstmann ordinarily being complete, I would regard the question of the identity of praerogator as being settled were it not for the fact that he indicated that the type was labeled "salicis," but neglected to refute or otherwise discuss Linnaeus' indication that praerogator had been reared from the lymantriid Leucoma salicis (L.). The manner in which the praerogator type is mounted (see Roman, 1932) and the supposed deterioration of the specimen with time would seem to necessitate (1) consideration of the Linnaean host record and (2) comparison of the praerogator type with males of Hyposoter species which could be expected to parasitize $L$. salicis. This seems all the more necessary in view of the fact that I have seen specimens of a European species of Hyposoter, not colored unlike interruptum, which were reared from a lymantriid, and which have cocoons agreeing with Roman's description of the one mounted next to the praerogator type.

Limneria pterophorae Ashmead, 1890 (1889). U. S. Natl. Mus., Proc. 12: 435. . Contrary to Ashmead's statement, the label of the holotype reads: "From Tortrix on apple."

Campoplex (Angitia) basizona Viereck, 1924. Canad. Ent. 56: 67. J. C. basizona had been placed in Hyposoter by Townes (1945); the holotype was reared from Archips rosanus (L.) and agrees well with other material of interruptum pterophorae which I studied in the Canadian Natl. Collection. N. syn.

Taxonomy: Roman, 1932. Ent. Tidskr. 53: 10 (type of $I$. praerogator). -Townes, 1945. Amer. Ent. Soc., Mem. 11: 660, 664. -Townes, 1970 (1969). Amer. Ent. Inst., Mem. 13: 177. -Horstmann, 1973. Beitr. z. Ent. 23: 134-135 (generic placement, suppression of name interruptum). 
johanseni (Viereck). Que., R. I., S. Dak.

Campoctonoides johanseni Viereck, 1925. Canad. Ent. 57 (7): 177 (key); 58 (12): 297. ơ, ९.

laricinellum (Strobl). Europe. Introduced in Maine, N. H., Vt., Mass., Conn., N. Y., and Ont. between 1931 and 1939 and very recently in Idaho, without becoming established, at least at release sites in eastern North America. Host: Coleophora laricella ( $\mathrm{Hbn}$.). The host cited was the target species for all of the introductions in North America. In most publications the name nana (Gravenhorst) was applied to this species, but Horstmann (1969) stated that the type of nana was not found in the Gravenhorst collection, and he applied the name in accordance with specimens identified as nana in the Thomson collection.

Angitia laricinella Strobl, 1904. Naturw. Ver. f. Steiermark, Mitt. 40: 86. o, \&.

Taxonomy: Horstmann, 1969; 1973. Beitr. z. Ent. 19: 439, 443; 23: 133-134.

Biology: Thorpe, 1933. Bul. Ent. Res. 24: 273-277, 288. - Dowden, 1934. Ent. Soc. Amer., Ann. 27: 601-602, 603. - Graham, 1944. Ent. Soc. Ontario, Ann. Rpt. 74: 48-52. -Dowden, 1962.

U. S. Dept. Agr., Agr. Handb. 226: 11 (releases only). -McGugan and Coppel, 1962.

Commonwealth Inst. Biol. Control, Tech. Commun. 2: 38, 42, 79-80, 162, 199.

laticeps (Viereck). Southwestern B. C.

Campoplex (Hyposoter) laticeps Viereck, 1925; 1926. Canad. Ent. 57 (8): 204 (key); 58 (9): 220. 9 .

lyonetiae (Viereck). Southern B. C. Host: Lyonetia speculella Clem.

Nemeritis lyonetiae Viereck, 1925; 1926. Canad. Ent. 57 (7): 178 (key); 58 (7): 178. o. In the 1926 portion of Viereck's revision as "Campoplex (Nemeritis) lyonetiae."

minutum (Viereck). N. Y., N. C., Colo., B. C.

Campoplex (Hyposoter) minutus Viereck, 1925; 1926. Canad. Ent. 57 (8): 204 (key); 58 (9): 221. 9. Preocc. by Holmgren, 1856 and also secondarily by Cushman, 1922; not renamed here because of uncertain synonymy.

mollipla (Holmgren). Rhodesia, South Africa, Mauritius. Introduced in Calif. in 1966, without becoming established. Host: Phthorimaea operculella (Zell.). The host cited was the target species for the release in Calif. I have used the spelling mollipla and regard molliplum as an unjustified emendation because mollipla is indecipherable; for that reason Holmgren's proposal of it with an upper case M must be accepted as indicating that it is a proper name, as was done by Dalla Torre (1901), who acted as first revisor in transferring the species to Limnerium as mollipla.

Limneria Mollipla Holmgren, 1869 (1868). Eug. Resa, pt. 2 (Zool.), sect. 1 (Ins.), p. 417. ơ. Limnerium stellenboschense Cameron, 1905. So. African Phil. Soc., Trans. 15: 200..

Limnierium(!) iratum Cameron, 1905. Albany Mus., Rec. 1: 309. ๆ.

Limnerium longiceps Cameron, 1906. So. African Mus., Ann. 5: 100. $\$$.

Diadegma fasciannulata Morley, 1915. Ann. and Mag. Nat. Hist. (8) 16: 340. Nomen nudum.

Diadegma molliplum Townes and Townes, 1973. Amer. Ent. Inst., Mem. 19: 156. Emend.

Taxonomy: Dalla Torre, 1901. Cat. Hym., v. 3, p. 99. - Townes and Townes, 1973. Amer. Ent. Inst., Mem. 19: 156 (syn. and lectotype selections).

Biology: Edwards, 1939. Mauritius Dept. Agr., Sci. Ser., Bul. 13: 7. - Oatman and Platner, 1966. Environmental Ent. 3: 264 (release only).

obliteratellum (Viereck). Southern B. C.

Campoplex (Hyposoter) obliteratella Viereck, 1925; 1926. Canad. Ent. 57 (8): 204 (key); 58 (9): 222. ㅇ.

obscurum (Cresson). Que. w. to s. B. C., s. to Ind., Iowa, and Colo. Host: Crambus trisectus (Wlk.), Ostrinia obumbratalis (Led.).

Mesoleptus obscurus Cresson, 1864. Ent. Soc. Phila., Proc. 3: 261. \&.

Campoplex (Hyposoter) convergens Viereck, 1925; 1926. Canad. Ent. 57 (8): 203 (key); 58 (8): 200. .

Campoplex (Ischnoscopus) vinalis Viereck, 1925; 1926. Canad. Ent. 57 (9): 223 (key); 58

(8): 197. \&. 
openangorum (Viereck). Maine w. to s. B. C., s. to N. J., s. Tex., and s. Calif. Host: Homoeosoma electellum (Hulst), Zophodia convolutella (Hbn.), "Tortrix" on gooseberry.

Campoplex (Angitia) openangorum Viereck, 1917 (1916). Conn. State Geol. and Nat. Hist. Survey Bul. 22: 265. ơ.

paenesessile (Viereck). Southeastern Ont.

Campoplex (Hyposoter) paenesessilis Viereck, 1925; 1926. Canad. Ent. 57 (8): 204 (key); 58 (9): 222. \&.

parviforme (Viereck). Mass. w. to s. B. C., s. to s. Miss. and central Tex. Host: Gelechia trialbamaculella Cham., Acrobasis caryae Grt., A. juglandis (LeB.), A. vaccinii Riley.

Campoplex (Angitia) parviform is Viereck, 1917 (1916). Conn. State Geol. and Nat. Hist. Survey Bul. 22: 265. .

parvum (Provancher). Que.

Limneria parva Provancher, 1874. Nat. Canad. 6: 147..

pattoni (Ashmead). Southeastern N. Y., s. Mich., Ill., Kans., and n. Ariz., s. to s. Fla., s. Tex., and s. Calif.; West Indies and Mexico s. to El Salvador; Hawaii. Host: Herpetogramma phaeopteralis $(\mathrm{Gn}$.$) , Loxostege rantalis (\mathrm{Gn}$.$) , Loxostege sticticalis (L.), Udea rubigalis$ (Gn.).

Limneria Pattoni Ashmead, 1890 (1889). U. S. Natl. Mus., Proc. 12: 434. ठ.

Limneria eurycreontis Ashmead 1890 (1889). U. S. Natl. Mus., Proc. 12: 434. 9.

Limneria mississippiensis Ashmead, 1894. U. S. Dept. Agr., Insect Life 7: 243..

Amorphota paenexareolata Viereck, 1905. Kans. Acad. Sci., Trans. 19: 309. ð.

Amorphota confluens Viereck, 1906. Amer. Ent. Soc., Trans. 32: 217.. .

Cymodsa simplicicomis Viereck, 1916. Biol. Soc. Wash., Proc. 29: 168..

pendulum Walley. Southeastern N. Y., n.w. S. C., s. Mich.

Diadegma pendula Walley, 1967. Canad. Ent. 99: 937. $\$$.

psilocorsis Walley. Conn., N. Y., N. J., Md., n. Va., e. N. C., Ont., Mich., Mo. Host: Psilocorsis sp., $P$. cryptolechiella (Cham.), $P$. quercicella Clem.

Diadegma psilocorsis Walley, 1967. Canad. Ent. 99: 934. ठ, १.

pulicalvariae Walley. P. E. I. w. to s. B. C., s. to e. N. C., n.w. S. C., and e.-central Ill. Host: Coleotechnites sp., C. apicitripunctella (Clem.), Eucordylia atrupictella Dietz, Pulicalvaria martini Free., P. thujaella (Kft.).

Diadegma pulicalvariae Walley, 1967. Canad. Ent. 99: 928. ð, \&.

solum (Viereck). B. C., Wash.

Nemeritis solus Viereck, 1925; 1926. Canad. Ent. 57 (7): 179 (key); 58 (7): 180. 9 . In the 1926 portion of Viereck's revision as "Campoplex (Nemeritis) solus."

stenosomum (Viereck). Que. w. to s. B. C., s. to w. N. C., n. Ohio, and n.w. Oreg. Host: Carcina quercana (F.).

Nothanomaloides stenosomus Viereck, 1925. Roy. Soc. Canada, Proc. and Trans. (3) 19 (5): 272. . .

trachas (Viereck). Southern Alta.

Nemeritis trachas Viereck, 1925; 1926. Canad. Ent. 57 (7): 179 (key); 58 (7): 180. \&. In the 1926 portion of Viereck's revision as "Campoplex (Nemeritis) trachas."

truncatum (Viereck). Arctic N. W. T.

Campoplex (Hyposoter) truncatus Viereck, 1925; 1926. Canad. Ent. 57 (8): 203 (key); 58 (8): 200. .

ungavae Walley. Newfoundland (n. Labrador), n. Que., Colo. Ecology: The specimens from Colo. were collected at elevations of $11,700 \mathrm{ft}$. and 12,000 ft. in the Rocky Mts.

Diadegma ungavae Walley, 1967. Canad. Ent. 99: 939. ठ', ?.

\section{Genus ERIBORUS Foerster}

Zaporus Foerster, 1868. Naturh. Ver. Rheinlande, Verh. 25: 152.

Type-species: Campoplex dorsalis Gravenhorst. By subsequent monotypy from inclusion by Schmiedeknecht, 1907.

Eriborus Foerster, 1868. Naturh. Ver. Rheinlande, Verh. 25: 153.

Type-species: Campoplex perfidus Gravenhorst. Desig. by Morley, 1913 from two species included by Schmiedeknecht, 1907. 
Bosmina Cameron, 1899. Manchester Lit. and Phil. Soc., Mem. and Proc. 43 (3): 120. Preocc. by Baird, 1845 .

Type-species: Bosmina spinipes Cameron. Monotypic.

Hymenobosmina Dalla Torre, 1901. Wien. Ent. Ztg. 20: 52. N. name for Bosmina Cameron.

Neobosmina Cameron, 1906. Entomologist 39: 250. Probably a lapsus for Hymenobosmina Dalla Torre, as evidenced bt Cameron's inclusion of Bosmina mandibularis Cameron and by the fact that he gave no indication that he was describing a new genus; possibly not treatable as a lapsus without more definite proof.

Type-species: Neobosmina pilosella Cameron. Desig. by Viereck, 1914.

This is a large genus of the Old World. The number of Palearctic species appears to be small, and it is my impression that more Eriborus species occur in the Oriental Region that in other tropical and subtropical parts of the Old World.

Revision: Momoi, 1970. Pacific Insects 12: 384-388 (spp. of Ryukyu Archipelago).

Taxonomy: Townes, Townes, and Gupta, 1961. Amer. Ent. Inst., Mem. 1: 243 (syn.). -Oehlke,

1964. Ent. Abhandl. 29: 571 (footnote), - Horstmann, 1969. Beitr. z. Ent. 19: 414, 415.

molestae (Uchida). Korea, Japan. Introduced between 1932 and 1953 at 321 localities from Mass. w. to Ill., s. to Ga. and Ark., according to Allen (1962); there was temporary establishment at least from many of the releases between 1932 and 1937, but the species has apparently not persisted anywhere in the United States. The host cited was the target species for releases in the United States.

Dioctes molestae Uchida, 1933. Wash. Acad. Sci., Jour. 23: 148..

Biology: Garman, 1939. Conn. (State) Agr. Expt. Sta., Bul. 428: 65-66, 67. -Allen, Holloway, and Haeussler, 1940. U. S. Dept. Agr., Cir. 561: 51-52. - Haeussler, 1940. U. S. Dept. Agr., Tech. Bul. 728: 21-24, 48-49, 59. - Allen, 1954. Jour. Econ. Ent. 47: 278. -Allen, 1962. U. S. Dept. Agr., Tech. Bul. 1265: 120.

terebrans (Gravenhorst). Mass. and Ont. w. to N. Dak., s. to Md., Ill., and Iowa; Eurasia. Introduced. Host: Ostrinia nubilalis ( $\mathrm{Hbn}$.$) , lepidopteran in red pine shoot? One$ specimen in the U.S. Natl. Museum collection is labeled as having been reared from a red pine tip infested by Rhyacionia buoliana (D. and S.).

Campoplex terebrans Gravenhorst, 1829. Ichn. Europaea, v. 3, p. 503. o, ?.

Angitia (Dioctes) gigantea Szepligeti, 1916. Mus. Natl. Hungarici, Ann. 14: 373..

Eugnomus pyraustae Okamoto, 1921. Hokkaido Agr. Expt. Sta., Rpt. 12: 15. ठ.

Angitia (Dioctes) punctoria Roman, 1923. Ent. Tidskr. 44: 171. o, ?.

Taxonomy: Aubert, 1964. Soc. Linn. de Lyon, Bul. Mens. 33: 64 (syn.). -Townes, 1965. Polskie Pismo Ent. 35: 410 (syn.). - Townes, Momoi, and Townes, 1965. Amer. Ent. Inst., Mem. 5: 304 (syn.). - Horstmann, 1969. Beitr. z. Ent. 19: 453-454.

Biology: Clark, 1934. U. S. Dept. Agr., Tech. Bul. 455: 9, 11, 20-21, 28, 31. - Ellinger and Sachtleben, 1929. Biol. Reichsanst. f. Land-u. Forstw., Arb. 17: 327. -Clark and Carter, 1943. Jour. Econ. Ent. 36: 120. - Baker, Bradley, and Clark, 1949. U. S. Dept. Agr., Tech. Bul. 983: 74, 75-90, 91 .

\section{Genus LATHROSTIZUS Foerster}

Lathrostizus Foerster, 1868. Naturh. Ver. Rheinlande, Verh. 25: 154.

Type-species: Lathrostiza sternocera Thomson. Desig. by Viereck, 1914 from two species included by Thomson, 1887.

Lathrostiza Thomson, 1887. Opusc. Ent. 11: 1153. Emend.

This is a small Holaretic genus. The known hosts include nematine sawflies of the genera Pontania, Euura, and Hoplocampa.

Revision: Horstmann, 1971. Deut. Ent. Gesell., Mitt. 30 (1): 8-12; 30 (2): 16-18 (European spp.). 
euurae (Ashmead). Western Mont., s.w. Idaho, Utah., s. Ariz., w. Nev., s. Calif. Host: Euura sp. Pontania sp. I suspect that the species studied by Caltagirone (1964) and Finlayson (1975) is not euurae.

Limneria eunrae Ashmead, 1890 (1889). U. S. Natl. Mus., Proc. 12: 433. §, $\$$. The type locality is Pahreah, Kane Co., Utah.

Biology: Caltagirone, 1964. Ent. Soc. Amer., Ann. 57: 287-289 (possibly not euurae).

-Finlayson, 1975. Ent. Soc. Canada, Mem. 94: 80-81, 132, 137 (possibly not euurae). modestus (Brues). Arctic N. W. T.

Dioctes modestus Brues, 1919. Rpt. Canad. Arctic Exped. 1913-18, v. 3, pt. G, p. 23. ठ, ९.

Taxonomy: Townes, 1970 (1969). Amer. Ent. Inst., Mem. 13: 187 (generic placement).

\section{Genus OLESICAMPE Foerster}

Limneria Holmgren, 1859 (1858). Svenska Vetensk.-Akad., Ofvers. af ... Forhandl. 15: 326. Preoce. by Adams, 1851.

Type-species: Campoplex longipes Gravenhorst. Desig. by Viereck, 1912. The type-species is Gravenhorst's identification of Ichneumon longipes Mueller.

Olesicampe Foerster, 1868. Naturh. Ver. Rheinlande, Verh. 25: 153.

Type-species: Campoplex longipes Gravenhorst. Desig. by Viereck, 1912 from 26 species included by Thomson, 1887. The type-species is Gravenhorst's identification of Ichneumon longipes Mueller.

Omoborus Foerster, 1868. Naturh. Ver. Rheinlande, Verh. 25: 154.

Type-species: Omoborns kincaidi Davis. By subsequent monotypy from inclusion by Davis, 1898.

Holocremnus Foerster, 1868. Naturh. Ver. Rheinlande, Verh. 25: 157.

Type-species: Limneria cothurnata Holmgren. Desig. by Viereck, 1914 from 22 species included by Thomson, 1887.

Olesicampa Thomson, 1887. Opuse. Ent. 11: 1053, 1139. Emend.

Holocremna Thomson, 1887. Opusc. Ent. 11: 1053, 1176. Emend.

Limnerium Ashmead, 1900. Canad. Ent. 32: 368. N. name for Limneria Holmgren.

Zaplatystoma Viereck, 1925. Canad. Ent. 57 (7): 177, 180, 181.

Type-species: $Z$ aplatystoma typicum Viereck. By orig. indication and also subsequent desig. of Viereck, 1926.

This is a large genus. As presently defined in the structural sense, it appears to include species from all zoogeographic regions, but by far the greatest number of species occur in the Holarctic Region. From our knowledge of the habits of a considerable number of the species occurring in the Holarctic Region there has developed the supposition that parasitism of sawfly larvae clearly distinquishes Olesicampe from Hyposoter (parasites of Lepidoptera larvae). Structural differentiatiton of the two genera is rather arbitrary, however, particularly when one looks at the world fauna, in which ease the differentiation of Olesicampe from Lemophagus also appears arbitrary. Although it seems certain that some of the species currently placed in Olesicampe will prove not to be parasites of sawflies, it appears equally as certain that nearly all of the Nearctic and Palearctic species of Olesicampe are parasites of sawflies. In all cases known to me, Olesicampe species kill the host after it has spun its cocoon and emerge as adults from the host cocoon.

alaskensis (Ashmead). N. H., s.e. Alaska, B. C., Wash., Oreg.

Olesicampa alaskensis Ashmead, 1902. Wash. Acad. Sci., Proc. 4: 235. ð.

annulata (Provancher). Que.

Pyracmon annulatum Provancher, 1879. Nat. Canad. 11: 182..

atypica (Viereck). Western B. C.

Pyracmonoides atypicum Viereck, 1925. Canad. Ent. 57 (7): 177 (key); 57 (12): 300. ठో.

banffensis (Viereck). Southeastern Man., s.w. Alta., Wash.

Campoplex (Ameloctonus) pauxillus Viereck, 1925; 1926. Canad. Ent. 57 (9): 224 (key); 58 (11): 278 .. .

Campoplex (Ameloctonus) banffensis Viereck, 1925; 1926. Canad. Ent. 57 (9): 224 (key); 58 (11): 278 . ㅇ. 
barbata (Provancher). Que., Conn., N. Y., N. J., Pa.

Mesoleptus barbatus Provancher, 1886. Addit. Corr. Faune Ent. Canada Hym., p. 98. $\uparrow$.

Campoplex (Holocremnus) metacomet Viereck, 1917 (1916). Conn. State Geol. and Nat.

Hist. Survey Bul. 22: 264. 9 .

beginii (Ashmead). Que.

Prionopoda beginii Ashmead, 1896. Amer. Ent. Soc., Trans. 23: 198. ๆ.

benefactor Hinz. N. S., N. B., Maine, s.-central Pa., n. Minn., s. Man.; Europe. Introduced. Host: Pristiphora erichsonii ( $\mathrm{Htg}$.). The host cited was the target species for releases of benefactor in North America, and benefactor is not known to parasitize other species of sawflies in Europe.

Olesicampe benefactor Hinz, 1969. Canad. Ent. 101: 181. ठ, ?.

Biology: Muldrew, 1967. Canad. Ent. 99: 312-321 (as "sp. near nematorum" [Tschek]). - Turnock and Muldrew, 1971. Commonwealth Inst. Biol. Control, Tech. Commun. 4:

182-186, 187-193. - Pschorn-Walcher and Zinnert, 1971. Commonwealth Inst., Biol. Control, Tech. Bul. 14: 24-28. - Embree and Underwood, 1972. Canad. Ent. 104: 89-96.

-Pschorn-Walcher, 1972. Studienrichtung Forst-u. Holzwirtsch., v. 4, p. 461-464, 465, 467.

-Kulman, Thompson, and Witter, 1974. Gt. Lakes Ent. 7: 23-25.

brachyura (Ashmead). N. Y., Mich.

Limneria brachyura Ashmead, 1890 (1889). U. S. Natl. Mus., Proc. 12: 431 . $\%$.

Limnerium brachyurum Dalla Torre, 1901. Cat. Hym., v. 3, p. 91. Emend.

californica (Cresson). Southern Calif.

Limneria californica Cresson, 1879 (1878). Acad. Nat. Sci. Phila., Proc. 30: 369. ठో.

eushmani (Viereck). N. Y., N. C., Ont., Sask., Wash.

Campoplex (Ameloctonus) diversus Viereck, 1925; 1926. Canad. Ent. 57 (9): 224 (key); 58 (11): 277. ९. Preocc. by Norton, 1863.

Campoplex (Ameloctonus) cushmani Viereck, 1926. Canad. Ent. 58 (11): 279. N. name for $C$. (A.) diversus Viereck.

decora (Viereck). Southern B. C.

Zaplatystoma decorum Viereck, 1925; 1926. Canad. Ent. 57 (7): 181 (key); 58 (2): 31. ؟.

delicata (Viereck). Ont.

Campoplex (Ameloctonus) delicatus Viereck, 1925; 1926. Canad. Ent. 57 (9): 224 (key); 58 (11): 278 . + .

dentata (Provancher). Que.

Macrus dentatus Provancher, 1874. Nat. Canad. 6: 150. क. The "lectotype" selected by Gahan and Rohwer (1918) was rejected by Barron (1975) in favor of a specimen which agrees with the original description and appears to be the holotype.

Taxonomy: Gahan and Rohwer, 1918. Canad. Ent. 50: 28. - Barron, 1975. Nat. Canad. 102: $460,548$.

egregia (Viereck). Ont.

Zaplatystoma egregium Viereck, 1925; 1926. Canad. Ent. 57 (7): 181 (key); 58 (2): 30..

extrema (Holmgren). Greenland.

Limneria extrema Holmgren, 1872. Svenska Vetensk.-Akad., Ofvers. af ... Forhandl. 29 (6): 98. + .

Taxonomy: Roman, 1930. Ann. and Mag. Nat. Hist. (10) 5: 287.

flaviclypeus (Viereck). Que., R. I., N. Y., Va.

Limneria sericea Provancher, 1875. Nat. Canad. 7: 148. ठ. Apparently preocc. in Olesicampe by Campoplex sericeus Holmgren, 1856.

Holocremnus flaviclypeus Viereck, 1921. Psyche 28: 75. ठ์.

flavirictus (Cresson). Que., N. H., R. I., Conn., N. Y., Pa., S. Dak.

Mesoleptus flavirictus Cresson, 1864. Ent. Soc. Phila., Proc. 3: 263. 9.

Zaplatystoma cinereum Viereck, 1925; 1926. Canad. Ent. 57 (7): 181 (key); 58 (1): 7. \&.

fossata (Viereck). Ont.

Pyracmon fossatum Viereck, 1925; 1926. Canad. Ent. 57 (7): 180 (key); 58 (1): 6. ઠิ.

johnsoni (Viereck). N. H.

Zaplatystoma johnsoni Viereck, 1925; 1926. Canad. Ent. 57 (7): 181 (key); 58 (2): 32 .. 
kincaidi (Davis). Western Wash.

Omoborus kincaidi Davis, 1898 (1897). Amer. Ent. Soc., Trans. 24: 363. ठ.

Omoborus kincaidii Dalla Torre, 1901. Cat. Hym., v. 3, p. 118. Emend.

lata (Viereck). Southeastern Man., s.w. Alta.

Zaplatystoma simplex Viereck, 1925; 1926. Canad. Ent. 57 (7): 181 (key); 58 (2): 30 ..

Zaplatystoma latum Viereck, 1925; 1926. Canad. Ent. 57 (7): 181 (key); 58 (1): 7. ठ.

lophyri (Riley). Que. s. to n. Fla., w. to Minn. and n.e. Iowa. Host: Neodiprion abbotii (Leach),

N. lecontei (Fitch), N. pinetum (Nort.), N. swainei Midd., N. sp. in virginiana complex. Limneria lophyri Riley, 1877. Mo. State Ent., Ann. Rpt. 9: 32. ઠै, ९.

Biology: Tripp, 1961. Canad. Ent. 93: 51-52, 55 (also fig. final-instar larva). - Riordan, 1963. Canad. Jour. Zool. 41: 1242.

macellator (Thunberg). Europe. Introduced in N. S., N. B., Que., Vt., and Ont. between 1933 and 1940, without becoming established. Host: Gilpinia frutetorum (F.), G. polytoma (Htg.). The hosts cited were apparently the ones from which rearings were made of individuals released in North America, and most of the rearings were apparently from G. polytoma. The target species for the releases in North America was G. hercyniae (Htg.), and hercyniae was not recorded as a host of macellator by Oehlke (1966). Oehlke apparently did not study type specimens other than that of Campoplex retectus Hartig, and his suppression of retectus as a synonym of macellator is apparently based upon Roman's (1912) suppression of Holocremna frutetorum Thomson as a synonym of macellator. My notes on the lectotype of frutetorum indicate that it probably pertains to the present species, but there is a definite need for careful study by one revisor of all three of the types in question. A specimen matched by me with one in the Holmgren collection labeled as lectotype of Limneria cothumata Holmgren (But possibly not yet selected by publication) indicates that cothurnata is erroneously treated as a synonym of macellator by Oehlke (1966) and Aubert (1973).

Ichneumon macellator Thunberg, 1822; 1824. Acad. Imp. des Sci. St. Petersburg, Mem. 8: 265; 9: 320. [male].

Campoplex retectus Hartig, 1838. Jahresber. Fortschr. Forstwiss. Forstl. Naturk. 1: 272. ㅇ.

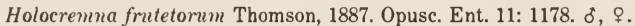

Olesicampe ratzeburgi auct., 1936-1975. Limneria ratzeburgi Tschek (1871) was suppressed with a query as a synonym of macellator by Oehlke (1966), but Aubert (1973) indicated that synonymy to be incorrect.

Taxonomy: Tschek, 1871. Zool.-Bot. Gesell. Wien, Verh. 21: 64-65 (description of $L$. ratzeburgi). -Roman, 1912. Zool. Bidr. Uppsala 1: 266, 291 -Oehlke, 1966 (1965). Beitr. z. Ent. 15: 865-867. - Aubert, 1973. Soc. Linn. Lyon, Bul. Mens. 42: 23. -Finlayson, 1975.

Ent. Soc. Canada, Mem. 94: 78, 79-80 131, 137 (final-instar larva).

Biology: Finalyson and Reeks, 1936. Canad. Ent. 68: 160-166. -Morris, Cameron, and Jepson, 1937. Bul. Ent. Res. 28: 364-367. -Lovaszy, 1939. Ent. Soc. Fenn., Ann. 5: 226-228.

-Finlayson and Finlayson, 1958. Canad. Ent. 90 (9): 558; 90 (10): 587, 589. - Dowden,

1962. U. S. Dept. Agr., Agr. Handb. 226: 15 (release only). -McGugaan and Coppel, 1962.

Commonwealth Inst. Biol. Control, Tech. Commun.. 2: 39, 92, 98, 161-162

mimetica (Viereck). Southwestern Alta., Wash., Oreg.

Zaplatystoma mimeticum Viereck, 1925; 1926. Canad. Ent. 57 (7): 181 (key); 58 (2): 31. ‥

nematicida (Viereck). Southern B. C. Host: Sawfly on ribes sp.

Campoplex (Ameloctonus) nematicidus Viereck, 1925; 1926. Canad. Ent. 57 (9): 224 (key); 58 (10): 258 . ․

nigridorsis (Viereck). Southeastern Ont.

Campoplex (Ameloctonus) nigridorsis Viereck, 1925; 1926. Canad. Ent. 57 (9): 224 (key); 58 (11): 277 . ㅇ.

obscuripes (Viereck). N. Mex.

Limnerium obscuripes Viereck, 1903. In Skinner, Amer. Ent. Soc., Trans. 29: 91.. ocellata (Viereck). Southeastern Ont.

Zaplatystoma ocellatum Viereck, 1925; 1926. Canad. Ent. 57 (7): 181 (key); 58 (1): 8. ơ. 
patula (Viereck). Southeastern Man.

Pyracmon patulum Viereck, 1925; 1926. Canad. Ent. 57 (7): 180 (key); 58 (1): 5 . \&.

peraffinis (Ashmead). Tex.

Limneria peraffinis Ashmead, 1890 (1889). U. S. Natl. Mus., Proc. 12: 435..

petiolata (Viereck). Ont.

Zaplatystoma petiolatum Viereck, 1925; 1926. Canad. Ent. 57 (7): 181 (key); 58 (2): 31. ơ.

pikonemae Walley. N. S., N. B., Que., Ont., n. Minn., s.e. B. C. Host: Pikonema alaskensis (Roh.), P. dimmockii (Cr.).

Olesicampe pikonemae Walley, 1942. Canad. Ent. 74: 193. ठं, ९.

pteronideae (Rohwer). Northern Va. Host: Nematus erythrogaster Nort.

Homalomma pteronideae Rohwer, 1915. U. S. Natl. Mus., Proc. 49: 219. ð.

ruficornis (Provancher), revised status. Que.

Limneria mificomis Provancher, 1875. Nat. Canad. 7: 147.. My notes on the holotype of mificomis indicate that it is not conspecific with the holotype of $O$. dentata (see discussion of dentata); ruficorris had been suppressed as synonym of dentata by Provancher (1879); the holotype of ruficornis was found by Barron (1975).

Taxonomy: Provancher, 1879. Nat. Canad. 11: 181. - Barron, 1975. Nat. Canad. 102: 538. typica (Viereck). Que., N. Y.

Zaplatystoma typicum Viereck, 1925; 1926. Canad. Ent. 57 (7): 181 (key); 58 (1): 7. ठै, ९.

virginiensis (Viereck). N. Y., n. Va.

Holocremnus virginiensis Viereck, 1921. Psyche 28: 76. १.

\section{Genus LEMOPHAGUS Townes}

Lemophagus Townes, 1965. Polskie Pismo Ent. 35: 415.

Type-species: Lemophagus curtus Townes. Monotypic and orig. desig.

Species so far referred to this small genus are native to Japan, Europe, and northern Africa and are parasites of Chrysomelidae. The egg is laid in the larva of the host which is killed after it has constructed its pupal cell.

curtus Townes. N. Y., w. Pa., w. W. Va., Ohio, s. Mich., n. Ind.; Europe. Introduced. Host: Oulema melanopus (L.). The host cited was the target species for releases of L. curtus in North America. Data on recoveries and establishment of $L$. curtus was furnished by Mr. T. L. Burger. Establishment in W. Va. may still be uncertain, but in other states the species has been recovered in Counties other than those in which it was released; recoveries have been made at distances as great as 68 miles from any known release point.

Lemophagus curtus Townes, 1965. Polskie Pismo Ent. 35: 415. ठ', ᄋ.

Taxonomy: Montgomery and DeWitt, 1975. Ent. Soc. Amer., Ann. 68: 574-578 (egg and larva).

Biology: Stehr, Gage, Burger, and Montgomery, 1974. Environmental Ent. 3: 453-454 (initial recoveries).

\section{Genus HYPOSOTER Foerster}

Rhythmonotus Foerster, 1868. Naturh. Ver. Rheinlande, Verh. 25: 151, 220. The variant spelling "Rhytmonotus" appeared on p. 220.

Type-species: Rhythmonotus singularis Schmeideknecht. By subsequent monotypy from inclusion by Schmidedknecht, 1909.

Hyposoter Foerster, 1868. Naturh. Ver. Rheinlande, Verh. 25: 152.

Type-species: Limnerius (Hyposoter) parorgyiae Viereck. Monotypically included and desig. by Viereck, 1910.

Ischnoscopus Foerster, 1868. Naturh. Ver. Rheinlande, Verh. 25: 152.

Type-species: Ischnoscopus synchlorae Ashmead. By subsequent monotypy from inclusion by Ashmead, 1898.

Ameloctonus Foerster, 1868. Naturh. Ver. Rheinlande, Verh. 25: 157. 
Type-species: Banchus fugitivus Say. Desig. by Viereck, 1914 from two species included by Ashmead, 1900.

Ebiicha Seyrig, 1935. Paris, Mus. d'Hist. Nat., Mem. 4: 88.

Type-species: Ebiicha crocata Seyrig. Monotypic and orig. desig.

Neozachresta Blanchard, 1949. In Havrylenko and Winterhalter, Insectos del Parque Nac. Nahuel Huapi, Buenos Aires, p. 46. Nomen nudum (fig. only).

This very large genus is known from all zoogeographic regions. The hosts are larval Lepidoptera, in nearly all cases those which do not conceal themselves when feeding (i.e. predominantly macrolepidoptera). It seems to me that Hyposoter, as presently defined, includes as bewildering a diversity of forms as any genus in the family. It would appear that the task of breaking the genus into smaller ones that are more meaningful phyletically will require a great deal of research that is not likely to be accomplished soon.

Taxonomy: Townes, 1970 (1969). Amer. Ent. Inst., Mem. 13: 181-182 (syn.). -Townes and Townes, 1973. Amer. Ent. Inst., Mem. 19: 157 (syn. revised).

affinis (Cresson). Mass., N. Y., Ill.

Mesoleptus affinis Cresson, 1864. Ent. Soc. Phila., Proc. 3: 263. “ $"=\subsetneq$. Preocc. by Holmgren, 1856, but not renamed here because of the possibility that a synonym has been described.

annulipes (Cresson). N. S. w. to w. N. W. T. and s. B. C., s. to central Fla., s. Tex., n. Utah, and s. Calif. Host: Agrotis ipsilon (Hufn.), Anicla infecta (Ochs.), Autographa precationis (Gn.), Catocala sp., C. antinympha (Hbn.), Ceramica picta (Harris), Eupsilia sp. on oriental cherry, Helioth is zea (Bod.)?, Pseudaletia unipuncta (Haw.), Pyrrhia umbra (Hufn.), Spodoptera exigua (Hbn.), S. frugiperda (J. E. S.), S. ornithogalli (Gn.), Syngrapha epigaea (Grt.), Vanessa atalanta (L.), geometrid on Rhododendron, Eustixia pupula $\mathrm{Hbn}$.

Mesoleptus annulipes Cresson, 1864. Ent. Soc. Phila., Proc. 3: 257..+

Hyposoter interjectus Gahan, 1914. U. S. Natl. Mus., Proc. 48: 156. ๆ. H. interjectus was incorrectly suppressed as a synonym of nigrolineatus (Viereck) by Townes (1945); although the name interjectus could perhaps be used subspecifically for the annulipes population in the southeastern United States, I have decided that this should not be done before the relationship between annulipes and exiguae (Viereck) is reassessed. It should be noted that specimens similar in coloration to those found in the southeast occasionally are found as far north as Mass. and Mich.; whether or not the holotype of Campoplex eurythemeae Viereck is such a specimen remains to be seen (see synonymy for exiguae). N. syn.

Campoplex (Ischnoscopus) mitralis Viereck, 1925; 1926. Canad. Ent. 57 (9): 223 (key); 58 (8): 197. \&.

Campoplex (Ischnoscopus) truncatellus Viereck, 1925; 1926. Canad. Ent. 57 (9): 223 (key); 58 (8): 197 . ‥

Campoplex (Ameloctonus) confusus Viereck, 1925; 1926. Canad. Ent. 57 (9): 224 (key); 58 (11): 277 . .

Taxonomy: Townes, 1945, Amer. Ent. Soc., Mem. 11: 663-664, 668-669 (syn.). -Finlayson, 1975. Ent. Soc. Canada, Mem. 94: 73, 74, 127, 128, 137 (final-instar larva).

Biology: Wood and Nielson, 1960. Canad. Ent. 92: 761. -Guppy, 1967. Canad. Ent. 99: 96, 100.

asper (Viereck). Southwestern Alta.

Campoplex (Ameloctonus) asper Viereck, 1925; 1926. Canad. Ent. 57 (9): 224 (key); 58 (10): 259. ․

degrysei (Viereck). Southern Sask.

Campoplex (Ameloctonus) degrysei Viereck, 1925; 1926. Canad. Ent. 57 (9): 224 (key); 58 (10): 259. .

Taxonomy: Finlayson, 1975. Ent. Soc. Canada, Mem. 4: 72-73, 126, 137 (final-instar larva). dimidiatus (Ashmead). Western Ky., n. Ala., s.w. Miss.

Zachresta dimidiata Ashmead, 1894. U. S. Dept. Agr., Insect Life 7: 243. . 
disippi (Viereck). Que., N. J., Ont., Ohio, Mich., Ariz., w. Wash., n. Calif. Host: Limenitis archippus (Cram.), Euchloe olympia Ed.

Campoplex (Ameloctonus) disippi Viereck, 1925; 1926. Canad. Ent. 57 (9): 224 (key); 58 (11): 276. ㅇ.

erythrinus (Viereck). Md., s. Sask., s. e. B. C.

Campoplex (Hyposoter) erythrinus Viereck, 1925; 1926. Canad. Ent. 57 (8): 203 (key); 57 (8): 199. ㅇ.

exiguae (Viereck). Southern Sask.?, n. Utah, Ariz., Calif.; Mexico; Hawaii. Host: Autographa californica (Spey.), Catabena esula (Druce), Heliothis phloxiphaga (G. and R.), H. zea (Bod.), Peridroma saucia (Hbn.), Pseudaletia unipuncta (Haw.), Spodoptera exigua (Hbn.), S. praefica (Grt.), Trichoplusia ni (Hbn.), Manduca quinquemaculata (Haw.), $M$. sexta (L.), Cynthia cardui (L.)?, Ascia monuste (L.), Colias eurytheme (Bdv.)?

Campoplex (Hypothereutes) exiguae Viereck, 1912. U. S. Natl. Mus., Proc. 42: 638. .

Campo plex (Ameloctonus) eurythemeae Viereck, 1925; 1926. Canad. Ent. 47 (9): 223 (key); 58 (10): 258. $\delta, ~ ᄋ$. Viereck's type specimens were reared from Colias eurytheme at Kinistino, Sask. Townes (1945) suppressed C. eurythemeae as a synonym of exiguae, perhaps incorrectly (see synonymy for annulipes).

Taxonomy: Townes, 1945. Amer. Ent. Soc., Mem. 11: 665.

Biology: Swezey, 1927. Hawaii. Ent. Soc., Proc. 6: 404-407. - Williams, 1931. Handb. Ins. ... Hawaii. Sug. Cane Fields, p. 268-269. - Blanchard and Conger, 1932. Jour. Econ. Ent. 25: 1065. - Michelbacher and Essig, 1938. Calif. Agr. Expt. Sta. Bul. 625: 21. -Puttler and van den Bosch, 1959. Jour. Econ. Ent. 52: 327-329. - Puttler, 1961. Ent. Soc. Amer, Ann. 54: 25-30. -Smilowitz, 1973. Ent. Soc. Amer., Ann. 66: 93-99. - Smilowitz and Iwantsch, 1973. Environmental Ent. 2: 759-763. - Smilowitz, 1974. Ent. Soc. Amer., Ann. 67: 317-320. -Smilowitz and Iwantsch, 1975. Canad. Ent. 107: 689-694. -Jowyk and Smilowitz, 1975. N. Y. Ent. Soc., Jour. 83: 261. - Smilowitz, Martinka, and Jowyk, 1975. N. Y. Ent. Soc., Jour. 83: 262-263. - Iwantsch and Smilowitz, 1975. Canad. Ent. 107: 927-934. - Iwantsch and Smilowitz, 1975. Jour. Insect Physiol. 21: 1151-1157. - Beegle and Oatman, 1976. Ent. Expt. et Appl. 20: 77-80.

frigidus (Lundbeck). Eastern Greenland. Host: Anarta sp., "Hadena" sp.

Limneria frigida Lundbeck, 1897 (1896). Dansk Naturhist. For. Kjobenhavn, Vidensk. Meddel. (for 1896), p. 236. ठै, क.

Taxonomy: Roman, 1934. Ann. and Mag. Nat. Hist. (10) 14: 610-611.

fugitivus (Say). N. S. w. to w. Wash., s. to central Fla., s.e. Tex., and central Calif. Host: Malacosoma americanum (F.), Malacosoma californicum absimile (Dyar), M. c. californicum (Pack.), M. c. fragile (Str.), M. c. pluviale (Dyar), M. c. recenseo Dyar, $M$. constrictum (Hy. Ed.), M. disstria Hbn., Euchaetias egle (Drury), Hyphantria cunea (Drury), Anisota consularis Dyar, A. senatoria (J. E. S.), A. stigma (F.), A.virginiensis pellucida(J. E. S.), A. v. virginiensis (Drury), Dryocampa mibicunda rubicunda (F.), Datana integerrima G. and R., D. ministra (Drury), Schizura concinna (J. E. S.), Orgyia definita (Pack.), O. pseudotsugata (McD.), Automeris io (F.), Hemileuca maia (Drury). Banchus fugitivus Say, 1836. Boston Jour. Nat. Hist. 1: 247. ठ,..

Limneria Guignardi Provancher, 1886. Addit. Corr. Faune Ent. Canada Hym., p. 87. $\delta, ~ \wp$. Limneria oedemasiae Ashmead, 1890 (1889). U. S. Natl. Mus., Proc. 12: 436. ठ, $\%$.

Limnerium Guignardii Dalla Torre, 1901. Cat. Hym., v. 3, p. 97. Emend.

Hyposoter fugitivus var. pacificus Cushman, 1919. Ent. Soc. Wash., Proc. 21: 119. ठ, ๆ. N. syn.

Taxonomy: Cushman and Gahan, 1921. Ent. Soc. Wash., Proc. 23: 159. - Viereck, 1925. Canad. Ent. 57: 104. - Cushman, 1925. Ent. Soc. Wash., Proc. 27: 164-166.

Biology: Fiske, 1903. N. H. Agr. Expt. Sta., Tech. Bul. 6: 200, 202-206. -Bogavac, 1956. Zastita Bilja 7: 29-46. - Langston, 1957. Calif., Univ., Pubs. Ent. 14: 21-22, 23.

-Barrows, 1976. Ent. News 87: 101-102 (sexual bahavior).

fuscitarsis (Viereck). Que., Ont., Mich., n. Minn., n. N. Dak., w. Wash., n. Calif.; Europe. Host: Biston betularia cognataria (Gn.), Erranis tiliaria (Harris), Paleacrita vernata (Pack.), 
Phigalea titea (Cram.), brown looper with stripes, Malacosoma disstria $\mathrm{Hbn}$. I have seen European specimens at the American Entomological Institute.

Campoplex (Ameloctonus) fuscitarsis Viereck, 1925; 1926. Canad. Ent. 57 (9): 224 (key); 58 (11): 279 . . .

galvestonensis (Viereck). Southeastern Tex.

Amorphota galvestonensis Viereck, 1906. Amer. Ent. Soc., Trans. 32: 219. \&.

grahami (Viereck). Que., Conn., Pa., Md., w. N. C., Ala., Tex.

Campoplex (Holocremnus) grahami Viereck, 1925; 1926. Canad. Ent. 57 (8): 203 (key); 58 (7): 182. ․

luctus (Davis). N. H., arctic N. W. T. Ecology: In N. H. presumably occurring only in the alpine region of Mt. Washington.

Canidia luctus Davis, 1898 (1897). Amer. Ent. Soc., Trans. 24: 364. 9.

Zachrestoides intermedia Viereck, 1925; 1926. Canad. Ent. 57 (7): 179 (key); 58 (1): 3. ठ.

nigrolineatus (Viereck). Colo., n.e. N. Mex. Host: Faronta diffusa (Wlk.).

Hypothereutes nigrolineatus Viereck, 1912. U. S. Natl. Mus., Proc. 43: 590..

noctuae (Ashmead). Conn., Va., s. Ont., n. Mich. Host: Elaphria versicolor (Grt.).

Limneria noctuae Ashmead, 1890 (1889). U. S. Natl. Mus., Proc. 12: 437. $\delta$. Notes in the U. S. Natl. Museum indicate that the holotype was reared from a larva of $E$. versicolor, a number of which had been found in Va. on birch, walnut, and dead leaves of oak on July 5,1884 ; the date " $12 / 7 / 84$ " which is on the label of the holotype is indicated in the notes as July 12,1884 , the emergence date of the specimen.

Hyposoter diversicolor Viereck, 1912. U. S. Natl. Mus., Proc. 43: 590. ㅇ.

Angitia triops Walley, 1929. Canad. Ent. 61: 191. ठ. N. syn.

notatus (Gravenhorst). Interior Alaska; Europe. The specimen upon which the Alaskan record is based is in the collection of the American Entomological Institute; it was identified by Dr. Henry K. Townes. I thank Dr. Townes for allowing me to publish the record.

Campoplex notatus Gravenhorst, 1829. Ichn. Europaea, v. 3, p. 570. ठ, ?.

occidentali (Viereck). Southeastern Alta. Host: Oidaematophomis occidentalis Wlsm.

Campoplex (Hyposoter) occidentali Viereck, 1925; 1926. Canad. Ent. 57 (8): 204 (key); 58 (9): 219. + .

parorgyiae (Viereck). Que., Maine, Mass., Ont., Mich., Wis. Host: Dascychira sp. on fir, D. obliquata (G. and R.), D. plagiata (Wlk.). Finlayson (1966) discussed the intriguing false cocoon which is spun by this species, the true cocoon being situated inside the skin of the host larva.

Limnerium (Hyposoter) parorgyiae Viereck, 1910. U. S. Natl. Mus., Proc. 38: 382. ơ, \&.

Biology: Finlayson, 1966. Canad. Ent. 98: 139.

Taxonomy: Finlayson, 1975. Ent. Soc. Canada, Mem. 94: 70, 72, 126, 137 (final-instar larva). pectinatus (Thomson). Eastern Greenland; Europe. Host: Gynaephora groenlandica (Hom.). Anilasta pectinata Thomson, 1887. Opusc. Ent. 11: 1171. \&.

Limneria Deichmanni Nielsen, 1907. Meddel. om Gronland 29: 386. §, \&.

Taxonomy: Roman, 1930. Ann. and Mag. Nat. Hist. (10) 5: 287.

Biology: Johansen, 1910. Meddel om Gronland 43: 44, 46. - Nielsen, 1910. Meddel. om Gronland 43: 56 .

planatus (Viereck). Northern Idaho, s. B. C.

Campoplex (Diadegma) planata Viereck, 1925; 1926. Canad. Ent. 57 (9): 227 (key); 58 (11): 281. $\%$. In the 1926 portion of Viereck's revision as "Campoplex (Ecphora) planata."

plesius (Viereck). Ont.

Campoplex (Hyposoter) plesius Viereck, 1925; 1926. Canad. Ent. 57 (8): 203 (key); 58 (8): 201. + .

popofensis (Ashmead). Que. w. to interior and s.w. Alaska, s. to Md., N. Mex., and n. Calif.; Europe. The European record is based upon my identification of a single male from the Netherlands in the U. S. Natl. Museum collection.

Ameloctnus popofensis Ashmead, 1902. Wash. Acad. Sci., Proc. 4: 237. $\%$.

Campoplex (Diadegma) mificruris Viereck, 1925; 1926. Canad. Ent. 57 (9): 227 (key); 58 (11): 280 . ㅇ. 
rivalis (Cresson), n. comb. N. S. w. to Man. and w. Wash., s. to s. Ala., central Tex., s. Ariz., and s. Calif.; Mexico s. to Costa Rica. Host: Apantesis sp., Diacrisia virginica (F.)., Estigmene acrea (Drury), Euchaetias egle (Drury), Hyphantria cunea (Drury), $H$. textor (Harris), Leptarctia californiae (Wlk.).

Limneria rivalis Cresson, 1872. Amer. Ent. Soc., Trans. 41: 173. “ $\delta "=q ?$ ? $q$ misdet.). I regard Cresson's (1916) statement - type No. 1588, U. S. N. M., "male abdomen gone" as fixing as lectotype that specimen which Cresson regarded as the male of rivalis and which has been labeled as such in what appears to be the hand of R. A. Cushman. There is nothing in Cresson's introductory remarks to indicate that it was his intention only to select lectotypes for species having syntypes in the Academy of Natural Sciences, but Cushman (1925) regarded Cresson's statement about the type of rivalis as "not to be taken as type selection, for he is here merely quoting from Crawford and Rohwer's statement regarding the condition of the Cresson types in the National Museum." Cushman found that both syntypes lacked abdomens, but because the female symbol on Cresson's identification label appears to have been put there by Cresson, Cushman had no doubt about which of the two specimens Cresson had referred to as the male, and there are no grounds for his contention that Cresson did not select a lectotype.

Therefore, Cushman's selection of Cresson's female as lectotype is invalid. The female is a specimen of Hyposoter grahami (Viereck), a species having the ovipositor much longer than typical species of Hyposoter. I am undecided about the sex of the rivalis lectotype, but Cresson's characterization of the abdomen (apparently of both sexes) as "subcompressed at tip" and his color description of the abdomen of the "male" would appear to indicate that the lectotype is a female.

Limneria pilosula Provancher, 1886. Addit. Corr. Faune Ent. Canada Hym., p. 89. §, ๆ. N. syn.

Limneria ephestiae Riley, 1890. In Riley and Howard, U. S. Dept. Agr., Insect Life 3: 158. Nomen nudum.

Limneria ephestriae Ashmead, 1896. Amer. Ent. Soc., Trans. 23: 195. ठ, ?. The type specimens bear labels with Riley's number $239 x$; the only notes pertaining to number $239 x$ read: "Campoplex sp. ... parasitic on something feeding on wax - perhaps Ephestia zeae." The discrepancies in the dates cited by Ashmead and by Riley and Howard (1890), would appear to indicate that Riley got his notes mixed up. N. syn. Amorphota perrivalis Viereck, 1905. Kans. Acad. Sci., Trans. 19: 307. §, ๆ. N. syn. Campoplex (Hypotherentes) clarus Viereck, 1925; 1926. Canad. Ent. 57 (8): 204 (key); 58 (9): 224. ․ N. syn.

Campoplex (Ameloctonus) cuneae Viereck, 1925; 1926. Canad. Ent. 57 (9): 223 (key); 58 (10): 257. ․ . N. syn.

Taxonomy: Cresson, 1916. Amer. Ent. Soc., Mem. 1: 1-2, 51. -Cushman, 1925. Ent. Soc. Wash., Proc. 27: 166.

Biology: Timberlake, 1912. U. S. Dept. Agr., Bur. Ent., Tech. Ser. 19: 72, 90-91. -Dustan, 1921. Ent. Soc. Nova Scotia, Proc. 6: 81-88. - Tothill, 1922. Canada Dept. Agr., Bul. (n. s.) 3: 59-74. - Baerg, 1928. Ark. Agr. Expt. Sta. Bul. 224: 23, 24. -Swain, 1937. Colo.-Wyo. Acad. Sci., Jour, 3 (2 and 3): 43. - Swain, Green, and Portman, 1938. Kans. Ent. Soc., Jour. 11: 7-9. -Daviault, 1942. La Foret Quebecoise 4: 398.

rubiginosus Cushman. Mass., Conn. Host: Dasychira basiflava (Pack.), D. obliquata (G. and R.). The final-instar larva constructs a false cocoon like that of parorgyiae; the true cocoon is spun inside the skin of the host larva.

Hyposoter rubiginosus Cushman, 1924. U. S. Natl. Mus., Proc. 64 (4): 11. o, ?. synchlorae (Ashmead). N. H., Mass., N. Y., N. J., Pa., Md., w. N. C., Mich., Ill.? Host: Synchlora sp., S. aerta (F.).

Limneria mfa Riley, 1890. In Riley and Howard, U. S. Dept. Agr., Insect Life 3: 157. Nomen nudum.

Limneria rufa Ashmead, 1896. Amer. Ent. Soc., Trans. 23: 193. ¿. Preocc. by Bridgman, 1882. N. syn. Townes (1945) incorrectly indicated that the syntypes are female and not male. Ashmead stated the type locality is Mo., but Riley and Howard (1890) indicated that the specimens are from South Pass, Ill. Riley's notes indicate that the specimens 
were reared from larvae of what is now called Synchlora aerta which had been sent by T. A. E. Holcomb of South Pass, Ill. I have not been able to determine that there is or ever was a South Pass in Ill., and the matter merits further research because the syntypes of rufa were reared together with those of Aplodes mibivora Riley, presently a synonym of Synchlora aerta.

Ischioscopus syuchlorae Ashmead, 1898. In Dimmock and Ashmead, Ent. Soc. Wash., Proc. 4: 168. o.

Limnerium Sarntheinii Dalla Torre, 1901. Cat. Hym., v. 3, p. 104. N. name for L. rufa Ashmead. N. syn.

Taxonomy: Townes, 1945. Amer. Ent. Soc., Mem. 11: 672.

xanthocerus (Viereck). N. H. s. to Va., w. to Mich.

Ameloctonus xanthocerus Viereck, 1921. Psyche 28: 70..

\section{Genus BENJAMINIA Viereck}

Benjaminia Viereck, 1912. U. S. Natl. Mus., Proc. 42: 633.

Type-species: Charops fuscipennis Provancher. Monotypic and orig. desig.

Zachrestoides Viereck, 1925. Canad. Ent. 57: 177.

Type-species: Zachrestoides euphydryadis Viereck. Orig. desig.

This is a small Holaretic genus. The species B. fumigator Aubert and B. polonica Sawoniewicz were rather recently described from Europe. The North American species which have been reared parasitize Nymphalidae of the genera Euphydryas and Melitaea. I have seen material that appears to represent three undescribed Nearctic species.

fuscipennis (Provancher). Southwestern Alta.?, w. Nev., n.e. and s. Calif. Host: Euphydryas chalcedona (D. and H.).

Charops fuscipenuis Provancher, 1888. Addit. Corr. Faune Ent. Canada Hym., p. 365. $q$. euphydryadis (Viereck). Que., Mass. Host: Euphydryas phaeton (Drury), Melitaea harrisii Scud.

Zachrestoides euphydryadis Viereck, 1925; 1926. Canad. Ent. 57 (7): 179 (key); 58 (1): 3..

\section{Genus ECHTHRONOMAS Foerster}

Echthronomas Foerster, 1868. Naturh. Ver. Rheinlande, Verh. 25: 151.

Type-species: Casinaria ochrostoma Holmgren. By subsequent monotypy from inclusion by Schmiedeknecht, 1908.

This is a small genus of Holaretic and Oriental distribution.

Revision: Walley, 1944. Canad. Ent. 76: 158-159.

ochreofrons lexiphaga Walley. Que. w. to s. B. C., s. to Md., W. Va., and Mich. Host: Crambidia casta (Pack.), Tigrioides bicolor (Grt.).

Echthronomas ochreofrons lexiphaga Walley, 1944. Canad. Ent. 76: 159. §, ᄋ.

Taxonomy: Finlayson, 1975. Ent. Soc. Canada, Mem. 94: 82, 83, 134, 137 (final-instar larva).

ochreofrons ochreofrons Cushman. Md. w. to n.e. Kans., s. to n. Fla.

Echthronomas ochreofrons Cushman, 1924. U. S. Natl. Mus., Proc. 64 (4): 12..

\section{Genus CAMPOCTONUS Viereck}

Campoctonus Viereck, 1912. U. S. Natl. Mus., Proc. 42: 633.

Type-species: Limueria corrupta Cresson. Monotypic and orig. desig.

Campoctonoides Viereck, 1925. Canad. Ent. 57: 177.

Type-species: Campoctonoides currani Viereck. Orig. desig.

This is a Neotropic and Nearctic genus of small to moderate size. No hosts are known. Mr. G. S. Walley has completed a revision of the Nearctic species which undoubtedly will be published before the appearance of this catalog.

belfragei (Ashmead). R. I. w. to s. Mich., s. to e. N. C. and Tex.

Limineria Belfragei Ashmead, 1890 (1889). U. S. Natl. Mus., Proc. 12: 435. §. 
carinatus (Provancher). Que. w. to n.w. Wis., s. to W. Va. and Mo.

Campoplex carinatus Provancher, 1879. Nat. Canad. 11: 150..+

Campoctonoides beaulnei Viereck, 1925. Canad. Ent. 57 (7): 177 (key); 57 (12): 297..

corruptus (Cresson). Central Tex., Colo.

Limneria corrupta Cresson, 1872. Amer. Ent. Soc., Trans. 4: 172..

currani (Viereck). Que., Maine, N. H., N. Y., Pa., Ont., Mich.

Campoctonoides currani Viereck, 1925. Canad. Ent. 57 (7): 177 (key); 57 (12): 296. ô,.

harringtoni (Viereck). Que., N. H., Vt., Conn., Ont., Mich.

Campoctonoides harringtoni Viereck, 1925. Canad. Ent. 57 (7): 177 (key): 57 (12): 297..

\section{Genus XANTHOCAM POPLEX Morley}

Xanthocampoplex Morley, 1913. Fauna Brit. India, Hym., v. 3, pt. 1, p. 445.

Type-species: Xanthocam poplex orientalis Morley. Monotypic and orig. desig. The type-species is regarded as a synonym of $X$. nigromaculatus (Cameron).

This is a large genus which is distributed throughout the world, but with species most numerous in the tropics. The hosts are lepidopterous caterpillars which do not conceal themselves when feeding.

Revision: Gupta and Gupta, 1971. Oriental Insects 5: 153-164 (Indian spp.). orbitalis (Walley). Southern Mich., n.e. Kans., s. Sask., Alta.

Nepiera albomaculata Ashmead, 1922. In Crevecoer, Kans. Acad. Sei., Trans. 30: 387.

Nomen nudum.

Cam poctonus orbitalis Walley, 1944. Canad. Ent. 76: 160..+

Taxonomy: Townes, 1970 (1969). Amer. Ent. Inst., Mem. 13: 190 (generic placement).

\section{Genus MICROCHAROPS Roman}

Microcharops Roman, 1910. Ent. Tidskr. 31: 178.

Type-species: Limneria taitica Holmgren. Monotypic and orig. desig.

Charopsimorpha Viereck, 1912. U. S. Natl. Mus., Proc. 42: 635.

Type-species: Charops tibialis Cresson. Orig. desig.

Paracharops Blanchard, 1940. In Kreibohm de la Vega, Tucuman Estac. Expt. Agr., Rev.

Indus. y Agr. 3: 170. Nomen nudum (fig. only).

Paracharops Blanchard, 1942. Soc. Cient. Argentina, An. 134: 107.

Type-species: Paracharops annulatus Blanchard. Monotypic and orig. desig.

This is a genus of small to moderate size which is not known with certainty to occur outside of the New World. The occurrence of $M$. taitica (Holmgren) in Tahiti has apparently not been confirmed by the collection of additional specimens, and it may be that the holotype is mislabeled.

bimaculata (Ashmead). Mo., Tex.; West Indies and Mexico s. to Argentina. Host: Alabama argillacea (Hbn.), Plathypena scabra (F.).

Charops bimaculata Ashmead, 1895. Zool. Soc. London, Proc. 65: 778. ९.

Charops unicinctus Ashmead, 1900. Ent. Soc. London, Trans. 48: 272. ๆ.

Paracharops annulatus Blanchard, 1940. In Kreibohm de la Vega, Tucuman Estac. Expt. Agr., Rev. Indus. y Agr. 3: 170. Nomen nudum (fig. only).

Paracharops annulatus Blanchard, 1942. Soc. Cient. Argentina, An. 134: 107. “ $\delta "=\wp$.

Taxonomy: Townes and Townes, 1966. Amer. Ent. Inst., Mem. 8: 155 (syn.).

tibialis (Cresson). Conn., Va., Ga., s. Mich., Ill., n.e. Kans., Tex.; Mexico, Cuba, Costa Rica,

Brazil. Host: Symmerista albifrons (J. E. S.), S. canicosta Francl., Asterocampa celtis

(B. and L.), A. clyton (B. and L.).

Charops tibialis Cresson, 1872. Amer. Ent. Soc., Trans. 4: 173. ठे.

Limneria? insolens Cresson, 1874 (1873). Acad. Nat. Sci. Phila., Proc. 25: 386. o,.+

Charops apaturae Riley, 1890. In Riley and Howard, U. S. Dept. Agr., Insect Life 3: 155.

Nomen nudum.

Charops apaturae Ashmead, 1896. Amer. Ent. Soc., Trans. 23: 193. ठै.

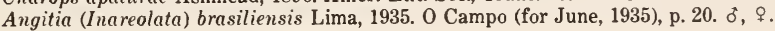

Preocc. in Microcharops by Szepligeti, 1906. 
UNPLACED TAXa OF CAMPOPLEgINI

Pyrachmon(!) idahoensis Davis, 1898 (1897). Amer. Ent. Soc., Trans. 24: 363. . Northern Idaho. Neither of the two syntypes has been found.

\section{SubFamily CREMASTINAE}

Members of this subfamily are internal parasites of Lepidoptera and, to a lesser extent, Coleoptera which are concealed while feeding (i.e. leaf rollers, borers, etc.). Dr. Clement Dasch is preparing a revision of the Nearctic species.

\section{Genus XIPHOSOMELLA Szepligeti}

Xiphosomella Szepligeti, 1905. In Wytsman, Gen. Ins., Fasc. 34, p. 4.

Type-species: Xiphosomella brasiliensis Szepligeti. Monotypic.

Pristomerus subg. Areolopristomerus Cushman, 1920. U. S. Natl. Mus., Proc. 58: 274.

Type-species: Pristomerus (Areolopristomerus) smithi Cushman. Orig. desig.

This large genus is mostly Neotropical. In addition to the two Nearctic species listed below, I know a third one from Florida which is apparently undescribed.

Revision: Johnson, 1969. Mich. Ent. 2: 27-28.

dubia (Brues). Mass., s.e. Ont., and Mich., s. to Fla. and Tex.

Pristomeridia! dubia Brues, 1911. Psyche 18: 24. \&.

Pristomerus (Areolopristomerus) smithi Cushman, 1920. U. S. Natl. Mus., Proc. 58: 274.. setoni Johnson. N. C., Ky., S. C., Fla.

Xiphosomella setoni Johnson, 1969. Mich. Ent. 2: 27. đँ, ‡.

\section{Genus PRISTOMERUS Curtis}

Pristomerus Curtis, 1836. Brit. Ent., v. 13, no. 624.

Type-species: Pachymerus vulnerator Gravenhorst. Monotypic and orig. desig. The type-species designation is Gravenhorst's identification of Ichneumon vulnerator Panzer.

Pristomeridia Ashmead, 1900. U. S. Natl. Mus., Proc. 23: 100.

Type-species: Porizon agilis Cresson. Monotypic and orig. desig.

Pristocelus Szepligeti, 1905. In Wytsman, Gen. Ins., fasc. 34, p. 48.

Type-species: Pristocelus atriceps Szepligeti. Monotypic.

Neopristomerus Viereck, 1912. U. S. Natl. Mus., Proc. 43: 592.

Type-species: Pristomerus appalachianus Viereck. Orig. desig.

Nesanomalon Morley, 1913. Rev. Ichn. Brit. Mus., v. 2, p. 56.

Type-species: Nesanomalon dimidiatum Morley. Monotypic.

Revision: Cushman, 1920. U. S. Natl. Mus., Proc. 58: 272-280.

austrinus Townes and Townes. Mass. s. to Ga., w. to Ind. and Tex.; Mexico, Guatemala. Host: Acrobasis caryivorella Rag., A. vaccinii Riley, Epiblema scudderianum (Clem.), Grapholitha molesta (Bsk.), Gretchena bolliana (Sling.), Gypsonoma haimbachiana (Kft.), Laspeyresia pomonella (L.).

Porizon? agilis Cresson, 1872. Amer. Ent. Soc., Trans. 4: 175. + . Preocc. by Holmgren, 1860.

Pristomerus austrinus Townes and Townes, 1951. In Muesebeck et al., U. S. Dept. Agr., Agr. Monog. 2: 386. N. name for Porizon agilis Cresson.

Biology: Franklin and Morse, 1914. Mass. Agr. Expt. Sta., Bul. 150: 56. -Franklin, 1915;

1916; 1917. Mass. Agr. Expt. Sta., Bul. 160: 109; 168: 39-40; 180: 229.

baumhoferi Cushman. Ont., S. Dak. w. to Ida., s. to Tex. and Ariz. Host: Rhyacionia frustrana bushnelli (Bsk.), Periploca ceanothiella (Cosens).

Pristomerus baumhoferi Cushman, 1930 (1929). U. S. Natl. Mus., Proc. 76 (25): 9. ठ,. euryptychiae Ashmead. N. Y. s. to Alab., w. to Wis., Kans., and Tex. Host: Ancylis comptana (Froel.), Ecdytolopha insiticiana Zeller, Epiblema otiosanum (Clem.), E. strenuanum (Wlk.), Grapholitha molesta (Bsk.), Gypsonoma haimbachiana (Kft.), Laspeyresia 
pomonella (L.), Proteoteras willingana (Kft.), Acrobasis caryivorella Rag., A. juglandis (LeB.), Vanessa atalanta (L.).

Pristomerus mellaethorax Riley, 1890. In Riley and Howard, U. S. Dept. Agr., Insect Life 3: 156. Nomen nudum.

Pristomerus euryptychiae Ashmead, 1896. Amer. Ent. Soc., Trans. 23: 192. \%. The type locality is Kirkwood, Mo.; Ashmead erroneously stated that it is D. C.

Pristomerus (Pristomerus) ocellatus Cushman, 1920. U. S. Natl. Mus., Proc. 58: 277. ơ, \&.

Biology: Pepper and Driggers, 1934. Ent. Soc. Amer., Ann. 27: 596. - Haden, 1935. Del. Agr. Expt. Sta., Bul. 194: 12-41. - Rice, 1937. Jour. Econ. Ent. 30: 112. -Allen, Holloway, and

Haeussler, 1940. U. S. Dept. Agr. Cir. 561: 12, 58.

laticeps Cushman. Conn., N. Y., N. J., Ont., Va.

Pristomerus (Pristomerus) laticeps Cushman, 1920. U. S. Natl. Mus., Proc. 58: 277..

Pristomerus (Pristomerus) idei Viereck, 1925. Canad. Ent. 57: 74...

minutus Cushman. Calif. Host: Coleotechnites milleri (Bsk.).

Pristomerus (Pristomernes) minutus Cushman, 1920. U. S. Natl. Mus., Proc. 58: 279..

olamonus Viereck. Mass. s. to D. C., w. to S. Dak. and Kans. Ecology: Occurs on flowers of Solidago in late summer and fall.

Pristomerus aciculatus Ashmead, 1900 (1899). In Smith, N. J. State Bd. Agr., Ann. Rpt. 27, Sup., p. 584. Nomen nudum.

Pristomerus olamonus Viereck, 1917 (1916). Conn. State Geol. and Nat. Hist. Survey Bul. 22: 274.. .

Pristomerus (Pristomemis) fuscipennis Cushman, 1920. U. S. Natl. Mus., Proc. 58: 275. ठ', †.

spinator (Fabricius). Mass. s. to Fla., w. to Alta. and Calif.; Mexico, Virgin Islands, Honduras, Guyana?, Brazil; Hawaii. Host: Acrobasis caryivorella Rag., A. vaccinii Riley, Canarsia sp., Elasmopalpus lignosellus (Zell.), Loxostege sticticalis (L.), Heliothis virescens (F.), H. zea (Bod.), Spodoptera frugiperda (J. E. S.), S. praefica (Grt.), Trichoplusia ni (Hbn.), Phthorimaea operculella (Zell.), Colias eurytheme Bdv.

Ophion spinator Fabricius, 1804. Systema Piezatorum, p. 138.. . Temporarily preocc. in Ichneumon by Fabricius, 1798.

Ichneumon femorator Thunberg, 1822; 1824. Acad. Imp. des Sci. St. Petersburg, Mem. 8: 261; 9: 311. N. name for O. spinator Fabricius. Preocc. by Kirby, 1802.

Pristomerus pacificus Cresson, 1879 (1878). Acad. Nat. Sci. Phila., Proc. 30: 370. $q$.

Pristomerus appalachianus Viereck, 1905. Kans. Acad. Sci., Trans. 19: 299. ठँ, .

Pristomerus coloradensis Brues, 1911. Psyche 18: 23. $९$. N. syn.

Pristomerus (Neopristomerus) melleus Cushman, 1920. U. S. Natl. Mus., Proc. 58: 279. ठ, ९. N. syn.

Pristomerus Bollowi Enderlein, 1921. Stettin. Ent. Ztg. 82: 9. ठ. N. syn.

Neopristomerus woodworthi Viereck, 1921. Ent. News 32: 172. ठ, ค. N. syn.

Taxonomy: Townes and Townes, 1966. Amer. Ent. Inst., Mem. 8: 158 (Syn.).

Biology: Luginbill, 1928. U. S. Dept. Agr., Tech. Bul. 34: 65. - Vickery, 1929. U. S. Dept.

Agr., Tech. Bul. 138: 39. - Leuck, 1966. Jour. Econ. Ent. 59: 800.

\section{Genus DIMOPHORA Foerster}

Dimophora Foerster, 1868. Naturh. Ver. Rheinlande, Verh. 25: 155.

Type-species: Dimophora robusta Brischke. Desig. by Viereck, 1914 from three species included by Brischke, 1880.

Dimophorus Thomson, 1890. Opusc. Ent. 14: 1356. Emend.

Oligotmema Cushman, 1920. U. S. Natl. Mus., Proc. 58: 280.

Type-species: Oligotmema prima Cushman. Monotypic and orig. desig.

prima (Cushman). Ont., Colo., Idaho, Utah, Ariz. The type locality is Fort Collins, Colo.

Oligotmema prima Cushman, 1920. U. S. Natl. Mus., Proc. 58: 281..

Taxonomy: Cushman, 1922. U. S. Natl. Mus., Proc. 60 (21): 22. 


\section{Genus EIPHOSOMA Cresson}

Eiphosoma Cresson, 1865. Ent. Soc. Phila., Proc. 4: 52.

Type-species: Eiphosoma annulatum Cresson. Desig. by Viereck, 1914.

Xiphosoma Marshall, 1892. Soc. Ent. de France, Ann. 61: 65. Emend.

Brachixiphosoma Viereck, 1912. U. S. Natl. Mus., Proc. 42: 147.

Type-species: Eiphosoma pyralidis Ashmead. Monotypic and orig. desig.

Chartionedys Enderlein, 1921. Stettin. Ent. Ztg. 82: 3.

Type-species: Chartionedys compressum Enderlein. Orig. desig.

Hanauella Enderlein, 1921. Stettin. Ent. Ztg. 82: 6.

Type-species: Hanauella armillata Enderlein. Monotypic and orig. desig.

This is a very large genus of the New World, most of the species being Neotropic. Pyraloidea appear to be the principle hosts.

Revision: Cushman, 1920. U. S. Natl. Mus., Proc. 58: 269-272.

dentator (Fabricius). Southern Tex.; West Indies; Mexico s. to Argentina. Host: Mimorista

flavidissimalis (Grt.), Ufa rubidinella (Zell.).

Ophion dentator Fabricius, 1804. Systema Piezatorum, p. 138. [female].

Eiphosoma annulata Cresson, 1865. Ent. Soc. Phila., Proc. 4: 54. ठ, $९$.

Eiphosoma bruesi Cushman, 1920. U. S. Natl. Mus., Proc. 58: 272. १. N. syn.

Eiphosoma Saueri Lima, 1953 (1951). [Rio de Janeiro] Mus. Nac., Arq. 42: 188. §, $९$.

Taxonomy: Townes and Townes, 1966. Amer. Ent. Inst., Mem. 8: 162 (syn.).

nigrolineatum (Brulle). Fla.; Mexico, Guatemala, French Guiana, Guyana, Peru, Paraguay.

Collyria nigro-lineata Brulle, 1846. In Lepeletier, Hist. Nat. Ins. Hym., v. 4, p. 178..

Eiphosoma mexicana Cresson, 1874 (1873). Acad. Nat. Sci. Phila., Proc. 25: 380..

Taxonomy: Townes and Townes, 1966. Amer. Ent. Inst., Mem. 8: 163 (syn.).

pyralidis Ashmead. N. Y. s. to N. C., w. to Kans. Host: Pyralid on Soligdago.

Eiphosoma pyralidis Riley, 1890. In Riley and Howard, U. S. Dept. Agr., Insect Life 3: 156. Nomen nudum.

Eiphosoma pyralidis Ashmead, 1896. Amer. Ent. Soc., Trans. 23: 191. §ै.

septentrionale Brues. Conn. s. to S. C., w. to Ill. and Ala.

Eiphosoma septentrionale Brues, 1911. Psyche 18: 22..

texanum Cresson. Tex., Utah, Ariz.; Mexico, Trinidad, Guyana, Brazil.

Eiphosoma texana Cresson, 1872. Amer. Ent. Soc., Trans. 4: 176..

\section{Genus PSEUDERIPTERNUS Viereck}

Casinaria subg. Pseuderipternus Viereck, 1917 (1916). Conn. State Geol. and Nat. Hist. Survey Bul. 22: 269.

Type-species: Podogaster radiolatus Provancher. Monotypic.

This genus may occur in both South and North America; a USNM specimen of a large undescribed species was caught by the U. S. Public Health Service aboard an airplane which had arrived at Miami, Fla. from Buenos Aires, Argentina via Lima, Peru and Guayaquil, Ecuador. The species are collected among coarse grasses along lake shores or in salt marshes. Schoenobiine pyralids may be the usual hosts.

Revision: Cushman, 1917. U. S. Natl. Mus., Proc. 53: 505-508.

brevicauda Cushman. N. H., N. Y., Ont., Mich., Ohio. Host: Schoenobius melinellus (Clem.).

Pseuderiptermus brevicauda Cushman, 1917. U. S. Natl. Mus., Proc. 53: 506. ठ, ९.

elongatus (Davis). Mass., N. J., Ga. Ecology: Occurs in salt marshes on Spartina.

Ateleuti (!) elongatus Davis, 1898 (1897). Amer. Ent. Soc., Trans. 24: 362 ..

Pseuderipternus gracilipes Cushman, 1917. U. S. Natl. Mus., Proc. 53: 507. ठ̀, 9.

radiolatus (Provancher). Que. s. to $\mathrm{Md}$.

Podogaster radiolatıs Provancher, 1875. Nat. Canad. 7: 329..

\section{Genus TANYCHELA Townes}

Tanychela Townes, 1971. Amer. Ent. Inst., Mem. 17: 19. 
Type-species: Tanychela aurea Townes. Monotypic and orig. desig.

The type-species occurs in southeastern Brazil. An undescribed species occurs in California; it has been reared from a stream-dwelling pyralid, Argyractis sp.

\section{Genus CREMASTUS Gravenhorst}

Cremastus Gravenhorst, 1829. Ichn. Europaea, v. 3, p. 730.

Type-species: Cremastus spectator Gravenhorst. Desig. by Westwood, 1840.

Celor Kokujev, 1901. Soc. Ent. Rossicae, Horae 35: 210.

Type-species: Celor semenowi Kokujev. Monotypic.

Pseudocremastus Szepligeti, 1905. In Wytsman, Gen. Ins., fasc. 34, p. 50.

Type-species: Pseudocremastus radialis Szepligeti. Monotypic.

Zaleptopygus Viereck, 1911. U. S. Natl. Mus., Proc. 41: 294.

Type-species: Zaleptopygus obereae Viereck. Monotypic and orig. desig.

According to Townes (1971) this is a large Holarctic genus for which the usual hosts are coleopterous stem borers or gall makers, although there are also rearings recorded from lepidopterous larvae.

Taxonomy: Townes, 1958. Insects of Micronesia, v. 2, no. 2, p. 65. -Townes, 1971. Amer. Ent. Inst., Mem. 17: 16.

anomalus Cushman. Colo.

Cremastus (Zaleptopygus) anomalus Cushman, 1917. U. S. Natl. Mus., Proc. 53: 542..

bilineatus Cushman. N. J., Mich.

Rhythmonotus bilineatus Ashmead, 1900 (1899). In Smith, N. J. State Bd. Agr., Ann. Rpt. 27, Sup., p. 581. Nomen nudum.

Cremastus (Zaleptopygus) bilineatus Cushman, 1917. U. S. Natl. Mus., Proc. 53: 545. ठ, ․ californicus (Provancher). Calif. Barron (1975) placed this species in Cremastus.

Porizon Californicum Provancher, 1888. Addit. Corr. Faune Ent. Canada Hym., p. 364. ð.

Taxonomy: Barron, 1975. Nat. Canad. 102: 438-439.

champlaini Cushman. N. Y., Pa., Va., Mich., S. Dak. Host: "Elaphidion" sp.

Cremastus (Zaleptopygus) champlaini Cushman, 1922. U. S. Natl. Mus., Proc. 60 (21): 22. $\delta, ?$.

eressoni Kerrich. Colo.

Porizon albipennis Cresson, 1865. Ent. Soc. Phila., Proc. 4: 287. \&. Preoce. by Zetterstedt, 1838.

Cremastus cressoni Kerrich, 1959. Ann. and Mag. Nat. Hist. (13) 2: 50. N. name for $P$. albipennis Cresson.

doreaschemae Cushman. N. Y. Host: Dorcaschema nigrum (Say).

Cremastus (Zaleptopygus) dorcaschemae Cushman, 1920. U. S. Natl. Mus., Proc. 58: 287. ¿. + .

Biology: Blackman and Stage, 1924. N. Y. State Col. Forestry, Tech. Pub. 17: 182.

egregiacolor (Viereck). Kans., Colo., N. Mex.

Thersilochus egregiacolor Viereck, 1905. Kans. Acad. Sci., Trans. 19: 302. ๆ.

Cremastus (Zaleptopygus) terebratus Cushman, 1917. U. S. Natl. Mus., Proc. 53: 539..+

fuscipennis (Cresson). Kans., Tex., Colo.

Porizon fuscipennis Cresson, 1865. Ent. Soc. Phila., Proc. 4: 287...

Pcrizon audax Cresson, 1872. Amer. Ent. Soc., Trans. 4: 174. ठ'.

gallaecola Cushman. Ont., Va., Tex. Host: Gnorimoschema gallaesolidaginis (Riley).

Cremastus (Zaleptopygus) gallaecola Cushman, 1917. U. S. Natl. Mus., Proc. 53: 546. o, o.

hyalinipennis (Cresson). N. J. s. to Fla., w. to S. Dak. and Tex.

Porizon hyalinipennis Cresson, 1872. Amer. Ent. Soc., Trans. 4: 174. §, ๆ.

incompletus (Provancher). Que. s. to N. C., w. to Man.

Mesoleptus incompletus Provancher, 1875. Nat. Canad. 7 (9): 270. ठ, ᄋ.

Atractodes fusiformis Provancher, 1875. Nat. Canad. 7 (11): 332. ?.

Morphology: Peck, 1937. Canad. Jour. Res., Sect. D. (Zool. Sci.) 15: 245, 246, 149, 250. 
mordellistenae (Cushman). Colo. Host: Mordellistena aemula LeC., M. morula LeC.

Cremastus mordellistenae Ashmead, 1895. In Baker, Ent. News 6: 29. Nomen nudum.

Cremastus (Zaleptopygus) mordellistenae Cushman, 1917. U. S. Natl. Mus., Proc. 53: 539. $\delta$, ?.

Taxonomy: Cushman, 1927. U. S. Natl. Mus., Proc. 72 (13): 20-21.

nigriclypealis Cushman. N. Mex.

Cremastus (Zaleptopygus) nigriclypealis Cushman, 1917. U. S. Natl. Mus., Proc. 53: 543. ㅇ.

nordi Townes. Mich. Host: Oberea shaumii LeC.

Cremastus nordi Townes, 1965. Mich. Acad. Sci., Arts, and Letters, Papers 50: 105. o, $\uparrow$. orbitalis (Cresson). Md., Ala., Tex.

Porizon orbitalis Cresson, 1872. Amer. Ent. Soc., Trans. 4: 174. ठ,.+

orbus (Davis). Conn., N. Y., N. J., Pa., Mich., Ill., La. Host: Oberea tripunctata Swed.

Leptopygus orbus Davis, 1898 (1897). Amer. Ent. Soc., Trans. 24: 365. đo, ९.

Zaleptopygus obereae Viereck, 1911. U. S. Natl. Mus., Proc. 41: 295. ¿', ๆ.

Taxonomy: Cushman, 1920. U. S. Natl. Mus., Proc. 58: 284.

quintilis (Viereck). Kans. Walkley (1967) apparently saw no specimens of this species before deciding to place it with a query in Cremastus rather than Trathala; it may prove to belong in the latter genus.

Thersilochus mimeticus Viereck, 1905. Kans. Acad. Sci., Trans. 19: 300. ․

Thersilochus quintilis Viereck, 1905. Kans. Acad. Sci., Trans. 19: 301. ठे.

Taxonomy: Walkley, 1967. In Krombein et al., U. S. Dept. Agr., Agr. Monog. 2, Sup. 2, p. 207. rohweri Cushman. $\mathrm{Pa}$.

Cremastus (Zaleptopygus) rohueri Cushman, 1917. U. S. Natl. Mus., Proc. 53: 541..

snowi (Viereck). Kans. Walkley (1967) apparently saw no specimens of this species before deciding to place it with a query in Cremastus rather than Trathala; it may prove to belong in the latter genus.

Thersilochus snowi Viereck, 1905. Kans. Acad. Sci., Trans. 19: 299. \&.

Taxonomy: Walkley, 1967. In Krombein et al., U. S. Dept. Agr., Agr. Monog. 2, Sup. 2, p. 207. vierecki (Cockerell). N. Mex.

Porizon Vierecki Cockerell, 1903. Ann. and Mag. Nat. Hist. (7) 12: 200. ठ。.

\section{Genus DOLICHOPSELEPHUS Ashmead}

Dolichopselephus Ashmead, 1890. Colo. Biol. Assoc., Bul. 1: 23.

Type-species: Dolichopselephus cockerelli Ashmead. Monotypic.

cockerelli Ashmead. Sask., Colo.

Dolichopselephus cockerelli Ashmead, 1890. Colo. Biol. Assoc., Bul. 1: 23. ๆ.

\section{Genus TRATHALA Cameron}

Trathala Cameron, 1899. Manchester Lit. and Phil. Soc., Mem. and Proc. 43: 122.

Type-species: Trathala striata Cameron. Monotypic.

Epicremastus Szepligeti, 1905. In Wytsman, Gen. Ins., fasc. 34, p. 51.

Type-species: Epicremastus concolor Szepligeti. Monotypic.

Paurolexis Cameron, 1906. Bombay Nat. Hist. Soc., Jour. 17: 282.

Type-species: Paurolexis flavus Cameron. Monotypic.

Haristaeus Cameron, 1910 (1909). Amer. Ent. Soc., Trans. 35: 442.

Type-species: Haristaeus nigrifrons Cameron. Monotypic.

This large genus is worldwide in distribution.

Taxonomy: Townes, 1958. Insects of Micronesia, v. 2, no. 2, p. 66. -Townes, 1971. Amer. Ent. Inst., Mem. 17: 17-18.

aciculata (Davis). Mass., Conn., Mich., Ga.

Cremastus aciculatus Davis, 1898 (1897). Amer. Ent. Soc., Trans. 24: 364. ð. 
brunneipennis (Walley), n. comb. Ont.

Cremastus (Zaleptopygus) brunneipennis Walley, 1933. Canad. Ent. 65: 253. §, ?.

cleridivora (Cushman). N. C., Ga., Mo., Kans., Idaho. Host: Enoclerus quadriguttatus (Oliv.), E. sphegus (F.), Temnochila virescens (F.).

Cremastus (Zaleptopygus) cleridivorus Cushman, 1917. U. S. Natl. Mus., Proc. 53: 534..

delicata (Cresson). Tex.

Porizon? delicatus Cresson, 1872. Amer. Ent. Soc., Trans. 4: 176. đ.

flavoorbitalis (Cameron). Japan s. to Australia, w. to India; Hawaii. Introduced between 1929 and 1933 in Mass., R. I., Conn., N. Y., Ont., and Ohio and in 1935 and 1936 in Va.; recoveries were made in Mass., R. I., Ont., Ohio, and Va., but the species apparently has not persisted anywhere in North America. Host: Ostrinia mubilalis (Hbn.), Grapholitha molesta (Bsk.). The hosts listed were the target species for releases of $T$. flavoorbitalis in North America.

Tarytia flavo-orbitalis Cameron, 1907. Bombay Nat. Hist. Soc., Jour. 17: 589. ${ }^{\circ}$

Cremastus hymeniae Viereck, 1911. U. S. Natl. Mus., Proc. 40: 189. ठै, १.

Diaparsis coreanus Uchida, 1928. Hokkaido Imp. Univ., Faculty Agr., Jour. 21: 285. ठో, १.

Diaparsis coreanus var. kondonis Uchida, 1928. Hokkaido Imp. Univ., Faculty Agr., Jour.

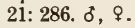

Taxonomy: Cushman, 1933. Ent. Soc. Wash., Proc. 35: 73.

Biology: Bradley and Burgess, 1934. U. S. Dept. Agr. Tech. Bul. 441: 1-15.

Morphology: Peck, 1937. Canad. Jour. Res., Sect. D (Zool. Sci.) 15: 245-247.

granulata (Davis). Mich.

Cremastus granulatus Davis, 1898 (1897). Amer. Ent. Soc., Trans. 24: 365. ठ, ๆ.

Taxonomy: Cushman, 1920. U. S. Natl. Mus., Proc. 58: 284 (lectotype selection).

hartii (Ashmead). N. J., D. C.?, Ky.?, Ill.

Cremastus hartii Ashmead, 1895. Ill. State Lab. Nat. Hist., Bul. 4: 277. ठ, \&.

Taxonomy: Hart, 1895. Ill. State Lab. Nat. Hist., Bul. 4: 271 (collecting locality and date).

-Cushman, 1930 (1929). U. S. Natl. Mus., Proc. 76 (25): 11 (discussion of syntypes,

excluding those in Ashmead collection).

latithorax (Cushman). Tex.

Cremastus (Zaleptopygus) latithorax Cushman, 1920. U. S. Natl. Mus., Proc. 58: 286.

nemoralis (Davis). Mass., N. Y., Mich.

Cremastus nemoralis Davis, 1898 (1897). Amer. Ent. Soc., Trans. 24: 364. ơ, ๆ.

Taxonomy: Cushman, 1920. U. S. Natl. Mus., Proc. 58: 284. (discussion of syntypes).

obesa (Cushman). Md.

Cremastus (Zaleptopygus) obesus Cushman, 1920. U. S. Natl. Mus., Proc. 58: 285..

plesia (Cushman). Mich.

Cremastus (Zaleptopygus) plesius Cushman, 1917. U. S. Natl. Mus., Proc. 53: 535..

protracta (Cushman), n. comb. Wash. Ecology: The host of the holotype was reared from Aster eastoni. Host: Coleophora sp.

Cremastus protractus Cushman, 1935. Wash. Acad. Sci., Jour. 25: 563. 9.

retiniae (Cresson). N. Y., Md.?, D. C.?, Va.? Host: Rhyacionia rigidana (Fern.).

Cremastus retiniae Cresson, 1880. In Comstock, U. S. Dept. Agr., Ann. Rpt. for 1879, p. 238. $\delta$. Notes in the U.S. Natl. Museum indicate that Comstock reared two specimens, one of which was placed in the Cresson collection and may actually be the one upon which Cresson based his description. The notes refer to a letter dated June 9, 1880 which Comstock received from Cresson and a letter dated June 23, 1880 which Comstock sent to Cresson.

Taxonomy: Cushman, 1917. U. S. Natl. Mus., Proc. 53: 537 (discussion of the broken specimen presumed to be the holotype and its comparison with specimens which apparently were not reared from Rhyacionia rigidana).

rosae (Cushman). N. J., Va.

Cremastus (Zaleptopygus) rosae Cushman, 1917. U. S. Natl. Mus., Proc. 53: 536.. 
rostrata (Cushman). Mass., Conn., N. Y., Pa., Md. Ecology: Occurs on flowers of Solidago.

Cremastus (Zaleptopygus) rostratus Cushman, 1917. U. S. Natl. Mus., Proc. 53: 532. §.

similis (Cushman). R. I., Conn., N. J., Pa., N. C., Idaho.

Cremastus (Zaleptopygus) similis Cushman, 1917. U. S. Natl. Mus., Proc. 53: 535..

tetralophae (Cushman). Fla.

Cremastus (Zaleptopygus) tetralophae Cushman, 1917. U. S. Natl. Mus., Proc. 53: 537. ठँ, q.

\section{Genus NELEOTHYMUS Foerster}

Neleothymus Foerster, 1868. Naturh. Ver. Rheinlande, Verh. 25: 200.

Type-species: Neleothymus (?) rufo-ornatus Cameron. By subsequent monotypy

from inclusion by Cameron, 1905.

According to Townes (1971) only two species are known.

Taxonomy: Townes, 1958. Insects of Micronesia, v. 2, no. 2, p. 68. -Townes, 1971. Amer. Ent.

Inst., Mem. 17: 16-17.

attenuatus (Cushman). S. C., Tex. Townes (1971) said that N. attenuatus may be only subspecifically distinct from the type-species.

Cremastus (Zaleptopygus) attenuatus Cushman, 1920. U. S. Natl. Mus., Proc. 58: 286. §, ㅇ.

\section{Genus NEOCREMASTUS Cushman}

Neocremastus Cushman, 1917. U. S. Natl. Mus., Proc. 53: 509.

Type-species: Porizon stigmaterus Cresson. Monotypic and orig. desig.

Townes (1971) said he has seen specimens of five Nearctic species, three of them being undescribed. He also speculated that the genus probably occurs in Eurasia.

Taxonomy: Townes, 1958. Insects of Micronesia, v. 2, no. 2, p. 66. -Townes, 1971. Amer. Ent. Inst., Mem. 17: 18.

mellipes (Provancher). Que., N. Y., N. J.

Atractodes mellipes Provancher, 1875. Nat. Canad. 7: 332..

stigmaterus (Cresson). Tex.

Porizon stigmaterus Cresson, 1872. Amer. Ent. Soc., Trans. 4: 174. ठ, १.

\section{Genus TEMELUCHA Foerster}

Temelucha Foerster, 1868. Naturh. Ver. Rheinlande, Verh. 25: 148.

Type-species: Porizon macer Cresson. Desig. by Perkins, 1962 from four species included by Ashmead, 1900.

Paracremastus Szepligeti, 1900. Termes. Fuzetek 23: 28.

Type-species: Paracremastus genalis Szepligeti. Monotypic.

Tarytia Cameron, 1907. Bombay Nat. Hist. Soc., Jour. 17: 587.

Type-species: Tarytia basimacula Cameron. Desig. by Viereck, 1914.

Androna Cameron, 1911. Transvaal Mus., Ann. 2: 185. Syn. uncertain.

Type-species: Androna fuscicomis Cameron. Desig. by Viereck, 1914.

Cremastus subg. Cremastidea Viereck, 1912. U. S. Natl. Mus., Proc. 43: 587.

Type-species: Cremastus (Cremastidea) chinensis Viereck. Monotypic and orig. desig. The type-species is regarded as a synonym of $T$. biguttula (Matsumura).

Neocremastus Meyer, 1930. Rev. Russe d'Ent. 24: 67. Preocc. by Cushman, 1917; syn. uncertain.

Type-species: Neocremastus asiaticus Meyer. Monotypic.

This very large genus is worldwide in distribution. The species typically parasitize lepidopterous larvae which conceal themselves in feeding.

Revision: Cushman, 1917. U. S. Natl. Mus., Proc. 53: 509-532 (as Cremastus, subg. Crematus).

Taxonomy: Townes, 1958. Insects of Micronesia, v. 2, no. 2, p. 68. 
brevicauda (Cushman). N. Mex.

Cremastus (Cremastus) brevicauda Cushman, 1917. U. S. Natl. Mus., Proc. 53: 528. ठ, १.

brevinervis (Cushman). Ariz.

Cremastus (Cremastus) brevinervis Cushman, 1920. U. S. Natl. Mus., Proc. 58: 282..

brevipetiolus (Cushman). N. Y., N. J., Pa., Md., Va.

Cremastus (Cremastus) brevipetiolus Cushman, 1917. U. S. Natl. Mus., Proc. 53: 525. ठँ, ๆ.

Temeleucha brevipetiolata (!) Walkley, 1967. In Krombein et al., U. S. Dept. Agr., Agr.

Monog. 2, Sup. 2, p. 208.

bruneiceps (Cushman). D. C.

Cremastus (Cremastus) bruneiceps Cushman, 1920. U. S. Natl. Mus., Proc. 58: 283. ․

carpocapsae (Cushman). Ohio. Host: Grapholitha molesta (Bsk.), Laspeyresia pomonella (L.).

Cremastus carpocapsae Cushman, 1930 (1929). U. S. Natl. Mus., Proc. 76: 11. ठ,.

chilonis (Cushman). Mich., Sask., Alta. Host: Stenochilo forbesellus (Fern.).

Cremastus chilonis Cushman, 1935. Wash. Acad. Sci., Jour. 25: 562. ठ', १.

Biology: Frohne, 1939. Amer. Micros. Soc., Trans. 58: 233, 325, 347.

cookii (Weed). N. Y. w. to Idaho, s. to Va., Kans. and Ariz. Host: Ancylis comptana (Froel.).

Cremastus cookii Weed, 1888. Ent. Amer. 4: 150. ¿, ?.

Cremastus cookii var. rufus Weed, 1888. Ent. Amer. 4: 151. ठ.

Temelucha websteri Ashmead, 1900 (1899). In Smith, N. J. State Bd. Agr., Ann. Rpt. 27, Sup., p. 584. Nomen nudum.

Biology: Fink, 1932. Jour. Agr. Res. 44: 555, 556. - Haden, 1935. Univ. Del. Agr. Expt. Sta., Bul. 194: 29-42. - Summerland, 1938. Kans. Acad. Sci., Trans. 40: 165.

enagoges (Cushman). N. J. s. to S. C., w. to Wis. and Kans. Host: Archips cerasivoranus (Fitch), Sparganothis sulfureana (Clem.), Epiblema strenuanum (Wlk.), Grapholitha molesta (Bsk.), Lapeyresia pomonella (L.), Rhyacionia frustrana (Comst.), R. frustrana bushnelli (Bsk.), Mompha eloisella (Clem.), "Phalonia" oenotherana (Riley).

Cremastus (Cremastus) epagoges Cushman, 1917. U. S. Natl. Mus., Proc. 53: 531. §,.

Biology: Isely and Ackerman, 1923. Ark., Univ., Agr. Expt. Sta. Bul. 189: 47. -Cushman, 1927. Jour. Agr. Res. 34: 618. - Haden, 1935. Del. Agr. Expt. Sta. Bul. 194: 22-41. - Rice, 1937. Jour. Econ. Ent. 30: 108-115.

evetriae (Cushman). N. Mex., Ariz. Host: Rhyacionia frustrana bushnelli (Bsk.).

Cremastus (Cremastus) evetriae Cushman, 1917. U. S. Natl. Mus., Proc. 53: 530. \&.

facilis (Cresson). Mass., Ont., and Iowa, s. to Fla., Tex., and N. Mex. Host: Crambus topiarius Zell., Hellula undalis (F.), Ostrinia obumbratalis (Led.), O. penitalis (Grt.), Isophrictis similiella (Chamb.).

Porizon facilis Cresson, 1872. Amer. Ent. Soc., Trans. 4: 175. ठ, ๆ. Porizon macer Cresson, 1872. Amer. Ent. Soc., Trans. 4: 175. ठ', ᄋ.

Biology: Franklin, 1921. Mass. Agr. Expt. Sta. Bul. 206: 159.

ferruginea (Davis). Mass., S. Dak., and Idaho, s. to Fla. and N. Mex. Host: Diatraea crambidoides Grt.

Cremastus ferrugineus Davis, 1898 (1897). Amer. Ent. Soc., Trans. 24: 364. §, १. Atrometus angitiodes Viereck, 1905. Kans. Acad. Sci., Trans. 19: 311.. .

Cremastus (Cremastus) graciliventris Cushman, 1917. U. S. Natl. Mus., Proc. 53: 522..+

Taxonomy: Cushman, 1920. U. S. Natl. Mus., Proc. 58: 282.

flaviceps (Cushman). Tex., Colo.

Cremastus (Cremastus) flaviceps Cushman, 1917. U. S. Natl. Mus., Proc. 53: 521. đ, ?.

forbesi (Weed). Mass. s. to S. C., w. to S. Dak. and Colo. Host: Argyrotaenia velutinana (Wlk.), Acleris minuta (Rob.), Sparganothis sulfureana (Clem.), Epiblema strenuanum (Wlk.), Episimus argutanus (Clem.), Grapholitha molesta (Bsk.), Rhopobota naevana (Hbn.), Aroga trialbamaculella (Chamb.), Filatima persicaeella (Murtf.), Coleophora fuscedinella Zell.

Cremastus forbesi Weed, 1887. Ill. State Lab. Nat. Hist., Bul. 3: 42 ..

Cremastus forbesii Dalla Torre, 1901. Cat. Hym., v. 3, p. 34. Emend.

Cremastus (Cremastus) tortricidis Cushman, 1917. U. S. Natl. Mus., Proc. 53: 528.. 
Taxonomy: Walkley, 1958. In Krombein et al., U. S. Dept. Agr., Agr. Monog. 2, Sup. 1, p. 61 (syn.).

Biology: Driggers, 1930. N. J. Agr. Expt. Sta. Bul. 510: 17. - Haden, 1935. Del. Agr. Expt. Sta. Bul. 194: 16-35.

gracilipes (Cushman). Ont., Pa., Tex. Host: Dicymolomia julianalis (Wlk.), Epiblema strenuanum (Wlk.).

Cremastus (Cremastus) gracilipes Cushman, 1917. U. S. Natl. Mus., Proc. 53: 520..

Taxonomy: Cushman, 1930 (1929). U. S. Natl. Mus., Proc. 76 (25): 10.

gracilis (Cushman). N. J., Ky.

Cremastus (Cremastus) gracilis Cushman, 1917. U. S. Natl. Mus., Proc. 53: 519..

hamiltonensis (Viereck). Kans.

Thersilochus hamiltonensis Viereck, 1905. Kans. Acad. Sci., Trans. 19: 301. ¿.

grapholithae (Cushman). N. J. s. to Fla., w. to Kans. and Tex. Host: Grapholitha molesta (Bsk), Laspeyresia caryana (Fitch).

Cremastus grapholithae Cushman, 1935. Wash. Acad. Sci., Jour. 25: 561. §,.

interruptor (Gravenhorst). Conn., N. Y., N. J., Ont., Mich.; Europe. Ecology: Arthur et al. (1964) have shown that $T$. interruptor is cleptoparasitic upon Orgilus obscurator (Nees). Introduced. Host: Rhyacionia buoliana (D. and S.). R. buoliana was the target host for introductions in North America; it was not learned until after T. interruptor was established that it almost exclusively oviposits into $R$. buoliana larvae which have already been parasitized by 0 . obscurator and develops at the expense of the latter. Therefore it appears that $T$. interruptor is detrimental with respect to control of $R$. buoliana because it limits the effectiveness of 0 . obscurator. Walkley's (1967) Idaho record for this species was based upon a misidentified specimen.

Cremastus interruptor Gravenhorst, 1829. Ichn. Europaea, v. 3, p. 736. o, 9.

Cremastus opthalmicus Holmgren, 1860 (1858). Svenska Vetensk.-Akad., Handl. (n. f.) 2: 108. $\delta$.

Taxonomy: Walkley, 1967. In Krombein et al., U. S. Dept. Agr., Agr. Monog. 2, Sup. 2, p. 208.

Biology: Thorpe, 1930. Bul. Ent. Res. 21: 390. -Thorpe, 1932. Parisitology 24: 109-110.

- Authur, Stainer, and Turnbull, 1964. Canad. Ent. 96: 1030-1034.

longigenalis (Cushman). Que., Maine, N. H.

Temelucha scutellata Ashmead, 1900. In Slosson, Ent. News 11: 320. Nomen nudum.

Cremastus (Cremastus) longigenalis Cushman, 1917. U. S. Natl. Mus., Proc. 53: 516..

minor (Cushman). Mass s. to La., w. to Kans. and Tex. Host: Epiblema strenuanum (Wlk.), Grapholitha molesta (Bsk.), Rhopobota naevana (Hbn.), Scrobipalpula artemisiella (Kft.), Celama sorghiella (Riley).

Cremastus (Cremastus) minor Cushman, 1917. U. S. Natl. Mus., Proc. 53: 521. ð,,

Biology: Driggers, 1930. N. J. Agr. Expt. Sta. Bul. 510: 17. - Merritt, 1933. Mich. Agr. Expt.

Sta., Quart. Bul. 15: 225. - Pepper and Driggers, 1934. Ent. Soc. Amer., Ann. 27: 596.

-Haden, 1935. Del. Agr. Expt. Sta. Bul. 194: 14-41. - Rice, 1937. Jour. Econ. Ent., 30: 112,

114. - Steenburgh and Boyce, 1938. Ent. Soc. Ont., Ann. Rpt. 69: 72.

Morphology: Peck, 1937. Canad. Jour. Res., Sect. D (Zool. Sci.) 15: 245-247, 249, 250.

platynotae (Cushman). Ariz., Calif. Host: Platynota stultana Wlshm.

Cremastus (Cremastus) platynotae Cushman, 1917. U. S. Natl. Mus., Proc. 53: 526. đo, ๆ.

pterophori (Cushman). Wis. Host: Oidaematophorus lacteodactylus (Chamb.).

Cremastus pterophori Cushman, 1930 (1929). U. S. Natl. Mus., Proc. 76 (25): 13. ð,.

recta (Provancher). N. B. s. to N. C., w. to Wis.

Cremastus rectus Provancher, 1874. Nat. Canad. 6: 175. $\%$.

Cremastus (Cremastus) longiventris Cushman, 1917. U:. S. Natl. Mus., Proc. 53: 517..

rhyacioniae (Cushman). S. Dak., Mont. Host: Rhyacionia frustrana bushnelli (Bsk.).

Cremastus rhyacioniae Cushman, 1930 (1929). U. S. Natl. Mus., Proc. 76 (25): 12. ơ, ?

ruficeps (Cushman). Wis.

Cremastus (Cremastus) ruficeps Cushman, 1917. U. S. Natl. Mus., Proc. 53: 518.. 
sinuata (Cushman). Tex., Calif. Host: Cactobrosis strigalis (B. and McD.), Rumatha

glaucatella (Hulst).

Cremastus (Cremastus) sinuatus Cushman, 1926. U. S. Natl. Mus., Proc. 67 (23): 12. oै, ९.

\section{SUBFAMILY PHRUDINAE}

This small subfamily includes ten genera, three of which are represented by Nearctic species. The few species which have been reared are internal larval parasites of Coleoptera.

\section{Genus EAROBIA Townes}

Earobia Townes, 1951. In Townes and Townes, Ent. Soc. Wash., Proc. 53: 307.

Type-species: Earobia minor Townes. Monotypic and orig. desig.

Echthrolaricobius Perkins, 1953. Entomophaga 3: 146.

Type-species: Echthrolaricobius paradoxus Perkins. Monotypic and orig. desig.

This genus is known from two described species, one European and one North American. A specimen from northern Idaho in the U. S. Natl. Museum collection may represent an undescribed species. The European E. paradoxus has been reared from a species of Laricobius.

Taxonomy: Townes, 1971. Amer. Ent. Inst., Mem. 17: 27-28.

minor Townes. N. Y.

Earobia minor Townes, 1951. In Townes and Townes, Ent. Soc. Wash., Proc. 53: 307. ठ, ๆ.

\section{Genus PHRUDUS Foerster}

Astrenis Foerster, 1868. Naturh. Ver. Rheinlande, Verh. 25: 148.

Type-species: Hambergiella sinuata Roman. Monotypically included and desig. by

Perkins, 1962.

Phrudus Foerster, 1868. Naturh. Ver. Rheinlande, Verh. 25: 196.

Type-species: Phrudus monilicornis Bridgman. By subsequent monotypy from inclusion by Dalla Torre, 1901.

Phrudus Bridgman, 1886. Ent. Soc. London, Trans. 19: 361. Preocc. by Foerster, 1868.

Type-species: Phrudus monilicomis Bridgman. Monotypic.

Ktenostilpnus Strobl, 1901. Naturw. Ver. Steiermark, Mitt. 37: 256.

Type-species: Ktenostilpnus aequearticulatus Strobl. Monotypic. The type-species is regarded as a synonym of $P$. monilicomis Bridgman.

Orona Cameron, 1905. Invertebrata Pacifica 1: 131. Preocc. by Haeckel, 1887.

Type-species: Orona petiolaris Cameron. Monotypic.

Mengersenia Schmiedeknecht, 1907. Hym. Mitteleuropas, p. 606.

Type-species: Mengersenia paradoxa Schmiedeknecht. Monotypic.

Hambergiella Roman, 1909. In Hamberg, Naturw. Untersuch. des Sarekgebirges in

Schwedisch-Lappland, v. 4, p. 359.

Type-species: Hambergiella sinuata Roman. Monotypic.

Vendolius Roman, 1914. Arkiv for Zool. 9 (2): 35.

Type-species: Vendolius stilpninus Roman. Monotypic. The type-species is regarded as a synonym of $P$. monilicornis Bridgman.

This is a small Holarctic genus. Townes (1971) said he knew about 15 species, most of which were undescribed.

Taxonomy: Townes, 1971. Amer. Ent. Inst., Mem. 17: 28-29.

dakota Cushman. Western S. Dak.

Phrudus dakota Cushman, 1927. U. S. Natl. Mus., Proc. 72 (13): 17..

exarealatus Cushman. N. Y.

Phrudus exarealatus Cushman, 1927. U. S. Natl. Mus., Proc. 72 (13): 19..

petiolaris (Cameron). Mid-coastal Calif.

Orona petiolaris Cameron, 1905. Invertebrata Pacifica 1: 131..

\section{Genus PEUCOBIUS Townes}

Pencobius Townes, 1971. Amer. Ent. Inst., Mem. 17: 29. 
Type-species: Peucobius fulvus Townes. Orig. desig.

This genus is not known to occur outside the Nearctic Region.

fulvus Townes. Md., w. N. C., Mich. Ecology: The holotype and six paratypes were collected in Md. in late April; they were swept from branches of Pinus virginiana bearing staminate cones which had not yet shed their pollen.

Peucobius fulvus Townes, 1971. Amer. Ent. Inst., Mem. 17: 30. ठँ, ९.

piceus Townes. N. Mex., n. Utah, e. Calif. Ecology: Three paratypes from Utah were collected on June 19 at an elevation of $8000 \mathrm{ft}$.; they were swept from branches of Pinus contorta bearing staminate cones which had not shed their pollen. The significance of the latter circumstance seems obscured by the fact that a paratype from Cloudcroft, N. Mex. was collected on August 28, certainly well after the pines there had shed their pollen.

Peucobius piceus Townes, 1971. Amer. Ent. Inst., Mem. 17: 30. ठ, ?.

\section{SubFamily TERSILOCHINAE}

This is a small subfamily including 15 described genera, ten of which are represented by Nearctic species. Most of the species are apparently internal larval parasites of Coleoptera. However, one Nearctic species of an undescribed genus has been reared from the eriocraniid microlepidopteran Dyseriocrania griseocapitella (Wlshm.), and at least several species of the genus Allophroides have been reared from sawflies of the genus Xyela. Perhaps the systematic position of the hosts is not so important as the fact that all or most of them construct pupal cells, cases, or cocoons in the soil.

Taxonomy: Townes, 1971. Amer. Ent. Inst., Mem. 17: 33-49 (genera of world).

\section{Genus ALLOPHROIDES Horstmann}

Allophroides Horstmann, 1971. Zool. Staatssamml. Muenchen, Veroeffentl. 15: 52. Type-species: Porizou boops Gravenhorst. Orig. desig.

This is a Holarctic genus of moderate size. None of the Nearctic species have been described. Labels on specimens in the U.S. Natl. Museum collection and unpublished rearing notes of R. A. Cushman indicate that at least several Nearctic species have been reared from larvae of Xyela. Some of these species do not agree very well with the generic redefinition of Townes (1971), particularly with respect to the position of the glymma on the first tergite. Apparently, the limits of the genus will either have to be greatly broadened or significantly restricted.

\section{Genus PROBLES Foerster}

Probles Foerster, 1868. Naturh. Ver. Rheinlande, Verh. 25: 147.

Type-species: Probles melanarius Szepligeti. By subsequent monotypy from inclusion by Szepligeti, 1899. The type-species is regarded as a synonym of $P$. erythrostomus (Gravenhorst).

This is a moderately large genus; according to Townes (1971) its distribution is worldwide. Horstmann (1971) recognized three subgenera in his treatment of the European species.

Revision: Horstmann, 1971. Zool. Staatssamml. Muenchen, Veroeffentl. 15: 81-97 (European spp.).

Taxonomy: Townes, 1971. Amer. Ent. Inst., Mem. 17: 37-38.

maturus (Provancher). Que., Wyo.

Thersilochus maturus Provancher, 1886. Addit. Corr. Faune Ent. Canada Hym., p. 92. $\&$.

Taxonomy: Townes, 1971. Amer. Ent. Inst., Mem. 17: 38.

\section{Genus BARYCNEMIS Foerster}

Barycnemis Foerster, 1868. Naturh. Ver. Rheinlande, Verh. 25: 147.

Type-species: Porizou claviventris Gravenhorst. By subsequent monotypy from inclusion by Brischke, 1880 .

Leptopygus Foerster, 1868. Naturh. Ver. Rheinlande, Verh. 25: 148. 
Type-species: Ichneumon harpurus Schrank. Desig. by Viereck, 1914 from two species included by Thomson, 1889.

Cratophion Thomson, 1889. Opusc. Ent. 13: 1363.

Type-species: Porizon gravipes Gravenhorst. Desig. by Viereck, 1914.

Cyrtophion Thomson, 1889. Opusc. Ent. 13: 1367.

Type-species: Porizon dissimilis Gravenhorst. Desig. by Viereck, 1914.

Zasternaulax Viereck, 1912. U. S. Natl. Mus., Proc. 42: 647.

Type-species: Zasternaulax simplicicomis Viereck. Monotypic and orig. desig.

Porizonidea Viereck, 1914. U. S. Natl. Mus., Bul. 83: 122, 158. The alternate spelling

"Parizonidea" appeared on p. 158.

Type-species: Ichneumon exhaustator Fabricius. Monotypic. Article 68 (c) of the International Code of Zoological Nomenclature indicates that I. exhaustator is the type-species of Porizonidea by monotypy, in spite of Viereck's original designation, which reads: "Type.--(Porizon hostilis Gravenhorst)=Porizon exhaustator (Fabricius)."

This is a Holarctic genus of moderate size.

Taxonomy: Townes, 1971. Amer. Ent. Inst., Mem. 17: 38-40.

bellator (Mueller). N. H., N. Y., Colo.; Greenland; Europe.

Ichneumon bellator Mueller, 1776. Zool. Danicae Prodromus, p. 158. Sex not indicated.

Barycnemis slossonae Ashmead, 1906. In Slosson, Ent. News 17: 324. Nomen nudum.

Barycnemis slossonae Cushman, 1922. U. S. Natl. Mus., Proc. 61 (8): 8 ..

Taxonomy: Townes, 1971. Amer. Ent. Inst., Mem. 17: 40

borealis (Provancher). Que.

Porizon boreale Provancher, 1879. Nat. Canad. 11: 206. "ๆ" = ठ. Preocc. by Zetterstedt, 1838 and Provancher, 1877; not renamed here because of uncertain synonymy. Contrary to the argument of Barron (1975), Townes (1945) was correct in treating this as a description of a new species rather than as a redescription of Porizon borealis Provancher, 1877, a synonym of $B$. rugosa (Provancher). Were it not for the fact that Provancher indicated that his 1879 description was that of a new species, Barron's argument might have some validity. According to Barron, Provancher's 1877 and 1879 descriptions are based on different specimens which are not conspecific.

Taxonomy: Townes, 1945. Amer. Ent. Soc., Mem. 11: 704. -Barron, 1975. Nat. Canad. 102: 434.

exhaustator (Fabricius). Maine, N. H., Ont.; Europe.

Ichneumion exhaustator Fabricius, 1798. Sup. Ent. System., p. 226. Sex not indicated.

Porizon hostilis Gravenhorst, 1829. Ichn. Europaea, v. 3, p. 753. đ’, ๆ.

Porizon gravipes Gravenhorst, 1829. Ichn. Europaea, v. 3, p. 757. $९$.

Thersilochus errabundus Provancher, 1886. Addit. Corr. Faune Ent. Canada Hym., p. 92. \%. N. syn.

Notopygus americana Harrington, 1892. Canad. Ent. 24: 98. ․ N. syn.

Taxonomy: Townes, 1971. Amer. Ent. Inst., Mem. 17: 40.

harpura (Schrank). Que., N. Y., S. Dak., Colo., N. Mex., Idaho, s. B. C.; Europe.

Ichneumon harpurus Schrank, 1802. Fauna Boica, v. 2, pt. 2, p. 294. $\subsetneq$.

Cremastus angularis Provancher, 1874. Nat. Canad. 6: 176. $\delta$.

Mesoleptus micans Provancher, 1875. Nat. Canad. 7: 114. " $\delta "=\delta, ~ q$.

Porizon elongatum Provancher, 1886. Addit. Corr. Faune Ent. Canada Hym., p. 91. o, o.

Atractodes politus Ashmead, 1890. Colo. Biol. Assoc., Bul. 1: 23. ठ, ९. N. syn. Preoce. in

Atractodes by Provancher, 1874.

Porizon canaliculatus Viereck, 1903. In Skinner, Amer. Ent. Soc., Trans. 29: 93. ơ. N. syn.

Taxonomy: Townes, 1971. Amer. Ent. Inst., Mem. 17: 39-40.

linearis Ashmead. Del., Ont.

Barycnemis linearis Ashmead, 1895. Ent. Soc. Wash., Proc. 3: 328. ๆ.

rugosa (Provancher). Que., N. H., N. Y.

Porizon borealis Provancher, 1877. Nat. Canad. 9: 14. ð. Preocc. by Zetterstedt, 1839.

Porizon rugosum Provancher, 1879. Nat. Canad. 11: 206. "o " = ठ์. 
Leptopygus monticola Ashmead, 1897. In Slosson, Ent. News 8: 237. Nomen nudum. simplicicornis (Viereck). Colo., Mont., Wash., Oreg. Host: Pissodes sp.

Zasternaulax simplicicornis Viereck, 1912. U. S. Natl. Mus., Proc. 42: 647. ठै.

\section{Genus PECTINOLOCHUS Aubert}

Tersilochus subg. Pectinolochus Aubert, 1960. Soc. Ent. de Mulhouse, Bul. 16: 65. Type-species: Tersilochus (Pectinolochus) unguiculator Aubert. Monotypic.

Polemolochus Aubert, 1964. Soc. Ent. de Mulhouse, Bul. 20: 39.

Type-species: Thersilochus ensifer Brischke. Monotypic and orig. desig.

This is a Holarctic genus. Townes (1971) said he had seen 14 species, most of which were undescribed, but he did not indicate how many of these are Nearctic. Horstmann (1971) treated four European species.

Revision: Horstmann, 1971. Zool. Staatssamml. Muenchen, Veroeffentl. 15: 55-58.

Taxonomy: Townes, 1971. Amer. Ent. Inst., Mem. 17: 41.

\section{Genus TERSILOCHUS Holmgren}

Tersilochus Holmgren, 1859 (1858). Svenska Vetensk.-Akad., Ofvers af ... Forhandl. 15: 329.

Type-species: Porizon jocator Gravenhorst. Monotypic. The type-species is Gravenhorst's misidentification of Ichneumon jocator Fabricius. The correct name for jocator in the sense of Gravenhorst is $T$. cognatus Holmgren.

Thersilochus(!) Holmgren, 1860 (1858). Svenska Vetensk.-Akad. Handl. (n. f.) 2: 135.

This is a Holarctic genus of moderate size.

Revision: Horstmann, 1971. Zool. Staatssamml. Muenchen, Veroeffentl. 15: 114-134

(European spp.).

Taxonomy: Horstmann, 1969 (1968). Opusc. Zool. 102: 1-2.

alaskensis (Ashmead). Southwestern Alaska.

Isurgus alaskensis Ashmead, 1902. Wash. Acad. Sci., Proc. 4: 239..

conotracheli (Riley). Que. s. to w. N. C., w. to Iowa. Host: Conotrachelus anaglypticus (Say), C. nenuphar (Herbst), C. retentus (Say).

Porizon conotracheli Riley, 1871. Mo. State Ent., Ann. Rpt. 3: 28. §, ९.

Biology: Cushman, 1916. Jour. Agr. Res. 6: 847-855.

deficiens (Provancher). Ont.

Stilpnus deficiens Provancher, 1888. Addit. Corr. Faune Ent. Canada Hym., p. 359..

\section{Genus STETHANTYX Townes}

Stethantyx Townes, 1971. Amer. Ent. Inst., Mem. 17: 42.

Type-species: Stethantyx nearctica Townes. Montypic and orig. desig.

This is a Neotropic and Nearctic genus of moderate size.

nearctica Townes. Md., D. C., e. N. C., n.w. S. C.; n. Mexico.

Stethantyx nearctica Townes, 1971. Amer. Ent. Inst., Mem. 17: 43. ठ์, ९.

\section{Genus ALLOPHRYS Foerster}

Allophrys Foerster, 1868. Naturh. Ver. Rheinlande, Verh. 25: 147.

Type-species: Thersilochus oculatus Ashmead. Desig. by Viereck, 1914 from three species included by Szepligeti, 1905.

This is a small Neotropic, Nearctic, Oriental, and Ethiopian genus. An undescribed species occurs in the southeastern U. S. A.

\section{Genus PHRADIS Foerster}

Ischnobatis Foerster, 1868. Naturh. Ver. Rheinlande, Verh. 25: 148. 
Phradis Foerster, 1868. Naturh. Ver. Rheinlande, Verh. 25: 148.

Type-species: Thersilochus (Phradis) brevis Brischke. By subsequent monotypy from inclusion by Brischke, 1880 .

Eutomus Foerster, 1868. Naturh. Ver. Rheinlande, Verh. 25: 148.

Type-species: Isurgus lanceolatus Szepligeti. Monotypically included and desig. by

Viereck, 1914.

Isurgus Foerster, 1868. Naturh. Ver. Rheinlande, Verh. 25: 148.

Type-species: Isurgus lanceolatus Szepligeti. Desig. by Viereck, 1914 from nine species included by Szepligeti, 1899.

This is a Holaretic genus of moderate size. Horstmann (1971) treated 11 European species, and Townes (1971) said he had seen five Nearctic species, all of which he believed to be undescribed.

Revision: Horstmann, 1971. Zool. Staatssamml. Muenchen, Veroeffentl. 15: 67-77 (European spp.).

Taxonomy: Townes, 1971. Amer. Ent. Inst., Mem. 17: 46.

\section{Genus DIAPARSIS Foerster}

Ischnobatis Foerster, 1868. Naturh. Ver. Rheinlande, Verh. 25: 148.

Type-species: Thersilochus (Ichnobatis[!]) stramineipes Brischke. By subsequent monotypy from inclusion by Brischke, 1880.

Diaparsis Foerster, 1868. Naturh. Ver. Rheinlande, Verh. 25: 149.

Type-species: Porizon nutritor Gravenhorst. Desig. by Perkins, 1962 from 12 species included by Thomson, 1889. The type-species is Gravenhorst's misidentification of Ophion nutritor Fabricius. According to Horstmann (1971) nutritor in the sense of Gravenhorst is a synonym of Diaparsis truncata (Gravenhorst).

Diaparsus Thomson, 1889. Opusc. Ent. 13: 1369. Emend.

Luchatema Walkley, 1956. Ent. News 67: 154

Type-species: Luchatema baldufi Walkley. Monotypic and orig. desig.

According to Townes (1971) this is a large genus of Holarctic, Oriental, and Ethiopian distribution. Horstmann (1971) treated seven European species. Two European species which are parasites of Oulema melanopus (L.) have been released in North America; one of these, $D$. carinifer (Thomson), has not become established; the other, a new species soon to be described by Dr. Klaus Horstmann, is established or at least has been recovered in w. N. Y., Pa., w. W. Va., Ohio, s. Mich., and n. Ind. according to unpublished information supplied by T. L. Burger.

Revision: Horstmann, 1971. Zool. Staatssamml. Muenchen, Veroeffentl. 15: 100-107 (European spp.).

Taxonomy: Perkins, 1962. Brit. Mus. (Nat. Hist.) Ent., Bul. 11: 417, 431. - Horstmann, 1969 (1968). Opusc. Zool. 102: 2. -Townes, 1971. Amer. Ent. Inst., Mem. 17: 47-48.

americana (Brues). Mass., R. I., N. Y., Md., W. Va., Colo.?, N. Mex.? Ecology: Occurs in late summer and fall on flowers of Solidago.

Heterocola americana Brues, 1916. Ent. News 27: 331. .

Taxonomy: Townes, 1971. Amer. Ent. Inst., Mem. 17: 48.

baldufi (Walkley). Mass. w. to s. Sask., s. to central Ill., n.e. Kans., and s.w. Wyo. Host: Rhynchites bicolor (F.).

Luchatema baldufi Walkley, 1956. Ent. News 67: 154. o, ․

carinifer (Thomson). Europe. Introduced in Michigan in 1967 and a number of times since, without becoming established. Stehr and Haynes (1972) reported the species as established, but the record of establishment applies not to carinifer but to Diasparsis n. sp. (see above introductory paragraph on Diaparsis).

Thersilochus carinifer Thomson, 1889. Opusc. Ent. 13: 1392. ๆ. Bibliographic information published by Laboulbene (1889) indicates that fascicle 13 of Opusc. Ent. was published prior to June $12,1889$. 
Thersilochus carinatus Bridgman, 1889. Ent. Soc. London, Trans. 37: 430. 9. Information published by Wheeler (1912) shows that Bridgman's paper was published on Oct. 28, 1889.

Thersilochus vernalis Szepligeti, 1899. Termes. Fuzetek 22: 228. ๆ.

Taxonomy: Laboulbene, 1889. Soc. Ent. de France, Ann. (6) 9: cxxiv in Bul. - Wheeler, 1912 (1911). Ent. Soc. London, Trans. 59: 759. - Horstmann, 1971. Zool. Staatssamml. Muenchen, Veroeffentl. 15: 103.

Biology: Stehr and Haynes, 1972. Jour. Econ. Ent. 65: 405-407. - Dysart, Maltby, and Brunson, 1973. Entomophaga 18: 139-142. - Montgomery and Dewitt, 1975. Ent. Soc. Amer., Ann. 68: 574-578 (egg and larval instars).

\section{Genus ANEUCLIS Foerster}

Aneuclis Foerster, 1868. Naturh. Ver. Rheinlande, Verh. 25: 147.

Type-species: Isurgus rufipes Szepligeti. Desig. by Viereck, 1914 from five species and two synonyms included by Szepligeti, 1905.

This is a small genus of Holarctic, Oriental, and Ethiopian distribution. According to Townes (1971) there is one Nearctic species; apparently, it is undescribed.

Revision: Horstmann, 1971. Zool. Staatssamml. Muenchen, Veroeffentl. 15: 59-63 (European spp.).

Taxonomy: Townes, 1971. Amer. Ent. Inst., Mem. 17: 48-49.

UNPLACED TAXA OF TERSILOCHINAE

According to Townes and Townes (1951), the three native species which here remain unplaced have elongate thyridea. Some of these may prove to belong in Probles. The introduced species which I have added to the unplaced category also have elongate thyridea, but do not seem referable to Probles because of the shortness of their ovipositors (as long as apical depth of abdomen) combined with the shortness of the "foveate groove" on the mesopleurum.

Taxonomy: Townes and Townes, 1951. In Muesebeck et al., U. S. Dept. Agr., Agr. Monog. 2: 394.

Aneuclis(?) erythrostomus Cameron, 1905. Invertebrata Pacifica 1: 131. 9 . Western Nev. If the species belongs in Probles it would be preocc. by erythrostomus (Gravenhorst), 1829.

Taxonomy: Townes, 1961. Ent. Soc. Wash., Proc. 63: 103.

Porizon argentinensis Blanchard, 1945. Soc. Ent. Argentina, Rev. 12: 308. ๆ. Argentina, Uruguay. Introduced in s. Calif. in 1946, without becoming established. Host: Listroderes costirostris obliquus (Klug). See P. parkeri Blanchard.

Taxonomy: Kerrich, 1961. Eos 37: 497-503.

Biology: Parker, Berry, and Silveria, 1950. U. S. Dept. Agr., Tech. Bul. 1016: 1-14, 26-28.

-Wilson and Wearne, 1962. Austral. Jour. Agr. Res. 13: 253.

Morphology: Short, 1959. U. S. Natl. Mus., Proc. 110: 496 (final-instar larva).

Porizon parkeri Blanchard, 1945. Soc. Ent. Argentina, Rev. 12: 305. + . Argentina, Uruguay. Introduced in s. Calif. in 1946; it did not become established, although an undescribed thelytokous species which was identified as the "parthenogenetic strain" of parkeri by Kerrich (1961) is widely established in s. Calif. according to Clancy (1969). Host:

Listroderes costirostris obliquus (Klug). The undescribed thelytokous species which is established in Calif. is more similar in coloration to P. argentinensis (which see) than to $P$. parkeri and, therefore, was probably released in Calif. along with the former species. These three species, which have also been released in Australia, appear to represent an undescribed genus.

Taxonomy: Kerrich, 1961. Eos 37: 497-503.

Biology: Parker, Berry, and Silveria, 1950. U. S. Dept. Agr., Tech. Bul. 1016: 1-14, 26-28. -Wilson and Wearne, 1962. Austral. Jour. Agr. Res. 13: 253. -Clancy, 1969. Jour. Econ. Ent. 62: 743-745. 
Thersilochus montanus Ashmead, 1890. Colo. Biol. Assoc., Bul. 1: 23. ठ. Western Colo. I have studied the holotype and suppose it may belong in the genus Probles as defined by Townes (1971); because placement of the species in Probles would preoccupy Probles (Euporizon) montanus Horstmann (1971), I leave it unplaced pending both identification of the female and a more precise redefinition of Probles.

Taxonomy: Horstmann, 1971. Zool. Staatssamml. Muenchen, Veroeffentl. 15: 91. -Townes, 1971. Amer. Ent. Inst., Mem. 17: 37-38.

Thersilochus pallidipes Dalla Torre, 1901. Cat. Hym., v. 3, p. 43. Emend. of pallipes Provancher and syn. of provancheri Ashmead (which see).

Thersilochus pallipes Provancher, 1882. Nat. Canad. 13: 367. \&. Que. Preocc. by Holmgren, 1860; replaced by provancheri Ashmead (which see).

Taxonomy: Barron, 1975. Nat. Canad. 102: 526.

Thersilochus Provancheri Ashmead, 1890. Colo. Biol. Assoc., Bul. 1: 24. N. name for pallipes Provancher.

Thersilochus provancheri Cushman, 1922. U. S. Natl. Mus., Proc. 61 (8): 30 . Unnecessary n. name for pallipes Provancher; preocc. by Ashmead, 1890. Cushman was unaware that Ashmead (1890) had validated the name provancheri, and thought that it had been published only as a nomen nudum.

\section{SUBFAMILY OPHIONINAE}

Townes (1971) divided the subfamily into two tribes, the Ophionini and the Enicospilini. Ophioninae are internal parasites, and the usual hosts are larvae of Lepidoptera. Ophion nigrovarius (Provancher), however, is a larval parasite of Phyllophaga (Coleoptera: Scarabaeidae).

Taxonomy: Cushman, 1947. U. S. Nat. Mus., Proc. 96: 417-482 (genera of world). -Townes, 1971. Amer. Ent. Inst., Mem. 17: 49-82 (genera of world).

\section{TRIBE OPHIONINI}

Fourteen genera are currently recognized, and seven of these are represented by Nearctic species.

\section{Genus OPHION Fabricius}

Ophion Fabricius, 1798. Sup. Ent. System., p. 210, 235.

Type-species: Ichneumon luteus Linnaeus. Desig. by Curtis, 1835.

Paniscus schrank, 1802. Fauna Boica, v. 2, pt. 2, p. 316. See introductory discussion of genus Netelia.

Type-species: Ichneumon luteus Linnaeus. Monotypic.

Psylonychia Szepligeti, 1905. In Wytsman, Gen. Ins., fasc. 34, p. 21.

Type-species: Stenophthalmus algiricus Szepligeti. Monotypically included and desig. by Cushman, 1947.

Stenophthalmus Szepligeti, 1905. In Wytsman, Gen. Ins., fasc. 34, p. 23. Preocc. by Becker, 1903.

Type-species: Stenophthalmus algiricus Szepligeti. Desig. by Viereck, 1914.

Ophion subg. Pachyprotonia Kohl, 1906 (1905). In Penther and Zederbauer, Wien. Mus.

der Naturgesch., Ann. 20: 223.

Type-species: Ophion (Pachyprotoma) capitatus Kohl. Monotypic.

Australophion Morley, 1912. Rev. Ichn. Brit. Mus., v. 1, p. 30.

Type-species: Ophion peregrinus Smith. Monotypic.

Neophion Morley, 1912. Rev. Ichn. Brit. Mus., v. 1, p. 30.

Type-species: Neophion crassus Morley. Desig. by Viereck, 1914.

Ophion subg. Platophion Hellen, 1926. Soc. pro Fauna et Flora Fenn., Acta. 56 (6): 13.

Type-species: Ophion areolaris Brauns. Desig. by Cushman, 1947.

Potophion Cushman, 1947. U. S. Natl. Mus., Proc, 96: 442.

Type-species: Potophion caudatus Cushman. Monotypic and orig. desig.

This very large genus is worldwide in distribution. 
Revision: Hooker, 1912. Amer. Ent. Soc., Trans. 38: 21-50.

bilineatus Say. Ind. The type locality would presumably have been southwestern Ind. The original description gives the length of bilineatus as "seven-twentieths of an inch," but because the additional remarks of Say (1836) seem to confirm placement of this species in Ophion, that measurement was presumably an error for seven-tenths of an inch.

Ophion bilineatus Say, 1829. Contrib. Maclurian Lyceum to Arts and Sci. 1: 75. Sex not indicated. No type specimen is known to remain in existence.

Taxonomy: Say, 1836. Boston Jour. Nat. Hist. 1: 239, 240. -Townes and Townes, 1951. In Muesebeck et al., U. S. Dept. Agr., Agr. Monog. 2: 402.

coloradensis (felt). Colo.

Genophion coloradensis Felt, 1904. N. Y. State Mus., Bul. 76: 124..

crassus (Morley). N. S.

Neophion crassus Morley, 1912. Rev. Ichn. Brit. Mus., v. 1, p. 31. ठ.

elongatus Hooker. Colo., N. Mex., Ariz.

Ophion bilineatus elongatus Hooker, 1912. Amer. Ent. Soc., Trans. 38: 30. ‥

epallidus Walkley. Southern Colo.

Ophion bilineatus var. pallida Cockerell, 1889. Sci. Gossip 25: 92. Sex not indicated.

Preocc. by Taschenberg, 1875.

Ophion epallidus Walkley, 1958. In Krombein et al., U. S. Dept. Agr., Agr. Monog. 2, Sup. 1, p. 62. N. name for pallida Cockerell.

flavidus Brulle. N. Y. s. to Fla., w. to n.e. Kans. and s. Tex.; West Indies, Costa Rica, Guatamala, Brazil, Paraguay, Uruguay, Argentina. Host: Agrotis ipsilon (Hufn.), Heliothis zea (Bod.), Peridroma saucia (Hbn.), Spodoptera eridania (Cram.).

Ophion flavidus Brulle, 1846. In Lepeletier, Hist. Nat. Ins. Hym., v. 4, p. 143. [female]. Ophion biangularis Taschenberg, 1875. Ztschr. f. Naturw. 46: 432..

Ophion ancyloneura Cameron, 1886. Biol. Cent.-Amer., Hym., v. 1, p. 294..

Ophion diversus Szepligeti, 1906. Mus. Natl. Hungarici, Ann. 4: 131. o, + .

Ophion concolor Szepligeti, 1906. Mus. Natl. Hungarici, Ann. 4: 131. ठ. Preocc. by C'resson, 1865.

Ophion politor Morley, 1912. Rev. Ichn. Brit. Mus., v. 1, p. 56 . $q$.

Taxonomy: Townes and Townes, 1966. Amer. Ent. Inst., Mem. 8: 168-169 (syn.).

Morphology: Cushman, 1947. U. S. Natl. Mus., Proc., v. 96, pl. 52, fig. 43 (metathorax and propodeum).

idoneus Viereck. Mass. w. to s. Man., s. to n. Va., Tenn., and n.e. Kans. Host: Sunira bicolorago (Gn.).

Ophion idoneum Viereck, 1905. Kans. Acad. Sci., Trans. 19: 312. ठँ.

Morphology: Cushman, 1947. U. S. Natl. Mus., Proc., v. 96, pl. 49, fig. 3 (final-instar larva). magniceps Hooker. Mont.?, Calif.

Ophion abnormis magniceps Hooker, 1912. Amer. Ent. Soc., Trans. 38: 36. \& (o misdet.?).

nigrovarius Provancher. N. S. s. to n. Va., w. to Minn., Colo., and Tex. Host: Phyllophaga fusca (Froel.). The name bifoveolatus Brulle was for many years incorrectly applied to this species; see Enicospilus bifoveolatus (Brulle).

Ophion nigrovarius Provancher, 1874. Nat. Canad. 6: 104. ¿,.

Eurycamptus nova-scotiae Morley, 1912. Rev. Ichn. Brit. Mus., v. 1, p. 29. ๆ.

Taxonomy: Townes, 1961. Ent. Soc. Wash., Proc. 63: 106, 111. - Barron, 1975. Nat. Canad. 102: 519 .

slossonae Davis. N. H. w. to w. S. Dak., s. to n. Ga. and s. Tex. Host: Acronicta americana (Harris).

Ophion slossonae Davis, 1893. Ent. News 4: 135. đ.

Ophion fermiginipennis Felt, 1904. N. Y. State Mus., Bul. 76: 122. $\subsetneq$.

tityri Packard. Mass., N. Y., N. J., Mich. Host: Epargyreus clarus (Cram.).

Ophion tityri Packard, 1881. Boston Soc. Nat. Hist., Proc. 21: 19. ठ. 


\section{Genus CLISTORAPHA Cushman}

Clistorapha Cushman, 1947. U. S. Natl. Mus., Proc. 96: 450.

Type-species: Ophion subfuliginosus Ashmead. Monotypic and orig. desig.

This is a small Holarctic genus.

subfuliginosa (Ashmead). Ariz.; n.w. Mexico.

Ophion subfuliginosus Ashmead, 1894. Calif. Acad. Sci., Proc. (2) 4: 126. ठ, ๆ.

\section{Genus BOETHONEURA Cushman}

Boethoneura Cushman, 1947. U. S. Natl. Mus., Proc. 96: 451.

Type-species: Boethoneura arida Cushman. Monotypic and orig. desig.

This is a small Nearctic and Neotropic genus.

arida Cushman. Ariz., Nev.: n.w. Mexico.

Boethoneura arida Cushman, 1947. U. S. Natl. Mus., Proc. 96: 452..

\section{Genus TROPHOPHION Cushman}

Trophophion Cushman, 1947. U. S. Natl. Mus., Proc. 96: 447.

Type-species: Trophophion tenuiceps Cushman. Monotypic and orig. desig.

Only one species is known.

tenuiceps Cushman. Ariz., s. Calif.

Trophophion tenuiceps Cushman, 1947. U. S. Natl. Mus., Proc. 96: 449. ¿, ․

\section{Genus APATOPHION Shestakov}

Apatophion Shestakov, 1926. Konowia 5: 262.

Type-species: Apatophion mirsa Shestakov. Monotypic and orig. desig.

This is a small Holarctic genus. According to Townes (1971) there are two undescribed species in the central United States.

Taxonomy: Townes, 1971. Amer. Ent. Inst., Mem. 17: 59-60.

\section{Genus GENOPHION Felt}

Genophion Felt, 1904. N. Y. State Mus., Bul. 76: 123.

Type-species: Genophion gilletti Felt. Orig. desig.

Chilophion Cushman, 1947. U. S. Natl. Mus., Proc. 96: 454.

Type-species: Ophion abnormus Felt. Monotypic and orig. desig.

This is a small Nearctic genus, a number of species being undescribed.

Taxonomy: Townes, 1971. Amer. Ent. Inst., Mem. 17: 61-62 (syn.).

abnormus (Felt). Southwestern S. Dak., s.w. Kans., s.e. Wyo., Colo.

Ophion abnormum Felt, 1904. N. Y. State Mus., Bul. 76: 121..

Eremotylus felti Viereck, 1905. Kans. Acad. Sci., Trans. 19: 312..

Ophion abnorm is Hooker, 1912. Amer. Ent. Soc., Trans. 38: 47. Emend.

costalis (Cresson). Colo., s. Idaho, s. Oreg.

Ophion costale Cresson, 1879 (1878). Acad. Nat. Sci. Phila., Proc. 30: 366. \&. Cresson cited the type locality as "Klamath Co., California," but there has never been a Klamath Co. anywhere except in Oreg.

Genophion gilletti Felt, 1904. N. Y. State Mus., Bul. 76: 123.

\section{TRIBE ENICOSPILINI}

Only four of the 20 genera currently recognized genera have Nearctic species, the species of Enicospilini being most numerous in the tropics. 


\section{Genus RHYNCHOPHION Enderlein}

Rhynchophion Enderlein, 1912. Zool. Anz. 39: 630.

Type-species: Rhynchophion odontandroplax Enderlein. Monotypic and orig. desig.

This is a small Neotropic and Nearctic genus.

flammipennis (Ashmead). Southeastern Ariz.; Mexico, Nicaragua, Ecuador.

Thyreodon flammipennis Ashmead, 1894. Calif. Acad. Sci., Proc. (2) 4: 125. ๆ.

\section{Genus THYREODON Brulle}

Thyreodon Brulle, 1846. In Lepeletier, Hist. Nat. Ins. Hym., v. 4, p. 150.

Type-species: Thyreodon cyaneus Brulle. Desig. by Hooker, 1912.

Athyreodon Ashmead, 1900. U. S. Natl. Mus., Proc. 23: 87.

Type-species: Athyreodon thoracicus Ashmead. Monotypic and orig. desig. The type-species is regarded as a synonym of $T$. atriventris atriventris (Cresson).

Tipulophion Kriechbaumer, 1901. Ztschr. System. Hym. Dipt. 1: 75.

Type-species: Tipulophion gigas Kriechbaumer. Monotypic. The type-species is regarded as a subspecies of $T$. atriventris (Cresson).

Macrophion Szepligeti, 1905. In Wytsman, Gen. Ins., fasc. 34, p. 32.

Type-species: Macrophion ornatus Szepligeti. Desig. by Viereck, 1912. The type-species is regarded as a synonym of $T$. atriventris atriventris (Cresson).

Oleter Shestakov, 1926. Konowia 5: 259.

Type-species: Oleter selenaction Shestakov. Monotypic and orig. desig. The type-species is regarded as a synonym of $T$. laticinctus Cresson.

This is a large genus of Neotropic and Nearctic distribution, the majority of the species being Neotropic.

atricolor atricolor (Olivier). Que. w. to s. Man., s. to Fla. and e. Tex. Host: Lapara coniferarum (J. E. S.), L. bombycoides Wlk., Paonias excaecatus (J. E. S.).

Ophion atricolor Olivier, 1812 (1811). In Olivier and Latreille, Encycl. Meth., Dict. Ins., v. 8, p. 511 . ㅇ.

Thyreodon brullei Viereck, 1917 (1916). Conn. State Geol. and Nat. Hist. Survey Bul. 22: 287. $\delta, ~ ₹$. Validated as a "new name" for "T. morio Authors, not Fabricius." Viereck gave a few descriptive remarks, gave data for two specimens he had seen from Conn., and referred to the figure of Howard (1902). The specimen in the U. S. National Museum upon which Howard's figure is based is here selected as lectotype; it is a female collected at Nyack, N. Y. by J. L. Zabriskie in 1883.

Taxonomy: Howard, 1902. The Insect Book, pl. 10, fig. 15.

atricolor flavicornis (Say). Kans., Colo., N. Mex., s.e. Idaho, Utah, Ariz.

Anomalon flavicornis Say, 1823. West. Quart. Rptr. 2: 73. Sex not indicated.

Thyreodon snowi Viereck, 1905. Kans. Acad. Sci., Trans. 19: 313..

Thyreodon morio transitionalis Viereck, 1906. Amer. Ent. Soc., Trans. 32: 225..

fernaldi Hooker. Colo., Ariz.; n. Mexico.

Thyreodon fernaldi Hooker, 1912. Amer. Ent. Soc., Trans. 38: 131. §, ९.

ornatipennis Cresson. N. Mex.; n. Mexico.

Thyreodon ornatipennis Cresson, 1874 (1873). Acad. Nat. Sci. Phila., Proc. 25: 376..

\section{Genus SIMOPHION Cushman}

Simophion Cushman, 1947. U. S. Natl. Mus., Proc. 96: 446.

Type-species: Simophion excarinatus Cushman. Monotypic and orig. desig.

A single species is known to the author. Cushman said he had seen four undescribed species, and it is likely that at least some of them were only color variants of excarinatus. It is apparently not known if the Palearctic species $S$. calvus Viktorov and S. victorovi Malyavin really belong in Simophion.

excarinatus Cushman. Southwestern Tex., s. N. Mex., s. Ariz., s.e. Calif.

Simophion excarinatus Cushman, 1947. U. S. Natl. Mus., Proc. 96: 447. \&. 


\section{Genus ENICOSPILUS Stephens}

Enicospilus Stephens, 1829. System. Cat. Brit. Ins., p. 352. Nomen nudum.

Enicospilus Stephens, 1835. Illus. Brit. Ent., v. 7, p. 126.

Type-species: Enicospilus merdarius Stephens. By subsequent monotypy from inclusion by Stephens, 1845. E. merdarius Stephens is preocc. in Enicospilus by merdarius (Gravenhorst); merdarius Stephens is a synonym of Enicospilus ramidulus (Linnaeus) (n. syn.). The details of the excellent discussion by Hooker (1912) appear to be correct except that Stephens (1845) did not cite any author for the name Enicospilus merdarius, and Stephens (1846) indicated that the figure to which the combination Enicospilus merdarius referred was $E$. combustus (Gravenhorst), presently a synonym of $E$. ramidulus (Linnaeus), and he distinguished $E$. combustus from $E$. merdarius (Gravenhorst).

Henicospilus Agassiz, 1846. Nomencl. Zool., Index Univ., p. 138. Emend.

Allocamptus Foerster, 1868. Naturh. Ver. Rheinlande, Verh. 25: 150.

Type-species: Ophion undulatus Gravenhorst. By subsequent monotypy from inclusion by Thomson, 1888.

Ophion subg. Dispilus Kriechbaumer, 1894. Berlin. Ent. Ztschr. 39: 309.

Type-species: Ophion (Dispilus) natalensis Kriechbaumer. Monotypic.

Pleuroneurophion Ashmead, 1900. U. S. Natl. Mus., Proc. 23: 86.

Type-species: Pleuroneurophion hawaiiensis Ashmead. Monotypic and orig. desig.

Cymatoneura Kriechbaumer, 1901 (Jan.). Ztschr. System. Hym. Dipt. 1 (1): 22.

Type-species: Ophion undulatus Gravenhorst. Desig. by Viereck, 1912 from four species included by Kriechbaumer, 1901 (Mar.).

Pterospilus Kriechbaumer, 1901. Ztschr. System. Hym. Dipt. 1 (3): 156. Preocc. by

Rondani, 1856.

Type-species: Ophion (Enicospilus) dubius Tosquinet. Desig. by Viereck, 1914.

Trispilus Kriechbaumer, 1901. Ztschr. System. Hym. Dipt. 1 (3): 156.

Type-species: Ophion (Enicospilus) trimaculatus Tosquinet. Monotypic.

Abanchogastra Perkins, 1902. Ent. Soc. London, Trans. 50: 141.

Type-species: Abanchogastra debilus Perkins. Monotypic.

Metophion Szepligeti, 1905. In Wytsman, Gen. Ins., fasc. 34, p. 28.

Type-species: Metophion bicolor Szepligeti. Desig. by Viereck, 1914.

Ceratospilus Szepligeti, 1905. In Wytsman, Gen. Ins., fasc. 34, p. 28.

Type-species: Ceratospilus biroi Szepligeti. Monotypic.

Atoponeura Szepligeti, 1905. In Wytsman, Gen. Ins., fasc. 34, p. 34.

Type-species: Atoponeura concolor Szepligeti. Monotypic. The type-species is a synonym of $E$. atoponeurus Cushman.

Ophiom orpha Szepligeti, 1905. In Wytsman, Gen. Ins., fasc. 34, p. 34. Preoce. by Nilsson, 1836.

Type-species: Ophion curvinervis Cameron. Desig. by Hooker, 1912. The type-species is a synonym of $E$. cameronii (Dalla Torre).

Cryptocamptus Brethes, 1909. Buenos Aires, Mus. Nac. de Hist. Nat., An. 19: 230. This name was proposed as a "new name" for Allocamptus "Thomson," which, according to present rules of nomenclature, Brethes incorrectly regarded as being a misidentification of Allocamptus Foerster.

Type-species: Ophion undulatus Gravenhorst. Monotypic.

Amesospilus Enderlein, 1914. In Michaelson, Beitr. z. Kenntnis d. Land-u. Suesswasserfauna Deut.-Suedwestafrikas, v. 1, p. 222.

Type-species: Ophion unicallosus Snellen van Vollenhoven. Orig. desig.

Eremotyloides Perkins, 1915. Ent. Soc. London, Trans. 62: 530.

Type-species: Eremotylus orbitalis Ashmead. Monotypic.

Schizospilus Seyrig, 1935 (1936). Paris, Mus. d'Hist. Nat., Mem. (n. s.) 4: 79.

Type-species: Schizospilus divisus Seyrig. Orig. desig.

Townes (1971) stated that Enicospilus is probably the largest genus of Ichneumonidae and estimated the number of species to be well over a thousand. Species occur throughout the world but are most numerous in tropical regions.

Revision: Hooker, 1912. Amer. Ent. Soc., Trans. 38: 52, 92, 135-158. 
Taxonomy: Stephens, 1845. Illus. Brit. Ent., v. 7, list of plates (follows p. 310). - Stephens, 1846. Illus. Brit. Ent., Sup., p. 3. -Townes, 1971. Amer. Ent. Inst., Mem. 17: 78-79.

americanus (Christ). N. S. w. to Minn., s. to Fla., s. Tex., and mid-coastal Calif.; Mexico, Costa Rica, Guatemala, Brazil?, Argentina. Host: Actias luna (L.), Antheraea polyphemus (Cram.), Automeris io (F.), Callosamia promethea (Drury), Hyalophora cecropia (L.), $H$. columbia (Sm.), H. euryalus (Bdv.), Rothschildia orizaba (West.), Samia cynthia (Drury). Before World War II, the name macrumus (Linnaeus) was erroneously applied to this species, usually in combination with the generic names Eremotylus or Ophion.

Ichneumon luteus americanus Christ, 1791. Naturgesch. Class. Nomencl. Ins., p. 358, pl. 37 , fig. 5 . .

Ophion rugosus Brulle, 1846. In Lepeletier, Hist. Nat. Ins. Hym., v. 4, p. 138. Sex not indicated.

Ophion cecropiae Scudder, 1963. Boston Soc. Nat. Hist., Proc. 9: 188-189. Nomen nudum. Ophion cecropiae Sanborn, 1863. Sec. Mass. Bd. Agr., Ann. Rpt. 10: 169. Sex not indicated. Ophion mexicanus Cresson, 1874 (1873). Acad. Nat. Sci. Phila., Proc. 25: 374. 9.

Eremotylus Druryi Kriechbaumer, 1901. Ztschr. System. Hym. Dipt. 1: 152. đ, ๆ.

Taxonomy: Townes, 1961. Ent. Soc. Wash., Proc. 63: 111 (syn.).

Biology: Riley, 1870. Amer. Ent. 2: 100-101. -Riley, 1872. Mo. State Ent., Ann. Rpt. 4: 107-108. -Smith, 1908. Jour. Econ. Ent. 1: 294-297.

appendiculatus (Felt). N. J., N. C., S. C., Ala., Fla.; West Indies, Mexico, Brazil. Ophion (Eniscopilus [!]) appendiculatus Felt, 1902. Psyche 9: 308. [female].

arcuatus (felt). Mass. w. to Ill., s. to Ga. and Miss.; Puerto Rico, Mexico, Argentina. Host: Scoliopteryx libatrix (L.), Heterocampa guttivitta (Wlk.), Schizura concinna (J. E. S.).

Ophion (Eniscopilus [!]) arcuatum Felt, 1902. Psyche 9: 308. \%. Preocc. by Brulle, 1846; not renamed here because of uncertain synonymy.

bifoveolatus (Brulle). Pa. Townes (1961) said "this is an uncommon species ... that occursimostly in the southeastern United States." The name bifoveolatus was for years incorrectly applied to Ophion nigrovarius Provancher.

Ophion bifoveolatus Brulle, 1846. In Lepeletier, Hist. Nat. Ins. Hym., v. 4, p. 138. [male]. Ophion stramineus Taschenberg, 1875. Ztschr. f. die Gesam. Naturw. [Halle] 46: 431. ․

Taxonomy: Townes, 1961. Ent. Soc. Wash., Proc. 63: 111.

cubensis (Norton). Fla.; West Indies.

Ophion cubensis Norton, 1863. Ent. Soc. Phila., Proc. 1: 358..

flavus (Fabricius). Fla.; West Indies, Mexico, Guatemala, Nicaragua, Guyana, Colombia, Brazil, Paraguay, Argentina.

Ichneumon flavus Fabricius, 1775. Systema Ent., p. 341. [female].

Ichneumon flavarius Thunberg, 1822; 1824. Acad. Imp. des Sci. St. Petersburg, Mem. 8: 262; 9: 314. Unecessary n. name for I. flavus Fabricius.

Ophion concolor Cresson, 1865. Ent. Soc. Phila., Proc. 4: 56. [female].

Enicospilus guyanensis Cameron, 1911. Timehri (3) 1: 179. [female].

Taxonomy: Townes and Townes, 1966. Amer. Ent. Inst., Mem. 8: 178-179 (syn.).

glabratus (Say). Md. s. to Fla., w. to s. Calif; Puerto Rico, Dominican Republic, Jamaica, Mexico, Costa Rica, Panama. Host: Diacrisia virginica (F.), Ecpantheria scribonia (Stoll), Halisidota maculata (Harris), Hyphantria cunea (Drury), Isia isabella (J. E. S.), Dasychira basiflava (Pack.).

Ophion glabratus Harris, 1935. In Hitchcock, Rpt. Geol. Mineral. Bot. Zool. Mass., ed. 2, p. 585. Nomen nudum.

Ophion glabratus Say, 1836. Boston Jour. Nat. Hist. 1: 239. Sex not indicated.

Ophion arctiae Riley, 1890. In Riley and Howard, U. S. Dept. Agr., Insect Life 3: 155. Nomen nudum.

Eremotylus arctiae Ashmead, 1896. Amer. Ent. Soc., Trans. 23: 192. $₹$ (ơ misdet.).

Allocamptus cubitalis Morley, 1912. Rev. Ichn. Brit. Mus., v. 1, p. 25. + . Preocc. by Szepligeti, 1906.

Enicospilus excubitalis Walkley, 1958. In Krombein et al., U. S. Dept. Agr., Agr. Monog. 2, Sup. 1, p. 62. N. name for $A$. cubitalis Morley. 
Taxonomy: Townes, 1961. Ent. Soc. Wash., Proc. 63: 103 (syn.).

merdarius (Gravenhorst). Que. w. to s.e. Alaska, s. to Fla., s. Tex., and s. Calif.; West Indies, Mexico, Nicaragua; South America; Asia; Europe. Host: Alabama argillacea (Hbn.), Ceramica picta (Harris), Leucania latiuscula H.-S., L. multilinea Wlk., Feltia subterranea (F.), Peridroma saucia (Hbn.), Pseudaletia unipuncta (Haw.), Scoliopteryx libatrix (L.), Scotogramma trifolii (Rott.), Spodoptera frugiperda (J. E. S.), S. ornithogalli (Gn.), Heterocampa guttivitta (Wlk.), Schizura concinna (J. E. S.), S. unicomis (J. E. S.), Drepana bilineata (Pack.).

Ophion merdarius Gravenhorst, 1829. Ichn. Europaea, v. 3, p. 698. đ’, ?.

Ophion purgatus Say, 1836. Boston Jour. Nat. Hist. 1: 239. d, ?.

Ophion lateralis Brulle, 1846. In Lepeletier, Hist. Nat. Ins. Hym., v. 4, p. 141. [female]. Ophion flaviceps Brulle, 1846. In Lepeletier, Hist. Nat. Ins. Hym., v. 4, p. 142. [female].

Ophion volubilis Holmgren, 1869 (1868). Eug. Resa, pt. 2, sec. 1, p. 410. ठ, \&.

Taxonomy: Townes and Townes, 1966. Amer. Ent. Inst., Mem. 8: 181-182 (syn.).

texanus (Ashmead). N. Y., s.w. Va., Ohio, Tex., s.e. Wash., n.e. Calif.

Thyreodon texanus Ashmead, 1890 (1889). U. S. Natl. Mus., Proc. 12: 422. ठ.

\section{SUBFAMILY MESOCHORINAE}

It is certain that most of the members of this subfamily are hyperparasitic, and I speculate that those Mesochorinae which may eventually be proven not to be hyperparasitic will be shown to be cleptoparasitic. Some species of Mesochorinae parasitize other Ichneumonidae, but a greater number parasitize Braconidae. At least four Nearctic species of Mesochorus have been reared from Tachinidae. The hosts of Mesochorinae are internal parasites of various insects, most of the latter being phytophagous. Mesochorinae have been reared from parasites of Lepidoptera, Symphyta, Coleoptera, Miridae, and, according to Dr. C. C. Loan (personal communication, 1975), even Psocoptera. Mesochorines insert the ovipositor into the secondary host and in turn locate the early-instar larva or even the egg of a primary parasite and oviposit inside the latter.

Dasch (1971) said that "considerable evidence seems to indicate that many species [of Mesochorinae] are primary parasites of lepidopterous and coleopterous larvae," but this statement appears to be inaccurate. For Mesochorinae to be primary parasites of these hosts, they would have to spin their own cocoons or emerge from lepidopterous pupae. I do not know of any case in which a mesochorine specimen is mounted with a lepidopterous pupa from which it emerged or is otherwise known with certainty to have emerged from a lepidopterous pupa. In substantiated cases of emergence from lepidopterous pupae, proof of primary parasitism could be made only through dissection of the host remains, because mesochorines may be able to parasitize primary parasites which oviposit into lepidopterous larvae and emerge from the pupae (such as Anomaloninae [Dasch (1971) cited a published record of a Trichionotus sp. as a host], Metopiinae Ichneumoninae, certain Campopleginae, or meteorideine Braconidae). In any case, the majority of mesochorine specimens labeled as being reared from Coleoptera or Lepidoptera have emerged from cocoons, and when these specimens are mounted together with the cocoons from which they have emerged, the cocoons prove to be those of Braconidae or other Ichneumonidae. The only possible exception that I am aware of is Plectochorus iwatensis (Uchida), a Eurasian species which apparently spins a cocoon of its own and thus appears to be a primary parasite of Grapholitha molesta (Bsk.) (cf. Haeussler, 1940). It is remotely possible that some of the species of Mesochorinae which have been reared from cocoons of sawflies could be primary parasites, but this could not be established without dissecting the contents of the cocoons and determining that they do not include the larval remains of an additional ichneumonid or an ichneutine braconid.

Revision: Dasch, 1971. Amer. Ent. Inst., Mem. 16: 1-376 (Nearctic spp.). -Dasch, 1974. Amer. Ent. Inst., Mem. 22: 1-509 (Neotropic spp.).

Biology: Haeussler, 1940. U. S. Dept. Agr., Tech. Bul. 728: 24-25 (Plectochorus iwatensis [Uchida]).

\section{Genus CIDAPHUS Foerster}

Cidaphus Foerster, 1868. Naturh. Ver. Rheinlande, Verh. 25: 149. 
Type-species: Cidaphus thuringiacus Brauns. Desig. by Viereck, 1914 from two species included by Brauns, 1890. Perkins (1962) regarded the type-species as a synonym of $C$. alarius (Gravenhorst).

Plesiophthalmus Foerster, 1868. Naturh. Ver. Rheinlande, Verh. 25: 170. Preocc. by Motschoulsky, 1858.

Type-species: Mesochorus alarius Gravenhorst. By subsequent monotypy from inclusion by Brischke, 1871.

Mater Schulz, 1911. Zool. Ann. 4: 22. N. name for Plesiophthalmus Foerster.

Tetragonalys Morley, 1913. Rev. Ichn. Brit. Mus., v. 2, p. 132.

Type-species: Tetragonalys barbarica Morley. Desig. by Morley, 1913.

Plesiophthalmidea Viereck, 1914. U. S. Natl. Mus., Bul. 83: 119.

Type-species: Plesiophthalmus paniscoides Ashmead. Monotypic and orig. desig.

Ophthalmochorus Roman, 1925 (1924). Arkiv for Zool. 17 A (4): 29. N. nam̉e for Plesiophthalmus Foerster.

This is a moderate sized genus of practically worldwide distribution.

Revision: Cushman, 1924. U. S. Natl. Mus., Proc. 64 (20): 4-6.

Taxonomy: Perkins, 1962. Brit. Mus. (Nat. Hist.) Ent., Bul. 11: 414.

australis Cushman. Que., Ont., n. Minn., and B. C., s. to Va., Ala., Idaho, and Wash.

Cidaphus australis Cushman, 1924. U. S. Natl. Mus., Proc. 64 (20): 6. $\$$.

Cidaphus melleus Walley, 1935. Canad. Ent. 67: 112. o, ๆ.

occidentalis Cushman. Newfoundland (Labrador and insular) w. to Alaska, s. to N. H., Ohio, Colo., Ariz., and Wash.

Cidaphus occidentalis Cushman, 1924. U. S. Natl. Mus., Proc. 64 (20): 5. ₹.

paniscoides (Ashmead). Maine, Ont., and Mich., s. to n.w. S. C., w. Ky., and N. Mex. Ecology:

Can be presumed to have been reared from a parasite of Heterocampa manteo (Dbldy.).

Plesiophthalmus paniscoides Ashmead, 1892. Ent. News 3: 107. ठ。.

sinuosus Dasch. Ariz.; Mexico.

Cidaphus sinuosus Dasch, 1971. Amer. Ent. Inst., Mem. 16: 13. ð’, ᄋ.

\section{Genus ASTIPHROMMA Foerster}

Astiphromma Foerster, 1868. Naturh. Ver. Rheinlande, Verh. 25: 170.

Type-species: Mesochorus scutellatus Gravenhorst. Desig. by Morley, 1913 from six species included by Brischke, 1880.

Astiphrommus Thomson, 1886. Soc. Ent. de France, Ann. (6) 5: 327. Emend.

Dolichochorus Strobl, 1904 (1903). Naturw. Ver. f. Steiermark, Mitt. 40: 108.

Type-species: Dolichochorus longiceps Strobl. Monotypic.

Mesochorella Szepligeti, 1911. In Wytsman, Gen. Ins., fasc. 114, p. 48.

Type-species: Mesochorus nigriceps Brischke. Monotypic.

Pseudoacoenitus Kiss, 1924. Siebenbuerg. Ver. Naturw., Verh. u. Mitt. 72-74: 96.

Type-species: Pseudoacoenitus transsylvanicus Kiss. Monotypic.

Demophorellus Hedwig, 1955. Bombus 1: 379.

Type-species: Demophorellus mimulus Hedwig. Monotypic.

This is a moderately large Holarctic genus.

Revision: Nakanishi, 1969. Sieboldia 4: 50-74 (Japanese spp., except those without smooth scutellum).

alsium Dasch. Alta., interior Alaska, n. B. C., w. Wash.

Astiphromma alsium Dasch, 1971. Amer. Ent. Inst., Mem. 16: 35. ठ, \&.

aquilonare Dasch. Northern Que. and N. W. T., s. to s. Que., Alta., and B. C. Ecology: Can be presumed to have been reared from parasites of $P$ ikonema alaskensis (Roh.) and $P$. dimmockii (Cr.).

Astiphromma aquilonare Dasch, 1971. Amer. Ent. Inst., Mem. 16: 44. ठ, ․ calvum Dasch. Ariz.

Astiphromma calvum Dasch, 1971. Amer. Ent. Inst., Mem. 16: 43. đo, ๆ. 
cordatum Dasch. Northern Mich., Alta.

Astiphromma cordatum Dasch, 1971. Amer. Ent. Inst., Mem. 16: 24..

coronale Dasch. N. Y., Pa., Md., Ont., Ohio, Mich.

Astiphromma coronale Dasch, 1971. Amer. Ent. Inst., Mem. 16: 30. ¿, ๆ.

euryops Dasch. Ohio, w. N. C., e. Tenn.

Astiphromma euryops Dasch, 1971. Amer. Ent. Inst., Mem. 16: 32. ð, ९.

eximium Dasch. Pa., Mich., n. B. C.

Astiphromma eximium Dasch, 1971. Amer. Ent. Inst., Mem. 16: 25. \&.

exitiale Dasch. Newfoundland (insular), n. Que., w. N. W. T., and interior Alaska, s. to Md., w.

N. C., Colo., and Idaho.

Astiphromma exitiale Dasch, 1971. Amer. Ent. Inst., Mem. 16: 33. đ, \&.

gilvicrus Dasch. N. Y., Mich., s.e. Minn.

Astiphromma gilvicrus Dasch, 1971. Amer. Ent. Inst., Mem. 16: 21. ठ, १.

leucogrammum (Holmgren). Northern Que. w. to n. Alaska, s. to s. Que., Man., Colo., and w. Wash.; n. Eurasia. Ecology: Reared or presumed to have been reared from parasites of the following Tenthredinidae-- Hemimichroa crocea (Geoff.)., Pikonema alaskensis (Roh.), and Nematus sp. Host: Lamachus angularius (Davis).

Mesochorus leucogrammus Holmgren, 1860 (1858). Svenska Vetensk.-Akad. Handl. (n. f.) 2 (8): 121 .. .

luculentum Dasch. Colo., B. C., e. Wash. Ecology: One paratype can be presumed to have been reared from a parasite of a tenthredinid, and two others were collected at elevations of $9800 \mathrm{ft}$. and $10300 \mathrm{ft}$. on Mt. Evans in Colo.

Astiphromma luculentum Dasch, 1971. Amer. Ent. Inst., Mem. 16: 40. ठ, ๆ.

nitidum Dasch. Western Alta. Ecology: The unique holotype can be presumed to have been reared from a parasite of the geometrid, Lycia ursaria Wlk.

Astiphromma nitidum Dasch, 1971. Amer. Ent. Inst., Mem. 16: 39. ठ.

pectorale Ashmead. Que. s. to Tenn., w. to Wis., e. Kans., and Tex. Ecology: Can be presumed to have been reared from parasites of the geometrids, Alsophila pometaria (Harris) and Erannis tiliaria (Harris).

Astiphromma pectoralis Ashmead, 1892. Ent. News 3: 107. ठ.

perditum Dasch. Que. w. to s. Man., s. to n.w. S. C. and s. Ill.

Astiphromma perditum Dasch, 1971. Amer. Ent. Inst., Mem. 16: 41. ठँ, ‡.

psychron Dasch. Northern Que.

Astiphromma psychron Dasch, 1971. Amer. Ent. Inst., Mem. 16: 46..

rutilum Dasch. N. Y., w. N. C., n.w. S. C., Ohio, s.e. Mich., e. Kans., Tex.

Astiphromma rutilum Dasch, 1971. Amer. Ent. Inst., Mem. 16: 22. o, $\%$.

simile Dasch. Conn., N. J., n.w. S. C., Ohio, Mich., Ky.

Astiphromma simile Dasch, 1971. Amer. Ent. Inst., Mem. 16: 37. ठ,.+

splenium (Curtis). Que. w. to Alaska, s. to Md., w. N. C., Colo., and n. Calif.; Eurasia. Ecology: Reared or presumed to have been reared from parasites of the following-- Caripeta divisata Wlk., Cladara limitaria (Wlk.), C. nigroangulata (Stkr.), Dysstroma citrata (L.), Eupithecia placidata Taylor, $E$. unicolor Hulst, Lambdina fiscellaria fiscellaria (Gn.), L. f. lugubrosa (Hulst), Melanolophia imitata (Wlk.), Nepytia canosaria (Wlk.), Dasychira grisefacta (Dyar)?, Leucoma salicis (L.), Malacosoma disstria (Hbn.), Enargia decolor (Wlk.), and a tenthredinid. Host: Meteorus hyphantriae Riley?, Zemiotes reticulatus (Mues.), Phobocampe geometrae (Ash.).

Mesochorus sericans Curtis, 1833. Brit. Ent., v. 10, pl. 424. " $\delta "=q$. Described from Ireland (presumably Belfast). Examination of material which the U. S. Natl. Museum aquired from A. W. Stelfox leads me to believe that sericans, as illustrated by Curtis, is quite probably an abnormally melanic specimen of splenium. N. syn. (uncertain).

Mesochorts Splenium Curtis, 1833. Brit. Ent., v. 10, pl. 424. ð. Dr. H. K. Townes informed me (personal commun., 1977) that he saw notes which Dr. J. F. Perkins made in studying what is now the lectotype (see Fitton, 1976) which indicated that $M$. strenuus Holmgren is a synonym of splenizm, and Dr. Townes suggested that I consult the original description of splenium to see if it agreed with what Dr. Perkins had concluded. Having done so, I see no reason to doubt that Dr. Perkins was correct. 
Mesochorus strenuus Holmgren, 1860 (1858). Svenska Vetensk.-Akad. Handl. (n. f.). 2 (8): 119. ठ, \&. N. syn.

Plectiscus pleuralis Provancher, 1875. Nat. Canad. 7: 330. “o" = §. N. syn.

Plectiscus provancheri Dalla Torre, 1901. Cat. Hym., v. 3, p. 24. Unnecessary n. name for $P$. pleuralis Provancher; preocc. secondarily only by virtue of a bibliographic error which led Dalla Torre to erroneously place Tryphon pleuralis Cresson, 1864, in Plectiscus. N. syn.

Mesochorus orcae Ashmead, 1902. Wash. Acad. Sci., Proc. 4: 239. ठ. N. syn.

Astiphromma kiotense Uchida, 1933. Insecta Matsumurana 8: 57. ठో, १. N. syn.

Astiphromma sachalinense Uchida, 1933. Insecta Matsumurana 8: 57.. . N. syn.

Taxonomy: Townes, 1939. Canad. Ent. 71: 96. -Townes, Momoi, and Townes, 1965. Amer.

Ent. Inst., Mem. 5: 341 (syn.). -Fitton, 1976. Brit. Mus. (Nat. Hist.) Ent., Bul. 32: 323

(lectotypes selected for Curtis names).

\section{Genus MESOCHORUS Gravenhorst}

Mesochorus Gravenhorst, 1829. Ichn. Europaea, v. 2, p. 960.

Type-species: Mesochorus splendidulus Gravenhorst. Desig. by Curtis, 1833.

Edrisa Cameron, 1907. Tijdschr. v. Ent. 50: 111.

Type-species: Edrisa pilicomis Cameron. Monotypic.

Zamesochorus Viereck, 1912. U. S. Natl. Mus., Proc. 42: 152.

Type-species: Zamesochorus orientalis Viereck. Monotypic and orig. desig.

Cryptochorus Aubert, 1965. Soc. Ent. de Mulhouse, Bul. 21: 22.

Type-species: Cryptochorus obliterator Aubert. Monotypic and orig. desig.

This very large genus is worldwide in distribution.

acuminatus Thomson. N. B. w. to w. Ont., s. to Md. and Ill. Ecology: Reared or presumed to have been reared from parasites of the following-Sphingidae (Cressonia juglandis [Smith], Darapsa versicolor [Harris], Manduca sp., Sphinx kalmiae [J. E. S.]) and Notodontidae (Heterocampa guttivitta [Wlk.], Pheosia rimosa Pack.). Host: Apanteles sp., Microplitis sp.

Mesochorus acuminatus Thomson, 1885. Soc. Ent. de France, Ann. (6) 5: 343. ठ'.

agilis Cresson. Newfoundland (Labrador) w. to Alaska, s. to N. Y., Mich., N. Mex., Ariz., and n.e. Calif.; Greenland; Europe; n. Mexico. Ecology: Reared from larval parasites of Coleoptera (Curculionidae)and presumed to have been reared from a parasite of Crambidia casta (Pack.) (Lepidoptera, Arctiidae). Host: Bathyplectes curculionis (Thom.), Dimophora sp.

Mesochomis agilis Cresson, 1865. Ent. Soc. Phila., Proc. 4: 266..

Mesochomis nigriceps Thomson, 1885 Soc. Ent. de France, Ann. (6) 5: 334. §, ९. Preocc. by Brischke, 1880.

Mesochorus punctipleuris Thomson, 1885. Soc. Ent. de France, Ann. (6) 5: 334. ơ,. .

Mesochorus Thomsonii Dalla Torre, 1901. Cat. Hym., v. 3, p. 59. N. name for nigriceps Thomson.

alaskensis Dasch. Southwestern Alaska.

Mesochorus alaskensis Dasch, 1971. Amer. Ent. Inst., Mem. 16: 109. $\$$.

americanus Cresson. Newfoundland (insular) and n. Que. w. to s.w. Alaska, s. to Fla., s. Tex., Ariz., and Oreg.; n.e. Asia, Europe. Ecology: Reared or presumed to have been reared from parasites of the following Lepidoptera-- Thecla sp., Colias philodice Godt., Acronicta oblinita (J. E. S.)?, Amathes c-nigmum (L.), Autographa californica (Spey.), Eurois sp., Peridroma saucia (Hbn.), Pseudaletia unipuncta (Haw.), Spodoptera ormithogalli (Gn.), Hemaris sp., Manduca sp., M. quinquemaculata (Haw.), M. sexta (Joh.), Ctenucha virginica (Charp.), Enchaetias egle (Drury), Caripeta divisata Wlk., Semiothisa "granitata" auct., S. sexmaculata (Pack.), Bucculatrix canadensisella Cham. Host: Apanteles sp., A. congregatus (Say), A. glomeratus (L.), A. laeviceps Ash., A. mufocoxalis Riley, A. scitulus Riley, A. xylinus (Say), Meteorus sp.

Mesochorus americanus Cresson, 1872. Canad. Ent. 4: 23..

Mesochorus scitulus Cresson, 1872. Canad. Ent. 4: 24. ơ, ?. 
Mesochorus aprilinus Riley, 1890. In Riley and Howard, U. S. Dept. Agr., Insect Life 3: 156. Nomen nudum.

Mesochomus aprilinus Ashmead, 1896. Amer. Ent. Soc., Trans. 23: 195. \&. The syntype referred to as the "type" by Dasch (1971) is apparently from D. C., not from "Lafayette, Indiana" as Dasch stated.

Mesochorus frontalis Ashmead, 1899 (1898). In Jordan, Fur Seals and Fur-Seal Isls. N. Pacific, v. 4, p. 336. ठ. The type locality is Ostrov Bering (i.e. Bering Isl.), U. S. S. R.

Taxonomy: Dasch, 1971. Amer. Ent. Inst., Mem. 16: 258-262.

apantelis Dasch. Que. s. to Fla., w. to Mich., Mo., and Tex. Ecology: Reared or presumed to have been reared from parasites of the following- "Vanessa" sp., Hymenia recurvalis (F.), Cosmopteryx sp. on morning glory, Bedellia minor Bsk., and a leaf miner on Vitus. Host: Apanteles sp. ex "Vanessa" sp.

Mesochorus apantelis Dasch, 1971. Amer. Ent. Inst., Mem. 16: 266. đ, ?.

applanatus Dasch. Northern Que. w. to w. N. W. T., s. to Md., n. Ga., Colo., and Oreg. Ecology: Presumed to have been reared from parasites of the following Lepidoptera and Symphyta-- Semiothisa sexmaculata (Pack.), Empria multicolor (Nort.), Macremphytus testaceus (Nort.), and Monophadnoides geniculatus (Htg.).

Mesochorus applanatus Dasch, 1971. Amer. Ent. Inst., Mem. 16: 154. ơ, ?.

arcticus Dasch. Subarctic Alaska.

Mesochorus arcticus Dasch, 1971. Amer. Ent. Inst., Mem. 16: 175. ․

areolatus Provancher. N. S., Que., N. Y., w. N. C., n. Ga., Ont., Mich., Sask., Alta., Alaska, B. C., Wash. Ecology: Presumed to have been reared from a parasite of Semiothisa "granitata" auct.

Mesochorus areolatus Provancher, 1883. Nat. Canad. 14: 5. ‡.

asperifrons Dasch. Western N. C., n.w. S. C., Ohio, s. Mich., Ky., s. Ala., Ill., e. Kans., Ariz.

Mesochorus asperifrons Dasch, 1971. Amer. Ent. Inst., Mem. 16: 268. ¿, ?.

balteatus Dasch. Que., N. H., N. Y., N. J., Md., w. N. C., Ont., Ohio, Ala.

Mesochorus balteatus Dasch, 1971. Amer. Ent. Inst., Mem. 16: 162. §, ९.

bellus Dasch. Minn., s. Man.

Mesochorus bellus Dasch, 1971. Amer. Ent. Inst., Mem. 16: 208. ․

bucculentus Dasch. Northern Mich., B. C., Wash., n.e. Calif.

Mesochorus bucculentus Dasch, 1971. Amer. Ent. Inst., Mem. 16: 223. ठ,.+

calais Viereck. N. H., Ont., Sask., and Alta., s. to Va., Ohio, and Mich.

Mesochorus calais Viereck, 1917 (1916). Conn. State Geol. and Nat. Hist. Survey Bul. 22: 280. . .

carolinensis Dasch. Western N. C., n.w. S. C., n. Fla., s. Ont., s. Mich., e. Tenn.

Mesochoris carolinensis Dasch, 1971. Amer. Ent. Inst., Mem. 16: 133. ․

coronatus Dasch. Que. w. to n. Yukon and Alaska, s. to N. J., s.e. Iowa, S. Dak., Colo., and n.e. Calif.

Mesochorus coronatus Dasch, 1971. Amer. Ent. Inst., Mem. 16: 230. o, ๆ.

cupreatus Dasch. P. E. I. s. to w. N. C., w. to n. Alta. and Wash. Host: Dimophora sp.

Mesochorus cupreatus Dasch, 1971. Amer. Ent. Inst., Mem. 16: 106. ‡.

curvulus Thomson. Northern Que., N. W. T., and Alaska, s. to n.w. S. C., e. Kans., Ariz., and n.e. Calif.; Europe. Ecology: Reared from parasites of Miridae (Dicyphus sp., Halticus intermedius Uhler, Lopidea marginalis Reut., Lygus lineolaris [Beauv.], Phytocoris sp., Plagiognathus conicola Knight, P. politus Uhler, Slaterocoris stygicus [Say]) and adult Chrysomelidae (Phyllotreta striolata [F.]); apparently also reared from parasites of Lepidoptera (Melanolophia imitata [Wlk.] and Autographa sp.). Host: Leiophron spp., L. sp. near maculipennis (Ash.), Peristenus sp. near pallipes (Curt.), P. plagiognathi (Loan), Microctonus vittatae Mues.

Mesochorus curvulus Thomson, 1885. Soc. Ent de France, Ann. (6) 5: 343. ठ, ․

Mesochorus kincaidi Ashmead, 1902. Wash. Acad. Sci., Proc. 4: 238..

Mesochorus phyllotretae Jourdheuil, 1957. Soc. Ent. de France, Bul. 62: 42. ơ, ?.

deletus Dasch. Alta., interior Alaska, n. B. C., Wash.

Mesochorus deletus Dasch, 1971. Amer. Ent. Inst., Mem. 16: 170. ठ", ․ 
dentatus Dasch. N. Y., Ky., Minn., Colo., Alta., s.e. B. C., n. Idaho. Ecology: Presumed to have been reared from a parasite of Arge pectoralis (Leach).

Mesochorus dentatus Dasch, 1971. Amer. Ent. Inst., Mem. 16: 125. đo, ?.

discitergus (Say). Newfoundland (insular) w. to interior Alaska, s. to Fla., Tex., Ariz, and Wash.; West Indies and Mexico s. to Brazil and Peru; Eurasia; South Africa? Ecology: Reared or presu ned to have been reared from parasites of the following-- Papilionidae (Papilio polyxenes asterius Stoll.), Pieridae (Colias eurytheme Bdv.), Geometridae (Anthelia hyperboria Hulst, Biston betularia cognataria [Gn.], Caripeta sp., $C$. angustiorata Wlk.?, C. divisata Wlk., Ectropis sp., Enypia packardata Tay., Epirrita autumnata henshawi [Swett], Eupithecia sp., Lambdina fiscellaria fiscellaria [Gn.], L. $f$. lugubrosa [Hulst], Lobophora nivigerata Wlk., Melanolophia imitata [Wlk.], Nepytia canosaria [Wlk.], N. phantasmaria [Stkr.], Pleuroprucha insularia [Gn.], Semiothisa "granitata" auct., S. oweni [Swett]), Limacodidae (Prolimacodes badia [Hbn.], Noctuidae (Caenurgina erechtea [Cramer], Celama triquetrana [Fitch], Ceramica picta [Harris], Feralia jocosa [Gn.], Heliothis zea [Bod.], Panthea portlandia Grt., Peridroma saucia [Hbn.], Pseudaletia unipuncta [Haw.], Spodoptera frugiperda [J. E. S.]), Sphingidae (Manduca sexta [Joh.]), Arctiidae (Euchaetias egle [Drury], Halisidota s H. caryae [Harris], H. maculata [Harris], H. tessellaris [J. E. S.], Tyria jacobaea [L.] Lymantriidae (Dasychira plagiata [Wlk.], D. vagana [B. and McD.]), Notodontidae (Notodonta sp.), Zygaenidae (Harrisina americana [Gn.]), Lyonetiidae (Bedellia minor Bsk.), sp. of Pterophoridae, and Tenthredinidae (Anoplonyx sp.). Host: A panteles sp., A.glomeratus (L.), A. lunatus (Pack), A. militaris (Walsh), A. paleacritae Riley, Meteorus communis (Cr.), Microplitis melianae Vier.?

Cryptus discitergus Say, 1836. Boston Jour. Nat. Hist. 1: 231.. .

Mesochorus vitreus Walsh, 1861. Ill. State Agr. Soc., Trans. 4: fig. 4; p. 364, p. 368. §, ९. Synonymy uncertain because in revising the concept of discitergus Dasch (1971) erroneously selected as "lectotypes" of vitreus two female specimens which are not Walsh type material and bear no label in the handwriting of Walsh. The alternate spelling "vitrens" appeared in the legend for Walsh's figure 4.

Mesochorus obliquus Cresson, 1872. Canad. Ent. 4: 24. 9.

Mesochorus facialis Bridgman, 1884. Ent. Soc. London, Trans. 32: 431. ठ', ๆ.

Mesochorus pulchellus Cook and Davis, 1891. Mich. Agr. Expt. Sta. Bul. 73: 10. Mesochorus infernalis Viereck, 1911. U. S. Natl. Mus., Proc. 40: 192. ठ, ?.

Mesochomes nigrisignus Viereck, 1911. U. S. Natl. Mus., Proc. 40: 192. $\uparrow$.

Mesochorus concinnatus Wilkinson, 1929. Bul. Ent. Res. 20: 105. ठ, ९. Uncertain syn.; placed as a synonym of discitergus by Dasch (1971); placed instead as a synonym of $M$. ornatus Wilkinson (an Ethiopian species) by Townes and Townes (1973) who erroneously stated that "omatus is listed erroneously [by Dasch] as a synonym [of discitergus] and the record from South Africa is based on a misdetermined specimen of ornatus."

Mesochorus narangae Uchida, 1930. Insecta Matsumurana 4: 129. §, ๆ.

Mesochorus facialis var. nigristemmaticus Uchida, 1931. Insecta Matsumurana 5: 158. . Mesochorus havrolenkoi Blanchard, 1949. In Havrolenko and Winterhalter, Insectos del Parque Nac. Nuhuel Huapi, Buenos Aires, p. 48. Nomen nudum (figure only).

Taxonomy: Dasch, 1971. Amer. Ent. Inst., Mem. 16: 252-257. -Townes and Townes, 1973. Amer. Ent. Inst., Mem. 19: 186. - Dasch, 1974. Amer. Ent. Inst., Mem. 22: 250-254.

distentus Dasch. Eastern Wash. Mesochorus distentus Dasch, 1971. Amer. Ent. Inst., Mem. 16: 236. ठै.

divaricatus Dasch. Colo. Mesochorus divaricatus Dasch, 1971. Amer. Ent. Inst., Mem. 16: 225. ठ, ๆ.

dreisbachi Dasch. Que. w. to Alaska, s. to Ky., e. Kans., Utah, and n. Calif. Mesochorus dreisbachi Dasch, 1971. Amer. Ent. Inst., Mem. 16: 99. ठ, ๆ. ejuncidus Dasch. Western N. C., Colo., Ariz., B. C., Wash., Oreg. Mesochorus ejuncidus Dasch, 1971. Amer. Ent. Inst., Mem. 16: 182. §, ๆ. elongatus Dasch. Central and s.e. Ariz. Mesochorus elongatus Dasch, 1971. Amer. Ent. Inst., Mem. 16: 83. ð’, १. 
erythraeus Dasch. Alta., s.e. B. C. Ecology: Reared or presumed to have been reared from parasites of the following-- Eupithecia placidata Tay., Neoalcis califormiaria $\mathrm{f}$. latifaciaria (Pack.), Semiothisa "granitata" auct., and Anomogyna sp. Host: Hyposoter sp.

Mesochorus erythraeus Dasch, 1971. Amer. Ent. Inst., Mem. 16: 191. ठ, ?.

exsertus Dasch. N. S. w. to Yukon and Alaska, s. to Md., n.w. S. C., e. S. Dak., Colo., Ariz., and Oreg. Ecology: Reared or presumed to have been reared from parasites of the following-- Semiothisa "granitata" auct., Neodiprion sp., Cimbex americana Leach, and Trichiosoma triangulum Kby. Host: Enicospilus merdarius (Gravenhorst).

Mesochorus exsertus Dasch, 1971. Amer. Ent. Inst., Mem. 16: 156. ¿, ๆ.

flavidus Dasch. Pa., w. N. C., Ohio, Tenn., e. Kans.

Mesochorus flavidus Dasch, 1971. Amer. Ent. Inst., Mem. 16: 123. ठ, ๆ.

foersteri Dasch. N. S., n. Man. and s.w. Yukon, s. to Pa., Mich., Colo., w. Mont., and s. B. C. Mesochorus foersteri Dasch, 1971. Amer. Ent. Inst., Mem. 16: 107..

fuliginatus Dasch. Newfoundland (Labrador) w. to n. B. C., s. to Maine, Mich., N. Mex., Utah, and n.e. Calif. Ecology: One specimen can be presumed to have been reared from a parasite of the chrysomelid, Pyrrhalta decora carbo (LeC.).

Mesochorus fuliginatus Dasch, 1971. Amer. Ent. Inst., Mem. 16: 90. ठ, ๆ.

gelidus coriaceus Dasch. Northern Que., n.e. N. W. T., n. Yukon.

Mesochorus gelidus coriaceus Dasch, 1971. Amer. Ent. Inst., Mem. 16: 204. ठ, ?.

gelidus gelidus Dasch. Colo. Ecology: The four type specimens were collected on Mt. Evans, Colo. at elavations between $9800 \mathrm{ft}$. and $13200 \mathrm{ft}$.

Mesochorus gelidus gelidus Dasch, 1971. Amer. Ent. Inst., Mem. 16: 204. ठ, ९.

gemmatus Dasch. Que., N. Y., Pa., Md., Ohio, s. Mich.

Mesochorus gemmatus Dasch, 1971. Amer. Ent. Inst., Mem. 16: 111. o, ९.

globulator (Thunberg). Southern Man., w. N. W. T., Alta.; Europe. Host: Mesoleius tenthredinis Morl., Olesicampe benefactor Hinz.

Ichneumon globulator Thunberg, 1822; 1824. Acad. Imp. des Sci. St. Petersbug, Mem. 8: $266 ; 9: 322$. [female].

Mesochorus dimidiatus Holmgren, 1860 (1858). Svenska Vetensk.-Akad. Handl. (n. f.) 2 (8): 118. ơ.

Mesochorus crassimanus Holmgren, 1860 (1858). Svenska Vetensk.-Akad. Handl. (n. f.) 2 (8): 125. ․

Taxonomy: Roman, 1912. Ent. Tidskr. 33: 67 (syn.). - Roman, 1912. Zool. Bidr. Uppsala 1: 258 (syn.).

grandisops Dasch. Southern B. C., Wash., Calif.; n. Mexico. Ecology: Reared or presumed to have been reared from parasites of the following-Lambdina fiscellaria lugubrosa (Hulst), Melanolophia imitata (Wlk.), Nepytia canosaria (Wlk.), and Semiothisa "granitata" Host: Meteorus hyphantriae Riley.

Mesochorns grandisops Dasch, 1971. Amer. Ent. Inst., Mem. 16: 189. đँ, ๆ.

hamatus Townes. Que. s. to Md., w. to n.w. Mich. and e. Kans.

Mesochorus basalis Cresson, 1872. Canad. Ent. 4: 22. ๆ. Preocc. by Curtis, 1833.

Mesochorus hamatus Townes, 1945. Amer. Ent. Soc., Mem. 11: 753. N. name for basalis Cresson.

hesperus Dasch. Southern Alta., s.w. Yukon.

Mesochorus hesperus Dasch, 1971. Amer. Ent. Inst., Mem. 16: 211. ठ.

hirticoleus Dasch. Northwestern S. C., n. Fla., Iowa, s. La.

Mesochorvs hirticoleus Dasch, 1971. Amer. Ent. Inst., Mem. 16: 137. §, १.

holmgreni Dasch. Maine, R. I., w. Va., n. Fla., Ohio, n. Wis. Ecology: One of the paratypes can be presumed to have been reared from a parasite of Heterarthrus nemoratus (Fall.), but the holotype was collected at light in northern Fla.

Mesochorns holmgreni Dasch, 1971. Amer. Ent. Inst., Mem. 16: 84. o, ๆ.

imitatus Dasch. R. I., N. Y., Pa., W. Va., n.w. S. C., Ohio, Mich.

Mesochorns imitatus Dasch, 1971. Amer. Ent. Inst., Mem. 16: 152. o, ๆ. 
inaequidens Dasch. N. S., Que., Mass., Ont., w. Wyo., Colo., Alta., w. Nev., s. B. C., Wash., and n. Calif.

Mesochorus inaequidens Dasch, 1971. Amer. Ent. Inst., Mem. 16: 116. ठ', ९.

incultus Dasch. N. B.w. to B. C., s. to n.w. S. C., s. Ariz., and n. Calif. Ecology: Paratypes should be presumed to have been reared from parasites of the following-- Geometridae (Caripeta sp. C. divisata Wlk., Erannis tiliaria [Harris], Lambdina fiscellaria lugubrosa [Hulst], Melanolophia imitata [Wlk.], Nepytia canosaria [Wlk.], Pero behrensarius [Pack.]?, Semiothisa sp., S. sexmaculata [Pack.], Synaxis pallulata [Hulst]), Aretiidae (Halisidota sp.), Noctuidae (Feralia comstocki [Grt.], F. jocosa [Gn.], Lithophane petulca Grt., Zale sp., Z. duplicata [Beth.], Z. minerea norda [Smith]), Gracilariidae (Marmara arbutiella Bsk.), and Tenthredinoidea ("green bracken sawfly"). Host: Microplitus sp. ex Melanolophia imitata (Wlk.).

Mesochorus incultus Dasch, 1971. Amer. Ent. Inst., Mem. 16: 101. ठ, ᄋ.

inflatus Dasch. Ohio. Known only from the holotype.

Mesochorus inflatus Dasch, 1971. Amer. Ent. Inst., Mem. 16: 161..

infuscatus Dasch. N. S., Que., Md., Ohio.

Mesochorus infuscatus Dasch, 1971. Amer. Ent. Inst., Mem. 16: 159. ठ', ९.

inobseptus Dasch. Northern Alaska. Host: Tachinid ex larva of Chrysolina subsulcata (Mann.). Mesochorus inobseptus Dasch, 1971. Amer. Ent. Inst., Mem. 16: 128. o, ?.

intonsus Dasch. N. S. s. to e. N. C. and n.w. S. C., w. to Wị. and e. Kans. Ecology: One of the paratypes can be presumed to have been reared from a parasite of Macremphytus tarsatus (Say).

Mesochorus intonsus Dasch, 1971. Amer. Ent. Inst., Mem. 16: 114. ð, ๆ.

iridescens Cresson. Northern Calif.

Mesochorus iridescens Cresson, 1879 (1878). Acad. Nat. Sci. Phila., Proc. 30: 369..

jucundus Provancher. Que. w. to Wash., s. to n. Fla., s.e. Tex., Utah, and Oreg.

Mesochorus jucundus Provancher, 1883. Nat. Canad. 14: 5. $\$$.

kamouraskae Dasch. Northern Que. w. to n.w. Alta., s. to Pa., Ont., Mich., and s.w. Alta. Ecology: One of the paratypes should be presumed to have been reared from a parasite of Caripeta angustiorata Wlk.

Mesochorus kamouraskae Dasch, 1971. Amer. Ent. Inst., Mem. 16: 168. §, ๆ.

kansensis Dasch. Southern Kans. Known only from the holotype.

Mesochorus kansensis Dasch, 1971. Amer. Ent. Inst., Mem. 16: 132..

kentuckiensis Dasch. Ont., w. Ky.

Mesochorus kentuckiensis Dasch, 1971. Amer. Ent. Inst., Mem. 16: 127. o, \&.

longiscutatus Dasch. Que. w. to n. Yukon and Alaska, s. to w. N. C., n. Mich., Colo., and s. B. C. Ecology: Two paratypes can be presumed to have been reared from parasites of the following microlepidoptera-- Cerostoma dorsimaculella $\mathrm{Kft}$. (Yponomeutidae) and a gelechiid.

Mesochomis longiscutatus Dasch, 1971. Amer. Ent. Inst., Mem. 16: 173. ठ์,.

luteipes Cresson. R. I., N. J., Pa., n. Ga., n. Fla., Tex.; w. Mexico.

Mesochorus luteipes Cresson, 1872. Canad. Ent. 4: 22..

maleficus Dasch. N. Y., Ont., n. Mich., Colo., Alta. Ecology: One of the paratypes can be presumed to have been reared form a parasite of a tenthredinid.

Mesochorus maleficus Dasch, 1971. Amer. Ent. Inst., Mem. 16: 149..

marylandicus Dasch. Md., n. Va., n. Ala.

Mesochorus marylandicus Dasch, 1971. Amer. Ent. Inst., Mem. 16: 89. ð, ․

masoni Dasch. Newfoundland (insular), w. to s. coastal Alaska, s. to Maine, Ont., n. Minn., Colo., and Oreg. Ecology: Reared or presumed to have been reared from parasites of the following-- Pikonema alaskensis (Roh.), P. dimmockii (Cr.), Neodiprion sp., $N$. abietis (Harris), N. pratti banksianae Roh., N. pratti pratti (Dyar), N. tsugae Midd., N. virginiana Roh. Host: Lamachus angularius (Davis).

Mesochorus masoni Dasch, 1971. Amer. Ent. Inst., Mem. 16: 120. ठ, ๆ.

melleus Cresson. R. I., N. Y., Pa., n.w. S. C., Ohio.

Mesochorus melleus Cresson, 1872. Canad. Ent. 4: 24. ठ. 
moabae Dasch. Southeastern Utah. Ecology: The only two specimens known were collected at an elevation of $9200 \mathrm{ft}$.

Mesochorus moabae Dasch, 1971. Amer. Ent. Inst., Mem. 16: 147..+

naknekensis Dasch. Northern Que. w. to w. N. W. T. and Alaska, s. to N. H., Colo., and n.e. Calif. Ecology: One of the paratypes should be presumed to have been reared from a parasite of Spargania magnoliata Gn. (Geometridae).

Mesochorus naknekensis Dasch, 1971. Amer. Ent. Inst., Mem. 16: 63, 177. o, ๆ. The misspelling "naknakensis" appeared on p. 63.

nigripes Ratzeburg. Western Colo. The overwhelming evidence is that this species was unintentionally introduced along with Bathyplectes stenostigma (Thomson) in 1969. Host: Bathyplectes curculionis (Thom.), B. stenostigma (Thom.). The fact that only females of $M$. nigripes are known from Colo. suggest the possibility that two morphologically similar species may be confused under the name nigripes in Europe.

Mesochorus nigripes Ratzeburg, 1852. Ichn. d. Forstins., v. 3, p. 119. ठ.

Mesochorus gibbulus Holmgren, 1856 (1854). Svenska Vetensk.-Akad. Hand. 75: 60..

noctivagus Viereck. Northwestern S. C., e. Kans.

Mesochorus noctivagus Viereck, 1905. Kans. Acad. Sci., Trans. 19: 303..

obliteratus Dasch. Pa., Mich., n. Man., e. Wash. Host: Grisdalemyia sp. ex Chrysomela sp.

Mesochrus obliteratus Dasch, 1971. Amer. Ent. Inst., Mem. 16: 206. ơ, ๆ.

obsoletus Dasch. Western B. C.

Mesochorus obsoletus Dasch, 1971. Amer. Ent. Inst., Mem. 16: 241. ठ.

ontariensis Dasch. Md., Ont., Mich.

Mesochorts ontariensis Dasch, 1971. Amer. Ent. Inst., Mem. 16: 80. ơ, ९.

ottawaensis (Harrington). N. S. w. to n. Alta. and Oreg., s. to N. H., n. Mich., e. N. Dak., Colo., and $\mathrm{n}$. Utah.

Ischyrocnemis ottawaensis Harrington, 1892. Canad. Ent. 24: 98. ․

parallelus Dasch. Western Va.

Mesochorus parallelus Dasch, 1971. Amer. Ent. Inst., Mem. 16: 82...

parvus Dasch. Maine, N. H., Mass., N. Y., s.e. Fla., Ont., n. Mich. Ecology: Two of the paratypes can be presumed to have been reared from parasites of Bucculatrix canadensisella Chamb. and Heterarthrus nemoratus (Fall.).

Mesochorus parvus Dasch, 1971. Amer. Ent. Inst., Mem. 16: 248. ઠ, ๆ.

paulus Dasch. N. Y. Known only from the holotype.

Mesochorus paulus Dasch, 1971. Amer. Ent. Inst., Mem. 16: 250. ठ.

peltatus Dasch. Western Mich., Alta., interior Alaska, s.w. B. C., Wash.

Mesochorus peltatus Dasch, 1971. Amer. Ent. Inst., Mem. 16: 104. ठ, ९.

perniciosus Viereck. Southwestern Ont. s. to Iowa and Kans., w. to Alta., w. Mont., e. Idaho, n.e. Utah, and N. Mex. Ecology: Reared from parasites of Loxostege sticticalis (L.) and Cyclophora serrulata (Pack.). Host: Apanteles laeviceps Ash., Cremnops vulgaris (Cr.).

Mesochomis perniciosus Viereck, 1911. U. S. Natl. Mus., Proc. 39: 407. \&.

personatus Dasch. Que., n. Ont., Alta., and s. B. C., s. to Maine, Mich., and Oreg. Ecology: One of the paratypes can be presumed to have been reared from a parasite of Eupithecia luteata Pack.

Mesochorus personatus Dasch, 1971. Amer. Ent. Inst., Mem. 16: 166. ơ, ๆ.

pictilis Holmgren. N. S. w. to s. B. C., s. to n.w. S. C., e. Ill., Idaho, and s.w. Oreg. Ecology: Can be presumed to have been reared from parasites of the following-- Geometridae (Aethalura anticaria [Wlk.], Biston betularia cognataria [Gn.], Campaea perlata [Gn.], Deilinea sp., Ectropis crepuscularia [D. and S.], Iridopsis emasculata [Dyar], Semiothisa "granitata" auct.), Noctuidae (Bomolocha albalienalis [Wlk.], Lithophane sp.) and Pyralidae (Promylea lunigerella Rag.).

Mesochorus pictilis Holmgren, 1860 (1858). Svenska Vetensk.-Akad. Handl. (n. f.) 2 (8): 131. $\delta$, , .

platygorytos Dasch. Que. Ecology: The unique holotype should be presumed to have been reared from a parasite of Psilocorsis sp.

Mesochorus platygorytos Dasch, 1971. Amer. Ent. Inst., Mem. 16: 86.. 
plumosus Dasch. N. Y., Ont., Ohio, Mich., Colo., Idaho, e. Wash. Ecology: Oviposits into adult Chrysomelidae (Phyllotreta armoraciae [Koch], $P$. striolata $[\mathrm{F}$.$] ) which have been$ parasitized by euphorine Braconidae. Host: Microctonus vittatae Mues. The paratype of Mesochorus plumosus from D. C. was reared together with seven paratypes of Microctonus vittatae Mues.

Mesochorus plumosus Dasch, 1971. Amer. Ent. Inst., Mem. 16: 246. ơ, ๆ.

prolatus Dasch. Que., w. N. W. T., Alta., interior Alaska, w. B. C.

Mesochorus prolatus Dasch, 1971. Amer. ent. Inst., Mem. 16: 180. đ, ․

punctifrons Dasch. Western N. C., Ohio, s. Ill., s. B. C. Ecology: The holotype was collected at an elevation between $4800 \mathrm{ft}$. and $5300 \mathrm{ft}$. on Mt. Pisgah, N. C. Host: Leiophron sp. ex Plagiognathus sp. on Solidago.

Mesochorus punctifrons Dasch, 1971. Amer. Ent. Inst., Mem. 16: 212. ơ, \&.

recurvatus Dasch. Southwestern B. C. Known only from the holotype.

Mesochorus recurvatus Dasch, 1971. Amer. Ent. Inst., Mem. 16: 172. $\uparrow$.

restrictus Dasch. Que., s.e. Ont., n.e. Alta., s.e. Utah, s. B. C., n. Calif.

Mesochorus restrictus Dasch, 1971. Amer. Ent. Inst., Mem. 16: 113. o,.

sabulosus Dasch. Southern Colo., Utah. Ecology: The holotype was collected at Great Sand Dunes, Alamosa Co., Colo.

Mesochorus sabulosus Dasch, 1971. Amer. Ent. Inst., Mem. 16: 129. ð。,.

scabrosus Dasch. Northeastern Pa. Known only from the holotype.

Mesochorus scabrosus Dasch, 1971. Amer. Ent. Inst., Mem. 16: 209..

solidus Dasch. R. I., s.w. Mich., Colo., s. B. C.

Mesochorus solidus Dasch, 1971. Amer. Ent. Inst., Mem. 16: 220. ð, ९.

spinosus Dasch. Ariz.

Mesochorus spinosus Dasch, 1971. Amer. Ent. Inst., Mem. 16: 75. ð.

sulcatus Dasch. Western Va. Ecology: The only three specimens known were collected at Mountain Lake, Va.

Mesochorus sulcatus Dasch, 1971. Amer. Ent. Inst., Mem. 16: 74..

sylvarum Curtis. Newfoundland (n. Labrador) w. to n. Yukon and Alaska, s. to n.w. S. C., Mo., Colo., and n. Calif.; n. Eurasia; n. Mexico. Ecology: Reared or presumed to have been reared from parasites of the following-- Tortricidae (Acleris chalybeana [Fern.], $A$. variana [Fern.], Archips sp., Choristoneura conflictana [Wlk.], C. fumiferana [Clem.], C. rosaceana [Harris], Sparganothis pettitana [Rob.]), Olethreutidae (E pinotia sp., $E$. solandriana [L.], Grapholitha molesta [Bsk.], Pseudexentera sp., Zeiraphera sp., $Z$. canadensis M. and F.), Gelechiidae (Anacampsis inocuella [Zell.], A. niveopulvella [Chamb.]), Noctuidae (Feralia sp.), and Notodontidae (Cerura borealis [Bdv.]). Host: Meteorus sp.?, Microgaster peroneae Wly., Enytus eureka Ash., Glypta fumiferanae (Vier.), G. inversa Cr., Actia diffidens Curran.

Mesochorus sylvarum Curtis, 1833. Brit. Ent., v. 10, pl. 464. $\$$.

Mesochorus atriventris Cresson, 1872. Canad. Ent. 4: 21. ¿.

Mesochorus politus Provancher, 1883. Nat. Canad. 14: 4. . Preocc. by Gravenhorst, 1829.

Mesochorus provancheri Dalla Torre, 1901. Cat. Hym., v. 3, p. 57. N. name for politus Provancher.

Mesochorus silvarum Dalla Torre, 1901. Cat. Hym., v. 3, p. 57. Emendation.

tachinae Ashmead. N. S. w. to B. C., s. to e. N. C., n. Ga., Ill., Colo., and n. Calif. Ecology: Reared or presumed to have been reared from parasites of the following-- Geometridae (Aethalura anticaria [Wlk.], Caripeta divisata Wlk., Cladara limitaria [Wlk.], C. nigroangulata [Stkr.], Cyclophora pendulinaria [Gn.], Deilinea sp., Ectropis crepuscularia [D. and S.], Enypia packardata Tay.?, Erannis tiliaria [Harris], Eupithecia sp., E. luteata bifasciata [Dyar], E. transcanadata MacKay, Hydriomena renunciata columbiata Tay., Hyperetis amicaria [H.-S.], Iridopsis emasculata [Dyar]?, Lambdina fiscellaria lugubrosa [Hulst], Nematocampa filamentaria Gn., Nepytia phantasmaria [Stkr.], Semiothisa sp., S. "granitata" auct.), Noctuidae (Feralia sp., $F$. jocosa [Gn.], Hypena humuli [Harris], Zale minerea norda [Smith]), Dioptidae (Phryganidea sp.), Tortricidae (Acleris variana [Fern.] and tortricid), and Oecophoridae 
(Psilocorsis sp.). Host: Actia interrupta Curran, Chaetophlepsis orbitalis Web., C. semiothisae Brooks, Ictericophyto tibialis (Curran), tachinids, dipterous parasites.

Mesochorus tachinae Ashmead, 1898. In Dimmock and Ashmead, Ent. Soc. Wash., Proc. 4: 168. ㅇ.

tachypus Holmgren. Newfoundland (Labrador), w. N. W. T., and Alaska, s. to P. E. I., s. Que., Ont., N. Mex., and n.w. Calif.; Europe. Ecology: Reared or presumed to have been reared from parasites of the following-- Olethreutidae (Epinotia solandriana [L.], Pseudexentera improbana oregonana [Wlk.], Zeiraphera sp.), Tortricidae (Acleris variana [Fern.], Choristoneura occidentalis Free.), Gelechiidae (Anacampsis niveopulvella [Cham.], Coleotechnites starki [Free.]), Geometridae (Alsophila pometaria [Harris], Operophtera sp.), Lasiocampidae (Malacosoma disstria $\mathrm{Hbn}$. ), and sp. of Noctuidae. Host: Apanteles fumiferanae Vier., Microgaster peroneae Wly.

Mesochorus tachypus Holmgren, 1860 (1858). Svenska Vetensk.-Akad. Handl. (n. f.) 2 (8): 130. ס, ?.

Mesochorus diversicolor Viereck, 1912. U. S. Natl. Mus., Proc. 42: 149. o,.+

tantillus Dasch. N. B., n. and s. Que., N. H., Ont., n. Mich., Sask., s.e. B. C. Ecology: Paratypes should be presumed to have been reared from parasites of the following--

Tenthredinidae (Anoplonyx luteipes [Cr.]) and Geometridae (Semiathisa dispuncta [Wlk.], S. "granitata" auct.).

Mesochorus tantillus Dasch, 1971. Amer. Ent. Inst., Mem. 16: 164. ठ̀, ๆ.

totonacus Cresson. Ohio, s. Mich., n.e. Kans.; n. and s. Mexico. The type locality is in southern Mexico.

Mesochorus totonacus Cresson, 1872. Canad. Ent. 4: 23. "q" = $\delta$.

Mesochorus totanacus Cresson, 1874 (1873). Acad. Nat. Sci., Proc. 25: 388. "ๆ” = 0 . The holotype is the same specimen as that of totonacus.

transversus Dasch. Northern Que., N. H.

Mesochoris transversus Dasch, 1971. Amer. Ent. Inst., Mem. 16: 269. ठ.

tumidifrons Dasch. Northern Va., n.e. Kans. Ecology: The single paratype can be presumed to have been reared from a parasite of a sawfly larva.

Mesochorus tumidifrons Dasch, 1971. Amer. Ent. Inst., Mem. 16: 214. . .

tundracolus Dasch. Southwestern Alaska. Ecology: The three specimens known were collected on tundra at Naknek, Alaska.

Mesochorus tundracolus Dasch, 1971. Amer. Ent. Inst., Mem. 16: 179. ठ, ๆ.

ukiahensis Dasch. Northwestern Calif. Known only from the holotype.

Mesochorus ukiahensis Dasch, 1971. Amer. Ent. Inst., Mem. 16: 227. \&.

unicarinatus Dasch. Que. w. to n. Yukon, s. to Md., n. Ga., Tex., and n.w. Oreg. Host: Chaetophlepsis orbitalis Web. ex Lambdina fiscellaria lugubrosa (Hulst).

Mesochorus unicarinatus Dasch, 1971. Amer. Ent. Inst., Mem. 16: 87. ơ, ๆ.

uniformis Cresson. N. S. w. to w. Yukon, s. to Ga., Tex., s. N. Mex., s. Ariz., and s. Calif.; Mexico. Ecology: Reared or presumed to have been reared from parasites of the following-- Sphingidae (Ceratomia amyntor [Geyer]), Lymantriidae Lymantria dispar [L.], Orgyia sp., O. psedotsugata [McD.]), Noctuidae (Xylomyges perlubens Grt.), Geometridae (Caripeta sp., C. angustiroata Wlk., C. divisata Wlk., Ectropis crepuscularia [D. and S.], Eufidonia notataria [Wlk.], Eupithecia annulata [Hulst], Glena nigricaria [B. and McD.], Lambdina fiscellaria luguborsa [Hulst], Melanolophia imitata [Wlk.], Semiothisa sp., S. sp. on Larix, S. dispuncta [Wlk.], S. oweni [Swett], S. setonana [McD.], sexmaculata [Pack.], Stenoporpia sp.), Tortricidae (Acleris variana [Fern.], Choristoneura fumiferana [Clem.]), Oecophoridae (Semioscopis inornata Wlshm.), and Diprionidae (Neodiprion abietis [Harris], N. pinetum [Nort.]). Host: Casinaria limenitidis (How.), Phobocampe pallipes (Prov.), P. unicincta (Grav.), Apanteles melanoscelus (Ratz.).

Mesochorus uniformis Cresson, 1872. Amer. Ent. Soc., Trans. 4: 171. " $"=q$ and misdet. ơ.

Paniscus mufulus Provancher, 1876. Nat. Canad. 8: 328..+

Astiphromma mexicanus Ashmead, 1894. Calif. Acad. Sci., Proc. 4: 129.. 
validus Dasch. Mass. and s.e. Alta., s. to e. N. C., n.w. S. C., n. La., Okla., s. Ariz. and central Calif.

Mesochorus validus Dasch, 1971. Amer. Ent. Inst., Mem. 16: 130. ठ, ๆ.

varianus Dasch. Newfoundland (insular) w. to central Alta. and s.w. B. C., s. to n.w. S. C., s. Wis., Minn., and n.w. Oreg. Host: Lamachus angularius (Davis).

Mesochorus varianus Dasch, 1971. Amer. Ent. Inst., Mem. 16: 150. ठં, ९.

vittator (Zetterstedt). Newfoundland (Labrador) w. to n.w. Alaska, s. to Ala., w. Tex., Ariz., and s. Calif.; Eurasia; Mexico, Costa Rica. Ecology: Reared or presumed to have been reared from parasites of two species of Tenthredinidae and many species of

Lepidoptera (too numerous to list) of diverse habits. Host: Diadegma insulare (Cr.), Dimophora sp., "Hyposoter annulipes (Cresson)" ex Lambdina fiscellaria lugubrosa (Hulst) and Nepytia umbrosaria nigrovenaria (Pack.), Phobocampe n. sp., P. flavipes (Prov.), Apanteles glomeratus (L.)?, A. medicaginis Mues.?, Microgaster peroneae Wly. $M$. vittator is apparently by far the most frequently collected species of Mesochorus in North America.

Tryphon vittator Zetterstedt, 1838. Ins. Lapponica Descr., Hym., p. 387. $\%$.

Mesochorus brunneus Brischke, 1880. Naturf. Gesell. Danzig, Schr. (n. f.) 4: 184. ठ。.

Campoplex pieridicola Packard, 1881. Boston Soc. Nat. Hist., Proc. 21: 20. “ๆ" = ठे.

yosemite Dasch. Colo., s. Idaho, n.e. Calif.

Mesochorus yosemite Dasch, 1971. Amer. Ent. Inst., Mem. 16: 196. \&.

\section{Genus STICTOPISTHUS Thomson}

Stictopisthus Thomson, 1886. Soc. Ent. de France, Ann. (6) 5: 327, 344.

Type-species: Stictopisthus bilineatus Thomson. Desig. by Viereck, 1914.

This is a moderate sized genus of worldwide distribution.

argaleus Dasch. Que., s. Sask., and w. Yukon, s. to Md., w. N. C., and n.w. Ark. Ecology: Should be presumed as having been reared from parasites of the following-- Tortricidae (Archips argyrospilus [Wlk.], Choristoneura pinus Free., C. rosaceana [Harris], and a "tortricid sp."), Pyralidae (Desmia funeralis [Hbn.], Nephopteryx subcaesiella [Clem.]), Yponomeutidae (Zelleria haimbachi Bsk.), Gracilariidae (Lithocolletis robiniella Clem.), and a leaf miner on Robinia pseudoacacia. The paratypes in the U. S. Natl. Museum collection show considerably more variation than is allowed for in either Dasch's key to Stictopisthus females or in his description of argaleus (the key and description also disagree with each other in respect to the dimensions of the ovipositor sheath), and two species may be confused under the name argaleus.

Stictopisthus argaleus Dasch, 1971. Amer. Ent. Inst., Mem. 16: 277. đ, ९.

artus Dasch. N. Y., s. Ind., w. Mont.

Stictopisthus artus Dasch, 1971. Amer. Ent. Inst., Mem. 16: 283. ठ, ?.

bilineatus Thomson. Southern Sask. s. to w. Tex., w. to s. Alta., Wash., and s. Calif.; s. Mexico; Europe. Ecology: Can be presumed to have been reared from parasites of the following microlepidoptera-- Scythris sp. and Plutella xylostella (L.).

Stictopisthus bilineatus Thomson, 1886. Soc. Ent. de France, Ann. (6) 5: 344. [male, female].

crenatus Dasch. Newfoundland (Labrador), w. N. W. T., and s.w. Alaska, s. to N. J., Mich. and n. Idaho. Ecology: Can be presumed to have been reared from parasites of the following microlepidoptera-- Gracilaria burgessiella Zell., Lithocolletis sp., Acleris sp., and Choristoneura pinus Free.

Stictopisthus crenatus Dasch, 1971. Amer. Ent. Inst., Mem. 16: 281. §, ๆ. electilis (Cresson). Eastern N. C., n.w. S. C., Kans., Okla., Tex., s.e. Ariz.; Mexico.

Mesochorus electilis Cresson, 1872. Amer. Ent. Soc., Trans. 4: 171. ๆ.

exilis Dasch. Central Utah. Known only from the holotype.

Stictopisthus exilis Dasch, 1971. Amer. Ent. Inst., Mem. 16: 287. ठ.

flaviceps (Provancher). Que. w. to w. N. W. T., s. to Md., n.w. S. C., Mo., Colo., and n. Calif. Ecology: Can be presumed to have been reared from parasites of the following-Tortricidae (Archips argyrospilus [Wlk.], Choristoneura fumiferana [Clem.], C. pinus 
Free.), Olethreutidae (Ancylis comptana [Froel.]), and Yponomeutidae (Zelleria haimbachi Bsk.).

Mesochorus flaviceps Provancher, 1879. Nat. Canad. 11: 210..

floridanus Dasch. Northern Fla. Ecology: The single paratype can be presumed to have been reared from a parasite of the "spotted leaf tyer on oak."

Stictopisthus floridanus Dasch, 1971. Amer. Ent. Inst., Mem. 16: 288. o', ?.

lanceolatus Dasch. N. B. w. to central Alta. and s. B. C., s. to Pa., Ohio, and Wis. Ecology: Can be presumed to have been reared from parasites of the following microlepidoptera-Choristoneura fumiferana (Clem.), Sparganothis pettitana (Rob.), Anacampsis niveopulvella (Cham.).

Stictopisthus lanceolatus Dasch, 1971. Amer. Ent. Inst., Mem. 16: 279. ठ゚, ๆ.

\section{SUBFAMILY DIPLAZONTINAE}

The members of this medium sized subfamily are internal parasites of Diptera larvae. The eggs are deposited in the early-instar larvae or eggs of the host, and the adults emerge from the host puparia. The usual hosts are aphidophagous Syrphidae, although phytophagous Syrphidae and even Diptera of other families are sometimes parasitized.

Revision: Davis, 1895. Amer. Ent. Soc., Trans. 22: 25-27. - Dasch, 1964. Amer. Ent. Inst., Mem. 3: 1-304 (Nearctic spp.). - Dasch, 1964. Amer. Ent. Inst., Contrib. 1 (1): 1-77

(Neotropic spp.).

Taxonomy: Townes, 1971. Amer. Ent. Inst., Mem. 17: 216-232 (genera of world).

\section{Genus SYRPHOCTONUS Foerster}

Syrphoctonus Foerster, 1868. Naturh. Ver. Rheinlande, Verh. 15: 162.

Type-species: Bassus exsultans Gravenhorst. By subsequent monotypy from inclusion by Woldstedt, 1877.

Homotropus Foerster, 1868. Naturh. Ver. Rheinlande, Verh. 25: 162.

Type-species: Bassus elegans Gravenhorst. Desig. by Walkley, 1958 from 29 species included by Thomson, 1890. Walkley (1958) considered the type-species as having been designated by Viereck (1914) when the latter author designated B. elegans as the type-species of Homocidus Morley (Viereck's [1914] designation of $B$. bicapillaris Walsh as the type-species of Homotropus has no validity because $B$. bicapillaris was not placed in Homotropus until 1895). The fact that Homocidus (which see) has no standing in nomenclature (and therefore has no type-species), prevents Viereck's (1912) designation of B. elegans as the "type-species" of Homocidus from being the valid designation for Homotropus by isogeneritypy.

Homoporus(!) Thomson, 1890. Opusc. Ent. 14: 1488. There is no doubt that Homoporus is a lapsus for Homotropus because Thomson used the name Homotropus in his conspectus generum on page 1465 of the same paper. Twelve years earlier Thomson had given the name Homoporus to a genus of Chalcidoidea, which makes it easy to explain how he could have made the error of introducing the name Homoporus in his manuscript which dealt with Homotropus.

Homovidus Morley, 1911. Brit. Ichn., v. 4, p. 87. N. name for Homoporus Thomson, 1890.

This large Neotropic, Holarctic, Oriental and Ethiopian genus was called Homotropus in the most recent works on Diplazontinae. Suppression of Homotropus as a synonym of Syrphoctomus is necessitated by the first revisor decision of Benoit (1955) and by the following facts. Viereck (1914) designated Bassus biguttatus Gravenhorst as the type-species of Syrphoctonus, believing that this species was eligible for designation by virtue of Woldstedt's (1877b) placement of it in Syrphoctonus along with three other species, including B. exsultans Gravenhorst. However, Woldstedt (1877a) had monotypically included $B$. exsultans, which makes it the type-species of Syrphoctonus. Syrphoctonus of recent authors is herein called Woldstedtius (which see).

Taxonomy: Woldstedt, 1877a (1876). Acad. Imp. des Sci. St. Petersburg, Bul. 22: 391.

-Woldstedt, 1877b. Acad. Imp. des Sci. St. Petersburg, Bul. 23: 441. - Viereck, 1912. Ent.

Soc. Wash., Proc. 14: 175. - Viereck, 1914. U. S. Natl. Mus., Bul. 83: 72, 142. 
alaskensis (Ashmead). Que., s. Maine, s.e. Yukon, Alaska. Males are unknown.

Homotropus alaskensis Ashmead, 1902. Wash. Acad. Sci., Proc. 4: 226. ₹.

albopictus (Davis). Northern Que. w. to n. Yukon and Alaska, s. to n. Va., w. N. C., Minn., n. N. Mex., and n. Calif. The two "subspecies" recognized by Dasch (1964) had broadly overlapping ranges.

Homotropus bicapillaris var. albopictus Davis, 1895. Amer. Ent. Soc., Trans. 22: 28. $q$.

Homotropus albopictus ithacae Dasch, 1964. Amer. Ent. Inst., Mem. 3: 103. ठ, ९. N. syn.

aquilonius (Dasch), n. comb. Greenland.

Homotropus aquilonius Dasch, 1964. Amer. Ent. Inst., Mem. 3: 135. ๆ.

arizonensis (Dasch), n. comb. Northern Colo., Ariz., e. Calif. Ecology: Occurs at higher altitudes.

Homotropus arizonensis Dasch, 1964. Amer. Ent. Inst., Mem. 3: 114. ठँ, ๆ.

badius (Dasch), n. comb. Central Calif.

Homotropus badius Dasch, 1964. Amer. Ent. Inst., Mem. 3: 170. ઠ, ९.

belangerii (Provancher). Que. s. to Md. and. w. N. C., w. to Wis. and n. Ill. Host: Syrphid.

Bassus Belangerii Provancher, 1874. Nat. Canad. 6 (1): 31 (key); 6 (2): 56 . ?.

columbiensis (Dasch), n. comb. Southwestern Alta. and B. C. s. to Colo., Utah, and n. Calif. Host: Syrphid.

Homotropus columbiensis Dasch, 1964. Amer. Ent. Inst., Mem. 3: 123. ठ, ๆ.

compactus (Dasch), n. comb. Northwestern Mich., Colo., w. N. W. T., w. Wash., s.w. Oreg.

Homotropus compactus Dasch, 1964. Amer. Ent. Inst., Mem. 3: 119. §, ๆ.

confertus (Dasch), n. comb. Que., n. N. Mex., w. B. C.

Homotropus confertus Dasch, 1964. Amer. Ent. Inst., Mem. 3: 142. §, १.

costalis (Provancher), n. comb. Que. This name is transferred from synonymy with Promethes sulcator (Gravenhorst) because there appear to be no valid grounds for rejecting the lectotype of Gahan and Rohwer (1917) as Townes (1939) and Barron (1975) have done. Because Provancher stated that he had two specimens, lack of agreement with the original description alone is not proof that the Gahan and Rohwer lectotype was not an original syntype.

Bassus costalis Provancher, 1874. Nat. Canad. 6 (1): 31 (key); 6 (2): 58. ๆ.

Taxonomy: Gahan and Rohwer, 1917. Canad. Ent. 49: 332. -Townes, 1939. Canad. Ent. 71:

93. - Barron, 1975. Nat. Canad. 102: 455.

cressonii Davis. Nev. Known only from the holotype.

Syrphoctonus cressonii Davis, 1895. Amer. Ent. Soc., Trans. 22: 27. ๆ.

cultiformis (Davis). Colo., Alaska.

Otoblastus cultiformis Davis, 1897. Amer. Ent. Soc., Trans. 24: 273. 9.

Otoblastus cultriformis(!) Dalla Torre, 1901. Cat. Hym., v. 3, p. 311.

Homotropus cultriformis Dasch, 1964. Amer. Ent. Inst., Mem. 3: 179. Unjustified emend.

decoratus (Cresson). Colo., n. Utah, s.e. Ariz., s. B. C., Wash., Oreg., Calif.; n.w. Mexico. Host: Syrphid spp.

Bassus decoratus Cresson, 1879 (1878). Acad. Nat. Sci. Phila., Proc. 30: 375. o.

elegans (Gravenhorst). Que., e. N. W. T., Ont.; Europe.

Bassus elegans Gravenhorst, 1829. Ichn. Europaea, v. 3, p. 313. $\delta$.

Bassus rufonotatus Holmgren, 1858 (1856). Svenska Vetensk.-Akad. Handl. (n. f.) 1: 369. $\delta, ?$.

fossatus (Dasch), n. comb. Newfoundland (Labrador) w. to n. Yukon and Alaska, s. to Mass., n. Mich., n. Colo., and n.w. Oreg. The ranges of the two "subspecies" described by Dasch (1964) were largely overlapping.

Homotropus fossatus fossatus Dasch, 1964. Amer. Ent. Inst., Mem. 3: 159. §, ๆ.

Homotropus fossatus aureopectus Dasch, 1964. Amer. Ent. Inst., Mem. 3: 160. ठ, ๆ. N. syn.

fraudulentus fraudulentus (Dasch), n. comb. Colo., s. Alta., n. Idaho, interior Alaska, ๙. Yukon, s. B. C.

Homotropus fraudulentus fraudulentus Dasch, 1964. Amer. Ent. Inst., Mem. 3: 151. ơ, १. 
fraudulentus recurvatus (Dasch), n. comb. Northwestern Wash., n.e. Calif.

Homotropus fraudulentus recurvatus Dasch, 1964. Amer. Ent. Inst., Mem. 3: 152. o, ९.

imperfectus (Dasch), n. comb. Newfoundland (Labrador), n.w. Mich., s. B. C., Wash., n.w. Oreg. Host: Syrphid.

Homotropus imperfectus Dasch, 1964. Amer. Ent. Inst., Mem. 3: 155. ð, §.

labradorensis (Dasch), n, comb. Newfoundland (n. Labrador), Colo., s.w. Alta.

Homotropus labradorensis Dasch, 1964. Amer. Ent. Inst., Mem. 3: 136. ठ, ๆ.

laevis Brues. Maine w. to interior Alaska, s. to S. C., s. Ill., N. Mex., and Wash. Host: Syrphid on Populus.

Syrphoctonus laevis Brues, 1908. Wis. Nat. Hist. Soc., Bul. 6: 53..

maculifrons (Cresson). Minn. w. to central Alta. and s. B. C., s. to n.w. Iowa, n. N. Mex., n. Ariz., and s. Calif.; n.w. Mexico; Hawaii. Host: Eupeodes volucris O. S., Metasyrphus perplexus (Osb.), Scaeva pyrastri (L.).

Bassus maculifrons Cresson, 1865. Ent. Soc. Phila., Proc. 4: 272..

Bassus semifasciatus Walsh, 1873. Acad. Sci. St. Louis, Trans. 3: 87. ${ }^{\circ}$. This synonymy is dubious because the lost type of $B$. semifasciatus is thought to have been collected in Ill.

melanogaster (Holmgren). Northern Que., N. W. T., interior Alaska, w. Wash.; Greenland.

Bassus melanogaster Holmgren, 1872. Svenska Vetensk.-Akad., Ofvers. af ... Forh. 29 (6): 98. $\delta$.

minimus (Cresson), Que. s. to n. Fla., w. to Minn., e. Kans., and Ark.

Tryphon minimus Cresson, 1864. Ent. Soc. Phila., Proc. 3: 281. $\$$.

Bassus ruficrus Walsh, 1873. Acad. Sci. St. Louis, Trans. $3: 86 . " \delta "=\uparrow$.

nigriclypealis (Dasch), n. comb. Southern Que., s.w. Alta.; Greenland.

Homotropus nigriclypealis Dasch, 1964. Amer. Ent. Inst., Mem. 3: 110. $\%$.

nigritarsus fuscitarsus (Provancher). Newfoundland (insular) w. to n. Yukon and Alaska, s. to N. Y., s. Man., N. Mex., and s. Calif.; Mexico. Host: Eupeodes volucris O. S. S. nigritarsus nigritarsus (Gravenhorst) is Eurasian.

Tryphon humeralis Provancher, 1875. Nat. Canad. 7 (4): 117. “९” = ठ. Preoce. by Gravenhorst, 1829.

Bassus fuscitarsus Provancher, 1875. Nat. Canad. 7 (5): 143. " $\delta "=$ ?.

nigritarsus groenlandicus (Holmgren). Greenland.

Bassus groenlandicus Holmgren, 1872. Svenska Vetensk.-Akad., Ofvers af ... Forh. 29 (2): 97. $\delta$.

novitus (Dasch), n. comb. Interior Alaska. Known only from the holotype.

Homotropus novitus Dasch, 1964. Amer. Ent. Inst., Mem. 3: 130. ठै.

nudus (Dasch), n. comb. Northern Que. w. to interior Alaska, s. to s. Mich., Colo., and n.e. Calif. Homotropus nudus Dasch, 1964. Amer. Ent. Inst., Mem. 3: 111. o, ९.

pacificus (Cresson). Western N. W. T. and Alaska s. to w. S. Dak., N. Mex., and s. Calif.; n. Mexico. Host: Bigonicheta sp.

Bassus maculifrons Holmgren, 1869 (1868). Eug. Resa I, Zool. I, Ins., p. 410. ९. Preocc. by Cresson, 1865.

Bassus pacificus Cresson, 1879 (1878). Acad. Nat. Sci. Phila., Proc. 30: 376. ठ’, ๆ.

Bassus xanthopsis Ashmead, 1890 (1889). U. S. Natl. Mus., Proc. 12: 440. ठ。.

pallipes (Gravenhorst). N. S. w. to Alaska, s. to Pa., n.w. S. C., n. Minn., Colo., and s. Calif.; Europe.

Bassus pallipes Gravenhorst, 1829. Ichn. Europaea, v. 3, p. 325. “ठ” = \&.

Bassus pallipennis Provancher, 1874. Nat. Canad. 6: 31. 9.

Bassus pallidipes(!) Bignell, 1898. Devonshire Assoc., Trans. 30: 500. Lapsus for $B$. pallipes Gravenhorst.

Homotropus pallidipennis Dalla Torre, 1901. Cat. Hym., v. 3, p. 238. Emend. of $B$. pallipennis Provancher.

Homotropus pallidipes Dalla Torre, 1901. Cat. Hym., v. 3, p. 238. Emend. of B. pallipes Gravenhorst.

pectoralis (Provancher). Que. w. to s. Yukon and interior Alaska, s. to n. Va., s. Wis., and Colo.

Bassus pectoralis Provancher, 1874. Nat. Canad. 6: 32. ठ. 
pleuralis pleuralis (Cresson). N. H. s. to n.w. S. C., w. to Mich., e. Iowa, Ark., and s. Tex. Host: Syrphid predator of grape aphid.

Bassus pleuralis Cresson, 1868. Amer. Ent. Soc., Trans. 2: 111. \&.

pleuralis syrphicola (Ashmead). Southern Alta. and s. B. C. s. to n. Colo., n. Utah, n.e. Nev., and central Calif. Host: Metasyrphus perlexus (Osb.), Scaeva pyrastri (L.).

Bassus syrphicola Ashmead, 1890 (1889). U. S. Natl. Mus., Proc. 12: 439. đ’, ๆ.

quadrangularis (Dasch), n. comb. Eastern Mass., n.e. N. J., Colo., s. Alta., n. Idaho, n. Yukon, interior Alaska, B. C.

Homotropus quadrangularis Dasch, 1964. Amer. Ent. Inst., Mem. 3: 106. đ’, ૧.

robsonensis (Dasch), n. comb. Southeastern B. C. Known only from two specimens.

Homotropus robsonensis Dasch, 1964. Amer. Ent. Inst., Mem. 3: 183. ठै, १.

robustus Davis. Southeastern Mich., s. Alta., s. B. C., Wash.

Syrphoctonus robustus Davis, 1895. Amer. Ent. Soc., Trans. 22: 25. ठ.

rufulus (Dasch), n. comb. Southern Maine w. to s.w. Ont. and interior Alaska, s. to n.w. S. C. and n. Ill. Dasch (1964) stated that one of the paratypes was from "Louisiana (no locality)"; his dissertation (Dasch, 1953) indicated that the specimen was a male from the C. F. Baker collection and was in the U. S. Natl. Museum collection. I find no paratype from La. in that collection and therefore cannot verify from the Baker notebook that it was really collected in La. (in rare cases the notebook data pertaining to a particular "Baker number" do not agree with the locality on the specimen label).

Homotropus rufulus Dasch, 1964. Amer. Ent. Inst., Mem. 3: 104. ¿, ๆ.

Taxonomy: Dasch, 1953. Taxonomic study Nearctic Diplazoninae, Ph. D. Thesis, Cornell Univ., p. 217.

sicarius (Dasch), n. comb. Newfoundland (n. Labrador), n. Que., N. W. T., interior Alaska. Host: Simuliid.

Homotropus sicarius Dasch, 1964. Amer. Ent. Inst., Mem. 3: 161. ठં, १.

signatus (Gravenhorst). Newfoundland (insular) and n. Que. w. to n. Alaska, s. to N. J., s. Ohio, n. Iowa, n. Colo., and n.w. Oreg.; Eurasia. Host: Platycheirus erraticus Curran, Sphaerophoria contigua Macq.

Bassus signatus Gravenhorst, 1829. Ichn. Europaea, v. 3, p. 325..

Tryph on nigricomis Zetterstedt, 1838. Insecta Lapponica, Hym., p. 399..

Tryphon compressiventris Cresson, 1868. Amer. Ent. Soc., Trans. 2: 105. ठ, ๆ.

Homotropus hygrobius Thomson, 1890. Opusc. Ent. 14: 1524. ठै, ९.

Zootrephes montanus Davis, 1895. Amer. Ent. Soc., Trans. 22: 24. ठ์, १.

tarsatorius (Panzer). Northern Que. w. to Alaska, s. to N. Y., n. Mich., Colo., and s.w. Oreg.; Eurasia. Host: Syrphid spp.

Bassus tarsatorius Panzer, 1809 (1806-1809). Faunae Ins. German., Heft 102, pl. 19

[female].

Bassus exsultans Gravenhorst, 1829. Ichn. Europaea, v. 3, p. 328. ð.

Bassus insignis Gravenhorst, 1829. Ichn. Europaea, v. 3, p. 349. $९$.

Bassus flavus Desvignes, 1862. Ent. Soc. London, Trans. 10: 219. ठ.

Bassus pulchellus Desvignes, 1862. Ent. Soc. London, Trans. 10: 221. ð.

Bassus indicus Cameron, 1909. Bombay Nat. Hist. Soc., Jour. 19: 728. ठ.

Homoporus flavitrochanterus Uchida, 1956. Insecta Matsumurana 19: 99. ठ,.

teres (Dasch), n. comb. Colo. Ecology: Occurs in the Rocky Mts. at altitudes between $9600 \mathrm{ft}$. and $12000 \mathrm{ft}$.

Hom otropus teres Dasch, 1964. Amer. Ent. Inst., Mem. 3: 113. ठै, ९.

venustus (Dasch), n. comb. Colo., n. Utah, s. Idaho.

Homotropus venustus Dasch, 1964. Amer. Ent. Inst., Mem. 3: 138. §, १.

vitreus (Dasch), n. comb. Newfoundland (n. Labrador) w. to Alaska, s. to N. S., n. Mich., n.w. Wyo., and n.w. Calif.

Homotropus vitreus Dasch, 1964. Amer. Ent. Inst., Mem. 3: 173. ठં, १.

\section{Genus XESTOPELTA Daseh}

Xestopelta Dasch, 1964. Amer. Ent. Inst., Mem. 3: 208.

Type-species: Syrphoctonus vertebratus Cushman. Orig. desig. 
This is a very small genus of Holaretic and Ethiopian (one Madagascan sp.) distribution.

vertebrata (Cushman). N. H., Vt., N. W. T., B. C., w. Wash.

Syrphoctonus bilineatus Ashmead, 1900. In Slosson, Ent. News 11: 320. Nomen nudum.

Himertosoma quinquecinctum Ashmead, 1902. In Slosson, Ent. News 13: 320. Nomen nudum.

Syrphoctonus vertebratus Cushman, 1922. U. S. Natl. Mus., Proc. 61 (8): 29. ठ.

\section{Genus ENIZEMUM Foerster}

Enizemum Foerster, 1868. Naturh. Ver. Rheinlande, Verh. 25: 162.

Type-species: Bassus tibialis Cresson. By subsequent monotypy from inclusion by Davis, 1895.

This is a small Holarctic, Oriental, and Ethiopian genus.

huronense Dasch. Northern Mich. Known only from two specimens.

Enizemum huronense Dasch, 1964. Amer. Ent. Inst., Mem. 3: 199. ठ.

imitatum Dasch. Ariz., n.e. Calif. Known only from two specimens.

Enizemum imitatum Dasch, 1964. Amer. Ent. Inst., Mem. 3: 196. ¿.

insidiosum Dasch. Coastal Calif. The only specimen known was collected at Carmel, Calif.

Enizemum insidiosum Dasch, 1964. Amer. Ent. Inst., Mem. 3: 197. ๆ.

matanuskae Dasch. Southern Yukon, Alaska. Known only from the holotype and one paratype.

Enizemum matanuskae Dasch, 1964. Amer. Ent. Inst., Mem. 3: 191. o.

ornatum (Gravenhorst). N. S., Sask., Colo., N. Mex., Alta., Alaska, s. Yukon, B. C.; Eurasia. Host: Metasyrphus lapponicus (Zett.).

Bassus deplanatus Gravenhorst, 1829. Ichn. Europaea, v. 3, p. 341. ठ.

Bassus ormatus Gravenhorst, 1829. Ichn. Europaea, v. 3, p. 340. ठ, ๆ.

Bassus carinulatus Ruthe, 1859. Stettin. Ent. Ztg. 20: 373. o, ๆ.

Enizemum neomexicanum Brues, 1908. Wis. Nat. Hist. Soc., Bul. 6: 54. ․

petiolatum (Say). N. B. w. to s.e. Alta., s. to e. N. C., s. Ala., n.e. Kans, and s. Colo. Host: Metasyrphus americanus (Wied.).

Pimpla? petiolatus Say, 1836. Boston Jour. Nat. Hist. 1: 224. $\delta$.

Bassus tibialis Cresson, 1868. Amer. Ent. Soc., Trans. 2: 110..

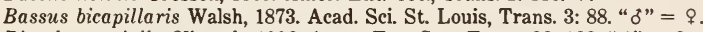

Pimpla parvialba Viereck, 1906. Amer. Ent. Soc., Trans. 32: 182. “ $\delta "=\subsetneq$.

scorteum Dasch. Northern Que., N. W. T., n. Colo., s.e. B. C.

Enizemum scorteum Dasch, 1964. Amer. Ent. Inst., Mem. 3: 194. ठ, ?.

tridentatum Dasch. Northern Colo., s.w. Alta., interior Alaska.

Enizemum tridentatum Dasch, 1964. Amer. Ent. Inst., Mem. 3: 189. §, ๆ.

\section{Genus WOLDSTEDTIUS Carlson, $n$. genus}

Syrphoctonus Foerster sensu Dasch, 1964. Amer. Ent. Inst., Mem. 3: 200-208.

The type-species of this new genus is Bassus biguttatus Gravenhorst, which was formerly regarded as the type-species of Syrphoctonus Foerster (which see). The genus is rather small, and its species occur in the Neotropic, Holarctic, and Oriental regions.

Taxonomy: Dasch, 1964. Amer. Ent. Inst., Mem. 3: 200-208 (Nearctic spp.). -Dasch, 1964.

Amer. Ent. Inst., Contrib. 1 (1): 45-63 (Neotropic spp.).

citropectoralis (Schmiedeknecht), n. comb. N. Y., Pa., e. Ohio, n. Mich., interior Alaska, s.e. B.

C.; Europe.

Homocidus citropectoralis Schmiedeknecht, 1926. Opusc. Ichn., v. 5, p. 3412. o.

flavolineatus (Gravenhorst), n. comb. N. S. w. to n. Yukon and Alaska, s. to e. S. C., s. Ala., n.w. Ark., s. Colo., and n. Calif.; Mexico, Ecuador; Eurasia. Host: Allograpta obliqua

(Say), Metasyrphus americanus (Wied.), M. lapponicus (Zett.), Ocyptamus clavatus (F.), O. fascipennis (Wied.).

Bassus flavolineatus Gravenhorst, 1829. Ichn. Europaea, v. 3, p. 337. \&.

Bassus bimaculatus Holmgren, 1858 (1856). Svenska Vetensk.-Akad. Handl. (n. f.) 1: 360. $\delta$. 
Bassus agilis Cresson, 1868. Amer Ent. Soc., Trans. 2: 111. ठ.

Bassus froutalis Cresson, 1868. Amer. Ent. Soc., Trans. 2: 111. $९$. Preocc. by Zetterstedt, 1838.

Bassus junctus Provancher, 1883. Nat. Canad. 14: 10. “ $\delta "=q$. patei (Dasch), n. comb. Northern Colo., Alaska.

Syrphoctonus patei Dasch, 1964. Amer. Ent. Inst., Mem. 3: 207. ㅇ.

\section{Genus CAMPOCRASPEDON Uchida}

Campocraspedon Uchida, 1957. Hokkaido Imp. Univ., Faculty Agr., Jour. 50: 237.

Type-species: Campocraspedon satoi Uchida. Monotypic and orig. desig.

This is a small Holaretic genus.

foutsi (Cushman). Maine, Mass., N. Y., Md., D. C., e. N. C., s.e. Ont., Ohio, e. Ill.

Syrphoctonus foutsi Cushman, 1927. U. S. Natl. Mus., Proc. 72 (13): 12. ठ, ๆ.

truncatus Dasch. Northern Colo., Alaska, s.e. B. C., n. Idaho.

Campocraspedon truncatus Dasch, 1964. Amer. Ent. Inst., Mem. 3: 214. ठ。, ๆ.

\section{Genus PHTHORIMA Foerster}

Phthorima Foerster, 1868. Naturh. Ver. Rheinlande, Verh. 25: 162.

Type-species: Bassus compressus Desvignes. By subsequent monotypy from inclusion by Thomson, 1890 .

Phthorimus Thomson, 1890. Opusc. Ent. 14: 1474. Emend.

This is a small Holaretic genus.

bidens (Davis). N. B. s. to Md., w. to s.w. Ont. and n. Colo. Host: Neocnemodon coxalis (Curran), syrphid on hickory bark.

Otoblastus bidens Davis, 1897. Amer. Ent. Soc., Trans. 24: 273. ¿.

Phthorima sulciclypeus Cushman, 1920. U. S. Natl. Mus., Proc. 58: 265.

compressa (Desvignes). Colo., s. Alta., interior Alaska, n. Yukon, B. C.

Bassus compressus Desvignes, 1856. Cat. Brit. Ichn. in Brit. Mus., p. 91. $\$$.

Bassus ibalioidis Kriechbaumer, 1878. Ent. Nachr. 4: 211..

Homoporus niger Morley, 1906 (1905). Ent. Soc. London, Trans. 53: 422. o.

extensor Cushman. N. S. w. to s.e. B. C., s. to D. C., s.e. Tenn., and n.w. Colo.

Phthorima extensor Cushman, 1920. U. S. Natl. Mus., Proc. 58: 264. \&.

rufipleurum Dasch. N. H., Mass., Conn., N. Y., Md., Ont., Ohio, Mich., w. N. W. T.

Phthorima rufipleurum Dasch, 1964. Amer. Ent. Inst., Mem. 3: 221. ठ, ๆ.

townesi Dasch. Mass., N. Y., n. W. Va., Ont., Ohio, Mich., Iowa.

Phthorima townesi Dasch, 1964. Amer. Ent. Inst., Mem. 3: 224. ठ, ๆ.

sulcigena Dasch. Southeastern B. C. Known only from the holotype.

Phthorima sulcigena Dasch, 1964. Amer. Ent. Inst., Mem. 3: 228. ठ.

\section{Genus SYRPHOPHILUS Dasch}

Syrphophilus Dasch, 1964. Amer. Ent. Inst., Mem. 3: 59.

Type-species: Bassus bizonarius Gravenhorst. Orig. desig.

This is a small Holaretic genus.

asperatus Dasch. Interior Alaska.

Syrphophilus asperatus Dasch, 1964. Amer. Ent. Inst., Mem. 3: 71. ๆ.

bizonarius (Gravenhorst). Newfoundland (insular) w. to interior Alaska, s. to w. N. C., N. Mex., and n. Calif.; Eurasia. Host: Syrphids.

Bassus bizonarius Gravenhorst, 1829. Ichn. Europaea, v. 3, p. 350. ठ.

Bassus cingulatus Holmgren, 1858 (1856). Svenska Vetensk.-Akad. Handl. (n. f.) 1: 369. đ.

Bassus frontalis Brischke, 1871. Phys.-Oekonom. Gesell. Koenigsberg, Schr. 11: 104. o.

Preocc. by Zetterstedt, 1838 and Cresson, 1868.

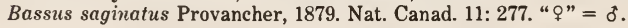


Zootrephes maudae Davis, 1895. Amer. Ent. Soc., Trans. 22: 22. ¿, $q$. This name appeared in Davis' key and applies to the same lectotype as does $Z$. inconstans Davis.

Zootrephes inconstans Davis, 1895. Amer. Ent. Soc., Trans. 22: 23, 29. ¿, ₹. This name applies to the same lectotype as does $Z$. maudae Davis (above).

Homocidus iwatensis Uchida, 1930. Hokkaido Imp. Univ., Faculty Agr., Jour. 25: 257.. .

Homocidus satoi Uchida, 1930. Hokkaido Imp. Univ., Faculty Agr., Jour. 25: 257. ð, $q$.

ichneumonoides (Provancher). Newfoundland (insular) w. to Alaska, s. to Mass., n. Mich., N. Mex., n. Idaho, and w. Wash.

Bassus ichneumonoides Provancher, 1874. Nat. Canad. 6 (1): 31 (key); 6 (2): 57. o, \&.

Bassus cingulatus Provancher, 1883. Nat. Canad. 14: 11. ?. Preoce. by Holmgren, 1858.

Zootrephes similis Brues, 1908. Wis. Nat. Hist. Soc., Bul. 6: 52 ..

tricinctorius (Thunberg). Northern Que. w. to Alaska, s. to n.w. S. C., s.w. Mo., N. Mex., and n.e. Calif.; Eurasia. Host: Syrphids.

Ichneumon tricinctorius Thunberg, 1822; 1824. Acad. Imp. des Sci. St. Petersburg, Mem. 8: $278 ; 9: 357$. [male].

Bassus cinctus Gravenhorst, 1829. Ichn. Europaea, v. 3, p. 327. §.

Bassus lateralis Gravenhorst, 1829. Ichn. Europaea, v. 3, p. 342. " $\delta "=$ ?.

Bassus scabriculus Holmgren, 1858 (1856). Svenska Vetensk.-Akad. Handl. (n. f.) 1: 357. ठ์, \&.

Bassus albicinctus Desvignes, 1862. Ent. Soc. London, Trans. 10: 218. ठ.

Bassus hyperboreus Marshall, 1877. Ent. Monthly Mag. 13: 241. ठ.

Bassus scapulatus Provancher, 1883. Nat. Canad. 14: 11..

Homocidus takaozanus Uchida, 1930. Hokkaido Imp. Univ., Faculty Agr., Jour. 25: 259. §.

Syrphophilus tricinctorius niveus Dasch, 1964. Amer. Ent. Inst., Mem. 3: 70. ¿, ๆ. N. syn.; range almost completely overlapped by what Dasch considered to be the nominate subspecies.

tricinctus (Ashmead). Northern Que. w. to Alaska, s. to Colo., s.w. Alta., and w. Wash.

Bioblapsis tricincta Ashmead, 1902. Wash. Acad. Sci., Proc. 4: 224. 8 . The type locality is Berg Bay, Glacier Bay Natl. Monument, Alaska.

\section{Genus TYMMOPHORUS Schmiedeknecht}

Tymmophorus Schmiedeknecht, 1913. Opusc. Ichn. 34: 2714.

Type-species: Tymmophorus lacustris Schmiedeknecht. Monotypic.

This small genus is Holarctic and apparently Neotropic (Mexico).

fasciventris Dasch. Northern Colo., Alaska, and Yukon.

Tymmophorus fasciventris Dasch, 1964. Amer. Ent. Inst., Mem. 3: 85. ठ, १.

gelidus Dasch. Arctic and subarctic N. W. T.; aretic Greenland.

Tymmophorus gelidus Dasch, 1964. Amer. Ent. Inst., Mem. 3: 87. ठ, ๆ.

gillettii (Davis). Colo. Known only from the holotype.

Syrphoctonus gillettii Davis, 1895. Amer. Ent. Soc., Trans. 22: 26..

obscuripes (Holmgren). Northern Que. w. to n. Yukon and Alaska, s. to n. Colo., n.w. Wyo., and n.e. Calif.; Europe. In Dasch's (1964) revision of the North American Diplazontinae the name graculus (Gravenhorst) is incorrectly applied to this species. Pfankuch (1910) studied the now lost holotype (presumably destroyed in World War II) of Bassus graculus Gravenhorst; he found that B. graculus is a species of Hemitelini and noted that Thomson's (1890) suppression of $B$. obscuripes Holmgren as a synonym of graculus is incorrect. If specimens in the U.S. Natl. Museum collection are correctly identified, B. graculus Gravenhorst represents an undescribed European genus of Phygadeuontina.

Bassus obscuripes Holmgren, 1858 (1856). Svenska Vetensk.-Akad. Handl. (n. f.) 1: 369 . o, ㅇ.

Bassus mufocinctus Desvignes, 1862. Ent. Soc. London, Trans. 10: 215. ð’ ๆ.

Tymmophorus graculus nigrofemoratus Dasch, 1964. Amer. Ent. Inst., Mem. 3: 79. ठ, ?. N. syn.; range completely overlapped by what Dasch treated as the nominate subspecies.

Taxonomy: Thomson, 1890. Opusc. Ent. 14: 1494-1495. - Pfankuch, 1910. Deut. Ent. Ztschr.

(for 1910), p. 275-276. 
rufiventris (Gravenhorst). Newfoundland and n. Que. w. to N. W. T. and Alaska, s. to Conn., w. N. C., s. Iowa, n. Idaho, and n.w. Oreg.; Europe.

Bassus mifiventris Gravenhorst, 1829. Ichn. Europaea, v. 3, p. 312. ð.

Bassus suspiciosus Brischke, 1871. Phys.-Oekonom. Gesell. Koenigsberg, Schr. 11: 106. $q$. Zootrephes antennatus Davis, 1895. Amer. Ent. Soc., Trans. 22: 23. o, o.

Tymmophorus lacustris Schmiedeknecht, 1913. Opusc. Ichn., v. 5, p. 2714..

thunbergi Dasch. Que., N. H., Mass., Ont., n. Man., Alaska, B. C. The occurrence of this species at Nome, Alaska (on the Seward Peninsula) makes it highly probable that it will prove to be Holaretic.

Tymmophorus thunbergi Dasch, 1964. Amer. Ent. Inst., Mem. 3: 79. o, \&.

\section{Genus DIPLAZON Viereck}

Bassus auct., nec Fabricius. Although no species of Diplazontinae were placed in Bassus by Fabricius, the name was for many years applied to to Diplazontinae, in later years more particularly to species of Diplazon.

Diplazon Nees ab Esenbeck, 1819 (1818). In Gravenhorst, Nova Acta Leopoldina 9: 292. Nomen nudum. Diplazon Nees ab Esenbeck is cited as a synonym of Bassus Fabricius in this paper by Gravenhorst. In his discussion of Bassus, Gravenhorst referred to a footnote consisting of a quotation from a letter he had received from Nees ab Esenbeck on Dec. 25, 1918 wherein Nees ab Esenbeck mentioned the name Diplazon. Nothing in the footnote makes the name available. Gravenhorst did nothing to validate Diplazon because he did not associate it with a valid specific name (even when names of genera described without included species are placed in synonymy, species are not thereby placed in them).

Diplazon Viereck, 1914. U. S. Natl. Mus., Bul. 83: 46.

Type-species: Ichneumon laetatorius Fabricius. Monotypic and orig. desig.

This is a moderate sized genus of worldwide distribution.

albotibialis Dasch. Northern Que., Alaska.

Diplazon albotibialis Dasch, 1964. Amer. Ent. Inst., Mem. 3: 53. ð, ?.

algidus Dasch. Newfoundland (n. Labrador) w. to n. Yukon and Alaska, s. to n. Man., Colo., s.w. Alta., and B. C.; n.e. Greenland; Norwegian Lapland.

Diplazon algidus Dasch, 1964. Amer. Ent. Inst., Mem. 3: 51. d, ?.

angustus Dasch, P. E. I., n. Man., w. N. W. T., n. Yukon, interior Alaska, n.e. Calif.

Diplazon angustus Dasch, 1964. Amer. Ent. Inst., Mem. 3: 46. ¿, ?.

bradleyi Dasch. Que., s. Man., n. Colo., w. N. W. T., Alaska, B. C., w. Wash.

Diplazon bradleyi Dasch, 1964. Amer. Ent. Inst., Mem. 3: 37. §, $\uparrow$.

cascadensis Dasch. Southwestern Alta., n.w. Wash. The type locality is Cascade Mt., Banff Natl. Park, Alta. (not "Banff, at 7,000-8,000 ft. in the Cascade Mts.").

Diplazon cascadensis Dasch, 1964. Amer. Ent. Inst., Mem. 3: 49. đ’, ․

constrictus Dasch. Colo., n.e. Calif.

Diplazon constrictus Dasch, 1964. Amer. Ent. Inst., Mem. 3: 47. ठ, ९.

deletus Thomson. Northern Que. w. to Alaska, s. to Conn., w. N. C., Colo., n. Utah, and n.w. Oreg.; Europe. The subspecific classification of Dasch (1964) is difficult to reconcile zoogeographically, particularly in view of the fact that nothing is known about populations of deletus which presumably exist in northeastern Asia; therefore, no subspecies of deletus are recognized here.

Bassus deletus Thomson, 1890. Opusc. Ent. 14: 1471. ¿, ․

Diplazon deletus fuscifemoratus Dasch, 1964. Amer. Ent. Inst., Mem. 3: 43. ð, ․ N. syn.

flavifrons Dasch. Southwestern B. C., w. Wash., n.w. Calif.

Diplazon flavifrons Dasch, 1964. Amer. Ent. Inst., Mem. 3: 39. đ, ?.

galenensis Dasch. Southern Idaho. Known from two specimens collected at an elevation of $8600 \mathrm{ft}$. on Galena Summit, Blaine Co., Idaho.

Diplazon galenensis Dasch, 1964. Amer. Ent. Inst., Mem. 3: 45. ơ, ?.

insulcatus Dasch. Southwestern Alta., w. Wash.

Diplazon insulcatus Dasch, 1964. Amer. Ent. Inst., Mem. 3: 58. đ, ?. 
laetatorius (Fabricius). Newfoundland (insular) w. to B. C., s. to Fla., s. Tex., and s. Calif.; Mexico, West Indies, Brazil, Peru, Argentina, Chile; most of Old World. Host:

Allograpta obliqua (Say), Metasyrphus americanus (Wied.), M. perplexus (Osb.), $M$. vinelandi (Curran), Paragus (Pandasyopthalmus) tibialis (Fall.), Pseudodorus clavatus (F.), Sphaerophoria contigua Macq., Syrphus rectus O. S., S. vittatifrons Shan. This is probably the most frequently collected species of Ichneumonidae; it is certainly the most widely distributed one. It usually reproduces thelytokously. Males occur sporadically in the U. S.; Dasch (1964) studied males from 19 states from coast to coast. He said that males are not known to occur outside the Nearctic Region.

Ichneumon laetatorius Fabricius, 1781. Species Insectorum, v. 1, p. 424..

Ichneumon dichrous Schrank, 1781. Enum. Ins. Austriae, p. 352. "ठ" $=$ ?.

Anomalon attractus Say, 1826. Boston Jour. Nat. Hist. 1: 241. ๆ.

Bassus albovarius Wollaston, 1858. Ann. and Mag. Nat. Hist. (3) $1: 23$. " $\delta^{\prime} "=९$ ?

Bassus sycophanta Cresson, 1868. Amer. Ent. Soc., Trans. 2: 112. ठ, $९$.

Bassus cinctipes Holmgren, 1869 (1868). Eug. Resa I, Zool. I, Ins., p. 409. §.

Bassus tripictierus Walsh, 1873. Acad. Sci. St. Louis, Trans. 3: 85. ơ, ๆ.

Scolobates varipes Smith, 1878. Ent. Soc. London, Trans. 26: 3. ․

Bassus venustulus Saussure, 1890. In Granidier, Hist. Madagascar, v. 20, Hym., Pt. 1, pl. 15 , figs. $23,23 \mathrm{a}$. " $\delta "=?$ ?

Bassus laetatorius var. terminalis Davis, 1895. Amer. Ent. Soc., Trans. 22: 19. \&.

Bassus balearicus Kriechbaumer, 1895. Soc. Espan. de Hist. Nat., Bol. 23: 246 ..

Bassus generosus Cameron, 1898. Manchester Lit. and Phil. Soc., Mem. and Proc. 42: 31..

Scolobates variipes Dalla Torre, 1901. Cat. Hym., v. 3, p. 328. Emend.

Bassus laetatorius var. senegalensis Ferriere, 1925. Agron. Colon. 12 (88): 148. [female].

Bassus laetatorius ikiti Cheesman, 1936. Roy. Ent. Soc. London, Trans. 85: 182..

Taxonomy: Dasch, 1964. Amer. Ent. Inst., Mem. 3: 15-22.

Biology: Kelly, 1914. Jour. Econ. Ent. 7: 294-297. - Kamal, 1926. Jour. Econ. Ent. 19: 724, 727. - Kamal, 1939. Egypt Min. Agr., Tech. and Sci. Serv. Bul. 207: 12-13, 26-31, 46-47.

- Butler and Dasch, 1958. Ariz. Agr. Expt. Sta., Tech. Bul. 135: 5-7.

orbitalis (Cresson). Northern Que. w. to n. Yukon and Alaska, s. to N. Y., n. Minn., w. S. Dak., N. Mex., and s. Calif.; Mexico. Host: Syrphus opinator O. S.

Bassus orbitalis Cresson, 1865. Ent. Soc. Phila., Proc. 4: 272. ?.

Bassus cinctulus Cresson, 1879 (1878). Acad. Nat. Sci. Phila., Proc. 30: 375. ठै, ९.

Bassus orbitalis Ashmead, 1890 (1889). U. S. Natl. Mus., Proc. 12: 439. ९. Preocc. by Cresson, 1865.

pectoratorius (Thunberg). Newfoundland (insular and Labrador) w. to n. Alaska, s. to N. Y., s. Mich., n. N. Mex., and n.e. Calif.; s. Mexico; Eurasia. Host: Trichopsomyia sp.

Ichneumon pectoratorius Thunberg, 1822; 1824. Acad. Imp. des Sci. St. Petersburg, Mem. $8: 280 ; 9: 366$. o.

Ichneumon angustorius Thunberg, 1822; 1824. Acad. Imp. des Sci. St. Petersburg, Mem. 8: $280 ; 9: 366$.. .

Bassus pectoratorius Gravenhorst, 1829. Ichn. Europaea, v. 3, p. 333. đ, ?. Preocc. in Diplazon by Thunberg, 1822.

Bassus pulchripes Provancher, 1875. Nat. Canad. 7 (5): 143. " $\delta "=?$.

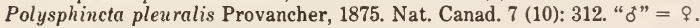

Homocidus akaashii Uchida, 1931. In Takagi, Chosen Govt.-Gen., Forest Expt. Sta. Bul. 12: 24 (German), 50 (Japanese). " $\delta "=?$.

Bassus urupensis Uchida, 1935. Insecta Matsumurana 9: 118. ठै, ₹.

Taxonomy: Roman, 1912. Zool. Bidr. Upsala 1: 232-233, 271.

scutellaris (Cresson). Que. w. to s.e. Alta. and n. Oreg., s. to n. Ga., s. La., and n.e. Tex.; s. Mexico. Host: Pseudodoros clavatus (F.).

Bassus scutellaris Cresson, 1868. Amer. Ent. Soc., Trans. 2: 112. ¿, ๆ.

tetragonus (Thunberg). Newfoundland (Labrador) w. to n. Yukon and Alaska, s. to w. N. C., Colo., and n.w. Calif.; Eurasia. Host: Syrphus ribesii (L.).

Ichneumon tetragonus Thunberg, 1822; 1824. Acad. Imp. des Sci. St. Petersburg, Mem. 8: 280; 9: 365. [male]. 
Ichneumon hortorius Thunberg, 1822; 1824. Acad. Imp. des Sci. St. Petersburg, Mem. 8: 280; 9: 365. ठ.

Ichneumon ustorius Thunberg, 1822; 1824. Acad. Imp. des Sci. St. Petersburg, Mem. 8: 281; 8: 366. ठै.

Bassus tricinctus Gravenhorst, 1829. Ichn. Europaea, v. 3, p. 351. đ.

Bassus nemoralis Holmgren, 1858 (1856). Svenska Vetensk.-Akad. Handl. (n. f.) 1: 354. ¿, ‥

Bassus concinuus Cresson, 1868. Amer. Ent. Soc., Trans. 2: 111. $\$$.

Bassus amoenus Provancher, 1874. Nat. Canad. 6 (1): 3 (key); 6 (2): 55 ..

Bassus albicoxus Provancher, 1874. Nat. Canad. 6 (1): 3 (key); 6 (2): 56. o..

Bassus albicomis(!) Provancher, 1879. Nat. Canad. 11: 273. Lapsus for B. albicoxus.

Diplazon tetragonus rufigaster Dasch, 1964. Amer. Ent. Inst., Mem. 3: 28. §, ${ }^{\circ}$. N. syn.; range totally overlapped by what Dasch treated as the nominate subspecies.

Taxonomy: Roman, 1912. Zool. Bidr. Uppsala 1: 259, 282, 287.

tibiatorius occidentalis Dasch. Colo., Alta., Ariz., s. Yukon, B. C., w. Wash., s.e. Oreg., n.e. Calif. D. tibiatorius tibiatorins (Thunberg) is Eurasian. The paratype of $D$. $t$. occidentalis from "Valence" is a misidentified French specimen of the nominate subspecies.

Diplazon tibiatorius occidentalis Dasch, 1964. Amer. Ent. Inst., Mem. 3: 34. đ, ?. walleyi Dasch. Northern Man., arctic and subarctic w. N. W. T., s. Yukon.

Diplazon walleyi Dasch, 1964. Amer. Ent. Inst., Mem. 3: 23. §, $\$$.

\section{Genus PROMETHES Foerster}

Promethes Foerster, 1868. Naturh. Ver. Rheinlande, Verh. 25: 162.

Type-species: Bassus sulcator Gravenhorst. By subsequent monotypy from inclusion by Woldstedt, 1877 .

Liopsis Foerster, 1868. Naturh. Ver. Rheinlande, Verh. 25: 162.

Type-species: Bassus sulcator Gravenhorst. Monotypically included and desig. by Viereck, 1912.

Promethus Thomson, 1890. Opusc. Ent. 14: 1465, 1475. Emend.

This small genus is Neotropic, Holaretic, and Oriental.

gravenhorsti Dasch. Newfoundland (insular), N. B., Mass., n. N. Y., n. Mich., Alta., interior Alaska, B. C., n.w. Wash.; Japan? Host: Syrphids.

Promethes gravenhorsti Dasch, 1964. Amer. Ent. Inst., Mem. 3: 236. ठ, १.

nomininguis Dasch. Southern Que.

Promethes nomininguis Dasch, 1964. Amer. Ent. Inst., Mem. 3: 240. §, $\$$.

striatus Dasch. Western Pa., e. Ohio, n. Colo., n.w. Alta.

Promethes striatus Dasch, 1964. Amer. Ent. Inst., Mem. 3: 238. ¿, ९.

sulcator (Gravenhorst). Newfoundland (insular) and n. Que. w. to n. Yukon and Alaska, s. to Pa., n. Ill., e. S. Dak., Colo., Ariz., and n.w. Calif.; Eurasia.

Bassus sulcator Gravenhorst, 1829. Ichn. Europaea, v. 3, p. 320. ठ, \&.

Bassus areolatus Holmgren, 1856 (1854). Svenska Vetensk.-Akad. Handl. 75: 85. đ̊, ९. Bassus longicornis Provancher, 1883. Nat. Canad. 14: 12..

Bassus aciculatus Provancher, 1888. Addit. Corr. Faune Ent. Canada Hym., p. 368.. Preoce. by Ruthe, 1859 .

Bassus auriculatus Provancher, 1888. Addit. Corr. Faune Ent. Canada Hym., p. 429..

Promethes sulcator splendidus Dasch, 1964. Amer. Ent. Inst., Mem. 3: 236. o, range completely overlapped by what Dasch treated as the nominate subspecies.

\section{Genus SUSSABA Cameron}

Sussaba Cameron, 1909. Bombay Nat. Hist. Soc., Jour. 19: 728.

Type-species: Sussaba bicarinata Cameron. Monotypic.

This is a moderate sized genus of Neotropic, Holarctic, and Oriental distribution. 
cognata faceta Dasch. N. S., Que., Maine, N. H., Vt., Mass., N. Y., w. N. C., n. Ga., Ont. n. Mich., e. Tenn., Alaska, s. B. C., w. Wash., w. Oreg., n.w. Calif. Two more or less sympatric Eurasian "subspecies" were recognized by Dasch (1964) and by Townes, Momoi, and Townes (1965). They are S. cognata cognata (Holmgren), which was described from southern Lapland, and S. cognata albicoxa (Thomson), which was described from southern Sweden, Germany, and France.

Promethes albicoxis Ashmead, 1906. In Slosson, Ent. News 17: 324. Nomen nudum or lapsus for and misidentification of $P$. albicoxa Thomson.

Sussaba cognata faceta Dasch, 1964. Amer. Ent. Inst., Mem. 3: 265. ơ, \&.

Taxonomy: Townes, Momoi, and Townes, 1965. Amer. Ent. Inst., Mem. 5: 414.

coloradensis Dasch. Northern Colo. Known only from the holotype which was collected four miles west of Cameron Pass, Colo. on July 23, 1894 by C. F. Baker.

Sussaba coloradensis Dasch, 1964. Amer. Ent. Inst., Mem. 3: 270. . .

dorsalis cultriformis (Ashmead). N. S. w. to s.e. Alta., s. to N. J., s.w. Va., and Nebr. Host: Platycheirus erraticus Curran, Sphaerophoria philantnus (Meig.), syrphid on cabbage, syrphid on reed canary grass. Single specimens apparently not otherwise separable from d. cultriformis were recorded by Dasch from s.e. B. C., s. Yukon, and s.w. Alaska, well within the range of the nominate subspecies.

Trematopygus? cultriformis Ashmead, 1890 (1889). U. S. Natl. Mus., Proc. 12: 441. \&.

dorsalis dorsalis (Holmgren). Newfoundland (Labrador) w. to n. Yukon and Alaska, s. to insular Newfoundland, s. central Que., n. Colo., and n. Calif.; Eurasia.

Bassus dorsalis Holmgren, 1858 (1856). Svenska Vetensk.-Akad. Handl. (n. f.) 1: 367. ð, ๆ. Bassus maculatus Desvignes, 1862. Ent. Soc. London, Trans. 10: 216. o, ?.

elongata (Provancher). Newfoundland (n. Labrador) w. to n. Yukon and Alaska, s. to Vt., $n$. Mich., Tex., N. Mex., n. Utah, and n. Calif.; Eurasia.

Bassus elongatus Provancher, 1874. Nat. Canad. 6 (1): 31 (key); 6 (2): 57. o, ₹.

Bassus monticola Snellen van Vollenhoven, 1875. Pinacographia, p. 4 and pl. 1, fig. 9. ठ.

Promethus laticarpus Thomson, 1890. Opusc. Ent. 14: 1481. o, ๆ.

Otoblastus erodens Davis, 1897. Amer. Ent. Soc., Trans. 24: 273. ठ, १.

Promethes unicinctus Ashmead, 1902. Wash. Acad. Sci., Proc. 4: 224. + . Townes (1945) stated that the holotype is a composite specimen, but I do not think he was correct; therefore, his selection of the thorax as "lectotype" is of doubtful significance. Dasch (1964) incorrectly stated that the type locality is "Berg Bay, Alaska;" it is Kukak Bay, Alaska.

Promethes laticarpus watanabei Uchida, 1957. Hokkaido Imp. Univ., Faculty Agr., Jour. 50: 248. ठ, ?. Syn.? Dasch (1964) stated that he believed watanabei (described from Hokkaido) to be a subspecies of elongatus, but he did not use either of the trinomials $S$. elongatus watanabei or $S$. elongatus elongatus. Moreover, Dasch apparently also studied typical specimens of elongata from Japan (see his p. 253).

Taxonomy: Townes, 1945. Amer. Ent. Soc., Mem. 11: 560. -Dasch, 1964. Amer. Ent. Inst., Mem. 3: 242, 250-254.

nigrithorax Dasch. Northern Que., n.e. N. W. T., Colo., Alaska. The Baker notebook indicates that the female paratype cited by Dasch as "Colorado, C. Baker (Washington)" was collected at an elevation of $9500 \mathrm{ft}$. at Chambers Lake, Colo. on July 18, 1895 by C. F. and N. E. Baker. A male for which the same data apply is labeled by Dasch as a paratype of nigrithorax but is evidently the specimen he cited as a paratype of pulchella coriacea Dasch from "Colorado (no locality)." In addition, a specimen from "Camp 334, Alaska" (a place at the east end of Mt. McKinley Natl. Park and now known as Carlo) which Dasch labeled as a paratype of nigrithorax is cited in his revision as a paratype of pulchella coriacea. If nigrithorax is a valid species and if the one paratype of nigrithorax and two "paratypes" of pulchella coriacea discussed above are correctly identified as nigrithorax they are apparently the only known specimens of this species which were not collected above or beyond timberline.

Sussaba nigrithorax Dasch, 1964. Amer. Ent. Inst., Mem. 3: 249. o, ?.

placita Dasch. Southeastern B. C., n. Calif.

Sussaba placita Dasch, 1964. Amer. Ent. Inst., Mem. 3: 269. ठ̀, ๆ. 
pulchella coriacea Dasch. P. E. I. s. to w. N. C., w. to n.w. Mich. and s.e. Minn. Dasch said "S. pulchella coriacea is most closely related to nigrithorax ..."; nigrithorax has a range which overlaps that known for S. pulchella pulchella (Holmgren) in North America (see foregoing discussion of nigrithorax).

Sussaba pulchella coriacea Dasch, 1964. Amer. Ent. Inst., Mem. 3: 247. ठ, ९.

pulchella pulchella (Holmgren), Northern Que., N. W. T.; Europe; n. India.

Bassus pulchellus Holmgren, 1858 (1856). Svenska Vetensk.-Akad. Handl. (n. f.) 1: 366. ठ, ‥

Bassus aciculatus Ruthe, 1859. Stettin. Ent. Ztg. 20: 373..

Sussaba bicarinata Cameron, 1909. Bombay Nat. Hist. Soc., Jour. 19: 728..

punctiventris (Thomson). Boreal Que. w. to s. Yukon, s. to Mass., n. Mich., Colo., Ariz., and Oreg.; Europe.

Homotropus punctiventris Thomson, 1890. Opusc. Ent. 14: 1500..

rohweri (Brues). Southeastern Sask., s. Yukon, and Alaska, s. to N. Mex., Ariz., and n. Calif.; Mexico. Host: Metasyrphus perplexus (Osb.). The occurrence of this species at Nome, Alaska (on the Seward Peninsula) makes it highly probable that it will prove to be Holaretic.

Promethes rohweri Brues, 1908. Wis. Nat. Hist. Soc., Bul. 6: 51. §, ๆ.

rugipleuris ellesmerae Dasch. Northern N. W. T. Known from a series of 67 specimens collected at one locality on the eastern side of Ellesmere Island. It seems unlikely that this taxon could represent anything more than the end of a cline.

Sussaba migipleuris ellesmerae Dasch, 1964. Amer. Ent. Inst., Mem. 3: 263. đ, ?.

rugipleuris rugipleuris Dasch. N. W. T., s.e. Wyo., n. Yukon, Alaska.

Sussaba rugipleuris mugipleuris Dasch, 1964. Amer. Ent. Inst., Mem. 3: 262. đ, ๆ.

\section{SUBFAMILy OXYTORINAE}

The subfamily Oxytorinae (=Microleptinae) includes a number of genera about which so little is known that their phylectic relationships with other ichneumonid genera are particularly in doubt. Hence, their position in the classification of the family is somewhat a matter of speculation. Oxytorus and Microleptes are two of these genera of doubtful affinities. Of the 24 genera of Oxytorinae recognized by Townes (1971), 19 have Nearctic species. Species of some genera have been reared from Mycetophilidae, but for most of the genera no hosts are known.

Taxonomy: Townes, 1971. Amer. Ent. Inst., Mem. 17: 179-206 (genera of world).

\section{Genus MICROLEPTES Gravenhorst}

Microleptes Gravenhorst, 1829. Ichn. Europaea, v. 1, p. 679.

Type-species: Microleptes splendidulus Gravenhorst. Monotypic.

Miomeris Foerster, 1868. Naturh. Ver. Reinlande, Verh. 25: 171.

Type-species: Miomeris aquisgranensis Foerster. Monotypically included and desig.

by Foerster, 1871.

Mionomeris Schulz, 1906. Spolia Hym., p. 94. Emend.

Gnathoniella Schmiedeknecht, 1924. Ent. Monthly Mag. 60: 47.

Type-species: Gnathoniella egregia Schmiedeknecht. Monotypic.

Microcleptes Walkley, 1967. In Krombein et al., U. S. Dept. Agr., Agr. Monog. 2, Sup. 2, p. 180. Unjustified emend. Mr. George Steyskal is of the opinion (personal commun., 1976) that Hopper (1959) was correct in asserting that Gravenhorst's name Microleptes was a lapsus in light of the Latin definition (meaning stealer of little things) which Gravenhorst gave for the Greek words from which he derived Microleptes. However, Steyskal feels that it is not provable that Gravenhorst's Greek word which transliterates as leptes was a lapsus for cleptes rather than lestes (the latter meaning the same thing). Therefore, the ichneumonid name Microcleptes must be treated as an unjustified emendation and, therefore, does not date from Gravenhorst (1829) and is preoccupied by Newman, 1840; Stal, 1866; and Simpson, 1928, instead of preoccupying them. 
This is a small Holarctic genus. Townes (1971) said that "the relationships of Microleptes are uncertain," and that "it may, or may not belong to the present subfamily."

Revision: Stelfox, 1961. Ent. Monthly Mag. 97: 181-182 (British spp.).

Taxonomy: Hopper, 1959. Ent. Soc. Wash., Proc. 61: 166 (derivation of Microleptes).

-Townes, 1971. Amer. Ent. Inst., Mem. 17: 183-184 (syn., etc.).

splendidulus Gravenhorst. Eastern Que., s. Mich.

Micraleptes splendidulus Gravenhorst, 1829. Ichn. Europaea, v. 1, p. 679..

Miomeris glabriventris Thomson, 1888. Opusc. Ent. 12: 1317. ठ’, ๆ.

Taxonomy: Stelfox, 1961. Ent. Monthly Mag. 97: 181-182.

\section{Genus OXYTORUS Foerster}

Delolytus Foerster, 1868. Naturh. Ver. Rheinlande, Verh. 25: 189. It should be noted that v. 25 of Naturh. Ver. Rheinlande, Verh. was published in two halves; Delolytus appeared in the first half and Oxytorus and Callidiotes appeared in the second half. If it is subsequently shown that the first half was published before either the second half or the authors separates of the entire paper, Delolytus could no longer be suppressed by Oxytorus or Callidiotes.

Type-species: Mesoleptus caxator Gravenhorst. By subsequent monotypy from inclusion by Foerster, 1876. The type-species is regarded as a synonym of $O$. luridator (Gravenhorst).

Callidiotes Foerster, 1868. Naturh. Ver. Rheinlande, Verh. 25: 199.

Type-species: Mesoleptus coxator Gravenhorst. By subsequent monotypy from inclusion by Foerster, 1876.

Oxytorus Foerster, 1868. Naturh. Ver. Rheinlande, Verh. 25: 199.

Type-species: Oxytorus armatus Thomson. By subsequent monotypy from inclusion by Thomson, 1883 .

Pantoporthus Foerster, 1868. Naturh. Ver. Rheinlande, Verh. 25: 209.

Type-species: Ichneumon luridator Gravenhorst. Monotypically included and desig. by Perkins, 1962 .

Mesatractodes Morley, 1907. Brit. Ichn., v. 2, p. 257.

Type-species: Atractodes properator Haliday. Monotypic. The type-species is regarded as a synonym of 0 . luridator (Gravenhorst).

Paracanidia Viereck, 1912. U. S. Natl. Mus., Proc. 42: 642.

Type-species: Paracanidia elyi Viereck. Monotypic and orig. desig.

Prosmoridea Cushman, 1915. Ent. Soc. Wash., Proc. 17: 141.

Type-species: Prosmarus elongatus Davis. Monotypic and orig. desig. This is a Holarctic genus of moderate size.

albopleuralis (Provancher). Que. s. to S. C. and n. Ga., w. to Mich.

Mesoleptus albopleuralis Provancher, 1879. Nat. Canad. 11: 224. ठં.

Atractodes nitens Provancher, 1882. Nat. Canad. 13: 368. §, ?.

Prosmosus(!) punctifrons Davis, 1898 (1897). Amer. Ent. Soc., Trans. 24: 309. “ $"=$ q.

antennatus (Cresson). Que. s. to s. Ga., w. to Wis. and La.

Mesoleptus antennatus Cresson, 1864. Ent. Soc. Phila., Proc. 3: 272. ठ.

Mesoleptus facetus Cresson, 1868. Amer. Ent. Soc., Trans. 2: 100. ð.

Mesoleptus rufomixtus Provancher, 1886. Addit. Corr. Faune Ent. Canada Hym., p. 97. "૧" = ठ ( $\delta$ misdet.).

Mesaleptus filiformis Provancher, 1886. Addit. Corr. Faune Ent. Canada Hym., p. 98. $q$.

Formerly preocc. in Cryptus by Fonscolombe, 1850, and Rudow, 1886.

Exolytus concameris Davis, 1898 (1897). Amer. Ent. Soc., Trans. 24: 356. ㅇ.

Cryptus Genelinii Dalla Torre, 1902. Cat. Hym., v. 3, p. 573. N. name for M. filiformis

Provancher.

Paracanidia elyi Viereck, 1912. U. S. Natl. Mus., Proc. 42: 643..

elongatus (Davis). Southern Va., N. C., Tex.

Prosmosus(!) elongatus Davis, 1898 (1897). Amer. Ent. Soc., Trans. 24: 310.. 


\section{Genus HYPERACMUS Holmgren}

Hyperacmus Holmgren, 1858 (1856). Svenska Vetensk. Akad. Handl. (n. f.) 1: 322.

Type-species: Exochus crassicomis Gravenhorst. Monotypic.

Nothaima Cameron, 1902. Bombay Nat. Hist. Soc., Jour. 14: 429.

Type-species: Nothaima bicarinata Cameron. Monotypic.

This is a small Holaretic and Oriental genus.

crassicornis (Gravenhorst). N. Y., Alaska; Eurasia. Host: Yponomeuta malinella Zell. The

foregoing is a European host record of Meyer (1927); it needs confirmation.

Exochus crassicomis Gravenhorst, 1829. Ichn. Europaea, v. 2, p. 347. ?.

Biology: Meyer, 1927. [Leningrad] Gosud. Inst. Opytn. Agron. (State Inst. Expt. Agron.),

Otd. Prikl. Ent. (Bur. Appl. Ent.), Izv. (Rpts.), Trudy po Prikl. Ent. (Works on Appl. Ent.). 3: 89 .

\section{Genus ENTYPOMA Foerster}

Entyponı Foerster, 1868. Naturh. Ver. Rheinlande, Verh. 25: 171.

Type-species: Entypoma robustum Foerster. Monotypically included and desig. by Foerster, 1871.

Entelechia Foerster, 1871. Naturh. Ver. Rheinlande, Verh. 28: 110. Preocc. by Gistel, 1848. Type-species: Entelechia suspiciosa Foerster. Monotypic.

Entypomus Thomson, 1888. Opusc. Ent. 12: 1289. Emend.

Entelechius Thomson, 1888. Opusc. Ent. 12: 1290. Emend.

This is a small Holarctic genus. According to Townes (1971), an undescribed species occurs in "Arctic and Arctic-Alpine North America."

Taxonomy: Townes, 1971. Amer. Ent. Inst., Mem. 17: 189-190.

\section{Genus ALLOMACRUS Foerster}

Allomacmis Foerster, 1868. Naturh. Ver. Rheinlande, Verh. 25: 177.

Type-species: Allomacrus pimplarius Thomson. By subsequent monotypy from inclusion by Thomson, 1888 .

Sibiriakoffia Holmgren, 1881 (1880). Novas Species Ins. Cura et Labore A. E.

Nordenskioldii e Novaia Semlia Coactorum, p. 13.

Type-species: Sibiriakoffia arctica Holmgren. Monotypic.

Two species are known, one being Holarctic and the other Japanese.

arcticus (Holmgren). Colo., interior Alaska, B. C., Wash.; n. Eurasia.

Sibiriakoffia arctica Holmgren, 1881 (1880). Novas Species Ins. Cura et Labore A. E.

Nordenskioldii e Novaia Semlia Coactorum, p. 14. $\delta^{*}$, $९$.

Allomacrus pimplarius Thomson, 1888. Opusc. Ent. 12: 1282. ठ, ๆ.

Taxonomy: Townes, 1971. Amer. Ent. Inst., Mem. 17: 190-191 (syn., distribution).

\section{Genus APOCLIMA Foerster}

Apoclima Foerster, 1868. Naturh. Ver. Rheinlande, Verh. 25: 171.

Type-species: Apoclima signaticorne Foerster. Monotypically included and desig. by Foerster, 1871.

This is a small Neotropic, Holarctic, and Oriental genus. Apparently one or more unidentified or undescribed species occur in the Nearctic region.

Taxonomy: Townes, 1971. Amer. Ent. Inst., Mem. 17: 191-192.

\section{Genus CYLLOCERIA Schiodte}

Cylloceria Schiodte, 1839 (1838). Rev. et Mag. Zool. 1: 140.

Type-species: Phytodietus caligatus Gravenhorst. Desig. by Viereck, 1914.

Chalinocerus Ratzeburg, 1852. Ichn. d. Forstins., v. 3. p. 130. 
Type-species: Chalinocerus longicornis Ratzeburg. Monotypic. The type-species is regarded as a synonym of $C$. melancholica (Gravenhorst).

Asphragis Foerster, 1868. Naturh. Ver. Rheinlande, Verh. 25: 166.

Type-species: Lissonota occupator Gravenhorst. Desig. by Viereck, 1914, from four species included by Schmiedeknecht, 1888.

Chalinoceras(!) Ashmead, 1900. U. S. Natl. Mus., Proc. 23: 166, 209.

This is a moderately large Holarctic and Neotropic genus.

lugubris (Cresson). Colo., N. Mex., s.w. Alta., interior Alaska, B. C.

Lampronota? lugubris Cresson, 1879 (1878). Acad. Nat. Sci. Phila., Proc. 30: 379..

Cylloceria fuscolina Davis, 1898 (1897). Amer. Ent. Soc., Trans. 24: 371. ठ.

nodosa Walley. Northern Man., interior Alaska.

Cylloceria nodosa Walley, 1941. Canad. Ent. 73: 166. ठ,,.

sexlineata (Say). Maine w. to s. B. C., s. to n. Fla., n.e. Kans., Colo., and Wash. Townes and

Townes (1951) believed that two or more species were confused under this name.

Anomalon sexlineata Say, 1829. Contrib. Maclurian Lyceum to Arts and Sci. 1: 74. ㅇ.

Cylloceria occidentalis Cresson, 1870. Amer. Ent. Soc., Trans. 3: 160. o, ९. Formerly preocc. in Lampronota by Cresson, 1870, p. 161.

Lampronota sexcarinata Davis, 1895. Amer. Ent. Soc., Trans. 22: 30. $\uparrow$.

Lampronota errans Dalla Torre, 1901. Cat. Hym., v. 3, p. 515. N. name for C. occidentalis Cresson.

Lampronota aciculata Cameron, 1905. Invertebrata Pacifica 1: 129. ㅇ.

Taxonomy: Cushman and Gahan, 1921. Ent. Soc. Wash., Proc. 23: 157. - Townes and Townes, 1951. In Muesebeck et al., U. S. Dept. Agr., Agr. Monog. 2: 342.

\section{Genus ANISERES Foerster}

Aniseres Foerster, 1871. Naturh. Ver. Rheinlande, Verh. 28: 92.

Type-species: Aniseres pallipes Foerster. Desig. by Viereck, 1914.

This is a small Holaretic genus.

lubricus Foerster. Greenland; Europe.

Aniseres lubricus Foerster, 1871. Naturh. Ver. Rheinlande, Verh. 28: 93. ठ.

spectabilis (Foerster). Nearctic Region; Europe.

Aniseres pallipes Foerster, 1871. Naturh. Ver. Rheinlande, Verh. 28: 93. ठ์.

Proclitus spectabilis Foerster, 1871. Naturh. Ver. Rheinlande, Verh. 28: 116. \&.

Taxonomy: Thomson, 1888. Opusc. Ent. 7: 1304 (syn.). -Townes, 1971. Amer. Ent. Inst., Mem. 17: 193 (distribution).

\section{Genus PANTISARTHRUS Foerster}

Pantisarthrus Foerster, 1871. Naturh. Ver. Rheinlande, Verh. 28: 109.

Type-species: Pantisarthrus inaequalis Foerster. Desig. by Viereck, 1914.

This is a small Neotropic, Holarctic, and Oriental genus.

inaequalis Foerster. Que.?, N. Y., Ont.? Host: Mycetophilid.

Pantisarthrus inaequalis Foerster, 1871. Naturh. Ver. Rheinlande, Verh. 28: 110. $q$.

Bassus dorsalis Provancher, 1886. Addit. Corr. Faune Ent. Canada Hym., p. 112..

Preocc. by Holmgren, 1858. Described from either Que. or Ont.

Taxonomy: Townes, 1971. Amer. Ent. Inst., Mem. 17: 194.

\section{Genus PROCLITUS Foerster}

Clepticus Haliday, 1838. Ann. Nat. Hist. 2: 116. Preocc. by Cuvier, 1829.

Type-species: Clepticus praetor Haliday. Desig. by Westwood, 1840.

Proclitus Foerster, 1868. Naturh. Ver. Rheinlande, Verh. 25: 172.

Type-species: Proclitus grandis Foerster. Desig. by Viereck, 1914.

Aclastoneura Kriechbaumer, 1896. Ent. Nachr. 22: 359. 
Type-species: Aclastoneura tricolor Kriechbaumer. Monotypic.

Mischoxorides Ashmead, 1900 Canad. Ent. 32: 368. N. name for Clepticus Haliday.

This is a large genus; it is apparently known from all zoogeographic regions including the Australian Region (one Samoan sp.).

longicaudus (Provancher). Que., Maine, N. H., N. Y., N. J., N. C., Ga., Ala.

Cremastus longicaudus Provancher, 1882. Nat. Canad. 13: 367. ठ́,.+

royi (Provancher). Que. s. to s. Ga.

Cremastus Royi Provancher, 1882. Nat. Canad. 13: 366. §, $?$.

\section{Genus DIALIPSIS Foerster}

Dialipsis Foerster, 1868. Naturh. Ver. Rheinlande, Verh. 25: 171.

Type-species: Dialipsis exilis Foerster. Desig. by Viereck, 1914, from seven species included by Foerster, 1871.

Parentypoma Strobl, 1901 (1900). Siebenbuerg. Ver. f. Naturw., Hermannstadt, Verh. u. Mitt. 50: 71.

Type-species: Parentypoma femoratum Strobl. Monotypic. The type-species is regarded as a synonym of exilis Foerster.

According to Townes (1971) this is a Holarctic genus of moderate size. Presumably there are one or more unidentified or undescribed Nearctic species.

Taxonomy: Townes, 1971. Amer. Ent. Inst., Mem. 17: 195-196.

\section{Genus PLECTISCIDEA Viereck}

Plectiscidea Viereck, 1914. U. S. Natl. Mus., Bul. 83: 118.

Type-species: Plectiscus collaris Gravenhorst. Orig. desig.

This is a very large genus of Neotropic, Holarctic, Oriental, and Ethiopian distribution.

arctica (Roman). Greenland.

Plectiscus arcticus Roman, 1930. Ann. and Mag. Nat. Hist. (10) 5: 284. ‥

carinata (Provancher). Que., N. Y.

Orthocentmes carinatus Provancher, 1879. Nat. Canad. 11: 281. §.

collaris (Gravenhorst). Greenland; Eurasia.

Plectiscus collaris Gravenhorst, 1829. Ichn. Europaea, v. 2, p. 287. ๆ.

glabrifrons (Davis). Northern Ill.

Catastenus glabrifrons Davis, 1897. Amer. Ent. Soc., Trans. 24: 342. ठ.

humeralis (Provancher). Que., B. C., w. Wash.

Mesochorus humeralis Provancher, 1883. Nat. Canad, 14: 4. $\subsetneq$.

hyperborea (Holmgren). Greenland; Eurasia.

Plectiscus hyperboreus Holmgren, 1869. Svenska Vetensk.-Akad. Handl. (n. f.) 8 (pt. 5): 21. ¿. + .

Plectiscus bistriatus Thomson, 1888. Opusc. Ent. 12: 1299. ठ์, ․

Taxonomy: Roman, 1916. Archiv for Zool. 10 (22): 9.

lurida (Foerster). Greenland; Europe.

Pantisarthrus luridus Foerster, 1871. Naturh. Ver. Rheinlande, Verh. 28: 100. $\$$. nasoni (Davis). N. Y., n. Ill.

Miomeris nasoni Davis, 1897. Amer. Ent. Soc., Trans. 24: 244.. .

Miomeris nasonii Dalla Torre, 1901. Cat. Hym., v. 3, p. 20. Emend.

nigra (Provancher), Que.

Plectiscus niger Provancher, 1883. Nat. Canad. 14: 6. §, ㅇ.

orcae (Ashmead). N. H., N. Y., Alaska.

Plectiscus orcae Ashmead, 1902. Wash. Acad. Sci., Proc. 4: 240. $\subsetneq$.

parva (Cushman). N. H.

Aperilaptus(!) parvus Ashmead, 1897. In Slosson, Ent. News 8: 237. Nomen nudum.

Plectiscus parvus Cushman, 1922. U. S. Natl. Mus., Proc. 61 (8): 22.. 
patula (Viereck). N. H., N. Mex., Wash.

Mesochorus areolatus Viereck, 1903. In Skinner, Amer. Ent. Soc., Trans. 29: 92. \&. Preocc. by Provancher, 1883.

Mesochorus patulus Viereck, 1911. U. S. Natl. Mus., Proc. 40: 192. N. name for $M$. areolatus Viereck.

\section{Genus APERILEPTUS Foerster}

Aperileptus Foerster, 1868. Naturh. Ver. Rheinlande, Verh. 25: 170.

Type-species: Plectiscus albipalpus Gravenhorst. Included and desig. by Foerster, 1871 .

This is a moderately large genus, apparently of Neotropic, Holarctic, Oriental, and Ethiopian distribution.

gracilis (Provancher). Que., Maine, N. H., N. Y.

Phytodietus gracilis Provancher, 1875. Nat. Canad. 7: 331. \&.

Proedrus delicatus Ashmead, 1897. In Slosson, Ent. News 8: 237. Nomen nudum.

Aperileptus clypeatus Ashmead, 1902. In Slosson, Ent. News 13: 6. Nomen nudum.

Aperiletus(!) clypeatus Cushman, 1922. U. S. Natl. Mus., Proc. 61 (8): 4 ..

Aperileptus delicatus Cushman, 1922. U. S. Natl. Mus., Proc. 61 (8): 5..

valerius (Davis). N. Y., n. Ill.

Catastenus valerius Davis, 1897. Amer. Ent. Soc., Trans. 24: 243. \&.

\section{Genus BLAPTICUS Foerster}

Gnathochorisis Foerster, 1868. Naturh. Ver. Rheinlande, Verh. 25: 152.

Type-species: Gnathochorisis flavipes Foerster. Monotypically included and desig. by Foerster, 1871.

Blapticus Foerster, 1868. Naturh. Ver. Reinlande, Verh. 25: 171.

Type-species: Blapticus leucostomus Foerster. Monotypically included and desig. by Foerster, 1871.

Laepserus Foerster, 1868. Naturh. Ver. Rheinlande, Verh. 25: 205.

Type-species: Blapticus crassulus Thomson. Included and desig. by Perkins, 1962.

Acroblapticus Schmiedeknecht, 1911. Opusc. Ichn., v. 4, p. 2173.

Type-species: Blapticus dentifer Thomson. Desig. by Viereck, 1914.

Townes (1971) said that this is a large genus, which is known from all regions except the Australian. According to Townes and Townes (1951) undescribed Nearctic species of this genus are transcontinental in the Canadian and Transitional Zones.

Taxonomy: Townes and Townes, 1951. In Muesebeck et al., U. S. Dept. Agr., Agr. Monog. 2: 342. - Perkins, 1962. Brit. Mus. (Nat. Hist.) Ent., Bul. 11: 410, 425, 434 (syn.). - Townes,

1971. Amer. Ent. Inst., Mem. 17: 200-201.

\section{Genus SYMPLECIS Foerster}

Symplecis Foerster, 1868. Naturh. Ver. Rheinlande, Verh. 25: 151.

Type-species: Symplecis alpicola Foerster. Desig. by Viereck, 1914, from three species included by Foerster, 1871.

This is a large genus, apparently of Neotropic, Holarctic, Oriental, and Ethiopian distribution. clipeator (Lundbeck). Greenland.

Hemiteles clipeator Lundbeck, 1897 (1896). Dansk Naturhist. For. (Kjobenhavn), Vidensk.

Meddel. (for 1896), p. 228. ठ'.

Taxonomy: Townes, 1961. Ent. Soc. Wash., Proc. 63: 106.

sitkensis (Ashmead). N. H., Alaska, B. C., Wash.

Stiboscopus sitkensis Ashmead, 1902. Wash. Acad. Sci., Proc. 4: 172. ठ๋.

\section{Genus CATASTENUS Foerster}

Catastenus Foerster, 1868. Naturh. Ver. Rheinlande, Verh. 25: 170 
Type-species: Catastenus femoralis Foerster. Monotypically included and desig. by Foerster, 1871.

Townes (1971) indicated that Catastenus could be regarded as an aberrant section (a species group?) of Symplecis; he maintained its generic status pending further development of the classification of the subfamily.

This is a small Holarctic and Ethiopian genus. Townes and Townes (1951) said that "undescribed Nearctic species of this genus are transcontinental in the Transitional Zone." However, Townes (1971) said that it is an unresolved question whether there are in the Holarctic Region a number of closely related species or just a single variable one.

Taxonomy: Townes and Townes, 1951. In Muesebeck et al., U. S. Dept. Agr., Agr. Monog. 2:

342. -Townes, 1971. Amer. Ent. Inst., Mem. 17: 202.

\section{Genus EUSTERINX Foerster}

Holomeristus Foerster, 1868. Naturh. Ver. Rheinlande, Verh. 25: 171.

Type-species: Holomeristus tenuicinctus Foerster. Monotypically included and desig. by Foerster, 1871.

Eusterinx Foerster, 1868. Naturh. Ver. Rheinlande, Verh. 25: 172.

Type-species: Eusterinx oligomera Foerster. Desig. by Viereck, 1914 from nineteen species included by Foerster, 1871.

Trestis Foerster, 1868. Naturh. Ver. Rheinlande, Verh. 25: 174.

Type-species: Trestis tricincta Ashmead. By subsequent monotypy from inclusion by Ashmead, 1902.

Ischyracis Foerster, 1868. Naturh. Ver. Rheinlande, Verh. 25: 175. Apparently, Horstmann

(1974) regarded Ischyracis as distinct from Eusterinx.

Type-species: Catomicrus alpigenus Strobl. Monotypically included and desig. by Perkins, 1962. The type-species is regarded as a synonym of Eusterinx bispinosa (Strobl), n. comb.

Catomicrus Thomson, 1888. Opusc. Ent. 12: 1291.

Type-species: Catomicrus trichops Thomson. Monotypic. The type-species is regarded as a synonym of $E$. pusilla (Zetterstedt).

Dallatorrea Ashmead, 1902. Wash. Acad. Sci., Proc. 4: 205.

Type-species: Dallatorrea armata Ashmead. Monotypic.

Stroblia Schmiedeknecht, 1911. Opusc. Ichn., v. 4, p. 2182. Preocc. by Pokorny, 1893.

Type-species: Catomicrus alpigenus Strobl. Monotypic.

Acanthostroblia Roman, 1925. Arkiv for Zool. 17A (4): 21. N. name for Stroblia

Schmiedeknecht.

Cymodusoides Viereck, 1925. Canad. Ent. 57: 74.

Type-species: Cymodusoides gracilis Viereck. Orig. desig.

This is a large genus apparently known from the Neotropic, Holarctic, Oriental, and Ethiopian Regions.

armata (Ashmead). N. Y., N. C., Ont., Alaska, Wash., Oreg., Calif.

Dallatorrea armata Ashmead, 1902. Wash. Acad. Sci., Proc. 4: 205. ठో.

Cymodusoides plesius Viereck, 1925. Canad. Ent. 57: 74..

gracilis (Viereck). Que.

Cymodusoides gracilis Viereck, 1925. Canad. Ent. 57: 74. .

oligomera Foerster. N. H., N. Y., Pa.; Europe.

Eusterinx oligomera Foerster, 1871. Naturh. Ver. Rheinlande, Verh. 28: 109. đ, $\$$.

Diatora compressa Ashmead, 1902. In Slosson, Ent. News 13: 320. Nomen nudum.

Polyaulon compressum Cushman, 1922. U. S. Natl. Mus., Proc. 61 (8): 24 . 9.

Taxonomy: Townes, 1971. Amer. Ent. Inst., Mem. 17: 204 (syn.).

rufula (Provancher). Que., N. H., N. Y., N. J.

Phygadeuon mifulus Provancher, 1879. Nat. Canad. 11: 76. ९. Possibly preocc. secondarily in Phygadeuon by Gmelin, 1790.

tenuicincta (Foerster). Que., N. H., Vt., N. Y., Ohio, n. Mich.; Europe.

Holomeristus tenuicinctus Foerster, 1871. Naturh. Ver. Rheinlande, Verh. 28: 81.. 
Mesoleptus fungicola Ashmead, 1894. In Webster, Cincinnati Soc. Nat. Hist., Jour. 17: 50. $\delta$ ".

Taxonomy: Townes, 1971. Amer. Ent. Inst., Mem. 17: 204 (syn.).

trifasciata (Ashmead). Alaska; e. U. S. S. R.

Catastenus trifasciatus Ashmead, 1899 (1898). In Jordan, Fur Seals and Fur-Seal Isls. No.

Pacific, v. 4, p. 336. 9 . The type locality is Ostrov Mednyy (= Copper Isl.), Commander

Isls., U. S. S. R.

Thestis(!) tricincta Ashmead, 1902. Wash. Acad. Sci., Proc. 4: 187. @.

Catastenus alaskensis Ashmead, 1902. Wash. Acad. Sci., Proc. 4: 240. §, ₹.

\section{Genus HELICTES Haliday}

Helictes Haliday, 1837. In Curtis, Guide Arrang. Brit. Ins., ed. 2, p. 106.

Type-species: Ichneumon erythrostoma Gmelin. Desig. by Westwood, 1840.

Myriarthrus Foerster, 1868. Naturh. Ver. Rheinlande, Verh. 25: 172, 218. Unnecessarily proposed n. name for Helictes Haliday.

Paipila Cameron, 1905. Amer. Ent. Soc., Trans. 30: 358.

Type-species: Paipila longipes Cameron. Monotypic.

This is a large genus; it is Holaretic and Neotropic, the majority of the species occuring in Chile and the Andes Mts.

ruficornis Davis. N. Y., n. Ill.

Helictes ruficornis Davis, 1897. Amer. Ent. Soc., Trans. 24: 245. “ $\delta "=q$.

\section{Genus MEGASTYLUS Schiodte}

Megastylus Schiodte, 1839 (1838). Rev, et Mag. Zool. 1: 139.

Type-species: Megastylus cruentator Schiodte. Desig. by Foerster, 1871.

Idioxenus Foerster, 1868. Naturh. Ver. Rheinlande, Verh. 25: 171.

Type-species: Megastylus mediator Schiodte. Included and desig. by Foerster, 1871.

The type-species is regarded as a synonym of $M$. crientator Schiodte.

Dicolus Foerster, 1868. Naturh. Ver. Rheinlande, Verh. 25: 171.

Type-species: Dicolus insectator Foerster. Desig. by Viereck, 1914, from four species included by Foerster, 1871. The type-species is regarded as a synonym of $M$. impressor Schiodte.

Megalostylus Schulz, 1906. Spolia Hym., p. 94. Emend.

Letosha Cameron, 1909. Bombay Nat. Hist. Soc., Jour. 19: 724.

Type-species: Letosha longicoxis Cameron. Monotypic.

Myriarthridea Viereck, 1914. U. S. Natl. Mus., Bul. 83: 97.

Type-species: Myriarthrus cingulator Foerster. Orig. desig.

Miomeroides Kiss, 1924. Siebenbuerg. Ver. f. Naturw., Hermannstadt, Verh. u. Mitt. 72-74: 113.

Type-species: Miomeroides transsylvanicus Kiss. Monotypic. This is a very large genus of Neotropic, Holarctic, Oriental, and Ethiopian distribution. The largest concentration of species is said to occur in the Neotropic Region.

caseyi (Ashmead). N. Y., N. J., Pa., Del, Va., e. N. C., n.e. Ga. Host: Orfelia inops (Coq.).

Spanotecnus caseyi Ashmead, 1896. Amer. Ent. Soc., Trans. 23: 196. §.

flavopictus (Gravenhorst). Que., N. H., Ont., Wis., n. Ill., Minn., n. Utah., s. Calif.; Europe.

Plectiscus flavopictus Gravenhorst, 1829. Ichn. Europaea, v. 2, p. 983. [male].

Megastylus lineator Schiodte, 1839 (1838). Rev. et Mag. Zool. 1: 139. "ๆ" = o .

Myriarthrus Cingulator Foerster, 1871. Naturh. Ver. Rheinlande, Verh. 28: 103. o, ๆ.

Mesoleptus (Megastylus!) albocollaris Cresson, 1868. Amer. Ent. Soc., Trans. 2: 100. $\$$. N. syn.

Orthocentrus albofasciatus Provancher, 1883. Nat. Canad. 14: 13. ․ N. syn.

Aperileptus pleuralis Ashmead, 1902. In Slosson, Ent. News 13: 321. Nomen nudum.

Megastylus ashneadi Cushman, 1922. U. S. Natl. Mus., Proc. 61 (8): 18. ․ N. syn. 
Taxonomy: Davis, 1897. Amer. Ent. Soc., Trans. 24: 246. -Townes, 1945. Amer. Ent. Soc., Mem. 11: 540 (syn.). - Townes and Townes, 1951. In Muesebeck et al., U. S. Dept. Agr., Agr. Monog. 2: 343. - Rossem, 1974. Tijdschr. v. Ent. 117: 278-279 (syn.).

\section{SUBFAMILY ORTHOCENTRINAE}

The size of this subfamily is moderate; although only seven genera are currently recognized, three of them are large and two are moderately large. According to Townes (1971) most of the species occurring outside the Holaretic Region are undescribed. Some of the species synonymy indicated in the unpublished revision of Smith (1958) was published by Smith (1965); in cases where they appear reliable unpublished species synonymies and changes in species nomenclature indicated by Smith in her dissertation are published here (the majority of which involve types in the U.S. Natl. Museum collection). Mycetophilidae are apparently the usual hosts.

Revision: Davis, 1897. Amer. Ent. Soc., Trans. 24: 219-226. - Smith, 1958. Rev. Subfam. Orthocentrinae Amer. No. of Mexico; unpublished Ph. D. dissertation, Univ. of Wis., 373 pp., 8 pl. (261 figs.).

Taxonomy: Smith, 1965. In Townes, Momoi, and Townes, Amer. Ent. Inst., Mem. 5: 398, 399, 400, 401, 402, 403. - Townes, 1971. Amer. Ent. Inst., Mem. 17: 208-216 (genera of world).

\section{Genus ORTHOCENTRUS Gravenhorst}

Orthocentrus Gravenhorst, 1829. Ichn. Europaea, v. 3, p. 358.

Type-species: Orthocentrus fulvipes Gravenhorst. Desig. by Westwood, 1840.

Tapinops Foerster, 1868. Naturh. Ver. Rheinlande, Verh. 25: 160.

Type-species: Orthocentrus califomicus Ashmead. By subsequent monotypy from inclusion by Ashmead, 1896.

Atmetus Foerster, 1868. Naturh. Ver. Rheinlande, Verh. 25: 160.

Type-species: Atmetus tetrazonatus Ashmead. Desig. by Viereck, 1914, from three species included by Ashmead, 1896.

Phaenosemus Foerster, 1868. Naturh. Ver. Rheinlande, Verh. 25: 160.

Type-species: Phaenosemus sitkensis Ashmead. By subsequent monotypy from inclusion by Ashmead, 1902.

Exochiscus Walsh, 1873. Acad. Sci. St. Louis, Trans. 3: 96.

Type-species: Exochiscus pusillus Walsh. Monotypic.

Pachyonyx Walsh, 1873. Acad. Sci. St. Louis, Trans. 3: 100. Nomen nudum (published in synonymy).

Pachyonyx Viereck, 1914. U. S. Natl. Mus., Bul. 83: 108. Preocc. by Schoenherr, 1837.

Type-species: Orthocentrus trifasciatus Walsh. Monotypic and orig. desig.

Orthocentrellus Benoit, 1954. Rev. de Zool. et de Bot. Africaines 50: 1.

Type-species: Orthocentrellus elongaticornis Benoit. Monotypic and orig. desig.

This large genus is worldwide in distribution. According to Townes (1971) it includes most of the larger species of the subfamily.

Taxonomy: Townes, 1971. Amer. Ent. Inst., Mem. 17: 211-212.

asper (Gravenhorst). Que. w. to Yukon and Alaska, s. to S. C., Kans., Colo., Ariz., and Calif.; Europe.

Exochus asper Gravenhorst, 1829. Ichn. Europaea, v. 1, p. 694. [female].

Orthocentrus discolor Holmgren, 1858 (1856). Svenska Vetensk.-Akad. Handl. (n. f.) 1: 332. ¿. 8 .

Phaenosemus sitkensis Ashmead, 1902. Wash. Acad. Sci., Proc. 4: 231. ơ.

Taxonomy: Pfankuch, 1913. Deut. Ent. Ztschr. (for 1913), p. 180 (syn.). -Townes, 1971.

Amer. Ent. Inst., Mem. 17: 209 (syn.).

cupulatus Smith. N. W. T., Alaska; e. U. S. S. R.

Atmetus insularis Ashmead, 1899 (1898). In Jordan, Fur Seals and Fur-Seal Isls. No. Pacific, v. 4, p. 337. ठ. Preocc. in Orthocentrus by Ashmead, 1894. The type locality is Ostrov Mednyy (=Copper Isl.), Commander Isls., U. S. S. R.

Orthocentrus cupulatus Smith, 1965. In Townes, Momoi, and Townes, Amer. Ent. Inst., Mem. 5: 399. N. name for A. insularis Ashmead. 
Taxonomy: Roman, 1909. In Hamberg, Naturw. Untersuch. Sarekgebirges

Schwedish-Lappland, v. 4, p. 352 (syn.). - Smith, 1958. Rev. Subfam. Orthocentrinae Amer.

No. of Mexico; unpublished Ph. D. dissertation, Univ. of Wis., p. 153, 157-158.

decoratus Townes. Calif.

Atmetus californicus Ashmead, 1896. Amer. Ent. Soc., Trans. 23: 204. \&. Preocc. in Orthocentrus by Ashmead, 1890.

Orthocentrus decoratus Townes, 1945. Amer. Ent. Soc., Mem. 11: 546. N. name for $A$. californicus Ashmead.

frontator (Zetterstedt). N. S. w. to Yukon and Alaska, s. to Ga., Kans., Colo., and n.e. Calif.; Eurasia.

Tryphon frontator Zetterstedt, 1838. Insecta Lapponica Hym., p. 389. [female].

Exochiscus pusillus Walsh, 1873. Acad. Sci. St. Louis, Trans. 3: 97. "

Alomya abdominalis Provancher, 1875. Nat. Canad. 7 (4): 121. ठ, ๆ. N. syn.

Orthocentrus Canadensis Provancher, 1875. Nat. Canad. 7 (5): 142. ठ. N. syn.

Orthocentrus californicus Ashmead, 1890 (1889). U. S. Natl. Mus., Proc. 12: 442 . ?. N. syn.

Orthocentrus medialis Davis, 1897. Amer. Ent. Soc., Trans. 24: 224. ․ N. syn.

Camerotops(!) asperus Davis, 1897. Amer. Ent. Soc., Trans. 24: 226. ₹. N. syn.

Atmetus pectoralis Ashmead, 1906. In Slosson, Ent. News 17: 324. Nomen nudum.

Taxonomy: Townes, 1971. Amer. Ent. Inst., Mem. 17: 209 (syn.).

fulvipes Gravenhorst. Nearctic Region; Eurasia. Nearctic localities were not indicated by

Townes (1971).

Orthocentrus fulvipes Gravenhorst, 1829. Ichn. Europaea, v. 3, p. 363. ठ.

Orthocentrus carinatus Uchida, 1932. Hokkaido Imp. Univ., Faculty Agr., Jour. 33: 211. ठ. Preocc. by Provancher, 1879.

Orthocentrus badifrons Uchida, 1942. Insecta Matsumurana 16: 125. o, ₹.

Taxonomy: Smith, 1965. In Townes, Momoi, and Townes, 1965. Amer. Ent. Inst., Mem. 5: 399

(syn.). - Townes, 1971. Amer. Ent. Inst., Mem. 17: 209 (syn.).

repentinus Holmgren. Greenland; Europe.

Orthocentrus repentinus Holmgren, 1858 (1856). Svenska Vetensk.-Akad. Handl. (n. f.) 1: 327. $\delta, ~ ?$.

Taxonomy: Roman, 1930. Ann. and Mag. Nat. Hist. (10) 5: 284.

rugulosus (Provancher). Que.

Glypta rugulosa Provancher, 1883. Nat. Canad. 14: 14. “ $\delta "=? ?$ Smith (1958) said that the sex of the lectotype was uncertain, but more likely to be female than male.

Taxonomy: Smith, 1958. Rev. Subfam. Orthocentrinae Amer. No. of Mexico; unpublished Ph. D. dissertation, Univ, of Wis., p. 92-94, 357.

spurius Gravenhorst. N. S. w. to N. W. T. and Alaska, s. to Maine, Mich., Colo,, and Calif.; Eurasia.

Orthocentrus spurius Gravenhorst, 1829. Ichn. Europaea, v. 3, p. 362. ․

Orthochentrus protuberans Holmgren, 1858 (1856). Svenska Vetensk.-Akad. Handl. (n. f.) 1: 333 . o, ?.

Taxonomy: Smith, 1965. In Townes, Momoi, and Townes, Amer. Ent. Inst., Mem. 5: 400

(syn.).

stigmaticus Holmgren. Newfoundland (Labrador) w. to Alaska, s. to S. C., La., Colo., Ariz., and Calif.; Eurasia.

Orthocentrus stigmaticus Holmgren, 1858 (1856). Svenska Vetensk.-Akad. Handl. (n. F.) 1: 325. $\delta, ?$.

Orthocentrus stigmaticus Walsh, 1873. Acad. Sci. St. Louis, Trans. 3: 101. "q" = o.

Orthocentrus stigmaticus f. borealis Roman, 1915. In Spengel, Zool. Jahrb., Abt. f. System., Geog., u. Biol. Tiere 39: 92. ठ’, ?. Syn.?

Taxonomy: Roman, 1925. Ent. Meddel. 14: 425. -Townes, 1971. Amer. Ent. Inst., Mem. 17: 209 (syn.).

tetrazonatus (Ashmead). N. S. w. to Alaska, s. to S. C., Ala., Colo., Utah, and Calif.

Atmetus tetrazonatus Ashmead, 1896. Amer. Ent. Soc., Trans. 23: 204. ?. 
trifasciatus Walsh. Ill.?

Orthocentrus trifasciatus Walsh, 1873. Acad. Sci. St. Louis, Trans. 3: 100. d, \&.

\section{Genus PICROSTIGEUS Foerster}

Picrostigeus Foerster, 1868. Naturh. Ver. Rheinlande, Verh. 25: 159.

Type-species: Orthocentrus setiger Brischke. Desig. by Viereck, 1912, from three species included by Thomson, 1897.

This is a small Holarctic genus. Smith (1958) indicated that there are four undescribed Nearctic species.

Taxonomy: Smith, 1958. Rev. Subfam. Orthocentrinae Amer. No. of Mexico; unpublished Ph.

D. dissertation, Univ. of Wis., p. 181-192.

\section{Genus STENOMACRUS Foerster}

Synoplus Foerster, 1868. Naturh. Ver. Rheinlande, Verh. 25: 159.

Type-species: Synoplus brevipennis Ashmead. Desig. by Viereck, 1902, from two species included by Ashmead, 1902.

Mnesidacus Foerster, 1868. Naturh. Ver. Rheinlande, Verh. 25: 159.

Type-species: Mnesidacus apicalis Ashmead. By subsequent monotypy from inclusion by Ashmead, 1896.

Hypoleptus Foerster, 1868. Naturh. Ver. Rheinlande, Verh. 25: 159.

Type-species: Hypoleptus columbianus Ashmead. By subsequent monotypy from inclusion by Ashmead, 1896.

Deleter Foerster, 1868. Naturh. Ver. Rheinlande, Verh. 25: 160.

Type-species: Deleter obscurus Davis. Desig. by Viereck, 1914, from three species included by Davis, 1897.

Stenomacrus Foerster, 1868. Naturh. Ver. Rheinlande, Verh. 25: 160.

Type-species: Orthocentrus silvaticus Holmgren. Desig. by Viereck, 1912, from 37 species included by Thomson, 1898.

Camaratops Foerster, 1868. Naturh. Ver. Rheinlande, Verh. 25: 160.

Type-species: Neurateles ulmicola Ashmead. Desig. by Viereck, 1914, from four species included by Davis, 1897.

This is a large genus of worldwide distribution.

Taxonomy: Townes, 1971. Amer. Ent. Inst., Mem. 17: 212-213 (syn.).

americanus (Ashmead). Newfoundland (Labrador) w. to B. C., s. to Md., Ill., Kans., Colo., and Calif.

Neuratelus americanus Ashmead, 1896. Amer. Ent. Soc., Trans. 23: 203. $\%$.

Deleter obscurus Davis, 1897. Amer. Ent. Soc., Trans. 24: 221. ठ.

brevipennis (Ashmead). Alaska. Ecology: Smith (1958) studied 35 females collected on flowers of Senecio.

Synoplus brevipennis Ashmead, 1902. Wash. Acad. Sci., Proc. 4: 226. $\$$.

Synoplus pleuralis Ashmead, 1902. Wash. Acad. Sci., Proc. 4: 227. 9.

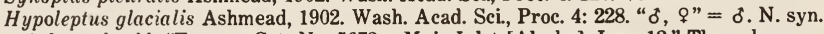
Ashmead said: "Type. - Cat. No. 5673, ...Muir Inlet [Alaska], June 12." The only specimens to be found in the U.S. Natl. Museum collection bearing type no. 5673 are two conspecific males from St. Paul Isl., Alaska; one of these bears Ashmead's label identifying it as a male of Hypoleptus glacialis. No specimens from Muir Inlet match the original description and none bear an Ashmead label identifying them as $H$. glacialis.

Biology: Smith, 1958. Rev. Subfam. Orthocentrinae Amer. No. of Mexico; unpublished Ph. D. dissertation, Univ. of Wis., p. 308.

californicus (Ashmead). Newfoundland (Labrador) w. to B. C., s. to Md., Kans., Colo., Ariz., and Calif. Host: "Cecidomyia on Salix scouleriana var. flavescens."

Brephoctonus califomicus Ashmead, 1896. Amer. Ent. Soc., Trans. 23: 202. ठ。. 
Taxonomy: Smith, 1958. Rev. Subfam. Orthocentrinae Amer. No. of Mexico; unpublished Ph. D. dissertation, Univ. of Wis., p. 316-322.

columbianus (Ashmead). Que., N. W. T., and Yukon, s. to Va., Ill., Colo., and Wash.

Hypoleptus columbianus Ashmead, 1896. Amer. Ent. Soc., Trans. 23: 203. ठ.

dubiosus (Ashmead). Colo., Alaska.

Neurateles dubiosis Ashmead, 1902. Wash. Acad. Sci., Proc. 4: 228. §.

femoralis (Holmgren). Newfoundland (Labrador), N. W. T., Yukon, and Alaska, s. to Va., Ill., Colo., Ariz., and Oreg.; Eurasia.

Orthocentrus silvaticus Holmgren, 1858 (1856). Svenska Vetensk.-Akad. Handl. (n. f.) 1: 342. ठ․ ๆ.

Orthocentrus femoralis Holmgren, 1858 (1856). Svenska Vetensk.-Akad. Handl. (n. f.) 1: 346. ơ, ㅇ.

Orthocentrus nigricoxis Provancher, 1888. Addit. Corr. Faune Ent. Canada Hym., p. 369. q.

Mnesidaeus(!) apicalis Ashmead, 1898. Amer. Ent. Soc., Trans. 23: 202. ․

Atmetus nigritus Ashmead, 1896. Amer. Ent. Soc., Trans. 23: 204. \&. N. syn.

Stenomacrus intritus Davis, 1897. Amer. Ent. Soc., Trans. 24: 225. ठ. N. syn.

Stenomacrus borealis Ashmead, 1899 (1898). In Jordan, Fur Seals and Fur-Seal Isls. No.

Pacific, v. 4, p. 338 . . N. syn.

Deleter flavifrons Ashmead, 1902. Wash. Acad. Sci., Proc. 4: 229. ठ. N. syn.

Orthocentrus nigritus Ashmead, 1902. Wash. Acad. Sci., Proc. 4: 231. o. Preoce. in Stenomacrus by Ashmead, 1896. N. syn.

Taxonomy: Smith, 1958. Rev. Subfam. Orthocentrinae Amer. No. of Mexico; unpublished Ph.

D. dissertation, Univ. of Wis., p. 223-231. -Townes, 1971. Amer. Ent. Inst., Mem. 17: 209.

hastatus Davis. Northern Calif. Known only from the holotype which was collected in Siskiyou Co., Calif.

Stenomacrus hastatus Davis, 1897. Amer. Ent. Soc., Trans. 24: 225..

kincaidi (Ashmead). Southwestern Alaska.

Deleter kincaidi Ashmead, 1902. Wash. Acad. Sci., Proc. 4: 229. ð, \&.

laticollis (Holmgren). Greenland; n.w. Asia.

Orthocentrus laticollis Holmgren, 1883. Ent. Tidskr. 4: 158. ㅇ.

mellipes (Provancher). Que. Known only from the lectotype.

Bassus mellipes Provancher, 1888. Addit. Corr. Faune Ent. Canada Hym., p. 429. $\$$.

Taxonomy: Townes, 1945. Amer. Ent. Soc., Mem. 11: 551 (syn.). - Smith, 1958. Rev. Subfam.

Orthocentrinae Amer. No. of Mexico; unpublished $\mathrm{Ph}$. D. dissertation, Univ. of Wis., p.

$322-324$.

monticola (Cushman). Newfoundland (Labrador), N. W. T., and Alaska, s. to N. Y., Colo., and Wash.

Hypoleptus monticola Ashmead, 1897. In Slosson, Ent. News 8: 237. Nomen nudum.

Hypolepus(!) alticola Ashmead, 1906. In Slosson, Ent. News 17: 324. Nomen nudum.

Hypoleptus monticola Cushman, 1922. U. S. Natl. Mus., Proc. 61 (8): 16. ₹.

premitus (Davis). Que. w. to Yukon and Alaska, s. to Fla., Ill., Colo., and Wash.

Camerotops(!) premitus Davis, 1897. Amer. Ent. Soc., Trans. 24: 226. " ${ }^{\prime} "=q$.

Phaenosemus alticola Ashmead, 1897. In Slosson, Ent. News 8: 237. Nomen nudum.

Camarotops kodiakensis Ashmead, 1902. Wash. Acad. Sci., Proc. 4: 232. ․ N. syn.

Brephoctonus hygrotrecha Viereck, 1917 (1916). Conn. State Geol. and Nat. Hist. Survey Bul. 22: 305. ठ, ๆ. N. syn.

Stenomacrus alticola Cushman, 1922. U. S. Natl. Mus., Proc. 61 (8): 27 ..

Taxonomy: Smith, 1958. Rev. Subfam. Orthocentrinae Amer. No. of Mexico; unpublished Ph.

D. dissertation, Univ. of Wis., p. 309-314.

terebrator Roman. Greenland.

Stenomacrus terebrator Roman, 1934. Ann. and Mag. Nat. Hist. (10) 14: 608. ९.

ulmicola (Ashmead). N. H. s. to Fla., w. to Wis., Iowa, Kans., and Okla. Host: "Leaf miner on elm."

Brephoctonus flavosus Ashmead, 1896. Amer. Ent. Soc., Trans. 23: 202. ð. 
Neurateles ulmicola Ashmead, 1896. Amer. Ent. Soc., Trans. 23: 203..+

Neurateles liriodendri Ashmead, 1896. Amer. Ent. Soc., Trans. 23: 203. ठ, ९. undulatus (Davis). Northern Ill.

Deleter undulatus Davis, 1897. Amer. Ent. Soc., Trans. 24: 221. ๆ (ð’ misdet.).

\section{Genus LEIPAULUS Townes}

Leipaulus Townes, 1945. Amer. Ent. Soc., Mem. 11: 552.

Type-species: Deleter suffuscus Davis. Monotypic and orig. desig.

This is a genus of moderate size; Townes (1971) had seen 20 species. The genus is known from the Holarctic, Oriental, Australian, and Ethiopian Regions. There is at least one undescribed Nearctic species.

Taxonomy: Townes, 1958. Ent. Soc. Wash., Proc. 60: 221 (syn.). -Townes, 1971. Amer. Ent. Inst., Mem. 17: 215 (name resurrected).

ridibundus (Gravenhorst). Nearctic Region; Europe.

Orthocentrus ridibundus Gravenhorst, 1829. Ichn. Europaea, v. 3, p. 366. ठ。.

Taxonomy: Townes, 1971. Amer. Ent. Inst., Mem. 17: 215 (distribution). suffuseus (Davis). N. S. w. to B. C., s. to S. C., La., Colo., Ariz., and Calif. Deleter suffuscus Davis, 1897. Amer. Ent. Soc., Trans. 24: 221. ठँ.

\section{Genus PLECTISCUS Gravenhorst}

Plectiscus Gravenhorst, 1829. Ichn. Europaea, v. 2, p. 978.

Type-species: Plectiscus impurator Gravenhorst. Desig. by Westwood, 1840.

Brephoctonus Foerster, 1868. Naturh. Ver. Rheinlande, Verh. 25: 159.

Type-species: Plectiscus impurator Gravenhorst. Monotypically included and desig. by Foerster, 1871.

According to Townes (1971) this genus is Neotropic, Holarctic, and Oriental; 15 species were known to him, 14 of them being either undescribed or unidentified.

Taxonomy: Townes, 1958. Ent. Soc. Wash., Proc. 60: 221. - Townes, 1971. Amer. Ent. Inst., Mem. 17: 215-216.

\section{Genus NEURATELES Ratzeburg}

Neurateles Ratzeburg, 1848. Ichn. d. Forstins., v. 2, p. 86.

Type-species: Neurateles papyraceus Ratzeburg. Monotypic.

Neuratelus(!) Foerster, 1868. Naturh. Ver. Rheinlande, Verh. 25: 159, 218.

This is a Neotropic and Holarctic genus of moderate size.

alaskensis (Ashmead), n. comb. N. H., N. W. T., Colo., Alta., Alaska.

Hypoleptus alaskensis Ashmead, 1902. Wash. Acad. Sci., Proc. 4: 227. $९$ (o misdet.). A female in the U. S. Natl. Museum collection is here selected as lectotype It is labeled "8-22, [18]97, St. Paul Isl., Alaska, Type No. 5672, Hypoleptus alaskensis Ashm. [written by Ashmead], Lectotype, Hypoleptus alaskensis Ashmead, Revision L. K. Smith [written by Lois K. Smith]."

Taxonomy: Townes, 1945. Amer. Ent. Soc., Mem. 11: 549 (identification apparently based on a specimen which was then a syntype). - Smith, 1958. Rev. Subfam. Orthocentrinae Amer.

No. of Mexico; unpublished Ph. D. dissertation, Univ. of Wis., p. 350-352.

leucopsis (Ashmead). Colo.

Orthocentrus leucopsis Ashmead, 1890. Colo. Biol. Assoc., Bul. 1: 24. ठ.

UNPLACED TAXA OF ICHNEUMONIDAE

Anomalon laterale Brulle, 1846. In Lepeletier, Hist. Nat. Ins. Hym., v. 4, p. 175.. "L'Amerique sept.; Bastard."

Taxonomy: Townes, 1961. Ent. Soc. Wash., Proc. 63: 104.

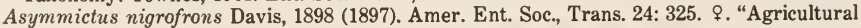
College, Michigan." 
Atractodes provancheri Dalla Torre, 1902. Cat. Hym., v. 3, p. 723. N. name for A. singularis Provancher (which see).

Atractodes rufipes Provancher, 1874. Nat. Canad. 6: 151. o, \&. Que.

Taxonomy: Barron, 1975. Nat. Canad. 102: 551.

Atractodes singularis Provancher, 1876. Nat. Canad. 8: 328. §. Que. Preocc. by Foerster, 1876; replaced by $A$. provancheri Dalla Torre (which see).

Taxonomy: Barron, 1975. Nat. Canad. 102: 568.

Bassus areolatus Provancher, 1874. Nat. Canad. 6 (1): 31 (key); 6 (2): 58. . Preocc. by Holmgren, 1856.

Taxonomy: Barron, 1975. Nat. Canad. 102: 428-429.

Campoplex? Arcticus Curtis, 1853. In Ross, Narrative of Second Voyage in Search of a No.-W. Passage 1829-33, App., p. Ixii. sex not indicated. Arctic America.

Taxonomy: Townes, 1961. Ent. Soc. Wash., Proc. 63: 105.

Cratichneumon Davisi Bradley, 1904. Ztschr. System. Hym. Dipt. 4: 107.. Colo.

Cremastus piceus Cresson, 1872. Amer. Ent. Soc., Trans. 4: 176.. . Bosque Co., Tex. The holotype was presumably to have been deposited in the U. S. Natl. Museum collection, but has not been found.

Taxonomy: Cresson, 1916. Amer. Ent. Soc., Mem. 1: 49.

Habronyx! flavistigma Davis, 1898 (1897). Amer. Ent. Soc., Trans. 24: 362. ठ. N. Y.

Hemiteles cincticomis Ashmead, 1890. Colo. Biol. Assoc., Bul. 1: 21. ๆ. Colo. Host: A panteles laeviceps Ash. The type locality was stated to be Cusack Ranch, but the type specimens of Apanteles laeviceps (described by Ashmead in the same paper) are labeled: West Cliff, Colo.

Hemiteles texanus Ashmead, 1890 (1889). U. S. Natl. Mus., Proc. 12: 404. . Tex. No type specimen can be found; the species was entered by Ashmead in the U. S. Natl. Museum type catalog under no. 2011, and may have been so labeled by Ashmead, because in his manuscript for his 1900 work on the classification of Ichneumonoidea Ashmead recorded the name of the species and its type catalog number.

Ichneumon paradoxus Provancher, 1882. Nat. Canad. 13 (no. 154): 306 (key); 13 (no. 155): 325. क. Que.

Taxonomy: Barron, 1975. Nat. Canad. 102: 526-527.

Ichneumon quadri-punctatus Provancher, 1886. Addit. Corr. Faune Ent. Canada Hym., p. 33. §. Ont. Preocc. by Schrank, 1871.

Taxonomy: Barron, 1975. Nat. Canad. 102: 539.

Limneria illepida Cresson, 1872. Amer. Ent. Soc., Trans. 4: 172. ठ. Tex.

Mesoleptus fasciatus Provancher, 1885. Canad. Ent. 17: 116. ठ. Southwestern B. C.

Taxonomy: Barron, 1975. Nat. Canad. 102: 469.

Mesostenus rufotinctus Provancher, 1874. Nat. Canad. 6: 301. §. Que.

Taxonomy: Barron, 1975. Nat. Canad. 102: 555.

Orthocentrus lucens Provancher, 1879. Nat. Canad. 11: 280. \&. Que.

Taxonomy: Smith, 1958. Rev. Subfam. Orthocentrinae Amer. No. of Mexico; unpublished Ph.

D. dissertation, Univ. of Wis., p. 360-361. - Barron, 1975. Nat. Canad. 102: 500.

Pezomachus thripites Taylor, 1860. A mer. Agr. 19: 300. . No locality.

Phygadeuon excavatus Provancher, 1874. Nat. Canad. 6: 285. ?. Que.

Taxonomy: Barron, 1975. Nat. Canad. 102: 468.

Tryphon exobscurus Walkley, 1958. In Krombein, U. S. Dept. Agr., Agr. Monog. 2, sup. 1, p. 62. Unnecessary n. name for Stilpuus obscumus Cresson (which see).

Stilpnus obscurus Cresson, 1865. Ent. Soc. Phila., Proc. 4: 259. ठ. Colo. Formerly preocc. secondarily in Tryphon by T. obscumus Stephens, 1835. The replacement name Tryphon exobscurus Walkley (which see) was proposed while S. obscurus stood as "Tryphon obscurus (Cresson)" among the unplaced species of Ichneumonidae; therefore, $T$. exobscurus is an unnecessarily proposed replacement name. 
UNPLACED NOMINA NUdA OF ICHNEUMONIDAE

The following nomina nuda are not placeable in the synonymy of described species because they have not been associated with particular specimens since they were published. Most of them probably pertain to specimens which by now have been destroyed.

Unplaceable nomina nuda published by Harris (1835): Cryptus annulipes, C. attractus, C. bucephalus, C. calceatus, C. cardinalis, C. clyta, C. crescentus, C. ectypus, C. facetus, C. facilis, C. isochromus, C. laxus, C. leucotelus, C. mellipes, C. palmapectus, C. pleuriticus, C. polyspeimes, C. recurvulus, C. spinulosus, C. subspinosus, C. tennelluius, C. versicolor, Ichneumon (Ichneumon) ales, I. (I.) anxifer, I. (Trogus) atratus, I. (I.) baculus, I. (I.) biarquatus, I. (I.) dimelapsus, I. (I.) metathoracicus, I. (I.) orbitarius, I. (I.) petiolatus, I. (I.) plantaris, I. (I.) platicerus, I. (I.) spatiosus, I. (I.) stolophomis, I. (I.) trichocemis, I. (I.) wau.

Miscellaneous unplaceable nomina nuda published in the references, cited: Anomalon Cecropiae Harris (1833), Bathymetis tegularis Ashmead (in Slosson, 1900), B. washingtonensis Ashmead (in Slosson, 1906), Campoplegidea (Viereckiana) triangularis Viereck (1926), Campoplex paniscus Osborn (1892), Centeterus suturalis Ashmead (in Riley and Howard, 1890, p. 152), Cremastus fumipennis Ashmead (1900, p. 584), Cryptus propitius "Cr." Ashmead (1890, p. 43), Eiphosoma femorata "Cress." Ashmead (1900, p. 580), Exochoides borealis "Cress." Evans (1896), Hemiteles mesochori "Ashm." Crevecoeur (1922), Hemiteles orgyiae "Riley" Ashmead (1890, p. 43), Ichneumon altemator "S." Harris (1833), I. aranearum Clarkson (1890), I. basiator "S." Harris (1833), I. cingor "S." Harris (1833), Ichyracis (!) americana Ashmead (in Slosson, 1906), Lampronota succincta "Cr." Riley and Howard (1890, p. 464), Limneria oligiae Ashmead (in Riley and Howard, 1890, p. 158), Megarhyssa magnifica Viereck (1910), Mesochorus? chrysopae Ashmead (in Riley and Howard, 1890, p. 156), Mesoleius bicolor Davis (in Slosson, 1894), Ophion imbecilis "S." Harris (1833), Polysphincta phycitis Riley (in Riley and Howard, 1890, p. 464), Rhythmonotus bilineatus Ashmead, 1900, p. 581), Scambus monta "Cress." Washburn (1918), Sinophorus johnsoni Ashmead (1900, p. 581), Spilocryptus lividicorpus "Cress." Procter (1938), Spudastica rufipes Ashmead (1900, p. 581), Thyreodon costale "Cress." Viereck (1928).

Taxonomy: Harris, 1833; 1835. In Hitchcock, Rpt. Geol. Min. Bot. Zool. Mass., p. 587; ed. 2, p. 584-585. - Ashmead, 1890. Colo. Biol. Assoc., Bul. 1: 43. - Clarkson, 1890. Canad. Ent. 22: 122. - Riley and Howard, 1890. U. S. Dept. Agr., Insect Life 3: 151-158, 460-464. -Osborn, 1892. Iowa Agr. Expt. Sta., Bul. 18: 515. -Slosson, 1894. Ent. News 5: 4. - Evans, 1896. Canad. Ent. 28: 11. -Ashmead, 1900. In Smith, N. J. State Bd. Agr., Ann. Rpt. 27, sup., p. 563-585. -Slosson, 1900; 1906. Ent. News 11: 319; 17: 324. - Viereck, 1910. In Smith, N. J. State Mus., Ann. Rpt. (for 1909), p. 627. -Washburn, 1918. Minn. State Ent., Ann. Rpt. 17: 172. - Crevecoeur, 1922. Kans. Acad. Sci., Trans. 30: 386. - Viereck, 1926. Roy. Soc.

Canada, Proc. and Trans. (3) 20 (5): 178. - Viereck, 1928. N. Y. State Mus. Bul. 274: 185. -Procter, 1938. Biol. Survey Mt. Desert Region, v. 6, p. 402.

\title{
Family STEPHANIDAE
}

\author{
BY ROBERT W. CARLSON
}

This small family is worldwide in distribution, but with species apparently most numerous in the tropic and subtropic parts of the world. They are parasites of coleopterous and hymenopterous wood borers.

Revision: Elliot, 1922. Zool. Soc. London, Proc. 92: 705-831 (spp. of world, largely from literature). -Townes, 1949. U. S. Natl. Mus., Proc. 99: 361-370.

\section{Genus SCHLETTER ERIUS Ashmead}

Schlettererius Ashmead, 1900. U. S. Natl. Mus., Proc. 23: 150.

Type-species: Stephanus cinctipes Cresson. Monotypic and orig. desig.

Only a single species is known.

cinctipes (Cresson). Southwestern S. Dak., n. Idaho, and s. B. C. s. to s.e. Ariz. and s. Calif.; Australia (Tasmania). Ecology: Kirk (1975) reared the species from Pinus ponderosa, Picea engelmanni, and Abies concolor infested by species of Sirex, Urocerus, and Xeris. The species has also emerged from Pseudotsuga menziesii. Host: Sirex noctilio $F$. 
Siricidae. Taylor (1967) developed a laboratory culture in Tasmania on Sirex noctilio from field collected cinctipes adults shipped from Calif. Additional material was imported from Ariz. and N. Mex., and cinctipes has been released and established in Tasmania as a parasite of Sirex noctilio (Taylor, 1977, p. 430). S. noctilio does not occur within the natural range of Schlettererius cinctipes.

Stephanus cinctipes Cresson, 1880. Amer. Ent. Soc., Trans. 8: xviii in Proc..

Biology: Taylor, 1967. Austral. Ent. Soc., Jour. 6: 13-19 (life history, behavior, egg, larva). -Kirk, 1975. Pan-Pacific Ent. 51: 58-59. -Taylor, 1977 (1976). Entomophaga 21: 429-440 (introduction and establishment of various parasitic Hym. on Sirex noctilio).

\section{Genus MEGISCHUS Brulle}

Megischus Brulle, 1846. In Lepeletier, Hist. Nat. Ins. Hym., v. 4, p. 537.

Type-species: Megischus annulator Brulle. Desig. by Viereck, 1914. The type-species is regarded as a synonym of $M$. furcatus (Lepeletier and Serville).

Bothrioceros Sichel, 1860. Soc. Ent. de France, Ann. (3) 8: 759.

Type-species: Bothrioceros europoeus Sichel. Desig. by Viereck, 1914.

Hemistephanus Enderlein, 1906. Stettin. Ent. Ztg. 67: 301.

Type-species: Stephanus macrurus Schletterer. Orig. desig.

According to Townes (1949, stephanid revision, p. 363) Megischus is a genus of about 40 valid species and is pantropic in distribution.

arizonicus Townes. Southeastern Ariz.; n.w. Mexico.

Megischus arizonicus Townes, 1949. U. S. Natl. Mus., Proc. 99: 368. ð, १.

bicolor (Westwood). Mass. w. to s. Ont., n. Iowa., and e. Utah., s. to s. Fla., s. Tex., s. Ariz., and

s. Calif. Ecology: Specimens are recorded as having emerged from Quercus, Carya,

Cercidium, and Pinus. Host: Buprestid in Cercidium torreyanum.

Stephanus bicolor Westwood, 1841. Ann. Nat. Hist. 7: 538..

Stephanus Sickmanni Schletterer, 1889. Berlin. Ent. Ztschr. 33: 152. \&. N. syn.

Megischus floridanus Davis, 1898 (1897). Amer. Ent. Soc., Trans. 24: 349. ठ, ๆ.

Megischus canadensis Davis, 1898 (1897). Amer. Ent. Soc., Trans. 24: 349.. N. Nyn.

Stephanus Sickmannii Dalla Torre, 1901. Cat. Hym., v. 3, p. 9. Emend.

Biology: Townes, 1949. U. S. Natl. Mus., Proc. 99: 367 (behavior and ecology).

brunneus (Cresson). Southern Fla.; Cuba.

Megischus brunneus Cresson, 1865. Ent. Soc. Phila., Proc. 4: 84. o,.+

Stephanus brineus Dalla Torre, 1901. Cat. Hym., v. 3, p. 6. Emend.

californicus Townes. Northern Calif. s. to s. Calif.

Megischus californicus Townes, 1949. U. S. Natl. Mus., Proc. 99: 364. ơ, ๆ.

texanus Cresson. Southwestern Okla., s. Tex., Ariz., s. Calif.; n.w. Mexico.

Megischus texanus Cresson, 1872. Amer. Ent. Soc., Trans. 4: 190. ₹. 



\title{
Superfamily CHALCIDOIDEA
}

\author{
By GORDON GORDH
}

The Chalcidoidea are among the most difficult groups of Hymenoptera to identify because of their small size and the lack of adequate keys to the North American species. Several species vie for the distinction of being the smallest insect (about $0.2 \mathrm{~mm}$ long), and most species are less than 3-4 $\mathrm{mm}$ long. The characters used to distinguish chalcidoids from other Hymenoptera include the presence of a prepectus, failure of the pronotum to meet the tegula, 13 or fewer segments comprising the geniculate antenna, and drastically reduced wing venation.

Ashmead (1904) recognized 14 families and provided the first comprehensive modern classification of the Chalcidoidea. Despite its many errors, this was a prodigious work and remarkable considering the primitive optical equipment and state of knowledge about the Chalcidoidea at that time. Nikol'skaya (1952) elevated the number of families to 24, and Boucek and Hoffer (1957) (subsequently translated by Peck, 1964) recognized 18 families. In this catalog Burks has reduced the number of families to eleven. Casual thought may lead one to wonder why there is so much inconsistency among workers regarding higher classification of chalcidoids. These classifications are based on external morphology, and the chalcidoids are exceedingly plastic morphologically. This plasticity generates differences of opinion over the limits of higher taxa because workers weight characters differently.

Chalcidoids are found in all zoogeographical regions, in all terrestrial habitats, and all families are found in each zoogeographic region. Despite their omnipresence, chalcidoids remain one of the poorest known superfamilies. Taxonomically, the western Palearctic fauna is best known, followed by the Nearctic. The remainder of the zoogeographical regions (Neotropical, Ethiopian, Australian, and Oriental) are almost completely unknown with respect to their endemic faunas. Much of our knowledge of chalcidoids stems from species which are associated with agriculture.

The body size and searching habits of chalcidoids make them suitable for fossilization in resinous amber, but fossil records of the Chalcidoidea are incomplete. Fewer than 50 species are known, and these belong to less than half of the chalcidoid families. The most comprehensive accounts of fossil chalcidoids are by Brues (1910), Doutt (1973), and Yoshimoto (1975). The last study provides a summary of knowledge about fossil chalcidoids. Yoshimoto (1975) reports that mymarids, trichogrammatids, and tetracampids are referable to the Cretaceous Period (70-90 million years before present).

Owing to the paucity of knowledge about fossil chalcidoids and their morphological plasticity, the relationship of this superfamily to other parasitic Hymenoptera has not been conclusively established. We are not certain that the Chalcidoidea are monophyletic in the Hennigian sense, although some investigators have that opinion. An interpretation of chalcidoid phylogeny based on the known fossil record is provided by Yoshimoto (1975).

The actual numerical dimension of the Chalcidoidea can only be speculated. The ichneumonid specialist Henry Townes (1969) has estimated that there are 60,000 species of Ichneumonidae. 
DeBach (1974) has estimated that somewhere between 70-90 percent of the parasitic Hymenoptera remain to be described. I believe that the Chalcidoidea will ultimately be recognized as larger than the Ichneumonidae. There are some who would disagree with this estimate, but their estimates are based on impressions developed from examining species that repeatedly have been submitted for identification. These species mostly are associated with the agroecosystem and represent only a portion of the total chalcidoid fauna. My primary interest in making these assertions is to stimulate research on the Chalcidoidea because they are a fertile area for investigations in biology, behavior, ecology, and systematics.

Chalcidoids have diverse and frequently specialized feeding habits. Most species of chalcidoids are parasitic, but phytophagy probably has evolved several times in the Chalcidoidea because it is found in several distantly related taxa and many unrelated species of plants serve as hosts. Phytophagy is found most frequently in association with gall-forming habits, but the evolutionary significance of this observation remains unknown.

Agaonids demonstrate the most intimate expression of phytophagy in the Chalcidoidea. This group is poorly represented in North America because all agaonids develop in fig seeds (Ficus spp.), and these plants occur naturally only in tropical and subtropical climates. All figs are dependent on agaonids for pollination, and agaonids can only develop within the receptacles of Ficus. Host specificity seems to be the trend in agaonids with each species of fig having its own agaonid for pollination (Ramirez, 1970 a,b; Grandi, 1961). Numerous other chalcidoids are associated with Ficus as inquilines (Hill, 1967 a,b).

Other taxa of chalcidoids with phytophagous species include the Eurytomidae, Torymidae, brachyscelidiphagine Pteromalidae, and Tanaostigmatidae.

Some ecologists prefer to use the term parasitoid to characterize parasitic insects. Protelean parasite is a phrase often used to distinguish between typical parasites and insects that are parasitic in the larval stage only (Askew, 1971).

One definition of parasitism for all parasitic organisms is impractical because animal species are parasitic in many different ways. The parasitological definition of parasitism in the sense of parasitic worms and protozoa is unsuitable in the present context because parasitic chalcidoids do not behave in a manner consistent with that definition. Therefore it seems more appropriate to list some of the biological attributes of parasitic chalcidoids. Parasitic chalcidoids are characterized as follows: (1) they are obligate parasites in the larval stage only; (2) they require only one host to complete development; (3) they attack related taxa (other arthropods and usually insects); (4) if the parasite completes development, the host invariably dies; (5) the ratio of size between the parasite and host approximates unity (except in some cases where the parasitic larvae are gregarious or polyembryonic delevopment occurs).

Adults of some species host feed, but the significance of this behavior is not always clear. Host feeding may provide nutrients necessary for ovary or egg development, or it may be a convenient source of nutrients necessary for sustaining life (Flanders, 1953; Doutt, 1964; Quezada et al., 1973).

Parasitism by insects reaches its most elaborate development in the Chalcidoidea. Primary parasitism (larval development on a phytophagous host) is the most common type of parasitism by chalcidoids. Hyperaparasitism (a parasite attacking another species of parasite) is found almost exclusively in the Hymenoptera, and reaches its most extensive development in the Chalcidoidea as indicated by the fact that most families have hyperparasitic species. Further evidence of the extensiveness of hyperparasitism in this superfamily is found in the fact that several types of hyperparasitism have evolved in the group. These include secondary (a parasite attacking a primary parasite), tertiary (a parasite attacking a secondary parasite) and quaternary (a parasite attacking a tertiary parasite). Hyperparasitism probably evolves out of primary parasitism in situations involving strong interspecific competition.

An unusual type of hyperparasitism occurs in Coccophagoides utilis Doutt and various related genera such as Coccophagus, Encarsia, and Prospaltella. Female larvae develop as primary parasites of armored-scale insects, and the male larvae develop as hyperparasites of their own females (Broodryk and Doutt, 1966). This phenomenon is called adelphoparasitism or autoparasitism and appears restricted to the aphelinines (Zinna, 1961; Flanders, 1959, 1967).

Parasitic chalcidoids can be categorized on the basis of where the egg is deposited and how the larva feeds. Most species attack the host directly, but adult female eucharitids and perilampine pteromalids oviposit on vegetation and the first-instar larva (planidium) searches for the host (Smith, 1912; Clausen, 1940 a,b). Species in which the adult female directly attacks the host 
lay their eggs on the host's body and the larvae develop externally, or deposit their eggs inside the host's body and the larvae develop internally. There is a tendency for parasites that attack exposed hosts to develop internally (exception: elachertine Eulophidae), and parasites that attack concealed hosts to develop externally.

The intra- and interspecific relationships among parasitic chalcidoids vary. Some species are solitary (one parasite per host), and others are gregarious (several parasites per host). When more than one parasite species develops on a host simultaneously, the condition is termed multiple parasitism. When more eggs of one parasite species are laid on a host than can develop to maturity, the condition is termed superparasitism. Supernumerary individuals are eliminated through larval combat or physiological suppression (Salt, 1961).

The distinction between parasitism and predation sometimes fails, and some chalcidoids could be called predators. A prime distinction between parasites and predators is that predators frequently consume several prey, but parasites consume only one host per individual. The eunotine pteromalids and some mymarids could be regarded as egg predators because their larvae feed externally on scale-insect eggs in the "brood chamber" after they are oviposited by the female scale-insect (Clausen, 1940 a).

Parasitic species that attack many species of hosts are called polyphagous; parasitic species that attack only a few species of hosts are called stenophagous; and parasitic species that attack only one species of host are monophagous. Complete host specificity is difficult to establish because it is based essentially on negative evidence. The fact that a parasite will not attack a host under some conditions does not constitute proof that it will not parasitize that species. Nevertheless, there is a tendency towards specialization in the Chalcidoidea, and this is reflected by: (1) repeated recovery of a parasite from a host species over a large area, but not from related host species that occur sympatrically; (2) demonstrated preference for a host species when a choice is available; (3) superior reproductive capability on a host species; and (4) physical limitations that prevent a parasite from attacking a potential host.

Some polyphagous chalcidoids appear to prefer habitats rather than a taxonomically cohesive group of hosts. For example, Zagrammosoma species parasitize leaf-mining insects whether they are Lepidoptera, Diptera, or perhaps Hymenoptera. In contrast, related Diglyphus species parasitize only leaf-mining agromyzid Diptera. Other chalcidoids are extremely polyphagous. Dibrachys cavus (Walker) is an example. This species, like several others, has an exceedingly long host list that includes representatives of several orders. It usually develops as a primary parasite, but frequently also acts as a facultative hyperparasite (Graham, 1969). No explanation has been provided as to why one species should be so polyphagous and a closely related, morphologically similar species should be stenophagous or even monophagous.

Likewise, there are associations between host stage attacked and the taxonomic assignment of the parasite. For instance, the Trichogrammatidae and Mymaridae exclusively develop on the egg stage of other insects and the spalangine pteromalids are pupal parasites (Annecke and Doutt, 1961; Boucek, 1963; Doutt and Viggiani, 1968).

Chalcidoids parasitize more hosts in more different taxonomic categories than any other group of parasitic insects. This spectrum extends from spider eggs (Desantisca) to aculeate Hymenoptera (Melittobia, Leucospidae). A detailed account of the biology of chalcidoids requires more space than is available here. However, a short summary of some interesting host relationships is provided.

A bizarre host association is found in Ixodiphagus and Hunterellus (Encyrtidae) whose species are primary, internal parasites of tick larvae and nymphs. These genera are cosmopolitan and may prove to be beneficial insects in tick control (Cooley and Kohls, 1934; Cole, 1965; Doube and Heath, 1975).

The mymarid Caraphractus cinctus Walker is unusual in that it parasitizes dytiscid beetle eggs that are submerged beneath the surface of the water. The female parasite swims in the water by vibrating her wings and oviposits in the host's eggs. Females have considerable discriminative ability, and can detect eggs that have been parasitized (Jackson, 1958, 1966).

The Eucharitidae are parasitic on Formicidae. The association apparently is an old one, and eucharitids oviposit on vegetation visited by worker ants. The eggs hatch, and the triungulin larvae are phoretically transported to the ant nest. Inside the nest the triungulin larvae eventually move into the brood chamber where they parasitize immature ants (Clausen, 1923; $1940 \mathrm{~b}, \mathrm{c}$ ).

Other information about host association of chalcidoids is limited by a lack of knowledge about the immature stages of many groups of potential hosts. However, the higher taxonomic catego- 
ries that include the most host species for chalcidoids include Lepidoptera, Homoptera, Diptera, Coleoptera, and Hymenoptera. Chalcidoids generally have failed to adapt to the nymphal stage of paurometabolous insects. The host spectrum of chalcidoids is being expanded constantly by more comprehensive biological studies of other insects. Given the diversity of habits, host associations, and stages attacked, it seems reasonable to conclude that any insect potentially includes several niches where a chalcidoid can develop.

All known Hymenoptera develop parthenogenetically and chalcidoids demonstrate three types: arrhenotoky, thelytoky, and deuterotoky. Arrhenotoky is the most common type of parthenogenesis among chalcidoids. Uninseminated arrhenotokous females deposit haploid eggs that develop into hemizygous males. Inseminated arrhenotokous females produce female offspring from fertilized eggs and males from unfertilized eggs. Arrhenotoky is a mechanism whereby lethal and deliterious genes can be relatively rapidly eliminated from a population and superior genotypes can be relatively rapidly selected.

Thelytoky is parthenogenesis in which males are unknown or rare and females produce females by various asexual mechanisms. Cytologically, diploidy is maintained by apomixsis and automixsis. Apomixsis (ameiotic thelytoky) is characterized by an absence of meiosis, and chromosome number is not reduced. Automixis (meiotic thelytoky) has reduction divisions, and diploidy is maintained in several ways. Rossler and DeBach (1973) review the methods of maintaining a constant chromosome number.

Thelytoky is common among parasitic Hymenoptera, but the extent of thelytoky in the Chalcidoidea is not known because our knowledge of their biology is limited. Many species are known from the original description only, and many species have been described from the female sex only. Thelytoky may be more common than now realized. In the rather well known genus Aphytis, DeBach (1969) records that about $30 \%$ of the species are thelytokous.

The evolutionary significance of thelytoky is an issue of debate. Traditional views hold that thelytoky is an "evolutionary blind alley". However, Rossler and DeBach (1972) have shown that at least one species of thelytokous chalcidoid has females that are capable of sexual reproduction.

Deuterotoky is parthenogenesis in which unfertilized eggs develop into both sexes. The cytological mechanism of deuterotoky has not been examined in chalcidoids. This form of parthenogenesis is common in some other animals, and has been reported in some species of chalcidoids (Doutt, 1959).

The cytogenetics of the Hymenoptera have been reviewed by Crozier (1975). That paper points to a lack of knowledge developed about chalcidoid karyotypes and cytological phenomena.

Hymenoptera are haplodiploid and this has been confused with sex determination. The correlation between males being haploid and females being diploid is positive and strong, but haploidy and diploidy in themselves do not determine sex. Diploid males are known to occur (Whiting, 1945). Several theories have been advanced to explain sex determination in the Hymenoptera, but in no instance has one theory proven adequate to explain determination in all groups (Whiting, 1940, 1943; daCunha and Kerr, 1957; Slobodchikoff and Daly, 1971). Crozier (1975) suggests that any general theory should accommodate the multiple allele case with as little modification as possible.

Polyembryony is a cytological phenomenon in which a single egg develops into many individual progeny. Among Hymenoptera the process occurs in the Platygastridae (Proctotrupoidea) and copidosomatine Encyrtidae (Silvestri, 1906; Leiby, 1922, 1926).

Sex ratio in many species of animals approximates unity. In arrhenotokous chalcidoids the sex ratio usually is female biased and fluctuates between 60 and 80 percent female. Numerous factors have been implicated in the determination of sex ratio including size, stage, or species of host (Abdelrahman, 1974 a,b; Avidov and Podoler, 1968; Clausen, 1940 a), rate of oviposition (Abdelrahman, 1974 b), egg orientation (King, 1961), genetic factors (Wilkes, 1964), differential mortality (Roberts, 1933; Flanders, 1937; Abdelrahman, 1974 a), density fluctuations (Flanders, 1956), nutrition (Flanders, 1965; Moran et al., 1969), and many others. This list could be lengthened substantially and its only limitation now is lack of research.

Mayr (1969) defines sibling species as "pairs or groups of closely related species which are reproductively isolated but morphologically identical or nearly so." Recent studies of chalcidoids have demonstrated that this group has many sibling species complexes (Hafez and Doutt, 1954; Claridge and Askew, 1960; DeBach, 1959, 1960, 1969; Khasimuddin and DeBach, 1976, a,b,c; Rao and DeBach, 1969 a,b,c). These complexes suggest that chalcidoids are in an active state of 
evolution and speciating rapidly. Factors of chalcidoid biology that promote rapid speciation include: (1) short generation time; (2) several generations per season; (3) intensive inbreeding via sib mating; (4) microgeographic isolation; and (5) host preference.

Chalcidoids are the most important group in applied biological control. Other taxa (Tachinidae, Ichneumonidae, Braconidae, Proctotrupoidea) are used extensively in biological control, but species-for-species chalcidoids have been used more successfully. DeBach (1964) lists 25 pest species with which complete biological control was achieved. Chalcidoids are responsible for control in 13 of these programs, a number far greater than any other taxonomic group. Agricultural pests in these control programs include many Homoptera, but some Coleoptera have also been controlled by chalcidoids (Taylor, 1937; Tooke, 1953; Williams et al., 1951).

It is a pleasure to acknowledge the comments and suggestions on the preceding account made by the following individuals: Kenneth Cooper, Paul DeBach, Eric Grissell, Peter Price, and David Rosen.

Taxonomy: Ashmead, 1904. Carnegie Mus., Mem. 1 (4): 225-555. -Brues, 1910. N. Y. Ent.

Soc., Jour. 18 (1): 1-22 (Fossils). - Nikol'skaya, 1952. Akad. Nauk SSSR 44, 593 pp.

-Boucek and Hoffer, 1957. Klic Zuireny CRS 2: 208-288. -DeBach, 1959. Ent. Soc. Amer., Ann. 52 (4): 354-362. -DeBach, 1960. Ent. Soc. Amer., Ann. 53 (6): 701-705. - Annecke and Doutt, 1961. Rep. So. Africa Dept. Agr. Tech. Serv., Ent. Mem. 5: 1-71. - Boucek, 1963.

Mus. Natl. Pragae, Acta Ent. 35: 429-512. -Peck, Boucek, and Hoffer, 1964. Canad. Ent.

Soc., Mem. 34: 120 pp. - Doutt and Viggiani, 1968. Calif. Acad. Sci., Proc. (4) 35 (20):

477-586. -Townes, 1969. Amer. Ent. Inst., Mem. 11: 1-300. -Graham, 1969. Brit. Mus.

(Nat. Hist.) Ent., Bul. Sup. London, 16: 908 pp. - Doutt, 1973. Pan-Pacific Ent. 49 (3):

221-228 (fossils), - Yoshimoto, 1975. Canad. Ent. 107 (5): 499-528 (fossils).

Biology: Silvestri, 1906. Lab. Zool. Gen. e Agr. Portici, Bol. 1: 17-64. -Smith, 1912. U. S.

Dept. Agr., Tech. Ser. 19 (4): 33-69. - Leiby, 1922. Jour. Morph. 37: 195-285. -Clausen,

1923. Ent. Soc. Amer., Ann. 16 (3): 195-219. -Leiby, 1926. Ent. Soc. Amer., Ann. 19 (3):

290-299. - Roberts, 1933. U. S. Dept. Agr., Tech. Bul. 365: 1-21. - Cooley and Kohls, 1934.

5th Pacific Sci. Congr., Proc. 5: 3375-3381. - Flanders, 1937. Calif. Univ. Pubs., Ent. 6 (15): 401-422. - Taylor, 1937. Biol. Cont. Ins. Fiji 239 pp. -Clausen, 1940 a. Entomoph. Insects, 688 pp. -Clausen, 1940 b. Ent. Soc. Wash., Proc. 42 (8): 161-170. -Clausen, 1940 c. Wash.

Acad. Sci., Jour. 30: 504-516. - Whiting, 1940. Jour. Morph. 66 (2): 323-355. - Whiting, 1943. Genetics 28: 365-382. - Whiting, 1945. Quart. Rev. Biol. 20: 231-260. - Williams et al., 1951. Bul. Ent. Res. 42 (1): 23-28. - Tooke, 1953. Union So. Africa Dept. Agr., Ent. Mem. 3, 282 pp. - Flanders, 1953. Jour. Econ. Ent. 46 (4): 541-544. - Hafez and Doutt, 1954. Canad. Ent. 86 (2): 90-96. - Flanders, 1956. Insectes Sociaux 3 (2): 322-334. - daCunha and Kerr, 1957. Forma et Functios 1 (1): 33-36. -Jackson, 1958. Roy. Ent. Soc. Lond., Trans. 110 (17): 533-556. -Doutt, 1959. Ann. Rev. Ent. 4: 161-182. -Flanders, 1959. Ent. Expt. et Apl. 2 (2): 125-142. - Claridge and Askew, 1960. Entomophaga 5 (2): 141-153. - Grandi, 1961. Univ. Bologna Inst. Ent., Bol. 26: 1-13. - King, 1961. Nature 189 (4761): 330-331. -Salt, 1961. Soc. Expt. Biol., Symp. 15: 96-119. -Zinna, 1961. Lab. Ent. Agr. "Filippo Silvestri", Portici, Bol. 19: 301-358. - DeBach, 1964. in: Biol. Control Ins. Pests Weeds, pp. 673-713. - Doutt, 1964. in: Biol. Control Ins. Pests Weeds, pp. 145-167. - Wilkes, 1964. Science 144 (3616): 305-307. - Cole, 1965. WHO-EBL 43: 65. - Flanders, 1965. Amer. Nat. 99: 489-494. - Broodryk and Doutt, 1966. Hilgardia 37 (9): 233-254. -Jackson, 1966. Roy. Ent. Soc. Lond., Trans. 118 (2): 23-49. -Flanders, 1967. Entomophaga 12 (5): 415-427. - Hill, 1967 a. Figs (Ficus spp.) of Hong. Kong, 130 pp. - Hill, 1967 b. Jour. Nat. Hist. 1: 413-434. - Avidov and Podoler, 1968. Israel Jour. Ent. 3 (1): 1-16. - Mayr, 1969. Principles Syst. Zool., 428 pp. -Moran et al., 1969. Roy. Ent. Soc. Lond., Trans. 121 (2): 41-58. -DeBach, 1969. Israel Jour. Ent. 4: 11-28. - Rao and DeBach, 1969 a. Hilgardia 39 (19): 515-553. - Rao and DeBach, 1969 b. Hilgardia 39 (19): 555-567. - Rao and DeBach, 1969 c. Evolution 23: 525-533. - Ramirez, 1970 a. Univ. Kans., Sci. Bul. 49 (1): 1-44. - Ramirez, 1970 b. Evolution 24 (4): 680-691. -Askew, 1971. Parasitic Insects, 316 pp. - Slobodehikoff and Daly, 1971. Amer. Zool. 11: 273-282. - Rossler and DeBach, 1972. Entomophaga 17 (4): 391-423. - Rossler and DeBach, 1973. Hilgardia 42 (5): 149-176. —Quezada, DeBach and Rosen, 1973. Hilgardia 41 (18): 543-604. -A Adelrahman, 1974 a. Austral. Jour. Zool. 22 (2): 213-230. - Abdelrahman, 1974 b. Austral. Jour. Zool. 22 (2): 231-247. -DeBach, 1974. Biol. Control by Nat. Enemies, 323 pp. - Crozier, 1975. Hymen. Anim. Cytogen. 3: Ins. 7, 95 pp. 
-Doube and Heath, 1975. Jour. Med. Ent. 12 (4): 443-447. - Khasimuddin and DeBach, 1976 a. Entomophaga 21 (1): 81-92. - Khasimuddin and DeBach, 1976 b. Entomophaga 21 (1): 113-122. - Khasimuddin and DeBach, 1976 c. Ent. Soc. Amer., Ann. 69 (1): 15-20.

\section{Family TORYMIDAE}

By E. E. GRISSELL

This family, represented in every zoogeographical region, contains in excess of 70 genera and 600 species. Members of the subfamily Agaoninae are exclusively phytophagous. Most members of the Megastigminae are phytophagous, but a few parasitic species are known in Europe. The other subfamilies of Torymidae are largely parasitic, frequently on gall-forming insects. Hosts are reported in the Coleoptera, Diptera, Hymenoptera, Lepidoptera and Orthoptera.

Revision: Crawford, 1914. Ent. Soc. Wash., Proc. 16: 123 (Nearctic key). - Hoffmeyer, 1930.

Ent. Meddel. 17: 232-285 (Palearctic key).-Nikol'skaya, 1952. Chalcid fauna of the U. S. S. R., pp. 101-149 (Palearctic key; Eng. transl. 1963). -Joseph, 1964. Roy. Ent. Soc. London, Proc., Ser. B. Taxonomy 33: 63-66 (classification).

Taxonomy: Peck, 1963. Canad. Ent., Sup. 30: 526-590 (bibliography).

Morphology: Breland, 1938. N. Y. Ent. Soc., Jour. 46: 355-399. -Copland and King, 1972.

Roy. Ent. Soc. London, Trans. 124: 191-212 (female reproductive system).

\section{SubFamily AGAONINAE}

By B. D. BuRKS

The members of this subfamily develop as gall makers within the fruits of figs, Ficus spp. As Hill (1967) has stated, "Pollination of fig flowers is effected through a unique symbiotic association with chalcid wasps. No other means of pollination is available to the plant, and in their turn the wasps cannot develop anywhere except in the gall flowers of the figs."

Taxonomy: Grandi, 1963. Univ. Bologna, Ist. di Ent., Bol. 26: 319-373 (world cat. of genera and spp.). - Wiebes, 1966. Zool. Verhandel. 83, 44 pp. (world host list). - Hill, 1967. Figs of Hong Kong, Hong Kong Univ. Press, pp. 91-98 (world genera).

Biology: Hill, 1967. Figs of Hong Kong, Hong Kong Univ. Press, pp. 7-12, 99-102.

\section{Genus BLASTOPHAGA Gravenhorst}

\section{Genus BLASTOPHAGA Subgenus BLASTOPHAGA Gravenhorst}

Blastophagus Gravenhorst, 1827 (1826). Uebers. Arb. Schles. Gesell. Vaterland. Kultur, p. 23. Suppressed by Opinion 694, Internatl. Comn. Zool. Nomencl., 1964.

Type-species: Blastophagus grossomim Gravenhorst. Monotypic.

Blastophaga Gravenhorst, 1829. Schles. Gesell. Vaterland. Kultur, Beitr. Ent., p. 27.

Emend. Validated by Opinion 694, Internatl. Comn. Zool. Nomencl., 1964.

Kradibia Saunders, 1883. Ent. Soc. London, Trans., pp. 20, 23.

Type-species: Kradibia cowani Saunders. Monotypic.

Kradibiella Girault, 1915. Queensland Mus., Mem. 4: 313.

Type-species: Kradibiella nigricorpus Girault. Orig. desig.

Paraceratosolen Girault, 1915. Queensland Mus., Mem. 4: 312.

Type-species: Paraceratosolen latipennis Girault. Orig. desig.

Taxonomy: China, 1960. Bul. Zool. Nomencl. 18: 69-72 (request for validation of Blastophaga Gravenhorst, 1829, and suppression of Blastophagus Gravenhorst, 1827). -Internatl.

Comn. Zool. Nomencl., 1964. Opinion 694, Bul. Zool. Nomencl. 21: 31-32 (validation of

Blastophaga Gravenhorst, type-species B. grossorum Gravenhorst). - Hill, 1967. Figs of

Hong Kong, Hong Kong Univ. Press, p. 91.

psenes (Linnaeus). Ariz., Calif.; worldwide in frost-free areas. Introduced from Algeria. Host:

Fruit of the inedible caprifig. First introduced into California in 1890 to 
pollinate and thus to improve the quality of cultivated edible figs. Ten years of effort were required before this insect was successfully established. Fig wasp.

Cynips Psenes Linnaeus, 1758. Syst. Nat., ed. 10, p. 554. Nom. nud., but validated by Opinion 694, Internatl. Comn. Zool. Nomencl., 1964.

Cynips Psenes Linnaeus, 1767. Syst. Natl., ed. 12, tom. 1, pars 2, p. 919.

Blastophaga grossorum Gravenhorst, 1829. Beitr. Ent., besonders in Bezug auf die Schles. Fauna, v. 1, pp. 27-29.

Taxonomy: Condit and Enderud, 1956. Hilgardia 25: 64-85, 616 (bibliography on caprification).

Biology: Grandi, 1929. R. Ist. Super. Agr., Lab. di Ent., Bol. 2: 1-145. -Quayle, 1938. Insects of Citrus and other Subtropical Fruits, pp. 408-416. - Buscalioni and Grandi, 1938. R. Univ. Bologna, Ist. Ent., Bol. 10: 245-266. -Joseph, 1954. Agra Univ., Jour. Res. (Sci.) 3: 408. -Grandi, 1955. Accad. Naz. dei Lincei, Atti, Mem., Cl. Sci., (8) 5: 3. -Grandi, 1956. Univ. Bologna, Ist. Ent., Bol. 21: 111. - Mrak, 1957. Food Tech. 11: 547. - Kuttamathiathu, 1958. Ann. Sci. Nat., Zool. et Biol. Anim., (11) 20: 201. -Serafimova, 1965. Akad. na Selsk. Nauki. Gradinar., Nauka 2: 269.

Morphology: Grandi, 1929. R. Ist. Super. Agr., Lab. di Ent., Bol. 2: 1-145.

\section{Genus BLASTOPHAGA Subgenus SECUNDEISENIA Schulz}

Eisenia Ashmead, 1904. Carnegie Mus., Mem. 1: 233. Preoce. by Malm, 1877, and Vaillant, 1889.

Type-species: Eisenia mexicana Ashmead. Orig. desig.

Eiseniella Ashmead, 1906. Ent. Soc. Wash., Proc. 8: 31. N. name. Preocc. by Michaelsen, 1900.

Secundeisenia Schulz, 1906. Spolia Hym., p. 146. N. name for Eisenia Ashmead.

Pegosca pus Cameron, 1906. Estac. Centr. Agron. Cuba, Prim. Informe, An., p. 275.

Type-species: Pegoscapus longiceps Cameron. Monotypic.

Allopade Strand, 1911. Arch. f. Naturgesch. 77: 210. N. name for Eisenia Ashmead.

Blastophaga subg. Valentinella Grandi, 1919. Lab. Zool. Gen. e Agr. Portici, Bol. 13: 18, 25.

Type-species: Valentinella estherae Grandi, Desig. by Gahan and Fagan, 1923.

Blastophaga subg. Valentiniella Grandi, 1928. R. Ist. Super. Agr., Lab. di Ent., Bol. 1: 69. Emend.

Taxonomy: Hill, 1967. Figs of Hong Kong, Hong Kong Univ. Press, p. 91. mexicana (Ashmead). Fla.; West Indies, Mexico. Host: Ficus aurea, F. laevigata.

Eisenia mexicana Ashmead, 1904. Carnegie Mus., Mem. 1: 233. ₹.

Taxonomy: Gahan and Peck, 1946. Wash. Acad. Sci., Jour. 36: 315.

Biology: Butcher, 1964. Fla. Ent. 47: 235-238.

\section{SUBFAMILY IDARNINAE}

By E. E. GRISSELL

Members of this subfamily are not well known taxonomically or biologically. All have been reared from the receptacles of $F i c u s$, but little exact biological information is available. Known biologies indicate these wasps are parasitic upon pollinating Agaoninae.

\section{Genus COLYOSTICHUS Mayr}

Colyostichus Mayr, 1885. Zool.-Bot. Gesell. Wien, Verh. 35: 157-158, 237.

Type-species: Colyostichus longicauda Mayr. Desig. by Ashmead, 1904.

brevicaudis Mayr. Fla. Host: Ficus altissima.

Colyostichus brevicaudis Mayr, 1885. Zool.-Bot. Gesell. Wien, Verh. 35: 239. \&.

Taxonomy: Butcher, 1964. Fla. Ent. 47: 237 (in key). 


\section{Genus NEOSYCOPHILA Grandi}

Neosycophila Grandi, 1923. Genova Mus. Civ. Stor. Nat., Ann. 51: 106.

Type-species: Neosycophila omeomorpha Grandi. Orig. desig.

Taxonomy: Burks, 1967. In Krombein, et al., U. S. Dept. Agr., Agr. Monog. 2, Sup. 2: 249.

-Burks, 1969. Fla. Ent. 52: 119-120.

bicolor (Ashmead). Fla.; W. Indies. Host: Ficus citrifolia.

Sycophila bicolor Ashmead, 1900. Ent. Soc. London, Trans. pp. 252, 335. \&, ठ゚.

Taxonomy: Butcher, 1964. Fla. Ent. 47: 237 (in key).

incerta (Ashmead). Fla.; W. Indies. Host: Ficus citrifolia.

Sycophila incerta Ashmead, 1900. Ent. Soc. London, Trans., pp. 253, 335..

\section{Genus IDARNES Walker}

Idarnes Walker, 1843. Ann. and Mag. Nat. Hist. 12: 47.

Type-species: Idarnes carme Walker. Monotypic.

Tetragonaspis Mayr, 1885. Zool.-Bot. Gesell. Wien, Verh. 35: 205.

Type-species: Tetragonaspis gracilicornis Mayr. Desig. by Gahan and Fagan, 1923.

Ganosoma Mayr, 1885. Zool.-Bot. Gesell. Wien, Verh. 35: 204.

Type-species: Ganosoma robustum Mayr. Desig. by Gahan and Fagan, 1923.

Taxonomy: Butcher, 1964. Fla. Ent. 47: 237 (In key). -Gordh, 1975. Kans. Univ. Sci. Bul. 50: 389-455 (external morph., biol., key to Neotropical spp.).

carme Walker. Fla.; W. Indies, Puerto Rico, Brazil. Host: Ficus aurea.

Idarnes carme Walker, 1843. Ann. and Mag. Nat. Hist. 12: 47..+

\section{SUBFAMILY TORYMINAE}

By E. E. GrisSEll

Revision: Crawford, 1914. Ent. Soc. Wash., Proc. 16: 122-126. - Hoffmeyer, 1930. Ent. Meddel. 17: 232-285.

Taxonomy: Breland, 1938. N. Y. Ent. Soc., Jour. 46: 355-399 (phylogeny).

\section{Genus ALLOTORYMUS Huber}

Allotorymus Huber, 1927. U. S. Natl. Mus., Proc. 70 (14): 104.

Type-species: Syntomas pis splendens Provancher. Orig. desig.

splendens (Provancher). Ont., Colo., B. C.

Syntomaspis splendens Provancher, 1887. Addit. Corr. Faune Ent. Canada Hym., p. 196. ,$\delta$.

Taxonomy: Huber, 1927. U. S. Natl. Mus., Proc. 70 (14): 105 (female, male). -Burks, 1964 (1963). Canad. Ent. 95: 1262.

\section{Genus TORYMUS Dalman}

Callimome Spinola, 1811. Paris Mus. d'Hist. Nat., Ann. 17: 146-148. Suppressed by Internatl. Comn. Zool. Nomencl., 1944, Opinion 155, pp. 227-238.

Type-species: Ichneumon bedegnaris Linnaeus. Desig. by Curtis, 1835.

Misocampe Latreille, 1818. Nouv. Dict. Hist. Nat., ed. 2, p. 213. Suppressed by Internatl. Comn. Zool. Nomencl., 1944, Opinion 155, pp. 227-238.

Type-species: Ichneumon bedeguaris Linnaeus. Desig. by Gahan and Fagan, 1923.

Torymus Dalman, 1820. Svenska Vetensk. Akad., Handl. 41: 135, 178.

Type-species: Ichneumon bedeguaris Linnaeus. Desig. by Ashmead, 1904.

Misocampus Stephens, 1829. Cat. Brit. Ins., v. 1, p. 395. Emend.

Syntomaspis Foerster, 1856. Hym. Stud. 2: 43-44.

Type-species: Torymus eurytonus Foerster. Desig. by Gahan and Fagan, 1923. The type-species is considered a synonym of Torymus cyaneus Boheman.

Lioterphus Thomson, 1875. Skand. Hym. v. 4, pp. 60, 99. 
Type-species: Torymus pallidicornis Boheman. Desig. by Ashmead, 1904. Hemitorymus Ashmead, 1904. Carnegie Mus., Mem. 1: 243.

Type-species: Hemitorymus thoracicus Ashmead. Orig. desig.

Members of this genus exhibit a diverse range of habits. A few species are phytophagous, but the majority are parasitic on gall-forming Hymenoptera and Diptera. A few parasitize gall-forming Psyllidae. Several species are known to develop on the host larva as well as phytophagously in surrounding plant tissue.

Revision: Huber, 1927. U. S. Natl. Mus., Proc. 70 (14): 1-114. -Grissell, 1976. Univ. Calif.

Pubs. Ent. 79: 1-120.

Taxonomy: Hobbs, 1948. Pan-Pacific Ent. 24: 95-96. - Goodpasture and Grissell, 1975. Canad. Jour. Genet. and Cytol. 17: 413-422.

advenus (Osten Sacken). Conn., N. J., N. Y., D. C., N. C., Fla., La. Host: Asphondylia rudbeckiae conspicua 0 . S.; cecidomyiid gall in blossom of Vernonia noveboracensis; Procecidochares atra (Loew); Andricus quercuspetiolicola (0. S.)?, Callirhytis quercusventricosa (Bass.)?, Diastrophus nebulosus (O. S.)?

Callimome advena Osten Sacken, 1870. Amer. Ent. Soc., Trans. 3: 59-60. §, ९.

aea (Walker). N. Y., N. J., Pa., W. Va., Minn., Utah, Calif. Ecology: From seeds of Amelanchier canadensis. Host: Megastigmus amelanchieris Cush.

Callimome aea Walker, 1843. Ann. and Mag. Nat. Hist. 12: 104..

Syntomaspis amelanchieris Cushman, 1917. Ent. Soc. Wash., Proc. 19: 82-83. ․, ơ.

Taxonomy: Burks, 1975. Brit. Mus. (Nat. Hist.) Ent., Bul. 32 (4): 151.

Biology: Cushman, 1917. Ent. Soc. Wash., Proc. 19: 84. - Milliron, 1949. Amer. Midland Nat. 41: 393-395.

aeneoscapus (Huber). Wyo., Idaho, Utah, Ariz., Oreg., Nev., Calif. Ecology: From gall on Chrysothamnus. Host: Diarthronomyia artemisiae Felt, Rhopalomyia salviae Felt.

Callimome aeneoscapum Huber, 1927. U. S. Natl. Mus., Proc. 70 (14): 35 ..

aereus (Huber). D. C., Va., Fla., Mo., Tex., Ariz. Ecology: From galls on Quercus laurifolia, Q. macrocarpa?, Q. schneckii. Host: Dryocosmus imbricariae (Ashm.).

Callimame aereum Huber, 1927. U. S. Natl. Mus., Proc. 70 (14): 71. ₹, o.

alaskensis (Huber). Alaska.

Callimome alaskensis Huber, 1927. U. S. Natl. Mus., Proc. 70 (14): 31-32...

anthomyiae Ashmead. Ga., Fla. Host: Chalcodermus inaequicollis Horn; muscid leaf miner (probably Pegomya sp.) of cultivated plant.

Torymus anthomyiae Ashmead, 1887. Amer. Ent. Soc., Trans. 14: 189. ․

asteridis (Huber). N. H., Conn. Ecology: From cecidomyiid gall on aster.

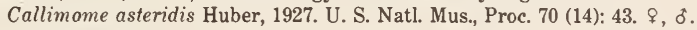

atheatus Grissell. Tex., N. Mex., Idaho, Utah, Ariz., Oreg., Nev., Calif. Ecology: From fruits of Sphaeralcea.

Torymus atheatus Grissell, 1976. Univ. Calif. Pubs. Ent. 79: 63., ¡.

atriplicis (Huber). Ariz., Calif. Host: Asphondylia neomexicana (Ckll.).

Callimome atriplicis Huber, 1927. U. S. Natl. Mus., Proc. 70 (14): 44. ९.

aucupariae (Rodzianko). Minn. Host: Probably Megastigmus aucupariae Ratz.

Syntomaspis aucupariae Rodzianko, 1908. Soc. Imp. Nat. Moscou, Bul. (n. s.) 21: 602. ^, ठ. axillaris Ashmead. Va., W. Va.

Torymus axillaris Ashmead, 1894. Amer. Ent. Soc., Trans. 21: 333. ?.

azureus Boheman. Mont., N. Mex.; Holarctic. Ecology: From Picea engelmanni cones (N. Amer. record). Host: Perrisia strobi Winn.; Laspeyresia strobilella (L.) (Palearctic region).

Torymus azureus Boheman, 1834. Svenska Vetensk. Akad., Handl. 54: 369-370. ९.

baccharidis (Huber). Calif. Host: Rhopalomyia californica Felt on Baccharis.

Callimome baccharidis Huber, 1927. U. S. Natl. Mus., Proc. 70 (14): 46-47. ₹, ơ.

Callimome pilularidis Huber, 1927. U. S. Natl. Mus., Proc. 70 (14): 45-46. \&, ơ. 
Biology: Doutt, 1961. Ent. Soc. Amer., Ann. 54: 51 (baccharicidis). -Burks, 1965. Ent. News

65: 74-76 (host). -Force, 1970. Ent. Soc. Amer., Ann. 63: 1675-1688 (baccharicidis).

-Force, 1974. Science 184: 624-632.

bedeguaris (Linnaeus). Que., Ont., Ill., Iowa, Nebr., Alta., Utah, Ariz., Wash., Oreg., Nev., Calif.; Europe. Host: Diplolepis bicolor (Harris), D. ignota (0. S.), D. polita (Ashm.), D. rosae (L.), D. tuberculatrix (Ckll.), D. variabilis (Bass.).

Ichneumon Bedeguaris Linnaeus, 1758. Syst. Nat., ed. 10, p. 567. $\$$.

Torymus elegans Boheman, 1834. Svenska Vetensk. Akad., Handl. 54: 352. ๆ, ठ.

Callimome divisus Walker, 1871. Notes on Chalcid., pt. 2, p. 34. $\%$.

Callimome druparum Mayr, 1874. Zool.-Bot. Gesell. Wien, Verh. 24: 103. Misident. of druparum Boheman.

Callimome chrysochlora Huber, 1927. U. S. Natl. Mus., Proc. 70 (14): 37-39. Misident., in part, of chrysochlora Osten Sacken.

Taxonomy: Mayr, 1874. Zool.-Bot. Gesell. Wien, Verh. 24: 103 (misdet. of druparum

Buheman). - Huber, 1927. U. S. Natl. Mus., Proc. 70 (14): 37-39. (misdet., in part, of chrysochlora Osten Sacken).

Biology: Judd, 1959. Canad. Ent. 91: 728-730.

bicoloratus (Huber). N. Mex., Idaho, Ariz., Wash., Oreg., Calif. Host: Amphibolips trizonata Ashm., Callirhytis quercuspomiformis (Bass.), Diplolepis bicolor (Harris)?, gall on Quercus chrysolepis.

Callimome bicoloratum Huber, 1927. U. S. Natl. Mus., Proc. 70 (14): 73. ๆ, ठ.

boharti Grissell. N. Mex., Ariz., Nev., Calif.

Torymus boharti Grissell, 1976. Univ. Calif. Pubs. Ent. 79: 65. १, §.

brodiei (Ashmead). Ont., Ill. Host: Acraspis erinacei (Beut.), A. pezomachoides (0. S.)?; Mayetiola rigidae (0. S.).

Syntomaspis Brodiei Ashmead, 1887. Amer. Ent. Soc., Trans. 14: 187. ๆ, §.

californicus (Ashmead). Oreg., Calif. Ecology: From pimply gall on Quercus douglasi, ?strawberry gall on Quercus dumosa. Host: Andricus chrysolepidicola (Ashm.), A. lasius (Ashm.), A. quercuscaliformicus (Bass.), Disholcaspis corallina (Bass.), D. chrysolepidis (Beut.), D. plumbella Kinsey, D. simulata Kinsey, D. truckeensis (Ashm.), $D$. sp. on Quercus douglasi, Besbicus mirabilis Kinsey, B. conspicuus (Kinsey), Callirhytis quercusagrifoliae (Bass.), C. quercuspomiformis (Bass.), C. sp. on Quercus chrysolepis, Heteroecus pacificus (Ashm.), Trichoteras vacciniifoliae (Ashm.).

Syntomaspis californica Ashmead, 1886. Amer. Ent. Soc., Trans. 13: 127. 9.

Callimome californica subdolum Huber, 1927. U. S. Natl. Mus., Proc. 70 (14): 85-86. ㅇ, ð. capillaceus albitarsis (Huber). Ill., Kans., Tex., Colo., N. Mex., Idaho, Utah, Ariz., Nev., Calif. Ecology: From stem gall on Ambrosia, seed-pod gall on Mimosa biuncifera, gall on Solidago rigida. Host: Asphondylia helianthiglobulus 0 . S., cecidomyiid flower gall on Ratibida columnaris, Lasioptera sp. on Aster, tephritid gall on Chrysothamnus; Desmoris fulvus (Lec.).

Callimome albitarse Huber, 1927. U. S. Natl. Mus., Proc. 70 (14): 80.

Biology: Breland, 1939. Ent. Soc. Amer., Ann. 32: 719, 724.

capillaceus capillaceus (Huber). Tex., N. Mex., Ariz., Calif.; Mexico (Baja California Norte, San Luis Potosi, Sonora, Veracruz). Ecology: From gall on Hymenoclea; seed pods of Prosopis. Host: Asphondylia neomexicana (Ckll.), websteri Felt, A. sp. bud galls on Larrea divaricata, Mayetiole rigidae (O. S.), cecidomyiid galls on Rhus copallina lanceolata (buds) and Artemisia? leaves.

Callimome capillaceum Huber, 1927. U. S. Natl. Mus., Proc. 70 (14): 74-75..

Syntomaspis medicaginis Gahan, 1919. Ent. Soc. Amer., Ann. 12: 162. \&, ठ̀. Preocc. by Mayr, 1874.

Callimome sativae Huber, 1927. U. S. Natl. Mus., Proc. 70 (14): 77. N. name.

capite (Huber). D. C., Wis., Utah, Nev. Ecology: From mine on Solidago. Host: Lasioptera sp.

Callimome capite Huber, 1927. U. S. Natl. Mus., Proc. 70 (14): 32-33. ₹, ơ.

cecidomyiae (Walker). Que., Ont., N. Y., Ohio, Kans., Wash., Calif. Host: Cecidomyia communis (nomen nudum), C. spongivora Walk., Rhabdophaga strobiloides (O. S.).

Callimome Cecidom yiae Walker, 1844. Ann. and Mag. Nat. Hist. 14: 15.. 
Callimome strobiloides Huber, 1927. U. S. Natl. Mus., Proc. 70 (14): 40 ..

Taxonomy: Burks, 1975. Brit. Mus. (Nat. Hist.) Ent., bul. 32 (4): 151-152.

chrysochlorus (Osten Sacken). Conn.?, Colo., Alta., Idaho, Wash. Host: Diplolepis bicolor

(Harris), D. dichloceras (Harris), D. fusiformans (Ashm.), D. lens Weld, D. polita

(Ashm.). Previous records for this species (Peck, 1963, Canad. Ent., Sup. 30, p. 538)

mostly apply to $T$. bedeguaris and $T$. solitarius. Records given here are only for those specimens which I have examined.

Callimome chrysochlora Osten Sacken, 1870. Amer. Ent. Soc., Trans. 3: 63-64. ९, ơ.

eitripes (Huber). Colo., N. Mex., Idaho, Utah, Ariz., B. C., Wash., Oreg., Calif. Ecology: From stem gall on Helianthus lenticularis. Host: Euaresta billlans (Wied.). Gymnocarena tricolor (Doane), Eutreta diana (0. S.).

Callimome citripes Huber, 1927. U. S. Natl. Mus., Proc. 70 (14): 48. \&, ठ.

coccineus (Huber). Maine, Mass., Conn., Va. Host: Amphibolips confluenta (Harris), $A$. quercusspongifica $(0 . \mathrm{S}$.).

Callimome coccineum Huber, 1927. U. S. Natl. Mus., Proc. 70 (14): 68-69..

coeruleus (Ashmead). Fla. Ecology: From gall on Rubus sp. Host: Amphibolips confluenta (Harris).

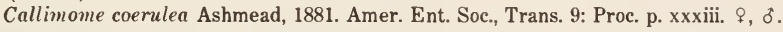

coloradensis (Huber). Kans.(?), Colo., Idaho, Utah, Wash. Host: Cecidomyiid gall on Artemisia, Dasineura? sp. on Helianthus.

Callimome coloradensis Huber, 1927. U. S. Natl. Mus., Proc. 70 (14): 49. \&, ð.

cruentatus (Huber). Conn. Host: Cynipid leaf gall on Quercus virginiana.

Callimome cruentatum Huber, 1927. U. S. Natl. Mus., Proc. 70 (14): 50-51. ९, ơ.

dasyneurae (Huber). Ohio, Tex., Wyo., N. Mex., Utah, Ariz., Nev., Calif. Host: Dasineura ulmea Felt, Walshomyia cupressi Gagne, W. sp. nr. juniperina Felt.

Callimome dasyneurae Huber, 1927. U. S. Natl. Mus., Proc. 70 (14): 56-57. \&, o.

dennoi Grissell. Calif. Host: Walshomyia sp. nr. juniperina Felt.

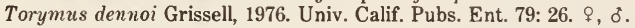

denticulatus (Breland). Utah, Ariz., Calif.; Mexico (Chihuahua). Ecology: From staminate flw. gall on Quercus argrifolia, leaf gall on Q. utahensis and Q. turbinella. Host: Andricus crystallinus Bass., A. kingi Bass., A. tostus (Kinsey), Antron clavuloides (Kinsey), A. quercusechinus (0. S.) bisex. gen., Callirhytis uvellae Weld, Dros pedicellatum (Kinsey), Dryocosmus dubiosus (Full.) bisex. gen., Sphaeroteras trimaculosum (Mck. and Eg.). .

The host Andricus tostus is known only from Mexico.

Callimome denticulata Breland, 1939. Brooklyn Ent. Soc., Bul. 34: 85-86. ஒ, ठ.

diabolus Moser. N. Y. Host: Phytophaga sp. on Celtis occidentalis.

Torymus diabolus Moser, 1965. N. Y. State Mus., Sci. Ser., Bul. 402: 26-27. \&.

dryophantae (Ashmead). Fla. Host: Bassettia quercuscatesbaei (Ashm.).

Syntomaspis dryophantae Ashmead, 1887. Amer. Ent. Soc., Trans. 14: 187..

dubiosus (Huber). D. C. Ecology: From leaf gall on Carya.

Callimome dubiosum Huber, 1927. U. S. Natl. Mus., Proc. 70 (14): 24-25. \&.

duplicatus (Huber). Que., south to Fla., west to Nebr. Host: Diastrophus cuscutaeformis $0 . \mathrm{S}$.

Callimome duplicatum Huber, 1927. U. S. Natl. Mus., Proc. 70 (14): 27-28. $\uparrow$, ơ.

durus (Osten Sacken). Conn., D. C. Host: Diplosis caryae O. S.

Callimome dura Osten Sacken, 1870. Amer. Ent. Soc., Trans. 3: 59. ठ。.

ebrius (Osten Sacken). Conn., N. J., D. C., Va., Ohio, Tex. Host: Lasioptera vitis O. S.

Callimome ebria Osten Sacken, 1870. Amer. Ent. Soc., Trans. 3: 58-59. \&, o.

elegantissimus (Ashmead). Ont.?, Fla. Host: Disholcaspis quercusvirens (Ashm.); Xanthoteras quercusforticorne (Walsh)?

Callimome elegantissima Ashmead, 1881. Amer. Ent. Soc., Trans. 9: Proc. p. xxxiv. $\uparrow$.

fagopirum (Provancher). Eastern seaboard to Fla., northern U. S., southern Canada. Host:

Dasineura rosarum (Hardy), D. serrulatae (0. S.), Rhabdophaga salicifolia Felt; 
Diastrophus cuscutaeformis 0 . S., D. kincaidii Gill., D. nebulosus (0. S.), D. turgidus Bass., Disholcaspis quercusvirens (Ashm.).

Callimome brevicauda Osten Sacken, 1870. Amer. Ent. Soc., Trans. 3: 62. ․, §. Preocc. by Walker, 1833.

Callimone(!) fagopimum Provancher, 1881 (Aug.). Nat. Canad. 12: 291. ९, ઠ.

Callimome Sackenii Ashmead, 1881 (Oct.). Amer. Ent. Soc., Trans. 9: Proc. p. xxxii. N. name.

Callimome brevissimicauda Ashmead, 1881. Amer. Ent. Soc., Trans. 9: Proc. p. xxxiii. 9.

Callimome virentis Ashmead, 1881. Amer. Ent. Soc., Trans. 9: Proc. p. xxxiv. 9.

Callimome fagopyrum Provancher, 1883. Petite Faune Ent. Canada Hym., p. 820.

Misspelling, in index only.

Torymus ostensackenii Dalla Torre, 1898. Cat. Hym. v. 5, p. 311. N. name for brevicauda O. S.

Callimome alamedensis Huber, 1927. U. S. Natl. Mus., Proc. 70 (14): 28-29. , ठ.

ferrugineipes (Huber). N. Mex., Ariz., Calif.

Callimome fermigineipes Huber, 1927. U. S. Natl. Mus., Proc. 70 (14): 33. ๆ, ठ.

festivus Hobbs. Alaska, N. W. T., Oreg. Host: Dasineura sp. in seeds of Thuja and Chamaecyparis.

Torymus festivus Hobbs, 1950. Pan-Pacific Ent. 26: 173-174. + , ơ.

flavicoxa (Osten Sacken). Que., Maine, N. H., Mass., Conn., Ont., N. J., Va., B. C., Oreg., Calif. Host: Belonocnema treatae Mayr, Diastrophus nebulosus (0. S.), Diplolepis radicum (0. S.), D. terrigena Weld, Liposthenes glechomae (L.).

Callimome flavicoxa Osten Sacken, 1870. Amer. Ent. Soc., Trans. 3: 61. ․

Cleonymus superbus Provancher, 1888. Nat. Canad. 17: 407. $\$$.

Taxonomy: Burks, 1964 (1963). Canad. Ent. 95: 1257.

flaviventris Ashmead. Conn.?, Kans.

Torymus flaviventris Ashmead, 1888. Kans. Agr. Expt. Sta., Bul. 3: App. p. iv. .

floridensis Peck. Fla. Ecology: From gall on Quercus phellos or Q. laurifolia. Host: Amphibolips quercusfuliginosa (Ashm.).

Callimome robustum Huber, 1927. U. S. Natl. Mus., Proc. 70 (14): 72. . Preoce. by Ratzeburg, 1852.

Torymus floridensis Peck, 1951. In Muesebeck et al., U. S. Dept. Agr., Agr. Monog. 2: 523. N. name.

frankiei Grissell. Calif. Host: Walshomyia cupressi Gagne.

Torymus frankiei Grissell, 1973. Pan-Pacific Ent. 49: 236. ९, ठ.

fullawayi (Huber). Ariz., Oreg., Calif.; Mexico (Michoacan). Host: Andricus quercuscalifornicus (Bass.), A. tibialis (Kinsey), Callirhytis quercusagrifoliae (Bass.), C. quercuspomiformis (Bass.), Disholcaspis plumbella Kinsey, Dryocosmus dubiosus (Full.) unisex. and bisex. gen., Heteroecus pacificus (Ashm.).

Syntomaspis caerulea Fullaway, 1912. N. Y. Ent. Soc., Jour. 20: 275. ९. Preocc. by Ashmead, 1881.

Callimome fullawayi Huber, 1927. U. S. Natl. Mus., Proc. 70 (14): 19. N. name.

Taxonomy: Breland, 1939. Brooklyn Ent. Soc., Bul. 34: 87.

fulvus (Huber). Md., Iowa, Nebr.

Callimome fulvum Huber, 1927. U. S. Natl. Mus., Proc. 70 (14): 26-27..

hainesi Ashmead. Tex., N. Mex., Ariz., Calif.; Mexico to El Salvador. Host:

Asphondylia websteri Felt.

Torymus hainesi Ashmead, 1893. Ent. News 4: 278. ๆ.

Callimome asphondyliae Gahan, 1919. Ent. Soc. Amer., Ann. 12: 161-162. đ, \&. Preoce. by

Kieffer and Jorgensen, 1910.

helianthi Brodie. Ont., Tex., Utah. Host: Trishormomya helianthi (Brodie).

Torymus helianthi Brodie, 1894. Biol. Rev. Ontario 1: 45-46. ?.

Torymus brevis Breland, 1948. Ent. Soc. Wash., Proc. 50: 57. , ð.

Taxonomy: Breland, 1948. Ent. Soc. Wash., Proc. 50: 58.

Biology: Breland and Schmitt, 1948. Ent. News 59: 230. 
hircinus Ashmead. Va. (? lapsus for w. Va.), W. Va. Ecology: From twig gall on willow. Torymus hircinus Ashmead, 1894. Amer. Ent. Soc., Trans. 21: 333. \&, o.

hirsutus (Huber). Ariz. Host: Tanaostigmodes stem gall on Acacia greggii.

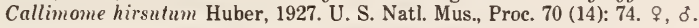

huberi (Hoffmeyer). Tex. Host: Cecidomyiid? gall on Celtis sp.

Callimome tarsale Huber, 1927. U. S. Natl. Mus., Proc. 70 (14): 76. §, ९. Preocc. by Walker, 1833.

Callimome huberi Hoffmeyer, 1929. Ent. Meddel. 16: 333. N. name.

kinseyi (Huber). Mont., Idaho, Utah, Nev., Calif. Host: Diarthonomyia artemisiae Felt, cecidomyiid galls on Chrysothamnus and Erigeron, Trypeta sp. on Chrysothamnus viscidiflorus.

Callimome kinseyi Huber, 1927. U. S. Natl. Mus., Proc. 70 (14): 44. \&, ð.

koebelei (Huber). Tex., Mont., Wyo., N. Mex., Idaho, Utah, Ariz., Wash., Nev., Calif.; Mexico (Nuevo Leon). Host: Rhopalom yia californica Felt.

Callimome koebelei Huber, 1927. U. S. Natl. Mus., Proc. 70 (14): 52. \&, ð.

Biology: Doutt, 1961. Ent. Soc. Amer., Ann. 54: 51. -Force, 1970. Ent. Soc. Amer., Ann. 63: 1675-1688. - Force, 1974. Science 184: 624-632.

larreae Grissell. Tex., N. Mex., Ariz., Calif.

Torymus larreae Grissell, 1976. Univ. Calif. Pubs. Ent. 79: 76. ९, ठे.

lissus (Walker). Fla., Ill. Ecology: From leaf gall on Quercus laurifolia. Host: Belonocnema treatae Mayr, Disholcaspis quercusomnivora (Ashm.), D. quercusvirens (Ashm.).

Callimome lissus Walker, 1843. Soc. Ent. de France, Ann. 1: 150. ठ.

Callimome aenea Ashmead, 1881. Amer. Ent. Soc., Trans. 9: Proc. p. xxxiii. $\uparrow$, ๖. Callimome dryorhizoxeni Ashmead, 1885. Amer. Ent. Soc., Trans. 12: Proc. p. xiii. $q$.

Torymus omnivorae Ashmead, 1887. Amer. Ent. Soc., Trans. 14: 188. o, q.

Taxonomy: Burks, 1975. Brit. Mus. (Nat. Hist.) Ent., Bul. 32 (4): 152.

lividus (Ashmead). Fla., La.

Callimome lividus Ashmead, 1885. Amer. Ent. Soc., Trans. 12: Proc. p. xiii. . $^{2}$

longicauda (Provancher). Que., Ont.

Callimone(!) longicauda Provancher, 1883. Nat. Canad. 14: 34. \&.

Taxonomy: Burks, 1964 (1963). Canad. Ent. 95: 1256.

longior Brodie. Ont., N. Dak., Tex., Ariz., Calif. Host: Trishoromomya helianthi (Brodie).

Torymus longior Brodie, 1894. Biol. Rev. Ontario 1: 45-46. ?.

longiscapus Grissell. Calif. Host: Callirhytis agrifoliae (Ashm.).

Torymus longiscapus Grissell, 1976. Univ. Calif. Pubs. Ent. 79: 78. \&, ð.

longistigmus (Huber). Idaho, Wash., Calif. Host: Woody cecidomyiid gall on willow.

Callimome longistigmum Huber, 1927. U. S. Natl. Mus., Proc. 70 (14): 47. ‡, ठ.

magnificus (Osten Sacken). N. H., Conn., N. Y., N. J., D. C., Fla., Kans., Colo., Utah. Host: Diplolepis radicum (0. S.).

Callimome magnifica Osten Sacken, 1870. Amer. Ent. Soc., Trans. 3: 62. ९, ठ.

mellipes (Huber). Mass., Conn. Host: Cecidomyijd gall on Populus sp.

Callimome mellipes Huber, 1927. U. S. Natl. Mus., Proc. 70 (14): 23. १, ठ.

memnonius Grissell. Tex. Host: Disholcaspis cinerosa (Bass.).

Torymus memnonius Grissell, 1973. Pan-Pacific Ent. 49: 237-238. ๆ, §.

mexicanus Ashmead. Ariz.; Mexico (Guanajuato, Durango). Host: Andricus championi Ashm.

Torymus Mexicanus Ashmead, 1899. Ent. News 10: 195. $?$, ð.

missouriensis (Huber). N. C., Ind., Mo. Host: Cecidomyiid stem gall on Rubus; cynipid gall.

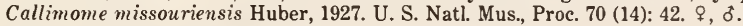

multicolor (Huber). Calif. Host: Cecidomyiid gall on Ephedra sp.

Callimome multicolor Huber, 1927. U. S. Natl. Mus., Proc. 70 (14): 51-52..

neuroterus Ashmead. Fla. Host: Neuroterıs quercusminutissimus (Ashm.).

Torymus neuroterus Ashmead, 1887. Amer. Ent. Soc., Trans. 14: 188. ठ̉. 
nitidulus Walker. Maine, Mont.; Europe, Asia. Host: Oligotrophus betulae Winn. The host was recorded in Europe.

Callimome nitidulus Walker, 1833. Ent. Mag. 1: 138. ठ.

Torymus pallidicornis Boheman, 1834 (1833). Svensk. Vetensk. Akad., Handl. 56: 363..

Taxonomy: Eady, 1958. Ent. Monthly Mag. 94: 260.

obscurus (Breland). Ind., Ky., Tenn., Ala., Miss., Ill., Mo., Tex., Ariz., Calif.; Mexico (Nuevo

Leon). Host: Lasioptera murtfeldtiana Felt.

Callimome obscura Breland, 1939. Ent. Soc. Amer., Ann. 32: 721. $९, ~ ठ$.

Biology: Satterthwait, 1948. Jour. Econ. Ent. 41: 729-730.

occidentalis (Huber). Oreg., Nev., Calif. Host: Cecidomyiid galls on Juniperus occidentalis.

Callimome occidentale Huber, 1927. U. S. Natl. Mus., Proc. 70 (14): 79. ९, ठ.

ochreatus Say. Ind. Ecology: In Liatris receptacle. Type material destroyed.

Torymus ochreatus Say, 1836. Boston Jour. Nat. Hist. 1: 275. §, ठ.

osborni (Huber). Wyo. Host: Cynipid on Rosa sp.

Callimome osborni Huber, 1927. U. S. Natl. Mus., Proc. 70 (14): 93. ९, ठ.

oviperditor (Gahan). Kans., Idaho. Host: Cicadetta calliope (Wlkr.), Tibicen aurifera Say.

Syntomaspis oviperditor Gahan, 1927. Ent. Soc. Wash., Proc. 29: 99-100. ९, ठ.

pachypsyllae (Ashmead). Ohio, Kans., Tex., N. Mex., Idaho. Host: Pachypsylla venusta 0. S., $P$. celtidismamma Riley, $P$. celtidisvesicula Riley.

Monodontomerus pachypsyllae Ashmead, 1888. Kans. Agr. Expt. Sta., Bul. 3: App. p. III. १, $\delta$.

Taxonomy: Moser, 1965. N. Y. State Mus., Sci. Ser., Bul. 402: 22, 33-34.

pavidus Say. Ind. Type material destroyed.

Torymus pavidus Say, 1836. Boston Jour. Nat. Hist. 1: 275. ठ.

perplexus (Huber). Oreg. Host: Besbicus mirabilis (Kinsey).

Callimome perplexum Huber, 1927. U. S. Natl. Mus., Proc. 70 (14): 49 ..

persimilis Ashmead. Va., (? lapsus for W. Va.), W. Va. Host: Cecidomyiid gall on willow.

Torymus persimilis Ashmead, 1894. Amer. Ent. Soc., Trans. 21: 334. $\$$.

potamius Grissell. Idaho, Utah, Ariz., Nev., Calif. Host: Pontania sp. galls.

Torymus potamius Grissell, 1976. Univ. Calif. Pubs. Ent. 79: 34-35. ९, o.

prunicola (Huber). N. Mex., Ariz.

Callimome prunicola Huber, 1927. U. S. Natl. Mus., Proc. 70 (14): 91. \&.

racemariae (Ashmead). N. Y. to Fla., Ala., w. to Ill., Colo., Tex. Host: Amphibolips confluenta (Harr.), A. gainesi Bass., A. quercusfuliginosa (Ashm.), A. quercusinanis (0. S.), A. quercusjuglans (0. S.), A. quercusracemaria (Ashm.), Disholcaspis cinerosa (Bass.), D. quercusglobulus (Fitch), D. quercusmamma (Walsh), D. terrestris Weld, Dryocosmus imbricariae (Ashm.).

Callimome recemareae Ashmead, 1881. Amer. Ent. Soc., Trans. 9: Proc. p. xxxiii. §, ð. Syntomaspis racemariae Ashmead, 1887. Amer. Ent. Soc., Trans. 14: 187. Emend.

Biology: Balduf, 1926. Canad. Ent. 58: 137-143, 163.

Morphology: Snodgrass, 1910. U. S. Natl. Mus., Proc. 39: 65.

rhoditidis (Huber). Mass. Host: Diplolepis sp. on Rosa.

Callimome rhoditidis Huber, 1927. U. S. Natl. Mus., Proc. 70 (14): 34 . ९, §.

rudbeckiae Ashmead. Ont., Colo. Ecology: From gall on Rudbeckia sp. Host: Cecidomyiid on Desmodium grandiflorum.

Torymus midbeckiae Ashmead, 1890. Colo. Biol. Assoc., Bul. 1: 26, 45. \&, ठ. rugglesi Milliron. Del., Md., Va. Ecology: From Ilex opaca seeds.

Torymus rugglesi Milliron, 1959. Ent. Soc. Amer., Ann. 52: 52. १, ठ.

scalaris (Huber). Fla., Wis., Kans., Tex., Ariz., Calif. Host: Pachypsylla celtidisgemma Riley.

Callimome scalaris Huber, 1927. U. S. Natl. Mus., Proc. 70 (14): 21. ‡, ठ.

solidaginis (Huber). Conn., N. Y., N. C. Host: Cecidomyiid.

Callimome solidaginis Huber, 1927. U. S. Natl. Mus., Proc. 70 (14): 92 . \&, ठ. 
solitarius (Osten Sacken). Colo., Alta., Idaho, Utah, Ariz., Wash., Nev., Calif. Host:

Diastrophus kincaidii Gill., Diplolepis bicolor (Harris), D. spinosa (Ashm.), D. tuberculatrix (Ckll.).

Callimome salitaria Osten Sacken, 1870. Amer. Ent. Soc., Trans. 3: 64. ‥

Callimome rosae Huber, 1927. U. S. Natl. Mus., Proc. 70 (14): 35-36..

Callimome tubularis Huber, 1927. U. S. Natl. Mus., Proc. 70 (14): 39-40. \&, ১.

Taxonomy: Huber, 1927. U. S. Natl. Mus., Proc. 70 (14): 37-39 (misdet., in part, of chrysochlora Osten Sacken).

splendidulus Dalla Torre. Ont. Host: Mayetiola rigidae (0. S.).

Callimome splendidus Walker, 1844. Ann, and Mag. Nat. Hist. 14: 14. Preoce. by Foerster, 1841.

Torymus splendidulus Dalla Torre, 1898. Cat. Hym., v. 5, p. 313. N. name.

Taxonomy: Burks, 1975. Brit. Mus. (Nat. Hist.) Ent., Bul. 32 (4): 152-153.

subcalifornicus Grissell. Oreg., Calif. Host: Trichoteras vaccinifoliae (Ashm.).

Torymus subcalifornicus Grissell, 1976. Univ. Calif. Pubs. Ent. 79: 44. \&, ठ.

sulcatus (Huber). Oreg., Calif. Host: Disholcaspis truckeensis (Ashm.), Heteroecus flavens (McC. and Egb.).

Callimome sulcatum Huber, 1927. U. S. Natl. Mus., Proc. 70 (14): 22 ..

texanus (Hoffmeyer). Tex., Ariz.; Mexico (Monterey). Host: Amphibolips globulus Beut., $A$. trizonata Ashm., Atrusca aggregata (Weld), A. bella (Bass.), A. congesta (Kinsey), A. simulatrix (Kinsey), Discholcaspis cinerosa (Bass.).

Callimome texanum Hoffmeyer, 1930. Ent. Meddel. 17: 213. ㅇ, ઠ.

Taxonomy: Breland, 1939. Brooklyn Ent. Soc., Bul. 34: 87.

thalassinus (Crosby). Conn., N. Y., Ohio, Minn., Wyo., N. Mex., Idaho, Utah, Ariz., Wash., Oreg., Nev., Calif. Host: Harmolita sp. from Bouteloua sp., Elymus sp., Dactylis glomerata, Lolium multiflorum, L. temulentum, Muhlenbergia sp., Phleum sp.

Syntomaspis thalassinus Crosby, 1908. Canad. Ent. 40: 43., ,.

Callimome rohweri Huber, 1927. U. S. Natl. Mus., Proc. 70 (14): 58. \&, ठ.

theon (Walker). Fla.

Callimome theon Walker, 1843. Soc. Ent. de France, Ann. 1: 149. ․

Taxonomy: Burks, 1975. Brit. Mus. (Nat. Hist.) Ent., Bul. 32 (4): 153.

thompsoni Fyles. Que. Ecology: From plum fruit.

Torymus Thomsoni Fyles, 1904 (1903). Ent. Soc. Ontario, Ann. Rpt. 34: 10-11..

Torymus thompsoni Fyles, 1916 (1915). Ent. Soc. Ontario, Ann. Rpt. 46: 55. Emend.

tubicola (Osten Sacken). Que., Mass. to N. C. and Ohio, Mo., La., Tex., Colo., N. Mex., Utah, Ariz., Oreg., Calif.; Mexico (Baja California Norte, Nayarit). Host: Acraspis villosa Gill., Amphibolips globulus Beut., A. quercuscitriformis (Ashm.), A quercusinanis (0. S.), A. quercusspongifica (0. S.), Andricus crystallinus Bass., A. kingi Bass., $A$.

quercuscalifornicus (Bass.), $A$. quercusflocci (Walsh), $A$. quercuspetiolicola (Bass.), $A$. reniformis $\mathrm{McC}$. and $\mathrm{Egb}$., Antron dumosae (Kinsey)?, A. quercusechinus (0. $\mathrm{S}$.), $A$. douglasii (Ashm.), Atrusca bella (Bass.), A. congesta (Kinsey), A. simulatrix (Kinsey), $A$. vanescens (Kinsey), Belonocnema kinseyi Weld, Besbicus conspicuus (Kinsey), B. mirabilis (Kinsey), B. multipunctatus (Beut.), Callirhytis congregata (Ashm.), C. quercusoperator (O. S.), C. quercuspomiformis (Bass.), C. quercusventricosa (Bass.), C. seminator (Harr.), C. tubicola (0. S.), Disholcaspis cinerosa (Bass.), D. colorado (Gill.), $D$. corallina (Bass.), D. plumbella Kinsey, D. quercusglobulus (Fitch), D. quercusmamma (Walsh), D. rubens (Gill.), D. simulata Kinsey, D. s. vancouverensis Kinsey, D. terrestris Weld, Dros pedicellatum (Kinsey), Dryocosmus castanopsidis (Beut.), Heteroecus pacificus (Ashm.), Trichoteras vacciniifoliae (Ashm.), Xanthoteras politum (Bass.).

Callimome tubicola Osten Sacken, 1870. Amer. Ent. Soc., Trans. 3: 60. ð。, ?.

Callimome melanocerae Ashmead, 1885. Amer. Ent. Soc., Trans. 12: Proc. p. xiii..+

Callimome citriformi Ashmead, 1885. Amer. Ent. Soc., Trans. 12: Proc. p. xiii. 9.

Syntomaspis citriformis Ashmead, 1887. Amer. Ent. Soc., Trans. 14: 187. Emend.

Callimome castanopsidis Huber, 1927. U. S. Natl. Mus., Proc. 70 (14): 64-65. ๆ, ठ.

Callimome giganticum Huber, 1927. U. S. Natl. Mus., Proc. 70 (14): 65-66., , ठ. 
Callimome gahani Huber, 1927. U. S. Natl. Mus., Proc. 70 (14): 69. , ठ. A questionable synonym.

Callimome rubenidis Huber, 1927. U. S. Natl. Mus., Proc. 70 (14): 78. ๆ, ऽ.

Callimome minutissimum Huber, 1927. U. S. Natl. Mus., Proc. 70 (14): 78-79...

umbilicatus (Gahan). Tex., N. Mex., Utah, Ariz., Oreg., Calif.; Mexico (Chihuahua, Morelos, Puebla, Sonora). Ecology: From flower heads of Viguiera deltoidea and Senecio douglasii. Host: Asphondylia neomexicana (Ckll.), A. sp. bud and flower galls on Clematis drummondii, Lasioptera sp. on Aster spinosus, cedidomyiid galls on Ambrosia sp. (terminal stem), Larrea sp. (stem), Mimulus sp., Schrankia sp. (seed pod gall), Suaeda sp.; tephritid stem gall on Eupatorium adenophorum.

Syntomaspis umbilicata Gahan, 1919. Ent. Soc. Amer., Ann. 12: 163. \&, o .

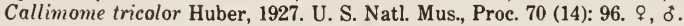

varians (Walker). N. S., Que., Maine, Vt., Conn., Ont., N. Y., Pa., Va., N. C., Ohio, Mich., Man., B. C.; Europe. Ecology: From seeds of apple, Crataegus spp., Malus silvestris, Pyrus spp., Sorbus intermedia, and S. latifolia?

Callimome varians Walker, 1833. Ent. Mag. 1: 122. . .

Torymus druparum Boheman, 1834 (1833). Svensk. Vetensk. Akad., Handl. 54: 361.

Taxonomy: Eady, 1958. Ent. Monthly Mag. 94: 260 (Syntomaspis Foerster). -Olsson, 1957.

Vaxtskyd. 21: 58 (syn.: druparum Boheman).

Biology: Crosby, 1909. N. Y. (Cornell) Agr. Expt. Sta., Bul. 265: 369-375. -Cushman, 1916. Jour. Agr. Res. 7: 487. - Knight, 1922. N. Y. (Cornell) Agr. Expt. Sta., Bul. 410: 490.

-Lathrop, 1936. Maine Agr. Expt. Sta., Bul. 384: 392. - Hammer, 1939. Jour. Econ. Ent. 32: 259-264. - Lathrop and Dirks, 1944. Jour. Econ. Ent. 37: 199-204. - Frost, 1951. Pa.

Agr. Expt. Sta., Bul. 535: 19, 22, 28.

vesiculi Moser. N. Y., s. to Ga., w. to Idaho and Ariz. Host: Pachypsylla celtidismamma Riley, $P$. celtidisvesicula Riley.

Torymus vesiculi Moser, 1956. Kans. Ent. Soc., Jour. 29: 58. ‡, ठ.

Taxonomy: Moser, 1965. N. Y. State Mus., Bul. 402: 21-22, 33-34.

warreni (Cockerell). N. Y., N. C., Tex., Colo., N. Mex., Utah, Ariz., Calif.; Mexico (Baja California Norte). Host: Amphibolips globulus Beut., Antron dumosae (Kinsey), Disholcaspis cinerosa (Bass.), D. colorado (Gill.), D. edura Weld, D. priniformis Kinsey, D. quercusglobulus (Fitch), D. quercusmamma (Walsh), D. rubens (Gill.), D. spongiosa (Karsch).

Syntomaspis warreni Cockerell, 1911. Ent. News 22: 82. ․

Callimome cinerosum Huber, 1927. U. S. Natl. Mus., Proc. 70 (14): 84-85..

xanthopus (Schulz). Kans. Host: Cecidomyiid on cedar.

Megastigmus? flavipes Ashmead, 1888. Kans. Agr. Expt. Sta., Bul. 3: App. p. III. ठ. Preocc. by Walker, 1833.

Megalostigmus xanthopts Schulz, 1906. Spolia Hym., p. 147. N. name.

Torymus abortus Crosby, 1914. Ent. News 25: 27. N. name.

\section{Genus DIOMORUS Walker}

Diomorus Walker, 1834. Ent. Mag. 2: 159.

Type-species: Diomorus nobilis Walker. Monotypic.

Dihomerus Schulz, 1906. Spolia Hym., p. 148. Emend.

viridis (Provancher). Que.

Haltichella viridis Provancher, 1887. Addit. Corr. Faune Ent. Canada Hym., p. 192. $\subsetneq$.

Taxonomy: Burks, 1964 (1963). Canad. Ent. 95: 1259 (prob. = zabriskiei Cresson).

zabriskiei Cresson. N. Y., N. J., W. Va., Kans., B. C., Calif. Host: Crossocerus fergusoni Pate, C. insolens (Fox), Ectemnius lapidarius (Panz.), E. stirpicola (Pack.), E. (Hyprocrabro) pancimaculatus (Pack.), E. (H.) spiniferis (Fox), Euplilis (Corynopus) arapaho Pate, E. (C.) rufigaster (Pack.), Ceratina dupla Say.

Diomoris zabriskii(!) Cresson, 1878. Psyche 2: 189..

Diomorns zabriskiei Peck, 1951. In Muesebeck, et. al., U. S. Dept. Agr., Agr. Monog. 2: 527. Valid emend. 
Biology: Krombein, 1960. Ent. News 71: 32,67. - Krombein, 1964. Biol. Soc. Wash., Proc. 77: 102-103.

\section{Genus PHYSOTHORAX Mayr}

Physothorax Mayr, 1885. Zool.-Bot. Gesell. Wien, Verh. 35: 159, 196.

Type-species: Physothorax disciger Mayr. Desig. by Gahan and Fagan, 1923.

Members of this genus have been reared from the receptacles of figs. As with Idarninae, the exact relationship of wasp to host is not known.

Revision: Burks, 1969. Fla. Ent. 52: 115-119 (Nearctic spp.).

bidentulus Burks. Fla. Host: Ficus altissima?, $F$. aurea, $F$. citrifolia.

Physothorax bidentulus Burks, 1969. Fla. Ent. 52: 118-119. ९, o.

pallidus Ashmead. Fla.; W. Indies. Host: Ficus aurea, F. citrifolia.

Physothorax pallidus Ashmead, 1900. Ent. Soc. London, Trans., p. 254. $\uparrow$, ठ์.

russelli Crawford. Fla. Host: Ficus aurea.

Physothorax russelli Crawford, 1910 (1909). Ent. Soc. Wash., Proc. 11: 204. ․

Taxonomy: Butcher, 1964. Fla. Ent. 47: 237 (fig associates).

\section{SUBFAMILY ERIMERINAE}

By E. E. Grissel,L

Members of this subfamily are parasites of insects in grass stems.

Taxonomy: Breland, 1938. N. Y. Ent. Soc., Jour. 46: 357 (phylogeny).

\section{Genus ERIMERUS Crawford}

Erimerus Crawford, 1914. Ent. Soc. Wash., Proc. 16: 123.

Type-species: Torymus wickhami Ashmead. Orig. desig.

wickhami (Ashmead). Utah. Ecology: From galls on Hilaria (Harmolita)?.

Torymus wickhami Ashmead, 1904. Ent. News 15: 302..

Taxonomy: Crawford, 1914. Ent. Soc. Wash., Proc. 16: 123.

\section{Genus PSEUDERIMERUS Gahan}

Pseuderimerus Gahan, 1919. U. S. Natl. Mus., Proc. 55: 124.

Type-species: Pseuderimerns mayetiolae Gahan. Orig. desig.

Taxonomy: Peck, et al., 1964. Ent. Soc. Canad., Mem. 34: 21 (placed as Monodontomerinae). femoratus Gahan. Calif. Host: Mayetiola destructor (Say).

Pseuderimerus femoratus Gahan, 1934 (1933). U. S. Dept. Agr., Misc. Pub. 174: 32-33.. mayetiolae Gahan. Calif. Host: Mayetiola destructor (Say).

Pseuderimerus mayetiolae Gahan, 1919. U. S. Natl. Mus., Proc. 55: 125. \&, o.

Taxonomy: Hill and Pinckney, 1940. U. S. Dept. Agr., Tech. Bul. 715: 10-13.

Biology: Packard, 1928. U. S. Dept. Agr., Tech. Bul. 81: 14. -Gahan, 1934 (1933). U. S. Dept. Agr., Misc. Pub. 174: 30-32.

semiflavus Gahan. Calif. Host: Mayetiola destructor (Say).

Pseuderimerus semiflavus Gahan, 1934 (1933). U. S. Dept. Agr., Misc. Pub. 174: 33..

\section{SUBFAMILY MONODONTOMERINAE}

By E. E. GrisSEll

The Monodontomerinae are a loose assemblage of taxa not particularly well defined morphologically or biologically. All species are parasitic, with hosts in the Diptera, Hymenoptera, Lepidoptera, and Coleoptera. 
Revision: Crawford, 1914. Ent. Soc. Wash., Proc. 16: 123-124 (key to genera). - Szelenyi, 1957. Mus. Nat. Hungarici, Ann. Hist.-Nat., n. s., 8: 381-388 (key to genera). - Szelenyi, 1960. Acad. Sci. Hungarici, Acta Zool. 5: 141-146 (rev. key to genera).

\section{Genus LIODONTOMERUS Gahan}

Lochites Foerster, 1856. Hym. Stud., v. 2, pp. 43, 44, 120. Preocc. by Lochites Gistl, 1848 (Protozoa).

Type-species: Lochites papaveris Foerster. Monotypic.

Liodontomerus Gahan, 1914. U. S. Natl. Mus., Proc. 48: 159.

Type-species: Liodontomerus perplexus Gahan. Orig. desig.

Lochitisca Ghesquiere, 1946. Rev. de Zool. et de Bot. Africaines 34: 368. N. name for Lochites Foerster.

Members of this genus are parasitic upon Bruchophagus in leguminous seeds.

Taxonomy: Nikol'skaya, 1952. Chalcid fauna of the U. S. S. R. 44: 135 (Holaretic. Eng. transl. 1963). - Burks, in Butler and Hansen, 1958. Pan-Pacific Ent. 34: 224.

Biology: Neunzig and Gyrisco, 1959. Jour. Econ. Ent. 52: 899-901.

insuetus Gahan. Nebr., Kans., Okla., N. Mex., Utah, Ariz., Calif.; Holarctic. Host:

Bruchophagus gibbus (Boh.)?, B. platyptera (Walk.), B. roddi (Guss.).

Liodontomerus insuetus Gahan, 1917. U. S. Natl. Mus., Proc. 53: 208. .

Biology: Butler, et al., 1968. Ariz. Univ. Agr. Exp. Sta., Tech. Bul. 185: 7.

longfellowi (Girault). N. Y., Md., Va., W. Va., Ohio, Mich., Minn., Iowa, S. Dak., Utah, Idaho, Oreg.; Holarctic. Host: Bruchophagus gibbus (Boh.), B. platyptera (Walk.) complex.

Idiomacromerus longfellowi Girault, 1917 (May 14). Descr. Hym. Chalcidoid. Variorum cum Observ. III, p. 8. ९, ठ.

Liodontomerus secundus Gahan, 1917 (May 26). U. S. Natl. Mus., Proc. 53: 208. ๆ, ð.

Biology: Urbahns, 1919. Jour. Agr. Res. 16: 169-170. - Butler and Hansen, 1958. Pan-Pacific Ent. 34: 227.

perplexus Gahan. Iowa, S. Dak., Utah, Ariz., Calif.; Holaretic. Host: Bruchophagus platyptera (Walk.) complex.

Liodontomerus perplexus Gahan, 1914. U. S. Natl. Mus., Proc. 48: 159. ๆ, ठ.

Biology: Urbahns, 1920. U. S. Dept. Agr., Bul. 812: 17-18. - Sorenson, 1930. Utah Agr. Expt. Sta., Bul. 218: 27-32. - Butler, et al., 1968. Ariz. Univ. Agr. Exp. Sta., Tech. Bul. 185: 7-9.

\section{Genus IDIOMACROMERUS Crawford}

Idiomacromerus Crawford, 1914. Ent. Soc. Wash., Proc. 16: 124.

Type-species: Idiomacromerus bimaculipennis Crawford. Orig. desig.

bimaculipennis Crawford, Kans., Utah, Calif. Host: Eurytoma compressa Bugbee, E. seminis Bugbee.

Idiomacromerus bimaculipennis Crawford, 1914. Ent. Soc. Wash., Proc. 16: 124..

\section{Genus PLATYKULA Huber}

Platykula Huber, 1927. U. S. Natl. Mus., Proc. 70 (14): 106.

Type-species: Syntomaspis albihirta Ashmead. Orig. desig.

albihirta (Ashmead). Fla.

Syntomaspis albihirta Ashmead, 1887. Amer. Ent. Soc., Trans. 14: 187. \&.

\section{Genus DIMEROMICRUS Crawford}

Dimeromicrus Crawford, 1910. U. S. Natl. Mus., Proc. 38: 127.

Type-species: Dimeromicrus ashmeadi Crawford. Orig. desig.

cecidomyiae (Ashmead). Fla., Tex. Host: Cecidomyiid on Baccharis halimifolia.

Megastigma(!) cecidomyiae Ashmead, 1887. Amer. Ent. Soc., Trans. 14: 185. ๆ, o.

Lochites auriceps Ashmead, 1894. Linn. Soc. London, Jour., Zool. 25: 153. ๆ, ठ́.

Taxonomy: Milliron, 1949. Amer. Midland Nat. 41: 347. 
smithi (Schread). Conn. Host: Caryomyia sp. gall.

Lochites smithi Schread, 1937. Brooklyn Ent. Soc., Bul. 32: 102. \&, ठ.

\section{Genus MONODONTOMERUS Westwood}

Monodontomerus Westwood, 1833. London, Edinb. and Dublin Phil. Mag. and Jour. (3) 2: 443.

Type-species: Monodontomemus obscurus Westwood. Monotypic.

Paroligosthenus Cameron, 1913 (1912). Indian Forest Rec. 4: 94.

Type-species: Paroligosthenus trichiopthalmus Cameron. Monotypic.

Revision: Gahan, 1941. U. S. Natl. Mus., Proc. 90: 461-482 (Nearctic spp.). - Steffan, 1952.

Paris Mus. d' Hist. Nat., Bul. 24: 288-290 (Europe, N. Africa). - Nikol'skaya, 1952. Chalcid

fauna of the U. S. S. R. 44: 137-140 (Palaearctic. Eng. transl. 1963).

aereus Walker. N. B. ?, New England; India; Holarctic. Host: Archips argyrospilus (Walk.),

Malacosoma americanum (F.), Nygmia phaeorrhoea (Donov.), Orgyia lencostigma (J. E.

Smith), Porthetria dispar (L.); Blepharipa scutellata (R. D.), Carcelia laxifrons Vill., Compsilura concinnata (Meig.), Exorista larvarum (L.), Townsendiellomyia nidicola (Tns.); Apanteles lacteicolor Vier., A. melanoscelus (Ratz.), Iseropus coelebs (Walsh), Meteorus versicolor (Wesm.), Phobocompe unicincta (Grav.).

Monodontomerus aereus Walker, 1834. Ent. Mag. 2: 158..

Taxonomy: Muesebeck, 1931. Jour. Agr. Res. 43: 445-460.

Biology: Howard and Fiske, 1911. U. S. Dept. Agr., Bur. Ent. Bul. 91: 86-308. - Muesebeck and Dohanian, 1927. U. S. Dept. Agr., Bul. 1487: 19-20. - Burgess and Crossman, 1929. U. S. Dept. Agr., Tech. Bul. 86: 77-80. - Proper, 1934. Jour. Agr. Res. 48: 361-376. -Clausen, 1956. U. S. Dept. Agr., Tech. Bul. 1139: 114-116. - Wilbert, 1960. Entomophaga 5: 203.

-Blunck and Wilbert, 1962. Ztschr. f. Angew. Ent. 50: 203.

bakeri Gahan. Colo.

Monodontomerus bakeri Gahan, 1941. U. S. Natl. Mus., Proc. 90: 475. ๆ.

clementi Grissell. Wyo. Host: Dianthidium heterulkei Schwarz.

Monodontomerus clementi Grissell, 1973. Pan-Pacific Ent. 49: 235. \&, o.

dentipes (Dalman). Que., Maine, Conn., Ont., N. Y., N. J., Pa., Ohio, Mich., Wis., Idaho.;

Holarctic. Host: Orgyia pseudotsugata (McD.); Tachinidae; Diprion similis (Htg.),

Gilpinia hercyniae (Htg.), Rogas unicolor (Wesm.).

Torymus dentipes Dalman, 1820. Svenska Vetensk. Akad., Handl. 41: 173, 178. ð,.

Monodontomerus viridaeneus Provancher, 1881. Nat. Canad. 12: 290. ๆ.

Taxonomy: Finlayson, 1960. Canad. Ent. 92: 37, 39, 44 (immature stages).

Biology: Morris, Cameron, and Jepson, 1937. Bul. Ent. Res. 28: 377-380, 389, 391. -Finlayson and Finlayson, 1958. Canad. Ent. 90: 558-559. - Drooz and Fedde, 1972. Environ. Ent. 1: 522-523.

Morphology: Bucher, 1948. Canad. Jour. Res. 26D: 230-281.

dianthidii Gahan. Calif. Host: Dianthidium sp.

Monodontomerus dianthidii Gahan, 1941. U. S. Natl. Mus., Proc. 90: 464. ९, o.

emarginatus Gahan. Colo. Host: Megachile? sp.

Monodontomerus emarginatus Gahan, 1941. U. S. Natl. Mus., Proc. 90: 476. $\subsetneq$.

indiscretus Gahan. Maine. Host: Heterarthrus nemoratus (Fall.).

Monodontomerus indiscretus Gahan, 1941. U. S. Natl. Mus., Proc. 90: 469..+

mandibularis Gahan. N. Y., D. C., Ohio, Ill., Mo., La. Host: Anthophora abrupta Say, A. bomboides Kirby, Melitoma taurea (Say), Osmia cordata Robt.

Monodontomerus mandibularis Gahan, 1941. U. S. Natl. Mus., Proc. 90: 474. $९$, ঠ.

Biology: Rau, 1947. Ent. Soc. Amer., Ann. 40: 221-226.

mexicanus Gahan. Ind., Calif.; Mexico. Host: Trypoxylon (Trypargilum) mexicanum Sauss.,

Parancistrocerus vagus (Sauss.), Ancyloscelis armata Smith.

Monodontomerus mexicanus Gahan, 1941. U. S. Natl. Mus., Proc. 90: 468. ๆ, o.

Biology: Torchio, 1974. Kans. Ent. Soc., Jour. 47: 58. 
minor (Ratzeburg). Conn., N. Y., south to Va., west to Calif.; Europe. Host: Thyridopteryx ephemeraeformis (Haw.), Phryganidia californica Pack., Samia cynthia (Drury), Malacosoma americana (F.), Grapholitha molesta (Busck), Choristoneura fumiferana (Clem.)?; Gambrus extrematis (Cress.). Recorded as hyperparasite of Lepidoptera in European literature.

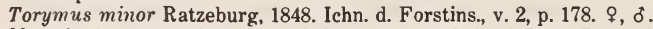

Monodontomerus subobsoletus Gahan, 1941. U. S. Natl. Mus., Proc. 90: 480. ९, ठ.

Taxonomy: Grissell, 1973. Pan-Pacific Ent. 49: 233-234 (figs.).

Biology: Allen, 1962. U. S. Dept. Agr., Tech. Bul. 1265: 102.

montivagus Ashmead. Ont., Del., Ill., Mo., Mont., Colo., N. Mex., Utah, B. C., Calif. Host: Choristoneura fumiferana (Clem.); Anthidium emarginatum (Say), Megachile pacifica (Panzer), Dianthidium pudicum (Cress.), D. pudicum consimile (Ashm.), D. curvatum sayi Ckll., Osmia cordata Robertson, O. texana Cress.; Anthophora abrupta Say, A. linsleyi Timb., A. bomboides neomexicana Ckll., A. occidentalis Cress., Melissodes? sp.; Xylocopa tabaniformis orpifex Smith; Bombus morrisoni Cress.; Ancistrocerus tuberculocephalus (Sauss.).

Monodontomerus montivagus Ashmead, 1890. Colo. Biol. Assoc. Bul. 1: 25, 45.. Monodontomerus americanus Girault, 1917. Descr. Stellarum Nov., p. 11. $\subsetneq$.

Taxonomy: Grissell, 1973. Pan-Pacific Ent. 49: 236.

Biology: Linsley and McSwain, 1942. Amer. Midland Nat. 27: 403, 409-412.

obscurus Westwood. N. Y., Md., Pa., D. C., W. Va., Ga., Mo., Iowa, Idaho; Holaretic. Host: Osmia cordata Robt., O. lignaria Say, Megachile pacifica (Panzer).

Monodontomerus obscurus Westwood, 1833. London, Edinb. and Dublin Phil. Mag. and Jour. Sci. (3) 2: 443 . .

Taxonomy: Steffan, 1952. Paris Mus. d'Hist. Nat., Bul. (2) 24: 289-290. —Eady, 1958. Ent. Monthly Mag. 94: 269.

Biology: Eves, 1970. Melanderia (Wash. State Ent. Soc.) 4: 1-18. -Hobbs and Krunic, 1971. Canad. Ent. 103: 674-685.

Morphology: Radu and Botoc, 1968. Stud. Univ. Babes, Bolyai Ser. Biol. 13: 71-76 (female genitalia).

saltuosus Grissell. N. Mex., Calif. Host: Orgyia pseudotsugata (McD.).

Monodontomerus saltuosus Grissell, 1973. Pan-Pacific Ent. 49: 232-233. ஒ, ठ.

\section{Genus ZAGLYPTONOTUS Crawford}

Zaglyptonotus Crawford, 1914. Ent. Soc. Wash., Proc. 16: 124-125.

Type-species: Zaglyptonotus schwarzi Crawford. Orig. desig.

mississippiensis Breland. Ala., Miss. Host: Neotephritis finalis (Loew).

Zaglyptonotus mississippiensis Breland, 1938. Ent. Soc. Amer., Ann. 31: 205. ९, ठ.

schwarzi Crawford. Fla., Kans., Tex., Colo., Idaho. Host: Desmoris fulvus (Lec.)?; Isophrictis similiella (Chamb.); tephritid seed maggot from ironweed.

Zaglyptonotus schwarzi Crawford, 1914. Ent. Soc. Wash., Proc. 16: 126..

Biology: Brandhorst, 1943. Kans. Acad. Sci., Trans. 46: 168. - Needham, 1948. Ecol. Monog. 18: 446.

\section{Genus GLYPHOMERUS Foerster}

Glyphomerus Foerster, 1856. Hym. Stud., v. 2, pp. 43, 44, 145.

Type-species: Ichneumon stigma Fabricius. Orig. desig.

Oligosthenus Foerster, 1856. Hym. Stud., v. 2, p. 145. Unnecessary n. name.

Taxonomy: Boucek, 1970. R. Lab. Ent. Agr. Portici, Bol. 27: 28-32 (Palearctic spp.).

stigma (Fabricius). Que. to Fla., Oreg., Calif.; Europe, Japan. Host: Diplolepis rosae (L.);

Melitoma taurea (Say).

Ichneumon stigma Fabricius, 1793. Ent. System. v. 2, p. 188. 
Oligosthenus bimaculatus Provancher, 1887. Addit. Corr. Faune Ent. Canada Hym., p. 196. i.

Taxonomy: Ashmead, 1887. Amer. Ent. Soc., Trans. 14: 186.

\section{Genus ERIDONTOMERUS Crawford}

Eridontomerus Crawford, 1907. N. Y. Ent. Soc., Jour. 15: 178-179.

Type-species: Eridontomerns primus Crawford. Orig. desig.

isosomatis (Riley). N. Y. and Mich. to Tenn., Utah, Ariz. Host: Mayetiola destructor (Say); Harmolita albomaculata (Ashm.), H. linearis (Walk.), H. longula (Dalm.), H. festucae P. and E., H. grandis (Riley), H. hordei (Harris), H. maculata (How.), H. secale (Fitch), $H$. tritici (Fitch), H. vaginicola (Doane), H. websteri (How.).

Stictonotus isosomatis Riley, 1882. U. S. Dept. Agr., Ann. Rpt. for 1881-1882, p. 186. + , o. Eridontomerus primus Crawford, 1907. N. Y. Ent. Soc., Jour. 15: 179. ๆ, ठ.

Taxonomy: Gahan, 1921 (1920). Ent. Soc. Wash., Proc. 22: 235.

Biology: Phillips and Poos, 1927. Jour. Agr. Res. 34: 483-488. -Knowlton and Janes, 1933.

Utah Agr. Expt. Sta., Bul. 243: 11-12.

\section{Genus PSEUDOTORYMUS Masi}

Holaspis Mayr, 1874. Zool.-Bot. Gesell. Wien, Verh. 24: 83. Preocc. by Lankester, 1873 (Pisces).

Type-species: Torymus militaris Boheman. Desig. by Ashmead, 1904.

Pseudotorymus Masi, 1922. Genova Mus. Civ. Stor. Nat., Ann. 49: 235. N. name for Holaspis Mayr.

lazulellus (Ashmead). N. B., Que., Conn., w. to Colo. Ecology: From clover heads; oak galls. Host: Harmolita sp. in rye stems, $H$. sp. in timothy stems.

Syntomaspis lazulella Ashmead, 1890. Colo. Biol. Assoc., Bul. 1: 26, 45. ?.

Biology: Webster, 1906 (1905). Ent. Soc. Wash., Proc. 7: 116.

\section{Genus CRYPTOPRISTUS Foerster}

Cryptopristus Foerster, 1856. Hym. Stud., v. 2, pp. 43, 44.

Type-species: Torymus caliginosus Walker. Monotypic.

Websterellus Ashmead, 1893. Ohio Agr. Exp. Sta., Tech. Ser., Bul. 1 (3): 164.

Type-species: Websterellus tritici Ashmead. Monotypic.

harrisii (Fitch). N. Y., Va., Ohio, Ky., Kans. Host: Harmolita grandis (Riley), H. hordei

(Harris)?, H. tritici (Fitch).

Torymus Harrisii Fitch, 1862 (1861). N. Y. State Agr. Soc., Trans. 21: 152. \&, ð.

Websterellus tritici Ashmead, 1893. Ohio Agr. Expt. Sta., Tech. Ser., Bul. 1 (3): 164. \&, ð.

Cryptopristus americanus Girault, 1917. Descr. Stellarum Nov., p. 8..

Biology: Webster, 1893. U. S. Dept. Agr., Insect Life 6: 151. - Gahan, 1921 (1920). Ent. Soc.

Wash., Proc. 22: 237.

\section{Genus DITROPINOTUS Crawford}

Ditropinotus Crawford, 1907. N. Y. Ent. Soc., Jour. 15: 178.

Type-species: Ditropinotus aureoviridis Crawford. Orig. desig.

aureoviridis Crawford. N. Y. to Ala. and Kans., Utah, Oreg. Host: Mayetiola destructor (Say);

Eurytoma parva Phillips, Harmolita linearis (Wlkr.), H. elymicola P. and E., H. grandis

(Riley), H. secale (Fitch), H. tritici (Fitch), H. vaginicola (Doane), Eurytoma spp.,

Merisoporus chalcidiphagus (W. and R.).

Ditropinotus aureoviridis Crawford, 1907. N. Y. Ent. Soc., Jour. 15: 178. ๆ, ठ.

Ditropinotus flavicoxus Gahan, 1912. Ent. Soc. Wash., Proc. 14: 5. \&, ठ.

Taxonomy: Gahan, 1934 (1933). U. S. Dept. Agr., Misc. Pub. 174: 25-30.

Biology: Hill, Pinckney, and Udine, 1939. U. S. Dept. Agr., Tech. Bul. 689: 5, 10, 13.

-Chamberlain, 1941. U. S. Dept. Agr., Tech. Bul. 784: 25-28, 35-38. 
Morphology: Hill and Pinckney, 1940. U. S. Dept. Agr., Tech. Bul. 715: 6, 11-13.

\section{Genus ANTISTROPHOPLEX Crawford}

Antistrophoplex Crawford, 1914. Ent. Soc. Wash., Proc. 16: 122-125.

Type-species: Antistrophoplex bicoloripes Crawford. Orig. desig.

bicoloripes Crawford. Iowa, Kans. Host: Antistrophus lygodesmiaepisum Walsh on Lygodesmia.

Antistrophoplex bicoloripes Crawford, 1914. Ent. Soc. Wash., Proc. 16: 125..

Biology: Brandhorst, 1964. Ent. Soc. Amer., Ann. 57: 74-77.

\section{Genus MICRODONTOMERUS Crawford}

Microdontomerus Crawford, 1907. N. Y. Ent. Soc., Jour. 15: 178, 179.

Type-species: Torymus anthonomi Crawford. Orig. desig.

anthidii (Ashmead). Calif. Host: Dianthidium pudicum consimile (Ashm.).

Torymus anthidii Ashmead, 1896. Ent. News 7: 24. ㅇ.

anthonomi (Crawford). N. J., Va., S. C., Mo., La., Tex., Utah, Idaho, Wash., Oreg. Host: Acanthoscelides homi (Pic), Bruchus brachialis Fahr., B. pisomim (L.), Brachytarsoides alternatus (Say), Anthonomus grandis Boh.; Ancylis comptana fragariae (W. and R.), Coleophora malivorella Riley; Bracon mellitor Say, Leptochilus sp.

Torymus anthonomi Crawford, 1907. Canad. Ent. 39: 133. \&, ठ.

Taxonomy: Pierce, Cushman, and Hood, 1912. U. S. Dept. Agr. Bur. Ent., Bul. 100: 1, 31, 49, 57-62.

fumipennis Crawford. Wyo., s. to N. Mex., w. to Pacific Coast. Host: Malacosoma califormicum (Pack.), M. fragile Stretch, Choristoneura rosaceana (Harr.).

Microdontomerns fumipennis Crawford, 1917 (1916). Insecutor Inscitiae Menstruus 4: 141-142. ㅇ, ठ.

Biology: Langston, 1957. Calif. Univ. Pubs., Ent. 14: 29-30.

\section{Genus ROPTROCERUS Ratzeburg}

Pachyceras Ratzeburg, 1844. Ichn. d. Forstins., v. 1, p. 217. Suppressed by Internatl. Comn. Zool. Nomencl., 1957, Opinion 437, pp. 25-40.

Type-species: Pachyceras xylophagorum Ratzeburg. Autobasic.

Roptrocerus Ratzeburg, 1848. Ichn. d. Forstins., v. 2, p. 209. Unnecessary n. name for Pachyceras thought to be preocc. by Pachycerus Gyllenhall, 1826. Validated by Internatl. Comn. Zool. Nomencl., 1957 (Opinion 437).

Type-species: Pachyceras xylophagorum Ratzeburg. Desig. by Ashmead, 1904.

Rhoptroceris Dalla Torre, 1898. Cat. Hym., v. 5, p. 98. Emend.

Taxonomy: Hedqvist, 1963. Studia. Forest. Suecica 11: $61-70$ (Palearctic spp.).

xylophagorum (Ratzeburg). Que. and N. H. to N. C. and La., w. to B. C., Wash., and Ariz. Host: Orthotomicus caelatus (Eichh.), Phloeosinus dentatus (Say)?, Polygraphus rufipennis (Kby.), Scolytus mugulosus (Ratz.), Dendroctonus frontalis Zimm., D. monticolae Hopk., D. psendotsugae Hopk., Ips calligraphus (Germ.), I. grandicollis (Eich.)?, I. pini (Say).

Pachyceras Xylophagorum Ratzeburg, 1844. Ichn. d. Forstins., v. 1, p. 218. 9.

Pachyceras Eccoptogastri Ratzeburg, 1844. Ichn. d. Forstins., v. 1, p. 218..

Roptrocerus rectus Provancher, 1887. Addit. Corr. Faune Ent. Canada. Hym., p. 202. $\subsetneq$. Platygerrhus(?) scolyti Ashmead, 1894. Amer. Ent. Soc., Trans. 21: 335. “o" = ठ.

Taxonomy: Hedqvist, 1963. Studia. Forest. Suecica 11: 66-70. -Burks, 1964 (1963). Canad. Ent. 95: 1261.

Biology: Evenden, 1943. U. S. Dept. Agr., Cir. 664: 17. —Reid, 1957. Canad. Ent. 89: 6-7. -Berisford et al., 1970. Canad. Ent. 102: 489. 


\section{SubFamily MEGASTIGMINAE}

By E. E. Grissell

\section{Genus MEGASTIGMUS Dalman}

Megastigmus Dalman, 1820. Svenska Vetensk. Akad., Handl. 41: 178.

Type-species: Pteromalus bipunctatus Swederus. Desig. by Crosby, 1913.

Trogocarpus Rondani, 1877. Soc. Ent. Ital., Bol. 9: 204.

Type-species: Torymus ballestrerii Rondani. Monotypic.

Megalostigmus Schulz, 1906. Spolia Hym., p. 147. Emend.

Xanthosomoides Girault, 1913. Canad. Ent. 45: 220.

Type-species: Xanthosomoides maculatipennis Girault. Orig. desig.

Epimegastigmus Girault, 1915. Queensland Mus., Mem. 4: 297, 307.

Type-species: Xanthosomoides fulvipes Girault. Orig. desig.

Nearctic species of this genus are phytophagous in rosaceous and coniferous seeds. Some European species are reported to be parasitic on Cynipidae.

Revision: Milliron, 1949. Amer. Midland Nat. 41: 257-420 (Nearctic spp.). -Boucek, 1970.

Ent. Gaz. 21: 265-275 (west European spp.).

Biology: Lessmann, 1962. Ztschr. f. Angew. Ent. 49: 363-371 (immature stages). - Lessmann, 1962. Ztschr. f. Angew. Ent. 50: 233-241 (host plants).

aculeatus aculeatus (Swederus). Mass., N. Y., N. C., Ohio, Ill.; Europe, Iran, Japan, China.

Host: Rosa canina, $R$. eglanteria, $R$. virginiana, $R$. palustris?

Pteromalus Aculeatus Swederus, 1795. Svenska Vetensk. Akad., Handl. 16: 221-222. ․

Taxonomy: Balduf, 1957. Ent. Soc. Amer., Ann. 50: 479-483. -Balduf, 1959. Ill. Biol. Monog.

26: 124-130 (also biology).

aculeatus nigroflavus Hoffmeyer. N. J. and Pa., south to Va., west to Ill.; Japan, Russia. Host: $R o s a$ eglanteria, $R$. gallica, $R$. multiflora, $R$. virginiana.

Megastigmus aculeatus var. nigroflavus Hoffmeyer, 1931. Ent. Meddel. 16: 324-326. $\uparrow, ~ \delta$.

Biology: Balduf, 1969. Ill. Biol. Monog. 26: 124-126.

albifrons Walker. Ariz., Calif. Host: Pinus ponderosa.

Megastigmus albifrons Walker, 1869. Roy. Ent. Soc. London, Trans., p. 314. ठ.

Taxonomy: Burks, 1975. Brit. Mus. (Nat. Hist.) Ent., Bul. 32 (4): 151.

Biology: Keen, 1958. U. S. Dept. Agr., Tech. Bul. 1169: 102-105.

amelanchieris Cushman. N. H., Vt., N. Y., Pa., W. Va., Minn. Host: Amelanchier canadensis,

A. laevis X humilis, A. sanguinea, Sorbus aucuparia.

Megastigmus amelanchieris Cushman, 1918 (1917). Ent. Soc. Wash., Proc. 19: 81. ‡, ð.

Biology: Milliron, 1949. Amer. Midland Nat. 41: 363.

americanus Milliron. N. H., Ont., N. Y. Host: Sorbus aucuparia?

Megastigmus slossonae Crosby, 1913. Ent. Soc. Amer., Ann. 6: 157. + . Nomen nudum.

Megastigmus americanus Milliron, 1949. Amer. Midland Nat. 41: 285, 347, 349, 365. ๆ, ठ.

Taxonomy: Gahan, 1951. Canad. Ent. 83: 172.

atedius atedius Walker. Ont., Colo., Calif.; Europe. Host: Picea engelmannii?, $P$. pungens, $P$. sitchensis; Abies arizonica?. Introduced into Europe from No. America.

Megastigmus Atedius Walker, 1851. Ann. and Mag. Nat. Hist. 7: 214. ९.

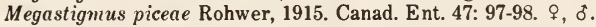

Megastigmus zwolferi Scheffer-Immel, 1957. Ztschr. f. Angew. Ent. 41: 52-57. ๆ, §.

Taxonomy: Boucek, 1970. Ent. Gaz. 21: 265-267 (synonymy).

Biology: Keen, 1958. U. S. Dept. Agr., Tech. Bul. 1169: 106. - Hedlin, 1973. Canad. Ent. 105: 118.

atedius montana Milliron. Mont. Host: Picea engelmannii.

Megastigmus piceae var. montana Milliron, 1949. Amer. Midland Nat. 41: 305, 347, 352., ¿. 
Biology: Keen, 1958. U. S. Dept. Agr., Tech. Bul. 1169: 106.

brevicaudis Ratzeburg. Minn. Host: Sorbus ancuparia.

Megastigmus brevicaudis Ratzeburg, 1852. Ichn. d. Forstins., v. 3, p. 225. .

Biology: Milliron, 1949. Amer. Midland Nat. 41: 363-365, 393, 402.

caperatus Milliron. Ont. Host: Picea? sp.

Megastigmus caperatus Milliron, 1949. Amer. Midland Nat. 41: 306, 347, 350. .

flavipes Ashmead. Fla.

Megastigmus flavipes Ashmead, 1886. Amer. Ent. Soc., Trans. 13: 128. ð.

floridanus Milliron. Fla.

Megastigmus floridanus Milliron, 1949. Amer. Midland Nat. 41: 342, 348, 350..

formosus Milliron. Que., Ont. Host: Crataegus? sp., Rasa? sp.

Megastigmus formosus Milliron, 1949. Amer. Midland Nat. 41: 339, 348, 350. $\$$.

gahani Milliron. Minn., Mo., Colo. Host: Physacarpus apulifolius var. intermedius, $P$. opulifolius var. luteus?

Megastigmus gahani Milliron, 1949. Amer. Midland Nat. 41: 275, 347, 351, 365. \&, o.

hoffmeyeri Walley. Que., Ont., N. Y. Host: Abies amabilis?; Tsuga canadensis.

Megastigmus spermotrophus var. canadensis Hoffmeyer, 1930. Ent. Meddel. 17: 218. $\uparrow$, o. Preocc. by Ashmead, 1887.

Megastigmus spermatrophus var. haffmeyeri Walley, 1932. Canad. Ent. 64: 188. N. name.

laricis Marcovitch. N. Y. Host: Larix laricina.

Megastigmus laricis Marcovitch, 1914. Canad. Ent. 46: 435. + , ठ.

lasiocarpae Crosby. Colo., Alta., B. C., Wash. Host: Abies amabilis, A. lasiocarpa.

Megastigmus lasiocarpae Crosby, 1913. Ent. Soc. Amer., Ann. 6: 163. ๆ, ð.

Biology: Keen, 1958. U. S. Dept. Agr., Tech. Bul. 1169: 105.

melanus Milliron. Mich.?

Megastigmus melanus Milliron, 1949. Amer. Midland Nat. 41: 302, 347, 351.. .

milleri Milliron. B. C., Calif. Host: Abies grandis, A. magnifica var. shastensis.

Megastigmus milleri Milliron, 1949. Amer. Midland Nat. 41: 323, 344, 347, 352. \&, o.

Taxonomy: Hussey and Klingler, 1954. Ent. Monthly Mag. 90: 198-201.

Biology: Keen, 1958. U. S. Dept. Agr., Tech. Bul. 1169: 106.

nigrovariegatus Ashmead. N. S. to Va., w. to Alaska, Calif. Host: Rosa acicularis, $R$.

acicularis var. engelmannii, $R$. arkansana, $R$. blanda, $R$. californica, $R$. canina, $R$. carolina, $R$. eglanteria, $R$. lunelli, $R$. macounii, $R$. palustris, $R$. pyrifera, $R$. migosa, $R$. setigera, $R$. spaldingii, $R$. spinosissima, $R$. suffulta, $R$. ultramantana, $R$. virginiana, $R$. woodsii, $R$. xanthina.

Megastigmus nigrovariegatus Ashmead, 1890. Colo. Biol. Assoc., Bul. 1: 26, 45..

Taxonomy: Balduf, 1945. Ent. Soc. Wash., Proc. 47: 185-198. - Milliron, 1949. Amer. Midland

Nat. 41: 373-390. - Balduf, 1957. Ent. Soc. Amer., Ann. 50: 478-483. - Balduf, 1959. Ill.

Biol. Monog. 26: 130-145. -Boucek, 1971. Ent. Gaz. 22: 43-46.

physocarpi Crosby. Que., Ont., Mich., Ind., Minn., Mo., Idaho. Host: Physacarpus opulifolius, $P$. opulifolins var. intermedius.

Megastigmus physacarpi Crosby, 1913. Ent. Soc. Amer., Ann. 6: 158. \&, o.

Biology: Milliron, 1949. Amer. Midland Nat. 41: 365-366.

pinus marginatus Hoffmeyer. Oreg. Host: Abies grandis.

Megastigmus pinus var. marginatus Hoffmeyer, 1930. Ent. Meddel. 17: 216. ơ.

pinus pinus Parfitt. Conn., Colo., Wash., Oreg., Nev., Calif.; Scotland. Host: Abies amabilis, A. cancolar, A. grandis, A. lasiocarpa, A. magnifica, A. magnifica var. shastensis, $A$. nobilis, A. venusta, Picea sitchensis?, Thuja plicata?

Megastigmus Pinus Parfitt, 1857. Zoologist 15: 5543. \&.

Megastigmus pinus var. crosbyi Hoffmeyer, 1930. Ent. Meddel. 17: 215. \&.

Biology: Laidlaw, 1931. Scot. Forestry Jour. 45: 179-184. - Hussey and Klingler, 1954. Ent. Monthly Mag. 90: 198-201 (pinus Parfitt and var. crosbyi Hoffmeyer). - Keen, 1958. U. S.

Dept. Agr., Tech. Bul. 1169: 106-108. - Hussey, 1959. Ent. Monthly Mag. 95: 237. 
rafni Hoffmeyer. Colo., N. Mex., Idaho, B. C., Oreg., Calif. Host: Abies concolor, A. grandis, A. magnifica, A. magnifica var. shastensis, Pseudotsuga taxifolia?

Megastigmus rafni Hoffmeyer, 1928. Ent. Meddel. 16: 331. ؟.

Taxonomy: Hoffmeyer, 1930. Ent. Meddel. 17: 216-217.

Biology: Keen, 1958. U. S. Dept. Agr., Tech. Bul, 1169: 108-110.

specularis Walley. N. B., N. H., Mass?, Conn.?, Minn., Man., Sask. Host: Abies balsamea.

Megastigmus specularis Walley, 1932. Canad. Ent. 64: 187. ․ ऽ.

Megastigmus groenblomi Kangas, 1945. Ann. Ent. Fenn. 11: 177-183. \&, ð.

Taxonomy: Boucek, 1970. Ent. Gaz. 21: 267-268 (synonymy).

Biology: Hedlin, 1957 (1956). Canad. Ent. 88: 691-697. -Annila, 1970. Ann. Ent. Fenn. 36:

186-190 (European hosts).

spermotrophus nigrodorsatus Milliron. Calif. Host: Pseudotsuga macrocarpa.

Megastigmus spermotrophus var. nigrodorsatus Milliron, 1949. Amer. Midland Nat. 41:

$316,346,353$. ค, ठ.

Biology: Keen, 1958. U. S. Dept. Agr., Tech. Bul. 1169: 111.

spermotrophus spermotrophus Wachtl. Colo., N. Mex., B. C., Wash., Oreg., Calif.; Scotland, Germany, New Zeal. Host: Pseudotsuga taxifolia, P. menziesii; Abies? spp.

Megastigmus spermotrophus Wachtl, 1893. Wien. Ent. Ztg. 12: 25. ^, ठ。.

Megastigmus spermatotrophus Dalla Torre, 1898. Cat. Hym., v. 5, p. 287. Emend.

Biology: Crosby, 1909. N. Y. (Cornell) Agr. Expt. Sta., Bul. 265: 379-380. -Miller, 1916. Jour. Agr. Res. 6: 65-68. - Milliron, 1949. Amer. Midland Nat. 41: 367-368, 390-391. - Hussey, 1955. Roy. Ent. Soc. London, Trans. 106: 133-151. - Hedlin, 1958. Ent. Soc. B. C., Proc. 55: 37. - Keen, 1958. U. S. Dept. Agr., Tech. Bul. 1169: 110-111. - Hussey, 1959. Ent.

Monthly Mag. 95: 237.

tsugae heterophyllae Milliron. B. C. Host: Tsuga heterophylla.

Megastignu tsugae var. heterophyllae Milliron, 1949. Amer. Midland Nat. 41: 309, 347, 353. $\uparrow, \delta$.

Biology: Keen, 1958. U. S. Dept. Agr., Tech. Bul. 1169: 111.

tsugae tsugae Crosby. Western U. S. Host: Abies amabilis?, Tsuga mertensiana.

Megastigmus tsugae Crosby, 1913. Ent. Soc. Amer., Ann. 6: 162..+

Biology: Keen, 1958. U. S. Dept. Agr., Tech. Bul. 1169: 111.

\section{Genus EUMEGASTIGMUS Hussey}

Eumegastigmus Hussey, 1956. Roy. Ent. Soc. London, Proc., Ser. B: Taxonomy 25: 157. Type-species: Eumegastigmus hypogea Hussey. Orig. desig.

transvaalensis Hussey. Calif.; S. Africa, Canary Isls. Host: Schinus molle seeds.

Eumegastigmus transvaalensis Hussey, 1956. Roy. Ent. Soc. London, Proc., Ser. B:

Taxonomy 25: 161. ๆ, ठ́.

Biology: Harper and Lockwood, 1961. Calif. Dept. Agr., Bul. 50: 129.

\section{SUBFAMILY PODAGRIONINAE}

By E. E. GrISSELL

Members of this subfamily are parasitic in mantid egg cases.

Taxonomy: Ferriere, 1955. Soc. Roy. Ent. de Belg., Mem. 27: 207. -Burks, 1958. In

Krombein, et al., U. S. Dept. Agr., Agr. Monog. 2, Sup. 1: 82. - Habu, 1962. Faun. Jap.,

Chalcid., Leucospid., Podagrionid., p. 178.

\section{Genus PODAGRION Spinola}

Podagrion Spinola, 1811. Paris Mus. d'Hist. Nat., Ann. 17: 147.

Type-species: Podagrion splendens Spinola. Monotypic.

Palmon Dalman, 1825. Svenska Vetensk. Akad., Handl. 56: 388. 
Type-species: Palmon bellator Dalman. Desig. by Gahan and Fagan, 1923.

Priomerus Walker, 1833. Ent. Mag. 1: 116, 118.

Type-species: Priomerus pachymerus Walker. Monotypic.

Pachytomus Westwood, 1847. Ent. Soc. London, Trans. 4: 260.

Type-species: Pachytomus klugianus Westwood. Monotypic.

Notopodion Dahlbom, 1857. Ofvers. Svenska Vetensk. Akad., Forh. 14: 295.

Type-species: Podagrion splendens Spinola. Desig. by Gahan and Fagan, 1923.

Bactyrischion Costa, 1857. Accad. della Sci. Fis. e Mat. Napoli, Mem. (A) 2: 223.

Type-species: Bactyrischion bicoloratum Costa. Monotypic.

Blephonira Holmgren, 1868. Eug. Resa, Zool., 6, Ins. 1: 438.

Type-species: Blephonira fulvipes Holmgren. Monotypic.

Cyanostola Saussure, 1890. In Grandidier, Hist. Madagascar 20, Hym. 1, pl. 15, fig. 30.

Type-species: Cyanostola coerulea Saussure. Monotypic.

Notopodinm Schulz, 1906. Spolia Hym., p. 144. Emend.

Podagrium Schulz, 1906. Spolia Hym., p. 150. Emend.

Podagrionella Girault, 1913. Arch. f. Naturgesch. 79 (A) pt. 6: 96.

Type-species: Podagrionella bella Girault. Monotypic.

Pachytomoidella Girault, 1913. Wis. Nat. Hist. Soc., Bul. 11: 40.

Type-species: Pachytomoidella magniclavus Girault. Orig. desig.

Propodagrion Girault, 1915. Queensland Mus., Mem. 4: 287.

Type-species: Propodagrion worcesteri Girault. Orig. desig.

Propachytomoides Girault, 1917. Insecutor Inscitiae Menstruus 5: 152.

Type-species: Propachytomoides semialbiclavus Girault. Orig. desig.

Taxonomy: Ferriere, 1955. Soc. Roy. Ent. de Belg., Mem. 27: 216.

brasiliense Howard. Fla.; W. Indies. Host: Mantid egg mass.

Podagrion brasiliensis Howard, 1894. Linn. Soc. London, Jour., Zool. 25: 83..

Taxonomy: Gahan, 1951. Canad. Ent. 83: 176.

crassiclava Gahan, Fla., Tex., Ariz.; Mexico. Host: Mantis sp., Stagmomantis limbata (Hahn).

Podagrion crassiclava Gahan, 1922. U. S. Natl. Mus., Proc. 61 (24): 6. ९, ठै.

mantidiphagum Girault. Ariz.; Mexico, W. Indies. Host: Egg mass of undet. mantid.

Podagrion mantidiphagnm Girault, 9117. Entomologist 50: 37.,$+ \delta$.

mantis Ashmead. N. J. to Fla., w. to Mo., La., Kans., Tex., Ariz., Calif.; Mexico, Hawaii. Host:

Stagmomantis carolina (Johan.), S. limbata (Hahn)?, Tenodera angustipennis Sauss., T. aridifolia sinensis Sauss.

Podagrion mantis Ashmead, 1886. Canad. Ent. 18: 57. $\uparrow$.

Biology: Breland, 1941. Ent. Soc. Amer., Ann. 34: 99-133. -Gurney, 1959. Ent. Soc. Wash.,

Proc. 61: 23.

\section{UNPLACED TAXA OF TORYMINAE}

By E. E. Grissell.

Diomorus biorhizae Ashmead, 1887. Amer. Ent. Soc., Trans. 14: 186. + . Ont. Host: Xanthoteras quercusforticome (Walsh).

Taxonomy: Burks, 1967. In Krombein, et al., U. S. Dept. Agr., Agr. Monog. 2, Sup. 2: 250

(Probably a species of Torymus; type apparently lost).

Lochites punctata Ashmead, 1887. Amer. Ent. Soc., Trans. 14: 185. ठ. Fla.

\section{Family PTEROMALIDAE}

By B. D. Burks

This is the largest and most difficult family of the Chalcidoidea. Almost all species are parasitic, but a very few are gall formers, a few are phytophagous, and some others should be considered to be predaceous. The latter feed, as larvae, on a succession of eggs or larvae of their prey, while enclosed within stems of grasses or other herbaceous plants. 
Revision: Kurdjumov, 1913. Ent. Obozr. 13: 1-24 (genera), -Graham, 1969. Brit. Mus. (Nat. Hist.) Ent., Bul. Sup. 16: 1-908 (British and North Western European species, with numerous North American forms considered).

Taxonomy: Ashmead, 1904. Carnegie Mus., Mem. 1: 270-285, 311-334. -Girault, 1913-1915. Queensland Mus., Mem. 2: 303-334; 3: 313-346; 4: 185-202. - Boucek, 1957. In Kratochvil, Klic. Zvireny CSR, v. 2, pp. 220-242 (Eng. transl., 1964.. Ent. Soc. Canada, Mem. 34: 26-58). -Riek, 1970. In CSIRO, Ins. Australia, pp. 920-923.

\section{SUBFAMILY ORMYRINAE}

\section{Genus MONOBAEUS Foerster}

Monobaeus Foerster, 1860. Naturh. Ver. Rheinlande, Verh. 17: 95.

Type-species: Monobaeus cingulatus Foerster. Desig. by Ashmead, 1904.

hegeli Girault. Mich.

Monobaeus hegeli Girault, 1917. Ent. News 28: 106. ․

\section{Genus ORMYRUS Westwood}

Ormyrus Westwood, 1832. London, Edinb. and Dublin Phil. Mag. and Jour. Sei. (3) 1: 127. Type-species: Ormyrus punctiger Westwood. Monotypic.

Periglyphus Boheman, 1833. Svenska Vetensk. Akad., Handl. 54: 378.

Type-species: Periglyphus gastris Boheman. Monotypic.

Siphonura Nees, 1834. Hym. Ichn. Aff. Monog., v. 2, p. 81.

Type-species: Siphonura variolosa Nees. Desig. by Gahan and Fagan, 1923.

Cyrtosoma Perris, 1840. Soc. Ent. de France, Ann. 9: 96.

Type-species: Cyrtosoma papaveris Perris. Monotypic.

Wania Risbec, 1951. Inst. Franc. d'Afr. Noire, Mem. 13: 294.

Type-species: Wania ornata Risbec. Monotypic.

brunneipes Provancher. Que., Ont., s. to Fla., w. to Mich. and Ill. Ecology: Emerges from bud galls of Acraspis erinacei (Beut.) on Quercus alba; from twig galls of Callirhytis quercusventricosa (Bass.), Disholcaspis bassetti (Gil.), and D. quercusmamma (Walsh) on Quercus spp.; from stem galls of Aulacidea podagrae (Bass.) on Lactuca sp.; from stem galls of Diastrophus nebulosus (O. S.) on Rubus sp.

Ormyrus brinneipes Provancher, 1887 (May). Addit. Corr. Faune Ent. Canada Hym., p. 198. ㅇ. .

Ormyrus ventricosus Ashmead, 1887 (Nov.). Amer. Ent. Soc., Trans. 14: 189. ठ。.

Taxonomy: Burks, 1964 (1963). Canad. Ent. 95: 1259 (syn.).

Biology: Triggerson, 1914. Ent. Soc. Amer., Ann. 7: 8-9.

distinctus Fullaway. Calif. Ecology: Emerges from twig or stem gall made by Disholcaspis simulata Kins. on Quercus dumosa.

Ormymis distinctus Fullaway, 1912. N. Y. Ent. Soc., Jour. 20: 276..

dryorhizoxeni Ashmead. Fla. Ecology: Emerges from fig-shaped root gall of Belonocnema treatae Mayr on Quercus virginiana.

Ormyrus dryorhizoxeni Ashmead, 1885. Amer. Ent. Soc., Trans. 12: Proc. p. xiv. $\$$.

labotus Walker. Fla. Ecology: Emerges from twig galls made by Callirhytis difficilis (Ashm.) and Disholcaspis quercusvirens (Ashm.) on Quercus.

Ormyrus labotus Walker, 1843. Soc. Ent. de France, Ann. (2) 1: 148. \&, o.

Ormyrus andricus Ashmead, 1886. Amer. Ent. Soc., Trans. 13: 128. $\%$.

Taxonomy: Burks, 1975. Brit. Mus. (Nat. Hist.) Ent., Bul. 32: 153 (syn.; lectotype designated). minutus Ashmead. N. J., Fla., Mich. Ecology: Emerges from leaf petiole gall of Neuroterus noxiosus (Bass.) on Quercus spp.

Ormyrus minutus Ashmead, 1887. Amer. Ent. Soc., Trans. 14: 189., , ठ.

quercipilulae (Fitch). Maine, N. Y., N. J. Ecology: Emerges from oak leaf gall of Acraspis pezomachoides (0.S.).

Pteromalus Querci-pilulae Fitch, 1859 (1858). N. Y. State Agr. Soc., Trans. 18: 819. 
quercus Ashmead. Fla. Ecology: Emerges from twig gall of Callirhytis quercusbatatoides

(Ashm.) on Quercus virginiana.

Ormyrus quercus Ashmead, 1886. Amer. Ent. Soc., Trans. 14: 128. \&, ð.

rosae Ashmead. N. J., s. to Fla., w. to Kans., and Colo. Ecology: Emerges from leaf gall of

Diplolepis ignota (0. S.) on Rosa.

Ormyrus rosae Ashmead, 1885. Amer. Ent. Soc., Trans. 12: Proc. p. xiv. ?.

thymus Girault. Calif.

Ormyrus thymus Girault, 1917. Brooklyn Ent. Soc., Bul. 12: 87..+

unifasciatipennis Girault. Calif.

Ormyrus unfasciatipennis(!) Girault, 1917. Brooklyn Ent. Soc., Bul. 12: 87..

unimaculatipennis Girault. La.

Ormyrus unimaculatipennis Girault, 1916. Canad. Ent. 48: 342..+

vacciniicola Ashmead. Maine, Ont., s. to N. C. Ecology: Emerges from stem gall of Hemadas nubilipennis (Ashm.) on Vaccinium.

Ormyrus vacciniicola Ashmead, 1887. Amer. Ent. Soc., Trans. 14: 189..

Biology: Driggers, 1927. N. Y. Ent. Soc., Jour. 35: 254-258. - McAlister and Anderson, 1932.

Jour. Econ. Ent. 25: 1165-1169. -Judd, 1959. Amer. Micros. Soc., Trans. 78: 213-214.

\section{SUbFamily PERILAMPINAE}

Taxonomy: Riek, 1966. Austral. Jour. Zool. 14: 1207-1236 (subfam. of Pteromalidae).

\section{Genus EUPERILAMPUS Walker}

Euperilampus Walker, 1871. Notes on Chalcid., pt. 4, p. 67.

Type-species: Perilampus gloriosus Walker. Orig. desig.

Taxonomy: Burks, 1969. Ent. Soc. Wash., Proc. 71: 78-79.

krombeini Burks. N. Mex., Ariz. Superficially looks much like a chrysidid.

Euperilampus krombeini Burks, 1969. Ent. Soc. Wash., Proc. 71: 79., ठ์.

triangularis (Say). Que., Maine., s. to Fla., w. to Kans., Colo.

Perilampus triangularis Say, 1828. Contrib. Maclur. Lyc. Phila. 1: 78.

Taxonomy: Glover, 1878. U. S. Dept. Agr., Ann. Rpt. for 1877, p. 101. -Crawford, 1914. Ent.

Soc. Wash., Proc. 16: 69.

Morphology: Burks, 1938. Ent. Soc. Amer., Ann. 31: 161 (venation).

\section{Genus PERILAMPUS Latreille}

Perilampus Latreille, 1809. Gen. Crust. Ins., v. 4, p. 30.

Type-species: Diplolepis violacea Fabricius. Desig. by Latreille, 1810.

Cinipsillum Lamarck, 1817. Hist. Nat. Anim. sans Vert., v. 4, p. 156.

Type-species: Chalcis violacea Panzer. Desig. by Gahan and Fagan, 1923.

Cynipsillum Agassiz, 1845. Nomencl. Zool., Index Univ., p. 325. Emend.

The species described as Perilampus alexinus Walker is Chalcididae, genus Brachymeria Westwood (Burks, 1975, Brit. Mus. (Nat. Hist.) Ent., Bul. 32: 164).

Revision: Smulyan, 1936. U. S. Natl. Mus., Proc. 83: 369-412. - Steffan, 1952. Soc. Ent. de France, Bul. 57: 68-74 (Palearctic spp.).

anomocerus Crawford. N. C., Colo., Idaho.

Perilampus anomocerus Crawford, 1914. Ent. Soc. Wash., Proc. 16: 72. \&, ơ.

canadensis Crawford. Que., Ont., N. Y., Pa., Md., Va., Minn., La. Host: Ectemmius (Hypocrabro) continuus (F.), E. (H.) stirpicola (Pack.), E. (H.) pancimaculatus (Pack.), Euplilis sp.

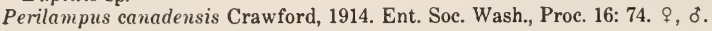

Biology: Krombein, 1960. Ent. News 71: 32, 66. - Harman and Kulman, 1962. Jour. Econ.

Ent. 55: 1007. - Krombein, 1964. Biol. Soc. Wash., Proc. 77: 101-102. 
carinifrons Crawford. Wis., Tex.

Perilampus carinifrons Crawford, 1914. Ent. Soc. Wash., Proc. 16: 71. \&, ठ.

carolinensis Smulyan. Vt., Conn., N. Y., N. J., Va., N. C.

Perilampus carolinensis Smulyan, 1936. U. S. Natl. Mus., Proc. 83: 376. $\uparrow, ~ \delta$.

chrysopae Crawford. Que., Ont., s. to Fla., w. to Wash., Oreg., Calif.; Mexico. Host: Chrysopa sp., C. californica Coq., C. oculata Say, C. mifilabris Burm., Sympherobius angustus (Banks). May also parasitize ichneumonid primary parasites of Chrysopidae.

Perilampus chrysopae Crawford, 1914. Ent. Soc. Wash., Proc. 16: 73. \&, ठ.

Perilampus chrysopae var. laevicephalus Crawford, 1917 (1916). Insecutor Inscitiae Menstruus 4: 144 . + , $\delta$.

Taxonomy: Kerrich, 1958. Opusc. Ent. 23: 82 (difficult to separate from Palearctic sp.).

Biology: Smith, 1917. Psyche 24: 66-68. - Parker, 1924. Soc. Ent. de Francé, Ann. 93: 275. -Clancy, 1946. Univ. Calif. Pubs., Ent. 7: 440-448.

crawfordi Smulyan. N. Y., N. J., Pa., Md., Va.

Perilampus craufordi Smulyan, 1936. U. S. Natl. Mus., Proc. 83: 384. \&, ठ.

fulvicornis Ashmead. Que., s. to Fla., w. to B. C. and Calif. Host: Zenillia sp.; Agathis acrobasidis (Cush.), A. pini Mues., Apanteles sp., A. cacoeciae Riley, A. epinotiae Vier., Ascogaster sp., A. quadridentata Wesm., Bracon variabilis (Prov.), Calliephialtes grapholithae (Cress.), Macrocentrus pallisteri DeG., Meteorns sp., M. trachynotus Vier., Orgilus maculiventris (Cress.), Parasierola punctaticeps Kief., Phanerotoma fasciata Prov., P. tibialis (Hald.), Pimplopterus inconstans (Cush.), Temelucha cooki (Weed). Perilampis(!) fulvicomis Ashmead, 1886. Amer. Ent. Soc., Trans. 13: 126. o.

Taxonomy: Peck, 1963. Canad. Ent., Sup. 30: 517. -Finlayson, 1967. Canad. Ent. 99: 1261 (larva).

Biology: Nickels et al., 1950. U. S. Dept. Agr., Tech. Bul. 1011: 20-21. -Judd, 1952. Nova Scotia Inst. Sci., Proc. 22: 2. - Raizenne, 1952. Canad. Div. Forest Biol., Forest Lep. South. Ont. and Par., p. 170. - Miller, 1953. Ohio Jour. Sci. 53: 62-63. -Miller, 1955. Ohio Jour. Sci. 55: 317-319. - Miller and Neiswander, 1956. Ohio Agr. Expt. Sta., Res. Bul. 779: 19.

-Schaffner, 1959. U. S. Dept. Agr., Misc. Pub. 767: 87. - Beique, 1960. Canad. Ent. 92: 859. - Bennett, 1961. Tenn. Acad. Sci., Jour. 36: 353. - Harman and Kulman, 1962. Jour.

Econ. Ent. 55: 1007. -Guajardo and Ortiz, 1966. Soc. Nuevoleon Hist. Nat., Bol. 1: 45. gahani Smulyan. Colo., N. Mex.

Perilampus gahani Smulyan, 1936. U. S. Natl. Mus., Proc. 83: 401. ठ.

granulosus Crawford. N. J., s. to Ala., w. to Kans. and Tex. Host: Ancylis comptana fragariae W. and R., Gnorimoschema operculella (Zell.). Almost certainly a secondary parasite of these hosts.

Perilampus granulosus Crawford, 1914. Ent. Soc. Wash., Proc. 16: 73. ๆ, ठ.

hyalinus Say. Que., Ont., s. to Fla., w. to B. C., and Calif. Host: Acemyia tibialis Coq., Acridomyia canadensis Snyder, Blaeoxipha atlanis (Ald.), B. hunteri (Hough), B. kellyi (Ald.), B. reversa (Ald.), Blepharipa scutellata (R.-D.), Compsilura concinnata (Meig.), Diplostichus lophyri (Towns.), Helicobia rapax (Walk.), Lespesia euchaetiae (Web.), L. frenchii (Will.), L. melalophae (Allen), Mericia aldrichi (Towns.), M. ampela (Walk.), Sarcophaga sp., Senotainia trilineata (V. d. W.), Servaisia coloradensis (Ald.); Apanteles hyphantriae Riley, A. melanoscelus (Ratz.), Campoplex sp., C. validus (Cress.), Diprion sp., Hyposoter fugitivus Say, H. pilosulus (Prov.), Meteorus hyphantriae Riley, Microplitis croceipes (Cress.), Monoctenus fulvus (Nort.), Neodiprion abbotii (Leach), N. lecontei (Fitch), N. pinetum (Nort.), N. pratti banksianae Roh., N. pratti (Dyar), N. swainei Midd., N. virginiana Roh., Phobocampe pallipes (Prov.). This may be a species complex, rather than a single species; careful rearings have produced specimens, at present indistinguishable, that are either primary or secondary parasites.

Perilampus hyalinus Say, 1828. Contrib. Maclur. Lyc. Phila. 1: 79.

Perilampus Entellus Walker, 1843. Ann. and Mag. Nat. Hist. (1) 12: 103. , ठ.

Perilampus cyaneus Brulle, 1846. In Lepeletier, Hist. Nat. Ins. Hym., v. 4, p. 573.

Perilampus aciculatus Provancher, 1887. Addit. Corr. Faune Ent. Canada Hym., p. 199.. 
Taxonomy: Finlayson, 1963. Canad. Ent. 95: 499-501 (larvae). -Burks, 1964 (1963). Canad. Ent. 95: 1259-1260 (aciculatus Prov.). - Burks, 1975. Brit. Mus. (Nat. Hist.) Ent., Bul. 32: 150 (entellus; syn., lectotype).

Biology: Cook and Davis, 1891. Mich. Agr. Expt. Sta., Bul. 76: 16. -Quaintance and Brues, 1905. U. S. Dept. Agr., Bur. Ent. Bul. 50: 122. - Smith, 1912. U. S. Dept. Agr., Bur. Ent., Tech. Ser. 19: 34-63. - Thompson, 1915. Bul. Sci. France et Belg. 48: 321-324, 339-348 (planidium). - Smith, 1916. Jour. Econ. Ent. 9: 481. - Smith, 1916. Science 44: 925-926. -Smith, 1917. Psyche 24: 64-68. - Parker, 1924. Soc. Ent. de France, Ann. 93: 272, 300. -Proper, 1934. Jour. Agr. Res. 48: 373. -Decker, 1935. Iowa State Col., Jour. Sci. 9: 569. -Flanders, 1937. Jour. Econ. Ent. 30: 970. - Frisch, 1937. Psyche 43: 84-85. - Lal, 1939. Current Sci. 8: 58. - Smith, 1940 (1939). Ent. Soc. Ont., Ann. Rpt. 70: 61-62. -Salt, 1941. Cambridge Phil. Soc., Biol. Rev. 16: 252. - Baldwin and Coppel, 1950 (1949). Canad. Ent. 81: 244. - Craighead, 1950. U. S. Dept. Agr., Misc. Pub. 657: 612. -Raizenne, 1952. Canad. Div. Forest Biol., Forest Lep. South. Ont. and Par., p. 31. - Smith, 1958. Canad. Jour. Res. 36: 254-258. -Tripp, 1962. Canad. Ent. 94: 1251. -Riordan, 1963. Canad. Jour. Zool. 41: 1242. - Becker and Benjamin, 1964. Jour. Econ. Ent. 57: 356. - Medler, 1965. Ent. Soc. Amer., Ann. 58: 140. - Huggans and Blickenstaff, 1966. Mo. Agr. Expt. Sta., Res. Bul. 903: 36. -Wilkinson et al., 1966. Ent. Soc. Amer., Ann. 59: 791. - Hinks, 1971. Canad. Ent. 103: 182-187.

laevis Provancher. Described from Ont. but probably not North American. Boucek, 1974 (Jour. Ent. (B) 43: 134) has described a new genus, Peckianus, for this species and places it in the Eutrichosomatinae.

Perilampus laevis Provancher, 1887. Addit. Corr. Faune Ent. Canada Hym., p. 199. $\%$. lepreos Walker. Ga. Type lost.

Perilampus lepreos Walker, 1946. List. Hym. Brit. Mus., Chalcid., v. 1, p. 89.

muesebecki Smulyan. N. H., N. Y., Pa., D. C., Fla., Nebr., Kans., Colo.

Perilampus muesebecki Smulyan, 1936. U. S. Natl. Mus., Proc. 83: 407. १, ठ.

nitidus Smulyan. Pa., La.

Perilampus canadensis var. nitidus Smulyan, 1936. U. S. Natl. Mus., Proc. 83: 393. \&, ठ.

Taxonomy: Peck, 1951. In Muesebeck, et al., U. S. Dept. Agr., Agr. Monog. 2: 517. ocellatus Smulyan. Ga., Mo.

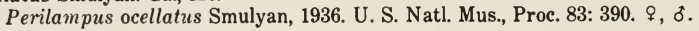
platygaster Say. Que., Ont., s. to N. C., w. to Colo. and Tex. Host: Meteorus dimidiatus (Cress.).

Perilampus platigaster! Say, 1836. Boston Jour. Nat. Hist. 1: 274.

Biology: Strauss, 1916. U. S. Dept. Agr., Bul. 419: 10.

prothoracicus Smulyan. Ont., N. H., Md., Va., Mich., La., Nebr., Wash. Host: Laspeyresia pomonella (L.). Probably actually a secondary parasite.

Perilampus fulvicornis var. prothoracicus Smulyan, 1936. U. S. Natl. Mus., Proc. 83: 403. .

Taxonomy: Peck, 1963. Canad. Ent., Sup. 30, p. 523.

Biology: Raizenne, 1952. Canad. Div. Forest Biol., Forest Lep. South. Ont. and Par., pp. 243-244.

regalis Smulyan. N. C., Mo.

Perilampus regalis Smulyan, 1936. U. S. Natl. Mus., Proc. 83: 378. \&.

robertsoni Crawford. Ont., Ill., Nebr., Colo.

Perilampus robertsoni Crawford, 1914. Ent. Soc. Wash., Proc. 16: 71. ९, ठ.

rohweri Smulyan Ont., N. J.

Perilampus rohweri Smulyan, 1936. U. S. Natl. Mus., Proc. 83: 396., ơ.

similis Crawford. Man., s. to Tex., w. to Alta., Oreg., Calif. Host: Cremnops vulgaris (Cress.), Meteorus loxostegei Vier.

Perilampus similis Crawford, 1914. Ent. Soc. Wash., Proc. 16: 73. 9.

Biology: Simmonds, 1947. Bul. Ent. Res. 38: 145, 378. 
stygicus Provancher. Que., Maine, s. to Va., w. to Kans., La. Host: Macrocentrus sp.

Perilampus stygicus Provancher, 1888. Addit. Corr. Faune Ent. Canada Hym., p. 406..

Taxonomy: Burks, 1964 (1963). Canad. Ent. 95: 1260.

subcarinatus Crawford. N. Y., Ala., Tex., Nebr., Colo., Idaho, Calif.

Perilampus subcarinatus Craw ford, 1914. Ent. Soc. Wash., Proc. 16: 70. \&.

Perilampus bakeri Craw ford, 1914. Ent. Soc. Wash., Proc. 16: 72. \&, ठ.

Taxonomy: Girault, 1916. Jour. Ent. and Zool. 8: 121 (syn.).

tristis Mayr. N. Y., s. to Va., w. to Mich. and Ky.; Europe. Host: Ascogaster quadridentata

Wesm., Cremastus sp.

Perilampus tristis Mayr, 1905. Zool.-Bot. Gesell. Wien, Verh. 55: 564. १, ơ.

Perilampus batavus van Burgst, 1919 (1918). Tijdschr. v. Ent. 61: 146.

Perilampus capitatus Smulyan, 1936. U. S. Natl. Mus., Proc. 83: 397. ₹, ठ.

Taxonomy: Ruschka, 1924. Deut. Ent. Ztschr. 1: 93 (syn.). -Steffan, 1952. Soc. Ent. de France, Bul. 57: 69, 72 (syn.).

Biology: Bergold and Ripper, 1937. Ztschr. f. Parasitenk. 9: 394-417. -Simmonds, 1944. Sci. Agr. 25: 1-30. -Jaynes and Marucci, 1947. Jour. Econ. Ent. 40: 11-12. - Geier, 1957. Rev. Suisse de Zool. 64: 514. -Zech, 1959. Ztschr. f. Angew. Ent. 44: 214. -Zwolfer, 1963.

Ztschr. f. Angew. Ent. 51: 352. - Balduf, 1966. Ent. Soc. Amer., Ann. 59: 1046-1049.

-Gothilf, 1969. Entomophaga 14: 199.

Morphology: Parker, 1924. Soc. Ent. de France, Ann. 93: 265, 275 (larva). -Domenichini, 1953. Univ. Milano, Bol. Zool. e Bach. 19: 229 (gaster).

\section{Genus CHRYSOLAMPUS Spinola}

Chrysolampus Spinola, 1811. Paris Mus. d'Hist. Nat., Ann. 17: 147.

Type-species: Diplolepis splendidula Spinola. Monotypic.

Elatus Walker, 1848. List Hym. Brit. Mus., Chalcid., v. 2, pp. 104, 153.

Type-species: Elatus thenae Walker. Monotypic.

Lamprostylus Foerster, 1856. Hym. Stud., v. 2, p. 42 (no species).

Type-species: Lamprostylus punctatus Foerster. Included by Foerster, 1859.

Parelatus Girault, 1916. Queensland Mus., Mem. 5: 226.

Type-species: Elatus ater Girault. Orig. desig.

Revision: Crawford, 1914. Ent. Soc. Wash., Proc. 16: 74.

Taxonomy: Boucek, 1956. Mus. Natl. Pragae, Acta Ent. 1: 87-88. - Kerrich, 1958. Opusc. Ent. 33: 82 .

anobii Burks. Va. Ecology: Reared from wood infested with anobiid beetles.

Chrysolampus anobii Burks, 1969. Ent. Soc. Wash., Proc. 71: 80. १, ठ.

lycti Crawford. W. Va. Host: Lyctus striatus Melsh.

Chrysolampus lycti Crawford, 1914. Ent. Soc. Wash., Proc. 16: 75.,$+ ~ \delta$.

pareipunctatus Crawford. Calif.

Chrysolampus parcipunctatus Crawford, 1914. Ent. Soc. Wash., Proc. 16: 75. $९$.

schwarzi Crawford. Utah.

Chrysolampus schwarzi Crawford, 1914. Ent. Soc. Wash., Proc. 16: 76..

sisymbrii (Ashmead). N. Mex.

Elatus sisymbrii Ashmead, 1896. Amer. Ent. Soc., Trans. 23: 218. ठ.

\section{SUBFAMILy BRACHYSCELIDIPHAGINAE}

This subfamily, with numerous members in South America and Australia, has only one species in North America, and none in the Palearctic region.

Taxonomy: Gahan and Ferriere, 1947. Ent. Soc. Amer., Ann. 40: 271-302. -Graham, 1969.

Brit. Mus. (Nat. Hist.) Ent., Bul. Sup. 16: 95. 


\section{Genus HEMADAS Crawford}

Hemadas Crawford, 1909. Canad. Ent. 41: 98.

Type-species: Megorismus nubilipennis Ashmead. Orig. desig.

Parhabritys Girault, 1917. Deser. Hym. Chalcidoid. Variorum cum Observ. V, p. 2.

Type-species: Megorismus nubilipennis Ashmead. Orig. desig.

Revision: Gahan and Ferriere, 1947. Ent. Soc. Amer., Ann. 40: 292.

nubilipennis (Ashmead). Maine, Ont., Conn., N. J., Va., Fla., Ohio, Ind. Ecology: Produces stem galls on Vaccinium spp.

Megorismus nubilipennis Ashmead, 1887. Amer. Ent. Soc., Trans. 14: 192..

Biology: Driggers, 1927. N. Y. Ent. Soc., Jour. 35: 253-259. -McAlister and Anderson, 1932.

Jour. Econ. Ent. 25: 1164-1169. - Judd, 1959. Amer. Micros. Soc., Trans. 78: 212-214.

Morphology: Snodgrass, 1910. U. S. Natl. Mus., Proc. 39: 65.

\section{SUBFAMILY EUTRICHOSOMATINAE}

\section{Genus EUTRICHOSOMA Ashmead}

Eutrichosoma Ashmead, 1899. Ent. Soc. Wash., Proc. 4: 204 (no species).

Type-species: Eutrichosoma mirabile Ashmead. Desig. by Ashmead, 1904.

mirabile Ashmead. Md., D. C., Ga., Kans., Okla., Tex., N. Mex., Mont., Idaho. Host: Auleutes tenuipes (Lec.), Smicronyx tychoides (Lec.).

Eutrichosoma mirabile Ashmead, 1904. Carnegie Mus., Mem. 1: 291. ๆ.

Eutrichosoma albipes Crawford, 1908 (1907). Ent. Soc. Wash., Proc. 9: 158. \&, o.

Taxonomy: Gahan and Peck, 1946. Wash. Acad. Sci., Jour. 36: 315.

Biology: Pierce, 1910. Jour. Econ. Ent. 3: 453. - Pierce et al., 1912. U. S. Dept. Agr., Bur.

Ent. Bul. 100: 75, 79.

\section{SubFAMILy CLEONYMINAE}

Revision: Kerrich and Graham, 1957. Soc. Brit. Ent., Trans. 12: 265-311 (British and Swedish spp., with some Nearctic spp.). - Boucek, 1959 (1958). Mus. Natl. Pragae, Acta Ent. 32: 353-386 (genera of the world). - Graham, 1969. Brit. Mus. (Nat. Hist.) Ent., Bul. Sup. 16: 35-42 (Western European spp.).

\section{TRIBE CLEONYMINI}

\section{Genus HEYDENIA Foerster}

Heydenia Foerster, 1856. Hym. Stud., v. 2, pp. 46, 48, 49.

Type-species: Heydenia pretiosa Foerster. Monotypic.

Revision: Hedqvist, 1957. Opusc. Ent. 22: 39-48 (world fauna).

unica Cook and Davis. Md., Va., N. C., Ga., Ala., W. Va., Mich., Tex., Mont., Ariz., Calif. Host:

Dendroctonus sp., D. frontalis Zimm., Ips sp., Phloeosinus sp., Pityophthorus sp.,

Polygraphus sp., Scolytus rugulosus (Ratz.).

Heydenia unica Cook and Davis, 1891. Mich. Agr. Expt. Sta., Bul. 73: 15. ९, ठ.

Biology: De Leon, 1934. Canad. Ent. 66: 60 (under name hubbardi, nom. nud.). - Franklin, 1969. Ga. Ent. Soc., Jour. 4: 121.

\section{Genus CLEONYMUS Latreille}

Cleonymus Latreille, 1809. Gen. Crust. Ins., v. 4, p. 29.

Type-species: Diplolepis depressa Fabricius. Desig. by Latreille, 1810.

californicus Girault. Calif.

Cleonymus californicus Girault, 1917. Jour. Ent. and Zool. 9: 11. ?. 
nigriclavus Girault. Fla.

Cleonymus nigriclavus Girault, 1917. Deser. Hym. Chalcidoid. Variorum cum Observ. III, p. 6. ․

\section{TRIBE CHALCEDECTINI}

Taxonomy: Steffan, 1968. Entomophaga 13: 209-211. -Graham, 1969. Brit. Mus. (Nat. Hist.). Ent., Bul. Sup. 16: 36.

\section{Genus CHALCEDECTUS Walker}

Chalcedectus Walker, 1852. Ann. and Mag. Nat. Hist. (2): 10: 47.

Type-species: Chalcedectus maculicomis Walker. Monotypic.

Chalcodectus Dalla Torre, 1898. Cat. Hym., v. 5, pp. 186, 569. Emend.

Chalcedectes Ashmead, 1899. Ent. Soc. Wash., Proc. 4: 201. Emend.

Episystole Girault, 1927. So. Austral. Mus., Rec. 3: 317.

Type-species: Episystole poeta Girault. Orig. desig.

Neochalcodectus Masi, 1936. Soc. Ent. Ital., Bol. 68: 68.

Type-species: Neochalcodectus sinaiticus Masi. Monotypic.

Taxonomy: Boucek, 1959. Mus. Natl. Pragae, Acta Ent. 33: 568.

texanus Brues. Tex.

Chalcedectes texanus Brues, 1907. Wis. Nat. Hist. Soc., Bul. 5: 106. ð.

\section{Genus EUCHRYSIA Westwood}

Euchrysia Westwood, 1874. Thesaurus Ent. Oxon., p. 139.

Type-species: Euchrysia cleptidea Westwood. Desig. by Ashmead, 1904.

Revision: Girault, 1917. Brooklyn Ent. Soc., Bul. 12: 14-15.

hyalinipennis Ashmead. N. C., Fla., Mo., Tex., N. Mex., Ariz., Calif. Host: Chrysobothris deleta Lec., C. mali Horn, Oncideres rhodosticta Bates.

Euchrysia hyalinipennis Ashmead, 1896. Amer. Ent. Soc., Trans. 23: 231. ?. maculipennis Ashmead. Calif.

Euchrysia maculipennis Ashmead, 1896. Amer. Ent. Soc., Trans. 23: 232. ð.

similis Girault. Kans.

Euchrysia similis Girault, 1917. Brooklyn Ent. Soc., Bul. 12: 15. ๆ.

\section{TRIBE TRIGONODERINI}

Taxonomy: Hedqvist, 1968. Ent. Tidskr. 89: 35-63. -Graham, 1969. Brit. Mus. (Nat. Hist.)

Ent., Bul. Sup. 16: 98-123.

\section{Genus EPISTENIA Westwood}

Epistenia Westwood, 1832. In Griffith, Cuvier's Animal Kingdom, v. 15 (Insecta, v. 2), p. 432.

Type-species: Epistenia coeruleata Westwood. Monotypic.

Dasyglenes Ashmead, 1888. Canad. Ent. 20: 173, 174.

Type-species: Dasyglenes osmiae Ashmead. Monotypic.

Idiobia Brethes, 1927. Ent. Mitt. 16: 330.

Type-species: Idiobia schmidti Brethes. Monotypic.

Revision: Hedqvist, 1968. U. S. Natl. Mus., Proc. 124: 1-8.

Taxonomy: Boucek, 1959 (1958). Mus. Natl. Pragae, Acta Ent. 32: 381 (syn.). burksi Hedqvist. Ind., Tex. Ecology: Reared from nest of twig-inhabiting aculeate.

Epistenia burksi Hedqvist, 1968. U. S. Natl. Mus., Proc. 124: 3. ₹, ठ.

coeruleata Westwood. N. Y., N. J., Va., Ga., Fla., Mo., Tex., Ariz., Nev., Calif. Host: Ceratina sp., Ectemnius sp., Isodontia elegans (Smith), Leptochilus republicanus zendaloides 
(Robt.), Osmia sp., Trypargilum sp., T. collinum rubrocinctum (Pack.), T. tridentatum (Pack.).

Epistenia coeruleata Westwood, 1832. In Griffith, Cuvier's Animal Kingdom, v. 15

(Insecta, v. 2), p. 432.

Dasyglenes osmiae Ashmead, 1888. Canad. Ent. 20: 174..

Biology: Krombein, 1959. Ent. News 70: 19.

media Hedqvist. N. Y., Tex., Nev., Calif.

Epistenia media Hedqvist, 1968. U. S. Natl. Mus., Proc. 124: 5. १, ठ.

odyneri Ashmead. Ga., Mich., N. Mex., Ariz., Calif. Host: Leptochilus rufobasilaris (Ashm.).

Epistenia odyneri Ashmead, 1896. In Davidson, Psyche 7: 336. ․

polita (Say). D. C., V.a, N. C., Ga., Fla.

Spalangius(!) politus Say, 1828. Contrib. Maclur. Lyc. Phila. 1: 79. $\$$.

Taxonomy: Gahan, 1951. Canad. Ent. 83 : 174 (reasons for placing in Episteria).

regalis Cockerell. Colo. Ecology: Reared from nest of Odynerus. This is probably a synonym of coeruleata Westwood.

Epistenia regalis Cockerell, 1934. Psyche 41: 228. .

\section{Genus PTINOBIUS Ashmead}

Ptinobius Ashmead, 1896. Ent. Soc. Wash., Proc. 4: 11.

Type-species: Charitopus magnificus Ashmead. Monotypic.

Megormyrus Cockerell, 1926. Psyche 33: 36.

Type-species: Megormyrus amabilis Cockerell. Monotypic.

Revision: Rohwer, 1919. Ent. Soc. Wash., Proc. 21: 4-6.

Taxonomy: Boucek, 1959 (1958). Mus. Natl. Pragae, Acta Ent. 32: 363.

agrili Rohwer. Calif. Host: Agrilus angelicus Horn.

Ptinobius agrili Rohwer, 1919. Ent. Soc. Wash., Proc. 21: 5., ठ.

amabilis (Cockerell). Colo. Host: Hoplitis producta (Cress.), Stelis sp., S. sexmaculata Ashm.

Megormymus amabilis Cockerell, 1926. Psyche 33: 37. $q$.

californicus Crawford. Calif.

Ptinobius californicus Crawford, 1917 (1916). Insecutor Inscitiae Menstruus 4: 142..

magnificus (Ashmead). Que., N. J., W. Va., Va., Kans., Tex. Host: Agrilus ruficollis (F.), Amphicerus bicaudatus (Say), Lixus scrobicollis Boh., Tessaropa tenuipes (Hald.).

Charitopus magnificus Ashmead, 1888. Kans. Agr. Expt. Sta., Bul. 3: App. p. IV. ․

Ptinobius dysphagae Girault, 1915. Ent. News 26: 130. o.

Taxonomy: Girault, 1917 (1916). Insecutor Inscitiae Menstruus 4: 142, 144.

Biology: Hopkins, 1891. W. Va. Agr. Expt. Sta., Bul. 15: 84.

texanus Crawford. Tex. Host: Araecerus fasciculatus (Deg.).

Ptinobius texanus Crawford, 1917 (1916). Insecutor Inscitiae Menstruus 4: 142., , o.

\section{Genus PLATYGERRHUS Thomson}

Platygerrhus Thomson, 1878. Hym. Scand., v. 5, pp. 4, 13.

Type-species: Platygerrhus gracilis Thomson. Monotypic.

Taxonomy: Kerrich and Graham, 1957. Soc. Brit. Ent., Trans. 12: 300-303. - Hedqvist, 1968.

Ent. Tidskr. 89: 36-39. - Graham, 1969. Brit. Mus. (Nat. Hist.) Ent., Bul. Sup. 16: 108-122. algonquina (Girault). Que., N. H., Conn., Ill.

Trigonoderus algonquina Girault, 1917. Ent. News 28: 396. ․

americanus Hedqvist. Ariz., Alaska, Calif.

Platygerrhus americanus Hedqvist, 1968. Ent. Tidskr. 89: 38. ๆ.

\section{Genus PLUTOTHRIX Foerster}

Plutothrix Foerster, 1856. Hym. Stud., v. 2, pp. 46, 49. No species. 
Type-species: Plutothrix foersteri Mayr. Desig. by Mayr, 1904 by subsequent reference.

Anoglyphis Foerster, 1878. Naturh. Ver. Rheinlande, Verh. 35: 49.

Type-species: Anoglyph is nubilosa Foerster. Orig. desig.

unguttus (Girault). Que., Ont., N. H., Conn., N. Y., N. J., Md., D. C., Va., Ga., Ill., Mo., Nebr.,

Tex. Ecology: Parasitizes Coleoptera living in shelf fungi. Host: Diaperis sp., Euparius

marmoreus Oliv., Thymalus sp.

Trigonodernes unguttus Girault, 1917. Ent. News 28: 396. ㅇ.

Taxonomy: Hedqvist, 1968. Ent. Tidskr. 89: 42.

Biology: Graves, 1960. Ent. Soc. Amer., Ann. 53: 74.

\section{Genus TRIGONODERUS Westwood}

Trigonoderus Westwood, 1832. London, Edinb., and Dublin Phil. Mag. and Jour. Sci. (3) 1: 127.

Type-species: Trigonoderus princeps Westwood. Monotypic.

Pterolycus Ratzeburg, 1848. Ichn. d. Forstins., v. 2, p. 208.

Type-species: Pteromalus (Pterolycus) brandtii Ratzeburg. Desig. by Gahan and Fagan, 1923.

Revision: Girault, 1917. Ent. News 28: 396-397.

aegeriae Ashmead. Fla.

Trigonoderns aegeriae Ashmead, 1887. Amer. Ent. Soc., Trans. 14: 192. 9.

Taxonomy: Hedqvist, 1968. Ent. Tidskr. 89: 46 (may belong in Habrocytus). irvingi Girault. Colo.

Trigonoderus irvingi Girault, 1917. Deser. Hym. Chalcidoid. Variorum cum Observ. V, p. 15. ㅇ.

nonstylatus Girault. Calif.

Trigonoderus nonstylatus Girault, 1917. Ent. News 28: 396. ‥

Taxonomy: Hedqvist, 1968. Ent. Tidskr. 89: 44 (prob. belongs elsewhere).

\section{Genus OGLOBLINISCA Hedqvist}

Ogloblinisca Hedqvist, 1968. Ent. Tidskr. 89: 50.

Type-species: Ogloblinisca maculata Hedqvist. Orig. desig.

americana Hedqvist. Ont., Maine, Mass., Md., N. C., S. C.

Ogloblinisca americana Hedqvist, 1968. Ent. Tidskr. 89: 54. ๆ, ठ.

\section{Genus JANSSONIELLA Kerrich}

Janssoniella Kerrich, 1957. In Kerrich and Graham, Soc. Brit. Ent., Trans. 12: 303.

Type-species: Janssoniella caudata Kerrich. Orig. desig.

caudata Kerrich. N. J., Idaho, B. C., Calif.; Europe. Ecology: Reared from bracket fungi infested with Coleoptera. Host: Cis sp.

Janssoniella caudata Kerrich, 1957. In Kerrich and Graham, Soc. Brit. Ent., Trans. 12: 304. ‥

intermedia Hedqvist. B. C.; Europe.

Janssoniella intermedia Hedqvist, 1968. Ent. Tidskr. 89: 57, 58. ९.

\section{Genus GASTRACANTHUS Westwood}

Gastracanthus Westwood, 1833. Mag. Nat. Hist. 6: 121.

Type-species: Gastracanthus pulcherrimus Westwood. Monotypic.

Hetroxys Westwood, 1833. Mag. Nat. Hist. 6: 495. N. name, unnecessarily proposed.

Etroxys Foerster, 1956. Hym. Stud., v. 2, pp. 66, 71. Emend.

Aetroxys Walker, 1872. Notes on Chalcid., p. 110. Emend.

Photismus Thomson, 1878. Hym. Scand., v. 5, pp. 4, 15.

Type-species: Photismus nubilosus Thomson. Monotypic. 
Heteroxys Dalla Torre, 1898. Cat. Hym., v. 5, p. 101. Emend. conicus (Girault). Que., Ont., Maine, N. Y., N. J., Md., Ind., B. C.

Trigonoderus conicus Girault, 1917. Ent. News 28: 396. $\%$.

Taxonomy: Kerrich and Graham, 1957. Soc. Brit. Ent., Trans. 12: 283-284. -Boucek, 1959

(1958). Mus. Natl. Pragae, Acta Ent. 32: 365.

\section{SUBFAMILY COLOTRECHNINAE}

Taxonomy: Boucek, 1957. In Kratochvil, Klic Zvireny CSR 2: 232 (tribe). -Boucek, 1964. Canad. Ent., Mem. 34: 41 (subfamily). -Graham, 1969. Brit. Mus. (Nat. Hist.) Ent., Bul. Sup. 16: 850 .

\section{Genus COLOTRECHNUS Thomson}

\section{Genus COLOTRECHNUS Subgenus COLOTRECHNUS Thomson}

Colotrechnus Thomson, 1878. Hym. Scand., v. 5, p. 46.

Type-species: Colotrechnus subcoeruleus Thomson. Monotypic.

The typical subgenus does not occur in North America.

\section{Genus COLOTRECHNUS Subgenus ZANONIA Masi}

Zanonia Masi, 1921. Genova Mus. Civ. Stor. Nat., Ann. (3) 9: 184.

Type-species: Zanonia viridis Masi. Monotypic.

Taxonomy: Masi, 1922. Soc. Ent. Ital. Bol. 54: 111 (closely rel. to Colotrechnus Thomson).

-Delucchi, 1956. Ztschr. f. Angew. Ent. 39: 233 (syn. of Colotrechnus Thomson). -Burks,

1958. Fla. Ent. 41: 13 (subg. of Colotrechnus Thomson).

ignotus Burks. N. C., Fla., Okla., Tex., Ariz., Calif. Ecology: Reared from heads of Bidens and other Compositae.

Colotrechnus (Zanonia) ignotus Burks, 1958. Fla. Ent. 41: 14. \&, ð.

\section{SUBFAMILY MACROMESINAE}

Taxonomy: Graham, 1969. Brit. Mus. (Nat. Hist.) Ent., Bul. Sup. 16: 42.

\section{Genus MACROMESUS Walker}

Macromesus Walker, 1848. List Hym. Brit. Mus., Chalcid., pt. 2, pp. 106, 161.

Type-species: Macromesus amphiretus Walker. Monotypic.

Wesenbergia Kryger, 1943. Ent. Meddel. 22: 360.

Type-species: Wesenbergia occulata Kryger. Orig. desig.

Taxonomy: Graham, 1959. Ent. Monthly Mag. 95: 73-78 (Macromesinae of Pteromalidae).

-Hedqvist, 1960. Ent. Tidskr. 81: 140. - Boucek, 1961. Mus. Natl. Pragae, Acta Ent. 34: 57

(near Tridymini). - Hedqvist, 1963. Stud. Forest. Suecica II, pp. 57-58 (Cheiropachinae).

americanus Hedqvist. Ariz., Oreg., Calif. Host: Cylindrocopturus longulus (Lec.), C. eatoni

Buc., Pseudohylesinus nebulosus (Lec.), Scolytus praeceps Lec., S. unispinosus Lec., S. ventralis Lec.

Macromesus americanus Hedqvist, 1960. Ent. Tidskr. 81: 140. \&, ¿.

\section{SUbFamily SPALANGIINAE}

Revision: Boucek, 1963. Mus. Natl. Pragae, Acta Ent. 35: 429-512 (world fauna). -Boucek, 1965. Mus. Natl. Pragae, Acta Ent. 36: 593-602 (Ethiopian and Nearctic faunas).

\section{Genus SPALANGIA Latreille}

Spalangia Latreille, 1805. Hist. Nat. Crust. Ins., v. 13, p. 227.

Type-species: Spalangia nigra Latreille. Monotypic.

Prospalangia Brethes, 1915. Soc. Cient. Argentina, An. 79: 316.

Type-species: Prospalangia platensis Brethes. Orig. desig. 
Taxonomy: Ashmead, 1894. Ent. Soc. Wash., Proc. 3: 27-37. - Richardson, 1913. Jour. Morph.

24: 515. -Masi, 1917. Novitates Zool. 24: 188-189. - Burks, 1969. Smithsn. Contrib. Zool., 2:

1-7. (types in USNM).

attae Burks. Tex.; El Salvador. Ecology: Occurs in debris of nests of Atta mexicana (Smith) and A. texana (Buckley).

Spalangia attae Burks, 1969. Smithsn. Contrib. Zool., 2: 1. . .

cameroni Perkins. N. H., Miss., La., Tex., Ariz., Calif.; Cosmopolitan. Host: Anastrepha suspensa (Loew), Fannia femoralis (Stein), Haematobia irritans (L.), Hippelates collusor (Towns.), Musca domestica (L.), Muscina sp., Ophyra sp., Phaenicia sp., Stomoxys calcitrans (L.).

Spalangia cameroni Perkins, 1910. Fauna Hawaii., Hym. Sup. 2: 656. \&, ठ.

Spalangia muscidarum var. texensis Girault, 1920. U. S. Natl. Mus., Proc. 58: 213. ठ๖.

Spalangia melanogaster Masi, 1940. R. Lab. Ent. Agr. Portici, Bol. 3: 295. ठ".

Spalangia atherigonae Risbec, 1951. Inst. Franc. d’Afr. Noire, Mem. 13: 361. \&, ১.

Biology: Timberlake, 1924. Hawaii. Ent. Soc., Proc. 5: 426. -Simmonds, 1929. Agr. Jour. Fiji 2: 35. - Lever, 1934. Trop. Agr. 11: 36-37. - Sychevskaya 1963. Zool. Zhur. 42: 860.

-Legner et al., 1966. Calif. Agr. 20: 11. - Legner, 1966. Jour. Econ. Ent. 59: 99. - Legner et al., 1967. Ent. Soc. Amer., Ann. 60: 462-468. - Legner and Gerling, 1967. Ent. Soc.

Amer., Ann. 60: 678-691. - Legner and Olton, 1968. Ent. Soc. Amer., Ann. 61: 1306-1314.

-Gerling and Legner, 1968. Ent. Soc. Amer., Ann. 61: 1436-1443. - Legner, 1969. Ent. Soc. Amer., Ann. 62: 220-226. - Wylie, 1971. Canad. Ent. 103: 1537-1544. - Wylie, 1972. Canad.

Ent. 104: 209-214 (oviposition).

drosophilae Ashmead. Que. and Ont., s. to Fla., w. to B. C., s. to Calif. Host: Drosophila sp., D. melanogaster Meig., Hippelates collusor (Towns.), Meromyza americana Fitch, Oscinella carbonaria (Loew), O. frit (L.), O. minor (Ad.), O. soror (Macq.), Pseudogaurax anchora (Loew).

Spalangia drosophilae Ashmead, 1887. Amer. Ent. Soc., Trans. 14: 199..

Biology: Lindquist, 1936. Jour. Econ. Ent. 29: 1154-1158. -Simmonds, 1944. Bul. Ent. Res. 35: 222. -Simmonds, 1946. Bul. Ent. Res. 37: 95-97. - Simmonds, 1952. Bul. Ent. Res. 43: 533-540. - Simmonds, 1953. Bul. Ent. Res. 44: 387-393, 773-778. - Simmonds, 1954. Bul. Ent. Res. 45: 527-537 (oviposition). -Simmonds, 1956. Bul. Ent. Res. 47: 361-376. - Legner et al., 1966. Ent. Soc. Amer., Ann. 59: 977-984. - Legner, 1969. Ent. Soc. Amer., Ann. 62: 220-226.

endius Walker. Ont., N. Y., N. J., Md., N. C., S. C., Fla., Nebr., Calif.; Cosmopolitan. Host: Ceratitis capitata (Wied.), Dacus dorsalis Hendel, Fannia leucosticta (Meig.), $F$. scalaris (F.), Haematobia irritans (L.), Musca domestica L., Muscina sp., Ophyra sp., Stomoxys calcitrans (L.), Sarcophaga sp.

Spalangia endius Walker, 1839. Monog. Chalcid., v. 2, p. 96. ठ.

Spalangia muscidarum var. stomoxysiae Girault, 1916. Soc. Ent. 31: 57. .

Spalangia philippinensis Fullaway, 1917. Hawaii. Ent. Soc., Proc. 3: 292. १, ठ.

Spalangia orientalis Graham, 1932. In Handschin, Austral. Council. Sci. and Indus. Res., Pam. 31: 21.

Biology: Lindquist, 1936. Jour. Econ. Ent. 29: 1154-1158 (stomoxysiae). - Legner and Brydon, 1966. Ent. Soc. Amer., Ann. 59: 638-651. - Legner and Olton, 1968. Ent. Soc. Amer., Ann. 61: 1306-1314.

erythromera Foerster. N. H., Conn., Ont., Sask.; Europe.

Spalangia erythromera Foerster, 1850. Naturh. Ver. Rheinlande, Verh. 7: 512 ..

Spalangia Umbellatarum Foerster, 1850. Naturh. Ver. Rheinlande, Verh. 7: 513. \&, ð.

Spalangia spuria Foerster, 1850. Naturh. Ver. Rheinlande, Verh. 7: 515..

Taxonomy: Boucek, 1963. Mus. Natl. Pragae, Acta Ent. 35: 466 (syn.).

haematobiae Ashmead. Ont., s. to Va., w. to Alta. and Calif.; Mexico, West Indies. Host: Haematobia irritans (L.).

Spalangia haematobiae Ashmead, 1894. Ent. Soc. Wash., Proc. 3: 37..

Taxonomy: Boucek, 1963. Mus. Natl. Pragae., Acta Ent. 35: 475 (S. impuncta Howard, Neotropical species, a possible syn.). 
nigra Latreille. N. Y., N. J., Md., Va., N. C., S. C., Ohio, Mich., Ill., Miss., Nebr., Tex., Colo., Calif.; Cosmopolitan. Host: Haematobia irritans (L.), Hylemya antiqua (Meig.), Musca domestica L., Rhagoletis completa Cress., Stomoxys calcitrans (L.).

Spalangia nigra Latreille 1805. Hist. Nat. Crust. Ins., v. 13, p. 288.

Spalangia hirta Haliday, 1833. Ent. Mag. 1: 334. ?.

Spalangia rugosicollis Ashmead, 1894. Ent. Soc. Wash., Proc. 3: 36. \&.

Spalangia muscae Howard, 1911. The House Fly, p. 90. Inadvertently descr.; attrib. to Girault.

Taxonomy: Boucek, 1963. Mus. Natl. Pragae., Acta Ent. 35: 443 (syn.). - Burks, 1969.

Smithsn. Contrib. Zool. 2: 5 (types in USNM).

Biology: Parker and Thompson, 1928. Soc. Ent. de France, Ann. 97: 437-439. - Legner, 1969.

Ent. Soc. Amer., Ann. 62: 220-226.

Morphology: Parker, 1924. Soc. Ent. de France, Ann. 93: 310-311 (larva).

nigripes Curtis. N. Y., Ill., Ark., Colo.; Cosmopolitan. Host: Fannia leucosticta (Meig.), F. scalaris (F.), Lucilia sp.; Musca domestica L.

Spalangia nigripes Curtis, 1839. Brit. Ent., v. 16, fol. 740..

Spalangia hyaloptera Foerster, 1850. Naturh. Ver. Rheinlande, Verh. 7: 509., ,.

Spalangia formicaria Kieffer, 1905. Berlin. Ent. Ztschr. 50: 1. ?.

Spalangia muscarum Girault, 1920. U. S. Natl. Mus., Proc. 58: 213..

Taxonomy: Boucek, 1963. Mus. Natl. Pragae, Acta Ent. 35: 461 (syn.).

nigroaenea Curtis. N. B. and Ont., s. to Va., w. to B. C. and Calif.; Cosmopolitan. Host: Fannia sp., Musca domestica L., Muscina sp., Ophyra sp., Stomoxys calcitrans (L.).

Spalangia nigroaenea Curtis, 1839. Brit. Ent., v. 16, fol. 740. ठ.

Spalangia homalaspis Foerster, 1850. Naturh. Ver. Rheinlande, Verh. 7: 505. ९, ठ.

Spalangia astuta Foerster, 1851. Naturh. Ver. Rheinlande, Verh. 8: 1. \&.

Spalangia muscidarum Richardson, 1913. Psyche 20: 38., ठ ठ.

Spalangia sundaica Graham, 1932. In Handschin, Austral. Council Sci. and Indus. Res., Pam. 31: 22, 24. ₹, ठ.

Taxonomy: Boucek, 1963. Mus. Natl. Pragae, Acta Ent. 35: 448 (syn.). -Graham, 1969. Brit. Mus. (Nat. Hist.) Ent., Bul. Sup. 16: 52 (syn.).

Biology: Pinkus, 1913. Psyche 20: 148-158 (muscidarum). -Richardson, 1913. Jour. Morph. 24: 513-549 (muscidarum). -Roberts, 1935. Jour. Agr. Res. 50: 493 (muscidarim).

- Legner et al., 1967. Ent. Soc. Amer., Ann. 60: 462-468. - Legner and Olton, 1968. Ent.

Soc. Amer., Ann. 61: 1306-1314.

Morphology: Burks, 1938. Ent. Soc. Amer., Ann. 31: 161 (muscidarum, forewing).

\section{SUBFAMILY CEROCEPHALINAE}

Revision: Gahan, 1946. U. S. Natl. Mus., Proc. 96: 349-376.

Taxonomy: Hedqvist, 1969. Ent. Soc. Wash., Proc. 71: 449-466 (key to genera).

\section{Genus CHOETOSPILA Westwood}

Choetospila Westwood, 1874. Thesaurus Ent. Oxon., p. 137, pl. 25.

Type-species: Choetospila elegans Westwood. Monotypic.

Chaetospila Dalla Torre, 1898. Cat. Hym., v. 5, p. 207. Emend.

Spalangiomorpha Girault, 1913. Queensland Mus., Mem. 2: 333.

Type-species: Spalangiomorpha fasciatipennis Girault. Orig. desig.

elegans Westwood. Que., s. to Fla., w. to B. C., s. to Calif.; Cosmopolitan. Host: Callosobmuchus chinensis (L.), C. maculatus (F.), Caulophilus oryzae (Gyll.), Lasioderma serricome (F.), Rhyzopertha dominica (F.), Sitophilus granarius (L.), S. linearis (Herbst), S. oryzae (L.), Stegobium paniceum (L.). This is one of the commonest chalcidoids in the entire world; it has both winged and wingless forms, often mixed in the same lot.

Choetospila elegans Westwood, 1874. Thesaurus Ent. Oxon., p. 137. 9.

Spalangiomorpha fasciatipennis Girault, 1913. Queensland Mus., Mem. 2: 333..

Spalangia metallica Fullaway, 1913. Hawaii. Ent. Soc., Proc. 2: 286. $९$. 


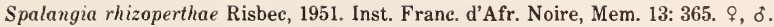
Cerocephala oryzae Risbec, 1951. Inst. Franc. d'Afr. Noire, Mem. 13: 366. ㅇ, ठో.

Taxonomy: Boucek, 1963. Mus. Natl. Pragae, Acta Ent. 35: 505 (syn.). -Graham, 1969. Brit. Mus. (Nat. Hist.) Ent., Bul. Sup. 16: 61 (syn.). - Hedqvist, 1969. Ent. Soc. Wash., Proc. 71: 451 (syn.).

Biology: Bare, 1942. Jour. Econ. Ent. 35: 186. - Williams and Floyd, 1971. Jour. Econ. Ent. 64: $1407-1408$.

\section{Genus CHOETOSPILISCA Hedqvist}

Choetospilisca Hedqvist, 1969. Ent. Soc. Wash., Proc. 71: 452.

Type-species: Choetospilisca tabidoides Hedqvist. Orig. desig.

tabida (Gahan). Md. Ecology: Thought to parasitize a cossonine beetle living in a dead tree branch.

Choetospila tabida Gahan, 1946. U. S. Natl. Mus., Proc. 96: 354. ‡, ઠ.

\section{Genus CEROCEPHALA Westwood}

Cerocephala Westwood, 1832. Mag. Zool. 2: Cl. ix, pl. 4.

Type-species: Cerocephala cornigera Westwood. Monotypic.

E pimacrus Walker, 1833. Ent. Mag. 1: 368.

Type-species: Epimacrus rufus Walker. Monotypic.

Sciatheras Ratzeburg, 1848. Ichn. d. Forstins., v. 2, p. 209.

Type-species: Sciatheras trichotus Ratzeburg. Monotypic.

Cerocephala subg. Parasciatheras Masi, 1917. Novitates Zool. 24: 189.

Type-species: Cerocephala (Parasciatheras) caelebs Masi. Monotypic.

Proamotura Girault, 1920. Insecutor Inscitiae Menstruus 8: 143.

Type-species: Proamotura aquila Girault. Monotypic.

Taxonomy: Hedqvist, 1969. Ent. Soc. Wash., Proc. 71: 459.

dubarae Wallace. Pa. Host: Hadrobregmus carinatus (Say).

Cerocephala dubarae Wallace, 1959. Brooklyn Ent. Soc., Bul. 54: 84. \&, ð.

rufa (Walker). Ohio, Mich., Colo.; Europe. Ecology: A secondary parasite of Scolytidae. Host:

Dendrosoter sp., Spathius sp.

Epimacrus rufus Walker, 1833. Ent. Mag. 1: 369. .

\section{Genus ACEROCEPHALA Gahan}

Acerocephala Gahan, 1946. U. S. Natl. Mus., Proc. 96: 369.

Type-species: Cerocephala atroviolacea Crawford. Orig. desig.

aenigma Gahan. Calif., Oreg.

Acerocephala aenigma Gahan, 1946. U. S. Natl. Mus., Proc. 96: 371. , o.

atroviolacea (Crawford). Colo., N. Mex., Ariz., Calif. Host: Conophthorus edulis Hopk., C.

flexilis Hopk., Cylindrocopturus sp.

Cercocephala(!) atroviolacea Crawford, 1913. U. S. Natl. Mus., Proc. 45: 315..

Biology: Keen, 1958. U. S. Dept. Agr., Tech. Bul. 1169: 49, 98.

\section{Genus THEOCOLAXIA Girault}

Theocolaxia Girault, 1924. Lese Majeste, New Insecta and Robbery, p. 1.

Type-species: Theocolaxia lessingi Girault. Orig. desig.

pityophthori (Ashmead). N. C., Fla. Host: Pityophthorus consimilis Lec., Thysanoes

fimbricornis Lec.

Cerocephala pityophthori Ashmead, 1894. Ent. Soc. Wash., Proc. 3: 32 ..

scolytivora (Ashmead). Fla. Host: Loganius ficus Schwarz.

Cerocephala scolytivora Ashmead, 1894. Ent. Soc. Wash., Proc. 3: 33. ๆ, ð. 


\section{SUBFAMILY DIPARINAE}

In this subfamily the females usually are wingless, or with rudimentary wings, and the males are fully winged; the sexes also have quite different antennae. Consequently the males and females of the same species often have been placed in different subfamilies, or even superfamilies.

Taxonomy: Gahan, 1946. U. S. Natl. Mus., Proc. 96: 375 (Lelapinae). - Boucek, 1954. Mus.

Natl. Pragae, Acta Ent. 29: 54 (Diparinae). -Graham, 1969. Brit. Mus. (Nat. Hist) Ent.,

Bul. Sup. 16: 63-66.

\section{Genus DIPARA Walker}

Dipara Walker, 1833. Ent. Mag. 1: 371, 373.

Type-species: Dipara petiolata Walker. Monotypic.

Tricoryphus Foerster, 1856. Hym. Stud., v. 2, p. 46. No species.

Type-species: Tricoryphus fasciatus Thomson. Desig. by Thomson, 1876, by subsequent reference.

Apterolelaps Ashmead, 1901. Fauna Hawaii., v. 1, p. 312.

Type-species: Apterolelaps nigriceps Ashmead. Orig. desig.

Apterolaelaps Schulz, 1906. Spolia Hym., p. 144. Emend.

Apterolaelaps Girault, 1916. Canad. Ent. 48: 264. Preocc. by Schulz, 1906.

Type-species: Apterolaelaps nigriscutum Girault. Monotypic.

Hispanolelaps Mercet, 1927. Eos 3: 60.

Type-species: Hispanolelaps coxalis Mercet. Orig. desig.

Afrolelaps Hedqvist, 1963. Cult. Co. Diam. Angola, Publ. 63: 47.

Type-species: Afrolelaps maculata Hedqvist. Orig. desig.

The female of this genus is wingless, commonly taken in Berlese samples; the male is winged and looks entirely different.

Taxonomy: Boucek, 1954. Mus. Natl. Pragae, Acta Ent. 29: 52-54 (syn.). -Graham, 1969. Brit. Mus. (Nat. Hist.) Ent., Bul. Sup. 16: 64-65 (syn.).

latipennis Ashmead. Colo.

Dipara latipennis Ashmead, 1890. Colo. Biol. Assoc., Bul. 1: 26, 45. ठ. nigriceps (Ashmead). W. Va.

Apterolelaps nigriceps Ashmead, 1901. Fauna Hawaii, v. 1, p. 312. ․

Apterolaelaps nigriscutum Girault, 1916. Canad. Ent. 48: 264..+

Taxonomy: Gahan and Fagan, 1923. U. S. Natl. Mus., Bul. 124: 16 (type of each species the same specimen).

\section{Genus SPALANGIOLAELAPS Girault}

Spalangiolaelaps Girault, 1917. Ent. News 28: 22.

Type-species: Spalangiolaelaps argenticoxa Girault. Orig. desig.

argenticoxa Girault. Md.

Spalangiolaelaps argenticoxa Girault, 1917. Ent. News 28: 23. ?.

\section{Genus TRIMICROPS Kieffer}

Trimicrops Kieffer, 1906. Soc. Sci. de Bruxelles, Ann. 30: 142.

Type-species: Trimicrops claviger Kieffer. Monotypic.

Genus originally placed in the Ceraphronidae. There is an undescribed Nearctic species.

\section{SUBFAMILY EUNOTINAE}

Revision: Masi, 1931. Eos 7: 411-459.

Taxonomy: Graham, 1969. Brit. Mus. (Nat. Hist.) Ent., Bul. Sup. 16: 67-68. 


\section{Genus MORANILA Cameron}

Tomocera Howard, 1881. In Comstock, U. S. Dept. Agr., Ann. Rpt. for 1880, p. 368. Preocc. by Desmarest, 1858 .

Type-species: Tomocera californica Howard. Monotypic.

Moranila Cameron, 1883. Ent. Soc. London., Trans. 1883: 188.

Type-species: Moranila testaceiceps Cameron. Monotypic.

Dilophogaster Howard, 1886. Ent. Amer. 2: 98. N. name for Tomocera.

Eunotomyia Masi, 1917. Novitates Zool. 24: 297.

Type-species: Eunotomyia festiva Masi. Monotypic.

Revision: Mercet, 1924. Real Soc. Espan. Hist. Nat., Bol. 24: 422-426.

californica (Howard). Calif.; Mexico, Hawaii, South Sea Isls., Australia; Africa, Eurasia.

Ecology: The larva of this species preys on the eggs within the body of the female

scales; rarely it attacks larvae of other primaries. Host: Antonina bambusae Mask.,

Asterolecanium sp., Ceroplastes sp., Coccus hesperidum L., Saissetia coffeae (Walk.), S.

nigra (Niet.), S. oleae (Bern.); Microterys flavus (How.).

Tomocera californica Howard, 1881. In Comstock, U. S. Dept. Agr., Ann. Rpt. for 1880 , pp. 252, 368. ९, ठ์.

Moranila testaceiceps Cameron, 1883. Ent. Soc. London, Trans. 1883: 188.

Tomocera ceroplastis Perkins, 1906. Hawaii. Ent. Soc., Proc. 1: 75. ๆ.

Tomocera glabriventris Girault, 1915. Queensland Mus., Mem. 4: 207..

Tomocera flaviceps Girault, 1915. Queensland Mus., Mem, 4: 208. ๆ.

Taxonomy: Timberlake, 1924. Hawaii. Ent. Soc., Proc. 5: 425.

Biology: Craw, 1891. Calif. State Bd. Hort., Bul. 57: 7. - Riley, 1891. U. S. Dept. Agr., Ann.

Rpt. for 1890, p. 251. - Coquillett, 1892. U. S. Dept. Agr., Div. Ent. Bul. 26: 31. - Craw,

1902. Calif. State Bd. Hort., Rpt. for 1901-1902, p. 200. -Quayle and Rust, 1911. Calif. Agr.

Expt. Sta., Bul. 223: 189. - Essig, 1913. Calif. State Comn. Hort., Monthly Bul. 2: 272-273.

-Smith and Compere, 1928. Univ. Calif. Pubs., Ent. 4: 241-245, 317-321. - Essig, 1931.

Hist. of Ent., pp. 139-143, 334-335, 336, 387. - Smith, 1933. Ent. Soc. Amer., Ann. 26: 524.

- Hawkins, 1942. Ann. and Mag. Nat. Hist. (11) 9: 884. - Smith, 1944. Hilgardia 16: 282.

-Flanders, 1953 (1952). Ent. Soc. Amer., Ann. 45: 546-547. - Clausen, 1956. U. S. Dept.

Agr., Tech. Bul. 1139: 26. -Flanders, 1958. Jour. Econ. Ent. 51: 247.

\section{Genus EUNOTUS Walker}

Eunotus Walker, 1834. Ent. Mag. 2: 297.

Type-species: Eunotus cretaceus Walker. Monotypic.

Tritypus Ratzeburg, 1852. Ichn. d. Forstins., v. 3, p. 227.

Type-species: Tritypus areolatus Ratzeburg. Monotypic.

Megapelte Foerster, 1856. Hym. Stud., v. 2, p. 63. N. name unnecessarily proposed for Eunotus, preocc. in Botany.

americanus Girault. Maine, N. Dak., Okla., Mont. Host: Eriopeltis festucae Fonsc.

Eunotus americanus Girault, 1915. Ent. Soc. Amer., Ann. 8: 273. ‡, ठ.

eretaceus Walker. N. H., N. Y.; Europe. Host: Eriopeltis festucae Fonsc.

Eunotus cretaceus Walker, 1834. Ent. Mag. 2: 298. " $\delta "=?$.

Eunotus festucae Masi, 1928. Soc. Ent. Ital., Bol. 60: 128. ๆ, ठ.

Biology: Graham, 1969. Brit. Mus. (Nat. Hist.) Ent., Bul. Sup. 16: 72.

lividus Ashmead. Que., Ont., N. Y., N. J., Ohio, N. C., Ga., Fla., Kans., Colo. Host: Lecanium cormi Bouche, L. nigrofasciatum Perg., Pulvinaria vitis (L.).

Eunotus lividus Ashmead, 1892. Ent. Soc. Wash., Proc. 2: 288. \&.

Biology: Smith, 1906. N. J. Agr. Expt. Sta., Ann. Rpt. 26: 606-607. -Johnson, 1906. Colo. Agr.

Expt. Sta., Bul. 116: 11. -Essig, 1938. Ins. West. N. Amer., p. 840.

\section{Genus MESOPELTITA Ghesquiere}

Mesopeltis Masi, 1917. Novitates Zool. 24: 197. Preocc. by Cope, 1867.

Type-species: Mesopeltis atrocyanea Masi. Monotypic. 
Mesopeltita Ghesquiere, 1946. Rev. de Zool. et de Bot. Africaines 39: 370. N. name. atrocyanea (Masi). Tex.; Cent. and So. Amer., West Indies, East Indies. Host: Saissetia sp.

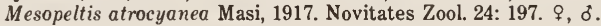

Taxonomy: Waterston, 1917. Bul. Ent. Res. 7: 252-257.

Biology: Compere, 1940. Hilgardia 13: 414-415.

\section{Genus SCUTELLISTA Motschulsky}

Scutellista Motschulsky, 1859. Etudes Ent. 8: 172, 177.

Type-species: Scutellista cyanea Motschulsky. Monotypic.

Aspidocoris Costa, 1863. Accad. Aspiranti Nat. Napoli, Ann. (3) 3: 25.

Type-species: Aspidocoris cyaneus Costa. Monotypic.

Enargopelte Foerster, 1878. Naturh. Ver. Rheinlande, Verh. 35: 62.

Type-species: Enargopelte obscura Foerster. Monotypic.

cyanea Motschulsky. Del., s. to Fla., w. to Calif.; Cosmopolitan. Living material imported from Italy in 1895, cultured in D. C., and liberated in La. in 1898. Another introduction from South Africa into Calif. was carried out in 1901. Both were successful, and cyanea is now so common in North America it is often assumed to be native. Host: Ceroplastes cirripediformis Comst., C. floridensis Comst., Coccus hesperidum L., Lecanium corni Bche., Phenacoccus artemisiae Ehrh., Saissetia coffeae (Walk.), S. nigra (Nietn.), S. oleae (Bern.).

Encyrtus caeruleus Fonscolombe, 1832. Ann. Sci. Nat., Zool. (1) 26: 304.

Scutellista cyanea Motschulsky, 1859. Etudes Ent. 8: 172. $₹$, ठ. Although caeruleus Fonscolombe has priority, Graham, 1969 (Brit. Mus. (Nat. Hist.,) Ent., Bul. Sup. 16: 76), intends to submit an application to the International Commission to have it suppressed, in view of the very large volume of literature there is that uses the name cyanea Motschulsky.

Biology: Marlatt, 1901. U. S. Dept. Agr., Yearbook for 1900, pp. 274-275. - Howard, 1903. U. S. Dept. Agr., Ann. Rpt., for 1902, pp. 228-229. -Marlatt, 1904. U. S. Dept. Agr., Div. Ent. Bul. (n. s.) 44: 50-56. - Ehrhorn, 1905. Calif. State Comnr. Hort., Monthly Cir., November, pp. 2-6. -Martelli, 1908. Lab. Zool. Gen. e. Agr. Portici, Bol. 2: 226, 238, 246. -Quayle, 1910. Jour. Econ. Ent. 3: 446-451. - Howard and Fiske, 1911. U. S. Dept. Agr., Bur. Ent. Bul. 91: 31-33. - Quayle, 1911. Calif. Agr. Expt. Sta., Bul. 214: 456-459. -Quayle and Rust, 1911. Calif. Agr. Expt. Sta., Bul. 223: 179-183. - Essig, 1913. Calif. State Comn. Hort., Monthly Bul. 2: 118-119, 270-271. -Essig, 1915. Calif. State Comn. Hort., Monthly Bul. 4: Sup. pp. 152, 154, 374. - Smith, 1916. Jour. Econ. Ent. 9: 479-481. - Smith, 1921. Jour. Econ. Ent. 14: 349. - Essig, 1926. Ins. Western N. Amer., p. 825. - Smith and Compere, 1928. Univ. Calif. Pubs. Ent. 4: 241-245, 322-332. - Essig, 1931. Hist. of Ent., pp. 335-337, 360, 388. -Quayle, 1932. Calif. Agr. Expt. Sta., Bul. 542: 43. - Smith, 1933. Ent. Soc.

Amer., Ann. 26: 523-525. - Compere, 1937. Bul. Ent. Res. 28: 51. - Smith, 1944. Hilgardia 16: 281. - Woglum et al., 1947. Jour. Econ. Ent. 40: 818-819. - Flanders, 1953 (1952). Ent. Soc. Amer., Ann. 45: 544-547. - Clausen, 1956. U. S. Dept. Agr., Tech. Bul. 1139: 108.

-Flanders, 1958. Jour. Econ. Ent. 51: 247. - Flanders, 1959. Jour. Econ Ent. 52: 596-597. -Gaxho, 1960. Tirana U. Shtet., Bul. Ser. 14: 55. -Talhouk, 1961. Entomophaga 6: 208.

- Inserra, 1968. Entomologica 4: 45-77. - Nuzzaci, 1969. Entomologica 5: 9-36, 127-138.

Morphology: Mercet, 1910. Real Acad. Ci. Madrid, Rev. 9: 185-191 (larva, pupa). - Parker, 1924. Soc. Ent. de France, Ann. 93: 371 (larva, egg). - Balachowsky and Mesnil, 1935. Ins. Nuisables Plantes Cult., v. 1, p. 572 (larva). -Domenichini, 1953. Bol. Zool. Agr. e Bach. Univ. Milano 19: 258 (gaster).

\section{Genus TOMOCERODES Girault}

Tomocerodes Girault, 1916. Canad. Ent. 48: 246.

Type-species: Tomocerodes americana Girault. Monotypic.

americana Girault. Ariz.; Mexico. Host: Lecanodiaspis prosopidis (Mask.).

Tomocerodes americana Girault, 1916. Canad. Ent. 48: 247. ‡, ठ. 


\section{SUBFAMILY ASAPHINAE}

Taxonomy: Graham, 1969. Brit. Mus. (Nat. Hist.) Ent., Bul. Sup. 16: 77-78.

\section{Genus ASAPHES Walker}

Asaphes Walker, 1834. Ent. Mag. 2: 151.

Type-species: Asaphes vulgaris Walker. Monotypic.

Isocratus Foerster, 1856. Hym. Stud., v. 2, pp. 53, 58. N. name, unnecessarily proposed; Asaphes preocc. in Botany.

Parectroma Brethes, 1913. Buenos Aires Mus. Nac. de Hist. Nat., An. 24: 91.

Type-species: Parectroma huebrichi Brethes. Orig. desig.

Taxonomy: De Santis, 1960. Fac. Agron, Revista (3) 36: 113 (syn.).

californicus Girault. Colo., Utah, Wash., Oreg., Calif. Host: Aphelinus sp., Aphidius sp., Praon sp., Trioxys pallidus (Hal.).

Asaphes californicus Girault, 1917. Deser. Hym. Chalcidoid. Variorum cum Observ. V, p. 1. ๆ.

Biology: van den Bosch et al., 1962. Jour. Econ. Ent. 55: 861.

lucens (Provancher). N. B., Que., Ont., s. to Fla., w. to B. C. and Calif. Host: Aphelinus sp., Aphidius phorodontis Ashm., A. polygonaphis (Fitch), Diaretiella rapae (M'Int.), Lysiphlebus testaceipes (Cress.), Praon aguti Smith, P. simulans (Prov.), Trioxys utilis Mues.

Euplectrus lucens Provancher, 1887. Addit. Corr. Faune Ent. Canada Hym., p. 207.. Megorismus Fletcheri Crawford, 1909. Canad. Ent. 41: 98., ठ.

Asaphes americana Girault, 1914. Ent. Soc. Wash., Proc. 16: 114. ๆ, ठ.

Taxonomy: Burks, 1964 (1963). Canad. Ent. 95: 1258 (syn.).

Biology: Spencer, 1926. Ent. Soc. Amer., Ann. 19: 145. -Griswold, 1929. Ent. Soc. Amer., Ann. 22: 449. -Shands et al., 1955. Ent. Soc. Wash., Proc. 57: 132-135. -Sekhar, 1958. Ent. Soc. Amer., Ann. 51: 1-7. - Pimentel, 1961. Jour. Econ. Ent. 54: 886. - Manglitz and Hill, 1964. Nebr. Agr. Expt. Sta., Res. Bul. 217: 10. - Wage et al., 1965. U. S. Dept. Agr., Tech. Bul. 1338: 29.

rufipes Brues. Maine, Ont., Mass., Conn., N. Y., w. to B. C., Wash. Host: Aphelinus sp., Aphidius sp., Praon sp.

Asaphes rufipes Brues, 1908. Wis. Nat. Hist. Soc., Bul. 6: 160..

Biology: Cardiff, 1915. Wash. Agr. Expt. Sta., Bul. 127: 32. -Shands et al., 1955. Ent. Soc.

Wash., Proc. 57: 132-135. -Johansen, 1957. Northwest Sci. 31: 72.

vulgaris Walker. Greenland; Europe. Host: Aphidius sp., Praon sp., Trioxys sp. There are numerous host records for this widespread, common, Palearctic species in the literature; most of them have not been verified. This is probably always a hyperparasite of aphids.

Asaphes vulgaris Walker, 1834. Ent. Mag. 2: 152 . $९$, ठ์.

Taxonomy: Delucchi, 1955. Soc. Roy. Ent. Belg., Mem. 27: 174. -Graham, 1969. Brit. Mus.

(Nat. Hist.) Ent., Bul. Sup. 16: 78-83.

Biology: Vukasovic, 1931. Soc. Ent. Jugosl., Acta 5-6: 94-97. - Dunn, 1949. Bul. Ent. Res. 40: 103-117. -Evenhuis, 1964. Entomophaga 9: 229. - Broussal, 1968. [Paris] Acad., des Sci., Compt. Rend. (D) 266: 1586.

\section{Genus BAIRAMLIA Waterston}

Bairamlia Waterston, 1929. Parasitology 21: 103.

Type-species: Bairamlia fuscipes Waterston. Orig. desig.

marylandensis (Girault). Md.

Pirene marylandensis Girault, 1916. Brooklyn Ent. Soc., Bul. 11: 88. ๆ.

Taxonomy: Waterston, 1929. Parasitology 21: 103. 


\section{Genus HYPERIMERUS Girault}

Hyperimerus Girault, 1917. Deser. Hym. Chalcidoid. Variorum cum Observ. III, p. 5. Type-species: Hyperimerus corvus Girault. Orig. desig.

Mespilon Graham, 1957. Ent. Monthly Mag. 92: 406.

Type-species: Mespilon exiguum Graham. Orig. desig.

Taxonomy: Burks, 1967. In Krombein and Burks, U. S. Dept. Agr., Agr. Monog. 2, Sup. 2 : 251, 255 (Torymidae). - Boucek, 1965. Mus. Natl. Pragae, Acta Ent. 36: 549 (syn.).

-Graham, 1969. Brit. Mus. (Nat. Hist.) Ent., Bul. Sup. 16: 78, 83 (Pteromalidae).

corvus Girault. Calif.; Mexico. Host: Chrysopa sp., Hemerobius sp., Sympherobius sp. Closely associated with Psendococcus in its native environment.

Hyperimerus corvus Girault, 1917. Descr. Hym. Chalcidoid Variorum Cum. Observ. III, p. 5. ㅇ.

\section{SUbFAMILY PANSTENONINAE}

Taxonomy: Erdos, 1955. Mus. Natl. Hung., Ann. Hist. Nat. (n. s.) 6: 296. —Graham, 1969. Brit. Mus. (Nat. Hist.) Ent., Bul. Sup. 16: 92.

\section{Genus PANSTENON Walker}

Panstenon Walker, 1846. List Hym. Brit. Mus. Chalcid. v. 1, p. 29.

Type-species: Miscogaster oxylus Walker. Monotypic.

Candonia Walker, 1850. Ann. and Mag. Nat. Hist. (2) 5: 125.

Type-species: Caudonia agylla Walker. Monotypic.

Taxonomy: Graham, 1957. In Kerrich and Graham, Soc. Brit. Ent., Trans. 12: 276 (syn.). columbianum Ashmead. D. C.

Panstenon columbiana Ashmead, 1896. Amer. Ent. Soc., Trans. 23: 231. ?.

\section{Genus BRACHYCAUDONIA Ashmead}

Brachycaudonia Ashmead, 1904. Carnegie Mus., Mem. 1: 283, 285.

Type-species: Brachycaudonia californica Ashmead. Orig. desig. californica Ashmead. Calif.

Brachycaudonia californica Ashmead, 1904. Carnegie Mus., Mem. 1: 282, 368. .

Taxonomy: Gahan and Peck, 1946. Wash. Acad. Sci., Jour. 36: 315.

\section{SUBFAMILy MISCOGASTERINAE}

\section{TRIBE SPHEGIGASTERINI}

\section{Genus SPHEGIGASTER Spinola}

Sphegigaster Spinola, 1811. Paris Mus. d'Hist. Nat., Ann. 17: 149.

Type-species: Diplolepis pallicornis Spinola. Desig. by Ashmead, 1904.

Trigonogastra Ashmead, 1904. Carnegie Mus., Mem. 1: 330, 331.

Type-species: Trigonogastra aurata Ashmead. Orig. desig.

Taxonomy: Delucchi, 1958. Bol. Zool. Agr. e di Bach. (2) 1: 56 (syn.). aurata (Ashmead). Mich., Mont.

Trigonogastra aurata Ashmead, 1904. Carnegie Mus., Mem. 1: 330. $\$$.

Taxonomy: Gahan and Peck, 1946. Wash. Acad. Sci., Jour. 36: 317 (type).

flavicornis (Walker). B. C.; Europe. Introduced from England into B. C. in mid 1930's; recovered 1939. Host: Phytomyza ilicis Curtis.

Merismus flavicomis Walker, 1833. Ent. Mag. 1: 377. ठ.

Taxonomy: Graham, 1969. Brit. Mus. (Nat. Hist.) Ent., Bul. Sup. 16: 136 (Diplolepis pallicornis Spinola, 1808, might prove to be the same). 
Biology: Cameron, 1939. Bul. Ent. Res. 30: 178-180, 192-197. -McLeod, 1954. Ent. Soc. Brit. Columbia, Proc. 50: 22.

\section{Genus SYNTOMOPUS Walker}

Syntomopus Walker, 1833. Ent. Mag. 1: 371, 372.

Type-species: Syntomopus thoracicus Walker. Desig. by Westwood, 1840.

affinis Ashmead. D. C., Ill.

Syntomopus affinis Ashmead, 1896. Amer. Ent. Soc., Trans. 23: 228..

americanus Ashmead. Conn., N. Y., s. to Fla., w. to Oreg., Calif.; Mexico, Cent. Amer. Host: Melanagromyza angelicae (Frost), M. virens (Loew).

Syntomopus americanus Ashmead, 1894. Cincinnati Soc. Nat. Hist., Jour. 17: 51. ‡, ठ.

Biology: Lange, 1944. Jour. Econ. Ent. 37: 394-395.

\section{Genus CYRTOGASTER Walker}

Cyrtogaster Walker, 1833. Ent. Mag. 1: 317, 381.

Type-species: Cyrtogaster mufipes Walker. Desig. by Westwood, 1840.

Dicormus Foerster, 1841. Beitr. Monog. Pteromalinen, p. 38.

Type-species: Dicormus aquisgranensis Foerster. Monotypic.

Taxonomy: Foerster, 1856. Hym. Stud., v. 2, p. 55 (syn.).

trypherus (Walker). Del., s. to Fla., w. to Calif. Ecology: Common in alfalfa fields. Host:

Brachydeutera argentata (Walk.), Drosophila sp.

Lampretatus trypherus Walker, 1843. Soc. Ent. de France, Ann. (2) 1: 158. "ๆ" = ठ".

Cyrtogaster glasgowi Crawford, 1914. Insecutor Inscitiae Menstruus 2: 36. ๆ, ठ๋.

Taxonomy: Burks, 1975. Brit. Mus. (Nat. Hist.) Ent., Bul. 32: 161 (syn.).

vulgaris Walker. B. C., Wash.; Europe. Ecology: Commonly intercepted in quarantine in living herbaceous vegetation from England, Scotland, and Continental Europe. Introduced from England into B. C. in mid-1930's and recovered. Host: Phytomyza sp., P. ilicis Curtis, $P$. nigra Meig.

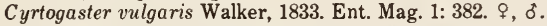

Cyrtogaster thoracica Walker, 1833. Ent. Mag. 1: 382 ..

Cyrtogaster rufipes Walker, 1833. Ent. Mag. 1: 383. ㅇ, ठ.

Cyrtogaster tenuis Walker, 1833. Ent. Mag. 1: 384. .

Cyrtogaster cingulipes Walker, 1833. Ent. Mag. 1: 384. ㅇ.

Dicormus aquisgranensis Foerster, 1841. Beitr. Monog. Pteromalinen, p. 38. ठో.

Lamprotatus Acarnas Walker, 1848. List Hym. Brit. Mus., Chalcid., v. 2, pp. 111. 168..

Cyrtogaster biglobus Foerster, 1861. Progr. Realsch. Aachen 1860-1861, p. 33. ठ。.

Sphegigaster degener Walker, 1872. Notes on Chalcid., p. 117. \%.

Taxonomy: Delucchi, 1955. Soc. Roy. Ent. de Belg., Mem. 27: 174-175 (syn.). -Askew, 1965.

Entomophaga 10: 180-181 (syn.). -Graham, 1969. Brit. Mus. (Nat. Hist.) Ent., Bul. Sup. 16:

142-143 (syn.; types).

Biology: Cameron, 1939. Bul. Ent. Res. 30: 178-180, 197-199. - Askew, 1965. Entomophaga 10: 185-186 (hosts in Europe). -Graham, 1969. Brit. Mus. (Nat. Hist.) Ent., Bul. Sup. 16: 143 (hosts in England).

\section{Genus LOPHOCOMODIA Ashmead}

Lophocomodia Ashmead, 1888. Kans. Agr. Expt. Sta., Bul. 3: App. p. Vl.

Type-species: Lophocomodia americana Ashmead. Monotypic.

americana Ashmead. Kans.

Lophocomodia americana Ashmead, 1888. Kans. Agr. Expt. Sta., Bul. 3: App. p. VI. đ̋.

\section{TRIBE MISCOGASTERINI}

Taxonomy: Graham, 1969. Brit. Mus. (Nat. Hist.) Ent., Bul. Sup. 16: 149-150 (approx. equal to Lamprotatini of older classifications). 


\section{Genus HALTICOPTERA Spinola}

Halticoptera Spinola, 1811. Paris Mus. d'Hist. Nat., Ann. 17: 148.

Type-species: Diplolepis flavicomis Spinola. Desig. by Ashmead, 1904.

Pachylarthrus Westwood, 1832. London, Edinb. and Dublin Phil. Mag. and Jour. Sci. (3) 1: 127.

Type-species: Pachylarthrus insignis Westwood. Monotypic.

Phagonia Curtis, 1832. Brit. Ent., v. 9, folio 427.

Type-species: Diplolepis flavicomis Spinola. Orig. desig.

Dicyclus Walker, 1833. Ent. Mag. 1: 371, 455.

Type-species: Dicyclus aeueus Walker. Desig. by Westwood, 1840.

Phacostomus Nees, 1834. Hym. Ichn. Aff. Monogr., v. 2, p. 121.

Type-species: Diplolepis patellana Dalman. Monotypic.

Megorismus Walker, 1846. List Hym. Brit. Mus., Chalcid., v. 1, p. 29.

Type-species: Miscogaster daiphron Walker. Monotypic.

Tityros Walker, 1848. List Hym. Brit. Mus., Chalcid., v. 2, pp. 108, 164.

Type-species: Tityros poreia Walker. Monotypic.

Megalorismus Schulz, 1906. Spolia Hym., v. 147. Emend. of Megorismus.

Taxonomy: Graham, 1969. Brit. Mus. (Nat. Hist.) Ent., Bul. Sup. 16: 155-159 (syn.; key to European spp.).

brodiei Ashmead. Ont. Ecology: Emerged from twig or leaf midrib galls of Xanthoteras quercusforticome (Walsh). This sp. may not be Halticoptera; types not located.

Halticoptera brodiei Ashmead, 1896. Amer. Ent. Soc., Trans. 14: 192. 9.

circulus (Walker). Que. and Maine, s. to Fla., w. to B. C., Wash., Oreg., Calif.; Mexico, Europe. Host: Agromyza parvicomis Loew, Cerodontha dorsalis (Loew), Lirianyza melampyga (Loew), L. langei Frick, L. pictella (Thoms.), Mayetiola destructor (Say),

Melanagromyza virens (Loew), Meromyza americana Fitch, Oscinella sp., O. frit (L.), Phytobia angulata (Loew), P. clara (Melander), P. lateralis (Macq.), Phytomyza delphiniae Frost. This species has used the name aenea (Walker) or patellana (Dalman) in all North American literature since 1933.

Dicyclus circulus Walker, 1833. Ent. Mag. 1: 456.. .

Dicyclus fuscicomis Walker, 1833. Ent. Mag. 1: 456. 9.

Pteromalus palpigerus Zetterstedt, 1838. Ins. Lap. Descr., Hym., p. 425.

Pteromalus brevicomis Zetterstedt, 1838. Ins. Lap. Descr., Hym., p. 426. Preocc. by

Walker, 1835.

Miscogaster Daiphron Walker, 1839. Monog. Chalcid., v. 1, p. 198. \&.

Miscogaster Crius Walker, 1839. Monog. Chalcid., v. 1, p. 201. 9.

Miscogaster Suilius Walker, 1839. Monog. Chalcid., v. 1, p. 202. “o" = $\delta$.

Cyrtogaster liqueatus Ashmead, 1894. Amer. Ent. Soc., Trans. 21: 336. ठ。.

Cyrtogaster occidentalis Ashmead, 1896. Amer. Ent. Soc., Trans. 23: 230. ๆ, ठ.

Cyrtogaster citripes Ashmead, 1896. Amer. Ent. Soc., Trans. 23: 230. ð.

Polycyrtus(!) floridanus Ashmead, 1896. Amer. Ent. Soc., Trans. 23: 230. ठ.

Pteromalus lapponicus Dalla Torre, 1898. Cat. Hym., v. 5, p. 131. N. name for brevicomis Zetterstedt.

Polycystus foersteri Crawford, 1913. U. S. Natl. Mus., Proc. 45: 313. \&, ठ.

Taxonomy: Gahan, 1934 (1933). U. S. Dept. Agr., Misc. Pub. 174: 116 (aenea). -Ferriere, 1952. Soc. Venez. Stor. Nat., Bol. 6: 172 (patellana). -Graham, 1969. Brit. Mus (Nat.

Hist.) Ent., Bul. Sup. 16: 163-164 (syn.; circulus).

Biology: Lange, 1944. Jour. Econ. Ent. 37: 394-395. - Hills and Taylor, 1951. Jour. Econ. Ent. 44: 760-762. - Morrill and Kieckhefer, 1971. Jour. Econ. Ent. 64: 1129-1131.

goodi Crawford. N. S., Que., Wash.

Halticoptera goodi Crawford, 1915. Insecutor Inscitiae Menstruus 3: 107. \&, ठ.

rosae Burks. Maine, Ont., R. I., Wis., Minn., Sask., Utah, Alaska. Host: Rhagoletis basiola (0. S.).

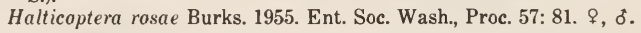

Biology: Balduf, 1959. Ill. Biol. Monog. 26: 41-50, 170-173. 
stella Girault. Ariz., Calif. Host: Aciurina maculata (Cole).

Halticoptera stella Girault, 1917 (May). Descr. Hym. Chalcidoid. Variorum cum Observ.

III, p. 1. ?.

Megorismus poloni Girault, 1917 (June). Psyche 24: 97..

\section{Genus MERISMUS Walker}

Merismus Walker, 1833. Ent. Mag. 1: 371, 375.

Type-species: Merismus rufipes Walker. Desig. by Westwood, 1840.

rufipes Walker. Va.; Europe. Probably an adventive.

Merismus rufipes Walker, 1833. Ent. Mag. 1: 378. ๆ.

\section{Genus SELADERMA Walker}

Seladerma Walker, 1834. Ent. Mag. 2: 288.

Type-species: Seladerma laetum Walker. Desig. by Westwood, 1840.

diaeus (Walker). Ont. Ecology: Host probably an agromyzid.

Lamprotatus Diaeus Walker, 1844. Ann. and Mag. Nat. Hist. (1) 14: 16..

Taxonomy: Graham, 1969. Brit. Mus. (Nat. Hist.) Ent., Bul. Sup. 16: 203 (Seladerma).

-Burks, 1975. Brit. Mus. (Nat. Hist.) Ent., Bul. 32: 156.

Biology: Grahàm, 1969. Brit. Mus. (Nat. Hist.) Ent., Bul. Sup. 16: 203 (type labeled, "Bred from pupa of Vanessa cardui," but that is erroneous and refers to next species in Walker's publication, Pteromalus puparum (L.); true host of diaeus probably an agromyzid).

\section{Genus BUBEKIA Dalla Torre}

Brachycrepis Ashmead, 1888. Canad. Ent. 20: 174, 176. Preocc. by Leconte, 1854.

Type-species: Brachycrepis tricarinatus Ashmead. Monotypic.

Bubekia Dalla Torre, 1897. Wien. Ent. Ztg. 16: 84. N. name.

Bubeckia Dalla Torre, 1898. Cat. Hym., v. 5, p. 568. Misspelling.

Revision: Gahan, 1934 (1933). U. S. Dept. Agr., Misc. Pub. 174: 114.

carolinensis (Ashmead). N. C.

Acroclisis carolinensis Ashmead, 1896. Amer. Ent. Soc., Trans. 23: 228. ठ.

fallax Gahan. Ind., Tenn., Iowa, Kans., Okla. Host: Mayetiola destructor (Say), Meromyza americana Fitch.

Bubekia fallax Gahan, 1934 (1933). U. S. Dept. Agr., Misc. Pub. 174: 114-116. \&, o.

Biology: Morrill and Kieckhefer, 1971. Jour. Econ. Ent. 64: 1129-1131.

lasiopterae (Ashmead). Ohio. Host: Asteromyia agrostis (O. S.).

Megorismus lasiopterae Ashmead, 1893. Ohio Agr. Expt. Sta., Tech. Ser., Bul. 1: 160. o.

tricarinata (Ashmead). Kans.

Brachycrepis tricarinatus Ashmead, 1888. Canad. Ent. 20: 176. ९.

\section{Genus PARACAROTOMUS Ashmead}

Paracarotomus Ashmead, 1894. Amer. Ent. Soc., Trans. 21: 335.

Type-species: Paracarotomus cephalotes Ashmead. Monotypic.

cephalotes Ashmead. Va.

Paracarotomus cephalotes Ashmead, 1894. Amer. Ent. Soc., Trans. 21: 336. o.

\section{Genus MISCOGASTER Walker}

Miscogaster Walker, 1833. Ent. Mag. 1: 371, 458.

Type-species: Halticoptera hortensis Walker. Desig. by Ashmead, 1904.

Mischogaster Thomson, 1876. Hym. Scand., v. 4, pp. 220, 239. Emend.

Taxonomy: Delucchi, 1955. Lunds Univ., Arsskr. (n. s.) 50 (20): 6-10, 55-56. 
abnormicolor Girault. Fla.

Miscogaster abnormicolor Girault, 1917. Descr. Hym. Chalcidoid. Variorum cum Observ. III, p. 8. 9 .

aurata (Ashmead). Wis., Ill.

Stictomischus auratus Ashmead, 1896. Amer. Ent. Soc., Trans. 23: 221. ๆ.

biguttata Girault. Fla.

Miscogaster biguttata Girault, 1917. Psyche 24: 97.,$~ ð$.

discoloripes Girault. Fla.

Miscogaster discoloripes Girault, 1917. Deser. Hym. Chalcidoid. Variorum cum Observ. III, p. 9. 9.

flora Girault. Fla.

Miscogaster flora Girault, 1917. Psyche 24: 96..

keatsi Girault. Md.

Miscogaster keatsi Girault, 1917. Chalcidoidea Nova Marilandensis III, p. 5. \&.

marilandica Girault. Md., Fla.

Miscogaster marilandica Girault, 1916. Brooklyn Ent. Soc., Bul. 11: 87. ‡.

ungutta Girault. Md.

Miscogaster ungutta Girault, 1917. Ent. News 28: 23..

\section{Genus LAMPROTATUS Westwood}

Lamprotatus Westwood, 1833. Mag. Nat. Hist. 6: 121.

Type-species: Lamprotatus splendens Westwood. Monotypic.

Lampretatus Walker, 1843. Soc. Ent. de France, Ann. (2) 1: 155. Misspelling.

Lamprostatus Girault, 1917. Psyche 24: 96. Misspelling.

There are several published references to Lamprotatus pilicomis Thomson, 1876 (Hym. Scand., v. 4, p. 229) from Greenland, as well as Sweden. After those records were published Graham, 1969 (Brit. Mus. (Nat. Hist.) Ent., Bul. Sup. 16: 201-202) found that the type series of pilicornis is mixed. He has designated a lectotype for the species, placing it in synonymy under Seladerma tarsale (Walker). The Greenland records of pilicomis need to be re-examined.

canadensis Girault. Alta.

Lamprostatus canadensis Girault, 1917. Psyche 24: 96. ๆ.

conicus Girault. Alaska.

Lamprostatus conicus Girault, 1917. Deser. Hym. Chalcidoid. Variorum cum Observ. V, p. 11. ?.

salemus (Walker). Fla.

Lampretatus salemus Walker, 1843. Soc. Ent. de France, Ann. (2) 1: 156. ?.

Taxonomy: Burks, 1975. Brit. Mus. (Nat. Hist.) Ent., Bul. 32: 161 (type fragmentary, sp. cannot be placed; better material may be found later).

\section{TRIBE ORMOCERINI}

Taxonomy: Graham, 1969. Brit. Mus. (Nat. Hist) Ent., Bul. Sup. 16: 250-252 (approx. equal to

Tridymini of older classifications; key to European genera).

\section{Genus ELACHERTODOMYIA Girault}

Elachertodomyia Girault, 1917. Canad. Ent. 49: 110.

Type-species: Secodes phloeotribi Ashmead. Orig. desig.

This very strange appearing chalcid is probably misplaced in this tribe and may, in fact, be misplaced in the Pteromalidae. Unfortunately the material of it that is now available is in fragmentary condition. The genus Secodes Foerster is Eulophidae, but Girault felt that this genus, based on an Ashmead species described in Secodes, belonged in Pteromalidae.

Taxonomy: Girault, 1917. Canad. Ent. 49: 110. 
phloeotribi (Ashmead). Conn., N. J., Va. Host: Chramesus hicoriae Lec., Lixus musculus Say, Phloeotribus frontalis (Oliv.), Pseudopityophthorus minutissimus (Zimm.).

Secodes phloeotribi Ashmead, 1896. Amer. Ent. Soc., Trans. 23: 233. १, ठ.

Biology: Chittenden, 1898. Ent. Soc. Wash., Proc. 4: 78.

\section{Genus ORMOCERUS Walker}

Ormocerus Walker, 1834. Ent. Mag. 2: 168.

Type-species: Ormoceris vermalis Walker. Desig. by Westwood, 1840.

Hormocerus Foerster, 1856. Hym. Stud., v. 2, pp. 59, 60. Emend.

Terobia Foerster, 1878. Naturh. Ver. Rheinlande, Verh. 35: 64.

Type-species: Terobia dispila F.oerster. Orig. desig.

Taxonomy: Delucchi, 1955. Soc. Roy. Ent. de Belg., Mem. 27: 175 (syn.). -Peck, 1963. Canad.

Ent., Sup. 30: 903 (N. Amer. spp. unplaced).

flora Girault. Fla.

Terobia flora Girault, 1920. U. S. Natl. Mus., Proc. 58: 216. + , ঠ.

vulgaris Ashmead. Alaska.

Terobia vulgaris Ashmead, 1902. Wash. Acad. Sci., Proc. 4: 144., ò.

\section{Genus PARASYNTOMOCERA Girault}

Parasyntomocera Girault, 1917. Chalcidoidea Nova Marilandensis II, p. 2.

Type-species: Parasyntomocera hillmeadia Girault. Orig. desig.

hillmeadia Girault. Md.

Parasyntomocera hillmeadia Girault, 1917. Chalcidoidea Nova Marilandensis II, p. 2..

\section{Genus ERIXESTUS Crawford}

Erixestus Crawford, 1910. U. S. Natl. Mus., Proc. 38: 87.

Type-species: Erixestus winnemana Crawford. Monotypic.

winnemana Crawford. Que., Md., Va. Ecology: An egg parasite. Host: Calligrapha bigsbyana (Kby.), C. scalaris (Lec.).

Erixestus winnemana Crawford, 1910. U. S. Natl. Mus., Proc. 38: 88. \&, ठ.

Biology: Daviault, 1941. Nat. Canad. 68: 106-107.

\section{Genus SYSTASIS Walker}

Systasis Walker, 1834. Ent. Mag. 2: 228, 296.

Type-species: Systasis encyrtoides Walker. Desig. by Westwood, 1840.

Syntasis Ashmead, 1904. Carnegie Mus., Mem. 1: 274, 275. Misspelling.

diplosidis Eckel. Mass., Fla., Miss., Ohio, Mich., Wis., Calif. Host: Cecidomyia resinicola (O. S.), C. resinicoloides Will.

Syntasis diplosidis Eckel, 1903. Ent. News 14: 283. ․

Biology: Williams, 1909. Ent. News 20: 7 (Syntasis).

Morphology: Eckel, 1902. Ent. News 14: 283, pl. xiv (larva, adult).

encyrtoides Walker. Wis., Alaska, Oreg.; Europe. Host: Contarinia sp. Numerous dipterous hosts recorded in Palearctic literature.

Systasis encyrtoides Walker, 1834. Ent. Mag. 2: 296. $९, \delta$.

Tridymus punctatus Ratzeburg, 1852. Ichn. d. Forstins., v. 3, p. 227.

Hormocerus impletus Walker, 1872. Notes on Chalcid. pt. 6, p. 96 ..

Systasis longicornis Thomson, 1878. Hym. Scand., v. 5, p. 204..

Taxonomy: Graham, 1969. Brit. Mus. (Nat. Hist.) Ent., Bul. Sup. 16: 261 (syn.; types).

Biology: Parnell, 1963. Roy. Ent. Soc. London, Trans. 115: 271-272. -Ferron, 1964. Ann. des

Epiphyt. (C) 15: 277. - Kralovic, 1964. Biologia Bratislava 19: 265.

Morphology: Solinas, 1965. Entomologica [Bari] 1: 248 (immature stages). 


\section{Genus GASTRANCISTRUS Westwood}

Gastrancistrus Westwood, 1833. London, Edinb. and Dublin Phil. Mag. and Jour. Sci. (3) 2: 444.

Type-species: Gastrancistrus vagans Westwood. Monotypic.

Glyphe Walker, 1834. Ent. Mag. 2: 168, 170.

Type-species: Glyphe autumnalis Walker. Monotypic.

Tridymus Ratzeburg, 1848. Ichn. d. Forstins., v. 2, p. 183.

Type-species: Tridymus a phidum Ratzeburg. Desig. by Ashmead, 1904, p. 273.

Ashmead, 1904, p. 392, Desig. Pteromalus salicis Nees, but designation on p. 273 has priority.

Tripedias Foerster, 1856. Hym. Stud., v. 2, p. 60 . No species.

Type-species: Gastrancistrus tripedias Boucek. Desig. by Boucek, 1964.

Trydymus Girault, 1917. Psyche 24: 98. Misspelling, often used.

Revision: Graham, 1969. Brit. Mus. (Nat. Hist.) Ent., Bul. Sup. 16: 270-327. (Tridymus aphidum Ratzeburg an unfortunate choice for type-species of Tridymus; Pteromalus salicis Nees might be more satisfactory; application may be made to Internat. Comn. to change type-species).

Taxonomy: Walker, 1846. List Hym. Brit. Mus., Chalcid., v. 1, p. 25 (syn.). - Boucek, 1964. Ceskoslov. Spolec. Ent. Casopis 61: 259 (syn.).

aeneicornis (Girault), n. comb. N. Y. Ecology: Associated with plum tree.

Trydymus aeneicornis Girault, 1917. Psyche 24: 98. ․

americensis (Girault). N. comb. Mich. Ecology: Reared from cecidomyiid stem gall on Salix.

Trydymus americensis Girault, 1917. Descr. Hym. Chalcidoid. Variorum cum Observ. III, p. 8 . .

aphidis (Girault), n. comb. Conn., N. Y., Ark. Ecology: Reared from leaf or tendril galls on grape. Host: Lasioptera vitis $\mathrm{O}$. S.

Trydymus aphidis Girault, 1917. U. S. Natl. Mus., Proc. 53: 450. $q$.

aureipes (Girault), n. comb. Fla.

Trydymus aureipes Girault, 1917. U. S. Natl. Mus., Proc. 53: 449..

biguttatipennis (Girault), n. comb. Conn., Fla.

Trydymus biguttatipennis Girault, 1917. U. S. Natl. Mus., Proc. 53: 449. .

clavicornis (Girault), n. comb. Sask.

Trydymus clavicornis Girault, 1917. Descr. Hym. Chalcidoid. Variorum cum Observ. V, p. 15. ㅇ.

Taxonomy: Girault, 1920. U. S. Natl. Mus., Proc. 58: 214 (redescription as "N. sp." on same specimens used in 1917).

gargantua (Girault), n. comb. N. H., Conn., N. Y., Mich., Minn. Ecology: Reared from gall on Salix.

Trydymus gargantua Girault, 1917. Psyche 24: 98..

metallicus (Ashmead), n. comb. N. Y., N. J., Kans. Ecology: Reared from twig galls of basket willow, Salix purpurea. Host: Rhabdophaga salicis Schr. This sp. may be a synonym of Gastrancistrus salicis (Nees).

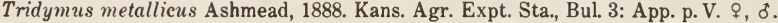
nigriclavus (Girault), n. comb. Md.

Trydymus nigriclavus Girault, 1917. Chalcidoidea Nova Marilandensis II, p. 2.. oblongus (Provancher), n. comb. Que.

Semiotellus oblongus Provancher, 1881. Nat. Canad. 12: 295. \&.

Taxonomy: Burks, 1964 (1963). Canad. Ent. 95: 1262 (type).

poloni (Girault), n. comb. N. H.

Trydymus poloni Girault, 1917. Psyche 24: 98. ค.

robiniaecola (Ashmead), n. comb. Va., W. Va.

Tridymus robiniaecola Ashmead, 1894. Amer. Ent. Soc., Trans. 21: 334. ९, ð. 
salicis (Nees). N. Y.; Europe. Ecology: Reared from galls on Salix. Host: Rhabdophaga salicis Schr. Species identified by Ashmead, reared in N. Y. from galls on Salix, the plants possibly of European origin.

Pteromalus salicis Nees, 1834. Hym. Ichn. Aff. Monog., v. 2, pp. 105, 424. \&, ठ.

Seladerma Capreae Walker, 1848. List Hym. Brit. Mus., Chalcid., v. 2, p. 112. Preocc. by Linnaeus, 1761.

Taxonomy: Graham, 1969. Brit. Mus. (Nat. Hist.) Ent., Bul. Sup. 16: 303 (syn., types).

Biology: Felt, 1902. N. Y. State Mus., Bul. 53: 744.

\section{TRIBE PIRENINI}

Taxonomy: Ferriere, 1934. Schweiz. Ent. Gesell., Mitt. 16: 83-92 (key to genera). -Graham, 1969. Brit. Mus. (Nat. Hist.) Ent., Bul. Sup. 16: 329-330 (revised key to European genera).

\section{Genus PIRENE Haliday}

Macroglenes Westwood, 1832. London, Edinb. and Dublin Phil. Mag. and Jour. Sci. (3) 1: 127.

Type-species: Macroglenes oculatus Westwood. Monotypic.

Pirene Haliday, 1833. Ent. Mag. 1: 336.

Type-species: Pirene varicomis Haliday. Desig. by Westwood, 1840.

Corynocere Nees, 1834. Hym. Ichn. Aff. Monog., v. 2, p. 123.

Type-species: Corynocere deplanata Nees. Desig. by Gahan and Fagan, 1923.

Phocion Girault, 1925. Insecutor Inscitiae Menstruus 13: 91.

Type-species: Phocion ipswichi Girault. Orig. desig.

Pirenisca Ghesquiere, 1946. Rev. de Zool. et de Bot. Africaines 34: 369. N. name, unnecessarily proposed for Pirene.

Taxonomy: Graham, 1969. Brit. Mus. (Nat. Hist.) Ent., Bul. Sup. 16: 334-335 (syn.;

Macroglenes has priority, but Pirene more often used; application being made to Internat.

Comn. for retention of Pirene).

marylandica Girault. Md. Type fragmentary; placement of this sp. in Pirene may be erroneous.

Pirene marylandica Girault, 1916. Canad. Ent. 48: 116. ․

penetrans (Kirby). N. J., Ont., Mich., Oreg.; Europe. Host: Contarinia tritici (Kirby), Sitodiplosis mosellana (Gehin).

Ichneumon penetrans Kirby, 1800. Linn. Soc. London, Trans. 5: 109. ?, ठ.

Macroglenes oculatus Westwood, 1832. London, Edinb. and Dublin Phil. Mag. and Jour.

Sci. (3) 1: 127. ठ์.

Macroglenes brevicornis Thomson, 1878. Hym. Scand., v. 5, p. 189..

Taxonomy: Graham, 1969. Brit. Mus. (Nat. Hist.) Ent., Bul. Sup. 16: 341 (syn.).

Biology: Johansson, 1936. Stat. Vaxtskyd., Med. 15: 4-6, 13-18.

\section{Genus SPATHOPUS Ashmead}

Spathopus Ashmead, 1904. Carnegie Mus., Mem. 1: 272.

Type-species: Spathopus anomalipes Ashmead. Orig. desig.

Taxonomy: Boucek, 1964. Ceskoslov. Spolec. Ent., Casopis 61: 255-257 (redescription). anomalipes Ashmead. Fla.

Spathopus anomalipes Ashmead, 1904. Carnegie Mus., Mem. 1: 272. "o" = $\delta$.

Taxonomy: Gahan and Peck, 1946. Wash. Acad. Sci., Jour. 36: 316 (type).

\section{Genus HERBERTIA Howard}

Herbertia Howard, 1894. Linn. Soc. London, Jour., Zool. 25: 98.

Type-species: Herbertia lucens Howard. Monotypic.

Revision: Burks, 1959. Ent. Soc. Wash., Proc. 61: 249-255. 
Taxonomy: Ferriere, 1934. Schweiz. Ent. Gesell., Mitt. 16: 84-93.

wallacei Burks. Pa., Md., Va., Ohio, Tex.; Mexico. Host: Phytomyza ilicicola Loew.

Herbertia wallacei Burks, 1959. Ent. Soc. Wash., Proc. 61: 254. \&, ð.

\section{Genus DIPACHYSTIGMA Crawford}

Dipachystigma Crawford, 1911. U. S. Natl. Mus., Proc. 39: 618.

Type-species: Dipachystigma cushmani Crawford. Monotypic.

cushmani Crawford. La. Host: Stephanoderes sp.

Dipachystigma cushmani Crawford, 1911. U. S. Natl. Mus., Proc. 39: 619. \&.

secundum Girault. D. C.

Dipachystigma secunda Girault, 1917. Descr. Stellarum Nov., p. 15. $\subsetneq$.

\section{Genus MORODORA Gahan}

Morodora Gahan, 1933. Canad. Ent. 65: 31.

Type-species: Morodora armata Gahan. Monotypic.

armata Gahan. Mont., B. C. Host: Protocalliphora asiovora S. and D., P. avium S. and D.

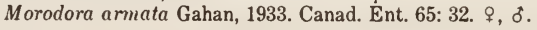

\section{Genus PARECRIZOTES Girault}

Parecrizotes Girault, 1916. Ent. Soc. Amer., Ann. 9: 304.

Type-species: Parecrizotes marylandensis Girault. Orig. desig.

marylandensis Girault. N. Y., Pa., Md., D. C., Va.

Parecrizotes marylandensis Girault, 1916. Ent. Soc. Amer., Ann. 9: 305. ¿.

\section{Genus STIGMATOCREPIS Ashmead}

Stigmatocrepis Ashmead, 1904. Carnegie Mus., Mem. 1: 273, 274.

Type-species: Stigmatocrepis americana Ashmead. Orig. desig.

americana Ashmead. Fla.

Stigmatocrepis americana Ashmead, 1904. Carnegie Mus., Mem. 1: 273. ^, §.

Taxonomy: Gahan and Peck, 1946. Wash. Acad. Sci., Jour. 36: 316 (types).

\section{SubFamily PTEROMALINAE \\ TRIBE CRATOMINI}

\section{Genus CRATOMUS Dalman}

Cratomus Dalman, 1820. Svenska Vetensk. Akad., Handl. 41: 173, 177.

Type-species: Cynips megacephalus Fabricius. Monotypic.

Caratomus Dalman, 1822. Svenska Vetensk. Akad., Handl. 43: 403. Emend.

cancellatus Cockerell. Colo.

Cratomus cancellatus Cockerell, 1916. Ent. News 27: 417. ठ.

leucophthalmus Ashmead. Ont., Pa., D. C.

Caratomus leucophthalmus Ashmead, 1888. Canad. Ent. 20: 55. ठ.

megacephalus (Fabricius). N. Y., N. J., D. C., Ill.

Cynips megacephala Fabricius, 1793. Ent. System., v. 2, p. 103.

Caratomius megalocephalus Schulz, 1906. Spolia Hym., p. 144. Emend.

\section{TRIBE PACHYNEURINI \\ Genus CORUNA Walker}

Comina Walker, 1833. Ent. Mag. 1: 371, 379.

Type-species: Coruna clavata Walker. Monotypic.

Coryna Foerster, 1856. Hym. Stud., v. 2, p. 59. Emend.; preocc. by Bosc, 1802. 
Pachycrepis Foerster, 1856. Hym. Stud., v. 2, pp. 51, 54, 59. N. name unnecessarily proposed for Comuna Walker, preocc. in Botany.

clavata Walker. N. B., Maine, N. J., Wash., Calif.; Europe. Host: A phidius sp., Praon sp.

Comena clavata Walker, 1833. Ent. Mag. 1: 380 . \&, ठ.

Chrysolampus legenarius Nees, 1834. Hym. Ichn. Aff. Monog., v. 2, p. 132. ठ.

Pteromalus aphidivorus Foerster, 1841. Beitr. Monog. Pteromalinen, p. 28. ठ.

Pteromalus segmentarius Foerster, 1841. Beitr. Monog. Pteromalinen, p. 28. oे.

Gastrancistrus Hierocles Walker, 1848. List Hym. Brit. Mus., Chalcid., v. 2, pp. 105, 158. ठ.

Coryna dubia Buckton, 1879. Monog. Brit. Aphides, v. 2, p. 86.

Taxonomy: Graham, 1969. Brit. Mus. (Nat. Hist.) Ent., Bul. Sup. 16: 845 (șyn.).

Biology: Haviland, 1922. Quart. Jour. Micros. Sci. 66: 321-338. - Ferriere and Voukassovitch, 1928. Soc. Ent. de France, Bul. 1928: 28. -Dunn, 1949. Bul. Ent. Res. 40: 103, 117.

- MacGillivray and Spicer, 1953. Canad. Ent. 85: 426-430. - Shands et al., 1955. Ent. Soc.

Wash., Proc. 57: 132-135. - Stary, 1962. Zool. Listy 11: 267.

\section{Genus EUNEURA Walker}

Enneura Walker, 1844. Ann. and Mag. Nat. Hist. (1) 14: 331.

Type-species: Euneura augurus Walker. Monotypic.

Eunevra Agassiz, 1846. Nomencl. Zool., p. 427. Emend.

Hypsicamara Foerster, 1856. Hym. Stud., v. 2, pp. 52, 54. No species.

Type-species: Hypsicamara ratzeburgi Reinhard. Desig. by Reinhard, 1859, by subsequent reference.

Hypsicamera Dalla Torre, 1898. Cat. Hym., v. 5, p. 168. Emend.

Morphological characters to distinguish this genus from Pachyneuron are extremely vague and weak, but the species of Euneura are ecologically distinct in that they are known to be only secondary parasites of aphids on pines and other gymnosperms.

lachni (Ashmead). N. B., Maine, s. to Fla., w. to Utah, Idaho, B. C., Calif. Host: Pausia sp., P. californica (Ashm.), P. ponderosae (Mues.).

Pachycrepis lachni Ashmead, 1887. Amer. Ent. Soc., Trans. 14: 193..+

Taxonomy: Gahan, 1942. U. S. Natl. Mus., Proc. 92: 46.

\section{Genus PACHYNEURON Walker}

Pachyneuron Walker, 1833. Ent. Mag. 1: 371, 380.

Type-species: Pachyneuron formosum Walker. Monotypic.

Pachynevron Blanchard, 1840. Hist. Nat. Anim. Artic., Ins., v. 3, pp. 260, 266. Emend.

Pachynevrum Agassiz, 1846. Nomencl. Zool. p. 778. Emend.

Serimus Brethes, 1913. Buenos Aires Mus. Nac. de Hist. Nat., An. 24: 90.

Type-species: Serimus argentinus Brethes. Orig. desig.

Propachyneuronia Girault, 1917. Psyche 24: 102.

Type-species: Encyrtus siphonophorae Ashmead. Monotypic.

Neopachyneuron Girault, 1917. Descr. Hym. Chalcidoid. Variorum cum Observ. V, p. 9.

Type-species: Pachyneuron eros Girault. Monotypic.

Atrichoptilus Delucchi, 1956 (1955). Ztschr. f. Angew. Ent. 38: 141.

Type-species: Pachyneuron aeneum Masi. Orig. desig.

Revision: Delucchi, 1956 (1955). Ztschr. f. Angew. Ent. 38: 122-139 (European spp.).

Taxonomy: De Santis, 1957. Univ. Nac. de La Plata, Notas del Mus. 19: 118 (syn.). - Peck, 1963. Canad. Ent., Sup. 30: 612 (syn.). - Boucek, 1965. Mus. Natl. Pragae, Acta Ent. 11:

16-18 (syn.).

albutius (Walker). Va., s. to Fla., w. to B. C. and Calif.; Mexico. Host: Allograpta exotica

(Wied.), A. obliqua (Say), Baccha clavata (F.), B. fuscipenuis Say, Eupeodes volucris 0.

S., Mesograpta polita (Say), Metasyrphus americanus (Wied.), M. confertus Fluke,

Parargus tibialis (Fall.), Scaeva pyrastri (L.), Sphaerophoria cylindrica (Say), Syrphus

opinator 0. S., S. philadelphicus Macq., S. rectus O. S., S. ribesii (L.), S. torvus O. S.

Pachynevron albutius Walker, 1843. Soc. Ent. de France, Ann. (2) 1: 158.. 


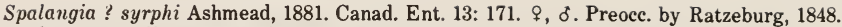
Pachyneuron allograptae Ashmead, 1887. U. S. Dept. Agr., Div. Ent. Bul. 14: 15. ${ }^{\circ}$, $\delta$.

Taxonomy: Burks, 1975. Brit. Mus. (Nat. Hist.) Ent., Bul. 32 : 154 (syn.).

Biology: Kamal, 1926. Jour. Econ. Ent. 19: 725-727. - Kamal, 1939. Egypt Min. Agr., Tech. and Sci. Serv., Bul., Ent. Sect. 207: 36, 46-47. - Knight, 1944. Jour. Econ. Ent. 37: 101. - Bean, 1950. Jour. Econ. Ent. 43: 109-110. - Weems, 1954. Ohio Jour. Sci. 54: 51. - Brown and Clark, 1960. Canad.Ent. 92: 808. - Harper, 1963. Canad. Ent. 95: 871.

altiscutum Cook. N. B., Ont., Maine and N. H., s. to S. C., w. to Mich., Colo., Calif. Host: Cremifania nigrocellulata Czerny, Leucopis sp., L. americana Mall., L. obscura Hal., $L$. pinicola Mall. Numerous other host records have been published, from Lepidoptera, Coccidae, Pseudoccidae, and other Chalcidoidea, but these need to be restudied. Pachyneuron altiscuta Cook, 1885 (1884). Mich. State Hort. Soc., Ann. Rpt. 14: 91. ๆ, o.

Biology: Clancy, 1944. Jour. Econ. Ent. 37: 450-451. -Judd, 1950 (1949). Ent. Soc. Amer., Ann. 42: 461-464. - Brown and Clark, 1957 (1956). Canad. Ent. 88: 679-682. - Clark and Brown, 1957. Canad. Ent. 89: 408-409. - Clark and Brown, 1962. Canad. Ent. 94: 1174. -Peterson, 1962. Canad. Ent. 94: 740.

anthomyiae Howard. Fla.; Hawaii. Host: Leucopis sp.

Pachyneuron anthomyiae Howard, 1885. In Hubbard, Insects Affecting the Orange, p.

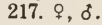

Biology: Swezey, 1921. Jour. Econ. Ent. 14: 256.

californicum Girault. B. C., Wash., Oreg., Calif.; Mexico. Host: Chrysopa califormica Coq., C. majuscula Banks.

Pachyneuron californicum Girault, 1917. Psyche 24: 90. $₹$, o.

Biology: Clancy, 1946. Univ. Calif. Pubs., Ent. 7: 454-456.

eros Girault. Utah, B. C., Wash., Oreg., Calif.; Hawaii. Host: Lencopis sp., L. bella Loew.

Pachyneuron eros Girault, 1917. Descr. Hym. Chalcidoid. Variorum cum Observ. V, p. 1..

Biology: Timberlake, 1926. Hawaii. Ent. Soc., Proc. 6: 308.

groenlandicum (Holmgren). Greenland. Ecology: Reared from syrphid.

Pteromalus groenlandicus Holmgren, 1872. Ofvers. Kongl. Vetensk.-Akad., Forh. 29: 100. १, ơ.

Taxonomy: Hendriksen and Lundbeck, 1917. Meddel. Gruenland 22: 550-551.

hammari Crawford. N. Mex., Ariz.

Pachyneuron hammari Crawford, 1914. Insecutor Inscitiae Menstruus 2: 36. $q, \delta$.

mucronatum Girault. Kans., Tex., Ariz., Calif.; Mexico. Ecology: Associated with coccids on Opuntia. Host: Leucopis sp.

Pachyneuron mucronatum Girault, 1917 (1916). Insecutor Inscitiae Menstruus 4: 116..

Biology: Brandhorst, 1943. Kans. Acad. Sci., Trans. 46: 168.

siphonophorae (Ashmead). Que., Maine, s. to Fla., w. to B. C., Wash., Oreg., Calif.; Hawaii, Mexico, West Indies, Cent. and So. Amer. Host: Aphidius sp., Diaeretiella sp., D. rapae (M'Int.), Lysiphlebus sp., L. testaceipes (Cress.), Praon sp., Trioxys sp. Numerous records have been published of this species as a primary parasite of a long list of species of aphids; rearings show, however, that this is a secondary parasite.

Encyrtus siphonophorae Ashmead, 1886. Amer. Ent. Soc., Trans. 13: 131. $?$.

Pachyneuron aphidivora Ashmead, 1887. U. S. Dept. Agr., Div. Ent. Bul. 14: 14..

Pachyneuron maidaphis Ashmead, 1888. Fla. Agr. Expt. Sta., Bul. 2: 23. .

Pachyneuron micans Howard, 1890. U. S. Dept. Agr., Insect Life 2: 246. $\uparrow$, o.

Taxonomy: Gahan, 1924 (1923). Ent. Soc. Wash., Proc. 25: 187 (syn.).

Biology: Cole, 1925. Jour. Econ. Ent. 18: 222. - Horsfall, 1926. Iowa Univ., Nat. Hist. 11: 51. -Spencer, 1926. Ent. Soc. Amer., Ann. 19: 147. -Folsom and Bondy, 1930. U. S. Dept.

Agr., Cir. 116: 8. - MacGillivray and Spicer, 1953. Canad. Ent. 85: 427. - Shands et al., 1955. Ent. Soc. Wash., Proc. 57: 132-135. - van den Bosch et al., 1962. Jour. Econ. Ent. 55: 861. -Jackson et al., 1971. Jour. Econ. Ent. 64: 1435. 
syrphicola Ashmead. Fla. Host: Baccha clavata (F.), B. fuscipennis Say, Metasyrphus americanus (Wied.).

Pachyneuron syrphi Ashmead, 1886. Amer. Ent. Soc., Trans. 13: 131. §, ठ. Preoce. by Ratzeburg, 1848 and Ashmead, 1881.

Pachyneuron syrphicola Ashmead, 1887. Amer. Ent. Soc., Trans. 14: 193. N. name.

Biology: Miller, 1929. Fla. Agr. Expt. Sta., Bul. 203: 459-461.

texanum Girault. Ohio, La., Tex., N. Mex. Ecology: Reared from syrphid.

Pachyneuron texanum Girault, 1917. Psyche 24: 90..

validum Waterston. Calif. Host: Euphyllura arbuti Schwarz.

Pachyneuron validum Waterston, 1923. Bul. Ent. Res. 14: 110.,$~ ठ$.

virginicum Girault. Maine, Va., Ill. Host: Aphidius sp.

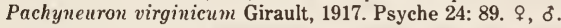

Biology: Wage et al., 1965. U. S. Dept. Agr., Tech. Bul. 1338: 29.

\section{Genus PACHYCREPOIDEUS Ashmead}

Pachycrepoideus Ashmead, 1904. Carnegie Mus., Mem. 1: 329.

Type-species: Pachycrepoideus dubius Ashmead. Orig. desig.

Anisopteromalia Boucek, 1954. Mus. Natl. Pragae, Acta Ent. 29: 57.

Type-species: Anisopteromalia crassinervis Boucek. Orig. desig.

Taxonomy: Boucek, 1957 (1956). Ceskoslov. Spolec. Ent., Casopis 53: 165 (syn.).

vindemiae (Rondani). Ont., s. to Fla., w. to B. C., Calif.; Cosmopolitan. Host: Anastrepha sp., Calliphora sp., Ceratitis capitata (Wied.), Drosophila melanogaster Meig., Fannia canicularis (L.), F. scalaris (F.), Haematobia irritans (L.), Hylemya brassicae (Bouche), Lucilia illustris (Meig.), Musca domestica L., Phaenicia sericata (Meig.), Phormia regina (Meig.), Piophila casei (L.), Rhagoletis sp., $R$. fausta (0. S.), Stomoxys calcitrans (L.).

Encyrtus vindemiae Rondani, 1875. Com. Agr. Parmense, Bol. 8: 145.

Encyrtus vindemmiae Rondani, 1876. Soc. Ent. Ital., Bol. 8: 84. Emend.

Pachycrepoideus dubius Ashmead, 1904. Carnegie Mus., Mem. 1: 329. 9.

Anisopteromalia crassinervis Boucek, 1954. Mus. Natl. Pragae, Acta Ent. 29: 57..

Pachycrepoideus elongata Delucchi, 1956 (1955). Ztschr. f. Angew. Ent. 38: 141..

Taxonomy: Delucchi, 1956 (1955). Ztschr. f. Angew. Ent. 38: 139-141 (syn.). -Graham, 1969.

Brit. Mus. (Nat. Hist.) Ent., Bul. Sup. 16: 846-847 (syn.).

Biology: Girault and Sanders. 1910. Psyche 17: 108-117. - Martelli, 1910 (1909). Lab. Zool.

Gen. e Agr. Portici, Bol. 4: 169-172. -Silvestri, 1917. Lab. Zool. Gen. e Agr. Portici, Bol.

12: 143-145. - Pemberton and Willard, 1918. Jour. Agr. Res. 15: 461-463. -Roberts, 1935.

Jour. Agr. Res. 50: 493. -Crandall, 1939. Ent. Soc. Amer., Ann. 32: 632-654. - Nostvik, 1954. Oikos 5: 195-204. - Steve, 1959. Jour. Econ. Ent. 52: 530-531. - Azab et al., 1964 (1963). Soc. Ent. d'Egypte, Bul. 47: 280. —Sychevskaja, 1963. Zool. Zhur. 42: 858. - Legner et al., 1965. Puerto Rico Univ., Jour. Agr. 49: 372.

Morphology: Parker, 1924. Soc. Ent. de France, Ann. 93: 309 (larva).

\section{TRIBE RHAPHITELINI}

\section{Genus RHAPHITELUS Walker}

Rhaphitelus Walker, 1834. Ent. Mag. 2: 168, 178.

Type-species: Rhaphitelus maculatus Walker. Monotypic.

Styloceras Ratzeburg, 1844. Ichn. d. Forstins., v. 1, p. 207.

Type-species: Styloceras ladenbergii Ratzeburg. Desig. by Gahan and Fagan, 1923.

Rhaphidotelus Agassiz, 1846. Nomencl. Zool., p. 932. Emend.

Storthygocerus Ratzeburg, 1848. Ichn. d. Forstins., v. 2, p. 208. N. name for Styloceras, thought to be inappropriate.

Eucerchysius Brethes, 1913. Buenos Aires, Mus. Nac. de Hist. Nat., An. 24: 103.

Type-species: Eucerchysius scolyti Brethes. Monotypic. 
Evidently it is difficult to spell this generic name. Thomson, 1878 (Hym. Scand., v. 5, p. 37) spelled it Raphitelus and Kurdjumov, 1913 (Ent. Obozr. 13: 4) spelled it Rhaphiteles. Gahan and Fagan, 1923 (U. S. Natl. Mus., Bul. 124: 138) spelled its synonym Styloceras as Stylocerus.

Revision: Boucek, 1957. Mus. Natl. Pragae, Acta Ent. 2: 76-78 (European fauna).

Taxonomy: De Santis, 1952. Soc. Ent. Argentina, Rev. 15: 270 (syn.). - Hedqvist, 1963. Stud. Forest. Suecica 11: 93-94.

maculatus Walker. Que., s. to N. C., w. to Wash., Oreg., Calif.; Europe. Host: Hylesinus sp., Magdalis sp., M. armicollis (Say), M. barbita (Say), Pissodes strobi (Peck), Phloeosinus punctatus Lec., Phloeotribus sp., Scolytus multistriatus (Marsham), S. migulosus (Ratz.).

Rhaphitelus maculatus Walker, 1934. Ent. Mag. 2: 179. “

Pteromalus Hecato Walker, 1839. Monog. Chalcid., v. 1, p. 271. ठ.

Pteromalus subulifer Foerster, 1841. Beitr. Monog. Pteromalinen, p. 30..

Taxonomy: Masi, 1919. Genova, Mus. Civ. Stor. Nat., Ann. (3) 8: 160-161. -Graham, 1969.

Brit. Mus. (Nat. Hist.) Ent., Bul. Sup. 16: 420-421 (syn., types).

Biology: Smith, 1899. Ent. Amer. 5: 216. - Russo, 1938. R. Lab. Ent. Agr. Portici, Bol. 2: 216-225. - Ferriere, 1948. Schweiz. Ent. Gesell., Mitt. 21: 527-528. - Leuchs, 1955. Ztschr. Pflanzenkrank. u. Pflanzensch. 62: 550. -Jamnicky, 1959. Biologia, Bratislava 14: 817.

-Szczepanski, 1960. Polskie Pismo Ent. 30: 409. -Chararas, 1962. Encyc. Ent. 38: 452.

Morphology: Domenichini, 1953. Bol. Zool. Agr. e di Bach 19: 251 (gaster).

\section{Genus METACOLUS Foerster}

Metacolus Foerster, 1856. Hym. Stud., v. 2, pp. 65, 70.

Type-species: Metacolus unifasciatus Foerster. Monotypic.

Pterosema Foerster, 1878. Naturh. Ver. Rheinlande, Verh. 35: 44.

Type-species: Pterosema varicolor Foerster. Orig. desig.

Revision: Burks, 1965. Ent. Soc. Wash., Proc. 67: 116-119.

Taxonomy: Boucek, 1957. Mus. Natl. Pragae, Acta Ent. 2: 76 (syn.). - Hedqvist, 1963. Stud.

Forest. Suecica 11: 97.

fasciatus Girault. N. Dak., s. to N. Mex., w. to Wash., Oreg., Calif. Ecology: Probably a primary parasite of scolytid beetles in gymnospermous trees, but usually reared in association with several other parasites. Its exact host relationships are difficult to establish.

Metacolus fasciatus Girault, 1917. Descr. Stellarum Nov., p. 14. $\subsetneq$.

Metacolus bifasciatus Girault, 1917. Descr. Stellarum Nov., p. 14., ¿.

Taxonomy: Burks, 1953. Ent. Soc. Wash., Proc. 55: 44 (syn.).

keeni Burks. N. Mex., Calif. Ecology: Probably a primary parasite of scolytid beetles in pines.

Metacolus keeni Burks, 1965. Ent. Soc. Wash., Proc. 67: 118. ․, §.

\section{TRIBE PTEROMALINI}

\section{Genus DINOTISCUS Ghesquiere}

Dinotus Foerster, 1856. Hym. Stud., v. 2, pp. 66, 70. No species. Preocc. by Guettard, 1770.

Type-species: Dinotus bidentulus Thomson. Desig. by Ashmead, 1904.

Dinotiscus Ghesquiere, 1946. Rev. de Zool. et de Bot. Africaines 34: 370. N. name.

Revision: Crawford, 1912. U. S. Natl. Mus., Proc. 43: 169 (Cecidostiba Thomson), - Hedqvist, 1963. Stud. Forest. Suecica 11: 83-93 (Palearctic spp., Dinotiscus).

Taxonomy: Graham, 1969. Brit. Mus. (Nat. Hist.) Ent., Bul. Sup. 16: 568 (Nearctic spp. placed in Cecidostiba belong in Dinotiscus).

acutus (Provancher). N. S. and Que., s. to Va. and W. Va., w. to B. C., Wash., Oreg., Calif.

Host: Dendroctonus monticolae Hopk., Polygraphus rufipennis (Kby.).

Dinotus acutus Provancher, 1887. Addit. Corr. Faune Ent. Canada Hym., p. 201..

Cecidostiba ashmeadi Crawford, 1912. U. S. Natl. Mus., Proc. 43: 170.. 
Taxonomy: Peck, 1951. In Muesebeck, et al., U. S. Dept. Agr., Agr. Monog. 2: 557 (syn.).

burkei (Crawford). Colo., N. Mex., Idaho, Utah, Ariz., Wash., Oreg., Calif. Host: Dendroctonus brevicomis Lec., D. engelmanni Hopk., D. obesus (Mann.).

Cecidostiba burkei Crawford, 1912. U. S. Natl. Mus., Proc. 43: 170. \&.

Biology: Massey and Wygant, 1954. U. S. Dept. Agr., Cir. 944: 22, 26.

dendroctoni (Ashmead). Va., W. Va., N. C., Ga., Wis., Mont., Idaho, B. C., Wash., Calif. Host: Cylindrocopturus furnissi Buch., Dendroctonus frontalis Zimm., D. monticolae Hopk., D. pseudotsugae Hopk., Ips grandicollis (Eichh.), Polygraphus rufipennis (Kby.).

Cecidostiba dendroctoni Ashmead, 1894. Amer. Ent. Soc., Trans. 21: 337..

Biology: Furniss, 1942. Jour. Econ. Ent. 35: 859. - Evenden et al., 1943. U. S. Dept. Agr., Cir. 664: 17. -Fronk, 1947. Va. Agr. Expt. Sta., Tech. Bul. 108: 10. -Franklin, 1969. Ga. Ent. Soc., Jour. 4: 121.

elongatus (Ashmead). Fla.

Dinotus elongatus Ashmead, 1888. Canad. Ent. 20: 175. \&.

polygraphi (Ashmead). Maine, Va., W. Va. Host: Polygraphus rufipennis (Kby.).

Cecidostiba polygraphi Ashmead, 1894. Amer. Ent. Soc., Trans. 21: 338. , ठ’.

thomsoni (Crawford). Wyo., Mont., Wash., Oreg., Calif. Host: Pissodes sp., Scolytus ventralis Lec.

Cecidostiba thom soni Crawford, 1912. U. S. Natl. Mus., Proc. 43: 171. ๆ, ठ.

\section{Genus RHOPALICUS Foerster}

Rhopalicus Foerster, 1856. Hym. Stud., v. 2, pp. 66, 70.

Type-species: Cleonymus maculifer Foerster. Monotypic.

pulchripennis (Crawford). Que., and Maine, s. to Md. and Miss., w. to B. C., Wash., Oreg., Calif. Host: Cylindrocopturus eatoni Buch., C. furmissi Buch., Dendroctonus brevicomis Lec., D. monticolae Hopk., D. murrayanae Hopk., D. ponderosae Hopk., Pissodes sp., P. proximatus Hopk., P. strobi (Peck), P. terminalis Hopk., Pseudohylesinus nebulosus (Lec.), Scolytus unispinosus Lec.

Spintherns pulchripennis Crawford, 1912. U. S. Natl. Mus., Proc. 43: 168..+

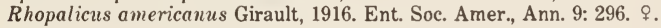

Taxonomy: Gahan, 1924. U. S. Natl. Mus., Proc. 65 (4): 16 (syn.).

Biology: Taylor, 1929. Ent. Amer. (n. s.) 10: 17-22, 66-67. -DeLeon, 1934. Canad. Ent. 66: 61. -Furniss, 1942. Jour. Econ. Ent. 35: 859. - Reid, 1957. Canad. Ent. 89: 7. -Keen, 1958. U.

S. Dept. Agr., Tech. Bul. 1169: 21, 100. —Stark and Wood, 1964. Canad. Ent. 96: 1217.

tutela (Walker). Que., Ont., Maine, N. H., Conn., N. Y., Pa., Mich., Wis.; Europe. Introduced from Europe into Ont. and Que. in mid 1930's, but known to be established in New England in 1920. Host: Ips pini (Say), Pissodes strobi (Peck).

Cheiropachus tutela Walker, 1836. Ent. Mag. 4: 14. $\$$, ơ.

Cleonymus maculifer Foerster, 1840. Beitr. Monog. Pteromalinen, p. 34. $\subsetneq$.

Pteromalus suspensus Ratzeburg, 1844. Ichn. d. Forstins., v. 1, p. 189.

Pteromalus Spinolae Ratzeburg, 1844. Ichn. d. Forstins., v. 1, p. 189. + , §. Preocc. by Foerster, 1841.

Pteromalus immaculatus Ratzeburg, 1844. Ichn. d. Forstins., v. 1, pp. 189, 205.

Pteromalus lunula Ratzeburg, 1848. Ichn. d. Forstins., v. 2, p. 193. 9.

Pteromalus multicolor Ratzeburg, 1848. Ichn. d. Forstins., v. 2, p. 193. N. name for spinolae Ratzeburg.

Pteromalus aemulus Ratzeburg, 1848. Ichn. d. Forstins., v. 2, p. 203.

Rhopalicus Annellus Thomson, 1878. Hym. Scand., v. 5, p. 42. ๆ, ð.

Taxonomy: Kurdjumov, 1913. Ent. obozr. 13: 10 (syn.). -Ferriere, 1948. Schweiz. Ent.

Gesell., Mitt. 21: 520 (syn.). - Hedqvist, 1963. Stud. Forest. Suecica 11: 71-79 (characters).

-Graham, 1969. Brit. Mus. (Nat. Hist.) Ent., Bul. Sup. 16: 413 (types).

Biology: Hanson, 1937. Bul. Ent. Res. 28: 206. - Nuorteva, 1956. Acta Ent. Fenn. 13: 64.

-Chararas, 1959. Soc. Ent. de France, Bul. 64: 11. - Chararas, 1962. Encyc. Ent. 38: 450. 
- Hedqvist, 1963. Stud. Forest. Suecica 11: 71. - Nuorteva, 1964. Ann. Ent. Fenn. 30: 14.

-Titova, 1966. Ent. Obozr. 45: 58.

\section{Genus CHEIROPACHUS Westwood}

Cheiropachus Westwood, 1828. Zool. Jour. 4: 23.

Type-species: Diplolepis quadrum Fabricius. Orig. d «sig.

Cheiropachys Haliday, 1833. Ent. Mag. 1: 268. Emend.

Pachychirus Agassiz, 1846. Nomencl. Zool., p. 777. N. name, unnecessarily proposed for

Cheiropachus, thought to be preocc.

Chiropachys Vollenhoven, 1871. Schetsen Hym., v. 3, pl. 10. Emend.

Tropidogastra Ashmead, 1904. Carnegie Mus., Mem. 1: 323.

Type-species: Tropidogastra arizonensis Ashmead. Orig. desig.

Revision: Gahan, 1938. Ent. Soc. Wash., Proc. 40: 219-220.

arizonensis (Ashmead). La., Tex., N. Mex., Idaho, Ariz., Wash., Oreg., Calif. Host: Phloeosinus $\mathrm{sp}$.

Tropidogastra arizonensis Ashmead, 1904. Carnegie Mus., Mem. 1: 323. ․

Dinarmus arizonicus Girault, 1917 (1916). Insecutor Inscitiae Menstruus 4: 109..

Taxonomy: Gahan, 1938. Ent. Soc. Wash., Proc. 40: 220 (type of each sp. the same specimen). brunneri Crawford. Mont., Wyo., Wash., Oreg., Calif. Host: Phloeosinus sp., Pissodes sp., Pseudohylesinus nebulosus (Lec.), Scolytus un ispinosus Lec., S. ventralis Lec.

Cheiropachus brunneri Crawford, 1912. U. S. Natl. Mus., Proc. 43: 165. ^, ठ.

Biology: Bushing and Bright, 1965. Canad. Ent. 97: 201.

obscuripes Brues. Ont., N. Y., s. to N. C., w. to Ill. Host: Phloeotribus liminaris (Harr.), Scolytus sp.

Cheiropachys obscuripes Brues, 1910. Wis. Nat. Hist. Soc., Bul. 8: 80. $\uparrow$.

quadrum (Fabricius). Que., Ont., N. H., s. to N. C. and Ala., w. to B. C., Wash., Oreg., Calif.; Europe. Host: Magdalis aenescens Lec., Phloeosinus canadensis Swaine, P. punctatus Lec., Scolytus multistriatus (Marsham), S. rugulosus (Ratz.). For almost 100 years this sp. has been called colon Linnaeus, following Thomson, 1878 (Hym. Scand., v. 4, p. 33); however, Graham, 1969 (Brit. Mus. (Nat. Hist.) Ent., Bul. Sup. 16: 417) saw Linnaeus's and Fabricius's types and established that quadrum Fabricius is the correct name for this species. Sphex colon Linnaeus belongs in Dinotiscus Ghesquiere.

Ichneumon quadrum Fabricius, 1787. Mantissa Insectorum, v. 1, p. 270.

Pteromalus bimaculatus Swederus, 1795. Svenska Vetensk. Akad., Handl. 16: 222.

Cleonymus maculipennis Curtis, 1827. Brit. Ent., v. 4, fol. 194. ठ.

Pteromalus bicaliginosus Ratzeburg, 1844. Ichn. d. Forstins., v. 1, p. 190. ठ.

Pteromalus binaevius Ratzeburg, 1844. Ichn. d. Forstins., v. 1, p. 190. d.

Pteromalus Fraxini Ratzeburg, 1844. Ichn. d. Forstins., v. 1, p. 191. .

Pteromalus binimbatus Ratzeburg, 1844. Ichn. d. Forstins., v. 1, p. 191. \&.

Pteromalus binubeculatus Ratzeburg, 1844. Ichn. d. Forstins., v. 1, p. 191..

Pachychirus intermedius Foerster, 1856. Hym. Stud., v. 2, p. 70.

Taxonomy: Kurdjumov, 1913. Ent. Obozr. 13: 22-23 (syn.). _Graham, 1969. Brit. Mus. (Nat. Hist.) Ent., Bul. Sup. 16: 416-417 (syn.).

Biology: Johnson, 1899. Ent. Soc. Wash., Proc. 4: 343. - Russo, 1938. R. Lab. Ent. Agr. Portici, Bol. 2: 181-195. - Ferriere, 1948. Schweiz. Ent. Gesell., Mitt. 21: 522-523.

-Hedqvist, 1963. Stud. Forest. Suecica 11: 103-107. - Russo, 1963. R. Lab. Ent. Agr.

Portici, Bol. 21: 16-18. - Beaver, 1967. Soc. Brit. Ent., Trans. 17: 145.

Morphology: Snodgrass, 1941. Smithsn. Misc. Coll. 99: 36-37 (male genitalia).

\section{Genus HABRITYS Thomson}

Dimachus subg. Habritys Thomson, 1878. Hym. Scand., v. 5, pp. 50, 54.

Type-species: Pteromalus brevicomis Ratzeburg. Monotypic.

Habritus Ashmead, 1904. Carnegie Mus., Mem. 1: 276. Error.

Habrytis Nikol'skaya, 1952. Keys to Fauna USSR 44: 233. Error. 
brevicornis (Ratzeburg). Md., Mich., Ind., Idaho, Calif.; Europe. Host: Crabro sp., Crossocerus sp., Ectemnius sp.

Pteromalus brevicomis Ratzeburg, 1844. Ichn. d. Forstins., v. 1, p. 201.

Pteromalus (Schizonotus) Pannewitzii Ratzeburg, 1852. Ichn. d. Forstins., v. 3, p. 230. .

Taxonomy: Graham, 1969. Brit. Mus. (Nat. Hist.) Ent., Bul. Sup. 16: 427 (syn.).

Biology: Saunt, 1925. Ent. Monthly Mag. 61: 257-258 - Hallet, 1927. Cardiff Nat. Soc., Trans. 60: 54. -Callan, 1936. Soc. Brit. Ent., Jour. 1: 128. - Valkeila, 1959. Hyont. Aikak., Suom. 25: 180-181. - Askew, 1962. Entomologist 95: 126.

latro Wallace, Que., N. Y., Va., Mich., Wis. Host: Ceratiua dupla Say, Ectemuius stirpicola (Pack.), Euplilis sp.

Habritys latrus Wallace, 1954. Carnegie Mus., Ann. 33: 199..+

Habritys latro Krombein, 1960. Ent. News 71: 32. Emend.

Biology: Krombein, 1960. Ent. News 71: 32, 67. - Krombein, 1964. Biol. Soc. Wash., Proc. 77: 103.

\section{Genus ACAENACIS Girault}

Acaenacis Girault, 1917. New Chalcid Flies, p. 1a.

Type-species: Semiotellus ficigerae Ashmead. Orig. desig.

lausus (Walker). Pa., Fla., Ark. Ecology: Emerges from galls of Disholcaspis quercusvirens (Ashmead) on twigs of live oak.

Pteromalus Lausus Walker, 1847. Ann. and Mag. Nat. Hist. (1) 19: 392. . .

Pteromalus Dipsas Walker, 1847. Ann. and Mag. Nat. Hist. (1) 19: 394. ठ.

Semiotellus ficigerae Ashmead, 1885. Amer. Ent. Soc., Trans. 12: Proc. p. xvii. $\uparrow$, ठ.

Taxonomy: Burks, 1975. Brit. Mus. (Nat. Hist.) Ent., Bul. 32: 159 (syn.; lectotypes of lausus and dipsas).

\section{Genus MEGATRYDYMUS Girault}

Megatrydymus Girault, 1917. New Chalcid Flies, p. 1a.

Type-species: Megatrydymus taciti Girault. Orig. desig.

agrili (Rohwer). Oreg., Calif. Host: Agrilus angelicus Horn.

Dinotus agrili Rohwer, 1919. Ent. Soc. Wash., Proc. 21:6..

Taxonomy: Burks, 1967. In Krombein and Burks, U.S. Dept. Agr., Agr. Monog. 2, Sup. 2, p. 269.

taciti Girault. N. J., Ark., Colo., Oreg., Calif. Ecology: Reared from cynipid galls on oak. Megatrydymus taciti Girault, 1917. New Chalcid Flies, p. 1a. ô.

\section{Genus PERNIPHORA Ruschka}

Perniphora Ruschka, 1923. Ent. Mitt. 12: 198.

Type-species: Perniphora robusta Ruschka. Monotypic.

americana Miller. N. B., Maine, N. H., N. Y., Mont., Wash. Ecology: Probably parasitic on species of Trypodendron developing in logs of birch and conifers.

Permiphora americana Miller, 1965. Canad. Ent. 97: 78. $९, \delta$.

\section{Genus OXYSYCHUS Deluechi}

Oxysychus Delucchi, 1956. Ztschr. f. Angew. Ent. 39: 240, 246.

Type-species: Dinarmus silvestrii Masi. Orig. desig.

acanthocini (Ashmead). Que., W. Va., Fla. Host: Acanthocinus obsoletus (Oliv.).

Metastenus (?) acanthocini Ashmead, 1887. Amer. Ent. Soc., Trans. 14: 198. \&, ठ.

Biology: Hopkins, 1893. W. Va. Agr. Expt. Sta., Bul. 32: 226. - Beaulne, 1953 (1951). Que.

Soc. Prot. Pl., Ann. Rpt. 32-33: 197.

callidii (Ashmead). N. J., Va. Host: Callidium antennatum Newm.

Aetroxys callidii Ashmead, 1896. Amer. Ent. Soc., Trans. 23: 223.. 
facialis (Provancher). Que., Ont., Pa.

Charitopus facialis Provancher, 1887. Addit. Corr. Faune Ent. Canada Hym., p. 203. ơ.

Taxonomy: Burks, 1964 (1963). Canad. Ent. 95: 1256.

\section{Genus ANISOPTEROMALUS Ruschka}

Anisopteromalus Ruschka, 1912. Zool.-Bot. Gesell. Wien, Verh. 42: 243.

Type-species: Anisopteromalus mollis Ruschka. Monotypic.

Aplastomorpha Crawford, 1913. U. S. Natl. Mus., Proc. 45: 252.

Type-species: Aplastomorpha pratti Crawford. Monotypic.

calandrae (Howard). N. Y., s. to Fla., w. to Oreg., Calif.; Cosmopolitan. Host: E phestia elutella (Hbn.); Callosobruchus chinensis (L.), C. maculatus (F.), C. phaseoli (Gyll.), Caulophilus oryzae (Gyll.), Lasioderma serricorne (F.), Sitophilus granarius (L.), S. oryzae (L.), S. zeamaise Mots., Stator pruininus (Horn), Stegobium paniceum (L.). Pteromalus calandrae Howard, 1881. U. S. Dept. Agr., Ann. Rpt. for 1880, p. 273. ơ. Meraporus Vandinei Tucker, 1910. Canad. Ent. 42: 342. \%, ठ̊.

Anisopteromalus mollis Ruschka, 1912. Zool.-Bot. Gesell. Wien, Verh. 42: 243. ९, ठै. Aplastomorpha pratti Crawford, 1913. U. S. Natl. Mus., Proc. 45: 252. ๆ, ठ́.

Neocatolaccus mamezophagus Ishii and Nagasawa, 1942. Kontyu 16: 67. ‡, ठ.

Taxonomy: Gahan, 1923. Ent. Soc. Wash., Proc. 25: 188 (type of calandrae destroyed). -Ferriere, 1939. Bul. Ent. Res. 30: 165-166 (possible syn.). -Tachikawa, 1966. Jap. Jour. Appl. Ent. Zool. 10: 99 (syn.).

Biology: Runner, 1919. U. S. Dept. Agr., Bul. 737: 36. - Waterston, 1921. Roy. Soc., Rpt. Grain Pests Com. 9: 10-21. - Cotton, 1923. Jour. Agr. Res. 23: 549-556. - Back and Cotton, 1938. U. S. Dept. Agr., Farmers' Bul. 1260: 41-42. - Back, 1939. Jour. Econ. Ent. 32: 747. -Ayyar, 1940. Indian Jour. Ent. 2: 224. - Ayyar, 1941. Indian Acad. Sci., Proc. (B) 14: 443-444, - Bare, 1942. Jour. Econ. Ent. 35: 185. - Reed and Vinzant, 1942. U. S. Dept. Agr., Cir. 635: 12. - Cotton, 1942. Amer. Miller 71: 60. -Whiting, 1947. Jour. Hered. 38: 150. - Chatterji, 1955. Zool. Soc. India, Proc. 8: 11-23. - Ghani and Sweetman, 1955. Biologia, Lahore 1: 115-139. - Beratlief, 1966. Prot. Pl., Bucharest 4: 253. -Gothilf, 1969. Entomophaga 14: 199.

Morphology: Cabal Concha, 1956. Rev. Fac. Nac. Agron. Colombia 18: $61-72$ (immature stages).

\section{Genus DINARMUS Thomson}

Dimachus subg. Dinarmus Thomson, 1878. Hym. Scand., v. 5, pp. 50, 56.

Type-species: Dinarmus acutus Thomson. Desig. by Ashmead, 1904.

Bruchobius Ashmead, 1904. Carnegie Mus., Mem. 1: 314, 315.

Type-species: Bruchobius laticeps Ashmead. Orig. desig.

Sphaerakis Masi, 1924. Genova, Mus. Civ. Stor. Nat., Ann. 51: 156.

Type-species: Sphaerakis mayri Masi. Monotypic.

Taxonomy: Delucchi, 1956. Ztschr. f. Angew. Ent. 39: 240. - Ferriere and Delucchi, 1957.

Entomophaga 2: 121.

acutus (Thomson). N. J., Pa., N. C., Mich., Ky., Tenn., Minn., Nebr., Wash., Oreg.; Europe. Host: Bruchidius ater (Marsham), Bruchus brachialis Fahr.

Dimachus (Dinarmus) acutus Thomson, 1878. Hym. Scand., v. 5, p. 56. \&.

Sphaerakis mayri Masi, 1924. Genova, Mus. Civ. Stor. Nat., Ann. 51: 157. ๆ, ð’.

Taxonomy: Mani, 1939. Indian Jour. Ent. 1: 76. - Delucchi, 1956. Ztschr. f. Angew. Ent. 39:

243 (syn.). - Graham, 1969. Brit. Mus. (Nat. Hist.) Ent., Bul. Sup. 16: 434-435 (Pteromalus robustus Walker, 1847. Ann. and Mag. Nat. Hist. 19: 230, described from a single male, may be the same as acutus).

Biology: Delucchi, 1962. Awamia 2: 123.

Morphology: Domenichini, 1953. Bol. Zool. Agr. e di Bach. 19: 218 (gaster). 
laticeps (Ashmead). D. C., s. to Fla., w. to Calif.; Cosmopolitan. Host: Acanthoscelides obtectus (Say), Bruchus pisorum (L.), Callosobruchus maculatus (F.).

Brichobius laticeps Ashmead, 1904. Carnegie Mus., Mem. 1: xi, 313. $q$.

Taxonomy: Waterston, 1921. Roy. Soc., Rpt. Grain Pests Com. 9: 14-16. -Delucchi, 1956.

Ztschr. f. Angew. Ent. 39: 243-246.

Biology: Paddock and Reinhard, 1919. Tex. Agr. Expt. Sta., Bul. 256: 80-81. -Masi, 1924.

Genova, Mus. Civ. Stor. Nat., Ann. 51: 152. -Chatterji, 1954. Indian Jour. Ent. 16: 77.

-Cheema and Misra, 1962. Current Sci. 31: 21. - Luca, 1964. Inst. Franc. d'Afr. Noire,

Bul. (A) 26: 1201.

\section{Genus NORBANUS Walker}

Norbanus Walker, 1843. Soc. Ent. de France, Ann. (2) 1: 159.

Type-species: Norbanus dysaules Walker. Desig. by Ashmead, 1904.

Arthrolysis Foerster, 1856. Hym. Stud., v. 2, p. 52. No species.

Type-species: Pteromalus scabriculus Nees. Desig. by Ashmead, 1904.

Picroscytus Thomson, 1878. Hym. Scand., v. 5, pp. 50, 58.

Type-species: Pteromalus scabriculus Nees. Monotypic.

Stylophorella Ashmead, 1904. Carnegie Mus. Mem. 1: 275.

Type-species: Stylophorella perplexa Ashmead. Orig. desig.

dysaules Walker. Fla.

Norbanus dysaules Walker, 1843. Soc. Ent. de France, Ann. (2) 1: 158. \&, o.

Taxonomy: Burks, 1975. Brit. Mus. (Nat. Hist.) Ent., Bul. 32: 157 (Lectotype designated). perplexus (Ashmead). N. J., Del., Tenn., Kans., Tex.

Stylophorella perplexa Ashmead, 1904. Carnegie Mus., Mem. 1: 275...

Taxonomy: Gahan and Peck, 1946. Wash. Acad. Sci., Jour. 36: 316.

pisius Walker. Fla. Host: Euscepes porcellus Boh.

Norbanus pisins Walker, 1843. Soc. Ent. de France, Ann. (2) 1: 160..

Pteromalus Hybreas Walker, 1847. Ann. and Mag. Nat. Hist. (1) 19: 397. .

Taxonomy: Burks, 1975. Brit. Mus. (Nat. Hist.) Ent., Bul. 32: 160 (syn.).

\section{Genus HOMOPORUS Thomson}

Merisus subg. Homoporns Thomson, 1878. Hym. Scand., v. 5, pp. 60, 64.

Type-species: Pteromalus fulviventris Walker. Desig. by Ashmead, 1904.

Phaenacra Foerster, 1878. Naturh. Ver. Rheinlande, Verh. 35: 51.

Type-species: Phaenacra nubigera Foerster. Monotypic.

Parapteromalus Ashmead, 1904. Carnegie Mus., Mem. 1: 320.

Type-species: Parapteromalus isosomatis Ashmead. Orig. desig.

Merisoporus Masi, 1926. Genova, Mus. Civ. Stor. Nat., Ann. 50: 226.

Type-species: Pteromalus luniger Nees. Orig. desig.

Pseudomerisus Erdos and Novicky, 1953. In Erdos, Acta Biol. Hung. 4: 236.

Type-species: Pseudomerisus stipae Erdos and Novicky, Orig. desig.

This genus corresponds to Merisus as used in all North American literature published after about 1900. Following the publication by Delucchi, 1956 (Ztschr. f. Angew. Ent. 39: 229-233) the genus Merisus Walker has been limited to Palearctic species, and all North American species are placed in Homoporus Thomson.

Taxonomy: Delucchi, 1957. Ztschr. f. Angew. Ent. 40: 418-419 (syn.). -Graham, 1969. Brit. Mus. (Nat. Hist.) Ent., Bul. Sup. 16: 444-458 (syn.; key to British, and some other European, spp.; types).

atriscapus (Gahan), n. comb. N. Dak. Ecology: Reared from stems of Stipa comata.

Merisus atriscapus Gahan, 1927. U. S. Natl. Mus., Proc. 71 (4): 4. ९, ठં.

chalcidiphagus (Walsh and Riley). Ont., N. Y., s. to S. C., w. to Oreg. and Calif.; Europe. Host: Ditropinotus aureoviridis (Cwfd.), Eurytoma parva Phil., Harmolita sp., $H$. 
albomaculata (Ashm.), H. elymicola P. and E., H. grandis (Riley), H. hordei (Harr.), H. linearis (Walk.), H. secale (Fitch), H. tritici (Fitch), H. vaginicola (Doane).

Pteromalus Nypsius Walker, 1839. Ann. and Mag. Nat. Hist. (1) 4: 274..

Semiotellus chalcidiphagus Walsh and Riley, 1869. Amer. Ent. 1: 152. ๆ, ơ.

Homoporus crassinervis Thomson, 1878. Hym. Scand., v. 5, p. 68. ․

Taxonomy: Erdos, 1953. Acad. Sci. Hung., Acta Biol. 4: 239 (placed in Phaenacra).

-Delucchi, 1957. Ztschr. f. Angew. Ent. 40: 417-418 (placed in Homoporus). -Graham, 1969. Brit. Mus. (Nat. Hist.) Ent., Bul. Sup. 16: 449 (types; nypsius Walker, 1839, has priority over chalcidiphagus Walsh and Riley, 1869, but the latter is well known and generally accepted).

Biology: Riley, 1887. U. S. Dept. Agr., Ann. Rpt. for 1886, pp. 540-542. -Webster, 1893. U. S. Dept. Agr., Insect Life 6: 151. -Webster, 1909. U. S. Dept. Agr., Bur. Ent. Cir. 106: 8-9. -Phillips, 1918. U. S. Dept. Agr., Farmers' Bul. 1006: 11, 13. - Phillips and Poos, 1921. Jour. Agr. Res. 21: 405-406. - Phillips and Poos, 1923. U. S. Dept. Agr., Farmers' Bul. 1323: 8. -Gahan, 1934 (1933). U. S. Dept. Agr., Misc. Pub. 174: 104-109. -Cannon, 1963. Canad. Ent. 95: 34.

cognatus (Gahan), n. comb. Calif. Host: Mayetiola destructor (Say).

Merisus cognatus Gahan, 1934 (1933). U. S. Dept. Agr., Misc. Pub. 174: 102..

destruetor (Say). P. E. I., Que., Ont., Vt., N. Y., s. to S. C., w. to Wash., Oreg., Calif.; Europe. Host: Mayetiola destructor (Say); Platygaster zosine Walk.

Ceraphron destructor Say, 1817. Acad. Nat. Sci. Phila., Jour. (1) 1: 47-48, 63.

Merisus intermedius Lindeman, 1887. Soc. Imp. Nat. Moscou, Bul. (2) 1: 179-183, 192. ₹, o.

Taxonomy: Gahan, 1934 (1933). U. S. Dept. Agr., Misc. Pub. 174: 89-95 (syn.). -Szelenyi, 1956. Mus. Nat. Hung., Ann. Hist. Nat. (n. s.) 7: 171-172. (Homoporus). -Delucchi, 1957. Ztschr. f. Angew Ent. 40: 418-419 (Homoporus subg. Phaenacra).

Biology: Fitch, 1862 (1861). N. Y. State Agr. Soc., Trans. 21: 827-829, 843. - Howard, 1884. Psyche 4: 206. - Forbes, 1885. Ill. State Ent., Rpt. 14: 44-49. - Riley, 1885. U. S. Natl. Mus., Proc. 8: 413-416. - Osborn, 1898. U. S. Dept. Agr., Div. Ent., Bul. (n. s.) 16: 28-31. -Washburn, 1902. Minn. Agr. Expt. Sta., Bul. 77: 6-7. - Packard, 1916. Jour. Agr. Res. 6: 373-377. - McCulloch, 1923. Kans. Agr. Expt. Sta., Tech. Bul. 11: 64. - Hill and Smith, 1928. Jour. Agr. Res. 36: 153-155. - Hill et al., 1939. U. S. Dept. Agr., Tech. Bul. 689: 4-15. -Lapina, 1948. Zool. Zhur. 27: 331. - Hill, 1953. U. S. Dept. Agr., Cir. 923: 2-15.

Morphology: Hill and Pinckney, 1940. U. S. Dept. Agr., Tech. Bul. 715: 8 , 13 (immature stages).

febriculosus (Girault). P. E. I., Que., Vt., s. to S. C., w. to Sask., N. Dak., Nebr., Kans., Okla.; Europe. Host: Mayetiola destructor (Say); Bracon cephi (Gah.), Eupelmus allynii (French), Harmolita sp., H. albomaculata (Ashm.), H. grandis (Riley), H. hordei (Harr.), H. tritici (Fitch), H. vaginicola (Doane), Platygaster zosine Walk. Merisus febriculosus Girault, 1917. Descr. Stellarum Nov., p. 17.. Homoporus filicornis Erdos, 1953. Mus. Nat. Hung., Ann. Hist. Nat., (n. s.) 6: 241. ๆ.

Taxonomy: Gahan, 1921 (1920). Ent. Soc. Wash., Proc. 22: 238-239. (febriculosus misdet. as isosomatis Ashm.). - Gahan, 1934 (1933). U. S. Dept. Agr., Misc. Pub. 174: 95-99 (descr., bibliog.; occurs in Europe). - Szelenyi, 1956. Mus. Nat. Hung., Ann. Hist. Nat. (n. s.) 7: 168 (Homoporus). -Graham, 1969. Brit. Mus. (Nat. Hist.) Ent., Bul. Sup. 16: 453 (some doubts of syn. of febriculosus and filicornis).

Biology: Phillips and Poos, 1923. U. S. Dept. Agr., Farmers' Bul. 1323: 8. - Hill and Smith, 1928. Jour. Agr. Res. 36: 153-154. - Hill et al., 1939. U. S. Dept. Agr., Tech. Bul. 689: 4-7, 11-15. - Cannon, 1963. Canad. Ent. 95: 34.

Morphology: Hill and Pinckney, 1940. U. S. Dept. Agr., Tech. Bul. 715: 8-13 (larvae).

flaviventris (Girault), n. comb. Md.

Merisus flaviventris Girault, 1915. Ent. Soc. Amer., Ann. 8: 282. ๆ.

harmolitae (Gahan), n. comb. Calif.

Merisus harmolitae Gahan, 1928. U. S. Natl. Mus., Proc. 71 (4): 2. ๆ, ơ. 
isosomatis (Ashmead), n. comb. Ind., Ill. Host: Harmolita sp.

Parapteromalus isosomatis Ashmead, 1904. Carnegie Mus., Mem. 1: 320, 384 ..

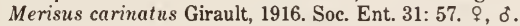

Taxonomy: Gahan and Peck, 1946. Wash. Acad. Sci., Jour. 36: 316 (syn.).

Biology: Webster, 1903 (1902). Ind. Acad. Sci., Proc. for 1902, p. 103 (Nomen nudum).

mordellistenae (Crawford), n. comb. Pa., Md., D. C., Va., w. to Kans., Tex., Calif. Host:

Mordellistena pnstulata (Melsh.); Mayetiola destructor (Say); Harmolita sp.

Merisus mordellistenae Crawford, 1910. Ent. Soc. Wash., Proc. 12: 145. ․

Taxonomy: Gahan, 1934 (1933). U. S. Dept. Agr., Misc. Pub. 174: 99-102.

Morphology: Hill and Pinckney, 1940. U. S. Dept. Agr., Tech. Bul. 715: 9, 11-13 (larvae).

octoguttatus (Girault), n. comb. Md.

Merisus octoguttata Girault, 1915. N. Y. Ent. Soc., Jour. 23: 166. ๆ.

semilongifasciatus (Girault), n. comb. Md.

Merisus semilongifasciata Girault, 1915. Ent. Soc. Amer., Ann. 8: 282. ․

texensis (Girault), n. comb. Tex.

Merisus texensis Girault, 1917. Descr. Stellarum Nov., p. 17. \&.

\section{Genus CALLITULA Spinola}

Callitula Spinola, 1811. Paris Mus. d'Hist. Nat., Ann. 17: 151.

Type-species: Callitula bicolor Spinola. Monotypic.

Micromelus Walker, 1833. Ent. Mag. 1: 371, 464.

Type-species: Micromelus rifomaculatus Walker. Desig. by Westwood, 1840.

Baeotomus Foerster, 1856. Hym. Stud., v. 2, p. 145. N. name, unnecessarily proposed for

Micromelus, thought to be preoce. in Botany.

Taxonomy: Gahan, 1934 (1933). U. S. Dept. Agr., Misc. Pub. 174: 111-113. - Szelenyi, 1956.

Mus. Nat. Hung., Ann. Hist. Nat. (n. s.) 7: 167-170.

bicolor Spinola. N. Y., s. to Va., w. to N. Dak. and Kans.; Europe. Host: Mayetiola destructor (Say), Meromyza americana Fitch, Oscinella frit (L.); Platygaster zosine Walk.

Callitula bicolor Spinola, 1811. Paris Mus. d'Hist., Nat. Ann. 17: 151.

Micromelus rufo-maculatus Walker, 1833. Ent. Mag. 1: 465. , ठ์.

Pteromalus plagiatus Nees, 1834. Hym. Ichn. Aff. Monog., v. 2, p. 115..

Taxonomy: Nees, 1834. Hym. Ichn. Aff. Monog., v. 2, p. 115 (syn.). -Gahan, 1934 (1933). U. S. Dept. Agr., Misc. Pub. 174: 109-114 (syn.). -Boucek, 1964. Entomophaga 9: 10. - Graham, 1969. Brit. Mus. (Nat. Hist.) Ent., Bul. Sup. 16: 461 (types).

Biology: Hill and Smith, 1928. Jour. Agr. Res. 36: 153-155. - Hill et al., 1939. U. S. Dept. Agr., Tech. Bul. 689: 13. - Lapina, 1948. Zool. Zhur. 27: 331. - Simmonds, 1952. Bul. Ent. Res. 43: 513, 528-533, 539-540. - Simmonds, 1953. Bul. Ent. Res. 44: 386-393. - Hemer,

1959. Ztschr. f. Angew. Ent. 44: 339.

Morphology: Hill and Pinckney, 1940. U. S. Dept. Agr., Tech. Bul. 715: 5, 11-13 (larvae). cyrnus (Walker). Md., s. to Fla., w. to Ill. Host: Mayetiola destructor (Say).

Lampretatus cymus Walker, 1843. Soc. Ent. de France, Ann. (2) 1: 157.

Cryptoprymnus illinoensis Ashmead, 1896. Amer. Ent. Soc., Trans. 23: 228. 9.

Taxonomy: Burks, 1975. Brit. Mus. (Nat. Hist.) Ent., Bul. 32: 155 (syn.).

\section{Genus PSILOCERA Walker}

Psilocera Walker, 1833. Ent. Mag. 1: 371, 373.

Type-species: Psilocera obscura Walker. Monotypic.

Metopon Walker, 1834. Ent. Mag. 2: 302.

Type-species: Metopon atrum Walker. Monotypic.

Eupsilocera Westwood, 1839. Introd. Mod. Class. Ins., v. 2, Synopsis, p. 69. N. name, unnecessarily proposed for Psilocera.

Metopum Agassiz, 1846. Nomencl. Zool., p. 670. Emend. 
Dichalysis Foerster, 1856. Hym. Stud., v. 2, pp. 52, 56. N. name, unnecessarily proposed for Psilocera.

Psilocera was twice renamed by authors who thought the name was preoccupied by Psilocerus Ruthe, 1831. Graham, 1969 (Brit. Mus. (Nat. Hist.) Ent., Bul. Sup. 16: 463) is not sure the North American species referred to Psilocera really belong to it.

californica (Ashmead). Ga., Kans., Calif.

Metapon(!) californicum Ashmead, 1896. Amer. Ent. Soc., Trans. 23: 229. १, ठ.

rufipes (Ashmead). N. H., N. J., D. C., Ga., Fla., S. Dak., Kans. Host: Chlamisus plicatus (F.).

Metapon(!) rufipes Ashmead, 1896. Amer. Ent. Soc., Trans. 23: 229. \&, o.

\section{Genus CATOLACCUS Thomson}

Pteromalus subg. Catolaccus Thomson, 1878. Hym. Scand., v. 5, pp. 146, 152.

Type-species: Catolaccus cavigena Thomson. Monotypic.

Merisoides Masi, 1911. Lab. Zool. Gen. e Agr. Portici, Bol. 5: 141.

Type-species: Merisoides crassiceps Masi. Monotypic.

The European species cavigena Thomson and crassiceps Masi are generally accepted to be synonyms of ater Ratzeburg. Graham, 1969 (Brit. Mus. (Nat. Hist.) Ent., Bul. Sup. 16: 467) is not, however, entirely satisfied that this is true.

Revision: Crawford, 1908 (1907). Ent. Soc. Wash., Proc. 9: 160. -Burks, 1954. U. S. Dept. Agr., Tech. Bul. 1093: 4-8.

Taxonomy: Delucchi, 1956. Ztschr. f. Angew. Ent. 39: 230 (syn.).

aeneoviridis (Girault). Que., Ont., Mass., s. to Fla., w. to B. C. and Calif.; Mexico, West Indies. Ecology: An obligate secondary parasite. Host: Apanteles sp., A. aristoteliae Vier., $A$. congregatus (Say), A. flaviconchae Riley, A. marginiventris (Cress.), A. medicaginis Mues., A. militaris (Walsh), Bathyplectes sp., B. curculionis (Thoms.), Campoletis argentifrons (Cress.), Casinaria limenitidis (How.), Goniozus platynotae Ashm., Hormius basalis (Prov.), Hyposoter pilosulus (Prov.), Macrocentrus sp., Meteorus sp., $M$. acronyctae Mues., Rogas la phygmae Vier.

Arthrolytus aeneoviridis Girault, 1911. Canad. Ent. 43: 351, 372. \&, ठ.

Dibrachys meteori Gahan, 1913. U. S. Natl. Mus., Proc. 46: 436. १, ठ์.

Taxonomy: Girault, 1920. U. S. Natl. Mus., Proc. 58: 212.

Biology: Vickery, 1929. U. S. Dept. Agr., Tech. Bul. 138: 21, 32-35, 38, 53-54. -Atkins et al., 1957. Ent. Soc. Amer., Ann. 50: 257. -Allen and Smith, 1958. Hilgardia 25: 29.

cyanoideus Burks. Maine, Mass., Ohio, Mich., Ill., Minn., Iowa, Nebr., Wyo. Host: Apanteles sp., Hyposoter sp., H. fugitivus (Say).

Catolaccus cyanoideus Burks, 1954. U. S. Dept. Agr., Tech. Bul. 1093: 7. ๆ, ठ.

fragariae Rohwer. Del., Ga., Tenn. Host: Anthonomus signatus Say, Apion decoloratum Smith.

Catolaccus fragariae Rohwer, 1934. Ent. Soc. Wash., Proc. 36: 44. ९, ठ์.

Biology: Bissell, 1938. Jour. Econ. Ent. 31: 536.

grandis (Burks), n. comb. Tex., Ariz.; Mexico, Cent. Amer. Introduced into Texas and Arizona from Mexico, but may not be established. Host: Anthonomus grandis Boh.

Heterolaccus grandis Burks, 1954. U. S. Dept. Agr., Tech. Bul. 1093: 9. ๆ, o.

Taxonomy: Delucchi, 1958. Bol. Zool. Agr. e di Bach. (2) 1: 53-54 (Nearctic spp. placed in Heterolaccus belong elsewhere).

Biology: Cross and Mitchell, 1969. Ent. Soc. Amer., Ann. 62: 235-236.

hunteri Crawford. Del., Va., N. C., S. C., Ga., Ala., Miss., Ark., Tex., Ariz., Calif.; Mexico, Guatemala, Hawaii. Host: Acanthoscelides bisignatus (Horn.), A. compressicomis (Schaef.), Anthonomus aeneolus Dietz, A. albopilosus Dietz, A. disjunctus Lec., $A$. eugenii Cano, A. grandis Boh., A. heterothecae Pierce, $A$. nebulosus Lec., A. nigrinus Boh., A. squamosus Lec., A. thurberiae Pierce, Gerstaeckeria nobilis (Lec.), Prionomerus calceatus Say, Rynchaenus pallicomis (Say), Smicraulax tuberculatus 
Pierce, Tach ypterellus quadrigibbus (Say), Zygobaris xanthoxyli Pierce. Introduced from Guatemala into Hawaii for control of Anthonomus eugenii Cano.

Catolaceus hunteri Crawford, 1908 (1907). Ent. Soc. Wash., Proc. 9: 160. ๆ, o.

Biology: Pierce et al., 1912. U. S. Dept. Agr., Bur. Ent. Bul. 100: 42, 51, 54-66. -Pierce and Cushman, 1915. Ent. Soc. Wash., Proc. 17: 166.

kansensis (Girault). N. C., S. C., Wis., Ill., Miss., Iowa, La., Kans., Idaho, Ariz., Calif. Host: Chrysopa sp.

Habrocytus kansensis Girault, 1917. Descr. Hym. Chalcidoid. Variorum cum Observ., V, p. 3. ‥

Arthrolytus kansensis Girault, 1920. U. S. Natl. Mus., Proc. 58: 211. ?. Redescription, based on same specimens as Habrocytus kansensis; both a synonym and homonym. victoria Burks. Tex., Idaho, Utah, Ariz., Calif. Host: Apanteles sp.

Catolaccus victoria Burks, 1954. U. S. Dept. Agr., Tech. Bul. 1093: 6. ๆ, ð.

\section{Genus ENDOMYCHOBIUS Ashmead}

Endomychobius Ashmead, 1896. Amer. Ent. Soc., Trans. 23: 227.

Type-species: Endom ychobius flavipes Ashmead. Orig. desig.

flavipes Ashmead. D. C. Host: Endomychus biguttatus Say.

Endom ychobius flavipes Ashmead, 1896. Amer. Ent. Soc., Trans. 23: 227. ๆ, ठ.

Taxonomy: Girault, 1920. U. S. Natl. Mus., Proc. 58: 212.

\section{Genus PSYCHOPHAGUS Mayr}

Pteromalus subg. Diglochis Thomson, 1878. Hym. Scand., v. 5, pp. 147, 156. Preocc. by Foerster, 1856.

Type-species: Pteromalus omnivorus Walker. Monotypic.

Psychophagus Mayr, 1904. Zool.-Bot. Gesell. Wien, Verh. 54: 598. N. name.

omnivorus (Walker). Que., Ont., s. to Del., w. to Wis. and Colo.; Europe. Ecology: Both a primary and secondary parasite. A common European species, introduced and first recovered in Massachusetts in 1894. Host: Achatodes zeae (Harr.), Archippus packardianus (Fern.), Catocala sp., Choristoneura fumiferana (Clem.), Cnidocampa flavescens (Walk.), Datana ministra (Drury), Diacrisia virginica (F.), Estigmene acrea (Drury), Grapholitha molesta (Busck), G. packardi (Zell.), Ichthyura inclusa Hbn., Macronoctua onusta Grote, Malacosoma americanum (F.), M. disstria Hbn., Nygmia phaeorrhoea (Donov.), Orgyia leucostigma (Smith), Platysamia cecropia (L.), Porthetria dispar (L.), Stilpnotia salicis (L.), Utetheisa bella (L.), Vanessa atalanta (L.);

Compsilura concinnata (Meig.); Cephalcia marginata Middk., Gilpinia hercyniae (Htg.), Itoplectis conquisitor (Say), Macrocentrus peroneae Mues., Neodiprion sp., N. lecontei (Fitch), Pristiphora geniculata (Htg.).

Pteromalus omnivorus Walker, 1835. Ent. Mag. 3: 204. ․, o.

Pteromalus Processionae Ratzeburg, 1844. Ichn. d. Forstins., v. 1, p. 194. ๆ.

Pteromalus rotundatus Ratzeburg, 1844. Ichn. d. Forstins., v. 1, p. 194, footnote. Preocc. by Fonscolombe, 1832.

Pteromalus Antorides Walker, 1845. Linn. Soc. London, Proc., Zool. 1: 262. o".

Pteromalus Coeruleocephalae Ratzeburg, 1852. Ichn. d. Forstins., v. 3, p. 237.

Pteromalus chrysorrhoeae Dalla Torre, 1898. Cat. Hym., v. 5, p. 117. N. name for rotundatus Ratzeburg.

Taxonomy: Kurdjumov, 1913. Ent. Obozr. 13: 16 (syn.). -Bakkendorf, 1955. Ent. Meddel. 27: 137-143. - Boucek, 1961. Mus. Natl. Pragae, Acta Ent. 34: 83-84 (syn.). -Graham, 1969. Brit. Mus. (Nat. Hist.) Ent., Bul. Sup. 16: 473-474 (syn.; Ichneumon cyniphidis Linnaeus, 1758 (Syst. Nat., ed. 10, v. 1, p. 567) might be the same as omnivorus).

Biology: Kirkland, 1902. U. S. Dept. Agr., Div. Ent. Bul. (n. s.) 31: 95. -Fiske, 1903. N. H. Agr. Expt. Sta., Tech. Bul. 6: 182, 188, 217. - Proper, 1934. Jour. Agr. Res. 48: 370-371. -Schaffner and Griswold, 1934. U. S. Dept. Agr., Misc. Pub. 188: 36, 153. - Raizenne, 1952. Canada Div. Forest Biol., Lep. South. Ont. and Par. pp. 95, 100. - Boucek and 
Sedivy, 1954. Folia Zool. et Ent. (3) 17: 176. -Keen, 1958. U. S. Dept. Agr., Tech. Bul. 1169: 25, 100. - Bogavac, 1958. Zash. Bilja 46: 80. - Schaffner, 1959. U. S. Dept. Agr., Misc. Pub. 767: 89. - Blais, 1960. Canad. Ent. 92: 388. - Capek, 1963. Banska Stiavnica Hosp. Ved. Prace, no. 4, p. 267. - Forbes and Daviault, 1964. Canad. Ent. 96: 1128. - Postans, 1964. Ent. Rec. and Jour. Var. 76: 166.

Morphology: Finlayson, 1963. Canad. Ent. 95: 499, 501-502 (immature stages).

tortricis (Brues). Que., Ont., Maine, N. H., Mass., N. Y., Wis., Minn., Wyo. Host: Choristoneura conflictana (Walk.), C. fumiferana (Clem.), C. pinus Freem.; Apechthis ontario (Cress.), Itoplectis conquisitor (Say).

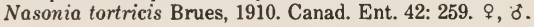

Taxonomy: Gahan, 1932. Ent. Soc. Amer., Ann. 25: 738 (tr. to genus Amblymerus). -Peck, 1951. In Muesebeck et al., U. S. Dept. Agr., Agr. Monog. 2: 557 (tr. to genus

Psychophagus). - Peck, 1963. Canad. Ent. Sup. 30: 698 (lectotype).

Biology: Dowden et al., 1948. Jour. Econ. Ent. 41: 459, 461. -Daviault, 1950. Que. Soc. Prot. Pl., Ann. Rpt. 31: 41. -Dowden and Carolin, 1950. Jour. Econ. Ent. 43: 779. -McGugan and Blais, 1959. Canad. Ent. 91: 766, 770-776, 779. - Dixon and Benjamin, 1963. Jour. Econ. Ent. 56: 267.

\section{Genus CAPELLIA Delucchi}

Capellia Delucchi, 1958. Bol. Zool. Agr. e di Bach. (2) 1: 59.

Type-species: Eurydinota mifiventris Girault. Orig. desig.

Hylocomus Graham, 1959. Soc. Brit. Ent., Trans. 13: 107.

Type-species: Metopon (Dirhicnus) magnicornis Thomson. Orig. desig.

Taxonomy: Delucchi, 1958. Bol. Zool. Agr. e di Bach. (2) 1: 57-60. -Boucek, 1965. Mus. Natl.

Pragae, Acta Ent. 36: 550 (syn.).

cyrene (Walker). Fla.

Micromelus cyrene Walker, 1843. Soc. Ent. de France, Ann. 2: 154..

Taxonomy: Burks, 1975. Brit. Mus. (Nat. Hist.) Ent., Bul. 32: 155.

rufiventris (Girault). Ga., Miss., Minn., Calif. Ecology: Parasitizes midge larvae developing in pine resin. Host: Retinodiplosis sp.

Ezrydinota mufiventris Girault, 1920. U. S. Natl. Mus., Proc. 58: 212..

\section{Genus SCEPTROTHELYS Graham}

Sceptrothelys Graham, 1956. Ent. Monthly Mag. 92: 89.

Type-species: Pteromalus grandiclava Walker. Orig. desig.

deione (Walker). Maine, s. to N. C., w. to B. C., Wash., Oreg., Calif.; Europe. Host: Coleophora fuscedinella Zell., C. laricella (Hbn.), C. malivorella Riley, C. pruniella Clem., $C$. sacramenta Hein.

Miscogaster Deione Walker, 1839. Monog. Chalcid., v. 1, p. 199. \&.

Pteromalus Charops Walker, 1839. Monog. Chalcid., v. 1, p. 242. ठ.

Pteromalus Aecus Walker, 1848. List Hym. Brit. Mus., Chalcid., pt. 2, p. 211.. .

Metopon punctatum Thomson, 1878. Hym. Scand., v. 4, p. 169. 9 .

Metopon aeneiscapus Thomson, 1878. Hym. Scand., v. 4, p. 169.

Eurydinota lividicorpus Girault, 1917. Brooklyn Ent. Soc., Bul. 12: 86. ๆ, ठ.

Taxonomy: Graham, 1969. Brit. Mus. (Nat. Hist.) Ent., Bul. Sup. 16: 485 (syn.).

Biology: Anon., 1934. Wis. Agr. Expt. Sta., Bul. 428: 101. -Doner, 1936. Ent. Soc. Amer.,

Ann. 29: 227-231. - Beacher, 1947. Ent. Soc. Amer., Ann. 40: 532-544. -Schaffner, 1959. U.

S. Dept. Agr., Misc. Pub. 767: 88.

grandiclava (Walker). Ind., Nebr., Wyo., Colo.; Europe. Introduced from Europe along with its host, but when or how is unknown. Host: Bathyplectes sp.

Pteromalus grandiclava Walker, 1835. Ent. Mag. 3: 193. $९$.

Pteromalus claviger Foerster, 1841. Beitr. Monog. Pteromalinen, p. 24..

Taxonomy: Graham, 1969. Brit. Mus. (Nat. Hist.) Ent., Bul. Sup. 16: 486 (syn.). 
intermedia Graham. W. Va., Tenn., Wyo., Colo.; Europe. Introduced from Europe along with its host, but how or when is unknown. Host: Bathyplectes sp.

Sceptrothelys intermedia Graham, 1969. Brit. Mus. (Nat. Hist.) Ent., Bul. Sup. 16: 486. + , o.

\section{Genus PTEROMALUS Swederus}

Pteromalus Swederus, 1795. Svenska Vetensk. Akad., Handl. 16: 201.

Type-species: Ichneumon puparum Linnaeus. Desig. by Westwood, 1840.

Many authors believe that this genus and Habrocytus Thomson are essentially inseparable.

cassotis Walker. Maine, s. to Fla., w. to Mich., Tex., and Calif. Host: Chlosyne lacinia Geyer, Danaus plexippus (L.), Limenitis archippus (Cramer), L. arthemis astyanax (F.),

Papilio cresphontes Cramer, P. polyxenes asterius Stoll.

Pteromalus Cassotis Walker, 1847. Ann. and Mag. Nat. Hist. (1) 19: 393. o.

Pteromalus archippi Howard, 1889. In Scudder, Butterflies of Eastern U. S. and Canada, pp. 1872, 1891.. .

Taxonomy: Burks, 1975. Brit. Mus. (Nat. Hist.) Ent., Bul. 32: 154 (lectotype; syn.).

Biology: Scudder, 1889. Butterflies of Eastern U. S. and Canada, p. 747. - Schaffner and Griswold, 1934. U. S. Dept. Agr., Misc. Pub. 188: 6, 153. -Drummond et al., 1970. Lep.

Soc. Jour. 24: 140.

coeruleiventris (Ashmead). Mass., N. Y., D. C., Ill., Kans. Host: Orgyia leucostigma (Smith).

Sphegigaster coeruleiventris Ashmead, 1888. Kans. Agr. Expt. Sta., Bul. 3: App. p. VI. 9.

Pteromalus cuproideus Howard, 1897. U. S. Dept. Agr., Div. Ent., Tech. Ser. 5: 28, 55., $\delta$.

Biology: Girault, 1908. Psyche 15: 89-96.

doryssus Walker. Fla.

Pteromalus Doryssus Walker, 1847. Ann. and Mag. Nat. Hist. (1) 19: 395. ९, ठ. Types lost.

Taxonomy: Burks, 1975. Brit. Mus. (Nat. Hist.) Ent., Bul. 32: 157.

eryx Walker. Fla.

Pteromalus Eryx Walker, 1847. Ann. and Mag. Nat. Hist. (1) 19: 397. ð. Type fragmentary.

Taxonomy: Burks, 1975. Brit. Mus. (Nat. Hist.) Ent., Bul. 32: 158.

eurymi Gahan. Tenn., Kans., Utah, Ariz., Calif. Host: Colias eurytheme Bdv.

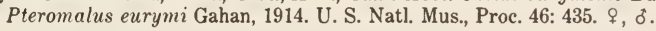

Biology: Wildermuth, 1914. U. S. Dept. Agr., Bul. 124: 21-23. -Wildermuth, 1920. U. S. Dept.

Agr., Farmers' Bul. 1094: 9.

euthymus Walker. Fla. Type lost.

Pteromalus Euthymus Walker, 1847. Ann. and Mag. Nat. Hist. (1) 19: 393. o.

Taxonomy: Burks, 1975. Brit. Mus. (Nat. Hist.) Ent., Bul. 32: 158.

fuscipes (Provancher). Que.

Semiotellus fuscipes Provancher, 1881. Nat. Canad. 12: 295. ㅇ.

Taxonomy: Burks, 1964 (1963). Canad. Ent. 95: 1262 (may be the same as Pteromalus vanessae Howard, but poor condition of Provancher's type prevents a certain decision).

hemileucae Gahan. N. Mex.; Mexico. Host: Hemilenca oliviae Ckll.

Pteromalus hemileucae Gahan, 1917. U. S. Natl. Mus., Proc. 53: 210..

puparum (Linnaeus). Newfoundland, Que. and Ont., s. to Fla., w. to B. C. and Calif;;

Cosmopolitan. Accidentally introduced from Europe about a century ago. Host: Agraulis vanillae (L.), Colias philodice (Godart), Cynthia cardui (L.), C. carye (Hbn.), Epargyreus tityrus (F.), Eurema lisa (Bdv. and LeC.), Argyrotaenia velutinana (Walk.), Lambdina fiscellaria (Guenee), Limenitis archippus (Cramer), Malacosoma americanum (F.), Nymphalis antiopa (L.), Papilio polyxenes asterius Stoll, Pieris protodice (Bdv. and LeC.), P. rapae (L.), Polygonia satyrus (Edw.), Thyridopteryx 
ephemeraeform is (Haw.), Vanessa atalanta (L.), V. virginiensis (Drury). Other hosts reported in the world literature.

Ichneumon puparum Linnaeus, 1758. Syst. Nat., ed. 10, v. 1, p. 567.

Pteromalus latifrons Walker, 1835. Ent. Mag. 2: 501.. .

Pteromalus cephalotes Walker, 1836. Ent. Mag. 3: 481..

Pteromalus comes Walker, 1836. Ent. Mag. 3: 492..

Pteromalus Omytus Walker, 1839. Monog. Chalcid., v. 1, p. 238. o.

Pteromalus Brassicae Curtis, 1842. Roy. Agr. Soc., Jour. 3: 311. ๆ.

Pteromalus Pontiae Curtis, 1842. Roy. Agr. Soc., Jour. 3: 312. $\delta$.

Pteromalus Orinus Walker, 1845. Linn. Soc. London, Proc., Zool. 1: 263. .

Pteromalus nigricans Walker, 1872. Notes on Chalcid., p. 121. $\$$. Preoce. by Foerster, 1841.

Pteromalus brassicae Packard, 1877. In Hayden, U. S. Geol. and Geog. Survey, Rpt. 9: 747. ᄋ. Preocc. by Curtis, 1842.

Pteromalus pieridis Provancher, 1881. Nat. Canad. 12: 296. $\&, \delta$.

Pteromalus nigritulus Dalla Torre, 1898. Cat. Hym., v. 5, p. 137. N. name for nigricans Walker.

Taxonomy: Graham, 1969. Brit. Mus. (Nat. Hist.) Ent., Bul. Sup. 16: 489 (syn.).

Biology: Packard, 1877. In Hayden, U. S. Geol. and Geog. Survey, Rpt. 9: 748-749.

-Saunders, 1878. Canad. Ent. 10: 185. - Saunders, 1880. Canad. Ent. 12: 193. - Webster, 1889. Ind. Agr. Expt. Sta., Bul. 25: 13. -Chittenden, 1901. U. S. Dept. Agr., Div. Ent. Bul. (n. s.) 30: 70. -Fiske, 1903. N. H. Agr. Expt. Sta., Tech. Bul. 6: 223-224. -Matheson, 1907. Canad. Ent. 39: 205. -Doten, 1911. Nebr. Agr. Expt. Sta., Bul. 78: 20-24. -Wilson, 1919. Wis. Agr. Expt. Sta., Res. Bul. 45: 22-23. -Twinn, 1924. Ent. Soc. Ont., Ann. Rpt. 54: 86. -Parker and Thompson, 1925. Ent. Soc. Amer., Ann. 18: 386. -Faure, 1926. Contrib. Etude Pieride du Chou, pp. 63-72. - Essig, 1931. Hist. of Ent., pp. 331-333, 390. -Schaffner and Griswold, 1934. U. S. Dept. Agr., Misc. Pub. 188: 153. -Greenshields, 1939. Amer. Nat. 73: 89-91 (genetics). -Richards, 1940. Jour. Anim. Ecol. 9: 282-285. -Whiting, 1940. Amer. Nat. 74: 377-379 (genetics). - Kurir, 1946. Zentbl. Gesam. Forst. and Holzwirtsch. 70: 81-86. -Clausen, 1951. Jour. Econ. Ent. 44: 6. -Clausen, 1956. U. S. Dept. Agr., Tech. Bul. 1139: 49. - Blunck, 1957. Jour. Econ. Ent. 50: 836. - Wiltshire, 1958. Roy. Ent. Soc. London, Trans. 110: 241. -Masslenikova, 1958. Ent. Obozr. 37: 542. -Blunck and Wilbert, 1959 (1957). Internatl. Cong. Crop Prot., Proc. 1: 1017. - Ho, 1962. Ent. Sinica, Acta 11: 47. - Kaitazoff, 1963. Sofia. Rast. Zashch. 11: 22. -Bouletreau and David, 1967. Entomophaga 12: 1-4.

Morphology: Parker, 1924. Soc. Ent. de France, Ann. 93: 267, 291, 309 (larva). - Burks, 1938. Ent. Soc. Amer., Ann. 31: 161 (wing venation). -Snodgrass, 1941. Smithsn. Misc. Coll. 99 (14): 36-37 (male genitalia). - Flanders, 1942. Ent. Soc. Amer., Ann. 35: 254 (female genitalia). -Domenichini, 1953. Bol. Zool. Agr. e di Bach. 19: 248 (gaster).

vanessae Howard. Maine, s. to Fla., w. to Mont. and Calif. Host: Ascia monuste (L.), Malacosoma disstria Hbn., Nymiphalis antiopa (L.), Papilio cresphontes Cramer, $P$. palamedes (Dru.), P. polyxenes asterius Stoll., P. thaos L., Polygonia comma (Harr.), P. interrogationis (F.), Vanessa atalanta (L.).

Pteromalus puparim var. vanessae Howard, 1889. In Scudder, Butterflies of Eastern U. S. and Canada, pp. 1872, 1890, 1891.. .

Biology: Schaffner and Griswold, 1934. U. S. Dept. Agr., Misc. Pub. 188: 154.

venustus Walker. Ont., S. Dak., Alta., Idaho, Utah; Europe. Accidentally introduced, certainly before 1965. Host: Megachile relativa Cress., $M$. rotundata (F.).

Pteromalus venustus Walker, 1835. Ent. Mag. 2: 494..

Pteromalus planiscuta Thomson, 1878. Hym. Scand., v. 4, p. 155. ‡, ठ.

Taxonomy: Graham, 1969. Brit. Mus. (Nat. Hist.) Ent., Bul. Sup. 16: 491 (syn.). -Peck, 1969. Canad. Ent. 101: 418-422 (separation of various par. of Megachile rotundata).

Biology: Hobbs, 1968. Canad. Ent. 100: 781-784. -Peck, 1969. Canad. Ent. 101: 420-421. - Hobbs and Krunic, 1971. Canad. Ent. 103: 674-685. 


\section{Genus HABROCYTUS Thomson}

Colas Curtis, 1827. Brit. Ent., v. 4, fol. 166.

Type-species: Colas dispar Curtis. Orig. desig.

Colax Curtis, 1829. Guide to Brit. Ins., p. 6. Emend. Preoce. by Huebner, 1816.

Gnatho Curtis, 1829. Guide to Brit. Ins., p. 118. N. name.

Metopachia Westwood, 1839. Introd. Mod. Class. Ins., v. 2, Synopsis, p. 71.

Type-species: Colas dispar Curtis. Orig. desig.

Etroxys subg. Habrocytus Thomson, 1878. Hym. Scand., v. 5, pp. 88, 109.

Type-species: Pteramalus albipennis Walker. Desig. by Ashmead, 1904.

Metopopachia Dalla Torre, 1898. Cat. Hym., v. 5, p. 159. Emend.

The status of this genus is anything but clear. Many authors consider it and Pteromalus Swederus to intergrade. In addition there is the problem of the name Colas Curtis, its isogenotypic synonym Metopachia Westwood, and the emended or new names Gnatho Curtis, Colax Curtis, and Metopopachia Dalla Torre. All of these are based on the distinctive European species dispar. All but Metopopachia have priority over Habrocytus Thomson. Graham, 1969 (Brit. Mus. (Nat. Hist.) Ent., Bul. Sup. 16: 495) does not think it advisable to use the name Colas for this genus because of the widespread usage of the name Habrocytus. There is also a great possibility that the species-group dispar will eventually be recognized as a distinet genus, in which case the name Colas will be available for it. In the meantime, priority is not recognized. Disregard of priority occurs elsewhere in the Chalcidoidea.

Revision: Girault, 1917. Canad. Ent. 49: 178-181. -Graham, 1969. Brit. Mus. (Nat. Hist.) Ent.,

Bul. Sup. 16: 494-561 (British and some European with a few N. Amer. spp.). acutiventris Peck. Que.

Pteramalus acutus Provancher, 1881. Nat. Canad. 12: 297. . Preocc. by Fonscolombe, 1832.

Pteromalus canadensis Dalla Torre, 1898. Cat. Hym., v. 5, p. 115. N. name. Preoce. by Ashmead, 1887.

Habrocytus acutiventris Peck, 1951. In Muesebeck, et. al., U. S. Dept. Agr., Agr. Monog. 2: 561. N. name.

Taxonomy: Burks, 1964 (1963). Canad. Ent. 95: 1260.

americus Girault. N. Amer.

Habrocytus americus Girault, 1917. Deser. Hym. Chalcidoid. Variorum cum Observ. V, p. 3 .. .

analis (Ashmead). Nev., Calif. Host: Hylaeus varifrons (Cress.), Omalus sp., Pemphredon grinnelli (Roh.).

Aetraxys analis Ashmead, 1895. In Davidson, Psyche 7: 316. ๆ, ठ.

Biology: Parker and Bohart, 1966. Pan-Pacific Ent. 42: 94.

anthonomi (Ashmead). Ont., Conn., N. J., D. C., Va., N. C., Ky., Wis., Tex., N. Mex. Host: Anthonomus musculus Say, A. nigrinus Boh., A. signatus Say.

Catalaccus anthonomi Ashmead, 1893. In Chittenden, U. S. Dept. Agr., Insect Life 5: 185. †, $\delta$.

arkansensis Girault. Ill., Minn., Mo., Ark.

Habrocytus arkansensis Girault, 1917. Canad. Ent. 49: 180, 182. \&, ठ.

aulacis Girault. Conn., Pa., Md., Ohio, Mich. Ecology: Emerges from stem gall of Aulacidea sp. on wild lettuce.

Habrocytus aulacis Girault, 1917. Canad. Ent. 49: 180, 181..

bedeguaris (Thomson). Maine, Ont., Colo., Idaho, B. C.; Europe. Host: Diplolepis rosae (L.).

Etroxys (Habrocytus) Bedeguaris Thomson, 1878. Hym. Scand., v. 5, p. 123. ९, ठे.

Taxonomy: Callan, 1944. Roy. Ent. Soc. London, Proc. (B) 13: 90.

Biology: Voukassovitch, 1931. C. R. Soc. Biol. 106: 698. - Blair, 1945. Roy. Ent. Soc. London,

Proc. (A) 20: 26. -Judd, 1959. Canad. Ent. 91: 728-730. - Gijswijt, 1962. Ent. Ber. 22: 250.

borrowi Girault. Conn., Nebr., Colo., Idaho, Wash., Calif.

Habrocytus borrowi Girault, 1917. Canad. Ent. 49: 178, 179, 182.. 
Biology: Caltagirone, 1964. Ent. Soc. Amer., Ann. 57: 287.

britannicus Girault. B. C.

Habrocytus brittanicus(!) Girault, 1926. Insecutor Inscitiae Menstruus 14: 132..

canadensis (Ashmead). N. H., Ont., N. J. Ecology: Emerges from gall of Xanthoteras quercusforticome (Walsh).

Megastigma(!) canadensis Ashmead, 1887. Amer. Ent. Soc., Trans. 14: 186. ठ。.

Taxonomy: Crosby, 1913. Ent. Soc. Amer., Ann. 6: 168 (male pteromalid).

cerealellae (Ashmead). N. B. and Que., s. to Fla., w. to Alaska and Calif.; Cosmopolitan. Host: Sitotroga cerealella (Oliv.).

Catolaccus cerealellae Ashmead, 1902. Psyche 9: 345. + , $。$.

Taxonomy: Crawford, 1908 (1907). Ent. Soc. Wash., Proc. 9: 160.

Biology: Noble, 1932. Calif. Univ. Pubs., Ent. 5: 311-354. -Fulton, 1933. Ent. Soc. Amer., Ann. 26: 536-553. - Fulton, 1937. In Galtsoff, Culture Methods for Invertebrate Animals, pp. $497-498$.

coloradensis (Ashmead). Colo., Idaho.

Rhopalicus coloradensis Ashmead, 1890. Colo. Biol. Assoc., Bul. 1: 27, 45..

damo (Walker). Fla.

Pteromalus Damo Walker, 1847. Ann. and Mag. Nat. Hist. (1) 19: 395..

Taxonomy: Graham, 1969. Brit. Mus. (Nat. Hist.) Ent., Bul. Sup. 16: 561. - Burks, 1975. Brit. Mus. (Nat. Hist.) Ent., Bul. 32: 156.

epicles (Walker). Fla.

Pteromalus Epicles Walker, 1847. Ann. and Mag. Nat. Hist. (1) 19: 394. ๆ.

Taxonomy: Graham, 1969. Brit. Mus. (Nat. Hist.) Ent., Bul. Sup. 16: 561. - Burks, 1975. Brit. Mus. (Nat. Hist.) Ent., Bul. 32: 157.

franciseanus Girault. Calif.

Habrocytus franciscanus Girault, 1917. Canad. Ent. 49: 180, 181. ․

languriae Ashmead. Conn., N. J., N. Y., Pa., Del., D. C., Va., Ill., Mo., La., Kans., Ariz., Alaska, Calif. Host: Dirabius rectirostris (Lec.), Languria angnstata (Beauv.), L. mozardi (Latr.); Janus integer (Nort.).

Habrocytus languriae Ashmead, 1896. Amer. Ent. Soc., Trans. 23: 220. ‡, ð.

Taxonomy: Gahan, 1919. U. S. Natl. Mus., Proc. 55: 127.

Biology: Wildermuth and Gates, 1920. U. S. Dept. Agr., Bul. 889: 19.

lividus Gahan. Colo. Host: Tachypterellus consors cerasi List.

Habrocytus lividus Gahan, 1931. Wash. Acad. Sci., Jour. 21: 37.,$~ ð$.

Biology: List, 1932. Colo. Agr. Expt. Sta., Bul. 385: 63.

medicaginis Gahan. Ont., Conn., N. Y., s. to Va., w. to Man., Oreg. and Calif.; Hawaii, Europe, Asia, Africa, Australia. Host: Bruchophagus sp.

Habrocytus medicaginis Gahan, 1914. U. S. Natl. Mus, Proc. 48: 163. ․

Biology: Urbahns, 1916. Jour. Agr. Res. 7: 147-153. - Williamson, 1918. Minn. State Ent., Ann. Rpt. 17:106-109. - Urbahns, 1920. U. S. Dept. Agr., Bul. 812: 18. - Sorenson, 1930.

Utah Agr. Expt. Sta., Bul. 218: 27-32. - Nikol'skaya, 1934. Cent. Asia Sci. Res. Cotton Inst., Bul. 4-5: 128-129. - Sorenson, 1934. Utah Acad. Sci., Arts and Letters, Proc. 11: 244.

- Beardsley, 1956. Hawaii. Ent. Soc., Proc. 16: 11. - Butler and Hansen, 1958. Pan-Pacific

Ent. 34: 228. - Neunzig and Gyrisco, 1959. Jour. Econ. Ent. 52: 899. - Carillo and

Dickason, 1963. Oreg. Agr. Expt. Sta., Tech. Bul. 68: 31.

melanicrus (Provancher). Que.

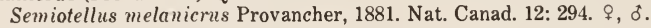

Taxonomy: Burks, 1964 (1963). Canad. Ent. 95: 1262.

obscuripes Ashmead. Minn., Colo., Idaho. Ecology: Emerges from galls of Diplolepis on rose.

Habrocytus obscuripes Ashmead, 1890. Colo. Biol. Assoc., Bul. 1: 26, 45. ๆ.

Taxonomy: Girault, 1917. Canad. Ent. 49: 182. 
onerati (Fitch). Ont., N. Y., N. J. Ecology: Emerges from twig galls on oak.

Pteromalus onerati Fitch, 1859 (1858). N. Y. State Agr. Soc., Trans. 18: 812. ๆ, ơ.

phycidis Ashmead. N. B., Ont., s. to Del., and Pa., w. to B. C. and Calif. Host: Acrobasis juglandis (Le B.), A. mubrifasciella (Pack.), Archippus packardianus (Fern.),

Choristoneura fumiferana (Clem.), Coleophora laricella (Hbn.), C. malivorella Riley, C.

pruniella Clem., Dioryctria reniculella (Grote), Exoteleia pinifoliella Chamb.,

Rhyacionia frustrana (Comst.), Spilonota ocellana (D. and S.).

Habrocytus phycidis Ashmead, 1898. Ent. Soc. Wash., Proc. 4: 157..

Habrocytus dux Girault, 1917. Canad. Ent. 49: 181, 182. $\%$.

Taxonomy: Gahan, 1930. U. S. Natl. Mus., Proc. 77 (8): 8 (syn.).

Biology: Muesebeck and Dohanian, 1927. U. S. Dept. Agr., Bul. 1487: $27(d u x)$. - Doner, 1936. Ent. Soc. Amer., Ann. 29: 226, 231. - Beacher, 1947. Ent. Soc. Amer., Ann. 532-544.

-Raizenne, 1952. Canada Div. Forest Biol., Forest Lep. South. Ont. and Par., p. 259.

- Legner, 1962. Ent. Soc. Amer., No. Cent. Br., Proc. 17: 116. -Dixon and Benjamin, 1963.

Jour. Econ. Ent. 56: 267. - Legner and Oatman, 1963. Jour. Econ. Ent. 56: 731. - Cody et

al., 1967. Mich. Ent. 1: 163. - Finlayson, 1967. Canad. Ent. 99: 1263 (immature stages).

piercei Crawford. Conn., N. Y., N. J., Md., W. Va., Ohio, Wis., La., N.Dak., Tex., Colo., Calif.

Host: Anthonomus grandis Boh., A. musculus Say, A. nebulosus Lec., Microlarinus

lareynii (duVal), M. lypriformis (Wall.), Tachypterellus consors cerasi List, $T$. quadrigibbus (Say); Coleophora malivorella Riley.

Habrocytus piercei Crawford, 1911. U. S. Natl. Mus., Proc. 40: 443..

Biology: Pierce et al., 1912. U. S. Dept. Agr., Bur. Ent. Bul. 100: 52-63. -List, 1932. Colo.

Agr. Expt. Sta., Bul. 385: 59-61. - Hammer, 1936. N. Y. Agr. Expt. Sta., Tech. Bul. 240: 45.

-Gould and Geissler, 1940. Jour. Econ. Ent. 33: 815. -Wilson, 1965. Canad. Ent. 97: 968.

-Goeden and Ricker, 1970. Jour. Econ. Ent. 63: 827-831.

purpureiventris (Ashmead). Minn., Nebr., Kans., Okla., Tex. Ecology: Parasitic on a tephritid maggot in the seeds of iron weed.

Syntasis(!) purpureiventris Ashmead, 1888. Kans. Agr. Expt. Sta., Bul. 3: App., P. VI. o.

quinquefasciatus Girault. N. Mex.

Habrocytus quinquefasciatus Girault, 1916. Ent. Soc. Amer., Ann. 9: 298. ๆ, ठ.

Taxonomy: Girault, 1917. Descr. Hym. Chalcidoid. Variorum cum Observ. V, p. 5. rhodobaeni Ashmead. Va., Kans. Host: Rhodobaenus tredecimpunctatus (Illiger).

Habrocytus rhodobaeni Ashmead, 1896. Amer. Ent. Soc., Trans. 23: 220. $ๆ$.

rosae Girault. Conn., N. Y., Nebr., Mont., Alta., Colo., B. C., Calif. Ecology: Emerges from galls of Diplolepis fusiformans (Ashm.) and D. ignota (0. S.).

Habrocytus rhodobaeini(!) var. rosae Girault, 1917. Canad. Ent. 49: 180, 181. ๆ.

simillimus Gahan. Ariz. Host: Melanagromyza gibsoni (Mall.).

Habrocytus simillimus Gahan, 1919. U. S. Natl. Mus., Proc. 55: 127. + , o.

thyridopterigis Howard. Maine and Ont., s. to N. C., w. to Wis., Mo., Ark. Host: Acrobasis rubrifasciella (Pack.), Coleophora fuscedinella Zell., C. laricella (Hbn.) C. malivorella Riley, C. pruniella Clem., C. ulmifoliella McD., Coleotechnites apicitripunctella (Clem.), Malacosoma americanum (F.), Orygia leucostigma (Smith), Rhyacionia buoliana (Schiff.), $R$. frustrana (Comst.), R. rigidana (Fern.), Thyridopteryx ephemeraeform is (Haw.).

Habrocytus thyridopterigis Howard, 1897. U. S. Dept. Agr., Div. Ent., Tech. Ser. 5: 34..

Biology: Cushman, 1927. Jour. Agr. Res. 34: 617. -Doner, 1936. Ent. Soc. Amer., Ann. 29: 230-234. - Balduf, 1937. Ent. Soc. Wash., Proc. 39: 179-180. - Raizenne, 1952. Canada Div. Forest Biol., Forest Lep. South. Ont. and Par., p. 170. - Waddell, 1952. Ent. Soc. Brit. Columbia, Proc. 48: 88. - Schaffner, 1959. U. S. Dept. Agr., Misc. Pub. 767: 89. - Harman and Kulman, 1962. Jour. Econ. Ent. 55: 1007. - Kulman, 1965. Jour. Econ. Ent. 58: 68, 864.

\section{Genus LONCHETRON Graham}

Lonchetron Graham, 1956. Ann. Ent. Fenn. 22: 80. 
Type-species: Lonchetron fennicum Graham. Orig. desig. giraulti (Peck). Ont.

Habrocytus canadensis Girault, 1917. Canad. Ent. 49: 179, 181, 182. क. Preocc. by

Ashmead, 1887.

Habrocytus giraulti Peck, 1951. In Muesebeck, et al., U. S. Dept. Agr., Agr. Monog. 2: 562. N. name.

\section{Genus BELONURA Ashmead}

Belonura Ashmead, 1896. Amer. Ent. Soc., Trans. 23: 224.

Type-species: Belonura singularis Ashmead. Orig. desig.

singularis Ashmead. Maine, Mass., Conn., Va., Ga., Fla., La. Host: Cirrula gigantea Cress., Dimecoenia spinosa (Loew).

Belonura singularis Ashmead, 1896. Amer. Ent. Soc., Trans. 23: 225. ९.

\section{Genus CAENACIS Foerster}

Caenacis Foerster, 1856. Hym. Stud., v. 2, p. 64. No species.

Type-species: Caenacis grandiclava Thomson. Desig. by Ashmead, 1904. asinus Girault. Calif.

Caenacis asinus Girault, 1917. New Chalcid Flies, p. 3..

cupraeus (Provancher). Que., Ont. Host: Megachile albitarsis Cress., M., centruncularis (L.).

Semiotellus cupraeus Provancher, 1881. Nat. Canad. 12: 295. ठ゚.

Semiotellus cupreus Dalla Torre, 1898. Cat. Hym., v. 5, p. 211. Emend.

Taxonomy: Burks, 1964 (1963). Canad. Ent. 95: 1261.

\section{Genus PSILONOTUS Walker}

Psilonotus Walker, 1834. Ent. Mag. 2: 168, 179.

Type-species: Psilonotus adamas Walker. Monotypic.

Janvartsovia Nikol'skaya 1954. Zool. Inst. Leningrad, Trudy 16: 412.

Type-species: Janvartsovia betulae Nikolskaja. Orig. desig.

Taxonomy: Graham, 1958. Ent. Monthly Mag. 94: 120 (syn.).

achaeus Walker. Ont.; Europe. Ecology: Associated with Betula.

Psilonotus Achaeus Walker, 1848. Ent. Mag. 2: 105, 161..

Pteromalus Cyamon Walker, 1848. Ent. Mag. 2: 123, 176. o.

Psilonotus viridulus Thomson, 1878. Hym. Scand., v. 5, p. 83. \&.

Taxonomy: Graham, 1957. Ent. Monthly Mag. 93: 231 (syn.). -Graham, 1969. Brit. Mus. (Nat.

Hist.) Ent., Bul. sup. 16: 627 (types).

\section{Genus KARPINSKIELLA Boucek}

Karpinskiella Boucek, 1955 (1954). Roczniki Nauk Lesnych 11: 86.

Type-species: Karpinskiella pityophthori Boucek. Orig. desig.

The adults of these parasites emerge from adult scolytid hosts.

Taxonomy: Hedqvist, 1963. Stud. Forest. Suecica 11: 115.

paratomicobia Hagen and Caltagirone. Utah, Ariz., Calif. Host: Dendroctonus pseudotsugae Hopk.

Karpinskiella paratomicobia Hagen and Caltagirone, 1968. Pan-Pacific Ent. 44: 241. ९, ठ.

Biology: Furniss, 1968. Ent. Soc. Amer., Ann. 61: 1384 (life hist.).

\section{Genus MESOPOLOBUS Westwood}

Mesopolobus Westwood, 1833. London, Edinb. and Dublin Phil. Mag. and Jour. Sci. (3) 2: 443.

Type-species: Mesopolobus fasciiventris Westwood. Monotypic.

Platymesopus Westwood, 1833. London, Edinb. and Dublin Phil. Mag. and Jour. Sci. (3) 2: 444. 
Type-species: Platymesopus tibialis Westwood. Monotypic.

Platyterma Walker, 1834. Ent. Mag. 2: 303.

Type-species: Platyterma nobile Walker. Desig. by Westwood, 1839.

Amblymerus Walker, 1834. Ent. Mag. 2: 303, 306.

Type-species: Amblymerus amaenus Walker. Desig. by Westwood, 1839.

Eutelus Walker, 1834. Ent. mag. 2: 351, 356.

Type-species: Eutelus dilectus Walker. Desig. by Westwood, 1839.

Xenocrepis Foerster. 1856. Hym. Stud., v. 2, p. 64. No species.

Type-species: Xenocrepis pura Mayr. Included by Mayr, 1904.

Asemantus Foerster, 1878. Naturh. Ver. Rheinlande, Verh. 35: 51.

Type-species: Asemantus amphibolus Foerster. Orig. desig.

Syntomocera Foerster, 1878. Naturh. Ver. Rheinlande, Verh. 35: 52. Preocc. by Schiner, 1861.

Type-species: Syntomocera clavicomis Foerster. Orig. desig.

Disema Foerster, 1878. Naturh. Ver. Rheinlande, Verh. 35 54. Preocc. by Maeklin, 1875.

Type-species: Disema pallipes Foerster. Orig. desig.

Eutelus subg. Platytermus Thomson, 1878. Hym. Scand., v. 5, p. 75. Emend.

Zacalochlora Crawford, 1913. U. S. Natl. Mus., Proc. 45: 251.

Type-species: Zacalochlora milleri Crawford. Monotypic.

Baeoponerus Masi, 1924. Genova, Mus. Civ. Stor. Nat., Ann. 50: 222.

Type-species: Baeoponerus aeneus Masi. Monotypic.

Euamblymerus Hincks, 1944. Roy. Ent. Soc. London, Proc. (B) 13: 37. N. name for part of Amblymernis.

Syntomocerella Ghesquiere, 1946. Rev. de Zool. et de Bot. Africaines 34: 369. N. name for Syntomocera Foerster.

Disemisca Ghesquiere, 1946. Rev. de Zool. et de Bot. Africaines 34: 369. N. name for Disema Foerster.

Ahlbergiella von Rosen, 1955. Ent. Tidskr. 76: 88.

Type-species: Eutelus aequus Walker. Orig. desig.

As presently defined, this genus is a rather amorphous one, with no non-integrating characters and an extremely lengthy generic synonymy. It is likely that future workers will divide it into subgenera or into several genera, for all of which there will be available names.

Taxonomy: Graham, 1957. Ent. Monthly Mag. 93: 220-230 (syn.). -von Rosen, 1958. Opuse.

Ent. 23: 203-240. —von Rosen, 1959. Ent. Tidskr. 79: 131-146. - von Rosen, 1959. Ent.

Tidskr. 80: 146-162. - von Rosen, 1960. Opusc. Ent. 25: 1-29 - von Rosen, 1960. Ent.

Tidskr. 82: 1-48. - von Rosen, 1961. Ent. Meddel. 31: 116-122. -von Rosen, 1962. K.

Lantbr. Hogsk., Ann. 28: 141-148. - Hedqvist, 1963. Stud. Forest. Suecica 11: 57, 121.

-von Rosen, 1966. Ent. Tidskr. 87: 78-84. - Graham, 1969. Brit. Mus. (Nat. Hist.) Ent.,

Bul. Sup. 16: 638-639 (syn.). - Boucek, 1971. Polskie Pismo Ent. 41: 310 (syn.).

aequus (Walker). Nebr.; Europe. Ecology: Essentially a predator, developing in grass, alfalfa, and other plant stems, feeding on eggs or larvae of other insects. Host: Delphacodes pellucida (F.). Also other, undetermined hosts.

Eutelus aequus Walker, 1834. Ent. Mag. 2: 364. \&.

Pteromalus purpureus Walker, 1835. Ent. Mag. 2: 493 ..

Pteromalus contractus Walker, 1835. Ent. Mag. 3: 188. 9.

Pteromalus Leogoras Walker, 1839. Monog. Chalcid., v. 1, p. 269. o..

Pteromalus Odites Walker, 1845. Linn. Soc. London, Proc. (Zool.) 1: 261. ๆ.

Pteromalus Temesa Walker, 1848. List Hym. Brit. Mus., Chalcid., v. 2, pp. 124, 188 ठ.

Metastenus purıs Walker, 1872. Notes on Chalcid., p. 118. $\&$.

Eutelus (Platytermus) decipiens Thomson, 1878. Hym. Scand., v. 5, p. 77.. .

Mormoniella oviphaga Ahlberg, 1925. Centralanst. for Forsoksv. pa Jordbruksomradet. Meddel. (Ent.) 46: 82.

Amblymerus graminum Hardh, 1950. Suom-hyont. Aikak. 16: 88.. . Male a different species.

Taxonomy: Graham, 1957. Ent. Monthly Mag. 93: 222-236 (syn.; types). - von Rosen, 1955.

Ent. Tidskr. 76: 88-90 (syn.). — Graham, 1969. Brit. Mus. (Nat. Hist.) Ent., Bul. Sup. 16: 655 (syn.). 
Biology: von Rosen, 1956. K. Lantbr. Hogsk., Ann. 23: 20-39. - Raatikainen, 1962. Ann. Agr. Fenn. 1: 220.

betulae (Girault), n. comb. N. Y. Host: Oligotrophus betulae (Winnertz). Eutelus betulae Girault, 1917. Psyche 24: 93. + , $。$.

Taxonomy: Graham, 1969. Brit. Mus. (Nat. Hist.) Ent., Bul. Sup. 16: 628 (this sp. may be some European Psilonotus).

bruchophagi (Gahan). N. Y., w. to B. C., Wash., Oreg., Calif.; Europe. Host: Bruchophagus sp. Eutelus bruchophagi Gahan, 1917. U. S. Natl. Mus., Proc. 53: 212. ๆ, ठ’.

Taxonomy: von Rosen, 1958. Opusc. Ent. 23: 207, 232. -von Rosen, 1960. Opusc. Ent. 25: 12.

Biology: Urbahns, 1919. Jour. Agr. Res. 16: 171-172. - Sorenson, 1930. Utah Agr. Expt. Sta., Bul. 218: 27-32. -Sorenson, 1934. Utah Acad. Sci. Arts and Letters, Proc. 11: 243-244. - Butler and Hansen, 1958. Pan-Pacific Ent. 34: 228. - Neunzig and Gyrisco, 1959. Jour. Econ. Ent. 52: 899-901. - Carillo and Dickason, 1963. Oreg. State Univ. Agr. Expt. Sta., Tech. Bul. 68: 25.

confusus (Ashmead), n. comb. Mont., Idaho, Utah, Alaska. Ecology: Secondary parasite of scolytid beetles. Host: Karpinskiella paratomicobia H. and C., Tomicobia tibialis Ashm. Might be the same as the European Mesopolobus typographi (Ruschka), 1924.

Eutelus confusus Ashmead, 1902. Wash. Acad. Sci., Proc. 4: 145. १, ठ.

Biology: Furniss, 1968. Ent. Soc. Amer., Ann. 61: 1385.

fuscipedes Burks, n. name. Mich.

Platyterma fuscipes Ashmead, 1896. Amer. Ent. Soc., Trans. 23: 223. . Preocc. by Walker, 1834.

justicia (Girault), n. comb. N. Mex., Calif. Host: Diarthronomyia chrysanthemi Ahlberg. Amblymerus justicia Girault, 1917. Descr. Stellarum Nov., p. 21., ¿.

Taxonomy: von Rosen, 1961. Ent. Tidskr. 82: 43.

mayetiolae (Gahan). Wash., Oreg., Calif. Host: Ceutorhynchus assimilis (Payk.); Mayetiola destructor (Say); Harmolita sp.

Eutelus mayetiolae Gahan, 1919. U. S. Natl. Mus., Proc. 55: 128. ๆ, §.

Taxonomy: von Rosen, 1958. Opusc. Ent. 23: 207, 228.

Biology: Gahan, 1934 (1933). U. S. Dept. Agr., Misc. Pub. 174: 65-67. -Carlson et al., 1952 (1951). Jour. Econ. Ent. 44: 963-964.

milleri (Crawford). Colo., N. Mex., Mont., Idaho, Oreg., Calif. Host: Barbara colfaxiana

(Kearf.), Choristoneura fumiferana (Clem.), Orgyia pseudotsugata McD., Laspeyresia sp.

Zacalochlora milleri Crawford, 1913. U. S. Natl. Mus., Proc. 45: 251..

Taxonomy: Boucek, 1971. Polskie Pismo Ent. 41: 310.

Biology: Keen, 1958. U. S. Dept. Agr., Tech. Bul. 1169: 100-102.

morys (Walker). Idaho, Wash., Oreg., Calif.; Europe. Host: Ceutorhynchus assimilis (Payk.).

Pteromalus morys Walker, 1848. List Hym. Brit. Mus., Chalcid., v. 2, p. 125, 197. o.

Disema pallipes Foerster, 1878. Naturh. Ver. Rheinlande, Verh. 35: 54. ठ.

Xenocrepis pura Mayr, 1904. Zool.-Bot. Gesell. Wien, Verh. 54: 584. ठ.

Taxonomy: Graham, 1957. Ent. Monthly Mag. 93: 235 (syn.; types). -von Rosen, 1960. Ent. Tidskr. 82: 32-33 (syn.), - von Rosen, 1960. Opusc. Ent. 25: 9.

Biology: McLeod, 1953. Ent. Soc. Brit. Columbia, Proc. 49: 13-17. - Walz, 1957. Ent. Soc. Amer., Ann. 50: 220. - von Rosen, 1958. Opusc. Ent. 23: 234. -Jourdheuil, 1960. Ann. des Epiphyt. 11: 462.

nobilis (Walker). Minn., S. Dak., Wyo., Colo.; Europe. Ecology: Phytophagous in grass seeds. Host: Avena sp., Bromus sp.

Platyterma nobile Walker, 1834. Ent. Mag. 2: 304 ..

Platyterma citripes Ashmead, 1896. Amer. Ent. Soc., Trans. 23: 223..

Taxonomy: Graham, 1957. Ent. Monthly Mag. 93: 221 (types). -von Rosen, 1959. Ent. Tidskr. 80: 160 (syn.). 
Biology: von Rosen, 1962. K. Lantbr. Kogsk., Ann. 28: 144 (phytophagous). oeax (Walker). Fla.

Pteromalus Oeax Walker, 1847. Ann. and Mag. Nat. Hist. (1) 19: 395..

Taxonomy: Burks, 1975. Brit. Mus. (Nat. Hist.) Ent., Bul. 32: 160.

ruskini (Girault), n. comb. Colo.

Eutelus ruskini Girault, 1917 (1916). Insecutor Inscitiae Menstruus 4: 113. \&.

salicis (Girault), n. comb. Mass. Ecology: Emerges from cecidomyiid gall on Salix.

Eutelus salicis Girault, 1917. Psyche 24: 94..

subfumatus (Ratzeburg). Ont., Que.? Introduced into southeastern Canada from Europe in the 1930 's for biological control of Diprion spp.; not known to be established. Host: Diprion sp., Gilpinia hercyniae (Htg.).

Pteromalus subfumatus Ratzeburg, 1852. Ichn. d. Forstins., v. 3, pp. 236-237. .

Eutelus punctiger Thomson, 1878. Hym. Scand., v. 5, p. 75. $\%$.

Platyterma ecksteini Wolff, 1916. Ztschr. f. Angew. Ent. 3: 166-169. \&, o.

Taxonomy: Nowicki, 1939. Ztschr. f. Angew. Ent. 25: 473 (syn.). -Otten, 1942. Arb. ueber. Physiol. u. Angew. Ent. 9: 114-117. - von Rosen, 1958. Opusc. Ent. 23: 223-224. -Graham, 1969. Brit. Mus. (Nat. Hist.) Ent., Bul. Sup. 16: 768 (syn.; types).

Biology: Morris et al., 1937. Bul. Ent. Res. 28: 381-391. -Gauss, 1960. Ztschr. f. Angew. Ent. 47: 50. - von Rosen, 1961. Ent. Tidskr. 82: 36.

verditer (Norton). N. B., Que., Ont., Maine, s. to N. J. and Pa., w. to B. C., Wash., Oreg. Host: Archippus packardianus (Fern.), Barbara colfaxiana (Kearf.), Choristoneura fumiferana (Clem.), C. pinus Freem., Dioryctria disclusa Hein., Epinotia nanana (Treit.), Epizeuxis aemula (Hbn.), Taniva albolineana (Kearf.); Actia interrupta Curr.; Diprion similis (Htg.), Gilpinia hercyniae (Htg.), Itoplectis conquisitor (Say),

Macrocentrus peroneae Mues., Neodiprion abietis (Harr.), N. lecontei (Fitch), N. tsugae Midd., Phytodietus fumiferanae Roh., $P$. vulgaris Cress.

Pteromalus verditer Norton, 1869. Amer. Ent. Soc., Trans. 2: 327. ₹, o.

Taxonomy: Gahan, 1932. Ent. Soc. Amer., Ann. 25: 738 (types). -Gahan, 1938. Ent. Soc. Wash., Proc. 40: 222. - von Rosen, 1958. Opusc. Ent. 23: 223-225 (Mesopolobus).

Biology: Britton, 1918. Conn. Agr. Expt. Sta., Bul. 203: 283-284, 287-288. -Gahan, 1932. Ent. Soc. Amer., Ann. 25: 738. - Dowden et al., 1948. Jour. Econ. Ent. 41: 459, 461. - Dowden and Carolin, 1950. Jour. Econ. Ent. 43: 779. - Raizenne, 1952. Canada Div. Forest Biol., Forest Lep. South. Ont. and Par., p. 221. - Benjamin and Drooz, 1954. Jour. Econ. Ent. 47: 589. -Keen, 1958. U. S. Dept. Agr., Tech. Bul. 1169: 98-99. -Schaffner, 1959. U. S. Dept. Agr., Misc. Pub. 767: 88. - Blais, 1960. Canad. Ent. 92: 388. - Kulman and Hodson, 1961. Jour.Econ. Ent. 54: 222. _-Dixon and Benjamin, 1963. Jour. Econ. Ent. 56: 267. - Paradis and Leroux, 1965. Ent. Soc. Canada, Mem. 43: 58.

Morphology: Finlayson, 1960. Canad. Ent. 92: 934-939 (immature stages). -Finlayson, 1963. Canad. Ent. 95: 500 (immature stages).

\section{Genus MERAPORUS Walker}

Meraporus Walker, 1834. Ent. Mag. 2: 298.

Type-species: Meraporus graminicola Walker. Desig. by Westwood, 1839.

Parmicromelus Girault, 1917. Descr. Hym. Chalcidoid. Variorum cum Observ. V, p. 4.

Type-species: Parmicromelus europaeus Girault. Orig. desig.

Taxonomy: Waterston, 1921. Roy. Soc., Rpt. Grain Pests Com. 9: 11. -Graham, 1957. Ent. Monthly Mag. 93: 217.

requisitus Tucker. S. C., La. Host: Sitophilus oryza (L.).

Meraporus requisitus Tucker, 1910. Canad. Ent. 42: 344. ơ.

Taxonomy: Graham, 1969. Brit. Mus. (Nat. Hist.) Ent., Bul. Sup. 16: 681 (requisitus unlikely to be a true Meraporis). 


\section{Genus PSEUDOCATOLACCUS Masi}

Pseudocatolaccus Masi, 1908. Lab. Zool. Gen. e Agr. Portici, Bol. 3: 138.

Type-species: Pseudocatolaccus asphondyliae Masi. Monotypic.

Taxonomy: Burks, 1954. U. S. Dept. Agr., Tech. Bul. 1093: 14-15.

americanus Gahan. Tex., N. Mex. Idaho, Utah, Ariz. Ecology: Develops in galls on alfalfa, Bidens, Larrea, possibly other plants. Host: Asphondylia sp., A. websteri Felt.

Pseudocatolaccus Americanus Gahan, 1919. Ent. Soc. Amer., Ann. 12: 164. ‡, ठ’.

Taxonomy: Graham, 1969. Brit. Mus. (Nat. Hist.) Ent., Bul. Sup. 16: 695 (might be the same as the European asphondyliae Masi).

\section{Genus PERIDESMIA Foerster}

Peridesmia Foerster, 1856. Hym. Stud., v. 2, p. 65. No species.

Type-species: Isocyrtus (Trichomalus) aquisgranensis Mayr. Desig. by Gahan, 1923.

Taxonomy: Delucchi, 1956 (1955). Ztschr. f. Angew. Ent. 38: 147-150.

discus (Walker). Ga.; Europe. Ecology: Larva consumes eggs of Hypera inside alfalfa stems. Introduced from Europe into Calif. and Atlantic Coast states; known to be established only in Ga. Host: Hypera postica (Gyll.).

Pteromalus discus Walker, 1835. Ent. Mag. 2: 482. ‥

Pteromalus subquadratus Walker, 1836. Ent. Mag. 3: 478. “o” = $\delta$.

Pteromalus Phyllus Walker, 1839. Monog. Chalcid., v. 1, p. 272. ㅇ.

Peridesmia phytonomi Gahan, 1923. Wash. Acad. Sci., Jour. 13: 410. ₹, §.

Taxonomy: Graham, 1956. Ent. Monthly Mag. 92: 246 (syn.). -Graham, 1969. Brit. Mus. (Nat. Hist.) Ent., Bul. Sup. 16: 701-702.

Biology: Chamberlin, 1924. Jour. Econ. Ent. 17: 625. - Flanders, 1935. Ent. Soc. Amer., Ann. 28: 438-444. - Strong, 1935. U. S. Dept. Agr., Bur. Ent. Plant Quar., Ann. Rpt. for 1935, p. 59. - Flanders, 1942. Ent. Soc. Amer., Ann. 35: 253 (eggs and ovaries). -Flanders, 1944. Jour. Econ. Ent. 37: 410 (diapause). -Coles and Puttler, 1963. Jour. Econ. Ent. 56: 611.

Morphology: Parker, 1924. Soc. Ent. de France, Ann. 93: 316 (larvae). - Miller, 1972. Ent. Soc. Amer., Ann. 65: 1119-1124 (antennae).

\section{Genus SPANIOPUS Walker}

Spaniopus Walker, 1833. Ent. Mag. 1: 371, 466.

Type-species: Spaniopus dissimilis Walker. Monotypic.

Polycelis Thomson, 1878. Hym. Scand., v. 4, pp. 131, 143. Preocc. by Ehrenberg, 1831.

Type-species: Pteromalus conspersus Walker. Desig. by Ashmead, 1904.

Polyscelis Ashmead, 1894. Cincinnati Soc. Nat. Hist., Jour. 17: 52. Emend. Preoce. by Girard, 1850.

Neopolycelis Hincks, 1944. Roy. Ent. Soc. London, Proc. (B) 13: 38. N. name for Polycelis Thomson.

Taxonomy: Gahan, 1922. U. S. Natl. Mus., Proc. 61(24): 10-12. -Graham, 1956. Ent. Monthly Mag. 92: 250.

dissimilis (Walker). Ont., Pa., Md., Va., Ill.; Europe. Ecology: Either a primary or secondary parasite of hosts developing in grass stems. Host: Mayetiola destructor (Say); Platygaster zosine Walk.

Spaniopus dissimilis Walker, 1833. Ent. Mag. 1: 466. o.

Polyscelis modestus Gahan, 1922. U. S. Natl. Mus., Proc. 61 (24): 11. ₹, ठ.

Taxonomy: Gahan, 1934 (1933). U. S. Dept. Agr., Misc. Pub. 174: 67-70 (modestus).

Biology: Myers, 1925 (1924). Jour. Agr. Res. 29: 289-295. - Hill and Smith, 1928. Jour. Agr. Res. 36: 153-155. - Hill and Smith, 1931. Ent. Soc. Wash., Proc. 33: 182-183. -Gahan, 1934 (1933). U. S. Dept. Agr., Misc. Pub. 174: 67-70. - Hill et al., 1939. U. S. Dept. Agr., Tech. Bul. 689: 12-13. - Hill and Pinckney, 1940. U. S. Dept. Agr., Tech. Bul. 715: 9-13.

Morphology: Hill and Smith, 1931. Ent. Soc. Wash., Proc. 33: 183-185 (immature stages). 
websteri (Ashmead). Md., Ind. Ecology: Emerges from stem gall on Lactuca canadensis; possibly parasitic on gall-making cynipid or its Eurytoma parasite.

Polyscelis Websteri Ashmead, 1894. Cincinnati Soc. Nat. Hist., Jour. 17: 52. ^, ठ.

Taxonomy: Gahan, 1922. U. S. Natl. Mus., Proc. 61 (24): 11.

Biology: Webster, 1894. Cincinnati Soc. Nat. Hist., Jour. 17: 36.

\section{Genus TRICHOMALUS Thomson}

Isocyrtus subg. Trichomalus Thomson, 1878. Hym. Scand., v. 5, pp. 131, 134.

Type-species: Trichomalus punctimucha Thomson. Desig. by Ashmead, 1904.

Lanceosoma Erdos, 1953. Acta. Biol. Hung, 4: 234.

Type-species: Lanceosoma althaeae Erdos. Orig. desig.

Revision: Delucchi and Graham, 1956. Beitr. z. Ent. 6: 543-576. -Graham, 1969. Brit. Mus. (Nat. Hist.) Ent., Bul. Sup. 16: 707-737.

Taxonomy: Graham, 1956. Ent. Monthly Mag. 92: 247-250 (syn.; types).

deiphon (Walker). Fla.

Metopon deiphon Walker, 1843. Soc. Ent. de France, Ann. (2) 1: 161...

Taxonomy: Burks, 1975. Brit. Mus. (Nat. Hist.) Ent., Bul. 32: 156.

eurypon (Walker). Fla.

Pteromalus eurypon Walker, 1847. Ann. and Mag. Nat. Hist. (1) 19: 398. ‥

Taxonomy: Burks, 1975. Brit. Mus. (Nat. Hist.) Ent., Bul. 32: 158.

habis (Walker). Fla.

Lampretatus habis walker, 1843. Soc. Ent. de France, Ann. (2) 1: 155. ค.

Taxonomy: Burks, 1975. Brit. Mus. (Nat. Hist.) Ent., Bul. 32: 158.

inseitus (Walker). N. Y. Ohio; Europe. Host. Rhynchaenus pallicornis Say. Other carculionid hosts recorded in Palearctic Literature.

Pteromalus inscitus Walker, 1835. Ent. Mag. 2: 499. 9.

Pteromalus affinis Walker, 1835. Ent. Mag. 2: 492. ㅇ.

Pteromalus tristis Walker, 1835. Ent. Mag. 2: 500. ‥

Pteromalus microcerus Walker, 1835. Ent. Mag. 2: 500. $\%$.

Pteromalus Deiochus Walker, 1839. Monog. Chalcid., v. 1, p. 240. ठ์.

Pteromalus reconditus Foerster, 1841. Beitr. Monog. Pteromalinen, p. 13. $q$.

Pteromalus Diachymatis Ratzeburg, 1844. Ichn. d. Forstins., v. 1, p. 203. ठ.

Pteromalus Orchestis Ratzeburg, 1844. Ichn. d. Forstins., v. 1, p. 205. ․

Pteromalus Lampe Walker, 1848. List. Hym. Brit. Mus., Chalcid., v. 2, pp. 125, 192..

Isocyrtus (Trichomalus) subnudus Thomson, 1878. Hym. Scand., v. 5, p. 140. $\$, \delta$.

Taxonomy: Graham, 1956. Ent. Monthly Mag. 92:248-250 (syn.; types). -Graham, 1969. Brit.

Mus. (Nat. Hist.) Ent., Bul. Sup. 16: 728-729 (syn.; types).

Biology: Mundinger, 1951. Jour. Econ. Ent. 44: 30.

perfectus (Walker). Idaho, B. C., Wash., Oreg., Calif,; Europe. Host: Ceutorhynchus assimilis (Payk.). Almost all North American literature about this species used the name fasciatus Thomson, a misidentification.

Pteromalus perfectus Walker, 1835. Ent. Mag. 2: 488. .

Pteromalus decorts Walker, 1835. Ent. Mag. 2: 496..

Pteromalus decisus Walker, 1835. Ent. Mag. 3: 185. ㅇ.

Pteromalus opulentus Foerster, 1841. Beitr. Monog. Pteromalinen, p. 26. ㅇ.

Isocyrtus (Trichomalus) laevinucha Thomson, 1878. Hym. Scand., v. 5, p. 140. ๆ, o.

Taxonomy: Graham, 1956 Ent. Monthly Mag. 92: 250 (syn.; types). -Delucchi and Graham, 1956. Beitr. z. Ent. 8: 551, 571-572 (descr.; syn.). - Peck, 1963. Canad. Ent. Sup. 30: 669 (correction of ident. of N. Amer. specimens). -Graham, 1969. Brit. Mus. (Nat.Hist.) Ent., Bul. Sup. 16: 729 (types). 
Biology: Baker, 1936. Canad. Ent. 68: 192. -Doucette, 1944. Wash. Agr. Expt. Sta., Bul. 455: 124. - Doucette, 1948. Jour. Econ. Ent. 41: 764-765. - Hanson et al., 1948. Wash., Agr.

Expt. Sta., Bul. 498: 14. -McLeod, 1953. Ent. Soc. Brit. Columbia, Proc. 49: 12-17. -Walz, 1957. Ent. Soc. Amer., Ann. 50: 219. -Jourdheuil, 1960. Ann. des Epiphyt. 11: 462.

statutus (Foerster). Va.; Europe. Host: Oscinella frit (L.).

Pteromalus statutus Foerster, 1841. Beitr. Monog. Pteromalinen, p. 20. $\$$.

Pteromalus fertilis Foerster, 1841. Beitr. Monog. Pteromalinen, p. 20..

Taxonomy: Graham, 1969. Brit. Mus. (Nat. Hist.) Ent., Bul. Sup. 16: 719 (syn.; characters of gaster).

\section{Genus EUPTEROMALUS Kurdjumov}

Eupteromalus Kurdjumov, 1913. Ent. Obozr. 13: 12.

Type-species: Pteromalus nidulans Thomson. Orig. desig. Type-species originally cited by Kurdjumov as nidulans Foerster, but, although a Foerster type exists in Vienna, Foerster did not describe it; Thomson described it and cited Foerster as author.

Nemicromelus Girault, 1917. Descr. Hym. Chalcidoid. Variorum cum Observ. V, p. 4.

Type-species: Merisus subapterus riley. Orig. desig.

The genus Trichomalopsis Crawford, described 2 months before Eupteromalus Kurdjumov, and up to now considered to be exclusively Oriental, might prove to be inseperable from Eupteromalus.

Revision: Graham, 1969. Brit. Mus. (Nat. Hist.) Ent., Bul. Sup. 16: 737-777 (Europe and N. Amer.).

Taxonomy: Gahan, 1921 (1920). Ent. Soc. Wash., Proc. 22: 240-241. -Gahan, 1934 (1933). U. S. Dept. Agr., Misc. Pub. 174: 80 (syn.).

albopilosus Graham. Wyo., Colo.; Europe. Host: Bathyplectes curculionis (Thomson).

Eupteromalus albopilosus Graham, 1969. Brit. Mus. (Nat. Hist.) Ent., Bul. Sup. 16: 753. , o.

americanus Gahan. Mich., Wis., Iowa, N. Dak., Wyo., Colo., Wash., Oreg., Calif. Host: Mayetiola destructor (Say).

Eupteromalus americanus Gahan, 1934 (1933). U. S. Dept. Agr., Misc. Pub. 174: 82. ९, ơ.

Biology: Hill, 1953. U. S. Dept. Agr., Cir. 923: 3.

cognatus Gahan. Ohio. Host: Epeira foliata (Fourc.), E. undata (Oliv.), Philodromus aureolus (Oliv.).

Eupteromalus cognatus Gahan, 1924. U. S. Natl. Mus., Proc. 65 (4): 16. ๆ, §.

Biology: Auten, 1925. Ent. Soc. Amer., Ann. 18: 242.

dubius (Ashmead). D. C., Ohio, Ind., Wis., Ill., Minn., Iowa, Nebr. Ecology: Secondary parasite. Host: Lissonota sp., Microplitis gortynae Riley; Lydella radicis (Townsend), $L$. thompsoni Herting, Pyraustomyia penitalis (Coq.).

Meraporus dubius Ashmead, 1896. Amer. Ent. Soc., Trans. 23: 219. १, ठे.

Biology: Breakey, 1930. Ent. Soc. Amer., Ann. 23: 186. - Blickenstaff et al., 1953. Iowa State Col., Jour. Sci. 27: 374-375.

leguminis Gahan. Wyo., Idaho, Utah, Nev., Oreg. Host: Bruchus pisorum (L.), Hypera postica (Gyll.); Bathyplectes sp.

Eupteromalus leguminis Gahan, 1937. Ent. Soc. Wash., Proc. 39: 63. ๆ, o.

peregrinus Graham. Que., Ont., Maine and Mass., s. to Del.; B. C., Wash., Oreg.; Europe.

Introduced from Europe beginning in 1906, first recovered in 1908 in Mass.; colonized in Washington State beginning in 1931 and recovered in 1935. Host: Nygmia phaeorrhoea (Donov.), Porthetria dispar (L.), Stilpnotia salicis (L.); Lydella sp.; Apanteles lacteicolor Vier., A. melanoscelus (Ratz.), Meteorus versicolor (Wesm.), Rogas unicolor (Wesm.). When first introduced into North America from Europe this species was eited in North American literature under the name nidulans Thomson (or incorrectly as nidulans Foerster). This name was changed quickly to egregius Foerster (now considered a 
misidentification). Usage in North American literature reverted to nidulans about 1920 and remained there until 1956. That year Graham placed nidulans Thomson in synonymy under apicalis Walker and hemipterus Walker. The first of these being preoccupied, usage of hemipterus was followed. However, in 1969, in his revision of the European and North American species of Eupteromalus, Graham stated that there are no undoubted North American records of hemipteris. He described peregrinus for the European species that has been commonly known here as egregius or nidulans in a very large amount of literature.

Eupteromalus peregrinus Graham, 1969. Brit. Mus. (Nat. Hist.) Ent., Bul. Sup. 16: 764. १, o.

Taxonomy: Howard, 1908. U. S. Dept. Agr., Ann. Rpt. for 1907, pp. 454-455. - Kurdjumov, 1912. Ent. Obozr. 12: 228-229. - Kurdjumov, 1913. Ent. Obozr. 13: 19. -Gahan, 1914. U. S. Natl. Mus., Proc. 48: 163. - Viereck, 1917 (1916). Conn. State Geol. and Nat. Hist. Surv., Bul. 22: 773. - Graham, 1969. Brit. Mus. (Nat. Hist.) Ent., Bul. Sup. 16: 764-765.

Biology: Fiske, 1910. Parasites of Gypsy and Brown-Tail Moths introd. into Mass., pp. 54-55. - Howard and Fiske, 1911. U. S. Dept. Agr., Bur. Ent. Bul. 91: 61, 65, 69, 262, 268-278, 309. -Johannsen, 1912. Maine Agr. Expt. Sta., Bul. 207: 457-458. -Muesebeck, 1918. Jour. Agr. Res. 14: 192, 201. - Burgess and Crossman, 1927. U. S. Dept. Agr., Bul. 1469: 18-19. -Muesebeck and Dohanian, 1927. U. S. Dept. Agr., Bul. 1487: 28-29. - Burgess and Crossman, 1929. U. S. Dept. Agr., Tech. Bul. 86: 138-142. - Brown, 1931. U. S. Dept. Agr., Cir. 176: 11-12. - Proper, 1931. Jour.Agr. Res. 43: 37-56. -Proper, 1934. Jour. Agr. Res. 48: 368-369. -Jones et al., 1938. U. S. Dept. Agr., Cir. 459: 7-8, 14-19, 23-24. -Salt, 1941. Cambridge Phil. Soc., Biol. Rev. 16: 247-259. -Clausen, 1956. U. S. Dept. Agr., Tech. Bul. 1139: 103-104. -Russo, 1959. R. Lab. Ent. Agr. Portici, Bol. 17: 176. sarcophagae Gahan. Mich., Kans., Idaho, Ariz. Host: Blaesoxipha kellyi (Ald.).

Eupteromalus sarcophagae Gahan, 1914. U. S. Natl. Mus., Proc. 48: 163. ๆ, o.

Taxonomy: Gahan, 1921 (1920). Ent. Soc. Wash., Proc. 22: 240.

subapterus (Riley). Ont., N. Y., s. to N. C., w. to Minn., Okla., and Oreg. Host: Mayetiola destructor (Say), Meromyza americana Fitch; Platygaster zosine Walk.

Pteromalus? fulvipes Forbes, 1885. Ill. State Dept. Agr., Trans. 22: App. p. 47. \&, ठ. Preocc. by Walker, 1836.

Merisus (Homoporus) subapterus Riley, 1885. U. S. Natl. Mus., Proc. 8: 416., , ర.

Taxonomy: Gahan, 1934 (1933). U. S. Dept. Agr., Misc. Pub. 174: 75-82. - Hill and Pinckney, 1940. U. S. Dept. Agr., Tech. Bul. 715: 7-13 (immature stages).

Biology: Osborn, 1898. U. S. Dept. Agr., Bur. Ent. Bul. (n. s.) 16: 28-33. - Packard, 1916. Jour. Agr. Res. 6: 377-381. - McColloch, 1923. Kans. Agr. Expt. Sta., Tech. Bul. 11: 63, 67-69.

-Hill et al., 1939. U. S. Dept. Agr., Tech. Bul. 689: 1-15. - Hill, 1953. U. S. Dept. Agr., Cir. 923: 2-4, 7, 9-14.

tachinae Gahan. Ont., Ohio, Ind., Tenn., Iowa, La., Kans., Tex. Host: Ostrinia nubilalis (Hbn.), Pseudaletia unipuncta (Haw.); Archytas sp., Hypoderma lineatum (Vill.).

Eupteromalus tachinae Gahan, 1917. U.S. Natl. Mus., Proc. 53: 211. \&.

Biology: Baker, 1915. Ent. Soc. Ont., Ann. Rpt. $45: 87$ (Eupteromalus sp.).

viridescens (Walsh). Ont. and N. H., s. to Fla., w. to B. C., Wash., Oreg., Calif. Host:

Pyraustomyia penitalis (Coq.); Apanteles congregatus (Say), A. limenitidis (Riley), A. marginiventris (Cress.), A. medicaginis Mues., A. militaris (Walsh), A. papaipemae Mues., A. smerinthi Riley, Bathyplectes curculionis (Thoms.), Bracon canlicola (Gah.), B. lutus Prov., Cratichneumon astutus (Holmgr.), Diadegma insularis (Cress.), Horogenes insularis (Cress.), Macrocentmis pallisteri DeG., Microplitis ceratomiae Riley, $M$. gortynae Riley.

Glyphe viridascens Walsh, 1861. Ill. State Agr. Soc. Trans. 4: 264, 370. .

Glyphe viridescens Walsh, 1865. Ill. State Agr. Soc., Trans. 5: 11, 483. Emend.

Taxonomy: Gahan, 1921 (1920). Ent. Soc. Wash., Proc. 22: 240. 
Biology: Girault, 1912. Wis. Nat. Hist. Soc., Bul. 10: 31-46. - Balduf, 1929. Ohio Jour. Sci. 29: 226-227, 237. -Decker, 1935. Iowa State Coll., Jour. Sci. 9: 572-576. - Walker and Anderson, 1936. Va. Truck Expt. Sta., Bul. 93: 1382-1383. -Gilmore, 1938. Jour. Econ. Ent. 31: 715. - Hamlin et al., 1949. U. S. Dept. Agr., Tech. Bul. 975: 41, 44, 50-51, 55-58, 83. -Harcourt, 1960. Canad. Ent. 92: 423. -Puttler 1966. Jour. Econ. Ent. 59: 483.

\section{Genus GYRINOPHAGUS Ruschka}

Gyrinophagus Ruschka, 1914. Zool.-Bot. Gesell. Wien, Verh. 64: 208. Type-species: Gyrinophagus luteipes Ruschka. Monotypic.

Taxonomy: Delucchi, 1956 (1955). Ztschr. f. Angew. Ent. 38: 150-153.

dineutis (Ashmead). N. J., Mich., Iowa. Host: Dineutes assimilis (Kirby), Gyrinus sp. Cyrtogaster dineutis Ashmead, 1894. Canad. Ent. 26: 26. $\$$.

Biology: Butcher, 1933. Ent. Soc. Amer., Ann. 26: 83. -Galtsoff et al., 1937. Culture Methods for Invertebrate Animals, pp. 496-497.

\section{Genus SISYRIDIVORA Gahan}

Sisyridivora Gahan, 1951. Ent. Soc. Amer., Ann. 44: 100.

Type-species: Sisyridivora cavigena Gahan. Orig. desig.

Taxonomy: Graham, 1969. Brit. Mus. (Nat. Hist.) Ent., Bul. Sup. 16: 778.

cavigena Gahan. Ohio. Host: Climacia areolaris (Hagen).

Sisyridivora cavigena Gahan, 1951. Ent. Soc Amer., Ann. 44: 102. ๆ, ठ.

Biology: Brown, 1951. Ent. Soc. Amer., Ann. 44: 103-110.

\section{Genus NASONIA Ashmead}

Nasonia Ashmead, 1904. Carnegie Mus., Mem. 1: 317, 318.

Type-species: Nasonia brevicornis Ashmead. Orig. desig.

Mormoniella Ashmead, 1904. Carnegie Mus., Mem. 1: 316, 317.

Type-species: Mormoniella brevicornis Ashmead. Orig. desig.

Ashmead placed Nasonia and Mormoniella in different tribes, but the same specimens were type material of both type-species. A very large amount of literature has been published about this genus, about half of it using the name Mormoniella, which has page priority. However, Brues revised the genus, and as first reviser, he selected the name Nasonia.

Revision: Brues, 1910. Canad. Ent. 42: 260.

Taxonomy: Kurdjumov, 1913. Ent. Obozr. 13: 5 (Mormoniella). -Gahan, 1927. U. S. Natl. Mus., Proc. 71 (4): 5 (Mormoniella). -Gahan and Peck, 1946. Wash. Acad. Sci., Jour. 36: 316 (type-species). -Peck, 1951 In Muesebeck, et al., U. S. Dept. Agr., Agr. Monog. 2: 559 (Nasonia). -Edwards, 1952. Ent. Monthly Mag. 88: 1056 (Mormoniella). - Hedqvist, 1963. Stud. Forest. Suecica 11: 125 (Nasonia).

vitripennis (Walker). Que., s. to Fla., w. to B. C. and Calif.; Cosmopolitan. Host: Calliphora sp., C. vicina R.-D., Cochliomyia hominivorax (Coq.), C. macellaria (F.), Fannia sp., $F$. canicularis (L.), $F$. femoralis (Stein), $F$. scalaris (F.), Hubneria estigmenensis (Sellers), Hypoderma sp., Lucilia sp., L. illnstris (Meig.), Musca sp., M. domestica L., Omotoma fumiferanae (Tothill), Ophyra aenescens (Wied.), O. leucostoma (Wied.), Phaenicia eximia (Wied.), P. mexicana (Macq.), P. sericata (Meig.), Phomia regina (Meig.), Piophila casei (L.), Polietes lardaria (F.), Protocalliphora avium S. and D., P. metallica (Towns.), P. sialia S. and D., Sarcophaga sp., Synthesiomyia nudiseta (Wulp).

Pteromalus vitripennis Walker, 1836. Ent. Mag. 3: 492. .

Pteromalus muscarum Hartig, 1838. Forstwiss. Forst. Naturk., Jahrb. 1: 256.

Pteromalus abnormis Boheman, 1856. Ofvers. Svensk. Vetensk.-Akad., Forh. 15:58, 59. \&, o.

Dicyclus pallinervosus Walker, 1872. Notes on Chalcid., p. 117. \&.

Stictonotus insuetus Walker, 1872. Notes on Chalcid., p. 117. \&.

Mormoniella brevicornis Ashmead, 1904. Carnegie Mus., Mem. 1: 316. $q$.

Nasonia brevicornis Ashmead, 1904. Carnegie Mus., Mem. 1: 317.. 
Platymesopus macellariae Brethes, 1913. Buenos Aires Mus. Nac. de Hist. Nat., An. 24: 92. + .

Taxonomy: Gahan, 1927. U. S. Natl. Mus., Proc. 71 (4): 5. -Gahan and Peck, 1946. Wash. Acad. Sci., Jour. 36: 316. - De Santis, 1957. La Plata Univ. Nac., Mus. Notas 19: 169. -Tonapi, 1958. Roy. Ent. Soc. London, Trans. 110: 550. - Saul, 1960. Rev. Suisse de Zool. 67: 270. - De Santis, 1960. Fac. Agron., Rev. (3) 36: 116-117. - Hedqvist, 1963. Stud.

Forest. Suecica 11: 125-127. - Graham, 1969. Brit. Mus. (Nat. Hist.) Ent., Bul. Sup. 16: 779.

Biology: Girault and Sanders, 1910. Psyche 17: 9-28. - Howard, 1911. The House Fly, pp. 90-93. - Tiegs, 1922. Roy. Soc. So. Austral., Trans. and Proc. 46: 319-527. - Parker and Thompson, 1928. Soc. Ent. de France, Ann. 97: 435-437. - Smit, 1931. So. Afr. Dept. Agr., Vet. Serv., Rpt. 17: 404-407. - Cousin, 1933. Bul. Biol. France et Belg. 67: 371-400. -Evans, 1933. Bul. Ent. Res. 24: 385-405. - Roberts, 1933. Ecology 14: 307. - Roberts, 1935. Jour. Agr. Res. 50: 481-492. - Laing, 1937. Jour. Anim. Ecol. 6: 304-305. -Jacobi, 1939. Arch. Neerland. de Zool. 3: 197-282. -De Bach and Smith, 1941. Ecology 22: 365-368. -De Bach and Smith, 1941. Jour. Econ. Ent. 34: 741-745. - Van der Merwe, 1943. Ent. Soc. So. Afr., Jour. 6: 48-64. - De Bach, 1943. Pan-Pacific Ent. 19: 112-119. - Moursi, 1946. Soc. Roy. Ent. d'Egypte, Bul. 30: 21-59. - Ulyett, 1950. Bul. Ent. Res. 40: 533-537. -Whiting, 1950. Genetics 35: 699. - Whiting, 1954. Evolution 40: 135. - Edwards, 1954. Behaviour 7: 88-112. - Whiting, 1955. Genetics 40: 602. - Whiting, 1958. Tenth Internatl. Cong. Ent., Proc. v. 2, p. 857. -Whiting, 1958. Assoc. Southeast. Biol., Bul. 5: 16. -Schneiderman and Horwitz, 1958. Jour. Expt. Biol. 35: 520. - Wylie, 1958. Canad. Ent. 90: 597. - Ohgushi, 1959. Zool. Soc. of Japan, Zool. Mag. 68: 426. -Barras, 1960. Behaviour 15: 185-209, 210-218. - Barras 1961. Behaviour 18: 288-312. -Ohgushi, 1961. Jap. Jour. Appl. Ent. and Zool. 5: 154. - Saunders, 1962. Jour. Insect Physiol. 8: 309. - Nagel and Pimentel, 1963. Canad. Ent. 95: 208. - Wylie, 1963. Canad. Ent. 95: 881-886. - King and Hopkins, 1963. Jour. Expt. Biol. 40: 751-761. - Beard, 1964. Jour. Insect Path. 6: 1-7. - Nagel and Pimentel, 1964. Ecology 45: 658-660. - Wylie, 1964. Canad. Ent. 96: 1023. -Wylie, 1965. Canad. Ent. 97: 279-286, 970-977. - Saunders, 1966. Jour. Ins. Physiol. 12: 570. - Whiting, 1967. Quart. Rev. Biol. 42: 333-406. - Wylie, 1967. Canad. Ent. 99: 742-748. -Walker, 1967. Ecology 48: 294. - Chabora, 1967. Canad. Ent. 99: 763. - Barras, 1969. Behaviour 35: 304-312. - Wylie, 1970. Canad. Ent. 102: 886-894. - Chabora and Pimentel, 1970. Ent. Soc. Amer., Ann. 63: 479-486. - Chabora and Chabora, 1971. Ent. Soc. Amer., Ann. 64: 558-562. - Wylie, 1971. Canad. Ent. 103: 1537-1544.

Morphology: Parker, 1924. Soc. Ent. de France, Ann. 93: 309 (larva). - Evans, 1933. Bul. Ent. Res. 24: 400-403. -Cutler, 1955. Roy. Ent. Soc. London, Proc. (A) 30: 73-81. -Tonapi, 1958. Roy. Ent. Soc. London, Trans. 110: 550-551 (spiracles). - King, 1962. Roy Ent. Soc. London, Proc. (A) 37: 73, 121. - Slifer, 1969. Biol. Bul. 136: 253-263 (antennae). -Sanger and King, 1971. Entomologist 104: 137-149 (male genitalia). - Miller, 1972. Ent. Soc. Amer., Ann. 65: 1119-1124 (antennae).

\section{Genus UROLEPIS Walker}

Urolepis Walker, 1846. List Hym. Brit. Mus., Chalcid., v. 1, p. 26.

Type-species: Ormocerus maritimus Walker. Monotypic.

Halizoa Foerster, 1856. Hym. Stud., v. 2, p. 145. N. name, unnecessarily proposed for Urolepis thought to be preocc.

Pteromalus subg. Halizous Thomson, 1878. Hym. Scand., v. 5, pp. 146, 147. Emend.

rufipes (Ashmead). N. Y., Minn., Nebr., Kans., Tex., Utah, Oreg., Calif. Host: Hydropyrus hians (Say), Setacera pacifica (Cress.).

Halizoa rufipes Ashmead, 1896. Amer. Ent. Soc., Trans. 23: 225. \&, ठ.

\section{Genus DIGLOCHIS Foerster}

Diglochis Foerster, 1856. Hym. Stud., v. 2, p. 65 . No species.

Type-species: Pteromalus complanatus Ratzeburg. By subsequent ref. by Mayr, 1904.

Pteromalus subg. Trichoglenus Thomson, 1878. Hym. Scand., v. 5, pp. 146, 149.

Type-species: Pteromalus complanatus Ratzeburg. Monotypic. 
Trichoglenes Ashmead, 1896. Amer. Ent. Soc., Trans. 23: 225. Emend.

Taxonomy: Graham, 1969. Brit. Mus. (Nat. Hist.). Ent., Bul Sup. 16: 782-783 (identity of complanatus Ratzeburg questionable; application to Internatl. Comn. may be necessary). oceidentalis (Ashmead). Conn., Wis., Minn., Man., Sask., Alta., B. C., Wash., Oreg. Host: Chrysops sp., C. aestuans Wulp, C. excitans Walk., C. frigidus O. S., C. furcatus Walk., C. mitus O. S., C. nigripes Zett., Hybomitra affinis (Kby.), H. frontalis (Walk.), Tabanus sp.

Trichoglenes occidentalis Ashmead, 1896. Amer. Ent. Soc., Trans. 23: 225. ๆ.

Biology: Philip, 1931. Minn. Agr. Expt. Sta., Tech. Bul. 80: 68. - Miller, 1951 Canad. Jour. Zool. 29: 261. -James, 1952. Ent. Soc. Ont., Ann. 82: 70-74. -James, 1964 (1963). Canad. Ent. 95: 1229-1231 (life hist.).

\section{Genus TOMICOBIA Ashmead}

Tomicobia Ashmead, 1899. Ent. Soc. Wash., Proc. 4: 203. No species.

Type-species: Tomicobia tibialis Ashmead. Desig. by Ashmead, 1904.

Ipocoelius Ruschka, 1924. Ent. Tidskr. 45: 6.

Type-species: I pocoelius seitneri Ruschka. Orig. desig.

The adults of these parasites emerge from the adults of their scolytid hosts.

Revision: Hedqvist, 1959. Opusc. Ent. 24: 177-184. -Graham, 1969. Brit. Mus. (Nat. Hist.)

Ent., Bul. Sup. 16: 784-787.

Taxonomy: Gahan, 1938. Ent. Soc. Wash., Proc. 40: 221-222 (syn.).

peratripes (Girault). N. C.

Nasonia peratripes Girault, 1917. Descr. Hym. Chalcidoid. Variorum cum Observ. III, p. 1. ․

Taxonomy: Hedqvist, 1959. Opuse. Ent. 24: 184. - Whiting, 1967. Quart. Rev. Biol. 42: 336. tibialis Ashmead. Maine, s. to N. C., w. to Idaho and Calif. Host: Ips sp., I. calligraphus (Germ.), I. confusus (Lec.), I. grandicollis (Eich.), I. oregoni (Eich.), I. pini (Say), Orthotomicus caelatus (Eich.), Pityophthorus sp.

Tomicobia tibialis Ashmead, 1904. Carnegie Mus., Mem. 1: 283..

Biology: Hopkins, 1914 (1913). Ent. Soc. Wash., Proc. 15: 160. - Reid, 1957. Canad. Ent. 89: 7-8. - Ruckes, 1963. Pan-Pacific Ent. 39: 45. - Bedard, 1965. Boyce Thompson Inst. Plant Res., Contrib. 23: 77-81. - Rice, 1969. Boyce Thompson Inst. Plant Res., Contrib. 24: 189-194. - Rice, 1971. Pan-Pacific Ent. 47: 1-8 (flight).

\section{Genus ARTHROLYTUS Thomson}

Pteromalus subg. Arthrolytus Thomson, 1878. Hym. Scand., v. 5, pp. 147, 158.

Type-species: Arthrolytus punctatus Thomson. Desig. by Ashmead, 1904.

Taxonomy: Burks, 1969. Ent. Soc. Wash., Proc. 71: 298-300.

fasciatus (Provancher). Que., N. H., Mass., Pa.

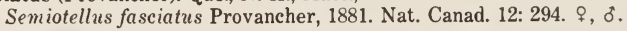

Taxonomy: Burks, 1964 (1963). Canad. Ent. 95: 1261-1262.

muesebecki Burks. Calif. Ecology: Emerges from galls of Andricus brunneus Fullaway on leaves of Quercus donglasii and Callirhytis quercusagrifoliae (Bassett) on leaf axils of several species of Quercus.

Arthrolytus muesebecki Burks, 1969. Ent. Soc. Wash., Proc. 71: 302. ๆ, o.

\section{Genus CYCLOGASTRELLA Bukovskij}

Cyclogastrella Bukovskij, 1938. Ent. Obozr. 27: 153.

Type-species: Cyclogastrella quercina Bukovskij. Monotypic.

Taxonomy: Graham, 1969. Brit. Mus. (Nat. Hist.) Ent., Bul. Sup. 16: 796-797

(Pseudomicromelus Gahan and Fagan, name formerly used for this genus in the Holaretic region, is generically different and is Australian). 
deplanata (Nees). Calif.; Europe. Ecology: Adults often swarm in buildings, congregating on windows. Host: Anarsia lineatella Zell. Other lepidopterous hosts recorded in Palearctic literature.

Pteromalus deplanatus Nees, 1934. Hym. Ichn. Aff. Monog., v. 2, p. 110. ९, ठ. Ormocerus simplex Walker, 1834. Ent. Mag. 2: 169. ठ.

Pteromalus domesticus Walker, 1835. Ent. Mag. 2: 481. ㅇ.

Pteromalus Artemon Walker 1839. Monog. Chalcid. v. 1, p. 218. $\delta$.

Pteromalus Merope Walker, 1839. Monog. Chalcid., v. 1, p. 219. ठँ.

Pteromalus Phasis Walker, 1848. List Hym. Brit. Mus., Chalcid., pt. 2, pp. 123, 175 . o.

Pteromalus Acco Walker, 1848. List Hym. Brit. Mus., Chalcid., pt. 2, pp. 124, 177. $ๆ$.

Pteromalus Androbins Walker, 1848. List Hym. Brit. Mus., Chalcid., pt. 2, pp. 126, 200..

Cyclogastrella quercina Bukovskij, 1938. Ent.Obozr. 27: 154. ९, ठ.

Taxonomy: Walker, 1845. Zoologist 3: 1142 (syn.). -Gahan, 1938. Ent. Soc. Wash., Proc. 40: 226. -Graham, 1956. Ent. Monthly Mag. 92: 258. - Boucek, 1965. Mus. Natl. Pragae, Acta Ent. 11: 26-27. -Graham, 1969. Brit. Mus. (Nat. Hist.) Ent., Bul. Sup. 16: 796 (syn.).

Biology: Scott, 1919. Ent. Monthly Mag. 55: 13-16. - Scott, 1922. Ent. Monthly Mag. 58: 56-60. -Gahan, 1933. Ent. Soc. Wash., Proc. 35: 44.

\section{Genus EPIPTEROMALUS Ashmead}

Epipteromalus Ashmead, 1904. Carnegie Mus., Mem. 1: 319.

Type-species: Epipteromalus algonquinensis Ashmead. Orig. desig.

Taxonomy: Kurdjumov, 1913. Ent. Obozr. 13: 4 (syn. of Trichomalus Thomson). algonquinensis Ashmead. Ill.

Epipteromalus algonquinensis Ashmead, 1904. Carnegie Mus., Mem. 1:319. ․

Polycystus gibbus Girault, 1920. U. S. Natl. Mus., Proc. 58: 212. ․

Taxonomy: Gahan and Peck, 1946. Wash. Acad. Sci. Jour. 36: 315 (syn.; both species described from same specimens).

\section{Genus TRITNEPTIS Girault}

Tritneptis Girault, 1908. Psyche 15: 92.

Type-species: Tritneptis hemerocampae Girault. Orig. desig.

Revision: Gahan, 1938. Ent. Soc. Wash., Proc. 40: 213-214. -Graham, 1969. Brit. Mus. (Nat. Hist.) Ent., Bul. Sup. 16: 800-804 (European fauna). - Burks, 1971. Biol. Soc. Wash., Proc. 84: 1-6.

Taxonomy: Girault, 1924. Insecutor Inscitiae Menstruus 12: 174. (syn. of Dibrachys). diprionis Gahan. Que., Ont., Maine, Mass., Minn.; Europe. Host: Diprion similis (Htg.), Gilpinia frutetorum (F.), G. hercyniae (Htg.), Neodiprion lecontei (Fitch), N. pinetum (Nort.) N. pratti (Dyar), N. sertifer (Four.), Pikonema alaskensis (Roh.), P. dimmockii (Cress.), Pristiphora geniculata (Htg.).

Tritneptis diprionis Gahan, 1938. Ent. Soc. Wash., Proc. 40: 217. ๆ, ठ.

Taxonomy: Finlayson, 1963. Canad. Ent. 95: 479, 482, 483, 500 (immature stages).

Biology: Forbes and Daviault, 1964. Canad. Ent. 96: 1128.

doris Burks. Wyo., Utah. Host: Coloradia doris Barnes, Hemileuca sp.

Tritneptis doris Burks, 1971. Biol. Soc. Wash., Proc. 84: 3. $\uparrow$, o.

hemerocampae Viereck, N. S., N. B., P. E. I., Que., s. to Va., w. to B. C., Wash., Oreg., Calif. Host: Argyrotaenia velutinana (Walk.), Coleophora malivorella Riley, Diacrisia virginica (F.), Estigmene acrea (Dru.), Grapholitha molesta (Busck), Orgyia leucostigma (J. E. Smith), Laspeyresia pomonella (L.), Papilio polyxenes asterius Stoll, Platyprepia guttata (Bdvl.), Stilpnotia salicis (L.).

Tritneptis hemierocampae Girault, 1908. Psyche 15: 90, 92. ㅇ, $\delta$.

Coelopisthia diacrisiae Crawford, 1910. Ent. Soc. Wash., Proc. 12: 145. $\uparrow$.

Amblymerus lipardis Viereck, 1924. Canad. Ent. 56: 69. ९, ơ. 
Taxonomy: Girault, 1924. Insecutor Inscitiae Menstruus 12: 174 (syn. of boucheanus Ratzeburg). -Gahan, 1938. Ent. Soc. Wash., Proc. 40: 217 (Girault's syn. incorrect).

Biology: Glendenning, 1924. Canada Dept. Agr., Pam. (n. s.) 50: 13 (lipardis). - Schaffner and Griswold, 1934. U. S. Dept. Agr, Misc. Pub. 188: 6, 153. -Jaynes and Marucci, 1947. Jour. Econ. Ent. 40: 11. - Brunson, 1957. Jour.Econ. Ent. 50: 375. -Allen, 1962. U. S. Dept. Agr., Tech. Bul. 1265: 102. - McNay, 1963. Canad. Ins. Pest Rev. 41: 20.

klugii (Ratzeburg). Que., Ont., Maine, Mich., Wis., Minn., Man., Sask., Mont., B. C., Wash., Oreg., Calif.; Europe. Possibly introduced from Europe along with its sawfly hosts; records have not been found. Host: Gilpinia hercyniae (Htg.), Mesoleius tenthredinis Morley, Neodiprion pratti banksianae Roh., N. sertifer (Four.), N. tsugae Midd., Pristiphora erichsonii (Htg.). North American literature about this species before 1939 is mostly under the name nematicida Packard; type of Packard's species has not been found, but it is most likely a syn of Dibrachys cavus (Walker).

Pteromalus klugii Ratzeburg, 1844. Ichn. d. Forstins., v. 1, p. 198..

Biology: Hewitt, 1911. Canad. Ent. 43: 297. - Hewitt, 1912. Canada Dept. Agr., Div. Ent. Bul. 5: 28-31. - Swaine, 1912. Ent. Soc. Ont., Ann. Rpt. 43: 87. - Finlayson and Reeks, 1936. Canad. Ent. 68: 163. - Finlayson, 1939 (1938). Ent. Soc. Ont., Ann. Rpt. 69: 34-35. -Furniss and Dowden, 1941. Jour. Econ. Ent. 34: 49-51. - Hopping et al., 1943. Sci. Agr. 24 54-61. - Lejeune and Hildahl, 1954. Canad. Ent. 86: 337-344. -Graham, 1956. Forest Sci. 2: 152-153. - Struble, 1957. Forest Sci. 3: 312. -Griffiths, 1959. Canad. Ent. 91: 508. -Schneiderman and Horwitz, 1958. Jour. Expt. Biol. 35: 520-551. -Drooz, 1960. U. S. Dept. Agr., Tech. Bul 1212: 33. - Ohnesorge, 1962. Ztschr. f. Angew. Ent. 49: 142. -Gauss, 1964. Ztschr. f. Angew. Ent. 54: 226.

Morphology: Finlayson, 1963. Canad. Ent. 95: 483, 500 (immature stages).

koebelei Gahan. Calif. Possibly a parasite of Caliroa cerasi (L.).

Tritueptis koebelei Gahan, 1938. Ent. Soc. Wash., Proc. 40: 218. ๆ, ơ.

scutellata (Muesebeck). N. H., Mass., Conn. Host: Apanteles melanoscelus (Ratz.).

Coelopisthia scutellata Muesebeck, 1927. Jour. Agr. Res. 34: 331. ๆ, ठ์.

Biology: Muesebeck and Dohanian, 1927. U. S. Dept. Agr., Bul. 1487: 27.

\section{Genus DIBRACHYS Foerster}

Revision: Boucek, 1965. Mus. Natl. Pragae, Acta Ent. 11: (Central European fauna). -Graham, 1969. Brit. Mus. (Nat. Hist.) Ent., Bul. Sup. 16: 804-814 (European fauna).

\section{Genus DIBRACHYS Subgenus ALLODIBRACHYS Boucek}

Dibrachys subg. Allodibrachys Boucek, 1965. Mus. Natl. Pragae, Acta Ent. 11: 30. Type-species: Dibrachys hians Boucek. Orig. desig.

No Nearctic species at present referred to this subgenus.

\section{Genus DIBRACHYS Subgenus DIBRACHYS Foerster}

Dibrachys Foerster, 1856. Hym. Stud., v. 2, p. 65. No species.

Type-species: Pteromalus boucheanus Ratzeburg. Desig. by Thomson, 1878. Coelopisthoidea Gahan, 1913. Canad. Ent. 45: 179.

Type-species: Coleopisthoidea cladiae Gahan. Orig. desig.

Taxonomy: Graham, 1969. Brit. Mus. (Nat. Hist.) Ent., Bul. Sup. 16: 804 (Ratzeburg described no species of Dibrachys, but fragmentary remains of a specimen in Vienna identified by him as Dibrachys look like a Colotrechnus).

cavus (Walker). Newfoundland, Que., N. S., N. B., Maine, s. to Fla., w. to Alaska, B. C. and Calif; worldwide. Ecology: This is the most polyphagous of chalcids; if all known host records are correct, it may be a primary, secondary, or tertiary parasite, attacking many orders of insects, plus spiders. Host: Epeira sp., E. foliata (Fourc.), Philodromus aureolus (Oliv.); Forficula auricularia L.; Chrysopa sp., C. califormica Coq., C. lateralis Guer., C. majuscula Banks, C. oculata Say, C. rufilabris Burm., Sympherobius 
califomicus Banks; Bruchus brachialis Fahr., Coleomegilla maculata (Deg.), Hypera postica (Gyll.), Sitophilus granarius (L.), S. oryzae (L.), Stegobium paniceum (L.); Acranicta clarescens Guen., A. lepusculina Guen., Actebia fennica (Tausch.), Actias luna (L.), Amathes c-nigrum (L.), A. collaris (G. and R.), Anarsia lineatella Zell., Anthophila pariana (Clerck), Archips cerasivoranus (Fiteh), A. fervidamus (Clem.), A semiferanus (Walk.), Archippus packardianus (Fern.), Argyrotaenia citrana (Fern.), A. velutinana (Walk.), Barbara colfaxiana (Kearf.), Choristoneura pinus (Freem.), $C$. rosaceana (Harr.), Coleophora malivorella Riley, Dichomeris marginella (F.), Dicymolomia pegasalis (Walk.), Dioryctria disclusa Hein., Ennomos subsignarius (Hbn.), Epiblema scudderianum (Clem.), Epizeuxis aemula (Hbn.), Eurukuttarus confederata (Grote), Fumaria casta (Pallas), Galleria mellonella (L.), Gnorimoschema gallaesolidaginis (Riley), Grapholitha molesta (Busck), Halisidota argentata Pack., Orgyia pseudotsugata (McD.), Hyphantria cunea (Dru.), Lambdina fiscellaria (Guen.), Laspeyresia pamonella (L.), Malacosoma americanum (F.), M. californicum (Pack.), $M$. constrictum (Hy. Edw.), M. disstria Hbn., Nemapogon granellus (L.), Nygmia phaeorrhoea (Donov.), Oeneis melissa semidea (Say), Orgyia antiqua (L.), $O$. leucostigma (Smith), O. vetusta (Bdvl.), Ostrinia nubilalis ( $\mathrm{Hbn})$, O. obumbratalis (Led.), Papaipema nebris (Guen.), Pectinophora gossypiella (Saund.), Peridroma saucia (Hbn.), Phryganidia californica Pack., Phthorimaea operculella (Zell.), Pieris brassicae (L.), P. rapae (L.), Platyptilia cardnidactyla (Riley), Platysamia cecropia (L.), Plodia interpunctella (Hbn.), Plutella xylostella (L.), Polia legitima (Grote), P. purpurissata (Grote), Porthetria dispar (L.), Rhyacionia sp., Sitotroga cerealella (Oliv.), Spilonota ocellana (D. and S.), Stilpnotia salicis (L.), Taniva albolineana (Kearf.), Thyridopteryx ephemeraeformis (Haw.), Udea mbigalis (Guen.); Actia intermipta Curr., Bigonicheta spinipennis (Meig.), Carcelia gnava (Meig.), Compsilura concinnata (Meig.), Erynnia tortricis (Coq.), Lydella sp., Mericia aldrichi (Twns.), Nemorilla pyste (Walk.), Ocytata pallipes (Fall.), Phormia regina (Meig.), Phryxe vulgaris (Fall.), Protocalliphora sp., Pseudopetichaeta erecta (Coq.), Pyraustomyia penitalis (Coq.), Rhagoletis cingulata (Loew); Apanteles clisiocampae Ashm., A. glomeratus (L.), A. hyphantriae Riley, A. lacteicolor Vier., A. melanoscelus (Ratz.), Arenetra canadensis Cress., Ascogaster quadridentata Wesm., Bathyplectes sp., B. curculionis (Thoms.), Bathythrix pimplae How., Bracon sp., B. gelechiae Ashm., Campoplex phthorimaeae (Cush.), C. validus (Cress.), Casinaria limenitidis (How.), Chelonus shoshoneonorum Vier., Diadegma acutum (Vier.), Dibrachys sp., Diprion similis (Htg.), Erigorgus sp., Gambrus extrematis (Cress.), Gilpinia hercyniae (Htg.), Habrocytus sp., H. phycidis Ashm., Hyposoter fugitivus (Say), H. pilosulus (Prov.), Iseropus coelebs (Walsh), Itoplectis behrensii (Cress.), I. conquisitor (Say), Macrocentrus sp., M. ancylivorns Roh., $M$. peroneae Mues., Mastrus carpocapsae (Cush.), M. pilifrons (Prov.), M. smithii (Pack.), Megachile sp., Meteorus sp., M. acronyctae Mues., M. communis Cress., M. hyphantriae Riley, $M$. versicolor Wesm., Nematus ribesii (Scop.), Neodiprion abietis (Harr.), $N$. abbotii (Leach), N. excitans Roh., N. lecontei (Fitch), N. pratti (Dyar), N. sertifer (Four.), Neopareophora litura (Klug), Perilitus coccinellae (Schr.), Phaeogenes walshiae Ashm., Pimpla aequalis Prov., P. sanguineipes (Cress.), Phobocampe clisiocompae (Weed), P. pallipes (Prov.), Phytodietus vulgaris Cress., Polistiphaga fulva (Cress.), Polyblastus pedalis (Cress.), Priaphorus morio (Lep.), Pristiphora bivittata (Nort.), $P$. erichsonii (Htg.), Pteromalus sp., Rogas stigmator (Say), Sigalphus bicalor (Cress.), Sceptrothelys deione (Walk.), Spilochalcis sp., Tetrastichus sp., Theronia atalantae fulvescens Cress.

Pteromalus cai'us Walker, 1835. Ent. Mag. 2: 477. ₹, o.

Pteromalus decedens Walker, 1835. Ent. Mag. 2: 478. $q$, o.

Pteromalus perversus Walker, 1835. Ent. Mag. 2: 479. "†" = §.

Pteromalus tenuis Ratzeburg, 1844. Ichn. d. Forstins., v.1, p. 195. o.

Pteromalus Boucheanus Ratzeburg, 1844. Ichn d. Forstins., v. 1, p. 196..

Cleonymus Clisiocampae Fitch, 1856 (1855). N. Y. State Agr. Soc., Trans. 15: 431. ค, o. Cheiropachus nigro-cyaneus Norton, 1869. Amer. Ent. Soc., Trans. 2: 327. .

Pteromalus gelechiae Webster, 1883. Ill. State Dept. Agr., Trans. (n. s.) 12:151. ๆ, o.

Pteromalus nematicida Packard, 1883, U. S. Dept. Agr., Ann. Rpt. for 1883, p. 146.

Pteromalus chionobae Howard, 1889. In Scudder, Butterflies of Eastern U. S. and Canada, pp. 1872,1889 . ․ 
Arthrolytus apatelae Ashmead, 1893. Ohio Agr. Expt. Sta., Tech. Ser., Bul. 1: 162. $\subsetneq$. Arthrolytus pimplae Ashmead, 1894. Amer. Ent. Soc., Trans. 21: 339. + , ठ.

Trichomalus trujilloi Blanchard, 1937. Rev. Chil. Hist. Nat. 41: 178. ๆ.

Taxonomy: Gahan, 1938. Ent. Soc. Wash., Proc. 40: 211 (syn.). -Gahan, 1942. U. S. Natl. Mus., Proc. 92: 45-46 (syn.). - Finlayson, 1960. Canad. Ent. 92: 20-47 (taxonomy of immature stages). - Boucek, 1965. Mus. Natl. Pragae, Acta Ent. 11: 30 (variation). -Graham, 1969. Brit. Mus. (Nat. Hist.) Ent., Bul. Sup. 16: 810-811 (syn.; types; Diplolepis microgastri Bouche, 1834 (Naturgesch. der Ins., p. 168), types of which are presumed lost, might be the same as cavus).

Biology: Howard, 1897. U. S. Dept. Agr., Div. Ent., Tech. Ser. 5: 7, 35-38, 49-52. -Fiske, 1903. N. H. Agr. Expt. Sta., Tech. Bul. 6: 182, 206-208, 213, 220, 224-227. -Brodie, 1909. Canad. Ent. 41: 8. -Smith, 1912. U. S. Dept. Agr., Tech. Ser. 19: 55, 62. -Smith, 1916. Jour. Econ. Ent. 9: 484. -Graf, 1917. U. S. Dept. Agr., Bul. 427: 33-36, 40-46. -Graham, 1918. Ent. Soc. Amer., Ann. 11: 175-182.-Middleton, 1923. U.S. Dept. Agr., Bul. 1182: 16-17. - Howard, 1925. Ent. News 36: 130. - Balduf, 1926. Ent. Soc. Amer., Ann. 19: 497. -Flanders, 1926. Pan-Pacific Ent. 3: 44. - Paddock, 1926. Amer. Bee Jour. 66: 555.

-Muesebeck and Dohanian, 1927. U. S. Dept. Agr., Bul. 1487: 4, 12, 25-27. - Allen, 1932. Jour. Econ. Ent. 25: 362-365. - Garman and Brigham, 1933. Conn. Agr. Expt. Sta., Bul. 356: 77-78. - Hoffmann, 1936. Brooklyn Ent. Soc., Bul. 31: 211. - Marsh, 1936. Canad. Ent. 68: 215-216. - Marsh, 1937. Ecology 18: 108-111. - Morris et al., 1937. Bul. Ent. Res. 28: 383, 390-391. -Cristobal, 1938. La Plata Univ., Lab. Zool. Agr., Bol. 4: 5. -Gontarski, 1939. Ztschr. f. Morph. u. Oekol. der Tiere 35: 203-220. - Haeussler, 1940. U. S. Dept. Agr., Tech. Bul. 728: 44, 53, 54. - Boyce, 1941. Ent. Soc. Ont., Ann. Rpt. 71: 41. - Lloyd, 1944. Sci. Agr. 24: 459,462, 468.-Simmonds, 1944. Bul. Ent. Res. 35: 225.-Simmonds, 1944. Sci. Agr. 25: 1-30. - Wellington, 1945. Jour. Econ. Ent. 38: 396. - Clancy, 1946. Univ. Calif. Pubs., Ent. 7: 459. - Doutt and Finney, 1947. Jour. Econ. Ent. 40: 577. - Baker et al., 1949. U. S. Dept. Agr., Tech. Bul. 983: 178. - Smith and Kido, 1949. Hilgardia 19: 50-51. - Craighead, 1950. U. S. Dept. Agr., Misc. Pub. 657: 615-616. - Flanders, 1954. Ecology 35: 248.

- Harville, 1956. Microentomology 20: 116, 129, 137. - Reeks and Smith 1956. Canad. Ent. 88: 572-573. - Lyons, 1957. Canad. Ent. 89: 75. - Langston, 1957. Calif. Univ. Pubs., Ent. 14: 6-25. -Schaffner, 1959. U. S. Dept. Agr., Misc. Pub. 767: 29-30, 89. - Baeva, 1959. Akad. Nauk. Tadzh. SSR Inst. Zool. and Par., Trudy 119: 55, 69, 77. - Richter, 1960. Ent. Ztschr. 70: 115. - Wylie, 1960. Entomophaga 5: 120. - Bendel-Janssen, 1962. Ztschr. f. Pflanzenkrank. 9: 527. - Allen, 1962. U. S. Dept. Agr., Tech. Bul. 1265: 103-106. - Dixon and Benjamin, 1963 Jour. Econ. Ent. 56: 267. - Halstead, 1963. G. B. Pest Inf. Res. Bd., Rpt. for 1962, pp. 5-6. - Legner and Oatman, 1963. Jour. Econ. Ent. 56: 731. - Becker and Benjamin, 1964. Jour. Econ. Ent. 57: 356. - Tza, 1964. Acta Ent. Sinica 13: 689. - Mook and Haeck, 1965. Arch. Neerland de Zool. 16: 302. - Kamenova, 1967. Zool. Zhur. 46: 1800. -Moiseenko, 1967. Minsk. Akad. Nauk BSSR, Dok. 15: 86-87.

Morphology: Parker, 1924. Soc. Ent. de France, Ann. 93: 267, 290, 308 (larvae). -Morris et al., 1937. Bul. Ent. Res. 28: 383-384 (larvae). -Finlayson, 1963. Canad. Ent. 95: 501 (immature stages).

confusus (Girault). N. B., Ont., D. C., Wis., Man., Sask., Alta., Idaho, B. C.; Europe. Host: Megachile sp.

Coelopisthia confusa Girault, 1916. Canad. Ent. 48: 246. ๆ.

Dibrachys maculipennis Szelenyi, 1957. Inst. Prot. Pl. Hung., Ann. 8: 307. ९, ठ.

Taxonomy: Peck, 1969. Canad. Ent. 101: 418-422.

daphne Girault. Tex., Wash., Calif. Host: Sympherobius barberi (Banks), S. californicus Banks. Dibrachys daphne Girault, 1917. Deser. Hym. Chalcidoid. Variorum cum Observ. III, p. 9. \%.

saltans (Ratzeburg). Md., Va., N. Dak., Wash.; Europe. Host: Cladius sp.

Pteromalus saltans Ratzeburg, 1852. Ichn. d. Forstins., v. 3, p. 232. \&, ठ. Coelopisthoidea cladiae Gahan, 1913. Canad. Ent. 45: 179. $९$, $\delta$.

Taxonomy: Gahan, 1938. Ent. Soc. Wash., Proc. 40: 212 (syn.; Ratzeburg types examined in 1927). -Graham, 1969. Brit. Mus. (Nat. Hist.) Ent., Bul. Sup. 16: 809 (Ratzeburg type now destroyed, status of species questionable). 


\section{Genus DIBRACHOIDES Kurdjumov}

Dibrachoides Kurdjumov, 1913. Ent. Obozr. 13: 2-3, 12.

Type-species: Pteromalus dynastes Foerster. Orig. desig.

Revision: Graham, 1969. Brit. Mus. (Nat. Hist.) Ent., Bul. Sup. 16: $814-817$ (Palearctic fauna). dynastes (Foerster). Que. Neb., Wyo., Utah, Wash., Oreg., Calif; Europe. Introduced from

Europe for biological control of the alfalfa weevil in 1911-1913: recovered in 1918. Host:

Hypera nigirostris (F.), $H$. postica (Gyll.), $H$. mimicis (L.).

Pteromalus dynastes Foerster, 1841. Beitr. Monog. Pteromalinen, p. 24. $९$.

Pteromalus transversus Foerster, 1841. Beitr. Monog. Pteromalinen, p. 18..

Pteromalus (Dibrachys) acutus Thomson, 1878. Hym. Scand., v. 5, p. 162. १, ठ઼.

Taxonomy: Graham, 1956. Ent. Monthly Mag. 92: 260 (druso Walker). -Graham, 1969. Brit. Mus. (Nat. Hist.) Ent., Bul. Sup. 16: 815-816 (use of druso for this species an error; syn.).

Biology: Rockwood, 1920. Canad. Ent. 52: 39. -Chamberlin, 1924. U. S. Dept. Agr., Cir. 301: 3-5. - Chamberlin, 1924. Jour. Econ. Ent. 17: 628. -Smith, 1930. Ent. Soc. Amer., Ann. 23: 577-593. - Chamberlin, 1933. Ent. Soc. Wash., Proc. 35: 106. - Essig and Michelbacher, 1933. Calif. Agr. Expt. Sta., Bul. 567: 70-71. - Kaufmann, 1939. Ztschr. f. Angew. Ent. 26: 425-426. - Clausen, 1956. U. S. Dept. Agr., Tech. Bul. 1139: 50. - Fisher et al., 1961. Jour. Econ. Ent. 54: 197. - Delucehi, 1962. Awamia 2: 124. - van den Bosch et al., 1961. Calif. Agr. 15: 11. - Coles and Puttler, 1963. Jour. Econ. Ent. 56: 611. - Ismailov, 1967. Zashch. Rast. 12: 35 .

\section{Genus PARADIBRACHYS Girault}

Paradibrachys Girault, 1917. Descr. Hym. Chacidoid. Variorum cum Observ. V, p. 1. Type-species: Paradibrachys guizoti Girault. Orig. desig.

guizoti Girault. Calif.

Paradibrachys guizoti Girault, 1917. Descr. Hym. Chalcidoid. Variorum cum Observ. V, p. 1. . .

\section{Genus NEOCATOLACCUS Ashmead}

Neocatolaccus Ashmead, 1904. Carnegie Mus., Mem. 1: 320, 322.

Type-species: Catolaccus tylodermae Ashmead. Orig. desig.

cratylus (Walker). Fla.

Pteromalus Cratylus Walker, 1847. Ann. and Mag. Nat. Hist. (1) 19: 392 ..

Taxonomy: Burks, 1975. Brit. Mus. (Nat. Hist.) Ent., Bul. 32: 155.

moneilemae Gahan. Tex. Host: Moneilema ulkei Horn.

Neocatolaccus moneilemae Gahan, 1936. U. S. Natl. Mus., Proc. 83: 484. \&, o.

tylodermae (Ashmead). N. H., s. to Fla., w. to Mich., Ill., Kans., Ariz. Host: Ampeloglypter sesostris (Lec.), Cylindrocopturus longulus (Lec.), Lixus musculus Say, L. parcus Lec., L. scrobicollis Boh., Microlarinus lypriformis (Woll.), M. lareynii (du V.), Onychobaris subtonsa Lec., Trichobaris texana Lec., Tyloderma foveolatum Say.

Catolaccus tylodermae Ashmead, 1893. Ohio Agr. Expt. Sta., Tech. Ser., Bul. 1: 161. \&, ठ์.

Biology: Wester, 1956. Ent. Soc. Wash., Proc. 58: 286. -Goeden and Ricker, 1970. Jour. Econ. Ent. 63: 827-831.

\section{Genus HYPOPTEROMALUS Ashmead}

Hypopteromalus Ashmead, 1900. In Smith, Ins. of N.J., Sup., p. 559.

Type-species: Pteromalus tabacum Fitch. Monotypic.

inimicus Muesebeck. N. B., Que., Ont., s. to Va., w. to N. Dak. and Kans. Host: Apanteles sp.,

A. lacteicolor Vier., A. melanoscelus (Ratz.), Hyposoter fugitivus (Say).

Hypopteromalus inimicus Muesebeck, 1927. Jour. Agr. Res. 34: 332. ๆ, ठో.

Biology: Muesebeck and Dohanian, 1927. U.S. Dept. Agr., Bul. 1487: 28. - Proper, 1934. Jour Agr. Res. 48: 361.-Doner, 1936. Ent. Soc. Amer., Ann. 29: 226. - Raizenne, 1952. Canada 
Div. Forest Biol., Forest Lep. South. Ont. and Par., p. 258. - Hill and Hough, 1957. Va.

Agr. Expt. Sta., Tech. Bul. 130: 16. -Dixon and Benjamin, 1963. Jour. Econ. Ent. 56: 267.

percussor Girault. Colo., N. Mex., Ariz., Nev., Wash., Oreg., Calif. Host: Apanteles sp., A. polychrosidis Vier., A. smerinthi Riley, Bracon politiventris (Cush.), Diadegma eureka (Ashm.), D. pterophorae (Ashm.), Heterospilus atriceps (Ashm.), Hyposoter sp., Itoplectis quadricingulatus (Prov.).

Hypopteromalus percussor Girault, 1917. Brooklyn Ent. Soc., Bul. 12: 118. + . Emend. to persursor by Essig, 1926 (Ins. West. No. Amer., p. 823).

Biology: Waddell, 1952. Ent. Soc. Brit. Columbia, Proc. 48: 87-88.

tabacum (Fitch). N. B., Que., s. to Fla., w. to Minn., Iowa, Kans., Tex. Host: Apanteles sp., A. congregatus (Say), A. melanoscelus (Ratz.), Microplitis ceratomiae Riley. Often misdet. as viridescens Walsh, in old literature.

Pteromalus Tabacum Fitch, 1864. N. Y. State Agr. Soc., Trans. 23: 792. \&.

Taxonomy: Gahan, 1921 (1920). Ent. Soc. Wash., Proc. 22: 241.

Biology: Webster, 1912. Iowa Acad. Sci., Proc. 19: 209-213 (viridescens). - Muesebeck and Dohanian, 1927. U. S. Dept. Agr., Bul. 1487: 12, 28. - Fulton, 1940. Ent. Soc. Amer., Ann. 32: 231-244. - Raizenne, 1952. Canada Div. Forest Biol., Forest Lep. South. Ont. and Par., p. 10. - Lawson, 1959. Ent. Soc. Amer., Ann. 52: 743.

\section{Genus HETEROSCHEMA Gahan}

Heteroschema Gahan, 1919. U. S. Natl. Mus., Proc. 55: 126.

Type-species: Heteroschema prima Gahan. Monotypic.

Taxonomy: Gahan, 1938. Ent. Soc. Wash., Proc. 40: 222-224.

aeneiventris (Ashmead). Kans.

Sphegigaster aeneiventris Ashmead, 1888. Kans. Agr. Expt. Sta., Bul. 3: App. p. VI. o. punctata (Ashmead). Fla., Miss., Mo., Ariz.; West Indies. Host: Dioxyna piccicola (Bigot), Melanagromyza virens (Loew).

Glyphe punctata Ashmead, 1894. Linn. Soc. London, Jour., Zool. 25: 162. \&.

rugosopunctata (Ashmead). Tex., Ariz.; West Indies. Host: Melanagramyza gibsoni (Mall.).

Pteromalus migosopunctatus Ashmead, 1894. Linn. Soc. London, Jour., Zool. 25: 165. ₹, o. Heteroschema prima Gahan, 1919. U. S. Natl. Mus., Proc. 55: 126. , ठ.

Biology: Gahan, 1938. Ent. Soc. Wash., Proc. 40: 223.

\section{Genus SCHIZONOTUS Ratzeburg}

Pteromalus subg. Schizonotus Ratzeburg, 1852. Ichn. d. Forstins., v. 3, p. 230.

Type-species: Schizonotus sieboldi Ratzeburg. Desig. by Ashmead, 1904.

Revision: Boucek, 1958. Mus. Natl. Pragae, Acta Ent. 32: 395-404 (European spp.).

Taxonomy: Masi, 1921. Genova, Mus. Civ. Stor. Nat., Ann. (3) 9: 236. -Graham, 1956. Ent.

Monthly Mag. 92: 255. - Graham, 1969. Brit. Mus. (Nat. Hist.) Ent., Bul. Sup. 16: 818.

latus (Walker). Maine, s. to Fla., w. to Minn., Wyo., Idaho; Europe. Host: Chrysomela alnicola Brown, C. intermupta (F.), C. knabi Brown, C. scripta (F.), Plagiodera versicolora (Laich.). Much of the literature published in North America used the name sieboldi Ratzeburg, a Palearctic species that apparently does not occur here.

Pteromalus latus Walker, 1835. Ent. Mag. 2: 481. ․

Arthrolytus incongruens Masi, 1907. Lab. Zool. Gen. e Agr. Portici, Bol. 1: 252. ๆ, o. Coelopisthia smithii Gahan, 1913. Canad. Ent. 45:179.

Biology: Cushman, 1918 (1917). Ent. Soc. Wash., Proc. 19: 128. -Dowden, 1939. Jour. Agr.

Res. 58: 581-592. -Craighead, 1950. U. S. Dept. Agr., Misc. Pub. 657: 616.

rotundiventris (Girault). N. J., Md., Va. Host: Plagiodera versicolora (Laich.).

Coelopisthia rotundiventris Girault, 1917(1916). Insecutor Inscitae Menstruus 4: 113. 


\section{Genus COELOPISTHIA Foerster}

Coelopisthia Foerster, 1856. Hym. Stud., v. 2, p. 65. No species.

Type-species: Pteromalus cephalotes Walker. Desig. by Ashmead, 1904.

Pteromalus subg. Coelopisthus Thomson, 1878. Hym. Scand., v. 5, p. 162. Emend.

Kranophorus Graham, 1956. Ent. Monthly Mag. 92: 257. N. name, unnecessarily proposed.

Type-species: Pteromalus extentus Walker. Orig. desig.

Taxonomy: Graham, 1956. Ent. Monthly Mag. 92: 257 (Ashmead's designation of cephalotes as type-species of Coelopisthia based on a misidentification of that species by Thomson). -Peck, 1963. Canad. Ent., Sup. 30: 665 (use of Coelopisthia in conventional sense should

be retained and the matter referred to the Internatl. Comn.).

bicarinata Girault. N. H., Md., D. C., Ind. Ecology: Emerges from nest of Vesprila sp.

Coelopisthia bicarinata Girault, 1916. Soc. Ent. 31: 57. \&, ơ.

forbesii (Dalla Torre). N. Y., N. J., Ill., La. Host: A pantesis nais (Drury), Catocala sp.

Pteromalns pallipes Forbes, 1885. Ill. State Dept. Agr., Trans. 22: App., pp. 46, 49. Preocc. by Spinola, 1808 .

Pteromalus Forbesii Dalla Torre, 1898. Cat. Hym., v. 5, p. 125. N. name.

Taxonomy: Gahan, 1934 (1933). U. S. Dept. Agr., Misc. Pub. 174: 145-146.

fumosipennis Gahan. Md. Ecology: Emerges from lepidopterous pupa.

Coelopisthia fumosipemnis Gahan, 1909. Canad. Ent. 41: 431. . .

intermedia Girault. D C.

Coelopisthia intermedia Girault, 1916. Soc. Ent. 31: 57..+

suborbicularis (Provancher). Que., N. H., Md., Ill.

Semiotellus suborbicularis Provancher, 1881. Nat. Canad. 12: 296. ․

Taxonomy: Burks, 1964 (1963). Canad. Ent. 95: 1262.

Biology: Fiske, 1903. N. H. Agr. Expt. Sta., Tech. Bul. 6: 182, 197, 228. -McAtee, 1927. Ent. Soc. Wash., Proc. 29: 182. - Langston, 1957. Calif. Univ. Pubs., Ent. 14: 37, 40.

\section{Genus MUSCIDIFURAX Girault and Sanders}

Muscidifurax Girault and Sanders, 1910. Psyche 17: 146.

Type-species: Muscidifurax raptor Girault and Sanders. Orig. desig.

Muscidivorax Kurdjumov, 1913. Ent. Obozr. 13: 5. Misspelling.

Revision: Kogan ad Legner, 1970. Canad. Ent. 102: 1268-1290.

raptor Girault and Sanders. Md., s. to Fla., w. to Calif.; cosmopolitan. Host: Cochliomyia macellaria (F.), Fannia canicularis (L.), Musca domestica L., Phormia regina (Meig.), Stomoxys calcitrans (L.).

Muscidifurax raptor Girault and Sanders, 1910. Psyche 17: 145. ๆ, o.

Biology: Crandall, 1939. Ent. Soc. Amer., Ann. 32: 652. - DeBach and Smith, 1941. Jour.

Econ. Ent. 34: 741-745. - DeBach, 1943. Pan-Pacific Ent. 19: 112-118. - Legner et al.,

1965. Puerto Rico Univ., Jour. Agr. 49: 372. - Wylie, 1967. Canad. Ent. 99: 742-748.

- Legner, 1969. Ent. Soc. Amer., Ann. 62: 382-385. - Sharma, 1971. Madras Agr. Jour. 58:

442. - Wylie, 1971. Canad. Ent. 103: 1537-1544. - Chabora and Chabora, 1971. Ent. Soc.

Amer., Ann. 64: 558-562. - Legner, 1972. Ent. Soc. Amer., Ann. 65: 254-263.

Morphology: Sanger and King, 1971. Entomologist 104: 137-149 (male genitalia).

zaraptor Kogan and Legner. Kans., N. Mex., Utah, Ariz., Calif. Host: Musca domestica Linn. Muscidifurax zaraptor Kogan and Legner, 1970. Canad. Ent. 102: 1279-1285. ․, ơ.

Biology: Wylie, 1971. Canad. Ent. 103: 1537-1544 (oviposition).

\section{Genus LARIOPHAGUS Crawford}

Lariophagus Crawford, 1909. Ent. Soc. Wash., Proc. 11: 52.

Type-species: Lariophagus texamus Crawford. Monotypic.

Revision: Gahan, 1927. U. S. Natl. Mus., Proc. 71 (4): 7. 
Taxonomy: Kurdjumov, 1913. Ent. Obozr. 13: 15-16. - Graham, 1957. Ent. Monthly Mag. 93:

217. -Graham, 1969. Brit. Mus. (Nat. Hist.) Ent., Bul. Sup. 16: 823.

distinguendus (Foerster). Ont., s. to Fla., w. to B. C. and Calif.; Cosmopolitan. Ecology: Almost always taken as a parasite of Coleoptera infesting stored products, but occasionally collected in open country, usually in the Tropics. Host: Bruchus brachialis Fahr., Lasioderma serricome (F.), Rhyzopertha dominica (F.), Stegobium paniceum (L.), Sitophilus granarius (L.), S. oryzae (L.), S. zeamaize Mots.

Pteromalus distinguendus Foerster, 1840. Beitr. Monog. Pteromalinen, p. 17. $\delta$. Pteromalus Calamis Walker 1849. Ann. and Mag. Nat. Hist. (2) 3: 207. ๆ, ठ.

Pteromalus oryzinus Rondani, 1874. Soc. Ent. Ital., Bol. 6: 131.

Meraporus utibilis Tucker, 1910. Canad. Ent. 42: 341. \&.

Taxonomy: Gahan, 1921 (1920). Ent. Soc. Wash., Proc. 22: 239 (syn.). - Waterston, 1921. Roy. Soc., Rept. Grain Pests Com. 9: 9, 13-15 (syn.). -Ruschka, 1921. Ztschr. f. Angew. Ent. 7: 463-465 (syn.). - Graham, 1969. Brit. Mus. (Nat. Hist.) Ent., Bul. Sup. 16: 824 (syn.).

Biology: Hase, 1920 (1919). Gesell. f. Naturf. Freunde, Sitzber., pp. 402-432. - Nakayama, 1931. Agr. Expt. Sta., Chosen, Jour. 18: 65.-Smirov and Polejaev, 1937. Zool. Zhur 16: 999-1012. -Pechuman, 1937. Jour. Econ. Ent. 30: 563. -Bare, 1942. Jour. Econ. Ent. 35: 185. - McNay, 1954. Ent. Soc. Ont., Ann. Rpt. 84: 149. - Kashef, 1956 (1955). Soc. Ent. de France, Ann. 124: 58-88. - Kashef, 1959. Soc. Ent. Egypte, Bul. 43: 171. - Kashef, 1961. Ztschr. f. Parasitenk. 21 65-70. - Kashef, 1964. Behaviour 23: 31-42. - Gonen and Kugler, 1970. Israel Jour. Ent. 5: 133-140. - Van den Assem, 1971. Arch. Neerland Zool. 21 372-402.

Morphology: Kashef, 1954. Soc. Ent. de France, Bul. 59: 93-96 (immature stages). dryorhizoxeni (Ashmead). Pa., Fla. Ecology: Emerges from root gall on live oak formed by Belonocnema (=Dryorhizoxenus) treatae Mayr.

Macroglenes dryorhizoxeni Ashmead, 1886. Amer. Ent. Soc., Trans. 13: 133. \&.

Taxonomy: Gahan, 1951. Canad. Ent. 83: 175.

texanus Crawford. S. C., Ga., Miss., Tex., Ariz., Calif.; Hawaii. Host: Algarobius prosopis (Lec.), Anthonomus grandis Boh., Callosobruchus maculatus (F.), Mimosestes sallaei (Sharp).

Lariophagus texanus Crawford, 1909. Ent. Soc. Wash. Proc. 11: 51. \&, ð.

Biology: Pierce et al., 1912. U. S. Dept. Agr., Bur. Ent. Bul. 100: 42, 52-62. -Bissell, 1940. Jour. Econ. Ent. 33: 845. - Hinckley, 1960. Hawaii. Ent. Soc., Proc. 17: 267. - Hinckley, 1961. Ecology 42: 529 .

\section{Genus SYSTELLOGASTER Gahan}

Systellogaster Gahan, 1917. U. S. Natl. Mus., Proc. 53: 209.

Type-species: Systellogaster ovivora Gahan. Orig. desig.

ovivora Gahan. Que., Pa., Ohio, Md., Ill., Okla. Host: Blatta orientalis L., Parcoblatta penusylvanica (DeG.).

Systellogaster ovivora Gahan, 1917. U. S. Natl. Mus., Proc. 53: 209. ९, ช.

Biology: Edmunds, 1953. Ent. News 64: 228-230. _Judd, 1955. Canad. Ent. 87: 98-99. -Roth and Willis, 1960. Smithsn. Misc. Coll. 141: 248.

\section{Genus TRIMEROMICRUS Gahan}

Trimeromicrus Gahan, 1914. U. S. Natl. Mus., Proc. 48: 161.

Type-species: Trimeromicrus maculatus Gahan. Orig. desig.

maculatus Gahan. Ill., Mo., S. Dak., Nebr., Kans., Okla., Tex., N. Mex., Idaho, Utah, Ariz., Wash., Oreg., Calif.; Mexico. Host: Centorhynchus assimilis (Payk.), Smicronyx fulvus (Lec.); Asphondylia websteri Felt; Bruchophagus sp.

Trimeromicrus maculatus Gahan, 1914. U. S. Natl. Mus., Proc. 48: 162. ९, ठ.

Biology: Gahan, 1919. Ent. Soc. Amer., Ann. 12: 165-166. -Urbahns, 1919. Jour. Agr. Res. 16: 172-173. -Urbahns, 1920. U. S. Dept. Agr., Bul. 812: 18. -McLeod, 1953. Ent. Soc. Brit. 
Columbia, Proc. 49: 14-16. - Walz, 1957. Ent. Soc. Amer., Ann. 50: 220. -Neunzig and Gyrisco, 1959. Jour. Econ. Ent. 52: 899-901. - Carillo and Dickason, 1963. Oreg. State Agr. Expt. Sta., Tech. Bul. 68: 25, 31.

\section{Genus ZATROPIS Crawford}

Zatropis Crawford, 1908. Ent. Soc. Wash., Proc. 9: 159.

Type-species: Zatropis catalpae Crawford. Monotypic.

Revision: Crawford, 1921. Ent. Soc. Wash., Proc. 23: 171-172.

Taxonomy: Burks, 1955. Ent. Soc. Wash., Proc. 57: 37.

albiclavus (Girault). N.Y., Md., Ohio, Mich., Wis., Idaho, Utah, Ariz. Host: Asphondylia sp., Dasineura gleditchiae (0. S.).

Eurydinoteloides albiclavus Girault, 1917. Chalcidoidea Nova Marilandensis III, p. 5..

Taxonomy: Burks, 1955. Ent. Soc. Wash., Proc. 57: 37.

capitis Burks. Utah, Nev., Oreg., Calif.

Zatropis capitis Burks, 1955. Ent. Soc. Wash., Proc. 57: 35. \&, o.

catalpae Crawford. N. Y., w. to Ill. and Minn. Host: Contarinia johnsoni Felt., Dasineura gleditchiae (0. S.), Hyperdiplosis phlox Greene. Rearing records for this species published before 1950 cite Diplosis catalpae Comstock as host, but that is a cecidomyiid that is now considered to be unplaced.

Zatropis catalpae Crawford, 1908 (1907). Ent. Soc. Wash., Proc. 9: 159. ๆ, ১.

Biology: Gossard, 1908. Ohio Agr. Expt. Sta., Bul. 197: 12.-Quaintance and Shear, 1921. U.

S. Dept. Agr., Farmers' Bul. 1220: 11. - Neiswander, 1962. Ohio Agr. Expt. Sta., Res. Bul. 915: 16.

chalcis Burks. S. C., Fla. Host: Anthonomus grandis Boh., A. thurberiae Pierce.

Zatropis chalcis Burks, 1955. Ent. Soc. Wash., Proc. 57: 34. + , ठ.

coeliodis (Ashmead). Conn., N. J., Va., Ga. Host: Acanthoscelis acephalus (Say), Chalcodermus inaequicollis Horn.

Catolaccus coeliodis Ashmead, 1896. Amer. Ent. Soc., Trans. 23: 226. + , ¿. dymnus (Walker). Fla.

Pteromalus Dymnus Walker, 1847. Ann. and Mag. Nat. Hist. (1) 19: 397..

Taxonomy: Burks, 1975. Brit. Mus. (Nat. Hist.) Ent., Bul. 32: 157. hermeas (Walker). Fla.

Pteromalus Hermeas Walker, 1847. Ann. and Mag. Nat. Hist. (1) 19: 394. \&.

Taxonomy: Burks, 1975. Brit. Mus. (Nat. Hist.) Ent., Bul. 32: 159.

incertus (Ashmead). N. Y., s. to Fla., w. to Colo., N. Mex., Ariz.; Mexico, Cent. Amer., W. I.

Host: Acanthoscelides horni (Pic), A. submuticus (Sharp), Anthonomus aeneolus Dietz, $A$. albopilosus Dietz, $A$. aphanostephi Pierce, $A$. disjunctus Lec., $A$. engenii Cano, $A$. fulvus Lec., A. grandis Boh., A. nigrinus Boh., A. signatus Say, Apion sp., A. crassum Fall, $A$. decoloratum Smith, A. griseum Smith, A. nigrum Smith, Auleutes tenuipes

Lec., Baris cuneipennis Casey, Bruchus brachialis Fahr., Ceutorhynchus sp.,

Chalcodermus aeneus Boh., C. inaequicollis Horn., Rhynchaenus pallicornis (Say), Sitophilus oryzae (L.), Smicraulax tuberculatus Pierce, Smicronyx fulvus (Lec.),

Tachypterellus concors cerasi List, T. quadrigibbus (Say), Zygobaris xanthoxyli Pierce.

Catolaccus incertus Ashmead, 1893. In Chittenden, U. S. Dept. Agr., Insect Life 5: 186. , o.

Biology: Pierce, 1908. U. S. Dept. Agr., Bur. Ent. Bul. 73: 25-48. -Pierce et al., 1912. U. S. Dept. Agr., Bur. Ent. Bul. 100: 51-67, 91-92. - Pierce and Cushman, 1915. Ent. Soc. Wash., Proc. 17: 165-166. - Tucker, 1922. Kans. Acad. Sci., Trans. 30: 144. - Fenton and Dunham, 1929. U. S. Dept. Agr., Tech. Bul. 112: 66. -List, 1932. Colo. Agr. Expt. Sta., Bul. 385: 63-64. - Balduf, 1959. Ill. Biol. Monog. 26: 146.

Morphology: Snodgrass, 1910. U. S. Natl. Mus., Proc. 39: 65. 
nigroaeneus (Ashmead). Conn., Va., Fla., Mo., Nebr. Ecology: Emerges from galls made by Lepidoptera, Diptera or Coleoptera.

Catolaccus nigroaeneus Ashmead, 1894. Amer. Ent. Soc., Trans. 21: 338. ₹, ơ.

Biology: Brandhorst, 1943. Kans. Acad. Sci., Trans. 46: 169.

orontas (Walker). Fla., Ill., Iowa, Kans. Host: Acanthoscelides horni (Pic), A. submuticus (Sharp).

Pteromalus Orontas Walker, 1847. Ann. and Mag. Nat. Hist. (1) 19: 396. \&.

Meraporus bruchivorus Ashmead, 1893. Ohio Agr. Expt. Sta., Tech. Ser., Bul. 1: 161. ๆ, ð.

Taxonomy: Burks, 1975. Brit. Mus. (Nat. Hist.) Ent., Bul. 32: 160 (syn.; lectotypes designated for orontas and bruchivoris).

perdubius (Girault). Mass., N. Y., N. J., D. C., Ohio, Ill., Minn. Host: Anthonomus grandis Boh., A. musculus (Say), A. uubiloides Fall, A. signatus (Say), Smicronyx tychoides Lec.

Catolaccus perdubius Girault, 1916. Canad. Ent. 48: 114. $\%$, $\delta$.

Biology: Cross and McGovern, 1969. Ent. Soc. Amer., Ann. 62: 674.

rosaecolis Burks. Wis., Ill., Minn., Mo., Nebr. Host: Rhynchites bicolor (F.).

Zatropis rosaecolis Burks, 1955. Ent. Soc. Wash., Proc. 57: 32. \&, o.

Biology: Balduf, 1959. Ill. Biol. Monog. 26: 120-121.

timaea (Walker). Fla.

Pteromalus Timaea Walker, 1847. Ann. and Mag. Nat. Hist. (1) 19: 396..

Taxonomy: Burks, 1975. Brit. Mus. (Nat. Hist.) Ent., Bul. 32: 161.

tortricidis Crawford. Pa., Fla., Wis., Calif.; Hawaii. Host: Etiella zinckenella (Treit.), Polychrosis viteana (Clem.).

Zatropis tortricidis Crawford, 1921. Ent. Soc. Wash., Proc. 23: 172. ₹, ठ.

Biology: Flanders, 1930. Calif. Dept. Agr., Monthly Bul. 19: 418, - Bianchi, 1940. Hawaii. Ent. Soc., Proc. 10: 380.

\section{Genus HEMITRICHUS Thomson}

Dimachus subg. Hemitrichus Thomson, 1878. Hym. Scand., v. 5, pp. 50, 54.

Type-species: Dimachus (Hemitrichus) rufipes Thomson. Monotypic.

Uriella Ashmead, 1896. Amer. Ent. Soc., Trans. 23: 221.

Type-species: Uriella rufipes Ashmead. Orig. desig.

Taxonomy: Gahan and Wallace, 1950. Ent. News 61: 97 (syn.).

seniculus (Nees). Que., s. to Fla., w. to Mich. and Kans.; Europe. Ecology: Reared from unknown beetle feeding in dog food or rat dung; often found in museums and other public buildings.

Pteromalus seniculus Nees, 1834. Hym. Ichn. Aff. Monog., v. 2, pp. 101, 423. ․

Pteromalus Phylacis Walker, 1848. List Hym. Brit. Mus., Chalcid., v. 2, pp. 124, 185. o.

Dimachus (Hemitrichus) rufipes Thomson, 1878. Hym. Scand., v. 5, p. 54. 9.

Uriella mifipes Ashmead, 1896. Amer. Ent. Soc., Trans. 23: 222. \&, ठ.

Hemitrichus assimilis Masi, 1922. Soc. Ent. Ital., Bol. 54: 158..

Taxonomy: Delucchi, 1955. Univ. Lund, Acta (2) 50: 173 (syn.). -Graham, 1969. Brit. Mus.

(Nat. Hist.) Ent., Bul. Sup. 16: 827 (syn.).

Biology: Kuitert, 1949. Fla. Ent. 32: 178 (rufipes).

\section{Genus METASTENUS Walker}

Metastenus Walker, 1834. Ent. Mag. 2: 301.

Type-species: Metastenus concinnus Walker. Monotypic.

Scymnophagus Ashmead, 1904. Carnegie Mus., Mem. 1: 319, 321.

Type-species: Scymnophagns townsendi Ashmead. Orig. desig.

Taxonomy: Graham, 1956. Ent. Monthly Mag. 92: 256 (syn.).

coeruleus Ashmead. Kans. Generic placement of this sp. may be wrong, but the type is lost.

Metastenus coeruleus Ashmead, 1888. Kans. Agr. Expt. Sta., Bul. 3: App. p. VI.. 
townsendi (Ashmead). Va., N.C., S.C., Ga., Ind., Ill., Wis., Mont., Wash., Oreg., Calif.; Mexico, West Indies, Japan. Host: Azya trinitatis Marsh., Cryptognatha nodiceps Marsh., C. simillima Sicard, Hyperaspis lateralis Muls., Pentilia insidiosa Muls., Scymnus sp., S. guttulatus Lec.

Scymnophagus townsendi Ashmead, 1904. Carnegie Mus., Mem. 1: 319. ๆ, ठ.

Xenocrepis mexicana Girault, 1916. Ent. News 27: 227. ๆ, ठ.

Tripolycystus cryptognathae Girault, 1920. U. S. Natl. Mus., Proc. 58: 211. ค, o.

Taxonomy: Gahan and Peck, 1946. Wash. Acad. Sci., Jour. 36: 316 (types of townsendi and mexicana the same specimens). - Burks, 1954. U. S. Dept. Agr., Tech. Bul. 1093: 13 (syn.). -Delucchi, 1954. Bul. Ent. Res. 45: 265. -Graham, 1956. Ent. Monthly Mag. $92: 256$ (generic placement).

\section{Family EURYTOMIDAE}

By B. D. Burks

Although phytophagous chalcidoids are to be found scattered among several families, there is a higher proportion of phytophagous species in the Eurytomidae than in any other chalcidoid family. Many of the eurytomids develop in seeds, and others are gall formers. Many others, however, are parasites and some are both parasitic and phytophagous in their development. These latter begin development as parasites and then complete it as phytophagous feeders. Malyshev, 1968 (Genesis of the Hymenoptera, English translation, London, pp. 35, 53, 67), considers the Eurytomidae the most primitive family of the Chalcidoidea, and he discusses types of larval development in this family. There are very few other workers in Hymenoptera that agree with Malyshev that the Eurytomidae is the most primitive family of the Chalcidoidea; the prevailing opinion, based on both habits and morphology, is that the Torymidae is the most primitive.

Revision: Burks, 1971. Amer. Ent. Soc., Trans. 97: 1-89 (World genera).

Taxonomy: Bugbee, 1936. Ent. Amer. (n. s.) 16: 169-222 (phylogeny). -Ferriere, 1950.

Schweiz. Ent. Gesell., Mitt. 23: 378-379 (European fauna). -Claridge, 1961. Soc. Brit. Ent.,

Trans. 14: 170-183 (British fauna). -Graham, 1970. Roy. Ent. Soc. London, Proc., Ser. B:

Taxonomy 39: 139-152 (Palearctic fauna).

\section{SUBFAMILy RILEYINAE}

\section{Genus MACRORILEYA Ashmead}

Macrorileya Ashmead, 1900. In Smith, NJ. State Bd. Agr., Ann. Rpt. 27 (Sup.): 555.

Type-species: Rileya oecanthi Ashmead. Monotypic.

oecanthi (Ashmead). N. J., Va., N. C., Ill., Nebr., Idaho, Ariz., Calif. Ecology: Parasitizes eggs of tree crickets. Host: Oecanthus sp., O. californicus Sauss., O. latipennis Riley, O. nigricornis Walk., O. quadripunctatus Beut., O. niveus (Deg.).

Rileya oecanthi Ashmead, 1894. Amer. Ent. Soc., Trans. 21: 321. \&, ठ.

Biology: Smith, 1916. Jour. Econ. Ent. 9: 479. - Smith, 1930. Univ. Calif. Pubs., Ent. 5: 165-172. - Smith, 1931 (1930). Calif. Agr. Expt. Sta., Bul. 505: 11-12. - Udine and

Pinckney, 1940. Pa. State Acad. Sci., Proc. 14: 81-84.

\section{Genus RILEYA Ashmead}

Rileya Ashmead, 1888 (June). Ent. Amer. 4: 42. No species.

Type-species: Rileya cecidomyiae Ashmead. Included by Ashmead, 1888 (July).

Kans. Agr. Expt. Sta., Bul. 3, App. p. III.

Ashmeadia Howard, 1889. Canad. Ent. 21: 59. N. name for Rileya Ashmead, thought to be preoccupied by Rileya Ashmead, 1888 (July).

Xenopelte Cameron, 1913. Timehri 3: 126.

Type-species: Xenopelte couridae Cameron. Monotypic.

Tragiicola Brethes, 1918. Soc. Ent. de France, Bul. (1918): 83.

Type-species: Tragiicola haumani Brethes. Monotypic. 
Revision: Gahan, 1918. Ent. Soc. Wash., Proc. 20: 136-150.

americana Girault. Mo. Ecology: Reared from midge galls in flower heads of Helenium. Host: Asphondylia autumnalis Beut.

Rileya americana Girault, 1916. Canad. Ent. 48: 339. ㅇ.

cecidomyiae Ashmead. Conn., N. J., Md., N. C., Fla., Ill., Kans., Tex., N. Mex., Idaho, Ariz. Ecology: Reared from stem galls. Host: Asphondylia sp., A. ilicicola Foote, Dasyneura sp.

Rileya cecidomyiae Ashmead, 1888. Kans. Agr. Expt. Sta., Bul. 3: App. p. III. ९, ơ.

Rileya tegularis Gahan, 1918. Ent. Soc. Wash., Proc. 20: 147.

Taxonomy: Burks, 1967. U. S. Dept. Agr., Agr. Monog. 2, Sup. 2: 271 (synonymy).

Biology: Highland, 1964. Jour. Econ. Ent. 57: 83.

compressiventris Gahan. Tex. Ecology: Reared from leaf galls on leguminous trees, prob.

Mimosa or Lencaena. Host: Asphondylia sp.

Rileya compressiventris Gahan, 1918. Ent. Soc. Wash., Proc. 20: 143. ๆ, ð.

hegeli Girault. Fla.

Rileya hegeli Girault, 1916. Canad. Ent. 48: 340. ․

heterogaster Gahan. Tex. Ecology: Reared from leaf-axil galls on leguminous trees, prob. Mimosa or Leucaena. Host: Asphondylia sp.

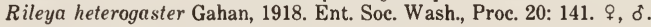

Morphology: Bugbee, 1936. Ent. Amer. (n. s.) 16: 179.

mellea Ashmead. Fla. Ecology: Reared from leaf galls on Eugenia.

Rileya mellea Ashmead, 1894. Amer. Ent. Soc., Trans. 21: 321. ․

opuntiae Gahan. Tex. Ecology: Reared from galls on cactus. Host: Asphondylia opuntiae Felt.

Rileya opuntiae Gahan, 1936. U. S. Natl. Mus., Proc. 83: 482..

piercei Grawford. Fla., Ariz.

Rileya piercei Crawford, 1914. Ent. Soc. Wash., Proc. 16: 29. ठ.

similaris Gahan. Tex. Ecology: Reared from galls on leguminous trees, prob. Mimosa or Leucaena. Host: Asphondylia sp.

Rileya similaris Gahan, 1918. Ent. Soc. Wash., Proc. 20: 148. ๆ, o.

\section{SUBFAMILY HARMOLITINAE}

\section{Genus HARMOLITA Motschulsky}

Isosoma Walker, 1832. Ent. Mag. 1: 13-14. Preoce. by Billberg, 1820.

Type-species: Eurytoma longula Dalman. Desig. by Westwood, 1840.

Harmolita Motschulsky, 1863. Soc. Imp. Nat. Moscou, Bul. 36: 58.

Type-species: Harmolita longicornis Motschulsky. Monotypic.

Philachyra Walker, 1871. Notes on Chalcid., p. 7.

Type-species: Philachyra ips Walker. Monotypic.

Xanthosoma Ashmead, 1888. Ent. Amer. 4: 42-43. No species. -Ashmead, 1894. Amer.

Ent. Soc., Trans. 21: 320 . One species.

Type-species: Xanthosoma nigricornis Ashmead. Desig. by Ashmead, 1894.

Isosomocharis Ashmead, 1888. Ent. Amer. 4: 42-43. No species. -Ashmead, 1894. Amer.

Ent. Soc., Trans. 21: 331. One species.

Type-species: Isosomocharis sulcata Ashmead. Desig. by Ashmead, 1894.

Harmolyta Dalla Torre, 1898. Cat. Hym., v. 5, p. 154. Emend.

Urios Girault, 1911. N. Y. Ent. Soc., Jour. 19: 175.

Type-species: Urios vestali Girault. Orig. desig.

Exanthosoma Girault, 1915. Queensland Mus., Mem. 4: 265.

Type-species: Exanthosoma funeralis Girault. Monotypic.

Isthmosoma Hedicke, 1921. Arch. f. Naturgesch. 86, A, 11: 165. N. name for Isosoma

Walker.

Ahtola Claridge, 1961. Soc. Brit. Ent., Trans. 14: 174.

Type-species: Isosoma atrum Walker. Orig. desig. 
The members of this genus are commonly called jointworms. The larvae make galls in the stems of cereal grains and grasses.

Revision: Phillips and Emery, 1919. U. S. Natl. Mus., Proc. 55: 433-471 (Nearctic spp.).

- Hedicke, 1921. Arch. f. Naturgesch. 86, A, 11: 1-167 (Palearctic spp.). - Phillips, 1936. U.

S. Dept. Agr., Tech. Bul. 518: 1-25 (Nearctic spp.).

Taxonomy: Gahan, 1922. U. S. Natl. Mus., Proc. 61 (24): 7-8 (generic characters). -Gahan, 1922. Ent. Soc. Wash., Proc. 24: 33-58 (world host data). - Gahan, 1957. Brooklyn Ent. Soc., Bul. 52: 82-83 (Harmolita type-species). - Claridge, 1958. Ent. Monthly Mag. 94: 81-85

(Tetramesa). - Claridge, 1961. Roy. Ent. Soc. London, Trans. 113: 175-216 (Holaretic spp.).

-Burks, 1971. Amer. Ent. Soc., Trans. 97: 51-54, 82-86.

agropyrocola Phillips and Emery. N. Dak., Utah. Host: Agropyron spp.

Harmolita agropyrocola Phillips and Emery, 1919. U. S. Natl. Mus., Proc. 55: 458..

agrostidis (Howard). Calif. Host: Agrostis sp.

Isosoma agrostidis Howard, 1896. U. S. Dept. Agr., Div. Ent., Tech. Ser. 2: 12..

ainsliei Phillips. S. Dak. Host: Elymus sp.

Harmolita ainsliei Phillips, 1936. U. S. Dept. Agr., Tech. Bul. 518: 4, 10. ๆ, ठ․

albomaculata (Ashmead). N. H., Vt., s. to Va., w. to N. Dak., Nebr., Kans.; Europe, Asia. Host: Phleum pratense.

Isosoma albomaculatum Ashmead, 1894. Amer. Ent. Soc. Trans. 21: 329. ๆ, ơ.

Taxonomy: Claridge, 1961. Roy. Ent. Soc. London, Trans. 113: 211.

Biology: Phillips, 1920. U. S. Dept. Agr., Bul. 808: 15-16. - Phillips and Poos, 1921. Jour. Agr. Res. 21: 421. - Phillips and Poos, 1927. Jour. Agr. Res. 34: 475, 483.

bambusae Phillips. Ga., Ala.; S. Russia, China, Japan. Host: Bamboo. Grasses of the tribe Bambuseae.

Harmolita bambusae Phillips, 1936. U. S. Dept. Agr., Tech. Bul. 518: 20. $\uparrow$.

Biology: Agekian, 1966. Zool. Zhur. 45: 1724.

bromicola (Howard). Conn., Calif. Host: Bromus ciliatus.

Isosoma bromicola Howard, 1896. U. S. Dept. Agr., Div. Ent., Tech. Ser. 2: 17. ९, ơ.

californica (Howard). Calif. Ecology: Develops in the stems of wild grasses.

Isosoma californicum Howard, 1896. U. S. Dept. Agr., Div. Ent., Tech. Ser. 2: 10. ^, ठ.

captiva (Lintner). N. Y., Ind., Ill. Said to have been reared from wheat.

Isosoma captivum Lintner, 1888. N. Y. State Mus., Nat. Hist., Rpt. 41: 34. ₹, ठ.

Taxonomy: Phillips, 1920. U. S. Dept. Agr., Bul. 808: 16. cinnae Phillips and Poos. Ohio. Host: Cinna amindinacea.

Harmolita cinnae Phillips and Poos, 1922. Kans. Univ., Sci. Bul. 14: 352. ๆ, ơ.

comatae Phillips. N. Dak. Host: Stipa comata.

Harmolita comatae Phillips, 1936. U. S. Dept. Agr., Tech. Bul. 518: 9..

cornuta (Walker). N. Y., Pa., Va., Ohio, Mich., Ind., Kans.; Europe. Host: Agropyron repens. Isosoma cornutum Walker, 1832. Ent. Mag. 1: 19. đ.

Harmolita agropyrophila Phillips and Emery, 1919. U. S. Natl. Mus., Proc. 55: 450. ช̊, ๆ.

Taxonomy: Claridge, 1961. Roy. Ent. Soc. London, Trans. 113: 212 (syn.).

Biology: Phillips, 1920. U. S. Dept. Agr., Bul. 808: 20 (agropyrophila).

dakota Phillips. N. Dak. Host: Elymus.

Harmolita dakota Phillips, 1936. U. S. Dept. Agr., Tech. Bul. 518: 14. ९, o.

danthoniae Phillips. Mich. Host: Danthonia spicata.

Harmolita danthoniae Phillips, 1936. U. S. Dept. Agr., Tech. Bul. 518: 18. ๆ.

elymi (French). Maine, s. to Fla., w. to Wash., Oreg., Calif. Host: Elymus canadensis, E. glaucus, E. virginicus.

Isosoma Elymi French, 1882. Canad. Ent. 14: 10..

Biology: Phillips, 1920. U. S. Dept. Agr., Bul. 808: 20. - Phillips and Poos, 1927. Jour. Agr. Res. 34: 475 . 
elymicola Phillips and Emery. N. Y., Va., Ohio, Mich., Ill., Mo. Host: Elymus spp. Harmolita elymicola Phillips and Emery, 1919. U. S. Natl. Mus., Proc. 55: 460. \&, o.

Biology: Phillips, 1920. U. S. Dept. Agr., Bul. 808: 21. - Phillips and Poos, 1921. Jour. Agr. Res. 21: 409, 416, 421.

elymivora Phillips and Emery. Va., Ohio, Ind., Ill., Ark., Kans. Host: Elymus spp. Harmolita elymivora Phillips and Emery, 1919. U. S. Natl. Mus., Proc. 55: 464. \&; ठ.

Biology: Phillips, 1920. U. S. Dept. Agr., Bul. 808: 21. - Phillips and Poos, 1921. Jour. Agr. Res. 21: 421.

elymophaga Phillips and Emery. Wash., Calif. Host: Elymus condensatus, E. triticoides. Harmolita elymophaga Phillips, 1927. Ent. Soc. Wash., Proc. 29: 127. \&, ठ.

elymophila Phillips and Emery. Calif. Host: Elymus spp.

Harmolita elymophila Phillips and Emery, 1919. U. S. Natl. Mus., Proc. 55: 462. ₹, o. elymophthora Phillips and Emery. N. Dak., Nebr. Host: Elymus spp.

Harmolita elymophthora Phillips and Emery, 1919. U. S. Natl. Mus., Proc. 55: 465. ๆ, ð.

Biology: Phillips, 1920. U. S. Dept. Agr., Bul. 808: 22-23.

elymoxena Phillips and Emery. Calif. Host: Elymus glaucus.

Harmolita elymoxena Phillips and Emery, 1919. U. S. Natl. Mus., Proc. 55: 459. \&, ठ.

festucae Phillips and Emery. N. Y., N. J., Pa., Va., Ohio. Host: Festuca sp., F. elatior. This may be a synonym of the European Harmolita girandi von Schlechtendal.

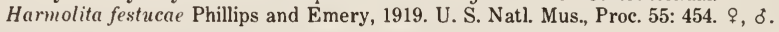

Taxonomy: Claridge, 1961. Roy. Ent. Soc. London, Trans. 113: 194.

Biology: Phillips, 1920. U. S. Dept. Agr., Bul. 808: 18-19. - Phillips and Poos, 1927. Jour. Agr. Res. $34: 475,483$.

flavicoxa Phillips. N. Mex. Host: Elymus sp.

Harmolita flavicoxa Phillips, 1936. U. S. Dept. Agr., Tech. Bul. 518: 13. ๆ, ठ゚.

gahani Phillips. S. Dak. Host: Elymus sp.

Harmolita gahani Phillips, 1936. U. S. Dept. Agr., Tech. Bul. 518: 18..

gillettei Phillips and Emery. Colo.

Harmolita gillettei Phillips and Emery, 1919. U. S. Natl. Mus., Proc. 55: 467..

grandis (Riley). Ont., N. Y., s. to N. C., w. to Wash., Oreg., Calif. Ecology: This species has two generations per year, an apterous early spring generation (form minuta) and a late spring or early summer winged generation (form grandis). Host: Triticum spp., cereal wheats. This may be a synonym of the European Harmolita aptera (Portschinsky). Wheat strawworm.

Isosoma tritici Riley, 1882. Amer. Nat. 16: 247. ․ Preoce. by Fitch, 1859.

Isosoma grandis Riley, 1884. Brooklyn Ent. Soc., Bul. 7: 111. . Winged gen.

Isosoma grande form minutum Howard, 1896. U. S. Dept. Agr., Div. Ent., Tech. Ser. 2: 10. Wingless gen.

Urios vestali Girault, 1911. N. Y. Ent. Soc., Jour. 19: 176. ․

Biology: Webster and Reeves, 1909. U. S. Dept. Agr., Bur. Ent. Cir. 106: 1-11. -Gossard, 1911. Ohio Agr. Expt. Sta., Bul. 233: 66. - Doane, 1916. Calif. State Comn. Hort., Monthly Bul. 5: 69-72. - Phillips, 1920. U. S. Dept. Agr., Bul. 808: 6-8. —Phillips and Poos, 1921. Jour. Agr. Res. 21: 409, 421. - Knowlton, 1931. Jour. Econ. Ent. 24: 414-416. - Knowlton, 1932. Jour. Econ. Ent. 25: 1169-1170. - Knowlton and Janes, 1933. Utah Agr. Expt. Sta., Bul. 243: 1-8. - Balachowsky and Mesnil, 1935. Ins. nuisables aux Plantes Cult., v. 1, p. 1087. - Smith, 1943. Kansas State Bd. Agr., Rpt. 62: 394. - Flanders, 1950. Jour. Econ. Ent. 43: 719. - Phillips and Poos, 1953. U. S. Dept. Agr., Farmers' Bul, 1323: 1-6. -Knowiton and Lieberman, 1954. Utah Agr. Col., Ext. Cir. 194, 2pp. - Painter et al., 1954. Kansas Agr. Expt. Sta., Bul. 367: 43.

hageni (Howard). Mass. Host: Agropyron repens.

Isosoma hageni Howard, 1896. U. S. Dept. Agr., Div. Ent., Tech. Ser. 2: 12..

hesperus Phillips and Emery. N. Dak., S. Dak., Nebr., Kans., Utah. Host: Elymus spp.

Harmolita hesperus Phillips and Emery, 1919. U. S. Natl. Mus., Proc. 55: 457. + , o. 
Biology: Phillips, 1920. U. S. Dept. Agr., Bul. 808: 22-23.

holei Phillips. Oreg. Host: Holcus sp.

Harmolite holci Phillips, 1936. U. S. Dept. Agr., Tech. Bul. 518: 19. १, ơ.

hordei (Harris). P. E. I., Que., Ont., s. to N. C., w. to Ill., Kans., Colo.; Europe, Asia. Host: Hordeum vulgare, barley. Barley jointworm.

Ichneumon hordei Harris, 1830. New England Farmer 9: 2. (Transf. to Eurytoma in footnote on same page).

Pteromalus? fulvipes Fitch, 1859. N. Y. State Agr. Soc., Jour. 10: 114.

Eurytoma flavipes Fitch, 1862 (1861). N. Y. State Agr. Soc., Trans. 21: 845. Preocc. by Walker, 1834.

Biology: Gossard, 1911. Ohio Agr. Expt. Sta., Bul. 233: 70. - Phillips, 1920. U. S. Dept. Agr., Bul. 808: 11-13. - Cannon, 1963. Canad. Ent. 95: 28. - Sterling and MacLaren, 1964. Canad. Jour. Plant Sci. 44: 53-56.

iphis (Walker). Fla.

Eurytoma Iphis Walker, 1846. List Hym. Brit. Mus., v. 1, p. 85..

Taxonomy: Burks, 1975. Brit. Mus. (Nat. Hist.) Ent., Bul. 32 (4): 163.

jonesi Phillips. Calif. Host: Elymus sp.

Harmolita jonesi Phillips, 1936. U. S. Dept. Agr., Tech. Bul. 518: 15. ๆ, ठ̊.

kingi Phillips. Sask. Host: Hordeum jubatum.

Harmolita kingi Phillips, 1927. Ent. Soc. Wash., Proc. 29: 128. ๆ, ठ๋.

koebelei Phillips. Calif.

Harmolita koebelei Phillips, 1936. U. S. Dept. Agr., Tech. Bul. 518: 11. \&.

linearis (Walker). N. Y., Pa., Ohio, Mich., Ind.; Europe, Asia. Host: Agropyron spp.

Isosoma lineare Walker, 1832. Ent. Mag. 1: 22. †.

Harmolita atlantica Phillips and Emery, 1919. U. S. Natl. Mus., Proc. 55: 461. \&, ठ๋.

Taxonomy: Claridge, 1961. Roy. Ent. Soc. London, Trans. 113: 192 (syn.). -Zerova, 1966. Zool. Zhur. 45: 1508.

Biology: Phillips, 1920. U. S. Dept. Agr., Bul. 808: 19-20. —Phillips and Poos, 1921. Jour. Agr. Res. 21: 409, 416, 421. - Phillips and Poos, 1927. Jour. Agr. Res. 34: 475, 483. - Bailey, 1960. Entomologist 93: 40 (parasites).

lolii Gahan. Oreg., Calif. Host: Lolium multiflomım, L. temulentum.

Harmolita lolii Gahan, 1922. U. S. Natl. Mus., Proc. 61 (24): 9. ‡, §.

longicornis (Walker). N. Y., Va., S. Dak., Oreg.; Europe. Host: Phalaris arundinacea. Isosoma longicorne Walker, 1832. Ent. Mag. 1: 17. ठ'.

Harmolita phalaridis Phillips and Poos, 1922. Kans. Univ., Sci. Bul. 14: 531. ๆ, ठ์.

Taxonomy: Claridge, 1961. Roy. Ent. Soc. London, Trans. 113: 209 (syn.).

longipetiolata Phillips. N. Dak. Host: Stipa comata.

Harmolita longipetiolata Phillips, 1936. U. S. Dept. Agr., Tech. Bul. 518: 16..

longula (Dalman). Mass., N. Y., Pa., Va., Ohio, Mich., Ind., Tenn., Utah; Europe. Host: Dactylus glomerata.

Eurytoma longula Dalman, 1820 Svenska Vetensk. Akad., Handl. 41: 173, pl. 7, fig. 15. Harmolita dactylicola Phillips and Emery, 1919. U. S. Natl. Mus., Proc. 55: 446. ‡, o.

Taxonomy: Claridge, 1961. Roy. Ent. Soc. London, Proc. 113: 210 (syn.).

Biology: Phillips, 1920. U. S. Dept. Agr., Bul. 808: 16. -Phillips and Poos, 1927. Jour. Agr. Res. $34: 475,483$.

maculata (Howard). Mass., N. Y., Va., Mich., Ind., Ky., Ill., Mo.; Europe. Host: Bromus sp., Bromus secalinus.

Isosoma maculatum Howard, 1896. U. S. Dept. Agr., Div. Ent., Tech. Ser. 2: 15..

Biology: McConnell, 1918. Jour. Econ. Ent. 11: 170. - Phillips, 1920. U. S. Dept. Agr., Bul. 808: 19. - Phillips and Poos, 1921. Jour. Agr. Res. 21: 421. - Phillips and Poos, 1927. Jour. Agr. Res. 34: 475, 483-484. - Claridge, 1961. Roy. Ent. Soc. London, Trans. 113: 213.

minuenda Phillips. N. Dak. Host: Elymus sp.

Harmolita mimenda Phillips, 1936. U. S. Dept. Agr., Tech. Bul. 518: 6. ๆ. 
montana (Ashmead). Mont., Colo.

Isosoma montanum Ashmead, 1894. Amer. Ent. Soc., Trans. 21: 329..

neocaptiva Peck. N. Y., Ind., Ill. Host: Poa pratensis.

Isosoma captivum Howard, 1896. U. S. Dept. Agr., Div. Ent., Tech. Ser. 2: 13. ๆ, o.

Preocc. by Lintner, 1888.

Harmolita neocaptiva Peck, 1951. In Muesebeck et al., U. S. Dept. Agr., Agr. Monog. 2: 571. N. name.

Biology: Phillips, 1920. U. S. Dept. Agr., Bul. 808: 16-17, 23.

nigricornis (Ashmead). Fla.

Xanthosoma nigricomis Ashmead, 1894. Amer. Ent. Soc., Trans. 21: 320..

occidentalis Phillips and Emery. N. Mex. Host: Agropyron sp.

Harmolita occidentalis Phillips and Emery, 1919. U. S. Natl. Mus., Proc. 55: 465. + , ठ.

Biology: Phillips and Poos, 1921. Jour. Agr. Res. 21: 421.

oregon Phillips. Oreg. Host: Elymus sp.

Harmolita oregon Phillips, 1936. U. S. Dept. Agr., Tech. Bul. 518: 14..

Harmolita oregonensis Peck, 1951. In Muesebeck et al., U. S. Dept. Agr., Agr. Monog. 2: 571. Emend.

ovatella Burks, n. name. Kans. Host: Elymus sp.

Harmolita ovata Phillips and Emery, 1919. U. S. Natl. Mus., Proc. 55: 458. ‡, o. Preoce. by Isosoma ovata Szepligeti, 1901.

Biology: Phillips, 1920. U. S. Dept. Agr., Bul. 808: 22-23.

pacifica Phillips. Calif.

Harmolita pacifica Phillips, 1936. U. S. Dept. Agr., Tech. Bul. 518: 12. \&, ठ.

panici Phillips and Poos. Va. Host: Panicum clandestimum.

Harmolita panici Phillips and Poos, 1922. Kans. Univ., Sci. Bul. 14: 351. ๆ, o.

Biology: Phillips and Poos, 1921. Jour. Agr. Res. 21: 421 (Harmolita sp.).

poacola Gahan. Conn., Ind. Host: Poa pratensis.

Harmolita poce Phillips and Emery, 1919. U. S. Natl. Mus., Proc. 55: 445. ₹, o. Preoce. by Isosoma poae Schlechtendal, 1891.

Harmolita poacola Gahan, 1922. Ent. Soc. Wash., Proc. 24: 46, 52. N. name.

Biology: Phillips, 1920. U. S. Dept. Agr., Bul. 808: 17-18.

poophila Phillips and Emery. Colo. Host: Poa sp., P. lucida.

Harmolita poophila Phillips and Emery, 1919. U. S. Natl. Mus., Proc. 55: 463. ₹, o.

Harmolita poaphila Peck, 1951. In Muesebeck et al., U. S. Dept. Agr., Agr. Monog. 2: 572. Emend.

poosi Phillips. Va.

Harmolita poosi Phillips, 1936. U. S. Dept. Agr., Tech. Bul. 518: 10..

rufipes Phillips and Emery. Ill., Nebr., Kans., N. Mex., Utah. Host: Elymus spp.

Harmolita rufipes Phillips and Emery, 1919. U. S. Natl. Mus., Proc. 55: 453. ‡, ठ.

Biology: Phillips, 1920. U. S. Dept. Agr., Bul. 808: 21-23.

sativi Phillips. Ill. Host: Triticum, wheat.

Harmolita sativi Phillips, 1936. U. S. Dept. Agr., Tech. Bul. 518: 7. ๆ.

secale (Fitch). N. Y., Pa., Va., Ohio, Mich., Ind., Nebr., Kans., Utah, Alta. Host: Secale, cultivated rye.

Eurytoma Secale Fitch, 1861. Amer. Agr. 20: 235-236.

Biology: Phillips, 1920. U. S. Dept. Agr., Bul. 808: 13. - Holmes and Blakeley, 1971. Canad. Ent. 103: 277.

stipicola Phillips. N. Dak. Host: Stipa comata.

Harmolita stipicola Phillips, 1936. U. S. Dept. Agr., Tech. Bul. 518: 8. .

stipiphaga Phillips. N. Dak. Host: Stipa comata.

Harmolita stipiphaga Phillips, 1936. U. S. Dept. Agr., Tech. Bul. 518: 17. \&.

stipiphila Phillips. N. Dak.

Harmolita stipiphila Phillips, 1936. U. S. Dept. Agr., Tech. Bul. 518: 16. ․ 
sulcata (Ashmead). Fla.

Isosomocharis sulcata Ashmead, 1894. Amer. Ent. Soc., Trans. 21: 331. \&.

tibialis (Ashmead). S. Dak., Mont., Oreg. Host: Phalaris sp., P. amudinacea.

Isosomorpha tibialis Ashmead, 1894. Amer. Ent. Soc., Trans. 21: 331. \&, o.

Harmolite phalaricola Phillips and Poos, 1922. Kans. Univ., Sci. Bul. 14: 353..

tritici (Fitch). Ont., N. Y., s. to N. C., w. to Wash., Oreg., Calif.; Europe, Asia. Host: Triticum spp., cereal wheats. Wheat jointworm.

Pteromalus? tritici Fitch, 1859. N. Y. State Agr. Soc., Jour. 10: 115.

Decatoma basilaris Provancher, 1881. Nat. Canad. 12: 290. \&, o.

Isosoma nigrum Cook, 1885. Rural New Yorker 44: 314. $९$, ठ̊.

Taxonomy: Burks, 1964 (1963). Canad. Ent. 95: 1257 (basilaris). -Zerova, 1966. Zool. Zhur. 45: 1513 (key to Ukraine spp.)

Biology: Pettit, 1907. Mich. Agr. Expt. Sta., Bul, 244: 106-109. - Knowlton and Janes, 1933. Utah Agr. Expt. Sta., Bul. 243: 8-9. - Balachowsky and Mesnil, 1935. Ins. nuisables aux

Plantes Cult., v. 1, p. 1086. - Phillips and Dicke, 1935. Jour. Agr. Res. 50: 359-386.

-Phillips and Poos, 1940. U. S. Dept. Agr., Farmers' Bul. 1006: 1-12. - Chamberlin, 1941.

U. S. Dept. Agr., Tech. Bul. 784: 1-46. -Zerova, 1966. Zool. Zhur. 45: 1506.

utahensis Phillips. Utah. Ecology: Swept from wheat.

Harmolita utahensis Phillips, 1936. U. S. Dept. Agr., Tech. Bul. 518: 11. ๆ.

vaginicola (Doane). Que., Ont., s. to Va., w. to Utah, Wash., Oreg.; Europe. Host: Triticum spp., cereal wheats.

Isosoma vaginicola Doane, 1916. Jour. Econ. Ent. 9: 399.. .

Biology: Knowlton and Janes, 1933. Utah Agr. Expt. Sta., Bul. 243: 9. -Zerova, 1966. Zool. Zhur. 45: 1508.

websteri (Howard). Que., Ont., s. to Va., w. to Utah, Calif. Host: Secale cereale, rye. Isosoma websteri Howard, 1896. U. S. Dept. Agr., Div. Ent., Tech. Ser. 2: 15.. . Isosoma hirtifrous Howard, 1896. U. S. Dept. Agr., Div. Ent., Tech. Ser. 2: 16.. Isosoma fitchi Howard, 1896. U. S. Dept. Agr., Div. Ent., Tech. Ser. 2: 20. $\uparrow$, ठ์.

Biology: Phillips and Poos, 1927. Jour. Agr. Res. 34: 483. - Knowlton, 1932. Jour. Econ. Ent. 25: 1171-1172. - Knowlton and Janes, 1933. Utah Agr. Expt. Sta., Bul. 243: 9-10.

\section{Genus GAHANIOLA Erdos}

Gahaniola Erdos, 1952. Folia Ent. Hung. (n. s.). 5: 117.

Type-species: Harmolita phyllostachitis Gahan. Orig. desig.

phragmitis Erdos. Often introduced in reeds from Europe; may be established in Phragmites growing on East Coast. Host: Phragmites communis.

Gahaniola phragmitis Erdos, 1952. Folia Ent. Hung. (n. s.) 5: 119. ․

Taxonomy: Erdos, 1955. Allat. Kozlem. 45: 37, 46 (male).

phyllostachitis (Gahan). Fla., Ala.; Russia, China, Japan. Ecology: Specimens sometimes emerge from imported bamboo poles at scattered localities in the U. S. Host:

Phyllostachys bambusoides.

Harmolita phyllostachitis Gahan, 1922. Ent. Soc. Wash., Proc. 24: 55. ๆ.

Biology: Agekian, 1966. Zool. Zhur. 45: 1724.

\section{Genus CATHILARIA Burks}

Cathilaria Burks, 1971. Amer. Ent. Soc., Trans. 97: 34.

Type-species: Harmolita opuntiae Muesebeck. Orig. desig.

opuntiae (Muesebeck). Tex., N. Mex., Ariz., Nev., Calif. Host: Hilaria mutica. Originally thought to have emerged from Opuntia.

Harmolita opuntiae Muesebeck, 1932. Ent. Soc. Wash., Proc. 34: 110. \&, ơ.

Biology: Muesebeck, 1933 (1932). Ent. Soc. Wash., Proc. 34: 158 (correction of host record). 


\section{Genus ISOSOMODES Ashmead}

Isosomodes Ashmead, 1888. Ent. Amer. 4: 42-43. No species. -Ashmead, 1894, Amer. Ent. Soc., Trans. 21: 332 . One species.

Type-species: Isosoma gigantea Ashmead. Desig. by Ashmead, 1894.

giganteus (Ashmead). D. C., Va., Fla.; West Indies.

Isosoma gigantea Ashmead, 1886. Amer. Ent. Soc., Trans. 13: 127. o.

\section{Genus SYSTOLE Walker}

Systole Walker, 1832. Ent. Mag. 1: 13, 22.

Type-species: Systole albipennis Walker. Monotypic.

Taxonomy: Erdos, 1951. Folia Ent. Hung. (n. s.) 4: 57-58 (Palearctic spp.). - Erdos, 1952.

Folia Ent. Hung. (n. s.) 5: 121-126 (Palearctic spp.). - Claridge, 1959. Ent. Monthly Mag.

95: 39 (British spp.). - Claridge, 1961. Soc. Brit. Ent., Trans. 14: 171-179 (type-species).

albipennis Walker. Ont.; Europe, Orient. Ecology: Phytophagous in seeds of umbellifers. Host:

Anethum graveolens, Coriandrum sativum, Cuminum cyminum, Dancus carota,

Foeniculum vulgare, Pimpinella anisum, Torilis japonica.

Systole albipenn is Walker, 1832. Ent. Mag. 1: 22. ․

Taxonomy: Masi, 1919. Mus. Civ. Stor. Nat. Genova, Ann. (3) 8: 147-148. -Masi, 1933. Soc.

Ent. Ital., Bol. 65: 219-220 (male). - Boucek, 1952. Folia Zool. et Ent. 1: 4 (separation of spp.). - Claridge, 1959. Ent. Monthly Mag. 95: 39-40 (description of male and female).

Biology: Marchal, 1900. Soc. Ent. de France., Ann. 69: 111 (geniculata). -Batra et al., 1959.

Current Sci. [India] 28: 451 (larva). -Wadhi, 1963. Indian Jour. Ent. 25: 384 (hosts).

geniculata Foerster. Colo., Idaho, Calif.; Europe, Orient. Ecology: Phytophagous in seeds of umbellifers. Host: Coriandrum sativum, Dancus carota, Foeniculum vulgare,

Pimpinella anisum.

Systole geniculata Foerster, 1861. Prog. Realsch. Aachen, p. xxxiii.

Biology: Sakimura, 1946. Hawaii. Ent. Soc., Proc. 12: 481 (feeding habits). - Roberts, 1963. Jour. Econ. Ent. 56: 541 (in carrot seeds).

minuta Ashmead. Fla.

Systole minuta Ashmead, 1894. Amer. Ent. Soc., Trans. 21: 319. १, ठ.

\section{SUBFAMILy EUDECATOMINAE}

\section{Genus EUDECATOMA Ashmead}

Eudecatoma Ashmead, 1888. Ent. Amer. 4: 42-43. No species. -Ashmead, 1894, Amer. Ent. Soc., Trans. 21: 319. One species.

Type-species: Decatoma batatoides Ashmead. Desig. by Ashmead, 1894.

Decatomidea Ashmead, 1888. Ent. Amer. 4: 42-43. No species. -Ashmead, 1894, Amer. Ent. Soc., Trans. 21: 322. Two species.

Type-species: Decatomidea xanthochroa Ashmead. Desig. by Ashmead, 1894.

The world literature on this genus up to 1944 used the name Decatoma Spinola, 1811. Then Hincks made the decision that Decatoma Spinola was a synonym of Eurytoma Illiger, 1807, leaving this genus to take the next available name, Endecatoma Ashmead, 1888. This decision was not based on a study of types, but was based on an entry in Dalla Torre's 1898 Catalogus Hymenopterorum. Since 1944 the literature has employed the name Eudecatoma. It is to be hoped that if Spinola's types are ever found a study of them will show this change to have been justified.

Revision: Balduf, 1932. U. S. Natl. Mus., Proc. 79 (28): 1-95 (Decatoma).

Taxonomy: Hincks, 1944. Roy. Ent. Soc. London., Proc., Series B: Taxonomy 13: 37

(nomenclature). -Peck, 1963. Canad. Ent., Sup. 30: 833-844 (change subsp. to var.). arizonica (Balduf). Ariz. Host: Andricus ruginosus Bass.

Decatoma foliatae var. arizonica Balduf, 1932. U. S. Natl. Mus., Proc. 79 (28): 82. , `. 
autumnalis (Girault). Calif.

Decatoma autumnalis Girault, 1920. U. S. Natl. Mus., Proc. 58: 209..

batatoides (Ashmead). N. J., Fla. Host: Callirhytis quercusbatatoides (Ashm.). Decatoma batutoicles Ashmead, 1881. Canad. Ent. 13: 136.

bicolor (Ashmead). Fla., La. Host: Belonocnema treatne Mayr.

Decatoma bicolor Ashmead, 1881. Amer, Ent. Soc., Trans. 9: Proc. p. xxxii. ?.

catesbaei (Ashmead). Fla. Host: Bassettia quercuscatesbaei (Ashm.).

Decatoma catesbaei Ashmead, 1881. Amer. Ent. Soc., Trans. 9: Proc. p. xxxii. .

Decatoma catesbii Dalla Torre, 1898. Cat. Hym., v. 5, p. 327. Emend.

compressa (Girault). Calif.

Decatoma compressa Girault, 1920. U. S. Natl. Mus., Proc. 58: 209. ๆ.

disholcaspis (Balduf). Tex., Colo., N. Mex., Ariz. Host: Adleria sp., Andricus ruginosus Bass., Disholcaspis sp., D. cinerosa (Bass.).

Decatoma disholcaspis Balduf, 1932. U. S. Natl. Mus., Proc. 79 (28): 23. १, ठ.

Biology: Judd, 1966. Marcellia 32: 256 (in Eurura gall on Salix).

dorsalis (Fitch). Mass., N. Y., s. to Fla., w. to Kans., Tex. Host: Acraspis erinacei (Beut.), Andricus aciculatu.s Beut., A. quercusflocci (Walsh), A. quercuspetiolicola (Bass.), Callirhytis tumifica (O. S.), Disholcaspis quercusglobulus (Fitch), D. quercusmamma (Walsh), Neuroterus quercusmajalis (Bass.), Xanthoteras quercusforticorne (Walsh).

Spalangia Querci-lanae var. dorsalis Fitch, 1859. N. Y. State Agr. Soc., Trans. 18: 816.

dubia doanei (Fullaway). Colo., Utah, Calif. Host: Disholcaspis canescens (Bass.); $D$. chrysolepillis (Beut.), D. corallina (Bass), D. eldoradensis (Beut.), D. plumbella Kinsey.

Decatoma doanei Fullaway, 1912. N. Y. Ent. Soc., Jour. 20: 279. \&.

dubia dubia (Walsh). Mass., Ont., s. to N. C., w. to Utah., Ariz. Host: Belonocnema quercusvireus (O. S.), Callirhytis quercuspunctata (Bass.), Disholcaspis quercusglobulus (Fitch), D. quercusmamma (Walsh), D. spongiosa (Karsch), Dryocosmus imbricariae (Ashm.).

Decatoma varians var. dubia Walsh, 1870. Amer. Ent. and Bot. 2: 300. ₹, ठ.

dubia rufosa (Balduf). N. Y., Va., S. C., Ga., Fla., Ala., Ill., Tex. Host: Belonocnema quercusvirens (O. S.), Disholcaspis quercusglobulus (Fitch), D. quercusmamma (Walsh), D. spongiosa (Karsch).

Decatoma dubia var. mfosa Balduf, 1932. U. S. Natl. Mus., Proc. 79 (28): 41. ๆ, ठ.

flamminneiventris (Girault). Tex., Colo., N. Mex. Host: Prodoxus sp., P. quinquepunctellus (Chamb.), P. y-inversus Riley.

Decatoma flamminneiventris Girault, 1920. U. S. Natl. Mus., Proc. 58: 208. ?, ठ.

flava (Ashmead). Mass., s. to N. C., w. to Mo., Tex., N. Mex. Host: Acraspis erinacei (Beut.), A. macrocarpae Bass., A. pezomachoides (0. S.), Andricus aciculatus Beut., A. murtfeldtae Ashm., A. quercuspetiolicola (Bass.), A. tubularius Weld, Callirhytis seminator (Harr.), Dryocosmus floridensis (Beut.), Loxaulus humilis (Weld), Neuroterus noxiosus (Bass.), N. quercusbatatus (Fitch).

Decatoma flava Ashmead, 1881. Canad. Ent. 13: 134. ㅇ, o.

Biology: Triggerson, 1914. Ent. Soc. Amer., Ann. 7: 8-9.

flavipes (Balduf). Ariz. Host: Dryocosmus coxii (Bass.).

Decatoma flavipes Balduf, 1932. U. S. Natl. Mus., Proc. 79 (28): 52. १, ठ.

florida (Girault). Fla. Andricus quercusflocci (Walsh) may be the host of this species.

Decatoma florida Girault, 1917. Descr. Hym. Chalcidoid. Variorum cum Observ. V, p. 6..

Taxonomy: Girault, 1920. U. S. Natl. Mus., Proc. 58: 208 (repetition of privately published original description).

foliatae (Ashmead). Va., Fla., Ill., Mo. Host: Andricus quercusfoliatus (Ashm.), Callirhytis flavipes (Gill.), Disholcaspis quercusglobulus (Fitch), Dryocosmus imbricariae (Ashm.).

Decatoma foliatce Ashmead, 1881. Canad. Ent. 13: 136. ‡, ठั.

globuli (Balduf). Ill. Host: Audricus ruginosus Bass, A. tectumarum Kinsey, Disholcaspis eldoradensis (Beut.), D. quercusglobulus (Fitch), D. spongiosa (Karsch), Xanthotheras quercusforticorne (Walsh).

Decatoma globuli Balduf, 1932. U. S. Natl. Mus., Proc. 79 (28): 47. ค, o. 
gracilis (Fullaway). Calif. Host: Andricus quereuscalifornicus (Bass.).

Decatoma gracilis Fullaway, 1912. N. Y. Ent. Soc., Jour. 20: 280. ठ.

isis (Girault). Calif. Host: Andricus clirysolepidicola (Ashm.), A. quercuscalifornicus (Bass.), A. spectabilis Kinsey, Callirhyt is quercuspomiformis (Bass.), C. quercussuttoni (Bass.).

Decatoma is is Girault, 1917. Descr. Stellarum Nov., p. 10..

lanae (Ashmead). Fla. Host: Callirhytis quercustumerii (Ashm.).

Decatoma lanae Ashmead, 1881. Canad. Ent. 13: 135. + ,.

lobatae (Balduf). Calif. Host: Andricus wiltzae Full, Neuroterus varians Kinsey.

Decatoma lobatae Balduf, 1932. U. S. Natl. Mus., Proc. 79 (28): 45..

marylandica (Girault). N. S., Md., D. C. Host: Neuroternes quercusbatatus (Fitch).

Decatoma marylandica Girault, 1916. Brooklyn Ent. Soc., Bul. 11: 112..

mellea (Curtis). P. E. I., Que., N. Y., Oreg.; Holaretic. Host: Mayetiola destructor (Say); Ditropinotus aurcoviridis Cwfd., Eurytoma parva Phill., Harmolita hordei (Harr.), $H$. linearis (Walk.), H. tritici (Fitch).

Decatoma mellea Curtis, 1831. Brit. Ent. 8: 345. “ $\delta "=q$.

Decatoma amsterdamensis Girault, 1917. Descr. Stellarum Nov., p. 10. ๆ, ઠ.

Taxonomy: Gahan, 1934 (1933). U. S. Dept. Agr., Misc. Pub. 174: 38-41 (amsterdamensis). -Claridge, 1959. Soc. Brit. Ent., Trans. 13: 160 (syn.).

Biology: Chamberlin, 1941. U. S. Dept. Agr., Tech. Bul. 784: 29, 40. -Cannon, 1963. Canad. Ent. 95: 34.

michiganica (Girault). Mich.

Decatoma michiganica Girault, 1920. U. S. Natl. Mus., Proc. 58: 209..

mimosae (Balduf). Ariz. Ecology: Reared from gall on Mimosa biuncifera. Host: Tanaostigmodes sp.

Decatoma mimosae Balduf, 1932. U. S. Natl. Mus., Proc. 79 (28): 25. ‡, ठ.

nigriceps excrucians (Walsh). Ill. Host: Callirhyt is seminator (Harr.).

Decatoma nigriceps var. excrucians Walsh, 1870. Amer. Ent. and Bot. 2: 301. \&, ơ.

nigriceps nigriceps (Walsh). Mass., Conn., Va., Ill., Mo., Kans. Host: Callirhytis tumifica (0. S.), Disholcaspis quercusmamma (Walsh), Xanthoteras quercusforticorne (Walsh).

Decatoma nigriceps Walsh, 1870. Amer. Ent. and Bot. 2: 300. ๆ, ठ.

novascotiae (Balduf). N. S., Va. Host: Callirhytis cornigera (O. S.); Neuroterus quercusbatatus (Fitch).

Decatoma novascotiae Balduf, 1932. U. S. Natl. Mus., Proc. 79 (28): 50. , ઠ.

nubilistigma (Walsh). Que., Mass., N. Y., N. J., Ill., Kans. Ecology: Reared from Euura sp. gall on Salix discolor.

Decatoma mubilistigma Walsh, 1870. Amer. Ent. and Bot. 2: 301. ๆ, o.

occidentalis flavifrons (Balduf). Ariz. Ecology: Reared from gall on live oak.

Decatoma occidentalis var. flavifrons Balduf, 1932. U. S. Natl. Mus., Proc. 79 (28): 61. ठ.

occidentalis occidentalis (Balduf). Conn., Colo., N. Mex., Utah, Ariz., Oreg., Calif. Host: Adleria weldi (Beut.), Andricus chrysolepidicola (Ashm.), A. lasius (Ashm.), A. lasius var. areolaris Kinsey, A. ruginosus Bass., Antron quercusechinus (O. S.), Disholcaspis canescens (Bass.), D. corallina (Bass.), D. eldoradensis (Beut.), D. truckeensis (Ashm.), Xanthoteras eburneum (Bass.).

Decatoma occidentalis Balduf, 1932. U. S. Natl. Mus., Proc. 79 (28): 58 . ९, ઠ . pezomachoides (Balduf). Ohio. Host: Acraspis pezomachoides (O. S.).

Decatoma pezomachoides Balduf, 1932. U. S. Natl. Mus., Proc. 79 (28): 69.. pomiformis (Balduf). Calif. Host: Callirhytis quercuspomiform is (Bass.).

Decatoma pomiform is Balduf, 1932. U.S. Natl. Mus., Proc. 79 (28): 70. ๆ, ठ. querci (Ashmead). Fla. Ecology: Reared from dipterous galls on Quercus catesbaei.

Decatoma querci Ashmead, 1881. Canad. Ent. 13: 135. ठ.

quercilanae (Fitch). Que., Ont., s. to Fla., w. to Tex., Colo., Ariz. Host: Acraspis inflata (Kinsey), Audricus aciculatus Beut., A. murtfeldtae Ashm., A. pattoni (Bass.), A. que'cusflocci (Walsh), A. quercuspetiolicola (Bass.), Callirhytis flavipes (Gill.), C. quercusscitula (Bass.), C. seminator (Harr.), C. tumifica (O. S.), Disholcaspis 
quercusglobulus (Fitch), D. quercusmamma (Walsh), Neuroterus quercusbatatus (Fitch), N. quercusmajalis (Bass.), Xanthoteras quercusforticorne (Walsh).

Spalangia Querci-lanae Fitch, 1850. N. Y. State Agr. Soc., Trans. 18: 816.

Decatoma hyalipennis Walsh, 1870. Amer. Ent. and Bot. 2: 301. १, ठ.

Decatoma flavicollis Ashmead, 1885. Amer. Ent. Soc., Trans. 12: Proc. p. xiii. ค, o. Preocc. by Walker, 1834 .

Decatoma floridana Smith, 1886. Ent. Amer. 2: 19. N. name for flavicollis Ashm. quinqueseptae (Balduf). Calif. Host: Andricus quercuspetiolicola (Bass.).

Decatoma quinqueseptae Balduf, 1932. U. S. Natl. Mus., Proc. 79 (28): 78. ๆ, ठ.

simplicistigma (Walsh). Ill., Kans., Colo. Host: Acraspis erinacei (Beut.), Andricus quercuspetiolicola (Bass.).

Decatoma simplicistigma Walsh, 1870. Amer. Ent. and Bot. 2: 301. ๆ, ð.

subimmaculata (Girault). Calif. Host: Andricus lasius (Ashm.), A. lasius var. sublasius Kinsey, A. spectabilis Kinsey, Callirhytis quercuspomiformis (Bass.), Disholcaspis truckeensis (Ashm.), Heteroecus pacificus (Ashm.).

Decatoma subimmaculata Girault, 1917. Jour. Ent. and Zool. 9: 11. ․

texana (Balduf). Tex.

Decatoma texana Balduf, 1932. U. S. Natl. Mus., Proc. 79 (28): 22 . ․, ठ.

vacciniicola (Balduf). Ont., Que., s. to Va., w. to Ill., La. Host: Hemadas nubilipennis (Ashm.).

Decatoma vacciniicola Balduf, 1932. U. S. Natl. Mus., Proc. 79 (28): 12. ₹, ơ.

Biology: Glick, 1939. U. S. Dept. Agr., Tech. Bul. 673: 45. -Judd, 1959. Amer. Micros. Soc.,

Trans. 78: 213.

varians (Walsh). Ont., s. to Fla., w. to Tex., Colo., Calif. Host: Andricus chrysolepidicola (Ashm.), A. chrysolepidicola var. pugnus Kinsey, Callirhytis frequens (Gill.), C. quercusgemmaria (Ashm.), C. quercus punctulata (Bass.), Disholcaspis eldoradensis (Beut.), D. quercusglobulus (Fitch), Dryocosmus imbricariae (Ashm.), Sphaeroteras caepuliforme (Beut.).

Decatoma varians Walsh, 1870. Amer. Ent. and Bot. 2: 300. ․ ¿.

Decatoma phellos Ashmead, 1881. Canad. Ent. 12: 136. ठ.

Decatoma kelloggi Fullaway, 1912. N. Y. Ent. Soc., Jour. 20: 278. ค, ๖.

wiltzae (Balduf). Conn., Ariz., Calif. Host: Andricus wiltzae Full.

Decatoma wiltzae Balduf, 1932. U. S. Natl. Mus., Proc. 79 (28): 83 . ९, o.

xanthochroa (Ashmead). Fla., Tex. Host: Andricus murtfeldtae Ashm., Callirhytis flavipes (Gill.).

Decatomidea xanthochroa Ashmead, 1894. Amer. Ent. Soc., Trans. 21: 322. .

Decatoma brevilobae Balduf, 1932. U. S. Natl. Mus., Proc. 79 (28): 56. ‡, ठ.

\section{Genus SYCOPHILA Walker}

Sycophila Walker, 1871. Notes on Chalcid., p. 63.

Type-species: Sycophila decatomoides Walker. Desig. by Ashmead, 1904.

Isanisa Walker, 1875. Entomologist 8: 15.

Type-species: Isanisa decatomoides Walker. Monotypic.

Pseudisa Walker, 1875. Entomologist 8: 15.

Type-species: Pseudisa smicroides Walker. Monotypic.

Taxonomy: Burks, 1971. Amer. Ent. Soc., Trans. 97: 72-73.

butcheri Burks. Fla. Host: Ficus aurea, F. laevigata.

Sycophila butcheri Burks, 1969. Fla. Ent. 52: 120. , ১.

\section{SUBFAMILY AXIMINAE}

Genus AXIMA Walker

Axima Walker, 1862. Ent. Soc. London, Trans. (3) 1: 373.

Type-species: Axima spinifrons Walker. Monotypic. 
zabriskiei Howard. Que., N. Y., N. J., Va., W. Va., Mich., Ind., Mo., Tex., Calif. Host: Ceratina calcarata Robt., C. dupla Say.

Axima zabriskiei Howard, 1890. U. S. Dept. Agr., Insect Life 2: 365. ‡, ठ.

Biology: Rau, 1928. Ent. Soc. Amer., Ann. 21: 382. - Krombein, 1960. Ent. News 71: 32, 68. Morphology: Burks, 1966. Ent. News 77: 199-202 (immature stages).

\section{Genus BEPHRATOIDES Brues}

Bephratoides Brues, 1909 (1908). Wis. Nat. Hist. Soc., Bul. 6: 158.

Type-species: Bephratoides maculatus Brues. Orig. desig.

agrili (Ashmead). N. J., Va., W. Va. Host: Agrilus otiosus Say.

Eurytoma agrili Ashmead, 1894. Amer. Ent. Soc., Trans. 21: 325. \&.

maculatus Brues. Tex.; Mexico. Ecology: Bred from mesquite infested with wood-boring

Coleoptera.

Bephratoiles maculutus Brues, 1909 (1908). Wis. Nat. Hist. Soc., Bul. 6: 158..

\section{Genus IPIDEURYTONA Boucek and Novicky}

Ipideurytomu Boucek and Novicky 1954. Ent. Tidskr. 75: 267.

Type-species: Ipileurytoma spessivtsevi Boucek and Novicky. Orig. desig.

polygraphi (Ashmead). N. Y., W. Va., Colo., B. C. Host: Polygraphus sp., Trypodendrou sp.

This and the European species, spessictsevi Boucek and Novicky, are very closely

related, and they may be synonyms.

Decatomidell polygruphi Ashmead, 1894. Amer. Ent. Soc., Trans. 21: 322..

Taxonomy: Bugbee, 1956. Ent. Soc. Amer., Ann. 49: 506.

\section{Genus CHRYSEIDA Spinola}

Chryseida Spinola, 1840. Rev. Zool. 3: 18.

Type-species: Chryseidla superciliosa Spinola. Monotypic.

Revision: Burks, 1956. Brooklyn Ent. Soc., Bul. 51: 109-116.

bennetti Burks. Tex.; Mexico, West Indies. Ecology: Reared from bruchids in the seeds of

Havardia brevifolia, Rhynchosia sp., and Cajanus cajan.

Chryseida bennetti Burks, 1956. Brooklyn Ent. Soc., Bul. 51: 115. \&.

inopinata Brues. Tex.; Mexico. Ecology: Reared from bruchids in leguminous seeds.

Cleryseida inopinata Brues, 1907. Wis. Nat. Hist. Soc., Bul. 5: 103. ?.

\section{SUBFAMILy HEIMBRINAE}

\section{Genus HEIMBRA Cameron}

Heimbra Cameron, 1910. Amer. Ent. Soc., Trans. 35: 433.

Type-species: Heimbra acuticollis Cameron. Monotypic.

Taxonomy: Burks, 1971. Amer. Ent. Soc., Trans. 97: 54-56.

opaca (Ashmead). Kans., Mont., Colo., N. Mex., Utah, Ariz., Calif.

Euperilampus opacus Ashmead, 1894. Amer. Ent. Soc., Trans. 21: 318. ?.

Taxonomy: Crawford, 1914. Ent. Soc. Wash., Proc. 16: 69 (type abnormal; sp. belongs in

Eurytomu). - Burks, 1971. Amer. Ent. Soc., Trans. 97: 56 (nomenclature).

\section{SubFamily PRODECATOMINAE}

\section{Genus PRODECATOMA Ashmead}

Prolecatoma Ashmead, 1904. Carnegie Mus., Mem. 1: 261, 263, 463.

Type-species: Prodecatoma flac'escens. Ashmead Orig. desig. 
cooki (Howard). Conn., N. Y., Md., Va., Fla., Ohio, Mich., Calif. Ecology: Develops in seeds of wild and cultivated grapes and some nearly related Vitaceae. Host: Parthenocissus quinquefolin, Vitis sp., V. culifornica, V. labrusca.

Decatomidea cooki Howard, 1896. U. S. Dept. Agr., Div. Ent., Tech. Ser, 2: 23. q, o.

Prodecatoma phytophaya Crosby, 1909. Canad. Ent. 41: 50. ९. ठ.

Taxonomy: Gahan, 1951. Canad. Ent. 83: 173-174 (types).

Biology: Crosby, 1909. N. Y. Agr. Expt. Sta., Bul. 265: 382. - Rohwer, 1913. U. S. Dept. Agr., Bur. Ent., Tech. Ser. 20: 158 (oviposition).

Morphology: Bugbee, 1936. Ent. Amer. 16: 178.

maga (Girault). Calif. Host: Audrieus chrysolepidicola (Ashm.), Disholcaspis p/umbella Kinsey.

Eurytoma hegeli var. maga Girault, 1920. U. S. Natl. Mus., Proc. 58: 207. $ๆ, \delta$.

Taxonomy: Peck, 1951. In Muesebeck et al., U. S. Dept. Agr., Agr. Monog. 2: 577 (change from var. to sp.).

\section{Genus BEPHRATELLOIDES Girault}

Bephratoides Girault, 1913. Arch. f. Naturgesch. 79 A (6): 60. Preoce. by Brues, 1908. Type-species: Bephratu paragunyensis Craw ford. Orig. desig.

Bephratelloides Girault, 1913. Ent. New's 24: 459. N. name.

This genus has for many years taken the name Bephrata Cameron, 1884. A recent study of the type of the the type-species of Bephrata showed that the true Bephrata is quite different and has been misidentified since the time of Ashmead, 1888.

Taxonomy: Burks, 1971. Amer. Ent. Soc., Trans. 97: 26-27.

cubensis (Ashmead). Fla.; West Indies, Mexico, Cent. and S. Amer. Ecology: Develops in the seeds of Soursop, Cherimoya, Sugar-apple or Sweetsop, and Custard-apple, Annona spp. Host: Annona cherimola, A. muricata, A. reticulata, A. squamosa.

Bephrata cubensis Ashmead, 1894. Amer. Ent. Soc., Trans. 21: 321. ?.

Biology: Crawford, 1911. U. S. Natl. Mus., Proc. 41: 274. - Bruner and Acuna, 1923. Estacion Expt. Agron., Santiago, Cuba, pp. 3-12 (life history). - Dozier, 1932. Porto Rico Dept. Agr., Jour. 16: 109-112. - Osorio, 1937. Rev. Agr. Habana 2: 10-19 (reproduction). -Alvorado, 1939. Los ins. daninos ... en Guatemala, pp. 267-270. - Martorell, 1945. Puerto Rico Univ., Jour. Agr. 29: 557.

\section{SUBFAMILy EURYTOMINAE}

\section{Genus TENUIPETIOLUS Bugbee}

Tenuipetiolus Bugbee, 1951. Kans. Ent. Soc., Jour. 24: 37.

Type-species: Eurytoma albipes Ashmead. Orig. desig.

medicaginis (Gahan). Tex., Ariz., Calif.; Mexico. Ecology: Parasitizes dipterous hosts in galled seed pods of alfalfa and Mentzelia. Host: Asphondylia mentzeliae Ckll., A. websteri Felt.

Eurytoma medicaginis Gahan, 1919. Ent. Soc. Amer., Ann. 12: 159. ๆ, ठั. mentha Bugbee. N. Mex. Ecology: Parasitizes dipterous larvae in pods of Poliomintha incana.

Tenuipetiolus mentha Bugbee, 1951. Kans. Ent. Soc., Jour. 24: 38, 44. ๆ, ठ์.

ruber Bugbee. N. Y., s. to Va., w. to Tenn. and Ariz. Ecology: Parasite of gall makers on Rosaceae. Host: Diastrophus cuscutaeform is 0. S., D. nebulosus (0. S.), Diplolepis rosae (L.).

Tenuipetiolus rubra Bugbee, 1951. Kans. Ent. Soc., Jour. 24: 39. ९, ठ.

teredon (Walker). N. Y., Va., N. C., Fla., Miss., Kans., Tex. Ecology: Emerges from cecidomyiid galls on Ambrosia, Helianthus, Xanthium. Host: Asphondylia helianthiglobulus O. S.

Enrytoma teredon Walker, 1843. Soc. Ent. de France, Ann. (2) 1: 153. १, ठ.

Eurytoma albipes Ashmead, 1881. Amer. Ent. Soc., Trans. 9: Proc. p. xxxi. ㅇ, ठ․ 
Taxonomy: Burks, 1975. Brit. Mus. (Nat. Hist.) Ent., Bul. 32 (4): 163 (syn.; lectotype designated).

\section{Genus PHYLLOXEROXENUS Ashmead}

Phylloxeroxenus Ashmead, 1888. Ent. Amer. 2: 42-43. No species. -Ashmead, 1894. Amer. Ent. Soc., Trans. 21: 328. One species.

Type-species: Eurytoma phylloxerae Ashmead. Desig. by Ashmead, 1894.

phylloxerae (Ashmead). N. Y., Va., Fla., La. Ecology: Reared from Phylloxera galls, but probably parasitic on cecidomyiid larvae living in those galls. Recorded from galls of Phylloxera caryaecaulis Fitch, P. caryaescissae Riley, P. deplanata Pergande.

Eurytoma phylloxerae Ashmead, 1881. Amer. Ent. Soc., Trans. 9: Proc. p. xxx..

\section{Genus EURYTOMOCHARIS Ashmead}

Eurytomocharis Ashmead, 1888. Ent. Amer. 4: 42-43. No species. -Ashmead, 1894. Amer. Ent. Soc., Trans. 21: 327. One species.

Type-species: Eurytomocharis minuta Ashmead. Desig. by Ashmead, 1894.

Revision: Bugbee, 1966. Amer. Midland Nat. 75: 367-382.

Taxonomy: Bugbee, 1956. Ent. Soc. Amer., Ann. 49: 505-506 (generic characters).

armillata Bugbee. S. Dak. Host: Spartina sp.

Eurytomocharis armillate Bugbee, 1966. Amer. Midland Nat. 75: 373. ?. ashmeadi (Peck). Fla.

Eurytomocharis minuta Ashmead, 1894. Amer. Ent. Soc., Trans. 21: 327. ₹, o. Preocc. by Walker, 1832, when minuta Ashmead was transferred to Eurytoma in 1951.

Eurytoma ashmeadi Peck, 1951. In Muesebeck et al., U. S. Dept. Agr., Agr. Monog. 2: 575. N. name.

eragrostidis Howard. N. Y., D. C., Ind., Ill., Iowa, N. Mex. Host: Agropyron sp., Agrostis alba, Andropogon saccharoides, Eragrostis cilianensis, E. erosa, E. poooides, Muhlenbergia porteri, M. wrightii, Oryzopsis hymenoides, Sporobolus airoides.

Eurytomocharis eragrostidis Howard, 1896. U. S. Dept. Agr., Div. Ent., Tech. Ser. 2: 21. $\uparrow, \delta$.

Taxonomy: Bugbee, 1966. Amer. Midland Nat. 75: 380 (may be a complex).

glyceriae Bugbee. Ind. Host: Glyceria striata.

Eurytomocharis glyceriae Bugbee, 1966. Amer. Midland Nat. 75: 374. ๆ, ó.

muhlenbergiae (Howard). Mo. Host: Muhlenbergia schreberi.

Isosomomorpha muhlenbergiae Howard, 1896. U. S. Dept. Agr., Div. Ent., Tech. Ser. 2: 20. ․

Taxonomy: Bugbee, 1966. Amer. Midland Nat. 75: 378 (may not belong in Eurytomocharis). pascuorum Bugbee. N. Mex. Host: Bouteloua curtipendula, B. gracilis, Eragrostis erosa, Stipa comata.

Eurytomocharis pascuorum Bugbee, 1966. Amer. Midland Nat. 75: 376. ९, ð.

planitiae Bugbee. Iowa, N. Mex. Host: Boutelona curtipendula, B. gracilis.

Eurytomocharis planitiae Bugbee, 1966. Amer. Midland. Nat. 75: 376. ९, ঠ. pythes (Walker). Fla.

Eurytoma pythes Walker, 1843. Soc. Ent. de France, Ann. (2) 1: 154. 9.

Taxonomy: Burks, 1975. Brit. Mus. (Nat. Hist.) Ent., Bul. 32 (4): 163.

sporoboli Bugbee. N. Mex. Host: Sporobolus airoides.

Eurytomocharis sporoboli Bugbee, 1966. Amer. Midland Nat. 75: 373. ९, ठ.

triodiae Howard. N. Y., D. C., Va., Mich., Ind., Kans. Host: Triodia flava.

Eurytomocharis triodiae Howard, 1896. U. S. Dept. Agr., Div. Ent., Tech. Ser. 2: 21. q, ð.

Biology: Bugbee, 1966. Amer. Midland Nat. $75: 378$ (life hist.). 


\section{Genus EVOXYSOMA Ashmead}

Evoxysoma Ashmead, 1888. Ent. Amer. 4: 42-43. No species. -Ashmead, 1894. Amer. Ent. Soc., Trans. 21: 328 . One species.

Type-species: Systole brachyptere Ashmead. Desig. by Ashmead, 1894.

Euoxysoma Dalla Torre, 1898. Cat. Hym., v. 5, p. 345. Emend.

Euxysoma Cameron, 1905. Ztschr. Syst. Hym. Dipt. 5: 344. Misspelling.

brachyptera (Ashmead). Fla.

Systole brachyptera Ashmead, 1886. Amer. Ent. Soc., Trans. 13: 126. \&.

vitis (Saunders). Conn., Ont., N. Y., N. J., N. C., Ohio, Mo. Ecology: Develops in seeds of wild and cultivated grape; its development in the seeds causes grape fruits to wither. Host: Vitis sp.

Isosoma vitis Saunders, 1869. Canad. Ent. 2: 25. ₹, o.

Taxonomy: Bugbee, 1967. U. S. Natl. Mus., Proc. 118: 516.

Biology: Riley, 1870. Mo. State Bd. Agr., Ann. Rpt. 5: 92-93. -Saunders, 1871. Ont. Fruit Growers Assoc., Ann. Rpt. 1870: 109-111. - Crosby, 1909. N. Y. Agr. Expt. Sta., Bul. 265: 380. - Rohwer, 1913. U. S. Dept. Agr., Bur. Ent., Tech. Ser. 20: 158 (oviposition).

\section{Genus BRUCHOPHAGUS Ashmead}

Bruchophagus Ashmead, 1888. Ent. Amer. 4: 42, 43. No species. - Ashmead, 1894. Amer. Ent. Soc., Trans. 21: 328. Three species.

Type-species: Bruchophayus boreal is Ashmead. Desig. by Ashmead, 1894.

Systolodes Ashmead, 1888. Ent. Amer. 4: 42, 43. No species.-Ashmead, 1894. Amer. Ent.

Soc., Trans. 21: 320 . One species.

Type-species: Systolodes brevicornis Ashmead. Desig. by Ashmead, 1894

This genus contains the best known species of seed chalcids, most of them developing in leguminous seeds. In 1888, when Ashmead named the genus, he thought that its species parasitized bruchids that developed in leguminous seeds. Even after the phytophagous nature of some of the species had been clearly demonstrated, he refused to accept it. As late as 1904, long after the clover seed chalcids had been shown by competent workers to be phytophagous, he wrote: Dr. A. D. Hopkins claims that Bruchophagus funebris is phytophagous and states he has proven it by a series of experiments. I think, however, some mistake has been made and I cannot accept Dr. Hopkins' observation as conclusive. ...I am inclined to think that both Drs. Howard and Hopkins are wrong, and that Bruchophagus funebris is a parasite upon some Bruchus (Carnegie Mus., Mem. 1: 260).

Taxonomy: Girault, 1916. Canad. Ent. 48: 338-339 (brief review of spp.). - Boucek, 1954. Mus. Natl. Pragae, Acta Ent. 30: 76 (subg. of Eurytoma). -Fedoseeva, 1954. Mosk. Univ.

Vestnik 9 (5): 113-118. - Fedoseeva, 1958. Zool. Zhur. 37: 1345-1351. -Claridge, 1961. Soc. Brit. Ent., Trans. 14: 178.

Biology: Burks, 1958 (1957). Ent. Soc. Wash., Proc. 59: 273-277 (hosts). -Fedoseeva, 1960. Nauch. Dok. Vyssh. Shkoly. Biol. 3: 14-18 (ecology).

borealis Ashmead. Ont. Originally said to have been bred from a Bruchus, but that is almost certainly incorrect.

Bruchophagus borealis Ashmead, 1894. Amer. Ent. Soc., Trans. 21: 328. \&, o.

Taxonomy: Girault, 1916. Canad. Ent. 4: 338.

caraganae (Nikolskaja). Man., N. Dak., Sask.; Europe, Asia. Host: Caragana arborescens, C. frutex, C. pygmaea, C. sophoraefolia.

Eurytoma caraganae Nikol'skaya, 1952. Opred. Faune SSSR 44: 176, 187. क, 。

Taxonomy: Bugbee, 1956. Ent. Soc. Amer., Ann. 49: 505.

Biology: Znoiko, 1952. Ent. Obozr. 32: 49-55 (life history and parasites in Palearetic region).

- Hedlin, 1957 (1956). Canad. Ent. 88: 622-625 (in Nearctic region).

gibbus (Boheman). Cosmopolitan; common throughout North America. Host: Melilotus sp.,

Trifolium sp. Clover seed chalcid.

Eurytoma gibba Boheman, 1836 (1835). Svenska Vetensk. Akad., Handl. 56: 244.. 
Eurytoma mucianus Walker, 1848. List Hym. Ins. Brit. Mus. 2: 152. ठ.

Eurytoma funebris Howard, 1880. U. S. Dept. Agr., Ann. Rept. for 1879, p. 196. \&, ठ. Systolodes brevicornis Ashmead, 1894. Amer. Ent. Soc., Trans. 21: 320. ₹, ó.

Taxonomy: Nikolskaja, 1932. Plant Prot., Leningrad, fasc. 1: 107-109 (syn.). - Ferriere, 1950. Schweiz. Ent. Gesell., Mitt. 23: 39 (syn.). - Hellen, 1953. Notulae Ent. 33: 18 (platyptera). -Fedoseeva, 1954. Mosk. Univ. Vestnik 9: 115, 117 (gibbus). -Claridge, 1959. Ent. Monthly Mag. 95: 38 (platyptera). - Strong, 1962. Ent. Soc. Amer., Ann. 55: 1-4 (gibbus). -Graham, 1970. Roy. Ent. Soc. London, Proc., Series B: Taxonomy. 39: 145 (gibbus).

Biology: Hopkins, 1896. U. S. Dept. Agr., Div. Ent., Bul. (n. s.) 6: 73 (funebris, phytophagous). -Hopkins, 1898. U. S. Dept. Agr., Div. Ent., Bul. (n. s.) 17: 45 (funebris). -Pettit, 1899. Mich. Agr. Expt. Sta., Bul. 175: 366 (funebris). - Titus, 1904. U. S. Dept. Agr., Div. Ent., Bul. (n. s.) 44: 77-80 (funebris). - Folsom, 1909. In Forbes, Ill. State Ent., Ann. Rpt. 25: 50-61 (funebris). - Pettit, 1910. Mich. Agr. Expt. Sta., Bul. 258: 48-49 (funebris).

-Gossard, 1911. Ohio Agr. Expt. Sta., Bul. 233: 77 (funebris). -Kurdjumov, 1912. Mess. Ent. Kiev 1: 86-88 (gibba). - Howard, 1914. U. S. Dept. Agr., Ann. Rpt. Ent. 1914: 192 (funebris).--Essig, 1915. Calif. State Comn. Hort., Monthly Bul. 4: 368 (funebris).

-Crosby and Leonard, 1916. N. Y. State Dept. Agr., Bul. 87: 2870 (furebris).

-Washburn, 1918. Minn. State Ent., Ann. Rpt. 17: 190 (funebris). -Urbahns, 1919. Jour. Agr. Res. 16: 165-173 (funebris, parasites). - Urbahns, 1920. U. S. Dept. Agr., Bul. 812: 1-19 (funebris, life history, parasites). - Sorenson, 1930. Utah Agr. Expt. Sta., Bul. 218: 1-33 (funebris). - Bigger, 1936. Ill. State Acad. Sci., Trans. 28: 62 (funebris, influence on clover production). -Smith, 1943. Kans. State Bd. Agr., Rpt. 62: 395 (funebris). - Shull, 1944. Idaho Agr. Expt. Sta., Bul. 252: 15, 56 (gibbus). -Kolobova, 1950. Ent. Obozr. 31: 63-70 (gibbuss). -Sorenson and Knowlton, 1951. Utah Agr. Expt. Sta., Ext. Bul. 219: 1-2 (gibbus). - Lofgren, 1956. S. Dak. Agr. Expt. Sta., Ext. Cir. 533: 7-8 (gibbus). -Rosen, 1959. Swed. Stat. Vaxt. Vaxt. 23: 56 (gibba). -Perju, 1961. Cluj. Inst. Agron. 17: 233 (gibbus). - Carillo and Dickason, 1963. Oreg. State Univ. Agr. Exp. Sta., Tech. Bul. 68: 11 (gibbus).

mexicanus Ashmead. Tex., N. Mex., Idaho, Utah., Ariz., Calif. Host: Astragalus sp., $A$. mollissimus. Loco-weed chalcid.

Bruchophagus mexicanus Ashmead, 1894. Amer. Ent. Soc., Trans. 21: 328. ๆ, o.

Biology: Trelease and Trelease, 1937. Science 85: 590 (immunity to selenium). noctua Girault. Ariz.

Bruchophagus noctua Girault, 1917. New Chalcid Flies, p. 1a.

platypterus (Walker). Cosmopolitan; widely distributed in North America. Host: Lotus sp., L. corniculatus. Trefoil seed chalcid.

Systole platyptera Walker, 1834. Ent. Mag. 2: 153.

Bruchophagus kolobovae Fedoseeva, 1956. A kad. Nauk. SSSR Dok. 111: 491. \&, ơ.

Taxonomy: Fedoseeva, 1958. Zool. Zhur. 37: 1349. - Perju, 1960. Acad. RPR Bucharest, Comun. 10: 575. - Szelenyi, 1961. Budapest. Noven. Kut. Inst., Evkon 8: 133, 136. - Strong, 1962. Ent. Soc. Amer., Ann. 55: 1-4 (kolobovae). -Graham, 1970. Roy. Ent. Soc. London, Proc., Series B: Taxonomy 39: 143 (syn.).

Biology: Crevecoeur, 1946. Soc. Ent. de Belg., Bul. et Ann. 82: 273 (gibbus). - Neunzig and Gyrisco, 1958. Jour. Econ. Ent. 51: 409 (Bruchophagus sp.). - Batiste, 1967. Hilgardia 38: 427 (koloborae, immature stages).

roddi (Gussakovsky). Cosmopolitan; widely distributed in North America. Host: Medicago sp., $M$. arabica, $M$. hispida, $M$. sativa. Alfalfa seed chalcid.

Euryfoma(!) roddi Gussakovsky, 1933. In Rodd, Gussakovsky, and Antova, Pests of dry-farming crops of Central Asia, Tashkent, pp. 122, 150. + , ¿.

Bruchophagus gibbus medicaginis Kolobova, 1950. Ent. Obozr. 31: 70. ค, ơ.

Taxonomy: Nikolskaja, 1952 (English trans. 1963). Keys to Fauna USSR 44: 173, 175. -Fedoseeva, 1954. Mosk. Univ. Vestnik 9 (5): 116. -Fedoseeva, 1958. Zool. Zhur. 37: 1349. -Perju, 1960. Acad. RPR Bucharest, Comun. 10: 575. - Strong, 1962. Ent. Soc., Amer., Ann. 55: 1-4. 
Biology: Sorenson, 1934. Utah. Acad. Sci., Proc. 11: 241-244 (funebris). - Harin, 1934.

Central Asia Cotton Inst., Bul. 4-5: 85-114 (gibbus). - Wille, 1943. Estac. Expt. Agr. de La

Molina, p. 357 (funebris). - Figuero and Lima, 1940. Bol. de Agr. Sao Paulo 41: 307

(gibbus). - Strong, 1962. Hilgardia 32: 229-248. - Carillo and Dickason, 1963. Oreg. State

Univ. Agr. Expt. Sta., Tech. Bul. 68: 25. - Strong et al., 1963. Hilgardia 35: 1-12.

-Kralovic, 1964. Biologia, Bratislava 19: 620 (length of life).

sculptus (Ashmead). Fla.

Eurytoma sculpta Ashmead, 1887. Amer. Ent. Soc., Trans. 14: 195. ๆ.

Taxonomy: Bugbee, 1956. Ent. Soc. Amer., Ann. 49: 505.

\section{Genus EURYTOMA Illiger}

Eurytoma Illiger, 1807. Mag. f. Insektenkunde 6: 192.

Type-species: Chalcis abrotani Panzer. Desig. by Westwood, 1840.

Decatoma Spinola, 1811. Mus. d'Hist. Nat., Ann. 17: 151.

Type-species: Diplolepis adonidum Rossi. Desig. by Ashmead, 1894.

Eunetoma Dahlbom, 1857. Ofvers. Svensk. Vet. Akad., Forh. 14: 292.

Type-species: Chalcis abrotani Panzer. Desig. by Gahan and Fagan, 1923.

Enneatoma Dalla Torre, 1898. Cat. Hym. 5: 332. Emend.

Bephratella Girault, 1913. Arch. f. Naturgesch. 79(6): 95.

Type-species: Bephratella nympha Girault. Orig. desig.

Eurytoma subg. Dieurytoma Erdos, 1957. Allat. Kozlem. 46: 61.

Type-species: Eurytoma amygdali Enderlein. Orig. desig.

Eurytoma subg. Hydateurytoma Erdos, 1957. Allat. Kozlem. 46: 58.

Type-species: Eurytoma palustris Erdos. Orig. desig.

Eurytoma subg. Moneurytoma Erdos, 1957. Allat. Kozlem. 46: 59.

Type-species: Eurytoma aquatica Erdos. Orig. desig.

Some species of Eurytoma are phytophagous, others pass part of their larval development as parasites and then complete their growth by feeding on plant tissues, but the bulk of the species are primary or secondary parasites. Many species are placed in Eurytoma not because they are greatly like the type-species, but because it has not as yet been possible to place them elsewhere.

Revision: Bugbee, 1967. U. S. Natl. Mus., Proc. 118: 433-552.

Taxonomy: Claridge, 1959. Ent. Monthly Mag. 95: 2 (identity of type-species). - Graham,

1970. Roy. Soc. London, Proc., Series B: Taxonomy 39: 145-152 (Palearctic species).

abatos Walker. Que., s. to Fla., w. to B. C., Oreg., and Colo. Host: Magdalis armicollis (Say), Scolytus multistriatus (Marsh.), S. rugulosus (Ratz.).

Eurytoma abatos Walker, 1843. Soc. Ent. de France, Ann. (2) 1: 152. f.

Taxonomy: Burks, 1975. Brit. Mus. (Nat. Hist.) Ent., Bul. 32 (4): 162 (syn.).

Eurytoma cressinelura Ashmead, 1894. Amer. Ent. Soc., Trans. 21: 324-327 ๆ, ठ. acuta absona Bugbee. Colo. Host: Diplolepis sp.

Eurytoma acuta absona Bugbee. 1951. Ent. Soc. Amer., Ann. 44: 230. श, ơ.

acuta acuta Bugbee. Utah. Host: Diplolepis arefacta (Gill.), D. tuberculatrix (Ckll.).

Eurytoma acuta acuta Bugbee, 1951. Ent. Soc. Amer., Ann. 44: 225. \&, ठ’.

acuta gemina Bugbee. Ariz.

Eurytoma acuta gemina Bugbee, 1951. Ent. Soc. Amer., Ann. 44: 232. ‡, ơ.

acuta intermedia Bugbee. N. Dak. Host: Diplolepis sp.

Eurytoma acuta intermedia Bugbee, 1951. Ent. Soc. Amer., Ann. 44: 228. \&, ठ.

acuta ramosa Bugbee. Mich., Minn., Man. Host: Diplolepis tuberculatrix (Ckll.).

Eurytoma acuta ramosa Bugbee, 1951. Ent. Soc. Amer., Ann. 44: 229. ๆ, б.

altifossa Bugbee. Man. Ecology: Emerged from unknown gall on Oxytropis lamberti.

Eurytoma altifossa Bugbee, 1967. U. S. Natl. Mus., Proc. 118: 487. ๆ, o.

apiculae Bugbee. Calif. Host: Ceratina dallatorreana Friese, C. nanula Ckll., C. punctigena Ckll., Ectemnius spiniferus (Fox).

Eurytoma apiculae Bugbee, 1966. Pan-Pacific Ent. 42: 210. ๆ, ठ. 
Biology: Daly et al., 1967. Ent. Soc. Amer., Ann. 60: 1279.

appendigaster (Swederus). Ont., N. B., Maine, s. to N. J., w. to N. Y., Pa.; Europe. Probably inadvertently introduced from Europe along with Apanteles. Host: Apanteles melanoscelus (Ratz.), Cremastus minor Cush.; Compsilura concinnata (Meig.).

Pteromalus Appendigaster Swederus, 1795. Svenska Vetensk. Akad. Handl. 16: 217.

Taxonomy: Ferriere, 1950. Schweiz. Ent. Gesell., Mitt. 23: 383 (types). -Claridge, 1959. Ent. Monthly Mag. 95: 4. - Claridge, 1960. Ent. Medd. 29: 248 (appendigaster Mayr not Swederus = verticillata $\mathrm{F}$.).

Biology: Muesebeck and Dohanian, 1927. U. S. Dept. Agr., Bul. 1487: 20-21. - Worawski, 1934. Wydaw. Szk. Glow. Gospod. Wiej. 1: 5 (secondary parasite of Gypsy moth).

-Rosenberg, 1935. Bul. Ent. Res. 25: 244-246 (immature stages). -Allen et al., 1940. U.

S. Dept. Agr., Cir. 561: 50. - Haeussler, 1940. U. S. Dept. Agr., Tech. Bul. 728: 34-35, 52-54 (primary and secondary parasite). - Parker, 1951. U. S. Dept. Agr., Tech. Bul. 1036: 19 (immature stages). - Wilbert, 1960. Entomophaga 5: 203. - Allen, 1962. U. S. Dept. Agr., Tech. Bul. 1265: 106-108. -Zelinskaya, 1964. In Kasianenko, Akad. Nauk Ukraine RSR Inst. Zool., Trudy 20: 199. -Stone, 1965. U. S. Dept. Agr., Tech. Bul. 1321: 24.

atripes Gahan. N. Y., Pa., N. J., Md., Ohio, Tenn., N. Dak., Alta., Wash., Oreg. Host: Mayetiola destructor (Say); Cephus cinctus Nort.

Eurytoma atripes Gahan, 1934 (1933). U. S. Dept. Agr., Misc. Pub. 174: 36. \&, ơ.

Biology: Nelson, 1953. Canad. Ent. 85: 249-251.

Morphology: Hill and Pinckney, 1940. U. S. Dept. Agr., Tech. Bul. 715: 8, 11-13 (immature stages).

baccae Bugbee. Md., Kans. Host: Ancylis comptana fragariae (W. and R.). This species might also be a secondary parasite, attacking an ichneumonid primary parasite, Temehucha cooki (Weed).

Eurytoma baccue Bugbee, 1967. U. S. Natl. Mus., Proc. 118: 497..

bicolor Walsh. Conn. and Ont., s. to Va., w. to Nebr. Host: Antistrophus minor Gill., $A$. lygodesmiaepisum Walsh, Aulacidea tumida (Bass.); Eurosta solidaginis (Fitch).

Eurytoma bicolor Walsh, 1870. Amer. Ent. and Bot. 2: 298. ๆ, ठ.

bigeloviae Ashmead. Colo., Utah, Calif. Host: Aciurina bigeloviae (Ckll.).

Eurytoma bigeloviae Ashmead, 1890. Colo. Biol. Assoc., Bul. 1: 25, 45 . ․

Enrytoma chalcidiformis Girault, 1917. Descr. Hym. Chalcidoid. Variorum cum Observ. V, p. 3. ㅇ.

Taxonomy: Bugbee, 1956. Ent. Soc. Amer., Ann. 49: 504 (syn.).

bolteri Riley. Vt., s. to N. C., w. to N. Dak., Kans. Host: Gnorimoschema gallaesolidaginis (Riley).

Eurytoma Bolteri Riley, 1869. Mo. State Bd. Agr., Ann. Rpt. 4: 177. , §.

Biology: Leiby, 1922. N. Y. Ent. Soc., Jour. 30: 93. -Barber, 1938. N. Y. Ent. Soc., Jour. 46: 173-175. - Miller, 1963. Ohio Jour. Sci. 63: 72.

Morphology: Snodgrass, 1910. U. S. Natl. Mus., Proc. 39: 65, fig. 46 (thorax).

brevivena Bugbee. Ariz. Host: Disholcaspis mibens (Gill.).

Eurytoma brevivena Bugbee, 1958. Ent. Soc. Amer., Ann. 51: 198. , đ.

bromi (Howard). N. Y., Ohio, Calif. Host: Bromus ciliatus.

Isosoma bromi Howard, 1896. U. S. Dept. Agr., Div. Ent., Tech. Ser. 2: 11. \&, ठ.

Taxonomy: Bugbee, 1956. Ent. Soc. Amer., Ann. 49: 505.

calcarea calcarea Bugbee. Utah. Host: Diplolepis variabilis (Bass.).

Eurytoma calcarea calcarea Bugbee, 1951. Ent. Soc. Amer., Ann. 44: 242. ‡, o.

calcarea ignobilis Bugbee. Nebr. Host: Diplolepis bicolor (Harr.).

Eurytoma calcarea ignobilis Bugbee, 1951. Ent. Soc. Amer., Ann. 44: 243. , §.

calcarea infima Bugbee. Ill. Host: Diplolepis bicolor (Harr.).

Eurytoma calcarea infïma Bugbee, 1951. Ent. Soc. Amer., Ann. 44: 246. ९, ơ.

calcarea lucida Bugbee. Ill. Host: Diplolep is bicolor (Harr.).

Eurytoma calcarea lucida Bugbee, 1951. Ent. Soc. Amer., Ann. 44: 245. \&, o. 
calcarea mimica Bugbee. Maine, Mass. Host: Diplolepis bicolor (Harr.).

Eurytoma calcarea mimica Bugbee, 1951. Ent. Soc. Amer., Ann. 44: 247. ๆ, ठ.

calcarea singularis Bugbee. Mass. Host: Diplolepis nebulosa (Bass.).

Eurytoma calcarea singularis Bugbee, 1951. Ent. Soc. Amer., Ann. 44: 248. ค, o.

californica californica Ashmead. Wash., Oreg., Calif. Host: Andricus quercuscalifornicus (Bass.), Callimytis quercuspomiform is (Bass.), Disholcapspis corallina (Bass.), D. plumbella Kinsey, D. ureshingtoneusis (Gill.).

Eurytoma californica Ashmead, 1887. Amer. Ent. Soc., Trans. 14: 195. ₹, ठ.

californica nana Bugbee. Calif. Host: Callirhytis quercnspomiformis (Bass.). Sexual generation, leaf galls.

Eurytoma culifornica nana Bugbee, 1969. Pan-Pacific Ent. 45: 63. ๆ, ठ.

calycis Bugbee. Ont. Ecology: Develop in young pine shoots, infested shoots showing distortion and retarded growth. Host: Pinus banksiana.

Enrytoma culycis Bugbee, 1961. Canad. Ent. 93: 33. , o.

Biology: Thomas and Herdy, 1961. Canad. Ent. 93: 34-39.

ceanothi Bugbee. Ariz. Host: Cetnothus greggii seeds.

Eurytoma ceanothi Bugbee, 1971. Kans. Ent. Soc., Jour. 44: 111. \&, ठั.

celtigalla Bugbee. Tex. Ecology: Emerges from leaf or twig galls on Celtis. Host: Mayetiola celtiphyllia Felt.

Eurytoma celtigalla Bugbee, 1957. Kans. Ent. Soc., Jour. 30: 49. ‡, ठ.

cleri Ashmead. Que. and N. Y., s. to N. C., w. to Mont., N. Mex., Calif. Host: Dendroctonus frontalis Zimm., D. monticolar Hopk., Ips confusus (Lec.), I. oregoni (Eich.), Pissodes strobi (Peck). When originally described thought, incorrectly, to parasitize a clerid beetle.

Eurytoma cleri Ashmead, 1894. Amer. Ent. Soc., Trans. 21: 323. \&.

Taxonomy: Bugbee, 1970. Ent. Soc. Amer., Ann. 63: 435.

conica Provancher. Que., Ont., s. to N. C., w. to B. C., Oreg., Calif. Host: Cylindrocopturus longulus (Lec.), Deulroctonus brericomis Lec., D. frontalis Zimm., Phloeosinus dentatus Lec., Pissode's strobi (Peck).

Eurytoma conica Provancher, 1887. Addit. Corr. Faune Ent. Canada Hym., pp. 192, 438. ‥

Eurytoma phloeosini Ashmead, 1894. Amer. Ent. Soc., Trans. 21: 327. ठ.

Isosoma abnorme Ashmead, 1896. Amer. Ent. Soc., Trans. 23: 219..

Taxonomy: Bugbee, 1956. Ent. Soc. Amer., Ann. 49: 504 (syn.), - Burks, 1964 (1963). Canad.

Ent. 95: 1259 (Provancher type).

contractura Bugbee. Ont. Host: Melanagromyza schineri (Giraud).

Eurytoma contractura Bugbee, 1967. U. S. Natl. Mus., Proc. 118: 471. \&, o.

crassa Bugbee. Ohio, Ind., Ill., La., Tex., N. Mex. Host: Aciurina notata (Coq.), Callachna gibba (Loew).

Eurytoma crassa Bugbee, 1967. U. S. Natl. Mus., Proc. 118: 488. ‡, ठ.

diastrophi Walsh. Que., s. to N. C., w. to Colo., N. Mex. Ecology: Should occur wherever blackberry grows. Host: Diastrophus cuscutaeformis O. S., D. nebulosus (O. S.), D. niger Bass.

Eurytoma diastropli Walsh, 1870. Amer. Ent. and Bot. 2: 299. ๆ, ठ.

discordans Bugbee. Que., Ont., Maine, Mass., Va., Mich., Ind., Wis., Alta. Host: Diplolepis variabilis (Bass.), Periclistus pirata (0. S.), Synophromorpha sylvestris (0. S.).

Eurytoma discordans Bugbee, 1951. Ent. Soc. Amer., Ann. 44: 218, 220. ㅇ, ठ.

dorcaschemae Ashmead. N. J., N. C., Kans., Sask. Host: Dorcaschema alternatum (Say).

Eurytoma dorcaschente Ashmead, 1888. Kans. Agr. Expt. Sta., Bul. 3: App. p. II.

extremitatis Bugbee. Va. Host: Rhyacionia frustrana (Comst.).

Eurytoma extremitatis Bugbee, 1968. Kans. Ent. Soc., Jour. 41: 404. , o.

flavicrurensa Bugbee. Oreg. Host: Diplolepis polita (Ashm.).

Eurytoma flavicmurensa Bugbee, 1951. Ent. Soc. Amer., Ann. 44: 258. ?. 
flavicrus Bugbee. S. C. Ecology: Reared from undetermined gall on Nyssa sylvatica. Eurytoma flaticrus Bugbee, 1967. U. S. Natl. Mus., Proc. 118: 469. \&, ठ.

flavifacies Bugbee. Calif. Host: Andricus chrysolepilicola (Ashm.).

Eurytoma flavifacies Bugbee, 1969. Pan-Pacific Ent. 45: 62. ๆ, ठ.

flavovultus Bugbee. Tex. Host: Pachypsylla venusta (0. S.).

Eurytoma flavovultus Bugbee, 1957. Kans. Ent. Soc., Jour. 30: 45. ९, ठ.

foligalla Bugbee. Calif. Host: Antron douglassii (Ashm.), A. quercusechinus (0. S.), Besbicus multipunctatus (Beut.), Callirhytis quercuspomiform is (Bass.), Disholcaspis eldoradensis (Beut.).

Eurytoma foligalla Bugbee, 1969. Pan-Pacific Ent. 45: 60. ๆ, ठ.

fossae Bugbee. Calif. Ecology: Bred from willow galls produced by species of Euura; may parasitize the gall-maker or inquilines and parasites.

Eurytoma fossae Bugbee, 1967. U. S. Natl. Mus., Proc. 118: 484. ₹, o.

furva Bugbee. Calif. Host: Disholcaspis washingtonensis (Gill.).

Eurytoma furva Bugbee, 1958. Ent. Soc. Amer., Ann. 51: 198. ๆ, o.

fusca Bugbee. N. Y., Kans., Wash. Ecology: Reared from apple curculio material; Tachypterellus quadrigibbus (Say) and other species of Tachypterellus may be hosts.

Eurytoma fusca Bugbee, 1967. U. S. Natl. Mus., Proc. 118: 502. ๆ, ठ.

gigantea Walsh. N. B., Que., Ont., s. to Fla., w. to N. W. T., Mont., Kans., Colo. Host: Eurosta solidagin is (Fitch).

Eurytoma gigantea Walsh, 1870. Amer. Ent. and Bot. 2: 300..

Callimome Duckeri Ashmead, 1887. Amer. Ent. Soc., Trans. 14: 194. Nom. nud.

Ormyrus elongatus Ashmead, 1887. Amer. Ent. Soc., Trans. 14: 194. Nom. nud.

Ormyrus prolongatus Ashmead, 1887. Amer. Ent. Soc., Trans. 14: 194. Nom. nud.

Taxonomy: Ashmead, 1887. Amer. Ent. Soc., Trans. 14: 194-198 (male).

Biology: Hughes, 1934. Ent. News 45: 119-122. - Uhler, 1951. Cornell Univ. Agr. Expt. Sta., Mem. 300: 41. -Judd, 1953. Canad. Ent. 85: 295. - Miller, 1959. Tenn. State Acad. Sci.,

Jour. 34: 249.

gossypii Bugbee. S. C., Ark., La., Okla., Tex., Ariz.; Mexico. Host: Anthonomus grandis Boh.

Eurytoma gossypii Bugbee, 1967. U. S. Natl. Mus., Proc. 118: 493. ․ ठ’.

hecale Walker. N. Y, s. to Fla., w. to Ill., Kans. Host: Acraspis erinacei (Beut.), A. pezomachoides (O. S.), A. quercushirta (Bass.), Amphibolips cooki Gill., A. quercusspongifica (0. S.), Andricus ignotus (Bass.), A. pattoni (Bass.), A. quercusflocci (Walsh), A. quercusfoliatus (Ashm.), Callirhytis lanata (Gill.), C. seminator (Harr.), Disholcaspis quercusglobulus (Fitch), D. quercusmamma (Walsh), D. spongiosa (Karsch), Dryocosmus imbricariae (Ashm.), Sphaeroteras melleum (Ashm.).

Eurytoma hecale Walker, 1843. Soc. Ent. de France, Ann. (2) 1: 151..

Eurytoma auriceps Walsh, 1870. Amer. Ent. and Bot. 2: 299. ․ ठ.

Eurytoma auriceps var. seminatrix Walsh, 1870. Amer. Ent. and Bot. 2: 299., ठ .

Eurytoma vagabunda Ashmead, 1881. Canad. Ent. 13: 134. $\%$

Taxonomy: Bugbee, 1956. Ent. Soc. Amer., Ann. 49: 503 (syn.). -Burks, 1975. Brit. Mus. (Nat. Hist.) Ent., Bul. 32 (4): 162 (syn.; lectotype designated).

Biology: Triggerson, 1914. Ent. Soc. Amer., Ann. 7: 9-11 (auriceps).

illinoisensis Girault. N. S., Que., Ont., Wis., Ill., Iowa, S. Dak., N. Mex. Host: Harmolita sp. Eurytoma illimoisensis Girault, 1920. U. S. Natl. Mus., Proc. 58: 206. ๆ.

imminuta Bugbee. Utah, Nev., Oreg. Host: Diplolepis variabilis (Bass.).

Eurytoma imminuta Bugbee, 1951. Ent. Soc. Amer., Ann. 44: 259. $\&$, ơ.

incerta incerta Fullaway. Sask., Oreg., Calif. Ecology: Reared from Diplolepis galls modified by inquilines. Host: Periclistus piceus Fullaway, P. californicus Ashm.

Eurytoma incerta Fullaway, 1912. N. Y. Ent. Soc., Jour. 20: 277. ‡, ठ.

Taxonomy: Bugbee, 1951. Ent. Soc. Amer., Ann. 44: 237 (reduced to subsp.).

incerta varia Bugbee. Calif. Ecology: Reared from gall of Diplolepis tuberculatrix var. descansonis $\mathrm{K}$. and $\mathrm{A}$.

Eurytoma incerta varia Bugbee, 1951. Ent. Soc. Amer., Ann. 44: 237. ?. 
iniqua Bugbee. Colo. Host: Diplolepis neglecta (Gill.).

Eurytoma iniquus Bugbee, 1951. Ent. Soc. Amer., Ann. 44: 253. ๆ, ठ.

inornata Bugbee. Md. Host: Euplilis (Coryuopus) coarctata modesta (Roh.), E. (C.) rufigaster (Pack.), Trypoxylon sp.

Eurytoma inormata Bugbee, 1962. Kans. Ent. Soc., Jour. 35: 347. ๆ, ठ์.

Biology: Krombein, 1964. Biol. Soc. Wash., Proc. 77: 103-104.

juniperina Marcovitch. N. H., Conn., Ont., N. Y., Del., Minn., N. Dak. Ecology: Phytophagous form, developing in seeds of juniper. Host: Junipe'rus virginiana, J. scopulormm.

Eurytoma juniperinus Marcovitch, 1915. Ent. Soc. Amer., Ann. 8: 166. ₹, ơ.

Eurytoma juniperinus var. Crosbyi Marcovitch, 1915. Ent. Soc. Amer., Ann. 8: 168 i. N. syn.

lacunae Bugbee. Md. Ecology: Reared from a cecidomyiid gall on Baccharis halimifolia.

Eurytoina lacunae Bugbee, 1967. U. S. Natl. Mus., Proc. 118: 476. + , o.

levivultus Bugbee. Ohio. Host: Pachypsylla celtidisgemma Riley.

Eurytoma levirultus Bugbee, 1957. Kans. Ent. Soc., Jour. 30: 48. ๆ, ठ.

levo Bugbee. Va. Ecology: Reared from pine gall made by a xyelid. Host: Xyela gallicaulis Smith.

Eurytoma le'to Bugbee, 1967. U. S. Natl. Mus., Proc. 118: 499. ₹, ठ.

longavena Bugbee. B. C. Host: Diplolepis bicolor (Harr.).

Eurytoma longacena Bugbee, 1951. Ent. Soc. Amer., Ann. 44: 249.,$+ \delta$.

lutae Bugbee. Mich. Ecology: Reared from a composite naturalized from Europe, Inula heleninm.

Eurytoma Intue Bugbee, 1967. U. S. Natl. Mus., Proc. 118: 462. \&, ठ.

lycti Ashmead. N. J., Md., Va., W. Va., Kans. Host: Lyctus striatus Melsh.

Eurytoma lycti Ashmead, 1894. Amer. Ent. Soc., Trans. 21: 325. ๆ.

Taxonomy: Bugbee, 1951. Kans. Ent. Soc., Jour. 24: 38 (generic placement).

magdalidis Ashmead. Que., Ont., N. Y. Va., N. C., W. Va., Kans., Colo., Calif. Host: Authribus cornutus Say, Cylindrocopturus longulus (Lec.), Magdalis armicollis (Say), Oncideres cingulata (Say).

Eurytoma magdalidis Ashmead, 1894. Amer. Ent. Soc., Trans. 21: 326. ๆ.

mali Bugbee. N. Y., Wis., Kans., Wash. Host: Tachypterellus consors cerasi List, T. quadrigibbus maguus List., T. q. quadrigibbus (Say).

Eurytoma mali Bugbee, 1967. U. S. Natl. Mus., Proc. 118: 512. ๆ, ठ.

mammae Bugbee. Va., W. Va., Ind. Ecology: Rearings suggest that host may be the scolytid beetle, Leperisinus aculeatus (Say) or the pemphredonine wasp, Stigmus sp.

Eurytoma mammae Bugbee, 1967. U. S. Natl. Mus., Proc. 118: 451..

minnesota Girault. Minn. Ecology: Reared from quackgrass, Agropyron repeus.

Eurytoma minnesota Girault, 1916. Canad. Ent. 48: 338. ๆ, o.

neomexicana Girault. Kans., Sask., Colo., N. Mex., Nev. Ecology: Reared from grasses and from the seeds of Aplopappus spinulosus.

Eurytoma neomexicana Girault, 1920. U. S. Natl. Mus., Proc. 58: 205. ९, ठ.

Biology: Brandhorst, 1943. Kans. Acad. Sci., Trans. 46: 169 (phytophagous).

nigricoxa Provancher. Ont., Man., B. C. Host: Periclistus sp.

Eurytoma nigricoxa Provancher, 1887. Addit. Corr. Faune Ent. Canada Hym. p. 192. $q$.

Taxonomy: Burks, 1964 (1963). Canad. Ent. 95: 1259.

obtusa Bugbee. N. J. Possibly introduced from Europe along with its host in 1930. Host:

Bruchus brachialis Fahr.

Eurytoma obtusa Bugbee, 1967. U. S. Natl. Mus., Proc. 118: 507. ๆ, §.

obtusilobae Ashmead. Mass., s. to Fla., w. to Man., Tex. and Oreg. Host: Diplolepis radicum (O. S.).

Eurytoma obtusilobae Ashmead, 1885. Amer. Ent. Soc., Trans. 12: Proc. p. xii. ๆ, o. 
obtusiventris Gahan. Mass., Ont., N. Y., Va., Ohio, Ind., Mich., Miss., La., Kans., Okla., Colo., N. Mex.; Mexico. Ecology: This species seems ordinarily to be parthenogenetic. Host: Eurosta solidaginis (Fitch), Neotephritis finalis (Loew).

Eurytoma obtusiventris Gahan, 1934. Ent. News 45: 117..

Biology: Hughes, 1934. Ent. News 45: 119-122. - Uhler, 1951. Cornell Univ. Agr. Expt. Sta., Mem. 300: 40. - Miller, 1959. Tenn. Acad. Sci., Jour. 34: 249.

orchidearum (Westwood). Que., Ont., Mass., N. Y., N. J., D. C., Fla., Ill., La., Tex., Calif.; Cosmopolitan in Tropical and Subtropical regions. Ecology: North American records from area north of Southern Florida and Southern California are from greenhouses and conservatories. Host: Cattleya spp. Also other orchids having pseudobulbs.

Isosoma Orchidearum Westwood, 1869. Gard. Chron. p. 1230. §, ठ.

Eurytoma phoenix Girault, 1917. Deser. Hym. Chalcidoid. Variorum cum Observ. V, p. 11. †.

Taxonomy: Gahan, 1922. Ent. Soc. Wash., Proc. 24: 41 (generic placement). -Bugbee, 1956. Ent. Soc. Amer., Ann. 49: 504 (syn.).

Biology: Felt, 1916. N. Y. State Mus., Bul. 180: 336. -Moore, 1916. N. J. Agr. Expt. Sta., Bul. 308: 3-12. -Timberlake, 1924. Hawaii. Ent. Soc., Proc. 5: 420. - Aczel, 1936. Roy.

Hungarian Hort. Col., Bul. 2: 41-43. - Brandao, 1942. Sitios e Fazendas 7: 73. - Figueiredo, 1942. Biologico 8: 136-138. -Gomes, 1942. Rev. Agron., Porte Alegre 6: 568-569. - Swezey, 1945. Hawaii. Ent. Soc., Proc. 12: 359-360. - Brandao, 1945. Brasil Min. da Agr., Bol. 34: 67-68. - Lepage and Figueiredo, 1947. Circolo Paulista de Orquidofilos, Bol., p. 12. - Bess, 1953. Hawaii. Farm Sci. 1: 3-6 (immature stages). - Look, 1954. Hawaii. Ent. Soc., Proc. 15: $264,271$.

pachyneuron Girault. P. E. I., Que., s. to N. C., w. to B. C., Wash., Oreg., Calif. Ecology: This species begins its development as a parasite and completes its larval growth by feeding on plant tissues in grass stems. Host: Harmolita spp., Mayetiola destructor (Say);

Elymuss spp., Triticum spp.

Eurytoma pachyneuron Girault, 1916. Canad. Ent. 48: 337..

Enrytoma phoebus Girault, 1920. U. S. Natl. Mus., Proc. 58: 204. ๆ.

Eurytoma pater Girault, 1920. U. S. Natl. Mus., Proc. 58: 207. ․

Taxonomy: Bugbee, 1956. Ent. Soc. Amer., Ann. 49: 503 (syn.).

Biology: Phillips, 1917. Jour. Econ. Ent. 10: 145 (pater). - Gahan, 1922. Ent. Soc. Wash., Proc. 24: 37 (pater). —Gahan, 1934 (1933). U. S. Dept. Agr., Misc. Pub. 174: 33-36 (phoebus). -Jones, 1932. Jour. Econ. Ent. 25: 412 (pachyneuron). - Hill and Pinckney, 1940. U. S. Dept. Agr., Tech. Bul. 715: 8 (phoebus, immature stages). -Chamberlin, 1941.

U. S. Dept. Agr., Tech. Bul. 784: 40 (phoebus, larva). - Brandhorst, 1943. Kans. Acad. Sci.,

Trans. 46: 174 (pater). -Cannon, 1963. Canad. Ent. 95: 34 (phoebus).

parva Phillips. N. Y., D. C., Va., Pa., Ohio, Ind., Kans., Sask., Alta. Host: Cephus cinctus Nort., Harmolita tritici (Fitch).

Eurytoma bolteri var. parva Phillips, 1918. U. S. Dept. Agr., Farmers' Bul. 1006: 11, 14. \&.

Taxonomy: Phillips, 1927. Jour. Agr. Res. 34: 743 (change from var. to sp.).

Biology: Phillips, 1918. U. S. Dept. Agr., Farmers' Bul. 1006: 11 (life hist.). - Phillips, 1927. Jour. Agr. Res. 34: 743-758 (host relationships). - Phillips and Poos, 1940. U. S. Dept. Agr., Farmers' Bul. 1006 (rev.): 10-11 (life hist.). - Chamberlin, 1941. U. S. Dept. Agr., Tech. Bul. 784: 32-35 (parasites).

phloeotribi Ashmead. Que., N. Y., N. J., D. C., Va., W. Va., N. C., Idaho, Oreg., Calif. Host: Phlocosinus sequoiae Hopk., Phloeotribus dentifrons (Blackm.), P. frontalis (Oliv.), Pityophthorus liquidambarus Blackm., Pseudopityophthorus minutissimus (Zimm.), P. prninosus (Eich.), Scolytus abietis Blackm., S. muticus Say, Stephanoderes dissimilis (Zimm.).

Eurytoma phlocotribi Ashmead, 1894. Amer. Ent. Soc., Trans. 21: 326. \&.

Taxonomy: Bugbee, 1970. Ent. Soc. Amer., Ann. 63: 437.

Biology: Beal and Massey, 1945. Duke Univ. School Forestry, Bul. 10: 71, 111, 122. 
picea Bugbee. B. C., Wash. Host: Pissodes sitchenisis Hopk.

Eurytoma picea Bugbee, 1967. U. S. Natl. Mus., Proc. 118: 510. ९, ठ์.

pini Bugbee. Que., s. to S. C., w. to Mo., Ark., Man., Nebr. Host: Dioryctria zimmermani

(Grote), Eucosma gloriola Hein., Rlyyacionia buoliana (Schiff.), R. frustrana (Comst.),

$R$. rigidana (Fern.).

Eurytoma pini Bugbee, 1958. Kans. Ent. Soc., Jour. 31: 197. ๆ, §.

Biology: Watson and Arthur, 1959. Canad. Ent. 91: 481 (prob. secondary). - Miller, 1959.

Jour. Econ. Ent. 52: 768. - Rennels, 1960. Ill. Univ. Agr. Expt. Sta., Bul. 660: 17. - Arthur, 1961. Canad. Ent. 93: 1-13 (immature stages; cleptoparasitic). - Harman and Kulman, 1962. Jour. Econ. Ent. 55: 1007. - Eikenbary and Fox, 1965. S. C. Agr. Expt. Sta., Tech. Bul. 1017: 6. -Kulman, 1965. Jour. Econ. Ent. 58: 864 (hyperparasitic). -Finlayson, 1967. Canad. Ent. 99: 1265 (immature stages).

pissodis Girault. N. S., Maine, s. to Va., w. to Wash., Oreg., Calif. Host: Pissodes engelmanni Hopk., P. strobi (Peck), P. terminalis Hopk.

Eurytoma pissodis Girault, 1917. Brooklyn Ent. Soc., Bul. 12: 88. ๆ, o.

Biology: Graham, 1918. Ent. Soc. Amer., Ann. 11: 175-180. - Graham, 1926. Cornell Univ. Agr. Expt. Sta., Bul. 449: 26-29. - Taylor, 1929. Ent. Amer. (n. s.) 9: 228, 10: 60. - Stark and Wood, 1964. Canad. Ent. 96: 1217. -Stevenson, 1967. Canad. Ent. 99: 15-18 (immature stages).

profunda Bugbee. Fla., Tex. Ecology: Has been reared from stems of ragweed and a Solanum, as well as from a cynipid gall, but its actual host is unknown; very unlikely to be phytophagous.

Decatoma maculipes Ashmead, 1886. Amer. Ent. Soc., Trans. 13: 126. \&. Preoce. in Eurytoma by Motschulsky, 1863.

Eurytoma profunda Bugbee, 1967. U. S. Natl. Mus., Proc. 118: 454. N. name.

prunicola Walsh. Ont., s. to S. C., w. to Ill., Kans., Tex. Host: Amphibolips gainesi Bass., A. quercusjuglans (0. S.), Callirlytis quercusventricosa (Bass.), Disholcaspis quercusglobulus (Fitch).

Eurytoma prunicola Walsh, 1870. Amer. Ent. and Bot. 2: 298. ๆ, o.

Eurytoma prunicola var. globulicola Walsh, 1870. Amer. Ent. and Bot. 2: 299.

Taxonomy: Bugbee, 1967. U. S. Natl. Mus., Proc. 118: 473 (syn.).

querci Fullaway. Calif. Host: Andricus lasius (Ashm.), Paracraspis guadaloupensis (Full.).

Euryfoma querci Fullaway, 1912. N. Y. Ent. Soc., Jour. 20: 278. ๆ, ठ.

querciglobuli querciglobuli (Fitch). N. H. and Ont., s. to Ga., w. to Minn., Tex. Host:

Disholcaspis quercusglobulus (Fitch), D. quercusmamma (Walsh).

Macroglenes Querci-globuli Fitch, 1859. N. Y. State Agr. Soc., Trans. 18: 812.

Eurytoma punctiventris Walsh, 1870. Amer. Ent. and Bot. 2: 299. ?.

Taxonomy: Bugbee, 1958. Ent. Soc. Amer., Ann. 51: 193-196.

Biology: Judd, 1957. Ent. News 68: 195.

querciglobuli rubra Bugbee. Fla., Miss. Host: Disholcaspis quercusvirens (Ashm.), D. spongiosa (Karsch).

Eurytoma querciglobuli inbra Bugbee, 1958. Ent. Soc., Amer., Ann. 51: 196. \&.

querciglobuli utahensis Bugbee. Utah. Host: Disholcaspis colorado (Gill.).

Eurytoma querciglobuli utaliensis Bugbee, 1958. Ent. Soc. Amer., Ann. 51: 197. \&.

rhois Crosby. Ont., Conn., N. Y., Pa., D. C., N. C., Fla., Ohio, Mich., Ind., Tenn., Mo., Ark., La., Kans. Ecology: Phytophagous in seeds of sumac. Host: Rhus copallina, R. glabra, $R$. typhina.

Eurytoma rhois Crosby, 1909. Canad. Ent. 41: 52. ९, ơ.

Biology: Crosby, 1909. Cornell Univ. Agr. Expt. Sta., Bul. 265: 385-388. - Gahan, 1922. Ent. Soc. Wash., Proc. 24: 42. - Bridwell, 1923. Wash. Acad. Sci., Jour. 13: 262. - Bugbee, 1939.

Ent. Soc. Amer., Ann. 32: 418-427. - Bugbee, 1941. Kans. Acad. Sci., Trans. 44: 228-233.

-Schread et al., 1942. Conn. Agr. Expt. Sta., Bul. 492: 496. - Neunzig, 1964. Ent. Soc.

Wash., Proc. 66: 87. - Wadhi et al., 1967 (1966). Indian Jour. Ent. 28: 498 (introd. into

India from Canada). 
rubribacca Bugbee. Idaho. Ecology: Reared from gall on wild raspberry, $R u b u s$ sp. Eurytoma rubribacca Bugbee, 1968. Kans. Ent. Soc., Jour. 41: 406. $₹$, ठ.

rubrigalla Bugbee. Mich. Ecology: Parasitizes inquilines and parasites of a cynipid gall maker, Diastrophues nebulosus (O. S.), on bramble, Rubres sp. Host: Ormyrus sp., Synophromorpha sylvestris (0. S.).

Eurytoma rubrigalla Bugbee, 1968. Kans. Ent. Soc., Jour. 41: 405. ๆ, ठे.

salicigalla Bugbee. Nev., Calif. Host: Enura exigrae Smith, E. lasiolepis Smith.

Eurytoma salicigalla Bugbee, 1970. Ent. Soc., Amer., Ann. 63: 434. ๆ, ठै.

Biology: Smith, 1970. Ent. Soc. Amer., Ann. 63: 1781 (initially parasitic, completing development by feeding on plant tissue).

salicisaquatica Bugbee. Nev., Calif. Host: Euura exiguae Smith, E. lasiolepis Smith, E. lemmonicte Smith.

Enrytoma salicisaquatica Bugbee, 1970. Ent. Soc. Amer., Ann. 63: 433. ๆ, ठ.

Biology: Smith, 1970. Ent. Soc. Amer., Ann. 63: 1781 (initially parasitic, completing development by feeding on plant tissue).

sciromatis Bugbee. N. C., Ga., Fla., La. Ecology: Phytophagous in a fungus causing cankers on pine branches and trunks. Host: Cronartium fusiforme.

Eurytoma sciromatis Bugbee, 1962. Kans. Ent. Soc., Jour. 35: 346. ₹, ठ̊.

Biology: Coulson and Franklin, 1970. Canad. Ent. 102: 353-357 (not parasitic on Dioryctria, but phytophagous).

semicircula Bugbee. Tex. Ecology: Reared from cerambycid larvae in fruits of Sapindus drummondii, the soapberry. Host: Leptostylus vogti Dillon.

Eurytoma semicircula Bugbee, 1967. U. S. Natl. Mus., Proc. 118: 453. ๆ.

seminis Bugbee. Kans., Okla. Ecology: Phytophagous in sumac seeds. Host: Rlus trilobuta. Eurytoma seminis Bugbee, 1941. Kans. Ent. Soc., Jour. 14: 98. ๆ, ठ.

semivenae Bugbee. N. Y., Ohio, Ark., Kans., Tex. Ecology: Reared from psyllid galls on hackberry. Host: Pachypsylla celtidismamma Riley, P. celtidisvesicula Riley. Eurytoma semivenae Bugbee, 1957. Kans. Ent. Soc., Jour. 30: 47. \&, ठ.

Biology: Moser, 1965. N. Y. State Mus. and Sci. Serv., Bul. 402: 22 (feeds both on gall maker and gall cell wall).

solenozopheriae Ashmead. Que., Maine, Mass., Conn., N. Y., N. J., Pa., D. C. Ecology:

Parasitizes a chalcid gall maker on blueberry. Host: Hemadas nubilipenuis (Ashm.). Eurytoma solenozopheriae Ashmead, 1887. Amer. Ent. Soc., Trans. 14: 196. $\%$, ठ.

Biology: Driggers, 1927. N. Y. Ent. Soc., Jour. 35: 254-258 (parasite of chalcid gall maker, not of cynipid gall maker). - McAlister and Anderson, 1932. Jour. Econ. Ent. 25: 1166.

sphaera Bugbee. La. Host: Disholcaspis quercusglobulus (Fitch), D. spongiosa (Karsch).

Eurytoma sphaera Bugbee, 1967. U. S. Natl. Mus., Proc. 118: 458. ๆ, o.

spina Bugbee. Sask., Oreg. Host: Diplolepis tuberculatrix (Ckll.).

Eurytoma spina Bugbee, 1951. Ent. Soc. Amer., Ann. 44: 250. ๆ, ठ.

spongiosa curvavena Bugbee. Minn. Host: Diplolepis spinosa (Ashm.).

Eurytoma spongiosa curvavena Bugbee, 1951. Ent. Soc. Amer., Ann. 44: 257. ๆ, ठै.

spongiosa spongiosa Bugbee. Ont. and Mass., s. to Va., w. to Sask., Utah. Ecology: Reared from spiny rose galls on wild roses. Host: Diplolepis dichlocera (Harris), D. rosae (L.), D. treberculatrix (Ckll.).

Eurytoma sporigiosa Bugbee, 1951. Ent. Soc. Amer., Ann. 44: 254. ๆ, ð.

squamosa Bugbee. Idaho, Wash., Calif. Ecology: Phytophagous in seeds of Ceanothus. Host:

Ceanothus cordulatus, $C$. dicaricatns, $C$. integerrimus, $C$. sanguineus, $C$. thyriaflorus, C. celntimus.

Eurytoma squamosa Bugbee, 1967. U. S. Natl. Mus., Proc. 118: 495. ₹, ठ́.

stigmi Ashmead. Nev., Oreg., Calif. Host: Hoplitis producta gracilis (Mich.), Hylaeus

(Paraprosopis) polifolii (Ckll.), Pemphredon giffardi (Roh.), Solierella similis (Brid.),

Stigmus inordinatus Fox, Trypoxylon sculleni Sandh.

Eurytoma stigmi Ashmead, 1895. In Davidson, Psyche 7: 271. ९, ठ. 
Biology: Parker and Bohart, 1966. Pan.-Pacifie Ent. 42: 94-96 (hosts).

studiosa Say. Que., s. to Fla., w. to B. C., Wash., Oreg., Calif. Ecology: Occurs wherever oaks grow. Host: Acraspis erinucei (Beut.), A. gemula (Bass.), A. macrocarpae Bass., $A$. pezomachoides (O.S.), A. quercushirta (Bass.), A. villosa Gill., Andricus ignotus (Bass.), A. quercusflocci (Walsh), A. quercuspetiolicola (Bass.), Callirhytis clavula (O. S.), C. elongatu (Kinsey), C. seminator (Harr.), Disholcaspis quercusglobulus (Fitch), D. quercussuccimipes (Ashm.), D. spongiosu (Karsch), D. washingtonensis (Gill.).

Eurytoma studiosu Say, 1836. Boston Jour. Nat. Hist. 1: 272. ?.

Eurytomu lanulue Fitch, 1859. N. Y. State Agr. Soc., Trans. 18: 817.

Eurytoma succinipedis Ashmead, 1881. Amer. Ent. Soc., Trans. 9: Proc., p. xxxi. \&, ơ.

Taxonomy: Bugbee, 1956. Ent. Soc. Amer., Ann. 49: 504 (syn.). - Bugbee, 1967. U. S. Natl. Mus., Proc. 118: 504 (syn.).

Biology: Walsh, 1870. Amer. Ent. and Bot. 2: 299. -Triggerson, 1914. Ent. Soc. Amer., Ann. 7: 9 .

terrea Bugbee. Oreg. Host: Diplolepis polita (Ashm.).

Eurytoma terrea Bugbee, 1951. Ent. Soc. Amer., Ann. 44: 238. ?, ठ.

tomici Ashmead. N. Y., Md., Va., Ga., Miss., La., Tex., Colo., Alta., Wash., Oreg., Calif. Host: Cylindrocopturus cutoni Buch., C. furnissi Buch., C. longulus (Lec.), Dendroctonus brecicom is Lec., Phloeosinus sp., Pityogenes plagiatus (Lec.).

Eurytoma tomici Ashmead, 1894. Amer. Ent. Soc., Trans. 21: 325. ठ.

Taxonomy: Bugbee, 1970. Ent. Soc. Amer., Ann. 63: 436 (redescription).

Biology: Furniss, 1942. Jour. Econ. Ent. 35: 858. - Bushing and Bright, 1965. Canad. Ent. 97: 200 (hosts).

tumoris Bugbee, Calif. Ecology: Phytophagous in branches of pines. Host: Pinus silvestris. Eurytoma tumoris Bugbee, 1962. Kans. Ent. Soc., Jour. 35: 345. $\uparrow$, ठ์.

Biology: Stark and Koehler, 1964. Pan-Pacific Ent. 40: 41 (immature stages).

tylodermatis Ashmead. Ont., s. to S. C., w. to Wis., Colo., Ariz. Host: Parasitic on bruchids and curculionids. Acanthoscelides horni (Pic), Amblycerus robiniae (F.), Baris sp., Chalcodermus aeneus Boh., Conotrachelus elegans Boh., Cylindrocopturus longulus (Lec.), Lixus musculus Say, L. scrobicollis Boh., Macrorhoptus sphaeralciae Pierce, Mimosestes sallaei (Sharp), Orthoris crotchii Lec., Smicraulax tuberculatus Pierce, Tachypterellus consors cerasi List, T. quadrigibbus (Say), Trichobaris texana Lec., $T$. trinotata (Say), Tyloderma foveolatum Say.

Eurytoma tylodermatis Ashmead, 1896. Amer. Ent. Soc., Trans. 23: 218. ९, ठै.

Taxonomy: Burks, 1967. In Krombein and Burks, U. S. Dept. Agr., Agr. Monog. 2, Sup. 2, p. 274.

Biology: Pierce, 1908. U. S. Dept. Agr., Bur. Ent. Bul. 73: 25-48. -Pierce, 1908. Jour. Econ.

Ent. 1: 119-121. - Cushman, 1911. Jour. Econ. Ent. 4: 496. - Pierce et al., 1912. U. S.

Dept. Agr., Bur. Ent. Bul. 100: 41-68. - Hunter and Pierce, 1912. U. S. Dept. Agr., Bur.

Ent. Bul. 114: 141. - List, 1932. Colo. Agr. Expt. Sta., Bul. 385: 54-59. - Parker and

Lamerson, 1934. Kans. Ent. Soc., Jour. 7: 90-92. - Hammer, 1936. N. Y. State Agr. Expt.

Sta., Tech. Bul. 240: 44-45. - Yip, 1936. Jour. Econ. Ent. 29: 624-626. - Ritcher, 1936. Jour.

Econ. Ent. 29: 698-699. - Beacher, 1947. Ent. Soc. Amer., Ann. 40: 533. - Nickels et al.,

1950. U. S. Dept. Agr., Tech. Bul. 1011: 3, 20. -Miller, 1953. Ohio Jour. Sci. 53: 60.

-Bugbee, 1967. U. S. Natl. Mus., Proc. 118: 492-493.

vernonia Bugbee. Pa., Miss., Kans., Okla. Ecology: Parasite of trypetid maggots in seeds of

Ironweed, Vernonia, and Sunflower, Helianthus. Host: Neaspilota alba (Loew),

Neotephritis finalis (Loew), Tomoplagia obliqua (Say).

Eurytoma vernonia Bugbee, 1967. U. S. Natl. Mus., Proc. 118: 481. ๆ, ठ.

Biology: Schwitzgebel and Wilbur, 1943. Kans. Ent. Soc., Jour. 16: 7-11 (Eurytoma sp.).

UNPLACEd SPECiES OF EURytoma ILliger

Eurytoma abuormicornis Walsh, 1870. Amer. Ent. and Bot. 2: 299.. Type lost. 
Eurytoma albitarsis Ashmead, 1902. In Chittenden, U. S. Dept. Agr., Div. Ent. Bul. 38: 88. Nom. nud.

Eurytoma aulacis Ashmead, 1892. In Brodie, Canad. Ent. 24: 12. Nom. nud.

Eurytoma cretheis Walker, 1843. Soc. Ent. de France, Ann. 2: 150. + . Type fragmentary.

Taxonomy: Burks, 1975. Brit. Mus. (Nat. Hist.) Ent., Bul. 32 (4): 162.

Lamprostylus floridauus Ashmead, 1887. Amer. Ent. Soc., Trans. 14: 193. ठ. Species placed in Eurytoma by Peck, 1951. In Muesebeck et al., U. S. Dept. Agr., Agr. Monog. 2: 576. Species cannot be placed from unassociated male.

Eurytoma hegeli Girault, 1921. U. S. Natl. Mus., Proc. 58: 207. Eurytoma hegeli var. maga Girault described, but Eurytoma hegeli Girault not described.

Isosoma nevadensis Ashmead, 1894. Amer. Ent. Soc., Trans. 21: 330. ठ. Species placed in Eurytoma by Peck, 1951. In Muesebeck et al., U. S. Dept. Agr., Agr. Monog. 2: 577. Species cannot be placed from unassociated male.

Eurytoma orbiculata Say, 1836. Boston Jour. Nat. Hist. 1: 272. ठ. Type lost.

Macroglenes quercipisi Fitch, 1859. N. Y. State Agr. Soc., Trans. 18: 818. Species placed in Eurytoma by Ashmead, 1900. In Smith, N. J. State Bd. Agr., Ann. Rpt. 27, Sup., p. 554.

Fragmentary specimen in U.S. N. M. labeled type does not agree with orig. descr.

\section{Family CHALCIDIDAE}

By B. D. BurKs

In 1923 Gahan and Fagan (U. S. Natl. Mus., Bul. 124: 24, 31, 133) changed the application of the well-known names Chalcis, Brachymeria, Smicra and Smiera. These names had been used extensively in the literature for almost a century. The changes very well may have been erroneous, because of the fact that Gahan and Fagan had examined none of the types of the type-species involved. Their conclusions were based entirely on a study of the literature, principally volume 5 of Dalla Torre's Catalogus Hymenopterorum, published in 1898. That work was a bibliographic, not a taxonomic, one. However, these changes in the application of familiar names were accepted by all subsequent workers except for Schmitz, who published a large work on the Ethiopian Chalcididae in 1946. All other works in the world literature followed Gahan and Fagan. An enormous literature that used these names as redefined by Gahan and Fagan has been published in the last 50 years. It would be a mistake at this late date to try to reverse the changes made by Gahan and Fagan, irrespective of their soundness. It should be kept in mind, however, that the application of those names before and after 1923 is quite different.

Taxonomy: Schmitz, 1946. Exploration Parc Natl. Albert, Mission De Witte, fasc. 48: 3-191 (African fauna). - Boucek, 1951. Mus. Natl. Pragae, Acta Ent. 27 (Sup.): 1-108 (European fauna). -Erdos, 1955. Magyar. Allat. 12 (Hymenoptera 2, pt. 2): 7-11 (key to genera). -Boucek, 1956. Res. Council Israel, Bul. 5B: 228-250 (Near East fauna). - Nikolskaja, 1960. Fauna SSSR (n. s.) 76: 41-191 (Russian fauna). - Habu, 1962. Fauna Japonica, Chalcididae, Leucospididae, and Podagrionidae, pp. 2-164 (Japanese fauna).

Biology: Steffan, 1958. Tenth Internatl. Cong. Ent., Proc. 1: 799-804 (world distrib.).

Morphology: Steffan, 1957. Paris Mus. Natl. d'Hist. Nat., Bul. (2) 19: 315-322 (abdominal petiole).

\section{SUBFAMILY HALTICHELLINAE}

The questions that have remained pending for many years concerning the application of the generic names Haltichella and Hockeria should be referred to the International Commission on Zoological Nomenclature for settlement. Usage of those names here follows the preponderant application of those names in current literature.

Revision: Steffan, 1951-1953. Feuille des Nat. (n. s.) 6: 1-7, 81-85; 8: 7-12, 33-36 (French fauna). - Steffan, 1951. Paris Mus. d'Hist. Nat., Mem. (n. s., A) 4: 51-86 (genera related to Enchalcidia). - Steffan, 1957. Soc. Ent. de France, Ann. 126: 139-158 (genera related to Chirocera). - Habu, 1960. Natl. Inst. Agr. Sci. Japan, Bul. (C) 11: 218-296 (Japanese fauna). 


\section{Genus HALTICHELLA Spinola}

Haltichella Spinola, 1811. Paris Mus. d'Hist. Nat., Ann. 17: 148.

Type-species: Chalcis pusilla Fabricius. Desig. by Westwood, 1840.

Halticella Stephens, 1829. Nomencl. Brit. Ins., p. 36, Emend.

Microchalcis Kieffer, 1904. Berlin. Ent. Ztschr. 49: 255.

Type-species: Microchalcis quadridens Kieffer. Monotypic.

Taxonomy: Masi, 1936. Soc. Ent. d'Egypte, Bul. 20: 252-254 (identity of type-species).

-Kerrich and Menon, 1949. Ent. Monthly Mag. 85: 207-211 (identity of type-species).

onatas (Walker). S. C., Ga., Fla., Miss., La., Kans., Tex. Host: Grapholitha molesta (Busck).

Hockeria onatas Walker, 1843. Soc. Ent. de France, Ann. (2) 1: 146. ․

Halticella longicornis Ashmead, 1887. Amer. Ent. Soc, Trans. 14: 185. ๆ.

Taxonomy: Burks, 1975. Brit. Mus. (Nat. Hist.) Ent., Bul. 32 (4): 164 (synonymy; lectotype designated).

Biology: Nettles, 1934. Jour. Econ. Ent. 27: 815-816 (longicornis).

rhyacionia Gahan. Mass. and N.Y., s. to S.C., w. to Nebr., Colo., Tex. Host: Rhyacionia bushnelli (Busck), R. frustrana (Comst.), R. rigidana (Fern.).

Haltichella rhyacioniae Gahan, 1927. Jour. Agr. Res. 34: 545. ๆ, ठ.

Biology: Underhill, 1934. Va. Agr. Expt. Sta., Bul. 349: 12. - Miller and Neiswander, 1959.

Ohio Agr. Expt. Sta., Res. Bul. 840: 18. - Schaffner, 1959. U. S. Dept. Agr., Misc. Pub. 767: 91.

xanticles (Walker). Que., s. to Fla., w. to Sask., Nebr., Kans., Okla., Tex. Host: Bucculatrix canadensiella Chamb., Coleophora laricella ( $\mathrm{Hbn}$.), Exoteleia pinifoliella (Chamb.), Grapholitha molesta (Busck.), Solenobia walshella Clem.; Apanteles melanoscelns (Ratz.).

Hockeria xanticles Walker, 1843. Soc. Ent. de France., Ann. (2) 1: 147. क.

Haltichella americana Howard, 1885. U. S. Dept. Agr., Bur. Ent. Bul. 5: 9, 36. ๆ.

Taxonomy: Burks, 1975. Brit. Mus. (Nat. Hist.) Ent., Bul. 32 (4): 165 (synonymy; lectotype designated).

Biology: Muesebeck and Dohanian, 1927. U. S. Dept. Agr., Bul. 1487: 18 (hyperparasitism). -Friend, 1927. Conn. (State) Agr. Expt. Sta., Bul. 288: 395 (primary parasite). - Allen, 1962. U. S. Dept. Agr., Tech. Bul. 1265: 108-109 (primary parasite).

\section{Genus HOCKERIA Walker}

Hockeria Walker, 1834. Ent. Mag. 2: 21, 34.

Type-species: Chalcis bispinosa Fabricius. Desig. by Kirby, 1883.

Stomatoceras Kirby, 1883. Linn. Soc. London, Jour., Zool. 17: 54, 62.

Type-species: Halticella liberator Walker. Orig. desig.

Centrochalcis Cameron, 1905. Ztschr. System. Hym. Dipt. 5: 230.

Type-species: Centrochalcis octodentata Cameron. Monotypic.

Hypochalcis Girault, 1915. Ent. News 26: 325.

Type-species: Chalcis modestns Masi. Orig. desig.

Taxonomy: Masi, 1936. Soc. Ent. d'Egypte, Bul. 20: 252-254 (identity of type-species).

-Kerrich and Menon, 1949. Ent. Monthly Mag. 85: 209 (identity of type-species). - Erdos,

1955. Magyar. Allat. (Hymenoptera 2, pt. 2): 8-9, 20 (Hungarian spp.).

americensis (Girault). N. J.

Stomatoceras unipunctatipennis americensis Girault, 1918. Ent. News 29: 127..

eriensis (Wallace). Del., s. to N. C., w. to Wash., Calif. Host: Mymeleon sp., M. immaculatus

Deg.

Stomatoceras rubra var. eriensis Wallace, 1942. Carnegie Mus., Ann. 29: 31. $q$, $\delta$.

Taxonomy: Steffan, 1959. Vie et Milieu 10: 304 (change from var. to sp.).

rubra (Ashmead). Va., Fla., Ark., Kans., Tex., Ariz., Calif.; Mexico. Host: Harrisina brillians B. and $\mathrm{MeD}$.

Stomatocera(!) rubra Ashmead, 1894. Amer. Ent. Soc., Trans. 21: 332. \&. 
tenuicornis (Girault). Mont., Ariz., Calif.

Stomatoceras tenuicomis Girault, 1918. Ent. News 29: 127. \&.

unipunctatipennis (Girault). N. Y., s. to Fla., w. to Wash., Oreg., Calif. Host: Neodiprion sp., N. excitans Rohwer.

Stomatoceras unipunctatipenn is Girault, 1918. Ent. News 29: 127. ๆ.

\section{Genus SCHWARZELLA Ashmead}

Schuarzella Ashmead, 1904. Carnegie Mus., Mem. 1: 256.

Type-species: Schuarzella arizonensis Ashmead. Monotypic.

The female of this genus has not been identified.

arizonensis Ashmead. N. Mex., Ariz., Calif.

Schwarzella arizonensis Ashmead, 1904. Carnegie Mus., Mem. 1: 256, 388. o.

UNPLACED TAXON IN HALTICHELLINAE

Hockeria perpulcra Walsh, 1861. Prairie Farmer (n. s.) 8: 258.

\section{SubFamily DIRHININAE}

Revision: Masi, 1947. Eos 33: 39-78 (world fauna to 1936).

Taxonomy: Burks, 1936. Natl. Acad. Sci., Proc. 22: 284-286 (Nearctic species). - Boucek, 1956.

Res. Council Israel, Bul. 5B: 249-250 (Mediterranean fauna). - Habu, 1960. Natl. Inst. Agr.

Sci. Japan, Bul. (C) 11: 309-310 (generic synonymy and subgenera).

\section{Genus DIRHINUS Dalman}

Dirhiuus Dalman, 1818. Svenska Vetensk. Akad., Handl. 39: 75.

Type-species: Dirhinus excavatus Dalman. Monotypic.

Dirhinus Dalman, 1823. Analecta Ent., p. 29. Emend.

Eniaca Kirby, 1883. Linn. Soc. London, Jour., Zool. 17: 54, 57.

Type-species: Chalcis comigera Jurine. Orig. desig.

Dirrhinoidea Girault, 1912. Arch. f. Naturgesch. 78A (9): 165.

Type-species: Dirminoidea maculata Girault. Orig. desig.

Parenaica Crawford, 1913. U. S. Natl. Mus., Proc. 45: 312.

Type-species: Parenaica schwarzi Crawford. Orig. desig.

Eniacella Girault, 1913. Wis. Nat. Hist. Soc., Bul. 11: 35.

Type-species: Eniacella ruficomis Girault. Orig. desig.

Revision: Burks, 1947. Ent. Soc. Wash., Proc. 49: 136-140.

Morphology: Greathead, 1959. Ent. Monthly Mag. 95: 105 (larvae). perideus Burks. Ill., Tex.

Dirhinus perideus Burks, 1947. Ent. Soc. Wash., Proc. 49: 137. o.

sehwarzi (Crawford). Tex., Ariz., Calif. Host: Melitara doddalis Dyar, Olycella junctolineella (Hulst), Pseudoschinia elautalis (Grote).

Pareniaca schu'ar $\approx$ i Crawford, 1913. U. S. Natl. Mus., Proc. 45: 312 ..

texanus (Ashmead). N. C., S. C., Ga., Ala., Ind., Tenn., Kans., Okla., Tex., Ariz.; Mexico. Host: Blaesoxipha plinthopyga (Wied.).

Eniaca texana Ashmead, 1896. Amer. Ent. Soc., Trans. 23: 217. ․

Dirhinus paoli Burks, 1947. Ent. Soc. Wash., Proc. 49: 137. o.

Biology: Roberts, 1935. Jour. Agr. Res. 50: 490-491.

\section{SUBFAMILY CHALCIDINAE}

Revision: Burks, 1940. U. S. Natl. Mus., Proc. 88: 237-354.

Taxonomy: Burks, 1939. Arb. ueber Morph. u. Taxonom. Ent. 6: 276-277 (key to genera). - Haupt, 1954. Deut. Ent. Ztschr. (n. s.) 1: 180-193 (Central European fauna), - Habu, 1960. Natl. Inst. Agr. Sci. Japan, Bul. (C) 11: 333-345 (Japanese fauna). 


\section{Genus METADONTIA Ashmead}

Metadontia Ashmead, 1888. Ent. Amer. 4: 87. No species. - Ashmead, 1904, Carnegie Mus., Mem 1: 252. One species.

Type-species: Smicra montana Ashmead. Desig. by Ashmead, 1904.

Plagiosmicra Cameron, 1904. Invertebrata Pacifica 1: 56.

Type-species: Plagiosmicra ashmeadi Cameron. Monotypic.

amoena (Say). Md., s. to Fla., w. to Ill., Mo., Kans., Ariz., Calif.; Mexico, Cent. and S. Amer. Host: Strymon ceerops (F.), S. melinus (Hbn.).

Chalcis amoena Say, 1836. Boston Jour. Nat. Hist. 1: 270.

Smicra montana Ashmead, 1887. Amer. Ent. Soc., Trans. 14: 183. o.

Plagiosmicra ashmeadi Cameron, 1904. Invertebrata Pacifica 1: 56..

Biology: Samuelson, 1961. Pan-Pacific Ent. 37: 190.

\section{Genus CHALCIS Fabricius}

Chalcis Fabricius, 1789 (1787). Mantissa Insectorum, v. 1, p. 272.

Type-species: Chalcis sispes Fabricius. Desig. by Latreille, 1810.

Smiera Spinola, 1811. Paris Mus. d'Hist. Nat., Ann. 17: 147.

Type-species: Chalcis sispes Fabricius. Desig. by Ashmead, 1904.

Smicra Spinola, 1837. Mag. Zool., 7 Cl. IX, explan. pl. 180. Emend.

In the European literature, Chalcis sispes Fabricius is uniformly treated as a synonym of Chalcis myrifex (Sulzer). The species of Chalcis are parasitic on Stratiomyidae throughout the Holarctic region. The stratiomyid eggs are laid in masses on plants or other objects above the water line in aquatic environments such as cattail bogs. The Chalcis adults, despite their relatively large size, oviposit in these eggs. When the stratiomyid eggs hatch the larvae migrate into the water. The Chalcis larvae remain inside them until the stratiomyids are fully grown. When the stratiomyids are ready to pupate they migrate to mud banks or other similar sites, above the water line. The Chalcis parasites then quickly complete their development and their adults emerge through round holes they cut in the exuviae of the stratiomyids.

Revision: Burks, 1940. U. S. Natl. Mus., Proc. 88: 243-260.

Taxonomy: Gahan and Fagan, 1923. U. S. Natl. Mus., Bul. 124: 31 (Chaleis must be used in the sense of Smicra and Smiera). - Schmitz, 1946. Exploration Pare Natl. Albert, Mission De Witte, fasc. 48: 70-72 (Smiera should be used for this genus).

barbara (Cresson). N. H., Conn., Mass., N. J., Fla., Mich., Ill., Iowa, Mo., Ark., N. Dak., Kans., Tex., Wyo., Colo.; Mexico. Host: Odontomyia sp., O. cincta Olivier, Stratiomys nomma Wied.

Smicra barbara Cresson, 1872. Amer. Ent. Soc., Trans. 4: 47. "

Smicra rufofemorata Cresson, 1872. Amer. Ent. Soc., Trans. 4: 39. ठ. Preoce. by

Rosenhauer, 1856.

Biology: Hart, 1895. Ill. State Lab. Nat. Hist., Bul. 4: 250, 271.

canadensis (Cresson). N. B., Ont., N. Y., W. Va., Mich., Wis., Ill., La. Host: Hedriodiscus vertebratus (Say), Odontomyia sp.

Smicra canadensis Cresson, 1872. Amer. Ent. Soc., Trans. 4: 39. ơ.

Biology: Judd, 1953. Amer. Midland Nat. 49: 817-819.

divisa (Walker). Kans., Okla., Tex., N. Mex., Ariz., Oreg., Calif.; Mexico.

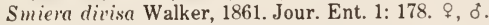

Morphology: Daly, 1963. Ent. Soc. Amer., Ann. 56: 303.

flebilis (Cresson). Maine, Mass., Conn., Ont., N. Y., N. J., Va., Ga., Fla., Mich., Ill., Minn. Smicra flebilis Cresson, 1872. Amer. Ent. Soc., Trans. 4: 39. ठै.

lasia Burks. Ariz., Calif.

Chalcis lasia Burks, 1940. U. S. Natl. Mus., Proc. 88: 248. ๆ, ơ.

megalomis Burks. Mich., Ill., Iowa, Wyo., Colo., Oreg. Host: Stratiomys sp.

Chalcis megalom is Burks, 1940. U. S. Natl. Mus., Proc. 88: 250. $\subsetneq$. 
microgaster Say. Ont., Pa., Md., Ga., Ohio, Mich., Wis., Ill., Minn., Kans., Okla., Tex.

Chalcis microgaster Say, 1824. In Keating, Narr. Long's 2nd Exped., App. p. 326.

neptis Burks. Nebr., Colo., N. Mex., Idaho, Utah, Ariz., Wash., Oreg., Calif.

Chalcis neptis Burks, 1940. U. S. Natl. Mus., Proc. 88: 251. + , o.

phoenicapoda Burks. Ga., Fla.

Smicra rufipes Kirby, 1883. Linn. Soc. London, Jour., Zool. 17: 70. Preocc. by Olivier, 1790.

Chalcis phoenicapoda Burks, 1940. U. S. Natl. Mus., Proc. 88: 257. N. name.

Taxonomy: Peck, 1963. Canad. Ent., Sup. 30: 869 (rufipes Kirby valid name for sp.).

\section{Genus SPILOCHALCIS Thomson}

Spilochalcis Thomson, 1876 (1875). Hym. Scand., v. 4, p. 15.

Type-species: Chalcis xanthostigma Dalman. Monotypic.

Diplodontia Ashmead, 1888. Ent. Amer. 4: 87.

Type-species: Smicra carolina Ashmead. Desig. by Ashmead, 1904.

Eustypiura Ashmead, 1904. Carnegie Mus., Mem. 1: 251, 253, 412.

Type-species: Eustypiura bicolor Ashmead. Orig. desig.

Enneasmicra Ashmead, 1904. Carnegie Mus., Mem. 1: 252, 253, 449.

Type-species: Smicra exinaniens Walker. Orig. desig.

Octosmicra Ashmead, 1904. Carnegie Mus., Mem. 1: 252, 253, 450.

Type-species: Octosmicra laticeps Ashmead. Orig. desig.

Heptasmicra Ashmead, 1904. Carnegie Mus., Mem. 1: 252, 253, 451.

Type-species: Smicra obliterans Walker. Orig. desig.

Hexasmicra Ashmead, 1904. Carnegie Mus., Mem. 1: 252, 254, 454.

Type-species: Smicra transversa Walker. Orig. desig.

Pentasmicra Ashmead, 1904. Carnegie Mus., Mem. 1: 252, 254, 455.

Type-species: Pentasmicra brasiliensis Ashmead. Orig. desig.

Tetrasmicra Ashmead, 1904. Carnegie Mus., Mem. 1: 252, 254, 456.

Type-species: Smicra concitata Walker. Orig. desig.

Trismicra Ashmead, 1904. Carnegie Mus., Mem. 1: 252, 254, 456.

Type-species: Smicra contracta Walker. Monotypic.

Cameron in 1910 (Amer. Ent. Soc., Trans. 35: 422-425), under the heading Spilochalcis Thomson, made a mistake and spelled the generic name for two of his three new species Spilosmicra. All authors have accepted this as a lapsus. In 1944 Graham (Ent. Soc. Ont., Ann. Rpt. 74: 49) recorded the European species Spilochalcis xanthostigma (Dalman) from Ontario (name spelled zanthostigmata by error). In 1965 I was able to find and re-examine the specimen on which this record was based; it was albifrons (Walsh).

Revision: Burks, 1940. U. S. Natl. Mus., Proc. 88: 243, 263-343.

SPECIES Group Transitiva

dorsata (Cresson). N. C., Ga., Fla., Ill., Mo., Kans., Tex.; Mexico.

Smicra dorsata Cresson, 1872. Amer. Ent. Soc., Trans. 4: 49..

Spilochalcis missonriensis Howard, 1885. U. S. Dept. Agr., Bur. Ent. Bul. 5: 6. ․

eubule (Cresson). Ga., Fla.; West Indies. Host: Enrema nicippe Cram., Phoebis sennae (L.).

Smiera Eubule Cresson, 1865. Ent. Soc. Phila., Proc. 4: 93.

exornata (Cresson). Tex., Ariz., Calif.; Mexico, Cent. Amer., West Indies. Mimorista flavidissimalis (Grote) listed questionably as a host.

Smicra exormata Cresson, 1872. Amer. Ent. Soc., Trans. 4: 50. o.

phoenica Burks. Tex., Ariz., Calif.; Mexico, Cent. Amer. Host: Chlosyne lacinia crocale (Edw.). Spilochalcis phoenica Burks, 1940. U. S. Natl. Mus., Proc. 88: 278. ९, §.

Biology: Drummond et al., 1970. Lepidopterists Soc., Jour. 24: 140.

transitiva (Walker). Ga., Fla.; West Indies.

Smiera transitiva Walker, 1862. Ent. Soc. London, Trans. (3) 1: 371..

Smiera pulchra Cresson, 1865. Ent. Soc. Phila., Proc. 4: 94.

Taxonomy: Burks, 1975. Brit. Mus. (Nat. Hist.) Ent. Bul. 32 (4): 165. 
SPECIES GROUP NigricorNis

coxalis (Cresson). N. Y., N. J., Pa., Md., Va., N. C., S. C., Ga., Iowa, Mo., Ark., Tex. Smicra coxalis Cresson, 1872. Amer. Ent. Soc., Trans. 4: 45. $\delta$.

Spilochalcis virens Howard, 1885. U. S. Dept. Agr., Bur. Ent. Bul. 5: 6. ठ.

flammeola (Cresson). Tex.

Smicra flammeola Cresson, 1872. Amer. Ent. Soc., Trans. 4: 48. १, ठ.

lasnierii (Guerin). Fla.; West Indies.

Chalcis Lasnierii Guerin, 1845. Iconogr. Regne Anim., Ins., v. 1, p. 412; v. 2, pl. 67. .

Chalcis lanieri Guerin, 1857. In de la Sagra, Hist. Fis. Polit. y Nat. Cuba, v. 7, p. 753. Emend.

Taxonomy: Gahan, 1934. Soc. Cubana de Hist. Nat., Mem. 8: 131-132.

Morphology: Burks, 1938. Ent. Soc. Amer., Ann. 31: 157-161 (forewing venation).

nigricornis (Fabricius). N. H., s. to Fla., w. to N. Dak. and Tex. Host: Adoneta spinuloides (H.-S.), Limacodes sp., Parasa indetermina (Bdv.).

Chalcis nigricornis Fabricius, 1798. Sup. Ent. System. p. 243.

Chalcis bracata Sanborn, 1863 (1862). Mass. Bd. Agr., Rpt. 10: 172. \&.

Smicra bracata coaequalis Cresson, 1872. Amer. Ent. Soc., Trans. 4: 46. ठ.

Smicra carolina Ashmead, 1887. Amer. Ent. Soc., Trans. 14: 183. ठ́.

Diplodontia secunda Girault, 1917. Deser. Hym. Chalcidoid. Variorum cum Observ. V, p. 10. ㅇ.?.

Taxonomy: Girault, 1920. U. S. Natl. Mus., Proc. 58: 194..

nortonii (Cresson). Conn., s. to Ga., w. to Ill. and Tex. Host: Limacodes sp., Phobetron pithecium (A. and S.), Prolimacodes badia (Hbn.).

Smicra Nortonii Cresson, 1872. Amer. Ent. Soc., Trans. 4: 45. ठ.

Biology: Schaffner, 1959. U. S. Dept. Agr., Misc., Pub. 767: 91.

SPECIES GROUP FEMORATA

delicata (Cresson). Mo., La., Tex.; West Indies.

Smicra delicata Cresson, 1872. Amer. Ent. Soc., Trans. 4: 54. ๆ.

elachis Burks. Fla., La.; West Indies.

Spilochalcis elach is Burks, 1940. U. S. Natl. Mus., Proc. 88: 294. $\subsetneq$.

enocki Ashmead. Ala., La., Tex.; Brazil. An adventive species, always taken at or near a southern port city.

Spilochalcis enocki Ashmead, 1904. Carnegie Mus., Mem. 1: 439. \&.

erythrina (Walker). Ark., Tex.; Mexico.

Smiera erythrina Walker, 1861. Jour. Ent. 1: 179. "ọ" =

Spilochalcis clora Burks, 1940. U. S. Natl. Mus., Proc. 88: 306. ठ̊. N. syn.

femorata (Fabricius). Ga., Fla., Tex.; Mexico, Cent. Amer., West Indies. Ecology: Perhaps the commonest species of Spilochalcis in the West Indies and Central America, particularly in cultivated areas.

Crabro femoratus Fabricius, 1775. Systema Ent., p. 375.

Smiera ignea Cresson, 1865. Ent. Soc. Phila., Proc. 4: 92.

Smicra mirabilis Cresson, 1872. Amer. Ent. Soc., Trans. 4: 53. 6.

Biology: Gowdey, 1921. Jamaica Dept. Agr., Ent. Cir. 4: 4.

hirtifemora (Ashmead). D. C., Va., N. C., S. C., Ga., Fla., Ohio, Tenn., Ill., La., Tex.; Mexico, Cent. and S. Amer., West Indies. Ecology: Both a primary and secondary parasite. Host: Mesogramma polita (Say), M. polygonastyla (Mete.), Platychimes sp.; Apanteles marginiventris (Cress.).

Smicra hirtifemora Ashmead, 1885. Amer. Ent. Soc., Trans. 12: Proc. p. x. ठౌ.

Spilochalcis syrphidis Wolcott, 1923. Porto Rico Dept. Agr., Jour. 7: 57.

igneoides (Kirby). N. H., s. to Fla., w. to Mont. and Ariz.; Mexico, Cent. Amer. Host: Acrobasis caryivorella Rag., A. indigenella (Zell.), A. juglandis (LeB.), Eurukuttarus confederata 
(Grote), Gretchena deludana (Clem.), Heliothis zea (Boddie), Spodoptera frugiperda (Smith).

Smicra igneoides Kirby, 1883. Linn. Soc. London, Jour., Zool. 17: 71.

Smicra vittata Ashmead, 1885. Amer. Ent. Soc., Trans. 12: Proc. p. x. ؟.

Spilochalcis mesillae Cockerell, 1897. Ann. Mag. Nat. Hist. (6) 19: 403..

Biology: Miller, 1963. Ohio Jour. Sci. 63: 70.

mariae (Riley). N. Y., s. to Fla., w. to Ill., Colo., Calif. Host: Hyalophora cecropia (L.), $H$. promethea (Drury), Philosamia cynthia (Drury), Rothschildia sp., Telea polyphemus (Cram.), Thyridopteryx ephemeraeformis (Haw.).

Chalcis maria Riley, 1870. Amer. Ent. 2: 101. đ, १.

Chalcis mariae Riley, 1872. Mo. State Bd. Agr., Ann. Rpt. 7: 109, 123. Emend.

Biology: Schaffner and Griswold, 1934. U. S. Dept. Agr., Mise. Pub. 188: 26, 152. -Balduf, 1937. Ent. Soc. Wash., Proc. 39: 180.

phais Burks. S. C., Tex., Ariz.

Spilochalcis phais Burks, 1940. U. S. Natl. Mus., Proc. 88: 307. ₹, ð.

\section{SPECIES Group Xanthostigma}

apaiis Burks. Tex.

Spilochalcis apaiis Burks, 1940. U. S. Natl. Mus., Proc. 88: 315. ․

arcana (Cresson). Mass., Del., Ala., N. Dak., Tex., Mont., Colo., Ariz.

Smicra arcana Cresson, 1872. Amer. Ent. Soc., Trans. 4: 44. ¿.

Suicra encausta Cresson, 1872. Amer. Ent. Soc., Trans. 4: 46. " $\delta "=q$.

bioculata (Cresson). Va., Fla., Ill., Iowa, Kans., Tex., Colo.

Smicra bioculata Cresson, 1872. Amer. Ent. Soc., Trans. 4: 43. ठ.

Smicra bioculata var. faceta Cresson, 1872. Amer. Ent. Soc., Trans. 4: 43. ơ.

juxta (Cresson). Md., Ill., Kans., Tex.; Mexico, Cent. and S. Amer., West Indies.

Smicra juxta Cresson, 1872. Amer. Ent. Soc., Trans. 4: 54. + .

Spilochalcis nigropleuralis Ashmead, 1904. Carnegie Mus., Mem. 1: 436. $ๆ, \delta$.

Taxonomy: Gahan, 1948. Wash. Acad. Sci., Jour. 38: 244 (type of nigropleuralis). lecta (Cresson). Tex., Calif.; Mexico.

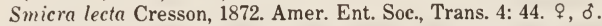

melana Burks. Maine, N. Y., Md., Va., Ill., Mo. Host: Pachyschelus laevigatus (Say).

Spilochalcis melana Burks, 1940. U. S. Natl. Mus., Proc. 88: 316 . ๆ, ơ.

odontotae Howard. N. J., D. C., N. C., Fla., Ariz.; Mexico. Host: Xenochalepus dorsalis (Thunb.).

Spilochalcis odontotae Howard, 1885. U. S. Dept. Agr., Bur. Ent. Bul. 5: 7, 32. ơ.

Biology: Chittenden, 1902. U. S. Dept. Agr., Div. Ent. Bul. 38: 82. -Krauss, 1952. Hawaii. Ent. Soc., Proc. 15: 124.

pallens (Cresson). S. C., Tex. Host: A panteles marginiventris (Cress.), Meteorus laphygmae Vier., Rogas laphygmae Vier.

Smiera palens Cresson, 1865. Ent. Soc. Phila., Proc. 4: 96.

Smicra pallens Cresson, 1865. Ent. Soc. Phila., Proc. 4: 196. Emend.

Biology: Vickery, 1929. U. S. Dept. Agr., Tech. Bul. 138: 21, 32-35, 50-52, 58.

pallipes (Smith). Fla., Minn. Host: Archips semiferanus (Walk.).

Chalcis flavipes Ashmead, 1885. Amer. Ent. Soc., Trans. 12: Proc. p. xi. ơ. Preocc. by

Fabricius, 1793; Panzer, 1801.

Chalcis pallipes Smith, 1886. Ent. Amer. 2: 19. N. name.

Chalcis pallidipes Dalla Torre, 1898. Cat. Hym., v. 5, p. 391. Emend.

subobsoleta (Cresson). Ill., Iowa, N. Dak., S. Dak., Kans., Tex. Mont., Wyo., Colo., Oreg.

Suicra subobsoleta Cresson, 1872. Amer. Ent. Soc., Trans. 4: 42. ठ.

tanais Burks. Tex., Calif.; Mexico. Host: Gnorimoschema sp.

Spilochalc is tanais Burks, 1940. U. S. Natl. Mus., Proc. 88: 309. ९, o.

xantha Burks. Tex., N. Mex., Ariz.

Spilochalcis xantha Burks, 1940. U. S. Natl. Mus., Proc. 88: 320 .. 
SPECIES Group SidE

Host records based on the rearing of a single male should be disregarded in this species group. albifrons (Walsh). Que, Maine, s. to Fla., w. to B. C., Wash., Oreg., Calif.; Mexico. Host: Exema dispar Lacord., Xenochalepus dorsalis (Thunb.); Ancylis comptana (Froel.), A. comptana fragariae (W. and R.), A. divisana (Walk.), Alsophila pometaria (Har.), Argyresthia aureoargentella Brow., A. laricella Kearf., A. thuiella (Pack.), Arogalea cristifasciella (Chamb.), Bedellia somnulentella (Zell.), Bucculatrix erariabilis Braun, Bomoloche deceptalis (Walk.), Choristoneura rostecena (Har.), Coleophore fletcherella Fern., C. fuscedinella Zell., C. Iaricella (Hbn.), C. malirorella Riley, C. pruniella Clem., Cremona cotoneastri Busck, Orgyia lencostigma (A. and S.),

Spodoptera exigua (Hbn.), Plutella maculipennis (Curtis), Psendaletia unipuncta (Haw.); A penteles atelantae (Pack.), A. congregatus (Say), A. griffini Vier., A. lacteicolor Vier., A. militaris (Walsh), Bathyplectes exigua (Grav.), Gelis minimus (Walsh).

Chalcis albifrons Walsh, 1861. Ill. State Agr. Soc., Trans. 4: 364, 369.

Spilochalcis toreine ancylae Girault, 1920. U. S. Natl. Mus., Proc. 58: 192. ค, ठ .

Biology: Daviault, 1942. La Foret Quebec. 4: 399. - Beacher, 1947. Ent. Soc. Amer., Ann. 40: 533-534. - Waddell, 1952. Ent. Soc. Brit. Columbia, Proc. 48: 97. - Harcourt, 1960. Canad.

Ent. 92: 423. - Eidt and Sippell, 1961. Canad. Ent. 93: 17. - Puttler, 1961. Ent. Soc. Amer., Ann. 54: 29. - Eidt, 1962. Canad. Ent. 94 : 34 (immature stages). - Poinar and Gyrisco, 1963. Jour. Econ. Ent. 56: 534 (primary parasite). - Kulman, 1965. Jour. Econ. Ent. 58: 864 (secondary parasite). - Puttler, 1966. Jour. Econ. Ent. 59: 483 (secondary parasite). - Cody et al., 1967. Mich. Ent. 1: 163.

delumbis (Cresson). Que., Ont., s. to Fla., w. to Wash., Oreg., Calif. Host: Chlamisus plicatus

(F.), Hypera rumicis (L.). Lema nigrovittata (Guer.), L. trilineata (Oliv.).

Smicra delumbis Cresson, 1872. Amer. Ent. Soc., Trans. 4: 40. , ठ.

Taxonomy: Smith, 1943. Kans. State Bd. Agr., Rpt. 62: 392 (description).

Biology: Chamberlin, 1933. Ent. Soc. Wash., Proc. 35: 106-107. -Weaver and Dorsey, 1965.

Ent. Soc. Amer., Ann. 58: 934. - Puttler, 1966. Jour. Econ. Ent. 59: 475.

dema Burks. Pa., Va., N. C., Ind., Mo., Kans., N. Mex., Ariz., Calif.; Mexico. Host: Frumenta nundinella (Zell.).

Spilochalcis dema Burks, 1940. U. S. Natl. Mus., Proc. 88: 330. ․ ठ.

flavopicta (Cresson). N. Y., s. to Fla., w. to Ill., Kans., N. Mex., Ariz., Calif.; Mexico, West Indies. Host: Acrobasis caryivorella Rag., Anacampsis fragariella Busck, A. innocnella (Zell.), Ancylis comptana (Froel.), A. comptana fragariae (W. and R.), Celama sorghiella (Riley), Cryptothelea nigrita (B. and McD.), Eurukuttamis confederata (Grote), Homoeosoma electellum (Hulst), Phalonia sp., Pieris protodice (B. and L.), Rhyacionia frustrana (Comst.), Sparganothis sulfureana (Clem.); Diadegma insulare (Cress.), Meteorns laphygmae Vier.

Smiera flavopicta Cresson, 1865. Ent. Soc. Phila., Proc. 4: 99.

Smicra delira Cresson, 1872. Amer. Ent. Soc., Trans. 4: 41. ס.

Smicra mendica Cresson, 1872. Amer. Ent. Soc., Trans, 4: 41. ठँ.

Smicra decem-punctata Ashmead, 1881. Amer. Ent. Soc., Trans. 9: Proc. p. xxix. 9.

Biology: Reinhard, 1938. Tex. Agr. Expt. Sta., Bul. 559: 31-32. - Underhill, 1943. Va. Agr. Expt. Sta., Bul. 349: 12. - Needham, 1948. Ecol. Monog. 18: 446.

leptis Burks. S. C., Ill., Ark., N. Dak., Nebr., Kans., Mont., Colo., N. Mex., Utah, Ariz., Idaho, Nev., Wash., Oreg., Calif. Host: Ancylis comptana (Froel.), Archips argyrospilus (Walk.), Cnephasia longana (Haw.), Rhyacionia frustrana (Comst.), Spilonota ocellana (D. and S.), Zelleria haimbachi Busck.

Spilochalcis leptis Burks, 1940. U. S. Natl. Mus., Proc. 88: 340., ठ.

Biology: Eikenbary and Fox, 1965. S. C. Agr. Expt. Sta., Tech. Bul. 1017: 6. sanguiniventris (Cresson). N. J., Va., N. C., Ga., Fla., Ark., Okla., Tex., Ariz., Calif. Host: Exema conspersa (Mann.), Nuzonia pallidula (Boh.); Plutella maculipennis (Curtis); Meteorus sp.

Smicra sanguiniventris Cresson, 1872. Amer. Ent. Soc., Trans. 4: 36, 43. ․ 
Smicra sanguineiventris Dalla Torre, 1898. Cat. Hym., v. 5, p. 381. Emend.

Biology: Rolston et al., 1965. Kans. Ent. Soc., Jour. 38: 366 (pupal parasite).

side (Walker). Maine, s. to Fla., w. to Wash., Oreg., Calif., Mexico, West Indies. Ecology: May be either a primary or secondary parasite. Host: Ceutorhynchus assimilis (Payk.), Hypera nigrirostris (F.), H. rumicis (L.), Rhynchaenus pallicormis (Say); Anagasta kuehniella (Zell.), Anarsia lineatella Zell., Ancylis comptana (Froel.), A. comptana fragariae (W. and R.), A. divisana (Walk.), Argyresthia thuiella Pack., Argyrotaenia velutinana (Walk.), Bucculatrix thurberiella Busck, Chorentis silphiella Grote, Choristoneura rosaceana (Har.), Coleophora fletcherella Fern., C. fuscedinella Zell., C. laricella (Hbn.), C. malivorella Riley, C. pruniella Clem., Depressaria heracliana (L.), Epinotia nanana (Treit.), Exoteleia pinifoliella (Chamb.), Galleria mellonella (L.), Grapholitha molesta (Busck), Hulstia undulatella (Clem.), Spodoptera frugiperda (A. and S.), Plutella maculipennis (Curtis), Recurvaria piceaella Kearf.; Apanteles congregatus (Say), A. medicagin is Mues., A. melanoscelus (Ratz.), A. militaris (Walsh), Campoletis argentifrons (Cress.), Diadegma insulare (Cress.), Meteorus laphygmae Vier., M. versicolor (Wesm.). This sp. is often reared in the laboratory; progeny in laboratory cultures may be much larger and differently proportioned than were their parents from the wild.

Smiera side Walker, 1843. Soc. Ent. de France, Ann. (2) 1: 145. ؟.

Smicra torvina Cresson, 1872. Amer. Ent. Soc., Trans. 4: 40. $\%$.

Taxonomy: Burks, 1975. Brit. Mus. (Nat. Hist.) Ent., Bul. 32 (4): 165.

Biology: Vickery, 1929. U. S. Dept. Agr., Tech. Bul. 138: 21, 32-33, 52-53, 58 (torvina).-Doner, 1936. Ent. Soc. Amer., Ann. 29: 234 (torvina).-Arthur, 1958, Canad. Ent. 90:

590-595 (immature stages). - Schaffner, 1959. U. S. Dept. Agr., Misc. Pub. 767: 91. -Allen, 1962. U. S. Dept. Agr., Tech. Bul. 1265: 111. - Roberts, 1966. Boyce Thomson Inst.,

Contrib. 23: 169 .

\section{Genus CERATOSMICRA Ashmead}

Ceratosmicra Ashmead, 1904. Carnegie Mus., Mem. 1: 251, 253, 369.

Type-species: Ceratosmicra petiolata Ashmead. Monotypic.

Mischosmicra Ashmead, 1904. Carnegie Mus., Mem. 1: 251, 253, 381.

Type-species: Mischosmicra kahlii Ashmead. Monotypic.

Melanosmicra Ashmead, 1904. Carnegie Mus., Mem. 1: 251, 253, 380, 447.

Type-species: Melanosmicra immaculata Ashmead. Orig. desig.

Sayiella Ashmead, 1904. Carnegie Mus., Mem. 1: 251, 253, 388.

Type-species: Smicra debilis Say. Orig. desig.

Eusayia Ashmead, 1904. Ent. Soc. Wash., Proc. 6: 126. N. name, unnecessarily proposed for Sayiella, thought to be preoce. by Sayella Dall, 1885.

Revision: Burks, 1940. U. S. Natl. Mus., Proc. 88: 343-351. - Burks, 1968. Ent. Soc. Wash.,

Proc. 70: 170-174.

campoplegicis Burks. Calif. Host: Apanteles koebelei Riley, Campoplegini (undet.).

Ceratosmicra campoplegicis Burks, 1968. Ent. Soc. Wash., Proc. 70: 172. $\%$.

debilis (Say). R. I., s. to Fla., w. to Minn., Iowa, Kans., Tex., Ariz., Calif.; Mexico, West Indies, Cent. and S. Amer.

Chalcis debilis Say, 1836. Boston Jour. Nat. Hist. 1: 271.

Smicra longipetiola Ashmead, 1885. Amer. Ent. Soc., Trans. 12: Proc. p. x. ð.

Mischosmicra Kahlii Ashmead, 1904. Carnegie Mus., Mem. 1: 251. ?.

immaculata (Cresson). Tex.; Mexico, Cent. and S. Amer. Host: Apanteles sp., Campoletis sonorensis (Cam.), Meteorus sp.

Smiera immaculata Cresson, 1865. Ent. Soc. Phila., Proc. 4: 97.

meteori Burks. Mass., s. to N. C., w. to Ill., La., Tex. and Wash.; Mexico. Host: A panteles delicatus How., A. hyphantriae Riley, A. melanoscelus (Ratz.), Casinaria limenitidis (How.), Meteorns hyphantriae Riley.

Ceratosmicra meteori Burks, 1940. U. S. Natl. Mus., Proc. 88: 346. $९$, ठ. 
paya Burks. Ga., Ill., Mo., Kans., Tex., Calif.

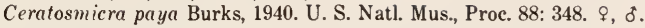

provancheri Burks. Mass., Pa.

Ceratosmicra provancheri Burks, 1968. Ent. Soc. Wash., Proc. 70: 171..

\section{SUBFAMILY BRACHYMERIINAE}

Taxonomy: Steffan, 1950. Soc. Ent. de France, Bul. 55: 146-150 (tribal classification). -Steffan, 1950. Paris Mus. d'Hist. Nat., Bul. (2) 22: 596-602 (tribal classification).

-Steffan, 1956. Soc. Ent. de France, Bul. 61: 238-242 (generic list with synonymy).

-Steffan, 1959. Mus. Natl. Pragae, Acta Ent. 33: 288 (key to tribes). - Habu, 1960. Natl.

Inst. Agr. Sci. Japan, Bul. (C) 11: 140-141 (key to tribes).

\section{Genus ACANTHOCHALCIS Cameron}

\section{Genus ACANTHOCHALCIS Subgenus ACANTHOCHALCIS Cameron}

Acanthochalcis Cameron, 1884. Biol. Cent.-Amer., Hym., v. 1, p. 100.

Type-species: Acanthochalcis nigricans Cameron. Monotypic.

Taxonomy: Girault, 1920. U. S. Natl. Mus., Proc. 58: 193-194. -Steffan, 1959. Mus. Natl.

Pragae, Acta Ent. 33: 307.

nigricans Cameron. Kans., Okla., Tex., N. Mex., Ariz., Calif.; Mexico.

Acanthochalcis nigricans Cameron, 1884. Biol. Cent.-Amer., Hym., v. 1, p. 100. $\&$.

\section{Genus ACANTHOCHALCIS Subgenus BELOCHALCIS Steffan}

Acanthochalcis subg. Belochalcis Steffan, 1959. Mus. Natl. Pragae, Acta Ent. 33: 308.

Type-species: Acanthochalcis unispinosa Girault. Monotypic.

unispinosa Girault. Tex., Ariz., Calif. This species is probably the largest one in the Chalcidoidea.

Acanthochalcis unispinosa Girault, 1917. New Chalcid Flies, p. 5.

\section{Genus PHASGONOPHORA Westwood}

Phasgonophora Westwood, 1832. In Griffith, Cuvier's Animal Kingdom 15 (Insecta 2), p. 432 , pl. 77 , fig. 2.

Type-species: Phasgonophora snlcata Westwood. Monotypic.

Phasganophora Sichel, 1865. Soc. Ent. de France, Ann. (4) 5: 347. Emend.

suleata Westwood. N. B., Maine, N. H., s. to Fla., w. to Oreg., Calif. Host: Agrilus anxius Gory, A. bilineatus (Weber), Chrysobothris femorata (Olivier).

Phasgonophora sulcata Westwood, 1832. In Griffith, Cuvier's Animal Kingdom 15 (Insecta 2), p. 432. ‥

Smicra gigantea Ashmead, 1881. Canad. Ent. 13: 90. ^.

Taxonomy: Burks, 1940. U. S. Natl. Mus., Proc. 88: 351 (gigantea Ashm.).

Biology: Blackman and Stage, 1924. N. Y. State Col. Forestry, Syracuse Univ., Tech. Pub. 17:

$19,22,25$. - Rhodes, 1924. In Blackman and Stage, N. Y. State Col. Forestry, Syracuse

Univ., Tech. Pub. 17: 188. - Hoffman, 1940. Brooklyn Ent. Soc., Bul. 35: 63. -Nash et al.,

1951. Maine Forest Serv., Bul. 15: 40. - Barter, 1957. Canad. Ent. 89: 32.

\section{Genus TRIGONURA Sichel}

Phasganophora subg. Trigonura Sichel, 1865. Soc. Ent. de France, Ann. (4) 5: 347, 358, 376.

Type-species: Phasganophora (Trigonura) crassicauda Sichel. Monotypic.

Bactrochalcis Kieffer, 1912 (1911). Soc. Ent. de France, Ann. 80: 463.

Type-species: Bactrochalcis reticulata Kieffer. Monotypic.

Centrocha/cis Cameron, 1913. Indian Forest Rec. 4: 92. Preocc. by Cameron, 1905.

Type-species: Centrochalcis ruficaudis Cameron. Monotypic. 
Centrochalcidea Gahan and Fagan, 1923. U. S. Natl. Mus., Bul. 124: 28. N. name for Centrochalcis Cameron.

Revision: Burks, 1959. Ent. Soc. Amer., Ann. 52: 75-81.

algerti Burks. Tex., N. Mex., Ariz., Calif. Host: Chrysobothris octocola Lec., C. piuta Wick.

Trigonura algerti Burks, 1959. Ent. Soc. Amer., Ann. 52: 77. $\$, \delta$.

californica Rohwer. Utah, Ariz., Oreg., Calif. Host: Chrysobothris femorata (Olivier), C. mali Horn.

Trigonura califomica Rohwer, 1917. U. S. Natl. Mus., Proc. 53: 171. + , o.

elegans (Provancher). Que., Conn., Ont., N. Y., Pa., W. Va., Ill., Ark. Host: Chrysobothris femorata (Olivier), C. sexsignata Say, Magdalis armicollis (Say), M. barbita (Say), $M$. olyra (Herbst).

Phasgonophora elegans Provancher, 1887. Addit. Corr. Faune Ent. Canada, Hym., p. 191. ㅇ.

Trigonura hicoriae Rohwer, 1919. Canad. Ent. 51: 160. $९$, ठ̊.

Biology: Kaston, 1937. Conn. (State) Agr. Expt. Sta., Bul. 396: 357, 358. (hicoriae).

insularis (Cresson). Fla.; West Indies.

Phasgonophora insularis Cresson, 1865. Ent. Soc. Phila., Proc. 4: 102. , ठ.

pini Burks. Idaho, B. C., Wash., Oreg., Calif.

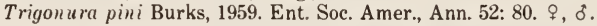

tarsata (Dalla Torre). N. B., Que., N. H., Vt., Mass., Ont., N. Y., Pa., Va., W. Va., N. C., Ohio.

Host: Magdalis a micollis (Say), M. barbita (Say), Pissodes strobi (Peck).

Chaleis tarsalis Ashmead, 1894. Amer. Ent. Soc., Trans. 21: 332. o. Preoce. by

Motschulsky, 1863.

Chalcis tarsata Dalla Torre, 1898. Cat. Hym., v. 5, p. 393. N. name.

Biology: Hoffman, 1940. Brooklyn Ent. Soc., Bul. 35: 63.

ulmi Burks. Que., Ont., Vt., Conn., N. Y., N. J., Pa., N. C., Mich., Ill., Iowa, N. Dak. Host:

Magdalis armicollis (Say), Scolytus sp., S. quadrispinosus Say.

Trigonura ulmi Burks, 1959. Ent. Soc. Amer., Ann. 52: 80. ․, ठ’.

\section{Genus BRACHYMERIA Westwood}

Revision: Masi, 1929. Soc. Ent. Ital., Mem. 8: 117-120 (Ethiopian species). -Blanchard, 1935. Soc. Ent. Argentina, Rev. 7: 103-109 (Argentine species). - Burks, 1936. Ill. State Acad. Sci., Trans. 29: 251-254 (Illinois species). - Boucek, 1951. Mus. Natl. Pragae, Acta Ent. 27, Sup., 1: 17-29 (European species). - Erdos, 1955. Fauna Hung. 12 (2): 7-16 (Hungarian species). - Steffan, 1959. Cahiers des Nat. (n. s.) 15: 35-43 (French species). - Burks, 1960. Amer. Ent. Soc., Trans. 86: 225-273 (Neartic species). - Habu, 1960. Natl. Inst. Agr. Sci. Japan, Bul. (C) 11: 142-212 (Japanese species). -Joseph et al., 1973. Univ. Calicut, Zool. Monog. 1: 5-209 (Oriental species).

Taxonomy: Gahan and Fagan, 1923. U. S. Natl. Mus., Bul. 124: 24, 31 (Brachymeria should repalce Chalcis of authors, not Fabricius). - Schmitz, 1946. Exploration Parc Natl. Albert, Mission De Witte, fasc.48: 15 (Chalcis correct name for this genus). - Ghesquiere, 1946. Rev. Zool. et Bot. Africaines 39: 372 (Brachymeria correct name for this genus).

\section{Genus BRACHYMERIA Subgenus BRACHYMERIA Westwood}

Brachymeria Westwood, 1829. In Stephens, Nomencl. Brit. Ins., v. 1, p. 36.

Type-species: Chalcis minnta Fabricius. Desig. by Westwood, 1840.

Tumidicoxa Girault, 1911. Zool. Jahrb., Abt. f. System. 31: 378.

Type-species: Tumidicoxa nigra Girault. Orig. desig.

Ceyxia Girault, 1911. Zool. Jahrb., Abt. f. System. 31: 382.

Type-species: Ceyxia frmipennis Girault. Orig. desig.

Brachepitelia Girault, 1913. Canad. Ent. 45: 106.

Type-species: Brachepitelia mbripes Girault. Orig. desig.

Pseudepitelia Girault, 1913. Canad. Ent. 45: 104.

Type-species: Psendepitelia rubrifemur Girault. Orig. desig.

Tumidicoxella Girault, 1913. Roy. Soc. So. Austral., Trans. 37: 74. 
Type-species: Tumidicoxella nigricoxa Girault. Orig. desig.

Tumidicoxoicles Girault, 1913. Arch. f. Naturgesch. 79A (6): 86.

Type-species: Tumidicoxoides kurandaensis Girault. Monotypic.

Taxonomy: Habu, 1960. Natl. Inst. Agr. Sci. Japan, Bul. (C) 11: 144 (changed from genus to subgenus).

aeca Burks. N. S., Que., Maine, s. to Fla., w. to B. C., N. Mex. Host: Chaetophlepsis sp.

Probably parasitize other Tachinidae that parasitize Lepidoptera or Tenthredinidae.

Brachymeria (Brachymeria) neca Burks, 1960. Amer. Ent. Soc., Trans. 86: 242. ?, ठ. alexinus (Walker). Ga.

Perilampus alexinus Walker, 1846. List. Hym. Brit. Mus., Chalcid., v. 1, p. 89. ठ.

Taxonomy: Burks, 1975. Brit. Mus. (Nat. Hist.) Ent., Bul. 32 (4): 164 (transferred to Brachymeria).

belfragei (Crawford). Tex.; Mexico, Cent. Amer.

Chalcis belfrayei Crawford, 1910 (1909). Ent. Soc. Wash., Proc. 11: 205. ๆ.

coloradensis (Cresson). N. H., Ont., s. to Fla., w. to B. C., Calif.; Holarctic. Ecology: Oviposit on the wing in grasshoppers containing sarcophagid or tachinid parasites. Host:

Blaesoxipha hunteri (Hough), B. kellyi (Ald.), Ceracia dentata (Coq.).

Chalcis femorata Dalman, 1820. Svenska Vetensk. Akad., Handl. 41: 143. + . Preoce. by

Panzer, 1801.

Chaleis colorudeusis Cresson, 1872. Amer. Ent. Soc., Trans. 4: 60. ठ.

Chalcis Dalmanni (!) Thomson, 1875. Hym. Scand., v. 4, p. 17. ठ, ․ N. name for femorata Dalman.

Chalcis tuchinae Howard, 1885. U. S. Dept. Agr., Bur. Ent. Bul. 5: 8, 32, 36. $q$.

Biology: Burks, 1941. Ill. State Acad. Sci., Trans. 33: 208. - Smith, 1944. Canad. Ent. 76 : 29-32. - Smith, 1957. Canad. Jour. Res, 36: 258. - Spencer, 1958. Tenth Internatl. Ent. Cong., Proc. 4: 497. - Nikolskaja, 1960. Akad. Nauk SSSR, Zool. Inst., Trudy 27: 222.

-Steffan, 1962. Fragmenta Ent. 4: 23. -Smith, 1965. Canad. Jour. Zool. 43 : 187.

- Huggans and Blickenstaff, 1966. Mo. Agr. Expt. Sta., Res. Bul. 903: 36.

comitator (Walker). N. Y., N. J., Fla., Tex.; Mexico, s. to Brazil. An adventive species, always brought in in bananas. Host: Ceramidia sp., C. butleri (Moesch.), C. viridis (Druce).

Chalcis comitator Walker, 1862. Ent. Soc. London, Trans. (3) 1: 350. o.

Biology: Harrison, 1963. Jour. Econ. Ent. 56: 284 (both primary and secondary parasite).

compsilurae (Crawford). Maine, Ont., s. to N. C., w. to Man., Mont., Colo., N. Mex., B. C., Oreg. Host: Blepharipa seutellata (R.-D.), Carcelia amplexa (Coq.), C. laxifrons Vill.,

Compsilura concinnata (Meig.), Euphorocera claripennis (Macq.), E. edwardsii (Will.),

Exorista larvarum (L.), Leschenaultia fulvipes (Bigot), Lespesia aletia (Riley), L.

frenchii (Will.), Parasetigena agilis (R.-D.), Pelatachina pellucida Coq.,

Tounsendiellomyia nidicola (Tns.).

Chalcis compsilurue Crawford, 1911. U. S. Natl. Mus. Proc. 41: 272. ₹, ơ.

Biology: Dowden, 1935. Jour. Agr. Res. 50: 495-523. - Salt, 1941. Cambridge Phil. Soc., Biol.

Rev. 16: 253-255. - Flanders, 1944. Jour. Econ. Ent. 37: 409-410. - Kulman and Hodson,

1961. Jour. Econ. Ent. 54: 221. - Dixon and Benjamin, 1963. Jour. Econ. Ent. 56: 267.

fonscolombei (Dufour). N. J., s. to Fla., w. to Ill., Mo., Kans., Colo., Ariz., Calif.; world-wide, in all faunal regions. Host: Blaesoxipha impar (Ald.), B. plinthopyga (Wied.), Calliphora coloradensis Hough, Cochliom yia macellaria (F.), Lucilia illustris (Meig.), Orchellia caesarion (Meig.), Phaenicia mexicana (Macq.), P. sericata (Meig.), Phormia regina (Meig.), Sarcophaga sp., S. haemorrhoidalis (Fall.), Synthesiomyia nudiseta (Wulp).

Chalcis podagrica Fonscolombe, 1832. Ann. des Sci. Nat. 26: 277. Preocc. by Fabricius, 1787.

Chalcis Fonscolombei Dufour, 1841. Soc. Ent. de France, Ann. 10: 12. N. name.

Taxonomy: Burks, 1936. Ill. State Acad. Sci., Trans. 29: 254 (lectotype). -Gahan, 1942. U. S. Natl. Mus., Proc. 92: 49 (redescription). 
Biology: Roberts, 1933. Ent. News 44: 158. - Roberts, 1933. U. S. Dept. Agr., Tech. Bul. 365: 1-21. - Roberts, 1933. Ecology 14: 311-312. -Jannone, 1934. Lab. Zool. Gen. e Agr. Portici, Bol. 28: 146. - Roberts, 1935. Jour. Agr. Res. 50: 489-490. - Nikolskaja, 1960. Akad. Nauk SSSR, Zool. Inst., Trudy 27: 222.

hammari (Crawford). Md., s. to Fla., w. to Ill., Mo., Kans., Calif. Host: Acroba sis caryae Grote, A. juglandis (LeB.), Ancylis comptana fragariae (W. and R.), Archips argyrospilus (Walk.), Argyrotaenia citrana (Fern.), Filatima monotaeniella (Bott.), Grapholitha molesta (Busck), Laspeyresia caryana (Fitch), L. pomonella (L.), Platynota sultana Wlshm., Psorosina hammondi (Riley).

Chalcis hammari Crawford, 1915. Insecutor Inscitiae Menstruus 3: 89. ‡, ठ.

Biology: Nettles, 1934. Jour. Econ. Ent. 27: 815-816. - Nickels et al., 1950. U. S. Dept. Agr.,

Tech. Bul. 1011: 2, 18. - Bennett, 1961. Tenn. Acad. Sci., Jour. 36: 353.

incerta (Cresson). Fla.; West Indies, British Guiana, Brazil. Ecology: Both primary and secondary parasite. Host: Alabama argillacea (Hbn.), Ascia monuste (L.), Brassolis sophorce (L.), Calpodes ethlins (Stoll), Eantis thraso Hbn., Lymire albipennis (H.-S.), Megalopyge krugii Dewitz, Mesocondyla concordalis Hbn., M. gastralis Guen., Phoebis semae (L.), Pieris monuste (L.), Sylepta sp.; Carcelia flavirostris (Wulp).

Chalcis incerta Cresson, 1865. Ent. Soc. Phila., Proc. 4: 101.

Taxonomy: Wolcott, 1936. Puerto Rico Univ., Jour. Agr. 20: 535 (description and fig.). -Dinther, 1960. Surinam. Landproefsta. (B) 76: 126 (description and fig.).

Biology: Waterston, 1923. Bul. Ent. Res. 14: 104. - Cleare and Squire, 1934. Agr. Jour. Brit. Guiana 5: 190. -Fife, 1939. Puerto Rico Agr. Expt. Sta., Bul. 39: 6. -Needham, 1948. Ecol. Monog. 18: 446.

intermedia (Nees). Maine, N. H., Vt., Mass., R. I., Conn., N. Y., N. J., Pa., Del., Md.; Europe, N. Africa. Introduced first in 1905 from Europe, and repeatedly introduced until 1933; first recovered in Mass. in 1942. Recovered in large numbers since 1960. Host: Porthetria dispar (L.). Numerous other hosts in Lepidoptera and some in Diptera recorded in the literature.

Chalcis intermedia Nees, 1834. Hym. Ichn. Aff. Monog., v. 2, p. $29 . \delta$.

Biology: Howard and Fiske, 1911. U. S. Dept. Agr., Bur. Ent. Bul. 91: 240-309 (flavipes). -Masi, 1916. Mus. Civ. Stor. Nat. Genova, Ann. (3) 7: 78 (flavipes)._Fahringer, 1921. Ztschr. f. Wiss. Insektenbiol. 17: 43. - Mercet, 1923. Rev. Fitopat. 1: 17. - Burgess and Crossman, 1929. U. S. Dept. Agr., Tech. Bul. 86: 116-118. - Mercet, 1932. Par. Ins. Perjudiciales, pp. 66-68. - Dowden, 1935. Jour. Agr. Res. 50: 497-509. -Schedl, 1936. Ztschr. Angew. Ent. 22, Beiheft, pp. 169-170. - Boucek and Sedivy, 1954. Folia Zool. et Ent. 3: 183. - Karnozitzky, 1957. Bulgar. A kad. Nauk Zool. Inst., Trud. 4: 51, 97. - Martelli and Arru, 1958. Bol. Zool. Agr. e Bachicolt. (2) 1: 26. - Kolomiets, 1958. Ent. Obozr. 37: 608. - Romanyk, 1959. Acad. de Cien. Exact., Fis. y Nat., Madrid, Rev. 53: 402. - Burks, 1960. Ent. News 71: 62. - Romanyk and Ruperez, 1960. Entomophaga 5: 231.

- Hazdistevic, 1961. Zastita Bilja 56-66: 107. - Stefanov and Keremedziev, 1961. Sofia Vissch. Lesotekh. Inst. Nauch., Trud. 9: 165. - Capek, 1963. Banska Stiavnica. Vyskum. Ustav Lesn. Hosp. Ved. Prace 4: 265. -Zelinskaya, 1964. Akad. Nauk Ukrain. RSR, Inst. Zool., Trudy 20: 199. - Leonard, 1966. Ent. News 77: 25. - Prokopy, 1968. Jour. Econ. Ent. 61: 351. - Leonard, 1971. Canad. Ent. 103: 654. - Doane, 1971. Ent. Soc. Amer., Ann. 64: 753.

molestae Burks. Md., s. to Fla., w. to Ind., Tenn., Miss. Host: Anchylopera platanana Clem., Ancylis comptana fragariae (W. and R.), Arogalea cristifasciella (Chamb.), Grapholitha molesta (Busck).

Brachymeria (Brachymeria) molestae Burks, 1960. Amer. Ent. Soc., Trans. 86: 245. ๆ, ठ.

Biology: Eikenbary and Fox, 1965. S. C. Agr. Expt. Sta., Tech. Bul. 1017: 6.

ovata (Say). Conn., N. Y., and Ont., s. to Fla., w. to Oreg. and Calif.; Mexico. Ecology: Oviposits in the pupae of over 100 species of Lepidoptera of the families Psychidae to Papilionidae, the limiting factor being size, pupae of $1.5 \mathrm{~cm}$. or greater length, and exposure---it finds its hosts on the wing, not by crawling into crevices.

Chalcis ovata Say, 1824. In Keating, Narr. Long's 2nd Exped., App. p. 326. 
Leucospis integre Haldeman, 1844. Acad. Nat. Sci. Phila., Proc. 2: 53. ठ.

Chalcis orate var. abiesae Girault, 1917. Deser. Stellarum Nov., p. 19. ๆ, ठ.

Taxonomy: Cresson, 1872. Amer. Ent. Soc., Trans. 4: 35 (redescription of ovata Say, probably synonym of integre Hald.). - Rohwer, 1918. Ent. Soc. Wash., Proc. 20: 18 (var. abiesae). -Burks, 1960. Amer. Ent. Soc., Trans. 86: 259 (synonymy).

Biology: Howard, 1897. U. S. Dept. Agr., Div. Ent., Tech. Ser. 5: 25-28._Snodgrass, 1917. Ind. State Ent., Ann. Rpt. 9: 180, 188-189. - Burks, 1936. Ill. State Acad. Sci., Trans. 29: 253 (hibernation). - Balduf, 1937. Ent. Soc. Wash., Proc. 39: 180-181. - Donohoe and Kaloostian, 1937. Jour. Econ. Ent. 30: 967-968. -Genung, 1959. Fla. Ent. 42: 40.

-Schaffner, 1959. U. S. Dept. Agr., Misc. Pub. 767: 91 (life cycle). - Bennett, 1961. Tenn. Acad. Sci., Jour. 36: 353 (habits). - Allen, 1962. U. S. Dept. Agr., Tech. Bul. 1265: 110-111 (life hist.). - Arthur, 1962. Canad. Ent. 94: 1087. -Oatman and Jenkins, 1962. Mo. Univ., Col. Agr., Res. Bul. 789: 13. -Ciesla, 1964. Ent. Soc. Amer., Ann. 57: 595. - Roberts, 1966. Boyce Thompson Inst., Contrib. 23: 169.

Morphology: Burks, 1936. Ill. State Acad. Sci., Trans. 29: 253 (male genitalia). - Snodgrass, 1941. Smithsn. Inst., Misc. Collect. 99: 36-37 (male genitalia).

robusta (Cresson). Fla.; West Indies. Host: Celerio lineata (F.), Spodoptera frugiperda (Smith), Lymire ednardsi Grote, Megalopyge krngii Dewitz, M. opercularis (A. and S.), Mocis latipes (Guen.), Neonympha sp., Papilio cresphontes Cram.

Chalcis robusta Cresson, 1865. Ent. Soc. Phila., Proc. 4: 101.

Chalcis robustella Wolcott, 1924 (1923). Puerto Rico Dept. Agr., Jour. 7: 56.

Biology: Genung, 1959. Fla. Ent. 42: 40.

russelli Burks. Miss., Tex., N. Mex., Ariz.; Mexico. Host: Chelymorpha cassidea (F.), Coptocycla (Psalidonota) texana (Schaeffer), Nuzonia sp.

Brachymeria (Brachymeria) russelli Burks, 1960. Amer. Ent. Soc., Trans. 86: 240. ९, o. slossonae (Crawford). Fla. Host: Ephyriades brunnea floridensis B. and C.

Chalcis slossonae Crawford, 1910 (1909). Ent. Soc. Wash., Proc. 11: 205. ๆ, ठ์.

Biology: Tamburo and Butcher, 1955. Fla. Ent. 38: 68.

tegularis (Cresson). Tenn., Wis., Ill., Ark., Tex., w. to Wash., Oreg., Calif. Ecology: A secondary parasite of grasshoppers. Host: Ceracia dentata (Coq.), Hemithrixion oestriforme B. and B.

Chalcis tegularis Cresson, 1872. Amer. Ent. Soc., Trans, 4: 60. ․

Biology: Burks, 1940. Ill. State Acad. Sci., Trans. 33: 208. - St. Amand and Cloyd, 1954. Jour. Parasitol. 40: 83. - Smith, 1957. Canad. Jour. Zool. 36: 259. - Spencer, 1958. Tenth

Internatl. Cong. Ent., Proc. 4: 501.

truncatella Burks. Sask., Nebr., Kans., Tex., Colo., N. Mex., Ariz., Calif.

Brachymeria (Brachymeria) truncata Burks, 1960. Amer. Ent. Soc., Trans. 86: 234. ९, o. Preocc. by Brachymeria truncata (Schmitz), 1946.

Brachymeria truncatella Burks, 1967. In Krombein and Burks, U. S. Dept. Agr., Agr. Monog. 2, Sup. 2: 279. N. name.

weemsi Burks. Ga., Fla.

Brachymeria (Brachymeria) weemsi Burks, 1960. Amer. Ent. Soc., Trans. 86: 236. 9.

\section{Genus BRACHYMERIA Subgenus GAHANULA Burks}

Brachymeria subg. Gahanula Burks, 1960. Amer. Ent. Soc., Trans. 86: 261.

Type-species: Brachymeria discreta Gahan. Orig. desig.

discreta Gahan. Tex., Ariz., Calif,; Mexico, Hawaii. Ecology: Reared from nest of Polistes infested with moth larvae.

Brachymeria discreta Gahan, 1942. U. S. Natl. Mus., Proc. 92: 43.,$+ \delta$.

discretoidea Gahan. Tex., Ariz.; Cent. Amer. Ecology; Reared from nests of Trigona infested with moth larvae.

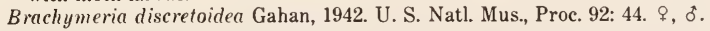




\section{Genus BRACHYMERIA Subgenus PSEUDOBRACHYMERIA Burks}

Brachymeria subg. Psendobrachymeria Burks, 1960. Amer. Ent. Soc., Trans. 86: 263.

Type-species: Psendochalcis conica Ashmead. Orig. desig.

This is the taxon that took the name Psendochalcis in Ashmead's 1904 classification (Carnegie Mus., Mem. 1: 249-250, 407). The true genus Pseudochalcis Kirby was shown by Steffan in 1956 to be a synonym of Stypiura Kirby (Soc. Ent. de France, Bul. 61: 240).

columbiana (Howard). D. C., Va., N. C., Fla., La. Ecology: Said to have been reared from Coccidae, but more likely emerged from Laetilia coccidivora (Comst.), a moth that preys on coccids.

Chalcis columbiana Howard, 1885. U. S. Dept. Agr., Bur. Ent. Bul. 5: 8, 36. .

Chalcis louisiana Girault, 1917. Descr. Stellarum Nov., p. 6. ?.

conica (Ashmead). Tex.; Mexico. West Indies, S. and Cent. Amer.

Pseudochalcis conica Ashmead, 1904. Carnegie Mus., Mem. 1: 407..

flegiae Burks. Fla., Tex. Host: Palpita flegia (Cram.).

Brachymeria (Pseudobrachymeria) flegine Burks, 1960. Amer. Ent. Soc., Trans. 86: 271. , o.

laetiliae Burks. N. C., Okla., N. Mex., Ariz., Calif. Host: Laetilia coccidivora (Comst.), L. zamacrella Dyar.

Brachymeria (Psendobrachymeria) laetiliae Burks, 1960. Amer. Ent. Soc., Trans. 86: 268. १, $\delta$.

pedalis (Cresson). Fla., Tex., Colo., N. Mex., Ariz., Calif.; Mexico. Ecology: Parasitizes moths living on cactus. Host: Noctuelia elautalis (Grote), Melitara prodenialis Walk., $M$. dentata Grote, Olycella junctolineella (Hulst), Ozamia clarefacta Dyar. The Argentine species Brachymeria (Psendobrachymeria) cactoblastidis Blanchard may be a synonym of this species.

Chalcis pedalis Cresson, 1872. Amer. Ent. Soc., Trans. 4: 60..

psyche Burks. Fla. Host: Oiketicus abbotii Grote.

Brachymeria (Pseudobrachymeria) psyche Burks, 1960. Amer. Ent. Soc., Trans. 86: 267. ๆ.

\section{Family LEUCOSPIDIDAE}

By B. D. BURKS

All members of the Leucospididae are primary parasites of aculeate Hymenoptera, developing on the fully grown larvae or pupae. The adult female drills through the cell wall of the host with her lengthy ovipositor, and also through the cocoon inside the cell if there is one, and deposits her egg inside. This egg is suspended by a slender stalk. When the egg hatches, the active larva searches out its host, attaches to it, and feeds at various places on its body. Later instars are more quiescent. Pupation occurs inside the cell of the host, and the adult uses its mandibles to break an opening to the outside. The adults often are taken by sweeping flowers, because they feed on pollen. They tend to resemble their hosts in body form and color.

Revision: Weld, 1922. U. S. Natl. Mus., Proc. 61 (6): 1-43 (N. Amer. spp.; key to females). -Boucek, 1959. Mus. Natl. Pragae, Acta Ent. 33: 435-444 (European spp.). - Nikolskaja, 1960. Fauna USSR, n. S., v. 7, n. 5, pp. 192-212 (Russian spp.). - Habu, 1962. Fauna Japonica, pp. 165-177 (Japanese spp.).

Taxonomy: Mani, 1937. Indian Mus., Rec. 39: 287-293 (spp. of India). -Mani, 1938. Cat. Indian Ins. 23: 46-49, 146. - Steffan, 1948. Soc. Ent. de France, Bul. 53: 81-84. - Burks, 1961. Studia Ent. Rio de Janeiro 4: 540 (S. Amer. spp.).

Biology: Clausen, 1940 (reprint 1962). Entomophagous Ins., pp. 236-238.

\section{Genus LEUCOSPIS Fabricius}

Leucospis Fabricius, 1775. Syst. Ent., p. 361.

Type-species: Leucospis dorsigera Fabricius. Monotypic.

Coelogaster Schrank, 1780. Schrift. Gesell. Naturf. Freunde Berlin 1: 303 (no species).

Type-species: Coelogaster passavianus Schrank. Included by Schrank, 1782. 
Lencaspis Burmeister, 1835. Arch. f. Naturgesch. 1 (2): 47. Emend.

Leucopsis Turton, 1802. In Linnaeus Syst. Nat. 3: 503 (error, frequently repeated; Leucopsis Berthold, 1827, Recognized as valid in Aves).

Leucospis subg. Metallopsis Westwood, 1839. Ztschr. f. Ent. 1: 264.

Type-species: Leucospis (Metallopsis) cayennensis Westwood. Monotypic.

Exochlaenus Shipp, 1894. Ent. Monthly Mag. 30: 245.

Type-species: Leucospis anthidioides Westwood. Orig. desig.

Parexoclaenus Girault, 1915. Queensland Mus., Mem. 4: 355.

Type-species: Parexoclaenus vespoides Girault. Orig. desig.

Exoclaenoides Girault, 1915. Queensland Mus., Mem. 4: 356.

Type-species: Exoclaenoides unicinctus Girault. Orig. desig.

affinis affinis Say. Widespread in Canada and the U. S. except for S. Fla. and the extreme southwestern Sonoran zone. Host: Anthidium emarginatum (Say), A. maculosum Cress., Ashmeadiella meliloti aridula Ckll., Dianthidium pudicum consimile (Ashm.), Hoplitis producta (Cress.), Megachile sp., M. brevis Say, M. gentilis Cress., M. inermis Prov., $M$. montivaga Cress., $M$. relativa Cress., Osmia atriventris Cress., O. kincaidii Ckll., O. pumila Cress., O. simillima Smith, Stelis sp., S. sexmaculata Ashm. There is an undescribed subspecies of affinis in the southwestern Sonoran region.

Leucospis affinis Say, 1824. In Keating, Narr. Long's 2nd Exped., App. p. 327. \&, ð.

Leucospis subnotata Westwood, 1834. Ent. Mag. 2: 215. ․

Leucospis fraterna Say, 1836. Boston Jour. Nat. Hist. 1: 269. ๆ, ठ.

Leucospis basalis Westwood, 1839. Ztschr. f. Ent. 1: 264. ठ, ๆ.

Leucospis Canadensis Walker, 1860. Jour. Ent. 1: 17. o.

Taxonomy: Burks, 1975. Brit. Mus. (Nat. Hist.) Ent., Bul. 32 (4): 166.

Leucospis bicincta Viereck, 1906. Amer. Ent. Soc., Trans. 32: 227. ठ。.

Biology: Graenicher, 1906. Wis. Nat. Hist. Soc., Bul. 4: 153-159. - Medler, 1958. Ent. News 69: 21-24. - Medler and Koerber, 1958. Ent. Soc. Amer., Ann. 51: 340-344. - Medler, 1958. Canad. Ent. 90: 326-327. - Medler, 1964. Canad. Ent. 96: 920. - Johansen and Eves, 1966. Wash. Agr. Expt. Sta., Cir. 469: 5. - Parker and Bohart, 1966. Pan-Pacific Ent. 42: 95-97. -Medler, 1967. Ent. Soc. Amer., Ann. 60: 342. - Krombein, 1967. Trap-nesting wasps and bees, pp. 434-436. -Medler and Lussenhop, 1968. Wis. Coll. Agr., Res. Bul. 274: 20-47.

Morphology: Snodgrass, 1910. U. S. Natl. Mus., Proc. 39: 65, figs. 35-39 (thorax). -Burks, 1938. Ent. Soc. Amer., Ann. 31: 158, fig. 5 (wing venation). -Snodgrass, 1941. Smithsn. Misc. Collect. 99: 36-37 (male genitalia). - Bradley, 1955. Soc. Roy. d'Ent. de Belg., Mem. 27: 134 , fig. 6 (wing venation).

affinis floridana Cresson. Cent. and S. Fla. Host: Chalicodoma (Chelostomoides) sp., C. (C.) georgica Cress., Megachile (Sayapis) sp.

Leucospis affinis var. floridana Cresson, 1872. Amer. Ent. Soc., Trans. 4: 33. , o.

Taxonomy: Weld, 1922. U. S. Natl. Mus., Proc. 61 (6): 10, 26.

Biology: Krombein, 1967. Trap-nesting wasps and bees, pp. 436-437.

birkmani Brues. Fla., Tex., Ariz.; Mexico.

Leucospis birkmani Brues, 1925. Psyche 32: 23. ․

robertsoni Crawford. Fla., Ala.

Leucospis robertsoni Crawford, 1909. Ent. Soc. Wash., Proc. 11: 51. ๆ, ठี.

slossonae Weld. Ga., Fla., Ala. Host: Anthidiellum sp.

Leucospis slossonae Weld, 1922. U. S. Natl. Mus., Proc. 61 (6): 11. १, ठ.

texana Cresson. N. C., Ga., Tex.

Leucospis texana Cresson, 1872. Amer. Ent. Soc., Trans. 4: 31, 191. ठ.

\section{Family EUCHARITIDAE}

By B. D. BURKs

All members of this family are parasitic on ants. They are, like most parasites of ants, highly modified in structure. Ashmead, 1904 (Carnegie Mus., Mem. 1: 267) characterizes them as being, 
"the most singular looking and wonderfully shaped chalcids known, the structure of the thorax, and particularly of the scutellum, being most wonderfully and curiously modified and developed; this development, in connection with the brilliant colors of its members, makes the group the most striking and attractive of any in the superfamily." However, disregarding these adaptive differences, but considering the fundamental structure of the thorax, it is clear that the eucharitids are descended from the same ancestral stem that produced the present-day pteromalids.

Revision: Ruschka, 1924. Deut. Ent. Ztschr., 1924: 82-89. -Gahan, 1940. U. S. Natl. Mus., Proc. 88: 425-458.

Biology: Wheeler and Wheeler, 1937. Ent. Soc. Amer., Ann. 30: 163-175. -Clausen, 1940. Wash. Acad. Sci., Jour. 30: 504-516.

\section{SUbFAMILy ORASEMINAE}

\section{Genus ORASEMA Cameron}

Orasema Cameron, 1884. Biol. Cent.-Amer., Hym. 1, p. 104.

Type-species: Orasema stramineipes Cameron. Monotypic. Illustrations accompanying description of stramineipes mislabeled flavipes.

Semora Cameron, 1909. Amer. Ent. Soc., Trans. 35: 432. Preocc. by Peckham, 1892.

Type-species: Semora xanthopus Cameron. Orig. desig.

Semorella Ghesquiere, 1946. Rev. Zool. Bot. Africaines 39: 368. N. name.

Semorata Strand, 1947. Folia Zool. Hydrobiol. 11: 393. N. name.

Revision: Gahan, 1940. U. S. Natl. Mus., Proc. 88: 436-458.

Taxonomy: Kerrich, 1963. Bul. Ent. Res. 54: 366.

aureoviridis Gahan. Tex.

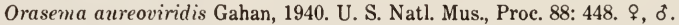
bakeri Gahan. Colo., Ariz.

Orasema bakeri Gahan, 1940. U. S. Natl. Mus., Proc. 88: 452 . ๆ, ơ.

beameri Gahan. Colo.

Orasema beameri Gahan, 1940. U. S. Natl. Mus., Proc. 88: 447. ९, ð.

cockerelli Gahan. Iowa, Kans., Colo., N. Mex., Ariz.

Orasema cockerelli Gahan, 1940. U. S. Natl. Mus., Proc. 88: 453. \&, đ̊.

coloradensis Wheeler. Va., Fla., Iowa, La., Kans., Tex., Colo., N. Mex. Host: Pheidole bicarinata vinelandica Forel, Solenopsis molesta (Say).

Orasema coloradensis Wheeler, 1907. Amer. Mus. Nat. Hist., Bul. 23: 12-14. \&, o.

Biology: Clausen, 1940. Wash. Acad. Sci., Jour. 30: 504-507.

minuta Ashmead. Fla.

Orasema minuta Ashmead, 1888. Ent. Amer. 3: 188. đo.

neomexicana Gahan. N. Mex.; Mexico.

Orasema neomexicana Gahan, 1940. U. S. Natl. Mus., Proc. 88: 450..

occidentalis Ashmead. Calif.

Orasema occidentalis Ashmead, 1892. Ent. Soc. Wash., Proc. 2: 355. ‡.

robertsoni Gahan. Fla. Host: Pheidole dentata Mayr.

Orasema robertsoni Gahan, 1940. U. S. Natl. Mus., Proc. 88: 451. ․

Biology: van Pelt, 1950. Ent. News 61: 161.

simulatrix Gahan. Ariz.

Orasema simulatrix Gahan, 1940. U. S. Natl. Mus., Proc. 88: 450. \&.

smithi Howard. Va.

Ora sema Smithi Howard, 1897. Linn. Soc. London, Jour., Zool. 26: 134. ؟.

texana Gahan. Tex.

Orasema texana Gahan, 1940. U. S. Natl. Mus., Proc. 88: 440. \&.

tolteca Mann. Ariz.; Mexico. Host: Pheidole sp.

Orasema tolteca Mann, 1914. Psyche 21: 183-184. \&, o. 
violacea Ashmead. N. C., Fla.

Orasema violacea Ashmead, 1888. Ent. Amer. 3: 187. ठ.

viridis Ashmead. N. C., N. Mex., Ariz.; Mexico.

Orasema viridis Ashmead, 1895. Calif. Acad. Sci., Proc. (2) 5: 553.

Biology: Smith, 1912. U. S. Dept. Agr., Bur. Ent. Tech. Ser. 19: 57-59.

Morphology: Parker, 1924. Soc. Ent. de France, Ann. 93: 270 (larva).

wheeleri Wheeler. Tex., Colo. Host: Pheidole ceres Whlr., P. sciophila Whlr., P. tepicana

Pergande.

Orasema wheeleri Wheeler, 1907. Amer. Mus. Nat. Hist., Bul. 23: 14. ‡.

\section{SUBFAMILY EUCHARITINAE}

\section{Genus PSEDOCHALCURA Ashmead}

Pseudochalcura Ashmead, 1904. Carnegie Mus., Mem. 1: 268, 269, 468.

Type-species: Eucharis gibbosa Provancher. Orig. desig.

arizonensis (Crawford). Ariz.

Chalcura arizonensis Crawford, 1914. Ent. Soc. Wash., Proc. 16: 29. १.

Biology: Pierce and Morrill, 1914. Ent. Soc. Wash., Proc. 16: 22. -Clausen, 1940. Wash. Acad.

Sci., Jour. 30: 505-509.

californica (Ashmead). Oreg., Calif.

Chalcura californica Ashmead, 1892. Ent. Soc. Wash., Proc. 2: 356. ठ.

gibbosa (Provancher). Que., N. H., Mich. Host: Camponotus novaeboracensis (Fitch).

Eucharis gibbosa Provancher, 1881. Nat. Canad. 12: 292. ؟.

Taxonomy: Burks, 1964 (1963). Canad. Ent. 95: 1258.

Biology: Wheeler, 1907. Amer. Mus. Nat. Hist., Bul. 23: 16.

\section{Genus STILBULA Spinola}

Stilbula Spinola, 1811. Paris Mus. Hist. Nat., Ann. 17: 150.

Type-species: Ichneumon cyniform is Rossi. Monotypic.

floridana (Ashmead). Fla.

Lophyrocera floridana Ashmead, 1888. Ent. Amer. 3: 187. o.

Taxonomy: Gahan, 1940. U. S. Natl. Mus., Proc. 88: 435-436.

montana Ashmead. Colo.

Stilbula montana Ashmead, 1890. Colo. Biol. Assoc., Bul. 1: 24, 45..

septentrionalis (Brues). Ariz.

Schizaspidia septentrionalis Brues, 1907. Wis. Nat. Hist. Soc., Bul. 5: 104..

\section{Genus LOPHYROCERA Cameron}

Lophyrocera Cameron, 1884. Biol. Cent.-Amer., Hym. 1, pp. 101, 103.

Type-species: Lophyrocera stramineipes Cameron. Desig. by Ashmead, 1904.

apicalis Ashmead. Calif.

Lophyrocera apicalis Ashmead, 1892. Ent. Soc. Wash., Proc. 2: 357.. nigromaculata Cameron. Ariz.; Cent. Amer.

Lophyrocera nigromaculata Cameron, 1884. Biol. Cent.-Amer., Hym. 1, p. 104.

\section{Genus KAPALA Cameron}

Kapala Cameron, 1884. Biol. Cent.-Amer., Hym. 1, p. 102.

Type-species: Eucharis furcata Fabricius. Monotypic.

Capala Schulz, 1906. Spolia Hym., p. 150. Emend.

floridana (Ashmead). Fla.

Thoracantha floridana Ashmead, 1885. Ent. Amer. 1: 96. o.

Taxonomy: Ashmead, 1885. Amer. Ent. Soc., Trans. 12: Proc. p. xi. 
furcata (Fabricius). Ga., Tex.; West Indies, Cent. and South Amer.

Eucharis furcata Fabricius, 1804. Systema Piezatorum, p. 158.

Taxonomy: Brues, 1907. Wis. Nat. Hist. Soc., Bul. 5: 105.

\section{Genus PSEUDOMETAGEA Ashmead}

Pseudometagea Ashmead, 1899. Ent. Soc. Wash., Proc. 4: 239, 241. No species -Ashmead, 1904, Carnegie Mus., Mem. 1: 267. One species.

Type-species: Metagea schwarzii Ashmead. Desig. by Ashmead, 1904.

Revision: Burks, 1961. Ent. News 72: 253-257.

bakeri Burks. Iowa, Wyo., Colo.

Pseudometagea bakeri Burks, 1961. Ent. News 72: 256. $q$, $\delta$.

schwarzii (Ashmead). Que. and Ont., s. to Md. and D. C., w. to Wis., Iowa, Nebr. Host: Lasius neoniger Emery.

Metagea schwarzii Ashmead, 1892. Ent. Soc. Wash., Proc. 2: 356. ơ,. .

Pseudometagea hillmeadia Girault, 1916. Brooklyn Ent. Soc., Bul. 11: 113. ๆ.

Biology: Ayre, 1962. Canad. Jour. Zool. 40: 157-164.

\section{Family EUPELMIDAE}

By B. D. BURKS

In many classifications the eupelmids are placed in the family Encyrtidae. However, all the eupelmids agree in possessing an array of characters that indicate that they and the encyrtids diverged separately from the evolutionary stem of the chalcidoids at a remote time in the development of the superfamily. Eupelmids may be recognized by having the margin of the prepectus projecting over the margin of the mesepisternum, in having the forecoxae and midcoxae widely separated, and in having the midcoxae so formed that they can be rotated either anteriorly or posteriorly. The encyrtids do not have those characters.

Morphology: Reid, 1941. Roy. Ent. Soc. London, Trans. 91: 433-434.

\section{SUBFAMILY TANAOSTIGMATINAE}

This group is primarily Neotropical and Australian, with only a very few Nearctic species. All the species of this subfamily, except one, are known to be gall makers. The one exception is Tanaostigmodes tychii Ashmead, which was supposed to be parasitic on a seed weevil, Tychins, when it was described. This rearing has not been repeated, and the record may be incorrect.

\section{Genus TANAOSTIGMODES Ashmead}

Tanaostigmodes Ashmead, 1896. Ent. Soc. Wash., Proc. 4: 9, 18.

Type-species: Tanaostigmodes howardii Ashmead. Orig. desig.

Two of the species of Tanaostigmodes, albiclavus Girault and howardii Ashmead, often have cynipid inquilines in their galls.

Revision: Crawford, 1911. U. S. Natl. Mus., Proc. 40: 442.

albiclavus Girault. Ariz. Ecology: Produce large stem galls on Acacia greggi, Mimosa biuncifera.

Taneostigmodes(!) albiclavus Girault, 1917. Descr. Stellarum Nov., p. 4. \&.

howardii Ashmead. Ariz., Calif. Ecology: Produce small, spherical bud galls on Acacia greggi, Mimosa biuncifera, Prosopis sp.

Tanaostigmodes howardii Ashmead, 1896. Ent. Soc. Wash., Proc. 4: 19. \&.

slossonae Crawford. Fla. Ecology: Produce seed galls on Galactia striata, G. volubilis.

Tanaostigmodes slossonae Crawford, 1911. U. S. Natl. Mus., Proc. 40: 442. ९, ठ.

tychii Ashmead. Calif. Host: Tychius semisquamosus Lec.

Tanaostigmodes tychii Ashmead, 1896. Ent. Soc. Wash., Proc. 4: 19. ․ 


\section{SubFamily CALOSOTINAE}

Taxonomy: Boucek, 1958. Mus. Natl. Pragae, Acta Ent. 32: 354-355. -Boucek, 1964. Ent. Soc. Canada, Mem. 34: 60.

\section{Genus CALOSOTA Curtis}

Calosota Curtis, 1836. Brit. Ent. 13: 596.

Type-species: Calosota vernalis Curtis. Orig. desig.

Calosoter Walker, 1837. Ent. Mag. 4: 358.

Type-species: Calosoter vernalis Walker. Desig. by Westwood, 1840.

Taxonomy: Bolivar y Pieltain, 1929. Eos 5: 123. - Hedqvist, 1963. Studia Forest. Suecica 11: 139. -Graham, 1969. Roy. Ent. Soc. Lond., Proc. (B) 38: 89-91 (Identity of type-species).

longiventris (Ashmead). Idaho, Calif.

Calosoter longiventris Ashmead, 1896. Ent. Soc. Wash., Proc. 4: 12. १, ठ.

metallica (Gahan). Idaho, Utah, Wash., Oreg., Calif. Ecology: Either a primary or secondary parasite, feeding on other insects that develop in grass stems. Host: Mayetiola destructor (Say), Harmolita grandis (Riley), H. tritici (Fitch) as primary parasites;

Ditropinotus aureoviridis Crawford, Eurytoma parva Phillips as secondary parasites.

Calosoter metallicus Gahan, 1922. U. S. Natl. Mus., Proc. 61 (24): 16. o, ๆ.

Biology: Knowlton and Janes, 1933. Utah Agr. Expt. Sta. Bul. 243: 12. -Gahan, 1934 (1933).

U. S. Dept. Agr., Misc. Pub. 174: 58-60. -Chamberlain, 1941. U. S. Dept. Agr., Tech. Bul.

784: 38-40. - Nikolskaja, 1952. Opred. Fauna USSR 44: 483. - Phillips and Poos, 1953. U.

S. Dept. Agr., Farmers Bul. 1323, p. 5. - Nikolskaja, 1963. Keys Fauna USSR 44: 497

(Eng. transl.).

\section{Genus EUSANDALUM Ratzeburg}

Eusandalum Ratzeburg, 1852. Ichn. d. Forstins., v. 3, p. 199.

Type-species: Eusandalum abbreviatum Ratzeburg. Desig. by Ashmead, 1904.

Polymoria Foerster, 1856. Hym. Stud., v. 2, p. 31. No included species.

Type-species: Polymoria coronata Thomson. First included species, Thomson, 1875.

Ratzeburgia Foerster, 1856. Hym. Stud., v. 2, pp. 31, 145.

Type-species: Eusandalum abbreviatum Ratzeburg. Desig. by Gahan and Fagan, 1923.

Mesensandalum Girault, 1915. Queensland Mus., Mem. 4: 34.

Type-species: Meseusandalum cyaneiventris Girault. Orig. desig.

Polymorioides Masi, 1941. Mus. Civ. Stor. Nat. Genova, Ann. 61: 154.

Type-species: Polymorioides tessellatus Masi. Orig. desig.

Revision: Girault, 1917. Jour. Ent. and Zool. 9: 8-10.

Taxonomy: Risbec, 1952. Inst. Sci. Madagascar, Mem. (E) 2: 98 (generic synonymy).

-Boucek, 1967. Acta Ent. Bohemoslov. 64: 261-266 (generic synonymy). -Boucek, 1970.

Soc. Ent. Ital., Mem. 49: 78-80 (corrected synonymy).

acmaeoderae Girault. Calif. Host: Acmaeodera sp. in Ceanothus integerrimus.

Eusandalum acmaeoderae Girault, 1917 (March). Jour. Ent. and Zool. 9: 9.

Ensandalum acmaeorerae(!) Rohwer, 1917 (June). U. S. Natl. Mus., Proc. 53: 171..

alpinum Girault. Calif.

Eusandalum alpinum Girault, 1917. Jour. Ent. and Zool. 9: 8. ९.

amphicerovorum (Ashmead). N. J., Kans. Host: Amphicerns bicaudatus (Say).

Ratzburgia(!) amphicerovora Ashmead, 1888. Kans. Agr. Expt. Sta., Bul. 3, App. p. V. "ণ" $=$ q.

arizona Girault. Ariz.

Eusandalum arizona Girault, 1917. Jour. Ent. and Zool. 9: 9. ९.

californicum Girault. Calif.

Eusandalum californicum Girault, 1917. Jour. Ent. and Zool. 9: 8. \&.

coquillettii (Ashmead). Calif. Host: Oeme gracilis Lec.

Ratzeburgia coquillettii Ashmead, 1896. Ent. Soc. Wash., Proc. 4: 11. ‡. 
cyaneum (Ashmead). Ariz., Calif.

Ratzeburgia eyanea Ashmead, 1896. Ent. Soc. Wash., Proc. 4: 11. ؟.

georgia Girault. D. C., Ga.

Eusandalum georgia Girault, 1917. Jour. Ent. and Zool. 9: 8. ․

hubbardii (Ashmead). N. J., D. C., Fla., Mont., Wash. Host: Leptostylus biustus Lec. Ratzeburgia hubbardii Ashmead, 1896. Ent. Soc. Wash., Proc. 4: 12. ๆ.

Biology: De Leon, 1934. Canad. Ent. 66: 60.

hyalinipennis (Ashmead). Tex., Calif.

Ratzeburgia hyalimiperenis Ashmead, 1896. Ent. Soc. Wash., Proc. 4: 12. ‡.

obscurum Girault. Wash.

Eusandalum obscurum Girault, 1917. Jour. Ent. and Zool. 9: 8. ․

\section{SUBFAMILY EUPELMINAE}

Taxonomy: Ashmead, 1896. Ent. Soc. Wash., Proc. 4: 4-20. -Ruschka, 1921 (1920). Zool.-Bot. Gesell. Wien., Verhandl. 70: 234-315 (European fauna), - Masi, 1943. Mus. Civ. Stor. Nat., Ann. 61: 153 (key to genera). - Ferriere, 1938. Soc. Ent. France, Ann. 107: 25-26.

-Ferriere, 1954. Schweiz. Ent. Gesell., Mitt. 27: 1-21 (brachypterous forms). - Hedqvist, 1963. Studia Forest. Suecica 11: 131-132 (bark-beetle parasites).

\section{Genus METAPELMA Westwood}

Metapelma Westwood, 1835. Zool. Soc. London, Proc. 3: 69.

Type-species: Metapelma spectabilis Westwood. Monotypic.

Halidea Foerster, 1856. Hym. Stud., v. 2, p. 31. No species. -Foerster, 1860. Naturh. Ver. Rheinlande, Verhandl. 17: 113. Two species.

Type-species: Halidea insignis Foerster. Desig. by Gahan and Fagan, 1923.

Halidayella Dalla Torre, 1897. Wien. Ent. Ztg. 16: 85. N. name for Halidea, unnecessarily proposed.

Revision: Ferriere, 1938. Soc. Ent. France, Ann. 107: 25-43.

schwarzi (Ashmead). Conn., N. Y., N. J., s. to Fla., w. to Mo., Ark., Ariz., Oreg., Calif. Host: Apteromechus ferratus (Say), Magdalis armicollis (Say).

Halidea Schwarzi Ashmead, 1890. Ent. Soc. Wash., Proc. 1: 265. ๆ.

spectabile Westwood. Conn., N. Y., N. J., s. to Fla., w. to Kans., Tex. Host: Agrilus angelicus Horn, Chrysobothris femorata (Olivier), Cylas elegantulus (Summers), Magdalis olyra (Hbst.), M. paudura (Say).

Metapelma spectabilis Westwood, 1835. Zool. Soc. London, Proc. 3: 69. ๆ.

Biology: Blackman and Stage, 1924. N. Y. State Col. Forestry, Syracuse Univ., Tech. Pub. 17: 25. - Rhoads, 1924. In Blackman and Stage, N. Y. State Col. Forestry, Syracuse Univ., Tech. Pub. 17: 185. - Beal and Massey, 1945. Duke Univ. School Forest., Bul. 10: 69.

\section{Genus EUPELMUS Dalman}

Eupelmus Dalman, 1820. Svenska Vetensk. Akad., Handl. 41: 136, 180.

Type-species: Eupelmus memnonius Dalman. Desig. by Westwood, 1840.

Cerambycobius Ashmead, 1896. Ent. Soc. Wash., Proc. 4: 7, 10, 17.

Type-species: Eupelmus cleri Ashmead. Orig. desig.

Revision: Crawford, 1908. Ent. Soc. Wash., Proc. 9: 157-158 (Cerambycobius).

allynii (French). P. E. I., Ont., Man., common throughout U. S. Host: Languria mozardi Latr.; Coleophora malivorella Riley, Epiblema otiosana (Clem.), Tischeria malifoliella Clem.; Lasioptera vernoniae Beut., Mayetiola destructor (Say), Meromyza americana Fitch, $M$. saltatrix (L.); Antistrophus pisum (Walsh) galls, Bracon cephi (Gahan), Bruchophagus spp., Cephus cinctus Nort., C. pygmaeus (L.), Ditropinotus aureoviridis Cwfd., Eupteromalus subapterus (Riley), Eurytoma parva Phillips, Habrocytus languriae Ashm., Harmolita albomaculata (Ashm.), H. elymi (French), H. elymicola P. and E., $H$. elymivora P. and E., H. elymophaga P. and E., H. grandis (Riley), $H$. holci Phillips, $H$. 
hordei (Harris), H. linearis (Walk.), H. maculata (How.), H. tritici (Fitch), H. vaginicola (Doane), Homopoms chalcidiphagus (W. and R.), H. destructor (Say), H. febriculosus (Grlt.), Pediobius metallicus (Nees), Platygaster hiemalis Pack., P. zosine Walk., Tetrastichus charoba (Walk.), Trachelus tabidus (F.).

Isosoma allynii French, 1881. Prairie Farmer 52: 418.

Taxonomy: Parker, 1924. Soc. Ent. France, Ann. 93: 266, 286. -Gahan, 1934 (1933). U. S. Dept. Agr., Misc. Pub. 174: 41-46.

Biology: Packard, 1916. Jour. Agr. Res. 6: 370-373. - Phillips and Poos, 1921. Jour. Agr. Res. 21: 405-426. -Gahan, 1934 (1933). U. S. Dept. Agr., Misc. Pub. 174: 41-46. - Hill, Pinckney and Udine, 1939. U. S. Dept. Agr., Tech. Bul. 689: 3-15. - Chamberlain, 1941. U. S. Dept. Agr., Tech. Bul. 784: 29, 39. - Wester, 1956. Ent. Soc.Wash., Proc. 58: 285-286. - Neunzig and Gyrisco, 1959. Jour. Econ. Ent. 52: 900-901. - Allen, 1962. U. S. Dept. Agr., Tech. Bul. 1265: 98-99. - Brandhorst, 1964. Ent. Soc. Amer., Ann. 57: 75-76. - Batiste, 1967. Hilgardia 38: 463. -Morrill and Kieckhefer, 1971. Jour. Econ. Ent. 64: 1129-1131.

Morphology: Hill and Pinckney, 1940. U. S. Dept. Agr., Tech. Bul. 715: 2-3, 7, 11-13. amicus Girault. Mass., N. Y., s. to Ga., w. to Ark., Tex., N. Mex. Host: Acanthoscelides alboscutellatus (Horn), A. floridae (Horn), Authonomus grandis Boh., Bruchus brachialis Fahr., B. pisorum (L.), Chalcodermus aeneus Boh., Desmoris fulvus Lec., Mimosestes amicus (Horn), Scolytus multistriatus (Marsh.); Acrobasis caryae Grote, $A$. caryivorella Rag., Coleophora malivorella Riley, Dioryctria disclusa Hein., Grapholitha molesta (Busck), Rhyacionia frustrana (Comst.), Ulophora grotei Rag.; Macrocentmes sp.

Eupelmus cyaniceps var. amicus Girault, 1916. Canad. Ent. 48: 244. ९.

Biology: Fenton and Dunnam, 1929. U. S. Dept. Agr., Tech. Bul. 112: 66. - Beacher, 1947. Ent. Soc. Amer., Ann. 40: 532-544. - Brunson, 1948. Jour. Econ. Ent. 41: 119. - Nickels et al., 1950. U. S. Dept. Agr., Tech. Bul. 1011: 3, 20. - Schaffner, 1959. U. S. Dept. Agr., Misc. Pub. 767: 87. - Allen, 1962. U. S. Dept. Agr., Tech. Bul. 1265: 97-98.

ashmeadi Melander and Brues. Mass.

Eupelmus Ashmeadi Melander and Brues, 1903. Biol. Bul. 5: 21. ․

auratus Ashmead. Fla., La. Host: Disholcaspis quercusvirens (Ashm.), Callirhytis quercusrugosa (Ashm.) galls.

Eupelmus auratus Ashmead, 1886. Amer. Ent. Soc., Trans. 12: 128. 9.

bardus Girault. Calif.

Eupelmus bardus Girault, 1917. Deser. Hym. Chalcidoid. Variorum cum Observ. V, p. 3...

biguttus Girault. Md.

Eupelmus 2-guttus Girault, 1917. Ent. News 28: 256 \&. (biguttus on p. 494).

Eupelmus duoguttus Peck, 1963. Canad. Ent., Sup. 30, p. 485. Emend.

brevicauda (Crawford). Tex., Ariz. Host: Acanthoscelides submuticus (Sharp).

Cerambycobius brevicauda Crawford, 1908 (1907). Ent. Soc., Wash., Proc. 9: 158..

bruchivorus (Crawford). Va., N. C., Tex. Host: Acanthoscelides horni (Pic), Mimosestes sallaei (Sharp).

Cerambycobius bruchivorus Crawford, 1908 (1907). Ent. Soc. Wash., Proc. 9: 158...

charitopoides Girault. W. Va., La.

Eupelmens charitopoides Girault, 1916. Canad. Ent. 48: 244...

cleri Ashmead. Va., N. C. Host: Thanasimus trifasciatus (Say), undet. clerid in white pine.

Eupelmus cleri Ashmead, 1894. Amer. Ent. Soc., Trans. 21: 339. ^, ठ.

coceidis Girault. Tex. Host: Coccus hesperidum L.

Eupelmus coccidis Girault, 1916. Ent. News 27: 223. ๆ.

conigerae Ashmead. N. J., Fla. Host: Callirhytis quercusventricosa (Bass.) gall.

Eupelmus conigerae Ashmead, 1885. Amer. Ent. Soc., Trans. 12: Proc. p. xv. ๆ.

cushmani (Crawford). La., Tex.; Hawaii, Cent. and So. Amer. Host: Acanthoscelides ochraceicolor (Pic), Authonomus grandis Boh., Araecerus fasciculatus (Deg.), Cylindrocopturus adspersus (Lec.), C. longulus (Lec.), Lixus scrobicollis Boh., Mimosestes sallaei (Sharp), Trichobaris texana Lec.

Cerambycobius cushmani Crawford 1908 (1907). Ent. Soc. Wash., Proc. 9: 158. ․ 
Cerambycobius townsendi Crawford, 1912. U. S. Natl. Mus., Proc. 43: 166. §, ठ.

Taxonomy: Gahan, 1951. Canad. Ent. 83: 172.

Biology: Pierce, 1910. Jour. Econ. Ent. 3: 455. - Pierce, Cushman and Hood, 1912. U. S. Dept. Agr., Bur. Ent. Bul. 100: 51-62. - Pierce and Cushman, 1915. Ent. Soc. Wash., Proc. 17: 165. - Hambleton, 1937. Arch. Inst. Biol. Sao Paulo 8: 96-97. - Pemberton, 1954. Hawaii. Ent. Soc., Proc. 15: 287. - Hinckley, 1959. Hawaii. Ent. Soc., Proc. 17: 267. - Hinckley, 1961. Ecology 42: 528-529.

Morphology: Snodgrass, 1910. U. S. Natl. Mus., Proc. 39: 65.

cyaniceps Ashmead. Ont., s. to Fla., w. to Calif. Host: Acanthoscelides horni (Pic), A. obtectus (Say), A. ochraceicolor (Pic), A. submuticus (Sharp), Amblycerus robiniae (F.),

Anthonomus albopilosus Dietz, A. grandis Boh., Apion rostrum Say, Clindrocopturus adspersus Lec., C. longulus Lec., Gibbobruchus mimus (Say), Lixus musculus Say, L. scrobicollis Boh., Mimosestes sallaei (Sharp), Smicraulax tuberculatus Pierce, Trichobaris compacta Casey, T. texana Lec., Tychius sordidus Lec.; Bucculatrix fusicola Braun, E piblema strenuana (Walk.), Grapholitha molesta (Busck), Heliodines ion is Clarke, Laspeyresia pomonella (L.), Rhyacionia buoliana (Schiff.), R. frustrana (Comst.); Bracon sp., Glypta sp., Hyposoter fugitivus (Say).

Eupelmus cyaniceps Ashmead, 1886. Amer. Ent. Soc., Trans. 13: 129. ๆ.

Taxonomy: Finlayson, 1962. Canad. Ent. 94: 277-279 (immature stages).

Biology: Pierce, 1908. U. S. Dept. Agr., Bur. Ent. Bul. 73: 29-48. - Pierce, Cushman and Hood, 1912. U. S. Dept. Agr., Bur. Ent. Bul. 100: 31-68. - Pierce and Cushman, 1915. Ent. Soc., Wash., Proc. 17: 165-167. - Tucker, 1922. Kans. Acad. Sci., Trans. 30: 144. - Breland, 1948. Ent. News 59: 234. - Wester, 1956. Ent. Soc. Wash., Proc. 58: 286. -Allen, 1962. U. S. Dept. Agr., Tech. Bul. 1265: 96-97. - Brandhorst, 1962. Ent. Soc. Amer., Ann. 55: 477. - Harman and Kulman, 1962. Jour. Econ. Ent. 55: 1007. - Kulman, 1965. Jour. Econ. Ent. 58: 68 .

Morphology: Parker, 1924. Soc. Ent. France, Ann. 93: 266.

cynipidis Ashmead. Fla., La. Host: Callirhytis quercusbatatoides (Ashm.) gall. Eupelmus cynipidis Ashmead, 1882. Canad. Ent. 14: 36..+

dryophantae Ashmead. Fla. Host: Dryocosmus quercuslaurifoliae (Ashm.) gall. Eupelmus dryaphantae Ashmead, 1886. Amer. Ent. Soc., Trans. 13: 130. ₹, o.

ficigerae (Ashmead). Fla. Host: Andricus femoratus Ashm., Disholcaspis quercusvirens (Ashm.).

Megastigma (!) ficigerae Ashmead, 1887. Amer. Ent. Soc., Trans. 14: 185. ठ. flavovariegatus Ashmead. Kans. Ecology: Emerged from an undet. cynipid gall.

Eupelmus flavovariegatus Ashmead, 1888. Kans. Agr. Expt. Sta., Bul. 3: App. p. IV., , o. floridanus Howard. Fla.

Eupelmus Floridanus Howard, 1880. Canad. Ent. 12: 209. ठ̊.

fonteia Walker. Fla.

Eupelmus fonteia Walker, 1847. Ann. and Mag. Nat. Hist. (1) 20: 19. 9.

Taxonomy: Burks, 1975. Brit. Mus. (Nat. Hist.) Ent., Bul. 32: 149 (lectotype designated). inyoensis Girault. Utah, Calif. Host: Saissetia oleae (Bern.); Asphondylia adenostoma Felt; Aphycus lounsburyi How., Pimplopterus sp.

Eupelmns inyoensis Girault, 1916. Ent. News 27: 223. $९, \delta$.

Taxonomy: Smith and Compere, 1928. Calif. Univ. Pubs., Ent. 4: 295-297.

Biology: Compere, 1925. Calif. Univ. Pubs., Ent. 3: 296. -Flanders, 1940. Ent. Soc. Amer., Ann. 33: 252. - Tilden, 1951. Microentomology 16: 164, 173. -Flanders, 1953 (1952). Ent. Soc. Amer., Ann. 45: 544, 547. - Doutt, 1961. Ent. Soc. Amer., Ann. 54: 51.

juglandis Ashmead. N. Y., Va., N. C., Kans. Host: Scolytus mgulosus (Ratz.).

Eupelmus juglandis Ashmead, 1894. Amer. Ent. Soc., Trans. 21: 340. ?.

lamachus Walker. Fla.

Eupelmus Lamachus Walker, 1847. Ann. and Mag. Nat. Hist. (1) 20: 20.. 
Taxonomy: Burks, 1975. Brit. Mus. (Nat. Hist.) Ent., Bul. 32: 150.

limneriae Howard. Conn., s. to Fla. Host: Grapholitha molesta (Busck), Homaledra sabalella

(Chamb.); Campoplex validus (Cress.), Ceratosmicra sp., Macrocentmis ancylivorus

Roh.

Eupelmus limneriae Howard, 1897. U. S. Dept. Agr., Div. Ent., Tech. Ser. 5: 39, 56. \&, ठ.

Biology: Allen, 1962. U. S. Dept. Agr., Tech. Bul. 1265: 93-95.

macrocarpae Ashmead. Ill., Kans. Host: Acraspis erinacei (Beut.), A. pezomachoides (0. S.),

Disholcaspis quercusmamma (Walsh) galls.

Eupelmus macrocarpae Ashmead, 1888. Kans. Agr. Expt. Sta., Bul. 3: App. p. IV..

Biology: Balduf, 1926. Canad. Ent. 58: 160-163.

marylandicus Girault. Md.

Eupelmus marylandicus Girault, 1916. Canad. Ent. 48: 242..

momphae Gahan. Conn., Ga., Ala., Tex. Host: Mompha brevivittella (Clem.), Phalonia cephalanthana Hein.

Eupelmus momphae Gahan, 1910. Canad. Ent. 42: 205..

neococcidis Peck. Md., La., Tex., Ariz. Host: Stagmomantis carolina (Johan.), S. limbata (Hahn), Tenodera angustipennis Sauss.

Eupelmus brevicanda Gahan, 1910. Canad. Ent. 42: 205. \&. Preoce. by Crawford, 1908.

Eupelmus coccidis Girault, 1917. Descr. Stellarum Nov., p. 6. N. name. Preocc. by Girault, 1916.

Eupelmus neococcidis Peck, 1951. U. S. Dept. Agr., Agr. Monog. 2: 510. N. name.

Biology: Breland, 1941. Ent. Soc. Amer., Ann. 34: 108. -Gurney, 1959. Ent. Soc. Wash., Proc. 61: 23 .

neomexicanus Girault. N. Mex.

Enpelmus neomexicanus Girault, 1906. Ent. Soc. Amer., Ann. 9: 307..

pini Taylor. N. H., Mass., Conn., N. Y. Host: Pissodes strobi (Peck).

Eupelmus pini Taylor, 1927. Brooklyn Ent. Soc., Bul. 22: 205. ๆ.

Biology: Taylor, 1929. Ent. Amer. 10: 12-16, 66.

popa Girault. Va., s. to Fla., w. to Mo., Okla., Tex.; Hawaii, West Indies, Cent. and So. Amer., Orient, Africa, Australia. Host: Contarinia sorghicola (Coq.).

Eupelmus popa Girault, 1917. Descr. Hym. Chalcidoid. Variorum cum Observ. V, p. 4..

Taxonomy: Gahan, 1922. U. S. Natl. Mus., Proc. 61 (24): 14.

Biology: Woodruff, 1929. Jour. Econ. Ent. 22: 160-167. -Walter, 1941. U. S. Dept. Agr., Tech.

Bul. 778: 18-20. - Passlow, 1958. Queensland Jour. Agr. Sci. 15: 35. - Harris, 1961. Bul.

Ent. Res. 52: 134. -Piore and Viggiani, 1965. Lab. Ent. Agr., Bol. 23: 23.

quercus Ashmead. Fla. Host: Disholcaspis quercusvirens (Ashm.) gall.

Eupelmus quercus Ashmead, 1886. Amer. Ent. Soc., Trans. 13: 130. ๆ.

rosae Ashmead. Fla., La., Kans. Host: Diplolepis spp. galls on rose.

Eupelmus rosae Ashmead, 1882. Canad. Ent. 14: 36. ₹.

rubicola (Ashmead). Fla. Known only from a single male reared from an undet. dipterous larva from the stem of Rubus; originally described in the Scelionidae, but the type specimen is Eupelmus.

Xenomerus mbicola Ashmead, 1887. Ent. Amer. 3: 100. ठ.

Taxonomy: Ashmead, 1893. U. S. Natl. Mus., Bul. 45: 185 (sp. incorrectly trans. from

Scelionidae to Pteromalidae).

speciosus Girault. D. C., Tex. Host: Andricus quercuslaniger (Ashm.) gall.

Eupelmus speciosus Girault, 1916. Canad. Ent. 48: 243. .

sphaericephalus Ashmead. Fla.

Eupelmus sphaericephalus Ashmead, 1886. Amer. Ent. Soc., Trans. 13: 129. 9.

spongipartus Foerster. N. B., Conn., Ont., N. Y., Pa., Md., Ohio, Wis.; Europe. Introduced from Europe. Host: Grapholitha molesta (Busck); Apanteles melanoscelus (Ratz.), Diprion 
similis (Htg.), Glypta rufiscutellaris Cress., Macrocentrus ancylivorus Roh., Meteorus versicolor (Wesm.).

Enpelmus spongipartus Foerster, 1860. Naturh. Ver. Rheinlande, Verh. 17: 123., \&.

Taxonomy: Finlayson, 1962. Canad. Ent. 94: 277-279 (immature stages).

Biology: Muesebeck and Dohanian, 1927. U. S. Dept. Agr., Bul. 1487: 12, 21-23. -Proper,

1934. Jour. Agr. Res. 48: 366. - Brunson, 1948. Jour. Econ. Ent. 41: 119. -Brunson and

Allen, 1948. Jour. Econ. Ent. 41: 447. - Reeks and Smith, 1956. Canad. Ent. 88: 572.

-Allen, 1962. U. S. Dept. Agr., Tech. Bul. 1265: 95-96.

utahensis Girault. Wyo., Utah. Host: Metatephritis fenestrata Foote.

Eupelmus cyaniceps var. utahensis Girault, 1916. Canad. Ent. 48: 244. 9.

Biology: Fronk et al., 1964. Ent. Soc. Amer., Ann. 57: 575.

\section{Genus ARACHNOPHAGA Ashmead}

Arachnophaga Ashmead, 1896. Ent. Soc. Wash., Proc. 4: 9, 10, 18.

Type-species: Eupelmus piceus Riley. Orig. desig.

Brasemopsis Brethes, 1913. Buenos Aires Mus. Nac. de Hist. Nat., An. 24: 106.

Type-species: Brasemopsis halysidotae Brethes. Monotypic.

The name Arachnophaga is somewhat unfortunate for this genus. Half the North American species are not parasitic on spiders, but develop at the expense of Lepidoptera or their hymenopterous primary parasites. One species also parasitizes the primary parasites of Chrysopa.

Revision: Gahan, 1943. U. S. Natl. Mus., Proc. 94: 339-363.

Taxonomy: De Santis, 1960. Rev. Fac. Agron. La Plata 36: 110 (generic synonymy).

abstrusa Gahan. Tex. Host: Cyrtarachne sp. egg sacs.

Arachnophaga abstrusa Gahan, 1943. U. S. Natl. Mus., Proc. 94: 362. १, ठ.

aldrichi Gahan. Mass., Pa., N. J., Md., Tenn., Miss., Tex. Host: Undet. spider egg sacs.

Arachnophaga aldrichi Gahan, 1943. U. S. Natl. Mus., Proc. 94: 360. ๆ.

aureicorpus (Girault). S. C., Tex.

Anastatus aureicorpus Girault, 1916. Ent. Soc. Amer., Ann. 9: 299. 9.

costalis Gahan. N. J., Del., Md. Host: Eurukuttarus confederata (Grote), Grapholitha molesta (Busck), Zamopsyche commentella Dyar; Macrocentrus sp.

Arachnophaga costalis Gahan, 1943. U. S. Natl. Mus., Proc. 94: 346..

Biology: Allen, 1962. U. S. Dept. Agr., Tech. Bul. 1265: 100.

ferruginea Gahan. Va., Fla. Host: Epeira pegnia Walck., Gasteracanthus cancriformis (L.) egg sacs.

Arachnophaga ferruginea Gahan, 1943. U. S. Natl. Mus., Proc. 94: 361..+

frontalis Gahan. Conn., N. J., Va., S. C., Tex., Utah, Ariz. Host: Anarsia lineatella Zell., Grapholitha molesta (Busck), Gypsonoma sp., Thyridopteryx meadi Edw.; Macrocentrus ancylivorus Roh., Neodiprion pinusrigidae (Nort.).

Arachnophaga frontalis Gahan, 1943. U. S. Natl. Mus., Proc. 94: 357. १, ठ.

Biology: Allen, 1962. U. S. Dept. Agr., Tech. Bul. 1265: 99-100.

longiceps (Brues). Tex. Host: Papilio sp.

Anastatus longiceps Brues, 1907. Wis. Natl. Hist. Soc., Bul. 5: 108. \&.

Biology: Allen, 1962. U. S. Dept. Agr., Tech. Bul. 1265: 100.

nocua Gahan. Tex. Host: Apanteles sp. Secondary parasite of Estigmene acrea (Drury).

A rachnophaga nocua Gahan, 1943. U. S. Natl. Mus., Proc. 94: 348. \&, ठ.

picea (Riley). N. J., Ill., Ariz., Calif. Host: Argiope argentata (F.), Diguetia canities (McCook), Epeira gibberosa (Hentz), Mastophora comigera (Hentz), Phidippus opifex McCook, Theridion globosa (Hentz) egg sacs. Secondary parasite, primary parasite unknown, of Chrysopa californica Coq.

Eupelmus piceus Riley, 1892. In Howard, Ent. Soc. Wash., Proc. 2: 296. + , ठ.

Taxonomy: Clancy, 1946. Calif. Univ. Pubs., Ent. 7: 459-460. 
Biology: Weese, 1925. Ill. Biol. Monog. 9 (4): 19, 46-52. - Weese, 1930. Okla. Acad. Sci., Proc.

10: 18-19. -Clancy, 1946. Calif. Univ. Pubs., Ent. 7: 459-460. - Cazier and Mortenson, 1962.

So. Calif. Acad. Sci., Bul. 61: 74.

scutata Gahan. Ill. Host: Undet. spider egg sacs.

Arachnophaga scutata Gahan, 1943. U. S. Natl. Mus., Proc. 94: 353. ๆ, ơ.

\section{Genus EUPELMELLA Masi}

Macroneura Walker, 1837. Ent. Mag. 4: 353. Preocc. by Macronevra Macquart, 1834.

Type-species: Macroneura maculipes Walker. Monotypic.

Macronevra Blanchard, 1840. Hist. Nat. Anim. Articules, v. 3, p. 273. Emend.

Eupelmella Masi, 1919. Mus. Civ. Stor. Nat. Genova, Ann. 48: 306.

Type-species: Eupelmus degeeri Dalman. Orig. desig.

Taxonomy: Ferriere, 1954. Schweiz. Ent. Gesell., Mitt. 27: 4. - Hedqvist, 1963. Studia Forest. Suecica 11, p. 132.

dryorhizoxeni (Ashmead). Mass., N. Y., Pa., Md., D. C., Va., Fla., Ala., Ill., Mo., Nebr., Kans. Host: Rhabdophaga salicistritichoides (Walsh); Belonocnema treatae Mayr, Diplolepis dichlocera (Harris), D. ignota (O. S.) galls. This species, having been reliably recorded as reared from a variety of galls, probably does not parasitize the gall makers, but more likely attacks some inquilines or parasites of the gall makers.

Eupelmus dryorhizoxeni Ashmead, 1886. Amer. Ent. Soc., Trans. 13: 129. ๆ, ठ.

Eupelmus rhizophelus Brues, 1903. Biol. Bul. 4: 186, 189.

Taxonomy: Burks, 1967. In Krombein and Burks, U. S. Dept. Agr., Agr. Monog. 2, Sup. 2, p. 246 (synonymy).

Biology: Melander and Brues, 1903. Biol. Bul. 5: 21.

epicaste (Walker). Fla., Kans., Tex. Host: Meteorus sp., M. laphygmae Vier.

Eupelmus Epicaste Walker, 1847. Ann. and Mag. Nat. Hist. (1) 20:20. .

Taxonomy: Burks, 1975. Brit. Mus. (Nat. Hist.) Ent., Bul. 32: 149 (synonymy).

Eupelminus meteori Gahan, 1913. U. S. Natl. Mus., Proc. 46: 437..

Biology: Luginbill, 1928. U. S. Dept. Agr., Tech. Bul. 34: 74-75. - Vickery, 1929. U. S. Dept.

Agr., Tech. Bul. 138: 21, 32, 55, 58.

melanderi (Brues). Wash. Host: Diplolepis sp. galls on rose.

Eupelmus melanderi Brues, 1907. Wis. Nat. Hist. Soc., Bul. 5: 54..+

vesicularis (Retzius). Que., N. B. and Maine, s. to N. C., w. to B. C., s. to Calif;; Europe, N.

Africa, Middle East, Asia Minor. Ecology: This is one of the most polyphagous chalcidoids, having for hosts Orthoptera, Hemiptera, Coleoptera, Lepidoptera, Diptera, and Hymenoptera. The list of names of its hosts reported in the world literature is extremely lengthy, and the list of these hosts that are reliably known for only North America is tiresomely long. E. vesicularis is usually a primary parasite, but it may also be secondary. Introduced probably from Europe in straw, and first reported in Pennsylvania in 1915. Host: Anthonomus signatus Say, Bruchus brachialis Fahr., Ceutorhynchus assimilis (Payk.), Cylindrocopturus furnissi Buch., Gyrinus sp., Hypera postica (Gyll.)., H. rumicis (L.), Tachypterellus consors cerasi List; Argyresthia thuiella (Pack.), Archippus packardianns (Fern.), Coleophora laricella (Hbn.), C. pruniella Clem., C. salmani Hein., Euruknttarns confederata (Grote), Grapholitha molesta (Busck), Malacosoma disstria Hbn., M. pluviale (Dyar), Porthetria dispar (L.), Rhyacionia buoliana (Schiff.), Stilpnotia salicis (L.); Hylemya sp., Mayetiola destructor (Say); Agathis calcarata (Cress.), Apanteles melanoscelus (Ratz.), A. laricellae Mason, Aulacidea podagrae (Bass.), A. tumida (Bass.) galls, Bathyplectes curculionis (Thomson), Bracon cephi (Gahan), Bruchophagus sp., Cephus cinctus Nort., C. pygmaens (L.), Dahlbominus fuscipennis (Zett.), Diplolepis sp. galls, Ditropinotus aureoviridis Cwfd., Eupelmus allynii (French), Eurytoma parva Phillips, Harmolita albomaculata (Ashm.), H. elymi (French), $H$. festucae P. and E., H. grandis (Riley), $H$. hordei (Harr.), H. linearis (Walker), H. longula (Dalm.), H. maculata (How.), H. tritici 
(Fitch), H. vaginicola (Doane), Janus integer (Nort.), Neodiprion abietis (Harr.), N. pratti banksianae Roh., N. leconti (Fitch), N. sertifer (Geof.), Platygaster zosine Walker. Ichneumon vesicularis Retzius, 1783. Genera et Species Insectorum, p. 70.

Eupelmus degeeri Dalman, 1820. Svenska Vetensk. Akad., Handl. 41: 379.. Eupelmus gerri Nees, 1834. Hym. Ichn. Aff. Monog., v. 2, p. 76. Emend.

Theocolax canadensis Provancher, 1883. Nat. Canad. 14: 34. $\&$.

Eupelmus albitarsis Costa, 1883. Accad. Sci. Fis. e Mat. Napoli, Atti 2: 101..

Euryscapus saltator Lindeman, 1887. Soc. Imp. Nat. Moscou, Bul. (2) 1: 190. $\subsetneq$.

Eupelminus coleopterophagus Girault, 1916. Ent. Soc. Amer., Ann. 9: 306..

Taxonomy: Gahan, 1934 (1933). U. S. Dept. Agr., Misc. Pub. 174: 52-58. - Hill and Pinckney, 1940. U. S. Dept. Agr., Tech. Bul. 715: 6-7, 11-13. - Finlayson, 1960. Canad. Ent. 92: 37-44 (immature stages.).-Hedqvist, 1963. Studia Forest. Suecica 11, p. 133.-Finlayson, 1963. Canad. Ent. 95: 499 (immature stages).-Burks, 1964 (1963). Canad. Ent. 95: 1262.

Biology: McConnell, 1918. Jour. Econ. Ent. 11: 168. - Muesebeck and Dohanian, 1927. U. S. Dept. Agr., Bul. 1487: 12, 23-24. - Phillips and Poos, 1927. Jour. Agr. Res. 34: 473-482.

-Doner, 1936. Ent. Soc. Amer., Ann. 29: 226-236. -Morris, 1938. Parasitology 30: 20-32.

- Hill, Pinckney and Udine, 1939. U. S. Dept. Agr., Tech. Bul. 689: 4-14. - Chamberlain, 1941. U. S. Dept. Agr., Tech. Bul. 784: 25, 29, 38-39. - Nelson, 1953. Canad. Ent. 85: 249. -Neunzig and Gyrisco, 1959. Jour. Econ. Ent. 52: 901. - Rivosecchi, 1960. Parassitologia 2: 289. - Chararas, 1962. Encyclopedie Ent., v. 38, p. 459. -Gijswijt, 1962. Ent. Ber. 22: 250. -Allen, 1962. U. S. Dept. Agr., Tech. Bul. 1265: 100-101. - Angalet and Andres, 1965. Jour. Econ. Ent. 58: 1167. - Balduf, 1966. Ent. Soc. Amer., Ann. 59: 1048. - Williams, 1969. Ent. Monthly Mag. 105: 124.

\section{Genus MEROSTENUS Walker}

Merostenus Walker, 1837. Ent. Mag. 4: 354.

Type-species: Merostenus phedyma Walker. Monotypic.

Urocryptus Westwood, 1840. Introd. Mod. Class. Ins., Synopsis p. 72. Preocc. by Temminck, 1838.

Type-species: Eupelmus excavatus Dalman. Orig. desig.

Eupelminus Dalla Torre, 1897. Wien. Ent. Ztg. 16: 85. N. name for Urocryptus.

exeavatus Dalman. Utah?; Europe. Introduced, but not known to be established. Host: Hypera postica (Gyll.).

Eupelmus excavatus Dalman, 1820. Svenska Vetensk. Akad., Handl. 41: 382..

Merostenus phedyma Walker, 1837. Ent. Mag. 4: 355. ठ.

Biology: Chamberlin, 1924. U. S. Dept. Agr., Cir. 301: 2-4. -Essig and Michelbacher, 1933. Calif. Agr. Expt. Sta., Bul. 567: 61, 69.

\section{Genus ANASTATUS Motschulsky}

Anastatus Motschulsky, 1860 (1859). Etudes Ent. 8: 116.

Type-species: Anastatus mantoidae Motschulsky. Monotypic.

Antigaster Walsh and Riley, 1869. Amer. Ent. 1: 156.

Type-species: Antigaster mirabilis Walsh and Riley. Monotypic.

Solindenia Cameron, 1883. Roy. Ent. Soc. London, Trans. 1883: 189.

Type-species: Solindenia picticomis Cameron. Monotypic.

Paraguaya Girault, 1911. Zool. Jahrb., Abt. f. System. 31: 385.

Type-species: Paraguaya pulchripennis Girault. Monotypic.

Ooderelloides Girault, 1913. Roy. Soc. So. Austral., Trans. 37: 6,9, 10.

Type-species: Ooderelloides nigripurpurea Girault. Orig. desig.

Pseudooderella Brethes, 1922. Soc. Cient. Argentina, An. 93: 127.

Type-species: Pseudooderella catamarcensis Brethes. Monotypic.

Revision: Burks, 1967. Amer. Ent. Soc., Trans. 93: 423-431.

Taxonomy: De Santis, 1960. Rev. Fac. Agron. La Plata (3) 36: 111 (generic synomymy). 
disparis Ruschka. Maine, s. to N. J.; Europe, Korea, Japan. Introduced from Russia and Japan; the first recoveries in 1910. Host: Porthetria dispar (L.); Apanteles melanoscelus (Ratz.). Development as a secondary parasite may occur only in laboratory or insectary cultures. N. Amer. literature before 1929 used the name bifasciatus.

Anastatus bifasciatus var. disparis Ruschka, 1920. Zool.-Bot. Gesell. Wien., Verh. 70: 265. o, ?.

Taxonomy: Pieltain, 1934. Eos 10: 286-290. - Tachikawa, 1965. In Yasumatsu et al., Icon. Ins. Jap., v. 3, p. 281 (disparis syn. of japonicus (Ashmead). - Hirose et al., 1968. Kyushu Univ. Faculty Agr., Jour. 14: 450, footnote.

Biology: Fiske, 1910. Parasites of Gipsy and Brown-Tail Moths Introduced into Mass. pp. 16-51. - Howard and Fiske, 1911. U. S. Dept. Agr., Bur. Ent. Bul. 91: 75, 168-176. -Muesebeck and Dohanian, 1927. U. S. Dept. Agr., Bul. 1487: 24. - Burgess and Crossman, 1929. U. S. Dept. Agr., Tech. Bul. 86: 23-31. - Felker, 1940. N. H. Dept. Agr., Bien. Rpt. 14: 122. - Brown and Sheals, 1944. Jour. Forestry 42: 400. -Clausen, 1956. Ü. S. Dept. Agr., Tech. Bul. 1139: 76. - Karnozitzky, 1957. Bulg. Akad. Nauk. Zool. Inst., Trud. 4: 37, 97. - Templado, 1957. Inst. Biol. Apl. Pubs. Barcelona 25: 126. - Vasic and Salatic, 1959. Zast. Bilja 52-53: 45. - Stefanov and Keremedziev, 1961. Viss. Lesot. Inst. Sofia, Nauch., Trud. 9: 162. - Tadic, 1961. Zast. Bilja 13: 63-64. - Salatic, 1963. Zast. Bilja 14: 693-699. -Bjegovic, 1963. Zast. Bilja 14: 544. - Bjegovic, 1964. Zast. Bilja 15: 369. -Dissescu and Ceianu, 1967. Rev. Padurilor 82: 470. - Kochetova, 1968. Zool. Zhur. 47: 1572.

drassi (Riley). Mo. Host material preserved with original type specimen appears to be cocoon of a dryinid.

Eupelmus drassi Riley, 1892. In Howard, Ent. Soc. Wash., Proc. 2: 297. \&.

floridanus Roth and Willis. Fla. Host: Eurycotis floridana (Walker). Anastatus floridanus Roth and Willis, 1954. Amer. Ent. Soc., Trans. 80: 31., ,

Biology: Roth and Willis, 1954. Amer. Ent. Soc., Trans. 80: 33-39. - Roth and Willis, 1960. Smithsn. Inst., Misc. Coll. 141: 245-246.

furnissi Burks. Oreg. Host: Coloradia pandora Blake, Pseudohazis sp. Anastatus fumissi Burks, 1967. Amer. Ent. Soc., Trans. 93: 426. ๆ.

gemmarii (Ashmead). Fla. Originally said to have been reared from galls of Callirhytis quercusgemmaria (Ashm.), but in the subsequent nearly 90 years it has not been reared again from this rather common gall. The host record may be incorrect. Eupelmus gemmarii Ashmead, 1886. Amer. Ent. Soc., Trans. 13: 129. ․

hirtus (Ashmead). N. Y., s. to Fla. Host: Thyanta custator (F.).

Eupelmus hirtus Ashmead, 1885. Amer. Ent. Soc., Trans. 12: Proc. p. xiv. ๆ, ठ.

mantis (Ashmead). Fla., Ga., Ill., Miss., Ark., Okla., Tex. Host: Stagmomantis carolina (Johan.).

Eupelmus mantis Ashmead, 1885. Amer. Ent. Soc., Trans. 12: Proc. p. xv. ๆ, ơ.

microcentri Gahan. Pa., D. C., Ill., Kans., Tex., N. Mex., Ariz. Host: Microcentrum sp. Anastatus microcentri Gahan, 1922. U. S. Natl. Mus., Proc. 61 (24): 12. ๆ, ठ’.

mirabilis (Walsh and Riley). N. J., s. to Fla., w. to Kans., Tex.; Mexico. Host: Amblycoryphe oblongifolia (Deg.), Microcentrum retinerve (Burm.), M. rhombifolium (Sauss.); Acrostemum hilare (Say), Brochymena sp.

Antigaster mirabilis Walsh and Riley, 1869. Amer. Ent. 1: 156. \&.

Taxonomy: Riley, 1874. Mo. State Bd. Agr., Ann. Rpt. 9: 162-165.

Biology: Howard, 1880. Canad. Ent. 12: 209-210. - Howard, 1881. U. S. Dept. Agr., Ann. Rpt. for 1880, pp. 250-251. - Griffiths, 1952. Fla. Ent. 35: 137-138.

pearsalli Ashmead. Mass., N. Y., N. J., Pa., Va., N. C., Ohio, Wis., Ark. Host: Acrosternum hilare (Say), Archimerus alternatus (Say), Banasa dimidiata (Say); Paonias astylus (Drury), Telea polyphemus (Cramer); Apanteles melanoscelus (Ratz.).

Anastatus pearsalli Ashmead, 1898. Ent. News 9: 24. \&.

Biology: Muesebeck and Dohanian, 1927. U. S. Dept. Agr., Bul. 1487: 24-25. 
reduvii (Howard). Md., s. to Fla., w. to Kans., Tex.; West Indies, Cent. and North. South Amer. Host: Microcentrum sp.; Acrosternum hilare (Say), Anasa tristis (Deg.), Arilus cristatus (L.), Tetyra bipunctata (H.-S.); Anisota senatoria (S. and A.), Estigmene acrea (Drury), Telea polyphemus (Cramer).

Eupelmus reduvii Howard, 1880. Canad. Ent. 12: 207. đ, ?.

Revision: Waterston, 1923. Bul. Ent. Res. 14: 104-108.

Biology: Underhill, 1934. Va. Agr. Expt. Sta., Bul. 294: 17-18. -Cleare and Squire, 1934. Agr. Jour. Brit. Guiana 5: 189. - Breland, 1941. Ent. Soc. Amer., Ann. 34: 110.

ruficollis (Cameron). Calif. Host: Microcentrum rhombifolium (Sauss.), Scudderia furcata Brunner. In much California literature this sp. is treated under the name mirabilis. Brasema ruficollis Cameron, 1905. Invertebrata Pacifica 1: 125..

Anastatus rugosicollis Crawford, 1913. U. S. Natl. Mus., Proc. 46: 347.

Taxonomy: Essig, 1926. Insects of West. No. Amer., p. 843.

Biology: Issac, 1905. Calif. State Comn. Hort., Bien. Rpt. 1: 102 (mirabilis). -Essig, 1913. Calif. State Comn. Hort., Monthly Bul. 2: 22, 274 (mirabilis).

semiflavidus Gahan. Kans., Tex., N. Mex., Ariz., Calif. Host: Hemilenca nevadensis Stretch, $H$. oliviae Ckll.

Anastatus semiflavidus Gahan, 1914. U. S. Natl. Mus., Proc. 48: 160. \&, ठ.

Biology: Caffrey, 1921. Jour. Agr. Res. 21: 373-384. - Wildermuth and Frankenfeld, 1933. Jour. Econ. Ent. 26: 794-798. - Frankenfeld and Barnes, 1933. Jour. Econ. Ent. 26: 799-805. -Barnes and Frankenfeld, 1935. Jour. Econ. Ent. 28: 917-924. - Barnes, 1944. Jour. Econ. Ent. 37: 544-545. -Clausen, 1956. U. S. Dept. Agr., Tech. Bul. 1139: 50.

tenuipes Bolivar and Pieltain. Md., s. to Fla., w. to Ill., Kans., Tex., Ariz.; Cosmopolitan. Ecology: Well established in buildings infested with brownbanded roaches, and competing successfully with Comperia merceti (Comp.), an encyrtid parasite of the same roach. An adventive species, often intercepted at ports of entry, following its host into North America; first established in Arizona in 1939, widespread in Gulf Coast by 1940. Host: Supella supellectilium (Serv.).

Anastatus tenuipes Bolivar y Pieltain, 1925. Soc. Roy. Ent. Egypte, Bul. 9: 43. ?. Anastatus blattidarum Ferriere, 1930. Bul. Ent. Res. 21: 33..

Solindenia blattiphagus Mani, 1936. Indian Mus., Rec. 38: 131. ठ, ?.

Taxonomy: Roth and Willis, 1960. Smithsn. Inst., Misc. Coll. 141: 246. -Burks, 1967. Amer. Ent. Soc., Trans. 93: 430.

Biology: Pruthi and Mani, 1940. India Imp. Council Agr. Res., Misc. Bul. 30: 12. -Flock, 1941. Brooklyn Ent. Soc., Bul. 36: 1-4. -Tinkham, 1948. Amer. Midland Nat. 40: 557. -Weber, 1951. Hawaii. Ent. Soc., Proc. 14: 223. - Roth and Willis, 1960. Smithsn. Inst. Misc. Coll. 141: 246-247.

zeli (Ashmead). Fla. Host: Zelus longipes (L.).

Eupelmus zeli Ashmead, 1886. Amer. Ent. Soc., Trans. 13: 130. \&.

Taxonomy: Burks, 1967. Amer. Ent. Soc., Trans. 93: 431.

\section{Genus PHLEBOPENES Perty}

Phlebopenes Perty, 1833. Delect. Anim. Articul. Brasil., fasc. 3, p. 132.

Type-species: Phlebopenes splendidus Perty. Monotypic.

Prionopelma Westwood, 1835. Zool. Soc. London, Proc. 3: 51.

Type-species: Prionopelma viridis Westwood. Monotypic.

Revision: Roman, 1920. Arkiv for Zool. 12: 24-30.

Taxonomy: Burks, 1964. Ent. News 75: 1-2. - De Santis, 1967. Comision Invest. Cient. Prov. Buenos Aires, Notas 4(8): 3 (Argentine sp.).

hetricki Burks. Md., Ga., Fla.

Phlebopenes hetricki Burks, 1964. Ent. News 75: 2-5. + . 


\section{Genus ZAISCHNOPSIS Ashmead}

Ischnopsis Ashmead, 1896. Ent. Soc. Wash., Proc. 4: 16. Preocc. by Walsingham, 1881. Type-species: Ischnopsis ophthalmica Ashmead. Orig. desig.

Zaischnopsis Ashmead, 1904. Ent. Soc. Wash., Proc. 6: 126. N. name. schwarzii (Ashmead). Fla.

Charitopus schwarzii Ashmead, 1896. Ent. Soc. Wash., Proc. 4: 11. ․

Taxonomy: Gahan, 1951. Canad. Ent. 83: 172.

\section{Genus ENCYRTASPIS Ashmead}

Encyrtaspis Ashmead, 1904. Carnegie Mus., Mem. 1: 290, 492.

Type-species: Encyrtaspis brasiliensis Ashmead. Monotypic.

Revision: Gahan, 1943. U. S. Natl. Mus., Proc. 94: 363-369.

californica (Ashmead). N. Mex., Calif. Host: Anarsia lineatella Zell., Evetria sp.

Tineobins californicus Ashmead. 1896. Ent. Soc. Wash., Proc. 4: 15..

laticeps (Brues). Tex.

Anastatus laticeps Brues, 1907. Wis. Nat. Hist. Soc., Bul. 5: 107. \&.

semirufa Gahan. N. Y., s. to Fla., w. to La., Tex., Ariz. Host: Grapholitha molesta (Busck), Laetilia coccidivora (Comst.); Macrocentrus ancylivorus Roh.

Encyrtaspis semirufus Gahan, 1927. U. S. Natl, Mus., Proc. 71 (4): 10. ९, ठ.

Biology: Haeussler, 1930. Jour. Agr. Res. 41: 366. -Allen, 1962. U. S. Dept. Agr., Tech. Bul. 1265: 101-102.

\section{Genus LECANIOBIUS Ashmead}

Lecaniobins Ashmead, 1896. Ent. Soc. Wash., Proc. 4: 8, 17.

Type-species: Lecaniobins cockerellii Ashmead. Orig. desig.

Zalophothrix Crawford, 1908. Ent. Soc. Wash., Proc. 9: 156.

Type-species: Zalophothrix mirum Crawford. Orig. desig.

Revision: Compere, 1939. Calif. Univ. Pubs., Ent. 7: 79-83.

Taxonomy: Crawford, 1911. U. S. Natl. Mus., Proc. 41: 275. -Gahan, 1924. U. S. Natl. Mus., Proc. 65 (4): 3-4. - Gahan, 1943. U. S. Natl. Mus., Proc. 94: 339.

capitatus Gahan. Tex.; Mexico, Cent. Amer., S. Amer. Host: Ceroplastes sp., Saissetia hemispherica (Targ.-Toz.), S. nigra (Niet.), S. oleae (Oliv.).

Lecaniobius capitatus Gahan, 1924. U. S. Natl. Mus., Proc. 65 (4): 4-6. ₹.

cockerellii Ashmead. Fla.; West Indies, Cent. and S. Amer. Host: Saissetia nigra (Niet.), S. oleae (Oliv.); Scutellista cyanea Mots.

Lecaniobius cockerellii Ashmead, 1896. Ent. Soc. Wash., Proc. 4: 17. 9.

Zalophothrix mirum Crawford, 1908. Ent. Soc. Wash., Proc. 9: 157..

Taxonomy: Smith and Compere, 1928. Calif. Univ. Pubs., Ent. 4: 242, 297-301.

utilis Compere. Calif.; S. Amer. Introduced from Argentina into Calif., first recovered in 1935.

Later introduced from Calif. into Peru and Brazil. Host: Saissetia oleae (Oliv.).

Lecaniobins utilis Compere, 1939 (Sept.). Calif. Univ. Pubs., Ent. 7: 79. १, ठ’.

Biology: Wille, 1937. Lima, Peru, Estac. Expt. Agr. de la Molina, Mem. 9: 121 (manuscript name). - Wille, 1937. Lima, Peru, Estac. Expt. Agr. de la Molina, Informe 42: 4-11 (manuscript name). - Wille, 1938. Lima, Peru, Estac. Expt. Agr. de la Molina, Mem. 10: 194-196 (manuscript name). - Wille, 1939 (Jan.). Lima, Peru, Estac. Expt. Agr. de la Molina, Mem. 11: 218-219 (manuscript name). -Compere, 1939 (Sept.). Calif. Univ. Pubs., Ent. 7: 79-83 (life history). - Flanders, 1942. Jour. Econ. Ent. 35: 687. -Flanders, 1944. Jour. Econ. Ent. 37: 409. - Clausen, 1956. U. S. Dept. Agr., Tech. Bul. 1139: 108. 


\section{Family ENCYRTIDAE}

By GORDON GORDH

The higher classification of the Encyrtidae used in this catalog differs drastically from that proposed in the 1951 edition. Some explanation is necessary. Burks has considered the Signiphoridae and Aphelinidae as subfamilies of the Encyrtidae. In the 1951 catalog the aphelinids were considered a subfamily of the Eulophidae and the signiphorids were treated as a distinct family (Thysanidae). The aphelinids and signiphorids appear more nearly related to the Encyrtidae than to other families of chalcidoids. In placing the aphelinids under the Encyrtidae, the subfamilies of aphelinids (sens $\imath$ Ferriere, 1965, Faune de l'Europe Bassin Medit., 1: 1-206) have been relegated to tribal status.

Recently Trjapitzin (1973, Ent. Rev. 52 (1): 118-125; Ent. Rev. 52 (2): 287-295) has treated the higher classification of the Encyrtidae (sensu stricto) and provided a radical reorganization at the tribal and subfamilial levels. His classification has been adopted in the present treatment of the Encyrtidae. In so doing, however, the placement of several genera remains undecided. These will be treated in a separate publication.

In this section the term "cosmopolitan" means the species is found throughout North America.

I thank D. Miller and M. Stoetzel (Systematic Entomology Laboratory, IIBIII, U. S. Dept. Agr., Beltsville, Maryland) for providing correct names for homopterous hosts. D. P. Annecke (Plant Protect. Res. Inst., Pretoria, South Africa) gave his advice on the placement of several species earlier referred to Aphycus.

The hosts cited in this section are only those reported for North America.

\section{SUbFamily APHELININAE}

Taxonomy: Ferriere, 1965. Faune de l'Europe Bassin Medit. 1: 1-206.-Nikol'skaya and Jashnosh, 1966. Akad. Nauk SSSR 91: 1-294.-Nikol'skaya and Jashnosh, 1968. Akad. Nauk SSSR 52: 3-42.

\section{TRIBE APHELININI}

\section{Genus APHELINUS Dalman}

Aphelinus Dalman, 1820. Svenska Vetensk. Akad., Handl. 21: 181.

Type-species: Entedon abdominalis Dalman. Monotypic.

Agonioneurus Westwood, 1833. Mag. Nat. Hist. 6: 122.

Type-species: Agonioneurus basalis Westwood. Monotypic.

Myina Nees, 1834. Hym. Ichn. Aff. Monog., v. 2, p. 189.

Type-species: Myina abdominalis Nees. Designated by Gahan and Fagan, 1923.

Eriophilus Haldeman, 1851. Pa. Farm Jour. 1: 130.

Type-species: Eriophilus mali Haldeman. Monotypic.

Anozus Foerster, 1856. Hym. Stud., v. 2, p. 84.

Type-species: Anozus siphonophorae Ashmead. By subsequent monotypy.

Misina Rondani, 1870. Arch. Zool., Anat. e Fisiol. (2) 2: 11. Erroneous subsequent spelling.

This genus is cosmopolitan and consists of approximately 45 described species which are primary internal parasites of aphids. Some species are useful in biological control of aphid pests.

Taxonomy: Mercet, 1912. Trab. Mus. Cien. Nat. 10 (1): 1-306. - Kurdjumov, 1913. Rev. Russe d'Ent. 13 (2): 266-270. -Girault, 1913. Queensland Mus., Mem. 2: 183-184. -Girault, 1915.

Queensland Mus., Mem. 4: 45-47. - Timberlake, 1924. Hawaii. Ent. Soc., Proc. 5 (3):

405-411. -Gahan, 1924. U. S. Natl. Mus., Proc. 65 (4): 7-12. - De Santis, 1946. La Plata

Mus. Rev., Zool. (n. s.) 5: 1-21. -Jasnosh, 1963. Ent. Rev. 42 (1): 178-185. -Agarwal, 1964.

Indian Acad. Sci., Proc. (B) 60 (5): 331-332. - Yoshimoto, 1965. Pacific Insects 7 (4): 690 , 694-695. - Hayat, 1972. Entomophaga 17 (1): 49-58. -Graham, 1976. Syst. Ent. 1 (2):

123-146.

asychis Walker. Okla., Tex., Calif. Imported into the United States from Iran for the biological control of the greenbug, Schizaphis graminum, in the midwest. In California the parasite attacks $R$. maidis along the Pacific coast. Host: Schizaphis graminus (Rond.), Rhopalosiphum maidis (Fitch). The synonomy listed here is essentially that of Ferriere 
(1965), with the exception of his consideration of semiflavus as a junior synonym of Walker's asychis.

Myina abdominalis Nees, 1834. Hym. Ich. Aff. Monog. v. 2, p. 190. [misidentification]. $\delta$, ㅇ.

Aphelinus Asychis Walker, 1839. Monog. Chalcid., v. 1, p. 2..

Aphelinus Euthria Walker, 1839. Monog. Chalcid., v. 1, p. 3. \&.

Myina affinis Foerster, 1841 [1840]. Beitr. Monog. Pteromalinen, p. 44. .

Aphelinus brevicalcar Thomson, 1876 (1875). Hym. Scand., v. 4, p. 185.

Aphelinus dubia Kurdjumov, 1913. Rev. Russe d'Ent. 13 (2): 268.

Aphelinus brachyptera Kurdjumov, 1913. Rev. Russe d'Ent. 13 (2): 268.

Aphelinus brevipennis Girault, 1917. Descr. Stellarum Nov., p. 18.

Taxonomy: Ferriere, 1965. Faune de l'Europe Bassin Medit. 1: 75. -Graham, 1976. Syst. Zool. 1 (2): 124, 127, 128-129.

Biology: Jackson and Eikenbary, 1971. Ent. Soc. Amer., Ann. 64 (1): 81-85. - Rainey et al., 1971. Ent. Soc. Amer., Ann. 64 (1): 169-176. - Huffaker, 1971. Biol. Control, pp. 72-73. - van den Bosch and Messenger, 1973. Biol. Control, pp. 77, 139. - Michel, 1967. C. R. Acad. Sci., Paris 264: 936-939. - Michel, 1969. Entomophaga 14 (4): 439-446. -Monadjemi, 1972. Soc. Ent. de France, Ann. (n. s.) 8 (2): 441-449. - Michel, 1973. Entomophaga 18 (4): 349-382. -Griffin, 1931. Ann. Mag. Nat. Hist. (10) 7: 498 [Date of Publication of "Beitrage zur Monographie der Pteromalinen Nees [Hymenoptera]]".

aureus Gahan. Calif. Host: Chaitophorus salicicola (Essig). Aphelinus aureus Gahan, 1924. U. S. Natl. Mus., Proc. 65 (4): 9. ơ,.

automatus Girault. Va., Ill. Host: Hysteronenra setariae (Thos.). A phelimus automatus Girault, 1911. Entomologist 44: 178. ?.

chaonia Walker. Calif. Adventive. Host: Aphis spiraecola Patch, Toxoptera aurantii (Fonsc.). Aphelinus Chaonia Walker, 1839. Monog. Chalcid. v. 1, p. 4. ơ, ?.

Myina flavicornis Foerster, 1841 [1840]. Beitr. Monogr. Pteromalinen, p. 45. ₹. Aphelinus transversus Thomson, 1876 (1875). Hym. Scand., v. 4, p. 185. 9.

flaviventris Kurdjumov. Fla. Adventive.

Aphelinus flaviventris Kurdjumov, 1913. Rev. Russe d'Ent. 13 (2): 268. Described as flaviventris Foerster.

Taxonomy: Graham, 1976. Syst. Ent. 1 (2): 130.

howardii Dalla Torre. Calif.

Aphelinus flaviceps Howard, 1895. U. S. Dept. Agr., Div. Ent., Tech. Bul. 1: 25. ठ’.

Preoccupied.

Aphelinus Howardii Dalla Torre, 1898. Cat. Hym., v. 5, p. 221. N. name.

jucundus Gahan. Que., w. to Ont., s. to Wis., Oreg., s. to Calif. Host: Acyrthosiphon cornelli

(Patch), A. pseudodirhodum (Patch), Cryptomyzus ribis (L.), Macrosiphum euphorbiae (Thos.).

Aphelinus jucundus Gahan, 1924. U. S. Natl. Mus., Proc. 65 (4): 8-9..

Biology: Griswold, 1927. Jour. Econ. Ent. 20 (1): 93. -Griswold, 1929. Ent. Soc. Amer., Ann. 22 (3): 438-457.

lapisligni Howard. Idaho w. to Oreg. Host: Nearctaphis bakeri (Cowen).

A phelinus lapisligni Howard, 1917. Biol. Soc. Wash., Proc. 30 (18): 77-78. 9.

Biology: Smith, 1923. Idaho Agr. Exp. Sta., Res. Bul. 3: 55-57.

mali (Haldeman). Cosmopolitan. Host: Aphis monardae Oestl., A. pomi DeGeer, Brevicoryne brassicae (L.), Colopha eragrostidis Midd., Coleophora malivorella Riley, Eriosoma crataegi (Oestl.), E. lanigerum (Haus.), Lepidosaphes ulmi (L.), Macrosiphum floridae (Ashm.), M. rosae (L.), Prociphilus fraxinifolii (Riley), Myzus lythri (Schrank),

Schizaphis graminum (Rond.), Tetraneura graminis Monell. Records of non-homopterous hosts must be verified.

Eriophilus mali Haldeman, 1851. Pa. Farm Jour. 1: 130-131. ठ, q.

Blastothrix rosae Ashmead, 1886. Amer. Ent. Soc., Trans. 13: 130. ․

Aphelinus varicomis Girault, 1909. Psyche 16 (2): 29-31.. 
Taxonomy: Howard, 1895. U. S. Dept. Agr., Div. Ent., Tech. Ser. 1: 24-25. -De Santis, 1948. La Plata Mus. Rev. Zool. (n. s.) 5: 103. - Ferriere, 1965. Faune l'Eur. Bassin Medit. 1: 66-69. - Graham, 1976. Syst. Ent. 1 (2): 124, 127.

Biology: Lundie, 1924. N. Y. (Cornell) Agr. Exp. Sta., Mem. 79: 1-27. -Telenga, 1936. Trudy VIZR, Ser. 1 (1): 7-75. -Gibson, 1939. VII Internat. Kong. Ent., Verhandl. 3: 1454.

-Yothers, 1953. U. S. Dept. Agr., Agr. Res. Admin., Bur. Ent. Pl. Quar. E 861, 61 pp.

-Evenhius, 1958. Tijdsch. Plant. Wagen., pp. 3-103. - Lung, Wang, and Tang, 1960. Acta Ent. Sinica 10 (1): 6. -Evenhuis, 1962. Entomophaga 7 (3): 215-220. -Boldyreva, 1970. Ent. Rev. 49 (4): 457-459. - Huffaker, 1971. Biol. Control, pp. 83, 410. - van den Bosch and Messenger, 1973. Biol. Control, pp. 29, 30, 79. See Peck, 1963. Can. Ent. Sup. pp. 263-267 for an extensive bibliography.

marlatti (Ashmead). Ont., Kans. Host: Aphis sp. on Cineraria.

Baeocharis Marlatti Ashmead, 1888. Kans. Agr. Exp. Sta., Bul. 3: (appendix) p. V. o, ๆ. Aphelinus subapterus Girault, 1916. Ent. News 27 (9): 405. ठ์.

Taxonomy: Gahan, 1924. U. S. Natl. Mus., Proc. 65 (4): 12.

Biology: McLeod, 1938. Ent. Soc. Ontario, Ann. Rept. 68: 45-48.

nigritus Howard. S. C. w. to Tex., n. to Minn.; Calif. Ecology: In northern localities found in greenhouses. Host: Hysteroneura setariae (Thos.), Schizaphis graminus (Rond.), Pseudococcus sp. on Artemisia. Pseudococcid host should be verified.

Aphelinus nigritus Howard, 1908. Ent. News 19 (8): 366-367..

Biology: Webster and Phillips, 1912. U. S. Dept. Agr., Bur. Ent., Bul. 110: 123. -Wood, 1958. Jour. Econ. Ent. 51 (4): 553. -Jackson et al., 1970. Jour. Econ. Ent. 63 (3): 733-736. -Archer et al., 1974. Ent. Soc. Amer., Ann. 67 (1): 11-14.

perpallidus Gahan. Ont., N. Y., Iowa, Oreg., Calif. Host: Chromaphis juglandicola (Kltb.), Monellia costalis (Fitch), Monellia sp. on hickory, M. sp. on pecans, Myzocallis fumipennella (Fitch).

Aphelinus perpallidus Gahan, 1924. U. S. Natl. Mus., Proc. 65 (4): 10. ठ', ९.

sanborniae Gahan. Pa., Ohio, Ont. w. to N. Dak. Host: Kakimia houghtonensis (Troop), Sanbornia juniperi Perg.

Aphelinus sanbomiae Gahan, 1924. U. S. Natl. Mus., Proc. 65 (4): 7-8. ठ, ९.

semiflavus Howard. Cosmopolitan. Host: Acyrthosiphon comelli (Patch), A. pisum (Harris), Chaitophorus viminalis Monell, Hyadaphis erysimi (Kltb.), Macrosiphum avenae (F.), Macrosiphoniella sanborni (Gill.), Myzus persicae (Sulz.), Myzus sp. on Aquilegia, Rhopalomyzus poae (Gill.), Schizaphis graminus (Rond.), Therioaph is maculata (Buck.). Aphelinus semiflavus Howard, 1908. Ent. News 19 (8): 366, 367. ठ, ๆ. Aphelinus brevipennis Girault, 1917. Descr. Stellarum Nov., p. 18.

Taxonomy: Janssen, 1961. Beitr. z. Ent. 11 (5-6): 671-678.

Biology: Hartley, 1922. Ohio Jour. Sci. 22 (8): 209-236. - van den Bosch, 1957. Jour. Econ. Ent. 50 (3): 353. - van den Bosch, 1959. Jour. Econ. Ent. 52 (1): 136-141. - Schlinger and Hall, 1959. Jour. Econ. Ent. 52 (1): 154. - Barnes, 1960. Jour. Econ. Ent. 53 (6): 1094. - Schaefers and Allen, 1962. Hilgardia 32: 426. - Force and Messenger, 1964. Ent. Soc. Amer., Ann. 57 (4): 405-413. -Wilbert, 1964. Beitr. z. Ent. 14 (1-2): 159-219. -Wilbert, 1965. Zeitschr. Morph. Oekol. Tiere 55: 804-834. - Specht, 1969. Ent. Soc. Amer., Ann. 62 (5): 1207. - Manglitz and Schalk, 1970. Jour. Kans. Ent. Soc. 43 (3): 309-314.

siphonophorae (Ashmead). Fla. Host: Macrosiphum sp.

Anozus siphonophorae Ashmead, 1888. Canad. Ent. 20 (6): 104..

toxopteraphidis Kurdjumov. Calif. Released, possibly established.

Aphelinus toxopteraphidis Kurdjumov, 1913. Rev. Russe d'Ent. 13 (2): 269. ઠ,.

Taxonomy: Graham, 1976. Syst. Ent. 1 (2): 124.

varipes (Foerster). Okla., Tex. Host: Schizaph is graminum (Rond.).

Myina varipes Foerster, 1840 (1841). Beitr. Monogr. Pteromalinen, p. 45..

Taxonomy: Griffin, 1931. Ann. and Mag. Nat. Hist. (10) 7: 498 (nomenclature). - Graham, 1976. Syst. Ent. 1 (2): 125, 127, 133. 
Biology: Jackson et al., 1970. Jour. Econ. Ent. 63 (3): 733-736. - Archer et al., 1974. Ent. Soc. Amer., Ann. 67 (1): 11-14.

\section{Genus APHYTIS Howard}

Aphytis Howard, 1900. Canad. Ent. 32 (6): 168.

Type-species: Aphytis Chilensis Howard. Monotypic.

Prospaphelinus DeGregorio, 1914. Agr. Siciliana, Ann. 3 (4): 406.

Type-species: Prospaphelinus silvestrii DeGregorio. Monotypic.

About 90 species of Aphytis are known. They are primary external parasites of armored scale insects and some species are important biological control agents of various diaspidine pests.

Taxonomy: Mercet, 1932. Eos 8 (4): 353-365. - De Santis, 1948. La Plata Rev. Mus. Zool. (n.

s.) 5: 113-138. - Compere, 1955. Calif. Univ., Pubs. Ent. 10 (4): 271-320. -Quednau, 1964.

So. Africa Ent. Soc., Jour. 27 (1): 86-116. -DeBach, 1969. Israel Jour. Ent. 4 (1): 11-28. -Jashnosh, 1972. Ent. Rev. 51 (2): 146-152. —Jashnosh, 1973. Ent. Rev. 52 (4): 478-485. -Rosen and DeBach, 1974. Bul. SROP, pp. 21-38. -Graham, 1976. Syst. Ent. 1 (2):

133-134. -DeBach and Rosen, 1976. Ent. Soc. Amer., Ann. 69 (3): 541-545.

Biology: DeBach, 1974. Biol. Control by Nat. Enem., 323 pp. - Rosen and DeBach, 1976. Mushi 46 (1): 1-17.

abnormis (Howard). N. J. s. to D. C. Host: Lepidosaphes ulmi (L.), Lepidosaphes sp. on Salix caprea.

Aphelinus abnormis Howard, 1881. U. S. Dept. Agr., Ann. Rept. for 1880, pp. 353, 355. $₹$.

Taxonomy: DeBach and Azim, 1962. Mushi 36 (1): 1.

chilensis Howard. Cosmopolitan. Host: Aspidiotus nerii Bouche, Aspidiotus sp. on Pinus radiata, Chionaspis pinifoliae (Fitch), Furchadiaspis zamiae (Morg.), Hemiberlesia rapax (Comst.). It seems that what previous writers have called chilensis will turn out to be a complex of morphologically similar forms.

Aphytis Chilensis Howard, 1900. Canad. Ent. 32 (6): 168. ․

Aphelinus longiclavae Mercet, 1911. Assoc. Espan. Prog. Cien., Cong. Valencia, p. 128. ठ, ㅇ.

Trichogrammatoidea signiphoroides Brethes, 1913. Buenos Aires Mus. Nac. de Hist. Nat., An. 24: 99-100. .

Aphelinus capitis Rust, 1915. Ent. News 26 (2): 73-74. .

Taxonomy: Brethes, 1916. Buenos Aires Mus. Nac. de Hist. Nat., An. 27: 429. -Mercet, 1921.

Real Soc. Hist. Nat., Bol. 50: 299-300. -Timberlake, 1924. Hawaii. Ent. Soc., Proc. 5 (3):

411-412. -Gahan, 1924. U. S. Natl. Mus., Proc. 65 (4): 11. -Compere, 1955. Calif. Univ.,

Pubs. Ent. 10 (4): 283-285. -Quednau, 1964. So. Africa Ent. Soc., Jour. 27 (1): 94-96.

chrysomphali (Mercet). N. Y. s. to Fla., w. to Calif. Host: Acutaspis umbonifera (Newstead), Aonidiella aurantii (Mask.), A. citrina (Coq.), Chrysomphalus dictyospermi (Morg.).

Aphelinus chrysomphali Mercet, 1912. Soc. Espan. Hist. Nat., Bol. 12: 135-140. $\uparrow$.

Prospaphelinus silvestrii DeGregorio, 1914. Agr. Siciliana, Ann. 3 (4): 406. Questionable synonym.

Aphelinus quaylei Rust, 1915. Ent. News 26 (2): 75-76. 9 . Questionable synonym.

Taxonomy: De Santis, 1948. La Plata Mus. Rev. Zool. (n. s.) 5: 122-126. -Compere, 1955.

Calif. Univ., Pubs. Ent. 10 (4): 314-316. -Quednau, 1964. So. Africa Ent. Soc., Jour. 27 (1):

113-114. -DeBach and Rosen, 1976. Ent. Soc. Amer., Ann. 69 (3): 541-545.

Biology: Quayle, 1932. Calif. Agr. Exp. Sta., Bul. 542: 31-33. -Woglum et al., 1947. Jour.

Econ. Ent. 40 (6): 818-820. - DeBach, 1954. Lab. Zool. Gen. e Agr. Portici, Bol. 33: 134-151.

-Smith, 1957. Canad. Ent. 89 (5): 219-230. -Muma, 1959. Jour. Econ. Ent. 52 (4): 577-586.

- DeBach and Sisojevic, 1960. Ecology 41: 153. - DeBach and Sundby, 1963. Hilgardia 34

(5): 105-166. - Quednau, 1964. So. Africa Agr. Sci., Jour. 7: 335-345. - Huffaker, 1971. Biol.

Control, pp. 74, 170-171, 180-182, 185, 186, 464. - Abdelrahman, 1974. Aust. Nat. (Austral.)

Jour. Zool. 22 (2): 203-229.

citrinus Compere. Calif. Host: Aonidiella citrina (Coq.).

Aphytis citrinus Compere, 1955. Calif., Univ., Pubs. Ent. 10 (4): 309, 312-313. १. 
Taxonomy: DeBach, 1959. Ent. Soc. Amer., Ann. 52 (4): 360-361.

coheni DeBach. Calif. Host: Aonidiella aurantii (Mask.), A. citrina (Coq.), Chrysomphalus dictyospermi (Morg.).

Aphytis coheni DeBach, 1960. Ent. Soc. Amer., Ann. 58 (6): 704, 705. ठ, ๆ.

Taxonomy: Rao and DeBach, 1969. Hilgardia 39 (19): 515-567.

Biology: Fleschner, 1963. Pan-Pacific Ent. 39 (2): 114-116. - Huffaker, 1971. Biol. Control, pp. 171, 464. - Sternlicht, 1973. Entomophaga 18 (4): 339-342.

comperei DeBach and Rosen. Tex. Host: Aonidiella aurantii (Mask.). Aphytis comperei DeBach and Rosen, 1976. Ent. Soc. Amer., Ann. 69 (3): 543. 9.

dealbatus Compere. Calif. Host: Lepidosaphes ulmi (L.).

Aphytis dealbatus Compere, 1955. Calif. Univ., Pubs. Ent. 10 (4): 278, 286-287. \&.

diaspidis (Howard). N. Y. s. to Va., La., Calif. Host: Abgrallaspis oxycoccus (Wogl.), Acutaspis agavis (Towns. and Ckll.), Aonidiella aurantii (Mask.), Chionaspis furfura (Fitch), $C$. pinifoliae (Fitch), Hemiberlesia rapax (Comst.), Parlatoria pergandii Comst., Quadraspidiotus perniciosus (Comst.). It appears quite likely that other species of Aphytis have been misidentified as diaspidis.

Aphelinus diaspidis Howard, 1881. U. S. Dept. Agr., Ann. Rept. for 1880, p. 355. ð, ९.

Taxonomy: De Santis, 1948. La Plata Mus. Rev. Zool. (n. s.) 5: 133-135. -Compere, 1955. Calif. Univ., Pubs. Ent. 10 (4): 289-294. -Quednau, 1964. So. Africa Ent. Soc., Jour. 27 (1): 98-99.

Biology: Quayle, 1910. Jour. Econ. Ent. 3 (5): 398-401. -Alam, 1956. Nat. Acad. Sci. India, Proc., Allahabad 26 (B): 69-74.

fisheri DeBach. Calif. Introduced, establishment questionable. Host: Aonidiella aurantii (Mask.), Aspidiotus nerii Bouche.

Aphytis fisheri DeBach, 1959. Ent. Soc. Amer., Ann. 52 (4): 359, 362. o, १.

Taxonomy: Quednau, 1964. So. Africa Ent. Soc., Jour. 27 (1): 114.

Biology: DeBach and Landi, 1959. Calif. Agr. 13: 9. - van den Bosch and Messenger, 1973.

Biol. Control, p. 77. - Huffaker, 1971. Biol. Control, pp. 75, 184.

hispanicus (Mercet). Fla. w. to Calif. Host: Parlatoria pergandii Comst., Aonidiella aurantii (Mask.).

Aphelinus maculicornis var. hispanicus Mercet, 1912. Mus. Cien. Nat. Madrid Trab., ser. Zool. 10: 82. ?.

Taxonomy: Mercet, 1930. Rev. Biol. y. Forest. Limnologia, (Ser. B) 2 (2): 51, 53-54

(misidentification of hispanicus as A. maculicornis (Masi)). -Compere, 1955. Calif. Univ., Pubs. Ent. 10 (4): 289, 294. -DeBach, 1959. Ent. Soc. Amer., Ann. 52 (4): 359-360.

-Quednau, 1964. So. Africa Ent. Soc., Jour. 27 (1): 92 (key), 99, 100. - Muma and Selheim, 1966. Fla. State Hort. Soc., Proc. 79: 87-89.

holoxanthus DeBach. Fla. w. to Calif. Introduced and successfully established. Host: Aonidiella aurantii (Mask.) (in lab.), Aspidiotus nerii Bouche, Chrysomphalus aonidum (L.).

Aphytis holoxanthus DeBach, 1960. Ent. Soc. Amer., Ann. 53 (6): 704-705. ठ, \&.

Taxonomy: Quednau, 1964. So. Africa Ent. Soc., Jour. 27 (1): 93 (key), 115. - Muma and

Selheim, 1966. Fla. State Hort. Soc., Proc. 79: 87 (key), 90. - Rao and DeBach, 1969.

Hilgardia 39 (19): 515-567.

Biology: Huffaker, 1971. Biol. Control, pp. 170-172, 460-461. - DeBach, 1974. Biol. Control by Nat. Enem., pp. 175-177, 202-203, 291.

immaculatus Compere. Calif. Introduced, establishment questionable. Host: Aonidiella aurantii (Mask.), Lepidosaphes beckii (Newm.).

Aphytis immaculatus Compere, 1955. Calif. Univ., Pubs. Ent. 10 (4): 279, 281, 283, 307-308. $\delta$, \&.

Biology: Clausen, 1956. Pan-Pacific Ent. 32 (3): 126-127. 
lepidosaphes Compere. Fla., Tex., Calif. Host: Lepidosaphes beckii (Newm.). Aphytis lepidosaphes Compere, 1955. Calif. Univ., Pubs. Ent. 10 (4): 279, 307. ठ',.

Taxonomy: Quednau, 1964. So. Africa Ent. Soc., Jour. 27 (1): 93 (key), 107.

Biology: DeBach, 1959. Ent. Soc. Amer., Ann. 52 (4): 354-362. -Dean, 1961. Ent. Soc. Amer., Ann. 54 (6): 918-920. - DeBach and Landi, 1961. Hilgardia 31 (14): 459-497. -DeBach and Argyriou, 1967. Entomophaga 12 (4): 325-342. - Huffaker, 1971. Biol. Control, pp. 130-131, $171,462$.

lingnanensis Compere. Fla., Tex., Calif. Host: Aonidiella aurantii (Mask.), A. citrina (Coq.) (in lab.), Aspidiotus nerii Bouche, Diaspis echinocacti (Bouche) (in lab.).

Aphytis lingnanensis Compere, 1955. Calif. Univ., Pubs. Ent. 10 (4): 279, 303-305. ơ, ․

Taxonomy: DeBach, 1959. Ent. Soc. Amer., Ann. 52 (4): 356, 357, 359 (key), 360. -Quednau, 1964. So. Africa Ent. Soc., Jour. 27 (1): 93 (key), 107. - Rao and DeBach, 1969. Hilgardia 39 (19): 515-567.

Biology: van den Bosch and Messenger, 1973. Biol. Control, pp. 77. -DeBach et al., 1956. Ent. Soc. Amer., Ann. 49 (3): 235-239 (as Aphytis "A"). -DeBach and White, 1960. Calif. Agr. Exp. Sta., Bul. 770, 58 pp. - DeBach and Sisojevic, 1960. Ecology 41 (1): 153-160. -Gordh and DeBach, 1976. Canad. Ent. 108 (6): 583-589. - Huffaker, 1971. Biol. Control, pp. $74-75,85,89,170-171,180-186$.

maculicornis (Masi). Calif. Host: Parlatoria oleae (Colvee).

Aphelinus maculicomis Masi, 1911. Lab. Zool. Gen. e Agr. Portici, Bol. 5 (4): 158-159..

Taxonomy: Doutt, 1954. Jour. Econ. Ent. 47 (1): 39-40. - Hafez and Doutt, 1954. Canad. Ent. 86 (2): 90-96. - Sugonyayev, 1962. Akad. Nauk SSSR Izv., ser. Biol. 5: 755. - Ahmad and Ghani, 1971. Bul. Ent. Res. 61 (1): 69-74. - Khasimuddin and DeBach, 1976. Entomophaga 21 (1): 81-92.

Biology: Clausen, 1956. U. S. Dept. Agr., Tech. Bul. 1139: 6, 33, 82. - Huffaker et al., 1962. Hilgardia 32 (13): 541-636. - Huffaker and Kennett, 1966. Hilgardia 37 (9): 283-335.

- Huffaker, 1971. Biol. Control, pp. 30-31, 42, 48, 73, 118, 129, 172-179. - Khasimuddin and DeBach, 1975. Ent. Soc. Amer., Ann. 68 (5): 893-896.

melanostictus Compere. Calif. Host: Quadraspidiotus juglansregiae (Comst.).

Aphyt is melanostictus Compere, 1955. Calif. Univ., Pubs. Ent. 10 (4): 278, 287. §o,.+

melinus DeBach. Calif. Host: Aonidiella aurantii (Mask.), A. citrina (Coq.) (in lab.), Diaspis echinocacti (Bouche) (in lab.), Hemiberlesia lataniae (Sign.).

Aphyt is melinus DeBach, 1959. Ent. Soc. Amer., Ann. 52 (4): 359, 361-362. ơ, ₹.

Taxonomy: Quednau, 1964. So. Africa Ent. Soc., Jour. 27 (1): 93 (key), 114-115. - Quednau, 1965. So. Africa Agr. Sci., Jour. 8: 43-56. - Rao and DeBach, 1969. Hilgardia 39 (19): 515-567.

Biology: DeBach and Landi, 1959. Calif. Agr. 13: 9. - DeBach and Sundby, 1963. Hilgardia 34 (5): 105-166. -Quednau, 1964. So. Africa Agr. Sci., Jour. 7: 335-340. - Huffaker, 1971. Biol. Control, pp. 75, 89, 120, 180, 184-186, 188, 190, 464. - Sternlicht, 1973. Entomophaga 18 (4): 339-342. -McLaren and Buchanan, 1973. Austral. Jour. Zool. 21 (1): 111-117.

-Abdelrahman, 1974. Austral. Jour. Zool. 22 (2): 203-247.

mytilaspidis (LeBaron). Cosmopolitan. Host: Aspidiotus nerii Bouche, Aulacaspis rosae (Bouche), Carulaspis juniperi (Bouche), Chionaspis furfura (Fitch), C. salicisnigrae (Walsh), C. heterophyllae Cooley, C. pinifoliae (Fitch), Dynaspidiotus britannicus (Newst.), Lepidosaphes ulmi (L.), Lepidosaphes sp. on Ptelea trifoliata, Parlatoria blanchardi (Targ.-Tozz.), Pinnaspis aspidistrae (Sign.), Quadraspidiotus juglansregiae (Comst.), Q. ostraeaformis (Curt.), Q. perniciosus (Comst.). Aphytis mytilaspidis is noteworthy in that it has an arrhenotokous and a thelytokous form. Moreover, Rossler and DeBach (1973) have shown that thelytokous females are capable of utilizing sperm of males from an arrhenotokous population.

Aphelinus mytilaspidis LeBaron, 1870. Amer. Ent. and Bot. 2: 360..

Taxonomy: Compere, 1955. Calif. Univ., Pubs. Ent. 10 (4): 309-310. -DeBach and Azim, 1962. Mushi 36 (1): 1-8. - Rossler and DeBach, 1972. Entomophaga 17 (4): 391-423. - Rossler 
and DeBach, 1972. Entomophaga 17 (4): 425-435. - Khasimuddin and DeBach, 1976. Entomophaga 21 (1): 113-122.

Biology: Imms, 1916. Quart. Jour. Micros. Sci. 61: 218-272. -Griswold, 1925. N. Y. (Cornell) Agr. Expt. Sta., Mem. 93: 44-47. -Essig, 1931. Hist. of Ent., p. 339. -Clausen, 1956. U. S. Dept. Agr., Tech. Bul. 1139, p. 31. -Flanders, 1957. Jour. Econ. Ent. 50 (2): 171-172. -Flanders, 1960. Jour. Econ. Ent. 53 (5): 757-758. - Tadic, 1961. Arh. za Poljopriv Nauke 14: 188. - Chumakova, 1961. Ent. Rev. 40 (2): 170-179. -Sorokina, 1971. Ent. Rev. 50 (3): $312,315,316$. - Rossler and DeBach, 1973. Hilgardia 42 (5): 149-176. - Khasimuddin and

DeBach, 1975. Ent. Soc. Amer., Ann. 68 (5): 893-896.

proclia (Walker). Cosmopolitan. Host: Aonidiella aurantii (Mask.), Aspidiotus destructor Sign., A. nerii Bouche, Aulacaspis rosae (Bouche), Chrysomphalus aonidum (L.), C. dictyospermi (Morg.), Diaspidiotus uvae (Comst.), Diaspis bromeliae (Kern.), D. echinocacti (Bouche), Hemiberlesia rapax (Comst.), Lepidosaphes beckii (Newm.), $L$. gloveri (Pack.), L. ulmi (L.), Pinnaspis strachani (Cooley), Pseudaonidia duplex (Ckll.), Pseudaulacaspis pentagona (Targ.-Tozz.), Quadraspidiotus juglansregiae (Comst.), Unaspis euonymi (Comst.). Aphytis proclia probably has been misidentified often and in fact morphological entities previously assigned to proclia constitute a sibling species complex.

Aphelinus Proclia Walker, 1839. Monog. Chalcid. v. 1, pp. 9-10. \&.

Aphelimus fuscipenuis Howard, 1881. U. S. Dept. Agr., Ann. Rpt. for 1880, p. 356. \&.

Taxonomy: De Santis, 1948. La Plata Mus. Rev. Zool. (n. s.) 5: 133-138. -Compere, 1955.

Calif. Univ., Pubs. Ent. 10 (4): 278, 287. -DeBach, 1959. Ent. Soc. Amer., Ann. 52 (4): 358. -Chumakova, 1960. Leningr. Vsesoi. Inst. Zasch. Rast., Trudy 15: 57. -Chumakova, 1961. Leningr. Vsesoi. Inst. Zasch. Rast., Trudy 15: 316.

Biology: Smith, 1897. N. J. Agr. Expt. Sta., Ann. Rpt. 17: 483-519. -Quayle, 1911. Calif. Agr. Expt. Sta., Bul. 214: 463-466. - Essig, 1931. Hist. of Ent., pp. 339-341. -Chumakova, 1961. Ent. Rev. 40 (2): 171-179. - Goryunova, 1964. Trudy VIZR 22 (1): 40-55. -Sumaroka, 1967. Ent. Rev. 46 (2): 179-185. -Sorokina, 1971. Ent. Rev. 50 (3): 311-312.

\section{Genus CENTRODORA Foerster}

Centrodora Foerster, 1878. Naturh. Ver. Rheinlande, Verh. 35: 66.

Type-species: Centrodora amoena Foerster. Monotypic.

Paraphelinus Perkins, 1906. Hawaii. Sugar Planters' Assoc. Expt. Sta., Div. Ent., Bul. 1 (8): 264.

Type-species: Paraphelirus xiphidii Perkins. Monotypic.

Proaphelinoides Girault, 1917. Descr. Stellarum Nov., p. 4.

Type-species: Proaphelinoides elongat iformis Girault. Orig. desig.

Microeupelmus Otten, 1941. Arb. Morph. Taxon. Ent. 8 (4): 259.

Type-species: Microeupelmus acridiphagus Otten. Orig. desig.

Pechlaneria Soyka, 1948. Ent. Nachr. 2 (7): 46.

Type-species: Pechlaneria alpina Soyka. Orig. desig.

Centrodora is a cosmopolitan genus containing approximately 30 species. The species of $\mathrm{Cen}$ trodora attack Orthoptera and Homoptera eggs, but at least one species is purported to parasitize Diptera and other Hymenoptera. A host-parasite catalog of Centrodora has been prepared by Hayat, 1974.

Taxonomy: Mercet, 1918. Soc. Espan. Hist. Nat., Bol. 18: 103-109. -Mercet, 1930. Eos. 6 (4): 287-295. - Annecke, 1965. So. Africa Agr. Sci., Jour. 8: 1133-1138. - Valentine, 1966. New Zeal. Jour. Sci. 9: 331-335. - Hayat, 1973. Entomophaga 18 (1): 41-46. - Hayat, 1974. Polski Pismo Ent. 44 (2): 287-298 (host-parasite catalog). -Graham, 1976. Syst. Ent. 1 (2): 135-136.

speciosissima (Girault). N. Y. s. to Va., w. to Ky., Ill. Host: Conocephalus fuscus (F.), Conocephalus sp., Phytophaga destructor (Say), Harmolita tritici (Fitch), Platygaster zosine Walk.

Agonioneuris locustamım Giraud, 1863. Zool.-Bot. Gesell. Wien, Verhandl. 13: 1278-1279. $\delta$, ․ Questionable synonym.

Paraphelinus speciosissimus Girault, 1911. N. Y. Ent. Soc., Jour. 19 (3): 181-182. ๆ. 
Taxonomy: Gahan, 1934 (1933). U. S. Dept. Agr., Misc. Pub. 174: 124-128. -Erdos, 1958. Folia Ent. Hungarica 6: 165-184. - Nikol'skaya and Yashnosh, 1966. Opred. Fauny SSSR 91, pp. 156-161.

Biology: McConnell, 1916. Ent. Soc. Amer., Ann. 9 (1): 97-102. - Hill and Smith, 1928. Jour. Agr. Res. 36 (2): 153-155.

Morphology: Hill and Pinckney, 1940. U. S. Dept. Agr., Tech. Bul. 715: 5, 11-13.

\section{Genus MARIETTA Motschulsky}

Marietta Motschulsky, 1863. Soc. Nat. Imp. Moscou, Bul. 36 (2): 51.

Type-species: Marietta leopardina Motschulsky. Monotypic.

Perissopterus Howard, 1895. U. S. Dept. Agr., Div. Ent., Tech. Ser. 1: 20.

Type-species: Aphelinus pulchellus Howard. Orig. desig.

Pseudaphelinus Brethes, 1918. Soc. Rural Argentina, An. 53: 157.

Type-species: Pseudaphelinus caridei Brethes. Monotypic.

Paraphytis Compere, 1925. Amer. Ent. Soc., Trans. 51 (871): 129-130.

Type-species: Paraphytis vittata Compere. Orig. desig.

This cosmopolitan genus contains approximately 35 species. Most, if not all, are external hyperparasites associated with scale insects.

Taxonomy: Compere, 1936. Calif. Univ., Pubs. Ent. 6 (12): 277-322. - Nikol'skaya and

Jashnosh, 1966. Opred. Fauny SSSR 91: 162-166. - Annecke and Insley, 1972. So. Africa

Ent. Soc., Jour. 35 (1): 1-15.

carnesi (Howard). Del. s. to Va., Calif. Host: Comperiella bifasciata How. on Lepidosaphes beckii (Newm.) and Quadraspidiotus perniciosus (Comst.), Plagiomerus diaspidis Crawford on Diaspis echinocacti (Bouche).

Perissopterus camesi Howard, 1910. Ent. News 21 (4): 162-163. \&.

Biology: Azim, 1961. Mushi 35 (14): 107.

graminicola Timberlake. Md. s. to Fla., w. to Tex. Host: Anagyrus antoninae Timb. on unknown host.

Marietta graminicola Timberlake, 1925. Hawaii. Ent. Soc., Proc. 6 (1): 180-184. ठ, ๆ.

Biology: Dean and Schuster, 1958. Jour. Econ. Ent. 51 (3): 364.

javensis (Howard). Calif.? Adventive, establishment questionable. Host: Coccophagus lycimnia (Wlkr.), Microterys flavus (Howard).

Perissopterus javensis Howard, 1907. U. S. Dept. Agr., Bur. Ent., Tech. Ser. 12 (4): 87, 88. o, .

Biology: Timberlake, 1913. Jour. Econ. Ent. 6 (3): 300.

mexicana (Howard). N. Y. s. to Va., Calif. Host: Metaphycus lounsburyi How., Signiphora merceti Malen. Also on undetermined parasites of Coccus hesperidum L., Lecanium nigrofasciatum Perg., Lepidosaphes ulmi (L.), Quadraspidiotus perniciosus (Comst.).

Perissopterus mexicanus Howard, 1895. U. S. Dept. Agr., Div. Ent., Tech. Ser. 1: 21-23. ठ', १.

Biology: Smith, 1933. Ent. Soc. Amer., Ann. 26 (3): 525. - Essig, 1931. Hist. of Ent., pp. 348, 349, 354. - Flanders, 1940. Ent. Soc. Amer., Ann. 33 (2): 252. - Cox, 1942. Jour. Econ. Ent. 35 (5): 700-701. - DeBach et al. 1958. Jour. Econ. Ent. 51 (1): 115.

pulchella (Howard). Cosmopolitan. Ecology: Attacking undetermined parasites on Chionaspis americana Johns., C. pinifoliae (Fitch), Lecanodiaspis sp. on cottonwood and willow, Pseudaulacaspis pentagona (Targ.-Tozz.), Quadraspidiotus forbesi (Johns.), Q. juglansregiae (Comst.), Q. perniciosus (Comst.).

Aphelinus pulchellus Howard, 1881. U. S. Dept. Agr., Ann. Rpt. for 1880, p. 356. \&.

Biology: Felt, 1916. N. Y. State Mus. Bul. 180: 84. - Peterson, 1962. Canad. Ent. 94 (4): 740. -Willoughby and Kosztarab, 1974. Va. Polytech. Inst. St. Univ., Res. Div. Bul. 92: 24.

\section{Genus MARLATTIELLA Howard}

Marlattiella Howard, 1907. U. S. Dept. Agr., Bur. Ent., Tech. Ser. 12: 73. 
Type-species: Marlattiella prima Howard. Orig. desig.

This genus is presently monotypic and widespread. The type-species attacks pear white scale.

Taxonomy: Rosen and DeBach, 1970. Mushi 43 (3): 39-44.

prima Howard. Md. Host: Lopholeucaspis japonica (Ckll.).

Marlattiella prima Howard, 1907. U. S. Dept. Agr., Bur. Ent., Tech. Ser. 12: 73.

Taxonomy: Tachikawa, 1962. Shikoku Ent. Soc., Trans. 7 (3): 74-79. - Nikol'skaya and Jashnosh, 1966. Opred. Fauny SSSR 91: 150.

Biology: Compere, 1936. Calif. Univ., Pubs. Ent. 6 (12): 279-281.

\section{Genus MESIDIA Foerster}

Mesidia Foerster, 1856. Hym. Stud., v. 2, p. 30. No species included.

Type-species: Mesidia pumila Mayr. Subsequent monotypy.

This small Holarctic genus is composed of primary internal aphid parasites.

Foerster (1856) described Mesidia in a key but did not include any species. Subsequently, Mayr (1904) described $M$. pumila which was the first and only included species. Mercet (1928) indicated and Nowicki (1929) suggested that pumila was a junior synonym of Myina annulipes Walker. Graham (1961) was unable to find the type-specimen of annulipes, but on the basis of three collections of specimens agreeing with Walker's original decription, Nowicki's examination of the type of pumila, and Mercet's illustration of the male antenna of the specimen thought to be annulipes, Graham concluded the two were synonymous.

Taxonomy: Mercet, 1928. Soc. Espan. Hist. Nat., Bol. 28: 507-512. - Nowicki, 1929. Neue Beitr. Syst. Insektenk. 4 (13-14): 160. -Graham, 1961. Ent. Monthly Mag. 97 (1164-1166):

140-142. - Ferriere, 1962. Schweiz. Ent. Gesell., Mitt. 35 (1-2): 139-143. -Ferriere, 1965.

Faune l'Europe Bassin Medit. 1: 52-56. - Nikol'skaya and Jashnosh, 1966. Opred. Fauny

SSSR 91: 153-156. -Graham, 1976. Syst. Ent. 1 (2): 143.

gillettei Howard. Ill., Colo. Host: Brachycolus tritici Gill.

Mesidia gillettei Howard, 1914. Ent. Soc. Wash., Proc. 16 (2): 80..

Taxonomy: Dozier, 1933. Ent. Soc. Wash., Proc. 35 (6): 90-91.

nigra Lagace. Calif. Introduced. Host: Iziphya punctata Hille Ris Lamb.

Mesidia nigra Lagace, 1969. Ent. Soc. Amer., Ann. 62 (3): 530-531. o, ?.

Biology: Lagace, 1969. Ent. Soc. Amer., Ann. 62 (3): 532-536.

\section{Genus TUMIDISCAPUS Girault}

Tumidiscapus Girault, 1911. N. Y. Ent. Soc., Jour. 19 (3): 182.

Type-species: Tumidiscapus flavus Girault. Orig. desig.

Six species of Tumidiscapus have been described, with 4 from North America. The North American species attack tettigoniid and cercopid eggs.

Taxonomy: Gahan, 1932. Ent. Soc. Amer., Ann. 25 (4): 740-742. -Milliron, 1947. Ent. Soc.

Wash., Proc. 49 (7): 193-197. - Hayat, 1974. Polski Pismo Ent. 44 (2): 294-295 (catalog).

cercopiphagus Milliron. Fla., Mich., Wis. Host: Aphrophora saratogensis (Fitch).

Tumidiscapus cercopiphagns Milliron, 1947. Ent. Soc. Wash., Proc. 49 (7): 193-195. o, ९.

flavus Girault. Pa. w. to S. Dak., Tenn. Host: Orchelimum vulgare Harris, Phytophaga destructor (Say), Lasioptera sp. on Muhlenbergia.

Tumidiscapus flav'ns Girault, 1911. N. Y. Ent. Soc., Jour. 19 (3): 182-183. ơ.

orchelimumsis Gahan. Pa., Va., Ill. Host: Orchelimum vulgare Harris.

Tumidiscapus orchelimumsis Gahan, 1932. Ent. Soc. Amer., Ann. 25 (4): 741-742. ठ̊, ?.

orthopterae Gahan. Fla. Host: Tettigoniid eggs on Andropogon abbreviatus.

Tumidiscapus orthopterae Gahan, 1919. U. S. Natl. Mus., Proc. 55: 406-407. ơ, ९. 


\section{TRIBE COCCOPHAGINI}

\section{Genus ABLERUS Howard}

Ablerus Howard, 1894. U. S. Dept. Agr., Insect Life 7 (1): 7-8.

Type-species: Centrodora clisiocampae Ashmead. Monotypic.

Ablerus has about 35 species, is predominantly Australian in distribution, and is composed of hyperparasites.

Taxonomy: Girault, 1913. Queensland Mus., Mem. 2: 189-194. - Girault, 1932. New Pests from Australia (priv. pub., no page numbers). - De Santis, 1948. La Plata Mus. Rev. Zool. (n. s.) 5 (32): 198-212 (So. Amer. spp.). - Annecke and Insley, 1970. Bul. Ent. Res. 60 (2): 247-248.

Biology: Comber, 1967. New Zeal. Jour. Sci. 10 (3): 641.

americanus Girault. D. C. Host: Diaspidiotus uvae (Comst.).

Ablerus americanus Girault, 1916. Soc. Ent. 31 (8): 44. .

clisiocampae (Ashmead). N. Y. s. to Fla., w. to La., Minn. Host: Chionaspis furfura (Fitch), Melanaspis obscura Comst.), Pseudaulacaspis pentagona (Targ.-Tozz.), Quadraspidiotus forbesi (Johns.), Q. perniciosus (Comst.).

Centrodora clisiocampae Ashmead, 1894. Ent. Soc. Wash., Proc. 3 (1): 10..

Biology: Baker, 1933. U. S. Dept. Agr., Cir. 295: 8-9. - Hodson, 1939. Ent. Soc. Amer., Ann. 32 (1): 131-136. - Hughes, 1960. Fla. Ent. 43 (2): 90-92.

perspeciosus Girault. D. C. Host: Chrysompahlus aonidum (L.), Pseudaulacaspis pentagona (Targ.-Tozz.).

Ablerus perspeciosus Girault, 1916. Ent. Soc. Amer., Ann. 9 (3): 292..

Azotus silvestrii Compere, 1926. Calif. Univ., Pubs. Ent. 4 (1): 9-11. ๆ.

\section{Genus ANERISTUS Howard}

Aneristus Howard, 1895. Canad. Ent. 27 (12): 351.

Type-species: Aneristus ceroplastae Howard. Monotypic.

Aneristus is a pantropical genus predominantly found in South America and Africa. It is composed of less than 20 species that are internal parasites of soft-scale insects.

Taxonomy: Dozier, 1932. Puerto Rico Dept. Agr., Jour. 16 (2): 94-102. -Compere, 1936. Calif.

Univ., Pubs. Ent. 6 (2): 285-288 (key). - Ghesquiere, 1949. Soc. Ent. de Belg., Bul. et Ann.

85 (5-6): 156-167 (catalog).

ceroplastae Howard. La. w. to Calif. Host: Coccus hesperidum L., C. psendomagnoliarum

(Kuw.), Saissetia coffeae (Walk.).

Aneristus ceroplastae Howard, 1895. Canad. Ent. 27 (2): 351. ?.

Coccophagus orientalis Howard, 1896. U. S. Natl. Mus., Proc. 18: 633-634..

Taxonomy: Gahan, 1924. U. S. Natl. Mus., Proc. 64 (4): 13-14.

Biology: Smith and Compere, 1928. Calif. Univ., Pubs. Ent. 4 (9): 242, 246-247.

youngi Girault. La., Tex. Host: Ceroplastes sp. on Chrysanthemum, Coccus hesperidum L., Saissetia coffeae (Walk.).

Aneuistus(!) youngi Girault, 1917. Deser. Hym. Chalcidoid. Variorum Cum Observ. V, p. 11.

\section{Genus ASPIDIOTIPHAGUS Howard}

Aspidiotiphagus Howard, 1894. U. S. Dept. Agr., Insect Life 6 (3): 230.

Type-species: Coccophagus citrinus Craw. Monotypic.

Prospaltoides Brethes, 1914. Nunquam Otiosus, Buenos Aires, p. 12.

Type-species: Prospaltoides howardi Brethes. Monotypic. Considered a synonym of citrinus Craw.

Aspidiotiphagus is comprised of fewer than 10 species. It is cosmopolitan in distribution, and its members are internal primary parasites of armored-scale insects. 
Taxonomy: Paoli, 1926. Soc. Ent. Ital., Bol. 58: 97-105. - Dozier, 1927. Puerto Rico Dept. Agr., Jour. 10 (3-4): 274-277. - Mercet, 1930. Rev. de Biol. y Forest. Limnologia 2 (B): 69-72. - Compere, 1936. Calif. Univ., Pubs. Ent. 6 (12): 294-295. - Alam, 1956. Roy. Ent. Soc. London, Trans. 108 (8): 359-363.

citrinus agilior Berlese. Va., Fla. Host: Unaspis enonymi (Comst.).

Aspidiotiphagus citrinus var. agilior Berlese, 1916. Redia 12 (1): 5, 7, 10. \&.

citrinus citrinus (Craw). Cosmopolitan. Host: Aonidiella aurantii (Mask.), A. citrina (Coq.), Aspidiotus destructor Sign., A. nerii Bouche, Camulaspis visci (Schrank), Chionaspis pinifoliae (Fiteh), Chrysomphalus aonidum (L.), C. dictyospermi (Morg.), Coccus hesperidum L., Diaspidiotus ancylus (Putn.), Dynaspidiotus britannicus (Newst.), Diaspis bromeliae (Kern.), D. echinocacti (Bouche), Kuwanaspis hikosani (Kuw.), Lepidosaphes beckii (Newm.), L. ulmi (L.), Melanaspis tenebricosa (Comst.), Nuculaspis californica (Col.), Parlatoria oleae (Colv.), P. pergandii Comst., Pinnaspis a spidistrae (Sign.), P. strachani (Cooley), Pseudaonidia duplex (Ckll.), Pseudaulacaspis pentagona (Targ.-Tozz.). The morphological form called citrinus may consist of sibling species. Coccophagus citrin us Craw, 1891. Calif. State Bd. Hort., Bul. 57: 5.

Prospaltoides howardi Brethes, 1914. Nunquam Otiosus, Buenos Aires, pp. 13-14.

Taxonomy: Howard, 1894. U. S. Dept. Agr., Insect Life 6 (3): 229-230.

Biology: Howard, 1895. U. S. Dept. Agr., Div. Ent., Tech. Ser. 1: 7, 31. - Isaac, 1905. Calif. State Comm. Hort., Bien. Rpt. 1: 95. - Essig, 1931. Hist. of Ent., pp. 341-342, 386. -Benassy, 1958. Entomophaga 3 (2): 104. - Hughes, 1960. Fla. Ent. 43 (2): 90-92. -Benassy, 1961. Ann. des Epiphyt. 12 (C): 42. - Chumakova, 1965. Ent. Rev. 44 (3): 305-308. -Sorokina, 1971. Ent. Rev. 50 (3): 313-316. - Brewer, 1971. Austral. Jour. Zool. 19 (1): 53-63. - Huffaker, 1971. Biol. Control, pp. 48, 49, 78. - DeBach, 1974. Biol. Control by Nat. Enem., p. 133.

Morphology: Parker and Thompson, 1925. Ent. Soc. Amer., Ann. 18 (3): 387.

lounsburyi (Berlese and Paoli). Fla. Host: Aonidiella aurantii (Mask.), Chrysomphalus aonidum (L.), C. dictyospermi (Morg.).

Prospaltella lounsburyi Berlese and Paoli, 1916. Redia 11 (1-2): 305.

Taxonomy: Muma, 1959. Jour. Econ. Ent. 52 (4): 579. - Annecke, 1963. So. Africa Ent. Soc., Jour. 26 (1): 206.

Biology: Mathis, 1947. Fla. Ent. 29 (2-3): 33.

\section{Genus AZOTUS Howard}

Azotus Howard, 1898. Ent. Soc. Wash., Proc. 4 (2): 138.

Type-species: Azotus marchali Howard. Monotypic. Considered a synonym of Encyrtus atomon Walker.

Dimacrocerus Brethes, 1914. Nunquam Otiosus, Buenos Aires, p. 4.

Type-species: Dimacrocerus platensis Brethes. Orig. desig.

Azotus is a cosmopolitan genus consisting of fewer than 30 species that are usually hyperparasites of armored-scale insects, whiteflies, and possibly beetles and cicada eggs according to Nikol'skaya (1952).

Taxonomy: Mercet, 1923. Soc. Espan. de Hist. Nat., Bol. 23 (9): 410-413. -Nowicki, 1926. Polski Pismo Ent. 5 (1-2): 104-113 (Palearctic key). - Ferriere, 1927. Rev. Suisse de Zool. 34 (2): 57-59. -Alam, 1956. Roy. Ent. Soc. London, Trans. 108 (8): 358, 376-379. - Agarwal, 1964. Indian Acad. Sci., Proc. (B) 60: 326-331. - Annecke and Insley, 1970. Bul. Ent. Res. 60 (2): 237-247. - De Santis, 1974. Rev. Chilena Ent. 8 (1): 11-15 (argentinean spp.).

Biology: Nikol'skaya, 1952. Chalcid Fauna of USSR p. 295 (English translation 1963; p. 301). americanus Dozier. Del. Host: Lecanium corni Bouche, Lepidosaphes uhmi (L.), Quadraspidiotns perniciosus (Comst.).

Azotus americanus Dozier, 1928. Ent. Soc. Wash., Proc. 30 (2): 36. ठ̊.

marchali Howard. D. C., Md., Va. Host: Diaspidiotus uvae (Comst.).

Azotus marchali Howard, 1898. Ent. Soc. Wash., Proc. 4 (2): 138-139. ơ. 


\section{Genus COCCOPHAGOIDES Girault}

Coccophagoides Girault, 1915. Queensland Mus., Mem. 4: 58.

Type-species: Coccophagus abnormicornis Girault. Orig. desig.

Diaspiniphagus Silvestri, 1927. Lab. Zool. Gen. e Agr. Portici, Bol. 20: 35-36.

Type-species: Prospalta similis Masi. Orig. desig.

This genus consists of less than 10 species. One species, $C$. utilis Doutt, acts in concert with Aphytis maculicomis (Masi) to achieve biological control of the olive scale, Parlatoria oleae (Colv.), in California. This is an excellent example of multiple parasite importation success.

Taxonomy: Mercet, 1928. Soc. Espan. de Hist. Nat., Bol. 28: 511-512. - Nowicki, 1929. Neue Beitr. Syst. Insektenk. 4 (13-14): 158. -Compere, 1936. Calif. Univ., Pubs. Ent. 6 (12): 292-293. - Doutt, 1966. Hilgardia 37 (9): 219-231.

Biology: Broodryk and Doutt, 1966. Hilgardia 37 (9): 233-254. -Finney, 1966. Hilgardia 37

(9): 337-343. - Kennett et al., 1966. Hilgardia 37 (9): 255-282. - van den Bosch and

Messenger, 1973. Biol. Control, pp. 39, 110, 111. - DeBach, 1974. Biol. Control by Nat.

Enem., pp. 171, 204.

fuscipennis (Girault). Ill. Host: Melanaspis obscura (Comst.). Transfered from Prospaltella Ashmead, teste H. Compere (in litt.).

Prospaltella fuscipennis Girault, 1908. Psyche 15 (6): 120-121. ?.

Biology: Baker, 1933. U. S. Dept. Agr., Cir. 295: 8-9.

kuwanae (Silvestri). Conn. s. to N. J., w. to Ohio, Calif. Host: Pseudaulacaspis pentagona

(Targ.-Tozz.), Quadraspidiotus perniciosus (Comst.).

Diaspiniphagus Kuwanae Silvestri, 1927. Lab. Zool. Gen. e. Agr. Portici, Bol. 20: 39-41. \&.

Taxonomy: Compere, 1936. Calif. Univ., Pubs. Ent. 6 (12): 293. -Doutt, 1966. Hilgardia 37

(9): 223, 224, 226.

Biology: Flanders, 1960. Jour. Econ. Ent. 53 (5): 757.

similis (Masi). Cosmopolitan. Host: Diaspidiotus viticola (Leon.), Quadraspidiotus ostreaefomis (Curt.), Q. permiciosus (Comst.), Targionia vitis (Sign.).

Prospalta similis Masi, 1908. Lab. Zool. Gen. e Agr. Portici , Bol. 3: 148-149..

Prospaltella ilicis Mercet, 1921. Soc. Espan. de Hist. Nat. Tomo 50 Aniv., pp. 304-305, 308. १.

Taxonomy: Silvestri, 1927. Lab. Zool. Gen. e Agr. Portici , Bol. 20: 36-38 (redescribed in

Diaspiniphagus). -Flanders, 1960. Jour. Econ. Ent. 53 (5): 757 (distribution).

utilis Doutt. Calif. Host: Parlatoria oleae (Colv.).

Coccophagoides utilis Doutt, 1966. Hilgardia 37 (9): 224-226. o, ๆ.

Biology: Broodryk and Doutt, 1966. Hilgardia 37 (9): 233-254. - Kennett et al., 1966.

Hilgardia 37 (9): 255-282. - Huffaker and Kennett, 1966. Hilgardia 37 (9): 283-335.

-DeBach, 1974. Biol. Control by Nat. Enem., pp. 171, 204.

\section{Genus COCCOPHAGUS Westwood}

Coccophagus Westwood, 1833. London, Edinb, and Dublin Phil. Mag. and Jour. Sci. 3 (3): 344.

Type-species: Entedon scutellaris Dalman. Desig. by Westwood, 1840.

Paracharitopus Brethes, 1913. Buenos Aires Mus. Nac. de Hist., Nat., An. 24: 105.

Type-species: Paracharitopus lecanii Brethes. Monotypic.

Onophilus Brethes, 1918. Soc. Rural Argentina, An. 53: 155.

Type-species: Onophilus caridei Brethes. Monotypic.

Parencarsia Mercet, 1930. Eos 6 (2): 198.

Type-species: Coccophagus krygeri Mercet. Orig. desig.

Coccophagus contains about 140 species and is worldwide in distribution. Some species have been important in biological control of lecaniine coccids. 
Taxonomy: Girault, 1915. Queensland Mus., Mem. 4: 55-57. -Mercet, 1928. Soc. Espan. de Hist. Nat., Bol. 28: 509-510. - Mercet, 1930. Rev. de Biol. Forest. y Limnologia Ser. B 2: 87-91. - Compere, 1931. U. S. Natl. Mus., Proc. 78 (7): 1-132. -Mercet, 1931. Eos 7 (4): 399-410. -Compere, 1940. Hilgardia 13 (7): 395-405. - Risbec, 1952. Madagascar Inst. Sci., Mem. 2 (E): 152. - Alam, 1956. Roy. Ent. Soc. London, Trans. 108 (8): 363-367. -Tachikawa, 1957. Japanese Jour. Appl. Ent. Zool. 1 (1): 61-64. -Sugonyayev and Chung-yun, 1960. Ent. Rev. 39 (3): 503-507. - Agarwal, 1964. Indian Acad. Sci., Proc. (B) 59: 267-274. -Yoshimoto, 1965. Pacific Insects 7 (4): 699. - Hayat, 1971. Entomophaga 16 (4): 421-432. - Hayat, 1974. Jour. Nat. Hist. 8: 179-186. - Hayat, 1974. Oriental Insects 8 (3): 291-297. -Graham, 1976. Syst. Ent. 1 (2): 137-142.

Biology: Flanders, 1936. Science 83 (2160): 499. -Flanders, 1936. Jour. Econ. Ent. 29 (3): 468. -Flanders, 1936. Ent. Soc. Amer., Ann. 29 (2): 251-255. —Zinna, 1961. Lab. Ent. Agr.

Portici, Bol. 19: 303-317. - Flanders, 1953. Ent. Soc. Amer., Ann. 47 (1): 87.

albicoxa Howard. Calif. Host: Physokermes insignicola (Craw), Toumeyella parvicornis (Ckll.), T. pinicola Ferris.

Coccophagus albicoxa Howard, 1911. Jour. Econ. Ent. 4 (2): 276..

Coccophagus coxalis Girault, 1916. Ent. News 27 (1): 34-35. ?.

anthracinus Compere. Calif. Introduced from S. Africa, possibly established. Host: Saissetia oleae (Oliv.).

Coccophagus anthracinus Compere, 1925. Calif. Univ., Pubs. Ent. 3 (3): 309-311..

Taxonomy: Compere, 1931. U. S. Natl. Mus., Proc. 78 (7): 26. -Compere, 1940. Hilgardia 13 (7): $397,401$.

baldassarii Compere. Calif. Introduced, possibly established. Host: Saissetia oleae (Oliv.). Coccophagus baldassarii Compere, 1931. Calif. Univ., Pubs. Ent. 5 (12): 251-252..

capensis Compere. Calif. Host: Parasaissetia nigra (Nietn.), S. oleae (Oliv.). Coccophagus modestus of American authors, not Silvestri.

Coccophagus modestus var. capensis Compere, 1931. U. S. Natl. Mus., Proc. 78 (7): 83.

Biology: Smith and Compere, 1926. Calif. Univ., Pubs. Ent. 4 (3): 51-61. - Essig, 1931. Hist. of Ent., pp. 346, 386. - Flanders, 1936. Jour. Econ. Ent. 29 (2): 468. - Cendana, 1937. Calif. Univ., Pubs. Ent. 6 (14): 390-396. - Clausen, 1956. U. S. Dept. Agr., Tech. Bul. 1139, p. 93.

caridei (Brethes). Calif. Introduced, possibly established. Host: Coccus hesperidum L., C. pseudomagnoliarum (Kuw.), Planococcus citri (Risso), Saissetia hemisphaerica (Targ.-Tozz.), S. oleae (Oliv.).

Onophilus Caridei Brethes, 1918. Soc. Rural Argentina, An. 52: 156.

Coccophagus heteropneusticus Compere, 1939. Calif. Univ., Pubs. Ent. 7 (5): 83-84. ठ,.+

Biology: Flanders, 1939. Jour. Econ. Ent. 32 (6): 888-890. - Flanders, 1942. Jour. Econ. Ent. 35 (5): 687 . - Flanders, 1949. Canad. Ent. 81 (11): 261.

cinguliventris Girault. Md. w. to Ill., Wis. Host: Lecanium corni Bouche, L. nigrofasciatum Perg.

Coccophagus cinguliventris Girault, 1909. Psyche 16 (4): 79-80. ․

Taxonomy: Girault, 1916. Ent. Soc. Amer., Ann. 9 (3): 297-298 (male described).

cowperi Girault. Tex. w. to Calif. Host: Saissetia oleae (Oliv.), Coccus hesperidum L., Parasaissetia nigra (Nietn.).

Coccophagus couperi Girault, 1917. Deser. Stellarum Nov., p. 1..

Taxonomy: Gahan, 1927. U. S. Natl. Mus., Proc. 71 (4): 24-25. -Masi, 1907. Lab. Zool. Gen. e Agr. Portici, Bol. 1: 239-243 (misident. as flavoscutellum Ashm.). -Compere, 1931. U. S. Natl. Mus., Proc. 78 (7): 57, 60. - Flanders, 1953. Ent. Soc. Amer., Ann. 46 (1): 90-91. -Alam, 1956. Ent. Soc. London, Trans. 108 (8): 363-364.

Biology: Clausen, 1956. U. S. Dept. Agr., Tech. Bul. 1139, p. 94. -Flanders, 1959. Jour. Econ. Ent. 52 (4): 597.

eleaphilus Silvestri. Calif. Host: Saissetia oleae (Oliv.).

Coccophagus eleaphilus Silvestri, 1915. Lab. Zool. Gen. e Agr. Portici, Bol. 9: 318-320. ठ, ㅇ. 
eritreaensis Compere. Calif. Introduced. Host: Cocens pseudomagnoliamem (Kuw.), Saissetia oleae (Oliv.).

Coccophagus eritreaensis Compere, 1931. Calif. Univ., Pubs. Ent. 5 (12): 254. ơ, ‥

Biology: Flanders, 1959. Jour. Econ. Ent. 52 (4): 597.

flavifrons Howard. Pa. s. to Fla., w. to Tex. Host: Chionaspis pinifolize (Fitch), Coccus hesperidum L., Leeanium sp. on Pinus palustris, Toumeyella liviodendri (Gmel.).

Coccophagns flavifrons Howard, 1885. U. S. Dept. Agr., Bur. Ent., Bul. 5: 25. ठ.

Coccophagnis koebelei Howard, 1885. U. S. Dept. Agr., Bur. Ent., Bul. 5: 25. ơ.

fletcheri Howard. N. Y. Host: Lecanium fletcheri Ckll.

Coccophagus fletcheri Howard, 1897. U. S. Dept. Agr., Div. Ent., Bul. (n. s.) 7: 63. 9.

fraternus Howard. N. Y. s. to Fla., w. to Mich., Colo. Host: Lecanium nigrofasciatum Perg., $L$. persicae (F.), Pulvinaria acericola (W. and R.).

Coccophagus fraternus Howard, 1881. U. S. Dept. Agr., Ann. Rept. for 1880, p. 359..+

Coccophagus fuscipes Howard, 1881. U. S. Dept. Agr., Ann. Rept. for 1880, p. 359. o, ?.

Taxonomy: Howard, 1895. U. S. Dept. Agr., Div. Ent., Tech. Ser. 1: 34.

gurneyi Compere. Calif. Host: Phenacoccns gossypii T. and C., P. solani Ferris, Planococcus citri (Risso), Pseudococcus calceolariae (Maskell), P. comstocki (Kuw.), P. longispinus

(Targ.-Tozz.), P. maritimus (Ehrh.), Tetracnemus peregrinus Compere.

Coccophagus gurneyi Compere, 1929. Calif. Univ., Pubs. Ent. 5 (1): 1-3. o, ᄋ.

Biology: Compere and Smith, 1932. Hilgardia 6 (17): 585-617. -Cendana, 1937. Calif. Univ., Pubs. Ent. 6 (14): 340-359. -Clancy, 1944. Jour. Econ. Ent. 37 (3): 450. -DeBach, 1949.

Ecology 30 (1): 16-24. - Clausen, 1956. U. S. Dept. Agr., Tech. Bul. 1139, p. 92. - Bartlett and Lloyd, 1958. Jour. Econ. Ent. 51 (1): 92.

hawaiiensis Timberlake. Calif. Introduced, possibly established. Host: Coccus pseudomagnoliarum (Kuw.), Lecanium sp., Parasaissetia nigra (Nietn.), Pulvinaria sp.

Coccophagus hawailensis Timberlake, 1926. Hawaii. Ent. Soc., Proc. 6 (2): 315-317..+

immaculatus Howard. N. Y. s. to Fla., Ala., w. to Colo., Calif. Host: Coccus hesperidum L., Eriococcus azaleae Comst., Lecanium sp. on Mulberry, Pulvinaria bigeloviae Ckll., Quadraspidiotus pemiciosus (Comst.), Saissetia coffeae (Walk.), Toumeyella parvicomis (Ckll.), T. turgida (Ckll.).

Coccophagus immaculatus Howard, 1881. U. S. Dept. Agr., Ann. Rept. for 1880, p. 358. ठ", \&.

Biology: Felt, 1916. N. Y. State Mus., Bul. 180: 65.

insidiator (Dalman). Mass., N. Y., Colo. Host: Gossyparia spuria (Mod.).

Entedon insidiator Dalman, 1825. Svenska Vetensk. Akad., Handl. 46: 371-372. o, ๆ.

Coccophagus niger Masi, 1909. Lab. Zool. Gen. e. Agr. Portici, Bol. 4: 35-36. क .

Coccophagus gossypariae Gahan, 1927. U. S. Natl. Mus., Proc. 71 (4): 24..

Biology: Griswold, 1927. Ent. Soc. Amer., Ann. 20 (4): 553-555.

japonicus Compere. Calif. Introduced, possibly established. Host: Ceroplastes sp., Coccus psendomagnoliarum (Kuw.), Pulvinaria sp.

Coccophagres japonicus Compere, 1924. So. Calif. Acad. Sci., Bul. 23 (4): 117, 120, 122-123. ‥

longifasciatus Howard. Ill. Host: Lecanium nigrofasciatum Perg.

Aphelinus Inaron Walker, 1839. Monog. Chalcid. v. 1, p. 10. ठ. Questionable synonym.

Coccophagus longifasciatus Howard, 1907. U. S. Dept. Agr., Bur. Ent., Tech. Bul. 12 (4): 80-81. ठ, ?.

Taxonomy: Mercet, 1931. Eos 7 (4): 400.

lycimnia (Walker). Cosmopolitan. Host: Ceroplastes floridensis Comst., Coccus hesperidum L., C. psendomagnolianm (Kuw.), Icerya purchasi Mask., Kermes sp., Lecanium comi Bouche, L. fletcheri Ckll., L. nigrofasciatum Perg., L. persicae (F.), L. pruinosum Coq., L. quercifex Fitch, Lepidosaphes beckii (Newm.) (?), Parasaissetia nigra (Nietn.), Parlatoria pergandii Comst., Phenacoccus acericola King, Physokermes insignicola (Craw), Planococcus citri (Risso), Pulvinaria acericola (W. and R.), P. amygdali Ckll., 
P. bigeloviae Ckll., P. vitis (L.), P. floccifera (Westw.), Quadraspidiotus perniciosus (Comst.), Saissetia coffeae (Walk.), Saissetia oleae (Oliv.), Tonymeyella liriodendri (Gmel.).

Aphelinus Lycimnia Walker, 1839. Monog. Chalcid. v. 1, p. 11. \&.

Platygaster Lecanii Fitch, 1859. N. Y. State Agr. Soc., Trans. 18: 805-806.

Coccophagus lecanii Smith, 1878. Amer. Nat. 12: 661. \&.

Coccopahgus ater Howard, 1881. U. S. Dept. Agr., Ann. Rept. for 1880, pp. 359-360. ơ, $\uparrow$.

Coccophagus cognatus Howard, 1881. U. S. Dept. Agr., Ann. Rept. for 1880, p. 359. ठ, ₹.

Coccophagus flavoscutellum Ashmead, 1881. Fla. Agr. 4: 65. ठ, 9.

Coccophagus vividus Howard, 1885. U. S. Dept. Agr., Bur. Ent., Bul. 5: 24, 43. ठ, ९.

Coccophagus californicus Howard, 1889. U. S. Dept. Agr., Insect Life 1 (9): 269-270..

Coccophagus coccidis Girault, 1917. Descr. Stellarum Nov., p. 2.

Coccophagus corni Alam, 1956. Roy. Ent. Soc. Lond., Trans. 108 (8): 363, 364-365. ठ, ?.

Coccophagus taxi Alam, 1956. Roy. Ent. Soc. Lond., Trans. 108 (8): 364, 365-367. o, ?.

Taxonomy: Graham, 1976. Syst. Ent. 1 (2): 139.

Biology: Flanders, 1936. Science 84 (2169): 85. - Flanders, 1936. Jour. Econ. Ent. 29 (2): 468. -Flanders, 1936. Ent. Soc. Amer., Ann. 29 (2): 253. -Flanders, 1942. Ecology 23: 120.

-Flanders, 1943. Jour. Econ. Ent. 36 (5): 802. - Clausen, 1956. U. S. Dept. Agr., Tech. Bul. 1139, pp. 94-95. - Peterson, 1962. Canad. Ent. 94 (7): 740. - Sonina, 1962. Akad. Nauk. Uzbek. SSR, Biol. Zhur. 3: 62. - Sugonyayev, 1962. A kad. Nauk. SSSR Izv., Ser. Biol. 5: 755. - Phillips, 1963. Canad. Ent. 95 (4): 402. -Sorokina, 1971. Ent. Rev. 50 (3): 313, 315, 316.

mexicensis Girault. Calif. Introduced, possibly established. Host: Saissetia oleae (Oliv.). Coccophagus mexicensis Girault, 1917. Descr. Stellarum Nov., p. 2. \&.

Biology: Clausen, 1959. Pan-Pacific Ent. 35 (2): 107.

nigritus Compere. Calif. Introduced, possibly established. Host: Saissetia oleae (Oliv.). Coccophagus nigritus Compere, 1931. U. S. Natl. Mus., Proc. 78 (7): 18, 81-82. .

Biology: van den Bosch et al., 1955. Jour. Econ. Ent. 48 (1): 54.

ochraceus Howard. La., Calif. Host: Lecanium cormi Bouche, Parasaissetia nigra (Nietn.), Saissetia coffeae (Walk.), S. oleae (Oliv.).

Coccophagus ochraceus Howard, 1895. U. S. Dept. Agr., Div. Ent., Tech. Ser. 1: 38-39. đ, ㅇ.

Coccophagus bifasciaticorpus Girault, 1916. Soc. Ent. 31: 44. ठ, 9.

Taxonomy: Smith and Compere, 1928. Calif. Univ., Pubs. Ent. 4 (9): 259-261.

perflavus Girault. Wis. Host: Kermes sp., Lecanium corni Bouche.

Coccophagus perflavus Girault, 1916. Soc. Ent. 31: 43-44. ठ', $९$.

pulvinariae Compere. Calif. Introduced. Host: Coccus hesperidum L., Parasaissetia nigra (Nietn.), Saissctia oleae (Oliv.).

Coccophagus pulvinariae Compere, 1931. U. S. Natl. Mus., Proc. 78 (7): 53-54. §, \&.

Biology: Clausen, 1956. U. S. Dept. Agr., Tech. Bul. 1139, pp. 94-95. -Flanders, 1959. Jour.

Econ. Ent. 52 (4): 597.

purpureus Ashmead. Fla.

Coccophagus purpureus Ashmead, 1886. Amer. Ent. Soc., Trans. 13: 132. ๆ.

quaestor Girault. Wis. Host: Toumeyella parvicornis (Ckll.).

Coccophagus quaestor Girault, 1917. Descr. Stellarum Nov., p. 2..

rusti Compere. Calif. Host: Saissetia oleae (Oliv.).

Coccophagus rusti Compere, 1928. In Smith and Compere, Calif. Univ., Pubs. Ent. 4 (9): 261-262. . .

Biology: Flanders, 1942. Jour. Econ. Ent. 35 (5): 687. -Clausen, 1956. U. S. Dept. Agr., Tech. Bul. 1139 , p. 95.

scutatus Howard. Calif. Host: Kermes nigropunctatus Ehrh. and Ckll.

Coccophagus scutatus Howard, 1895. U. S. Dept. Agr., Div. Ent., Tech. Ser. 1: 38. §, ^. 
scutellaris (Dalman). Fla., Oreg., Calif. Host: Coccus hesperidum L., C. pseudomagnoliarum (Kuw.), Lecanium cormi Bouche, Saissetia coffeae (Walk.), S. oleae (Oliv.).

Entedon scutellaris Dalman, 1825. Svenska Vetensk. Akad., Handl. 46: 365, 371. §, $९$. Coccophagus lunulatus Howard, 1894. U. S. Dept. Agr., Insect Life 6 (3): 232..

Taxonomy: Graham, 1976. Syst. Ent. 1 (2): 141-142.

Biology: Smith and Compere, 1928. Calif. Univ., Pubs. Ent. 4 (9): 242, 254-257. -Cendana, 1937. Calif. Univ., Pubs. Ent. 6 (14): 379-390. -Flanders, 1959. Jour. Econ. Ent. 52 (1): 74. -Flanders, 1959. Jour. Econ. Ent. 52 (4): 597. —Sonina, 1961. Akad. Nauk. Uzbek SSR., Biol. Zhur. 3: 62.

timberlakei Compere. Utah. Host: Pulvinaria bigeloviae Ckll. Coccophagus timberlakei Compere, 1931. U. S. Natl. Mus., Proc. 78 (7): 28-29.. yoshidae Nakayama. Calif. Introduced. Host: Coccus pseudomagnoliarum (Kuw.), C. hesperidum L.

Coccophagus yoshidae Nakayama, 1921. Phillippine Jour. Sci. 18 (1): 98-99. 9.

Biology: Compere, 1924. So. Calif. Acad. Sci., Bul. 23 (4): 119. - Smith and Compere, 1928. Calif. Univ., Pubs. Ent. 4 (9): 263-264. - Sugonyaev and Chung-yun, 1960. Ent. Rev. 39 (3): 503, 506 .

\section{Genus ENCARSIA Foerster}

Encarsia Foerster, 1878. Naturh. Ver. Rheinlande, Verh. 35: 65-66.

Type-species: Encarsia Tricolor Foerster. Orig. desig.

Doloresia Mercet, 1912. (Madrid) Mus. de Cien. Nat., Trab. 10: 294-295.

Type-species: Doloresia filicomis Mercet. Orig. desig.

The genus Encarsia is morphologically similar to Prospaltella. Encarsia consists of about 50 species distributed throughout the world. They are primary internal parasites of whiteflies and armored scale insects. Males of some species are purported to be hyperparasites on females of the same species.

Taxonomy: Howard, 1907. U. S. Dept. Agr., Bur. Ent., Tech. Bul. 12 (4): 76-79. -Nowicki, 1929. Neue Beitr. Syst. Insektenk. 4: 158-160. - Mercet, 1930. Eos 6 (2): 191-193. - Mercet, 1930. Rev. de Biol. Forest. y Limnologia 2 (B): 77-80. - Agarwal, 1964. Indian Acad. Sci., Proc. 49: 282-285. -Jashnosh, 1973. Ent. Rev. 52 (2): 578-585. —Graham, 1976. Syst. Ent. 1 (2): 142-143.

Biology: Steuben, 1949. Biol. Zentbl. 68: 413-429. -Flanaders, 1953. Ent. Soc. Amer., Ann. 46 (1): 92. - Dysart, 1966. Ent. Soc. Amer., Ann. 59 (1): 28-33. -Gerling, 1966. Ent. Soc.

Amer., Ann. 59 (1): 142-143. -Gerling, 1966. Canad. Ent. 98 (7): 707-724. -Gerling, 1967.

Ent. Soc. Amer., Ann. 60 (6): 1310.

angelica Howard. Calif. Host: Aleuroplatus coronatus (Quaint.), Aleyrodes sp. on willow.

Encarsia angelica Howard, 1895. U. S. Dept. Agr., Div. Ent., Tech. Ser. 1: 30 . ठ.

basicineta Gahan. Fla. Host: Aleurothrixus floccosus (Mask.).

Encarsia basicincta Gahan, 1927. U. S. Natl. Mus., Proc. 71 (4): 20-21. ๆ.

coquilletti Howard. Idaho, Wash., Ariz., Calif. Host: Aleyrodes sp. on Sonchus.

Encarsia coquilletti Howard, 1895. U. S. Dept. Agr., Div. Ent., Tech. Ser. 1: 29. ठ, ๆ.

formosa Gahan. Cosmopolitan. Host: Trialeurodes vaporariorum (Westw.).

Encarsia formosa Gahan, 1924. U. S. Natl. Mus., Proc. 65 (4): 14-16. ठ, ๆ.

Biology: Speyer, 1927. Bul. Ent. Res. 17 (3): 301-308. -McLeod, 1938. Sci. Agr. 18: 529-535. -Burnett, 1948. Ecology 29: 181-189. - Burnett, 1949. Ecology 30: 113-133. - Burnett, 1958. Canad. Ent. 90 (3): 179-191, 225-229. - Burnett, 1962. Canad. Ent. 94 (7): 673.

-Timofeeva, 1963. Zasch. Rast. Vred. i Boleznei. 8: 44. - Curry and Pimentel, 1971. Ent.

Soc. Amer., Ann. 64 (5): 1188-1190. - Huffaker, 1971. Biol. Control, pp. 195, 200-202, 211.

luteola Howard. Mass., Conn., D. C., Calif. Host: Trialeurodes fernaldi (Morr.), T. packardi (Morr.).

Encarsia luteola Howard, 1895. U. S. Dept. Agr., Div. Ent., Tech. Ser. 1: 29. ९. 
Biology: Morrill and Back, 1912. U. S. Dept. Agr., Bur. Ent., Bul. 102: 8. -Poinar, 1964. Jour. Ent. 57: 382.

meritoria Gahan. Fla. w. to Calif. Host: Trialeurodes floridensis (Quaint.).

Encarsia meritoria Gahan, 1927. U. S. Natl. Mus., Proc. 71 (4): 19-20. ठ, १.

pergandiella Howard. N. Y. s. to D. C., w. to Ill., Wash., Calif. Host: Aleuroplatus coronatus (Quaint.), Trialeurodes abutilonea (Hald.), T. vaporariorum (Westw.).

Encarsia pergandiella Howard, 1907. U. S. Dept. Agr., Bur. Ent., Tech. Bul. 12 (4): 78.. Encarsia versicolor Girault, 1908. Psyche 15 (3): 53. ठै, ?.

Biology: Garman, 1922. Ky. Agr. Expt. Sta., Bul. 241: 92-93. -Dysart, 1966. Ent. Soc. Amer., Ann. 59 (1): 28-33. -Gerling, 1966. Canad. Ent. 98 (7): 707-724.

quaintancei Howard. D. C. w. to Ill. Host: Aleyrodes sp. on Polygonum.

Encarsia quaintancei Howard, 1907. U. S. Dept. Agr., Bur. Ent., Tech. Ser. 12 (4): 79..

Biology: Dysart, 1966. Ent. Soc. Amer., Ann. 59 (1): 28-33.

variegata Howard. Fla. Host: Paraleyrodes perseae (Quaint.).

Encarsia variegata Howard, 1908. Ent. Soc. Wash., Proc. 10 (1-2): 64.

Biology: Morrill and Back, 1912. U. S. Dept. Agr., Bur. Ent., Bul. 102: 8.

\section{Genus LOUNSBURYIA Compere and Annecke}

Lounsburyia Compere and Annecke, 1961. So. Africa Ent. Soc., Jour. 24 (1): 28-29.

Type-species: Coccophagus trifasciatus Compere. Orig. desig.

This African genus of coccophagines consists of only a few species which are similar to Coccophagus. The type-species was imported into California for the biological control of the black scale, Saissetia oleae (Oliv.).

trifasciata (Compere). Calif. Introduced. Host: Saissetia oleae (Oliv.).

Coccophagus trifasciatus Compere, 1925. Calif. Univ., Pubs. Ent. 3 (3): 311-313. ઠ์,.

Taxonomy: Compere, 1931. U. S. Natl. Mus., Proc. 78 (7): 1-132. - Compere and Annecke, 1961. So. Africa Ent. Soc., Jour. 24 (1): 28-32.

Biology: Cendana, 1937. Calif. Univ., Pubs. Ent. 6 (14): 372-379. -Flanders, 1942. Ecology 23: 120.

\section{Genus PHYSCUS Howard}

Physcus Howard. 1895. U. S. Dept. Agr., Div. Ent., Tech. Ser. 1: 43.

Type-species: Coccophagus varicornis Howard. Monotypic.

Encyrtophyscus De Santis, 1948. La Plata Mus. Rev., Zool. (n. s.) 5: 192-193.

Type-species: Physcus flavoflagellatus De Santis. Orig. desig.

Physcus consists of about 40 species distributed throughout the world. Females are internal parasites of scale insects; males develop as hyperparasites of females of their own species (sometimes called facultative adelphoparasitism) or on other primary parasites (sometimes called heterotrophic arrhenoparasitism).

Taxonomy: Howard, 1914. Ent. Soc. Wash., Proc. 16 (2): 82-84. - Mercet, 1930. Rev. de Biol. Forest. y Limnologia 2 (B): 61-63. - De Santis, 1940. La Plata Univ. Nac., Fac. Agr. Rev. 24 (3): 29-44. - Erdos, 1958. Folia Ent. Hungarica (n. s.) 11 (5): 85. -Compere and Annecke, 1961. So. Africa Ent. Soc., Jour. 24 (1): 20-26. - Agarwal, 1964. Indian Acad. Sci., Proc. (B) 60: 320-324. -Jashnosh, 1968. Ent. Rev. 47 (1): 117-124. -Jashnosh, 1973. Ent. Rev. 52 (4): 578-585. - Graham, 1976. Syst. Ent. 1 (2): 144.

Biology: Jashnosh, 1968. Ent. Rev. 47 (1): 117-124. -Fisher, 1961. Jour. Econ. Ent. 54 (3): 444. - Williams, 1971. Bul. Ent. Res. 61 (3): 463-484.

flaviventris Howard. Tex. Ecology: Associated with Antonina graminis (Mask.). Introduced. Physcus flaviventris Howard, 1910. Ent. News 21 (4): 162..

fulvus Compere and Annecke. Calif. Introduced. Host: Lepidosaphes beckii (Newm.). Physcus fulvus Compere and Annecke, 1961. So. Africa Ent. Soc., Jour. 24 (1): 21-23. ơ, \&. 
Biology: Flanders, 1953. Lab. Zool. Gen. e Agr. Portici, Bol. 33: 22 (as Physcus "B").

-Clausen, 1956. U. S. Dept. Agr., Tech. Bul. 1139, p. 122 (sp. "B").

howardi Compere. Calif. Host: Nuculaspis californica (Col.).

Physcus hou'ardi Compere, 1928. Calif. Univ., Pubs. Ent. 4 (8): 223. ơ, १.

stanfordi Howard. Calif. Host: Stramenaspis kelloggi (Col.).

Physcus stanfordi Howard, 1914. Ent. Soc. Wash., Proc. 16 (2): 84. .

testaceus Masi. Calif. Introduced, possibly established. Host: Lepidosaphes ulmi (L.), Lepidosaphes sp.

Physcus testaceus Masi, 1909. Lab. Zool. Gen. e. Agr. Portici, Bol. 4: 36-37. ๆ.

Biology: Flanders, 1957. Jour. Econ. Ent. 50 (2): 171-172.

varicornis (Howard). Que. s. to Fla., w. to Wis., s. to Neb., Calif. Host: Chionaspis americana Johns., C. furfura (Fitch), C. pinifoliae (Fitch), Diaspidiotus ancylus (Putn.), D. uvae (Comst.), Lecanium nigrofasciatum Perg., Melanaspis obscura (Comst.), Nuculaspis californica (Col.), Quadraspidiotus jugalusregiae (Comst.), Q. perniciosus (Comst.).

Coccophagus varicorn is Howard, 1881. U. S. Dept. Agr., Ann. Rept. for 1880, p. 360..

Physcus variicomis Dalla Torre, 1898. Cat. Hym., 5: 226. Unjustified emendation.

Taxonomy: Girault, 1911. N. Y. Ent. Soc., Jour. 19 (3): 183.

Biology: Baker, 1933. U. S. Dept. Agr., Cir. 295: 8-9.

\section{Genus PROSPALTELLA Ashmead}

Prospalta Howard, 1894. U. S. Dept. Agr., Insect Life 7 (1): 6. Preoceupied by Walker, 1857.

Type-species: Prospalta murtfeldiae Howard. Monotypic.

Prospaltella Ashmead, 1904. Ent. Soc. Wash., Proc. 6 (2): 126. New name.

Mimatomus Cockerell, 1911. Ent. News 22 (10): 464.

Type-species: Mimatomus peltatus Cockerell. Monotypic.

The genus Prospaltella is cosmopolitan and contains about 40 species. Morphologically it resembles Aspidiotiphagus and Encarsia. Many species are primary internal parasites of scale insects and whiteflies, but some species have hyperparasitic males.

Taxonomy: Howard, 1908. Ent. Soc. Amer., Ann. 1 (4): 281-284. -Malenotti, 1917. Redia 12:

195-196. -Mercet, 1921. Real Soc. Espan. Hist. Nat. 50: 300, 304-308. - Silvestri, 1930.

Lab. Zool. Gen. e. Agr. Portici, Bol. 25: 49-68. - Mercet, 1930. Rev. Biol. Forest. y

Limnologia 2 (B): 72-77. - Mercet, 1931. Soc. Espan. Hist. Nat., Bol. 31 (9): 659-669.

-Alam, 1956. Roy. Ent. Soc. London, Trans. 108 (8): 357-384. - Agarwal, 1964. Indian

Acad. Sci., Proc. (B) 59: 274-282. - Yoshimoto, 1965. Pacific Insects 7 (4): 695-696.

- Shafee, 1973. Entomophaga 18 (3): 251-258, - Ferriere, 1961. Schweiz. Ent. Gesell., Mitt.

34 (3): 253-269.

Biology: Chumakova and Goryunova, 1962. Ent. Rev. 42 (2): 178-181.

aurantii (Howard). Cosmopolitan. Host: Abgrallaspis howardi (Ckll.), Aleuroplatus coronatus (Quaint.), Aonidiella aurantii (Mask.), A. citrina (Coq.), Aonidomytilus concolor (Ckll.), Aspidiotus nerii Bouche, Chionaspis sp., Chrysomphalus dictyospermi (Morg.), Diaspidiotus ancylus (Putn.), D. ancylus var. on linden, Hemiberlesia rapax (Comst.), Kermes nigropunctatus Ehrh. and Ckll., Lecanium corni Bouche, L. nigrofasciatum Perg., L. persicae (F.), Lepidosaphes beckii (Newm.), L. gloverii (Pack.), L. ulmi (L.), Pseudaonidia duplex (Ckll.), Quadraspidiotus forbesi (Johns.), Q. juglansregiae (Comst.), $Q$. perniciosus (Comst.). It is probable that $P$. aurantii is a complex of sibling species. Coccophagus aurantii Howard, 1894. U. S. Dept. Agr., Insect Life 6 (3): 231-232. 9.

Taxonomy: Rust, 1913, Ent. News 24 (4): 161.

Biology: Taylor, 1907. Colo. Agr. Exp. Sta., Bul. 120: 10. -Essig, 1913. Calif. State Comn.

Hort., Month. Bul. 2: 276. -Griffiths and Stearns, 1947. Fla. Ent. 30 (1-2): 4-7. - Benassy, 1958. Entomophaga 3 (2): 104. - Muma, 1959. Jour. Econ. Ent. 52 (4): 579.

bella Gahan. N. Y., Mich., Calif. Host: Chionaspis pinifoliae (Fitch).

Prospaltella bella Gahan, 1927. U. S. Natl. Mus., Proc. 71 (4): 21-22. §, ๆ. 
berlesei (Howard). D. C. s. to Fla., w. to La. Host: Melanaspis obscura (Comst.), Pseudaulacaspis pentagona (Targ.-Tozz.).

Prospalta berlesei Howard, 1906. Ent. News 17 (8): 291-293..+

Taxonomy: Silvestri, 1908. Lab. Zool. Gen. e Agr. Portici, Bol. 3: 22-28. -Masi, 1908. Lab. Zool. Gen. e Agr. Portici, Bol. 3: 143-146. -Flanders, 1960. Jour. Econ. Ent. 53 (5): 757. -Ferriere, 1961. Schweiz. Ent. Gesell., Mitt. 34 (3): 256, 261-263.

Biology: Baker, 1933. U. S. Dept. Agr., Cir. 295: 8-9. -Gireau, 1956. Phytoma 82: 29. -Benassy, 1957. Entomophaga 2 (4): 283. - Benassy, 1958. Ann. Epiphyt. 9 (C): 459. -Benassy, 1961. Ann. Epiphyt. 12 (C): 127.

Morphology: Snodgrass, 1910. U. S. Natl. Mus., Proc. 39: 66. brasiliensis (Hempel). Fla. Host: Aleurothrixus floccosus (Mask.).

Prospalta brasiliensis Hempel, 1904. Bol. da Agr. Sao Paulo (ser. 5) 1: 20-21. ๆ.

citrella Howard. Fla., Ariz., Calif. Host: Aleuroplatus corouatus Quaint., Kermes sp. on Quercus undulata.

Prospaltella citrella Howard, 1908. Ent. Soc. Amer., Ann. 1 (4): 282-283..

diaspidicola Silvestri. Mass. s. to Va., w. to Ill., Tex. Host: Quadraspidiotus perniciosus (Comst.).

Prospaltella diaspidicola Silvestri, 1909. Real Accad. dei Lincei (ser. 5): 18 (11): 564-565. \%.

Taxonomy: Flanders, 1960. Jour. Econ. Ent. 53 (5): 757 (questionable synonym of berlesei (Howard)).

elongata Dozier. La. w. to Calif. Host: Lepidosaphes gloveri (Pack.).

Prospaltella elongata Dozier, 1937. Puerto Rico Univ., Jour. Agr. 21 (2): 128-129..

fasciata Malenotti. D. C. s. to Fla., w. to Tex. Host: Carulaspis visci (Schraeder), Pseudaonidia duplex (Ckll.).

Prospaltella fasciata Malenotti, 1916. Redia 12 (1-2): 195-196. ․

Taxonomy: Ferriere, 1961. Schweiz. Ent. Gesell., Mitt. 34 (3): 255, 259-260.

Biology: Benassy and Bianchi, 1960. Entomophaga 5 (2): 168.

fasciativentris Girault. Mich., Ill. Host: Chionaspis furfura (Fitch), Diaspidiotus aesculi (Johns.), Quadraspidiotus forbesi (Johns.), Q. juglansregiae (Comst.), Q. perniciosus (Comst.).

Prospaltella fasciativeutris Girault, 1908. Psyche 15 (6): 117-120..

forbesi Dozier. Del. Host: Quadraspidiotus forbesi (Johns.).

Prospaltella forbesi Dozier, 1928. Ent. Soc. Wash., Proc. 30 (2): 37-38. .

murtfeldtiae (Howard). D. C. w. to Mo., Ark. Host: Diaspidiotus uvae (Comst.), Pseudaulacaspis pentagona (Targ.-Tozz.), Quadraspidiotus forbesi (Johns.).

Prospalta murtfeldtii(!) Howard, 1894. U. S. Dept. Agr., Insect Life 7 (1): 6-7.. peltata (Cockerell). Colo. Host: Aleyrodes pruinosa euphorbiarum Ckll.

Mimatomus peltatus Cockerell, 1911. Ent. News 22 (10): 464. \&.

perniciosi Tower. N. Y. s. to Va., w. to Kans., Calif. Host: Lepidosaphes ulmi (L.), Quadraspidiotus perniciosus (Comst.).

Prospaltella perniciosi Tower, 1913. Ent. Soc. Amer., Ann. 6 (1): 125-126. ठ, \&.

Taxonomy: Ferriere, 1961. Schweiz. Ent. Gesell., Mitt. 34 (3): 266-267.

Biology: Tower, 1914. Jour. Econ. Ent. 7 (6): 422. -Tower, 1914. Ent. Soc. Amer., Ann. 7 (3): 249. - Rice, 1937. Abs. Ph. D. Diss., Ohio St. Univ., pp. 267-278. -Flanders, 1939. Jour. Econ. Ent. 32 (6): 890. - Flanders, 1944. Science 100 (2591): 168. -Flanders, 1944. Jour. Econ. Ent. 37 (1): 105. - DeBach, 1953. Jour. Econ. Ent. 46 (6): 1103. -Clausen, 1956. U. S. Dept. Agr., Tech. Bul. 1139, p. 124. - Flanders, 1956. Lab. Zool. Gen. e Agr. Portici, Bol. 33: 23. -Chumakova, 1957. Zool. Zhur. 36 (4): 534. - Benassy and Bianchi, 1960.

Entomophaga 5 (2): 168. - Flanders, 1960. Jour. Econ. Ent. 53 (5): 757. - Popova, 1962.

Biol. Control Agr. Pests and Diseases 1: 147-176. - Chumakova and Goryunova, 1963. Ent. Rev. 42 (2): 178-181. - Sorokina, 1971. Ent. Rev. 50 (3): 311, 315, 316. - Huffaker, 1971. 
Biol. Control, pp. 74-75, 181, 186. - DeBach, 1974. Biol. Control by Nat. Enem., pp. 179, $180,181$.

perspicuipennis Girault. Ill.

Prospaltella perspicuipennis Girault, 1910. N. Y. Ent. Soc., Jour. 18 (4): 234-236. \&. quercicola Howard. Calif. Ecology: Aleuroplatus coronatus (Quaint.), A. gelatinosus (Ckll.).

Prospaltella quercicola Howard, 1908. Ent. Soc. Amer., Ann. 1 (4): 282, 284..

\section{TRIBE ERIAPORINI}

\section{Genus MYIOCNEMA Ashmead}

Myiocnema Ashmead, 1900. Canad. Ent. 32 (11): 349.

Type-species: Myiocnema Comperei Ashmead. Monotypic.

Myiocnema is a monotypic genus found in the Oriental and Australian regions. It has been propagated in the laboratory in North America and may have become established here.

comperei Ashmead. Calif. Introduced, possibly established. Host: Parasaissetia nigra (Nietn.).

Myiocnema Comperei Ashmead, 1900. Canad. Ent. 32 (11): 349. ?.

\section{TRIBE PTEROPTRICINI}

\section{Genus ARCHENOMUS Howard}

Archenomus Howard, 1898. Ent. Soc. Wash., Proc. 4 (2): 136-137.

Type-species: Archenomus bicolor Howard. Monotypic.

Pteroptrichoides Fullaway, 1913. Hawaii. Sugar Planters' Assoc. Expt. Sta., Div. Ent., Ann. Rept. 1912, pp. 27-28.

Type-species: Pteroptrichoides perkinsi Fullaway. Orig. desig.

Pseudopteroptrix Fullaway, 1918. Hawaii. Ent. Soc., Proc. 3 (5): 464.

Type-species: Pseudopteroptrix imitatrix Fullaway. Monotypic.

Less than 15 species of Archenomus are known. They are parasites of armored scale insects.

bicolor Howard. Va. s. to Ga., Ohio, Oreg. Host: Aspidiotus sp. on sweet gum,

Pseudaulacaspis pentagona (Targ.-Tozz.).

Archenomus bicolor Howard, 1898. Ent. Soc. Wash., Proc. 4 (2): 137-138. đo, ๆ.

Biology: Sorokina, 1971. Ent. Rev. 50 (3): 310, 315, 316.

imitatrix (Fullaway). Fla. Adventive. Host: Howardia biclavis (Comst.).

Pseudopteroptrix imitatrix Fullaway, 1918. Hawaii. Ent. Soc., Proc. 3 (5): 464.

\section{Genus ERETMOCERUS Haldeman}

Eretmocerus Haldeman, 1850. Amer. Jour. Sci. Arts (2) 9: 111.

Type-species: Eretmocerus corni Haldeman. Monotypic.

Ricinusa Risbec, 1951. Mem. Inst. Fr. Africa Noire 13: 403.

Type-species: Ricinusa aleyrodiphaga Risbec. Monotypic.

Eretmocerus contains about 25 species which are found throughout the world, but predominantly in the tropics. They are parasites of whiteflies and some have been important in biological control (see DeBach, 1974).

Taxonomy: Howard, 1895. U. S. Dept. Agr., Div. Ent., Tech. Ser. 1: 16. - Mercet, 1931. Eos 7

(4): 395-399. -Dozier, 1932. Ent. Soc. Wash., Proc. 34 (7): 112-118. -Compere, 1936. Calif.

Univ., Pubs. Ent. 6 (12): 316-321. -Tachikawa, 1962. Shikoku Ent. Soc., Trans. 7 (3): 73.

-Yoshimoto, 1965. Pacific Insects 7 (4): 690-691. -Gerling, 1969. Lab. Ent. Agr. Portici,

Bol. 27: 79-87. -Gerling, 1970. So. Africa Ent. Soc., Jour. 33 (2): 325-329. - Hayat, 1972.

Entomophaga 17 (1): 99-106. -Gerling, 1972. Ent. Ber. 32 (8): 156-161.

Biology: DeBach, 1974. Biol. Control by Nat. Enem., pp. 140-143, 167, 202.

californicus Howard. Calif. Host: Aleyrodes sp. on Quercus agrifolia.

Eretmocerus californicus Howard, 1895. U. S. Dept. Agr., Div. Ent., Tech. Ser. 1: 16-17. o, ․ 
corni Haldeman. N. Y., N. J., Pa. Host: Trialeurodes packardi (Morr.).

Eretmocerus comi Haldeman, 1850. Amer. Jour. Sci. Arts (2) 9: 110.

Taxonomy: Howard, 1895. U. S. Dept. Agr., Div. Ent., Tech. Ser. 1: 16.

haldemani Howard. Fla. w. to Calif., Ill. Host: Aleyrodes spp. on Ambrosia, Erigonum, Hardenbergia, Quercus, and Solidago; Aleuroplatus coronatus (Quaint), Aleurothrixus floccosus (Mask.), Trialeurodes abutilonea (Hald.), T. vaporariorum (Westw.). Eretmocerus haldemani Howard, 1908, Ent. Soc. Wash., Proc. 10 (1-2): 65.

Biology: Watson and Berger, 1932. Fla. Agr. Expt. Sta., Ext. Bul. 67: 56-57. -Watson and Berger, 1937. Fla. Agr. Expt. Sta., Ext. Bul. 88: 53-55. - Dysart, 1966. Ent. Soc. Amer., Ann. 59 (1): 28-33. -Gerling, 1967. Ent. Soc. Amer., Ann. 60 (6): 1306-1321.

illinoisensis Dozier. Ill.

Eretmocerus illinoisensis Dozier, 1932. Ent. Soc. Wash., Proc. 34 (7): 115. ð. portoricensis Dozier. Fla. Host: Aleurothrixus floccosus (Mask.).

Eretmocerus portoricensis Dozier, 1932. Ent. Soc. Wash., Proc. 34 (7): 115-116. $q$.

\section{SUBFAMILY SIGNIPHORINAE}

The names Signiphoridae and Thysanidae have been used interchangeably. Thysanus Walker is older (1840) and Thysanidae was used in the 1951 edition of the catalog. Signiphorinae is used here because it is the commonly used name. Signiphora Ashmead and Thysanus have been synonymized. However, Rozanov (1965) and others have shown that the genera are distinct. The Signiphorinae were characterized by Howard (1894).

De Santis (1968) divided the Signiphoridae into the Signiphorinae and Thysaninae. His subfamilies have been retained as tribes.

Taxonomy: Howard, 1894. U. S. Dept. Agr., Insect Life 6 (3): 234. -Girault, 1913. U. S. Natl.

Mus., Proc. 45: 189-233. -Mercet, 1916. Soc. Espan. de Hist. Nat., Bol. 16: 519-533.

- Mercet, 1917. Rev. Acad. Cien. Madrid 16 (4): 160-170. - Nikol'skaya, 1950. Doklady

Akad. Nauk SSSR 75 (2): 319-321. - Rozanov, 1965. Ent. Rev. 44 (4): 508-515. - De Santis, 1968. Rev. Fac. Agron., La Plata 44 (1): 7-16 (nomenclature). - Hayat, 1970. Entomophaga 15 (4): 387-399. - De Santis, 1973. Univ., Fac. Agron., Rev. La Plata 49 (2): 143-153.

-Subba Rao, 1974. Bul. Ent. Res. 64 (4): 525-531.

Morphology: Domenichini, 1954. Ann. Fac. Agr., Inst. Ent. Agr. (n. s.) 3: 117-132.

\section{TRIBE SIGNIPHORINI}

\section{Genus SIGNIPHORA Ashmead}

Signiphora Ashmead, 1880. Orange Insects, pp. 29, 30.

Type-species: Signiphora flavopalliata Ashmead. Monotypic.

Signiphora consists of about 20 species which are parasites of armored scale insects and whiteflies.

Taxonomy: Girault, 1913. U. S. Natl. Mus., Proc. 45: 189-233. -Mercet, 1916. Soc. Espan. de

Hist. Nat., Bol. 16: 519-533. - Malenotti, 1918. Redia 13 (1): 39-45. -Nikol'skaya, 1950.

Doklady Akad. Nauk SSSR 75 (2): 319-321. - Ferriere, 1953. Schweiz. Ent. Gesell., Mitt. 26

(1): 5. - Rozanov, 1965. Ent. Rev. 44 (4): 508-515. - De Santis, 1973. Univ. Fac. Agron.,

Rev. La Plata 49 (2): 143-153.

aleyrodis Ashmead. Pa., Tex., Calif. Host: Aleuroplatus coronatus (Quaint.), Chrysomphalus aonidum (L.), C. dictyospermi (Morgan).

Signiphora aleyrodis Ashmead, 1900. U. S. Natl. Mus., Proc. 22: 409, 412. \&.

aspidioti Ashmead. Ga.

Signiphora aspidioti Ashmead, 1900. U. S. Natl. Mus., Proc. 22: 410, 412..

borinquensis Quezada, DeBach and Rosen. Calif. Introduced, possibly established. Host: Aspidiotus destructor Sign., Diaspis echinocacti (Bouche).

Signiphora borinquensis Quezada, DeBach and Rosen, 1973. Hilgardia 41 (18): 549-552. ठै, †.

Biology: Quezada et al., 1973. Hilgardia 41 (18): 543-604. 
citrifolii (Ashmead). Florida. Host: Aleuroplatus coronatus (Quaint.), A. gelatinosus (Ckll.), Aleyrodes sp. on Quercus agrifolia.

Signiphora Citrifolii Ashmead, 1880. Orange Insects, p. 66..

coquilletti Ashmead. N. Y. s. to Fla., Calif. Host: Aleyrodes sp., Diaspis boisduvali Sign.

Signiphora coquilletti Ashmead, 1900. U. S. Natl. Mus., Proc. 22: 409, 412..

flava Girault. Calif. Host: Aspidiotus spinosus Comst., Hemiberlasia rapax (Comst.). Signiphora flava Girault, 1913. U. S. Natl. Mus., Proc. 45: 213-214..

flavella Girault. Fla. w. to Tex. Host: Hemiberlasia lataniae Sign., Aspidiotus sp. Signiphora flavella Girault, 1913. U. S. Natl. Mus., Proc. 45: 214-215. \&.

Signiphora basilica Girault, 1913. U. S. Natl. Mus., Proc. 45: 215..

flavopalliata Ashmead. Ga., Fla. w. to La., Calif. Ecology: This species is apparently hyperparasitic. Host: Aleyrodes sp., Aonidiella aurantii (Mask.), A. citrina (Coq.), Chionaspis sp. on Magnolia, Chrysomphalus dictyospermi (Morg.), Hemiberlesia lataniae (Sign.), H. rapax (Comst.), Lepidosaphes beckii (Newm.), L. gloveri (Pack.), Prospaltella sp., Pseudaonidia duplex (Ckll.).

Signiphora flavopalliatus Ashmead, 1880. Orange Insects, pp. 29, 31. \&. As flavo-palliatus on p. 31 .

Biology: Muma, 1959. Jour. Econ. Ent. 52 (4): 577-587. - Hughes, 1960. Fla. Ent. 43 (2): 90.

louisianae (Dozier). Fla. w. to La. Host: Hemiberlasia lataniae Sign.

Thysanus louisianae Dozier, 1933. Ent. Soc. Wash., Proc. 35 (6): 100. ठั.

merceti Malenotti. La., Calif. Host: Chrysomphalus dictyospermi (Morgan), Hemiberlesia lataniae (Sign.), H. rapax (Comst.).

Signiphora merceti Malenotti, 1917 (1916). Redia 12 (1-2): 181-182. ๆ.

Taxonomy: Malenotti, 1916. Soc. Espan. de Hist. Nat., Bol. 16: 529.

Biology: Cressman, 1933. Jour. Econ. Ent. 26 (3): 704.

occidentalis Howard. Fla., Calif. Host: Aleyrodes sp., Aonidiella anrantii (Mask.), A. citrina (Coq.), Hemiberlasia lataniae (Sign.), Quadraspidiotus juglansregiae (Comst.),

Lepidosaphes gloveri (Pack.).

Signiphora occidentalis Howard, 1894. U. S. Dept. Agr., Insect Life 6 (3): 233, 235. ठ, ๆ. thoreauini Girault. Calif. Host: Aspidiotus hederae (Vallot).

Signiphora thoreauini Girault, 1916. Psyche 23 (2): 41..

townsendi Ashmead. D. C., Tex. Host: Aleyrodes sp., Hemiberlesia lataniae (Sign.), Pseudaulacaspis pentagona (Targ.-Tozz.), Quadraspidiotus perniciosus (Comst.). Signiphora townsendi Ashmead, 1900. U. S. Natl. Mus., Proc. 22: 410, 412. ?.

\section{TRIBE THYSANINI}

\section{Genus CHARTOCERUS Motschulsky}

Chartocerus Motschulsky, 1859. Etudes Ent. 8: 171-172.

Type-species: Chartocerus musciformis Motschulsky. Monotypic.

Signiphora subg. Matritia Mercet, 1916. Soc. Espan. de Hist. Nat., Bol. 16: 523.

Type-species: Signiphorina conjugalis Mercet. Orig. desig. Boucek (in Peck et al., 1964) synonymized Xana with Matritia.

Xana Kurdjumov, 1917 (1916). Jour. Appl. Ent. 1 (1): 80-81.

Type-species: Xana nigra Kurjumov. Monotypic. Junior secondary homonym of Signiphora nigra Ashmead, 1900. I have not seen the type-specimen of Chartocerus (Xana) niger (Kurdjumov). If the synonymy of Rozanov (1965) is correct, a replacement name for Kurdjumov's species must be proposed.

Signiphorina Nikol'skaya, 1950. Doklady Akad. Nauk. SSSR 75 (2): 321.

Type-species. Signiphorina mala Nikol'skaya. Monotypic.

Chartocerus contains about 10 species that parasitize various Homoptera and Diptera.

Taxonomy: De Santis, 1968. Rev. Fac. Agron. La Plata 44 (1): 11-13. - Hayat, 1970.

Entomophaga 15 (4): 388, 390-399. 
dactylopii (Ashmead). Tex. w. to Calif. Host: Phenacoccus solenopsis Tins., Leucopis sp. predaceous on Phenacoccus gossypii Towns. and Ckll., Pseudococcus ephedrae (Coq.).

Signiphora dactylopii Ashmead, 1900. U. S. Natl. Mus., Proc. 22: 410.

elongatus (Girault). N. J. s. to Ga., w. to S. Dak., Calif. Host: Coccus hesperidum L., Pseudococcus comstocki (Kuw.), coccid on Muhlenbergia, Acerophagus notativentris (Gir.), Achrysopophagus modestus Timb., Anagyrus yuccae (Coq.), Clansenia purpurea (Ishii), Pseudleptomastix squammulata Gir., Tetrastichus minutus (How.), Zarhopalus corvinus Gir.

Neosigniphora elongata Girault, 1916. Psyche 23 (2): 41-42. $\$$.

Taxonomy: Timberlake, 1924. Calif. Univ., Pubs. Ent. 3 (2): 246-248. - Novitzky, 1954. Univ. Milano Bol. di Zool. Agr. e Bach. 20: 207. -Ferriere, 1957. Opusc. Zool. 10: 6.

Biology: Clausen, 1924. Calif. Univ., Pubs. Ent. 3 (2): 257-266, 281-284. -Clancy, 1944. Jour. Econ. Ent. 37 (3): 451.

fasciatus (Girualt). Tex. w. to Calif. Host: Coccus viridus Green, Melanaspis lilacina (Ckll.), Parasaissetia nigra (Nietn.).

Signiphora fasciata Girault, 1913. U. S. Natl. Mus., Proc. 45: 206, 219-220, 221, 229. ðै, ๆ.

Biology: Arnaud, 1959. Ent. News 70 (6): 163 (primary parasite).

mexicanus (Ashmead). Calif. Host: Aspidiotus hederae (Vallot).

Signiphora mexicana Ashmead, 1900. U. S. Natl. Mus., Proc. 22: 411. \&.

niger (Ashmead). N. Y. s. to Fla., Ill., Calif. Host: Aphycus lounsburyi (How.), Chrysomphalus aonidum (L.), Clausenia purpurea Ishii, Coccus hesperidum L., Pseudococcus comstocki (Kuw.), Leptomastidea abnormis (Gir.), Saissetia oleae (Oliv.).

Signiphora nigra Ashmead, 1900. U. S. Natl. Mus., Proc. 22: 410..

Taxonomy: Smith and Compere, 1928. Calif. Univ., Pubs. Ent. 4 (9): 242, 245, 332-334.

Biology: Compere, 1925. Calif. Univ., Pubs. Ent. 3 (3): 296. -Clancy, 1944. Jour. Econ. Ent. 37 (3): 451.

nigrellus (Girault). Tex. Host: Melanaspis tenebricosus (Comst.).

Signiphora nigrella Girault, 1913. U. S. Natl. Mus., Proc. 45: 215. ․

pulcher (Girault). N. J. s. to N. C., Ill., Ark. Host: Aulacaspis rosae (Bouche), Chionaspis americana Johns., Lecanium nigrofasciatum Perg., Pseudaulacaspis pentagona (Targ.-Tozz.), Quadraspidiotus perniciosus (Comst.).

Signiphora pulchra Girault, 1913. U. S. Natl. Mus., Proc. 45: 215-217, 229. o, ๆ.

Signiphora nigrita Girault, 1913. U. S. Natl., Mus., Proc. 45: 215.

unifasciatus (Ashmead). Ga., Fla. Host: Ceropsylla sideroxyli Riley.

Signiphora unifasciata Ashmead, 1900. U. S. Natl. Mus., Proc. 22: 410. ₹.

\section{Genus THYSANUS Walker}

Thysanus Walker, 1840. Ann. Nat. Hist. 4: 234.

Type-species: Thysanus ater Haliday. Monotypic.

Triphasius Foerster, 1856. Hym. Stud. v. 2, pp. 83, 84. Unnecessary new name.

Plastocharis Foerster, 1856. Hym. Stud., v. 2, p. 145. Unnecessary new name.

Neosigniphora Rust, 1913. Ent. News 24 (4): 164.

Type-species: Neosigniphora nigra Rust. Monotypic.

Species of Thysanus are hyperparasites of armored scale insects. Two species are known.

Taxonomy: Silvestri, 1918. Lab. Zool. Gen. e Agr. Portici, Bol. 12: 266-271. - Nikol'skaya, 1950. Doklady Akad. Nauk SSSR 75 (2): 319-321. - Ferriere, 1953. Schweiz. Ent. Gesell., Mitt. 26 (1): 5. - Yoshimoto, 1965. Pacific Insects 7 (4): 703-704. - Rozanov, 1965. Ent. Rev. 44 (4): 508-515. - Quezada, DeBach and Rosen, 1973. Hilgardia 41 (18): 543-604.

-Subba Rao, 1974. Bul. Ent. Res. 64 (4): 525-531.

ater Haliday. Md. Ecology: Primary parasite attacking Melanaspis obscura (Comst.). Thysanus ater Haliday, 1840. Ann. Nat. Hist. 4: 234. 


\section{SUBFAMILy TETRACNEMINAE}

\section{TRIBE ANAGYRINI}

\section{Genus ANAGYRUS Howard}

Anagyrus Howard, 1896. U. S. Natl. Mus., Proc. 18: 638-639. Type-species: Anagyrus greeni Howard. Monotypic.

Epidinocarsis Girault, 1913. Arch. f. Naturgesch. 79A (6): 83.

Type-species: Epidinocarsis tricolor Girault. Monotypic.

Anagyrus is distributed throughout the world; its species are parasites of mealybugs.

Taxonomy: Timberlake, 1924. Calif. Univ., Pubs. Ent. 3 (2): 224-231. -Ishii, 1928. Imp. Agr.

Expt. Sta. Japan, Bul. 3 (2): 84-92. - Compere, 1939. Bul. Ent. Res. 30 (1): 3-7.

-Timberlake, 1941. B. P. Bishop Mus., Occas. Papers 16 (9): 218. - Compere, 1947. Calif.

Univ., Pubs. Ent. 8 (1): 20-22. - Hoffer, 1953. Ochr. Pirody 8 (4): 84. - Tachikawa, 1956.

Mem. Ehime Univ., Sect 6. 1 (2): 138-141, 147-152. -Trjapitzin, 1968. Vses. Ent. Obshch.,

Trudy 52: 90-92. -Graham, 1969. Polskie Pismo Ent. 39 (2): 219-220.

antoninae Timberlake. Fla. w. to Tex. Host: Antonina graminis (Mask.).

Anagyrus (Epidinocarsis) antoninae Timberlake, 1920. Hawaii. Ent. Soc., Proc. 4 (2): 409-413. ठ, ?.

Biology: Riherd, 1950. Fla. Ent. 33 (1): 18-22. - Riherd, 1951. Jour. Econ. Ent. 44 (4): 622-623. -Clausen, 1956. U. S. Dept. Agr., Tech. Bul. 1139, pp. 4,61, 75. -Questel and Genung, 1957. Fla. Ent. 40 (4): 123-125. - Dean and Schuster, 1958. Jour. Econ. Ent. 51 (3): 363-365. -Dean, 1960. Jour. Econ. Ent. 53 (4): 694. - Huffaker, 1971. Biol. Control, pp. 228, 229.

-DeBach, 1974. Biol. Control by Nat. Enem., p. 169.

clauseni Timberlake. Calif. Host: Pseudococcus maritimus (Ehrh.). Anagyrus clauseni Timberlake, 1924. Calif. Univ., Pubs. Ent. 3 (2): 226-228..

fusciventris (Girault). Calif. Host: Pseudococcus longispinus (Targ.-Tozz.).

Epidinocarsis fusciventris Girault, 1915. Queensland Mus., Mem. 4: 144. ₹.

Anagyrus nigricornis Timberlake, 1919. Hawaii. Ent. Soc., Proc. 4 (1): 197-199. ơ,.

Biology: Flanders, 1940. Jour. Econ. Ent. 33 (5): 757-758. -Flanders, 1940. Calif. Citrog. 25 (5): 146, 154-155. -Clausen, 1956. U. S. Dept. Agr., Tech. Bul. 1139, p. 75.

graminicolens Dozier. Tex. Host: Antonia graminis (Mask.). This may be a synonym of Cerchysius pulchricomis Howard, 1894.

Anagyrus graminicolens Dozier, 1937. Puerto Rico Univ., Jour. Agr. 21 (2): 123..

nigritus (Howard). Calif.

Aphycus nigritus Howard, 1898. U. S. Natl. Mus., Proc. 21: 241, 243..

pallidipes Ashmead. N. Y. s. to Fla., w. to Tex.

Anagyrus pallidipes Ashmead, 1900. U. S. Natl. Mus., Proc. 22: 354. ठ.

pseudococci (Girault). Calif. Introduced. Host: Pseudococcus citri (Risso). Epidinocarsis pseudococci Girault, 1915. Entomologist 48: 185. o, ․

Biology: Flanders, 1939. Jour. Econ. Ent. 32 (6): 889. -Flanders, 1953. Jour. Econ. Ent. 46 (2): 268. - Bartlett and Lloyd, 1958. Jour. Econ. Ent. 51 (1): 92-93.

pulcher (Ashmead). Conn. s. to Fla.

Dinocarsis pulcher Ashmead, 1888. Ent. Amer. 4 (1): 17. \&.

putonophilus Compere. Calif. Host: Puto ambiguus (Full.), P. yuccae (Coq.).

Anagyrus putonophilus Compere, 1947. Calif. Univ., Pubs. Ent. 8 (1): 20, 22..

Biology: Maple, 1947. Calif. Univ., Pubs. Ent. 8 (2): 45, 57-59.

smithi Doutt. Calif. Host: Spilococcus implicatus Ferris.

Anagyrus smithi Doutt, 1952. Hawaii. Ent. Soc., Proc. 14 (3): 401-402. ơ, \&.

thyridopterygis (Ashmead). N. J. s. to Fla. Host: Thyridopteryx ephemeraeformis (Haw.)?

Host is probably an associated coccid.

Dinocarsis thyridopterygis Ashmead, 1886. Canad. Ent. 18 (5): 97. ९. 
townsendi (Howard). N. Mex. Host: Phenacoccus sp. on cotton.

A phycus tou'nsendi Howard, 1898. U. S. Natl. Mus., Proc. 21: 243. ․

yuccae (Coquillett). Calif. Host: Anisococcus crawii (Coq.), Pseudococcus maritimus (Ehrh.),

$P$. sp. on grapes, Puto yuccue (Coq.), Achrysopophetgus modestus Timb.

Blastothrix yuccae Coquillett, 1890. West. Amer. Scientist 7: 44. ?.

Epidinocarsis subalbicorn is Girault, 1916. Psyche 23 (2): 44-45. ?.

Anagyrus ferrisi Compere, 1926. Calif. Univ., Pubs. Ent. 4 (1): 18-22. đ’, ๆ.

Taxonomy: Gahan, 1949. Hawaii. Ent. Soc., Proc. 13 (3): 359-360.

Biology: Clausen, 1924. Calif. Univ., Pubs. Ent. 3 (2): 256-266, 274-276. -Maple, 1947. Calif.

Univ., Pubs. Ent. 8 (2): 55-59.

Morphology: Maple, 1937. Ent. Soc. Amer., Ann. 30 (1): 146.

\section{Genus ANATHRIX Burks}

Awathrix Burks, 1952. N. Y. Ent. Soc., Jour. 60 (3): 179-180.

Type-species: Anathrix urgyrus Burks. Orig. desig.

argyrus Burks. Que. s. to Va., Tex. Host: Ferrisia viryata (Ckll.).

Anathrix argyrus Burks, 1952. N. Y. Ent. Soc., Jour. 60 (3): 181-182. \&.

\section{Genus ANUSIA Foerster}

Auusia Foerster, 1856. Hym. Stud. v. 2, p. 32. No species included.

Type-species: Auusiu nasicornis Foerster. Desig. by Gahan and Fagan, 1923.

Taxonomy: Mercet, 1921. Fauna Iberica Himen. Fam. Encirtidos, pp. 87-89. -Graham, 1958.

Ent. Tidskr. 79 (3-4): 148-149. -Graham, 1969. Polskie Pismo Ent. 39 (2): 214.

neomexicana Ashmead. N. Mex. w. to Calif. Host: Amonostherium lichtensioides (Ckll.).

Anusia neomexicana Ashmead, 1900. U. S. Natl. Mus., Proc. 22: 348..

\section{Genus APOANAGYRUS Compere}

A poanayyrus: Compere, 1947. Calif. Univ., Pubs. Ent. 8 (1): 18.

Type-species: A poanagyrus califonicus Compere. Monotypic.

californicus Compere. Ariz., Calif. Host: Pseudococeus solani (Ckll.).

Apoanagyrus califormicus Compere, 1947. Calif. Univ., Pubs. Ent. 8 (1): 18-19. o, \&.

Biology: Maple, 1947. Calif. Univ., Pubs. Ent. 8 (2): 63-66.

\section{Genus LEPTOMASTIDEA Mercet}

Leptomastidea Mercet, 1916. Soc. Espan. de Hist. Nat., Bol. 16: 112.

Type-species: Leptomastidea aurantiaca Mercet. Monotypic.

Tanaomastix Timberlake, 1918. Calif. Univ., Pubs. Ent. 1 (8): 362-364.

Type-species: Paraleptomastix abnorm is Girault. Orig. desig.

Less than fifteen species of Leptomastidea are known. All are thought to be primary internal parasites of mealybugs.

Taxonomy: Timberlake, 1923. Ent. Soc. Wash., Proc. 25 (3): 59. - Mercet, 1924. Soc. Espan. de Hist. Nat., Bol. 24: 252-258. - Mercet, 1921. Fauna Iberica, Himen., Encirtidos, pp. 7, $15-18,27,56,64,76,107-114,243$. - Risbec, 1952. Mem. Inst. Sci. Madagascar, Ser. E, Ent. 2: 5, 10-15. - Ferriere, 1953. Schweiz. Ent. Gesell., Mitt. 26 (1): 17. - Trjaptizin, 1965. Ent. Rev. 44 (4): $517-518$.

abnormis (Girault). Que. s. to Fla., w. to La., Calif. Host: Phenacoccus gossypii Tnsd. and Ckll., Planococcus citri (Risso), P. kraunhiae (Kuw.).

Paraleptomastix abnormis Girault, 1915. Entomologist 48: 184-185. ơ, ๆ.

Biology: Smith, 1917. Jour. Econ. Ent. 10 (2): 262-268. -Armitage, 1920. Calif. Dept. Agr., Monthly Bul. 9: 446. - Compere and Smith, 1932. Hilgardia 6 (17): 610-611. -McLeod, 1940 (1939). Ent. Soc. Ontario, Ann. Rept. 70: 65-66. - Maple, 1947. Calif. Univ., Pubs. Ent. 8 (2): 
91-93. -Clausen, 1956. U. S. Dept. Agr., Tech. Bul. 1139, p. 109. - Huffaker, 1971. Biol.

Control, p. 196.

claripennis (Timberlake). Calif. Host: Dysmicoccus ryani (Coq.).

Tanaomastix claripennis Timberlake, 1918. Calif. Univ., Pubs. Ent. 1 (8): 363, 365-366. q.

\section{Genus LEPTOMASTIX Foerster}

Leptomastix Foerster, 1856. Hym. Stud. v. 2, pp. 34, 37. No species included.

Type-species: Leptomastix histrio Mayr. Subsequent monotypy.

Sterhocomu Foerster, 1856. Hym. Stud., v. 2, pp. 33, 36, 37.

Type-species: Sterthocoma histrio Foerster. Monotypic.

Stenoterys Thomson, 1876 (1875). Hym. Scand, v. 4, pp. 115, 128.

Type-species: Stenoterys orbitalis Thomson. Monotypic.

Calocerinella Girault, 1913. Wis. Nat. Hist. Soc., Bul. 11: 46.

Type-species: Calocerinella trifasciata Girault. Monotypic.

This rather large genus of internal parasites of pseudoccoids is poorly represented in North America.

Taxonomy: Ruschka, (1922). Zool.-Bot. Gesell. Wien, Verhandl. 72 (2): 12. -Compere, 1938.

Bul. Ent. Res. 29 (3): 323-325. - Compere, 1939. Bul. Ent. Res. 30 (1): 24. -Compere, 1939.

Calif. Univ., Pubs. Ent. 7 (4): 57-58. - Kryger, 1950. Ent. Meddel. 26 (2): 107-108. - Risbec,

1952. Mem. Inst. Sci. Madagascar, Ser. E, Ent. 2: 15-19. - Trjapitzin, 1965. Ent. Rev. 44

(4): 518-520. -Graham, 1969. Polskie Pismo Ent. 39 (1): 216-219.

dactylopii Howard. Que. s. to La., Calif., Wash. Host: Phenacoccus gossypii Tnsol. and Ckll., P. soluni Ferris, Plunococcus citri (Risso), Pseudococcus culceolarice (Mask.), P. comstocki (Kuv.), P. longispinus (Targ.-Tozz.), P. maritimus (Ehrh.).

Leptomastix dactylopii Howard, 1885. U. S. Dept. Agr., Bur. Ent., Bul. 5: 23-24, 42. ठ์, ?.

Taxonomy: Compere, 1939. Calif. Univ., Pubs. Ent. 7 (4): 57-58.

Biology: Flanders, 1939. In Compere, Calif. Univ., Pubs. Ent. 7 (4): 58. -Watson, 1939.

Citrus Grower (Fla.) 1 (17): 11. - Bess, 1939. Ent. Soc. Amer., Ann. 32 (1): 202-206.

-McLeod, 1940 (1939). Ent. Soc. Ontario, Ann. Rept. 70: 65-66. - Clancey, 1944. Jour.

Econ. Ent. 37 (3): 450. - Maple, 1947. Calif. Univ., Pubs. Ent. 8 (2): 115. - Huffaker, 1971.

Biol. Control, p. 195. See Peck (1963) for an extensive bibliography of this species.

\section{Genus PARANUSIA Brethes}

Paranusia Brethes, 1913. Buenos Aires Mus. Nac. de Hist. Nat., An. 24: 102.

Type-species: Paranusia bifasciata Brethes. Orig. desig.

Philoponectroma Brethes, 1913. Buenos Aires Mus. Nac. de Hist. Nat., An. 24: 104.

Type-species: Philoponectroma pectinatum Brethes. Orig. desig.

G!rranusia Brethes, 1920. Rev. Chile Hist. Nat. 24: 137.

Type-species: Gyranusia porteri Brethes. Orig. desig.

An unidentified species is found in California on Sphaeralcia.

Taxonomy: Timberlake, 1923. Ent. Soc. Wash., Proc. 25 (3): 60. -Timberlake, 1924. Calif.

Univ., Pubs. Ent. 3 (2): 225. - De Santis, 1950. La Plata Mus. Rev. Zool. (n. s.) 6: 54, 60-61.

\section{Genus PARASTENOTERYS Girault}

Parastenoterys. Girault, 1915. Queensland Mus., Mem. 4: 165.

Type-species: Parustenoterys punctatus Girault. Orig. desig.

Parectromoides Girault, 1915. Queensland Mus., Mem. 4: 171.

Type-species: Purctromoides magniscutellum Girault. Orig. desig.

niveiclava Girault. Md.

Parastenoterys nievelara Girault, 1917. Chalcidoidea Nova Marilandensis II, p. 1. \&.

Taxonomy: Girault, 1920. U. S. Natl. Mus., Proc. 58: 191. 


\section{Genus PSEUDLEPTOMASTIX Girault}

Pseudleptomastix Girault, 1915. Ent. Soc. Amer., Ann. 8 (3): 272.

Type-species: Psendleptomastix squammulatus Girault. Monotypic.

squammulata Girault. Calif. Host: Amonostherium lichtensioides (Ckll.), Pseudococcus maritimus (Ehrh.).

Pseulleptomastix sqnammulatus Girault, 1915. Ent. Soc. Amer., Ann. 8 (3): 272..

Paraleptomastrix notatus Girault, 1917. Entomologist 50: 38. ?.

Pseulleptomastix flutulescens Compere, 1926. Calif. Univ., Pubs. Ent. 4 (1): 22-24. ठ,.

Taxonomy: Timberlake, 1924. Calif. Univ., Pubs. Ent. 3 (2): 232-235. -Compere, 1947. Calif.

Univ., Pubs. Ent. 8 (1): 17.

Biology: Clausen, 1924. Calif. Univ., Pubs. Ent. 3 (2): 257-266. -Clausen, 1924. Calif. Univ., Pubs. Ent. 3 (2): 277-279. - Maple, 1947. Calif. Univ., Pubs. Ent. 8 (2): 112-113.

\section{Genus RHOPUS Foerster}

Rhopus Foerster, 1856. Hym. Stud., v. 2, pp. 34, 37, 151.

Type-species: Encyitus piso Walker. Orig. desig.

Xunthoencyrtuss Ashmead, 1902. Canad. Ent. 34 (11): 302.

Type-species: Xanthoencyrtus nigrocla atus Ashmead. Monotypic.

Mirastymachus: Girault, 1915. N. Y. Ent. Soc., Jour. 23 (3): 166.

Type-species: Mirastymachus europaeus Girault. Orig. desig.

Scelioencystus Girault, 1915. Queensland Mus., Mem. 4: 161.

Type-species: Scelioencyrtus nigriclavus Girault. Orig. desig.

Pholidocerus Mercet, 1918. Soc. Espan. de Hist. Nat., Bol. 18 (3-4): 237-239.

Type-species: Pholidoceras bruchyptera Mercet. Monotypic.

Pholidocterode's Ferriere, 1955. Lab. Zool. Gen. e Agr. Portici, Bol. 33: 358.

Type-species: Philodoceras parvula Mercet. Monotypic.

This genus consists of approximately 30 species which are parasites of scale insects. The North American fauna has been poorly studied, but several species are known from Europe.

Taxonomy: Mercet, 1928. Eos 4 (1): 5-7. - Hoffer, 1955. Acta Mus. Nat. Pragae 11 (1): 17-22. -Ghesquiere, 1956. Lab. Zool. Gen. e Agr. Portici, Bol. 33: 683-692. -Ghesquiere, 1957.

Neotropica 3 (10): 17-22. - Ting-hsi, 1961. Ent. Rev. 40 (1): 72-74. -De Santis, 1965. Com.

Invest. Cient. Prov. Buenos Aires, An. 4: 53-56. -Graham, 1969. Polskie Pismo Ent. 39 (2): 220-224.

Biology: Webster, 1903 (1902). Ind. Acad. Sci., Proc,, p. 103.

americanus (Girault). D. C., Del., Oreg.

Mirastymachus americamus Girault, 1915. N. Y. Ent. Soc., Jour. 23 (3): 167. ९.

nigroclavatus (Ashmead). Va. w. to Nebr., S. Dak. Host: Coceid on Panicum sp., Pseudaonidia sp. on P. xalapense.

Xanthoencyrtus nigroclatatus Ashmead, 1902. Canad. Ent. 34 (11): 302 ..

Biology: Webster, 1903 (1902). Ind. Acad. Sci., Proc. p. 103.

\section{TRIBE CHRYSOPLATYCERINI}

\section{Genus CHRYSOPLATYCERUS Ashmead}

Rileya Howard, 1888. In Smith, Ent. Amer. 4 (4): 80. Preoce. by Rileya Ashmead, 1888. Type-species: Rileya spleudeus Howard. Monotypic.

Chrysoplatycertus Ashmead, 1889. Canad. Ent. 21 (1): 38. N. name.

This small genus consists of fewer than five described species. The species of Chrysoplatycerus are parasites of pseudococcids and thus may be of some importance in biological control.

Taxonomy: Timberlake, 1922. U. S. Natl. Mus., Proc. 61 (2): 1-10.

ferrisi Timberlake. Calif. Host: Anisococcus adenostomae (Ferris).

Chrysoplatycerus ferrisi Timberlake, 1922. U. S. Natl. Mus., Proc. 61 (2): 6. §, §. 
Biology: Maple, 1947. Calif. Univ., Pubs. Ent. 8 (2): 115.

howardii Ashmead. Fla. Host: Pseudococcus sp.

Chrysoplatycerns hourardii Ashmead, 1900. U. S. Natl. Mus., Proc. 22: 405. \&.

splendens (Howard), Que. (greenhouses), Fla., Calif. Host: Dysmicoccus ryani (Coq.),

Planococus citri (Risso), Pseudococcus longispinus (Targ.-Tozz.), P. maritimus (Ehrh.).

Rileya spleudens Howard, 1888. In Smith, Ent. Amer. (4) 4: 80. ?.

Biology: Clausen, 1924. Calif. Univ., Pubs. Ent. 3 (2): 256-266, 279. -Clancy, 1944. Jour.

Econ. Ent. 37 (3): 450 . - Maple, 1947. Calif. Univ., Pubs. Ent. 8 (2): 115. See Peck (1963)

for an extensive bibliography of this species.

\section{TRIBE ERICYDNINI}

\section{Genus CLAUSENIA Ishii}

Clausenia Ishii, 1923. Japan Dept. Agr. and Com., Imp. Plant Quar. Sta. Bul. 3: 98-100. Type-species: Clausenia purpurea Ishii. Orig. desig.

Clauseniu consists of less than a dozen described species, most of which are African. With more research on the group it should prove to be considerably larger. All known species are parasites of mealybugs. At least one species, C. purpurea, is exceptionally important in biological control of the Comstock mealybug in the United States and Canada.

Taxonomy: Rosen, 1965. Roy. Ent. Soc. London, Proc. (B) 34 (5-6): 61-64. - Kerrich, 1967.

Brit. Mus. (Nat. Hist.) Ent., Bul. 20 (5): 181-188. - Annecke and Mynhardt, 1970. Ent. Soc.

So. Africa, Jour. 33 (1): 42-47.

purpurea Ishii. Ont. s. to Va. Introduced. Host: Pseudococcus comstocki (Kuw.).

Clausenia purpurea Ishii, 1923. Japan Dept. Agr. and Com., Imp. Plant Quar. Sta., Bul. 3: 100-101. ठ, ?.

Biology: Cox, 1940. Jour. Econ. Ent. 33 (3): 446. -Rivnay, 1942. Bul. Soc. Fouad Ier Ent. 26: 1-19. - Clancy, 1944. Jour. Econ. Ent. 37 (3): 450-451. - Haeussler and Clancy, 1944. Jour.

Econ. Ent. 37 (4): 503. - Hough, Clancy and Pollard, 1945. Jour. Econ. Ent. 38 (4): 423-425.

Morphology: Flanders, 1942. Ent. Soc. Amer., Ann. 35 (3): 252, 262.

\section{TRIBE PAURIDIINI}

\section{Genus PAURIDIA Timberlake}

Pauridia Timberlake, 1919. Hawaii. Ent. Soc., Proc. 4 (1): 206-207.

Type-species: Pauridia peregrina Timberlake. Orig. desig.

This monotypic genus has been employed in biological control programs against Pseudococcus spp. throughout the world.

peregrina Timberlake. Tex., Calif. Introduced. Host: Planococcus citri (Risso), P. kraunhine

(Kuw.), Psendococcus maritimus (Ehrh.).

Panridia peregrina Timberlake, 1919. Hawaii. Ent. Soc. Proc. 4 (1): 208. ठ, ९.

Biology: Armitage, 1920. Calif. Dept. Agr., Monthly Bul. 9: 446. -Essig, 1931. Hist. of Ent., pp. 361, 389. - Clausen, 1956. U. S. Dept. Agr., Tech. Bul. 1139, p. 36. -DeBach, 1964. Biol. Control Insect Pests Weeds, p. 442.

\section{TRIBE RHINOENCYRTINI}

\section{Genus RHINOENCYRTUS Mercet}

Rhinoencyrtus Mercet, 1918. Soc. Espan. de Hist. Nat., Bol. 18 (3-4): 234-235.

Type-species: Rhinoencyrtus malenotti Mercet. Monotypic.

An unidentified species is found in Nebraska, Kansas, and Oklahoma.

\section{Genus AENASIUS Walker}

Aenasius Walker, 1846. Ann. and Mag. Nat. Hist. 17 (III): 181. 
Type-species: Encyitus Hyettus Walker. Orig. desig.

This genus holds about 25 species which seem to be exclusively Neotropical in distribution. All known species are presumed primary parasites of the genera Psendococcus, Phenacocens and Puto.

Taxonomy: Compere, 1937. Hawaii. Ent. Soc., Proc. 9 (3): 383-404. - Kerrich, 1967. Brit. Mus. (Nat. Hist.) Ent., Bul. 20 (5): 195-225.

advenus Compere. Fla.

Aenasius advena Compere, 1937. Hawaii. Ent. Soc., Proc. 9 (3): 384, 388-389, 393. ơ, ‥ Aenasius ianthinus Compere, 1937. Hawaii. Ent. Soc., Proc. 9 (3): 388, 391, 393-394. \&.

flandersi Kerrich. Calif. Ecology: On Pittosporum.

Aenasius flandersi Kerrich, 1967. Brit. Mus. (Nat. Hist.) Ent., Bul. 20 (5): 204-205, 221..

maplei Compere. Calif. Host: Pluto yuccre (Coq.).

Aenusius maplei Compere, 1937. Hawaii. Ent. Soc., Proc. 9 (3): 384, 390, 397. o, 9.

Biology: Maple, 1947. Calif. Univ., Pubs. Ent. 8 (2): 55-57.

nitens Kerrich. Nebraska.

Aenasius nitens Kerrich, 1967. Brit. Mus. (Nat. Hist.) Ent., Bul. 20 (5): 211-212, 224..

paulistus Compere. California? Introduced, possibly established. Host: Pseudococcus muritimus (Ehrh.).

Aentsius paulistus. Compere, 1937. Hawaii. Ent. Soc., Proc. 9 (3): 383-385, 401-403. o, . personatus Kerrich. Fla. Ecology: On Hibiscus tiliaceus.

Aenasius pe'sonatus Kerrich, 1967. Brit. Mus. (Nat. Hist.) Ent., Bul. 20 (5): 198, 200, 221. ․

\section{Genus CHALCASPIS Howard}

Chalcespis Howard, 1895. U. S. Natl. Mus., Proc. 17: 606.

Type-species: Chaleuspis pergundei Howard. Monotypic.

Closely related to Aentsins but considerably smaller, Chalcaspis seems to have adapted itself to more xeric conditions than Aenasius. Chulcaspis consists of less than 10 species which are also mealybug parasites.

Taxonomy: Kerrich, 1967. Brit. Mus. (Nat. Hist.) Ent., Bul. 20 (5): 191-195.

arizonensis Girault. Ariz. Idaho, Mo., Wash., Calif. Host: Phenacoccus solenopsis Tinsley.

Chalcaspis arizonensis Girault, 1915. Ent. Soc. Amer., Ann. 8 (3): 280..

pergandei Howard. Mass., s. to D. C., S. Dak. s. to Tex.

Chalcaspis pergandei Howard, 1895. U. S. Natl. Mus., Proc. 17: 606..

phenacocei (Ashmead). Md. s. to Fla., w. to lowa, Idaho, N. Mex., w. Calif.

Blepyrus phenacocci Ashmead, 1902. Canad. Ent. 34 (11): 301. ठै, १.

Biology: Maple, 1947. Calif. Univ., Pubs. Ent. 8 (2): 115.

\section{TRIBE TETRACNEMINI}

\section{Genus CALOCERINUS Howard}

Calocerinus Howard, 1892. U. S. Natl. Mus., Proc. 15: 362, 368.

Type-species: Tetrachemus floridanus Ashmead. Monotypic.

floridanus (Ashmead). Fla.

Tetrancmus(!) floridanus Ashmead, 1885. Amer. Ent. Soc., Trans. 12: Proc. p. xviii. o.

Generic name a lapsus for Tetracnemus.

Taxonomy: Girault, 1917. Descr. Stellarum Nov., p. 7.

\section{Genus ARHOPOIDEUS Girault}

Athopoideus Girault, 1915. Queensland Mus., Mem. 4: 174-175.

Type-species: Athopoideus brevicornis Girualt. Monotypic.

Hungariella Erdos, 1946. Ann. Hist. Nat., Nat. Mus. Hung. 39: 144. 
Type-species: Hungariella picene Erdos. Orig. desig.

The taxonomic status of members of the genus Arhopoideus has been confused but recently clarified by the work of Tachikawa (1974) and Annecke (unpublished). Part of the problem stems from the misinterpretation of Tetracnemus. Westwood. Arhopoideus is comprised of less than 10 species all of which are mealybug parasites.

Taxonomy: Erdos, 1955. Acta Zool. (Budapest) 1 (3-4): 216-218. - Hoffer, 1959. Mus. Nat.

Pragae, Acta Ent. 33: 13-15. - Hoffer, 1960. Mus. Nat. Pragae, Acta Faun. Ent. 6: 101-102.

- Kerrich, 1967. Brit. Mus. (Nat. Hist.) Ent., Bul. 20 (5): 147, 154-166. -Tachikawa and

Valentine, 1971. Shikoku Ent. Soc., Trans. 11 (1): 21-30. - Tachikawa, 1974. Shikoku Ent.

Soc., Trans. 12 (1-2): 23-31.

peregrinus (Compere). Calif. Introduced. Host: Pseudococcus calceolariae (Mask.), P. longispinus (Targ.-Tozz.), P. maritimus (Ehrh.).

Tetracnemus peregrimus Compere, 1939. Calif. Univ., Pubs. Ent. 7 (4): 59-61. ठँ, ९.

Biology: Flanders, 1940. Jour. Econ. Ent. 33 (5): 757. -Flanders, 1944. Jour. Econ. Ent. 37 (2): 308-309. - DeBach, 1949. Ecology 30 (1): 16-24. -Clausen, 1956. U. S. Dept. Agr., Tech. Bul. 1139 , p. 130.

pretiosus (Timberlake). Calif. Host: Pseudococcus calceolariae (Mask.), P. longispinus (Targ.-Tozz.), P. murtitimus (Ehrh.).

Tetracnemus pretiosus Timberlake, 1929. Calif. Univ., Pubs. Ent. 5 (1): 5-11. ठ, \&.

Biology: Compere and Smith, 1932. Hilgardia 6 (17): 585, 601-605, 609-617. -Quayle, 1932. Calif. Agr. Expt. Sta., Bul. 542: 51. -Clancy, 1934. Calif. Univ., Pubs. Ent. 6 (8): 231-248. -Maple, 1947. Calif. Univ., Pubs. Ent. 8 (2): 114-115. - DeBach, 1949. Ecology 30 (1): 16-24. - Clausen, 1956. U. S. Dept. Agr., Tech. Bul. 1139, p. 130. - Bartlett and Lloyd, 1958. Jour. Econ. Ent. 51 (1): 92. - DeBach, 1974. Biol. Control by Nat. Enem., p. 138.

\section{Genus TETRACNEMUS Westwood}

Tetracnemus Westwood, 1837. Mag. Nat. Hist. 1: 258.

Type-species: Tetrucnemus dicersicorn is Westwood. Monotypic.

Tetiacladia Howard, 1892. U. S. Natl. Mus., Proc. 15: 367.

Type-species: Tetracladia texana Howard. Desig. by Ashmead, 1900.

Paracalocerinus: Girault, 1915. Queensland Mus., Mem. 4: 142.

Type-species: Paracalocerinus australiensis Girault. Orig. desig.

Masia Mercet, 1920 (1919). Soc. Espan. de Hist. Nat., Bol. 19 (9-10): 470-472.

Type-species: Masia bifasciatella Mercet. Orig. desig.

Anusiella Mercet, 1923. Soc. Espan. de Hist. Nat., Bol. 23 (6): 287-289.

Type-species: Anusiella heydeni Mercet. Orig. desig.

Placoceras Erdos, 1946. Frag. Faun. Hung. 9: 1.

Type-species: Placoceras colocense Erdos. Monotypic.

Comperencyrtus De Santis, 1964. Com. Cien., Ann., Buenos Aires, An. 4: 106.

Type-species: Comperencyrtus maculipennis De Santis. Orig. desig.

Taxonomy: Erdos, 1955 Acta Zool. (Budapest) 1 (3-4): 221-229. - Hoffer, 1960. Mus. Nat.

Pragae, Acta Faun. Ent. 6: 101-102. - Kerrich, 1967. Brit. Mus. (Nat. Hist.) Ent., Bul. 20

(5): 149 .

americanus (Girault). Kans., Va.

Parucaloceriuus americanus Girault, 1916. Ent. News 27 (5): 225-226. \&.

gracilis (Howard). Fla.

Tetracladia gracilis Howard, 1892. U. S. Natl. Mus., Proc. 15: 362, 368. ठ゚.

marilandius (Girault). Md., Ill.

Paracalocerinus marilandia Girault, 1917. Chalcidoidea Nova Marilandensis I, p. 1-2..

Taxonomy: Dozier, 1933. Ent. Soc. Wash., Proc. 35 (6): 94-95.

tertius (Girault). Calif., Utah. Host: Eriococcus sp.

Paracaloceriuus tertius Girault, 1917. Deser. Stellarum Nov., pp. 7-8. ๆ.

texanus (Howard). Tex.

Tetracladia texana Howard, 1892. U. S. Natl. Mus., Proc. 15: 362, 367-368. o. 


\section{Genus ANARHOPUS Timberlake}

Anarhopus Timberlake, 1929. Calif. Univ., Pubs. Ent. 5 (2): 15-18.

Type-species: Anarhopns sydneyensis Timberlake. Orig. desig.

sydneyensis Timberlake. Calif. Host: Pseudococcus calceolariae (Mask.), P. longispinus

(Targ.-Tozz.).

Anarhopus sydneyensis Timberlake, 1929. Calif. Univ., Pubs. Ent. 5 (2): 5, 18. \&.

Biology: Compere and Flanders, 1934. Jour. Econ. Ent. 27 (5): 966-973. -Flanders, 1940.

Calif. Citrog. 25 (5): 146, 154-155. - Clancy, 1944. Jour. Econ. Ent. 37 (3): 450. - Maple,

1947. Calif. Univ., Pubs. Ent. 8 (2): 59-60. - DeBach, 1949. Ecology 30 (1): 16-25. -Clausen,

1956. U. S. Dept. Agr., Tech. Bul. 1139, pp. 75, 130. -Flanders, 1959. Jour. Econ. Ent. 52

(1): 75 .

UNPlaced TaXa of StbFamlly TETRACNeminaE

The following genera have not been placed in tribes of the Tetracneminae.

\section{Genus CIRRHENCYRTUS Timberlake}

Cirrhencyrtus Timberlake, 1918. Calif. Univ., Pubs. Ent. 1 (8): 360-362.

Type-species: Psendococcobins ehrhorni Timberlake. Orig. desig.

ehrhorni (Timberlake). Calif. Host: Dysmicoccus ryani (Coq.), Spilococens sequoiae (Colm.).

Psendococcobius ehrhorni Timberlake, 1916. U. S. Natl. Mus., Proc. 50: 564. \&.

Taxonomy: Timberlake, 1918. Calif. Univ., Pubs. Ent. 1 (8): 362.

Biology: Maple, 1947. Calif. Univ., Pubs. Ent. 8 (2): 115.

\section{Genus ECTROMATOPSIS Compere}

Ectromatopsis Compere, 1947. Calif. Univ., Pubs. Ent. 8 (1): 13-15.

Type-species: Ectroma americanum Howard. Orig. desig.

americana (Howard). N. Mex. w. to Calif. Host: Phenacocens solani Ferris.

Ectroma americanum Howard, 1898. U. S. Natl. Mus., Proc. 21: 248. .

Taxonomy: Compere, 1947. Calif. Univ., Pubs. Ent. 8 (1): 13, 14, 15.

Biology: Maple, 1947. Calif. Univ., Pubs. Ent. 8 (2): 78-80.

\section{Genus NEODUSMETIA Kerrich}

Neodusmetia Kerrich, 1964. Entomophaga 9 (1): 76.

Type-species: Dusmetia sangeani Subba Rao. Orig. desig.

Taxonomy: Burks, 1958 (1957). Brooklyn Ent. Soc., Bul. 52 (4): 124-125. - Richards, 1958.

Roy. Ent. Soc. London, Proc. (B) 27 (3-4): 61, - Kerrich, 1964. Entomophaga 9 (1): 75-77.

sangwani (Subba Rao). Fla. w. to Ariz. Host: Antonina graminis (Mask.).

Dusmetia sangwani Subba Rao. 1957. Ind. Acad. Sci., Proc. 46: 385-386. ๆ, o.

Dusmetia indica Burks, 1958 (1957). Brooklyn Ent. Soc., Bul. 52 (4): 125-127. \&, o.

Biology: Dean, Schuster and Bailey, 1961. Jour. Econ. Ent. 54 (5): 953. -Beardsley, 1961.

Hawaii. Ent. Soc., Proc. 17 (3): 327. - Kerrich, 1964. Entomophaga 9 (1): 75. -DeBach,

1974. Biol. Control by Nat. Enem., p. 168-169.

\section{Genus PARALEUROCERUS Girault}

Paraleurocerus Girault, 1915. N. Y. Ent. Soc., Jour. 23 (3): 172.

Type-species: Paralenrocerns bicoloripes Girault. Orig. desig.

Gibberella Miller, 1961. Canad. Ent. 98 (6): 494.

Type-species: Gibberella scutellata Miller. Orig. desig.

bicoloripes Girault. N. S., Ont., Mass., Tex. Host: Cameraria caryaefoliella (Clem.),

Lithocolletis sp. mining cherry leaf, L. spp. on Alnus crispa, Carya sp., Corylus sp.,

Fagns sp., Hamamelis sp., Prunus sp., L. Incetiella Clem. on Tilia americana.

Paralenrocerns bicoloripes Girault, 1915. N. Y. Ent. Soc., Jour. 23 (3): 172-173. , ठ。. 
Gibberella scutellutu Miller, 1961. Canad. Ent. 98 (6): 495, 496. o', १.

Biology: Fitzgerald and Simeone, 1971. Ent. Soc. Amer., Ann. 64 (4): 774-777 (polyembryony).

\section{Genus TETRACNEMOPSIS Ashmead}

Tetrecuemopsis Ashmead, 1900. U. S. Natl. Mus., Proc. 22: 330, 358.

Type-species: Tetracnemus westwoodi Cockerell. Orig. desig.

westwoodi (Cockerell). Que., Me., Colo. Host: Phentroccus minimus Tinsley.

Tetrucneurus uesturoodi Cockerell, 1898. Canad. Ent. 30 (8): 224. ơ, ?.

\section{SUBFAMILY ENCYRTINAE}

\section{TRIBE APHYCINI}

\section{Genus ACEROPHAGUS Smith}

Acerophagus Smith, 1880. No. Amer. Ent. 1: 83.

Type-species: Acerophryns coccois Smith. Monotypic.

Rhopoidens Howard, 1898. U. S. Natl. Mus., Proc. 21: 235.

Type-species: Rhopoitleus citrinus Howard. Monotypic.

This genus is comprised of fewer than fifteen species and seems restricted to North America and the Caribbean.

Taxonomy: Timberlake, 1916. U. S. Natl. Mus., Proc. 50: 574-579. -Timberlake, 1918. Calif.

Univ., Pubs. Ent. 1 (8): 347-351. - Rosen, 1969. Hilgardia 40 (2): 41-72.

antennalis Rosen. Calif. Host: Dysmicoccus ryani (Coq.).

Acerophreguts auteruulis Rosen, 1969. Hilgardia 40 (2): 42, 43, 44, 45, 50-52. o, ๆ.

californicus Rosen. Calif. Host: Spilococcus pressus Ferris.

Acerophayus californicus Rosen, 1969. Hilgardia 40 (2): 43, 45, 68-69. \&.

citrinus (Howard). Calif., Nev. Host: Quadruspuliotus perniciosus (Comst.)?, Aulecaspis rosae (Bouche).

Rhopoidens citrintes Howard, 1898. U. S. Natl. Mus., Proc. 21: 235. \&.

coccois Smith. Mass. s. to N. J., w. to Ill., Calif. Host: Phenacoccus acericola King, Pulcinaria vitis (L.).

Acerophagus coccois Smith, 1880. No. Amer. Ent. 1: 84 ..

Biology: Howard, 1881. U. S. Dept. Agr., Ann. Rept. for 1880, p. 361.

erii Timberlake. Utah. Host: Amonostherius lichtensioides (Ckll.).

Acerophagus erii Timberlake, 1916. U. S. Natl. Mus., Proc. 50: 575, 577-578. ‡, ठ.

fasciipennis Timberlake. Calif. Host: Auisococcus crawii (Coq.).

Acerophagus fasciipennis Timberlake, 1918. Calif. Univ., Pubs. Ent. 1 (8): 347, 348-349. ơ, ․

Biology: Maple, 1947. Calif. Univ., Pubs. Ent. 8 (2): 54, 109.

gutierreziae Timberlake. N. Mex. Host: Spilococcus gutierreziae (Ckll.).

Acerophagus gutierreziae Timberlake, 1916. U. S. Natl. Mus., Proc. 50: 575, 577. \&, §.

notativentris (Girault). Calif. Host: Pseudococcus maritimus (Ehrh.), P. sp. on grape.

Pseudaphycus notaticentris Girault, 1917. Deser. Hym. Chalcidoid Variorum Cum Observ.

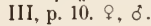

Biology: Clausen, 1924. Calif. Univ., Pubs. Ent. 3 (2): 256-266, 271-274. -Maple, 1947. Calif. Univ., Pubs. Ent. 8 (2): 54. - Flanders, 1959. Jour. Econ. Ent. 52 (1): 72.

pallidus Timberlake. Calif. Host: Phenacoccus solani Ferris, Pseudococcus maritimus (Ehrh.), Spilococcus atriplicis (Ckll.), S. eriogoni (Ehrh.).

Acerophagus pallidus: Timberlake, 1918. Calif. Univ., Pubs. Ent. 1 (8): 348, 350-351. ๆ, ơ.

Biology: Flanders, 1944. Jour. Econ. Ent. 37 (2): 312. -Maple, 1947. Calif. Univ., Pubs. Ent. 8 (2): $54-55,109$.

texanus (Howard). Tex. Host: Ferrisia virgata (Ckll.).

Aphycus texanus. Howard, 1898. U. S. Natl. Mus., Proc. 21: 245. \&. 


\section{Genus AENASIOIDEA Girault}

Aenasioidea Girault, 1911. Canad. Ent. 43 (5): 171-173.

Type-species: Aenusioidea latiscapus Girault. Orig. desig.

Taxonomy: Timberlake, 1916. U. S. Natl. Mus., Proc. 50: 579-585. -Mercet, 1925. Eos 1 (1): 30-31. - Hoffer, 1955. Acta Mus. Nat. Pragae 11 B (1): 1-22. - Compere and Annecke, 1960. Jour. Ent. Soc. So. Africa 23 (2): 386, 382.

armitagei Compere. Calif. Host: Kermes? on native oak. Aentsioidea armitugei Compere, 1926. Calif. Univ., Pubs. Ent. 4 (1): 30-31. \&.

ferrierei Burks. Md. Host: Aclerda audropogonis McConnell on Audropogon virginicus. Aenasioidea ferrierei Burks, 1964. Entomophaga 9 (1): 18-20.

kermicola Timberlake. Utah, Calif. Host: Kermes galliformis Riley, K. nigropunctatus Ehrh. and Ckll.

Aenusioiden kermicolı Timberlake, 1916. U. S. Natl. Mus., Proc. 50: 580, 583-584. ๆ, o.

latiscapus Girault. Ill. Host: Kermes pubescens Bogue.

Aenasioiden latiscapus Girault, 1911. Canad. Ent. 43 (5): 173-174. \&.

pulchella (Howard). N. Y., N. J., Okla. Host: Kermes pubescens Bogue, K. sp. on Quercus celutinu.

Aphycus pulchellus Howard, 1898. U. S. Natl. Mus, Proc. 21: 242. ?.

trimblei Dozier. Pa. Host: Lecunium quercifex Fitch.

Acuatsioiden trimblei Dozier, 1935. Ent. Soc. Wash., Proc. 37 (9): 183-184. +, đ.

\section{Genus APHYCUS Mayr}

Aphycus Mayr, 1876 (1875). Zool.-Bot. Gesell. Wien, Verhandl. 25: 695.

Type-species: Encyrtus apicalis Dalman. Desig. by Ashmead, 1900.

Pseudococrobius. Timberlake, 1916. U. S. Natl. Mus., Proc. 50: 563.

Type-species: A plyfeus terryi Fullaway. Orig. desig.

Waterstonia Mercet, 1917. Soc. Espan. de Hist. Nat., Bol. 17 (5): 268.

Type-species: Waterstonia prima Mercet. Orig. desig.

Euaphycu.s Mercet, 1921. Fauna Iberica, Himen., Encirtidos, pp. 197-212.

Type-species: Encyrtus hederaceus Westwood. Desig. by Mercet.

It is difficult to estimate the size of Aphycus because of the confusion which has existed over the genera Metuphycus and Aphycus. In the 1951 Hymenoptera Catalog the species of Metaphycus were synonymized under Aphycus. Compere and Annecke (1960) discussed the problem and indicated that sound structural differences exist between the genera. Graham (1969) noted that Mercet misidentified Encyrtus hederaceus Westwood, the type-species of Euaphycus. Most species of Euaphycus fall under Metaphycus whereas the type-species is assignable to A pliycus.

Taxonomy: Timberlake, 1916. U. S. Natl. Mus., Proc. 50: 587-639. - Mercet, 1917. Soc. Espan. de Hist. Nat., Bol. 77 (2): 128-139. - Mercet, 1925. Eos. 1 (1): 14-18. - Ishii, 1928. Imp. Agr. Exp. Sta. Japan, Bul. 3 (2): 121-123. -Compere, 1947. Calif. Univ., Pubs. Ent. 8 (1): 1-13. -Hoffer, 1955. Acta Soc. Ent. Cechosl. 51: 82-94. - Alam, 1957. Roy. Ent. Soc. London, Trans, 109 (15): 434-438. - Compere and Annecke, 1960. Ent. Soc. So. Africa, Jour. 23 (2): 377, 378. -Trjapitzin, 1962. Zool. Inst. Leningrad, Trudy 30: 281-286. -Graham, 1969.

Polski Pismo Ent. 39 (2): 224-228.

annulipes (Ashmead). Ont. s. to Fla. Host: Lecanium cormi Bouche, L. nigrofasciatum Perg., L. sp. on Quereus nigra.

Coccophugus ammulipe's Ashmead, 1882. Canad. Ent. 14 (2): 37. \&.

apicalis (Dalman). Establishment in U. S. questionable.

Encyitus apiculis Dalman, 1820. Svenska Vetensk. Akad., Handl. 41: 153-154.

Taxonomy: Mercet, 1921. Fauna Iberica, Himen., Encirtidos, pp. 228-231.

bifasciatus (Timberlake). N. H. Host: Phenacoccus sp. on apple.

Pséulococcobius bifasciatus Timberlake, 1916. U. S. Natl. Mus. Proc. 50: 564, 566-567. , ठ.

Taxonomy: Compere, 1939. Calif. Univ., Pubs. Ent. 7 (4): 62. 
brunneus Howard. N. Y., N. J. Host: Aulacaspis rosae (Bouche).

Aphycus brumneus Howard, 1885. U. S. Dept. Agr., Bur. Ent., Bul. 5: 17, 31, 36...

Aphycus bruneus. Dalla Torre, 1898. Cat. Hym., v. 5, p. 251. Unjustified emendation.

ceroplastis Howard. Fla.?, N. Mex. Host: Ceroplastes floridensis Comst.? C. irregularis Ckll., C. sp. on Artemisio.

Aphycus ceroplastis Howard, 1885. U. S. Dept. Agr., Bur. Ent., Bul. 5: 18, 31, 41. ๆ, ठ.

cockerelli Howard. N. Mex. Host: Lecanimm sp. on osage orange.

A phycus cockerelli Howard, 1898. U. S. Natl. Mus., Proc. 21: 243. १.

hederaceus (Westwood). Establishment in U. S. questionable. Host: Pulvinaria accricola (W. and R.).

Encyrtus hederaceus Westwood, 1837. London, Edinb. and Dublin Phil. Mag. and Jour. Sci. 10 (3): 441 . . .

Taxonomy: Howard, 1900. U. S. Dept. Agr., Div. Ent., Bul. 22: 23. -Compere, 1957. Portici

R. Lab. Ent. Agr., Bol. 15: 222. -Graham, 1958. Ent. Tidskr. 79 (3-4): 173. -Graham, 1969.

Polskie Pismo Ent. 39 (2): 224-225.

immaculatus Howard. Calif. Host: Aonidiella aurantii (Mask.).

Aphycus imumuculatus Howard, 1894. U. S. Dept. Agr., Insect Life 6 (3): 235-236. ठ.

\section{Genus BLASTOTHRIX Mayr}

Blastothrix Mayr, 1876 (1875). Zool.-Bot. Gesell. Wien, Verhandl. 25: 697.

Type-species: Eucyrtus sericeus: Dalman. Desig. by Ashmead, 1900.

Anagyropsis Girault, 1917. Insecutor Inscitiae Menstruus 5 (7-9): 136.

Type-species: Anagymus purpureus Girault. Orig. desig.

The cosmopolitan genus Blastothrix has been poorly studied and at present consists of approximately thirty-five species. All species appear to be primary, internal parasites of coccids and kermococcils. Undoubterlly, the North American fauna is larger than indicated here.

Taxonomy: Ruschka, 1923 (1922). Zool.-Bot. Gesell. Wien, Verhandl. 72 (2): 1-6. - Girault, 1924. Homo Perniciosus and New Hymen. (Private Pub.), p. 4. - Alam, 1961. Beitr. zur

Ent. 11 (7-8): 807-812. —Sugonyayev, 1965. Ent. Rev. 44 (2): 189-198. —Graham, 1969.

Polskie Pismo Ent. 39 (2): 241-243.

adjutabilis Howard. Va. s. to Fla. Host: Lecanium spp. on Crataegus, Japaneese persimmon and oak.

Blastathrix adjutabilis Howard, 1881. U. S. Dept. Agr., Ann. Rpt. for 1880, pp. 365-366. ₹. incerta Howard. Fla. Host: Lecanium sp.? on mesquite, Lecanium sp.

Blastothrix incerta Howard, 1881. U. S. Dept. Agr., Ann. Rpt. for 1880, p. 366. $\delta$.

longipennis Howard. Ont. s. to N. Y., D. C. w. to Minn.; N. Mex. w. to Calif., B. C. Host:

Kermes pubescens. Bogue, Lecanium corni Bouche, L. fletcheri Ckll., L. pruinosum Coq., L. quercifix Fitch.

Blastothrix longipenuis Howard, 1881. U. S. Dept. Agr., Ann. Rept. for 1880, p. 366. q.

Taxonomy: Girault, 1915. Ent. Soc. Amer., Ann. 8 (3): 274.

Biology: Glendenning, 1931. Brit. Columbia Ent. Soc., Proc. 28 (1): 30-31. -Lyne, 1934. Calif.

Dept. Agr., Monthly Bul. 23: 232. -Maple, 1947. Calif. Univ., Pubs. Ent. 8 (2): 67-68.

- Huffaker, 1971. Biol. Control, pp. 271.

sericea (Dalman). Que. s. to Pa., La., B. C. Host: Kermes sp. on ash, Lecanium coryli (L.), L. nigrofasciatum Perg, Baccha fascipennis Wied.?

Eucyrtus serice'us Dalman, 1820. Svenska Vetensk. Akad., Handl. 41: 357..

Taxonomy: Girault, 1915. Ent. Soc. Amer. Ann. 8 (3): 274. - Silvestri, 1919. Lab. Zool. Gen. e Agr. Portici, Bol. 13: 163-173. - Mercet, 1921. Fauna Iberica, Himen., Encirtidos, pp.

249-251.

Biology: Glendenning, 1933. Canad. Ent. 65 (8): 169-171. - Maple, 1947. Calif. Univ., Pubs. Ent. 8 (2): 68-69. - Huffaker, 1971. Biol. Control, pp. 318-319. 


\section{Genus BOTHRIOCRAERA Timberlake}

Bothriocraer Timberlake, 1916. U. S. Natl. Mus., Proc. 50: 567-568.

Type-species: Bothriocraera flacipes Timberlake. Orig. desig.

bicolor Compere and Zinna. Introduced, possibly established.

Bothriocrere bicolor Compere and Zinna, 1955. Lab. Ent. Agr. Portici, Bol. 14: 94, 95, 101-105. ठ, . .

flavipes Timberlake. Utah. Host: Mealybug on Elymus.

Bothriocraera flaripes Timberlake, 1916. U. S. Natl. Mus., Proc. 50: 568-569. §, ?.

\section{Genus ERYTHRAPHYCUS Compere}

Erythraphycus Compere, 1947. Calif. Univ., Pubs. Ent. 8 (1): 7-8, 10.

Type-species: Erythraphycus argyrocomns: Compere. Orig. desig.

This small but distinctive genus can readily be identified by its bright scarlet coloration as the name implies. Species of Erythraphycus apparently parasitize eriococcids. An undescribed species parasitizes a pseudococid of the genus Stemmatomerinx.

argyrocomus Compere. Calif. Host: Eriococens sp. on croton, asters, and Ericameria sp.

E'ythraphycus argyrocomus Compere, 1947. Calif. Univ., Pubs. Ent. 8 (1): 8, 10-11. o,.

Biology: Maple, 1947. Calif. Univ., Pubs. Ent. 8 (2): 84-86, 88.

calvus Compere. Calif.

Erythropliycus culens Compere, 1947. Calif. Univ., Pubs. Ent. 8 (1): 10, 11-12. \&.

matteolus Compere. Calif.

Erythraphycus matteolus Compere, 1947. Calif. Univ., Pubs. Ent. 8 (1): 10, 11. o.

\section{Genus MELANAPHYCUS Compere}

Melanaphycus Compere, 1947. Calif. Univ., Pubs. Ent. 8 (1): 4, 5.

Type-species: Psenlococcobius fumipennis Timberlake. Orig. desig.

clauseni (Timberlake). Calif. Host: Amonostherimm lichtensioilles (Ckll.), A. sp.? on cactus,

Eriococeus adenostomae Ehrh., E. palustris Dodds.

Psendococcobius clauseni Timberlake, 1918. Calif. Univ., Pubs. Ent. 1 (8): 358-360. đ.

Biology: Dodds, 1923. Jour. Ent. and Zool. 15 (4): 57-60.

fumipennis (Timberlake). Calif. Host: Eriococcus sp., Phenacocess solani Ferris,

Pseudococcus solani (Ckll.).

Pseudococcobius fumipenn is Timberlake, 1918. Calif. Univ., Pubs. Ent. 1 (8): 356-258. ơ, ㅇ.

fuscipennis (Howard). Calif. Host: Lecanimm corni Bouche.

Aphyers fuscipenn is Howard, 1898. U. S. Natl. Mus., Proc. 21: 241-242. ․

Taxonomy: Timberlake, 1916. U. S. Natl. Mus., Proc. 50: 597-599. -Compere, 1947. Calif.

Univ., Pubs. Ent. 8 (1): 5-6.

Biology: Maple, 1947. Calif. Univ., Pubs. Ent. 8 (2): 115.

\section{Genus METAPHYCUS Mercet}

Mefaphycus Mercet, 1917. Soc. Espan. de Hist. Nat., Bol. 17 (2): 129, 138-139.

Type-species: Mefuphy/cus zebratıs Mercet. Monotypic.

As indicated earlier, controversy has existed over the status of Aphycus and Metaphycus. Most encyrtid specialists now believe the genera are distinct and Trjapitzin (1973) has placed them in separate subtribes of the Aphycini.

Taxonomy: Mercet, 1925. Eos 1 (1): 28. -Timberlake, 1926. Hawaii. Ent. Soc., Proc. 6 (2): 310. - Compere, 1940. Bul. Ent. Res. 31 (1): 7-13, 27. - Gomes, 1941. Esc. Nac. de Agron. (Rio de Janerio), Bol. 2: 30-34. - Compere, 1947. Calif. Univ., Pubs. Ent. 8 (1): 2-5. -Alam, 1957. Roy. Ent. Soc. London, Trans. 109 (15): 425-426. - Compere, 1958 (1957). Portici Lab.

Ent. Agr., Bol. 15: 221-230. -Compere and Annecke, 1960. Ent. Soc. So. Africa, Jour. 23 
(2): 376-378, 382-385. - Sugonyayev, 1960. Ent. Rev. 39 (2): 235-250. - Trjapitzin, 1967.

Akad. Nauk SSSR Zool. Inst., Trudy 41: 185-186. - Graham, 1969. Polskie Pismo Ent. 39 (2): 229-232. - Annecke and Mynhardt, 1971. Rev. Zool. Bot. Africaines. 83 (3-4): 322-360. -Annecke and Mynhardt, 1972. Rev. Zool. Bot. Africaines. 85 (3-4): 227-274. - Trjapitzin, 1973. Ent. Rev. 52 (2): 287-295.

alberti (Howard). Calif. Host: Coccus hesperielum L.

Apliycus ullerti Howard, 1898. U. S. Natl. Mus., Proc. 21: 241-247. ठ, + .

Taxonomy: Maple, 1947. Calif. Univ., Pubs. Ent. 8 (2): 94-95. -Compere, 1958 (1957). Portici Lab. Ent. Agr., Bol. 15: 221-230.

Biology: Timberlake, 1913. Jour. Econ. Ent. 6 (3): 294-295.

californicus (Howard). Pa., Md., Calif. Host: Lecanium nigrofasciatum Perg. Aphycus califormicus: Howard, 1898. U. S. Natl. Mus., Proc. 21: 241, 245. 9.

Taxonomy: Compere and Annecke, 1961. Ent. Soc. So. Africa, Jour. 24 (1): 34 . -Annecke and Mynhardt, 1972. Rev. Zool. Bot. Africaines. 85 (3-4): 272.

Biology: Huffaker, 1971. Biol. Control, p. 271.

coquilletti (Howard). Utah, Calif. Host: Pnlvinaria bigeloviae Ckll. Aphycus coqnilletti Howard, 1898. U. S. Natl. Mus., Proc. 21: 241, 244. ๆ.

Taxonomy: Timberlake, 1929. Pan-Pacific Ent. 6 (1): 43.

eriococei (Timberlake). Fla., Tex., Utah, Calif. Host: Eriococcus quercus (Comst.), Coccus hesperidum (L.).

Aphlycrs eriococci Timberlake, 1916. U. S. Natl. Mus., Proc. 50: 631-632. .

eruptor (Howard). Va. s. to Fla. Host: Ceroplastes floridensis Comst., Ceroplastes sp.?

Aphycus ernptor Howard, 1881. U. S. Dept. Agr., Ann. Rept. for 1880, p. 364-365. ठ, ?.

Biology: Maple, 1947. Calif. Univ., Pubs. Ent. 8 (2): 115.

flammeus Compere. Calif. Host: Leconinm quercifex Fitch.

Metuphysus flumme'us Compere, 1947. Calif. Univ., Pubs. Ent. 8 (1): 13. ठ, १.

Biology: Maple, 1947. Calif. Univ., Pubs. Ent. 8 (2): 95.

flavus (Howard). N. Y. s. to Fla., w. to Tex. Host: Coccus hesperidum L., C.

psendomagnoliarmm (Kuw.), Lepidosaphes gloverii (Pack.), Pulvinaria acericola (W. and R.), Saissetia oleae (Oliv.), Tachardia sp., Toumeyella liriodendiri (Gmel.).

A plycus flavus Howard, 1881. U. S. Dept. Agr. Ann. Rept. for 1880, p. 365..

Biology: Huffaker, 1971. Biol. Control, p. 463.

helvolus (Compere). Calif. Host: Cocens hesperidum L., C. psendomagnolianm (Kuw.), Lecaninm cormi Bouche, Parasaissetia nigra (Nietn.), Saissetia coffeae (Walker), S. olece (Oliv.).

Aphycus helrolus Compere, 1926. Calif. Univ., Pubs. Ent. 4 (1): 25-29. ठ, ๆ.

Taxonomy: Compere, 1958 (1957). Portici Lab. Ent. Agr., Bol. 15: 221-230. - Compere and Annecke, 1960. Ent. Soc. So. Afr., Jour. 23 (2): 375-389. -Annecke, 1964. Rep. So. Afr. Dept. Agr. Tech. Serv., Ent. Mem. 7: 11-13.

Biology: Smith and Compere, 1928. Calif. Univ., Pubs. Ent. 4 (9): 242, 274. -Flanders, 1942. Jour. Econ. Ent. 35 (5): 690-695. - Woglum of al., 1947. Jour. Econ. Ent. 40 (5): 819. -Clausen, 1956. U. S. Dept. Agr., Tech. Bul. 1139, pp. 80-81. -Flanders, 1959. Jour. Econ. Ent. 52 (1): 74; 52 (4) 596-599. - Damaino, 1963. Rev. di Agr. Subtrop. e Trop. 57: 452. - Huffaker, 1971. Biol. Control, pp. 76, 265. - van den Bosch and Messenger, 1973. Biol. Control, pp. 52, 59, 66, 77, 78.

Morphology: Flanders, 1942. Ent. Soc. Amer., Ann. 35 (3): 253, 262-265.

howardi (Cockerell). N. Mex. w. to Calif. Host: Eriococcus tinsleyi Ckll., E. sp. on Ericameria.

Aphycus Hourardi Cockerell, 1898. Canad. Ent. 30 (10): 276. ९.

Taxonomy: Compere, 1947. Calif. Univ., Pubs. Ent. 8 (1): 12.

Biology: Maple, 1947. Calif. Univ., Pubs. Ent. 8 (2): 94-97. 
johnsoni (Howard). Ont., Que. s. to N. C., w. to Ill. Host: Coccus hesperidum L., Kermes sp. Lecuninm corni Bouche, L. nigrofasciatum Perg.

A phycus johnson i Howard, 1898. U. S. Natl. Mus., Proc. 21: 241, 244..

kincaidi Timberlake. Wash. Host: Lecrnium coryli (L.).

Metuphycus kiucrirli Timberlake, 1929. Pan-Pacific Ent. 6 (1): 43-45. o, ๆ.

kingi (Timberlake). Mass., Ohio. Host: Pulvinarin sp.

A phycus kingi Timberlake, 1916. U. S. Natl. Mus., Proc. 50: 589, 613-614. ․

lecanii (Howard). Calif. Host: Lecuninm comi Bouche, L. pubescens Ehrh., L. quercifex Fitch, Physotermes insignicolu (Craw).

Aphycus lecunii Howard, 1898. U. S. Natl. Mus., Proc. 21: 240, 242. + (ơ misdet.).

Biology: Maple, 1947. Calif. Univ., Pubs. Ent. 8 (2): 115.

lounsburyi (Howard). Mass., Calif. Host: Snissetia olette (Oliv.).

Aphycus tonnsburyi Howard, 1898. U. S. Natl. Mus., Proc. 21: 241, 244. क.

Taxonomy: Smith and Compere, 1928. Calif. Univ., Pubs. Ent. 4 (9): 275-292. -Annecke and Mynhardt, 1971. Rev. Zool. Bot. Africaines 83 (3-4): 335-338, 355.

Biology: Clausen, 1942. Jour. Econ. Ent. 35 (5): 748. -Flanders, 1942. Ent. Soc. Amer., Ann. 35 (2): 252, 262. - Flandlers, 1942. Jour. Econ. Ent. 35 (5): 696. - Flanders, 1943. Jour.

Econ. Ent. 36 (6): 922-925. -Flanders, 1944. Jour. Econ. Ent. 37 (3): 409. -Maple, 1947.

Univ. Calif. Pubs., Ent. 8 (2): 95, 97-99. -Woglum et al., 1947. Jour. Econ. Ent. 40 (6): 819.

-Clausen, 1956. U. S. Dept. Agr., Tech. Bul. 1139, p. 81. - Beardsley, 1962. Hawaii. Ent.

Soc., Proc. 18 (1): 16. -DeBach, 1964. Biol. Control Insect Pests and Weeds, pp. 318, 411, 475, 682. - DeBach, 1974. Biol. Control by Nat. Enem, pp. 28, 29, 286.

Morphology: Compere, 1947. Calif. Univ., Pubs. Ent. 8 (1): 8-9.

luteolus (Timberlake). Calif. Host: Coccus hesperidum L., C. psendomagnoliarum (Kuw.), Lecunimm cormi Bouche, Snissetin oleae (Oliv.).

Aphycus luteolus Timberlake, 1916. U. S. Natl. Mus., Proc. 50: 591, 592, 636-637. o, ․

Taxonomy: Compere, 1958 (1957). Portici Lab. Ent. Agr., Bol. 15: 229. -Smith and Compere, 1928. Calif. Univ., Pubs. Ent. 4 (9): 274-275. -Compere and Annecke, 1960. Ent. Soc. So. Afr., Jour. 23 (2): 385.

Biology: Flanders, 1942. Jour. Econ. Ent. 35 (2): 263. -Flanders, 1942. Jour. Econ. Ent. 35 (6): 832-833. - Maple, 1947. Calif. Univ., Pubs. Ent. 8 (2): 96, 99-100. - Woglum et al., 1947. Jour. Econ. ent. 40 (6): 819-820. -Flanders, 1959. Jour. Econ. Ent. 52 (1): 74; 52 (4): 596-599. - DeBach, 1964. Biol. Control of Insect Pests and Weeds, pp. 351, 451.

- Huffaker, 1971. Biol. Control, p. 79.

maculipennis (Timberlake). Mass. Host: Lecanium comi Bouche.

Aphycus maculipennis Timberlake, 1916. U. S. Natl. Mus., Proc. 50: 589, 591, 593-594. ठ’, ‥

Taxonomy: Annecke and Mynhardt, 1971. Rev. Zool. Bot. Africaines 83 (3-4): 357.

maculipes (Howard). Ont., Mass. s. to S. C., w. to Ill. Host: Coccus hesperidum L., Lecunium corni Bouche, L. sp. on Quercus nigra, L. sp.

Aphycus maculipes Howard, 1885. U. S. Dept. Agr., Bur. Ent., Bul. 5: 18-19, 31, 41. ơ, o. mexicanus (Howard). Pa., La. Host: Ceroplastes cirripediform is Comst.

Aphycus mexicanus Howard, 1898. U. S. Natl. Mus., Proc. 21: 241, 247. .

oregonensis (Howard). Oreg. Host: Phlinaria sp. on Oregon flowering currant, $P$. sp. on Ribes.

Aphycus oregonensis Howard, 1898. U. S. Natl. Mus., Proc. 21: 241, 246. ๆ (o misdet.).

physokermis (Timberlake). Calif. Host: Physokermes insignicola (Craw).

Aphycus physsoker'm is Timberlake, 1916. U. S. Natl. Mus., Proc. 50: 589, 591, 606-607. o, ․

Taxonomy: Compere and Annecke, 1960. Ent. Soc. So. Afr., Jour. 23 (2): 385. - Annecke and Mynhardt, 1972. Rev. Zool. Bot. Africaines 85 (3-4): 270-271.

psyllidis Compere. Calif. Host: Paratrioza cockerelli (Sulc).

Metaphycus psyllidis Compere, 1943. Pan-Pacific Ent. 19 (2): 71-73. o, ․ 
Taxonomy: Compere and Annecke, 1960. Ent. Soc. So. Afr., Jour. 23 (2): 385. - Annecke and Mynhardt, 1972. Rev. Zool. Bot. Africaines 85 (3-4): 271.

pulvinariae (Howard). Cosmopolitan. Host: Lecunium corni Bouche, L. fletcheri Ckll., $L$. nigrofasciatum Perg., $L$. sp. on Japaneese persimmon, $L$. sp. on wild goose plum, Parasuissetiu nigra (Nietn.), Pulviuaria acericola (W. and R.), P. ritis (L.), P. sp. on plum, $P$. sp. on willow.

Apliycus pulcinuriue Howard, 1881. U. S. Dept. Agr., Ann. Rept. for 1880, p. 365..

punctipes (Dalman). N. Amer.?

Eucyrtus punctipes Dalman, 1820. Svenska Vetensk. Akad., Handl. 41: 154.

rileyi (Timberlake). Ont. s. N. Y., w. to Mo., Tex. Host: Lecanium corni Bouche, Lecanium sp. on Japaneese persimmon.

Aplyycus rileyi Timberlake, 1916. U. S. Natl. Mus., Proc. 50: 589-591, 600-601. §, ๆ.

schwarzi (Timberlake). Ariz.

A phycus schu'a: $\approx$ T Timberlake, 1916. U. S. Natl. Mus., Proc. 50: 589, 599..+

similis (Timberlake). Tex. Host: Lecaninm sp. on Japaneese persimmon.

Aphycus similis Timberlake, 1916. U. S. Natl. Mus., Proc. 50: 589, 605-606. ?.

Biology: Maple, 1947. Calif. Univ., Pubs. Ent. 8 (2): 115.

stanleyi Compere. Calif. Host: Coccus hesperidum L., C. pseudomagnoliarum (Kuw.), Eucalyunatus tessellutus (Sign.), Suissetin olecte (Oliv.).

Metuphycus stumleyi Compere, 1940. Bul. Ent. Res. 31 (1): 10, 11, 20. ठ, ?.

Taxonomy: Compere, 1940. Hilgardia 13 (7): 417-419. - Compere and Annecke, 1960. Ent. Soc. So. Afr., Jour. 23 (2): 385 . - Annecke and Mynhardt, 1972. Rev. Zool. Bot. Africaines $85(3-4): 262-265$.

stomachosus (Girault). Mass. s. to Va., w. to Ill. Host: Lecanium nigrofasciatum Perg. Apliycus stomuchosus: Girault, 1909. Psyche 16 (4): 77-79. o, ?.

subfasciatus (Timberlake). Kans. Host: Lecunium corni Bouche.

Aphycus subfasciatus. Timberlake, 1916. U. S. Natl. Mus., Proc. 50: 589, 591, 601-602. o, q.

\section{Genus PSEUDAPHYCUS Clausen}

Pseudaphycu.s Clausen, 1915. Calif. Agr. Exp. Sta., Bul. 258: 41.

Type-species: Pseudaphycus angelicus. Howard. Monotypic.

Psilomirimus Brethes, 1916. Buenos Aires Mus. Nac. de Hist. Nat., An. 27: 424.

Type-species: Psilomirinus flavidulus Brethes. Orig. desig.

Representatives of the genus Pseulaphycus are internal parasites of pseudococcids. Some species, (P. utilis, $P$. malimus), have been useful in biological control programs.

Taxonomy: Timberlake, 1916. U. S. Natl. Mus., Proc. 50: 569-574. - Mercet, 1925. Eos 1 (1):

10-14. - Ferriere, 1937. Bul. Ent. Res. 28 (2): 316-317. -Gahan, 1946. U. S. Natl. Mus.,

Proc. 96: 311-327. - De Santis, 1947. Soc. Ent. Argentina Rev. 13 (1-5): 281-287. - Hoffer,

1954. Acta. Soc. Ent. Cechosl. 51: 81, 102-103. - Compere and Annecke, 1960. Ent. Soc. So.

Afr., Jour. 23 (2): 377, 379. - Hoffer, 1960. Mus. Nat. Pragae, Acta Faun. Ent. 6: 94-97.

abstrusus Gahan. Va. Host: Pséurlococcus comstocki (Kuw.).

Pseudapliycus alsstrusus Gahan, 1946. U. S. Natl. Mus., Proc. 96: 313, 316-317. ơ, ๆ.

alveolatifrons Gahan. N. J. Host: Pseuelococcus comstocki (Kuw.).

Pséudaphycus aleeolatifions Gahan, 1946. U. S. Natl. Mus., Proc. 96: 314, 326-327. o, o.

angelicus (Howard). Que., Calif. Host: Dysmicoccus ryani (Coq.), Phenacoccus gossypii Tns. and Ckll., Pseulococcus calceolariae (Mask.), P. longispinus (Targ.-Tozz.), P. maritimus (Ehrh.), P. sp. on Artemisia californica, $P$. sp. on passion flowers.

Aphycus angelicus Howard, 1898. U. S. Natl. Mus., Proc. 21: 241, 245. ․

Taxonomy: Timberlake, 1916. U. S. Natl. Mus., Proc. 50: 573-574.

Biology: Flanders, 1940. Jour. Econ. Ent. 33 (5): 756-758. - Haeussler and Clancy, 1944. Jour. Econ. Ent. 37 (4): 504-509. - Maple, 1947. Calif. Univ., Pubs. Ent. 8 (2): 110-111. 
graminicola Timberlake. N. Mex., Utah. Host: Trionymus utahensis (Ckll.), pseudococcoid on Elymus condensatus.

Pseudaphycus graminicola Timberlake, 1916. U. S. Natl. Mus., Proc. 50: 570-571. đ, ?.

limatulus Gahan. Md. Host: Phenacoccus sp. on Audropogon sp.

Pseudaphycus limatulus Gahan, 1946. U. S. Natl. Mus., Proc. 96: 313, 324-325. ס, ?.

malinus Gahan. Ont., Conn. s. to Va., w. to Mo. Host: Pseudoccus comstocki (Kuw.).

Pseudaphycus malinus Gahan, 1946. U. S. Natl. Mus., Proc. 96: 313, 317-319. ó, ९.

Taxonomy: Jasnosh, 1957. Ent. Oboz. 36 (3): 720. - Hoffer, 1960. Mus. Nat. Pragae, Acta

Faun. Ent. 6: 95, 97. - Sugonyayev, 1962. Akad. Nauk SSSR Izv., ser. Biol., 5: 754-766.

Biology: Clausen, 1956. U. S. Dept. Agr., Tech. Bul. 1139, p. 125. -Sugonyayev, 1960. Ent.

Rev. 39 (2): 235. -DeBach, 1964. Biol. Control Insect Pests and Weeds, p. 681. - DeBach,

1974. Biol. Control. by Nat. Enem., p. 160.

meracus Gahan. Va. Host: Ferrisia virgata (Ckll.).

Pseuduphycus meracus Gahan, 1946. U. S. Natl. Mus., Proc. 96: 314, 325-326. o, \&.

meritorius Gahan. Va. Host: Fervisia virgata (Ckll.).

Pseudaphycus meritorius Gahan, 1946. U. S. Natl. Mus., Proc. 96: 312, 314-315. §, ₹.

mundus Gahan. Va. s. to Fla., w. to La. Host: Dysmicoccus bonirsis (Kuw.), Phenacoccus yossypii Tns. and Ckll., Pseudococcus comstocki (Kuw.), P. longispinus (Targ.-Tozz.).

Pseudaphycus mundus Gahan, 1946. U. S. Natl. Mus., Proc. 96: 313, 321-324. ơ, .

Biology: Bynum, 1938. La. Agr. Expt. Sta., Bul. 298: 27-29. - Clancy and Pollard, 1947. Jour.

Econ. Ent. 40 (4): 579.

perdignus Compere and Zinna. Calif., released, possibly established.

Pse'udaphycus perdignus. Compere and Zinna, 1955. Portici Lab. Ent. Agr., Bol. 14: 94, 105-108. $\delta$, ?.

prosopidis Timberlake. N. Mex. Host: Spilococcus prosopidis (Ckll.).

Pseulaphycus prosopidis Timberlake, 1916. U. S. Natl. Mus., Proc. 50: 570, 571-572. \&.

websteri Timberlake. Ind., Ill. Host: Psendococcus maritinus (Ehrh.), mealybug on stem of Elymus virginicus.

Psenilaphycus uebsteri Timberlake, 1916. U. S. Natl. Mus., Proc. 50: 570, 572. \&.

\section{Genus STEMMATOSTERES Timberlake}

Stemmatostere's Timberlake, 1918. Calif. Univ., Pubs. Ent. 1 (8): 352-354.

Type-species: Stemmatosteres apterus Timberlake. Orig. desig.

This morphologically aberrant genus consists of only a few species which seem restricted to the Holarctic Region. A North American species is parasitic on pseudococcids.

Taxonomy: Hoffer, 1955. Acta Soc. Ent. Cechosl. 51: 109-111. - Compere and Annecke, 1960.

Ent. Soc. So. Afr., Jour. 23 (2): 381. - Hoffer, 1960. Mus. Nat. Pragae, Acta Faun. Ent. 6:

98.

apterus Timberlake. Calif. Host: Dysmicoccus timberlakei (Ckll.).

Stemmatosteres apterus Timberlake, 1918. Calif. Univ., Pubs. Ent. 1 (8): 354-355. §, .

Biology: Maple, 1947. Calif. Univ., Pubs. Ent. 8 (2): 109, 114.

kuchari Yoshimoto. Alta.

Stemmatostere's kuchuri Yoshimoto, 1972. Canad. Ent. 104 (11): 1837-1839. ठ, \&.

\section{Genus TACHARDIOBIUS Timberlake}

Tachardiobius Timberlake, 1926. U. S. Natl. Mus., Proc. 69 (3): 19-22.

Type-species: Tachardiobius nigricaus Timberlake. Orig. desig.

nigricans Timberlake. Ariz., Calif. Host: Tachardiella larreae (Comst.).

Tachardiobius nigrican.s Timberlake, 1926. U. S. Natl. Mus., Proc. 69 (3): 22-23. o, o.

\section{Genus TIMBERLAKIA Mercet}

Timberlakia Mercet, 1925. Eos 1 (1): 9-10.

Type-species: Acerophagus curopa'us Mercet. Orig. desig. 
The only species of this genus was imported from Europe in attempts to control the Rhodes grass scale, Antonina graminis (Maskell). Biological control of this pest is achieved by another parasite, Neodnsmetia sangwani (Subba Rao), but T. enropenea (Mercet) has become established.

Taxonomy: Compere and Annecke, 1960. Ent. Soc. So. Afr., Jour. 23 (2): 377, 378. - Hoffer, 1960. Mus. Nat. Pragae, Acta Faun. Ent. 6: 98.

Biology: Dean and Schuster, 1958. Jour. Econ. Ent. 51 (3): 365. - Dean, 1960. Jour. Econ. Ent. 53 (4): 694. - Schuster et al., 1971. In: Huffaker, Biol. Control, p. 228.

europaea (Mercet). Fla., Tex. Introduced from Europe. Host: Antonina graminis (Mask.). Acerophugus europaeus Mercet, 1921. Fauna Iberica, Himen., Encirtidos, pp. 191-193. ठ, ‥

Biology: Huffaker, 1971. Biol. Control, p. 228.

\section{TRIBE ARRHENOPHAGINI}

\section{Genus ARRHENOPHAGUS Aurivillius}

Arrhenophagus Aurivillius, 1888. Ent. Tidskr. 9: 144-146.

Type-species: Arhenophagus chionaspidis Aurivillius. Monotypic.

Mymariella Risbec, 1951. Inst. Fr. Afr. Noire, Mem. 13: 402-403.

Type-species: Mymariellu parlutoreae Risbec. Monotypic.

Arhenophagus consists of fewer than five species, but is widespread in distribution. Its species are parasitic on armored scale insects.

Taxonomy: Girault, 1915. N. Y. Ent. Soc., Jour. 23 (4): 241-242. -Timberlake, 1924. Hawaii.

Ent. Soc., Proc. 5 (3): 433. - Agarwal, 1963. Ztschr. f. Parasitenk. 22 (5): 394-397.

chionaspidis Aurivillius. Md. s. to Fla. Host: Anlucaspis rosae (Bouche), Quadraspidiotus perniciosus (Comst.), Q. forbesi (Johns.).

Arhenophagus chionuspidis Aurivillius, 1888. Ent. Tidskr. 9: 146. ?.

Coccobius diaspidis Ashmead, 1900. U. S. Natl. Mus., Proc. 22: 408. §.

Taxonomy: Girault, 1911. N. Y. Ent. Soc., Jour. 19 (3): 177-179. -Girault, 1915. N. Y. Ent. Soc., Jour. 23 (4): 241-242. - Ferriere, 1953. Rev. Path. Veg. d'Ent. Agr. France 32 (2): 116. -Tachikawa, 1957. Jap. Jour. Appl. Ent. and Zool. 1 (3): 174-179. - Hoffer, 1964. Acta Soc.

Ent. Cechosl. 61 (2): 118-122. - Trjapitzin, 1968. Vses. Ent. Obshch., Trudy 52: 47.

Biology: Benassy, 1958. (Paris) Acad. Sci. Compt. Rend. 246 (1): 179-181. -Zak-Ogaza, 1961.

Polskie Pismo Ent. 31 (26): 356.

Morphology: Dominichini, 1953. Zool. Agr. Bach Univ. Milano, Bol. 19: 242.

\section{TRIBE BOTHRIOTHORACINI}

\section{Genus BOTHRIOTHORAX Ratzeburg}

Bothriothorax Ratzeburg, 1844. Ichn. d. Forstins., v. 1, table facing p. 4; pp. 208-209.

Type-species: Bothriothorax altensteinii Ratzeburg. Monotypic. The type-species is considered a synonym of Encyrtus clavicornis Dalman.

Trimorphocerus Dahlbom, 1857. Ofvers. Svenska Vetensk, Akad. Forh. 14 (8): 293-294 (no species included).

Type-species: Bothriothorax alteusteinii Ratzeburg. Desig. by Gahan and Fagan, 1923.

This Holaretic genus consists of about 15 species that are parasites of syrphid flies.

Taxonomy: Howard, 1895. U. S. Natl. Mus., Proc. 17: 607-611. - Graham, 1958. Ent. Tidskr. 79 (3-4): 161-165. - Kerrich, 1963. Beitr. zur Ent. 13 (3-4): 364. -Trjapitzin, 1967. Akad Nauk SSSR, Zool. Inst., Trudy 41: 209-212.

Biology: Heiss, 1938. Ill. Biol. Monog. 16 (4): 19, 99, 100. -Graves, 1960. Ent. Soc. Amer., Ann. 53 (1): 74. 
ealifornicus Howard. Calif. Host: Scaeva pyrasfri (L.), Syrphus nitens Zett., S. opinator O. S. Bothriothorax califomicus Howard, 1895. U. S. Natl. Mus., Proc. 17: 607, 609-610. \&.

Biology: Kamal, 1926. Jour. Econ. Ent. 19 (5): 726-728.

faridi Kamal. Calif. Host: Syrphus opinator O. S.

Bothriothorex faridi Kamal, 1926. Canad. Ent. 58 (11): 283-284. ơ, ९.

Biology: Kamal, 1939. Egypt Min. Agr. Tech. and Sci. Serv. Ent. Sect., Bul. 207: 33, 46, 48. macroglenes Ashmead. Kans.

Bothriothorex macroglenes Ashmead, 1888. Kans. Agr. Expt. Sta., Bul. 3: app. p. V. $q$.

nigripes Howard. N. Mex., Calif. Host: Eupeodes volucris O. S.

Bothriothorax nigripes Howard, 1895. U. S. Natl. Mus., Proc. 17: 607, 610. ?.

Biology: Kamal, 1939. Egypt Min. Agr. Tech. and Sci. Serv. Ent. Sect., Bul. 207: 33, 46, 48. -Maple, 1947. Calif. Univ., Pubs. Ent. 8 (2): 70-71.

noveboracensis Howard. N. H. s. to N. J.

Bothriothorax noveboracensis Howard, 1895. U. S. Natl. Mus., Proc. 17: 607,609..

peculiaris Howard. N. H. s. to Va., w. to Wis. Host: Metasyrphus americanus (Johns.), Syrphus rectus O. S., S. ribesii (L.).

Bothriothorax peculiaris Howard, 1885. U. S. Dept. Agr., Bur. Ent., Bul. 5: 20-21, 43. o, ๆ. rotundiform is Howard. Calif., Colo., Wash.

Bothriothorax rotundiform is Howard, 1895. U. S. Natl. Mus., Proc. 17: 607, 610-611. \&.

virginiensis Howard. Va.

Bothriothorax virginiensis Howard, 1885. U. S. Dept. Agr., Bur. Ent., Bul. 5: 20, 43. ․

\section{Genus TRJAPITZINELLUS Viggiani}

Trjapitzinellus Viggiani, 1967. Portici Lab. Ent. Agr., Bol. 25: 166-167.

Type-species: Trjapitzinellus semidaliphagus Viggiani. Orig. desig.

This genus consists of two species, one from Italy and one from California. Both are larval-pupal parasites of Coniopterygidae.

microrphanos Gordh. Calif. Host: Conwentzia sp., Parasemidalis sp.

Triapitzinellus microrphanos Gordh, 1973. Pan-Pacific Ent. 49 (1): 51-55.

\section{Genus ZETETICONTUS Silvestri}

Arutus Howard, 1897. Linn. Soc. London, Jour., Zool. 26: 155-156. Preoce. by Aratus Milne-Edwards, 1853.

Zeteticontus Silvestri, 1915. Portici Lab. Zool., Bol. 9: 343-344.

Type-species: Zeteficontus abilis Silvestri. Orig. desig.

Mimencyrtus Girault, 1915. Queensland Mus., Mem. 4: 115.

Type-species: Mirrencyltus glabriscutellam Girault. Orig. desig.

Aratiscus. Ghesquiere, 1946. Rev. Zool. Bot. Africaines 39 (4): 368. N. name for Aratus Howard.

Prolitomastix Hoffer, 1954. Ochr. Prirody 9 (6): 172.

Type-species: Prolitomastix restoniceusis Hoffer. Orig. desig.

Zeteticontus is cosmopolitan and contains about ten species. Members of the genus are nitidulid beetle parasites.

insularis (Howard). Fla. Host: Anastrepha ludens (Loew). Kerrich examined the holotype of $H$. insularis and considered it to be an Aratus (=Zeteticontus). This is interesting because iusularis is a fly parasite whereas all other species of Zeteficontus parasitize nitidulids.

Bothriothorax insularis Howard, 1896. Linn. Soc. London, Jour., Zool. 26: 147. o, ?.

Taxonomy: Kerrich, 1963. Beitr. zur Ent. 13 (3-4): 367-368. 


\section{TRIBE CERAPTEROCERINI}

\section{Genus AMMONOENCYRTUS De Santis}

Ammonocneyrtus De Santis, 1964. Com. Inv. Cient. Prov. Buenos Aires, An. 4: 376-378. Type-species: Cerapterocerus bouriensis Brethes. Orig. desig.

This New World genus contains two hyperparasitic species that attack parasites of soft-scale insects.

Taxonomy: Annecke, 1967. Roy. Ent. Soc. London, Trans. 119 (4): 101, 159-160.

ealifornicus (Compere). Calif. Host: Primary parasite of Coccus hesperidum L., Saissetia olene (Oliv.), Ceroplastes cirripediform is Comst., Metapleyens lounsburyi (Howard).

Eusemion californicum Compere, 1925. Calif. Univ., Pubs. Ent. 3 (3): 296, 304-306. ठ, १.

Biology: Compere, 1925. Calif. Univ., Pubs. Ent. 3 (3): 306-308. - Smith, 1933. Ent. Soc.

Amer., Ann. 26 (3): 525-528. - Flanders, 1940. Ent. Soc. Amer., Ann. 33 (2): 252.

-Flanders, 1943. Jour. Econ. Ent. 36 (6): 923-924. - Maple, 1947. Calif. Univ., Pubs. Ent. 8

(2): 89-90.

\section{Genus ANICETL'S Howard}

Aniretus Howard, 1896. U. S. Natl. Mus., Proc. 18: 639.

Type-species: Anicefus ceylonensis Howard. Monotypic.

Asteropueus: Howard, 1898. U. S. Natl. Mus., Proc. 21: 231.

Type-species: Asteropasus primus Howard. Monotypic.

Hubrole popterygis Girault, 1915. Queensland Mus., Mem. 4: 86.

Type-species: Hubrolepopterygis felix Girault. Monotypic.

Krishnieriella Mani, 1935. Ree. Indian Mus. 37 (4): 421-422.

Type-species: Krishniericlla ceroplastod is Mani. Orig. desig.

Anicetus contains about 20 species which are parasitic on soft scales, especially Ceroplastes. The genus is predominantly Ethiopian and Oriental in distribution.

Taxonomy: Girault, 1916. Ent. Soc. Amer., Ann. 9 (3): 302. -Mercet, 1925. Soc. Roy. Ent.

Egypt, Bul. for 1925, p. 50. - Subba Rao, 1965. Roy. Ent. Soc. London, Proc. (B) 34 (5-6):

71. - Trjapitzin, 1965. Ent. Rev. 44 (4): 524-525. - Annecke, 1967. Roy. Ent. Soc. London,

Trans. 119 (4): 99-169. - Hayat, 1976. Ent. Monthly Mag. 111 (1328-1330): 49-50.

annulatus Timberlake. Tex., Calif. Host: Coccus hesperidum L.

Anicetıs annulatus Timberlake, 1919. Hawaii. Ent. Soc., Proc. 4 (1): 227-231. ơ, ?.

Biology: Maple, 1947. Calif. Univ., Pubs. Ent. 8 (2): 60.

toumeyellae Milliron. Del. s. to Va. Host: Toumeyella liriodendri (Gmel.), Ceroplastes sp. on lilly.

Anicetus toume yellae Milliron, 1959. Ent. Soc. Amer., Ann. 62 (1): 28, 29-30. ơ, ?.

\section{Genus CERAPTEROCERUS Westwood}

Cerapteroceru. Westwood, 1833. Mag. Nat. Hist. 6: 495.

Type-species: Curapterocerus mirabilis. Westwood. Monotypic.

Telegraphus. Ratzeburg, 1848. Ichn. d. Forstins., v. 2, pp. 152-153.

Type-species: Telegraphus maculipennis Ratzeburg. Monotypic. The type-species is considered a synonym of Cerapterocerus mirabilis Westwood.

This small genus consists of only a few species which are parasitic on mealybugs.

Taxonomy: Timberlake, 1924. Hawaii. Ent. Soc., Proc. 5 (3): 432. -Agarwal, 1963. Ztschr. f.

Parasitenk. 22 (5): 398-400. - Doblado, 1966. Graellsia 22: 54.

floridanus Ashmead. Fla.

Cerapterocerus floridamus Ashmead, 1887. Amer. Ent. Soc., Trans. 14: 190. ơ. 


\section{Genus EUSEMION Dahlbom}

Eusemion Dahlbom, 1857. Ofvers. Svenska Vetenska. Akad., Forh. 14 (8): 293. No species included.

Type-species: Encyrtus corniger. Haliday. Subsequent monotypy (Thomson, 1876 (1875)).

Eusemion is a small genus consisting of less than five species as the genus is understood by Annecke (1967). These insects are hyperparasitic on primary parasites of soft scales.

Taxonomy: Compere, 1925. Calif. Univ., Pubs. Ent. 3 (3): 303-308. -Compere, 1938. Bul. Ent.

Res. 29 (3): 319-320. - Ferriere, 1949. Schweiz. Ent. Gesell., Mitt. 22 (4): 383. - Annecke,

1967. Roy. Ent. Soc. London, Trans. 119 (4): 100, 103-104.

longipennis (Ashmead). Fla., Calif. Host: Metaphycus flarus (Howard), Microterys flarus

(Howard) on Lecanium sp.

Mira longipennis Ashmead, 1888. Ent. Amer. 4 (1): 17. ๆ.

Biology: Timberlake, 1913. Jour. Econ. Ent. 6 (3): 301-302.

\section{TRIBE CHALCERINYINI}

\section{Genus ECHTHROGONATOPUS Perkins}

Echthroyonatopus Perkins, 1906. Hawaii. Sugar Planters' Assoc. Expt. Sta., Div. Ent., Bul. $1(8): 256$.

Type-species: Echthroyonatopus exitiosus. Perkins. Desig. by Girault, 1915.

This is a small genus, consisting of fewer than five species. They are parasites of dryinids, but the North American species was reported to have been recovered from a mealybug. An undetermined species occurs in Florida on Dysmicoccus patulae (Rao).

Taxonomy: Girault, 1915. Queensland Mus., Mem. 4: 76.

pachycephalus Perkins. Ohio. Host: Dryinid.

Echthrogonatopus pachycephalus. Perkins, 1906. Hawaii. Sugar Planters' Assoc. Expt. Sta. Div. Ent. Bul. 1 (8): 257. ९.

Taxonomy: Girault, 1922. Insecutor Inscitiae Menstruus 10 (7-9): 150. -Girault, 1934. New

Capsidae and Hymen. (Priv. pub., no page number.)

\section{Genus HELEgONATOPUS Perkins}

Helegonatopus Perkins, 1906. Hawaii. Sugar Planters' Assoc. Expt. Sta., Div. Ent., Bul. 1 (8): 257.

Type-species: Helegonatopus pseudophanes Perkins. Monotypic.

Taxonomy: Timberlake, 1918. Hawaii. Ent. Soc., Proc. 4 (1): 185. - Timberlake, 1924. Hawaii.

Ent. Soc., Proc. 5 (3): 432. -Williams, 1931. Handb. Ins. and Other Invert. of Hawaii.

Sugar Cane Flds., p. 255.

pseudophanes Perkins. Fla., Ohio, Ky. Host: Gonatopus sp., ex. dryinid on Amblysellus curtisi.

Helegouatopus pséudophanes Perkins, 1906. Hawaii. Sugar Planters' Assoc. Expt. Sta., Div. Ent., Bul. 1 (8): 258. .

\section{TRIBE CHEILONEURINI}

\section{Genus APTERENCYRTUS Ashmead}

Apterencyrtus Ashmead, 1905. Canad. Ent. 37 (1): 5.

Type-species: Apterencyitus pulchricornis Ashmead. Monotypic. The type-species is considered a synonym of Chiloneurus microphagus Mayr.

Chiloneuriuus Mercet, 1921. Fauna Iberica, Himen., Encirtidos, p. 646.

Type-species: Chiloneurus microphagus Mayr. Orig. desig.

This cosmopolitan genus of scale parasites consists of fewer than 10 species. 
Taxonomy: Gahan, 1951. Canad. Ent. 83 (7): 171. - Ferriere, 1955. Schweiz. Ent. Gesell., Mitt. 28 (1): 117-118. - Hoffer, 1957. Acta. Soc. Ent. Cechosl. 54 (4): 349-352. - Alam, 1957. Roy. Ent. Soc. London, Trans. 109 (15): 423, 438-441. - Trjapitzin, 1967. Akad. Nauk SSSR Zool. Inst., Trudy 41: 213-214. -Graham, 1969. Polskie Pismo Ent. 39 (2): 270-271.

microphagus (Mayr). Conn. s. to Fla., Calif. Host: Lecanium nigrofasciatum Perg., Lepidosaphes ulmi (L.), Quadraspidiotus juglansregiae (Comst.), Q. perniciosus (Comst.).

Eucyntus Lumbinus. Walker, 1838. Ent. Mag. 5: 422. F.

Eucyrfus Euryclea Walker, 1844. Ann. and Mag. Nat. Hist. 14: 184..

Chilone'urus microphayus Mayr, 1876 (1875). Zool.-Bot. Gesell. Wien, Verhandl. 25: 745, 746. ㅇ.

Chiloneurus diaspidinarum Howard, 1894. U. S. Dept. Agr., Insect Life 7 (3): 256.. Apterencyrtus pulchricornis Ashmead, 1905. Canad. Ent. 37 (1): 5. ?

A phicléncyitus aspidlioti Girault, 1915. Ent. Soc. Amer., Ann. 8 (3): 283, 284..

Hubrolepis muyri Ruschka, 1915. Ztschr. Angew. Ent. 2: 403-404. 9.

Apterencyitus zomutus Alam, 1957. Roy. Ent. Soc. London, Trans. 109 (15): 439, 441..

Although Eucyrtus lumbinus: Walker has priority over Cheilonenrus microphagns:

Mayr, the latter name is well known and has been frequently published. Therefore microphuyns is retained here as the accepted name in the interest of stability.

Taxonomy: Gahan, 1924. U. S. Natl. Mus., Proc. 65 (4): 1-2.

Biology: Griswold, 1925. N. Y. (Cornell) Agr. Expt. Sta., Mem. 93: 44-47.

\section{Genus BOUCEKIELLA Hoffer}

Boncetivilla Hoffer, 1954. Ochr. Prirody 9 (6): 172, 173.

Type-species: Boucekiella depressat Hoffer. Orig. desig.

Urotyudarichus Ferriere, 1955. Soc. Ent. de France, Bul. 60 (1-2): 9-10.

Type-species: Urotyularichus autoninae Ferriere. Orig. desig.

depressa Hoffer. Tex. Introduced for biological control of the Rhodes grass scale, Antonina graminis (Mask). Host: Chaetococcus phragmitis (Marchal).

Boncekiella depressa Hoffer, 1954. Ochr. Prirody 9 (6): 172-173. ?.

Urotyudaricus antonince Ferriere, 1955. Soc. Ent. de France, Bul. 60 (1-2): 10..

Taxonomy: Hoffer, 1957. Mus. Nat. Pragae, Acta Ent. 31 (486): 220.

Biology: Huffaker, 1971. Biol. Control, pp. 228.

\section{Genus CHEILONEURUS Westwood}

Cheilone'urus Westwood, 1833. London, Edinb. and Dublin Phil. Mag. and Jour. Sei. 3 (3): 343.

Type-species: Encyrtus elegans Dalman. Monotypic.

Chiloneurus Foerster, 1856. Hym. Stud. v. 2, pp. 32, 34, 50. Unjustified emend.

Cristatithorax Girault, 1911. Canad. Ent. 43 (5): 169.

Type-species: Cristatithorax pulcher Girault. Monotypic.

Metacheilonenins Hoffer, 1957. Acta Soc. Ent. Cechosl. 54 (4): 336-337.

Type-species: Metacheilonenrus moestus Hoffer. Orig. desig.

Taxonomy: Gahan, 1914. Ent. Soc. Amer., Ann. 7 (3): 247-248. -Ruschka, 1923. Zool.-Bot.

Gesell. Wien, Verhandl. 72 (1): 6-10. - Compere, 1931. Calif. Univ., Pubs. Ent. 5 (11): 233.

-Compere, 1938. Bul. Ent. Res. 29 (3): 327-328, - Geyer, 1947. Ent. Soc. So. Afr., Jour. 10

(1): 98. - Alam, 1957. Roy. Ent. Soc. London, Trans. 109 (15): 423, 441-444. - Hoffer, 1957.

Acta Soc. Ent. Cechosl. 54 (4): 339-348. -Claridge, 1958. Ent. Monthly Mag. (4th. Ser.) 94

(1130): 156-161. - Trjapitzin, 1964. Zool. Zhur. 43 (10): 1463-1465. -Graham, 1969. Polskie

Pismo Ent. 39 (2): 273-275.

albicornis Howard. Ont. s. to S. C., w. to La., n. to Wis., Colo. Host: Kermess sp. on oak, Lecanimm caryae Fitch, L. corni Bouche, L. fletcheri Ckll., L. nigrofasciatum Perg., 
Physokermes piceae (Schr.), Pulvinaria acericola (W. and R.), P. vitis (L.), P. sp. on poison ivy.

Chiloneurus albicornis Howard, 1881. U. S. Dept. Agr., Ann. Rept. for 1880, pp. 363-364. ‥

Taxonomy: Girault, 1916. Ent. Soc. Amer., Ann. 9 (3): 300-301 (male, female).

cupreicollis Ashmead. Fla. Host: Lecunium sp. on oak.

Chiloneurus cupreicollis Ashmead, 1886. Amer. Ent. Soc., Trans. 13: 131. ․

cushmani Crawford. Va. Host: Kermes sp.

Cheilonearus cushmani Crawford, 1911. Ent. Soc. Wash., Proc. 13 (2): 126. ठ, \&.

dubius Howard. Mass. w. to Wis., Mo. Host: Kermes sp., Lecanium sp. from dwarf mountain pine, $L$. sp. from Scotch pine.

Chiloneurus dubius Howard, 1885. U. S. Dept. Agr., Bur. Ent., Bul. 5: 17, 42. ठ.

elegans (Dalman). N. Y. s. to Pa., Va. Host: Mayetiola destructor (Say), Platygaster zosine Walk.

Eucyrtus eleyans: Dalman, 1820. Svenska Vetensk. Akad., Handl. 41: 151..

Taxonomy: Claridge, 1958. Ent. Monthly Mag. 94 (1130): 157-158.

Biology: Gahan, 1934 (1933). U. S. Dept. Agr. Misc. Pub. 174: 60-64. - Hill et al., 1939. U. S. Dept. Agr., Tech. Bul. 689: 5, 12. - Ferriere, 1952. Ninth Internat. Cong. Ent. Amsterdam, Trans. v. 1, p. 594.

Taxonomy: Ferriere, 1956. Lab. Zool. Gen. e. Agr. Portici, Bol. 33: 354.

Biology: Sugonyayev, 1958. Ent. Rev. 37 (2): 260.

Morphology: Hill and Pinckney, 1940. U. S. Dept. Agr., Tech. Bul. 715: 5-6, 11-13.

inimicus Compere. Fla. w. to Calif. Host: Metaphycus lounsburyi (How.), M. physokemis (Timb.).

Cheiloneurns inimicus Compere, 1925. Calif. Univ., Pubs. Ent. 3 (3): 296, 197-302. ơ, ?.

Taxonomy: Maple, 1947. Calif. Univ., Pubs. Ent. 8 (2): 71.

Biology: McCoy and Selheim, 1970. Ent. Soc. Amer., Ann. 63 (2): 618. - Compere, 1925. Calif. Univ., Pubs Ent. 3 (3): 301-302.

lineascapus Gahan. Md., La., Calif. Host: Kermes sp. on lilac, K. sp. on oak, Saissetia oleae (Oliv.), Metaphycus lounsburyi (How.).

Cheiloneurns lineascapus Gahan, 1910. Canad. Ent. 42 (6): 207-208..

Taxonomy: Compere, 1925. Calif. Univ., Pubs. Ent. 3 (3): 296.

Biology: Smith, 1933. Ent. Soc. Amer., Ann. 26 (3): 525.

Morphology: Maple, 1947. Calif. Univ., Pubs. Ent. 8 (2): 115.

noxius Compere. Calif. Host: Saissetia olene (Oliv.), Metaphycus lounsburyi How.

Cheiloneurus noxius Compere, 1925. Calif. Univ., Pubs. Ent. 3 (3): 296, 302-303..

Taxonomy: Smith and Compere, 1928. Calif. Univ., Pubs. Ent. 4 (9): 242, 272-274.

Biology: Flanders, 1940. Ent. Soc. Amer., Ann. 33 (2): 252. - Lepelly, 1937. Bul. Ent. Res. 28 (2): 181-183. - Weseloh, 1969. Ent. Soc. Amer., Ann. 62 (2): 299-305. - Weseloh, 1971. Ent. Soc. Amer., Ann., 64 (3): 580-586. - Weseloh, 1971. Ent. Soc. Amer., Ann. 64 (6): 1188-1190. -Weseloh, 1972. Ent. Soc. Amer., Ann. 65 (1): 41-46. - Weseloh and Bartlett, 1971. Ent. Soc. Amer., Ann. 64 (6): 1259-1264.

Morphology: Maple, 1947. Calif. Univ., Pubs. Ent. 8 (2): 71.

pulcher (Girault). Ill. Host: Kermes pubescens. Bogue.

Cristatithor'ar pulche' Girault, 1911. Canad. Ent. 43 (5): 170. ․

pulvinariae Dozier. D. C. s. to Fla. Host: Metaphycus flav'us (How.) parasitic on Pulvinaria sp. Cheilone trus pulvinariae Dozier, 1927 (1925). Puerto Rico Dept. Agr., Jour. 9 (4): 363-365. ¿, ㅇ. 
swezeyi Ashmead. Conn., Ohio. Host: Ormenis septentrionalis (Spin.), Psilodryinus typhlocybae (Ashm.).

Cheiloneurus suezeyi Ashmead, 1903. Ent. News 14 (6): 193. ơ, ?.

Biology: Swezey, 1903. Ohio Nat. 3: 446-447.

\section{Genus CHRYSOPOPHAGUS Ashmead}

Chrysopophayus Ashmead, 1894. U. S. Dept. Agr., Insect Life 7 (3): 245-246.

Type-species: Chrysopophayus compressicornis Ashmead. Monotypic.

Suronotum Perkins, 1906. Hawaii. Sugar Planters' Assoc. Expt. Sta., Div. Ent., Bul. 1 (8): 259-260.

Type-species: Suronotum austrulice Perkins. Desig. by Gahan and Fagan, 1923.

Chrysopophagus consists of less than ten species.

Taxonomy: Ashmead, 1900. U. S. Natl. Mus., Proc. 22: 331, 350-351. -Girault, 1924. Homo

Perniciosus and New Hymen. not paged. (priv. pub.). - Subba Rao, 1957. Indian Acad. Sci.,

Proc. (B) 46 (6): 382-383.

amplicornis (Gahan). Tex. w. to Calif. Host: Eriococcus sp. on Bouteloua.

Cheiloneurus auplicorn is Gahan, 1914. Ent. Soc. Amer., Ann. 7 (3): 247. .

Biology: Maple, 1947. Calif. Univ., Pubs. Ent. 8 (2): 115.

banksi Howard. Tex., N. Mex.

Chrysopophagns bunksi Howard, 1898. U. S. Natl. Mus., Proc. 21: 247-248. \&.

compressicornis Ashmead. N. C., S. C. w. to Iowa, Mo., Calif. Host: Chrysopa califomica Coq., C. majuscula Banks, C. plorabuuda Fitch, C. ruflabris Burm.

Chrysopophayus compressicornis Ashmead, 1894. U. S. Dept. Agr., Insect Life 7 (3): 246. s, ㅇ.

Biology: Clancy, 1946. Calif. Univ., Pubs. Ent. 7 (13): 432-440. - Maple, 1947. Calif. Univ., Pubs. Ent. 8 (2): 72. - Muma, 1959. Fla. Ent. 42 (4): 150-152.

flaccus (Walker). N. C. s. to Fla., Ohio, Calif. Host: Dryinid.

Encyrtus (Cerchysius) Flaccus Walker, 1847. Ann. and Mag. Nat. Hist. 20 (130): 21. ?.

Saranotum americanum Perkins, 1906. Hawaii. Sugar Planters' Assoc. Expt. Sta., Div.

Ent., Bul. 1 (8): 260.

Taxonomy: Burks, 1975. Brit. Mus. (Nat. Hist.) Ent., Bul. 32 (4): 147-148.

kansensis Girault. Kans.

Chrysopophagus kansensis Girault, 1917. U. S. Natl. Mus., Proc. 53: 447. ․

\section{Genus DIVERSINERVUS Silvestri}

Dirersinerrus Silvestri, 1915. Lab. Zool. Gen. e Agr. Portici, Bol. 9: 301-304.

Type-species: Dirersinerrus elegans Silvestri. Orig. desig.

Cheilone'nroides Girault, 1915. Queensland Mus., Mem. 4: 96, 122.

Type-species: Cheiloneuroides bicristatus Girault. Orig. desig. The type-species is considered a synonym of Dirersinervas elegans Silvestri.

Diversinere'us is predominantly an African genus consisting of fewer than ten species which parasitize lecaniine scale insects.

Taxonomy: Girault, 1917. Insecutor Inscitiae Menstruus 5: 37. -Compere, 1931. Calif. Univ., Pubs. Ent. 5 (11): 233-235. - Compere, 1940. Hilgardia 13 (7): 407. - Trjapitzin, 1961. Ent.

Rev. 40 (3): 369.

elegans Silvestri. Calif. Host: Saissetia oleae (Oliv.).

Dicersinervus elegans Silvestri, 1915. Lab. Zool. Gen. e Agr. Portici, Bol. Gen. e Agr., Bol. 9: 304-305. ठे, ․

Cheiloneuroides bicristatıs Girault, 1915. Queensland Mus., Mem. 4: 96-97.

Diversinere'us meridionalis Compere, 1931. Calif. Univ., Pubs. Ent. 5 (11): 237-239. o, ₹.

Biology: Compere, 1931. Calif. Univ., Pubs. Ent. 5 (11): 241-245, 249. 


\section{Genus PARASYRPOPHAGUS Girault}

Parasyrpophaguss Girault, 1915. Queensland Mus., Mem. 4: 105.

Type-species: Parasyrpophagus funeralis Girault. Orig. desig.

This genus has been recovered in India, Australia and the Holarctic Region. It contains four or five species. In North America it is represented by material from California under a manuscript name of Girault.

Taxonomy: Mercet, 1921. Fauna Iberica Himen., Encirtidos, pp. 58, 73, 82, 270. - Hoffer,

1957. Acta. Soc. Ent. Cechosl. 54 (4): 329-330.

\section{Genus PROCHILONEURUS Silvestri}

Prochiloneurus Silvestri, 1915. Lab. Zool. Gen. e Agr. Portici, Bol. 9: 350-351.

Type-species: Prochiloneurus pulchellus Silvestri. Orig. desig.

Achrysopophagus Girault, 1915. Queensland Mus., Mem. 4: 89.

Type-species: Achrysopophayus ociductus Girault. Orig. desig.

Approximately thirty species have been assigned to Achrysopophagus and Prochiloneurus. All of the species originally assigned to Achrysopophougus are hyperparasitic on mealybugs and perhaps soft seale insects. The genus is cosmopolitan.

Taxonomy: Mercet, 1919. Soc. Espan. de Hist. Nat., Bol. 19 (9-10): 473-474. - Mercet, 1929.

Eos 5 (4): 359. -Compere, 1938. Bul. Ent. Res. 29 (3): 325-327. —Domenichini, 1952. Zool.

Agr. Bach. Univ. Milano, Bol. 17 (3): 175-179. - Hoffer, 1957. Acta Soc. Ent. Cechosl. 54

(4): 329, 348-349. - Trjapitzin, 1968. Vses. Ent. Obshch., Trudy 52: 116-122.

americanus (Girault). D. C.

Achrysopophuyus americanus Girault, 1917. Deser. Stellarum Nov., p. 16..

dactylopii (Howard). D. C., N. Mex., Minn. Host: Phenacoccus solenopsis Tinsley, Planococcus citri (Risso).

Chiloneurus dactylopii Howard, 1885. U. S. Dept. Agr., Bur. Ent., Bul. 5: 17, 42. ઠ,.

Taxonomy: Kerrich, 1953. Bul. Ent. Res. 44 (4): 798-799.

Biology: Kirkpatric, 1952. Rept. Cacao Res. 1952, p. 65.

modestus (Timberlake). Calif. Host: Pseudococcus maritimus (Ehrh.), Anagyrus yuccae (Coq.), Zarhopalus corvinus (Gir.).

Achrysopophugus modestus. Timberlake, 1924. Calif. Univ., Pubs. Ent. 3 (2): 240-243..

Biology: Clausen, 1924. Calif. Univ., Pubs. Ent. 3 (2): 257-266, 284-286. - Maple, 1947. Calif.

Univ., Pubs. Ent. 8 (2): 55.

\section{Genus TINEOPHOCTONUS Ashmead}

Timeophoctonus Ashmead, 1900. U. S. Natl. Mus., Proc. 22: 328, 351.

Type-species: Phachodiscus armatus. Ashmead. Orig. desig.

This is a Holaractic genus consisting of only a few species. The host associations of Tincophoctomus are not clear. Armatus has been reported as an anobiid parasite in Europe (its host still unknown in North America) whereas tineaceorus attacks tineid larvae.

Taxonomy: Viggiani, 1966. Doriana 4 (168): 1-5. - Mercet, 1932. Eos 8 (3): 311-316.

armatus (Ashmead). Fla. Host: Anobium punctatum (DeG.).

Phacnodiscus armatus Ashmead, 1888. Ent. Amer. 4 (1): 17..

Taxonomy: Mercet, 1932. Eos 8 (3): 312-316.

tineaevorus (Ashmead). Fla. Host: Tineid larva in gall of Andricus pattoni (Bass.).

Leptomastix tineac'ora Ashmead, 1887. Amer. Ent. Soc., Trans. 14: 191..

Taxonomy: Ashmead, 1888. Ent. Amer. 4 (1): 16.

\section{Genus TYNDARICHUS Howard}

Tyndarichus Howard, 1910. U. S. Dept. Agr. Tech. Ser. Bur. Ent., Bul. 19: 5-6. Type-species: Tyndarichus nata Howard. Orig. desig. 
Tyndarichus has less than 10 described species some of which are apparently hyperparasitic on other chalcidoids that attack Lepidoptera eggs. An undetermined species is found from Wis. w. to Mont., s. to Nebr., Fla., Calif.

Taxonomy: Mercet, 1918. Rev. Mont. Madrid 42: 775-781. - Mercet, 1919. Rev. Appl. Ent. (A) 7: 229-230. - Nowicki, 1928. Ztschr. f. Wiss. Insektenbiol. 4 (1): 17, 24-25. - Eady, 1960.

Bul. Ent. Res. 50 (4): 669-670. - Paine, 1964. So. Pacific Comm. Tech. Paper 145: 40.

\section{TRIBE COMPERIINI}

\section{Genus COMPERIA Gomes}

Comperin Gomes, 1942 (1941). Esc. Nac. Agron. Rio de Janerio, Bol. 2 (1): 41-42.

Type-species: Dicurmosis merceti Compere. Orig. desig.

This genus consists of fewer than five described species and presumably has its origin in Africa. One species parasitizes cockroach oothecae.

Taxonomy: Annecke, 1969. Ent. Soc. So. Afr., Jour. 32 (2): 447.

merceti (Compere). Cosmopolitan. Host: Supella longipalpa (Serville).

Dirrernosis merceti Compere, 1938. Bul. Ent. Res. 29 (3): 317-319. \&.

Comperin merceti var. falsicorn is Gomes, 1942 (1941). Esc. Nac. Agron. Rio de Janeiro,

Bol. 2 (1): 43-44. 8, क.

Biology: Lawson, 1954. Kans. Ent. Soc., Jour. 27 (4): 128-142. -Gordh, 1973. Jour. Ent. (A) 47 (2): $115-123$.

\section{TRIBE COPIDOSOMATINI}

\section{Genus AGENIASPIS Dahlbom}

Ageniaspis Dahlbom, 1857. Ofvers. Svenska Vetensk. Akad., Forh. 14 (8): 293. No species included.

Type-species: Encyrtus fuscicollis Dalman. Desig. by Ashmaed, 1904.

Holcothorax Mayr, 1876 (1875). Zool.-Bct. Gesell. Wien, Verhandl. 25: 691.

Type-species: (Encyrtus) Holcothorax testaceipes (Ratzeburg). Desig. by Gahan and Fagan, 1923.

Ageniaspis contains fewer than 10 species, most of which are parasites of Lepidoptera. One species, fuscicollis (Dalman), is polyembryonic. The genus appears to be cosmopolitan.

Taxonomy: Narayanan, 1960. Natl. Inst. Sci. India, Proc. (B) 26: 23. -Trjapitzin, 1967. Akad. Nauk SSSR Zool. Inst., Trudy 41: 180. - Trjapitzin, 1968. Vses. Ent. Obshch., Trudy 52:

100-101. -Graham, 1969. Polskie Pismo Ent. 39 (2): 292-293.

bucculatricis (Howard). Ont. s. to D. C., w. to Mo. Host: Bucculatrix pomifoliella Clem., galls of Rhabdophaga cornuta Walsh and $R$. siliqua Walsh.

Encyrtus bucculatrix Howard, 1883 (1882). In Lintner, Injurious Insects N. Y., Ann. Rept. 1: $160-161$. .

\section{Genus COELOPENCYRTUS Timberlake}

Coelopencyrtus Timberlake, 1919. Hawaii. Ent. Soc., Proc. 4 (1): 218-221.

Type-species: Coelopencyrtus odyneri Timberlake. Orig. desig.

Nesencyrtus Timberlake, 1919. Hawaii. Ent. Soc., Proc. 4 (1): 223-224.

Type-species: Adelencyrtus kaalae Ashmead. Orig. desig.

Batrachencyitus Jansson, 1957. Ent. Tidskr. 78 (1): 71-74.

Type-species: Batrachencyrtus callidii Jansson. Orig. desig.

Coelopencyrtus contains about ten species, all of which are parasites of aculeate Hymenoptera. The genus appears throughout the world, with the possible exception of South America. With more thorough investigations of aculeate biology Coelopencyrtus may become a larger genus. 
Taxonomy: Timberlake, 1922. Hawaii. Ent. Soc., Proc. 5 (1): 135-139. - Burks, 1958. Wash. Acad. Sci., Jour. 48 (1): 22-26. - Trjapitzin, 1960. Ent. Rev. 39 (2): 500-502. -Annecke, 1968. Ent. Soc. So. Afr., Jour. 31 (2): 249-258. - Hedqvist, 1973. Ent. Tidskr. 94 (1-2): 94-96.

hylaei Burks. Md., Nebr. Host: Hylaeus cressoni (Ckll.), Hylaeus sp.

Coelopencyrtus hylaei Burks, 1958. Wash. Acad. Sci., Jour. 48 (1): 25-26. ठ, ๆ.

Biology: Brandhorst, 1962. Ent. Soc. Amer., Ann. 55 (4): 477.

hylaeoleter Burks. Ont., Idaho, Utah, Calif. Host: Hylaens sp., H. ellipticus (Kirby).

Coelopencyitus hylaeoleter Burks, 1958. Wash. Acad. Sci., Jour. 48 (1): 24-25. ठै, ९.

Biology: Krombein, 1967. Trap-nesting wasps and bees, p. 433 (host, life history).

\section{Genus COPIDOSOMA Ratzeburg}

Copidosoma Ratzeburg, 1844. Ichn. d. Forstins. v. 1, table facing p. 40, p. 157.

Type-species: Copidosoma boncheanum Ratzeburg. Monotypic.

Litomastix Thomson, 1876 (1875), Hym. Scand., v. 4, pp. 118, 171.

Type-species: Eucyrtus chalconotus Dalman. Desig. by Ashmead, 1900.

Berecyntus Howard, 1898. U. S. Natl. Mus., Proc. 21: 237-238.

Type-species: Berecyutus bakeri Howard. Monotypic.

Copidosomopsis Girault, 1915. Queensland Mus., Mem. 4: 94.

Type-species: Copidosomopsis perminutus Girault. Monotypic.

Paracopidosomopsis Girault, 1916. Psyche 23 (2): 49.

Type-species: Berecyntus floridanus Ashmead. Orig. desig. The type-species is considered a synonym of Copidosoma truncatellum (Dalman).

Verdunia Mercet, 1917. Soc. Espan. de Hist. Nat., Bol. 17 (3): 203-204.

Type-species: Verdunia gloriosa Mercet. Orig. desig.

Litomastiellus Mercet, 1921. Fauna Iberica, Himen., Encirtidos, p. 443.

Type-species: Litomastix (Litomastiellus) claviger Mercet. Desig. by Peck, 1951.

Limastotix Mercet, 1921. Fauna Iberica, Himen., Encirtidos, p. 443.

Type-species: Litomastix (Limastotix) hispanicus Mercet. Monotypic.

Neocopidosoma Ishii, 1923. Japan Dept. Agr. and Com., Imp. Plant Quar. Sta., Bul. 3: 101.

Type-species: Neocopidosoma komabae Ishii. Orig. desig.

Berecyutiscus Ghesquiere, 1946. Rev. Zool. Bot. Africaines 34: 368. N. name for Berecyutus Howard.

Arrenoclav'ss Doutt, 1948. Pan-Pacific Ent. 24 (3): 145-148.

Type-species: Copidosoma koehleri Blanchard. Orig. desig.

This is a large, cosmopolitan genus whose members are polyembryonic parasites of Lepidoptera. Polyembryony in this instance seems to be an evolutionary strategy whereby a parasite of comparatively low reproductive potential has succeeded in maximizing its efficiency by completely consuming a host sometimes thousands of times larger than its own body size.

Taxonomy: Masi, 1911. Lab. Zool. Agr. Portici, Bol. 5 (4): 163-169. -Mercet, 1923. Soc.

Espan. de Hist. Nat., Bol. 23 (1): 51, 54. - Ferriere, 1949. Schweiz. Ent. Gesell., Mitt. 22

(4): 374. - Graham, 1958. Ent. Tidskr. 79 (3-4): 167-169. -Graham, 1969. Polskie Pismo

Ent. 39 (2): 300-305.

bakeri (Howard). Cosmopolitan. Host: Chorizagrotis sp., C. auxiliaris (Grote), C. thanatologia Dyar, Agrotis venerabilis Wlkr., Euxoa flavicollis (Smith), E. detersa (Wlkr.), $E$.

tristicula (Morr.), Cymodes devastator (Brace), Feltia ducens Wlkr., $F$. sp.

Berecyutus bakeri Howard, 1898. U. S. Natl. Mus., Proc. 21: 238..

Berecyntus bakeri var. arizonensis Girault, 1916. Psyche 23 (2): 50 . ․

Berecyntus bakeri var. gemma Girault, 1916. Psyche 23 (2): 49-50. ठै, ๆ.

Berecyutus bakeri var. euxoae Strickland, 1916. Canad. Dept. Agr., Ent. Branch, Bul. 13: 21-22. ․

Biology: Gibson, 1915. Canada Dept. Agr., Ent. Branch, Bul. 10: 11. - Snow, 1925. Jour. Econ. Ent. 18 (4): 606 . - King and Atkinson, 1928. Ent. Soc. Amer., Ann. 21 (2): 174 -Huffaker, 1971. Biol. Control, p. 267. 
celaenae Howard. Que., s. to Conn., w. to Mo., s. to Miss. Host: Euxoa scolastica McD., Lacinipolia reniger (Steph.).

Copidosoma celaenae Howard, 1885. U. S. Dept. Agr., Bur. Ent., Bul. 5: 11-12, 42..

deceptor Miller. Cosmopolitan. Host: Epinotia nanana (Treit.), Acleris variana (Fern.), Duvita vittella Busck, Eucordylia huntella Kief., Recurvaria apicitripunctella Clem., $R$. canusella Free., $R$. milleri Busck, $R$. moreonella Hein., $R$. nanella (Hbn.), R. starki Freem., $R$. thujaella Kearf., Exoteleia dodecella (L.), E. pinifoliella (Chamb.), Argyresthia aureoargentella Brower.

Copidosoma deceptor Miller, 1958. Pan-Pacific Ent. 34 (2): 58-60. ₹, ठ̊.

Biology: Stark, 1961. Canad. Jour. Zool. 39 (6): 893-905. -Telford, 1961. Jour. Econ. Ent. 54

(2): 348. - Richards, 1963. Canad. Ent. 95 (5): 519.

gelechiae Howard. N. H. s. to N. C., Ont., Minn. s. to Mo., Ariz. Host: Epiblema scuederiana (Clem.), Gnorimoschema gallaeasterella (Kell.), G. gallaesolidaginis (Riley), G. salinaris Busck.

Copidosoma gelechiae Howard, 1885. U. S. Dept. Agr., Bur. Ent., Bul. 5: 10-11, 42. §, ₹. Psilophrys hyalinipennis Howard, 1885. U. S. Dept. Agr., Bur. Ent., Bul. 5: 21, 42 . ठ. Psilophrys pallipes Ashmead, 1888. Kans. Agr. Expt. Sta., Bul. 3: App. p. V. ?. Psilophrys pallidipes Schulz, 1906. Spolia Hym., p. 146. Unjustified emend.

Copidosoma gelechice var. sagı Girault, 1920. U. S. Natl. Mus., Proc. 58: 188-189. đ’, ?.

Biology: Patterson, 1919. Jour. Hered. 10: 346. - Barber, 1938. N. Y. Ent. Soc., Jour. 46 (2): 169-171, 174-175. - Schaffner, 1959. U. S. Dept. Agr., Misc. Pub. 737: 37, 86. -Miller, 1963. Ohio Jour. Sci. 63: 71.

Morphology: Leiby, 1922. Jour. Morph. 37 (1): 195-285.

geniculatum (Dalman). Ont., Mass., N. Y., Conn. Host: Rhyacionia buoliana (Schiff.). Eucyrtus geniculatus Dalman, 1820. Svenska Vetensk. Akad., Handl. 41: 361. ठ.

Taxonomy: Mayr, 1876 (1875). Zool.-Bot. Gesell. Wien, Verhandl. 25: 734, 735, 736-737.

Biology: Dowden, 1934. Ent. Soc. Amer., Ann. 27 (4): 600.

intermedium Howard. N. J., Mo., Kans. Host: Gnorimoscliema gallaeasterella (Kell.). Copidosoma intermedium Howard, 1885. U. S. Dept. Agr., Bur. Ent., Bul. 5: 12, 42. ઠ์, ๆ.

lymani Howard. Ont. Host: Aracampsis lupinella Busck, Rhyacionia buoliana (Schiff.). Copidosoma Lymani Howard, 1907. Canad. Ent. 39 (3): 103..

melanocerum (Ashmead). D. C., N. C., lowa, Kans. Host: Feltia sp. (Haw.).

Liothorax melanocera Ashmead, 1900. U. S. Natl. Mus., Proc. 22: 363..

truncatellum (Dalman). Que. to Fla., w. to Tex. and Ariz. Host: Anomis erosa Hbn., Autographa sp., Spodoptera ornithogalli (Guen.), Trichoplusia ni ( $\mathrm{Hbn})$, Zeuzera pyrina (L.).

Encyrtus truncatellus Dalman, 1820. Svenska Vetensk. Akad., Handl. 41: 168-169. Berecyntus floridanus Ashmead, 1900. U. S. Natl. Mus., Proc. 22: 365. ९.

Taxonomy: Mercet, 1921. Fauna Iberica, Himen., Encirtidos, pp. 456-457.

Biology: Silvestri, 1906. Lab. Zool. Agr. Portici, Bol. 6: 3-51. - Silvestri, 1937. Harvard Univ., Mus. Compar. Zool., Bul. 81: 472-487. - Stoner and Weeks, 1974. Environm. Ent. 3 (6): 957-960. - Hunter and Bartlett, 1975. Ent. Soc. Amer., Ann. 68 (1): $61-62$ (karyotype).

- Hunter and Stoner, 1975. Environm. Ent. 4 (3): 381-382.

turni (Packard). N. H., Conn., N. J. Host: Papilio glaucus L.

Encyrtus turmi Packard, 1881 (1880). Boston Soc. Nat. Hist., Proc. 21: 32-33. ठ, ๆ.

Taxonomy: Howard, 1889. In Scudder, Butterflies of Eastern U. S. and Canada, pp. 1872, 1888.

vagum Howard. Que., N. J., Mo. Host: Filitima psendoacaciella (Chamb.).

Copidosoma vagum Howard, 1885. U. S. Dept. Agr., Bur. Ent., Bul. 5: 11, 31, 42. ठ, ^.

\section{Genus PARABLASTOTHRIX Mercet}

Parablastothrix Mercet, 1917. Soc. Espan. de Hist. Nat., Bol. 17 (9): 538-540.

Type-species: Parablastothrix vespertinus Mercet. Monotypic. 
Parablastothrix contains only a few species and is Holarctic in distribution. The type-species has been reported as a parasite of buprestid larvae whereas the North American representative of the genus has been recorded from small Lepidoptera.

Taxonomy: Mercet, 1932. Soc. Ent. France, Liv. Cent., pp. 685-686. - Miller, 1965. Canad.

Ent. 97 (7): 750-753. - Erdos, 1955. Budapest Magyar Nemz. Muz., Ann. Hist. Nat. (n. s.) 6: 292-294. -Erdos, 1963. Beitr. zur Ent. 13 (3-4): 285.

nearctica Miller. Mich., W. Va., Miss. Host: Obrussa sp., Coptodisca sp. on Vaccinium arboreum.

Parablastothrix nearctica Miller, 1965. Canad. Ent. 97 (7): 750, 751-753. o, ?.

\section{Genus PARALITOMASTIX Mercet}

Paralitomastix Mercet, 1921. Fauna Iberica, Himen., Encirtidos, pp. 8, 27, 58, 70, 438. Type-species: Encyrtus varicornis Nees. Orig. desig.

Pseudolitomastix Risbec, 1954. Inst. Fr. Afr. Noire, Bul. 16: 1068.

Type-species: Litomastix creona Risbec. Orig. desig.

A cosmopolitan genus consisting of about a dozen species. Paralitomastix attacks Lepidoptera larvae.

Taxonomy: Risbec, 1952. Mem. Inst. Sci. Madagascar, Ser. E, Ent. 2: 6, 38-40. - Risbec, 1954. Inst. Fr. Afr. Noire, Bul. 16 (4): 1067-1068. - Trjapitzin, 1967. Akad. Nauk SSSR Zool.

Inst., Trudy 41: 206-207. - Graham, 1969. Polskie Pismo Ent. 39 (2): 294-295.

pyralidis (Ashmead). Ont., Mich., Md. s. to Fla., w. to Utah, Calif. Host: Anarsia lineatella Zell., Trichotaphe flavocostella Clem., T. setosella Clem.

Eucyrtus(!) pyralidis Ashmead, 1888. Ent. Amer. 4 (1): 15. ․ Generic name is a lapsus for Encyrtus.

Copidosoma variegatum Howard, 1888. U. S. Dept. Agr., Insect Life 1 (8): 197. \&.

Taxonomy: Ashmead, 1900. U. S. Natl. Mus., Proc. 22: 366-367.

Biology: Pack, 1930. Utah Agr. Expt. Sta., Bul. 216: 15-16. -Maple, 1947. Calif. Univ., Pubs.

Ent. 8 (2): 109. -Clausen, 1956. U. S. Dept. Agr., Tech. Bul. 1139, p. 22.

\section{Genus PENTALITOMASTIX Eady}

Pseudolitomastix Eady, 1960. Bul. Ent. Res. 50 (4): 667-668. Preocc. by Pseudolitomastix Risbec.

Type-species: Pseudolitomastix nacoleiae Eady. Monotypic.

Pentalitomastix Eady, 1960. Bul. Ent. Res. 51 (1): 173. N. name for Pseudolitomastix Eady.

This genus has not been recorded from Africa or South America, but it probably occurs there also. Pentalitomastix presently consists of fewer than five species of polyembryonic parasites of Lepidoptera larvae.

Taxonomy: Eady, 1960. Bul. Ent. Res. 51 (1): 173. - Hoffer, 1960. Mus. Nat. Pragae, Acta

Faun. Ent. 6: 105-108. - Paine, 1964. So. Pacific Comm., Tech. Paper 145, p. 29.

-Trjapitzin, 1967. Akad. Nauk SSSR Zool. Inst., Trudy 41: 207-208.

plethoricus Caltagirone. Calif. Introduced, possibly established. Host: Laspeyresia carayana on pecan, Paramyelois transitella (Walk.) on pod of Tamarindus indica.

Pentalitomastix plethoricus Caltagirone, 1966. Pan-Pacific Ent. 42 (2): 145-149. o, ?.

Biology: Caltagirone, 1971 (1970). Lab. Ent. Agr. Filippo Silvestri Portici, Bol. 28: 98-112.

\section{Genus PENTACNEMUS How ard}

Pentacnemus Howard, 1892. U. S. Natl. Mus., Proc. 15: 362, 366-367.

Type-species: Pentacnemns bucculatricis Howard. Monotypic.

This monotypic genus is known only from North America. The type-species is a parasite of lepidopterous larvae. 
bucculatricis Howard. Cosmopolitan. Host: Coleotechnites thujaella Kearf., Argyresthia thuiella (Pack.), Argyresthia libocedrella Busck on Libocedrus decurrens.

Pentacnemus bucculatricis Howard, 1892. U. S. Natl. Mus., Proc. 15: 366-367. o, ?.

Biology: Underhill, 1943. Va. Agr. Expt. Sta., Bul. 349: 22.

\section{TRIBE DISCODINI}

\section{Genus DISCODES Foerster}

Discodes Foerster, 1856. Hym. Stud., v. 2, pp. 32, 34, 144.

Type-species: Encyrtus aeneus Dalman. Orig. desig.

Phaenodiscus Foerster, 1856. Hym. Stud., v. 2, p. 144. N. name for Discodes, thought to be too much like Discoidea Gray and Discoides Klein.

This genus presently contains fewer than ten species. It is Holarctic in distribution and parasitizes Coccidae. There is an undescribed species in California and Washington which feeds on Asterolecanium arabidis (Sign.).

Taxonomy: Ashmead, 1900. U. S. Nat. Mus., Proc. 22: 376. - Hoffer, 1954 (1953). Acta. Soc.

Ent. Cechosl. 50: 156-157, 167-174. - Trjapitzin, 1967. Akad. Nauk SSSR Zool. Inst., Trudy 41: 212-213. -Trjapitzin, 1968. Vses. Ent. Obshch., Trudy 52: 114. -Graham, 1969. Polskie Pismo Ent. 39 (2): 280-282.

arizonensis (Howard). Tex., Colo., N. Mex., Ariz.

Phaenodiscus arizonensis Howard, 1898. U. S. Natl. Mus., Proc. 21: 248..

unicolor (Ashmead). Va., Ga., Fla.

Aphycus unicolor Ashmead, 1888. Ent. Amer. 4 (1): 15. ๆ.

\section{TRIBE ENCYRTINI}

\section{Genus ENCYRTUS Latreille}

Encyrtus Latreille, 1809. Gen. Crust. Ins., v. 4, p. 31.

Type-species: Chrysis infidus Rossi. Desig. by Latreille, 1810.

Eucomys Foerster, 1856. Hym. Stud., v. 2, pp. 32, 34 .

Type-species: Encyrtus swederi Dalman. Orig. desig.

Comys Foerster, 1856. Hym. Stud., v. 2, pp. 144-145. N. name for Eucomys thought to be preocc. by Eucomis in Liliaceae.

Howardia Dalla Torre, 1897. Wien. Ent. Ztg. 16: 86. Preocc. by Howardia Berlese and Leonardi, 1896.

Type-species: Bothriothorax peckhami Ashmead. Monotypic.

Howardiella Dalla Torre, 1898. Cat Hym., v. 5, p. 228. N. name for Hourarlia Dalla Torre.

Allorhopoideus Brethes, 1916. Mus. Argentina Cient. Nat., An. 27: 425.

Type-species: Allorhopoideus mirabilis Brethes. Orig. desig.

Prorhopoideus Brethes, 1921. Soc. Ent. de France, Bul. for 1921, p. 80.

Type-species: Prorhopoideus Baezi Brethes. Monotypic.

Encyrtus contains over 40 species. It is cosmopolitan in distribution and parasitizes Coccilae.

Taxonomy: Graham, 1969. Polskie Pismo Ent. 39 (2): 305-311.

albicoxa (Ashmead). Fla. w. to Calif. Host: Coccus hesperielum L., Plunococests citri (Risso).

Pseudococcus longispinus (Targ.-Tozz.).

Comys albicoxa Ashmead, 1885. Amer. Ent. Soc., Trans, 12: Proc. pp. xvi-xvii. 8. ४. atys (Girault). N. Y.

Eucomys atys Girault, 1917. Descr. Hym. Chalcidoid. Variorum cum Observ. V, p. 2. : . barbatus Timberlake. Calif.

Encyrtus barbatus Timberlake, 1919. Hawaii. Ent. Soc., Proc. 4 (2): 209-212. ठ, ?.

Biology: Ișhii, 1932. Japan Dept. Agr. and Com., Imp. Agr. Expt. Sta., Bul. 3 (3): 181, 187-188, 194. 
bicolor (Howard). Ont. s. to D. C., w. to Mich., La., Kans., Colo., Calif. Host: Coccus hesperidum L., Lecanium comi Bouche, L. fletcheri Ckll.

Comys bicolor Howard, 1881. U. S. Dept. Agr. Ann., Rept. for 1880, pp. 350, 362-363. đ,

Biology: Hubbard, 1885. Insects Affecting the Orange, p. 52. - Craw, 1894. Calif. State Bd.

Hort., Bien. Rpt. 4: 97.

californicus (Girault). Calif. Host: Lecanium corni Bouche, L. quercifex Fitch.

Eucomys californicus Girault, 1917. Descr. Hym. Chalcidoid. Variorum cum Observ. V, p. 2.. .

Biology: Maple, 1947. Calif. Univ., Pubs. Ent. 8 (2): 115.

cyanocephalus Dalman. Europe, Ont.? Host: Lecanium caryae Fitch, L. comi Bouche.

Encyrtus cyanocephalus Dalman, 1820. Svenska Vetensk. Akad., Handl. 41: 344..

Biology: Jarvis, 1911 (1910). Ent. Soc. Ontario, Ann. Rpt. 41: 75.

fuscus (Howard). Ont., Que., N. Y., Mass., Conn., N. J., Ohio, Ala., Kans., Calif. Host: Lecanium corni Bouche, L. nigrofasciatum Perg., L. pruinosum Coq., L. spp. on laurel-leaved oak, on Heteromeles and on Quercus nigra, Pulvinaria vitis (L.), Saissetia coffeae (Walk.).

Comys fusca Howard, 1881. U. S. Dept. Agr., Ann. Rpt. for 1880, p. 363. o, ?.

Chiloneurus maculatipennis Provancher, 1887. Addit. Corr. Faune Ent. Canada Hym., pp. 203-304. ?.

Taxonomy: Ashmead, 1900. U. S. Natl. Mus., Proc. 22: 360. - Burks, 1964 (1963). Canad. Ent. 95 (12): 1256.

Biology: Isaac, 1905. Calif. State Comn. Hort., Bien. Rpt. 1: 99. -Smith, 1915. Calif. State Comn. Hort., Monthly Bul. 4: 269.

gastron Walker. Fla.

Encyrtus gastron Walker, 1847. Ann. and Mag. Nat. Hist. 20 (130): 21. \&.

Taxonomy: Burks, 1975. Brit. Mus. (Nat. Hist.) Ent., Bul. 32 (4): 148.

infelix (Embleton). N. Y. Host: Saissetia coffeae (Walk.).

Comys infelix Embleton, 1902. Ent. Soc. London, Trans., p. 223-224..

Taxonomy: Embleton, 1904. Linn. Soc. London, Trans., Zool. (2): 9: 231-254.

Biology: Silvestri, 1920 (1919). Lab. Zool. Agr. Portici, Bol. 13: 127-192. - Thorpe, 1936.

Parasitology 28 (4): 517-540. - Maple, 1937. Ent. Soc. Amer., Ann. 30 (1): 144, 148-151.

-Maple, 1947. Calif. Univ. Pubs., Ent. 8 (2): 82-83, 86-87. - Hamlen, 1975. Environm. Ent. 4 (6): 972-974.

infidus (Rossi). Europe, No. Amer.?

Chrysis! Infida Rossi, 1790. Fauna Etrusca, v. 2, p. 80.

Ichneumon infidus Rossi, 1794. Mant. Insect., 2 Append.: 111-112.

Pteromalus Scutellatus Swederus, 1795. Svenska Vetensk Akad., Handl. (2) 16: 218. ठ, ๆ.

Taxonomy: Ashmead, 1900. U. S. Natl. Mus., Proc. 22: 360.

Biology: Clausen, 1932. Ent. Soc. Amer., Ann. 25 (4): 670-687. -Maple, 1947. Calif. Univ., Pubs. Ent. 8 (2): 84, 87-88. - Sugonyayev, 1958. Ent. Rev. 37 (2): 308-309. -Kon, 1974.

Ent. Rev. 53 (4): 8-21.

kansensis (Girault). Kans.

Eucomys kansensis Girault, 1917. Descr. Hym. Chalcidoid. Variorum cum Observ. V, p. 2. ㅇ.

lecaniorum (Mayr). Europe, No. Amer.?

Comys Lecanionum Mayr, 1876 (1875). Zool.-Bot. Gesell. Wien, Verhandl. 25: 740, 741. ?.

Allorhopoideus mirabilis Brethes, 1916. Mus. Nac. Hist. Nat. Buenos Aires, An. 27: 425.

Taxonomy: Ashmead, 1900. U. S. Natl. Mus., Proc. 22: 360.

marilandicus alpinus (Girault). N. Y.

Eucomys marilandicus var. alpinus Girault, 1917. Deser. Hym. Chalcidoid. Variorum cum Observ. V, p. 2. . 
marilandicus marilandicus (Girault). Maine, Md., N. C.

Eucomys marilandicus Girault, 1917. Deser. Hym. Chalcidoid. Variorum cum Observ. V, p. 2.. .

Encyrtus marylandicus Gahan, 1928. in: Crosby and Leonard, N. Y. (Cornell) Agr. Expt. Sta., Mem. 101: 979. Unjustified emend.

peckhamii (Ashmead). Que., Ont. s. to N. C., w. Wis., Tenn. Host: Lecanium comi Bouche, L. quercifex Fitch.

Bothriothorax Peckhamii Ashmead, 1886. Amer. Ent. Soc., Trans. 13: 132. đ, ๆ.

Howarliella pechliami Ashmead, 1900. U. S. Nat. Mus., Proc. 22: 361.

Taxonomy: Girault, 1920. U. S. Natl. Mus., Proc. 58: 183.

reate Walker. Fla.

Encyrtus Reate Walker, 1847. Ann. and Mag. Nat. Hist. 20 (130): 22. đ.

Taxonomy: Burks, 1975. Brit. Mus. (Nat. Hist.) Ent., Bul. 32 (4): 148.

\section{TRIBE HABROLEPIDINI}

\section{Genus ADELENCYRTUS Ashmead}

Adelencyrtus Ashmead, 1900. U. S. Natl. Mus., Proc. 22: 341, 400.

Type-species: Encyrtns chionaspidlis Howard. Orig. desig.

Epiencyrtiodes Girault, 1915. Queensland Mus., Mem. 4: 108.

Type-species: Epiencyrtiodes quadridentatus Girault. Orig. desig.

Rotrencyrtus Risbec, 1959. Bul. Acad. Malgache 35: 39.

Type-species: Rotrencyrtus depressus Risbec. Monotypic.

Adelencyrins presently holds about a dozen species. The genus is cosmopolitan in distribution and its members are parasites of scale insects.

Taxonomy: Tachikawa, 1956. Insecta Matsumurana 20 (3-4): 93. - Hoffer, 1960. Mus. Nat.

Pragae, Acta Ent. 6: 114-115. - Compere and Annecke, 1961. Ent. Soc. So. Afr., Jour. 24

(1): 47-58.

aulacaspidis (Brethes). Ill., Nebr., Calif. Host: Aulacaspis rosae (Bouche).

Prionomitus aulacaspidis Brethes, 1914. Ann. Zool. Aplicada 1: 29-30. .

Taxonomy: Ferriere, 1949. Schweiz. Ent. Gesell., Mitt. 22 (4): 371. -Ferriere, 1953. Rev.

Path. Veg. d'Ent. Agr. France 32 (2): 116.

Biology: Benassy, 1958. Acad. Sci. Compt. Rend. 246 (1): 179. - Tshumakova, 1961. Ent. Rev.

40 (2): 170-179. - Sugonyayev, 1962. Akad. Nauk SSSR Izv. Ser. Biol. 5: 754-766.

-Tshumakova, 1965. Ent. Rev. 44 (3): 305-308. - Sorokina, 1973. Ent. Rev. 52 (3): 397-398.

odonaspidis Fullaway. Fla. w. to Tex. Host: Odonaspis sp., Antonina graminis (Mask.) (?).

Adelencyrtus odonaspidis Fullaway, 1913. Hawaii. Agr. Exp. Sta., Ann. Rept. for 1912. pp. $27,28,30,31$..

Taxonomy: Timberlake, 1919. Hawaii. Ent. Soc., Proc. 4 (1): 191. -Timberlake, 1924. Hawaii.

Ent. Soc., Proc. 5 (3): 432.

Biology: Swezey, 1915. Jour. Econ. Ent. 8 (5): 452. - Beardsley, 1961. Hawaii. Ent. Soc., Proc. 17 (3): 327.

\section{Genus ANABROLEPIS Timberlake}

Anabrolepis Timberlake, 1920. Hawaii. Ent. Soc., Proc. 4 (2): 431-432.

Type-species: Anabrolepis extranea Timberlake. Orig. desig.

Anabrolepis has not yet been reported from Africa or South America, otherwise it is cosmopolitan in distribution. It includes less than 10 described species which are parasites of the Diaspididae.

Taxonomy: Ishii, 1928. Imp. Agr. Sta. Japan, Bul. 3 (2): 148-149. -Tachikawa, 1956. Insecta Matsumurana 20 (3-4): 94. - Subba Rao, 1957. Indian Acad. Sci., Proc. Sec. B. 46 (6): 382. -Hoffer, 1960. Mus. Nat. Pragae, Acta Faun. Ent. 6: 114. 
zetterstedtii (Westwood). Maine w. to Mich., B. C. Host: Quadraspidiotus ostreaeform is (Curt.), Q. perniciosus (Comst.), Lepidosaphes ulmi (L.).

Encyrtus Zetterstedtii Westwood, 1837. London, Edinb. and Dublin Phil. Mag. and Jour. Sci. (3) 10: 440.

Encyrtus dendripennis Ratzeburg, 1852. Ichn. Forstins., v. 3, p. 189. \&.

Eupelmus pictipenuis Six, 1867. Tijdschr. Ent. 2 (2): 219.

Taxonomy: Girault, 1920. U. S. Nat. Mus., Proc. 58: 188. -Timberlake, 1920. Hawaii. Ent.

Soc., Proc. 4 (2): 432. -Gahan, 1924. U. S. Natl. Mus., Proc. 65 (4): 2-3. -Ferriere, 1940. Bul. Ent. Res. 31 (2): 133. - Hoffer, 1960. Mus. Nat. Pragae, Acta Faun. Ent. 6: 114.

-Compere and Annecke, 1961. Ent. Soc. So. Afr., Jour. 24 (1): 58. - Botoc, 1963. Cluj. U.

Baes-Bolyai Studia, Biol. Ser. 8 (2): 82 . —Graham, 1969. Polskie Pismo Ent. 39 (2): 291-292.

Biology: Zak-Ogaza, 1961. Polskie Pismo Ent. 31 (2): 366. - Sugonyayev, 1962. Akad. Nauk

SSSR Izv., Ser. Biol. 5: 754-766. - Bakkendorf, 1965. Ent. Meddel. 20 (2): 112.

\section{Genus COCCIDENCYRTUS Ashmead}

Coccidencyrtus Ashmead, 1900. U. S. Natl. Mus., Proc. 22: 339, 345, 383.

Type-species: Eucyrtus ensifer Howard. Orig. desig.

Coccidencyrtoiles Blanchard, 1940. Soc. Cient. Argent., An. 130: 107.

Type-species: Coccidencyrtoides anuulipes Blanchard. Desig. by De Santis, 1956.

It is difficult to determine precisely the size of Coccidencyrtus because of the questioned generic placement of many species. The genus is cosmopolitan in distribution and parasitizes scale insects.

Taxonomy: Risbec, 1952. Mem. Inst. Sci. Madagascar, Ser. E. Ent. 2: 46. -Compere and

Annecke, 1961. Ent. Soc. So. Afr., Jour. 24 (1): 59-65. - Tshumakova, 1961. Ent. Rev. 40

(2): 323. -Trjapitzin, 1963. Ent. Rev. 42 (4): 479-480. - Hoffer, 1963. Mus. Nat. Pragae,

Acta Ent. 35: 562. -De Santis, 1964. Com. Inv. Cient. Prov. Buenos Aires, An. 4: 229.

ensifer (Howard). Maine s. to Fla., Wis. Host: Aspidiotus corticalis (Ckll.), Quadraspidiotus juglansregiae (Comst.), Q. perniciosus (Comst.), Rhizaspidiotus dearnessi (Ckll.).

Encyitus ensifer Howard, 1885. U. S. Dept. Agr., Bur. Ent., Bul. 5: 13, 31, 42. ठ, ?.

Taxonomy: Girault, 1915. Ent. Soc. Amer., Ann. 8 (3): 284. -Compere, 1928. Calif. Univ.,

Pubs. Ent. 4 (8): 212.

ochraceipes Gahan. N. Y. Host: Diaspis boisduvali Sign.

Coccidencyitus ochraceipes Gahan, 1927. U. S. Natl. Mus., Proc. 71 (4): 18-19..

\section{Genus COMPERIELLA Howard}

Comperiella Howard, 1906. Ent. News 17 (4): 121-122.

Type-species: Comperiella bifasciata Howard. Monotypic.

Pseudanusia Girault, 1915. Queensland Mus., Mem. 4: 155.

Type-species: Pseudauusia pia Girault. Orig. desig.

Habrolepistia Mercet, 1921. Fauna Iberica, Himen., Encirtidos, pp. 7, 8, 12, 14, 15, 27, 60, $66,668-669$.

Type-species: Habrolepistia cerapterocera Mercet. Orig. desig. The type-species is considered a synonym of $C$. bifasciata.

Comperiella contains fewer than five species and, with the exception of South America, has been recovered on every continent. It is composed of primary, internal parasites of armored scale insects.

Taxonomy: Timberlake, 1923. Ent. Soc. Wash., Proc. 25 (3): 59. - Compere, 1926. Calif. Univ.,

Pubs. Ent. 4 (2): 44-50. - Mercet, 1926. Eos 2 (4): 320. - Ayyar, 1934. Indian Mus., Rec. 36

(2): 220. - Subba Rao, 1966. Mushi 39 (13): 135. - Prinsloo and Annecke, 1976. Ent. Soc.

So. Afr., Jour. 39 (2): 185-188.

bifasciata Howard. Fla., Calif. Host: Aonidiella aurantii (Mask.), A. citrina (Coq.), Chrysomphalus aonidum (L.). There appear to be at least two distinct races cf this species.

Comperiella bifasciata Howard, 1906. Ent. News 17 (4): 122. ․ 
Biology: Flanders, 1942. Jour. Econ. Ent. 35 (6): 834-835. - Smith, 1942. Jour. Econ. Ent. 35 (6): 809-812. -Flanders, 1943. Jour. Econ. Ent. 36 (2): 233-235. -Flanders, 1944. Ent. Soc. Amer., Ann. 37 (3): 365. - Swezey, 1923. Hawaii. Ent. Soc., Proc. 5 (2): 301 . - Timberlake, 1924. Hawaii. Ent. Soc., Proc. 5 (3): 433. -Compere and Smith, 1927. Calif. Univ., Pubs. Ent. 4 (4): 64-70. - Moutia, 1934. Mauritius Dept. Agr., Ann. Rpt. for 1933, p. 27. - Coy, 1938. Calif. Dept. Agr., Bul, 27 (4): 445-446. - Swezey et al., 1939. Hawaii. Ent. Soc., Proc. 10 (2): 351. - Smith, 1941. Calif. Citrog. 26 (3): 58, 76. - Campbell, 1943. Austral. Coun. Sci. Ind. Res., Jour. 16 (1): 41-42. - Woglum, et al., 1947. Jour. Econ. Ent. 40 (6): 820. - Maple, 1947. Calif. Univ., Pubs. Ent. 8 (2): 74, 76. —DeBach, 1948. Jour. Econ. Ent. 41 (6): 985.

-DeBach, 1952. Calif. Citrog. 37 (4): 136. -Flanders, 1956. Lab. Zool. Gen. Agr. Fac. Agr. Portici, Bol. 33: 14. -Tshumakova, 1957. Ent. Oboz. 36 (3): 643-651. -Smith, 1957. Canad.

Ent. 85 (5): 220. - Azim, 1961. Mushi 35 (14): 104. - Annecke, 1962. So. Afr. Jour. Agr. Sci. 5 (2): 281-282. - Rimes, 1962. West. Austral. Dept. Agr., Jour. 3 (11): 881. - DeBach, 1965. Canad. Ent. 97 (8): 859. - Subba Rao, 1966. Mushi 39 (13): 135-138. - Trjapitzin, 1968. Vses. Ent. Obshch., Trudy 52: 75. - DeBach, 1964. Biol. Control Insect Pests and Weeds, pp. 133, 288, 323, 350, 354, 451, 676. - Brewer, 1971. Austral. Jour. Zool. 19 (1): 53-63. -Huffaker, 1971. Biol. Control, pp. 74-75, 79, 181, 186. - DeBach, 1974. Biol. Control by Nat. Enem., pp. 179, 180, 181, 200, 203, 206. A more extensive bibliography is provided by Peck (1963).

\section{Genus HABROLEPIS Foerster}

Habrolepis Foerster, 1856. Hym. Stud., v. 2, pp. 34, 38.

Type-species: Encyrtus nubilipemu is Walker. Orig. desig. The type-species is considered a synonym of Encyrtus dalmanni Westwood.

Gymnoneura Risbec, 1951. Mem. Inst. Fr. Afr. Noire 13: 157.

Type-species: Gymnoneura bambeyi Risbec. Monotypic.

Habrolepis contains about a dozen species which develop as primary internal parasites of scale insects. Some species have been used in biological control programs with varying degrees of success. The genus has not been reported from South America and one species, $H$. rouxi, was introduced into North America for biological control of the California red scale.

Taxonomy: Timberlake, 1921. Hawaii. Ent. Soc., Proc. 4 (2): 432. - Ferriere, 1953. Rev. Path. Veg. d'Ent. Agr. France 32 (2): 115. -Tachikawa, 1956. Insecta Matsumurana 20 (3-4): 95.

- Hoffer, 1960. Mus. Nat. Pragae, Acta Faun. Ent. 6: 114. -Delucchi, 1965. Entomophaga

10 (3): 295-304. -Graham, 1969. Polskie Pismo Ent. 39 (2): 290-291. -Annecke and

Mynhardt, 1970. Entomophaga 15 (2): 127-148.

dalmanni (Westwood). Mass., Conn., Ohio. Host: Asterolecanium quercicola (Bouche), $A$. variolosum (Ratz.), Lepidosaphes ulmi (L.).

Encyrtus Dalmanni Westwood, 1837. London. Edinb. and Dublin Phil. Mag. and Jour. Sci. 10 (3): 440.

Habrolepis Dalmani Mayr, 1876 (1875). Zool.-Bot. Gesell. Wien, Verh. 25: 751. §’,. Unjustified emend.

Biology: Maple, 1947. Calif. Univ., Pubs. Ent. 8 (2): 90. - Balachowsky, 1929. Ann. Epiphy. 14 (4): 303, 304. - Nicholls, 1933. Tasmanian Jour. Agr. 4 (1): 24-26. -Gourlay, 1935. New Zeal. Jour. Sci. Tech. 16 (4): 216-235. -Nicholson, 1935. Austral. Council Sci. Indus. Res., Ann. Rpt. for 1934-1935, 9 (209): 33. - Evans, 1939. Tasmanian Jour. Agr. 10 (4): 202-203. -Evans, 1945. Ann. Appl. Biol. 32 (2): 179-180. -Tsalev and V'loheva, 1963. Gorsko Stopanstvo 19 (1): 23. - Tsaleff and Valeheva, 1963. Sofia. Rast. Zashch. 11 (9): 27.

-Delucchi and Traboulsi, 1965. Soc. Ent. de France, Ann. (n. s.) 1 (2): 495-500.

rouxi Compere. Calif. Introduced. Host: Aonidiella aurantii Mask. on eitrus.

Habrolepis rouxi Compere, 1936. Bul. Ent. Res. 27 (3): 493-496. ․

Biology: Compere, 1937. Calif. Citrog. 23 (2): 58, 88. -Flanders, 1942. Ecology 23 (1): 120-121. - Flanders, 1944. Jour. Econ. Ent. 37 (3): 444-445. - Flanders, 1945. Amer. Nat. 79 (781): 126, 131, 133-136. - Flanders, 1946. Pan-Pacific Ent. 22 (1): 35. -Omer-Cooper and Whitehead, 1950. Citr. Grower, no. 195, p. 3. - Flanders, 1956. Lab. Zool. Gen. Agr. Fac. Agr. Portici, Bol. 33: 55. -Smith, 1957. Canad. Ent. 89 (5): 219-230. - Weber, 1957. Hawaii. 
Ent. Soc., Proc. 16 (2): 183. -Compere, 1961. Hilgardia 31 (7): 173-278. - Annecke, 1962. So. Afr. Jour. Agr. Sci. 5 (2): 281. -Annecke, 1963. Ent. Soc. So. Afr., Jour. 26 (1): 207, 220. -Delucchi and Traboulsi, 1965. Ent. Soc. de France, Ann. (n. s.) 1 (2): 499. - Huffaker, 1971. Biol. Control, p. 74.

\section{Genus NEOCOCCIDENCYRTUS Compere}

Neococcidlencyrtus Compere, 1928. Calif. Univ., Pubs. Ent. 4 (8): 209-212.

Type-species: Neococcillencyrtus aulula Compere. Orig. desig. The type-species designation of aulula is a lapsus of $n$. alula.

This small genus consists of a few species which are Neotropical and Holarctic in distribution. Its members are parasites of scale insects.

poutiersi (Mercet). Calif. Host: Furchadaspis zamiae (Morg.).

Coccilencyrtus poutiersi Mercet, 1922. Soc. Espan. de Hist. Nat., Bol. 22 (9): 399-402.

Neococcidencyrtus alula Compere, 1928. Calif. Univ., Pubs. Ent. 4 (8): 213-214. ơ, ๆ.

\section{Genus PLAGIOMERUS Crawford}

Plagiomerus Crawford, 1910. U. S. Natl. Mus., Proc. 38: 89.

Type-species: Plagiomerus diaspidlis Crawford. Orig. desig.

This genus contains three species and it appears to be Nearctic in distribution. The occurrence of one species, $P$. diuspidis, in the Palearctic appears due to accidental introduction with parasitized host material.

Taxonomy: Gahan, 1924. U. S. Natl. Mus., Proc. 65 (4): 1. - Trjapitzin, 1968. Vses. Ent.

Obshch., Trudy 52: 76.

cyaneus (Ashmead). Fla.

Comys cyumea Ashmead, 1888. Ent. Amer. 4 (1): 17. \&.

Taxonomy: Dozier, 1926. Puerto Rico Dept. Agr., Jour. 10 (3-4): 273-274.

diaspidis Crawford. Md. s. to Fla., w. to Calif. Host: Diaspis echinocacti (Bouche).

Plagiomerus diaspidis Crawford, 1910. U. S. Natl. Mus., Proc. 38: 90. ९.

Biology: Gordh and Lacey, 1976. Ent. Soc. Wash., Proc. 78 (2): 132-144.

\section{Genus PSEUDHOMALOPODA Girault}

Pseudhomalopoda Girault, 1915. N. Y. Ent. Soc., Jour. 23 (3): 171.

Type-species: Pseudhomalopoda prima Girault. Orig. desig.

Pseudhomalopoda contains fewer than five species which are distributed in the Pacific and Holarctic regions. The species are parasites of scale insects.

Taxonomy: Tachikawa, 1956. Insecta Matsumurana 20 (3-4): 90-96. -Tachikawa, 1963. Mem.

Ehime Univ. Sec. 6 (Agr.) 9 (1): 17, 95, 101-102.

prima Girault. Fla. w. to Tex. Host: Aleurocanthus woglumi Ashby?, Aonidiella aurantii

(Mask.), Chrysomphalus aonidum (L.).

Pseudhomalopoda prima Girault, 1915. N. Y. Ent. Soc., Jour. 23 (3): 171-172...

Biology: Griffiths and Stearns, 1947. Fla. Ent. 30 (1): 4-7. - Muma and Clancy, 1961. Fla.

State Hort. Soc., Proc. 74: 29-32. -Clancy et al., 1963. Jour. Econ. Ent. 56 (5): 604.

-Anonymous, 1964. Fitofolo 17 (43): 28.

\section{TRIBE HOMALOTYLINI}

\section{Genus ANISOTYLUS Timberlake}

Anisotylus Timberlake, 1919. U. S. Natl. Mus., Proc. 56: 170-171.

Type-species: Homalotylus similis Ashmead. Orig. desig.

A small genus with fewer than five species, Anisotylus is found in North America and Japan. The species of this genus are parasitic on cocinellid beetle larvae. 
pallentipes Timberlake. Mo., Ariz.

Anisotylus pallentipes Timberlake, 1919. U. S. Natl. Mus., Proc. 56: 171, 175-176. \&.

similis similis (Ashmead). Fla. Host: Scymnus cervicalis Muls.

Homalotylus similis Ashmead, 1887. Amer. Ent. Soc., Trans. 14: 190. ?.

Taxonomy: Timberlake, 1919. U. S. Natl. Mus., Proc. 56: 171-173.

similis texanus Timberlake. Tex. Host: Hyperaspis bigeminata (Rand.).

Anisotylus similis texanus Timberlake, 1919. U. S. Natl. Mus., Proc. 56: 171, 173..

similis utahensis Timberlake. Utah, Calif. Host: Scymnus americanus Muls., S. lacustrus Lec. Anisotylus similis utahensis Timberlake, 1919. U. S. Natl. Mus., Proc. 56: 171, 174. o, $९$.

\section{Genus HOMALOTYLUS Mayr}

Homalotylus Mayr, 1876 (1875). Zool.-Bot. Gesell. Wien, Verhandl. 25: 752-753.

Type-species: Encyrtus flaminius Dalman. Desig. by Ashmead, 1900.

Nobrimus. Thomson, 1876 (1875). Hym. Scand., v. 4, pp. 116, 137-138.

Type-species: Encyrtus flaminius Dalman. Desig. by Timberlake, 1919.

Mendozaniella Brethes, 1913. Buenos Aires Mus. Nac. de Hist. Nat., An. 24: 97-98.

Type-species: Mendozaniella mirabilis Brethes. Monotypic.

Hemaenasoidea Girault, 1916. Ent. Soc. Amer., Ann. 9 (3): 307.

Type-species: Hemaenasoidea oculata Girault. Monotypic.

Lepidaphycus Blanchard, 1936. Soc. Ent. Argentina, Rev. 8: 13-14.

Type-species: Lepidaphycus bosqui Blanchard. Orig. desig.

This cosmopolitan genus consists of about 35 described species. They are internal parasites of coccinellid beetle larvae.

Taxonomy: Timberlake, 1919. U. S. Natl. Mus., Proc. 56: 134-170. -Masi, 1919. Genova Mus.

Civ. Stor. Nat., Ann. (3) 48: 295-300, - Risbec, 1951. Inst. Fr. Afr. Noire, Mem. 13: 151-153.

-Risbec, 1952. Inst. Sci. Madagascar Ser. E, Ent., Mem. 2: 5, 6, 25. - Hoffer, 1959. Mus.

Nat. Pragae, Acta Ent. 33: 30. - Hoffer, 1963. Mus. Nat. Pragae, Acta Ent. 35: 582-591.

-De Santis, 1963. Com. Inv. Cient. Prov. Buenos Aires, An. 4: 162. - Graham, 1969.

Polskie Pismo Ent. 39 (2): 233-235.

Biology: Geyer, 1947. Ent. Soc. So. Afr., Jour. 10 (1): 102. -Zinna, 1961 (1960). Portici Lab.

Ent. Agr. Filippo Silvestri, Bol. 18: 260-261.

affinis Timberlake. Calif. Host: Hyperaspis osculans Lec.

Homalotylus affinis Timberlake, 1919. U. S. Natl. Mus., Proc. 56: 162, 165-166. \&.

albitarsus Gahan. Md. Host: Lecauium? nigrofasciatum Perg. on peach; coccinellid.

Homalotylus albitarsus Gahan, 1910. Canad. Ent. 42 (6): 206-207. ‥

cockerelli Timberlake. Tex. Host: Dactylopius confusus (Ckll.) ?, Pseudococcus sp.?, Hyperaspidius trimaculatus (L.).

Homalotylus cocherelli Timberlake, 1919. U. S. Natl. Mus., Proc. 56: 162, 163-165. ठ, ๆ.

flaminius (Dalman). La.

Eucyrtus flaminius Dalman, 1820. Svenska Vetensk. Akad., Handl. 41: 340-346. ơ.

Le pidaphycus bosqni Blanchard, 1936. Rev. Soc. Ent. Argentina 8: 14-15.

Mendozaniella mirabilis Brethes, 1913. Buenos Aires Mus. Nac. de Hist. Nat., An. 24: 98-99.

Taxonomy: Masi, 1907. Lab. Zool. Portici, Bol. 1: 288-290. - Masi, 1919. Genova Mus. Civ.

Stor. Nat., Ann. 48: 296-298. - Mercet, 1921. Fauna Iberica, Himen., Encirtidos, pp.

519-522, 712. - Mercet, 1923. Soc. Espan. de Hist. Nat., Bol. 23 (3): 143. - Timberlake, 1924. Hawaii. Ent. Soc., Proc. 5 (3): 430. - Pruthi and Mani, 1940. Imp. Council Agr. Res.,

Misc. Bul. (India) 30: 14. - d'Araujo e Silva, 1945. Bol. Fitossan. 1 (1): 29-35. -Ferriere,

1949. Schweiz. Ent. Gesell., Mitt. 22 (4): 378-379. - Rogojanu, 1955. Bucharest Acad.

Repub. Romine, Fil. Cluj. Stud. Cercet. Sti., (2), 6 (3-4): 79. -Tawfik et al., 1962. Soc. Ent.

Egypt, Bul. 46: 503. - Bakkendorf, 1965. Ent. Meddel. 30 (2): 133-134. -Trjapitzin, 1968.

Vses. Ent. Obshch., Trudy 52: 68-69.

hyperaspidis Timberlake. Utah, Calif. Host: Hyperaspis undulata (Say).

Homalotylus hyperaspidis Timberlake, 1919. U. S. Natl. Mus., Proc. 56: 162, 167-169. ठै, ๆ. 
punetifrons Timberlake. Fla.

Homalotylus punctifrons Timberlake, 1919. U. S. Natl. Mus., Proc. 56: 162, 169-170...

terminalis californicus Girault. Mass., s. to S. C., Utah, Calif. Host: Adalia bipunctata (L.), Coccinella novemnotata Hbst., C. quinquenotata Kby., C. transversoguttata Fald., Hippodamia convergens Guer., Dison ycha sp.

Homalotylus obscurus var. californicus Girault, 1915. Ent. Soc. Amer., Ann. 8 (3): 274. 9.

terminalis terminalis (Say). Eastern U. S., Tex. Host: Coleomegilla maculata (Deg.), C. sp., Cycloneda sanguinea (L.), C. sanguinea immaculata (F.); Chilocorns similis (Rossi); Coccinella novemnotata Hbst., C. sanguinea (L.); Hippodamia convergens Guer., Neomysia pullata (Say), Psyllobora vigintimaculata (Say); Scymmus sp.

Serlion(!) terminalis Say, 1828. Contrib. Maclur. Lyc. Phila. 1: 80 . Generic name a lapsus for Scelio.

Eutelus! scymmate Shimer, 1869. Amer. Ent. Soc., Trans. 2: 385. ठे.

Homalotylus obscurns Howard, 1885. U. S. Dept. Agr., Bur. Ent., Bul. 5: 22, 32, 43 . ₹.

\section{Genus ISODROMUS Howard}

Isodromus Howard, 1887. U. S. Dept. Agr., Ann. Rept. for 1886. p. 488.

Type-species: Isodromus iceryae Howard. Monotypic.

Parataneostigma Girault, 1915. Ent. Soc. Amer., Ann. 8 (3): 275.

Type-species: Parataneostigma nigriaxillae Girault. Monotypic. The type-species is considered a synonm of Isodromus iceryae Howard.

Isodromus is a cosmopolitan genus consisting of 13 species that parasitize chrysopids and hemerobiids.

Taxonomy: Timberlake, 1919. U. S. Natl. Mus., Proc. 56: 176-190. - Annecke, 1962. Ent. Soc.

So. Afr., Jour. 25 (2): 188-191. - Trjapitzin, 1968. Vses. Ent. Obshch., Trudy 52: 69.

atriventris Ashmead. Ont., Que. s. to Fla. Host: Chrysopa lateralis Guer.

Isodromus atriventrus Ashmead, 1900. U. S. Natl. Mus., Proc. 22: 379. ๆ.

iceryae Howard. Cosmopolitan. Host: Sympherobins angustus (Banks), S. californicus (Banks),

Chrysopa californica Coq., C. lateralis Guer., C. rufilabris Burm.

Isodromus iceryae Howard, 1887. U. S. Dept. Agr., Ann. Rept. for 1886. p. 488..

Parataneostigma nigriaxillae Girault, 1915. Ent. Soc. Amer., Ann. 8 (3): 275..

Isodromus pulcher Girault, 1917. Descr. Stellarum Nov., p. 16. \&.

Biology: Riley, 1889. U. S. Dept. Agr., Ann. Rept. for 1888, pp. 85-86. -Clancy, 1946. Calif.

Univ., Pubs. Ent. 7 (13): 426-432. - Maple, 1947. Calif. Univ., Pubs. Ent. 8 (2): 91-92.

-Muma, 1959. Fla. Ent. 42 (3): 151, 152.

montanus Slosson. N. H., Colo. Host: Chrysopa sp. Type lost, but may be Isodromus vinulus (Dalman).

Isodromus montanus Slosson, 1895. Ent. News 6 (9): 278.

niger Ashmead. Mass. s. to D. C., w. to Wis., Calif. Host: Sympherobius angustus (Banks), Chrysopa californica Coq, C. majuscula Banks, C. oculata Say.

Isodromus niger Ashmead, 1900. U. S. Natl. Mus., Proc., 22: 379..

Biology: Clancy, 1946. Calif. Univ., Pubs. Ent. 7 (13): 418-426. -Maple, 1947. Calif. Univ.,

Pubs. Ent. 8 (2): 91-92.

puncticeps (Howard). Eastern U. S., Calif. Host: Chrysopa sp.

Encyrtus puncticeps Howard, 1885. U. S. Dept. Agr., Bur. Ent., Bul. 5: 14, 42 ..

Aphycus chrysopae Ashmead, 1888. Ent. Amer. 4 (1): 15. ?.

\section{TRIBE IXODIPHAGINI}

\section{Genus HUNTERELLUS Howard}

Huuterellus Howard, 1908. Canad. Ent. 40 (7): 240-241.

Type-species: Hunterellus hookeri Howard. Monotypic.

Hunterellus is worldwide in distribution and contains fewer than five species. They are parasites of tick nymphs. 
Taxonomy: Howard, 1908. Canad. Ent. 40 (7): 239-241. - Risbec, 1954. Inst. Fr. Afr. Noire, Bul. Ser. A 16 (4): 1070-1071. - Oliver, 1964. Pan-Pacific Ent. 40 (4): 227-230.

Biology: Doube and Heath, 1975. Jour. Med. Ent. 12 (4): 443-447.

hookeri Howard. Mass. s. to Fla. w. to Mont., Idaho, Calif. Host: Dermacentor andersoni Stiles, D. purumapterus Neum., D. cariabilis (Say), Haemaphysalis leporispalustris (Pack.), Ixodes dentutus Marx, I. muris B. and S., I. scapularis Say, Rhipicephalus sanyuinens (Latr.).

Hunterellus. Hookeri Howard, 1908. Canad. Ent. 40 (7): 241. đ, ?.

Ixodiphagus Caucurtei du Buysson, 1912. Arch. de Parasitol. 15: 246-247. ठ, ᄋ.

Habrolepis caniphila Risbec, 1951. Inst. Fr. Afr. Noire, Mem. 13: 170-172.

Taxonomy: Gahan, 1934. Ent. Soc. Wash., Proc. 36 (6): 89-97. -Quaraishi, 1958. Amer. Midland Nat. 59 (2): 489-504.

Biology: Wood, 1911. Jour. Econ. Ent. 4 (5): 425-431. - Cooley, 1927. Mont. State Bd. Ent., Bien. Rpt. 6: 15-17. - Cooley and Kohls, 1928. Science 67 (1748): 656. - Cooley, 1929 (1927-1928). Mont. State Bd. Ent., Bien. Rpt. 7: 10-16; 17-31. -Morton, 1929 (1927-1928). Mont. State Bd. Ent., Bien. Rpt. 7: 32-35. - Parker and Butler, 1929 (1927-1928). Mont. State Bd. Ent., Bien. Rpt. 7: 35-38. -Cooley, 1930. Mont. State Bd. Ent., Bien. Rpt. 8: 16-25. - Cooley and Kohls, 1934. Fifth Pacific Sci. Cong., Proc. B. 5: 3375-3381. - Bishopp, 1938. U. S. Dept. Agr., Cir. 478: 23. —Smith and Cole, 1943. Jour. Econ. Ent. 36 (4): 569-572. -Ushakova, 1962. Kazan Inst. Zool. Akad. Nauk SSSR, Trudy 16: 183-185.

\section{Genus IXODIPHAGUS Howard}

Ixodiphayus Howard, 1907. Ent. News 18 (9): 377.

Type-species: Ixodiphagus texanus Howard. Monotypic.

Ixodiphayus is apparently a monotypic genus distributed throughout the Holarctic Region. The type-species parasitizes tick nymphs.

Taxonomy: Hoffer, 1963. Mus. Nat. Pragae, Acta Ent. 35: 591.

texanus Howard. Mass., Minn. w. to Idaho, Tex. Host: Dermacentor variabilis (Say), Haemaphysalis leporispalustris (Pack.), Ixodes cookei Pack., I. dentatus Marx, I. scapularis Say, Rhipicephalus sanguineus (Latr.).

Ixodiphagus texanus Howard, 1907. Ent. News 18 (9): 376, 377-378..

Taxonomy: Gahan, 1934. Ent. Soc. Wash., Proc. 36 (6): 89-97. -Quaraishi, 1958. Amer. Midland Nat. 59 (2): 502.

Biology: Larson, 1937. Jour. Parasitol. 24: 496-498. - Larson and Green, 1938. Jour. Parasitol. 24: 363-368. -Smith et al., 1946. U. S. Dept. Agr., Tech. Bul. 905: 72.

\section{TRIBE MICROTERYINI}

\section{Genus AGROMYZAPHAGUS Gahan}

Agromyzaphagus Gahan, 1912. Ent. Soc. Wash., Proc. 14 (1): 6-7.

Type-species: Agromyzaphagus detrimentosus Gahan. Orig. desig.

This monotypic genus is Holarctic. It parasitizes flies of the genus Lencopis.

Taxonomy: Mercet, 1926. Eos 2 (4): 317. - Trjapitzin, 1968. Vses. Ent. Obshch., Trudy 52: 65-66.

detrimentosus Gahan. Md. w. to Wis., Utah, Calif. Host: Leucopis nigricornis Egger?, L. sp. on plum.

Agromyzaphagus detrimentosus Gahan, 1912. Ent. Soc. Wash., Proc. 14 (1): 7. ठ, ?.

\section{Genus APHIDENCYRTUS Ashmead}

Aphidencyrtus Ashmead, 1900. U. S. Natl. Mus., Proc. 22: 340, 347, 398.

Type-species: Encyrtus aphidiphagus Ashmead. Orig. desig. The type-species is considered a synonym of Eucyrtus aphidivorus Mayr. 
This is a cosmopolitan genus consisting of about 20 species which are hyperparasites (and perhaps primary parasites) of aphids.

Taxonomy: Gahan, 1923. Ent. Soc. Wash., Proc. 25 (9): 187-188. -Narayanan, 1941. Indian Jour. Ent. 3 (1): 62. -Risbec, 1952. Inst. Sci. Madagascar Ser. E, Ent., Mem. 2: 6, 52.

-Alam, 1961. Beitr. zur Ent. 11 (7-8): 803-807. - Hoffer, 1965. Acta Ent. Bohemoslov. 62

(2): 110-128. - Trjapitzin, 1967. Akad. Nauk SSSR Zool. Inst., Trudy 41: 202-205.

_Graham, 1969. Polskie Pismo Ent. 39 (2): 252-255.

aphidivorus (Mayr). Maine, Conn. s. to Fla., w. to La., Idaho. Host: Rhopalosiphonius solani (Thos.), Nearctaphis bateri (Cowen), Carariella aquatica (G. and B.), Brevicoryne brassicae (L.), Acyrthosiphon cornelli (Patch), M. avenae (F.), M. liriodendri (Monell), Myzus persicne (Sulz.), Schizuph is gruminum (Rond.), Trialeurodes vaporariorum (Westw.), Aphelinus juncundus Gahan, A. sanborniae Gahan, A. semiflavus How., A. sp., Aphidius testuceipes (Cress.), A. spp.

Encyrtus aphitlirorus Mayr, 1876 (1875). Zool.-Bot. Gesell. Wien, Verhandl. 25: 712-713, 724. o, ?.

Eupelmus schizoneurue Ashmead, 1885. Amer. Ent. Soc., Trans. 12: Proc. p. xvi. o, o (under Encyrtus).

Encyitus uphidliphagus Ashmead, 1887. U. S. Dept. Agr., Div. Ent., Bul. 14: 14..

Encyrtus? megourne Ashmead, 1887. U. S. Dept. Agr., Div. Ent., Bul. 14: 19. §, ᄋ.

Encyrtus Websteri Howard, 1890. U. S. Dept. Agr., Insect Life 2 (7-8): 247-248. đ, ?.

Microterys submetalicus Mercet, 1921. Fauna Iberica, Himen., Encirtidos, p. 354. Preocc. by Howard, 1896.

Syrphophagus silvestrinus Ghesquiere, 1956 Lab. Zool. Gen. e Agr. Portici, Bol. 33: 701. (n. name for suburetulicus Mercet).

Syrphophayus merceti Erdos, 1957. Folia Ent. Hungarica (n. s.) 10 (1): 45 (n. name for submetalicus Mercet).

Taxonomy: Gahan, 1924 (1923). Ent. Soc. Wash., Proc. 25 (9): 187-188. -Gahan, 1927. U. S.

Natl. Mus., Proc. 71 (4): 18. - Gahan, 1930. U. S. Natl. Mus., Proc. 77 (8): 6-7. - Mercet, 1932. Los paras. los ins. perjud. Barcelona, pp. 108-109. - Narayanan, 1941. Indian Jour. Ent. 3 (1): 62. -Ferriere, 1961. Entomophaga 6 (1): 48-49. - Bakkendorf, 1965. Ent. Meddel. 30 (2): 114-115. - Hoffer, 1965. Acta. Ent. Bohemoslov. 62 (2): 112-115.

Biology: Pashchenko, 1961. Kazakh. Akad. Sel'sk. Nauk. Nauch. Inst. Zash. Rast., Trudy 6:

218. - Szalay-Marzso and Solymosy, 1961-1962. Acta Agron. (Budapest). 11 (3-4): 329-342.

-Akhvledinana, 1963. Akad. Nauk Gruzinskoi SSR, Soobshch, 30 (6): 781. - Hassan, 1963.

United Arab Repub. Min. Agr., Agr. Ext. Dept., p. 5. -Grigorov, 1964. Rast. Zashch. 12

(4): 32. - Sharma, 1965. Paris Univ. Facul. Sci. Theses, Ser. A, 4510, p. 109. - Radev, 1968.

Rast. Nauki (Sofia) 5 (10): 126.

lachni (Ashmead). Fla. Host: Cinara australi (Ashm.).

Eupelmus lachni Ashmead, 1885. Amer. Ent. Soc., Trans. Proc. p. xvi. $\&$ (under Encyrtus).

Taxonomy: Gahan, 1927. U. S. Natl. Mus., Proc. 71 (4): 18.

\section{Genus AVETIANELLA Trjapitzin}

Avetianella Trjapitzin, 1968. Vses. Ent. Obshch., Trudy 52: 97-99.

Type-species: Acetianella capnodiobia Trjapitzin. Orig. desig.

An undetermined species has been taken in California on Pinus lambertiana.

\section{Genus CERCHYSIUS Westwood}

Cerchysius Westwood, 1832. London, Edinb. and Dublin Phil. Mag. and Jour. Sci. (3) 1: 127. Type-species: Eucyrtus urocerus Dalman. Desig. by Westwood, 1840. The type-species is considered a synonym of Eucyrtus subplanus Dalman.

There are about twenty species of Cerchysius distributed throughout the world. Members of the genus are probably parasites of Diptera. 
Taxonomy: Girault, 1918. Ent. News 29 (2): 65-66. - Kerrich, 1954. Ann. and Mag. Nat. Hist. (12) 8: $371-379$.

elasmoceri Ashmead. D. C., Va. Host: Monophylla terminata (Say).

Cerchysius elusmoceri Ashmead, 1900. U. S. Natl. Mus., Proc. 22: 379-380. \&.

Taxonomy: Girault, 1917 (1916). Insecutor Inscitiae Menstruus 4 (10-12): 119-120. -Girault, 1918. Ent. News 29 (2): 65.

hubbardii Ashmead. Wash., Calif. Host: Vrilletta hubburli Schwarz (?nomen nudum) infesting stems of Alleuroffic occielentalis.

Cerchysius lubbariii Ashmead, 1900. U. S. Natl. Mus., Proc. 22: 380. ๆ.

marilandicus Girault. Md., Wise, Ind., N. H.

Cerchyssius marilundicus Girault, 1917 (1916). Insecutor Inscitiae Menstruus 4 (10-12): 119-120. ․

Cerchysiuss murylandicuss Peck, 1951. U. S. Dept. Agr., Agr. Monog. 2: 483. Unjustified emendation.

pallipes (Provancher). Ont.

Copialosoma pallipes Provancher, 1887. Addit. Corr. Faune Ent. Canada Hym., p. 205. .

Copiclosomu pullilipes Dalla Torre, 1898. Cat. Hym. v. 5, p. 243. Unjustified emend.

Taxonomy: Burks, 1964 (1963). Canad. Ent. 95 (12): 1257.

\section{Genus MICROTERYS Thomson}

Sceptrophorus Foerster, 1856. Hym. Stud., v. 2, pp. 34, 38.

Type-species: Encyrtus sceptriger Foerster. Desig. by Ashmead, 1900.

Microterys: Thomson, 1876 (1875). Hym. Seand. v. 4, pp. 118, 155.

Type-species: Eucyrtus syleius Dalman. Desig. by Ashmead, 1900.

A pentilicus: Fullaway, 1913. Hawaii Agr. Expt. Sta., Rpt. for 1912, p. 26.

Type-species: Apentelicus kotinskyi Fullaway. Orig. desig.

The names Microterys and Sceptrophorus have been used interchangeably in the literature. Rosen (1973, Bul. Zool. Nomencl. 30 (2): 108-111) proposed that Sceptrophorts be suppressed.

The actual number of Microterys spp. can only be speculated at this time. Currently we recognize over 170 names in the genus, some of which are undoubtedly junior synonyms. The genus probably contains over 100 valid species. The New World fauna is poorly known.

This genus is important to biological control because many species are primary parasites of soft scale insects. Representatives of Microterys have been reported on all families of scale insects except the Diaspididae and Asterolecanidae.

Taxonomy: Girault, 1917. Descr. Stellarum Nov., p. 13. - Mercet, 1917. Soc. Espan. de Hist.

Nat., Bol. 17 (2): 128-139. - Timberlake, 1923. Ent. Soc. Wash., Proc. 25 (3): 58-59.

-Compere, 1926. Calif. Univ., Pubs. Ent. 4 (2): 34. - Ishii, 1928. Imp. Agr. Sta. Japan, Bul.

3 (2): 130. -Compere, 1939. Bul. Ent. Res. 30 (1): 16. -Erdos, 1957. Acta. Zool.

(Budapest). 3 (1-2): 37. - Annecke, 1962. Ent. Soc. So. Afr., Jour. 25 (2): 30. - Bakkendorf,

1965. Ent. Meddel. 30 (2): 144. - Pilipyuk and Sugonyayev, 1971. Ent. Rev. 50 (1): 78-84.

- Rosen, 1973. Ent. Soc. Austral., Jour. 12 (4): 248-252, - Prinsloo, 1975. Ent. Soc. So. Afr.,

Jour. 38 (1): 19-37. - Prinsloo and Rosen, 1975. Ent. Soc. So. Afr., Jour. 38 (1): 85-88.

-Rosen, 1976. Ent. Soc. Amer., Ann. 69 (3): 479-485.

cincticornis Ashmead. N. H., Mass., Ill. Host: Kermes pubescens Bogue.

Microterys cincticornis Ashmead, 1900. U. S. Natl. Mus., Proc. 22: 390.

claripennis Compere. Calif., N. C., Pa. Host: Lecanium comi Bouche.

Microterys claripennis Compere, 1928. Calif. Univ., Pubs. Ent. 4 (8): 216-217. ठ; ;.

dubiosus (Dalla Torre). Calif. Host: Icerya purchasi Mask.

Encyrtus dubius. Howard, 1889. U. S. Dept. Agr., Insect Life 1 (9): 270. ठ. Preoce. by

Fonscolombe, 1840.

Encyritus dubiosus Dalla Torre, 1898. Cat. Hym., v. 5, p. 257. N. name.

flavus (Howard). Ont., N. J., Ohio, Ill., Fla., Calif. Host: Coccus hesperidum L., C. psendomagnoliarmm (Kuw.), Lecanium corni Bouche, L. fletcheri Ckll., Pulvinaria vitis (L.), Saissetia coffeae (Walk.).

Encyrtus flatus Howard, 1881. U. S. Dept. Agr., Ann. Rpt. for 1880, p. 367. §, \&. 
Biology: Isaac, 1905. Calif. State Commr. Hort., Bien. Rpt. 1: 99, 102. -Timberlake, 1913. Jour. Econ. Ent. 6 (3): 298. -Maple, 1947. Calif. Univ., Pubs. Ent. 8 (2): 98-100, 102-103. -Bartlett and Lagace, 1961. Ent. Soc. Amer., Ann. 54 (2): 222-227. -Rubtsov, 1963.

Zashch. Rast. Vred. Boleznei 8 (10): 58. - Bartlett, 1964. Ent. Soc. Amer., Ann. 57 (3): 344. - Bartlett and Ball, 1964. Ent. Soc. Amer., Ann. 57 (4): 496-503. -Gogua, 1965. Zashch.

Rast. Vred. Boleznei 19 (1): 47. - Huffaker, 1971. Biol. Control, p. 463. -Sorokina, 1973.

Ent. Rev. 52 (3): 396-397.

fuscicornis (Howard). Md., Minn. Host: Toumeyella parvicomis (Ckll.).

Eucyrtus fuscicorn is Howard, 1885. U. S. Dept. Agr., Div. Ent., Bul. 5: 13, 42..

interpunctus (Dalman). Europe, Greenland, No. Amer.?

Encyitus interpunctus Dalman, 1820. Svenska Vetensk. Akad., Handl. 41: 157-158. $\%$.

lachni (Ashmead). Fla. Host: Cincre australi (Ashm.).

Homulotylus luchni Ashmead, 1886. Amer. Ent. Soc., Trans. 13: 132..

lunatus (Dalman). Europe, No. Amer.?

Eucyrtus lunutus Dalman, 1820. Svenska Vetensk. Akad., Handl. 41: 156..

marginatus Ashmead. N. Mex.

Microterys marginatus Ashmead, 1900. U. S. Natl. Mus., Proc. 22: 292. ๆ.

marilandicus (Girault). Md.

Sceptrophorus marilundicus Girault, 1917. Ent. News 28 (6): 256-257.

Sceptrophorus marylandicus Peck, 1951. U. S. Dept. Agr., Agr. Monog. 2: 483. Unjustified emend.

mazzinini Girault. Calif. Host: Physokermes insignicola (Craw).

Microteryss mazzinini Girault, 1917. Descr. Stellarum Nov., pp. 12, 13. ठ, १.

montinus (Packard). N. H. Host: Lecanium sp.?

Encyrtus Montinus Packard, 1874. In Hitchcock and Huntington, Geol. of N. H., v. 1, p. 347. $\%$.

Taxonomy: Howard, 1888. Ent. Soc. Wash., Proc. 1 (2): 91-92.

physokermis Compere. Calif. Host: Physokermes insignicola (Craw).

Microterys physsokermis Compere, 1926. Calif. Univ., Pubs. Ent. 4 (1): 43-44. \&.

speciosissimus Girault. Ill. Host: Kermes pubescens Bogue.

Microterys speciosissimus Girault, 1911. Canad. Ent. 43 (5): 175. ․

sublestus (Howard). Conn., Fla. Host: Lecanium sp.? on Pinus palustris, L. sp.

Encyrtus sublestus Howard, 1885. U. S. Dept. Agr., Bur. Ent., Bul. 5: 12-13, 42. ठో.

sylvius (Dalman). Europe, No. Amer.?

Encyitus sylvius Dalman, 1820. Svenska Vetensk. Akad., Handl. 41: 154. ९.

Taxonomy: Mercet, 1921. Fauna Iberica, Himen., Encirtidos, pp. 394-397. ठँ, ๆ.

tessellatus (Dalman). Greenland, No. Amer.?

Encyrtus tessellatus Dalman, 1820. Svenska Vetensk. Akad., Handl. 41: 342-344..

Taxonomy: Ashmead, 1900. U. S. Natl. Mus., Proc. 22: 393. -Carpenter, 1938. Ann. and Mag. Nat. Hist. (11) 1 (5): 542. - Bakkendorf, 1965. Ent. Meddel. 30 (2): 151.

titiani Girault. Calif. Host: Lecanium comi Bouche.

Microterys titiani Girault, 1917. Deser. Stellarum Nov., p. 13. ठ, ?.

Biology: DeBach, 1939. Jour. Econ. Ent. 32 (5): 728-729.

xanthopsis Compere. Utah, Ariz., Calif. Host: Lecanium corni Bouche, L. persicae (F.).

Microterys xanthopsis Compere, 1926. Calif. Univ., Pubs. Ent. 4 (2): 39, 41-42..

yolandae Compere. Calif. Host: Kermes cockerelli Ehrh.

Microterys yolandae Compere, 1926. Calif. Univ., Pubs. Ent. 4 (2): 39-41..

\section{Genus OOBIUS Trjapitzin}

Oobius Trjapitzin, 1963. Mus. Nat. Pragae, Acta Ent. 35: 543, 544-545.

Type-species: Tyudarichus rudneri Nowicki. Orig. desig. 
Oobius is a small genus, consisting of about five species, and is Holarctic and Ethiopian in distribution. These insects are parasites in the eggs of buprestid beetles. An undetermined species is found in Arizona and California. It has been taken from Pinus muricata, Libocedrus decurrens, and reared from Melanophila californica Van Dyke on P. ponderosa.

\section{Genus OOENCYRTUS Ashmead}

Ooencyrtus Ashmead 1900. U. S. Natl. Mus., Proc. 22: 338, 345, 381.

Type-species: Eucyrtus clisiocampae Ashmead. Orig. desig.

Schediuss Howard, 1910. U. S. Dept. Agr., Bur. Ent., Tech. Ser. 19 (1): 2-3.

Type-species: Schedius kuvanae Howard. Orig. desig.

Ooencyrtus is another cosmopolitan genus the size of which is difficult to determine. All species are egg parasites of other insects.

Taxonomy: Timberlake, 1923. Ent. Soc. Wash., Proc. 25 (3): 59. -Mercet, 1925. Eos 1 (3): 324-328. -Ferriere, 1931. Bul. Ent. Res. 22 (2): 281-286. - Hoffer, 1963. Mus. Nat. Pragae, Acta Ent. 35: 560-580. - Bakkendorf, 1965. Ent. Meddel. 30 (2): 158-159. - Trjapitzin, 1967. Akad. Nauk Zool. Inst., Trudy. 41: 198-202.

Biology: Chu, 1934. Chekiang Prov., China, Bur. Ent. Yearbook (Hangchow) 3: 169. -Sasamoto, 1939. Zool. Mag. (Tokyo) 51 (1): 24-33. - Phillips, 1941. Roy. Ent. Soc. London, Trans. 91 (5): 136-143. - Wolcott and Martorell, 1944. Puerto Rico Univ., Jour. Agr. 27 (2): 93. - Geyer, 1947. Ent. Soc. So. Afr., Jour. 10 (1): 100-102. - Anderson and Kaya, 1974. Ent. Soc. Amer., Ann. 67 (6): 845-849. - Kaya and Anderson, 1974. Environ. Ent. 3 (3): 659-663.

anabrivorus Gahan. Wyo. Host: Anabrus simplex Hald. Ooencyrtus anabrivorus Gahan, 1942. U. S. Natl. Mus., Proc. 92: 49-51. ¿, ९.

anasae (Ashmead). N. C., Fla., La., Kans. Host: Solubea pugnax (F.), Anasa tristis (Deg.). Eucyrtus anasae Ashmead, 1887. U. S. Dept. Agr., Div. Ent., Bul. 14: 23-24..

Biology: Ingram, 1927. U. S. Dept. Agr., Farmers' Bul. 1543: 4. - Douglas and Ingram, 1942. U. S. Dept. Agr., Cir. 632: 6.

californicus Girault. Calif. Host: Anasa tristis (Deg.).

Oenocyrtus californicus Girault, 1917. Deser. Stellarum Nov. p. 22. ๆ. Generic name a lapsus for Ooencyitus.

Biology: Maple, 1947. Calif. Univ., Pubs., Ent. 8 (2): 104-105.

chrysopae Crawford. Fla. Host: Chrysopid.

Ooencyrtus clirysopae Crawford, 1913. U. S. Natl. Mus., Proc. 46 : 347 . $\$$.

clisiocampae (Ashmead). Cosmopolitan. Host: Malacosoma americanum (F.), M. disstria Hbn., M. fragile (Str.).

Encyitus clisiocampae Ashmead, 1893. Ohio Agr. Expt. Sta., Tech. Ser., Bul. 1: 163. ․

Biology: Hodson, 1939. Ent. Soc. Amer., Ann. 32 (1): 131-136. -Kaya and Anderson, 1972.

Environ. Ent. 1 (4): 523-524. - Anderson and Kaya, 1973. Environ. Ent. 2 (4): 705-711.

johnsoni (Howard). Md., Va., N. C., Fla., Tex., Calif. Host: Arilus cristatus (L.), Chlorochroa sayi Stal, Murgautia histrionica (Hahn), coceinellid eggs.

Eucyrtus Johnsoni Howard, 1898. Canad. Ent. 30: 18. đ, ?.

Biology: Drake, 1920. Fla. State Plant Bd., Quart. Bul. 1: 81. -Essig, 1922. Jour. Ent. and

Zool. 14 (4): 76. - White and Brannon, 1933. U. S. Dept. Agr., Farmers' Bul. 1712: 5.

-Maple, 1937. Ent. Soc. Amer., Ann. 30 (1): 123-154. - Huffaker, 1941. Jour Econ. Ent. 34

(1): 117-118. -DeBach, 1942. Jour. Econ. Ent. 35 (5): 787. - Maple, 1947. Calif. Univ., Pubs.

Ent. 8 (2): 105-107.

kuvanae (Howard). New England. Host: Nygmia phaeorrhoea (Donov.), Porthetria dispar (L.), Stilpuotia salicis (L.), Apanteles melanoscelus (Ratz.).

Schedius kucanae Howard, 1910. U. S. Dept. Agr., Bur. Ent., Tech. Bul. 19 (1): 3-5. ठ, ?.

Ooencyrtus kuwanai Peck, 1951. In Muesebeck et al., U. S. Dept. Agr., Agr. Monog. 2: 496. Unjustified emend. 
Biology: Howard and Fiske, 1911. U. S. Dept. Agr., Bur. Ent., Bul. 91: 86, 176-188, 307. -Crossman, 1925. Jour. Agr. Res. 30: 643-675. - Muesebeck and Dohanian, 1927. U. S. Dept. Agr., Bul. 1487: 25. - Burgess and Crossman, 1929. U. S. Dept. Agr., Tech. Bul. 86 : 31-38. - Parker, 1933. Jour. Agr. Res. 46: 23-34. -Lloyd, 1935. Nature 135 (3412): 472-473. -Maple, 1947. Calif. Univ., Pubs. Ent. 8 (2): 107-109. - Clausen, 1956. U. S. Dept. Agr., Tech. Bul. 1139: 116-118. - Templado, 1957. Inst. Biol. Barcelona, Apl. Pubs. 25: 119. - Hitcheock, 1959. Jour. Econ. Ent. 52 (4): 764-765. -Tadic et al., 1959. Zast. Bilja 52-53: 47-52. - Dowden, 1961. Jour. Econ. Ent. 54 (5): 876 . - Bjegovic, 1963. Zast. Bilja 14 (75): 544. - Weseloh, 1971. Ent. Soc. Amer., Ann. 64 (5): 1050-1057.

moneilemae Gahan. Tex. Host: Moneilema crassa Lec.

Ooencyrtus moneilemae Gahan, 1925. Ent. Soc. Wash., Proc. 27 (8): 167-168. d, ?.

\section{Genus PLATENCYRTUS Ferriere}

Platencyrtus Ferriere, 1955. Soc. Ent. de France, Bul. 60 (1-2): 11-12.

Type-species: Platencyrtus parkeri Ferriere. Orig. desig.

Platencyrtus Erdos and Novicky, 1955. Beitr. zur Ent. 5 (1-2): 197.

Type-species: Platencyrtus esuriens Erdos and Novicky. Orig. desig.

Interestingly, both Ferriere and Erdos and Novicky selected the same generic name for identical species. Ferriere's publication date preceeds that of Erdos and Novicky and therefore has priority. This monotypic genus parasitizes mealybugs on Phragmites.

parkeri Ferriere. N. Y.

Platencyrtus parkeri Ferriere, 1955 (Jan.). Soc. Ent. de France, Bul. 60 (1): 11-12. ð, ९.

Platencyrtus esuriens Erdos and Novicky, 1955 (June). Beitr. zur. Ent. 5: 197, ơ, ९.

\section{Genus PSEUDENCYRTUS Ashmead}

Pseudencyrtus Ashmead, 1900. U. S. Natl. Mus., Proc. 22: 340, 346, 396.

Type-species: Encyrtus cecidomyiae Howard. Orig. desig.

A small genus consisting of approximately nine species, Pseudencyrtus is Holarctic in distribution and parasitizes Diptera.

Taxonomy: Erdos, 1957. Acta. Zool. (Budapest). 3 (1-2): 39. -Graham, 1958. Ent. Tidskr. 79

(3-4): 158. - Bakkendorf, 1965. Ent. Meddel. 30 (2): 162-163. -Graham, 1969. Polskie Pismo

Ent. 39 (2): 250-252.

bolus (Walker). Ont.

Encyrtus Bolus Walker, 1844. Ann. and Mag. Nat. Hist. (1) 14: 17..

Taxonomy: Burks, 1975. Brit. Mus. (Nat. Hist.) Ent., Bul. 32 (4): 147-148.

cecidomyiae (Howard). Que., Ont. s. to Fla., w. to Mich. Host: Mayetiola rigidae (O. S.), Rhabdophaga strobiloides (O. S.).

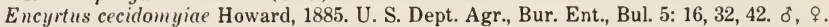

Taxonomy: Girault, 1916. Ent. News 27 (9): 402.

pleuralis (Ashmead). Ohio. Host: Atomaria sp.(?).

Encyrtus pleuralis Ashmead, 1893. Ohio Agr. Expt. Sta., Tech. Ser., Bul. 1: 163. @.

\section{Genus PSEUDENCYRTOIDES Gordh and Trjapitzin}

Pseudencyrtoides Gordh and Trjapitzin, 1975. Ent. Rev, 54 (4): 872-873.

Type-species: Pseudencyitoides cupressi Gordh and Trjapitzin. Orig. desig.

cupressi Gordh and Trjapitzin. Calif. Host: Cecidomiid galls on Cupressus.

Pseudencyrtoides cupressi Gordh and Trjapitzin, 1975. Ent. Rev. 54 (4): 873-875. \&, ठ.

\section{Genus SYRPHOPHAGUS Ashmead}

Syrphophagus Ashmead, 1900. U. S. Natl. Mus., Proc. 22: 340, 346, 397.

Type-species: Encyrtus mesograptae Ashmead. Orig. desig. The type-species is considered to be a synonym Pteromalus quadrimaculatus Ashmead. 
Syrphophagus is a cosmopolitan genus of fly parasites and is related to Pseudencyrtus. About 25 species are recognized.

Taxonomy: Graham, 1958. Ent. Tidskr. 79 (3-4): 160. - Agarwal, 1962. Indian Jour. Ent. 24 (4): 244-251. - Hoffer, 1965. Mus. Nat. Pragae, Acta Ent. 36: 364-369. -De Santis, 1966. Com. Inv. Cient. Prov. Buenos Aires, Notas 3 (9): 7-8. - Erdos, 1957. Acta. Zool.

(Budapest) 3 (1-2): 37-39. - Yasumatsu, 1963. Mushi 37 (10): 124. - Ghesquiere, 1956. Lab. Zool. Gen. Agr. Fac. Agr. Portici, Bol. 33: 701.

quadrimaculatus (Ashmead). S. C. s. to Fla., w. to La. Host: Syrphus ribesii (L.), Roxomerus polita (Say).

Pteromalus 4-muculatae Ashmead, 1881. Canad. Ent. 13 (8): 171-172. ơ, ๆ.

Encyrtus mesograptae Ashmead, 1896. Amer. Ent. Soc., Trans. 23: 232..

Taxonomy: Girault, 1916. Canad. Ent. 48 (10): 344.

smithi Kamal. Calif. Host: Syrphus nitens Zett., S. opinator O. S.

Syrphophugus smithi Kamal, 1926. Canad. Ent. 58 (12): 284. \&.

Biology: Kamal, 1939. Egypt Min. Agr., Tech. and Sci. Serv., Ent. Sect., Bul. 207: 34, 46, 48.

\section{Genus TACHINAEPHAGUS Ashmead}

Tachinaephugus Ashmead, 1904. Carnegie Mus., Mem. 1 (4): 304.

Type-species: Tachinaephagus zealundicus Ashmead. Orig. desig.

Austrulencyrtus Johnson and Tiegs, 1921. Roy. Soc. Queensland, Proc. 33 (6): 118-123.

Type-species: Australencyrtus giraulti Johnson and Tiegs. Orig. desig.

Tachinecphagus Girault, 1917. Insecutor Inscitiae Menstruus 5 (7-9): 142.

Type-species: Tachinacphayus australiensis Girault. Orig. desig.

Stenosterys: Dodd, 1921. In Froggatt, Agric. Gaz. N. S. Wales 32 (10): 728. Unjustified emend. of Stenoter'ys Thomson.

Australomalotylus Risbec, 1956. Ann. Parasit. Hum. Comp. 30 (1-2): 169.

Type-species: Australomalotylus Rageani Risbec. Monotypic.

Tachinaephayus is cosmopolitan in distribution and contains fewer than five species. Apparently all species are parasites of fly pupae.

Taxonomy: Girault, 1924. Homo Perniciosus and New Hymenoptera p. 4. -Ghesquiere, 1960.

Rev. Zool. Bot. Africaines 62 (1-2): 53-58.

Biology: Hardy, 1924. Queensland Agr. Jour. 22 (5): 349-350.

zealandicus Ashmead. Calif, No. Car. Adventive. Host: Diptera pupae.

Tachinaephagus zealandicus Ashmead, 1904. Carnegie Mus., Mem. 1 (4): 304.

Tachinacphagus australiensis Girault, 1917. Insecutor Inscitiae Menstruus 5 (7-9): 142-143.

Stenosterys fulvoventralis Dodd, 1921. Agr. Gaz. N. S. Wales 32 (10): 730-731.

Australencyrtus givaulti Johnson and Tiegs, 1921. Roy. Soc. Queensland, Proc. 33 (6): 118-123.

Australomalotylus rageaui Risbec, 1956. Ann. Parasitol. Hum. Comp. 30 (1-2): 170-173.

Taxonomy: Gahan, 1938. Ent. Soc. Wash., Proc. 40 (8): 210-211. - Ghesquiere, 1960. Rev.

Zool. Bot. Africaines 62 (1-2): 55-56. -Timberlake, 1941. B. P. Bishop Mus., Occas. Papers

16 (9): 216, 226-227.

Biology: Johnson and Tiegs, 1921. Roy. Soc. Queensland, Proc. 33 (6): 107-110, 117.

\section{Genus TRICHOMASTHUS Thomson}

Trichomasthus Thomson, 1876 (1875). Hym. Scand., v. 4, pp. 117, 142-143.

Type-species: Encyitus cyaneus Dalman. Desig. by Gahan and Fagan, 1923.

Coccidoxenus Crawford, 1913. U. S. Natl. Mus., Proc. 45: 248.

Type-species: Coccidoxenus portoricensis Crawford. Orig. desig.

Stenoteropsis Girault, 1915. Queensland Mus., Mem. 4: 176, 181.

Type-species: Stenoteropsis abjectus Girault. Orig. desig.

Tetracnemella Girault, 1915. Queensland Mus., Mem. 4: 170, 182.

Type-species: Tetracnemella australiensis Girault. Orig. desig. 
Trichomasthus is a cosmopolitan genus containing over forty described species, most of which are apparently parasites of soft-scale insects.

Taxonomy: Trjapitzin, 1964. Zool. Zhur. 43 (10): 1457-1462. -Alam, 1957. Roy. Ent. Soc.

London, Trans. 109 (15): 446-450. - Annecke, 1964. Ent. Soc. So. Afr., Jour. 26 (2): 390-410.

-Trjapitzin, 1968. Ent. Rev. 47 (1): 125. —Graham, 1969. Polskie Pismo Ent. 39 (2):

267-269. - Girault, 1924. Homo Perniciosus and New Hymenoptera, p. 10. - Compere,

1937. Bul. Ent. Res. 28 (1): 44-45. - Risbec, 1952. Mem. Inst. Sci. Madagascar Ser. E., Ent. 2: 30-35. -Robinson, 1960. Ent. Soc. So. Afr., Jour. 23 (2): 371-374. (as Coccidoxemus).

albimanus Thomson. N. H., Minn., Kans. Host: Eriopelt is festucae (Fonsc.).

Trichomasthus albimanu.s Thomson, 1876 (1875). Hym. Scand., v. 4, 144.

Taxonomy: Masi, 1926. Soc. Ent. Ital., Bol. 58 (9-10): 162. - Rubtzov, 1954. Vses. Ent. Obshch., Trudy 44: 217.

Biology: Tshumakova, 1961. Ent. Rev. 40 (2): 177. -Zag-Ozaga, 1961. Polskie Pismo Ent. 31 (2): 362, 367. - Sugonyayev, 1962. Akad. Nauk SSSR Izv., Ser. Biol. 5: 760.

cyanifrons (Dalman). N. H., Va., Calif. Host: Lecanium comi Bouche.

Encyrtus cyanifrons Dalman, 1820. Svenska Vetensk. Akad., Handl. 41: 159.

Taxonomy: Mercet, 1923. Soc. Espan. de Hist. Nat., Bol. 23 (1): 49-50. -Alam, 1957. Roy.

Ent. Soc. London, Trans. 109 (15): 447.

Biology: Flanders, 1952. Jour. Econ. Ent. 45 (6): 1078. -Zag-Ozaga, 1961. Polskie Pismo Ent. 31 (2): 362. - Sugonyayev, 1962. Akad. Nauk SSSR Izv., Ser. Biol. 5: 754-766.

mexicanus (Girault). Fla. w. to Ariz.

Coccidoxenus mexicanus Girault, 1917. Descr. Stellarum Nov. p. 21..

niloticus Compere. Calif. Released, possibly established. Host: Saissetia oleae (Oliv.).

Coceidoxenus niloticus Compere, 1940. Hilgardia 13 (7): 395, 405-407. ơ, ๆ.

nubilipennis (Girault). Va. w. to Ill.

Anagyrus uubilipennis Girault, 1909. Psyche 16 (4): 76-77. o, ?.

TRIBE MIRAINI

\section{Genus BAEOCHARIS Mayr}

Baeocharis Mayr, 1876 (1875). Zool.-Bot. Gesell. Wien, Verhandl. 25: 767-768.

Type-species: Baeocharis pascuorum Mayr. Monotypic.

Sphaeropisthus Thomson, 1876 (1875). Hym. Scand., v. 4, pp. 116, 131-132.

Type-species: Sphaeropisthus pascuorum Thomson. Monotypic. The type-species may be a junior synonym of Baeocharis pascuorum Mayr, but see Ferriere (1955).

This genus consists of three Holarctic species that are parasites of scale insects.

Taxonomy: Ruschka, 1912. Zool.-Bot. Gesell. Wien, Verhandl. 62 (7): 240. -Ferriere, 1955.

Ent. Schweiz. Gesell., Mitt. 26 (1): 7.

annulicornis (Ashmead). Fla.

Sphaeropisthus amnulicornis Ashmead, 1900. U. S. Natl. Mus., Proc. 22: 369. o.

auriceps (Ashmead). Fla.

Sphaeropisthus auriceps Ashmead, 1900. U. S. Natl. Mus., Proc. 22: 369-370..+

pascuorum Mayr. N. H. Host: Eriopeltis festucae (Fonsc.).

Baeocharis pascuorum Mayr, 1876 (1875). Zool.-Bot. Gesell. Wien, Verhandl. 25: 768. ठ,.

Encyrtus flavoscutatus Six, 1876. Tijdschr. Ent. 19: 135.

Taxonomy: Trjapitzin, 1968. Vses. Ent. Obshch., Trudy 52: 51.

\section{Genus MAYRIDIA Mercet}

Mayridia Mercet, 1921. Fauna Iberica, Himen., Encirtidos, pp. 426-427.

Type-species: Mayridia pulchra Mercet. Orig. desig. 
This is a Holaretic genus containing 13 species. Host records for this genus are incomplete, but at least two species have been associated with Aclerda and Trionymus. These host genera belong to different coccoid families and are associated with grasses.

Taxonomy: Mercet, 1921. Fauna Iberica, Himen., Encirtidos pp. 426-436. -Erdos, 1957. Acta

Zool. (Budapest). 3 (1-2): 47, 48-54. - Bakkendorf, 1965. Ent. Meddel. 30 (2): 138-139.

-Trjapitzin, 1967. Akad. Nauk SSSR Zool. Inst., Trudy 41: 205-206. -Graham, 1969.

Polskie Pismo Ent. 39 (2): 272-273.

americana Timberlake. N. Dak., S. Dak., Utah. Host: Trionymus utahensis (Ckll.).

Mayrilia americana Timberlake, 1926. U. S. Natl. Mus., Proc. 69 (2629): 28-33. o, ๆ.

ferrierei Burks. N. J. Host: Aclerda xalapenseae McCon. on Panicum xalapense.

Mayridiu ferrierei Burks, 1964. Entomophaga 9 (1): 17-18. ठ, ?.

\section{Genus MIRA Schellenberg}

Miru Schellenberg, 1803. Genres de Mouches Dipteres, p. 68.

Type-species: Mira macrocera Schellenberg. Monotypic.

Dicelloceras Menzel, 1855. Stettin. Ent. Ztg. 17: 270.

Type-species: Dicelloceras vibrans Menzel. Monotypic.

Euryscapus Foerster, 1856. Hym. Stud., v. 2, pp. 32, 35.

Type-species: Eucyrtus platycerus Dalman. Orig. desig.

Lonchoceras Dahlbom, 1857. Ofvers. K. Vetensk. Akad., Forh. 14 (8): 292.

Type-species: Encyrtus platycerus Dalman. Subsequent monotypy (Thomson, 1876 (1875)).

Euzkalia Mercet, 1921. Fauna Iberica, Himen., Encirtidos, pp. 14, 28, 45, 48, 59, 71, 81, 552-553.

Type-species: Enzkadia integralis Mercet. Orig. desig.

Mira is a small genus and is Holarctic in distribution.

Taxonomy: Mercet, 1921. Fauna Iberica, Himen., Encirtidos, pp. 181-183. - Mercet, 1922. Soc.

Espan. de Hist. Nat., Bol. 22 (5): 264-267. - Erdos, 1957. Acta Zool. (Budapest). 3 (1-2):

24-25.

macrocera Schellenberg. Idaho.

Mira macrocera Schellenberg, 1803. Genres de Mouches Dipteres, pp. 68-69.

\section{TRIBE NEOCLADINI}

\section{Genus CARABUNIA Waterston}

Carabunia Waterston, 1928. Bul. Ent. Res. 19 (3): 249.

Type-species: Carabunia myersi Waterston. Orig. desig.

Carabunia is a monotypic genus found in the neotropics. It has been employed in biological control of the spittle bug Clastoptera undulata Uhler.

Biology: Myers, 1930. Bul. Ent. Res. 21 (3): 341-351. - Maple, 1947. Calif. Univ., Pubs. Ent. 8

(2): 70. -Dustan, 1960. Burmuda Dept. Agr., Bul. 33: 1-11.

myersi Waterston. Fla. Host: Clastoptera undulata Uhler.

Carabunia myersi Waterston, 1928. Bul. Ent. Res. 19 (3): 249-251. o, ?.

Biology: Bennett and Hughes, 1963. Entomophaga 8 (1): 49-66.

\section{Genus ZARHOPALUS Ashmead}

Zarhopalus Ashmead, 1900. U. S. Natl. Mus., Proc. 22: 342, 406.

Type-species: Zarhopalus sheldoni Ashmead. Orig. desig.

Anagyrella Girault, 1915. N. Y. Ent. Soc., Jour. 23 (3): 168-169.

Type-species: Anagyrella corvina Girault. Monotypic.

A genus consisting of six species, Zarhopalus is Nearctic and Ethiopian in distribution. One species has been described from the Caribbean. These insects are mealybug parasites. 
Taxonomy: Timberlake, 1924. Calif. Univ., Pubs. Ent. 3 (2): 235-236. -Joubert, 1943. Union So. Africa, Dept. Agr. Forestry, Bul. 243, p. 4. - Bennett, 1957. Canad. Ent. 89 (12): 571-572.

corvinus (Girault). Que., Calif. Host: Pseudococcus maritimus (Ehrh.), P. sp. Anagyrella corvina Girault, 1915. N. Y. Ent. Soc., Jour. 23 (3): 169..

Biology: Clausen, 1924. Calif. Univ., Pubs. Ent. 3 (2): 256-271. -Maple, 1947. Calif. Univ., Pubs. Ent. 8 (2): 55, 115.

inquisitor (Howard). Md. s. to Fla., w. to Ariz. Host: Planococcus citri (Risso).

Eucyrtus inquisitor Howard, 1881. U. S. Dept. Agr., Ann. Rept. for 1880, p. 367..

sheldoni Ashmead. N. Y., Calif. Host: Pseudococcus maritimus (Ehrh.).

Zarhopalus sheldoni Ashmead, 1900. U. S. Natl. Mus., Proc. 22: 406. ๆ.

Biology: Clausen, 1924. Calif. Univ., Pubs. Ent. 3 (2): 257-265. - Clancy and Pollard, 1947. Jour. Econ. Ent. 40 (4): 578-579.

\section{TRIBE PRIONOMASTICINI}

\section{Genus HEXACLADIA Ashmead}

Hexacladia Ashmead, 1891. U. S. Dept. Agr., Insect Life 3 (11-12): 456.

Type-species: Hexacladia smithii Ashmead. Desig. by Ashmead, 1900.

Sophencyrtus Crawford, 1911. U. S. Natl. Mus., Proc. 41: 275-276.

Type-species: Sophencyrtus tou'nsendi Crawford. Orig. desig.

Hexacladia is a New World genus composed of six species. They are parasites of true bugs of the families Coreidae, Pyrrhocoridae and Pentatomidae.

Taxonomy: Howard, 1892. U. S. Natl. Mus., Proc. 15: 364-366. - Ashmead, 1900. U. S. Natl. Mus., Proc. 22: 337, 377. - Timberlake, 1926. U. S. Natl. Mus., Proc. 96 (3): 12. -De Santis, 1965. Com. Inv. Cien. Prov. Buenos Aires, An. 4: 114. - Burks, 1972. Ent. Soc. Wash., Proc. 74 (4): 363-371.

hilaris Burks. Ohio w. to Kans. Host: Acrostermum hilare (Say).

Hexacladia hilaris Burks, 1972. Ent. Soc. Wash., Proc. 74 (4): 363, 367-368. ठ, ๆ.

smithi Ashmead. Fla. Host: Euschistus crenator (F.).

Hexacladia smithi Ashmead, 1891. U. S. Dept. Agr., Insect Life 3 (11-12): 455, 457. §, ९.

\section{TRIBE PSEUDORHOPINI}

\section{Genus PSEUDORHOPUS Timberlake}

Pseudorhopus Timberlake, 1926. U. S. Natl. Mus., Proc. 69 (3): 9.

Type-species: Encyrtus testacens Ratzeburg. Orig. desig.

Apparently some authors have confused this genus with Rhopus. Pseudorhopus is Holarctic and contains four species. They parasitize Physokermes, but also have been reported attacking Lecanium, Lepidosaphes, and other armored scale insect genera.

Taxonomy: Ghesquiere, 1956. Lab. Zool. Gen. Agr. Fac. Agr. Portici, Bol. 33: 686. -Alam, 1957. Roy. Ent. Soc. London, Trans. 109 (15): 423, 459-462. - Hoffer, 1960. Mus. Nat.

Pragae, Acta Faun. Ent. 6: 94.

Biology: Zak-Ogaza, 1961. Polskie Pismo Ent. 31 (2): 357. - Sugonyayev, 1962. Akad. Nauk.

SSSR Izv., Ser. Biol. 5: 754-766. —-Schmutterer, 1965. Ztschr. f. Angew. Ent. 56 (4): 305.

fuscus (Girault). Que., Ont. The host is apparently a coccid, not Choristoneura fumiferana (Clem.) as previously recorded.

Rhopoideus fuscus Girault, 1912. Canad. Ent. 44 (1): 5-8. ?.

Biology: Girault, 1920. U. S. Natl. Mus., Proc. 58: 184.

hartmani Timberlake. Tex. Host: Lecanium sp.

Pseudorhopus hattuani Timberlake, 1926. U. S. Natl. Mus., Proc. 69 (3): 10-12. o,..

Taxonomy: Alam, 1957. Roy. Ent. Soc. London, Trans. 109 (15): 460. 


\section{TRIBE PSILOPHRYDINI}

\section{Genus PSILOPHRYS Mayr}

Psilophrys Mayr, 1876 (1875). Zool.-Bot. Gesell. Wien, Verhandl. 25: 727.

Type-species: Encyrtus longicomis Walker. Monotypic.

Psilophrys is another small, Holarctic genus composed of three or four species. One species has been reported attacking Kermes. Material in the U.S. National Museum Collection indicates that armata may parasitize Aroga.

Taxonomy: Trjapitzin, 1968. Vses. Ent. Obshch., Trudy 52: 69. - Graham, 1969. Polskie Pismo Ent. 39 (2): 235.

armata Ashmead. N. J., Fla. Host: Aroga triablamaculella (Chambers).

Psilophrys armatus Ashmead, 1888. Ent. Amer. 4 (1): 16. ơ, ?.

\section{TRIBE THOMSONISCINI}

\section{Genus QUAYLEA Timberlake}

Quaylea Timberlake, 1919. Hawaii. Ent. Soc., Proc. 4 (1): 214-216.

Type-species: Cerchysins whittieri Girault. Orig. desig.

This is a monotypic genus from Australia. Quaylea whittieri was introduced along with other parasites of the Black scale complex in the belief that it was a primary parasite. It is actually a hyperparasite, as suspected by foreign-explorer George Compere.

whittieri (Girault). Calif. Introduced. Host: Saissetia oleae (Oliv.), Aphycus lounsburyi How., Scutellista cyanea Mots., Tomocera californica How.

Cerchysius whittieri Girault, 1918. Ent. News 29 (2): 66.

Hemencyrtus crawii Timberlake, 1919. Hawaii. Ent. Soc., Proc. 4 (1): 216.

Quaylea aliena Timberlake, 1919. Hawaii. Ent. Soc., Proc. 4 (1): 216-218. o, १.

Taxonomy: Girault, 1918. Ent. News 29 (2): 65-66. - Timberlake, 1922. Hawaii. Ent. Soc., Proc. 5 (1): 166-167. - Timberlake, 1924. Hawaii. Ent. Soc., Proc. 5 (3): 430 . - Smith and Compere, 1928. Calif. Univ. Pubs., Ent. 4 (9): 292-295.

Biology: Flanders, 1943. Jour. Econ. Ent. 36 (6): 922-925. -Flanders, 1944. Ent. Soc. Amer., Ann. 37 (3): 365.

Taxonomy: Maple, 1947. Calif. Univ., Pubs. Ent. 8 (2): 74, 76.

Biology: Woglum et al., 1947. Jour. Econ. Ent. 40 (6): 820. -Clausen, 1956. U. S. Dept. Agr., Tech. Bul. 1139, pp. 125-126.

\section{TRIBE TRECHNITINI}

\section{Genus PRIONOMITUS Mayr}

Prionomitus Mayr, 1876 (1875). Zool.-Bot. Gesell. Wien, Verhandl. 25: 701.

Type-species: Encyrtus chlorinus Dalman. Monotypic. The type-species is considered a synonym of Encyrtus mitratus Dalman.

Prionomitus is Holarctic in distribution and contains about six species. All the species are probably parasites of psyllids.

Taxonomy: Brethes, 1914. Ann. Zool. Aplic. Chile 1: 29-30. -Masi, 1919. Genova Mus. Civ.

Stor Nat., Ann. Ser. 3, 8 (48): 154-155. -Mercet, 1926. Eos 2 (4): 313-315. -Ferriere, 1961.

Entomophaga 6 (1): 41-42. - Erdos, 1963. Beitr. zur Ent. 13 (3-4): 285. - Hoffer, 1963. Mus.

Nat. Pragae, Acta Ent. 35: 553-556. -Graham, 1969. Polskie Pismo Ent. 39 (2): 245-246.

Biology: Ferriere, 1926. Soc. Ent. de France, Ann. 95 (2): 189-192.

mitratus (Dalman). Wis., Utah, B. C. s. to Calif. Host: Psyllid nymphs.

Encyrtus mitratus Dalman, 1820. Svenska Vetensk. Akad., Handl. 41: 352. ๆ.

Encyrtus chlorinus Dalman, 1820. Svenska Vetensk. Akad., Handl. 41: 352 . o.

Encyrtus coniferae Walker, 1837. Ent. Mag. 4: 461. ¿, ९. 
Biology: Jensen, 1957. Hilgardia 27 (2): 71-99. . - Ferriere, 1926. Soc. Ent. de France, Ann. 95 (2): 189-193. - Lal, 1934. Parasitology 26 (3): 327-328. - Bonnemaison and Missonier, 1956. Ann. Epiphyt., Ser. C 7 (2): 310-314. -McMullen, 1964. Wash. State Hort. Assoc., Proc. 60, p. 81. - Harizanov, 1966. Priroda (Sofia) 15 (3): 68-69. - McMullen, 1966. Canad. Ent. 98 (3): 236-237.

tiliaris (Dalman). No. Amer.(?).

Encyrtus tiliaris Dalman, 1820. Svenska Vetensk. Akad., Handl. 41: 171.

Encyrtus subcupratus Walker, 1837. Ent. Mag. 4: 460. ơ, ๆ.

Encyrtus subcupratus var. E. Walker, 1837. Ent. Mag. 4: 461.

Taxonomy: Masi, 1919. Genova Mus. Civ. Stor. Nat., Ann. Ser. 38 (48): 154-155. - Ferriere, 1961. Entomophaga 6 (1): 42.

\section{Genus PSYLLAEPHAGUS Ashmead}

Psyllaephagus Ashmead, 1900. U. S. Natl. Mus., Proc. 22: 339, 345, 382.

Type-species: Encyrtus pachypsyllae Howard. Orig. desig.

Metaprionomitus Mercet, 1921. Fauna Iberica, Himen., Encirtidos, pp. 27, 58, 70, 81, 260-261.

Type-species: Metaprionomitus intermedius Mercet. Orig. desig.

Shakespearia Girault, 1928. Some New Hexapods Stolen from Authority, p. 3 (priv. publ.). Type-species: Shakespearia flabellata Girault. Monotypic.

Calluniphilus Erdos, 1961. Acta. Zool. (Budapest) 7 (3-4): 413-414.

Type-species: Calluniphilus vendicus Erdos. Orig. desig.

Mercetia Bakkendorf, 1965. Ent. Meddel. 30 (2): 139-140.

Type-species: Copidosoma lusitanica Mercet. Orig. desig.

Psyllaephagus is a genus with over 100 described species. It is probably cosmopolitan, but has not been reported from the Neotropical Region. As the name implies, species of Psyllaephagus are parasites of psyllids. However, some species apparently are hyperparasites of other species of Psyllaephagus.

Taxonomy: Ashmead, 1902. Canad. Ent. 34 (11): 302. - Waterston, 1922. Bul. Ent. Res. 13 (1): 42-47. - Ferriere, 1926. Soc. Ent. France, Ann. 95 (2): 191-192. - Gahan and Waterston, 1926. Bul. Ent. Res. 16 (4): 373-375. - Mercet, 1926. Eos 2 (4): 313-315. -Alam, 1957. Roy. Ent. Soc. London, Trans. 109 (15): 423, 456-459. - Ferriere, 1961. Entomophaga 6 (1): 42-48. - Riek, 1962. Austral. Jour. Zool. 10 (4): 684-757. - Trjapitzin, 1967. Akad. Nauk SSSR Zool. Inst., Trudy 41: 190-194. -Trjapitzin, 1968. Vses. Ent. Obshch., Trudy 52: 54. -Graham, 1969. Polskie Pismo Ent. 39 (2): 248-249.

arbuticola Gahan and Waterston. Calif. Host: Euphyllura arbuti Schwarz.

Psyllaephagus arbuticola Gahan and Waterston, 1926. Bul. Ent. Res. 16 (4): 373-375. o, $\%$. pachypsyllae (Howard). Md. s. to N. C., w. to Kans., Calif. Host: Pachypsylla celtidisgemma Riley, P. venusta (O. S.), Trioza beameri Tuthill.

Encyrtus pachypsyllae Howard, 1885. U. S. Dept. Agr., Bur. Ent., Bul. 5: 15, 32, 42. o, ․

Biology: Jensen, 1957. Hilgardia 27: 79, 95. - Waterston, 1922. Bul. Ent. Res. 13 (1): 43. -Appleby and Neiswander, 1962. Ohio Agr. Expt. Sta., Res. Cir. 111, pp. 13. - Moser, 1965. N. Y. State Mus. Sci. Serv., Bul. 402, p. 18.

trioziphagus (Howard). Md. s. to N. C., w. to Ohio, Calif. Host: Trioza diospyri (Ashm.), Kun'ayama medicaginis (Cwfd.).

Eucyrtus trioziphagus Howard, 1885. U. S. Dept. Agr., Bur. Ent., Bul. 5: 14 32, 42. ઠ์, ๆ.

Biology: Eddy, 1927. Ohio Jour. Sci. 27 (4): 196-197. -Cazier, 1964. Pan-Pacific Ent. 40 (2):

73.

vectius (Walker). Florida. Host: Trioza magnolice (Ashm.).

Encyrtus Vectius Walker, 1847. Ann. and Mag. Nat. Hist. (1) 20: 21. ठ.

Encyrtus solus Howard, 1885. U. S. Dept. Agr., Bur. Ent., Bul. 5: 15, 32, 42..

Taxonomy: Gahan and Waterston, 1926. Bul. Ent. Res. 16 (4): 375 . - Burks, 1975. Brit. Mus. (Nat. Hist.) Ent., Bul. 32 (4): 148-149. 


\section{Genus TRECHNITES Thomson}

Trechuites Thomson, 1876 (1875). Hym. Scand. v. 4, pp. 118, 169-170.

Type-species: Metallon fuscitarsis Thomson. Monotypic.

Psylledontus Crawford, 1910. U. S. Natl. Mus., Proc. 38: 88-89.

Type-species: Psylledontus insidiosus Crawford. Orig. desig.

Metallonella Girault, 1915. Queensland Mus., Mem. 4: 77.

Type-species: Metallonella anstraliensis Girault. Orig. desig.

Metallon Thomson, 1876 (1875). In Thomson, Hym. Scand. v. 4., pp. 169-170. Lapsus for Trechnites Thomson.

Trechuites is a Holarctic genus consisting of nine described species. The North American representative of the genus has been recovered from pear psylla.

Taxonomy: Hoffer, 1960. Mus. Nat. Pragae, Acta Faun. Ent. 6: 109-114. -Ferriere, 1961.

Entomophaga 6 (1): 39-41. -Graham, 1969. Polskie Pismo Ent. 39 (2): 243-245.

insidiosus (Crawford). Oreg., Calif. Host: "pear psylla."

Psylledontus insidiosus Crawford, 1910. U. S. Natl. Mus., Proc. 38: 89. o, १.

Biology: Madsen et al., 1963. Canad. Ent. 95 (8): 842-843. -McMullen, 1966. Canad. Ent. 98

(3): 236-239. -Westigard et al., 1968. Jour. Econ. Ent. 61 (3): 740-743.

UNPLACEd TAXa of SUbFamily EnCYRTinae

The following genera have not been placed in the tribal classification of the Encyrtinae.

\section{Genus ATROPATES Howard}

Atropates Howard, 1898. U. S. Natl. Mus., Proc. 21: 236.

Type-species: Atropates collinsi Howard. Monotypic.

A genus with only two described species, one from India and one from North America, Atropates parasitizes Pulvinaria and Lac insects.

Taxonomy: Ferriere, 1935. Bul. Ent. Res. 26 (3): 400-401. -Mani, 1938. Cat. Indian Ins., pt.

23, p. 95. - Mahdihassan, 1957. Ztschr. f. Angew. Ent. 40 (1): 80.

collinsi Howard. N. Y., Wash. Host: Pulvinaria sp.

Atropates collinsi Howard, 1898. U. S. Natl. Mus., Proc. 21: 236-237. ठ, ๆ.

\section{Genus APHYCOIDEUS Williams}

Aphycoideus Williams, 1916. Psyche 23 (5): 153.

Type-species: Aphycoideus io Williams. Monotypic.

io Williams. Mass. Host: Malacosoma americanum (F.).

Aphycoideus io Williams, 1916. Psyche 23 (5): 153. ․

Aplycoileus io Girault, 1917. Descr. Hym. Chalcidoid. Variorum cum Observ. V, p. 5.

\section{Genus BLEPYRUS Howard}

Blepyrus Howard, 1898. U. S. Natl. Mus., Proc. 21: 233-234.

Type-species: Blepyrus mexicanus Howard. Desig. by Ashmead, 1900.

Coccophoctouus Ashmead, 1900. U. S. Natl. Mus., Proc. 22: 337, 344, 375.

Type-species: Coccophoctouns dactylopii Ashmead. Orig. desig. The type-species is considered a synonym of Blepyrus mexicanus.

Blepyrus contains five species which are mealybug parasites. Species in the genus are known from North America, Africa and the Pacific.

Taxonomy: Timberlake, 1922. Hawaii. Ent. Soc., Proc. 5 (1): 168-173. -Gahan, 1942. U. S.

Natl. Mus., Proc. 92: 47-49. - Kerrich, 1967. Brit. Mus. (Nat. Hist.) Ent., Bul. 29 (5):

225-226.

insularis (Cameron), Miss., Tex. Host: Ferrisia virgata (Ckll.).

Encyrtus(?) insularis Cameron, 1886. In Blackburn and Cameron, Manchester Lit. and

Phil. Soc., Mem. and Proc. (3) 10: 243.

Blepyrus mexicanus Howard, 1898. U. S. Natl. Mus., Proc. 21: 234. ठै, ९. 
Blepyms marsdeni Howard, 1898. U. S. Natl. Mus., Proc. 21: 234-235. ؟.

Blepyrus texanus Howard, 1898. U. S. Natl. Mus., Proc. 21: 235. ?.

saccharicola Gahan. Fla., La. Host: Pseudococcus sp. on sugarcane.

Blepyrus saccharicola Gahan, 1942. U. S. Natl. Mus., Proc. 92: 47-49. §, १.

\section{Genus CERAPTROCEROIDEUS Girault}

Ceraptroceroideus Girault, 1916. Psyche 23 (2): 47.

Type-species: Ceraptroceroideus cinctipes Girault. Orig. desig.

A monotypic genus known only from the type-locality.

cinctipes Girault. Kans. (Wellington). Host: Rhizaspidiotus deamessi (Ckll.).

Ceraptroceroideus cinctipes Girault, 1916. Psyche 23 (2): 47-48. o, ?.

\section{Genus CHESTOMORPHA Ashmead}

Chestomarpha Ashmead, 1900. U. S. Natl. Mus., Proc. 22: 335, 343, 370.

Type-species: Chestomorpha biform is Ashmead. Orig. desig.

biformis Ashmead. N. Mex., Ariz.

Chestomorpha biformis Ashmead, 1900. U. S. Natl. Mus., Proc. 22: 370..

\section{Genus EPAENASOMYIA Girault}

Epaenasomyia Girault, 1917. Chalcidoidea Nova Marilandensis iii, p. 3.

Type-species: Epaenasom yia varicom is Girault. Orig. desig.

varicornis Girault. Maryland.

Epaenasomyia varicomis Girault, 1917. Chalcidoidea Nova Marilandensis III. p. 3.

\section{Genus FORCIPESTRICIS Burks}

Forcipestricis Burks, 1968. Ent. News 79 (9): 237-238.

Type-species: Forcipestricis gazeani Burks. Orig. desig.

Forcipestris presently consists of two species, one from Puerto Rico and the other from Eastern North America. Both are larval-pupal parasites of ceratopogonid midges.

Taxonomy: Gordh, 1975. Fla. Ent. 58 (4): 239-241.

gazeaui Burks. Md. Host: Forcipomyia simulata Walley.

Forcipestricis gazeaui Burks, 1968. Ent. News 79 (9): 238-240. ठ’, ․

\section{Genus GAHANIELLA Timberlake}

Gahaniella Timberlake, 1926. U. S. Natl. Mus., Proc. 69: 23-26.

Type-species: Gahaniella californica Timberlake. Orig. desig.

Gahaniella only has three species which are found in Australia, North and South America. All three are presumably hyperparasitic on other encyrtids that attack soft scale-insects and mealybugs.

Taxonomy: Kerrich, 1953. Bul. Ent. Res. 44 (4): 800-802.

californica Timberlake. Calif. Host: Lecanium comi Bouche.

Gahaniella californica Timberlake, 1926. U. S. Natl. Mus., Proc. 69 (3): 26-27. ठ, ?.

Taxonomy: Kerrich, 1953. Bul. Ent. Res. 44 (4): 800-802.

saissetia Timberlake. Fla. Host: Coccus hesperidum L., Saissetia oleae (Oliv.).

Gahaniella saissetiae Timberlake, 1926. U. S. Natl. Mus., Proc. 69 (3): 27-28. ઠ , ๆ.

Taxonomy: Compere, 1939. Calif. Univ., Pubs. Ent. 7 (5): 89.

\section{Genus HEXACNEMUS Timberlake}

Hexacnemus Timberlake, 1926. U. S. Natl. Mus., Proc. 69 (3): 12-15.

Type-species: Hexacnemus armitagei Timberlake. Monotypic. 
This monotypic genus has been found only in North America. The type-species has been reported to parasitize mealybugs as well as Sympherobius.

armitagei Timberlake. Fla., Calif. Host: Sympherobius californicus Banks, S. sp., mealybug on citrus.

Hexacnemus armitagei Timberlake, 1926. U. S. Natl. Mus., Proc. 69 (3): 15-16. o, ๆ.

\section{Genus CAENOCERCUS Thomson}

Caenocercus Thomson, 1876 (1875). Hym. Scand., v. 4, p. 145.

Type-species: Caenocercus puncticollis Thomson. Monotypic.

Bothriencyrtus Timberlake, 1919 (1918). Hawaii. Ent. Soc., Proc. 4 (1): 185, 212-213.

Type-species: Bothriothorax planifrous Howard. Orig. desig. The type-species name is a lapsus for Bothriothorex planiform is Howard.

A small genus with a Holarctic distribution, Caenocercus probably parasitizes Neuroptera.

Taxonomy: Erdos, 1963. Beitr. zur Ent. 13 (3-4): 286-287.

planiformis (Howard). N. C., Miss., Wash., Calif. Host: Hemerobiid.

Bothriothorax planiformis Howard, 1895. U. S. Natl. Mus., Proc. 17: 611. ๆ.

\section{Genus EPICERCHYSIUS Girault}

Epicerchysius Girault, 1915. N. Y. Ent. Soc., Jour. 23 (3): 167-168.

Type-species: Epicerchysius xanthipes Girault. Monotypic.

xanthipes Girault. Tex.

Epicerchysius xanthipes Girault, 1915. N. Y. Ent. Soc., Jour. 23 (3): 168. ९.

\section{Genus FORMICENCYRTUS Girault}

Fornicencyrtus Girault, 1916. Psyche 23 (2): 45.

Type-species: Formicencyrtus thoreauini Girault. Orig. desig.

thoreauini Girault. N. Mex., Ariz. Host: Dactylopins confusus (Ckll.).

Formicencyrtus thoreanini Girault, 1916. Psyche 23 (2): 45-46. ?.

\section{Genus EPANUSIA Girault}

Epanusia Girault, 1913. Arch. f. Naturgesch. 79 (A) (6): 91.

Type-species: Epanusia bifasciatus Girault. Orig. desig.

albiclava Girault. D. C., Okla.

Epanusia albiclava Girault, 1916. Psyche 23 (2): 44 ..

xerophila (Brues). Kans., Tex.

Anusia xerophila Brues, 1906. Ent. News 17 (2): 61-62. ठ.

\section{Genus EPIENCYRTUS Ashmead}

Epiencyrtus Ashmead, 1900. U. S. Natl. Mus., Proc. 22: 340, 346, 396-397.

Type-species: Encyrtus thyreodontis Ashmead. Orig. desig.

A genus of about five species that are hyperparasitic in Lepidoptera. Epiencyrtus appears cosmopolitan in distribution, but it has not been reported from Africa.

Taxonomy: Graham, 1958. Ent. Tidskr. 79 (3-4): 152-153.

artaceae (Howard). Fla. Host: Ophionine ichneumonid.

Encyrtus artaceae Howard, 1881. U. S. Dept. Agr., Ann. Rept. for 1880, pp. 252-253. ơ, ₹.

Taxonomy: Ashmead, 1900. U. S. Natl. Mus., Proc. 22: 397.

thyreodontis (Ashmead). Mass. Host: Thyreodon atricolor (Oliv.).

Encyrtus thyreodontis Ashmead, 1898. Ent. Soc. Wash., Proc. 4 (2): 156. \&.

Biology: Dimmock, 1898. Ent. Soc. Wash., Proc. 4 (2): 149. 


\section{Genus EURYHOPALUS Howard}

Euryhopalus Howard, 1898. U. S. Natl. Mus., Proc. 21: 237.

Type-species: Euryhopalus schwarzi Howard. Monotypic.

Synaspidia Timberlake, 1923. Hawaii. Ent. Soc., Proc. 5 (3): 397-399.

Type-species: Synaspidia pretiosa. Timberlake. Orig. desig.

Taxonomy: Gahan, 1942. U. S. Natl. Mus., Proc. 92: 49. - Kerrich, 1967. Brit. Mus. (Nat.

Hist.) Ent., Bul. 20 (5): 190, 235, 246.

schwarzi Howard. Fla.

Euryhopalus sehwarzi Howard, 1898. U. S. Natl. Mus., Proc. 21: 237..

\section{Genus HABROLEPOPTERYX Ashmead}

Habrolepopteryx Ashmead, 1900. U. S. Natl. Mus., Proc. 22: 330, 359.

Type-species: Psilophrys pulchripennis Ashmead. Orig. desig.

marilandia Girault. Md.

Habrolepopteryx marilandia Girault, 1917. Chalcidoidea Nova Marilandensis I, p. 1..

Habrolepopteryx marylandia Peck, 1951. U. S. Dept. Agr., Agr. Monog. 2: 479. Unjustified emendation.

pulchripennis aeneiscapus Girault. Fla.

Habrolepopteryx pulchripennis var. aeneiscapus Girault, 1916. Ent. News 27 (5): 225..

pulchripennis pulchripennis (Ashmead). Fla., N. C., N. J. Host: Eriococcus carolinae Williams.

Psilophrys pulchripennis Ashmead, 1888. Ent. Amer. 4 (1): 16..

Taxonomy: Girault, 1916. Ent. News 27 (5): 225.

\section{Genus HABROLEPOIDEA Howard}

Habrolepoidea Howard, 1894. Linn. Soc. London, Jour., Zool. 25: 89-90.

Type-species: Habrolepoidea glauca Howard. Monotypic.

Zarhopaloides Girault, 1915. Queensland Mus., Mem. 4: 99.

Type-species: Z arhopaloides axillaris Girault. Orig. desig.

Habrolepoidea contains about 8 species, at least some of which are parasitic on bruchid eggs. The genus is found in North America, the Caribbean, and possibly Australia.

depressa Girault. Ill. Host: Megacyllene robiniae (Forst.).

Habrolepoidea depressa Girault, 1916. Canad. Ent. 48 (10): 343-344. §, ?.

perplexa Girault. $\mathrm{Pa}$.

Habrolepoidea perplexa Girault, 1917. Descr. Hym. Chalcidoid. Variorum cum Observ. V, p. 8 . .

Taxonomy: Girault, 1920. U. S. Natl. Mus., Proc. 58: 185-187.

tarsalis Girault. Ind.

Habrolepoidea tarsalis Girault, 1916. Canad. Ent. 48 (10): 344. ?.

\section{Genus HAMBLETONIA Compere}

Hambletonia Compere, 1936. Hawaii. Ent. Soc., Proc. 9 (2): 172-173.

Type-species: Hambletonia pseudococcina Compere. Orig. desig.

This monotypic genus is found in tropical habitats. It has not been reported from Africa.

pseudococcina Compere. Fla. Host: Dysmicoceus brevipes (Ckll.).

Hambletonia pseudococcina Compere, 1936. Hawaii. Ent. Soc., Proc. 9 (2): 173-174. ơ,.

Biology: Carter, 1937. Jour. Econ. Ent. 30 (2): 370-372. -Plank, 1938. Puerto Rico Agr. Expt.

Sta., Rpt. for 1937. pp. 98-99. - Bartlett, 1939. Puerto Rico Univ., Jour. Agr. 23: 67-71.

-Clausen, 1956. U. S. Dept. Agr., Tech. Bul. 1139: 106. 


\section{Genus HEMAENASIUS Ashmead}

Hemaenasius Ashmead, 1900. U. S. Natl. Mus., Proc. 22: 336, 374.

Type-species: Hemaenasius confusus Ashmead. Orig. desig.

Hemiaenasius Schulz, 1906. Spolia Hym., p. 146. Unjustified emend.

confusus Ashmead. D. C.

Hemaenasius confusus Ashmead, 1900. U. S. Natl. Mus., Proc. 22: 374. \&.

Taxonomy: Girault, 1920. U. S. Natl. Mus., Proc. 58: 183.

\section{Genus HOLCENCYRTUS Ashmead}

Holcencyrtus Ashmead, 1900. U. S. Natl. Mus., Proc. 22: 339, 346, 394.

Type-species: Aphycus niger Ashmead. Orig. desig.

Holcencyrtus contains four species that are New World and Ethiopian in distribution. These insects are parasites of soft scale insects.

niger (Ashmead). Fla.

Aphycus niger Ashmead, 1888. Ent. Amer. 4 (1): 15. ठ.

physokermis Girault. Me., N. H., Wis., Oreg. Host: Physokermes piceae, (Schr.).

Holcencyrtus physokermis Girault, 1916. Ent. News 27 (5): 226-227. ठં, १.

\section{Genus HENICOPYGUS Ashmead}

Henicopygus Ashmead, 1900. U. S. Natl. Mus., Proc. 22: 329, 355-356.

Type-species: Henicopygus subapterus Ashmead. Orig. desig.

subapterus Ashmead. Mont., Colo., Tex.

Henicopygus subapterus Ashmead, 1900. U. S. Natl. Mus., Proc. 22: 356..

Biology: Brues and Melander, 1903. Biol. Bul. 5: 21.

\section{Genus MEROMYZOBIA Ashmead}

Meromyzobia Ashmead, 1900. U. S. Natl. Mus., Proc. 22: 328, 349.

Type-species: Ericydnus maculipennis Ashmead. Orig. desig.

Meromyzobia presently is known only from North and South America. It contain seven species, one of which has been reported to be a parasite of Orthoptera eggs.

Taxonomy: Ashmead, 1900. U. S. Natl. Mus., Proc. 22: 349-350.

americana (Ashmead). Fla.

Prionomastix americana Ashmead, 1888. Ent. Amer. 4 (1): 16. o.

bifasciata (Ashmead). Colo.

Homalotylus bifasciatus Ashmead, 1890. Colo. Biol. Assoc., Bul. 1: 28, 46. \&.

flava Ashmead. D. C.

Meromyzobia flava Ashmead, 1900. U. S. Natl. Mus., Proc. 22: 350. ơ.

flavicincta (Ashmead). Fla.

Choreia flavicincta Ashmead, 1888. Ent. Amer. 4 (1): 17. ?.

maculipennis (Ashmead). N. J., Ohio. Host: Anthracophaga ingrata (Will.), Meromyza americana Fitch.

Ericydnus maculipennis Ashmead, 1893. Ohio Agr. Expt. Sta., Tech. Ser., Bul. 1: 162-163. o.

unifasciata Ashmead. Miss.

Meromyzobia unifasciata Ashmead, 1900. U. S. Natl. Mus., Proc. 22: 350. ๆ.

\section{Genus NEBAOCHARIS Girault}

Nebaocharis Girault, 1916. Psyche 23 (2): 43.

Type-species: Nebaocharis hemipterus Girault. Orig. desig.

hemiptera Girault. Colo.

Nebaocharis hemipterus Girault, 1916. Psyche 23 (2): 43. 


\section{Genus PARAPHAENODISCUS Girault}

Paraphaenodiscus Girault, 1915. Queensland Mus., Mem. 4: 93, 123.

Type-species: Paraphaenodiscus verus Girault. Orig. desig.

Aschitus Mercet, 1921. Fauna Iberica, Himen., Encirtidos pp. 59, 71, 599-600.

Type-species: Aschitus incertus Mercet. Orig. desig.

Paraphaenodiscus presently holds about 17 names. These parasites are predominantly Palearctic and Ethiopian in distribution and attack aclerdids and mealybugs.

Taxonomy: Risbec, 1951. Inst. Fr. Noire, Mem. 13: 147-151. - Hoffer, 1954 (1953). Acta Soc.

Ent. Cechosl. 50: 156-157, 162-167. - Hoffer, 1953. Ochr. Prirody 8 (4): 88. - Ferriere, 1956.

Schweiz. Ent. Ges., Mitt. 29 (4): 391-396. - Hoffer, 1958. Acta. Soc. Ent. Cechosl. 55 (3):

250-263.

subterraneus Ferriere. Tex.(?).

Paraphaenodiscus subterranens Ferriere, 1956. Schweiz. Ent. Gesell., Mitt. 29 (4): 391-393, 395. $\delta, ?$.

\section{Genus PARAPSILOPHRYS How ard}

Parapsilophrys Howard, 1898. U. S. Natl. Mus., Proc. 21: 232-233.

Type-species: Parapsilophrys gelechiae Howard. Monotypic.

gelechiae Howard. Wis. w. to Wyo., Utah. Host: Gelechia sp. on cottonwood, Gelechia lynceella Zeller.

Parapsilophrys gelechiae Howard, 1898. U. S. Natl. Mus., Proc. 21: 233. ¿, ?.

\section{Genus PENTELICUS Howard}

Pentelicus Howard, 1895. U. S. Natl. Mus., Proc. 17: 606, 611-612.

Type-species: Pentelicus aldrichi Howard. Monotypic.

aldrichi Howard. N. H., S. Dak., Nebr.

Pentelicus aldrichi Howard, 1895. U. S. Natl. Mus., Proc. 17: 612. \%.

Taxonomy: Girault, 1920. U. S. Natl. Mus., Proc. 58: 183.

\section{Genus PHEIDOLOXENUS Ashmead}

Pheidoloxenus Ashmead, 1904. Carnegie Mus., Mem. 1 (4): 328, 385.

Type-species: Pheidoloxenus wheeleri Ashmead. Orig. desig.

Pheidoloxenus Girault, 1915. Ent. Soc. Amer., Ann. 8 (3): 273. Preocc. by Ashmead, 1904.

Type-species: Pheidoloxenus wheeleri Girault. Monotypic.

Pheidoloxeniscus Ghesquiere, 1946. Rev. Zool. Bot. Africaines 34 (4): 369. N. name for Pheidoloxenus Girault.

wheeleri Ashmead. Tex. Ecology: Nest of Pheidole tepicana Perg.

Pheidoloxenus wheeleri Ashmead, 1904. Carnegie Mus., Mem. 1 (4): 328, 385. \&.

Pheidoloxenus wheeleri Girault, 1915. Ent. Soc. Amer., Ann. 8 (3): 273. Preoce. by

Ashmead, 1904.

Taxonomy: Wheeler, 1907. Amer. Mus. Nat. Hist., Bul. 23: 17-18.

\section{Genus PSILOPHRYOIDEA Compere}

Psilophryoidea Compere, 1928. Calif. Univ. Pubs., Ent. 4 (8): 214-215.

Type-species: Psilophryoidea comesor Compere. Orig. desig.

comesor Compere. Calif. Host: Kermes cockerelli Ehrh.

Psilophryoidea comesor Compere, 1928. Calif. Univ., Pubs. Ent. 4 (8): 215. ?.

\section{Genus RHYTIDOTHORAX Ashmead}

Rhytidothorax Ashmead, 1900. U. S. Natl. Mus., Proc. 22: 337, 344, 377.

Type-species: Rhytidothorax marlatti Ashmead. Orig. desig.

marlatti Ashmead. Kans.

Rhytidothorax marlatti Ashmead, 1900. U. S. Natl. Mus., Proc. 22: 377. १. 


\section{Genus TETRALOPHIELLUS Ashmead}

Tetralophiellus Ashmead, 1900. U. S. Natl. Mus., Proc. 22: 330, 357.

Type-species: Tetralophiellus brevicollis Ashmead. Orig. desig.

brevicollis Ashmead. Fla., Mo.

Tetralophiellus brevicollis Ashmead, 1900. U. S. Natl. Mus., Proc. 22: 357. §.

\section{Genus TETRALOPHIDEA Ashmead}

Tetrulophidea Ashmead, 1900. U. S. Natl. Mus., Proc. 22: 327, 348.

Type-species: Tetralophidea bakeri Ashmead. Orig. desig.

bakeri Ashmead. Mo., Mont. s. to N. Mex.

Tetrulophidea bakeri Ashmead, 1900. U. S. Natl. Mus., Proc. 22: 348-349. §.

\section{Genus THYSANOMASTIX Perkins}

Thysanomastix Perkins, 1907. Hawaii. Sugar Planters' Assoc. Expt. Sta., Div. Ent., Bul. 4: 55.

Type-species: Thysunomastix koebelei Perkins. Monotypic.

koebelei Perkins. Ariz. Host: Cuerna lateralis (F.).

Thysanounastix koebelei Perkins, 1907. Hawaii. Sugar Planters' Assoc. Expt. Sta., Div.

Ent., Bul. 4: 55. .

\section{Genus ZAOMMOENCYRTUS Girault}

Zaommoencyrtus Girault, 1916. Psyche 23 (2): 46.

Type-species: Zaommoencyitus submicans Girault. Orig. desig.

submicans Girault. Pa. Host: Alobates pernsylvanica (Deg.).

Zaommoencyitus submicans Girault, 1916. Psyche 23 (2): 46-47..

\section{Family EULOPHIDAE}

By B. D. Burks

Taxonomy: Boucek, 1957. In Kratochvil, Klic Zvireny CRS 2: 269-278 (key to Central

European genera; English translation, 1964, Ent. Soc. Canada, Mem. 34: 91-104).

-Graham, 1959. Soc. Brit. Ent., Trans. 13: 169-204 (British fauna). - Boucek, 1959. Mus.

Natl. Pragae, Acta Ent. 33: 117-194 (Central European fauna). - Boucek, 1963. Beitr. z.

Ent. 13: 257-281. - Boucek, 1965. Mus. Natl. Pragae, Acta Ent. 36: 5-90. -Boucek and

Askew, 1968. Index of Entomophagous Insects, Eulophidae (excl. Tetrastichinae), Le

Francois, 254 pp. (Catalog of European fauna).

\section{Subfamily EULOPHINAE}

\section{TRIBE EULOPHINI}

Taxonomy: Graham, 1959. Soc. Brit. Ent., Trans. 13: 173-185 (Eulophinae; keys to British genera and species). - Boucek, 1959. Mus. Natl. Pragae, Acta Ent. 33: 117-120 (Eulophinae; key to genera). - Boucek, 1965. Ent. Soc. Canada, Mem. 34: 91-96 (Eulophinae; key to genera). - Yoshimoto, 1965. Pacific Insects 7: 670 (Eulophinae; key to Hawaiian genera).

-Miller, 1970. Ent. Soc. Canada, Mem. 68: 5-10 (Eulophinae; key to genera).

\section{Genus PNIGALIO Schrank}

Prigalio Schrank, 1802. Fauna Boica 2, pt. 2, p. 315.

Type-species: Ichneumon pectinicomis Linnaeus. Monotypic.

Notanisomorphomyia Girault, 1913. Queensland Mus., Mem. 2: 289.

Type-species: Notanisomorphomyia albicoxa Girault. Orig. desig.

Revision: Miller, 1970. Ent. Soc. Canada, Mem. 68: 11-31.

Taxonomy: Ferriere, 1952. Soc. Veneziana Storia Nat., Bol. 6: 175. -Erdos, 1954. Mus. Nat.

Hung., Ann. Hist.-Nat. (n. s.) 5: 325 (=Eulophus Geoffroy). 
coloni (Girault). Calif. (Walnut Creek). Ecology: From leaf miner in Convolvulus.

Sympiesis coloni Girault, 1917. Descr. Hym. Chalcidoid. Variorum cum Observ. III, p. 2.. .

flavipes (Ashmead). N. B., Que., Maine, s. to Va., w. to B. C., Wash., Oreg., Calif. Ecology:

Prefers hosts making blotch or tentiform mines in the leaves of deciduous plants. Host:

Antispila isabella Clem., Argyresthia aureoargentella Brower, A. thuiella (Pack.),

Coleophora pruniella Clem., Gracillaria sp., Lithocolletis sp., L. celtisella Chamb., $L$. ganlthiella Wlshm., L. malimalifoliella Braun, L. picturella Braun, L. populiella Chamb., L. salicifoliella Chamb., Nepticula sp., Tischeria sp., T. castanaeella Chamb.; Caliroa cerasi (L.), Fenusa pusilla (Lep.), Heterarthrus nemoratus (Fallen), Metallus rohweri MacG.; Agromyza sp., Liriom yza sp.

Sym piesis flavipes Ashmead, 1886. Amer. Ent. Soc., Trans. 13: 133. \&.

Sympiesis tischerice Ashmead, 1888. Kans. Agr. Expt. Sta., Bul. 3: App. p. VI..

Sympiesis quercicola Ashmead, 1888. Kans. Agr. Expt. Sta., Bul. 3: App. p. VII. $q$.

Biology: Lindquist, 1962. Canad. Ent. 94: 530 (tischeriae).

kukakensis (Ashmead). Alaska (Kukak Bay).

Eulophus kukakensis Ashmead, 1902. Wash. Acad. Sci., Proc. 4: 147. ठ.

maculipes (Crawford). N. B., Que., Maine, s. to Va., w. to Alaska, B. C., Ariz. Ecology: Prefers leaf-mining hosts on broad leaved deciduous plants and some evergreens; hosts make blotch or tentiform mines. Host: Octotoma plicatulum (F.); Argyresthia aureoargentella Brower, A. thuiella (Pack.), Bucculatrix ainsliella Murtf., B. packardella Chamb., Cameraria hamadryadella (Clem.), C. hamameliella (Busck), Chrysopora sp., Coptodisca splendoriferella (Clem.), Leucanthiza dircella Braun, Lithocolletis sp., $L$. cincinnatiella Chamb., L. crataegella Clem., L. malimalifoliella Braun, $L$. ostensackenella (Fitch), L. ostryaefoliella Clem., L. tremuloidella Braun, Nepticula sp., Paraclemensia acerifoliella (Fitch), Phyllocnistis populiella Chamb., Tischeria sp., $T$. ambrosiaeella Chamb., T. malifoliella Clem.; Agromyzn sp., A. aristata Mall., Liriom yza melampyga (Loew), Phytagromyza sp., P. populicola (Walk.); Fenusa ulmi Sund., Heterarthrus nemoratus (Fallen), Metallus rohweri MacG.

Sympiesis maculipes Crawford, 1913. U. S. Natl. Mus., Proc. 45: 258. ९, o.

Sympiesis dandolini Girault, 1917. New Chalcid Flies, p. 1., ऽ.

Biology: Schaffner, 1959. U. S. Dept. Agr., Mise. Pub. 767: 81. -Gibbons and Butcher, 1961. Jour. Econ. Ent. 54: 684. - Cheng and LaRoux, 1966. Ent. Soc. Quebec, Ann. 11: 89.

metacomet (Crawford). N. B., Que., Maine, Vt., Conn., Ont., N. Y., Ohio, La., Wis., Mo., Tex., B. C., Calif. Ecology: Prefers as hosts insects making blotch mines in the leaves of deciduous plants. Host: Rhynchaenus pallicornis (Say); Autispila nyssaefoliella Clem., Cameraria caryaefoliella (Clem.), C. hamadryadella (Clem.), Coleophora sp., C. pruniella Clem., Lithocolletis sp., L. aceriella (Clem.), L. picturatella Braun, Lyonetia salicella Busck, Parornix geminatella (Pack.), Tischeria sp.; Fenusa ulmi Sund., Nematus sp., Pontania sp., P. s-desmodioides (Walsh).

Sympiesis metacomet Crawford, 1913. U. S. Natl. Mus., Proc. 45: 257..

Euloph us lineaticoxa Girault, 1916. Soc. Ent. 31: 37. ?.

nemati (Westwood). Ont.; Europe. Host: Pontania sp.

Eulophus uemati Westwood, 1838. Mag. Nat. Hist. (n. s.) 2: 392.

Eulophus Tischbein ii Ratzeburg, 1848. Ichn. d. Forstins., v. 2, p. 154. ठ, ९.

Taxonomy: Graham, 1963. Soc. Brit. Ent., Trans. 15: 183.

Biology: Askew, 1965. Roy. Ent. Soc. London, Proc. (B) 34: 4.

minio (Walker). N. B., Que., s. to Fla., w. to Man., N. Dak., Nebr., Tex. Ecology: An ectoparasite of hosts that form blotch mines on the leaves of deciduous plants. Host: Brachys sp., Exema sp., Mantura floridana Cr., Rhynchaenus pallicornis (Say); Autispila sp., Argyresthia thuiella (Pack.), Chrysopora sp., Coptodisca sp., $C$. splendoriferella (Clem), Leucanthiza amphicarpeaefoliella Clem., Lithocolletis sp., L. celtisella Chamb., L. crataegella Clem., Nepticula sp., Omix sp., Paromix geminatella (Pack.), P. kalmiella (Dietz), Protolithocolletis lathyri Braun, Tischeria sp., T. malifoliella Clem.; Agromyza melampyga Loew, A. parvicomis Loew, Liriomyza sp., Phytagromyza populicola (Walk.), Phytomyza sp., P. ilicicola Loew, P. ilicis Curtis. Eulophus Minio Walker, 1847. Ann. and Mag. Nat. Hist. 20: 26.. 
Elachistus proximus Ashmead, 1894. Amer. Ent. Soc., Trans. 21: 340..

Eulophus gutticentris Girault, 1906. Ent. News 17: 305. ?, ठ.

Sympiesis felti Crawford, 1911. U. S. Natl. Mus., Proc. 40: 448. $\subsetneq$.

Sympiesis agromyzae Gahan, 1913. U. S. Natl. Mus., Proc. 46: 440..

Sympiesis agromyzae var, penusylvanicus Girault, 1917. Descr. Stellarum Nov., p. 7..

Sympiesis wordsuorthi Girault, 1917. Descr. Hym. Chalcidoid. Variorum cum Observ. III, p. 10. .

Taxonomy: Burks, 1975. Brit. Mus. (Nat. Hist.) Ent., Bul. 32 (4): 175 (synonymy; lectotype designated).

pallipes (Provancher). Ont.

Caccophagus(!) pallipes Provancher, 1887. Addit. Corr. Faune. Ent. Canada Hym., p. 206. ㅇ.

Coccophagns pallilipes Dalla Torre, 1898. Cat. Hym., v. 5, p. 226. Emend.

Taxonomy: Burks, 1964 (1963). Canad. Ent. 95: 1257.

uroplatae (Howard). N. B., Que., Maine, s. to Fla., w. to Utah, Ariz., Oreg., Calif. Ecology:

Prefers hosts that are leaf-miners forming blotch mines on deciduous plants. Host:

Baliosus ruber (Web.), Microrhopala vittata (F.), Odontota suturalis Thunb.,

Rhynchaenus pallicornis (Say), Xenochalepus dorsalis (Thunb.); Ancylis comptana

fragariae (W. and R.), Antispila sp., Cameraria hamadryadella (Clem.), Coleophora sp.,

C. salmani Hein., Gracillaria belfrageella Chamb., Leucanthiza dircella Braun,

Lithocolletis sp., L. celtisella Chamb., L. cincinnatiella Chamb., Neurobathra

strigifinitella (Clem.), Tischeria malifoliella Clem.

Sympiezns uroplatae Howard, 1885. Ent. Amer. 1: 117. o.

Sympiesis unicarinatus Ashmead, 1894. Amer. Ent. Soc., Trans. 21: 343. ๆ.

Taxonomy: Girault, 1916. Soc. Ent. 31: 37.

Biology: Chittenden, 1902. U. S. Dept. Agr., Div. Ent. Bul. 38: 82.

\section{Genus SYMPIESIS Foerster}

Sympiesis Foerster, 1856. Hym. Stud., v. 2, pp. 74, 76.

Type-species: Eulophus sericeicomis Nees. Orig. desig.

Teleogmius Foerster, 1856. Hym. Stud., v. 2, pp. 72, 74.

Type-species: Teleogmus orbitalis Foerster. Monotypic.

Sympiezus Thomson, 1878. Hym. Scand., v. 5, p. 208. Emend.

Pseudopheliminus Girault, 1913. Queensland Mus., Mem. 2: 286.

Type-species: Psendopheliminus longiventris Girault. Orig. desig.

Notanisomorphella Girault, 1913. Queensland Mus., Mem. 2: 287.

Type-species: Notanisomorphella australiensis Girault. Orig. desig.

Moroceras Erdos, 1954. Mus. Nat. Hung., Ann. Hist. Nat. (n. s.) 5: 323.

Type-species: Moroceras biro Erdos. Orig. desig.

Sympiesis subg. Cladosympiesis Graham, 1959. Soc. Brit. Ent., Trans. 13: 182.

Type-species: Eulophus gordius Walker. Orig. desig.

Revision: Boucek, 1959. Mus. Natl. Pragae, Acta Ent. 33: 121-138 (Central European species, with subgenera). -Miller, 1970. Ent. Soc. Canada, Mem. 68: 31-121.

Taxonomy: Boucek, 1959. Mus. Natl. Pragae, Acta Ent. 33: 121. -Delucchi, 1962. Awamia 5:

60. -Graham, 1963. Soc. Brit. Ent., Trans. 15: 187.

acrobasidis Miller. Va., Fla., Miss., Tex. Acrobasis sp., A. caryivorella Rag., A. indigenella (Zell.), A. juglandis (LeB.).

Sympiesis acrobasidis Miller, 1970. Ent. Soc. Canada, Mem. 68: 76. \&, ১.

ancylae Girault. N. B., Que., Ont., N. Y., Md., Va., N. C., Ohio, Tenn., Ill., Minn., Iowa, Ark.,

Kans., Alta., Calif. Ecology: Parasitizes hosts that roll leaf margins of deciduous plants.

Host: Ancylis comptana fragariae (W. and R.), Gelechia sp., Sparganothis sulphureana (F.).

Sympiesis ancylae Girault, 1917. U. S. Natl. Mus., Proc. 53: 448. \&.

Biology: Lewis, 1925. Jour. Econ. Ent. 18: 609-612. - Balduf, 1959. Ill. Biol. Monog. 26: 146. 
argenticoxae Girault. Que., Ont., Md., Va., W. Va., Ohio, Tenn., Ill., Mo., Man. Ecology: Parasitizes hosts living in rolled leaves or between leaves tied together with silk. Host: Ancylis divisana Walk., Coleophora malivorella Riley, Psilocorcis quercicella Clem.

Sympiesis argenticoxae Girault, 1917 (1916). Insecutor Inscitiae Menstruus 4: 120..

bimaculatipennis (Girault). N. B., Que., Maine, s. to Va., w. to Alaska, s. to Calif. Ecology:

Prefers lepidopterous hosts that make blotch mines or skeletonize leaves of deciduous plants; has been recorded as parasitizing leaf rollers. Host: Agonopterix posticella (Wlsm.), Ancylis comptana fragariae (W. and R.), Lithocolletis sp., L. blanchardella (F.), Ornix sp., Paromix geminatella (Pack.), Spilonota lariciana (Hein.), S. ocellana (D. and S.), Tischeria malifoliella (Clem.).

Astichus bimaculatipennis Girault, 1912. Canad. Ent. 44: 8. ₹.

Sympiesis bimaculata Crawford, 1913. U. S. Natl. Mus., Proc. 45: 259..+

Sympiesis meteori Girault, 1916. Soc. Ent. 31: 37. \&.

Biology: Sadava and Miller, 1967. Canad. Ent. 99: 436-442.

conica (Provancher). N. B., Que., Maine, s. to Fla., w. to N. W. T., B. C., Wash., Oreg., Calif.

Ecology: Parasitizes hosts that make blotch or tentiform mines in the leaves of deciduous plants; ectoparasitic on host larvae. Host: Bucculatrix sp., Caloptilia rhombifoliella (Chamb.), Cameraria caryaefoliella (Clem.), C. hamadryadella (Clem.), Choristonenra conflictana (Walk.), Coleophora pruniella Clem., Coleotechnites milleri (Busck), Epinotia laracana Kft., Gracillaria alnivorella Chamb., G. azaleella Brants, G. negundella Chamb., Lithocolletis sp., L. alnicolella Wlshm., L. blancardella (F.), L. cincinnatiella (Chamb.), L. crataegella Clem., L. lucetiella Clem., L. salicifoliella Chamb., L. tremuloidella Braun, Nepticula sp., Parornix geminatella (Pack.), Phyllocnistis sp., Tischeria malifoliella Clem.; Sciaphila sp.; Apanteles sp.

Metacolus conicus Provancher, 1887. Addit. Corr. Faune Ent. Canada Hym., p. 200. Coccophagus compressicornis Provancher, 1887. Addit. Corr. Faune Ent. Canada Hym., p. 206. ․

Sympiesis nigripes Ashmead, 1888. Kans. Agr. Expt. Sta., Bul. 3: App. p. VII. ㅇ, ð. Sympiesis massasoit Crawford, 1913. U. S. Natl. Mus., Proc. 45: 258. ๆ, ठ์.

Taxonomy: Burks, 1964 (1963). Canad. Ent. 95: 1257, 1259.

Biology: Schaffner, 1959. U. S. Dept. Agr., Misc. Pub. 767: 81. - Miller, 1970. Ent. Soc. Canada, Mem. 68: 42.

dolichogaster Ashmead. Que., Ont., Maine, s. to Fla., w. to Kans., B. C., Idaho; Europe. Ecology: Prefers lepidopterous hosts that mine deciduous leaves in early development and then live in leaf rolls in later development. Host: Caloptilia fraxinella (Ely), Episimus argutanns (Clem.), Gracillaria sp., G. belfrageella Chamb., G. cuculipennella (Hbn.), G. negundella Chamb., G. perseae Busck, G. sassafrassella Chamb., Hydriomena renunciata (Wlkr.).

Sympiesis dolichogaster Ashmead, 1888. Kans. Agr. Expt. Sta., Bul. 3: App. p. VII. $\$$. Sympiesis nowickii Szelenyi 1941. Frag. Faun. Hung. 4: 27..

Taxonomy: Girault, 1916. Soc. Ent. 31: 36-37. - Boucek, 1959. Mus. Natl. Pragae, Acta Ent. 33: 130 .

enargiae Miller. N. B., Que., Ont., N. W. T., B. C. Ecology: Parasitic on lepidopterous larvae that hide between leaves tied with silk or in rolled or curled leaves. Host: Enargia decolor (Walk.).

Sympiesis enargiae Miller, 1970. Ent. Soc. Canada, Mem. 68: 42. , ð.

fragariae Miller. Conn., Pa., Del., Md., Va., W. Va., Ga., Ohio, Wis., Kans. Ecology: Parasitizes lepidopterous larvae that live within rolled leaves or within cases. Host: Ancylis comptana fragariae (W. and R.), Anthophila pariana (Clerck), Argyrotaenia velutimana (Walk.), Coleophora malivorella Riley, Tetralopha robustella Zell.

Sympiesis fragariae Miller, 1970. Ent. Soc. Canada, Mem. 68: 68. \&, ठ.

marylandensis Girault. N. B. and Que., s. to Va., w. to B. C., s. to Calif. Ecology: Parasitizes lepidopterous hosts that make blotch mines in deciduous leaves. Host: Caloptilia elongella (L.), Coleotechnites thujaeella Kearf., Lithocolletis sp., L. basistrigella Clem., L. blancardella (F.), L. celtisella Chamb., L. crataegella Clem., L. felinelle Hein., $L$. 
lucidicostella Clem., L. malimalifoliella Braun, L. propinquinella Braun, L. robiniella Clem., L. salicifoliella Chamb., Paromix geminatella (Pack.), Peronea chalybeana Fern., Phyllocnistis populiella Chamb.; Heterarthrus nemoratus (Fallen).

Sympiesis marylandensis Girault, 1917 (Feb.). Entomologist 50: 37. \&.

Sympiesis rex Girault, 1917 (March). New Chaleid Flies, p. 2.

Sympiesis miltoni Girault, 1917 (May). Descr. Hym. Chalcidoid. Variorum cum Observ. III, p. 7. . .

Sympiesis lexingtonensis Girault, 1917 (Aug.). Deser. Hym. Chalcidoid. Variorum cum Observ. V, p. 6. $q$.

marylandia Girault. Que., Ont., N. H., Md., Minn. Ecology: Has been reared from oak leaves, probably from leaf miners.

Sympiesis marilandia Girault, 1917. Chalcidoidea Nova Marilandensis, p. 1..

Sympiesis marylandia Peck, 1951. In Muesebeck et al., U. S. Dept. Agr., Agr. Monog. 2: 427. Emend.

stigmata Girault. Ill., Sask., Wyo., Alta., Idaho, Ariz., B. C., Oreg., Calif. Ecology: Parasitizes leaf miners or case bearers on deciduous leaves. Host: Coleophora pruniella Clem., Gracillaria negundella Chamb., Lithocolletis felinelle Hein., Tischeria omissa Braun.

Sympiesis stigmatus Girault, 1917 (May). Deser. Stellarum Nov., p. 15. ๆ.

Sympiesis substigmatus Girault, 1917 (Aug.). U. S. Natl. Mus., Proc. 53: 447. \&.

stigmatipennis Girault. N. B., Que., Ont., s. to S. C., w. to B. C., s. to Calif. Ecology: Parasitic on lepidopterous larvae mining foliage of coniferous plants as well as others having deciduous foliage; it is possible these are alternate hosts. Host: Argyresthia thuiella (Pack.), Argyrotaenia citrana (Fern.), Chrysoesthia sexguttella (Thunb.), Coleophora eleagnisella Kearf., Coleotechnites apicitripunctella (Clem.), C. gibsonella (Freem.), C. milleri (Busck), C. starki (Freem.), Exoteleia dodecella (L.), E. pinifoliella (Chamb.), Keiferia lycopersicella (Wlsm.), Ocnerostoma piniariella Zell., Phthorimaea operculella (Zell.), Polyhymno luteostrigella Chamb., Rhyacionia buoliana (Schiff.), R. frustrana (Comst.).

Sympiesis stigmatipennis Girault, 1917. Deser. Stellarum Nov, p. 14. ₹, ठ.

Sympiesis guttatipennis Girault, 1917. Descr. Stellarum Nov., p. 15. ․

Biology: Graf, 1917. U. S. Dept. Agr., Bul. 427: 33-38.

tricladus (Provancher). Ont.

Eulophus tricladus Provancher, 1887. Addit. Corr. Faune Ent. Canada Hym., p. 208. $?$, o.

Taxonomy: Burks, 1964 (1963). Canad. Ent. 95: 1258.

viridula (Thomson). N. B., Que., Ont., N. Y., Pa., Ohio, Mich., Ind., Wis., Ill., Minn., Iowa, Mo., N. Dak., S. Dak., Nebr., Wyo., Colo., Alta.; Europe. Ecology: Parasitizes host in its burrow within stalk. Introduced from Europe for biological control; liberated in 1930, and occasional specimens recovered. First found in established colonies in 1938, in Ohio and Michigan. Host: Ostrinia unbilalis (Hbn.), O. obumbratalis (Led.), O. penitalis (Grote), Papaipema nebris (Guen.).

Eulophus viridulus Thomson, 1878. Hym. Scand., v. 5, p. 233. \&.

Taxonomy: Ellinger and Sachtleben, 1928. Internatl. Corn Borer Invest., Sci. Rpt. (1): 126-129. - Boucek, 1959. Mus. Natl. Pragae, Acta Ent. 33: 123, 125, 134.

Biology: Dudich, 1928. Internatl. Corn Borer Invest., Sci. Rpt. (1): 188. - Thompson and Parker, 1928. U. S. Dept. Agr., Tech. Bul. 59: 17. - Sachtleben, 1930. Internatl. Corn Borer Invest., Sci. Rpt. 3: 52, 108-111. - Parker and Smith, 1933. Ent. Soc. Amer., Ann. 26: 21-39. - Baker and Bradley, 1940 (1939). Sixth Pacific Sci. Cong., Proc. 4: 332-333. - Wishart, 1943. Ent. Soc. Ontario, Ann. Rpt. 73: 28-29. - Arbuthnot, 1953. North Central States Br. Ent. Soc. Amer., Proc. 8th Ann. Meet., pp. 30-31. - Blickenstaff et al., 1953. Iowa State Col., Jour. Sci. 27: 360. - York et al., 1955. Jour. Econ. Ent. 48: 765. -Clausen, 1956. U. S. Dept. Agr., Tech. Bul. 1139: 129-130. - Rolston et al., 1958. Ohio Agr. Expt. Sta., Res. Bul. 819: 20. - Peters et al., 1961. Mo. U. Coll. Agr., Res. Bul. 757: 14. -Hazdistevic, 1961. Zast. Bilja 65-66: 107. -Goos, 1965. Polskie Pismo Ent. (B) 37-38: 66. - Hudon, 1965. Phytoprotection 46: 113. - Frye, 1971. N. Dak. Res. Rpt. 27: 1-16. 


\section{Genus NECREMNUS Thomson}

Necremnus Thomson, 1878. Hym. Scand., v. 5, pp. 208, 234.

Type-species: Eulophus leucarthros Nees. Desig. by Ashmead, 1904.

Revision: Gahan, 1941. Wash. Acad. Sci., Jour. 31: 196-203. - Boucek, 1959. Mus. Natl.

Pragae, Acta Ent. 33: 147-155 (Central European spp.). - Graham, 1959. Soc. Brit. Ent., Trans. 13: 184 (British spp.).

breviramulus Gahan. Ill., Mo., Kans. Host: Hypera compta (Say), H. eximia (LeC.).

Necremnus breviramulus Gahan, 1941. Wash. Acad. Sci., Jour. 31: 197, 199. \&, ¿.

californicus (Girault). N. Dak., Calif.

Eulophus californicus Girault, 1917. U. S. Natl. Mus., Proc. 53: 446..

comptus Gahan. Calif.

Necremmus comptus Gahan, 1941. Wash. Acad. Sci., Jour. 31: 197, 198. \&.

Taxonomy: Boucek, 1959. Mus. Natl. Pragae, Acta Ent. 33: 150 (? syn. of artynes Walker). cyriades (Walker). Fla., D. C. Host: Hedia ochroleucana (Hbn.).

Eulophus Cyriades Walker, 1847. Ann. and Mag. Nat. Hist. (1) 20: 25. ठ.

Taxonomy: Burks, 1975. Brit. Mus. (Nat. Hist.) Ent., Bul. 32 (4): 142.

duplicatus Gahan. Idaho, Wash. Host: Ceutorhynchus assimilis (Payk.).

Necremnus duplicatus Gahan, 1941. Wash. Acad. Sci., Jour. 31: 197, 198, 201. ๆ, ઠ.

Taxonomy: Boucek, 1959. Mus. Natl. Pragae, Acta Ent. 33: 152 (? syn. of tidius Walker).

Biology: Hanson, Carlson, and Breakley, 1948. Wash. Agr. Expt. Sta., Bul. 498: 14-15. -Walz, 1957. Ent. Soc. Amer., Ann. 50: 220.

iphinoe (Walker). Fla.

Eulophus Iphinoe Walker, 1847. Ann. and Mag. Nat. Hist. (1) 20: 25. ठॅ.

Eulophus Gobryas Walker, 1847. Ann. and Mag. Nat. Hist. (1) 20: 26. "ठ" = .

Taxonomy: Burks, 1975. Brit. Mus. (Nat. Hist.) Ent., Bul. 32 (4): 145 (synonymy; lectotype designated).

oregonensis Gahan. Oreg. Host: Hypera rumicis (L.).

Necremnus oregonensis Gahan, 1941. Wash. Acad. Sci., Jour. 31: 197, 200. \&, ð.

Biology: Chamberlin, 1933. Ent. Soc. Wash., Proc. 35: 107 (Necremnus sp.).

\section{Genus HEMIPTARSENUS Westwood}

Hemiptarsenus Westwood, 1833. Mag. Nat. Hist. 6: 122.

Type-species: Hemiptarsenus fulvicollis Westwood. Desig. by Westwood, 1840.

Hemiptarsenoideus Girault, 1916. Queensland Mus., Mem. 5: 220.

Type-species: Hemiptarsenoideus semialbiclava Girault. Desig. by Gahan and Fagan, 1923.

Cleolophus Mercet, 1924. R. Soc. Esp. Hist. Nat., Bol. 24: 461.

Type-species: Cleolophus autonomus Mercet. Orig. desig.

Taxonomy: Boucek, 1959. Mus. Natl. Pragae, Acta Ent. 33: 144. - Hedqvist, 1963. Stud.

Forest. Suecica 11: 142.

americanus (Girault). N. Y., D. C., Md., Va., Colo.

Hemiptarsenoideus americanus Girault, 1916. U. S. Natl. Mus., Proc. 51: 47. .

\section{Genus PARDiAUlomelLA Girault}

Pardiaulomella Girault, 1915. Queensland Mus., Mem. 3: 295.

Type-species: Pardiaulomella consonus Girault. Orig. desig.

ibseni Girault. D. C., Va., Fla., Ohio, Iowa, Ark., Tex. Host: Desmia funeralis (Hbn.).

Pardianlomella ibseni Girault, 1916. U. S. Natl. Mus., Proc. 51: 50. ๆ, ठ.

Biology: Strauss, 1916. U. S. Dept. Agr., Bul. 419: 9-12. 


\section{Genus DIAULOMORPHA Ashmead}

Diaulomorpha Ashmead, 1900. Linn. Soc. N. S. Wales, Proc. 25: 347.

Type-species: Dianlomorpha australiensis Ashmead. Monotypic.

borrowi (Girault). Calif. This species is represented only by a fragmentary type specimen.

Eulophus borrowi Girault, 1917. Deser. Hym. Chalcidoid. Variorum cum Observ. III, p. 9. 오.

Taxonomy: Girault, 1920. U. S. Natl. Mus., Proc. 58: 201.

\section{Genus DIGLYPHUS Walker}

Diglyphns Walker, 1844. Ann. and Mag. Nat. Hist. 14: 409.

Type-species: Cirrospilus chabrias Walker. Monotypic.

Solenotus Foerster, 1856. Hym. Stud., v. 2, pp. 74, 76.

Type-species: Solenotus viridis Foerster. Monotypic.

Diaulus Ashmead, 1904. Carnegie Mus., Mem. 1: 356, 357. Preocc. by Mueller, 1879.

Type-species: Diaulus begini Ashmead. Monotypic.

Solenonotus Schulz, 1906. Spolia Hym., p. 143. Emend. Preoce. by Reuter, 1871.

Revision: Crawford, 1912. U. S. Natl. Mus., Proc. 43: 183-185 (Diaulinus).

Taxonomy: Gahan and Fagan, 1923. U. S. Natl. Mus., Bul. 124: 43. -Ferriere, 1952. Soc.

Veneziana Storia Nat., Bol. 6: 176. -Graham, 1959. Soc. Brit. Ent., Trans. 13: 178. - Peck, 1963. Canad. Ent., Sup. 30: 102-104.

begini (Ashmead). Que., N. H., N. Y., Md., Ind., Kans., Wyo., N. Mex., Idaho, Calif.; Mexico.

Host: Agromyza parvicom is Loew, Phytomyza albiceps Meig., P. atricomis Meig.

Dianlus begini Ashmead, 1904. Carnegie Mus., Mem. 1: 356, 372. ๆ.

Taxonomy: Gahan and Peck, 1946. Wash. Acad. Sci., Jour. 36: 315.

Biology: Webster and Parks, 1913. Jour. Agr. Res. 1: 78. - Sweetman, 1936. Biol. Control of

Insects, pp. 146-147. - Doutt, 1957. Jour. Econ. Ent. 50: 373.

intermedius (Girault). R. I., Fla., Ill., Calif. Host: Liriomyza propepusilla Frost, Phytomyza atricomis Meig.

Diaulinus intermedius Girault, 1916. Canad. Ent. 48: 265. ९.

Dianlinus carlylei Girault, 1917. Descr. Hym. Chalcidoid. Variorum cum Observ. III, p. 6. \%.

Taxonomy: Girault, 1920. U. S. Natl. Mus., Proc. 58: 203.

Biology: Michelbacher et al., 1952. Jour. Econ. Ent. 45: 473.

pulchripes (Crawford). Ont., N. Y., Md., Ind., Ill., Mich., Host: Agromyza parvicomis Loew, Liriomyza melampyga (Loew), Phytobia posticata (Meig.), Sargus lucens Loew.

Diaulinus pulchripes Crawford, 1912. U. S. Natl. Mus., Proc. 43: 184. ๆ.

websteri (Crawford). Maine, Mass., N. Y., Kans., Utah, Ariz., Nev., Calif. Host: Agromyza parvicomis Loew, Cerodontha dorsalis (Loew), Meoneura obscurelia (Fall.), Phytobia artemisiae (Kalt.).

Diaulinus websteri Crawford, 1912. U. S. Natl. Mus., Proc. 43: 184. ๆ, ठ.

Biology: Webster and Parks, 1913. Jour. Agr. Res. 1: 78-79. - Hills and Taylor, 1951. Jour.

Econ. Ent. 44: 760.

\section{Genus NOTANISOMORPHA Ashmead}

Notanisomorpha Ashmead, 1904. Carnegie Mus., Mem. 1: 356, 357.

Type-species: Notanisomorpha collaris Ashmead. Orig. desig.

ainsliei Crawford. N. Y., Del., Ind., La., Colo., Utah. Host: Agrom yza parvicornis Loew, Phytobia angulata (Loew).

Notanisomorpha ainsliei Crawford, 1912. U. S. Natl. Mus., Proc. 43: 185. ð’, ९. calavius (Walker). Md., Fla.

Eulophus Calavius Walker, 1847. Ann. and Mag. Nat. Hist. (1) 20: 24. ค, ઠ .

Taxonomy: Burks, 1975. Brit. Mus. (Nat. Hist.) Ent., Bul. 32 (4): 141 (lectotype designated). 
collaris Ashmead. Que., N. Y., Md., Ga., Tex., Idaho.

Notanisomorpha collaris Ashmead, 1904. Carnegie Mus., Mem. 1: 356, 382. .

Taxonomy: Crawford, 1912. U. S. Natl. Mus., Proc. 43: 185. -Girault, 1917. Descr. Hym.

Chalcidoid. Variorum cum Observ. III, p. 2. - Gahan and Peck, 1946. Wash. Acad. Sci., Jour. 36: 316.

longifasciata Girault. Que., Ont., N. J., Ind. Host: Phytobia angulata (Loew).

Notanisomorpha longifasciata Girault, 1917. Descr. Hym. Chalcidoid. Variorum cum Observ. III, p. 2. .

meromyzae Gahan. Ind., N. Dak., S. Dak., Kans. Host: Meromyza americana Fitch.

Notanisomorpha meromyzae Gahan, 1917. U. S. Natl. Mus., Proc. 53: 216. ค, ð.

nevadensis Girault. Nev.

Notanisomorpha nevadensis Girault, 1917. Descr. Hym. Chalcidoid. Variorum cum Observ III, p. 1. $\%$.

noncarinata Girault. Ariz.

Notanisomorpha noncarinata Girault, 1917. Descr. Hym. Chalcidoid. Variorum cum

Observ. III, p. 1. $ๆ$.

particola Girault. Fla.

Notanisomorpha particola Girault, 1916. Soc. Ent. 31: 42 ..

\section{Genus EULOPHUS Olivier}

Eulophus Geoffroy, 1762. Hist. Abrege des Insectes, v. 2, p. 312. Not available, teste Opinion 228, Internatl. Comn. Zool. Nomencl., 1954.

Type-species: Ichneumon ramicomis Fabricius. Desig. by Latreille, 1810.

Eulophus Olivier, 1791. Encycl. Meth., v. 6, p. 454.

Type-species: Ichneumon ramicornis Fabricius. Monotypic.

Comedo Schrank, 1802. Fauna Boica 2, pt. 2, p. 315.

Type-species: Ichnenmon larvarum Linnaeus. Monotypic.

Cratotechus Thomson, 1878. Hym. Scand., v. 5, pp. 208, 219.

Type-species: Ichneumon larvarum Linnaeus. Desig. by Ashmead, 1904.

Cratotrechus Dalla Torre, 1898. Cat. Hym., v. 5, p. 55. Emend.

Comedo subg. Onychocomedo Graham, 1959. Soc. Brit. Ent., Trans. 13: 183.

Type-species: Eulophus thespius Walker. Orig. desig.

Revision: Crawford, 1912. U. S. Natl. Mus., Proc. 43: 186-188 (comedo).

Taxonomy: Boucek, 1959. Mus. Natl. Pragae, Acta Ent. 33: 160. -Gijswijt, 1964. Ent. Ber.

24: 31 (Eulophus Muller, 1764).

anomocerus (Crawford). Que., Ont., Conn., N. Y., N. J., Va., W. Va., Mich., N. Dak. Host: Anthophila pariana (Clerck), Schizura unicornis (Smith).

Comedo anomocerns Crawford, 1912. U. S. Natl. Mus., Proc. 43: 187. ๆ, ઠ.

Biology: Schaffner and Griswold, 1934. U. S. Dept. Agr., Misc. Pub. 188: 81, 154. - Raizenne, 1952. Canad. Dept. Agr., Forest Lep. and Par., p. 91.

basalis Say. Ind., Mo.

Eulophus basalis Say, 1836. Boston Jour. Nat. Hist. 1: 273. ․

Comedo omari Girault, 1917. Descr. Hym. Chalcidoid. Variorum cum Observ. III, p. 9. \&.

brevicapitatus (Cook and Davis). Que., Mass., Mich., La. Host: Euplexia benesimilis McD., Heterocampa bilineata (Pack.), H. manteo (Dbldy.), Symmerista albifrons (Smith).

Cratotechus brevicapitatus Cook and Davis, 1891. Mich. Agr. Expt. Sta., Bul. 73: 12. , o.

Biology: Dimmock, 1898. Ent. Soc. Wash., Proc. 4: 150. - Schaffner and Griswold, 1934. U. S. Dept. Agr., Misc. Pub. 188: 154.

koebelei (Crawford). Calif. Host: Orgyia vetusta (Bdvl.).

Comedo koebelei Crawford, 1912. U. S. Natl. Mus., Proc. 43: 187. \&.

magnisulcatus Girault. Maine, s. to W. Va. Host: Coleophora laricella (Hbn.) C. malivorella Riley, C. pruniella Clem.

Eulophus magnisulcatus Girault, 1916. Ent. News 27: 404. .

Biology: Schaffner, 1959. U. S. Dept. Agr., Misc. Pub. 767: 43, 81. 
nebulosus (Provancher). Ont., Mass., s. to Fla., w. to Wis. Host: Amphipyra pyramidoides Guen., Lithophane sp.

Miotropis nebulosa Provancher, 1887. Addit. Corr. Faune Ent. Canada Hym., p. 208. \&.

Comedo hookeri Craw ford, 1912. U. S. Natl. Mus., Proc. 43: 188. १.

Biology: Schaffner and Griswold, 1934. U. S. Dept. Agr., Misc. Pub. 188: 49, 154.

neomexicanus (Girault). N. Mex.

Comedo neomexicanus Girault, 1917. New Chalcid Flies, p. 4.

Taxonomy: Girault, 1920. U. S. Natl. Mus., Proc. 58: 201.

orgyiae (Fitch). Que., Ont., N. Y., N. J., Pa., N. C., Miss., Wis., Wash., Oreg., Calif. Host:

Acronicta grisea Walk., Alsophila pometaria (Harris), Caloptilia rhoifoliella (Chamb.), Gluphisia septentrion is Walk., Orgyia leucostigma (J. E. Smith), O. plagiata (Walk.), Orthosia hibisci (Gn.), Stenoma algidella (Walk.).

Trichogramma? orgyiae Fitch, 1856. Country Gentleman 7: 235.

Taxonomy: Fitch, 1856. N. Y. State Agr. Soc., Trans. 15: 448-449. - Howard, 1897. U. S. Dept. Agr., Div. Ent., Tech. Ser. 5: 28. -Girault, 1920. U. S. Natl. Mus., Proc. 58: 201.

Biology: Raizenne, 1952. Canad. Dept. Agr., Forest Lep. and Par., pp. 39, 49, 92, 97, 109, 257. smerinthi (Ashmead). Ont., N. H., Mass., Md. Host: Alsophila pometaria (Harris), Amphipyra pyramidoides Guen., Paonias excaecata (Smith).

Cratotechus smerinthi Ashmead, 1898. Ent. Soc. Wash., Proc. 4: 158. \&, o.

Taxonomy: Girault, 1920. U. S. Natl. Mus., Proc. 58: 201. - Burks, 1964 (1963). Canad. Ent. 95: 1257.

Biology: Dimmock, 1898. Ent. Soc. Wash., Proc. 4: 150. - Schaffner and Griswold, 1934. U. S. Dept. Agr., Misc. Pub. 188: 52, 154.

\section{Genus DAHLBOMINUS Hincks}

Microplectron Dahlbom, 1857. Ofvers. Svenska Vetensk.-Akad., Forh. 14: 292 (no species). -Thomson, 1878. Hym. Scand., v. 5, p. 222. One species. Preocc. by Streubel, 1842. Type-species: Entedon fuscipennis Zetterstedt. Included by Thomson, 1878.

Dahlbominus Hincks, 1945. Entomologist 78: 90. N. name.

fuscipennis (Zetterstedt). Newfoundland, Que., Ont., Maine, N. Y., Conn., Pa., N. J., Del., Md., Va., N. C., Mich., Wis., Ill., Minn., Mo.; Europe. Introduced for biological control from Europe in 1933 in Eastern Canada and in 1935 in Northeastern U. S. Recovered promptly and much subsequent spread by natural dissemination. Host: Diprion similis (Htg.), Gilpinia frutetomum (F.), G. hercyniae (Htg.), Neodiprion lecontei (Fitch), $N$. nanulus Schedl, N. pinetum (Nort.), N. pratti (Dyar), N. sertifer (Geof.), N. swainei Midd., N. tsugae Midd., Pristiphora erichsonii (Htg.).

Entedon fuscipennis Zetterstedt, 1838. Insecta Lapponica, p. 427 [recte 429]...

Taxonomy: Boucek, 1959. Mus. Natl. Pragae, Acta Ent. 33: 145. - Finlayson, 1960. Canad. Ent. 92: 37-44 (immature stages).

Biology: Morris and Cameron, 1935. Bul. Ent. Res. 26: 407-418. -Ullyett, 1936. Bul. Ent. Res. 27: 195-217. - Ullyett, 1936. Roy. Ent. Soc. London, Proc. (B) 120: 253-291. - Dowden, 1939. Jour. Econ. Ent. 32: 623. -Miller, 1940. U. S. Bur. Ent. Plant Quar. ET-161: 1-5. -Balch, 1941 (1940). N. S. Dept. Lands and Forests, Rpt., pp. 72-74. - Wilkes, 1942. Roy. Ent. Soc. London, Proc. (B) 130: 400-415. - Wilkes, 1947. Roy. Ent. Soc. London, Proc. (B) 134: 227-245. - Burnett, 1951. Amer. Nat. 85: 337. - Reeks, 1953. Canad. Jour. Agr. Sci. 33: 408. - Burnett, 1953. Ecology 34: 322. -Coppel, 1954. Canad. Ent. 86: 168. - Burnett, 1956. Ent. Soc. Amer., Ann. 49: 55. -Clausen, 1956. U. S. Dept. Agr., Tech. Bul. 1139: 101-102. - Riordan, 1957. Canad. Jour. Zool. 35: 603. - Burnett, 1958. Canad. Ent. 90: 279. -Finlayson and Finlayson, 1958. Canad. Ent. 90: 587. - Milin, 1959. Zast. Bilja 51: 40. -Finlayson, 1960. Canad. Ent. 92: 38 (fuliginosus (Nees)). - Szmidt, 1960. Anz. f. Schadlingsk. 33: 20. - Szmidt, 1961. Poznan. Wyzsza Skola Roln. Rocz. Dodatek 6: 11. - Kepler and Benjamin, 1960. Forest Sci. 6: 262. - Bobb, 1962. Brooklyn Ent. Soc., Bul. 57: 102. - Bobb, 1963. Jour. Econ. Ent. 56: 620. -Finlayson, 1963. Canad. Ent. 95: 498. 
-Morris, Schroeder, and Bobb, 1963. Pine Sawfly in Va., Va. Div. Forestry. pp. 15-16.

-Wilkes, 1964. Science 144: 305-307 (fuliginosus (Nees)), - Avramenko, 1964. Zashch.

Rast. Vred. Boleznei 9: 53. - Pschorn-Walcher, 1964. Pflanzenschutz 31: 62. - Becker and

Benjamin, 1964. Jour. Econ. Ent. 57: 356. - Bobb, 1965. Jour. Econ. Ent. 58: 926.

-Kolonits, 1965. Erdeszeti Kutat. 61: 231. - Rose, 1965. Canad. Dept. Forestry, Forest

Ent. and Path., Ann. Rpt. p. 89. - Rose and Sippell, 1966. Canad. Ent. 98: 41. - Stadnitskii, 1966. Zashch. Rast. Vred. Boleznei 11: 50. - Byers and Wilkes, 1970. Canad. Jour. Zool. 48: 959-964.

\section{Genus DIMMOCKIA Ashmead}

Dimmockia Ashmead, 1904. Carnegie Mus., Mem. 1: 357.

Type-species: Eulophus incongruus Ashmead. Monotypic.

Crateulophus Masi, 1917. Novitates Zool. 24: 206.

Type-species: Crateulophus niger Masi. Monotypic.

incongrua (Ashmead). Ont., Mass., s. to Fla., w. to Ill. Host: Anacampsis innocuella (Zell.), Argyrotoxa semipurpurana (Kearf.), Episimus argutanus (Clem.), Sphecodina abbotii (Swains.), Sparganothis peltitana (Rob.); Exorista larvarum (L.), Winthemia datanae (Tsn.); Apanteles clisiocampae Ashm., A. congregatus (Say), A. melanoscelus (Ratz.), Psychophagus omnivorus (Wlk.), Sphecophaga burra (Cress.). Almost always a secondary parasite.

Eulophus incongruus Ashmead, 1898. Ent. Soc. Wash., Proc. 4: 158. ๆ, ठ.

Dimmockia botticellini Girault, 1917. New Chalcid Flies, p. 2.

Biology: Muesebeck and Dohanian, 1927. U. S. Dept. Agr., Bul. 1487: 12, 29-30. - Proper, 1934. Jour. Agr. Res. 48: 362. -Schaffner, 1959. U. S. Dept. Agr., Misc. Pub. 767: 82.

-Kulman, 1965. Jour. Econ. Ent. 58: 68.

Morphology: Snodgrass, 1910. U. S. Natl. Mus., Proc. 39: 66.

marylandica Girault. Md. Type of this sp. lost and no other specimens known.

Dimmockia marylandica Girault, 1920. U. S. Natl. Mus., Proc. 58: 202. ․

pallipes Muesebeck. Mass., Wis., Ill. Ecology: Probably always secondary. Host: Apanteles sp., A. melanoscelus (Ratz.).

Dimmockia pallipes Muesebeck, 1927. Jour. Agr. Res. 34: 333. , §.

Biology: Muesebeck and Dohanian, 1927. U. S. Dept. Agr., Bul. 1487: 12, 30. - Forbes et al., 1961. Canad. Dept. Forestry, Ann. Rpt., p. 33.

\section{Genus DICLADOCERUS Westwood}

Dicladocerus Westwood, 1832. London, Edinb. and Dublin Phil. Mag. and Jour. Sci. (3) 1: 128.

Type-species: Dicladocerus westwoodii Westwood. Monotypic.

Diglyphus Thomson, 1878. Hym. Scand., v. 5, p. 208. Misspelling. Preocc. by Walker, 1844.

Diglyph is Thomson, 1878. Hym. Scand., v. 5, p. 235.

Type-species: Diglyphis aeniscapus Thomson. Desig. by Gahan and Fagan, 1923.

Diaulinus Schulz, 1906. Spolia Hym., p. 146. N. name for Diglyphus Thomson.

Taxonomy: Graham, 1959. Soc. Brit. Ent., Trans. 13: 180.

albitarsis (Ashmead). D. C.

Eulophus albitarsis Ashmead, 1900. Ent. News 11: 623..

dicladus (Say). Ind.

Eulophus dicladus Say, 1836. Boston Jour. Nat. Hist. 1: 273. ․

westwoodii Westwood. Ont.; Europe. Introduced from Europe for biological control, 1938. Host: Coleophora laricella ( $\mathrm{Hbn}$.).

Dicladocerus Westwoodii Westwood, 1832. London, Edinb. and Dublin Phil. Mag. and Jour. Sci. (3) 1: 128. , ठ.

Taxonomy: Ferriere, 1933. In Thorpe, Bul. Ent. Res. 24: 290. -Boucek, 1959. Mus. Natl.

Pragae, Acta Ent. 33: 145. - Graham, 1963. Soc. Brit. Ent., Trans. 15: 180. 
Biology: Thorpe, 1933. Bul. Ent. Res. 24: 277-280. - Graham, 1944. Ent. Soc. Ontario, Ann. Rpt. 74: 50-51. - Pschorn-Walcher, 1964. Commonwealth Inst. Biol. Control, Tech. Bul. 4: 27.

\section{TRIBE EUPLECTRINI}

Taxonomy: Ferriere, 1941. Bul. Ent. Res. 32: 17-48 (fauna of Europe, Asia, Africa). -Gadd, 1945. Bul. Ent. Res. 36: 331-337 (generic characters). - Boucek, 1957. In Kratochvil, Klic Zvireny CSR 2: 270. - Lin, 1963. Taiwan Mus., Quart. Jour. 16: 102 (Oriental fauna).

\section{Genus EUPLECTRUS Westwood}

Euplectrus Westwood, 1832. London, Edinb. and Dublin Phil. Mag. and Jour. Sci. (3) 1: 128. Type-species: Euplectrus maculiventris Westwood. Monotypic.

Diplectrou Dahlbom, 1857. Ofvers. Svenska Vetensk.-Akad., Forh. 14: 292 (no species). -Dalla Torre, 1898. Cat. Hym., v. 5, p. 74. Seventeen species.

Type-species: Pteromalus bicolor Swederus. Desig. by Gahan and Fagan, 1923.

Pachyscapha Howard, 1897 (1896). Linn. Soc. London, Jour., Zool. 26: 159.

Type-species: Pachyscapha insularis Howard. Monotypic.

This is one of the very few chalcidoid genera that spin cocoons; these usually are placed under the emaciated body of the host larva.

Revision: Girault, 1916. Canad. Ent. 48: 265.

bicolor (Swederus). Maine, Mass., N. J.; Europe, N. Africa. Host: Amathes c-nigrum (L.), Epiglea amiata (Grote).

Pteromalus Bicolor Swederus, 1795. Svenska Vetensk. Akad., Handl. 16: 204.

Taxonomy: Graham, 1963. Soc. Brit. Ent., Trans. 15: 172.

Biology: Silvestri, 1911. Lab. Zool. Gen. e Agr. Portici, Bol. 5: 308. - Lacroix, 1924. Ent.

News 35: 217. - Thomsen, 1927. Dansk. Naturalhist., Meddel. 84: 73-89. - Beckwith, 1929.

N. Y. Ent. Soc., Jour. 37: 415. - Bischoff, 1929. Ztschr. f. Wiss. Insektenbiol. 24: 78-82.

-Steiner, 1936. Ztschr. f Angew. Ent. 23: 212-214.

Morphology: Domenichini, 1953. Bol. Zool. Agr. e Bach. 19: 270.

catocalae Howard. N. J., Md., Ill., Mo. Host: Catocala sp.

Euplectrus catocalae Howard, 1885. U. S. Dept. Agr., Bur. Ent. Bul. 5: 27. १, o.

comstockii Howard. Conn., s. to Fla., w. to S. Dak., Ariz.; Cent. and S. Amer. Host: Alabama argillacea (Hbn.), Autographa sp., Heliothis zea (Boddie), Plathypena scabra (F.), Spodoptera frugiperda (J. E. Smith), S. omithogalli (Guen.), Trichoplusia ni (Hbn.).

Euplectrus Comstockii Howard, 1880. Canad. Ent. 12: 158. ठ.

Biology: Schwarz, 1881. Amer. Nat. 15: 61-63. - Howard, 1914 (1913). Ent. Soc. Wash., Proc.

15: 161. - Luginbill, 1928. U. S. Dept. Agr., Tech. Bul. 34: 72-73. - Bibby, 1942. Jour. Econ. Ent. 35: 943.

frontalis Howard. Que., Ont., N. H., N. J., Va., Kans. Host: Amathes c-nigrum (L.). Euplectrus frontalis Howard, 1885. U. S. Dept. Agr., Bur. Ent. Bul. 5: 27. 9.

Biology: Fyles, 1896. Ent. News 7: 44.

hircinus (Say). Ind., Kans.

Eulophus hirciuus Say, 1836. Boston Jour. Nat. Hist. 1: 274.

insularis (Howard). Fla.; West Indies, S. Amer.

Pachyscapha insularis Howard, 1896. Linn. Soc. London, Jour., Zool. 26: 159. ठँ.

junctus Gahan. Fla. Host: Isoparce cupressi (Bdvl.).

Euplectrus junctus Gahan, 1927. U. S. Natl. Mus., Proc. 71 (4): 30..

leucotrophis Howard. Fla.

Euplectrus leucotrophis Howard, 1885. U. S. Dept. Agr., Bur. Ent. Bul. 5: 26. ðे.

marginatus Ashmead. Fla., Tenn.

Euplectus(!) marginatus Ashmead, 1885. Amer. Ent. Soc., Trans. 12: Proc. p. xviii. $q$, o. 
mellipes Provancher. Que., Ont., Maine, N. H., Wis., Alaska. Host: Coleophora laricella (Hbn.), Feralia jocosa (Guen.).

Euplectrus mellipes Provancher, 1887. Addit. Corr. Faune Ent. Canada Hym., p. 207. 9.

Taxonomy: Burks, 1964 (1963). Canad. Ent. 95: 1258.

Biology: Guppy, 1959. Canad. Ent. 91: 426. - Evans, 1960. Ent. Soc. Amer., Ann. 53: 566.

-Evans, 1962. Canad. Ent. 94: 597.

pachyscapha Girault. Kans.

Euplectmes pachyscapha Girault, 1917. New Chalcid Flies, p. 2. ‡, ð.

plathypenae Howard. N. J., s. to Fla., w. to Nebr., Kans., Tex.; West Indies, Cent. and S.

Amer. Host: Diatraea saccharalis (F.), Heliothis zea (Boddie), Leucania latiuscula

(H.-S.), Manduca sexta (L.), Peridroma niargaritosa (Haw.), Platlypena scabra (F.),

Pseudaletia unipnncta (Haw.), Spodoptera exigua (Hbn.), S. frugiperda (J. E. Smith), S. ornithogalli (Guen.), S. sunia (Guen.).

Euplectrus(!) platyhypenae(!) Howard, 1885. U. S. Dept. Agr., Bur. Ent. Bul. 5: 26. ๆ, ठ์.

Biology: Vickery, 1929. U. S. Dept. Agr., Tech. Bul. 138: 16-21, 42-45, 55-59. -Crumb, 1929.

U. S. Dept. Agr., Tech. Bul. 88: 155. - Simmonds, 1932. Agr. Jour. Fiji 5: 8. - Wilson, 1933.

Fla. Ent. 17: 3, 7-12. -Clausen, 1956. Pan-Pacific Ent. 32: 126. -Bennett, 1961. Tenn.

Acad. Sci., Jour. 36: 353. - Marin Acosta, 1966. Agron. Trop. 16: 155. -Burrell, 1967. Jour.

Econ. Ent. 60: 114.

semimarginatus Girault. Tex.

Euplectrus semimarginatus Girault, 1917. Descr. Hym. Chalcidoid. Variorum cum Observ. V, p. 1. ․

\section{Genus EUPLECTROMORPHA Girault}

Euplectromorpha Girault, 1913. Queensland Mus., Mem. 2: 276.

Type-species: Euplectromorpha unifasciata Girault. Orig. desig.

americana Girault. Md.

Euplectromorpha americana Girault, 1916. Insecutor Inscitiae Menstruus 4: 114. ठ.

\section{TRIBE ELACHERTINI}

Taxonomy: Boucek, 1957. In Kratochvil, Klic Zvireny CSR 2: 270.

\section{Genus DIAULINOPSIS Crawford}

Diaulinopsis Crawford, 1912. U. S. Natl. Mus., Proc. 43: 182.

Type-species: Diaulinopsis callichroma Crawford. Monotypic.

Achrysocharelloidea Girault, 1913. Roy Soc. So. Australia, Trans. 37: 109.

Type-species: Achrysocharelloidea pax Girault. Monotypic.

albiscapus (Girault). Md., Minn.

Achrysocharelloidea albiscapus Girault, 1916. Canad. Ent. 48: 336. ․

callichroma Crawford. Md., s. to Fla., w. to Calif.; Mexico., West Indies, Northern S. Amer.

Host: Agromyza sp., Cerodontha dorsalis (Loew), Liriomyza sp., Phytobia artemisiae (Kaltb.).

Diaulinopsis callichroma Crawford, 1912. U. S. Natl. Mus., Proc. 43: 183. ๆ, ठ․

\section{Genus ARDALUS Howard}

Ardalus Howard, 1896. Linn, Soc. London, Jour., Zool. 26: 161.

Type-species: Ardalus aciculatus Howard. Desig. by Ashmead, 1904.

Revision: Gahan, 1922. U. S. Natl. Mus., Proc. 61 (24): 20.

insuetus (Gahan). Fla., La., Tex. Host: Lerema accius (A. and S.).

Euplectrus insuetus Gahan, 1914. U. S. Natl. Mus., Proc. 48: 164. 9.

Taxonomy: Gahan, 1922. U. S. Natl. Mus., Proc. 61 (24): 19-20.

Biology: Ainslie, 1922. Fla. Ent. 6: 14. 


\section{Genus PARAOLINX Ashmead}

Paraolinx Ashmead, 1894. Linn. Soc. London, Jour., Zool. 25: 166.

Type-species: Paraolinx lineatifrons Ashmead. Monotypic.

Leucodesmia Howard, 1895. U. S. Dept. Agr., Insect Life 7: 403.

Type-species: Leucodesmia typica Howard. Monotypic.

Revision: Miller, 1964. Canad. Ent. 96: 1352-1362.

canadensis Miller. Que., Maine, Fla., Ohio, Calif.; Mexico. Ecology: An external parasite of gelechiid larvae. Host: Coleotechnites sp., C. apicitripunctella (Clem.), Homadaula anisocentra Meyrick.

Paraolinx canadensis Miller, 1964. Canad. Ent. 96: 1354. ๆ, ठ์.

taedae Miller. N. C., Ark. Host: Rhyacionia frustrana (Comst.).

Paraolinx tuedae Miller, 1964. Canad. Ent. 96: 1356. $\%, \delta$.

typica (Howard). Va., N. C., Fla., La., Ariz., Calif.; West Indies. Host: Laetilia coccidivora (Comst.), Paramyelois transitella (Walk.), Pyroderces rileyi (Wlsm.).

Leucodesmia typica Howard, 1895. U. S. Dept. Agr., Insect Life 7: 402. ๆ, ठ.

Lencodesmia nigriventris Girault, 1916. U. S. Natl. Mus., Proc. 51: 46. \&.

Taxonomy: Miller, 1964. Canad. Ent. 96: 1358.

\section{Genus STENOMESIUS Westwood}

Stenomesius Westwood, 1833. London, Edinb. and Dublin Phil. Mag. and Jour. Sci. (3) 3: 343.

Type-species: Stenomesius pulchellus Westwood. Desig. by Westwood, 1840.

harrisinae Ashmead. N. J., Fla. Host: Harrisina americana (Guer.).

Stenomesius harrisinae Ashmead, 1887. Amer. Ent. Soc., Trans. 14: 200. ९.

levana (Walker). Fla.

Elachestus Levana Walker, 1847. Ann. and Mag. Nat. Hist. (1) 20: 27. \&.

Taxonomy: Burks, 1975. Brit. Mus. (Nat. Hist.) Ent., Bul. 32 (4): 145 (lectotype designated).

\section{Genus MIOTROPIS Thomson}

Miotropis Thomson, 1878. Hym. Scand., v. 5, pp. 187, 197.

Type-species: Miotropis sulcicristata Thomson. Desig. by Ashmead, 1904.

Mionotropis Schulz, 1906. Spolia Hym., p. 143. Emend.

Stenomesioideus Ashmead, 1904. Carnegie Mus., Mem. 1: xi, 355, 389.

Type-species: Stenomesioideus melleus Ashmead. Monotypic.

Stenomesioidea Girault, 1916. U. S. Natl. Mus., Proc. 51: 43.

Type-species: Stenomesioidea mellea Girault. Orig. desig.

melleus Ashmead. D. C. Host: Coleophora caespititiella Zell.

Stenomesioideus melleus Ashmead, 1904. Carnegie Mus., Mem. 1: xi, 355. ․

Stenomesioidea mellea Girault, 1916. U. S. Natl. Mus., Proc. 51: 44..

\section{Genus ELACHERTUS Spinola}

Elachertus Spinola, 1811. Paris Mus. d'Hist. Nat., Ann. 17: 151.

Type-species: Diplolepis lateralis Spinola. Desig. by Gahan and Fagan, 1923.

Microterus Spinola, 1811. Paris Mus. d'Hist. Nat., Ann. 17: 151.

Type-species: Diplolepis petiolata Spinola. Desig. by Gahan and Fagan, 1923.

Elachestus Nees, 1834. Hym. Ichn. Aff. Monog., v. 2, p. 135. Emend.

Elachistus Foerster, 1856. Hym. Stud., v. 2, p. 73. Emend.

Epardalus Girault, 1917. Descr. Hym. Chalcidoid. Variorum cum Observ. III, p. 5.

Type-species: Elachistus cidariae Ashmead. Orig. desig.

aeneoniger Girault. Ont., N. Y., Ohio, Wis., Minn., B. C., Oreg. Host: Ancylis comptana fragariae (W. and R.), Argyrotaenia pinatubana (Kearf.), Argyresthia orea sella Clem.

Choristoneura fumiferana (Clem.).

Elachistus aeneoniger Girault, 1917. Descr. Hym. Chalcidoid. Variorum cum Observ. III, p. 2. . . 
eacoeciae Howard. N. H., Mass., N. J., Pa., D. C., Va., Mo., Utah, Oreg. Host: Ancylis comptana fragariae (W. and R.), Archips argyrospilus (Walk.), Choristoneura rosaceana (Harr.), Argyrotaenia velutinana (Walk.), Heterocampa guttiritta (Walk.), Hyphantria cunea (Drury), Schizura unicornis (Smith); Eulophus orgyiae (Fitch).

Elachistus cacoeciae Howard, 1885. U. S. Dept. Agr., Bur. Ent. Bul. 5: 28. ð.

Biology: Carolin and Coulter, 1959. Jour. Econ. Ent. 52: 552.

cidariae Ashmead. N. H., Mass. Host: Lygris diversilineata (Hbn.).

Elachistus cidariae Ashmead, 1898. Ent. Soc. Wash., Proc. 4: 157. \&.

Taxonomy: Girault, 1917. Descr. Hym. Chalcidoid. Variorum cum Observ. III, p. 5.

coxalis Howard. D. C., Va., Mich., Calif. Host: Paralobesia viteana (Clem.), Parornix geminatella (Pack.).

Elachistus coxalis Howard, 1885. U. S. Dept. Agr., Bur. Ent. Bul. 5: 28. ₹.

Biology: Hill and Hough, 1957. Va. Agr. Expt. Sta., Tech. Bul. 130: 16.

glacialis Ashmead. Colo., Alaska, Wash., Oreg. Host: Barbara colfaxiana (Kearf.), Mellisopus latiferreanus (Wlsm.).

Elachistus glacialis Ashmead, 1902 Wash. Acad. Sci., Proc. 4: 147. \&, đ.

Biology: Keen, 1958. U. S. Dept. Agr., Tech. Bul. 1169: 94.

hyphantriae Crawford. Mass., N. Y., N. J., Ark., Tex., Colo. Host: Hyphantria cunea (Drury), Orgyia definita (Pack.).

Elachertus hyphantriae Crawford, 1911. U. S. Natl. Mus., Proc. 39: 622. 9.

Biology: Schaffner and Griswold, 1934. U. S. Dept. Agr., Misc. Pub. 188: 37, 155. - Raizenne, 1952. Canad. Div. Forest Biol., Forest Lep. S. Ont. and Par., p. 31.

louisiana (Girault). La.

Epardalus lonisiana Girault, 1917. Descr. Hym. Chalcidoid. Variorum cum Observ. III, p. 5. .

marylandicus Girault. Mass., Conn., N. J., Md. Host: Diacrisia virginica (F.), Hyphantria cunea (Drury).

Elachistus marylandicus Girault, 1916. Brooklyn Ent. Soc., Bul. 11: 112. ?.

Biology: Schaffner and Griswold, 1934. U. S. Dept. Agr., Misc. Pub. 188: 36, 155. —Swain, 1937. Ent. News 48: 246.

multidentatus (Girault). Fla.

Parentedon multidentatus Girault, 1917. Descr. Hym. Chalcidoid. Variorum cum Observ. III, p. 5 . + .

pini Gahan. Maine, Vt., Mass., Va., Mich. Host: Dioryctria sp., Rhyacionia frustrana (Comst.). Elachertus pini Gahan, 1927. Jour. Agr. Res. 34: 547. $\$$, ठ̊.

Biology: Cushman, 1927. Jour. Agr. Res. 34: 617.

proteoteratis Howard. Que., Ont., Conn., N. J., Pa., Mich., Mo., Idaho, Ariz., B. C., Calif. Host: Proteoteras aesculana Riley, Stenoma algidella (Walk.).

Elachistus proteoteratis Howard, 1885. U. S. Dept. Agr., Bur. Ent. Bul. 5: 27..

Euplectrus viridaeneus Provancher, 1887. Addit. Corr. Faune Ent. Canada Hym., p. 207; errata. $\$$.

Taxonomy: Burks, 1964 (1963). Canad. Ent. 95: 1252.

Biology: Waddell, 1952. Ent. Soc. B. C., Proc. 48: 88.

spilosomatis Howard. N. J. Host: Diacrisia virginica (F.). Described only by a figure of pupae.

Elachistus spilosomatis Howard, 1891. U. S. Dept. Agr., Insect Life 4: 195.

\section{Genus HYSSOPUS Girault}

Hyssopus Girault, 1916. Canad. Ent. 48: 115.

Type-species: Hyssopus thymus Girault. Monotypic.

Hyssopiscus Ghesquiere, 1946. Rev. Zool. Bot. Africaines 34: 370. N. name, unnecessarily proposed. 
benefactor (Crawford). N. Y., Md., Ohio, B. C. Host: Petrova albicapitana (Busck), P. comstockiana (Fern.), P. metallica (Busck). P. virginiana (Busck).

Elachertus benefactor Crawford, 1912. U. S. Natl. Mus., Proc. 43: 182..

evetriae (Girault). Minn., Idaho, Oreg. Host: Barbara colfaxiana taxifoliella (Busck), Melissopus latiferreanus (Wlsm.), Petrova albicapitana (Busck), P. wenzeli (Kearf.).

Elachistus evetriae Girault, 1917. Descr. Hym. Chalcidoid. Variorum cum Observ. III, p. 1. ?.

Biology: Dohanian, 1942. Jour. Econ. Ent. 35: 837, 840. - Miller and Altmann, 1958. Ohio Jour. Sci. 58: 278-280. - Keen, 1958. U. S. Dept. Agr., Tech. Bul. 1169: 95.

johannseni (Crawford). Maine, Va., Miss. Host: Laspeyresia sp.

Elachertus johannseni Crawford, 1912. U. S. Natl. Mus., Proc. 43: 181..

novus Girault. Calif.

Hyssopus novus Girault, 1917. Descr. Hym. Chalcidoid. Variorum cum Observ. III, p. 3.. rhyacioniae Gahan. Ont., s. to Fla., w. to Mich., Ark., Tex. Host: Dioryctria abietella D. and S., D. amatella (Hulst), D. cambiicola (Dyar), D. zimmermani (Grote), Rhyacionia frustrana (Comst.).

Hyssopus rhyacioniae Gahan, 1927. Jour. Agr. Res. 34: 546. ๆ, ठ̊.

Biology: Cushman, 1927. Jour. Agr. Res. 34: 617. -Underhill, 1943. Va. Agr. Expt. Sta., Bul. 349: 12.

sanninoideae (Girault). Conn., Va., Ark. Host: Sanninoidea extiosa (Say), Synanthedon scitula (Harr.).

Elachistus sanninoideae Girault, 1917. Brooklyn Ent. Soc., Bul. 12: 85. ๆ, ð’.

Biology: Underhill, 1935. Jour. Econ. Ent. 28: 396.

thymus Girault. Ont. and N. Y., s. to Fla., w. to Idaho and Calif. Host: Dioryctria auranticella (Grote), D. xanthoenobares Dyar, D. zimmermani (Grote), Petrova camstockiana (Fern.), P. wenzeli (Kearf.), Rhyacionia buoliana (Schiff.), $R$. frustrana (Comst.), $R$. rigidana (Fern.).

Hyssopus thymus Girault, 1916. Canad. Ent. 48: 115. \&.

Biology: Slate, 1936. Conn. Agr. Expt. Sta., Bul. 381: 181. -Friend, Plumb, and Hicock, 1938. Jour. Econ. Ent. 31: 511. - Miller, 1953. Ohio Jour. Sci. 53: 61-62. - Miller and Altman, 1958. Ohio Jour. Sci. 58: 278-280. - Keen, 1958. U. S. Dept. Agr., Tech. Bul. 1169: 95. -Watson and Arthur, 1959. Canad. Ent. 91: 480-484. - Schaffner, 1959. U. S. Dept. Agr., Misc. Pub. 767: 84. - Hartman and Kulman, 1962. Jour. Econ. Ent. 55: 1007. - Syme, 1970. Canad. Ent. 102: 1523-1527. - Syme, 1971. Canad. Ent. 103: 1691-1696. - Purrington and Uleman, 1972. Ent. Soc. Amer., Ann. 65: 280-281.

\section{Genus PSEUDOLYNX Girault}

Pseudolynx Girault, 1916. Ent. News 27: 152.

Type-species: Psendolynx io Girault. Orig. desig.

flavimaculata Girault. Minn.

Pseudolynx flavimaculatus Girault, 1916. Ent. News 27: 153. ‡.

io Girault. Mass.

Pseudolynx io Girault, 1916. Ent. News 27: 152. ๆ.

marilandia Girault. Md.

Pseudolynx marilandia Girault, 1917. Chalcidoidea Nova Marilandensis [I]. p. 1. $q$.

\section{Genus MIROLYNX Girault}

Mirolynx Girault, 1916. U. S. Natl. Mus., Proc. 51: 131.

Type-species: Mirolynx flavitibiae Girault. Orig. desig.

flavitibiae Girault. Calif.

Mirolynx fla vitibiae Girault, 1916. U. S. Natl. Mus., Proc. 51: 131. १, o.

\section{Genus GROTIUSOMYIA Girault}

Grotiusomyia Girault, 1917. Psyche 24: 95. 
Type-species: Grotiusomyia flavicornis Girault. Orig. desig.

flavicornis Girault, D. C., N. C. Ecology: Parasitic on pyralid leaf miner on oak. Grotiusomyia flavicornis Girault, 1917. Psyche 24: 95. ․

Taxonomy: Girault, 1918. Ent. News 29: 126.

\section{Genus APTEROLOPHUS Gahan}

Apterolophus Gahan, 1919. Ent. Soc. Wash., Proc. 21: 3.

Type-species: Apterolophus pulchricomis Gahan. Monotypic.

pulchricornis Gahan. N. Y., S. C., Ind. Ecology: Taken sifting treehole litter.

Apterolophus pulchricomis Gahan, 1919. Ent. Soc. Wash., Proc. 21: 3. \&.

\section{Genus GIRAULTIA Gahan and Fagan}

Cirrospilopsis Girault, 1915. Queensland Mus., Mem. 3: 263. Preocc. by Brethes, 1913.

Type-species: Cirrospilopsis nigrivariegatus Girault. Orig. desig.

Giraultia Gahan and Fagan, 1923. U. S. Natl. Mus., Bul. 124: 66. N. name.

fuscipennis (Girault). Md.

Cirrospilopsis fuscipennis Girault, 1916. Ent. Soc. Amer., Ann. 9: 293. ․

metallicus (Girault). Md.

Cirrospilopsis metallicus Girault, 1917. Psyche 24: 100..+

sapientia (Girault). D. C.

Cirrospilopsis sapientia Girault, 1917. Descr. Hym. Chalcidoid. Variorum cum Observ. V, p. 13. $\%$.

\section{Genus CIRROSPILOIDEUS Ashmead}

Cirrospiloideus Ashmead, 1904. Carnegie Mus., Mem. 1: 354, 355.

Type-species: Miotropis platynotae Howard. Orig. desig.

Alophus Ashmead, 1904. Carnegie Mus., Mem. 1: 353, 519. Preocc. by Schoenherr, 1826.

Type-species: Alophus flavus Ashmead. Orig. desig.

Alophomyia Ashmead, 1904. Ent. Soc. Wash., Proc. 6: 126. N. name.

Diglyphomorphomyia Girault, 1913. Queensland Mus., Mem. 2: 281.

Type-species: Diglyphomorphom yia nigriscutellum Girault. Orig. desig.

Sympiesomorphellens Girault, 1913. Arch. f. Naturgesch. 79A (6): 75.

Type-species: Sympiesomorphelleus suttneri Girault. Orig. desig.

bicoloriceps (Girault). La. Host: Keiferia inconspicuella (Murtf.).

Sympiesomorphellens bicoloriceps Girault, 1919. Ent. Soc. Amer., Ann. 9: 302...

californicus (Girault). Calif.

Sympiesomorphelleus califormicus Girault, 1916. Jour. Ent. and Zool. 8: 119. \&.

johnsoni Girault. Maine, D. C., Ill.

Cirrospiloideus johnsoni Girault, 1917. Descr. Hym. Chalcidoid. Variorum cum Observ. III, p. 7 . ..

mediolineatus Girault. Md.

Cirrospiloideus mediolineatus Girault, 1917. Chalcidoidea Nova Marilandensis. II, p. 2. q.

Taxonomy: Girault, 1920. U. S. Natl. Mus., Proc. 58: 198.

nigriceps (Girault). Tex.

Sympiesomorphellens nigriceps Girault, 1916. U. S. Natl. Mus., Proc. 51: 44..

nigriprothorax (Girault). Kans.

Sympiesomorphelleus nigriprothorax Girault, 1916. U. S. Natl. Mus., Proc. 51: 131..

platynotae (Howard). Fla. Host: Platynota rostrana (Walk.).

Miotropis platynotae Howard, 1885. In Hubbard, Insects Affecting the Orange, p. 217. \&, б.

seminigriventris Girault. Pa., Ohio. Host: Eumkuttarus confederata (Grote).

Cirrospiloidens seminigriventris Girault, 1917. Deser. Hym. Chalcidoid. Variorum cum Observ. V, p. 1. . 


\section{Genus PECKELACHERTUS Yoshimoto}

Peckelachertus Yoshimoto, 1970. Canad. Ent. 102: 908.

Type-species: Peckelachertus diprioni Yoshimoto. Orig. desig.

diprioni Yoshimoto. Que. Host: Gilpinia frutetorum (F.).

Peckelachertus diprioni Yoshimoto, 1970. Canad. Ent. 102: 908. ९, ठ.

\section{Genus CIRROSPILUS Westwood}

Cirrospilus Westwood, 1832. London, Edinb. and Dublin Phil. Mag. and Jour. Sci. (3) 1: 128.

Type-species: Cirrospilus elegantissimus Westwood. Monotypic.

Psendiglyphomyia Girault, 1913. Queensland Mus., Mem. 2: 267.

Type-species: Pseudiglyphomyia biguttata Girault. Orig. desig.

Atoposomoidea Howard, 1910. U. S. Dept. Agr., Bur. Ent., Tech. Bul. 19: 9.

Type-species: Atoposomoidea ogimae Howard. Monotypic.

Plesiospilus Ferriere, 1953. Univ. Bologna, Ist. di Ent., Bol. 19: 398.

Type-species: Eulophus unistriatus Foerster. Orig. desig.

Taxonomy: Delucchi, 1958. Entomophaga 3: 253. - Boucek, 1959. Mus. Natl. Pragae, Acta

Ent. 33: 172 (subgenera).

americanus (Girault), Ohio.

Pseudiglyphomyia americana Girault, 1916. U. S. Natl. Mus., Proc. 51: 43, 45, 48..

cinctithorax (Girault). N. B., Que., Ont., Maine, Mass., Ill., Wis. Host: Argyresthia freyella

Wlshm., Bucculatrix ainsliella Murtf., B. canadensisellea Chamb., Coleophora

fuscedinella Zeller, C. pruniella Clem., Lithocolletis salicifoliella Clem., L.

tremuloidiella Braun, Phyllocnistis populiella Chamb.; Heterarthrus nemoratus (Fall.),

Meteorus versicolor (Wesm.).

Pseudiglyphomyia cinctithorax Girault, 1916. U. S. Natl. Mus. Proc. 51: 45. ?.

Biology: Proper, 1934. Jour. Agr. Res. 48: 366. - Doner, 1936. Ent. Soc. Amer., Ann. 29: 226.

-Schaffner, 1959. U. S. Dept. Agr., Misc. Pub. 767: 84.

columbia (Girault). D. C.

Pseudiglyphomyia columbia Girault, 1917. Descr. Hym. Chalcidoid. Variorum cum Observ. V, pp. 6, 7. $ᄋ$.

coptodiscae (Girault). Maine, s. to N. J., Ky. Host: Coptodisca splendoriferella (Clem.).

Pseudiglyphomyia coptodiscae Girault, 1916. Canad. Ent. 48: 266. ๆ, ठ.

eunapius Walker. Fla.

Cirrospilus Eunapius Walker, 1847. Ann. and Mag. Nat. Hist. (1) 20: 27..

Taxonomy: Burks, 1975. Brit. Mus. (Nat. Hist.) Ent., Bul. 32 (4): 143 (lectotype designated).

flavicinctus Riley. Maine, s. to D. C., w. to Kans. and Wash. Host: Archips semiferanus

(Walk.), Bucculatrix ainsliella Murtf., B. pomifoliella Clem., Coleophora fuscedinella

Zell., C. malivorella Riley, C. pruniella Clem.; Heterarthms nemoratus (Fallen).

Cirrospilus flavicinctus Riley, 1883. In Lintner, First Ann. Rpt. Injurious Ins. N. Y., p.

159. $\%$, o.

Cirrospilus flavomaculatus Ashmead, 1894. Amer. Ent. Soc., Trans. 21: 341..

Biology: Christensen, 1934. Wis. Agr. Expt. Sta., Bul. 428: 101. - Doner, 1936. Ent. Soc.

Amer., Ann. 29: 233-234. —Schaffner, 1959. U. S. Dept. Agr., Misc. Pub. 767: 84.

flavifacies (Girault). Calif.

Pseadiglyphomyia flavifacies Girault, 1916. U. S. Natl. Mus., Proc. 51: 43. 9.

flavoviridis Crawford. Utah, Ariz., Nev., Calif. Host: Agromyza parvicom is Loew, Cerodontha dorsalis (Loew), Liriomyza sp.

Cirrospilus flavoviridis Crawford, 1913. U. S. Natl. Mus., Proc. 45: 317. ๆ, ठ.

giraulti Peck. U. S. Host: Bucculatrix sp.

Psendiglyphomyia pulchra Girault, 1916. U. S. Natl. Mus., Proc. 51: 45. . Preoce. by Masi, 1911.

Cirrospilus giraulti Peck, 1951. U. S. Dept. Agr., Agr. Monog. 2: 458. N. name. 
inimicus Gahan. Ill. Host: Gambrus extrematis (Cress.).

Cirrospilus inimicus Gahan, 1934. Ent. Soc. Wash., Proc. 36: 123. \&, ১.

Biology: Marsh, 1938. N. Y. Ent. Soc., Jour. 46: 27-29.

marilandi Girault. Conn., Md., N. C. Host: Coptodisca sp.

Cirrospilus marilandi Girault, 1917. Descr. Hym. Chalcidoid. Variorum cum Observ. III, p. 4. .

marilandicus (Girault). Md.

Pseudiglyphomyia marilandica Girault, 1917. Psyche 24: 91..

niger Howard. N. J. Host: Vanessa atalanta (L.); Eulophus sp.

Cirrospilus niger Howard, 1889. In Scudder, Butterflies of Eastern U. S. and Canada, p. 1872. ․, $\delta$.

nigrivariegata (Girault). Ind., Iowa, Kans., S. Dak. Host: Paromix geminatella (Pack.), Tischeria malifoliella (Clem.).

Psendiglyphomyia nigrivariegata Girault, 1917. Descr. Hym. Chalcidoid. Variorum cum Observ. III, p. 7. ?.

ocellatus Girault. Que., Conn., Ill. Host: Bucculatrix canadensisella (Chamb.).

Cirrospilus ocellatus Girault, 1917. U. S. Natl. Mus., Proc. 53: 446. \&.

ovisugosus Crosby and Matheson. N. Y. Host: Poecilocapsus lineatus (F.).

Cirrospilus ovisugosus Crosby and Matheson, 1915. Canad. Ent. 47: 181. ९, o.

pictus (Nees). Que., Ont., Maine; Europe. Introduced from Europe for biological control; first liberated in Ontario in 1935. Host: Coleophora laricella (Hbn.); Fenusa pusilla (Lep.), Heterarthrus nemoratus (Fallen).

Eulophuss pictus Nees, 1834. Hym. Ichn. Aff. Monog., v. 2, p. 165. \&, ठ.

Taxonomy: Ferriere, 1933. In Thorpe, Bul. Ent. Res. 24: 289-290.

Biology: Dowden, 1941. U. S. Dept. Agr., Tech. Bul. 757: 8-9, 37-41. —Sundby, 1958 (1957).

Norsk. Ent. Tidsk., Sup. 2, pp. 18-21.

pulcheria Girault. Kans.

Cirrospilus pulcheria Girault, 1917. Descr. Hym. Chalcidoid. Variorum cum Observ. V, p. 8. .

Taxonomy: Girault, 1920. U. S. Natl. Mus., Proc. 58: 195.

purpureus Ashmead. Fla.

Cirrospilus purpureus Ashmead, 1886. Amer. Ent. Soc., Trans. 13: 133. ․

unguttatipennis (Girault). Calif.

Pseudiglyphomyia unguttatipennis Girault, 1916. Jour. Ent. and Zool. 8: 120. ?.

\section{Genus ZAGRAMMOSOMA Ashmead}

Hippocephalus Ashmead, 1888. Kans. Agr. Expt. Sta., Bul. 3: App., p. VII. Preocc. by Swainson, 1839.

Type-species: Hippocephalus multilineatus Ashmead. Monotypic.

Zagrammosoma Ashmead, 1904. Carnegie Mus., Mem. 1: 354. N. name.

Zagrammatosoma Schulz, 1906. Spolia Hym., p. 142. Emend.

Atoposoma Masi, 1907. Lab. Zool. Gen. e. Agr. Portici, Bol. 1: 276.

Type-species: Atoposoma variegatum Masi. Monotypic.

Taxonomy: Boucek, 1959. Mus. Natl. Pragae, Acta Ent. 33: 172-173 (subgenus of Cirrospilus).

americanum Girault. Colo., Ariz., Calif. Host: Coleotechnites milleri (Busck).

Zagrammosoma americana Girault, 1916. U. S. Natl. Mus., Proc. 51: 125, 126. ๆ.

centrolineatum Crawford. Calif. Host: Lithocolletis mediodorsella (Braun).

Zagrammosoma centrolineata Crawford, 1913. U. S. Natl. Mus., Proc. 45: 256..

flavolineatum Crawford. Colo., Calif. Host: Phthorimaea operculella (Zell.).

Zagrammosoma flavolineata Crawford, 1913. U. S. Natl. Mus., Proc. 45: 255.. 
interlineatum Girault. Mass., D. C., Fla., Ohio. Host: Exoteleia pinifoliella (Chamb.), Lithocolletis cincinnatiella (Chamb.).

Zagrammosoma interlineata Girault, 1916. U. S. Natl. Mus., Proc. 51: 125..

Biology: Schaffner, 1959. U. S. Dept. Agr., Misc. Pub. 767: 84.

mirum Girault. Calif. Host: Lithocolletis crataegella Clem.; Liriomyza pictella (Thomson).

Zagrammosoma mira Girault, 1916. Jour. Ent. and Zool. 8: 119. . .

multilineatum (Ashmead). Md., D. C., S. C., W. Va., Fla., Ohio, Ind., La., Kans. Host:

Lithocolletis sp., Paromix geminatella (Pack.), Phyllocnistis magnoliella Ashm., Tischeria malifoliella (Clem.); Agromyza parvicomis Loew.

Hippocephalus mrultilineatus Ashmead, 1888. Kans. Agr. Expt. Sta., Bul. 3: App. p. VII. \&, $\delta$.

Zagrammosoma multilineata var. punicea Girault, 1911. Arch. f. Naturgesch. 77 (1), sup. 2: 123. ?. N. syn.

Biology: Phillips, 1914. Jour. Agr. Res. 2: 27.

nigrolineatum Craw ford. Maine, Calif. Host: Argyresthia thuiella (Pack.).

Zagrammosoma nigrolineata Crawford, 1913. U. S. Natl. Mus., Proc. 45: 257. “\%” = . sanguineum Girault. Colo.

Zagrammosoma sanguinea Girault, 1916. U. S. Natl. Mus., Proc. 51: 133. ९.

\section{Genus MIRZAGRAMMOSOMA Girault}

Mirzagrammosoma Girault, 1915. Ent. Soc. Amer., Ann. 8: 279.

Type-species: Mirzagrammosoma lineaticeps Girault. Monotypic.

lineaticeps Girault. Fla.; Cent. America, West Indies. Host: Leucoptera coffeella (Guerin); Liriomyza archboldi Frost.

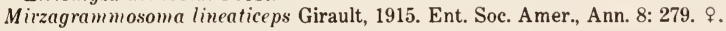

\section{Genus AULOGYMNUS Foerster}

Aulogymnus Foerster, 1851. Naturh. Ver. Rheinlande, Verh. 8: 24.

Type-species: Aulogymmus aceris Foerster. Monotypic.

Olynx Foerster, 1856. Hym. Stud., v. 2, p. 72.

Type-species: Ichneumon gallarum Linnaeus. Orig. desig.

Taxonomy: Boucek, 1965. Mus. Natl. Pragae, Acta Ent. 36: 551.

minyas (Walker). Fla.

Eulophus Minyas Walker, 1847. Ann. and Mag. Nat. Hist. (1) 20: 26. \&.

Taxonomy: Burks, 1975. Brit. Mus. (Nat. Hist.) Ent., Bul. 32 (4): 146 (lectotype designated).

\section{Subfamily ENTEDONTINAE}

\section{TRIBE EUDERINI}

Taxonomy: Erdos, 1956. Rov. Kozlem. (n. s.) 9: 2 (tribe). -Graham, 1959. Soc. Brit. Ent.,

Trans. 13: 203 (subfamily). - Boucek, 1963. Beitr. z. Ent. 13: 257 (subfamily).

\section{Genus ACRIAS Walker}

Acrias Walker, 1847. Ann. and Mag. Nat. Hist. (1) 20: 29.

Type-species: Acrias nileus Walker. Monotypic.

Taxonomy: Boucek, 1963. Beitr. z. Ent. 13: 258.

nileus Walker. Pa., Fla.

Acrias nileus Walker, 1847. Ann. and Mag. Nat. Hist. (1) 20:29. 9.

Taxonomy: Burks, 1975. Brit. Mus. (Nat. Hist.) Ent., Bul. 32 (4): 146.

\section{Genus EUDERUS Haliday}

Euderus Haliday, 1844 (1843). Ent. Soc. London, Trans. 3: 298.

Type-species: Entedon amphis Walker. Monotypic. 
Secodella Girault, 1913. Arch. f. Naturgesch. 79A (6): 48.

Type-species: Secollella lineata Girault. Monotypic.

Omphalomorpha Girault, 1913. Arch. f. Naturgesch. 79A (6): 103.

Type-species: Omphalomorpha viridis Girault. Monotypic.

Allomphale Silvestri, 1914. Lab. Zool. Gen. e. Agr. Portici, Bol. 9: 217.

Type-species: Allomphale cavasolae Silvestri. Monotypic.

Secodelloidea Girault, 1917. Speciosissima Genera Nova Eulophidorum, p. 2.

Type-species: Secodella rugosa Crawford. Orig. desig.

Euderus subg. Euderoides Yoshimoto, 1971. Canad. Ent. 103: 550.

Type-species: Euderus (Euderoides) purpureus Yoshimoto. Orig. desig.

Eudemis subg. Neoeuderus Yoshimoto, 1971. Canad. Ent. 103: 552.

Type-species: Euderus (Neoeuderus) viridilineatus Yoshimoto. Orig. desig.

Euderus subg. Leipocrossus Yoshimoto, 1971. Canad. Ent. 103: 555.

Type-species: Entedon (Euderus) herillus Walker. Orig. desig.

Revision: Crawford, 1915. Ent. Soc. Wash., Proc. 17: 142-144 (Secollella). -Girault, 1924.

Insecutor Inscitiae Menstruus 12: 94. - Erdos, 1951. Acta Biol. Acad. Sci. Hung. 2: 202

(Hungarian fauna). - Boucek, 1963. Beitr. z. Ent. 13: 257-267 (Palearctic fauna).

-Yoshimoto, 1971. Canad. Ent. 103: 541-578.

Taxonomy: Ferriere, 1931. Bul. Ent. Res. 22: 134. -Peck, 1963. Canad. Ent., Sup. 30: 197. acrobasis (Crawford). N. S., Que., Ont., N. Y., W. Va., Ga., Fla., Tex., Alta., Idaho. Host:

Acrobasis caryae (Grote), A. juglandis (LeB.), Laspeyresia pomonella (L.).

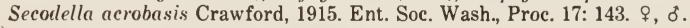

Biology: Wakeland, 1929. Jour. Econ. Ent. 22: 985.

alaskensis Yoshimoto. Alaska.

Euderus alaskensis Yoshimoto, 1971. Canad. Ent. 103: 576. \%.

albitarsis (Zetterstedt). N. S., Que., Ont., Va., W. Va., Man., Sask., Alta.; Europe. Introduced from Europe for biological control in the early 1930's; first recovered in Ontario. Host: Coleophora laricella ( $\mathrm{Hbn}$.).

Entedon albitarsis Zetterstedt, 1838. Ins. Lapp., v. 1, p. 430. ․

Entedon Mithras Walker, 1839. Monog. Chalcid., v. 1, p. 93 . ठ。.

Entedon Amphis Walker, 1839. Monog. Chalcid., v. 1, p. 106..

Euderus viridis Thomson, 1878. Hym. Scand., v. 5, p. 278. 9.

Taxonomy: Boucek, 1963. Beitr. z. Ent. 13: 262.

Biology: Arru, 1962. Bol. Zool. Agr. e Bach, (2) 4: 275.

argyresthiae (Crawford). N. B., Que., s. to Fla., w. to B. C., Wash., Oreg., Calif. Host: Argyresthia altematella Kearf., A. laricella Kearf., Coleotechnites milleri (Busck), Rhyacionia frustrana (Comst.), Spilonota ocellana (D. and S.).

Secodella argyresthiae Crawford, 1915. Ent. Soc. Wash., Proc. 17: 100. $q, ~ \delta$.

Biology: Furniss, 1942. Jour. Econ. Ent. 35: 858. - Eidt and Sippell, 1961. Canad. Ent. 93: 17. -Legner and Oatman, 1963. Jour. Econ. Ent. 56: 731. - Eikenbary and Fox, 1965. S. C.

Agr. Expt. Sta., Tech. Bul. 1017: 6.

californicus Yoshimoto. Calif.

Euderus (Leipocrossus) californicus Yoshimoto, 1971. Canad. Ent. 103: 558. ․

canadensis Yoshimoto. Man., N. W. T.

Euderus (Secodelloidea) canadensis Yoshimoto, 1971. Canad. Ent. 103: 548. ๆ, ठ.

chillcotti Yoshimoto. Ont., Sask. Host: Agrilus criddlei Frost.

Euderus chillcotti Yoshimoto, 1971. Canad. Ent. 103: 565. ₹.

crawfordi Peck. Ariz., Calif. Ecology: Emerged from cynipid galls. Host: Dryocosmus coxii (Bass.), Plagiotrochus suberi Weld.

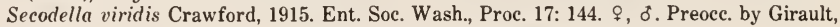
1913.

Euderus crawfordi Peck, 1951. U. S. Dept. Agr., Agr. Monog. 2: 462. N. name. 
cushmani (Crawford). N. S., N. B., Que., s. to N. Y., w. to Sask. and Idaho. Host: Anarsia lineatella Zell., Argyresthia laricella Kft., A. thuiella (Pack.), Coleophora fuscedinella Zell., C. laricella (Hbn.), C. pruniella Clem., Dioryctria zimmermani (Grote), E piblema strenuanum (Walk.), Epinotia nanana (Treit.), Grapholitha packardi (Zell.),

Paralobesia viteana (Clem.), Proteoteras willingana (Kft.), Spilonota ocellana (D. and S.); Mastrus laricellae (Mason).

Secodella cushmani Crawford, 1915. Ent. Soc. Wash., Proc. 17: 142. ९, ठ̊.

Biology: Balduf, 1959. Ill. Biol. Monog. 26: 74. - Schaffner, 1959. U. S. Dept. Agr., Misc. Pub. 767: 85. - Eidt and Sippell, 1961. Canad. Ent. 93: 16. - Eidt, 1962. Canad. Ent. 94: 34 (hyperparasite). - Daviault and Ducharme, 1966. Canad. Ent. 98: 697.

elongatus Ashmead. Fla. Type fragmentary; unrecognizable.

Euderus elongatus Ashmead, 1887. Amer. Ent. Soc., Trans. 14: 201. \&.

fuscedinellae Yoshimoto. N. B., Ont. Host: Coleophora fuscedinella Zell.

Euderus fuscedlinellae Yoshimoto, 1971. Canad. Ent. 103: 565..

glaucus Yoshimoto. Ont., Fla., Tex. Host: Epiblema obfuscanum Dyar.

Euderus glaucus Yoshimoto, 1971. Canad. Ent. 103: 564. 9.

herillus (Walker). Va., Ga., Fla. Host: Desmia funeralis ( $\mathrm{Hbn}$.).

Enteton (Euderus) Herillus Walker, 1847. Ann. and Mag. Nat. Hist. (1) 20: 23. 9.

Taxonomy: Burks, 1975. Brit. Mus. (Nat. Hist.) Ent., Bul. 32 (4): 144.

lividus (Ashmead). Fla. This species has been misidentified from India, and has been confused with Chrysocharis lividus Ashmead in Nearctic literature. The latter is a quite different, Neotropical species, the type of which may be in the British Museum; it is catalogued in the U. S. N. M. collection, but is missing.

Oxyomorpha livida Ashmead, 1886. Amer. Ent. Soc., Trans. 13: 135..+

magnificus Yoshimoto. N. C.

Euderns (Neoeuderus) magnificus Yoshimoto, 1971. Canad. Ent. 103: 554. $\%$.

marylandicus Girault. Md. Type fragmentary; unrecognizable.

Euderus marylanelicus Girault, 1917. Chalcidoidea Nova Marilandensis. II, p. 1..

masoni Yoshimoto. Ont., Va., S. C., Fla., Calif.

Euderus masoni Yoshimoto, 1971. Canad. Ent. 103: 562. ․

multilineatus (Girault). Tex.

Secodes multilimeatus Girault, 1917. Brooklyn Ent. Soc., Bul. 12: 85..

pecki Yoshimoto. Que., Man.

Euderus pecki Yoshimoto, 1971. Canad. Ent. 103: 561. $\%$.

purpureus Yoshimoto. Ont., Va. Host: Grapholitha molesta (Busck).

Euderus (Euderoides) purpureus Yoshimoto, 1971. Canad. Ent. 103: 550. 9.

rubriscapus (Girault). N. S., Que., Ont., Mass., N. Y., Md., Va., W. Va., N. C.

Secodella rugosus var. mbriscapus Girault, 1916. Soc. Ent. 31: 36..

Taxonomy: Burks, 1967. U. S. Dept. Agr., Agr. Monog., Sup. 2: 232 (changed to species).

rugosus (Crawford). N. S., Que., Ont., s. to Fla., w. to Minn., Kans., Okla.

Secodella rugosus Crawford, 1915. Ent. Soc. Wash., Proc. 17: 143. \%.

saperdae Miller. Ont., Minn., Sask. Host: Saperda moesta LeC.

Euderus saperdae Miller, 1965. Canad. Ent. 97: 1070. ㅇ, ठ.

solidaginis Yoshimoto. Ont. Host: Campoplex depressus Viereck.

Euderns solidagin is Yoshimoto, 1971. Canad. Ent. 103: 566. $q$.

subopacus (Gahan). N. S., Que., Ont., Mass., Va., W. Va., Ohio, La., Man., Sask., Alta., Calif.

Host: Cylindrocopturus eatoni Buchanan; Acrobasis caryae Grote, Grapholitha molesta (Busck), Rhyacionia buoliana (Schiff.), R. frustrana (Comst.), Spilonota ocellana (D. and S.); Bracon variabilis (Prov.).

Secodella subopaca Gahan, 1927. Jour. Agr. Res. 34: 548. ๆ, o.

Biology: Cushman, 1927. Jour. Agr. Res. 34: 617.

viridilineatus Yoshimoto. Ont.

Euderus (Neoeuderus) viridilineatus Yoshimoto, 1971. Canad. Ent. 103: 553. ơ. 
vockerothi Yoshimoto. Fla.

Euderus vockerothi Yoshimoto, 1971. Canad. Ent. 103: 562..

\section{Genus ASTICHUS Foerster}

Astichus Foerster, 1856. Hym. Stud., v. 2, pp. 78, 80.

Type-species: Euderus arithmeticus Foerster. Monotypic.

Taxonomy: Masi, 1925. Soc. Ent. Ital., Bol. 57: 84. - Costa Lima, 1959. Acad. Brasil. de Cien., An. 31: 122. -Boucek, 1963. Beitr. z. Ent. 13: 273 (key to European species). - Yoshimoto, 1970. Canad. Ent. 102: 658 (key to Nearctic species).

arithmeticus (Foerster). N. C., Ind., Ill., Idaho, Ariz., Calif.; Europe. Ecology: Emerged from bracket fungi, Polyporus and Poria, containing cisid beetles.

Euderus arithmeticus Foerster, 1851. Naturh. Ver. Rheinlande, Verh. 8: 18..

arizonensis Ashmead. Ariz. Type missing; this may not be Astichus.

Astichus arizonensis Ashmead, 1888. Canad. Ent. 20: 101. ठ.

auratus Ashmead. Fla. Ecology: Emerged from cynipid gall. Host: Neuroterus quercusminutissimus Ashm. Types in very poor condition; this almost certainly is not Astichus.

Astichus auratus Ashmead, 1887. Amer. Ent. Soc., Trans. 14: 200..

notus Yoshimoto. Que., Ont. Ecology: Emerged from bracket fungi, Polyporns and Ganoderma, containing beetles.

Astichus notus Yoshimoto, 1970. Canad. Ent. 102: 656. + , o.

pulchrilineatus Gahan. N. Y., Va., N. C., Idaho., Ariz., Calif.; Mexico. Ecology: Emerged from bracket fungi, Polyporns, Ports, Cryptoporns, containing cisid beetles. Host: Brachycis sp., B. brevicollis Casey, Ceracis sp.

Astichuss pulchrilineatus Gahan, 1927. U. S. Natl. Mus., Proc. 71 (4): 28., o.

\section{TRIBE TETRASTICHINI}

Taxonomy: Kurdjumov, 1913. Russk. Ent. Obozr. 13: 243-256 (Palearctic spp.; Russian text transl. into French by Nowicki, 1927. Eos 3: 513-517). - Ferriere, 1960. Acta Hym. 1: 105-106 (key to genera). -Graham, 1961. Ent. Monthly Mag. 97: 34-64 (European spp.). -Domenichini, 1965. Bol. Zool. agr. e di Bach., (2) 6: 61-204 (key to genera; species groups of Palearctic spp.). - Domenichini, 1966. Index Palearctic Tetrastichinae, Le Francois, 101 pp.

\section{Genus CERATONEURA Ashmead}

Ceratoneura Ashmead, 1894. Linn. Soc. London, Jour., Zool. 25: 178.

Type-species: Ceratoneura petiolata Ashmead. Desig. by Ashmead, 1904.

Ceratotetrastichodes Girault, 1917. Speciosissima Genera Nova Eulophidorum, p. 2.

Type-species: Ceratoneura pretiosa Gahan. Orig. desig.

petiolata Ashmead. Fla., Ariz.; West Indies, Mexico, Venezuela. Ecology: Reared from gall on Larrea.

Ceratoneura petiolata Ashmead, 1894. Linn. Soc. London, Jour., Zool. 25: 179. \&, ð. pretiosa Gahan. Tex.

Ceratoneura pretiosa Gahan, 1914. U. S. Natl. Mus., Proc. 48: 165. ๆ, ð.

Biology: Gahan, 1941. Ent. Soc. Wash., Proc. 43: 2.

\section{Genus PARASPALANGIA Ashmead}

Paraspalangia Ashmead, 1904. Carnegie Mus., Mem. 1: 334.

Type-species: Paraspalangia anmulipes Ashmead. Monotypic.

Stigmatotrastichus Girault, 1916. Ent. Soc. Amer., Ann. 9: 303.

Type-species: Stigmatotrastichus emersoni Girault. Orig. desig.

annulipes Ashmead. Tex.

Paraspalangia annulipes Ashmead, 1904. Carnegie Mus., Mem. 1: 334 ..

Stigmatotrastichus emersoni Girault, 1916. Ent. Soc. Amer., Ann. 9: 304. \&. 
Taxonomy: Gahan and Peck, 1946. Wash. Acad. Sei., Jour. 36: 316.

\section{Genus WINNEMANA Crawford}

Winnemana Crawford, 1911. U. S. Natl. Mus., Proc. 39: 620.

Type-species: Winnemana argei Crawford. Orig. desig.

Ootetrastichoides Ii, 1936. Kontyu 10: 221-225.

Type-species: Ootetrastichoides habachi Ii. Monotypic.

Taxonomy: Domenichini, 1966. Index Palearctic Tetrastichinae, Le Francois, p. 15.

argei Crawford. Md. Ecology: Egg parasite. Host: Arge pectoralis (Leach).

Winnemana argei Crawford, 1911. U. S. Natl. Mus., Proc. 39: 620. ९, ơ.

Biology: Schwarz, 1909. Ent. Soc. Wash., Proc. 11: 107.

\section{Genus THRIPOSOMA Crawford}

Thriposoma Crawford, 1913. U. S. Natl. Mus., Proc. 45: 255.

Type-species: Thriposoma grafi Crawford. Orig. desig.

grafi Crawford. Calif.

Thriposoma grafi Crawford, 1913. U. S. Natl. Mus., Proc. 45: 255..

\section{Genus OMPHALOMOPSIS Girault}

Omphalomopsis Girault, 1917. Brooklyn Ent. Soc., Bul. 12: 88.

Type-species: Omphalomopsis marilandia Girault. Orig. desig.

marilandia Girault. Md.

Omphalomopsis marilandia Girault, 1917. Brooklyn Ent. Soc., Bul. 12: 88..

\section{Genus THYMUS Girault}

Thymus Girault, 1916. Canad. Ent. 48: 113.

Type-species: Encyrtus albocinctus (Ashmead). Orig. desig.

Thymiscus Ghesquiere, 1946. Rev. Zool. Bot. Africaines 34: 371. N. name, unnecessarily proposed.

albocinctus (Ashmead). Fla. Ecology: Reared from eynipid gall on Quercus nigra.

Eupelmus albocinctus Ashmead, 1885. Amer. Ent. Soc., Trans. 12: Proc. p. xvi..

\section{Genus PROTHYMUS Girault}

Prothymus Girault, 1917. New Chalcid Flies, p. 1.

Type-species: Prothymus novus Girault. Orig. desig.

novus Girault. Fla., Mo.

Prothymus notus Girault, 1917. New Chaleid Flies, p. 1.

\section{Genus GALEOPSOMYIA Girault}

Galeopsomyia Girault, 1916. Ent. News 27: 348.

Type-species: Euderus columbianus Ashmead. Orig. desig.

haemon (Walker). N. Y., s. to Fla., w. to Mo., Tex., N. Mex. and Ariz. Host: Asphondylia helianthiglobulus 0. S., Rhopalomyia sp. gall on Solidago.

Tetrastichus haemon Walker, 1847. Ann. and Mag. Nat. Hist., (1), 20: 28. ๆ.

Enderus columbiana Ashmead, 1888. Canad. Ent. 20: 104. ?.

Taxonomy: Girault, 1912. Canad. Ent. 44: 50-52. - Burks, 1971. Ent. Soc. Wash., Proc. 73: 82.

-Burks, 1975. Brit. Mus. (Nat. Hist.) Ent., Bul. 32 (4): 144 (synonymy).

nigrocyanea (Ashmead). D. C., N. C., Fla., La., Tex., Calif. Host: Belonocnema treatae Mayr.

Gyrolasia nigrocyaneus Ashmead, 1886. Amer. Ent. Soc., Trans. 13: 134. +.

\section{Genus PARAGALEOPSOMYIA Girault}

Paragaleopsomyia Girault, 1917. Speciosissima Genera Nova Eulophidorum, p. 1.

Type-species: Paragaleopsomyia eja Girault. Orig. desig. 
eja Girault. Ariz., Oreg., Calif.

Paragaleopsomyia eja Girault, 1917. Speciosissima Genera Nova Eulophidorum, p. 1..

gallicola Gahan. Tex., Ariz. Ecology: Reared from cecidomyiid gall on Pluchea borealis.

Paragaleopsomyia gallicola Gahan, 1919. Ent. Soc. Amer., Ann. 12: 167. ₹, ð.

\section{Genus GALEOPSOMOPSIS Girault}

Galeopsomopsis Girault, 1917. Speciosissima Genera Nova Eulophidorum, p. 1.

Type-species: Galeopsomopsis multisulcata Girault. Orig. desig.

squamosa Girault. Calif.

Galeopsomopsis squemosus Girault, 1917. New Chalcid Flies, p. 3.

transcarinata Gahan. Ariz. Host: Asphondylia websteri Felt.

Galeopsomopsis transcurinatus Gahan, 1919. Ent. Soc. Amer., Ann. 12: 168. , ð.

\section{Genus TETRASTICHUS Haliday}

Tetrastichus Walker, 1842. Ann. and Mag. Nat. Hist. (1) 10: 116. Genus suppressed by Opinion 720, Internatl. Comn. Zool. Nomencl., 1965.

Type-species: Cirrospilus lycidas Walker. Desig. by Peck, 1951.

Tetrastichuss Haliday, 1844. Ent. Soc. London, Trans. 3: 297. Placed on Official list of Generic Names in Zoology by Opinion 720, Internatl. Comn. Zool. Nomencl., 1965.

Type-species: Cirrospilus attalus Walker. Monotypic. Placed on Official list of Specific Names in Zoology by Opinion 720, Internatl. Comn. Zool. Nomenel., 1965.

Trichoceres Ratzeburg, 1844. Ichn. d. Forstins., v. 1, insert opp. p. 40, p. 171.

Type-species: Trichoceres erythrophthalmus Ratzeburg. Monotypic.

Geniocerus Ratzeburg, 1848. Ichn. d. Forstins., v. 2, p. 175. N. name, unnecessarily proposed.

Baryscapus Foerster, 1856. Hym. Stud., v. 2, p. 84. No species.--Ashmead, 1887. Amer.

Ent. Soc., Trans. 14: 202. One species.

Type-species: Baryscapus centricolae Ashmead. Included by Ashmead, 1887.

Solenoderus Motschulsky, 1863. Soc. Imp. Nat. Moscou, Bul. 36: 71.

Type-species: Solenoderus cyaniventris Motschulsky. Monotypic.

Oomyzus Rondani, 1870. Comizio Agr. Parma, Bol. 3: 140.

Type-species: Oomyzus gallerucae (Fonscolombe). Monotypic.

Myiom isa Rondani, 1877. Soc. Ent. Ital., Bol. 9: 189.

Type-species: Myiomisa microscopica Rondani. Monotypic.

Tetrastichodes Ashmead, 1887. Amer. Ent. Soc., Trans. 14: 203.

Type-species: Tetrastichus floridanus Ashmead. Monotypic.

Lygellus Giard, 1896. Soc. de Biol. (Paris), Compt. Rend., p. 839.

Type-species: Lygellus epilachnae Giard. Monotypic.

Neotetrastichus Perkins, 1912. Hawaii. Sugar Planters' Assoc. Expt. Sta., Div. Ent. Bul. 10: 14.

Type-species: Neotetrastichus mimus Perkins. Monotypic.

Epitetrastichus Girault, 1913. Queensland Mus., Mem. 2: 205 (footnote), 229.

Type-species: Epitetrastichus speciosissimus Girault. Orig. desig.

Neomphaloidella Girault, 1913. Roy. Soc. So. Australia, Trans. 37: 69.

Type-species: Neomphaloidella fasciativentris Girault. Monotypic.

Epom phaloides Girault, 1913. Arch. f. Naturgesch. 79A (6): 49.

Type-species: Epomphaloides flavus Girault. Orig. desig.

Neotetrastichodes Girault, 1913. Queensland Mus., Mem. 2: 228.

Type-species: Neotetrastichodes flavus Girault. Orig. desig.

A prostoceroloides Girault, 1913. Queensland Mus., Mem. 2: 243.

Type-species: Aprostoceroloides speciosus Girault. Orig. desig.

Hadrothrix Cameron, 1913. Indian Forest Rec. 4: 102. N. Syn.

Type-species: Hadrothrix purpurea Cameron. Monotypic.

Blattotetrastichus Girault, 1917. Ent. News 28: 257.

Type-species: Entedon hagenowii Ratzeburg. Orig. desig.

Paromphaloidomyiia Girault, 1917. New Chaleid Flies, p. 1.

Type-species: Paromphaloidom yiia homeri Girault. Orig. desig. 
Tamarixia Mercet, 1924. R. Soc. Espan. Hist. Nat., Bol. 24: 57.

Type-species: Tamarixia bicolor Mercet. Orig. desig.

Anellaria Bakkendorf, 1934. Ent. Meddel. 19: 8.

Type-species: Anellaria conomeli Bakkendorf. Monotypic.

Pachyscapus Erdos, 1954. Mus. Nat. Hungarici, Ann. Hist. Nat., n. s., 5: 364.

Type-species: Ceranisus crino (Walker). Orig. desig.

The genus Sphenolepis Nees, 1834 (Hym. Ichn. Aff. Monog., v. 2, p. 265), along with its synonym Peltephorus Erdos, 1961 (Mus. Nat. Hungarici, Ann. Hist. Nat. 53: 483, 489), has been placed as a synonym of Tetrastichus Haliday by Boucek, 1961 (Mus. Nat. Pragae, Acta Ent. 34: 475). Sphenolepis is a wingless, aberrant form. It is, nevertheless, in Boucek's opinion, the same genus as Tetrastichus. Since it has priority over Tetrastichus, Boucek expressed his intention to petition the International Commission to suppress it. However, Sphenolepis and Tetrastichus ean, and should, be separated generically.

Revision: Girault, 1913. Queensland Mus., Mem. 2: 199-216 (Australian spp.). - Kurdjumov, 1913. Russk. Ent. Obozr. 13: 243-256 (Palearctic spp.). - Masi, 1940. R. Lab. Ent. Agr.

Portici, Bol. 3: 309-323 (African spp.), -Szelenyi, 1941. Ztschr. f. Angew. Ent. 28: 398-415 (some Palearctic spp.). - Burks, 1943 (reprinted 1971). U. S. Natl. Mus., Proc. 93: 505-608 (Nearctic spp.).

Taxonomy: Bakkendorf, 1953. Ent. Meddel. 26: 564. - Boucek, 1961. Mus. Natl. Pragae, Acta Ent. 34: 475-476 (Sphenolepis). - Graham, 1961. Ent. Monthly Mag. 97: 34-64 (all spp. in A prostocetus). - Burks, 1962. Bul. Zool. Nomencl. 19: 306-307. (Proposal for suppression of Tetrastichus. Walker, 1842). - Peck, 1963. Canad. Ent., Sup. 30, pp. 120-156 (Nearctic catalog). - Domenichini, 1964. Entomophaga 9: 33-38 (par. of Coleoptera). -Domenichini, 1965. Bol. Zool. agr. e di Bach. (2) 6: 65-194 (Palearctic species groups). -Domenichini, 1966. Palearctic Tetrastichinae, Le Francois, pp. 15-54 (Palearctic catalog and host list). -Domenichini, 1967. Bol. Zool. agr. e di Bach. (2) 8: 75-110 (Palearctic spp.).

acutus Ashmead. Fla. Type lost.

Tetrastich us acutus Ashmead, 1886. Amer. Ent. Soc., Trans. 13: 134. ठ゚.

aeneoviridis (Girault), Ill. Ecology: In puparia. Host: Syrphidae.

Trichapornes aeneoviridis Girault, 1912. Canad. Ent. 44: 75. ‡, ð.

agrili Crawford. N. Y. Host: Agrilus sinuatus (Oliv.). Also occurs in Europe, probably known under another name.

Tetrastichus agrili Crawford, 1914. Insecutor Inscitiae Menstruus 2: 181. \&.

ainsliei Gahan. Conn., N. Y., Md., Va., N. C., Ill., Minn., Iowa, N. Dak., S. Dak., Kans., Okla., Tex., Colo. Host: Cylindrocopturus adspersus (Lec.), Mordellistena sp., M. pustulata (Melsh.); Mayetiola destructor (Say).

Tetrastichus ainsliei Gahan, 1917. U. S. Natl. Mus., Proc. 53: 214. \&, ठ.

Neomphaloidella mediogutta Girault, 1917. Ent. News 28: 255. ๆ.

alaskensis Ashmead. Alaska. Type unidentifiable.

Tetrastichus alaskens is Ashmead, 1902. Wash. Acad. Sci., Proc. 4: 146. ठ。.

anthophilus Burks. N. H., Ill. Host: Rhopalomyia anthophila (O. S.).

Tetrastichus anthophilus Burks, 1947. Ent. News 58: 85. ๆ, ठ.

anthracinus Ashmead. Alaska. Type unidentifiable.

Tetrastichus anthracinus Ashmead, 1902. Wash. Acad. Sci., Proc. 4: 146..+

asparagi Crawford. S. Canada, Eastern U. S., Utah., Ariz., Wash., Oreg.; Europe. Probably introduced with its host plant. Host: Criocerus asparagi (L.).

Eulophus coeruleus Nees, 1834. Hym. Ichn. aff. Monog., v. 2, p. 174. \&.

Tetrastichus asparagi Crawford, 1909. Ent. Soc. Wash., Proc. 11: 150. ๆ. Consensus of opinion is that the name asparagi should be retained for this species because of wide usage in the economic literature. See Graham, 1961. Ent. Monthly Mag. 97: 39-40 and Domenichini, 1966. Palearctic Tetrastichinae, Le Francois, p. 19. It may be desirable to refer this matter to the Commission.

Biology: Howard, 1910. Jour. Econ. Ent. 3: 257-260. -Russell and Johnston, 1912. Jour. Econ.

Ent. 5: 429. -Johnston, 1915. Jour. Agr. Res. 4: 303. - Ross, 1915. Agr. Gaz. Canada 2: 
1055. - Paillot, 1917. Ann. du Serv. des Epiphyt. 4: 335. -Chittenden, 1923. Oreg. Bd. Hort., Rpt. 17: 187. -Felt, 1923. N. Y. State Ent., Rpt. 35: 92. - Beaulne, 1935. Quebec Soc. Protect. Plants, Ann. Rpt. 27: 59. - Sweetman, 1936. Biol. Control of Insects, pp. 145-146. - Clausen, 1956. U. S. Dept. Agr., Tech. Bul. 1139: 53. - Askew, 1971. Parasitic Insects, p. 136.

auplopus Burks. Va. Host: Auplopus sp.

Tetrastichus auplopus Burks, 1963. Biol. Soc. Wash., Proc. 76: 55. ㅇ.

baldufi Burks. Ill. Host: Neuroterus quercusverncarum (O. S.), gall.

Tetrastichus baldlufi Burks, 1943. U. S. Natl. Mus., Proc. 93: 540. \&, ठ.

banksii Howard. N. J., D. C., Fla., Ala., Mo. Ecology: In sacs of epeirid spiders.

Tetrastichus banksii Howard, 1892. Ent. Soc. Wash., Proc. 2: 299. ․

barbarae Burks. Mont., N. Mex., Oreg. Ecology: In Abies cones infested with Barbara colfaxiana (Kearf.), Pinus ponderosa cones, Psendotsnga menziesii cones; possibly secondary.

Tetrastichus barbarae Burks, 1963. Biol. Soc. Wash., Proc. 76: 52., đ.

blastophagi (Ashmead). D. C., Fla. Host: Callirhytis blastophaga (Ashm.) gall.

Hyperteles blastophagi Ashmead, 1887. Amer. Ent. Soc., Trans. 14: 202. \&, ठ.

brevicornis (Panzer). Ont.; Europe. Probably an adventive sp. Host: Contarinia sp. in Fraximus seeds.

Cynips brevicomis Panzer, 1804. System. Nomencl. . . S Schaeffers ... Insekten, p. 134.

brevistigma Gahan. N. H., Mass., Conn., R. I., N. Y., D. C., Ohio, Ind., Ky., Wash., Oreg., Calif. Host: Pyrrhalta luteola (Muller) pupae. This parasite is native to North America and its host is introduced; its original host must have been some related, native chrysomelid.

Tetrastichus brevistigma Gahan, 1936. Ent. Soc. Wash., Proc. 38: 76. ๆ, ठ.

Biology: Berry, 1938. U. S. Dept. Agr., Cir. 485, 11 pp. -Clausen, 1956. U. S. Dept. Agr., Tech. Bul. 1139: 67.

bruchivorus Gahan. France. Introduced, but not established in N. C., Oreg. from France. Host: Bruchus brachialis Fahr.

Tetrastichus bruchivorus Gahan, 1942. Ent. Soc. Wash., Proc. 44: 8. ₹, ठ.

Biology: Clausen, 1956. U. S. Dept. Agr., Tech. Bul. 1139: 52.

bruchophagi Gahan. U. S.; Holaretic, South. S. Amer., Africa; prob. worldwide. Host: Bruchophagus spp.

Tetrastichus brucophagi(!) Gahan, 1913. U. S. Natl. Mus., Proc. 46: 439. ?, o.

Tetrastichus bruchophagi Girault, 1916. U. S. Natl. Mus., Proc. 51: 128, 132. Emend.

Biology: Urbahns, 1917. Jour. Agr. Res. 8: 277-282. -Gahan, 1919. Ent. Soc. Amer., Ann. 12:

167. - Urbahns, 1920. U. S. Dept. Agr., Bul. 812: 17. - Nikolskaya, 1932. Zashch. rast. 1:

107-111. - Nikolskaya, 1934. Nikhl. nauch. iss. khlopk. inst. (Tashkent) 4-5: 120-122.

- Butler and Hansen, 1958. Pan-Pacific Ent. 34: 224-226. - Neunzig and Gyrisco, 1959.

Jour. Econ. Ent. 52: 899. - Carrillo and Dickason, 1963. Oreg. State Univ. Agr. Expt. Sta.,

Tech. Bul. 86: 25, 31. - Batiste, 1967. Hilgardia 38: 463. - Watts and Bellotti, 1967. Jour.

Econ. Ent. 60: 961.

byersi Burks. Mich., Ind. Host: Dolichopeza americana Needham, D. walleyi (Alex.) pupae.

Tetrastichus byersi Burks, 1963. Biol. Soc. Wash., Proc. 76: 53. १, ठ.

cassidis Burks. Md., La. Host: Deloyala guttata (Oliv.), Metriona bicolor (F.), larvae.

Tetrastichus cassidis Burks, 1943. U. S. Natl. Mus., Proc. 93: 555. ९, ठ.

centricolae (Ashmead). N. C. Ecology: Reared from gall of Atrusca quercuscentricola (0. S.). Type too broken to be recognized specifically.

Baryscapus centricolae Ashmead, 1887. Amer. Ent. Soc., Trans. 14: 202. \&.

Taxonomy: Burks, 1943. U. S. Natl. Mus., Proc. 93: 603 (Transferred to Tetrastichus).

charoba (Walker). Generally dist. in wheat-producing areas of U. S. and Canada; Holaretic. Ecology: Usually a primary parasite, but occasionally secondary, developing in other 
parasites of the Hessian fly. Host: Mayetiola destructor (Say), Dasineura leguminicola (Lintner).

Cirrospilus charoba Walker, 1840 (1839). Ann. Nat. Hist. 4: 30. ९. This name does not have strict priority over other Walker names for this sp., but was selected by Graham (1961. Ent. Monthly Mag. 97: 51) because of usage. Graham lists 12 European synonyms of charoba.

Tetrastichus carinatus Forbes, 1885. Ill. State Dept. Agr., Trans. 22 (App.): 48. \&.

Taxonomy: Gahan, 1934 (1933). U. S. Dept. Agr., Misc. Pub. 174: 138-142, 144. - Hill and

Pinckney, 1940. U. S. Dept. Agr., Tech. Bul. 715: 10-13. -Graham, 1961. Ent. Monthly Mag.

97: 51-52 (extensive European synonymy). - Domenichini, 1965. Bol. Zool. agr. e di Bach.

(2) 6: 155-156 (synonymy).

Biology: Hill et al., 1939. U. S. Dept. Agr., Tech. Bul. 689: 4-7, 10-15. -Lapina, 1948. Zool.

Zhur. 27: 331. -Hill, 1953. U. S. Dept. Agr., Cir. 923: 3.

chlamytis Ashmead. Maine, s. to Fla., w. to Miss., Minn., Tex., and Utah. Host: Chlamisus sp., C. gibbosus (F.), Exema dispar Lacordaire, E. mormona Karren.

Tetrastichus chlamytis Ashmead, 1896. Amer. Ent. Soc., Trans. 23: 234. ๆ, ১.

chrysopae (Crawford). Md., s. to Fla., w. to Minn., La., Mont., Oreg. and Calif.; Mexico, West Indies, Brazil. Host: Chrysopa sp., C. californica Coq., C. oculata Say, C. plorabunda Fitch, C. rufilabris Burm.

Geniocerus chrysopae Crawford, 1915. U. S. Natl. Mus., Proc. 48: 584. \&.

A prostoceroloides annapolis Girault, 1917. Chalcidoidea Nova Marilandensis. II, p. 2..

Biology: Clancy, 1946. Calif. Univ. Pubs., Ent. 7: 448-454. -Muma, 1959. Fla. Ent. 42: 151.

clito (Walker). Ont., N. Y., Pa.; Europe. Adventive, first found in Ont. in 1951. Host: Cassida rubiginosa Mull.

Cirrospilus clito Walker, 1840 (1839). Ann. Nat. Hist. 4: 30. ठ.

Taxonomy: Graham, 1961. Ent. Monthly Mag. 97: 39. - Peck, 1963. Canad. Ent., Sup. 30: 128.

Biology: Domenichini, 1966. Palearetic Tetrastichinae, Le Francois, p. 25 (Holarctic hosts and Distribution).

coerulescens Ashmead. N. B., s. to Fla., w. to Alaska, Oreg. and Calif. Ecology: Secondary or tertiary parasite of numerous Coleoptera, Lepidoptera, Neuroptera. Host: Apanteles sp., A. congregatus (Say), A. melanoscelus (Ratz.), Bracon sp., B. gelechiae Ashmead, B. hebetor Say, Catolaccus aeneoviridis (Girault), Dibrachys cavus (Walk.), Hyposoter pilosulus (Prov.), Meteorus acronyctae Mues., Microgaster sp., Pteromalus sp.

Tetrastichus coerulescens Ashmead, 1898. Ent. Soc. Wash., Proc. 4: 130. १, ठ์.

Tetrastichus doteni Crawford, 1911. Ent. Soc. Wash., Proc. 13: 234. ‡, o.

Biology: Wester, 1956. Ent. Soc. Wash., Proc. 58: 284. —Schaffner, 1959. U. S. Dept. Agr., Misc. Pub. 767: $38,82$.

compsivorus Crawford. Miss., Okla., Tex. Host: Compsus auricephalus (Say).

Tetrastichus compsivorus Crawford, 1915 (1914). Insecutor Inscitiae Menstruus 2: 180., o.

cormus Burks. Ill. Host: Aulacidea podagrae (Bass.) gall, Hemadas nubilipennis (Ashm.) gall. The record from Hemadas is questionable.

Tetrastichus comuns Burks, 1943. U. S. Natl. Mus., Proc. 93: 579. १, ठ.

crino (Walker). Pa., Md., S. C., Ark., Okla., Tex.; Europe. Host: Oecanthus sp., O. nigricornis quadripunctatus Beut. eggs.

Cirrospilus crino Walker, 1838. Ann. Nat. Hist. 1: 382. ठ.

Tetrastichus dispar Silvestri, 1920. Lab. Zool. Gen. e Agr. Portici, Bol. 14: 249. ๆ, ð. Preocc. by Masi, 1916.

Tetrastichus oecanthivorus Gahan, 1932. Ent. Soc. Amer., Ann. 25: 743. N. name for dispar Silvestri.

Tetrastichus oecanthivorus var. compar Gahan, 1932. Ent. Soc. Amer., Ann. 25: 743. १, ठ. Tetrastichus dubius Bakkendorf, 1955. Ent. Meddel. 27: 152. ठ์.

Taxonomy: Domenichini, 1965. Bol. Zool. agr. e di Bach. (2) 6: 136. -Domenichini, 1966.

Palearctic Tetrastichinae, Le Francois, p. 27. 
Biology: Udine and Pinckney, 1940. Pa. Acad. Sci., Proc. 14: 81-83.

diarthronomyiae Gahan. Md. Host: Diarthronomyia chrysanthemi Ahlb.

Tetrastichus diarthronomyiae Gahan, 1923. Ent. Soc. Wash., Proc. 25: 65. \&.

Biology: Hamilton, 1924. Md. Agr. Expt. Sta., Bul. 269: 32.

dolosus Gahan. Md., Va., Ohio, Iowa, Ark., La., Kans., Tex., Mont., Idaho, Ariz., Calif. Ecology: This may be either a primary or secondary parasite. Host: Ancylis comptana fragariae (W. and R.), Coleophora laricella (Hbn.), Evora hemidesma (Zell.), Fascista cercerisella (Chamb.), Homadaula anisocentra Meyrick, Paromix sp.; Euplectrus comstockii How., E. plathypenae How.

Tetrastichus dolosus Gahan, 1917. U. S. Natl. Mus., Proc. 53: 215. ‡, ठ. dyrus Burks. Mont., Wyo., Colo. Host: Aphalara curta Caldw., Trioza spp.

Tetrastichus dyrus Burks, 1943. U. S. Natl. Mus., Proc. 93: 541. ९, ठ.

Taxonomy: Graham, 1961. Ent. Monthly Mag. 97: 42. ecus (Walker). Maine, Mass., Del., Ohio, Wis., Mont.; Europe. Host: Coleophora laricella (Hbn.), Coptodisca splendoriferella (Clem.); Fenusa ulmi Sund., Heterarthrus nemoratus (Fallen), Phanomeris phyllotomae Mues.; Rhynchaenus pallicornis (Say). Numerous other hosts in European literature.

Cirrospilus ecus Walker, 1838. Ann. Nat. Hist. 2: 204. ठ, ९.

Eulophus cyclogaster Ratzeburg, 1844. Ichn. d. Forstins., v. 1, p. 167. $\subsetneq$.

Eulophus xanthops Ratzeburg, 1844. Ichn. d. Forstins., v. 1, p. 170. $\%$.

Taxonomy: Graham, 1961. Ent. Monthly Mag. 97: 48. - Domenichini, 1965. Bol. Zool. agr. e di Bach. (2) 6: 130-131. - Domenichini, 1966. Palearctic Tetrastichinae, Le Francois, p. 28.

Biology: Berry, 1938. Jour. Agr. Res. 57: 859-863. - Dowden, 1941. U. S. Dept. Agr., Tech. Bul. 757: 8, 10, 32-35. - Sundby 1957. Norsk Ent. Tidsskr., sup. 2, pp. 44-47. - Deluechi, 1958. Entomophaga 3: 245, 263-265. -Schaffner, 1959. U. S. Dept. Agr., Misc. Pub. 767: 83. -Capek, 1963. Banska Stiav. Vysk. Ust. Lesn. Hosp. Ved. Prace 4: 270. -Celli, 1965.

Univ. Bologna, Ist. di Ent., Bol. 27: 56. -Cheng and LeRoux, 1966. Ent. Soc. Quebec, Ann. 11: 88 .

erynniae Domenichini. Calif.; Europe. Ecology: A secondary parasite. Probably inadvertently introduced along with its tachinid host. Host: Erynniopsis rondanii Townsend, parasitic on Pyrrhalta luteola (Muller).

Tetrastichus erynniae Domenichini, 1965. Bol. Zool. agr. e di Bach. (2) 6: 123. \&, ठ.

euplectri Gahan. La., Tex. Host: Euplectrus plathypenae How., Meteorus sp.

Tetrastichus euplectri Gahan, 1914. U. S. Natl. Mus., Proc. 48: 167.,$+ \delta$.

evonymellae (Bouche). Wash., Calif. Introduced from Europe. Host: Leucoptera spartifoliella Hbn.

Eulophus evonymellae Bouche, 1834. Naturgesch. d. Ins., p. 172. \&, ठ.

faustus Burks. Wis., Minn., Mont., Idaho, Wash., Calif. Host: Rhagoletis fausta (0. S.).

Tetrastichus faustus Burks, 1943. U. S. Natl. Mus., Proc. 93: 582..

Biology: Balduf, 1959. Ill. Biol. Monog. 26, p. 146.

flavipes Ashmead. Fla. Ecology: Reared from gall of Disholcaspis quercusvirens (Ashmead). Type lost.

Tetrastichus flavipes Ashmead, 1886. Amer. Ent. Soc., Trans. 13: 135. ९.

flavopictus (Ashmead). Fla. Type lost.

Ceranisus flavopictus Ashmead, 1887. Amer. Ent. Soc., Trans. 14: 202. ठ。.

Taxonomy: Burks, 1943. U. S. Natl. Mus., Proc. 93: 604 (Transferred to Tetrastichus).

flora (Girault). Md., D. C., Ga., Fla., Tenn. Host: Monarthropalpus buxi (Lab.).

Aprostocetus flora Girault, 1917. New Chalcid Flies, p. 3. Prob. described from female.

Epitetrastichus tricolor Girault, 1917. Descr. Stellarum Nov., p. 9..

fumipennis (Girault). N. Y., Md., D. C., Va., Ohio, Ind., Ill., Iowa. Host: Asteromyia carbonifera (0. S.) gall on Solidago.

Neomphaloidella fumipennis Girault, 1917. Chalcidoidea Nova Marilandensis. [I], p. 2.. . gala Walker. Fla.

Tetrastichus Gala Walker, 1847. Ann. and Mag. Nat. Hist. (1) 20: 28.. 
Taxonomy: Burks, 1975. Brit. Mus. (Nat. Hist.) Ent., Bul. 32 (4): 143.

galactopus (Ratzeburg). East Coast states, w. to Kans.; cosmopolitan. Host: Apanteles glomeratus (L.), par. of Pieris. Other hosts are given in European literature. This species has been named microgastri or rapo by numerous American and European authors.

Eulophus galactopus Ratzeburg, 1844. Ichn. d. Forstins., v. 1, p. 169. ․

Eulophus vinulae Ratzeburg, 1844. Ichn. d. Forstins., v. 1, p. 169. $\$$.

Tetrastichus lissonotus Moeller, 1886. Ent. Tidskr. 7: 83. ๆ, ठ.

Taxonomy: Graham, 1961. Ent. Monthly Mag. 97: 37-38, 47. -Domenichini, 1965. Bol. Zool. agr. e di Bach. (2) 6: 120-121.

Biology: Masi, 1908. Lab. Zool. Gen. e Agr. Portici, Bol. 3: 133. - Richards, 1940. Jour. Anim. Ecol. 9: 270-286. -Delucchi, 1950. Redia 35: 441-450. -Clausen, 1940. Entomophagous Insects, pp. 143-144. - Wilbert, 1960. Entomophaga 5: 203. -Janssen, 1960. Ztschr. f. Pflanzenkrank. 67: 20. -Mook and Haechk, 1965. Arch. Neerland de Zool. 16: 302.

-Wilkinson, 1966. Jour. Econ. Ent. 59: 1012.

Morphology: Domenichini, 1953. Bol. Zool. Agr. e di Bach. (1) 19: 278.

gallerucae (Fonscolombe). Mass., Conn., N. Y., N. J., D. C., Va. Introduced from Europe. Host: Pyrrhalta luteola (Muller)eggs.

Pteromalus gallerucae Fonscolombe, 1832. Ann. Sci. Nat. 26: 302.

Oomyzus xanthomelaenae Rondani, 1873. Soc. Ent. Ital., Bol. 5: 148.

Taxonomy: Marchal, 1905. Soc. Ent. de France, Bul. 1905: 81-83. -Boucek, 1957. Mus. Natl. Pragae, Acta Ent. 31: 177-181. -Domenichini, 1964. Entomophaga 9: 37.

Biology: Marchal, 1905. Soc. Ent. de France, Bul. 1905: 64-68. - Howard, 1908. Jour. Econ. Ent. 1: 281-289. - Silvestri, 1910. Lab. Zool. Gen. e Agr. Portici, Bol. 4: 273-276. - Howard, 1910. Jour. Econ. Ent. 3: 257. - Howard, 1925. Ent. News 36: 129. -Berry, 1938. Jour. Agr. Res. 57: 859-863.

Morphology: Masi, 1908. Lab. Zool. Gen. e Agr. Portici, Bol. 3: 131-133. -Silvestri, 1910. Lab. Zool. Gen. e Agr. Portici, Bol. 4: 272-273 (larva).

garryana Burks. B. C., Oreg., Wash. Host: Besbicus mirabilis (Kinsey), several cynipid galls on Quercus garryana.

Tetrastichus garryana Burks, 1963. Biol. Soc. Wash., Proc. 76: 49. १, ठ.

Biology: Evans, 1963. Canad. Ent. 95: 1002-1005. -Evans, 1967. Canad. Ent. 99: 187-196. gelastus Burks. Fla. Host: Trioza on Chinese elm.

Tetrastichus gelastus Burks, 1963. U. S. Natl. Mus., Proc. 93: 539..

gentilei Del Guercio. Fla.; West Indies, Europe, Fiji; cosmopolitan. Host: Gynaikothrips ficorum (Marchal), G. uzeli (Zimmermann), Hoplothrips pedicularius (Haliday), Liothrips laureli (Mason), L. oleae (Costa), L. urichi Karny. The male is unknown and probably does not exist.

Tetrastichus Gentilei Del Guercio, 1911. Accad. Georgofili Firenze, Atti 8: 222-227.

Tetrastichus thripophonus Waterston, 1923. Bul. Ent. Res. 13: 453.. .

Tetrastichus tatei Dozier, 1937. Univ. Puerto Rico., Jour. Agr. 21: 129..

Taxonomy: Domenichini, 1965. Bol. Zool. agr. e di Bach. (2) 6: 178-179.

Biology: Del Guercio, 1911. Accad. Georgofili Firenze, Atti 8: 222-227. -Mason, 1922. Ent. News 33: 199. - Del Guercio, 1931. Redia 19: 75-195. - Melis, 1935. Redia 21: 120-129.

-Bournier, 1967. Soc. Ent. de France, Ann. (n. s.) 3: 173-179.

gerstaeckeriae Gahan. Tex. Host: Gerstaeckeria nobilis Lec., G. porosa Lec.

Tetrastichus gerstaeckeriae Gahan, 1936. U. S. Natl. Mus., Proc. 83: 485. ९, ठ๋.

gibboni (Girault). Okla., Ariz. Host: Languria mozardi Latr.

Ootetrastichus gibboni Girault, 1917. Brooklyn Ent. Soc., Bul. 12: 86. ․

gigas Burks. Wash., Oreg., Calif. Host: Andricus quercuscalifornicus (Bassett) gall.

Tetrastichus gigas Burks, 1943. U. S. Natl. Mus., Proc. 93: 560. ․, ठ’.

granulatus Walker. Ont.

Tetrastichus gramulatus Walker, 1844. Ann. and Mag. Nat. Hist. (1) 14: 17. \&. 
Taxonomy: Burks, 1975. Brit. Mus. (Nat. Hist.) Ent., Bul. 32 (4): 143 (lectotype designated).

hagenowii (Ratzeburg). S. C., Ga., Fla., Ala., Miss., La., Tex.; worldwide. Ecology: Commonly found in roach-infested, heated buildings throughout North America, but able to exist in a state of nature only in the far south. Host: Blatta orientalis (L.), Periplaneta americana (L.), P. australasiae (F.), P. brunnea Burm., P. fuliginosa (Serv.), Eurycotis floridana (Walk.).

Entedon hagenowii Ratzeburg, 1852. Ichn. d. Forstins., v. 3, p. 211.

Tetrastichus floridanus Ashmead, 1887. Amer. Ent. Soc., Trans. 14: 203.,$+ \delta$.

Tetrastichoides(!) browni Ashmead, 1905. U. S. Natl. Mus., Proc. 29: 113. @.

Tetrastichodes asthenogmus Waterston, 1915. Bul. Ent. Res. 5: 340..

Taxonomy: Gahan, 1914. U. S. Natl. Mus., Proc. 48: 168. - Burks, 1943. U. S. Natl. Mus., Proc. 93: 554. - Roth and Willis, 1960. Smithsn.-Inst., Misc. Collect. 141: 249. - Domenichini, 1965. Bol. Zool. agr. e di Bach. (2) 6: 185.

Biology: Usman, 1949. Current Sci. (India) 18: 407. -Roth and Willis, 1954. Amer. Ent. Soc., Trans. 80: 53-72. -Edmunds, 1955. Ent. Soc. Amer., Ann. 48: 210-213. -Cameron, 1955.

Bul. Ent. Res. 46: 137-147. -Cameron, 1957. Bul. Ent. Res. 48: 205-206. - Roth and Willis, 1960. Smithsn. Inst., Misc. Collect. 141: 251-253.

Morphology: Cameron, 1955. Bul. Ent. Res. 46: 137-147.

haitiensis Gahan. Fla.; West Indies. Introduced from Puerto Rico and recovered, but not certainly established. Host: Diaprepes abbreviatus (L.), D. quadrivittatus (Oliv.), Pachnaeus litus (Germar).

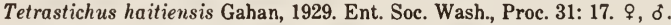

Biology: Myers, 1932. Ent. Soc. London., Trans. 80: 135-136. - Wolcott, 1934. Puerto Rico Univ., Jour. Agr. 18: 426-427. - Myers, 1935. Bul. Ent. Res. 26: 237. -Wolcott, 1936. Puerto Rico Univ., Jour. Agr. 20: 521. - Tucker, 1936. Barbados Dept. Sci. and Agr., Agr. Jour. 5: 7-11. - Tucker and Wolcott, 1936. Internatl. Soc. Sugar Cane Technol., Proc. 5th Cong., pp. 403-404. - Wolcott, 1937. Puerto Rico Univ., Jour. Agr. 20: 884, 900, 901, 912. -Wolcott and Martorell, 1944. Puerto Rico Univ., Jour. Agr. 27: 97. -Wolcott, 1948.

Puerto Rico Univ., Jour. Agr. 32: 776-777. _James, 1954. Jamaica Dept. Agr., Bul. 54: 11. hesperius Burks. Ill. Ecology: Emerged from cynipid galls. Host: Diplolepis ignota (0. S.). Tetrastichus hesperius Burks, 1947. Ent. News 58: 88. $\%, \delta$.

hibus Burks. Calif. Ecology: Emerged from cup-gall on Artemisia ladoviciana.

Tetrastichus hibus Burks, 1943. U. S. Natl. Mus., Proc. 93: 582. \&, ð.

hillmeadia (Girault). Md.

Ootetrastichus hillmeadia Girault, 1917. Chalcidoidea Nova Marilandensis. III, p. 2. + .

holbeini Girault. W. Va., Mo., Calif. Host: Chrysobothris femorata (Oliv.), C. mali Horn.

Tetrastichus holbeini Girault, 1917. New Chalcid Flies, p. 2. $\$$.

homeri (Girault). Va., S. C., Ga., Fla., Iowa. Host: Asteromyia carbonifera (0. S.) leaf gall on Solidago.

Paromphaloidomyiia homeri Girault, 1917. New Chalcid Flies, p. 1.

Tetrastichus argyrus Burks, 1943. U. S. Natl. Mus., Proc. 93: 558. ९, ð.

hunteri Crawford. Miss., Ark., La., Tex. Host: Anthonomus grandis Boh.

Tetrastichus hunteri Crawford, 1909. Ent. Soc. Wash., Proc. 11: 150. $q$.

Biology: Pierce, 1910. Jour. Econ. Ent. 3: 453. - Pierce et al., 1912. U. S. Dept. Agr., Bur.

Ent. Bul. 100: 56-63. - Hunter and Pierce, 1912. U. S. Dept. Agr., Bur. Ent. Bul. 114: 142.

ichthyus Burks. Tex. Host: Neuroterus quercusrileyi (Bass.), Xanthoteras emoryi (Ashm.).

Both records are questionable.

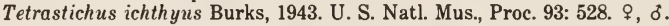

impexus Girault. Va. Host: Disholcaspis quercusglobulus (Fitch) gall.

Tetrastichus impexus Girault, 1917. New Chalcid Flies, p. 2.

incertus (Ratzeburg). Que., N. H., Vt., Mass., Conn., N. Y., N. J., Pa., Del., Md., Va., W. Va.,

Ky.; Europe. Introduced from Europe. Host: Hypera postica (Gyll.).

Eulophus incertus Ratzeburg, 1844. Ichn. d. Forstins., v. 1, p. 168.

Tetrastichus erdoesi Domenichini, 1965. Bol. Zool. agr. e di Bach. (2), 6: 99. 
Taxonomy: Burks, 1971. Ent. Soc. Wash., Proc. 73: 429-431.

Biology: Chamberlin, 1924. Jour. Econ. Ent. 17: 623. -Chamberlin, 1925. Jour. Econ. Ent. 18: 597. - Coles and Puttler, 1963. Jour. Econ. Ent. 56: 610. - Miller, 1966. Jour. Econ. Ent. 59: 1532. - Streams and Fuester, 1967. Jour. Econ. Ent. 60: 1575. -Schroeder et al., 1969.

Ent. Soc. Amer., Ann. 62: 812-815. - Horn, 1970. Jour. Econ. Ent. 63: 303-304. - Mailloux and Pilon, 1970. Soc. Ent. Quebec, Ann. 15: 123-127. - Miller, 1970. Jour. Econ. Ent. 63: 719-721. - Richardson, et al., 1971. Canad. Ent. 103: 1653-1658. - Horn, 1971. Canad. Ent. 103: 83-94.

johnsoni Ashmead. N. H., Md., Ill., Mo., Ariz. Ecology: Primary parasite of larvae of spider wasps. Host: Phanagenia bombycina (Cresson), Dipogon sayi Banks. Tetrastichus johnsoni Ashmead, 1896. Amer. Ent. Soc., Trans. 23: 233. ๆ.

Biology: Krombein, 1967. Trap-nesting wasps and bees, pp. 424-426.

julis (Walker). W. Va., Ohio, Mich. Introduced from Europe. Host: Oulema melanopus (L.). Original introduction material from Italy and Southern France for liberation in North America identified by G. Domenichini, 1964. Species name mis-spelled tulis in some literature.

Cirrospilus julis Walker, 1839. Ann. and Mag. Nat. Hist. (1) 2: 354. ठ, १.

Cirrospilus Tulis(!) Walker, 1839. Monog. Chalcid., v. 1, p. 333. This mis-spelling was used in all known literature until 1961.

Taxonomy: Graham, 1961. Ent. Monthly Mag. 97: 38. -Domenichini, 1965. Bol. Zool. agr. e di Bach. (2) 6: 90 .

Biology: Hodson, 1929. Bul. Ent. Res. 20: 10 (Tetrastichus sp.).

juniperi (Crawford). N. Y., Va., Ohio, Ill., Idaho, Oreg. Ecology: Reared from juniper berries that are infested with cecidomyiid larvae or larvae of Anthonomus juniperinus Sanb. Geniocerus juniperi Crawford, 1915. U. S. Natl. Mus., Proc. 48: 585..

Biology: Marcovitch, 1915. Ent. Soc. Amer., Ann. 8: 169. -Gahan, 1922. Ent. Soc. Wash., Proc. 24: 48-51. - Morgan and Hedlin, 1960. Canad. Ent. 92: 610. - Appleby and

Neiswander, 1966. Ohio Agr. Expt. Sta., Res. Bul. 980: 6-9.

lasius Burks. Ohio., Tex. Host: Asteromyia agrostis (0. S.).

Tetrastichoides(!) lasiopterae Ashmead, 1894. Cincinnati Soc. Nat. Hist., Jour. 17: 54. ९, ठ์. Preocc. by Lindemann, 1881.

Tetrastichus lasius Burks, 1943. U. S. Natl. Mus., Proc. 93: 596. N. name.

lissus Burks. Ariz., Calif. Ecology: Reared from Astragalus mollissimus. Host: Strymon melinus $\mathrm{Hbn}$.

Tetrastichus lissus Burks, 1943. U. S. Natl. Mus., Proc. 93: 527. §.

Biology: Samuelson, 1961. Pan-Pacific Ent. 37: 190.

longicorpus (Girault). N. Mex. Host: Rhyacionia frustrana bushnelli (Busck).

Neotetrastichodes longicorpus Girault, 1916. U. S. Natl. Mus., Proc. 51: 129..

malacosomae Girault. Que., N. Y., Mass., Conn., Del., Pa., N. C., Mich., Ark., Nebr., Colo., N. Mex., Idaho, Nev., Oreg., Calif. Host: Malacosoma americanum (F.), M. californicum (Pack.), M. disstria $\mathrm{Hbn}$., $M$. fragile Stretch, $M$. pluviale recenseo Dyar.

Tetrastichus malacosomae Girault, 1917 (1916). Insecutor Inscitiae Menstruus 4: 110., , o.

Biology: Langston, 1957. Calif. Univ. Pubs., Ent. 14: 26-27.

malophilus Burks. Ohio, Idaho. Host: Crossidius hirtipes Lec., Rhynchaenus pallicornis (Say). Tetrastichus malophilus Burks, 1943. U. S. Natl. Mus., Proc. 93: 585..

marcovitchi (Crawford). Maine, N. Y., Ind., Ill., Wis., N. Dak., Idaho, Nev. Host: Dasineura balsamicola (Lintn.), Oligotrophus betheli Felt, undet. cecidomyiid in juniper berries.

Geniocerus marcovitchi Crawford, 1915. U. S. Natl. Mus., Proc. 48: 586. १, o.

Biology: Marcovitch, 1915. Ent. Soc. Amer., Ann. 8: 170. - Giese and Benjamin, 1959. Forest

Sci. 5: 205. - Appleby and Neiswander, 1966. Ohio Agr. Expt. Sta., Res. Bul. 980: 13.

marylandensis (Girault). Mass., Md., D. C., Va., Ga., Fla., Ill., Miss., Mo., La. Host: Rhyacionia frustrana (Comst.), Exoteleia pinifoliella (Chamb.); undet. cecidomyiids.

Epitetrastichus marylandensis Girault, 1916. Ent. Soc. Amer., Ann. 9: 295. \&. 
Epitetrastichus cuneiformis Girault, 1917. Descr. Stellarum Nov., p. 18. ‥

Biology: Schaffner, 1959. U. S. Dept. Agr., Misc. Pub. 767: 82.

megachilidis Burks. Fla., Ohio, Ariz., Utah, Nev., Wash., Calif. Ecology: Parasites emerge from prepupae of the host. Host: Megachile (Eutricharaea) concinna Smith, $M$. (Litomegachile) gentilis Cress., $M$. (E.) rotundata (F.), M. (Melanosaumis) xylocopoides Smith.

Tetrastichus megachilidis Burks, 1963. Biol. Soc. Wash., Proc. 76: 57. १, ठ.

Biology: Butler and Wargo, 1963. Pan-Pacific Ent. 39: 205. - Krombein, 1967. Trap-nesting wasps and bees, pp. 427-430. - Butler and Ritchie, 1965. Pan-Pacific Ent. 41: 156.

melanis Burks. N. H., Mass., Fla., Ont., Minn., Wash. Host: Coccinella sp., C. quinquenotata Kirby. This is probably a synonym of a European species.

Tetrastichus melanis Burks, 1943. U. S. Natl. Mus., Proc. 93: 529. ₹, ð.

Biology: Newcomer, 1958. Pan-Pacific Ent. 34: 89.

microrhopalae Ashmead. Man., N. J., D. C., Va., Ill. Host: Microrhopala xerene Newm., $M$. vittata $(\mathrm{F}$.).

Tetrastichus microrhopalae Ashmead, 1896. Amer. Ent. Soc., Trans. 23: 234. ๆ, §. milleri Burks. Calif. Ecology: Secondary parasite of Recurvaria milleri (Busck).

Tetrastichus milleri Burks, 1963. Biol. Soc. Wash., Proc. 76: 56..

minutus (Howard). Maine and Ont., s. to Fla., w. to B. C. and Calif.; Mexico, West Indies, Central America. Ecology: Probably always a secondary parasite, but often recorded from primary hosts. Host: Aphis gossypii Glov., A. pomi Deg., Lecanium comi Bouche, L. nigrofasciatum Perg., L. persicae (F.), Phenacocens acericola King, P. helianthi (Ckll.), Physokermes insignicola (Craw), Pseudococcus juniperi Ehrh., P. comstocki (Kuw.), Pulvinaria bigeloviae Ckll., Saissetia oleae (Oliv.); Adalia bipunctata (L.), Cycloneda sangninea (L.), C. sanguinea immaculata (F.); Coccophagus albicoxa How., C. lycimnia (Wlkr.), Anagyrus yuccae (Coq.), Aphycus lounsburyi How., A. physokermis Timb., Blastothrix longipennis How., Chalcaspis phenacocci (Ashm.), Chrysoplatycerus ferrisi Timb., C. splendens How., Clausenia purpurea Ishii, Homalotylus terminalis (Say), Microterys mazzinini Gir., Praon sp., Pseudleptomastix squammulata Gir., Zarhopalus corvinus (Gir.), Pachyneuron californicum Gir.

Astichus minutus Howard, 1881. U. S. Dept. Agr., Ann. Rpt. for 1880, p. 369. ठठ.

Tetrastichus lecanii Ashmead, 1885. Amer. Ent. Soc., Trans. 12: Proc. p. xix. ९.

Tetrastichus blepyri Ashmead, 1902. Canad. Ent. 34: 302. ?.

Tetrastichus (Tetrastichodes) detrimentosus Gahan, 1913. U. S. Natl. Mus., Proc. 46: 439. ,$\delta$.

Taxonomy: Gahan, 1924. U. S. Natl. Mus., Proc. 65 (4): 19. -Burks, 1943. U. S. Natl. Mus., Proc. 93: 580 .

Biology: Timberlake, 1924. Calif. Univ. Pubs. Ent. 3: 248-251. -Clausen, 1924. Calif. Univ. Pubs. Ent. 3: 257-266, 286-287. - Smith and Compere, 1928. Calif. Univ. Pubs. Ent. 4: 242, 306-308. -Clancy, 1948. Jour. Econ. Ent. 37: 450-451. - Judd, 1949. Nova Scotia Inst. Sci., Proc. 22: 64-67. - Flanders, 1953 (1952). Ent. Soc. Amer., Ann. 45: 544-547. - Samarasinghe and Leroux, 1966. Ent. Soc. Quebec, Ann. 11: 234.

modestus Howard. N. H., s. to Fla., w. to Mich., Nebr., and Calif. Ecology: Secondary parasite of Lepidoptera. Host: Apanteles atalantae (Pack.), A. edwardsii Riley, A. pyraustae Vier., Microgaster congregatiformis Vier.

Tetrastichus modestus Howard, 1889. In Scudder, Butterflies of Eastern U. S. and Canada, pp. 1872, 1894. \&, ठ.

Epitetrastichus mundicomis Girault, 1917. Chalcidoidea Nova Marilandensis. III, p. 1..

Biology: Schaffner, 1959. U. S. Dept. Agr., Misc. Pub. 767: 83.

nebraskensis (Girault). Maine, N. J., Md., S. C., Ind., Mich., Minn., Iowa, Mo., Nebr., Tex., N. Mex., Oreg. Ecology: Occurs in clover and alfalfa fields and in meadows. Host:

Contarinia wattsi Gagne, Dasineura leguminicola (Lintn.).

Neomphaloidella nebraskensis Girault, 1916. Canad. Ent. 48: 103. 9. 
Biology: MacNay, 1954. Canad. Ins. Pest Rev. 32: 305. -Guppy, 1961. Canad. Ent. 93: 69.

-Moser, 1965. N. Y. State Mus. and Sci. Serv., Bul. 402: 30.

neuroteri (Ashmead). N. Y., D. C., Va., Fla., Ohio, Ill., Iowa, Mo., Tex. Host: Neuroterus quercusrileyi (Bass.), N. saltarius Weld.

Hyperteles neuroteri Ashmead, 1887. Amer. Ent. Soc., Trans. 14: 203. ๆ, ơ.

Taxonomy: Balduf, 1929. Canad. Ent. 61: 221.

nordi Burks. Pa., W. Va., Mich. Host: Agrilus champlaini Frost, A. homi Kerr.

Tetrastichus nordi Burks, 1963. Biol. Soc. Wash., Proc. 76: 51. ๆ, ठ.

Biology: Nord, et al., 1965. Forest Sci. 11: 39.

oklahoma (Girault). Ill., Minn., Okla., Utah. Ecology: Emerged along with Harmolita sp. from grass stems.

Neomphaloidella oklahoma Girault, 1917. Descr. Stellarum Nov., p. 9. ๆ, ठ.

ovipransus Crosby and Leonard. Va., Ark. Host: Blepharida rhois (Forst.) eggs.

Tetrastichus ovipransus Crosby and Leonard, 1917. Ent. News 28: 368. ๆ.

pandora Burks. Oreg. Host: Coloradia pandora Blake.

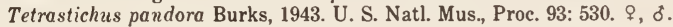

paracholus Burks. Ont., N. J., D. C., Va., N. C., Wis., Minn. Host: Gnorimoschema gallaesolidaginis (Riley).

Tetrastichus paracholus Burks, 1943. U. S. Natl. Mus., Proc. 93: 551. ๆ, ठ․

pattersonae Fullaway. Utah, Calif. Host: Antron quercusechinus (0. S.), Callirhytis quercuspomiform is (Bass.), Disholcaspis chrysolepidis (Beut.).

Tetrastichus pattersonae Fullaway, 1912. N. Y. Ent. Soc., Jour. 20: 280. ․

Taxonomy: Burks, 1943. U. S. Natl. Mus., Proc. 93: 563.

pausiris (Walker). Ont.; Europe. Adventive; first found in Ont. in 1953. Host: Dasineura leguminicola (Lintn.).

Cirrospilus pausiris Walker, 1839. Monog. Chalcid., v. 1, p. 327. + .

Taxonomy: Peck, 1963. Canad. Ent., Sup. 30, p. 143. - Domenichini, 1965. Bol. Zool agr. e di Bach. (2) 6: 143.

Biology: Guppy, 1961. Canad. Ent. 93: 69-70.

phidippi Burks. Ariz. Host: Phidippus opifex (McCook) eggs.

Tetrastichus phidippi Burks, 1963. Biol. Soc. Wash., Proc. 76: 60. ९, ठ๋.

politi Burks. Va., Tex. Host: Xanthoteras politum (Bass.) gall.

Tetrastichus politi Burks, 1963. Biol. Soc. Wash., Proc. 76: 48. + , ठ.

polynemae Ashmead. N. Y., Del., Ill. Ecology: Parasitizes both damselfly eggs and chalcids developing in them. Host: Lestes sp.; Polynema needhami (Ashm.).

Tetrastichus polynemae Ashmead, 1900. Ent. News 11: 616..

Ootetrastichus mymaridis Girault, 1916. U. S. Natl. Mus., Proc. 51: 130..

Taxonomy: Girault, 1916. U. S. Natl. Mus., Proc. 51: 130.

pompilicola Graham. Labrador. Host: Anoplius nigerrimus (Scop.).

Tetrastichus pompilicola Graham, 1960. In Lindroth and Graham, Opusc. Ent. 25: 94.. productus Riley. P.E.I., Que., N. J., Ohio, Minn., Mo., Kans. Host: Janus abbreviatus (Say). Long incorrectly thought to be a parasite of the Hessian fly.

Tetrastichus productus Riley, 1885. U. S. Natl. Mus., Proc. 8: 419. ठ, \&.

Taxonomy: Gahan, 1934 (1933). U. S. Dept. Agr., Misc. Pub. 174: 143.

psyllaephagus Burks. Ariz. Host: Trioza collaris Crawford nymph.

Tetrastichus psyllaephagus Burks, 1963. Biol. Soc. Wash., Proc. 76: 54. ๆ, o.

Biology: Cazier, 1964. Pan-Pacific Ent. 40: 71.

pulchriventris (Girault). Md., La., Okla.

Neomphaloidella pulchriventris Girault, 1916. Canad. Ent. 48: 101..

punctatifrons (Girault). Ariz. Host: Paraleucoptera albella (Chamb.). This host record may not be correct.

Epitetrastichus punctatifrons 'Girault, 1916. U. S. Natl. Mus., Proc. 51: 128.. 
racemariae Ashmead. Ont., Conn., N. J., Md., Va., Fla., W. Va., Ill, Minn., Nebr., Kans., Okla., Tex., N. Mex., Calif. Host: Amphibolips quercuscinerea (Ashm.), A. quercusprunus (W. and R.), A. quercusracemaria (Ashm.), Andricus quercusflocci (Walsh), A. lasius (Ashm.), Callirhytis quercuspomiformis (Bass.), Disholcaspis cinerosa (Bass.), D. quercusmamma (Walsh), Heteroecus pacificus (Ashm.), Neuroterus noxius (Bass.), $N$. quercusbatatus (Fitch) galls.

Tetrastichus racemariae Ashmead, 1886. Amer. Ent. Soc., Trans. 13: 134. $ๆ, \delta$.

Tetrastichus californicus Ashmead, 1887. Amer. Ent. Soc., Trans. 14: 203..

Hyperteles flocci Ashmead, 1887. Amer. Ent. Soc., Trans. 14: 203. १, ठ.

Tetrastichus phegus Burks, 1943. U. S. Natl. Mus., Proc. 93: 559. ‡, ð.

Taxonomy: Judd, 1963. Canad. Field-Nat. 77: 64.

repulsus Girault. Iowa.

Tetrastichus repulsus Girault, 1917. New Chalcid Flies, pp. 2, 4.

rhosaces (Walker). Va.; Europe. Ecology: Primary parasite of cassidine beetle larvae on thistles. Adventive; first found in Va. in 1972. Host: Cassida mibiginosa Mueller.

Cirrospilus rhosaces Walker, 1839. Monog. Chalcid. v. 1, p. 293. " $\delta "=$ ?.

Cirrospilus racilla Walker, 1839. Monog. Chalcid. v. 1, p. 312. \&.

Taxonomy: Graham, 1961. Ent. Monthly Mag. 97: 37.

Biology: Domenichini, 1966. Palearctic Tetrastichinae, Le Francois, p. 47.

rosae Ashmead. Conn., N. J., D. C., Va., Fla., Mich., Colo., Idaho, B. C., Calif. Host: Diplolepis ignota (0. S.); D. ostensackeni (Beut.).

Tetrastichus rosae Ashmead, 1886. Amer. Ent. Soc., Trans. 13: 134. $\$$ (o misdet.).

rugglesi Rohwer. N. Y., Conn., W. Va., Minn. Host: Agrilus arcuatus (Say), A. champlaini Frost, $A$. rubicola Abeille.

Tetrastichus rugglesi Rohwer, 1919. Canad. Ent. 51: 160. \&.

saundersii (Packard). Ont., Conn., N. J. Host: Strymon edwardsii (Saund.), S. falacer (Godt.).

Eulophus Saundersii Packard, 1881. Boston Soc. Nat. Hist., Proc. 21: 34. ठ.

scolyti Ashmead. N. J., W. Va. Host: Scolytus rugulosus (Ratz.).

Tetrastichus scolyti Ashmead, 1894. Amer. Ent. Soc., Trans. 21: 343..

scriptus Burks. N. J., S. C., Ohio. Host: Euplectrus sp. Host record questionable.

Tetrastichus scriptus Burks, 1943. U. S. Natl. Mus., Proc. 93: 550. ๆ.

semiauraticeps (Girault). Maine, Colo., Ariz., Calif. Ecology: Emerged from needle gall on Pinus ponderosa, bud gall on Pinus scopulorum.

Epitetrastichus semiauraticeps Girault, 1916. U. S. Natl. Mus., Proc. 51: 127. \&.

semideae (Packard). N. H., Conn. Host: Oeneis melissa (Say).

Eulophus semideae Packard, 1874. In Hitcheock and Huntington, Geol. of N. H., pt. 1, p. 347., , o.

semilongifasciatus (Girault). Md., D. C.

Neomphaloidella semilongifasciata Girault, 1916. Soc. Ent. 31: 35. \&.

silvaticus Gahan. N. B., Maine, Vt., Conn., N. Y., Ont., Mich., Wis., Ill., Minn., N. Dak., Wash., Oreg., Calif. Host: Malacosoma disstria Hbn. eggs.

Tetrastichus silvaticus Gahan, 1937. Ent. Soc. Wash., Proc. 39: 266. ․ §.

Biology: Hobson, 1939. Ent. Soc. Amer., Ann. 32: 131-136. - Struble and Bedard, 1958.

Pan-Pacific Ent. 34: 184.

sobrius Gahan. Fla., Ariz., Calif. Host: Asphondylia sp., A. websteri Felt.

Tetrastichus sobrius Gahan, 1919. Ent. Soc. Amer., Ann. 12: 166. + , $\delta$.

sokolowskii Kurdjumov. N. Y., Ont., Mo.; Europe, India, Japan, South Africa. Adventive in No. Amer.; first found in Ont. in 1952. Host: Plutella xylostella (L.).

Tetrastichus sokolowskii Kurdjumov, 1912. Russ. Ent. Obozr. 12: 238. ๆ, ð.

Tetrastichus sokolovskii Kurdjumov, 1913. Russ. Ent. Obozr. 13: 254. Emend.

Biology: Cheerian and Basheer, 1939. Indian Acad. Sci., Proc. 9: 87-98. - Ullyett, 1947. Dept. Agr. So. Afr., Ent. Mem. 2: 101-106. - Harcourt, 1953. Canad. Ent. 85: 251. - Hareourt, 1960. Canad. Ent. 92: 422. - Pschorn-Walcher, 1964. Commonwealth Inst. Biol. Control, Tech. Bul. 4: 33 . 
solidaginis Burks. Que., N. H., Ohio, Mich., Utah. Host: Eurosta solidaginis (Fitch) gall.

Tetrastichus solidaginis Burks, 1943. U. S. Natl. Mus., Proc. 93: 534. \&, ð.

spilopteris Burks. N. Mex., Oreg., Calif. Host: Andricus kingi Bass., Dryocosmus bicornis (McC. and E.), Neuroterus saltatorius (Edw.), galls.

Tetrastichus spilopteris Burks, 1943. U. S. Natl. Mus., Proc. 93: 564. \&, ð.

stanfordiensis Fullaway. Calif. Ecology: Reared from cynipid galls. Type lost.

Tetrastichus stanfordiensis Fullaway, 1912. N. Y. Ent. Soc., Jour. 20: 281..

strobilus Burks. Minn., Mont., N. Mex., Idaho, Utah, Wash., Oreg., Calif. Ecology: Reared from pine, spruce, and Douglas fir cones. Host: Barbara colfaxiana (Krft.). Perhaps on other insects in cones.

Tetrastichus strobilus Burks, 1943. U. S. Natl. Mus., Proc. 93: 552. ‡, ठ.

Biology: Keen, 1958. U. S. Dept. Agr., Tech. Bul. 1169: 95-96. - Hedlin, 1960. Canad. Ent. 92: 832.

tesserus Burks. N. Y., Md., Va., Mich., Ill., Iowa. Host: Asteromyia sp. gall on Solidago.

Tetrastichus tesserus Burks, 1943. U. S. Natl. Mus., Proc. 93: 552. ๆ, ठ์.

thanasimi Ashmead. Pa., W. Va., Mich., Mont., Calif. Host: Cymatodera sp., Thanasimus sp., T. dubius (F.), T. trifasciatus (Say).

Tetrastichus thanasimi Ashmead, 1894. Amer. Ent. Soc., Trans. 21: 343..

theclae (Packard). New England, Host: Strymon falacer (Godt.).

Eulophus theclae Packard, 1881. Boston Soc. Nat. Hist., Proc. 21: 34. "ठ" =

tibialis (Ashmead). Mass., Del., Ont., N. Y., W. Va., Iowa. Ecology: A secondary parasite. Host: Apanteles sp., Olesicampe sp., Homalotylus sp.

Tetrastichodes tibialis Ashmead, 1894. Amer. Ent. Soc., Trans. 21: 344..

Biology: Dimmock, 1898. Ent. Soc. Wash., Proc. 4: 150.

tineivorus Ferriere. N. H., Mass., Conn., Md., Ohio, Mo., Calif.; Europe, South Africa; prob. Cosmopolitan. Ecology: A secondary parasite of tineid moths living in fibers or detritus. Host: A panteles carpatus (Say).

Tetrastichus tineivorus Ferriere, 1941. Schweiz. Ent. Gesell., Mitt. 18: 376. ๆ, ठ.

Tetrastichus carpatus Burks, 1943. U. S. Natl. Mus., Proc. 93: 566. \$, ठै.

Taxonomy: Gahan, 1951. Canad. Ent. 83: 171.

Biology: Back, 1945. Ent. Soc. Wash., Proc. 47: 183.

triozae Burks. Nebr., Kans., Mont., Colo., N. Mex., Idaho, Ariz., Wash., Calif. Ecology: Ubiquitous parasite of psyllid nymphs in arid or semi-arid regions; the Tetrastichus larva develops as an external parasite, feeding beneath the body of its host. Host: Arytaina minuta Cwfd., Calophya californica Schw., C. nigrella Jens., C. triozomima Schw., Euphalerus vermiculosus Cwfd., Paratrioza cockerelli (Sulc.), Pexopsylla cercocarpi Jens., Trioza albifrons Cwfd., T. beameri Tuth.

Tetrastichus triozae Burks, 1943. U. S. Natl. Mus., Proc. 93: 542.,$~ ð$.

Biology: Pletsch, 1947. Mont. Agr. Expt. Sta., Bul. 446: 74-78. -Jensen, 1957. Hilgardia 27: 79-80, 86-96.

trisulcatus Provancher. N. B., s. to Fla., w. to Man., Ky., Ill. and Minn. Host: Arge sp., $A$. pectoralis (Leach), A. scapularis (Klug).

Tetrastichus trisulcatus Provancher, 1887. Addit. Corr. Faune Ent. Canada Hym., p. 211. “o" $=$ ?.

Hyperteles hylotomae Ashmead, 1888. Canad. Ent. 20: 105. $\subsetneq$.

Taxonomy: Burks, 1964 (1963). Canad. Ent. 95: 1262.

Biology: Schwarz, 1909. Ent. Soc. Wash., Proc. 11: 107. - Raizenne, 1957. Canada Dept. Agr., Pub. 1009: 8-9.

Morphology: Finlayson, 1963. Canad. Ent. 95: 479, 483, 498 (immature stages).

turionum (Hartig). Mass., Conn., N. J., Ont., N. Y. Introduced from Europe; first recovered in Mass. in 1934. Host: Rhyacionia buoliana (Schiff.).

Eulophus turionum Hartig, 1838. Jahresber. ueber die Fortsch. der Forstw. u. Forstl. Naturk. 1: 268. $\subsetneq$, ठ. 
Biology: Dowden, 1934. Ent. Soc. Amer., Ann. 27: 600. - Bergold and Ripper, 1937. Ztschr. f.

Parasitenk. 9: 399, 414-415. -Clausen, 1956. U. S. Dept. Agr., Tech. Bul. 1139: 130-131.

-Juillet, 1959. Canad. Ent. 91: 716-718. - Schaffner, 1959. U. S. Dept. Agr., Misc. Pub. 767: 83. - Adlung, 1962. Ztschr. f. Angew. Ent. 50: 456. - Adlung and Sailer, 1963. Allg. Forst. u. Jagdztg. 134: 230. - Eichhorn et al., 1965. Anz. f. Schadlingsk. 38: 107.

ulysses (Girault). Md.

Aprostocetus ulysses Girault, 1916. Brooklyn Ent. Soc., Bul. 11: 112. $\$$.

varicornis (Girault). Maine, Mass., Md., N. C. Host: Epinotia nanana (Treit.), Rhyacionia frustrana (Comst.).

E pitetrastichus varicornis Girault, 1917. Descr. Hym. Chalcidoid. Variorum cum Observ. III, p. 4. $\%$.

Biology: Schaffner, 1959. U. S. Dept. Agr., Misc. Pub. 767: 83.

venustus Gahan. Que., Maine, Ind., Minn., Iowa, Nebr., Idaho, Ariz., Calif. Ecology: Commonly reared from small leguminous seeds; exact host not established. A closely related, or identical, form was reared in a greenhouse as phytophagous in stems of sweet clover, but the cultures could not be maintained.

Tetrastichus venustus Gahan, 1914. U. S. Natl. Mus., Proc. 48: 168. $\$$.

Biology: Urbahns, 1920. U. S Dept. Agr., Bul. 812: 18. -Teitelbaum and Black, 1954.

Phytopathology 44: 548 (phytophagous in sweet clover). - Butler and Hansen, 1958.

Pan-Pacific Ent. 34: 224-226.

verrucarii Balduf. N. Y., D. C., Va., Ga., Ohio, Ill., Wis., Utah, Calif. Host: Neuroterus floccosus (Bass.), N. niger Gill., N. quercusverrucarum (0. S.).

Tetrastichus vermicarii Balduf, 1929. Canad. Ent. 61: 221. , ð.

Biology: Balduf, 1929. Canad. Ent. 61: 125-130.

whitmani (Girault). Maine, Md., Ill., Wis., Minn., S. Dak. Host: Dasineura balsamicola (Lintn.), Physonota unipunctata (Say).

Aprostocetus whitmani Girault, 1916. Ent. Soc. Amer., Ann. 9: 296. ㅇ, ð.

Aprostocetus marilandicus Girault, 1917. Ent. News 28: 21.. .

Biology: Giese and Benjamin, 1959. Forest Sci. 5: 205.

\section{Genus APROSTOCETUS Westwood}

Aprostocetus Westwood, 1833. London, Edinb. and Dublin Phil. Mag. and Jour. Sci. (3) 2: 444.

Type-species: Aprostocetus caudatus Westwood. Monotypic.

Lonchentedon Ratzeburg, 1852. Ichn. d. Forstins., v. 3, p. 215.

Type-species: Eulophus longicaudatus Foerster. Monotypic.

Tetrastichomorpha Girault, 1913. Queensland Mus., Mem. 2: 227.

Type-species: Tetrastichomorpha flava Girault. Orig. desig.

Neomphaloidomyia Girault, 1917. Brooklyn Ent. Soc., Bul. 12: 118.

Type-species: Hyperteles polynemae Ashmead. Orig. desig.

Gyrolachnus Erdos, 1954. Mus. Nat. Hungarici, Ann. Hist. Nat., n. s., 5: 365.

Type-species: Gyrolachnus longulus Erdos. Orig. desig.

Revision: Burks, 1967. Ent. Soc. Amer., Ann. 60: 756-760.

ajax (Girault). D. C., Mich., N. Dak.

Tetrastichomorpha ajax Girault, 1916. U. S. Natl. Mus., Proc. 51: 132. ․

americanus Ashmead. Va. and W. Va., w. to Ind., Mo., Tex., and Calif.; s. to Costa Rica. Host: Ceratina sp., C. dupla Say, C. ignara Cress., C. nanula Ckll., C. sequoiae Mich., Axima zabriskiei How., parasite on Ceratina.

Aprostocetus americanus Ashmead, 1888. Canad. Ent. 20: 106. $\$$.

animus Girault. N. Mex. Type fragmentary.

Aprostocetus animus Girault, 1917. Descr. Hym. Chalcidoid. Variorum cum Observ. III, p. 6. ‥

bewicki Girault. Wash.

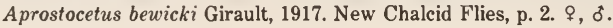


cincinnatus (Girault). Md.

Neomphaloides cincinnatus Girault, 1917. Psyche 24: 92 ..

coelioxydis Burks. N. C., Ohio, Ark., Kans. Ecology: Reared from nests of leaf-cutter bees.

Host: Coelioxys sp., prob. octodentata Say, a parasite of Megachile brevis Say.

A prostocetus coeliaxydis Burks, 1967. Ent. Soc. Amer., Ann. 60: 758. १, ठ.

daira (Walker). Que., Ont., Ohio, Nebr.; Europe. Host: Orellia ruficauda (F.). Possibly other tephritids serve as hosts.

Cirrospilus daira Walker, 1839. Monog. Chalcid., v. 1, p. 330.. .

Aprostocetus canadensis Ashmead, 1888. Canad. Ent. 20: 106. $\%$.

Taxonomy: Graham, 1961. Ent. Monthly Mag. 97: 47.

Biology: Detmers, 1927. Ohio Agr. Expt. Sta., Bul. 414: 26-29.

diplosidis Crawford. N. C., s. to Fla., w. to Kans. and Tex.; worldwide in warm-temperate and tropical zones. Host: Contarinia sorghicola (Coq.).

Aprostocetus diplosidis Crawford, 1907. N. Y. Ent. Soc., Jour. 15: 180. ๆ, ठ.

Biology: Dean, 1911. U. S. Dept. Agr., Bur. Ent. Bul. 85 (4): 55-57. - Walter, 1941. U. S.

Dept. Agr., Tech. Bul. 778: 18. - Piore and Viggiani, 1965. Lab. Ent. Agr. Portici, Bol. 23: 1-36.

epidius (Walker). Ont., N. Y., Fla., Ill. Ecology: Emerged from undet. gall-maker on elderberry.

Tetrastichus epidius Walker, 1847. Ann. and Mag. Nat. Hist. 20: 28. $\%$.

Aprostocetus granulatus Ashmead, 1888. Canad. Ent. 20: 105. ․

Tetrastichus microcosmus Girault, 1917. Descr. Stellarum Nov., p. 22. N. name for granulatus Ashmead, unnecessarily proposed.

Taxonomy: Burks, 1975. Brit. Mus. (Nat. Hist.) Ent., Bul. 32 (4): 142 (synonymy; lectotype designated).

fidius Girault. Fla., Miss., Ill., N. Mex.; West Indies. Host: Taxadiomyia cupressiananassa (0. S.). Other gall-making midges may serve as hosts.

Aprostocetus fidius Girault, 1917. New Eulophidae, p. 1..

Biology: Myers, 1930. Bul. Ent. Res. 21: 309-313. -Breland, 1939. Ent. Soc. Amer., Ann. 32: 726.

florida (Girault). Fla. Type fragmentary.

Neomphaloidella florida Girault, 1917. New Chalcid Flies, p. 4. + ,.

irvingi (Girault). N. Mex.

Neomphaloidella irvingi Girault, 1917. Brooklyn Ent. Soc., Bul. 12: 118..

kansasia Girault. Kans. Type fragmentary.

Aprostocetus kansasia Girault, 1917. Brooklyn Ent. Soc., Bul. 12: 88..

oncideridis (Gahan). W. Va. Host: Oncideres cingulata (Say).

Tetrastichus oncideridis Gahan, 1932. Ent. Soc. Amer., Ann. 25: 745. ₹, ठ.

oviductus (Girault). Md.

Epitetrastichus oviductus Girault, 1917 (1916). Insecutor Inscitiae Menstruus 4: 111. q.

polynemae (Ashmead). N. H., N. Y., Ill., Minn. Ecology: Parasitize eggs of Odonata. Host:

Anax junius (Drury) Lestes spp.

Hyperteles polynemae Ashmead, 1900. Ent. News 11: 615. ஒ, ठ.

\section{Genus HYPERTETRASTICHUS Moser}

Hypertetrastichus Moser, 1965. N. Y. State Mus. and Sci. Serv., Bul. 402: 15.

Type-species: Hypertetrastichus ithacus Moser. Orig. desig.

ithacus Moser. N. Y., Ohio, W. Va. Host: Moserina maculata Delucchi in Pachypsylla galls.

Hypertetrastichus ithacus Moser, 1965. N. Y. State Mus. and Sci. Serv., Bul, 402: 15. ๆ.

Biology: Moser, 1965. N. Y. State Mus. and Sci. Serv., Bul. 402: 16.

\section{Genus CRATAEPUS Foerster}

Crataepus Foerster, 1878. Naturh. Ver. Rheinlande, Verh. 35: 61.

Type-species: Crataepus aquisgranensis Foerster. Orig. desig. 
marbis (Walker). Ont., Man.; Holaretic. Host: Orellia ruficauda (F.).

Cirrospilus marbis Walker, 1839. Monog. Chalcid., v. 1, p. 330..

Crataepus fletcherii Ashmead, 1892. Canad. Ent. 24: 309..

Taxonomy: Gradwell, 1953. Ent. Monthly Mag. 89: 73-75.

Biology: MacNay, 1961. Canad. Ins. Pest Rev. 39: 273.

\section{Genus BURKSIA Fullaway}

Burksia Fullaway, 1955. Hawaii. Ent. Soc., Proc. 15: 409.

Type-species: Burksia viridimaculata Fullaway. Orig. desig.

viridimaculata Fullaway. Fla., Calif.; Hawaii, West Indies, Colombia, Argentina, Europe.

Ecology: Assoc. with armyworm larvae in Bermuda grass.

Burksia viridimaculata Fullaway, 1955. Hawaii. Ent. Soc., Proc. 15: 410..

Taxonomy: Domenichini, 1965. Bol. Zool. agr. e di Bach. (2) 6: 140. ․

\section{Genus FLOCKIELLA Timberlake}

Flockiella Timberlake, 1957. Pan-Pacific Ent. 33: 109.

Type-species: Flockiella eucalypti Timberlake. Orig. desig.

eucalypti Timberlake. Calif. Ecology: Reared from seed capsules of Eucalyptus umbellata.

Probably introduced from Australia.

Flockiella eucalypti Timberlake, 1957. Pan-Pacific Ent. 33: 110..

Biology: Flock, 1957. Pan-Pacific Ent. 33: 153-155.

\section{Genus SYNTOMOSPHYRUM Foerster}

Syntomosphyrum Foerster, 1878. Naturh. Ver. Rheinlande, Verh. 35: 60.

Type-species: Syntomosphyrum fulvipes Foerster. Monotypic.

Tetrastichopsis Girault, 1916. U. S. Natl. Mus., Proc. 51: 132.

Type-species: Tetrastichopsis prionomeri Girault. Orig. desig.

Tetrastichomyia Girault, 1916. U. S. Natl. Mus., Proc. 51: 48.

Type-species: Miotropis clisiocampae Ashmead. Orig. desig.

Revision: Burks, 1952. Ent. Soc. Wash., Proc. 54: 258-264.

Taxonomy: Waterston, 1915. Bul. Ent. Res. 5: 364.

blattae Burks. W. Va., N. C., Ohio. Host: Parcoblatta sp. oothecae.

Syntomos phyrum blattae Burks, 1952. Ent. Soc. Wash., Proc. 54: 263. १, ठ.

Biology: Edmunds, 1952. Ent. News 63: 143. —Edmunds, 1953. Ent. News 64: 228-229.

-Roth and Willis, 1960. Smithsn. Inst., Misc. Collect. 141: 248.

clisiocampae (Ashmead). Conn. and N. Y., s. to S. C., w. to Wis. and Tex. Host: Achatodes zeae

(Harr.), Diatraea crambidoides (Grote), Grapholitha molesta (Busck), Malacosoma

americanum (F.), Ostrinia mubilalis ( $\mathrm{Hbn}$.), Sanninoidea exitiosa (Say); Microplitis gortynae Riley.

Miotropis clisiocampae Ashmead, 1894. Amer. Ent. Soc., Trans. 21: 341. १.

Biology: Balduf, 1929. Ohio Jour. Sci. 29: 227-228. - Proper, 1934. Jour. Agr. Res. 48: 370.

- Baker et al., 1949. U. S. Dept. Agr., Tech. Bul. 983: 178.

esurus (Riley), Que. and N. B., s. to Ga., w. to Man., Kans., Tex. Host: Acrobasis juglandis

(LeB.), Alabama argillacea ( $\mathrm{Hbn}$.$) , Anomis erosa ( \mathrm{Hbn}$.$) , Choristoneura fumiferana$

(Clem.), C. pinus Freem., Diatraea saccharalis (F.), Grapholitha molesta (Busck),

Gretchena bolliana (Slingerland), Hyphantria cunea (Drury), Malacosoma disstria Hbn.,

Nygmia phaeorrhoea (Donov.), Orgyia leucostigma (J. E. Smith), Porthetria dispar (L.),

Stenoma algidella (Walk.).

Cirrospilus esurus Riley, 1879. Canad. Ent. 11: 162. ९, ơ.

Syntomosphyrum orgyiae Ashmead, 1894. Amer. Ent. Soc., Trans. 21: 343. ๆ. 
Biology: Howard, 1897. U. S. Dept. Agr., Div. Ent., Tech. Ser. 5: 38-39. - Driggers, 1931. N. J. Agr. Expt. Sta., Ann. Rpt. 52: 192-193. - Clarke, 1933. Ga. State Bd. Ent., Bul. 77: 30-31, 36. -Allen, 1962. U. S. Dept. Agr., Tech. Bul. 1265: 91-92. -Dixon and Benjamin, 1963.

Jour. Econ. Ent. 56: 267.

ischnopterae (Girault). Md., D. C., Fla., Minn. Ecology: Possibly a secondary parasite, attacking Evaniidae in roach oothecae. Host: Ischnoptera sp., Parcoblatta sp. egg cases.

Epomphaloides ischnopterae Girault, 1917. Ent. News 28: 257. ९, ठ.

Biology: Roth and Willis, 1960. Smithsn. Inst., Misc. Collect. 141: 249.

orgyiazele Burks, n. name. D. C. Host: Orgyia leucostigma (J. E. Smith).

Tetrastichomyia orgyiae Girault, 1916. Brooklyn Ent. Soc., Bul. 11: 111. ₹. Preocc. by Syntomosphyrum orgyiae Ashmead, 1894.

philodromi (Gahan). Ohio, Nebr. Host: Philodromus aureolus (Oliv.).

Tetrastichus philodromi Gahan, 1924. U. S. Natl. Mus., Proc. 65 (4): 18. ๆ, ठ.

Biology: Auten, 1925. Ent. Soc. Amer., Ann. 18: 242.

prionomeri (Girault). Tenn., La. Host: Odontopus calceatus Say.

Tetrastichopsis prionomeri Girault, 1916. U. S. Natl. Mus., Proc. 51: 132..

silvensis (Girault). Md.

Tetrastichomyia silvensis Girault, 1919. Brooklyn Ent. Soc., Bul. 11: 111 \&.

\section{Genus MELITTOBIA Westwood}

Melittobia Westwood, 1847. Ent. Soc. London, Trans. 5: Proc. pp. xviii, lxv.

Type-species: Melittobia audouinii Westwood. Monotypic.

Anthophorabia Newport, 1849. Gard. Chron, p. 183.

Type-species: Anthophorabia retusa Newport. Monotypic.

Philopison Cameron, 1908. Deut. Ent. Ztschr., p. 559.

Type-species: Philopison clavicomis Cameron. Monotypic.

Sphecophagus Brethes, 1910. Buenos Aires Mus. Nac. de Hist. Nat., An. 20: 208.

Type-species: Sphecophagus sceliphronidis Brethes. Monotypic.

Sphecophilus Brethes, 1910. Buenos Aires Mus. Nac. de Hist. Nat., An. 20: 310. N. name, unnecessarily proposed for Sphecophagus.

Taxonomy: De Santis, 1949. La Plata Univ. Nac., Mus. Notas 14: 276. - Risbec, 1951. Inst.

Franc. d'Afr. Noire, Mem. 13: 90. - Risbec, 1952. Inst. Sci. Madagascar, Mem., Ser. E, 2:

253. -Ferriere, 1960. Acta Hym. 1: 106. - Domenichini, 1965. Bol. Zool. agr. e di Bach. (2) 6: $63-64$.

Biology: Balfour-Browne, 1922. Parasitology 14: 349-370. - Parker and Thompson, 1928. Soc.

Ent. de France, Ann. 97: 449-463. - Clausen, 1940. Entomophagous Insects, pp. 141-148.

-Simmonds, 1944. Sci. Agr. 25: 11, 27. -van Lith, 1955. Tijdschr. v. Ent. 98: 29.

-Valkeila, 1959. Ann. Ent. Fenn. 25: 180.

chalybii Ashmead. Throughout U. S. and South. Canad. Ecology: Attacks almost any insect in laboratory cultures or insectaries, but in nature apparently develops only in aculeate Hymenoptera and their parasites.

Melittobia chalybii Ashmead, 1892. Ent. Soc. Wash., Proc. 2: 231. $₹$, ठ.

Biology: Buckell, 1928. Pan-Pacific Ent. 5: 14-22. -Schmieder, 1933. Biol. Bul. 65: 338-354.

-Schmieder, 1938. Biol. Bul. 74: 256-266. - Schmieder, 1939. Ent. News 50: 128-131.

-Flanders, 1944. Jour. Econ. Ent. 37: 410. - Medler, 1958. Ent. News 69: 21-23. - Medler,

1958. Ent. Soc. Amer., Ann. 51: 340-344. - Krombein, 1964. Biol. Soc. Wash., Proc. 77: 101.

-Medler, 1964. Canad. Ent. 96: 1334. -Medler, 1965. Ent. Soc. Wash., Proc. 67: 113.

-Fye, 1965. Canad. Ent. 97: 876. - Edwards and Pengelly, 1966. Ent. Soc. Ontario, Proc.

96: 98. - Krombein, 1967. Trap-nesting wasps and bees, pp. 430-433. - Medler, 1967. Amer.

Midland Nat. 78: 350. - Sheldon, 1968. Psyche 75: 111. - Medler and Lussenhop, 1968. Wis.

Coll. Agr., Res. Bul. 274: 20-47. - Peck, 1969. Canad. Ent. 101: 419-420. - Hobbs and

Krunio, 1971. Canad. Ent. 103: 674-685.

megachilis (Packard). Vt., N. Y., N. J., Wis., Nebr. Host: Anthophora sp., Ceratina sp., Crabro sp., Megachile sp., Monodontomerus sp., Sceliphron caementarium (Drury).

Anthophorabia megachilis Packard, 1864. Essex Inst., Proc. 4: 134.. 
Pteromalus gerardi Hickok, 1875. Poughkeepsie Soc. Nat. Hist., Proc. 1: 131. $\subsetneq$, $\delta$. Melittobia megalochilae Schulz, 1906. Spolia Hym., p. 143. Emend.

Chrysocharis aeneus Brues, 1909 (1908). Wis. Nat. Hist. Soc., Bul. 6: 161. \&.

Biology: Packard, 1869. Guide to Study of Insects, p. 206. - Howard, 1892. Ent. Soc. Wash.,

Proc. 2: 247.

\section{TRIBE ENTEDONTINI}

\section{Genus EUDEROMPHALE Girault}

Euderomphale Girault, 1916. Canad. Ent. 48: 410.

Type-species: Euderomphale fuscipennis Girault. Orig. desig.

Aleurodiphagus Nowicki, 1929. Neue Beitr. z. System. Insektenk. 4: 154.

Type-species: Pteroptrix flavimedia Howard. Desig. by Peck, 1951.

This genus was placed in the subfamily Aphelininae in the 1951 Catalog (U. S. Dept. Agr., Agr. Monog. 2: 432), and in the First Supplement (1958. U. S. Dept. Agr., Agr. Monog., Sup. 1: 64) it was incorrectly placed as a synonym of Cardiogaster Motschulsky.

Revision: Dozier, 1932. Ent. Soc. Wash., Proc. 34: 120.

Taxonomy: Compere and Annecke, 1961. Ent. Soc. S. Afr., Jour. 24: 65-68 (Cardiogaster in

Eulophidae). -Peck, 1963. Canad. Ent., Sup. 30: 238 (Cardiogaster in Entedontinae).

-Graham, 1963. Soc. Brit. Ent., Trans. 15: 273 (Euderomphale in Entedontinae).

flavimedia (Howard). Md., N. Mex., Calif. Host: Aleyrodes sp., A. pruinosa Bemis, $A$. spiraeoides Quaint.

Gyrolasia flavimedia Howard, 1881. U. S. Dept. Agr., Ann. Rpt. for 1880, p. 369. ठ.

Euderomphale fuscipennis Girault, 1916. Canad. Ent. 48: 410. ?.

hyalina (Compere and Annecke). Calif. Host: Aleyrodes sp.

Cardiogaster hyalina Compere and Annecke, 1961. Ent. Soc. S. Afr., Jour. 24: 68..

Biology: Poinar, 1964. Jour. Econ. Ent. 57: 382.

quercicola Dozier. La. Host: Tetraleurodes sp.

Euderomphale quercicola Dozier, 1933. Ent. Soc. Wash., Proc. 35: 85. ๆ, ठ.

\section{Genus CERANISUS Walker}

Ceranisus Walker, 1840. Entomologist 1 (vi): pl. N, fig. 2; explanation of plate.

Type-species: Ceranisus pacuvius Walker. Monotypic.

Thripoctenus Crawford, 1911. Ent. Soc. Wash., Proc. 13: 233.

Type-species: Thripoctenus russelli Crawford. Monotypic.

Cryptomphale Girault, 1917. Speciosissima Genera Nova Eulophidorum, p. 2.

Type-species: Thripoctenus nubilipennis Williams. Orig. desig.

Taxonomy: Burks, 1943. U. S. Natl. Mus., Proc. 93: 509. -Bakkendorf, 1957. Ent. Meddel. 28:

1. -Graham, 1959. Soc. Brit. Ent., Trans. 13: 203.

americensis (Girault). Utah, Alta. Ecology: Reared from thrips in alfalfa.

Thripoctenus americensis Girault, 1917. U. S. Natl. Mus. Proc. 53: 448. .

nubilipennis (Williams). Mass. Host: Cryptothrips rectangularis Hood, Megalothrips spinosus Hood.

Thripoctenus nubilipennis Williams, 1916. Psyche 23: 54. $९$, o.

russelli (Crawford). Calif. Host: Caliothrips fasciatus (Perg.), Frankliniella tritici (Fitch), Taeniothrips simplex (Mor.), Thrips tabaci Lind.

Thripoctenus russelli Crawford, 1911. Ent. Soc. Wash., Proc. 13: 233. ๆ.

Biology: Russell, 1912. U. S. Dept. Agr., Bur. Ent., Tech. Ser. 23: 25-52. -Bailey, 1933.

Hilgardia 7: 501-502. - Bailey, 1937. Calif. Agr. Expt. Sta., Bul. 609: 26.

\section{Genus EUOPHTHALMOMYIA Ashmead}

Euophthalmomyia Ashmead, 1904. Carnegie Mus., Mem. 1: 339, 340.

Type-species: Euophthalmomyia pallidipes Ashmead. Orig. desig. 
Euophthalmoneyia Ashmead, 1904. Carnegie Mus., Mem. 1: 375. Misspelling.

pallidipes Ashmead. D. C.

Enophthalmomyia pallidipes Ashmead, 1904. Carnegie Mus., Mem. 1: 339, 375. \&.

\section{Genus OMPHALE Haliday}

Omphale Haliday, 1833. Ent. Mag. 1: 339.

Type-species: Omphale salicis Haliday. Monotypic.

Smaragdites Westwood, 1833. Mag. Nat. Hist. 6: 419.

Type-species: Smaragdites admirabilis Westwood. Monotypic.

Secodes Foerster, 1856. Hym. Stud., v. 2, pp. 78, 81.

Type-species: Secodes fagi Foerster. Monotypic.

Taxonomy: Graham, 1963. Soc. Brit. Ent., Trans. 15: 240.

bicincta Ashmead. W. Va., Fla.

Omphale bicincta Ashmead, 1888. Canad. Ent. 20: 103. ơ.

\section{Genus HUBBARDIELLA Ashmead}

Hubbardiella Ashmead, 1904. Carnegie Mus., Mem. 1: 339, 340.

Type-species: Hubbardiella arizonensis Ashmead. Orig. desig.

Miromphalomyia Girault, 1916. Entomologist 49: 249.

Type-species: Miromphalomyia perilampoides Girault. Orig. desig.

arizonensis Ashmead. Ariz.

Hubbardiella arizonensis Ashmead, 1904. Carnegie Mus., Mem. 1: 339, 378. \&.

Miromphalom yia perilampoides Girault, 1916. Entomologist 49: 250..

Taxonomy: Gahan and Fagan, 1923. U. S. Natl. Mus., Bul. 124: 90.

\section{Genus CLOSTEROCERUS Westwood}

Closterocerus Westwood, 1833. Mag. Nat. Hist. 6: 419.

Type-species: Closterocerus trifasciatus Westwood. Monotypic.

Revision: Crawford, 1912. U. S. Natl. Mus., Proc. 43: 175.

californicus Girault. Calif. Host: Nepticula juglandifoliella Clem.

Closterocerns utahensis var. californicus Girault, 1916. U. S. Natl. Mus., Proc. 51: 46. \&.

cincinnatus Girault. Ohio.

Closterocerus utahensis cincinnatus Girault, 1916. U. S. Natl. Mus., Proc. 51: 47. ठั.

cinctipennis Ashmead. Que., s. to Fla., w. to Wis., Iowa., Mo. Ecology: Parasitizes both eggs and early-instar larvae. Host: Brachys aerosus (Melsh.), B. ovatus (Web.); Bucculatrix canadensisella (Chamb.), Cameraria hamadryadella (Clem.), C. ulmella (Chamb.), Nepticula gossypii F. and L.; Caliroa cerasi (L.), Neodiprion excitans Roh., N. lecontei (Fitch), N. mgifrons Midd., N. swainei Midd., N. virginiana Roh.

Closterocerus cinctipennis Ashmead, 1888. Canad. Ent. 20: 104. ó.

Biology: Webster, 1911. Ent. Soc. Amer., Ann. 4: 185. - Weiss and Nicolay, 1918. Psyche 25: 128-130. - Schedl, 1939. VII Internatl. Kong. Ent., Verh. 3, pp. 2066-2090. - Benjamin, 1955. U. S. Dept. Agr., Tech. Bul. 1118, pp. 24-26. - Morris, Schroeder, and Bobb, 1963.

Pine Sawfly in Va., Va. Div. Forestry, p. 13.

tau Girault. Calif.

Closterocerus tau Girault, 1917. Psyche 24: 101. ․

tricinctus (Ashmead). Maine, Ont., s. to Va., w. to Wis., Ill., Kans. Host: Microrliopala xerene (Newm.); Argyresthia thuiella (Pack.), Cameraria guttifinitella (Clem.), Coleotechnites thujaeella (Kearf.), Coptodisca splendoriferella (Clem.), Cosmopteryx sp., Exoteleia pinifoliella (Chamb.), Lithocolletis sp., L. lucetiella Clem., L. populiella Chamb., L. tremuloidella Braun, Paraclemensia acerifoliella (Fitch), Tischeria malifoliella (Clem.); Agromyza parvicomis Loew, Liriomyza melampyga (Loew), Meoneura obscurella (Fall.), Phytom yza ilicis Curtis.

Pleurotropis tricincta Ashmead, 1888. Kans. Agr. Expt. Sta. Bul. 3: App. p. VIII. \&.

Biology: Schaffner, 1959. U. S. Dept. Agr., Misc. Pub. 767: 84. 
Morphology: Snodgrass, 1922. Smithsn. Inst., Ann. Rpt. for 1920, p. 494.

trifasciatus Westwood. Maine, Mass., Minn., S. Dak., Ariz., Calif.; Europe. Host: Liriomyza pictella (Thomson).

Closterocerus trifasciatus Westwood, 1833. Mag. Nat. Hist. 6: 420.

Biology: Sundby, 1957. Norsk Ent. Tidsskr., sup. 2, p. 41.

utahensis Crawford. Conn., Md., Utah, Ariz., Calif. Host: Bucculatrix thurberiella (Busck); Agromyza parvicornis Loew; Fenusa pusilla (Lep.).

Closterocerus utahensis Crawford, 1912. U. S. Natl. Mus., Proc. 43: 175. $\$$.

Biology: Clancy, 1946. Jour. Econ. Ent. 39: 328. - Hills and Taylor, 1951. Jour. Econ. Ent. 44: 760-762.

winnemanae Crawford. Md. Host: Arge pectoralis (Leach).

Closterocerus winnemanae Crawford, 1912: U. S. Natl. Mus., Proc. 43: 176. ๆ, §.

\section{Genus EPRHOPALOTUS Girault}

Eprhopalotus Girault, 1916. U. S. Natl. Mus., Proc. 51: 49.

Type-species: Eprhopalotus purpureithorax Girault. Orig. desig.

purpureithorax Girault. Tex. Ecology: Emerged from cecidomyiid gall on oak.

Eprhopalotus purpureithorax Girault, 1916. U. S. Natl. Mus., Proc. 51: 49..

\section{Genus EMERSONELLA Girault}

Enersonella Girault, 1916. Soc. Ent. 31: 36.

Type-species: Emersonella lemae Girault. Orig. desig.

Revision: Girault, 1922. No. Amer. Spp. of Emersonella and Entedon. One page.

lemae Girault. Del., D. C., Va., N. C., Mich., Miss. Host: Lema sp., L. trilineata (Oliv.).

Emersonella lemae Girault, 1916. Soc. Ent. 31: 36. ๆ, o.

Biology: Chittenden, 1924. Ent. Soc. Wash., Proc. 26: 46.

niveipes Girault. N. Y., D. C., Va. Host: Chelymorpha cassidea (F.).

Emersonella niveipes Girault, 1917. Deser. Hym. Chalcidoid. Variorum cum Observ. III, p. 3.. .

\section{Genus CHRYSOCHARIS Foerster}

Chrysocharis Foerster, 1856. Hym. Stud., v. 2, pp. 79, 82.

Type-species: Chrysocharis femoralis Foerster. Desig. by Ashmead, 1904.

Omphalchrysocharis Girault, 1917. Deser. Hym. Chalcidoid. Variorum cum Observ. V, p. 3.

Type-species: Omphalchrysocharis orientalis Girault. Orig. desig.

Kratochviliana Malac, 1943. Ent. Listy (Folia Ent) Brno 6: 1.

Type-species: Kratochviliana moravica Malac. Orig. desig.

Epilampsis Delucchi, 1954. Neue Arten Subfam. Entedontinae, p. 3.

Type-species: Chrysocharis boops Thomson. Orig. desig.

Taxonomy: Boucek, 1961. Min. Sel. Kruzy. Moldav. SSR, Trudy 7: 28. -Graham, 1963. Soc.

Brit. Ent., Trans. 15: 205.

ainsliei Crawford. Conn., S. C., Wis., Tex., Idaho, Utah, Ariz., Wash., Calif. Host: Coleophora pruniella Clem.; Agromyza parvicomis Loew, Liriomyza pictella (Thomson).

Chrysocharis ainsliei Crawford, 1912. U. S. Natl. Mus., Proc. 43: 174. ๆ, ठ.

Biology: Webster and Parks, 1913. Jour. Agr. Res. 1: 79-80. -Oatman, 1960. Jour. Econ. Ent. 53: 682 .

cubensis Gahan. Fla.; West Indies.

Chrysocharis cubensis Gahan, 1932. Ent. Soc. Amer., Ann. 25: 748. ๆ, ठ.

gemma (Walker). B. C.; Europe. Host: Phytomyza ilicis Curtis.

Entedon gemma Walker, 1839. Monog. Chalcid. v. 1, p. 53. ठ.

Taxonomy: Delucchi, 1954. Schweiz. Ent. Ges., Mitt. 27: 300 (Epilampsis). 
Biology: Cameron, 1939. Bul. Ent. Res. 30: 178-186. - Downes and Andison, 1940. Jour. Econ. Ent. 33: 948. - Cameron, 1941. Parasitology 33: 29-38. -McLeod, 1954. Ent. Soc. B. C., Proc. 50: 22-23. - Busse, 1953. Hamburg. Zool. Mus., Ent. Mitt. 1: 98.

giraulti Yoshimoto. Que., Ont., D. C., Mo., Man., Colo., Alta., B. C. Ecology: Reared from chloropid on daisy.

Omphalchrysocharis petiolatus Girault, 1918. Ent. News 29: 131. ๆ, ठ. Preocc. in Chrysocharis by Foerster, 1861 and Thomson, 1878.

Chrysocharis giraulti Yoshimoto, 1973. Canad. Ent. 105: 1384. N. name.

laricinellae (Ratzeburg). N. B., N. S., Que., Ont., Maine, Vt., N. H., Mass., Conn., N. Y., Wis., Idaho; Europe. Introduced for biological control from Central Europe in 1931; there is some evidence it was already here before it was introduced. Host: Coleophora laricella (Hbn.); Fenusa pusilla (Lep.), F. ulmi Sund., Heterarthmis nemoratus (Fall.).

Entedon laricinellae Ratzeburg, 1848. Ichn. d. Forstins., v. 2, p. 161. ठ..

Taxonomy: Ferriere, 1933. In Thorpe, Bul. Ent. Res. 24: 290. -Boucek, 1961. Min. Sel. Kruzy. Moldav SSR, Trudy 7: 28. - Peck, 1963. Canad. Ent., Sup. 30, pp. 205-207.

Biology: Thorpe, 1933. Bul. Ent. Res. 24: 277-280. - Dowden, 1941. U. S. Dept. Agr., Tech. Bul. 757: 9-11, 44-49. - Graham, 1949. Ent. Soc. Ontario, Ann. Rpt. 79: 45-50. -Clausen, 1956. U. S. Dept. Agr., Tech. Bul. 1139: 92. - Graham, 1958. Ent. Soc. Ontario, Ann. Rpt. 88: 37-41. -Schaffner, 1959. U. S. Dept. Agr., Misc. Pub. 767: 85. -Quednau, 1966. Ent.

Soc. Quebec, Ann. 11: 200. - Quednau, 1967. Canad. Ent. 99: 326, 631.

majoriani (Girault). Fla.; West Indies, Brazil. Introd. into Hawaii for biological control. Host: Liriomyza commelinae (Frost), L. sorosis (Will.), Phytobia maculosa (Mall.).

Chrysocharodes majoriani Girault, 1917. Descr. Hym. Chalcidoid. Variorum cum Observ. III, p. 10. .

mallochi Gahan. Conn., Ill. Host: Liriomyza felti (Mall.).

Chrysocharus(!) mallochi Gahan, 1917. U. S. Natl. Mus., Proc. 53: 213. ๆ, ठ.

orientalis (Girault). N. H., Mass. Host: Phytomyza ilicicola Loew.

Omphalchrysocharis orientalis Girault, 1917. Descr. Hym. Chalcidoid. Variorum cum Observ. V, p. 3. .

oscinidis Ashmead. Kans. Ecology: Parasitizes dipterous leaf miners in cottonwood leaves.

Chrysocharis oscinidis Ashmead, 1888. Kans. Agr. Expt. Sta., Bul. 3: App. p. VIII. ठ̊.

Taxonomy: Girault, 1916. U. S. Natl. Mus., Proc. 51: 42.

pallipes (Gahan). Ont., Conn., Md., Ohio, B. C. Host: Rhynchaenus pallicomis (Say); Nepticula lindquisti Freem., Phyllocnistis populiella Chamb.; Mayetiola destructor (Say); Fenusa pusilla (Lep.).

Derostenus pallipes Gahan, 1917. U. S. Natl. Mus., Proc. 53: 214. ๆ.

Taxonomy: Gahan, 1932. Ent. Soc. Amer., Ann. 25: 748.

Biology: Lindquist, 1962. Canad. Ent. 94: 530. - Condrashoff, 1964. Canad. Ent. 96: 869.

parksi Crawford. N. Y., Idaho, Utah, Ariz., Calif. Host: Agromyza parvicomis Loew, Cerodontha femoralis (Meig.), Liriomyza munda Frick, L. pictella (Thomson), Phytomyza atricomis Meig.

Chrysocharis parksi Crawford, 1912. U. S. Natl. Mus., Proc. 43: 173. १, ठ.

Biology: Webster and Parks, 1913. Jour. Agr. Res. 1: 79-80. - Harding, 1965. Jour. Econ. Ent. 58: 443.

pubicornis (Zetterstedt). Que., Ohio, Man., N. W. T., B. C.; Europe. Host: Phytomyza ilicicola Loew, $P$. ilicis Curtis.

Entedon pubicomis Zetterstedt, 1838. Insect. Lappon., v. 1, p. 427. $\delta$.

Entedon punctellus Zetterstedt, 1838. Insect. Lappon., v. 1, p. 431. ठ.

Entedon cydon Walker, 1839. Monog. Chalcid., v. 1, p. 58. $q$.

Entedon eropus Walker, 1839. Monog. Chalcid., v. 1, p. 75. ठ.

Entedon syma Walker, 1839. Monog. Chalcid., v. 1, p. 98. ․

Entedon amyrtaeus Walker, 1839. Monog. Chalcid., v. 1, p. 111. ₹, ठ.

Entedon Hersilia Walker, 1840. Ann. and Mag. Nat. Hist. 4: 235. ठ.

Derostenus aeneiscapus Thomson, 1878. Hym. Scand., v. 5, p. 267. §, ठ. 
Taxonomy: Boucek and Askew, 1968. Index Palearctic Eulophidae (excl. Tetrastichinae), Le Francois, p. 116. - Yoshimoto, 1973. Canad. Ent. 105: 1400.

salutaris (Crosby). N. Y. Host: Nepticula slingerlandella Kearf.

Derostenus salutaris Crosby, 1911. Canad. Ent. 43: 414. ¿.

Biology: Crosby, 1911. N. Y. (Cornell) Agr. Expt. Sta., Bul. 308: 222.

thomsoni (Crawford). Que., Ont., N. Y., Ind., Alaska, B. C. Host: Phytobia angulata (Loew), P. incisa (Meig.).

Entedon thomsoni Crawford, 1913. U. S. Natl. Mus., Proc. 45: 316. ₹, ठ'.

viridis Provancher. Ont., Ohio. Ecology: Emerges from cynipid galls on Lactuca.

Chrysocharis viridis Provancher, 1887. Addit. Corr. Faune Ent. Canada Hym., p. 209..

Chrysocharis compressicornis Ashmead, 1894. Cincinnati Soc. Nat. Hist., Jour. 17: 53. \&.

Taxonomy: Burks, 1964 (1963). Canad. Ent. 95: 1257.

\section{Genus NEOCHRYSOCHARIS Kurdjumov}

Neochrysocharis Kurdjumov, 1912. Ent. Obozr. 12: 234.

Type-species: Neochrysocharis immaculatus Kurdjumov. Orig. desig.

imbrasus (Walker). Fla.

Entedon imbrasus Walker, 1847. Ann. and Mag. Nat. Hist. (1) 20: 23..

Taxonomy: Burks, 1975. Brit. Mus. (Nat. Hist.) Ent., Bul. 32 (4): 145.

\section{Genus ENAYSMA Delucehi}

\section{Genus ENAYSMA Subgenus ENAYSMA Delucchi}

Enaysma Delucchi, 1954. Neue Arten d. Subfam. Entedontinae, p. 1.

Type-species: Enaysma zwolferi Delucchi. Orig. desig. The typical subgenus does not occur in N. Amer.

\section{Genus ENAYSMA Subgenus PENTENAYSMA Graham}

Enaysma subg. Pentenaysma Graham, 1959. Soc. Brit. Ent., Trans. 13: 196.

Type-species: Eulophus latreillei Curtis. Orig. desig.

Taxonomy: Miller, 1962. Canad. Ent. 94: 1039-1040.

arienascapus Miller. Que., Ont. Host: Lithocolletis sp., L. ostryaefoliella Clem.

Enaysma arienascapus Miller, 1962. Canad. Ent. 94: 1050. ๆ, ठ์.

carioca Miller. Que., Ont. Host: Lithocolletis sp.

Enaysma carioca Miller, 1962. Canad. Ent. 94: 1043. \&, ठ.

clypeata Miller. Que. Host: Lithocolletis sp.

Enaysma clypeata Miller, 1962. Canad. Ent. 96: 1047, 1050. ठ̊.

gahani Miller. Que., Ont. Host: Lithocolletis sp., L. lucetiella Clem.

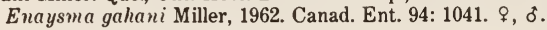

hirtiscapus Miller. Ont. Host: Lithocolletis tiliacella Chamb.

Enaysma hirtiscapus Miller, 1962. Canad. Ent. 94: 1047. ๆ, ठ.

myricae Miller. N. S. Host: Lithocolletis sp.

Enaysma myricae Miller, 1962. Canad. Ent. 94: 1043-1047. \&, ठ.

\section{Genus MOSERINA Delucchi}

Moserina Delucchi, 1962. Kans. Ent. Soc., Jour. 35: 389.

Type-species: Moserina maculata Delucchi. Orig. desig.

maculata Delucchi. Ohio. Host: Pachypsylla celtidismamma (Riley), P. celtidisvesicula Riley.

Moserina maculata Delucchi, 1962. Kans. Ent. Soc., Jour. 35: 392. ‡, ठ.

Biology: Moser, 1965. N. Y. State Mus, and Sci. Serv., Bul. 402: 14-15. - Rowan, 1971. Fla.

Ent. 54: 63-64. 


\section{Genus ACHRYSOCHAROIDES Girault}

Achrysocharoides Girault, 1913. Roy. Soc. So. Australia, Trans. 37: 72.

Type-species: Chrysocharis sarcophagus Girault. Orig. desig.

Neoderostenus Girault, 1913. Queensland Mus., Mem. 2: 144.

Type-species: Neoderostenus australiensis Girault. Orig. desig.

bipunctatus (Girault). Maine, Md. Host: Lithocolletis tremuloidiella Braun.

Neoderostenus bipunctatus Girault, 1916. Canad. Ent. 48: 409. ๆ.

guizoti Girault. Ind.

Achrysocharoides guizoti Girault, 1917. Deser. Hym. Chalcidoid. Variorum cum Observ. V, p. 11. ?.

titiani Girault. Ind.

Achrysocharoides titiani Girault, 1916. U. S. Natl. Mus., Proc. 51: 42 . ๆ.

\section{Genus RHICNOPELTOMYIA Girault}

Rhicnopeltamyia Girault, 1913. Queensland Mus., Mem. 2: 174.

Type-species: Rhicnopeltamyia washingtoni Girault. Orig. desig.

achrysocharoides Girault. D. C.

Rhicnopeltomyia achrysocharoides Girault, 1916. U. S. Natl. Mus., Proc. 51: 39.

belisarii Girault. East. U. S.

Rhicnopeltomyia belisarii Girault, 1917. New Chalcid Flies, p. 4.

carlylei Girault. Md.

Rhienapeltomyia carlylei Girault, 1917. Descr. Hym. Chalcidoid. Variorum cum Observ. V, p. 6 . \&.

Rhicnopeltomyia carlylei var. poeta Girault, 1920. U. S. Natl. Mus., Proc. 58: 197. \&. N. syn.

marylandensis Girault. Md.

Rhicnopeltomyia marylandensis Girault, 1916. U. S. Natl. Mus., Proc. 51: 39..

marylandi Girault. Md.

Rhicnopeltomyia marylandi Girault, 1917. New Chalcid Flies, pp. 4, 5.

Taxonomy: Girault, 1920. U. S. Natl. Mus., Proc. 58: 196.

scutellata Girault. D. C.

Rhicnopeltomyia seutellata Girault, 1916. U. S. Natl. Mus., Proc. 51: 40. १.

viridiscutellum Girault. D. C.

Rhicnopeltomyia viridiscutellum Girault, 1916. U. S. Natl. Mus., Proc. 51: 40. $\subsetneq$.

\section{Genus RHICNOPELTOIDEA Girault}

Rhicnopeltoidea Girault, 1917. Descr. Hym. Chalcidoid. Variorum cum Observ. V, p. 3.

Type-species: Rhicnopeltoidea amsterdamensis Girault. Orig. desig.

amsterdamensis Girault. Maine, N. Y., Ind. Host: Lithocolletis corylisella (Chamb.),

Cameraria guttifinitella (Clem.), C. picturatella Braun.

Rhicnopeltoidea amsterdamensis Girault, 1917. Descr. Hym. Chalcidoid. Variorum cum Observ. V, p. 3. ?.

\section{Genus CARLYLEIA Girault}

Carlyleia Girault, 1917. Ent. News 28: 20.

Type-species: Carlyleia marilandica Girault. Orig. desig.

marilandica Girault. Md.

Carlyleia marilandica Girault, 1917. Ent. News 28: 20..

\section{Genus CHRYSOCHAROMYIA Girault}

Chrysocharamyia Girault, 1915. Queensland Mus., Mem. 3: 207.

Type-species: Chrysocharomyia elongata Girault. Orig. desig. 
eleganta Girault. Md.

Chrysocharomyia eleganta Girault, 1917. Ent. News 28: 21..

elegantissima Girault. N. Y. Host: Phytomyza obscurella Fall.

Chrysocharomyia elegantissima Girault, 1917. Descr. Stellarum Nov., p. 20. $q$.

occidentalis Girault. Calif.

Chrysocharomyia occidentalis Girault, 1916. U. S. Natl. Mus., Proc. 51: 41..

omari Girault. $\mathrm{Pa}$.

Chrysocharomyia omari Girault, 1917. Descr. Hym. Chalcidoid. Variorum cum Observ. III, p. 9. .

splendidissima Girault. $\mathrm{Pa}$.

Chrysocharomyia splendidissima Girault, 1917. Descr. Stellarum Nov., p. 20..

\section{Genus HOPLOCREPIS Ashmead}

Hoplocrepis Ashmead, 1890. Ent. Soc. Wash., Proc. 1: 235.

Type-species: Hoplocrepis albiclavus Ashmead. Orig. desig.

albiclavus Ashmead. Mass., Fla.; West Indies.

Hoplocrepis albiclavus Ashmead, 1890. Ent. Soc. Wash., Proc. 1: 236. ‡.

\section{Genus PARACHRYSOCHARIS Girault}

Parachrysocharis Girault, 1913. Queensland Mus., Mem. 2: 177.

Type-species: Parachrysocharis javensis Girault. Orig. desig.

semiflava Girault. Wis., Tex. Host: Auplopus sp.

Parachrysocharis semiflava Girault, 1917. Canad. Ent. 49: 129. $\%, ~ §$.

\section{Genus ACHRYSOCHARIS Girault}

Achrysocharis Girault, 1913. Arch. f. Naturgesch. 79A (6): 104.

Type-species: Achrysocharis bifasciatus Girault. Monotypic.

Taxonomy: Girault, 1913. Soc. Ent. 28: 100. -Girault, 1913. Queensland Mus., Mem. 2: 163.

aemilia Girault. Fla. Host: Cecidomyiid on Eugenia buxifolia.

Achrysocharis aemilia Girault, 1917. New Chalcid Flies, p. 3. .

athanasii Girault. Md.

Achrysocharis athanasii Girault, 1917. Descr. Hym. Chalcidoid. Variorum cum Observ. III, p. 3. .

divina Girault. Md.

Achrysocharis divina Girault, 1917. Ent. News 2: 22. $?$.

donna Girault. N. Y. Host: Taphrocerus gracilis (Say).

Achrysocharis donna Girault, 1917. Deser. Stellarum Nov., p. 22. $\%$.

kansensis Girault. Minn., Kans. Host: Schizocerella pilicornis (Holmg.).

Achysocharis(!) kansensis Girault, 1916. U. S. Natl. Mus., Proc. 51: 42 ..

partifuscipennis Girault. Md.

Achrysocharis partifuscipennis Girault, 1916. Ent. Soc. Amer. Ann. 9: 294..

phenacaspia Yoshimoto. Calif. Host: Phenacaspis pinifoliae (Fitch).

Achrysocharis phenacapsia(!) Yoshimoto, 1972. Canad. Ent. 104: 1483..

\section{Genus ACHRYSOCHARELLA Girault}

Achrysocharella Girault, 1913. Queensland Mus., Mem. 2: 171.

Type-species: Achrysocharella dubia Girault. Orig. desig.

Wolfiella Krausse, 1917. Ztschr. f. Forst. u. Jagdw. 49: 29.

Type-species: Wolfiella miforum Krausse. Monotypic.

North American species that were placed in Derostenus Westwood are generically misplaced and belong here.

Revision: Crawford, 1912. U. S. Natl. Mus., Proc. 43: 179 (Derostenus). 
acuminaticornis Girault. D. C.

Achrysocharella acuminaticomis Girault, 1916. U. S. Natl. Mus., Proc. 51: 50..

acuminativentris Girault. D. C.

Achrysocharella acuminativentris Girault, 1917. Deser. Hym. Chalcidoid. Variorum cum Observ. III, p. 6. .

agromyzae (Crawford). N. Y., s. to Fla., w. to N. Dak. and Ariz. Host: Agromyza sp., Liriomyza sorosis (Will.); Mantura floridana (Crotch).

Derastenus agromyzae Crawford, 1913. U. S. Natl. Mus., Proc. 45: 314, 315. ‡, ठ’.

americana Girault. D. C.

Achrysocharella americana Girault, 1916. Ent. Soc. Amer., Ann. 9: 295.

arizonensis (Crawford). Utah, Ariz., Calif. Host: Agromyza sp., Liriomyza pictella (Thomson). Derostenus arizonensis Crawford, 1913. U. S. Natl. Mus., Proc. 45: 315. \$, ठ’.

Biology: Webster and Parks, 1913. Jour. Agr. Res. 1: 80.

damastes (Walker). Fla.

Closteracernts Damastes Walker, 1847. Ann. and Mag. Nat. Hist. (1) 20: 22. ․

Taxonomy: Burks, 1975. Brit. Mus. (Nat. Hist.) Ent., Bul. 32 (4): 142.

diastatae (Howard). Conn. to Fla. and Kans. Host: Agramyza parvicomis Loew, Diastata sp., Phytobia angulata (Loew); Fenusa pusilla (Lep.).

Entedon diastatae Howard, 1881. U. S. Dept. Agr., Ann. Rpt. for 1880, p. 246. \&, ठ.

Biology: Phillips, 1914. Jour. Agr. Res. 2: 26-27.

fullawayi (Crawford). Conn., Va., La., S. Dak., Calif.; Hawaii, Mexico. Host: Argyresthia thuiella (Pack.); Agramyza parvicomis Loew; Fenusa pusilla (Lep.).

Derostenus fullowayi(!) Crawford, 1913. U. S. Natl. Mus., Proc. 46: 348. ๆ.

Achrysocharis camilli Girault, 1917. New Chalcid Flies, p. 5.

Derostenus fullawayi Glick, 1939. U. S. Dept. Agr., Tech. Bul. 673: 47. Emend.

Taxonomy: Girault, 1920. U. S. Natl. Mus., Proc. 58: 196.

Biology: Underhill, 1943. Va. Agr. Expt. Sta., Bul. 349: 22.

leucopus (Ashmead). Ohio, Kans. Ecology: Reared from leaf miner on beech.

Derostenus lencopus Ashmead, 1888. Kans. Agr. Expt. Sta., Bul. 3: App. p. VIII. \&.

obscurinotata Girault. Md.

Achrysocharella obscurinatata Girault, 1916. Ent. Soc. Amer., Ann. 9: 306. ९.

partiaeneiceps Girault. Md.

Achrysocharella partiaeneiceps Girault, 1917. New Eulophidae, p. 1. $\subsetneq$.

pictipes (Crawford). Md., S. C., Ind., Kans., Colo., Utah. Host: Agromyza sp., Phytobia lateralis (Macq.).

Derostenus pictipes Crawford, 1912. U. S. Natl. Mus., Proc. 43: 180. ९, ১.

pulchrella Girault. D. C.

Achrysocharella pulchrella Girault, 1917. Psyche 24: 94..

punctiventris (Crawford). Ind., Wyo., Utah, Idaho, Calif. Host: Agromyza parvicomis Loew, Liriomyza sp.

Derostenus punctiventris Crawford, 1912. U. S. Natl. Mus., Proc. 43: 180. \&.

Biology: Phillips, 1914. Jour. Agr. Res. 2: 28.

silvia Girault. Maine, s. to Md., w. to Wis., Calif. Host: Coleophora la ricella (Hbn.),

Coleotechnites apicitripunctella (Clem.), C. milleri (Busck), Exoteleia pinifoliella

(Chamb.), Tetralopha robustella Zell.

Achrysocharella silvia Girault, 1917. Two New Achrysocharellae, p. 1. \&.

Taxonomy: Girault, 1920. U. S. Natl. Mus., Proc. 58: 197.

Biology: Schaffner, 1959. U. S. Dept. Agr., Misc. Pub. 767: 85.

variipes (Crawford). N. Y., s. to Fla., w. to Mich., La., Tex. Host: Agromyza sp.

Derostenus variipes Crawford, 1913. U. S. Natl. Mus., Proc. 45: 315. ๆ.

Taxonomy: Gahan, 1914. U. S. Natl. Mus., Proc. 48: 164. 


\section{Genus LOPHOCOMUS Haliday}

Lophocomus Haliday, 1844 (1843). Ent. Soc. London, Trans. 3: 297.

Type-species: Cirrospilus anaitis Walker. Monotypic.

verticillatus Ashmead. Kans.

Lophocomus verticillatus Ashmead, 1888. Kans. Agr. Expt. Sta., Bul. 3: App. p. VIII. ð.

\section{Genus HORISMENUS Walker}

Horismenus Walker, 1843. Ann. and Mag. Nat. Hist. 11: 117.

Type-species: Horismenus cleodora Walker. Monotypic.

Horisemus Crawford, 1907. N. Y. Ent. Soc., Jour. 15: 180. Undoubtedly an error for Horismenus, but published in such a way as to validate it as a generic name in Zoology.

Type-species: Horisemus lixivorus Crawford. Monotypic.

Pseudomphale Schrottky, 1909. Soc. Cient. Argentina, An. 67: 209.

Type-species: Pseudomphale opsiphanis Schrottky. Monotypic.

Pediobioidea Girault, 1911. Canad. Ent. 43: 407.

Type-species: Pediobioidea cyanea Girault. Monotypic. Synonymized under Horismenus when described.

Triolynx Cameron, 1913. Timehri, R. Agr. Com. Soc. Brit. Guiana, Jour. 3: 130.

Type-species: Triolynx clavicornis Cameron. Monotypic.

Akonda Cameron, 1913, Timehri, R. Agr. Com. Soc. Brit. Guiana, Jour. 3: 131.

Type-species: Akonda hipparchia Cameron. Monotypic.

Perhymenes Brethes, 1916. Buenos Aires Mus. Nac. de Hist. Nat, An. 27: 427.

Type-species: Perhymenes schrottkyi Brethes. Monotypic.

Dirphiphagus Brethes, 1917. An. Zool. Apl. 4: 25.

Type-species: Dirphiphagus ancilla Brethes. Orig. desig.

Holcopeltomorpha Blanchard, 1942. Soc. Cient. Argentina, An. 134: 126.

Type-species: Holcopeltomorpha christenseni Blanchard. Orig. desig.

Revision: Burks, 1971. Ent. Soc. Wash., Proc. 73: 68-83.

Taxonomy: Boucek, 1965. Mus. Natl. Pragae, Acta Ent. 36: 84 (synonymy). -De Santis, 1968

(1967). Cat. Hym. Argentinos, Buenos Aires, p. 141 (synonymy).

atroscapus (Girault). N. C., Fla. Host: Acrobasis rubrifasciella (Pack.), Tetralopha subcanalis (Walk.).

Pseudomphale atroscapus Girault, 1917. Descr. Stellarum Nov., p. 20..

bruchophagus Burks. Tex. Host: Mimosestes sallei (Sharp).

Horismenus bruchophagus Burks, 1971. Ent. Soc. Wash., Proc. 73: 72. ₹, ठ.

carolinensis Burks. N. C. Host: Chrysobothris femorata (Oliv.), Oncideres cingulata (Say). Despite these seemingly reliable host records, this species probably is actually a secondary parasite.

Horismenus carolinensis Burks, 1971. Ent. Soc. Wash., Proc. 73: 73. १, §.

depressus Gahan. Tex., Calif. Host: Bruchus sp., Stator pruininus (Horn).

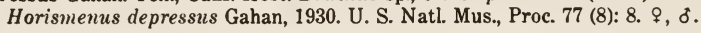

floridanus (Ashmead). N. J., s. to Fla., w. to Ill., Kans., Tex., Calif. Host: A panteles sp., $A$. schizurae Ashm.

Holcopelte floridana Ashmead, 1888. Canad. Ent. 20: 102. $\subsetneq$.

Biology: Gahan, 1934 (1933). U. S. Dept. Agr., Misc. Pub. 174: 128. -Gilmore, 1938. Jour.

Econ. Ent. 31: 715. -Fulton, 1940. Ent. Soc. Amer., Ann. 32: 233. -Nickels, 1951. Jour.

Econ. Ent. 44: 434. -Painter, 1955. Jour. Econ. Ent. 48: 41.

fraternus (Fitch). Conn., s. to Fla., w. to Wis., Kans., Tex. Host: Coleophora priniella Clem., Cameraria caryaefoliella (Clem.), Parornix geminatella (Pack.), Tischeria malifoliella (Clem.); Apanteles sp., Euplectrus comstockii How., Sympiesis sp.

Trichogramma? fraterna Fitch, 1856. Country Gentleman 7: 235.

Elachistus euplectri Howard, 1885. In Riley, U. S. Dept. Agr., Ent. Comn., Rpt. 4, Appendix, p. 108. $\$, \delta$.

Holcopelte violacea Ashmead, 1887. Amer. Ent. Soc., Trans. 14: 200. §. 
Taxonomy: Packard, 1890. U. S. Dept. Agr., Ent. Comn., Rpt. 5, p. 265.

Biology: Dunnam, 1924. Iowa Agr. Expt. Sta., Bul. 220: 65. - Doner, 1936. Ent. Soc. Amer., Ann. 29: 234. -Copenhafer and Parker, 1938. Kans. Ent. Soc., Jour. 11: 46. - Glick, 1939. U. S. Dept. Agr., Tech. Bul. 673: 48. - Nickels, 1948. Jour. Econ. Ent. 4: 114. -Beckham et al., 1950. Va. Agr. Expt. Sta., Tech. Bul. 114: 12. -Schaffner, 1959. U. S. Dept. Agr., Misc. Pub. 767: 85 .

ignotus Burks. Fla. Host: Homaledra sabalella (Chamb.).

Horismenus ignotus Burks, 1971. Ent. Soc. Wash., Proc. 73: 76. ๆ.

latrodecti Burks. Tex. Ecology: A secondary parasite in egg sacs of the black widow spider, probably parasitizing a chloropid fly, Pseudogaurax signatus (Loew), the primary parasite.

Horismenus latrodecti Burks, 1971. Ent. Soc. Wash., Proc. 73: 77. ९, ठ.

lixivorus Crawford, Tex., Ariz. Host: Lixus musculus Say., L. perforatus LeC., L. scrobicollis Boh.

Horisemus(!) lixivorus Crawford, 1907. N. Y. Ent. Soc., Jour. 15: 180. \&, ठ.

Biology: Pierce, 1910. Jour. Econ. Ent. 3: 453.

microgaster (Ashmead). Maine, s. to N. C., w. to Iowa, Kans., Tex. Host: Apion decoloratum Smith; Acleris minuta (Rob.), Anchylopera nebeculana Clem., Ancylis comptana fragariae (W. and R.), Celama sarghiella (Riley), Charistoneura rasaceana (Har.), Caleophora laricella (Hbn.), C. malivorella Riley, Dichomeris marginella (F.), Exoteleia pin ifoliella (Chamb.), Pararnix geminatella (Pack.), Phyllocnistis populiella Chamb., Pterophorus periscelidactylus Fitch, Tetralopha robustella Zell.; Apanteles sp., A. congregatus (Say), A. glomeratus (L.), A. melanoscelus (Ratz.), Charinaeus sp., Microgaster sp., Microplitis ceratomiae Riley, Oncophanes americanus (Weed).

Holcopelte microgaster Ashmead, 1888. Canad. Ent. 20: 102. $\delta$.

Pediobioidea cyanea Girault, 1911. Canad. Ent. 43: 407. $\$$, ¿.

Pseudomphale ancylae Girault, 1916. Ent. News 27: 223. ๆ, ठे.

Biology: Leach, 1916. U. S. Dept. Agr., Bul. 435: 11. - Proper, 1934. Jour. Agr. Res. 48: 365. - Hill and Hough, 1957. Va. Agr. Expt. Sta., Tech. Bul. 130: 16. - Schaffner, 1959. U. S. Dept. Agr., Misc. Pub. 767: 85.

missouriensis (Ashmead). N. Y., s. to Ga., w. to S. Dak., Kans., Okla., Ariz. Host: Acanthoscelides sp., Amblycerus sp., Gibbobruchus sp.

Holcopelte missouriensis Ashmead, 1888. Canad. Ent. 20: 101..

Holcopelte popenoei Ashmead, 1888. Canad. Ent. 20: 101..

Taxonomy: Girault, 1934. Miridae et Hym. Nova Austral., p. 3 (synonymy).

nitens (Howard). D. C. Ecology: A secondary parasite in egg sacs of epeirid spiders.

Halcopelte nitens Howard, 1892. Ent. Soc. Wash., Proc. 2: 298. १, ठै.

productus (Ashmead). Tex., N. Mex., Ariz., Calif. Host: Acanthascelides horni (Pic), Algarabius prosopis (LeC.), Mimosestes amicus (Horn).

Holcopelte producta Ashmead, 1894. Amer. Ent. Soc., Trans. 21: 342., , ठ.

sardus (Walker). Fla.

Entedon (Horismenus) sardus Walker, 1847. Ann. and Mag. Nat. Hist. (1) 20: 23. \&.

Taxonomy: Burks, 1975. Brit. Mus. (Nat. Hist.) Ent., Bul. 32 (4): 147.

Elachristus(!) flavipes Ashmead, 1886. Amer. Ent. Soc., Trans. 13: 133. ๆ.

texanus (Girault). Conn., s. to Ga., w. to Iowa, Kans., Ariz. Ecology: A parasite of small

Diptera living in grass stems. Host: Eumetopiella rufipes (Macq.), Mayetiola destructor (Say), Meromyza americana Fitch.

Pseudomphale texana Girault, 1917 (1916). Insecutor Inscitiae Menstruus 4: 120. ९.

Biology: Gahan, 1934 (1933). U. S. Dept. Agr., Misc. Pub. 174: 128.

\section{Genus PEDIOBIUS Walker}

Pediobius Walker, 1846. Ann. and Mag. Nat. Hist. (1) 17: 184.

Type-species: Entedon (Pediobius) imbreus Walker. Desig. by Ashmead, 1904, p.

384. Incorrectly desig. on p. 344 . 
Rhopalotus Foerster, 1856. Hym. Stud., v. 2, p. 78.

Type-species: Elachertus cothurnatus Ratzeburg. Desig. by Ashmead, 1904.

Pleurotropis Foerster, 1856. Hym. Stud., v. 2, pp. 78, 82. No species. -Foerster, 1861.

Progr. Realsch. Aachen, p. xxxvii, no. 58. One species.

Type-species: Pleurotropis isomera Foerster. Included by Foerster, 1861.

Cluthaira Cameron, 1912. Linn. Soc. New South Wales, Proc. 37: 211.

Type-species: Cluthaira agaristae Cameron. Monotypic.

Pseudacrias Girault, 1913. Arch. f. Naturgesch. 79A (6): 104.

Type-species: Pseudacrias micans Girault. Orig. desig.

Mestocharomyia Girault, 1915. Queensland Mus., Mem. 3: 188.

Type-species: Mestocharomyia lividus Girault. Orig. desig.

Eupleurotropis Girault, 1917. Speciosissima Genera Nova Eulophidorum, p. 3.

Type-species: Pleurotropis testaceipes Crawford. Orig. desig.

Pseudacriasoides Girault, 1917. Deser. Stellarum Nov., p. 9.

Type-species: Pleurotropis utahensis Crawford. Orig. desig.

Epipleurotropis Girault, 1917. Descr. Hym. Chalcidoid. Variorum cum Observ. III, p. 7.

Type-species: E pipleurotropis longfellowi Girault. Orig. desig.

Boucek, 1965 (Mus. Nat. Pragae, Acta Ent. 36: 7) states that Microtems Spinola, 1811, is very likely the same as Pediobius: Walker, 1846, and should, thus, have priority. He decided, however, to continue to use Pediobius as the name of this genus because of usage and because Microteris is a long forgotten name. In my opinion the case for recognizing Microterus is very weak, at least on the basis of the presently available information. If a case to present to the Commission were drawn up, the only name for this genus that could be retained on the basis of usage is Pleurotropis Foerster, 1856. That is the name that was used for it for over a century.

Revision: Crawford, 1912. U. S. Natl. Mus., Proc. 43: 177-179 (Pleurotropis). - Boucek, 1965.

Mus. Nat. Pragae, Acta Ent. 36: 5-90 (Palearctic fauna). - Burks, 1966. Ent. Soc. Wash.,

Proc. 68: 33-43.

Taxonomy: Waterston, 1915. Bul. Ent. Res. 5: 343-346. - Ferriere, 1953. Univ. Bologna, Ist.

di Ent., Bol. 19: 400. -Graham, 1959. Soc. Brit. Ent., Trans. 13: 186. - Boucek, 1965. Mus.

Natl. Pragae, Acta Ent. 36: 7-10. - Boucek and Askew, 1968. Index Palearctic Eulophidae

(excl. Tetrastichinae), Le Francois, p. 88.

albipes (Provancher). Maine, Ont., s. to Va., w. to Ill. Host: Apanteles congregatus (Say),

Dibrachys cavus (Walk.), Eupteromalus peregrinus Graham.

Holcopelte albipes Provancher, 1887. Addit. Corr. Faune Ent. Canada Hym., p. 210. ठ。.

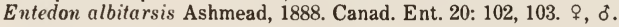

Taxonomy: Girault, 1924. Insecutor Inscitiae Menstruus 12: 94. - Burks, 1964 (1963), Canad.

Ent. 95: 1259.

aphidiphagus (Ashmead). Que., Fla., Ind., Ill., Kans. Ecology: Parasitic on tineid larvae in oak galls; reared from galls of Amphibolips quercusinanis (O. S.) and A. quercusspongifica (O.S.).

Entedon aphidiphagus Ashmead, 1887. Amer. Ent. Soc., Trans. 14: 201..+

Asecodes quericola Ashmead, 1888. Kans. Agr. Expt. Sta., Bul. 3: App. p. VIII. $\uparrow, ~ \delta$.

Taxonomy: Gahan, 1951. Canad. Ent. 83: 170.

bucculatricis (Gahan). Que., Maine, Conn. Host: Bucculatrix canadensisella (Chamb.),

Phyllocnistis populiella Chamb.; Xenochalepus dorsalis (Thunb.).

Pleurotropis bucculatricis Gahan, 1927. Psyche 34: 171. ㅇ, o.

Biology: Schaffner, 1959. U. S. Dept. Agr., Misc. Pub. 767: 85.

chloropidis Burks. N. Y., W. Va. Ecology: Parasitizes chloropid flies that are egg-predators on bagworms. Host: Pseudogaurax sp., $P$. anchora (Loew).

Pediobius chloropidis Burks, 1966. Ent. Soc. Wash., Proc. 68: 42. ‡, ठ.

crocidophorae Burks. S. C., La. Host: Crocidophora pustuliferalis Led.

Pediobius crocidophorae Burks, 1966. Ent. Soc. Wash., Proc. 68: 36. ๆ, o. 
lithocolletidis (Ashmead). Maine, Conn., Va., N. C., Ind., Ill., Kans. Host: Anthonomus nigrinus Boh.; Argyresthia thuiella (Pack.), Cameraria guttifinitella (Clem.), Lithocolletis sp.; Phytobia jucunda (Wulp), Phytomyza ilicis Curt.

Entedon lithocolletidis Ashmead, 1888. Kans. Agr. Expt. Sta., Bul. 3: App. p. VIII. ‡, ठ์.

Biology: Fitzgerald and Simeone, 1971. Ent. Soc. Amer., Ann. 64: 770-773.

lonchaeae Burks. Maine, Ont., N. H., Mass., N. Y., N. J., Pa. Ecology: Parasitizes fly larvae (prob. Lonchaea corticis Taylor) that invade burrows of the weevil Pissodes strobi (Peck), in terminal growth of white pine. Host: Lonchaea sp.

Pediobius lonchaeae Burks, 1966. Ent. Soc. Wash., Proc. 68: 37. १, ठ゚.

longfellowi (Girault). Maine, $\mathrm{Pa}$. Host: Cameraria aceriella (Clem.), Lithocolletis sp.

Epipleurotropis longfellowi Girault, 1917. Descr. Hym. Chalcidoid. Variorum cum Observ. III, p. 7. $\%$.

longus (Girault). Ind. Ecology: Reared from canary grass, Phalaris sp., that also yielded Harmolita longicomis (Walker).

Pleu rotropis longus Girault, 1916. Canad. Ent. 48: 342 . $?$.

metallicus (Nees). Most areas in North America where wheat is grown; Europe. Introduced for biological control into the Midwest and Maryland, from England, in 1891-1894. Host: Mayetiola destructor (Say).

Eulophus metallicus Nees, 1834. Hym. Ichn. Affin. Monog., v. 2, p. 176. \&, ठ.

Entedon Epigonus Walker, 1839. Monog. Chalcid., v. 1, p. 112. ๆ, ठ.

Semiotellus nigripes Lindeman, 1887. Soc. Imp. Nat. Mosc., Bul. (2) 1: 179, 185, 192.

Taxonomy: Walker, 1848. List Hym. Ins. Brit. Mus., v. 2, p. 136. -Forbes, 1892. U. S. Dept. Agr., Insect Life 5: 72. - Gahan, 1934 (1933). U. S. Dept. Agr., Misc. Pub. 174: 132 (metallicus). - Ferriere, 1953. Univ. Bologna, Ist. di Ent., Bol. 19: 400. -Graham, 1959.

Soc. Brit. Ent., Trans. 13: 191. - Boucek, 1965. Mus. Natl. Pragae, Acta Ent. 36: 65 (epigonus).

Biology: Riley, 1892. U. S. Dept. Agr., Ann. Rpt. for 1891, p. 235. -Riley, 1893. U. S. Dept. Agr., Ann. Rpt. for 1892, p. 158. - Riley, 1893. U. S. Dept. Agr., Insect Life 6: 133.

-Osborn, 1898. U. S. Dept. Agr., Div. Ent. Bul. 16: 28, 38-41. - Howard and Fiske, 1911.

U. S. Dept. Agr., Bur. Ent. Bul. 91: 30. -McConnell, 1916. Jour. Econ. Ent. 9: 145. -Wade and Myers, 1921. Ent. Soc. Wash., Proc. 23: 202. - Howard, 1924. Natl. Acad. Sci., Proc. 10: 18. -Gahan, 1934 (1933). U. S. Dept. Agr., Misc. Pub. 174: 132. - Hill et al., 1939. U. S. Dept. Agr., Tech. Bul. 689: 4-15. - Hill and Pinckney, 1940. U. S. Dept. Agr., Tech. Bul. 715: 9-13. -Clausen, 1956. U. S. Dept. Agr., Tech. Bul. 1139: 123.

nawai (Ashmead). Ont., New England; Europe, Japan. Introduced inadvertently from Europe, along with parasites of the gypsy moth, before 1920. Host: Apanteles melanoscelus (Ratz.), Dibrachys cavus (Walk.), Eupteromalus peregrinus Graham; Compsilura concinnata (Meig.).

Derostenus nawai Ashmead, 1904. N. Y. Ent. Soc., Jour. 12: 160., o.

Biology: Muesebeck and Dohanian, 1927. U. S. Dept. Agr., Bul. 1487: 12, 31-32. - Proper, 1934. Jour. Agr. Res. 48: 362-375. - Haeussler, 1940. U. S. Dept. Agr., Tech. Bul. 728: 33.

-Arthur, 1962. Canad. Ent. 941: 1087.

niger (Ashmead). Ill., Fla.

Closterocerus niger Ashmead, 1896. Amer. Ent. Soc., Trans. 23: 232. ठ。.

nigritarsis (Thomson). Que., Ont., s. to Va., w. to Alta. and S. Dak. Introduced for biological control from Europe in 1935 , but it was already here as an apparently different species. Host: Mayetiola destructor (Say); Cephus cinctus Nort., C. pygmaens (L.), Trachelus tabidus (F.).

Pleurotropis uigritarsis Thomson, 1878. Hym. Scand., v. 5, p. 251. \&, ठ.

Pleurotropis benefica Gahan, 1921. Ent. Soc. Wash., Proc. 23: 117. \&, ठ.

Taxonomy: Gahan, 1932. Ent. Soc. Amer., Ann. 25: 751. - Gahan, 1934 (1933). U. S. Dept. Agr., Misc. Pub. 174: 131. - von Rosen, 1956. K. Lantbrukshog, Ann. 23: 19. -Graham, 1959. Soc. Brit. Ent., Trans. 13: 190. 
Biology: Gahan, 1920. U. S. Dept. Agr., Bul. 834: 12 (Pleurotropis sp.). -Salt, 1931. Bul. Ent. Res. 22: 534-541. - Baird, 1940 (1939). Ent. Soc. Ont., Ann. Rpt. 70: 53. - Udine, 1941. U. S. Dept. Agr., Cir. 607: 7. -Smith, 1949 (1947). Ent. Soc. Ont., Ann. Rpt. 78: 39-42. -Smith, 1959. Canad. Ent. 91: 699-701. - von Rosen, 1959. Ent. Tidskr. 80: 163.

perdubius (Girault). Utah.

Amestocharis perdubius Girault, 1917. Deser. Stellarum Nov., p. 8. \&.

phyllotretae (Riley). Mo., La. Host: Phyllotreta zimmermanni (Crotch).

Pleurotropis phyllotretae Riley, 1885. U. S. Dept. Agr., Ann. Rpt. for 1884, p. 307. \&, o.

rugosithorax (Crawford). Ind., Kans., Utah. Host: Agromyza sp., Phytobia angulata (Loew). Pleurotropis mugosithorax Crawford, 1912. U. S. Natl. Mus., Proc. 43: 179. ९, ठ.

Pleurotropis kansensis Girault, 1918. Ent. News 29: 128. ?.

Biology: Webster and Parks, 1913. Jour. Agr. Res. 1: 82, 84.

sexdentatus (Girault). Mass., N. J., Ohio, N. C., Kans. Ecology: A primary or secondary parasite of small Lepidoptera. Host: Acrobasis comptoniella Hulst, Ancylis comptana fragariae (W. and R.); Meteorus sp.

Pseudacrias sexdentatus Girault, 1916. Soc. Ent. 31: 36. \&.

Biology: Patterson, 1915. Biol. Bul. 29: 340-341. -Schaffner, 1959. U. S. Dept. Agr., Misc. Pub. 767: 86.

singularis (Howard). D. C. Host: Cameraria hamadryadella (Clem.). Described from the pupa; recognizably a Pediobius but cannot be specifically placed at present.

Chrysocharis singularis Howard, 1882. Amer. Nat. 16: 61.

Biology: Howard, 1891. U. S. Dept. Agr., Insect Life 4: 194.

splendens (Cook and Davis). Mich. Host: Eulophus sp.

Derostenus splendens Cook and Davis, 1891. Mich. Agr. Expt. Sta., Bul. 73: 13. §,

tarsalis (Ashmead). N. H., s. to N. C., w. to Wash., Oreg., Calif. Ecology: A common secondary parasite of Lepidoptera. Host: Compsilura concinnata (Meig.), Winthemia datanae (Twns.); Apanteles clisiocampae Ashm., A. hyphantriae Riley, A. lacteicolor Vier., $A$. melanoscelus (Ratz.), Bracon gelechiae Ashm., Casinaria limenitidis (How.), Dibrachys cavus (Walk.), Dimmockia incongrua (Ashm.), D. pallipes Mues., Eupelmella vesicularis (Retz.), Eupelmus sp., Eupteromalus peregrinus Graham, Eurytoma sp., Gambrus extrematis (Cress.), Gelis tenellus (Say), Habrocytus phycidis Ashm., Hyposoter fugitivus (Say), Iseropus coelebs (Walsh), Itoplectis conquisitor (Say), Mastrus sp., Phobocampe clisiocampae (Weed), Rogas stigmator (Say), Schizonotus latus (Walk.). Asecodes albitarsis Ashmead, 1888. Canad. Ent. 20: 103. . Preocc. by Ashmead, 1888. Holcopelte tarsalis Ashmead, 1894. Amer. Ent. Soc., Trans. 21: 341. ठ, ๆ.

Pleurotropis ashmeadi Crawford, 1912. U. S. Natl. Mus., Proc. 43: 177. N. name, for albitarsis.

Taxonomy: Gahan, 1927. U. S. Natl. Mus., Proc. 71 (4): 26.

Biology: Fiske, 1903. N. H. Agr. Expt. Sta., Tech. Bul. 6: 182, 206, 213, 229. -Smith, 1916. Jour. Econ. Ent. 9: 484. -Muesebeck and Dohanian, 1927. U. S. Dept. Agr., Bul. 1487: 12, 31. - Proper, 1934. Jour. Agr. Res. 48: 361-370. - Marsh, 1937. Ecology 18: 108-111. -Dowden, 1939. Jour. Agr. Res. 58: 591. - Reeks and Smith, 1956. Canad. Ent. 88: 572.

- Schaffner, 1959. U. S. Dept. Agr., Misc. Pub. 767: 86.

testaceipes (Crawford). S. C.

Pleurotropis testaceipes Crawford, 1914. Insecutor Inscitiae Menstruus 2: 37. \%.

utahensis (Crawford). Maine, Man., N. Dak., Mont., Utah. Host: Cephus cinctus Nort. Originally described as a parasite of an agromyzid, but that was a mistake.

Pleurotropis utahensis Crawford, 1913. U. S. Natl. Mus., Proc. 45: 316. ९, ó.

Taxonomy: Phillips, 1914. Jour. Agr. Res. 2: 28. -Gahan, 1921. Ent. Soc. Wash., Proc. 23: 113-117.

Biology: Ainslie, 1920. U. S. Dept. Agr., Bul. 841: 23-24. -Ainslie, 1929. U. S. Dept. Agr., Tech. Bul. 157: 19-20. - Munro et al., 1949. N. Dak. Agr. Expt. Sta., Bimon. Bul. 11: 90. -Nielson, 1949. Canad. Ent. 81: 174-180. -Davis et al., 1955. N. Dak. Agr. Expt. Sta., Bimon. Bul. 18: 64-65. 
wilderi (Howard). Que., N. Y., Pa., D. C., Md., S. C., Ga., Minn., Ark., Calif. Ecology: A secondary parasite in spider egg sacs, emerging from ichneumonid cocoons. Host: Gelis sp., Tromatobia rufopectus (Cress.).

Mestocharis wilderi Howard, 1892. Ent. Soc. Wash., Proc. 2: 298. १, ठ.

Taxonomy: Girault, 1911. N. Y. Ent. Soc., Jour. 19: 179. -Crawford, 1912. U. S. Natl. Mus., Proc. 43: 179.

williamsoni (Girault). N. J., Ill., N. Dak., Utah. Ecology: Parasitizes conopid flies that develop in bumblebee nests. Host: Physocephala sagittaria (Say), P. texana (Will.).

Mestocharis williamsoni Girault, 1911. N. Y. Ent. Soc., Jour. 19: 179. ^, ð.

Taxonomy: Frison, 1926. Ent. Soc. Amer., Ann. 19: 222, 232. -Frison, 1927. Ill. State Nat.

Hist. Survey, Bul. 16: 222.

\section{Genus ENTEDON Dalman}

Entedon Dalman, 1820. Svenska Vetensk. Akad., Handl. 41: 136, 181.

Type-species: Entedon cyanellus Dalman. Desig. by Ashmead, 1904.

Eriglyptus Crawford, 1907. N. Y. Ent. Soc., Jour. 15: 179.

Type-species: Eriglyptus robustus Crawford. Orig. desig.

Entedonella Girault, 1913. Queensland Mus., Mem. 2: 154.

Type-species: Entedonella magnifica Girault. Orig. desig.

Revision: Girault, 1922. No. Amer. spp. of Emersonella and Entedon, 1 page. -Graham, 1971. Roy. Ent. Soc. London, Trans. 123: 313-358 (British Fauna).

Taxonomy: Girault, 1917 (1916). Insecutor Inscitiae Menstruus 4: 110 (synonymy).

- Hedqvist, 1963. Stud. Forest. Suecica 11: 144.

bigeloviae Ashmead. Kans., N. Mex., Utah, Ariz., Oreg. Host: Aciurina bigeloviae (Ckll.).

Entedon bigeloviae Ashmead, 1894. Amer. Ent. Soc., Trans. 21: 342. ?.

columbianus Ashmead. D. C.

Entedon columbiana Ashmead, 1888. Canad. Ent. 20: 103..

leucogramma (Ratzeburg). Conn., N. Y., Pa., Va., N. C., S. C., Ohio, Ind., Iowa, La., Calif.; Europe. Introduced from Europe for biological control. Host: Scolytus multistriatus (Marsh.), S. rugulosus (Ratz.).

Ichneumon (Elachestus) Leucogramma Ratzeburg, 1844. Forst.-Ins. d. Wald. Preuss., v. 3, p. 28. $\delta$.

Taxonomy: Erdos, 1944. Species Hung. Entedon Dalm., Kalocsa, Hung., p. 43. - Hedqvist, 1963. Stud. Forest. Suecica 11: 145-146. -Graham, 1963. Soc. Brit. Ent., Trans. 15: 194-195. -Boucek, 1965. Mus. Natl. Pragae, Acta Ent. 36: 34.

Biology: Pechuman, 1937. Brooklyn Ent. Soc., Bul. 32: 17. - Hoffman, 1942. U. S. Dept. Agr., Misc. Pub. 466: 20. - Beal and Massey, 1945. Duke Univ., Forestry Bul. 10: 67. - Leuchs, 1955. Ztschr. f. Pflanzenkrank. 62: 550. - Saunders, 1957. Ent. Monthly Mag. 93: 273.

-Capek, 1963. Banska Stiav. Vyskum Ustav Les. Hosped Ved. Prace 4: 269. - Beaver, 1966. Roy. Ent. Soc. London, Proc. (A) 41: 37. - Beaver, 1967. Jour. Anim. Ecol. 36: 437.

leucopus (Ashmead). Fla.

Pleurotropis leucopus Ashmead, 1888. Canad. Ent. 20: 102..+

occidentalis Girault. Utah, Oreg., Calif.

Entedon occidentalis Girault, 1916. U. S. Natl. Mus., Proc. 51: 48. \&.

robustus (Crawford). D. C. Host: Anthonomns nigrinus Boh.

Eriglyptus robustus Crawford, 1907. N. Y. Ent. Soc., Jour. 15: 180. १, ठ.

tachypterelli Gahan. N. Y., Colo. Host: Tachypterellus consors cerasi List, T. quadrigibbus (Say).

Entedon tachypterelli Gahan, 1931. Wash. Acad. Sci., Proc. 21: 38. \&, ठ.

Biology: List, 1932. Colo. Agr. Expt. Sta., Bul. 385: 59, 61-62. - Hammar, 1936. N. Y. State Agr. Expt. Sta., Tech. Bul. 240: 44-45.

washingtoni Girault. D. C.

Entedon washingtoni Girault, 1917 (1916). Insecutor Inscitiae Menstruus 4: 109.. 


\section{Genus PARACRIAS Ashmead}

Paracrias Ashmead, 1904. Carnegie Mus., Mem. 1: 343, 344, 510.

Type-species: Paracrias laticeps Ashmead. Orig. desig.

Euplectrentedon Girault, 1917. Speciosissima Genera Nova Eulophidorum, p. 3.

Type-species: Euplectrentedon mirus Girault. Orig. desig.

mirus (Girault). N. Y., Ohio, lowa. Host: Thysanocnemis sp.

Euplectrentedon mimus Girault, 1917. Speciosissima Genera Nova Eulophidorum, p. 3. $\subsetneq$.

\section{Genus CHRYSONOTOMYIA Ashmead}

Chrysonotomyia Ashmead, 1904. Carnegie Mus., Mem. 1: 344, 370.

Type-species: Eulophus auripunctatus Ashmead. Orig. desig.

auripunctata (Ashmead). Fla.; West Indies. Ecology: Develops as parasite in galls on

Coccolobus uvifera and Pithecolobium. Host: Ctenodactylomyia watsoni Felt.

Eulophus auripunctatus Ashmead, 1894. Linn. Soc. London, Jour., Zool. 25: 166..

\section{Genus EMERSONOPSIS Girault}

Emersonopsis Girault, 1917. Canad. Ent. 49: 110.

Type-species: Entedon arizonensis Ashmead. Orig. desig.

Revision: Girault, 1924. Insecutor Inscitiae Menstruus 12: 93.

arizonensis (Ashmead). N. Dak., Idaho, Utah, Ariz.

Entedon arizonensis Ashmead, 1888. Canad. Ent. 20: 103. \&.

cupreicollis (Ashmead). Kans.

Entedon cupreicollis Ashmead, 1888. Kans. Agr. Expt. Sta., Bul. 3: App. p. VIII. \&, ð.

\section{Genus NESOMYIA Ashmead}

Nesomyia Ashmead, 1904. Carnegie Mus., Mem. 1: 344, 382.

Type-species: Nesomyia albipes Ashmead. Orig. desig.

cimbicis Brues. Wis. Host: Cimbex americana Leach.

Nesomyia cimbicis Brues, 1909 (1908). Wis. Nat. Hist. Soc., Bul. 6: 162. \&.

Biology: Girault, 1912. Ent. News 23: 81-82.

\section{SUBFAMILy ELASMINAE}

Taxonomy: Ferriere, 1947. Schweiz. Ent. Gesell., Mitt. 20: 567. -Compere, 1947. Bul. Ent. Res. 38: 381. -Burks, 1965. Biol. Soc. Wash., Proc. 78: 201-202. -Riek, 1967. Austral. Jour. Zool. 15: 145 .

\section{Genus ELASMUS Westwood}

Elasmus Westwood, 1833. London, Edinb. and Dublin Phil. Mag. and Jour. Sci. (3) 3: 343.

Type-species: Eulophus flabellatus Fonscolombe. Monotypic.

Aneure Nees, 1834. Hym. Ichn. Aff. Monog., v. 2, p. 194.

Type-species: Aneure nuda Nees. Desig. by Gahan and Fagan, 1923.

Cyclopleura Cameron, 1913 (1912). Indian Forest Rec. 4: 96.

Type-species: Cyclopleura fumipennis Cameron. Desig. by Gahan and Fagan, 1923.

Austelasmus Riek, 1967. Austral. Jour. Zool. 15: 148. N. syn.

Type-species: Elasmus trifasciativentris Girault. Orig. desig.

The original description of Aneure Nees does not at all sound like a characterization of Elasmus, or even of a chalcidoid. Peck, 1963. Canad. Ent. Sup. 30: 319 lists the synonymy of Aneure under Elasmus as questionable. This synonymy, however, dates from Foerster, 1856. Hym. Stud., v. 2, p. 72. A careful reading of Foerster shows that he speaks of Anuere with a confidence that could only have been achieved through his having studied the Nees type specimens. This synonymy should be accepted despite the description.

Revision: Girault, 1918. No. Amer. Hym. Elasmidae, Sydney, Austral, pp. 1-4. -Burks, 1965.

Biol. Soc. Wash., Proc. 78: 201-207. 
albicoxa Howard. N. J., D. C., N. C., Ind., Mo., Idaho. Host: Callisto geminatella (Pack.), Coptodisca splendoriferella (Clem.), Paromix sp.

Elasmus albicoxa Howard, 1885. U. S. Dept. Agr., Bur. Ent. Bul. 5: 30. ơ.

Elasmus aspidiscae Girault, 1917 (1916). Insecutor Inscitiae Menstruus 4: 117..

Taxonomy: Burks, 1965. Biol. Soc. Wash., Proc. 78: 206.

albizziae Burks. N. J. s. to Va., w. to Kans. Host: Homadaula anisocentra (Meyrick).

Elasmus albizziae Burks, 1965. Biol. Soc. Wash., Proc. 78: 204-206. ๆ.

Biology: Burks, 1971. Wash. Acad. Sci., Jour. 61: 195 (occurrence of male).

apanteli Gahan. Pa., N. C., Ohio, Ala., Wis., Ark., Sask., Wash., Oreg. Host: Apanteles marginiventris (Cress.), Meteorus laphygmae Vier., Phobocampe pallipes (Prov.), undet. Campoplegini.

Elasmus apanteli Gahan, 1913. U. S. Natl. Mus., Proc. 46: 438. ๆ.

Biology: Vickery, 1915. Jour. Econ. Ent. 8: 391.

atratus Howard. N. H., Mass., Conn., D. C., Ohio, Wis., Oreg. Host: Apanteles sp., A. delicatus How., A. hyphantriae Riley, A. melanoscelus (Ratz.), A. solitarius (Ratz.), Campoplex validus (Cress.), Hyposoter pilosulus (Prov.), Meteorus hyphantriae Riley, $M$. trachynotus Vier., Phobocampe pallipes (Prov.).

Elasmus atratus Howard, 1897. U. S. Dept. Agr., Div. Ent. Tech. Ser. 5: 40, 56. ‡, ð.

Biology: Muesebeck and Dohanian, 1927. U. S. Dept. Agr., Bul. 1487: 29 - Balduf, 1929. Ohio Jour. Sci. 29: 237. - Proper, 1934. Jour. Agr. Res. 48: 365. -McGugan and Blais, 1959. Canad. Ent. 91: 763. - Schaffner, 1959. U. S. Dept. Agr., Misc. Pub. 767: 86. -Forbes et al., 1961. Canad. Forest. Ann. Rpt., Forest Ins. and Dis. Survey, p. 33.

borrowi Girault. D. C.

Elasmus borrowi Girault, 1917 (1916). Insecutor Inscitiae Menstruus 4: 117. ․

floridensis Girault. Fla.

Elasmus floridensis Girault, 1916. Soc. Ent. 31: 42 . \&.

maculatus Howard. Fla.; West Indies. Host: A panteles spp.

Elasmus maculatus Howard, 1894. Linn. Soc. London, Jour., Zool. 25: 103. \&.

marylandicus Girault. Conn., Md., N. C., Okla. Host: Lepidopterous larva in stem of Ambrosia artemisiaefolia.

Elasmus marylandicus Girault, 1915. Ent. Soc. Amer., Ann. 8: 281..+

Biology: Schread et al., 1942. Conn. Agr. Expt. Sta., Bul. 461: 502.

meteori Ashmead. Fla., Ill., Iowa, Mo., Ark. Host: Apanteles canarsiae Ashm., Meteorus sp., $M$. vulgaris (Cress.).

Elasmus meteori Ashmead, 1898. Ent. Soc. Wash., Proc. 4: 128., ,.

Morphology: Burks, 1938. Ent. Soc. Amer., Ann. 31: 161 (wing venation).

mordax Girault. Md., D. C. Host: Cameraria guttifinitella (Clem.).

Elasmus mordax Girault, 1917 (1916). Insecutor Inscitiae Menstruus 4: 114..

nigripes Howard. N. J., Mo., Tex. Host: Porphyrosela desmodiella (Clem.).

Elasmus nigripes Howard, 1885. U. S. Dept. Agr., Bur. Ent. Bul. 5: 30. ठ.

Elasmus missouriensis Girault, 1917 (1916). Insecutor Inscitiae Menstruus 4: 117. .

Taxonomy: Burks, 1965. Biol. Soc. Wash., Proc. 78: 206.

polistis Burks. Md., Ga., Pa., Tex. Host: Polistes annularis (Linn.), P. exclamans Vier., P. fuscatus (Fab.), P. major Beauv.

Elasmus polistis Burks, 1971. Wash. Acad. Sci., Jour. 61: 195. १, ठ.

pulex Girault. Md.

Elasmus pulex Girault, 1916. Soc. Ent. 31: 43. ㅇ.

Elasmus daedalus Girault, 1917. Descr. Hym. Chalcidoid. Variorum cum Observ. V, p. 8. ․

setosiscutellatus Crawford. Md. s. to Fla., w. to Wis., Kans., Ariz., and Calif.; Mexico. Host: Apanteles spp. on lepidopterous larvae.

Elasmus setosiscutellatus Crawford, 1910 (1909). Ent. Soc. Wash., Proc. 11: 206. ๆ, ठ. 
tischeriae Howard. N. J., D. C., Va., Kans. Host: Tischeria solidaginifoliella Clem. Elasmus tischeriae Howard, 1885. U. S. Dept. Agr., Bur. Ent. Bul. 5: 30 . . zigzag Girault. Fla.

Elasmus zigzag Girault, 1917. Descr. Stellarum Nov., p. 16. $\$$.

\section{UNPLACED SPECIES OF ELASMUS WESTWOOD}

The following species were described from unassociated males and cannot at present be placed. See Burks, 1965. Biol. Soc. Wash., Proc. 78: 203.

Elasmus pullatus Howard, 1885. U. S. Dept. Agr., Bur. Ent. Bul. 5: 30. ઠ. Elasmus varius Howard, 1885. U. S. Dept. Agr., Bur. Ent. Bul. 5: 29. §.

\section{Family MYMARIDAE}

By B. D. BURKS

All members of this family are egg parasites. The mymarids are easily recognized as a distinct family, but their fundamental thoracic structure shows them to have been derived from the same stem that produced the present-day Eulophidae.

Revision: Girault, 1929. N. Amer. Hym. Mymaridae, pp. 6-27. -Debauche, 1949. Mus. Roy. Hist. Nat. Belg., Mem. 108: 1-248 (Palearctic fauna). - Debauche, 1949. Cong. Belg., Inst. Parcs Nat., Expl. Parc Nat. Albert, Miss. de Witte, 49: 1-105 (Ethiopian fauna). - Kryger, 1950. Ent. Meddel. 26: 1-97 (Palearctic fauna). - Annecke and Doutt, 1961. So. Afr. Dept. Agr., Tech. Ser., Ent. Mem. 5: 1-71 (World genera).

\section{SUBFAMILy ALAPTINAE}

TRIBE ANAGRINI

\section{Genus ANAGRUS Haliday}

Anagrus Haliday, 1833. Ent. Mag. 1: 346.

Type-species: Ichneumon atomus Linnaeus. Desig. by Westwood, 1840.

Pteratomus Packard, 1864. Essex Inst., Proc. 4: 137.

Type-species: Pteratomus putnamii Packard. Monotypic.

Packardiella Ashmead, 1904. Carnegie Mus., Mem. 1: 364. N. name, unnecessarily proposed for Pteratomus Packard.

Paranagrus Perkins, 1905. Hawaii. Sugar Planters' Assn., Div. Ent. Bul. 1: 199.

Type-species: Paranagmis optabilis Perkins. Desig. by Gahan and Fagan, 1923.

armatus (Ashmead). Ont., Conn., and N. Y., s. to Fla., w. to Oreg. and Calif.; West Indies, South Amer., Hawaii, Australia. Host: Delphacodes sp., Edwardsiana rosae (L.), Empoasca fabae (Harr.), Typhlocyba pomaria McAtee.

Litus armatus Ashmead, 1887. Canad. Ent. 19: 193. ․

Eustochus xanthothorax Ashmead, 1887. Canad. Ent. 91: 193. \&.

Anagrıs columbi Perkins, 1905. Hawaii. Sugar Planters' Assn., Div. Ent. Bul. 1: 198..

Anagrus spiritus Girault, 1911. Ent. News 22: 207., ઠ.

Taxonomy: Girault, 1911. Amer. Ent. Soc., Trans. 37: 277, 289.

Biology: Childs, 1918. Oreg. Agr. Expt. Sta., Bul. 148: 27.

delicatus Dozier. Ill., Calif.

Anagrus delicatus Dozier, 1936. Hawaii. Ent. Soc., Proc. 9: 177. ㅇ, ð.

epos Girault. Pa., Md., Va., Fla., Ill., N. Mex., Calif. Host: Edwardsiana prenicola (Edw.), Empoasca fabae (Harr.), Erythroneura comes (Say), E. plena Beamer, Typhlocyba pomaria McAtee, $T$. quercus (F.).

Anagrus epos Girault, 1911. Amer. Ent. Soc., Trans. 37: 292. ९, ठ.

Biology: Ackerman, 1919. U. S. Dept. Agr., Bul. 805: 28. -Mulla, 1956. Jour. Econ. Ent. 49: 438-441. - Mulla, 1957. Ent. Soc. Amer., Ann. 50: 85. 
giraulti Crawford. Ga., Ala., Idaho, Utah, Calif. Host: Arilus cristatus (L.), Circulifer tenellus (Baker), Homalodisca coagulata (Say).

Anagrus giraulti Crawford, 1913. U. S. Natl. Mus., Proc. 45: 259. ९, ó.

Biology: Stahl, 1920. Jour. Agr. Res. 20: 250. - Henderson, 1941. U. S. Dept. Agr., Cir. 593:

2-10. - Turner and Pollard, 1959. U. S. Dept. Agr., Tech. Bul. 1188: 26-27.

nigriceps Girault, new status. Oreg., Calif. Host: Edwardsiana prunicola (Edw.), E. rosae (L.). Anagrus armatus var. nigriceps Girault, 1915. Ent. Soc. Amer., Ann. 8: 276. $९$.

Biology: Mulla, 1956. Jour Econ. Ent. 49: 438. -Mulla, 1957. Ent. Soc. Amer., Ann. 50: 86.

nigrieventris Girault, new status. Ont., Conn., s. to S. C., w. to Ill., N. Mex., Utah; New

Zealand. Host: Empoasca fabae (Harr.), Typhlocyba pomaria McAtee.

Auagrus armatus var. nigriventris Girault, 1911. Amer. Ent. Soc., Trans. 37: 291..

Biology: Ackerman, 1919. U. S. Dept. Agr., Bul. 805: 28. - Armstrong, 1936. Ent. Soc. Ont., Ann. Rpt. 66: 17-22. - Dumbleton, 1937. New Zeal. Jour. Sci. and Technol. 18: 868.

-Steiner, 1938. Conn. Pomol. Soc., Proc. 47: 23-25. - Steiner, 1938. Jour. Econ. Ent. 31: 233-240.

puella Girault. Ill., Colo.

Auagrus puella Girault, 1911. Amer. Ent. Soc., Trans. 37: 293. + , ‘.

putnamii Packard. Vt.

Pteratomus Putuamii Packard, 1864. Essex Inst., Proc. 4: 137. ơ.

\section{Genus STETHYNIUM Enock}

Stethynium Enock, 1909. Roy. Ent. Soc. London, Trans., 1909: 452.

Type-species: Stethynium triclavatum Enock. Monotypic.

annulatum Doutt. Calif.

Stethynium annulatum Doutt, 1947. Pan-Pacific Ent. 23: 152. ․

faunum Girault. Ill.

Stethynium faunum Girault, 1911. Amer. Ent. Soc, Trans. 37: 298. ๆ, ơ.

\section{TRIBE ALAPTINI}

\section{Genus ALAPTUS Westwood}

Alaptus Westwood, 1839. Introd. Mod. Class. Ins., v. 2, p. 79.

Type-species: Mymar minimus Westwood. Orig. desig.

Parvulinus Mercet, 1912. Soc. Esp. Hist. Nat., Bol. 12: 331.

Type-species: Parrulimus auranti Mercet. Monotypic.

Metalaptus Malenotti, 1917. Redia 12: 339.

Type-species: Metalaptus torquatus Malenotti. Monotypic.

There has long been a difference of opinion as to the author of this genus and its type-species. They have been listed as Alaptus Haliday, with type-species as Alaptus minimus Haliday, Mymar minimus Walker, Alaptus minimus Walker or Alaptus fusculus Haliday. However, Annecke and Doutt, 1961 (So. Afr. Dept. Agri., Tech. Ser., Ent. Mem. 5: 8) are of the opinion that the information given by Westwood in his original citation of Alaptus and Mymar minimus validate him as author of both. This is the most reasonable of all the arguments that have been advanced in this matter.

Some members of this genus are the smallest known insects, being less than 200 microns in overall body length.

Taxonomy: Debauche, 1949. Cong. Belg., Inst. Pares Nat., Expl. Parc Nat. Albert, Miss. de Witte, 49: 9.

auranti (Mercet). La.; Europe. Ecology: Originally thought to parasitize Coccidae, but actual hosts probably Psocoptera.

Parvulinus auranti Mercet, 1912. Soc. Esp. Hist. Nat., Bol. 12: 333. ๆ.

Metalaptus torquatus Malenotti, 1917. Redia 12: 339. $₹$, ठ.

Taxonomy: Mercet, 1917. Asoc. Esp. Prog. Ciencia. Cong. de Valladolid, 4: 367. -Cressman et al., 1935. Jour. Agr. Res. 50: 282. 
Biology: Dingler, 1923. Ztschr. f. Angew. Ent. 9: 236-239.

caecilii Girault. Maine, Fla., Ill., Calif. Host: Caecilius aurantiacus (Hag.), C. manteri Som., Ectopsocus califomicus (Banks), Psocus sp.

Alaptus caecilii Girault, 1908. Ent. Soc. Amer., Ann. 1: 189. \&, đ.

Taxonomy: Girault, 1910. N. Y. Ent. Soc., Jour. 18: 241-243. -Ferriere. 1930. Bul. Ent. Res. 21: 41-42.

Biology: Sommerman, 1943. Ent. Soc. Wash., Proc. 45: 35.

eriococci Girault. Calif. Ecology: Parasite of psocids.

Alaptus eriococci Girault, 1908. Ent. Soc. Amer., Ann. 1: 191. \&, ठ.

globosicornis Girault. Fla.; Hawaii, Australia. Host: Liposcelis divinatorins (Mull.), Psocus sp. Alaptus globosicorn is Girault, 1908. Ent. Soc. Amer., Ann. 1: 188. ․

Taxonomy: Girault, 1911. Arch. f. Naturgesch. 77 (1) sup. 2: 132.

iceryae Riley. Ill., Calif. Ecology: Thought to parasitize Icerya sp.

Alaptus iceryae Riley, 1889. U. S. Dept. Agr., Ann. Rpt. for 1888, p. 86.

Taxonomy: Girault, 1908. Ent. Soc. Amer., Ann. 1: 186. -Girault, 1910. N. Y. Ent. Soc., Jour. 18: 240-243.

intonsipennis Girault. Ill.

Alaptus intonsipennis Girault, 1910. N. Y. Ent. Soc., Jour. 18: 244. \&.

psocidivorus Gahan. Calif. Ecology: Parasite of psocid eggs, probably Ectopsocus califormicus

Banks.

Alaptus psocidivorus Gahan, 1927. Pan-Pacific Ent. 3: 180. ९, ठ.

Biology: Spruyt, 1927. Pan-Pacific Ent. 3: 182-184.

\section{Genus DICOPUS Enock}

Dicopus Enock, 1909. Roy. Ent. Soc. London, Trans. 1909: 455.

Type-species: Dicopus minutissima Enock. Monotypic.

halitus Girault. Que.

Dicopus halitus Girault, 1911. Ent. News 22: 347. ठ.

\section{SUBFAMILY MYMARINAE}

TRIBE OOCTONINI

\section{Genus ARESCON Walker}

Arescon Walker, 1846. Ann. and Mag. Nat. Hist. 18: 49.

Type-species: Mymar dimidiatus Curtis. Monotypic.

Panthus Walker, 1846. Ann. and Mag. Nat. Hist. 18: 52.

Type-species: Panthus crassicomis Walker. Desig. by Gahan and Fagan, 1923.

Leimacis Foerster, 1847. Linnaea Ent. 2: 208.

Type-species: Leimacis rufula Foerster. Monotypic.

Limacis Foerster, 1856. Hym. Stud., v. 2, p. 120. Emend.

Xenomymar Crawford, 1913. U. S. Natl. Mus., Proc. 46: 343.

Type-species: Xenomymar urichi Crawford. Orig. desig.

Neurotes Enock, 1914. Roy. Ent. Soc. London, Proc. 1913: cxxxiv.

Type-species: Neurotes iridescens Enock. Monotypic.

aspidioticola (Ashmead). Fla. Ecology: This parasite lays its egg beneath the female scale; the larva hatches and consumes the eggs contained in the body of the scale. It then pupates, and the adult chews a hole in the scale to escape. Host: Lepidosaphes beckii (Newm.), $L$. gloverii (Pack.).

Aphelinus aspidioticola Ashmead, 1879. Canad. Ent. 11: 159. ․

Taxonomy: Howard, 1885. U. S. Dept. Agr., Div. Ent. Bul. 5: 43 (Mymarinae). -Girault, 1911. Arch. f. Naturgesch. 77 (1) Sup. 2: 132 (types lost). - Mercet, 1912. Mus. Nac. Cien. Nat.

Madrid, Trab. 10: 95 (genus ?). 
Biology: Ashmead, 1880. Orange Insects, pp. 7-9. - Hubbard, 1885. U. S. Dept. Agr., Insects Affecting the Orange, pp. 24, 70.

\section{Genus GONATOCERUS Nees}

Gonatocertss Nees, 1834. Hym. Ichn. Affin. Monog., v. 2, p. 192.

Type-species: Gonatocerus longicornis Nees. Monotypic.

Lymaenon Walker, 1846. Ann. and Mag. Nat. Hist. 18: 49.

Type-species: Lymaenon acuminatus Walker. Desig. by Gahan and Fagan, 1923.

Rachistus Foerster, 1847. Linnaea Ent. 2: 203.

Type-species: Ooctonus litoralis Haliday. Desig. by Gahan and Fagan, 1923.

Rhachistus Dalla Torre, 1898. Cat. Hym., v. 5, p. 429. Emend.

Oophilus Enock, 1909. Roy. Ent. Soc. London, Trans. 1909: 458.

Type-species: Oophilus longicauda Enock. Monotypic.

Agonatocerus Girault, 1913. Canad. Ent. 45: 276.

Type-species: Agonatocerus hnmboldti Girault. Orig. desig.

Gonatoceroides Girault, 1913. Entomologist 46: 255.

Type-species: Gonatoceroides australica Girault. Orig. desig.

Kryger, 1934 (Ent. Meddel. 18: 503-505) published a paper stating that Gonatocerns Nees was not a mymarid, but a chalcidid. Nees' type was destroyed many years ago, so this conclusion was based on a reading of the original description of the genus. The next available name for this genus being Lymaenon Walker, numerous authors used it. However, a more careful rereading of Nees' discursive but reasonably exact description of Gonatocems by some later authors led them to the conclusion that Kryger had been mistaken. The characters Nees gives are certainly those of a mymarid. Soyka, 1946 (Zentbl. Gesammtgeb. Ent. 1: 36) first published this correction, and others published it subsequently. Consequently the name Lymaenon was widely used for this genus for only about 10 years.

americanus Brues. Wis.

Gonatocerus americanus Brues, 1907. Wis. Nat. Hist. Soc., Bul. 5: 109. §.

anthonomi Girault. Ill., Ga., Tex., N. Mex.

Gonatocerns anthonomi Girault, 1905. Ent. News 16: 288. १, o.

Gonatocerus texanus Girault, 1911. Amer. Ent. Soc., Trans 37: 270. \&.

ashmeadi Girault. Ga., Miss., La., Tex. Host: Cuerna costalis (F.), Homalodisca coagulata (Say), Oncometopia orbona (F.).

Gonatocerus dolichocerus var. ashmeadi Girault, 1916. Ent. News 27: 8. ९, o.

Biology: Turner and Pollard, 1959. U. S. Dept. Agr., Tech. Bul. 1188: 26-27.

aureus Girault. IIl.

Gonatocerus aureus Girault, 1911. Amer. Ent. Soc., Trans. 37: 263...

brunneus Girault. Ill.

Gonatocerus brunneus Girault, 1911. Amer. Ent. Soc., Trans. 37: 261. १, ठ.

Gonatocerus maevins Girault, 1911. Amer. Ent. Soc., Trans. 37: 272..

californicus Girault. Calif.

Gonatocerus californicus Girault, 1911. Amer. Ent. Soc., Trans. 37: 271. \&.

capitatus Gahan. Utah, Ariz., Calif. Host: Circulifer terllus (Baker).

Gonatoceros(!) capitatus Gahan, 1932. Ent. Soc. Amer., Ann. 25: 754. \&, ठ.

dolichocerus Ashmead. Ga., Fla., Ill. Host: Ceresa bubalus (F.).

Gonatoce'rus dolichocerus Ashmead, 1887. Canad. Ent. 19: 192. ‡.

fasciatus Girault. D. C., Va., Ga., Ill. Host: Homalodisca coagulata (Say).

Gonatocerus fasciatus Girault, 1911. Amer. Ent. Soc., Trans. 37: 265. ‡.

Biology: Turner and Pollard, 1959. U. S. Dept. Agr., Tech. Bul. 1188: 26-27.

illinoiensis Girault. Ill.

Gonatocerns illinoiensis Girault, 1917. Psyche 24: 91. ₹.

koebelei Perkins. Fla.; Mexico. Host: Draeculacephala mollipes (Say), D. producta (Walker). Gonatoceus(!) koebelei Perkins, 1912. Hawaii. Sugar Planters' Assoc. Expt. Sta., Div. Ent. Bul. 10: 22. $\&$, ठ. 
latipennis Girault. N. Y., Pa.

Gonatocerus latipennis Girault, 1911. Amer. Ent. Soc., Trans. 37: 268. o.

maga Girault. Ill.

Gonatocerus maga Girault, 1911. Amer. Ent. Soc., Trans. 37: 267. \&.

marilandicus Girault. Md., Ga. Host: Gypona sp.

Gonatocerus marilandicus Girault, 1917 (1916). Insecutor Inscitiae Menstruus 4: 115. .

maximus Girault. Ill.

Gonatocerns maximus Girault, 1911. Amer. Ent. Soc., Trans. 37: 264..

mexicanus Perkins. Fla., Tex., Ariz., Calif. Host: Draeculacephala mollipes (Say).

Gonatocerus mexicamus Perkins, 1912. Hawaii. Sugar Planters' Assoc. Expt. Sta., Div. Ent.

Bul. 10: 21.,$+ \delta$.

Gonatocerus eximius Gahan, 1913. U. S. Natl. Mus., Proc. 46: 441. ‡.

Gonatocerus gibsoni Crawford, 1915. U. S. Natl. Mus., Proc. 48: 586., đ.

Biology: Gibson, 1915. U. S. Dept. Agr., Bul. 254: 14.

nigritarsis Ashmead. Fla.

Gonatocerns nigritarsis Ashmead, 1887. Canad. Ent. 19: 192. ?.

novifasciatus Girault. Ga., Tenn., Calif. Host: Graphocephala versuta (Say).

Gonatocerus novifasciatus Girault, 1911. Amer. Ent. Soc., Trans. 37: 266. \&.

Taxonomy: Girault, 1916. Brooklyn Ent. Soc., Bul. 11: 112.

Biology: Turner and Pollard, 1959. U. S. Dept. Agr., Tech. Bul. 1188: 26-27.

ornatus Gahan. Ariz. Host: Stictocephala festina (Say).

Gonatocerus omatus Gahan, 1918. Ent. Soc. Wash., Proc. 20: 23.,$~ \delta$.

ovicenatus Leonard and Crosby. N. Y. Host: Idiocerus decimusquartus (Schrank).

Gonatocerus ovicenatus Leonard and Crosby, 1915. Jour. Econ. Ent. 8: 545. ?, ठ.

partifuscipennis Girault. Md.

Gonatocerus partifuscipennis Girault, 1916. Canad. Ent. 48: 102. क.

pygmaeus Girault. Miss.

Gonatocernss pygmaeus Girault, 1911. Amer. Ent. Soc., Trans. 37: 269..

rivalis Girault. Va., Ill., Kans. Ecology: Parasitizes cicadellid eggs in cane stems.

Gonatocerus rivalis Girault, 1911. Amer. Ent. Soc., Trans. 37: 257. \&, ¿゙.

tenuipennis Girault. III.

Gonatocerus brunneus var. tenuipennis Girault, 1911. Amer. Ent. Soc., Trans. 37: 263. + .

titillatus Girault. Utah.

Gonatocerus titillatus Girault, 1917. Broolkyn Ent. Soc., Bul. 12: 87..

triguttus Girault. Tex.; West Indies.

Gonatocerus triguttus Girault, 1916. Ent. Soc. Amer., Ann. 9: 297. \&, ठ.

utahensis Girault. Utah.

Gonatocerns utahensis Girault, 1917. U. S. Natl. Mus., Proc. 53: 446. ․

\section{Genus COSMOCOMOIDEA Howard}

Cosmocomoidea Howard, 1908. Ent. Soc. Wash., Proc. 10: 68.

Type-species: Cosmocomoidea morrilli Howard. Monotypic.

Taxonomy: Debauche, 1948. Mus. Roy. Hist. Nat. Belg., Mem. 108: 114 (syn. of Ooctonus

Haliday). -Ogloblin, 1959. Munchen. Ent. Gesell., Mitt. 49: 50 (subg. of Lymaenon

Walker). -Annecke and Doutt, 1961. So. Afr. Dept. Agr., Tech. Ser., Ent. Mem. 5: 4, 14-15 (subg. of Lymaenon Walker).

morrilli Howard. Ga., Fla., Tex.; Mexico, Cent. Amer. Host: Homalodisca coagulata (Say).

Cosmocomoidea morrilli Howard, 1908. Ent. Soc. Wash., Proc. 10: 69. ๆ, ठ’.

Taxonomy: Girault, 1917. Entomologist 50: 36. - Whittaker, 1931. Ent. Soc. Wash., Proc. 3: 192.

Biology: Turner and Pollard, 1959. U. S. Dept. Agr., Tech. Bul. 1188: 26-27. 


\section{Genus OOCTONUS Haliday}

Ooctonus Haliday, 1833. Ent. Mag. 1: 269, 343.

Type-species: Ooctonus insignis Haliday. Desig. by Westwood, 1840.

Sphecomicrus Walker, 1846. Ann. Mag. Nat. Hist. 18: errata; and also p. 50.

Type-species: Ooctonus insignis Haliday. Desig. by Peck, 1951.

Revision: Whittaker, 1931. Ent. Soc. Wash., Proc. 33: 189-192.

americanus Girault. N. J., D. C., Ohio. Host: Philaenus spumarius (L.).

Oocton us americanus Girault, 1916. Ent. News 27: 69. \&.

Biology: Weaver and King, 1954. Ohio Agr. Expt. Sta., Res. Bul. 741: 15-17.

aphrophorae Milliron. Ohio, Wis. Host: Aphrophora saratogensis (Fitch).

Oocton us aphrophorae Milliron, 1947. Ent. Soc. Amer., Ann. 40: 217. १, ठ์.

auripes Whittaker. B. C.

Oocton us auripes Whittaker, 1931. Ent. Soc. Wash., Proc. 33: 190..

canadensis Whittaker. B. C.

Ooctonus canadensis Whittaker, 1931. Ent. Soc. Wash., Proc. 33: 191. \&.

fuscipes Whittaker. Conn., B. C.

Ooctonus fuscipes Whittaker, 1931. Ent. Soc. Wash., Proc. 33: 189. \&.

occidentalis Whittaker. B. C.

Ooctonus occidental is Whittaker, 1931. Ent. Soc. Wash., Proc. 33: 191. \&.

quadricarinatus Girault. N. Y.

Ooctonus quadricarinatus Girault, 1916. Ent. Soc. Amer., Ann. 9: 301. ठ́.

silvensis Girault. D. C.

Ooctonus silvensis Girault, 1916. Ent. News 27: 70. \&.

\section{Genus CAMPTOPTERA Foerster}

Camptoptera Foerster, 1856. Hym. Stud., v. 2, pp. 116, 119, 144.

Type-species: Camptoptera papaveris Foerster. Monotypic.

Pteroclisis Foerster, 1856. Hym. Stud., v. 2, p. 144. N. name, unnecessarily proposed for

Camiptoptera.

Stichothrix Foerster, 1856. Hym. Stud., v. 2, pp. 117, 118, 121.

Type-species: Stichothrix cardui Foerster. Monotypic.

Macrocamptoptera Girault, 1910. N. Y. Ent. Soc., Jour. 18: 239.

Type-species: Camptoptera metotarsa Girault. Orig. desig.

Congolia Ghesquiere, 1942. Rev. Zool. Bot. Africaines 36: 320.

Type-species: Congolia sycophila Ghesquiere. Monotypic.

Taxonomy: Soyka, 1953. Natuurh. Maandbl. 42: 57-60.

brunnea Dozier. Del.

Camptoptera brunnea Dozier, 1933. Ent. Soc. Wash., Proc. 35: 97..

metotarsa Girault. Va.

Camptoptera metotarsa Girault, 1905. Psyche 12: 91..

Taxonomy: Girault, 1910. N. Y. Ent. Soc., Jour. 18: 238-240.

pulla Girault. Del., Ill., Calif.

Camptoptera pulla Girault, 1909. Ent. Soc. Amer., Ann. 2: 27. ९.

Taxonomy: Girault, 1910. N. Y. Ent. Soc., Jour. 18: 236-238.

TRIBE ANAPHINI

\section{Genus PARALLELAPTERA Enock}

Parallelaptera Enock, 1909. Roy. Ent. Soc. London, Trans. 1909: 454.

Type-species: Parallelaptera panis Enock. Monotypic.

Anthemiella Girault, 1911. Ent. Soc. Wash., Proc. 13: 185.

Type-species: Anthemiella rex Girault. Orig. desig.

Taxonomy: Girault, 1912. Ent. News 23: 297. 
rex (Girault). Ill., Minn., Calif. Host: Circulifer tenellns (Baker).

Anthemiella rex Girault, 1911. Ent. Soc. Wash., Proc. 13: 185. ․

\section{Genus ERYTHMELUS Enock}

Erythmelus Enock, 1909. Roy. Ent. Soc. London, Trans. 1909: 454.

Type-species: Erythmelus goochi Enock. Monotypic.

Enaesir.s Enock, 1909. Roy. Ent. Soc. London, Trans. 1909: 456.

Type-species: Enaesius agilis Enock. Desig. by Gahan and Fagan, 1923.

Taxonomy: Debauche, 1948. Mus. Roy. Hist. Nat. Belg., Mem. 108: 192. - Annecke and Doutt, 1961. S. Afr. Dept. Agr., Tech. Ser., Ent. Mem. 5: 18.

flandersi Doutt. Calif.

Erythmelus flandersi Doutt, 1949. Pan-Pacific Ent. 25: 77. , ऽ.

gracilipes (Girault). N. Mex.

Anaphes gracilipes Girault, 1916. Ent. News 27: 7..

gracilis (Howard). N. J., s. to Ga., w. to Calif. Host: Aspidiotus perniciosus Comst., Lepidosaphes ulmi (L.).

Anaphes gracilis Howard, 1881. U. S. Dept. Agr., Ann. Rpt. for 1880, p. 370..

Anaples cinctiventris Girault, 1911. Amer. Ent. Soc., Trans. 37: 286. $\%$.

Biology: Johnson, 1900. U. S. Dept. Agr., Div. Ent. Bul. (n. s.) 26: 73-74.

io (Girault). Ill., Calif.

Anagrus io Girault, 1911. Amer. Ent. Soc., Trans. 37: 294. o.

miridiphagus Dozier. Calif.; Puerto Rico.

Erythmelus miridiphagus Dozier. 1937. Puerto Rico Univ., Jour. Agr. 21: 133. \&. picinus (Girault). N. Mex.

Anaphes picinus Girault, 1916. Ent. News 27: 6. ․

psallidis Gahan. S. C., Miss., Ark., La., Tex., Ariz., Calif. Host: Psallus seriatus (Reut.).

Erythmelus psallidis Gahan, 1937. Ent. Soc. Wash., Proc. 39: 268. ๆ, §.

Biology: Strong, 1938. U. S. Dept. Agr., Bur. Ent. and P. Q., Ann. Rpt. for 1938, p. 52.

-Ewing and Crawford, 1939. Jour. Econ. Ent. 32: 303-305.

\section{Genus ANAPHES Haliday}

Anaphes Haliday, 1833. Ent. Mag. 1: 269, 346.

Type-species: Ichneumon prnctum Shaw. Desig. by Internatl. Comn. Zool.

Nomencl., Opinion 729, 1965.

Clinom ymar Kieffer, 1913. Soc. Agr. Alger., Bul. 4: 100.

Type-species: Clinomymar peyerimhoffi Kieffer. Orig. desig.

Stammeriella Soyka, 1950. Ent. Nachr. Burgdorf 3: 120.

Type-species: Stammeriella wolfsthali Soyka. Orig. desig.

Synamaphes Soyka, 1946. Zentbl. Gesamtgeb. Ent. 1: 181.

Type-species: Synanaphes ranalteri Soyka. Orig. desig.

Ferrierella Soyka, 1946. Zentbl. Gesamtgeb. Ent. 1: 182.

Type-species: Ferrierella neopratensis Soyka. Orig. desig.

Gahan, 1949 (Wash. Acad. Sci., Jour. 39: 204-205) published a paper about Anaphes and Mymar in which he changed the application these names had had in literature for about a century. As a result, these names were used in the sense he advocated in the 1951 Hymenoptera Catalog, its First Supplement, and Peck's 1963 catalog. However, Hincks, 1952 (Soc. Brit. Ent., Trans. 11: 163) had proposed submitting this matter to the Internatl. Comn. on Zool. Nomencl., requesting that traditional usage be restored. Annecke and Doutt, 1963 (Bul. Zool. Nomencl. 20: 134-136) formally submitted a petition to the Commission requesting the restoration of traditional usage.

This was approved in Opinion 729, 1965.

alaskae Annecke and Doutt. Alaska.

Anaphes alaskae Annecke and Doutt, 1961. So. Afr. Dept. Agr., Tech. Ser., Ent. Mem. 5: 47.,$+ \delta$. 
anomocerus Girault. Tex., Ariz. Host: Psallus seriatus (Reut.).

Anaphes iole anomocerus Girault, 1929. No. Amer. Hym. Mymaridae, p. 13. ठ.

Biology: Strong, 1938. U. S. Dept. Agr., Bur. Ent. and P. Q., Ann. Rpt. for 1938, p. 52. -Ewing and Crawford, 1939. Jour. Econ. Ent. 32: 303-305.

behmani Girault. N. Y., Mich.

Anaphes behmani Girault, 1929. No. Amer. Hym. Mymaridae, p. 14. ๆ, ठ.

flavipes (Foerster). Ont., N. Y., Pa., Md., Va., W. Va., Ohio, Mich., Ind.; Europe. Introduced from Europe for biological control in 1966; first recovered in Mich. Host: Oulema melanopus (L.).

Gonatocerus flavipes Foerster, 1841. Beitr. Monog. Pteromalinen, p. 45. ㅇ. Anaphes lemae Bakkendorf, 1970. Entomophaga 15: 153. $ๆ, \delta$.

Biology: Anderson and Paschke, 1968. Ent. Soc. Amer., Ann. 61: 1-5. -Anderson and Paschke, 1969. Ent. Soc. Amer., Ann. 62: 1316-1321. - Anderson and Paschke, 1970. Ent. Soc. Amer., Ann. 63: 820-828. - Maltby et al., 1971. Jour. Econ. Ent. 64: 693-697. - Morris and Moorhead, 1971. Ent. Soc. Amer., N. Cent. Br., Proc. 26: 41-46. -Dysart, 1971. Entomophaga 16: 445-452.

hereules Girault. Ill. Anaphes hercules Girault, 1911. Amer. Ent. Soc., Trans. 37: 285. ․

iole Girault. Ill., Calif. Host: Hypera nigrirostris (F.). Anaphes iole Girault, 1911. Amer. Ent. Soc., Trans. 37: 284. $\&$.

nigrellus Girault. Ill. Anaphes nigrellus Girault, 1911. Amer. Ent. Soc., Trans. 37: 282..+

ovijentatus (Crosby and Leonard). N. Y., La., Calif. Host: Lygus hesperus Knight, L. lineolaris (P. deB.).

Anagrus ovijentatus Crosby and Leonard, 1914. Canad. Ent. 46: 181. ๆ.

Biology: Romney and Cassidy, 1945. Jour. Econ. Ent. 38: 497. -Sillings, 1971. Ent. Soc. Amer., N. Cent. Br., Proc. 26: 105. - Stoner and Surber, 1971. Jour. Econ. Ent. 64: 1566-1567.

pallipes (Ashmead). Va., Fla. Alaptus pallipes Ashmead, 1887. Canad. Ent. 19: 193. \$.

Taxonomy: Girault, 1910. N. Y. Ent. Soc., Jour. 18: 243-244. -Girault, 1911. Amer. Ent. Soc., Trans. 37: 278-279.

perdubius Girault. S. C., Minn., Utah. Host: Halticus bracteatus (Say). Anaphes perdubius Girault, 1916. Ent. News 27: 6. $?$.

pratensis Foerster. Conn., Ill., Utah.; Europe. Introduced from Italy for biological control in 1911-1913, but not recovered; introduced again in 1925 and first recovered in 1926. Host: Hypera postica (Gyll.), H. punctata (F.).

Anaphes pratensis Foerster, 1847. Linnaea Ent. 2: 211. + , ठ.

Taxonomy: Girault, 1911. Ent. News 22: 364.

Biology: Pack, 1930. Utah Agr. Expt. Sta., Bul. 216: 29-30. -Clausen, 1956. U. S. Dept. Agr., Tech. Bul. 1139: 116.

sinipennis Girault. Ill.

Anaphes sinipennis Girault, 1911. Amer. Ent. Soc., Trans. 37: 280..

\section{Genus PARACLERUCHUS Yoshimoto}

Paracleruchus Yoshimoto, 1971. Canad. Ent. 103: 1079.

Type-species: Paracleruchus pieloui Yoshimoto. Orig. desig.

pieloui Yoshimoto. N. B. Ecology: Reared from birch bracket fungus, Polyporus betulinus.

Paracleruchus pieloui Yoshimoto, 1971. Canad. Ent. 103: 1079. ๆ, ठ.

Biology: Pielou and Verma, 1968. Canad. Ent. 100: 1179-1199 (Clemichus sp.).

\section{Genus PATASSON Walker}

Patasson Walker, 1846. Ann. and Mag. Nat. Hist. 18: viii, 50. 
Type-species: Panthus crassicornis Haliday. Monotypic.

Anaphoidea Girault, 1909. N. Y. Ent. Soc., Jour. 17: 167.

Type-species: Anaphoidea sordidata Girault. Orig. desig.

Anaphoides Enock, 1915. Hastings and East Sussex Nat. 2: 181 (no species). - Peck, 1951.

In Muesebeck et al., U. S. Dept. Agr., Agr. Monog. 2: 414. One species.

Type-species: Patasson crassicomis (Haliday). Desig. by Peck, 1951.

Antoniella Soyka, 1950. Ent. Nachr. Burgdorf 3: 121.

Type-species: Fulmekiella stubaiensis Soyka. Orig. desig.

Mariella Soyka, 1950. Ent. Nachr. Burgdorf 3: 123.

Type-species: Mariella superaddita Soyka. Orig. desig.

Revision: Doutt, 1949. Pan-Pacific Ent. 25: 155-160 (Anaphoidea).

brunneus (Doutt). Calif.

Anaphoidea brunnea Doutt, 1949. Pan-Pacific Ent. 25: 159-160. ?.

calendrae (Gahan). N. J., Ind., Miss., Mo. Host: Calendra callosa (Oliv.), C. costipennis (Horn),

C. destructor (Chitt.), C. minima (Hart), C. parvula (Gyll.), C. pertinax (Oliv.).

Anaphoidea calendrue Gahan, 1927. U. S. Natl. Mus., Proc. 71 (4): 32. १, ठ́.

Biology: Satterthwaite, 1931. N. Y. Ent. Soc., Jour. 39: 171.

confertus (Doutt). Calif.

Anaphoidea conferta Doutt, 1949. Pan-Pacific Ent. 25: 155-160. ․

conotracheli (Girault). Conn., s. to Ga., w. to Minn., Utah, Tex. Host: Conotrachelus nenuphar

(Herbst), Craponius incequalis (Say); Rhagoletis pomonella (Walsh); Schizocerella pilicornis (Holmgr.).

Anaphes conotracheli Girault, 1905. Ent. News 16: 220. $\%$, ð.

Biology: Johnson and Girault, 1906. U. S. Dept. Agr., Bur. Ent. Cir. 73: 5-6. - Brooks, 1910.

W. Va. Agr. Expt. Sta., Bul. 126: 110. - Pierce, 1910. Jour. Econ. Ent. 3: 453. -Quaintance and Jenne, 1912. U. S. Dept. Agr., Bur. Ent. Bul. 103: 140-142. - Porter and Alden, 1921. Ent. Soc. Wash., Proc. 23: 62. - Porter, 1922. Wash. Acad. Sci., Jour. 12: 165. - Porter, 1928. U. S. Dept. Agr., Tech. Bul. 66: 29. -Dozier et al., 1932. Del. Agr. Expt. Sta., Bul. 175: 38. - Moultrie, 1952. Ga. Dept. Ent., Bul. 97: 19. -Garman et al., 1953. Conn. Agr. Expt. Sta., Bul. 575: 7.

gerrisophaga (Doutt). Calif. Host: Gerris sp.

Anaphoidea gerrisophaga Doutt, 1949. Pan-Pacific Ent. 25: 156-160..

longiclava (Doutt). Calif.

Anaphoidea longiclava Doutt, 1949. Pan-Pacific Ent. 25: 158. ․

Iuna (Girault). Que., Ont., N. Y., N. J., Del., Md., W. Va., Mich., Ky., Wis., Ill., Utah; Europe. Introduced from Italy in 1911 and 1925 along with Anaphes pratensis Foerster. Host: Hypera postica (Gyll.).

Anaphoidea luna Girault, 1914. Ent. Soc. Wash., Proc. 16: 109. १, ठ๋.

Biology: Silvestri, 1915. Lab. Zool. Agr. Portici, Bol. 10: 80-83. -Chamberlin, 1924. U. S. Dept. Agr., Cir. 301: 2-3. -Chamberlin, 1924. Jour. Econ. Ent. 17: 627. - Hamlin et al., 1949. U. S. Dept. Agr., Tech. Bul. 975: 58, 83. -Clausen, 1956. U. S. Dept. Agr., Tech. Bul. 1139: 116.

pullicrura (Girault). Ill.

Anaphoidea pullicrura Girault, 1910. N. Y. Ent. Soc., Jour. 18: 252. \&, ð.

sordidatus (Girault). N. J., Ill. Host: Tyloderma foveolatum Say.

Anaphoidea sordidata Girault, 1909. N. Y. Ent. Soc., Jour. 17: 169. \&, ð.

\section{TRIBE MYMARINI}

\section{Genus MYMAR Curtis}

Mymar Curtis, 1832. Brit. Ent. v. 9, p. 411.

Type-species: Mymar pulchellum Curtis. Desig. by Internatl. Comn. Zool. Nomenel., Opinion 729, 1965.

Pterolinononyktera Malac, 1943. Folia Ent. Brno 6: 51.

Type-species: Pterolinononyktera obenbergeri Malac. Orig. desig. 
Oglobliniella Soyka, 1946. Zentbl. Gesamtgeb. Ent. 1: 180. N. name for Mymar.

Refer to remarks about the nomenclature of this genus under Anaphes Haliday.

cincinnati Girault. Md.

Mymar cincinnati Girault, 1917. Psyche 24: 99. o.

Taxonomy: Annecke and Doutt, 1961. So. Afr. Jour. Agr. Sci. 4: 551-552 (prob. syn. of $M$ ymar regale Enock).

pulchellum Curtis. Pa.; Europe.

Mymar pulchellus Curtis, 1832. Brit. Ent. v. 9, p. 411. + , ठ.

Mymar venustum Girault, 1911. N. Y. Ent. Soc., Jour. 19: 94, 188. \&.

Taxonomy: Annecke and Doutt, 1961. So. Afr. Jour. Agr. Sci. 4: 550-551 (syn.).

\section{Genus NEOMYMAR Crawford}

Neomymar Crawford, 1913. U. S. Natl. Mus., Proc. 46: 351.

Type-species: Neomymar vierechi Crawford. Orig. desig.

vierecki Crawford. Md., Va., Fla., Iowa.

Neomymar Vierecki Crawford, 1913, U. S. Natl. Mus., Proc. 46: 351...

Neomymar vierecki marilandi Girault, 1917. Chalcidoidea Nova Marilandensis III p. 2.. . N. syn.

\section{Genus CARAPHRACTUS Walker}

Caraphractus Walker, 1846. Ann. and Mag. Nat. Hist. 18: 49-52.

Type-species: Caraphractus cinctus Walker. Monotypic.

cinctus Walker. N. Y., N. W. T.; Europe. Host: Gerris remigis Say, Notonecta sp.; Dytiscus sp. Caraphractus cinctus Walker, 1846. Ann. and Mag. Nat. Hist. 18: 52. ․

Biology: Matheson and Crosby, 1912. Ent. Soc. Amer., Ann. 5: 68-70. - Hungerford, 1919.

Kans. Univ., Sci. Bul. 11: 32. -Jackson, 1958. Roy. Ent. Soc. London, Trans. 110: 533-554.

\section{Genus ACMOPOLYNEMA Ogloblin}

Acmopolynema Ogloblin, 1946. Iowa State Col., Jour. Sci. 20: 286.

Type-species: Stichothrix bifasciatipennis Girault. Orig. desig.

bifasciatipenne (Girault). Mass., N. Y., s. to N. C., w. to Kans. and Tex. Host: Auaxipha exigua (Say), Oecanthus sp., O. nigricomis nigricomis Walker, O. nigricomis quadripunctatus Beut., O. nivens (Deg.).

Stichothrix bifasciatipennis Girault, 1908. Psyche 15: 115.. .

Polynema bifasciatipenne var. varium Girault, 1917. Psyche 24: 92. \&, ठै. N. syn.

Biology: Parrott and Fulton, 1914. N. Y. State Agr. Expt. Sta., Bul. 388: 426. - Brandhorst, 1943. Kans. Acad. Sci., Trans. 46: 169-172.

\section{Genus BARYPOLYNEMA Ogloblin}

Barypolynema Ogloblin, 1946. Iowa State Col., Jour. Sci. 20: 282.

Type-species: Barypolynema reticulatum Ogloblin. Orig. desig.

aspidioti (Girault). Tex.; Mexico. Host: Psallus seriatus (Reut.).

Polynema a spidioti Girault, 1911. Ent. News 22: 358. §ै.

Taxonomy: Girault, 1912. Ent. News 23: 298 (correction). - Ogloblin, 1946. Iowa State Col., Jour. Sci. 20: 285.

medicae Annecke and Doutt. D. C., Calif.

Barypolynema medicae Annecke and Doutt, 1961. So. Afr. Dept. Agr. Tech. Ser., Ent. Mem. 5: 57. ㅇ, ठ์.

saga (Girault). D. C., Kans. Host: Opsins stactogalus Fieber.

Anagrus saga Girault, 1911. Amer. Ent. Soc., Trans. 37: 296. ؟.

Biology: Lawson, 1929. Ent. Soc. Amer., Ann. 22: 130. 


\section{Genus STEPHANODES Enock}

Stephanodes Enock, 1909. Roy. Ent. Soc. London, Trans. 1909: 457.

Type-species: Stephanodes elegans Enock. Monotypic.

psecas (Girault). Ill., Iowa.

Polynema psecas Girault, 1911. Amer. Ent. Soc., Trans. 37: 319., ,.

Taxonomy: Girault, 1912. N. Y. Ent. Soc., Jour. 20: 41 (Stephanodes). -Girault, 1912. Canad.

Ent. 44: 89 (? syn. of enockii Girault, European sp.).

\section{Genus POLYNEMA Haliday}

Polynema Haliday, 1833. Ent. Mag. 1: 269, 347.

Type-species: Ichneumon ovulomm Linnaeus. Desig. by Westwood, 1840.

Eutriche Nees, 1834. Hym. Ichn. Aff. Monog., v. 2, p. 186.

Type-species: Eutriche gracilis Nees. Monotypic.

Callitriche Agassiz, 1848. Nomencl. Zool. Index Univ., pp. 173, 439. Emend of Eutriche, Preocc. by Poli, 1791.

Cosmocoma Foerster, 1856. Hym. Stud., v. 2, pp. 117, 120. N. name for Polynema, unnecessarily proposed.

Valkerella Westwood, 1878. Linn. Soc. London, Zool., Proc. 1: 584.

Type-species: Polynema natans Lubbock. Orig. desig.

Walkerella Westwood, 1883. Roy. Ent. Soc. London, Trans. (2) 1: 32.

Type-species: Walkerella temeraria Westwood. Orig. desig.

Maidliella Soyka, 1946. Zentbl. Gesamtgeb. Ent. 1: 178.

Type-species: Maidliella neofuscipes Soyka. Orig. desig.

Novickyella Soyka, 1946. Zentbl. Gesamtgeb. Ent. 1: 179.

Type-species: Novickyella gracilior Soyka. Orig. desig.

Taxonomy: Soyka, 1956. Zool.-Bot. Ges. Wien., Abhandl. 19: 32.

bimaculatipenne Girault. Tex.

Polynema bimaculatipenne Girault, 1911. Amer. Ent. Soc., Trans. 37: 304. $\subsetneq$.

boreum Girault. S. Dak. Ecology: Swept from wheat.

Polynema striaticome var. boreum Girault, 1916 (1915). Ent. News 27: 8. ․

Taxonomy: Burks, 1969. In Krombein and Burks, U. S. Dept. Agr., Agr. Monog. 2, Sup. 2, p. 216.

caesariatipenne Girault. D. C., Kans. Ecology: Reared from seed pod of ironweed.

Polynema caesariatipenne Girault, 1911. Amer. Ent. Soc., Trans. 37: 305. . ciliatum (Say). Ind.

Psilus ciliatus Say, 1828. Contrib. Maclur. Lyc. Phila. 1: 80.

consobrinus Girault. Ga., Ohio, Mich., Ill., Minn., Iowa. Host: Enchenopa binotata (Say); Anthonomus signatus Say.

Polynema consobrinus Girault, 1911. Amer. Ent. Soc., Trans. 37: 308, 309. ९, ơ.

Taxonomy: Girault, 1911. Ent. News 22: 467.

enchenopae Girault. Ill. Host: Enchenopa binotata (Say).

Polynema enchenopae Girault, 1911. N. Y. Ent. Soc., Jour. 19: 15. $q, ~ \delta$.

eutettixi Girault. Idaho, Utah, Calif.; Mexico. Host: Circulifer tenellus (Baker).

Polynema eutettexi Girault, 1917. Descr. Stellarum Nov., p. 18.,+ ¿.

Polynema entettixi Stahl, 1920. Jour. Agr. Res. 20: 250. Emend.

Biology: Stahl, 1920. Jour. Agr. Res. 20: 250.

florum Girault. B. C.

Polynema florum Girault, 1929. No. Amer. Hym. Mymaridae, pp. 18, 28. ؟. graculus Girault. Wis., Ill., Tex.

Polynema graculus Girault, 1911. Amer. Ent. Soc., Trans. 37: 308. o.

howardii (Ashmead). Colo., Calif. Host: Ceresa bubalus (F.).

Cosmocoma elegans Howard, 1881. U. S. Dept. Agr., Ann. Rpt. for 1880, p. 371. ठ. Preocc. by Polynema elegans Foerster, 1847. 
Cosmocoma Howardii Ashmead, 1887. Canad. Ent. 19: 194. N. name.

Cosmocoma Howardi Dalla Torre, 1890. Wien. Ent. Ztg. 9: 97. N. name.

Taxonomy: Girault, 1911. Amer. Ent. Soc., Trans. 37: 300-302. đ.

imitatrix Gahan. Ariz. Host: Stictocephala festina (Say).

Polynema imitatrix Gahan, 1918. Ent. Soc. Wash., Proc. 20: 24. १, ठ.

longipes (Ashmead). Del., Fla., Ohio, Ind., Ill., Tenn. Ecology: Common on wheat plants.

Ooctonus longipes Ashmead, 1887. Canad. Ent. 19: 192. \&.

Polynema citripes Girault, 1909. Psyche 16: 106.

Taxonomy: Girault, 1911. Amer. Ent. Soc., Trans. 37: 316, 324. -Girault, 1911. N. Y. Ent.

Soc., Jour. 19: 19, 22.

maculipes (Ashmead). Fla.

Cosmocoma maculipes Ashmead, 1887. Canad. Ent. 19: 194. ठ์.

Taxonomy: Girault, 1911. Amer. Ent. Soc., Trans. 37: 306-308.

marilandicum Girault. Md.

Polynema marilandicum Girault, 1917. Deser. Hym. Chalcidoid. Variorum cum Observ. V, p. 2. .

mymaripenne Dozier. Del.

Polynema mymaripennis Dozier, 1933. Ent. Soc. Wash., Proc. 35: 96. १.

nativum Girault. B. C.

Polynema nativum Girault, 1929. No. Amer. Hym. Mymaridae, pp. 19, 28.

needhami Ashmead. Ill. Host: Lestes dryas Kirby; L. unguiculatus Hagen.

Polynema needhami Ashmead, 1900. Ent. News 11: 616. ๆ, o.

picipes Girault. N. Y., Ga.

Polynema picipes Girault, 1905. Psyche 12: 91 . $?$.

Polynema piceipes Girault, 1911. N. Y. Ent. Soc., Jour. 19: 18, 22. Emend.

Taxonomy: Girault, 1911. Amer. Ent. Soc., Trans. 37: 313.

pratensiphagum Walley. Ont. Host: Lygus lineolaris (P. de B.).

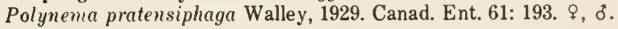

Biology: Painter, 1929. Ent. Soc. Ont., Ann. Rpt. 60: 105.

regina Girault. B. C.

Polynema regina Girault, 1912. Ent. Soc. Wash., Proc. 14: 24..

sibylla Girault. Va., Ill., Wis.

Polynema sibylla Girault, 1911. Amer. Ent. Soc., Trans. 37: 311. १, ठ.

striaticorne Girault. N. S., s. to Va., w. to B. C. and Calif. Host: Ceresa borealis (Fairm.); C. bubalus (F.), C. taurina (Fitch), Oncopsis sobrius (Walk.), Stictocephala inermis (F.).

Polynema striaticorne Girault, 1911. N. Y. Ent. Soc., Jour. 19: 12. १, ठ.

Taxonomy: Girault, 1911. Amer. Ent. Soc., Trans. 37: 302-308.

Biology: Balduf, 1928. Ent. Soc. Amer., Ann. 21: 419-435. -Craighead, 1950. U. S. Dept. Agr., Misc. Pub. 657: 619.

Morphology: Burks, 1938. Ent. Soc. Amer., Ann. 31: 161 (venation).

zetes Girault. D. C., Ill.

Polynema zetes Girault, 1911. Amer. Ent. Soc., Trans. 37: 314. १.

\section{Family TRICHOGRAMMATIDAE}

By B. D. Burks

All members of this family are parasites in the eggs of other insects. Their thoracic structures show them to have affinities with the Eulophidae, but they must have diverged from the eulophid stem at some remote time in chalcidoid evolution. Since all trichogrammatids have 3 -segmented tarsi, lack the strigil of the foretibia, have greatly reduced antennae, never have the abdomen petiolate, and the forewing usually bears characteristic lines of cilia, they are widely separated from their nearest relatives in the Eulophidae. 
Revision: Girault, 1912 Wis. Nat. Hist. Soc., Bul. 10: 81-100. -Girault, 1914. Wis. Nat. Hist. Soc., Bul. 12: 55-71. - Girault, 1918. No. Amer. Hym. Trichogrammatidae, Sydney, Austral. 11 pp. - Doutt and Viggiani, 1968. Calif. Acad. Sci. Proc. (4) 35: 477-586.

Taxonomy: Kryger, 1918. Ent. Meddel. 12: 257-354 (European spp.). - Mani, 1938. Cat. Indian Insects, pt. 23, pp. 133-141 (bibliography and cat. of Indian spp.). - Kloete and Hincks, 1945. Check List Brit. Insects, A rboath, Scotland, p. 303 (list Brit. spp.).

\section{Genus OLIGOSITA Walker}

Oligosita Walker, 1851. Ann. and Mag. Nat. Hist. (2)7: 212-213. (Cited as Haliday MS.)

Type-species: Oligosita collina Walker. Monotypic.

Westwoodella Ashmead, 1904. Carnegie Mus., Mem. 1: 359.

Type-species: Oligosita subfasciata Westwood. Monotypic.

Paroligosita Kurdjumov, 1911. Russ. Ent. Obozr. 11: 434.

Type-species: Paroligosita bella Kurdjumov. Orig. desig.

Pseudoligosita Girault, 1913. Queensland Mus., Mem. 2: 104.

Type-species: Pseudoligosita amoldi Girault. Orig. desig.

Zorontogramma Silvestri, 1915. Lab. Zool. Agr. Portici, Bol. 9: 327.

Type-species: Zorontogramma distinctum Silvestri. Orig. desig.

americana Girault. Ind. and Ill., s. to S. C., Ga., Tex., and N. Mex. Host: Dorycephalus platyrhynchus Osb., Homalodisca insolita (Walk.), cicadellid eggs in grasses.

Oligosita americana Girault, 1909. Psyche 16: 106. $\%$.

Taxonomy: Girault, 1911. Amer. Ent. Soc., Trans. 37: 56-62.

elarimaculosa (Girault). Va., Ill.

Westwoodella clarimaculosa Girault, 1911. Amer. Ent. Soc., Trans. 37: 67..

comosipennis (Girault). N. Y.

Westwoodella comosipennis Girault, 1911. Amer. Ent. Soc., Trans. 37: 66..

marilandia Girault. Md.

Oligosita marilandia Girault, 1917. Chalcidoid. nova Marilandensis II, p. 1. ؟.

plebeia (Perkins). Okla.; Mexico. Host: Cicadellid eggs in cane.

Westwoodella plebeia Perkins, 1912. Hawaii. Sugar Planters' Assoc. Expt. Sta., Div. Ent. Bul. 10: 16. ?.

sanguinea (Girault). Conn. w. to N. Dak., s. to Fla., Ariz., Calif.; Mexico and Brazil Host: Cicadellid eggs in wheat, grasses, and clover.

Westwoodella sanguinea Girault, 1911. Amer. Ent. Soc., Trans. 37: 58-62. ‡, ठ.

Oligosita sanguinea var. claripes Girault, 1916. Ent. News 27: 4. 9.

subfasciatipennis (Girault). Vt., Wis., Iowa, N. Dak., Wash. Host: Cicadellid eggs in wheat.

Westwoodella subfasciatipennis Girault, 1911. Amer. Ent. Soc., Trans. 37: 63-66.

\section{Genus MEGAPHRAGMA Timberlake}

Megaphragma Timberlake, 1924. Hawaii. Ent. Soc., Proc. 5: 413.

Type-species: Megaphragma mymaripenne Timberlake. Monotypic.

Sethosiella Kryger, 1932. Soc. Ent. d'Egypte, Bul. p. 38.

Type-species: Sethosiella priesneri Kryger. Monotypic.

Members of this genus, being parasites in thrips eggs, are thought to be the smallest of all insects. Some specimens have an overall body length of only 170 or 180 microns. However, some of the mymarids of the genus Alaptus Haliday have a body length of only 200 microns and are much more slender, so that it is difficult to decide which is actually the smaller.

Revision: Ghesquiere, 1939. Rev. Zool. Bot. Africaines 33: 39.

mymaripenne Timberlake. La., Calif.; Hawaii; Haiti. Host: Eggs of Heliothrips

haemorthoidalis Bouche and Leucothrips sp.

Megaphragma mymaripenne Timberlake, 1924. Hawaii. Ent. Soc., Proc. 5: 413..

Biology: Dozier, 1932. Ent. Soc. Wash., Proc. 34: 29-30. 


\section{Genus HYDROPHYLITA Ghesquiere}

Hydrophylax Matheson and Crosby, 1912. Ent. Soc. Amer., Ann. 5: 65. Preocc. by

Fitzinger, 1843.

Type-species: Hydrophylax aquivolans Matheson and Crosby. Monotypic.

Hydrophylita Ghesquiere, 1946. Rev. Zool. Bot. Africaines 39: 371. N. name.

Lutzimicron Costa Lima, 1960. Sao Paulo Inst. Biol., Arq. 27: 197.

Type-species: Lutzimicron lestesi Costa Lima. Monotypic.

Taxonomy: DeSantis, 1964. Comision inv. Cient. Prov. B. A., Notas 2(3): 3-5. - Doutt and

Viggiani, 1968. Calif. Acad. Sci., Proc. (4) 35: 493.

aquivolans (Matheson and Crosby). N. Y., Ohio, Kans. Host: Eggs of Ischnura verticalis (Say).

Hydrophylax aquivolans Matheson and Crosby, 1912. Ent. Soc. Amer., Ann. 5: 65. ठ, ?.

Biology: Davis, 1962. Limnol. and Oceanog. 7: 390-392.

\section{Genus PARACENTROBIA Howard}

Paracentrobia Howard, 1897. Linn. Soc. London, Jour., Zool. 26: 178.

Type-species: Paracentrobia punctata Howard. Monotypic.

Abbella Girault, 1911. Amer. Ent. Soc., Trans. 37: 9.

Type-species: Abbella subflava Girault. Orig. desig.

Ittys Girault, 1911. Amer. Ent. Soc., Trans. 37: 25.

Type-species: Trichogramma ceresarum Ashmead. Monotypic.

Brachistella Girault, 1911. N. Y. Ent. Soc., Jour. 19: 184.

Type-species: Trichogramma acuminata Ashmead. Monotypic.

Jassidophthora Perkins, 1912. Hawaii. Sugar Planters' Assoc. Expt. Sta., Div. Ent. Bul. 10: 17.

Type-species: Jassidophthora prima Perkins. Monotypic.

Abbellisca Ghesquiere, 1946. Rev. Zool. Bot. Africaines 39: 371. N. name, unnecessarily proposed.

Taxonomy: Doutt and Viggiani, 1968. Calif. Acad. Sci., Proc. (4) 35: 562.

acuminata (Ashmead). N. Y. and Minn. s. to Fla., La., Tex., and Calif.; Mexico, West Indies.

Host: Lestes dryas Kirby, L. unguiculatus Hagen, Cuerna costalis (Fab.),

Draeculacephala minor (Walk.), D. mollipes (Say), D. portola (Ball), Homalodisca

insolita (Walk.). There is some evidence that a complex of species is at present under this one name.

Trichogramma acuminatum Ashmead, 1888. Canad. Ent. 20: 107., o.

Brachista pallida Ashmead, 1900. Ent. News 11: 616..

Biology: Gibson, 1915. U. S. Dept. Agr., Bul. 254: 14. - Turner and Pollard, 1959. U. S. Dept. Agr., Tech. Bul. 1188: 26-27.

americana (Girault). Utah. Host: Cicadellid eggs in Elymus.

Abbella americana Girault, 1917. U. S. Natl. Mus., Proc. 53: 445. ‡, ठ.

auriscutellum (Girault). Ariz; Mexico. Host: Draeculacephala mollipes (Say).

Abbella auriscutellum Girault, 1916. Ent. News 27: 4..

Biology: Gibson, 1915. U. S. Dept. Agr., Bul. 254: 14.

ceresarum (Ashmead). N. S., N. J., Ohio, Ill., Calif. Host: Ceresa borealis Fairm., C. bubalus (Fab.), C. taurina (Fitch), Stictocephala inermis (Fab.).

Trichogramma ceresarum Ashmead, 1888. Canad. Ent. 20: 107. ๆ.

livii (Girault). Md.

Neobrachistella livii Girault, 1918. No. Amer. Hym. Trichogrammatidae, Sydney, Austral., p. 11. \&.

nympha (Girault). Tex. Host: Cicadellid eggs in stems of Ambrosia; eggs of Psallus seriatus (Reuter).

Abbella nympha Girault, 1911. Entomologist 44: 197..

perditrix (Gahan). Ariz. Host: Stictocephala festina (Say).

Abbella (Ittys) perditrix Gahan, 1918. Ent. Soc. Wash., Proc. 20: 25. ^, ठ์. 
prima (Perkins). Fla., Tex.; Mexico. Host: Cicadellid eggs in cane.

Jassidophthora prima Perkins, 1912. Hawaii. Sugar Planters' Assoc. Expt. Sta., Div. Ent. Bul. 10: 18. o., $\delta$.

subflava (Girault). D. C., S. C., Ill., Kans., S. Dak., Idaho, Wash., Calif.; Mexico, Argentina, Australia. Host: Blissus leucopterus (Say) (?), Balclutha impicta (Van Duzee), Circulifer tenellus (Baker), Deltocephalus minutus Van Duzee, D. sonorus Ball, Empoasca solana De Long, Halticus bracteatus (Say). The conspecificity of the North American and Australian specimens of this species should be reinvestigated, even though the identifications of both were made by the author of this species. A careful reading of the paper by McColloch and Yuasa, cited below, shows that the record of subflava from the eggs of the chinch bug is either incorrect or fortuitous.

Abbella subflava Girault, 1911. Amer. Ent. Soc., Trans. 37: 11. $\subsetneq$, o.

Biology: McColloch and Yuasa, 1915. Ent. News 26: 147-148. - Stahl, 1920. Jour. Agr. Res. 20: 250. - Henderson, 1941. U. S. Dept. Agr., Cir. 593: 1-18. - Henderson, 1955. U. S. Dept. Agr., Cir. 967: 1-16. -Flock et al., 1962. Jour. Econ. Ent. 55: 279.

\section{Genus UFENS Girault}

Ufens Girault, 1911. Amer. Ent. Soc., Trans. 37: 32.

Type-species: Trichogramma nigrum Ashmead. Orig. desig.

Ufensia Girault, 1913. Queensland Mus., Mem. 2: 101.

Type-species: Ufensia pretiosa Girault. Orig. desig. Genus redescribed the following year with the same type-species in Ent. Soc. Wash., Proc. 16: 118.

Neocentrobia Blood, 1923. Bristol Nat. Soc., Ann. Rpt. and Proc. 2: 101. Nom. nud.

Neocentrobia Blood and Kryger, 1928. Ent. Meddel. 16: 203. Preocc. by Girault, 1912.

Type-species: Neocentrobia hirticomis Blood and Kryger. Orig. desig.

Stephanotheisa Soyka, 1931. Natuurh. Maandbl. 20: 111.

Type-species: Stephanotheisa vitoldi Soika. Monotypic.

Grantanna Girault, 1939. Ohio Jour. Sci. 39: 324. N. name for Neocentrobia.

Taxonomy: Doutt and Viggiani, 1968. Calif. Acad. Sci., Proc. (4) 35: 576.

beneficus Dozier. Tex.; Mexico, West Indies. Host: Orthopterous eggs, probably of Tettigoniidae, deposited on leaf surfaces.

Ufens beneficus Dozier, 1932. Ent. Soc. Wash., Proc. 34: 33. १, ठ.

niger (Ashmead). Del., Md., w. to Ohio, Ill., Idaho, and Wash., s. to Fla., La., Tex., and Calif.;

Mexico, West Indies. Host: Colladonus geminatus (Van Duzee), Cuerna costalis (Fab.),

Keonolla confluens (Uhler), Draeculacephala mollipes (Say), Homalodisca sp.,

Saccharosydne saccharivora (Westw.). This may represent a complex of species.

Trichogramma nigrum Ashmead, 1888. Canad. Ent. 20: 107..

spiritus Girault. Md., Ga., Fla., La. Host: Homalodisca coagulata (Say), Oncometopia orbona (Fab.).

Ufens spiritus Girault, 1918. No. Amer. Hym. Trichogrammatidae, Sydney, Austral., p. 6.

Ufens spiritus americanus Girault, 1918. No. Amer. Hym. Trichogrammatidae, Sydney, Austral., p. 6.

\section{Genus BRACHYUFENS Viggiani}

Brachyufens Viggiani, 1968. In Doutt and Viggiani, Calif. Acad. Sci., Proc., (4) 35: 566. Type-species: Ufens osborni Dozier. Orig. desig.

osborni (Dozier). Fla.; West Indies. Host: Diaprepes spp., Pachnaeus litus (Germ.). This may be a secondary parasite.

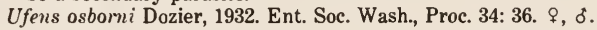

Biology: Tucker, 1936. Barbados Agr. Jour. 5: 9. -Baranowski, 1960. Fla. Ent. 43: 197.

\section{Genus ZAGELLA Girault}

Zagella Girault, 1918. No. Amer. Trichogrammatidae, Sydney, Austral., pp. 2, 7.

Type-species: Paracentrobia flavipes Girault. Orig. desig. 
Burksiella De Santis, 1957. La Plata Univ. Nac, Facultad de Cien. Nat. y Mus., Notas de Mus. 19: 133.

Type-species: Burksiella subannulata De Santis. Orig desig.

Taxonomy: Doutt and Viggiani, 1968. Calif. Acad. Sci., Proc. (4) 35: 572.

flavipes (Girault). D. C., Ga., Calif. Host: Lestes sp., lepidopterous eggs.

Paracentrobia flavipes Girault, 1905. Ent. News 16: 287. ९, ठ.

\section{Genus TRICHOGRAMMA Westwood}

Trichogramma Westwood, 1833 (June). London, Edinb. and Dublin Phil. Mag. and Jour. Sci. (3) 2: 444.

Type-species: Trichogramma evanescens Westwood. Monotypic.

Calleptiles Haliday, 1833 (July). Ent. Mag. 1: 340.

Type-species: Calleptiles latipennis Haliday. Monotypic.

Pentarthron Packard, 1872 (1871). Rec. Amer. Ent., p. 8.

Type-species: Trichogramma ? minuta Riley. Monotypic.

Trichogramma subg. Aprobosca Westwood, 1878. Linn. Soc. London, Trans., Zool., (2) 1: 592.

Type-species: Trichogramma (Aprobosca) erosicornis Westwood. Monotypic.

Oophthora Aurivillius, 1898 (1897). Ent. Tidskr. 18: 250.

Type-species: Oophthora semblidis Aurivillius. Monotypic.

Pentarth rum Dalla Torre, 1898. Cat. Hym., v. 5, p. 3. Emend.

Xanthoatomus Ashmead, 1904. Carnegie Mus., Mem. 1: xi, 360.

Type-species: Xanthoatomus albipes Ashmead. Orig. desig.

Neotrichogramma Girault, 1911. Amer. Ent. Soc., Trans. 37: 38-39.

Type-species: Neotrichogramma acutiventre Girault. Orig. desig.

Trichogramma subg. Trichogrammatana Girault, 1932. New lower Hymenoptera from Australia and India, Brisbane, Austral., p. 1.

Type-species: Trichogramma singularis Girault. Monotypic.

The latest revision of this genus was published in 1960. Although it was a very great improvement over the 1918 revision, it left most workers unsatisfied. At present other revisional works are in progress, and new papers revising Trichogramma may be published at about the time this catalog appears. Several undescribed species from North America are at present known to be in manuscript. Fundamental studies are also currently being made on the genetics, hybridization, male genitalia, and biologies of the described species of Trichogramma. Consequently, the arrangement of the species in this catalog is provisional.

Due to the fact that much of the older literature on biology cannot now be assigned to individual species as they are listed in this catalog, a large part of the biological literature on Trichogramma that was published before 1960 has been omitted. This literature is cited in full elsewhere; see Peck, 1963. Canad. Ent., Sup. 30: 51-73.

Any species of this genus can be reared in the laboratory or insectary on the eggs of almost any convenient host, although Salt, 1938. Bul. Ent. Res. 29: 223-246 showed that a few insect eggs may be physically or chemically unsuitable. The true host specificity for Trichogramma in nature seems to be to appropriate insect eggs that are deposited in particular environmental niches rather than simply to the eggs of particular host species. Consequently, host species are not listed here for the species of Trichogramma, but their ecological requirements, as far as they are known, are indicated.

Revision: Girault, 1918. N. Amer. Hym. Trichogrammatidae, Sydney, Austral., p. 4. -Quednau, 1960. Biol. Bund. fur Land- u. Forstwirtsch., Mitt. 100: 11-50.

Taxonomy: Flanders, 1937. Ent. Soc. Amer., Ann. 30: 208-210. -Flanders, 1938. Jour. Econ.

Ent. 31: 456-457. - Ishii, 1941. Kontyu 14: 169-176 (Japanese spp., male genitalia).

-Quednau, 1956. Ber. Hundertjahr Deut. Ent. Ges. Berlin, pp. 87-92. - Quednau, 1956.

Ztschr. Pflantzenkrank. u. Pflantzensch. 63: 333-344. - Telenga, 1959. First Internatl.

Cong. Insect Path. Biol. Control Prague, Trans. pp. 355-360. - Flanders and Quednau, 1960. Entomophaga 5: 285-294. - Quednau, 1960 Biol. Bund fur Land- u. Forstwirtsch., Mitt. 100: 11-50. - Tseng, 1965. Acta Ent. Sinica 14: 404 (Chinese spp., male genitalia). 
-Nagarkatti and Nagaraja, 1968. Commonwealth Inst. Biol. Control, Tech. Bul. 10: 81-96 (hybridization, male genitalia). - Doutt and Viggiani, 1968. Calif. Acad. Sci., Proc., (4) 35: 533-535. -Chepetilnikova, 1970 (1968). Ann. Zool. Ecol. Anim., pub. 70-3, pp. 71-76. -Fazaluddin and Nagarkatti, 1971. Ent. Soc. Amer., Ann. 64: 1470-1471. - Nagarkatti and Nagaraja, 1971. Bul. Ent. Res. 61: 13-31 (male genitalia).

Biology: Evans, 1930. Austral. Jour. Council Sci. Indus. Res. 3: 106-116. -Marchal, 1931. Paris Acad. des Sci., Compt. Rend. 192: 316-318. - Thompson, 1932. Indian Jour. Agr. Sci. 2: 413-415. - Nikolskaja, 1933. Zashch. rast. 3: 25-34. - Schread and Garman, 1933. Conn. Agr. Expt. Sta., Bul. 353: 691-756. - Schread and Garman, 1934. N. Y. Ent. Soc., Jour. 42: 263-283. - Flanders, 1935 Pan-Pacific Ent. 11: 175-177. - Bowen, 1936. Ent. Soc. Amer., Ann. 29: 119-125. - Marchal, 1936. Ann. des Epiphyt. et de Phytogenet., n. ser., 2: 447-567. -Meyer, 1938. Zool. Zhur. 17: 924-932. - Meyer, 1941. Leningrad Inst. Zool. Appl. Phytopath., Bul. 12: 273-277. - Meyer, 1941. Trichogramma, Tadzhikistan Agr., 176 pp. -Kovaleva, 1954. Zool. Zhur. 33: 77-86. -Quednau, 1956. Ztschr. f. Parasitenk. 17: 360-364. -Kovaleva, 1957. Zool. Zhur. 36: 225-229. -Quednau, 1959. Ztschr. f. Pflanzenkrank. 66: 77-86. - Mayer, 1960. Biol. Bund. fur Land- u. Forstwirtsch., Mitt. 100: 3-10. - Stein, 1960. Entomophaga 5: 237-259. -Klink, 1961. Ztschr. f. Angew. Zool. 48: 476-492. -Quednau, 1961. Entomophaga 6: 155-161. - Parnell, 1964. Roy. Ent. Soc. London, Trans. 116: 80.

-Kot, 1964. Ekol. Polska., (A) 2: 243-303. - Nagarkatti, 1970. Current Sci. 39(4): 76-78.

euproctidis (Girault). Mass., D. C., Ill.; Europe, Japan. Ecology: Insect eggs deposited in fields and forest-edge, orchards are parasitized.

Pentarthron euproctidis Girault, 1911. Amer. Ent. Soc., Trans. 37, 46. ठ.

Taxonomy: Nagarkatti and Nagaraja, 1971. Bul. Ent. Res. 61: 18.

Biology: Schread, 1934. Conn. Agr. Expt. Sta., Bul. 360: 463. -Garman, 1936. Conn. Agr. Expt. Sta., Bul. 383: 326. - Neiswander, 1936. Ohio Agr. Expt. Sta., Bul. 569: 19. - Allen et al., 1940. U. S. Dept. Agr., Cir. 561: 18, 40, 59. - Flanders, 1968. Ent. Soc. Amer., Ann. 61 : $1122-1124$.

evanescens Westwood. Scattered areas throughout S. Canada and the U. S. Ecology: Insect eggs deposited on herbaceous vegatation, primarily in cultivated areas, are parasitized. Introd. from Europe.

Trichogramma evanescens Westwood, 1833. London, Edinb. and Dublin Phil. Mag. and Jour. Sci. (3) 2: 444.

Taxonomy: Quednau, 1960. Biol. Bund. fur Land- u. Forstwirtsch., Mitt. 100: 11-50. -Nagarkatti and Nagaraja, 1971. Bul. Ent. Res. 61: 18.

Biology: Gatenby, 1918. Quart. Jour. Micros. Sci. 63: 161-174. -Thompson and Parker, 1928. U. S. Dept. Agr., Tech. Bul. 59: 17. - Hase, 1929. Internatl. Corn Borer Invest., Sci. Rpt. 2: 85-89. - Salt, 1935. Roy Soc. London, Proc. (B) 117: 413-415. -Zimin, 1935. Zashch. rast. 1: 69-80. - Marchal, 1936. Ann. des Epiphyt. et de Phytogenet., n. s., 2: 495-522. - Salt, 1936. Jour. Expt. Biol. 13: 363-375. - Salt, 1937. Roy. Soc. London, Proc. (B) 122: 57-75. - Laing, 1937. Jour. Anim. Ecol. 6: 298-317. - Dirsh, 1937. Zashch. rast. 15: 69-80. -Salt, 1938. Bul. Ent. Res. 29: 223-246. - Laing, 1938. Jour. Expt. Biol. 15: 281-302. —Salt, 1939 (1938). Parasitology 30: 511-522. - Salt, 1940. Roy. Ent. Soc. London, Proc. (A) 15: 81-95. - Meyer, 1940. Zashch. Rast. Byul. 4: 70-77. -Salt, 1942 (1941). Biol. Rev. Cambridge Phil. Soc. 16: 242-262. - Telenga, 1956. Ent. Obozr. 35: 599-609. - Kot, 1960. Polskie Pismo, Ent. (B) 1-2: 23-30. - Lee, 1961. Acta Ent. Sinica 10: 340. - Pu and Liu, 1962. Acta Ent. Sinica 11: 409. -Kaitazov, 1963. Rast. Zashch. Sofia 11: 20. -Kot, 1964. Ekol. Polska, (A) 12: 247. -Karpova, 1965. Ent. Obozr. 44: 500. - Oatman et al., 1968. Ent. Soc. Amer., Ann. 61: 956-959. -Oatman et al., 1968. Jour. Econ. Ent. 61: 724-730. - Lewis and Redlinger, 1969. Ent. Soc. Amer., Ann. 62: 1482-1484. -Oatman et al., 1970. Ent. Soc. Amer., Ann. 63: 633-635. -Shchichenkov, 1971. A kad. Nauk Eston. SSR Inst. Zool. i Bot., Apr., pp. 152-155. -Iren and Gurkan, 1971. Bitki Koruma Bul. 11: 157-168. - Parker et al., 1971. Jour. Econ. Ent. 64: 721-735. - Lewis et al., 1971. Jour. Econ. Ent. 64: 557-558.

fasciatum (Perkins). Fla., La., and S. Gulf Coast of Tex.; Mexico, West Indies, Cent. Amer., No. S. Amer. Ecology: Insect eggs on sugarcane, corn, and other Gramineae; also eggs deposited on vegetation in tropical or subtropical savannah habitats are parasitized. Pentarthron fasciatum Perkins, 1912. Hawaii. Sugar Planters' Assn., Ent. Ser. Bul. 10: 19. 
Taxonomy: Quednau, 1960. Biol. Bund. fur Land- u. Forstwirtsch., Mitt. 100: 11-50.

-Nagarkatti and Nagaraja, 1971. Bul. Ent. Res. 61: 20.

Biology: Burrell and McCormick, 1962. Jour. Econ. Ent. 55: 880. -Breniere, 1965.

Entomophaga 10: 274. - Chen, 1967 (1966). Mushi 39(suppl.): 104. - Drummond et al., 1970. Lepidopterists' Soc., Jour. 24: 140.

minutum Riley. S. Canada, U. S. except for most southern and southwestern areas. Ecology: Insect eggs deposited in arboreal habitats are parasitized.

Trichogramma minutum Riley, 1871. Mo. State Bd. Agr., Ann. Rpt. 6: 157.

Taxonomy: Flanders, 1953. Ent. Soc. Amer., Ann. 46: 85. -Quednau, 1960. Biol. Bund. fur Land- u. Forstwirtsch., Mitt. 100: 11-50. - Nagarkatti and Nagaraja, 1971. Bul. Ent. Res. 61: $21,23$.

Biology: Langston, 1957. Univ. Calif. Pubs., Ent. 14: 25-26. - Downey, 1958 (1957). Ill. State Acad. Sci., Trans. 50: 299. - Schaffner, 1959. U. S. Dept. Agr., Misc. Pub. 767: 81. —Glass, 1963. Ent. Soc. Amer., Ann. 56: 564. -Kulman, 1965. Ent. Soc. Amer., Ann. 58: 241-243. -Flanders, 1968. Ent. Soc. Amer., Ann. 61: 1122-1124. - Oatman et al., 1970. Ent. Soc. Amer., Ann. 63: 633-635. -Fazalludin and Nagarkatti, 1971. Ent. Soc. Amer., Ann. 64: 1470-1471.

pretiosum Riley. S. Canada, U. S. except most southern and southwestern areas. Ecology: Insect eggs deposited on herbaceous vegetation in campestral habitats are parasitized. Trichogramma pretiosa Riley, 1879. Canad. Ent. 11: 161. \&, o.

Taxonomy: Flanders, 1953. Ent. Soc. Amer., Ann. 46: 85. -Flanders, 1968. Ent. Soc. Amer., Ann. 61: 1122-1124. -Orphanides and Gonzalez, 1970. Ent. Soc. Amer., Ann. 63: 1784-1785. - Nagarkatti and Nagaraja, 1971. Bul. Ent. Res. 61: 24-25.

Biology: Oatman, 1966. Jour. Econ. Ent. 59: 831. - Orphanides and Gonzalez, 1970. Ent. Soc. Amer., Ann. 63: 1734-1740. -Oatman et al., 1970. Ent. Soc. Amer., Ann. 63: 633-635. -Orphanides and Gonzalez, 1971. Ent. Soc. Amer., Ann. 64: 824-834. - Fazalludin and Nagarkatti, 1971. Ent. Soc. Amer., Ann. 64: 1470-1471. -Oatman and Platner, 1971. Jour. Econ. Ent. 64: 501-506.

retorridum (Girault). Iowa s. to no. New Mexico, w. to Great Basin and Pacific Coast Range in Central Calif. Ecology: Insect eggs deposited in dry, but not arid, environments are parasitized.

Pentarthron retorridum Girault, 1911. Amer. Ent. Soc., Trans. 37: 52. ๆ, ठ.

Taxonomy: Quednau, 1960. Biol. Bund fur Land- u. Forstwirtsch., Mitt. 100: 11-50. - Nagarkatti and Nagaraja, 1971. Bul. Ent. Res. 61: 25-27.

Biology: Webster, 1912. Jour. Econ. Ent. 5: 335-336. - Stern and Atallah, 1965. Ent. Soc. Amer., Ann. 58: 76-81. - Orphanides and Gonzalez, 1971. Ent. Soc. Amer., Ann. 64: 824-834. semblidis (Aurivillius). Canada and No. U. S.; Europe. Ecology: Insect eggs deposited in aquatic or semi-aquatic habitats are parasitized. In nature this species parasitizes the eggs of such insects as Chrysops, Tabanus, Sialis, and Chauliodes that occur in an aquatic habitat. When it is reared in the insectary on such hosts as the eggs of Ephestia the progeny are so different they would be taken for another species were their derivation not known.

Oophthora semblidis Aurivillius, 1897. Ent. Tidskr. 18: 253., ठ .

Taxonomy: Quednau, 1960. Biol. Bund fur Land- u. Forstwirtsch., Mitt. 100: 11-50. -Kolomiets, 1962. Akad. Nauk SSSR Sibirskoi Otdel. Biol. Inst., p. 134. - Nagarkatti and Nagaraja, 1971. Bul. Ent. Res. 61: 26-27.

Biology: Cameron, 1926. Bul. Ent. Res. 17: 38-39. - Salt, 1937. Parasitology 29: 539-553. -Van Steenburgh, 1938. Ent. Soc. Ontario, Ann. Rpt. 69: 74-75. - Salt, 1939 (1938). Parasitology 30: 511-522. - Reid, 1941. Roy. Ent. Soc. London, Trans. 91: 434. - Salt, 1942 (1941). Cambridge Phil. Soc., Biol. Rev. 16: 239-264. -Quednau, 1955. Nachr. Deut. Pflanzenschutsdienst. 7: 145-148. - Quednau, 1957. Deut. Ent. Ztschr. (N. F.) 4: 364.

Morphology: Bouillon, 1949. La Cellule 53: 35-95. 
semifumatum (Perkins). West Tex., N. Mex., Ariz., Southern Calif.; Hawaii, Mexico, Colombia. Ecology: Insect eggs deposited in semi-arid habitats are parasitized.

Pentarthron semifumatum Perkins, 1910. Fauna Hawaii., v. 2, pt. 6, p. 659. \&.

Taxonomy: Quednau, 1960. Biol. Bund fur Land- u. Forstwirtsch., Mitt. 100: 11-50. -Nagarkatti and Nagaraja, 1971. Bul. Ent. Res. 61: 27-29.

Biology: Hinckley, 1961. Jour. Econ. Ent. 54: 207. - Stern and Bowen, 1963. Ent. Soc. Amer., Ann. 56: 358-372. - Poinar, 1964. Jour. Econ. Ent. 57: 381. - Stern and Atallah, 1965. Ent. Soc. Amer., Ann. 58: 76-81. - Stern et. al., 1965. Ent. Soc. Amer., Ann. 58: 234-240. -Elbadry, 1965. Ent. Soc. Amer., Ann. 58: 209-212. - Bowen and Stern, 1966. Ent. Soc. Amer., Ann. 59: 823-834. - Stern and Shorey, 1968. Jour. Econ. Ent. 61: 898-901. - Taylor, 1969. Ghana Jour. Sci. 9: 30-34. - Davis, 1969. Hawaii. Ent. Soc., Proc. 20: 521-525. -Oatman et al., 1970. Ent. Soc. Amer., Ann. 63: 633-635. -Taylor and Stern, 1971. Ent. Soc. Amer., Ann. 64: 1381-1390.

\section{UNPLACEd SPECIES OF TRIChOGRamma WESTWOOD}

The following species have for many years been listed as synonyms of minutum Riley. Now that minutum itself is being redefined, all its synonyms must be re-evaluated.

Trichogramma minutissimum Packard, 1881. Boston Soc. Nat. Hist., Proc. 21: 37. \&, đ. Trichogramma odontotae Howard, 1885. Ent. Amer. 1: 117. + ,.

Trichogramma intermedium Howard, 1889. In Scudder, Butterflies of Eastern U. S. and Canada, pp. 1872, 1895. $\%$, ठ.

Xanthoatomus albipes Ashmead, 1904. Carnegie Mus., Mem. 1: xi, 360. $\uparrow$.

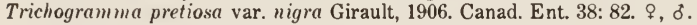

Trichogramma helocharae Perkins, 1907. Hawaii. Sugar Planters' Assoc. Expt. Sta., Div. Ent. Bul. 4: 58. (Probably not Trichogramma).

\section{Genus TRICHOGRAMMATOMYIA Girault}

Trichogrammatomyia Girault, 1916. Canad. Ent. 48: 268.

Type-species: Trichogrammatomyia tortricis Girault. Orig. desig.

tortricis Girault. Ont., N. B., Conn., N. Y. Host: Archips argyrospilus (Wlkr.), A. cerasivoranus (Fitch).

Trichogrammatomyia tortricis Girault, 1916. Canad. Ent. 48: 268. ๆ, ठ.

Biology: Baird, 1918. Agr. Gaz. Canada 5: 766, 771. - Chapman, Pearce, and Avens, 1941.

Jour. Econ. Ent. 34: 643-644.

\section{Genus POROPOEA Foerster}

Poropoea Foerster, 1851. Naturh. Ver. Rheinlande, Verh. 8: 28.

Type-species: Poropoea stollwerckii Foerster. Monotypic.

Poropoea subg. Poropoeoides Nowicki, 1936. Ztschr. f. Angew. Ent. 23: 125.

Type-species: Poropoea (Poropoeoides) bohemica Nowicki. Monotypic.

attelaborum Girault. S. E. U. S.; Puerto Rico. Host: Attelabus analis Illiger.

Poropoea attelaborum Girault, 1911. Amer. Ent. Soc., Trans. 37: 68. ठ.

\section{Genus XENUFENS Girault}

Xerufens Girault, 1916. Ent. News 27: 5.

Type-species: Xenufens ruskini Girault. Monotypic.

ruskini Girault. Fla.; Cuba. Host: Calpodes ethlius (Stoll), Lerema accius (A. and S.), Prenes nero (Fab.), Urbanus proteus (L.), undet. Hesperiidae eggs.

Xenufens ruskini Girault, 1916. Ent. News 27: 6.

\section{Genus GIRAULTIOLA Nowicki}

Giraultiola Nowicki, 1936. Ztschr. f. Angew. Ent. 23: 136.

Type-species: Brachysticha fidiae Ashmead. Monotypic. This species has been considered also to be the type-species of Brachista Walker, 1851, by subsequent 
reference of Ashmead, 1894; see Gahan and Fagan, 1923. U. S. Natl. Mus. Bul. 124: 23. Nowicki, 1936, rejects this and designates fidiae type-species of his new genus, but does so on the the basis of very weak arguments. Doutt and Viggiani, 1968, accept Nowicki's action, however, in order to preserve Brachista as usage dictates; that is, with B. pungens (Mayr) as type-species. Brachista in that sense does not occur in North America.

Taxonomy: Nowicki, 1936. Ztschr. f. Angew. Ent. 23: 127, 136. -Doutt and Viggiani, 1968. Calif. Acad. Sci., Proc. (4) 35: 497, 552.

fidiae (Ashmead). Pa., Va., Ohio. Host: Magicicada septendecim (L.); Fidia viticida Walsh. Brachysticha fidiae Ashmead, 1894. Cincinnati Soc. Nat. Hist., Jour. 17: 171. ๆ.

Lathromeris cicadae Howard, 1898. Canad. Ent. 30: 102. ९, ơ.

Biology: Johnson and Hammar, 1910. U. S. Dept. Agr., Bur. Ent. Bul. 89: 51, 56-57. - Marlatt, 1898. U. S. Dept. Agr., Bur. Ent. Bul. 14(n. s.): 99. - Hyslop, 1936. Jour. Econ. Ent. 29: 676.

\section{Genus TUMIDICLAVA Girault}

Tumidiclava Girault, 1911. Amer. Ent. Soc., Trans. 37: 6.

Type-species: Tumidiclava pulchrinotum Girault. Orig. desig.

Orthonenra Blood and Kryger, 1928. Ent. Medd. 16: 211. Preoce. by Macquart, 1829.

Type-species: Orthoneura bimaculata Blood and Kryger. Orig. desig.

Orthoneurella Blood and Kryger, 1929. Ent. Medd. 16: 322. N. name.

pulchrinotum Girault. Fla., Ill., La. Host: Eggs of Tettigoniidae.

Tumidiclava pulchrinotum Girault, 1911. Amer. Ent. Soc., Trans. 37: 8..

\section{Genus ZAGA Girault}

Zaga Girault, 1911. Amer. Ent. Soc., Trans. 37: 30.

Type-species: Zaga latipenn is Girault. Orig. desig.

latipennis Girault. Del., Va., Ill., La., Idaho, Utah. Host: Eggs of Entylia sinuata (Fab.), undet. membracid eggs.

Zaga latipennis Girault, 1911. Amer. Ent. Soc., Trans. 37: 31. ؟.

\section{Genus APHELINOIDEA Girault}

A phelinoidea Girault, 1911. Amer. Ent. Soc., Trans. 37: 2.

Type-species: Aphelinoidea semifuscipennis Girault. Orig. desig.

Lathromeroides Girault, 1913. Ent. News 24: 211.

Type-species: Lathromeroides longicorpus Girault. Orig. desig.

Diaclava Blood and Kryger, 1928. Ent. Medd. 16: 213.

Type-species: Diaclava waterhousei Blood and Kryger. Orig. desig.

Krygeriola Nowicki, 1934. Polski Pismo Ent. 12: 3.

Type-species: Krygeriola dolichoptera Nowicki. Monotypic.

Thalesanna Girault, 1938. Rev. de Ent. 8: 80.

Type-species: Aphelinoidea nigrioculae Girault. Orig. desig.

Lathromeroides subg. Lengerkeniola Nowicki, 1946. Zentbl. Gesamtgeb. Ent. 1: 45.

Type-species: Lengerkeniola bischoffi Nowicki. Monotypic.

Encyrtogramma De Santis, 1957. La Plata Univ. Nac., Facultad de Cien. Nat. y Mus., Notas del Mus. 19: 33.

Type-species: Encyrtogramma habros De Santis. Orig. desig.

Tanygramma De Santis, 1957. La Plata Univ. Nac., Facultad de Cien. Nat. y Mus., Notas del Mus. 19: 37.

Type-species: Tanygramma xiphias De Santis. Orig. desig.

Taxonomy: Doutt and Viggiani, 1968. Calif. Acad. Sci., Proc. (4) 35: 527.

neomexicana (Girault). Iowa, N. Dak., Mont., N. Mex., Idaho, Calif. Host: Undet. hemipterous eggs in grasses.

Lathromeroides neomexicanus Girault, 1916. Ent. News 27: 5 . ค. 
plutella Girault. Va., Ill., Tex., N. Mex., Idaho, Utah, Ariz., Calif.; Mexico. Host: Circulifer tenellus (Baker).

Aphelinoidea plutella Girault, 1912. Ent. News 23: 296. ㅇ, ठ゚.

Biology: Henderson, 1941. U. S. Dept. Agr., Cir. 593: 1-18. - Henderson, 1955. U. S. Dept.

Agr., Cir. 967: 1-16. -Flock et al., 1962. Jour. Econ. Ent. 55: 279.

semifuscipennis Girault. Ill., Okla., Tex. Host: Leafhopper eggs in grasses.

Aphelinoidea semifuscipennis Girault, 1911. Amer. Ent. Soc., Trans. 37: 4. ․

\section{Genus LATHROMEROIDEA Girault}

Lathromeroidea Girault, 1912. Queensland Mus., Mem. 1: 94.

Type-species: Lathromeroidea nigra Girault. Orig. desig.

Centrobiopsis Girault, 1918. No. Amer. Hym. Trichogrammatidae, Sydney, Austral., pp. 4, 7.

Type-species: Centrobia odonatae Ashmead. Orig. desig.

Taxonomy: Doutt and Viggiani, 1968. Calif. Acad. Sci., Proc. (4) 35: 506-507.

odonatae (Ashmead). N. Y., Ill. Host: Lestes uncatus Kirby, L. unguiculatus Hagen.

Centrobia odlonatae Ashmead, 1900. Ent. News 11: 616. $\%$.

\section{Genus USCANA Girault}

Uscana Girault, 1911. Amer. Ent. Soc., Trans. 37: 22.

Type-species: Uscana semifumipennis Girault. Monotypic.

Bruchoctonus Grese, 1924. In Korab, Saratov Admin. State Assoc. Sugar Indus., Bul. 7: 116-117.

Type-species: Bruchoctonus senax Grese. Monotypic. Lathromeris of authors, not Foerster, 1856.

marilandica Girault. Md. Host: Callosobruchus maculatus (Fab.).

Uscana marilandica Girault, 1918. No. Amer. Hym. Trichogrammatidae, Sydney, Austral., p. 10.

semifumipennis Girault. N. J., D. C., N. Dak., Tex., Mont., Ariz.; Hawaii. Host: Acanthoscelides alboscutellatus (Horn), Althaeus hibisci (Oliv.), Callosobruchus maculatus (Fab.), Stator limbatus (Horn).

Uscana semifumipennis Girault, 1911. Amer. Ent. Soc., Trans. 37: 23. \&, o.

Biology: Paddock and Reinhard, 1919. Tex. Agr. Expt. Sta., Bul. 256: 81-83. -Steffan, 1954.

Paris Mus. d'Hist. Nat., Bul. (2) 26: 669.

\section{UNPLACED TAXA IN CHALCIDOIDEA}

By B. D. Burks

Entedon antiopae Packard, 1881. Boston Soc. Nat. Hist., Proc. 21: 36. ठ. Type not located.

Stenomesius? aphidicola Ashmead, 1880. Orange Insects, p. 67. \&, ठ. Type lost.

Smicra Bimaculatas Strecker, 1878. U. S. War Dept., Ann. Rpt. 2 (3): 1878. Type not located.

Diomorus biorhizae Ashmead, 1887. Amer. Ent. Soc., Trans. 14: 186. $\%$. Type lost; from original description not Diomoris.

Halticoptera brodii Ashmead, 1887. Amer. Ent. Soc., Trans. 14: 192. ९. Type lost; from original description not Halticoptera.

Caccophagus brunneus Provancher, 1887. Addit. Corr. Faune Ent. Canada Hym., p. 205. Type broken, but fragments look to be Pteromalini.

Taxonomy: Dalla Torre, 1898. Cat. Hym., v. 5, p. 224 (Coccophagus). -Burks, 1964 (1963).

Canad. Ent. 95: 1257 (type).

Camptotera clacata Provancher, 1888. Addit. Corr. Faune Ent. Canada Hym., p. 404. + , $\delta$. Type lost.

Entedon coquilletti Riley, 1889. U. S. Dept. Agr., Ann. Rpt. for 1888, p. 86. Type lost.

Stinoplus cyaneus Ashmead, 1894. Amer. Ent. Soc., Trans. 21: 338. ¿. Type lost.

Trichogramma flavus Ashmead, 1880. Orange Insects, p. 33. \&. Type lost.

Solenotus fletcheri Cockerell, 1889. Colo. Biol. Assoc., Rpt. 6: 2. Type lost. 
Lencospis integra Haldeman, 1844. Acad. Nat. Sci. Phila., Proc. 2: 53. ठ. Type lost; from original description not Lencospis; Bracymeria?

Taxonomy: Cresson, 1872. Amer. Ent. Soc., Trans. 4: 35.

Cricellius megachilis Ashmead, 1897. South. Calif. Acad. Sci., Proc. 1 (3): 6. \&, ठ. Type missing.

Semiotellus minimns Provancher, 1881. Nat. Canad. 12: 295.. ९. Type fragmentary.

Taxonomy: Burks, 1964 (1963). Canad. Ent. 95: 1262 (type).

Meraporus monticola Ashmead, 1889. Colo. Biol. Assoc., Rpt. 3: 4. Type lost.

Pteromalus nigricornis Provancher, 1881. Nat. Canad. 12: 297. ₹. Type fragmentary, but not Pteromalus.

Taxonomy: Burks, 1964 (1963). Canad. Ent. 95: 1260 (type).

Eurytoma orbiculata Say, 1836. Boston Jour. Nat. Hist. 1: 272. Type lost.

Rhopalicus pallipies Provancher, 1888. Addit. Corr. Faune Ent. Canada Hym., p. 407. ₹. Type lost, but from original description, not Rhopalicus.

Taxonomy: Burks, 1964 (1963). Canad. Ent. 95: 1261.

Eulophus ramosus Provancher, 1881. Nat. Canad. 12: 297. ९, ठ. Type lost.

Taxonomy: Burks, 1964 (1963). Canad. Ent. 95: 1258 (type).

Trigonoderns taripes Viereck, 1903. Amer. Ent. Soc., Trans. 29: 75. ?. Type lost. 



\title{
Superfamily CYNIPOIDEA
}

\author{
By B. D. Burks
}

The Cynipoidea have gone through an evolutionary development that approximately parallels that of the Chalcidoidea. Both superfamilies have parasitic and phytophagous forms, although the Cynipoidea does not include known genera that have phytophagous as well as parasitic species. In the Chalcidoidea several genera include phytophagous and parasitic species; in the Cynipoidea no such mixtures occur below the family level. It should be borne in mind, however, that the present classification of the Cynipoidea may have given unjustifiable weight to the habits of the forms placed in the various higher categories. In any case, in each superfamily it is debatable whether the phytophagous or parasitic habit is the more primitive. Although all authorities agree that the members of each superfamily came originally from phytophagous ancestors, there is disagreement as to whether the first Hymenoptera recognizable as representing either superfamily were parasitic or phytophagous. If they were parasitic, as many authorities believe, the present-day phytophagous species are secondarily evolved from parasitic ancestors. The close agreement in essential morphological characters among all members of each superfamily excludes the possibility of polyphyletic origin for the parasitic and phytophagous forms.

Revision: Dalla Torre and Kieffer, 1910. Das Tierreich, 24, Hymenoptera, Cynipidae, 891 pp. (world monograph, literature through 1905). - Weld, 1952. Cynipoidea 1905-1950. Ann Arbor, Mich., Privately Printed, 351 pp. (supplement to Dalla Torre and Kieffer; illustrated keys).

Taxonomy: Felt, 1940. Plant Galls and Gall Makers, pp. 78-228; 254-269; 329-338 (illustrated keys to galls). - Weld, 1957. Cynipid Galls of Pacific Slope. Ann Arbor, Mich., Privately Printed, $80 \mathrm{pp}$. (illustrated keys to galls). - Weld, 1959. Cynipid Galls of the Eastern United States, Ann Arbor, Mich., Privately Printed, 158 pp. (illustrated keys to galls). -Weld, 1960. Cynipid Galls of the Southwest. Ann Arbor, Mich., Privately Printed, 51 pp. (illustrated keys to galls).

Biology: Mani, 1964. Ecology of Plant Galls, 434 pp.

\section{Family IBALIIDAE}

\section{SUBFAMILy IBALIINAE \\ Genus IBALIA Latreille}

Ibalia Latreille, 1802. Hist. Nat. Crust. Ins. v. 3, p. 306 Type-species: Ophion cultellator Fabricius. Monotypic.

Sagaris Panzer, 1806. Krit. Rev. Insektenf. Deutschlands, v. 2, p. 91. Type-species: Ophion cultellator Fabricius. Monotypic. 
Parasitic on Siricidae. The European species lencospoides Hochenwarth has been successfully introduced into New Zealand for the control of Sirex noctilio (Fabricius) in plantings of introduced species of Pinus. I. lencospoides is now considered to be a senior synonym of cultellator Fabricius.

Taxonomy: Weld, 1952. Cynipoidea 1905-1950, p. 150 (key to U. S. spp.).

Biology: Cameron, 1965. Commonwlth. Inst. Biol. Control, Tech. Bul. 5: 18. anceps Say. Minn., Ark., Tex.

Ibalia anceps Say, 1824. In Keating, Narr. Long's 2nd Exped., App., p. 325..

leucospoides ensiger Norton. Transcont. introd. into N. Zeal. and Australia. Ibalia

lencospoides leucospoides (Hochenwarth) is Palearctic. Host: Siricidae and Syntexidae in conifers.

Ibalia ensiger Norton, 1862. Ent. Soc. Phila., Proc. 1: 200..

Biology: Wickman, 1964. Pan-Pacific Ent. 40: 19. -Wickman, 1967. Ent. Soc. Amer., Ann. 60: 1294. -Cameron, 1968. Pan-Pacific Ent. 44: 168. -Zondag, 1969. New Zeal. Jour. Sci. 12: 744.

maculipennis Haldeman. Que., Ont., Eastern U. S. Host: Tremex colomba (L.). Differs from scalpellator Westwood only by slight differences in color, teste Weld, 1952. Cynipoidea 1905-1950, p. 150.

Ibalia maculipenn is Haldeman, 1846. Acad. Nat. Sci. Phila., Proc. 3: 127. \&.

Ibalia fasciipemnis Kieffer, 1909. Soc. Hist. Nat. Metz, Bul. 26: 57. ․

Morphology: Snodgrass, 1941. Smithsn. Misc. Collect. 99: 37 (male genitalia).

montana Cresson. Labrador, Nev., Wash., Oreg., Calif.

Ibalia montana Cresson, 1879. Amer. Ent. Soc., Trans. 7: Proc. xvii. $९$.

ruficollis Cameron. N. Mex., Ariz.; Mexico. Host: Sirex in conifers.

Ibalia mificollis Cameron, 1884. Roy. Ent. Soc. London, Trans. 1884: 488. ?.

rufipes rufipes Cresson. Nova Scotia, N. B., Que., Ont., Man., Alta., Host: Sirex cyaneus Fab., Urocerns gigas flavicomis (Fab.). The subspecies mifipes drewseni Borries is Palearctic. Ibalia rufipes Cresson, 1879. Amer. Ent. Soc., Trans. 7: Proc. xvii. $\$$.

Ibalia gigantea Yoshimoto, 1970. Canad. Ent. 102: 1196. $९, \delta$.

scalpellator Westwood. Ga.

Ibalia scalpellator Westwood, 1837. In Guerin, Mag. Zool. 7: cl. 9, pl. 179, fig. 2. ठో.

\section{Family LIOPTERIDAE}

\section{SUBFAMILY MESOCYNIPINAE}

Mostly exotic. Habits unknown.

\section{Genus PARAMBLYNOTUS Cameron}

Paramblyuotus Cameron, 1908. Entomologist 41: 299.

Type-species: Paramblynotus punctulatus Cameron. Desig. by Rohwer and Fagan, 1917.

Allocynips Kieffer, 1914. Philippine Jour. Sci. 9 D : 185.

Type-species: Allocynips miceps Kieffer. Monotypic.

Mayrella Hedicke, 1922. Deut. Ent. Ztschr., p. 190.

Type-species: Mayrella formosana Hedicke. Monotypic.

Baviana Barbotin, 1954. Soc. Ent. France, Bul. 59: 125.

Type-species: Baviana ferruginea Barbotin. Monotypic.

Decellea Benoit, 1956. Rev. Zool. Bot. Africaines 53: 51.

Type-species: Decellea yangambicola Benoit. Monotypic.

Taxonomy: Weld, 1962 (1961). Ent. Soc. Wash., Proc. 63: 279. - Maa, 1962. Taiwan Mus.,

Quart. Jour. 15: 124.

zonatus Weld. Tex.

Paramblymotus zonatus Weld, 1944. Ent. Soc. Wash., Proc. 46: 56, fig. 2. ๆ. 


\section{Genus KIEFFERIELLA Ashmead}

Kiefferia Ashmead, 1903. Psyche 10: 10. Preocc. by Mik, 1895 and Kunstler and Chaine, 1902.

Type-species: Kiefferia rugosa Ashmead. Monotypic.

Kiefferiella Ashmead, 1903. Ent. Soc. Wash., Proc. 5: 221. N. name.

acmaeodera Weld. Idaho.

Kiefferiella acmaeodera Weld, 1956. Ent. Soc. Wash., Proc. 58: 291. ․

rugosa (Ashmead). Calif. (Santa Cruz Mts.).

Kiefferia rugosa Ashmead, 1903. Psyche 10: 10.

Taxonomy: Weld, 1921. U. S. Natl. Mus., Proc. 59: 435..

\section{Family FIGITIDAE}

\section{SUBFAMILY ASPICERATINAE}

Parasites in the puparia of Syrphidae.

\section{Genus PARASPICERA Kieffer}

Paraspicera Kieffer, 1907. Ent. Ztschr. Stuttgart 21: 152.

Type-species: Paraspicera bakeri Kieffer. Monotypic.

bakeri Kieffer. Md., D. C., Ill., Wis.

Paraspicera bakeri Kieffer, 1907. Ent. Ztschr. Stuttgart 21: 152. $\delta$.

Taxonomy: Weld, 1944. Ent. Soc. Wash., Proc. 46: 57. (female).

clarimontis (Kieffer). Calif.

Aspicera clarimontis Kieffer, 1907. Ent. Ztschr. Stuttgart 21: 152..

utahensis (Ashmead), n. comb. Utah.

Aspicera utahensis Ashmead, 1896. Amer. Ent. Soc., Trans. 23: 183..

\section{Genus PROSASPICERA Kieffer}

Prosaspicera Kieffer, 1907. Ent. Ztschr. Stuttgart 21: 152.

Type-species: Prosaspicera ensifera Kieffer. Desig. by Rohwer and Fagan, 1917.

albihirta (Ashmead). Fla.

Aspicera albihirta Ashmead, 1887. Amer. Ent. Soc., Trans. 14: 156..

similis (Ashmead). Pa., Fla., Ark.

Aspicera similis Ashmead, 1887. Amer. Ent. Soc., Trans. 14: 156. ?.

Aspicera albinervis Kieffer, 1910. Lab. Zool. Gen. e Agr. Portici, Bol. 4: 337. ๆ, ठ.

\section{Genus OMALASPIS Giraud}

Omalaspis Giraud, 1860. Zool.-Bot. Gesell. Wien, Verhandl. 10: 155.

Type-species: Omalaspis norica Giraud. Monotypic.

Lambertonia Kieffer, 1901. Soc. Ent. France, Bul. 1901, pp. 158, 159.

Type-species: Lambertonia abnormis Kieffer. Desig. by Ashmead, 1903.

Tavaresia Kieffer, 1901. Soc. Ent. France, Bul. 1901, pp. 158, 160.

Type-species: Tavaresia carinata Kieffer. Desig. by Ashmead, 1903.

Taxonomy: Weld, 1931. Ent. Soc. Wash., Proc. 33: 22. - Weld, 1952. Cynipoidea 1905-1950, p. 168.

nigra (Hartig). N. Y., Del., Va., Ala., Ill., Okla., Colo., Idaho; Europe. Prob. adventive. Host:

Syrphid puparia.

Figites niger Hartig, 1840 (1839). Ztschr. f. Ent. 2: 202. ․

\section{Genus CALLASPIDIA Dahlbom}

Callaspidia Dahlbom, 1842. Onychia och Callaspidia, p. 10.

Type-species: Callaspidia De fonscolombei Dahlbom. Desig. by Rohwer and Fagan, 1917. 
provancheri Ashmead. Que., Maine, N. H., Mass., N. Y., Conn., Pa., Mich., Ind., Ill., Wis., Idaho. Host: Metasyrphus americauus (Wiedemann).

Callaspidia provancheri Ashmead, 1887. In Provancher, Addit. Corr. Faune Ent. Canada Hym., p. 167. .

\section{SUBFAMILY ANACHARITINAE}

Parasitic in the cocoons of lace-wing flies: Chrysopa, Sympherobius, Hemerobius.

\section{Genus XYALASPIS Hartig}

Xyalaspis Hartig, 1843. Ztschr. f. Ent. 4: 416.

Type-species: Xyalaspis laevigata Hartig. Monotypic.

Conaspicera Hedicke, 1914. Nyt. Mag. Nat. Kristiana 52: 354.

Type-species: Conaspicera norvegica Hedicke. Orig. desig.

flavipes Ashmead. Md., Va.

Xyalaspis flavipes Ashmead, 1896. Amer. Ent. Soc., Trans. 23: 183. ठ.

microstyla Kieffer. Ala.

Xyalaspis microstyla Kieffer, 1907. Ent. Ztschr. Stuttgart 21: 151. ठ.

\section{Genus ACOTHYREUS Ashmead}

Acothyreus Ashmead, 1887. Amer. Ent. Soc., Trans. 14: 157.

Type-species: Acothyreus osceola Ashmead. Monotypic.

mellipes Provancher. Que.

Acothyreus mellipes Provancher, 1888. Addit. Corr. Faune Ent. Canada Hym., p. 438. ․ osceola Ashmead. Fla.

Acothyreus osceola Ashmead, 1887. Amer. Ent. Soc., Trans. 14: 157. ठ.

\section{Genus ANACHARIS Dalman}

Anacharis Dalman, 1823. Anal. Ent., p. 96.

Type-species: Cynips eucharoides Dalman. Monotypic.

Megapelmus Hartig, 1840 (1839). Ztschr. f. Ent. 2: 186.

Type-species: Megapelmus spheciformis Hartig. Monotypic.

flavicornis Kieffer. Wis.

Anacharis flavicormis Kieffer, 1909. Soc. Hist. Nat. Metz, Bul. 26: 80. ठ.

lamyi Cockerell. N. Mex.

Anacharis mexicana Ashmead, 1896. Amer. Ent. Soc., Trans. 23: 184. \&. Preocc. by

Cameron, 1884.

Anacharis lamyi Cockerell, 1899. Kans. Acad. Sci., Trans. 16: 213. N. name.

Anacharis ushmeadi Dalla Torre and Kieffer, 1902. In Wytsman, Gen. Ins., fasc. 9, p. 141.

N. name, unnecessarily proposed.

levifrons Kieffer. $\mathrm{Pa}$.

Anacharis levifrous Kieffer, 1907. Ent. Ztschr. Stuttgart 21: 143. \&.

marginata Provancher. Que. (Cap Rouge).

Anacharis marginata Provancher, 1887. Addit. Corr. Faune Ent. Canada Hym., p. 168. $\delta$. melanoneura Ashmead. Va., S. C., Ga., Fla., La., Tex.

Anacharis melanoneura Ashmead, 1887. Amer. Ent. Soc., Trans. 14: 158. o.

pediculata Provancher. Ont. (Ottawa).

Anacharis pediculata Provancher, 1887. Addit. Corr. Faune Ent. Canada Hym., p. 169. o. punctatifrons Kieffer. Calif.

Anacharis punctatifrons Kieffer, 1907. Ent. Ztschr. Stuttgart 21: 143. ๆ.

Taxonomy: Kieffer, 1908. Soc. Sci. Bruxelles, Ann. 32: 64. ठ.

subcompressa (Provancher). Que., Ill., Iowa.

Encoila subcompressa Provancher, 1881. Nat. Canad. 12: 237..

tripartita Kieffer. Calif.

Anacharis tripartita Kieffer, 1907. Ent. Ztschr. Stuttgart 21: 143. ․ 


\section{Genus HEXACHARIS Kieffer}

Hexacharis Kieffer, 1907. Ent. Ztschr. Stuttgart 21: 142.

Type-species: Hexacharis flavipes Kieffer. Monotypic.

flavipes Kieffer. Colo.

Hexacharis flavipes Kieffer, 1907. Ent. Ztschr. Stuttgart 21: 142. ठँ.

\section{Genus AEGILIPS Walker}

Aegilips Walker, 1835. Ent. Mag. 3: 160.

Type-species: Cynips nitidula Dalman. Desig. by Westwood, 1840.

aciculatus Provancher. Canada.

Aegilips aciculatus Provancher, 1881. Nat. Canad. 12: 239. ठ, ㅇ.

clarimontis Kieffer. Calif. Host: Chrysopa californica Coq.

Aegilips clarimontis Kieffer, 1907. Ent. Ztschr. Stuttgart 21: 143..

nevadensis Kieffer. Nev.

Aegilips nevadensis Kieffer, 1908. Soc. Sci. Bruxelles, Ann. 32: 63. ठ.

obtusilobae Osten Sacken. D. C.

Aegilips! obtusilobae Osten Sacken, 1861. Ent. Soc. Phila., Proc. 1: 68. ๆ.

reticulata Kieffer. Calif.

Aegilips reticulata Kieffer, 1908. Soc. Sci. Bruxelles, Ann. 32: 63. ठ゚.

rugata Kieffer. Colo.

Aegilips rmgata Kieffer, 1907. Ent. Ztschr. Stuttgart 21: 144. ९.

trisecta Kieffer. Wis.

Aegilips trisecta Kieffer, 1907. Ent. Ztschr. Stuttgart 21: 143. ठ.

victoriae Ashmead. B. C. (Victoria).

Aegilips victoriae Ashmead, 1896. Amer. Ent. Soc., Trans. 23: 184. \&.

\section{Subfamily FIGITINAE}

Parasitic in the puparia of Diptera.

\section{Genus NERALSIA Cameron}

Neralsia Cameron, 1883. Biol. Centr.-Amer., Hym., v. 1, p. 74.

Type-species: Neralsia rufipes Cameron. Monotypic.

Solenaspis Ashmead, 1887. Amer. Ent. Soc., Trans. 14: 155. Preocc. by Osten Sacken, 1881.

Type-species: Solenaspis hyalinipennis Ashmead. Monotypic.

Xyalosema Dalla Torre and Kieffer, 1910. Das Tierreich, v. 24, p. 94. N. name for

Solenaspis Ashmead.

armata (Say). East and middle U. S. Host: Sarcophaga bullata Parker, S. plinthopyga Wied.

Diplolepis armatus Say, 1836. Boston Jour. Nat. Hist. 1: 266. ơ.

Biology: Roberts, 1935. Jour. Agr. Res. 50: 487-488.

hyalinipennis (Ashmead). Va. s. to Fla. Ecology: Reported on human excrement.

Solenaspis hyalinipenuis Ashmead, 1887. Amer. Ent. Soc., Trans. 14: 155. 9.

Xyalosema dubiosa Kieffer, 1910. Lab. Zool. Gen. e Agr. Portici, Bol. 4: 338. ơ, ?.

nigriventris (Kieffer). Nev.

Xyalophora impatiens var, nigriventris Kieffer, 1908. Soc. Sci. Bruxelles, Ann. 32: 64. ठै.

\section{Genus XYALOPHORA Kieffer}

Xyalophora Kieffer, 1901. Soc. Ent. France, Bul. p. 344.

Type-species: Figites clavatus Giraud. Orig. desig.

leviventris Kieffer. Colo.

Xyalophora levicentris Kieffer, 1908. Soc. Sci. Bruxelles, Ann. 32: 64. ठ.

quinquelineata (Say). Transcont. in Transit. zone. Host: Sarcophaga sp.

Diplolepis 5-lineata Say, 1836. Boston Jour. Nat. Hist. 1: 267. \&.

Xyalophora armata var, nigricornis Kieffer, 1907. Ent. Ztschr. Stuttgart 21: 157. ठ, \&. 
singularis (Ashmead). Ill.

Solenaspis singularis Ashmead, 1896. Amer. Ent. Soc., Trans. 23: 183. ठै, ๆ.

\section{Genus PARASCHIZA Weld}

Paraschiza Weld, 1944. Ent. Soc. Wash., Proc. 46: 58.

Type-species: Paraschiza cupressana Weld. Orig. desig.

cupressana Weld. Calif. Ecology: Taken from holes of Citellus in mushrooms.

Paraschiza cupressana Weld, 1944. Ent. Soc. Wash., Proc. 46: 58. ․

\section{Genus LONCHIDIA Thomson}

Lonchidia Thomson, 1861. Ofvers. Svensk. Vet.-Akad., Forh. 18: 413.

Type-species: Figites maculipenuis Dahlbom. Desig. by Foerster, 1869.

hirta Provancher. Que. (Cap Rouge).

Lonchilia hirta Provancher, 1887. Addit. Corr. Faune Ent. Canada Hym., p. 170..

\section{Genus MELANIPS Walker}

Melanips Walker, 1835. Ent. Mag. 3: 161. No species. -Giraud, 1860. Zool.-Bot. Gesell.

Wien, Verh. 10: 163. Seven species.

Type-species: Scytodes opacus Hartig. Desig. by Foerster, 1869.

Scytodes Hartig, 1840 (1839). Ztschr. f. Ent. 2: 187, 202. Preocc. by Latreille, 1804.

Type-species: Scytodes opacus Hartig. Desig. by Rohwer and Fagan, 1917.

Amblynofus Hartig, 1843. Ztschr. f. Ent. 4: 419. N. name for Scytodes Hartig.

bilineatus (Kieffer). Idaho, Wash.

Amblynotus bilineatus Kieffer, 1909. Soc. Hist. Nat. Metz, Bul. 26: 82. ๆ.

coxalis (Kieffer). Nev., Calif.

Amblynotus, jowensis(!) var. coxalis Kieffer, 1907. Ent. Ztschr. Stuttgart 21: 161. o, 9. coxalis var. dipterorum (Kieffer). Ark.

Amblynotus coxalis var. dipterorum Kieffer, 1910. Lab. Zool. Gen. e Agr. Portici, Bol. 4: 339. ס.

iowensis Ashmead. Iowa.

Melauips iouensis Ashmead, 1887. Amer. Ent. Soc., Trans. 14: 158. ơ, ๆ.

opacus (Hartig). Calif.; Europe.

Scytodes opacus Hartig, 1840. Ztschr. f. Ent. 2: 202. ठ, ?.

Biology: Belizin, 1966. Kishinev. Moldavian Nauch.-Issled Inst. Sadov. Vinograd.: Vinod. Ent.,

Trudy 13: 9. (Russian hosts).

semirugosus (Crawford). N. Y. (Adirondack Mts.).

Amblynotus semirugosus Crawford, 1917. Ent. Soc. Wash., Proc. 19: 172..

slossonae (Crawford). N. H. (Mt. Washington).

Amblynofus slossonae Crawford, 1917. Ent. Soc. Wash., Proc. 19: 171. \&.

\section{Genus SAROTHRUS Hartig}

Sarothrus Hartig, 1840 (1839). Ztschr. f. Ent. 2: 187.

Type-species: Sarothrus canaliculatus Hartig. Desig. by Foerster, 1869.

Amphithectus Hartig, 1840 (1839). Ztschr. f. Ent. 2: 203.

Type-species: Amphithectus dahlbomii Hartig. Monotypic.

californicus Kieffer. Calif.

Sarotheus califormicus Kieffer, 1907. Ent. Ztschr. Stuttgart 21: 161. ठ, ๆ.

canadensis Kieffer. Ont., Colo.

Sarothrus canadensis Kieffer, 1907. Ent. Ztschr. Stuttgart 21: 161. \&.

nasoni Ashmead. 1ll. (Algonquin).

Sarathrus(!) nasoni Ashmead, 1896. Amer. Ent. Soc., Trans. 23: 182. ?.

\section{Genus TRISCHIZA Foerster}

Trischiza Foerster, 1869. Zool.-Bot. Gesell. Wien, Verh. 19: 364, 367. 
Type-species: Figites agaricolarum Dahlbom. Monotypic.

Figitodes Ashmead, 1887. Amer. Ent. Soc., Trans. 14: 150.

Type-species: Figitodes atricornis Ashmead. First included species, Ashmead, 1896. atricornis (Ashmead). N. Mex. (Santa Fe).

Figitodes atricornis Ashmead, 1896. Amer. Ent. Soc., Trans. 23: 182. \&.

leviventris Kieffer. Nev. (Ormsby Co.).

Trischiza leviventris Kieffer, 1907. Ent. Ztschr. Stuttgart 21: 161. ठ.

\section{Genus ZYGOSIS Foerster}

$Z$ ygosis Foerster, 1869. Zool.-Bot. Gesell. Wien, Verh. 19: 363, 365.

Type-species: Figites urticeti Dahlbom. Orig. desig.

Diceraea Foerster, 1869. Zool.-Bot. Gesell. Wien, Verh. 19: 364, 367.

Type-species: Figites urticeti Dahlbom. Orig. desig.

Thyreocere Ashmead, 1887. Amer. Ent. Soc., Trans. 14: 154.

Type-species: Thyreocera nigrifemora Ashmead. Monotypic.

laeviesutum (Provancher). Que.

Figites laeviscutum Provancher, 1887. Addit. Corr. Faune Ent. Canada Hym., p. 170. o, $ᄋ$.

Thyreocera nigrifemora Ashmead, 1887. Amer. Ent. Soc., Trans. 14: 155..

\section{Genus FIGITES Latreille}

Figites Latreille, 1802. Hist. Nat. Crust. Ins., v. 3, p. 307.

Type-species: Cyuips scutellaris Rossi. Desig. by Latreille, 1810.

Psilogaster Hartig, 1840 (1839). Ztschr. f. Ent. 2: 187.

Type-species: Psilogaster anthomyiarum Bouche. Desig. by Rohwer and Fagan, 1917.

Pychuotrichia Foerster, 1869. Zool.-Bot. Gesell. Wien, Verh. 19: 363, 366.

Type-species: Pychuotrichia erythropa Foerster. Orig. desig.

Omalaspoides Hedicke, 1913. Ent. Mitt. 2: 146.

Type-species: Omalaspoides letzneri Hedicke. Orig. desig.

Seitneria Tavares, 1928. Broteria, Rev. Luso-Brazil. Ser. Zool. 25: 5.

Type-species: Seitneria austriaca Tavares. Monotypic.

albinervis Kieffer. Wis. (Polk Co.).

Figites albinervis Kieffer, 1909. Soc. Hist. Nat. Metz, Bul. 26: 82. ơ.

coloradensis Ashmead. Colo. (Westcliffe).

Figites coloradensis Ashmead, 1890. Colo. Biol. Assoc., Bul. 1: 12, 38..

consobrinus Giraud. D. C., Va.; Europe. Prob. adventive. Host: Sarcophaga sp.

Figites consobrinus Giraud, 1860. Zool.-Bot. Gesell. Wien, Verh. 10: 153. ơ, q.

floridanus Ashmead. Fla. (Jacksonville).

Figites floridanus Ashmead, 1887. Amer. Ent. Soc., Trans. 14: 155..

floridanus var. dubius Kieffer. Pa., Ark.

Figites dubius Kieffer, 1907. Ent. Ztschr. Stuttgart 21: 161. o.

Figites floridanus var, dubius Kieffer, 1910. Lab. Zool. Gen. e Agr. Portici, Bol. 4: 339. đ.

floridensis Weld. N. Y., Va., Fla., Ala., Tex.

Omalaspis floridauus Ashmead, 1887. Amer. Ent. Soc., Trans. 14: 155. ठ. Preoce. by Ashmead, 1887.

Figites floridensis Weld, 1944. Ent. Soc. Wash., Proc. 46: 62. ๆ. N. name.

impatiens Say. Ind.

Figites impatiens Say, 1836. Boston Jour. Nat. Hist. 1: 268. $q$.

inermis (Provancher). Que. (Cap Rouge).

Onychia inermis Provancher, 1887. Addit. Corr. Faune Ent. Canada Hym., p. 171. o. parvulus Kieffer. Colo.

Figites par'ulus Kieffer, 1907. Ent. Ztschr. Stuttgart 21: 161. ठ.

popenoei Crawford. D. C.

Figites popenoei Crawford, 1915. U. S. Natl. Mus., Proc. 48: 582. §, ๆ. 


\section{Family EUCOILIDAE}

Parasites in the puparia of Diptera.

Taxonomy: Quinlan, 1967. R. Ent. Soc. London, Proc. (B) 36: 1-10 (key to genera).

\section{Genus KLEIDOTOMA Westwood}

\section{Genus KLEIDOTOMA Subgenus KLEIDOTOMA Westwood}

Kleidotoma Westwood, 1833. Mag. Nat. Hist. 6: 494.

Type-species: Kleidotoma psiloides Westwood. Monotypic.

Clidotoma Westwood, 1869. In Foerster, Zool.-Bot. Gesell. Wien, Verh. 19: 342, 348.

Emend.

Schizosema Kieffer, 1901. Feuille Jeunes Nat. (4)31: 161.

Type-species: Cothonaspis emarginatus Hartig. Desig. by Ashmead, 1903.

Coptereucoila Ashmead, 1887. Amer. Ent. Soc., Trans. 14: 151.

Type-species: Copterencoila americana Ashmead. Monotypic.

Trithoptrasema Kieffer, 1901. Soc. Ent. France Bul., p. 344.

Type-species: Kleidotoma americana Ashmead. Monotypic.

americana Ashmead. Que. (Cap Rouge).

Kleidotoma americana Ashmead, 1887. Amer. Ent. Soc., Trans. 14: 152, line 6..

Trithoptrasema ashmeadi Rohwer and Fagan, 1911. U. S. Natl. Mus., Proc. 53: 377,

footnote. N. name, unnecessarily proposed.

ashmeadi (Kieffer). Fla. (Jacksonville).

Coptereucoila americana Ashmead, 1887. Amer. Ent. Soc., Trans. 14: 152, top line..

Preoce. by Ashmead, 1887.

Cleidotoma (Cleidotoma(!)) ashmeadi Kieffer, 1901. Feuille Jeunes Nat. (4)31: 161. N. name.

fossa Kieffer. Calif. (San Mateo Co.).

Kleidotoma fossa Kieffer, 1908. Soc. Sci. Bruxelles, Ann. 32: 60. $\%$.

marginata (Gillette). Ill. (Quincy, Normal).

Copterencoila marginata Gillette, 1891. Ill. State Lab. Nat. Hist., Bul. 3: 203. \&. marginata var. glabra Kieffer. Calif. (San Mateo Co.).

Kleidotoma marginata var. glabra Kieffer, 1908. Soc. Sci. Bruxelles, Ann. 32: 61. ठ, ๆ.

\section{Genus KLEIDOTOMA Subgenus TETRARHOPTRA Foerster}

Tetrarhoptra Foerster, 1869. Zool.-Bot. Gesell. Wien, Verh. 19: 342, 349.

Type-species: Kleidotoma heterotoma Thomson. Orig. desig.

Tetratoma Cameron, 1890. Monog. Brit. Phytophagous Hym., v. 3, p. 223.

Type-species: Kleidotoma heterotoma Thomson. Desig. by Rohwer and Fagan, 1917.

alaskensis (Ashmead). Alaska (St. Paul Island).

Tetrarhapta(!) alaskensis Ashmead, 1902. Wash. Acad. Sci., Proc. 4: 141. ठ', ๆ.

lugens Kieffer. Colo., Calif.

Kleidotoma lugens Kieffer, 1908. Soc. Sci. Bruxelles, Ann. 32: 62. ๆ.

tristis Kieffer. Calif. (San Mateo Co.).

Kleidotoma (Tetraihoptra) tristis Kieffer, 1908. Soc. Sci. Bruxelles, Ann. 32: 62..

\section{Genus KLEIDOTOMA Subgenus KLEIDOTOMIDEA Rohwer and Fagan}

Kleidotomidea Rohwer and Fagan, 1917. U. S. Natl. Mus., Proc. 53: 369.

Type-species: Kleidotoma hexatoma Thomson. Orig. desig.

californica Kieffer. Calif.

Kleidotoma (Hexacola) califomica Kieffer, 1908. Soc. Sci. Bruxelles, Ann. 32: 62. ठ, १.

\section{Genus KLEIDOTOMA Subgenus HEPTAMERIS Foerster}

Heptameris Foerster, 1869. Zool.-Bot. Gesell. Wien, Verh. 19: 342, 350.

Type-species: Eucoela pygmaea Dahlbom. Monotypic. 
oscinidis (Ashmead). Ohio. Host: Oscinella sp. in wheat stems.

Heptameris oscinidis Ashmead, 1893. Ohio Agr. Expt. Sta., Tech. Ser., Bul. 1(3): 159. 9.

\section{UNPLACEd SPECIES in Kleidotoma Westwood}

avenae (Fitch). N. Y. Ecology: Captured in grain field.

Allotria Avence Fitch, 1861(1860). N. Y. State Agr. Soc. Trans. 20: 842. ठै.

carolinensis Kieffer. "Carolina."

Kleilotoma carolinensis Kieffer, 1910. Lab. Zool. Gen. e Agr. Portici, Bol. 4: 334. ठ̊.

rufitarsis (Ashmead). Kans. (Riley Co.).

Copterencoilia(!) rufitarsis Ashmead, 1888. Kans. Agr. Expt. Sta., Bul. 3: App. p. I. 9.

\section{Genus HEXACOLA Foerster}

Hexucola Foerster, 1869. Zool.-Bot. Gesell. Wien, Verh. 19: 342, 349.

Type-species: Eucoela picicrus Giraud. Monotypic.

Hexuplasta Foerster, 1869. Zool.-Bot. Gesell. Wien, Verh. 19: 345, 359.

Type-species: Cothonaspis hexatoma Hartig. Orig. desig.

Taxonomy: Weld, 1962 (1961). Ent. Soc. Wash., Proc. 63: 280.

hexatoma (Hartig). Va.; Europe. Prob. introduced with its host. Host: Oscinella frit (L.).

Cothonaspis hexatoma Hartig, 1841. Ztschr. f. Ent. 3: 357..

subaperta (Kieffer). Pa. (Jeannette).

Ganaspis subaperta Kieffer, 1907. Ent. Ztschr. Stuttgart 21: 131. \&.

websteri (Crawford). Kans. (Wellington). Host: Euxesta nitidiventris Loew.

Hexaplaste websteri Crawford, 1915. U. S. Nat. Mus., Proc. 48: 582. १.

\section{Genus EUTRIAS Foerster}

Eutrias Foerster, 1869, Zool.-Bot. Gesell. Wien, Verh. 19: 344, 357.

Type-species: Eucoela tritoma Thomson. Monotypic.

tritoma (Thomson). Tex. Introduced from Europe. Host: Sepsidae in cow dung.

Eucoela tritoma Thomson, 1861. Ofvers. Svensk. Vet.-Akad., Forh. 18: 403. ․

\section{Genus EUCOILA Westwood}

Eucoila Westwood, 1833. Mag. Nat. Hist. 6: 494.

Type-species: Eucoila crassinerva Westwood. Monotypic.

Encoela Agassiz, 1846. Nomencl. Zool. Index Univ., p. 146. Emend.

Psilodora Foerster, 1869. Zool.-Bot. Gesell. Wien, Verh. 19: 348, 354.

Type-species: Cothonas pis boyenii Hartig. Orig. desig.

Lytosema Kieffer, 1901. Feuille Jeunes Nat. (4)31: 162.

Type-species: Eucoila guerini Dahlbom. Desig. by Ashmead, 1903.

atricornis (Kieffer). "Carolina."

Lytosema atricornis Kieffer, 1910. Lab. Zool. Gen. e Agr. Portici, Bol. 4: 330. ठ.

cultra (Girault). Ill. (Urbana).

Psilodora cultra Girault, 1920. U. S. Natl. Mus., Proc. 58: 182..

erythropa (Ashmead). Va. s. to Ga., w. to Mo., Tex. Ecology: Reported on human excrement.

Cothonaspis erythropus. Ashmead, 1888. Kans. Agr. Expt. Sta., Bul. 3: App. p. I. ơ.

hirticornis (Kieffer). $\mathrm{Pa}$.

Lytosema hirticornis Kieffer, 1910. Lab. Zool. Gen. e Agr. Portici, Bol. 4: 330..

impatiens (Say). N. Y., Ill., Tex., N. Mex. Introduced into Hawaii. Host: Sarcophaga sp.,

Haematobia irritans (L.), dung-fly larvae.

Diplolepis impatiens Say, 1836. Boston Jour. Nat. Hist. 1: 267. ठँ.

Kleidotoma cupulifera Provancher, 1881. Nat. Canad. 12: 238. ठै, १.

rufocincta (Kieffer). Western and Southwest. U. S. Host: Maggots in cow dung and blow-fly larvae in carrion.

Psilodora rufocincta Kieffer, 1997. Ent. Ztschr. Stuttgart 21: 131. ơ.

rufoscutata Kieffer. Ark. (Fayetteville).

Encoila rufoscutata Kieffer, 1910. Lab. Zool. Gen. e Agr. Portici, Bol. 4: 332. ठ. 
septemspinosa Gillette. Ill. (Quincy).

Eucoila 7-spinosa Gillette, 1891. Ill. State Lab. Nat. Hist., Bul. 3: 204. ९.

vagabunda (Ashmead). Gulf coast, Fla. to Tex.

Kleidotoma vagabunda Ashmead, 1885. Amer. Ent. Soc., Trans. 12: 302..

\section{Genus APOREUCOELA Kieffer}

Aporeucoela Kieffer, 1908. Soc. Sci. Bruxelles, Ann. 32: 49.

Type-species: A porencoela fuscipes Kieffer. Monotypic.

floridana (Ashmead). Fla. (Archer).

Piezobria floridana Ashmead, 1896. Amer. Ent. Soc., Trans. 23: 185. $\%$.

fuscipes Kieffer. Calif. (Claremont).

Aporeucoela fuscipes Kieffer, 1908. Soc. Sci. Bruxelles, Ann. 32: 49..

\section{Genus TRYBLIOGRAPHA Foerster}

\section{Genus TRYBLIOGRAPHA Subgenus TETRAPLASTA Ashmead}

Tetraplasta Ashmead, 1903. Psyche 10: 68.

Type-species: Tetraplasta unica Ashmead. Orig. desig.

Taxonomy: Weld, 1952. Cynipoidea 1905-1950, p. 220.

bakeriana (Kieffer). Calif. (San Mateo Co.).

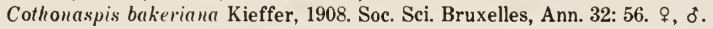

pictipennis (Kieffer). Calif. (Claremont).

Cothonaspis (Tetraplasta) pictipennis Kieffer, 1909. Soc. Hist. Nat. Metz, Bul. 26: 70. o, ㅇ.

\section{Genus TRYBLIOGRAPHA Subgenus PENTAPLASTIDia Weld}

Trybliographa subg. Pentaplastidia Weld, 1951. U. S. Dept. Agr., Agr. Monog. 2, p. 603. Type-species: Cothonaspis (Pentarhoptra) clarimontis Kieffer. Orig. desig.

Taxonomy: Weld, 1951. U. S. Dept. Agr., Agr. Monog. 2, p. 603. clarimontis (Kieffer). Calif. (Claremont).

Cothonaspis (Pentarhoptra) clarimontis Kieffer, 1909. Soc. Hist. Nat. Metz, Bul. 26: 72. .

\section{Genus TRYBLIOGRAPHA Subgenus DIDYCTIUM Riley}

Didyctium Riley, 1879. In Comstock, Rpt. on Cotton Ins., pp. 197-198.

Type-species: Didyctium zigzag Riley. Monotypic.

Didictyum Comstock, 1879. Rpt. on cotton Ins., pp. 214, 500. Emend.

Didictium Weld, 1952. Cynipoidea 1905-1950, p. 221. Emend.

Taxonomy: Weld, 1962 (1961). Ent. Soc. Wash., Proc. 63: 280.

fungicola (Crawford). D. C.

Hexaplasta fungicola Crawford, 1915. U. S. Natl. Mus., Proc. 48: 581. q. lucida (Rohwer). N. Y. (Syracuse).

Hexaplasta lucida Rohwer, 1920. U. S. Natl. Mus., Proc. 57: 219. ठ, ‡.

marlatti (Crawford). Va. (Warrenton).

Hexaplasta marlatti Crawford, 1915. U. S. Natl. Mus., Proc. 48: 580. ठ’, q. minuta (Crawford). Tenn. (Nashville).

Hexaplasta minuta Crawford 1917 (1916). Insecutor Inscitiae Menstruus 4: 101.. zigzag (Riley). Fla., Ala. Host: Megaselia aletine (Comst.).

Didyctium zig-zag Riley, 1879. In Comstock, Rpt. on Cotton Ins., pp. 198, 214, 500. ठ, ๆ.

Taxonomy: Weld, 1962 (1961). Ent. Soc. Wash., Proc. 63: 280.

\section{Genus TRYBLIOGRAPHA Subgenus TRYBLIOGRAPHA Foerster}

Trybliographa Foerster, 1869. Zool.-Bot. Gesell. Wien, Verh. 19: 345, 359.

Type-species: Cothonaspis scutellaris Hartig. Orig. desig. 
Dimicrostrophis Provancher, 1886. Addit. Corr. Faune Ent. Canada Hym., p. 160. No included spp.

Dimicrosthophis(!) Ashmead, 1887. In Provancher, Addit. Corr. Faune Ent. Canada Hym., p. 172.

Type-species: Dimicrostrophis ruficomis Ashmead. First included sp.

Dimicrosthopis Sharp, 1888. Zool. Rec. 24 (Ins.): 204. Emend.

Dusmetiola Tavares, 1924. Broteria, Rev. Luso-Brazil., Ser. Zool. 21: 18.

Type-species: Dusmetiola hispanica Tavares. Monotypic.

fuscostriata (Kieffer). Calif. (San Mateo).

Cothonaspis fuscostriata Kieffer, 1908. Soc. Sei. Bruxelles, Ann. 32: 55. o, \&.

neocera (Kieffer). Pa. (Jeannette).

Cothonaspis (Anectoclis) neocera Kieffer, 1907. Ent. Ztschr. Stuttgart 21: 131. §, f.

rapae (Westwood). Ont., N. Y., N. J., Mich., Ill., Minn., Colo., B. C., Wash. Introduced from

Europe. Host: Hylemya sp.

Eucoila rapae Westwood, 1835. Mag. Nat. Hist. 8: 178 . ठ, ․

Pseudeucoila gillettei Washburn, 1906. Minn. Agr. Expt. Sta., Bul. 100: 8. ๆ.

Biology: Wishart and Monteith, 1954. Canad. Ent. 56: 145-154 (immature stages).

ruficornis (Ashmead). Que. (Cap Rouge).

Dimicrostrophis ruficornis Ashmead, 1887. In Provancher, Addit. Corr. Faune Ent.

Canada Hym., p. 173. + .

\section{Genus TRYBLIOGRAPHA Subgenus Undetermined}

aperta (Kieffer). Calif. (San Mateo Co.).

Eucoila (Rhoptromeris) aperta Kieffer, 1908. Soc. Sci. Bruxelles, Ann. 32: 58. ð.

bakeriana var. nigriventris (Kieffer). Calif. (San Mateo).

Cothonaspis bakeriana var. nigriventris Kieffer, 1909. Soc. Hist. Nat. Metz, Bul. 26: 73. o.

coloradensis (Kieffer). Colo.

Cothonaspis coloradensis Kieffer, 1907. Ent. Ztschr. Stuttgart 21: 136. ठ.

klagesi (Kieffer). Pa. (Jeannette).

Cothonaspis klagesi Kieffer, 1907. Ent. Ztschr. Stuttgart 21: 136. ठे.

melanopa (Ashmead). Ohio. Host: Leucopis sp.

Hexaplasta melanopa Ashmead, 1894. Cincinnati Soc. Nat. Hist., Jour. 17: 40, 45. ठै.

nigricornis (Provancher). Ont. (Ottawa).

Dimicrostrophis nigricomis Provancher, 1888. Addit. Corr. Faune Ent. Canada Hym., p. 436. \&.

\section{Genus PSICHACRA Foerster}

Psichacra Foerster, 1869. Zool.-Bot. Gesell. Wien, Verh. 19: 344, 356.

Type-species: Cothonaspis longicornis Hartig. Monotypic.

laticeps (Kieffer). Nev. (Ormsby Co.).

Encoila (Psichacra) laticeps Kieffer, 1908. Soc. Sci. Bruxelles, Ann. 32: 57..+

troglodytes (Kieffer). Wis. (Polk Co.).

Eucoila (Psichacra) troglodytes Kieffer, 1909. Soc. Hist. Nat. Metz, Bul. 26: 74. ㅇ.

\section{Genus GANASPIS Foerster}

Ganaspis Foerster, 1869. Zool.-Bot. Gesell. Wien, Verh. 19: 334, 355.

Type-species: Ganaspis mundata Foerster. Monotypic.

diastrophi Ashmead. Nebr.

Ganaspis diastrophi Ashmead, 1896. Amer. Ent. Soc., Trans. 23: 184. ठ, १.

nigra (Kieffer). Pa. (Jeannette).

Miteucoela nigra Kieffer, 1907. Ent. Ztschr. Stuttgart 21: 121..

reclusa Kieffer. Calif.

Ganaspis reclusa Kieffer, 1908. Soc. Sei. Bruxelles, Ann. 32: 51.. 


\section{Genus GANASPIDIUM Weld}

Ganaspidium Weld, 1955. Ent. Soc. Wash., Proc. 57: 274.

Type-species: Ganaspidium pusillae Weld. Monotypic.

pusillae Weld. Tex. Host: Liriomyza sp., a serpentine leaf miner on peas.

Ganaspidium pusillae Weld, 1955. Ent. Soc. Wash., Proc. 57: 274. ๆ, o.

\section{Genus HYPOLETHRIA Foerster}

Hypolethria Foerster, 1869. Zool.-Bot. Gesell. Wien, Verh. 19: 343, 354.

Type-species: Encoela melanoptera Hartig. Monotypic.

vitellinipes (Kieffer). Pa. (Jeannette).

Encoela vitellinipes Kieffer, 1907. Ent. Ztschr. Stuttgart 21: 138. ठ.

\section{Genus RHOPTROMERIS Foerster}

Rhoptromeris Foerster, 1869. Zool.-Bot. Gesell. Wien, Verh. 19: 344, 356.

Type-species: Cothonaspis encera Hartig. Orig. desig.

nigroclavata (Kieffer). Pa. (Jeannette).

Eucoela (Rhoptromeris) nigrocla'ate Kieffer, 1907. Ent. Ztschr. Stuttgart 21: 138. o, ๆ.

\section{Genus AGLAOTOMA Foerster}

Aglaotoma Foerster, 1869. Zool.-Bot. Gesell. Wien, Verh. 19: 334, 354.

Type-species: Cothonaspis colrina Hartig. Monotypic.

Cryptencoela Kieffer, 1904. In Andre, Spec. Hym. Eur. Alg., v. 7 bis, p. 618.

Type-species: Cothonaspis codrina Hartig. Desig. by Rohwer and Fagan, 1917.

Aglaotomilea Rohwer and Fagan, 1917. U. S. Natl. Mus., Proc. 53: 360.

Type-species: Aglaotoma foetsteri Kieffer. Orig. desig.

texana Crawford. Tex. (Dallas).

Aglaotoma texana Crawford, 1913. U. S. Natl. Mus., Proc. 45: 309. ठ, ๆ.

\section{Genus PSEUDEUCOILA Ashmead}

\section{Genus PSEUDEUCOILA Subgenus HEXAMEROCERA Kieffer}

Hexamerocera Kieffer, 1901. Feuille Jeunes Nat. (4) 31: 174, 175, 176.

Type-species: Encoila mfiventris Giraud. Desig. by Ashmead, 1903.

maculipes (Ashmead). Fla.

Hexaplasta maculipes Ashmead, 1887. Amer. Ent. Soc., Trans. 4: 152. ‡.

quadripunctata (Kieffer). Calif.

Encoela mexicana Ashmead, 1895. Calif. Acad. Sci., Proc. (2)5: 541. . Preocc. by

Cameron, 1889.

Encoela (Psichacra) quadripunctata Kieffer, 1901. Feuille Jeunes Nat. (4)31: 176. N. name. zimmermanni (Kieffer). "Carolina."

Encoela (Hexamerocera) zimmermanni Kieffer, 1910. Lab. Zool. Gen. e Agr. Portici, Bol. 4: 333. 9.

\section{Genus PSEUDEUCOILA Subgenus PSEUdeUCOILA Ashmead}

Psendéncoila Ashmead, 1903. Ent. Soc. Wash., Proc. 5: 222.

Type-species: Eucoela (Cothonaspis) trichopsila Hartig. Monotypic.

alaskensis (Ashmead). Alaska (Seldovia).

Encoela alaskensis Ashmead, 1902. Wash. Acad. Sci., Proc. 4: 142. ‡.

bochei Weld. Pa., Md., Va., Ohio. Host: Drosophila spp. in decayed fruit.

Psendercoila bochei Weld, 1944. Ent. Soc. Wash., Proc. 46: 65. \&, ठ.

Biology: Weld, 1944. Ent. Soc. Wash., Proc. 46: 65-66. -Jenni, 1951. Acta Zool. 32: 177.

- Bakker et al., 1967. Ent. Expt. et Appl. 10: 295. - Meyer-Grassmann, 1967. Rev. Suisse de Zool. 74: 411. - Streams, 1968. Ent. Soc. Amer., Ann. 61: 158-164. 
hunteri (Crawford). Tex. (Dallas). Host: Liriomyza sp., a cotton leaf miner.

Encoila hunteri Crawford, 1913. U. S. Natl. Mus., Proc. 45: 310.

stigmata (Say). Mass., N. Y., N. J., D. C., Va., Ind., Ill., Canada.

Diplolepis stigmata Say, 1836. Boston Jour. Nat. Hist. 1: 268. \&.

Kleidotoma maculipennis Provancher, 1881. Nat. Canad. 12: 237. §.

\section{Genus PSEUdeUCOILA Subgenus MACROCEREUCOILA Ashmead}

Macrocerencoila Ashmead, 1887. Amer. Ent. Soc., Trans. 14: 153.

Type-species: Macrocerencoila longicornis Ashmead. Monotypic.

ashmeadiana (Dalla Torre and Kieffer). Fla.

Macrocerencoila longicorn is Ashmead, 1887. Amer. Ent. Soc., Trans. 14: 153. đ. Preoce. by Hartig, 1840.

Eucoela (Mucrocerencoela(!)) Ashmeadiana Dalla Torre and Kieffer, 1902. In Wytsman, Gen. Ins., fasc. 9, p. 26. N. name.

Encoila (Macrocereucoila) ashmeadi Dalla Torre and Kieffer, 1910. Das Tierreich, v. 24, p. 181.

\section{Genus PSEUDEUCOILA Subgenus Undetermined}

bruneocineta (Kieffer). Pa. (Jeannette).

Eucoela bruneocincta Kieffer, 1907. Ent. Ztschr. Stuttgart 21: 138. ठ.

clavatipalpis (Kieffer). Ont. (Toronto).

Encoela claratipalpis Kieffer, 1907. Ent. Ztschr. Stuttgart 21: 138. ठ.

mellipes (Say). Ont., Ind., Ill.

Figites mellipes Say, 1836. Boston Jour. Nat. Hist. 1: 269. ․

Kleidotoma minima Provancher, 1883. Nat. Canad. 14: 20..

nigrimanus (Kieffer). Calif. (Claremont).

Eucoela nigrimanus Kieffer, 1907. Ent. Ztschr. Stuttgart 21: 138. đ.

nudicollis (Kieffer). Wis. (Polk Co.).

Eucoila (Eucoila) nudicollis Kieffer, 1909. Soc. Hist. Nat. Metz, Bul. 26: 74. ठ.

pedata (Say). Ind.

Diplolepis pedata Say, 1836. Boston Jour. Nat. Hist. 1: 267. ठ.

rubripes (Ashmead). Fla. (Jacksonville).

Eucoila rubripes Ashmead, 1887. Amer. Ent. Soc., Trans. 14: 153. o.

siphonophorae (Ashmead). Fla. (Jacksonville).

Eucoila siphonophorae Ashmead, 1887. U. S. Dept. Agr., Div. Ent., Bul. 14: 21. ð. xystiformis (Ashmead). Fla. (Jacksonville).

Dimicrostroph is xystiform is Ashmead, 1887. Amer. Ent. Soc., Trans. 14: 153. o'.

\section{Genus COTHONASPIS Hartig}

Cothonaspis Hartig, 1840 (1839). Ztschr. f. Ent. 2: 186.

Type-species: Cothonaspis pentatomus Hartig. Desig. by Foerster, 1869.

Psilosema Kieffer, 1901. Feuille Jeunes Nat. (4)31: 160.

Type-species: Cothonaspis pentatoma Giraud. Desig. by Rohwer and Fagan, 1917.

The type-species of this genus, Cothonaspis pentatoma Giraud, 1860, is a homonym of Cothonaspis pentatoma Hartig, 1840, and was renamed giraudi by Dalla Torre and Kieffer, 1910.

americana (Girault). Ill. (Urbana).

Microstilba americana Girault, 1920. U. S. Natl. Mus., Proc. 58: 182. \&.

pratti (Crawford). Tex. (Dallas).

Psilosema pratti Crawford, 1913. U. S. Natl. Mus., Proc. 45: 310. \&, ठ.

Genus EUCOILIDEA Ashmead

Eucoilidea Ashmead, 1887. Amer. Ent. Soc., Trans. 14: 154.

Type-species: Eucoilidea canadensis Ashmead. Desig. by Ashmead, 1903. 
Eucoelidea Dalla Torre, 1893. Cat. Hym., v. 2, p. 15. Emend.

arcuata Kieffer. Wis. (Polk Co.).

Eucoelidia(!) arcuata Kieffer, 1909. Soc. Hist. Nat. Metz., Bul. 26: 65. ठ, ๆ.

canadensis Ashmead. Que. (Cap Rouge).

Eucoilidea canadensis Ashmead, 1887. Amer. Ent. Soc., Trans. 14: 154..

crenulata Kieffer. Colo. (Gunnison).

Encoilidea cremulata Kieffer, 1908. Soc. Sci. Bruxelles, Ann. 32: 47. \&.

fuscipes Kieffer. Calif. (Claremont).

Eucoilidia(!) fuscipes Kieffer, 1907. Ent. Ztschr. Stuttgart 21: 112. ठ.

longicornis Ashmead. Fla. (Jacksonville).

Eucoilidea longicornis Ashmead, 1887. Amer. Ent. Soc., Trans. 14: 154. ठో.

rufipes Gillette. Ill. (Morris).

Eucoilidea rufipes Gillette, 1891. Ill. State Lab. Nat. Hist., Bul. 3: 205..

\section{Family ALLOXYSTIDAE}

Parasites of braconid or chalcidoid primary parasites of aphids or other HemipteraHomoptera.

Taxonomy: Fallen, 1963. Fauna Fenn. 15: 3-23.

\section{Genus LYTOXYSTA Kieffer}

Lytoxysta Kieffer, 1909. Naturw. Ztschr. f. Forst. u. Landw. 7: 479.

Type-species: Lytoxysta brevipalpis Kieffer. Desig. by Rohwer and Fagan, 1917.

brevipalpis Kieffer. Mass., Ohio, Ark., Idaho, Utah.

Lytoxysta brevipalpis Kieffer, 1909. Naturw. Ztschr. f. Forst. u. Landw. 7: 480. \&.

Taxonomy: Weld, 1939. Ent. Soc. Wash., Proc. 41: 53 (male).

brevipalpis var. nigra Kieffer. Ark.

Lytoxysta brevipalpis var. nigra Kieffer, 1909. Naturw. Ztschr. f. Forst. u. Landw. 7: 480. ․

\section{Genus ALLOXYSTA Foerster}

Allotria Westwood, 1833. Mag. Nat. Hist. 6: 494. Preocc. by Huebner, 1823.

Type-species: Allotria victrix Westwood. Monotypic.

Xystus Hartig, 1840 (1839). Ztschr. f. Ent. 2: 186. Preocc. by Schoenherr, 1826.

Type-species: Xystus erythrocephalus Hartig. Desig. by Rohwer and Fagan, 1917.

Alloxysta Foerster, 1869. Zool.-Bot. Gesell. Wien, Verh. 19: 338, 340.

Type-species: Xystus macrophadnus Hartig. Monotypic.

Pezophycta Foerster, 1869. Zool.-Bot. Gesell. Wien, Verh. 19: 338, 339.

Type-species: Xystus brachypterus Hartig. Orig. desig.

Nephycta Foerster, 1869. Zool.-Bot. Gesell. Wien, Verh. 19: 338, 339.

Type-species: Nephycta discreta Foerster. Orig. desig.

abdominalis Baker. Colo. (Ft. Collins).

Alloxysta abdominalis Baker, 1896. Canad. Ent. 28: 135..

affinis (Baker), Colo. (Ft. Collins).

Dylita(!) affïis Baker, 1896. Canad. Ent. 28: 132. ‡.

alaskensis Ashmead. Alaska (Muir Inlet, St. Paul Is.).

Alloxysta alaskensis Ashmead, 1902. Wash. Acad. Sci., Proc. 4: 142. o, ๆ.

ambrosiae (Ashmead). Mass. (Cambridge).

Allotria ambrosiae Ashmead, 1897. Ent. Soc. Wash., Proc. 4: 149, 156. \&.

apicalis Baker. Colo. (Ft. Collins).

Alloxysta apicalis Baker, 1896. Canad. Ent. 28: 135. ․

areolata (Kieffer), n. comb. Mass. (Forest Hills).

Charips areolata Kieffer, 1909. Naturw. Ztschr. f. Forst. u. Landw. 7: 481. ठ, \&. 
bakeri (Kieffer), n. comb. Calif. (San Mateo).

Allotria bakeri Kieffer, 1907. Ent. Ztschr. Stuttgart 21: 162. \&.

bicolor (Baker). Colo. (Ft. Collins).

Dylita(!) bicolor Baker, 1896. Canad. Ent. 28: 132. @.

brassicae (Ashmead), n. comb. N. Y., Fla., Mich., Mo., N. Dak., Ariz., Calif.

Allotria brissicue Ashmead, 1887. U. S. Dept. Agr., Div. Ent., Bul. 14: 14. ‡, ठ์.

coloradensis (Baker). Colo. ( $\mathrm{Ft}$. Collins).

Dylita(!) colorulensis Baker, 1896. Canad. Ent. 28: 133. §.

gracilis Baker. Colo. (Ft. Collins).

Alloxystu grucilis Baker, 1896. Canad. Ent. 28: 134. ․

hayhursti (Kieffer), n. comb. Mass. (Forest Hills).

Churips huyhursti Kieffer, 1909. Naturw. Ztschr. f. Forst. u. Landw. 7: 481. ठ, ?.

lachni (Ashmead). Fla.

Allotria lachini Ashmead, 1885. Amer. Ent. Soc., Trans. 12: 297, 302. 8, ?.

leguminosa (Weld), n. comb. Idaho, Utah, Oreg. Host: Aphelinus lapisligui How. in Roepkea bukeri (Cowen).

Charips (Charips) leyuminosa Weld, 1920. Ent. News 31: 15. ๆ, ठ.

longiventris Baker. Colo. (Ft. Collins).

Alloxysta longiventris Baker, 1896. Canad. Ent. 28: 134..

magna Baker. Colo. (Ft. Collins).

Alloxysta mulymu Baker, 1896. Canad. Ent. 28: 134. ๆ.

megourae (Ashmead). Fla. (Jacksonville). Ecology: Reared from tomato aphis.

Allotrit meyourte Ashmead, 1887. U. S. Dept. Agr., Div. Ent., Bul. 14: 19. ?.

robusta Baker. Colo. (Ft. Collins).

Alloxysta robusta Baker, 1896. Canad. Ent. 28: 133. . .

ruficeps (Baker). Colo. (Ft. Collins).

Dylitu(!) rufictes Baker, 1896. Canad. Ent. 28: 132. ?.

rufipleura Baker. Colo. (Ft. Collins).

Alloxysta rufipleura Baker, 1896. Canad. Ent. 28: 135. ठ.

similis (Baker). Colo. (Ft. Collins).

Dylite(!) similis Baker, 1896. Canad. Ent. 28: 133. ¿.

tritici (Fitch). N. Y., N. J., D. C., Va., N. C., Ohio, Ind: Ecology: Reared from Schizaphis gramiunm (Rond.). Host: Aphidius nigripes (Ashmead).

Allotria tritici Fitch, 1861 (1860). N. Y. State Agr. Soc., Trans. 20: 841. \&.

vagans Kieffer. Mass. (Forest Hills). Ecology: Reared from Hyalopteroides humilis (Walk.).

Alloxysta vagan. Kieffer, 1909. Naturw. Ztschr. f. Forst. u. Landw. 7: 480. @.

victrix (Westwood). Greenland; Europe.

Allotria victrix Westwood, 1833. Mag. Nat. Hist. 6: 495 . .

xanthopsis (Ashmead). Fla., Calif.

Allotria xauthopsis Ashmead, 1896. Amer. Ent. Soc., Trans. 23: 185. oे.

\section{Genus DILYTA Foerster}

Dilyta Foerster, 1869. Zool.-Bot. Gesell. Wien, Verh. 19: 338, 340.

Type-species: Dilyta subclavata Foerster. Orig. desig.

Charips Marshall, 1870. Ent. Monthly Mag. 6: 181.

Type-species: Charips microcera Marshall. Monotypic.

Glyptoxysta Thomson, 1877. Opusc. Ent., v. 8, pp. 811, 814.

Type-species: Glyptoxysta heterocera Thomson. Desig. by Ashmead, 1903.

necans (Kieffer), n. comb. Mass. (Forest Hills).

Glyptoxysta necans Kieffer, 1909. Naturw. Ztschr. f. Forst. u. Landw. 7: 481. ๆ.

\section{Genus HEMICRISIS Foerster}

Hemicrisis Foerster, 1869. Zool.-Bot. Gesell. Wien, Verh. 19: 338, 339.

Type-species: Hemicrisis ruficom is Kieffer. Monotypic. 
brevicornis Kieffer. Nev. (Ormsby Co.).

Hemicrisis brevicomis Kieffer, 1907. Ent. Ztschr. Stuttgart 21: 162. o.

nevadensis Kieffer. Nev. (Ormsby Co.).

Hemicrisis nevadensis Kieffer, 1907. Ent. Ztschr. Stuttgart 21: 162..

\section{Genus PHAENOGLYPHIS Foerster}

Phaenoglyphis Foerster, 1869. Zool.-Bot. Gesell. Wien, Verh. 19: 338.

Type-species: Phaenoglyphis xanthochroa Foerster. Monotypic.

Auloxysta Thomson, 1877. Opuse. Ent., v. 8, p. 811.

Type-species: Auloxysta nigripes Thomson. Desig. by Ashmead, 1903.

Bothrioxysta Kieffer, 1902. Soc. Hist. Nat. Met2, Bul. (2) 10: 11.

Type-species: Auloxysta nigripes Thomson. Desig. by Rohwer and Fagan, 1917.

americana Baker. Colo. (Ft. Collins).

Phaenoglyphis americana Baker, 1896. Canad. Ent. 28: 131. o.

\section{Family CYNIPIDAE}

All the species of this family inhabit plants, either as gall-makers or as inquilines. The latter develop in galls produced by other Cynipidae, by Chalcidoidea, or by Diptera. The first subfamily, Synerginae, contains only inquilines, or as often designated in cynipid literature, guests. The second subfamily, Cynipinae, is composed entirely of gall producing species.

The arrangement of genera and species used here is based on the published papers of the late L. H. Weld, his unpublished notes, and his arrangement of the U.S. N. M. collection. The nomenclature used here may or may not agree with that used by Felt in his 1940 publication, Plant Galls and Gall Makers, 364 pp. All evidence is that Mr. Weld thoroughly considered Felt's nomenclature before he prepared the Cynipidae section of the 1951 Hymenoptera Catalog.

As was done in the 1951 Hymenoptera Catalog, two large papers by A. C. Kinsey are cited as separate publications. This is done primarily because those works were widely distributed by Kinsey as separate volumes. The complete references for them are as follows: Kinsey, 1930. The Gall Wasp Genus Cynips, Ind. Univ. Studies $16(84,85,86)$ : 1-577, June, Sept., Dec. 1929, issued Feb. 1930. (Waterman Inst. Sci. Res. Pub. 42; Contrib. Dept. Zool., Ind. Univ. No. 220, Ent. Ser. No. 7). Kinsey, 1936. The Origin of Higher Categories in Cynips, Ind. Univ. Pubs., Sci. Ser. No. 4: 1-334, issued Nov. 1936. (Contrib. Dept. Zool., Ind. Univ. No. 242, Ent. Ser. No. 10).

\section{SUBFAMILY SYNERGINAE}

All members of this subfamily develop as inquilines, or guests, in galls on various plants. Although all the species of this subfamily emerge from galls, in no instance do they induce the formation of the galls. There is, however, evidence that some inquilines cause slight changes in the structure of the galls they inhabit. Their entire development occurs in galls induced by members of the subfamily Cynipinae, some chalcidoids, or the dipterous gall makers in the family Cecidomyiidae. It often occurs, however, that so many inquilines emerge from the galls, and so few of the gall-makers emerge (in some instances no gall-makers emerge), that it is easy to misjudge the habits of the inquilines. As a matter of fact, some of the inquilines have been described as gall-makers, but in no instance is that true. Mani, 1964, (Ecology of Plant Galls, pp. 236-238), gives a summary of the existing literature on cynipid inquilines.

The subfamily name Synerginae was first proposed by Ashmead, 1896, (Amer. Ent. Soc., Trans. 23: 186). This group somewhat corresponds to the "Group Inquilinae" proposed by Hartig, 1840, (Ztschr. f. Ent. 2: 197). Hartig's name Inquilinae is not available for use because it is not based on a generic name in the Cynipidae. Actually, Hartig's name Inquilinae was a descriptive term that meant "Einmieter" or lodger.

\section{Genus SAPHONECRUS Dalla Torre and Kieffer}

Saphouecrus Dalla Torre and Kieffer, 1910. Das Tierreich, Lief. 24, p. 605.

Type-species: Synergus connatus Hartig. Orig. desig.

Guests in galls on oak. 
brevicornis (Ashmead). Calif.

Synergus brevicornis Ashmead, 1896. Amer. Ent. Soc., Trans. 23: 189. \&, ठ.

Taxonomy: Weld, 1952. U. S. Natl. Mus., Proc. 102: 315.

brevis Weld. N. Mex., Ariz. Host: Andricus ruginosus Bassett gall.

Saphonecrus brevis Weld, 1926. U. S. Natl. Mus., Proc. 68(10): 109. ९, ð.

favanus Weld. D. C., Mo. Host: Dryocosmus favus Beutenmueller gall.

Saphonecrus favanus Weld, 1944. U. S. Natl. Mus., Proc. 95: 1. \&, ð.

gemmariae (Ashmead). Fla. Host: Callirhytis quercusgemmaria (Ashmead) gall.

Sapholytus gemmarice Ashmead, 1885. Amer. Ent. Soc., Trans. 12: 297, 302. ð.

\section{Genus SYNERGUS Hartig}

Synergus Hartig, 1840 (1839). Ztschr. f. Ent. 2: 186.

Type-species: Synergus vulgaris Hartig. Desig. by Foerster, 1869.

Sapholytus Foerster, 1869. Zool.-Bot. Gesell. Wien, Verh. 19: 332, 337.

Type-species: Synergus apicalis Hartig. Monotypic.

Guests in galls on oak.

agrifoliae Ashmead. Calif. Host: Neurotems saltatorius (Edwards) gall.

Synergus agrifolicie Ashmead, 1896. Amer. Ent. Soc., Trans. 23: 189. ․, ઠ์.

Synergus maculatus Fullaway, 1911. Ent. Soc. Amer., Ann. 4: 371. @, ठ.

Symergus obscurus McCracken and Egbert, 1922. Stanford Univ., Pubs., Univ. Ser. Biol.

Sci. 3(1): 57. .

Taxonomy: Weld, 1952. U. S. Natl. Mus., Proc. 102: 337.

atra Gillette. Colo. Host: Disholcaspis mbens (Gillette) gall.

Synergus atra Gillette, 1896. Amer. Ent. Soc., Trans. 23: 86. + , ठ.

atripennis Ashmead. Fla. Host: Disholcaspis spongiosa (Karsch) gall.

Synergus atripennis Ashmead, 1896. Amer. Ent. Soc., Trans. 23: 189. ․

atripes Gillette. Colo. Host: Atrusca brevipennata (Gillette) gall.

Synergus atripes Gillette, 1896. Amer. Ent. Soc., Trans. 23: 90, 96. \&, ठ.

batatoides Ashmead. Fla. Host: Callirhytis quercusbatoides (Ashmead) gall.

Synergus batatoides Ashmead, 1885. Amer. Ent. Soc., Trans. 12: 297, 301. \&, ठ.

bellus McCracken and Egbert. Calif.

Synergus bellus McCracken and Egbert, 1922. Stanford Univ., Pubs., Univ. Ser. Biol. Sci. 3(1): 54 . $ค$, ठ .

bicolor Ashmead. Fla. Host: Andricus quercusfoliatus (Ashmead) gall.

Syuergus bicolor Ashmead, 1885. Amer. Ent. Soc., Trans. 12: 297, 302. ๆ, ठ.

campanula Osten Sacken. N. Y., N. J., D. C., Ill., Wis. Host: Disholcaspis quercusglobulus

(Fitch) gall.

Synergus campanula Osten Sacken, 1865. Ent. Soc. Phila., Proc. 4: 376..

castanopsidis (Beutenmueller). Calif. Host: Dryocosmus castanopsidis (Beutenmueller) gall.

Periclistus castanopsidis Beutenmueller, 1918. Ent. News 29: 251. ?.

citriformis (Ashmead). Fla. Host: Amphibolips quercuscitriformis (Ashmead) gall.

Ceroptres citriform is Ashmead, 1885. Amer. Ent. Soc., Trans. 12: 300. ?, ठ.

confertus McCracken and Egbert. Calif. Host: Andricus confertus McCracken and Egbert gall.

Synergus confertus McCracken and Egbert, 1922. Stanford Univ., Pubs., Univ, Ser. Biol.

Sci. 3(1): 55. \&, o.

coniferae Ashmead. Fla. Host: Callirhytis quercusventricosa (Bassett) gall.

Synergus coniferae Ashmead, 1885. Amer. Ent. Soc., Trans. 12: 297, 301. ๆ, ơ.

davisi (Beutenmueller). N. J. Host: Callirhytis querensgemmaria (Ashmead) gall.

Andricus darisi Beutenmueller, 1907. Amer. Mus. Nat. Hist., Bul. 23: 463. ๆ, ठ.

digressus McCracken and Egbert. Calif.

Synergus digressus McCracken and Egbert, 1922. Stanford Univ., Pubs., Univ. Ser. Biol. Sci. 3(1): 52. ๆ, ठ. 
dimorphus Osten Sacken. D. C.

Symergus dimorphus Osten Sacken, 1865. Ent. Soc. Phila., Proc. 4: 376. ๆ, o.

distinctus McCracken and Egbert. Calif. Host: Disholcaspis canescens (Bassett) gall.

Syuergus distinctus McCracken and Egbert, 1922. Stanford Univ., Pubs., Univ. Ser. Biol.

Sci. 3(1): 58. ㅇ, o.

dorsalis (Provancher). Calif.

Ceroptres dorsalis Provancher, 1888. Addit. Corr. Faune Ent. Canada Hym., p. 298. $q$, ठ.

duricoria Gillette. Del. Host: Disholcaspis quercusmamma (Walsh) gall.

Synergus duricoria Gillette, 1896. Amer. Ent. Soc., Trans. 23: 90, 93. ‡.

erinacei Gillette. N. Y., Iowa.

Syuergus erinacei Gillette, 1896. Amer. Ent. Soc., Trans. 23: 90, 94. \%, o.

ficigerae Ashmead. Fla. Host: Disholcaspis quercusvirens (Ashmead) gall.

Synergus ficigerae Ashmead, 1885. Amer. Ent. Soc., Trans. 12: 297, 301. $९$, o.

flavens McCracken and Egbert. Calif. Host: Heteroecus flaweus (McCracken and Egbert) gall. Syuergus flacens MeCracken and Egbert, 1922. Stanford Univ., Pubs., Univ. Ser. Biol. Sci. 3(1): 55 . 9 .

flavus Kieffer. Calif. Host: Callirhytis quercuspomiformis (Bassett) gall. Syuergus fluvus Kieffer, 1904. Soc. Hist. Nat. Metz, Bul. (2) 11: 133. \&, o.

garryana Gillette. Wash., Oreg. Host: Disholcaspis eldoradensis (Beutenmueller) gall.

Synergus garryana Gillette, 1893. Canad. Ent. 25: 110., ,

incisus Gillette. Colo. Host: Callirhytis frequents (Gillette) gall.

Synergus incisus Gillette, 1896. Amer. Ent. Soc., Trans. 23: 90, 92. , ठ.

laeviventris (Osten Sacken). D. C. Host: Amphibolips quercusspongifica (Osten Sacken) gall. Synophrus laevireutris Osten Sacken, 1861. Ent. Soc. Phila., Proc. 1: 57. ․

lignicola (Osten Sacken). D. C., N. Y., Mich., Ind. Host: Callirhytis comigera (Osten Sacken), Callirhytis quercuspunctata (Bassett) galls.

Cynips (Syuerges!) liguicola Osten Sacken, 1862. Ent. Soc. Phila., Proc. 1: 252. ‡, ¿.

Synerges(!) rhoditiformis Walsh, 1864. Ent. Soc. Phila., Proc. 2: 499. ๆ, ठ.

magnificus Weld. Calif. Host: Disholeaspis trnckeensis (Ashmead) gall.

Syuergus magnificus Weld, 1957. U. S. Natl. Mus., Proc. 107: 107. ₹, ठ.

magnus Gillette. Mich. Host: Amphibolips cookii Gillette gall.

Synergus magnus Gillette, 1891. Ill. State Lab. Nat. Hist., Bul. 3: 202. .

medullae Ashmead. Fla. Host: Callirhytis quercusmedullae (Ashmead) gall.

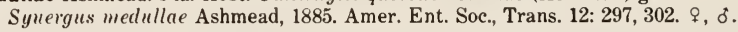

mendax Walsh. Ill. Host: Callirluytis quercuspunctata (Bassett) gall.

Synerges(!) mendax Walsh, 1864. Ent. Soc. Phila., Proc. 2: 498. ㅇ.

multiplicatus Fullaway. Calif. Host: Audricus chrysolepidicola (Ashmead) gall.

Syuergus multiplicatus Fullaway, 1911. Ent. Soc. Amer., Ann. 4: 370. + , o.

niger Fullaway. Calif.

Syuergus uiger Fullaway, 1911. Ent. Soc. Amer., Ann. 4: 369. , ठ.

nigroornatus McCracken and Egbert. Calif. Host: Heteroecus pacificus (Ashmead) gall.

Syuergus uigro-ornatus McCracken and Egbert, 1922. Stanford Univ., Pubs., Univ. Ser.

Biol. Sci. 3(1): 57. ๆ, o.

obtusilobae (Ashmead). Fla.

Ceroptres ohtusilobae Ashmead, 1885. Amer. Ent. Soc., Trans. 12: 300. ๆ.

ochreus Fullaway. Calif. Host: Callirhytis quercusponiform is (Bassett) gall.

Syuergus ochreus Fullaway, 1911. Ent. Soc. Amer., Ann. 4: 368..

oneratus oneratus (Harris). Mass., N. Y., N. J., D. C., Mich., Ill., Iowa. Host: Dicholcaspis quercusglobulus (Fitch), Adleria quercusstrobilaua (Osten Sacken) galls.

Cymips oneratus. Harris, 1841. Rpt. Ins. Mass. Injurious to Veg., p. 398.

oneratus coloradensis Gillette. Colo. Host: Disholcaspis rubens (Gillette), Atrusca brevipennata (Gillette) galls.

Syuergus oneratus var. coloradeusis Gillette, 1896. Amer. Ent. Soc., Trans. 23: 90. १, ठ. 
pacificus McCracken and Egbert. Calif. Host: Heteroecus pacificus (Ashmead) gall.

Synergus pacificus McCracken and Egbert, 1922. Stanford Univ., Pubs., Univ. Ser. Biol. Sci. 3(1): 56. o, ?.

pomiformis (Ashmead). Calif. Host: Callihytis quercuspomiformis (Bassett) gall.

Ceroptres pomiform is Ashmead, 1885. Amer. Ent. Soc., Trans. 12: 300. ơ.

profusus McCracken and Egbert. Calif. Host: Disholcaspis canescens (Bassett) gall.

Synergus profusus: McCracken and Egbert, 1922. Stanford Univ., Pubs., Univ. Ser. Biol.

Sci. 3(1): 59. \&, $\delta$.

punctatus Gillette. Colo. Host: Disholcuspis rubens (Gillette), Xanthoteras ebumeum (Bassett) galls.

Synergus punctata Gillette, 1896. Amer. Ent. Soc., Trans. 23: 90, 94. \&, ơ.

quercuslana (Fitch). N. Y., Iowa. Host: Andricus quercusflocci (Walsh) gall.

Cynips Quercus-lana Fitch, 1859 (1858). N. Y. State Agr. Soc., Trans. 18: 814..

reniformis McCracken and Egbert. Host: Andricus reniformis McCracken and Egbert gall.

Symergus reniformis McCracken and Egbert, 1922. Stanford Univ., Pubs., Univ. Ser. Biol. Sci. 3(1): 53. \&, ठ์.

rutulus McCracken and Egbert. Calif. Host: Disholcaspis plumbella Kinsey gall.

Symergus rutulus MeCracken and Egbert, 1922. Stanford Univ., Pubs., Univ. Ser. Biol. Sci. 3(1): 60. .

similis Gillette. Colo. Host: Atrusca brevipenuata (Gillette) gall.

Syuergus similis Gillette, 1896. Amer. Ent. Soc., Trans. 23: 90, 92..

splendidus Fullaway. Calif. Host: Callirhytis quercuspomifomnis (Bassett) gall.

Syuergus splendidus Fullaway, 1911. Ent. Soc. Amer., Ann. 4: 369. $९$.

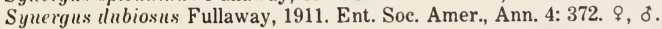

succinipedis (Ashmead). Fla. Host: Disholcaspis quercussuccinipes (Ashmead) gall.

Ceroptres succinipedis Ashmead, 1885. Amer. Ent. Soc., Trans. 12: 300. ९.

varicolor Fullaway. Calif. Host: Callirhytis quercuspomiformis (Bassett) gall.

Syuergus varicolor Fullaway, 1911. Ent. Soc. Amer., Ann. 4: 371. ९, ठ.

variegatus McCracken and Egbert. Calif. Host: Heteroecus pacificus (Ashmead) gall.

Syuergus variegatus MeCracken and Egbert, 1922. Stanford Univ., Pubs., Univ. Ser. Biol.

Sci. 3(1): 51. ๆ, ठ์.

villosus Gillette. Mich. Host: Acraspis villosa (Gillette) gall.

Syuergus villosus Gillette, 1891. Ill. State Lab. Nat. Hist., Bul. 3: 202. \&.

virentis (Ashmead). Fla. Host: Belonocnewna quercusvirens (Osten Sacken) gall.

Ceroptres virentis Ashmead, 1885. Amer. Ent. Soc., Trans. 12: 300. 9.

walshii Gillette. Ill.

Synophrus albipes Walsh, 1864. Ent. Soc. Phila., Proc. 2: 479, 496. ‡, ठ. Preoce. by Hartig, 1841.

Syuergus walshii Gillette, 1896. Amer. Ent. Soc., Trans. 23: 97. N. name.

\section{Genus SYNOPHRUS Hartig}

Synophrus Hartig, 1843. Ztschr. f. Ent. 4: 411.

Type-species: Symophrus politus Hartig. Monotypic.

mexicanus (Gillette). N. Mex.

Syuergus mexicana Gillette, 1896. Amer. Ent. Soc., Trans. 23: 90, 96. ₹.

\section{Genus SYNOPHROMORPHA Ashmead}

Syuophromorpha Ashmead, 1903. Psyche 10: 145.

Type-species: Synophromorpha salicis Ashmead. Orig. desig.

Guests in galls on $R u b u s$ and Rosa. Unfortunately the type-species of this genus, $S$. salicis Ashmead, is from an unknown locality and its host was supposed to be a dipterous gall-maker on Salix. The type of salicis has not been located and probably does not exist.

Taxonomy: Weld, 1952. Cynipoidea 1905-1950, p. 266. 
rubi Weld. Ill. Host: Diastrophus cuscutaeformis (Osten Sacken) gall.

Synophromorpha rubi Weld, 1952. U. S. Natl. Mus., Proc. 102: 317. ९, ठ.

sylvestris (Osten Sacken). Conn., Ont., N. Y., N. J., D. C., Mich. Host: Diplolepis ignota (Osten Sacken) gall.

Synophrus sylvestris Osten Sacken, 1861. Stettin Ent. Ztg. 22: 415. ९.

Taxonomy: Weld, 1952. U. S. Natl. Mus., Proc. 102: 316.

terricola Weld. D. C., Va. Host: Diastrophus bassetti Beutenmueller, D. radicum Bassett galls. Synophromorpha terricola Weld, 1952. U. S. Natl. Mus., Proc. 102: 316. ๆ, ठ์.

\section{Genus PERICLISTUS Foerster}

Periclistus Foerster, 1869. Zool.-Bot. Gesell. Wien, Verh. 19: 332, 337.

Type-species: Aylax caninae Hartig. Monotypic.

Guests in galls on roses.

arefactus McCracken and Egbert. Calif. Host: Diplolepis arefacta (Gillette) gall.

Periclistns arefactus McCracken and Egbert, 1922. Stanford Univ., Pubs., Univ. Ser. Biol.

Sci. 3(1): 62 . $९$, ठ.

californicus Ashmead. Calif. Host: Diplolepis polita (Ashmead) gall.

Periclistus californicuss Ashmead, 1896. Amer. Ent. Soc., Trans. 23: 188. \&, ठ.

obliquus Provancher. Calif.

Periclistus obliquus Provancher, 1888. Addit. Corr. Faune Ent. Canada, Hym. p. 397..

piceus Fullaway. Calif. Host: Diplolepis polita (Ashmead) gall.

Periclistus piceus Fullaway, 1911. Ent. Soc. Amer., Ann. 4: 374. \&, ठ.

pirata (Osten Sacken). D. C. Host: Diplolepis ignota (Osten Sacken) gall.

Aulax pirata Osten Sacken, 1863. Ent. Soc. Phila., Proc. 2: 42., , ১.

Rhodites globulns Beutenmueller, 1892. Amer. Mus. Nat. Hist., Bul. 4: 247. ๆ, ठ.

semipiceus (Harris). Mass. Host: Diplolepis sp., galls on rose roots.

Cynips semipiceus Harris, 1841. Rpt. Ins. Mass. Injurious to Veg., p. 400. $\uparrow, \delta$.

smilacis Ashmead. Fla. Host: Diastrophus smilacis Ashmead gall. Host may be incorrect.

Periclistus smilacis Ashmead, 1896. Amer. Ent. Soc., Trans. 23: 188. ९, ठ.

\section{Genus MYRTOPSEN Rubsaamen}

Myrtopsen Rubsaamen, 1908. Marcellia 6: 136.

Type-species: Myrtopsen mayri Rubsaamen. Monotypic.

Reared from woody galls on leguminous trees and shrubs.

mimosae Weld. Ariz. Host: Tanaostigmodes sp. galls on Mimosa binncifera.

Myrtopsen mimosae Weld, 1926. U. S. Natl. Mus., Proc. 68(10): 116. ๆ, ơ.

\section{Genus CEROPTRES Hartig}

Ceroptres Hartig, 1840 (1839). Ztschr. f. Ent. 2: 186, 197.

Type-species: Ceroptres clavicornis Hartig. Desig. by Foerster, 1869.

Guests in galls on oak.

catesbaei Ashmead. Fla. Host: Bassettia quercuscatesbaei (Ashmead) gall.

Ceroptres catesbaei Ashmead, 1885. Amer. Ent. Soc., Trans. 12: 301. ९, ठ.

confertus (McCracken and Egbert). Calif. Host: Andricus confertus McCracken and Egbert gall.

Periclistus confertus McCracken and Egbert, 1922. Stanford Univ., Pubs., Univ. Ser. Biol. Sci. 3(1): 62 . .

frondosae Ashmead. Mo.

Ceroptres frondosae Ashmead, 1896. Amer. Ent. Soc., Trans. 23: 186. ๆ.

inermis (Walsh). Ill. Host: Cincticornia pilulae (Osten Sacken) gall.

Amblynotus inerm is Walsh, 1864. Ent. Soc. Phila., Proc. 2: 498. ค, ठ. 
lanigerae Ashmead. Fla. Host: Andricus quercuslaniger (Ashmead) gall.

Ceroptres lanigerae Ashmead, 1885. Amer. Ent. Soc., Trans. 12: 301. \&.

minutissimi Ashmead. Fla. Host: Neuroterus quercusmimutissimus (Ashmead) gall.

Ceroptres minutissimi Ashmead, 1885. Amer. Ent. Soc., Trans. 12: 301. \&, ठ․

montensis Weld. Calif. Host: Andricus reniform is McCracken and Egbert gall.

Ceroptres montensis Weld, 1957. U. S. Natl. Mus., Proc. 107: 108. ९, ठ.

niger Fullaway. Calif. Specimen now labeled as Type in California Academy of Science is not a Ceroptres, but an undetermined gall-maker; original description of niger is clearly that of a true Ceroptres.

Ceroptres niger Fullaway, 1911. Ent. Soc. Amer., Ann. 4: 373. \&.

Taxonomy: Weld, 1952. Cynipoidea 1905-1950, p. 268.

petiolicola (Osten Sacken). D. C., Ill. Host: Audricus quercuspetiolicola (Bassett) gall. Amblymotus petiolicola Osten Sacken, 1861. Ent. Soc. Phila., Proc. 1: 67. ₹.

Amblynotus ensiger Walsh, 1864. Ent. Soc. Phila., Proc. 2: 487, 496..

politus Ashmead. Va. Ecology: Ovipositing in leaf of red oak.

Ceroptres politus Ashmead, 1896. Amer. Ent. Soc., Trans. 23: 187. \&, ठ.

quercusarbos (Fitch). N. Y. Host: Cullirhytis cluculu (Osten Sacken) gall.

Cynips Quercus-(1)bos Fitch, 1859 (1858). N. Y. State Agr. Soc., Trans. 18: 809. ठ。.

quercusficus (Fitch). N. Y. Host: Xanthoteras quercusforticorne (Walsh) gall.

Cynips Quercus-ficus Fitch, 1859 (1858). N. Y. State Agr. Soc., Trans. 18: 812. ๆ, ơ.

quercusobtusilobae Karsch. Tex. Host: Galls on Quercus stellata.

Diplole pis q. obtusilobae Karsch, 1880. Ztschr. f. Gesam. Naturw. 53: 292. ๆ.

Cynips obtusilobce Dalla Torre, 1893. Cat. Hym., v. 2, p. 74.

Ceroptres obtusilobensis Weld, 1951. U. S. Dept. Agr., Agr. Monog. 2, p. 614.

quercuspisum (Fitch). N. Y. Host: Acraspis pezomachoides (Osten Sacken) gall.

Cynips Quercus-pisum Fitch, 1859 (1858). N. Y. State Agr. Soc., Trans. 18: 818. ๆ, o.

quercustuber (Fitch). N. Y. Host: Callirhytis clarula (Osten Sacken) gall.

Cynips Quercus-tuber Fitch, 1859 (1858). N. Y. State Agr. Soc., Trans. 18: 806. §, ठ.

rufiventris Ashmead. Mo. Host: Andricns quercusostensackenii (Bassett) gall.

Ceroptres rufiecentris Ashmead, 1896. Amer. Ent. Soc., Trans. 23: 186..

\section{Genus EUCEROPTRES Ashmead}

Euceroptres Ashmead, 1896. Amer. Ent. Soc., Trans. 23: 187.

Type-species: Euceroptres primus Ashmead. Monotypic.

Guests in galls on oak.

maritimus Weld. Calif. Host: Callirhytis quercussuttoni (Bassett) gall.

Euceroptres maritimus Weld, 1926. U. S. Natl. Mus., Proc. 68 (10): 113, 116. ๆ, ठ.

montanus Weld. Calif. Host: Disholcaspis truckeensis (Ashmead) gall.

Euceroptres montanus Weld, 1926. U. S. Natl. Mus., Proc. 68(10): 113, 116. ๆ, ơ.

primus Ashmead. Fla. Host: Andricus quercuspetiolicola (Bassett) gall and other oak galls.

Euceroptres primus Ashmead, 1896. Amer. Ent. Soc., Trans. 23: 187. १, ठ.

Aylax(?) futilis Osten Sacken, 1861. Ent. Soc. Phila., Proc. 1: 51,64. ơ.

\section{SUBFamily CYNIPINAE}

In this subfamily all species are gall-makers. The species of the first few genera, Gonaspis through Diplolepis, produce galls on plants other than Quercus. From the genus Neuroterus to the end of the subfamily all but two of the species produce galls only on Quercus. The two exceptions are Andricus mendocimensis Weld, which is a gall-maker on the tanbark oak, Lithocarpus densiflorus, and Dryocosmus castanopsidis (Beutenmueller), which produces galls on Castanopsis chrysophylla and C. sempervirens. Lithocarpus and Castanopsis have by some Botanists been considered to be synonyms of Quercus. The prevalent current opinion is that those two genera are very closely related to Quercus, but are distinct.

The subfamily Cynipinae is limited here as it was by Ashmead, 1903. (Psyche 10: 145). This 
corresponds somewhat with the old term Psenides Hartig, 1840. (Ztschr. f. Ent. 2: 187). The name Psenides Hartig is not based on any generic name in the Cynipoidea, but is a descriptive term meaning "Gallenerzeuger" or gall producer.

There are European species of gall-makers that are commonly intercepted at our ports of entry, but they are not known to have been established in North America. The best known of these is Andricus kollari (Hartig). This produces bud galls on Quercus rober and other European oaks. The galls produced by this species are imported for the production of permanent inks that are required by law in some states for signatures to certain documents. The cynipid gall-makers occasionally have been known to emerge in factories where these inks are produced, and some factory workers have complained that they were stung by the cynipids. Many of the species of oaks on which this cynipid produces galls in Europe are grown in North America as rare ornamentals. This cynipid has not yet been found developing here. "Nut galls" or "Aleppo galls," produced by Adleria gallaetinctoriae (Olivier), are also commonly imported, as are the acorn galls of Audricus glandium (Giraud). The cynipids producing these galls are not known to be established in North America.

Taxonomy: Eady and Quinlan, 1963. Handb. Ident. Brit. Ins. 8(1a): 1-81.

\section{Genus GONASPIS Ashmead}

Gonaspis Ashmead, 1897. Psyche 8: 68.

Type-species: Diustrophus scutellaris Gillette. Orig. desig.

Produce galls on Potentilla.

potentillae (Bassett). N. B. s. to Va., w. to Ill., Mo. Ecology: Produces globular galls in leaf axils of Potentilla spp.

Diastrophus poteutillae Bassett, 1864. Ent. Soc. Phila., Proc. 3: 689. १, o, gall.

Diastrophus scutellaris Gillette, 1891. Ill. State Lab. Nat. Hist., Bul. 3: 191.

Taxonomy: Weld, 1959. Cynipid Galls Eastern U. S., p. 84.

\section{Genus ANTISTROPHUS Walsh}

Antistrophus Walsh, 1869. Amer. Ent. 2: 74.

Type-species: Antistrophus Iygodesmiaepisum Walsh. Monotypic.

Asclepiadiphila Ashmead, 1897. Canad. Ent. 29: 263.

Type-species: Asclepiadiphila stephanotidis Ashmead. Monotypic.

Produce galls on various composites.

bicolor Gillette. Ill. Ecology: Said to produce galls on Silphium integrifolium.

Antistrophus bicolor Gillette, 1891. Ill. State Lab. Nat. Hist., Bul. 3: 197.

chrysothamni (Beutenmueller). Ariz. Ecology: Produce galls on Chrysothamnus sp. that are stem swellings covered with feltlike pubescence.

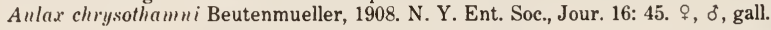

laciniatus Gillette. Ill. Ecology: Produces minute galls among disk florets in flower heads of Silphium laciniatum.

Antistrophus laciniatus Gillette, 1891. Ill. State Lab. Nat. Hist., Bul. 3: 194. \&, đ, gall.

lygodesmiaepisum Walsh. Ill., N. Dak., S. Dak., Kans., Wyo., Colo., N. Mex. Ecology: Produces pea-shaped galls along stem of Lygodesmia juncea.

Antistrophus lygodesmiaepisum Walsh, 1869. Amer. Ent. 2: 73. ๆ, ठ, gall.

Autistrophus pisum Ashmead, 1885. Amer. Ent. Soc., Trans. 12: 294.

Asclepialiphila stephanotidis Ashmead, 1897. Canad. Ent. 29: 263. ๆ, ठ, gall.

microseris (McCracken and Egbert). Calif. Ecology: Produces gall on stem of Microseris sp.

Aylax microseris McCracken and Egbert, 1922. Stanford Univ., Pubs., Univ. Ser. Biol. Sci. $3(1): 45$. , gall.

minor Gillette. Ill. Ecology: Bred from galls hidden in stems of Silphium laciniatum.

Antistrophus minor Gillette, 1891. Ill. State Lab. Nat. Hist., Bul. 3: 196. ๆ, o, gall.

Aulax Gillettei Kieffer, 1902. Soc. Hist. Nat. Metz., Bul. (2) 10: 95. N. name unnecessarily proposed. 
rufus Gillette. Ill., Kans. Ecology: Bred from galls hidden in stem of Silphium laciniatum. Antistrophus rufus Gillette, 1891. Ill. State Lab. Nat. Hist., Bul. 3: 195. \&, ð’, gall.

silphii Gillette. Va., Ill., Nebr. Ecology: Produces club-shaped subterminal stem galls on Silphium perfoliatum.

Antistrophus silphii Gillette, 1891. Ill. State Lab. Nat. Hist., Bul. 3: 192. , ơ, gall.

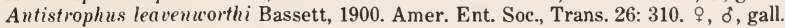

\section{Genus DIASTROPHUS Hartig}

Diastrophus Hartig, 1840 (1839). Ztschr. f. Ent. 2: 186.

Type-species: Diastrophus rubi Hartig. Monotypic.

Produce galls on $R u b u s$, Fragaria, Potentilla.

bassettii Beutenmueller. N. Y., N. J., Pa. Ecology: Produce irregularly globose galls half buried in ground at tips of running $R u b u s$ stems.

Diastrophus bassettii Beutenmueller, 1892. Amer. Mus. Nat. Hist., Bul. 4: 248. ठ, gall.

cuscutaeformis Osten Sacken. Conn. to S. C., w. to Ont., Ill., Iowa. Ecology: Produce seedlike galls on $R u b u s$ stems near ground level.

Diastrophns cuscutaeform is Osten Sacken, 1863. Ent. Soc. Phila., Proc. 2: 39. ๆ, ó, gall.

fragariae Beutenmueller. R. I., N. Y., s. to Va., w. to Ont., Ill. Ecology: Produce galls on petiole of strawberry, Fragaria virginiana.

Diastrophus fragariae Beutenmueller, 1915. Canad. Ent. 47: 353. ठै, gall.

Taxonomy: Weld, 1926. U. S. Natl. Mus., Proc. 68 (10): 118 (description of female).

fusiformans Ashmead. Ont., Colo. Ecology: Produce galls on Potentilla sp. that are slight swellings, often curved, in stems.

Diastrophus fusiformans Ashmead, 1890. Colo. Biol. Assoc., Bul. 1: 13, 38. $q$, gall.

kincaidii Gillette. Colo., Idaho, B. C., Wash., Oreg., Calif. Ecology: Produce lumpy and pithy stem galls on Rubus parviflorus.

Diastrophus kincaidii Gillette, 1893. Canad. Ent. 25: 110. \&, o, gall.

Diastrophus kincaidii var. anstrior Kinsey, 1922. Ind. Univ. Studies 53: 54. ๆ, ơ, gall.

minimus Bassett. Mass., Conn., N. J. Ecology: Produce small, oval galls on internodes of Potentilla canadensis.

Diastrophus minimus Bassett, 1900. Amer. Ent. Soc., Trans. 26: 325. ๆ, đ̃, gall.

nebulosus (Osten Sacken). Conn. to Fla., w. to Ont., Kans., Okla. Ecology: Produce stem galls on $R$ ubus sp., blackberries, that are large, abrupt, pithy, subterminal swellings with longitudinal grooves.

Cynips (Diastrophus?) uebulosus Osten Sacken, 1861. Stettin. Ent. Ztg. 22: 415. \&, gall.

niger Bassett. Mass., N. Y., D. C., Mich., Ill., Mo., Ark. Ecology: Produce spindle-shaped stem galls on Potentilla canadensis.

Diastrophus niger Bassett, 1900. Amer. Ent. Soc., Trans. 26: 324. + , gall.

piceus Provancher. Ont. (Ottawa).

Diastrophus piceus Provancher, 1886. Addit. Corr. Faune Ent. Canada Hym., p. 161. ๆ, ठ.

radicum Bassett. Conn. s. to N. C., w. to Ont., Mich., Colo. Ecology: Produce irregular, globose root galls on black raspberry, $R$ ubus occidentalis.

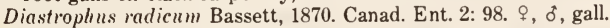

smilacis Ashmead. Ill. Originally deseribed from specimens said to be from gall on Smilax; this species has not been reared again since. The plant record may be incorrect.

Diastrophus smilacis Ashmead, 1896. Amer. Ent. Soc., Trans. 19: 135. \&, gall.

tumefactus Kinsey. Que., Ont. Ecology: Produce enlarged stem galls on Potentilla.

Diastroplu us tumefactus Kinsey, 1920. Amer. Mus. Nat. Hist., Bul. 42: 299. \&, gall.

turgidus Bassett. Que., Maine, Ont., Conn., D. C., N. Y., Ind., Ill., Mo. Ecology: Produce abrupt stem sweeling galls on red raspberries, $R u b u s$ strigosus.

Diastrophus turdigus(!) Bassett, 1870. Canad. Ent. 2: 99. ๆ, gall.

Diastrophus turgidus Bassett, 1870. Canad. Ent. 2: 100. 


\section{Genus LIPOSTHENES Foerster}

Liposthenus (!) Foerster, 1869. Zool.-Bot. Gesell. Wien, Verh. 19: 332.

Liposthenes Foerster, 1869. Zool.-Bot. Gesell. Wien, Verh. 19: 336.

Type-species: Aulax glechomae Hartig. Orig desig.

Produce galls on Nepeta hedercicea, in Europe and North America.

glechomae (Linnaeus). Maine s. to Va., w. to Ont., W. Va., Ill. Europe. Ecology: Produce globular, green, fleshy galls on Nepeta hederacea. Introduced from Europe with its host plant and established in the Eastern U.S. and Ontario.

Cynips Glechomae Linnaeus, 1758. Syst. Nat., Ed. 10, p. 553. \&, gall.

Diastrophus similis Bassett, 1881. Canad. Ent. 13: 95. ๆ, gall.

Aulax Latreillei Kieffer, 1898. Wien. Ent. Ztg. 17: 257. §, ठ’, gall.

Taxonomy: Weld, 1952. Cynipoidea 1905-1950, p. 273.

\section{Genus AYLAX Hartig}

Aylax Hartig, 1840 (1839). Ztschr. f. Ent. 2: 186, 195.

Type-species: Cynips rhoeadis Bouche. Desig. by Ashmead, 1903.

Aulax Hartig, 1843. Ztschr. f. Ent. 4: 412. Emend.

Pseudaulax Ashmead, 1903. Psyche 10: 213.

Type-species: Cynips hieracii Linnaeus. Orig. desig.

papaveris (Perris). North America ?; Europe. Ecology: Produce galls in seed-heads of Papaver.

Introduced from Europe into North America many times but not certainly known to

be established here.

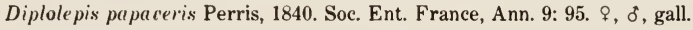

quinquecostatus (Provancher). Ont. (Toronto).

Diastrophus 5-costatus Provancher, 1883. Nat. Canad. 14: 19. \&, o.

\section{Genus PHANACIS Foerster}

Phanacis Foerster, 1860. Naturh. Ver. Rheinlande, Verh. 17: 145.

Type-species: Phanacis centaureae Foerster. Monotypic.

Timaspis Mayr, 1881. Zwanzig. Jahresber. Comm.-Oberrealsch. I. Bez. Wien., p. 18.

Type-species: Diastroplus lampsanae Karsch. Monotypic.

Gillettea Ashmead, 1897. Psyche 8: 69.

Type-species: Gillettea taraxici Ashmead. Orig. desig.

Taxonomy: Eady and Quinlan, 1963. Handb. Ident. Brit. Ins. 8 (1a): 17-18.

hypochaeridis (Kieffer). Wash., Oreg., Calif.; Europe. Ecology: Produce stem swelling galls on Hypochaeris radicata. Introduced from Europe into Pacific Coast states.

Anlax hypochaeridis Kieffer, 1887. Zool.-Bot. Gesell. Wien, Verh. 37: 205. \&, gall.

taraxaci (Ashmead). Ont., N. Y., Ill., Minn., Iowa; Hawaii, Europe. Ecology: Produce fusiform galls on petiole, leaf midrib, or base of peduncle. Introduced from Europe along with its host plant, Taraxacum officinale.

Gillettea taraxaci Ashmead, 1897. Psyche 8: 69. ․ ऽ, gall.

\section{Genus AULACIDEA Ashmead}

Aulacidea Ashmead, 1897. Psyche 8: 68.

Type-species: Aulax mulgediicola Ashmead. Orig. desig.

Produce galls on various composites.

abdita Kinsey. Que. Ecology: Produce cell-like galls in pith of Lactuca. This is doubtfully distinct from harringtoni (Ashmead).

Aulacidea abdita Kinsey, 1920. Amer. Mus. Nat. Hist., Bul. 42: 296. ₹, ठ', gall.

ambrosiaecola (Ashmead). Mo. (Kirkwood). Ecology: Supposed to produce galls on Ambrosia, but has not been found again since it was described.

Aulax ambrosiaecola Ashmead, 1896. U. S. Natl. Mus., Proc. 19: 134. ₹, §, gall. 
annulata Kinsey. Mass. (Sharon). Ecology: Produce galls on Lactuca. This may be a synonym of tumida (Bassett).

Aulacidea anmulata Kinsey, 1920. Amer. Mus. Nat. Hist., Bull. 42: 298. \&, ठ, gall.

harringtoni (Ashmead). Ont. to D. C., w. to Mo. Ecology: Produce cell-like galls in pith of stems of Lactnea rillosa, probably other species of Lactuca also.

Aulax harringtoni Ashmead, 1887. Amer. Ent. Soc., Trans. 14: 146..

Aulax bicolor Gillette, 1891. Ill. State Lab. Nat. Hist., Bul. 3(1): 201. \&.

Aulax mulgetlicola Ashmead, 1896. U. S. Natl. Mus., Proc. 19: 133., , ‘, gall.

Aulax cavicola Ashmead, 1896. U. S. Natl. Mus., Proc. 19: 134. \&.

nabali (Brodie). Que. to N. C., w. to Ill. Ecology: Produce stem galls on Prenanthes, these hemispherical swellings on the stem just below surface of ground.

Aulax nabali Brodie, 1892. Canad. Ent. 24: 12. ?, ठ, gall.

podagrae (Bassett). N. Y., Pa., Va., Ill, Mo. Ecology: Produce knotty stem galls on Lactuca cumad'nsis, these scattered along stem at leaf bases.

Aulax pollagrae Bassett, 1890. Amer. Ent. Soc., Trans. 17: 91. $\subsetneq$, o, gall.

tumida (Bassett). Ont. to Va., w. to Ill. Ecology: Produce galls that are swellings near apex of stem of Lactuca canadensis and Sonchus.

Anlax tumidus Bassett, 1890. Amer. Ent. Soc., Trans. 17: 92. \&, đ, gall.

Aulax sonchicola Ashmead, 1896. U. S. Natl. Mus., Proc. 19: 134. ơ, ơ, gall.

Aulacidea solidagin is Girault, 1903. Ent. News 14: 323. $?$, ơ, gall.

\section{Genus DIPLOLEPIS Foureroy}

Diplolepis Geoffroy, 1762. Hist. Abregee des Ins., v. 2, p. 308. Not available for nomenclatorial purposes, Internatl. Comm. Zool. Nomencl., Opinion 228, 1954.

Diplolepis Fourcroy, 1785. Ent. Parisiensis, pt. 2, p. 391.

Type-species: Cynips rosae Linnaeus. Desig. by Karsch, 1880.

Rhorlites Hartig, 1840 (1839). Ztschr. f. Ent. 2: 186.

Type-species: Cynips rosae Linnaeus. Desig. by Foerster, 1869.

Hololexis Foerster, 1869. Zool.-Bot. Gesell. Wien, Verh. 19: 330, 333.

Type-species: Hololexis rufipes Foerster. Monotypic.

Tribalia Walsh, 1864. Ent. Soc. Phila., Proc. 2: 470.

Type-species: Tribalia batatorum Walsh. Monotypic.

Lytorhodites Kieffer, 1902. Soc. Hist. Nat. Metz., Bul. (2) 10: 96.

Type-species: Rhodites arefactus Gillette. Desig. by Rohwer and Fagan, 1917.

Produce galls on Rosa. It is unfortunately true that the bulk of the literature about this genus used the generic name Rhodites. There is some sentiment for asking the Commission to place Rhodites on the list of conserved names, but no such proposal has been presented. As the years pass and literature accumulates using the name Diplolepis, the likelihood of such a proposal being made to the Commission becomes increasingly less likely.

arefacta (Gillette). Colo., Ariz., Utah, Nev., Wash. Ecology: Produce galls on small shoots of Rosa.

Rhodites arefactus Gillette, 1894. Canad. Ent. 26: 157. ๆ, ơ, gall.

ashmeadi (Beutenmueller). Oreg. Ecology: Produce globose galls on Rosa nuthana stems.

Rhodites ashmieadi Beutenmueller, 1918. Canad. Ent. 50: 306. $\uparrow$, gall.

bassetti bassetti (Beutenmueller). Wash., Oreg. Ecology: Produce clusters of small, woody galls with fine, curled filaments on twigs of Rosa nutkana.

Rhodites bassetti Beutenmueller, 1918. Canad. Ent. 50: 307. ^, o, gall.

bassetti lucida Kinsey. Idaho, Oreg. Ecology: Produce clusters of small woody galls with stout, straight filaments on twigs of Rosa nutkana.

Diplolepis bassetti var. Incida Kinsey, 1922. Ind. Univ. Studies 53: 57. ^, ठ, gall.

bicolor (Harris). Maine to Va., w. to Ill. Ecology: Produce spherical, spiny leaf galls on Rosa; galls may completely conceal leaves.

Cynips bicolor Harris, 1841. Rpt. Ins. Mass. Injurious to Veg., p. 399. ९, §ै, gall. 
californica (Beutenmueller). Wash., Oreg., Calif. Ecology: Produce fairly large, spherical galls on terminals of $R$ osa twigs; gall covered with dense, irregular filaments and semi-aborted leaves.

Rhodites califomicns Beutenmueller, 1914. Brooklyn Ent. Soc., Bul. 9: 88. ๆ, ð, gall.

dichlocera (Harris). Ont. to Va. w. to Ill. Ecology: Produce fusiform stem galls on Rosa; galls usually with prickly surface.

Cynips dichlocerns Harris, 1841. Rpt. Ins. Mass. Injurious to Veg., p. 399. §, §, gall.

fulgens (Gillette), Conn., Ont., N. Y., N. J., W. Va., Ill., Minn., S. Dak., Colo. Ecology: Produce potatolike root galls on Rosa blanda.

Rhodites fulgens Gillette, 1894. Canad. Ent. 26: 159. .

fusiformans fusiformans (Ashmead). Ont., Ill., Nebr., Colo., Ariz. Ecology: Produce fusiform or abrupt, one-sided enlargements of stems of Rosa.

Rhodites fusiformans Ashmead, 1890. Colo. Biol. Assoc., Bul. 1: 14. ‡, ¿, gall.

fusiformans mendocinensis Kinsey. Calif. Ecology: Produce polythalamous stem galls on Rosa.

Diplolepis fusiformans var. mendocimensis Kinsey, 1922. Ind. Univ. Studies 53: 62. ₹, o, gall.

fusiformans minuta Kinsey. Calif. Ecology: Produce small stem galls on Rosa, each gall containing 4 or less cells.

Diplolepis fusiformans var. minuta Kinsey, 1922. Ind. Univ. Studies 53: 61. \&, o, gall.

gracilis (Ashmead). Mass., Conn., Ont., N. Y., Ill., Wis., Utah. Ecology: Produce galls on under side of Rosa leaves; galls single or in clusters, each one globular with flattened top.

Rhodites gracilis Ashmead, 1897. U. S. Natl. Mus., Proc. 19: 135. \&, ठ, gall.

ignota (Osten Sacken). Ont. to Va., w. to Ill. Ecology: Produce globular, hard, many-celled galls on under side of leaves of Rosa; several galls may coalesce into an irregular mass; surface of gall covered with mealy, white bloom. Mealy rose gall.

Rhodites ignota Osten Sacken, 1863. Ent. Soc. Phila., Proc. 2: 45, 49, 63. $₹$, đ, gall.

Rhodites carolina Ashmead, 1887. Amer. Ent. Soc., Trans. 14: 133, 148. , gall.

lens Weld. Wash., Oreg., Calif. Ecology: Produce small lens-shaped leaf galls on Rosa nutkana.

Diplolepis lens Weld, 1952. U. S. Natl. Mus., Proc. 102: 320. ‡, ठ.

mayri (Schlechtendal). N. J., Ohio; Europe. Ecology: Produce lobed, terminal stem galls on Rosa rubiginosa. Introduced from Europe; first identified from New Jersey specimens in 1914.

Rhodites mayri Schlechtendal, 1877 (1876). Jabresber. Ver. Zwickau, p. 59. ९, gall.

nebulosa (Bassett). Conn., Ont., N. Y., N. J., Ill. Ecology: Produce small, globular galls on under side of leaves of Rosa; galls with a few, weak spines.

Rhodites nebulosus Bassett, 1890. Amer. Ent. Soc., Trans. 17: 63., gall.

neglecta (Gillette). Colo. Ecology: Produce abrupt, corky enlargements of small stems of $R$ osa; surface of galls smooth.

Rhodites neglectus Gillette, 1894. Canad. Ent. 26: 158. ९, §, gall.

nodulosa (Beutenmueller). Mass., Md., Mich., Ill. Ecology: Produce hardly perceptible enlargements of base of lateral branches of $R o s a$, branches dying beyond galled area.

Rhodites nodulosus Beutenmueller, 1909. Ent. News 20: 247. \&, gall.

oregonensis (Beutenmueller). Oreg. Ecology: Produce galls in buds of $R o s a$ in spring, these galls greatly distorting the buds.

Rhodites oregonensis Beutenmueller, 1918. Canad. Ent. 50: 305. \&, gall.

ostensackeni (Beutenmueller). Oreg. Ecology: Produce root galls on Rosa nutkana.

Rhodites ostensacheni Beutenmueller, 1918. Canad. Ent. 50: 307. \&, gall.

polita (Ashmead). Ariz., Oreg., Calif. Ecology: Produce spherical, spiny leaf galls on Rosa californica.

Rhodites polita Ashmead, 1890. Colo. Biol. Assoc., Bul. 1: 14. ₹, §, gall.

Rhodites occidentalis Beutenmueller, 1922. Brooklyn Ent. Soc., Bul. 17: 45. + , o, gall.

pustulatoides (Beutenmueller). Va., Ind., Tenn., Colo., Utah, Oreg. Ecology: Produce small, round or ovate galls on upper surface of $R$ osa leaves.

Rhodites pustulatoides Beutenmueller, 1914. Brooklyn Ent. Soc., Bul. 9: 89. १, ठ. 
radicum (Osten Sacken). Ont. and Mass. to Va., w. to Sask., Wash., Oreg. Ecology: Produce large, potatolike galls on roots or stems of Rosa at ground level; galls usually hidden by soil surface litter.

Rhodites rarlicum Osten Sacken, 1863. Ent. Soc. Phila., Proc. 2: 42, 45, 46. ९, ठ, gall.

Tribalia batatorum Walsh, 1864. Ent. Soc. Phila., Proc. 2: 470. q.

Rhorlites utahensis Bassett, 1890. Amer. Ent. Soc., Trans. 17: 62. \&, ठ, gall.

Diplolepis radicum var. johısoni Kinsey, 1922. Ind. Univ. Studies 53: 67. \&, o, gall.

Diplolepis radicum var. plena Kinsey, 1922. Ind. Univ. Studies 53: 70. \&, gall.

Diplolepis radicum var. divergens Kinsey, 1922. Ind. Univ. Studies 53: 70. $\uparrow, ~ \delta$, gall.

Diplolepis ralicum var. angustior Hunter, 1923. Psyche 30: 173. ?, ठ, gall.

rosae (Linnaeus). Que. to Va., w. to Kans.; Europe. Ecology: Produce large, 2-to 4-inch diameter, spherical stem galls on Roso eylanteria and $R$. rugosa; surface of gall densely filamentous. Introduced from Europe, first found in Toronto, Ont. in 1868. Mossy rose gall.

Cynips rosce Linnaeus, 1758. Syst. Nat., Ed. 10, p. 553. \&, gall.

rosaefolii (Cockerell). Ont., N. Y., Ohio, Mich., Ill. Ecology: Produce lentil-shaped leaf galls on Rosa.

Rhorlites rosaefolii Cockerell, 1889. Ent. Monthly Mag. 25: 324, 363. , gall.

Rhodites lenticularis Bassett, 1890. Amer. Ent. Soc., Trans. 17: 59. ^, ठ, gall.

similis (Ashmead). Wyo., Colo., N. Mex. Ecology: Produce semi-spherical twig galls on Rosa; surface of galls smooth.

Rhoelites similis Ashmead, 1896. U. S. Natl. Mus., Proc. 19: 136. \&, §, gall.

spinosa (Ashmead). Ohio, Wis., Ill., Man., Minn., Sask., Alta. Ecology: Produce irregularly lobed, subterminal stem galls on Rosa; surface of galls densely spinose.

Rhodites spinosa Ashmead, 1887. Amer. Ent. Soc., Trans. 14: 134. gall.

Rhodites spinosissima Gillette, 1889. Iowa Agr. Expt. Sta., Bul. 7: 284. Preocc. by Giraud, 1859.

Rhorlites multispinosa Gillette, 1890. Ent. Amer. 6: 25. \&, o, gail.

terrigena Weld. Calif. Ecology: Produce subterranean galls at crown of Rosa plants; gall rather shaped like a bunch of grapes.

Diplolepis terrigena Weld, 1952. U. S. Natl. Mus., Proc. 102: 320. \&, đ, gall.

tuberculatrix (Cockerell). N. Dak., Colo., N. Mex., Utah, Wash., Oreg., Calif. Ecology: Produce abrupt, semi-spherical stem galls on Rosa; galls with numerous cells and outer surface bears scattered spines.

Rhodites tuberculator Cockerell, 1888. West. Amer. Sci. 4: 60. $q$, gall.

Diplolepis tuberculatrix var. coloradensis form coloradensis Kinsey and Ayres, 1922. Ind. Univ. Studies 53: 149., , $\delta$, gall.

Diplolepis tuberculatrix var. coloradensis form subcoloradensis Kinsey and Ayres, 1922. Ind. Univ. Studies 53: 150. \&, gall.

Diplolepis tuberculatrix var. wasatchensis Kinsey and Ayres, 1922. Ind. Univ. Studies 53: 153. $\uparrow, \delta$, gall.

Diplolepis tubereulatrix var. versicolor Kinsey and Ayres, 1922. Ind. Univ. Studies 53: 156. \%, gall.

Diplolepis tuberculatrix var. melanderi Kinsey and Ayres, 1922. Ind. Univ. Studies 53: 156. $\&$, ¿, gall.

Diplolepis tuberculatrix var. rubriderma Kinsey and Ayres, 1922. Ind. Univ. Studies 53: 157. $\$$, ठ, gall.

Diplolepis tuberculatrix var. sierranensis Kinsey and Ayres, 1922. Ind. Univ. Studies 53: 158. $९, \delta$, gall.

Diplolepis tuberculatrix var. descansanis Kinsey and Ayres, 1922. Ind. Univ. Studies 53: 159. $\&$, ठ, gall.

tumida (Bassett). Utah. Ecology: Produce terminal stem swellings on Rosa.

Rhodites tumidus Bassett, 1890. Amer. Ent. Soc., Trans. 17: 60. ₹, ơ, gall.

Diplolepis tuberculatrix var. tumida form xerophila Kinsey and Ayres, 1922. Ind. Univ.

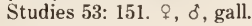


variabilis (Bassett). N. Dak., N. Mex., Utah, Ariz., Wash., Oreg. Ecology: Produce irregularly round, smooth, russet colored leaf galls on Rosa.

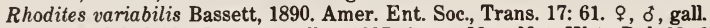

Rhodites globuloides Beutenmueller, 1907. Amer. Mus. Nat. Hist., Bul. 23: 638. . variabilis var. lutescens Kinsey. Colo.

Diplolepis variabilis var. lutescens Kinsey, 1922. Ind. Univ. Studies 53: 77. ‡, §. variabilis var. rufopicea Kinsey. Colo.

Diplolepis variabilis var. rufopicea Kinsey, 1922. Ind. Univ. Studies 53: 76. ‡, ð. variabilis var. sculpta Kinsey. Utah.

Diplolepis variabilis var. sculpta Kinsey, 1922. Ind. Univ. Studies 53: 75., , ठ.

verna (Osten Sacken). P. E. I., Ont., s. to D. C. Ecology: Produce rounded enlargements of small Rosa stems.

Rhodites verna Osten Sacken, 1863. Ent. Soc. Phila., Proc. 2: 41, 45, 47. ๆ, ơ, gall. weldi (Beutenmueller). Calif. Ecology: Produce clusters of leaf galls on $R$ osa.

Rhodites weldi Beutenmueller, 1913. Insecutor Inscitiae Menstruus 1: 93. ¿, gall.

\section{Genus NEUROTERUS Hartig}

Neuroterus Hartig, 1840 (1839). Ztschr. f. Ent. 2: 185, 192.

Type-species: Neuroterus politus Hartig. Desig. by Ashmead, 1903.

Spathegaster Hartig, 1840 (1839). Ztschr. f. Ent. 2: 186.

Type-species: Spathegaster petioliventris Hartig. Monotypic.

Ameristus Foerster, 1869. Zool.-Bot. Gesell. Wien, Verh. 19: 330,333.

Type-species: Neuroterus politus Hartig. Desig. by Rohwer and Fagan, 1917.

Dolichostrophus Ashmead, 1887. Amer. Ent. Soc., Trans. 14: 129 (footnote).

Type-species: Cynips irregularis Osten Sacken. Monotypic.

Neuroterus subg. Neospathegaster Kinsey, 1923. Ind. Univ. Studies 58: 28, 35, 121.

Type-species: Cynips vesicula Bassett. Orig. desig.

Neuroterus subg. Diplobius Kinsey, 1923. Ind. Univ. Studies 58: 27, 28-31, 35.

Type-species: Cynips floccosa Bassett. Orig. desig.

Neuroterus subg. Pseudoneuroterus Kinsey, 1923. Ind. Univ. Studies 58: 28, 130.

Type-species: Cynips macropterus Hartig. Orig. desig.

Produce galls on white oaks only.

affinis (Bassett). Conn. Ecology: Produce bud galls on Quercus prinoides.

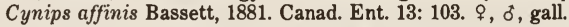

argentatus Weld. Ariz. Ecology: Produce leaf galls on Quercus gambelii, Q. oblongifolia.

Neuroterus argentatus Weld, 1944. U. S. Natl. Mus., Proc. 95: 2. $\uparrow$, gall.

bassettii Dalla Torre. Conn. Ecology: Produce leaf galls on Quercus alba.

Neuroterus pallipes Bassett, 1890. Amer. Ent. Soc., Trans. 17: 89.,$+ \delta$, gall. Preocc. by

Schenck, 1863.

Neuroterus bassettii Dalla Torre, 1892. Wien. Ent. Ztg. 11: 131. N. name.

clarkeae Beutenmueller. Mass. Ecology: Produce stem galls on Quercus alba.

Neuroternis clarkeae Beutenmueller, 1910. Amer. Mus. Nat. Hist., Bul. 28: 132. $\&$, đ, gall. clavensis Weld. Colo., N. Mex., Ariz. Ecology: Produce stem galls on Quercus gambelii, Q. subterminella.

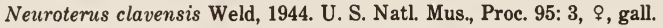

cockerelli Beutenmueller. Colo. Ecology: Produce leaf galls on Quercus sp.

Neuroterus cockerelli Beutenmueller, 1910. Amer. Mus. Nat. Hist., Bul. 28: 125. $\uparrow$, gall.

congregatus Gillette. Colo. Ecology: Produce bud galls on Quercus sp.

Neuroterus congregatus Gillette, 1893. Ent. News 4: 166. ठ’, gall.

consimilis Bassett. Conn. Ecology: Produce stem galls on Quercus alba.

Neuroterus consimilis Bassett, 1900. Amer. Ent. Soc., Trans. 26: 335. $~$, gall.

contortus (Weld). Tex. Ecology: Produce galls at bases of sprouts of Quercus breviloba.

Xystoteras contorta Weld, 1921. U. S. Natl. Mus., Proc. 59: 191, 209., gall. Agamic gen.

Xystoteras contortus, bisexual form principalis Kinsey, 1923. Ind. Univ. Studies 58: 92. $\%$, $\delta$, gall. Sexual gen. 
cupulae Kinsey. Calif. Ecology: Produce galls in cup at base of acorn on Quereus lobata. Neuroterus cupulae Kinsey, 1922. Ind. Univ. Studies 53: 99. \&, gall.

distortus Bassett. Conn., N. Y., N. J., Ill. Ecology: Produce stem galls on Querctus bicolor. Neuroterus distortus Bassett, 1900. Amer. Ent. Soc., Trans. 26: 336. ๆ, ठ, gall.

dubius Bassett. Conn. Call unknown.

Neuroterus dubia Bassett, 1900. Amer. Ent. Soc., Trans. 26: 335. ๆ, ð.

dubius var. digressus Kinsey. Calif.

Neuroterus dubius var. digressus Kinsey, 1923. Ind. Univ. Studies 58: 32, 96. ๆ.

engelmanni Kinsey. Calif. Ecology: Produce leaf galls on Quercus engelmanni.

Neuroterus engelmanni Kinsey, 1922. Amer. Mus. Nat. Hist., Bul. 46: 293. ₹, gall.

escharensis Weld. Ill. Ecology: Produce stem galls on Quercus bicolor:

Nenroterus escharensis Weld, 1926. U. S. Natl. Mus., Proc. 68 (10): 5. ๆ, gall.

evanescens Kinsey. Tex. Ecology: Produce galls on aments of Quercus breviloba.

Neuroterus evanescens Kinsey, 1922. Ind. Univ. Studies 53: 100. \&, ठ, gall.

evolutus Weld. Calif. Ecology: Produce stem galls on Quercus douglasii, Q. lobata.

Neuroterus evolutus Weld, 1926. U. S. Natl. Mus., Proc. 68 (10): 6. ₹, gall.

exiguissimus Bassett. Mass., Conn., N. Y., N. J., Va. Ecology: Produce leaf galls on Quercus alba.

Neuroterus exiguissimus Bassett, 1900. Amer. Ent. Soc., Trans. 26: 332. ๆ, gall.

exiguus Bassett. Conn., N. Y., N. J., Va. Ecology: Produce galls on aments of Quereus stellata.

Neuroterus exigutus Bassett, 1900. Amer. Ent. Soc., Trans. 26: 333. ₹, o, gall.

floccosus (Bassett). Ont. to Va., w. to Ill. Ecology: Produce leaf galls on Quercus bicolor.

Cynips floccosa Bassett, 1881. Canad. Ent. 13: 111. + , gall.

Neuroterts verrucartut var. pernotus Kinsey, 1923. Ind. Univ. Studies 58: 30, 74. \&, gall.

floricola Kinsey. Calif. Ecology: Produce ament galls on Quercus douglasii.

Neuroterus floricola Kinsey, 1922. Ind. Univ. Studies 53: 101. ๆ, o, gall.

floricomus Weld. Ariz. Ecology: Produce galls on aments of Quercus arizonica, Q. oblongifolia, Q. reticulata, Q. toumeyi.

Neuroterus floricomus Weld, 1957. U. S. Natl. Mus., Proc. 107: 109. \&, o, gall.

florulentus Weld. Calif. Ecology: Produce galls on aments of Quercus dumosa, Q. lobata.

Neuroterus florulentus Weld, 1957. U. S. Natl. Mus., Proc. 107: 110. ๆ, ठ', gall.

fragilis Bassett. Calif. Ecology: Produce leaf galls on Quercus douglasii, Q. dumosa.

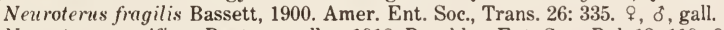

Neuroterus pacificus Beutenmueller, 1918. Brooklyn Ent. Soc., Bul. 13: 119. ‡, o, gall.

fugiens Weld. Ill. Ecology: Produces leaf galls on Quereus macrocarpa.

Neuroterus fugiens Weld, 1926. U. S. Natl. Mus., Proc. 68: (10): 12. \&, ठ, gall.

gillettei Bassett. Conn., Va. Ecology: Produces leaf galls on Quercus stellata.

Neuroterus Gillettei Bassett, 1900. Amer. Ent. Soc., Trans. 26: 334. ₹, ठ’, gall.

howertoni Bassett. N. Mex., Ariz. Ecology: Produce leaf galls on Quercus arizonica, Q. oblongifolia.

Neuroterus houertoni Bassett, 1890. Amer. Ent. Soc., Trans. 17: 90. $\%$, gall.

lamellae Weld. Ariz. Ecology: Produce leaf galls on Quercus subturbinella.

Neuroterns lamellae Weld, 1957. U. S. Natl. Mus., Proc. 107: 109-110. \&, gall.

minutus (Bassett). Mass., Conn., Ont., Pa., Va. Ecology: Produce bud galls on Quercus alba.

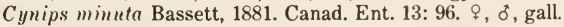

niger Gillette. Mass., Mich., Wis., Iowa. Ecology: Produce leaf galls on Quercus macrocarpa.

Neuroterus nigrum Gillette, 1888. Mich. State Bd. Agr., Rpt. 27: 475. \&, gall.

niger var. alimas Kinsey. Tex. Ecology: Produce leaf galls on Quercus virginiana.

Neuroterus niger var. alimas Kinsey, 1923. Ind. Univ. Studies 58: 30, 42. ₹, ơ, gall.

niger var. arizonicae Kinsey. Ariz. Ecology: Produce leaf galls on Quercus arizonica.

Neuroterus niger var. arizonicae Kinsey, 1923. Ind. Univ. Studies 58: 30, 43. , gall.

niger var. griseae Kinsey. Tex. Ecology: Produce leaf galls on Quercus grisen.

Neuroterus niger var, griseae Kinsey, 1923. Ind. Univ. Studies 58: 31, 44. §, gall. 
niger var. nigripes Kinsey. Tex. Ecology: Produce leaf galls on Quercus breviloba, Q. stellata. Neuroterus niger var. nigripes Kinsey, 1923. Ind. Univ. Studies 58: 14, 31, 45. ९, gall.

niger var. pattersoni Kinsey. Tex. Ecology: Produce leaf galls on Quercus breviloba, $Q$. stellata.

Neuroterus niger var. pattersoni Kinsey, 1923. Ind. Univ. Studies 58: 14, 31, 47. ₹, o, gall. Sexual gen.

Neuroterus niger var. pattersoni, agamic form hiemalis Kinsey, 1923. Ind. Univ. Studies 58: 47. . Agamic gen.

noxiosus (Bassett). Mass., Conn., s. to W. Va., w. to Ill. Ecology: Produce galls on Quercus bicolor, sexual generation on leaves, agamic generation on stems.

Cynips noxiosus Bassett, 1881. Canad. Ent. 13: 108. \&, ơ, gall. Sexual and agamic gen.

Nenroterns noxiosus form rermalis Kinsey, 1920. Amer. Mus. Nat. Hist., Bul. 42: 337. ๆ, $\delta$, gall. Sexual gen.

pallidus Bassett. Conn., N. Y., N. J. Ecology: Produce galls on aments on Quercus bicolor:

Neuroterus pallielus Bassett, 1890. Amer. Ent. Soc., Trans. 17: 88. ₹, ठ, gall.

papillosus Beutenmueller. N. Y., N. J., Ind., Ill. Ecology: Produce leaf galls on Quercus bicolor.

Neuroterus pupillosus: Beutenmueller, 1910. Amer. Mus. Nat. Hist., Bul. 28: 121. ₹, ठ, gall.

perminimus Bassett. Ont., N. Y., Md., Va., Ohio, Ill. Ecology: Produce leaf galls on Quercus ulbu.

Nenroterus perminimus Bassett, 1900. Amer. Ent. Soc., Trans. 26: 332. \&, o, gall.

quercicola Dalla Torre. Utah. Ecology: Produce leaf galls on Quercus sp.

Neuroterus politus Bassett, 1890. Amer. Ent. Soc., Trans. 17: 89. ठ, gall. Preoce. by Hartig, 1840.

Neuroteras quercicola Dalla Torre, 1892. Wien. Ent. Ztg. 11: 131. N. name.

quercicola var. pubescens Kinsey. Ariz.

Neuroterus quercicola var. pubescens Kinsey, 1923. Ind. Univ. Studies 58: 114. $q$, gall.

quercusbatatus (Fitch). Conn., Ont., s. to Fla., w. to Ill. Ecology: Produce stem galls on Quercus alba, in both sexual and agamic generations.

Cynips Quercus-batatus Fitch, 1859 (1858). N. Y. State Agr. Soc., Trans. 18: 810. \&, o. Sexual gen.

Cynips q. batatus Fitch, 1864. In Bassett, Ent. Soc. Phila., Proc. 3: 684. ₹, o, gall.

Neuroterus batatus var. bisexualis Kinsey, 1920. Amer. Mus. Nat. Hist., Bul. 42: 334. \&, o, gall.

quercusbatatus var. prini Kinsey. R. I. Ecology: Produce stem galls on Quercus prinus.

Neuroterus batatus var. prini, bisexual form prini Kinsey, 1923. Ind. Univ. Studies 58: 33,

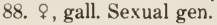

Neuroterus batatus var. prini, agamic form deprini Kinsey, 1923. Ind. Univ. Studies 58: 89. $\uparrow$, gall. Agamic gen.

quercusirregularis (Osten Sacken). N. Y., w. to Mo., Okla., Tex. Ecology: Produce leaf galls on Quercus breviloba, Q. stellata.

C!ynips quercusirregularis Osten Sacken, 1861. Ent. Soc. Phila., Proc. 1: 65. o, gall.

Cynips irregularis Osten Sacken, 1865. Ent. Soc. Phila., Proc. 4: 340, 344, 349, 353, 379.

quercusirregularis var. albipleurae Kinsey. Tex.

Nenroterus irregularis var, albipleurae Kinsey, 1923. Ind. Univ. Studies 58: 14, 34, 99., , gall.

quercusirregularis var. variegatus Kinsey. Okla.

Neuroterus irregularis var. ériegatus Kinsey, 1923. Ind. Univ. Studies 58: 14, 35, 102. \&, $\delta$.

quercusmajalis (Bassett). Ont. to Fla., w. to Ill., Mo. Ecology: Produce leaf galls on Quercus alba.

Cynips q. majalis Bassett, 1864. Ent. Soc. Phila., Proc. 3: 682. \&, §, gall.

Cynips majalis Osten Sacken, 1865. Ent. Soc. Phila., Proc. 4: 353.

quercusminutissimus (Ashmead). Fla. Ecology: Produce leaf galls on Quercus virginiana.

Cynips q. minutissima Ashmead, 1885. Amer. Ent. Soc., Trans. 12: Proc. p. vii. $₹$, gall.

Neuroterus minutissimus: Ashmead, 1885. Amer. Ent. Soc., Trans. 12: 296. 
quercusrileyi (Bassett). Mass. to Va., w. to Ind., Mo., Okla., Tex. Ecology: Produce stem galls on Quercus muehlenbergii, Q. prinoides, Q. prinus.

Cynips. q. rileyi Bassett, 1881. Amer. Nat. 15: 149. ${ }^{\text {, gall. }}$

Neurotems Rileyi Ashmead, 1885. Amer. Ent. Soc. Trans. 12: 296.

quercusrileyi var. atripleurae Kinsey. Okla.

Neurotems rileyi var. atripleurae Kinsey, 1923. Ind. Univ. Studies 58: 32, 118. \&, gall.

quercusrileyi var. mutatus Kinsey. Tex.

Neurotems rileyi var. mutatus Kinsey, 1923. Ind. Univ. Studies 58: 20, 32, 118. \&, gall.

quercusrileyi var. thompsoni Kinsey. Mass.

Neuroterus thompsoni Kinsey, 1920. Amer. Mus. Nat. Hist., Bul. 42: 301. ᄋ, o, gall.

Neuroterus rileyi var. thompsoni Kinsey, 1923. Ind. Univ. Studies 58: 32, 120.

quercusverrucarum (Osten Sacken). N. Y. to Fla., w. to Okla., Tex. Ecology: Produce leaf galls on Quercus breviloba, Q. chapmani, Q. macrocarpa, Q. stellata.

Cynips qnercus verrucarum Osten Sacken, 1861. Ent. Soc. Phila., Proc. 1: 62. \&, gall.

Cyuips verrucurum Osten Sacken, 1865. Ent. Soc. Phila., Proc. 4: 354.

quercusverrucarum var. inficiens Kinsey. Tex.

Neuroterus cermcarum var. inficiens Kinsey, 1923. Ind. Univ. Studies 58: 14, 30, 71. + , gall.

quercusverrucarum var. macrocarpae Kinsey. Tex.

Neuroterus verrucarum var. macrocarpae Kinsey, 1923. Ind. Univ. Studies 58: 30, 72., gall.

quercusverrucarum var. opacus Kinsey. Tex.

Neuroterus verncarum var. opacus Kinsey, 1923. Ind. Univ. Studies 58: 14, 15, 30, 73. \&, gall.

quercusverrucarum var. pulvinus Kinsey. Tex.

Neuroterus verrucarmm var. pulvinus Kinsey, 1923. Ind. Univ. Studies 58: 11, 15, 30, 75. \&, gall.

quercusverrucarum var, restrictus Kinsey. Fla.

Neuroterus verrucarum var. restrictus Kinsey, 1923. Ind. Univ. Studies 58: 14, 30, 77. \&, gall.

sadlerensis Weld. Oreg. Ecology: Produce leaf galls on Quercus sadleriana.

Neuroterus sallerensis Weld, 1926. U. S. Natl. Mus., Proc. 68 (10): 9. \&, o, gall.

saltarius Weld. Mich., Ind., Minn., Iowa, Mo. Ecology: Produce leaf galls on Quercus macrocarpa.

Neuroterus saltarius Weld, 1926. U. S. Natl. Mus., Proc. 68 (10): 11. $₹$, gall.

saltatorius (Edwards). Tex., Ariz., Calif. Ecology: Produce leaf galls in agamic and sexual generations on Quercus arizonica, Q. douglasii, Q. dumosa, Q. garryana, Q. lobata, Q. stellata, Q. virginiana.

Cynips Saltatorius Edwards, 1874. Pacific Rural Press 7: 97., gall.

Neuroterus decipiens Kinsey, 1922. Amer. Mus. Nat. Hist., Bul. 46: 292.

$\uparrow, \delta$, gall. Sexual gen.

Taxonomy: Rosenthal and Koehler, 1971. Ent. Soc. Amer., Ann. 64: 565-570.

saltatorius var. australis Kinsey. Tex.

Neuroterus saltatorius var. australis Kinsey, 1923. Ind. Univ. Studies 58: 31, 51. ๆ, gall.

saltatorius var. decrescens Kinsey. Ariz.

Nenroterus saltatorius var. decrescens Kinsey, 1923. Ind. Univ. Studies 58: 31, 52. \&, gall.

saltatorius var. texanus Kinsey. Tex.

Neuroterus saltatorins var. texanus Kinsey, 1923. Ind. Univ. Studies 58: 31, 56.

tantulus Weld. Md. Ecology: Produce leaf galls on Quercus alba.

Neuroterus tantulus Weld, 1952. U. S. Natl. Mus., Proc. 102: 321. \&, gall.

tectus Bassett. Mass., Conn., R. I., N. Y. Ecology: Produce stem galls on Quercus prinoides. Neuroterus tectus Bassett, 1900. Amer. Ent. Soc., Trans. 26: 331. \&, ठ, gall. Agamic gen.

Neuroterus tectus form abundans Kinsey, 1920. Amer. Mus. Nat. Hist., Bul. 42: 339. \&.

umbilicatus Bassett. Conn., Ont., s. to Va. Ecology: Produce leaf galls on Quercus bicolor.

Neuroterus umbilicatus Bassett, 1900. Amer. Ent. Soc., Trans. 26: 330. \&, gall. 
varians Kinsey. Calif. Ecology: Produce stem galls on Quercus douglasii, Q. lobata.

Neuroterus varians Kinsey, 1922. Amer. Mus. Nat. Hist., Bul. 46: 294. \$, gall.

vernus Gillette. Iowa. Ecology: Produce leaf galls on Quercus macrocarpa.

Neuroterus vernus Gillette, 1889. Iowa Agr. Expt. Sta., Bul. 7: 281. \&, gall.

vesicula (Bassett). Ont. to Va., w. to Ill., Iowa, Tex. Ecology: Produce bud galls on Quercus alba.

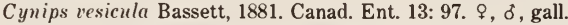

vesicula var. cerinus Kinsey. Tex. Ecology: Produce stem galls on Quercus stellata.

Neuroterns vesicula var. cerinus Kinsey, 1923. Ind. Univ. Studies 58: 15, 35, 125. §, §, gall.

vesicula var. ocularis Kinsey. Tex. Ecology: Produce bud galls on Quercus stellata.

Neuroterus vesicula var. ocularis Kinsey, 1923. Ind. Univ. Studies 58: 15, 35, 126. ๆ, ठ, gall.

virgens Gillette. Colo. Ecology: Produce stem galls on Quercus arizonica, Q. gambelii, Q. subturbinella.

Neuroterus virgens Gillette, 1895. Ent. News 4: 166. \&, o, gall.

washingtonensis Beutenmueller. Wash. Ecology: Produce leaf galls on Quercus garryana.

Neuroterus washingtonensis Beutenmueller, 1913. Canad. Ent. 45: 280. ‡, o, gall.

\section{Genus TRICHOTERAS Ashmead}

Trichoteras Ashmead, 1897. Psyche 8: 67.

Type-species: Trichoteras coquilletti Ashmead. Monotypic.

californicum (Beutenmueller). Calif. Ecology: Produce leaf galls on Quercus douglasii, Q. dumosa.

Philonix califomica Beutenmueller, 1911. Ent. News 22: 69. \&, gall.

coquilletti Ashmead. Ariz., Calif. Ecology: Produce leaf galls on Quercus chrysolepis, Q. wilcoxii.

Trichoteras coquilletti Ashmead, 1897. Psyche 6: 68. \&, gall.

frondeum Weld. Ariz., Calif. Ecology: Produce bud galls on Quercus chrysolepeis, Q. wilcoxii.

Trichoteras frondenm Weld. 1944. U. S. Natl. Mus., Proc. 95: 4. ₹, gall.

perfulvum Weld. Calif. Ecology: Produce leaf galls on Quercus chrysolepis.

Trichoteras perfulvum Weld, 1952. U. S. Natl. Mus., Proc. 102: 322. \&, gall.

rotundula Weld. Ariz., Calif. Ecology: Produce leaf galls on Quercus chrysolepis, Q. wilcoxii.

Trichoteras rotundula Weld, 1952. U. S. Natl. Mus., Proc. 102: 323. १, gall.

tubifaciens (Weld). Calif. Ecology: Produce leaf galls on Quercus garryana.

Xanthoteras tubifaciens Weld, 1926. U. S. Natl. Mus., Proc. 68 (10): 53. \&, gall.

vacciniifoliae (Ashmead). Calif. Ecology: Produce leaf galls on Quercus vaccinifolia, Q. chrysolepis.

Callirhytis vacciniifoliae Ashmead, 1896. U. S. Natl. Mus., Proc. 19: 130. + , gall.

\section{Genus PHYLLOTERAS Ashmead}

Phylloteras Ashmead, 1897. Psyche 8: 67.

Type-species: Biorhiza rubinus Gillette. Monotypic.

cupella (Weld). N. Mex., Ariz. Ecology: Produce leaf galls on Quercus arizonica, Q. oblongifolia, Q. reticulata, Q. subturbinella.

Trigonaspis cupella Weld, 1926. U. S. Natl. Mus., Proc. 68 (10): 50. , gall.

rubinum (Gillette). N. Y., Md., Va., N. C., Mich., Ill., Mo. Ecology: Produce leaf galls on Quercus alba.

Biorhiza mbinus Gillette, 1888. Mich. State Bd. Agr., Rpt. 27: 472. \&, gall.

sigma Weld. N. Y., Md., D. C., Va. Ecology: Produce leaf galls on Quercus alba.

Phylloteras sigma Weld, 1944. U. S. Natl. Mus., Proc. 95: 5. \&, gall.

\section{Genus XYSTOTERAS Ashmead}

Xystoteras Ashmead, 1897. Canad. Ent. 29: 260. 
Type-species: Xystoteres volutellae Ashmead. Monotypic.

nigrum (Fitch). N. Y., Mo. Ecology: Produce leaf galls on Quercus alba.

Biarhiza (!) nigra Fitch, 1859 (1858). N. Y. State Agr. Soc., Trans. 18: 782..

Acraspis politus Bassett, 1890. Amer. Ent. Soc., Trans. 17: 85. $\%$.

poculum (Osten Sacken). N. H., Vt., N. Y., Va., Ill., Mo. Ecology: Produce leaf galls on Quercus alba.

Cecidomyia poculum Osten Sacken, 1862. Smithsn. Misc. Collect. 6: 201. Gall.

Xystoteras poculum Weld, 1922. U. S. Natl. Mus., Proc. 61 (18): 7. \&, gall.

Taxonomy: Gagne, 1973. Ent. Soc. Amer., Ann. 66: 858.

volutellae Ashmead. Kans. Ecology: Produce leaf galls on Quercus macrocurpa.

Xystoteras volutellae Ashmead, 1897. Canad. Ent. 29: 260. $₹$, gall.

\section{Genus XANTHOTERAS Ashmead}

Xanthoteras Ashmead, 1897. Canad. Ent. 29: 261.

Type-species: Biorhiza forticorn is Walsh. Orig. desig.

eburneum (Bassett). Colo., N. Mex., Utah, Ariz. Ecology: Produce stem galls on Quercus reticulata, Q. submollis, Q. subturbinella.

Dryophanta eburne'us Bassett, 1890. Amer. Ent. Soc., Trans. 17: 10. \&, gall. Agamic gen.

Dryophanta similis Bassett, 1890. Amer. Ent. Soc., Trans. 17: 71. \&, gall. Preocc. by Adler, 1881.

Dryophante simillima Dalla Torre, 1893. Cat. Hym., v. 2, p. 54. N. name.

Dryophanta glabira Gillette, 1894. Canad. Ent. 26: 237. ₹, gall.

emoryi (Ashmead). N. Mex. Ecology: Produce leaf galls on Quercus sp.

Dryophanta emoryi Ashmead, 1896. U. S. Natl. Mus., Proc. 19: 115. ๆ, gall. Agamic gen.

fumosum (Weld). N. Mex., Ariz. Ecology: Produce root galls on Quercus gambelii, Q. reticulata, Q. submollis, Q. subturbinella.

Trigonaspis fumosa Weld, 1921. U. S. Natl. Mus., Proc. 59: 204. ₹, §, gall. Sexual gen.

mediocre Weld. Ariz. Ecology: Produce root galls on Quercus subturbinella.

Xanthoteras melliocre Weld, 1930. Ent. Soc. Wash., Proc. 32: 30., gall. Agamic gen.

obconicum (Weld). Calif. Ecology: Produce root galls on Quercus douglasii.

Trigonaspis obconica Weld, 1921. U. S. Natl. Mus., Proc. 59: 202. ९, ó, gall. Sexual gen.

ornatum (Kinsey). Tex. Ecology: Produce leaf galls on Quercus breviloba.

Trigonaspis ornata Kinsey, 1922. Ind. Univ. Studies 53: 139. \&, ठ, gall. Sexual gen.

politum (Bassett). N. J. to Fla., w, to Mo., Okla., Tex. Ecology: Produce leaf galls on Quercus chapmani, Q. stellata on coastal plains and inland lowlands.

Cynips polita Bassett, 1881. Canad. Ent. 13: 99., gall. Agamic gen.

pulchellum (Beutenmueller). Oreg., Calif.

Dryophanta pulchella Beutenmueller, 1911. Ent. News 22: 357. 9. Sexual gen.

pulchripenne (Ashmead). Ariz., Calif. Ecology: Produce leaf galls on Quercus arizonica, Q. oblongifolia, Q. reticulata, Q. subturbinella, Q. toumeyi.

Dryophanta pulchripennis Ashmead, 1896. U. S. Natl. Mus., Proc. 19: 115. \&, gall. Agamic gen.

Dryophanta porterae Cockerell, 1900. Canad. Ent. 32: 91. \&, gall.

pumiliventre (Bassett). Colo., Utah. Ecology: Produce root galls on Quercus sp.

Dryophanta pumiliventris Bassett, 1890. Amer. Ent. Soc., Trans. 17: 69. ó, ๆ. Sexual gen.

Belonocnema colorado Gillette, 1893. Ent. News 4: 210. 9.

Trigonaspis radicis Ashmead, 1896. U. S. Natl. Mus., Proc. 19: 113. ๆ, ơ, gall.

quercusforticorne (Walsh). N. H. to Va., w. to Minn. Ecology: Produce stem galls on Quercus alba.

Cynips q. forticornis Walsh, 1864. Ent. Soc. Phila., Proc. 2: 489. ₹, gall. Agamic gen.

Cynips (Teras) forticornis Osten Sacken, 1865. Ent. Soc. Phila., Proc. 4: 340, 350, 353.

Taxonomy: Fitch, 1859 (1858). N. Y. State Agr. Soc., Trans. 18: 812.

radicola (Ashmead). Ont., N. Y., N. J., Pa., D. C., Va., Ind., Ill., Mo. Ecology: Produce root galls on Quercus alba.

Dryophanta radicola Ashmead, 1896. U. S. Natl. Mus., Proc. 19: 116., gall. Sexual gen. 
teres Weld. Oreg., Calif. Ecology: Produce leaf galls on Quercus dumosa, Q. garryana.

Xanthoteras teres Weld, 1926. U. S. Natl. Mus., Proc. 68 (10): 52. \&, gall. Agamic gen. teres var. hildebrandae (Kinsey). Calif.

Cynips (Antron) teres var. hildebrandae Kinsey, 1930. Gall wasp genus Cynips, p. 217. , gall. Agamic gen.

\section{Genus PARACRASPIS Weld}

\section{Paracraspis Weld, 1952. U. S. Natl. Mus., Proc. 102: 324.}

Type-species: Callirhytis guaduloupensis Fullaway. Orig. desig.

guadaloupensis (Fullaway). Ariz., Calif. Ecology: Produce leaf galls on Quercus chrysolepis, Q. wilcoxii.

Callirhytis gnadaloupensis Fullaway, 1911. Ent. Soc. Amer., Ann. 4: 363. \&, gall.

insolens (Weld). Calif. Ecology: Produce leaf galls on Quercus chrysolepis.

Acraspis insolens Weld, 1926. U. S. Natl. Mus., Proc. 68 (10): 59. ๆ, gall.

patelloides (Trotter). Calif. Ecology: Produce leaf galls on Quercus chrysolepis.

Audricus? patelloides Trotter, 1911. Lab. Zool. Gen. e Agr. Portici, Bol. 5: 106. gall.

Acraspis patelloiles Weld, 1926. U. S. Natl. Mus., Proc. 68 (10): 60 . ๆ, gall.

\section{Genus ACRASPIS Mayr}

Acraspis Mayr, 1881. Zwanzig. Jahresber. Comm.-Oberrealsch. I. Bez. Wien. pp. 2, 29.

Type-species: Cynips pezomachoides Osten Sacken. Desig. by Rohwer and Fagan, 1917.

alaria Weld. Colo. Ecology: Produce leaf galls on Quercus gambelii.

Acraspis alaria Weld, 1922. U. S. Natl. Mus., Proc. 61 (18): 14. , gall.

arida (Kinsey). Tex. Ecology: Produce leaf galls on Quercus grisea.

Cyuips (Acraspis) arida Kinsey, 1930. Gall wasp genus Cynips, p. 313. \&, gall.

bandero (Kinsey). Colo. Ecology: Produce leaf galls on Quercus gambelii.

Cynips (Acraspis) bandero Kinsey, 1936. Origin of higher categories in Cynips, p. 284., gall.

conica (Kinsey). Ariz. Ecology: Produce leaf galls on Quercus grisea.

Cynips (Acraspis) conica Kinsey, 1930. Gall wasp genus Cynips, p. 338. $\uparrow$, gall.

echini Ashmead. Fla. Ecology: Produce leaf galls on Quercus bicolor.

Acraspis echini Ashmead, 1887. Amer. Ent. Soc., Trans. 14: 140. \&, gall.

Cynips (Acraspis) pezomachoides var. echinoides Kinsey, 1930. Gall wasp genus Cynips, p. 412. N. name, unneccessarily proposed.

erinacei (Beutenmueller). Ont. s. to Va., w. to Ill. Ecology: Produce galls on Quercus alba, sexual generation on the buds, agamic generation on leaves.

Philonix erinacei Beutenmueller, 1909. Amer. Mus. Natl. Hist., Bul. 26: 247. §, gall. Agamic gen.

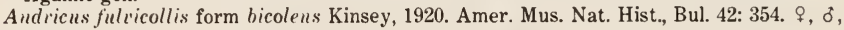
gall.

Taxonomy: Triggerson, 1914. Ent. Soc. Amer., Ann. 7: 6. १, ठ, gall. Bisexual gen.

gemula (Bassett). N. Y., N. J., w. to Kans. Ecology: Produce galls on Quercus alba, Q. michanxii, Q. muehlenbergii, Q. prinoides, sexual generation on the buds, agamic generation on leaves.

Cynips gemula Bassett, 1881. Canad. Ent. 13: 104. ๆ, o, gall.

gemula var. cruenta (Kinsey). Ill.

Cynips (Acraspis) gemmula(!) var. cruenta Kinsey, 1930. Gall wasp genus Cynips, p. 360. ; gall. Agamic gen.

gemula var. fuscata (Kinsey). Kans.

Cynips (Acraspis) gemmula(!) var, fuscata Kinsey, 1930. Gall wasp genus Cynips, p. 362. १, gall. Agamic gen.

gemula var. suspecta (Kinsey). Ind.

Cynips (Acraspis) gemmula(!) var. suspecta Kinsey, 1930. Gall wasp genus Cynips, p. 364 .

१, gall. Agamic gen. 
hibrida (Kinsey). Tenn. Ecology: Produce galls on leaves of Quercus alba.

Cynips (Acraspis) hibrida Kinsey, 1936. Origin of higher categories in Cynips, p. 273. \&, gall.

hirtior (Kinsey). Utah. Ecology: Produce leaf galls on Quercus utahensis.

Cynips (Acraspis) hirtior Kinsey, 1936. Origin of higher categories in Cynips, p. 286. $\uparrow$, gall. Agamic gen.

inflata (Kinsey). Ind. Ecology: Produce leaf galls on Quercus alba.

Cynips (Acraspis) inflata Kinsey, 1936. Origin of higher categories in Cynips, p. 274. $\&$, gall. Agamic gen.

longicornis (Bassett). Conn. Ecology: Produce stem galls on Quercus stellata.

Dryophanta longicorn is Bassett, 1900. Amer. Ent. Soc., Trans. 26: 327. ठ", ९. Sexual gen.

macrocarpae Bassett. Conn. Ecology: Produce leaf galls on Quercus macrocarpa.

Acraspis macrocarpae Bassett, 1890. Amer. Ent. Soc., Trans. 17: 84. , gall. Agamic gen.

Acraspis undulata Gillette, 1893. Ent. News 4: 28. ₹, gall. Agamic gen.

Cynips (Acraspis) hirta var. macrescens Kinsey, 1930. Gall wasp genus Cynips, p. 423. N. name, unnecessarily proposed.

pezomachoides (Osten Sacken). Ont. s. to N. C., w. to Minn., Colo. Ecology: Produce leaf galls on Quercus alba.

Cynips pezomachoides Osten Sacken, 1862. Ent. Soc. Phila., Proc. 1: 250. \&, gall. Agamic gen.

pezomachoides var. advena (Kinsey). Tenn.

Cynips (Acraspis) pezomachoides var. advena Kinsey, 1930. Gall wasp genus Cynips, p. 409. , gall. Agamic gen.

pezomachoides var. cincturata (Kinsey). Colo.

Cynips (Acraspis) pezomachoides var. cincturata Kinsey, 1930. Gall wasp genus Cynips, p. 377. \&, gall. Agamic gen.

pezomachoides var. derivatus (Kinsey). Ala.

Cynips (Acraspis) pezomachoides var. derivatus Kinsey, 1930. Gall wasp genus Cynips, p. 391. $\&$, gall. Agamic gen.

pezomachoides var. ozark (Kinsey). Mo.

Cynips (Acraspis) pezomachoides var. ozark Kinsey, 1930. Gall wasp genus Cynips, p. 378. q, gall. Agamic gen.

pezomachoides var. wheeleri (Kinsey). Mich.

Cynips (Acraspis) pezomachoides var. wheeleri Kinsey, 1930. Gall wasp genus Cynips, p. 380. \%, gall. Agamic gen.

prinoides (Beutenmueller). Mass., N. Y., N. J. Ecology: Produce leaf galls on Quercus prinoides.

Cynips (?) prinoides Beutenmueller, 1892. Amer. Mus. Nat. Hist., Bul. 4: 257. $\uparrow$, gall.

quercushirta (Bassett). Conn. s. to Va., w. to Ill., Tex., Utah. Ecology: Produce leaf galls on Quercus chapmani, Q. macrocarpa, Q. michanxii, Q. prinus, Q. utahensis.

Cynips q. hirta Bassett, 1864. Ent. Soc. Phila., Proc. 3: 688. $\%$, gall. Agamic gen.

Cynips (Teras) hirta Osten Sacken, 1865. Ent. Soc. Phila., Proc. 4: 340, $347,353$.

quercushirta var. obtrectans (Kinsey). Tex.

Cynips (Acraspis) hirta var. obtrectans Kinsey, 1930. Gall wasp genus Cynips, p. 420. $?$, gall. Agamic gen.

quercushirta var. opima (Kinsey). Ill.

Cynips (Acraspis) hirta var. opima Kinsey, 1930. Gall wasp genus Cynips, p. 421. \&, gall. Agamic gen.

quercushirta var. packorum (Kinsey). Utah.

Cynips (Acraspis) hirta var. packorum Kinsey, 1930. Gall wasp genus Cynips, p. 418. ?, gall. Agamic gen.

quercushirta var. scelesta (Kinsey). Mich.

Cynips (Acraspis) hirta var. scelesta Kinsey, 1930. Gall wasp genus Cynips, p. $422 . \uparrow$, gall. Agamic gen. 
ulterior (Kinsey). Colo. Ecology: Produce leaf galls on Quercus gambelii.

Cynips (Acraspis) ulterior Kinsey, 1936. Origin of higher categories in Cynips, p. 294. $\&$, gall. Agamic gen.

villosa Gillette. N. Y., Mich., Iowa, Kans., Tex., Utah, Ariz. Ecology: Produce leaf galls on Quercus arizonica, Q. grisea, Q. macrocarpa, Q. ntahensis.

Acraspis villosus Gillette, 1888. Mich. State Bd. Agr., Rpt. 27: 474. ๆ, gall. Agamic gen.

villosa var. apache (Kinsey). Ariz.

Cynips (Acraspis) villosa var. apache Kinsey, 1930. Gall wasp genus Cynips, p. 352. , gall. Agamic gen.

villosa var. calvescens (Kinsey). Utah.

Cynips (Acraspis) villosa var. calcescens Kinsey, 1930. Gall wasp genus Cynips, p. 354. ๆ, gall. Agamic gen.

villosa var. consocians (Kinsey). Kans.

Cynips (Acrespis) villosa var. cousociuns Kinsey, 1930. Gall wasp genus Cynips, p. 357. ㅇ, gall. Agamic gen.

villosa var. expositor (Kinsey). Tex.

Cyuips (Acraspis) villost var. expositor Kinsey, 1930. Gall wasp genus Cynips, p. 351. \&, gall. Agamic gen.

\section{Genus PHILONIX Fitch}

Plilouix Fitch, 1859 (1858). N. Y. State Agr., Soc., Trans. 18: 783.

Type-species: Plilonix fulvicollis Fitch. Desig. by Ashmead, 1903.

fulvicollis Fitch. N. Y., Mich., Tenn., Ill., Kans. Ecology: Produce leaf galls on Quercus alba, Q. chapmani, Q. macrocarpa. Specimens have been collected on snow in late autumn.

Philonix fulvicollis Fitch, 1859 (1858). N. Y. State Agr. Soc., Trans. 18: 783. \&. Agamic gen.

fulvicollis var. canadensis (Kinsey). Mich.

Cynips (Philonix) fulticollis var. canadensis Kinsey, 1930. Gall wasp genus Cynips, p. 273. o, gall.

fulvicollis var. major (Kinsey). Ill.

Cynips (Philonix) fulvicollis var. major Kinsey, 1930. Gall wasp genus Cynips, p. 257., , gall.

fulvicollis var. rubricosa (Kinsey). Tenn.

Cynips (Philonix) fulvicollis var. rubricosa Kinsey, 1930. Gall wasp genus Cynips, p. 254. o, gall.

fulvicollis var. vorisi (Kinsey). Kans.

Cynips (Philonix) fulvicollis var. vorisi Kinsey, 1930. Gall wasp genus Cynips, p. 255. ₹, gall.

gigas Weld. Tex. Ecology: Produce leaf galls on Quereus lyrata.

Philonix gigas Weld, 1922. U. S. Natl. Mus., Proc. 61 (18): 12. ๆ, gall.

insulensis (Kinsey). Wis., Ill., Minn., Iowa, S. Dak., Nebr., Wyo., Colo. Ecology: Produce leaf galls on Quercus gumbelii, Q. macrocarpa.

Cynips (Philonix) insulensis Kinsey, 1936. Origin of higher categories in Cynips, p. 210. , gall (agamic gen.).

lanaeglobuli (Ashmead). Fla. Ecology: Produce leaf galls on Quereus sp., probably $Q$. michanxii.

Acraspis lanacglobuli Ashmead, 1887. Amer. Ent. Soc., Trans. 14: 139. ₹, gall.

latigenae (Kinsey). Utah. Ecology: Produce leaf galls on Quercus utahensis.

Cynips (Philonix) latigenae Kinsey, 1936. Origin of higher categories in Cynips, p. 212. $\$$, gall.

nigra (Gillette). Conn., Mich., Iowa. Ecology: Produce leaf galls on Quercus alba.

Acraspis niger Gillette, 1889. Iowa Agr. Expt. Sta., Bul. 7: 282. $\%$, gall.

Acraspis Gillettei Bassett, 1900. Amer. Ent. Soc., Trans. 26: 323. \&. gall. 
nigricollis Fitch. N. Y. Collected on snow before 1858 and not known to have been found or reared since.

Philonix nigricollis Fitch, 1859 (1858). N. Y. State Agr. Soc., Trans. 18: 783. §.

Taxonomy: Kinsey, 1930. Gall wasp genus Cynips, p. 262 (syn. of fulvicollis Fitch).

pallipes (Bassett). Conn., N. Y., Md., D. C., Va., Ill. Ecology: Produce bud galls on Quercus albe.

Dryoplienta pallipes Bassett, 1900. Amer. Ent. Soc., Trans. 26: 327. \&, gall.

Taxonomy: Kinsey, 1930. Gall wasp genus Cynips, p. 269 (sexual form of fulvicollis Fitch ?).

\section{Genus LIODORA Foerster}

Liolor Foerster, 1869. Zool.-Bot. Gesell. Wien, Verh. 19: 331, 334.

Type-species: Liorlort sulcuta Foerster. Monotypic.

apiarium Weld. D. C., Va. Ecology: Produce leaf galls on Quercus alba.

Liorlore apiarium Weld, 1944. U. S. Natl. Mus., Proc. 95: 6. $\$$, gall.

clarkei (Bassett). Mass., Mo. Ecology: Produce bud galls on Quercus alba, Q. stellata.

Dryophuntu clarkei Bassett, 1890. Amer. Ent. Soc., Trans. 17: 69. ९, ठै, gall.

Dryophuntu cesiculoidles Ashmead, 1896. U. S. Natl. Mus., Proc. 19: 114. ๆ, ơ, gall.

comata Weld. Va. Ecology: Produce leaf galls on Quercus alba.

Liodort comatu Weld, 1952. U. S. Natl. Mus., Proc. 102: 325. + , ¿, gall.

\section{Genus DROS Kinsey}

Dros Kinsey, 1937. Rev. Ent. 7: 49.

Type-species: Dros petasum Kinsey. Orig. desig.

amphora (Weld). N. Mex., Ariz. Ecology: Produce leaf galls on Quercus arizonica, Q. oblongifolia.

Diplolepis amphora Weld, 1926. U. S. Natl. Mus., Proc. 68 (10): 17. \&, gall.

atrimentum (Kinsey). Calif. Ecology: Produce leaf galls on Quercus douglasii.

Andricus atrimentus Kinsey, 1922. Amer. Mus. Nat. Hist., Bul. 46: 279. \&, ð, gall.

pedicellatum (Kinsey). Calif. Ecology: Produce leaf galls on Quercus douglasii.

Andricus pedicellatus Kinsey, 1922. Amer. Mus. Nat. Hist., Bul. 46: 284. ₹, §, gall.

sessile (Weld). Ariz. Ecology: Produce leaf galls on Quercus arizonica, Q. oblongifolia.

Diplolepis sessilis Weld, 1926. U. S. Natl. Mus., Proc. 68 (10): 31. $\uparrow$, gall.

viscidum (Weld). Ariz. Ecology: Produce leaf galls on Quercus oblongifolia.

Liodora viscida Weld, 1944. U. S. Natl. Mus., Proc. 95: 5. ₹, gall.

\section{Genus ADLERIA Rohwer and Fagan}

Adleria Rohwer and Fagan, 1917. U. S. Natl. Mus., Proc. 53: 359.

Type-species: Cynips kollari Hartig. Orig. desig.

The name $C y n i p s$ was applied to this genus by Hartig and most other authors, but not Linnaeus and not Kinsey.

Taxonomy: Niblett, 1955. So. London Ent. and Nat. Hist. Soc., Proc. and Trans. 1953-54, p.

144 (Possible syn. of Andricus Hartig).

arizonica (Cockerell). Ariz. Ecology: Produce leaf galls on Quercus arizonica.

Holcaspis arizonica Cockerell, 1902. Canad. Ent. 34: 183. ๆ, gall.

dimorpha (Beutenmueller). N. Y., N. J., Md., Va., Mich., Ill., Iowa. Ecology: Produce leaf galls on Quercus alba, Q. macrocarpa.

Cynips dimorphus Beutenmueller, 1913. Amer. Ent. Soc., Trans. 39: 245. \&, gall.

flavicollis (Ashmead). Ill.

Cynips flacicollis Ashmead, 1896. U. S. Natl. Mus., Proc. 19: 133..

nigricens (Gillette). N. Y., N. J., Va., Ohio, Mich., Ill., Mo. Ecology: Produce leaf galls on Quercus bicolor:

Cynips nigricens Gillette, 1888. Mich. State Bd. Agr., Rpt. 27: 473. , gall.

Andricus Ashmeadii Bassett, 1890. Amer. Ent. Soc., Trans. 26: 320.. 
quercusstrobilana (Osten Sacken). Ont., Mass. to Va., w. to Ill., Iowa. Ecology: Produce stem galls on Quercus bicolor, Q. macrocarpa.

Cynips q. strobilana Osten Sacken, 1862. Ent. Soc. Phila., Proc. 1: 254. gall.

Cynips quercus strobilana Osten Sacken, 1864. In Bassett, Ent. Soc. Phila., Proc. 3: 690..

Cynips strobilana Osten Sacken, 1865. Ent. Soc. Phila., Proc. 4: 345, 349, 350.

vacciniiformis (Beutenmueller). Tex. Ecology: Produce leaf galls on Quercus stellata.

Cynips vacciniiform is Beutenmueller, 1913. Amer. Ent. Soc., Trans. 39: 247. ๆ, gall.

weldi (Beutenmueller). Ont., Mass. to Va., w. to Ill., Mo., Ark. Ecology: Produce leaf petiole galls on Quercus alba.

Cynips weldi Beutenmueller, 1918. Brooklyn Ent. Soc., Bul. 13: 118. $\&$, gall.

\section{Genus AMPHIBOLIPS Reinhard}

Ampliibolips Reinhard, 1865. Berlin Ent. Ztschr. 9: 10.

Type-species: Cynips spongifica Osten Sacken. Orig. desig.

Trissandricns Kieffer, 1910. Lab. Zool. Gen. e Agr. Portici, Bol. 4: 115.

Type-species: Trissandricus maculipennis Kieffer. Monotypic.

Revision: Beutenmueller, 1909. Amer. Mus. Nat. Hist., Bul. 26: 47-66.

acuminata Ashmead. Atlantic and Gulf Coast plains, Mississippi Valley n. to Mo. Ecology:

Produce bud and stem galls on Quercus cirerea, Q. falcata.

Amphibolips acuminata Ashmead, 1896. U. S. Natl. Mus., Proc. 19: 126. \&, gall.

arcuata (Kieffer). Ga. Ecology: Produce stem galls on Quercus sp.

Calliritytis arcuata Kieffer, 1910. Lab. Zool. Gen. e Agr. Portici, Bol. 4: 341..+

confluenta (Harris). Mass., Ont. to Va., w. to Ill., Iowa, Kans. Ecology: Produce leaf galls on red oaks.

Cynips confluentus Harris, 1841. Rpt. Ins. Mass. Injurious to Veg., p. 397. \&, gall.

Cynips aciculata Osten Sacken, 1861. Ent. Soc. Phila., Proc. 1: 56. $q$, gall.

cookii Gillette. Ont. to Va., w. to Mich., Wis., Ill., Mo. Ecology: Produce bud galls on Quercus rubra.

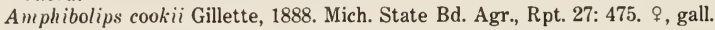

gainesi Bassett. Ark., Tex. Ecology: Produce acorn galls on Quercus laurifolia.

Amphibolips Gainesi Bassett, 1900. Amer. Ent. Soc., Trans. 26: 322. ९, gall.

globulus Beutenmueller. N. J. Ecology: Produce bud galls on Quercus marilandica.

Amphibolips globulus Beutenmueller, 1909. Amer. Mus. Nat. Hist., Bul. 26: 60. $\uparrow$, gall.

globus Weld. Va. Ecology: Produce bud galls on Quercus palustris.

Amphibolips globus Weld, 1952. U. S. Natl. Mus., Proc. 102: 325. ₹, o, gall. Sexual gen. and female of agamic gen.

gumia Kinsey. Ariz. Ecology: Produce stem galls on Quercus emoryi, Q. hypoleuca. Amphibolips gumia Kinsey, 1937. Rev. Ent. 7: 437. $\%$, gall.

melanocera Ashmead. Fla. Ecology: Produce bud galls on Quercus nigra.

Amphibolips melanocera Ashmead, 1885. Amer. Ent. Soc., Trans. 12: 299, 303. ठ’, gall.

murata Weld. Fla. Ecology: Produce bud galls on Quercus cinerea, Q. laurifolia, Q. myrtifolia, Q. pumila.

Amphibolips murata Weld, 1957. U. S. Natl. Mus., Proc. 107: 111-112., gall.

nigra Beutenmueller. Ariz.; Mexico. Ecology: Produce stem galls on Quercus emoryi, Q. hypoleuca.

Amphibolips nigra Beutenmueller, 1911. Ent. News 22: 198..

Taxonomy: Beutenmueller, 1917. Canad. Ent. 49: 348 (gall).

nubilipennis (Harris). Mass. to Va., w. to Mich., Ill., Iowa. Ecology: Produce leaf galls on red oaks.

Cynips mubilipennis Harris, 1841. Rpt. Ins. Mass. Injurious to Veg., p. 399. \&, gall.

Cynips q. sculptus Bassett, 1863. Ent. Soc. Phila., Proc. 2: 324. ๆ, ơ, gall.

quercuscinerea (Ashmead). Fla. Ecology: Produce stem galls on Quercus cinerea.

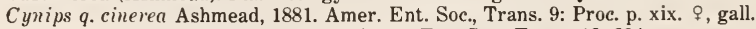

Amphibolips cinerea Ashmead, 1885. Amer. Ent. Soc., Trans. 12: 294. 
quercuscitriformis (Ashmead). Fla. Ecology: Produce bud galls on Quercus phellos.

Cynips q. citriform is Ashmead, 1881. Amer. Ent. Soc., Trans. 9: Proc. p. xxviii. ९, gall.

Amphibolips citriform is Ashmead, 1885. Amer. Ent. Soc., Trans. 12: 294.

quercuscoelebs (Osten Sacken). Mass., N. Y., D. C., Va. Ecology: Produce leaf galls on Quercus coccineu.

Cynips quercus coelebs Osten Sacken, 1861. Ent. Soc. Phila., Proc. 1: 61. ठँ, gall.

Cynips coelebs Osten Sacken, 1865. Ent. Soc. Phila., Proc. 4: 340, 345, 348, 355.

quercusfuliginosa (Ashmead). Fla. Ecology: Produce acorn galls on Quercus laurifoliu. Cynips q. fuligiuosu Ashmead, 1885. Amer. Ent. Soc., Trans. 12: Proc. p. vii. \&, gall.

A milhibolips fuliginosi Ashmead, 1885. Amer. Ent. Soc., Trans. 12: 294.

quercusilicifoliae (Bassett). Mass., Conn., N. Y., N. J., Pa., Va. Ecology: Produce leaf galls on Quercus ilicifolia.

Cynips q. ilicifoliue Bassett, 1864. Ent. Soc. Phila., Proc. 3: 681. \&, §, gall.

Cyuips ilicifoline Osten Sacken, 1865. Ent. Soc. Phila., Proc. 4: 340, 355.

quercusinanis (Osten Sacken). Ont. s. to Va. w. to Wis., Ill., Mo. Ecology: Produce leaf galls on Quercus rubra.

Cyuips q. iucuis Osten Sacken, 1862. Ent. Soc. Phila., Proc. 1: 242, 247. $\uparrow$, gall.

Cynips inunis Osten Sacken, 1865. Ent. Soc. Phila., Proc. 4: 344, 347, 354.

quercusjuglans (Osten Sacken). Mass. to Va., w. to Iowa, Mo. Ecology: Produce acorn galls on red oaks.

Cynips q. jugluus Osten Sacken, 1862. Ent. Soc. Phila., Proc. 1: 255. gall.

Cynips q. pruuns Walsh and Riley, 1869. Amer. Ent. 1: 104. ₹, gall.

quercusracemaria (Ashmead). Fla. Ecology: Produce leaf galls on Quercus lanrifolia.

Cynips q. recemuriu Ashmead, 1881. Amer. Ent. Soc., Trans. 9: Proc. p. xxvi. + , gall.

Amphibolips recemariu Ashmead, 1885. Amer. Ent. Soc., Trans. 12: 294.

quercusspongifica (Osten Sacken). Ont. to Va., w. to Ill. Ecology: Produce leaf galls on Quercus coccinea, Q. marilandica, Q. velutina.

Cyuips q. spongifica Osten Sacken, 1862. Ent. Soc. Phila., Proc. 1: 244, 247. + , gall.

Cyuips spongifica Osten Sacken, 1865. Ent. Soc. Phila., Proc. 4: 340, 344, 347, 354.

Cymips q. coccineae Osten Sacken, 1862. Ent. Soc. Phila., Proc. 1: 243. ?, gall.

Amphibolips Carolineusis Bassett, 1890. Amer. Ent. Soc., Trans. 17: 85. ๆ, gall.

Amphibolips longicom is Bassett, 1900. Amer. Ent. Soc., Trans. 26: 321. ๆ, gall.

Trissandricus maculipennis Kieffer, 1910. Lab. Zool. Gen. e Agr. Portici, Bol. 4: 115. \&.

spinosa Ashmead. Fla. Ecology: Produce bud galls on Quercus laurifolia.

Aulphibolips spinosa Ashmead, 1887. Amer. Ent. Soc., Trans. 14: 141. \&, gall.

tinctoriae Ashmead. N. Y. to Va., w. to Ill., Mo. Ecology: Produce bud galls on Quercus coccinea, Q. velutina.

Amphibolips tinctoriae Ashmead, 1896. U. S. Natl. Mus., Proc. 19: 125. , gall.

trizonata Ashmead. N. Mex., Ariz. Ecology: Produce stem galls on Quercus emoryi, Q. hypolenca.

Amphibolips trizonata Ashmead, 1896. U. S. Natl. Mus., Proc. 19: 125. ๆ, ठ, gall.

\section{Genus ANDRICUS Hartig}

Andricus Hartig, 1840 (1839). Ztschr f. Ent. 2: 185, 190.

Type-species: Andricus noduli Hartig. Desig. by Foerster, 1869.

A philothrix Foerster, 1869. Zool.-Bot. Gesell. Wien, Verh. 19: 331, 336.

Type-species: Cynips corticis Linnaeus. Monotypic.

Manderstiernia Radoszkowski, 1886. Soc. Nat. Moscou, Bul. 39: 304.

Type-species: Manderstjernia paradoxa Radoszkowski. Monotypic.

Euschmitzia Dettmer, 1925. Naturhist. Maand. Maastricht 14: 122.

Type-species: Euschmitzia rara Dettmer. Monotypic.

Oncaspis Dettmer, 1925. Naturhist. Maand. Maastricht 14: 123.

Type-species: Oncaspis filigranata Dettmer. Monotypic.

Eusymphagus Dettmer. 1930. Broteria, Rev. Luso-Brazil., Ser. Zool. 26: 54-57.

Type-species: Eusymphagus bellus Dettmer. Monotypic.

Druon Kinsey, 1937. Rev. Ent. 7: 56. 
Type-species: Druon protagion Kinsey. Orig. desig.

Femuros Kinsey, 1937. Rev. ent. 7: 65.

Type-species: Femuros repandae Kinsey. Orig. desig.

Feron Kinsey, 1937. Rev. Ent. 7: 69.

Type-species: Feron verutum Kinsey. Orig. desig.

Conobius Kinsey, 1938. Ind. Acad. Sci., Proc. 47: 262.

Type-species: Conobius strues Kinsey. Orig. desig.

aciculatus Beutenmueller. Mo., Ark., Tex. Ecology: Produce stem galls on Quercus stellata.

Andricus aciculatus Beutenmueller, 1909. Ent. News 20: 247. $\subsetneq$, gall.

albicomus Weld. Oreg. Ecology: Produce leaf galls on Quercus garryana.

Andricus albicomus Weld, 1952. U. S. Natl. Mus., Proc. 102: 328. $\uparrow$, gall.

albobalani Weld. Calif. Ecology: Produce acorn galls on Quercus douglasii, Q. dumosa, Q. lobata.

Audricus albobalani Weld, 1926. U. S. Natl. Mus., Proc. 68 (10): 68. ₹, gall.

biconicus Weld. D. C., Va., w. to Mo., Ark., Okla., Tex. Ecology: Produce leaf galls on Quercus stellata.

Audricus biconicus Weld, 1926. U. S. Natl. Mus., Proc. 68 (10): 68. \&, gall.

bracteatus Weld. Ariz. Ecology: Produce stem galls on Quercus arizonica, Q. oblongifolia, Q. reticulata, $Q$. toumeyi.

Andricus bracteutus Weld, 1944. U. S. Natl. Mus., Proc. 95: 7. + , gall.

brunneus Fullaway. Calif. Ecology: Produce leaf galls on Quercus douglasii, Q. dumosa, Q. garyaua, Q. lobatu.

Andricus biunneus Fullaway, 1911. Ent. Soc. Amer, Ann. 4: 353. \&, gall.

Taxonomy: Weld, 1952. U. S. Natl. Mus., Proc. 102: 327 (gall).

caepula (Weld). N. Mex., Ariz. Ecology: Produce leaf galls on Quercus arizonica, Q. oblongifolia, Q. subturbinella.

Diplolepis caepula Weld, 1926. U. S. Natl. Mus., Proc. 68 (10): 19. \&, gall.

capillatus (Weld). Md., D. C., Va. w. to Ill., Mo., Ark. Ecology: Produce leaf galls on Quercus alba .

Diplolepis capillata Weld, 1926. U. S. Natl. Mus., Proc. 68 (10): 20. $\%$, gall.

cellularius Gillette. Colo. Ecology: Produce bud galls on Quercus undulata.

Andricus cellularius Gillette, 1892. Ent. News 3: 247. \&, gall.

Neurotems cellula (!) Gillette, 1902. In Mayr, Zool.-Bot. Gesell. Wien, Verh. 52: 289.

chico Weld. Calif. Ecology: Produce bud galls on Quercus lobata.

Andricus chico Weld, 1952. U. S. Natl. Mus., Proc. 102: 328. $\&$, gall.

chinquapin (Fitch). Conn., N. Y. to Va., w. to Ill., Mo. Ecology: Produce leaf galls on Quercus alba, Q. bicolor, Q. prinoides.

Figites chinquapin Fitch, 1859 (1858). N. Y. State Agr. Soc., Trans. 18: 820. \&, gall.

Cynips quercus fusiformis Osten Sacken, 1861. Ent. Soc. Phila., Proc. 1: 61. $\$$, gall.

Cynips capsula Bassett, 1881. Canad. Ent. 13: 101. ₹, ठ, gall.

chrysobalani Weld. Calif. Ecology: Produce acorn galls on Quercus chrysolepis.

Andricus chryssobalani Weld, 1926. U. S. Natl. Mus., Proc. 68 (10): 71 . $९$, gall.

chrysolepidicola (Ashmead). Calif. Ecology: Produce stem galls in agamic generation, bud galls in sexual generation, on Quercus douglasii, Q. dumosa, Q. garryana, Q. lobata. Originally described incorrectly as produeing galls on Quercus chrysolepis.

Cynips chrysolepidicola Ashmead, 1896. U. S. Natl. Mus., Proc. 19: 124. ๆ, gall.

Cynips kelloggi Fullaway, 1911. Ent. Soc. Amer., Ann. 4: 345 ., gall.

Cynips rufe'scen.s MeCracken and Egbert, 1922. Stanford Univ., Pubs., Univ. Ser., Biol. Sci. 3 (1): 21 . + , gall.

Plagiotrichus (!) chrysolepidicola var. diminuens Kinsey, 1922. Ind. Univ. Studies 53: 114. q, gall.

Plagiotrichus (!) chrysolepidicola var. alutaceus Kinsey, 1922. Ind. Univ. Studies 53: 116. \%, gall.

Plagiotrichns (!) chrysolepidicola var. atricinctus Kinsey, 1922. Ind. Univ. Studies 53: 117. ๆ, gall. 
Plagiotrichus (!) chrysolepidicola var. compositus Kinsey, 1922. Ind. Univ. Studies 53: 118. \&, gall.

Biology: Burdick, 1967. Pan-Pacific Ent. 43: 227-231.

chrysolepidicola var. garryanae (Kinsey). Oreg. Ecology: Produce stem galls on Quercus garryana.

Plagiotrichus (!) chrysolepidicola var. garryanae Kinsey, 1922. Ind. Univ. Studies 53: 121. †, gall.

chrysolepidicola var. pugnoides (Kinsey). Calif. Ecology: Produce stem galls on Quercus lobata.

Plagiotrichus (!) chrysolepidicola var. pugnoides Kinsey, 1922. Ind. Univ. Studies 53: 120. $\uparrow$, gall.

chrysolepidicola var. pugnus (Kinsey). Calif. Ecology: Produce stem galls on Quercus lobata. Plagiotrichus(!) chrysolepidicola var. pugnus Kinsey, 1922. Ind. Univ. Studies 53: 120. , gall.

cinnamomeus Ashmead. Fla. Ecology: Produce bud galls on Quercus chapmani.

Andricus cinnamomens Ashmead, 1887. Amer. Ent. Soc., Trans. 14: 137. \&, gall.

Andricus calycicola Ashmead, 1887. Amer. Ent. Soc., Trans. 14: 141. \&, gall.

confertus McCracken and Egbert. Calif. Ecology: Produce leaf galls on Quercus lobata.

Andricus confertus McCracken and Egbert, 1922. Stanford Univ., Pubs., Univ. Ser., Biol. Sci. 3 (1): 32 . , gall.

coortus Weld. Calif. Ecology: Produce stem galls on Quercus douglasii, Q. dumosa.

Andricus coortus Weld, 1944. U. S. Natl. Mus., Proc. 95: 8. \&, gall.

coronus Beutenmueller. N. Y., D. C., Va., Ga., Ala. Ecology: Produce stem galls on Quercus palustris, $Q$. phellos.

Andricus coronus Beutenmueller, 1907. Amer. Mus. Natl. Hist., Bul. 23: 464. $\uparrow$, gall.

costatus Weld. Colo., N. Mex., Ariz. Ecology: Produce acorn galls on Quercus fendleri, Q. gambelii, Q. subturbinella.

Andricus costatus Weld, 1944. U. S. Natl. Mus., Proc. 95: 9. $\uparrow$, gall.

erassicornis (Ashmead). Fla. Ecology: Produce leaf galls on Quercus sp.

Callirhytis crassicornis Ashmead, 1896. U. S. Natl. Mus., Proc. 19: 130. \&, gall.

erenatus Weld. Calif. Ecology: Produce leaf galls on Quercus dumosa, Q. douglasii.

Andricus crenatus Weld, 1952. U. S. Natl. Mus., Proc. 102: 330. $\%$, gall.

crystallinus Bassett. Calif. Ecology: Produce leaf galls on Quercus donglasii, Q. dumosa, Q. garryana.

Andricus crystallinus Bassett, 1900. Amer. Ent. Soc., Trans. 26: 319. , gall. Agamic gen.

Biology: Doutt, 1960. Pan-Pacific Ent. 36: 167-170 (female, male, gall; sexual gen. on leaves of Quercus donglasii).

deciduatus Weld. Ill. Ecology: Produce bud galls on Quercus bicalor.

Andricus deciduatus Weld, 1926. U. S. Natl. Mus., Proc. 68 (10): 72 . $\&$, gall.

discalis (Weld). N. Mex., Ariz. Ecology: Produce leaf galls on Quercus subturbinella.

Diplolepis discalis Weld, 1926. U. S. Natl. Mus., Proc. 68 (10): 24. ๆ, gall.

discularis (Weld). Calif. Ecology: Produce leaf galls on Quercus garryana.

Diplolepis discularis Weld, 1926. U. S. Natl. Mus., Proc. 68 (10): 25 . , gall.

ellipsoidalis (Weld). Va. Ecology: Produce bud galls on Quercus falcata, Q. palustris. Amphibolips ellipsoidalis Weld, 1926. U. S. Natl. Mus., Proc. 68 (10): 105. , gall.

femoratus Ashmead. Fla. Ecology: Produce leaf galls on Quercus laurifolia, Q. phellos. Andricus femroratus Ashmead, 1887. Amer. Ent. Soc., Trans. 14: 141. ९, gall.

fimbrialis Weld. Calif. Ecology: Produce leaf galls on Quercus douglasii, Q. dumosa, Q. Iobata. Andricus fïmbrialis Weld, 1926. U. S. Natl. Mus., Proc. 68 (10): 74. ๆ, ơ, gall.

flavohirtus Beutenmueller. N. J., Ill. Ecology: Produce bud galls on Quercus bicolor. Andricus flarohirtns Beutenmueller, 1913. Insecutor Inscitiae Menstruus 1: 124. $\subsetneq$, gall. 
foliaformis Gillette. N. Y., Mich., Ill., Ariz. Ecology: Produce leaf galls on Quercus alba, Q. bicolor, Q. macrocarpa.

Andricus foliaform is Gillette, 1888. Mich. State Bd. Agr., Rpt. 27: 471. \&, gall. Audricus foliosus Weld, 1926. U. S. Natl. Mus., Proc. 68 (10): 76. $ๆ, \delta$, gall.

Taxonomy: Weld, 1967. In Krombein and Burks, U. S. Dept. Agr., Agr. Monog. 2, Supp. 2: 283.

formosalis Weld. Ariz. Ecology: Produce stem galls on Quercus emoryi. Andricus formosalis Weld, 1944. U. S. Natl. Mus., Proc. 95: 10., gall.

fullawayi Beutenmueller. Calif. Ecology: Produce leaf galls on Quercus lobata. Andricus fullaw ayi Beutenmueller, 1913. Amer. Ent. Soc., Trans. 39: 244. \&, gall.

furnessulus Weld. Ariz. Ecology: Produce stem galls on Quercus arizonica, Q. oblongifolia. Andricus furmessulus Weld, 1944. U. S. Nat1. Mus., Proc. 95: 12. $q$, gall.

howertoni Bassett. N. Mex., Ariz. Ecology: Produce stem galls on Quercus subturbinella. Andricus Houertoni Bassett, 1890. Amer. Ent. Soc., Trans. 17: 82. , gall.

ignotus (Bassett). Mass., Conn., Ill., Minn. Ecology: Produce leaf galls on Quercus bicolor, Q. macrocarpa.

Cynips ignota Bassett, 1881. Canad. Ent. 13: 106. ?, gall.

incertus Bassett. Conn., Ill. Ecology: Produce acorn galls on Quercus bicolor. Andricus incertus Bassett, 1900. Amer. Ent. Soc., Trans. 26: 317. \&. Andricus fimbriatus Weld, 1922. U. S. Natl. Mus., Proc. 61 (19): 29., gall.

incognitus Weld. Conn. Ecology: Produce leaf galls on Quercus stellata. Andricus iguotus Bassett, 1900. Amer. Ent. Soc., Trans. 26: 317. ๆ. Preocc. by Bassett, 1881.

Andricus incognitus Weld, 1951. U. S. Dept. Agr., Agr. Monog. 2: 634. N. name.

indistinctus Bassett. Ohio. Ecology: Produce stem galls on Quercus alba.

Andricus indistinctus Bassett, 1890. Amer. Ent. Soc., Trans. 17: 81. ₹, gall.

kingi Bassett. Calif. Ecology: Produce leaf galls in agamic and sexual generations on Quercus douglasii, Q. dumosa, Q. garryana, Q. lobata.

Andricus Kingi Bassett, 1900. Amer. Ent. Soc., Trans. 26: 316. \&, gall. Agamic gen. Andricus pistillaris Trotter, 1910. Lab. Zool. Gen. e Agr. Portici, Bol. 5: 117. \&, gall. Liodora dumosae Weld, 1957. U. S. Natl. Mus., Proc. 107: 111. १, §, gall. Sexual gen.

Taxonomy: Rosenthal and Koehler, 1971. Ent. Soc. Amer., Ann. 64: 565-570.

lasius (Ashmead). Ariz., Calif. Ecology: Produce leaf galls on Quercus chrysolepis, Q. wilcoxii. Callirhytis lasius Ashmead, 1896. U. S. Natl. Mus., Proc. 19: 132. + , gall.

lasius var, areolaris Kinsey. Calif.

Andricus lasius var, areolaris Kinsey, 1922. Ind. Univ. Studies 53: 19. ๆ, gall.

lasius var. sublasius Kinsey. Calif.

Audricus lasius var, sublasius Kinsey, 1922. Ind. Univ. Studies 53: 19. + , gall.

mamillaformis (Weld). Md., Va., N. C., Ill. Ecology: Produce bud galls on Quercus alba.

Callirhytis mamillaform is Weld, 1926. U. S. Natl. Mus., Proc. 68 (10): 96. ๆ, gall.

maxwelli Bassett. Tex. Ecology: Produce twig galls on Quercus sp.

Andricus Maxuelli Bassett, 1890. Amer. Ent. Soc., Trans. 17: 83. ९, ơ, gall.

mendocinensis Weld. Calif. Ecology: Produce subterranean galls, probably on the roots, on Lithocarpus deusiflora, the tanbark oak.

Andricus mendocinensis Weld, 1957. U. S. Natl. Mus., Proc. 107: 112. \&, gall.

montezuma Beutenmueller. Ariz.; Mexico. Ecology: Produce stem galls on Quercus arizonica, Q. oblongifolia, Q. reticulata, $Q$. toumeyi.

Andricus montezumus Beutenmueller, 1913. Amer. Ent. Soc., Trans. 39: 243. $\%$.

Taxonomy: Kinsey, 1920. Amer. Mus. Nat. Hist., Bul. 42: 306 (gall).

multicostatus Weld. Ariz. Ecology: Produce bud galls on Quereus subturbinella. Audricus multicostatus. Weld, 1952. U. S. Natl. Mus., Proc. 102: 331. \&, gall.

murtfeldtae Ashmead. N. J. to S. C., w. to Mo., Tex. Ecology: Produce bud galls on Quercus stellata.

Andricus murtfeldtae Ashmead, 1896. U. S. Natl. Mus., Proc. 19: 117. o, gall. 
Taxonomy: Weld, 1926. U. S. Natl. Mus., Proc. 68 (10): 78 (female).

occultatus (Weld). Calif. Ecology: Produce bud galls on Quercus douglasii, Q. dumosa, Q. lobata.

Diplolepis occultatus Weld, 1926. U. S. Natl. Mus., Proc. 68 (10): 28. \&, gall.

opertus (Weld). Calif. Ecology: Produce bud galls on Quercus douglasii, Q. lobata.

Callirylitis nigra Fullaway, 1911. Ent. Soc. Amer., Ann. 4: 362. \&. Preocc. by Tavares,

1902. Gall described originally for nigre Fullaway is another sp.

Diplolepis operta Weld, 1926. U. S. Natl. Mus., Proc. 68 (10): 29. $\%$, gall.

Andricus nigridius Weld, 1944. U. S. Natl. Mus., Proc. 95: 11. N. name for nigra Fullaway.

parmula Bassett. Calif. Ecology: Produce leaf galls on Quercus donglasii, Q. dumosa, Q. engelmanni, Q. garryana, Q. lobata.

Andricus parmula Bassett, 1900. Amer. Ent. Soc., Trans. 26: 312. \&, gall.

Dryophante discus: Bassett, 1900. Amer. Ent. Soc., Trans. 26: 326. \&, gall.

pattersonae Fullaway. Wash., Calif. Ecology: Produce leaf galls on Querens douglasii, Q. dumost, Q. garryana, Q. lobate.

Anilricus pattersonce Fullaway, 1911. Ent. Soc. Amer., Ann. 4: 352. \&, gall.

pattoni (Bassett). Conn. to Fla., w. to Okla., Tex. Ecology: Produce leaf galls on Quercus stellato.

Cynips pattoni Bassett, 1881. Canad. Ent. 13: 98. $\&$, gall.

pilula Bassett. Utah. Ecology: Produce leaf galls on Quercus gambelii.

Audricus (Callirhytis) pilula Bassett, 1890. Amer. Ent. Soc., Trans. 17: 77. ؟, gall.

Taxonomy: Weld, 1952. U. S. Natl. Mus., Proc. 102: 332 (male).

pilularis Weld. Ariz. Ecology: Produce leaf galls on Quercus arizonica, Q. gambelii, Q. oblongifolia, Q. reticulata, Q. subturbinella, Q. toumeyi.

Andricus pilularis Weld, 1952. U. S. Natl. Mus., Proc. 102: 333. \&, ठ, gall.

pisiformis Beutenmueller. N. J., Md., Va., Fla., Ill. Ecology: Produce bud galls on Quercus alba, Q. bicolor:

Andricus pisiformis Beutenmueller, 1911. Ent. News 22: 70. ค, gall.

prescotti Weld. Ariz. Ecology: Produce acorn galls on Quercus arizonica, Q. gambelii, Q. oblongifolia, Q. reticulata, Q. subturbinella.

Andricus prescotti Weld, 1952. U. S. Natl. Mus., Proc. 102: 331. $₹$, gall.

projectus Weld. Oreg. Ecology: Produce bud galls on Quercus chrysolepis.

Andricus projectus Weld, 1952. U. S. Natl. Mus., Proc. 102: 329. १, gall.

pulchellus Bassett. Conn. Ecology: Probably produce stem or leaf galls on Quercus prinoides.

Andricus pulchellus Bassett, 1900. Amer. Ent. Soc., Trans. 26: 314. \&.

quercuscalifornicus (Bassett). Wash., Oreg., Calif. Ecology: Produce stem galls on Quercus donglasii, Q. dumosa, Q. engelmanni, Q. garryana, Q. lobata.

Cynips q. californicus Bassett, 1881. Canad. Ent. 13: 51. $\&$, gall.

Andricus (Callirhytis) californicus Ashmead, 1885. Amer. Ent. Soc., Trans. 12: 294.

Andricus spongiola Gillette, 1894. Canad. Ent. 26: 235. , gall.

Andricus californicus var. fructiformis Kinsey, 1922. Ind. Univ. Studies 53: 12. ๆ, gall.

Andricus californicus var. intermedius Kinsey, 1922. Ind. Univ. Studies 53: 14. \&, gall.

quercusflocci (Walsh). Mass. to N. C., w. to Mich., Ill., Mo., Ark. Ecology: Produce leaf galls on Quercus alba.

Cynips quercus flocci Walsh, 1864. Ent. Soc. Phila., Proc. 2: 482. \&, gall.

Cynips (Andricus?) flocci Osten Sacken, 1865. Ent. Soc. Phila., Proc. 4: 348, 352.

Taxonomy: Fitch, 1859 (1858). N. Y. State Agr. Soc., Trans. 18: 814 (gall).

quercusfoliatus (Ashmead). Ga., Fla., Ala., Miss., Tex. Ecology: Produce bud galls on Quercus virginiana.

Cynips q. foliata Ashmead, 1881. Amer. Ent. Soc., Trans. 9: Proc. p. xii. ?, gall.

Andricus (Andricus) foliatus Ashmead. 1885. Amer. Ent. Soc., Trans. 12: 295.

quercusformosus (Bassett). Conn. s. to Fla., w. to Ill., Mo. Ecology: Produce stem galls on Quercus cinerea, Q. coccinea, Q. marilandica, Q. phellos, Q. rubra.

Cynips q. formosa Bassett, 1864. Ent. Soc. Phila., Proc. 3:679. \&, gall.

Cynips formosa Osten Sacken, 1865. Ent. Soc. Phila., Proc. 4: 341, 345, 349. 
Cynips q. capsuala Ashmead, 1885. Amer. Ent. Soc., Trans. 12: Proc. p. ix $\$$, gall. quercuslanigera (Ashmead). Ga., Fla., Ala., Miss., La., Tex. Ecology: Produce leaf galls on Quercus virginiana.

Cynips q. lanigera Ashmead, 1881. Amer. Ent. Soc., Trans. 9: Proc. p. xiii. \&, gall.

Andricus (Andricus) lanigera Ashmead, 1885. Amer. Ent. Soc., Trans. 12: 295.

quercusostensackenii (Bassett). Conn. to Va., w. to Ill. Ecology: Produce leaf galls on Quercus coccinea, Q. palustris.

Cynips q. Osten Sackenii Bassett, 1863. Ent. Soc. Phila., Proc. 2: 327. \&, o, gall.

Cynips Osten Sackenii Osten Sacken, 1865. Ent. Soc. Phila., Proc. 4: 345, 348, 355.

quercuspetiolicola (Bassett). Mass. to Va., w. to Tenn., Mo. Ecology: Produce leaf galls on Quercus alba and other white oaks.

Cynips q. petiolicola Bassett, 1863. Ent. Soc. Phila., Proc. 2: 325. \&, §, gall.

Cynips (Andricus) petiolicola Osten Sacken, 1865. Ent. Soc. Phila., Proc. 4: 339, 346, 349.

Audricus quinqueseptum Ashmead, 1885. Amer. Ent. Soc., Trans. 12: 299. ס, gall.

Andricus cicatricula Bassett, 1890. Amer. Ent. Soc., Trans. 17: 80. $९$, ơ, gall.

Andricus concolorans Kinsey, 1920. Amer. Mus. Nat. Hist., Bul. 42: 302. ๆ, o, gall.

quercussingularis (Bassett). Maine, Que. s. to N. C. Ecology: Produce leaf galls on Quercus mibra.

Cynips q. singularis Bassett, 1863. Ent. Soc. Phila., Proc. 2: 326. $९$, ठ, gall.

Cynips singularis Osten Sacken, 1865. Ent. Soc. Phila., Proc. 4: 345, 348, 355.

quercusutriculus (Bassett). Conn. to Fla., w. to Ill. Ecology: Produce leaf galls on Quercus alba, Q. chapmani, Q. stellata.

Cynips q. utricula Bassett, 1881. Canad. Ent. 13: 78. \&, o, gall.

Andricus (Andricus) utriculus Ashmead, 1885. Amer. Ent. Soc., Trans. 12: 295.

Andricus pruinosus Bassett, 1900. Amer. Ent. Soc., Trans. 26: 311. ₹, gall.

reniformis MeCracken and Egbert. Calif. Ecology: Produce stem galls on Quercus chrysolepis, Q. vaccinifolia.

Andricus reniform is McCracken and Egbert, 1922. Stanford Univ., Pubs., Univ. Ser., Biol. Sci. 3 (1): 31. \&, gall.

reticulatus Bassett. N. Mex., Ariz. Ecology: Produce leaf galls on Quercus arizonica, Q. gambelii, Q. oblongifolia, Q. reticulata, Q. subturbinella, Q. toumeyi.

Andricus (Callirhytis) reticulata Bassett, 1890. Amer. Ent. Soc., Trans. 17: 74. \&, gall.

rhizoxenus (Ashmead). Ariz. Ecology: Produce stem galls on Quercus reticulata.

Callirhytis rhizoxemus Ashmead, 1896. U. S. Natl. Mus., Proc. 19: 132. \&, gall.

robustus Weld. D. C., Va. to Fla., w. to Mo., Ark., Tex. Ecology: Produce leaf galls on Quercus stellata.

Andricus robustus Weld, 1926. U. S. Natl. Mus., Proc. 68 (10): 81 ., gall.

rugatus Weld. Mo., Ark. Ecology: Produce leaf galls on Quercus lyrata.

Andricus rugatus Weld, 1926. U. S. Natl. Mus., Proc. 68(10): 82. १, gall.

ruginosus Bassett. N. Mex., Ariz. Ecology: Produce stem galls on Quercus fendleri, Q. gambelii.

Andricus (Callirhytis) ruginosus Bassett, 1890. Amer. Ent. Soc., Trans. 17: 75. , gall.

scutella Weld. Ariz. Ecology: Produce leaf galls on Quercus gambelii, Q. subturbinella.

Andricus scutella Weld, 1930. Ent. Soc., Wash., Proc. 32: 29., gall.

spectabilis Kinsey. Calif. Ecology: Produce stem galls on Quercus chrysolepis.

Andricus spectabilis Kinsey, 1922. Amer. Mus. Nat. Hist., Bul. 46: 289. $\&$, gall.

spectabilis var. incisus Kinsey. Calif.

Andricus spectabilis var. incisus Kinsey, 1922. Ind. Univ. Studies 53: 45..

spectabilis var. ukiahensis Kinsey. Calif.

Andricus spectabilis var. uhialiensis Kinsey, 1922. Ind. Univ. Studies 53: 46. ₹.

spicatus (Bassett). Ariz. Ecology: Produce stem galls on Quercus arizonica, Q. oblongifolia, Q. toumeyi.

Loxaulus spicatus Bassett, 1900. Amer. Ent. Soc., Trans. 26: 329. ๆ, gall.

splendens Weld. Ariz. Ecology: Produce leaf galls on Quercus grisea, Q. subturbinella. Andricus splendens Weld, 1919. Canad Ent. 51: 254. \%, gall. 
stellaris Weld. Calif. Ecology: Produce leaf galls on Querens donglasii, Q. garryana.

Audricus stellaris Weld, 1926. U. S. Natl. Mus., Proc. 68(10): 84 . + , gall.

stramineus Weld. Ariz. Ecology: Produce stem galls on Quercus oblongifolia. Andricus strumine'ns: Weld, 1944. U. S. Natl. Mus., Proc. 95: 13. \&, gall.

stropus Ashmead. Va. to Fla., w. to Mo., Ark., Tex. Ecology: Produce bud galls on Quercus stellata.

Audricus stropus Ashmead, 1887. Amer. Ent. Soc., Trans. 14: 136. \&, gall.

Andricus atropus (!) Ashmead, 1910. In Smith, N. J. State Mus. Rpt. for 1909, p. 602.

sulfureus (Weld). Ariz. Ecology: Produce leaf galls on Quercus arizonicu, Q. oblongifolia.

Diplolepis sulfurens. Weld, 1926. U. S. Natl. Mus., Proc. 68 (10); 33. $\$$, gall.

tecturnarum Kinsey. N. Mex., Ariz. Ecology: Produce leaf galls on Qnercus arizonica, Q. yambelii, Q. oblongifoliu, Q. subturbinellu, Q. toumeyi.

Andricus tecturuarum Kinsey, 1920. Amer. Mus. Nat. Hist., Bul. 42: 312. \&, gall.

tenuicornis (Bassett). Ariz. Ecology: Produce leaf galls on Quercus arizonica. Cynips tenuicornis Bassett, 1881. Canad. Ent. 13: 92. \&, gall.

toumeyi Weld. N. Mex., Ariz. Ecology: Produce stem galls on Quercus subturbinella, Q. tonmeyi.

Audricus tonmeyi Well, 1926. U. S. Natl. Mus., Proc. 68 (10): 85 . ๆ, gall.

tubalis Weld. Ariz. Ecology: Produce stem galls on Qnercus arizonica, Q. oblongifolia. Aulricus tubalis Weld, 1926. U. S. Natl. Mus., Proc. 68 (10): 86 . ?, gall.

tubularius Weld. N. Mex., Ariz. Ecology: Produce stem galls on Quercus subturbinella. Andricus tubulurins: Weld, 1926. U. S. Natl. Mus., Proc. 68 (10): 87. , gall.

verensis Weld. Calif. Ecology: Produce bud galls on Quercus dumosa, Q. garyana. Andricus rermus. Weld, 1944. U. S. Natl. Mus., Proc. 95: 13., gall. Preoce. by Bassett, 1900.

Andricus vereusis Weld, 1951. U. S. Dept. Agr., Agr. Monog. 2: 636. N. name.

vernus (Bassett). Conn. Ecology: Specimen collected ovipositing in buds of Quercus ilicifolia. Amphibolips verna Bassett, 1900. Amer. Ent. Soc., Trans. 26: 321..

wheeleri Beutenmueller. N. Mex., Ariz. Ecology: Produce stem galls on Quercus arizonica, Q. oblongifolia, Q. subturbinella, Q. toumeyi.

Andricus wheeleri Beutenmueller, 1907. Amer. Mus. Nat. Hist., Bul. 23: 464. \&, gall.

wiltzae Fullaway. Calif. Ecology: Produce stem galls on Quercus dumosa, Q. Lobata. Audricus wiltzae Fullaway, 1911. Ent. Soc. Amer., Ann. 4: 353. $₹$, gall.

\section{Genus BESBICUS Kinsey}

Cynips subg. Besbicus Kinsey, 1930. Gall wasp genus Cynips, p. 222.

Type-species: Cynips (Besbicus) multipunctata var. conspicua Kinsey. Orig. desig.

conspicuus (Kinsey). Calif. Ecology: Produce stem galls on Quercus douglasii, Q. Lobata.

Cynips (Besbicus) multipunctata var. conspicua Kinsey, 1930. Gall wasp genus Cynips, p. 229. \&, gall.

Cynips conspicua Kinsey, 1936. Origin of higher categories in Cynips, p. 42.

heldae (Fullaway). Calif. Ecology: Produce leaf galls on Quercus lobata.

Cynips heldae Fullaway, 1911. Ent. Soc. Amer., Ann. 4: 345 . \&, gall.

indictus (Kinsey). Calif. Ecology: Produce leaf galls on Querens douglasii.

Cynips (Besbicus) multipunctata var. indicta Kinsey, 1930. Gall wasp genus Cynips, p. 228. $₹$, gall.

Cynips (Besbicus) indicta Kinsey, 1936. Origin of higher categories in Cynips, p. 324.

leachii (Kinsey). Calif. Ecology: Produce leaf galls on Querens garryana.

Cynips (Besbicus) mirabilis var. leachii Kinsey, 1930. Gall wasp genus Cynips, p. 238. \&, gall.

Cynips (Besbicus) leachii Kinsey, 1936. Origin of higher categories in Cynips, p. 325.

maculosus (Weld). Calif. Ecology: Produce leaf galls on Quercus dumosa.

Cynips maculosa Weld, 1926. U. S. Natl. Mus., Proc. 68 (10): 63. \&, gall. 
mirabilis (Kinsey). B. C., Wash., Oreg. Ecology: Produce leaf galls in agamic generation, bud galls in sexual generation, on Quercus garryana.

Cynips mirabilis Kinsey, 1922. Ind. Univ. Studies 53: 50. + , gall.

Biology: Evans, 1967. Canad. Ent. 99: 187-196.

multipunctatus (Beutenmueller). Calif. Ecology: Produce leaf galls on Quercus donglasii.

Dryophantu multipunctata Beutenmueller, 1911. Ent. News 22: 67. $\uparrow$, gall.

tritior (Kinsey). Calif. Ecology: Produce leaf galls on Quercus dumosa, Q. durata.

Cynips (Besbicus) maculosa var. tritior Kinsey, 1930. Gall wasp genus Cynips, p. 235. , gall.

Cynips (Besbicus) tritior Kinsey, 1936. Origin of higher categories in Cynjps, p. 325.

\section{Genus ATRUSCA Kinsey}

Cynips subg. Atruscu Kinsey, 1930. Gall wasp genus Cynips, p. 276.

Type-species: Cynips (Atrusca) dugesi var. simulatrix Kinsey. Orig. desig.

aggregata (Weld). Ariz. Ecology: Produce stem galls on Quercus arizonica, Q. oblongifolia, Q. toumeyi.

Diplolepis aggregata Weld, 1926. U. S. Natl. Mus., Proc. 68 (10): 15. ๆ, gall.

bella (Bassett). N. Mex., Ariz. Ecology: Produce leaf galls on Quercus arizonica, Q. oblongifolia, Q. reticulatu, Q. subturbinella, Q. toumeyi.

Cynips bella Bassett, 1881. Canad. Ent. 13: 93. $\&$, gall.

Holcaspis maculipenuis Gillette, 1894. Canad. Ent. 26: 236., gall.

brevipennata (Gillette). Colo. Ecology: Produce leaf galls on Quercus fendleri, Q. gambelii, Q. subturbinella.

Holcaspis brevipennata Gillette, 1893. Ent. News 4: 31., gall.

Andricus pellucidus Kinsey, 1920. Amer. Mus. Nat. Hist., Bul. 42: 309. ๆ, gall.

capronae (Weld). Ariz. Ecology: Produce leaf galls on Quercus subturbinella.

Diplole pis cupronue Weld, 1930. Ent. Soc. Wash., Proc. 32: 29. ๆ, gall.

catena (Kinsey). Tex. Ecology: Produce leaf galls on Quercus grisea.

Cynips catena Kinsey, 1936. Origin of higher categories in Cynips, p. 102. ๆ, gall.

cava (Weld). Tex. Ecology: Produce leaf galls on Quercus breviloba.

Diplolepis cava Weld, 1926. U. S. Natl. Mus., Proc. 68 (10): 22 . ๆ, gall.

elivorum (Kinsey). Ohio. Ecology: Produce leaf galls on Quercus stellata.

Cynips (Atrusca) centricola var. clivorum Kinsey, 1930. Gall wasp genus Cynips, p. 300., gall.

Cynips clivorum Kinsey, 1936. Origin of higher categories in Cynips, p. 181.

congesta (Kinsey). Tex. Ecology: Produce leaf galls on Quercus grisea.

Cynips (Atrusca) bella var. congesta Kinsey, 1930. Gall wasp genus Cynips, p. 292. \&, gall.

Cynips congesta Kinsey, 1936. Origin of higher categories in Cynips, p. 171.

cubitalis (Kinsey). Colo. Ecology: Produce leaf galls on Quercus gambelii.

Cynips (Atrusca) cubitalis Kinsey, 1936. Origin of higher categories in Cynips, p. 107. \&, gall.

pupoides (Kinsey). Tex. Ecology: Produce leaf galls on Quercus grisea.

Cynips (Atrusca) dugesi var. pupoides Kinsey, 1930. Gall wasp genus Cynips, p. 284. ?, gall.

Cymips pupoides Kinsey, 1936. Origin of higher categories in Cynips, p. 92.

quercuscentricola (Osten Sacken). N. J. s. to N. C., w. to Mo., Ark., Tex. Ecology: Produce leaf galls on Quercus stellata.

Cynips quercuscentricola Osten Sacken, 1861. Ent. Soc. Phila., Proc. 1: 58. \&, gall.

Cynips centricola Osten Sacken, 1865. Ent. Soc. Phila., Proc. 4: 339, 345, 347.

Cynips quercus-rubrae Karsch, 1880. Ztschr. f. Gesam. Naturw. 53: 293. \&, gall.

simulatrix (Kinsey). N. Mex., Ariz. Ecology: Produce leaf galls on Quercus arizonica, Q. gambelii, Q. grisea, Q. oblongifolia, Q. undulata.

Cynips (Atrusca) dugesi var. simulatrix Kinsey, 1930. Gall wasp genus Cynips, p. 280. , gall.

Cynips simulatrix Kinsey, 1936. Origin of higher categories in Cynips, p. 131. 
strians (Kinsey). Ill. Ecology: Produce leaf galls on Quercus stellata.

Cynips (Atrusca) centricola var. strians Kinsey, 1930. Gall wasp genus Cynips, p. 304. \&, gall.

Cynips strians Kinsey, 1936. Origin of higher categories in Cynips, p. 181.

subnigra (Kinsey). N. Mex. Ecology: Produce leaf galls on Quercus grisea.

Cynips (Atrusca) subrigra Kinsey, 1936. Origin of higher categories in Cynips, p. 140. $\uparrow$, gall.

vanescens (Kinsey). Ariz. Ecology: Produce leaf galls on Quercus grisea.

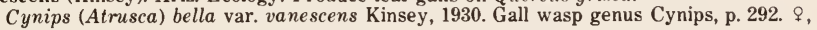
gall.

Cynips vanescens Kinsey, 1936. Origin of higher categories in Cynips, p. 178.

\section{Genus DISHOLCASPIS Dalla Torre and Kieffer}

Holcaspis Mayr, 1881. Zwanzig. Jahresber. Comm.-Oberrealsch. I. Bez. Wien. p. 35. toumeyi.

Type-species: Cynips globulus Fitch. Desig. by Ashmead, 1903.

Disholcaspis Dalla Torre and Kieffer, 1910. Das Tierreich, v. 24, p. 371. N. name.

Known only from agamic females emerging in the late fall from oak galls. The sexual generation for these species is unknown, or at least unrecognized. Members of this genus are known from North America only.

Revision: Beutenmueller, 1909. Amer. Mus. Nat. Hist., Bul. 26: 29-45.

acetabula Weld. Colo. Ecology: Produce root galls on Quercus gambelii, Q. reticulata, Q. subturbinella, Q. toumeyi.

Disholcaspis acefubula Weld, 1921. U. S. Natl. Mus., Proc. 59: 194. ₹, gall.

bassetti (Gillette). Ohio, Mich., Ill. Ecology: Produce stem galls on Quercus bicolor, Q. macrocarpa.

Holcaspis bassetti Gillette, 1888. Mich. State Bd. Agr., Rpt. 27: 472. \&, gall.

brevinota Weld. Tex. Ecology: Produce root galls on Quercus breviloba.

Disholcaspis bretinota Weld, 1921. U. S. Natl. Mus., Proc. 59: 197. §, gall.

canescens (Bassett). Calif. Ecology: Produce stem galls on Quercus douglasii, Q. dumosa, Q. lobata.

Holcaspis canescens Bassett, 1890. Amer. Ent. Soc., Trans. 17: 66. \&, gall.

chrysolepidis (Beutenmueller). Calif. Ecology: Produce twig galls on Quercus chrysolepis.

Holcaspis chrysolepidis Beutenmueller, 1911. Ent. News 22: 68. ๆ, gall.

cinerosa (Bassett). Tex. Ecology: Produce stem galls on Quercus virginiana.

Cynips cinerosa Bassett, 1881. Canad. Ent. 13: 10., gall.

colorado (Gillette). Colo. Ecology: Produce stem galls on Quercus sp., prob. Q. gambelii.

Holcaspis colorado Gillette, 1893. Ent. News 4:210. $\uparrow$, gall.

conalis Weld. Calif. Ecology: Produce stem galls on Quercus garryana.

Disholcaspis conalis Weld, 1926. U. S. Natl. Mus., Proc. 68 (10): 37. ๆ, gall.

corallina (Bassett). Calif. Ecology: Produce stem galls on Quercus douglasii.

Holcaspis corallina Bassett, 1890. Amer. Ent. Soc., Trans. 17: 66. 9 , gall.

eldoradensis (Beutenmueller). Wash., Oreg., Calif. Ecology: Produce stem galls on Quercus drmosa, Q. garryana, Q. lobata.

Holcaspis eldoradensis Beutenmueller, 1909. Amer. Mus. Nat. Hist., Bul. 26: 38. \&, gall.

edura Weld. Ariz. Ecology: Produce stem galls on Quercus arizonica, Q. oblongifolia, Q. reticulata.

Disholcaspis edura Weld, 1957. U. S. Natl. Mus., Proc. 107: 113. \&, gall.

fungiformis Kinsey. Tex. Ecology: Produce stem galls on Quercus virginiana.

Disholcaspis fungiform is Kinsey, 1920. Amer. Mus. Nat. Hist., Bul. 42: 312. ๆ, gall.

globosa Weld. N. Y., Va., Ill., Okla. Ecology: Produce root galls on Quereus alba.

Disholcaspis globosa Weld, 1921. U. S. Natl. Mus., Proc. 59: 196. ₹, gall.

heynei Kieffer. Tex.

Disholcaspis heynei Kieffer, 1910. Lab. Zool. Gen. e. Agr. Portici, Bol. 4: 113.. 
lacuna Weld. Ariz. Ecology: Produce root galls on Quercus gambelii.

Disholcaspis lacuna Weld, 1921. U. S. Natl. Mus., Proc. 59: 195. $\&$, gall.

mamillana Weld. Calif. Ecology: Produce stem galls on Quercus douglasii.

Disholcaspis mamillana Weld, 1957. U. S. Natl. Mus., Proc. 107: 115. \&, gall.

mellifica Weld. Calif. Ecology: Produce stem galls on Queretts garyana.

Disholcaspis mellifica Weld, 1957. U. S. Natl. Mus., Proc. 107: 114. ₹, gall.

pattersoni Kinsey. Tex. Ecology: Produce stem galls on Quercus breviloba.

Disholcospis puttersoni Kinsey, 1922. Ind. Univ. Studies 53: 78. , gall.

pedunculoides Weld. N. Mex., Ariz. Ecology: Produce acorn galls on Quercus arizonica, Q. oblongifolia, Q. subturbinella.

Disholcaspis pedunculoides Weld, 1926. U. S. Natl. Mus., Proc. 68 (10): 39. \&, gall.

perniciosa (Bassett). Colo., N. Mex., Utah, Ariz. Ecology: Produce stem galls on Quercus fendleri, Q. yambelii.

Holcaspis perviciosa Bassett, 1890. Amer. Ent. Soc., Trans. 17: 68. ๆ, gall.

Holcaspis monticolı Gillette, 1893. Ent. News 4: 30. $q$, gall.

persimilis (Ashmead). Miss. Ecology: Produce stem galls on Quercus sp.

Holcuspis persimilis Ashmead, 1896. U. S. Natl. Mus., Proc. 19: 126. $₹$, gall.

plumbella Kinsey. Calif. Ecology: Produce stem galls on Quercus douylasii, Q. dumosa.

Disholcaspis plumbella Kinsey, 1920. Amer. Mus. Nat. Hist., Bul. 42: 314. \&, gall.

prehensa Weld. Calif. Ecology: Produce stem galls on Quercus dumosa.

Disholcaspis prehensa Weld, 1957. U. S. Natl. Mus., Proc. 107: 113. \&, gall.

pruniformis Kinsey. Tex. Ecology: Produce stem galls on Quercus breviloba, Q. laceyi.

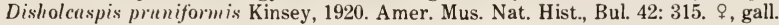

quercusglobulus (Fitch). Eastern U. S. Ecology: Produce stem galls on Quercus alba, Q. prinoides, Q. prinus.

Callaspidia Quercus-ylobulus Fitch, 1859 (1858). N. Y. State Agr. Soc., Trans. 18: 810. \&, gall.

Cynips regosa Bassett, 1881. Canad. Ent. 13: 100. $\%$, gall.

quercusmamma (Walsh). Conn. w. to Ill., Minn., Ark., Tex. Ecology: Produce stem galls on Quercus bicolor, Q. macrocarpa.

Cynips q. mamma Walsh, 1869. Amer. Ent. 1: 102 (footnote). \&, gall.

Diplolepis q. macrocarpae Karsch, 1880. Ztschr. f. Gesam. Naturw. 53: 291. \&, gall.

Holcaspis duricoria Mayr, 1881. Zwanzig. Jahresber. Comm.-Oberrealsch. I. Bez. Wien., p. 35. Nom. nud.

Holcaspis ! mamtma Cresson, 1887. Synopsis Amer. Hym., p. 179.

Holcaspis duricoria Bassett, 1890. Amer. Ent. Soc., Trans. 17: 64. ‡, gall.

quercusomnivora (Ashmead). Fla. Ecology: Produce stem galls on Quercus chapmani.

Cynips q. ommirora Ashmead, 1885. Amer. Ent. Soc., Trans. 12: Proc. p. vi. \&, gall.

Andricus (Audricus) ommirorus Ashmead, 1885. Amer. Ent. Soc., Trans. 12: 295.

quercussuccinipes (Ashmead). Fla. Ecology: Produce stem galls on Quercus virginiana.

Cynips q. succinipes Ashmead, 1881. Amer. Ent. Soc., Trans. 9: Proc. p. xi. $\$$, gall.

Andricus (Andricus) succinipe's Ashmead, 1885. Amer. Ent. Soc., Trans. 12: 295.

quercusvirens (Ashmead). S. C., Ga., Fla., Miss., La., Tex. Ecology: Produce stem galls on Quercus virginiana.

Cymips q. virens Ashmead, 1881. Amer. Ent. Soc., Trans. 9: Proc. p. x. ?, gall.

Audricus (Andricus) virens Ashmead, 1885. Amer. Erit. Soc., Trans. 12: 295.

Cynips q. fïcigera Ashmead, 1885. Amer. Ent. Soc., Trans. 12: Proc. p. vi. \&, gall.

rubens (Gillette). Colo., N.Mex., Ariz. Ecology: Produce stem galls on Quercus arizonica, Q.

fendleri, Q. gambelii, Q. oblongifolia, Q. reticulata, Q. subturbinella, Q. toumeyi.

Holcaspis rubens Gillette, 1893. Ent. News 4: 29. $₹$, gall.

sileri (Bassett). Utah. Ecology: Produce twig galls on Quercus sp.

Holcaspis sileri Bassett, 1890. Amer. Ent. Soc., Trans. 17: 67. \&, gall.

simulata Kinsey. Calif. Ecology: Produce stem galls on Quercus douglasii, Q. dumosa.

Disholcaspis simulata Kinsey, 1922. Ind. Univ. Studies 53: 79. ₹, gall. 
simulata var. vancouverensis Kinsey. Oreg., Calif. Ecology: Produce twig galls on Quercus garryana.

Disholcaspis simulatu var. ennconcerensis Kinsey, 1922. Ind. Univ. Studies 53: 81. \&, gall.

spissa Weld. Ariz. Ecology: Produce stem galls on Quercus arizonica, Q. havardi, Q. reticulata, Q. subturbinella.

Disholcuspis spissu Weld, 1957. U. S. Natl. Mus., Proc. 107: 114. ?, gall.

spongiosa (Karsch). Ga., Fla., Ala., Mo., Ark., Okla., Tex. Ecology: Produce stem galls on Quercus chapmani, Q. stellate.

Diplolepis spongiosa Karsch, 1880. Ztschr. f. Gesam. Naturw. 53: 295. \&, gall.

Cynips q. ficula Bassett, 1881. Canad. Ent. 13: 75. \&, gall.

sulcata (Ashmead). Ariz. Ecology: Produce leaf galls on Quercus arizonica, Q. oblongifolia, Q. reticulata, Q. subturbinella, Q. toumeyi.

Cyuips sulcutus Ashmead, 1896. U. S. Natl. Mus., Proc. 19: 123. \&, gall.

terrestris Weld. Va., N. C., Fla., Ala., Mo., Ark., Tex. Ecology: Produce root galls on Quercus maryaretta, Q. stellate.

Disholcuspis terrestris Weld, 1921. U. S. Natl. Mus., Proc. 59: 198. \&, gall.

truckeensis (Ashmead). Calif. Ecology: Produce stem galls on Quercus chrysolepis, Q. wilcoxii.

Holcuspis truckeensis Ashmead, 1896. U. S. Natl. Mus., Proc. 19: 127. , gall.

washingtonensis (Gillette). Wash., Oreg., Calif. Ecology: Produce twig galls on Quercus douglasii, Q. dumosa, Q. gamyana, Q. lobata.

Cynips wrashingtonensis Gillette, 1894. Canad. Ent. 26: 235. \&, gall.

\section{Genus ANTRON Kinsey}

Cynips subg. Autron Kinsey, 1930. Gall wasp genus Cynips, p. 180.

Type-species: Cynips (Antrou) echinus var. schulthessae Kinsey. Orig. desig.

acraspiformis (Weld). N. Mex. Ecology: Produce leaf galls on Quercus subturbinella, Q. toumeyi.

Diplolepis acraspiform is Weld, 1926. U. S. Natl. Mus., Proc. 68 (10): 14. ?, gall.

clavuloides (Kinsey). Calif. Ecology: Produce leaf galls on Quercus lobata.

Dryophanta clavula Beutenmueller, 1911. Ent. News 22: 67. $\uparrow$, gall. Preocc. in Cynips by Osten Sacken, 1865.

Cynips (Antron) teres var. clavuloides Kinsey, 1930. Gall wasp genus Cynips, p. 215. N. name.

douglasii (Ashmead). Calif. Ecology: Produce leaf galls in agamic generation and bud galls in sexual generation on Quercus douglasii, Q. dumosa, Q. lobata.

Holcaspis douglasii Ashmead, 1896. U. S. Natl. Mus., Proc. 19: 127. ๆ, gall. Agamic gen.

Dryophanta lobata McCracken and Egbert, 1922. Stanford Univ., Pubs., Univ. Ser., Biol. Sci. 3 (1): 13.,$+ \delta$, gall. Sexual gen.

Taxonomy: Kinsey, 1930. Gall wasp genus Cynips, p. 190.

dumosae (Kinsey). Calif. Ecology: Produce leaf galls on Quercus dumosa.

Cynips (Antron) echinus var. dumosae Kinsey, 1930. Gall wasp genus Cynips, p. 199. , gall. Agamic gen.

Cynips dumosae Kinsey, 1936. Origin of higher categories in Cynips, p. 77.

magdalenae Weld. N. Mex. Ecology: Produce leaf galls on Quercus subturbinella.

Antrou magdalenae Weld, 1957. U. S. Natl. Mus., Proc. 107: 116. , gall.

pileus Weld. Ariz. Ecology: Produce stem galls on Quercus subturbinella.

Antron pileus Weld, 1952. U. S. Natl. Mus., Proc. 102: 333. ๆ, ơ, gall.

plumbeum (Weld). Ariz. Ecology: Produce leaf galls on Quercus arizonica, Q. oblongifolia, Q. toumeyi.

Cynips plumbea Weld, 1926. U. S. Natl. Mus., Proc. 68 (10): 64. ?, gall.

quercusechinus (Osten Sacken). Calif. Ecology: Produce leaf galls in agamic generation and bud galls in sexual generation on Quercus douglasii, Q. dumosa, Q. lobata.

Cynips quercus echinus Osten Sacken, 1870. Amer. Ent. Soc., Trans, 3: 56. ₹, gall. Agamic gen. 
Cynips echinus Ashmead, 1885. Amer. Ent. Soc., Trans. 12: 295.

Andricus speciosus Bassett, 1890. Amer. Ent. Soc., Trans. 17: 81. , gall.

Andricus ribes Kinsey, 1922. Ind. Univ. Studies 53: 42. \&, o, gall. Sexual gen.

quercusechinus var. mistum (Kinsey). Calif. Ecology: Produce leaf galls on Quercus dumosa.

Cynips (Antron) echinus var. mista Kinsey, 1930. Gall wasp genus Cynips, p. 200. \&, gall.

quercusechinus var. schulthessae (Kinsey). Calif. Ecology: Produce galls on Quercus douglasii, Q. durata.

Cynips (Antron) echinus var. schulthessae, agamic form schulthessae Kinsey, 1930. Gall wasp genus Cynips, p. 202. \&, gall. Agamic gen.

Cynips (Autron) echinus var. schulthessae, bisexual form atrata Kinsey, 1930. Gall wasp genus Cynips, p. 204. \&, ठ, gall. Sexual gen.

quercusechinus var. vicinum (Kinsey). Calif. Ecology: Produce galls on Quercus douglasii.

Cynips (Antron) echinus var. vicina, agamic form vicina Kinsey, 1930. Gall wasp genus Cynips, p. 196. \&, gall. Agamic gen.

Cynips vicina, agamic form vicina Kinsey, 1936. Origin of higher categories in Cynips, p. 78.

Cynips (Antron) echinus var. vicina, bisexual form incepta Kinsey, 1930. Gall wasp genus Cynips, p. 198. \&, §, gall. Sexual gen.

quercusnubila (Bassett). Ariz. Ecology: Produce leaf galls on Quercus arizonica, Q. oblongifolia, Q. reticulata, $Q$. subturbinella, $Q$. toumeyi.

Cynips q. uubilu Bassett, 1881. Canad. Ent. 13: 56. \&, gall.

Dryophanta nubila Mayr, 1881. Zwanzig. Jahresber. Comm.-Oberrealsch. I. Bez. Wien., p. 39. Nom. nud.

Dryophanta nubila Ashmead, 1885. Amer. Ent. Soc., Trans. 12: 296.

russum (Kinsey). Ariz. Ecology: Produce leaf galls on Quercus arizonica, Q. oblongifolia.

Cynips (Acraspis) mbila var. russa Kinsey, 1930. Gall wasp genus Cynips, p. 343. \&, gall.

Cynips russa Kinsey, 1936. Origin of higher categories in Cynips, p. 255.

\section{Genus BELONOCNEMA Mayr}

Belonocnema Mayr, 1881. Zwanzig. Jahresber. Comm.-Oberrealsch. I. Bez. Wien., pp. 4, 16, 38.

Type-species: Belonocnema treatae Mayr. Monotypic.

Dryorhizoxenus Ashmead, 1882 (1881). Amer. Ent. Soc., Trans. 9: Proc. p. xxv.

Type-species: Dryorhizoxenus floridanus Ashmead. Monotypic.

kinseyi Weld. Tex. Ecology: Produce leaf galls on Quercus virginiana.

Belonocnema kinseyi Weld, 1921. U. S. Natl. Mus., Proc. 59: 241. $\subsetneq$, gall.

quercusvirens (Osten Sacken). Fla. Ecology: Produce pea-shaped leaf galls on Quercus virginiana.

Cymips q. vivens Osten Sacken, 1861. Ent Soc. Phila., Proc. 1: 57. gall.

Belonocnema fossoria Weld, 1921. U. S. Natl. Mus., Proc. 59: 240. $\%$, gall.

treatae Mayr. Fla. Ecology: Produce root galls on Quercus virginiana.

Belenocnema (!) Treatae Mayr, 1881. Zwanzig. Jahresber. Comm.-Oberrealsch. I. Bez.

Wien., p. 17, footnote. + , gall.

Dryorhizoxenus floridamus Ashmead, 1882 (1881). Amer. Ent. Soc., Trans. 9: Proc. p. xxv. $\uparrow, \delta$, gall.

\section{Genus SPHAEROTERAS Ashmead}

Sphaeroteras Ashmead, 1897. Psyche 8: 67.

Type-species: Biorrhiza (!) mellea Ashmead. Monotypic.

caepuliforme (Beutenmueller). N. Y., Md., Va., Fla., Ind., Ill., Mo., Ark., Tex. Ecology: Produce root galls on red oaks.

Biorhiza caepuliformis Beutenmueller, 1911. Ent. News 22: 69. $\&$, gall.

carolina (Ashmead). N. C., Fla., Mo., Ark., Tex. Ecology: Produce leaf galls on Quercus alba, Q. stellata.

Dryophanta carolina Ashmead, 1887. Amer. Ent. Soc., Trans. 14: 145. \&, gall. 
melleum (Ashmead). Fla. Ecology: Produce leaf galls on Querens chapmani. Biorhiza mellea Ashmead, 1887. Amer. Ent. Soc., Trans. 14: 128, 138. ?, gall.

melleum var. albicolens (Kinsey). Ga. Ecology: Produce leaf galls on Quercus alba. Cynips (Acraspis) mellea var. albicolens Kinsey, 1930. Gall wasp genus Cynips, p. 336. + , gall.

melleum var. anceps (Kinsey). Tex. Ecology: Produce leaf galls on Quercus breviloba. Cynips (Acruspis) mellea var. anceps Kinsey, 1930. Gall wasp genus Cynips, p. 323. $?$, gall.

melleum var. bifurcum (Kinsey). Miss. Ecology: Produce leaf galls on Quercus stellata. Cynips (Acraspis) mellea var. bifurca Kinsey, 1930. Gall wasp genus Cynips, p. 325. ?, gall.

melleum var. comptum (Kinsey). Tex. Ecology: Produce leaf galls on Quereus stellata. Cynips (Acruspis) mellea var. compta Kinsey, 1930. Gall wasp genus Cynips, p. 322. ๆ, gall.

melleum var. concolor (Kinsey). Fla. Ecology: Produce leaf galls on Quercus minima. Cynips (Acruspis) melleu var. concolor Kinsey, 1930. Gall wasp genus Cynips, p. 329. , gall.

melleum var. crassior (Kinsey). Ga. Ecology: Produce leaf galls on Quercus stellata.

Cynips (Acraspis) mellea var, crassior Kinsey, 1930. Gall wasp genus Cynips, p. 335. $\uparrow$, gall.

melleum var. litigans (Kinsey). Ala. Ecology: Produce leaf galls on Quercus stelluta.

Cynips (Acraspis) mellea var. litigans Kinsey, 1930. Gall wasp genus Cynips, p. 327. ?, gall.

ocala (Weld). Fla. Ecology: Produce root galls on Querens chapmani.

Biorhiza ocala Weld, 1921. U. S. Natl. Mus., Proc. 59: 207. ^, ठ’, gall.

rydbergiana (Cockerell). N. Mex. Ecology: Produce leaf galls on Quercus rydbergiana.

Dryophanta rydbergiana Cockerell, 1903. Canad. Ent. 35: 217. ९, gall.

texanum (Ashmead). Tex. Gall unknown.

Dryophanta texana Ashmead, 1887. Amer. Ent. Soc., Trans. 14: 145. \&.

trimaculosum (McCracken and Egbert). Calif. Ecology: Produce leaf galls on Quercus douglasii, Q. dumosa, Q. garmana, Q. lobata.

Callirhytis trimaculosa MeCracken and Egbert, 1922. Stanford Univ., Pubs., Univ. Ser., Biol. Sci. 3 (1): 41 . $\%$, gall.

unicum (Weld). Mo., Ark., Tex. Ecology: Produce leaf galls on Quercus stellata.

Diplolepis unica Weld, 1926. U. S. Natl. Mus., Proc. 68 (10): 34. ๆ, gall.

\section{Genus ZOPHEROTERAS Ashmead}

Zopheroteras Ashmead, 1897. Canad. Ent. 29: 261.

Type-species: Acraspis vaccinii Ashmead. Monotypic.

Parateras Ashmead, 1897. Canad. Ent. 29: 262.

Type-species: Parateras hubbardi Ashmead. Monotypic.

compressum (Gillette). Iowa. Ecology: Produce leaf galls on Quercus rubra.

Acraspis compressus Gillette, 1891. Ill. State Lab. Nat. Hist., Bul. 3: 197. \&, gall.

cuneatum Weld. Va., Mo., Ark. Ecology: Produce leaf galls on Quercus alba.

Zopheroteras cuneatum Weld, 1944. U. S. Natl. Mus., Proc. 95: 14. ๆ, gall.

guttatum Weld. Va. Ecology: Produce leaf galls on Quercus palustris.

Zopheroteras guttatum Weld, 1952. U. S. Natl. Mus., Proc. 102: 334. ๆ, gall.

hubbardi (Ashmead). Md., Va., N. C., Mich., Ill. Ecology: Produce leaf galls on Quercus coccinea, Q. velutina.

Parateras hubbardi Ashmead, 1897. Canad. Ent. 29: 262..+

sphaerula Weld. N. C., Ill., Mo. Ecology: Produce leaf galls on Quercus rubra.

Zopheroteras sphaerula Weld, 1926. U. S. Natl. Mus., Proc. 68 (10): 56. \&, gall.

vaccinii (Ashmead). D. C., Fla. Ecology: Produce leaf galls on Quercus stellata.

Acraspis vaccimii Ashmead, 1887. Amer. Ent. Soc., Trans. 14: 136.. 


\section{Genus LOXAULUS Mayr}

Loxaulus Mayr, 1881. Zwanzig. Jahresber. Comm.-Oberrealsch. I. Bez. Wien., pp. 9, 12, 33. Type-species: Loxaulus mammula Mayr. Monotypic.

Solen ozopheria Ashmead, 1887. Amer. Ent. Soc., Trans. 14: 149.

Type-species: Solenozopheria vaccinii Ashmead. Monotypic.

Compsodryoxenuss Ashmead, 1896. U. S. Natl. Mus., Proc. 19: 128.

Type-species: Compsodryoxenus maculipennis Ashmead. Desig. by Ashmead, 1903.

ashmeadi Kieffer. United States. Ecology: Produce hardly visible galls in wood of branches of English Oak, Qercus robur. Occurs only on introduced English Oaks, so presumably not of North American origin.

Loxaulus Aslimeadi Kieffer, 1902. Soc. Hist. Nat. Metz., Bul. (2) 10: 4. , gall.

beutenmuelleri Weld. N. J., Pa., Ill. Ecology: Produce leaf galls on Quercus rubra.

Loxaulus beutenmuelleri Weld, 1957. U. S. Natl. Mus., Proc. 107: 116-117. \&.

brunneus (Ashmead). Calif. Ecology: Produce stem galls on Quercus clirysolepis.

Compsolryoxenus brunneus Ashmead, 1896. U. S. Natl. Mus., Proc. 19: 129. \&, gall.

brunneus var. atrior (Kinsey). Calif. Ecology: Produce stem galls on Quercus lobata.

Compsodryoxenus brunueus var. atrior Kinsey, 1922. Ind. Univ. Studies 53: 49. \&, gall.

ferrugineus (Gillette). Iowa.

Chilaspis ferruginea Gillette, 1891. Ill. State Lab. Nat. Hist., Bul. 3: 200. .

humilis (Weld). Fla. Ecology: Produce root galls on Quercus chapmani, Q. stellata.

Compsodryoxenus lumilis Weld, 1921. U. S. Natl. Mus., Proc. 59: 190, 236. \&, gall.

illinoisensis (Weld). Ill. Ecology: Produce root galls on Quercus macrocarpa.

Compsodryoxenus illinoisensis Weld, 1921. U. S. Natl. Mus., Proc. 59: 191, 234. \&, gall.

maculipennis (Ashmead). Ariz. Ecology: Produce stem galls on live oaks.

Compsodryoxemus maculipennis Ashmead, 1896. U. S. Natl. Mus., Proc. 19: 129. $\&$, gall.

pattersoni (Kinsey). Tex. Ecology: Produce root galls on Quercus virginiana.

Compsodryoxenus pattersoni Kinsey, 1922. Ind. Univ. Studies 53: 49., gall.

quercusmammula (Bassett). Conn., N. J., Md., Va. Ecology: Produce stem galls on Quercus alba.

Cynips q. mammula Bassett, 1881. Canad. Ent. 13: 76. ๆ, §, gall.

Loxaulus mammula Mayr, 1881. Zwanzig. Jahresber. Comm.-Oberrealsch. I. Bez. Wien., p. 34.

tenuis (Weld). Colo. Ecology: Produce root galls on Quercus fendleri.

Compsodryoxenus tenuis Weld, 1921. U. S. Natl. Mus., Proc. 59: 190, 235. $\$$, gall.

trizonalis Weld. Calif. Ecology: Produce acorn galls in agamic generation and stem galls in sexual generation on Quercus chrysolepis.

Loxaulus trizonalis Weld, 1926. U. S. Natl. Mus., Proc. 68 (10): 45. $\%$, gall (agamic gen.); , ơ (sexual gen.).

vaccinii (Ashmead). Fla. Ecology: Produce stem galls on Quercus sp. The original statement that this sp. produced galls on Vaccinium was incorrect.

Solenozopheria vaccinii Ashmead, 1887. Amer. Ent. Soc., Trans. 14: 134, 149...

\section{Genus BASSETTIA Ashmead}

Bassettia Ashmead, 1887. Amer. Ent. Soc., Trans. 14: 146.

Type-species: Bassettia floridana Ashmead. Desig. by Ashmead, 1903.

aquaticae (Ashmead). Fla. Ecology: Produce stem galls on Quercus nigra.

Callithytis aquaticae Ashmead, 1887. Amer. Ent. Soc., Trans. 14: 144. \&, gall.

ceropteroides (Bassett). Conn. Ecology: Produce stem galls on Quercus velutina.

Callirhytis ceropteroide's Bassett, 1900. Amer. Ent. Soc., Trans. 26: 324. ₹, gall.

floridana Ashmead. Conn. s. to Fla. Ecology: Produce clumps of galls at bases of sprouts on Quercus chapmani; also observed to oviposit on Quercus prinoides.

Bassettia floridana Ashmead, 1887. Amer. Ent. Soc., Trans. 14: 147. ?.

Dryophanta corrngis Bassett, 1890. Amer. Ent. Soc., Trans. 17: 71..

Taxonomy: Weld, 1952. U. S. Natl. Mus., Proc. 102: 336. 
gemmae Ashmead. Mo.

Bassettia gemmae Ashmead, 1896. U. S. Natl. Mus., Proc. 19: 128. ๆ.

herberti (Weld). Calif. Ecology: Produce stem galls on Quercus agrifolia, Q. kelloggii, Q. wislizenii.

Eumayria herberti Weld, 1926. U. S. Natl. Mus., Proc. 68 (10): 108. $\uparrow$, gall.

ligni Kinsey. Calif. Ecology: Produce stem galls in agamic generation and leaf galls in sexual generation on Quercus douglasii, Q. dumosa, Q. Lobata.

Bassettia ligni Kinsey, 1922. Amer. Mus. Nat. Hist., Bul. 46: 291. ‡, gall.

Biology: Rosenthal and Koehler, 1971. Ent. Soc. Amer., Ann. 64: 565-570.

pallida Ashmead. Ga., Fla., Mo. Ecology: Produce stem galls on live oaks.

Bassettia pallicla Ashmead, 1896. U. S. Natl. Mus., Proc. 19: 128. ․

quercuscatesbaei (Ashmead). Fla. Ecology: Produce stem galls on Quercus catesbaei.

Cynips q. catesbaei Ashmead, 1881. Amer. Ent. Soc., Trans. 9: Proc. p. xv. \&, o, gall.

Andricus (Andricus) catesbaci Ashmead, 1885. Amer. Ent. Soc., Trans. 12: 295.

tenuana Weld. N. Mex., Ariz. Ecology: Produce root galls on Quercus gambelii, Q. subturbinella.

Bassettia tennana Weld, 1921. U. S. Natl. Mus., Proc. 59: 190, 232. \&, gall.

\section{Genus EUMAYRIA Ashmead}

Eumayria Ashmead, 1887. Amer. Ent. Soc., Trans. 14: 147.

Type-species: Ermayria floridana Ashmead. Monotypic.

eldoradensis (Beutenmueller). Oreg., Calif. Ecology: Produce acorn galls on Quercus agrifolia, Q. kelloggii, Q. wislizenii.

Andricus eldorudensis Beutenmueller, 1913. Brooklyn Ent. Soc., Bul. 8: 105. ठ.

floridana Ashmead. Va., Fla., Ind., Ill., Ark., Tex. Ecology: Produce root galls on red oaks.

Eumayria floridana Ashmead, 1887. Amer. Ent. Soc., Trans. 14: 147. १, ठ', gall.

invisa Weld. Fla. Ecology: Produce stem galls on Quercus myrtifolia.

Eumayria invisa Weld, 1952. U. S. Natl. Mus., Proc. 102: 335. $\&$, gall.

longipennis (Ashmead). Fla. Ecology: Produce stem galls on Quercus laurifolia.

Neuroterus longipennis Ashmead, 1887. Amer. Ent. Soc., Trans. 14: 132, 140. đ, gall.

\section{Genus TRISOLENIELLA Rohwer and Fagan}

Trisolenia Ashmead, 1887. Amer. Ent. Soc., Trans. 14: 142. Preocc. by Ehrenberg, 1861.

Type-species: Andricus saltatus Ashmead. Monotypic.

Trisoleniella Rohwer and Fagan, 1917. U. S. Natl. Mus., Proc. 53: 377. N. name.

brevicornis (Beutenmueller). N. J. Ecology: Observed ovipositing in the buds of Quercus alba. Andricus brevicormis Beutenmueller, 1913. Amer. Ent. Soc., Trans. 39: 245. $?$.

enigma (Weld). Va., Fla., Ill., Tex. Ecology: Produce root galls on Quercus catesbaei, Q. myrtifolia, Q. rubra, Q. texana.

Callirhytis enigma Weld, 1921. U. S. Natl. Mus. , Proc. 59: 219., gall.

bignelli (Dalla Torre and Kieffer). N. Y., N. J.

Trisolenia punctata Ashmead, 1896. U. S. Natl. Mus., Proc. 19: 129.. Preoce. in Andricus by Bignell, 1892 .

Andricus bignelli Dalla Torre and Kieffer, 1902. In Wytsman, Gen. Ins., fasc. 9, p. 61. N. name.

Amphibolips montana Beutenmueller, 1913. Insecutor Inscitiae Menstruus 1: 122. ․ saltata (Ashmead). N. C., Fla. Ecology: Produce bud galls on Quercus cinerea, Q. falcata.

Andricus saltatus ashmead, 1887. Amer. Ent. Soc., Trans. 14: 142. \&, gall.

\section{Genus ODONTOCYNIPS Kieffer}

Odontocynips Kieffer, 1910. Lab. Zool. Gen. e Agr. Portici, Bol. 4: 112.

Type-species: Odontocynips nebulosa Kieffer. Monotypic.

nebulosa Kieffer. Ga., Fla., Mo., Ark., Tex. Ecology: Produce root galls on Quercus stellata.

Odontocynips nebulosa Kieffer, 1910. Lab. Zool. Gen. e Agr. Portici, Bol. 4: 112. \&. 


\section{Genus HOLOCYNIPS Kieffer}

Holocynips Kieffer, 1910. Lab. Zool. Gen. e Agr. Portici, Bol. 4: 114.

Type-species: Holocynips emarginata Kieffer. Monotypic.

badia (Bassett). Conn., N. Y., s. to Fla., w. to Ill., Mo., Ark., Tex. Ecology: Produce galls at bases of sprouts of Quercus alba, Q. bicolor, Q. chapmani, Q. macrocarpa, Q. prinus, Q. stellata.

Amphibolips badius Bassett, 1900. Amer. Ent. Soc., Trans. 26: 323. 9.

Holocynips emarginata Kieffer, 1910. Lab. Zool. Gen. e Agr. Portici, Bol. 4: 114. ९, gall.

Callirhytis corallosa Weld, 1921. U. S. Natl. Mus., Proc. 59: 191, 216. ?, gall.

hartmani (Weld). Calif. Ecology: Produce root galls on Quercus chrysolepis.

Callirhyt is hartmani Weld, 1921. U. S. Natl. Mus., Proc. 59: 191, 214. ?, gall.

humicola (Kinsey). Oreg., Calif. Ecology: Produce root galls on Quercus agrifolia, Q. kelloggi, Q. wislizenii.

Audricus humicola Kinsey, 1922. Amer. Mus. Nat. Hist., Bul. 46: 283. \&, gall.

maxima (Weld). N. Y., Md., D. C., Va., Ill. Ecology: Produce root galls on Quercus alba, Q. bicolor, Q. macrocarpa, Q. prinus.

Callirhytis maxima Weld, 1921. U. S. Natl. Mus., Proc. 59: 191, 217. \&, gall.

\section{Genus PLAGIOTROCHUS Mayr}

Plagiotrochns Mayr, 1881. Zwanzig. Jahresber. Comm.-Oberrealsch. I. Bez. Wien., pp. 8, 12, 32.

Type-species: Cynips ilicis Fabricius. Desig. by Ashmead, 1903.

suberi Weld. Calif. Ecology: Produce stem galls on the introduced European cork oak, Quercus suber.

Plagiotrochus suberi Weld, 1926. U. S. Natl. Mus., Proc. 68 (10): 47. ๆ, gall.

\section{Genus DRYOCOSMUS Giraud}

Dryocosmus Giraud, 1859. Zool.-Bot. Gesell. Wien., Verh. 9: 353.

Type-species: Dryocosmus cerriphilus Giraud. Monotypic.

Entropa Foerster, 1869. Zool.-Bot. Gesell. Wien, Verh. 19: 330, 334.

Type-species: Entropa lissonota Foerster. Monotypic.

albidus Weld. N. Y., Va., N. C., Ill. Ecology: Produce leaf galls on Quercus coccinea, Q. velutina.

Dryocosmus albidus Weld, 1944. U. S. Natl. Mus., Proc. 95: 15. $?$, gall.

asymmetricus (Kinsey). Calif. Ecology: Produce stem galls on Quercus clirysolepis.

Plagiotrichus(!) asymmetricus Kinsey, 1922. Ind. Univ. Studies 53: 106. \&, gall.

asymmetricus var. annectens (Kinsey). Calif.

Plagiotrichus(!) asymmetricus var. annectens Kinsey, 1922. Ind. Univ. Studies 53: 107. , gall.

asymmetricus var. compactus (Kinsey). Calif.

Plagiotrichus(!) asymmetricus var. compactus Kinsey, 1922. Ind. Univ. Studies 53: 108. + , gall.

attractans (Kinsey). Calif. Ecology: Produce bud galls on Quercus wislizenii.

Audricus attractans Kinsey, 1922. Amer. Mus. Nat. Hist., Bul. 46: 281. ठ, gall.

castanopsidis (Beutenmueller). Oreg., Calif. Ecology: Produce staminate flower galls on Castanopsis chrysophylla, C. sempervirens.

Audricus castanopsidis Beutenmueller, 1917. Canad. Ent. 49: 345. ९, gall.

cinereae (Ashmead). N. Y., Pa., Va., S. C., Fla., Ill., Mo., Tex. Ecology: Produce leaf galls on Quercus cinerea and other red oaks.

Dryophanta cinereae Ashmead, 1887. Amer. Ent. Soc., Trans. 14: 144. \&, gall.

Andricus (Callirhytis) saccularius. Bassett, 1890. Amer. Ent. Soc., Trans. 17: 76. o, gall. coxii (Bassett). N. Mex., Ariz. Ecology: Produce stem galls on Quercus cmoryi, Q. hypolenca.

Cynips coxii Bassett, 1881. Canad. Ent. 13: 112. , gall.

Andricus coxi Bassett, 1900. Amer. Ent. Soc., Trans. 26: 320. ๆ, gall. 
Audricus Bassettianus Dalla Torre and Kieffer, 1902. In Wytsman, Gen. Ins., fasc. 9, p. 61. N. name for coxi Bassett, 1900.

coxii var. translatus (Kinsey). Ariz. Ecology: Produce stem galls on Quercus hypoleuca. Plagiotrichus(!) coxii var. translatus Kinsey, 1922. Ind. Univ. Studies 53: 125. \&, gall. deciduus (Beutenmueller). Md., Va., N. C., Tenn., Ill., Mo. Ecology: Produce leaf galls on Quercus rubru, Q. relutina.

Autricus decillua Beutenmueller, 1913. Insecutor Inscitiae Menstruus 1: 131. \&, gall.

dubiosus (Fullaway). Calif. Ecology: Produce leaf galls in agamic generation, ament galls in sexual generation, on Quercus agrifolia, Q. wislizenii.

Diplolepis dubiosa Fullaway, 1911. Ent. Soc. Amer., Ann. 4: 339. , o, gall. Sexual gen. Callirhytis bicomis McCracken and Egbert, 1922. Stanford Univ. Pubs., Univ. Ser., Biol. Sci. 3 (1): 42 . , gall. Agamic gen.

Biology: Doutt, 1959. Ent. Soc. Amer., Ann. 52: 69-74.

favus Beutenmueller. Pa. s. to Fla., w. to Ill., Mo., Ark., Tex. Ecology: Produce root galls on red oaks.

Dryocosmus furus Beutenmueller, 1911. Ent. News 22: 197. $\subsetneq$, gall.

floridensis (Beutenmueller). Va. s. to Fla., w. to Okla., Tex. Ecology: Produce stem galls on red oaks.

Dryophantu floriclensis Beutenmueller, 1917. Canad. Ent. 49: 349. ₹, gall.

Aulricus peltatus. Wells and Metcalf, 1921. Canad. Ent. 53: 212. \&, gall.

gigas (Kinsey). Calif. Ecology: Produce ament galls on Quereus douglasii.

Aullricus gigas Kinsey, 1922. Amer. Mus. Nat. Hist., Bul. 46: 282. ₹, ठ, gall.

imbricariae (Ashmead). Conn., N. Y. to Fla., w. to Mo., Okla., Tex. Ecology: Produce stem galls on red oaks.

Andricus inbrecariae (!) Ashmead, 1896. U. S. Natl. Mus., Proc. 19: 122. , gall.

Holcaspis fasciata Bassett, 1900. Amer. Ent. Soc., Trans. 26: 328. \&, gall.

minusculus Weld. Calif. Ecology: Produce leaf galls on Quercus agrifolia.

Dryocosmus minnseulus Weld, 1952. U. S. Natl. Mus., Proc. 102: 337. \&, gall.

quercuslaurifoliae (Ashmead). Fla. Ecology: Produce leaf galls on Quercus laurifolia, Q. nigra.

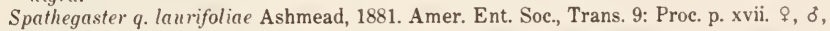
gall.

Cynips q. aquaticae Ashmead, 1881. Amer. Ent. Soc., Trans. 9: Proc. p. xvi. \$, ó, gall.

Dryophanta laurifoliae Ashmead, 1885. Amer. Ent. Soc., Trans. 12: 296.

Dryophanta aquaticae Ashmead, 1885. Amer. Ent. Soc., Trans. 12: 296.

quercusnotha (Osten Sacken). Conn., N. Y., N. J., Md., Va., Fla., Ill. Ecology: Produce leaf galls on Quercus palustris and other red oaks.

Cynips q. notha Osten Sacken, 1870. Amer. Ent. Soc., Trans. 3: 55. ๆ, ơ, gall.

Andricus (Callirhytis) notha Ashmead, 1885. Amer. Ent. Soc., Trans. 12: 295.

Andricus (Callirhytis) pusulatoides Bassett, 1890. Amer. Ent. Soc., Trans. 17: 74. ₹, gall.

quercuspalustris (Osten Sacken). Mass., Ont. to Fla., w. to Iowa, La. Ecology: Produce leaf galls on red oaks.

Cynips (Trigonaspis ?) quercus palustris Osten Sacken, 1861. Ent. Soc., Phila., Proc. 1: 62. १, ठ, gall.

Andricus (Callirhytis) palustris Ashmead, 1885. Amer. Ent. Soc., Trans. 12: 294.

Dryophanta liberaecellulae Gillette, 1890. Ent. Amer. 6: 24. , ठ, gall.

rileyi (Ashmead). N. Y. to Fla., w. to Mo., Tex. Ecology: Produce leaf galls on red oaks.

Andricus rileyi Ashmead, 1896. U. S. Natl. Mus., Proc. 19: 121. \&, gall.

\section{Genus HETEROECUS Kinsey}

Heteroecus Kinsey, 1922. Ind. Univ. Studies 53: 81.

Type-species: Andricus dasydactyli Ashmead. Orig. desig.

Revision: Kinsey, 1922. Ind. Univ. Studies 53: 81-100.

chrysolepidis (Ashmead). Calif. Ecology: Produce stem galls on Quercus chrysolepis.

Andricus chrysolepidis Ashmead, 1896. U. S. Natl. Mus., Proc. 19: 119. $\$$, gall. 
dasydactyli (Ashmead). Calif. Ecology: Produce stem galls in agamic generation and leaf galls in sexual generation on Quercus chrysolepis.

Andricus dasydactyli Ashmead, 1896. U. S. Natl. Mus., Proc. 19: 117. $q$, gall.

Biology: Rosenthal and Koehler, 1971. Ent. Soc. Amer., Ann. 64: 565-570.

dasydactyli var. pygmaeus Kinsey. Calif.

Heteroecus dasydactyli var. pygmaeus Kinsey, 1922. Ind. Univ. Studies 53: 91. \&, gall.

eriophora (Kieffer). Calif. Ecology: Produce twig galls on Quercus sp.

Callirhytis eriophora Kieffer, 1904. Soc. Hist. Nat. Metz., Bul. (2) 11: 132. \&, gall.

flavens (McCracken and Egbert). Calif. Ecology: Produce leaf galls on Quercus chrysolepis, Q. vaccinifolia.

Callirhytis flavens McCracken and Egbert, 1922. Stanford Univ. Pubs., Univ. Ser., Biol. Sci. 3(1): 40. ९, gall.

malus Kinsey. Calif. Ecology: Produce twig galls on Quercus chrysolepis.

Heteroecus malus Kinsey, 1922. Ind. Univ. Studies 53: 92. \&, gall.

melanoderma Kinsey. Ariz., Calif. Ecology: Produce stem galls on Qnercus chrysolepis, Q. wilcoxii. Date seed gall.

Heteroecus melanoderma Kinsey, 1922. Ind. Univ. Studies 53: 92. ₹, gall.

pacificus (Ashmead). Calif. Ecology: Produce stem galls in agamic generation and leaf galls in sexual generation on Quercus chrysolepis.

Andricus pacificus Ashmead, 1896. U. S. Natl. Mus., Proc. 19: 118., gall.

Callirhytis bakeri Kieffer, 1904. Soc. Hist. Nat. Metz., Bul. (2) 11: 132. ๆ, gall.

Biology: Lyon, 1963. Ent. Soc. Wash., Proc. 65: 250-254.

pacificus var. gracilis Kinsey. Calif.

Heteroecus pacificus var. gracilis Kinsey, 1922. Ind. Univ. Studies 53: 95. \&, gall.

pacificus var. subpacificus Kinsey. Calif.

Heteroecus pacificus var. subpacificus Kinsey, 1922. Ind. Univ. Studies 53: 95. \&, gall.

sanctaeclarae (Fullaway). Calif. Ecology: Produce stem galls on Quercus chrysolepis.

Callirhytis sanctae-clarae Fullaway, 1911. Ent. Soc. Amer., Ann. 4: 363. , gall.

sanetaeclarae var. aliud Kinsey. Calif.

Heteroecus sanctae-clarae var. aliud Kinsey, 1922. Ind. Univ. Studies 53: 98. \&, gall.

sanctaeclarae var. fuscior Kinsey. Calif.

Heteroecus sanctae-clarae var. fuscior Kinsey, 1922. Ind. Univ. Studies 53: 98. \&, gall.

\section{Genus CALLIRHYTIS Foerster}

Callirhytis Foerster, 1869. Zool.-Bot. Gesell. Wien, Verh. 19: 331, 335.

Type-species: Callirhytis hartigi Foerster. Monotypic.

apicalis (Ashmead), Calif. Ecology: Produce root galls on Quercus agrifolia, Q. kelloggii, Q. wislizenii.

Andricus apicalis Ashmead, 1896. U. S. Natl. Mus., Proc. 19: 120. $q$, gall.

attigua Weld. Tex. Ecology: Produce leaf galls on Quercus texana.

Callivhytis attigna Weld, 1926. U. S. Natl. Mus., Proc. 68 (10): 88., gall.

balanacea Weld. N. Y., Va., Mo. Ecology: Produce acorn galls on Quercus palustris.

Callirhytis balanacea Weld, 1944. U. S. Natl. Mus., Proc. 95: 16. , gall.

balanaspis Weld. D. C., Va., Mo., Ark., Tex. Ecology: Produce acorn galls on Quercus marilandica.

Callirhytis balanaspis Weld, 1922. U. S. Natl. Mus., Proc. 61 (19): 22. \&, gall.

balanella Weld. Ariz. Ecology: Produce acorn galls on Quercus emoryi.

Callirhytis balanella Weld, 1957. U. S. Natl. Mus., Proc. 107: 117. \&, gall.

balanoides Weld. N. Y., Va., Ill., Mo., Tex. Ecology: Produce acorn galls on Quercus velutina.

Callirhytis balanoides Weld, 1922 . U. S. Natl. Mus., Proc. 61 (19): 27. \&, gall.

balanopsis Weld. Va., Ga., Ala., Miss., Mo., Ark., Tex. Ecology: Produce acorn galls on Quercus marilandica.

Callirhytis balanopsis Weld, 1922. U. S. Natl. Mus., Proc. 61 (19): 26. \&, gall. 
balanosa Weld. Ill. Ecology: Produce acorn galls on Quercus coccinea.

Callirhytis balanosa Weld, 1922. U. S. Natl. Mus., Proc. 61 (19): 19. \%, gall.

bipapillata Weld. N. Y., Va. Ecology: Produce leaf galls on Quercus ilicifolia.

Callirhytis bipapillate Weld, 1944. U. S. Natl. Mus., Proc. 95: 17. ‡, ठै, gall.

blastophaga (Ashmead). Fla. Ecology: Produce ament galls on Querens cinerea. Andricus blastophagus Ashmead, 1887. Amer. Ent. Soc., Trans. 14: 143. \&, gall.

carmelensis Weld. Calif. Ecology: Produce acorn galls on Quercus agrifolia, Q. kelloggii, Q. uislizenii.

Callirhytis carmelensis Weld, 1922. U. S. Natl. Mus., Proc. 61 (19): 20. + , gall.

cistella Weld. Ariz. Ecology: Produce acorn galls on Quercus emoryi, Q. hypolenca. Callirhytis cistella Weld, 1952. U. S. Natl. Mus., Proc. 102: 338. \&, gall.

clarkei (Bassett). Mass., N. J., Va. Ecology: Produce ament galls on Querens ilicifolia. Andricus (Callirhytis) clarkei Bassett, 1890. Amer. Ent. Soc., Trans. 17: 79. ๆ, gall.

clavula (Osten Sacken). Mass., N. Y., Pa., N. J., D. C., N. C., Ill., Iowa. Ecology: Produce stem galls on Quercus alba.

Cynips clacula Osten Sacken, 1865. Ent. Soc. Phila., Proc. 4: 351. $₹$, gall.

congregata (Ashmead). Calif. Ecology: Produce ament galls on Quercus agrifolia, Q. wislizenii.

Andricus congregatus Ashmead, 1896. U. S. Natl. Mus., Proc. 19: 120. , gall.

cornigera (Osten Sacken). Mass. to Ga., w. to Iowa. Ecology: Produce stem galls on Quercus palustris and other red oaks.

Cynips cormigera Osten Sacken, 1865. Ent. Soc. Phila., Proc. 4: 358. , gall.

corrugis (Bassett). Conn., Va. Ecology: Produce acorn galls on Quercus velutina.

Cynips corrugis Bassett, 1881. Canad. Ent. 13: 109..

Callirhytis defecta Kieffer, 1910. Lab. Zool. Gen. e Agr. Portici, Bol. 4: 116. ๆ.

Taxonomy: Weld, 1952. U. S. Natl. Mus., Proc. 102: 338 (gall).

cressoni (Beutenmueller). Tex. Ecology: Produce bud galls on Quercus stellata.

Dryophanta cressoni Beutenmueller, 1913. Amer. Ent. Soc., Trans. 39: 247. ๆ, gall.

crypta (Ashmead). Ga., Fla., Ala., Miss., Tex. Ecology: Produce stem galls on Quercus cinerea, Q. marilandica.

Audricus cryptus Ashmead, 1887. Amer. Ent. Soc., Trans. 14: 145. ๆ, gall.

cryptica Weld. Fla., Ala. Ecology: Produce bud galls on Quercus myrtifolia.

Callirlytis cryptica Weld, 1922. U. S. Natl. Mus., Proc. 61 (18): 19. $\&$, gall.

difficilis (Ashmead). Ga. w. to Mo., Ark., Tex. Ecology: Produce stem galls on Quercus myrtifolia, Q. nigra, Q. phellos.

Andricus difficilis Ashmead, 1887. Amer. Ent. Soc., Trans. 14: 143., gall.

electrea Weld. Md., D. C., Va. Ecology: Produce acorn galls on Quercus prinus.

Callirhytis electrea Weld, 1944. U. S. Natl. Mus., Proc. 95: 18. ๆ, gall.

ellipsoida Weld. Ill. Ecology: Produce root galls on Quercus bicolor.

Callirhytis ellipsoida Weld, 1921. U. S. Natl. Mus., Proc. 59: 227. ๆ, gall.

elliptica Weld. Pa., D. C., Va., Ill. Ecology: Produce root galls on Quereus alba. Callirhytis elliptica Weld. 1921. U. S. Natl. Mus., Proc. 59: 228. + , gall.

elongata (Kinsey). Tex. Ecology: Produce stem galls on Quercus breviloba.

Plagiotrichus(!) elongatus Kinsey, 1922. Ind. Univ. Studies 53: 125. ^, gall.

elongata var. rufopleurae (Kinsey). Tex. Ecology: Produce stem galls on Quercus breviloba. Plagiotrichus(!) elongatus var. rufopleurae Kinsey, 1922. Ind. Univ. Studies 53: 128. ․ gall.

elongata var. stellatae (Kinsey). Tex. Ecology: Produce stem galls on Quercus stellata. Plagiotrichus(!) elongatus var. stellatae Kinsey, 1922. Ind. Univ. Studies 53: 128. \&, gall.

excavata (Ashmead). New England, N. C. Ecology: Produce stem galls on Quercus mibra. Andricus excavatus Ashmead, 1896. U. S. Natl. Mus., Proc. 19: 121., gall.

exigua (Bassett). Conn., D. C., Va. Ecology: Produce ament galls on Quercus stellata. Andricus exiguus Bassett, 1900. Amer. Ent. Soc., Trans. 26: 318. ๆ, ơ, gall. 
favosa (Bassett). N. Y., Pa., Md., Va., Ohio. Ecology: Produce leaf galls on Quercus palustris, Q. velutina.

Neuroterus favosus Bassett, 1890. Amer. Ent. Soc., Trans. 17: 87. \&, ठ, gall.

flavipes (Gillette). Ill., Minn., Iowa. Ecology: Produce leaf galls on Quercus macrocarpa. Nenroterus flavipes Gillette, 1889. Iowa Agr. Expt. Sta., Bul. 7: 281. \&, ठ์, gall.

flora Weld. Calif. Ecology: Produce leaf galls on Quercus agrifolia, Q. uislizeni. Callirh ytis flora Weld, 1922. U. S. Natl. Mus., Proc. 61 (18): 20 . , gall.

florensis Weld. Va. Ecology: Produce ament galls on Quercus marilandica. Callirhytis florensis Weld, 1944. U. S. Natl. Mus., Proc. 95: 19. ₹, ठ, gall.

floridana (Ashmead). Md., D. C., Va., N. C., Fla., Mo., Ark., La. Ecology: Produce stem galls on Quercus chapmani, Q. stellata.

Andricus floridanus Ashmead, 1887. Amer. Ent. Soc., Trans. 14: 137. \&, ơ, gall.

floripara Weld. Calif. Ecology: Produce ament galls on Quercus agrifolia.

Callirhytis floripara Weld, 1957. U. S. Natl. Mus., Proc. 107: 118. $९$, ơ, gall.

frequens (Gillette). Colo., N. Mex., Ariz. Ecology: Produce stem galls on Quercus gambelii, Q. havardi, $Q$. undulate.

Andricus frequens Gillette, 1892. Ent. News 3: 247. \&, gall.

frequens var. piceoderma (Kinsey). Colo.

Plagiotrichus(!) frequens var. piceoderma Kinsey, 1922. Ind. Univ. Studies 53: 131..

fructicola Ashmead. Pa., Va., S. C., Tenn. Ecology: Produce acorn galls on Quercus ilicifolia, Q. marilandica, Q. velutina.

Callirhytis fructicole Ashmead, 1896. U. S. Natl. Mus., Proc. 19: 131. \&, gall.

fructuosa Weld. N. Y., Md., Va., N. C., S. C., Ga., Ala., Ill.,Mo., Tex. Ecology: Produce acorn galls on red oaks.

Callirhytis fructnosa Weld, 1922. U. S. Natl. Mus., Proc. 61: (19): 14. \&, gall.

fulva Weld. Calif. Ecology: Produce root galls on Quercus chrysolepis. Callirhytis fulca Weld, 1921. U. S. Natl. Mus., Proc. 59: 226., gall.

furva Weld. Va., Mo. Ecology: Produce leaf galls on Quercus nigra, Q. palustris. Callirhytis furva Weld, 1952. U. S. Natl. Mus., Proc. 102: 341. $q$, gall.

gallaestriatae Weld. N. Y., Va., N. C., Ill. Ecology: Produce bud galls on Quercus coccinea, Q. palustris, Q. rubra, Q. velutina.

Callirhytis gallaestriatae Weld, 1926. U. S. Natl. Mus., Proc. 68 (10): 92 . ₹, gall.

gemmiformis (Beutenmueller). N. Y., N. J., Md., Va., Ill. Ecology: Produce bud galls on Quercus alba.

Andricus gemmiformis Beutenmueller, 1917. Canad. Ent. 49: 346. \&, gall.

glandulus (Beutenmueller). N. J. Ecology: Produce acorn galls on Quercus prinoides. Andricus glandulus Beutenmueller, 1913. Brooklyn Ent. Soc., Bul. 8: 103..

glomerosa Weld. Va. Ecology: Produce bud galls on Quercus coccinea.

Callirh ytis glomerosa Weld, 1957. U. S. Natl. Mus., Proc. 107: 119. \&, gall.

hopkinsi Weld. D. C., Va., W. Va. Ecology: Produce acorn galls on Quercus imbricaria.

Callirhytis hopkinsi Weld, 1952. U. S. Natl. Mus., Proc. 102: 339. ₹, gall.

infuscata (Ashmead). Ga., Fla. Ecology: Produce leaf galls on Quercus catesbaei and other red oaks on the coastal plains.

Andricus infiuscatus Ashmead, 1887. Amer. Ent. Soc., Trans. 14: 144. \&, gall.

intersita Weld. Va. Ecology: Females collected ovipositing in internodes of twigs of Quercus alba.

Callirhytis intersita Weld, 1957. U. S. Natl. Mus., Proc. 107: 119..

juvenca Weld. N. Mex., Ariz. Ecology: Produce leaf galls on Quercus arizonica, Q. gambelii, Q. oblongifolia, Q. reticulata, Q. subturbinella.

Callirhytis juenca Weld, 1944. U. S. Natl. Mus., Proc. 95: 20. ๆ, gall.

lanata (Gillette). Mass. s. to N. C., Ala., w. to Minn., Ark., Tex. Ecology: Produce leaf galls on Quercus coccinea, Q. rubra.

Dryophanta lanata Gillette, 1891. Ill. State Lab. Nat. Hist., Bul. 3: 198. ₹, gall.

lapillula Weld. D. C., Ill. Ecology: Produce acorn galls on Quercus bicolor.

Callirhytis lapillula Weld, 1922. U. S. Natl. Mus., Proc. 61 (19): 18. \&, gall. 
lupana Weld. Ariz. Ecology: Produce leaf galls on Quercus emoryi, Q. hypoleuca.

Callirhytis lupana Weld, 1944. U. S. Natl. Mus., Proc. 95: 21. \&, o, gall.

marginata Weld. Ill. Ecology: Produce root galls on Quercus coccinea.

Callirhytis marginata Weld, 1921. U. S. Natl. Mus., Proc. 59: 225. ₹, gall.

medularis Weld. Pa., Va., Ohio. Ecology: Produce stem galls on Quercus coccinea, Q. velutina. Callirhytis medularis Weld, 1957. U. S. Natl. Mus., Proc. 107: 121. ๆ, ठ, gall.

middletoni Weld. D. C., Va., Fla., Ala. Ecology: Produce acorn galls on Quercus phellos.

Callirhytis middletoni Weld, 1922. U. S. Natl. Mus., Proc. 61 (19): 25. , gall.

milleri Weld. Calif. Ecology: Produce acorn galls on Quercus agrifolia, Q. kelloggii, Q. wislizenii.

Callirhytis milleri Weld, 1922. U. S. Natl. Mus., Proc. 61 (19): 11. ९, gall.

Callirhytis essigi McCracken and Egbert, 1922. Stanford Univ., Pubs., Univ. Ser., Biol. Sci. 3 (1): 43 . , gall.

morrisoni (Ashmead). Ariz. Ecology: Produce leaf galls on Quercus sp.

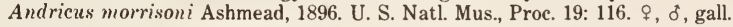

myrtifoliae (Beutenmueller). Fla. Ecology: Produce ament galls on Quercus myrtifolia.

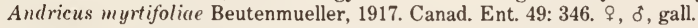

oblata Weld. Va. Ecology: Produce bud galls on Quercus coccinea, Q. falcata.

Callirhytis oblata Weld, 1952. U. S. Natl. Mus., Proc. 102: 340. , gall.

obtusilobae (Bassett). Conn. Ecology: Produce leaf galls on Quercus stellata.

Andricus obtusilobae Bassett, 1900. Amer. Ent. Soc., Trans. 26: 316..

ovata Weld. Fla., Ark., Tex. Ecology: . Produce root galls on Quercus catesbaei, Q. cinerea, Q. myrtifolia, Q. texana.

Callirhytis ovata Weld, 1921. U. S. Natl. Mus., Proc. 59: 222. ९, gall.

ovata var. melanica (Kinsey). Tex. Ecology: Produce root galls on Quercus schreckii.

Andricus ovata var. melanicus Kinsey, 1922. Ind. Univ. Studies 53: 32 . $\uparrow$, gall.

parva Weld. Va., W. Va., Mo. Ecology: Produce ament galls on Quercus imbricaria. Callirhytis parva Weld, 1922. U. S. Natl. Mus., Proc. 61 (18): 23. ₹, ठ, gall.

parvifoliae Ashmead. Fla. Ecology: Produce leaf galls on Quercus chapmani.

Callirhytis parvifoliae Ashmead, 1887. Amer. Ent. Soc., Trans. 14: 138. \&, gall.

parvula (Bassett). Conn. Ecology: Taken ovipositing in buds of Quercus ilicifolia; never reared and gall unknown.

Dryophanta parvula Bassett, 1900. Amer. Ent. Soc., Trans. 26: 326. $₹$.

patiens (Bassett). Conn. Ecology: Taken ovipositing in buds of Quercus ilicifolia; never reared and gall unknown. This may be a synonym of parvula.

Andricus patiens Bassett, 1900. Amer. Ent. Soc., Trans. 26: 312. ๆ.

pedunculata (Bassett). Conn., N. Y., Va., Ill. Ecology: Produce leaf galls on Quercus coccinea, Q. rubra.

Dryophanta pedunculata Bassett, 1890. Amer. Ent. Soc., Trans. 17: 72. ๆ, đ, gall.

perdens (Kinsey). Oreg., Calif. Ecology: Produce stem galls on Quercus agrifolia, Q. kelloggii, Q. vislizenii.

Andricus perdens Kinsey, 1922. Amer. Mus. Nat. Hist., Bul. 46: 286. + , gall.

perdens var. destructor (Kinsey). Calif.

Plagiotrichus(!) perdens var. destructor Kinsey, 1922. Ind. Univ. Studies 53: 134. \&, gall.

perditor (Bassett). Conn., N. Y., N. J., Va. Ecology: Produce acorn galls on Quercus ilicifolia; galls secrete honeydew.

Audricus perditor Bassett, 1900. Amer. Ent. Soc., Trans. 26: 313. \&, gall.

perfoveata (Kinsey). Calif. Ecology: Produce leaf galls on Quercus agrifolia, Q. kelloggii, Q. u'islizenii.

Andricus perfoceatus Kinsey, 1922. Amer. Mus. Nat. Hist., Bul. 46: 287. \&, gall.

perobscura Weld. Va. Ecology: Observed ovipositing in buds of Quercus velutina; gall unknown.

Callirhytis perobscura Weld, 1957. U. S. Natl. Mus., Proc. 107: 122..

perplexa (Ashmead). Mo. Ecology: Produce woolly leaf galls on Quercus sp.

Audricus perplexus Ashmead, 1896. U. S. Natl. Mus., Proc. 19: 122., gall. 
perrugosa Weld. N. J., Pa., Md., D. C., Va. Ecology: Taken ovipositing in terminal buds on sprouts of Quercus alba; probably form root galls.

Callirhytis perrugosa Weld, 1944. U. S. Natl. Mus., Proc. 95: 22..+

petrina Weld. Ariz. Ecology: Produce acorn galls on Quercus hypoleuca.

Callirhytis petrina Weld, 1922. U. S. Natl. Mus., Proc. 61 (19): 13. $९$, gall.

petrosa Weld. Ga., Fla., Tex. Ecology: Produce acorn galls on Quercus cinerea.

Callirhytis petrosa Weld, 1922. U. S. Natl. Mus., Proc. 61 (19): 15. \&, gall.

pigra (Bassett). Conn. s. to Fla., w. to Ill., Mo. Ecology: Produce leaf galls on Quercus coccinea, Q. velutina.

Cynips pigra Bassett, 1881. Canad. Ent. 13: 105. \&, gall.

Callirhytis cellae Ashmead, 1887. Amer. Ent. Soc., Trans. 14: 141. \&, gall.

piperoides (Bassett). Maine to N. C., w. to Ill. Ecology: Produce leaf galls on Quercus rubra and other red oaks.

Andricus piperoides Bassett, 1900. Amer. Ent. Soc., Trans. 26: 314. ₹, gall.

pulchra (Bassett). Mass., N. Y., Va., Ill. Ecology: Produce ament galls on Quercus rubra, Q. velutina.

Andricus (Callirhytis) pulchra Bassett, 1890. Amer. Ent. Soc., Trans. 17: 73. ९, o, gall.

quereifoliae (Ashmead). Fla. Ecology: Produce leaf galls on Quercus catesbaei.

Andricus quercifolice Ashmead, 1885. Amer. Ent. Soc., Trans. 12: 299. ठ, gall.

quercusagrifoliae (Bassett). Calif. Ecology: Produce leaf galls in agamic generation and leaf axil galls in sexual generation on Quercus agrifolia, Q. kelloggii, Q. wistizenii.

Cynips q. ayrifolicue Bassett, 1881. Canad. Ent. 13: 53. \$, gall.

Andricus (Callirhytis) agrifoliae Ashmead, 1885. Amer. Ent. Soc., Trans. 12: 294.

Andricus wisliceni(!) Ashmead, 1896. U. S. Natl. Mus., Proc. 19: 119. \&, gall.

Callirhytis clarimontis Kieffer, 1904. Soc. Hist. Nat. Metz, Bul. (2) 11: 132. $९$, gall.

Biology: Lyon, 1964. Ent. Soc. Wash., Proc. 66: 193.

quercusbatatoides (Ashmead). S. C., Ga., Fla., Ala., Miss., La. Ecology: Produce stem galls on Quercus virginiana.

Cynips (Dryocosmus!) quercus batoides Ashmead, 1881. Amer. Ent. Soc., Trans. 9: Proc. p. xi. $\&$, gall.

Cynips batatoides Packard, 1881. U. S. Ent. Comn., Bul. 7: 57.

Andricus (Andricus) batatoides Ashmead, 1885. Amer. Ent. Soc., Trans. 12: 296.

quercusclavigera (Ashmead). Fla. Ecology: Produce stem galls on Quercus laurifolia.

Cynips q. clavigera Ashmead, 1881. Amer. Ent. Soc., Trans. 9: Proc. p. xxvii. ?, gall.

Andricus (Andricus) clavigerns Ashmead, 1885. Amer. Ent. Soc., Trans. 12: 295.

quercusconfusa (Ashmead). Fla. Ecology: Produce leaf galls on Quercus lanrifolia.

Cynips q. confusa Ashmead, 1881. Amer. Ent. Soc., Trans. 9: Proc. p. xviii. \&, gall.

Neuroterus confusa Ashmead, 1885. Amer. Ent. Soc., Trans. 12: 296.

quercusfutilis (Osten Sacken). Mass. s. to Va., w. to Wis., Ark., Okla. Ecology: Produce root galls in agamic generation, leaf galls in sexual generation, on Quercus alba, Q. prinus.

Cynips quercus futilis Osten Sacken, 1861. Ent. Soc., Phila., Proc. 1: 63. đ, gall.

Cynips quercus papillata Osten Sacken, 1861. Ent. Soc. Phila, Proc. 1: 64. o', gall.

Cymips (Andricus) futilis Osten Sacken, 1865. Ent. Soc. Phila., Proc. 4: 346, 349, 352.

Cynips papillata Osten Sacken, 1865. Ent. Soc. Phila., Proc. 4: 346, 352.

Callirhytis radicis Bassett, 1889. Psyche 5: 237. ․ Preoce. by Fabricius, 1798.

Andricus radicicola Dalla Torre, 1893. Cat. Hym., v. 2, p. 95. N. name.

quercusgemmaria (Ashmead). Mass., N. J., Va., Ga., Fla., Ind., Ill., Tex. Ecology: Produce stem galls on Quercus cinerea and other red oaks.

Cynips q. gemmaria Ashmead, 1885. Amer. Ent. Soc., Trans. 12: Proc. p. ix. $\&$, gall.

Andricus (Andricus) gemmarins Ashmead, 1885. Amer. Ent. Soc., Trans. 12: 295.

quercusmedullae (Ashmead). Fla. Ecology: Produce stem galls on Quercus cinerea.

Cynips q. medullae Ashmead, 1885. Amer. Ent. Soc., Trans. 12: Proc. p. viii. \&, gall.

Andricus (Andricus) medullae Ashmead, 1885. Amer. Ent. Soc., Trans. 12: 295.

quercusmodesta (Osten Sacken). Conn., N. Y., D. C., Va., Ind., Okla., Tex. Ecology: Produce leaf galls on Quercus rubra, Q. velutina.

Cynips quercus modesta Osten Sacken, 1861. Ent. Soc. Phila., Proc. 1: 65. \&, gall. 
Cynips modesta Osten Sacken, 1865. Ent. Soc. Phila., Proc. 4: 346, 349, 357, 379.

Cynips papula Bassett, 1881. Canad. Ent. 13: 107., gall.

quercusnigrae (Osten Sacken). D. C., Va., N. C., Mo., Ark. Ecology: Produce leaf galls on Quercus marilandica.

Cynips quercus nigrae Osten Sacken, 1861. Ent. Soc. Phila., Proc. 1: 66. ๆ, đ, gall.

Andricus (Callirhytis) nigrae Ashmead, 1885. Amer. Ent. Soc., Trans. 12: 294.

quereusoperator (Osten Sacken). Nova Scotia s. to N. C., w. to Iowa, Mo., Ark., Tex. Ecology: Produce acorn galls in agamic generation, ament galls in sexual generation, on Quercus marilandica and other red oaks.

Cynips quercus operator Osten Sacken, 1862. Ent. Soc. Phila., Proc. 1: 256. ९, ð, gall. Sexual gen.

Cynips operator Osten Sacken, 1865. Ent. Soc. Phila., Proc. 4: 357.

Andricus operatola Bassett, 1900. Amer. Ent. Soc., Trans. 26: 315.. . Agamic gen.

Andricus operator var. consobrinus Kinsey, 1922. Ind. Univ. Studies 53: 26. ๆ, ơ, gall.

quercusoperator var. austrior (Kinsey). Tex. Ecology: Produce ament galls on Quercus schneckii.

Andricus operator var, austrior Kinsey, 1922. Ind. Univ. Studies 53: 26. ๆ, ơ, gall.

quercusoperator var. falsa (Kinsey). R. I. Ecology: Produce ament galls on Quercus ilicifolia.

Audricus operator var. falsus Kinsey, 1922. Ind. Univ. Studies 53: 27. ९, ठ, gall.

quercusoperator var. illustrans (Kinsey). N. H. Ecology: Produce ament galls on Quercus ilicifolia.

Andricus operator var, illustrans Kinsey, 1922. Ind. Univ. Studies 53: 28. ९, ¿, gall.

quercusphellos (Osten Sacken). Md., D. C., Va. Ecology: Produce stem galls on Quercus phellos.

Cynips quercus phellos Osten Sacken, 1861. Ent. Soc. Phila., Proc. 1: 70. \&, gall.

Amphibolips phellos Ashmead, 1885. Amer. Ent. Soc., Trans. 12: 294.

quercuspomiformis (Bassett). Calif. Ecology: Produce stem galls in agamic generation, leaf galls in sexual generation, on Quercus agrifolia, Q. wislizenii.

Cynips $q$. pom iform is Bassett, 1881. Canad. Ent. 13: 74. $\%$, gall. Agamic gen.

Andricus (Andricus) pomiformis Ashmead, 1885. Amer. Ent. Soc., Trans. 12: 295.

Callirhytis rossi Kieffer, 1903. Marcellia 2: 84. \&, gall.

Callirhytis maculipennis Kieffer, 1904. Soc. Hist. Nat. Metz, Bul. (2) 11: 131. ๆ, gall.

Andricus yosem ite Beutenmueller, 1911. Canad. Ent. 43: 211. ؟, gall.

Biology: Lyon, 1959. So. Calif, Acad., Sci. Bul. 58 (1): 33-37 (sexual gen. on leaves).

quercuspomiformis var. descansonis (Kinsey). Calif.

Andricus pomiformis var. descansonis Kinsey, 1922. Ind. Univ. Studies 53: 41. \&, gall.

quercuspomiformis var. distincta (Kinsey). Calif.

Andricus pom iform is var. distinctus Kinsey, 1922. Ind. Univ. Studies 53: 38. + , gall.

quercuspomiformis var. provineialis (Kinsey). Calif.

Andricus pom iform is var. provincialis Kinsey, 1922. Ind. Univ. Studies 53: 40. $q$, gall.

quercuspunctata (Bassett). Maine, Ont. to N. C., w. to Ill. Ecology: Produce stem galls on Quercus coccinea, Q. palustris, Q. velutina. Gouty gall.

Cynips q. punctata Bassett, 1863. Ent. Soc. Phila., Proc. 2: 323 . $\&$, gall.

Cynips q. podagrae Walsh, 1864. Ent. Soc. Phila., Proc. 2: 491. \&, gall.

Cynips punctata Osten Sacken, 1865. Ent. Soc. Phila., Proc. 4: 358.

Cynips podagrae Osten Sacken, 1865. Ent. Soc. Phila., Proc. 4: 358.

quercusrugosa (Ashmead). N. Y., Md., Va., Fla., Ill. Ecology: Produce leaf galls on Quercus imbricaria, Q. laurifolia, $Q$. phellos.

Cynips q. rugosa Ashmead, 1881. Amer. Ent. Soc., Trans. 9: Proc. p. xviii. $q, \delta$, gall.

Andricus (Andricus) rugosus Ashmead, 1885. Amer. Ent. Soc., Trans. 12: 295.

quercusscitula (Bassett). Mass., Conn., N. Y., N. J., Va., Ind., Ill. Ecology: Produce stem galls on Quercus coccinea, Q. velutina.

Cynips q. scitula Bassett, 1864. Ent. Soc. Phila., Proc. 3: 683. ?, ơ, gall.

Cynips scitula Osten Sacken, 1865. Ent. Soc. Phila., Proc. 4: 341, 358. 
quercussimilis (Bassett). Mass., Conn., N. Y., Md., Ga., Fla., Tex. Ecology: Produce stem galls on Quercus ilicifolia and other red oaks.

Cynips q. similis Bassett, 1864. Ent. Soc. Phila., Proc. 3: 685. ๆ, ơ, gall.

Cynips similis Osten Sacken, 1865. Ent. Soc. Phila., Proc. 4: 356.

quercussuttonii (Bassett). Calif. Ecology: Produce stem galls in agamic generation, leaf galls in sexual generation, on Quercus agrifolia, Q. kelloggii, Q. wislizenii.

Cynips Q. Suttonii Bassett, 1881. Canad. Ent. 13: 54. + , gall.

Audricus (Callirhytis) Suttoni Ashmead, 1885. Amer. Ent. Soc., Trans. 12: 294.

Callirhytis polythyra Kieffer, 1904. Soc. Hist. Nat. Metz, Bul. (2) 11: 132. \&, gall.

Biology: Lyon, 1969. Ent. Soc. Wash., Proc. 71: 61-65.

quercussuttonii var. Iustrior (Kinsey). Calif. Ecology: Produce stem galls on Quercus wislizenii.

Plagiotrichus(!) suttonii var. lustrior Kinsey, 1922. Ind. Univ. Studies 53: 137. \&, gall.

quercusturnerii (Ashmead). Fla. Ecology: Produce ament galls on Quercus nigra.

Cynips q. Turnerii Ashmead, 1881. Amer. Ent. Soc., Trans. 9: Proc. p. xvi. ๆ, gall.

Andricus (Andricus) Tumerii Ashmead, 1885. Amer. Ent. Soc., Trans. 12: 295.

Andricus topiarius Ashmead, 1887. Amer. Ent. Soc., Trans. 14: 136., gall.

quercusventricosa (Bassett). Mass., Conn., to Ala., w. to Ill. Ecology: Produce stem galls on Quercus ilicifolia, Q. imbricaria, Q. phellos.

Cynips q. ventricosus Bassett, 1864. Ent. Soc. Phila., Proc. 3: 681. ๆ, gall.

Cynips ventricosus Osten Sacken, 1865. Ent. Soc. Phila., Proc. 4: 358.

Cynips q. conifera Ashmead, 1881. Amer. Ent. Soc., Trans. 9: Proc. p. xxvii. $\$$, gall.

Neuroterus coniferns Ashmead, 1885. Amer. Ent. Soc., Trans. 12: 296.

rubida Weld. Pa., Md., Ind., Ill. Ecology: Produce root galls on Quercus coccinea, Q. rubra.

Callirhytis mbida Weld, 1921. U. S. Natl. Mus., Proc. 59: 224. ₹, gall.

rugulosa (Beutenmueller). N. J., D. C., Va., Ind., Ill. Ecology: Produce bud galls on Quercus rubra, Q. velutina.

Andricus mgulosus Beutenmueller, 1911. Canad. Ent. 43: 211. \&, gall.

seminator (Harris). Que. to Fla., w. to Minn., Iowa. Ecology: Produce large wooly, globular stem galls on Quercus alba. Wool sower; oak seed gall.

Cynips seminator Harris, 1841. Rpt. Ins. Mass. Injurious to Veg., p. 399., gall.

seminosa (Bassett). N. Y., Va., Ohio. Ecology: Produce stem galls on Quercus coccinea, Q. palustris.

Andricus (Callirhytis) seminostıs Bassett, 1890. Amer. Ent. Soc., Trans. 17: 76. $q$, gall.

serricornis (Kinsey). Calif. Ecology: Produce ament galls in sexual generation, leaf galls in agamic generation, on Quercus agrifolia, Q. wislizenï.

Andricus serricornis Kinsey, 1922. Amer. Mus. Nat. Hist., Bul. 46: 288. \&, o, gall. Sexual gen.

Dryocosmus grumatus Weld, 1952. U. S. Natl. Mus., Proc. 102: 336. $₹$, gall. Agamic gen.

Taxonomy: Lyon, 1970. Ent. Soc. Wash., Proc. 72: 176-178.

tuberosa (Bassett). Mass., Conn., N. J. Ecology: Produce stem galls on Quercus ilicifolia.

Andricus (Callirhytis) tuberosa Bassett, 1900. Amer. Ent. Soc., Trans. 26: 311. १, ơ, gall.

tubicola (Osten Sacken). D. C., Va., Miss., Okla., Tex. Ecology: Produce leaf galls on Quercus stellata.

Cynips tubicola Osten Sacken, 1861. Ent. Soc. Phila., Proc. 1: 60. $q$, gall.

Andricus texanus Beutenmueller, 1909. Ent. News 20: 248. \&, gall.

tumifica (Osten Sacken). N. Y., Va., N. C., Ill., Iowa. Ecology: Produce leaf galls on Quercus rubra, Q. velutina.

Cynips tumifica Osten Sacken, 1865. Ent. Soc. Phila., Proc. 4: 356. ‡, ơ, gall.

uvellae Weld. Calif. Ecology: Produce bud galls on Quercus agrifolia, Q. kelloggii, Q. uislizenii.

Callirhytis uvellae Weld, 1944. U. S. Natl. Mus., Proc. 95: 23. ๆ, gall.

vaccinii (Ashmead). N. Y., Ga., Fla., Mo., Okla., Tex. Ecology: Produce leaf galls on Quercus stellata.

Acraspis vaccinii Ashmead, 1887. Amer. Ent. Soc., Trans. 14: 136. gall. 
Andricus lustrans Beutenmueller, 1913. Amer. Ent. Soc., Trans. 39: 244. ₹.

Andricus impositus Beutenmueller, 1918. Ent. New's 29: 329. \&, gall.

Audricus dimorphns var. verifactor Kinsey, 1922. Ind. Univ. Studies 53: 15. \&, gall.

UNPLACED SPECIES IN SUPERFAMILY CYNIPOIDEA

The manuscript names included in this list have all appeared at least once in some publication other than the original one.

Andricus acinosus Bassett, 1881. In Mayr, Zwanzig. Jahresber. Comm.-Oberrealsch. I. Bez.

Wien., p. 28. MS.

Hexaplasta unnae Ashmead, 1897. In Slosson, Ent. New's 8: 237. MS.

Cynips! aspera Stebbins, 1910. Springfield Mus. Nat. Hist., Bul. 2: 26. gall.

Neuroterus atomus Ashmead, 1887. Amer. Ent. Soc., Trans. 14: 203. MS.

Kleilotoma bakeri Ashmead, 1900. In Howard, Wash. Acad. Sci., Proc. 2: 557. MS.

Oxylabis bifoceolata Brues, 1904. Canad. Ent. 36: 119. ठ. Transf. from Diapriidae.

Taxonomy: Weld, 1967. In Krombein and Burks, U. S. Dept. Agr., Agr. Monog. Sup. 2, p. 284. Cynips caducus Walsh, 1890. In Packard, U. S. Ent. Comn., Rpt. 5: 115. gall.

Audricus concinnus Bassett, 1882. Amer. Nat. 16: 246. MS.

Cynips! constricta Stebbins, 1910. Springfield Mus. Nat. Hist., Bul. 2: 20. gall.

Cynips (Neuroterus) crassitellus Provancher, 1881. Nat. Canad. 12: 233. 9 . Unique type in

Provancher Collection in Quebec in bad condition.

Cynips! cristata Stebbins, 1910. Springfield Mus. Nat. Hist., Bul. 2: 24. gall.

Callirhytis! flocculenta Trotter, 1910. Lab. Zool. Gen. e. Agr. Portici, Bol. 5: 115. gall.

Rhodites fusiformans Cockerell, 1890. Entomologist 23: 75. gall.

Cynips (Audricns) gibbosus. Provancher, 1881. Nat. Canad. 12: 232.,+ ઠ. Type in Provancher Collection in Quebec, but only thorax remains.

Rhodites globosus Cockerell, 1890. Entomologist 23: 75. gall.

Solenaspis hyalinus Ashmead, 1895. U. S. Dept. Agr., Insect Life 7: 326. Host: Mesograpta polita (Say) puparium. MS.

Neuroterus laurifoliae Ashmead, 1887. Amer. Ent. Soc., Trans. 14: 140. \&. Type lost.

Cynips maculatus Blanchard, 1840. I" Laporte, Hist. Nat. Anim. Articules, v. 3, p. 250. "Carolina."

Eucoila minor Provancher, 1888. Addit. Corr. Faune Ent. Canada Hym., p. 398. ๆ. Type probably lost; not located in Quebec or Ottowa collections.

Rhodites bicolor var. minor Trotter, 1910. Lab. Zool. Gen. e Agr. Portici, Bol. 5: 103. gall.

Aegilips monticola Ashmead, 1902. In Slosson, Ent. News 13: 320, 17: 323. MS.

Periclistidea monticola Ashmead, 1902. In Slosson, Ent. News 13: 5. Both generic and specific names MS.

Eumayria multiarticulata Ashmead, 1887. Amer. Ent. Soc., Trans. 14: 133. gall.

Kleidotoma nigrosus Ashmead, 1906. In Nason, Ent. News 17: 9. \%. MS.

Cyuips! obovata Stebbins, 1910. Springfield Mus. Nat. Hist., Bul. 2: 24. gall.

Neuroterus? perpusillus Trotter, 1910. Lab. Zool. Gen. e Agr. Portici, Bol. 5: 107. gall.

Figites pini Harris, 1833. Geol. Mass., Rpt., p. 587. MS.

Diplolepis potentillae Harris, 1833. Geol. Mass., Rpt. p. 587. MS.

Andricus psendocallidoma Trotter, 1910. Lab. Zool. Gen. e Agr. Portici, Bol. 5: 105. gall.

Cynips quercusfloccicola Riley, 1890. In Packard. U. S. Ent. Comn., Rpt. 5: 115. gall.

Cynips quercusfiondosa Bassett, 1864. Ent. Soc. Phila., Proc. 3: 688. gall.

Cynips quercusmellaria Riley, 1880. Amer. Ent. 3: 298. gall.

Cynips? sera Stebbins, 1910. Springfield Mus. Nat. Hist., Bul. 2: 24. gall.

Rhodites siluestrii Trotter, 1910. Lab. Zool. Gen. e Agr. Portici, Bol. 5: 103. gall.

Anacharis slossonae Ashmead, 1906. In Slosson, Ent. News 17: 323. MS.

Rhodites sphaericus Stebbins, 1910. Springfield Mus. Nat. Hist., Bul. 2: 38, 106. gall.

Rhodites spinosellus Cockerell, 1890. Entomologist 23: 75. gall.

Cynips (Rhodites!) tuberculosa Osten Sacken, 1861. Stettin Ent. Ztg. 22: 415. \&, ó, gall.

Trigonaspis? vaccinoides Trotter, 1910. Lab. Zool. Gen. e Agr. Portici, Bol. 5: 107. gall.

Dryophanta vesiculoides Riley, 1895. Science, n.s., 1: 462. MS. 

 \\ Superfamily EVANIOIDEA
}

\author{
By RoBert W. CARLSON
}

This superfamily includes three families, Evaniidae, Aulacidae, and Gasteruptiidae. There appears to be little evidence to indicate that the Aulacidae and Gasteruptiidae are actually related to the Evaniidae. There does appear to be some evidence to indicate that the Aulacidae and Gasteruptiidae are distantly related. Because there is no evidence to suggest that a common ancestor of Aulacidae and Gasteruptiidae would have been less closely related to ancestral Evaniidae than to the ancestor of any other group, there is little reason for not maintaining placement of the Aulacidae and Gasteruptiidae in the Evanioidea.

Revision: Kieffer, 1912. Das Tierreich, v. 30, XIX and 431 p. (spp. of world).

Taxonomy: Crosskey, 1951. Roy. Ent. Soc. London, Trans. 102: 282-301. -Muesebeck and

Walkley, 1956. U. S. Natl. Mus., Proc. 105: 319-419 (type-species).

Morphology: Crosskey, 1951. Roy. Ent. Soc. London, Trans. 102: 247-281.

\section{Family EVANIIDAE}

Members of this family are parasitic within the egg cases of cockroaches. Known hosts of the evaniids found in North America are members of the cockroach families Blattidae and Blatellidae. Species of Evaniidae are most numerous in the tropics.

Revision: Bradley, 1908. Amer. Ent. Soc., Trans. 34: 128-162. -Townes, 1949. U. S. Natl.

Mus., Proc. 99: 525-539.

Taxonomy: Hedicke, 1939. Hym. Cat., pt. 9, 50 p. (world catalog).

\section{Genus EVANIA Fabricius}

Erania Fabricius, 1775. Systema Ent., p. 345.

Type-species: Ichneumon appendigaster Linnaeus. Desig. by Curtis, 1829.

According to Townes (1958) Evania is comprised of larger species which occur mostly in the Oriental Region.

Taxonomy: Townes, 1958. Ins. of Micronesia, v. 19, no. 2, p. 84.

appendigaster (Linnaeus). Southeastern Mass., s.e. N. Y., s.e. Pa., D. C., Ga., Fla., Tenn., La., Tex., s. N. Mex., s. Ariz.; West Indies and Mexico s. to n. Argentina; Old World (especially warmer parts). Adventive. Host: Blatta orientalis L.?, Periplaneta americana (L.). I have found no published rearing records for North America, but because appendigaster has been reared from $P$. americana in other parts of the world there is no reason to doubt that it serves as a host in North America. I am not aware of 
records of appendigaster as a parasite of $B$. orientalis which have been confirmed by authoritative identification of the adult parasites. Therefore, I do not feel certain that such records do not in fact apply to Prosevania fuscipes (Illiger). North of a latitude of approximately 37 degrees in the eastern United States appendigaster apparently ranges inland only rather short distances from the Atlantic coast. Some of the names cited in the synonymy below will possibly prove to be synonyms of Prosevania fuscipes, but Westwood's (1844) description of a specimen in "the Linnaean cabinet" (presumably the appendigaster type) seems to indicate that the name appendigaster correctly applies to the present species.

Ichneumon appendigaster Linnaeus, 1758. Syst. Nat., ed. 10, p. 566. Sex not indicated.

Ichneumon niger Goeze, 1780. In Degeer, Des ... Degeer Abhandl. zur Gesch. des Insecten, v. 3 , p. 285 . Sex not indicated?

Evania laevigata Olivier, 1791. Encycl. Meth., Dict. Ins., v. 6, p. 453. \&.

Evania unicolor Say, 1824. In Keating, Narr. Long's 2nd Exped., v. 2 (App.), p. 320. Sex not indicated.

Evania Cubae Guerin-Meneville, 1834. Iconogr. Regne Anim., pl. 65, figs. 1-2. ठ. For date of publication see Cowan (1971, p. 28-29).

Evania Desjardinsii Blanchard, 1840. Hist. Nat. Anim. Artic., Ins., v. 3, p. 299. ठ.

Evania affinis Le Guillou, 1841. Soc. Ent. de France, Ann. 10: 311. ठ.

Evania appendigastra Hedqvist, 1973. Ent. Tidskr. 94: 178. Emend.

Taxonomy: Westwood, 1844 (1843). Ent. Soc. London, Trans. 3: 241-242. - Cowan, 1971. Soc.

Bibliog. Nat. Hist., Jour. 6: 18-29 (dating of E. cubae).

Biology: Cameron, 1957. Bul. Ent. Res. 48: 199-209. - Roth and Willis, 1960. Smithsonian Misc. Coll. 141: 236.

\section{Genus PROSEVANIA Kieffer}

Evania subg. Prosevania Kieffer, 1911. Soc. Ent. de France, Ann. 80: 157.

Type-species: Prosevania afra Kieffer. Desig. by Viereck, 1914. Described as a subgenus, but in the case of afra treated nomenclatorially as a genus.

This is a large genus of the Old World Tropics.

fuscipes (Illiger), n. comb. Northwestern Mass. w. to s. Ohio, s. to n.e. N. C. and Ga.; s.e.

Europe, n.w. Asia, n. Africa. Adventive. Host: Blatta orientalis L., Periplaneta americana (L.). The name punctata (Brulle) has erroneously been treated as the senior name for this species for many years (since 1919 in North America). The names Evania fuscipes Illiger (1807) and $E$. flavicornis Curtis (1829) were proposed for $E$. appendigaster Linnaeus as misidentified by Panzer (1799), Latreille (1805), and Jurine (1807). There is little reason to doubt that the species identified as appendigaster by any of these three authors is the present species, but Panzer's figure in particular leaves no doubt whatsoever and is, therefore, here selected as lectotype for both the names $E$. fuscipes Illiger and E. flavicomis Curtis.

Evania fuscipes Illiger, 1807. In Rossi, Fauna Etrusca, ed. 2, v. 2, p. 83. [male].

Evania flavicorn is Curtis, 1829. Brit. Ent., v. 6, pl. 257. [male].

Erania punctata Brulle, 1833. Exped. Sci. de Moree, v. 3, p. 378. sex not indicated. N. syn. Evania urbana Bradley, 1908. Amer. Ent. Soc., Trans. 34: 140. ठ, ๆ. N. syn.

Taxonomy: Panzer, 1799. Faunae Ins. German., fasc. 62, pl. 12. - Latreille, 1805. Hist. Nat. Crust. Ins., v. 13, p. 193. - Jurine, 1807. Nouv. Meth. Class. Hym. Dipt., v. 1, p. 85 and pl. 7 , fig. 6. - Bequaert, 1919. Brooklyn Ent. Soc., Bul. 14: 23.

Biology: Edmunds, 1952; 1953. Ohio Jour. Sci. 52: 29-30; 53: 121-122. -Edmunds, 1954. Ent. Soc. Amer., Ann. 47: 575-592.

\section{Genus EVANIELLA Bradley}

Evaniella Bradley, 1905. Canad. Ent. 37: 64.

Type-species: Evania unicolor Say as misidentified by Ashmead (1901). Orig. desig. According to Bradley (1908), Evaniella semaeoda Bradley is the species which Ashmead identified as unicolor. 
This is a large genus of Australian, Nearctic, and Neotropic distribution (particularly the latter).

Taxonomy: Ashmead, 1901. Canad. Ent. 33: 304. - Bradley, 1908. Amer. Ent. Soc., Trans. 34: 142-147.

californica (Ashmead). East-central Calif.

Evania Californica Ashmead, 1901. Canad. Ent. 33: 304. o.

Taxonomy: Snelling, 1963. Pan-Pacific Ent. 39: 108 (female described).

neomexicana (Ashmead). Southeastern N. Mex., s.e. Calif.

Evania Neomexicana Ashmead, 1901. Canad. Ent. 33: 304. ठ.

semaeoda Bradley. R. I. w. to s. Mich. and n.e. Kans., s. to s. Fla. and s. La.; West Indies.

Evaniella semceoda Bradley, 1908. Amer. Ent. Soc., Trans. 34: 144. ó, ๆ.

\section{Genus HYPTIA Illiger}

Hyptia Illiger, 1807. In Rossi, Fauna Etrusca, ed. 2, v. 2, p. 82. Appeared as "Hyptiam" in accusative case, Hyptia being the nominative equivalent. Fauna Etrusa, ed. 2, v. 2 not necessarily published prior to volume six of Mag. f. Insectenkunde, but usually treated as prior in synonymies pertaining to various other generic names.

Hyptia Illiger, 1807. Mag. f. Insektenkunde 6: 192.

Type-species: Evania petiolata Fabricius. Monotypic.

This is a large genus of the New World, with many more Neotropic species than Nearctic ones. Rearing data are few, but the species appear to be parasites of forest dwelling Blattoidea such as Parcoblatta spp.

femorata Townes. Western Tex.

Hyptia femorata Townes, 1949. U. S. Natl. Mus., Proc. 99: 537. ¿, ๆ.

floridana Ashmead. Western N. C. w. to n. La., s. to s. Fla.; Guatemala, Panama.

Hyptia Floridana Ashmead, 1901. Canad. Ent. 33: 303. ठे.

harpyoides Bradley. N. H. w. to s.e. Minn., s. to n.w. S. C., n. Miss., and n. Kans. Host: Parcoblatta uhleviana (Sauss.), P. virginica (Brunn.). This species occurs farther north than any other evaniid in North America.

Hyptia harpyoides Bradley, 1908. Amer. Ent. Soc., Trans. 34: 151. ठ, \&.

Hyptia brevicalcar var. glabriceps Kieffer, 1910. Soc. Ent. de France, Ann. 79: 72. o.

oblonga Townes. Southwestern Ga., s. Ala., and s.e. Ariz. s. to s. Fla.; s. Mex., Costa Rica.

Hyptia oblonga Townes, 1949. U. S. Natl. Mus., Proc. 99: 538. ơ, १.

reticulata (Say). Mass. w. to mid Mich., s. to s. Fla., s. La., and s.w. Tex.; s. Mexico.

Brachygaster reticulata Say, 1836. Boston Jour. Nat. Hist. 1: 223. sex not indicated.

Hyptia uyctoides Bradley, 1908. Amer. Ent. Soc., Trans. 34: 159. ठ’.

Hyptia prosetethetra Bradley, 1908. Amer. Ent. Soc., Trans. 34: 160. $\delta$.

thoracica (Blanchard). Mass., s. Ont., Wis., and n.e. Kans. s. to s. Fla. and s. Tex. Host: Parcoblatta sp., P. pensyluarica (Deg.).

Evania thoracica Blanchard, 1840. Hist. Nat. Anim. Artic., Ins., v. 3, p. 299. Sex not indicated.

Hyptiam thoracicum Shuckard, 1841. Entomologist 1: 120. o. Preoce. by Blanchard, 1840.

Evania dorsalis Westwood, 1851. Ent. Soc. London, Trans. (2) 1: 214. Unnecessary n. name for $E$. thoracica Blanchard, there being no E. thoracica Klug or Leach.

Evania brevicalcar Kieffer, 1904. Arkiv for Zool. 1: 541. o.

Hyptia mylacridomanes Bradley, 1908. Amer. Ent. Soc., Trans. 34: 153. ๆ.

Hyptia hyptiogastris Bradley, 1908. Amer. Ent. Soc., Trans. 34: 160. ठ。.

Hyptia texana Bradley, 1908. Amer. Ent. Soc., Trans. 34: 161. \&.

\section{Family AULACIDAE}

The approximately 150 species of this small family are distributed throughout the world. All are thought to be parasites of wood boring Coleoptera or Hymenoptera.

Revision: Bradley, 1902 (1901). Amer. Ent. Soc., Trans. 27: 319-330 (date according to Ent. News 13: 94). - Townes, 1950. U. S. Natl. Mus., Proc. 100: 87-120. 
Taxonomy: Hedicke, 1939. Hym. Cat., pt. 10, 28 p. (world catalog). -Townes, 1950. U. S.

Natl. Mus., Proc. 100: 85-86 (phyletic position). - Crosskey, 1951. Roy. Ent. Soc. London,

Trans. 102: 249. -Crosskey, 1953. Ann. and Mag. Nat. Hist. (12) 6: 758-759.

Biology: Crosskey, 1951. Roy. Ent. Soc. London, Trans. 102: 285.

Morphology: Short, 1959. Ent. Monthly Mag. 95: 217-219 (final-instar larva).

\section{Genus PRISTAULACUS Kieffer}

Aulacostethus Philippi, 1873. Stettin. Ent. Ztg. 34: 302. Preocc. by Waterhouse, 1869 and Uhler, 1871.

Type-species: Aulacostethus rubriventer Philippi. Monotypic.

Pristaulacus Kieffer, 1900 (1899). Soc. Ent. de France, Ann. 68: 813.

Type-species: Pristaulacus chlapou'skii Kieffer. Desig. by Kieffer, 1903.

Deruiodoutus Bradley, 1901. Ent. Student 2: 29.

Type-species: Aulacus montanus Cresson. Included and desig. by Bradley, 1902.

Oleisoprister Bradley, 1902 (1901). Amer. Ent. Soc., Trans. 27: 324.

Type-species: Aulucus fïmus Cresson. Orig. desig.

Auaulacus Semenov, 1903. Rev. Russe d'Ent. 3: 173. Preoce. by MacLeay, 1825.

Type-species: Aulacus sibiricola Semenov. Monotypic.

Semenowia Kieffer, 1903. In Andre, Spec. Hym. Eur. Alg., v. 7 (2nd), p. 382, 720. N. name

for Auaulacus Semenov; preocc. by Weise, 1889.

Odontaulacus Kieffer, 1903. Iu Andre, Spec. Hym. Eur. Alg. 7 (2nd), p. 382.

Type-species: Aulacus infitarsis Cresson. Desig. by Bradley, 1908.

Interaulacuss Bradley, 1908. Amer. Ent. Soc., Trans. 34: 123.

Type-species: Interaulacus kiefferi Bradley. Monotypic and orig. desig.

Semenovius Bradley, 1908. Amer. Ent. Soc., Trans. 34: 123. N. name for Auaulacus

Semenov and Semenoutia Kieffer.

Tropaulacuss Bradley, 1908. Amer. Ent. Soc., Trans. 34: 120, 125.

Type-species: Tropaulacus torridus Bradley. Monotypic and orig. desig.

Pristanlacus subg. Neaulacus Bradley, 1908. Amer. Ent. Soc., Trans. 34: 126.

Type-species: Aulacus occidentalis Cresson. Orig. desig.

Disaulacimus Kieffer, 1910. Soc. Ent. de France, Bul. 15: 350.

Type-species: Disanlacinus flavimanus Kieffer. By subsequent monotypy from inclusion by Kieffer, 1911.

Tetranlacinus Kieffer, 1910. Soc. Ent. de France, Bul. 15: 350.

Type-species: Pristualacus rufobalteatus Cameron. By subsequent monotypy from inclusion by Kieffer, 1911.

Psilaulacus Kieffer, 1910. Soc. Ent. de France, Bul. 15: 350.

Type-species: Psilaulacus annulatus Kieffer. By subsequent monotypy from inclusion by Kieffer, 1911.

Members of this large genus presumably occur throughout the forested regions of the world.

arizonicus (Townes). Southeastern Ariz.

Aulacostethus arizonicus Townes, 1950. U. S. Natl. Mus., Proc. 100: 98. ๆ.

bilobatus (Provancher). N. S. s. to w. N. C., w. to Wis. Ecology: Often associated with Tsuga.

Host: Melanophila fuleoguttata (Harris).

Aulacus bilobatus Provancher, 1878. Nat. Canad. 10: 237. ठ.

californicus (Townes). Northern Calif. Host: Paratimia conicola Fisher.

Aulacostethus californicus Townes, 1950. U. S. Natl. Mus., Proc. 100: 101. ठ, §.

canadensis (Townes). Maine, s. Man.

Aulacostethus canadensis Townes, 1950. U. S. Natl. Mus., Proc. 100: 102. ¿, ๆ.

editus (Cresson). Northern Mich., s. B. C., Wash., n. Calif. Host: Chrysophana placida (LeC.), Paratimia conicola Fisher.

Aulacus editus Cresson, 1880. Amer. Ent. Soc., Trans. 8: v in Proc..+

fasciatus (Say). Pa., D. C., Ohio, Mich., Ind., Mo., Ark. Ecology: One specimen in the U. S. Natl. Museum collection emerged from Carya wood.

Aulacus fasciatus Say, 1829. Contrib. Maclurian Lyceum to Arts and Sci. 1: 67.. 
flavicrurus (Bradley). Vt. w. to n. Mich., s. to n.w. S. C. and Ill.

Deraiodontus flavicrurus Bradley, 1902 (1901). Amer. Ent. Soc., Trans. 27: 322. ‥

Pristaulacus flavipes Kieffer, 1904. Arkiv for Zool. 1: 559. ठ.

foxleei (Townes). Western Mont., n. Idaho, s. B. C., Wash., Oreg., n. Calif. Host: Leptura obliterata Hald.

Aulacostethus foxleei Townes, 1950. U. S. Natl. Mus., Proc. 100: 107. ơ, ๆ.

melleus (Cresson). Nev., w. Wash., Oreg., n. Calif.

Aulacus melleus Cresson, 1879. Amer. Ent. Soc., Trans. 7: 255..

Aulacus consors Cresson, 1879. Amer. Ent. Soc., Trans. 7: 255. ठ.

Pristaulacus ferrugineus Kieffer, 1904. Soc. d'Hist. Nat. de Metz, Bul. (2) 11: 29. ९.

minor (Cresson). Northwestern Wyo., n. Utah, n.w. Mont., n. Idaho, s. B. C., Wash., Oreg., n.

Calif. Host: Se'manotus ligneus (F.), Melanophila drummondi (Kby.), M. intmesa Horn.

Aulacus minor Cresson, 1880. Amer. Ent. Soc., Trans. 8: vi in Proc.

montanus (Cresson). Southern B. C. s. to Nev. and s. Calif. Host: Xylotrechus nauticus

(Mann.), Chrysobothris sp.

Aulacus montanus Cresson, 1879. Amer. Ent. Soc., Trans. 7: 256..+

Derciodontus fuscalatus Bradley, 1902 (1901). Amer. Ent. Soc., Trans. 27: 321. \&.

Pristaulacus (Oleisoprister) dentatus Bradley, 1908. Amer. Ent. Soc., Trans. 34: 126. ¿.

niger (Shuckard), revised status. N. S. w. to Man. and Colo., s. to s. Fla. and Tex. Ecology:

Occurs on dead pine trees.

Aulacus niger Shuckard, 1841 (June). Entomologist 1: 124. Sex not indicated.

Aulacus ater Westwood, 1841 (Sept.). Ann. Nat. Hist. 7: 538. ?.

Aulacus Abbottii Westwood, 1841 (Sept.). Ann. Nat. Hist. 7: 538..

Pristaulacus [Pristaulacus] hopkinsii Bradley, 1908. Amer. Ent. Soc., Trans. 34: 127..

The variant spelling hopkinsi also appeared on p. 127 (key).

Pristaulacus aterrimus Kieffer, 1911. Soc. Ent. de France, Ann. 80: 230. Unnecessary n.

name for Aulacus ater Westwood, the latter not being preocc. by $A$. ater

Guerin-Meneville, 1844.

Pristaulacus floridana Rohwer, 1913. U. S. Natl. Mus., Proc. 45: 534..

Taxonomy: Westwood, 1843. Ent. Soc. London, Trans. 3: 265-266. -Townes, 1950. U. S. Natl. Mus., Proc. 100: 95-96.

occidentalis lavatus (Townes). Northern Idaho, s. B. C., w. Wash., Oreg., n. Calif.

Aulacostethus occidentalis lavatus Townes, 1950. U. S. Natl. Mus., Proc. 100: 106. ¿, ๆ.

occidentalis occidentalis (Cresson). Colo., N. Mex., n.w. Wyo., n. Idaho, n. Utah.

Aulacus occidentalis Cresson, 1879. Amer. Ent. Soc., Trans. 7: 255. ‡.

oregonus (Townes). Western Oreg.

Aulacostethus oregonus Townes, 1950. U. S. Natl. Mus., Proc. 100: 96. ठ, ९.

pacificus (Cresson). Colo., n. Idaho, s. B. C., Wash., w. Oreg.

Aulacus pacificus Cresson, 1879. Amer. Ent. Soc., Trans. 7: 256. ㅇ.

resutorivorus (Westwood). Que. w. to s. B. C., s. to n. Va., Colo., and n. Calif. Host: Arhopalus productus (LeC.)?

Aulacus Resutorieoms Westwood, 1851. Ent. Soc. London, Trans. (2) 1:224..

Aulacus firmus Cresson, 1879. Amer. Ent. Soc., Trans. 7: 256..

Aulacus subfirmus Bradley, 1901. Ent. Student 2: 31. [female]. Published as A. subfirmus "Viereck," but validated in key written by Bradley.

Oleisoprister subfirmus Viereck, 1902 (1901). In Bradley, Amer. Ent. Soc., Trans. 27: 325. . Preocc. in Pristaulacus by Bradley, 1901.

rufitarsis (Cresson). Que. w. to Alaska, s. to w. N. C., Minn., N. Mex., and n. Calif. Host: Graph isurus sp., Saperda calcarata Say, Chrysobothris caurina Horn, Melanophila drummondi (Kby.), M. fulvoguttata (Harris).

Aulacus rufitarsis Cresson, 1864. Ent. Soc. Phila., Proc. 3: 134..

Aulacus abdominalis Cresson, 1880. Amer. Ent. Soc., Trans. 8: v in Proc. $\subsetneq$.

Aulacus erythrogaster Kieffer, 1904. Arkiv for Zool. 1: 561. ठ, ᄋ.

Odontaulacus spinosipes Kieffer, 1910. Soc. Ent. de France, Ann. 79: 79. ๆ.

stigmaterus (Cresson). Que. s. to n. Ga., w. to Mich. and Mo.

Aulacus stigmaterus Cresson, 1864. Ent. Soc. Phila., Proc. 3: 134. 9. 
Pristanlacus punctaticeps Kieffer, 1910. Soc. Ent. de France, Ann. 79: 78. ๆ.

strangaliae Rohwer. N. S. s. to n. Va., w. to s. Man.

Pristaulacus strangaliae Rohwer, 1917. U. S. Natl. Mus., Proc. 53: 157. 9.

Pristaulacus (Oleisoprister) taughanic Bradley, 1926. Brooklyn Ent. Soc., Bul. 21: 173..

Pristaulacus (Oleisoprister) glabrescens Bradley, 1926. Brooklyn Ent. Soc., Bul. 21: 174. ․

torridus (Bradley). Southern Tex.

Tropaulacus torrilus Bradley, 1908. Amer. Ent. Soc., Trans. 34: 125. ․

violaceus (Bradley). D. C., Va., s. Ohio.

Deraiodontus violaceus Bradley, 1905. Ztschr. System. Hym. Dipt. 5: 26. đ, ๆ.

\section{Genus AULACUS Jurine}

Aulacus Jurine, 1801. In Panzer, Litteratur-Ztg. Erlangen, Intelligenzbl. 1: 163. Nomen nudum.

Aulacus Jurine, 1807. Nouv. Method. Class. Hym. Dipt., v. 1, p. 89.

Type-species: Aulacus striatus Jurine. Monotypic.

Aulacus subg. Aulacinus Westwood, 1869 (1868). Ent. Soc. London, Trans. 16: 331.

Type-species: Aulacus (Aulacinus) moerens: Westwood. Monotypic.

Pammegischia Provancher, 1882. Nat. Canad. 13: 302.

Type-species: Pammegischia burquei Provancher. Monotypic.

Parafoenus Kieffer, 1910. Soc. Ent. de France, Bul. 15: 350.

Type-species: Parafoenus formosus Kieffer. By subsequent monotypy from inclusion by Kieffer, 1911.

Neuraulacinus Kieffer, 1910. Soc. Ent. de France, Bul. 15: 350.

Type-species: Nenraulacinus braconiformis Kieffer. Desig. by Kieffer, 1912 from three species included by Kieffer, 1911.

Micraulacinus Kieffer, 1910. Soc. Ent. de France, Bul. 15: 350.

Type-species: Micraulacin us elegans Kieffer. By subsequent monotypy from inclusion by Kieffer, 1911.

Pycnanlacus Cushman, 1919. U. S. Natl. Mus., Proc. 76 (25): 17.

Type-species: Pycnaulacus brevicaudus Cushman. Monotypic and orig. desig.

Members of this moderate-sized genus presumably occur throughout the forested regions of the world.

aneurus Walkley. Southern N. Mex. Host: Dendroctonus sp.?, D. adjunctus Bland.? Muesebeck (1958) cited Dendroctonus sp. as a host without query, but none of the specimens in the

U. S. Natl. Museum collection are known to have been reared from Dendroctonus; notes in the Hopkins file indicate that some of them emerged from trees infested with $D$. adjunctus, and that all were associated with Dendroctonus. Because aneurus does not seem to be too large to be a parasite of $D$. adjunctus, it seems possible that rearings will confirm $D$. adjunctus as a host.

Aulacus aneurus Walkley, 1952. Ent. Soc. Wash., Proc. 54: 185. ठँ, ๆ.

Biology: Muesebeck, 1958. In Krombein et al., U. S. Dept. Agr., Agr. Monog. 2, Sup. 1, p. 88.

brevicaudus (Cushman). Southwestern Oreg. s. to n.w. and e.-central Calif. Ecology: Specimens have been reared from Almus rhombifolia and twigs of Salix bearing Euura galls.

Pycraulacus brevicaudus Cushman, 1930 (1929). U. S. Natl. Mus., Proc. 76 (25): 18..

burquei (Provancher). N. S. s. to Md., w. to Mich. Host: Xiphydria maculata Say.

Pammegischia Burquei Provancher, 1882. Nat. Canad. 13: 303..

digitalis Townes. Mass., Conn., Pa., n. W. Va., n. Ohio. Host: Xiphydria maculata Say.

Aulacus digitalis Townes, 1950. U. S. Natl. Mus., Proc. 100: 118. ठ, ९.

dispilus Townes. Southern Tex. Ecology: One specimen is reported to have emerged from Celtis laevigata.

Aulacus dispilus Townes, 1950. U. S. Natl. Mus., Proc. 100: 114..

lovei (Ashmead). Que., Vt., Mass., N. Y., N. J., Pa., Md. Host: Xiphydria abdominalis Say, X. champlaini Roh., $X$. tibialis Say.

Pammegischia Lovei Ashmead, 1901. Canad. Ent. 33: 301. ․

Pammegischia onelletii Bradley, 1902 (1901). Amer. Ent. Soc., Trans. 27: 329. ठ。. 
pallipes Cresson. N. B. w. to s. B. C., s. to n. Va., Mo., n. Idaho, and n.e. Wash.? Host:

Xiphydria mellipes Harris. In the U. S. Natl. Museum collection there are two females from Metaline Falls, Wash. (a locality cited for pallipes in Townes' [1950] revision of the Aulacidae) which are less melanistic than other pallipes specimens in the collection. They bear Hopkins no. 21306, the card for which indicates that they were collected while ovipositing in Pseudotsuga menziesii infested by Buprestis sp. P. menziesii is not known to be a host for any Xiphydriidae.

Aulacus pallipes Cresson, 1879. Amer. Ent. Soc., Trans. 7: xvii in Proc. o. Pammegischia xiphydriae Ashmead, 1901 (Nov. 8). Canad. Ent. 33: 300. ๆ. Pammegischia Weedi Ashmead, 1901 (Nov. 8). Canad. Ent. 33: 301. ठ.

Pammegischia xiphydriae Ashmead, 1901 (Nov. [31]). Ent. News 12: 278. ९. Preocc. by

Ashmead, 1901 (Nov. 8), which is based upon the same holotype.

Aulacus pallidipes Dalla Torre, 1902. Cat. Hym., v. 3, p. 1061. Emend.

Pammegischia ashmeadi Bradley, 1908. Amer. Ent. Soc., Trans. 34: 122. 9.

Pammegischia minnesotae Bradley, 1908. Amer. Ent. Soc., Trans. 34: 122. ס.

\section{Family GASTERUPTIIDAE}

This small family is nearly worldwide in distribution (unknown from Micronesia and Polynesia). Crosskey (1962) recognized two subfamilies, the Hyptiogastrinae with five genera and the Gasteruptiinae with one genus. Because Gasteruption includes the vast majority of Gasteruptiidae, there is little practical value in recognizing two subfamilies at this time.

The accounts of the biologies of Gasteruptiidae given by Hoeppner (1904) and Malyshev (1968) indicate that the larvae are predators or predator-inquilines in the nests of solitary bees and sphecids which nest in wood. According to Hoeppner, the egg of Gasteruption assectator (Linnaeus) is laid on a mature larva of the prey. After consuming the latter, the assectator larva invades the cell of a second prey larva and consumes it also. The species discussed by Malyshev deposited their eggs in proximity to an egg of a solitary bee, the exact positioning of eggs varying among species of gasteruptiids. Upon eclosion from the egg the gasteruptiid larva consumed the egg of the bee. Sometimes the larva would then complete its development by feeding upon the provisions in the same bee larval cell but often invaded one or more other cells where they consumed both bee larvae and provisions.

Revision: Townes, 1950. U. S. Natl. Mus., Proc. 100: 120-145.

Taxonomy: Hedicke, 1939. Hym. Cat., pt. 11, 54 p. (world catalog). -Crosskey, 1962. Roy. Ent. Soc. London, Trans. 114: 377-402 (genera of world).

Biology: Hoeppner, 1904. Allg. Ztschr. f. Ent. 9: 97-103. -Malyshev, 1968. Genesis of Hym. and ... their Evolution, p. 42-46.

Morphology: Crosskey, 1951. Roy. Ent. Soc. London, Trans. 102: 247-281. -Short, 1952. Roy. Ent. Soc. London, Trans. 103: 45-48, 49 (final-instar larva).

\section{Genus GASTERUPTION Latreille}

Gastemiption Latreille, 1796. Precis Caract. Gen. Ins., p. 113.

Type-species: Ichneumon assectator Linnaeus. Desig. by Viereck, 1914 from 83 species included by Schletterer, 1885. The discussion by Crosskey (1962, p. $396-397$ ) is based upon the erroneous assumption that species are included in a genus described without included species by virtue of suppression of its name in the synonymy of a genus having species.

Foenus Fabricius, 1798. Sup. Ent. System., p. 210, 240.

Type-species: Ichneumon assectator Linnaeus. Desig. by Curtis, 1832. I do not accept Latreille, 1810 as designator of any type-species.

Gastryptium Agassiz, 1846. Nomencl. Zool., Index Univ., p. 160. Emend.

Gasteryption Semenov, 1892. Acad. Imp. des Sei. St. Petersburg, Bul. (n. s.) 3: 12. Emend.

Schletterer (1890) suggested this spelling but used Gasternption.

Gasteryptium Schulz, 1906. Spolia Hym., p. 133. Emend.

Rhydinofoenus Bradley, 1909. Deut. Ent. Ztschr. (for 1909), p. 38.

Type-species: Rhydinofoenus kaweahensis Bradley. Orig. desig.

Trichofoenus Kieffer, 1910. Soc. Ent. de France, Ann. 79: 77. 
Type-species: Gasteruption merceti Kieffer. Orig. desig.

Dolichofoenus Kieffer, 1910. Soc. Ent. de France, Ann. 79: 77.

Type-species: Foenus raphidioides Westwood. Orig. desig.

Gastrhyptium Schulz, 1911. Zool. Ann. 4: 55. Emend.

Plutofoenus Kieffer, 1911. Soc. Ent. de France, Ann. 80: 177.

Type-species: Gasteruption paraguayense Schrottky. Monotypic and orig. desig.

This is a very large genus which is nearly worldwide in distribution. Crosskey (1962) was unable to find satisfactory means for distinguishing more than one genus for the 400 plus species now included in Gasteruption.

Taxonomy: Schletterer, 1890. Wien. Mus. der Naturgesch., Ann. 4: 375. -Crosskey, 1962.

Roy. Ent. Soc. London, Trans. 114: 394-398.

amputatum Townes. Colo., Ariz.

Gasteruption amputatum Townes, 1950. U. S. Natl. Mus., Proc. 100: 128. §, ๆ.

assectator (Linnaeus). N. S. w. to Alaska, s. to w. N. C., n.e. Kans., Ariz., and n. Calif.; Eurasia. Host: Hylaeus ellipticus (Kby.), Megachile rotundata (F.). Additional hosts are known from Europe.

Ichneumon assectator Linnaeus, 1758. Syst. Nat., ed. 10, p. 566. $\subsetneq$.

Icheumon anmularis Geoffroy, 1785. In Fourcroy, Ent. Parisiensis, v. 2, p. 398. Sex not indicated.

Ichneumon affectator(!) de Villers, 1789. C. Linnaei Ent., v. 3, p. 174.

Foenus montanus Cresson, 1864. Ent. Soc. Phila., Proc. 3: 132..

Foenus incertus Cresson, 1864. Ent. Soc. Phila., Proc. 3: 133. ठ, १.

Feonus(!) Arca Couper, 1870. Canad. Ent. 2: 110. ९. N. syn.

Foenus fumipennis Thomson, 1883. Opusc. Ent. 9: 848. ?.

Foenus bidentulus Thomson, 1883. Opusc. Ent. 9: 848. $\%$. Apparently no syntype from Gotland (=Gottland) could be found, and Hedqvist (1973) based his synonymy on a female from Norway which he incorrectly referred to as the lectotype.

Foenus borealis Thomson, 1883. Opusc. Ent. 9: 849. o, १.

Foenus nigritarsis Thomson, 1883. Opusc. Ent. 9: 849. ơ, ․

Gasternption assectator var. nitidulum Schletterer, 1885. Zool.-Bot. Gesell. Wien, Verh. 35: 276. $\delta, ?$.

Gastemeption micmura Kieffer, 1904. Arkiv for Zool. 4: 556. ๆ. N. syn.

Gasteruption micrura var. nigripectus Kieffer, 1904. Arkiv for Zool. 4: 556. ․ N. syn.

Gasteruption Nevadense Kieffer, 1904. Invertebrata Pacifica 1: 41. đ, ?.

Gasteruption Bakeri Kieffer, 1910. Soc. Ent. de France, Ann. 79: 75. ․ N. syn.

Trichofoenus canadensis Kieffer, 1910. Soc. Ent. de France, Ann. 79: 77. ․ N. syn.

Gasteruption Bakeri var. aberrans Strand, 1912. Arch. f. Naturgesch. 76A (6): 27. o, ㅇ. N. syn.

Foenus arcus Bradley, 1908. Amer. Ent. Soc., Trans. 34: 117. Emend.

Trichofoenus micrurus(!) Bradley, 1928. In Leonard, Cornell Univ. Agr. Expt. Sta., Mem. 101: 961 .

Trichofoenus breviterebrae Watanabe, 1934. Sapporo Nat. Hist. Soc., Trans. 13: 285. o, $q$.

Trichofoenus micrurus Hedicke, 1939. Cat. Hym., pt. 11, p. 43. Emend.

Gasteruption assectator utahensis Townes, 1950. U. S. Natl. Mus., Proc. 100: 126. ठ, ․ N. syn.

Taxonomy: Roman, 1932. Ent. Tidskr. 53: 3 (notes on type of assectator). -Pasteels, 1956. Mus. du Congo Belge, Ann. Zool. 50: 10 (syn.). - Hedqvist, 1973. Ent. Tidskr. 94: 181-182 (types of Thomson names).

Biology: Hoeppner, 1904. Allg. Zeit. f. Ent. 9: 97-103.

barnstoni barnstoni (Westwood). N. S. w. to Alaska, s. to n.e. W. Va., central Ohio, n. Ill., s. Man., and s. Alta.

Foenus Barnstoni Westwood, 1851. Ent. Soc. London, Trans. (2) 1: 220. $q$.

Gasteruption pensile Schletterer, 1890. Wien. Mus. der Naturgesch., Ann. 4: 483. .

Gasteruption barnstonii Dalla Torre, 1902. Cat. Hym., v. 3, p. 1065. Emend.

Foenus cressoni Bradley, 1908. Amer. Ent. Soc., Trans. 34: 113. ठ, ๆ.

Gasteruption Klagesi Kieffer, 1910. Soc. Ent. de France, Ann. 95: 75. ठ。. 
barnstoni perplexum (Cresson). Southern Sask. w. to s.w. Alta. and n.w. B. C., s. to N. Mex., Ariz., and $n$. Calif. Future collecting may show that the region of overlap between $b$. perplexum and the nominate form is too broad for them to be meaningfully treated as subspecies.

Foenus perplexus Cresson, 1864. Ent. Soc. Phila., Proc. 3: 131. .

Foenus fragilis Bradley, 1908. Amer. Ent. Soc., Trans. 34: 111. ๆ.

Gasteruption alticola Kieffer, 1910. Soc. Ent. de France, Ann. 79: 76. \&.

enode (Townes), n. comb. Ariz., s.e. Calif.

Rhydinofoenus enodis Townes, 1950. U. S. Natl. Mus., Proc. 100: 140..

floridanum bradleyi (Townes), n. comb. Southern Me. w. to s. Wis. and n.e. Kans., s. to w. N. C., n. Miss., and s. Tex. Two host records were given by Walkley (1967), but I find no specimens of $f$. brulleyi bearing host records in the U. S. Natl. Museum collection, and I have reason to doubt the accuracy of the identification of the parasites.

Rhydinofoenus: floridanus brudleyi Townes, 1950. U. S. Natl. Mus., Proc. 100: 139. o, \&.

Biology: Walkley, 1967. I" Krombein et al., U. S. Dept. Agr., Agr. Monog. 2, sup. 2, p. 285.

floridanum floridanum (Bradley). Northeastern N. C., s. Ga., Fla.; Cuba.

Foenus floridanus Bradley, 1908. Amer. Ent. Soc., Trans. 34: 112. ठै, ९.

kaweahense (Bradley). Southern La., s.e. Tex., central and s. Calif.; Mexico? Host: Ceratina pacifica (Smith). A specimen in the U. S. Natl. Museum collection is labeled "San Rafael Jicoltepec, collection Ashmead"; in the gasteruptiid revision of Townes (1950) that locality is cited as being in Mexico, but no place by that name exists in Mexico, and "Jicoltepec" is possibly a mispelling for Jilotepec.

Rhydinofoenus kaueahensis Bradley, 1909. Deut. Ent. Ztschr. (for 1909), p. 39..

Biology: Daly, Stage, and Brown, 1967. Ent. Soc. Amer., Ann. 60: 1279.

kirbii kirbii (Westwood). N. S., P. E. I., N. B., Que., N. Y., Ont., "Hudson Bay," Mich., Wis., Sask., s. B. C. Host: Hylaeus modestus Say.

Foenus Kirbii Westwood, 1851. Ent. Soc. London, Trans. (2) 1: 219..

Gateruption kirbyi(!) Dalla Torre, 1902. Cat. Hym., v. 3, p. 1068.

Gasteruptiou kirbyi Hedicke, 1939. Cat. Hym., pt. 11, p. 32. Emend.

kirbii russeum Townes. Colo., n.w. Wyo., n. Idaho, s. B. C., w. Wash., Oreg., n. Calif. Host: Hoplitus sambuci Titus, Megachile rotundata (F.).

Gateruption kirbii russents Townes, 1950. U. S. Natl. Mus., Proc. 100: 123. ठ, \&.

nevadae (Bradley). Southern N. Mex., w. Nev., n. and s. Calif.

Foenus nevadae Bradley, 1908. Amer. Ent. Soc., Trans. 34: 114. \&.

occidentale (Cresson). Northwestern Mont. w. to s. B. C., s. to Ariz. and s. Calif.

Foenus occidentalis Cresson, 1864. Ent. Soc. Phila., Proc. 3: 131. ๆ.

Gasteruption egregium Schletterer, 1890. Wien. Mus. der Naturgesch., Ann. 4: 486. \&.

pattersonae Melander and Brues, restored comb. Southern Idaho, n. Utah, central Wash. s. to s. Calif. Host: Dianthidium curvatum sayi Ckll.

Gasteruption pattersonae Melander and Brues, 1902. Biol. Bul. 3: 35. १.

Gasteruption pyirhoste'mum Kieffer, 1904. Invertebrata Pacifica 1: 41. ?.

Gasteruption rubrofasciatum Kieffer, 1904. Invertebrata Pacifica 1: 42. ठ.

septentrionale Schletterer, restored comb. Western Colo., s.w. Alta., n. Ariz., s. B. C., s.e. Oreg. Gasteruption septentionale Schletterer, 1890. Wien. Mus. der Naturgesch., Ann. 4: 480.. .

striatum (Townes), n. comb. Northern Idaho w. to s.w. B. C., s. to w. Nev. and s. Calif.

Rhydinofoetu us striatus Townes, 1950. U. S. Natl. Mus., Proc. 100: 132. ठ.

tarsatorium solare (Townes), n. comb. Northeastern Kans., s. Ariz.

Rhydinofoenus tarsatorius solaris Townes, 1950. U. S. Natl. Mus., Proc. 100: 137. o', ९.

tarsatorium tarsatorium (Say). Que. s. to e. S. C., w. to Iowa and Mo. Rau $(1922,1928)$ published two host records; there is one specimen of this subspecies in the U.S. Natl. Mus. collection bearing only Rau no. 4439, so one of the host records is possibly correct.

Foeuus tarsatorius Say, 1824. In Keating, Narr. Long's Exped., v. 2, p. 321..

Gasternption intricatum Kieffer, 1904. Arkiv for Zool. 1: 556..

Biology: Rau, 1922; 1928. Acad. Sci. St. Louis, Trans. 24: 43; 25: 404. 
1118 Hymenoptera in America North of Mexico

turbinatum (Townes), n. comb. Southeastern Ariz. This species is known from the Pinaleno and Chiricahua Mts.

Rhydinofoenus turbinatus Townes, 1950. U. S. Natl. Mus., Proc. 100: 138. ठ, ๆ. visaliae (Bradley). Southern Tex., s. Ariz., n.w. Oreg. s. to s. Calif.; n.w. Mexico. Host: Hylaeus cressoni Ckll.

Foenus visaliae Bradley, 1909. Deut. Ent. Ztschr. (for 1909), p. 40.. 


\section{Superfamily PELECINOIDEA}

By CARL F. W. MUESEBECK

Taxonomy: Handlirsch, 1933. Handbuch der Zoologie, v. 4 (2), Insecta 2, pp. 981-982.

\section{Family PELECINIDAE}

The relationships of this family have not been satisfactorily established. More commonly, although with some reservations, the group has been treated as a family of the Proctotrupoidea. Until its affinities are better understood it seems best to follow Handlirsch (1933) and consider it as representing an independent superfamily.

Taxonomy: Ashmead, 1900. U. S. Natl. Mus., Proc. 23: 3. -Ashmead, 1902. N. Y. Ent. Soc., Jour. 10: 242-243. - Schulz, 1903. Bayer. Akad. der Wiss., Math.-Phys. Kl. Sitzber. 33: 435-440.

Biology: Clausen, 1962. Entomophagous Insects, pp. 270-271 (This author suggests that although the Pelecinidae have been recorded as internal parasites of ground-inhabiting scarabaeid larvae the principal hosts may actually be coleopterous larvae living in decaying wood.).

\section{Genus PELECINUS Latreille}

Pelecinus Latreille, 1800. Bul. Sci. Soc. Philom., Paris, 2(44): 155.

Type-species: Ichneumon polycerator Fabricius. Desig. by Latreille, 1810.

Epicenastes Gistel, 1848. Naturgesch. Thierr. f. hoh. Schul., p. X, col. 1. N. name, unnecessarily proposed for Pelecinus Latreille, thought to be preocc. by Pelecinus Moench in Botany.

This genus, which comprises the family Pelecinidae, appears to be represented in North America by a single variable species that ranges from Canada far down into South America. It is quite possible that a critical study of the rather large accumulations of specimens contained in some of the principal insect collections will prove this supposed taxon to be actually a complex of several distinct species. Descriptions, in fact, have been published under a number of different specific names. At present, however, these are all treated as applicable to a single species.

Taxonomy: Latreille, 1825. Encycl. Meth., Ins., v. 10, pp. 29-30. -Klug, 1841. Ztschr. f. Ent. 3: 379-385. -Westwood, 1843. Ent. Soc. London, Trans. 3: 247-251. - Schletterer, 1889.

Berlin. Ent. Ztschr. 33: 226-237. - Brues, 1928. Psyche 35: 205-209.

Biology: Forbes, 1894. Ill. State Ent., Rpt. 18, p. 124. - Petch and Hammond, 1926. Ent. Soc. Ontario, 56th Ann. Rpt., pp. 86-87. - Hammond, 1944. Canad. Ent. 76: 130.

Morphology: Snodgrass, 1941. Smithsn. Misc. Collect. 99 (14): 38-40 (male genitalia). 
polyturator (Drury). Que. and Ont. s. to Argentina. Host: Phyllophaga anxia (Lec.); P. futilis (Lec.).

Ichneumon polyturator Drury, 1773. Illus. Nat. Hist., v. 2, p. 77, Index p. [92]. \&. Ichueumon polycerator Fabricius, 1776. Gen. Ins. ... mantissa specierum, p. 245. \&. Ichuenmon libellula Christ, 1791. Naturgesch. Class. Nomencl. Ins., p. 352. 9. Peleciuus clacator Latreille, 1817. Nov. Dict. Hist. Nat., v. 3, p. 237. o. Pelecinus tibiator Perty, 1833. Delect. Anim. Articul. Brasil, p. 131. \&. Pelecinus dichrous Perty, 1833. Delect. Anim. Articul. Brasil, p. 131.. Pelecinus Guerinii Romand, 1840. Mag. de Zool. (2), pl. 49, fig. 2. 9. Pelecin us anuulatus Klug, 1841. Ztschr. f. Ent. 3: 384. ठ. Pelecinus rufus Klug, 1841. Ztschr. f. Ent. 3: 384. §, १. Pelecinus thoracicus Klug, 1841. Ztschr. f. Ent. 3: 384. o. Peleciuus Dupouchelii Romand, 1842. Mag. de Zool. (2), pl. 86, fig. 1. ठ, ?. Pelecinus Spinolae Romand, 1842. Mag. de Zool., (2), pl. 86, fig. 2.. Pelceciuus brunneipes Patton, 1894. Amer. Nat. 28: 896. 9. 


\title{
Superfamily PROCTOTRUPOIDEA
}

\author{
By CARL. F. W. MUesebeck
}

This is a large and diverse group of parasitic Hymenoptera, but the North American proctotrupoid fauna has had little critical study with the result that apparently most of our species remain undescribed. The only comprehensive treatments of the North American Proctotrupoidea are that by Ashmead, in 1893, and that included by Kieffer in his monograph of the world fauna, which comprises three volumes that were published between 1914 and 1926. Kieffer used the name Serphoidea, based on Serphus Schrank, 1780, for this superfamily and that usage was followed generally in the literature of the next thirty years; but Serphus Schrank was set aside by the International Commission on Zoological Nomenclature in 1946 (Opinion 178), under suspension of the Rules, and its synonym Proctotrupes Latreille, 1796, with P. brevipennis Latreille as type-species, was added to the Official List of Generic Names in Zoology as Name No. 616. As a result of that action the name Proctotrupoidea has come into general use again.

I am indebted to Dr. Lubomir Masner, Biosytematics Research Institute, Canada Department of Agriculture, for much helpful advice and for new records, in connection with the preparation of this section of the Catalog.

Revision: Ashmead, 1893. U. S. Natl. Mus., Bul. 45: 5-472 (the Bethylidae and Dryinidae were included). -Kieffer, 1907-1914. In Andre, Spec. Hym. Eur. Alg., v. 10, pp. 1-1014 and v. 11, pp. 1-447. -Kieffer, 1914-1926. Das Tierreich, Lief. 42 (1914), pp. VI-XVII, 1-254; Lief. 44 (1916), pp. VI-XXX, 1-627; Lief. 48 (1926), pp. VII-XXXVI, 1-885.

Taxonomy: Ashmead, 1887. Ent. Amer. 3: 73-76, 97-100, 117-119. - Harrington, 1899. Roy. Soc. Canada, Trans. (2) 5: 117-206. - Ashmead, 1902-1903. N. Y. Ent. Soc., Jour. 10: 240-247 (1902); 11: 28-35 and 86-99 (1903). - Mani, 1941. Cat. Indian Ins., part 26, pp. 1-60.

-Risbec, 1950. Trav. Lab. d'Ent. du Sect. Soudanais de Recherches Agron., v. 2, pp.

511-637. - Muesebeck and Walkley, 1956. U. S. Natl. Mus., Proc. 105: 319-419 (Types of the genera and subgenera). -Masner, 1965. Brit. Mus. (Nat. Hist.), Bul., Ent., Sup. 1, pp. 3-154. -Masner, 1965. Psyche 72: 295-304. - Masner and Muesebeck, 1968. U. S. Natl. Mus. Bul. 270: 1-143. - Masner, 1969. Nat. Canad. 96: 775-784. - Kozlov, 1970. Ent. Obozr. 49:

203-226 (English transl.: Ent. Rev. 49: 115-127). - Kozlov, 1971. Soc. Ent. Unionis Sovet., Horae 54: 7-67.

Biology: Clausen, 1962. Entomophagous Insects, pp. 239-270.

Morphology: Snodgrass, 1941. Smithsn. Misc. Collect. 99 (14): 38-41. - Reid, 1941. Roy. Ent. Soc. London, Trans, 91: 428-430. - Pschorn-Walcher, 1955. Schweiz. Ent. Gesell., Mitt. 28: 214-219. 


\section{Family VANHORNIIDAE}

This family is represented by a single known species, specimens of which seem to be rare in collections. The group appears to be closely related to the Heloridae and the Roproniidae.

\section{Genus VANHORNIA Crawford}

Vanhornia Crawford, 1909. Ent. Soc. Wash., Proc. 11: 63.

Type-species: Vanhomia encnemidarum Crawford. Orig. desig.

euenemidarum Crawford. Que., Maine, N. H., Mass., Conn., N. Y., Pa., Md., Va. Host: Larvae of Eucnemidae.

Vanhomia eucnemidarum Crawford, 1909. Ent. Soc. Wash., Proc. 11: 63. \&, ơ.

\section{Family ROPRONIIDAE}

This is another small, little-known group that is poorly, if at all, represented in most collections. The species appear to be parasites of sawfly larvae.

Revision: Townes, 1948. U. S. Natl. Mus., Proc. 98: 85-89.

Taxonomy: Ashmead, 1898. Ent. Soc. Wash., Proc. 4: 132-133. - Bradley, 1905. Ent News 16: 14-17. - Yasumatsu, 1956. Insecta Matsumurana 19: 117-122. - Yasumatsu, 1958. Insecta Matsumurana 21: 112-114. - Heqvist, 1959. Ent. Tidskr. 80: 137-139. - Yasumatsu, 1961. Mushi 35: 68-69.

Biology: Chao, 1957. Fukien Agr. Jour. 5: 73-76 (Ropronia reported to be parasitic on sawfly larvae).

\section{Genus ROPRONIA Provancher}

Ropronia Provancher, 1886. Addit. Corr. Faune Ent. Canada Hym., pp. 152, 154.

Type-species: Ropronia pediculata Provancher. Monotypic.

Roptronia Ashmead, 1898. Ent. Soc. Wash., Proc. 4: 132. Error.

californica Ashmead. Calif., Oreg.

Roptronia(!) californica Ashmead, 1898. Ent. Soc. Wash., Proc. 4: 133. ठં.

garmani Ashmead. N. H. to Ga., w. to Iowa.

Roptronia (!) gamani Ashmead, 1898. Ent. Soc. Wash., Proc. 4: 132. ठ.

pediculata Provancher. Ont., N. Y. Host: Monoctenus suffusus (Cress.). (Record communicated by L. Masner in correspondence).

Ropronia pediculata Provancher, 1886. Addit. Corr. Faune Ent. Canada Hym., p. 154.. Ropronia ashmeadii Bradley, 1905. Ent. News 16: 17. ․

\section{Family HELORIDAE}

The members of this family are internal parasites of the larvae of Chrysopidae.

Revision: Pschorn-Walcher, 1955. Schweiz. Ent. Gesell., Mitt. 28: 233-250 (Palearctic species).

Taxonomy: Ashmead, 1893. U. S. Nat. Mus., Bul. 45: 330-331. -Ashmead, 1902. N. Y. Ent.

Soc., Jour. 10: 243. - Kieffer, 1914. Das Tierreich, Lief. 42, pp. 57-62. - Riek, 1955. Austral.

Jour. Zool. 3: 258-265. - Ceballos, 1965. Graellsia 21: 11-16.

Morphology: Oeser, 1961. Berlin Zool. Mus., Mitt. 37: 72-73 (ovipositor).

\section{Genus HELORUS Latreille}

Helorus Latreille, 1802. Hist. Nat. Crust. Ins., v. 3, p. 309.

Type-species: Helor'ts ater Latreille. Monotypic.

Copelus Provancher, 1881. Nat. Canad. 12: 206.

Type-species: Copelus paradoxus Provancher. Monotypic.

paradoxus (Provancher). As currently identified this species occurs throughout Continental

United States (except Alaska); known also from N. B. and B. C. Host: Chrysopa

majuscula Banks; Chrysopa spp.

Copelus paradoxus Provancher, 1881. Nat. Canad. 12: 207. ․ 
Biology: Clancy, 1946. Calif. Univ. Pub., Ent. 7, pp. 407-418. -Clausen, 1962. Entomophagous Insects, pp. 266-270.

\section{Family PROCTOTRUPIDAE}

The Proctotrupidae are principally internal parasites of the larvae of Coleoptera, including those of Carabidae, Staphylinidae, Nitidulidae, Erotylidae, Elateridae, Coccinellidae and Curculionidae. However, certain forms are said to have been reared from larvae of the dipterous family Mycetophilidae; and there is also what appears to be a reliable record (Newman, 1867) of the rearing of a species of Phaenoserphus from a centipede of the genus Lithobius.

Revision: Ashmead, 1893. U. S. Natl. Mus., Bul. 45: 331-344 (Nearctic species). - Kieffer, 1914. Das Tierreich, Lief. 42, pp. 1-57 (World fauna). - Nixon, 1938. Roy. Ent. Soc. London, Trans. 87: 431-465 (British species). - Riek, 1955. Austral. Jour. Zool. 3: 106-117 (Australian species).

Taxonomy: Brues, 1919. N. Y. Ent. Soc., Jour. 27: 1-19 (Key to Nearctic species). -Morley, 1922. Entomologist 55: 1-3, 59-60, 82-83, 108-110, 132-135, 157-161, 182-186.

-Pschorn-Walcher, 1958. Schweiz. Ent. Gesell., Mitt. 31: 57-64. -Masner, 1958. Beitr. z. Ent. 8: 477-481. - Pschorn-Walcher, 1958. Beitr. z. Ent. 8: 724-731. - Masner, 1961. Parc Natl. Upemba Miss. de Witte, fasc. 60 , pp. 37-47 (Key to the genera of the world).

-Kozlov, 1970. Ent. Obozr. 49: 203-209 (English transl.: Ent. Rev. 49: 115-118). - Kozlov, 1971. Soc. Ent. Unionis Sovet., Horae 54: 7-12.

Biology: Newman, 1867. Entomologist 3: 342-344. -Frohawk, 1886. Entomologist 19: 225. -Eastham, 1929. Parasitology 21: 1-21. -Zolk, 1924. Tartu Ulikooli Ent. Katsejaama Teadaanded 5: 1-10. -Williams, 1932. Hawaii. Ent. Soc., Proc. 8: 205-209. - Riek, 1955. Linn. Soc. N. S. Wales, Proc. 80: 147. -Jansson, 1960. Opusc. Ent. 25: 83-86. - Hedqvist, 1963. Ent. Tidskr. 84: 62-64. - Weidemann, 1965. Ztschr. f. Morph. u. Oekol. der Tiere 55: 425-480. - Masner, 1968. Acta Ent. Bohemoslov. 65: 464-466.

\section{Genus DISOGMUS Foerster}

Disogmus Foerster, 1856. Hym. Stud., v. 2, p. 99.

Type-species: Proctotrupes areolator Haliday. Monotypic.

In North America at least the genus seems to be relatively rare. It is most closely related to Proctotrupes Latreille. Published host records for species of Disogmus are very meager and apparently somewhat doubtful but suggest parasitization of carabid and pyrochroid larvae.

Taxonomy: Kieffer, 1914. Das Tierreich, Lief. 42, pp. 16-22. - Nixon, 1938. Roy. Ent. Soc.

London, Trans. 87: 447-450. - Pschorn-Walcher, 1958. Schweiz. Ent. Gesell., Mitt. 31: 58-59.

canadensis Harrington. Ont. (Ottawa).

Disogmus canadensis Harrington, 1889. Roy. Soc. Canada, Trans. (2) 5: 193. ?.

diversicornis Kieffer. Calif. (San Mateo).

Disogmus diversicornis Kieffer, 1906 (1905). Berlin. Ent. Ztschr. 50: 271. ठ.

glabratus Kieffer. Calif. (San Mateo).

Disogmus glabratus Kieffer, 1906 (1905). Berlin. Ent. Ztschr. 50: 271, 273. ठ.

pubescens Kieffer. Nev., (?) Ill. Host: Amara (Curtonotus) carinatus (LeC.).

Disogmus pubescens Kieffer, 1906 (1905). Berlin. Ent. Ztschr. 50: 271, 272. ஒ, ठ์.

torvus Whittaker. B. C. (Chilliwack).

Disogmus fortus Whittaker, 1930. Ent. Soc. Wash., Proc. 32: 68. ९, ठ.

\section{Genus PHAENOSERPHUS Kieffer}

Phaenoserphus Kieffer, 1908. In Andre, Spec. Hym. Eur. Alg., v. 10. p. 298.

Type-species: Proctotrupes curtipenuis Haliday. Desig. by Muesebeck and Walkley, 1951 .

Carabiphagus Morley, 1929. Suffolk Nat. Soc., Trans. 1: 40.

Type-species: Proctotrupes laevifious Foerster. Monotypic. 
There are no published host records for any North American form of this genus, but on the basis of rearings of Old-World species it appears that the hosts are mainly fungicolous beetle larvae of the families Carabidae and Staphylinidae. One remarkable observation has been recorded by Newman (1867), who described the emergence of specimens of $P$. calcar (Haliday) from a centipede of the genus Lithobius.

Taxonomy: Kieffer, 1908. In Andre, spec. Hym. Eur. Alg., v. 10, pp. 298-313. - Kieffer, 1914. Das Tierreich, Lief. 42, pp. 22-36. -Nixon, 1933. Roy. Ent. Soc. London, Trans. 87: 451-460. - Hellen, 1941. Notulae Ent. 21: 33-36. - Pschorn-Walcher, 1958. Schweiz. Ent. Gesell., Mitt. 31: 62-63.

Biology: Newman, 1867. Entomologist 3: 342-344. - Eastham, 1921. Parasitology 29: 1-21. - Raynaud, 1935. Misc. Ent. 36: 97-100. - Weidemann, 1965. Ztschr. f. Oekol. u. Morph. der Tiere 55: 446-480. - Masner, 1968. Acta Ent. Bohemoslov. 65: 464-465.

Morphology: Tonapi, 1958. Indian Jour. Ent. 20: 208, 209, figs. 31-33 (respiratory system). longipes Brues. Wash. (Almota).

Phatewoserphus longipes Brues, 1919. N. Y. Ent. Soc., Jour. 27: 9. ठ.

nevadensis (Kieffer). Calif., Nev.

Proctotrypes necudersis Kieffer, 1906 (1905). Berlin. Ent. Ztschr. 50: 275. ठ.

nigripes (Ashmead). Alaska, Oreg.

Proctotrypes nigripes Ashmead, 1902. Wash. Acad. Sci., Proc. 4: 136. ठ.

obliquus (Ashmead). Tex.

Proctotrypes obliqnus Ashmead, 1893. U. S. Natl. Mus., Bul. 45: 334, 338. ठ。.

\section{Genus PROCTOTRUPES Latreille}

Serphus Schrank, 1780. Schrift. Berlin. Gesell. Naturf. Freunde 1: 307.

Type-species: Serphus brachypterus Schrank. Monotypic. Suppressed by Internatl.

Comn. Zool. Nomencl., 1946 (Opinion 178).

Proctotrupes Latreille, 1796. Precis Caract. Gen. Ins., p. 108. No species. - Latreille, 1802.

Hist. Nat. Crust. Ins., v. 3, p. 308. One species.

Type-species: Proctotrupes brevipennis Latreille. First included species. Also desig. by Internatl. Comn. Zool. Nomencl., 1946 (Opinion 178), and the generic name added by the Commission to the Official List of Generic Names in Zoology as Name No. 616.

Erodorns Walckenaer, 1802. Faune Parisienne, Ins., v. 2, p. 47.

Type-species: Erodorus bimaculatus Walckenaer. Monotypic.

Proctmipes Rafinesque, 1815. Analyse, Nature ou Tabl. Univers, Palermo, p. 125. Emend.

Eriodorns Agassiz, 1846. Nomencl. Zool., p. 143. Emend.

Proctotrypes Agassiz, 1846. Nomencl. Zool., p. 309. Emend.

Proctotropis Gistel, 1848. Naturgesch. Thierr. f. hoh. Schul., p. 143. Emend.

Proctotripes Provancher, 1883. Petite Faune Ent. Canada, p. 558. Error.

There appear to be no published records of host association for any North American species. Masner (1968) has indicated that species of Proctotrupes are essentially parasites of the larvae of Carabidae.

Revision: Ashmead, 1893. U. S. Natl. Mus., Bul. 45: 333-344. - Kieffer, 1914. Das Tierreich, Lief. 42, pp. 7-16. - Brues, 1919. N. Y. Ent. Soc., Jour. 27: 2-6.

Biology: Masner, 1968. Acta Ent. Bohemoslov. 65: 464-465.

caudatus Say. Canadian, Transition and Upper Austral Zones.

Proctotrupes caudatus Say, 1824. In Keating, Narr. Long's 2nd Exped., v. 2, p. 329. 9.

Proctotrypes crenulatus Patton, 1879. Canad. Ent. 11: 64..+

cockerelli (Brues). Colo. (Eldoro).

Serphus cockerelli Brues, 1919. N. Y. Ent. Soc., Jour. 27: 3, 4. ठ.

debilis (Brues). Wash. (Wawawai).

Serphus debilis Brues, 1919. N. Y. Ent. Soc., Jour. 27: 3, 5. ठ.

florissantensis Rohwer. Iowa, Colo., Idaho.

Proctotrypes florissantensis Rohwer, 1909. Amer. Ent. Soc., Trans. 35: 134. ค, ठ. 
linellii Ashmead. N. Y.

Proctotrypes Linellii Ashmead, 1893. U. S. Natl. Mus., Bul. 45: 334, 337. ठ.

longiusculus Brues. N. Y., N. J., Pa.

Proctotrypes longinsculus Brues, 1909 (1908). Wis. Nat. Hist. Soc., Bul. 6: 155. ơ.

melliventris Ashmead. Fla. (Jacksonville).

Proctotrupes melliventris Ashmead, 1887. Ent. Amer. 3: 99. ठ'.

pallidus (Say). Transition and Upper Austral Zones.

Codrus pallidus Say, 1828. Contrib. Maclur. Lyc. Phila. 1: 80.

Proctotrypes coloradicus Cockerell, 1905. Ann. and Mag. Nat. Hist. (7) 15: 204. .

rufigaster Provancher. Ont., N. Y., Man.

Proctotrupes rufigaster Provancher, 1881. Nat. Canad. 12: 263. ๆ, ठ.

sequoiarum (Brues). Calif. (Marin County).

Serphus sequoiarmm Brues, 1919. N. Y. Ent. Soc., Jour. 27: 3, 4. ठ์.

terminalis Ashmead. Transcontinental in Transition and Upper Austral Zones.

Proctotrypes terminalis Ashmead, 1893. U. S. Natl. Mus., Bul. 45: 334, 337. ठै.

zabriskiei (Brues). N. Y. (Rochester).

Serphus zabriskiei Brues, 1919. N. Y. Ent. Soc., Jour. 27: 2, 3. ?.

\section{Genus CODRUS Panzer}

Codrus Panzer, 1801. Faunae Ins. German., Heft 85, no. 9.

Type-species: Codrus viger Panzer. Desig. by Morice and Durrant, 1915.

Exallonyx Kieffer, 1904. Soc. Hist. Nat. Metz, Bul. 23: 34.

Type-species: Exallonyx formicarius Kieffer. Orig. desig.

Although dipterous larvae, of the family Mycetophilidae, have been considered possible hosts it appears that the species of Codrus are essentially parasites of fungicolous beetle larvae. Masner (1968) has indicated that all reliable host records involve Staphylinidae only.

Taxonomy: Brues, 1919. N. Y. Ent. Soc., Jour. 27: 9-18. - Nixon, 1938. Roy. Ent. Soc. London, Trans. 87: 434-446. - Muesebeck and Walkley, 1951. U. S. Dept. Agr., Agr. Monog. 2, p. 665. - Pschorn-Walcher, 1958. Schweiz. Ent. Gesell., Mitt. 31: 61-62. - Weidemann, 1965. Ztschr. f. Morph. u. Oekol. der Tiere 55: 480-509.

Biology: Frohawk, 1886. Entomologist 19: 225. - Williams, 1932. Hawaii. Ent. Soc., Proc. 8: 205-209. - Hedqvist, 1963. Ent. Tidskr. 84: 63. -Weidemann, 1965. Ztschr. f. Morph. u. Oekol. der Tiere 55: 440-480. -Masner, 1968. Acta Ent. Bohemoslov. 65: 465.

angusticeps (Brues). Wash. (Orcas Isl.).

Proctotrypes angusticeps Brues, 1910 (1909). Wis. Nat. Hist., Soc., Bul. 7: 112..

ashmeadi (Brues). Maine.

Exallonyx ashmeadi Brues, 1919. N. Y. Ent. Soc., Jour. 27: 10, 13. ठ์.

californicus (Holmgren). Calif.

Proctotrupes californicus Holmgren, 1868. Eug. Resa I, Zool. 1, Ins., p. 434. ९, ơ.

canadensis (Ashmead). Que., Ont., N. Y.

Proctotrypes canadensis Ashmead, 1893. U. S. Natl. Mus., Bul. 45: 335, 342..

carinatus (Brues). Wash. (Oroville).

Exallonyx carinatus Brues, 1919. N. Y. Ent. Soc., Jour. 27: 11, 15. ठั.

carolinensis (Ashmead). Mass., Pa., Va., N. C., Mich., Ind.

Proctotrypes carolinensis Ashmead, 1893. U. S. Natl. Mus., Bul. 45: 335, 341. ठ.

crenaticornis (Kieffer). Calif. (Santa Clara).

Exallonyx crenaticornis Kieffer, 1906 (1905). Berlin. Ent. Ztschr. 50: 273, 274. ठ̊.

dentaticornis (Kieffer). Nev. (Ormsby County).

Exallonyx dentaticomis Kieffer, 1906 (1905). Berlin. Ent. Ztschr. 50: 273, 275. ð.

fallacicornis (Kieffer). Calif. (Santa Clara).

Exallonyx fallacicornis Kieffer, 1906 (1905). Berlin. Ent. Ztschr. 50: 274. ठ.

femoratus (Ashmead). Wyo., Wash.

Proctotrypes femoratus Ashmead, 1893. U. S. Natl. Mus., Bul. 45: 335, 344. 9. 
fuscicornis (Brues). Mass. (Wood's Hole).

Exallonyx fuscicomis Brues, 1919. N. Y. Ent. Soc., Jour. 27: 10, 12. ठ.

grandis (Brues). N. J. (Ramsey).

Exallonyx grandis Brues, 1919. N. Y. Ent. Soc., Jour. 27: 11, 17..

longiceps (Ashmead). Ont., Va., Ohio, Ark. Host: Staphylinus sp.

Proctotrypes longiceps Ashmead, 1893. U. S. Natl. Mus., Bul. 45: 335, 342..

medius (Ashmead). Ont. (Ottawa).

Proct trypes medlius Ashmead, 1893. U. S. Natl. Mus., Bul. 45: 335, 343. ₹.

obscuripes (Brues). Wash. (Puget Sound region).

Proctotrypes obscuripes Brues, 1910 (1909). Wis. Nat. Hist. Soc., Bul. 7: 112, 114. ठ.

pallidicornis (Brues). Conn., Wis.

Exallonyx pallidicomis Brues, 1919. N. Y. Ent. Soc., Jour. 27: 11, 14. ठ.

parvulus (Brues). Wash., Calif.

Exallonyx parculus Brues, 1919. N. Y. Ent. Soc., Jour. 27: 11, 16. o.

placidus (Brues). Wash. (Oreas Isl.).

Proctotrypes placidlus Brues, 1910 (1909). Wis. Nat. Hist. Soc., Bul. 7: 112, 113. ठ.

pleuralis (Brues). Wash. (Monroe).

Exallonyx pleuralis Brues, 1919. N. Y. Ent. Soc., Jour. 27: 10, 14. ठ.

quadriceps (Ashmead). Que., Ont., N. J.

Proctotrypes qualriceps Ashmead, 1893. U. S. Natl. Mus., Bul. 45: 335, 343..

serricornis (Brues). Wash. (Puget Sound region).

Proctotrypes serricormis Brues, 1910 (1909). Wis. Nat. Hist. Soc., Bul. 7: 112, 115. ठ.

similis (Brues). Wash., Calif.

Exallonyx similis Brues, 1919. N. Y. Ent. Soc., Jour. 27: 10, 11. ?.

simplicior (Brues). Wash. (Puget Sound region).

Proctotrypes simplicior Brues, 1910 (1909). Wis. Nat. Hist. Soc., Bul. 7: 112, 116. o.

simulans (Ashmead). Md., Va., W. Va., Ill.

Proctotrypes simulans Ashmead, 1893. U. S. Natl. Mus., Bul. 45: 335, 342. ․

texanus (Ashmead). Tex.

Proctotrypes texanns. Ashmead, 1893. U. S. Natl. Mus., Bul. 45: 335, 341. "ๆ" = o.

\section{Genus CRYPTOSERPHUS Kieffer}

Cryptoserphus Kieffer, 1907. In Andre, Spec. Hym. Eur. Alg., v. 10, p. 288. No species.

-Kieffer, 1908. I" Andre, Spec. Hym. Eur. Alg., v. 10, p. 313. Ten species.

Type-species: Cryptoserphus longicalcar Kieffer. Desig. by Kieffer, 1908.

Brachyserplus Hellen, 1941. Notulae Ent. 21: 42.

Type-species: Codrus parvulus Nees. Orig. desig.

The only published host record for a North American species is for C. obsoleta (Say), which is said to have been reared from a fungicolous beetle larva, but apparently reliable rearing records for certain European species of Cryptoserplins include as hosts the larvae of fungus gnats (Mycetophilidae) as well as fungicolous Coleoptera.

Taxonomy: Kieffer, 1914. Das Tierreich, Lief. 42, pp. 36-42. -Brues, 1919. N. Y. Ent. Soc., Jour. 27: 6-8. - Nixon, 1938. Roy. Ent. Soc. London, Trans. 87: 460-465. - Hellen, 1941. Notulae Ent. 21 : 41-42. - Pschorn-Walcher, 1958. Schweiz. Ent. Gesell., Mitt. 31: 59. -Masner, 1967. I" Krombein and Burks, U. S. Dept. Agr., Agr. Monog. 2, Sup. 2, p. 286.

Biology: Jansson, 1960. Opusc. Ent. 25: 83-86. - Masner, 1968. Acta Ent. Bohemoslov. 65: 464-466.

abruptus (Say). Que. and Ont. s. to Fla.; Tenn., Ind., Mich.

Proctotrupes abruptus Say, 1836. Boston Jour. Nat. Hist. 1: 378. \&.

Megaspilus lucens Provancher, 1883. Nat. Canad. 14: 33 . “o" = $\delta$.

Taxonomy: Masner, 1969. Nat. Canad. 96: 779.

belfragei (Ashmead). Tex.

Proctotrypes Belfiagei Ashmead, 1893. U. S. Natl. Mus., Bul. 45: 335, 340. ९. 
bruesi Muesebeck and Walkley. Conn. (Morris Cove).

Disogmus obsoletus Brues, 1905. Wis. Nat. Hist. Soc., Bul. 3: 186. \&. Preocc. by Say, 1836.

Cryptoserphus bruesi Muesebeck and Walkley, 1951. U. S. Dept. Agr., Agr. Monog. 2, p. 665. N. name.

elypeatus (Ashmead). N. Y. (Ithaca).

Proctotrypes clypeatus Ashmead, 1893. U. S. Natl. Mus., Bul. 45: 334, 339. ९.

flavipes (Provancher). N. B., Que., Ont., Md., N. C.

Proctotrupes pallipes Provancher, 1881. Nat. Canad. 12: 263. This name, which is preoce. by Jurine, 1807 , was used unintentionally in the key for $P$. flavipes, which heads the description on the following page.

Proctotrupes flavipes Provancher, 1881. Nat. Canad. 12: 264..

melanderi Brues. Wash. (Pullman).

Cryptoserphus melanderi Brues, 1919. N. Y. Ent. Soc., Jour. 27: 8. ठ.

obsoletus (Say). D. C., Va., Fla., Ind., Ont. Host: Stelidota strigosa (Gyll.).

Proctotrupes obsoletus Say, 1836. Boston Jour. Nat. Hist. 1: 377. ๆ.

occidentalis Brues. Idaho, Wash.

Cryptoserphns occidentalis Brues, 1919. N. Y. Ent. Soc., Jour. 27: 7. १.

\section{Family DIAPRIIDAE}

This is a large family in which apparently only a small percentage of the existing species have been described. Most of those whose host associations are known are parasites of Diptera.

Revision: Ashmead, 1893. U. S. Natl. Mus., Bul. 45: 345-448. - Kieffer, 1916. Das Tierreich, Lief. 44, pp. VI-XXX, 1-627.

Taxonomy: Jansson, 1939. Ent. Tidskr. 60: 167-172. - Masner, 1961. Inst. Sci. Madagascar, Mem. 12: 289-292. -Kozlov, 1971. Soc. Ent. Unionis Sovet., Horae 54: 12-33.

\section{SUBFAMILY AMBOSITRINAE}

Taxonomy: Masner, 1961. Inst. Sci. Madagascar, Mem. 12, pp. 289-295. - Masner, 1969. Ber. ueber die 10. Wanderversammlung Deut. Ent. no. 80, pp. 105-109.

\section{Genus PROPSILOMMA Kieffer}

Propsilomma Kieffer, 1916. Das Tierreich, Lief. 44, pp. xxiv, 351, 422.

Type-species: Psilomma columbianum Ashmead. Monotypic.

Taxonomy: Masner, 1964. Acta Soc. Ent. Cechoslov. 61: 130.

columbianum (Ashmead). D. C.

Psilomma columbianum Ashmead, 1893. U. S. Natl. Mus., Bul. 45: 379. ९, ơ.

\section{SUBFAMILY ISMARINAE}

Taxonomy: Thomson, 1858. Ofvers. Kongl. Vetensk.-Akad., Forh. 15: 377. - Hellen, 1963.

Fauna Fennica 14: 4. - Hellen, 1964. Fauna Fennica 18: 3-6.

\section{Genus ISMARUS Haliday}

Ismarus Haliday, 1835. Ent. Mag. 2: 467.

Type-species: Cinetus dorsiger Curtis. Monotypic.

Entomia Herrich-Schaeffer, 1840. Nomencl. Ent., v. 2, p. 127, pl. 6, fig. 21.

Type-species: Entomia campanulata Herrich-Schaeffer. Monotypic.

Entomins Haliday, 1857. Nat. Hist. Rev., v. 4, p. 169. Emend.

Agonophorus Dahlbom, 1858 (1857). Ofvers. Kongl. Vetensk.-Akad., Forh. 14: 289. No species. - Muesebeck, 1972. Ent. Soc. Wash., Proc. 74: 131. Three species.

Type-species: Ismarus rugulosus Foerster. Desig. by Muesebeck, 1972.

The species for which host associations are known are parasitic on Dryinidae. 
Taxonomy: Thomson, 1858. Ofvers. Kongl. Vetensk.-Akad., Forh. 15: 377. - Nixon, 1957. Roy. Ent. Soc. London, Handb. 8 (3), p. 11. - Dessart, 1967. So. Austral. Mus., Rec. 15: 553. -Muesebeck, 1972., Ent. Soc. Wash., Proc. 74: 131.

Biology: Chambers, 1955. Ent. Monthly Mag. 91: 114-115. americanus Fouts. Pa. (Carlisle).

Ismarus americauus Fouts, 1924. Ent. Soc. Wash., Proc. 26: 164. ․ nevadensis Kieffer. Nev. (Ormsby County).

Ismarus nevaden sis Kieffer, 1906 (1905). Berlin. Ent. Ztschr. 50: 276. ․

\section{SUBFAMILy BELYTINAE}

Revision: Ashmead, 1893. U. S. Natl. Mus., Bul. 45: 345-384. - Kieffer, 1908-1910. In Andre, Spec. Hym. Eur. Alg., v. 10, pp. 345-691 ( pp. 345-448 pub. in 1908, pp. 449-592 in 1909, pp. 593-691 in 1910). - Kieffer, 1916. Das Tierreich, Lief. 44, pp. 347-593 (World fauna).

-Nixon, 1957. Roy. Ent. Soc. London, Handb. 8 (3), 107 pp. (British species). - Hellen, 1964. Fauna Fennica 18: 6-66 (Finnish species).

Taxonomy: Foerster, 1856. Hym. Stud., v. 2, pp. 127-142. - Thomson, 1858. Ofvers. Kongl. Vetensk.-Akad., Forh. 15: 155-180. - Ashmead, 1902. N. Y. Ent. Soc., Jour. 10: 244-247. -Kieffer, 1910. I $u$ Wytsman, Gen. Ins., fasc. 107, pp. 1-47. - Masner, 1961. Inst. Sci. Madagascar, Mem. 12: 290-292. - Kozlov, 1971. Soc. Ent. Unionis Sovet., Horae 54: 12-18, 23-28.

\section{Genus CINETUS Jurine}

Cinetus. Jurine, 1807. Nouv. Meth. Class. Hym. Dipt., p. 310. No species. - Lepeletier and Serville, 1825. Encycl. Meth., Ins., v. 10, p. 210. One species.

Type-species: Cinetus iridipennis Lepeletier and Serville. First included species.

Also desig. by Kieffer, 1910.

Cinntus Curtis, 1829. Guide Brit. Ins., column 109. Error.

Leptorhaptus Foerster, 1856. Hym. Stud., v. 2, pp. 129, 137. No species. -Ashmead, 1893.

U. S. Natl. Mus., Bul. 45: 346, 349. Two species.

Type-species: Leptorhaptus conicus Ashmead. Desig. by Muesebeck and Walkley, 1951.

Stylidolon Ashmead, 1897. Canad. Ent. 29: 53.

Type-species: Stylidolon politum Ashmead. Monotypic.

Stylidodon Ashmead, 1902. N. Y. Ent. Soc., Jour. 10: 245. Error.

An unnamed European species has been recorded as parasitizing larvae of Mycetophilidae. No rearing records for any North American species have been published although one species is reported to have been taken in burrows of the bark beetle Phloeosinus canadensis Swaine, where it presumably had developed on some dipterous scavenger.

Taxonomy: Masner, 1964. Acta Soc. Ent. Cechoslov. 61: 126-130. -Masner, 1967. In

Krombein and Burks, U. S. Dept. Agr., Agr. Monog. 2, Sup. 2, p. 293.

californicus Ashmead. Calif. (Santa Cruz Mts.)

Cinetus californicus Ashmead, 1893. U. S. Natl. Mus., Bul. 45: $360,361 . " \delta "=$ \%

canadensis (Ashmead). Que., Ont. Ecology: With Phloeosinus canadensis Swaine.

Miota canadeusis Ashmead, 1897. Canad. Ent. 29: 54. ㅇ.

Biology: Schedl, 1932. Canad. Ent. 64: 1.

coloradensis (Ashmead). Colo. (Westcliffe).

Psilomma coloradense Ashmead, 1890. Colo. Biol. Assoc., Bul. 1: 11..

conicus (Ashmead). Que., Ont., D. C., Va.

Leptorhaptns conicns Ashmead, 1893. U. S. Natl. Mus., Bul. 45: 350. ₹, (male misdet.).

pleuralis Fouts. N. Y. (McLean Bogs).

Cinetus pleuralis Fouts, 1925. Ent. Soc. Wash., Proc. 27: 151. ๆ, ठ.

procerus Masner and Muesebeck. Va. (Arlington).

Zelotypa ruficornis Ashmead, 1893. U. S. Natl. Mus., Bul. 45: 365, 366. ठ. Preoce. by Curtis, 1831. 
Cinetus procems Masner and Muesebeck, 1968. U. S. Natl. Mus. Bul. 270: 25. N. name. subpolitus Masner. Ont. (Ottawa).

Stylidolon politum Ashmead, 1897. Canad. Ent. 29: 54. ㅇ. Preocc. by Thomson, 1858.

Cinetus subpolituss Masner, 1964. Acta Soc. Ent. Cechoslov. 61: 128. N. name.

texanus (Ashmead). Tex.

Zelotypa texana Ashmead, 1893. U. S. Natl. Mus., Bul. 45: 364, 365. ठ゚.

\section{Genus MIOTA Foerster}

Miota Foerster, 1856. Hym. Stud., v. 2, pp. 131, 141. No species. -Ashmead, 1890. Colo.

Biol. Assoc., Bul. 1: 12. One species.

Type-species: Miota glabra Ashmead. First included species.

Leptonetus Masner, 1964. Acta Soc. Ent. Cechoslov. 61: 128.

Type-species: Cinetus politus Thomson. Orig. desig.

Host relationships of members of this genus are unknown.

Taxonomy: Ashmead, 1893. U. S. Natl. Mus., Bul. 45: 351-353. -Masner, 1964. Acta Soc. Ent.

Cechoslov. 61: 128-129. - Masner, 1967. In Krombein and Burks, U. S. Dept. Agr., Agr.

Monog. 2, Sup. 2, p. 292.

alaskensis (Ashmead). Alaska (Virgin Bay).

Zelotypa alaskensis Ashmead, 1902. Wash. Acad. Sci., Proc. 4: 139. ð๋.

americana (Ashmead)., Fla.

Psilomma americana Ashmead, 1887. Canad. Ent. 19: 197. ठ.

analis Ashmead. "Carolina."

Miota analis Ashmead, 1893. U. S. Natl. Mus., Bul. 45: 351, 352. ๆ.

ashmeadi (Kieffer). Calif. (Claremont).

Leptorhaptus Ashmeadi Kieffer, 1909. Soc. Sci. de Bruxelles, Ann. 33: 377. ठ․

bakeri (Kieffer). Calif. (Claremont).

Leptorhaptus Bakeri Kieffer, 1909. Soc. Sci. de Bruxelles, Ann. 33: 377, 378. ठ.

bisulcata (Kieffer). Pa. (Jeannette).

Leptorhaptus bisulcatus Kieffer, 1909. Soc. Sci. de Bruxelles, Ann. 33: 377, 378. ơ.

elarimontis (Kieffer). Calif. (Claremont).

Leptorhaptus Clarimontis Kieffer, 1909. Soc. Sci. de Bruxelles, Ann. 33: 377, 379.. .

conformis Fouts. Calif. (Westwood).

Miota conform is Fouts, 1966. Ent. Soc. Wash., Proc. 68: 19..

filicornis (Kieffer). Calif. (San Mateo).

Zelotypa filicornis Kieffer, 1906 (1905). Berlin. Ent. Ztschr. 50: 279. ๆ.

flavicornis Kieffer. Colo. (Gunnison).

Miota flavicorn is Kieffer, 1906 (1905). Berlin. Ent. Ztschr. 50: 281. +.

glabra Ashmead. Colo. (Westcliffe).

Miota glabia Ashmead, 1890. Colo. Biol. Assoc., Bul. 1: 12. \&.

longinervis (Kieffer). Calif. (Claremont).

Leptorhaptus longinervis Kieffer, 1906 (1905). Berlin. Ent. Ztschr. 50: 281. \&.

monticola (Kieffer). Calif. (Claremont).

Cinetus monticola Kieffer, 1909. Soc. Sci. de Bruxelles, Ann. 33: 376. ؟.

pennsylvanica (Kieffer). Pa. (Pittsburgh).

Cinetus pemusyluanicus Kieffer, 1909. Soc. Sci. de Bruxelles, Ann. 33: 376. o’.

rufa (Ashmead). Va.

Leptorhaptus infus Ashmead, 1893. U. S. Natl. Mus., Bul. 45: 350. ค, ठ๋.

vera (Fouts). Fla.

Scorpioteleia rera Fouts, 1927. Ent. Soc. Wash., Proc. 29: 173. ‥

xanthocera (Kieffer). Pa. (Jeannette).

Cinetus xanthocer'us Kieffer, 1909. Soc. Sci. de Bruxelles, Ann. 33: 376, 377. ?. 


\section{Genus SCORPIOTELEIA Ashmead}

Scorpioteleia Ashmead, 1897. Canad. Ent. 29: 53.

Type-species: Scorpioteleia mirabilis Ashmead. Monotypic.

Taxonomy: Masner, 1964. Acta Soc. Ent. Cechoslov. 61: 130.

mirabilis Ashmead. Ont. (Kettle Isl.).

Scorpioteleia mirabilis Ashmead, 1897. Canad. Ent. 29: 53. ․

\section{Genus MACROHYNNIS Foerster}

Macrohymnis Foerster, 1856. Hym. Stud., v. 2, pp. 129, 136. No species. -Mayr, 1904.

Zool.-Bot. Gesell. Wien, Verhandl. 54: 593. One species.

Type-species: Macrohymmis lepidus Mayr. First included species.

Cirelaptus Nixon, 1957. Roy. Ent. Soc. London, Handb. 8 (3), pp. 7, 91.

Type-species: Cinelaptus fragilis Nixon. Orig. desig.

americanus Kieffer. $\mathrm{Pa}$. (Jeannette).

Macrohynnis americanıs Kieffer, 1909. Soc. Sci. de Bruxelles, 33: 338. ๆ.

\section{Genus ACLISTA Foerster}

Aclista Foerster, 1856. Hym. Stud., v. 2, pp. 128, 131, 133, 134, 135. No species. - Marshall, 1873. Cat. Brit. Hym.; Oxyura, p. 9. Three species, one of them doubtfully included.

Type-species: Acoretus scutellaris Thomson. Desig. by Muesebeck and Walkley, 1951.

Anectata Foerster, 1856. Hym. Stud., v. 2, pp. 129, 136. No species. -Ashmead, 1887.

Canad. Ent. 19: 198. One species.

Type-species: Anectata hirtifrons Ashmead. First included species.

Xenotoma Foerster, 1856. Hym. Stud., v. 2, pp. 129, 137. No species. -Foerster, 1861.

Programm Realschule Aachen, p. xliv. One species.

Type-species: Xenotoma nigricoxis Foerster. First included species.

Acoretus Haliday, 1857. Nat. Hist. Rev., v. 4, p. 169. Proposed as a subgenus of Belyta Jurine.

Type-species: Belyta rufopetiolata Nees. Monotypic.

Although the species of this genus are numerous and specimens are abundantly collected in the field nothing has been published concerning their habits, biology or host relations except in the case of A. fungicola (Crawford), which was reared in large numbers from dipterous larvae living in a mushroom fungus of the genus Boletus.

Taxonomy: Nixon, 1957. Roy. Ent. Soc. London, Handb. 8 (3), pp. 66-84. - Hellen, 1964.

Fauna Fennica 18: 18-32.

antennalis (Fouts). N. Y. (McLean Bogs).

Xenotoma (Xenotoma) antennalis Fouts, 1926. Brooklyn Ent. Soc., Bul. 21: 152, 154. .

aquilonia Muesebeck. Alaska (Muir Inlet).

Zelotypa borealis Ashmead, 1902. Wash. Acad. Sci., Proc. 4: 137, 138. $९$. Preocc. by Aclista borealis Ashmead, 1893, which is now in $Z$ ygota.

Aclista ashmeadi Muesebeck and Walkley, 1951. U. S. Dept. Agr., Agr. Monog. 2, p. 686.

N. name. Preoce. by Kieffer, 1905.

Aclista aquilonia Muesebeck, 1958. U. S. Dept. Agr., Agr. Monog. 2, Sup. 1, p. 91. N. name.

ashmeadi (Kieffer). Calif. (San Mateo). Doubtfully referable to Aclista.

Zelotypa Ashmeadi Kieffer, 1905. Soc. Hist. Nat. Metz, Bul. 24: 109. ð.

bradleyi (Fouts). Calif. (Cuyamaca Mts.).

Xenotoma bradleyi Fouts, 1927. Ent. Soc. Wash., Proc. 29: 172. ․

brunnipes Muesebeck and Walkley. Colo.

Xenotoma coloradensis Kieffer, 1909. Soc. Sci. de Bruxelles, Ann. 33: 368, 370. ð. Preoce. by Zelotypa coloradensis Ashmead, 1890, now in Pantoclis, when both were placed in Aclista by Muesebeck and Walkley, 1951.

Aclista brunnipes Muesebeck and Walkley, 1951. U. S. Dept. Agr., Agr. Monog. 2, p. 686. N. name. 
castanea (Kieffer). Pa. (Jeannette).

Xenotoma castanea Kieffer, 1908. Soc. Sci. de Bruxelles, Ann. 32: 44 . ․

clarimontis (Kieffer). Calif. (Claremont).

Xenotoma Clarimontis Kieffer, 1909. Soc. Sci. de Bruxelles, Ann. 33: 369, 374. ठ.

cubitalis Muesebeck and Walkley. Wis. (Polk County).

Xenotoma elinoneura Kieffer, 1909. Soc. Sci. de Bruxelles, Ann. 33: 368, 372. ס. Preocc. by Pantoclis clinoneura Kieffer, 1909, when both were placed in Aclista by Muesebeck and Walkley, 1951.

Aclista cubitalis Muesebeck and Walkley, 1951. U. S. Dept. Agr., Agr. Monog. 2, p. 686. N. name.

curvicauda (Fouts). N. Y. (McLean Bogs).

Xenotoma (Xenotoma) curvicauda Fouts, 1926. Brooklyn Ent. Soc., Bul. 21: 152, 155..

flavidipes (Kieffer). Fla. (Ft. George Isl.)

Zelotypa flavipes Ashmead, 1893. U. S. Natl. Mus., Bul. 45: 365. ठ. Preocc. by Pantoclis flavipes Ashmead, 1893, when also placed in Pantoclis by Kieffer, 1910.

Pantoclis ! flavidipes Kieffer, 1910. In Wytsman, Gen. Ins., fasc. 107, p. 27. N. name.

flavinervis (Kieffer). $\mathrm{Pa}$. (Jeanette).

Xenotoma flavinervis Kieffer, 1909. Soc. Sci. de Bruxelles, Ann. 33: 370, 375. ๆ, ð.

flavoris Muesebeck and Walkley. Pa., Wis.

Xenotoma Bakeri Kieffer, 1909. Soc. Sci. de Bruxelles, Ann. 33: 369, 373. ๆ, o. Preocc. by Pantoclis bakeri Kieffer, 1909, when both were placed in Aclista by Muesebeck and Walkley, 1951.

Aclista flavoris Muesebeck and Walkley, 1951. U. S. Dept. Agr., Agr. Monog. 2, p. 687. N. name.

foutsi Muesebeck and Walkley. Ont. (Gull Lake).

Anectata canadensis Fouts, 1924. Ent. Soc. Wash., Proc. 26: 165.. Preocc. by Pantoclis canadensis Ashmead, 1897, when both names were placed in Aclista by Muesebeck and Walkley, 1951.

Aclista foutsi Muesebeck and Walkley, 1951. U. S. Dept. Agr., Agr. Monog. 2, p. 687. N. name.

fungicola (Crawford). Va. (Clarendon). Ecology: A long series was reared from dipterous larvae in a fungus of the genus Boletus.

Zelotypa fungicola Crawford, 1915. U. S. Natl. Mus., Proc. 48: 583. ๆ, ठ.

fuscinervis (Kieffer). Pa. (Jeannette).

Xenotoma fuscinervis Kieffer, 1909. Soc. Sci. de Bruxelles, Ann. 33: 370, 375. \&, ठ.

harringtoni (Kieffer). Que. (Hull).

Pantoclis mandibularis Harrington, 1899. Roy. Soc. Canada, Trans. (2) 5: 198. \&. Preocc. by Ashmead, 1893.

Xenotoma (Zelotypa) harringtoni Kieffer, 1916. Das Tierreich, Lief. 44, pp. 544, 549. N. name.

hirtifrons (Ashmead). Ont. (Ottawa).

Anectata hirtifrons Ashmead, 1887. Canad. Ent. 19: 198..

insularis (Ashmead). Fla. (Ft. George Isl.).

Pantoclis insularis Ashmead, 1893. U. S. Natl. Mus., Bul. 45: 367, 369. \&, (male misdet.).

kiefferi (Fouts). Pa. (Jeannette).

Xenotoma xanthopus Kieffer, 1909. Soc. Sci. de Bruxelles, Ann. 33: 368, 371. ठ. Preocc. by Ashmead, 1893.

Xenotoma flaripes Kieffer, 1910. In Wytsman, Gen. Ins., fasc. 107, p. 33. N. name. Preocc. by Ashmead, 1893. See under A. flavidipes (Kieffer).

Xenotoma (Xenotoma) kiefferi Fouts, 1926. Brooklyn Ent. Soc., Bul. 21: 151, 153. N. name.

laeta (Kieffer). Calif. (Claremont).

Xenotoma laeta Kieffer, 1909. Soc. Sci. de Bruxelles, Ann. 33: 368, 371. ó.

longicornis (Provancher). Canada.

Spilomicrus longicomis Provancher, 1881. Nat. Canad. 12: 262..

Taxonomy: Masner, 1969. Nat. Canad. 96: 782. 
macrodyctium (Ashmead). Colo. (Westcliffe).

Cinetus macrodyctium Ashmead, 1893. U. S. Natl. Mus., Bul. 45: 360. \&, (male misdet.).

mandibularis (Ashmead). Tex.

Xenotoma mandibularis Ashmead, 1893. U. S. Natl. Mus., Bul. 45: 363. ९, (ơ misdet.).

megaplasta (Ashmead). Kans. (Manhattan).

Pantoclis megaplasta Ashmead, 1893. U. S. Natl. Mus., Bul. 45: 367, 368. .

Pantoclis megaloplasta Schulz, 1906. Spolia Hym., p. 151. Emend.

melanocera (Kieffer). Calif. (Claremont).

Xenotoma melanocera Kieffer, 1909. Soc. Sci. de Bruxelles, Ann. 33: 368, 370. ơ.

mellicornis Muesebeck and Walkley. Va. (Arlington).

Cinetus ruficomis Ashmead, 1893. U. S. Natl. Mus., Bul. 45: 359, 360. ๆ. Preoce. by Curtis, 1831.

Aclista mellicomis Muesebeck and Walkley, 1951. U. S. Dept. Agr., Agr. Monog. 2, p. 688. N. name.

mellipes (Say). Que., Ont., Va., Ind.

Cinetus mellipes Say, 1836. Boston Jour. Nat. Hist. 1: 279. ๆ.

morula Muesebeck and Walkley. Colo.

Anectata coloradensis Kieffer, 1908. Soc. Sci. de Bruxelles, Ann. 32: 42. \&. Preoce. by Zelotypa coloradensis Ashmead, 1890, when both were placed in Aclista by Muesebeck and Walkley, 1951, although the Ashmead species is now in Pantoclis.

Aclista morula Muesebeck and Walkley, 1951. U. S. Dept. Agr., Agr. Monog. 2, p. 688. N. name.

nevadensis Kieffer. Nev. (Ormsby County).

Aclista nevadensis Kieffer, 1906 (1905). Berlin. Ent. Ztschr. 50: 277. o.

pacifica Muesebeck and Walkley. Calif.

Anectata californica Ashmead, 1893. U. S. Natl. Mus., Bul. 45: 381. ९. Preoce. by Aclista californica Ashmead, 1893, although the latter is now in $Z$ ygota where it is preoccupied and has been renamed distans Muesebeck and Walkley, 1951.

Aclista pacifica Muesebeck and Walkley, 1951. U. S. Dept. Agr., Agr. Monog. 2, p. 688. N. name.

paludicola Muesebeck and Walkley. N. Y. (MeLean Bogs).

Xenotoma (Xenotoma) palustra Fouts, 1926. Brooklyn Ent. Soc., Bul. 21: 151, 153. . Preoce. by Aclista palustra Fouts, 1926, which is now in Zygota.

Aclista paludicola Muesebeck and Walkley, 1951. U. S. Dept. Agr., Agr. Monog. 2, p. 688. N. name.

parvicellula (Kieffer). Calif. (Claremont).

Xenotoma parvicellula Kieffer, 1909. Soc. Sci. de Bruxelles, Ann. 33: 368, 371. $q$.

pilosa (Fouts). N. Y. (McLean Bogs).

Xenotoma (Xenotoma) pilosa Fouts, 1926. Brooklyn Ent. Soc., Bul. 21: 150, 153. o.

polita (Ashmead). Colo. (Westeliffe).

Anectata polita Ashmead, 1893. U. S. Natl. Mus., Bul. 45: 381, 382. ठ.

rufopleuralis (Ashmead). Que. (Hull).

Miota rufopleuralis Ashmead, 1897. Canad. Ent. 29: 54..

rufosignata (Kieffer). Calif. (Claremont).

Xenotoma rufosignata Kieffer, 1909. Soc. Sci. de Bruxelles, Ann. 33: 369, 373. ९, ठ.

scutellata (Ashmead). Alaska.

Zelotypa scutellata Ashmead, 1902. Wash. Acad. Sci., Proc. 4: 137. ๆ.

similis (Ashmead). Va.

Cimetus similis Ashmead, 1893. U. S. Natl. Mus., Bul. 45: 359, 361. ․

trisuleata (Kieffer). Pa. (Jeannette).

Xenotoma trisulcata Kieffer, 1909. Soc. Sci. de Bruxelles, Ann. 33: 369, 372. ‥

vagabunda Muesebeck and Walkley. Pa. (Jeannette).

Xenotoma Klagesi Kieffer, 1909. Soc. Sci. de Bruxelles, Ann. 33: 369, 374. ९. Preoce. when it and Pantoclis klagesi Kieffer, 1909, were both placed in Aclista by Muesebeck and Walkley, 1951, although the latter name has now been restored to Pantoclis. 
Aclista vagabunda Muesebeck and Walkley, 1951. U. S. Dept. Agr., Agr. Monog. 2, p. 689. N. name.

xanthopus (Ashmead). N. J.

Xenotoma xanthopus Ashmead, 1893. U. S. Natl. Mus., Bul. 45: 363. ‡, ठ.

\section{Genus PANTOCLIS Foerster}

Pantoclis Foerster, 1856. Hym. Stud., v. 2, pp. 129, 137. No species. -Foerster, 1861.

Programm Realschule Aachen, p. xliii. One species.

Type-species: Pantoclis barycera Foerster. First included species.

Zelotypa Foerster, 1856. Hym. Stud., v. 2, pp. 130, 141. No species. -Ashmead, 1890. Colo. Biol. Assoc., Bul. 1: 12. One species.

Type-species: Zelotypa coloradensis Ashmead. First included species.

There appear to be no published indications of host associations for any species of this genus.

Revision: Kieffer, 1916. Das Tierreich, Lief. 44, pp. 475-506.

Taxonomy: Nixon, 1957. Roy. Ent. Soc. London, Handb. 8(3), pp. 41-54. - Hellen, 1964. Fauna

Fennica 18: 32-38.

aculeata Kieffer. Pa. (Pittsburgh).

Pantoclis aculeatus Kieffer, 1909. Soc. Sci. de Bruxelles, Ann. 33: 353, 357. ․

analis Ashmead. D. C.

Pantoclis analis Ashmead, 1893. U. S. Natl. Mus., Bul. 45: 367, 370..

aptera Kieffer. Alaska.

Pantoclis scutellata aptera Kieffer, 1916. Das Tierreich, Lief. 44, p. 498..

Taxonomy: Muesebeck and Masner, 1967. U. S. Dept. Agr., Agr. Monog. 2, Sup. 2, p. 294.

bakeri Kieffer. Pa. (Jeannette).

Pantoclis Bakeri Kieffer, 1909. Soc. Sci. de Bruxelles, Ann. 33: 353, 354. ठ。.

bruesi Kieffer. Pa., Wis.

Pantoclis Bruesi Kieffer, 1909. Soc. Sci. de Bruxelles, Ann. 33: 353, 357. ९.

californica Ashmead. Calif. (Santa Cruz Mts.).

Pantoclis californica Ashmead, 1893. U. S. Natl. Mus., Bul. 45: 367, 371. , (male misdet.).

canadensis Ashmead. Ont. (Ottawa).

Pantoclis canadensis Ashmead, 1897. Canad. Ent. 29: 55. \&.

clinoneura Kieffer. Pa. (Jeannette).

Pantoclis clinoneurus Kieffer, 1909. Soc. Sci. de Bruxelles, Ann. 33: 353, 355. ठ゙.

coloradensis (Ashmead). Colo. (Westcliffe).

Zelotypa coloradensis Ashmead, 1890. Colo. Biol. Assoc., Bul. 1: 12. "१" =

consimilis (Muesebeck). Ont. (Ottawa).

Pantoclis similis Ashmead, 1897. Canad. Ent. 29: 55. ठ. Preocc. by Cinetus similis Ashmead, 1893, when both were placed in Aclista by Muesebeck, 1958.

Aclista consimilis Muesebeck, 1958. U. S. Dept. Agr., Agr. Monog. 2, Sup. 1, p. 91. N. name.

dubiosa Kieffer. Calif. (Claremont).

Pantoclis dubiosa Kieffer, 1906 (1905). Berlin. Ent. Ztschr. 50: 278. \&.

duplicata (Muesebeck and Walkley). Calif. (Claremont).

Pautoclis califormicus Kieffer, 1909. Soc. Sci. de Bruxelles, Ann. 33: 352, 354. +. Preoce. by Ashmead, 1893.

Pantoclis californiae Kieffer, 1910. In Wytsman, Gen. Ins., fasc. 107, p. 26. N. name. Again proposed as n. name for californicus in 1926 (Das Tierreich, Lief. 44: 504). Placed in Aclista by Muesebeck and Walkley, 1951, and there preoccupied by Aclista califormiae Kieffer, 1910, which is now in Belyta.

Aclista duplicata Muesebeck and Walkley, 1951. U. S. Dept. Agr., Agr. Monog. 2, p. 686. N. name.

flavipes Ashmead. Va. (Arlington).

Pantoclis flavipes Ashmead, 1893. U. S. Natl. Mus., Bul. 45: 367, 370. 9. 
Pantoclis flavicrus Kieffer, 1916. Das Tierreich, Lief. 44, pp. 480, 500. Unnecessarily proposed as a $n$. name for $P$. flavipes Ashmead.

floridana Ashmead. Fla. (Jacksonville).

Pantoclis floridana Ashmead, 1893. U. S. Natl. Mus., Bul. 45: 367, 372. ९.

georgica (Ashmead). Ga.

Anectata georgica Ashmead, 1893. U. S. Natl. Mus., Bul. 45: 381, 382. ð.

integrifrons Kieffer. Pa. (Jeannette).

Pantoclis integrifrons Kieffer, 1909. Soc. Sci. de Bruxelles, Ann. 33: 353, 356. q. jeannettensis (Muesebeck and Walkley). Pa. (Jeannette).

Pantoclis micronenrus Kieffer, 1909. Soc. Sci. de Bruxelles, Ann. 33: 353, 355. o. Preocc. by Aclista microneura Kieffer, 1909, when placed in Aclista by Muesebeck and Walkley, 1951 , although that species is now in $Z$ ygota.

Aclista jeannettensis Muesebeck and Walkley, 1951. U. S. Dept. Agr., Agr. Monog. 2, p. 688. N. name.

klagesi Kieffer. Pa. (Jeannette).

Pantoclis Klagesi Kieffer, 1909. Soc. Sci. de Bruxelles, Ann. 33: 353, 358. ð.

monilicornis (Ashmead). Colo. (Westeliffe).

Belyta monilicomis Ashmead, 1890. Colo. Biol. Assoc., Bul. 1: 12..

montana Ashmead. Calif. (Santa Cruz Mts.).

Pantoclis montana Ashmead, 1893. U. S. Natl. Mus., Bul. 45: 367, 368. $\$$, (male misdet.). orthoneura Kieffer. Wis. (Polk County).

Pantoclis orthoneurus Kieffer, 1909. Soc. Sci. de Bruxelles, Ann. 33: 353, 358. ठ゚. rufescens Ashmead. Tex.

Pantoclis rufescens: Ashmead, 1893. U. S. Natl. Mus., Bul. 45: 367, 372. \&.

ruficauda Ashmead. Va. (Arlington).

Pantoclis ruficauda Ashmead, 1893. U. S. Natl. Mus., Bul. 45: 367, 370. \&. singularis Kieffer. $\mathrm{Pa}$. (Jeannette).

Pantoclis singularis Kieffer, 1909. Soc. Sci. de Bruxelles, Ann. 33: 352, 354. ð. subfusca Kieffer. Pa. (Jeannette).

Pantoclis subfuscus Kieffer, 1909. Soc. Sci. de Bruxelles, Ann. 33: 353, 355.. subobtusa Kieffer. Pa. (Jeannette).

Pantoclis subobtusus Kieffer, 1909. Soc. Sci. de Bruxelles, Ann. 33: 353, 358..

\section{Genus ZYGOTA Foerster}

Zygota Foerster, 1856. Hym. Stud., v. 2, pp. 128, 131, 133, 135. No species. - Marshall, 1873. Cat. Brit. Hym.; Oxyura, p. 9. Two species.

Type-species: Belyta abdominalis Nees. Desig. by Ashmead, 1893.

Carinia Kieffer, 1905. Soc. Sci. de Bruxelles, Ann. 29: 140.

Type-species: Carinia nitida Kieffer. Monotypic.

Tetrapsilus Kieffer, 1908. In Andre, Spec. Hym. Eur. Alg., v. 10, pp. 367, 397.

Type-species: Tetrapsilus filicomis Kieffer. Monotypic.

Although specimens are commonly collected nothing seems to be known concerning the biology or host relationships of members of this genus.

Taxonomy: Fouts, 1926. Brooklyn Ent. Soc., Bul. 21: 145-149. (under Aclista Foerster). -Nixon, 1957. Roy. Ent. Soc. London, Handb. 8 (3), pp. 54-65. - Hellen, 1964. Fauna Fennica $18: 38-45$.

americana Ashmead. Greenland, Que., Ont., Alaska.

Zygota Americana Ashmead, 1888. Canad. Ent. 20: 54. १, ठ.

arcuata (Kieffer). Pa. (Jeannette).

Aclista arcuata Kieffer, 1909. Soc. Sci. de Bruxelles, Ann. 33: 348, 349. o.

borealis (Ashmead). Ont. (Ottawa).

Aclista borealis Ashmead, 1893. U. S. Natl. Mus., Bul. 45: 376, 378. \&.

caudata (Harrington). Que. (Hull).

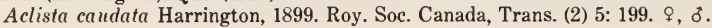


erassicornis (Harrington). Ont. (Ottawa).

Aclista crassicomis Harrington, 1899. Roy. Soc. Canada, Trans. (2) 5: 200. ठ̊.

distans Muesebeck and Walkley. Alaska, Calif.

Aclista californica Ashmead, 1893. U. S. Natl. Mus., Bul. 45: 375, 378. 9 . Preocc. by

Pantoclis californica Ashmead, 1893, when the latter was placed in Aclista by Muesebeck and Walkley, 1951, although it has now been restored to Pantoclis.

Zygota distans Muesebeck and Walkley, 1951. U. S. Dept. Agr., Agr. Monog. 2, p. 683. N. name.

dolichoneura (Kieffer). Nev. (Ormsby County).

Aclista dolichoneura Kieffer, 1909. Soc. Sci. de Bruxelles, Ann. 33: 349, 351. ठ̊.

dupla Muesebeck and Walkley. D. C.

Aclista mfopetiolata Ashmead, 1893. U. S. Natl. Mus., Bul. 45: 375, 376. 9 . Preoce. by

Nees, 1834.

Zygota dupla Muesebeck and Walkley, 1951. U. S. Dept. Agr., Agr. Monog. 2, p. 683. N. name.

emarginata (Kieffer). Wis. (Polk County).

Aclista (Zygota) emarginata Kieffer, 1909. Soc. Sci. de Bruxelles, Ann. 33: 348, 350. ठ̋.

excavata (Fouts). N. Y. (McLean Bogs).

Aclista excovato Fouts, 1926. Brooklyn Ent. Soc., Bul. 21: 146, 147. ठ.

inermis (Provancher). Que., Ont.

Aneurynchus (!) inermis Provancher, 1887. Addit. Corr. Faune Ent. Canada Hym., p. 176. “o” $=\delta$.

Taxonomy: Masner, 1969. Nat. Canad. 96: 777.

insignis (Kieffer). Pa. (Jeannette).

Aclista insignis Kieffer, 1909. Soc. Sci. de Bruxelles, Ann. 33: 349, 350. ¿.

levistylus (Kieffer). Pa. (Jeannette).

Aclista levistylu. Kieffer, 1909. Soc. Sci. de Bruxelles, Ann. 33: 348, 350. ठౌ.

longicornis (Ashmead). Va. (Arlington).

Zelotypa longicornis Ashmead, 1893. U. S. Natl. Mus., Bul. 45: 365. ठో.

microneura (Kieffer). Calif. (Claremont).

Aclista microneura Kieffer, 1909. Soc. Sci. de Bruxelles, Ann. 33: 349, 351. o.

monticola Muesebeck and Walkley. Calif. (Santa Cruz Mts.).

Aclista rufescens Ashmead, 1893. U. S. Natl. Mus., Bul. 45: 375, 376. . Preoce. by

Pantoclis mescens Ashmead, 1893, when the latter was placed in Aclista by Muesebeck and Walkley, 1951, although it has now been restored to Pantoclis.

Zygota monticola Muesebeck and Walkley, 1951. U. S. Dept. Agr., Agr. Monog. 2, p. 684.

obliterata (Fouts). N. Y. (McLean Bogs).

Aclista obliterata Fouts, 1926. Brooklyn Ent. Soc., Bul. 21: 146, 147. ठ.

palustra (Fouts). N. Y. (McLean Bogs).

Aclista palustra Fouts, 1926. Brooklyn Ent. Soc., Bul. 21: 145, 146. ठ.

rufa (Ashmead). Tex.

Aclista rufa Ashmead, 1893. U. S. Natl. Mus., Bul. 45: 375, 376...

scleroneura (Kieffer). Pa. (Jeannette).

Aclista scleroneura Kieffer, 1909. Soc. Sci. de Bruxelles, Ann. 33: 349, 352. ठ̊.

simulans (Fouts). N. Y. (McLean Bogs).

Aclista simulans Fouts, 1926. Brooklyn Ent. Soc., Bul. 21: 146, 148. ठ。.

texana Ashmead. Tex.

Zygota texana Ashmead, 1893. U. S. Natl. Mus., Bul. 45: 373, 374. 9.

\section{Genus ACROPIESTA Foerster}

Acropiesta Foerster, 1856. Hym. Stud., v. 2, pp. 129, 135, 136. No species. -Cameron, 1883.

Ent. Soc. London, Trans., p. 195. One species doubtfully included and therefore not available as type-species.--Ashmead, 1893. U. S. Natl. Mus., Bul. 45: 353. Two species.

Type-species: Acropiesta flacicauda Ashmead. Desig. by Muesebeck and Walkley, 1951. 
Pantopiesta Maneval, 1939. Soc. Ent.de France, Bul. 44: 169, 170.

Type-species: Cinetus flaviventris Thomson. Orig. desig.

Taxonomy: Nixon, 1957. Roy. Ent. Soc. London, Handb. 8(3), pp. 24-27.

flavicauda Ashmead. Ont. (Ottawa).

Acropiesta flavicauda Ashmead, 1893. U. S. Natl. Mus., Bul. 45: 354. ‡.

pulchella Whittaker. B. C. (Hollyburn).

Acropiesta pulchella Whittaker, 1930. Ent. Soc. Wash., Proc. 32: 75. \&, ठ.

pulchella var. melanocephala Whittaker. B. C. (Hollyburn).

Acropiesta pulchella var. melanocephala Whittaker, 1930. Ent. Soc. Wash., Proc. 32: 76. $\%$, $\delta$.

pulchella var. rufa Whittaker. B. C. (Hollyburn).

Acropiesta pulchella var. rufa Whittaker, 1930. Ent. Soc. Wash., Proc. 32: 76. १, ठ.

pulchella var. rufifrons Whittaker. B. C. (Hollyburn).

Acropiesta pulchella var. rufifions Whittaker, 1930. Ent. Soc. Wash., Proc. 32: 76. ९, ठ.

semirufa Fouts. Md. (Glen Echo).

Acropiesta semirufa Fouts, 1924. Ent. Soc. Wash., Proc. 26: 165. ․

subaptera Ashmead. Mich. (Marquette).

Acropiesta subaptera Ashmead, 1893. U. S. Nat. Mus., Bul. 45: 354. \&.

\section{Genus BELYTA Jurine}

Belyta Jurine, 1807. Nouv. Meth. Class. Hym. Dipt., p. 311.

Type-species: Belyta bicolor Jurine. Monotypic.

Belita Haliday, 1857. Nat. Hist. Rev., v, 4, p. 169. Emend.

Balyta Ashmead, 1893. U. S. Natl. Mus., Bul. 45: 366. Error.

Paraclista Kieffer, 1909. In Andre, Spec. Hym. Eur. Alg., v. 10, p. 476. Proposed as a subgenus of Belyta Jurine.

Type-species: Belyta brachyptera Thomson. Desig. by Kieffer, 1910.

Neobelyta Hellen, 1964. Fauna Fennica 18: 50. Proposed as a subgenus of Belyta Jurine.

Type-species: Belyta sanguinoleuta Nees. Orig. desig.

There are no host association records for any of the North American species of Belyta. One unnamed European species is said to have been reared from mycetophilid larvae.

Revision: Kieffer, 1916. Das Tierreich, Lief. 44, pp. 387-422.

Taxonomy: Hellen, 1964. Fauna Fennica 18: 49-56.

anthracina Whittaker. B. C. (Hollyburn).

Belyta anthracina Whittaker, 1931. Ent. Soc. Wash., Proc. 33: 179..

bisulcata Kieffer. Pa. (Jeannette).

Belyta bisulcata Kieffer, 1908. Soc. Sci. de Bruxelles, Ann. 32: 43. \&, ठ.

borealis Whittaker. B. C. (Hollyburn).

Belyta boreale Whittaker, 1931. Ent. Soc. Wash., Proc. 33: 179. \&.

californiae (Kieffer). Calif. (Placer County).

Zygota californica Ashmead, 1893. U. S. Natl. Mus., Bul. 45: 373. ठ. Preocc. by Aclista californica Ashmead, 1893, when transferred to Aclista by Kieffer, 1910.

Aclista californiae Kieffer, 1910. In Wytsman, Gen. Ins., fasc. 107, p. 24. N. name.

contempta Kieffer. Pa. (Pittsburgh).

Belyta contempta Kieffer, 1909. Soc Sci. de Bruxelles, Ann. 33: 359, 361. đ.

crassicornis (Ashmead). Va. (Arlington).

Pantoclis crassicornis Ashmead, 1893. U. S. Natl. Mus., Bul. 45: 367, 369. ९, (male misdet.).

despecta Kieffer. Wis. (Polk County).

Belyta despecta Kieffer, 1909. Soc. Sci. de Bruxelles, Ann. 33: 360, 362. đ.

erythropus Ashmead. Wis.

Belyta erythropus Ashmead, 1893. U. S. Natl. Mus., Bul. 45: 356, 357. \&. 
frontalis Ashmead. Del.

Belyta frontalis Ashmead, 1893. U. S. Natl. Mus., Bul. 45: 356. ?.

infuscata Kieffer. Pa. (Jeannette).

Belyta infuscata Kieffer, 1909. Soc. Sci. de Bruxelles, Ann. 33: 359, 361. ठ.

klagesi Kieffer. Pa. (Jeannette).

Belyta Klagesi Kieffer, 1909. Soc. Sci. de Bruxelles, Ann. 33: 360, 362. ठ.

longicollis Fouts. Pa. (Mount Holly Springs).

Belyta longicollis Fouts, 1926. Ent. Soc. Wash., Proc. 28: 174...

missouriensis (Ashmead). Mo. (St. Louis).

Aclista missouriensis Ashmead, 1893. U. S. Natl. Mus., Bul. 45: 375, 377. ठ゚.

nasuta (Provancher). Ont. (Ottawa).

Cinetus nasutus Provancher, 1887. Addit. Corr. Faune Ent. Canada Hym., p. 178. $q$.

Taxonomy: Masner, 1969. Nat. Canad. 96: 718.

nigripes Kieffer. Calif. (Claremont).

Belyta nigripes Kieffer, 1906 (1905). Berlin. Ent. Ztschr. 50: 280. ठ.

occidentalis (Muesebeck and Walkley). Calif. (Claremont).

Belyta californica Kieffer, 1909. Soc. Sci. de Bruxelles, Ann. 33: 360, 363. 8. Preocc. by

Ashmead, 1893, in Cinetuss as treated by Muesebeck and Walkley, 1951.

Cinetus occidentalis Muesebeck and Walkley, 1951. U. S. Dept. Agr., Agr. Monog. 2, p. 682. N. name.

peninsularis (Muesebeck and Walkley). Fla. (Jacksonville).

Aclista floridana Ashmead, 1893. U. S. Natl. Mus., Bul. 45: 376, 378. ठ. Preoce. by Pantoclis floridana Ashmead, 1893, when this name was transferred to Aclista by Muesebeck and Walkley, 1951, although it is now restored to Pantoclis.

Cinetus peninsularis Muesebeck and Walkley, 1951. U. S. Dept. Agr., Agr. Monog. 2, p. 682. N. name.

picipes (Ashmead). D. C.

Pantoclis picipes Ashmead, 1893. U. S. Natl. Mus., Bul. 45: 367, 368. o.

robustior Fouts. N. Y., Md.

Belyta robustior Fouts, 1925. Ent. Soc. Wash., Proc. 27: 152. $q$.

rostrata Harrington. Que. (Chelsea).

Belyta rostrata Harrington, 1899. Roy. Soc. Canada, Trans. (2) 5: 196. $q$.

rugifrons Fouts. N. Y., Md.

Belyta rugifrons Fouts, 1926. Brooklyn Ent. Soc., Bul. 21: 149. o.

rugosopetiolata (Ashmead). Va., La.

Aclista rugosopetiolata Ashmead, 1893. U. S. Natl. Mus., Bul. 45: 375, 377..

sanguinea Whittaker. B. C. (Hollyburn).

Belyta sanguinea Whittaker, 1931. Ent. Soc. Wash., Proc. 33: 177. \&, ơ.

sulcata Kieffer. Pa.

Belyta bisulcata Kieffer, 1909. Soc. Sci. de Bruxelles, Ann. 33: 359, 360. ㅇ, §. Preoce. by Kieffer, 1908.

Belyta sulcata Kieffer, 1910. In Wytsman, Gen. Ins., fasc. 107, p. 22. N. name.

texana Ashmead. Tex.

Belyta texana Ashmead, 1893. U. S. Natl. Mus., Bul. 45: 356, 357. ․

vera Kieffer. Wis. (Polk County).

Belyta vera Kieffer, 1909. Soc. Sci. de Bruxelles, Ann. 33: 359, 362. 8.

vilis Kieffer, Pa. (Pittsburgh).

Belyta vilis Kieffer, 1909. Soc. Sci. de Bruxelles, Ann. 33: 360, 363. o.

whittakeri (Muesebeck and Walkley). B. C. (Hollyburn).

Belyta excavata Whittaker, 1931. Ent. Soc. Wash., Proc. 33: 180. ․ Preocc. by Kieffer, 1910, when placed in Cimetus by Muesebeck and Walkley, 1951.

Cinetus whittakeri Muesebeck and Walkley, 1951. U. S. Dept. Agr., Agr. Monog. 2, p. 683. N. name.

xanthopus Kieffer. Wis. (Polk County).

Belyta xanthopus Kieffer, 1909. Soc. Sci. de Bruxelles, Ann. 33: 360, 364. ơ. 
xanthopus var. assimilis Kieffer. Pa., Wis.

Belyta xanthopus var. assimilis Kieffer, 1909. Soc. Sei. de Bruxelles, Ann. 33: 360, 364. ठै.

xanthostoma Kieffer. Pa. (Jeannette).

Belyta xauthostoma Kieffer, 1909. Soc. Sci. de Bruxelles, Ann. 33: 360, 363. ठ.

\section{Genus DIPHORA Foerster}

Diphora Foerster, 1856. Hym. Stud., v. 2, pp. 130, 140.

Type-species: Diphora westroodii Foerster. Monotypic.

Taxonomy: Nixon, 1957. Roy. Ent. Soc. London, Handb. 8 (3), p. 41.

nearetica Whittaker. B. C. (Hollyburn).

Diphora nearetica Whittaker, 1930. Ent. Soc. Wash., Proc. 32: 74. ๆ, ठ.

\section{Genus OXYLABIS Foerster}

Oxylabis Foerster, 1856. Hym. Stud., v. 2, pp. 128, 130, 133, 139.

Type-species: Cinetus picipes Nees. Desig. by Muesebeck and Walkley, 1951.

Lyteba Thomson, 1858. Ofvers. Kongl. Vetensk-Akad., Forh. 15: 155, 180.

Type-species: Belyta bisulca Nees. Monotypic.

Host associations unknown.

Revision: Kieffer, 1916. Das Tierreich, Lief. 44, pp. 363-374.

Taxonomy: Nixon, 1957. Roy. Ent. Soc. London, Handb. 8 (3), pp. 27-29.

arcuata Kieffer. Pa. (Jeannette).

Oxylabis arcuata Kieffer, 1909. Soc. Sei. de Bruxelles, Ann. 33: 346, 348. ठठ.

californica Kieffer. Calif. (San Mateo).

Oxylabis californica Kieffer, 1906 (1905). Berlin. Ent. Ztschr. 50: 279. ^.

earinifrons Kieffer. Wis. (Polk County).

Oxylabis carinifions Kieffer, 1909. Soc. Sci. de Bruxelles, Ann. 33: 346, 347. ठ̋.

fuscicornis (Ashmead). Que. (Hull).

Zelotypa fuscicornis Ashmead, 1897. Canad. Ent. 29: 55. ठ.

klagesi Kieffer. Pa. (Jeannette).

Oxylabis Klagesi Kieffer, 1908. Soc. Sci. de Bruxelles, Ann. 32: 42. ठో.

spinosa (Provancher). Que., Ont.

Aneurynchus (!) spinosus Provancher, 1881. Nat. Canad. 12: 262. ๆ.

\section{Genus ACANOSEMA Kieffer.}

Acanosema Kieffer, 1908. In Andre, Spec. Hym. Eur. Alg., v. 10, pp. 360, 367, 407.

Type-species: Acanosema mufum Kieffer. Orig. desig.

Cardiopsilus Kieffer, 1908. In Andre, Spec. Hym. Eur. Alg., v. 10, pp. 360, 405.

Type-species: Cardiopsilus productus Kieffer. Monotypic.

Taxonomy: Nixon, 1957. Roy. Ent. Soc. London, Handb. 8 (3), pp. 21-24. - Hellen, 1964.

Fauna Fennica 18: 56-57.

sylvanum Whittaker. B. C. (Hollyburn).

Acanosema syleana Whittaker, 1930. Ent. Soc. Wash., Proc. 32: 134. ๆ, ठ.

\section{Genus RHYNCHOPSILUS Kieffer}

Rhynchopsilus Kieffer, 1908. In Andre, Spec. Hym. Eur. Alg., v. 10, pp. 360, 400.

Type-species: Rhynchopsilus apertus Kieffer. Desig. by Kieffer, 1910.

Brunnicophilus Nixon, 1931. Ent. Rec. and Jour. Variation 43: 83.

Type-species: Brunnicophilus donisthorpei Nixon. Orig. desig.

Taxonomy: Nixon, 1957. Roy. Ent. Soc. London, Handb. 8 (3), pp. 13-15.

conicus (Ashmead). Va. (Arlington).

Aclista conica Ashmead, 1893. U. S. Natl. Mus., Bul. 45: 375, 377. ๆ. 


\section{Genus POLYPEZA Foerster}

Polypeza Foerster, 1856. Hym. Stud., v. 2, pp. 123, 127. No species. -Ashmead, 1893. U. S. Natl. Mus., Bul. 45: 385,387 . One species.

Type-species: Polypeza pergandei Ashmead. First included species.

Atelopsilus Kieffer, 1908. In Andre, Spec. Hym. Eur. Alg., v. 10, p. 360.

Type-species: Pantolyta brunuea Ashmead. Orig. desig.

Propantolyta Kieffer, 1910. In Andre, Spec. Hym. Eur. Alg., v. 10, pp. 697, 709.

Type-species: Polypeza pergandei Ashmead. Orig. desig.

Taxonomy: Masner and Sundholm, 1959. Acta Soc. Ent. Cechoslov. 56: 161-164. -Masner,

1964. Acta Soc. Ent. Cechoslov. 61: 131.

alaskensis (Ashmead). Alaska (Muir Inlet).

Spilomicrus alaskensis Ashmead, 1902. Wash. Acad. Sei., Proc. 45: 383. ․

brunnea (Ashmead). Wash. (Easton).

Pantolyta brunnea Ashmead, 1893. U. S. Natl. Mus., Bul. 45: 383. ?.

Taxonomy: Masner, 1964. Acta Soc. Ent. Cechoslov. 61: 131.

pergandei Ashmead. Va. (Arlington).

Polypeza Pergandei Ashmead, 1893. U. S. Natl. Mus., Bul. 45: 387. \&, o.

\section{Genus SYNACRA Foerster}

Synacra Foerster, 1856. Hym. Stud., v. 2, pp. 128, 130, 134. No species. -Marshall, 1873.

Cat. Brit. Hym.; Oxyura, p. 10. One species but two names.

Type-species: Diapria brachialis Nees. Desig. by Ashmead, 1893.

Artibolus. Haliday, 1857. Nat. Hist. Rev., v. 4, p. 173.

Type-species: Diapria brachialis Nees. Desig. by Muesebeck and Walkley, 1956.

Neuropria Kieffer, 1904. Soc. Hist. Nat. Metz, Bul. 23: 53.

Type-species: Neuropria sociabilis Kieffer. Monotypic.

Prosynacra Kieffer, 1905. Mus. Civ. Stor. Nat. Genova, Ann. (3) 2: 35, 37. No species.

- Kieffer, 1910. Lab. Zool. Portici, Bol. 4: 108. One species.

Type-species: Prosynacra nigriceps Kieffer. First included species.

Paratelopsilus Whittaker, 1930. Ent. Soc. Wash., Proc. 32: 73.

Type-species: Paratelopsilus canadensis Whittaker. Orig. desig.

Taxonomy: Pschorn-Walcher, 1957. Schweiz. Ent. Gesell., Mitt. 30: 74-76. -Masner, 1964.

Acta Soc. Ent. Cechoslov. 61: 131-132. - Masner, 1967. In Krombein and Burks, U. S.

Dept. Agr., Agr. Monog. 2, Sup. 2, p. 295.

canadensis (Whittaker). B. C. (Chilliwack).

Paratelopsilus canadensis Whittaker, 1930. Ent. Soc. Wash., Proc. 32: 73..

gracilis (Fouts). Mass. (Petersham). Ecology: Reared with Pissodes strobi (Peck).

Prosynacra gracilis Fouts, 1927. Ent. Soc. Wash., Proc. 29: 171..

insoleta Fouts. Minn. (St. Paul). Ecology: Reared from galls on raspberry roots.

Synacra insoleta Fouts, 1966. Ent. Soc. Wash., Proc. 68: 18. ‡, ठै.

\section{SUBFAMILY DIAPRIINAE}

Revision: Ashmead, 1893. U. S. Natl. Mus., Bul. 45: 384-448 (North American species).

-Kieffer, 1910-1911. In Andre, Spec. Hym. Eur. Alg., v. 10, pp. 691-1008 (pp. 691-752 pub. in 1910, pp. 753-1008 in 1911). - Kieffer, 1912 (1911). In Wytsman, Gen. Ins., fasc. 124, pp. 1-72. - Dodd, 1915. Roy. Soc. So. Austral., Trans. 39: 397-443 (Australian species).

-Kieffer, 1916. Das Tierreich, Lief. 44, pp. 3-347 (World fauna).

\section{Genus PARAMESIUS Westwood}

Paramesius Westwood, 1832. London, Edinb. and Dublin Phil. Mag. and Jour. Sci. (3) 1: 129.

Type-species: Paramesins rufipes Westwood. Monotypic.

Lipoglyptus Craw ford, 1910. U. S. Natl. Mus., Proc. 38: 123.

Type-species: Lipoglyptus primus Crawford. Orig. desig. 
Aparamesius Kieffer, 1913. Insecta 3: 436.

Type-species: Aparamesius carinatus Kieffer. Orig. desig.

Taxonomy: Baltazar, 1961. Philippine Jour. Sci. 90: 395.

analis (Ashmead). "Carolina," Tex.

Basalys analis Ashmead, 1893. U. S. Natl. Mus., Bul. 45: 443, 445. \&.

clavipes Ashmead. Ont. (Ottawa).

Paramesius clavipes Ashmead, 1888. Canad. Ent. 20: 53. .

foveatus (Provancher). Que. (Cap Rouge).

Spilomicrus foveatus Provancher, 1887. Addit. Corr. Faune Ent. Canada Hym., p. 176. "o" $=\delta$. Placement in Paramesius communicated by L. Masner in correspondence.

laetus Fouts. B. C. (Chilliwack).

Paramesins laetus Fouts, 1927. Ent. Soc. Wash., Proc. 29: 170. ?.

nigriclavis (Fouts). Ont., N. Y.

Aparamesins nigriclavis Fouts, 1926. Ent. Soc. Wash., Proc. 28: 169. $\%$.

oregonensis Ashmead. B. C., Oreg.

Paramesius oregonensis Ashmead, 1893. U. S. Natl. Mus., Bul. 45: 392, 395. ठ.

pallidipes Ashmead. D. C., Va., "Carolina."

Paramesius pallidipes Ashmead, 1893. U. S. Natl. Mus., Bul. 45: 392, 395. ๆ, o.

parvulus Ashmead. D. C., Va.

Paramesins pareulus Ashmead, 1893. U. S. Natl. Mus., Bul. 45: 392, 393. .

spinosus Ashmead. D. C., Va.

Paramesius spinosus Ashmead, 1893. U. S. Natl. Mus., Bul. 45: 392, 394. \&, o.

utahensis Ashmead. Utah (Utah Lake).

Paramesius utahensis Ashmead, 1893. U. S. Natl. Mus., Bul. 45: 392, 394. \&.

\section{Genus ENTOMACIS Foerster}

Entomacis Foerster, 1856. Hym. Stud., v. 2, pp. 121, 123. No species. - Marshall, 1873.

Cat. Brit. Hym.; Oxyura, p. 10. Two species.

Type-species: Diapria (Glyphidopria) platyptera Haliday. Desig. by Muesebeck and Walkley, 1951.

Hemilexis Foerster, 1856. Hym. Stud., v. 2, pp. 122, 123, 127. No species. -Ashmead, 1887. Canad. Ent. 19: 196. One species.

Type-species: Hemilexis mellipetiola Ashmead. First included species.

Glyphidopria Haliday, 1857. Nat. Hist. Rev., v. 4, p. 172. Proposed as a subgenus of Diapria Latreille.

Type-species: Diapria (Glyphidopria) platyptera Haliday. Desig. by Muesebeck and Walkley, 1951.

Hemilexodes Ashmead, 1893. U. S. Natl. Mus., Bul. 45: 386, 399.

Type-species: Hemilexodes floridana Ashmead. Orig. desig.

Adeliopria Ashmead, 1902. Biol. Bul. 3: 15.

Type-species: Adeliopria longii Ashmead. Orig. desig.

Taxonomy: Masner, 1964. Acta Soc. Ent. Cechoslov. 61: 134. - Sundholm, 1970. South African

Anim. Life 14: 321-324.

ambigua (Brues). Conn. (Colebrook). Ecology: Taken in nest of Aphaenogaster rudis picea (Emery).

Hemilexodes ambigna Brues, 1903. Amer. Ent. Soc., Trans. 29: 126..

californica (Ashmead). Wash., Calif. Host: Forcipomyia sp.

Hemilexis californica Ashmead, 1893. U. S. Natl. Mus., Bul. 45: 389, 390. §.

canadensis (Harrington). Canada.

Hemilexodes canadensis Harrington, 1899. Roy. Soc. Canada, Trans. (2) 5: 201..

floridana (Ashmead). Fla. (Jacksonville).

Hemilexodes floridana Ashmead, 1893. U. S. Natl. Mus., Bul. 45: 400. 9 . The male mentioned by Ashmead is a species of Aphidiidae.

longii (Ashmead). Tex. (Austin). Host: Forcipom yia wheeleri (Long) in an old ant nest. Adeliopria longii Ashmead, 1902. Biol. Bul. 3: 15. \&, ठ. 
Taxonomy: Masner 1964. Acta Soc. Ent. Cechoslov. 61: 134-135.

mellipetiola (Ashmead). Fla.

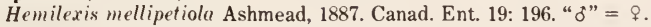

Hemilexis mellipetiolate Ashmead, 1893. U. S. Natl. Mus., Bul. 45: 389, 390. Emend. subemarginata (Ashmead). D. C., Va.

Hemilexis subemarginata Ashmead, 1893. U. S. Natl. Mus., Bul. 45: 389. १, (male misdet.).

\section{Genus HOPLOPRIA Ashmead}

Hoplopria Ashmead, 1893. U. S. Natl. Mus., Bul. 45: 385, 386, 388.

Type-species: Hoplopria pulchripenn is Ashmead. Orig. desig.

No Nearctic species have been described, but the collection of the U. S. National Museum of Natural History contains unnamed specimens, identified by L. Masner as belonging to this genus, from Md., S. C., and Fla.

\section{Genus SPILOMICRUS Westwood}

Spilomicrus Westwood, 1832. London, Edinb. and Dublin Phil. Mag. and Jour. Sci. (3) 1: 129.

Type-species: Spilomicrus stigmaticalis Westwood. Monotypic.

Chlidonia Herrich-Schaeffer, 1838. Faunae Ins. German., Heft 157, p. 24.

Type-species: Chlidonia moniliata Herrich-Schaeffer. Desig. by Viereck, 1914.

Loxotropa Foerster, 1856. Hym. Stud., v. 2, pp. 122, 123, 126.

Type-species: Psilus antennatus Jurine. Monotypic.

Loxoptera Mani, 1941. Cat. Indian Ins., pt. 26, pp. 39, 40, 41, 47. Error for Loxotropa Foerster.

Eriopria Kieffer, 1910. In Andre, Spec. Hym. Eur. Alg., v. 10, pp. 693, 744.

Type-species: Eriopria nigra Kieffer. Desig. by Kieffer, 1912.

Tritopria Kieffer, 1910. In Andre, Spec. Hym. Eur. Alg., v. 10, pp. 717, 748.

Type-species: Tritopita lusitanica Kieffer. Monotypic.

Cologlyptus Craw ford, 1910. U. S. Natl. Mus., Proc. 38: 123.

Type-species: Cologly ptus kiefferi Crawford. Orig. desig.

Scutellipria Szabo, 1961. Mus. Nat. Hungarici, Ann. Hist.-Nat. 53: 493.

Type-species: Scutellipria quinquepnnctata Szabo. Orig. desig.

One species of Spilomicrus has been reared from the pupa of a syrphid; otherwise there appear to be no reliable records of host association for members of this genus.

Revision: Kieffer, 1916. Das Tierreich, Lief. 44, pp. 283-307.

Taxonomy: Ashmead, 1893. U. S. Natl. Mus., Bul. 45: 385 (Tribe Spilomicrini proposed).

-Masner, 1964. Entomophaga 9: 81-85. -Sundholm, 1970. South African Anim. Life 14: 314-320.

armatus Ashmead. D. C.

Spilom icrus armatus Ashmead, 1893. U. S. Natl. Mus., Bul. 45: 397. ९.

atriclavus Ashmead. Ont. (Ottawa).

Spilomicrus atriclarus Ashmead, 1893. U. S. Natl. Mus., Bul. 45: 397, 398. ․

atropetiolatus (Ashmead). Colo. (Westcliffe).

Ismarus atropetiolatus Ashmead, 1890. Colo. Biol. Assoc., Bul. 1: 11. 9.

bifoveatus Kieffer. Pa. (Jeannette).

Spilomicrus biforeatus Kieffer, 1908. Soc. Sci. de Bruxelles, Ann. 32: 40. \&, ठ.

brevicornis (Ashmead). Colo.

Basalys brevicornis Ashmead, 1893. U. S. Natl. Mus., Bul. 45: 443, 446. ₹.

californicus (Ashmead). Calif. (Santa Cruz Mts.).

Basalys califorruica Ashmead, 1893. U. S. Natl. Mus., Bul. 45: 443, 446. 9 . The male is the holotype of Trichopria californiae (Kieffer), 1916.

flavicornis Ashmead. Va. (Arlington).

Spilomicrus flacicornis Ashmead, 1893. U. S. Natl. Mus., Bul. 45: 397, 398. ơ. 
foutsi Masner. N. Y.

Spilom icrus kiefferi Fouts, 1925. Ent. Soc. Wash., Proc. 27: 150. \&, ठ. Preoce. by

Crawford, 1910.

Spilomicrus foutsi Masner, 1967. In Krombein and Burks, U. S. Dept. Agr., Agr. Monog. 2, Sup. 2, p. 289. N. name.

ruficornis (Provancher). Canada.

Basalys ruficornis Provancher, 1881. Nat. Canad. 12: 261. ठ.

Taxonomy: Masner, 1969. Nat. Canad. 96: 778.

unifoveatus Kieffer. Pa. (Jeannette).

Spilomicrus uniforeatus Kieffer, 1908. Soc. Sci. de Bruxelles, Ann. 32: 41. ..

virginicus Fouts. Va. (Falls Church). Host: Xylota bicolor Loew.

Spilomicrus virginicus Fouts, 1926. Ent. Soc. Wash., Proc. 28: 168. ๆ.

\section{Genus PENTAPRIA Kieffer}

Pentapria Kieffer, 1905 (October). Genova Mus. Civ. Stor. Nat., Ann. (3) 2: 34. No species.

-Kieffer, 1905 (November). Soc. Hist. Nat. Metz (2) 12: 105. One species.

Type-species: Pentapria conjugens Kieffer. First included species.

Xenopria Fouts, 1939. Ent. Soc. Wash., Proc. 41: 260.

Type-species: Xenopria columbiana Fouts. Orig. desig.

Taxonomy: Masner, 1964. Acta Soc. Ent. Cechoslov. 61: 134.

columbiana (Fouts). B. C. (Kootenay Natl. Park). Host: A species of Stratiomyidae.

Xenopria columbiana Fouts, 1939. Ent. Soc. Wash., Proc. 41: 261. ?, ठ.

nigripes (Fouts). Wyo. (Saratoga).

Xenoprit nigripes Fouts, 1939. Ent. Soc. Wash., Proc. 41: 262. ๆ.

punctata (Fouts). Md. (Cabin John).

Xenopria punctata Fouts, 1939. Ent. Soc. Wash., Proc. 41: 263. ?.

\section{Genus ANEURHYNCHUS Westwood}

Aneurhynchus Westwood, 1832. London, Edinb. and Dublin Phil. Mag. and Jour. Sci. (3) 1: 129.

Type-species: Aneurhynchus galesiform is Westwood. Monotypic.

Anenryuch us Brulle, 1846. In Lepeletier, Hist. Nat. Ins. Hym., v. 4, p. 612. Emend.

Aneurrhynchus Marshall, 1873. Cat. Brit. Hym.; Oxyura, p. 11. Emend.

Glyptonota Foerster, 1856. Hym. Stud., v. 2, pp. 122, 126. No species. -Ashmead, 1893. U.

S. Natl. Mus., Bul. 45: 401 . One species.

Type-species: Glyptonota nigriclavata Ashmead, First included species.

Revision: Kieffer, 1916. Das Tierreich, Lief. 44, pp. 329-338.

Taxonomy: Masner and Sundholm, 1959. Acta Soc. Ent. Cechoslov. 56: 161-168.

floridanus Ashmead. Fla.

Anewhynchus floridanus Ashmead, 1893. U. S. Natl. Mus., Bul. 45: 404, 405. o'.

mellipes Ashmead. Ont. (Ottawa).

Aueurhynchus mellipes Ashmead, 1888. Canad. Ent. 20: 52. ?.

nigriclavatus (Ashmead). D. C.

Glyptonota nigriclavata Ashmead, 1893. U. S. Natl. Mus., Bul. 45: 401..

unifoveatus Kieffer. Pa. (Jeannette).

Aneurhynchus unifoveatus Kieffer, 1908. Soc. Sci. de Bruxelles, Ann. 32: 41. ठో.

virginicus Ashmead. W. Va. (Harpers Ferry).

Aneurhynchus virginicus Ashmead, 1893. U. S. Natl. Mus., Bul. 45: 404, 405. ð.

\section{Genus PSILUS Panzer}

Psilus Panzer, 1801. Faunae Ins. German., Heft 83, no. 11.

Type-species: Psilus cormutus Panzer. Monotypic.

Galesus Haliday, 1829. In Curtis, Guide Brit. Ins., column 108. 
Type-species: Psilus cormutus Panzer. Monotypic. Three species were listed but two of them were nomina nuda.

Coptera Say, 1836. Boston Jour. Nat. Hist. 1: 281.

Type-species: Coptera polita Say. Monotypic.

Anisopterc Herrich-Schaeffer, 1940. Nomencl. Ent. v. 2, pp. 57, 69. Preocc. by Berthold, 1827.

Type-species: Anisoptera egregia Herrich-Schaeffer. Monotypic.

Laches Gistel, 1848. Naturgesch. Thierr. f. hoh. Schul., p. viii. N. name for Anisoptera Herrich-Schaeffer.

Schizogalesus Kieffer, 1911. In Andre, Spec. Hym. Eur. Alg., v. 10, pp. 832, 833. Proposed as a subgenus of Galesus Haliday.

Type-species: Galesus (Schizogalesus) punctatus Kieffer. Desig. by Muesebeck and Walkley, 1951.

The few species of Psilus that have been reared from known hosts are parasites of Diptera, especially of Lonchaeidae and Tephritidae. An African species, P. silvestrii (Kieffer), which is a parasite of various tephritids of the genera Ceratitus and Dacus, was introduced into Hawaii as a possible aid in the control of the Mediterranean fruit fly.

Revision: Kieffer, 1916. Das Tierreich, Lief. 44, pp. 200-235 (World fauna). -Nixon, 1930.

Ann. and Mag. Nat. Hist. (10) 6: 399-414 (African species).

Taxonomy: Brues, 1906. Wis. Nat. Hist. Soc., Bul. 4: 150-152 (Key to No. Amer. species).

Biology: Clausen, 1940. Entomophagous Insects, pp. 261-262.

Morphology: Snodgrass, 1941. Smithsn. Misc. Collect. 99(4): 38-40 (male genitalia).

atricornis (Ashmead). Ont., Md., Va., Idaho, Wash. Host: Lonchaea corticis Taylor.

Galesus atricom is Ashmead, 1893. U. S. Natl. Mus., Bul. 45: 408, 409. ₹.

autumnalis (Brues). Wis. (Milwaukee County).

Galesus autumnalis Brues, 1906. Wis. Nat. Hist. Soc., Bul. 4: 150, 151. ?.

clarimontis (Kieffer). Calif. (Claremont).

Galesus clarimontis Kieffer, 1906 (1905). Berlin. Ent. Ztschr. 50: 285. ð.

microtomus (Kieffer). Calif. (San Mateo).

Galesus microtomus Kieffer, 1906 (1905). Berlin. Ent. Ztschr. 50: 285. ð.

pilosus (Ashmead). Tex.

Galesus pilosus Ashmead, 1893. U. S. Natl. Mus., Bul. 45: 409, 411. ठ.

politus (Say). Conn., Ont., N. Y., D. C., Md., Fla., Ind. Host: Rhagoletis cingulata (Loew), $R$. fausta (0. S.).

Coptera polita Say, 1836. Boston Jour. Nat. Hist. 1: 282. ঠ.

punctiger (Fouts). Tex. (Uvalde). Host: Drosophila sp.?

Galesus punctiger Fouts, 1926. Ent. Soc. Wash., Proc. 28: 170. $\subsetneq$, ठ.

quebecensis (Provancher). Que., D. C.

Galesus Quebecensis Provancher, 1881. Nat. Canad. 12: 260. §.

texanus (Ashmead). Tex.

Galesus texanus Ashmead, 1893. U. S. Natl. Mus., Bul. 45: 409, 411. ठ.

viereckii (Brues). Conn. (Colebrook).

Galesus viereckii Brues, 1905. Wis. Nat. Hist. Soc., Bul. 3: 187. ठँ.

\section{Genus MONELATA Foerster}

Monelata Foerster, 1856. Hym. Stud., v. 2, pp. 123, 127. No species. -Marshall, 1873. Cat. Brit. Hym.; Oxyura, p. 13. Three species.

Type-species: Diapria parvula Nees. Desig. by Ashmead, 1893.

Corynopria Haliday, 1857. Nat. Hist. Rev., v. 4, p. 170. Proposed as a subgenus of Diapria Latreille.

Type-species: Diapria petiolaris Nees. Desig. by Muesebeck and Walkley, 1951.

Entomopria Kieffer, 1912 (1911). In Wytsman, Gen. Ins., fasc. 124, pp. 4, 18.

Type-species: Corynopria solida Thomson. Monotypic.

There appear to be no published records of host association for any species of this genus. 
Taxonomy: Pschorn-Walcher, 1956. Schweiz. Ent. Gesell., Mitt. 29: 58-67.

hirticollis Ashmead. Ont. (Ottawa).

Monelata hirticollis Ashmead, 1888. Canad. Ent. 20: 54. .

mellicollis Ashmead. Fla. (Jacksonville).

Monelata mellicollis Ashmead, 1887. Canad. Ent. 19: 197..

nigra Whittaker. B. C. (Hollyburn).

Monelata nigra Whittaker, 1930. Ent. Soc. Wash., Proc. 32: 133. ․

\section{Genus BASALYS Westwood}

Bsalys Westwood, 1833. London, Edinb. and Dublin Phil. Mag. and Jour. Sci. (3) 3: 343.

Type-species: Basalys fumipennis Westwood. Monotypic.

Tropilopsis Ashmead, 1893. U. S. Natl. Mus., Bul. 45: 386, 402. Preoce. by Brauer and Bergenstamm, 1889.

Type-species: Tropidopsis clacata Ashmead. Orig. desig.

Ceratopria Ashmead, 1893. U. S. Natl. Mus., Bul. 45: 407, 428.

Type-species: Ceratopria longiceps Ashmead. Orig. desig.

Acilopria Kieffer, 1913. Insecta 3: 442.

Type-species: Acilopria nariicornis Kieffer. Desig. by Kieffer, 1916.

Nesopria Muesebeck and Walkley, 1956. U. S. Natl. Mus., Proc. 105: 374. N. name for Tropidopsis Ashmead.

A North American form was reared from a species of Anthomyiidae and another was found in the nest of a bee. There is also a record of a European species having been collected in an ant nest. Otherwise there seems to be nothing in the literature concerning the habits or host relations of members of this genus.

Revision: Kieffer, 1916. Das Tierreich, Lief. 44, pp. 192-200.

Taxonomy: Sundholm, 1960. Opusc. Ent. 25: 221. -Masner, 1964. Entomophaga 9: 85-86. ashmeadianus (Kieffer). "Canada."

Loxotropa ashmeadiana Kieffer, 1916. Das Tierreich, Lief. 44, pp. 171, 190. \&.

californicus (Ashmead). Calif. (Santa Cruz Mts.).

Loxotropa californica Ashmead, 1893. U. S. Natl. Mus., Bul. 45: 413, 415. ?.

Basalys barda Masner and Muesebeck, 1968. U. S. Natl. Mus. Bul. 270: 8. Unnecessarily proposed as a n. name for Loxotropa californica Ashmead.

columbianus (Ashmead). Md., D. C., Va. Ecology: Taken in nest of Lasioglossum pruinosum (Robertson).

Loxotropa colnmbiana Ashmead, 1893. U. S. Natl. Mus., Bul. 45: 413..

Loxotropa rifficornis Ashmead, 1893. U. S. Natl. Mus., Bul. 45: 413, 414. ठ. Preoce. by Thomson, 1858.

Loxotiopa ashmeadi Kieffer, 1911. In Andre, Spec. Hym. Eur. Alg., v. 10, p. 923. N. name for L. mficorn is Ashmead.

Taxonomy: Fouts, 1927. Ent. Soc. Wash., Proc. 29: 167.

Biology: Melander and Brues, 1903. Biol. Bul. 5: 9, 23.

flavipes (Ashmead). Md., D. C., Va., Ill.

Loxotropa flaripe's Ashmead, 1893. U. S. Natl. Mus., Bul. 45: 413, 415. ๆ, ठ.

fuscipennis Ashmead. D. C.

Basalys fuscipennis Ashmead, 1893. U. S. Natl. Mus., Bul. 45: 443, 444. o.

ganahlii Dalla Torre. D. C.

Basalys picipes Ashmead, 1893. U. S. Natl. Mus., Bul. 45: 443, 444. ठ์. Preoce. by Nees, 1834 .

Basalys ganahlii Dalla Torre, 1898. Cat. Hym., v. 5, p. 432. N. name.

longiceps (Ashmead). Va. (Arlington).

Ceratopria longiceps Ashmead, 1893. U. S. Natl. Mus., Bul. 45: 429. ?, (male misdet.).

microtoma Kieffer. Pa. (Sunbury).

Basalys microtoma Kieffer, 1908. Soc. Sci. de Bruxelles, Ann. 32: 39. ơ. 
modestus (Brues). Pa. (Lehigh Gap).

Loxotropa modesta Brues, 1905. Wis. Nat. Hist. Soc., Bul. 3, 188. \&.

nanus (Ashmead). Fla.

Loxotropa nana Ashmead, 1893. U. S. Natl. Mus., Bul. 45: 413, 415. \&.

nigrescens (Fouts). Sask., B. C.

Loxotropa nigrescens Fouts, 1927. Ent. Soc. Wash., Proc. 27: 169. \&.

pegomyiae (Brues). Minn. Host: Hylemya brassicae (Bouche).

Loxotropa pegomyiae Brues, 1907. Extr. from Rpt. Minn. State Ent., p. 1. \&, o.

pusillus (Ashmead). D. C., Va.

Ceratopria pusilla Ashmead, 1893. U. S. Natl. Mus., Bul. 45: 429, 430. §.

utahensis Ashmead. Utah (Canyon City).

Basalys utahensis Ashmead, 1893. U. S. Natl. Mus., Bul. 45: 443, 444. ठ".

\section{Genus IDIOTYPA Foerster}

Idiotypa Foerster, 1856. Hym. Stud., v. 2, pp. 122, 125. No species. -Marshall, 1873. Cat. Brit. Hym.; Oxyura, p. 11. Two species.

Type-species: Diapria (Mionopria) maritima Haliday. Desig. by Ashmead, 1893.

Mionopria Haliday, 1857. Nat. Hist. Rev., v. 4, p. 172. Proposed as a subgenus of Diaprla Latreille.

Type-species: Diaprin (Mionopria) maritima Haliday. Monotypic.

pallipes Fouts. N. Y. (McLean).

Idiotypu pallipes Fouts, 1925. Ent. Soc. Wash., Proc. 27: 102. ‡.

\section{Genus TRICHOPRIA Ashmead}

Trichopria Ashmead, 1893. U. S. Natl. Mus., Bul. 45: 407, 431.

Type-species: Trichopria pentaplasta Ashmead. Orig. desig.

Phaenopria Ashmead, 1893. U. S. Natl. Mus., Bul. 45: 407, 436.

Type-species: Phaenopria minutissima Ashmead. Orig. desig.

Planopria Kieffer, 1908. Soc. Hist. Nat. Metz, Bul. 25: 19.

Type-species: Diapria californica Ashmead. Desig. by Muesebeck and Walkley, 1951.

Orthopria Kieffer, 1911. In Andre, Spec. Hym. Eur. Alg., v. 10, pp. 983, 984.

Type-species: Diapria califormica Ashmead. Desig. by Muesebeck and Walkley, 1951.

Ashmeadopria Kieffer, 1912 (1911). In Wytsman, Gen. Ins., fasc. 124, pp. 8, 10, 59.

Type-species: Diapria verticillata Latreille. Desig. by Mani, 1941.

Rhopalopria Kieffer, 1912 (1911). In Wytsman, Gen. Ins., fasc. 124, pp. 8, 61.

Type-species: Rhopalopria vulgaris Kieffer. Monotypic.

Neodiapria Kieffer, 1916. Das Tierreich, Lief. 44, pp. xxi, 346.

Type-species: Tropidopria erynniae Kieffer. Monotypic.

Apparently the species of this genus are very numerous, most of them still undescribed. They are parasites of Diptera, including members of the families Tephritidae, Tachinidae, Syrphidae, Ephydridae, Stratiomyidae, Calliphoridae, Sarcophagidae, Drosophilidae, Glossinidae, Tabanidae, Chloropidae, Agromyzidae and Sciomyzidae.

Revision: Kieffer, 1916. Das Tierreich, Lief. 44, pp. 52-65 and 77-146.

Taxonomy: Mani, 1941. Cat. Indian Ins., pt. 26, pp. 44-47. -Sundholm, 1960. Opusc. Ent. 25: 218-222. - Masner, 1964. Acta Soc. Ent. Cechoslov. 61: 136. - Masner, 1965. Brit. Mus.

(Nat. Hist.), Bul., Ent., Sup. 1, p. 40.

Biology: Cros, 1935. Soc. d'Hist. Nat. de l'Afrique du Nord, Bul. 26: 131-136.

abdominalis Fouts. N. J. (Riverton).

Trichopria (Trichopria) abdominalis Fouts, 1926. Ent. Soc. Wash., Proc. 28: 174.. acutiventris (Brues). Tex. (near Austin). Ecology: In nest of Labidus coecus (Latreille).

Phaenopria acuticentris Brues, 1902. Amer. Nat. 36: 372. . . 
affinis (Ashmead). D. C.

Phaenopria affinis Ashmead, 1893. U. S. Natl. Mus., Bul. 45: 437, 440..

agromyzae (Fitch). N. Y. Host: Meoneura vagans (Fall.).

Diapria agromyzae Fitch, 1856 (1855). N. Y. State Agr. Soc., Trans. 15: 535. ९, ơ.

angustipennis Muesebeck. N. Y. (Ithaca). Host: Lemnaphila scotlandae Cress.

Trichopria angustipennis Muesebeck, 1939. Ent. Soc. Wash., Proc. 41: 60. ๆ, ó.

Biology: Scotland, 1939. Ent. Soc. Amer., Ann. 32: 717.

armata (Ashmead). Ont. (Ottawa).

Loxotropa armata Ashmead, 1888. Canad. Ent. 20: 53..

atrichomelinae Muesebeck. N. Y. Host: Atrichomelina pubera (Loew).

Trichopria atrichomelinae Muesebeck, 1972. Ent. News 83: 141. + , o.

bifovea Kieffer. Calif.

Diapria bifoceata Kieffer, 1906 (1905). Berlin. Ent. Ztschr. 50: 286, 287. ․ Preocc. by Ashmead, 1895.

Trichopria bifovea Kieffer, 1912 (1911). In Wytsman, Gen. Ins., fasc. 124: 64. N. name. bifoveolata (Ashmead). W. Va. (Harpers Ferry).

Ceratopria bifoceolata Ashmead, 1893. U. S. Natl. Mus., Bul. 45: 429, 430..

californiae (Kieffer). Calif. (Santa Cruz Mts.).

Basalys californiae Kieffer, 1916. Das Tierreich, Lief. 44,pp. 193, 199. ¿. See Spilomicrus californicus (Ashmead).

californica (Ashmead). Calif. (Santa Cruz Mts.).

Diapria californica Ashmead, 1893. U. S. Natl. Mus., Bul. 45: 421, 422. ๆ, ठ̊.

carolinensis Ashmead. Pa., "Carolina."

Trichopria carolinensis Ashmead, 1893. U. S. Natl. Mus., Bul. 45: 433, 434..

clarimontis (Kieffer). Calif. (Claremont).

Diapria clarimontis Kieffer, 1906 (1905). Berlin. Ent. Ztschr. 50: 286, 287. o.

columbiana (Ashmead). D. C., Va., Mich., Minn. Host: Hydrellia bergi Cress., H. sp.

Diapria columbiana Ashmead, 1893. U. S. Natl. Mus., Bul. 45: 422, 424..

crassiclava (Kieffer). Calif. (San Mateo).

Diapria crassiclava Kieffer, 1906 (1905). Berlin Ent. Ztschr. 50: 287, 288. .

dentata Muesebeck. Ala. (Town Creek). Host: A species of Syrphidae.

Trichopria dentata Muesebeck, 1967. Fla. Ent. 50: 59. $\%$, ठ.

discreta Muesebeck and Walkley. D. C.

Diapria tetraplasta Ashmead, 1893. U. S. Natl. Mus., Bul. 45: 422, 426.. . Preocc. by Ashmead, 1893.

Trichopria discreta Muesebeck and Walkley, 1951. U. S. Dept. Agr., Agr. Monog. 2, p. 678. N. name.

erythropus (Ashmead). D. C., Va., Fla.

Diapria erythropus Ashmead, 1893. U. S. Natl. Mus., Bul. 45: 421, 423. ₹, ठ゚.

erythrothorax (Ashmead). Fla. (Jacksonville).

Diapria erythrothorax Ashmead, 1887. Canad. Ent. 19: 196. ơ.

flavipes Ashmead. Va. (Arlington).

Trichopria flacipes Ashmead, 1893. U. S. Natl. Mus., Bul. 45: 433, 436..

floridana (Ashmead). Fla. (Jacksonville).

Cephalonomia floridana Ashmead, 1887. Canad. Ent. 19: 196. “ $\$ "=q$.

floridensis (Ashmead). Fla. (Fort George).

Galesus floridensis Ashmead, 1887. Canad. Ent. 19: 195. ठ.

Galesus floridanus Ashmead, 1893. U. S. Natl. Mus., Bul. 45: 410. Error.

foveata (Kieffer). Pa. (Jeannette).

Tropidopria foveata Kieffer, 1908. Soc. Sci. de Bruxelles, Ann. 32: 38. ठ.

haematobiae (Ashmead). Va., Tex. Host: Haematobia irritans (L.).

Phaenopria haematobiae Ashmead, 1893. U. S. Natl. Mus., Bul. 45: 437, 438..

harringtoni (Ashmead). Ont. (Ottawa).

Loxotropa Harringtoni Ashmead, 1888. Canad. Ent. 20: 53. ․ 
hirticollis (Ashmead). Fla., Tex. Host: Blaesoxipha plinthopyga (Wied.).

Cephalonomia hirticollis Ashmead, 1887. Canad. Ent. 19: 195. ㅇ.

Biology: Roberts, 1935. Jour. Agr. Res. 50: 491.

infuscatipes (Ashmead). Ont. (Ottawa).

Ceratipria (!) infuscutipes Ashmead, 1893. U. S. Natl. Mus., Bul. 45: 429, 431..

kiefferi Muesebeck, n. name. Calif. (Claremont).

Diupria montana Kieffer, 1906 (1905). Berlin. Ent. Ztschr. 50: 287, 288. \&. Preocc. by Ashmead, 1893.

megaplasta (Ashmead). Ont. (Ottawa).

Ceratopria megaplasta Ashmead, 1893. U. S. Natl, Mus., Bul. 45: 429, 430.

Ceratopria megaloplasta Schulz, 1906. Spolia Hym., p. 151. Emend.

melanocera (Kieffer). Calif. (San Mateo).

Diapria melenocert Kieffer, 1906 (1905). Berlin. Ent. Ztschr. 50: 287, 288. ๆ.

minutissima (Ashmead). Fla., Tenn.

Phaenopria minutissima Ashmead, 1893. U. S. Natl. Mus., Bul. 45: 437, 438. \&.

montana (Ashmead). Calif. (Santa Cruz Mts.).

Phaenopria montuna Ashmead, 1893. U. S. Natl. Mus., Bul. 45: 438, 440. ठॅ.

muscae (Ashmead). Calif.

Diopria muscae Ashmead, 1893. U. S. Natl. Mus., Bul. 45: 422, 426. ₹, ơ.

myoleptae Muesebeck. Fla. (Gainesville). Host: Myolepta varipes Loew.

Trichopriu myoleptu' Muesebeck, 1967. Fla. Ent. 50: 57. \&, o.

nevadensis (Kieffer). Nev. (Ormsby County).

Diapria necadensis Kieffer, 1906 (1905). Berlin. Ent. Ztschr. 50: 287, 288. ๆ.

occidentalis (Fouts). B. C., Calif. Host: Hippelates collusor (Townsend).

Phatenopria occidentalis Fouts, 1927. Ent. Soc. Wash., Proc. 29: 168. \&.

Biology: Legner, Bay and Medved, 1966. Ent. Soc. Amer., Ann. 59: 977-983.

pacifica Ashmead. Calif. (Santa Cruz Mts.).

Trichopria pucifica Ashmead, 1893. U. S. Natl. Mus., Bul. 45: 433, 436. \&.

paludis Muesebeck. N. Y. (Ithaca). Host: Lemnaphila scotlandae Cress.

Trichopria paludis Muesebeck, 1939. Ent. Soc. Wash., Proc. 41: 62. $\%$.

Biology: Scotland, 1939. Ent. Soc. Amer., Ann. 32: 717.

parkeri Fouts. Md. (Williamsport).

Trichopria parkeri Fouts, 1920. Ent. Soc. Wash., Proc. 22: 61. + , o.

parva (Ashmead). D. C.

Phaenopria parva Ashmead, 1893. U. S. Natl. Mus., Bul. 45: 438, 440. ઠ̋.

pentaplasta Ashmead. D. C., Va., Kans.

Trichopria pentaplasta Ashmead, 1893. U. S. Natl. Mus., Bul. 45: 432, 433. ๆ, ơ.

pezomachoides (Ashmead). Ont. (Ottawa).

Loxotropa pezomachoides Ashmead, 1888. Canad. Ent. 20: 53..

Phaenopria aptera Ashmead, 1893. U. S. Natl. Mus., Bul. 45: 437, 439..

popei (Muesebeck). N. Y., Fla., Mich. Host: Sepedon fuscipennis Loew, Elgiva sundewalli

Kloet and Hincks, Atrichomelina pubera (Loew), Dictya sp.

Phaenopria popei Muesebeck, 1950 (1949). Canad. Ent. 81: 234. ๆ, ठ.

Biology: Knutson and Berg, 1963. Canad. Ent. 95: 724-726.

popenoei Ashmead. Kans. (Riley County).

Trichopria Popenoei Ashmead, 1893. U. S. Natl. Mus., Bul. 45: 433, 435. ९, (male misdet.). popenoei var. illinoisensis Girault, Ill. (Urbana).

Trichopria popenoei var. illinoisensis Girault, 1920. U. S. Natl. Mus., Proc. 58: 178. ๆ, o. provancheri (Kieffer). Ont. (Ottawa).

Ashmeadopria prouancheri Kieffer, 1916. Das Tierreich, Lief. 44, pp. 122, 141. \&.

rufipes Ashmead. D. C.

Trichopria rufipes Ashmead, 1893. U. S. Natl. Mus., Bul. 45: 433, 434. \&, (male misdet.). 
schwarzii (Ashmead). Md., D. C., Va., Fla.

Phaenopria Schwarzii Ashmead, 1893. U. S. Natl. Mus., Bul. 45: 437, 439. .

tabanivora Fouts. Mass., Sask., Host: Chrysops mitis O. S., Tabanus reimeardtii Wied., T. nigrovittatus Macq.

Trichopria (Trichopria) tabanirora Fouts, 1926. In Cameron, Bul. Ent. Res. 17: 39. ?, o. tetraplasta (Ashmead). D. C.

Tropidopria tetraplasta Ashmead, 1893. U. S. Natl. Mus., Bul. 45: 417, 420. ^. texana (Ashmead). Tex.

Diapria texana Ashmead, 1893. U. S. Natl. Mus., Bul. 45: 421, 424. §.

unifoveata (Kieffer). Calif. (Santa Clara County).

Tropilopria unifoveatu Kieffer, 1906 (1905). Berlin. Ent. Ztschr. 50: 286. o゙.

utahensis (Ashmead). Utah (Salt Lake).

Diapria utahensis Ashmead, 1893. U. S. Natl. Mus., Bul. 45: 421, 423. .

villosicornis (Kieffer). Nev. (Ormsby County).

Loxotropa villosicornis Kieffer, 1906 (1905). Berlin. Ent. Ztschr. 50: 286. ð.

virginica (Ashmead). Va.

Diapria virginica Ashmead, 1893. U. S. Natl. Mus., Bul. 45: 422, 426..

virginiensis Masner. D. C., Va.

Phaenopria virginica Ashmead, 1893. U. S. Natl. Mus., Bul. 45: 437, 438. \&, o. Preocc. by Ashmead, 1893.

Trichopria viryimiensis Masner, 1967. In Krombein and Burks, U. S. Dept. Agr., Agr. Monog. 2, Sup. 2, p. 290. N. name.

zimmermanni Ashmead. "Carolina."

Trichopria Zimmermanni Ashmead, 1893. U. S. Natl. Mus., Bul. 45: 432, 434..

\section{Genus DIAPRIA Latreille}

Diapria Latreille, 1796. Precis. Caract. Gen. Ins., p. 110. No species. - Latreille, 1802. Hist. Nat. Crust. Ins., v. 3, p. 309. Two species.

Type-species: Ichneumon conicus Fabricius. Desig. by Latreille, 1810.

Tropidopria Ashmead, 1893. U. S. Natl. Mus., Bul. 45: 416.

Type-species: Ichneumon conicus Fabricius. Orig. desig.

Tropidobria Brethes, 1927. Ent. Mitt. 16: 334. Error.

Taxonomy: Sundholm, 1960. Opusc. Ent. 25: 215-223.

conica (Fabricius). Que. to N. C., west to Ont. and Colo; Europe. Host: Eristalis tenax (L.).

Ichneumon conicus Fabricius, 1775. Systema Ent. p. 343.

Cynips crassipes Fourcroy, 1785. Entomologia Parisiensis, p. 390.

Biology: Sanders, 1911. Canad. Ent. 43: 48-50. - Maneval, 1937. Mus. Roy. d'Hist. Nat. de Belg., Bul. 13: 7-9.

simulans (Ashmead). Ont. (Ottawa).

Tropidopria simulans Ashmead, 1893. U. S. Natl. Mus., Bul. 45: 417, 419. ९.

torquata (Provancher). Que., Ont.

Platymischus torquatus Provancher, 1887. Addit. Corr. Faune Ent. Canada Hym., p. 182.

ㅇ.

Taxonomy: Masner, 1969. Nat. Canad. 96: 780.

\section{Genus ACANTHOPRIA Ashmead}

Acanthopria Ashmead, 1896. Zool. Soc. London, Proc. 1895: 804.

Type-species: Acanthopria crassicomis Ashmead. Orig. desig.

There are no described North American species of this essentially Neotropical genus, but the collection of the U. S. National Museum of Natural History contains specimens of an undescribed species from Texas.

Taxonomy: Ferriere, 1929. Zool. Anz. 82: 166-168. 


\section{Genus DOLIOPRIA Kieffer}

Doliopria Kieffer, 1910. Ent. Rundschau 27 (8): 48. No species. - Kieffer, 1910. Ent. Rundschau 27 (9): 54 . One species.

Type-species: Doliopria flavipes Kieffer. First included species.

The meager published records indicate that members of this genus are usually found associated with ant colonies.

Taxonomy: Ferriere, 1929. Zool. Anz., 82: 156, 163-166.

Biology: Ferriere, 1929. Zool. Anz. 82: 156, 163-166.

americana Fouts. Pa., Va.

Doliopria americana Fouts, 1926. Ent. Soc. Wash., Proc. 28: 169..

\section{Genus AUXOPAEDEUTES Brues}

Auxopaedeutes Brues, 1903. Amer. Ent. Soc., Trans. 29: 126.

Type-species: Auxopaedeutes sodalis Brues. Monotypic.

Cracinopria Fouts, 1924. Ent. Soc. Wash., Proc. 26: 162.

Type-species: Trichopria marylandica Fouts. Orig. desig.

The species of Anxopaeleutes are apparently myrmecophiles.

Taxonomy: Masner, 1964. Acta Soc. Ent. Cechoslov. 61: 135-136. -Wing, 1951. Roy. Ent. Soc.

London, Trans. 102: 204-205.

crassicornis (Fouts). Md. (Hagerstown).

Cracinopria crassicomis Fouts, 1924. Ent. Soc. Wash., Proc. 26: 163, 164. \&.

emarginatus (Fouts). Md. (Hagerstown).

Cracinopria emarginata Fouts, 1924. Ent. Soc. Wash., Proc. 26: 163. ठ.

lyriformis Brues. Mass. (Boston). Ecology: In nest of Solenopsis molesta (Say).

A uxopaedentes lyriform is Brues, 1910. Wis. Nat. Hist. Soc., Bul. 8: 82. ?.

marylandicus (Fouts). Md. (Hagerstown).

Trichopria marylandica Fouts, 1920. Ent. Soc. Wash., Proc. 22: 62. ๆ, ठ.

perplexus (Fouts). Md. (Hagerstown).

Cracinopria perplexa Fouts, 1924. Ent. Soc. Wash., Proc. 26: 163, 164. ?.

sodalis Brues. Tex. Ecology: In nest of Solenopsis molesta (Say).

Auxopaedeutes sodalis Brues, 1903. Amer. Ent. Soc., Trans. 29: 127..

\section{Genus LEPIDOPRIA Kieffer}

Lepidopria Kieffer, 1910. In Andre, Spec. Hym. Eur. Alg., v. 10, p. 695 . No species.

-Kieffer, 1911. In Andre, Spec. Hym. Eur. Alg., v. 10, p. 869. One species.

Type-species: Lepidopria pedestris Kieffer. First included species.

Taxonomy: Wing, 1951. Roy. Ent. Soc. London, Trans. 102: 205.

aberrans Brues. Md. (Hagerstown). Host: Cryptomeigenia theutis (Wlkr.)? This species almost certainly does not belong in Lepidopria, but the holotype and only known specimen is in poor condition and its proper generic placement has not been determined.

Lepidoria (!) aberrans Brues, 1916. Psyche 23: 126. .

\section{Genus BRUESOPRIA Wing}

Bruesopria Wing, 1951. Roy. Ent. Soc. London, Trans. 102: 195.

Type-species: Bruesopria seeversi Wing. Orig. desig.

americana (Brues). D. C., Tenn. Ecology: In nest of Paratrechina parvula (Mayr).

Solenopsia americana Brues, 1936. Psyche 43: 16 ․

seeversi Wing. N. C. (Wake County). Ecology: With Solenopsis molesta (Say).

Bruesopria seeversi Wing, 1951. Roy. Ent. Soc. London, Trans. 102: 195. ?.

\section{Genus MYRMECOPRIA Ashmead}

Myrmecopria Ashmead, 1893. U. S. Natl. Mus., Bul. 45: 407, 446. 
Type-species: Loxotropa mellea Ashmead. Orig. desig.

mellea (Ashmead). Fla., Ala. Ecology: In nests of Eciton spp.

Loxotropa mellea Ashmead, 1887. Canad. Ent. 19: 196. o.

Taxonomy: Masner, 1964. Acta Soc. Ent. Cechoslov. 61: 132-133. Redescription, with first description of female.

Biology: Wing, 1951. Roy. Ent. Soc. London, Trans. 102: 207.

\section{UnPlaced TaXa OF Diapritdak}

Psilus abelominalis Say, 1836. Boston Jour. Nat. Hist. 1: 283. Ind.

Psilus upicalis Say, 1836. Boston Jour. Nat. Hist. 1: 283. Ind.

Psilus brevicornis Say, 1824. In Keating, Narr. Long's 2nd Exped., v. 2, p. 328. Ind.

Psilus colon Say, 1836. Boston Jour. Nat. Hist. 1: 284. Ind.

Psilus obtusus Say, 1828. Contrib. Maclur. Lyc. Phila. 1: 280. Ind.

Psilus terminatus Say, 1836. Boston Jour. Nat. Hist. 1: 282. Ind.

\section{Family SCELIONIDAE}

So far as known all species of this family are parasitic in the eggs of other insects or in the egg sacs of spiders.

Revision: Ashmead, 1893. U. S. Natl. Mus., Bul. 45: 136-247 (Nearctic fauna). - Kieffer, 1908.

Soc. Sci. de Bruxelles, Ann. 32: 111-251. - Kieffer, 1912-1913. In Andre, Spec. Hym. Eur.

Alg., v. 11, pp. 3-304 (pp. 3-160 pub. in 1912; pp. 161-304 in 1913). -Dodd, 1913. Roy. Soc.

So. Austral., Trans. 37: 130-181 (Australian fauna). - Kieffer, 1926. Das Tierreich, Lief. 48, pp. 1-557 (World fauna).

Taxonomy: Ashmead, 1903. N. Y. Ent. Soc., Jour. 11: 86-94. -Brues, 1909 (1908). In

Wytsman, Gen. Ins., fasc. 80, pp. 1-59. - Mani, 1941. Cat. Indian Ins., pt. 26, pp. 2-29.

-Kozlov, 1970. Ent. Obozr. 49: 209-219 (English transl.: Ent. Rev. 49: 118-123). - Kozlov, 1971. Soc. Ent. Unionis Sovet., Horae 54: 33-54.

Biology: Kieffer, 1926. Das Tierreich, Lief. 48, pp. 6-8. - Clausen, 1940. Entomophagous Insects, pp. 349-357.

\section{SubFamily SCELIONINAE}

Revision: Ashmead, 1893. U. S. Natl. Mus., Bul. 45: 167-247. - Kieffer, 1926. Das Tierreich, Lief. 48, pp. 264-557.

Taxonomy: Mani, 1941. Cat. Indian Ins., pt. 26, pp. 17-29. - Kozlov, 1970. Ent. Obozr. 49: 209-214 (English transl.: Ent. Rev. 49: 118-122). - Hellen, ijî. Fauna Fennica 23: 1-25.

\section{Genus SPARASION Latreille}

Sparasion Latreille, 1802. Hist. Nat. Crust. Ins., v. 3, p. 316.

Type-species: Sparasion cephalotes Latreille. Monotypic.

Oxyurms Lamarck, 1817. Hist. Nat. Anim. sans Vert., v. 4, p. 128. Preocc. by Rafinesque, 1810.

Type-species: Sparasion frontalis Latreille. Desig. by Muesebeck and Walkley, 1951.

Bebelus: Gistel, 1848. Naturgesch. Thierr. f. hoh. Schul., p. x. N. name for Oxyurus Lamarck.

Sparaison Brues, 1909 (1908). In Wytsman, Gen. Ins., fasc. 80, pp. 41, 56. Error.

The only species for which reliable records of host association are available is parasitic in the eggs of the Mormon cricket, Anabius simplex Hald. The North American species have not been critically studied; most material in the larger collections is unidentified. Apparently there are numerous undescribed species.

Revision: Kieffer, 1926. Das Tierreich, Lief. 48, pp. 282-299.

bakeri Kieffer. Colo.

Sparasion Bakeri Kieffer, 1908. Soc. Sci. de Bruxelles, Ann. 32: 26, 27. o. 
femorale Kieffer. Nev. (Ormsby County).

Sparasion femorale Kieffer, 1908, Soc. Sci. de Bruxelles, Ann. 32: 26. o.

graenicheri Brues. Wis. (Milwaukee).

Sparaison (!) graenicheri Brues, 1906. Wis. Nat. Hist. Soc., Bul. 4: 149. ๆ.

gregarium Brues. Md., Va.

Sparaison (!) gregarium Brues, 1907. Wis. Nat Hist. Soc., Bul. 5: 154. q.

humile Kieffer. Pa. (Jeannette).

Sparasion humile Kieffer, 1908. Soc. Sci. de Bruxelles, Ann. 32: 26, 27. ठ.

nigrum Ashmead. Pa., Md., Va.

Sparasion nigrum Ashmead, 1893. U. S. Natl. Mus., Bul. 45: 238, 239. ९, ơ.

pacificum Ashmead. Wash., Calif.

Sparasion pacificum Ashmead, 1893. U. S. Natl. Mus., Bul. 45: 238, 239. ơ.

pilosum Ashmead. Nev., Wash., Mont., Wyo., Utah. Host: Anabrus simplex Hald.

Sparasion pilosum Ashmead, 1893. U. S. Natl. Mus., Bul, 45: 238. \&, ठ.

Biology: Cowan, 1929. U. S. Dept. Agr., Tech. Bul. 161: 22-23. -Mills, 1942. Mont. Agr. Expt. Sta., Bul. 408: 11-13.

Morphology: Snodgrass, 1941. Smithsn. Misc. Collect. 99, pp. 38-40.

\section{Genus SCELIOMORPHA Ashmead}

Sceliomorpha Ashmead, 1893. U. S. Natl. Mus., Bul. 45: 210, 211, 239.

Type-species: Sceliomorpha longicomis Ashmead. Orig. desig.

There are no described Nearctic species of Sceliomorpha, but the Cornell University collection contains an unnamed specimen from Florida, as communicated by L. Masner in correspondence.

\section{Genus SCELIO Latreille}

Scelio Latreille, 180 J. Hist. Nat. Crust. Ins., v. 13, p. 226.

Type-species: Sculio mgulosus Latreille. Desig. by Latreille, 1810.

Scelionus Rafinesque, 1815. Analyse, p. 125. Emend.

Serlion Say, 1828. Contr. Maclur. Lyc. Philadelphia 1: 80. Error.

Scelion Blanchard, 1849. In Cuvier, Regne Animal, Ins., v. 2, p. 157; atlas pl. 116, fig. 4.

Emend.

Aleria Marshall, 1874. Ent. Monthly Mag. 10: 208.

Type-species: Aleria flavibarbis Marshall. Monotypic.

Caloptenobia Riley, 1878 (1877). U. S. Ent. Comn., Ann. Rpt. 1, p. 306.

Type-species: Caloptenobia ovivora Riley. Monotypic.

Discelio Kieffer, 1908. Soc. Sci. de Bruxelles, Ann. 32: 116, 124.

Type-species: Scelio thoracicus Ashmead. Desig. by Kieffer, 1926.

Dichacantha Kieffer, 1908. Soc. Sci. de Bruxelles, Ann. 32: 118,147.

Type-species: Trimorus luteus Cameron. Orig. desig.

Enneascelio Kieffer, 1910. Soc. Ent. de France, Bul. 1910: 293.

Type-species: Enneascelio exaratus Kieffer. Orig. desig.

Apparently all species of Scelio are parasitic in the eggs of grasshoppers.

Revision: Ashmead, 1893. U. S. Natl. Mus., Bul. 45: 241-247 (Nearctic species). - Kieffer,

1926. Das Tierreich, Lief. 48, pp. 308-345 (World species). - Dodd, 1927. Roy. Soc.

Queensland, Proc. 38: 127-175 (Australian fauna). - Nixon, 1958. Roy. Ent. Soc. London,

Trans. 111: 303-313 (African species). - Muesebeck, 1972. Smithsn. Contrib. Zool. 102: 1-33

(Nearctic species).

Biology: Pemberton, 1933. Hawaii. Ent. Soc., Proc. 8: 253-264. - Noble, 1935. Agr. Gaz. N. S.

Wales 46: 513-518. - Noble, 1938. Agr. Gaz. N. S. Wales 49: 143-147. -Murai, 1962.

Yamagata Agr. and For. Soc., Jour. 20: 21-29. - Great head, 1963. Roy. Ent. Soc. London,

Trans. 114: 488. 
caloptenorum Riley. Type missing and species too briefly characterized for identification. Scelio caloptenomum Riley 1885. Ent. Soc. Wash., Proc. 1: 22.

conformis Muesebeck. Md.

Scelio conform is Muesebeck, 1972. Smithsn. Contrib. Zool. 102: 4, 6. \&.

ernstii Riley. Fla., Ala., S. C., Tex.; Mexico, Guatemala, Brit. Honduras, Costa Rica, Panama, Trinidad, Venezuela, Peru, Brazil. Host: Schistocerca americana (Drury), S. paranensis (Burm.).

Scelio ernstii Riley, 1885. Ent. Soc. Wash., Proc. 1: 22. \&, ๖.

Scelio fuscipennis Ashmead, 1887. Ent. Amer. 3: 119. \%.

Scelio venezuelensis Marshall, 1892. In Buysson and Marshall, Soc. Ent. de France, Ann. 61: 74. . .

floridanus Ashmead. Fla., Calif.; Mexico. Host: Melanoplus differentialis (Thomas), $M$. sanguinipes (F.).

Scelio floridanus Ashmead, 1893. U. S. Natl. Mus., Bul. 45: 242, 247. \&.

hyalinipennis Ashmead. Fla., S. C., Tex.

Scelio hyalinipennis Ashmead, 1887. Ent. Amer. 3: 119. \&.

incertus Muesebeck. Tex.

Scelio incertus Muesebeck, 1972. Smithsn. Contrib. Zool. 102: 5, 10. ๆ.

insolitus Muesebeck. N. Y. (Paul Smiths).

Scelio insolitus Muesebeck, 1972. Smithsn. Contrib. Zool. 102: 4, 10..

oedipodae Ashmead. Ont., Va., Fla., Tex., Colo., Mont. Host: Originally cited as Oedipoda sp.

Scelio oedipodae Ashmead, 1893. U. S. Natl. Mus., Bul. 45: 242, 245. .

Scelio rufiventris Ashmead, 1893. U. S. Natl. Mus., Bul. 45: 242, 245..

opacus (Provancher). Throughout Austral Zone. Host: Melanoplus sanguinipes (F.), M. femurrubium (DeGeer), $M$. devastator Scud., M. differentialis (Thomas), M. bivittatus (Say), Cammula pellucida (Scud.), Ageneotettix deorum (Scud.).

Acerota opaca Provancher, 1887. Addit. Corr. Faune Ent. Canada Hym., p. 184. $\delta$.

Scelio calopteni Riley, 1893. In Ashmead, U. S. Natl. Mus., Bul. 45: 242, 246. $q$.

Scelio Luggeri Riley, 1893. In Ashmead, U. S. Natl. Mus., Bul. 45: 242, 246..

Scelio ashmeadi Viereck, 1903. Amer. Ent. Soc., Trans. 29: 74. ó.

Scelio striatigena Kieffer, 1904. Arkiv for Zool. 1: 530. ठ.

Scelio albipennis Kieffer, 1906 (1905). Berlin. Ent. Ztschr. 50: 270. ठ.

Scelio melleipes Kieffer, 1908. Soc. Sci. de Bruxelles, Ann. 32: 29, 30.

Biology: Pickford, 1964. Canad. Ent. 96: 1167-1172.

Morphology: Snodgrass, 1941. Smithsn. Misc. Collect. 99: 38-39, pl. 10, figs. Q and R. ovivorus (Riley). Mass., Conn., Pa., D. C., Va., N. C., Fla., Ill., Iowa, Ark., Tex. Host: Dissosteira carolina (L.).

Caloptenobia ovivora Riley, 1878 (1877). U. S. Ent. Comn., Ann. Rpt. 1, p. 306..

Scelio pallidicornis Ashmead, 1893. U. S. Natl. Mus., Bul. 45: 242, 244. d.

pallidipes Ashmead. S. C., Fla.

Scelio pallidipes Ashmead, 1893. U. S. Natl. Mus., Bul. 45: 242, 244. ठ.

pumilus Muesebeck. Tex. (Brownsville).

Scelio pumilus Muesebeck, 1972. Smithsn. Contrib. Zool. 102: 4, 15. \&.

rufulus Muesebeck. Kans., Nebr., Mont., Idaho, Ariz.

Scelio mufulus Muesebeck, 1972. Smithsn. Contrib. Zool. 102: 4, 16. \&, §.

semirufus Muesebeck. S. Dak. or Nebr. Host: Mermiria maculipennis Bruner.

Scelio semirufus Muesebeck, 1972. Smithsn. Contrib. Zool. 102: 4, 17. ๆ.

singularis Muesebeck. Mich., Iowa.

Scelio singnlaris Muesebeck, 1972. Smithsn. Contrib. Zool. 102: 4, 17. \&.

solus Muesebeck. Fla. (Mount Pleasant).

Scelio solus Muesebeck, 1972. Smithsn. Contrib. Zool. 102: 4, 18. \&.

squamosus Muesebeck. Fla. (Gainesville).

Scetio squamosus Muesebeck, 1972. Smithsn. Contrib. Zool. 102: 4, 19. ๆ. 
striativentris Kieffer. N. S., Que., Ont., Man., N. H., Vt., Mass., N. Y., Md., Va., N. C. (4000 ft.), Mich., Wis., Kans., N. Dak. Host: Melanoplus bivittatus (Say).

Scelio striaticentris Kieffer, 1908. Soc. Sci. de Bruxelles, Ann. 32: 29, 33. ठ.

venatus Brues. Ariz., Calif.

Scelio venata Brues, 1906. In Viereck, Amer. Ent. Soc., Trans. 32: 228. ?.

\section{Genus SYNODITELLA Muesebeck}

Synoditella Muesebeck, 1972. Smithsn. Contrib. Zool. 102: 3, 21.

Type-species: Sceliomorpha bisulca Ashmead. Orig. desig.

Females of species of this genus are phoretic.

Biology: Lanham and Evans, 1958. Pan-Pacific Ent. 34: 213-214. - Lanham and Evans, 1960.

Brooklyn Ent. Soc., Bul. 55: 84-87.

bisulca (Ashmead). Fla. Ecology: On females of Radinotatum carinatum (Walker).

Sceliomorpha! bisulca Ashmead, 1893. U. S. Natl. Mus., Bul. 45: 240. $९$.

bisulcata (Kieffer). Apparently occurs throughout Upper and Lower Austral Zones. Ecology:

Collected from bodies of females of melanoplus confusus $M$. differentialis (Thomas), $M$.

femurrubrum (DeGeer), M. keeleri luridus (Dodge), Dichromorpha viridis (Scud.),

Chortopliaga virilifasciata (DeGeer). Host: Melanoplus sp., M. differentialis (Thomas),

M. songuinipes (F.).

Scelio bisulcatus Kieffer, 1904. Arkiv for Zool. 1: 531. $\uparrow$.

Scelio monticola Brues, 1906. In Viereck, Amer. Ent. Soc., Trans. 32: 184. q.

Scelio striaticollis Brues, 1906. In Viereck, Amer. Ent. Soc., Trans. 32: 222..

\section{Genus GOVINDA Nixon}

Govinda Nixon, 1933. Ann. and Mag. Nat. Hist. (10) 12: 465.

Type-species: Govinda mila Nixon. Orig. desig.

Although there are no described North American species of this genus the U. S. National Museum of Natural History contains unnamed specimens, apparently representing several different species, from Texas, Oklahoma, Arizona, and California.

\section{Genus BARYCONUS Foerster}

Barycomus Foerster, 1856. Hym. Stud., v. 2, pp. 101, 104. No species. - Ashmead, 1887. Ent. Amer. 3: 118. One species.

Type-species: Baryconus floridanus Ashmead. First included species.

Hoploteleia Ashmead, 1893. U. S. Natl. Mus., Bul. 45: 210, 211, 227.

Type-species: Baryconus floridanus Ashmead. Orig. desig.

Rhacoteleia Cameron, 1905. Spolia Zeylanica 3: 72.

Type-species: Rhacoteleia pilosa Cameron. Monotypic.

Apegusoneura Cameron, 1912. Soc. Ent. 27: 69.

Type-species: Apegusoneura striolatus Cameron. Desig. by Muesebeck and Walkley, 1951.

In the unclassified material of Baryconus in the collection of the U. S. National Museum of Natural History there are several specimens labeled as having been reared from eggs of katydids (Tettigoniidae).

floridanus Ashmead. Va., Fla., Miss., La.

Baryconus floridanus Ashmead, 1887. Ent. Amer. 3: 118. ठ․

noveboracensis (Brues). N. Y. (New York City).

Hoploteleia noveboracensis Brues, 1908. Wis. Nat. Hist. Soc., Bul. 6: 49. ठ’.

\section{Genus MACROTELEIA Westwood}

Macroteleia Westwood, 1835. Zool. Soc. London, Proc. 3: 70.

Type-species: Macroteleia cleonymoides Westwood. Monotypic.

Romilius Walker, 1842. Ann. and Mag. Nat. Hist. 10: 274.

Type-species: Romilius zotale Walker. Desig. by Kieffer, 1910. 
Macrotelia Agassiz, 1846. Nomencl. Zool., p. 221. Emend.

Baeonenra Foerster, 1856. Hym. Stud., v. 2, pp. 100, 102. No species. -Ashmead, 1887.

Ent. Amer. 3: 99. Two species.

Type-species: Baeoneura floridana Ashmead. Desig. by Muesebeck and Walkley, 1956.

Baeeenra Ashmead, 1887. Ent. Amer. 3: 99. Error.

Prosapegus Kieffer, 1908. Soc. Sci. de Bruxelles, Ann. 32: 121, 147.

Type-species: Auteris elongata Ashmead. Orig. desig.

Stictoteleia Kieffer, 1926. Das Tierreich, Lief. 48, pp. xxix, 272, 546.

Type-species: Mucroteleia virginiensis Ashmead. Orig. desig.

The very meager records of host association indicate parasitization in the eggs of Tettigoniidae.

Revision: Kieffer, 1926. Das Tierreich, Lief. 48, pp. 520-544.

Taxonomy: Nixon, 1931. Eos 7: 367-379. - Dodd, 1933. Roy. Soc. Queensland, Proc. 44: 75-103.

-Masner, 1964. Acta Soc. Ent. Cechoslov. 61: 137-138. -Masner, 1965. Brit. Mus. (Nat.

Hist.), Bul., Ent. Sup. 1, p. 81.

elongata (Ashmead). Md., Va., Fla., Ala., Okla., Tex.

Anteris elonguta Ashmead, 1887. Ent. Amer. 3: 118. o.

famelica (Say). Ind.

Spartasion famelicuss Say. 1836. Boston Jour. Nat. Hist. 1: 276.

Taxonomy: Muesebeck, 1972. Smithsn. Contrib. Zool. 102, p. 13.

floridana (Ashmead). Md., Fla.

Baeonenu floridana Ashmead, 1887. Ent. Amer. 3: 99. ค, ð.

goldsmithi Girault. Ill.

Macroteleia floridana var. goldsmithi Girault, 1920. U. S. Natl. Mus., Proc. 58: 180.. macrogaster Ashmead. Pa., Ga., Tex.

Macroteleia macrogaster Ashmead, 1893. U. S. Natl. Mus., Bul. 45: 217. ठ, ( $\$$ misdet.). punctata Kieffer. Tex.

Macroteleia punctata Kieffer, 1904. Arkiv for Zool. 1: 532. ठં.

rugosa (Provancher). Canada.

Paphagus mugosus Provancher, 1881. Nat. Canad. 12: 293. ठ゚.

Taxonomy: Masner, 1969. Nat. Canad. 96: 779-780.

surfacei Brues. N. J. (Chester). Host: Sp. of Tettigoniidae (eggs).

Macroteleia surfacei Brues, 1907. Wis. Nat. Hist. Soc., Bul. 5: 153..

virginiensis Ashmead. Va. Host: Orchelimum glaberrimum (Burm.).

Macroteleia virginiensis Ashmead, 1893. U. S. Natl. Mus., Bul. 45: 217, 218. ๆ.

\section{Genus CALOTELEA Westwood}

Calotelea Westwood, 1837. In Hope, Ent. Soc. London, Trans. 2: 55.

Type-species: Calotelea aurantia Hope. Monotypic.

Callitelea Agassiz, 1846. Nomencl. Zool., pp. 60, 61. Emend.

Caloteleia Ashmead, 1893. U. S. Natl. Mus., Bul. 45: 209, 210, 212. Emend.

Calliscelio Ashmead, 1893. U. S. Natl. Mus., Bul. 45: 209, 218.

Type-species: Calliscelio laticinctus Ashmead. Orig. desig.

Ceratoteleia Kieffer, 1908. Soc. Sci. de Bruxelles, Ann. 32: 121.

Type-species: Caloteleia grenadensis Ashmead. Desig. by Kieffer, 1926.

Prosanteris Kieffer, 1908. Soc. Sci. de Bruxelles, Ann. 32: 121, 136.

Type-species: Anteris nigriceps Ashmead. Desig. by Kieffer, 1910.

Nenroteleia Kieffer, 1910. Soc. Ent. de France, Bul. 1910: 293.

Type-species: Neuroteleia rufa Kieffer. Orig. desig.

Lamproteleia Kieffer. 1910. Soc. Ent. de France, Bul. 1910: 293.

Type-species: Lamproteleia fasciatipennis Kieffer. Orig. desig.

Caenoteleia Kieffer, 1926. Das Tierreich, Lief. 48, pp. xxix, 266, 550. N. syn. (Placed in synonymy here on authority of L. Masner). 
Type-species: Caloteleia elegans Perkins. Monotypic.

Taxonomy: Masner, 1965. Brit. Mus. (Nat. Hist.), Bul., Ent., Sup. 1, p. 69.

erythrothorax (Kieffer), n. comb. Pa. (Jeannette).

Macroteleia erythrothorax Kieffer, 1908. Soc. Sci. de Bruxelles, Ann. 32: 22. \&.

marlattii Ashmead. Throughout Austral Zone. Ecology: Taken in mixed colony of Mymica sp. and Leptothorax sp. Host: Gryllus sp. (eggs).

Caloteleia Marlattii Ashmead, 1893. U. S. Natl. Mus., Bul. 45: 212, 214. ९, ઠ .

Macroteleia ruskini Girault, 1920. U. S. Natl. Mus., Proc. 58: 179. ?.

Biology: Severin, 1935. S. Dak. Agr. Expt. Sta., Bul. 295: 44.

nigriceps (Ashmead). Va., Fla., Ark.

Anteris nigriceps Ashmead, 1893. U. S. Natl. Mus., Bul. 45: 225, 226. '?, ठ.

rubriclava (Ashmead). Fla. (Jacksonville).

Acolus rubriclautus Ashmead, 1887. Ent. Amer. 3: 99. ๆ.

virginiensis (Ashmead). Va.

Anteris virginiensis Ashmead, 1893. U. S. Natl. Mus., Bul. 45: 225. ठ.

\section{Genus CREMASTOBAEUS Ashmead}

Cremastobaens Ashmead, 1893. U. S. Natl. Mus., Bul. 45: 210, 211, 228.

Type-species: Cremastobaeus bicolor Ashmead. Orig. desig.

Although no Nearctic species of this genus have been described, L. Masner reports that the Canadian National Collection contains unnamed specimens from Georgia, Florida, Missouri and Texas. There is also an unidentified specimen of Cremastobaeus from Alabama in the U. S. National Museum of Natural History.

\section{Genus PROBARYCONUS Kieffer}

Probaryconns Kieffer, 1908. Soc. Sci. de Bruxelles, Ann. 32: 118, 165, 168. Proposed as subg, of Baryconus.

Type-species: Baryconus (Probaryconus) spinosus Kieffer. Monotypic.

Amblyconus Kieffer, 1913. In Andre, spec. Hym. Eur. Alg., v. 11, p. 221. No species.

- Kieffer, 1914. In Andre, Spec. Hym. Eur. Alg., v. 11, p. 325. One species.

Type-species: Amblyconus quadridens Kieffer. First included species.

Taxonomy: Masner, 1965. Brit. Mus. (Nat. Hist.), Bul., Ent., Sup. 1, p. 90.

cinctiventris (Ashmead). Fla. (Jacksonville).

Baeoneura cinctiventris Ashmead, 1887. Ent. Amer. 3: 99. ๆ.

heidemannii (Ashmead). Va., D. C., Ga., Tex.

Caloteleia Heidemannii Ashmead, 1893. U. S. Natl. Mus., Bul. 45: 212, 213. ․

striatus (Ashmead). D. C.

Caloteleia striata Ashmead, 1893. U. S. Natl. Mus., Bul. 45: 212, 213. ๆ.

\section{Genus OETHECOCTONUS Ashmead}

Cacus Riley, 1893. In Ashmead, U. S. Natl. Mus., Bul. 45: 209, 210, 211, 223. Preocc. by Gistel, 1848.

Type-species: Cacus oecanthi Riley. Desig. by Ashmead, 1893.

Oethecoctonus Ashmead, 1900. Canad. Ent. 32: 368. N. name.

Cacellus Ashmead, 1903. N. Y. Ent. Soc., Jour. 11: 92 . Unnecessarily proposed as n. name for Cacus Riley.

Taxonomy: Masner, 1964. Acta Soc. Ent. Cechoslov. 61: 139-140.

oecanthi (Riley). N. Y., Pa., Va., Mich., Ind., La. Host: Oecanthus fultoni Walker, $O$. quadripunctatus Beut.

Cacus oecanthi Riley, 1893. In Ashmead, U. S. Natl. Mus., Bul. 45: 224. ‡, ơ.

\section{Genus LEPTOTELEIA Kieffer}

Leptoteleia Kieffer, 1908. Soc. Sci. de Bruxelles, Ann. 32: 120, 163. 
Type-species: Baryconus oecanthi Riley. Monotypic.

Taxonomy: Kieffer, 1926. Das Tierreich, Lief. 48, pp. 477-479. - Szabo, 1962 . Folia Ent.

Hungarica (n. s.) 15: 222. - Masner, 1964. Acta Soc. Ent. Cechoslov. 61: 138-139.

oecanthi (Riley). N. Y., Pa., Va., Nebr. Host: Oecunthus fultoni Walker, O. quadripunctatus Beut.

Baryconns oecunthi Riley, 1893. In Ashmead, U. S. Natl. Mus., Bul. 45: 215. \&, o.

Biology: Udine and Pinckney, 1940. Pa. Acad. Sci., Proc. 14: 81-84.

\section{Genus HOLO'TELEIA Kieffer}

Holoteleiu Kieffer, 1908. Soc. Sci. de Bruxelles, Ann. 32: 120, 169.

Type-species: Barycoutus (Holotelein) bicolor Kieffer. Orig. desig. This name, preocc. by Burycoutus bicolor Harrington, 1899, has been replaced by Holoteleia nigriceps Kieffer, 1926.

The following species are placed in Holoteleia on the authority of L. Masner, who has examined the holotypes.

bicolor (Harrington), n. comb. Ont., Alta.

Barycoutus bicolor Harrington, 1899. Canad. Ent. 31: 79., , o.

cincta (Harrington), n. comb. Ont., Sask., Wis.

Buryconus circtus Harrington, 1899. Canad. Ent. 31: 79..

parvipennis (Melander and Brues), n. comb. Mass., Ohio.

Caloteleia parripenuis Melander and Brues, 1903. Biol. Bul. 5: 22..

\section{Genus DUTA Nixon}

Duta Nixon 1933. Ann. and Mag. Nat. Hist. (10) 12: 306.

Type-species: Holoteleia tenuicomis Dodd. Orig. desig.

Chatanteris Priesner, 1951. Inst. Fouad I du Desert, Bul. 1: 136. N. syn. (teste L. Masner in correspondence).

Type-species: Chaetanteris serraticeps Priesner. Orig. desig.

No species of this genus have been described from North America but the U. S. National Museum of Natural History has isolated specimens of Duta, apparently representing several different species, from Maryland, District of Columbia, Virginia, Tennessee, Louisiana and Arizona.

\section{Genus OPISTHACANTHA Ashmead}

Opisthacantha Ashmead, 1893. U. S. Natl. Mus., Bul. 45: 209, 211, 221. Type-species: Opisthacantha mellipes Ashmead. Orig. desig.

Protrimorus Kieffer, 1908. Soc. Sci. de Bruxelles, Ann. 32: 146.

Type-species: Trimorus americanus Ashmead. Monotypic.

Taxonomy: Masner, 1964. Acta Soc. Ent. Cechoslov. 61: 140-141.

americanus (Ashmead). Va. (Arlington).

Trimorns americanus Ashmead, 1893. U. S. Natl. Mus., Bul. 45: 139. ઠ.

mellipes Ashmead. D. C.

Opisthacantha mellipes Ashmead, 1893. U. S. Natl. Mus., Bul. 45: 221. ^, ठ์.

\section{Genus PSILANTERIS Kieffer}

Psilanteris Kieffer, 1916. Broteria, Rev. Luso.-Brazil., Zool. ser., 14: 177.

Type-species: Auteris bicolor Kieffer. Orig. desig.

Taxonomy: Szabo, 1958. Mus. Natl. Hungarici, Ann. Hist.-Nat. 50: 271. - Kozlov, 1971. Soc.

Ent. Unionis Sovet., Horae 54: 41.

reticulatus (Fouts). D. C.

Anteris reticulatus Fouts, 1926. Ent. Soc. Wash., Proc. 28: 178. ^, ठ゚. 


\section{Genus PARIDRIS Kieffer}

Paridris Kieffer, 1908. Soc. Sci. de Bruxelles, Ann. 32: 122.

Type-species: Idris laeviceps Ashmead. Desig. by Kieffer, 1926.

Paranteris Kieffer, 1910. Soc. Ent. de France, Bul. 1910: 292.

Type-species: Paranteris nigriclava Kieffer. Orig. desig.

Taxonomy: Kieffer, 1912. Linn. Soc. London, Trans. (ser. 2), Zool. 15: 65. -Masner, 1965.

Brit. Mus. (Nat. Hist.), Bul., Ent., Sup. 1, p. 88.

brevipennis Fouts. Ill., S. Dak., La., Tex., Calif. Host: Gryllus spp. (eggs).

Paridris brevipennis Fouts, 1920. Ent. Soc. Wash., Proc. 22: 66. ๆ, ठ.

Biology: Severin, 1935. S. Dak. Agr. Expt. Sta., Bul. 295: 44.

laeviceps (Ashmead). Va. (Arlington).

Idris laeviceps Ashmead, 1893. U. S. Natl. Mus., Bul. 45: 235. ठ.

Idris leviceps Dalla Torre, 1898. Cat. Hym., v. 5, p. 497. Emend.

nigricornis (Brues). Conn. (Colebrook). Ecology: From mixed colony of Myrmica sp. and Leptothorax sp.

Idris nigricomis Brues, 1903. Amer. Ent. Soc., Trans. 29: 125. ð.

pallipes (Ashmead). Fla. (Jacksonville).

Thoron pallipes Ashmead, 1887. Ent. Amer. 3: 99. ․

\section{Genus PSEUDANTERIS Fouts}

Pseudanteris Fouts, 1927. Ent. Soc. Wash., Proc. 29: 177.

Type-species: Pseudanteris insignis Fouts. Orig. desig.

Taxonomy: Masner, 1964. Acta Soc. Ent. Cechoslov. 61: 141.

insignis Fouts. Ont., Md.

Pseudanteris insignis Fouts, 1927. Ent. Soc. Wash., Proc. 29: 177..

\section{Genus GRYON Haliday}

Gryon Haliday, 1833. Ent. Mag. 1: 271.

Type-species: Gryon misellus Haliday. Monotypic.

Acolus Foerster, 1856. Hym. Stud., v. 2, pp. 100, 102. No species. -Thomson, 1859 (1858).

Ofvers. Kongl. Vetensk.-Akad., Forh. 15: 422. Two species.

Type-species: Acolus opacus Thomson. Desig. by Ashmead, 1903.

Hadronotus Foerster, 1856. Hym. Stud., v. 2, pp. 101, 105. No species. -Foerster, 1861.

Programm Realschule Aachen, p. xli. One species.

Type-species: Hadronotus exculptus Foerster. First included species.

Plastogryon Kieffer, 1908. Soc. Sci. de Bruxelles, Ann. 32: 119, 141.

Type-species: Plastogryon foersteri Kieffer. Desig. by Brues, 1909 (1908).

Psilacolus Kieffer, 1908. Soc. Sci. de Bruxelles, Ann. 32: 179, 180.

Type-species: Acolus xanthogaster Ashmead. Desig. by Kieffer, 1926.

Holacolus Kieffer, 1912. In Andre Spec. Hym. Eur. Alg., v. 11, pp. 89, 94, 106.

Type-species: Acolus opacus Thomson. Desig. by Muesebeck and Walkley, 1956.

Telenomoides Dodd, 1913. Roy. Soc. So. Austral., Trans. 37: 158, 168.

Type-species: Telenomoides flavipes Dodd. Orig. desig.

Hadronotellus Kieffer, 1917. Ent. Meddel. (2) 11: 341.

Type-species: Hadronotell ins pedester Kieffer. Orig. desig.

Hadrophanurus Kieffer, 1926. Das Tierreich, Lief. 48, pp. xvi, 15, 130.

Type-species: Telenomus? penusylvanicus Ashmead. Orig. desig.

Heterogryou Kieffer, 1926. Das Tierreich, Lief, 48, pp. xxvi, 271, 446, 448.

Type-species: Plastogryon sagax Kieffer. Desig. by Muesebeck and Walkley, 1956.

Holalcus Risbec, 1950. Trav. Lab. d'Ent. du Sect. Soudanais de Recherches Agron., p. 577. Error for Holacolus Kieffer.

The species of Gryon are parasites in the eggs of Hemiptera, especially those of the family Coreidae. 
Revision: Ashmead, 1893. U S. Natl. Mus., Bul. 45: 229-234 (North American species). - Kieffer, 1926. Das Tierreich, Lief. 48, pp. 446-473 (World fauna). - Nixon, 1934. Ann. and Mag. Nat. Hist. (10) 14: 290-313 (African species).

Taxonomy: Brues, 1910. Wis. Nat. Hist. Soc., Bul. 8: 47. -Dodd, 1914. Arch. f. Naturgesch. 80 (A): 18-21. - Masner, 1961. Acta Soc. Ent. Cechoslov. 58: 158-163.

ajax (Girault). N. C., Tenn., Ala., La., Ohio, Ill., Mo., Ariz. Host: Anasa tristis (DeG.). Hadronotus ajax Girault, 1920. U. S. Natl. Mus., Proc. 58: 181. $\$$, ð.

Biology: Schell, 1943. Ent. Soc Amer., Ann. 36: 625-635. anasae (Ashmead). Fla. Host: Anasa tristis (DeG.), Euthochtha galeator (F.). Telenomus anasae Ashmead, 1887. U. S. Dept. Agr., Div. Ent., Bul. 14: 23. ๆ, ઠ. atriscapus (Gahan). Tex. Host: Namia pallidicomis Stal, N. femorata Stal, Leptoglossus phyllopus (L.).

Hadronotus atriscapus Gahan, 1927. U. S. Natl. Mus., Proc. 71 (4): 37. ९, ઠ. brevipennis (Harrington). Que. (Hull).

Hadronotus brevipennis Harrington, 1899. Roy. Soc. Canada, Trans. (2) 5: 188. \&, o. carinatifrons (Ashmead). Fla., Tex.; West Indies. Host: Anasa tristis (DeG.), Leptoglossus gonagra ( $\mathrm{F}$.).

Hadronotus carinatifrons Ashmead, 1894. Linn. Soc. London, Jour., Zool. 25: 229, 230. $९$. coracinus (Fouts). Tex. (Brownwood).

Synteleia coracina Fouts, 1927. Ent. Soc. Wash., Proc. 29: 178. \&.

floridanus (Ashmead). Fla. Host: Acanthocephala femorata (F.).

Hadronotus floridanus Ashmead, 1887. Ent. Amer. 3: 118. $?$.

insularis (Ashmead). N. C., Fla., La., Mo.; St. Vincent, Mexico. The U. S. records communicated by L. Masner.

Hadronotus insularis Ashmead, 1894. Linn. Soc. London, Jour., Zool. 25: 230. ९, ठ.

largi (Ashmead). Calif. (Los Angeles). Host: Largus succinctus (L.).

Hadronotus largi Ashmead, 1893. U. S. Natl. Mus., Bul. 45: 230, 231. ‡, o.

leptocorisae (Howard). Fla. (Crescent City). Host: Stenocoris tipuloides (DeGeer).

Hadronotus leptocorisae Howard, 1885. In Hubbard, Insects affecting the Orange, p. 215. \&, $\delta$.

myrmecophilus (Ashmead). Va., La. Host: Alydus euriuus (Say).

Hadronotus myrmecophilus Ashmead, 1893. U. S. Natl. Mus., Bul. 45: 230, 232. ठ。.

parkeri (Fouts). Md., Mich., Mo. Host: Lygaeus kalmii Stal, Oncopeltus fasciatus (Dallas).

Hadronotus parkeri Fouts, 1920. Ent. Soc. Wash., Proc. 22: 64. \&, ठ.

Biology: Kenaga, 1944. Ent. News 55: 173-174.

pennsylvanicus (Ashmead). Pa.

Telenomus! peunsylvanicus Ashmead, 1893. U. S. Natl. Mus., Bul. 45: 144, 160. ؟.

robustus (Brues). Tex. (Austin).

Hadronotus robustus Brues, 1907. Wis. Nat. Hist. Soc., Bul. 5: 156..

rugiceps (Ashmead). D. C.

Hadronotus rugiceps Ashmead, 1893. U. S. Natl. Mus., Bul. 45: 231, 233. ๆ.

rugosus (Howard). Fla. (Rockledge). Host: Dysdercus suturellus (H.-S.), Euthochtha galeator (F.).

Hadronotus rugosus Howard, 1889. U. S. Dept. Agr., Insect Life 1: 242. \&.

xanthogaster (Ashmead). D. C.

Acolus xanthogaster Ashmead, 1893. U. S. Natl. Mus., Bul. 45: 174..

\section{Genus MIROTELENOMUS Dodd}

Mirotelenomus Dodd, 1913. Roy. Soc. So. Austral., Trans. 37: 158, 173.

Type-species: Mirotelenomus abnom is Dodd. Monotypic.

Microtelenomus Kieffer, 1926. Das Tierreich, Lief. 48, pp. 15, 19. Error for Mirotelenomus Dodd.

There are no described North American species of this genus but a specimen of an undescribed species, from California, has been referred to Mirotelenomus by Masner. 


\section{Genus EMBIDOBIA Ashmead}

Embidobia Ashmead, 1895. Trinidad Field Naturalists' Club, Jour. 2: 264.

Type-species: Embidobia urichi Ashmead. Monotypic.

Efflatounina Priesner, 1951. Inst. Fouad I du Desert, Bul. 1: 126.

Type-species: Efflatounina gyrontoides Priesner. Orig. desig.

The species of this genus are parasitic in the eggs of Embioptera. No North American species of $E m b i d o b i a$ has been described but the U. S. National Museum of Natural History has an undescribed species from Texas which has been referred to this genus by Masner.

Taxonomy: Dodd, 1939. Linn. Soc. N. S. Wales, Proc. 64: 339-344. - Masner, 1964. Acta Soc.

Ent. Cechoslov. 61: 142-144. - Masner, 1968. Natal Mus., Ann. 20: 197. - Kozlov, 1970. Ent. Obozr. 49: 213 (English transl.: Ent. Rev. 49: 119-120). - Masner and Dessart, 1972.

Canad. Ent. 104: 505-506.

\section{Genus TIPHODYTES Bradley}

Limnodytes Marchal, 1900. Soc. Ent. de France, Ann. 69: 171, 174. Preoce. by Dumeril and Bibron, 1841.

Type-species: Limnodytes gerriphagus Marchal. Orig. desig.

Tiphodytes Bradley, 1902. Canad. Ent. 34: 179. N. name.

Hungaroscelio Szabo, 1957. Folia Ent. Hungarica (n. s.) 10: 289.

Type-species: Hungaroscelio kaszabi Szabo. Orig. desig.

Members of this genus are parasitic in the eggs of certain aquatic insects.

Taxonomy: Masner and Kozlov, 1965. Acta Ent. Bohemoslov. 62: 292.

Biology: Marchal, 1900. Soc. Ent. de France, Ann. 69: 171-173. -Matheson and Crosby, 1912.

Ent. Soc. Amer., Ann. 5: 67-68. - Henriksen, 1918. Ent. Meddel. 12: 142-143. - Martin,

1928. Ent. Amer. 8 (n. s.): 131-143.

gerriphagus (Marchal). Ont., Maine, N. Y., Mich., Calif.; Europe. Host: Gerris sp., Trepobates sp.

Limuodytes gerriphagus Marchal, 1900. Soc. Ent. de France, Ann. 69: 172, 175. ๑, ð.

Hungaroscelio kaszabi Szabo, 1957. Folia Ent. Hungarica (n. s.) 10: 290. ठో.

\section{Genus THORON Haliday}

Thoron Haliday, 1833. Ent. Mag. 1: 271.

Type-species: Thoron metallicus Haliday. Monotypic.

metallicus Haliday. Que., Ont., Mass.; Europe. Host: Nepa cinerea L.

Thoron metallicus Haliday, 1833. Ent. Mag. 1: 272.

Biology: Jansson, 1939. Entomologbladet 3: 13.

\section{Genus IDRIS Foerster}

Idris Foerster, 1856. Hym. Stud., v. 2, pp. 102, 105.

Type-species: Idris flavicomis Foerster. Monotypic.

Acoloides Howard, 1890. U. S. Dept. Agr., Insect Life 2: 269.

Type-species: Acoloides saitidis Howard. Monotypic.

Megacolus Priesner, 1951. Inst. Fouad I du Desert, Bul. 1: 121. Preocc. by Cameron, 1903.

Type-species: Megacolus desertorum Priesner. Monotypic.

Philoplanes Muesebeck and Walkley, 1956. U. S. Natl. Mus., Proc. 105: 384. N. name for Megacolus: Priesner.

The species of $I d$ ris are parasitic in the egg sacs of spiders.

Taxonomy: Masner, 1961. Acta Soc. Ent. Cechoslov. 58: 163-166. -Szabo, 1965. Mus. Natl.

Hungarici, Ann. Hist.-Nat. 57: 367-373.

bicolor (Ashmead). Ont. (Ottawa).

Acoloides bicolor Ashmead, 1893. U. S. Natl. Mus., Bul. 45: 170, 172.. 
emertonii (Howard). Mass., Conn.

Acoloides emertonii Howard, 1891. U. S. Dept. Agr., Insect Life 4: 202. ₹.

floridensis (Fouts). Fla. (Orlando).

Acoloides floridensis Fouts, 1927. Ent. Soc. Wash., Proc. 29: 179. ๆ.

howardii (Ashmead). D. C., Ind., Mich.

Acoloides Howardii Ashmead, 1893. U. S. Natl. Mus., Bul. 45: 170, 171..

melleus (Ashmead). Va. (Arlington).

Acoloides melleus Ashmead, 1893. U. S. Natl. Mus., Bul. 45: 170, 172..

saitidis (Howard). Ont., Pa., Ind., Nebr., Ariz. Host: Habrocestum pulex (Hentz), Phidippus opifex (McCook).

Acoloides suiticlis Howard, 1890. U. S. Dept. Agr., Insect Life 2: 270. ๆ, ઠ.

Taxonomy: Masner, 1964. Acta Soc. Ent. Cechoslov. 61: 142.

seminiger (Ashmead). Ont. (Ottawa).

Acoloides seminiger Ashmead, 1893. U. S. Natl. Mus., Bul. 45: 170, 173..

subapterus (Ashmead). Ont. (Ottawa).

Acoloides subapterus Ashmead, 1893. U. S. Natl. Mus., Bul. 45: 170, 173..

\section{Genus CERATOBAEUS Ashmead}

Ceratobaeus Ashmead, 1893. U. S. Natl. Mus., Bul. 45: 167, 175.

Type-species: Ceratobaeus cormutus Ashmead. Orig. desig.

The species of this genus are parasitic in spider egg sacs.

binotatus Ashmead. Md., D. C., Ind., Ont.

Ceratobaeus binotatus Ashmead, 1893. U. S. Natl. Mus., Bul. 45: 176. .

cornutus Ashmead. D. C.

Ceratobaeus comutus Ashmead, 1893. U. S. Natl. Mus., Bul. 45: 176. ๆ.

\section{Genus BAEUS Haliday}

Baens Haliday, 1833. Ent. Mag. 1: 270.

Type-species: Baeus seminulum Haliday. Monotypic.

Hyperbaeus Foerster, 1856. Hym. Stud., v. 2, p. 144. Unnecessarily proposed as a n. name for Baeus Haliday, which Foerster thought to be preoccupied by Baea Commerson in

Botany.

Psilobaens Kieffer, 1926. Das Tierreich, Lief. 48, pp. xvii, 132, 151.

Type-species: Baens curvatus Kieffer. Monotypic.

The species of Baeus are spider-egg parasites.

Revision: Kieffer, 1926. Das Tierreich, Lief. 48, pp. 146-151.

Taxonomy: Gahan, 1924. U. S. Natl. Mus., Proc. 65 (4): 20. - Masner, 1965. Brit. Mus. (Nat. Hist.), Bul., Ent. Sup. 1, p. 67.

americanus Howard. Que., N. Y., Ont., Ohio.

Baeus americanus Howard, 1890. U. S. Dept. Agr., Insect Life 2: 270..

latrodecti Dozier. Md., S. C., Mo., La., Kans., Tex., Calif.; West Indies, Hawaii. Host:

Latrodectus mactans (F.).

Baeus latrodecti Dozier, 1931. Ent. Soc. Wash., Proc. 33: 27. ९, ठ.

Baeus californicus Pierce, 1939 (1938). So. Calif. Acad. Sci., Bul. 37: 101, 103. ๆ, ठ.

Biology: Pemberton and Rosa, 1940. Hawaii. Planters Rec. 44: 73-80.

minutus Ashmead. Ont. (Ottawa).

Baeus minutus Ashmead, 1893. U. S. Natl. Mus., Bul. 45: 178. ๆ.

niger Ashmead. Ont., D. C.

Baeus niger Ashmead, 1893. U. S. Natl. Mus., Bul. 45: 178. \&.

Taxonomy: Harrington, 1901. Canad. Ent. 33: 331.

piceus Ashmead. Ont. (Ottawa).

Baeus piceus Ashmead, 1893. U. S. Natl. Mus., Bul. 45: 178, 179. ․ 
rotundiventris Gahan. Ohio (Middle Bass Isl.).

Baeus rotundiventris Gahan, 1924. U. S. Natl. Mus., Proc. 65 (4): 20. ९, ठ.

zabriskiei (Ashmead). N. Y.

Acolus Zabriskiei Ashmead, 1893. U. S. Natl. Mus., Bul. 45: 175. ठ’.

\section{SUbFamily TELEASINAE}

Revision: Ashmead, 1893. U. S. Natl. Mus., Bul. 45: 180-208 (North American species).

- Kieffer, 1926. Das Tierreich, Lief. 48, pp. 173-264 (World fauna). - Dodd, 1930. Linn.

Soc. N. S. Wales, Proc. 55: 41-91 (Australian fauna). - Nixon, 1936. Ann. and Mag. Nat.

Hist. (10) 17: 114-141; 161-191 (African fauna). --Szabo, 1966. Folia Ent. Hungarica (n. s.)

19: 9-108 (Palearetic species).

\section{Genus TELEAS Latreille}

Teleas Latreille, 1809. Gen. Crust. Ins., v. 4, p. 32.

Type-species: Scelio clavicomis Latreille. Desig. by Latreille, 1810.

There are apparently no reliable published host records for any North American species of Teleas.

americanus (Ashmead). Fla. (Jacksonville).

Prosacantha americana Ashmead, 1887. Ent. Amer. 3: 100. ․

canadensis Harrington. Que. (Hull).

Teleas canadensis Harrington, 1899. Canad. Ent. 31: 78. ${ }^{\circ}$.

coxalis Ashmead. Va. (Arlington).

Teleas coxalis Ashmead, 1893. U. S. Natl. Mus., Bul. 45: 199. .

lineaticeps Ashmead. D. C., Va.

Teleas lineaticeps Ashmead, 1893. U. S. Natl. Mus., Bul. 45: 198, 199. §.

mandibularis (Ashmead). Fla. (Jacksonville).

Prosacantha mandibularis Ashmead, 1887. Ent. Amer. 3: 117. ?.

pallidipes Ashmead. N. J.

Teleas pallidipes Ashmead, 1893. U. S. Natl. Mus., Bul. 45: 199, 200. ठ.

\section{Genus TRIMORUS Foerster}

Trimorus Foerster, 1856. Hym. Stud., v. 2, pp. 101, 104.

Type-species: Gryon namno Walker. Desig. by Ashmead, 1903.

Trichasius Provancher, 1887. Addit. Corr. Faune Ent. Canada Hym., p. 209.

Type-species: Trichasins clavatus Provancher. Monotypic.

Hoplogryon Ashmead, 1893. U. S. Natl. Mus., Bul. 45: 181, 200.

Type-species: Prosacantha minutissima Ashmead. Orig. desig.

Paragryon Kieffer, 1908. Soc. Sci. de Bruxelles, Ann. 32: 189, 199.

Type-species: Paragryon pedestris Kieffer. Desig. by Kieffer, 1926.

Allogryon Kieffer, 1910. In Wytsman, Gen. Ins., fasc. 80B, p. 95.

Type-species: Prosacantha caraborum Riley. Desig. by Muesebeck and Walkley, 1951.

Hemimorus Cameron, 1912. Soc. Ent. 27: 77.

Type-species: Hemimorus clavicomis Cameron. Monotypic.

The species of this genus are very numerous but most of the described North American forms are known only from single specimens. Practically nothing is known concerning the biology and host relations of the group, but the single apparently reliable rearing record suggests parasitization in eggs of Carabidae.

Revision: Fouts, 1948. U. S. Natl. Mus., Proc. 98: 91-148 (North American species).

Taxonomy: Maneval, 1937. Mus. Roy. d'Hist. Nat. de Belg., Bul. 13 (22): 17-27. -Masner,

1964. Acta Soc. Ent. Cechoslov. 61: 144.

aeneus (Provancher). Ont. (Ottawa).

Spalangia aenea Provancher, 1887. Addit. Corr. Faune Ent. Canada Hym., p. 200. ठ. 
Taxonomy: Masner, 1969. Nat. Canad. 96: 781.

amabilis Fouts. B. C. (Chilliwack).

Trimorus amabilis Fouts, 1948. U. S. Natl. Mus., Proc. 98: 102, 146..

annulicornis (Ashmead). D. C., Miss.

Prosacantha annulicorn is Ashmead, 1893. U. S. Natl. Mus., Bul. 45: 186, 188. .

apterus Fouts. D. C.

Trimorns apterus Fouts, 1948. U. S. Natl. Mus., Proc. 98: 97. 102..

bethunei (Sanders). Ill., Iowa, La. Ecology: In nest of Formica subrufa Roger.

Hoployryou Bethunei Sanders, 1910. Canad. Ent. 42: 15. ठ.

bilineatus (Ashmead). D. C.

Prosacantha bilinenta Ashmead, 1893. U. S. Natl. Mus., Bul. 45: 186, 194. \&.

borealis (Ashmead). Que., Ont.

Acolus borealis Ashmead, 1888. Canad. Ent. 20: 50. $\subsetneq$.

brevicarinatus Fouts. Md., D. C., Tex.

Trimorus brevicarinatus Fouts, 1948. U. S. Natl. Mus., Proc. 98: 101, 134. ๆ.

bruesi (Kieffer). Ont., Conn., N. Y.

Prosacantha brachyptere Ashmead, 1888. Canad. Ent. 20: 50. . Preoce. by Thomson, 1859.

Hoployryon bruesi Kieffer, 1910. In Wytsman, Gen. Ins., fasc. 80 B, p. 96 . N. name.

Hoployryon dolichopterus Kieffer, 1926. Das Tierreich, Lief. 48, pp. 189, 216. N. name.

brunneipes Fouts. N. Y. (McLean Bogs).

Trimorus brunneipes Fouts, 1948. U. S. Natl. Mus., Proc. 98: 100, 125. ?.

ealifornicus (Ashmead). Calif. (Santa Cruz Mts.).

Prosacantha californice Ashmead, 1893. U. S. Natl. Mus., Bul. 45: 186, 190..

canadensis (Ashmead). Ont. (Ottawa).

Acolus canadensis Ashmead, 1888. Canad. Ent. 20: 50. ?.

caraborum (Riley). Que., D. C., Va. Host: Chlaenius impunctifrons Say.

Prosacautha caraborum Riley, 1893. In Ashmead, U. S. Natl. Mus., Bul. 45: 186, 191. + , o.

elaripennis (Ashmead). Va.

Hoplogryon claripennis Ashmead, 1893. U. S. Natl. Mus., Bul. 45: 201, 203..

clarus Fouts. B. C. (Hollyburn).

Trimorus clarus Fouts, 1948. U. S. Natl. Mus., Proc. 98: 100, 131. ?.

clavatus (Provancher). Ont. (Ottawa).

Trichasius clavatus Provancher, 1887. Addit. Corr. Faune Ent. Canada Hym., p. 209. $\subsetneq$.

Taxonomy: Masner, 1969. Nat. Canad. 96: 783.

columbianus (Ashmead). D. C.

Prosacantha columbiana Ashmead, 1893. U. S. Natl. Mus., Bul. 45: 186, 194..+

concinnus Fouts. N. Y. (Suffern).

Hoplogryon coxalis Fouts, 1925. Ent. Soc. Wash., Proc. 27: 103. \&. Preoce. by Thomson, 1859.

Trimorus concinnus Fouts, 1948. U. S. Natl. Mus., Proc. 98: 101, 134. N. name.

contractus Muesebeck, n. name. Que., Ont.

Gryon flavipes Ashmead, 1893. U. S. Natl. Mus., Bul. 45: 206, 208. ๆ. Preocc. in Trimorus by Haliday, 1830 .

crassellus Fouts. Md., D. C.

Gryon columbianus Ashmead, 1893. U. S. Natl. Mus., Bul. 45: 206, 208. . Preoce. by

Ashmead, 1893.

Trimorus crassellus Fouts, 1948. U. S. Natl. Mus., Proc. 98: 98, 105. N. name.

crassiceps Fouts. B. C. (Hollyburn).

Trimorus crassiceps Fouts, 1948. U. S. Natl. Mus., Proc. 98: 98, 107. ₹.

crassicornis (Kieffer). Calif., Nev.

Hoplogryon crassicarnis Kieffer, 1906 (1905). Berlin. Ent. Ztschr. 50: 262. ๆ, ð.

crosbyi Fouts. N. Y. (Wolcott).

Trimorts crosbyi Fouts, 1948. U. S. Natl. Mus., Proc. 98: 98, 114. \&. 
distinctus Fouts. Tex. (Brownwood).

Trimorus distinctus Fouts, 1948. U. S. Natl. Mus., Proc. 98: 99, 115. ठ.

erythrogaster Fouts. Va. (Arlington).

Trimorus erythrogaster Fouts, 1948. U. S. Natl. Mus., Proc. 98: 98, 113. ठ.

erythropus (Ashmead). D. C.

Prosacantha erythropus Ashmead, 1893. U. S. Natl. Mus., Bul. 45: 187, 195..

exilis Fouts. B. C. (Chilliwack).

Trimorus exilis Fouts, 1948. U. S. Natl. Mus., Proc. 98: 98, 107..

finitimus Fouts. B. C. (Chilliwack).

Trimorus finitimus Fouts, 1948. U. S. Natl. Mus., Proc. 98: 98, 110..+

flavicoxa (Ashmead). Va.

Prosacantha flavicoxa Ashmead, 1893. U. S. Natl. Mus., Bul. 45: 187, 196..

flavocinctus Fouts. N. Y. (McLean Bogs).

Trimorus flavocinctus Fouts, 1948. U. S. Natl. Mus., Proc. 98: 100, 131. ․

flavopetiolatus (Ashmead). D. C., Va.

Prosacantha flacopetiolata Ashmead, 1893. U. S. Natl. Mus., Bul. 45: 187, 196. ๆ, ઠ๋.

formosus Fouts. B. C. (Chilliwack).

Trimorns formosus Fouts, 1948. U. S. Natl. Mus., Proc. 98: 97, 103..+

fumipennis (Ashmead). D. C., Fla.

Gryon fumipennis Ashmead, 1893. U. S. Natl. Mus., Bul. 45: 206. ㅇ.

fuscipennis (Ashmead). Fla. (Jacksonville).

Prosacantha fuscipennis Ashmead, 1887. Ent. Amer, 3: 117. ठ.

gracilicornis (Ashmead). "Carolina".

Prosacantha gracilicorn is Ashmead, 1893. U. S. Natl. Mus., Bul. 45: 187, 193. ․

grandis (Brues). N. Y., Md.

Hoplogryon grandis Brues, 1907. Wis. Soc. Nat. Hist., Bul. 5: 102..

improcerus Fouts. B. C. (Chilliwack).

Trimorus improcerus Fouts, 1948. U. S. Natl. Mus., Proc. 98: 99, 119,.

jucundus Fouts. Md. (Glen Echo).

Trimorus jucundus Fouts, 1948. U. S. Natl. Mus., Proc. 98: 100, 127..

kansasensis (Gahan). Kans. (Manhattan).

Hoplogryon kansasensis Gahan, 1912. Ent. Soc. Wash., Proc. 14: 7. ๆ.

leonardi Fouts. N. Y. (McLean Bogs).

Trimorus leonardi Fouts, 1948. U. S. Natl. Mus., Proc. 98: 100, 128..

lepidus Fouts. B. C. (Hollyburn).

Trimorus lepilus Fouts, 1948. U. S. Natl. Mus., Proc. 98: 102, 147..

linellii (Ashmead). N. Y. (Long Isl.).

Prosacantha Linellii Ashmead, 1893. U. S. Natl. Mus., Bul. 45: 187, 195...

lionotus Fouts. B. C. (Hollyburn).

Trimorus lionotus Fouts, 1948. U. S. Natl. Mus., Proc. 98: 99, 118. ठ์.

longipennis (Ashmead). Ont., Md., D. C., Va.

Prosacantha laevifions Ashmead, 1893. U. S. Natl. Mus., Bul. 45: 186, 190. .. Preoce. by

Thomson, 1858.

Hoplogryon longipennis Ashmead, 1893. U. S. Natl. Mus., Bul. 45: 201, 202..

Hoplogryon pteridis Ashmead, 1893. U. S. Natl. Mus., Bul. 45: 201, 203..

Prosacantha levis Dalla Torre, 1898. Cat. Hym., v. 5, p. 507. N. name for P. laevifrons Ashmead.

macrocerus (Ashmead). Fla. (Jacksonville).

Prosacantha macrocera Ashmead, 1887. Ent. Amer. 3: 117., ơ.

marylandicus (Ashmead). Md., D. C.

Prosacantha marylandica Ashmead, 1893. U. S. Natl. Mus., Bul. 45: 186, 193. \&, ơ.

melanopus (Ashmead). Ont., B. C.

Prosacantha melanopus Ashmead, 1893. U. S. Natl. Mus., Bul. 45: 186, 189..+ 
minor Fouts. Va. (Rosslyn).

Trimorus minor Fouts, 1948. U. S. Natl. Mus., Proc. 98: 101, 142..+

minutissimus (Ashmead). Fla. (Jacksonville).

Prosacantha minutissima Ashmead, 1887. Ent. Amer. 3: 117. \&.

minutus Fouts. Md. (Glen Echo).

Trimorus minutus Fouts, 1948. U. S. Natl. Mus., Proc. 98: 99, 117..

monticola Fouts. Pa. (Mount Holly Springs).

Trimorns monticola Fouts, 1948. U. S. Natl. Mus., Proc. 98: 101, 140. ?.

nanus (Ashmead). Utah (Utah Lake).

Prosacantha nana Ashmead, 1893. U. S. Natl. Mus., Bul. 45: 186, 191. \&.

nigricoxa Fouts. B. C. (Chilliwack).

Trimorns nigricoxa Fouts, 1948. U. S. Natl. Mus., Proc. 98: 101, 137..

nigripes (Ashmead). Oreg.

Prosacantha nigripes Ashmead, 1893. U. S. Natl. Mus., Bul. 45: 186, 188. ‡, ठ.

nigrobrunneus Fouts. Md. (Sudley).

Trimorus nigrobrunneus Fouts, 1948. U. S. Natl. Mus., Proc. 98: 102, 144.. nitidus Fouts. B. C.

Trimorus nitidus Fouts, 1948. U. S. Natl. Mus., Proc. 98: 98, 106..

notabilis Fouts. B. C. (Chilliwack).

Trimorus notabilis Fouts, 1948. U. S. Natl. Mus., Proc. 98: 99, 120..

obscuripes (Ashmead). Ont., D. C.

Hoplogryon obscuripes Ashmead, 1893. U. S. Natl. Mus., Bul. 45: 202, 204..

obscurus Fouts. B. C. (Chilliwack).

Trimorns obscurus Fouts, 1948. U. S. Natl. Mus., Proc. 98: 101, 139..

pallidipes (Ashmead). Va. (Arlington).

Xenomerus pallidipes Ashmead, 1893. U. S. Natl. Mus., Bul. 45: 184..

pennsylvanicus (Ashmead). "Penna."

Prosacantha pennsylvanica Ashmead, 1893. U. S. Natl. Mus., Bul. 45: 186, 189..

percurrens Fouts. B. C. (Hollyburn).

Trimorus percurrens Fouts, 1948. U. S. Natl. Mus., Proc. 98: 99, 116. ठ.

perspicuus Fouts. B. C. (Hollyburn).

Trimorus perspicuus Fouts, 1948. U. S. Natl. Mus., Proc. 98: 102, 145. ९.

petiolatus Fouts. N. Y. (Cinnamon Lake).

Trimorus petiolatus Fouts, 1948. U. S. Natl. Mus., Proc. 98: 100, 130. ๆ.

pictus Fouts. B. C. (Hollyburn).

Trimorus pictus Fouts, 1948. U. S. Natl. Mus., Proc. 98: 99, 119..

pleuralis (Ashmead). Pa., D. C.

Prosacantha pleuralis Ashmead, 1893. U. S. Natl. Mus., Bul. 45: 186, 195. \&.

pulchellus Fouts. B. C. (Chilliwack).

Trimorus pulchellus Fouts, 1948. U. S. Natl. Mus., Proc. 98: 101, 140. \&.

pulchricornis Fouts. Md. (Glen Echo).

Trimor'ts pulchricomis Fouts, 1948. U. S. Natl. Mus., Proc. 98: 98, 104. \&.

punctiger Fouts. Md. (Glen Echo).

Trimorus punctiger Fouts, 1948. U. S. Natl. Mus., Proc. 98: 101, 135. $\uparrow$.

punctithorax Fouts. B. C. (Chilliwack).

Trimorus punctithorax Fouts, 1948. U. S. Natl. Mus., Proc. 98: 98, 108. .

punctiventris (Ashmead). D. C., Va.

Prosacantha punctiventris Ashmead, 1893. U. S. Natl. Mus., Bul. 45: 186, 192. \&. pusillus (Ashmead). Fla. (Jacksonville).

Prosaca utha pusilla Ashmead, 1893. U. S. Natl. Mus., Bul. 45: 186, 192. \&. repentinus Fouts. Md. (Cabin John).

Trimorus repentinus Fouts, 1948. U. S. Natl. Mus., Proc. 98: 99, 124. ‡.

reticulatus Fouts. Md. (Glen Echo).

Trimorus reticulatus Fouts, 1948. U. S. Natl. Mus., Proc. 98: 101, 143. \&. 
robustus Fouts. B. C. (Chilliwack).

Trimorus robustus Fouts, 1948. U. S. Natl. Mus., Proc. 98: 98, 110..

rubripes Fouts. Md. (Glen Echo).

Trimorus rubripes var. rubripes Fouts, 1948. U. S. Natl. Mus., Proc. 98: 100, 122. ठ。.

rubripes var. rufocoxalis Fouts. Md. (Glen Echo).

Trimorus rubripes var. rufocoxulis Fouts, 1948. U. S. Natl. Mus., Proc. 98: 99, 123. ठ。.

rufocinctus Fouts. Md. (Glen Echo).

Trimorus rufocinctus Fouts, 1948. U. S. Natl. Mus., Proc. 98: 100, 130. ؟.

rufosignatus (Kieffer). N. Y., D. C.

Hoplogryon rufipes Ashmead, 1893. U. S. Natl. Mus., Bul. 45: 202, 205. \&. Preoce. by Thomson, 1859.

Hoplogryou rufosignatus Kieffer, 1910. In Wytsman, Gen. Ins., fasc. 80B, p. 97. N. name.

Hoplogryou ashmeudiunus Kieffer, 1926. Das Tierreich, Lief. 48, p. 215. N name.

schwarzii (Ashmead). D. C.

Prosacentha Schurerii Ashmead, 1893. U. S. Natl. Mus., Bul. 45: 186, 192 . \&.

sculpturatus Fouts. Md. (Glen Echo).

Trimorus sculpturetus Fouts, 1948. U. S. Natl. Mus., Proc. 98: 100, 129. ․

silvaticus Fouts. B. C. (Hollyburn).

Trimorus sileaticus Fouts, 1948. U. S. Natl. Mus., Proc. 98: 101, 132..

solitarius (Ashmead). Ont. (Ottawa).

Hoplogryou soliturius Ashmead, 1893. U. S. Natl. Mus., Bul. 45: 202, 205. ठ。.

striatifrons (Ashmead). Fla. (Jacksonville).

Prosacuntha striutifrous Ashmead, 1893. U. S. Natl. Mus., Bul. 45: 187, 188. ठ์.

striativentris (Ashmead). D. C.

Prosacantha striaticentris Ashmead, 1893. U. S. Natl. Mus., Bul. 45: 187, 197. ठ.

striopunctatus Fouts. Md., Pa.

Trimorus striopunctutus Fouts, 1948. U. S. Natl. Mus., Proc. 98: 98, 111. ๆ.

subapterus Fouts. B. C. (Chilliwack).

Trimorus subapterus Fouts, 1948. U. S. Natl. Mus., Proc. 98: 98, 109..

sulcatus (Kieffer). Tex.

Hoplogryou sulcatus Kieffer, 1904. Arkiv for Zool. 1: 538. §.

tenuicornis (Kieffer). Wash., Calif.

Hoplogryon tenuicomis Kieffer, 1906 (1905). Berlin. Ent. Ztschr. 50: 263. ठ。.

texanus Fouts. Tex. (Brownwood).

Trimorus texauus Fouts, 1948. U. S. Natl. Mus., Proc. 98: 101, 141. \$.

tripartitus (Kieffer). Pa. (Jeannette).

Hoplogryon tripartitum Kieffer, 1908. Soc. Sci. de Bruxelles, Ann. 32: 33. ơ.

utahensis (Ashmead). Utah (Park City).

Prosacautha utahensis Ashmead, 1893. U. S. Natl. Mus., Bul. 45: 186, 189. \&.

varius Fouts. Md. (Cabin John).

Trimorus carius Fouts, 1948. U. S. Natl. Mus., Proc. 98: 99, 120. ठ์.

vinctus Fouts. Iowa (Ames).

Hoplogryou similis Fouts, 1924. Ent. Soc. Wash., Proc. 26: 160 ․ Preoce. by Thomson, 1859.

Trimorus rinctus Fouts, 1948. U. S. Natl. Mus., Proc. 98: 101, 140. N. name. virginiensis (Kieffer). Va.

Hoplogiyou tibialis Ashmead, 1893. U. S. Natl. Mus., Bul. 45: 201, 203. + . Preoce. by

Foerster, 1841.

Hoplogryou virginiensis Kieffer, 1910. In Wytsman, Gen. Ins., fasc. 80B, p. 98. N. name.

whittakeri Fouts. B. C. (Chilliwack).

Trimorus whittakeri Fouts, 1948. U. S. Natl. Mus., Proc. 98: 101, 138. \&.

xanthognathus (Ashmead). Fla. (Jacksonville).

Prosacantha xanthognatha Ashmead, 1893. U. S. Natl. Mus., Bul. 45: 187, 197. o. 
xanthopus Fouts. Md. (Glen Echo).

Trimorus xanthopus Fouts, 1948. U. S. Natl. Mus., Proc. 98: 100, 126. \&.

\section{Genus TRISACANTHA Ashmead}

Trisacantha Ashmead, 1887. Ent. Amer. 3: 117.

Type-species: Trisacantha americana Ashmead. Monotypic.

Pentacantha Ashmead, 1888. Canad. Ent. 20: 51. Preocc. by Stal, 1871.

Type-species: Pentacantha canadensis Ashmead. Monotypic.

Trissacentha Ashmead, 1893. U. S. Natl. Mus., Bul. 45: 180, 182. Emend.

Propentacantha Kieffer, 1926. Das Tierreich, Lief. 48, pp. xxi, 173, 241. N. name for Peutacantha Ashmead.

Host relationships of members of this group are unknown.

americana Ashmead. Fla.

Trisacantha americana Ashmead, 1887. Ent. Amer. 3: 117. o.

canadensis (Ashmead). Ont., Kans.

Pentacantha Canadensis Ashmead, 1888. Canad. Ent. 20: 51. ?.

longicornis (Kieffer). Tex.

Pentacantha longicomis Kieffer, 1904. Arkiv for Zool. 1: 536. ठ.

rufitarsis (Kieffer). Calif. (Santa Clara).

Pentucantha rufitarsis Kieffer, 1906 (1905). Berlin. Ent. Ztschr. 50: 263. \&.

rugosa Ashmead. Va. (Arlington).

Trissacantha rugosa Ashmead, 1893. U. S. Natl. Mus., Bul. 45: 183. ठ.

striaticeps Kieffer. Tex.

Trissacantha striaticeps Kieffer, 1904. Arkiv for Zool. 1: 535. ठ.

\section{SUBFAMILy TELENOMINAE}

Most of the species of this subfamily develop as parasites in the eggs of Lepidoptera or Hemiptera but a few parasitize the eggs of Diptera and Neuroptera.

Revision: Ashmead, 1893. U. S. Natl. Mus., Bul. 45: 138-166 (Nearctic species). -Dodd, 1913.

Roy. Soc. So. Austral., Trans. 37: 157-174 (Australian species). - Kieffer, 1926. Das

Tierreich, Lief. 48, pp. 15-131 (World fauna). - Nixon, 1935. Roy. Ent. Soc. London, Trans.

83: 73-103 (African species).

Taxonomy: Ashmead, 1903. N. Y. Ent. Soc., Jour. 11: 87-88. - Nixon, 1937. Ann. and Mag.

Nat. Hist. (10) 20: 113-116. - Masner, 1961. First Internatl. Conf. Ins. Path. and Biol.

Control, Trans. pp. 375-381.

\section{Genus ARADOPHAGUS Ashmead}

Aradophagus Ashmead, 1893. U. S. Natl. Mus., Bul. 45: 138, 166.

Type-species: Aradophagus fasciatus Ashmead. Monotypic.

Taxonomy: Masner and Kozlov, 1965. Acta Ent. Bohemoslov. 62: 287-290.

fasciatus Ashmead. Mass., Fla., Tex.; Europe. Host: Mezira granulata (Say)?

Aradophagus fasciatus Ashmead, 1893. U. S. Natl. Mus., Bul. 45: 166. + , o.

\section{Genus EUMICROSOMA Gahan}

Eumicrosoma Gahan, 1913. U. S. Natl. Mus., Proc. 46: 442.

Type-species: Eumicrosoma beneficum Gahan. Orig. desig.

Baeoneurella Dodd, 1914. Roy. Soc. So. Austral., Trans. 38: 124.

Type-species: Baeoneura giraulti Dodd. Orig. desig.

Nardo Nixon, 1938. Ann and Mag. Nat. Hist. (11) 1: 278.

Type-species: Nardo cumaeus Nixon. Orig. desig.

Szelenyiella Szabo, 1957. Opuse. Zool. Inst. Zoosyst. Univ. Budapest, 2: 49.

Type-species: Szelenyiella platythoracis Szabo. Orig. desig. 
Taxonomy: Masner, 1965. Brit. Mus. (Nat. Hist.), Bul., Ent., Sup. 1, p. 108. - Masner and Kozlov, 1965. Acta Ent. Bohemoslov. 62: 291-292.

beneficum Gahan. Va., Fla., Ill., Iowa, S. Dak., Kans., Okla., Tex.; Brit. W. Indies; USSR. Host: Blissus leucopterus leucopterus (Say), B. leucopterus hirtus Mont., B. insularis Barber.

Eumicrosoma benefica Gahan, 1913. U. S. Natl. Mus., Proc. 46: 442. ?, o'.

Biology: McCulloch, 1915. Jour. Econ. Ent. 8: 248-260. - Dicke, 1937. Jour. Econ. Ent. 30: 376. bicolor (Ashmead). Va., Mich. Ecology: From unknown eggs on Poa compressa.

Baeoneura bicolor Ashmead, 1893. U. S. Natl. Mus., Bul. 45: 235. ‡.

\section{Genus TELENOMUS Haliday}

Telenomus Haliday, 1833. Ent. Mag. 1: 271.

Type-species: Telenomus brachialis Haliday. Desig. by Ashmead, 1893.

Hemisius Westwood, 1833. London, Edinb. and Dublin Phil. Mag. and Jour. (3) 2: 445.

Type-species: Hemisius minutus Westwood. Monotypic.

Phanurus Thomson, 1860. Ofvers. Kongl. Vetensk.-Akad., Forh. 17: 169, 172.

Type-species: Phanurus angustatus Thomson. Desig. by Ashmead, 1893.

Liophanurus Kieffer, 1912. In Andre, Spec. Hym. Eur. Alg., v. 11, pp. 9, 37.

Type-species: Telenomus spilosomatis Ashmead. Orig. desig.

Prophanurus Kieffer, 1912. In Andre, Spec. Hym. Eur. Alg., v. 11, pp. 9, 37.

Type-species: Teleas phalaenamm Nees. Orig. desig.

Aholcus Kieffer, 1913. In Alluaud and Jeannel, Voy. Afr. Orient., v. 1, p. 4.

Type-species: Aholeus monticola Kieffer. Orig. desig.

Neotelenomus Dodd, 1913. Roy. Soc. So. Austral., Trans. 37: 158, 171.

Type-species: Neotelenomus anthereae Dodd. Orig. desig.

Paridris Brethes, 1917 (not Kieffer, 1908). Zool. Aplicada, An. 4: 27.

Type-species: Paridris chilensis Brethes. Monotypic.

Revision: Ashmead, 1893. U. S. Natl. Mus., Bul. 45: 139-161 (North American species).

- Kieffer, 1926. Das Tierreich, Lief. 48, pp. 24-91 (World fauna). -Nixon, 1935. Roy. Ent.

Soc. London, Trans. 83: 74-92 (African species).

Taxonomy: Mayr, 1879. Zool.-Bot. Gesell. Wien, Verhandl. 29: 697-714. - Nixon, 1937. Ann. and Mag. Nat. Hist. (10) 20: 113-127. - Nixon, 1940. Ann. and Mag. Nat. Hist. (11) 6:

497-512. - Risbec, 1950. Trav. Lab. d'Ent. du Sect. Soudanais de Recherches Agron. 2, pp. 556-566. - Masner, 1961. Acta Soc. Ent. Cechoslov. 58: 166-167. - Masner, 1965. Brit. Mus.

(Nat. Hist.), Bul. Ent., Sup. 1, p. 109.

alsophilae Viereck. N. S., Mass., Conn., N. Y., Pa., N. J., Va., N. C., Wis., Minn., Man., Sask.

Host: Alsophila pometaria (Harris).

Telenomus alsophilne Viereck, 1924. Canad. Ent. 56: 111. ?, o.

Biology: Schread, 1945. Conn. Agr. Expt. Sta., Bul. 488: 416-418. -Ciesla, 1965. Jour. Econ.

Ent. 58: 702-704. - Rauschenberger and Talerico, 1967. Jour. Econ. Ent. 60: 881-882.

arzamae Riley. D. C., La. Host: Arzama densa (Wlkr.).

Telenomus arzamae Riley, 1893. In Ashmead, U. S. Natl. Mus., Bul. 45: 144, 157. ‡, §.

bakeri Kieffer. Calif. (San Mateo).

Telewomus Bakeri Kieffer, 1906 (1905). Berlin. Ent. Ztschr. 50: 261. ठँ.

bifidus Riley. D. C., Wis., Mo. Host: Hyphantria cunea (Drury).

Telenomus bifidus Riley, 1887. U. S. Dept. Agr., Ann. Rpt. for 1886, p. 531. \&, ठ.

californicus Ashmead. N. Mex., Idaho, Nev., Oreg., Calif. Host: Orgyia sp., O. pseudotsugata (McD.).

Telenomus californicus Ashmead, 1893. U. S. Natl. Mus., Bul. 45: 143, 150..

catalpae Muesebeck. Md., Va., Ga., Ark. Host: Ceratomia catalpne (Bdvl.).

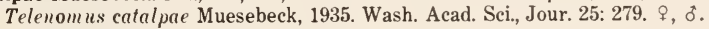

chrysopae Ashmead. D. C., Va., S. C., Fla., Ark., Minn., Kans. Host: Chrysopa spp., Lomamyia flavicornis (Wlkr.).

Telenomus chrysopae Ashmead, 1893. U. S. Natl. Mus., Bul. 45: 145, 159. ठ̌. 
clisiocampae Riley. Transition and Upper Austral Zones. Host: Malacosoma fragile (Stretch), $M$. disstria (Hbn.), M. amerieanum (F.).

Telenomus clisiocampae Riley, 1893. In Ashmead, U. S. Natl. Mus., Bul. 45: 145, 160. ‡, o.

Biology: Hodson, 1939. Ent. Soc. Amer., Ann. 32: 131-136. - Langston, 1957. Univ. Calif.

Pub., Ent. 14: 30-31.

coelodasidis Ashmead. Que., N. H., N. Y., D. C. Host: Schizura leptinoides (Grote), Heteroet!mpa guttiritta (Wlkr.).

Telenomus coelodusidlis Ashmead, 1893. U. S. Natl. Mus., Bul. 45: 145, 159. o.

coloradensis Crawford. Colo., Idaho, Wash. Host: Orgyia oslari Barnes, O. psecudotsuguta (McD.).

Telenomus colorulensis Craw ford, 1910 (1909). Ent. Soc. Wash., Proc. 11: 206. ๆ, ठ.

dalmani (Ratzeburg). Ont., Maine, Mass., N. Y.; Europe. Host: Notolophus antiquns (L.), Orgyia leucostigma (J. E. Smith).

Teleas Dulmanni Ratzeburg, 1844. Ichn. d. Forstins., v. 1, p. 185. \&, ð.

Telenomus Dulmani Mayr, 1879. Zool.-Bot. Gesell. Wien, Verhandl. 29: 699, 708. Emend.

Telenomus decorutor Mayr, 1879. Zool.-Bot. Gesell. Wien, Verhandl. 29: 709.

Telenomus dulmanii Dalla Torre, 1898. Cat. Hym., v. 5, p. 514. Emend.

Telenomus Orgyiue Fitch, 1863 (1862). N. Y. State Agr. Soc., Trans. 22: 679.

Telenomus fiskei Brues, 1910. Psyche 17: 106. $\%$, o.

Taxonomy: Wilcox, 1920. Psyche 27: 80-81.

dimmocki Ashmead. N. H., N. Y., Ga., Fla., Ohio, Kans., Tex. Host: Cosmopepla bimuculata (Thomas), Podisus maculie'utris (Say), Thyenta sp.

Telenomus dimmochi Ashmead, 1898. Ent. Soc. Wash., Proc. 4: 155. ९, ठ.

dolichocerus (Ashmead). Fla., Okla. Host: Emesaya brevipennis (Say).

Teleas dolichoeerns Ashmead, 1887. Ent. Amer. 3: 100. ठ.

emersoni (Girault). Ont., La., Ark., Tex., Sask., Nev., Ariz., Calif. Host: Tabanus lineola F., T. punctifer O. S., Chrysops aestuans Wulp, C. mitis O. S.

Phanurus emersoni Girault, 1916. Canad. Ent. 48: 150. \&, o.

Biology: Parman, 1928. U. S. Dept. Agr., Cir. 18: 1-6.

fimbriatus Kieffer. Wis.

Telenomus fimbriatus Kieffer, 1904. Arkiv for Zool. 1: 539. ․

flavipes (Ashmead). Va., Ind.

Phamums flavipes Ashmead, 1893. U. S. Natl. Mus., Bul. 45: 140, 141. §.

floridanus (Ashmead). Fla.

Phanurus floridanus Ashmead, 1893. U. S. Natl. Mus., Bul. 45: 140. ?.

geometrae Ashmead. N. B., N. H., D. C. Host: Geometrid on wild cherry.

Telenomus geometrae Ashmead, 1893. U. S. Natl. Mus., Bul. 45: 144, 157. \&, o.

gnophaelae Ashmead. Wash. (Easton). Host: Gnophaela latipennis (Bdvl.).

Telenomus gnophaclae Ashmead, 1893. U. S. Natl. Mus., Bul. 45: 143, 149. ?, ठ์.

goniopis Crawford. Mass., Md., Ark. Host: Goniops chrysocoma (O. S.).

Telenomus goviopis Crawford, 1913. U. S. Natl. Mus., Proc. 45: 243. ₹, o.

gossypiicola Ashmead. La. (Concordia Parish).

Telenomus gossypiicola Ashmead, 1893. U. S. Natl. Mus., Bul. 45: 144, 156. ๆ.

gracilicornis Ashmead. Que., Ont.

Telenomus gracilicornis Ashmead, 1893. U. S. Natl. Mus., Bul. 45: 143, 149..

graptae Howard. Que., N. H., D. C., Ill., Colo., Ariz. Host: Polygonia interrogationis (F.), P. progne Cram., Nymphalis antiopa (L.), Lycaena phlaeas hypophlaeas (Bdvl.), L. thoea Guerin, Plebejus icarioides Bdvl., Polites themistocles (Latr.), P. taumas (F.), Vanessa atalanta (L.),

Telenomus graptae Howard, 1889. In Scudder, Butterflies East. U. S., p. 1896. \&, §. heliothidis Ashmead. Kans., Tex., La., Fla.; Cuba. Host: Heliothis zel (Boddie), Spodoptera fingiperda (J. E. Smith).

Telenomus heliothidis Ashmead, 1893. U. S. Natl. Mus., Bul. 45: 144, 152. ?.

Biology: Winburn and Painter, 1932. Kans. Ent. Soc., Jour. 5: 11-15. 
heracleicola Brues. Wash. (Pullman). Host: Butterfly eggs.

Telenomus heracleicola Brues, 1906. Wis. Nat. Hist. Soc., Bul. 4: 148. ?, o.

hubbardi Ashmead. Fla. (Centerville). Host: Reduviidae.

Telenom us Hubbarli Ashmead, 1893. U. S. Natl. Mus., Bul. 45: 143, 146. \&.

hullensis Harrington. Que. (Hull).

Telenomus hullensis Harrington, 1899. Roy. Soc. Canada, Trans. (2) 5: 182..

ichthyurae Ashmead. Maine, D. C., Mich., Miss., Mo., Okla., Tex. Host: Ichthyura inclusa Hbn., Datana angnsii G. and R., D. integerrima G. and R.

Telenomus ichth yurce Ashmead, 1893. U. S. Natl. Mus., Bul. 45: 144, 153. \&, o.

infuscatipes (Ashmead). Fla. (Jacksonville).

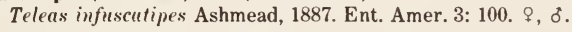

koebelei Ashmead. Calif. (Alameda).

Telenomus Koebelei Ashmead, 1893. U. S. Natl. Mus., Bul. 45: 143, 147..

lavernae Ashmead. D. C. Host: Psacaphora luciferella (Clem.).

Telenomus lavernue Ashmead, 1893. U. S. Natl. Mus., Bul. 45: 144, 158. \&.

longicornis Ashmead. N. Y. (Saranac).

Telenomus longicornis Ashmead, 1901. N. Y. State Mus., Bul. 47: 587. o.

maculipennis Ashmead. Fla. (Jacksonville).

Telenomus muculipenris Ashmead, 1893. U. S. Natl. Mus., Bul. 45: 144, 155..

minimus Ashmead. Va., Ill. Host: Psendaletia unipuncta (Haw.).

Telenomus minimus Ashmead, 1893. U. S. Natl. Mus., Bul. 45: 144, 152. \&.

nigriscapus Ashmead. Mich., Ill. Host: Diacrisin virginica (F.).

Telenomus nigriscapus Ashmead, 1893. U. S. Natl. Mus., Bul. 45: 143, 147. ๆ, ठ.

noctuae Ashmead. D. C. Host: Unknown noctuid.

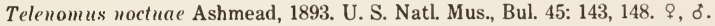

opacus (Howard). Calif. (Los Angeles).

Thoron opacus Howard, 1889. U. S. Dept. Agr., Insect Life 1: 268. ठే.

ovivorus (Ashmead). Ont., D. C., Ill., Kans., Idaho, Utah. Host: Nysius ericae (Schill.), N. angustatus Uhler.

Phanurus ovieorus Ashmead, 1893. U. S. Natl. Mus., Bul. 45: 140..

Biology: Wadley, 1940. Kans. Ent. Soc., Jour. 13: 6-7.

pamphilae Ashmead. Ont. (Ottawa). Host: Atrytone ruricola (Bdvl.).

Telenomus pamphilae Ashmead, 1899. In Harrington, Roy. Soc. Canada, Trans. (2) 5: 182. †.

pentatomus Kieffer. Nev. (Ormsby County).

Telenomus pentatomus Kieffer, 1906 (1905). Berlin. Ent. Ztschr. 50: 261. ๆ, ठ․

perplexus Girault. Ohio. Host: Euschistus variolarius (Pal. de Beauv.), E. tristigmus (Say).

Telenomus perplexus Girault, 1906. Psyche 13: 65. $\%$, ठ.

persimilis Ashmead. Conn., Va., Ohio, Mich., Ind., Ill., Tenn., La., Ark., Iowa.

Telenomus persimilis Ashmead, 1893. U. S. Nat1. Mus., Bul. 45: 143, 150..

podisi Ashmead. Transition and Upper Austral Zones. Host: Podisus maculiventris (Say), Oebalus puguax (F.), Chlorochroa sayi Stal, Euschistus impictiventris Stal, E. servus (Say), Cosmopepla bimaculata (Thos.), Trichopepla semicittata (Say), Holcostethus limbolarius (Stal), Thyanta sp.

Telenomus podisi Ashmead, 1893. U. S. Natl. Mus., Bul. 45: 144, 158. ๆ, ठో.

pusillus Ashmead. Va. (Arlington).

Telenomus pusillus Ashmead, 1893. U. S. Natl. Mus., Bul. 45: 143, 146. ؟.

quaintancei Girault. Md., Ga. Host: Samminoidea exitiosa (Say).

Telenomus quaintancei Girault, 1906. Psyche 13: 63. ๆ, ó.

Biology: Gahan, 1911. Jour. Econ. Ent. 4: 423-424.

reynoldsi Gordh and Coker. Calif., Wash. Host: Geocoris punctipes Say, G. pallens Stal.

Telenomus reynoldsi Gordh and Coker, 1973. Canad. Ent. 105: 1407. ₹, ठ.

rileyi Howard. Mo. Host: Asterocampa clyton (Say).

Telenomus rileyi Howard, 1889. In Seudder, Butterflies East. U. S., p. 1896. ơ. 
sphingis (Ashmead). N. C., Fla., Ohio, Tenn., Mo.; West Indies. Host: Manduca sexta (L.). Teleas sphingis Ashmead, 1887. U. S. Dept. Agr., Div. Ent., Bul. 14: 18. ๆ, ठ.

Telenomus monilicomis Ashmead, 1894. Linn. Soc. London, Jour., Zool. 25: 203. o.

spilosomatis Ashmead. D. C., Va., Ohio, Kans. Host: Diacrisia virginica (F.).

Telenomus spilosomatis Ashmead, 1893. U. S. Natl. Mus., Bul. 45: 144, 151. , ๖.

szelenyii Muesebeck. Wash. (South. Bellingham). Host: Stilpuotia salicis (L.).

Telenomuss szelenyii Muesebeck, 1974. Folia Ent. Hungarica 27: 135. ?.

tabanivorus (Ashmead). Mass., N. Y., Ga., Fla., Ala., Ohio, Ill., La., Ark. Host: Tabanus atratus F.

Phanurus tabanivorns Ashmead, 1895. Ill. State. Lab. Nat. Hist., Bul. 4: 274. \&, ठ.

Biology: Jones and Anthony, 1964. U. S. Dept. Agr., Tech. Bul. 1295: 34.

tetratomus Kieffer. Nev. (Ormsby County).

Telenomus tetratomus Kieffer, 1906 (1905). Berlin. Ent. Ztschr. 50: 261. ․

texanus Brues. Tex. Ecology: In nest of Eciton coecum (Latr.).

Telenomus texauns Brues, 1902. Amer. Nat. 36: 372..

\section{Genus DISSOLCUS Ashmead}

Dissolcus Ashmead, 1893. U. S. Natl. Mus., Bul. 45: 138, 164.

Type-species: Dissolcus nigricomis Ashmead. Orig. desig.

nigricornis Ashmead. Fla. (Jacksonville).

Dissolcus nigricorn is Ashmead, 1893. U. S. Natl. Mus., Bul. 45: 165. \&.

\section{Genus TRISSOLCUS Ashmead}

Trissolcus Ashmead, 1893. U. S. Natl. Mus., Bul. 45: 138, 161.

Type-species: Trissolcus brochymenae Ashmead. Orig. desig.

Asolcus Nakagawa, 1900. Spec. Rpt. Imp. Agr. Sta. Japan, v. 6, p. 17.

Type-species: Asolcus nigripedius Nakagawa. Monotypic.

A phanurus Kieffer, 1912. In Andre, Spec. Hym. Eur. Alg., v. 11, pp. 10, 69. Preocc. by Looss, 1907.

Type-species: Teleas semistriatus Nees. Orig. desig.

Immsia Cameron, 1913 (1912). Indian Forest Rec. 4: 104.

Type-species: Imusia carinifrons Cameron. Monotypic.

Microphanurus Kieffer, 1926. Das Tierreich, Lief. 48, pp. xv, 16, 91. N. name for Aphanurus Kieffer.

The species of Trissolcus seem to be exclusively parasitic in the eggs of Hemiptera. Two African species have been recorded from eggs of Lepidoptera but there appears to be some doubt concerning the accuracy of those records.

Revision: Ashmead 1893. U. S. Natl. Mus., Bul. 45: 161-164 (No. Amer. species). - Kieffer, 1926. Das Tierreich, Lief. 48, pp. 91-116, 126-130 (World species). - Nixon, 1935. Roy. Ent. Soc. London, Trans. 83: 95-103 (African species). - Nixon, 1938. Ann. and Mag. Nat. Hist. (11) 2: 122-139 (Asian species). - Nixon, 1943. Bul. Ent. Res. 34: 135-144 (Ethiopian and Indo-Malayan species).

Taxonomy: Watanabe, 1951. Shikoki Ent. Soc., Trans. 2: 21. -Masner, 1964. Acta Soc. Ent. Cechoslov. 61: 145-146.

basalis (Wollaston). Fla., La.; Africa; Australia; certain Pacific islands; West Indies. Host: Nezara viridula (L.).

Telenomus basalis Wollaston, 1858. Ann. and Mag. Nat. Hist. (3) 1: 25. ๆ, ठ.

Telenomus maderensis Wollaston, 1858. Ann. and Mag. Nat. Hist. (3) 1: 25..

Telenomus megacephalus Ashmead, 1894. Linn. Soc. London, Jour,, Zool. 25: 203, 212..

Telenoutus megalocephalus Schulz, 1906. Spolia Hym., p. 152. Emend.

Telenomus piceipes Dodd, 1919. Ent. Soc. London, Trans. 1919: 354. ‡, ठ.

Taxonomy: Priesner, 1931. Soc. Roy. Ent. d'Egypte, Bul. 15: 137-139. -Nixon, 1935. Roy.

Ent. Soc. London, Trans. 83: 100-102. -Nixon, 1943. Bul. Ent. Res. 34: 143. 
Biology: Miller, 1928. Fla. Ent. 12: 17-20. - Kamal, 1937. Soc. Roy. Ent. d'Egypte, Bul. 21: 181-207. - Noble, 1937. Agr. Gaz. N. S. Wales 48: 337-341. - Lever, 1941. Fiji Dept. Agr., Jour. 12: 45-47. - Smith, 1945. Queensland Agr. Jour. 61: 347-348. -Cumber, 1951. New Zeal. Jour. Sci. and Technol., Sect. B, 32: 30-37. -Cumber, 1953. New Zeal. Jour. Sci. and Technol., Sect. B, 34: 267-269. - Cumber, 1964. New Zeal. Jour. Sci. 7: 536-554.

brochymenae (Ashmead). Fla., Ind., Ark., Tex. Host: Brochymena arborea (Say), Acrosternum hilare (Say).

Telenomus Crochymenae (!) Ashmead, 1881. Fla. Agr. 4: 193. \&.

Telenomus brochymenae Ashmead, 1887. Ent. Amer. 3: 118. Emend.

cosmopeplae (Gahan). Ill. (Urbana). Host: Cosmopepla bimaculata (Thomas).

Telenomus cosmopeplae Gahan, 1926. Ent. Soc. Wash., Proc. 28: 67. १, ठ.

Biology: Balduf, 1926. Jour. Econ. Ent. 19: 829-841.

edessae Fouts. S. C., La., Kans. Host: Edessa bifida (Say), Acrostermum hilare (Say).

Trissolcus edesscee Fouts, 1920. Ent. Soc. Wash., Proc. 22: 65. ․

euschisti (Ashmead). Transition and Upper Austral Zones. Host: Euschistus sere'us (Say), Acrostermum hilare (Say), Perillus bioculatus (F.).

Telenomus euschristus (!) Ashmead, 1888. Kans. Agr. Expt. Sta., Bul. 3: App., p. II, \&.

Telenomus euschisti Ashmead, 1893. U. S. Natl. Mus., Bul. 45: 161, 162. Emend.

murgantiae Ashmead. D. C., N. C., Ga., Fla., La., Calif.; Hawaii. Host: Murgantia histriouica (Hahn).

Trissolcus murgantice Ashmead, 1893. U. S. Natl. Mus., Bul. 45: 162, 163. ९, ઠ.

Biology: Huffaker, 1941. Jour. Econ. Ent. 34: 117-118. -De Bach, 1942. Jour. Econ. Ent. 35:

787. - Fullaway, 1947. Hawaii. Ent. Soc., Proc. 13: 13.

podisi Ashmead. Conn., Pa., W. Va., Ohio, Mich., Ind., Ill., Mo., Calif. Host: Podisus maculicentris (Say), $P$. serieventris Uhler, Banasa dimidiata (Say).

Trissolcus podisi Ashmead, 1893. U. S. Natl. Mus., Bul. 45: 161, 162. ₹.

rufiseapus Ashmead. D. C.

Trissolcus rufiscapus Ashmead, 1893. U. S. Natl. Mus., Bul. 45: 162, 163...

rufitarsis Kieffer. Nev. (Ormsby County).

Trissolcus rufitarsis Kieffer, 1906 (1905). Berlin. Ent. Ztschr. 50: 262. ․

thyantae Ashmead. N. Y., Md., Ga., Ala., Ohio, Ind., Mo. Host: Thyanta sp., Nezara viridula (L.).

Trissolcus thyantac Ashmead, 1893. U. S. Natl. Mus., Bul. 45: 162, 163. \&.

utahensis (Ashmead). Colo., N. Mex., Ariz., Utah, Idaho, Alta., Calif.; Mexico. Host:

Chlorochroa sayi Stal, C. ligata (Say), C. uhleri Stal, Thyanta pallidovirens spinosa

Ruckes, Euschistus impictiventris (Stal), E. servus (Say).

Telenomus utahensis Ashmead, 1893. U. S. Natl. Mus., Bul. 45: 143, 148. ९, ó.

Hadronotus mesillae Cockerell, 1897. Canad. Ent. 29: 25. ơ.

Telenom us ashmeadi Morrill, 1907. Amer. Nat. 41: 419. $९$, ठ์.

Biology: Morrill, 1907. Amer. Nat. 41: 421-430. -Jubb and Watson, 1971. Ent. Soc. Amer., Ann. 64: 202-205, 452-456.

\section{Family PLATYGASTRIDAE}

Members of this family for which host associations are known are mainly parasites of Diptera, and especially of the Cecidomyiidae, but some are important parasites of mealybugs and whiteflies. Occasional species have been reared from wasp larvae of the subfamily Crabroninae, from hymenopterous galls, and from eggs of certain Coleoptera.

Revision: Ashmead, 1893. U. S. Natl. Mus., Bul. 45: 247-330. - Kieffer, 1926. Das Tierreich, Lief. 48 , pp. 557-884.

Taxonomy: Foerster, 1856. Hym. Stud., v. 2, pp. 20, 28, 106-116. -Thomson, 1859. Ofvers. Kongl. Vetensk.-Akad., Forh. 16: 69-88. - Marshall, 1873. Cat. Brit. Hym.; Oxyura, pp. 17-22. - Ashmead, 1903. N. Y. Ent. Soc., Jour. 11: 94-99. - Mani, 1941. Cat. Indian Insects, pt. 26, pp. 29-35. -Jansson, 1939. Ent. Tidskr. 60: 173-175. -Szabo, 1959. Mus. Natl. 
Hungarici, Ann. Hist.-Nat. 51: 389-390. - Kozlov, 1970. Ent. Obozr. 49: 219-225 (English transl.: Ent. Rev. 49: 123-126). - Kozlov, 1971. Soc. Ent. Unionis Sovet., Horae 54: 54-64.

Biology: Kieffer, 1926. Das Tierreich, Lief. 48, pp. 7-10. -Clausen, 1940. Entomophagous Insects, pp. 239-249.

\section{SubFAMILy INOSTEMMATINAE}

Taxonomy: Ashmead, 1903. N. Y. Ent. Soc., Jour. 11: 95-96. - Szabo, 1959. Mus. Natl. Hungarici, Ann. Hist.-Nat. 51: 390. - Kozlov, 1970. Ent. Obozr. 49: 220-222 (English transl.: Ent. Rev. 49: 123-124).

\section{TRIBE INOSTEMMATINI}

\section{Genus METACLISIS Foerster}

Metaclisis Foerster, 1856. Hym. Stud., v. 2, pp. 106, 109.

Type-species: Metuclisis areolatus Foerster. Monotypic.

Parinostemma Kieffer, 1914. In Andre, Spec. Hym. Eur. Alg., v. 11, p. 355.

Type-species: Inostemma quinda Walker. Orig. desig.

Taxonomy: Masner, 1965. Brit. Mus. (Nat. Hist.), Bul., Ent., Sup. 1, p. 131. - Hellen, 1968.

Notulae Ent. 48: 45. - Kozlov, 1970. Ent. Obozr. 49: 220 (English transl.: Ent. Rev. 49: 123).

carinata (Ashmead). D. C.

Monocrita carinata Ashmead, 1893. U. S. Natl. Mus., Bul. 45: 253, 254. .

floridana (Ashmead). Fla. (Jacksonville).

Acerota Floridlana Ashmead, 1887. Canad. Ent. 19: 128. ?.

\section{Genus INOSTEMMA Haliday}

Inostemma Haliday, 1833. Ent. Mag. 1: 270.

Type-species: Psilus boscii Jurine. Monotypic.

Acerota Foerster, 1856. Hym. Stud., v. 2, p. 107. No species. -Ashmead, 1887. Canad. Ent. 19: 128. Two species.

Type-species: Acerota caryae Ashmead. Desig. by Muesebeck and Walkley, 1951.

Brachinostemma Kieffer, 1916. Zentbl. f. Bakt., Parasitenk. u. Infektionskrankheiten, Abt. 2, 46: 551 .

Type-species: Brachinostemma mediterraneum Kieffer. Orig. desig.

Inocerota Szelenyi, 1939. Mus. Nat. Hungarici, Ann. 32 (Zool.): 121.

Type-species: Inocerota discessus Szelenyi. Orig. desig.

Revision: Kieffer, 1926. Das Tierreich, Lief. 48, pp. 579-595. -Szelenyi, 1938. Mus. Nat.

Hungarici, Ann. 31 (Zool.): 108-128 (Palearctic species).

Taxonomy: Masner, 1964. Acta Soc. Ent. Cechoslov. 61: 146-148.

Biology: Marchal, 1906. Arch. de Zool. Expt. et Gen. 34: 537-573. -Adler, 1908. Ztschr. f.

Wiss. Insektenbiol. 4: 306-307. - Myers, 1927. Bul. Ent. Res. 18: 129-133.

americanum (Ashmead). Fla. (Jacksonville).

Allotropa Americana Ashmead, 1887. Canad. Ent. 19: 125. ठ.

Monocrita melanostropha Ashmead, 1887. Canad. Ent. 19: 126. ?.

Acerota caryae Ashmead, 1887. Canad. Ent. 19: 128. ๆ, ठ゚.

belonocnemae (Ashmead). Fla. (Jacksonville). Host: Belonocnema treatae Mayr gall.

Metaclisis belonocnemae Ashmead, 1887. Canad. Ent. 19: 125. ๆ.

californicum Ashmead. Calif. (Los Angeles County). Host: Cecidomyiid gall-maker on Thelypodium integrifolium.

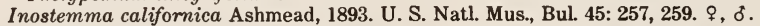

cecidomyiae (Ashmead). Calif. (Los Angeles County). Host: Cecidomyiid gall-maker on Ephedra californica.

Acerota cecidomyiae Ashmead, 1893. U. S. Natl. Mus., Bul. 45: 260, 261. ठ. 
horni Ashmead. Fla. (Jacksonville).

Inostemma Homi Ashmead, 1887. Canad. Ent. 19: 126. ९, ठ.

leguminicolae Fouts. N. Y. (Ithaca). Host: Dasineura legrtminicola (Lint.).

Inostemma legmminicolae Fouts, 1923. Ent. Soc. Wash., Proc. 25: 64..

leonardi (Fouts). N. Y. (McLean Bogs).

Acerota leonardi Fouts, 1925. Ent. Soc. Wash., Proc. 27: 147. $\delta$.

lintneri Ashmead. Ont., N. Y., D. C.

Inostemma Lintueri Ashmead, 1893. U. S. Natl. Mus., Bul. 45: 257, 259. ๆ.

packardi Ashmead. Fla. (Jacksonville).

Inostemma Packardi Ashmead, 1887. Canad. Ent. 19: 127. .

rileyi Ashmead. Fla. (Jacksonville).

Inostemma Rileyi Ashmead, 1887. Canad. Ent. 19: 127. ๆ.

\section{Genus ISOSTASIUS Foerster}

Isostasins Foerster, 1856. Hym. Stud., v. 2, pp. 106, 109.

Type-species: Platygaster punctiger Nees. Monotypic.

Monocrita Foerster, 1856. Hym. Stud., v. 2, pp. 106, 109.

Type-species: Inostenima atinas Walker. Monotypic.

Trisinostemma Kieffer, 1914. In Andre, Spec. Hym. Eur. Alg., v. 11, p. 357.

Type-species: Inostemma braesia Walker. Orig. desig.

Taxonomy: Masner, 1965. Brit. Mus. (Nat. Hist.), Bul., Ent., Sup. 1, p. 130.

fuscipennis Ashmead. D. C.

Isostasius fuscipennis Ashmead, 1893. U. S. Natl. Mus., Bul., 45: 255. \&. musculus Ashmead. Fla. (Jacksonville).

Isostasius musculus Ashmead, 1887. Canad. Ent. 19: 126. ९.

\section{Genus TETRABAEUS Kieffer}

Tetrabaeus Kieffer, 1912. In Andre, Spec. Hym. Eur. Alg., v. 11, p. 87.

Type-species: Aphanomemus americanus Brues. Orig. desig.

Crabroborus Muesebeck, 1963. Beitr. z. Ent. 13: 391.

Type-species: Crabroborus krombeini Muesebeck. Orig. desig.

Taxonomy: Masner, 1964. Acta Soc. Ent. Cechoslov. 61: 148-149.

americanus (Brues). Que., Md., Wis. Host: Ectemmius (Hypocrabro) paucimaculatus (Pack.),

Euplilis (Corynopus) rufigaster (Pack.), E. (C.) coarctata modesta (Roh.).

Aphanomerus americanus Brues, 1908. Wis. Nat. Hist. Soc., Bul. 6: 156. ๆ.

Crabroborus krombeini Muesebeck, 1963. Beitr. z. Ent. 13: 392. ๆ, ठ.

Biology: Krombein, 1964. Biol. Soc. Wash., Proc. 77: 104-108, fig. 11.

\section{Genus ACEROTELLA Masner}

Acerotella Masner, 1964. Acta Soc. Ent. Cechoslov. 61: 148.

Type-species: Acerota evantscens Kieffer. Orig. desig.

No North American species of Acerotella have been described, but the U. S. National Museum of Natural History has isolated specimens of the genus from Maine, New York, Maryland, and Michigan.

\section{Genus ALLOTROPA Foerster}

Allotropa Foerster, 1856. Hym. Stud., v. 2, pp. 106, 109.

Type-species: Inostemma mecrida Walker. Monotypic.

The species of Allotropa are parasites of mealybugs. Some seem to be important in the control of certain pest species.

ashmeadi Muesebeck. Conn., Md., Va., La. Host: Pseudococcus comstocki (Kuw.), Ferrisia virgata (Ckll.), Phenacoccus sp., Puto cupressi (Coleman).

Iphitrachelus americauns Ashmead, 1891 (1890). Ent. Soc. Wash., Proc. 2: 58. Nom. nud. 
Iphetrachelus (!) americanus Ashmead, 1893. U. S. Natl. Mus., Bul. 45: 250. o. Preoce. by Allotropa americana Ashmead, 1887, which is now in Inostemma.

Allotropa ashmeudi Muesebeck, 1939. Canad. Ent. 71: 159. N. name.

burrelli Muesebeck. Estab. in Conn., Del., Pa., Va., W. Va., Ohio. Introd. from Japan. Host: Psendococcus comstocti (Kuw.).

Allotropa burrelli Muesebeck, 1942. Brooklyn Ent. Soc., Bul. 37: 170. ९, ठ.

Biology: Clancy, 1944. Jour. Agr. Res. 69: 159-167. -Clausen, 1956. U. S. Dept. Agr., Tech. Bul. 1139: 74-75.

citri Muesebeck. Released and recovered in Calif. but doubtfully estab. Introd. from So.

China. Host: Planococcus citri (Risso).

Allotropa citri Muesebeck, 1954. Brooklyn Ent. Soc., Bul. 49: 18. ๆ, o.

convexifrons Muesebeck. Conn., N. Y., N. J., Va.; Japan, USSR. Host: Psendococcus comstochi

(Kuw.), P. longispinus (Targ.-Tozz.).

Allotropa concexifrons Muesebeck, 1942. Brooklyn Ent. Soc., Bul. 37: 171. ९, d.

Biology: Garman, Brigham, Schread and Smith, 1943. Conn. State Agr. Expt. Sta., Bul. 472: 232. - Haeussler and Clancy, 1944. Jour. Econ. Ent. 37: 503-509. -Shenderovskaya, 1967. Zashch. Rast. 12: 51. (In Russian).

merrilli Muesebeck. Fla., La. Host: Trionymus sp. on bald cypress.

Allotropa merrilli Muesebeck, 1954. Brooklyn Ent. Soc., Bul. 49: 20. १, ठ.

utilis Muesebeck. N. S., N. H., Vt., Ont., B. C.; Japan. Host: Phenacoccus aceris (Sign.), P. pergandei Ckll.

Allotrope utilis Muesebeck, 1939. Canad. Ent. 71: 158. ९, ठ.

Biology: Gilliatt, 1939. Canad. Ent. 71: 160-163. - Marshall and Pickett, 1944. Canad. Ent. 76: 19. - Wishart, 1947 (1946). Ontario Ent. Soc., 77th Ann. Rpt., p. 36. - McLeod, 1954. Ent.

Soc. Brit. Columbia, Proc. 50: 19. - Murakami, 1962. Kyushu Univ. Facul. Agr., Sci. Bul. 19: 390-402. -Murakami, 1963. Kyushu Univ. Facul. Agr., Sci. Bul. 20: 229-240.

\section{TRIBE IPHITRACHELINI}

The members of this group are set off sharply from the remainder of the Inostemmatinae by their 4-segmented tarsi. Nothing is known concerning their biology or host relations.

Taxonomy: Masner, 1957. Acta Soc. Ent. Cechoslov. 54: 54-61. - Hellen, 1968. Notulae Ent. 48: 45. - Kozlov, 1970. Ent. Obozr. 49: 222 (English transl.: Ent. Rev. 49: 124).

\section{Genus IPHITRACHELUS Walker}

Iphitrachelus Walker, 1835. Ent. Mag. 3: 273.

Type-species: Iphitrachelus lar. Walker. Monotypic.

Taxonomy: Jacks@n, 1966. Ent. Soc. Wash., Proc. 68: 265-268.

foutsi Jackson. Md. (Cabin John).

Iphitrachelus foutsi Jackson, 1966. Ent. Soc. Wash., Proc. 68: 265. ๆ.

\section{SUBFAMILY SCELIOTRACHELINAE}

Two genera of this group occur in North America. One of these, Fidiobia Ashmead, has generally been placed in the Inostemmatinae; the other, Amitus Haldeman, in the Platygastrinae. In the more recent treatments of these genera, however, the two are considered as being closely allied and as belonging in a distinct section of the family which is currently called the subfamily Sceliotrachelinae.

Taxonomy: Brues, 1909 (1908). In Wytsman, Gen. Ins., fasc. 80, pp. 12-13. -Szabo, 1959. Mus. Natl. Hungarici, Ann. Hist.-Nat. 51: 389-396 (proposal of tribal name Amitini for this group). - Masner, 1964. Psyche 71: 8-11. - Kozlov, 1970. Ent. Obozr. 49: 222-223 (English transl.: Ent. Rev. 49: 124-125).

\section{Genus FIDIOBIA Ashmead}

Fidiobia Ashmead, 1894. Cincinnati Soc. Nat. Hist., Jour. 17: 170. 
Type-species: Fidiobia flavipes Ashmead. Monotypic.

Rosneta Brues, 1908. Wis. Nat. Hist. Soc., Bul. 6: 157.

Type-species: Rosneta tritici Brues. Orig. desig.

Triclavus Brethes, 1916. Buenos Aires Mus. Nac. de Hist. Nat., An. 27: 411.

Type-species: Triclavus bonariensis Brethes. Monotypic.

Platyllotropa Szelenyi, 1938. Mus. Natl. Hungarici, Ann. Hist.-Nat. 31 (Zool.): 126.

Type-species: Platyllotropa gallicola Szelenyi. Orig. desig.

The species of Fibiobia, for which reliable rearing records are available, are parasitic in the eggs of Coleoptera (Curculionidae and Chrysomelidae).

drakei (Ogloblin). Iowa (Ames).

Triclavus drakei Ogloblin, 1944. Ent. Soc. Wash., Proc. 46: 156. ․

flavipes Ashmead. N. Y., Pa., Ohio. Host: Fidia viticida Walsh.

Fidiobia flavipes Ashmead, 1894. Cincinnati Soc. Nat. Hist., Jour. 17: 171. \&.

Rosneta tritici Brues, 1908. Wis. Nat. Hist. Soc., Bul. 6: 157..

rugosifrons Crawford. $\mathrm{Pa}$., Ind. Host: Hypera punctata (F.).

Fidiobia rugosifrons Crawford, 1917 (1916). Insecutor Inscitiae Menstruus 4: 141. \&, ठ.

\section{Genus AMITUS Haldeman}

Amitus Haldeman, 1850. Amer. Jour. Sci. (2)9: 109.

Type-species: Amitus aleurodinis Haldeman. Monotypic.

Zacrita Foerster, 1878. Naturh. Ver. Rheinlande, Verh. 35: 46.

Type-species: Zacrita longicom is Foerster. Orig. desig.

Passalida Brethes, 1914. Nunquam otiosus, Buenos Aires, p. 2.

Type-species: Passalida spinifera Brethes. Orig. desig.

The species of this genus, of which the host relations are known, are parasites of Aleyrodidae.

Taxonomy: Fouts, 1924. U. S. Natl. Mus., Proc. 63 (15): 8-10. - De Santis, 1941. Soc. Brasil.

Agron., Bol. 4: 5. - Debauche, 1947. Soc. Ent. de Belg., Bul. et Ann. 83: 282. - Szabo, 1959.

Mus. Natl. Hungarici, Ann. Hist.-Nat. 51: 389-390. -Masner, 1964. Psyche 71: 9. - Hellen,

1968. Notulae Ent. 48: 46.

aleurodinis Haldeman. Mass., Conn., Pa., N. J., D. C., Fla., Ill., Calif. Host: Tetraleurodes mori

(Quaint.), Trialeurodes fermaldi (Morrill), Aleuroplatus plumosus (Quaint.), Aleurochiton forbesii (Ashm.).

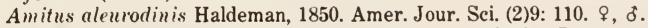

Elaptus (!) aleurodis Forbes, 1885. Ill. State Entomologist, Rept. 14: 110..

Anaphes mellicomis Ashmead, 1887. Canad. Ent. 19: 194. ?.

Taxonomy: Gahan, 1927. U. S. Natl. Mus., Proc. 71 (4): 39.

arcturus Whittaker. B. C. (Hollyburn).

Amitus arcturus Whittaker, 1930. Ent. Soc. Wash., Proc. 32: 69. \&, ठ์.

spiniferus (Brethes). Tex.; Mex., Brazil, Argentina. Host: Aleurothrixus flocosus (Maskell).

Passalida spiniferus Brethes, 1914. Nunquam otiosus, Buenos Aires, 1914, p. 3.

\section{SUbFamily PLATYGASTRINAE}

The species of this subfamily are essentially parasites of Cecidomyiidae; apparently very rarely cynipid or tenthredinid gall-makers are the hosts. Some species are polyembryonic.

Revision: Fouts, 1924. U. S. Natl. Mus., Proc. 63 (15): 1-145 (North American species).

Taxonomy: Kozlov, 1970. Ent. Obozr. 49: 223-224 (English transl.: Ent. Rev. 49: 125-126).

Biology: Marchal, 1906. Arch. de Zool. Expt. et Gen. 34: 573-627.

\section{Genus METANOPEDIAS Brues}

Metanopedias Brues, 1910. Amer. Mus. Nat. Hist., Bul. 28: 79.

Type-species: Metanopedias sicarius Brues. Monotypic. 
Taxonomy: Jackson, 1966. Ent. Soc. Amer., Ann. 59: 734-736. -Jackson and Masner, 1966.

Canad. Ent. 98: 1214-1219.

brunneipes (Ashmead). Throughout the U. S. and southeastern Canada; Mexico, Costa Rica, and the Caribbean. Host: Apparently various cecidomyiid gall-makers.

Trichacis brunneipes Ashmead, 1887. Canad. Ent. 19: 131..

Trichasis (!) mubicola Ashmead, 1893. U. S. Natl. Mus., Bul. 45: 295, 296. ९, ó.

Trichasis (!) arizonensis Ashmead, 1893. U. S. Natl. Mus., Bul. 45: 295, 296. §, o. Preoce. by Isorhombus arizonensis Ashmead, 1893, when the latter was placed in Trichacis.

Metanopedias sicarius Brues, 1910. Amer. Mus. Nat. Hist., Bul. 28: 79. ?.

\section{Genus TRICHACIS Foerster}

Trichacis Foerster, 1856. Hym. Stud., v. 2, pp. 108, 115.

Type-species: Platygaster pisis Walker. Desig. by Ashmead, 1893.

Trichasis Thomson, 1859. Ofvers. Kongl. Vetensk.-Akad.. Forh. 16: 70, 78. Emend.

Taxonomy: Fouts, 1924. U. S. Natl. Mus., Proc. 63 (15): 13-18.

Biology: Marchal, 1906. Arch. de Zool. Expt. et Gen. 34: 548-557 (Development of the European T. remulus (Walker) as a parasite of the Hessian fly, Mayetiola destructor (Say)).

arizonensis (Ashmead). Ariz. (Ft. Huachuca).

Isorhombus arizonensis Ashmead, 1893. U. S. Natl. Mus., Bul. 45: 277. \&.

cornicola (Ashmead). Mo. (Kirkwood). Host: Cecidomyiid gall-maker on Cornus paniculata.

Synopeas comicola Ashmead, 1893. U. S. Natl. Mus., Bul. 45: 286, 288. ๆ, ठ".

cornuta Fouts. Tex. (Brownwood).

Trichacis cornuto Fouts, 1925. Ent. Soc. Wash., Proc. 27: 93. $९$.

rufipes Ashmead. D. C., Va., Fla., Mo.

Trichasis (!) rufipes Ashmead, 1893. U. S. Natl. Mus., Bul. 45: 295. ९, ð.

texana Fouts. Tex. (Brownwood).

Trichacis texana Fouts, 1925. Ent. Soc. Wash., Proc. 27: 94. 9.

virginiensis Ashmead. Va. (Arlington).

Trichasis (!) virginiensis Ashmead, 1893. U. S. Natl. Mus., Bul. 45: 295, 297..

\section{Genus ISOCYBUS Foerster}

Isocybus Foerster, 1856. Hym. Stud., v. 2, pp. 108, 114.

Type-species: Platygaster grandis Nees. Desig. by Ashmead, 1893.

Revision: Kieffer, 1926. Das Tierreich, Lief. 48, pp. 718-732.

Taxonomy: Ashmead, 1893. U. S. Natl. Mus., Bul. 45: 327-330. -Fouts, 1924. U. S. Natl. Mus.,

Proc. 63 (15): 10-12.

auripes (Provancher). Que. (Cap Rouge).

Trichacis anripes Provancher, 1888. Addit. Corr. Faune Ent. Canada Hym., p. 403. "o" = o.

Taxonomy: Masner, 1969. Nat. Canad. 96: 783 (Lectotype selected).

canadensis (Provancher). Que., Ont., Mich., Iowa, Tex., Colo. The distribution and synonymy shown here are from the literature and seem open to some doubt.

Platygaster Canadeusis Provancher, 1887. Addit. Corr. Faune Ent. Canada Hym., p. 181. o.

Monocrita Canadensis Ashmead, 1887. Canad. Ent. 19: 126. “ๆ” =

Isocybus nigriclac'us Ashmead, 1893. U. S. Natl. Mus., Bul. 45: 328. ๆ.

Taxonomy: Ashmead, 1893. U. S. Natl. Mus., Bul. 45: 329. -Fouts, 1924. U. S. Natl. Mus.,

Proc. 63 (15): 11-12. - Masner, 1969. Nat. Canad. 96: 780.

\section{Genus PLATYGaSTER Latreille}

Platygaster Latreille, 1809. Gen. Crust. Ins., v. 4, p. 31.

Type-species: Scelio ruficomis Latreille. Monotypic. 
Epimeces Westwood, 1833. Mag. Nat. Hist. 6: 421. Preocc. by Billberg, 1820.

Type-species: Eipmeces ensifer Westwood. By elimination, Foerster, 1856.

Isorhombus Foerster, 1856. Hym. Stud., v. 2, pp. 107, 112, 113. No species. -Ashmead, 1887. Canad. Ent. 19:129. One species.

Type-species: Isorhombus hyalinipennis Ashmead. First included species.

Hypocampsis Foerster, 1856. Hym. Stud., v. 2, pp. 108, 115. No species. -Thomson, 1859.

Ofvers. Kongl. Vetensk.-Akad., Forh. 16: 70, 82. Three species.

Type-species: Hypocampsis hyalinata Thomson. Desig. by Ashmead, 1903.

Polygnotus Foerster, 1856. Hym. Stud., v. 2, pp. 108, 115.

Type-species: Platygaster striolatus Nees. Orig. desig.

Aneuron Brues, 1910. Wis. Nat. Hist. Soc., Bul. 8: 49.

Type-species: Anenron unormis Brues. Orig. desig.

Misocyclops Kieffer, 1914. In Andre, Spec. Hym. Eur. Alg., v. 11, pp. 353, 362.

Type-species: Platygaster ornatus Kieffer. Monotypic.

Purepimeces Kieffer, 1926. Das Tierreich, Lief. 48, pp. xxxiv, 563, 760. N. name for Epimeces Westwood.

Revision: Fouts, 1924. U. S. Natl. Mus., Proc. 63 (15): 23-108. - Kieffer, 1926. Das Tierreich, Lief. 48 , pp. $732-843$.

abicollis MacGown and Osgood. Maine. Host: Dasineura balsamicola (Lint.).

Platygaster abicoll is MacGown and Osgood, 1971. Canad. Ent. 103: 1143. ๆ, ð.

aciculata Ashmead. Pa.

Platygaster aciculatus Ashmead, 1893. U. S. Natl. Mus., Bul. 45: 323, 326. ठ'.

actinomeridis (Ashmead). D. C. Host: Cecidomyiid gall-maker on Verbesina alternifolia.

Polyynotus actinomericlis Ashmead, 1893. U. S. Natl. Mus., Bul. 45: 302, 317..

affinis Fouts. Tex. (Brownwood).

Platyguster affin is Fouts, 1925. Ent. Soc. Wash., Proc. 27: 94. \&.

alnicola (Ashmead). D. C. Host: Dasineura sermlatae (O. S.).

Polymecus alnicola Ashmead, 1893. U. S. Natl. Mus., Bul. 45: 278, 283. ๆ, ठ.

americana (Ashmead). Fla.

Epimece's americenus Ashmead, 1887. Canad. Ent. 19: 129. ๆ, (ơ misdet.).

aneura (Provancher). Que.

Anenrynchns (!) aneurus Provancher, 1887. Addit. Corr. Faune Ent. Canada Hym., p. 176. $" \supsetneq "=\delta "$.

Taxonomy: Masner, 1969. Nat. Canad. 96: 777.

anormis (Brues). N. Y., Mass.

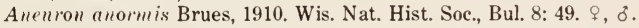

Taxonomy: Masner, 1965. Psyche 72: 301 (Lectotype designated).

antennariae (Ashmead). Wis. (Milwaukee). Host: Rhopalomyia antennariae (Whlr.).

Synopeas antennariae Ashmead, 1893. U. S. Natl. Mus., Bul. 45: 286, 288. ๆ, o.

anura Fouts. Tex. (Brownwood).

Platygaster anura Fouts, 1925. Ent. Soc. Wash., Proc. 27: 94. ๆ, ठ.

aphidis Ashmead. N. Y. (Richfield Springs).

Platygaster aph idlis Ashmead, 1893. U. S. Natl. Mus., Bul. 45: 323, 325. ठ.

artemisiae (Ashmead). Calif. (Lancaster). Host: Cecidomyiid on Artemisia californica.

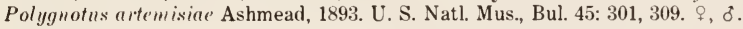

astericola (Ashmead). N. H. (Holderness). Host: Cecidomyiid gall-maker on Aster:

Polygnotus ustericola Ashmead, 1893. U. S. Natl. Mus., Bul. 45: 302, 320. ९, ठ̊.

asynaptae (Ashmead). Ill. (Maywood). Host: Asynapta sp. on willow.

Polygnotus asynaptae Ashmead, 1893. U. S. Natl. Mus., Bul. 45: 302, 315. ๆ, o.

atrae Fouts. Ariz. (Fort Grand). Host: Procecidochares atra (Loew).

Platygaste' atrae Fouts, 1924. U. S. Natl. Mus., Proc. 63 (15): 28, 87. ९, ơ.

atriplicis (Ashmead). Calif., Idaho. Host: Cecidomyiid gall-maker on Atriplex canescens.

Polygnotus atriplicis Ashmead, 1893. U. S. Natl. Mus., Bul. 45: 304, 308. ๆ, ठ̊. 
attenuata Walker. Ont.; Europe. Host: Dasineura alopecuri (Reuter). Platygaster attenuatus Walker, 1835. Ent. Mag. 3: 245. ๆ, ठ.

Biology: Gilbert, 1935. Canad. Ins. Pest Rev. 13: 88. - Graham, 1965. Canada Dept. Agr., Inform. Bul. 4: 54 .

baccharicola (Ashmead). Fla., Miss., La. Host: Originally cited as Cecidomyia baccharicola Ashm. MS.

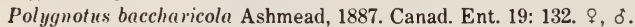

burkei (Rohwer). Calif. (Placerville). Host: Cecidomyiid on Pimus ponderosa.

Polygnotus burkei Rohwer, 1917. U. S. Natl. Mus., Proc. 53: 170. ․ §.

californica (Ashmead). Calif., Idaho. Host: Rhopalom yia califomica Felt.

Polygnotus californicuss Ashmead, 1893. U..S. Natl. Mus., Bul. 45: 302, 321. ‡, ð.

caryae Ashmead. N. Y. (Nyack). Host: Caryomyia holotricha (O. S.).

Platygaster caryae Ashmead, 1893. U. S. Natl. Mus., Bul. 45: 323., , o.

coloradensis (Ashmead). Colo., Utah, Idaho. Host: Rhopalom yia betheliana Ckll.

Polygnotus coloradensis Ashmead, 1893. U. S. Natl. Mus., Bul. 45: 302, 320. \&, §.

columbiana Fouts. Mo. (Cadet). Host: Cecidomyiid in elder flower bud.

Polygnotus alnicoln Ashmead, 1893. U. S. Natl. Mus., Bul. 45: 301, 310. . Preocc. by Polymecus alnicola Ashmead, 1893, p. 283, when this was placed in Platygaster.

Platygaster columbiana Fouts, 1924. U. S. Natl. Mus., Proc. 63 (15): 29, 95. N. name.

compressiventris (Ashmead). D. C.

Polymecus compressiventris Ashmead, 1893. U. S. Natl. Mus., Bul. 45: 278, 282 ..

confusa Fouts. Colo.

Ectadius pallipes Ashmead, 1890. Colo. Biol. Assoc., Bul. 1: 9. ९, ð. Preocc. by Say, 1829.

Ectadius pallidipes Dalla Torre, 1898. Cat. Hym., v. 5, p. 486. Emend. Preoce. by Dalla

Torre, 1898.

Platygaster confusa Fouts, 1924. U. S. Natl. Mus., Proc. 63 (15): 26, 44. N. name.

cynipicola (Ashmead). Va. (Arlington). Host: Neuroterus quercusbatatus (Fitch).

Polygnotns cymipicola Ashmead, 1893. U. S. Natl. Mus., Bul. 45: 302, 314. , " $\delta "=?$.

diplosidis (Ashmead). Mass. to N. C. and w. to Calif. Host: Cecidomyia piniinopis O. S.

Polygnotus diplosidis Ashmead, 1893. U. S. Natl. Mus., Bul. 45: 300, 306..

Polygnotus pinicola Ashmead, 1893. U. S. Natl. Mus., Bul. 45: 301, 307. $\%$, ð.

Taxonomy: Fouts, 1924. U. S. Natl. Mus., Proc. 63 (15): 58-60.

distincta Fouts. Calif. Host: Thecodiplosis piniradiatae (Snow and Mills), Cecidomyia resinicoloides Williams.

Platygaster distincta Fouts, 1926. Ent. Soc. Wash., Proc. 28: 176. ð.

errans Fouts. Fla., Ga., La.

Platygaster errans Fouts, 1924. U. S. Natl. Mus., Proc. 63 (15): 29, 93. ๆ.

erythropus (Ashmead). Ont. (Ottawa).

Metaclisis erythropus Ashmead, 1888. Canad. Ent. 20: 51. “o” =

eurotiae (Ashmead). Calif. Host: Cecidomyiid gall-maker on Eurotia.

Polygnotus eurotiae Ashmead, 1893. U. S. Natl. Mus., Bul. 45: 302, 315. ๆ.

euurae (Ashmead). Mo. (St. Louis). Host: Enura s-nodus Walsh.

Polygnotus eururae Ashmead, 1893. U. S. Natl. Mus., Bul. 45: 304, 318. ठ。.

exiguae Fouts. Colo. Host: Rhabdophaga coloradensis Felt on Salix exigua.

Platygaster exiguae Fouts, 1926. Ent. Soc. Wash., Proc. 28: 175. ?.

feltii Fouts. Tex. Host: Walshom yia texana Felt.

Platygaster feltii Fouts, 1920. Ent. Soc. Wash., Proc. 22: 70. ๆ, ठ.

filicaudis Fouts. Fla. (Paradise Key).

Platygaster filicaudis Fouts, 1925. Ent. Soc. Wash., Proc. 27: 95. \&, ठ.

filicornis (Ashmead). Ont., N. H., D. C., Wis. Host: Thecodiplosis piniresinosae Kearby and Benjamin.

Polygnotus filicorn is Ashmead, 1893. U. S. Natl. Mus., Bul. 45: 302, 321. ๆ, ઠ.

flavitarsis Fouts. Md. (Glen Echo).

Platygaster flavitarsis Fouts, 1926. Ent. Soc. Wash., Proc. 28: 176.. 
floridensis Ashmead. Fla. (Jacksonville).

Platygaster Floridensis Ashmead, 1887. Canad. Ent. 19: 132. ․

fumipennis Fouts. Calif. (San Francisco). Host: Cecidomyiid gall-maker on Baccharis pilularis. Platygaster fumipennis Fouts, 1924. U. S. Natl. Mus., Proc. 63 (15): 29, 87. १, ठ’.

fuscipennis Fouts. Md. (Glen Echo).

Platygaster fuscipennis Fouts, 1924. U. S. Natl. Mus., Proc. 63 (15): 26, 39. ‥

gahani Fouts. Calif., Oreg.

Platygaster gahani Fouts, 1924. U. S. Natl. Mus., Proc. 63 (15): 26, 55. .

herrickii Packard. Ont. to N. C. and w. at least to Nebr. Host: Mayetiola destructor (Say). Platygaster herrickii Packard, 1880. U. S. Ent. Comn., Bul. 4: 20, 21.

Taxonomy: Fouts, 1924. U. S. Natl. Mus., Proc. 63 (15): 47-48. -Gahan, 1934 (1933). U. S. Dept. Agr., Misc. Pub. 174: 14-18.

Biology: Hill and Emery, 1937. Jour. Agr. Res. 55: 199-213. - Hill, Pinckney and Udine, 1939. U. S. Dept. Agr., Tech. Bul. 689: 1-15. - Hill and Pinckney, 1940. U. S. Dept. Agr., Tech.

Bul. 715: 4, 11. - Hill, 1953. U. S. Dept. Agr., Circ. 923: 3.

hiemalis Forbes. Occurs throughout the wheat-growing areas of the United States from N. Y. and $\mathrm{Pa}$. to Oreg. and in southern Canada; also Europe and No. Africa. Host: Mayetiola destructor (Say).

Platygaster herrickii Fitch, 1866. Cultiv. and Country Gent. 28: 354. Nom. nud.

Platygaster minutus Lindeman, 1887. Soc. Imp. Nat. Moscou, Bul. (2) 1: 188. Preoce. by Zetterstedt, 1838.

Platygaster hiemalis Forbes, 1888. Psyche 5: 39. ㅇ, ð.

Platygaster minutula Dalla Torre, 1898. Cat. Hym., v. 5, p. 474. N. name for P. minutus Lindeman.

Taxonomy: Gahan, 1934 (1933). U. S. Dept. Agr., Misc. Pub. 174: 4-10. (See this paper for detailed references to the early literature on $P$. hiemalis).

Biology: Leiby and Hill, 1923. Jour. Agr. Res. 25: 337-349. - Hill, 1926. Jour. Agr. Res. 32: 261-275. - Hill, Pinckney and Udine, 1939. U. S. Dept. Agr., Tech. Bul. 689: 1-15. - Hill and Pinckney, 1940. U. S. Dept. Agr., Tech. Bul. 715: 3-4, 11. -Johannsen and Butt, 1941. Embryology of insects and myriapods......, pp. 311-316. - Hill, 1953. U. S. Dept. Agr., Circ. 923: 3.

huachucae (Ashmead). Ariz. (Ft. Huachuca). Ecology: From gall on sunflower.

Polygnotus huachucae Ashmead, 1893. U. S. Natl. Mus., Bul. 45: 302, 316. ?, ठ.

hyalinipennis (Ashmead). N. Y., Fla. Host: Caryom yia tubicola (O. S.).

Isorhombus hyalinipennis Ashmead, 1887. Canad. Ent. 19: 129. ?.

kalmiae Fouts. Md. (Glen Echo).

Platygaster kalmiae Fouts, 1925. Ent. Soc. Wash., Proc. 27: 95. o.

laevicollis (Ashmead). D. C., La.

Polygnotus laevicollis Ashmead, 1893. U. S. Natl. Mus., Bul. 45: 304, 320. đ.

lampronota Fouts. Idaho, Calif. Host: Rhopalom yia californica Felt.

Platygaster lampronota Fouts, 1924. U. S. Natl. Mus., Proc. 63 (15): 26, 48. ९, o.

Biology: Doutt, 1961. Ent. Soc. Amer., Ann. 54: 51.

laticeps (Ashmead). Fla. (Jacksonville).

Polygnotus laticeps Ashmead, 1893. U. S. Natl. Mus., Bul. 45: 311. ठ, (१ misdet.).

leguminicolae Fouts. Oreg. (Forest Grove). Host: Dasineura leguminicola (Lint.).

Platygaster leguminicolae Fouts, 1920. Ent. Soc. Wash., Proc. 22: 69. १, ठ.

linearis Fouts. S. Dak., Iowa. Host: Lasioptera echinochloa Felt.

Polymecus lasiopterce Gahan; 1917. U. S. Natl. Mus., Proc. 53: 217. ९, ठ. Preocc. by

Kieffer and Jorgensen, 1910.

Platygaster linearis Fouts, 1924. U. S. Natl. Mus., Proc. 63 (15): 29, 93. N. name.

longiventris (Ashmead). Fla. Host: Chilophaga gyrantis Gagne.

Isocybus longiventris Ashmead, 1887. Canad. Ent. 19: 130. ․ 
lucida Fouts. Colo., Calif., Alaska. Host: Cecidomyiids in cones of Picen engelmanni, P. sitchensis and P. glauca.

Platygaster lucida Fouts, 1924. U. S. Natl. Mus., Proc. 63 (15): 26, 54..

lupinicola (Ashmead). Calif. (San Francisco). Host: Cecidomyiid gall-maker on Lupiuns.

Polymecuss lupinicola Ashmead, 1893. U. S. Natl. Mus., Bul. 45: 278, 281. ๆ, (o misdet.).

mainensis MacGown and Osgood. Maine, N. H. Host: Dasineura balsamicola (Lint.).

Platyguster maimensis MacGown and Osgood, 1971. Canad. Ent. 103: 1144. ?, ó.

marylandica Fouts. Md. (Glen Echo).

Platyguster marylandica Fouts, 1924. U. S. Natl. Mus., Proc. 63 (15): 28, 85. ๆ, ठ.

melanocera (Ashmead). Fla.

Synopeas melanocert Ashmead, 1887. Canad. Ent. 19: 130. ․

Platygaster gracilis Ashmead, 1887. Canad. Ent. 19: 132. o.

melliseapus (Ashmead). D. C.

Polymecus melliscapus Ashmead, 1893. U. S. Natl. Mus., Bul. 45: 278, 282..

minutissima Fouts. Tex. (Brownwood).

Platygaster minutissima Fouts, 1925. Ent. Soc. Wash., Proc. 27: 96. đ.

nigricoxa Fouts. Calif. (San Francisco). Host: Dasinenra lupini Felt.

Platygaster nigricoxa Fouts, 1925. Ent. Soc. Wash., Proc. 27: 147. \&, ठ.

nigrifemur (Ashmead). Colo.

Ectadius nigrifemul. Ashmead, 1890. Colo. Biol. Assoc., Bul. 1: 10. ․ §.

nigripes (Ashmead). Colo. (Greeley).

Monocrite nigripes Ashmead, 1890. Colo. Biol. Assoc., Bul. 1: 9. ठ.

noveboracensis (Brues). N. Y. (Albany). Ecology: From a cecidomyiid gall.

Eritrissomerus noreboracensis Brues, 1910. Wis. Nat. Hist. Soc., Bul. 8: 48. ó.

obscuripennis Ashmead. Ont., N. Y., N. H., Pa. Host: Mayetiola rigidae (O. S.).

Platygaster obscuripenu is Ashmead, 1893. U. S. Natl. Mus., Bul. 45: 323, 325. o, (q misdet.).

oenone Fouts. B. C. (Revelstoke).

Platygaster oenoue Fouts, 1925. Ent. Soc. Wash., Proc. 27: 149..

opaca Ruthe. Greenland; Iceland, Europe.

Platygaster opacus Ruthe, 1859. Stettin. Ent. Ztg. 20: 313.

pallida Fouts. N. Y. (McLean Bogs).

Platygaster pallida Fouts, 1925. Ent. Soc. Wash., Proc. 27: 148. ठ.

pallipes Say. U. S.

Platygaster pallipes Say, 1828. Contrib. Maclur. Lyc. Phila. 1: 80.

Isocybus pallidlipes Dalla Torre, 1898. Cat. Hym., v. 5, p. 470. Emend.

pentatoma (Ashmead). Va. (Arlington).

Anopedias penfatomus Ashmead, 1893. U. S. Natl. Mus., Bul. 45: 292. 9.

perplexa Fouts. Colo. (Grant).

Platygaster perplexa Fouts, 1925. Ent. Soc. Wash., Proc. 27: 96. ठ.

picipes (Ashmead). D. C.

Polyurecus picipess Ashmead, 1893. U. S. Natl. Mus., Bul. 45: 278, 282. ․

pini Fouts. Wis., Mo., Colo. Host: Cecidomyiid on Pinus edulis, Lestodiplosis juniperiua (Felt).

Platygaster pini Fouts, 1924. U. S. Natl. Mus., Proc. 63 (15): 30, 99. ๆ, ठ์.

Biology: Haseman and MeLane, 1940. Ent. Soc. Amer., Ann. 33: 614.

pluto (Ashmead). Fla. (Jacksonville).

Hypocampsis Pluto Ashmead, 1887. Canad. Ent. 19: 131..

prolata MacGown. Ga. (Clark County).

Platygaster prolata MacGown, 1971. Canad. Ent. 103: 1637. ‥

relativa Fouts. N. H. (Holderness).

Platygaster relativa Fouts, 1924. U. S. Natl. Mus., Proc. 63 (15): 30, 104. ․

rohweri Fouts. Oreg., Calif. Ecology: From cones of Abies concolor and Pinus lambertiana.

Platygaster rohueri Fouts, 1924. U. S. Natl. Mus., Proc. 63: 30, 100. ๆ, ठ์. 
rubi (Ashmead). N. J., Va. Host: Lasioptera farinosa (0. S.).

Polygnotus rubi Ashmead, 1893. U. S. Natl. Mus., Bul. 45: 302, 315. ९.

rufidens Fouts. Md. (Glen Echo).

Platygaster mifidens Fouts, 1925. Ent. Soc. Wash., Proc. 27: 97. ठ.

rufipes (Ashmead). Va. (Arlington).

Synopeas rufipes Ashmead, 1893. U. S. Natl. Mus., Bul. 45: 286, 287. .

salicicola (Ashmead). Calif. (Los Angeles). Host: Cecidomyiid gall-maker on willow.

Polygnotuss salicicola Ashmead, 1893. U. S. Natl. Mus., Bul. 45: 300, 305. ๆ, ơ.

scorpoides Muesebeck and Walkley. Ont.

Ectadius canadensis Ashmead, 1888. Canad. Ent. 20: 51. .. Preocc. by Provancher, 1887.

Platygaster scorpoides Muesebeck and Walkley, 1951. U. S. Dept. Agr., Agr. Monog. 2, p.

714. N. name.

scutellator Fouts. Md. (Glen Echo).

Platygaster scutellator Fouts, 1925. Ent. Soc. Wash., Proc. 27: 96. ठ.

semiglabra (Girault): N. Y. Host: Rhopalomyia hirtipes (O. S.).

Polymecus semiglaber Girault, 1920. U. S. Natl. Mus., Proc. 58: 177. \&, ठ.

shastensis Fouts. Oreg., Calif. Ecology: From cones of Abies shastensis.

Platygaster shastensis Fouts, 1924. U. S. Natl. Mus., Proc. 63 (15): 26, 53. ๆ.

signata Fouts. Tex. (Brownwood).

Platygaster signata Fouts, 1925. Ent. Soc. Wash., Proc. 27: 97..

solidaginis (Ashmead). Pa. to Fla. Host: Asterom yia carbonifera (O. S.), cecidomyiid gallmaker on Soliclago.

Polyguotus solidagiuis Ashmead, 1887. Canad. Ent. 19: 131. ๆ, o.

Polyguofus anyulatus Ashmead, 1893. U. S. Natl. Mus., Bul. 45: 304, 319. ठ́.

Taxonomy: Fouts, 1924. U. S. Natl. Mus., Proc. 63 (15): 65-67. - Masner and Muesebeck, 1968. U. S. Natl. Mus. Bul. 270: 95.

striaticeps (Ashmead). Calif., Idaho. Host: Cecidomyiid gall-maker on Bigelovia or Artemisia. Polygnotus strinticeps Ashmead, 1893. U. S. Natl. Mus., Bul. 45: 301, 308. ๆ, ơ.

striaticollis (Ashmead). Fla. (Jacksonville).

Polygnotus striaticollis Ashmead, 1893. U. S. Natl. Mus., Bul. 45: 304, 319. o.

striatifrons Fouts. Md. (Glen Echo).

Platygaster striatifious Fouts, 1925. Ent. Soc. Wash., Proc. 27: 98. ठ.

tacita Fouts. Tex. (Brownwood).

Platygaster tacita Fouts, 1925. Ent. Soc. Wash., Proc. 27: 98. @.

taylori MacGown. Pa., Va. Host: Lasioptera nodulosa (Beutn.).

Platygaster taylori MacGown, 1974. Canad. Ent. 106: 437. ๆ, ठ.

texana Fouts. Tex. (Uvalde).

Platygaster texana Fouts, 1924. U. S. Natl. Mus., Proc. 63 (15): 28, 82. ?, ó.

tumida (Ashmead). D. C. Host: Cincticomia symmetrica (O. S.).

Polyguotus tumidus Ashmead, 1893. U. S. Natl. Mus., Bul. 45: 301, 310..+

utahensis (Ashmead). Utah, Idaho. Host: Cecidomyiid gall-maker on Artemisia tridentata.

Polyguotus utahensis Ashmead, 1893. U. S. Natl. Mus., Bul. 45: 301, 314. ơ.

Taxonomy: Fouts, 1924. U. S. Natl. Mus., Proc. 63 (15): 68-69. - Masner and Muesebeck, 1968. U. S. Natl. Mus. Bul. 270: 96.

vancouverensis (Ashmead). B. C. (Vancouver Isl.).

Polymecus vanconverensis Ashmead, 1893. U. S. Natl. Mus., Bul. 45: 278, 281. ․

variabilis Fouts. N. C., Mo. Host: Rlopalomyia carolina Falt or R. solidaginis (Loew) on goldenrod.

Platygaster variabilis Fouts, 1924. U. S. Natl. Mus., Proc. 63 (15): 30, 106. ๆ, ठ.

vernoniae (Ashmead). Va. (Arlington). Ecology: From gall on Vemonia noveboracensis.

Polyguotus vernoniae Ashmead, 1893. U. S. Natl. Mus., Bul. 45: 302, 317. ९, §.

virginiensis (Ashmead). Mass., N. H., Pa., Md., D. C., Va. Host: Thecodiplosis

cupressiananassa (0. S.).

Polygnotus virginiensis Ashmead, 1893. U. S. Natl. Mus., Bul. 45: 301, 309. ๆ, ơ. 
Polygnotus proximus Ashmead, 1893. U. S. Natl. Mus., Bul. 45: 301, 312. \&, ơ.

Taxonomy: Fouts, 1924. U. S. Natl. Mus., Proc. 63 (15): 77-79.

viticola (Ashmead). D. C. Host: Lasioptera vitis O. S.

Polygnotus viticola Ashmead, 1893. U. S. Natl. Mus., Bul. 45: 301, 313. ๆ, ठ. websteri Fouts. Ohio.

Platygaster websteri Fouts, 1924. U. S. Natl. Mus., Proc. 63 (15): 26, 50..

zosine Walker. N. Y., s. to Va. and w, to Iowa and Mo. Host: Mayetiola destructor (Say).

Platygaster zosine Walker, 1836. Ent. Mag. 3: 266. o.

Polygnotus zozini Marchal, 1897. Soc. Ent. de France, Ann. 66: 93. Emend.

Platygaster longicandatus Kieffer, 1906. Soc. Sci. de Bruxelles, Ann. 30: 131. \&, đ.

Platygaster brevicaudatus Kieffer, 1906. Soc. Sci. de Bruxelles, Ann. 30: 133. ‡, ठ.

Polygnotus vermalis Myers, 1917. U. S. Natl. Mus., Proc. 53: 256. \&, o.

Taxonomy: Gahan, 1934 (1933). U. S. Dept. Agr., Misc. Pub. 174: 10-14.

Biology: Hill, 1922. Ent. Soc. Wash., Proc. 34: 111-113. - Hill, 1923. Jour. Agr. Res. 25: 31-42.

-Leiby and Hill, 1924. Jour. Agr. Res. 28: 829-839. - Hill, Pinckney and Udine, 1939. U. S.

Dept. Agr., Tech. Bul. 689: 8-9. - Hill and Pinckney, 1940. U. S. Dept. Agr., Tech. Bul. 715:

3-4, 11. - Hill, 1953. U. S. Dept. Agr., Circ. 923: 1-15.

\section{Genus EUXESTONOTUS Fouts}

Euxestonotus Fouts, 1925. Ent. Soc. Wash., Proc. 27: 98.

Type-species: Platygaster error Fitch. Orig. desig.

Eoxestonotus Debauche, 1947. Soc, Ent. de Belg., Bul. et Ann. 83: 267.

Type-species: Eoxestonotus pini Debauche. Orig. desig.

Taxonomy: Fouts, 1925. Ent. Soc. Wash., Proc. 27: 98-100 (Key to No. Amer. species).

-Ghesquiere, 1948. Soc. Ent. de Belg., Bul. et Ann. 84: 42-43. -Masner, 1964. Acta Soc.

Ent. Cechoslov. 61: 151-152.

brevicornis Fouts. Md., Ohio. Host: Cecidomyiid on phlox.

Enxestonotus breeicorn is Fouts, 1925. Ent. Soc. Wash., Proc. 27: 99..

error (Fitch). Conn., N. Y., Pa., Md., D. C., Va., Ind. and possibly throughout the range of its host, the wheat midge. Host: Sitodiplosis mosellana Gehin.

Platygaster error Fitch 1861 (1860). N. Y. State Agr. Soc., Trans. 20: 838.

Taxonomy: Gahan, 1934 (1933). U. S. Dept. Agr., Misc. Pub. 174: 18-22.

Biology: Gahan, 1934 (1933). U. S. Dept. Agr., Misc. Pub. 174: 21-22.

flavipes Fouts. Md. (Glen Echo).

Euxestonotus flavipes Fouts, 1925. Ent. Soc. Wash., Proc. 27: 99..

rufidens Fouts. Pa. (Carlisle).

Euxestonotus rufidens Fouts, 1925. Ent. Soc. Wash., Proc. 27: 99. ð.

\section{Genus ERITRISSOMERUS Ashmead}

Evitrissomerus. Ashmead, 1893. U. S. Natl. Mus., Bul. 45: 363, 364, 398.

Type-species: Eritrissomerns cecidomyiae Ashmead. Orig. desig.

Revision: Fouts, 1924. U. S. Natl. Mus., Proc. 63 (15): 19-23.

Taxonomy: Masner, 1964. Acta Soc. Ent. Cechoslov. 61: 150.

cecidomyiae Ashmead. Fla. (Jacksonville). Host: Cecidomyiid gall-maker on hickory.

Eritrissomerus cecidomyiae Ashmead, 1893. U. S. Natl. Mus., Bul. 45: 299. ๆ, ठ.

floridanus (Ashmead). Fla. (Jacksonville).

Polygnotus floridanus Ashmead, 1893. U. S. Natl. Mus., Bul. 45: 304, 318. " pallipes Harrington. Que. (Hull).

Eritrissomerns pallipes Harrington, 1899. Roy. Soc. Canada, Trans. (2) 5: 191. ๆ, o. parvus Fouts. Md. (Cabin John).

Eritrissomerus pare'us Fouts, 1924. U. S. Natl. Mus., Proc. 63 (15): 19, 22 .. 


\section{Genus PIESTOPLEURA Foerster}

Catillus Foerster, 1856. Hym. Stud., v. 2, pp. 111, 144. Preoce. by Brongniart, 1822. Type-species: Plutygaster catillus Walker. Monotypic.

Piestopleura Foerster, 1856. Hym. Stud., v. 2, p. 144. N. name.

Revision: Kieffer, 1926. Das Tierreich, Lief, 48, pp. 627-631.

Taxonomy: Debauche, 1947. Soc. Ent. de Belg., Bul. et Ann. 83: 272. platygaster (Fouts). D. C.

Leptacis platygaster Fouts, 1925. Ent. Soc. Wash., Proc. 27: 100. 9.

Taxonomy: Masner and Muesebeck, 1968. U. S. Natl. Mus. Bul. 270: 83.

\section{Genus SYNOPEAS Foerster}

Synopeas Foerster, 1856. Hym. Stud., v. 2, pp. 108, 114. No species. -Thomson, 1859.

Ofvers. Kongl. Vetensk-Akad., Forh. 16: 71. Thirteen species.

Type-species: Synopeas inermis Thomson. Desig. by Muesebeck and Walkley, 1951.

Ectudius Foerster, 1856. Hym. Stud., v. 2, pp. 108, 113, 114, 144.

Type-species: Platygaster craterus Walker. Monotypic.

Polymecus Foerster, 1856. Hym. Stud., v. 2, p. 144. N. name, unnecessarily proposed for Ectudins Foerster, which Foerster thought to be preocc. by Eetadium E. Meyer in

Botany.

Sactogaster Foerster, 1856. Hym. Stud., v. 2, pp. 108, 113.

Type-species: Epimeces ventralis Westwood. Desig. by Ashmead, 1893.

Syropius Ashmead, 1896. Zool. Soc. London, Proc. for 1895, p. 802. Error.

Dolichotrypes Crawford and Bradley, 1911. Ent. Soc. Wash., Proc. 13: 124.

Type-species: Dolichotrypes hopkinsi Crawford and Bradley. Orig. desig.

Taxonomy: Ghesquiere, 1948. Soc. Ent. de Belg., Bul. et Ann. 84: 44. - Masner, 1960. Rev. de

Zool. et de Bot. Africaines 62: 3-5. - Masner, 1964. Acta Soc. Ent. Cechoslov. 61: 149-150.

- Muesebeck and Masner, 1967. U. S. Dept. Agr., Agr. Monogr. 2, Sup. 2, pp. 302-304.

abdominator (Fouts). Tex. (Brownwood).

Leptacis ablominator Fouts, 1925. Ent. Soc. Wash., Proc. 27: 101. \&.

aciculatum (Fouts). Md. (Glen Echo).

Leptacis aciculata Fouts, 1924. U. S. Natl. Mus., Proc. 63 (15): 115, 134. ๆ, of.

angustulum (Fouts). Md. (Glen Echo).

Leptacis augustula Fouts, 1925. Ent. Soc. Wash., Proc. 27: 100. १.

anomaliventre (Ashmead). N. H., Pa., Md., Fla., La.

Sactogaster anomaliventris Ashmead, 1887. Canad. Ent. 19: 130. ?.

ashmeadii Dalla Torre. Colo. (Westcliffe).

Synopeas ine'mis Ashmead, 1890. Colo. Biol. Assoc., Bul. 1: 10. ․ Preoce. by Thomson, 1859.

Synopeas aslimeadii Dalla Torre, 1898. Cat. Hym., v. 5, p. 483. N. name.

auripes (Ashmead). Va.

Polymecus auripe's Ashmead, 1893. U. S. Natl. Mus., Bul. 45: 278, 283. ๆ.

bradleyi (Fouts). N. Y. (Ithaca).

Leptacis bradleyi Fouts, 1924. U. S. Natl. Mus., Proc. 63 (15): 118, 132. क.

breviventre (Ashmead). D. C.

Leptacis brevicentris Ashmead, 1893. U. S. Natl. Mus., Bul. 45: 271, 273. ९, ( $\delta$ misdet.).

carinator (Fouts). Tex. (Brownwood).

Leptacis earinator Fouts, 1925. Ent. Soc. Wash., Proc. 27: 101. ․

cynipsiphilum (Ashmead). Fla. (Jacksonville). Ecology: Reared from an oak gall.

Leptacis cyuipsiphila Ashmead, 1887. Canad. Ent. 19: 129. ?, (ơ misdet).

dubiosum (Fouts). Tex. (Brownwood).

Leptacis dubiosa Fouts, 1925. Ent. Soc. Wash., Proc. 27: 101. ठ.

flavicorne (Ashmead). D. C.

Leptacis flaricornis Ashmead, 1893. U. S. Natl. Mus., Bul. 45: 271, 275. ९, ( $\delta$ misdet.). 
floridanum (Ashmead). Fla. (Jacksonville).

Leptacis floridanus Ashmead, 1893. U. S. Natl. Mus., Bul. 45: 271, 272. ठ, (؟ misdet.).

foutsi Masner. Md. (Cabin John).

Sactogaster longientris Fouts, 1924. U. S. Natl. Mus., Proc. 63 (15): 110, 111. §. Preoce. by Ashmead, 1893.

Synopeas foutsi Masner, 1967. In Krombein and Burks, U. S. Dept. Agr., Agr. Monog. 2, Sup. 2, p. 303. N. name.

globatum (Fouts). D. C.

Leptac is globata Fouts, 1924. U. S. Natl. Mus., Proc. 63 (15): 11, 139. \&, ð.

hopkinsi (Crawford and Bradley). Mass., N. Y., W. Va., N. C., Fla.

Dolichotrypes hopkinsi Crawford and Bradley, 1911. Ent. Soc. Wash., Proc. 13: 124., , ( " $\delta "=$ ? of another species).

howardii (Ashmead). D. C.

Sactogaster Howurlii Ashmead, 1888. Canad. Ent. 20: 52. ․

incertum (Ashmead). Fla. (Jacksonville).

Anopedias incertus Ashmead, 1887. Canad. Ent. 19: 130. \&.

longiventre (Ashmead). D. C., Va.

Leptacis longiventris Ashmead, 1893. U. S. Natl. Mus., Bul. 45: 271, 273. \&, ð.

maculipes (Ashmead). Fla. (Jacksonville).

Catillus maculipes Ashmead, 1887. Canad. Ent. 19: 128. \%.

mucronatum (Fouts). Pa. (Carlisle).

Sactogaster mucronata Fouts, 1924. U. S. Natl. Mus., Proc. 63 (15): 110, 114..

nigripes Ashmead. D. C.

Synopeas nigripes Ashmead, 1893. U. S. Natl. Mus., Bul. 45: 286. ठ.

pennsylvanicum (Fouts). Pa., Ohio. Host: Cecidomyiid on phlox.

Leptacis pennsyleanica Fouts, 1924. U. S. Natl. Mus., Proc. 63 (15): 117, 120..

pubescens (Ashmead). D. C., Ill.

Leptacis pubescens Ashmead, 1893. U. S. Natl. Mus., Bul. 45: 271, 275. o..

punctatum (Ashmead). D. C., Va., Fla.

Leptacis punctatus Ashmead, 1893. U. S. Natl. Mus., Bul. 45: 271, 272. ๆ, ठ.

rufiseapus Ashmead. Fla.

Synopeas rufïscapus Ashmead, 1893. U. S. Natl. Mus., Bul. 45: 286, 288. ९, ơ. rugosiceps (Kieffer). Va., Mich.

Leptacis rugiceps Ashmead, 1893. U. S. Natl. Mus., Bul. 45: 271, 272. ₹, (ơ misdet.). Preocc. by Amblyaspis rugiceps Ashmead, 1893, when both were placed in Leptacis.

Leptacis ashmeadi Fouts, 1924. U. S. Natl. Mus., Proc. 63 (15): 117, 124. N. name. Preoce. by Dalla Torre, 1898 .

Leptacis rugosiceps Kieffer, 1926. Das Tierreich, Lief. 48, pp. 637, 644. N. name. striatifrons (Ashmead). Fla. (Jacksonville).

Leptacis striatifions Ashmead, 1893. U. S. Natl. Mus., Bul. 45: 271, 273. ๆ.

texanum (Fouts). Tex. (Brownwood).

Leptacis texana Fouts, 1925. Ent. Soc. Wash., Proc. 27: 102. d.

varipes (Harrington). Que. (Hull).

Sactogaster varipes Harrington, 1899. Roy. Soc. Canada, Trans. (2) 5: 190. \&, o

\section{Genus GASTROTRYPES Brues}

Gastrotrypes Brues, 1922. Amer. Acad. Arts and Sci., Proc. 57: 270.

Type-species: Gastrotrypes spatulatus Brues. Orig. desig.

caudatus Brues. Mass. (Boston).

Gastrotrypes caudatus Brues, 1922. Amer. Acad. Arts and Sei., Proc. 57: 272..

\section{Genus LEPTACIS Foerster}

Leptacis Foerster, 1856. Hym. Stud., v. 2, pp. 107, 112.

Type-species: Ichneumon tipulae Kirby. Desig. by Ashmead, 1893. 
Xestonotus Foerster, 1856. Hym. Stud., v. 2, pp. 107, 112. No species. -Ashmead, 1887.

Canad. Ent. 19: 128. One species. Preoce. by Leconte, 1853.

Type-species: Xestonotus andriciphilus Ashmead. First included species.

Ceratacis Thomson, 1859. Ofvers. Kongl. Vetensk-Akad., Forh. 16: 69, 78.

Type-species: Ceratacis flatipes Thomson. Monotypic.

Tricholeptacis Kieffer, 1914. In Andre, Spec. Hym. Eur. Alg., v. 11, p. 357.

Type-species: Amblyaspis verticillatus Ashmead. Orig. desig.

Xestonotidea Gahan, 1919. U. S. Natl. Mus., Proc. 56: 524. N. name for Xestonotus

Foerster.

Prosamblyaspis Kieffer, 1926. Das Tierreich, Lief. 48, pp. 561, 610.

Type-species: Amblyaspis flacosignatus Kieffer. Monotypic.

Axestonotus Kieffer, 1926. Das Tierreich, Lief. 48, pp. 561, 625. N. name for Xestonotus Foerster.

Proleptacis Kieffer, 1926. Das Tierreich, Lief. 48, pp. 562, 632.

Type-species: Leptacis foersteri Kieffer. Orig. desig.

Anacoryphe Debauche, 1947. Soc. Ent. de Belg., Bul. et Ann. 83: 247.

Type-species: Anacoryphe orchymonti Debauche. Orig. desig.

Mandraka Risbec, 1953. Inst. Sci. de Madagascar, Mem. 3: 343.

Type-species: Mandratia panliani Risbec. Monotypic.

Revision: Fouts, 1924. U. S. Natl. Mus., Proc. 63 (15): 115-126 (No. Amer. species). - Kieffer, 1926. Das Tierreich, Lief. 48, pp. 635-651 (World fauna). - Masner, 1960. Rev. de Zool. et de Bot. Africaines 62: 1-34 (African species).

aliena Fouts. Md. (Glen Echo).

Leptacis aliena Fouts, 1927. Ent. Soc. Wash., Proc. 29: 176. ๆ, ơ.

americana (Ashmead). Que. to Fla.

Amblyaspis Americana Ashmead, 1887. Canad. Ent. 19: 129..

andriciphila (Ashmead). Fla. (Jacksonville).

Xestonotus audriciphilus Ashmead, 1887. Canad. Ent. 19: 128. ค.

gahani Fouts. Md. (Glen Echo).

Leptacis gahani Fouts, 1924. U. S. Natl. Mus., Proc. 63 (15): 117, 123. ๆ, ठ์.

longipes (Ashmead). Fla. (Jacksonville).

Amblyaspis longipes Ashmead, 1887. Canad. Ent. 19: 128. ठ.

longispina Fouts. Md.

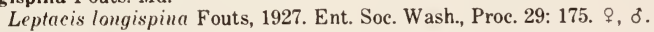

minuta (Ashmead). Mo. (St. Louis). Host: Cecidomyiid on squash.

Amblyaspis minutus Ashmead, 1893. U. S. Natl. Mus., Bul. 45: 267, 269. \&, ठ.

obscuricornis Fouts. Iowa (Ames).

Leptacis obscuricomis Fouts, 1924. Ent. Soc. Wash., Proc. 26: 161. ๆ.

pallipes Fouts. D. C.

Leptacis pallipes Fouts, 1924. U. S. Natl. Mus., Proc. 63 (15): 117, 121. ๆ.

puncticeps Ashmead. Pa., N. C., Fla.

Leptacis puncticeps Ashmead, 1893. U. S. Natl. Mus., Bul. 45: 271, 275. ठ.

rugiceps (Ashmead). D. C.

Amblyaspis rugiceps Ashmead, 1893. U. S. Natl. Mus., Bul. 45: 267, 269. ㅇ, ơ.

Taxonomy: Fouts, 1924. U. S. Natl. Mus., Proc. 63 (15): 122. - Masner and Muesebeck, 1968. U. S. Natl. Mus. Bul. 270: 82 .

\section{Genus AMBLY ASPIS Foerster}

Amblyaspis Foerster, 1856. Hym. Stud., v. 2, pp. 107, 112.

Type-species: Platygaster tritici Curtis. Desig. by Kieffer, 1926.

Revision: Kieffer, 1926. Das Tierreich, Lief. 48, pp. 610-625.

californica Ashmead. Oreg., Calif.

Amblyaspis californicus Ashmead, 1893. U. S. Natl. Mus., Bul. 45: 267, 268. ๆ, ठ̊. 
1186 Hymenoptera in America North of Mexico

occidentalis Ashmead. Ill., Kans.

Amblyaspis occidentalis Ashmead, 1893. U. S. Natl. Mus., Bul. 45: 267. \&.

petiolata Ashmead. Fla.

Amblyaspis petiolatus Ashmead, 1893. U. S. Natl. Mus., Bul. 45: 267, 268. १, ठ. 


\title{
Superfamily CERAPHRONOIDEA
}

\author{
By Carl F. W. Muesebeck
}

Superfamily rank for this group was first proposed by Masner in 1956 (Acta Faun. Ent. Mus. Nat. Pragae 1: 101), although without indication of basic differences from the Proctotrupoidea. In 1967, however, Masner and Dessart (Inst. Roy. Sci. Nat. de Belg., Bul. 43: 1-33) defined the superfamily in detail and recognized it as comprising two families, Ceraphronidae and Megaspilidae, the latter being divided into the subfamilies Megaspilinae and Lagynodinae. This classification appears to be sound. The members of this superfamily are remarkable for the possession of two apical spurs on the anterior tibiae.

In his 1914 revision of this group Kieffer used the name Calliceratidae, based on Calliceras Nees, 1834, since Ceraphron Jurine, 1807, which had been considered the type-genus of the family, was a junior homonym of Ceraphron Panzer, 1805. Kieffer was generally followed in the literature of the succeeding thirty years. However, in its Opinion 174, issued in 1946, the International Commission on Zoological Nomenclature suppressed Ceraphron Panzer, under suspension of the Rules, and validated Ceraphron Jurine with C. sulcatus Jurine, 1807, as type-species; since then the names Ceraphron and Ceraphronidae have again come into general use.

Apparently species of this superfamily are largely hyperparasites, developing especially on larvae of Aphidiidae, Braconidae, Ichneumonidae, Bethylidae, Dryinidae and Tachinidae. Some, however, are evidently primary parasites of Aleyrodidae, various small Diptera (i. e., Cecidomyiidae, Phoridae), certain neuropteroids and some cynipoid gall-makers; others occur in ant nests where they presumably develop as parasites of certain myrmecophilous Diptera.

Revision: Ashmead, 1893. U. S. Natl. Mus., Bul. 45: 102-136 (North American species). -Kieffer, 1907. In Andre, Spec. Hym. Eur. Alg., v. 10, pp. 5-261, 10 pls. (Old World species). - Kieffer, 1909. In Wytsman, Gen. Ins., fasc. 94, 24 pp., 2 pls. (generic key and assignment of species). - Kieffer, 1914. Das Tierreich, Lief. 42, pp. 63-238 (World fauna). -Dodd, 1914. Roy. Soc. So. Austral., Trans. 38: 85-118 (Australian fauna), - Hellen, 1966. Fauna Fennica 20: 3-45 (Finnish forms).

Taxonomy: Haliday, 1834. Ent. Mag. 1: 272. - Haliday, 1839. Hymenoptera Britannica, Hym. Synopsis, p. ii. - Foerster, 1856. Hym. Stud., v. 2, pp. 27, 97-99. -Ashmead, 1903. N. Y. Ent. Soc., Jour. 11: 33-35. - Masner, 1956. Acta Faun. Ent. Mus. Nat. Pragae 1: 101.

-Dessart, 1962. Soc. Roy. d'Ent. de Belg., Bul. et Ann. 98: 305-309 (key to genera).

- Masner and Dessart, 1967. Inst. Roy. Sci. Nat. de Belg., Bul. 43: 1-33.

Morphology: Reid, 1941. Roy. Ent. Soc. London, Trans. 91: 429-430. - Masner and Dessart, 1967. Inst. Roy. Sci. Nat. de Belg., Bul. 43: 6-25.

\section{Family CERAPHRONIDAE}

This family is treated here as restricted by Masner and Dessart in 1967 . 
Taxonomy: Masner and Dessart, 1967. Inst. Roy. Sci. Nat. de Belg., Bul. 43: 25-29.

\section{Genus CERAPHRON Jurine}

Ceraphron Jurine, 1807. Nouv. Meth. Class. Hym. Dipt., p. 303. Preoccupied by Ceraphron Panzer, 1805, but validated by the International Commission on Zoological Nomenclature in its Opinion 174, published in 1946, and placed on the Official List of generic names in zoology as name no. 615 .

Type-species: Ceraphron sulcatus Jurine. Desig. by Internatl. Comn. Zool.

Nomencl., Op. 174, 1946.

Calliceras Nees, 1834. Hym. Ichn. Aff. Monog., v. 2, p. 278.

Type-species: Calliceras fuscicornis Nees. Desig. by Blanchard, 1843.

Hadroceras Foerster, 1840. Beitr. Monog. Pteromalinen, p. xliv. Unnecessarily proposed as a new name for Calliceras Nees.

Megaspilidea Ashmead, 1888. Canad. Ent. 20: 48, 49.

Type-species: Megaspilidea minuta Ashmead. Monotypic.

Pristomicrops Kieffer, 1906. Soc. Sci. de Bruxelles, Ann. 30: 146.

Type-species: Pristomicrops clavatus Kieffer. Monotypic.

Cerataphron Schulz, 1906. Spolia Hym., p. 152. Emend.

Allomicrops Kieffer, 1914. Das Tierreich, Lief. 42, pp. xv, 69, 138.

Type-species: Ceraphron abnomis Perkins. Monotypic.

Eulagynodes Girault, 1917. New Javanese Hymenoptera, p. 9 (private pub.).

Type-species: Enlayynodes bicolor Girault. Orig. desig.

Ceranogmus Risbec, 1953. Inst. Francais d'Afrique Noire, Bul. 15: 560.

Type-species: Ceranogmus testacens Risbec. Monotypic.

Some species of Ceraphron develop as primary parasites and others as hyperparasites. There are few published rearing records for described North American species but in other parts of the world species of Ceraphron have been found to parasitize Diptera (Cecidomyiidae, Drosophilidae, Phoridae, Sciaridae and Syrphidae), Hymenoptera (Braconidae, Ichneumonidae, Dryinidae and Bethylidae), Homoptera (Aleyrodidae, Aphididae and Coccoidea, the last two possibly as hyperparasites) and certain small neuropteroids. Specimens of Ceraphron have also been taken in the nests of ants.

Revision: Ashmead, 1893. U. S. Natl. Mus., Bul. 45: 123-132. - Kieffer, 1914. Das Tierreich, Lief. 42 , pp. $70-114$.

Taxonomy: Dessart, 1965. Soc. Roy. d'Ent. de Belg., Bul. et Ann. 101: 110-158 (micropterous and brachypterous forms).

Biology: Haeussler, 1940. U. S. Dept. Agr., Tech. Bul. 728: 31. - LePelley, 1943. Roy. Ent. Soc. London, Trans. 93: 81.

abnormis Perkins. Calif.; Hawaiian Isls., Indonesia. Host: Haplogonatopus vitiensis Perkins and Echthrodelphax fairchildi Perkins.

Ceraphron abnormis Perkins, 1910. Fauna Hawaiiensis, v. 2, p. 617. \&, ઠ.

Eulagynodes bicolor Girault, 1917. New Javanese Hymenoptera, p. 9 (private pub.) 9.

Taxonomy: Masner, 1964. Acta Soc. Ent. Cechoslov. 61: 126.

Biology: Swezey, 1908. Hawaii. Ent. Soc., Proc. 2: 18-21.

amesicola (Ogloblin). Iowa (Ames).

Calliceras amesicola Ogloblin, 1944. Ent. Soc. Wash., Proc. 46: 155. ๆ.

amplus Ashmead. Pa., D. C. Host: Megaselia sp.

Ceraphron amplus Ashmead, 1893. U. S. Natl. Mus., Bul. 45: 124, 129..

auripes Ashmead. Ont. (Ottawa).

Ceraphron auripes Ashmead, 1893. U. S. Natl. Mus., Bul. 45: 124, 125. \&.

borealis (Whittaker). B. C. (Hollyburn).

Calliceras boreale Whittaker, 1930. Ent. Soc. Wash., Proc. 32: 71..+

brevicornis Brues. Wis. (Milwaukee).

Ceraphron brevicornis Brues, 1906. Wis. Nat. Hist. Soc., Bul. 4: 145, 146. ठ. 
californicus Ashmead. Calif. (Folsom).

Ceraphron califormicus Ashmead, 1893. U. S. Natl. Mus., Bul. 45: 124, 127. .

carinatus Ashmead. Md., D. C., Va.

Ceraphron carinatus Ashmead, 1893. U. S. Natl. Mus., Bul. 45: 125, 131. . The male described by Ashmead belongs in Lagynodes.

carlylei Girault. Ill., Iowa, La.

Ceraphron carlylei Girault, 1920. U. S. Natl. Mus., Proc. 58: 179. ९.

concinnus (Whittaker). B. C. (Hollyburn).

Calliceras concinna Whittaker, 1930. Ent. Soc. Wash., Proc. 32: 70. ð.

crassicornis Harrington. Ont. (Ottawa).

Ceraphron crassicomis Harrington, 1899. Canad. Ent. 31: 77. \&.

croceipes Brues. Tex. Ecology: In nest of Labidus coecus (Latr.).

Ceraphron croceipes Brues, 1902. Amer. Nat. 36: 369. 9.

faseiatus (Fouts). Md.

Calliceras fasciata Fouts, 1924. Ent. Soc. Wash., Proc. 26: 162. ․

flaviseapus Ashmead. D. C., Va.

Ceraphron flaviscapus Ashmead, 1893. U. S. Natl. Mus., Bul. 45: 124, 130..

fusciceps Ashmead. Md., D. C.

Ceraphron fusciceps Ashmead, 1893. U. S. Natl. Mus., Bul. 45: 124, 125. .

Ceraphron secundus Dalla Torre, 1898. Cat. Hym., v. 5, p. 527. Unnecessarily proposed as n. name.

glabricornis Kieffer. Nev. (Ormsby County).

Ceraphron glabricomis Kieffer, 1906 (1905). Berlin. Ent. Ztschr. 50: 260. ठ์.

melanocerus Ashmead. Ont. (Ottawa).

Ceraphron melanocerms Ashmead, 1893. U. S. Natl. Mus., Bul. 45: 124, 129..

melantatocephalus Dessart. Fla. (Jacksonville). Host: Belonocnema treatae Mayr.

Copidosoma melanocephalum Ashmead, 1886. Amer. Ent. Soc., Trans. 13: 131. “ $"=q$.

Preoce. in Ceraphron by Boheman, 1832.

Ceraphron melantatocephalus Dessart, 1967. Rec. So. Austral. Mus. 15: 551. N. name.

mellipes Ashmead. Fla. (Jacksonville).

Ceraphron mellipes Ashmead, 1893. U. S. Natl. Mus., Bul. 45: 125, 131. ठ', ๆ.

minutus (Ashmead). Ont. (Ottawa).

Megaspilidea minuta Ashmead, 1888. Canad. Ent. 20: 49. ๆ.

nevadensis Kieffer. Nev. (Ormsby County).

Ceraphron nevadensis Kieffer, 1906 (1905). Berlin. Ent. Ztschr. 50: 260. ๆ.

pacificus (Whittaker). B. C. (Chilliwack).

Calliceras pacifica Whittaker, 1930. Ent. Soc. Wash., Proc. 32: 129. ․

pallidipes (Fouts). Md. (Glen Echo).

Calliceras pallidipes Fouts, 1924. Ent. Soc. Wash., Proc. 26: 161. ‥

pallidiventris Ashmead. "Md. (Fort Pendleton)."

Ceraphron pallidirentris Ashmead, 1893. U. S. Natl. Mus., Bul. 45: 124, 126 ..

pedalis Ashmead. Va. (Arlington).

Ceraphron pedalis Ashmead, 1893. U. S. Natl. Mus., Bul. 45: 124, 130. ๆ.

punctatus Ashmead. Md., D. C., Va.

Ceraphron punctatus. Ashmead, 1893. U. S. Natl. Mus., Bul. 45: 124, 127. ð, ๆ.

quissetensis Brues. Mass. (Woods Hole).

Ceraphron quissetensis Brues, 1906. Wis. Nat. Hist. Soc., Bul. 4: 145, 147. ๆ.

schwarzi Muesebeck and Walkley. Md., D. C.

Ceraphron glaber Ashmead, 1893. U. S. Natl. Mus., Bul. 45: 125, 130. ठ', ๆ. Preoce. by

Boheman, 1832.

Ceraphron schwarzi Muesebeck and Walkley, 1951. U. S. Dept. Agr., Agr. Monog. 2, p. 668. N. name.

tertius Dalla Torre. D. C., Va.

Ceraphron basalis Ashmead, 1893. U. S. Natl. Mus., Bul. 45: 124, 127. , ठ. Preoce. by

Thomson, 1858. 
Ceraphron tertius Dalla Torre, 1898. Cat. Hym., v. 5, p. 528. N. name.

unicolor Ashmead. Wyo., Utah, Calif.

Ceraphron unicolor Ashmead, 1893. U. S. Natl. Mus., Bul. 45: 124, 128. \&.

whittakeri (Fouts). B. C., Oreg.

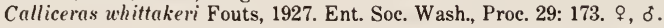

\section{Genus NEOCERAPHRON Ashmead}

Neoceraphron Ashmead, 1893. U. S. Natl. Mus., Bul. 45: 136.

Type-species: Ceraphron macroneurus Ashmead. Monotypic.

Neocerataphron Schulz, 1906. Spolia Hym., p. 152. Emend.

Taxonomy: Szelenyi, 1938. Folia Ent. Hungarica 3: 109-112. - Hellen, 1966. Fauna Fennica

20: 41. -Masner and Dessart, 1967. Inst. Roy. Sci. Nat. de Belg., Bul. 43: 18-19.

macroneurus (Ashmead). Fla.

Ceraphrou macroneurns Ashmead, 1887. Ent. Amer. 3: 97. ઠ.

\section{Genus APHANOGMUS Thomson}

Aphanogmus Thomson, 1858. Ofvers. Kongl. Vetensk.-Akad., Forh. 15: 287, 305.

Type-species: Aphanogmus fumipennis Thomson. Desig. by Ashmead, 1893.

From the little available information on the biology of members of this genus it appears that some species are primary parasites of certain Diptera, particularly Cecidomyiidae, and other species develop as hyperparasites.

Taxonomy: Szelenyi, 1940. Mus. Natl. Hungarici, Ann. (Zool.) 33: 122-136. -Dessart, 1962.

Soc. Roy. d'Ent. de Belg., Bul. et Ann. 98: 294-300. - Dessart, 1963. Soc. Roy. d'Ent. de

Belg., Bul. et Ann. 99: 387-416. - Dessart, 1964. Soc. Roy. d'Ent. de Belg., Bul. et Ann. 100:

259-278. - Dessart, 1965. Soc. Roy. d'Ent. de Belg., Bul. et Ann. 101: 158-178.

bicolor Ashmead. Ont. (Ottawa).

Aphanogmus bicolor Ashmead, 1893. U. S. Natl. Mus., Bul. 45: 133, 134..

canadensis Whittaker. B. C. (Hollyburn).

A phanogmus canadensis Whittaker, 1930. Ent. Soc. Wash., Proc. 32: 131. ठ.

dorsalis Whittaker. B. C. (Hollyburn).

A phanogmus dorsalis Whittaker, 1930. Ent. Soc. Wash., Proc. 32: 132. \&.

floridanus Ashmead. S. C., Fla., Ohio. Host: Arthrocnodax corolina Felt; Mycodiplosis acarivora (Felt).

Aphanogmus floridanus Ashmead, 1893. U. S. Natl. Mus., Bul. 45: 133, 134. §, ठ์.

harringtoni Muesebeck, n. name. Ont. (Ottawa). Host: Cecidomyiid gall-maker.

Aphanogmus salicicola Harrington, 1899. Canad. Ent. 31: 78. ^, ठ. Preocc. by Ashmead, 1893.

marylandicus Ashmead. Md. (Oakland).

A phanogmus marylaudicus Ashmead, 1893. U. S. Natl. Mus., Bul. 45: 133, 135..

niger Ashmead. D. C.

A phanogmus niger Ashmead, 1893. U. S. Natl. Mus., Bul. 45: 133. ठ.

obsoletus Whittaker. B. C. (Hollyburn).

Aphanogmus: obsoletus Whittaker, 1930. Ent. Soc. Wash., Proc. 32: 131. ๆ.

pallidipes Ashmead. Va. (Arlington).

A phanogmus pallidipes Ashmead, 1893. U. S. Natl. Mus., Bul. 45: 133, 135. \&.

salicicola (Ashmead). Calif. (Los Angeles).

Ceraphron salicicola Ashmead, 1893. U. S. Natl. Mus., Bul. 45: 124, 128..

subapterus Whittaker. B. C. (Chilliwack).

Aphanogmus subapterus Whittaker, 1930. Ent. Soc. Wash., Proc. 30: 130..

varipes Ashmead. Kans.

Aphonogmus varipes Ashmead, 1893. U. S. Natl. Mus., Bul. 45: 133, 135..

virginiensis Ashmead. Va. (Arlington).

Aphanogmus virginiensis Ashmead, 1893. U. S. Natl. Mus., Bul. 45: 133, 135.. 


\section{Genus ECITONETES Brues}

Ecitonetes Brues, 1902. Amer. Nat. 36: 370.

Type-species: Ecitonetes subapterus Brues. Monotypic.

subapterus Brues. Tex. (Austin). Ecology: In colony of Labidus coecus (Latr.).

Ecitonetes subapterus Brues, 1902. Amer. Nat. 36: 370. $\%$.

\section{Genus SYNARSIS Foerster}

Synarsis Foerster, 1878. Naturh. Ver. Rheinlande, Verh. 35: 57.

Type-species: Synarsis pulla Foerster. Orig. desig.

An undeseribed species occurs in Virginia.

Taxonomy: Szelenyi, 1936. Mus. Natl. Hungarici, Ann. (Zool.) 30: 50-57.

\section{Genus HOMALOCERAPHRON Dessart and Masner}

Homaloceraphron Dessart and Masner, 1969. Acta Ent. Bohemoslov. 66: 222.

Type-species: Homaloceraphron macrophthalmus Dessart and Masner. Orig. desig.

Host relationships are unknown.

macrophthalmus Dessart and Masner. Tex. (El Paso County).

Homaloceraphron macrophthalmus Dessart and Masner, 1969. Acta Ent. Bohemoslov. 66: 222. ㅇ.

microphthalmus Dessart and Masner. N. C. (Moore County).

Homaloceraphrou microphthalmus. Dessart and Masner, 1969. Acta Ent. Bohemoslov. 66: 225. ‥

\section{Family MEGASPILIDAE}

The treatment of this group is in line with that proposed by Masner and Dessart in 1967.

Taxonomy: Masner and Dessart, 1967. Inst. Roy. Soc. Nat. de Belg., Bul. 43: 25-29.

\section{SUBFAMILy MEGASPILINAE}

\section{Genus TRICHOSTERESIS Foerster}

Trichosteresis Foerster, 1856. Hym. Stud., v. 2, pp. 97, 99.

Type-species: Ceraphrou glaber Boheman. Desig. by Ashmead, 1893.

Thliboneura Thomson, 1858. Ofvers. Kongl. Vetensk.-Akad., Forh. 15: 287, 288.

Type-species: Ceraphron glaber Boheman. Desig. by Muesebeck and Walkley, 1951.

Neither of the two known North American species has been reared, but exotic forms have been recorded as parasitic in the puparia of Syrphidae.

floridana Ashmead. Fla. (Jacksonville).

Trichosteresis floridanus Ashmead, 1887. Ent. Amer. 3: 98. ๆ.

vitripennis Whittaker. B. C. (Chilliwack).

Trichosteresis vitripenu is Whittaker, 1930. Ent. Soc. Wash., Proc. 32: 72. \&.

\section{Genus MEGASPILUS Westwood}

Megaspilus Westwood, 1829. In Stephens, Nomencl. Brit. Ins., column 37.

Type-species: Ceraphron dux Curtis. Desig. by Westwood, 1839.

Habropelte Thomson, 1858. Ofvers. Kongl. Vetensk.-A kad., Forh. 15: 288.

Type-species: Ceraphron tibialis Boheman. Desig. by Ashmead, 1893.

Megaspilodes Ashmead, 1888. Canad. Ent. 20: 48.

Type-species: Ceraphron amuatus Say. Monotypic.

Megalospilus Schulz, 1906. Spolia Hym., p. 152. Emend.

Habropelta Schulz, 1906. Spolia Hym., p. 152. Emend.

Presumably species of Megaspilus are parasitic on Diptera, but reliable host records seem to be lacking. 
armatus (Say). Ont., Va., Ind.

Ceraphron armatus Say, 1836. Boston Jour. Nat. Hist. 1: 276.

Telenomus stygicus Provancher, 1887. Addit. Corr. Faune Ent. Canada Hym., p. 189.. fuscipennis (Ashmead). Que., Maine, D. C., Va., N. C., Iowa, La., Kans., Wyo., Wash.

Megaspilodes fuscipennis Ashmead, 1888. Kans. Agr. Expt. Sta., Bul. 3, App., p. III. $\subsetneq$. leviceps (Kieffer). Nev. (Ormsby county).

Habropelte leviceps Kieffer, 1906 (1905). Berlin. Ent. Ztschr. 50: 256, 257. \&.

nigerrimus (Kieffer). Calif. (Santa Clara).

Habropelte nigerrimus Kieffer, 1906 (1905). Berlin. Ent. Ztschr. 50: 256, 257. ठ, ?.

nigerrimus var. sublevis (Kieffer). Calif. (Santa Clara).

Habropelte nigerrimus var. sublevis Kieffer, 1906 (1905). Berlin. Ent. Ztschr. 50: 257. ठ。.

\section{Genus CONOSTIGMUS Dahlbom}

Conostigmus Dahlbom, 1858 (1857). Ofvers. Kongl. Vetensk.-Akad., Forh. 14: 291. No species. - Kieffer, 1907. In Andre, Spec. Hym. Eur. Alg., v. 10, pp. 80-173. Many species.

Type-species: Megaspilus alutacens Thomson. Desig. by Muesebeck and Walkley, 1951.

Eumegaspilus Ashmead, 1888. Canad. Ent. 20: 48, 49.

Type-species: Eumegaspilus canadensis Ashmead. Desig. by Muesebeck and

Walkley, 1951.

Eumegalospilus Schulz, 1906. Spolia Hym., p. 152. Emend.

Conostigmoides Dodd, 1914. Roy. Soc. So. Austral., Trans. 38: 88, 94.

Type-species: Eumegaspilus erythrothorax Ashmead. Orig. desig.

Hosts have been recorded for relatively few of the known species. However, several species, in North America and elsewhere, have been reared from the puparia of Syrphidae, others from the puparia of Tachinidae; and an African species has been recorded repeatedly from the puparia of the tsetse fly, Glossina palpalis Rob.-Desv. A number of other species have been found in the nests of ants where they presumably developed as parasites of myrmecophilous Diptera.

Revision: Kieffer, 1907. In Andre, Spec. Hym. Eur. Alg., v. 10, pp. 80-173. -Kieffer, 1914.

Das Tierreich, Lief. 42, pp. 166-221.

Taxonomy: Masner, 1964. Acta Soc. Ent. Cechoslov. 61: 124-125. - Hellen, 1966. Fauna

Fennica 20: 15-23.

ambiguus (Ashmead). D. C., Va.

Megaspilus ambiguus Ashmead, 1893. U. S. Natl. Mus., Bul. 45: 113, 115. \&, ठ.

arietinus (Provancher). Que. (Cap Rouge).

Isostasis (!) arietinus Provancher, 1887. Addit. Corr. Faune Ent. Canada Hym., p. 183..

Taxonomy: Masner, 1969. Nat. Canad. 96: 779.

ater Fouts. Calif. Host: Syrphid puparium.

Conostigmus ater Fouts, 1926. Ent. Soc. Wash., Proc. 28: 168..

bacilliger (Kieffer). Calif. (San Mateo).

Megaspilus bacilliger Kieffer, 1906 (1905). Berlin. Ent. Ztschr. 50: 258. ठ.

bakeri Kieffer. Calif.

Conostigmus Bakeri Kieffer, 1908. Soc. Sci. de Bruxelles, Ann. 32: 36. ठ.

californicus (Ashmead). Calif. (Folsom).

Megaspilus californicus Ashmead, 1893. U. S. Natl. Mus., Bul. 45: 114, 118. ठ.

canadensis (Ashmead). Ont. (Ottawa).

Eumegaspilus Canadensis Ashmead, 1888. Canad. Ent. 20: 49..

crawfordi (Mann). Md. (Great Falls). Ecology: In nest of Formica exsectoides Forel.

Megaspilus crawfordi Mann, 1920. Ent. Soc. Wash., Proc. 22: 60. ‡.

erythrothorax (Ashmead). Fla. (Jacksonville).

Eumegaspilus erythrothorax Ashmead, 1893. U. S. Natl. Mus., Bul. 45: 120. ९, §.

harringtoni (Ashmead). Ont. (Ottawa).

Megaspilus Harringtoni Ashmead, 1888. Canad. Ent. 20: 48. ठ, ?. 
hyalinipennis (Ashmead). Fla. (Jacksonville).

Megaspilus hyalinipennis Ashmead, 1887. Ent. Amer. 3: 98, \&.

inermis (Kieffer). Calif, (San Mateo).

Megaspilus inermis Kieffer, 1906 (1905). Berlin. Ent. Ztschr. 50: 258, 259. ठ.

integriceps (Kieffer). Calif. (San Mateo).

Meguspilus integriceps Kieffer. 1906 (1905). Berlin. Ent. Ztschr. 50: 258, 259. \&.

laeviceps (Ashmead). Md., D. C., Va.

Megaspilus laeciceps Ashmead, 1893. U. S. Natl. Mus., Bul. 45: 114, 118. ơ.

marylandicus (Ashmead). Md. (Oakland).

Megaspilns murylundicus Ashmead, 1893. U. S. Natl. Mus., Bul. 45: 113, 116. o.

nevadensis (Kieffer). Nev. (Ormsby County).

Megraspilns nerulensis Kieffer, 1906 (1905). Berlin. Ent. Ztschr, 50: 258, 259. ๆ.

nigripes (Kieffer). Calif. (Santa Clara).

Megaspilus nigripes Kieffer, 1906 (1905). Berlin. Ent. Ztschr. 50: 258. ơ.

orcasensis (Brues). Wash. (Puget Sound).

Megaspilus orcasensis Brues, 1910. Wis. Nat. Hist. Soc., Bul. 7: 118. ठ゚.

ottawensis (Ashmead). Ont. (Ottawa).

Enmegaspilus Ottunensis Ashmead, 1888. Canad. Ent. 20: 49. .

penmaricus (Ashmead). Pa. (Pen Mar).

Megaspilus pemmaricus Ashmead, 1893. U. S. Natl. Mus., Bul. 45: 113. .

pergandei (Ashmead). D. C.

Megaspilas Peryamlei Ashmead, 1893. U. S. Natl. Mus., Bul. 45: 114, 118. ơ.

popenoei (Ashmead). Kans., Ill.

Megaspilus Popenoei Ashmead, 1893. U. S. Natl. Mus., Bul. 45: 113, 114. ๆ.

pulchellus Whittaker. B. C. (Hollyburn).

Conostigmus pulchellus Whittaker, 1930. Ent. Soc. Wash., Proc. 32: 133. o.

rufoniger (Provancher). Que. (Cap Rouge).

Telenomus rufoniger Provancher, 1888. Addit. Corr. Faune Ent. Canada Hym., p. 403. o".

Taxonomy: Masner, 1969. Nat. Canad. 96: 782.

schwarzi (Ashmead). D. C.

Megaspilus Schrarzi Ashmead, 1893. U. S. Natl. Mus., Bul. 45: 113, 115. ๆ.

striatipes (Ashmead). Ont. (Ottawa).

Megaspilus striatipes Ashmead, 1893. U. S. Natl. Mus., Bul. 45: 113, 115. .

timberlakei Kamal. Calif. (San Diego). Host: Allograpta obliqua (Say) (puparia), Sphaerophoria cylindrica (Say).

Conostigmus timberlakei Kamal, 1926. Canad. Ent. 58: 285. ․

Biology: Kamal, [1939]. Egypt. Min. Agr. Tech. and Sci. Serv., Ent. Sect., Bul. 207: 42-44. trapezoidus Kieffer. Pa. (Jeannette).

Conostigmus trapezoidus Kieffer, 1908. Soc. Sci. de Bruxelles, Ann. (2) 32: 35. ơ.

virginicus (Ashmead). Mass., Va., Mich., Ind. Host: Blepharipa scutellata (R.-D.).

Megaspilus virginicus Ashmead, 1893. U. S. Natl. Mus., Bul. 45: 113, 117..

zaglouli Kamal. Calif. Host: Scaeva pyrastri (L.), Syrphus opinator O. S.

Conostigmens zaglonli Kamal, 1926. Canad. Ent. 58: 285. ๆ, ơ.

Biology: Kamal, [1939]. Egypt. Min. Agr. Tech. and Sci. Serv., Ent. Sect., Bul. 207: 40-42.

\section{Genus DENDROCERUS Ratzeburg}

Dendrocerus Ratzeburg, 1852. Ichn. d. Forstins., v. 3, p. 180.

Type-species: Dendrocerns lichtensteinii Ratzeburg. Monotypic.

Lygocerus Foerster, 1856. Hym. Stud., v. 2, pp. 97, 99. No species. -Marshall, 1868. Ent. Monthly Mag. 5: 158. Five species.

Type-species: Ceraphron ramicornis Boheman. Desig. by Ashmead, 1893.

Macrostigma Rondani, 1877. Soc. Ent. Ital., Bol. 9: 184.

Type-species: Macrostigmt a ahidum Rondani. Monotypic. 
Atritomus Foerster, 1878. Naturh. Ver. Rheinlande, Verh. 35: 56. Preocc. by Reitter, 1877. Type-species: Atritomus coccophagus Foerster. Orig. desig.

Prodendrocerns Kieffer, 1907. In Andre, Spec. Hym. Eur. Alg., v. 10, p. 11. No species. -Kieffer, 1909. in Wytsman, Gen. Ins., fase. 94, p. 6. One species.

Type-species: Dendrocerns ratzeburgi Ashmead. First included species.

Atritomellus Kieffer, 1914. Das Tierreich, Lief. 42, pp. xv, 139, 141. N. name for Atritomus Foerster.

Neolygocemss Ishii, 1951. Oyo-Dobuts.-Zasshi 16: 93.

Type-species: Neolygocerus koyamae Ishii. Monotypic.

Species of this genus are most commonly associated with sternorrhynchous Homoptera, especially aphids and mealybugs, and to a lesser extent chermids and psyllids. They usually develop either as hyperparasites through other Hymenoptera that are primary parasites, or as parasites of predatory larvae such as those of Syrphidae (various genera) and Chamaemyiidae (especially Leucopis and Cremanifania). Other recorded hosts include species of Coniopterygidae, Hemerobiidae and the phytophagous dipterous genera Mayetiola and Meromyza.

Taxonomy: Brues, 1910 (1909). Wis. Nat. Hist. Soc., Bul. 7: 120-121. -Jansson, 1944. Ent. Tidskr. 65: 190-194. - Ghesquiere, 1960. Soc. Roy. d'Ent. de Belg., Bul. et Ann. 96: 208-215. -Dessart, 1965. Soc. Roy. d'Ent. de Belg., Bul. et Ann. 101: 178-185. - Dessart, 1965.

Redia 49: 157-163. - Dessart, 1966. Inst. Roy. Sci. Nat. de Belg., Bul. 42(32): 1-16. - Hellen, 1966. Fauna Fennica 20: 4, 9-15.

Biology: Haviland, 1920. Quart. Jour. Micros. Sci. 65: 101-127. -Clausen, 1940.

Entomophagous Insects, pp. 257-261. - Muesebeck, 1959. Ent. News 70: 91. - Ghesquiere, 1960. Soc. Roy. d'Ent. de Belg., Bul. et Ann. 96: 205-208.

alaskensis (Ashmead). Alaska (St. Paul Isl.).

Lygocerns alaskensis Ashmead, 1902. Wash. Acad. Sci., Proc. 4: 140. ‡.

americanus (Ashmead). Md. (Odenton).

Atritomus americanus Ashmead, 1893. U. S. Natl. Mus., Bul. 45: 122. ð.

anomaliventris (Ashmead). Mich. (Marquette).

Megaspilus anomaliventris Ashmead, 1893. U. S. Natl. Mus., Bul. 45: 113, 114..

attentus (Muesebeck). Maine, N. Y., N. J., Ohio. Host: Aphidiidae in Macrosiphum euphorbiae (Thomas).

Lygocerus attentus Muesebeck, 1959. Ent. News 57: 94. , ठ゚.

californicus (Ashmead). Calif.

Lygocerns californicus Ashmead, 1893. U. S. Natl. Mus., Bul. 45: 109, 111. ठ.

constrictus (Brues). Wash.

Lygocerus constrictus Brues, 1910 (1909). Wis. Nat. Hist. Soc., Bul. 7: 119. ठ.

conwentziae Gahan. Mass. Host: Conwentzia hageni Banks.

Dendrocerus contentziae Gahan, 1919. Ent. Soc. Wash., Proc. 21: 122. ๆ, ১.

conwentziae var. rufus Gahan. Wash., Calif. Host: Conwentzia sp.

Dendrocerus contentziae var. rufus Gahan, 1919. Ent. Soc. Wash., Proc. 21: 123. ‡, ठ.

floridanus (Ashmead). Fla. (Jacksonville). Host: Cinara sp. (probably secondary).

Chirocerus floridanus Ashmead, 1881. Amer. Ent. Soc., Trans. 9: Proc., p. xxxiv. \&, ठ.

incompletus (Muesebeck). Maine. Host: Aphidiidae in Macrosiphum euphorbiae (Thomas).

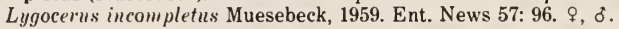

latifrons (Muesebeck). Calif. Host: Species of Hemerobiidae.

Lygocerns latifious Muesebeck, 1959. Ent. News 57: 93. ‡, ठ.

leucopidis (Muesebeck). Calif. Host: Leucopis sp.

Lygocerus lencopidis Muesebeck, 1959. Ent. News 57: 91. ?, ठ.

niger (Howard). Transition and Upper Austral Zones. Host: Aphidiidae parasitic in various aphids.

Megaspilus niger Howard, 1890. U. S. Dept. Agr., Insect Life 2: 247..

obscurellus Muesebeck, n. name. Calif. (San Mateo).

Atritomus californicus Kieffer, 1906 (1905). Berlin. Ent. Ztschr. 50: 256. ठ. Preocc. by Ashmead, 1893. 
pacificus (Ashmead). Calif. (Placer County).

Lygocerus pacificus Ashmead, 1893. U. S. Natl. Mus., Bul. 45: 109, 112. .

pallipes (Harrington). Que. (Hull).

Lygocerus pallipes Harrington, 1899. Canad. Ent. 31: 77. ९, ठ.

picipes (Ashmead). Ont., Ohio, S. C., Minn.

Lygocerus picipes Ashmead, 1893. U. S. Natl. Mus., Bul. 45: 108, 109..

pinicola (Muesebeck). Calif. Host: Leucopis atrifacies Aldrich.

Lygocerus pinicola Muesebeck, 1959. Ent. News 57: 92. ๆ, ð.

rufiventris (Ashmead). Fla.

Atritomus rufiventris Ashmead, 1887. Ent. Amer. 3: 98..

sexdentatus (Ashmead). D. C., W. Va

Lygocerns 6-dentatus Ashmead, 1893. U. S. Natl. Mus., Bul. 45: 109, 111. ᄋ, đ̊.

stigmatus (Say). Ont., Mich., Ind. Host: Species of Aphidiidae in aphid.

Ceraphron stigmatus Say, 1836. Boston Jour. Nat. Hist. 1: 277.

triticum (Taylor). U. S. Host: Mayetiola destructor (Say).

Ceraphron triticum Taylor, 1860. Amer. Agr., p. 300. ठ.

\section{Genus ECNOMOTHORAX Dessart and Masner}

Ecnomothorax Dessart and Masner, 1965. Soc. Roy. d'Ent. de Belg., Bul. et Ann. 101: 276.

Type-species: Ecnomothonax muesebecki Dessart and Masner. Orig. desig.

muesebecki Dessart and Masner. Mo., Ark.

Ecnomothorax muesebecki Dessart and Masner, 1965. Soc. Roy. d'Ent. de Belg., Bul. et Ann. 101: 277. $\%$, o.

\section{SUBFAMILY LAGYNODINAE}

Taxonomy: Masner and Dessart, 1967. Inst. Roy. Sci. Nat. de Belg., Bul. 43 (22): 1-33.

\section{Genus LAGYNODES Foerster}

Microps Haliday, 1833. Ent. Mag. 1: 272. Preoce. by Dahl, 1823; Wagler, 1830.

Type-species: Microps rubi Haliday. Monotypic.

Lagynodes Foerster, 1840. Beitr. Monog. Pteromalinen, p. xliv.

Type-species: Lagynodes rufus Foerster. Monotypic.

Triogmus Marshall, 1874. Ent. Annual, 1874, p. 134.

Type-species: Triogmus furcifer Marshall. Monotypic.

Plastomicrops Kieffer, 1906. Soc. Sci. de Bruxelles, Ann. 30: 145.

Type-species: Plastomicrops acuticornis Kieffer. Desig. by Muesebeck and Walkley,1956.

Lagnyodes Sharp, 1908. In Zool. Rec., 1906, p. 308. Error.

Laginodes Risbec, 1953. Inst. Francais d'Afrique Noire, Bul. 15: 560. Error.

There seem to be no reliable records of host association for species of Lagymodes. However, specimens of some species have been taken in ant nests.

Revision: Kieffer, 1914. Das Tierreich, Lief. 42, pp. 130-138. -Dessart, 1966. Inst. Roy. Sci. Nat. de Belg., Bul. 42 (18): 1-85.

Taxonomy: Szelenyi, 1936. Mus. Natl. Hungarici, Ann. (Zool.) 30: 56-64. 一Jansson, 1945.

Opusc. Ent. 10: 141-142.

longicornis (Ashmead). Fla (Ft. George Isl.).

Ceraphron longicornis Ashmead, 1893. U. S. Natl. Mus., Bul. 45: 125, 132. ठ์.

minutus Ashmead. D. C., Va.

Lagynodes minutus Ashmead, 1893. U. S. Natl. Mus., Bul. 45: 121..

xanthus Whittaker. B. C. (Hollyburn).

Lagynodes xanthus Whittaker, 1930. Ent. Soc. Wash., Proc. 32: 72 .. 



\title{
Superfamily TRIGONALOIDEA
}

\author{
By Robert W. Carlson
}

\section{Family TRIGONALIDAE}

According to Malyshev (1968) this small family includes about 70 species which are seattered throughout the world. The species are all parasitic. The hymenopterous or dipterous primary hosts are usually parasites or predators of larval Lepidoptera. It is thought that at least some species can be primary larval parasites of sawflies, and Cooper (1954) hypothesized that sawflies were the hosts of ancestral Trigonalidae. That seems quite possible in view of the isolated and undeterminable phyletic position of the family, but I know of no rearings of Nearctic trigonalids as primary or secondary parasites of sawflies.

Trigonalid eggs are deposited singly on the leaves of angiosperms, apparently always near the edges of leaves. They are tiny and tough-shelled, enabling them to be ingested without destruction by leaf feeding caterpillars. It appears that if the tough shell is not cracked when an egg is ingested hatching does not occur. Eclosion from the egg occurs in the intestine of the caterpillar, and the first instar trigonalid bores through the intestinal wall and apparently remains in the body cavity of the caterpillar without developing further pending parasitization of the caterpillar by an ichneumonid or tachinid or predation upon it by a social or solitary vespid. When the primary host is a social vespid, a first instar trigonalid would apparently be fed to a larval vespid by a foraging worker.

Revision: Townes, 1956. U. S. Natl. Mus., Proc. 106: 295-304.

Taxonomy: Schulz, 1907. In Wytsman, Gen. Ins., fasc. 61, 24 p. (Genera of world). -Bischoff, 1938. In Hedicke, Hym. Cat., pt. 5, 18 p. (world catalog).

Biology: Clausen, 1929; 1931. Ent. Soc. Wash., Proc. 31: 67-79; 33: 70-81. -Clausen, 1940.

Entomophagous Insects, p. 56-61. -Cooper, 1954. Ent. Soc. Wash., Proc. 56: 280-288.

-Malyshev, 1968. Genesis of Hym. and ... their Evolution, p. 88-95.

\section{Genus ORTHOGONALYS Schulz}

Orthogonalys: Schulz, 1905. Hym. Stud., p. 76.

Type-species: Orthogonalys boliviana Schulz. Monotypic.

Orthogoralos Schulz, 1907. In Wytsman, Gen. Ins., fasc. 61, p. 8. Emend.

Tapinogonalos Schulz, 1907. In Wytsman, Gen. Ins., fasc. 61, p. 14.

Type-species: Trigonalys pulchellus Cresson. Desig. by Viereck, 1914.

pulchella (Cresson). Southern Maine s. to n. Va., w. to w. N. Y. and W. Va. Host: Archytas aterrimus (R.-D.), Nilea lobeliae (Coq.).

Trigonalys pulchellus Cresson, 1867. Ent. Soc. Phila., Proc. 6: 351. ठ.

Biology: Townes, 1956. U. S. Natl. Mus., Proc. 106: 298 (oviposition behavior). 


\section{Genus LYCOGASTER Shuckard}

Lycogaster Shuckard, 1841. Entomologist 1: 123.

Type-species: Lycogaster pullata Shuckard. Monotypic.

pullata nevadensis (Cresson). Southwestern S. Dak., Colo., n. N. Mex., Nev., w. Oreg. Ecology: A number of specimens were reared from unknown pupal or larval-pupal parasites of Hyphantria cunea (Drury) at Boulder, Colo. Host: Euodynerus foraminatus scutellaris (Sauss.).

Trigonalys neradensis Cresson, 1879. Amer. Ent. Soc., Trans. 7: vii in Proc. o, $\%$.

pullata pullata Shuckard. Vt., Mass., R. I., N. Y., Md., D. C., n. Va., w. N. C., n. Ga., n. N. Dak.

Host: Euodynerus foraminatus foraminatus (Sauss.), Enicospilus americanus (Christ). Lycogaster pullatus Shuckard, 1841. Entomologist 1: 124. ․

Lycogaster pullatus var. hollensis Melander and Brues, 1902. Biol. Bul. 3: 36. o, o.

Biology: Cooper, 1954. Ent. Soc. Wash., Proc. 56: 280-288. -Townes, 1956. U. S. Natl. Mus., Proc. 106: 299-300.

\section{Genus POECILOGONALOS Schulz}

Poecilogonalos Schulz, 1907. In Wytsman, Gen. Ins., fasc. 61, p. 9.

Type-species: Trigonalys pulchella Westwood. Monotypic. The type-species is an objective synonym of $P$. thwaitsii (Westwood).

This genus includes only one Nearctic species, but according to Townes (1956, trigonalid revision, p. 300) Poecilogonalos is rather large and widely distributed.

costalis (Cresson). Southeastern Mass. s. to mid Fla., w. to s. Ohio and s.w. La. Ecology: Has been reared as a secondary parasite of Phosphila turbulenta Hbn. and Automeris io (F.). Host: Lespesia sp. ex Phosphila turbulenta $\mathrm{Hbn}$.

Trigonalys (Lycogaster) costalis Cresson, 1867. Ent. Soc. Phila., Proc. 6: 352. ठ.

Trigonalys sulcatus Davis, 1898 (1897). Amer. Ent. Soc., Trans. 24: 349. ठ。.

Biology: Townes, 1956. U. S. Natl. Mus., Proc. 106: 301-302 (oviposition behavior).

\section{Genus BAREOGONALOS Schulz}

Bareogonalos Schulz, 1907. In Wytsman, Gen. Ins., fasc. 61, p. 18.

Type-species: Trigonalys canadensis Harrington. Monotypic.

Nippogonalos Uchida, 1929. Insecta Matsumurana 3: 79.

Type-species: Nippogonalos jezoensis Uchida. Monotypic and orig. desig.

canadensis (Harrington). Southwestern B. C., n.w. Calif. Host: Vespula arenaria (F.), V. pensylvanica (Sauss.).

Trigonalys Canadensis Harrington, 1896. Canad. Ent. 28: 108. “ 0 ” =

Taxonomy: Harrington, 1898. In Taylor, Canad. Ent. 30: 15-16 (male described).

Biology: Taylor, 1898. Canad. Ent. 30: 14-15. 





SMTTHSONIAN INSTITUTION LIBRARIES

MilinifinimilinI 